Quality of

Surface Waters of the

United States,

1970

Part 2. South Atlantic Slope and Eastern Gulf of Mexico Basins

GEOLOGICAL SURVEY WATER-SUPPLY PAPER 2152 Prepared in cooperation with the States of Alabama, Florida, Georgia, Louisiana, Mississippi, North Carolina, Virginia, and with other agencies

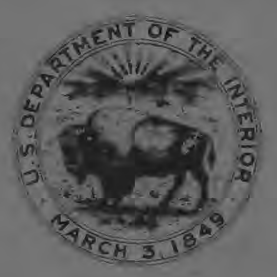




\section{Quality of}

Surface Waters of the

\section{United States,}

\section{0}

Part 2. South Atlantic Slope and Eastern Gulf of Mexico Basins

GEOLOGICAL SURVEY WATER-SUPPLY PAPER 2152 Prepared in cooperation with the States of Alabama, Florida, Georgia, Louisiana, Mississippi, North Carolina, Virginia, and with other agencies

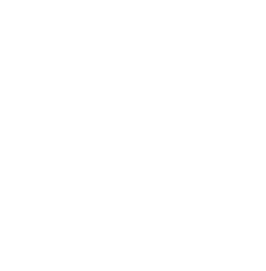




\section{UNITED STATES DEPARTMENT OF THE INTERIOR}

ROGERS C. B. MORTON, Secretary

\section{GEOLOGICAL SURVEY}

V. E. McKelvey, Director

Library of Congress catalog-card No. GS 43-68

For sale by the Superintendent of Documents, U.S. Government Printing Office Washington, D.C. 20402 - Price $\$ 5.45$ (paper cover)

Stock Number 2401-02579 


\section{PREFACE}

This report was prepared by the U.S. Geological Survey in cooperation with the States of Alabama, Florida, Georgia, Louisiana, Mississippi, North Carolina, Virginia, and with other agencies by personnel of the Water Resources Division, J. S. Cragwall. Jr. chief hydrologist, G. W. Whetstone, assistant chief hydrologist for Scientific Publications and Data Management, under the general direction of G. A. Billingsley, chief, Reports Section. and B. A. Anderson, chief, Data Reports Unit.

The data were collected under the supervision of district chiefs of the Water Resources Division as follows:

W. L. Broadhurst......................................... Tuscaloosa, Ala.

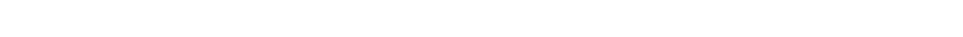

C. S. Conover........................................ Tallahassee, Fla.

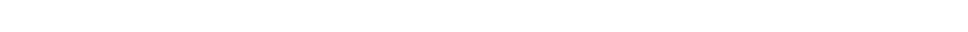

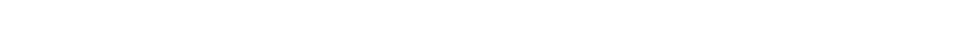

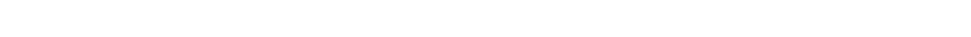

R. R. Meyer....................................... Baton Rouge, La.

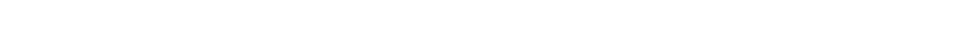




\section{CONTENTS}

Freface ............................................

List of Water-quality stations, in downstream order, for which

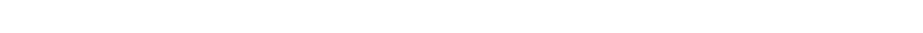

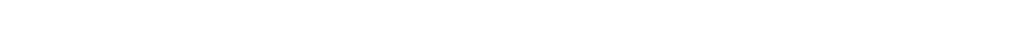

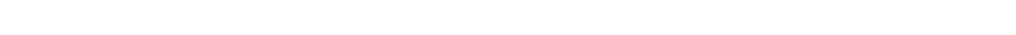

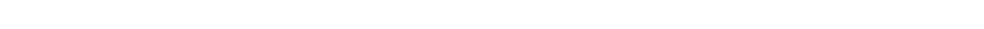

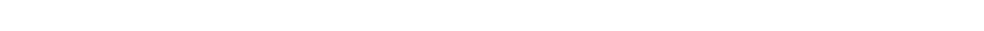

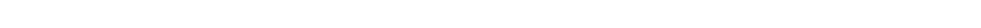

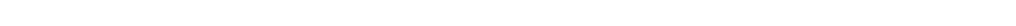

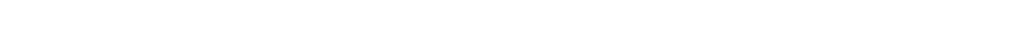

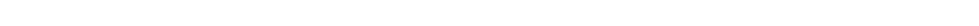

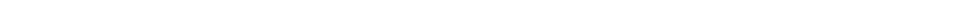

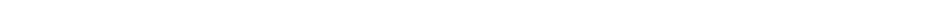

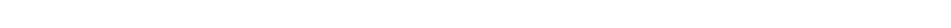

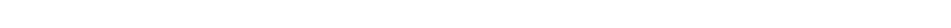

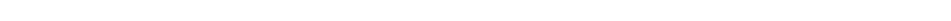

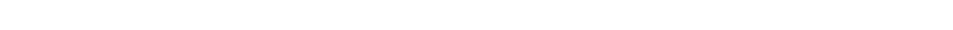

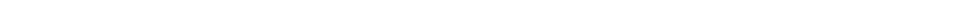

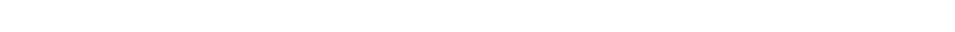

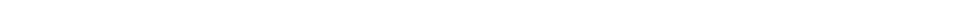

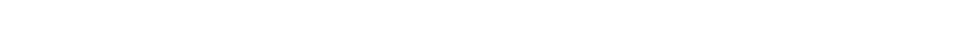

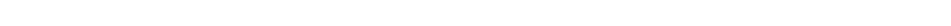

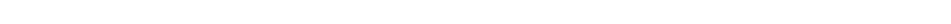

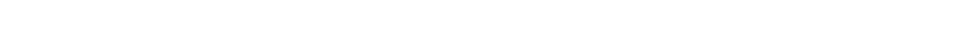

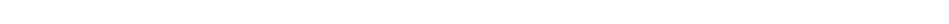

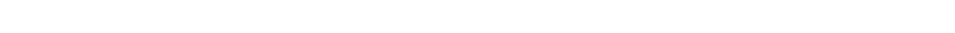

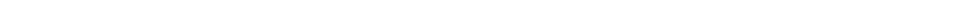

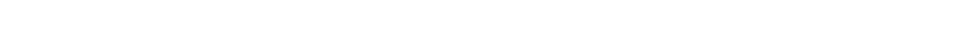

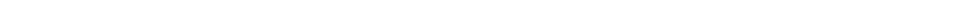

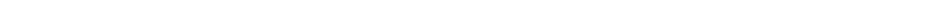

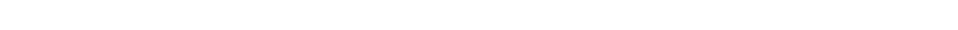

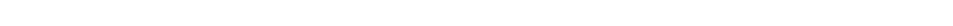

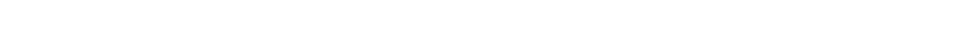

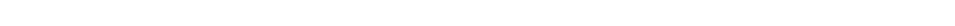

Cadmium ..........................................

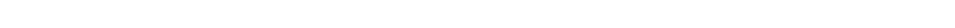

Cobalt............................................

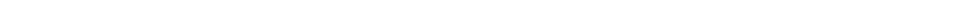

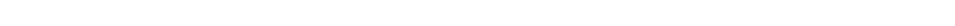

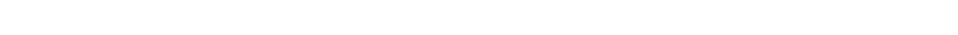

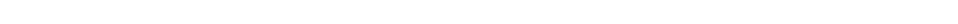

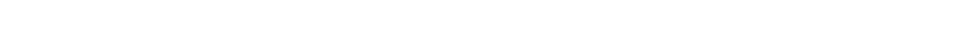

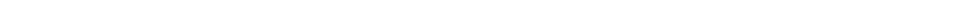

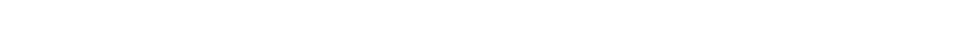

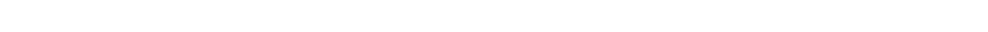

Dissolved solids...................................

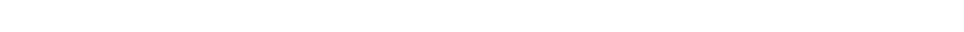

Acidity ...........................................

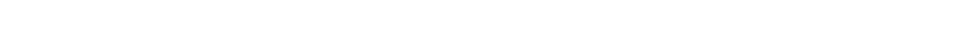

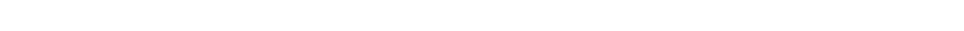

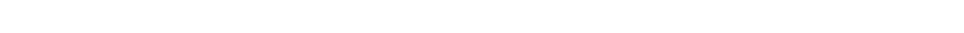

Temperature .....................................

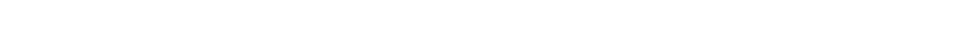

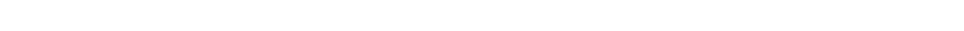

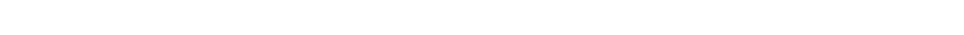

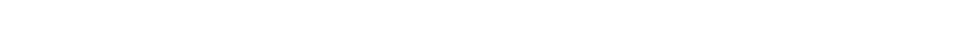

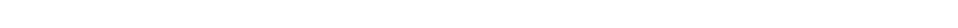


Composition of surface waters--Continued

Properties and characteristics of water--Continued

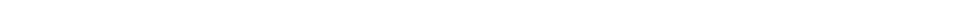

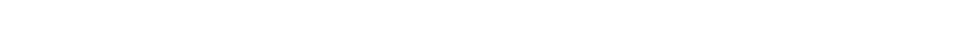

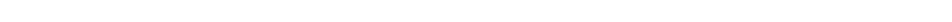

Sediment .........................................

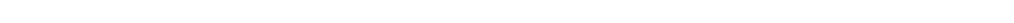

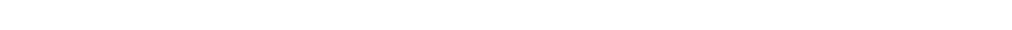

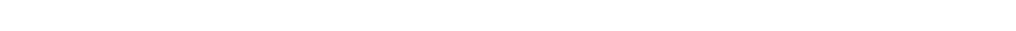

Division of work.

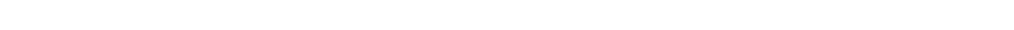

Index.

\section{ILLUSTRATION}

Figure 1. Map of the United States showing basins covered by the ten water-supply papers of quality of surface waters in 1970 . 


\section{WATER-QUALITY STATIONS. IN DOWNSTREAM ORDER, FOR WHICH RECORDS ARE PUBLISHED}

[Letters after station name designate type of data: (o) chemical, (t) vater temperature, (s) sediment]

SOUTH ATLANTIC SLOPE AND EASTERN GULF OF MEXICO BASINS JAMES RIVER BASIN

Jackson River (head of James River) at Falling Spring, Va. (ct).....

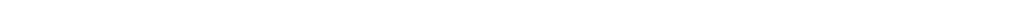
James River at Cartersville, Va. (ct) $\ldots \ldots \ldots \ldots \ldots \ldots \ldots \ldots \ldots \ldots \ldots$ Appomattox River:

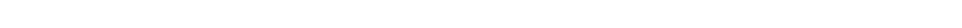

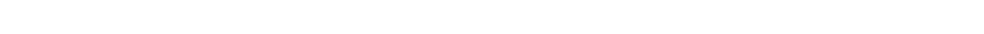
CHOWAN RIVER BASIN

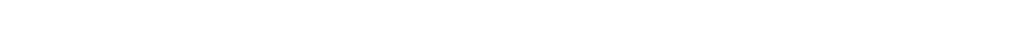

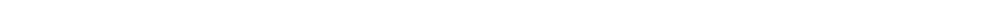
ROANOKE RIVER BASI N

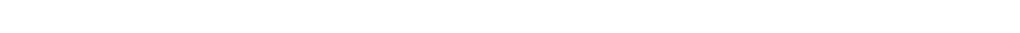

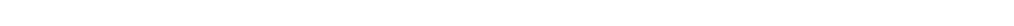
Dan River:

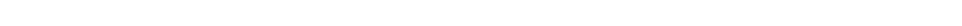

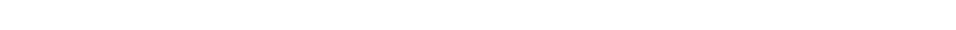

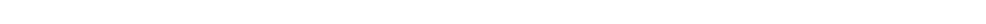

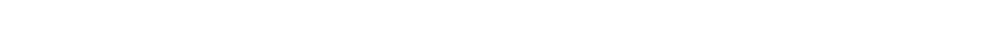

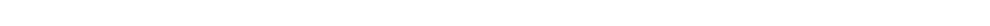

Hyco Creek near Leasburg, $N . C .(t) \ldots \ldots \ldots \ldots \ldots \ldots \ldots \ldots \ldots \ldots$ South Hyco Creek:

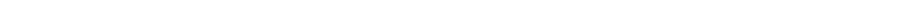

South Hyco Creek near Rosevilie, N.C. $(\mathrm{t}) \ldots \ldots \ldots \ldots \ldots \ldots \ldots \ldots \ldots$

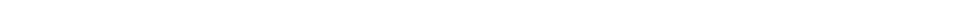

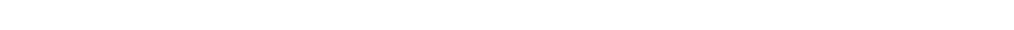
PAML ICO RI VER BASIN

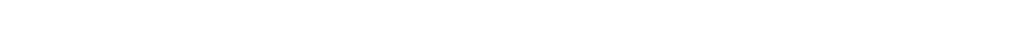

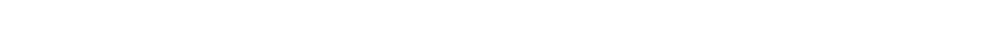
NEUSE RIVER BASIN

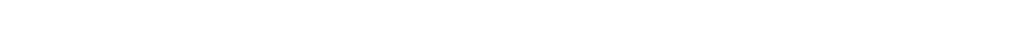
NEW RIVER BASIN

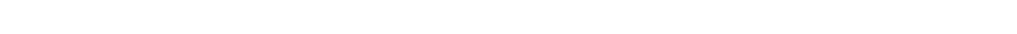
CAPE FEAR RIVER BASIN

Haw River (head of Cape Fear River) near Moncure, N.C. (c)........

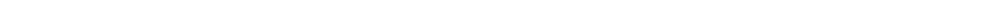

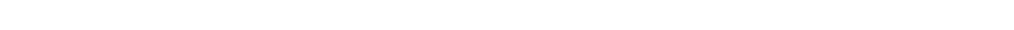
Cape Fear River at lock 2, near Elizabethtown, $\mathrm{N}_{\mathrm{C}}$. (c) $\ldots \ldots \ldots \ldots \ldots$

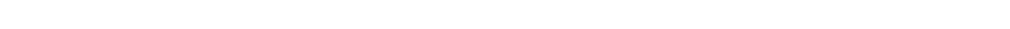

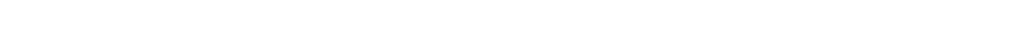
Northeast Cape Fear River at wilmington, $\mathrm{N}_{.} \mathrm{C}$. (c) $_{\ldots} \ldots \ldots \ldots \ldots \ldots \ldots \ldots \ldots$ WACCAMAW RIVER BASIN

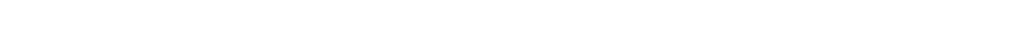
PEE DEE RIVER BASIN

Yadkin River (head of pee Dee River) at Wilkesboro, N.C. (ct)......

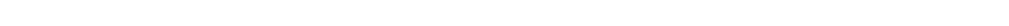

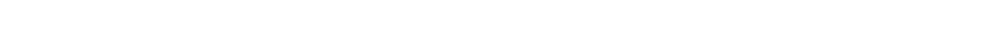

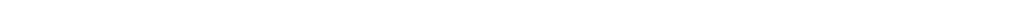

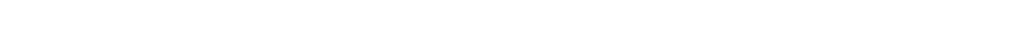

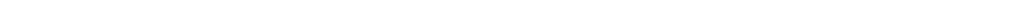

Lynches River near Pageland, S. $_{\text {. }}$ (c) $\ldots \ldots \ldots \ldots \ldots \ldots \ldots \ldots \ldots \ldots \ldots$

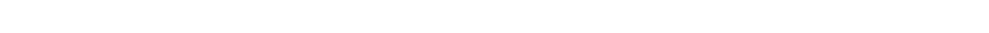

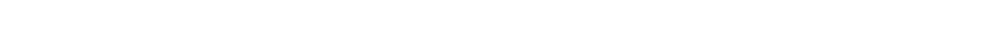

Little River:

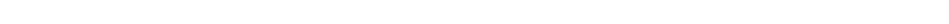

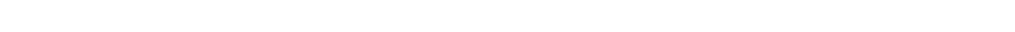


SOUTH ATLANTIC SLOPE AND EASTTERN GULF OF MEXICO BASINS--Cont inued

SANTEE RIVER BASIN

Catawba River (head of Santee River):

South Fork Catawba River:

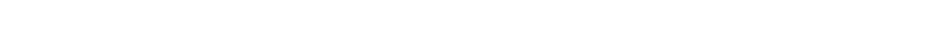

South Fork Catawba River near Elmores Crossroads, . $_{\text {. }}$ ( $\left.\mathrm{t}\right) \ldots \ldots \ldots$

Catawba River at State Highway 49, near Pineville, N.C. (c)........

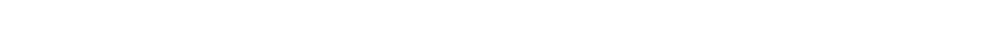

Wateree River (continuation of Catawba River):

Broad River (head of Conga ree River) near Earl, N.C. (c).........

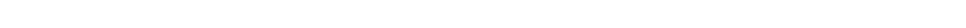

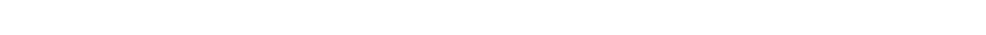

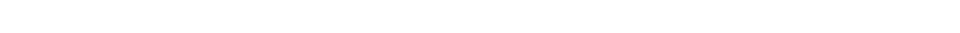
Pacolet River at pacolet Mills, s.C. (c)..................

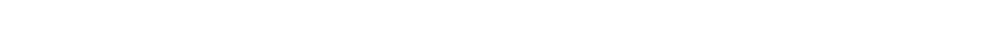
North Tyger River near Fairmont, $3 . \mathrm{C} .(\mathrm{t}) \ldots \ldots \ldots \ldots \ldots \ldots \ldots \ldots \ldots$

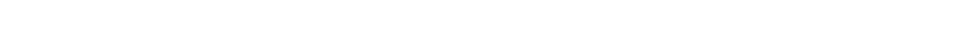

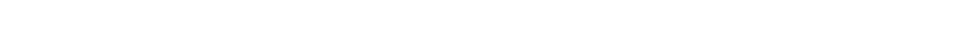

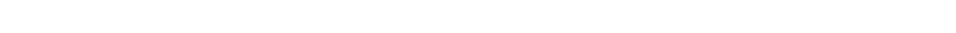

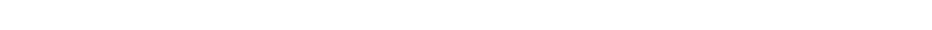

Reedy River near Ware Shoals, S.C. (c)..................

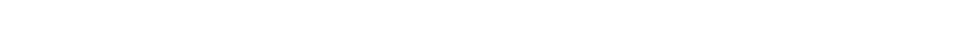

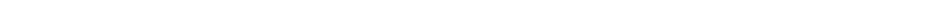

Congaree River (continuation of Broad River) near Cayce, S.C. (c).

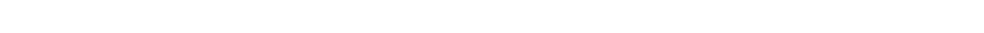

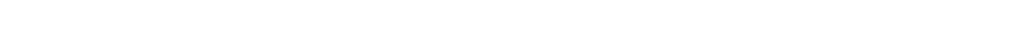

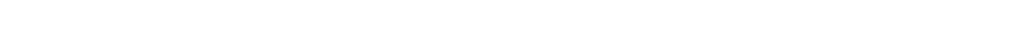
ASHLEY RIVER BASI N

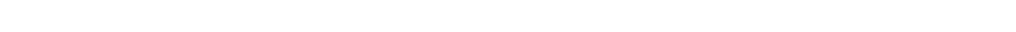
EDISTO RIVER BASIN

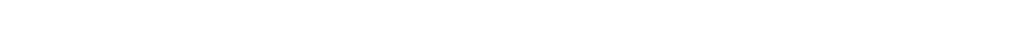

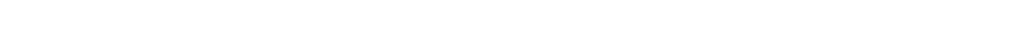
COMBAHEE RIVER BASIN

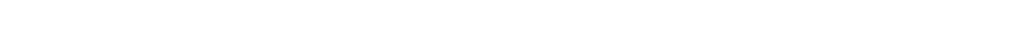

BEAUFORT RIVER BASIN

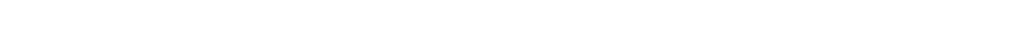

SAVANNAH RIVER BASIN

Chattooga River (head of Savannah River) near Clayton, Ga. (c).....

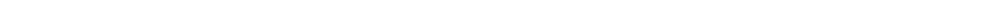

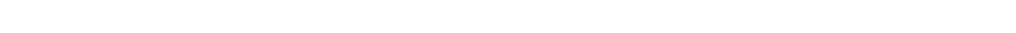

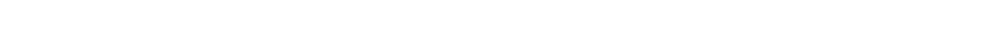

Savannah River at Burtons Ferry Bridge, near Milhaven, Ga. (ct).... ALTAMAHA RIVER BASI N

South River (head of Altamaha River):

Ocmulgee River (continuation of South River):

Falling Creek near Juliette, Ga. (ct)..................

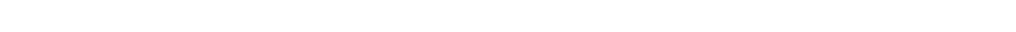

ST. MARYS RIVER BASIN

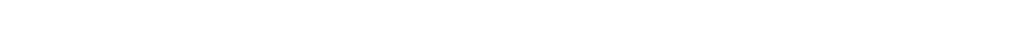

ST. JOHNS RIVER BASIN

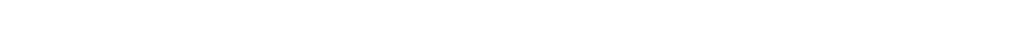

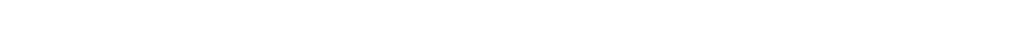

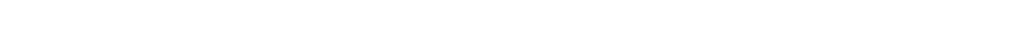

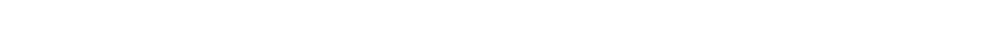

oklawaha River at State Highway 19 , near Sait Springs, Fia. (ct)..

LAKE OKEECHOBEE AND THE EVERGLADES BASINS

Lake Okeechobee:

Fisheating Creek at palmdale, Fla. (ct) .................

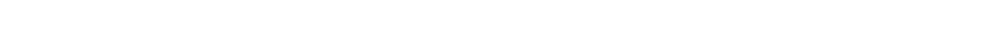

Canal $41 \mathrm{~A}$ at S-68 at Lake Istokpoga, near Lake placid, Fia. (ct)..

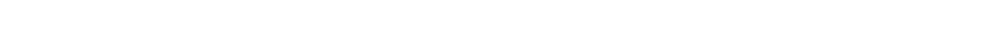

Lake Okeechobee at Pahokee, Fla. (ct) ....................... St. Lucie River:

South Fork St. Lucie River:

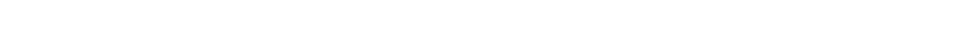

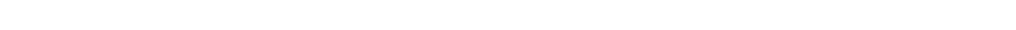

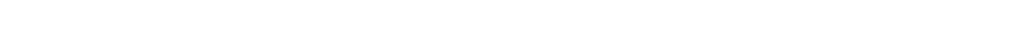
North New River Canal below HGS-4, near South Bay, Fla. (c)........

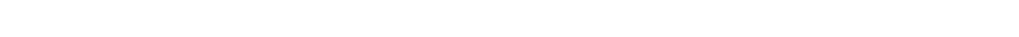

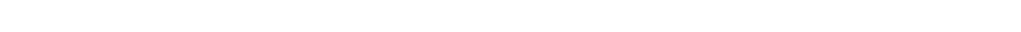


SOUTH ATLANTIC SLOPE AND EASTERN GULF OF MEXICO BASINS--COntinued LAKE OKEECHOBEE AND THE EVERGLADES BASINS--Continued

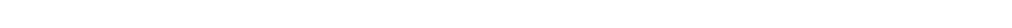

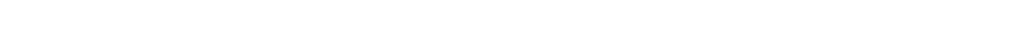
PEACE RIVER BASIN

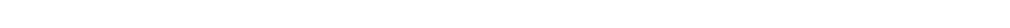

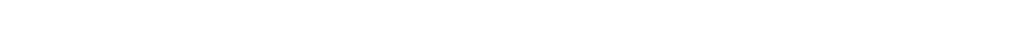
COASTAL BASINS BETWEEN MYAKKA RIVER AND HILLSBOROUGH RIVER

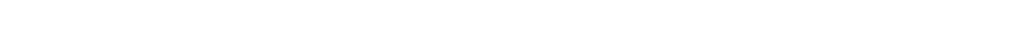

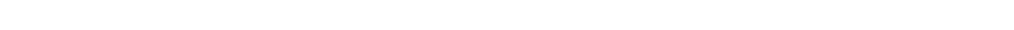
South Prong Alafia River near Lithia, Fla. (ct) $\ldots \ldots \ldots \ldots \ldots \ldots \ldots \ldots$

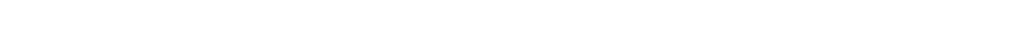

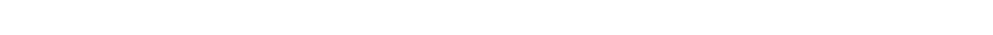
HILLSBOROUGH RIVER BASIN

Hillsborough River:

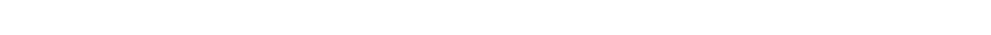
Cypress Creek near San Antonio, Fla (ct) $\ldots \ldots \ldots \ldots \ldots \ldots \ldots \ldots \ldots \ldots \ldots$ COASTAL BASINS BETWEEN HILLSBOROUGH RIVER AND WITHLACOOCHEE RIVER

Rocky Creek near Sulphur Springs, Fla. (ct) $\ldots \ldots \ldots \ldots \ldots \ldots \ldots \ldots \ldots$ Lake Tarpon near Tarpon Springs, Fla. (ct) ..................

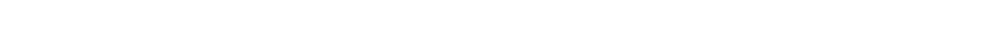

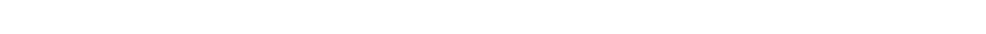
Chassahowitzka springs near Homosassa, Fla. (ct) ............... Chassahowitzka River near Homosassa, Fla. (ct)................ WI THLACOOCHEE RIVER BASI N

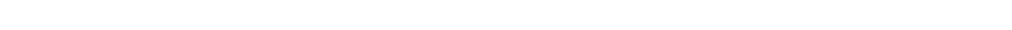

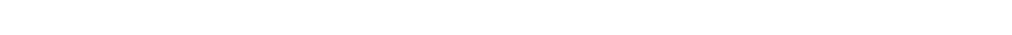

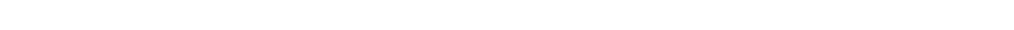
Rainbow Springs near Dunnellon, Fla. (ct) $\ldots \ldots \ldots \ldots \ldots \ldots \ldots \ldots \ldots$ SUWANNEE RIVER BASIN

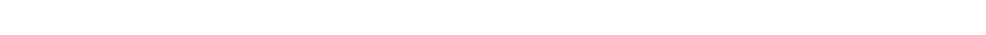

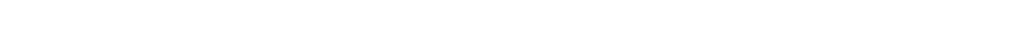
Santa Fe River at Worthington springs, $\left.\mathrm{Fi}_{\mathrm{a}}, \mathrm{c}_{\mathrm{t}}\right) \ldots \ldots \ldots \ldots \ldots \ldots \ldots \ldots$ COASTAL BASI NS BETWEEN AUCILLA RIVER AND OCHLOCKONEE RI VER

Sopchoppy River near Sopchoppy, Fla. (ct) .................. OCHLOCKONEE RIVER BASIN

Ochlockonee River near Havana, Fla. (ct) $\ldots \ldots \ldots \ldots \ldots \ldots \ldots \ldots \ldots \ldots$ APALACHICOLA RIVER BASI N

Chat tahoochee River near Roswell, Ga. (t) ................... Apalachicola River at Chattahoochee, Fla. $(\mathrm{ct}) \ldots \ldots \ldots \ldots \ldots \ldots \ldots \ldots \ldots \ldots$

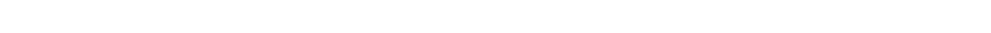
CHOCTAWHATCHEE RIVER BASIN

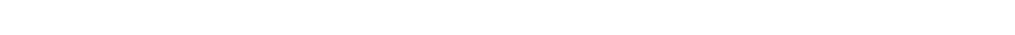
Choctawhatchee River at Caryville, Fla. (ct) $\ldots \ldots \ldots \ldots \ldots \ldots \ldots \ldots \ldots \ldots$ YELLOW RIVER BASIN

Yellow River at Milligan, Fla. (ct) $\ldots \ldots \ldots \ldots \ldots \ldots \ldots \ldots \ldots \ldots \ldots \ldots$ ESCANBIA RIVER BASIN

Conecuh River (head of Escambia River) at Brantley, Ala. (t)....... Little Escambia Creek below Chavers Creek, Ala. (c)............. Little Escambia Creek below Pollard Oil Field, Ala. (c)..........

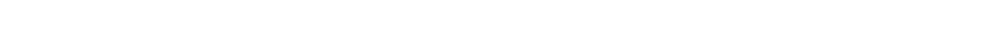
MOBILE RIVER BASIN

Coosawat tee River:

Oostanaula River (continuation of Coosa wattee River) at Resaca, Ga.

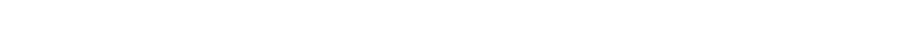

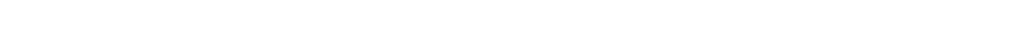
Etowah River at Canton, Ga. (c) $\ldots \ldots \ldots \ldots \ldots \ldots \ldots \ldots \ldots \ldots \ldots \ldots \ldots$

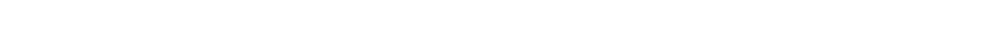

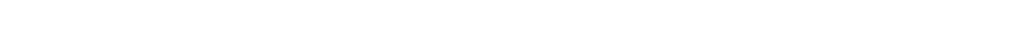
Coosa River at Childersburg, Ala. (ct) $\ldots \ldots \ldots \ldots \ldots \ldots \ldots \ldots \ldots \ldots \ldots \ldots \ldots$

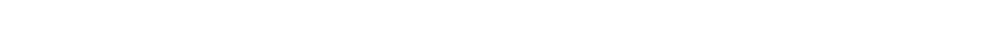

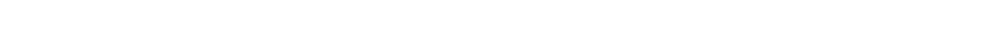

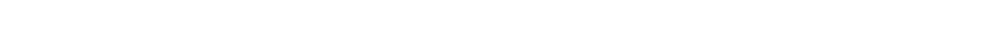
Alabama River (continuation of Coosa River) near Montgomery, $\mathrm{Ala}$.

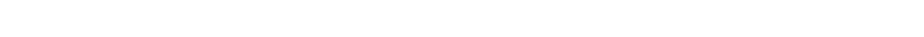

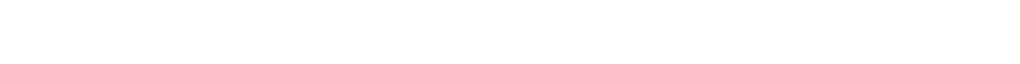

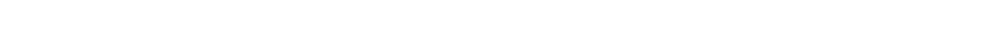

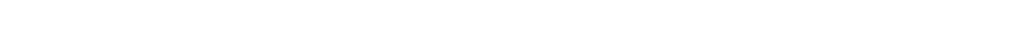

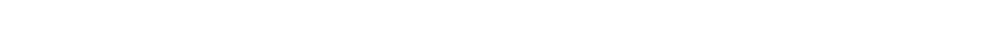

Page 199 201

203 207

212

214

215

216

219

220

221

223

224

227

229

231

232

234

237

239

241

242

244

247

249

253

255

256

258

261

262

263

265

266

266

266

267

269

270

271

272

274

276

277

278

279

280

282

284

285

287 
SOUTH ATLANTIC SLOPE AND EASTERN GULF OF MEXICO BASINS--Continued MOBILE RIVER BASIN--Continued

Alabama River

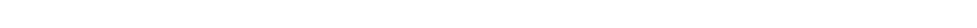
Mulberry Fork:

Sipsey Fork near Grayson, Ala. (cs)..................

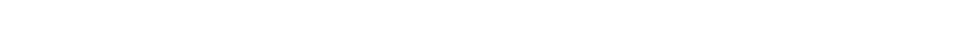

Tombigbee River at Demopolis lock and dam, near Coatopa, Aia. (c).

Okatuppa Creek:

Puss Cuss Creek near Gilbertown, Ala. (c)................

Mill Creek:

Little Mill Creek at Gilbertown, Ala. (c)...............

Little Nill Creek at mouth, near Gilbertown, Ala. (c)......

Surveyors Creek near Barrytown, Ala. (c) ................

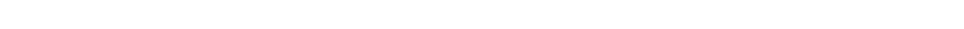

Tombigbee River at Coffeeville lock and dam, near Coffeyvilie,

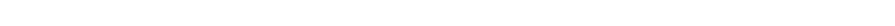

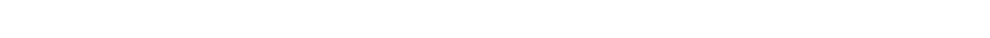
Mobile River:

Cedar Creek below Branch, near Citronelle, Ala. (c)............

Chickasaw Creek at county bridge, near Gulfcrest, Ala. (c)........ PASCAGOULA RIVER BASIN

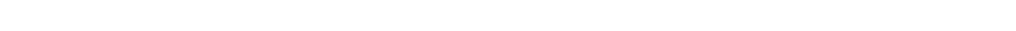

Tallahala Creek near Runnelstown, Miss. (c) $\ldots \ldots \ldots \ldots \ldots \ldots \ldots \ldots$

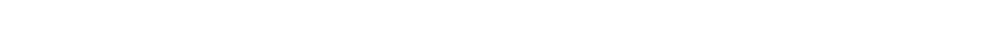

Chickasawhay River at En terprise, Miss. (c) ..................

Pascagoula River at Merrill, Miss. (ct) ....................

Pascagoula River near Benndale, Miss. (c) $\ldots \ldots \ldots \ldots \ldots \ldots \ldots \ldots \ldots \ldots$

Cypress Creek near Janice, Miss. (c) $\ldots \ldots \ldots \ldots \ldots \ldots \ldots \ldots \ldots \ldots \ldots$

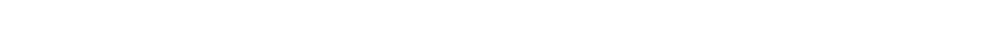

Escatawpa River:

Bennett Creek:

Beaver Pond Branch near Citronelle, Ala. (c).............. Sandy Ford Branch:

Unnamed tributary to Beaver Pond Branch at U.S. High-

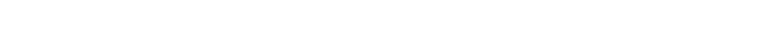

Beaver Pond Branch at mouth, near Citroneile, Ala.. (c)........

Puppy Creek on Russell Road near Citronelle, Ala. (c)..........

Puppy Creek at county bridge, near Citronelle, Ala. (c)........

Escatawpa River at Moss Point, Miss. (c)................... PEARL RIVER BASIN

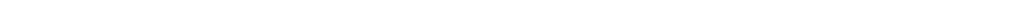

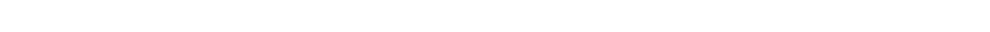

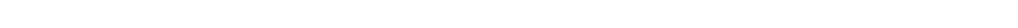

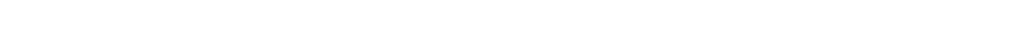

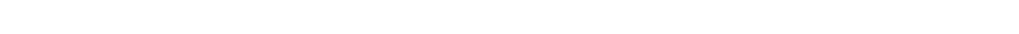

Pearl River near Columbia, Miss. (c) ......................

Pearl River near Bogalusa, La. (cts) .....................

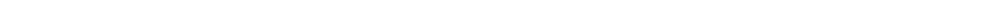

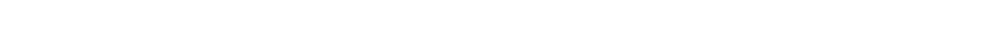
Analyses of samples collected at water-Quality partial-record

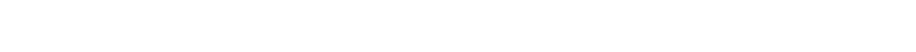

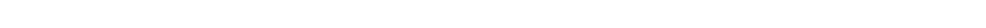

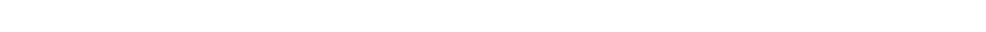

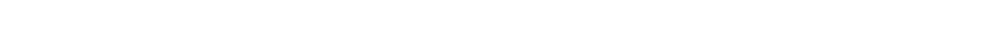

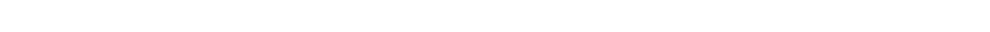

311 


\title{
QUALITY OF SURFACE WATERS OF THE
}

\author{
UNITED STATES, 1970
}

Part 2

\begin{abstract}
INTRODUCTION
\end{abstract}
The water-quality investigations of the United States Geological Survey are concerned with chemical and physical characteristics of surface- and ground-water supplies of the Nation. The data herein deal with the amounts of matter in solution and in suspension in streams, and represent that part of the National Water Data System collected by the U.S. Geological Survey in cooperation with State, municipal, and other Federal agencies.

The records of chemical analysis, water temperature, and suspended sediment of surface waters given in this volume serve as a basis for determining the suitability of waters for various uses. The flow and water quality of a stream are related to variations in rainfall and other forms of precipitation. In general, lower concentrations of dissolved solids may be expected during periods of high flow than during periods of low flow. Conversely, the suspended solids in some streams may change materially with relatively small variations in flow, whereas for other streams the quality of the water may remain relatively uniform throughout large ranges in discharge.

The Geological Survey has published annual records of chemical quality, water temperature, and suspended sediment since 1941. The records prior to 1948 were published each year in a single volume for the entire country, and in two volumes in 1948 and in 1949 . From 1950 to 1958 , the records were published in 4 volumes; from 1959 to 1963 in 5 volumes; from 1964 to 1967 in 6 volumes; and beginning with 1968 in 10 volumes. The drainage basins covered by the 10 volumes are shown in figure 1 . The shaded area in figure 1 represents the section of the country covered in this volume for the water year 1970 (October 1, 1960 to September 30, 1970).

To meet interim requirements, water-quality records have been released by the Geological Survey in annual reports, heginning with the 1964 water year, by State. These reports are entitled. "Water Resources Data for (State), Part 2. Water Quality Records." These reports are for limited distribution, and are designed primarily for local needs. Any revisions or corrections found necessary to the records published in these annual State reports have been made and published in this volume without reference.

The records herein are listed by drainage basins in a downstream direction along the main stream, and stations on tributaries are listed between stations on the main stream in the order in which those tributaries enter the main stream. Stations on tributaries entering above all mainstream stations are listed before the first mainstream stations. Stations on tributaries to tributaries are listed in a similar manner. In the list of water-quality stations in the front of this volume, the rank of the tributaries is indicated by indention. Each indention represents one rank.

As an added means of identification, a station number has been assigned for each stream location where regular measurements of water quantity or quality have been made. The numbers have been assigned to conform with the standard downstream order of listing gaging stations. The numbering system consists of an 8-digit number, such as 02012500 . The first 2 digits, "02" identifies the Part or hydrologic region used by the Geological Survey for reporting hydrologic data. The next 6 digits is the 
station number which represents the location of the station in the standard downstream order within each of the 16 parts (fig. 1). The complete number (02012500) appears just to the left of the station name. The assigned numbers are in numerical order but are not consecutive. Gaps are left in the numbers to allow for new stations that may be established.

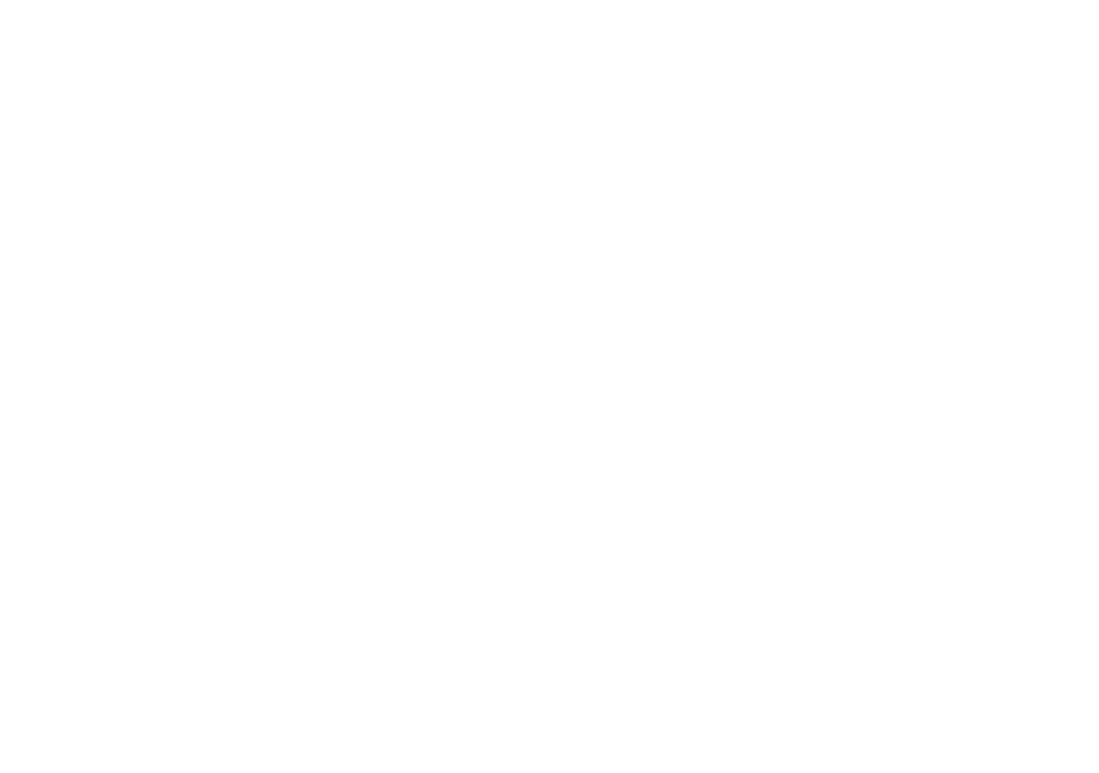

Figure 1.--Map of the United States showing basins covered by the 10 water-supply papers on quality of surface waters in 1970. The shaded part represents the section of the country covered by this volume; the unshaded part represents the section of the country covered by other water-supply papers.

Downstream order station numbers are not assigned to sites where only random water-quality samples are taken. These sites are classified as water-quality miscellaneous sites and as a means of location and identification a 15-digit number consisting of the latitude and Iongitude coordinates to the nearest second for each site plus a 2 -digit sequential number are assigned. For example, the station number for a waterquality miscellaneous site with lat $4228^{\prime} 47^{\prime \prime}$, long $07141^{\prime} 04^{\prime \prime}$ would be 42284707141.0401 .

Descriptive statements are given for each sampling station where chemical analyses, temperature measurements, or sediment determinations have been made. These statements include location of the station, drainage area, periods of records available, extremes of dissolved solids, hardness, specific conductance, temperature, sediment discharge, and other pertinent data. Records of discharge of the streams at or near the sampling station are included in most tables of analyses.

During the water year ending September 30, 1970, the Geological Survey maintained 180 stations on 119 streams for the study of chemical and physical characteristics of surface water. Samples were collected daily and monthly at 161 of these locations for chemical-quality studies. Samples also were collected less frequently at many other points. Water temperatures were measured continuously at 33 and daily at 5.3 stations. All surface water samples collected and analyzed during the 
year have not been included. Single analyses made of daily samples before compositing have not been reported. Specific conductance is determined and reported for almost all daily samples.

For chemical-quality stations equipped with noncontinuous-digital monitors, the records consist of daily maximum, minimum, and mean values for each constituent measured and are based upon hourly punches beginning at 0100 hours and ending at 2400 hours for the day of record. More detailed records (hourly values) may be obtained by writing the district office listed under Division of Work on page 22.

Quantities of suspended sediment are reported for 6 stations during the year ending September 30, 1970. Sediment samples were collected one or more times daily at most stations, depending on the rate of flow and changes in stage of the stream. Particle-size distributions of sediments were determined at 1 station.

Some of the stations for which data are published in this volume are included in special networks and programs. These stations are identified by their title, set in parentheses, under the station name.

Hydrologic bench-mark station is one that provides hydrologic data for a basin in which the hydrologic regimen will likely be governed solely by natural conditions. Data collected at a bench-mark station may be used to separate effects of natural from manmade changes in other basins which have been developed and in which the physiography, climate, and geology are similar to those in the undeveloped bench-mark basin.

International Hydrological Decade (IHD) River Stations provide a general index of runoff and materials in the water balance (discharge of water, and dissolved and transported solids) of the world. In the United States, IHD Stations provide indices of runoff and the general distribution of water in the principal river basins of the conterminous United States and Alaska.

Irrigation network stations are water-quality stations located at or near certain streamflow gaging stations west of the main stem of the Mississippi River. Data collected at these stations are used to evaluate the chemical quality of surface waters used for irrigation and the changes resulting from the drainage of irrigated lands. Prior to water year 1966, these data were published in the annual water-supply paper series, "Quality of Surface Waters for Irrigation, Western States."

Pesticide program is a network of regularly sampled water-quality stations where additional monthly samples are collected to determine the concentration and distribution of pesticides in streams whose waters are used for irrigation or in streams in areas where potential contamination could result from the application of the commonly used insecticides and herbicides.

Pesticides are chemical compounds used to control the growth of undesirable plants and animals. Major categories of pesticides include insecticides, miticides, fungicides, herbicides, and rodenticides. Since the first application of DDT as an insecticide in the early 1930's, there have been almost 60,000 pesticide formulations registered, each containing at least one of the approximately 800 different basic pesticide compounds (Goerlitz and Brown. 1972, p. 24). The LInited States annually produces about 1 billion pounds of these compounds. Although efforts are being made to substitute many of the chlorinated hydrocarbon pesticides with more specific, fast-acting, and easily degradable compounds, chlorinated hydrocarbon pesticides are still commonly used in many areas of the country.

Radiochemical program is a network of regularly sampled water-quality stations where additional samples are collected twice a year (at high and low flow) to be analyzed for radioisotopes. The streams that are sampled represent major drainage hasins in the conterminous United States.

Radioisotopes are isotope forms of an element that exhibit radioactivity. lsotopes are varieties of a chemical element that differ in atomic weight, but are very nearly exactly alike in chemical properties. The difference arises because the atoms of the 
isotopic forms of an element differ in the number of neutrons in the nucleus. For example: Ordinary chlorine is a mixture of isotopes having atomic weights 35 and 37 , with the natural mixture having atomic weight about 35.453. Many of the elements similarly exist as mixtures of isotopes, and a great many new isotopes have been produced in the operation of nuclear devices such as the cyclotron (Rose 1966). There are 275 isotopes of the 81 stable elements in addition to over 800 radioactive isotopes.

Radioisotopes that are determined in this program are those of uranium in micrograms per liter, radium as radium-226 in picocuries per liter, gross beta radiation as strontium/yttrium-90 in picocuries per liter, and gross alpha radiation as micrograms of uranium equivalent per liter.

A picocurie $(\mathrm{PC} / \mathrm{L}, \mathrm{pCi} / \mathrm{l})$ is one millionth of the amount of radioactivity represented by a microcurie, which is the quantity of radiation represented by one millionth of a gram of radium-226. A picocurie of radium results in 2.22 disintegration per minute.

\section{COLLECTION AND EXAMINATION OF DATA}

Quality of water stations usually are located at or near points on streams where streamflow is measured by the U.S. Geological Survey. The concentration of solutes and sediments at different locations in the stream-cross section may vary widely with different rates of water discharge depending on the source of the material and the turbulence and mixing of the stream. In general, the distribution of sediment in a stream section is much more variable than the distribution of solutes. 1t is necessary to sample some streams at several verticals across the channel and especially for sediment, to uniformly traverse the depth of flow. These measurements require special sampling equipment to adequately integrate the vertical and lateral variability of the concentration in the section. These procedures yield a velocity-weighted mean concentration for the section.

The near uniformly dispersed ions of the solute load move with the velocity of the transporting water. Accordingly, the mean section concentration of solutes determined from samples is a precise measure of the total solute load. The mean section concentration obtained from suspended sediment samples is a less precise measure of the total sediment discharge, because the sediment samplers do not traverse the bottom 0.3 foot of the sampling vertical where the concentration of suspended sediment is greatest and because a significant part of the coarser particles in many streams usually move in continuous contact with the bed and arc not represented in the suspended sediment sample. Hence, the computed sediment discharges presented in this report are usually less than the total sediment discharges. For most streams the difference between the computed and total sediment discharges will be small, in the order of a few percent.

\section{CHEMICAL QUALITY}

The methods of collecting and compositing water samples for chemical analysis are described by Brown, Skougstad, and Fishman (1970). No single method of compositing samples is applicable to all problems related to the study of water quality. Composites are made on the basis of dissolved-solids content as indicated by measurements of conductivity of daily samples, supplemented by other information such as chloride content, river stage, weather conditions, and other background information of the stream.

\section{TEMPERATURE}

Daily water temperatures were measured at most of the stations at the time samples were collected for chemical quality or sediment content. So far as practicable, the water temperatures were taken at about the same time each day. Large streams have a small diurnal temperature change while small, shallow streams may have a daily range of several degrees and may follow closely the changes in air temperature. Some streams may be affected by waste-heat discharges. 
At stations where continuously recording thermographs are present, the rec.rds consist of maximum and minimum temperatures for each day, and the monthly averages.

\section{SEDIMENT}

In general, suspended-sediment samples were collected daily with depth-integrating samplers (U.S. Inter-Agency, 196.3). At some stations, samples were collected at a fixed sampling point at one vertical in the cross section. Depth-integrated samples were collected periodically at three or more verticals in the cross section to determine the cross-sectional distribution of the concentration of suspended sediment with respect to that at the daily sampling vertical. In streams where transverse distribution of sediment concentration ranged widely, samples were taken at two or more verticals to define more accurately the average concentration of the cross section. During periods of high or rapidly changing flow, samples generally were taken several times a day and, in some instances, hourly.

Sediment concentrations were determined by filtration-evaporation method. At many stations the daily mean concentration for some days was obtained by plotting the velocity-weighted instantaneous concentrations on the gage-height chart. The plotted concentrations, adjusted if necessary, for cross-sectional distribution were connected or averaged by continuous curves to obtain a concentration graph. This graph represented the estimated velocity-weighted concentration at any time, and for most periods daily mean concentrations were determined from the graph. The days were divided into shorter intervals when the concentration or water discharge were changing rapidly. During some periods of minor variation in concentration, the average concentration of the samples was used as the daily mean concentration. During extended periods of relatively uniform concentration and flow, samples for a number of days were composited to obtain average concentrations and average daily sediment discharges for each period. (See Expression of Results, p. 6.)

For periods when no samples were collected, daily discharges of suspended sediment were estimated on the basis of water discharge, sediment concentrations observed immediately hefore and after the periods, and suspended-sediment discharges for other periods of similar water discharge. The estimates were further guided by precipitation records and sediment discharge at other stations in the same or adjacent basins.

In many instances where there were noobservations for several days, the suspendedsediment discharges for individual days were not estimated, because numerous factors influencing the quantities of transported sediment made it very difficult to make accurate estimates for individual days. However, estimated discharges of suspended sediment for missing days in an otherwise continuous period of sampling have been included in monthly and annual totals in order to provide a complete record. For some streams, samples were collected weekly, monthly, or less frequently, and only rates of sediment discharge at the time of sampling are shown.

In addition to the records of quantities of suspended sediment transported, records of particle sizes of sediment are included. The particle sizes of suspended sediment for many of the stations, and the particle sizes of the bed material for some of the stations were determined intermittently.

The size of particles carried in suspension by streams commonly ranges from colloids (finer than about 0.24 microns) to coarse sand $(2.0 \mathrm{~mm})$. The common methods of particle-size analysis cannot accommodate such a wide range. Hence, it was necessary to separate most samples into two parts. that part coarser than $0.062 \mathrm{~mm}$ and that part finer than $0.062 \mathrm{~mm}$. The separations were made by sieve or by fall velocity technique. The coarse fractions were classified by sieve separation or by visual-accumulation tuhe (U.S. Inter-Agency, 1957). The fine fractions were classified by the pipet method (Kilmer and Alexander, 1949) or the bottom withdrawal tube method (U.S. Inter-Agency, 194.3). 


\section{EXPRESSION OF RESULTS}

The quantities of solute concentrations analyzed in the laboratory are measured in either milligrams per liter or micrograms per liter. Milligrams per liter (mg/l, $\mathrm{MG} / \mathrm{L}$ ) is a unit which represents the weight of solute per unit volume of water. A inicrogram per liter $(\mu \mathrm{g} / \mathrm{l}, \mathrm{LG} / \mathrm{L})$ is one thousandth of a milligram per liter.

Milliequivalents per liter are not reported but they can be converted easily from milligrams per liter data. A milliequivalent per liter (me/l) is one thousandth of a gram equivalent weight of a constituent. Chemical equivalence in milliequivalents per liter can be obtained by (a) dividing the concentration in milligrams per liter by the combining weight of that ion, or (b) by multiplying the concentration (in mg/l) by the reciprocals of the combining weights. Table 1 on page 6 , lists the reciprocals of the combining atomic weights based on carbon-12 (International Union of Pure and Applied Chemistry, 1961).

The hardness of water is conventionally expressed in all water analyses in terms of an equivalent quantity of calcium carbonate. Such a procedure is required because hardness is caused by several different cations, present in variable proportions. It should be remembered that hardness is an expression in conventional terms of a property of water. The actual presence of calcium carbonate in the concentration given is not to be assumed. The hardness caused by calcium and magnesium (and other cations if significant) equivalent to the carbonate and bicarbonate is called carbonate hardness; the hardness in excess of this quantity is called noncarbonate hardness. Hardness or alkalinity values expressed in milligrams per liter as calcium carbonate may be converted to milliequivalents per liter by dividing by 50 .

The value usually reported as dissolved solids is the residue on evaporation after drying at $180^{\circ} \mathrm{C}$ for 1 hour. For some waters, particularly those containing moderately large quantities of soluble salts, the value reported is calculated from the quantities of the various determined constituents using the carbonate equivalent of the reported bicarbonate. The calculated sum of the constituents may be given instead of or in addition to the residue. In the analyses of most waters used for irrigation, the quantity of dissolved solids is given in tons per acre-foot as well as in milligrams per liter.

Table 1.--Factors for conversion of chemical constituents in milligrams per liter to milliequivalents per liter

$$
\begin{array}{llll}
\text { Multi- } & \text { Multi- } \\
\text { ply by } & \text { lon } & \text { ply by }
\end{array}
$$

Auninum $(\mathrm{Al}+3) \ldots \ldots . \ldots . \ldots 0 . \ldots 0788$

Ammonia as $\mathrm{NH}^{+1} \ldots \ldots \ldots . .05544$ Iron $\left(\mathrm{Fe}^{+3}\right)^{*} \ldots \ldots \ldots . . \ldots 5372$

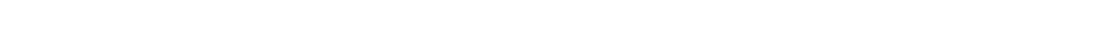

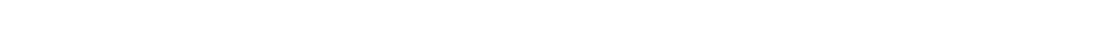

Eicarbonate $\left(\mathrm{HCO}_{3}{ }^{-1}\right) \ldots \ldots . .01639$ Magnesium $\left(\mathrm{Mg}{ }^{2}\right) \ldots \ldots . . .08226$

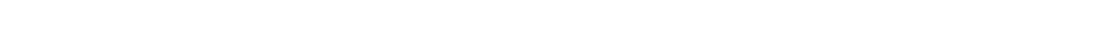

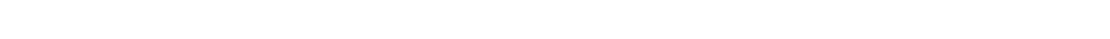

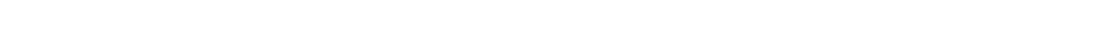

Carbonate $\left(\mathrm{CO}_{3}{ }^{-2}\right) \ldots \ldots . .033 .33$ Nitrate $\left(\mathrm{NO}_{3}^{-1}\right) \ldots \ldots . \ldots . . .01613$

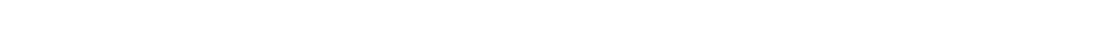

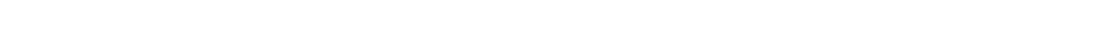

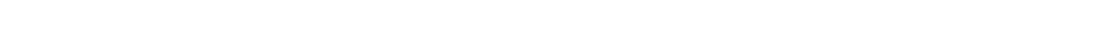

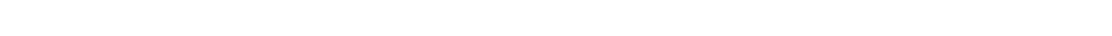

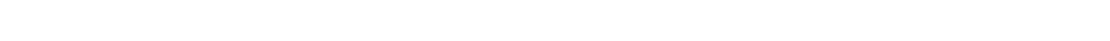

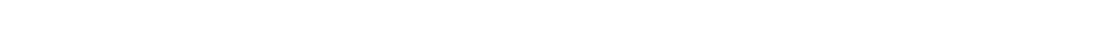

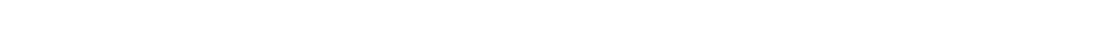

Hydroxide $\left(\mathrm{OH}^{-1}\right) \ldots \ldots \ldots . . . . . . . . . .0588060$

\footnotetext{
*Constituent reported in micrograms per liter; multiply by factor and divide results by 1.000
} 
Specific conductance is given for most analyses and was determined by means of a conductance bridge and using a standard potassium chloride solution as reference. Specific conductance values are expressed in micromhos per centimeter at $25 \mathrm{C}$. Specific conductance in micromhos is 1 million times the reciprocal of specific resistance at $25 \mathrm{C}$. Specific resistance is the resistance in ohms of a column of water 1 centimeter long and 1 square centimeter in cross section.

The discharge of the streams is reported in cubic feet per second (see Streamflow, p. 20) and the temperature in degrees Celsius (C). Color is expressed in units of the platinum-cobalt scale proposed by Hazen (1892). A unit of color is produced by one milligram per liter of platinum in the form of the chloroplatinate ion. Hydrogenion concentration is expressed in terms of $\mathrm{pH}$ units. By definition the pH value of a solution is the negative logarithm of the concentration of gram ions of hydrogen.

An average of analyses for the water year is given for most daily sampling stations. Most of these averages are arithmetical, time-weighted, or discharge-weighted; when analyses during a year are all on 10-day composites of daily samples with no missing days, the arithmetical and time-weighted averages are equivalent. A time-weighted average represents the composition of water that would be contained in a vessel or reservoir that had received equal quantities of water from the river each day for the water year. A discharge-weighted average approximates the composition of water that would be found in a reservoir containing all of the water passing a given station during the year. A discharge-weighted average is computed by multiplying the discharge for the sampling period by the concentrations of individual constituents for the corresponding period and dividing the sum of the products by the sum of the discharges. For most streams, discharge-weighted averages are lower than arithmetical averages because at times of high discharge the rivers generally have low concentrations of dissolved solids.

A program for computing these averages by digital computer was instituted in the 1962 water year. This program extended computations to include averages for $\mathrm{pH}$ values expressed in terms of hydrogen ion and averages for the concentration of individual constituents expressed in tons per day. Concentrations in tons per day are computed the same as daily sediment discharges.

The concentration of sediment in milligrams per liter is computed as $1,000,000$ times the ratio of the weight of sediment to the weight of water-sediment mixture. Daily sediment discharges are expressed in tons per day and except for subdivided days, are usually obtained by multiplying daily mean sediment concentrations in $\mathrm{mg} / \mathrm{l}$ by the daily mean discharge in cubic feet per second, and the conversion factor, normally 0.0027 .

For those days when the published sediment discharge value differs from the value computed, the reader can assume that the sediment discharge for that day was computed by the subdivided-day method.

Particle-size analyses are expressed in percentages of material finer than classified sizes (in millimeters). The size classification used in this report agrees with recommendations made by the American Geophysical Union Subcommittee on Sediment 'Terminology. The classification is as follows:

$\begin{array}{lcll}\text { Classification } & \text { Size } & (\mathrm{mm}) & \text { Method of analysis } \\ \text { Clay........... } & 0.00024 & -0.004 & \text { Sedimentation } \\ \text { Silt ............ } & .004 & -.062 & \text { Sedimentation } \\ \text { Sand........... } & .062 & -2.0 & \text { Sedimentation or sieve } \\ \text { Gravel........ } & 2.0 & -64.0 & \text { Sieve }\end{array}$

The particle-size distributions given in this report are not necessarily representative of all the particle sizes of sediment intransport in the natural stream. Most of the organic matter is removed and the sample is subjected to mechanical and chemical dispersion before analysis in distilled water. Chemical dispersion is not used for native-water analysis (Guy 1969).

l'rior to the 1968 water year, data for chemical constituents and concentrations of suspended sediment were reported in parts per million $(\mathrm{ppm})$ and water temperatures 
were reported in degrees Fahrenheit ('F). In October 1967, the U.S. Geological Survey began reporting data for chemical constituents and concentrations of suspended sediment in milligrams per liter ( $\mathrm{mg} / \mathrm{l}$ ) and water temperatures are given in degrees Celsius ( $\mathrm{C}$ ). In waters with a density of $1.000 \mathrm{~g} / \mathrm{ml}$ (grams per milliliter), milligrams per liter and parts per million can be considered equal. In waters with a density greater than $1.000 \mathrm{~g} / \mathrm{ml}$, values in milligrams per liter should be divided by the density to convert to parts per million. (See table 2 on page 9.) Temperature, in degrees Celsius may be converted to degrees $F$ ahrenheit by using table 3 on page 9.

\section{COMPOSITION OF SURFACE WATERS}

All natural waters contain dissolved mineral matter. The quantity of dissolved mineral matter in a natural water depends primarily on the type of rocks or soils with which the water has been in contact and the length of time of contact. Ground water is generally more highly mineralized than surface runoff because it remains in contact with the rocks and soils for much longerperiods. Some streams are fed by both surface runoff and ground water from springs or seeps. Such streams reflect the chemical character of their concentrated underground sources during dry periods and are more dilute during periods of heavy rainfall. The dissolved-solids content in a river is frequently increased by drainage from mines or oil fields, by the addition of industrial or municipal wastes, or--in irrigated regions--by drainage from irrigated lands.

The mineral constituents and physical properties of natural waters reported in the tables of analyses include those that have a practical bearing on water use. The results of analyses generally include silica, iron, calcium. magnesium, sodium, potassium (or sodium and potassium together calculated as sodium), carbonate, bicarbonate, sulfate, chloride, fluoride, nitrate, boron, $\mathrm{pH}$, dissolved solids, and specific conductance. Aluminum, manganese, color, acidity, dissolved oxygen, and other dissolved constituents and physical properties are reported for certain streams. Microbiologic (coliforms) and organic components (pesticides, total organic carbon) and minor elements (arsenic, cobalt, cadmium, copper, lead, mercury, nickel, strontium, zinc, etc.) are determined occasionally for some streams in connection with specific problems and the results are reported. The source and significance of the different constituents and properties of natural waters are discussed in the following paragraphs. The constituents are arranged in the order that they appear in the tables.

\section{MINERAL CONSTITLIENTS IN SOLUTION}

\section{Silica $\left(\mathrm{SiO}_{2}\right)$}

Silica is dissolved from practically all rocks. Some natural surface waters contain less than 5 milligrams per liter of silica and few contain more than $50 \mathrm{mg} / \mathrm{l}$, but the more common range is from 10 to $30 \mathrm{mg} / \mathrm{l}$. Silica affects the usefulness of a water because it contributes to the formation of boiler scale; it usually is removed from feed water for high-pressure boilers. Silica also forms troublesome deposits on the blades of steam turhines. However, it is not physiologically significant to humans, livestock, or fish, nor is it of importance in irrigation water.

\section{Aluminum (Al)}

Aluminum is usually present only in negligible quantities in natural waters except in areas where the waters have been in contact with the more soluble rocks of high aluminum content such as bauxite and certain shales. Acid waters often contain large amounts of aluminum. It may be troublesome in feed waters where it tends to be deposited as a scale on boiler tubes.

Iron $(\mathrm{Fe})$

Iron is dissolved from many rocks and soils. On exposure to air, normal basic waters that contain more than $1 \mathrm{mg} / \mathrm{l}$ of iron soon become turbid with the insoluble reddish 
Table 2.--Factors for conversion of sediment concentration in milligrams per liter to parts per million*

(All values calculated to three significant figures)

\begin{tabular}{|c|c|c|c|c|c|c|c|}
\hline \multicolumn{2}{|c|}{$\begin{array}{l}\text { Range of } \\
\text { concen- } \\
\text { tration } \\
\text { in } 1000 \\
\mathrm{mg} / \mathrm{l}\end{array}$} & $\begin{array}{l}\text { Di- } \\
\text { vide } \\
\text { by }\end{array}$ & $\begin{array}{l}\text { Range of } \\
\text { concen- } \\
\text { tration } \\
\text { in } 1000 \\
\mathrm{mg} / 1\end{array}$ & $\begin{array}{l}\text { Di- } \\
\text { vide } \\
\text { by }\end{array}$ & $\begin{array}{l}\text { Range of } \\
\text { concen- } \\
\text { tration } \\
\text { in } 1000 \\
\mathrm{mg} / 1\end{array}$ & $\begin{array}{l}\text { Di - } \\
\text { vide } \\
\text { by }\end{array}$ & $\begin{array}{l}\text { Range of } \\
\text { concen- } \\
\text { tration } \\
\text { in } 1000 \\
\mathrm{mg} / 1\end{array}$ \\
\hline 0 & -8 & 1.00 & $201-217$ & 1.13 & $411-424$ & 1.26 & $619-634$ \\
\hline 8.05 & ; -24 & 1.01 & $218-232$ & 1.14 & $427-440$ & 1.27 & $636-650$ \\
\hline 24.2 & -40 & 1.02 & $234-248$ & 1.15 & $443-457$ & 1.28 & $652-666$ \\
\hline 40.5 & -56 & 1.03 & $250-264$ & 1.16 & $460-473$ & 1.29 & $668-682$ \\
\hline 56.5 & -72 & 1.04 & $266-280$ & 1.17 & $476-489$ & 1.30 & $684-698$ \\
\hline 72.5 & -88 & 1.05 & $282-297$ & 1.18 & $492-506$ & 1.31 & $700-715$ \\
\hline 88.5 & -104 & 1.06 & $299-313$ & 1.19 & $508-522$ & 1.32 & $717-730$ \\
\hline 105 & -120 & 1.07 & $315-329$ & 1.20 & $524-538$ & 1.33 & $732-747$ \\
\hline 121 & -136 & 1.08 & $331-345$ & 1.21 & $540-554$ & 1.34 & $749-762$ \\
\hline 137 & -152 & 1.09 & $347-361$ & 1.22 & $556-570$ & 1.35 & $765-780$ \\
\hline 15.3 & -169 & 1.10 & $36.3-378$ & 1.23 & $572-585$ & 1.36 & $782-796$ \\
\hline 170 & -18.5 & 1.11 & $380-393$ & 1.24 & $587-602$ & 1.37 & $798-810$ \\
\hline 186 & -200 & 1.12 & $395-409$ & 1.25 & $604-617$ & 1.38 & \\
\hline
\end{tabular}

*Based on water density of $1.000 \mathrm{~g} / \mathrm{ml}$ and a specific gravity of sediment of $2.65 \mathrm{~g} / \mathrm{cc}$.

Table 3. --Degrees Celsius ( C) to degrees Fahrenheit ( F)* (Temperature reported to nearest $0.5^{\circ} \mathrm{C}$ )

$\begin{array}{rrrrrrrrrr}\text { C } & \text { F } & \text { C } & \text { F } & \text { C } & \text { F } & \text { C } & \text { F } & \text { C } & \text { F } \\ 0.0 & 32 & 10.0 & 50 & 20.0 & 68 & 30.0 & 86 & 40.0 & 104 \\ .5 & 33 & 10.5 & 51 & 20.5 & 69 & 30.5 & 87 & 40.5 & 105 \\ 1.0 & 34 & 11.0 & 52 & 21.0 & 70 & 31.0 & 88 & 41.0 & 106 \\ 1.5 & 35 & 11.5 & 53 & 21.5 & 71 & 31.5 & 89 & 41.5 & 107 \\ 2.0 & 36 & 12.0 & 54 & 22.0 & 72 & 32.0 & 90 & 42.0 & 108 \\ 2.5 & 36 & 12.5 & 54 & 22.5 & 72 & 32.5 & 90 & 42.5 & 108 \\ 3.0 & 37 & 13.0 & 55 & 23.0 & 73 & 33.0 & 91 & 43.0 & 109 \\ 3.5 & 38 & 13.5 & 56 & 23.5 & 74 & 33.5 & 92 & 43.5 & 110 \\ 4.0 & 39 & 14.0 & 57 & 24.0 & 75 & 34.0 & 93 & 44.0 & 111 \\ 4.5 & 40 & 14.5 & 58 & 24.5 & 76 & 34.5 & 94 & 44.5 & 112 \\ 5.0 & 41 & 15.0 & 59 & 25.0 & 77 & 35.0 & 95 & 45.0 & 113 \\ 5.5 & 42 & 15.5 & 60 & 25.5 & 78 & 35.5 & 96 & 45.5 & 114 \\ 6.0 & 43 & 16.0 & 61 & 26.0 & 79 & 36.0 & 97 & 46.0 & 115 \\ 6.5 & 44 & 16.5 & 62 & 26.5 & 80 & 36.5 & 98 & 46.5 & 116 \\ 7.0 & 45 & 17.0 & 63 & 27.0 & 81 & 37.0 & 99 & 47.0 & 117 \\ 7.5 & 45 & 17.5 & 6.5 & 27.5 & 81 & 37.5 & 99 & 47.5 & 117 \\ 8.0 & 46 & 18.0 & 64 & 28.0 & 82 & 38.0 & 100 & 48.0 & 118 \\ 8.5 & 47 & 18.5 & 65 & 28.5 & 83 & 38.5 & 101 & 48.5 & 119 \\ 9.0 & 48 & 19.0 & 66 & 29.0 & 84 & 39.0 & 102 & 49.0 & 120 \\ 9.5 & 49 & 19.5 & 67 & 29.5 & 85 & 39.5 & 10.3 & 49.5 & 121\end{array}$

${ }^{*} \mathrm{C}=5 / 9(\mathrm{~F}-32)$ or $\mathrm{F}=9 / 5(\mathrm{C})+32$. 
ferric compounds produced by oxidation. Surface waters, therefore, seldom contain as much as $1 \mathrm{mg} / 1$ of dissolved iron, although some acid waters carry large quantities of iron in solution. Iron causes reddish-brown stains on porcelain or enameled ware and fixtures and on fabrics washed in the water. The highest desirable level of concentrations of iron in culinary and drinking-water is $0.1 \mathrm{mg} / 1(100 \mu \mathrm{g} / 1)$ with a maximum permissible level of $1.0 \mathrm{mg} / 1(1,000 \mu \mathrm{g} / 1$ ). (International Standards for Drinking-Water (1SD-W), 1971).

\section{Manganese (Mn)}

Manganese is dissolved in appreciable quantities from rocks in some sections of the country. It resembles iron in its chemical behavior and in its occurrence in natural waters. However, manganese in rocks is less abundant than iron. As a result the concentration of manganese is much less than that of iron and is not regularly determined in many areas. It is especially objectionable in water used in laundry work and in textile processing. Concentrations as $10 \mathrm{w}$ as $0.2 \mathrm{mg} / 1(200 \mu \mathrm{g} / \mathrm{l}) \mathrm{may}$ cause a dark-brown or black stain on fabrics and porcelain fixtures. Appreciable quantities of manganese are often found in waters containing objectionable quantities of iron.

Calcium (Ca)

Calcium is dissolved from almost all rocks and soils, but the highest concentrations are usually found in waters that have been in contact with limestone, dolomite, and gypsum. Calcium and magnesium make water hard and are largely responsible for the formation of boiler scale. Most waters associated with granite or silicious sands contain less than $10 \mathrm{mg} / 1$ of calcium; waters in areas where rocks are composed of dolomite and limestone contain from 30 to $100 \mathrm{mg} / \mathrm{l}$; and waters that have come in contact with deposits of gypsum may contain several hundred $\mathrm{mg} / \mathrm{l}$.

Magnesium (Mg)

Magnesium is dissolved from many rocks, particularly from dolomitic rocks. 1ts effect in water is similar to that of calcium. The magnesium in soft waters may amount to only 1 or $2 \mathrm{mg} / 1$, but water in areas that contain large quantities of dolomite or other magnesium-bearing rocks may contain from 20 to $100 \mathrm{mg} / \mathrm{lor}$ more of magnesium.

Sodium and potassium ( $\mathrm{Na}$ and $\mathrm{K}$ )

Sodium and potassium are dissolved from practically all rocks. Sodium is the predominant cation in some of the more highly mineralized waters found in the western United States. Natural waters that contain only 3 or $4 \mathrm{mg} / \mathrm{l}$ of the two together are likely to carry almost as much potassium as sodium. As the total quantity of these constituents increases, the proportion of sodium becomes much greater. Moderate quantities of sodium and potassium have little effect on the usefulness of the water for most purposes, but waters that carry more than 50 to $100 \mathrm{mg} / 1$ of the two may require careful operation of steam boilers to prevent foaming. More highly mineralized waters that contain a large proportion of sodium salts may be unsatisfactory for irrigation.

Bicarbonate, carbonate and hydroxide $\left(\mathrm{HCO}_{3}, \mathrm{CO}_{3}, \mathrm{OH}\right)$

Bicarbonate, carbonate, or hydroxide is sometimes reported as alkalinity. The alkalinity of a water is produced by anions or molecular species of weak acids which are not fully dissociated above a pH of 4.5. Since the major causes of alkalinity in most natural waters are carbonate and bicarbonate ions dissolved from carbonate rocks, the results are usually reported in terms of these constituents. Although alkalinity may suggest the presence of definite amounts of carbonate, bicarbonate or hydroxide. there are other ions that contribute to alkalinity such as silicates, phosphates, borates, possibly fluoride, and certain organic anions which may occur in colored waters. The significance of alkalinity to the domestic, agricultural, and industrial user is usually dependent upon the nature of the cations ( $\mathrm{Ca}, \mathrm{Mg}, \mathrm{Na}, \mathrm{K}$ ) associated with it. Alkalinity in moderate amounts does not adversely affect most users.

Hydroxide may occur in water that has been softened by the lime process. lts presence in streams usually can be taken as an indication of contamination and does not represent the natural chemical character of the water. 


\section{Sulfide (S)}

Sulfide occurs in water as a result of bacterial and chemical processes, It usually is present as hydrogen sulfide. Variable amounts may be found in waters receiving sewage and (or) industrial wastes, such as from tanneries, papermills, chemical plants, and gas manufacturing work (California State Water Quality Control Board, 1963).

Waters containing sulfides, especially hydrogen sulfide, may he considered undesirable because of their odor. The toxicity to aquatic organisms differs significantly with the species and the nature of associated ions.

\section{Sulfate $\left(\mathrm{SO}_{4}\right)$}

Sulfate is dissolved from most sedimentary rocks. Large quantities may be derived from beds of gypsum, sodium sulfate deposits, and some types of shale. Organic material containing sulfur adds sulfate to the water as a phase of the sulfur cycle. In natural waters, concentrations range from a few $\mathrm{mg} / \mathrm{l}$ to several thousand $\mathrm{mg} / \mathrm{l}$.

$1 \mathrm{SD}-\mathrm{W}$ (1971) recommends $200 \mathrm{mg} / \mathrm{l}$ as the highest desirable level of sulfate concentration in drinking and culinary water.

Sulfates are less toxic to crops than chlorides.

\section{Chloride (Cl)}

Chlorice is dissolved from rock materials in all parts of the country. Surface waters in the humid regions are usually low in chloride, whereas streams in arid or semiarid regions may contain several hundred $\mathrm{mg} / 1$ of chloride leached from soils and rocks, especially where the streams receive return drainage from irrigated lands or are affected by ground-water inflow carrying appreciable quantities of chloride. Large quantities of chloride in water that contains a high content of calcium and maynesium increases the water's corrosiveness. The presence of abnormal concentrations of chloride and nitrogenous material together in water supplies indicates possible pollution by human or animal wastes.

\section{Fluoride (F)}

Fluoride has been reported as being present in some rocks to ahout the same extent as chloride. However, the quantity of fluoride in natural surface waters is ordinarily very small compared to that of chloride. Investigations have proved that fluoride concentrations of about 0.6 to $1.7 \mathrm{mg} / 1$ reduced the incidence of dental caries and that concentrations greater than $1.7 \mathrm{mg} / 1$ also protect the teeth from cavities but cause an undesirable black stain (Durfor and Becker, 1964, p. 20). Public Health Service, 1962, states, "When fluoride is naturally present in drinking water, the concentration should not average more than the appropriate upper control limit $(0.6$ to $1.7 \mathrm{mg} / \mathrm{l})$. Presence of fluoride in average concentration greater than two times the optimum values shall constitute grounds for rejection of the supply." Concentration higher than the stated limits may cause mottled enamel in teeth, endemic cumulative fluorosis, and skeletal effects.

\section{Bromide (Br)}

Bromine is a very minur element in the earth's crust and is normally present in surface waters in only minute quantities. Measurahle amounts may be found in some streams that receive industrial wastes, and some natural brines may contain rather high concentrations. It resembles chloride in that it tends to be concentrated in sea water. lodide (I)

Iodide is considerably less abundant both in rocks and water than bromine. Measurable amounts may be found in some streams that receive industrial wastes, and some natural brines may contain rather high concentrations. It occurs in sea water to the extent of less than $1 \mathrm{mg} / \mathrm{l}$. Rankama and Sahama (1950) report iodide present in rainwater to the extent of 0.001 to $0.003 \mathrm{mg} / \mathrm{l}$ and in river water in about the same amount. Few waters will contain over $2.0 \mathrm{mg} / 1$. 
Nitrogen, organic $(\mathrm{N})$

Organic nitrogen includes all nitrogenous organic compounds, such as amino acid, polypeptides, and proteins. It is present naturally in all surface waters as the result of inflow of nitrogenous products from the watershed and the normal biological life of the stream.

Organic nitrogen is not pathologically significant but is sometimes an indication of pollution.

Nitrogen, ammonia $\left(\mathrm{NH}_{4}\right.$, as $\mathrm{N}$ )

Ammonia nitrogen includes nitrogen in the forms of $\mathrm{NH}_{3}$ and $\mathrm{NH}_{4}^{+1}$. As a component of the nitrogen cycle, it is often present in water, but usually in.only small amounts. More than $0.1 \mathrm{mg} / 1$ usually indicates organic pollution (Rudolph, 19.31).

There is no evidence that ammonia nitrogen in water is physiologically significant to man or livestock. Fish, however, cannot tolerate large quantities.

Nitrite $\left(\mathrm{NO}_{2}\right)$

Nitrite is unstable in the presence of oxygen and is, therefore, absent or present in only minute quantities in most natural waters under aerobic condition. The presence of nitrite in water is sometimes an indication of organic pollution.

Recommended tolerances of nitrite in domestic water supplies differ widely. A generally accepted limit is $2 \mathrm{mg}$ ' 1 , but as little as $0.1 \mathrm{mg} / 1$ has been proposed (CaIifornia State Water Quality Control Board, 1963).

Nitrate $\left(\mathrm{NO}_{3}\right)$

Nitrate in water is considered a final oxidation product of nitrogenous material and may indicate contamination by sewage or other organic matter, such as agricultural runoff, or industrial waste. The quantities of nitrate present in surface waters are generally less than $5 \mathrm{mg} /]$ (as $\mathrm{NO}_{3}$ ) and have no effect on the value of the water for ordinary uses.

lt has been reported that as much as $2 \mathrm{mg} / \mathrm{l}$ of nitrate in boiler water tends to decrease intercrystalline cracking of boiler steel. Studies made by Faucett and Miller (1946), Waring (1949) and by the National Research Council (Maxcy, 1950) concluded that drinking water containing nitrates in excess of $44 \mathrm{mg} / 1$ (as $\mathrm{NO}_{3}$ ) should be regarded as unsafe for infant feeding. ISD-W (197I) sets $45 \mathrm{mg} / \mathrm{I}$ as the upper limit.

\section{Phosphorus (P)}

Phosphorus is an essential element in the growth of plants and animals. 1t occurs in water as organically bound phosphorus or as phosphate $\left(\mathrm{PO}_{4}\right)$. Some sources that contribute nitrate. such as organic wastes are also important sources of phosphorus. The addition of phosphates in water treatment constitutes a possible source although the dosage is usually small, In some areas phosphate fertilizers may yieId some phosphorus to water. Another important source is the use of phosphates in detergents. Domestic and industrial scwage effluents often contain considerable amounts of phosphorus. Concentrations of phosphorus found in water are not reported to be toxic to man, animaI, or fish. However, the element can stimulate the growth of algae, which may cause taste and odor problems in public water treatment and esthetic problems in recreation areas.

Boron (B)

Boron in small quantities has been found essential for plant growth, but irrigation water containing more than $1 \mathrm{mg} / 1$ boron is detrimental to citrus and other boronsensitive crops. Boron is reported in Survey analyses of surface waters in arid and semiarid regions of the Southwest and West where irrigation is practiced or contemplated, but few of the surface waters analyzed have harmful concentrations of boron. Dissolved solids

The reported quantity of dissolved solids--the residue on evaporation--consists mainly of the dissolved mineral constituents in the water. It may also contain some 
organic matter and water of crystallization. Waters with less than $500 \mathrm{mg} / 1$ of dissolved solids are usually satisfactory for domestic and someindustrial uses. Water containing several thou sand $\mathrm{mg} / 1$ of dissolved solids are sometimes successfully used for irrigation where practices permit the removal of soluble salts through the application of large volumes of water on well-drained lands, but generally water containing more than about $2.000 \mathrm{mg} / 1$ is considered to be unsuitahle for long-term irrigation under average conditions.

\section{Arsenic (AS)}

Arsenic compounds are present naturally in some waters, but the occurrence of quantities detrimental to health is rare. Weed killers, insecticides and many industrial effluents contain arsenic and are potential sources of water pollution. The upper limits of arsenic concentration in drinking-water should not exceed $0.05 \mathrm{mg} / 1(50 \mu \mathrm{g} / \mathrm{l})$ and it would seem wiser to keep the level as low as possible (ISD-W, 1971). Concentrations of 2-4 $\mathrm{mg}$ of arsenic per liter are reported not to interfere with the self-purification of streams (Rudolfs and others. 1944) but concentrations in excess of $15 \mathrm{mg} / \mathrm{l} \mathrm{may}$ be harmful to some fish.

Barium (Ba)

Barium may replace potassium in some of the igneous rock minerals, especially feldspar. and barium sulfate (barite) is a common barium mineral of secondary origin. Only traces of barium are present in surface water and sea water. Because natural water contains sulfate, barium will dissolve only in trace amounts. Barium sometimes occurs in brines from oil-well wastes.

Barium concentrations in excess of $1.0 \mathrm{mg} / \mathrm{l}$ is not suitable for drinking and culinary use because of the serious toxic effects of harium on heart, hlood vessels, and nerves.

Cadmium (Cd)

This element is found in nature largely in the form of the sulfide, and as an impurity in zinc-lead ores. The carbonate and hydroxide are not very soluble in water and will precipitate at high $\mathrm{pH}$ values; the chloride, nitrate, and sulfate are soluble and remain in solution under most pll conditions.

The extensive use of the element and its salts in metallurgy, electroplating, ceramics, and photography make it a frequent component of industrial wastes.

The results of animal studies suggest that very small amounts of cadmium can produce nephrotoxic and cardiovascular effects. The reproductive organs of animals are specifically affected after parenteral administration of very small amounts of cadmium salts. The level of cadmium concentration proposed for water use is $0.01 \mathrm{mg} / 1$ (10 $\mu \mathrm{g} / 1)$ or the lowest concentration that can be conveniently measured (ISD-W, 1971).

\section{Chromium (Cr)}

Few if any waters contain chromium from natural sources. Natural waters can probably contain only traces of chromium as a cation unless the pH is very low. When chromium is present in water, it is usually the result of pollution by industrial wastes. Concentrations of more than $0.05 \mathrm{mg} / 1$ of chromium in the hexavalent form constitute grounds for rejection of a water for domestic use on the basis of the standards of the U.S. Public Health Service (1962).

\section{Cobalt (Co)}

Cohalt occurs in nature in the mincrals smaltite, (Co,Ni)As, and cobaltite, CoAsS. Alluvial deposits and soils derived from shales often contain ccbalt in the form of phosphate or sulfate, but other soil types may be markedly deficient in cobalt in any form (Bear. 195.5). Ruminant animals may be adversely affected by grazing on land deficient in cobalt.

For domestic water supplies, no maximum safe concentration has heen established. 
Copper $(\mathrm{Cu})$

Copper is a fairly common trace constituent of natural water. Small amounts may be introduced into water by solution of copper and brass water pipes and other copperbearing equipment in contact with the water, or from copper salts added to control algae in open reservoirs. Copper salts such as the sulfate and chloride are highly soluble in waters with a low $\mathrm{pH}$ but in water of normal alkalinity the salts hydrolyze and the copper may be precipitated. In the normal $\mathrm{pH}$ range of natural water containing carbon dioxide, the copper might be precipitated as carbonate. The oxidized portions of sulfide-copper ore bodies contain other copper compounds. The presence of copper in mine water is common.

Copper imparts a disagreeable metallic taste to water. As little as $1.5 \mathrm{mg} / 1 \mathrm{can}$ usually be detected, and $5 \mathrm{mg} / 1$ can render the water unpalatable. Copper is not considered to be a cumulative systemic poison like lead and mercury; most copper ingested is excreted by the body and very little is retained. The pathological effects of copper are controversial, but it is generally believed very unlikely that humans could unknowingly ingest toxic quantities from palatable drinking water. The U.S. Public Health Service (1962) recommends that copper should not exceed $1.0 \mathrm{mg} / \mathrm{I}(1,000 \mu \mathrm{g} / 1)$ in drinking and culinary water. ISD-W, 1971 gives $0.05 \mathrm{mg} / \mathrm{l}(50 \mu \mathrm{g} / \mathrm{l})$ as the highest desirable level.

Lead ( $\mathrm{Pb}$ )

Lead seldom occurs in most natural waters, but industrial mine and smelter effluents may contain relatively large amounts of lead which contaminates the streams. Also, atmospheric contamination which is produced from several types of engine exhausts has considerably increased the availability of this element for solution in rainfall, resulting in contamination of lead in streams (Hem, 1970).

Lead in the form of sulfate is reported to be soluble in water to the extent of $31 \mathrm{mg} / \mathrm{l}$ (Seidell, 1940) at $25 \mathrm{C}$. In natural water this concentration would not be approached, however, since a $\mathrm{pH}$ of less than 4.5 would probably be required to prevent formation of lead hydroxide and carbonate. It is reported (Pleissner, 1907) that at $18 \mathrm{C}$ water free of carbon dioxide will dissolve the equivalent of $1.4 \mathrm{mg} / 1$ of lead and the solubility is increased nearly four fold by the presence of $2.8 \mathrm{mg} / 1$ of carbon dioxide in the solution. Presence of other ions may increase the solubility of lead. Reports on human tolerance of lead vary widely. U.S. Public Health Service (1962) states that lead shall not exceed $0.05 \mathrm{mg} / 1$ (50 $\mu \mathrm{g} / 1)$ in drinking and culinary water on carriers subject to Federal quarantine regulations. ISD-W, 1971 gives $0.10 \mathrm{mg} / 1(100 \mu \mathrm{g} / 1)$ as the upper limit.

\section{Lithium (Li)}

Lithium is present in some minerals but is not abundant in nature. From available information, most fresh waters rarely contain lithium of concentrations exceeding $10 \mathrm{mg} / 1$, but larger quantities may be present in brines and thermal waters. Lithium is used in metallurgy, medicinal water, and some types of glass and storage batteries. Waste from such industries may contain lithium.

\section{Mercury (Hg)}

Mercury is the only common metal which is liquid at ordinary temperatures. lt occurs free in nature but its chief source is cinnabar ( $\mathrm{HgS}$ ). Mercury compounds are virulent culminative poisons which are readily absorbed through the respiratory and gastrointestinal tracts or through unbroken skin (Weast and Selby, 1967).

The main source of high concentrations of dissolved mercury in water, in the form of highly toxic methyl mercury, $\mathrm{Hg}\left(\mathrm{CH}_{3}\right)_{2}$, comes from waste discharges from industrial users of mercury and from mercurial pesticides.

Fish from streams and lakes subject to mercury contamination have been found to contain amounts of mercury above the safe limits for food consumption. The U.S. Public Health Service has proposed that the upper limits of dissolved mercury in water for domestic use should not exceed 5 micrograms per liter $(0.005 \mathrm{mg} / \mathrm{l})$. 1SD-W, 1971 recommends $0.001 \mathrm{mg} / 1(1 \mu \mathrm{g}, 1)$ as the upper limits of concentration. 


\section{Nickel (Ni)}

Elemental nickel seldom occurs in nature, but its compounds are found in many ores and minerals. Many nickel salts are quite soluble and may contribute to water pollution. especially when discharged from metal-plating industries.

No set limit of nickel concentration has been established for public water supply. Strontium (Sr)

Strontium is a typical alkaline-earth element and is similar chemically to calcium. Strontium may be present in natural water in amounts up to a few $\mathrm{mg} / 1$ much more frequently than the available data indicate. In most surface water the amount of strontium is small in proportion to calcium. However, in sea water the ratio of strontium to calcium is $1: 30$.

Zinc (Zn)

Zinc is abundant in rocks and ores but is only a minor constituent in natural water because the free metal and its oxides are only sparingly soluble. In most alkaline surface waters it is present only in trace quantities, but more may be present in acid water. Chlorides and sulfates of zinc are highly soluble. Zinc is used in many commercial products, and industrial wastes may contain large amounts.

Zinc in water does not cause serious effects on health, but produces undesirable esthetic effects. 1SD-W, 1971 gives $5 \mathrm{mg} / 1(5,000 \mu \mathrm{g} / \mathrm{l})$ of zinc content as the highest desirable level for drinking water and $15 \mathrm{mg} / 1$ as the maximum permissible level.

\section{PROPERTIES AND CHARACTERISTICS OF WATER}

\section{Dissolved solids}

Theoretically, dissolved solids are anhydrous residues of the dissolved substances in water.

All solutes affect the chemical and physical properties of the water and result in an osmotic pressure. Water with several thousand $\mathrm{mg} / \mathrm{l}$ of dissolved solids is generally not palatable. although those accustomed to highly mineralized water may complain that less concentrated water tastes flat. The U.S. Public Health Service (1962) recommends that the maximum concentration of dissolved solids not exceed $500 \mathrm{mg} / 1$ in drinking and culinary water on carriers subject to Federal quarantine regulations, but permits 1,000 $\mathrm{mg} / \mathrm{l}$ if no better water is available. ISD-W (1971) recommends $500 \mathrm{mg} / 1$ as the highest desirable level and $1,500 \mathrm{mg} / 1$ as the maximum permissible level. Reported livestock tolerances range from 3,000 mg/1 (Colorado Agricultural Experiment Station, 1943) to $15,000 \mathrm{mg} / \mathrm{l}$ (Heller, 1933).

Industrial tolerances for dissolved solids differ widely, but few industrial processes will permit more than $1.000 \mathrm{mg} / 1$. The Geological Survey classifies the degree of salinity of these more mineralized bodies of water as follows (Swenson and Baldwin, 1965):

$$
\text { Dissolved solids (mg/1) Degree of salinity }
$$

$$
\begin{aligned}
& \text { Less than } 1,000 \ldots . . . \quad \text { Nonsaline. } \\
& 1,000 \text { to } 3,000 \ldots . . . \text { Slightly saline. } \\
& 3,000 \text { to } 10,000 . . . . . \text { Moderately saline. } \\
& 10,000 \text { to } 35,000 \ldots . . \text {. . Very saline. }
\end{aligned}
$$

\section{Hardness}

Hardness is the characteristic of water that receives the most attention in industrial and domestic use. It is commonly recognized by the increased quantity of soap required to produce lather. The use of hard water is also objectionable because it contributes to the formation of scale in boilers, water heaters, radiators, and pipes, with the resultant decrease in rate of heat transfer, possibility of boiler failure, and loss of flow. 
Hardness is caused almost entirely by compounds of calcium and magnesium. Other constituents--such as iron, manganese, aluminum, barium, strontium, and free acid--also cause hardness, although they usually are not present in quantities large enough to have any appreciable effect.

Generally, bicarbonate and carbonate determine the proportions of "carbonate" hardness of water. Carbonate hardness is the amount of hardness chemically equivalent to the amount of bicarhonate and carbonate in solution. Carbonate hardness is approximately equal to the amount of hardness that is removed from water by boiling.

Noncarbonate hardness is the difference between the hardness calculated from the total amount of calcium and magnesium in solution and the carbonate hardness. The scale formed at high temperatures by the evaporation of water containing noncarbonate hardness commonly is tough, heat resistant, and difficult to remove.

Although many people talk about soft water and hard water, there has been no firm line of demarcation. Water that seems hard to an easterner may seem soft to a westerner. In this report hardness of water is classified as follows:

\begin{tabular}{|c|c|}
\hline $\begin{array}{l}\text { Hardness range } \\
\text { (calcium carbonate in } \mathrm{mg} / \mathrm{l} \text { ) }\end{array}$ & Hardness description \\
\hline $0-60$ & Soft \\
\hline $61-120$. & Moderately hard \\
\hline $121-180 \ldots$ & Hard \\
\hline More than $180 \ldots$ & Very hard \\
\hline
\end{tabular}

Durfor and Becker, 1964, p. 23-27.

Acidity $\left(\mathrm{H}^{+1}\right)$

The use of the terms acidity and alkalinity is widespread in the literature of water analysis and is a cause of confusion to those who are more accustomed to seeing a $\mathrm{pH}$ of 7.0 used as a neutral point. Acidity of a natural water represents the content of free carbon dioxide and other uncombined gases, organic acids and salts of strong acids and weak bases that hydrolyze to give hydrogen ions. Sulfates of iron and aluminum in mine and industrial wastes are common sources of acidity.

Sodium adsorption ratio (SAR)

The term "sodium adsorption ratio (SAR)" was introduced by the U.S. Salinity Lahoratory Staff (19.54). It is a ratio expressing the relative activity of sodium ions in exchange reaction with soil and is an index of the sodium or alkali hazard to the soil. Sodium adsorption ratio is expressed by the equation:

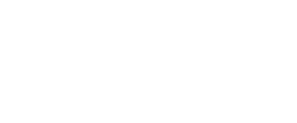

where the concentrations of the ions are expressed in milliequivalents per liter.

Waters are divided into four classes with respect to sodium or alkali hazard: low, medium, high, and very high, depending upon the SAR and the specific conductance. At a conductance of 100 micromhos per centimeter the dividing points are at SAR values of 10,18 , and 26 , but at 5,000 micromhos the corresponding dividing points are SAR values of approximately $2.5,6.5$, and 11 . Waters range in respect to sodium hazard from those which can be used for irrigation on almost all soils to those which are generally unsatisfactory for irrigation.

Specific conductance (micromhos per centimeter at $25 \mathrm{C}$ )

Specific conductance is a convenient, rapid determination used to estimate the amount of dissolved solids in water. It is a measure of the ability of water to transmit a small electrical current (see p. 7). The more dissolved solids in water that can transmit electricity the greater the specific conductance of the water. Commonly, the amount of dissolved solids (in $\mathrm{mg} / \mathrm{l}$ ) is about 65 percent of the specific conductance 
(in micromhos). This relation is not constant from stream to stream or from well to well and it may even vary in the same source with changes in the composition of the water (Durfor and Becker, 1964 p. 27-29).

Specific conductance of most waters in the eastern United States is less than 1,000 micromhos, but in the arid western parts of the country, a specific conductance of more than 1,000 micromhos is common.

\section{Hydrogen-jon concentration $(\mathrm{pH})$}

Hydrogen-ion concentration is expressed in terms of $\mathrm{pH}$ units (see p. 7). The values of $\mathrm{pH}$ often are used as a measure of the solvent power of water or as an indicator of the chemical behavior certain solutions may have toward rock minerals.

The degree of acidity or alkalinity of water, as indicated by the hydrogen-ion concentration, expressed as $\mathrm{pH}$, is related to the corrosive properties of water and is useful in determining the proper treatment for coagulation that may be necessary at water-treatment plants. A pH of 7.0 indicates that the water is neither acid nor alkaline. pH readings progressively lower than 7.0 denote increasing acidity and those progressively higher than 7.0 denote increasing alkalinity. The $\mathrm{pH}$ of most natural surface waters ranges between 6 and 8 . Some alkaline surface waters have pH values greater than 8.0 and waters containing free mineral acid or organic matter usually have $\mathrm{pH}$ values less than 4.5 .

The investigator who utilizes $\mathrm{pH}$ data in his interpretations of water analyses should be careful to place $\mathrm{pH}$ values in their proper perspective.

\section{Temperature}

Temperature is an important factor in properly determining the quality of water. This is very evident for such a direct use as an industrial coolant. Temperature is also important, but perhaps not so evident, for its indirect influence upon aquatic biota, concentrations of dissolved gases, and distribution of chemical solutes in lakes and reservoirs as a consequence of thermal stratification and variation.

Surface water temperatures tend to change seasonally and daily with air temperatures, except for the outflow of large springs. Superimposed upon the annual temperature cycle is a daily fluctuation of temperature which is greater in warm seasons than in cold and greater in sunny periods than with a cloud cover. Natural warming is due mainly to absorption of a solar radiation by the water and secondarily to transfer of heat from the air. Condensation of water vapor at the water surface is reported to furnish measurable quantities of heat. Heat loss takes place largely through radiation, with further losses through evaporation and conduction to the air and to the streambed. Thus the temperature of a small stream generally reaches a maximum in mid - to late afternoon due to solar heating and reaches a minimum from early to mid-morning after nocturnal radiation

\section{Color}

In water analysis the term "color" refers to the appearance of water that is free from suspended solids. Many turbid waters that appear yellow, red, or brown when viewed in the stream show very little color after the suspended matter has been removed. The yellow-to-brown color of some waters is usually caused by organic matter extracted from leaves, roots, and other organic substances in the ground. In some areas objectionable color in water results from industrial wastes and sewage. Clear deep water may appear blue as the result of a scattering of sunlight by the water molecules. Water for domestic use and some industrial uses should be free from any perceptible color. A color less than 15 units generally passes unnoticed (U.S. Public Health Service, 1962). Some swam? waters have natural color in excess of 300 units.

The extent to which a water is colored hy material in solution is com nonly reported as a part of a water analysis because a significant color in water may indicate the presence of organic material that may have some bearing on the dissolved solids content. Color in water is expressed in terms of units hetween 0 and 500 or more based on the above standard (see p. 7). 
Turbidity

Turbidity is the optical property of a suspension with reference to the extent to which the penetration of light is inhibited by the presence of insoluble material. Turbidity is a function of both the concentration and particle size of the suspended material. It is reported in terms of $\mathrm{mg} / \mathrm{l}$ of silica or Jackson turbidity units (JTU).

Turbid water is abrasive in pipes, pumps, and turbine blades. Although turbidity does not directly measure the safety of drinking water, it is related to the consumer's acceptance of the water. The highest desirable level of turbidity for drinking water is 5 JTU with a maximum permissible level of 25 JTU (ISD-W, 1971).

Density at $20^{\circ} \mathrm{C}$

Density is the mass of any substance per unit volume at a designated standard

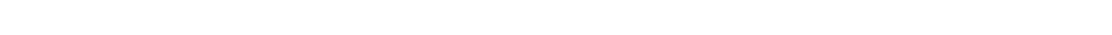
to-mass relation.

The density value has some use in industries that utilize brines and whose basic unit of concentration of dissolved material is density. Density is used primarily by the chemist in the computation of milligrams per liter for highly mineralized waters.

Dissolved oxygen (DO)

Oxygen dissolved in water is derived from the air and from the oxygen given off in the process of photosynthesis by aquatic plants.

Dissolved oxygen in water has no adverse physiological effect and actually increases the palatability of the water. No minimum concentration of dissolved oxygen required to support fish life has been listed because the oxygen requirements of fish vary with the species and age, with temperature, and with concentration of other substances in the water.

Dissolved oxygen is responsible for many of the corrosion problems in industry. Chemical oxygen demand (COD)

Chemical oxygen demand is a measure of the chemically oxidizable material in the water, and furnishes an approximation of the amount of organic and reducing material present. The determined value may correlate with natural-water color or with carbonaceous organic pollution from sewage or industrial wastes.

Biochemical oxygen demand (BOD)

Biochemical oxygen demand is a measure of the oxygen required to oxidize the organic material usable as a source of food by aerobic organisms.

Biological and microbiological information

Biological and microbiological information is an important aspect in the evaluation of water quality. The kinds and amount of aquatic biota in a stream or lake can be useful "indicators" of environmental conditions and particularly of the degree of pollution of water with organic wastes (Doudoroff and Warren, 1957). Biological information includes qualitative and quantitative analyses of plankton, bottom organisms, and particulate inorganic and amorphous matter present. Microbiological information includes quantitative identification of certain bacteriological indicator organisms.

Chlorophyll (plant pigment).--The concentrations of photosynthetic pigments in natural waters vary with time and changing aquatic conditions. Concentrations of chlorophyll $a, b$, and $c$ (spectrophotometric determination) are used to estimate the biomass and photosynthetic capacity of phytoplankton (blue-green algae). Ratios between the different forms $c_{1}$ chlorophyll are thought to indicate the taxonomic composition or the physiological state of the algae community (Slack, 1970).

Plankton.--Plankton is the floating (or weakly swimming) animal or plant life in a body of water consisting, chiefly of minute plants (as diatomes and blue-green algae) and of minute animals (as protozoan, entomostracans and various larvae). Algae are known to cause tastes and odor in water supply. 
Plankton population in water is obtained by count level (the number of organisms per milliliter).

Coliform bacteria.--Coliform organisms have long been used as indicators of sewage pollution, although the group includes bacteria from diverse natural sources and habitats. For example, members of the coliform group are indigenous to soil and vegetation as well as feces. Standards for drinking-water quality provide definite minimums as to number of samples examined and the maximum number of coliform organisms allowable per 100 milliliters $(\mathrm{ml})$ of finished water (Slack, 1970). The coliform population of water is determined either by the most probable number (MPN), or by the incubation membrane filter method, a direct count of coliform colonies per plate.

Fecal coliform bacteria.--Fecal coliform is that portion of the coliform group that is present in the intestinal tract of warm-blooded animals and is capable of producing gas from lactos in suitable culture medium at $44.5 \mathrm{C}$. Organisms from other sources generally cannot produce gas in this manner. (American Public Health Assoc. and others, 1965). Thus, in general, the presence of fecal coliform organisms indicates recent pollution (Slack, 1970).

\section{Organics}

Phenols. - Phenolic material in water resources is invariably the result of pollution. Phenols are widely used as disinfectants and in the synthesis of many organic compounds. Waste products from oil refineries, coke areas, and chemical plants may contain high concentrations. Fortunately, phenols decompose in the presence of oxygen and microorganisms, and their persistence downstream from point of entry is relatively short lived. The rate of decomposition is dependent on the environment.

Very low concentrations impart such a disagreeable taste to water that it is highly improbable that harmful amounts could be consumed unknowingly. Reported thresholds of detection of taste and odor range from 0.001 to $0.01 \mathrm{mg} / 1$.

Cyanide $(\mathrm{CN})$. - Cyanides are not found free in nature, but may become contaminants of water supplies by means of effluents from gasworks, coke ovens, steel mills, electroplating processes, and chemical industries. In natural streams and organic soils, simple cyanides are decomposed by bacterial action, whereas the metal-cyanide complexes are often quite stable and more resistant to degradation. The U.S. Public Health Service (1962) set a recommended limit of $0.01 \mathrm{mg}$ cyanide per liter and a mandatory limit of $0.2 \mathrm{mg} / 1$ for waters subject to interstate regulations. ISD-W (1971) sets the upper limit for drinking water as $0.05 \mathrm{mg} / 1$.

Detergents (methylene blue active substance, MBAS).--Anionic surfactants in detergents resist chemical oxidation and biological breakdown. Soap is an example of this class and the synthetic members are sodium salts of organic sulfonates or sulfates (Rose, 1966). Their persistence in water over long periods of time contributes to pollution of both ground water and surface water. Some of the effects produced from detergent pollution are unpleasant taste, odor, and foaming (Wayman, and others, 1962). Although the physiological implications of MBAS to human beings is unknown, prolonged ingestion of this material by rats is believed to be nontoxic (Paynter, 1960). The L'.S. Public Health Service (1962) recommends that MBAS should not exceed $0.5 \mathrm{mg} / 1 \mathrm{in}$ drinking and culinary waters. 1SD-W (1971) sets $0.2 \mathrm{mg} / 1$ as the highest desirable level and $1.0 \mathrm{mg} / 1$ as the maximum permissible level.

Total organic carbon (TOC).-- Total organic carbon is a measure of the organically related carbonaceous content of water. It includes all natural and manmade organic compounds which are combustible at a temperature of $950^{\circ} \mathrm{C}$.

\section{Sediment}

Fluvial sediment generally is regarded as that material which is transported by, suspended in, or deposited by water. Suspended sediment is that part which remains in suspension in water owing to the upward components of turbulent currents or by colloidal suspension. Much fluvial sediment results from the natural process of erosion, 
which in turn is part of the geologic cycle of rock transformation. This natural process may be accelerated by agricultural practices. Sediment also is contributed by a number of industrial and construction activities. In certain sections, waste materials from mining, logging, oil-field, and other industrial operations introduce large quantities of suspended material.

The quantity of sediment, transported or available for transportation, is affected by climatic conditions, form or nature of precipitation, character of the solid mantle, plant cover, topography, and land use. The mode and rate of sediment erosion, transport, and deposition is determined largely by the size distribution of the particles or more precisely by the fall velocities of the particles in water. Sediment particles in the sand size range (larger than $0.062 \mathrm{~mm}$ ) do not appear to be affected by flocculation or dispersion resulting from the mineral constituents in solution. In contrast, the sedimentation diameter of clay and silt particles in suspension may vary considerably from point to point in a stream or reservoir, depending on the mineral matter in solution and in suspension and the degree of turbulence present. The size of sediment particles in transport at any point depends on the type of erodible and soluble material in the drainage area, the degree of flocculation present, time in transport, and characteristics of the transporting flow. The flow characteristics include velocity of water, turbulence. and the depth, width, and roughness of the channel. As a result of these variable characteristics, the size of particles transported, as well as the total sediment load, is in constant adjustment with the characteristics and physical features of the stream and drainage area.

\section{STREAMFLOW}

Most of the records of stream discharge, used in conjunction with the chemical analyses and in the computation of sediment loads in this volume, are published in the Geological Survey water-supply paper series, "Surface Water Supply of the United States, 1966-70." The discharge reported for a composite sample is usually the average of daily mean discharges for the composite period. The discharges reported in the tables of single analyses are either daily mean discharges or discharges obtained at the time samples were collected and computed from a stage-discharge relation or from a discharge measurement.

\section{PUBLICATIONS}

Reports giving records of chemical quality and temperatures of surface waters and suspended-sediment discharges of streams in the area covered by this volume for the water years 1941-70, are listed below:

Numbers of water-supply papers containing records for Part 2, 1941-70

$\begin{array}{lrrrrrrr}\text { Year } & \text { WSP } & \text { Year } & \text { WSP } & \text { Year } & \text { WSP } & \text { Year } & \text { WSP } \\ 1941 & 942 & 1949 & 1162 & 1957 & 1520 & 1965 & 1961 \\ 1942 & 950 & 1950 & 1186 & 1958 & 1571 & 1966 & 1991 \\ 1943 & 970 & 1951 & 1197 & 1959 & 1641 & 1967 & 2011 \\ 1944 & 1022 & 1952 & 1250 & 1960 & 1741 & 1968 & 2092 \\ 1945 & 1030 & 1953 & 1290 & 1961 & 1881 & 1969 & 2142 \\ 1946 & 1050 & 1954 & 1350 & 1962 & 1941 & 1970 & 2152 \\ 1947 & 1102 & 1955 & 1400 & 1963 & 1947 & & \\ 1948 & 1132 & 1956 & 1450 & 1964 & 1954 & & \end{array}$

Geological Survey reports containing chemical quality, temperature, and sediment data obtained before 1941 are listed as follows. Publications dealing largely with the quality of ground-water supplies and only incidentally covering the chemical composition of surface waters are not included. Publications that are out of print are preceded by an asterisk. 
PROFESSIONAL PAPER

*135. Composition of river and lake waters of the United States, 1924.

BULLETINS

*479. The geochemical interpretation of water analyses, 1911.

770. The data of geochemistry, 1924 .

\section{WATER -SUPPIY PAPERS}

*108. Quality of water in the Susquehanna River drainage basin, with an introductory chapter on physiographic features. 1904.

*161. Quality of water in the upper Ohio River basin and at Erie, Pa., 1906.

*193. The quality of surface waters in Minnesota, 1907.

*236. The quality of surface waters in the United States, Part 1, Analyses of waters east of the one hundredth meridian, 1909.

*237. The quality of the surface waters of California, 1910.

*239. The quality of surface waters of Illinois, 1910.

*273. Quality of the water supplies of Kansas, with a preliminary report on stream pollution by mine waters in southeastern Kansas, 1911.

*274. Some stream waters of the western United States, with chapters on sediment carried by the Rio Grande and the industrial application of water analyses, 1911.

*339. Quality of the surface waters of Washington, 1914.

*363. Quality of the surface waters of Oregon, 1914.

*418. Mineral springs of Alaska, with a chapter on the chemical character of some surface waters of Alaska, 1917.

*596-B. Quality of water of Colorado River in 1925-26, 1928.

*596-D. Quality of water of Pecos River in Texas, 1928.

*596-E. Quality of the surface waters of New Jersey, 1.928.

*636-A. Quality of water of the Colorado River in 1926-28, 1930.

*636-B. Suspended matter in the Colorado River in 1925-28, 1930.

*638-D. Quality of water of the Colorado River in 1928-30, 1932.

*839. Quality of water of the Rio Grande basin above Fort Quitman, Tex., 1938.

*889-E. Chemical character of surface water of Georgia. 1944.

*998. Suspended sediment in the Colorado River, 1925-41, 1947.

1048. Discharge and sediment loads in the Boise River drainage basin, Idaho, $1939-40,1948$.

1110-C. Quality of water of Conchas Reservoir, New Mexico, 1939-49, 1952.

Many of the reports listed are available for consultation in the larger public and institutional libraries. Copies of Geological Survey publications still in print may be purchased at a nominal cost from the Superintendent of Documents, Government Printing Office, Washington, D.C. 20402, who will, upon request, furnish lists giving prices.

\section{COOPERATION}

Many municipal, State, and Federal agencies assisted in collecting records for these quality-of-water investigations. Many investigations were supported by funds appropriated directly to the U.S. Geological Survey. State, local, and Federal agencies that cooperated in these quality-of-water investigations are as follows:

Alabama--Geological Survey of Alabama, P. E. LaMoreaux, State geologist.

Florida--Florida Bureau of Geology; Florida Department of Transportation; Trustees of the Internal Improvement Trust Fund; Central and Southern Florida Flood Control District; Reedy Creek Improvement District; Southwest Florida Water Management District; Suwanee River Authority; counties of Broward, Charlotte, Collier, Dade, Escambia, Hillsborough, Indian River, Lake, Lee, 
Okaloosa, Orange, Palm Beach, Polk, Volusia, and Walton; cities of Boca Raton, Cocoa. Hallandale, consolidated Jacksonville, Miami, Miami Beach, Pompano Beach, Sarasota, and Tampa; Corps of Engineers, U.S. Army; Environmental Protection Agency; Fish and Wildlife Service, U.S. Department of the Interior; National Aeronautics and Space Administration, National Parks Service, U.S. Department of the Interior.

Georgia--Georgia Water Quality Control Board, R. S. Howard, Jr., executive secretary; Georgia Department of Mines, Mining, and Geology, J. H. Auvil, Jr., director.

Louisiana--Louisiana Department of Public Works, C. H. Downs, director; Environmental Protection Agency.

Mississippi--Mississippi Board of Water Commissioners, J. W. Pepper, water engineer; Mississippi Research and Development Center, Dr. K. C. Wagner, director; Mississippi Air and Water Pollution Control Commission, Glen Wood, Jr, , executive secretary; Pat Harrison Waterway District, S. T. Davis, executive director-secretary; U.S. Atomic Energy Commission; Environmental Protection Agency.

North Carolina--North Carolina Department of Water and Air Resources, G. E. Pickett, director; Environmental Protection Agency; Tennessee Valley Authority.

South Carolina-- Environmental Protection Agency.

Virginia--Virginia Department of Conservation and Economic Development, M. M. Sutherland, director; Corps of Engineers, U.S. Army.

\section{DIVISION OF WORK}

The quality-of-water work was performed by the Water Resources Division of the Geological Survey, J. S. Cragwall. Jr., chief hydrologist, and under the direction of the district chiefs listed in the preface.

Correspondence regarding the records in this report or any additional information should be directed to the district chief of the appropriate Geological Survey-Water Resources Division district office as indicated below.
State
District Office
Address

Alabama

Tuscaloosa 35486

University, Ala.

Florida

Tallahassee 32303

Georgia

Doraville 30340

1.ouisiana

Baton Rouge 70806

Mississippi

Jackson 39206

North Carolina

Raleigh 27602

South Carolina

Columbia 29201

Virginia

Richmond 23220
P. O. Box V

Suite F 240

325 John Knox Road

Suite B, 6481 Peachtree Industrial Blvd.

6554 Florida Boulevard

430 Bounds Street

Room 440, Century Station Post Office Building

P. O. Box 2857

Suite 200

2001 Assembly Street

Room 304

200 Grace Street 


\section{LITERATURE CITED}

Bartsch, A. F.. 1948, Biological aspects of stream pollution: Sewage Works Jour., vol. 20. p. 292-302.

Bear, F. E., 1955, Chemistry of the soil: New York, Reinhold Co., 373 p.

Brown. Eugene, Skougstad. M. W. and Fishman, M. J.. 1970. Methods for collection and analysis of water samples for dissolved minerals and gases: U.S. Geol. Survey Techniques of Water-Resources $\operatorname{lnv}$., book 5 , chap. A1, $160 \mathrm{p}$.

California State Water Quality Control Board, 1963, Water quality criteria: Pub. 3-A, p. 226.

Colorado Agriculture Experiment Station. 1943, Mineral tolerances in livestock drinking water: 56 th Ann. Rept.

Doudoroff. Peter, and Warren. C. E.. 1957, Biological indices of water pollution with special reference to fish populations; Biological problems in water pollution: Cincinnati. U.S. Pub, Health Service, Robert A. Taft Sanitary Eng. Cent., p. 144-163.

Durfor. C. N., and Becker. E., 1964, Public water supplies of the 100 largest cities in the United States; 1962: [i.S. Geol. Survey Water-Supply Paper 1812, p. 20.

Faucett. R. L... and Miller, H. C., 1946, Methemoglobinemia occurring in infants fed milk diluted with well waters of high nitrate content: Jour. Pediatrics, v. 29. p. 593.

Goerlitz. D. F., and Brown, Eugene, 1972, Methods for analysis of organic substances in water: U.S. Geol. Survey Techniques of Water-Resources Inv., book 5. chap. A.3, $40 \mathrm{p}$.

Guy, H. P.. 1969. Laboratory theory and methods for sediment analysis: U.S. Geol. Survey Techniques of Water-Resources Inv. . book .5, chap. C1, 57 p.

Hazen, Allen, 1892, A new color standard for natural waters: Am. Chem. Jour. v. 12, p. $427-428$.

Heller, V. G., 1933. The effect of saline and alkaline waters on domestic animals: Oklahoma Agr. Mech. Coll. Expt. Sta. Bull. 217.

Hem. J. D., 1970, Study and interpretation of chemical characteristics of natural water, 2d. ed: U.S. Geol. Survey Water-Supply Paper 1473, 363 p.

International Union of Pure and Applied Chemistry, 1961, Table of Atomic weights based on carbon-12: Chem. and Eng. News, v. 39, no. 42, Nov. 20, 1961, p. 43.

Kilmer. V. J., and Alexander, L. T., 1949, Methods of making mechanical analyses of soils: Soil Sci., v. 68, p. 15-24.

Lane, E. W.. and others, 1947. Report of the Subcommittee on sediment terminology: Am. Geophys. Union Trans., v. 28, no. 6, p. 936-938.

Magistad, O. C. , and Christiansen, J. E., 1944, Saline Soils, their nature and management: U.S. Dept. Agriculture Circ. 707, p. 8-9.

Maxcy. K. F., 1950, Report on the relation of nitrate concentrations in well waters to the occurrence of methemoglobinemia: Natl. Research Council, Bull. Sanitary Eng. and Environment, App. D., p. 271.

Paynter. O. E., 1960, The chronic toxicity of dodecylbenzene sodium sulfonate: U.S. Public Health Conference on Physiological Aspects of Water Quality Proc., Washington. D.C. . Sept. 8-9, 1960, p. 175-179.

Pleissner. M.. 1907. Llber die Lbslichkeit eimiger Bleiverbindungen in wasser: Arb. Kais. Gesundeitsamt. v. 26, p. 384-443.

Rankama, K., and Sahama, T. G., 1950, Geochemistry: Chicago Univ. Press, Chicago, I11., p. 767.

Riffenburg, H. B, 1925, Chemical character of ground waters of the northern Great Plains: U.S. Geol. Survey Water-Supply Paper 560-B, p. 31-52.

Rose, Arthur, and Elizabeth, 1966, The condensed chemical dictionary: Reinhold Pub. Corp., New York, 7th ed.. p. 257, 285.

Rudolfs, Willem. and others, 1944, Critical review of the literature of 1943: Sewage Works Jour., v. 16, p. 222.

Rudolph. Z, 1931. Principles of the determination of the physical and chemical standards of water for drinking. industrial, and domestic purposes: Water Pollution Abs. 4 (March).

Seidell. Atherton. 1940, Solubilities of inorganic and metal organic compounds. 3d ed., v. 1. D. van Nostrand, New York. p. 1409. 
Slack. K. V., 1970, Selected interim procedure's for biological and microbiological investigations: [1.S. Geol. Survey, Water Resources Division, preliminary rept. by WRD Committee on Biology and Microbiology. $80 \mathrm{p}$. (open file).

swension. 11. A. and Baldwin. H, I., 196.5, A Primer on water quality: Washington, L.S. Govt. Printing Office. $27 \mathrm{p}$.

(I 4 . Inter-Agency Committec on Water Resources. Subcommittee on Sedimentation, $A$ study of methodsused in measurement and analysis of scdiment loads in streams. Published by the St Anthony Falls llydraulic laboratory. Minncapolis, Minn. 1943. A study of new methods of size analysis of suspended-sediment samplers, Rept 7 .

1957. The development and calibration of visual-accumulation tube: Rept 11. 19.57. Some fundamentals of particle-size analysis: Rept. 12.

1959. Federal lnter-agency sedimentation instruments and reports: Rept. AA. 1963. Determinations of fluvial sediment discharge: Rept. 14.

TT.S. Public Health Service, 1962. Drinking water standards: I.S. Dept. Health, Education, and Welfare. Public lealth Sicrvice: Pub. no. 956.

[I.S. Salinity l, aboratory Staff. 1954. Diagnosis and improvement of saline and alkali soils: U.S. Dept. Agriculture, Agriculture llandb. 60, p. 1-160.

Waring, F. H, 1949, Significance of nitrates in water supplies: Am. Water Works Assoc. Jour., v. 41 , no. 2 , p. $147-150$.

Wayman. C. H. 1962, I.imitations of the methylene blue mothod for ABS determinations: LI.S. Geol. Survey, Prof. Paper 450-B. art. 49. p. B117-B120.

Wayman, C. H. . Robertson, J. B., and Page. II. G., 1962, Foaming characteristics of synthetic-detergent solutions: U.S. Geol. Survey, Prof. Paper 450D, art. 178, p. D198.

Weast, R. C., and Selby, S. M.. 1967, Handbook of chemistry and physics: Cleveland, The Chem. Rubber Co., 48th ed., p. B-120-121.

World Health Organization, 1971, International standards for drinking-water. 3d ed: Geneva, Switzerland. World Health Organization, $70 \mathrm{p}$. 
PART 2. SOUTH ATLANTIC SLOPE AND EASTERN GULF OF MEXICO BASINS

JAMES RIVER BASIN

02012500 JACKSON RI VER AT FALLING SPRING, VA.

LOCATION, - - Lat $37^{\circ} 52^{\prime} 36^{\prime \prime}$, long $79^{\circ} 58^{\prime} 38^{\prime \prime}$, Al leghany County, at gaging station on right bank 20 ft upstream from Smlth Bridge, $0.8 \mathrm{mile}$ south of town of Failing Spring. $1.6 \mathrm{~m} 1 \mathrm{les}$ downstream from Faling Spring Creek, and $5.5 \mathrm{miles}$ north of Covington.

DRAINAGE AREA. - -411 sq mi (revised).

PERIOD OF RECORD.--Chemical analyses: April 1929 to Yarch 1930, October 1947 to September 1948, October 1967 to

water temperatures: December 1968 to September 1970.

EXTREMES. - - 1969-70:

Specific conductance: Maximum dally, 426 micromhos July 9; minl mum da1ly, 77 m1cromhos Dec, 31 water temperatures: Maximum, $29.0^{\circ} \mathrm{C}$ Aug. 13,$14 ; \mathrm{m} 1 \mathrm{n} 1 \mathrm{mum}, 2.5^{\circ} \mathrm{C}$ Jan. $9-11$.

Period of record:

D1ssolved solids (1968-69): Kaximum, $167 \mathrm{mg} / 1 \mathrm{July} \mathrm{21-27,1969;}$ m1nimum, $74 \mathrm{mg} / 1$ Feb. 1-10, 1969 . Hardness (1968-69): Max1mum, $141 \mathrm{mg} / 1$ Oct. 14, 1968; minimum, $10 \mathrm{mg} / 1$ May $10,1969$.

Speciflc conductance (December 1968 to September 1970): Maximum dally, 426 micromhos July 9, 1970; min1mum dally, 77 micromhos Dec, 31, 1969

Wa ter temperatures: Maximum, $29.0^{\circ} \mathrm{C}$ Aug. $13,14,1970 ;$ minimum, freezing point on several days during winter per1od, 1968-69.

REMARKS. - Chemical-quality data represent equal-volume composites for the periods indicated prior to Nov. 1 and for every seventh day thereafter.

CHEMICAL ANALYSES, WATER YEAR OCTOBER 1969 TO SEPTEMBER 1970

\begin{tabular}{|c|c|c|c|c|c|c|c|c|c|c|}
\hline DATE & $\begin{array}{l}\text { MEAN } \\
\text { DIS- } \\
\text { CHARGE } \\
\text { (CFS) }\end{array}$ & $\begin{array}{l}\text { SILICA } \\
\text { ISID2) } \\
\text { (MG/L) }\end{array}$ & $\begin{array}{l}\text { OIS- } \\
\text { SOLVED } \\
\text { IRON } \\
\text { IFEI } \\
\text { (UG/L) }\end{array}$ & $\begin{array}{l}\text { CAL- } \\
\text { CIUN } \\
\text { (CA) } \\
\text { (MG/L) }\end{array}$ & $\begin{array}{c}\text { MAG- } \\
\text { NE- } \\
\text { SIUM } \\
\text { (MG) } \\
(M \in I L)\end{array}$ & $\begin{array}{l}\text { SODIUM } \\
\text { (NA) } \\
\text { (MG/L) }\end{array}$ & $\begin{array}{l}P O- \\
\text { IAS- } \\
\text { SIUM } \\
\text { (K) } \\
\text { (MG/L) }\end{array}$ & $\begin{array}{l}\text { BICAR- } \\
\text { B ONATE } \\
\text { (HCO3) } \\
\text { (MG/L) }\end{array}$ & $\begin{array}{l}\text { SULFATE } \\
\text { (SO4) } \\
\text { (MG/L) }\end{array}$ & $\begin{array}{l}\text { CHLC- } \\
\text { RIDE } \\
\text { ICL I } \\
\text { IMG ILI }\end{array}$ \\
\hline \multicolumn{11}{|l|}{ ОСТ. } \\
\hline$x-10$ & 122 & 5.3 & 0 & 39 & 6.6 & 1.9 & 1.8 & 116 & 32 & 2.4 \\
\hline $11-20$ & 96 & 5.7 & 20 & 46 & 4.9 & 2.2 & 2.4 & 123 & 39 & 2.8 \\
\hline $21 \ldots$ & 91 & 5.8 & 30 & 46 & 7.4 & 2.2 & 2.3 & 128 & 42 & 2.6 \\
\hline $24-31$ & 89 & 5.8 & $3 n$ & 46 & 7.4 & 2.2 & 2.3 & 128 & 42 & 2.6 \\
\hline \multicolumn{11}{|l|}{ Nov. } \\
\hline $10 \ldots$ & 114 & 5.7 & 0 & 43 & 6.0 & 2.0 & 1.6 & 120 & 37 & 3.7 \\
\hline $21 \ldots$ & 313 & 4.2 & 20 & 31 & 4.4 & 1.7 & 2.0 & 98 & 19 & 3.8 \\
\hline $28 \ldots$ & 251 & 4.2 & 0 & 31 & 5.3 & 2.1 & 1.6 & 96 & 27 & 3.0 \\
\hline \multicolumn{11}{|l|}{ DEC. } \\
\hline & 123 & 4.3 & 0 & 38 & 6.7 & 2.3 & 3.9 & 112 & 35 & 3.1 \\
\hline $11 . .$. & $233 n$ & 4.7 & 90 & 15 & 2.1 & 1.4 & 1.2 & 42 & 13 & 2.6 \\
\hline $18 \ldots$ & 317 & 4.6 & 0 & 25 & 4.1 & $2 . i$ & 1.2 & 77 & 19 & 3.6 \\
\hline $26 \ldots$ & 183 & 4.2 & 0 & 30 & 5.1 & 2.3 & 1.4 & 87 & 25 & 3.8 \\
\hline $31 \ldots$ & $1070 n$ & 4.0 & 0 & 10 & 1.6 & 2.0 & 1.2 & 31 & 10 & 2.2 \\
\hline \multicolumn{11}{|l|}{ JAN. } \\
\hline $03 .$. & 455 & 4.7 & 20 & 26 & 2.9 & 1.6 & .9 & 78 & 16 & 3.6 \\
\hline $15 \ldots$ & 268 & 4.8 & 20 & 32 & 3.9 & 1.6 & 1.1 & 92 & 22 & 3.8 \\
\hline $22 \ldots$ & 220 & 4.9 & 0 & 90 & 4.8 & 1.6 & 1.1 & 92 & 24 & 4.2 \\
\hline $29 \ldots$ & 337 & 4.2 & 0 & 20 & 4.3 & 1.5 & .8 & 80 & 19 & 3.6 \\
\hline \multicolumn{11}{|l|}{ FEB. } \\
\hline $05 \ldots$ & 670 & 4.3 & ? & 19 & 2.9 & 1.6 & .8 & 60 & 11 & 3.4 \\
\hline $12 \ldots$ & 489 & 4.2 & c & 20 & 3.4 & 2.5 & 1.0 & 60 & 12 & 3.6 \\
\hline $19 . .$. & 1900 & 4.4 & 90 & 15 & 3.5 & 1.8 & .7 & 45 & 14 & 2.2 \\
\hline $26 \ldots$ & 634 & 2.9 & in & 73 & 3.2 & 1.8 & .7 & 65 & if & 2.5 \\
\hline \multicolumn{11}{|l|}{ MAR. } \\
\hline $95 \ldots$ & 1330 & 4.0 & 0 & 17 & 2.6 & 2.0 & .6 & 52 & 17 & .9 \\
\hline $12 \ldots$ & 461 & 2.7 & 0 & 24 & 2.7 & 1.6 & .9 & 75 & 14 & 2.8 \\
\hline $19 .$. & 428 & 3.2 & $n$ & 25 & 3.0 & 1.5 & .9 & 17 & 16 & 2.8 \\
\hline $26 \ldots$ & 544 & 3.7 & o & 21 & 3.4 & 2.1 & 1.2 & 63 & 13 & $2 \cdot 3$ \\
\hline \multicolumn{11}{|l|}{$\triangle P R$. } \\
\hline n?... & 1220 & 4.1 & 0 & 17 & 2.7 & 2.1 & .8 & 54 & 8.8 & 3.0 \\
\hline$n 9 . .$. & 685 & 3.5 & 0 & 22 & 2.9 & 1.5 & .9 & 65 & 16 & 3.1 \\
\hline $16 \ldots$ & ano & 3.5 & c & 18 & 2.3 & 1.5 & .8 & 53 & 14 & 2.8 \\
\hline $23 \ldots$ & 611 & 3.5 & 10 & $2 n$ & 2.9 & 1.9 & . 8 & 63 & 13 & 2.0 \\
\hline $3 n \ldots$ & $11 \times 0$ & $5 . n$ & $2 n$ & 16 & 2.2 & I. B & .8 & 53 & 11 & 1.7 \\
\hline \multicolumn{11}{|l|}{ MAY } \\
\hline $14 \ldots$ & 2 an & 4.8 & 10 & 31 & 5.1 & 1. 8 & 1.1 & 92 & 19 & 2.4 \\
\hline $21 \ldots$ & 275 & 5.2 & 10 & 32 & 4.7 & 1.7 & 1.6 & 101 & 22 & 2.3 \\
\hline $29 \ldots$ & 150 & 6.0 & 10 & 35 & 5.3 & 1.7 & 1.7 & 109 & 25 & 2.5 \\
\hline \multicolumn{11}{|l|}{ JUAE } \\
\hline $24 \ldots$ & 149 & 6.2 & 80 & 38 & 4.9 & 1.5 & 1.6 & 112 & 28 & 2.2 \\
\hline $11 \ldots$ & 197 & 5.7 & 50 & 33 & $5 . n$ & 1.9 & 1.8 & 98 & 27 & 2.8 \\
\hline $19 .$. & 154 & 5.4 & 0 & 35 & 5.6 & 2. $:$ & 2.0 & $10 n$ & 25 & 3.1 \\
\hline \multirow{2}{*}{\multicolumn{11}{|c|}{ JULY }} \\
\hline & & & & & & & & & & \\
\hline $02 \ldots$ & 96 & 6.3 & 0 & 41 & 7.3 & 1.8 & 2.2 & 116 & 38 & 2.2 \\
\hline $09 . .$. & 327 & 9.4 & 30 & 12 & 7.2 & 2.8 & 5.8 & 151 & 98 & 4.0 \\
\hline $16 \ldots$ & 246 & 4.6 & 50 & 29 & 4.9 & 1.6 & 1.2 & 91 & 17 & 2.9 \\
\hline $23 .$. & 148 & 4.6 & 40 & 35 & 4.9 & 1.6 & 2.0 & 101 & 27 & 3.0 \\
\hline $39 . .$. & 158 & 5.3 & in & 36 & 4.7 & 3.0 & 2.4 & 101 & 29 & 3.2 \\
\hline \multicolumn{11}{|l|}{ AUG. } \\
\hline nE.... & 95 & 5.6 & 0 & 38 & 7.4 & 2.4 & 2.5 & 114 & 36 & 3.8 \\
\hline $13 . .$. & $1 \geqslant 1$ & 5.3 & $B O$ & 34 & 4.2 & 2.0 & 1.4 & 105 & 21 & 2.7 \\
\hline $27 \ldots$ & $13 n$ & 5.9 & $n$ & 31 & 6.7 & 2.1 & 2.1 & 95 & 33 & $3 . n$ \\
\hline \multicolumn{11}{|l|}{ SEPT. } \\
\hline $03 \ldots$ & 99 & 6.1 & 0 & 39 & 7.5 & 2.2 & 2.2 & 111 & 40 & 2.9 \\
\hline $\ln \ldots .$. & Q 7 & 6.3 & $6 C$ & 45 & 7.5 & 2.6 & 2.7 & 126 & 44 & 2.0 \\
\hline $17 \ldots$ & 76 & 6.3 & 0 & 44 & 9.6 & 2.1 & 2.6 & 123 & 45 & 2.9 \\
\hline 24. & 75 & 6.2 & 0 & 45 & 8.8 & 2.7 & 2.8 & 126 & 46 & 3.1 \\
\hline
\end{tabular}


JANES RIVER BASIN

02012500 JACKSON RIVER AT FALLING SPRING, VA..-Continued

CHEMICAL ANALYSES, hATER YEAR CCTOBER 1969 TO SEPTEMBER 1970

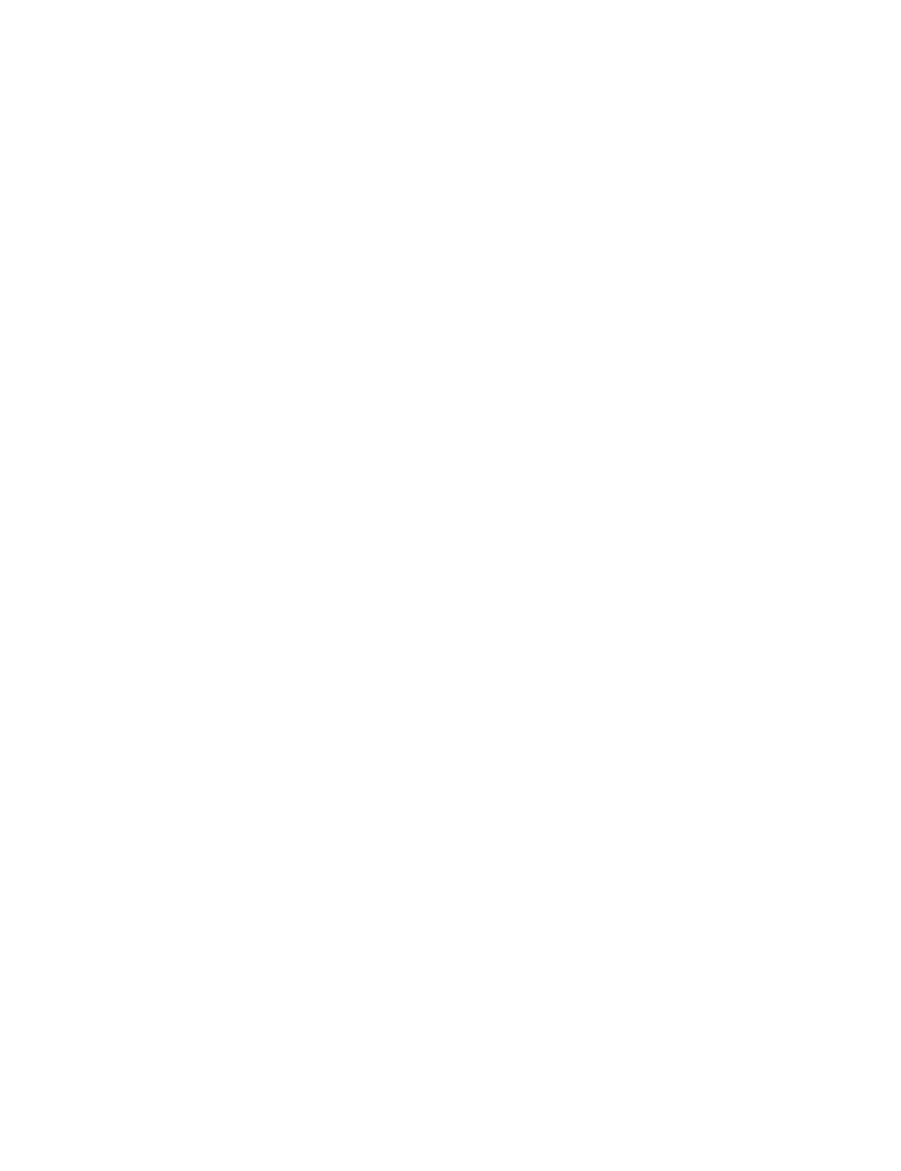


JAKES RIVER BASIN

02012500 JACKSON RIVER AT FALLING SPRING, VA.--COntinued

SPECIFIC CONDUCTANCE (MICROMHOS/CM AT $25^{\circ} \mathrm{C}$ ), WATER YEAR OCTOBER 1969 TO SEPTEMBER 1970

\begin{tabular}{|c|c|c|c|c|c|c|c|c|c|c|c|c|}
\hline DAY & OCTUBER & NJVEMBEK & DECEMBER & JANUARY & FEBRUARY & MARCH & APRIL & MAY & JUNE & JULY & AUGUS I & SEPIEMBER \\
\hline $\begin{array}{l}1 \ldots \ldots \\
2 \ldots \ldots \\
3 \ldots \ldots \\
4 \ldots \ldots \\
5 \ldots \ldots\end{array}$ & $\begin{array}{l}237 \\
241 \\
238 \\
236 \\
246\end{array}$ & $\begin{array}{l}2 B 1 \\
246 \\
247 \\
247\end{array}$ & $\begin{array}{l}230 \\
234 \\
229 \\
-\end{array}$ & $\begin{array}{r}\frac{93}{122} \\
=- \\
140\end{array}$ & $\begin{array}{l}160 \\
168 \\
132 \\
139 \\
136\end{array}$ & $\begin{array}{l}165 \\
173 \\
165 \\
146 \\
120\end{array}$ & $\begin{array}{l}122 \\
126 \\
101 \\
120 \\
131\end{array}$ & $\begin{array}{l}1 \overline{122} \\
130 \\
138 \\
-2\end{array}$ & $\begin{array}{l}216 \\
218 \\
223 \\
220 \\
237\end{array}$ & $\begin{array}{l}266 \\
268 \\
270 \\
-- \\
270\end{array}$ & $\begin{array}{l}211 \\
227 \\
233 \\
237 \\
243\end{array}$ & $\begin{array}{l}-\overline{269} \\
248 \\
340 \\
265\end{array}$ \\
\hline $\begin{array}{l}0 \ldots \ldots \\
y_{1} \ldots \ldots \\
y \ldots \ldots \\
0 \ldots \ldots\end{array}$ & $\begin{array}{l}246 \\
249 \\
245 \\
244 \\
245\end{array}$ & $\begin{array}{l}244 \\
243 \\
245 \\
238 \\
249\end{array}$ & $\begin{array}{l}236 \\
252 \\
237 \\
230 \\
205\end{array}$ & $\begin{array}{l}148 \\
146 \\
179 \\
208 \\
200\end{array}$ & $\begin{array}{l}140 \\
163 \\
168 \\
157 \\
146\end{array}$ & $\begin{array}{l}-- \\
122 \\
136 \\
146 \\
150\end{array}$ & $\begin{array}{l}136 \\
142 \\
127 \\
138 \\
139\end{array}$ & $\begin{array}{r}145 \\
-164 \\
164 \\
165 \\
165\end{array}$ & $\begin{array}{l}225 \\
227 \\
223 \\
228 \\
226\end{array}$ & $\begin{array}{l}275 \\
265 \\
267 \\
426 \\
277\end{array}$ & $\begin{array}{l}249 \\
203 \\
204 \\
198 \\
155\end{array}$ & $\begin{array}{l}244 \\
247 \\
250 \\
260 \\
280\end{array}$ \\
\hline $\begin{array}{l}\ldots \ldots \\
\ldots \ldots \ldots \\
\ldots \ldots \ldots\end{array}$ & $\begin{array}{l}249 \\
250 \\
258 \\
261 \\
261\end{array}$ & $\begin{array}{r}251 \\
-5 \\
265 \\
258 \\
252\end{array}$ & $\begin{array}{l}100 \\
111 \\
128 \\
140 \\
144\end{array}$ & $\begin{array}{l}216 \\
203 \\
206 \\
214 \\
220\end{array}$ & $\begin{array}{l}144 \\
154 \\
162 \\
160 \\
165\end{array}$ & $\begin{array}{l}155 \\
154 \\
153 \\
160 \\
157\end{array}$ & $\begin{array}{l}1 \overline{141} \\
153 \\
122 \\
122\end{array}$ & $\begin{array}{r}174 \\
180 \\
-189 \\
189 \\
195\end{array}$ & $\begin{array}{l}208 \\
209 \\
204 \\
204 \\
218\end{array}$ & $\begin{array}{r}275 \\
316 \\
271 \\
184 \\
--\end{array}$ & $\begin{array}{r}179 \\
187 \\
191 \\
198 \\
--\end{array}$ & $\begin{array}{l}280 \\
280 \\
278 \\
280 \\
268\end{array}$ \\
\hline $\begin{array}{l}6 \ldots \ldots \\
7 \ldots \ldots \\
8 \ldots \ldots \\
y_{1} \ldots \ldots\end{array}$ & $\begin{array}{l}205 \\
270 \\
260 \\
265\end{array}$ & $\begin{array}{l}249 \\
251 \\
256 \\
247 \\
221\end{array}$ & $\begin{array}{l}150 \\
160 \\
168 \\
169 \\
180\end{array}$ & $\begin{array}{r}220 \\
220 \\
216 \\
207 \\
--\end{array}$ & $\begin{array}{l}128 \\
138 \\
120 \\
110 \\
118\end{array}$ & $\begin{array}{r}159 \\
175 \\
177 \\
160 \\
--\end{array}$ & $\begin{array}{l}112 \\
118 \\
134 \\
142 \\
131\end{array}$ & $\begin{array}{l}196 \\
192 \\
200 \\
204 \\
197\end{array}$ & $\begin{array}{r}214 \\
212 \\
208 \\
-2 \\
214\end{array}$ & $\begin{array}{l}169 \\
150 \\
140 \\
173 \\
185\end{array}$ & $\begin{array}{l}200 \\
219 \\
235 \\
287 \\
--\end{array}$ & $\begin{array}{l}281 \\
275 \\
270 \\
260 \\
285\end{array}$ \\
\hline $\begin{array}{l}1 \ldots \ldots \\
2 \ldots \ldots \\
3 \ldots \ldots \\
4 \ldots \ldots\end{array}$ & $\begin{array}{r}273 \\
-- \\
-- \\
275 \\
271\end{array}$ & $\begin{array}{l}193 \\
172 \\
174 \\
190 \\
197\end{array}$ & $\begin{array}{r}188 \\
185 \\
182 \\
190 \\
--\end{array}$ & $\begin{array}{l}-- \\
215 \\
220 \\
210 \\
220\end{array}$ & $\begin{array}{l}127 \\
130 \\
153 \\
144 \\
146\end{array}$ & $\begin{array}{l}140 \\
135 \\
136 \\
142 \\
135\end{array}$ & $\begin{array}{r}130 \\
230 \\
94 \\
100\end{array}$ & $\begin{array}{l}199 \\
206 \\
208 \\
214 \\
215\end{array}$ & $\begin{array}{l}216 \\
224 \\
225 \\
237 \\
234\end{array}$ & $\begin{array}{l}190 \\
198 \\
198 \\
206 \\
204\end{array}$ & $\begin{array}{l}231 \\
243 \\
239 \\
331 \\
-2\end{array}$ & $\begin{array}{l}280 \\
280 \\
280 \\
282 \\
282\end{array}$ \\
\hline $\begin{array}{l}6 \ldots \ldots \\
7 \ldots \ldots \\
9 \ldots \ldots \\
0 \ldots \ldots \\
1 \ldots \ldots\end{array}$ & $\begin{array}{r}295 \\
289 \\
-- \\
285 \\
288 \\
291\end{array}$ & $\begin{array}{l}200 \\
206 \\
209 \\
220 \\
223 \\
--\end{array}$ & $\begin{array}{r}194 \\
195 \\
207 \\
194 \\
108 \\
77\end{array}$ & $\begin{array}{l}211 \\
200 \\
200 \\
199 \\
170 \\
136\end{array}$ & $\begin{array}{l}146 \\
150 \\
163 \\
-0 \\
-\end{array}$ & $\begin{array}{r}147 \\
142 \\
-- \\
-- \\
102 \\
118\end{array}$ & $\begin{array}{r}106 \\
116 \\
97 \\
104 \\
110 \\
-\end{array}$ & $\begin{array}{l}217 \\
220 \\
222 \\
215 \\
230 \\
223\end{array}$ & $\begin{array}{l}260 \\
242 \\
245 \\
251 \\
260 \\
-\end{array}$ & $\begin{array}{l}205 \\
216 \\
210 \\
174 \\
209 \\
217\end{array}$ & $\begin{array}{r}228 \\
214 \\
=- \\
=- \\
245\end{array}$ & $\begin{array}{c}280 \\
290 \\
382 \\
300 \\
305 \\
--\end{array}$ \\
\hline ERAGÉ & 260 & 231 & 179 & 190 & 145 & 147 & 123 & 189 & 225 & 230 & 223 & 280 \\
\hline
\end{tabular}

TEMPERATURE ( $\left.{ }^{\circ} \mathrm{C}\right)$ OF WATER, WATER YEAR OCTOBER 1969 TO SEPTEMBER 1970

\begin{tabular}{|c|c|c|c|c|c|c|c|c|c|c|c|c|}
\hline DAY & $O C T$ & NOV & DEC & JAN & $F E B$ & MAR & $A P R$ & MAY & JUN & JUL & $A \cup G$ & SEP \\
\hline $\begin{array}{l}1 \\
2 \\
3 \\
4 \\
5\end{array}$ & $\begin{array}{l}19.0 \\
21.5 \\
19.0 \\
19.0 \\
17.0\end{array}$ & $\begin{array}{l}14.0 \\
13.5 \\
12.0 \\
12.0\end{array}$ & $\begin{array}{r}5.0 \\
5.0 \\
5.0 \\
--\end{array}$ & $\begin{array}{r}10.0 \\
10.0 \\
=-0 \\
7.0\end{array}$ & $\begin{array}{l}7.5 \\
7.5 \\
5.0 \\
4.5 \\
5.0\end{array}$ & $\begin{array}{r}7.5 \\
8.5 \\
10.0 \\
=-.\end{array}$ & $\begin{array}{r}9.0 \\
9.5 \\
10.0 \\
12.0 \\
10.0\end{array}$ & $\begin{array}{c}17.0 \\
17.0 \\
19.0 \\
=-\end{array}$ & $\begin{array}{l}23.5 \\
25.5 \\
24.0 \\
23.0 \\
21.5\end{array}$ & $\begin{array}{r}26.0 \\
28.0 \\
28.5 \\
-.0 \\
25.0\end{array}$ & $\begin{array}{l}25.5 \\
25.0 \\
26.0 \\
25.0 \\
24.0\end{array}$ & $\begin{array}{l}20.0 \\
26.0 \\
26.0 \\
26.5\end{array}$ \\
\hline $\begin{array}{r}6 \\
7 \\
8 \\
9 \\
10\end{array}$ & $\begin{array}{l}20.5 \\
17.0 \\
17.5 \\
16.5 \\
18.0\end{array}$ & $\begin{array}{l}11.0 \\
10.5 \\
10.0 \\
10.5 \\
11.0\end{array}$ & $\begin{array}{l}5.0 \\
4.0 \\
5.0 \\
6.0 \\
7.0\end{array}$ & $\begin{array}{l}8.0 \\
4.0 \\
4.0 \\
2.5 \\
2.5\end{array}$ & $\begin{array}{l}5.0 \\
6.5 \\
7.0 \\
6.0 \\
5.5\end{array}$ & $\begin{array}{l}12.0 \\
10.5 \\
11.0 \\
12.0\end{array}$ & $\begin{array}{l}11.5 \\
11.5 \\
12.0 \\
12.5 \\
13.0\end{array}$ & $\begin{array}{r}15.5 \\
-2 \\
17.5 \\
18.5 \\
19.0\end{array}$ & $\begin{array}{l}21.5 \\
22.5 \\
23.0 \\
24.0 \\
23.0\end{array}$ & $\begin{array}{l}26.0 \\
24.5 \\
26.5 \\
24.0 \\
26.0\end{array}$ & $\begin{array}{l}26.0 \\
24.0 \\
23.0 \\
22.0 \\
20.0\end{array}$ & $\begin{array}{l}24.0 \\
24.0 \\
26.0 \\
25.0 \\
25.0\end{array}$ \\
\hline $\begin{array}{l}11 \\
12 \\
13 \\
14 \\
15\end{array}$ & $\begin{array}{l}17.0 \\
19.0 \\
19.0 \\
17.5 \\
17.5\end{array}$ & $\begin{array}{r}12.0 \\
-0 \\
10.0 \\
7.0 \\
7.0\end{array}$ & $\begin{array}{l}6.5 \\
7.0 \\
9.0 \\
9.0 \\
7.0\end{array}$ & $\begin{array}{l}2.5 \\
3.0 \\
3.0 \\
3.0 \\
3.5\end{array}$ & $\begin{array}{l}6.5 \\
7.0 \\
6.0 \\
7.0 \\
4.5\end{array}$ & $\begin{array}{r}11.0 \\
11.5 \\
9.5 \\
8.0 \\
8.5\end{array}$ & $\begin{array}{l}14.0 \\
14.0 \\
11.5 \\
14.5\end{array}$ & $\begin{array}{r}20.5 \\
19.5 \\
-5 \\
20.5 \\
21.0\end{array}$ & $\begin{array}{l}25.0 \\
26.0 \\
24.0 \\
22.5 \\
20.5\end{array}$ & $\begin{array}{c}25.0 \\
22.5 \\
23.0 \\
25.5 \\
--\end{array}$ & $\begin{array}{r}23.0 \\
28.0 \\
29.0 \\
29.0 \\
-\end{array}$ & $\begin{array}{l}23.0 \\
23.0 \\
23.5 \\
22.5 \\
25.0\end{array}$ \\
\hline $\begin{array}{l}16 \\
17 \\
18 \\
19 \\
20\end{array}$ & $\begin{array}{r}-- \\
16.5 \\
17.0 \\
15.5 \\
17.5\end{array}$ & $\begin{array}{l}7.0 \\
5.5 \\
7.0 \\
3.0 \\
9.0\end{array}$ & $\begin{array}{l}4.0 \\
4.5 \\
3.0 \\
3.5 \\
4.0\end{array}$ & $\begin{array}{r}4.5 \\
4.0 \\
4.0 \\
5.0 \\
--\end{array}$ & $\begin{array}{l}4.5 \\
7.0 \\
9.0 \\
6.0 \\
5.0\end{array}$ & $\begin{array}{r}7.0 \\
6.5 \\
8.0 \\
9.0 \\
--\end{array}$ & $\begin{array}{l}14.0 \\
14.0 \\
14.5 \\
15.0 \\
14.5\end{array}$ & $\begin{array}{l}20.0 \\
18.0 \\
18.0 \\
20.0 \\
21.5\end{array}$ & $\begin{array}{r}23.0 \\
25.5 \\
27.0 \\
-0 \\
25.0\end{array}$ & $\begin{array}{l}26.0 \\
25.0 \\
22.5 \\
24.5 \\
24.5\end{array}$ & $\begin{array}{r}26.0 \\
26.0 \\
25.0 \\
25.0 \\
.-0\end{array}$ & $\begin{array}{l}25.0 \\
24.0 \\
23.5 \\
23.0 \\
23.0\end{array}$ \\
\hline $\begin{array}{l}21 \\
22 \\
23 \\
24 \\
25\end{array}$ & $\begin{array}{r}15.0 \\
=- \\
15.0 \\
14.0\end{array}$ & $\begin{array}{l}8.0 \\
5.5 \\
8.0 \\
7.0 \\
8.0\end{array}$ & $\begin{array}{r}4.0 \\
3.5 \\
4.0 \\
3.5 \\
-.\end{array}$ & $\begin{array}{l}3.5 \\
3.0 \\
4.0 \\
4.0\end{array}$ & $\begin{array}{l}6.0 \\
3.0 \\
9.0 \\
3.0 \\
8.0\end{array}$ & $\begin{array}{r}9.0 \\
10.0 \\
11.0 \\
10.0 \\
10.5\end{array}$ & $\begin{array}{r}14.0 \\
15.5 \\
14.5 \\
15.0\end{array}$ & $\begin{array}{l}21.0 \\
22.0 \\
24.0 \\
24.5 \\
23.0\end{array}$ & $\begin{array}{l}24.0 \\
24.0 \\
26.0 \\
25.0 \\
25.0\end{array}$ & $\begin{array}{l}23.5 \\
22.5 \\
22.0 \\
24.5 \\
25.0\end{array}$ & $\begin{array}{r}25.5 \\
24.5 \\
22.5 \\
22.0 \\
=-\end{array}$ & $\begin{array}{l}23.5 \\
25.0 \\
26.0 \\
25.5 \\
24.5\end{array}$ \\
\hline $\begin{array}{l}26 \\
27 \\
28 \\
29 \\
30 \\
31\end{array}$ & $\begin{array}{r}13.0 \\
14.0 \\
-0 \\
10.5 \\
10.0 \\
11.0\end{array}$ & $\begin{array}{r}9.0 \\
7.0 \\
7.0 \\
9.0 \\
8.0 \\
=-\end{array}$ & $\begin{array}{r}4.0 \\
4.0 \\
5.0 \\
6.0 \\
6.5 \\
10.0\end{array}$ & $\begin{array}{l}5.5 \\
7.5 \\
5.5 \\
7.0 \\
6.0 \\
6.0\end{array}$ & $\begin{array}{r}7.5 \\
9.5 \\
7.0 \\
=- \\
=-\end{array}$ & $\begin{array}{r}9.5 \\
11.0 \\
=- \\
10.0 \\
10.5\end{array}$ & $\begin{array}{r}14.0 \\
16.0 \\
17.0 \\
17.0 \\
17.0 \\
=-\end{array}$ & $\begin{array}{l}21.0 \\
22.0 \\
23.5 \\
20.0 \\
18.5 \\
21.0\end{array}$ & $\begin{array}{r}24.0 \\
22.5 \\
25.0 \\
26.0 \\
26.0 \\
-.\end{array}$ & $\begin{array}{l}26.5 \\
24.5 \\
25.0 \\
27.0 \\
27.0 \\
26.0\end{array}$ & $\begin{array}{r}24.0 \\
24.0 \\
= \\
=- \\
= \\
25.0\end{array}$ & $\begin{array}{r}25.0 \\
22.0 \\
22.0 \\
18.5 \\
19.5 \\
--\end{array}$ \\
\hline AVG & 16.4 & 9.1 & 5.3 & 4.9 & 6.5 & 9.6 & 13.4 & 20.1 & 24.0 & 25.0 & 24.7 & 23.7 \\
\hline
\end{tabular}


LOCATION.-Lat $37^{\circ} 31^{\circ} 50^{\prime \prime}$, long $79^{\circ} 40^{\prime} 45^{\prime \prime}$, Botetourt County, at gaging station on left bank at Chesapeake and Ohio Rallway station at Buchanan, $300 \mathrm{ft}$ upstream from bridge on U.S. Highway 11, 1, 000 ft upstrear from Purgatory Creek, 1.5 miles downstream from Looney Creek, and at mile 301.2.

DHA INAGE AREA. $-2,075 \mathrm{sq}$ m1 (revised).

PERIOD OR RECORD. - Chemical analyses: April 1929 to March 1930, October 1947 to September 1948, October 1951 to September 1956, February 1967 to September 1970.

Water temperatures: October 1947 to September 1948, May 1951 to September 1956, April 1968 to September 1970. Sediment records: Kay 1951 to September 1956

EXTREYES. -1969-70:

Specific conductance: Maximum dally, 780 micrombos Sept, 29 ; minimum dally, 86 micromhos Jan. 1.

CHEMICAL ANALYSES, WATER YEAR OCTOBER 1969 TO SEPTEMBER 1970

\begin{tabular}{|c|c|c|c|c|c|c|c|c|c|c|}
\hline DATE & $\begin{array}{l}\text { MEAN } \\
\text { DIS- } \\
\text { CHARGE } \\
\text { (CFS) }\end{array}$ & $\begin{array}{l}\text { SI LICA } \\
\text { (SIO?) } \\
\text { (MG/L) }\end{array}$ & $\begin{array}{l}\text { OIS- } \\
\text { SULVEC } \\
\text { IRON } \\
\text { IFE) } \\
\text { (UG/L) }\end{array}$ & $\begin{array}{l}\text { CAL- } \\
\text { CIUN } \\
\text { (CA) } \\
\text { (MG/L) }\end{array}$ & $\begin{array}{c}\text { MAG- } \\
\text { NE- } \\
\text { SIUM } \\
\text { (MG) } \\
\text { (MC/L) }\end{array}$ & $\begin{array}{l}\text { SODIUM } \\
\text { (NA) } \\
(M G / L)\end{array}$ & $\begin{array}{l}\text { PO- } \\
\text { JAS- } \\
\text { SIUM } \\
\text { (K) } \\
\text { (MGA) }\end{array}$ & $\begin{array}{l}\text { AICAR- } \\
\text { SONATE } \\
\text { (HCD3) } \\
\text { (MG /L) }\end{array}$ & $\begin{array}{l}\text { SULFATE } \\
\text { (SO4) } \\
(\mathrm{MG} / \mathrm{L})\end{array}$ & $\begin{array}{l}\text { CHLO- } \\
\text { RIDE } \\
\text { (CL) } \\
(M G / L)\end{array}$ \\
\hline \multicolumn{11}{|l|}{ DCT. } \\
\hline $01-10$ & 671 & 4.2 & 10 & 43 & 7.3 & 32 & 3.8 & 126 & 64 & 39 \\
\hline $11-20$ & 467 & 3.9 & 0 & 45 & 7.0 & 45 & 4.3 & 141 & 49 & 50 \\
\hline $21-31$ & 416 & 5.2 & 60 & 51 & 9.? & 51 & 4.9 & 151 & 63 & 52 \\
\hline \multicolumn{11}{|l|}{ Nov. } \\
\hline$n 1 \ldots$ & 425 & 5.2 & 140 & 55 & e. 0 & 55 & 5.6 & 165 & 73 & 52 \\
\hline $10 \ldots$ & $59 \mathrm{~A}$ & 4.9 & 40 & 39 & 7.4 & 25 & 3.5 & 113 & $4 ?$ & 31 \\
\hline $14 \ldots$ & 5,5 & 5.1 & 40 & 44 & 0.0 & 24 & 3.1 & 123 & 45 & 46 \\
\hline $21 \ldots$ & 592 & 5.2 & AO & 46 & 6.5 & $4 \mathrm{I}$ & 4.0 & 134 & 58 & $5 n$ \\
\hline $29 \ldots$ & 652 & 4.9 & $3 n$ & 36 & 6.1 & 28 & 3.5 & 116 & 40 & 32 \\
\hline \multicolumn{11}{|l|}{$\mathrm{DEC}$. } \\
\hline $25 \ldots$ & 530 & 4.1 & 40 & 43 & 6.1 & 33 & 3.1 & 122 & 45 & 47 \\
\hline $12 \ldots$ & 9731 & 4.9 & in & 28 & 2.8 & 4.8 & 2.0 & 83 & 20 & 6.0 \\
\hline $13 \ldots$ & $539 n$ & 4. 9 & 60 & 16 & 2.5 & 4.7 & 1.6 & 52 & 16 & 5.0 \\
\hline $2^{n} \ldots$ & $134 n$ & $3 . ?$ & 50 & 23 & 3.9 & 22 & 3.2 & BA & 32 & 15 \\
\hline $27 \ldots$ & 919 & 5.1 & 50 & 33 & 4.2 & 24 & 3.3 & 95 & 31 & 28 \\
\hline \multicolumn{11}{|l|}{ JAN. } \\
\hline $03 .$. & 7930 & 4.8 & 60 & 16 & 2.7 & 3.8 & .8 & 48 & 16 & 3.6 \\
\hline $10 . .$. & 1270 & 5.1 & 40 & 25 & 4.1 & 10 & 1.6 & B1 & 19 & 14 \\
\hline $17 \ldots$ & 1250 & 5.0 & 40 & 30 & 5.1 & 23 & 2.5 & 98 & 29 & 23 \\
\hline $24 \ldots$ & $14 n n$ & 5.1 & 10 & 27 & 4.8 & 14 & 1.6 & 90 & $2 ?$ & 17 \\
\hline $31 \ldots$ & 5050 & 5.0 & ln & 20 & 3.1 & 6.2 & 1.0 & 56 & 16 & 7.0 \\
\hline \multicolumn{11}{|l|}{ FEP. } \\
\hline$n 7 . .$. & 2910 & 5.4 & 0 & $2 n$ & 4.4 & 6.9 & 1.2 & 60 & 16 & 11 \\
\hline $14 \ldots$ & 2460 & 5.3 & 30 & 24 & 2.0 & 0.6 & 1.3 & 64 & 19 & 12 \\
\hline $21 \ldots$ & 6960 & 4.8 & $4 n$ & 24 & 3. $c$ & 4.9 & .7 & 50 & 13 & 5.? \\
\hline PR... & 2420 & $4 . ?$ & 0 & 25 & $>0$ & 9.0 & 1.3 & 74 & 18 & 10 \\
\hline \multicolumn{11}{|l|}{ MAR. } \\
\hline$n 7 . .$. & 2ano & 3.9 & 0 & 24 & 3.6 & 11 & 1.3 & 76 & 19 & 12 \\
\hline $14 \ldots$ & 1647 & 3.7 & 30 & 30 & 4.0 & 12 & 1.7 & 94 & 23 & 15 \\
\hline $21 \ldots$ & $2 n 2 n$ & 4.2 & 40 & 30 & 3.9 & 11 & 1.6 & 95 & [ 9 & 16 \\
\hline $29 \ldots$ & 2140 & 3.2 & $? 0$ & 22 & $4 \cdot n$ & II & 1.6 & 70 & 19 & 13 \\
\hline \multicolumn{11}{|l|}{ APR. } \\
\hline$n 4 \ldots$ & 6997 & 4.5 & 10 & 17 & 2.7 & 4.6 & .9 & 50 & 23 & 6.6 \\
\hline $11 \ldots$ & 2440 & 3.7 & 1n & 23 & 3.7 & 9.0 & 1.2 & in & 19 & 12 \\
\hline $18 \ldots$ & $2 a n n$ & 4.1 & 10 & 22 & 3.3 & 3.0 & 1.1 & 61 & 29 & 9.5 \\
\hline $25 \ldots$ & $345 n$ & 4.1 & 30 & 27 & 3.5 & 17 & 1.9 & 77 & 22 & 15 \\
\hline \multicolumn{11}{|l|}{ MAY } \\
\hline$n ? \ldots$ & 3300 & 5.2 & 0 & 18 & 2.6 & 5.7 & 1.2 & 56 & 14 & 9.0 \\
\hline$n 9 .$. & 1740 & 4.0 & 30 & 25 & 4.0 & 13 & 1.6 & BO & 18 & 15 \\
\hline $16 \ldots$ & inan & 4.6 & 40 & 33 & 5.1 & 15 & 1.9 & 96 & 27 & 30 \\
\hline $23 . .$. & 1150 & 4.9 & 40 & 40 & 5.7 & 23 & $? .6$ & 111 & $3 n$ & 33 \\
\hline $30 \ldots$ & 6?n & $2 . ?$ & 10 & 44 & 5.8 & $2 n$ & 2.6 & 113 & 31 & 35 \\
\hline \multicolumn{11}{|l|}{ JUAF } \\
\hline os.... & 834 & 2.0 & $5 n$ & 43 & $E \cdot 1$ & 30 & 3.2 & 123 & 47 & 45 \\
\hline $13 \ldots$ & 570 & 5.0 & 130 & 45 & 6.1 & 46 & 4.7 & 138 & 53 & 47 \\
\hline $20 \ldots$ & 429 & 4.9 & 10 & 44 & C. B & 25 & 3.2 & 124 & 42 & 35 \\
\hline $27 \ldots$ & 354 & 3.6 & 10 & 54 & 7.2 & 38 & $4 . n$ & 135 & 48 & 56 \\
\hline \multicolumn{11}{|l|}{ JULY } \\
\hline $04 \ldots$ & 325 & 5.0 & 210 & 55 & 8.4 & 48 & 5.0 & 144 & 59 & 63 \\
\hline $11 \ldots$ & 3540 & 5.0 & 40 & 26 & 2.7 & 8.4 & 2.2 & 75 & 19 & 9.4 \\
\hline $18 \ldots$ & 765 & 4.2 & 20 & 42 & 4.9 & 21 & 3.0 & 114 & 41 & 28 \\
\hline $25 \ldots$ & 539 & 4.5 & 40 & 47 & 4.5 & 38 & 3.8 & 128 & 43 & 45 \\
\hline \multicolumn{11}{|l|}{ A บG. } \\
\hline$n 1 \ldots$ & 614 & 4.6 & 10 & 44 & 3.9 & 23 & 2.5 & 110 & 35 & $\begin{array}{l}3 ? \\
57\end{array}$ \\
\hline OR... & 356 & 5.2 & 40 & 51 & 7.6 & 47 & 4.6 & 139 & 58 & 57 \\
\hline $15 \ldots$ & 693 & 5.7 & 0 & 36 & 5.1 & 18 & 2.6 & 102 & 30 & 27 \\
\hline $22 \ldots$ & 553 & 4.8 & 40 & 53 & A. 3 & 43 & 4.3 & 132 & on & 56 \\
\hline & 471 & 5.7 & 30 & 49 & 9.0 & $5 ?$ & 4.1 & 139 & BI & 63 \\
\hline SEPT. & & & & & & & & & & \\
\hline $35 \ldots$ & 339 & 5.2 & 30 & 54 & 9.7 & 54 & 4.5 & 142 & 64 & 73 \\
\hline $12 \ldots$ & 352 & 4.9 & 40 & 42 & 7.5 & 42 & 5.3 & 113 & 53 & 53 \\
\hline $19 .$. & 274 & 4.1 & 20 & 50 & 9.0 & 53 & 4.5 & 142 & 77 & 85 \\
\hline $26 \ldots$ & ?व9 & 5.6 & 50 & 61 & ร.7 & 30 & 6.0 & 175 & B? & 92 \\
\hline
\end{tabular}


EXTREMES, 1969-70,--Cont1nued Nater temperatures: Maximum, $27.5^{\circ} \mathrm{C}$ July 4 and Aug. 2; minimum, freezing point on several days during December and January.

Period of record:

Dissolved solids (1929-30, 1947-48, 1955-56, April 1968 to September 1969): Maximum, 450 mg/1 Oct. 1-10, 1968; minimun, $70 \mathrm{mg} / 1 \mathrm{Mar} .11-20,1956$.

Hardness (1929-30, 1947-48, 1955-56, April 1968 to September 1969): Maximum, 204 mg/1 oct. 1-10, 1968; minımum, 48 mg/l April 11-20, 1956.

Specific conductance (1953-56, April 1968 to September 1970): Maximum da1ly, 945 micromhos Sept. 27, 1954;

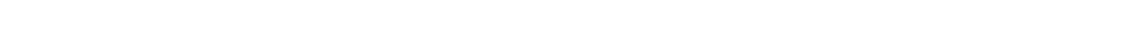

REKARKS.--Chemical-quality data represent equal-volume composites for the periods indicated prior to Nov, 1 and for every seventh day thereafter.

CHEMICAL ANALYSES, hATER YEAR CCTOBER 1969 TO SEPTEMBER 1970

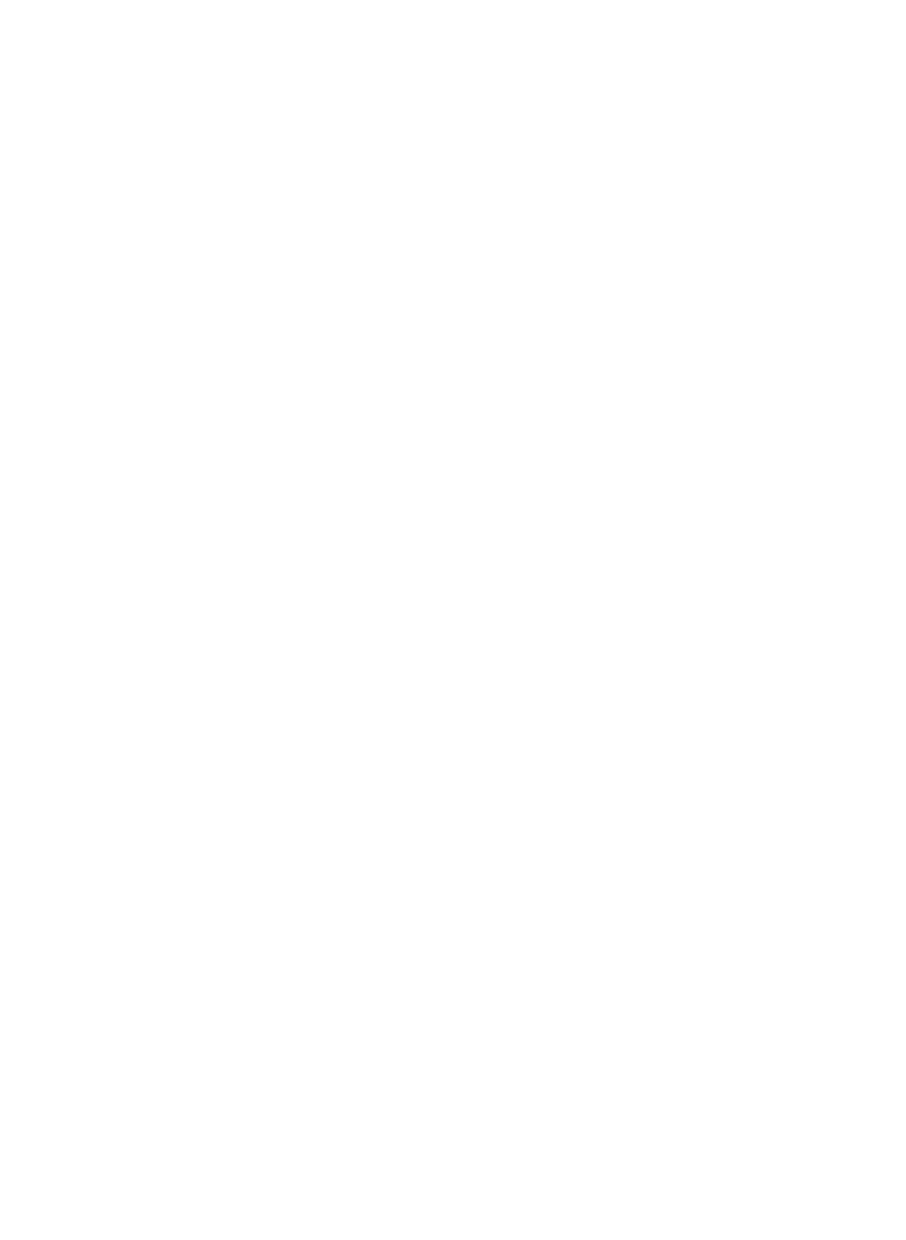


02019500 JAMES RIVER AT BUCHANAN, VA.--Continued

SPECIFIC CONDUCTANCE (MICROMHOS/CM AT $25^{\circ} \mathrm{C}$ ), WATER YEAR OCTOBER 1969 TO SEPTEMBER 1970

UAY OCTOBER NOVEMBEK DECEMBER JANUAKY rEBRUARY MARCH APRIL MAY JUNE JULY AUGUST SEPTEMBER

\begin{tabular}{|c|c|c|c|c|c|c|c|c|c|c|c|c|}
\hline $1 \ldots \ldots$ & 384 & 543 & 368 & 86 & 146 & 205 & 149 & 138 & 368 & 509 & 330 & 468 \\
\hline ¿.... & 365 & 325 & 389 & 108 & 156 & 210 & 155 & 146 & 389 & 487 & 388 & 555 \\
\hline $3 . .$. & 360 & 515 & 405 & 120 & 167 & 220 & 157 & 155 & 365 & 510 & 365 & 589 \\
\hline $4 \ldots .$. & 385 & 465 & 410 & 130 & 148 & 235 & 126 & 166 & 390 & 523 & 360 & 571 \\
\hline s..... & 405 & 488 & 425 & 140 & 147 & 255 & 130 & 181 & 382 & 552 & 405 & 564 \\
\hline $6 \ldots .$. & 403 & 375 & 400 & 155 & 157 & 250 & 133 & 185 & 385 & 559 & 401 & 583 \\
\hline $7 \ldots$ & 415 & 354 & 415 & 173 & 172 & 200 & 149 & 186 & 418 & 564 & 430 & 600 \\
\hline $8 \ldots$. & 410 & 344 & 393 & 185 & 180 & 195 & 156 & 196 & 400 & 569 & 470 & 650 \\
\hline$+\ldots \ldots$ & 405 & 358 & 425 & 195 & 195 & 198 & 158 & 208 & 449 & 568 & 485 & 680 \\
\hline $10 \ldots \ldots$ & 413 & 360 & 435 & 228 & 195 & 205 & 170 & 228 & 391 & 566 & 479 & 625 \\
\hline $11 \ldots \ldots$ & 435 & 410 & 380 & 245 & 100 & 210 & 184 & 224 & 355 & 185 & 360 & 510 \\
\hline$i<\ldots \ldots$ & 439 & 400 & 272 & 255 & 169 & 230 & 189 & 227 & 442 & 169 & 274 & 442 \\
\hline $13 \ldots$. & 450 & 392 & 131 & 260 & 180 & 235 & 198 & 245 & 442 & 200 & 342 & 550 \\
\hline $14 \ldots \ldots$ & 479 & 420 & 150 & 280 & 195 & 250 & 198 & 248 & 445 & 231 & 260 & 595 \\
\hline $13 . . .$. & 505 & 472 & 165 & 260 & 215 & 240 & $2 I 1$ & 252 & 363 & 256 & 278 & 551 \\
\hline $\begin{array}{l}16 \ldots \ldots \\
11 \ldots \ldots\end{array}$ & $\begin{array}{l}470 \\
4 \rightarrow 5\end{array}$ & $\begin{array}{l}451 \\
471\end{array}$ & $\begin{array}{l}169 \\
188\end{array}$ & $\begin{array}{l}208 \\
298\end{array}$ & $\begin{array}{l}203 \\
225\end{array}$ & $\begin{array}{l}233 \\
245\end{array}$ & $\begin{array}{l}142 \\
153\end{array}$ & $\begin{array}{l}260 \\
265\end{array}$ & $\begin{array}{l}359 \\
368\end{array}$ & $\begin{array}{l}282 \\
307\end{array}$ & $\begin{array}{l}305 \\
128\end{array}$ & $\begin{array}{l}493 \\
519\end{array}$ \\
\hline $10 \ldots .$. & 453 & 445 & 213 & 279 & 178 & 245 & 109 & 250 & 412 & 322 & 380 & 540 \\
\hline $1 \neq \ldots \ldots$ & 460 & 472 & 221 & 282 & 150 & 260 & - & 318 & 387 & 403 & 340 & 650 \\
\hline $20 . \ldots$ & 479 & 486 & 265 & 250 & 129 & 245 & 177 & 320 & 362 & 470 & 420 & 690 \\
\hline $21 \ldots \ldots$ & 490 & 475 & 258 & 248 & 127 & 255 & 188 & 310 & 403 & 415 & 435 & 730 \\
\hline $22 \ldots \ldots$ & $4 \times 4$ & 458 & 268 & 232 & 133 & 240 & 191 & 308 & 420 & 319 & 470 & 760 \\
\hline $23 . . .$. & 505 & 510 & 270 & 238 & 148 & 215 & 202 & 329 & 419 & 350 & 540 & 740 \\
\hline $24 \ldots \ldots$ & 452 & 486 & 282 & 249 & 166 & 197 & 190 & 345 & 445 & 401 & 515 & 720 \\
\hline $2 b \ldots \ldots$ & 475 & 370 & 305 & 200 & 170 & 195 & 212 & 251 & 429 & 405 & 515 & 740 \\
\hline $26 \ldots \ldots$ & 512 & 325 & 308 & 262 & 171 & 195 & 158 & 263 & 454 & 417 & 419 & 765 \\
\hline $27 \ldots \ldots$ & 532 & 360 & 321 & 280 & 185 & 200 & 167 & 285 & 469 & 475 & 482 & 742 \\
\hline Cd...... & $54 B$ & 361 & 260 & 260 & 193 & 205 & 165 & 320 & 476 & 479 & $47 \mathrm{C}$ & 749 \\
\hline $2 \rightarrow \ldots \ldots$ & 560 & 150 & 240 & 240 & -- & 210 & 150 & 322 & 479 & 438 & 516 & 780 \\
\hline $30 . . .6$ & $\$ 15$ & 365 & 280 & 227 & - & 197 & 131 & 345 & 480 & 371 & 509 & 765 \\
\hline $31 \ldots \ldots$ & 512 & $\cdots$ & 200 & 154 & - & 160 & - & 335 & -- & 491 & 489 & - \\
\hline AVERAGE & 458 & 427 & 293 & 220 & 170 & 220 & 167 & 251 & 412 & 412 & 411 & 630 \\
\hline
\end{tabular}

TEMPERATURE ( $\left.{ }^{\circ} \mathrm{C}\right)$ OF WATER, WATER YEAR OCTOBER 1969 TO SEPTEMBER 1970

\begin{tabular}{|c|c|c|c|c|c|c|c|c|c|c|c|c|}
\hline $04 Y$ & $\mathrm{OCT}$ & NOV & $O E C$ & JAN & FEB & MAR & $A^{\rho} \boldsymbol{R}$ & MAY & JUN & JUL & AUG & SEP \\
\hline $\begin{array}{l}1 \\
2 \\
3 \\
4 \\
5\end{array}$ & $\begin{array}{l}17.0 \\
17.5 \\
18.5 \\
19.5 \\
18.5\end{array}$ & $\begin{array}{l}11.0 \\
12.5 \\
12.0 \\
12.5 \\
12.0\end{array}$ & $\begin{array}{l}4.5 \\
4.0 \\
4.0 \\
3.0 \\
1.5\end{array}$ & $\begin{array}{r}4.5 \\
-.5 \\
4.5 \\
3.5 \\
2.0\end{array}$ & $\begin{array}{l}3.5 \\
4.5 \\
5.0 \\
2.0 \\
2.0\end{array}$ & $\begin{array}{l}6.0 \\
6.5 \\
9.0 \\
8.5 \\
8.5\end{array}$ & $\begin{array}{r}8.0 \\
8.5 \\
8.0 \\
10.0 \\
8.5\end{array}$ & $\begin{array}{l}17.5 \\
19.0 \\
18.0 \\
17.0 \\
15.0\end{array}$ & $\begin{array}{r}21.5 \\
-.0 \\
24.0 \\
23.0 \\
23.0\end{array}$ & $\begin{array}{l}24.5 \\
25.0 \\
25.5 \\
27.5 \\
26.0\end{array}$ & $\begin{array}{l}27.0 \\
27.5 \\
25.5 \\
25.0 \\
25.0\end{array}$ & $\begin{array}{l}24.5 \\
23.5 \\
26.0 \\
24.5 \\
24.0\end{array}$ \\
\hline $\begin{array}{r}6 \\
7 \\
8 \\
9 \\
10\end{array}$ & $\begin{array}{l}17.5 \\
17.0 \\
17.5 \\
16.5 \\
16.5\end{array}$ & $\begin{array}{r}10.0 \\
10.0 \\
10.0 \\
9.5 \\
9.0\end{array}$ & $\begin{array}{l}2.0 \\
2.0 \\
3.0 \\
4.0 \\
4.0\end{array}$ & $\begin{array}{l}2.0 \\
2.5 \\
0.5 \\
0.0 \\
0.0\end{array}$ & $\begin{array}{l}2.0 \\
3.5 \\
4.0 \\
4.5 \\
4.5\end{array}$ & $\begin{array}{l}7.5 \\
9.0 \\
8.0 \\
7.5 \\
8.0\end{array}$ & $\begin{array}{r}8.0 \\
8.0 \\
8.0 \\
10.0 \\
11.0\end{array}$ & $\begin{array}{l}15.5 \\
14.5 \\
14.5 \\
18.5 \\
19.0\end{array}$ & $\begin{array}{l}24.0 \\
22.5 \\
22.0 \\
22.0 \\
23.0\end{array}$ & $\begin{array}{l}23.0 \\
23.5 \\
23.5 \\
24.0 \\
23.5\end{array}$ & $\begin{array}{l}25.5 \\
24.5 \\
26.5 \\
24.0 \\
22.0\end{array}$ & $\begin{array}{l}23.5 \\
24.5 \\
24.5 \\
25.0 \\
24.0\end{array}$ \\
\hline $\begin{array}{l}11 \\
12 \\
13 \\
14 \\
15\end{array}$ & $\begin{array}{l}17.0 \\
17.5 \\
18.0 \\
18.0 \\
16.0\end{array}$ & $\begin{array}{r}9.5 \\
10.5 \\
9.5 \\
10.0 \\
7.0\end{array}$ & $\begin{array}{l}5.0 \\
5.5 \\
5.0 \\
5.5 \\
4.5\end{array}$ & $\begin{array}{l}0.0 \\
0.0 \\
0.0 \\
0.5 \\
0.0\end{array}$ & $\begin{array}{l}4.0 \\
3.5 \\
4.0 \\
3.0 \\
2.5\end{array}$ & $\begin{array}{l}8.5 \\
9.0 \\
9.0 \\
7.5 \\
6.5\end{array}$ & $\begin{array}{l}11.5 \\
12.5 \\
13.0 \\
12.5 \\
11.5\end{array}$ & $\begin{array}{l}19.5 \\
19.0 \\
20.0 \\
21.0 \\
21.5\end{array}$ & $\begin{array}{l}22.5 \\
23.0 \\
24.0 \\
24.0 \\
23.0\end{array}$ & $\begin{array}{l}22.0 \\
21.0 \\
22.0 \\
24.0 \\
24.5\end{array}$ & $\begin{array}{l}21.5 \\
20.0 \\
22.0 \\
23.0 \\
24.0\end{array}$ & $\begin{array}{l}23.0 \\
21.5 \\
23.5 \\
22.0 \\
23.5\end{array}$ \\
\hline $\begin{array}{l}21 \\
22 \\
23 \\
24 \\
25\end{array}$ & $\begin{array}{l}14.5 \\
14.0 \\
12.0 \\
10.5 \\
10.0\end{array}$ & $\begin{array}{l}4.0 \\
5.0 \\
4.0 \\
6.0 \\
4.5\end{array}$ & $\begin{array}{l}1.5 \\
2.5 \\
1.0 \\
1.5 \\
1.0\end{array}$ & $\begin{array}{l}0.0 \\
0.0 \\
0.0 \\
0.5 \\
0.5\end{array}$ & $\begin{array}{l}4.0 \\
3.5 \\
5.0 \\
5.0 \\
6.0\end{array}$ & $\begin{array}{l}8.0 \\
7.0 \\
7.0 \\
7.5 \\
6.5\end{array}$ & $\begin{array}{l}14.5 \\
15.0 \\
15.5 \\
16.5 \\
16.5\end{array}$ & $\begin{array}{l}21.5 \\
23.0 \\
23.0 \\
24.0 \\
24.5\end{array}$ & $\begin{array}{l}25.0 \\
24.0 \\
24.5 \\
24.0 \\
24.0\end{array}$ & $\begin{array}{l}24.0 \\
23.0 \\
22.0 \\
22.5 \\
26.0\end{array}$ & $\begin{array}{l}24.5 \\
26.0 \\
24.5 \\
23.5 \\
23.0\end{array}$ & $\begin{array}{r}22.0 \\
23.5 \\
-1 \\
24.0 \\
24.0\end{array}$ \\
\hline $\begin{array}{l}26 \\
27 \\
28 \\
29 \\
30 \\
31\end{array}$ & $\begin{array}{r}11.0 \\
10.5 \\
9.5 \\
8.5 \\
7.5 \\
10.0\end{array}$ & $\begin{array}{l}6.5 \\
6.0 \\
6.0 \\
6.0 \\
5.0 \\
=-\end{array}$ & $\begin{array}{l}0.0 \\
0.0 \\
0.0 \\
1.5 \\
2.5 \\
4.5\end{array}$ & $\begin{array}{l}1.5 \\
2.5 \\
3.5 \\
4.5 \\
3.5 \\
4.5\end{array}$ & $\begin{array}{c}4.0 \\
3.5 \\
5.0 \\
-- \\
-- \\
--\end{array}$ & $\begin{array}{r}8.0 \\
7.5 \\
10.0 \\
9.5 \\
3.5 \\
7.0\end{array}$ & $\begin{array}{c}15.0 \\
15.0 \\
16.0 \\
16.0 \\
17.0 \\
-.-\end{array}$ & $\begin{array}{l}24.0 \\
22.5 \\
21.5 \\
21.0 \\
20.0 \\
20.5\end{array}$ & $\begin{array}{r}24.0 \\
25.0 \\
22.5 \\
22.0 \\
22.5 \\
.-\end{array}$ & $\begin{array}{l}25.5 \\
25.5 \\
24.5 \\
26.0 \\
26.5 \\
26.0\end{array}$ & $\begin{array}{l}24.0 \\
24.0 \\
23.0 \\
26.0 \\
24.0 \\
25.0\end{array}$ & $\begin{array}{r}23.5 \\
23.5 \\
20.0 \\
18.5 \\
17.0 \\
-.\end{array}$ \\
\hline$\Delta V G$ & 14.5 & 1.9 & 2.7 & 1.6 & 3.8 & 7.6 & 12.3 & 19.6 & 23.4 & 24.4 & 24.2 & 23.2 \\
\hline
\end{tabular}


LOCATION,- Lat $37^{\circ} 40^{\prime} 15^{\prime \prime}$, long $78^{\circ} 05^{\prime} 10^{\prime \prime}$, Goochland County, at gaging station on left bank $200 \mathrm{ft}$ downstream from bridge on State Highwa 45 between Pemberton and Cartersvilie, 1.8 miles downstream from willis River, and at A INAGE AREA . --6,257 sq mi (revised).

PERIOD OF RECORD,--Chemical analyses: April 1929 to March 1930, October 1947 to September 1948 , January 1966 to September 1970 .

April 1968 to September 1970

EXTREMES. - 1969-70:

Speciflc conductance: Maximum daily, 420 micromhos Sept. 29; minimum daily, 80 micromhos Jan. 3.

Water temperatures: Maximum, $31.5^{\circ} \mathrm{C}$ July 3 ; minimum, freezing point on several days durıng December and Jan-

Period of record:

Dissolved solids (1928-29, 1968-69): Yaximum, 240 mg/l Oct. 1-7, 1968; minimum, 64 mg/1 July $11-20,1929$. Specific conductance: Maximum dailum, $122 \mathrm{mg} / 1$ Oct. 1-7, 1968; minlmum, $30 \mathrm{mg} / 1 \mathrm{Aug} .20,1969$.

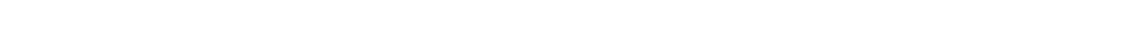
REMARKS.--Chemical-quality data represent equal-volume composites for the periods indicated prior to Nov. 1 and
for every seventh day thereafter.

CHEMICAL ANALYSES, WATER YEAR OCTOBER 1969 TO SEPTEMBER 1970

\begin{tabular}{|c|c|c|c|c|c|c|c|c|c|c|}
\hline DATE & $\begin{array}{l}\text { MEAN } \\
\text { OIS- } \\
\text { CHALGE } \\
\text { (CFS) }\end{array}$ & $\begin{array}{l}\text { SILICA } \\
\text { (SIOZ) } \\
\text { (MG/L) }\end{array}$ & $\begin{array}{l}\text { DIS- } \\
\text { SOLVEO } \\
\text { IRON } \\
\text { (FE) } \\
\text { (UG/L) }\end{array}$ & $\begin{array}{l}C A L- \\
C I U M \\
(C A) \\
(M G / L)\end{array}$ & $\begin{array}{l}\text { MAG- } \\
\text { NE- } \\
\text { SIUM } \\
\text { (MG) } \\
(M G / L)\end{array}$ & $\begin{array}{l}\text { SOD I UM } \\
\text { (NA) } \\
\text { (MG/L) }\end{array}$ & $\begin{array}{l}\text { PO- } \\
\text { TAS- } \\
\text { SIUM } \\
(K) \\
(M G / L)\end{array}$ & $\begin{array}{l}\text { BICAR- } \\
\text { BONATE } \\
\text { (HCDI) } \\
\text { (MGIL) }\end{array}$ & $\begin{array}{l}\text { SULFATE } \\
\text { (SO } 4) \\
\text { (MG/L) }\end{array}$ & $\begin{array}{l}\text { CHLD- } \\
\text { RIOE } \\
\text { ICLL) } \\
\text { (MG/L) }\end{array}$ \\
\hline \multicolumn{11}{|l|}{ ocr. } \\
\hline $01-10$ & 2330 & 6.3 & 140 & 30 & 2.1 & 12 & 3.5 & 67 & 33 & 13 \\
\hline $12-20$ & 1710 & 6.9 & 110 & 20 & 4.9 & 10 & 2.3 & 56 & 36 & 8.9 \\
\hline $2 \mid-31$ & 1430 & 4.9 & 190 & 27 & 5.4 & 13 & $x .0$ & 61 & 43 & 13 \\
\hline \multicolumn{11}{|l|}{ Nov. } \\
\hline $\begin{array}{l}12 . . . \\
20 .\end{array}$ & $\begin{array}{l}2240 \\
2120\end{array}$ & $\begin{array}{l}8.1 \\
8.5\end{array}$ & $\begin{array}{l}700 \\
590\end{array}$ & $\begin{array}{l}27 \\
24\end{array}$ & 5.9 & $\begin{array}{l}15 \\
16\end{array}$ & $\begin{array}{l}3.5 \\
2.7\end{array}$ & $\begin{array}{l}80 \\
58\end{array}$ & $\begin{array}{l}36 \\
41\end{array}$ & $\begin{array}{l}20 \\
20\end{array}$ \\
\hline $28 \ldots$ & 2420 & 7.9 & 310 & 24 & 5.5 & 15 & 2.3 & $\begin{array}{l}58 \\
65\end{array}$ & $\begin{array}{l}41 \\
40\end{array}$ & $\begin{array}{l}20 \\
17\end{array}$ \\
\hline \multicolumn{11}{|l|}{$D E C$} \\
\hline $31 \ldots$ & $\begin{array}{l}1860 \\
1830\end{array}$ & $\begin{array}{l}6.9 \\
8.3\end{array}$ & $\begin{array}{l}50 n \\
6 ? n\end{array}$ & 22 & 4.2 & 13 & 3.1 & 54 & 35 & $\begin{array}{l}15 \\
19\end{array}$ \\
\hline $\begin{array}{l}35 \ldots \\
12 \ldots\end{array}$ & $\begin{array}{r}1830 \\
11250\end{array}$ & $\begin{array}{l}8.3 \\
8.5\end{array}$ & $\begin{array}{l}620 \\
180\end{array}$ & $\begin{array}{l}25 \\
15\end{array}$ & 4.8 & 16.0 & 2.7 & $\begin{array}{l}58 \\
34\end{array}$ & $\begin{array}{l}41 \\
31\end{array}$ & $\begin{array}{l}10 \\
9.9\end{array}$ \\
\hline $26 \ldots$ & $363 n$ & 7.9 & $\begin{array}{r}180 \\
10\end{array}$ & $\begin{array}{l}13 \\
17\end{array}$ & 2.5 & $\begin{array}{l}9.0 \\
6.0\end{array}$ & 1.3 & 44 & 23 & $=2$ \\
\hline $27 \ldots$ & 3430 & 9.6 & 540 & 16 & 2.7 & 7.2 & 1.6 & 38 & 24 & 6.9 \\
\hline $30 \ldots$ & 4130 & 9.7 & 230 & 13 & 2.5 & 7.8 & 1.5 & 38 & 21 & 7.2 \\
\hline \multicolumn{11}{|l|}{ JAN. } \\
\hline $05 \ldots$ & 13400 & $t . ?$ & 190 & 15 & 2.5 & 3.2 & 1.0 & 41 & 14 & 3.6 \\
\hline $12 \ldots$ & 5100 & 9.4 & 679 & 16 & $2 . A$ & 5.0 & 1.2 & 47 & 18 & 6.1 \\
\hline $19 \ldots$ & 6200 & c. 5 & 493 & 16 & 2.3 & 5.7 & 2.0 & 46 & 16 & 7.3 \\
\hline $3^{n} \ldots$ & 5600 & 9.7 & $55 n$ & 12 & 3.1 & 5.6 & 1.0 & 35 & IA & 6.4 \\
\hline \multicolumn{11}{|l|}{ FEB. } \\
\hline$n 2 \ldots$ & 8600 & 7. $n$ & 350 & 22 & 4.9 & 10 & 1.6 & 76 & 23 & 11 \\
\hline $09 \ldots$ & 8120 & 8.7 & $2 \geq 0$ & 14 & 3.2 & 4.4 & .9 & 42 & 14 & 5.2 \\
\hline $23 \ldots$ & $117 x$ & 7.0 & 180 & $I_{R}$ & 2.9 & 4.4 & 1.1 & $4 B$ & 17 & 4.3 \\
\hline $27 \ldots$ & 7320 & 7.9 & 230 & 12 & 3.1 & 4.4 & .7 & 41 & 12 & 4.9 \\
\hline \multicolumn{11}{|l|}{ MAR. } \\
\hline$n 2 \ldots$ & 5940 & 7.4 & $\begin{array}{l}253 \\
120\end{array}$ & $\begin{array}{l}19 \\
2 n\end{array}$ & 4.2 & 3.1 & $\begin{array}{l}1.0 \\
1.1\end{array}$ & $\begin{array}{l}58 \\
54\end{array}$ & $\begin{array}{l}19 \\
24\end{array}$ & $\begin{array}{l}6.0 \\
7.0\end{array}$ \\
\hline $09 .$. & $\begin{array}{l}5990 \\
42 \cap 0\end{array}$ & 7.6 & $\begin{array}{l}12 n \\
13 n\end{array}$ & $\begin{array}{l}2 n \\
17\end{array}$ & 4.6 & 7.0 & 1.1 & 54 & $\begin{array}{l}24 \\
18\end{array}$ & $\begin{array}{l}7.9 \\
7.4\end{array}$ \\
\hline $16 \ldots$ & $42 n n$ & 7.5 & & $\begin{array}{l}17 \\
16\end{array}$ & 4.4 & $5 \cdot 8$ & $\begin{array}{l}1.0 \\
1.0\end{array}$ & 54 & 18 & $\begin{array}{l}1.4 \\
6.6\end{array}$ \\
\hline $23 \ldots$ & 8310 & $c^{2}, 3$ & $13 n$ & & 4.0 & 5.6 & 1.0 & 44 & 17 & 6.6 \\
\hline $27 \ldots$ & 6347 & 7.7 & $2 n 0$ & 14 & 3.4 & 5.4 & 1.0 & 44 & 13 & 7.2 \\
\hline $30 \ldots$ & 11500 & 8.4 & 110 & 11 & 2.6 & 4.4 & 1.5 & 32 & 15 & 5.5 \\
\hline \multicolumn{11}{|l|}{$A P Q$} \\
\hline $06 \ldots$ & 13370 & $7 \cdot 4$ & 60 & 15 & 3.0 & 4.0 & 1.0 & 46 & 14 & 5.4 \\
\hline $13 \ldots$ & 6410 & 7.7 & 50 & 16 & 3.3 & 4.0 & .9 & 48 & 18 & $\begin{array}{l}6.2 \\
8.7\end{array}$ \\
\hline $22 \ldots$ & 6760 & 7.5 & 130 & 19 & 3.6 & 7.0 & 1.2 & 55 & 20 & 8.7 \\
\hline $27 \ldots$ & 8730 & 8.2 & 50 & 13 & 3.4 & 5.7 & 1.0 & 47 & 14 & 5.8 \\
\hline \multirow{2}{*}{\multicolumn{11}{|c|}{ MAY }} \\
\hline & & & & & & & & & & \\
\hline $11 \ldots$ & 5360 & 8.7 & 80 & $2 n$ & 2.9 & 4.9 & 1.1 & 46 & 20 & 6.0 \\
\hline $18 \ldots$ & ston & 9.1 & $2^{n}$ & 19 & 3.6 & 6.2 & 1.4 & 54 & 20 & 6.5 \\
\hline $25 \ldots$ & 3010 & 8.5 & 40 & 22 & 3.0 & 7.9 & 1. & 53 & 27 & 8.3 \\
\hline $29 . .$. & 2980 & 8.7 & $2 n 0$ & 16 & 3.4 & 7.0 & 1.8 & 48 & 16 & 6.4 \\
\hline \multicolumn{9}{|l|}{ JUNE } & & \\
\hline 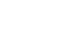 & $\begin{array}{l}21>0 \\
2040\end{array}$ & $\begin{array}{l}7.2 \\
6.2\end{array}$ & $\begin{array}{l}69 \\
50\end{array}$ & $\begin{array}{l}23 \\
24\end{array}$ & 5.1 & $10^{\circ}$ & 2.2 & 51 & 41 & 11 \\
\hline $\begin{array}{l}n . \ldots \\
15 \ldots\end{array}$ & $1740^{\circ}$ & $\begin{array}{l}6.2 \\
4.9\end{array}$ & $\begin{array}{l}50 \\
80\end{array}$ & $\begin{array}{l}24 \\
28\end{array}$ & 5.1 & 11 & 2.5 & 69 & 37 & 14 \\
\hline $\begin{array}{l}15 \ldots \\
22 \ldots\end{array}$ & 1440 & $\begin{array}{l}4.8 \\
4.7\end{array}$ & 50 & 30 & 5.9 & 15 & 2.6 & 74 & 41 & 19 \\
\hline $29 \ldots$ & 1100 & 3.6 & 1 & 33 & 5.7 & 19 & 2.9 & B 2 & 47 & 21 \\
\hline \multicolumn{11}{|l|}{ JuL $29 .}$. \\
\hline $1 \ldots$ & 1192 & 2.7 & 20 & 39 & 4.5 & 20 & 2.9 & 68 & 63 & 21 \\
\hline c5... & $138^{n}$ & 4.7 & in & 29 & 4.4 & 15 & 2.6 & 60 & 50 & 14 \\
\hline $13 \ldots$ & $405 n$ & 5.1 & $5 n$ & 38 & 5.6 & 18 & 3.0 & 51 & 73 & $\begin{array}{l}19 \\
33\end{array}$ \\
\hline $20 \ldots$ & 1757 & 4.3 & 5n & 39 & 5.5 & 26 & 3.6 & 86 & 54 & 33 \\
\hline $27 \ldots$ & 1610 & 7.2 & in & 27 & 4.0 & 10 & 2.6 & $5 n$ & 43 & 11 \\
\hline $32 \ldots$ & 1920 & 6.0 & 190 & 26 & 2.7 & ค. 8 & 2.2 & 31 & 47 & 9.3 \\
\hline \multicolumn{11}{|l|}{$\begin{array}{l}32, \ldots \\
A \cup G,\end{array}$} \\
\hline $03 \ldots$ & 2293 & 9.0 & 0 & 18 & 3.4 & 8.2 & 2.6 & $\begin{array}{l}48 \\
59\end{array}$ & $\begin{array}{l}25 \\
42\end{array}$ & \\
\hline $10 \ldots$ & $215^{\prime}$ & 6.9 & 20 & 25 & 4.2 & 14 & & 83 & 37 & $\begin{array}{l}15 \\
20\end{array}$ \\
\hline $17 \ldots$ & $161^{\circ}$ & 7.1 & $3 n$ & 33 & 3.6 & 17 & $\begin{array}{l}3.5 \\
3.1\end{array}$ & 55 & 54 & 25 \\
\hline $24 \ldots$ & $134 n$ & 6.8 & 20 & 29 & 7.4 & 17 & $\begin{array}{l}3.1 \\
2.9\end{array}$ & 62 & 52 & 20 \\
\hline $\begin{array}{l}31 \\
\text { SEPT. }\end{array}$ & 1090 & 4.8 & 10 & 29 & 6.6 & 16 & & & & \\
\hline $07 \ldots$ & 770 & 3.0 & 60 & 31 & 7.5 & 17 & 3.2 & 56 & 67 & 16 \\
\hline $14 \ldots$ & Iin & $2 \cdot 1$ & 20 & 35 & $2 \cdot 1$ & 26 & 4.4 & 65 & 76 & 28 \\
\hline $21 \ldots$ & 958 & 3.2 & 0 & 37 & 7.4 & 30 & 4.7 & 78 & 72 & 30 \\
\hline $23 \ldots$ & 657 & 3.2 & 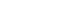 & 36 & 7.5 & 30 & 3.9 & 12 & 71 & 30 \\
\hline $29 .$. & КВ० & 3.4 & 10 & 37 & 8.3 & 30 & 5.1 & 74 & 81 & 30 \\
\hline
\end{tabular}


JAMES RIVER BASIN

02035000 JAMES RIVER AT CARTERSVLLE, VA.--Continued

CHEMICAL ANALYSES, WAIER YEAR CCTOBER 1969 IC SEPTEMBER 1970

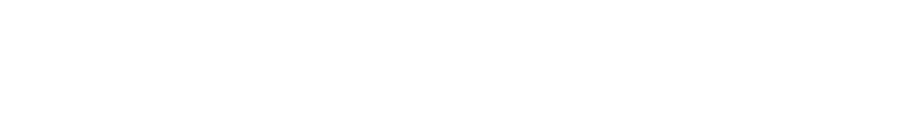

OCT

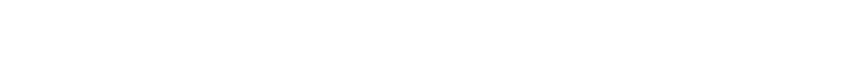

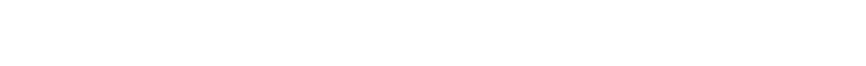

$\begin{array}{llllllllll}01 \ldots & .2 & 3.3 & .15 & 138 & 72 & 28 & 224 & 7.3 & 3 c \\ 05 \ldots . & .2 & 4.1 & .05 & 15 \varepsilon & 82 & 27 & 255 & 7.3 & 40 \\ 12 \ldots & .2 & 4.6 & .30 & 117 & 52 & 24 & 158 & 6.7 & 3 c \\ 20 \ldots & .2 & 3.8 & .00 & 97 & 53 & 17 & 146 & 7.2 & 40\end{array}$

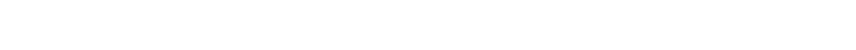

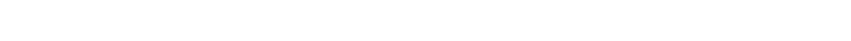

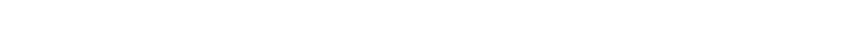

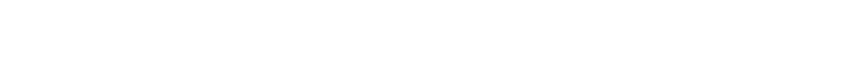

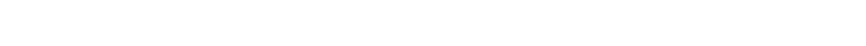

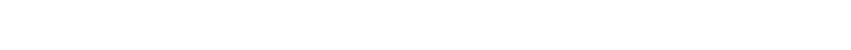

$\begin{array}{lllll}02 \ldots & .0 & 1.8 & .00 & \\ 09 . . . & .1 & 2.7 & .00 & .10\end{array}$

$\begin{array}{llll}09 \ldots & .1 & 2.7 & .00 \\ 16 \ldots & : 1 & 2.9 & .00\end{array}$

$23, \ldots:$

$\begin{array}{lll}27 \\ 30 \ldots & : 0\end{array}$

$\begin{array}{rrrrr}06 \ldots & .1 & 1.7 & .01 & 53 \\ 13 \ldots & .1 & 2 . \mathrm{C} & .00 & 104\end{array}$

$\begin{array}{ll}3.4 & .08 \\ 3.1 & .02\end{array}$

89
87
77

$\begin{array}{lllll}64 & 16 & 150 & 7.6 & 25 \\ 69 & 16 & 185 & 7.3 & 15\end{array}$

$\begin{array}{lllll}62 & 16 & 185 & 7.3 & 15 \\ 55 & 15 & 158 & 7.3 & 26 \\ 45 & 15 & 133 & 7.3 & 35\end{array}$

$\begin{array}{lllll}43 & 12 & 141 & 7.0 & 20 \\ 38 & 12 & 103 & 6.9 & 25\end{array}$

$27 \ldots:$

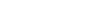

4... .2

$\begin{array}{rrrrr}11 \ldots . . & : 2 & 2.4 & .00 & 55 \\ 18 \ldots & : 1 & 6.4 & .00 & 104\end{array}$

$\begin{array}{lllll}1 & .1 & 3.8 & .00 & 102 \\ 25 \ldots & .2 & 3.8 & .00 & 123\end{array}$

JUNE

JUNE

O8,...

$15, \ldots$

$29,$.

JULY

$01 \ldots$

$13 .$.

$200-3$

$27, \ldots:$

$\begin{array}{lllll}\text { AUG } & & & & \\ 03 \ldots & .2 & 2.5 & .00 & 113 \\ 10 \ldots & .2 & 4.8 & .00 & 156 \\ 17 \ldots & .2 & 5.8 & .00 & 182\end{array}$

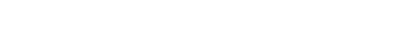

SEPT.

0.1 .00194

$\begin{array}{lll}50 & 12 & 116 \\ 54 & 14 & 131\end{array}$

116
131
152
123

$\begin{array}{rr}6.9 & 15 \\ 6.9 & 5\end{array}$

$6.9 \quad 10$

$\begin{array}{ll}6.7 & 25 \\ 6.8 & 15\end{array}$

$\begin{array}{lllll}7 \ldots . . & .3 & 0.1 & .00 & 196 \\ 14 \ldots & .3 & t .7 & .04 & 238\end{array}$

$\begin{array}{lllll}21 \ldots & .3 & 6.5 & .00 & 244 \\ 28 \ldots & .3 & 5.5 & .00 & 235\end{array}$

ANALYSES OF ADDITIONAL SAMPLES

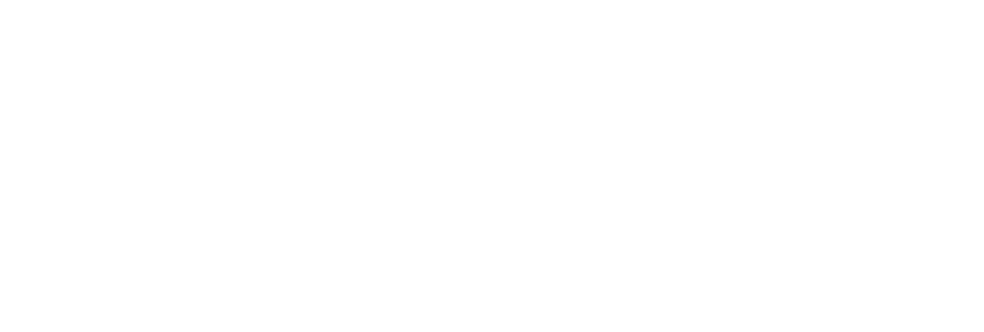

\begin{tabular}{|c|c|c|c|c|c|c|c|c|c|}
\hline $\begin{array}{l}30 . . \\
\text { Aug. }\end{array}$ & $\cdot 3$ & 7.2 & .08 & 159 & 87 & 42 & 265 & 7.1 & $4 C$ \\
\hline & .2 & 3.2 & .01 & $17 \mathrm{t}$ & 95 & 45 & 265 & 8.0 & 20 \\
\hline
\end{tabular}


JAKES RIVER BASIN

O2019500 JAMES RIVER AT BUCHANAN, VA.-Continued

SPECIFIC CONDUCTANCE (MICROMHOS/CM AT $25^{\circ} \mathrm{C}$ ), WATER YEAR OCTOBER 1969 TO SEPTEMBER 1970

DAY OCTOBER NOVEMBER DECEMBER JANUARY FEBRUARY

MARCH

$\begin{array}{llll}1 \ldots \ldots . & 239 & 251 & 250 \\ 2 \ldots \ldots & 245 & 247 & -25 \\ 3 \ldots \ldots & 233 & 251 & 250 \\ 40 . . & 235 & 264 & 251\end{array}$

$\begin{array}{lll}4 \ldots \ldots & 235 & 264 \\ 5 & 221 & 252\end{array}$

6.... $226 \quad 265 \quad 251$

$\begin{array}{lll}7 \ldots \ldots & 212 & 271 \\ 8 \ldots \ldots & 210 & 263\end{array}$

$\begin{array}{rrr}8 \ldots \ldots . & 210 & 263 \\ 10 . \ldots . & 203 & 278 \\ 103 & 193 & 261\end{array}$

$\begin{array}{lll}11 \ldots \ldots . & - & 260 \\ 12 \ldots \ldots . & 190 & 263 \\ 13 \ldots \ldots . & 183 & 277 \\ 14 \ldots \ldots & 189 & 261\end{array}$

260
263
277
261
259

$15 . . . .2003$

$16 \ldots \ldots \quad 195 \quad 258$

$17 \ldots \ldots . \quad 207 \quad 262$

$19 \ldots \ldots .205$

269
273
257

$\begin{array}{llr}21 \ldots \ldots . & 217 & - \\ 22 \ldots \ldots & 217 & 225\end{array}$

$\begin{array}{lll}23 \ldots \ldots . & 221 & 228 \\ 24 \ldots \ldots . & 239 & 218\end{array}$

$20 \ldots \ldots \quad 230 \quad 231$

$\begin{array}{lll}27 \ldots \ldots . & 239 & 234 \\ 28 . \ldots . . & 240 & 243\end{array}$

$\begin{array}{llr}28 \ldots \ldots . & 240 & 243 \\ 69 . \ldots \ldots & 225 & 239 \\ 30 \ldots \ldots & 241 & 245 \\ 31 \ldots \ldots & 243 & -\end{array}$

AYERAGE

$\begin{array}{rr}148 & 200 \\ 98 & 210 \\ 80 & 180 \\ -98 & 124 \\ 98 & 110 \\ 108 & 122 \\ 112 & 130 \\ 120 & 130 \\ 130 & 130 \\ 138 & 116\end{array}$

228
210
194

$\begin{array}{lll}169 & 136 & 106 \\ 158 & 136 & 120 \\ 249 & 155 & 140 \\ 171 & 155 & 148 \\ 178 & 158 & 150\end{array}$

202
195
183
170

$\begin{array}{rrr}135 & - & -- \\ 136 & -- & 142 \\ 136 & 167 & 140 \\ 148 & 130 & 148 \\ 146 & 132 & 155\end{array}$

158
163
164
148
142

155

146
124
130
140

$\begin{array}{ll}160 & 163 \\ 170 & 146 \\ 165 & 138 \\ 185 & 120 \\ 195 & 126\end{array}$

$\frac{145}{133}$

$\begin{array}{lll}146 & 7 & 136 \\ 145 & 170 & 134 \\ 164 & 165 & 142 \\ 138 & 175 & -- \\ 130 & 178 & -\end{array}$

114

180

176

140

165

158
200
210
180
124
110
122
130
130
130
116

$\begin{array}{lr}148 & 125 \\ 150 & 122 \\ 155 & 98 \\ 160 & 100 \\ 160 & - \\ 158 & 116 \\ 160 & 112 \\ 175 & 111 \\ 185 & 115 \\ 185 & 116\end{array}$

125
122
9
10

$\begin{array}{ll}25 & 134 \\ 98 & 14 \\ 90 & 133\end{array}$

$\begin{array}{ll}134 & 1 \\ 145 & 2 \\ 143 & 2 \\ 133 & 2 \\ 113 & 2 \\ 100 & \\ 102 & 2 \\ 113 & 2 \\ 127 & 206 \\ 130 & \end{array}$

$\begin{array}{ll}196 & 30 \\ 202 & 314 \\ 211 & 296\end{array}$

$\begin{array}{ll}210 & 294 \\ 203 & 255\end{array}$

$206 \quad 260$

$\begin{array}{llll}217 & 257 & 258 & 293 \\ 206 & 264 & 272 & 295\end{array}$

124
126
131
128
122

134

134
135
132

204

$203 \quad 210$

$\begin{array}{lll}277 & 261 & 310 \\ 274 & 219\end{array}$

$\begin{array}{lll}210 & 263 & 320 \\ 304 & 237 & 315\end{array}$

123
148
147
156
152

141

130
126
132
13

146

$\begin{array}{ll}165 & 140 \\ 165 & 123 \\ 165 & 120 \\ 160 & 128 \\ 103 & 146 \\ 105 & \end{array}$

$127 \quad 148$

150
155

148

$\begin{array}{llll}244 & 157 & \overrightarrow{15} & 370 \\ 248 & 287 & 257 & 361 \\ 238 & 304 & 239 & 388 \\ 267 & 35 & 247 & 362\end{array}$

$\begin{array}{llll}238 & 304 & 239 & 388 \\ 247 & 315 & 248 & 378 \\ 269 & 337 & 247 & 362\end{array}$

15

155
159
165
173

273
264
259

$\begin{array}{llll}273 & 377 & 264 & 380 \\ 264 & 401 & 263 & 350\end{array}$

$\begin{array}{lllll}173 & 259 & 389 & 301 & 340 \\ 177 & 282 & 331 & 283 & 350\end{array}$

$\begin{array}{lllll}172 & 279 & 197 & 266 & 380 \\ 181 & 296 & 200 & 278 & 38\end{array}$

$\begin{array}{lllll}181 & 296 & 200 & 278 & 383 \\ 184 & 275 & 179 & 270 & 369\end{array}$

$\begin{array}{lllll}183 & 288 & 183 & 270 & 369 \\ 194 & 302 & 214 & 273 & 420\end{array}$

199

239

276

$253 \quad 341$

TEMPERATURE $\left({ }^{\circ} \mathrm{C}\right)$ OF WATER, HATER YEAR OCTOBER 1969 TO SEPTEMBER 1970

\begin{tabular}{|c|c|c|c|c|c|c|c|c|c|c|c|c|}
\hline DAY & DC T & NOV & DEC & JAN & FEB & MAR & APR & MAY & JUN & JUL. & AUG & SEP \\
\hline $\begin{array}{l}1 \\
2 \\
3 \\
4 \\
5\end{array}$ & $\begin{array}{l}19.5 \\
20.0 \\
21.0 \\
20.5 \\
19.5\end{array}$ & $\begin{array}{l}13.0 \\
14.5 \\
15.0 \\
14.5 \\
12.5\end{array}$ & $\begin{array}{r}5.5 \\
-.5 \\
4.0 \\
3.5 \\
3.5\end{array}$ & $\begin{array}{r}2.5 \\
4.5 \\
5.0 \\
-.0 \\
3.0\end{array}$ & $\begin{array}{l}4.5 \\
5.0 \\
6.0 \\
4.5 \\
3.0\end{array}$ & $\begin{array}{l}6.0 \\
7.0 \\
7.0 \\
7.0 \\
7.5\end{array}$ & $\begin{array}{r}8.5 \\
10.0 \\
11.5 \\
10.0 \\
=-\end{array}$ & $\begin{array}{l}20.0 \\
20.5 \\
19.0 \\
17.5 \\
16.5\end{array}$ & $\begin{array}{l}24.0 \\
24.5 \\
26.0 \\
26.0 \\
26.0\end{array}$ & $\begin{array}{l}27.0 \\
28.5 \\
31.5 \\
29.5 \\
27.0\end{array}$ & $\begin{array}{l}28.5 \\
29.0 \\
28.0 \\
28.0 \\
27.0\end{array}$ & $\begin{array}{l}25.5 \\
25.5 \\
27.0 \\
26.5 \\
27.0\end{array}$ \\
\hline $\begin{array}{r}6 \\
7 \\
8 \\
9 \\
10\end{array}$ & $\begin{array}{l}19.0 \\
19.5 \\
19.5 \\
19.0 \\
19.5\end{array}$ & $\begin{array}{l}11.5 \\
11.5 \\
11.0 \\
10.5 \\
11.0\end{array}$ & $\begin{array}{l}3.0 \\
2.5 \\
3.5 \\
4.0 \\
5.0\end{array}$ & $\begin{array}{l}2.5 \\
2.5 \\
1.0 \\
0.0 \\
0.0\end{array}$ & $\begin{array}{l}4.5 \\
3.5 \\
3.5 \\
3.5 \\
4.0\end{array}$ & $\begin{array}{l}8.0 \\
8.0 \\
8.5 \\
9.0 \\
9.0\end{array}$ & $\begin{array}{r}9.5 \\
9.5 \\
10.5 \\
12.0 \\
13.0\end{array}$ & $\begin{array}{l}16.5 \\
16.5 \\
17.0 \\
18.5 \\
20.5\end{array}$ & $\begin{array}{l}27.0 \\
25.0 \\
25.0 \\
25.5 \\
26.0\end{array}$ & $\begin{array}{l}27.5 \\
29.5 \\
26.5 \\
26.5 \\
25.0\end{array}$ & $\begin{array}{l}26.5 \\
26.0 \\
26.0 \\
26.0 \\
24.0\end{array}$ & $\begin{array}{l}26.0 \\
24.0 \\
25.0 \\
25.0 \\
26.0\end{array}$ \\
\hline $\begin{array}{l}12 \\
12 \\
13 \\
14 \\
15\end{array}$ & $\begin{array}{l}-- \\
19.5 \\
19.5 \\
21.0 \\
18.5\end{array}$ & $\begin{array}{l}11.0 \\
11.0 \\
11.0 \\
10.5 \\
10.0\end{array}$ & $\begin{array}{r}5.5 \\
5.0 \\
5.0 \\
-.5 \\
4.5\end{array}$ & $\begin{array}{l}0.5 \\
2.5 \\
0.0 \\
1.0 \\
1.0\end{array}$ & $\begin{array}{l}5.0 \\
4.5 \\
3.5 \\
4.0 \\
3.5\end{array}$ & $\begin{array}{l}9.0 \\
9.0 \\
8.0 \\
8.0 \\
6.5\end{array}$ & $\begin{array}{l}13.0 \\
13.5 \\
11.5 \\
13.0 \\
12.0\end{array}$ & $\begin{array}{l}21.0 \\
22.0 \\
23.0 \\
24.0 \\
23.0\end{array}$ & $\begin{array}{l}26.0 \\
27.0 \\
27.0 \\
25.0 \\
24.0\end{array}$ & $\begin{array}{l}25.5 \\
26.5 \\
27.0 \\
27.5 \\
27.5\end{array}$ & $\begin{array}{l}24.0 \\
24.5 \\
25.5 \\
26.0 \\
27.0\end{array}$ & $\begin{array}{r}26.0 \\
24.5 \\
=.5 \\
25.0 \\
26.0\end{array}$ \\
\hline $\begin{array}{l}16 \\
17 \\
18 \\
19 \\
20\end{array}$ & $\begin{array}{l}17.5 \\
16.5 \\
15.0 \\
15.0 \\
16.0\end{array}$ & $\begin{array}{l}7.5 \\
7.5 \\
7.5 \\
8.5 \\
8.0\end{array}$ & $\begin{array}{l}4.5 \\
4.0 \\
3.0 \\
3.5 \\
3.0\end{array}$ & $\begin{array}{l}-- \\
-- \\
2.5 \\
1.0 \\
1.0\end{array}$ & $\begin{array}{l}2.5 \\
4.0 \\
5.0 \\
4.5\end{array}$ & $\begin{array}{l}2.0 \\
6.5 \\
7.0 \\
6.5 \\
7.0\end{array}$ & $\begin{array}{l}12.5 \\
14.0 \\
15.0 \\
15.0 \\
15.0\end{array}$ & $\begin{array}{l}21.5 \\
20.0 \\
19.0 \\
19.5 \\
21.0\end{array}$ & $\begin{array}{l}23.5 \\
26.0 \\
28.0 \\
28.5 \\
29.0\end{array}$ & $\begin{array}{l}27.0 \\
28.5 \\
27.5 \\
28.0 \\
29.0\end{array}$ & $\begin{array}{r}28.0 \\
28.0 \\
28.0 \\
28.0\end{array}$ & $\begin{array}{l}26.0 \\
26.0 \\
27.0 \\
26.5 \\
24.5\end{array}$ \\
\hline $\begin{array}{l}21 \\
22 \\
23 \\
24 \\
25\end{array}$ & $\begin{array}{l}11.5 \\
17.0 \\
14.0 \\
12.0 \\
11.0\end{array}$ & $\begin{array}{l}-. \\
5.0 \\
6.0 \\
8.0 \\
7.0\end{array}$ & $\begin{array}{l}2.5 \\
3.5 \\
2.0 \\
2.5 \\
1.5\end{array}$ & $\begin{array}{l}0 . c \\
0.1 \\
0 . c \\
0.0 \\
=-\end{array}$ & $\begin{array}{l}5.0 \\
6.0 \\
6.0 \\
6.0 \\
6.0\end{array}$ & $\begin{array}{r}8.0 \\
--0 \\
8.0 \\
9.0\end{array}$ & $\begin{array}{l}15.5 \\
16.0 \\
15.5 \\
17.5 \\
18.0\end{array}$ & $\begin{array}{l}23.0 \\
23.5 \\
25.0 \\
26.0 \\
26.0\end{array}$ & $\begin{array}{l}27.0 \\
28.0 \\
28.0 \\
27.0 \\
? 7.5\end{array}$ & $\begin{array}{l}26.0 \\
25.0 \\
24.0 \\
25.5 \\
26.5\end{array}$ & $\begin{array}{l}28.0 \\
21.5 \\
21.0 \\
25.0 \\
26.0\end{array}$ & $\begin{array}{l}24.5 \\
27.0 \\
27.0 \\
27.5 \\
27.5\end{array}$ \\
\hline $\begin{array}{l}26 \\
27 \\
28 \\
29 \\
30 \\
31\end{array}$ & $\begin{array}{l}12.0 \\
12.5 \\
12.5 \\
11.5 \\
10.5 \\
11.0\end{array}$ & $\begin{array}{r}8.0 \\
7.5 \\
7.0 \\
7.0 \\
6.0 \\
-.-\end{array}$ & $\begin{array}{l}0.0 \\
1.0 \\
1.0 \\
1.5 \\
1.5 \\
3.0\end{array}$ & $\begin{array}{l}--0 \\
2.0 \\
3.0 \\
5.0 \\
5.5 \\
4.0\end{array}$ & $\begin{array}{r}5.0 \\
5.0 \\
6.0 \\
=- \\
=-\end{array}$ & $\begin{array}{r}10.5 \\
9.5 \\
10.5 \\
10.0 \\
8.0 \\
8.0\end{array}$ & $\begin{array}{r}16.0 \\
16.5 \\
17.0 \\
18.0 \\
19.5 \\
-\end{array}$ & $\begin{array}{l}25.0 \\
25.0 \\
24.0 \\
23.0 \\
23.0 \\
23.0\end{array}$ & $\begin{array}{l}27.0 \\
27.0 \\
21.0 \\
24.0 \\
24.0 \\
.0\end{array}$ & $\begin{array}{l}28.5 \\
28.0 \\
28.5 \\
28.5 \\
29.0 \\
27.5\end{array}$ & $\begin{array}{l}27.5 \\
25.0 \\
29.0 \\
27.0 \\
28.0 \\
28.0\end{array}$ & $\begin{array}{l}27.0 \\
25.5 \\
23.5 \\
20.0 \\
19.0\end{array}$ \\
\hline AVG & 16.5 & 9.6 & 3.1 & 1.9 & 4.5 & 7.8 & 13.7 & $21 \cdot 3$ & 25.9 & 27.4 & 26.4 & 25.4 \\
\hline
\end{tabular}


02038850 HOLIDAY CAEEK NEAR ANDERSONVILLE, VA,
(Hydrologic bench-mark station)

LOCATION.--Lat $37^{\circ} 24^{\prime} 55^{\prime \prime}$, long $78^{\circ} 38^{\prime} 10^{\prime \prime}$, Appomattox County, at gaging station on right bank 350 ft downstream from bridge on State Highway 614, 1 mile upstream from Holiday Lake, and 5.2 miles southwest of Andersonville. DRA INAGE AREA. $-\mathbf{8 . 5 3} \mathrm{sq} \mathrm{mi}$.

PERIOD OF RECORD.--Chemical analyses: March 1967 to September 1970.

CHEMICAL ANALYSES, WATER YEAR OCTOBER 1969 TO SEPTEMBER 1970

\begin{tabular}{|c|c|c|c|c|c|c|c|c|c|c|}
\hline DATE & $\begin{array}{l}\text { MEAN } \\
\text { DIS- } \\
\text { CHARGE } \\
\text { (CFS) }\end{array}$ & $\begin{array}{l}\text { SILICA } \\
\text { (SIOZ) } \\
\text { I MG ILI) }\end{array}$ & $\begin{array}{l}\text { DIS- } \\
\text { SOLVEC } \\
\text { IPON } \\
\text { IFEI } \\
\text { IUG I I }\end{array}$ & $\begin{array}{l}\text { CAL- } \\
\text { CIUM } \\
(C A) \\
(M G / L)\end{array}$ & $\begin{array}{c}\text { MAG- } \\
\text { NE- } \\
\text { SIUM } \\
\text { (MG) } \\
\text { (MG/L) }\end{array}$ & $\begin{array}{l}\text { SOOI UM } \\
(N A) \\
(M G / L)\end{array}$ & $\begin{array}{l}\text { PO- } \\
\text { IAS - } \\
\text { SIUM } \\
\text { (K) } \\
\text { (MGILI }\end{array}$ & $\begin{array}{l}\text { BICAR - } \\
\text { BONAT E } \\
\text { (MCO3) } \\
\text { (MG/LL) }\end{array}$ & $\begin{array}{l}\text { SULFATE } \\
\text { (SO4) } \\
\text { (MG/L) }\end{array}$ & $\begin{array}{l}\text { CHLO- } \\
\text { RIDE } \\
\text { (CL) } \\
\text { (MG/L) }\end{array}$ \\
\hline $\begin{array}{r}\partial C T . \\
01 \ldots \\
15 \ldots\end{array}$ & $\begin{array}{l}1 . A \\
2.3\end{array}$ & $\begin{array}{l}12 \\
12\end{array}$ & $\begin{array}{l}510 \\
420\end{array}$ & $\begin{array}{l}3.8 \\
3.3\end{array}$ & $\begin{array}{l}1.0 \\
1.2\end{array}$ & $\begin{array}{l}3.0 \\
3.1\end{array}$ & .8 & $\begin{array}{l}19 \\
22\end{array}$ & $\begin{array}{l}2.4 \\
2.0\end{array}$ & $\begin{array}{l}2.0 \\
1.0\end{array}$ \\
\hline $\begin{array}{l}\text { NOV. } \\
13 . . . \\
\text { JAA. }\end{array}$ & 2.4 & 12 & 490 & 1.8 & 1.0 & 5.8 & .6 & 17 & 1.0 & 2.8 \\
\hline FER. & 8.7 & 11 & 460 & 3.4 & .9 & $2 . \theta$ & .4 & 14 & 3. $c$ & 3.3 \\
\hline $\begin{array}{l}10 . . \\
M A R .\end{array}$ & 12 & 9.1 & 280 & 2.3 & 1.2 & 2.4 & .5 & 10 & 5.8 & 2.5 \\
\hline${ }_{A P R}{ }^{21} \ldots$ & 12 & 2. 3 & $33 c$ & 3.4 & 1.4 & 2.4 & .7 & 14 & 5.0 & 3.0 \\
\hline MAY & 6.0 & 10 & 260 & 2.6 & 1.0 & 2.8 & .3 & 13 & $2 \cdot c$ & 2.0 \\
\hline $\begin{array}{l}25 \ldots . . \\
\text { JUNE }\end{array}$ & 3.2 & 11 & 610 & 2.8 & 1.7 & 2.8 & .6 & 20 & 1.6 & 1.6 \\
\hline${ }_{\text {JULY }}^{23} \ddot{*}$ & 1.7 & in & 100 & 5.0 & 2.6 & 3.3 & 1.3 & 26 & 2.8 & 2.8 \\
\hline $\begin{array}{l}23 \ldots \\
\text { AUG.. }\end{array}$ & 2.9 & 11 & 660 & 3.4 & 1.2 & 3.2 & .5 & 19 & 2.4 & 1.6 \\
\hline $26 . \ldots$ & $1 . n$ & 13 & $4 ! n$ & 4.0 & .7 & 4.0 & .7 & 21 & 3.2 & 1.8 \\
\hline
\end{tabular}

\begin{tabular}{|c|c|c|c|c|c|c|c|c|c|c|}
\hline LATE & $\begin{array}{l}F L U D- \\
R I C E \\
(F) \\
(M G / L)\end{array}$ & $\begin{array}{l}\text { VITRATE } \\
\text { (NU3) } \\
\text { (MG/L) }\end{array}$ & $\begin{array}{l}\text { PHCS- } \\
\text { PHATE } \\
\text { IPCA) } \\
\text { (MG IL }\end{array}$ & $\begin{array}{l}\text { DIS- } \\
\text { SCLVEC } \\
\text { SCLICS } \\
\text { IRESI- } \\
\text { DUE AI } \\
\text { IBO C) } \\
\text { INGILI }\end{array}$ & $\begin{array}{l}\text { HARC- } \\
\text { NESS } \\
(C A, M C) \\
\text { (MCIL) }\end{array}$ & $\begin{array}{l}\text { NON- } \\
\text { CAR- } \\
\text { BCNATE } \\
\text { HARD- } \\
\text { NESS } \\
\text { (KG/L) }\end{array}$ & $\begin{array}{l}\text { SPECI- } \\
\text { FIC } \\
\text { CCAL- } \\
\text { UCTANCE } \\
\text { (MICRO- } \\
\text { MHOS) }\end{array}$ & $\begin{array}{c}\text { PH } \\
\text { (UNITS) }\end{array}$ & $\begin{array}{l}\text { TENP- } \\
\text { ERATURE } \\
\text { (DEG C) }\end{array}$ & $\begin{array}{l}\text { CDLCR } \\
\text { IPLAT- } \\
\text { INUP- } \\
\text { CDBALT } \\
\text { UNITSI }\end{array}$ \\
\hline QCT. & & & & & & & & & & \\
\hline $01 \ldots$ & .2 & +3 & . CE & 46 & 14 & 0 & 44 & 6.8 & 15.0 & 25 \\
\hline vov. & .1 & .2 & .05 & 50 & 13 & 0 & 41 & 7.0 & 14.0 & 30 \\
\hline${ }_{\operatorname{SAN}}^{13} \cdot \cdots$ & .3 & $\cdot 2$ & .29 & 41 & $\varepsilon$ & 0 & 39 & 6.9 & 9.0 & 30 \\
\hline $\begin{array}{l}21 \ldots \\
F \in B .\end{array}$ & - $\mathrm{C}$ & .1 & .03 & 37 & 12 & 0 & 42 & 7.2 & -- & 15 \\
\hline MAR... & .1 & .0 & .02 & 44 & $1 \mathrm{c}$ & 2 & 35 & 6.5 & 3.5 & 35 \\
\hline $\begin{array}{l}31 \ldots \\
\triangle P R:\end{array}$ & .1 & $\cdot I$ & - CI & $3 \epsilon$ & 15 & 3 & 35 & 6.0 & 9.0 & 45 \\
\hline$M_{M Y Y}^{30} \cdot \cdots$ & .2 & .1 & .01 & 36 & 10 & 0 & 34 & 6.4 & 19.5 & 25 \\
\hline $\begin{array}{l}25 \ldots . . \\
\text { JUNE }\end{array}$ & .1 & .6 & .10 & 48 & 14 & 0 & $3 t$ & 7.1 & 23.0 & 40 \\
\hline JULY & +1 & .8 & .06 & 53 & 23 & 2 & 54 & 6.9 & 24.0 & 10 \\
\hline $\begin{array}{l}23 \ldots \\
\triangle \cup G .\end{array}$ & .1 & 1.4 & .17 & $4 \varepsilon$ & 14 & 0 & 37 & 6.7 & 24.0 & 50 \\
\hline $26 \ldots$ & .2 & -8 & $.5 \mathrm{C}$ & 45 & 13 & 0 & 39 & 6.8 & 21.0 & 23 \\
\hline
\end{tabular}


02042500 CHICKAHOMINY RIVER NEAR PROVIDENCE FORGE, VA.

LOCATION. - Lat $37^{\circ} 26^{\prime} 10^{\prime \prime}$, long $77^{\circ} 03^{\prime} 40^{\prime \prime}$, New Kent County, at gaging station on left bank 100 ft downstream from bridge on State Highway $618,1.1 \mathrm{miles}$ southwest of Providence Forge, and 1.7 miles downstream from Schiminoe creek.

DRAINAGE AREA.--248 sq mi (revised).

PERIOD OF RECORD.--Chemical analyses: October 1968 to September 1970.

CHEMICAL ANALYSES, WATER YEAR OCTOBER 1969 TO SEPTEMBER 1970

\begin{tabular}{|c|c|c|c|c|c|c|c|c|c|c|}
\hline DATE & $\begin{array}{l}\text { MEAN } \\
\text { DIS - } \\
\text { CHARGE } \\
\text { (CFS) }\end{array}$ & $\begin{array}{l}\text { SILICA } \\
\text { (SIOZ) } \\
\text { (4G/L) }\end{array}$ & $\begin{array}{l}\text { DIS- } \\
\text { SOLVED } \\
\text { IRON } \\
\text { (FE) } \\
\text { (UGAL) }\end{array}$ & $\begin{array}{l}\text { CAL- } \\
\text { CIUM } \\
\text { (CA) } \\
\text { (MGAL) }\end{array}$ & $\begin{array}{c}\text { MAG- } \\
\text { NE- } \\
\text { SIUM } \\
(M G) \\
(M G / L)\end{array}$ & $\begin{array}{l}\text { SOOI UM } \\
\text { (NA) } \\
\text { (MG/L) }\end{array}$ & $\begin{array}{l}\text { PO- } \\
\text { TAS- } \\
\text { SIUM } \\
\text { (K) } \\
\text { (MG/L) }\end{array}$ & $\begin{array}{l}\text { BICAR - } \\
\text { BONATE } \\
\text { (HCOZ) } \\
\text { (MG/L) }\end{array}$ & $\begin{array}{l}\text { SULFATE } \\
\text { (SOL) } \\
\text { (MGIL) }\end{array}$ & $\begin{array}{l}\text { CHLO- } \\
\text { RIDE } \\
\text { ICLI) } \\
\text { (MGLI) }\end{array}$ \\
\hline $\begin{array}{l}\text { OC } \mathrm{T} . \\
23 \ldots\end{array}$ & 42 & 9.4 & 330 & 7.6 & 1.8 & 7.1 & 2.5 & 33 & 4.2 & 10 \\
\hline $\begin{array}{l}19 . . . \\
\text { JAN." }\end{array}$ & 160 & 7.8 & 410 & 6.2 & 1.3 & 6.4 & 2.7 & 21 & 7.0 & 9.2 \\
\hline FER. & 400 & 7.7 & 310 & 5.2 & 2.1 & 8.0 & 1.8 & 10 & 13 & 12 \\
\hline $\begin{array}{l}20 \ldots \ldots \\
A P R_{0}\end{array}$ & 420 & 4.7 & 270 & 5.6 & 1.5 & 8.6 & 1.7 & 10 & 10 & 14 \\
\hline MAY & 680 & 4.0 & 200 & 5.2 & 1.4 & 6.4 & 2.3 & 10 & 11 & 10 \\
\hline JuLY $25 .$. & 61 & 7.0 & 810 & 7.6 & 1.3 & 9.1 & 2.5 & 30 & 5.4 & 11 \\
\hline $\begin{array}{l}\text { B.... } \\
\text { AUG. }\end{array}$ & 111 & R. 0 & 360 & 9.4 & 2.1 & 7.5 & 2.6 & 14 & 25 & 9.4 \\
\hline SEPT. & $1 \mathrm{C}$ & 6.7 & 440 & 10 & 1.6 & 10 & 2.9 & 40 & 5.6 & 12 \\
\hline $21 \ldots$ & 4.1 & 5.4 & 190 & 8.4 & 2.1 & 12 & 3.7 & 38 & 8.0 & 12 \\
\hline
\end{tabular}

\begin{tabular}{|c|c|c|c|c|c|c|c|c|c|c|}
\hline & & & & $\begin{array}{l}\text { CIS- } \\
\text { SCL VEC } \\
\text { SCLICS }\end{array}$ & & $\begin{array}{l}\text { NON- } \\
\text { CAR- }\end{array}$ & $\begin{array}{l}\text { SPECI- } \\
\text { FIC }\end{array}$ & & & COLCR \\
\hline & $\begin{array}{l}\text { FLUD- } \\
\text { RIDE } \\
\text { (F) }\end{array}$ & $\begin{array}{l}\text { NITRATE } \\
\text { (NO3) }\end{array}$ & $\begin{array}{l}\text { PHCS- } \\
\text { PHATE } \\
\text { (PD4) }\end{array}$ & $\begin{array}{l}\text { (RESI- } \\
\text { DUE AT } \\
180 \mathrm{CI}\end{array}$ & $\begin{array}{l}\text { FARC- } \\
\text { NESS } \\
\text { (CA,MG) }\end{array}$ & $\begin{array}{l}\text { BCNATE } \\
\text { HARD- } \\
\text { NESS }\end{array}$ & $\begin{array}{l}\text { COND- } \\
\text { UCTAACE } \\
\text { IMICRC- }\end{array}$ & PH & $\begin{array}{l}\text { TEMP- } \\
\text { ERATURE }\end{array}$ & $\begin{array}{l}\text { PPLAT- } \\
\text { INUM- } \\
\text { COBALI }\end{array}$ \\
\hline ATE & $(M G / L)$ & $\left(M_{G} / L\right)$ & $(M G / L)$ & $(M G / L)$ & $(M \in / L)$ & $(N G / L)$ & MHOSI & (UNITS) & (DEG C) & UNITSI \\
\hline
\end{tabular}

\begin{tabular}{|c|c|c|c|c|c|c|c|c|c|c|}
\hline $\begin{array}{l}\text { CCT. } \\
23 . . \\
\text { OEC. }\end{array}$ & .2 & .5 & $.2 t$ & 82 & 26 & 0 & 85 & 7.0 & 13.0 & $4 C$ \\
\hline $\begin{array}{l}10 \ldots \\
\text { JAR. }\end{array}$ & .0 & .7 & .13 & 66 & 21 & 4 & 81 & 6.6 & 5.5 & 40 \\
\hline $\begin{array}{c}O B \\
\text { FEB. }\end{array}$ & .1 & .3 & .11 & 81 & 22 & 14 & 96 & 6.4 & .5 & 45 \\
\hline $\begin{array}{l}20 \ldots \\
\triangle P R .\end{array}$ & .1 & .1 & .05 & 64 & $2 \mathrm{C}$ & 12 & 95 & 6.4 & 5.5 & 35 \\
\hline MAY & -1 & .0 & $.0 \varepsilon$ & 65 & 15 & 11 & 72 & 6.0 & 10.5 & 45 \\
\hline JuLY & .2 & 2.4 & .35 & $8 \mathrm{C}$ & 24 & 0 & 99 & 6.8 & 22.0 & $5 \mathrm{C}$ \\
\hline $07 . .$. & .2 & .9 & .31 & sc & 32 & 20 & 116 & 6.4 & 21.5 & 25 \\
\hline SEPT. & .1 & 1.5 & .32 & 88 & 32 & 0 & 116 & 6.9 & $22 . c$ & $4 C$ \\
\hline $21 \ldots$ & .1 & .5 & .24 & 76 & $3 \mathrm{C}$ & 0 & 120 & 6.8 & 21.0 & 35 \\
\hline
\end{tabular}


02050166 CHOWAN RIVER NEAR EURE, N. C.

LOCATION.--Lat $36^{\circ} 31^{\prime} 09^{\prime \prime}$, long $76^{\circ} 54^{\prime} 13^{\prime \prime}$, Gates County, water-quality recorder at Gatlington Landing, 1.8 m1les downstream from Somerton Creek, and 6.3 miles northwest of Eure.

DRAINAGE AREA. --2,550 sq $\mathrm{ml}$, approximately.

CHEMICAL ANALYSES, WATEK YEAR DCTOBER 1969 TO SEPTEMBER 1970

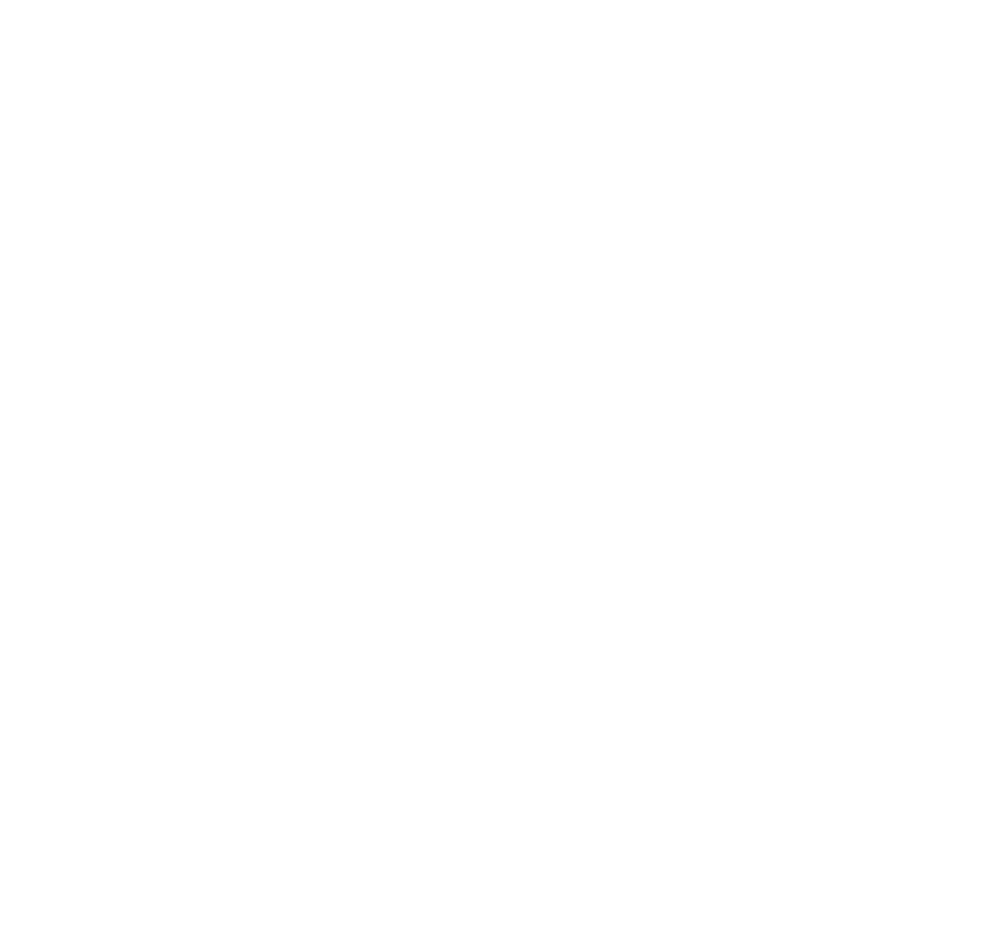

\begin{tabular}{|c|c|c|c|c|c|c|c|c|c|}
\hline $\begin{array}{r}\text { oct. } \\
28 . \ldots\end{array}$ & - & - & -- & -- & -- & - & - & -- & -- \\
\hline NOV. & & & & & & & & & \\
\hline $25 \ldots$ & -- & - & $-\infty$ & -- & -- & -- & $-\infty$ & -- & -- \\
\hline $02 \ldots$ & 19 & .3 & 2.6 & .94 & 99 & .13 & 26 & 0 & 1.1 \\
\hline $08 \ldots$ & 19 & .3 & 1.4 & 1.0 & 101 & .14 & 27 & 0 & 1.2 \\
\hline $15 \ldots$ & 57 & 1.0 & 3.9 & .78 & $? 36$ & .32 & 29 & 0 & 4.4 \\
\hline $18 \ldots$ & 106 & 1.6 & 6.6 & .89 & 350 & .48 & 40 & 0 & 7.1 \\
\hline $18 \ldots$ & - & - & -- & - & - & -- & -- & -- & - \\
\hline $22 \ldots$ & 89 & 1.4 & 8.0 & .94 & 354 & .48 & 36 & 0 & - \\
\hline $29 \ldots$ & 54 & .9 & 5.6 & .65 & -26 & .31 & 30 & 0 & 4.3 \\
\hline JAN. & & & & & & & & & \\
\hline $05 \ldots$ & 15 & .3 & 1.0 & .35 & 92 & .13 & 19 & 2 & 1.4 \\
\hline $19 \ldots$ & 17 & .2 & .8 & .44 & 107 & .15 & 24 & 2 & 1.4 \\
\hline $26 \ldots$ & 19 & .3 & 1.0 & .30 & 101 & .14 & 22 & I & 1.4 \\
\hline $\begin{array}{l}\text { FE8. } \\
05 . .\end{array}$ & 12 & .2 & .6 & - & 66 & .09 & 18 & 7 & 1.0 \\
\hline II... & 11 & .2 & .9 & .08 & 75 & .10 & 20 & 9 & $\begin{array}{r}1.0 \\
.8\end{array}$ \\
\hline $16 \ldots$ & 8.2 & .1 & .6 & .05 & 65 & .09 & 20 & 9 & .5 \\
\hline $25 \ldots$ & 12 & I & .8 & .21 & 81 & .11 & 26 & 8 & .9 \\
\hline MAR... & 14 & .2 & .7 & .29 & 86 & .12 & 21 & b & I. I \\
\hline $03 .$. & 9.9 & .1 & .8 & .58 & 65 & .09 & 21 & 10 & .5 \\
\hline $09 . .$. & 12 & .2 & 2.6 & .44 & 72 & .10 & $2 i$ & 6 & .9 \\
\hline $17 \ldots$ & 9.4 & .2 & 1.1 & .31 & 59 & .08 & 22 & 7 & .7 \\
\hline $23 \ldots$ & 12 & .2 & 1.0 & .24 & 71 & .10 & 22 & 7 & .9 \\
\hline $25 \ldots$ & 20 & .3 & 1.9 & .00 & $\therefore 9$ & .13 & 22 & 0 & 1.9 \\
\hline $30 \ldots$ & 21 & .2 & .8 & .45 & 93 & .13 & 21 & 4 & 1.1 \\
\hline$A P R$. & & & & & & & & & \\
\hline $06 \ldots$ & 6.4 & .1 & .7 & .00 & 63 & .09 & 18 & 9 & .4 \\
\hline $13 \ldots$ & 8.4 & .0 & 1.4 & .44 & 60 & .08 & 20 & 8 & .5 \\
\hline $20 \ldots$ & 8.5 & .0 & 1.6 & .20 & 61 & .08 & 21 & 4 & .6 \\
\hline $22 \ldots$ & 5.8 & .0 & 1.9 & .00 & 64 & .09 & 21 & 6 & .5 \\
\hline $27 \ldots$ & 10 & .0 & .9 & .36 & 79 & .11 & 27 & 2 & .7 \\
\hline JUNE & & & & & & & & & \\
\hline $17 \ldots$ & 11 & .2 & .8 & .40 & 83 & II & 27 & 0 & .8 \\
\hline $17 \ldots$ & -. & $\cdots$ & -- & -- & -- & $-\cdot$ & -- & -- & -- \\
\hline JULY & & & & 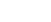 & & 10 & & 3 & \\
\hline $2 \mathrm{~L} \ldots$ & 10 & .2 & I. 3 & -- & 76 & .10 & 22 & 3 & .8 \\
\hline
\end{tabular}


02050160 CHOHAN RIVER NEAR EURE, N. C.--Continued

PERIOD OF RECORD. --Chemical analyges: October 1967 to September 1970.

Water temperatures: October 1967 to December 1968.

RMMARKS. --The second of two samples collected at the same time is a field determination.

CHEMICAL ANALYSES, WATER YEAR OCTOBER 1969 TO SEPTEMBER 1970

\begin{tabular}{|c|c|c|c|c|c|c|c|c|c|c|}
\hline & $\begin{array}{l}\text { PERCENT } \\
\text { SOOIUM }\end{array}$ & $\begin{array}{l}\text { BID- } \\
\text { CHEM- } \\
\text { ICAL } \\
\text { OXYGEN } \\
\text { DEMAND } \\
\text { (MG/L) }\end{array}$ & $\begin{array}{c}\text { PHENOLS } \\
\text { (UG/L) }\end{array}$ & $\begin{array}{l}\text { METHY- } \\
\text { LENE } \\
\text { BLUE } \\
\text { ACCIVE } \\
\text { SUB } \\
\text { STANCE } \\
\text { CMG/L) }\end{array}$ & $\begin{array}{l}\text { rUR- } \\
\text { 8IID } \\
\text { IIY } \\
\text { I JTUI }\end{array}$ & $\begin{array}{l}\text { SUS- } \\
\text { PENDD } \\
\text { SOLI IS } \\
\text { IMG/LI }\end{array}$ & $\begin{array}{l}\text { ALKA- } \\
\text { LINIYY } \\
\text { AS } \\
\text { CACO3 } \\
\text { (MG/L) }\end{array}$ & 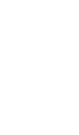 & $\begin{array}{l}\text { COPPER } \\
\text { (CU) } \\
\text { (UG/L) }\end{array}$ & $\begin{array}{c}\text { LEAD } \\
\text { (UPB) } \\
(U G / L)\end{array}$ \\
\hline ocr... & -- & -. & -- & - & -- & -- & .36 & -- & -- & - \\
\hline $\begin{array}{l}\text { Nov. } \\
25 . . .\end{array}$ & - & -- & -- & -- & - & -- & 26 & -- & - & -. \\
\hline $\begin{array}{l}\text { OEEC. } \\
\text { OE. } \\
02 . \ldots\end{array}$ & 49 & - & -- & .00 & - & -- & 27 & -- & -- & -- \\
\hline${ }_{08 . . .}^{02 .}$ & 49 & $=$ & $=$ &. $\overrightarrow{08}$ & $\overline{-}$ & $z$ & $\overline{28}$ & $=$ & -- & $=$ \\
\hline${ }_{150}^{10 .}$ & 76 & $=$ & $=$ & .12 & $\overline{--}$ & $\ddot{z}$ & $\overline{66}$ & $\because$ & $=$ & $\overline{-\sigma}$ \\
\hline $\begin{array}{l}15 \ldots . . \\
18 \ldots\end{array}$ & $\overrightarrow{82}$ & $=$ & $=$ &.$\overline{0 B}$ & $=$ & $=$ & $\overline{116}$ & -- & $=$ & $\overline{--}$ \\
\hline${ }_{22}^{18} \ldots$ & $\bar{z}$ & $=$ & $=$ &.$\overline{13}$ & $\bar{z}$ & $=$ & $\begin{array}{c}121 \\
98\end{array}$ & -- & $=$ & $=$ \\
\hline $22 \ldots$ & $=$ & $=$ & 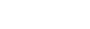 & -13 & $=$ & $\because$ & 98 & $\overline{--}$ & $=$ & $=$ \\
\hline $9 \ldots$ & $\begin{array}{l}76 \\
--\end{array}$ & $=$ & $=$ & .00 & $=$ & $=-$ & $\underline{58}$ & $=$ & - & $=-$ \\
\hline & 58 & -- & -- & .00 & -- & -- & 16 & -- & -- & -- \\
\hline$\because:$ & - & -- & - & $\bar{u}$ & - & -- & $\overline{3}$ & -- & -- & -- \\
\hline & -2 & - & -- & -1. & - & $\because$ & - & - & - & - \\
\hline $26 \ldots$ & 57 & $=$ & $\because$ & .06 & $=$ & -- & 21. & $\overline{--}$ & $=$ & -- \\
\hline $3 .$. & - & - & -- & - & - & -- & 10 & - & -- & -- \\
\hline $5 .$. & 50 & - & - & .25 & - & -- & 11 & -- & - & -- \\
\hline $\begin{array}{l}05 \ldots . . \\
{ }_{11}^{2} \ldots . .\end{array}$ & 46 & -- & $\overline{-}$ & .09 & $=$ & -- & $\overline{11}$ & $=$ & $=$ & -- \\
\hline $\begin{array}{l}11 \ldots . . \\
16 . . .\end{array}$ & $\overline{36}$ & $=$ & $\bar{z}$ &.$\overline{07}$ & $=$ & $=$ & $\overline{\mathrm{II}}$ & $\because$ & $=$ & $=$ \\
\hline${ }_{25}^{16 \ldots .:}$ & 44 & $=$ & $\overline{-}$ &.$\overline{07}$ & $=$ & $=$ & $\overline{18}$ & $=$ & $\bar{z}$ & $\because$ \\
\hline $\begin{array}{l}25 \ldots . . \\
26 .\end{array}$ & $\overline{52}$ & $=$ & $=$ &.$\overline{10}$ & $\overline{-}$ & $\because$ & $\begin{array}{l}22 \\
15 \\
15\end{array}$ & $\because$ & $z$ & $\because$ \\
\hline 6...” & & & & & & & & -- & -- & -- \\
\hline 3. & 33 & -- & -- & .08 & - & - & 11 & - & - & -- \\
\hline$\because:$ & 48 & - & $\overline{-}$ &.$\overline{10}$ & $\bar{z}$ & -- & $\overline{15}$ & $=$ & $\bar{z}$ & -- \\
\hline 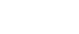 & 39 & $\overline{--}$ & -- &.$\overline{\mathrm{II}}$ & $=$ & $\bar{z}$ & $\overline{15}$ & $=$ & $=$ & $=$ \\
\hline 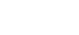 & $\overline{47}$ & $=$ & 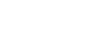 &.$\overline{05}$ & $\bar{z}$ & $\because$ & 75 & $\overline{--}$ & -- & $=$ \\
\hline$\ldots$ & $\overrightarrow{65}$ & $=$ & $=$ & $\overline{.10}$ & $\bar{z}$ & $\because$ & $\overline{23}$ & z- & $\overline{-}$ & $\because-$ \\
\hline$\because:$ & 42 & -- & -- & .22 & $=$ & -- & $\underline{17}$ & $=-$ & $=$ & -- \\
\hline AP? & 32 & -- & -- & .08 & - & -- & 9 & -- & -- & -- \\
\hline & $\overline{31}$ & $\because-$ & $=$ &.$\overline{08}$ & $\bar{z}$ & -- & $\overline{11}$ & $=$ & $=$ & $=$ \\
\hline & $\overline{36}$ & $\overline{-}$ & $=$ &.$\overline{10}$ & $=$ & $=$ & $\overline{17}$ & -- & $=$ & $=$ \\
\hline & $\overline{35}$ & -- & $=$ &.$\overline{04}$ & $\overline{-}$ & $=$ & $\overline{16}$ & -- & $=$ & $=$ \\
\hline$\ldots$ & 38 & - & -- & .08 & - & - & 25 & - & -- & -- \\
\hline Ji & & & & 00 & & -- & & -- & -- & -. \\
\hline & $-\cdots$ & $\overline{-}$ & $\because$ & -0 & $\overline{-}$ & 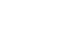 & $\begin{array}{l}31 \\
30\end{array}$ & - & - & - \\
\hline :.: & 42 & 1.1 & $\underline{0}$ & .05 & 5.0 & 15 & $\begin{array}{l}19 \\
20\end{array}$ & $\therefore$ & $\therefore$ & _o \\
\hline auc & -- & 1.3 & -- & - & - & - & - & - & - & - \\
\hline & -- & & & & - & -- & 18 & -- & 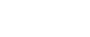 & $\ldots$ \\
\hline & $\because$ & 2.1 & $\overline{-}$ & $\bar{Z}$ & $\bar{z}$ & $\cdots$ & 32 & -- & $=$ & -- \\
\hline & $\begin{array}{c}21 N C \\
(2 N 1 \\
(U G / L)\end{array}$ & $\begin{array}{c}\text { CYANIOE } \\
\text { (CN) } \\
\text { (MG/L) }\end{array}$ & $\begin{array}{l}\text { CAD- } \\
\text { MtUM } \\
\text { ICOI } \\
(\mathrm{CU} / \mathrm{L}\end{array}$ & $\begin{array}{l}\text { O1 S- } \\
\text { SOLVE } \\
\text { OXYYGEN } \\
\text { (MG/LI) }\end{array}$ & $\begin{array}{l}\text { TOTAL } \\
\text { BETA } \\
\text { (PC/L) }\end{array}$ & 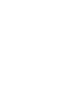 & 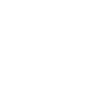 & $\begin{array}{c}\text { PH } \\
\text { (UNIIS) }\end{array}$ & $\begin{array}{l}\text { IEMP- } \\
\text { ERATURE } \\
\text { TOEG CI }\end{array}$ & $\begin{array}{l}\text { COLOR } \\
\text { IPLAT- } \\
\text { INUMA- } \\
\text { COBALT } \\
\text { UNITSI }\end{array}$ \\
\hline
\end{tabular}

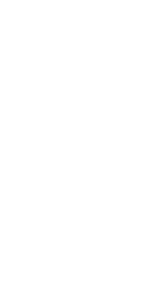

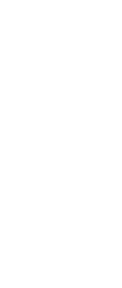

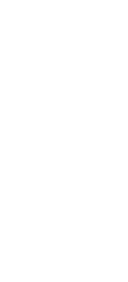

5
11
$=-$
$=-$
$=-$
$=$
72
$=-$
$=$
$=$

190

$\begin{array}{rrr}6.9 & 15.0 & -- \\ 6.0 & 10.0 & -- \\ 6.9 & 8.0 & 100 \\ -.0 & 8.0 & -- \\ 6.6 & 6.0 & 80 \\ 7.3 & 6.0 & -- \\ 6.8 & 7.0 & 180 \\ 7.1 & 7.0 & -- \\ 7.0 & 8.0 & 280 \\ 5.6 & 8.0 & - \\ 7.2 & 5.0 & 400 \\ 7.2 & 5.0 & -- \\ 7.1 & 3.0 & 180 \\ 7.2 & 3.0 & --\end{array}$




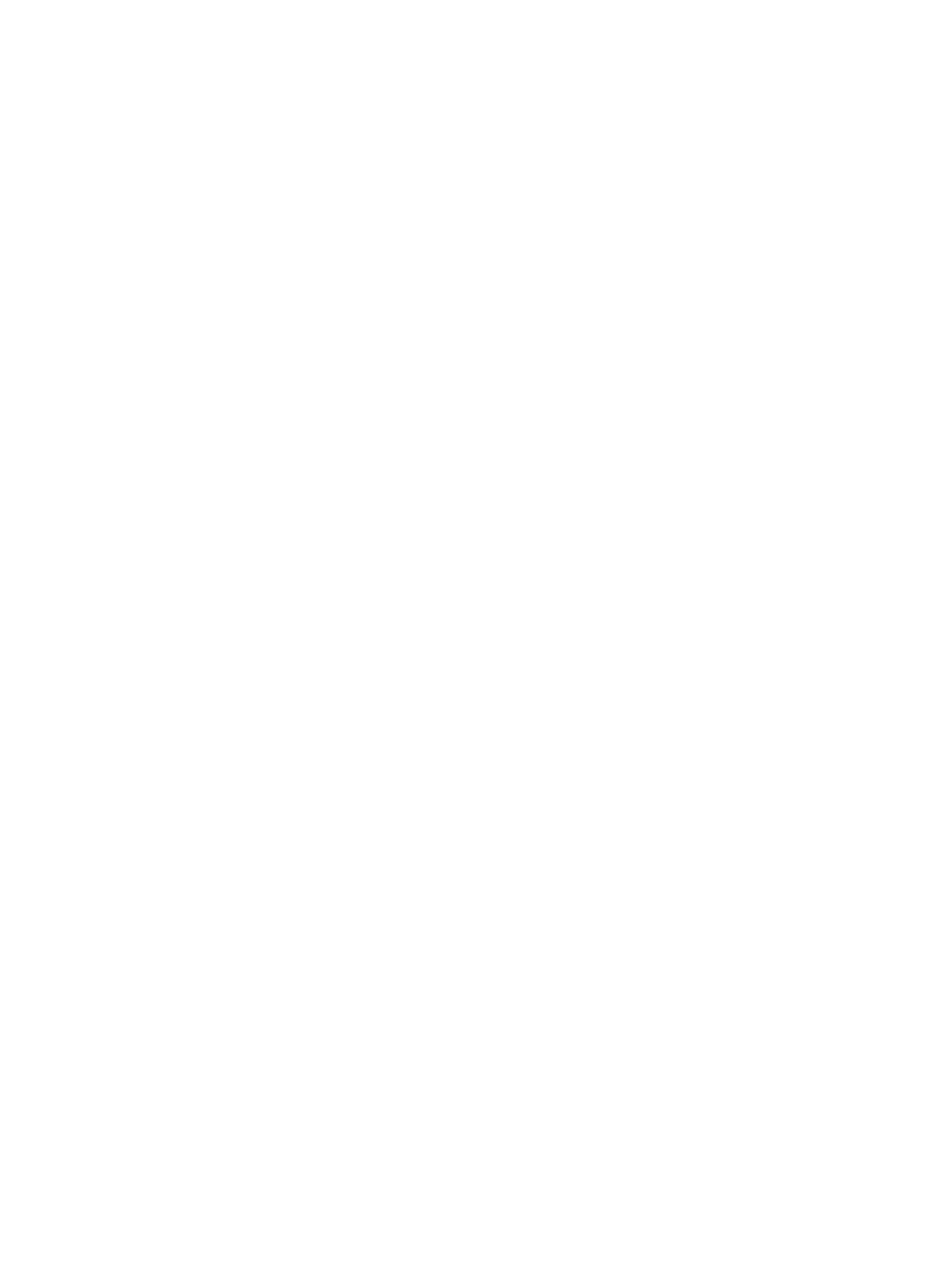


02052000 MEHERRIN RIVER AT EMPORIA, VA.

LOCATION.--Lat $36^{\circ} 41^{\prime} 20^{\prime \prime}$, long $77^{\circ} 32^{\prime} 20^{\prime \prime}$, Emporia City (revised), at gaging station on left bank at downstream side of bridge on U.S. Highwsy 301 and 2.1 miles upstresm from Failing Run.

DRAINAGE AREA, -747 sq $m 1$ (revised).

PERIOD OF RECORD.--Chemlcal analyses: March 1967 to September 1970.

Water temperatures: Apr11 1968 to September 1970.

EXTREMES. - $-1969-70$

Specific conductance: Maximum daily, 132 micromhos Mar. 5; mintmum da11y, 41 micromhos July 25.

Water temperatures: Maximum, $23.0^{\circ} \mathrm{C}$ Oct. 2; minimum, 1.5 ${ }^{\circ} \mathrm{C}$ Jan. 8, 10.

Period of record:

Dissolved solids (1968-69): Maximum, $89 \mathrm{mg} / 1$ Aug. 11-20, 1969; minimum, $53 \mathrm{mg} / 1 \mathrm{Jan} .21-31,1969$

Hardness (1968-69): Max1mum, $38 \mathrm{mg} / 1$ July 21-23, 1969; min1mum, $15 \mathrm{mg} / 1$ July 24-31, 1969.

Spectf1c conductance: Max1mum daily, 153 micromhos Sept. 29, 1968; min1mum da1ly, 39 m1cromhos Aug. 2, 4, 1969. Water temperatures: Maximum, $35.0^{\circ} \mathrm{C}$ July 14, 21, 22, 26, 1969; mintmum, 1.5 ${ }^{\circ} \mathrm{C}$ Jan. $8,10,1970$.

REMARKS. - Chemical-quality data represent equal-volume composites for the pertods indicated prior to November 1 and for every seventh day thereafter.

CHEMICAL ANALYSES, WATER YEAR OCTOBER 1969 TO SEPTEMBER 1970

\begin{tabular}{|c|c|c|c|c|c|c|c|c|c|c|}
\hline DATE & $\begin{array}{l}\text { MEAN } \\
\text { DIS- } \\
\text { CHARGE } \\
\text { (CFS) }\end{array}$ & $\begin{array}{l}\text { SILICA } \\
\text { (S IOLI) } \\
\text { (MG/L) }\end{array}$ & $\begin{array}{l}\text { DIS- } \\
\text { SOLVEO } \\
\text { IRON } \\
\text { (FE) } \\
\text { (UG/LI) }\end{array}$ & $\begin{array}{l}\text { CAL- } \\
\text { CIUM } \\
(C A) \\
(M G / L)\end{array}$ & $\begin{array}{l}\text { MAG- } \\
\text { NE- } \\
\text { SIUM } \\
\text { (MG) } \\
(M G / L)\end{array}$ & $\begin{array}{l}\text { SODIUM } \\
\text { (NA) } \\
\text { (MGIL) }\end{array}$ & $\begin{array}{l}\text { PO- } \\
\text { TAS- } \\
\text { SIUM } \\
\text { (K) } \\
\text { (MG/L) }\end{array}$ & $\begin{array}{l}\text { BICAR- } \\
\text { AONATE } \\
\text { (HCO3) } \\
\text { (MG/L) }\end{array}$ & $\begin{array}{l}\text { SULFATE } \\
\text { (SOA) } \\
\text { (MG/L) }\end{array}$ & $\begin{array}{l}\text { CHLD- } \\
\text { RIDE } \\
\text { (CL) } \\
\text { (MG/L) }\end{array}$ \\
\hline \multicolumn{11}{|l|}{ OCT. } \\
\hline $21-10$ & 372 & 13 & 250 & 4.4 & 1.9 & 6.2 & 3.5 & 25 & 6.2 & 5.7 \\
\hline $11-20$ & 157 & 15 & 110 & 4. 8 & 2.4 & 6.4 & 2.6 & 35 & 5.0 & 4.9 \\
\hline $2|-3|$ & 144 & 17 & 80 & 5.9 & 2.4 & 6.8 & 2.2 & 30 & 2.8 & 7.1 \\
\hline \multicolumn{11}{|l|}{ Nov. } \\
\hline & 173 & 18 & 190 & $7 . \mathrm{C}$ & 2.2 & 5.0 & 2.3 & 39 & 1.8 & 5.4 \\
\hline $14 \ldots$ & 244 & 17 & 300 & 7.0 & $2 . n$ & 6.4 & 2.3 & 39 & 2.6 & 6.6 \\
\hline $21 \ldots$ & $3 \times n$ & 17 & 290 & 6.2 & 2.1 & 6.4 & 2.0 & 36 & 4.4 & $t .5$ \\
\hline $28 \ldots$ & 198 & 17 & $24 \pi$ & 5.4 & 2.1 & 3.0 & 2.0 & 32 & 4.6 & 6.1 \\
\hline \multicolumn{11}{|l|}{ DEC. } \\
\hline $05 \ldots$ & 177 & 15 & $42 \mathrm{C}$ & 8.5 & 2.1 & 6.2 & 1.3 & 36 & 7.8 & 6.9 \\
\hline $12 \ldots$ & 1130 & 14 & 150 & 4.4 & 2.1 & 7.0 & 2.0 & 20 & 7.0 & 6.1 \\
\hline $19 . .$. & 318 & 14 & 140 & 4.? & 2.0 & 6.2 & 1.9 & 25 & 7.0 & $5 . \AA$ \\
\hline $26 \ldots$ & 1790 & 9.8 & 100 & 3.8 & 1.9 & 4.7 & 2.0 & 15 & & 4.9 \\
\hline \multicolumn{11}{|l|}{ JAN. } \\
\hline$n 2 \ldots$ & 755 & 13 & 160 & 4.6 & 1.9 & 5.3 & 1.4 & 21 & 8.6 & 4.4 \\
\hline $09 . .$. & 300 & 14 & $14 \mathrm{C}$ & 5.2 & 1.7 & 3.0 & 1.5 & 23 & $\cdots$ & 6.3 \\
\hline $16 \ldots$ & 383 & 16 & 120 & 4.9 & 2.2 & $6 . n$ & 1.5 & 29 & 5.0 & 6.3 \\
\hline $23, \ldots$ & 395 & 16 & 210 & 5.2 & 2.3 & 6.0 & 1.2 & 28 & 5.4 & 6.0 \\
\hline $3 n \ldots$ & 510 & 16 & 50 & 4.7 & 2.7 & 6.1 & 1.5 & 32 & 3.6 & 6.4 \\
\hline \multicolumn{11}{|l|}{ FEg. } \\
\hline $36 \ldots$ & 928 & 14 & 140 & 7.6 & $7 . h$ & 9.1 & 2.7 & 34 & 10 & 9.4 \\
\hline $13 \ldots$ & 734 & 12 & 100 & $7 . t$ & 1.8 & 5.7 & 1.6 & 30 & 8.2 & 4.6 \\
\hline $20 \ldots$ & 1740 & 15 & 190 & 6.0 & 1.7 & 5.8 & 1.3 & 26 & 7.0 & 5.2 \\
\hline $27 \ldots$ & $53 n$ & 16 & 380 & 7.0 & $3 . n$ & 6.1 & 1.4 & 31 & 7.0 & 5.2 \\
\hline \multicolumn{11}{|l|}{ MAP. } \\
\hline $07 \ldots$ & 570 & 14 & 250 & 6.8 & 1.6 & 6.0 & 1.9 & 38 & 4.0 & 4.5 \\
\hline $14 \ldots$ & 734 & 14 & 330 & 7.0 & 2.0 & 5.7 & 1.8 & 40 & 5.2 & 4.5 \\
\hline $21 \ldots$ & loin & 13 & $15 n$ & 5.4 & 2.6 & 4.6 & 1.2 & 22 & 11 & 5.1 \\
\hline $29 .$. & จดก & 12 & 80 & 4.4 & 2.4 & 5.5 & 1.6 & $2 ?$ & 8.0 & $4 . \mathrm{A}$ \\
\hline \multicolumn{11}{|l|}{$A P R$. } \\
\hline $34 \ldots$ & 3360 & 11 & so & 5.1 & 1.6 & 5.6 & 1.2 & 15 & 10 & 4.2 \\
\hline $11 \ldots$ & 630 & 14 & 50 & 4.7 & 1.9 & 6.6 & 2.0 & 28 & 6.6 & 6.4 \\
\hline $18 \ldots$ & 570 & 14 & $25 \mathrm{C}$ & 5.4 & 2.0 & 7.6 & 2.3 & 33 & 5.4 & 7.2 \\
\hline $25 \ldots$ & 452 & 14 & 210 & 5.2 & 2.1 & 12 & 3.5 & 34 & 6.2 & 9.4 \\
\hline \multicolumn{11}{|l|}{ MAY } \\
\hline$n \geq \ldots$ & 500 & 13 & 90 & $8 . n$ & 3.3 & 6.1 & 2.0 & 40 & 7.2 & 5.1 \\
\hline $09 \ldots$ & 530 & 14 & 100 & 6.4 & 3.2 & 12 & 4.8 & 33 & 7.2 & 12 \\
\hline $16 \ldots$ & $33 n$ & 15 & 200 & 6.2 & 2.9 & ค. B & 3.1 & 37 & 6.8 & 8.6 \\
\hline $23 \ldots$ & 268 & 15 & 340 & 8.4 & 2.6 & 6.6 & 3.1 & 45 & 5.2 & 7.2 \\
\hline $3 n . .$. & 210 & 15 & 50 & 7.2 & 2.? & 5.5 & 1.7 & 35 & 2.8 & 4.4 \\
\hline \multicolumn{11}{|l|}{ JLNF } \\
\hline Ob... & $2 \times 5$ & 16 & 50 & 7.2 & 1.9 & 5.7 & 1.8 & 38 & 2.8 & 5.1 \\
\hline $13 \ldots$ & 135 & 14 & 140 & 8.2 & 2.9 & 5.6 & 1.7 & 44 & 4.4 & 5.0 \\
\hline $2^{n} . .$. & $11 n$ & 14 & 140 & B.4 & $? .8$ & 5.5 & 1.8 & 45 & 4.4 & 5.0 \\
\hline $27 \ldots$ & > 30 & 12 & 110 & 5.0 & 2.3 & 4.9 & 1.5 & 32 & 6.0 & 4.5 \\
\hline \multicolumn{11}{|l|}{ JULY } \\
\hline $34 \ldots$ & 160 & 13 & 30 & 6.4 & 1.8 & 5.1 & 2.1 & 30 & $6 . c$ & 4.2 \\
\hline $11 \ldots$ & 4 เาก & 7.5 & 120 & 4.2 & . B & 3.0 & 2.3 & 12 & 7.0 & 2.6 \\
\hline $19 . .$. & 150 & 11 & 210 & 5.2 & 2.1 & 3.6 & 2.5 & 19 & 8.2 & 4.0 \\
\hline $25 \ldots$ & 1700 & 7.3 & 120 & 4.4 & .7 & 2.3 & 2.3 & 13 & 6.0 & 2.9 \\
\hline \multicolumn{11}{|l|}{ AUG. } \\
\hline $01 \ldots$ & 200 & 13 & 50 & $6 . c$ & 1.3 & 3.9 & 2.4 & 27 & 4.2 & 4.2 \\
\hline วв... & 159 & 14 & 710 & 6.8 & 1.6 & 4.3 & 2.6 & 33 & 2.6 & 4.2 \\
\hline $15 \ldots$ & $33 n$ & 14 & 130 & 6.4 & 1.2 & 4.6 & 6.1 & 27 & 5.2 & 3.8 \\
\hline $22 \ldots$ & 373 & 13 & 90 & 4.8 & 3.3 & 6.7 & 2.4 & 30 & 4.4 & 7.3 \\
\hline $20 .$. & 115 & 14 & 40 & 5.4 & $\because 7$ & 7.4 & 2.3 & 32 & 7.4 & 5.4 \\
\hline \multicolumn{11}{|l|}{ SЕPT. } \\
\hline $25 \ldots$ & 75 & 14 & 60 & 6.0 & 2.7 & 5.8 & 2.1 & 36 & $6 . c$ & 5.0 \\
\hline $12 \ldots$ & 62 & 14 & 60 & R. & 2.2 & 6.9 & 2.2 & 44 & 5.2 & 5.8 \\
\hline $19 \ldots$ & 51 & 13 & 30 & 6.8 & 3.2 & 8.1 & 2.4 & 42 & 3.0 & 7.7 \\
\hline $26 . \ldots$ & 46 & 11 & 50 & in & 1.7 & 6.0 & 2.3 & 44 & 3.2 & 5.0 \\
\hline
\end{tabular}


CHOWAN RIVER BASIN

02052000 MEHERRIN RIVER AT ENPORIA, VA,-mContInued

CHEMICAL ANALYSES, WATER YEAR CCTOBER 1969 TO SEPTEMBER 1970

\begin{tabular}{|c|c|c|c|c|c|c|c|c|c|}
\hline & & & & $\begin{array}{l}\text { CIS- } \\
\text { SCLVEC } \\
\text { SCLICS }\end{array}$ & & $\begin{array}{l}\text { NOA- } \\
\text { CAR- }\end{array}$ & $\begin{array}{l}\text { SPECI- } \\
\text { FIC }\end{array}$ & & COLCR \\
\hline & $\begin{array}{l}\text { FLUO- } \\
\text { RIOE } \\
\text { (F) }\end{array}$ & $\begin{array}{l}\text { NITRATE } \\
\text { (ND3) }\end{array}$ & $\begin{array}{l}\text { PHCS- } \\
\text { PHATE } \\
\text { (PC4) }\end{array}$ & $\begin{array}{l}\text { IRESI- } \\
\text { CUE AT } \\
18 O \mathrm{CI}\end{array}$ & $\begin{array}{l}\text { HARD- } \\
\text { NESS } \\
(\text { CA,MG) }\end{array}$ & $\begin{array}{l}\text { BONATE } \\
\text { HARC- } \\
\text { AESS }\end{array}$ & $\begin{array}{l}\text { COND- } \\
\text { UCTANCE } \\
\text { \& } \text { ICRC- }\end{array}$ & & $\begin{array}{l}\text { IPLAT- } \\
\text { IALM- } \\
\text { COEALT }\end{array}$ \\
\hline ATE & (MG/L) & $(M G / L)$ & $(M G / L)$ & (NG/L) & $\{M G / L\}$ & $(M G / L)$ & MHOSI & (UNITS) & (AITS) \\
\hline
\end{tabular}

\begin{tabular}{|c|c|c|c|c|c|c|c|c|c|}
\hline $\begin{array}{l}31-10 \\
011-2 c \\
21-31\end{array}$ & $\begin{array}{r}.2 \\
.1 \\
.2\end{array}$ & $\begin{array}{l}.4 \\
.3 \\
.4\end{array}$ & $\begin{array}{l}.45 \\
.06 \\
.04\end{array}$ & $\begin{array}{l}66 \\
78 \\
71\end{array}$ & $\begin{array}{l}19 \\
22 \\
24\end{array}$ & $\begin{array}{l}c \\
c \\
0\end{array}$ & $\begin{array}{l}64 \\
79 \\
83\end{array}$ & $\begin{array}{l}6.9 \\
6.8 \\
7.0\end{array}$ & $\begin{array}{l}40 \\
25 \\
25\end{array}$ \\
\hline \multicolumn{10}{|l|}{ NOV. } \\
\hline $07 \ldots$ & .2 & .1 & .02 & 67 & 26 & c & 77 & 7.1 & $3 \mathrm{C}$ \\
\hline $14 \ldots$ & .2 & .1 & .02 & 65 & 26 & 0 & 80 & 7.2 & 35 \\
\hline $21 \cdots$ & .2 & .2 & .04 & 64 & 24 & c & 79 & 6.8 & 35 \\
\hline $28 \ldots$ & .2 & .1 & .04 & 63 & 22 & 0 & 77 & 6.8 & $4 \mathrm{C}$ \\
\hline \multicolumn{10}{|l|}{ OEC. } \\
\hline $\begin{array}{l}05 \ldots \\
12 \ldots\end{array}$ & .2 & .2 & $\begin{array}{r}.03 \\
.20\end{array}$ & $\begin{array}{l}76 \\
76\end{array}$ & $\begin{array}{l}30 \\
20\end{array}$ & $\begin{array}{l}c \\
0\end{array}$ & $\begin{array}{l}96 \\
71\end{array}$ & $\begin{array}{l}7.2 \\
6.7\end{array}$ & $\begin{array}{l}25 \\
45\end{array}$ \\
\hline $19 \ldots$ & $\cdot 3$ & .1 & .06 & $E C$ & 18 & c & 69 & 6.7 & 35 \\
\hline $26 \ldots$ & .2 & $\cdot 8$ & .08 & 53 & 18 & 5 & 61 & 6.6 & $7 c$ \\
\hline JAN. & .3 & .4 & .08 & 66 & 20 & 2 & 63 & 6.9 & 40 \\
\hline $09 \ldots$ & .0 & .1 & .01 & 60 & 20 & 1 & 73 & 7.1 & 40 \\
\hline $\begin{array}{l}16 \ldots \\
23 \ldots\end{array}$ & .1 & .3 & .00 & $\begin{array}{l}65 \\
67\end{array}$ & $\begin{array}{l}21 \\
22\end{array}$ & 0 & $\begin{array}{l}75 \\
75\end{array}$ & $\begin{array}{l}6.7 \\
6.9\end{array}$ & $\begin{array}{l}10 \\
25\end{array}$ \\
\hline $\begin{array}{l}30 \ldots \\
E B\end{array}$ & .1 & .1 & .01 & 63 & 22 & c & 78 & 7.0 & 15 \\
\hline $06 \ldots$ & .2 & .5 & .40 & 76 & 30 & 2 & 106 & 7.1 & 20 \\
\hline $13 \ldots$ & .4 & .2 & .20 & 67 & 26 & 2 & 78 & 6.9 & 30 \\
\hline $20 \ldots$ & .1 & $\cdot 1$ & .04 & 56 & 22 & 0 & 72 & 6.9 & 25 \\
\hline $27 \ldots$ & - 1 & .1 & .04 & 64 & 26 & o & 94 & 6.8 & 25 \\
\hline \multicolumn{10}{|l|}{ MAR. } \\
\hline $07 \ldots$ & .2 & .2 & .12 & 61 & 24 & 0 & 78 & 7.3 & $2 \mathrm{c}$ \\
\hline $14 \ldots$ & .2 & .0 & .06 & 63 & 26 & c & 81 & 7.4 & 20 \\
\hline $21 \ldots$ & . $c$ & .0 &. $\mathrm{CH}_{4}$ & 74 & 24 & 6 & 76 & 6.2 & $4 \mathrm{C}$ \\
\hline$\underset{A P R}{28} \cdots$ & .1 & - c & .01 & 60 & 21 & 3 & 69 & 6.5 & 35 \\
\hline $04 \ldots$ & $\cdot 3$ & .0 & .37 & $5 e$ & 19 & 6 & 54 & 6.2 & 25 \\
\hline $11 \ldots$ & .2 & $\cdot 3$ & .00 & 60 & 20 & $c$ & 79 & 7.0 & 15 \\
\hline $18 \ldots$ & .2 & 1.0 & .01 & 77 & 22 & c & 87 & 6.9 & 15 \\
\hline $25 \ldots$ & $\cdot 1$ & 2.3 & .40 & 82 & 22 & 0 & 97 & 6.6 & 25 \\
\hline \multicolumn{10}{|l|}{ MAY } \\
\hline $\begin{array}{l}02 . . \\
09 .\end{array}$ & $\because 1$ & .5 & .05 & 74 & 34 & 0 & 89 & 6.9 & 25 \\
\hline $09 \ldots$ & .1 & 6.8 & .17 & 96 & 29 & 2 & 116 & 6.5 & 25 \\
\hline $10 \ldots$ & .1 & $3 \cdot 2$ & .25 & 81 & 28 & $c$ & 95 & 6.7 & 25 \\
\hline $23 \ldots$ & +1 & 1.3 & .05 & 90 & 32 & c & 96 & 6.8 & 45 \\
\hline \multirow{2}{*}{\multicolumn{8}{|c|}{ JUAE }} & & \\
\hline & & & & & & c & 77 & 6.7 & 5 \\
\hline $13 \ldots$ & .1 & .3 & .01 & 77 & 32 & 0 & 89 & 6.9 & 25 \\
\hline $20 \ldots$ & .1 & .2 & .02 & 76 & 32 & c & 89 & 7.0 & 30 \\
\hline${ }_{J U L}^{27} \ddot{Y}$ & .0 & 1.7 & .03 & 84 & 24 & c & 74 & 6.7 & 40 \\
\hline \multicolumn{10}{|l|}{$\begin{array}{l}\text { JuLY } \\
04 \ldots .\end{array}$} \\
\hline $\begin{array}{l}04 \ldots \\
11 \ldots\end{array}$ & .1 & 1.2 & .02 & 65 & 24 & c & 68 & 6.9 & 10 \\
\hline $\begin{array}{l}11 \ldots \\
18 \ldots\end{array}$ & .2 & 1.1 & .27 & 71 & 14 & 4 & 42 & 6.7 & 60 \\
\hline $\begin{array}{l}18 \ldots \\
25 \ldots\end{array}$ & .1 & .6 & . cs & IC & 22 & 6 & 55 & 6.5 & 50 \\
\hline $\begin{array}{l}25 \ldots \\
\text { AUG. }\end{array}$ & .2 & .3 & .09 & 60 & 14 & 4 & 41 & 6.2 & EC \\
\hline \multicolumn{10}{|l|}{ AUG. } \\
\hline $\begin{array}{l}15 \ldots \\
22 \ldots\end{array}$ & $\cdot 3$ & 1 & 2.6 & 65 & $\begin{array}{l}21 \\
26\end{array}$ & 1 & $\begin{array}{l}59 \\
76\end{array}$ & $\begin{array}{l}6.6 \\
7.2\end{array}$ & 15 \\
\hline $\begin{array}{l}22 \ldots \\
29 \ldots\end{array}$ & .2 & $\begin{array}{l}.8 \\
.5\end{array}$ & $\begin{array}{l}.10 \\
.18\end{array}$ & $\begin{array}{l}67 \\
67\end{array}$ & $\begin{array}{l}26 \\
26\end{array}$ & c & 74 & 6.9 & 8 \\
\hline \multicolumn{10}{|l|}{ SEPT. } \\
\hline $05 \ldots$ & .1 & .0 & .03 & $7 \mathrm{C}$ & 26 & C & 78 & 7.0 & 23 \\
\hline $12 \ldots$ & .2 & $\therefore \mathrm{C}$ & .06 & 76 & 29 & 0 & 90 & 7.0 & 20 \\
\hline $19 \ldots$ & .1 & 1.1 & .11 & 74 & 30 & 0 & 101 & 7.2 & 15 \\
\hline $26 \ldots$ & .2 & .6 & .02 & 66 & 31 & $c$ & 92 & 6.9 & 10 \\
\hline
\end{tabular}


CHOW AN RIVER BASIN

02052000 MEHERRIN RIVER AT EMPCRIA, VA, --Contínued

SPECIFIC CONDUCTANCE (MICROMHOS/CM AT $25^{\circ} \mathrm{C}$ ), WAJER YEAR OCTOBER 1969 TO SEPTEMBER 1970

OAY OCTOBER NOVEMBER DECEMBER JANUARY FEBRUARY MARCH APRIL
MAY

$\begin{array}{rr}80 & 80 \\ 80 & 93 \\ 77 & 12 \\ 105 & 10 \\ 92 & 13\end{array}$

$\begin{array}{lrrrrrr}1 \ldots \ldots & 75 & 76 & 77 & 59 & 80 & \\ 2 \ldots \ldots & 57 & 75 & 78 & 63 & 80 & \\ 3 \ldots \ldots & 58 & 83 & 84 & 62 & 77 & 122 \\ 5 \ldots \ldots & 59 & 78 & 90 & 68 & 105 & 100 \\ 5 . \ldots & 62 & 78 & 96 & 70 & 92 & 132\end{array}$

$6 \ldots . .6 \quad 64$

$\begin{array}{ll}9 \ldots \ldots . & 67 \\ 10 \ldots \ldots & 63\end{array}$

$11 \ldots . .6 \quad 69$

$12 \ldots \ldots . .740 .74$

$14 \ldots \ldots . .80 .89$

$10 \ldots . .5 \quad 79$

$\begin{array}{ll}18 \ldots \ldots & 89 \\ 14 . \ldots . .0 & 87\end{array}$

$\begin{array}{ll}14 \ldots \ldots & 80 \\ 20 . \ldots . & 81\end{array}$

$21 . \ldots .08$

$\begin{array}{ll}22 \ldots \ldots & 87 \\ 23 \ldots \ldots & 83\end{array}$

$\begin{array}{ll}24 \ldots \ldots . & 81 \\ 25 . \ldots . & 85\end{array}$

$26 \ldots . . .84$

$27 \ldots \ldots$

$29 \ldots \ldots$

$30 . . .$.

AVERAGE

$\begin{array}{rr}70 & 99 \\ 69 & 100 \\ 68 & 86 \\ 60 & 84 \\ 59 & 82\end{array}$

$\begin{array}{ll}77 & 70 \\ 77 & 76 \\ 76 & 7 \\ 74 & 73\end{array}$

70
76
72
73
75

73
72
71
73
78

$\begin{array}{rl}106 & 80 \\ 116 & 78 \\ 107 & 70 \\ 76 & 74\end{array}$

80
93
22
00

63
52
53
54
55

$\begin{array}{rll}122 & - & 72 \\ 89 & -- & 73 \\ 87 & -- & 65 \\ 88 & -- & 68 \\ 95 & -- & 74 \\ 82 & - & 70 \\ 88 & - & 71 \\ 102 & = & 72 \\ 116 & -- & 72\end{array}$

72
73
65
68
74
70
71
72
72
74

$\begin{array}{ll}61 & 76 \\ 67 & 80 \\ 68 & 80 \\ 74 & 82 \\ 79 & 78\end{array}$

$\begin{array}{ll}77 & 69 \\ 74 & 71 \\ 80 & 70 \\ 80 & 70 \\ 77 & 69\end{array}$

81
84
84
75
80

74
68
78
94

74
68
78
94
82

$\begin{array}{ll}74 & 79 \\ 84 & 75 \\ 88 & 89 \\ 81 & 70 \\ 75 & 70\end{array}$

$\begin{array}{ll}78 & 75 \\ 80 & 74 \\ 80 & 67 \\ 88 & 69\end{array}$

75
74
67
69
57

75
72
77
73
75

$\begin{array}{rr}102 & 80 \\ 99 & 93 \\ 94 & 73 \\ 68 & 72\end{array}$

$\begin{array}{ll}80 & 66 \\ 93 & 80 \\ 73 & 87 \\ 72 & 91 \\ 77 & 93\end{array}$

$\begin{array}{lll}79 & 58 & 75 \\ 94 & 57 & 78 \\ 78 & 56 & 75 \\ 77 & 57 & 80 \\ 78 & 56 & 80\end{array}$

$\begin{array}{rrr}71 & 76 & 95 \\ 77 & 69 & 100 \\ 79 & 67 & 96 \\ 83 & 71 & 96\end{array}$

96

$\begin{array}{ll}99 & 70 \\ 94 & 69\end{array}$

99
94
79
-

$\begin{array}{rrr}107 & - & 42 \\ 112 & -- & 42 \\ 70 & -- & 45 \\ 78 & -- & 46\end{array}$

$\begin{array}{ll}74 & 77 \\ 76 & 78 \\ 63 & 79 \\ 65 & 83\end{array}$

$\begin{array}{ll}65 & 83 \\ 72 & 82\end{array}$

TEMPERATURE $\left({ }^{\circ} \mathrm{C}\right)$ OF WATER, WATER YEAR OCTOBER 1969 TO SEPTEMBER 1970

\begin{tabular}{|c|c|c|c|c|c|c|c|c|c|c|c|c|}
\hline DAY & OCT & NOV & OEC & JAN & FEB & MAR & APR & MAY & JUN & JUL & AUG & SEP \\
\hline $\begin{array}{l}1 \\
2 \\
3 \\
4 \\
5\end{array}$ & $\begin{array}{l}22.0 \\
23.0 \\
20.0 \\
20.0 \\
19.0\end{array}$ & $\begin{array}{l}12.5 \\
15.0 \\
14.5 \\
14.0 \\
12.5\end{array}$ & $\begin{array}{l}6.5 \\
6.5 \\
7.0 \\
7.5 \\
6.0\end{array}$ & $\begin{array}{l}6 . r \\
5.5 \\
3.0 \\
4.5 \\
5.0\end{array}$ & $\begin{array}{l}6.5 \\
5.0 \\
7.0 \\
3.0 \\
5.0\end{array}$ & $\begin{array}{l}8.0 \\
6.0 \\
3.0 \\
8.0 \\
7.0\end{array}$ & $\begin{array}{l}6.5 \\
7.0 \\
6.5 \\
7.0 \\
5.5\end{array}$ & $\begin{array}{l}7.0 \\
5.0 \\
6.0 \\
5.5 \\
8.0\end{array}$ & $\begin{array}{l}= \\
=- \\
=-\end{array}$ & $\begin{array}{l}20.0 \\
16.0 \\
20.0 \\
20.0 \\
15.0\end{array}$ & $\begin{array}{l}18.0 \\
17.0 \\
16.0 \\
15.0 \\
17.0\end{array}$ & $\begin{array}{l}17.0 \\
17.0 \\
16.0 \\
16.0 \\
17.0\end{array}$ \\
\hline $\begin{array}{r}6 \\
7 \\
8 \\
9 \\
10\end{array}$ & $\begin{array}{l}20.0 \\
19.0 \\
20.5 \\
19.0 \\
20.5\end{array}$ & $\begin{array}{r}11.0 \\
8.0 \\
8.5 \\
10.0 \\
9.0\end{array}$ & $\begin{array}{l}5.0 \\
7.0 \\
6.5 \\
7.0 \\
8.0\end{array}$ & $\begin{array}{l}2.0 \\
2.5 \\
1.5 \\
3.0 \\
1.5\end{array}$ & $\begin{array}{l}8.5 \\
2.5 \\
7.0 \\
8.0 \\
2.0\end{array}$ & $\begin{array}{l}9.0 \\
6.5 \\
5.0 \\
6.0 \\
5.5\end{array}$ & $\begin{array}{l}6.0 \\
4.0 \\
5.0 \\
3.0 \\
4.5\end{array}$ & $\begin{array}{l}5.0 \\
5.0 \\
7.0 \\
6.5 \\
6.0\end{array}$ & $\begin{array}{l}=- \\
=- \\
--\end{array}$ & $\begin{array}{l}16.0 \\
17.0 \\
15.0 \\
14.0 \\
13.0\end{array}$ & $\begin{array}{l}16.0 \\
17.0 \\
15.0 \\
16.0 \\
15.0\end{array}$ & $\begin{array}{l}18.0 \\
25.0 \\
15.0 \\
18.0 \\
17.0\end{array}$ \\
\hline $\begin{array}{l}11 \\
12 \\
13 \\
14 \\
15\end{array}$ & $\begin{array}{l}20.0 \\
19.5 \\
21.0 \\
20.0 \\
17.5\end{array}$ & $\begin{array}{r}8.5 \\
8.0 \\
10.0 \\
8.0 \\
8.0\end{array}$ & $\begin{array}{r}10.0 \\
4.5 \\
3.0 \\
8.5 \\
7.0\end{array}$ & $\begin{array}{l}2.5 \\
2.0 \\
3.0 \\
3.0 \\
3.5\end{array}$ & $\begin{array}{l}7.0 \\
5.5 \\
3.0 \\
6.0 \\
4.0\end{array}$ & $\begin{array}{l}8.0 \\
6.0 \\
5.5 \\
3.0 \\
5.0\end{array}$ & $\begin{array}{l}4.0 \\
5.0 \\
4.5 \\
6.0 \\
4.5\end{array}$ & $\begin{array}{r}8.0 \\
5.5 \\
9.5 \\
15.0 \\
7.0\end{array}$ & $\begin{array}{l}=- \\
=- \\
=\end{array}$ & $\begin{array}{l}14.0 \\
14.0 \\
14.0 \\
13.0 \\
17.0\end{array}$ & $\begin{array}{l}15.0 \\
13.0 \\
13.0 \\
14.0 \\
15.0\end{array}$ & $\begin{array}{l}17.0 \\
16.0 \\
17.0 \\
16.0 \\
18.0\end{array}$ \\
\hline $\begin{array}{l}16 \\
17 \\
18 \\
19 \\
20\end{array}$ & $\begin{array}{l}20.5 \\
21.0 \\
12.5 \\
19.5 \\
20.0\end{array}$ & $\begin{array}{r}8.5 \\
8.5 \\
10.0 \\
6.5 \\
10.5\end{array}$ & $\begin{array}{l}7.0 \\
5.0 \\
5.0 \\
6.0 \\
3.5\end{array}$ & $\begin{array}{l}3.0 \\
2.0 \\
2.5 \\
3.0 \\
2.0\end{array}$ & $\begin{array}{l}4.5 \\
7.0 \\
7.5 \\
6.5 \\
7.0\end{array}$ & $\begin{array}{l}4.0 \\
4.0 \\
3.0 \\
3.0 \\
4.0\end{array}$ & $\begin{array}{l}5.0 \\
6.0 \\
6.5 \\
5.0 \\
7.0\end{array}$ & $\begin{array}{l}8.0 \\
6.0 \\
7.0 \\
7.0 \\
8.0\end{array}$ & $\begin{array}{l}-- \\
=- \\
--\end{array}$ & $\begin{array}{l}17.0 \\
18.0 \\
17.0 \\
18.0 \\
16.0\end{array}$ & $\begin{array}{l}16.0 \\
17.0 \\
17.0 \\
17.0 \\
16.0\end{array}$ & $\begin{array}{l}19.0 \\
19.0 \\
18.0 \\
18.0 \\
18.0\end{array}$ \\
\hline $\begin{array}{l}21 \\
22 \\
23 \\
24 \\
25\end{array}$ & $\begin{array}{l}20.0 \\
18.5 \\
18.5 \\
10.5 \\
15.5\end{array}$ & $\begin{array}{l}6.5 \\
5.0 \\
5.0 \\
6.0 \\
9.0\end{array}$ & $\begin{array}{l}3.0 \\
5.0 \\
5.0 \\
5.0 \\
5.0\end{array}$ & $\begin{array}{l}3.5 \\
3.0 \\
2.5 \\
4.5 \\
3.0\end{array}$ & $\begin{array}{l}7.0 \\
5.0 \\
2.0 \\
4.0 \\
6.0\end{array}$ & $\begin{array}{l}3.0 \\
4.0 \\
5.0 \\
5.0 \\
4.0\end{array}$ & $\begin{array}{l}5.0 \\
4.0 \\
6.0 \\
5.0 \\
7.0\end{array}$ & $\begin{array}{r}8.0 \\
9.0 \\
7.5 \\
10.0 \\
9.0\end{array}$ & $\begin{array}{l}=- \\
=- \\
=-\end{array}$ & $\begin{array}{l}14.0 \\
14.0 \\
15.0 \\
16.0 \\
15.0\end{array}$ & $\begin{array}{r}17.0 \\
17.0 \\
-0 \\
16.0 \\
16.0\end{array}$ & $\begin{array}{l}17.0 \\
17.0 \\
17.0 \\
18.0 \\
19.0\end{array}$ \\
\hline $\begin{array}{l}26 \\
27 \\
28 \\
29 \\
30 \\
31\end{array}$ & $\begin{array}{l}12.5 \\
14.5 \\
13.0 \\
12.5 \\
14.0 \\
13.0\end{array}$ & $\begin{array}{l}7.5 \\
9.0 \\
7.5 \\
8.0 \\
8.0 \\
--\end{array}$ & $\begin{array}{r}5.0 \\
5.0 \\
5.0 \\
5.0 \\
4.0 \\
-\ldots\end{array}$ & $\begin{array}{r}3.0 \\
10.0 \\
3.0 \\
2.5 \\
2.0 \\
7.0\end{array}$ & $\begin{array}{r}8.5 \\
5.0 \\
4.5 \\
-. \\
-\therefore \\
=-\end{array}$ & $\begin{array}{l}7.0 \\
3.5 \\
6.0 \\
6.0 \\
4.0 \\
4.0\end{array}$ & $\begin{array}{l}4.0 \\
3.0 \\
6.0 \\
4.0 \\
5.0 \\
-.\end{array}$ & $\begin{array}{r}10.0 \\
-0 \\
12.0 \\
12.0 \\
14.0 \\
13.0\end{array}$ & $\begin{array}{l}=- \\
=- \\
=- \\
--\end{array}$ & $\begin{array}{l}16.0 \\
17.0 \\
16.0 \\
17.0 \\
18.0 \\
17.0\end{array}$ & $\begin{array}{l}18.0 \\
18.0 \\
17.0 \\
18.0 \\
17.0 \\
17.0\end{array}$ & $\begin{array}{r}18.0 \\
15.0 \\
14.0 \\
14.0 \\
12.0 \\
---\end{array}$ \\
\hline AYG & 17.9 & 9.1 & 5.9 & 3.3 & 5.5 & 5.1 & 5.2 & 8.2 & -- & 16.0 & 16.2 & 16.7 \\
\hline
\end{tabular}


02060500 ROANOKE (STAUNTON) RIVER AT ALTAVISTA, VA.

LOCATION.--Lat $37^{\circ} 06^{\prime} 16^{\prime \prime}$, long $79^{\circ} 17^{\prime} 44^{\prime \prime}$, Pittsylvania County, at gaging station on right bank 12 ft upstream from bridge on U.S. Highway $29,0,3 \mathrm{mlle}$ south of Altavista, 0.3 mile downstream from Sycamore Creek, $3.5 \mathrm{~m} 11 \mathrm{es}$ upbridge on U.S. Highway $29,0,3$ mile south of Al
stream from Big Otter R1ver, and at mile 286.5 .

DRAINAGE AREA, $--1,789 \mathrm{sq} \mathrm{mi}$ (revised).

PER IOD OF RECORD.--Chernical analyses: October 1950 to Septeraber 1951, October 1955 to September 1956 , March 1967

Water temperatures: October 1950 to September 1951, February 1953 to September 1956, Apr11 1968 to September 1970.

Nater temperatures: October 1950 to September 1951,
Sediment records: February 1953 to September 1956.

EXTREMES, - -1969-70:

Specific conductance: Maximum da11y, 229 micromhos Nov. 7; min1mum da1ly, 107 microrahos Apr. 5.

Water temperatures: Maximum, $27.0^{\circ} \mathrm{C}$ July 3 ; minimum, $1.5^{\circ} \mathrm{C}$ Jan. $10,11$.

CHEMICAL ANALYSES, WATER YEAR OCTOBER 2969 TO SEPTEMBER 1970

\begin{tabular}{|c|c|c|c|c|c|c|c|c|c|c|}
\hline DATE & $\begin{array}{l}\text { MEAN } \\
\text { DIS- } \\
\text { CHARGE } \\
\text { (CFS) }\end{array}$ & $\begin{array}{l}\text { SIL ICA } \\
\text { ISI O2 I } \\
\text { I } 4 G / L \text { ) }\end{array}$ & $\begin{array}{l}\text { DIS- } \\
\text { SOLVED } \\
\text { IRON } \\
\text { IFE) } \\
\text { (UG/L) }\end{array}$ & $\begin{array}{l}\text { CAL- } \\
\text { CIUM } \\
\text { (CA) } \\
\text { (MGIL) }\end{array}$ & $\begin{array}{c}M A G- \\
M E- \\
S I U M \\
(M G) \\
(M G / L)\end{array}$ & $\begin{array}{l}\text { SOD I UM } \\
\text { (NA) } \\
\text { (MG/L) }\end{array}$ & $\begin{array}{l}\text { PO- } \\
\text { TAS- } \\
\text { SIUM } \\
\text { (K) } \\
\text { (MGIL) }\end{array}$ & $\begin{array}{l}\text { BICAR- } \\
\text { BONATE } \\
\text { ( HCO3) } \\
\text { ( MG/L) }\end{array}$ & $\begin{array}{l}\text { SULFATE } \\
\text { (SOA) } \\
\text { (MG/L) }\end{array}$ & $\begin{array}{l}\text { CHLO- } \\
\text { RIDE } \\
\text { ICLI } \\
\text { IMG/LI }\end{array}$ \\
\hline \multicolumn{11}{|l|}{ नCT。 } \\
\hline $\begin{array}{l}n 1-10 \\
11-2 n\end{array}$ & $\operatorname{lngn}$ & 6.5 & 70 & 19 & 4.5 & 6.4 & 3.5 & 75 & 12 & 6.9 \\
\hline $21-31$ & $\begin{array}{r}655 \\
1280\end{array}$ & 5.6 & 20 & 15 & 6.5 & 6.8 & 2.6 & 80 & 11 & 6.4 \\
\hline \multicolumn{11}{|l|}{ Nov. } \\
\hline \multicolumn{10}{|l|}{ MAR:" } & 8.8 \\
\hline $97 \ldots$ & 235 & 12 & 160 & 15 & 4.8 & 6.6 & 1.6 & 66 & 9.0 & 5.0 \\
\hline $12 \ldots$ & $31 \% 0$ & 13 & 150 & 15 & 5.1 & 15 & 2.1 & 88 & 12 & 3.1 \\
\hline $14 \ldots$ & 213 & 12 & 90 & 11 & 5.0 & 7.4 & 1.8 & 66 & 8.8 & 3.7 \\
\hline $21 \ldots$ & 245 & 12 & 20 & 15 & 5.2 & 8.6 & 1.9 & 66 & 11 & 7.2 \\
\hline $28 . .$. & 218 & $\ln$ & $4 n$ & 12 & 4.8 & 5.5 & 2.0 & 56 & 10 & 5.6 \\
\hline \multicolumn{11}{|l|}{ APR } \\
\hline$r_{4} \ldots$ & 554 & 12 & 50 & 10 & 4.4 & 7.6 & 1.6 & 47 & 8.6 & 6.0 \\
\hline $11 \ldots$ & 765 & 7.9 & $14 n$ & 12 & 5.3 & 5.7 & 2.0 & 60 & 7.8 & 5.9 \\
\hline $19 .$. & 75? & 5.6 & in & 13 & 5.6 & 5.7 & 1.9 & 65 & 11 & 7.0 \\
\hline $25 \ldots$ & 519 & 5.9 & 20 & 13 & 5.3 & 6.6 & .9 & 66 & 10 & 6.4 \\
\hline \multicolumn{11}{|l|}{ MAY } \\
\hline$n 2 \ldots$ & 590 & 5.0 & 20 & 15 & 5.6 & 4.5 & 1.8 & 64 & 10 & 6.4 \\
\hline $09 .$. & 910 & 6.0 & 60 & 14 & 6.9 & 4.7 & 1.8 & 69 & $! 1$ & 6.2 \\
\hline $16 \ldots$ & $109 n$ & 5.2 & 0 & 17 & 5.7 & 6.4 & 2.5 & 72 & 11 & 7.7 \\
\hline $23 \ldots$ & 756 & 4.2 & $r$ & 16 & 6.7 & 6.8 & 2.8 & 76 & 10 & 8.6 \\
\hline $30 . .$. & 550 & 4.0 & 10 & 18 & 6.5 & 6.6 & 2.3 & 78 & 12 & 8.4 \\
\hline \multicolumn{11}{|l|}{ JUNE } \\
\hline ns... & 145 & 11 & 0 & 17 & 4.4 & 4.2 & 2.5 & 70 & 9.8 & 6.0 \\
\hline $13 .$. & 135 & 14 & 70 & $\angle 1$ & 3.5 & 3.7 & $2 . n$ & 77 & 4.6 & 5.2 \\
\hline $2 n \ldots$ & 97 & 0.7 & 0 & 20 & 6.1 & 8.1 & 2.9 & 81 & 12 & 9.3 \\
\hline \multirow{2}{*}{\multicolumn{11}{|c|}{ JuLY }} \\
\hline & & & & & & & & & & \\
\hline $03 \ldots$ & 249 & B. ก & 10 & 20 & 5.1 & 6.0 & 2.9 & 77 & 9.8 & 7.6 \\
\hline $11 \ldots$ & 195 & 5.9 & 10 & 10 & 4.9 & 10 & 2.6 & 84 & 11 & 7.8 \\
\hline $19 .$. & $+2 n$ & 6.6 & 70 & 20 & 4.9 & 9.5 & 2.5 & B 2 & 13 & 7.6 \\
\hline $25 .$. & 271 & 5.8 & 20 & 18 & 4.1 & 3.0 & 3.2 & 60 & 14 & 4.0 \\
\hline \multicolumn{11}{|l|}{ ALG. } \\
\hline ni... & 227 & 13 & 30 & 18 & 5.6 & 6.4 & 3.6 & 80 & 10 & 6.4 \\
\hline $09 \ldots$ & 161 & 4.4 & 50 & 25 & 2.7 & 7.6 & 3.2 & 73 & 21 & 6.2 \\
\hline $15 . \ldots$ & 752 & 15 & 10 & 10 & 4.1 & 5.1 & 3.0 & 73 & 11 & 7.3 \\
\hline $22 \ldots$ & 384 & in & 50 & 14 & 3.8 & 4.8 & 3.1 & 50 & 9.8 & 4.3 \\
\hline \multicolumn{11}{|l|}{ SFPT. } \\
\hline ns.... & 412 & 10 & 30 & 14 & 5,6 & 4.8 & 2.7 & 66 & 12 & 5.1 \\
\hline $12 \ldots$ & 196 & in & $13 n$ & 15 & 5.3 & 6.3 & 2.5 & 70 & 12 & 5.7 \\
\hline $19 . .$. & 169 & 14 & 30 & 21 & 4.9 & 9.0 & 4.1 & 77 & 13 & 7.6 \\
\hline $26 \ldots$ & 109 & 11 & 40 & 19 & 5.3 & 6.8 & 3.1 & 78 & 10 & 6.0 \\
\hline
\end{tabular}

SPECIFIC CONDUCTANCE (MICROMHOS/CM AT $25^{\circ} \mathrm{C}$ ), WATER YEAR OCTOBER 1969 TO SEPTEMBER 2970

\begin{tabular}{|c|c|c|c|c|c|c|c|c|c|c|c|c|}
\hline $\begin{array}{c}\text { DAY } \\
1 \ldots \ldots \\
2 \ldots \ldots \\
3 \ldots \ldots \\
4 \ldots \ldots \\
5 \ldots \ldots\end{array}$ & $\begin{array}{r}\text { OCTOSER } \\
159 \\
135 \\
158 \\
138 \\
141\end{array}$ & $\begin{array}{c}\text { NOVEMBER } \\
153 \\
156 \\
168 \\
168 \\
169\end{array}$ & $\begin{array}{c}\text { DECEMBER } \\
161 \\
161 \\
158 \\
158 \\
164\end{array}$ & $\begin{array}{c}\text { JANUARY } \\
148 \\
140 \\
124 \\
118 \\
148\end{array}$ & $\begin{array}{c}\text { FEBRUARY } \\
154 \\
155 \\
149 \\
110 \\
136\end{array}$ & $\begin{array}{l}\text { MARCH } \\
140 \\
155 \\
149 \\
149 \\
150\end{array}$ & $\begin{array}{l}\text { APR IL } \\
132 \\
134 \\
140 \\
110 \\
107\end{array}$ & $\begin{array}{l}\text { MAY } \\
142 \\
132 \\
131 \\
146 \\
139\end{array}$ & $\begin{array}{l}\text { JUNE } \\
153 \\
155 \\
152 \\
154 \\
160\end{array}$ & $\begin{array}{l}\text { JULY } \\
164 \\
162 \\
160 \\
178 \\
182\end{array}$ & $\begin{array}{r}\text { AUGUST } \\
161 \\
161 \\
158 \\
158 \\
159\end{array}$ & $\begin{array}{c}\text { SEPTEMBER } \\
154 \\
155 \\
154 \\
136 \\
137\end{array}$ \\
\hline $\begin{array}{c}6 \ldots \ldots \\
7 \ldots \ldots \\
8 \ldots \ldots \\
9 \ldots \ldots \\
10 \ldots \ldots\end{array}$ & $\begin{array}{l}162 \\
162 \\
157 \\
159 \\
161\end{array}$ & $\begin{array}{l}172 \\
229 \\
136 \\
133 \\
166\end{array}$ & $\begin{array}{l}159 \\
159 \\
150 \\
152 \\
140\end{array}$ & $\begin{array}{l}148 \\
150 \\
158 \\
158 \\
160\end{array}$ & $\begin{array}{l}164 \\
139 \\
160 \\
143 \\
141\end{array}$ & $\begin{array}{l}158 \\
140 \\
138 \\
149 \\
153\end{array}$ & $\begin{array}{l}130 \\
136 \\
137 \\
135 \\
138\end{array}$ & $\begin{array}{l}141 \\
142 \\
139 \\
137 \\
137\end{array}$ & $\begin{array}{l}135 \\
136 \\
159 \\
161 \\
159\end{array}$ & $\begin{array}{l}193 \\
184 \\
165 \\
163 \\
164\end{array}$ & $\begin{array}{l}159 \\
160 \\
177 \\
178 \\
152\end{array}$ & $\begin{array}{l}137 \\
157 \\
158 \\
157 \\
158\end{array}$ \\
\hline $\begin{array}{l}11 \ldots \ldots \\
12 \ldots \ldots \\
13 \ldots \ldots \\
14 \ldots \ldots \\
15 \ldots \ldots\end{array}$ & $\begin{array}{l}169 \\
170 \\
154 \\
161 \\
164\end{array}$ & $\begin{array}{l}164 \\
168 \\
171 \\
169 \\
148\end{array}$ & $\begin{array}{l}140 \\
150 \\
144 \\
146 \\
175\end{array}$ & $\begin{array}{l}180 \\
165 \\
152 \\
150 \\
153\end{array}$ & $\begin{array}{l}159 \\
141 \\
134 \\
153 \\
153\end{array}$ & $\begin{array}{l}153 \\
190 \\
195 \\
148 \\
148\end{array}$ & $\begin{array}{l}123 \\
124 \\
138 \\
140 \\
138\end{array}$ & $\begin{array}{l}138 \\
138 \\
142 \\
148 \\
146\end{array}$ & $\begin{array}{l}162 \\
138 \\
136 \\
140 \\
163\end{array}$ & $\begin{array}{l}172 \\
169 \\
165 \\
165 \\
165\end{array}$ & $\begin{array}{l}150 \\
154 \\
142 \\
146 \\
142\end{array}$ & $\begin{array}{l}158 \\
146 \\
146 \\
157 \\
152\end{array}$ \\
\hline $\begin{array}{l}16 \ldots \ldots \\
17 \ldots \ldots \\
16 \ldots \ldots \\
19 \ldots \ldots \\
20 \ldots \ldots\end{array}$ & $\begin{array}{l}164 \\
167 \\
148 \\
144 \\
160\end{array}$ & $\begin{array}{l}148 \\
174 \\
173 \\
201 \\
174\end{array}$ & $\begin{array}{r}175 \\
166 \\
172 \\
-132\end{array}$ & $\begin{array}{l}168 \\
128 \\
130 \\
153 \\
169\end{array}$ & $\begin{array}{l}135 \\
134 \\
117 \\
113 \\
165\end{array}$ & $\begin{array}{l}149 \\
150 \\
150 \\
153 \\
158\end{array}$ & $\begin{array}{l}135 \\
131 \\
137 \\
138 \\
145\end{array}$ & $\begin{array}{l}146 \\
146 \\
147 \\
148 \\
145\end{array}$ & $\begin{array}{l}169 \\
211 \\
209 \\
214 \\
175\end{array}$ & $\begin{array}{l}165 \\
164 \\
165 \\
162 \\
158\end{array}$ & $\begin{array}{l}142 \\
142 \\
141 \\
140 \\
142\end{array}$ & $\begin{array}{l}155 \\
156 \\
158 \\
186 \\
175\end{array}$ \\
\hline $\begin{array}{l}21 \ldots \ldots \\
22 \ldots \ldots \\
23 \ldots \ldots \\
24 \ldots \ldots \\
25 \ldots \ldots\end{array}$ & $\begin{array}{l}157 \\
164 \\
163 \\
165 \\
164\end{array}$ & $\begin{array}{l}172 \\
145 \\
147 \\
173 \\
169\end{array}$ & $\begin{array}{l}130 \\
164 \\
164 \\
164 \\
180\end{array}$ & $\begin{array}{l}170 \\
172 \\
174 \\
148 \\
147\end{array}$ & $\begin{array}{l}125 \\
125 \\
120 \\
146 \\
160\end{array}$ & $\begin{array}{l}160 \\
160 \\
158 \\
155 \\
157\end{array}$ & $\begin{array}{l}139 \\
142 \\
139 \\
139 \\
135\end{array}$ & $\begin{array}{l}152 \\
150 \\
156 \\
152 \\
151\end{array}$ & $\begin{array}{l}172 \\
164 \\
165 \\
167 \\
169\end{array}$ & $\begin{array}{l}160 \\
164 \\
163 \\
163 \\
132\end{array}$ & $\begin{array}{l}142 \\
114 \\
114 \\
145 \\
146\end{array}$ & $\begin{array}{l}160 \\
176 \\
174 \\
170 \\
189\end{array}$ \\
\hline $\begin{array}{l}26 \ldots \ldots \\
27 \ldots \ldots \\
\angle 8 \ldots \ldots \\
\angle 9 \ldots \ldots \\
30 \ldots \ldots \\
31 \ldots \ldots\end{array}$ & $\begin{array}{l}165 \\
164 \\
163 \\
178 \\
166 \\
159\end{array}$ & $\begin{array}{l}169 \\
161 \\
171 \\
141 \\
137 \\
--\end{array}$ & $\begin{array}{l}132 \\
132 \\
136 \\
190 \\
155 \\
155\end{array}$ & $\begin{array}{l}156 \\
147 \\
151 \\
152 \\
172 \\
168\end{array}$ & $\begin{array}{r}163 \\
163 \\
148 \\
-- \\
=-\end{array}$ & $\begin{array}{l}158 \\
157 \\
137 \\
136 \\
146 \\
159\end{array}$ & $\begin{array}{l}139 \\
138 \\
136 \\
138 \\
139 \\
-\cdots\end{array}$ & $\begin{array}{l}159 \\
159 \\
161 \\
154 \\
163 \\
164\end{array}$ & $\begin{array}{l}164 \\
150 \\
148 \\
157 \\
168 \\
--\end{array}$ & $\begin{array}{l}134 \\
159 \\
159 \\
162 \\
160 \\
159\end{array}$ & $\begin{array}{l}146 \\
145 \\
146 \\
149 \\
146 \\
148\end{array}$ & $\begin{array}{l}170 \\
174 \\
175 \\
177 \\
178 \\
--\end{array}$ \\
\hline AVERAGE & 159 & 164 & 155 & 153 & 143 & 153 & 134 & 146 & 162 & 163 & 148 & 161 \\
\hline
\end{tabular}


Period of record:

D1ssolved solids (1950-51, 1968-69): Maximum, $386 \mathrm{mg} / 1 \mathrm{Jan} .16-17,1969$; min $1 \mathrm{mum}, 70 \mathrm{mg} / 1 \mathrm{Apr} .1-10,1951$.

Hardness (1950-51, 1968-69): Maximum, $106 \mathrm{mg} / 1$ Aug. 14-19, 1969; minimum, $34 \mathrm{mg} / \mathrm{i}$ Aug. 20 , 1969.

Specle condctance: Haximum da11y, 580 micromhos Jan. 17, 1969; minimum daily, 54 micromhos Aug. $18,1955$.

EMARKS.-Chemical-quality data represent equal-volume composites for the periods indicated prior to Nov, 1 and for every seventh day thereafter. No chemlcal analyses available for period Dec. 1ndicated prior to Nov. 1 and for
. Feb. 28 . CHEMICAL ANALYSES, hATER YEAR CCTCBER 1969 10 SEPTEMBER 1970

\begin{tabular}{|c|c|c|c|c|c|c|c|c|c|}
\hline DATE & $\begin{array}{l}F \in U C= \\
R I O E \\
(F) \\
(* G / L)\end{array}$ & $\begin{array}{l}\text { NITRATE } \\
(N O 3) \\
(N G / C)\end{array}$ & $\begin{array}{l}\text { FHCS - } \\
\text { PHATE } \\
(P C 4) \\
(N C / L)\end{array}$ & $\begin{array}{l}\text { CIS- } \\
\text { SCLVE } \\
\text { SCLIOS } \\
\text { IRESI- } \\
\text { CLE AT } \\
\text { IEO C J } \\
\text { INGIL] }\end{array}$ & $\begin{array}{l}\text { MARO- } \\
\text { NESS } \\
\text { (CA,MG) } \\
\text { (MG/L) }\end{array}$ & $\begin{array}{l}\text { NON- } \\
\text { CAR- } \\
\text { BONAIE } \\
\text { HARC- } \\
\text { AESS } \\
\text { (MG/L) }\end{array}$ & $\begin{array}{l}\text { SPECI- } \\
\text { FIC } \\
\text { COND- } \\
\text { UCIAACE } \\
\text { (MICRC- } \\
\text { MHOS) }\end{array}$ & $\begin{array}{c}\text { PH } \\
\text { (UNITS) }\end{array}$ & $\begin{array}{l}\text { CCECR } \\
\text { IPLAT- } \\
\text { IALPI- } \\
\text { CCEALI } \\
\text { LNITSI }\end{array}$ \\
\hline \multicolumn{10}{|l|}{$\mathrm{CCT}$} \\
\hline $\begin{array}{l}01-10 \\
11-2 C \\
21-31\end{array}$ & $\begin{array}{l}1 \\
: 1 \\
.2\end{array}$ & $\begin{array}{l}.9 \\
.5 \\
.5\end{array}$ & $\begin{array}{l}.05 \\
.04 \\
.07\end{array}$ & $\begin{array}{r}101 \\
99 \\
102\end{array}$ & $\begin{array}{l}66 \\
64 \\
70\end{array}$ & $\begin{array}{l}4 \\
0 \\
3\end{array}$ & $\begin{array}{l}153 \\
160 \\
164\end{array}$ & $\begin{array}{l}7.5 \\
7.4 \\
7.6\end{array}$ & $\begin{array}{r}25 \\
0 \\
15\end{array}$ \\
\hline \multicolumn{10}{|l|}{ NGV. } \\
\hline MAR:. & .2 & .6 &. $\mathrm{CC}$ & ९९ & 72 & 7 & 166 & 1.1 & 10 \\
\hline $\begin{array}{l}07 \ldots \\
12 \ldots\end{array}$ & $\begin{array}{l}.1 \\
.2\end{array}$ & $\begin{array}{r}\mathrm{I} . \mathrm{C} \\
.4\end{array}$ & $\begin{array}{l}.00 \\
.00\end{array}$ & $\begin{array}{r}86 \\
121\end{array}$ & $\begin{array}{l}58 \\
59\end{array}$ & $\begin{array}{l}4 \\
\mathrm{C}\end{array}$ & $\begin{array}{l}140 \\
190\end{array}$ & $\begin{array}{l}7.7 \\
7.5\end{array}$ & $\begin{array}{r}5 \\
15\end{array}$ \\
\hline $14 \ldots$ & .1 & 1.2 & .00 & 54 & 48 & c & 148 & 7.4 & 5 \\
\hline $21 \ldots$ & .1 & .9 & .18 & 102 & 58 & 4 & 160 & 7.5 & 15 \\
\hline $\begin{array}{l}28 \cdots \\
A P R\end{array}$ & .1 & - $c$ & .01 & $\varepsilon 4$ & 50 & 4 & 137 & 7.1 & 5 \\
\hline $04 \ldots$ & .2 & 1.5 & . CB & 86 & 43 & 4 & 110 & 6.8 & 15 \\
\hline $11 \ldots$ & . I &. $\mathrm{C}$ & .01 & 85 & 52 & 3 & 123 & 7.3 & $2 \mathrm{C}$ \\
\hline $18 \ldots$ & .2 & .0 & .00 & 89 & 56 & 2 & 137 & 7.4 & 5 \\
\hline $\operatorname{MAY}_{\text {MAY }}^{25} \cdots$ & $\cdot \bar{c}$ & .2 &. $\mathrm{CO}$ & 90 & 54 & 0 & 135 & 7.0 & 8 \\
\hline $02 \ldots$ & . [ & .4 & .00 & 92 & 60 & 8 & 132 & 7.2 & c \\
\hline $09 \ldots$ & .1 & .0 & .02 & 101 & 64 & 8 & 137 & 7.5 & c \\
\hline $16 \ldots$ & .1 & .9 & .00 & 95 & 65 & 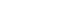 & 146 & 7.8 & 5 \\
\hline $23 \ldots$ & . [ & .7 & .00 & 95 & 68 & 6 & 156 & 7.7 & 5 \\
\hline $30 \ldots$ & . I & .9 & .01 & $1 C 5$ & 12 & e & 163 & 7.2 & C \\
\hline \multicolumn{10}{|l|}{ JUNE } \\
\hline $06 .$. & - I & 1.4 & .00 & 54 & 61 & 4 & 135 & 7.4 & c \\
\hline $13 \ldots$ & .2 & I. 7 & .01 & 100 & 66 & 4 & 136 & 7.1 & c \\
\hline $20 \ldots$ & .2 & I. 0 & .00 & 123 & 74 & 8 & 175 & 7.0 & 5 \\
\hline $27 \ldots$ & .2 & 1. $\mathrm{C}$ & .00 & $9 t$ & 64 & $\epsilon$ & 150 & 7.2 & 5 \\
\hline \multicolumn{10}{|l|}{ JULY } \\
\hline $03 \ldots$ & .2 & 1.5 & .06 & 106 & 70 & 7 & 160 & $7 \cdot 1$ & 5 \\
\hline $11 \ldots$ & .2 & .7 & .05 & 109 & 68 & 0 & 172 & 7.2 & c \\
\hline $18 \ldots$ & .1 & .6 & .00 & 107 & 70 & 3 & 165 & 7.4 & 5 \\
\hline $\begin{array}{r}25 \\
\text { AUG }\end{array}$ & .1 & 3.1 & .16 & 96 & 62 & 13 & 132 & 7.4 & 20 \\
\hline $\begin{array}{r}\text { AU } \\
01 . . .\end{array}$ & .2 & 2.8 & .21 & $11 \varepsilon$ & 69 & 4 & 161 & \multicolumn{2}{|c|}{ AUG. } \\
\hline $08 .$. & .2 & 4. $C$ & .35 & 133 & 73 & 13 & 177 & 7.1 & 15 \\
\hline $15 \ldots$ & .2 & $2 \cdot t$ & .06 & 107 & 65 & 5 & 142 & 7.4 & 5 \\
\hline $22 \ldots$ & .2 & $2 . t$ & .17 & $\subsetneq 1$ & 51 & 10 & 114 & 7.3 & 25 \\
\hline $29 \ldots$ & .2 & . 8 & .17 & 104 & 66 & 0 & 149 & 7.4 & 5 \\
\hline \multicolumn{10}{|l|}{ SEPT. } \\
\hline $05 \ldots$ & .2 & .5 & .04 & st & 58 & 4 & 137 & 7.4 & 13 \\
\hline $12 \ldots$ & .2 & $\therefore 7$ & .59 & 104 & 60 & 4 & 146 & 7.3 & $2 \mathrm{C}$ \\
\hline $19 \ldots$ & .3 & 3.7 & 3.6 & 117 & $\begin{array}{l}72 \\
68\end{array}$ & $\begin{array}{r}10 \\
4\end{array}$ & 186 & 7.7 & 10 \\
\hline $26 \ldots$ & .2 & I. 5 & .46 & 99 & 68 & 4 & 170 & 7.9 & $\varepsilon$ \\
\hline
\end{tabular}

TEMPERATURE $\left({ }^{\circ} \mathrm{C}\right)$ OF WATER, WATER YEAR OCTOBER 1969 TO SEPTEMBER 1970

\begin{tabular}{|c|c|c|c|c|c|c|c|c|c|c|c|c|}
\hline DAY & $O C T$ & NOV & DFC & JAN & FEB & MAR & $\triangle P R$ & MAY & JUN & JUL & AUG & SEP \\
\hline $\begin{array}{l}1 \\
2 \\
3 \\
4 \\
5\end{array}$ & $\begin{array}{l}19.0 \\
21.0 \\
20.0 \\
19.0 \\
18.0\end{array}$ & $\begin{array}{l}16.0 \\
16.0 \\
16.0 \\
15.0 \\
14.5\end{array}$ & $\begin{array}{r}10.0 \\
9.0 \\
8.0 \\
8.0 \\
8.5\end{array}$ & $\begin{array}{l}5.0 \\
5.0 \\
2.0 \\
2.0 \\
5.0\end{array}$ & $\begin{array}{l}7.0 \\
9.0 \\
4.5 \\
4.0 \\
3.5\end{array}$ & $\begin{array}{l}6.5 \\
7.0 \\
7.0 \\
7.0 \\
7.0\end{array}$ & $\begin{array}{l}11.0 \\
12.0 \\
10.0 \\
11.5 \\
12.0\end{array}$ & $\begin{array}{l}15.0 \\
14.0 \\
14.0 \\
14.0 \\
14.0\end{array}$ & $\begin{array}{l}17.5 \\
18.0 \\
19.0 \\
19.0 \\
19.0\end{array}$ & $\begin{array}{l}20.5 \\
19.5 \\
27.0 \\
26.0 \\
26.0\end{array}$ & $\begin{array}{l}25.0 \\
25.0 \\
21.0 \\
21.5 \\
21.0\end{array}$ & $\begin{array}{l}22.0 \\
23.0 \\
23.0 \\
23.0 \\
24.0\end{array}$ \\
\hline $\begin{array}{r}6 \\
7 \\
8 \\
9 \\
10\end{array}$ & $\begin{array}{l}18.5 \\
19.0 \\
20.0 \\
19.0 \\
18.5\end{array}$ & $\begin{array}{l}14.5 \\
14.0 \\
13.0 \\
13.0 \\
14.5\end{array}$ & $\begin{array}{l}5.0 \\
5.0 \\
8.5 \\
8.5 \\
9.0\end{array}$ & $\begin{array}{l}5.0 \\
6.0 \\
4.0 \\
4.0 \\
1.5\end{array}$ & $\begin{array}{l}4.5 \\
6.0 \\
6.0 \\
6.0 \\
7.0\end{array}$ & $\begin{array}{r}7.0 \\
10.0 \\
10.0 \\
7.5 \\
7.0\end{array}$ & $\begin{array}{l}10.0 \\
10.5 \\
12.0 \\
12.0 \\
12.0\end{array}$ & $\begin{array}{l}13.5 \\
15.0 \\
15.0 \\
16.0 \\
17.0\end{array}$ & $\begin{array}{l}21.0 \\
21.0 \\
19.0 \\
19.0 \\
18.5\end{array}$ & $\begin{array}{l}26.0 \\
25.0 \\
21.0 \\
21.0 \\
21.0\end{array}$ & $\begin{array}{l}21.0 \\
21.0 \\
25.0 \\
25.0 \\
20.0\end{array}$ & $\begin{array}{l}24.0 \\
24.0 \\
22.0 \\
23.0 \\
23.0\end{array}$ \\
\hline $\begin{array}{l}11 \\
12 \\
13 \\
14 \\
15\end{array}$ & $\begin{array}{l}21.0 \\
21.0 \\
20.0 \\
19.5 \\
18.0\end{array}$ & $\begin{array}{r}14.0 \\
14.5 \\
13.0 \\
13.0 \\
9.0\end{array}$ & $\begin{array}{l}9.0 \\
7.0 \\
7.0 \\
7.0 \\
8.0\end{array}$ & $\begin{array}{l}1.5 \\
4.5 \\
5.0 \\
5.0 \\
4.5\end{array}$ & $\begin{array}{l}6.0 \\
5.0 \\
5.0 \\
3.0 \\
3.0\end{array}$ & $\begin{array}{l}8.0 \\
7.0 \\
9.0 \\
9.0 \\
9.0\end{array}$ & $\begin{array}{l}12.0 \\
12.0 \\
11.0 \\
12.0 \\
12.0\end{array}$ & $\begin{array}{l}17.0 \\
18.0 \\
20.0 \\
18.0 \\
18.0\end{array}$ & $\begin{array}{l}20.0 \\
19.0 \\
19.0 \\
19.0 \\
18.0\end{array}$ & $\begin{array}{l}25.0 \\
25.0 \\
20.5 \\
21.0 \\
21.0\end{array}$ & $\begin{array}{l}20.5 \\
20.5 \\
20.5 \\
21.0 \\
25.0\end{array}$ & $\begin{array}{l}22.0 \\
23.0 \\
23.0 \\
23.0 \\
23.0\end{array}$ \\
\hline $\begin{array}{l}10 \\
17 \\
18 \\
19 \\
20\end{array}$ & $\begin{array}{l}18.5 \\
18.0 \\
15.0 \\
16.0 \\
19.0\end{array}$ & $\begin{array}{r}8.0 \\
13.0 \\
13.0 \\
13.0 \\
12.0\end{array}$ & $\begin{array}{l}8.0 \\
6.5 \\
7.0 \\
-- \\
4.0\end{array}$ & $\begin{array}{l}4.5 \\
4.0 \\
4.0 \\
4.0 \\
4.0\end{array}$ & $\begin{array}{l}4.0 \\
4.0 \\
7.0 \\
9.0 \\
6.0\end{array}$ & $\begin{array}{l}7.0 \\
8.0 \\
7.5 \\
7.5 \\
7.5\end{array}$ & $\begin{array}{l}13.0 \\
14.0 \\
15.0 \\
14.0 \\
14.0\end{array}$ & $\begin{array}{l}18.0 \\
18.0 \\
18.5 \\
18.5 \\
18.0\end{array}$ & $\begin{array}{l}19.0 \\
21.0 \\
20.0 \\
24.5 \\
25.0\end{array}$ & $\begin{array}{l}21.0 \\
20.5 \\
23.0 \\
23.0 \\
21.0\end{array}$ & $\begin{array}{l}25.0 \\
20.0 \\
21.0 \\
22.0 \\
21.0\end{array}$ & $\begin{array}{l}23.5 \\
23.0 \\
23.0 \\
24.0 \\
24.0\end{array}$ \\
\hline $\begin{array}{l}21 \\
22 \\
23 \\
24 \\
25\end{array}$ & $\begin{array}{l}18.0 \\
16.0 \\
16.0 \\
14.0 \\
16.0\end{array}$ & $\begin{array}{l}10.5 \\
10.0 \\
10.0 \\
11.0 \\
11.5\end{array}$ & $\begin{array}{l}4.0 \\
5.0 \\
5.5 \\
6.5 \\
5.0\end{array}$ & $\begin{array}{l}3.5 \\
3.5 \\
3.5 \\
3.0 \\
3.0\end{array}$ & $\begin{array}{r}7.0 \\
7.0 \\
-.0 \\
7.0\end{array}$ & $\begin{array}{r}10.0 \\
10.0 \\
3.5 \\
8.0 \\
9.0\end{array}$ & $\begin{array}{l}14.5 \\
15.0 \\
15.0 \\
15.0 \\
15.0\end{array}$ & $\begin{array}{l}17.0 \\
18.5 \\
18.0 \\
18.0 \\
17.0\end{array}$ & $\begin{array}{l}25.0 \\
19.5 \\
20.0 \\
20.0 \\
19.5\end{array}$ & $\begin{array}{l}21.0 \\
20.0 \\
20.0 \\
21.0 \\
26.0\end{array}$ & $\begin{array}{l}22.0 \\
22.0 \\
22.0 \\
21.0 \\
21.0\end{array}$ & $\begin{array}{l}22.0 \\
22.0 \\
24.0 \\
24.0 \\
24.0\end{array}$ \\
\hline $\begin{array}{l}26 \\
27 \\
28 \\
29 \\
30 \\
31\end{array}$ & $\begin{array}{l}16.0 \\
17.0 \\
17.0 \\
14.0 \\
16.0 \\
16.0\end{array}$ & $\begin{array}{r}12.0 \\
8.5 \\
11.5 \\
8.0 \\
8.0 \\
-.-\end{array}$ & $\begin{array}{l}5.0 \\
4.0 \\
4.5 \\
5.0 \\
5.0 \\
5.0\end{array}$ & $\begin{array}{l}7.0 \\
6.0 \\
7.0 \\
7.0 \\
7.0 \\
6.0\end{array}$ & $\begin{array}{r}6.0 \\
6.0 \\
6.5 \\
-- \\
=-\end{array}$ & $\begin{array}{r}9.0 \\
9.0 \\
13.0 \\
7.0 \\
9.0\end{array}$ & $\begin{array}{r}15.0 \\
15.0 \\
14.5 \\
19.0 \\
19.0 \\
--\end{array}$ & $\begin{array}{l}17.0 \\
19.0 \\
19.5 \\
19.0 \\
18.0 \\
18.0\end{array}$ & $\begin{array}{r}19.5 \\
23.0 \\
23.0 \\
22.0 \\
20.5 \\
. .-\end{array}$ & $\begin{array}{l}26.0 \\
21.0 \\
22.0 \\
21.0 \\
21.0 \\
20.5\end{array}$ & $\begin{array}{l}22.0 \\
23.0 \\
22.0 \\
24.0 \\
24.0 \\
22.5\end{array}$ & $\begin{array}{r}24.0 \\
23.0 \\
20.0 \\
20.0 \\
20.0 \\
-.\end{array}$ \\
\hline$\Delta V G$ & 17.8 & 12.3 & 6.5 & 4.4 & 5.6 & 8.2 & 13.3 & 17.0 & 20.2 & 22.3 & 22.1 & 22.8 \\
\hline
\end{tabular}


LOCATION.-1at $36^{\circ} 54^{\prime} 54^{\prime \prime}$, long $78^{\circ} 44^{\prime} 28^{\prime \prime}$, Halifax County, at gaging station on right bank 14 ft downstream from bridge on State Highway $746,2.8$ miles northwest of Randolph, 3.6 m1les upstream from Roanoke Creek, and at mile 227.3 .

DRAINAGE AREA.--2,977 sq mi (revised).

PER IOD OF RECORD.-Chemical analyses: April 1929 to March 1930, October 1950 to September 1956, February 1967 to September 1970

Water temperatures: October 1950 to September 1956, April 1968 to September 1970.

Sediment records: January 1954 to September 1970.

EXTREMES, $-1969-70$

Specific conductance: Maximum daily, 185 micromhos Sept. 29 ; minimum daily, 68 micromhos Aug. 11.

Fediment concentrations: Maximum daily, $850 \mathrm{mg} / 1 \mathrm{Jan} .22 ; \mathrm{minimum}$ daily, $1 \mathrm{mg} / 1$ Nov. 17, 18, 24, June 1 ,

Maximum daily, 27,500 tons Jan. 22; minimum daily, .4৬ ton July 7. CHEMICAL ANAL YSES, HATER YEAR OCTOBER 1969 TO SEPTEMBER 1970

\begin{tabular}{|c|c|c|c|c|c|c|c|c|c|c|}
\hline DATE & $\begin{array}{l}\text { MEAN } \\
\text { OIS- } \\
\text { CHARGE } \\
\text { (CFS) }\end{array}$ & $\begin{array}{l}\text { SIUICA } \\
\text { (S IOLZ) } \\
\text { IMG/LI }\end{array}$ & $\begin{array}{l}\text { DIS- } \\
\text { SOLVED } \\
\text { IRON } \\
\text { IFEI } \\
\text { (UG/LI }\end{array}$ & $\begin{array}{l}\text { CAL }= \\
\text { CIUM } \\
(C A) \\
(M G / L)\end{array}$ & $\begin{array}{l}\text { MAG- } \\
\text { NE- } \\
\text { SIUN } \\
\text { IMGI } \\
\text { (MCIL) }\end{array}$ & $\begin{array}{l}\text { SCDIUM } \\
\text { (NA) } \\
\text { (MG/L) }\end{array}$ & $\begin{array}{l}\text { PO- } \\
\text { TAS- } \\
\text { SIUM } \\
\text { (K) } \\
\text { (MGAL) }\end{array}$ & $\begin{array}{l}\text { BICAR- } \\
\text { BONATE } \\
\text { (HC Q3) } \\
\text { (MG/L) }\end{array}$ & $\begin{array}{l}\text { SULFATE } \\
\text { (SOA) } \\
(\mathrm{MG} / \mathrm{L})\end{array}$ & $\begin{array}{l}\text { CHLO- } \\
\text { RIDE } \\
\text { (CL) } \\
\text { IMG } / L)\end{array}$ \\
\hline \multicolumn{11}{|l|}{ DCT. } \\
\hline$n 1-10$ & 1430 & 7.0 & 0 & 14 & 5.7 & 9.5 & 2.3 & 72 & 11 & 7.6 \\
\hline $11-20$ & 17า & 6.5 & 0 & 14 & 6.0 & 8.8 & 2.5 & 74 & 12 & 7.2 \\
\hline $21-3 i$ & 1590 & 6.0 & 20 & 16 & 6.5 & 8.3 & 2.8 & 75 & 12 & 6.7 \\
\hline \multicolumn{11}{|l|}{ NOv. } \\
\hline $10 \ldots$ & $3 ? 2$ & 6.1 & 10 & 14 & 5.6 & 13 & 2.5 & 75 & 13 & 10 \\
\hline $21 \ldots$ & 1500 & 6.6 & 40 & 13 & 5.0 & 9,8 & 2.3 & $7 \overrightarrow{1}$ & 31 & 8.2 \\
\hline \multirow{2}{*}{\multicolumn{11}{|c|}{ DEC. }} \\
\hline & & & & & & & & & & \\
\hline $05 \ldots$ & 1200 & 4.1 & 10 & 15 & 5,9 & 10 & 2.3 & 80 & 13 & 9.8 \\
\hline $12 \ldots$ & 2947 & 7.0 & $4 n$ & 11 & 4.1 & 7.4 & 2.3 & 55 & ii & 8.4 \\
\hline $19 . .$. & $594 n$ & 5.9 & $n$ & 16 & 8.8 & 7.1 & 2.5 & 72 & 12 & 9.2 \\
\hline $26 \ldots$ & 1250 & 6.9 & 20 & 14 & 4.5 & 5.9 & 1,8 & 58 & 14 & 6.9 \\
\hline \multicolumn{11}{|l|}{ JAN. } \\
\hline$r 2 \ldots$ & 5620 & 7.2 & 20 & B. 3 & 2.8 & 5.2 & 1.8 & 31 & 11 & 5.2 \\
\hline na... & 9850 & 4.8 & 20 & 15 & 4.9 & 7.0 & 1.9 & 69 & 9.0 & 8.4 \\
\hline $18, \ldots$ & 1560 & 5.9 & 20 & 24 & 4.7 & 0.0 & 1.9 & 63 & 9.4 & 8.0 \\
\hline $25 \ldots$ & $25 n n$ & 12 & 50 & 11 & 5.0 & 6.8 & 1.5 & 58 & 9.6 & 5.6 \\
\hline \multicolumn{11}{|l|}{ FEB. } \\
\hline $01 \ldots$ & 924 & 9.5 & 40 & 8.7 & 4.6 & 6.1 & 1.6 & 43 & B. 4 & 0.1 \\
\hline$n 8 \ldots$ & 1570 & 0.1 & 30 & 11 & 5.5 & 6.9 & 1.7 & 56 & 7.4 & 6.2 \\
\hline $15 . .$. & 1180 & 9.0 & 20 & 12 & 3.4 & 7.2 & 1.4 & 56 & 11 & 5. 8 \\
\hline $22 \ldots$ & 1610 & 11 & $7 \mathrm{C}$ & 7.8 & $? .8$ & 9.3 & 1.3 & 41 & 12 & 6.2 \\
\hline \multicolumn{11}{|l|}{ MAR. } \\
\hline ก1.... & 1140 & 9.? & 40 & 13 & 4.1 & 9.6 & 1.6 & 60 & 9.0 & 6.9 \\
\hline OR... & 1160 & 7.4 & 0 & 14 & 4.8 & 6.6 & 1.8 & 68 & 8.8 & 6.4 \\
\hline $15 \ldots$ & B35 & 8.7 & 20 & 12 & 3.9 & B. 2 & 1.6 & 30 & 9.6 & 6.9 \\
\hline $22 .$. & 1360 & 9.0 & 23 & 12 & 4.5 & 5.6 & 1.8 & 50 & 10 & 5.6 \\
\hline \multirow{2}{*}{\multicolumn{11}{|c|}{ APR: }} \\
\hline & & & & & & & & & & \\
\hline$n 5 \ldots$ & $22 \mathrm{BO}$ & 10 & 49 & 6.2 & 2.6 & 6.0 & 1.6 & 30 & 6.6 & 3.6 \\
\hline $12 \ldots$ & 1580 & 0.1 & 20 & 9.6 & 3.3 & 9.4 & 1.6 & 50 & & 0.2 \\
\hline $19 \ldots$ & $16 ? 9$ & 9.1 & 30 & 110 & 3.6 & 7.9 & 1.6 & 56 & 9.8 & 5.9 \\
\hline $26 \ldots$ & $140 n$ & 7.5 & 10 & ii & 4.2 & 8.4 & 2.0 & 60 & 0.2 & 5.9 \\
\hline \multirow{2}{*}{\multicolumn{11}{|c|}{ MAY }} \\
\hline & & & & & & & & & & 7,3 \\
\hline $10 \ldots$ & 1860 & 8.5 & 50 & 12 & 4.9 & 5.5 & 1.8 & 55 & 9.0 & 5.4 \\
\hline $17 \ldots$ & $2 n \geqslant n$ & 7.6 & $8 n$ & 13 & 1.6 & 4.6 & 1.5 & 53 & 8.2 & 4.7 \\
\hline $24 \ldots$ & 1400 & 7.9 & 0 & $i 4$ & 4.9 & 6.9 & 2.3 & 65 & 10 & 8.7 \\
\hline $31 \ldots$ & $137 n$ & 7.7 & 10 & 14 & 4.9 & 5.8 & 2.3 & 60 & 10 & 7.8 \\
\hline JURE... & 255 & 7.3 & 0 & 17 & 3.5 & 10 & 2.8 & 70 & IC & 9.3 \\
\hline $14 \ldots$ & 910 & 6.6 & $c$ & 16 & E. 1 & 7.8 & 2,1 & 75 & 9.6 & 2.3 \\
\hline $21 \ldots$ & $33 n$ & 7.9 & 0 & 15 & 5.0 & 7.6 & 3.0 & 69 & 9.0 & 8.2 \\
\hline $28 .$. & 1 non & 4.8 & 10 & 18 & 6.2 & 6.8 & 2.6 & 79 & 12 & 9.2 \\
\hline \multicolumn{11}{|l|}{ JUty } \\
\hline $05 \ldots$ & 324 & 6.0 & 30 & 18 & 5.8 & 6.8 & 2.5 & 78 & 11 & B. 2 \\
\hline $12,$. & $12 n 0$ & 6.4 & 0 & 16 & 4.0 & 7.1 & 2.3 & 68 & in & 8.4 \\
\hline $10 \ldots$ & ดी? & 5.7 & 0 & is & 4.9 & 10 & 2.1 & 80 & 12 & 9.1 \\
\hline $26 \ldots$ & 1250 & 6.5 & 0 & 16 & 4.6 & 8.2 & 2.8 & 70 & 11 & Q.1 \\
\hline \multicolumn{11}{|l|}{ AUG." } \\
\hline $0 ? \ldots$ & 1110 & 0.7 & 40 & 15 & 5.3 & 9.2 & 2.6 & 71 & 11 & $\begin{array}{l}9.4 \\
8.8\end{array}$ \\
\hline $09 . .$. & 1030 & 3.7 & 20 & 24 & 5.0 & 9.1 & 2. 3 & 70 & 11 & 8.8 \\
\hline $16 \ldots$ & 1270 & 7.3 & 0 & 17 & 3.9 & 7.0 & 2.5 & 67 & 9.4 & 7.3 \\
\hline $23 \ldots$ & $115 n$ & 7.2 & 0 & 15 & 4.2 & 9.7 & 2.6 & 69 & $\begin{array}{l}10 \\
14\end{array}$ & 9.7 \\
\hline \multirow{2}{*}{\multicolumn{11}{|c|}{ SEPT. }} \\
\hline & & & & & & & & & 0.0 & \\
\hline $\begin{array}{l}96 \ldots . . \\
13 . . .\end{array}$ & $\begin{array}{l}1110 \\
1100\end{array}$ & $\begin{array}{l}7.9 \\
6.2\end{array}$ & $\begin{array}{l}80 \\
20\end{array}$ & 12 & $\begin{array}{l}4.9 \\
5.8\end{array}$ & $\begin{array}{l}5.8 \\
9.7\end{array}$ & $\begin{array}{l}2.5 \\
3.0\end{array}$ & $\begin{array}{l}62 \\
72\end{array}$ & 11 & \\
\hline $20 \ldots$ & 977 & 0.2 & 10 & 16 & 0.1 & 8.6 & 2.6 & 74 & 10 & 8.5 \\
\hline $27 .$. & 250 & 6.7 & 0 & 16 & 0.0 & 0.3 & 2.6 & 79 & 11 & 8.9 \\
\hline
\end{tabular}


Period of record:

Dissolved solids (1968-69): Maximum, $107 \mathrm{mg} / 1$ July 1-10, 1969; minimum, $73 \mathrm{mg} / 1 \mathrm{Mar} .21-31,1969$.

Hardness (1968-69): Maximum, $75 \mathrm{mg} / 1$ Sept. 21-30, 1968; minimum, $30 \mathrm{mg} / 1$ Aug. 22, 1969 .

Specific conductance (1968-69): Kaximum dat1y, 2i2 micromhos Oct. 3, 1968; minimum daily, 68 micromhos Aug. 11, 1970

Water temperatures (1968-1970): Maximum, $35.0^{\circ} \mathrm{C}$ Aug. 15, 1968; minimum, freezing point on many days during winter periods.

Sediment concentrations (1954-57, 1969-70): Maximum da11y, 2,060 mg/1 May 20, 1957; minimum daily, $1 \mathrm{mg} / 1$ on several days in 1968-69. Sediment discharge (1954-57, 1969-70): Maximum da11y, 71,500 tons Mar. 2, 1954; minimum da1ly, .48 ton July 7 ,
1970 .

REMARKS.--Chemical-quality data represent equal-volume composites for the periods indicated prior to Nov. 1 and for for every sevanth day thereafter. Sediment computations based on oncerweekly samples and water discharge hydrograph.

CHEMICAL ANALYSES, WATER YEAR CCTOBER 1969 TO SEMTEMBER 1970

\begin{tabular}{|c|c|c|c|c|c|c|c|c|c|}
\hline DATE & $\begin{array}{l}\text { FLUQ- } \\
\text { RIDE } \\
\text { (F) } \\
\text { (MG/L) }\end{array}$ & $\begin{array}{l}\text { NITRATE } \\
\text { (NO3) } \\
\text { (MG/L) }\end{array}$ & $\begin{array}{l}\text { FHCS } \\
\text { PHAIE } \\
(P C G \mid \\
\{P G / L \mid\end{array}$ & $\begin{array}{l}\text { CIS- } \\
\text { SCLVED } \\
\text { SCLICS } \\
\text { IRESI- } \\
\text { CLE AT } \\
\text { IEO CI } \\
\text { (FG/L) }\end{array}$ & $\begin{array}{l}\text { HARD- } \\
\text { NESS } \\
\text { (CA,HG) } \\
\text { (MG/L) }\end{array}$ & $\begin{array}{l}\text { NCA- } \\
\text { CAR- } \\
\text { BONATE } \\
\text { HARD- } \\
\text { NESS } \\
\text { (MG/L) }\end{array}$ & $\begin{array}{l}\text { SPECI- } \\
\text { FIC } \\
\text { COND- } \\
\text { UCTANCE } \\
\text { (MICRC- } \\
\text { MHOS) }\end{array}$ & $\begin{array}{c}\text { PH } \\
\text { (UNITS) }\end{array}$ & $\begin{array}{l}\text { COLCR } \\
\text { (PLAT- } \\
\text { INLP- } \\
\text { CORALT } \\
\text { UNITSI) }\end{array}$ \\
\hline \multicolumn{10}{|l|}{ OC T. } \\
\hline $0 \mathrm{~L}-1 \mathrm{C}$ & .1 & $\cdot 3$ & .03 & 57 & 58 & a & 146 & 7.7 & 5 \\
\hline $11-20$ & .2 & .1 &. $\mathrm{CC}$ & 100 & 60 & c & 160 & 7.3 & C \\
\hline $21-31$ & .2 & .3 & .01 & 101 & & 5 & 165 & 7.4 & 10 \\
\hline \multicolumn{10}{|l|}{ NOV. } \\
\hline $10 \ldots$ & .2 & .2 & .00 & $10 \mathrm{C}$ & 58 & 0 & 165 & 7.4 & $\begin{array}{r}5 \\
15\end{array}$ \\
\hline $21 \ldots$ & .2 & $\cdot 3$ & .01 & 99 & 54 & 0 & 155 & 7.5 & 15 \\
\hline $28 \ldots$ & .2 & .2 & .00 & 100 & 58 & 0 & 169 & 7.3 & 10 \\
\hline \multicolumn{10}{|l|}{ DEC. } \\
\hline $05 \ldots$ & .2 & .3 & .02 & 103 & 62 & c & 174 & 7.2 & 10 \\
\hline $12 \ldots$ & .2 & 1.4 & .02 & 85 & 44 & 0 & 146 & 7.0 & 30 \\
\hline $19 \ldots$ & .2 & .9 & .02 & 92 & 67 & e & 167 & 7.4 & 5 \\
\hline $26 \ldots$ & .1 & .8 & .01 & 91 & 54 & 6 & 146 & 7.8 & 5 \\
\hline \multicolumn{10}{|l|}{ IAN. } \\
\hline $02 \ldots$ & .2 & 2.5 & .27 & E8 & 32 & 6 & 105 & 7.3 & 35 \\
\hline $09 . .$. & .2 & .6 & .00 & 85 & 56 & 0 & 160 & 7.8 & 5 \\
\hline $18 \ldots$ & .1 & .8 & .00 & e8 & 54 & 3 & 153 & 7.8 & 5 \\
\hline $\begin{array}{l}25 \ldots \\
\text { FE } 8 .\end{array}$ & .2 & .9 & .01 & 83 & 48 & 0 & 144 & 7.4 & 10 \\
\hline $01 \ldots$ & .1 & .9 & .03 & 75 & 40 & 6 & 110 & 7.4 & 40 \\
\hline $08 \ldots$ & .1 & .4 & .01 & 76 & 50 & 4 & 126 & 7.7 & 15 \\
\hline $15 \ldots$ & .2 & $\cdot 3$ & .00 & 77 & 44 & 0 & 120 & 7.5 & ic \\
\hline $22 \ldots$ & .1 & .9 & .01 & 71 & 31 & 0 & 108 & 7.2 & 15 \\
\hline \multicolumn{10}{|l|}{ MAR. } \\
\hline $01 \ldots$ & .1 & .1 & .00 & 85 & 50 & 0 & 144 & 7.4 & 5 \\
\hline $08 \ldots$ & .2 & .0 & .05 & 83 & 55 & 0 & 150 & 7.7 & c \\
\hline $15 \ldots$ & .2 & .0 & .09 & 84 & 46 & 0 & 140 & 7.6 & 5 \\
\hline $22 \ldots$ & .1 & . $c$ & .00 & 72 & 48 & 6 & 114 & 7.5 & 10 \\
\hline $29 \ldots$ & .1 & .0 & .00 & 76 & 48 & 2 & 122 & 7.5 & 15 \\
\hline $\begin{array}{l}\text { APR. } \\
\text { OS.... }\end{array}$ & .1 & 1.0 & .19 & 69 & 26 & 2 & 75 & & 15 \\
\hline $12 \ldots$ & .1 & .0 & .00 & 74 & 38 & 0 & 111 & 6.9 & 13 \\
\hline $19 \ldots$ &.$i$ & .0 & .00 & 76 & 42 & 0 & iis & 6.9 & $\begin{array}{l}5 \\
c\end{array}$ \\
\hline $26 \ldots$ & .2 & .0 & .00 & e 7 & 45 & 0 & 127 & 7.1 & 0 \\
\hline \multicolumn{10}{|l|}{ MAY } \\
\hline $03 \ldots$ & .2 & .2 & .01 & 83 & 46 & 0 & 132 & 7.3 & 5 \\
\hline $10 \ldots$ & .1 & 1.4 & .00 & 98 & 49 & 4 & 120 & 7.1 & 15 \\
\hline $17 \ldots$ & .1 & .4 & .00 & 87 & 46 & 3 & 215 & 7.0 & 25 \\
\hline $24 \ldots$ & .1 & .9 & .05 & 101 & 55 & 2 & 142 & 7.1 & 0 \\
\hline $31 \ldots$ & .1 & 1.1 & .05 & 90 & 54 & t & 136 & 7.1 & 0 \\
\hline \multicolumn{10}{|l|}{ JUNE } \\
\hline $07 \ldots$ & .1 & .3 & .16 & 107 & 56 & c & 153 & 7.1 & 0 \\
\hline $14 \ldots$ & .2 & .3 & .01 & 100 & $\begin{array}{l}66 \\
58\end{array}$ & 1 & $\begin{array}{l}156 \\
146\end{array}$ & $\begin{array}{l}7.3 \\
6.9\end{array}$ & $\begin{array}{l}5 \\
5\end{array}$ \\
\hline $\begin{array}{l}21 \ldots \\
28 \ldots\end{array}$ & .2 & $\begin{array}{r}.6 \\
1.6\end{array}$ & $\begin{array}{l}.30 \\
.08\end{array}$ & $\begin{array}{r}98 \\
112\end{array}$ & $\begin{array}{l}38 \\
70\end{array}$ & $\begin{array}{l}1 \\
5\end{array}$ & $\begin{array}{l}146 \\
169\end{array}$ & $\begin{array}{l}6.9 \\
7.0\end{array}$ & $\begin{array}{l}5 \\
5\end{array}$ \\
\hline \multicolumn{10}{|l|}{ juer 28.} \\
\hline $05 \ldots$ & .1 & 1.0 & .11 & 107 & 68 & 4 & 163 & 6.9 & 5 \\
\hline $12 \ldots$ & .1 & 1.1 & .00 & 101 & 61 & 6 & 144 & 7.1 & 5 \\
\hline $19 \ldots$ & .1 & .4 & .00 & 111 & 66 & 0 & 163 & 7.0 & 5 \\
\hline $26 \ldots$ & .1 & .4 & .01 & 100 & 60 & 3 & 150 & 7.0 & 5 \\
\hline \multicolumn{10}{|l|}{ AUG. } \\
\hline $02 \ldots$ & .1 & 1.4 & .00 & 101 & 60 & 2 & 152 & 7.1 & 5 \\
\hline $09 .$. & .1 & $\therefore t$ & .00 & 99 & 56 & 0 & 149 & 7.1 & 10 \\
\hline $16 \ldots$ & .1 & 2.0 & .00 & 95 & 58 & 3 & 142 & 1.4 & 5 \\
\hline $23 \ldots$ & .1 & 1.5 & .01 & 93 & 56 & 0 & 146 & 7.3 & 5 \\
\hline $30 .$. & .2 & .7 & .01 & 54 & 62 & 5 & 148 & 7.4 & 5 \\
\hline \multicolumn{10}{|l|}{ SEPT. } \\
\hline $06 \ldots$ & .1 & .4 & .05 & 88 & 51 & 0 & 128 & 7.4 & 5 \\
\hline $13 \ldots$ & .1 & 1.3 & .04 & 112 & 58 & 0 & 152 & $7 \cdot 3$ & 3 \\
\hline $20 \ldots$ & -1 & $\cdot 3$ & .00 & 101 & 65 & 4 & 169 & 7.4 & 5 \\
\hline $27 \ldots$ & $\cdot 1$ & .1 & .00 & 98 & 34 & 0 & 170 & 7.4 & 5 \\
\hline
\end{tabular}


02066000 ROANOKE (STAUNTON) RIVER AT RANDOLPH, VA.--CONTInUed

SPECIFIC CONDUCTANCE (MICROMHOS/CM AT $25^{\circ} \mathrm{C}$ ), NATER YEAR OCTOBER 1969 TO SEPTEMBER 1970

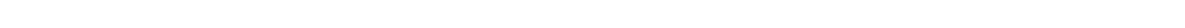

\begin{tabular}{|c|c|c|c|c|c|c|c|c|c|c|c|c|}
\hline $\begin{array}{l}1 \ldots \ldots \\
2 \ldots \ldots \\
3 \ldots \ldots \\
5 \ldots \ldots\end{array}$ & $\begin{array}{l}137 \\
108 \\
152 \\
147 \\
146\end{array}$ & $\begin{array}{l}157 \\
161 \\
161 \\
149 \\
104\end{array}$ & $\begin{array}{l}157 \\
157 \\
151 \\
147 \\
174\end{array}$ & $\begin{array}{r}82 \\
105 \\
103 \\
90 \\
84\end{array}$ & $\begin{array}{l}110 \\
104 \\
108 \\
110 \\
109\end{array}$ & $\begin{array}{l}144 \\
120 \\
120 \\
134 \\
136\end{array}$ & $\begin{array}{l}83 \\
99 \\
89 \\
30 \\
75\end{array}$ & $\begin{array}{l}130 \\
129 \\
132 \\
132 \\
110\end{array}$ & $\begin{array}{l}153 \\
142 \\
157 \\
164 \\
132\end{array}$ & $\begin{array}{l}170 \\
169 \\
158 \\
168 \\
163\end{array}$ & $\begin{array}{r}150 \\
152 \\
150 \\
167 \\
97\end{array}$ & $\begin{array}{l}142 \\
144 \\
144 \\
148 \\
149\end{array}$ \\
\hline $\begin{array}{c}0 \ldots \ldots \\
1 \ldots \ldots \\
\forall \ldots \ldots \\
10 \ldots \ldots\end{array}$ & $\begin{array}{l}137 \\
138 \\
144 \\
143 \\
148\end{array}$ & $\begin{array}{l}164 \\
165 \\
149 \\
153 \\
165\end{array}$ & $\begin{array}{l}176 \\
173 \\
154 \\
152 \\
151\end{array}$ & $\begin{array}{l}112 \\
160 \\
160 \\
160 \\
164\end{array}$ & $\begin{array}{l}98 \\
113 \\
126 \\
127 \\
106\end{array}$ & $\begin{array}{l}142 \\
146 \\
150 \\
150 \\
132\end{array}$ & $\begin{array}{r}75 \\
73 \\
98 \\
106 \\
106\end{array}$ & $\begin{array}{l}103 \\
146 \\
148 \\
143 \\
120\end{array}$ & $\begin{array}{l}149 \\
153 \\
155 \\
130 \\
128\end{array}$ & $\begin{array}{l}162 \\
146 \\
153 \\
150 \\
148\end{array}$ & $\begin{array}{l}109 \\
128 \\
132 \\
149 \\
112\end{array}$ & $\begin{array}{l}128 \\
134 \\
135 \\
138 \\
156\end{array}$ \\
\hline $\begin{array}{l}11 \ldots \ldots \\
12 \ldots \ldots \\
13 \ldots \ldots \\
14 \ldots \ldots \\
15 \ldots \ldots\end{array}$ & $\begin{array}{l}158 \\
153 \\
155 \\
155 \\
142\end{array}$ & $\begin{array}{l}150 \\
157 \\
156 \\
157 \\
168\end{array}$ & $\begin{array}{l}150 \\
146 \\
134 \\
147 \\
152\end{array}$ & $\begin{array}{l}140 \\
134 \\
136 \\
144 \\
144\end{array}$ & $\begin{array}{l}119 \\
126 \\
128 \\
132 \\
120\end{array}$ & $\begin{array}{l}142 \\
148 \\
148 \\
155 \\
140\end{array}$ & $\begin{array}{l}104 \\
111 \\
112 \\
111 \\
109\end{array}$ & $\begin{array}{l}128 \\
130 \\
146 \\
146 \\
123\end{array}$ & $\begin{array}{l}146 \\
157 \\
162 \\
156 \\
160\end{array}$ & $\begin{array}{l}148 \\
144 \\
144 \\
150 \\
135\end{array}$ & $\begin{array}{r}68 \\
76 \\
148 \\
141 \\
144\end{array}$ & $\begin{array}{l}151 \\
152 \\
152 \\
150 \\
150\end{array}$ \\
\hline $\begin{array}{l}10 \ldots \ldots \\
17 \ldots \ldots \\
18 \ldots \ldots \\
19 \ldots \ldots \\
20 \ldots \ldots\end{array}$ & $\begin{array}{l}170 \\
161 \\
151 \\
176 \\
179\end{array}$ & $\begin{array}{l}158 \\
157 \\
149 \\
144 \\
155\end{array}$ & $\begin{array}{l}135 \\
152 \\
168 \\
167 \\
164\end{array}$ & $\begin{array}{l}144 \\
152 \\
153 \\
124 \\
163\end{array}$ & $\begin{array}{l}122 \\
100 \\
105 \\
110 \\
112\end{array}$ & $\begin{array}{l}126 \\
124 \\
138 \\
136 \\
135\end{array}$ & $\begin{array}{l}115 \\
113 \\
114 \\
115 \\
116\end{array}$ & $\begin{array}{l}122 \\
115 \\
112 \\
121 \\
111\end{array}$ & $\begin{array}{l}154 \\
140 \\
149 \\
159 \\
159\end{array}$ & $\begin{array}{l}158 \\
150 \\
159 \\
163 \\
150\end{array}$ & $\begin{array}{l}142 \\
140 \\
144 \\
143 \\
143\end{array}$ & $\begin{array}{l}152 \\
163 \\
167 \\
170 \\
169\end{array}$ \\
\hline $\begin{array}{l}21 \ldots \ldots \\
22 \ldots \ldots \\
23 \ldots \ldots \\
24 \ldots \ldots \\
25 \ldots \ldots\end{array}$ & $\begin{array}{l}181 \\
152 \\
175 \\
170 \\
172\end{array}$ & $\begin{array}{l}148 \\
143 \\
144 \\
145 \\
158\end{array}$ & $\begin{array}{l}153 \\
153 \\
127 \\
120 \\
136\end{array}$ & $\begin{array}{l}164 \\
165 \\
163 \\
130 \\
144\end{array}$ & $\begin{array}{l}100 \\
108 \\
144 \\
128 \\
118\end{array}$ & $\begin{array}{l}132 \\
114 \\
112 \\
108 \\
124\end{array}$ & $\begin{array}{l}109 \\
122 \\
122 \\
132 \\
118\end{array}$ & $\begin{array}{l}130 \\
139 \\
133 \\
142 \\
141\end{array}$ & $\begin{array}{l}146 \\
156 \\
143 \\
163 \\
164\end{array}$ & $\begin{array}{l}162 \\
149 \\
148 \\
124 \\
145\end{array}$ & $\begin{array}{l}155 \\
150 \\
146 \\
141 \\
138\end{array}$ & $\begin{array}{l}167 \\
158 \\
158 \\
180 \\
178\end{array}$ \\
\hline $\begin{array}{l}\angle 0 \ldots \ldots \\
\angle 7 \ldots \ldots \\
\angle 0 \ldots \ldots \\
\angle 9 \ldots \ldots \\
10 \ldots \ldots \\
31 \ldots \ldots\end{array}$ & $\begin{array}{l}163 \\
157 \\
152 \\
164 \\
167 \\
167\end{array}$ & $\begin{array}{l}145 \\
159 \\
158 \\
101 \\
156 \\
--\end{array}$ & $\begin{array}{r}146 \\
95 \\
106 \\
110 \\
100 \\
110\end{array}$ & $\begin{array}{l}144 \\
126 \\
142 \\
150 \\
115 \\
117\end{array}$ & $\begin{array}{l}108 \\
140 \\
140 \\
-- \\
-\end{array}$ & $\begin{array}{r}126 \\
128 \\
129 \\
122 \\
122 \\
87\end{array}$ & $\begin{array}{l}127 \\
124 \\
118 \\
130 \\
128 \\
-\end{array}$ & $\begin{array}{r}132 \\
-- \\
144 \\
158 \\
136\end{array}$ & $\begin{array}{l}168 \\
169 \\
169 \\
171 \\
170 \\
-\end{array}$ & $\begin{array}{l}150 \\
149 \\
145 \\
116 \\
138 \\
142\end{array}$ & $\begin{array}{l}146 \\
148 \\
145 \\
148 \\
148 \\
146\end{array}$ & $\begin{array}{l}176 \\
170 \\
170 \\
185 \\
168 \\
--\end{array}$ \\
\hline AVERAGE & 157 & 155 & 144 & 135 & 116 & 131 & 107 & 131 & 154 & 150 & 136 & 156 \\
\hline
\end{tabular}

TEMPERATURE $\left({ }^{\circ} \mathrm{C}\right)$ OF WATER, WATER YEAR OCTOBER 1969 TO SEPTEMBER 1970

\begin{tabular}{|c|c|c|c|c|c|c|c|c|c|c|c|c|}
\hline DAY & OCT & Nor & DEC & JAN & FEB & MAR & $A P R$ & MAY & JUN & JUL & AUG & SEP \\
\hline $\begin{array}{l}1 \\
2 \\
3 \\
4 \\
5\end{array}$ & $\begin{array}{l}15.0 \\
20.0 \\
20.0 \\
18.0 \\
17.0\end{array}$ & $\begin{array}{l}13.0 \\
14.0 \\
15.0 \\
14.0 \\
13.0\end{array}$ & $\begin{array}{l}5.0 \\
4.0 \\
4.0 \\
5.0 \\
4.0\end{array}$ & $\begin{array}{l}4.0 \\
4.0 \\
3.0 \\
3.0 \\
3.0\end{array}$ & $\begin{array}{l}4.0 \\
7.0 \\
5.0 \\
3.0 \\
3.0\end{array}$ & $\begin{array}{r}8.0 \\
8.0 \\
8.0 \\
10.0 \\
10.0\end{array}$ & $\begin{array}{r}8.0 \\
10.0 \\
11.0 \\
10.0 \\
10.0\end{array}$ & $\begin{array}{l}20.0 \\
19.0 \\
16.0 \\
17.0 \\
16.0\end{array}$ & $\begin{array}{l}25.0 \\
23.0 \\
23.0 \\
23.0 \\
23.0\end{array}$ & $\begin{array}{l}24.0 \\
24.0 \\
24.0 \\
24.0 \\
24.0\end{array}$ & $\begin{array}{l}25.0 \\
25.0 \\
25.0 \\
24.0 \\
23.0\end{array}$ & $\begin{array}{l}24.0 \\
23.0 \\
24.0 \\
24.0 \\
24.0\end{array}$ \\
\hline $\begin{array}{r}6 \\
7 \\
8 \\
9 \\
10\end{array}$ & $\begin{array}{l}18.0 \\
18.0 \\
18.0 \\
17.0 \\
17.0\end{array}$ & $\begin{array}{r}12.0 \\
12.0 \\
11.0 \\
11.0 \\
8.0\end{array}$ & $\begin{array}{l}4.0 \\
4.0 \\
5.0 \\
5.0 \\
6.0\end{array}$ & $\begin{array}{l}-- \\
3.0 \\
2.0 \\
2.0\end{array}$ & $\begin{array}{l}2.0 \\
3.0 \\
4.0 \\
5.0 \\
5.0\end{array}$ & $\begin{array}{r}8.0 \\
10.0 \\
10.0 \\
9.0 \\
3.0\end{array}$ & $\begin{array}{l}10.0 \\
10.0 \\
10.0 \\
11.0 \\
12.0\end{array}$ & $\begin{array}{l}15.0 \\
14.0 \\
14.0 \\
19.0 \\
17.0\end{array}$ & $\begin{array}{l}23.0 \\
23.0 \\
23.0 \\
24.0 \\
24.0\end{array}$ & $\begin{array}{l}24.0 \\
23.0 \\
25.0 \\
25.0 \\
24.0\end{array}$ & $\begin{array}{r}24.0 \\
23.0 \\
23.0 \\
-0 \\
25.0\end{array}$ & $\begin{array}{l}24.0 \\
24.0 \\
24.0 \\
23.0 \\
24.0\end{array}$ \\
\hline $\begin{array}{l}11 \\
12 \\
13 \\
14 \\
15\end{array}$ & $\begin{array}{l}17.0 \\
17.0 \\
17.0 \\
18.0 \\
17.0\end{array}$ & $\begin{array}{r}12.0 \\
11.0 \\
10.0 \\
11.0 \\
7.0\end{array}$ & $\begin{array}{l}7.0 \\
6.0 \\
5.0 \\
5.0 \\
5.0\end{array}$ & $\begin{array}{l}2.0 \\
4.0 \\
2.0 \\
2.0 \\
2.0\end{array}$ & $\begin{array}{l}5.0 \\
4.0 \\
4.0 \\
5.0 \\
5.0\end{array}$ & $\begin{array}{r}10.0 \\
10.0 \\
8.0 \\
6.0 \\
6.0\end{array}$ & $\begin{array}{r}13.0 \\
13.0 \\
13.0 \\
8.0 \\
13.0\end{array}$ & $\begin{array}{l}18.0 \\
18.0 \\
18.0 \\
17.0\end{array}$ & $\begin{array}{l}23.0 \\
23.0 \\
23.0 \\
22.0 \\
21.0\end{array}$ & $\begin{array}{l}24.0 \\
24.0 \\
24.0 \\
24.0 \\
25.0\end{array}$ & $\begin{array}{l}22.0 \\
21.0 \\
23.0 \\
23.0 \\
22.0\end{array}$ & $\begin{array}{l}24.0 \\
23.0 \\
23.0 \\
22.0 \\
23.0\end{array}$ \\
\hline $\begin{array}{l}16 \\
17 \\
18 \\
19 \\
20\end{array}$ & $\begin{array}{r}16.0 \\
16.0 \\
16.0 \\
15.0\end{array}$ & $\begin{array}{r}9.0 \\
8.0 \\
9.0 \\
11.0 \\
9.0\end{array}$ & $\begin{array}{l}4.0 \\
4.0 \\
4.0 \\
5.0 \\
5.0\end{array}$ & $\begin{array}{l}2.0 \\
4.0 \\
4.0 \\
4.0 \\
2.0\end{array}$ & $\begin{array}{l}0.5 \\
4.0 \\
4.0 \\
5.0 \\
5.0\end{array}$ & $\begin{array}{l}6.0 \\
5.0 \\
6.0 \\
7.0 \\
7.0\end{array}$ & $\begin{array}{l}13.0 \\
13.0 \\
15.0 \\
13.0 \\
10.0\end{array}$ & $\begin{array}{l}18.0 \\
17.0 \\
17.0 \\
17.0 \\
17.0\end{array}$ & $\begin{array}{l}21.0 \\
23.0 \\
24.0 \\
24.0 \\
25.0\end{array}$ & $\begin{array}{l}25.0 \\
23.0 \\
25.0 \\
24.0 \\
25.0\end{array}$ & $\begin{array}{l}22.0 \\
22.0 \\
24.0 \\
24.0 \\
24.0\end{array}$ & $\begin{array}{l}23.0 \\
24.0 \\
23.0 \\
23.0 \\
23.0\end{array}$ \\
\hline $\begin{array}{l}21 \\
22 \\
23 \\
24 \\
25\end{array}$ & $\begin{array}{l}16.0 \\
15.0 \\
15.0 \\
14.0 \\
14.0\end{array}$ & $\begin{array}{r}8.0 \\
5.0 \\
9.0 \\
10.0 \\
7.0\end{array}$ & $\begin{array}{l}5.0 \\
5.0 \\
4.0 \\
4.0 \\
3.0\end{array}$ & $\begin{array}{l}2.0 \\
2.0 \\
2.0 \\
5.0 \\
4.0\end{array}$ & $\begin{array}{l}7.0 \\
6.0 \\
7.0 \\
8.0 \\
7.0\end{array}$ & $\begin{array}{l}7.0 \\
8.0 \\
8.0 \\
8.0 \\
8.0\end{array}$ & $\begin{array}{l}15.0 \\
13.0 \\
13.0 \\
14.0 \\
17.0\end{array}$ & $\begin{array}{r}20.0 \\
20.0 \\
22.0 \\
28.0 \\
--\end{array}$ & $\begin{array}{l}25.0 \\
24.0 \\
25.0 \\
25.0 \\
25.0\end{array}$ & $\begin{array}{l}25.0 \\
23.0 \\
23.0 \\
23.0 \\
24.0\end{array}$ & $\begin{array}{l}24.0 \\
24.0 \\
24.0 \\
23.0 \\
23.0\end{array}$ & $\begin{array}{l}23.0 \\
23.0 \\
23.0 \\
22.0 \\
23.0\end{array}$ \\
\hline $\begin{array}{l}26 \\
27 \\
29 \\
29 \\
30 \\
31\end{array}$ & $\begin{array}{l}14.0 \\
14.0 \\
13.0 \\
12.0 \\
12.0 \\
12.0\end{array}$ & $\begin{array}{l}9.0 \\
8.0 \\
8.0 \\
6.0 \\
6.0 \\
--\end{array}$ & $\begin{array}{l}2.0 \\
3.0 \\
2.0 \\
2.0 \\
3.0 \\
4.0\end{array}$ & $\begin{array}{l}5.0 \\
5.0 \\
4.0 \\
5.0 \\
5.0 \\
5.0\end{array}$ & $\begin{array}{r}8.0 \\
8.0 \\
9.0 \\
-. \\
-. \\
--\end{array}$ & $\begin{array}{r}10.0 \\
9.0 \\
9.0 \\
9.0 \\
9.0 \\
9.0\end{array}$ & $\begin{array}{r}15.0 \\
15.0 \\
17.0 \\
19.0 \\
20.0 \\
-0\end{array}$ & $\begin{array}{r}29.0 \\
-0 \\
20.0 \\
20.0 \\
24.0\end{array}$ & $\begin{array}{r}23.0 \\
24.0 \\
24.0 \\
25.0 \\
24.0 \\
.-\end{array}$ & $\begin{array}{l}25.0 \\
25.0 \\
25.0 \\
25.0 \\
25.0 \\
25.0\end{array}$ & $\begin{array}{l}24.0 \\
23.0 \\
23.0 \\
23.0 \\
24.0 \\
24.0\end{array}$ & $\begin{array}{l}24.0 \\
23.0 \\
22.0 \\
22.0 \\
20.0 \\
-\end{array}$ \\
\hline AVG & 15.9 & 9.8 & 4.2 & 3.3 & 5.0 & a. 1 & 12.8 & 18.7 & 23.5 & 24.2 & 23.4 & 23.1 \\
\hline
\end{tabular}


ROANOKE RIVER BASIN

0206600O ROANOKE (STAUNTON) RIVER AT RANDOLPH, VA.--Continued

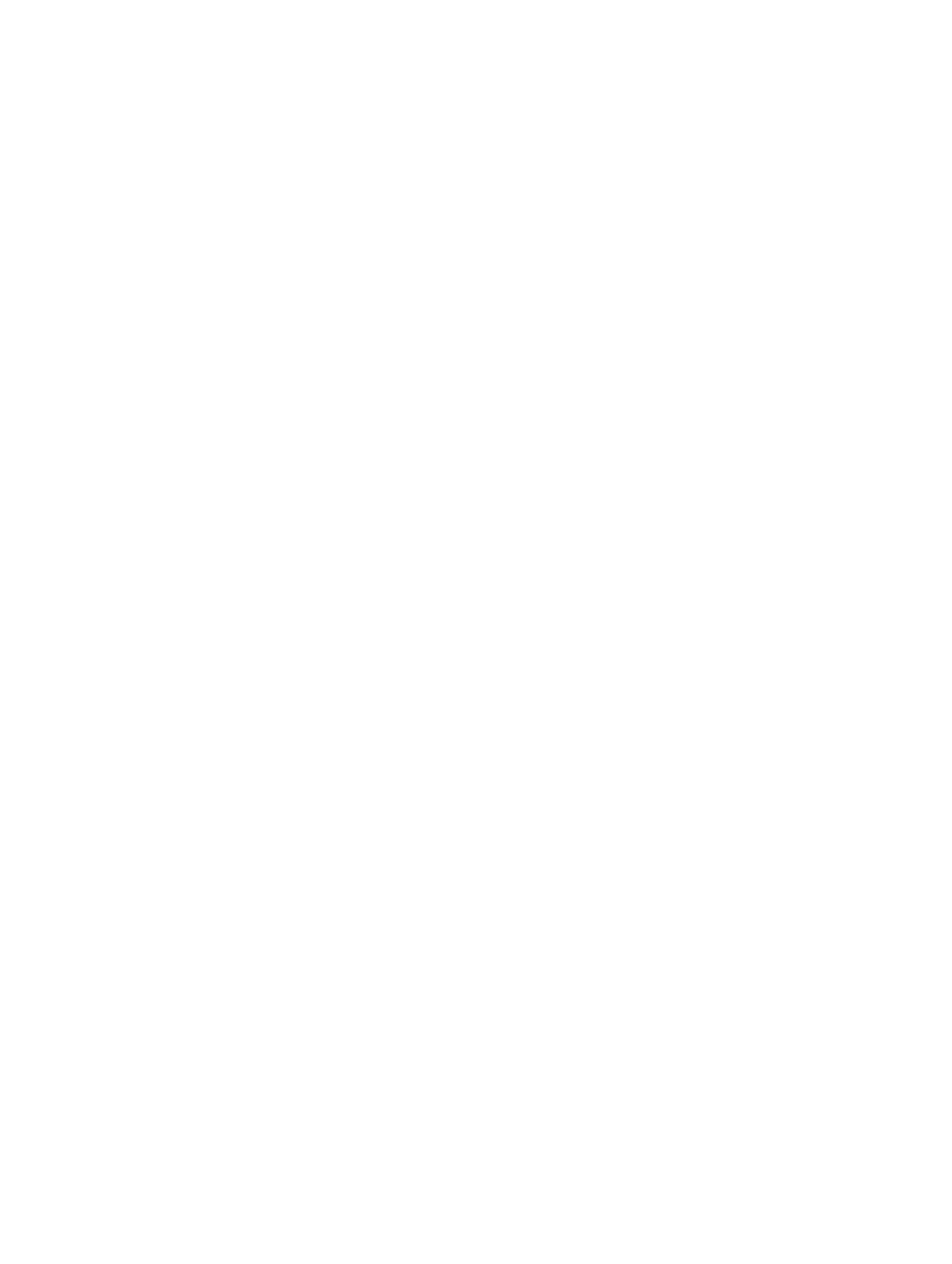


02066000 ROANOKE (STAUNTON) RIVER AT RANDOLPH, VA,--Continued

\begin{tabular}{|c|c|c|c|c|c|c|c|c|c|}
\hline & & $\triangle P R$ IL & & & MAY & & & JUNE & \\
\hline DAY & $\begin{array}{l}\text { MEAN } \\
\text { DI SCHARGE } \\
\text { (CFS) }\end{array}$ & $\begin{array}{l}\text { MEAN } \\
\text { CCNEEN- } \\
\text { SRATICN } \\
\text { IMG IL }\end{array}$ & $\begin{array}{l}\text { SECIMENT } \\
\text { DISCHARGE } \\
\text { (TCNSIOAY) }\end{array}$ & $\begin{array}{l}\text { MEAN } \\
\text { CISCHARGE } \\
\text { (CFS) }\end{array}$ & $\begin{array}{l}\text { MEAN } \\
\text { CONCEN- } \\
\text { IRATION } \\
\text { IMG ILI }\end{array}$ & $\begin{array}{l}\text { SEDIMENT } \\
\text { DISCHARGE } \\
\text { (TCAS/CAY) }\end{array}$ & $\begin{array}{l}\text { MEAN } \\
\text { DI SCHARGE } \\
\text { ICFS I }\end{array}$ & $\begin{array}{l}\text { MEAN } \\
\text { CCNCEA- } \\
\text { TRATICN } \\
\text { (NG/L) }\end{array}$ & $\begin{array}{l}\text { SEC INEAT } \\
\text { CISCHARGE } \\
\text { (ICASIOAYI }\end{array}$ \\
\hline $\begin{array}{l}1 \\
2 \\
3 \\
4 \\
5\end{array}$ & $\begin{array}{l}2390 \\
3150 \\
7220 \\
6210 \\
2280\end{array}$ & $\begin{array}{r}30 \\
145 \\
210 \\
175 \\
75\end{array}$ & $\begin{array}{r}194 \\
1230 \\
4090 \\
2930 \\
462\end{array}$ & $\begin{array}{l}157 \mathrm{C} \\
263 \mathrm{C} \\
1480 \\
1510 \\
344 \mathrm{C}\end{array}$ & $\begin{array}{l}15 \\
19 \\
14 \\
15 \\
20\end{array}$ & $\begin{array}{r}64 \\
135 \\
56 \\
61 \\
186\end{array}$ & $\begin{array}{r}515 \\
1010 \\
1620 \\
1490 \\
1270\end{array}$ & $\begin{array}{r}1 \\
6 \\
10 \\
8 \\
9\end{array}$ & $\begin{array}{l}1.4 \\
1 E \\
44 \\
32 \\
31\end{array}$ \\
\hline $\begin{array}{r}6 \\
7 \\
8 \\
9 \\
10\end{array}$ & $\begin{array}{l}1700 \\
2090 \\
2120 \\
1970 \\
1710\end{array}$ & $\begin{array}{l}50 \\
55 \\
55 \\
40 \\
30\end{array}$ & $\begin{array}{l}230 \\
310 \\
315 \\
213 \\
139\end{array}$ & $\begin{array}{l}4320 \\
4520 \\
3 E 2 C \\
2500 \\
1 E \in C\end{array}$ & $\begin{array}{l}35 \\
40 \\
35 \\
24 \\
20\end{array}$ & $\begin{array}{l}408 \\
488 \\
333 \\
162 \\
100\end{array}$ & $\begin{array}{r}1050 \\
865 \\
420 \\
747 \\
1380\end{array}$ & $\begin{array}{r}8 \\
7 \\
4 \\
5 \\
10\end{array}$ & $\begin{array}{l}24 \\
16 \\
4.5 \\
10 \\
37\end{array}$ \\
\hline $\begin{array}{l}11 \\
12 \\
13 \\
14 \\
15\end{array}$ & $\begin{array}{l}1650 \\
1580 \\
1430 \\
1860 \\
2020\end{array}$ & $\begin{array}{l}26 \\
25 \\
20 \\
25 \\
30\end{array}$ & $\begin{array}{l}116 \\
107 \\
77 \\
126 \\
164\end{array}$ & $\begin{array}{l}169 \mathrm{C} \\
2900 \\
2590 \\
3430 \\
267 \mathrm{C}\end{array}$ & $\begin{array}{l}18 \\
42 \\
35 \\
45 \\
40\end{array}$ & $\begin{array}{l}82 \\
329 \\
245 \\
417 \\
224\end{array}$ & $\begin{array}{r}1390 \\
1350 \\
1170 \\
910 \\
315\end{array}$ & $\begin{array}{r}1 C \\
10 \\
5 \\
8 \\
2\end{array}$ & $\begin{array}{c}2 \varepsilon \\
36 \\
28 \\
2 c \\
1.7\end{array}$ \\
\hline $\begin{array}{l}10 \\
17 \\
18 \\
19 \\
20\end{array}$ & $\begin{array}{l}1840 \\
1560 \\
1610 \\
1620 \\
1410\end{array}$ & $\begin{array}{l}18 \\
13 \\
14 \\
14 \\
24\end{array}$ & $\begin{array}{l}89 \\
55 \\
61 \\
61 \\
91\end{array}$ & $\begin{array}{l}1390 \\
207 c \\
2430 \\
2110 \\
173 C\end{array}$ & $\begin{array}{l}20 \\
30 \\
35 \\
30 \\
20\end{array}$ & $\begin{array}{r}75 \\
168 \\
230 \\
163 \\
93\end{array}$ & $\begin{array}{r}503 \\
1230 \\
2190 \\
1200 \\
859\end{array}$ & $\begin{array}{r}3 \\
7 \\
15 \\
12 \\
7\end{array}$ & $\begin{array}{l}4 \cdot 1 \\
23 \\
89 \\
25 \\
16\end{array}$ \\
\hline $\begin{array}{l}21 \\
22 \\
23 \\
24 \\
25\end{array}$ & $\begin{array}{l}1790 \\
1660 \\
1630 \\
1740 \\
1560\end{array}$ & $\begin{array}{l}20 \\
19 \\
17 \\
18 \\
17\end{array}$ & $\begin{array}{l}97 \\
85 \\
84 \\
85 \\
72\end{array}$ & $\begin{array}{l}1 \leqslant 30 \\
3560 \\
2090 \\
1490 \\
1290\end{array}$ & $\begin{array}{l}18 \\
35 \\
27 \\
15 \\
12\end{array}$ & $\begin{array}{r}79 \\
336 \\
152 \\
60 \\
42\end{array}$ & $\begin{array}{r}330 \\
427 \\
435 \\
1140 \\
1160\end{array}$ & $\begin{array}{l}2 \\
3 \\
3 \\
7 \\
8\end{array}$ & $\begin{array}{r}1.8 \\
3.5 \\
3.5 \\
232 \\
25\end{array}$ \\
\hline $\begin{array}{l}26 \\
27 \\
28 \\
29 \\
30 \\
31\end{array}$ & $\begin{array}{r}1400 \\
1520 \\
1810 \\
1820 \\
1860 \\
--\end{array}$ & $\begin{array}{l}15 \\
16 \\
17 \\
17 \\
17 \\
--\end{array}$ & $\begin{array}{l}57 \\
66 \\
83 \\
84 \\
85 \\
--\end{array}$ & $\begin{array}{l}1310 \\
1440 \\
1250 \\
1590 \\
1350 \\
1370\end{array}$ & $\begin{array}{r}13 \\
14 \\
10 \\
11 \\
4 \\
5\end{array}$ & $\begin{array}{l}46 \\
54 \\
34 \\
47 \\
15 \\
18\end{array}$ & $\begin{array}{r}1200 \\
1310 \\
1000 \\
394 \\
390 \\
--\end{array}$ & $\begin{array}{r}9 \\
10 \\
5 \\
2 \\
2 \\
--\end{array}$ & $\begin{array}{r}29 \\
25 \\
24 \\
2.1 \\
2.1 \\
--\end{array}$ \\
\hline TOTAL & 64216 & -- & 11858 & $68 C 30$ & -- & 4902 & 29310 & -- & 658.7 \\
\hline & & JUL. $Y$ & & & AUGUST & & & SEPTEMBER & \\
\hline DAY & $\begin{array}{l}\text { MEAN } \\
\text { OISCHARGE } \\
\text { (CFS) }\end{array}$ & $\begin{array}{l}\text { MEAA } \\
\text { CCNCEN- } \\
\text { IRAT IDN } \\
\text { IMG/LI }\end{array}$ & $\begin{array}{l}\text { SECIMENT } \\
\text { OISCHARGE } \\
\text { (TONS/CAY) }\end{array}$ & $\begin{array}{l}\text { NEAA } \\
\text { OISCHARGE } \\
\text { ICFSI }\end{array}$ & $\begin{array}{l}\text { MEAN } \\
\text { CONCEN- } \\
\text { TRATICN } \\
\text { (MG/L) }\end{array}$ & $\begin{array}{l}\text { SEC IMENT } \\
\text { DISCHARGE } \\
\text { (TCNS/DAY) }\end{array}$ & $\begin{array}{l}\text { MEAN } \\
\text { DISCHARGE } \\
\text { (CFS) }\end{array}$ & $\begin{array}{l}\text { MEAN } \\
\text { CCNCEN- } \\
\text { TRAIICN } \\
\text { (MGGL) }\end{array}$ & $\begin{array}{l}\text { SECINEAT } \\
\text { CISCHARCE } \\
\text { (TCAS/CAY) }\end{array}$ \\
\hline $\begin{array}{l}1 \\
2 \\
3 \\
4 \\
5\end{array}$ & $\begin{array}{r}1090 \\
1890 \\
1510 \\
1150 \\
324\end{array}$ & $\begin{array}{r}8 \\
10 \\
10 \\
9 \\
4\end{array}$ & $\begin{array}{c}24 \\
51 \\
41 \\
28 \\
3.5\end{array}$ & $\begin{array}{r}1560 \\
1110 \\
495 \\
2100 \\
2730\end{array}$ & $\begin{array}{r}105 \\
50 \\
20 \\
25 \\
110\end{array}$ & $\begin{array}{r}442 \\
150 \\
27 \\
142 \\
811\end{array}$ & $\begin{array}{r}528 \\
1270 \\
1280 \\
1440 \\
1290\end{array}$ & $\begin{array}{l}2 c \\
40 \\
4 C \\
85 \\
74\end{array}$ & $\begin{array}{r}29 \\
137 \\
138 \\
330 \\
258\end{array}$ \\
\hline $\begin{array}{r}6 \\
7 \\
8 \\
9 \\
10\end{array}$ & $\begin{array}{r}216 \\
179 \\
210 \\
404 \\
2230\end{array}$ & $\begin{array}{r}2 \\
1 \\
2 \\
3 \\
30\end{array}$ & $\begin{array}{c}1.2 \\
\because .48 \\
1.1 \\
181\end{array}$ & $\begin{array}{l}169 C \\
1550 \\
1270 \\
1 C 30 \\
147 C\end{array}$ & $\begin{array}{r}90 \\
95 \\
88 \\
80 \\
260\end{array}$ & $\begin{array}{r}411 \\
500 \\
302 \\
222 \\
1030\end{array}$ & $\begin{array}{r}1110 \\
500 \\
350 \\
670 \\
1410\end{array}$ & $\begin{array}{l}60 \\
3 C \\
15 \\
25 \\
5 C\end{array}$ & $\begin{array}{r}180 \\
41 \\
14 \\
45 \\
190\end{array}$ \\
\hline $\begin{array}{l}11 \\
12 \\
13 \\
14 \\
15\end{array}$ & $\begin{array}{r}2850 \\
1200 \\
388 \\
442 \\
1220\end{array}$ & $\begin{array}{l}35 \\
30 \\
18 \\
20 \\
35\end{array}$ & $\begin{array}{r}269 \\
97 \\
19 \\
24 \\
115\end{array}$ & $\begin{array}{l}8230 \\
4310 \\
3420 \\
3120 \\
2260\end{array}$ & $\begin{array}{r}48 \mathrm{C} \\
277 \\
75 \\
60 \\
18\end{array}$ & $\begin{array}{r}11400 \\
3220 \\
653 \\
565 \\
110\end{array}$ & $\begin{array}{r}1490 \\
1740 \\
1100 \\
400 \\
480\end{array}$ & $\begin{array}{l}6 c \\
75 \\
5 C \\
25 \\
3 C\end{array}$ & $\begin{array}{r}241 \\
352 \\
149 \\
27 \\
39\end{array}$ \\
\hline $\begin{array}{l}16 \\
17 \\
18 \\
19 \\
20\end{array}$ & $\begin{array}{r}1430 \\
1340 \\
1210 \\
907 \\
270\end{array}$ & $\begin{array}{r}50 \\
46 \\
35 \\
20 \\
B\end{array}$ & $\begin{array}{c}153 \\
166 \\
114 \\
49 \\
5.8\end{array}$ & $\begin{array}{r}127 c \\
540 \\
1230 \\
1370 \\
2010\end{array}$ & $\begin{array}{r}12 \\
5 \\
14 \\
15 \\
40\end{array}$ & $\begin{array}{c}41 \\
7.3 \\
46 \\
55 \\
217\end{array}$ & $\begin{array}{r}1140 \\
1160 \\
1300 \\
1230 \\
977\end{array}$ & $\begin{array}{r}70 \\
90 \\
120 \\
100 \\
50\end{array}$ & $\begin{array}{l}215 \\
282 \\
421 \\
332 \\
132\end{array}$ \\
\hline $\begin{array}{l}21 \\
22 \\
23 \\
24 \\
25\end{array}$ & $\begin{array}{r}598 \\
2190 \\
1730 \\
1620 \\
1470\end{array}$ & $\begin{array}{l}10 \\
35 \\
30 \\
28 \\
26\end{array}$ & $\begin{array}{r}16 \\
206 \\
140 \\
122 \\
103\end{array}$ & $\begin{array}{r}159 C \\
1420 \\
115 C \\
898 \\
1730\end{array}$ & $\begin{array}{l}35 \\
29 \\
20 \\
10 \\
25\end{array}$ & $\begin{array}{r}150 \\
111 \\
62 \\
24 \\
117\end{array}$ & $\begin{array}{r}370 \\
2440 \\
2770 \\
1200 \\
350\end{array}$ & $\begin{array}{r}3 c \\
12 C \\
125 \\
i v \\
35\end{array}$ & $\begin{array}{r}3 \mathrm{C} \\
751 \\
935 \\
227 \\
32\end{array}$ \\
\hline $\begin{array}{l}20 \\
27 \\
28 \\
29 \\
30 \\
31\end{array}$ & $\begin{array}{r}1050 \\
590 \\
648 \\
1380 \\
1510 \\
1420\end{array}$ & $\begin{array}{l}20 \\
15 \\
10 \\
25 \\
40 \\
35\end{array}$ & $\begin{array}{r}57 \\
28 \\
17 \\
93 \\
163 \\
134\end{array}$ & $\begin{array}{r}324 \mathrm{C} \\
1240 \\
743 \\
1620 \\
127 \mathrm{C} \\
350\end{array}$ & $\begin{array}{r}30 \\
12 \\
8 \\
10 \\
5 \\
3\end{array}$ & $\begin{array}{c}262 \\
40 \\
16 \\
44 \\
17 \\
2.8\end{array}$ & $\begin{array}{r}300 \\
250 \\
220 \\
393 \\
1100 \\
-\end{array}$ & $\begin{array}{l}31 \\
3 C \\
2 C \\
25 \\
35 \\
--\end{array}$ & $\begin{array}{r}25 \\
20 \\
12 \\
27 \\
164 \\
--\end{array}$ \\
\hline TOTAL & 34756 & -- & 2465.38 & 59016 & -- & 21177.1 & 30258 & -- & 5756 \\
\hline
\end{tabular}


02070500 MAYO RIVER NEAR PRICE, N. C.

LOCATION (revised), --Lat $36^{\circ} 32^{\prime} 02^{\prime \prime}$, long $7^{\circ} 59^{\prime} 31^{\prime \prime}$, Rockingham County, at Anglins Bridge on Secondary Road 1358 , $300 \mathrm{ft}$ upstream from gaging station, 0.5 mile downstream from confluence of North and South Mayo Rivers, 0.8 mile downstream from Virginia-North Carolina State line, and 4 miles west of Price.

DRA INAGE AREA. - -260 sq $\mathrm{ml}$.

PERIOD OF RECORD.-Chemical analyses: October 1949 to September 1950, October 1968 to September 1970. Water temperatures: October 1949 to September 1950.

EXTRENES. - -1949-50:

Dissolved sol1ds: Maximum, $57 \mathrm{mg} / 1$ Nov. 11-20, 1949; minimum, $36 \mathrm{mg} / 1$ May 11-20, 1950.

Hardness: Maximum, $19 \mathrm{mg} / 1$ Nov. 11-20, Dec. 1-10, 1949; minimum, $14 \mathrm{mg} / 1$ Mar. 21-30, May 1-10, 1950

Water temperatures: Maximum, $26.0^{\circ} \mathrm{C}$ July 18,1950 ; minimum, freezing point Dec. 17, 1949.

REMARKS.-The second of two samples collected at the same tjme is a field determination. CHEMICAL ANALYSES, WATER YEAR OCTOBER 1960 TI SEPTEMBER 1970

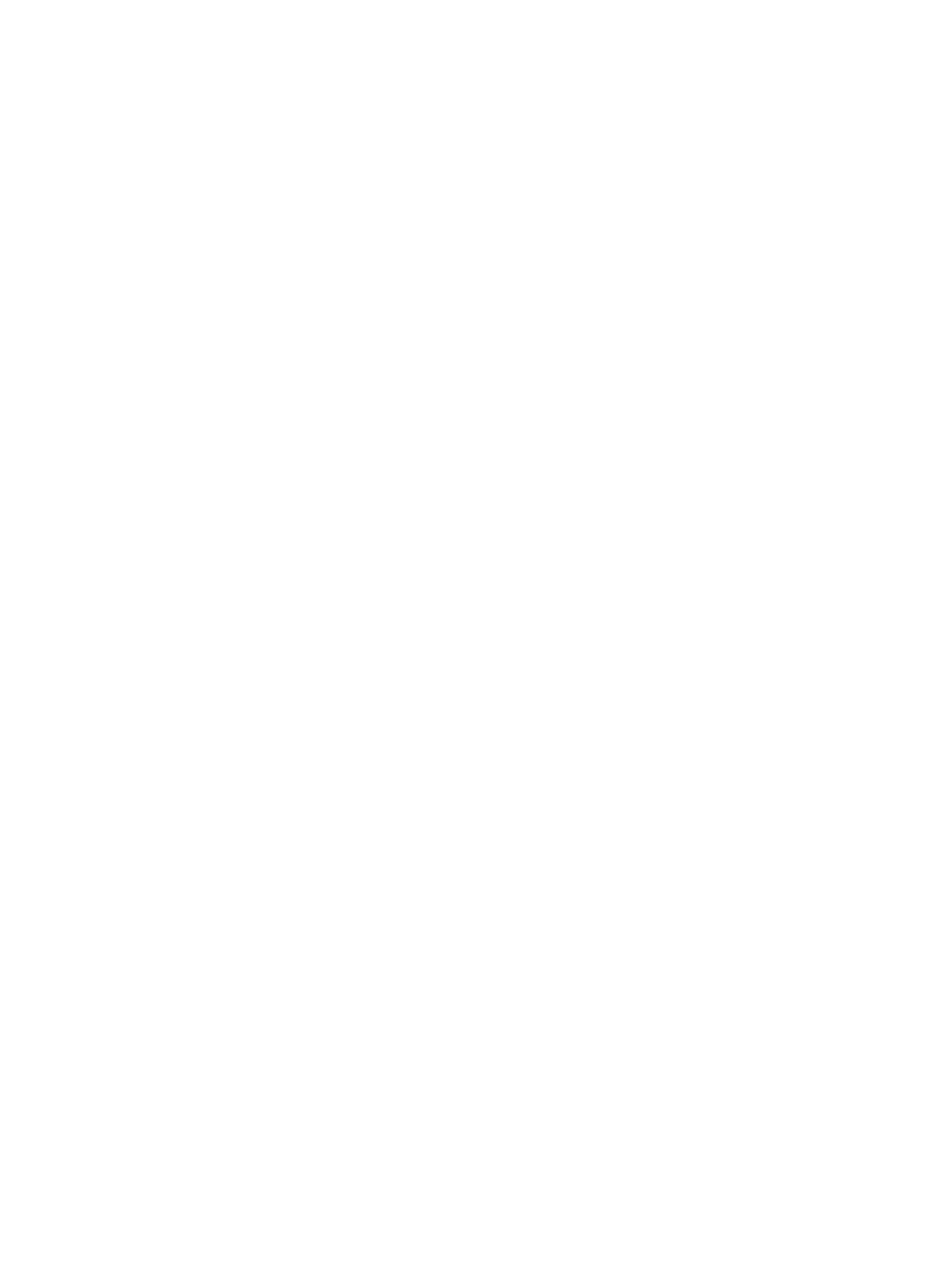


ROANOKE RIVER BASIN

02070500 MAYO RIVER NEAR PRICE, N, C..-Continued

CHEMICAL ANALYSES, WATER YEAR·OCTOBER 1969 TO SEPTEMBER 1970

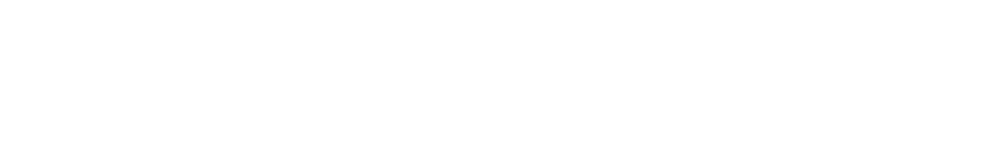

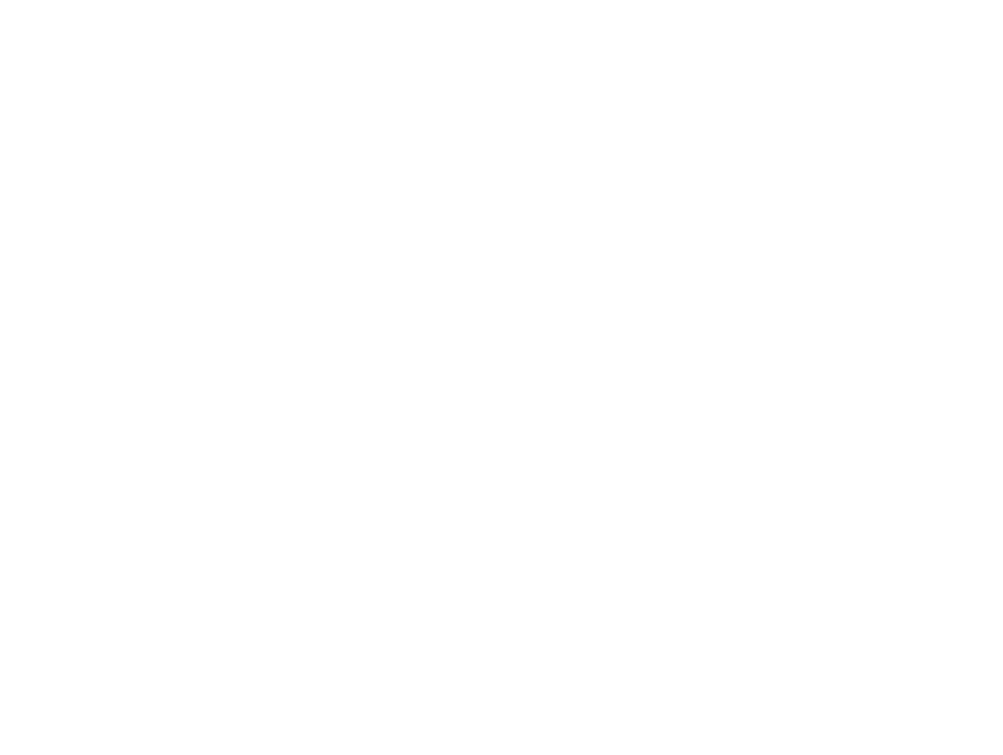

\begin{tabular}{|c|c|c|c|c|c|c|c|c|c|c|}
\hline $22 \ldots$ & - & $\cdots$ & - & - & - & $\sim$ & -- & -- & 15.0 & - \\
\hline $22 \ldots$ & -- & -- & -- & -- & 8.5 & $\cdots$ & 58 & 7.1 & 15.0 & - \\
\hline Nuv. & & & & & & & & & & \\
\hline $20 \ldots$ & -- & -- & - & -- & $\cdots$ & $\cdots$ & - & - & 8.0 & - \\
\hline $20 \ldots$ & -- & - & -- & - & 13.0 & $=$ & 58 & 6.8 & 8.0 & - \\
\hline $\begin{array}{l}\mathrm{OEC} . \\
23 . \ldots\end{array}$ & -- & -- & -- & -- & $=$ & $=-$ & 40 & 6.5 & 8.0 & 40 \\
\hline $23 \ldots$ & -- & - & -- & -- & I 1 .2 & $\sim-$ & 40 & 6.1 & B.0 & - \\
\hline JAN. & & & & & & & & & & \\
\hline $21 \ldots$ & - & -- & $=-$ & $\cdots$ & $=$ & - & -- & - & 1.0 & - \\
\hline $\begin{array}{c}21 \ldots \\
F E B\end{array}$ & -- & -- & -- & -- & 14.5 & -- & 55 & 6.9 & 1.0 & - \\
\hline $26 \ldots$ & $\cdots$ & $\cdots$ & - & -- & -- & $\cdots$ & - & $\cdots$ & 4.0 & -- \\
\hline $26 \ldots$ & -- & -- & -- & -- & 11.9 & -- & 50 & 7.2 & 4.0 & $\rightarrow$ \\
\hline MAR. & & & & & & & & & & \\
\hline $26 . \ldots$ & - & -- & - & -- & - & $\sim$ & 45 & 6.4 & 15.0 & 5 \\
\hline$\angle 6 \ldots$ & -- & -- & -- & - & 10.0 & - & 60 & 7.6 & 15.0 & - \\
\hline APR. & & & & & & & & & & \\
\hline $17 \ldots$ & -- & -- & - & -- & $=$ & - & -- & -- & 13.5 & - \\
\hline $17 \ldots$ & -- & -- & - & -- & 11.3 & -- & 50 & 6.9 & 13.5 & -- \\
\hline $20 \ldots$ & - & - & - & -- & - & 5,7 & 45 & 6.5 & 17.2 & 5 \\
\hline $20 \ldots$ & -- & - & $\cdots$ & - & 10.0 & - & 48 & 7.3 & 17.2 & - \\
\hline JUNE & & & & & & & & & & \\
\hline $18 \ldots$ & -- & -- & - & -- & 8.4 & 1.6 & 45 & 6.5 & 24.0 & 5 \\
\hline $18 \ldots$ & - & - & - & - & -- & - & 45 & -- & 24.0 & -- \\
\hline JULY & 0 & 10 & .00 & 0 & - & $=-$ & 53 & 7.0 & & 7 \\
\hline $28 \ldots$ & $\ldots$ & - & - & - & 7.4 & - & 60 & 6.9 & 21.4 & 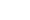 \\
\hline AUG. & & & & & & & & & & \\
\hline $20 \ldots$ & -- & - & - & -- & - & $=-$ & $=$ & -- & 22.8 & - \\
\hline $20 . \ldots$ & -- & -- & -- & - & 8.6 & - & 43 & 7.1 & 22.8 & -- \\
\hline $29 .$. & -- & -- & -- & -- & - & 2.9 & -- & -- & 150 & -- \\
\hline $29 . \ldots$ & - & -- & -- & -- & 11.1 & $=$ & 60 & 9.0 & 15.8 & $=$ \\
\hline
\end{tabular}


02074002 SMITH RIVEA NEAR EDEN, N. C.

(Formerly published as Smith River near' spray, N. C.)

LOCATION (revised).--Lat $36^{\circ} 31^{\prime} 15^{\prime \prime}$, long $79^{\circ} 45^{\prime} 10^{\prime \prime}$, Rockingham County, at bridge on Secondary Road 1714 at Eden, 0.8 mile downstream from gaging station, 2.1 miles downstream from Stuart Creek, and 3.1 miles upstream from mouth.

DRA INAGE AREA. -539 sq $\mathrm{mi}$.

PERIOD OF RECORD,--Chemical analyses: October 1949 to September 1950, October 1968 to September 1970.

EXTREMES, --1949-50:

Dissolved solids: Maximum, $57 \mathrm{mg} / 1$ Aug. 19, 1950; minimum, $46 \mathrm{mg} / 1 \mathrm{Jan}, 15$, May 17,1950 .

Hardness: Maximum, $24 \mathrm{mg} / \mathrm{i}$ July 16, Aug. 19, Sept. 17, 1950; mintmum, is mg/1 May i7, 1950 ,

REMARKS.--The second of two samples collected at the same time is a field determination,

CHEMICAL ANALYSES, hater yeAR OCTMBER 1969 to SEPTEMBER 1970

\begin{tabular}{|c|c|c|c|c|c|c|c|c|c|c|c|}
\hline DATE & IIME & $\begin{array}{l}\text { OIS- } \\
\text { CHARGE } \\
\text { ICFSI }\end{array}$ & $\begin{array}{l}\text { SILICA } \\
\text { ISIOZI } \\
\text { IMG/L) }\end{array}$ & $\begin{array}{l}\text { OLS- } \\
\text { SOLVED } \\
\text { IRON } \\
\text { IfES } \\
\text { IUG/ }\end{array}$ & $\begin{array}{l}\text { CAL- } \\
\text { CluM } \\
\text { ICA } \\
\text { I MG/LI }\end{array}$ & $\begin{array}{c}\text { MAG- } \\
\text { NE- } \\
\text { SIUM } \\
\text { IMG } \\
\text { IMG/L) }\end{array}$ & $\begin{array}{l}\text { Snd IUM } \\
\text { INAI } \\
\text { IMG }\end{array}$ & $\begin{array}{l}\text { PO- } \\
\text { IAS- } \\
\text { SIUM } \\
\text { IKI } \\
\text { (MG/L) }\end{array}$ & 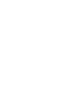 & $\begin{array}{l}\text { CAR- } \\
\text { BONATE } \\
\text { ICOBII } \\
\text { (MG/L) }\end{array}$ & $\begin{array}{l}\text { SULFAIE } \\
\text { (SS4) } \\
\text { (MG/L) }\end{array}$ \\
\hline 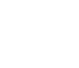 & $\begin{array}{l}1015 \\
1015\end{array}$ & 477 & $=$ & $=$ & $=$ & $=$ & $=$ & $=$ & z- & $=$ & $=$ \\
\hline $21:$. & $\begin{array}{l}1100 \\
1100\end{array}$ & 944 & $=$ & $=$ & $=$ & $=$ & $=$ & $=$ & 36 & $=$ & $=-$ \\
\hline $\begin{array}{r}{ }^{2 E C} . . \\
23 . . \\
23 . .\end{array}$ & $\begin{array}{l}1130 \\
1130\end{array}$ & $\begin{array}{l}1020 \\
1020\end{array}$ & 10 & $\therefore$ & 4.6 & 2.0 & 4.5 & 1.9 & $\begin{array}{l}23 \\
--\end{array}$ & 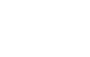 & 7.8 \\
\hline $21:$. & $\begin{array}{l}1230 \\
1230\end{array}$ & $\begin{array}{l}561 \\
561\end{array}$ & $=$ & $=$ & $=$ & $=$ & $=-$ & $=$ & -- & $=$ & $=$ \\
\hline 26. & $\begin{array}{l}1115 \\
1115\end{array}$ & 1140 & $=$ & $=$ & $=$ & $=$ & -- & -- & $=$ & $=$ & $=$ \\
\hline $\begin{array}{l}\text { AAR. } \\
266 . . \\
26 . .\end{array}$ & $\begin{array}{l}1015 \\
1025\end{array}$ & $\begin{array}{l}534 \\
534\end{array}$ & 14 & 31 & 5.2 & 2.4 & 10 & 1.5 & 34 & 0 & 7.6 \\
\hline $\begin{array}{c}\text { APR. } \\
17 \ldots . \\
17 . \\
17 .\end{array}$ & $\begin{array}{l}0854 \\
0854\end{array}$ & $\begin{array}{l}575 \\
575\end{array}$ & 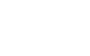 & $=$ & $=$ & $=$ & $=-$ & $=$ & $=$ & $=$ & $=-$ \\
\hline $\begin{array}{r}\text { MAY } \\
20 . \\
20 . \\
2 U N E\end{array}$ & $\begin{array}{l}0812 \\
0812\end{array}$ & $\begin{array}{l}912 \\
912\end{array}$ & $=$ & $=$ & $=$ & $=$ & $=$ & $=$ & $=$ & $=$ & -- \\
\hline $\begin{array}{l}18 . . \\
18 . \% \\
\text { Jur }\end{array}$ & $\begin{array}{l}1030 \\
2030\end{array}$ & $\begin{array}{l}568 \\
568\end{array}$ & 11 & - & 5.6 & 3.2 & $\begin{array}{l}8.0 \\
--\end{array}$ & 1.6 & 28 & $\stackrel{0}{-}$ & 7.4 \\
\hline $\begin{array}{r}2 \mathrm{~B} . \\
28 . \ldots \\
A 46 .\end{array}$ & $\begin{array}{l}1015 \\
1015\end{array}$ & $\begin{array}{r}528 \\
528\end{array}$ & 15 & 75 & 6.6 & 3.4 & 8.3 & 2.5 & 30 & $\begin{array}{c}0 \\
--\end{array}$ & 0.4 \\
\hline $\begin{array}{r}20 \% \\
20 \%\end{array}$ & $\begin{array}{l}2045 \\
1045\end{array}$ & $\begin{array}{l}904 \\
904\end{array}$ & $\because$ & $\because$ & $=$ & $=$ & $=$ & $=$ & $=$ & $=$ & $=$ \\
\hline 29.:. & $\begin{array}{l}1030 \\
1030\end{array}$ & $\begin{array}{l}436 \\
496\end{array}$ & $=$ & $=$ & $\bar{z}$ & $=$ & $=$ & $=$ & $=-$ & $=$ & $=$ \\
\hline DATE & $\begin{array}{l}\text { CHLO- } \\
\text { RIDE } \\
\text { ICLI } \\
\text { (MG/L) }\end{array}$ & $\begin{array}{l}\text { FLUU- } \\
\text { RIOEE } \\
\text { IFI } \\
\text { IMG/LI }\end{array}$ & $\begin{array}{l}\text { NITRA TE } \\
\text { (NO3) } \\
\text { (MG/L) }\end{array}$ & 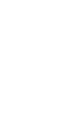 & $\begin{array}{l}\text { TOTAL } \\
\text { POHS- } \\
\text { PHORUS } \\
\text { PIP) } \\
\text { IPG/LI }\end{array}$ & $\begin{array}{l}\text { OIS- } \\
\text { SOLVED } \\
\text { SDLIDS } \\
\text { IRESI- } \\
\text { DUE AT } \\
\text { IBO CD } \\
\text { IMGLI) }\end{array}$ & $\begin{array}{l}\text { DIS- } \\
\text { SOLVED } \\
\text { SOLIOS } \\
\text { ITONS } \\
\text { PER } \\
\text { AC-FI, }\end{array}$ & $\begin{array}{l}\text { O1 S- } \\
\text { SOLVED } \\
\text { SOLIOS } \\
\text { TONS } \\
\text { PER } \\
\text { DAY } \\
\text { DAY }\end{array}$ & $\begin{array}{l}\text { MAROD- } \\
\text { MESS } \\
\text { ICA MGG } \\
\text { IMG /LI }\end{array}$ & $\begin{array}{l}\text { NON- } \\
\text { CAR- } \\
\text { CONATE } \\
\text { HARO- } \\
\text { NESS } \\
\text { IMG/L) }\end{array}$ & $\begin{array}{c}\text { SOOIU } \\
\text { ADD } \\
\text { SORP } \\
\text { IDON } \\
\text { RATIO }\end{array}$ \\
\hline $\begin{array}{l}\text { oct. } \\
22 \ldots \\
22 \ldots\end{array}$ & $=$ & $=$ & -- & $=$ & .14 & $=$ & $=$ & $=-$ & $=$ & $=$ & $=$ \\
\hline $\begin{array}{c}\text { Nov. } \\
21 . . . \\
21 \ldots\end{array}$ & $=$ & $=$ & $=$ & $\overline{-}$ & .40 & $=$ & $=$ & $=$ & $=$ & $\overline{-}$ & $=$ \\
\hline $\begin{array}{c}{ }^{E E C .} . \\
23 \ldots \\
23 \ldots\end{array}$ & 3.4 & $\therefore 1$ & 2.2 & .10 & $=$ & 78 & $\begin{array}{l}.11 \\
.1\end{array}$ & 215 & 20 & 1 & $\because 4$ \\
\hline $\begin{array}{c}\text { IAN. } \\
21 \ldots \\
21 \ldots . .\end{array}$ & $=$ & $=$ & $=$ & $=$ & .28 & -- & -- & $=$ & $=$ & - & $=$ \\
\hline $\begin{array}{r}\text { FEB. } \\
26 \ldots . .\end{array}$ & $=$ & $\because$ & $\bar{z}$ & $=$ & .11 & $=$ & $\because$ & $=$ & $=$ & $=$ & $=$ \\
\hline $\begin{array}{l}\text { MAR. } \\
26 \ldots . . \\
26 . .\end{array}$ & 9.1 & $\therefore 1$ & $\therefore$ & .30 & .12 & 63 & .09 & 90.8 & 23 & $\therefore$ & $\therefore 9$ \\
\hline $\begin{array}{l}\text { APR. } \\
17 \ldots . . \\
17 . .\end{array}$ & $=$ & $=$ & -- & $=$ & .12 & $=$ & $=$ & -- & $=$ & $=$ & $=-$ \\
\hline $\begin{array}{r}\text { MAY } \\
20 . . . \\
20 \ldots\end{array}$ & $=$ & $=$ & $=$ & $=$ & .13 & $=$ & $\because$ & $=$ & $=$ & $=$ & $=$ \\
\hline $\begin{array}{r}\text { JUNE } \\
18 \ldots . . \\
18 . .\end{array}$ & 9.6 & .0 & $: 7$ & .20 & .10 & 50 & .07 & 76.7 & 27 & -4 & $\therefore$ \\
\hline $\begin{array}{r}28 \ldots \ldots \\
28 \ldots\end{array}$ & 10 & $\therefore 1$ & 1.3 & $=$ & $=$ & $\stackrel{73}{-}$ & $\stackrel{.10}{--}$ & 104 & 30 & -6 & 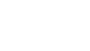 \\
\hline $\begin{array}{r}\text { AUG. } \\
20 . . \\
20 . .\end{array}$ & $=$ & $=$ & $=$ & $=$ & .07 & $=$ & $=$ & $\because$ & $=$ & $=$ & -- \\
\hline $\begin{array}{r}29 \ldots . \\
29 \ldots\end{array}$ & $=$ & $=$ & $=$ & -- & .02 & $=$ & -- & $=$ & -- & $=$ & $=-$ \\
\hline
\end{tabular}


02074002 SHITH RIVER NEAR EDEN, N. C.-mContinued

CHEMICAL ANALYSES, WATER YEAR OCTOBER 1969 TO SEPTEMBER 1970

\begin{tabular}{|c|c|c|c|c|c|c|c|c|c|c|c|}
\hline DATE & $\begin{array}{l}\text { PERCENT } \\
\text { SOOIUH }\end{array}$ & 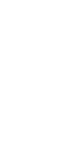 & $\begin{array}{l}\text { PHENOLS } \\
\text { (UG/L) }\end{array}$ & $\begin{array}{l}\text { TOTAL } \\
\text { KJELL } \\
\text { OAHL } \\
\text { NIIRO- } \\
\text { NEN } \\
\text { GEN } \\
\text { ING/L }\end{array}$ & 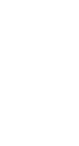 & $\begin{array}{l}\text { IUR- } \\
\text { BID- } \\
\text { IIY } \\
\text { (JTUI }\end{array}$ & $\begin{array}{l}\text { SUS- } \\
\text { PENDE } \\
\text { SOLLLDS } \\
\text { IMGAS }\end{array}$ & $\begin{array}{l}\text { ALKA- } \\
\text { LINIYY } \\
\text { AS } \\
\text { CACO } \\
\text { CMG/L }\end{array}$ & 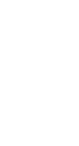 & $\begin{array}{l}\text { COPPER } \\
\text { (CU) } \\
\text { IUG }\end{array}$ & $\begin{array}{r}\text { LEAD } \\
\text { IPB } \\
\text { IUG/L) }\end{array}$ \\
\hline 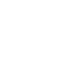 & $=$ & $=$ & $=$ & 1.8 & $=$ & $=-$ & $\overline{-}$ & $\overline{30}$ & $=$ & $=$ & $\therefore$ \\
\hline $\begin{array}{l}\text { NOV. } \\
21 . . .\end{array}$ & $=$ & $=$ & 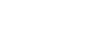 & 1.0 & $=$ & $=$ & $=$ & 30 & $=$ & -- & $=$ \\
\hline $\begin{array}{r}\text { DEC. } \\
23 . . . \\
23 . .\end{array}$ & 31 & $=$ & -0 & .26 & .08 & $=$ & $\overline{-}$ & 19 & $=-$ & $=$ & $=$ \\
\hline $\begin{array}{l}\text { JAN. } \\
21 . . . \\
21\end{array}$ & $=$ & $=$ & $=$ & - 40 & $=$ & $=$ & $=$ & $=$ & -- & $=$ & $=$ \\
\hline FEB: & & & & & & - & - & $\ldots$ & -- & - & -- \\
\hline $26 \ldots$ & $=$ & $\because$ & - & $\stackrel{30}{-10}$ & $=$ & $=$ & - & -- & -- & - & - \\
\hline $\begin{array}{l}\text { RAR:... } \\
266 . .\end{array}$ & 47 & $\overline{-}$ & $=-$ & .08 & .13 & $=$ & $\overline{--}$ & $\begin{array}{l}28 \\
28\end{array}$ & $=$ & $=$ & $=$ \\
\hline $\begin{array}{l}\text { APR. } \\
17 . . \\
17 . .\end{array}$ & $\ldots$ & -- & 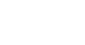 & .15 & $=$ & $=$ & $=$ & -- & $=$ & $=$ & $\because$ \\
\hline $\begin{array}{c}\operatorname{MaY} \\
20 \ldots\end{array}$ & -- & -- & -- & .13 & - & - & - & -- & -- & -- & $=$ \\
\hline $\begin{array}{l}20 . . . \\
\text { JUNE }\end{array}$ & 37 & -- & 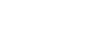 & .12 & .05 & -- & - & 23 & -- & - & -- \\
\hline $18 \%$ & -- & - & -- & $\div$ & - & -- & - & 28 & -- & - & -- \\
\hline $\begin{array}{r}28 . . . \\
28 . . .\end{array}$ & 35 & $\ddot{-8}$ & - & .23 & .06 & 16 & 135 & $\begin{array}{l}25 \\
18\end{array}$ & $\therefore$ & $\stackrel{0}{-}$ & $\therefore$ \\
\hline $\begin{array}{l}\text { AUG. } \\
20 . . .\end{array}$ & -- & - & 0 & .24 & - & -- & -- & $\ddot{0}$ & -- & - & $=$ \\
\hline SEPT: & -- & & . & & -- & -- & _- & 20 & .- & $\ldots$ & - \\
\hline $\begin{array}{l}29 \ldots \ldots \\
29 \ldots\end{array}$ & $\Rightarrow$ & 1.8 & - & .52 & -- & $=$ & - & - & -- & $\overline{-}$ & $\overline{-}$ \\
\hline
\end{tabular}

\begin{tabular}{|c|c|c|c|c|c|c|c|c|c|c|}
\hline DATE & $\begin{array}{l}Z I N C \\
(2 N) \\
(U \in / L) \\
(U \in M)\end{array}$ & $\begin{array}{c}\text { Cranide } \\
(\text { (MN) } \\
(M G / L)\end{array}$ & $\begin{array}{l}\text { CAD } \\
\text { MTIM } \\
\text { CCDD } \\
\text { (CG/L) }\end{array}$ & $\begin{array}{l}\text { DrS- } \\
\text { SOLVED } \\
\text { OXYGGN } \\
\text { IMG/LI }\end{array}$ & $\begin{array}{c}\text { TOTAL } \\
\text { BETA } \\
\text { BPI } \\
\text { IPCALI }\end{array}$ & $\begin{array}{c}\text { FECAL } \\
\text { COLL } \\
\text { FOR } \\
\text { ICOL. } \\
\text { PER } \\
100 \mathrm{HLI}\end{array}$ & $\begin{array}{l}\text { SPECLI- } \\
\text { FIC } \\
\text { CONDO- } \\
\text { UCTAACE } \\
\text { IMICRO- } \\
\text { MHOSI }\end{array}$ & $\begin{array}{c}\text { PH } \\
\text { (UNITS) }\end{array}$ & $\begin{array}{l}\text { IEMP- } \\
\text { ERATURE } \\
\text { InEG CI }\end{array}$ & $\begin{array}{l}\text { COLOR } \\
\text { ITPAI- } \\
\text { INUM- } \\
\text { COBALT } \\
\text { UNI TS }\end{array}$ \\
\hline T2.... & 20 & -- & $\overline{-}$ & $8 \overline{5.5}$ & $\overline{-}$ & 530 & $\overrightarrow{130}$ & $7 . \overline{7.2}$ & $15 . \overline{0}$ & $=$ \\
\hline i... & 10 & $=$ & $=$ & -- & $=$ & & $\overline{71}$ & $\because$ & - & -- \\
\hline c]..... & $\begin{array}{r}8 \\
-\end{array}$ & - & $\overline{-}$ & $\bar{z}$ & $=$ & -- & $\begin{array}{l}59 \\
68\end{array}$ & $\begin{array}{l}0.4 \\
7: 0\end{array}$ & $\begin{array}{l}8.0 \\
\forall .0\end{array}$ & 80 \\
\hline 21. & 30 & -- & $\bar{z}$ & $13 . \overline{6}$ & $\overline{-}$ & 1300 & $\overrightarrow{105}$ & $\because \because 0$ & 2.0 & $=$ \\
\hline$\ldots$ & 44 & -- & $=$ & $-\bar{q}$ & $=$ & -- & $\overrightarrow{105}$ & $\because 5$ & -- & -- \\
\hline $\begin{array}{l}\text { MAR. } \\
26 . . \\
26 . \ldots\end{array}$ & 15 & - & - & - & - & -- & 100 & 6.3 & 13.0 & 5 \\
\hline $7 \ldots$ & 15 & -- & - & - & - & -- & $-\bar{c}$ & -- & 13.5 & -- \\
\hline${ }_{\text {MaY }}^{17}$ & & & & 10.3 & & & 105 & 6.9 & 13.5 & \\
\hline${ }_{20}^{20} \ldots$ & 15 & -- & $=$ & $8 . \overline{5}$ & $\overline{-}$ & 1100 & $1 \overline{100}$ & $\overline{7.1}$ & $\begin{array}{l}17: 0 \\
17: 0\end{array}$ & $\because$ \\
\hline 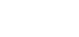 & 10 & - & -- & $\overline{6.5}$ & $\overline{-}$ & $\overline{130}$ & 94 & 0.3 & 25.0 & 5 \\
\hline $\begin{array}{c}\text { Uuty } \\
28 . . .\end{array}$ & 12 & .00 & 0 & -- & -- & -- & 98 & 6.6 & 23.5 & 7 \\
\hline & & & & & & & & & & \\
\hline & $-{ }^{4}$ & $=$ & $\overline{--}$ & $8 . \overline{2}$ & $\overline{-}$ & $\overline{--}$ & 82 & 0.6 & $\begin{array}{l}28.0 \\
28.0\end{array}$ & $\overline{-}$ \\
\hline${ }_{29}^{29} \ldots$ & 6 & $=$ & $=$ & $6-\overline{2}$ & 7.2 & $\overline{20}$ & $\overline{70}$ & 7 & 27.5 & $=$ \\
\hline
\end{tabular}


02074082 DAN RIVER AT EDEN, N. C.

LOCATION.--Lat $36^{\circ} 29^{\prime} 51^{\prime \prime}$, Iong $79^{\circ} 40^{\prime} 54^{\prime \prime}$, Rockingham County, temperature recorder at bridge on State Highway 700 , 1.2 miles downstream 'from Town Creek, 1.2 miles southeast of Eden, 5.1 miles downstream from Smith River, and 87.8 miles upstream from mouth.

DRAINAGE AREA. $-1,720$ sq mi, approximately.

PERIOD OF RECORD.--Water temperatures: July 1968 to September 1970.

EXTREMES, JuIy to September 1968 :

Water temperatures: Maximum, $35.0^{\circ} \mathrm{C}$ Aug. $26{ }^{\circ}$ minimum, $18.0^{\circ} \mathrm{C}$ sept. 14.

Water temperatures (1968-69): Maximum, 33.5 C June 30, July 1 ; minimum, $1.5^{\circ} \mathrm{C}$ Dec. 25

Water temperatures (1969-70): Maximum, $33.0^{\circ} \mathrm{C}$ June 19 , July 13 ; minimum, $1.5^{\circ} \mathrm{C}$ Jan. $10^{\circ}$

Period of record:

Water temperatures: Maximum, $35.0^{\circ} \mathrm{C}$ Aug. 26,1968 ; minimum, $1.5^{\circ} \mathrm{C}$ Dec. 25,1968 Jan. $10,1970$.

TEMPERATURE (०० ${ }^{\circ}$ ) OF WATER, JULY TO SEPTEMBER 1968 ICONTINUDUS ETHYL ALCOHOL-ACTUATED THERMOGRAPHI

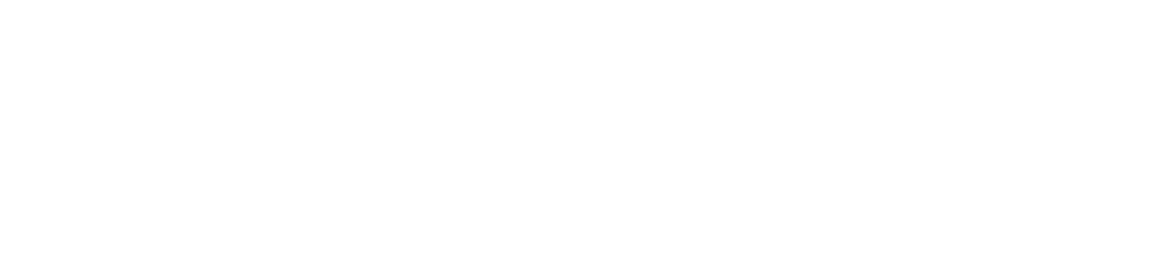


02074082 DAN RIVER AT EDEN, N. C.--Continued

TEMPERATURE $\left({ }^{\circ} \mathrm{C}\right)$ OF WATER, WATER YEAR OCTOBER 1968 TO SEPTEMBER 1969

$\begin{array}{ll}25.0 & 21.0 \\ 22.0 & 19.0 \\ 23.5 & 19.5 \\ 23.5 & 19.0 \\ 20.5 & 16.0 \\ 19.5 & 16.5 \\ 22.0 & 18.5 \\ 21.5 & 18.5 \\ 20.5 & 17.0 \\ 20.5 & 18.0 \\ 21.0 & 18.0 \\ 21.0 & 18.0 \\ 22.0 & 21.0 \\ 23.0 & 21.0 \\ 22.0 & 21.0 \\ 22.0 & 21.5 \\ 23.0 & 21.0 \\ 23.0 & 22.0 \\ 22.0 & 19.0 \\ 19.0 & 17.0 \\ 18.5 & 17.0 \\ 18.5 & 16.5 \\ 19.0 & 16.5 \\ 19.5 & 17.0 \\ 19.0 & 17.0 \\ 18.0 & 14.5 \\ 14.5 & 12.0 \\ 16.0 & 13.0 \\ 15.5 & 12.0 \\ 15.0 & 12.0 \\ 15.0 & 12.0 \\ 20.0 & 17.5 \\ & \end{array}$

NOV

$\begin{array}{rrrr}\text { MAX } & \text { MIN } & \text { MAX } & \text { M } \\ & & & \\ 15.0 & 13.5 & 14.0 & 11 \\ 18.0 & 15.0 & 14.5 & 11.0 \\ 20.0 & 16.0 & 14.5 & 12.0 \\ 20.5 & 16.5 & 14.5 & 13.0 \\ 21.0 & 16.5 & 14.0 & 11.0 \\ 19.0 & 16.5 & 12.0 & 9.5 \\ 19.5 & 16.5 & 11.0 & 8.5 \\ 19.5 & 15.5 & 10.0 & 6.0 \\ 17.0 & 14.5 & 8.5 & 5.5 \\ 15.5 & 13.0 & 8.0 & 4.0 \\ 14.0 & 12.0 & 7.0 & 4.0 \\ 13.0 & 8.5 & 6.0 & 3.5 \\ 8.5 & 6.5 & 6.5 & 4.5 \\ 10.5 & 8.5 & 8.5 & 5.5 \\ 12.0 & 10.0 & 8.0 & 5.0 \\ 14.5 & 11.0 & 5.5 & 3.5 \\ 14.5 & 13.5 & 5.5 & 3.5 \\ 16.5 & 14.5 & 5.0 & 2.0 \\ 14.5 & 11.0 & 5.0 & 2.0 \\ 11.0 & 10.0 & 5.5 & 4.0 \\ 11.0 & 8.5 & 5.5 & 3.5 \\ 11.5 & 8.5 & 6.0 & 4.0 \\ 12.0 & 9.0 & 6.5 & 5.0 \\ 13.5 & 10.0 & 6.0 & 3.0 \\ 13.5 & 11.0 & 5.0 & 1.0 \\ 13.0 & 10.0 & 5.0 & 3.0 \\ 13.0 & 10.5 & 6.0 & 3.0 \\ 14.0 & 11.5 & 9.5 & 5.0 \\ 15.5 & 14.5 & 9.5 & 6.5 \\ 14.5 & 13.5 & 9.5 & 7.0 \\ -5 & -5 & 10.5 & 7.0 \\ 15.0 & 12.0 & 8.5 & 6.0 \\ & & & \end{array}$

MAN

$1.5 \quad 10.0$

1.0

2.0

3. 0

$9.5 \quad 10.0$

$\begin{array}{rr}.5 & 10.0 \\ 6.0 & 6.5\end{array}$

$\begin{array}{ll}6.0 & 6.5 \\ 5.5 & 8.0\end{array}$

$\begin{array}{rr}4.5 & 9.0 \\ 3.5 & 9.5 \\ 4.5 & 10.0\end{array}$

$\begin{array}{ll}5.5 & 9.5 \\ 5.5 & 9.5\end{array}$

$\begin{array}{ll}3.0 & 9.5 \\ 3.5 & 9.0\end{array}$

$\begin{array}{ll}3.5 & 9.0 \\ 2.0 & 9.0 \\ 2.0 & 8.5\end{array}$

$\begin{array}{rr}8.0 & 8.5 \\ 4.0 & 11.0\end{array}$

$3.0 \quad 9.0$

$\begin{array}{rr}5.0 & 9.0 \\ 3.0 & 10.5\end{array}$

$\begin{array}{ll}3.0 & 11.0 \\ 1.5 & 11.0\end{array}$

$\begin{array}{rr}3.5 & 10.0 \\ 3.0 & 9.0 \\ 5.0 & 9.0\end{array}$

5.0
6.5 9.0

$\begin{array}{rr}9.5 & 9.0 \\ .0 & 11.0\end{array}$

$7.0 \quad 12.0$

\begin{tabular}{|c|c|c|c|c|}
\hline \multirow[b]{2}{*}{ MIN } & \multicolumn{2}{|c|}{ FEB } & \multicolumn{2}{|c|}{ MAR } \\
\hline & $\max$ & MIN & $\max$ & MIN \\
\hline $\begin{array}{l}6.5 \\
6.0 \\
5.0 \\
5.0 \\
5.0\end{array}$ & $\begin{array}{r}12.0 \\
11.0 \\
6.0 \\
6.5 \\
6.0\end{array}$ & $\begin{array}{r}10.5 \\
8.0 \\
6.5 \\
5.5 \\
4.5\end{array}$ & $\begin{array}{r}10.0 \\
6.0 \\
8.5 \\
9.0 \\
8.5\end{array}$ & $\begin{array}{l}6.5 \\
4.5 \\
5.0 \\
6.5 \\
7.0\end{array}$ \\
\hline $\begin{array}{l}8.0 \\
6.0 \\
5.5 \\
5.5 \\
5.5\end{array}$ & $\begin{array}{l}8.0 \\
9.0 \\
9.0 \\
8.5 \\
6.0\end{array}$ & $\begin{array}{l}5.5 \\
6.5 \\
7.0 \\
6.0 \\
4.5\end{array}$ & $\begin{array}{l}8.0 \\
7.0 \\
8.0 \\
8.0 \\
9.0\end{array}$ & $\begin{array}{l}7.0 \\
6.0 \\
6.0 \\
6.5 \\
6.5\end{array}$ \\
\hline $\begin{array}{l}6.5 \\
5.5 \\
6.5 \\
6.0 \\
6.0\end{array}$ & $\begin{array}{l}6.0 \\
6.5 \\
6.5 \\
6.0 \\
5.5\end{array}$ & $\begin{array}{l}4.0 \\
4.5 \\
4.5 \\
4.5 \\
3.0\end{array}$ & $\begin{array}{r}9.0 \\
9.0 \\
10.0 \\
10.5 \\
9.5\end{array}$ & $\begin{array}{l}8.0 \\
6.5 \\
7.0 \\
8.0 \\
7.0\end{array}$ \\
\hline $\begin{array}{l}6.5 \\
6.5 \\
6.5 \\
6.5 \\
8.0\end{array}$ & $\begin{array}{l}5.0 \\
4.5 \\
5.5 \\
7.0 \\
8.0\end{array}$ & $\begin{array}{l}3.0 \\
2.0 \\
3.5 \\
4.5 \\
4.5\end{array}$ & $\begin{array}{l}11.0 \\
13.0 \\
13.0 \\
12.0 \\
13.5\end{array}$ & $\begin{array}{r}8.5 \\
10.0 \\
11.0 \\
10.0 \\
9.5\end{array}$ \\
\hline $\begin{array}{l}6.0 \\
6.0 \\
8.5 \\
9.5 \\
9.5\end{array}$ & $\begin{array}{l}9.0 \\
8.0 \\
8.0 \\
8.5 \\
9.0\end{array}$ & $\begin{array}{l}6.0 \\
6.5 \\
6.0 \\
6.0 \\
6.5\end{array}$ & $\begin{array}{l}15.5 \\
16.0 \\
14.5 \\
14.0 \\
11.0\end{array}$ & $\begin{array}{l}13.0 \\
13.5 \\
12.0 \\
11.0 \\
10.0\end{array}$ \\
\hline $\begin{array}{l}8.0 \\
6.5 \\
7.0 \\
6.5 \\
8.0 \\
9.5\end{array}$ & $\begin{array}{r}10.0 \\
10.0 \\
10.0 \\
=- \\
=\end{array}$ & $\begin{array}{r}8.0 \\
7.0 \\
8.5 \\
=- \\
=-\end{array}$ & $\begin{array}{l}10.0 \\
10.0 \\
10.5 \\
11.5 \\
13.0 \\
14.0\end{array}$ & $\begin{array}{r}9.5 \\
9.5 \\
8.5 \\
9.5 \\
11.0 \\
12.0\end{array}$ \\
\hline 6.5 & 7.5 & 5.5 & 10.5 & 8.5 \\
\hline
\end{tabular}

\begin{tabular}{|c|c|c|c|c|c|c|c|c|c|c|c|c|}
\hline \multirow[t]{2}{*}{ DAY } & \multicolumn{2}{|c|}{$\triangle P R$} & \multicolumn{2}{|c|}{ MAY } & \multicolumn{2}{|c|}{ JUN } & \multicolumn{2}{|c|}{ JUL } & \multicolumn{2}{|c|}{ AUG } & \multicolumn{2}{|c|}{ SEP } \\
\hline & $\operatorname{MAX}$ & MI N & MAX & MIN & $\max$ & MIN & $\operatorname{Max}$ & MIN & $\max$ & MIN & $\max$ & MIN \\
\hline $\begin{array}{l}1 \\
2 \\
3 \\
4 \\
5\end{array}$ & $\begin{array}{l}14.5 \\
16.0 \\
18.0 \\
18.0 \\
17.0\end{array}$ & $\begin{array}{l}11.0 \\
12.0 \\
15.5 \\
16.0 \\
15.5\end{array}$ & $\begin{array}{l}20.5 \\
20.5 \\
20.5 \\
20.0 \\
23.0\end{array}$ & $\begin{array}{l}19.0 \\
18.5 \\
17.0 \\
18.0 \\
19.0\end{array}$ & $\begin{array}{l}30.5 \\
31.5 \\
29.5 \\
27.0 \\
27.0\end{array}$ & $\begin{array}{l}27.0 \\
28.0 \\
26.0 \\
24.5 \\
24.0\end{array}$ & $\begin{array}{l}33.5 \\
31.0 \\
30.5 \\
27.0 \\
30.5\end{array}$ & $\begin{array}{l}29.5 \\
28.5 \\
23.0 \\
25.0 \\
26.5\end{array}$ & $\begin{array}{l}28.0 \\
27.0 \\
27.0 \\
26.5 \\
26.5\end{array}$ & $\begin{array}{l}22.0 \\
24.5 \\
26.0 \\
25.5 \\
25.0\end{array}$ & $\begin{array}{l}28.5 \\
30.5 \\
30.5 \\
29.0 \\
29.0\end{array}$ & $\begin{array}{l}27.0 \\
28.0 \\
28.0 \\
27.0 \\
26.0\end{array}$ \\
\hline $\begin{array}{r}6 \\
7 \\
8 \\
9 \\
10\end{array}$ & $\begin{array}{l}16.5 \\
16.5 \\
19.0 \\
19.0 \\
18.5\end{array}$ & $\begin{array}{l}16.0 \\
14.5 \\
14.5 \\
15.5 \\
16.5\end{array}$ & $\begin{array}{l}23.5 \\
24.5 \\
24.5 \\
23.0 \\
22.0\end{array}$ & $\begin{array}{l}20.0 \\
22.0 \\
21.0 \\
20.0 \\
19.5\end{array}$ & $\begin{array}{l}29.0 \\
29.5 \\
29.5 \\
29.5 \\
28.0\end{array}$ & $\begin{array}{l}24.0 \\
25.5 \\
25.0 \\
26.5 \\
24.5\end{array}$ & $\begin{array}{l}31.5 \\
31.5 \\
28.5 \\
28.0 \\
28.0\end{array}$ & $\begin{array}{l}29.5 \\
28.5 \\
24.5 \\
27.0 \\
25.5\end{array}$ & $\begin{array}{l}26.0 \\
25.5 \\
26.0 \\
26.0 \\
30.0\end{array}$ & $\begin{array}{l}21.0 \\
21.5 \\
21.5 \\
22.0 \\
25.5\end{array}$ & $\begin{array}{l}29.0 \\
30.0 \\
30.0 \\
30.0 \\
29.0\end{array}$ & $\begin{array}{l}26.5 \\
26.0 \\
29.0 \\
28.5 \\
26.5\end{array}$ \\
\hline $\begin{array}{l}11 \\
12 \\
13 \\
14 \\
15\end{array}$ & $\begin{array}{l}19.0 \\
18.5 \\
18.0 \\
16.0 \\
16.0\end{array}$ & $\begin{array}{l}16.0 \\
16.0 \\
15.0 \\
14.5 \\
13.5\end{array}$ & $\begin{array}{l}21.0 \\
21.0 \\
21.5 \\
23.5 \\
24.0\end{array}$ & $\begin{array}{l}28.5 \\
18.0 \\
17.0 \\
20.5 \\
21.5\end{array}$ & $\begin{array}{l}24.5 \\
25.5 \\
28.5 \\
27.0 \\
23.5\end{array}$ & $\begin{array}{l}22.0 \\
23.0 \\
25.5 \\
21.0 \\
21.0\end{array}$ & $\begin{array}{l}28.0 \\
28.5 \\
28.5 \\
30.0 \\
31.5\end{array}$ & $\begin{array}{l}25.5 \\
25.5 \\
24.5 \\
26.5 \\
28.5\end{array}$ & $\begin{array}{l}30.0 \\
30.0 \\
29.5 \\
28.0 \\
28.5\end{array}$ & $\begin{array}{l}27.0 \\
26.5 \\
26.5 \\
26.0 \\
25.5\end{array}$ & $\begin{array}{l}27.0 \\
25.5 \\
24.5 \\
24.0 \\
28.0\end{array}$ & $\begin{array}{l}23.5 \\
23.0 \\
21.5 \\
20.5 \\
22.0\end{array}$ \\
\hline $\begin{array}{l}16 \\
17 \\
18 \\
19 \\
20\end{array}$ & $\begin{array}{l}16.0 \\
15.5 \\
16.5 \\
16.5 \\
14.5\end{array}$ & $\begin{array}{l}14.5 \\
13.0 \\
15.5 \\
14.5 \\
13.5\end{array}$ & $\begin{array}{l}24.5 \\
24.0 \\
24.0 \\
24.5 \\
23.0\end{array}$ & $\begin{array}{l}21.5 \\
21.5 \\
21.0 \\
22.0 \\
19.0\end{array}$ & $\begin{array}{l}21.0 \\
20.0 \\
21.5 \\
23.0 \\
24.0\end{array}$ & $\begin{array}{l}19.0 \\
19.0 \\
19.5 \\
21.5 \\
22.0\end{array}$ & $\begin{array}{l}33.0 \\
33.0 \\
33.0 \\
33.0 \\
33.0\end{array}$ & $\begin{array}{l}29.0 \\
29.0 \\
29.5 \\
29.5 \\
29.0\end{array}$ & $\begin{array}{l}28.0 \\
24.5 \\
29.0 \\
29.0 \\
29.5\end{array}$ & $\begin{array}{l}23.5 \\
23.5 \\
24.5 \\
28.0 \\
25.5\end{array}$ & $\begin{array}{l}28.0 \\
27.0 \\
28.0 \\
28.0 \\
24.0\end{array}$ & $\begin{array}{l}25.0 \\
25.0 \\
26.5 \\
23.5 \\
18.0\end{array}$ \\
\hline $\begin{array}{l}21 \\
22 \\
23 \\
24 \\
25\end{array}$ & $\begin{array}{l}16.0 \\
16.5 \\
16.0 \\
15.5 \\
16.0\end{array}$ & $\begin{array}{l}13.5 \\
14.5 \\
14.5 \\
13.5 \\
13.0\end{array}$ & $\begin{array}{l}22.0 \\
24.0 \\
24.5 \\
25.5 \\
25.0\end{array}$ & $\begin{array}{l}20.0 \\
21.0 \\
22.0 \\
22.0 \\
22.0\end{array}$ & $\begin{array}{l}25.0 \\
24.0 \\
25.0 \\
28.0 \\
29.0\end{array}$ & $\begin{array}{l}23.5 \\
21.5 \\
22.0 \\
24.5 \\
26.0\end{array}$ & $\begin{array}{l}33.0 \\
33.0 \\
32.0 \\
32.0 \\
30.5\end{array}$ & $\begin{array}{l}29.0 \\
29.5 \\
29.5 \\
30.0 \\
28.0\end{array}$ & $\begin{array}{l}28.5 \\
28.5 \\
25.0 \\
26.5 \\
30.5\end{array}$ & $\begin{array}{l}23.0 \\
23.5 \\
21.5 \\
23.5 \\
25.5\end{array}$ & $\begin{array}{l}18.0 \\
21.5 \\
23.0 \\
23.0 \\
21.5\end{array}$ & $\begin{array}{l}16.0 \\
17.0 \\
20.0 \\
21.5 \\
19.5\end{array}$ \\
\hline $\begin{array}{l}26 \\
27 \\
28 \\
29 \\
30 \\
31\end{array}$ & $\begin{array}{r}18.0 \\
18.5 \\
21.0 \\
22.0 \\
21.0 \\
.0\end{array}$ & $\begin{array}{r}14.5 \\
16.0 \\
18.5 \\
20.0 \\
19.0 \\
. .0\end{array}$ & $\begin{array}{l}25.5 \\
25.0 \\
24.0 \\
27.0 \\
29.5 \\
30.5\end{array}$ & $\begin{array}{l}23.0 \\
21.0 \\
20.5 \\
23.0 \\
25.0 \\
27.0\end{array}$ & $\begin{array}{r}29.5 \\
31.0 \\
32.0 \\
33.0 \\
33.5 \\
-\end{array}$ & $\begin{array}{r}26.5 \\
28.0 \\
29.0 \\
30.0 \\
30.0 \\
. .\end{array}$ & $\begin{array}{l}30.5 \\
30.5 \\
31.0 \\
31.0 \\
30.0 \\
30.0\end{array}$ & $\begin{array}{l}28.5 \\
28.5 \\
29.0 \\
29.5 \\
29.0 \\
26.5\end{array}$ & $\begin{array}{l}31.0 \\
30.5 \\
28.0 \\
26.5 \\
26.5 \\
29.0\end{array}$ & $\begin{array}{l}27.5 \\
24.5 \\
23.5 \\
22.0 \\
21.5 \\
24.5\end{array}$ & $\begin{array}{r}22.0 \\
24.0 \\
24.0 \\
24.0 \\
24.0 \\
-.\end{array}$ & $\begin{array}{r}20.5 \\
20.5 \\
21.5 \\
21.5 \\
21.0 \\
\ldots\end{array}$ \\
\hline AVG & 17.5 & 15.0 & 23.5 & 20.5 & 27.5 & 24.5 & 31.0 & 27.5 & 28.0 & 24.5 & 26.0 & 23.5 \\
\hline
\end{tabular}


ROANOKE RIVER BASIN

02074082 DAN RIVER AT EDEN, N. C.--Continued

TEMPERATURE ( $\left.{ }^{\circ} \mathrm{C}\right)$ OF WATER, WATER YEAR OCTOBER 1969 TO SEPTEMBER 1970 $\left({ }^{\circ} \mathrm{C}\right)$ OF WATER, WATER YEAR OCTOBER 1969 TO SEPTEMB
(CONTINUOUS ETHYL ALCOHOL-ACTUATED THERMOGRAPH)

\begin{tabular}{|c|c|c|c|c|c|c|c|c|c|c|c|c|}
\hline \multirow[t]{2}{*}{ DAY } & \multicolumn{2}{|c|}{ DCT } & \multicolumn{2}{|c|}{ NCV } & \multicolumn{2}{|c|}{ DEC } & \multicolumn{2}{|c|}{ JAN } & \multicolumn{2}{|c|}{ FEB } & \multicolumn{2}{|c|}{ MAR } \\
\hline & MAX & MIN & $\operatorname{MAX}$ & MIN & $\operatorname{mAX}$ & MIN & $\operatorname{MAX}$ & MIN & MAX & MIN & MAX & MIN \\
\hline $\begin{array}{l}1 \\
2 \\
3 \\
4 \\
5\end{array}$ & $\begin{array}{l}22.0 \\
24.5 \\
24.0 \\
24.5 \\
24.5\end{array}$ & $\begin{array}{l}20.0 \\
21.5 \\
22.0 \\
22.0 \\
21.0\end{array}$ & $\begin{array}{l}16.5 \\
16.5 \\
18.5 \\
19.0 \\
17.0\end{array}$ & $\begin{array}{l}15.0 \\
15.5 \\
15.5 \\
16.0 \\
14.0\end{array}$ & $\begin{array}{l}13.0 \\
13.0 \\
12.0 \\
12.0 \\
11.5\end{array}$ & $\begin{array}{r}10.0 \\
9.5 \\
9.5 \\
10.0 \\
9.5\end{array}$ & $\begin{array}{l}8.0 \\
8.0 \\
8.0 \\
8.0 \\
8.0\end{array}$ & $\begin{array}{l}6.5 \\
6.5 \\
6.0 \\
6.0 \\
6.5\end{array}$ & $\begin{array}{l}8.0 \\
9.5 \\
9.0 \\
8.0 \\
5.5\end{array}$ & $\begin{array}{l}6.0 \\
7.0 \\
8.5 \\
5.5 \\
5.0\end{array}$ & $\begin{array}{l}10.0 \\
12.0 \\
13.0 \\
13.5 \\
13.0\end{array}$ & $\begin{array}{r}8.0 \\
9.0 \\
11.0 \\
12.0 \\
12.0\end{array}$ \\
\hline $\begin{array}{r}6 \\
7 \\
8 \\
9 \\
10\end{array}$ & $\begin{array}{l}23.5 \\
22.0 \\
22.0 \\
21.5 \\
21.5\end{array}$ & $\begin{array}{l}21.0 \\
20.5 \\
21.0 \\
19.5 \\
19.5\end{array}$ & $\begin{array}{l}14.5 \\
14.5 \\
14.5 \\
13.0 \\
14.0\end{array}$ & $\begin{array}{l}11.5 \\
11.0 \\
10.5 \\
10.0 \\
10.5\end{array}$ & $\begin{array}{l}11.0 \\
11.0 \\
10.5 \\
10.0 \\
11.5\end{array}$ & $\begin{array}{l}9.5 \\
9.5 \\
9.0 \\
8.5 \\
8.5\end{array}$ & $\begin{array}{l}8.0 \\
8.5 \\
8.0 \\
6.5 \\
5.5\end{array}$ & $\begin{array}{l}6.0 \\
6.0 \\
5.5 \\
4.0 \\
1.5\end{array}$ & $\begin{array}{l}5.5 \\
6.5 \\
8.0 \\
9.0 \\
9.0\end{array}$ & $\begin{array}{l}4.5 \\
5.0 \\
5.5 \\
3.0 \\
8.0\end{array}$ & $\begin{array}{l}14.5 \\
14.0 \\
11.5 \\
14.5 \\
14.5\end{array}$ & $\begin{array}{r}11.5 \\
10.0 \\
9.0 \\
11.0 \\
12.0\end{array}$ \\
\hline $\begin{array}{l}11 \\
12 \\
13 \\
14 \\
15\end{array}$ & $\begin{array}{l}21.5 \\
22.0 \\
25.0 \\
24.5 \\
23.5\end{array}$ & $\begin{array}{l}19.5 \\
19.5 \\
20.5 \\
22.0 \\
21.0\end{array}$ & $\begin{array}{l}14.0 \\
14.5 \\
14.5 \\
13.5 \\
13.5\end{array}$ & $\begin{array}{l}11.0 \\
13.5 \\
12.0 \\
13.0 \\
10.5\end{array}$ & $\begin{array}{r}9.0 \\
9.5 \\
9.5 \\
9.0 \\
10.5\end{array}$ & $\begin{array}{l}7.0 \\
8.5 \\
8.0 \\
7.0 \\
8.0\end{array}$ & $\begin{array}{l}5.5 \\
5.0 \\
6.5 \\
7.0 \\
8.0\end{array}$ & $\begin{array}{l}3.0 \\
3.5 \\
4.0 \\
5.0 \\
6.0\end{array}$ & $\begin{array}{l}8.5 \\
8.5 \\
8.0 \\
8.0 \\
7.0\end{array}$ & $\begin{array}{l}6.5 \\
6.0 \\
5.5 \\
6.0 \\
5.0\end{array}$ & $\begin{array}{l}15.5 \\
15.5 \\
14.5 \\
13.5 \\
12.0\end{array}$ & $\begin{array}{l}13.0 \\
14.0 \\
12.0 \\
11.0 \\
10.0\end{array}$ \\
\hline $\begin{array}{l}16 \\
17 \\
18 \\
19 \\
20\end{array}$ & $\begin{array}{l}21.0 \\
20.0 \\
19.5 \\
15.5 \\
19.0\end{array}$ & $\begin{array}{l}19.5 \\
18.0 \\
14.5 \\
11.0 \\
15.0\end{array}$ & $\begin{array}{l}10.5 \\
10.5 \\
11.0 \\
13.5 \\
13.5\end{array}$ & $\begin{array}{r}7.0 \\
8.5 \\
9.5 \\
11.0 \\
10.0\end{array}$ & $\begin{array}{l}10.0 \\
10.0 \\
10.0 \\
10.5 \\
10.0\end{array}$ & $\begin{array}{l}7.0 \\
7.0 \\
8.0 \\
8.5 \\
7.0\end{array}$ & $\begin{array}{l}8.0 \\
8.5 \\
8.5 \\
7.0 \\
6.5\end{array}$ & $\begin{array}{l}5.5 \\
6.0 \\
6.5 \\
6.5 \\
5.5\end{array}$ & $\begin{array}{l}9.0 \\
8.0 \\
6.5 \\
8.5 \\
9.0\end{array}$ & $\begin{array}{l}6.5 \\
5.0 \\
5.0 \\
6.5 \\
7.0\end{array}$ & $\begin{array}{l}12.0 \\
12.0 \\
12.0 \\
11.5 \\
12.0\end{array}$ & $\begin{array}{l}10.0 \\
10.0 \\
10.5 \\
10.5 \\
11.0\end{array}$ \\
\hline $\begin{array}{l}21 \\
22 \\
23 \\
24 \\
25\end{array}$ & $\begin{array}{l}19.5 \\
19.5 \\
18.5 \\
16.5 \\
15.0\end{array}$ & $\begin{array}{l}16.5 \\
16.0 \\
15.0 \\
13.5 \\
11.5\end{array}$ & $\begin{array}{l}11.0 \\
10.0 \\
10.5 \\
13.0 \\
13.0\end{array}$ & $\begin{array}{r}9.5 \\
8.5 \\
8.5 \\
10.0 \\
10.5\end{array}$ & $\begin{array}{l}9.5 \\
8.5 \\
7.0 \\
8.0 \\
8.0\end{array}$ & $\begin{array}{l}7.0 \\
6.5 \\
5.5 \\
6.0 \\
6.0\end{array}$ & $\begin{array}{l}6.5 \\
8.0 \\
7.0 \\
6.0 \\
5.5\end{array}$ & $\begin{array}{l}5.0 \\
5.5 \\
6.0 \\
4.0 \\
4.0\end{array}$ & $\begin{array}{r}8.5 \\
9.0 \\
10.5 \\
10.0 \\
10.5\end{array}$ & $\begin{array}{l}6.0 \\
5.5 \\
8.0 \\
8.0 \\
9.0\end{array}$ & $\begin{array}{l}12.0 \\
12.0 \\
13.5 \\
12.0 \\
13.0\end{array}$ & $\begin{array}{l}11.5 \\
12.0 \\
10.0 \\
10.0 \\
10.5\end{array}$ \\
\hline $\begin{array}{l}26 \\
27 \\
28 \\
29 \\
30 \\
31\end{array}$ & $\begin{array}{l}14.0 \\
16.0 \\
16.0 \\
16.0 \\
15.0 \\
15.0\end{array}$ & $\begin{array}{l}11.5 \\
14.0 \\
14.5 \\
13.5 \\
12.0 \\
13.0\end{array}$ & $\begin{array}{r}13.0 \\
10.5 \\
12.0 \\
13.0 \\
13.0 \\
-.\end{array}$ & $\begin{array}{r}10.5 \\
9.5 \\
10.0 \\
9.5 \\
9.5 \\
-.-\end{array}$ & $\begin{array}{l}6.0 \\
5.5 \\
6.0 \\
8.5 \\
8.5 \\
8.5\end{array}$ & $\begin{array}{l}4.5 \\
4.5 \\
4.5 \\
5.5 \\
8.0 \\
6.5\end{array}$ & $\begin{array}{r}6.0 \\
9.0 \\
9.0 \\
10.0 \\
10.5 \\
8.5\end{array}$ & $\begin{array}{l}4.0 \\
6.0 \\
7.0 \\
8.0 \\
8.5 \\
6.5\end{array}$ & $\begin{array}{r}10.0 \\
9.0 \\
10.0 \\
-0 \\
-\end{array}$ & $\begin{array}{r}7.0 \\
6.0 \\
7.0 \\
=- \\
=-\end{array}$ & $\begin{array}{l}15.5 \\
15.5 \\
15.5 \\
15.5 \\
15.5 \\
15.0\end{array}$ & $\begin{array}{l}12.0 \\
13.0 \\
13.5 \\
14.0 \\
14.5 \\
13.0\end{array}$ \\
\hline AvG & 20.0 & 17.5 & 13.5 & 11.0 & 9.5 & 7.5 & 7.5 & 5.5 & 8.5 & 6.5 & 13.5 & 11.5 \\
\hline \multirow[t]{2}{*}{ BAY } & \multicolumn{2}{|c|}{ APR } & \multicolumn{2}{|c|}{ MAY } & \multicolumn{2}{|c|}{ JUN } & \multicolumn{2}{|c|}{ JUL } & \multicolumn{2}{|c|}{ AUG } & \multicolumn{2}{|c|}{ SEP } \\
\hline & MAX & MIN & MAX & MIN & $\operatorname{MAX}$ & MIN & MAX & MIN & $\operatorname{MAX}$ & MIN & MAX & MIN \\
\hline $\begin{array}{l}1 \\
2 \\
3 \\
4 \\
5\end{array}$ & $\begin{array}{l}15.0 \\
15.0 \\
13.5 \\
13.5 \\
13.5\end{array}$ & $\begin{array}{l}14.0 \\
11.5 \\
10.5 \\
11.0 \\
11.5\end{array}$ & $\begin{array}{l}22.0 \\
22.0 \\
21.0 \\
18.0 \\
13.5\end{array}$ & $\begin{array}{l}20.5 \\
20.5 \\
18.0 \\
13.5 \\
11.0\end{array}$ & $\begin{array}{l}28.0 \\
28.5 \\
29.0 \\
29.0 \\
27.0\end{array}$ & $\begin{array}{l}24.5 \\
25.0 \\
26.5 \\
26.0 \\
25.0\end{array}$ & $\begin{array}{l}30.0 \\
30.5 \\
30.5 \\
31.0 \\
28.5\end{array}$ & $\begin{array}{l}26.0 \\
28.5 \\
28.5 \\
28.0 \\
26.5\end{array}$ & $\begin{array}{l}30.0 \\
29.0 \\
30.0 \\
30.0 \\
28.0\end{array}$ & $\begin{array}{l}28.0 \\
26.5 \\
25.5 \\
26.5 \\
23.5\end{array}$ & $\begin{array}{l}29.5 \\
28.5 \\
28.5 \\
29.5 \\
29.5\end{array}$ & $\begin{array}{l}27.0 \\
27.0 \\
26.0 \\
26.5 \\
25.0\end{array}$ \\
\hline $\begin{array}{r}6 \\
7 \\
8 \\
9 \\
10\end{array}$ & $\begin{array}{l}13.5 \\
14.0 \\
14.5 \\
16.0 \\
16.0\end{array}$ & $\begin{array}{l}11.5 \\
12.0 \\
11.5 \\
13.5 \\
14.0\end{array}$ & $\begin{array}{l}14.5 \\
14.5 \\
15.5 \\
16.5 \\
19.0\end{array}$ & $\begin{array}{l}12.0 \\
11.5 \\
12.0 \\
13.5 \\
15.5\end{array}$ & $\begin{array}{l}26.5 \\
25.5 \\
29.0 \\
29.0 \\
29.5\end{array}$ & $\begin{array}{l}24.0 \\
23.5 \\
24.0 \\
25.0 \\
25.5\end{array}$ & $\begin{array}{l}31.0 \\
29.0 \\
31.5 \\
31.5 \\
29.0\end{array}$ & $\begin{array}{l}26.5 \\
26.0 \\
27.0 \\
29.0 \\
24.5\end{array}$ & $\begin{array}{l}28.0 \\
23.5 \\
23.5 \\
23.5 \\
21.0\end{array}$ & $\begin{array}{l}23.5 \\
21.0 \\
20.5 \\
21.0 \\
18.5\end{array}$ & $\begin{array}{l}28.5 \\
28.0 \\
29.0 \\
29.0 \\
28.0\end{array}$ & $\begin{array}{l}25.0 \\
25.5 \\
26.0 \\
26.5 \\
26.5\end{array}$ \\
\hline $\begin{array}{l}11 \\
12 \\
13 \\
14 \\
15\end{array}$ & $\begin{array}{l}16.5 \\
17.0 \\
18.5 \\
18.5 \\
18.0\end{array}$ & $\begin{array}{l}13.5 \\
14.0 \\
16.0 \\
15.5 \\
15.5\end{array}$ & $\begin{array}{l}21.0 \\
21.5 \\
21.5 \\
22.0 \\
23.5\end{array}$ & $\begin{array}{l}18.5 \\
18.5 \\
18.0 \\
18.5 \\
19.5\end{array}$ & $\begin{array}{l}29.5 \\
29.0 \\
29.5 \\
29.5 \\
25.5\end{array}$ & $\begin{array}{l}25.5 \\
26.0 \\
25.5 \\
25.0 \\
23.5\end{array}$ & $\begin{array}{l}26.5 \\
29.0 \\
33.0 \\
31.5 \\
32.0\end{array}$ & $\begin{array}{l}24.0 \\
24.5 \\
28.0 \\
30.0 \\
28.5\end{array}$ & $\begin{array}{l}18.5 \\
18.5 \\
19.0 \\
20.5 \\
21.5\end{array}$ & $\begin{array}{l}18.0 \\
18.0 \\
18.0 \\
17.0 \\
18.0\end{array}$ & $\begin{array}{l}28.0 \\
26.5 \\
24.5 \\
26.5 \\
26.5\end{array}$ & $\begin{array}{l}26.5 \\
24.0 \\
23.0 \\
23.5 \\
24.0\end{array}$ \\
\hline $\begin{array}{l}16 \\
17 \\
18 \\
19 \\
20\end{array}$ & $\begin{array}{l}19.0 \\
19.0 \\
19.5 \\
19.5 \\
21.5\end{array}$ & $\begin{array}{l}15.5 \\
16.5 \\
16.5 \\
17.0 \\
17.0\end{array}$ & $\begin{array}{l}22.0 \\
20.0 \\
20.0 \\
21.0 \\
21.5\end{array}$ & $\begin{array}{l}18.0 \\
16.5 \\
16.5 \\
19.0 \\
19.0\end{array}$ & $\begin{array}{l}28.5 \\
30.5 \\
31.5 \\
33.0 \\
31.5\end{array}$ & $\begin{array}{l}24.0 \\
25.5 \\
28.0 \\
29.0 \\
28.5\end{array}$ & $\begin{array}{l}=- \\
=- \\
=-\end{array}$ & $\begin{array}{l}=- \\
=- \\
=- \\
=-\end{array}$ & $\begin{array}{l}23.0 \\
25.5 \\
25.5 \\
24.5 \\
23.5\end{array}$ & $\begin{array}{l}20.0 \\
22.0 \\
23.0 \\
19.5 \\
19.0\end{array}$ & $\begin{array}{l}26.5 \\
26.5 \\
26.5 \\
26.5 \\
25.5\end{array}$ & $\begin{array}{l}24.0 \\
23.5 \\
23.5 \\
24.0 \\
23.5\end{array}$ \\
\hline $\begin{array}{l}21 \\
22 \\
23 \\
24 \\
25\end{array}$ & $\begin{array}{l}23.0 \\
23.0 \\
23.0 \\
23.0 \\
22.0\end{array}$ & $\begin{array}{l}19.0 \\
19.5 \\
19.5 \\
20.5 \\
19.5\end{array}$ & $\begin{array}{l}24.5 \\
25.5 \\
25.5 \\
24.5 \\
28.0\end{array}$ & $\begin{array}{l}21.5 \\
23.5 \\
23.5 \\
22.0 \\
24.5\end{array}$ & $\begin{array}{l}30.0 \\
32.0 \\
31.0 \\
31.5 \\
31.0\end{array}$ & $\begin{array}{l}27.0 \\
28.0 \\
28.5 \\
28.5 \\
25.5\end{array}$ & $\begin{array}{l}29.0 \\
24.5 \\
25.5 \\
25.5 \\
25.5\end{array}$ & $\begin{array}{l}24.5 \\
23.5 \\
23.5 \\
22.0 \\
24.5\end{array}$ & $\begin{array}{l}23.0 \\
22.0 \\
19.5 \\
21.5 \\
22.0\end{array}$ & $\begin{array}{l}18.0 \\
15.5 \\
16.0 \\
16.5 \\
18.0\end{array}$ & $\begin{array}{l}29.0 \\
29.0 \\
29.0 \\
28.5 \\
28.5\end{array}$ & $\begin{array}{l}24.0 \\
26.5 \\
26.0 \\
25.5 \\
25.5\end{array}$ \\
\hline $\begin{array}{l}26 \\
27 \\
28 \\
29 \\
30 \\
31\end{array}$ & $\begin{array}{r}21.0 \\
21.5 \\
21.5 \\
21.0 \\
21.5 \\
-.-\end{array}$ & $\begin{array}{r}19.5 \\
20.0 \\
20.5 \\
19.0 \\
20.5 \\
-.-\end{array}$ & $\begin{array}{r}28.5 \\
28.5 \\
28.0 \\
=- \\
=- \\
=-\end{array}$ & $\begin{array}{r}26.0 \\
25.0 \\
25.0 \\
=- \\
=- \\
=\end{array}$ & $\begin{array}{r}25.5 \\
25.5 \\
24.5 \\
25.0 \\
27.0 \\
-\end{array}$ & $\begin{array}{r}22.0 \\
23.0 \\
23.5 \\
23.0 \\
23.0 \\
.0\end{array}$ & $\begin{array}{l}25.5 \\
29.0 \\
29.5 \\
30.0 \\
29.5 \\
30.0\end{array}$ & $\begin{array}{l}23.5 \\
25.0 \\
26.5 \\
28.0 \\
28.0 \\
29.0\end{array}$ & $\begin{array}{l}23.0 \\
23.0 \\
24.5 \\
24.0 \\
26.0 \\
29.5\end{array}$ & $\begin{array}{l}18.0 \\
17.0 \\
18.0 \\
18.5 \\
22.0 \\
25.0\end{array}$ & $\begin{array}{r}28.5 \\
28.5 \\
26.5 \\
25.0 \\
23.0 \\
. .\end{array}$ & $\begin{array}{r}25.5 \\
26.0 \\
25.0 \\
21.0 \\
19.5 \\
--\end{array}$ \\
\hline AVG & 18.5 & 16.0 & 21.5 & 18.5 & 28.5 & 25.5 & 29.0 & 26.0 & 24.0 & 20.5 & 27.5 & 25.0 \\
\hline
\end{tabular}


02074218 DAN RIVER NEAR MAYFIELD, N. C.

LOCATION.-Lat $36^{\circ} 32^{\prime} 29^{\prime \prime}$, long $79^{\circ} 36^{\prime} 21^{\prime \prime}$, Rockingham County, at bridge on Secondary Road 1761, at North Carolinavirginia State line, 2.2 miles upstream from whiteoak Creek, and 3 miles northwest of Mayfield.

DRAINAGE AREA.--1,780 sq $\mathrm{mi}$, approximately.

PER IOD OF RECORD. -Chemical analyses: October 1967 to September 1969 (partial-record), October 1969 to September 1970 .

REMARKS.--The second of two samples collected at the same time is a field determination.

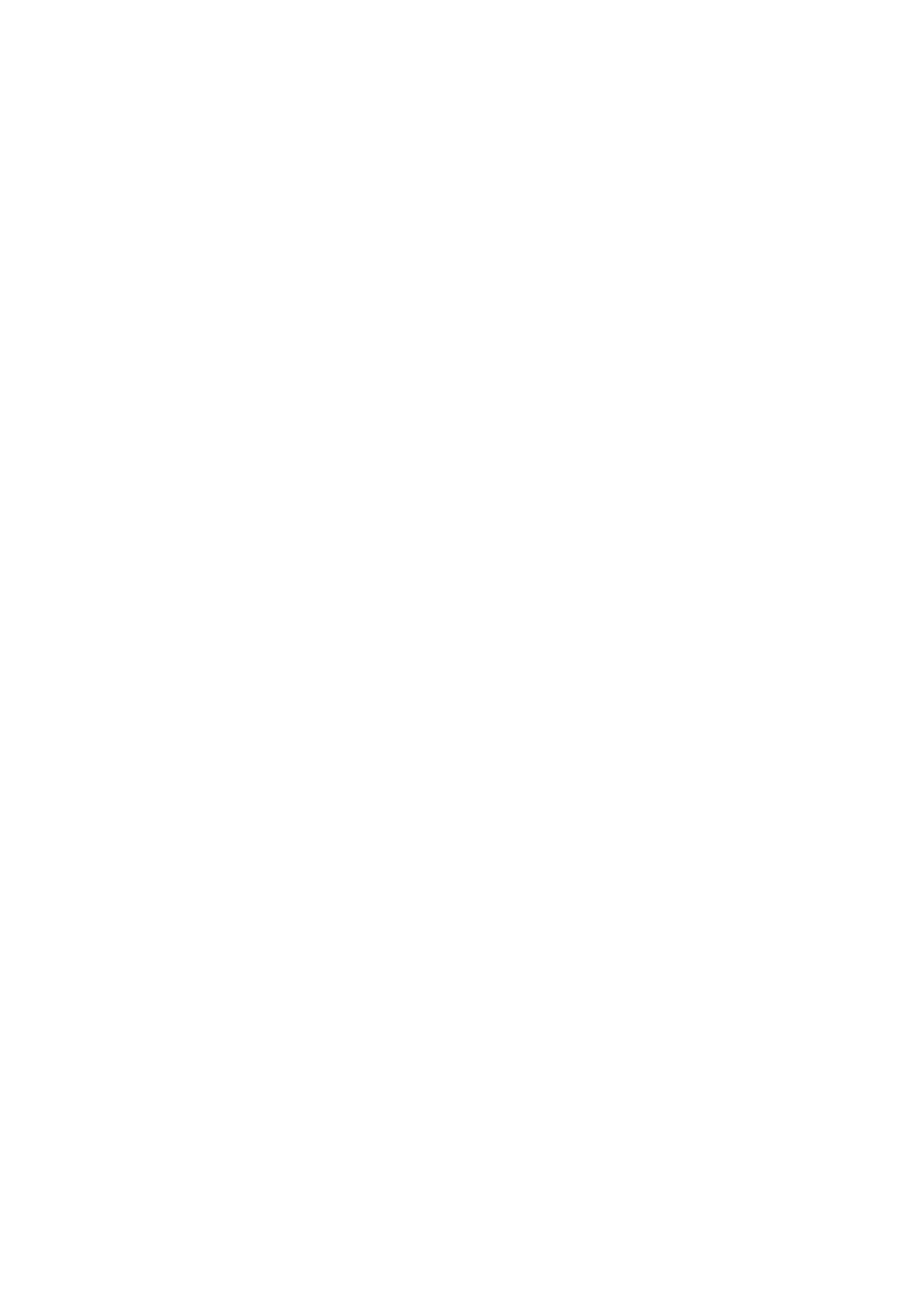


02075500 DAN RIVER AT PACES, Va.

LOCATION. -Lat $36^{\circ} 38^{\prime} 32^{\prime \prime}$, long $7^{\circ} \mathrm{O} \mathrm{s}^{\prime} 23^{\prime \prime}$, Halifax County, at gaging station on right bank $100 \mathrm{ft}$ upstream $\mathrm{from}$ bridge on State Highway $658,0.5$ mile southeast of Paces, 0.5 mile upstream from Big Toby Creek, $2.7 \mathrm{miles}$ upstream from Birch Creek, and at mile 36,0 .

DRA INAGE AREA, $--2,550 \mathrm{sq} \mathrm{mi}$, approximately.

PERIOD OF RECORD.--Chemical analyses: October 1955 to August 1956.

Water temperatures: January 1954 to September 1956

Sediment records: January 1954 to September 1970.

SUSPENDED-SEDIMENT DISCHARGE, HATER VEAR DCTOBER 1969 TO SEPTEMBER 1970

\begin{tabular}{|c|c|c|c|c|c|c|c|c|c|}
\hline \multirow[b]{2}{*}{ DAY } & \multicolumn{3}{|c|}{ OCTOBER } & \multicolumn{3}{|c|}{ NOVEMEER } & \multicolumn{3}{|c|}{ OEC.EMBER } \\
\hline & $\begin{array}{l}\text { MEAN } \\
\text { DISCHAR GE } \\
\text { (CFS) }\end{array}$ & $\begin{array}{l}\text { NEAA } \\
\text { CCNCEN- } \\
\text { TRAT ION } \\
\text { (MG/L) }\end{array}$ & $\begin{array}{l}\text { SECIMENT } \\
\text { DI SCHARGE } \\
\text { (TCNS/DAY) }\end{array}$ & $\begin{array}{l}\text { MEAN } \\
\text { DISCHARGE } \\
\text { (CFS) }\end{array}$ & $\begin{array}{l}\text { MEAN } \\
\text { CONCEN- } \\
\text { TRATICN } \\
\text { (MG/L) }\end{array}$ & $\begin{array}{l}\text { SEDIMENT } \\
\text { OISCHARGE } \\
\text { (IONS/DAY) }\end{array}$ & $\begin{array}{l}\text { MEAN } \\
\text { OI SCHARGE } \\
\text { (CFS) }\end{array}$ & $\begin{array}{l}\text { MEAN } \\
\text { CCNCEN- } \\
\text { TRATION } \\
\text { (MG/LI) }\end{array}$ & $\begin{array}{l}\text { SECIMENT } \\
\text { CISCHARGE } \\
\text { (TCAS/CAY) }\end{array}$ \\
\hline 1 & 1040 & 50 & 140 & 1040 & 27 & 76 & 951 & 24 & 42 \\
\hline 2 & 1220 & 57 & 188 & 1150 & 30 & 93 & 904 & 20 & 49 \\
\hline 3 & 2180 & 180 & 1060 & 1190 & 30 & 96 & 1240 & 35 & 117 \\
\hline 4 & 2230 & 190 & 1140 & 1210 & 35 & 114 & 1380 & 40 & 149 \\
\hline 5 & 1730 & 134 & 626 & 1220 & 35 & 115 & 1350 & 40 & 146 \\
\hline 6 & 1200 & 55 & 178 & $113 c$ & 32 & $9 B$ & 1300 & 40 & 140 \\
\hline 7 & 1040 & 57 & 160 & 1070 & 28 & $B 1$ & 1340 & 40 & 145 \\
\hline B & 1070 & so & 144 & 1080 & 28 & 82 & 1550 & 40 & 107 \\
\hline 8 & 1340 & 63 & 228 & ICBO & 28 & 82 & 2430 & 83 & 545 \\
\hline 10 & 1510 & 57 & 232 & 575 & $2 C$ & 53 & 2250 & 113 & 686 \\
\hline 11 & 1350 & 68 & $24 B$ & $E 53$ & 20 & 46 & 6300 & 195 & $332 \mathrm{C}$ \\
\hline 12 & 1230 & 55 & 183 & 993 & 30 & Bo & 8660 & 300 & 7010 \\
\hline 13 & 1090 & 50 & 147 & 1120 & 40 & 121 & 4080 & 110 & 1210 \\
\hline 14 & 943 & 45 & 115 & 1170 & 42 & 133 & 2730 & 78 & 575 \\
\hline 15 & 1240 & 55 & $1 \mathrm{~B} 4$ & 1110 & 30 & so & 2120 & $6 \mathrm{C}$ & 343 \\
\hline 16 & 1230 & 55 & 183 & 1090 & 30 & 88 & 1580 & 50 & 213 \\
\hline 17 & 1190 & 50 & 161 & 928 & 21 & 53 & 2170 & 65 & 381 \\
\hline is & 1220 & 60 & 198 & $\notin 47$ & 18 & 41 & 2110 & 60 & 342 \\
\hline 19 & 1220 & 59 & 194 & 1010 & 25 & 68 & 2050 & 50 & 277 \\
\hline 20 & 1010 & 50 & 136 & 1460 & 70 & 276 & 2050 & 47 & 260 \\
\hline dl & 809 & 30 & 66 & $154 \mathrm{C}$ & 75 & 393 & 1990 & 40 & 215 \\
\hline 22 & 929 & 40 & 100 & 1790 & 40 & 193 & 1900 & $4 \mathrm{C}$ & 205 \\
\hline 23 & 1010 & 45 & 123 & 1410 & 31 & 118 & 4670 & 85 & $107 c$ \\
\hline 24 & 1000 & 40 & 108 & 1170 & 42 & 133 & 4310 & 75 & 873 \\
\hline 25 & 956 & 25 & 65 & 1020 & 25 & 69 & 2960 & $5 C$ & $4 \mathrm{CO}$ \\
\hline 26 & 989 & 21 & 56 & 1190 & 30 & 96 & 3180 & 65 & 558 \\
\hline 27 & 966 & 19 & 50 & 1210 & 35 & 114 & 3410 & $10 \mathrm{C}$ & 921 \\
\hline$\geq e$ & 936 & 18 & 45 & $125 \mathrm{C}$ & 35 & 118 & 3460 & 100 & $9 \geq 4$ \\
\hline 29 & 1060 & 25 & 72 & 1070 & 30 & 87 & 2720 & 60 & 441 \\
\hline 30 & 1030 & 25 & 70 & 1070 & 30 & 87 & 2620 & $B C$ & 424 \\
\hline$\$ 1$ & 1030 & 25 & 70 & - & -- & $\cdots$ & 4200 & $15 \mathrm{C}$ & $17 c 0$ \\
\hline IOT AL & 36998 & - & 6670 & 34850 & -- & 3294 & 83965 & $\ldots$ & 23878 \\
\hline
\end{tabular}

\begin{tabular}{|c|c|c|c|c|c|c|c|c|c|}
\hline & & JANU ARY & & & FEBRUARY & & & NARCH & \\
\hline DAY & $\begin{array}{l}\text { MEAN } \\
\text { O1 SCHAR GE } \\
\text { (CFS) }\end{array}$ & $\begin{array}{l}\text { MEAN } \\
\text { CONCEN- } \\
\text { IRAT ION } \\
\text { I } \times G / L \text { II }\end{array}$ & $\begin{array}{l}\text { SECIMENT } \\
\text { OISCHARGE } \\
\text { (TCNS/OAY) }\end{array}$ & $\begin{array}{l}\text { MEAR } \\
\text { OI SCHARGE } \\
\text { (CFS) }\end{array}$ & $\begin{array}{l}\text { MEAN } \\
\text { CONCEN- } \\
\text { TRATION } \\
\text { (MG/L) }\end{array}$ & $\begin{array}{l}\text { SEOIMENT } \\
\text { OISCHARGE } \\
\text { ITONS/OAY: }\end{array}$ & $\begin{array}{l}\text { MEAN } \\
\text { DI SCHARGE } \\
\text { (CFS) }\end{array}$ & $\begin{array}{l}\text { MEAR } \\
\text { CONCEN- } \\
\text { TRAT ICN } \\
\text { (MG/L) }\end{array}$ & $\begin{array}{l}\text { SECIMENT } \\
\text { CI SCHARGE } \\
\text { ( TCAS/CAY) }\end{array}$ \\
\hline $\begin{array}{l}1 \\
2 \\
3 \\
4 \\
5\end{array}$ & $\begin{array}{l}7950 \\
5610 \\
3530 \\
3080 \\
2330\end{array}$ & $\begin{array}{r}300 \\
200 \\
130 \\
100 \\
30\end{array}$ & $\begin{array}{r}6440 \\
3030 \\
1240 \\
832 \\
189\end{array}$ & $\begin{array}{l}3500 \\
2690 \\
5080 \\
7450 \\
487 C\end{array}$ & $\begin{array}{l}260 \\
115 \\
385 \\
450 \\
360\end{array}$ & $\begin{array}{r}2460 \\
835 \\
5280 \\
9050 \\
4730\end{array}$ & $\begin{array}{l}2360 \\
1820 \\
1670 \\
1810 \\
1880\end{array}$ & $\begin{array}{l}35 \\
35 \\
30 \\
25 \\
30\end{array}$ & $\begin{array}{l}242 \\
172 \\
135 \\
122 \\
152\end{array}$ \\
\hline $\begin{array}{r}6 \\
7 \\
8 \\
9 \\
10\end{array}$ & $\begin{array}{l}1900 \\
2730 \\
2660 \\
2260 \\
1950\end{array}$ & $\begin{array}{l}25 \\
35 \\
28 \\
25 \\
20\end{array}$ & $\begin{array}{l}128 \\
258 \\
201 \\
153 \\
105\end{array}$ & $\begin{array}{l}3450 \\
2870 \\
2550 \\
2350 \\
2550\end{array}$ & $\begin{array}{l}300 \\
268 \\
250 \\
200 \\
225\end{array}$ & $\begin{array}{l}2790 \\
2080 \\
1720 \\
1270 \\
1550\end{array}$ & $\begin{array}{l}1930 \\
1910 \\
1770 \\
1570 \\
1530\end{array}$ & $\begin{array}{l}60 \\
45 \\
56 \\
38 \\
34\end{array}$ & $\begin{array}{l}313 \\
232 \\
268 \\
161 \\
14 C\end{array}$ \\
\hline $\begin{array}{l}11 \\
12 \\
13 \\
14 \\
15\end{array}$ & $\begin{array}{l}2010 \\
1510 \\
1740 \\
2120 \\
2050\end{array}$ & $\begin{array}{l}24 \\
25 \\
18 \\
30 \\
25\end{array}$ & $\begin{array}{r}130 \\
82 \\
85 \\
172 \\
138\end{array}$ & $\begin{array}{l}3380 \\
3140 \\
2800 \\
2630 \\
2460\end{array}$ & $\begin{array}{l}280 \\
200 \\
100 \\
300 \\
265\end{array}$ & $\begin{array}{r}2560 \\
1700 \\
756 \\
2130 \\
1760\end{array}$ & $\begin{array}{l}1640 \\
1690 \\
1900 \\
2100 \\
1970\end{array}$ & $\begin{array}{l}40 \\
45 \\
50 \\
56 \\
55\end{array}$ & $\begin{array}{l}177 \\
265 \\
257 \\
318 \\
253\end{array}$ \\
\hline $\begin{array}{l}16 \\
17 \\
18 \\
19 \\
20\end{array}$ & $\begin{array}{l}2030 \\
2020 \\
2270 \\
2520 \\
2690\end{array}$ & $\begin{array}{l}25 \\
25 \\
29 \\
49 \\
40\end{array}$ & $\begin{array}{l}137 \\
136 \\
178 \\
272 \\
291\end{array}$ & $\begin{array}{r}1980 \\
6080 \\
13100 \\
9690 \\
4920\end{array}$ & $\begin{array}{l}150 \\
360 \\
545 \\
225 \\
150\end{array}$ & $\begin{array}{r}802 \\
5910 \\
19300 \\
5520 \\
1990\end{array}$ & $\begin{array}{l}1630 \\
1470 \\
1740 \\
2600 \\
3050\end{array}$ & $\begin{array}{r}50 \\
40 \\
55 \\
100 \\
160\end{array}$ & $\begin{array}{r}220 \\
159 \\
258 \\
7 C 2 \\
1320\end{array}$ \\
\hline $\begin{array}{l}21 \\
22 \\
23 \\
24 \\
25\end{array}$ & $\begin{array}{l}2350 \\
1870 \\
1330 \\
1370 \\
1740\end{array}$ & $\begin{array}{l}35 \\
30 \\
25 \\
25 \\
28\end{array}$ & $\begin{array}{r}222 \\
151 \\
90 \\
92 \\
132\end{array}$ & $\begin{array}{l}2640 \\
3080 \\
2550 \\
2190 \\
254 C\end{array}$ & $\begin{array}{l}2 C \\
64 \\
6 C \\
55 \\
60\end{array}$ & $\begin{array}{l}786 \\
532 \\
413 \\
325 \\
411\end{array}$ & $\begin{array}{l}2730 \\
3000 \\
4230 \\
4170 \\
3270\end{array}$ & $\begin{array}{r}107 \\
115 \\
138 \\
135 \\
96\end{array}$ & $\begin{array}{r}789 \\
932 \\
1580 \\
1520 \\
755\end{array}$ \\
\hline $\begin{array}{l}20 \\
27 \\
28 \\
29 \\
30 \\
31\end{array}$ & $\begin{array}{l}1840 \\
1990 \\
2080 \\
1920 \\
3570 \\
5400\end{array}$ & $\begin{array}{r}32 \\
35 \\
40 \\
35 \\
240 \\
401\end{array}$ & $\begin{array}{r}149 \\
188 \\
225 \\
181 \\
2310 \\
5850\end{array}$ & $\begin{array}{r}2580 \\
2450 \\
2300 \\
=- \\
=- \\
=-\end{array}$ & $\begin{array}{l}65 \\
45 \\
38 \\
-- \\
-- \\
--\end{array}$ & $\begin{array}{r}453 \\
298 \\
242 \\
-- \\
-- \\
--\end{array}$ & $\begin{array}{l}2710 \\
2400 \\
2150 \\
2160 \\
2090 \\
2340\end{array}$ & $\begin{array}{l}68 \\
60 \\
45 \\
48 \\
46 \\
57\end{array}$ & $\begin{array}{l}498 \\
3 E S \\
261 \\
280 \\
2 \in 0 \\
3 \in 0\end{array}$ \\
\hline TUTAL & 20420 & -- & 23787 & 108330 & -- & 77653 & 69290 & -- & 13510 \\
\hline
\end{tabular}


02075500 DAN RIVER AT PACES, VA.--Continued

SUSPENDED-SEDIMENT DISCHARGE, WATER YEAR OCTOBER 1969 TO SEPTEMBER 1970

\begin{tabular}{|c|c|c|c|c|c|c|c|c|c|}
\hline & & $\triangle P R$ IL & & & MAY & & & JUNE & \\
\hline DAY & $\begin{array}{l}\text { MEAN } \\
\text { DISCHARGE } \\
\text { ICFSI }\end{array}$ & $\begin{array}{l}\text { MEAN } \\
\text { CONCEN- } \\
\text { IRAT IOA } \\
\text { IMG/LI }\end{array}$ & $\begin{array}{l}\text { SEOIMENT } \\
\text { CISCHARGE } \\
\text { (TCNS/OAY) }\end{array}$ & $\begin{array}{l}\text { NEAA } \\
\text { DISCHARGE } \\
\text { (CFS) }\end{array}$ & $\begin{array}{l}\text { MEAN } \\
\text { CCNCEN- } \\
\text { TRATICN } \\
\text { IMG/LI }\end{array}$ & $\begin{array}{l}\text { SEOINENT } \\
\text { OISCHARGE } \\
\text { (TONS IDAY) }\end{array}$ & $\begin{array}{c}\text { MEAN } \\
\text { DISCHARGE } \\
\text { (CFS) }\end{array}$ & $\begin{array}{l}\text { MEAN } \\
\text { CCNCEN- } \\
\text { TRATICA } \\
\text { IMG/LI }\end{array}$ & $\begin{array}{l}\text { SEC IMENT } \\
\text { CISCHARGE } \\
\text { ITCASIDAYI }\end{array}$ \\
\hline $\begin{array}{l}1 \\
2 \\
3 \\
4 \\
5\end{array}$ & $\begin{array}{l}2730 \\
4660 \\
8110 \\
6620 \\
4350\end{array}$ & $\begin{array}{r}85 \\
125 \\
240 \\
152 \\
51\end{array}$ & $\begin{array}{r}672 \\
1570 \\
5260 \\
2680 \\
599\end{array}$ & $\begin{array}{l}2680 \\
2150 \\
2020 \\
2510 \\
7730\end{array}$ & $\begin{array}{r}90 \\
95 \\
55 \\
374 \\
400\end{array}$ & $\begin{array}{r}651 \\
551 \\
518 \\
2530 \\
8350\end{array}$ & $\begin{array}{r}1070 \\
983 \\
1250 \\
1310 \\
1280\end{array}$ & $\begin{array}{l}63 \\
60 \\
65 \\
70 \\
68\end{array}$ & $\begin{array}{l}182 \\
159 \\
219 \\
248 \\
235\end{array}$ \\
\hline $\begin{array}{r}0 \\
7 \\
6 \\
9 \\
10\end{array}$ & $\begin{array}{l}3090 \\
2540 \\
2710 \\
2820 \\
2680\end{array}$ & $\begin{array}{l}45 \\
40 \\
45 \\
55 \\
50\end{array}$ & $\begin{array}{l}375 \\
274 \\
329 \\
410 \\
362\end{array}$ & $\begin{array}{l}7120 \\
4230 \\
3250 \\
2900 \\
2650\end{array}$ & $\begin{array}{r}360 \\
170 \\
5 C \\
80 \\
60\end{array}$ & $\begin{array}{r}6920 \\
1940 \\
814 \\
626 \\
429\end{array}$ & $\begin{array}{l}1510 \\
1740 \\
1250 \\
1050 \\
1050\end{array}$ & $\begin{array}{l}7 C \\
75 \\
65 \\
60 \\
6 C\end{array}$ & $\begin{array}{l}285 \\
352 \\
219 \\
170 \\
170\end{array}$ \\
\hline $\begin{array}{l}11 \\
12 \\
13 \\
14 \\
15\end{array}$ & $\begin{array}{l}2600 \\
2380 \\
1940 \\
1950 \\
2510\end{array}$ & $\begin{array}{l}50 \\
50 \\
51 \\
51 \\
55\end{array}$ & $\begin{array}{l}351 \\
321 \\
267 \\
269 \\
373\end{array}$ & $\begin{array}{l}1540 \\
1610 \\
2040 \\
2010 \\
1590\end{array}$ & $\begin{array}{l}55 \\
50 \\
60 \\
60 \\
60\end{array}$ & $\begin{array}{l}288 \\
217 \\
330 \\
326 \\
322\end{array}$ & $\begin{array}{l}1050 \\
1070 \\
1230 \\
1050 \\
1080\end{array}$ & $\begin{array}{l}6 C \\
65 \\
70 \\
73 \\
75\end{array}$ & $\begin{array}{l}170 \\
188 \\
232 \\
2 C 7 \\
219\end{array}$ \\
\hline $\begin{array}{l}16 \\
17 \\
18 \\
19 \\
10\end{array}$ & $\begin{array}{l}2510 \\
2140 \\
2050 \\
2040 \\
1590\end{array}$ & $\begin{array}{l}55 \\
53 \\
45 \\
45 \\
42\end{array}$ & $\begin{array}{l}373 \\
289 \\
249 \\
248 \\
192\end{array}$ & $\begin{array}{l}1980 \\
2250 \\
2500 \\
2670 \\
2110\end{array}$ & $\begin{array}{l}60 \\
60 \\
60 \\
65 \\
60\end{array}$ & $\begin{array}{l}321 \\
365 \\
415 \\
469 \\
342\end{array}$ & $\begin{array}{r}1480 \\
1180 \\
1020 \\
960 \\
993\end{array}$ & $\begin{array}{l}85 \\
80 \\
70 \\
65 \\
65\end{array}$ & $\begin{array}{l}340 \\
255 \\
193 \\
1 \in 8 \\
174\end{array}$ \\
\hline $\begin{array}{l}21 \\
22 \\
21 \\
24 \\
25\end{array}$ & $\begin{array}{l}1630 \\
1820 \\
1300 \\
1770 \\
1790\end{array}$ & $\begin{array}{l}166 \\
100 \\
100 \\
90 \\
90\end{array}$ & $\begin{array}{l}731 \\
491 \\
486 \\
430 \\
435\end{array}$ & $\begin{array}{l}1740 \\
1650 \\
1630 \\
1850 \\
1830\end{array}$ & $\begin{array}{l}55 \\
50 \\
50 \\
60 \\
60\end{array}$ & $\begin{array}{l}258 \\
223 \\
220 \\
300 \\
296\end{array}$ & $\begin{array}{l}959 \\
1060 \\
1200 \\
1130 \\
1080\end{array}$ & $\begin{array}{l}68 \\
70 \\
75 \\
72 \\
70\end{array}$ & $\begin{array}{l}176 \\
200 \\
243 \\
226 \\
204\end{array}$ \\
\hline $\begin{array}{l}26 \\
27 \\
28 \\
29 \\
30 \\
31\end{array}$ & $\begin{array}{r}1850 \\
1800 \\
2050 \\
3090 \\
3520 \\
-0\end{array}$ & $\begin{array}{r}85 \\
81 \\
95 \\
90 \\
103 \\
--\end{array}$ & $\begin{array}{l}425 \\
394 \\
470 \\
751 \\
950 \\
--\end{array}$ & $\begin{array}{l}1280 \\
1410 \\
1470 \\
1430 \\
1280 \\
1150\end{array}$ & $\begin{array}{l}55 \\
65 \\
70 \\
70 \\
65 \\
65\end{array}$ & $\begin{array}{l}190 \\
247 \\
278 \\
270 \\
225 \\
262\end{array}$ & $\begin{array}{c}2640 \\
5200 \\
2500 \\
1520 \\
940 \\
--\end{array}$ & $\begin{array}{l}350 \\
725 \\
306 \\
275 \\
250 \\
--\end{array}$ & $\begin{array}{r}2450 \\
10200 \\
2030 \\
1130 \\
635 \\
\ldots\end{array}$ \\
\hline IUTAL & 83440 & -- & 21035 & 75220 & -- & 29433 & 41835 & -- & 21913 \\
\hline
\end{tabular}

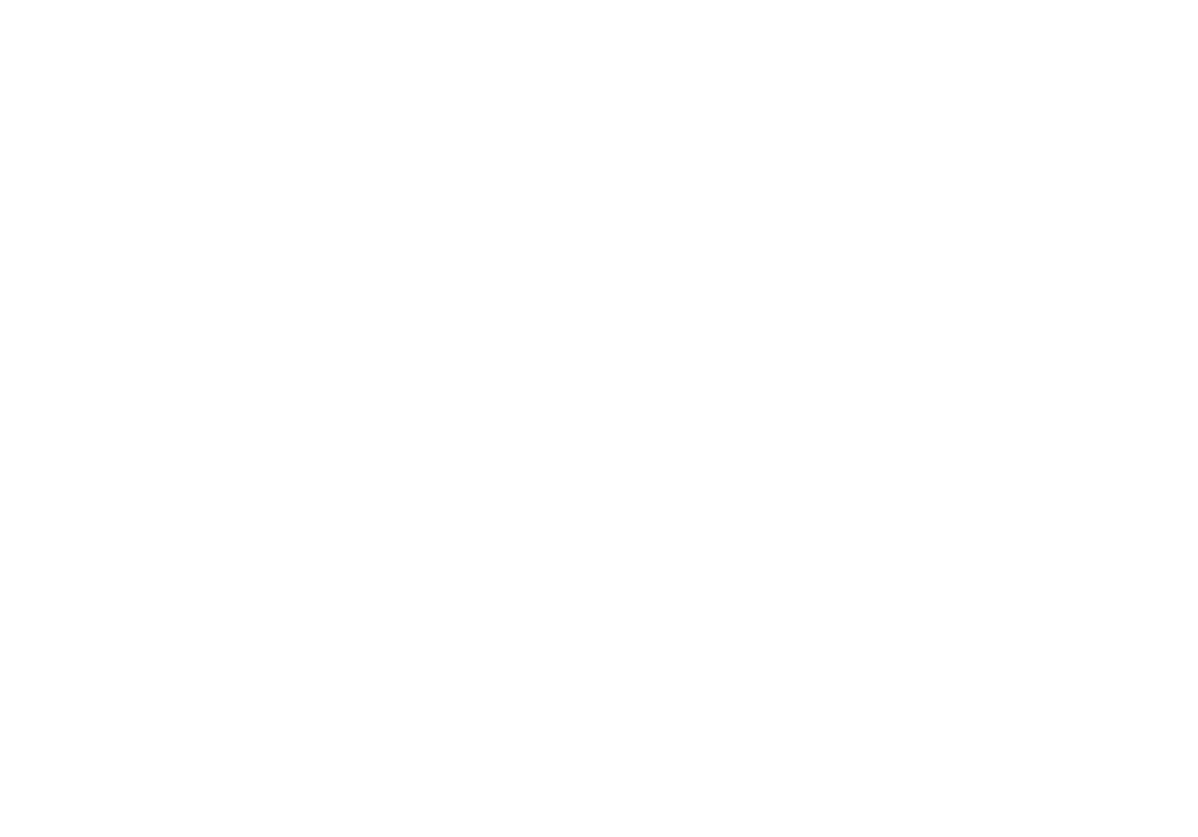


02077200 HYCO CREEK NEAR LEASBURG, $N$. C.

LOCATION, - Lat $36^{\circ} 24^{\circ} 07^{\prime \prime}$, long $79^{\circ} 12^{\prime} 13^{\prime \prime}$, Caswell County, temperature recorder at gaging statton on right bank 10 ft upstream from bridge on U.S. Highway 158, 1.5 miles upstream from K1lgore Creek (formerly Cobbs Creek), and 2.5 miles west of Leasburg.

DRAINAGE AREA, $-\mathbf{- 4 4 . 0} \mathrm{sq} \mathrm{ml}$.

PERIOD OF RECORD.--Water temperatures: May 1964 to September 1970.

EXTREYES, $-1969-70$ :

Water temperatures: Maxtmum, $25.5^{\circ} \mathrm{C}$ June 18,19 , July $2-4 ;$ minimum, $0.5^{\circ} \mathrm{C}$ on many days during December and Janusry.

Period of record:

Water temperatures: Maximum, $26.5^{\circ} \mathrm{C}$ June 22,1964 and on several days during June and July 1969; mintmum, freezing point on several days during winter periods most years.

TEMPERATURE $\left({ }^{\circ} \mathrm{C}\right)$ OF WATER, WATER YEAR OCTOBER 1969 TO SEPTEMBER 1970 (CONTINUOUS ETHYL ALCOHOL-ACTUATED THERMOGRAPH)

\begin{tabular}{|c|c|c|c|c|c|c|c|c|c|c|c|c|}
\hline \multirow[t]{2}{*}{ DAY } & \multicolumn{2}{|c|}{ DCT } & \multicolumn{2}{|c|}{ NOV } & \multicolumn{2}{|c|}{ DEC } & \multicolumn{2}{|c|}{ JAN } & \multicolumn{2}{|c|}{$F E B$} & \multicolumn{2}{|c|}{$M A R$} \\
\hline & $\operatorname{MAX}$ & MIN & MAX & MIN & $\max$ & MIN & $\operatorname{MAX}$ & MIN & $\operatorname{MAX}$ & MIN & $\operatorname{MAX}$ & MIN \\
\hline $\begin{array}{l}1 \\
2 \\
3 \\
4 \\
5\end{array}$ & $\begin{array}{l}16.0 \\
19.0 \\
19.5 \\
19.5 \\
19.0\end{array}$ & $\begin{array}{l}15.5 \\
16.0 \\
18.5 \\
18.0 \\
17.0\end{array}$ & $\begin{array}{l}11.0 \\
13.5 \\
14.5 \\
13.0 \\
10.5\end{array}$ & $\begin{array}{r}10.0 \\
11.0 \\
13.0 \\
10.0 \\
9.0\end{array}$ & $\begin{array}{l}4.5 \\
4.0 \\
3.5 \\
3.5 \\
3.0\end{array}$ & $\begin{array}{l}3.5 \\
3.0 \\
3.0 \\
3.0 \\
1.0\end{array}$ & $\begin{array}{l}8.0 \\
6.0 \\
4.0 \\
3.5 \\
1.5\end{array}$ & $\begin{array}{l}5.5 \\
4.0 \\
3.5 \\
1.5 \\
1.0\end{array}$ & $\begin{array}{l}6.5 \\
9.5 \\
9.5 \\
9.0 \\
4.5\end{array}$ & $\begin{array}{l}5.0 \\
6.0 \\
9.0 \\
4.5 \\
4.0\end{array}$ & $\begin{array}{r}9.0 \\
11.0 \\
13.0 \\
13.0 \\
13.0\end{array}$ & $\begin{array}{r}8.5 \\
9.0 \\
11.0 \\
12.0 \\
12.0\end{array}$ \\
\hline $\begin{array}{r}6 \\
7 \\
8 \\
9 \\
10\end{array}$ & $\begin{array}{l}18.0 \\
17.0 \\
17.0 \\
17.0 \\
16.5\end{array}$ & $\begin{array}{l}16.5 \\
16.5 \\
17.0 \\
15.5 \\
14.5\end{array}$ & $\begin{array}{l}9.5 \\
9.0 \\
8.0 \\
9.0 \\
9.5\end{array}$ & $\begin{array}{l}8.0 \\
6.5 \\
6.5 \\
7.0 \\
7.0\end{array}$ & $\begin{array}{l}1.5 \\
2.0 \\
4.5 \\
4.5 \\
5.5\end{array}$ & $\begin{array}{l}1.0 \\
1.5 \\
2.0 \\
4.5 \\
4.5\end{array}$ & $\begin{array}{l}1.0 \\
1.0 \\
1.0 \\
0.5 \\
0.5\end{array}$ & $\begin{array}{l}1.0 \\
1.0 \\
0.5 \\
0.5 \\
0.5\end{array}$ & $\begin{array}{l}5.0 \\
5.5 \\
6.0 \\
7.0 \\
8.0\end{array}$ & $\begin{array}{l}4.5 \\
4.0 \\
5.5 \\
6.0 \\
7.0\end{array}$ & $\begin{array}{r}13.0 \\
=- \\
12.0 \\
11.5\end{array}$ & $\begin{array}{r}11.5 \\
=- \\
11.0 \\
10.0\end{array}$ \\
\hline $\begin{array}{l}11 \\
12 \\
13 \\
14 \\
15\end{array}$ & $\begin{array}{l}15.5 \\
16.5 \\
17.0 \\
19.0 \\
18.0\end{array}$ & $\begin{array}{l}14.5 \\
14.5 \\
15.0 \\
16.5 \\
16.5\end{array}$ & $\begin{array}{l}9.5 \\
9.5 \\
9.0 \\
9.0 \\
7.0\end{array}$ & $\begin{array}{l}7.0 \\
8.5 \\
8.0 \\
7.0 \\
5.0\end{array}$ & $\begin{array}{l}6.0 \\
6.0 \\
5.5 \\
4.5 \\
4.5\end{array}$ & $\begin{array}{l}5.5 \\
5.5 \\
4.0 \\
4.0 \\
3.5\end{array}$ & $\begin{array}{l}0.5 \\
0.5 \\
0.5 \\
0.5 \\
0.5\end{array}$ & $\begin{array}{l}0.5 \\
0.5 \\
0.5 \\
0.5 \\
0.5\end{array}$ & $\begin{array}{l}8.0 \\
7.0 \\
6.5 \\
6.5 \\
6.5\end{array}$ & $\begin{array}{l}6.5 \\
6.0 \\
5.0 \\
6.0 \\
6.0\end{array}$ & $\begin{array}{r}12.0 \\
12.0 \\
10.0 \\
10.0 \\
9.0\end{array}$ & $\begin{array}{r}10.0 \\
10.0 \\
9.5 \\
8.5 \\
6.5\end{array}$ \\
\hline $\begin{array}{l}16 \\
17 \\
18 \\
19 \\
20\end{array}$ & $\begin{array}{l}16.5 \\
15.5 \\
13.5 \\
13.5 \\
14.5\end{array}$ & $\begin{array}{l}15.5 \\
13.5 \\
11.0 \\
10.0 \\
12.0\end{array}$ & $\begin{array}{l}5.0 \\
5.0 \\
5.5 \\
9.0 \\
8.0\end{array}$ & $\begin{array}{l}3.5 \\
3.0 \\
4.0 \\
5.5 \\
5.5\end{array}$ & $\begin{array}{l}3.5 \\
3.5 \\
1.5 \\
3.0 \\
2.0\end{array}$ & $\begin{array}{l}3.0 \\
1.0 \\
0.5 \\
1.5 \\
1.0\end{array}$ & $\begin{array}{r}0.5 \\
0.5 \\
0.5 \\
2.0 \\
--.\end{array}$ & $\begin{array}{r}0.5 \\
0.5 \\
0.5 \\
0.5 \\
-.-\end{array}$ & $\begin{array}{l}7.0 \\
7.0 \\
8.0 \\
9.5 \\
9.5\end{array}$ & $\begin{array}{l}6.5 \\
6.5 \\
6.5 \\
8.0 \\
8.0\end{array}$ & $\begin{array}{l}8.0 \\
8.0 \\
8.5 \\
9.5 \\
9.5\end{array}$ & $\begin{array}{l}5.5 \\
5.5 \\
8.0 \\
8.5 \\
9.5\end{array}$ \\
\hline $\begin{array}{l}21 \\
22 \\
23 \\
24 \\
25\end{array}$ & $\begin{array}{r}16.0 \\
14.5 \\
13.0 \\
10.0 \\
9.0\end{array}$ & $\begin{array}{r}14.5 \\
13.0 \\
10.0 \\
8.0 \\
7.0\end{array}$ & $\begin{array}{l}5.5 \\
4.0 \\
5.5 \\
6.5 \\
6.5\end{array}$ & $\begin{array}{l}4.0 \\
3.5 \\
3.5 \\
5.0 \\
5.5\end{array}$ & $\begin{array}{l}1.0 \\
3.5 \\
3.0 \\
3.0 \\
3.0\end{array}$ & $\begin{array}{l}0.5 \\
1.0 \\
2.0 \\
2.0 \\
2.0\end{array}$ & $\begin{array}{l}=- \\
=- \\
=-\end{array}$ & $\begin{array}{l}=- \\
-- \\
=- \\
--\end{array}$ & $\begin{array}{l}8.0 \\
7.0 \\
9.0 \\
9.0 \\
9.0\end{array}$ & $\begin{array}{l}5.5 \\
5.5 \\
7.0 \\
7.0 \\
8.5\end{array}$ & $\begin{array}{r}10.0 \\
10.0 \\
10.0 \\
9.5 \\
11.5\end{array}$ & $\begin{array}{r}9.5 \\
10.0 \\
9.0 \\
9.0 \\
9.0\end{array}$ \\
\hline $\begin{array}{l}26 \\
27 \\
28 \\
29 \\
30 \\
31\end{array}$ & $\begin{array}{l}11.0 \\
13.0 \\
12.0 \\
10.0 \\
10.0 \\
10.5\end{array}$ & $\begin{array}{r}9.0 \\
11.0 \\
10.0 \\
8.5 \\
6.5 \\
8.5\end{array}$ & $\begin{array}{l}6.0 \\
5.5 \\
5.5 \\
5.5 \\
5.5 \\
-.\end{array}$ & $\begin{array}{l}5.5 \\
4.0 \\
5.0 \\
4.5 \\
4.0 \\
-. .\end{array}$ & $\begin{array}{l}2.0 \\
2.0 \\
3.0 \\
4.0 \\
5.5 \\
8.0\end{array}$ & $\begin{array}{l}1.5 \\
1.5 \\
1.5 \\
3.0 \\
4.0 \\
5.5\end{array}$ & $\begin{array}{r}5.5 \\
6.0 \\
10.0 \\
10.0 \\
8.5\end{array}$ & $\begin{array}{l}-- \\
3.5 \\
5.0 \\
6.0 \\
8.5 \\
6.0\end{array}$ & $\begin{array}{l}9.0 \\
6.5 \\
8.5 \\
=- \\
=-\end{array}$ & $\begin{array}{r}6.0 \\
5.0 \\
6.0 \\
=- \\
=-\end{array}$ & $\begin{array}{l}14.5 \\
14.5 \\
13.5 \\
15.5 \\
15.5 \\
11.0\end{array}$ & $\begin{array}{r}11.5 \\
12.0 \\
10.5 \\
13.5 \\
10.5 \\
9.0\end{array}$ \\
\hline AvG & 15.0 & 13.0 & 8.0 & 6.5 & 3.5 & 2.5 & 3.0 & 2.0 & 7.5 & 6.0 & 11.5 & 9.5 \\
\hline \multirow[t]{2}{*}{ OAY } & \multicolumn{2}{|c|}{ APR } & \multicolumn{2}{|c|}{ MAY } & \multicolumn{2}{|c|}{ JUN } & \multicolumn{2}{|c|}{ JUL } & \multicolumn{2}{|c|}{ AUG } & \multicolumn{2}{|c|}{ SEP } \\
\hline & $\operatorname{MAX}$ & $\operatorname{MIN}$ & $\operatorname{MAX}$ & MIN & MAX & $\mathrm{MIN}$ & $\operatorname{MAX}$ & MIN & $\operatorname{MAX}$ & MIN & $\operatorname{MAX}$ & MIN \\
\hline $\begin{array}{l}1 \\
2 \\
3 \\
4 \\
5\end{array}$ & $\begin{array}{l}11.5 \\
14.5 \\
14.5 \\
13.0 \\
13.5\end{array}$ & $\begin{array}{l}11.0 \\
11.0 \\
11.5 \\
12.0 \\
12.0\end{array}$ & $\begin{array}{l}21.0 \\
20.5 \\
20.5 \\
17.0 \\
15.5\end{array}$ & $\begin{array}{l}19.5 \\
20.0 \\
17.0 \\
14.5 \\
13.5\end{array}$ & $\begin{array}{l}21.0 \\
23.5 \\
23.5 \\
23.0 \\
23.5\end{array}$ & $\begin{array}{l}20.0 \\
21.0 \\
22.0 \\
21.5 \\
21.5\end{array}$ & $\begin{array}{l}24.0 \\
25.5 \\
25.5 \\
25.5 \\
24.0\end{array}$ & $\begin{array}{l}21.5 \\
23.5 \\
24.0 \\
24.0 \\
23.5\end{array}$ & $\begin{array}{l}25.0 \\
25.0 \\
24.5 \\
24.5 \\
24.0\end{array}$ & $\begin{array}{l}24.0 \\
23.5 \\
22.0 \\
23.0 \\
22.0\end{array}$ & $\begin{array}{l}23.5 \\
23.0 \\
22.0 \\
23.5 \\
23.5\end{array}$ & $\begin{array}{l}22.0 \\
21.5 \\
21.5 \\
22.0 \\
22.0\end{array}$ \\
\hline $\begin{array}{r}6 \\
7 \\
8 \\
9 \\
10\end{array}$ & $\begin{array}{l}13.5 \\
13.0 \\
14.0 \\
16.5 \\
17.0\end{array}$ & $\begin{array}{l}11.5 \\
11.0 \\
10.5 \\
13.5 \\
14.5\end{array}$ & $\begin{array}{l}16.0 \\
16.0 \\
17.0 \\
19.0 \\
20.0\end{array}$ & $\begin{array}{l}15.0 \\
14.0 \\
14.0 \\
16.0 \\
18.5\end{array}$ & $\begin{array}{l}23.5 \\
22.0 \\
22.0 \\
22.0 \\
22=0\end{array}$ & $\begin{array}{l}21.0 \\
21.0 \\
19.5 \\
20.0 \\
19.5\end{array}$ & $\begin{array}{l}24.0 \\
23.5 \\
22.0 \\
22.0 \\
22.0\end{array}$ & $\begin{array}{l}23.5 \\
21.0 \\
20.0 \\
21.5 \\
21.0\end{array}$ & $\begin{array}{l}22.0 \\
21.5 \\
21.5 \\
21.5 \\
21.5\end{array}$ & $\begin{array}{l}20.0 \\
21.0 \\
21.0 \\
21.0 \\
20.0\end{array}$ & $\begin{array}{l}23.0 \\
22.0 \\
21.0 \\
21.5 \\
23.0\end{array}$ & $\begin{array}{l}21.0 \\
20.5 \\
20.0 \\
21.0 \\
21.0\end{array}$ \\
\hline $\begin{array}{l}11 \\
12 \\
13 \\
14 \\
15\end{array}$ & $\begin{array}{l}16.5 \\
17.0 \\
17.0 \\
16.0 \\
15.5\end{array}$ & $\begin{array}{l}14.0 \\
14.5 \\
15.5 \\
15.5 \\
15.0\end{array}$ & $\begin{array}{l}20.5 \\
21.5 \\
23.0 \\
23.0 \\
21.5\end{array}$ & $\begin{array}{l}19.5 \\
20.0 \\
20.5 \\
21.0 \\
20.5\end{array}$ & $\begin{array}{l}23.0 \\
23.5 \\
23.5 \\
23.5 \\
21.5\end{array}$ & $\begin{array}{l}20.0 \\
20.5 \\
21.0 \\
21.5 \\
20.5\end{array}$ & $\begin{array}{l}22.0 \\
23.0 \\
23.5 \\
23.5 \\
24.5\end{array}$ & $\begin{array}{l}21.5 \\
21.5 \\
22.0 \\
23.0 \\
23.0\end{array}$ & $\begin{array}{l}20.0 \\
20.0 \\
20.5 \\
21.5 \\
22.0\end{array}$ & $\begin{array}{l}19.5 \\
20.0 \\
20.0 \\
20.5 \\
21.0\end{array}$ & $\begin{array}{l}22.0 \\
21.5 \\
20.5 \\
21.5 \\
21.5\end{array}$ & $\begin{array}{l}21.5 \\
20.5 \\
19.0 \\
19.5 \\
20.0\end{array}$ \\
\hline $\begin{array}{l}16 \\
17 \\
18 \\
19 \\
20\end{array}$ & $\begin{array}{l}16.0 \\
16.0 \\
19.0 \\
19.0 \\
19.0\end{array}$ & $\begin{array}{l}13.5 \\
15.0 \\
15.5 \\
17.0 \\
16.5\end{array}$ & $\begin{array}{l}21.0 \\
21.0 \\
19.0 \\
19.0 \\
20.0\end{array}$ & $\begin{array}{l}20.5 \\
19.0 \\
17.0 \\
16.5 \\
18.0\end{array}$ & $\begin{array}{l}23.0 \\
24.0 \\
25.5 \\
25.5 \\
25.0\end{array}$ & $\begin{array}{l}21.0 \\
21.5 \\
23.5 \\
24.0 \\
23.5\end{array}$ & $\begin{array}{l}24.0 \\
23.5 \\
22.0 \\
22.0 \\
22.0\end{array}$ & $\begin{array}{l}23.0 \\
21.0 \\
20.0 \\
20.5 \\
21.5\end{array}$ & $\begin{array}{l}23.0 \\
23.0 \\
24.0 \\
23.0 \\
23.0\end{array}$ & $\begin{array}{l}21.5 \\
21.5 \\
23.0 \\
21.5 \\
21.5\end{array}$ & $\begin{array}{l}21.5 \\
21.5 \\
22.0 \\
22.0 \\
21.0\end{array}$ & $\begin{array}{l}19.0 \\
19.5 \\
20.5 \\
21.0 \\
19.0\end{array}$ \\
\hline $\begin{array}{l}21 \\
22 \\
23 \\
24 \\
25\end{array}$ & $\begin{array}{l}20.0 \\
19.0 \\
19.5 \\
20.0 \\
20.0\end{array}$ & $\begin{array}{l}16.0 \\
16.0 \\
16.5 \\
18.5 \\
18.5\end{array}$ & $\begin{array}{l}22.0 \\
23.0 \\
24.0 \\
24.5 \\
24.5\end{array}$ & $\begin{array}{l}20.0 \\
21.0 \\
21.0 \\
22.0 \\
22.0\end{array}$ & $\begin{array}{l}24.0 \\
24.5 \\
24.0 \\
23.5 \\
23.5\end{array}$ & $\begin{array}{l}23.5 \\
23.5 \\
23.5 \\
21.0 \\
22.0\end{array}$ & $\begin{array}{l}22.0 \\
20.5 \\
21.0 \\
23.0 \\
23.5\end{array}$ & $\begin{array}{l}20.5 \\
20.0 \\
20.0 \\
21.0 \\
22.0\end{array}$ & $\begin{array}{l}23.0 \\
23.0 \\
23.0 \\
23.0 \\
22.0\end{array}$ & $\begin{array}{l}22.0 \\
22.0 \\
22.0 \\
21.5 \\
21.0\end{array}$ & $\begin{array}{l}20.5 \\
21.0 \\
21.5 \\
22.0 \\
21.5\end{array}$ & $\begin{array}{l}19.0 \\
20.0 \\
20.5 \\
20.5 \\
20.0\end{array}$ \\
\hline $\begin{array}{l}26 \\
27 \\
28 \\
29 \\
30 \\
31\end{array}$ & $\begin{array}{c}19.0 \\
16.5 \\
17.0 \\
19.5 \\
21.0 \\
-.\end{array}$ & $\begin{array}{c}16.5 \\
16.0 \\
16.5 \\
16.5 \\
19.5 \\
. .-\end{array}$ & $\begin{array}{l}23.5 \\
23.0 \\
22.0 \\
21.5 \\
21.0 \\
20.0\end{array}$ & $\begin{array}{l}22.0 \\
20.0 \\
20.0 \\
20.5 \\
20.0 \\
19.5\end{array}$ & $\begin{array}{r}23.5 \\
24.0 \\
23.5 \\
21.0 \\
21.5 \\
-.\end{array}$ & $\begin{array}{r}22.0 \\
23.5 \\
21.0 \\
19.0 \\
19.0 \\
-.-\end{array}$ & $\begin{array}{l}23.5 \\
23.5 \\
23.5 \\
24.5 \\
24.5 \\
24.5\end{array}$ & $\begin{array}{l}22.0 \\
22.0 \\
22.0 \\
23.0 \\
23.5 \\
23.0\end{array}$ & $\begin{array}{l}21.5 \\
21.0 \\
22.0 \\
22.0 \\
23.0 \\
23.5\end{array}$ & $\begin{array}{l}20.5 \\
20.0 \\
20.5 \\
20.5 \\
21.0 \\
22.0\end{array}$ & $\begin{array}{c}21.0 \\
21.0 \\
19.5 \\
16.5 \\
14.0 \\
=-\end{array}$ & $\begin{array}{r}20.0 \\
19.5 \\
16.5 \\
14.0 \\
12.0 \\
-\end{array}$ \\
\hline AVG & 17.0 & 15.0 & 20.5 & 19.0 & 23.0 & 21.5 & 23.5 & 22.0 & 22.5 & 21.5 & 21.5 & 20.0 \\
\hline
\end{tabular}


02077240 DOUBLE CREEK NEAR ROSEVILLE, N, C.

LOCATION.--Lat $36^{\circ} 21^{\prime} 44^{\prime \prime}$, long $79^{\circ} 05^{\circ} 48^{\prime \prime}$, Person County, temperature recorder at gaging station on left bank 75 ft downstream from bridge on Secondary Road $1166,1 \mathrm{mile}$ upstream from confluence with Mill Creek, and $3 \mathrm{miles}$ nownstreami from bridge

DRA INAGE AREA. $-7,47 \mathrm{sq} \mathrm{mi}$

PERIOD OF RECORD. - Wa ter temperatures: May 1964 to September 1970.

EXTRENES. - 1969-70:

Wa ter temperatures: Maximum, $25.5^{\circ} \mathrm{C}$ on several days during July and August; minimum recorded, $1.0^{\circ} \mathrm{C}$ on several days in January.

Period of record:

Water temperatures:- Maximum, $29.5^{\circ} \mathrm{C}$ June 21,22 , 1964 ; minimum, freezing point on many days during moat years. EHARKS. - No temperature records available for Oct, 1 to Jan, 8.

TEMPERATURE $\left({ }^{\circ} \mathrm{C}\right)$ OF WATER, JANUARY TO SEPTEMBER 1970 ICONT INUOUS ETHYL ALCOHOL-ACTUATED THERMOGRAPHI)

\begin{tabular}{|c|c|c|c|c|c|c|c|c|c|c|c|c|}
\hline \multirow[t]{2}{*}{ DAY } & \multicolumn{2}{|c|}{ OCT } & \multicolumn{2}{|c|}{ NOV } & \multicolumn{2}{|c|}{ DEC } & \multicolumn{2}{|c|}{ JAN } & \multicolumn{2}{|c|}{ FEB } & \multicolumn{2}{|c|}{ MAR } \\
\hline & MAX & MIN & MAX & MIN & MAX & MIN & MAX & $\operatorname{MIN}$ & MAX & MIN & $\max$ & MIN \\
\hline $\begin{array}{l}1 \\
2 \\
3 \\
4 \\
5\end{array}$ & $\begin{array}{l}=- \\
= \\
=-\end{array}$ & $\begin{array}{l}=- \\
= \\
= \\
=\end{array}$ & $\begin{array}{l}= \\
= \\
= \\
=\end{array}$ & $\begin{array}{l}=- \\
=- \\
--\end{array}$ & $=$ & $\begin{array}{l}=- \\
=- \\
=\end{array}$ & $\begin{array}{l}= \\
= \\
=-\end{array}$ & $\begin{array}{l}\because \\
\therefore \\
-\end{array}$ & $\begin{array}{r}5.0 \\
10.0 \\
9.0 \\
5.5 \\
5.0\end{array}$ & $\begin{array}{l}1.5 \\
5.0 \\
5.5 \\
1.5 \\
2.0\end{array}$ & $\begin{array}{l}10.0 \\
12.0 \\
14.0 \\
12.0 \\
12.0\end{array}$ & $\begin{array}{r}7.0 \\
8.5 \\
10.5 \\
11.0 \\
10.5\end{array}$ \\
\hline $\begin{array}{r}6 \\
7 \\
8 \\
9 \\
10\end{array}$ & $\begin{array}{l}=- \\
=- \\
=-\end{array}$ & $\begin{array}{l}=- \\
=- \\
=-\end{array}$ & $\begin{array}{l}= \\
=- \\
=-\end{array}$ & $\begin{array}{l}= \\
=- \\
=\end{array}$ & $\begin{array}{l}\overline{-} \\
\overline{-}\end{array}$ & $\begin{array}{l}=- \\
=- \\
=-\end{array}$ & $\begin{array}{l}=- \\
1.0 \\
1.0\end{array}$ & $\begin{array}{l}\because- \\
1.0 \\
1.0\end{array}$ & $\begin{array}{l}5.5 \\
6.0 \\
7.0 \\
7.0 \\
8.0\end{array}$ & $\begin{array}{l}3.0 \\
3.0 \\
4.5 \\
6.0 \\
7.0\end{array}$ & $\begin{array}{l}13.0 \\
10.5 \\
13.0 \\
11.0 \\
11.0\end{array}$ & $\begin{array}{l}9.5 \\
6.0 \\
7.0 \\
8.5 \\
6.5\end{array}$ \\
\hline $\begin{array}{l}11 \\
12 \\
13 \\
14 \\
15\end{array}$ & $\begin{array}{l}=- \\
=- \\
=-\end{array}$ & $\begin{array}{l}= \\
=- \\
=-\end{array}$ & $\begin{array}{l}= \\
=- \\
=-\end{array}$ & $\begin{array}{l}=- \\
=- \\
=-\end{array}$ & $\begin{array}{l}= \\
= \\
=\end{array}$ & $\begin{array}{l}=- \\
\because- \\
=-\end{array}$ & $\begin{array}{l}1.0 \\
1.0 \\
1.0 \\
1.0 \\
1.0\end{array}$ & $\begin{array}{l}1.0 \\
1.0 \\
1.0 \\
1.0 \\
1.0\end{array}$ & $\begin{array}{l}8.0 \\
6.5 \\
6.0 \\
6.0 \\
7.0\end{array}$ & $\begin{array}{l}5.0 \\
4.0 \\
3.0 \\
4.5 \\
4.0\end{array}$ & $\begin{array}{r}12.0 \\
11.0 \\
10.0 \\
8.5 \\
6.5\end{array}$ & $\begin{array}{l}6.5 \\
8.0 \\
7.0 \\
5.5 \\
3.5\end{array}$ \\
\hline $\begin{array}{l}16 \\
17 \\
18 \\
19 \\
20\end{array}$ & $\begin{array}{l}= \\
=- \\
=-\end{array}$ & $\begin{array}{l}=- \\
=- \\
=- \\
=-\end{array}$ & $\begin{array}{l}-- \\
\overline{--} \\
\overline{--}\end{array}$ & $\begin{array}{l}=- \\
\ddot{-} \\
=-\end{array}$ & $\begin{array}{l}= \\
\overline{-} \\
\overline{-}\end{array}$ & $\begin{array}{l}=- \\
=- \\
=-\end{array}$ & $\begin{array}{l}1.0 \\
1.0 \\
3.5 \\
4.0 \\
3.5\end{array}$ & $\begin{array}{l}1.0 \\
1.0 \\
1.0 \\
3.5 \\
1.5\end{array}$ & $\begin{array}{r}7.0 \\
6.0 \\
8.5 \\
10.0 \\
8.0\end{array}$ & $\begin{array}{l}6.0 \\
5.5 \\
6.0 \\
7.0 \\
5.0\end{array}$ & $\begin{array}{r}8.0 \\
8.5 \\
8.0 \\
10.0 \\
9.5\end{array}$ & $\begin{array}{l}2.0 \\
2.0 \\
6.0 \\
8.0 \\
9.5\end{array}$ \\
\hline $\begin{array}{l}21 \\
22 \\
23 \\
24 \\
25\end{array}$ & $\begin{array}{l}= \\
=- \\
=-\end{array}$ & $=$ & $\begin{array}{l}= \\
= \\
=\end{array}$ & $\begin{array}{l}=- \\
=- \\
=\end{array}$ & $=$ & $\begin{array}{l}=- \\
=- \\
=-\end{array}$ & $\begin{array}{l}1.5 \\
1.0 \\
1.0 \\
1.0 \\
1.0\end{array}$ & $\begin{array}{l}1.0 \\
1.0 \\
1.0 \\
1.0 \\
1.0\end{array}$ & $\begin{array}{l}6.0 \\
8.0 \\
9.5 \\
9.0 \\
8.5\end{array}$ & $\begin{array}{l}3.0 \\
3.5 \\
7.0 \\
4.0 \\
6.5\end{array}$ & $\begin{array}{l}10.0 \\
10.0 \\
10.0 \\
10.0 \\
13.5\end{array}$ & $\begin{array}{l}8.0 \\
8.5 \\
7.0 \\
6.0 \\
0.5\end{array}$ \\
\hline $\begin{array}{l}26 \\
27 \\
28 \\
29 \\
30 \\
31\end{array}$ & $\begin{array}{l}-- \\
=- \\
=- \\
=-\end{array}$ & $\begin{array}{l}=- \\
= \\
= \\
=\end{array}$ & $\begin{array}{l}-- \\
=- \\
-- \\
-- \\
--\end{array}$ & $\begin{array}{l}=- \\
=- \\
=- \\
=\end{array}$ & $\begin{array}{l}= \\
= \\
= \\
=\end{array}$ & $\begin{array}{l}-- \\
-- \\
-- \\
--\end{array}$ & $\begin{array}{r}5.0 \\
5.5 \\
5.5 \\
10.5 \\
10.0 \\
5.5\end{array}$ & $\begin{array}{l}1.0 \\
3.0 \\
3.0 \\
5.5 \\
5.0 \\
2.0\end{array}$ & $\begin{array}{r}9.0 \\
8.5 \\
10.0 \\
-0 \\
=-\end{array}$ & $\begin{array}{r}4.0 \\
3.5 \\
5.5 \\
=- \\
=-\end{array}$ & $\begin{array}{l}15.5 \\
13.5 \\
14.0 \\
15.5 \\
11.5 \\
11.5\end{array}$ & $\begin{array}{r}10.0 \\
8.0 \\
6.5 \\
11.0 \\
8.0 \\
6.5\end{array}$ \\
\hline AVG & -- & -- & -- & - & - & -- & 3.0 & 2.0 & 7.5 & 4.5 & 11.0 & 7.5 \\
\hline \multirow[t]{2}{*}{ DAY } & \multicolumn{2}{|c|}{$A P R$} & \multicolumn{2}{|c|}{ MAY } & \multicolumn{2}{|c|}{ JUN } & \multicolumn{2}{|c|}{ JUL } & \multicolumn{2}{|c|}{ AUG } & \multicolumn{2}{|c|}{ SEP } \\
\hline & MAX & MIN & MAX & MIN & max & MIN & MAX & MIN & $\max$ & MIN & MAX & MIN \\
\hline $\begin{array}{l}1 \\
2 \\
3 \\
4 \\
5\end{array}$ & $\begin{array}{l}10.0 \\
14.0 \\
13.5 \\
10.0 \\
13.5\end{array}$ & $\begin{array}{r}9.0 \\
10.0 \\
8.0 \\
8.0 \\
8.5\end{array}$ & $\begin{array}{l}21.0 \\
20.5 \\
19.5 \\
14.5 \\
16.5\end{array}$ & $\begin{array}{l}16.0 \\
16.5 \\
14.5 \\
13.5 \\
12.0\end{array}$ & $\begin{array}{l}20.5 \\
21.5 \\
21.0 \\
21.0 \\
22.0\end{array}$ & $\begin{array}{l}18.5 \\
19.0 \\
19.5 \\
18.5 \\
19.5\end{array}$ & $\begin{array}{l}24.5 \\
25.5 \\
25.5 \\
25.5 \\
22.0\end{array}$ & $\begin{array}{l}20.0 \\
21.0 \\
22.0 \\
21.5 \\
21.0\end{array}$ & $\begin{array}{l}25.5 \\
25.5 \\
25.5 \\
24.0 \\
23.0\end{array}$ & $\begin{array}{l}22.0 \\
21.5 \\
21.0 \\
22.0 \\
20.5\end{array}$ & $\begin{array}{l}24.0 \\
22.0 \\
23.5 \\
25.0 \\
24.0\end{array}$ & $\begin{array}{l}21.5 \\
21.0 \\
21.0 \\
22.0 \\
21.5\end{array}$ \\
\hline $\begin{array}{r}6 \\
7 \\
8 \\
9 \\
10\end{array}$ & $\begin{array}{l}11.5 \\
13.0 \\
15.0 \\
18.0 \\
16.5\end{array}$ & $\begin{array}{r}8.0 \\
8.0 \\
6.5 \\
10.5 \\
10.5\end{array}$ & $\begin{array}{l}16.0 \\
15.5 \\
18.0 \\
20.0 \\
20.5\end{array}$ & $\begin{array}{l}13.0 \\
10.5 \\
11.5 \\
14.5 \\
16.0\end{array}$ & $\begin{array}{l}21.5 \\
20.5 \\
21.0 \\
21.0 \\
21.0\end{array}$ & $\begin{array}{l}19.0 \\
19.0 \\
15.0 \\
16.5 \\
16.5\end{array}$ & $\begin{array}{l}23.0 \\
23.5 \\
23.0 \\
23.5 \\
22.0\end{array}$ & $\begin{array}{l}20.0 \\
18.5 \\
19.0 \\
21.0 \\
21.5\end{array}$ & $\begin{array}{l}22.0 \\
22.0 \\
22.0 \\
21.5 \\
21.0\end{array}$ & $\begin{array}{l}21.0 \\
21.0 \\
20.5 \\
21.0 \\
19.5\end{array}$ & $\begin{array}{l}23.5 \\
23.6 \\
23.0 \\
23.5 \\
24.0\end{array}$ & $\begin{array}{l}20.5 \\
19.5 \\
19.5 \\
20.5 \\
21.0\end{array}$ \\
\hline $\begin{array}{l}11 \\
12 \\
13 \\
14 \\
15\end{array}$ & $\begin{array}{l}16.5 \\
18.0 \\
15.0 \\
15.0 \\
14.5\end{array}$ & $\begin{array}{r}9.0 \\
10.0 \\
12.0 \\
12.0 \\
11.5\end{array}$ & $\begin{array}{l}20.5 \\
25.5 \\
21.5 \\
22.0 \\
20.5\end{array}$ & $\begin{array}{l}17.0 \\
16.5 \\
17.0 \\
18.0 \\
18.0\end{array}$ & $\begin{array}{l}21.0 \\
22.0 \\
22.0 \\
21.0 \\
19.5\end{array}$ & $\begin{array}{l}18.0 \\
18.0 \\
19.0 \\
19.0 \\
18.0\end{array}$ & $\begin{array}{l}23.0 \\
23.5 \\
23.5 \\
23.5 \\
24.5\end{array}$ & $\begin{array}{l}21.0 \\
20.0 \\
20.5 \\
21.0 \\
21.0\end{array}$ & $\begin{array}{l}21.0 \\
21.0 \\
21.0 \\
22.0 \\
21.5\end{array}$ & $\begin{array}{l}19.5 \\
19.0 \\
20.0 \\
20.0 \\
20.0\end{array}$ & $\begin{array}{l}23.0 \\
21.5 \\
22.0 \\
23.0 \\
23.0\end{array}$ & $\begin{array}{l}21.5 \\
20.0 \\
18.0 \\
19.0 \\
19.5\end{array}$ \\
\hline $\begin{array}{l}16 \\
17 \\
18 \\
19 \\
20\end{array}$ & $\begin{array}{l}18.0 \\
15.5 \\
20.0 \\
16.5 \\
21.0\end{array}$ & $\begin{array}{r}9.5 \\
11.5 \\
12.0 \\
13.5 \\
13.0\end{array}$ & $\begin{array}{l}19.0 \\
19.0 \\
18.0 \\
19.0 \\
20.0\end{array}$ & $\begin{array}{l}18.0 \\
16.5 \\
13.5 \\
13.5 \\
14.5\end{array}$ & $\begin{array}{l}22.0 \\
23.5 \\
25.0 \\
25.0 \\
23.5\end{array}$ & $\begin{array}{l}19.0 \\
29.0 \\
21.0 \\
21.5 \\
21.0\end{array}$ & $\begin{array}{l}24.0 \\
23.0 \\
23.0 \\
22.0 \\
23.5\end{array}$ & $\begin{array}{l}21.5 \\
19.5 \\
18.5 \\
20.0 \\
21.0\end{array}$ & $\begin{array}{l}23.5 \\
23.5 \\
24.0 \\
24.5 \\
24.0\end{array}$ & $\begin{array}{l}20.5 \\
21.0 \\
21.5 \\
21.5 \\
21.5\end{array}$ & $\begin{array}{l}22.0 \\
23.0 \\
22.0 \\
22.0 \\
21.0\end{array}$ & $\begin{array}{l}19.0 \\
19.0 \\
20.5 \\
21.0 \\
19.0\end{array}$ \\
\hline $\begin{array}{l}21 \\
22 \\
23 \\
24 \\
25\end{array}$ & $\begin{array}{l}21.5 \\
16.5 \\
20.5 \\
21.0 \\
19.0\end{array}$ & $\begin{array}{l}14.0 \\
13.0 \\
14.5 \\
17.0 \\
15.5\end{array}$ & $\begin{array}{l}21.0 \\
21.5 \\
22.0 \\
23.0 \\
22.0\end{array}$ & $\begin{array}{l}17.0 \\
18.0 \\
18.5 \\
19.0 \\
19.5\end{array}$ & $\begin{array}{l}23.5 \\
23.5 \\
23.5 \\
23.0 \\
22.0\end{array}$ & $\begin{array}{l}20.5 \\
21.0 \\
21.0 \\
19.5 \\
21.0\end{array}$ & $\begin{array}{l}23.0 \\
10.5 \\
21.5 \\
23.5 \\
24.0\end{array}$ & $\begin{array}{l}19.5 \\
19.0 \\
19.0 \\
21.0 \\
21.5\end{array}$ & $\begin{array}{l}23.5 \\
23.0 \\
23.5 \\
23.0 \\
23.0\end{array}$ & $\begin{array}{l}21.0 \\
21.5 \\
22.0 \\
21.0 \\
20.0\end{array}$ & $\begin{array}{l}23.0 \\
23.5 \\
24.0 \\
23.5 \\
23.0\end{array}$ & $\begin{array}{l}19.0 \\
20.5 \\
21.0 \\
21.0 \\
20.0\end{array}$ \\
\hline $\begin{array}{l}26 \\
27 \\
28 \\
29 \\
30 \\
31\end{array}$ & $\begin{array}{r}16.5 \\
17.0 \\
16.5 \\
21.0 \\
21.0 \\
=-\end{array}$ & $\begin{array}{r}15.5 \\
15.0 \\
15.0 \\
15.0 \\
18.0 \\
-0\end{array}$ & $\begin{array}{l}21.0 \\
20.5 \\
20.0 \\
20.0 \\
18.5 \\
19.0\end{array}$ & $\begin{array}{l}19.5 \\
16.0 \\
17.0 \\
17.0 \\
16.5 \\
17.0\end{array}$ & $\begin{array}{r}23.0 \\
23.0 \\
21.0 \\
20.5 \\
21.5 \\
-\end{array}$ & $\begin{array}{r}20.5 \\
21.0 \\
18.0 \\
16.0 \\
17.0 \\
=-\end{array}$ & $\begin{array}{l}23.5 \\
23.5 \\
24.0 \\
25.5 \\
25.0 \\
25.0\end{array}$ & $\begin{array}{l}21.5 \\
21.0 \\
21.5 \\
22.0 \\
23.0 \\
21.5\end{array}$ & $\begin{array}{l}22.0 \\
22.0 \\
23.0 \\
23.5 \\
24.0 \\
24.5\end{array}$ & $\begin{array}{l}20.0 \\
19.0 \\
19.0 \\
19.5 \\
20.0 \\
21.0\end{array}$ & $\begin{array}{l}23.5 \\
22.0 \\
19.5 \\
16.5 \\
16.5 \\
--\end{array}$ & $\begin{array}{r}20.0 \\
19.5 \\
16.5 \\
13.5 \\
12.0 \\
-\end{array}$ \\
\hline A VG & 16.5 & 12.0 & 20.0 & 16.0 & 22.0 & 19.0 & 23.5 & 20.5 & 23.0 & 20.5 & 22.5 & 19.5 \\
\hline
\end{tabular}


02077250 SOUTH HYCO CAEEK NEAR ROSEVILLE, N. C.

LOCATION,.-lat $36^{\circ} 23^{\prime} 12^{\prime \prime}$, 1ong $79^{\circ} 06^{\prime} 22^{\prime \prime}$, Person County, temperature recorder at gaging station on right bank at downstream side of bridge on U.S. Highway $158,1.2$ miles downstream from Mill Creek, and 4.2 miles northwest of Roseville.

DRA INAGE AREA, $--55 \mathrm{sq}$ mi, approximately.

PER IOD OF RECORD.--Water temperatures: January 1967 to September 1970.

EXTRGMES, --1969-70:

Water temperatures: Maximum, $26.5^{\circ} \mathrm{C}$ July 15, 29, 30; minimum, $0.5^{\circ} \mathrm{C}$ on several days during December and January.

Period of record:

Water temperatures: Maximum, $30.5^{\circ} \mathrm{C}$ Aug. 22, 1968: minimum, freezing point on many days in January and February 1968 .

TEMPERATURE $\left({ }^{\circ} \mathrm{C}\right)$ OF WATER, WATER YEAR OCTOBER 1969 TO SEPTEMBER 1970 (CONTINUOUS ETHYL ALCOHOL-ACTUATED THERMOGRAPH)

OCT

MAX

1
2
3
5

15

18.5
18.5

18.0

16.0

NOV

MIN

MAX DEC

MAX JAN MIN

FEB

MI N

MAR

13.5

$$
\begin{aligned}
& 15.0 \\
& 16.5 \\
& 16.5 \\
& 15.5
\end{aligned}
$$

11.
13.5
14.5
12.

10.0
11.5
12.0
10.0
8.5

4.5
3.5
4.0
4.0
2.0

3.0
1.0
2.0
2.0

8.0
5.0
3.5
3.0
1.5

5.0
3.5
3.0
1.5
1.0

$\begin{array}{ll}.0 & 4.0 \\ .5 & 7.0 \\ .0 & 7.0 \\ .5 & 5.5 \\ .0 & 1.5\end{array}$

4.0
7.0
7.0
5.5
1.5

2.0
4.0
5.5
1.5
1.0

$\begin{array}{ll}1.0 & 3.0 \\ 1.0 & 3.5 \\ 1.0 & 4.0 \\ 1.0 & 4.5 \\ 1.0 & 5.5\end{array}$

1.0
2.0
3.5
4.0
4.5

15.5
15.5

$\begin{array}{ll}9.0 & 7.0 \\ 8.5 & 6.0\end{array}$

6.0
6.5
7.0

1.5
3.5
4.0
5.0
5.0

1.0
2.0
3.5
4.0
5.0

1.5
1.5
1.0
1.0

6.5

6.5

13.5

.

16.5

18.5
18.0

14.0
14.5
16.0

9.5
8.5
9.0

6.5
8.0
6.5
5.0

5.0
4.0

6.5
5.5
4.0

5.0
5.5
3.5
3.5
3.5

1.0

1.

1.0
0.5
0.5
0.5

5.5
5.5
4.5
4.5

.5
.5
.5
.5
.5

3.0

3.5

3.0

16.0
15.5

15.5
14.0
13.0

15.0

14.0
10.5
10.0

5.0
5.0

6.5
8.5

3.0
6.5

2.0
1.5
3.0

2.0
1.0
1.0

1.0

0.5

1.0
0.5

14.5

11. 5

8.5

5.0

1.5

1.5
1.0

1.0

1.5
2.0

14.5

12.0

11.5

$\begin{array}{ll}5.5 & 4.0 \\ 5.0 & 2.0\end{array}$

5.0
7.0

3.0
5.0

2.0

0.5
1.5
1.5
2.0
1.5

1.0
0.5

7.0

6.5

4.5

2.0

1. 5

0.5
0.5
1.0

1.5

12.0
12.0

12.0

9.0
10.0

11.0

8.0

$\begin{array}{ll}6.5 & 4.5 \\ 5.5 & 3.5\end{array}$

5.5
5.5
5.5

4.5

4.5
3.5

14.5

12. 5

B. 0

6.0

3.5

5.5
8.0

0.5
1.0
1.5

1.5
2.0

2.0
3.5
5.5

3.5

3.5
4.5
5.0

5.0
8.5

8.5
8.5

3.5

2.5

2.5

0.5
0.5

0.5
0.5
1.0

5.5
5.0
6.5
9.0

3.

1.0

0.5

0.5
0.5

0.5

0.5
2.0
3.0

3.0
4.5

4.5

3.5
1.5

DAY

MAX

A R

11.0
14.5

14.5
13.5
11.5

10.0

MAY

MIN

$\max$

UN

max

13.0

$$
\begin{aligned}
& 10.0 \\
& 10.0
\end{aligned}
$$

20.0

18.5

18.5

16.0

21.0
24.5

23.0

\section{5}

20.0

21.0

14.0

24.5

13.0

10.016 .5

14.5

23.0
14.0

23.5

22.0

20.0

20.0
20.0

$\begin{array}{lll}14.0 & 22.0 & 18.5 \\ 16.5 & 22.0 & 18.0\end{array}$

18.5

22.0

19.0

19.5

16.0

16.0

16.0
15.5

13.0

13.5

15.5

21.0
21.5

19.5
19.5
19.5

$\begin{array}{ll}23.0 & 19 . \\ 23.5 & 20 . \\ 23.0 & 21 .\end{array}$

$20.5 \quad 23.0 \quad 21.0$

16.5

16.0

19.0

$\begin{array}{ll}13.0 & 20.5 \\ 15.0 & 20.5\end{array}$

20.0

19.0
16.5

16.5
16.0
18.0

22.0
23.5

23.5
25.0
25.5

20.0

21.0

$\begin{array}{ll}25.0 & 22.0 \\ 25.5 & 23.5\end{array}$

20.0

20.5

$15.0 \quad 21.0$

$\begin{array}{lll}17.0 & 23.0 \\ 16.0 & 16.0 & 23.5\end{array}$

$\begin{array}{lll}19.5 & 16.0 & 24.5\end{array}$

20.0

24.023 .0

$\begin{array}{ll}24.0 & 23.0 \\ 24.0 & 23.0\end{array}$

21.5

21.0

21.0
19.0

19.0
19.0

22.

18.5
16.5

16.5
16.5

19.5

$\begin{array}{ll}16.5 & 23.0 \\ 15.5 & 22.0\end{array}$

16.521 .0

$\begin{array}{ll}15.5 & 21.0 \\ 19.0 & 20.0\end{array}$

19.0
18.5
19.0

24.0
23.0
21.0
21.5

21.0
22.0
20.0

18.0

23.0

24.5
25.5
25.5

25.5
25.5

24.5

23.5

25.0
24.5

25.0
25.0

24.0
25.0

25.0
25.0

25.5
26.5

26.5

26.0
25.5

25.5
24.5
24.5

24.5
24.0

24.0

22.0

24.0
25.0

25. 0

25.0
24.5
25.5

26.5

26.5
26.0

20.5

18.0

20.5

25.0

ui

AUG

4.5
4.5
4.5
6.0
5.0

5.5
5.5
7.0
6.5

5.5
5.5
7.0

3.0
2.0
5.5
4.5

5.5
5.0
6.5

5.5
5.0
6.5

2.0

3.5
2.0
4.5
.0

$-$

MIN

21.5
23.5
23.5

23.5
23.5

22.0 
02077300 HYCO RIVER AT MCGEHEES MILL, N. C.

LOCATION.--Lat $36^{\circ} 31^{\prime} 02^{\prime \prime}$, long $79^{\circ} 01^{\prime} 42^{\prime \prime}$, Person County, at gaging station on left bank $200 \mathrm{ft}$ downstream from bridge on Secondary Road 1322, at McGehees Mil1, and 1.7 miles downstream from Hyco Dam.

DRA INAGE AREA.--191 sq mi.

PERIOD OF RECORD.--Chemical analyses: October 1967 to September 1969 (partial-record), October 1969 to September 1970.

Water temperatures: August 1964 to September 1970.

CHEMICAL ANALYSES, WATER YEAR OCTOBER 1969 TO SEPTEMBER 1970

\begin{tabular}{|c|c|c|c|c|c|c|c|c|c|c|c|}
\hline DATE & TIME & $\begin{array}{c}\text { Ot S- } \\
\text { CHARGE } \\
\text { CHASSI }\end{array}$ & $\begin{array}{l}\text { SILICA } \\
\text { isto2 } \\
\text { (S1OL/L) }\end{array}$ & $\begin{array}{c}\text { DIS- } \\
\text { SOLVED } \\
\text { IRON } \\
\text { IFE } \\
\text { IUG/ }\end{array}$ & $\begin{array}{l}\text { CAL- } \\
\text { CIUM } \\
\text { (CA1, } \\
\text { (MGAL) }\end{array}$ & $\begin{array}{l}\text { MAG- } \\
\text { NEE- } \\
\text { SIUM } \\
\text { IMGG) } \\
\text { IMG/LIL }\end{array}$ & $\begin{array}{l}\text { SODIUM } \\
\text { (NA) } \\
\text { (NAA) }\end{array}$ & $\begin{array}{c}\text { PO- } \\
\text { TAS- } \\
\text { SIUM } \\
\text { IKI } \\
\text { (MG/L) }\end{array}$ & 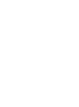 & $\begin{array}{l}\text { CAR- } \\
\text { BONATE } \\
\text { (CONA3) } \\
(\mathrm{MG} / \mathrm{L})\end{array}$ & $\begin{array}{c}\text { SULFAT } \\
\text { ISOA) } \\
\text { (MG/L }\end{array}$ \\
\hline $\begin{array}{c}\text { oct. } \\
22 . \ldots \\
22 \ldots\end{array}$ & 1630 & 27 & -- & -- & - & -. & - & -- & 42 & - & -- \\
\hline $\begin{array}{r}r_{20 .} \\
20 \ldots \\
20 . .\end{array}$ & $\begin{array}{l}1600 \\
1600\end{array}$ & $\begin{array}{l}23 \\
23\end{array}$ & $\because$ & -- & $=$ & $=$ & $=$ & $=$ & 44 & $=$ & $=$ \\
\hline $\begin{array}{l}22 . \\
22 \ldots\end{array}$ & $\begin{array}{l}1630 \\
1630\end{array}$ & $\begin{array}{l}A 47 \\
A 47\end{array}$ & 10 & $\therefore$ & ${ }^{10}$ & 4.1 & 0.4 & 2.2 & 42 & $\therefore$ & $\underline{14}$ \\
\hline $\begin{array}{r}22 \% \\
22\end{array}$ & $\begin{array}{l}2030 \\
1030\end{array}$ & $\begin{array}{l}54 \\
54\end{array}$ & -z & $=$ & -- & $\because$ & $\bar{z}$ & -- & $\because$ & $=-$ & $=$ \\
\hline 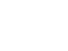 & $\begin{array}{l}1540 \\
1540\end{array}$ & $\begin{array}{l}139 \\
139\end{array}$ & $=$ & $=$ & $=$ & $=-$ & $=$ & $=$ & -- & $=$ & $=$ \\
\hline $\begin{array}{r}\text { MAR. } \\
26 \ldots . . \\
26 . \ldots\end{array}$ & $\begin{array}{l}1530 \\
1530\end{array}$ & $\begin{array}{l}A 280 \\
A 280\end{array}$ & $\underline{12}$ & 38 & 9.9 & $\begin{array}{l}3.8 \\
--\end{array}$ & 0.2 & 1.8 & 33 & - & 17 \\
\hline $\begin{array}{l}17 \ldots . . \\
17\end{array}$ & $\begin{array}{l}1425 \\
1425\end{array}$ & $\begin{array}{l}137 \\
137\end{array}$ & -- & $=$ & $=$ & $=-$ & $=$ & $=$ & -- & $=$ & $=$ \\
\hline $\begin{array}{r}\text { MAY } \\
20 \ldots \\
20 \ldots \\
20 \ldots\end{array}$ & $\begin{array}{l}1400 \\
1410 \\
1410\end{array}$ & $\begin{array}{l}121 \\
121 \\
121\end{array}$ & $\bar{z}$ & $\begin{array}{l}=- \\
=-\end{array}$ & $\bar{z}$ & $\begin{array}{l}=- \\
=-\end{array}$ & $\bar{z}$ & $\begin{array}{l}\overline{-} \\
\overline{--}\end{array}$ & $\begin{array}{l}-- \\
\overline{--}\end{array}$ & $=$ & $\begin{array}{l}-z \\
\overline{-}\end{array}$ \\
\hline $\begin{array}{r}\begin{array}{r}18 . \ldots \\
18 . . .\end{array} \\
18\end{array}$ & $\begin{array}{l}1345 \\
1345\end{array}$ & $\begin{array}{l}22 \\
22\end{array}$ & 13 & 13 & 9.0 & 4.6 & 5.9 & 1.8 & 35 & $\therefore$ & 15 \\
\hline $\begin{array}{r}28 \ldots \\
28 \ldots\end{array}$ & $\begin{array}{l}1415 \\
1415\end{array}$ & $\begin{array}{l}20 \\
20\end{array}$ & 13 & 154 & ${ }^{10}$ & 4.2 & 0.5 & 1.9 & 42 & $\therefore$ & 14 \\
\hline $\begin{array}{l}20 \ldots \\
20 \ldots\end{array}$ & $\begin{array}{l}1630 \\
1430\end{array}$ & $\begin{array}{l}100 \\
100\end{array}$ & -- & -- & $=$ & $=$ & $=$ & $=$ & $\because$ & $\because$ & -- \\
\hline S29.: & $\begin{array}{l}1445 \\
1445\end{array}$ & $\begin{array}{l}13 \\
13\end{array}$ & $=$ & $=$ & $=$ & -- & $=$ & -- & $=$ & $=$ & $=$ \\
\hline
\end{tabular}

a DAILY MEAN DISCHARGE.

\begin{tabular}{|c|c|c|c|c|c|c|c|c|c|c|c|}
\hline DATE & $\begin{array}{l}\text { CHLO- } \\
\text { RIOE } \\
\text { ICLI } \\
\text { I MG LLI }\end{array}$ & $\begin{array}{l}\text { FLUO- } \\
\text { RIOE } \\
\text { If } \\
\text { ( } M G / L)\end{array}$ & $\begin{array}{l}\text { NITRATE } \\
\text { INO3) } \\
\text { (MG/LI) }\end{array}$ & $\begin{array}{l}\text { ORTHO } \\
\text { PHOS- } \\
\text { PHATE } \\
\text { PHAT } \\
\text { IPO4 } \\
\text { IMG/LI }\end{array}$ & $\begin{array}{l}\text { TOTAL } \\
\text { PHOS } \\
\text { PHORUS } \\
\text { IPI } \\
\text { IMG/L) }\end{array}$ & 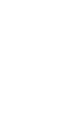 & $\begin{array}{l}\text { OIS- } \\
\text { SOLVED } \\
\text { SOL VIIS } \\
\text { TIONS } \\
\text { PER } \\
\text { AC-FrI }\end{array}$ & $\begin{array}{l}\text { DIS- } \\
\text { SOLVE } \\
\text { SOLIDS } \\
\text { TOLNS } \\
\text { PER } \\
\text { DAY I }\end{array}$ & $\begin{array}{l}\text { MARQ- } \\
\text { NESS } \\
\text { (ICA,MG) } \\
\text { (MGAL) }\end{array}$ & $\begin{array}{l}\text { NON- } \\
\text { CAR- } \\
\text { CARA } \\
\text { BONADE- } \\
\text { MERDS } \\
\text { NESS } \\
\text { (MG/L) }\end{array}$ & $\begin{array}{l}\text { SDUIUM } \\
\text { AD- } \\
\text { SORP- } \\
\text { rION } \\
\text { RATIO }\end{array}$ \\
\hline $\begin{array}{l}\text { oct. } \\
22 . . . \\
\text { Nov. }\end{array}$ & -- & -- & -- & -- & -- & -- & -- & -- & -- & - & -- \\
\hline 20. & $=$ & -- & $=$ & - & .01 & $z$ & $=$ & $\because$ & $\because$ & $=$ & $=$ \\
\hline 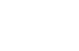 & 5.0 & .2 & 1.0 & .02 & .02 & 84 & .11 & 10.7 & 42 & -8 & $\therefore$ \\
\hline $\begin{array}{l}\text { JAN. } \\
222 \ldots \\
22 .\end{array}$ & $=$ & -- & -- & - & -- & -- & $=$ & $=$ & -- & $=$ & -- \\
\hline $\begin{array}{c}\text { FEB. } \\
26 . \ldots \\
26 . \ldots\end{array}$ & $=$ & $=$ & $=$ & $=$ & .04 & - & $=$ & $=$ & $=$ & $=$ & $=$ \\
\hline $\begin{array}{l}\text { MAR. } \\
26 . . \\
26 . \ldots\end{array}$ & 5.5 & $\therefore$ & .9 & .00 & .01 & 76 & .10 & 57.5 & $\because 0$ & $\underline{13}$ & .4 \\
\hline $\begin{array}{l}\text { APR: } \\
177 \ldots \\
17\end{array}$ & $=$ & -- & $=$ & $=$ &.$\overline{02}$ & -- & -- & $=$ & z- & $\overline{-z}$ & $z$ \\
\hline $\begin{array}{r}\operatorname{Mar} \\
20 .\end{array}$ & -- & -- & -- & -- & - & -- & -- & -- & _- & -- & -- \\
\hline $\begin{array}{l}20 \ldots \\
20 \ldots\end{array}$ & $\overline{-}$ & $\overline{--}$ & -- & $=$ & .02 & $=$ & $=$ & $\bar{z}$ & -- & $=$ & $=$ \\
\hline 年 & 6.6 & $\therefore 0$ & $\therefore$ & .00 & .02 & 72 & .10 & $\stackrel{4.28}{-1}$ & 42 & 13 & $\because 4$ \\
\hline $\begin{array}{r}28 \\
28 \ldots\end{array}$ & $\begin{array}{r}7.5 \\
--\end{array}$ & $\therefore$ & $\therefore 6$ & $=$ & $=$ & 80 & 11 & 4.32 & 42 & - -- & $\ddot{-4}$ \\
\hline $\begin{array}{l}\text { AUG. } \\
20 . . .\end{array}$ & - & -- & -- & - & .04 & -- & - & -- & -- & -- & - \\
\hline SEPI" & & & & & & & & & & & \\
\hline${ }_{290}^{29 \ldots}$ & $=-$ & $\overline{--}$ & 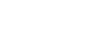 & $\bar{z}$ & - 00 & $\bar{z}$ & $\overline{-}$ & $\bar{z}$ & $\overline{--}$ & $=$ & $\bar{z}$ \\
\hline
\end{tabular}


ROANOKE RIVER BASIN

02077300 HYCO RIVER AT MCGEHEES MILL, N. C.--Continued

EXTREMES, --1969-70:

Water temperatures: Maximum, $29.5^{\circ} \mathrm{C}$ June 19, 20, Aug, 21, 22; minimum, 1.5 ${ }^{\circ} \mathrm{C}$ Jan, 24.

period of record:

Nater temperatures: Maximum, $33.0^{\circ} \mathrm{C}$ July 14, 1966, Aug. 7, 9, 19, 21, 22, 1968; minimum, freezing point Jan. 29-31, Feb. 1, 1966.

RFMARKS,--The second of two samples collected at the same time is a field determination.

CHEMICAL ANALYSES, WATER YEAR OCTDBER 1969 TO SEPTEMBER 1970

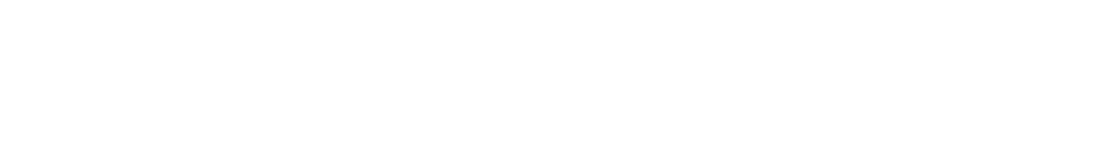

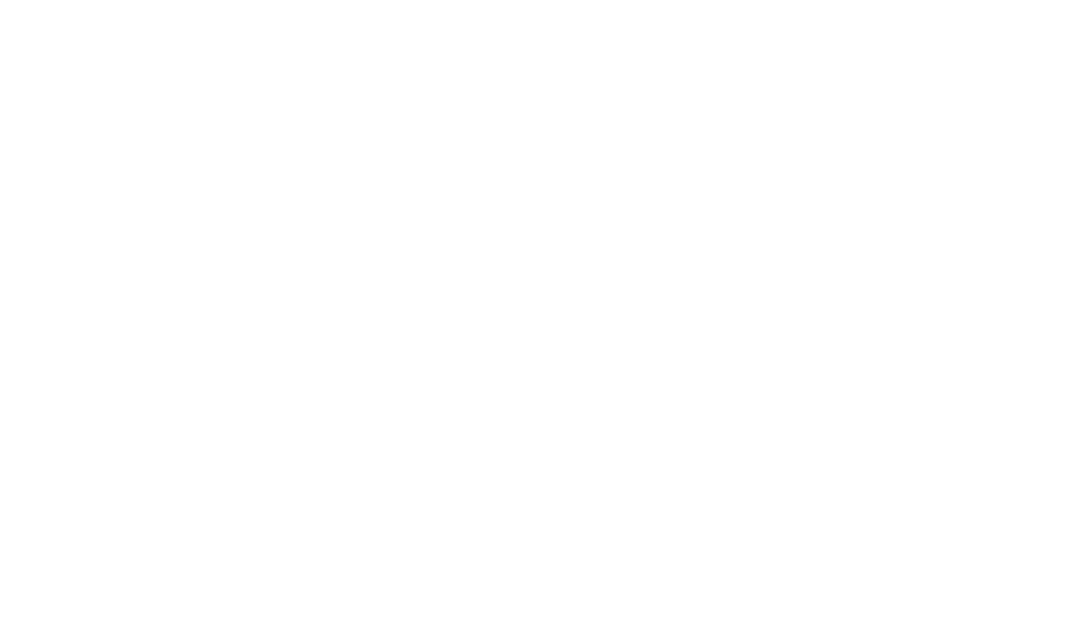

\begin{tabular}{|c|c|c|c|c|c|c|c|c|c|c|}
\hline DATE & $\begin{array}{c}21 N C \\
(2 N) \\
(U 6 / L)\end{array}$ & $\begin{array}{c}\text { cranioe } \\
\text { ILNI } \\
\text { IMG/LI) }\end{array}$ & $\begin{array}{l}\text { CAO- } \\
\text { MIUM } \\
\text { ICD } \\
\text { IUG/L }\end{array}$ & $\begin{array}{l}\text { DIS- } \\
\text { SOLVD } \\
\text { oxrGEN } \\
\text { IMG/LI) }\end{array}$ & $\begin{array}{l}\text { TOTAL } \\
B \in T A \\
\text { IPCAL) }\end{array}$ & $\begin{array}{c}\text { FECAL } \\
\text { COLI- } \\
\text { FORM } \\
\text { (COL. } \\
\text { PER } \\
100 \mathrm{ML})\end{array}$ & $\begin{array}{l}\text { SPECI- } \\
\text { FIC } \\
\text { CONO- } \\
\text { UCTANCE } \\
\text { (MICRO- } \\
\text { MHOSI) }\end{array}$ & $\begin{array}{c}\text { PH } \\
\text { CUNITSI }\end{array}$ & $\begin{array}{l}\text { TEMP- } \\
\text { ERA AURE } \\
\text { (DEG C }\end{array}$ & 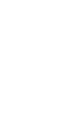 \\
\hline${ }_{22}{ }_{22 .} .$. & -- & -- & -- & 8.7 & - & 15 & 120 & 8.9 & 21.0 & -- \\
\hline 20. & - & z- & $=$ & -- & 4.9 & -- & $\because$ & - & 10.0 & -- \\
\hline $\begin{array}{l}20 \ldots . . \\
\text { DECC. }\end{array}$ & & & & & & & 143 & 7.6 & & \\
\hline $22 \ldots$ & $\bar{z}$ & $\overline{-}$ & $\bar{Z}$ & 13.0 & 509 & "- & $\begin{array}{l}\begin{array}{l}113 \\
115\end{array} \\
115\end{array}$ & $\begin{array}{l}6.9 \\
5.7\end{array}$ & $\begin{array}{r}8.0 \\
8.0\end{array}$ & $-{ }^{5}$ \\
\hline $\begin{array}{l}\text { JaN. } \\
22 \ldots \\
22\end{array}$ & -- & -- & - & -- & 4.9 & -- & - & $\because$ & 2.0 & -- \\
\hline FEA & & & & & & & & & & \\
\hline${ }_{26}^{26 \ldots} \ldots$ & $\ddot{-}$ & Z- & $=$ & $12 . \overline{2}$ & 3.8 & $\because=$ & $\overline{130}$ & 7.1 & $\begin{array}{l}9.00 \\
9.0\end{array}$ & $\because$ \\
\hline $26 \%$ & 15 & $=$ & $\bar{z}$ & $10 \overline{-0}$ & $=$ & $=$ & $\begin{array}{l}110 \\
120\end{array}$ & $\begin{array}{l}6.7 \\
6.8\end{array}$ & $\begin{array}{l}16.0 \\
16.0\end{array}$ & 20 \\
\hline $\begin{array}{c}\text { ARR } \\
17 \ldots\end{array}$ & -- & -- & -- & - & 3.0 & -- & $\overline{ }$ & $\because$ & 15.0 & -- \\
\hline${ }_{\text {MaY }}^{17}$ & 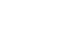 & & & 9.1 & & 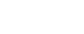 & & 7.5 & & -- \\
\hline${ }_{20}^{20} \ldots$ & $\overline{-}$ & $\overline{--}$ & $=$ & $\bar{z}$ & 6.9 & $\because=$ & $\bar{z}$ & $\overline{--}$ & $\begin{array}{l}27.0 \\
27.0\end{array}$ & $\because$ \\
\hline 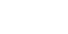 & -- & -- & -- & 7.5 & $\rightarrow$ & 51 & 116 & 8.1 & 27.0 & -- \\
\hline${ }_{118}^{18} \ldots$ & $\bar{z}$ & $=$ & $=$ & $7 . \overline{0}$ & =- & $=$ & $\begin{array}{l}115 \\
120\end{array}$ & $\begin{array}{l}6.7 \\
7: 0\end{array}$ & $\begin{array}{l}30.0 \\
30.0\end{array}$ & 5 \\
\hline $\begin{array}{l}\text { SULY } \\
28 . . .\end{array}$ & 5 & .00 & 0 & -.- & 7.0 & -- & 116 & 1.0 & 29.0 & 5 \\
\hline & & & - & & & & & & & \\
\hline & $=$ & -- & $\bar{z}$ & $7 . \overline{6}$ & 3.0 & $\because$ & 120 & $\pi$ & $\begin{array}{l}32.0 \\
32.0\end{array}$ & $=$ \\
\hline 290. & $\overline{-}$ & $\because$ & -- & -- & 6.0 & $\overline{1}$ & $\overline{-1}$ & -- & 22.0 & -- \\
\hline
\end{tabular}


02077300 HYCO RIVER AT MCGEHEES MILL, N. C.--Continued

\begin{tabular}{|c|c|c|c|c|c|c|c|c|c|c|c|c|}
\hline \multirow[t]{2}{*}{ DAY } & \multicolumn{2}{|c|}{ OCT } & \multicolumn{2}{|c|}{ NOV } & \multicolumn{2}{|c|}{ DEC } & \multicolumn{2}{|c|}{ JAN } & \multicolumn{2}{|c|}{$F \in B$} & \multicolumn{2}{|c|}{ MAR } \\
\hline & MAX & $\operatorname{MIN}$ & $M A X$ & $M] N$ & $\operatorname{MAX}$ & $M \ell N$ & $\max$ & MIN & MAX & MIN & MAX & MIN \\
\hline $\begin{array}{l}1 \\
2 \\
3 \\
4 \\
5\end{array}$ & $\begin{array}{l}23.5 \\
23.5 \\
24.0 \\
24.0 \\
23.5\end{array}$ & $\begin{array}{l}22.0 \\
23.0 \\
23.0 \\
22.0 \\
21.5\end{array}$ & $\begin{array}{l}14.5 \\
16.0 \\
16.5 \\
16.5 \\
14.5\end{array}$ & $\begin{array}{l}14.5 \\
14.5 \\
15.5 \\
14.5 \\
13.0\end{array}$ & $\begin{array}{l}9.5 \\
9.0 \\
9.0 \\
9.0 \\
7.0\end{array}$ & $\begin{array}{l}9.0 \\
8.0 \\
8.0 \\
7.0 \\
6.0\end{array}$ & $\begin{array}{l}8.0 \\
6.5 \\
7.0 \\
6.0 \\
6.0\end{array}$ & $\begin{array}{l}7.0 \\
6.0 \\
6.0 \\
5.5 \\
5.5\end{array}$ & $\begin{array}{l}8.5 \\
9.0 \\
8.5 \\
8.0 \\
7.0\end{array}$ & $\begin{array}{l}6.0 \\
7.0 \\
7.0 \\
6.5 \\
6.5\end{array}$ & $\begin{array}{r}9.0 \\
11.0 \\
11.0 \\
11.0 \\
9.5\end{array}$ & $\begin{array}{l}8.0 \\
9.0 \\
9.5 \\
9.0 \\
9.0\end{array}$ \\
\hline $\begin{array}{r}6 \\
7 \\
8 \\
9 \\
10\end{array}$ & $\begin{array}{l}22.0 \\
22.0 \\
22.0 \\
22.0 \\
22.0\end{array}$ & $\begin{array}{l}21.0 \\
21.0 \\
22.0 \\
20.0 \\
20.0\end{array}$ & $\begin{array}{l}13.5 \\
13.5 \\
13.5 \\
13.0 \\
13.5\end{array}$ & $\begin{array}{l}11.5 \\
12.0 \\
12.0 \\
12.0 \\
12.0\end{array}$ & $\begin{array}{l}7.0 \\
7.0 \\
7.0 \\
8.0 \\
8.0\end{array}$ & $\begin{array}{l}6.5 \\
7.0 \\
7.0 \\
8.0 \\
8.0\end{array}$ & $\begin{array}{l}6.0 \\
5.5 \\
5.0 \\
3.0 \\
3.0\end{array}$ & $\begin{array}{l}5.5 \\
5.0 \\
3.0 \\
2.0 \\
2.0\end{array}$ & $\begin{array}{l}8.0 \\
8.0 \\
8.0 \\
8.0 \\
8.0\end{array}$ & $\begin{array}{l}6.5 \\
6.5 \\
7.0 \\
8.0 \\
7.0\end{array}$ & $\begin{array}{l}10.5 \\
11.5 \\
13.5 \\
13.0 \\
12.0\end{array}$ & $\begin{array}{r}9.0 \\
9.0 \\
10.0 \\
10.0 \\
10.0\end{array}$ \\
\hline $\begin{array}{l}11 \\
12 \\
13 \\
14 \\
15\end{array}$ & $\begin{array}{l}22.0 \\
23.0 \\
23.0 \\
23.5 \\
23.0\end{array}$ & $\begin{array}{l}20.0 \\
20.0 \\
20.5 \\
22.0 \\
20.0\end{array}$ & $\begin{array}{l}13.5 \\
14.0 \\
13.5 \\
13.5 \\
12.0\end{array}$ & $\begin{array}{l}12.0 \\
13.5 \\
12.0 \\
12.0 \\
10.0\end{array}$ & $\begin{array}{l}8.5 \\
8.5 \\
7.0 \\
8.5 \\
9.5\end{array}$ & $\begin{array}{l}7.0 \\
7.0 \\
5.5 \\
7.0 \\
6.5\end{array}$ & $\begin{array}{l}4.0 \\
4.5 \\
4.0 \\
4.5 \\
4.0\end{array}$ & $\begin{array}{l}2.0 \\
3.5 \\
3.0 \\
3.5 \\
3.5\end{array}$ & $\begin{array}{l}8.0 \\
8.0 \\
9.0 \\
8.0 \\
8.5\end{array}$ & $\begin{array}{l}6.5 \\
6.5 \\
6.5 \\
7.0 \\
6.5\end{array}$ & $\begin{array}{l}13.0 \\
12.0 \\
10.5 \\
10.5 \\
10.0\end{array}$ & $\begin{array}{r}10.0 \\
10.0 \\
9.5 \\
9.0 \\
9.0\end{array}$ \\
\hline $\begin{array}{l}16 \\
17 \\
18 \\
19 \\
20\end{array}$ & $\begin{array}{l}20.5 \\
20.5 \\
19.0 \\
20.0 \\
20.5\end{array}$ & $\begin{array}{l}20.0 \\
19.0 \\
15.5 \\
16.5 \\
19.0\end{array}$ & $\begin{array}{l}11.0 \\
11.5 \\
12.0 \\
13.0 \\
12.0\end{array}$ & $\begin{array}{l}10.0 \\
10.0 \\
11.0 \\
12.0 \\
10.0\end{array}$ & $\begin{array}{l}7.0 \\
7.0 \\
7.0 \\
7.0 \\
6.5\end{array}$ & $\begin{array}{l}6.5 \\
6.0 \\
6.5 \\
6.5 \\
6.0\end{array}$ & $\begin{array}{l}4.0 \\
4.5 \\
6.0 \\
5.5 \\
4.5\end{array}$ & $\begin{array}{l}3.0 \\
4.0 \\
4.5 \\
4.5 \\
4.0\end{array}$ & $\begin{array}{l}8.0 \\
7.0 \\
8.0 \\
8.0 \\
8.5\end{array}$ & $\begin{array}{l}6.5 \\
6.5 \\
7.0 \\
7.0 \\
8.0\end{array}$ & $\begin{array}{l}11.0 \\
12.0 \\
10.5 \\
10.0 \\
10.5\end{array}$ & $\begin{array}{r}0.5 \\
8.0 \\
10.0 \\
10.0 \\
10.5\end{array}$ \\
\hline $\begin{array}{l}21 \\
22 \\
23 \\
24 \\
25\end{array}$ & $\begin{array}{l}20.5 \\
20.0 \\
18.5 \\
15.0 \\
14.5\end{array}$ & $\begin{array}{l}19.5 \\
17.0 \\
15.0 \\
14.0 \\
14.0\end{array}$ & $\begin{array}{l}10.5 \\
10.0 \\
11.0 \\
11.5 \\
11.5\end{array}$ & $\begin{array}{r}9.0 \\
9.0 \\
10.0 \\
11.0 \\
10.0\end{array}$ & $\begin{array}{l}7.0 \\
6.5 \\
6.5 \\
6.5 \\
6.5\end{array}$ & $\begin{array}{l}5.5 \\
6.5 \\
6.0 \\
6.5 \\
5.5\end{array}$ & $\begin{array}{l}4.0 \\
3.0 \\
2.0 \\
3.0 \\
4.0\end{array}$ & $\begin{array}{l}2.0 \\
2.0 \\
2.0 \\
1.5 \\
2.0\end{array}$ & $\begin{array}{l}9.0 \\
8.5 \\
8.5 \\
9.0 \\
9.0\end{array}$ & $\begin{array}{l}8.0 \\
8.0 \\
8.5 \\
8.5 \\
8.5\end{array}$ & $\begin{array}{l}10.5 \\
10.5 \\
10.5 \\
10.5 \\
11.5\end{array}$ & $\begin{array}{l}10.5 \\
10.5 \\
10.5 \\
10.5 \\
10.5\end{array}$ \\
\hline $\begin{array}{l}26 \\
27 \\
28 \\
29 \\
30 \\
31\end{array}$ & $\begin{array}{l}16.0 \\
17.0 \\
16.5 \\
14.0 \\
13.5 \\
14.5\end{array}$ & $\begin{array}{l}14.5 \\
16.0 \\
14.0 \\
13.0 \\
11.5 \\
13.5\end{array}$ & $\begin{array}{r}11.5 \\
11.0 \\
11.0 \\
11.0 \\
10.5 \\
=-\end{array}$ & $\begin{array}{r}11.0 \\
9.5 \\
10.5 \\
9.5 \\
9.5 \\
.--\end{array}$ & $\begin{array}{l}5.5 \\
5.0 \\
6.0 \\
6.0 \\
6.5 \\
8.0\end{array}$ & $\begin{array}{l}4.0 \\
4.5 \\
4.5 \\
5.5 \\
6.0 \\
6.5\end{array}$ & $\begin{array}{l}6.5 \\
6.0 \\
6.5 \\
9.0 \\
8.5 \\
8.0\end{array}$ & $\begin{array}{l}4.0 \\
4.0 \\
4.5 \\
6.5 \\
6.0 \\
6.0\end{array}$ & $\begin{array}{r}9.0 \\
8.5 \\
9.0 \\
=- \\
=-\end{array}$ & $\begin{array}{c}8.0 \\
8.0 \\
8.0 \\
=- \\
=- \\
=-\end{array}$ & $\begin{array}{l}13.0 \\
13.5 \\
14.0 \\
14.5 \\
13.5 \\
13.0\end{array}$ & $\begin{array}{l}11.5 \\
11.5 \\
12.0 \\
13.5 \\
12.0 \\
11.5\end{array}$ \\
\hline AvG & 20.0 & 18.5 & 12.5 & 11.5 & 7.5 & 6.5 & 5.0 & 4.0 & 8.0 & 7.0 & 11.5 & 10.0 \\
\hline \multirow[t]{2}{*}{ DAY } & \multicolumn{2}{|c|}{$A P R$} & \multicolumn{2}{|c|}{ MAY } & \multicolumn{2}{|c|}{ JUN } & \multicolumn{2}{|c|}{ JUL } & \multicolumn{2}{|c|}{ AUG } & \multicolumn{2}{|c|}{ SEP } \\
\hline & $\operatorname{MAX}$ & MIN & $\operatorname{MAX}$ & MIN & MAX & MIN & $\max$ & MIN & $\max$ & MIN & MAX & MIN \\
\hline $\begin{array}{l}1 \\
2 \\
3 \\
4 \\
5\end{array}$ & $\begin{array}{l}13.0 \\
13.0 \\
13.0 \\
13.5 \\
14.0\end{array}$ & $\begin{array}{l}13.0 \\
12.0 \\
13.0 \\
13.0 \\
13.0\end{array}$ & $\begin{array}{l}24.5 \\
24.5 \\
24.5 \\
22.0 \\
21.5\end{array}$ & $\begin{array}{l}23.0 \\
23.5 \\
22.0 \\
20.5 \\
20.5\end{array}$ & $\begin{array}{l}25.5 \\
26.0 \\
26.0 \\
26.0 \\
26.0\end{array}$ & $\begin{array}{l}24.5 \\
25.0 \\
25.5 \\
25.0 \\
25.0\end{array}$ & $\begin{array}{l}27.0 \\
28.0 \\
28.5 \\
28.0 \\
28.0\end{array}$ & $\begin{array}{l}25.5 \\
27.0 \\
27.0 \\
28.0 \\
26.5\end{array}$ & $\begin{array}{l}28.5 \\
28.5 \\
28.5 \\
28.0 \\
28.0\end{array}$ & $\begin{array}{l}28.0 \\
28.0 \\
26.5 \\
27.0 \\
26.5\end{array}$ & $\begin{array}{l}26.0 \\
25.5 \\
25.0 \\
25.0 \\
25.0\end{array}$ & $\begin{array}{l}25.5 \\
25.0 \\
24.5 \\
24.5 \\
25.0\end{array}$ \\
\hline $\begin{array}{r}6 \\
7 \\
8 \\
9 \\
10\end{array}$ & $\begin{array}{l}14.0 \\
13.5 \\
15.0 \\
16.0 \\
17.0\end{array}$ & $\begin{array}{l}13.5 \\
13.0 \\
13.0 \\
14.0 \\
14.5\end{array}$ & $\begin{array}{l}21.5 \\
22.0 \\
23.5 \\
24.5 \\
24.5\end{array}$ & $\begin{array}{l}21.5 \\
21.0 \\
21.0 \\
22.0 \\
23.5\end{array}$ & $\begin{array}{l}26.0 \\
26.0 \\
26.0 \\
26.0 \\
26.0\end{array}$ & $\begin{array}{l}25.0 \\
25.0 \\
24.0 \\
25.0 \\
24.5\end{array}$ & $\begin{array}{l}26.5 \\
28.0 \\
28.0 \\
28.0 \\
27.0\end{array}$ & $\begin{array}{l}25.5 \\
25.0 \\
26.5 \\
27.0 \\
25.5\end{array}$ & $\begin{array}{l}26.5 \\
26.0 \\
25.5 \\
25.5 \\
25.0\end{array}$ & $\begin{array}{l}26.0 \\
25.5 \\
25.5 \\
25.0 \\
22.0\end{array}$ & $\begin{array}{l}25.0 \\
25.0 \\
25.0 \\
24.5 \\
24.5\end{array}$ & $\begin{array}{l}25.0 \\
25.0 \\
24.5 \\
24.5 \\
24.5\end{array}$ \\
\hline $\begin{array}{l}11 \\
12 \\
13 \\
14 \\
15\end{array}$ & $\begin{array}{l}19.0 \\
20.0 \\
18.0 \\
18.0 \\
16.5\end{array}$ & $\begin{array}{l}14.5 \\
15.5 \\
16.0 \\
15.5 \\
15.5\end{array}$ & $\begin{array}{l}25.0 \\
26.0 \\
27.0 \\
28.0 \\
27.0\end{array}$ & $\begin{array}{l}23.5 \\
23.5 \\
24.5 \\
25.5 \\
25.5\end{array}$ & $\begin{array}{l}27.0 \\
28.0 \\
28.0 \\
28.0 \\
26.0\end{array}$ & $\begin{array}{l}25.0 \\
26.0 \\
26.5 \\
26.0 \\
25.0\end{array}$ & $\begin{array}{l}26.5 \\
26.5 \\
28.0 \\
28.0 \\
28.0\end{array}$ & $\begin{array}{l}25.5 \\
26.0 \\
26.5 \\
26.5 \\
27.0\end{array}$ & $\begin{array}{l}25.0 \\
25.5 \\
25.5 \\
26.0 \\
26.5\end{array}$ & $\begin{array}{l}22.0 \\
25.0 \\
25.5 \\
25.5 \\
25.5\end{array}$ & $\begin{array}{l}24.5 \\
24.5 \\
24.0 \\
24.0 \\
24.0\end{array}$ & $\begin{array}{l}24.5 \\
24.0 \\
23.5 \\
23.5 \\
23.5\end{array}$ \\
\hline $\begin{array}{l}16 \\
17 \\
18 \\
19 \\
20\end{array}$ & $\begin{array}{l}18.0 \\
18.0 \\
21.0 \\
20.0 \\
20.5\end{array}$ & $\begin{array}{l}15.0 \\
16.5 \\
17.0 \\
17.0 \\
16.5\end{array}$ & $\begin{array}{l}25.5 \\
24.5 \\
24.0 \\
25.5 \\
26.5\end{array}$ & $\begin{array}{l}26.5 \\
23.5 \\
22.0 \\
23.0 \\
24.0\end{array}$ & $\begin{array}{l}26.0 \\
28.5 \\
29.0 \\
29.5 \\
29.5\end{array}$ & $\begin{array}{l}25.0 \\
26.0 \\
27.0 \\
28.5 \\
28.0\end{array}$ & $\begin{array}{l}28.5 \\
28.5 \\
28.0 \\
28.0 \\
27.0\end{array}$ & $\begin{array}{l}27.0 \\
26.5 \\
26.0 \\
26.5 \\
27.0\end{array}$ & $\begin{array}{l}28.0 \\
28.0 \\
28.0 \\
28.0 \\
28.5\end{array}$ & $\begin{array}{l}26.0 \\
26.5 \\
26.5 \\
26.5 \\
27.0\end{array}$ & $\begin{array}{l}24.0 \\
24.5 \\
24.5 \\
24.5 \\
24.5\end{array}$ & $\begin{array}{l}24.0 \\
24.0 \\
24.5 \\
24.5 \\
23.5\end{array}$ \\
\hline $\begin{array}{l}21 \\
22 \\
23 \\
24 \\
25\end{array}$ & $\begin{array}{l}21.0 \\
20.5 \\
21.5 \\
21.5 \\
21.5\end{array}$ & $\begin{array}{l}18.5 \\
18.0 \\
19.0 \\
20.0 \\
20.0\end{array}$ & $\begin{array}{l}27.0 \\
28.0 \\
29.0 \\
29.5 \\
29.5\end{array}$ & $\begin{array}{l}25.5 \\
24.5 \\
25.5 \\
27.0 \\
27.0\end{array}$ & $\begin{array}{l}28.5 \\
28.5 \\
28.0 \\
27.0 \\
26.5\end{array}$ & $\begin{array}{l}27.0 \\
27.0 \\
27.0 \\
26.0 \\
26.0\end{array}$ & $\begin{array}{l}27.0 \\
25.5 \\
25.5 \\
28.0 \\
28.0\end{array}$ & $\begin{array}{l}25.5 \\
24.5 \\
24.5 \\
25.5 \\
26.5\end{array}$ & $\begin{array}{l}29.5 \\
29.5 \\
28.5 \\
28.0 \\
26.5\end{array}$ & $\begin{array}{l}28.0 \\
28.5 \\
28.0 \\
26.5 \\
26.0\end{array}$ & $\begin{array}{l}23.5 \\
24.0 \\
24.5 \\
24.5 \\
24.5\end{array}$ & $\begin{array}{l}23.0 \\
23.5 \\
24.0 \\
24.5 \\
24.5\end{array}$ \\
\hline $\begin{array}{l}26 \\
27 \\
28 \\
29 \\
30 \\
31\end{array}$ & $\begin{array}{r}21.0 \\
21.5 \\
21.0 \\
22.0 \\
24.5 \\
. .-\end{array}$ & $\begin{array}{c}20.5 \\
20.0 \\
20.5 \\
20.5 \\
22.0 \\
-.\end{array}$ & $\begin{array}{l}29.0 \\
28.0 \\
28.0 \\
26.5 \\
25.5 \\
26.5\end{array}$ & $\begin{array}{l}28.0 \\
25.5 \\
26.0 \\
24.5 \\
22.0 \\
23.5\end{array}$ & $\begin{array}{r}26.5 \\
26.0 \\
26.0 \\
24.5 \\
25.5 \\
=-\end{array}$ & $\begin{array}{r}25.5 \\
25.5 \\
24.5 \\
23.5 \\
24.0 \\
. .-\end{array}$ & $\begin{array}{l}27.0 \\
26.5 \\
28.0 \\
29.0 \\
29.0 \\
28.5\end{array}$ & $\begin{array}{l}26.5 \\
26.5 \\
26.5 \\
28.0 \\
28.0 \\
28.0\end{array}$ & $\begin{array}{l}26.5 \\
26.0 \\
25.5 \\
26.0 \\
26.0 \\
26.0\end{array}$ & $\begin{array}{l}26.0 \\
25.0 \\
25.0 \\
25.5 \\
25.5 \\
26.0\end{array}$ & $\begin{array}{r}24.5 \\
24.5 \\
24.0 \\
22.0 \\
20.0 \\
-.\end{array}$ & $\begin{array}{r}24.5 \\
24.0 \\
22.0 \\
20.0 \\
19.0 \\
=-\end{array}$ \\
\hline AVG & 18.0 & 16.5 & 25.5 & 24.0 & 27.0 & 25.5 & 27.5 & 26.5 & 27.0 & 26.0 & 24.5 & 24.0 \\
\hline
\end{tabular}


02081141 ROANOKE RIVER NEAR SANS SOUCI, N. C.

LOCATION.-Lat $35^{\circ} 53^{\prime} 51^{\prime \prime}$, long $76^{\circ} 43^{\circ} 49^{\prime \prime}$, Bertie County, at bridge on State Highway $45,2.4 \mathrm{miles}$ upstream from Conaby Creek, 4 miles southeast of Sans Souct, and 4.1 miles upstream from mouth.

DRAINAGE AREA. $-9,330$ sq mi, approximately.

PERIOD OF RECORD.--Chemical analyses: October 1967 to September 1969 (partial-record), October 1969 to September 1970.

REMARK. - The second of two samples collected at the same time is a field determination.

CHEMICAL ANALYSES, WATER YEAR OCTOBER 1969 TO SEPTEMBER 1970

\begin{tabular}{|c|c|c|c|c|c|c|c|c|c|c|c|}
\hline OATE & TIME & $\begin{array}{l}\text { SILICA } \\
\text { (SIO2) } \\
\text { I } A G / L)\end{array}$ & $\begin{array}{l}\text { OIS- } \\
\text { SOLVED } \\
\text { IRON } \\
\text { (FE) } \\
\text { (UG/L) }\end{array}$ & $\begin{array}{l}\text { CAL- } \\
\text { CIUA } \\
\text { (CA) } \\
\text { ( } \mathrm{AG} / \mathrm{L})\end{array}$ & $\begin{array}{c}\text { MAG- } \\
\text { NE- } \\
\text { SIUM } \\
(M G) \\
(M G / L)\end{array}$ & $\begin{array}{l}\text { SOOI UM } \\
\text { (NA) } \\
\text { (MG/L) }\end{array}$ & $\begin{array}{l}\text { PO- } \\
\text { TAS- } \\
\text { SIUM } \\
\text { (K) } \\
\text { (MG/L) }\end{array}$ & $\begin{array}{l}\text { BICAR- } \\
\text { BONATE } \\
\text { (HCO3) } \\
\text { (HG/L) }\end{array}$ & $\begin{array}{l}\text { CAR- } \\
\text { BONATE } \\
(\text { COB) } \\
(M G / L)\end{array}$ & $\begin{array}{l}\text { SULFATE } \\
\text { (SO4) } \\
\text { (MG/L) }\end{array}$ & $\begin{array}{l}\text { CHLO- } \\
\text { RIDE } \\
(C L) \\
(M G / L)\end{array}$ \\
\hline $\mathrm{OCT}_{28}$ & & & & & & & & & & & \\
\hline $\begin{array}{l}28 \ldots \\
28 . \ldots\end{array}$ & $\begin{array}{l}1325 \\
1325\end{array}$ & $=$ & $\Rightarrow$ & $\because$ & $\overline{-}$ & $\overline{=}$ & $\bar{E}$ & $\overline{48}$ & $=$ & $=$ & $\overline{-}$ \\
\hline Nov. & & & & & & & & & & & \\
\hline $25 \ldots$ & 1400 & - & -- & -- & -- & -- & - & -- & - & -- & - \\
\hline $\begin{array}{r}25 \ldots . . \\
D E C .\end{array}$ & 1400 & - & -- & -- & -- & - & - & 52 & - & -- & - \\
\hline $\begin{array}{l}18 \ldots \\
18 \ldots\end{array}$ & $\begin{array}{l}1410 \\
1410\end{array}$ & 7.6 & 160 & 7.9 & 2.3 & 11 & 2.7 & $\begin{array}{l}38 \\
36\end{array}$ & $\begin{array}{r}0 \\
--\end{array}$ & 6.8 & 11 \\
\hline $\begin{array}{c}\text { FEB. } \\
25 \ldots \\
\text { APR. }\end{array}$ & 0810 & 6.2 & 38 & 7.4 & 2.6 & 10 & 1.9 & 38 & 0 & 9.0 & B.7 \\
\hline$\underset{\text { JUNE }}{22 \ldots}$ & 1130 & - & -- & - & -- & - & - & - & -- & -- & -- \\
\hline $17 \ldots$ & 1200 & -- & -- & -- & -- & - & - & - & -- & - & -- \\
\hline $\begin{array}{l}\text { Julr } \\
21 \ldots . . \\
\text { AUG. }\end{array}$ & 1400 & 7.3 & 214 & 9.0 & 2.8 & 15 & 2.6 & 46 & 0 & 13 & 13 \\
\hline $\begin{array}{l}19 \ldots . \\
\text { SEPT. }\end{array}$ & 1045 & - & -- & -- & -- & -- & - & - & -- & -- & - \\
\hline $23 \ldots$ & 1130 & -- & -- & -- & -- & -- & - & -- & -- & - & - \\
\hline
\end{tabular}

\begin{tabular}{|c|c|c|c|c|c|c|c|c|c|c|}
\hline DATE & $\begin{array}{l}\text { ELUO- } \\
\text { RIDE } \\
\text { If } \\
\text { I MG } \\
\text { MG }\end{array}$ & $\begin{array}{c}\text { NI RRATE } \\
\text { (N03) } \\
\text { (HG/L) }\end{array}$ & $\begin{array}{l}\text { ORTHO } \\
\text { PPHS- } \\
\text { PHATE } \\
\text { PHO4) } \\
\text { (PG/L) }\end{array}$ & $\begin{array}{l}\text { TOTAL } \\
\text { PPIS - } \\
\text { PHOR } \\
\text { PHP } \\
\text { IP) } \\
\text { MMG/L }\end{array}$ & $\begin{array}{l}\text { OIS- } \\
\text { SOLVD } \\
\text { SOL IDS } \\
\text { RESI } \\
\text { OUE AT } \\
180 \text { CI } \\
\text { (MG/L) }\end{array}$ & 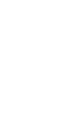 & $\begin{array}{c}\text { DIS- } \\
\text { SOLVED } \\
\text { SOLIDS } \\
\text { TroNs } \\
\text { PER } \\
\text { OAYY }\end{array}$ & 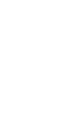 & $\begin{array}{l}\text { NON- } \\
\text { CAR- } \\
\text { CARATE } \\
\text { HARD- } \\
\text { NESS } \\
\text { NESS } \\
\text { MGG/LI }\end{array}$ & $\begin{array}{l}\text { SOOLU UM } \\
\text { AUD- } \\
\text { SORP } \\
\text { IION } \\
\text { RAIIIO }\end{array}$ \\
\hline 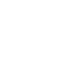 & $=$ & $=$ & $=$ & .02 & $\overline{-}$ & $=$ & -- & $\because$ & -- & $=$ \\
\hline $\begin{array}{r}N_{250}^{25} \ldots \\
{ }_{25} \ldots\end{array}$ & $=$ & $=$ & -- & .05 & $=$ & $=$ & $=$ & $=$ & $=$ & $=$ \\
\hline $\begin{array}{c}\text { OEC. } \\
18 . . . \\
18 \ldots\end{array}$ & $\therefore 2$ & $\therefore$ & .00 & $=$ & $\underline{77}$ & .10 & 26.0 & 29 & 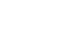 & $\therefore 9$ \\
\hline & .1 & .0 & .01 & -- & 71 & .10 & -- & 29 & 0 & .8 \\
\hline & - & -- & - & .05 & - & - & -- & -- & -- & - \\
\hline & - & -- & -- & .02 & -- & -- & -- & -- & -. & -- \\
\hline & . & .6 & -. & -- & 90 & .12 & -- & 34 & 0 & 1.1 \\
\hline & -- & -- & -- & .04 & -- & -- & -- & -- & -. & -- \\
\hline & -. & -- & -- & .01 & -_ & -- & -- & -. & -- & -- \\
\hline
\end{tabular}


ROANOKE RIVER BASIN

02081141 ROANOKE RIVER NEAR SANS SOUCI, N, C.--Continued

CHEMICAL ANALYSES, WATER YEAR OCTOBER 1969 TO SEPTEMBER 1970

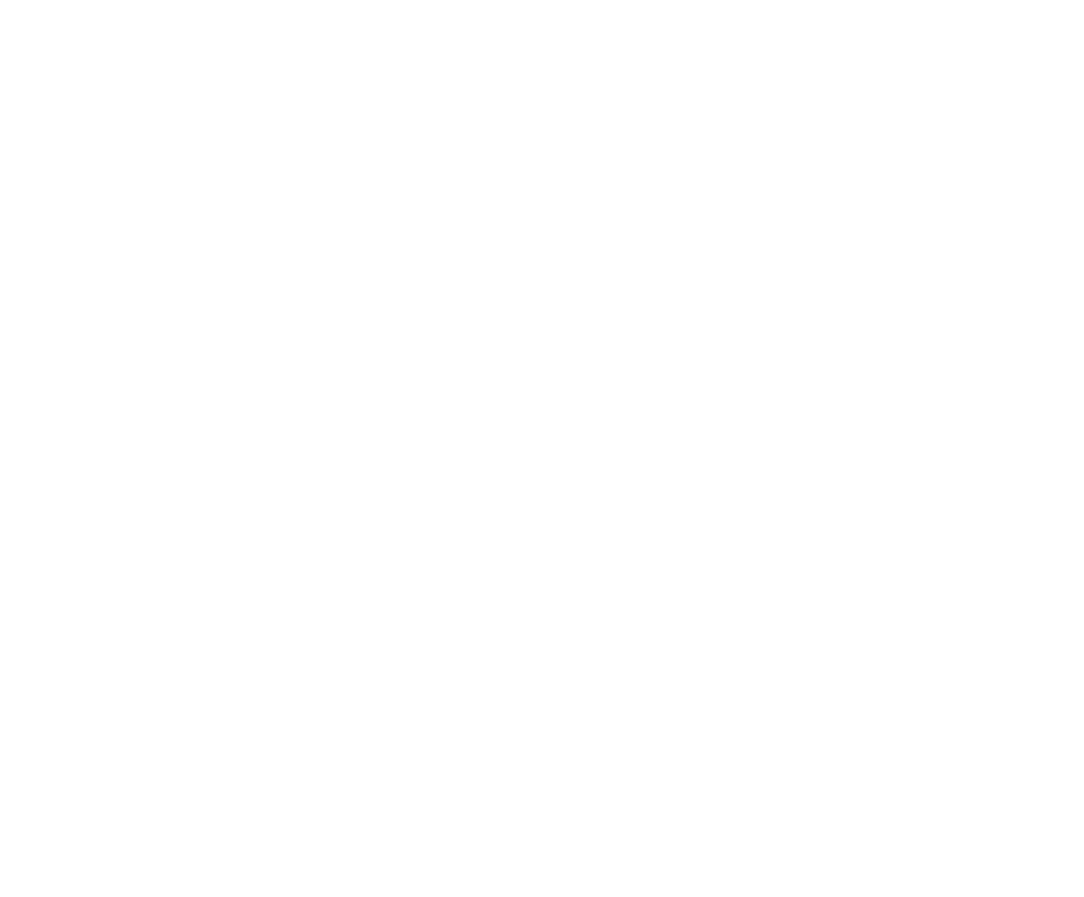

\begin{tabular}{|c|c|c|c|c|c|c|c|c|c|c|}
\hline 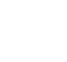 & $\overline{-}$ & -- & $\overline{-}$ & $7 .-6$ & -- & 1600 & $\overline{180}$ & $7 .-\overline{7.4}$ & 15.0 & $=$ \\
\hline $\begin{array}{r}25 . \\
{ }_{250}^{25} .\end{array}$ & $\overline{-}$ & $\overline{-}$ & $=$ & $\sqrt{7.5}$ & $=$ & $15-$ & 77 & $\overrightarrow{2}$ & $4=$ & - \\
\hline $\begin{array}{c}25 \ldots \cdot \\
\mathrm{DEC}\end{array}$ & & -- & & & $\cdots$ & & & & & \\
\hline $\begin{array}{l}18 \ldots \ldots \\
188 .\end{array}$ & $\overline{--}$ & $\overline{-}$ & $\overline{--}$ & $9 . \overline{6}$ & $=$ & 50 & $\begin{array}{l}\begin{array}{l}100 \\
125\end{array} \\
125\end{array}$ & $\begin{array}{l}.8 .8 \\
6.6\end{array}$ & 9.0 & -- \\
\hline $\begin{array}{l}\text { JAN. } \\
28\end{array}$ & -- & - & - & $\overline{13.4}$ & 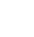 & $=$ & 150 & $\overline{7.3}$ & 2.0 & -- \\
\hline 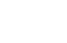 & $\ldots$ & -- & -- & . & - & -- & 43 & 6.8 & 70 & 15 \\
\hline 250. & - & -- & -- & 10.9 & $\ldots$ & -- & iir & 7.3 & 7.0 & 13 \\
\hline $25 \ldots$ & -- & $=$ & -- & 11.0 & -- & $\overline{44}$ & $\sqrt{135}$ & $\overrightarrow{7.4}$ & $\begin{array}{l}11: 0 \\
11: 0\end{array}$ & -- \\
\hline $22 \ldots$ & $z$ & $=$ & $=$ & $\sqrt{5.3}$ & $=$ & $\overline{56}$ & $\overline{148}$ & $0-\overline{6}$ & $18 \overline{-0}$ & $=-$ \\
\hline Mar & -- & -- & -- & - & 8.2 & --- & - & -- & -- & \\
\hline $27 \%:$ & -- & -- & - & 5.0 & $\because$ & - & 142 & 7.0 & 24.0 & -- \\
\hline $17 \ldots$ & $\overline{-}$ & $\because=$ & $=$ & 5 & 3.6 & $\because$ & $\overline{160}$ & $\overline{.7}$ & $28 . \overline{0}$ & $=$ \\
\hline $\operatorname{sir}_{21 \ldots} \ldots$ & 40 & 00 & 0 & -- & 8.6 & -- & 145 & 69 & 28.0 & 30 \\
\hline 211. & -- & - & -- & 5.2 & -0 & 84 & 160 & 6.8 & 28.0 & -- \\
\hline $19 \%$ & $\overline{--}$ & $\because-$ & - & $-\overrightarrow{5}$ & - & בים & $\overline{150}$ & $\because$ & 26.5 & $=$ \\
\hline SEPT: & & & & -- & -- & -- & -- & $\ldots$ & 27 & \\
\hline $23 \ldots$ & $=$ & -- & - & $6 . \overline{5}$ & $=$ & 382 & 140 & 7.2 & ${ }_{27}^{27.0}$ & \\
\hline
\end{tabular}


02084472 PAML ICO RIVER AT RASHINGTON, N, C.

LOCATION, --Lat $35^{\circ} 32^{\prime} 33^{\prime \prime}$, long $77^{\circ} 03^{\prime} 43^{\prime \prime}$, Bequfort County, at bridge on U.S. Highway 17 at Washington, and 0.7 mile downstream from Kennedy Creek.

DRAINAGE AREA. $--3,080 \mathrm{sq} \mathrm{mi}$, approximately.

PERIOD OF RECORD. --Chemical analyses: October 1961 to September 1986, January to April 1967, October 1967 to September 1969 (partial-record), October 1969 to September 1970.

Vater temperatures: October 1961 to September 1967.

EXTREMES. -1961-67:

Chloride: Maximum, 7,380 mg/1 Jan, 20 (B), 1966; minimum, $4.2 \mathrm{mg} / 1$ July 1 (T), 1962.

Specific conductance: Maximum daily, 20,400 micromhos Jan. 20 (B), 1966; mintmum daily, 40 micromhos July 31 (B), 1965 .

Water temperatures: Maximum, $32.0^{\circ} \mathrm{C}$ July 5 ( $\mathrm{T}$ ), 1966 ; minimum, $0.5^{\circ} \mathrm{C} \mathrm{Dec}, 21$ ( $\mathrm{T}$ ), 1963, Jan. 31 (B) and Feb. 1 ( T), 1966 .

REMARKS.--Salinity station prior to October 1967; top (T) and bottom (B) samples were collected once daily. The second of two samples collected at the same time is a field determination.

CHEMICAL ANALYSFS, WATER YEAR DCTMBFR 1969 TO SEPTEMBED 1970

\begin{tabular}{|c|c|c|c|c|c|c|c|c|c|c|}
\hline QATE & TIME & $\begin{array}{l}\text { SILICA } \\
\text { ISINZ) } \\
\text { IMGILI }\end{array}$ & $\begin{array}{l}\text { DIS- } \\
\text { SCLVED } \\
\text { IRTN } \\
\text { IFFI } \\
\text { (UG IL) }\end{array}$ & $\begin{array}{l}C A L- \\
C(U M \\
(C A) \\
(M G / L)\end{array}$ & $\begin{array}{c}M A G- \\
A F- \\
S I U M \\
(M G) \\
\{M G / L\}\end{array}$ & $\begin{array}{l}\text { SOOI UM } \\
\text { (NA) } \\
(M G / L)\end{array}$ & $\begin{array}{l}\text { PO- } \\
\text { TAS- } \\
\text { SIUM } \\
\text { (K) } \\
\text { (MG/L) }\end{array}$ & $\begin{array}{l}\text { BICAR- } \\
\text { BONATE } \\
(H C Q 3) \\
(M G / L)\end{array}$ & $\begin{array}{l}\text { CAR - } \\
\text { BONATE } \\
(C O 3) \\
(M G / L)\end{array}$ & $\begin{array}{l}\text { SULFATE } \\
\text { (SO4) } \\
\text { (MG/L) }\end{array}$ \\
\hline 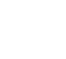 & $11 \mathrm{co}$ & -- & - & -- & -- & -- & - & 44 & -- & -- \\
\hline$\underset{\text { JUNE }}{18 . .}$ & 1145 & 11 & 130 & 36 & 76 & 720 & -- & 29 & c & -- \\
\hline JULY & 0815 & 13 & sn & 7.5 & 4.9 & 10 & 3.0 & 29 & 0 & 15 \\
\hline $21 \ldots$ & $15: 5$ & 0.0 & 171 & 5.3 & 2.0 & 7.7 & 2.5 & 16 & 0 & 9.6 \\
\hline
\end{tabular}

\begin{tabular}{|c|c|c|c|c|c|c|c|c|c|}
\hline DA TE & $\begin{array}{l}\text { CHL } \mathrm{O}- \\
\text { RIDE } \\
(\mathrm{CL} \mid \\
|\mathrm{MG} / \mathrm{L}|\end{array}$ & $\begin{array}{l}\text { FLUO- } \\
\text { RIDE } \\
\text { (F) } \\
\text { (MG/L) }\end{array}$ & $\begin{array}{l}\text { NITRATE } \\
\text { (NOZ) } \\
\text { (MGIL) }\end{array}$ & $\begin{array}{l}\text { CRTHO } \\
\text { PHOS- } \\
\text { PHATE } \\
\text { (PTG) } \\
\text { (NG/L) }\end{array}$ & $\begin{array}{l}\text { OIS- } \\
\text { SOLVED } \\
\text { SOLI IS } \\
\text { IRESI- } \\
\text { DUE AT } \\
\text { IRA CI } \\
\text { IMGILI }\end{array}$ & $\begin{array}{l}\text { DIS- } \\
\text { SOLVED } \\
\text { SULIDS } \\
\text { TTONS } \\
\text { PFR } \\
\text { AC-FTI }\end{array}$ & $\begin{array}{l}\text { HARC- } \\
\text { NESS } \\
(C A, M G) \\
(M G / L)\end{array}$ & $\begin{array}{l}\text { NON- } \\
\text { CAR- } \\
\text { BONATE } \\
\text { HARD- } \\
\text { NFSS } \\
\text { (MG/LI) }\end{array}$ & $\begin{array}{l}\text { SODIUM } \\
\triangle O- \\
\text { SORP- } \\
\text { TION } \\
\text { RATIO }\end{array}$ \\
\hline $\begin{array}{l}\text { OCT. } \\
2 R . . \\
\text { OEC. }\end{array}$ & -- & $\cdots$ & -- & -- & -- & - & -- & -- & -- \\
\hline $\begin{array}{l}\text { lR.... } \\
\text { JUVF }\end{array}$ & $144^{\circ}$ & .4 & $\cdots$ & - ${ }^{n}$ & 2600 & 3.54 & $\cdots$ & -- & 16 \\
\hline $\begin{array}{c}17 \ldots \\
\text { JuL }{ }^{17} \\
21 \ldots\end{array}$ & $1 \hat{~}$ & .1 & $\begin{array}{l}2.5 \\
1.4\end{array}$ & .20 & $1 n 7$ & $\begin{array}{l}.15 \\
.09\end{array}$ & 39 & 20 & 1.3 \\
\hline
\end{tabular}

\begin{tabular}{|c|c|c|c|c|c|c|c|c|c|c|}
\hline DATF & $\begin{array}{l}\text { PERCENT } \\
\text { SDDIUMY }\end{array}$ & 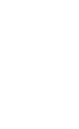 & $\begin{array}{l}\text { PHENCLS } \\
\text { IUG/LI, }\end{array}$ & 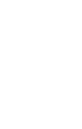 & $\begin{array}{l}\text { TUR- } \\
\text { RIN } \\
1 \text { IY } \\
\text { (JTUI }\end{array}$ & 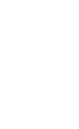 & 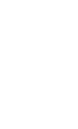 & $\begin{array}{l}\text { TOT AL } \\
\text { CHRO- } \\
\text { YIUM } \\
\text { ICR } \\
\text { IUG }\end{array}$ & $\begin{array}{l}\text { COPPER } \\
\text { ICU1 } \\
1 \cup 6 / 4\end{array}$ & $\begin{array}{l}\text { LEAO } \\
\text { IPBI } \\
\text { (UG/L) }\end{array}$ \\
\hline 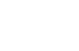 & -- & -- & -- & -- & -- & -- & 36 & -. & -- & -- \\
\hline $25 \%$ & -- & -- & -- & -- & -- & -- & - & -- & -- & -- \\
\hline $18 \ldots$ & 30 & -- & -- & $.4 \Gamma$ & $-\cdot$ & -- & 24 & -- & -- & -- \\
\hline $\begin{array}{lll}27 \\
\in \in P\end{array}$ & -- & -- & -- & -- & -- & -- & -- & -- & -- & -- \\
\hline $24 \ldots$ & -- & $=-$ & -- & -: & $=$ & $=$ & z & $=$ & $\because$ & $=$ \\
\hline $\begin{array}{c}\text { Mar. } \\
22 . .\end{array}$ & -- & -- & -- & -- & .. & -- & -- & -- & -- & -- \\
\hline $2 \rightarrow \cdots$ & -- & -- & -- & -- & -- & -- & -- & -- & -- & -- \\
\hline $\begin{array}{l}27 \ldots \\
27 \%\end{array}$ & $\because$ & $\because$ & $\because$ & $=$ & $\because$ & $=$ & $=$ & $\because$ & $\because$ & $\because$ \\
\hline 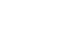 & 49 & $=$ & $\because$ & $\because$ & $=$ & -- & $\begin{array}{l}24 \\
-3\end{array}$ & -- & $=$ & $=$ \\
\hline JuYY & 40 & $\therefore$ & 0 & .04 & 25 & 70 & 13 & 0 & 0 & 0 \\
\hline 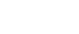 & & & & & $\cdots$ & -- & 16 & -- & -- & -- \\
\hline $\begin{array}{c}19 \ldots \\
S P P Y\end{array}$ & -- & -- & -- & -- & -- & -- & -- & -- & -. & $\cdots$ \\
\hline $2 \geqslant \cdots$ & $\because$ & -- & $=$ & - & -- & $=$ & -- & -- & -- & -: \\
\hline
\end{tabular}


02084472 PAMLICO RIVER AT MASHINGTON, N. C.-mContinued

CHEMICAL ANALYSES, WATER YEAR OCTDBER 1960 TO SEPTEMBER 1970

\begin{tabular}{|c|c|c|c|c|c|c|c|c|c|c|}
\hline DATE & $\begin{array}{l}\text { ZINC } \\
\text { (ZN) } \\
\text { (UG/L) }\end{array}$ & $\begin{array}{l}\text { CYANIDE } \\
\text { (CN) } \\
\text { (MG/L) }\end{array}$ & $\begin{array}{l}\text { CAD- } \\
\text { MIUM } \\
\text { (CD) } \\
\text { (UG/L) }\end{array}$ & $\begin{array}{l}\text { DIS- } \\
\text { SOLVFC } \\
\text { OXYGEN } \\
\text { (MG/L) }\end{array}$ & $\begin{array}{l}\text { TOTAL } \\
\text { AETA } \\
\text { (PCAL) }\end{array}$ & $\begin{array}{l}\text { FECAL } \\
\text { COLI- } \\
\text { FORN } \\
\text { (CDL. } \\
\text { PER } \\
100 \mathrm{ML} \text { ) }\end{array}$ & $\begin{array}{l}\text { SPECI- } \\
\text { FIC } \\
\text { COND- } \\
\text { UCTANCF } \\
\text { (MICRO- } \\
\text { MHOSI }\end{array}$ & $\begin{array}{c}\text { PH } \\
\text { (UNITS) }\end{array}$ & $\begin{array}{l}\text { TFMP- } \\
\text { ERATURE } \\
\text { (DEG CI }\end{array}$ & $\begin{array}{l}\text { COLOR } \\
\text { (PLAT- } \\
\text { INUM- } \\
\text { COBALT } \\
\text { UNITSI }\end{array}$ \\
\hline $\begin{array}{l}\text { CC, . } \\
28 . . .\end{array}$ & -- & -. & $\cdots$ & 0.1 & -- & 4300 & 4500 & 6.9 & 17.0 & -- \\
\hline $\begin{array}{l}\text { NOV. } \\
25 . . . \\
\text { DEC. }\end{array}$ & -- & -- & -- & B. 5 & -- & 400 & 8500 & 6.1 & $1 c .0$ & $\cdots$ \\
\hline JAN. & -- & -- & -- & 10.2 & -- & 700 & $350 \mathrm{n}$ & 6.8 & 5.0 & 40 \\
\hline $\begin{array}{l}27 . . . \\
F E R .\end{array}$ & - & -- & -- & 12.1 & $\cdots$ & -- & 10400 & 6.1 & 4.0 & -- \\
\hline $\begin{array}{l}24 \ldots \ldots \\
24 \ldots\end{array}$ & $\overline{-}$ & $=$ & 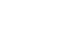 & 8.9 & 5.3 & $=$ & 63 & $6 . \overline{8}$ & 3.0 & $=$ \\
\hline $\begin{array}{l}\text { MAR: } \\
24 \ldots .\end{array}$ & - & -- & -- & 10.8 & -- & -- & 80 & 7.0 & 12.0 & $\cdots$ \\
\hline${ }_{M A Y}^{22} \cdots$ & - & - & -- & 7.3 & -- & $106 n$ & 73 & 6.5 & 18.0 & -- \\
\hline $27 \ldots$ & -- & -- & - & -- & 11 & -- & -- & -- & 24.5 & -- \\
\hline JUNE & -- & -- & -- & 7.0 & -- & $20 \mathrm{C}$ & $1 B C$ & 7.2 & 24.5 & $=$ \\
\hline $\begin{array}{l}17 \ldots \\
17 \ldots\end{array}$ & $=$ & $=$ & -- & $7 . \overline{6}$ & -- & 560 & $\begin{array}{l}202 \\
260\end{array}$ & $\begin{array}{l}6.4 \\
7.3\end{array}$ & $\begin{array}{l}26.5 \\
26.5\end{array}$ & $\begin{array}{l}25 \\
---\end{array}$ \\
\hline $\begin{array}{l}\text { JULY } \\
21 \ldots \\
21 \ldots\end{array}$ & 10 & .00 & $\begin{array}{r}0 \\
--\end{array}$ & 5.7 & 11 & 380 & $\begin{array}{r}86 \\
1000\end{array}$ & $\begin{array}{l}6.5 \\
6.3\end{array}$ & $\begin{array}{l}28.0 \\
28.0\end{array}$ & $\begin{array}{l}30 \\
--\end{array}$ \\
\hline $\begin{array}{l}\text { AUG. } \\
19 . . . \\
\text { SEPT. }\end{array}$ & -- & -- & -- & 7.0 & -- & 1820 & 130 & 6.9 & 27.0 & - \\
\hline $\begin{array}{l}22 \ldots \\
22 \ldots\end{array}$ & -- & $=-$ & $=$ & 5.8 & $\begin{array}{l}5.6 \\
-.-\end{array}$ & 1300 & $65 \overline{0}$ & 7.0 & 29.5 & $=$ \\
\hline
\end{tabular}

\begin{tabular}{|c|c|c|c|c|c|c|c|}
\hline & DOT & DDE & DOD & $\begin{array}{l}\text { CHLOR- } \\
\text { DANE }\end{array}$ & $\begin{array}{l}\text { NI- } \\
\text { ELORIN }\end{array}$ & ENDRIN & $\begin{array}{l}\text { HEPTA- } \\
\text { CHLOR }\end{array}$ \\
\hline DATE & (UG/L) & $(U G / L)$ & $(U G / L)$ & $(0 G / L)$ & $(U G / L)$ & (UG/L) & (UG/L) \\
\hline $\begin{array}{l}\text { IULY } \\
21 \ldots . .\end{array}$ & $<.01$ & .00 & .00 & $<.01$ & .00 & $<.01$ & .00 \\
\hline
\end{tabular}

\begin{tabular}{|c|c|c|c|c|c|c|}
\hline DATE & $\begin{array}{l}\text { HEPTA- } \\
\text { CHL DR } \\
\text { EPOXIDE } \\
\text { (UG/L) }\end{array}$ & $\begin{array}{l}\text { AL DRIN } \\
(U G / L)\end{array}$ & $\begin{array}{l}\text { LINOANE } \\
\text { IUGILI }\end{array}$ & $\begin{array}{l}\text { ENDJ- } \\
\text { SULFAN } \\
\text { (UG/L) }\end{array}$ & $\begin{array}{l}\text { TOX- } \\
\text { APHENE } \\
\text { (UG/L) }\end{array}$ & $\begin{array}{l}\text { METH- } \\
\text { OXY- } \\
\text { CHLOR } \\
\text { (UG/LI }\end{array}$ \\
\hline UL Y & & & & & & \\
\hline $21 \ldots$ & .00 & .00 & .00 & ח & $<.25$ & $<.02$ \\
\hline
\end{tabular}

02084540 DURHAM CREEK AT EDWARD, N. C.

LOCATION.,-Lat $35^{\circ} 19^{\prime} 25^{\prime \prime}$, long $76^{\circ} 52^{\prime} 26^{\prime \prime}$, Beaufort County, temperature recorder at gaging station on left bank 5 ft downstream from bridge on Secondary Road 1949, at Edward, and 6.8 miles upstream from mouth.

DRA INAGE AREA, --21 sq mi, approximateIy.

PERIOD OF RECORD. -.-Water temperatures: October 1965 to September 1970.

EXTR EMES - - 1969-70:

Water temperatures: Yaximum, $28.5^{\circ} \mathrm{C}$ June 21 ; minimum, freezing point on many days in January.

period of record:

Water temperatures: Maximum, $31.0^{\circ} \mathrm{C} J u l y ~ 13,1966$; minimus, freezing point on many days in January 1970. 
PAMLICO RIVER BASIN

02084540 DURHAM CREEK AT EDWARD, N. C..-Continued

TEMPERATURE (') OF WATER, WATER YEAR OCTOBER 1969 TO SEPTEMBER 1970

\begin{tabular}{|c|c|c|c|c|c|c|c|c|c|c|c|c|}
\hline \multirow[t]{2}{*}{ DAY } & \multicolumn{2}{|c|}{ OCT } & \multicolumn{2}{|c|}{ NOV } & \multicolumn{2}{|c|}{ DEC } & \multicolumn{2}{|c|}{ JAN } & \multicolumn{2}{|c|}{ FEB } & \multicolumn{2}{|c|}{ MAR } \\
\hline & $\operatorname{MAX}$ & MIN & MAX & MIN & MAX & MIN & $\max$ & MIN & $\max$ & MIN & $\max$ & MIN \\
\hline $\begin{array}{l}1 \\
2 \\
3 \\
4 \\
5\end{array}$ & $\begin{array}{l}19.0 \\
19.5 \\
20.5 \\
20.5 \\
20.0\end{array}$ & $\begin{array}{l}17.0 \\
18.5 \\
19.5 \\
20.0 \\
19.0\end{array}$ & $\begin{array}{l}14.5 \\
16.5 \\
16.5 \\
16.5 \\
15.5\end{array}$ & $\begin{array}{l}14.0 \\
14.5 \\
16.5 \\
15.5 \\
12.0\end{array}$ & $\begin{array}{l}8.0 \\
6.5 \\
5.5 \\
5.0 \\
4.0\end{array}$ & $\begin{array}{l}6.5 \\
5.5 \\
5.0 \\
4.0 \\
3.5\end{array}$ & $\begin{array}{l}= \\
=- \\
=-\end{array}$ & $\begin{array}{l}=- \\
=- \\
=- \\
--\end{array}$ & $\begin{array}{r}4.5 \\
8.5 \\
10.0 \\
10.0 \\
6.0\end{array}$ & $\begin{array}{l}3.0 \\
4.5 \\
8.5 \\
6.0 \\
4.0\end{array}$ & $\begin{array}{r}8.0 \\
8.0 \\
10.0 \\
10.5 \\
11.0\end{array}$ & $\begin{array}{r}5.5 \\
7.0 \\
8.0 \\
9.5 \\
10.5\end{array}$ \\
\hline $\begin{array}{r}6 \\
7 \\
8 \\
9 \\
10\end{array}$ & $\begin{array}{l}19.0 \\
18.5 \\
19.0 \\
19.5 \\
18.5\end{array}$ & $\begin{array}{l}18.5 \\
18.0 \\
18.5 \\
18.5 \\
18.0\end{array}$ & $\begin{array}{l}12.0 \\
10.5 \\
10.0 \\
10.0 \\
10.5\end{array}$ & $\begin{array}{r}10.5 \\
10.0 \\
9.5 \\
10.0 \\
10.0\end{array}$ & $\begin{array}{r}3.5 \\
5.0 \\
7.0 \\
8.0 \\
10.5\end{array}$ & $\begin{array}{l}3.0 \\
3.0 \\
5.0 \\
7.0 \\
8.0\end{array}$ & $\begin{array}{l}=-. \\
3.5 \\
3.5 \\
0.5 \\
0.0\end{array}$ & $\begin{array}{l}-0 \\
3.0 \\
1.0 \\
0.0 \\
0.0\end{array}$ & $\begin{array}{l}4.0 \\
5.0 \\
5.0 \\
6.0 \\
7.0\end{array}$ & $\begin{array}{l}3.5 \\
4.0 \\
4.5 \\
5.0 \\
6.0\end{array}$ & $\begin{array}{l}11.0 \\
10.0 \\
11.5 \\
11.5 \\
10.0\end{array}$ & $\begin{array}{r}10.0 \\
7.0 \\
8.0 \\
10.0 \\
8.0\end{array}$ \\
\hline $\begin{array}{l}11 \\
12 \\
13 \\
14 \\
15\end{array}$ & $\begin{array}{l}19.0 \\
19.5 \\
19.5 \\
19.5 \\
19.5\end{array}$ & $\begin{array}{l}18.5 \\
18.0 \\
19.0 \\
19.5 \\
18.5\end{array}$ & $\begin{array}{l}10.5 \\
10.5 \\
10.5 \\
11.0 \\
10.5\end{array}$ & $\begin{array}{r}10.0 \\
10.5 \\
10.5 \\
10.5 \\
8.0\end{array}$ & $\begin{array}{r}10.5 \\
10.5 \\
9.0 \\
6.5 \\
5.5\end{array}$ & $\begin{array}{r}10.5 \\
9.0 \\
6.5 \\
5.5 \\
5.0\end{array}$ & $\begin{array}{l}0.0 \\
0.0 \\
0.0 \\
0.0 \\
0.0\end{array}$ & $\begin{array}{l}0.0 \\
0.0 \\
0.0 \\
0.0 \\
0.0\end{array}$ & $\begin{array}{l}7.0 \\
6.0 \\
5.5 \\
6.0 \\
8.5\end{array}$ & $\begin{array}{l}5.5 \\
5.5 \\
4.5 \\
4.5 \\
5.5\end{array}$ & $\begin{array}{r}11.0 \\
11.5 \\
11.5 \\
11.0 \\
9.0\end{array}$ & $\begin{array}{r}8.5 \\
10.0 \\
11.0 \\
9.5 \\
6.5\end{array}$ \\
\hline $\begin{array}{l}16 \\
17 \\
18 \\
19 \\
20\end{array}$ & $\begin{array}{l}18.5 \\
18.5 \\
17.0 \\
15.5 \\
17.0\end{array}$ & $\begin{array}{l}17.0 \\
17.0 \\
15.5 \\
15.0 \\
15.0\end{array}$ & $\begin{array}{r}3.0 \\
6.5 \\
8.0 \\
10.0 \\
10.0\end{array}$ & $\begin{array}{l}6.0 \\
5.5 \\
6.5 \\
8.0 \\
9.5\end{array}$ & $\begin{array}{l}5.5 \\
3.5 \\
2.0 \\
3.5 \\
3.5\end{array}$ & $\begin{array}{l}3.5 \\
2.0 \\
1.0 \\
1.0 \\
2.0\end{array}$ & $\begin{array}{l}0.5 \\
3.0 \\
5.5 \\
5.5 \\
4.5\end{array}$ & $\begin{array}{l}0.0 \\
0.5 \\
3.0 \\
4.5 \\
2.0\end{array}$ & $\begin{array}{r}8.5 \\
8.0 \\
7.0 \\
9.5 \\
10.0\end{array}$ & $\begin{array}{l}7.0 \\
5.5 \\
4.5 \\
6.5 \\
7.0\end{array}$ & $\begin{array}{r}8.5 \\
8.0 \\
9.0 \\
9.0 \\
10.0\end{array}$ & $\begin{array}{l}6.5 \\
8.5 \\
7.0 \\
9.0 \\
9.0\end{array}$ \\
\hline $\begin{array}{l}21 \\
22 \\
23 \\
24 \\
25\end{array}$ & $\begin{array}{l}18.5 \\
17.0 \\
16.0 \\
14.0 \\
12.0\end{array}$ & $\begin{array}{l}17.0 \\
16.0 \\
14.0 \\
12.0 \\
11.5\end{array}$ & $\begin{array}{l}9.5 \\
6.5 \\
6.5 \\
8.0 \\
8.0\end{array}$ & $\begin{array}{l}6.5 \\
5.5 \\
5.5 \\
6.5 \\
7.0\end{array}$ & $\begin{array}{l}2.0 \\
5.5 \\
5.5 \\
5.0 \\
5.0\end{array}$ & $\begin{array}{l}1.0 \\
2.0 \\
5.0 \\
5.0 \\
4.5\end{array}$ & $\begin{array}{l}2.0 \\
0.0 \\
0.0 \\
0.0 \\
0.0\end{array}$ & $\begin{array}{l}0.0 \\
0.0 \\
0.0 \\
0.0 \\
0.0\end{array}$ & $\begin{array}{l}7.0 \\
6.0 \\
9.0 \\
9.0 \\
9.0\end{array}$ & $\begin{array}{l}4.5 \\
3.5 \\
6.0 \\
6.0 \\
0.5\end{array}$ & $\begin{array}{l}10.0 \\
11.0 \\
11.0 \\
11.0 \\
12.0\end{array}$ & $\begin{array}{l}10.0 \\
10.0 \\
10.0 \\
10.0 \\
10.0\end{array}$ \\
\hline $\begin{array}{l}26 \\
27 \\
28 \\
29 \\
30 \\
31\end{array}$ & $\begin{array}{l}14.0 \\
15.0 \\
15.0 \\
13.5 \\
13.0 \\
14.0\end{array}$ & $\begin{array}{l}12.0 \\
14.0 \\
13.5 \\
12.0 \\
12.0 \\
12.0\end{array}$ & $\begin{array}{l}7.0 \\
7.0 \\
8.0 \\
9.5 \\
8.5 \\
-.-\end{array}$ & $\begin{array}{l}7.0 \\
6.5 \\
6.5 \\
8.0 \\
8.0 \\
--\end{array}$ & $\begin{array}{r}5.5 \\
5.0 \\
4.0 \\
4.0 \\
8.0 \\
10.0\end{array}$ & $\begin{array}{l}4.5 \\
4.0 \\
3.5 \\
3.0 \\
3.5 \\
8.0\end{array}$ & $\begin{array}{l}4.0 \\
4.0 \\
4.5 \\
8.5 \\
3.5 \\
7.0\end{array}$ & $\begin{array}{l}0.0 \\
3.5 \\
3.5 \\
4.5 \\
7.0 \\
4.0\end{array}$ & $\begin{array}{r}9.0 \\
5.5 \\
8.0 \\
=- \\
=-\end{array}$ & $\begin{array}{r}5.5 \\
3.5 \\
5.0 \\
-- \\
--\end{array}$ & $\begin{array}{l}13.5 \\
13.5 \\
13.5 \\
14.5 \\
14.5 \\
10.0\end{array}$ & $\begin{array}{r}11.5 \\
12.0 \\
10.0 \\
11.5 \\
10.0 \\
9.0\end{array}$ \\
\hline$A \vee G$ & 17.5 & 16.5 & 10.0 & 9.0 & 6.0 & 4.5 & 2.5 & 1.5 & 7.5 & 5.5 & 11.0 & 9.0 \\
\hline \multirow[t]{2}{*}{ DAY } & \multicolumn{2}{|c|}{$A P R$} & \multicolumn{2}{|c|}{ MAY } & \multicolumn{2}{|c|}{ JUN } & \multicolumn{2}{|c|}{ JUL } & \multicolumn{2}{|c|}{ AUG } & \multicolumn{2}{|c|}{ SEP } \\
\hline & $\operatorname{MAX}$ & MIN & $\operatorname{MAX}$ & MIN & MAX & MIN & $\max$ & MIN & $\max$ & MIN & $\max$ & MIN \\
\hline $\begin{array}{l}1 \\
2 \\
3 \\
4 \\
5\end{array}$ & $\begin{array}{l}11.0 \\
16.0 \\
15.5 \\
14.5 \\
14.5\end{array}$ & $\begin{array}{r}9.0 \\
11.0 \\
12.0 \\
12.0 \\
13.0\end{array}$ & $\begin{array}{l}20.5 \\
20.5 \\
20.0 \\
20.0 \\
17.0\end{array}$ & $\begin{array}{l}20.0 \\
19.0 \\
19.5 \\
17.0 \\
16.5\end{array}$ & $\begin{array}{l}22.0 \\
22.0 \\
22.0 \\
23.0 \\
23.5\end{array}$ & $\begin{array}{l}20.5 \\
20.5 \\
21.0 \\
21.0 \\
22.0\end{array}$ & $\begin{array}{l}26.0 \\
25.0 \\
24.5 \\
26.5 \\
26.5\end{array}$ & $\begin{array}{l}23.5 \\
23.5 \\
23.0 \\
23.5 \\
25.0\end{array}$ & $\begin{array}{l}26.5 \\
27.0 \\
28.0 \\
28.0 \\
26.5\end{array}$ & $\begin{array}{l}25.5 \\
26.5 \\
26.5 \\
26.5 \\
25.5\end{array}$ & $\begin{array}{l}28.0 \\
26.5 \\
26.0 \\
26.5 \\
26.5\end{array}$ & $\begin{array}{l}26.5 \\
25.5 \\
24.5 \\
25.0 \\
25.5\end{array}$ \\
\hline $\begin{array}{r}6 \\
7 \\
8 \\
9 \\
10\end{array}$ & $\begin{array}{l}14.0 \\
13.5 \\
14.5 \\
18.0 \\
18.0\end{array}$ & $\begin{array}{l}11.5 \\
21.5 \\
10.0 \\
14.0 \\
16.5\end{array}$ & $\begin{array}{l}18.0 \\
18.0 \\
17.0 \\
19.5 \\
21.0\end{array}$ & $\begin{array}{l}17.0 \\
15.5 \\
15.5 \\
17.0 \\
19.0\end{array}$ & $\begin{array}{l}24.0 \\
23.0 \\
20.5 \\
21.0 \\
22.0\end{array}$ & $\begin{array}{l}22.0 \\
20.5 \\
19.5 \\
20.0 \\
20.0\end{array}$ & $\begin{array}{l}25.0 \\
24.5 \\
24.5 \\
34.5 \\
26.0\end{array}$ & $\begin{array}{l}23.5 \\
23.0 \\
22.0 \\
23.5 \\
24.5\end{array}$ & $\begin{array}{l}25.5 \\
25.5 \\
25.0 \\
24.5 \\
24.5\end{array}$ & $\begin{array}{l}25.0 \\
24.5 \\
24.5 \\
24.5 \\
24.5\end{array}$ & $\begin{array}{l}25.5 \\
25.5 \\
24.5 \\
23.0 \\
23.5\end{array}$ & $\begin{array}{l}25.5 \\
24.5 \\
23.0 \\
21.5 \\
22.0\end{array}$ \\
\hline $\begin{array}{l}11 \\
12 \\
13 \\
14 \\
15\end{array}$ & $\begin{array}{l}18.0 \\
17.0 \\
17.0 \\
19.0 \\
19.0\end{array}$ & $\begin{array}{l}15.5 \\
14.5 \\
16.0 \\
17.0 \\
15.5\end{array}$ & $\begin{array}{l}21.0 \\
23.0 \\
24.0 \\
24.5 \\
24.5\end{array}$ & $\begin{array}{l}20.5 \\
21.0 \\
22.0 \\
23.0 \\
23.0\end{array}$ & $\begin{array}{l}23.0 \\
24.5 \\
25.5 \\
24.0 \\
23.0\end{array}$ & $\begin{array}{l}21.0 \\
22.0 \\
23.5 \\
23.0 \\
21.5\end{array}$ & $\begin{array}{l}26.5 \\
26.0 \\
25.5 \\
25.5 \\
26.5\end{array}$ & $\begin{array}{l}25.5 \\
25.0 \\
24.0 \\
24.5 \\
24.5\end{array}$ & $\begin{array}{l}24.5 \\
24.5 \\
26.0 \\
26.0 \\
26.5\end{array}$ & $\begin{array}{l}24.5 \\
24.0 \\
24.0 \\
25.5 \\
25.5\end{array}$ & $\begin{array}{l}24.0 \\
24.0 \\
23.5 \\
23.0 \\
23.0\end{array}$ & $\begin{array}{l}23.5 \\
23.5 \\
23.0 \\
22.0 \\
22.0\end{array}$ \\
\hline $\begin{array}{l}16 \\
17 \\
18 \\
19 \\
20\end{array}$ & $\begin{array}{l}17.0 \\
17.0 \\
19.0 \\
18.5 \\
20.0\end{array}$ & $\begin{array}{l}14.0 \\
15.5 \\
16.5 \\
18.0 \\
18.0\end{array}$ & $\begin{array}{l}23.0 \\
22.0 \\
21.5 \\
20.0 \\
20.5\end{array}$ & $\begin{array}{l}21.5 \\
21.0 \\
19.0 \\
18.0 \\
18.0\end{array}$ & $\begin{array}{l}23.5 \\
25.5 \\
26.0 \\
28.0 \\
28.0\end{array}$ & $\begin{array}{l}21.5 \\
23.0 \\
24.0 \\
25.0 \\
26.0\end{array}$ & $\begin{array}{l}26.5 \\
26.0 \\
25.0 \\
24.5 \\
25.0\end{array}$ & $\begin{array}{l}25.5 \\
24.0 \\
24.0 \\
23.0 \\
23.5\end{array}$ & $\begin{array}{l}26.5 \\
26.5 \\
25.0 \\
24.5 \\
25.0\end{array}$ & $\begin{array}{l}26.0 \\
25.0 \\
24.5 \\
24.5 \\
24.5\end{array}$ & $\begin{array}{l}24.0 \\
24.0 \\
25.0 \\
25.5 \\
25.5\end{array}$ & $\begin{array}{l}23.0 \\
23.0 \\
24.0 \\
24.5 \\
24.5\end{array}$ \\
\hline $\begin{array}{l}21 \\
22 \\
23 \\
24 \\
25\end{array}$ & $\begin{array}{l}21.0 \\
21.0 \\
20.0 \\
21.0 \\
21.0\end{array}$ & $\begin{array}{l}20.0 \\
19.5 \\
19.5 \\
20.0 \\
20.5\end{array}$ & $\begin{array}{l}22.0 \\
24.5 \\
24.5 \\
24.5 \\
24.5\end{array}$ & $\begin{array}{l}20.5 \\
21.0 \\
22.0 \\
22.0 \\
23.0\end{array}$ & $\begin{array}{l}28.5 \\
27.0 \\
26.5 \\
26.0 \\
26.5\end{array}$ & $\begin{array}{l}26.5 \\
25.5 \\
25.0 \\
24.5 \\
25.5\end{array}$ & $\begin{array}{l}24.5 \\
24.0 \\
24.5 \\
25.5 \\
25.5\end{array}$ & $\begin{array}{l}24.0 \\
23.5 \\
23.5 \\
24.5 \\
25.0\end{array}$ & $\begin{array}{l}25.5 \\
25.5 \\
25.5 \\
25.5 \\
25.5\end{array}$ & $\begin{array}{l}25.0 \\
25.0 \\
25.0 \\
25.5 \\
25.0\end{array}$ & $\begin{array}{l}24.5 \\
25.5 \\
25.5 \\
25.5 \\
25.5\end{array}$ & $\begin{array}{l}23.5 \\
23.5 \\
24.0 \\
25.0 \\
25.0\end{array}$ \\
\hline $\begin{array}{l}26 \\
27 \\
28 \\
29 \\
30 \\
31\end{array}$ & $\begin{array}{c}21.0 \\
19.5 \\
19.5 \\
19.5 \\
20.0 \\
-0\end{array}$ & $\begin{array}{c}19.5 \\
19.5 \\
18.5 \\
19.0 \\
19.0 \\
--0\end{array}$ & $\begin{array}{l}23.0 \\
21.5 \\
21.5 \\
21.5 \\
21.0 \\
21.0\end{array}$ & $\begin{array}{l}21.0 \\
21.0 \\
21.0 \\
20.5 \\
20.5 \\
20.0\end{array}$ & $\begin{array}{l}26.5 \\
26.5 \\
26.5 \\
24.0 \\
24.5 \\
.-.\end{array}$ & $\begin{array}{r}25.5 \\
25.5 \\
24.0 \\
22.0 \\
21.5 \\
-.-\end{array}$ & $\begin{array}{l}25.5 \\
25.5 \\
25.5 \\
26.0 \\
25.5 \\
25.5\end{array}$ & $\begin{array}{l}25.0 \\
25.0 \\
25.0 \\
25.5 \\
25.0 \\
25.0\end{array}$ & $\begin{array}{l}25.0 \\
25.0 \\
25.0 \\
25.5 \\
26.5 \\
28.0\end{array}$ & $\begin{array}{l}24.5 \\
25.0 \\
24.5 \\
25.0 \\
25.5 \\
26.5\end{array}$ & $\begin{array}{r}25.5 \\
25.5 \\
24.5 \\
21.0 \\
19.0 \\
-0\end{array}$ & $\begin{array}{r}25.0 \\
25.0 \\
21.0 \\
19.0 \\
17.0 \\
--\end{array}$ \\
\hline AvG & 18.0 & 16.0 & 21.5 & 20.0 & 24.5 & 23.0 & 25.5 & 24.0 & 26.0 & 25.0 & 24.5 & 23.5 \\
\hline
\end{tabular}


02092162 NEUSE RIVER AT NEW BERN, N. C.

LOCATION. - Lat $35^{\circ} 06^{\prime} 42^{\prime \prime}$, long $77^{\circ} 01^{\prime} 37^{\prime \prime}$, Craven County, at bridge on U.S. Highway 17 at New Bern, and 0.9 mile upstream from Trent River.

DRA INAGE AREA, $--4,470 \mathrm{sq} \mathrm{md}$, approximately.

PERIOD OF RECORD, --Chemical analyses: October 1956 to September 1967, October 1967 to September 1969 (partialrecord), October 1969 to September 1970.

Water temperatures: October 1956 to September 1967.

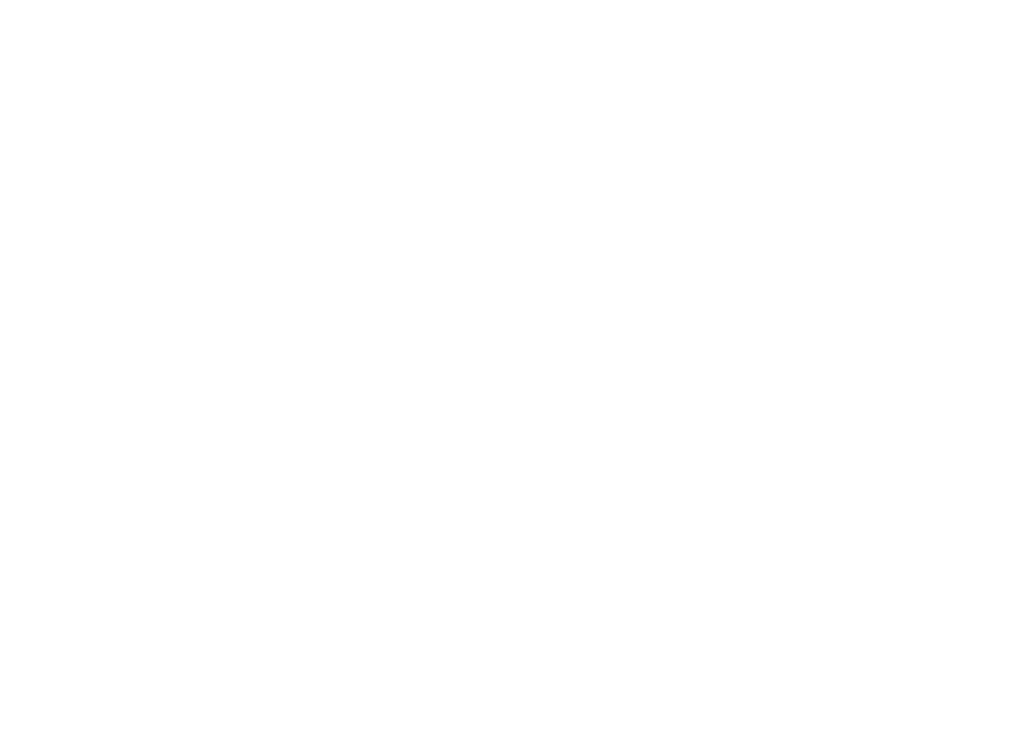

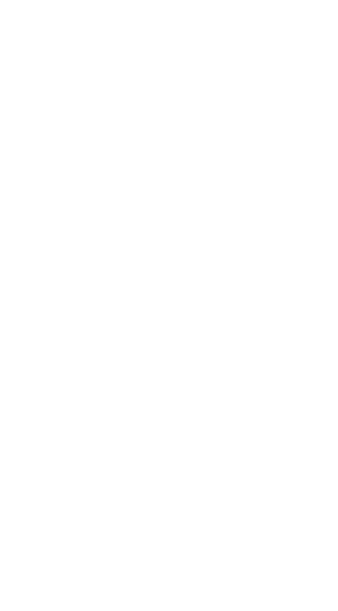

\begin{tabular}{|c|c|c|c|c|c|c|}
\hline$\rightarrow$ & -- & -- & 34 & - & -- & -- \\
\hline-- & - & -- & -- & -- & -- & -- \\
\hline- & - & - & -- & -- & -- & $=-$ \\
\hline .33 & -- & -- & 41 & $\cdots$ & - & -- \\
\hline -- & - & -- & - & -- & $\cdots$ & - \\
\hline-- & -- & -- & - & -- & -- & -- \\
\hline-- & -- & -- & - & -- & -- & -- \\
\hline- & - & -- & $\cdots$ & $\rightarrow$ & - & - \\
\hline-- & - & - & - & -- & -- & -- \\
\hline .17 & - & - & 20 & -- & -- & -- \\
\hline- & -- & -- & -- & -- & -- & -- \\
\hline-- & - & - & - & -- & -- & -- \\
\hline$\rightarrow$ & -- & - & -- & - & - & -- \\
\hline .20 & - & - & 31 & -- & -- & -- \\
\hline- & -- & -- & -- & -- & - & - \\
\hline- & -- & -- & -- & - & -- & -- \\
\hline- & - & - & - & $\cdots$ & $\cdots$ & - \\
\hline .09 & 20 & 21 & 19 & 0 & 0 & 0 \\
\hline-- & -- & -- & 18 & -- & -- & -- \\
\hline- & - & -- & - & -- & - & -- \\
\hline-- & -- & - & - & -- & - & -- \\
\hline$\rightarrow$ & - & - & - & -- & -- & -- \\
\hline- & -- & -- & 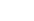 & - & -. & \\
\hline
\end{tabular}


EXTREMES. $-1956-67$ :

Chloride: Maximum, $10,300 \mathrm{mg} / 1$ Jan. $30(\mathrm{~T}), 1966$; minimum, $4.5 \mathrm{mg} / 1$ on several days in June, July 1961 , and August 1965 .

Spectfic conductance: Maximum da11y, 27,400 micromhos Jan, 30 (T), 1966; mintmum da1ly, 46 micromhos Oct, 15 , 1964

Water temperatures: Maximum, $31.5^{\circ} \mathrm{C}$ June 17,22 , Aug. $3,18(\mathrm{~T}), 1957$; mintmum, $0.5^{\circ} \mathrm{C}$ Feb, $18(\mathrm{~T}), 19,20$, 1958 , Feb. I (T), 1966 .

REMARKS.--Salinity station prior to October 1967; top (T) and bottom (B) samples were collected once daily. The second of two samples collected at the same time is a fleld determination.

CHEMICAL ANALYSES, WATER YEAR OCTOBER 1969 TO SEPTEMAER 1970

\begin{tabular}{|c|c|c|c|c|c|c|c|c|c|c|}
\hline DATE & $\begin{array}{c}\text { ZINC } \\
(2 N) \\
(U G / L)\end{array}$ & $\begin{array}{c}\text { CYANIDE } \\
\text { (CN) } \\
\text { (MG/L) }\end{array}$ & $\begin{array}{l}\text { CAD- } \\
M(U M \\
(C D) \\
(U G / L)\end{array}$ & $\begin{array}{l}\text { DIS- } \\
\text { SOLVED } \\
\text { DXYGEN } \\
\text { IMGILI }\end{array}$ & $\begin{array}{l}\text { TOTAL } \\
\text { BEIA } \\
\text { (B) } \\
\text { IPC/LI }\end{array}$ & $\begin{array}{l}\text { FECAL } \\
\text { COLI- } \\
\text { FORM } \\
\text { (CUL. } \\
\text { PER } \\
100 \mathrm{ML} \text { ) }\end{array}$ & $\begin{array}{l}\text { SPECI- } \\
\text { FIC } \\
\text { COND- } \\
\text { UCTANCE } \\
\text { (MICRO- } \\
\text { MHOS) }\end{array}$ & $\begin{array}{c}\text { PH } \\
\text { (UNITS) }\end{array}$ & $\begin{array}{l}\text { TEMP- } \\
\text { ERATURE } \\
\text { (OEG C) }\end{array}$ & $\begin{array}{l}\text { CULUR } \\
\text { IPLAT- } \\
\text { INUM- } \\
\text { CDBALT } \\
\text { UNITSS }\end{array}$ \\
\hline $\begin{array}{c}\text { OCT. } \\
28 . \ldots\end{array}$ & - & - & -- & 9.3 & -+ & 4000 & 5500 & 7.4 & 15.0 & -- \\
\hline $\begin{array}{l}\text { NOV. } \\
25 \ldots .\end{array}$ & -- & - & -- & - & 20 & - & -- & -- & -- & -- \\
\hline $\begin{array}{c}25 \ldots . . \\
\text { OEC. }\end{array}$ & -- & - & -- & 7.9 & - & 600 & 5500 & 6.5 & 11.0 & -- \\
\hline $\begin{array}{l}18 \ldots \\
18 \ldots\end{array}$ & -- & $=$ & $\because$ & $11 . \overline{0}$ & 35 & $\overline{150}$ & $\begin{array}{r}7260 \\
10900\end{array}$ & $\begin{array}{l}6.8 \\
7.3\end{array}$ & $\begin{array}{l}8.0 \\
8.0\end{array}$ & 30 \\
\hline $\begin{array}{l}\text { JAN, } \\
27 . . .\end{array}$ & - & $\rightarrow$ & - & -- & 22 & - & $\cdots$ & -- & -- & -- \\
\hline $\begin{array}{l}27 . \ldots \\
F E B .\end{array}$ & -- & -- & -- & 11.3 & - & -- & 1840 & 6.9 & 7.0 & -- \\
\hline $24 \ldots$ & - & -- & -- & - & 2.3 & -- & -- & - & -- & -- \\
\hline $\begin{array}{l}24 \ldots . . \\
\text { MAR. }\end{array}$ & -- & -- & -- & 9.4 & - & $\cdots$ & 1340 & 3.8 & 10.0 & -- \\
\hline $\begin{array}{l}24 \ldots \\
24 \ldots\end{array}$ & $=$ & $=$ & $=$ & - & $=$ & $\overline{-}$ & 110 & 6.2 & 14.0 & 30 \\
\hline APR. & . & 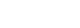 & & 0.9 & 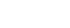 & 160 & $1<0$ & 7.2 & 14.0 & $-\alpha$ \\
\hline $\begin{array}{l}22 \ldots \\
22 \ldots \\
\text { MAY }\end{array}$ & 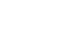 & $=-$ & $=$ & $9 . \overline{5}$ & ${ }^{14}$ & 56 & 105 & 6.0 & $19 . \overline{5}$ & $=-$ \\
\hline $\begin{array}{l}26 \ldots . . \\
26 \ldots \\
\text { JUNE }\end{array}$ & -- & $=$ & $=$ & $\begin{array}{l}7.4 \\
7.4\end{array}$ & ${ }^{18}$ & 2040 & $\begin{array}{l}1410 \\
1400\end{array}$ & $\begin{array}{l}6.8 \\
7.5\end{array}$ & $\begin{array}{l}25.0 \\
23.0\end{array}$ & $\begin{array}{l}55 \\
--\end{array}$ \\
\hline $16 \ldots$ & - & -- & - & - & 50 & -- & - & -- & 26.0 & -- \\
\hline JULY... & -- & - & - & 8.1 & - & -- & 5800 & 7.2 & 26.0 & -- \\
\hline $22 \ldots$ & & & & & & & & & & \\
\hline $22 \ldots$ & 30 & .00 & 0 & - & 8.8 & - & 234 & 7.0 & 27.3 & 70 \\
\hline $\begin{array}{c}22 . . . \\
\text { AUG. }\end{array}$ & - & - & -- & 6.7 & - & 420 & 260 & 7.5 & 27.5 & -- \\
\hline $18 \ldots$ & - & - & -- & -- & 16 & - & - & -- & 28.0 & -- \\
\hline $\begin{array}{l}18 . . . \\
\text { SEPT. }\end{array}$ & -- & - & - & 5.3 & -- & 236 & 3000 & 6.6 & 27.5 & -- \\
\hline $22 \ldots$ & -- & -- & - & -- & 72 & -- & - & -- & - & -- \\
\hline $22 \ldots$ & -- & - & - & 6.9 & -- & 60 & 6000 & 6.6 & 28.0 & -- \\
\hline
\end{tabular}

\begin{tabular}{|c|c|c|c|c|c|c|c|}
\hline WNTE & DOT & $D D E$ & DOD & $\begin{array}{l}\text { CHLOR- } \\
\text { DANE } \\
\text { IUG/L) }\end{array}$ & $\begin{array}{c}D I- \\
\text { ELORIN }\end{array}$ & ENOR IN & $\begin{array}{l}\text { HEPTA- } \\
\text { CHLOR }\end{array}$ \\
\hline & & & & & & & \\
\hline $22 \ldots$ & $<.01$ & .00 & .00 & $<.01$ & .00 & $<.01$ & .00 \\
\hline
\end{tabular}

\begin{tabular}{|c|c|c|c|c|c|c|}
\hline & $\begin{array}{l}\text { HEPIA- } \\
\text { CHLCR } \\
\text { EPOXIOE }\end{array}$ & & & $\begin{array}{l}\text { ENDO- } \\
\text { SULFAN }\end{array}$ & $\begin{array}{l}\text { POX- } \\
\text { APHENE }\end{array}$ & $\begin{array}{l}\text { ME TH- } \\
\text { OXY- } \\
\text { CHLOK }\end{array}$ \\
\hline OATE & $(\mathrm{UG} / \mathrm{L})$ & (UG/L) & (UG/L) & (UG/L) & (UG/L) & IUG/L) \\
\hline $\begin{array}{l}\text { IULY } \\
22 \ldots .\end{array}$ & .30 & .00 & .00 & .00 & $<.25$ & $<.02$ \\
\hline
\end{tabular}


02093032 NEW RIVER AT JACKSONVILLE, N. C.

LOCATION, --Lat $34^{\circ} 45^{\prime} 13^{\prime \prime}$, long $7^{\circ} 26^{\prime} 06^{\prime \prime}$, Onslow County, at bridge on U.S. Highway 17 at Jacksonville, and 0,3 mile downstream from Deep Gully Creek.

DRA INAGE AREA.--160 sq mi, approximately.

PER IOD OF RECORD. --Chemical analyses: October 1960 to September 1961, October 1967 to September 1969 (partial-

record), October 1969 to September 1970 .
Water temperatures: October 1960 to September 1961.

CHEMICAL ANALYSES, WATER YEAR OCTOBER 2969 TO SEPTEMBER 1970

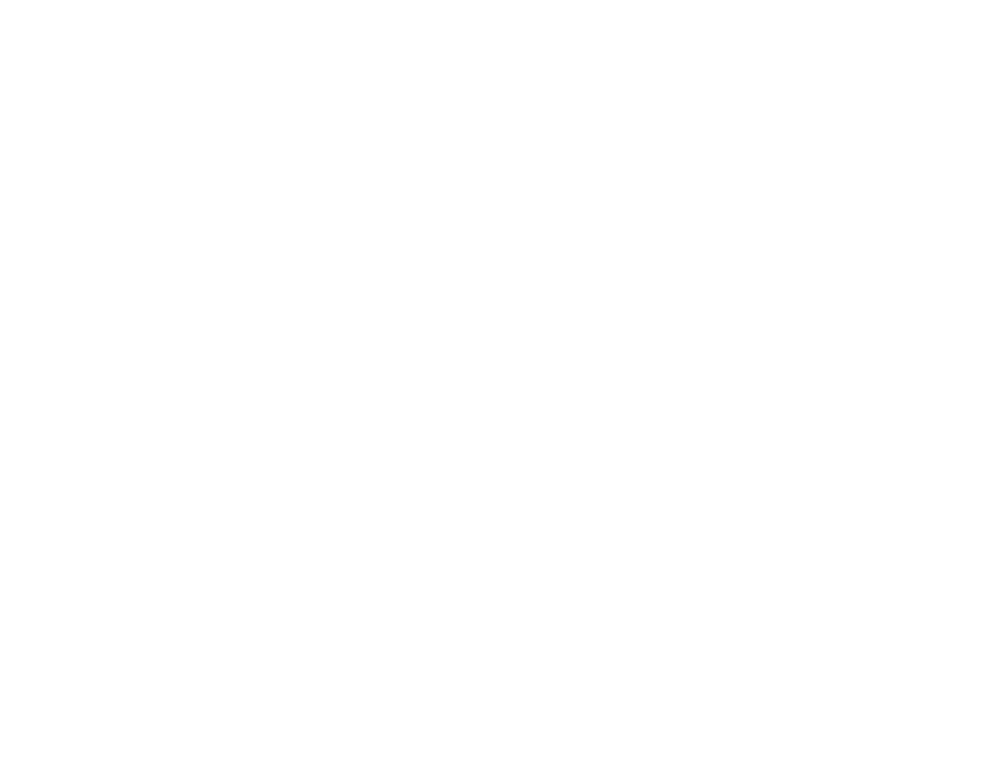

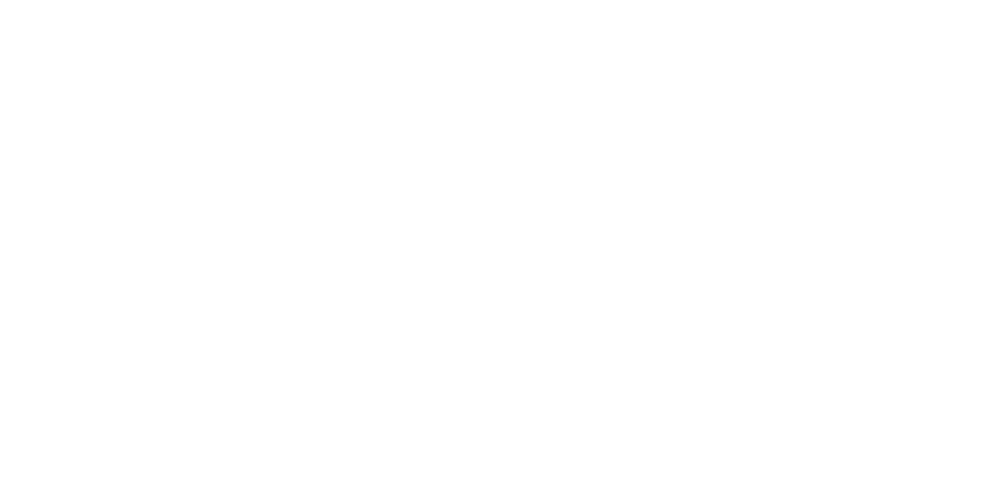

MG $/$ L IUG 
02093032 NEW RIVER AT JACKSONVILLE, N. C.- - Cont Inued

EXTREMES. --1960-61:

Chloride: Maximum, 7,380 mg/1 Sept. 26, 1961; minimum, $7.5 \mathrm{mg} / 1$ July 1-3, 1961

Spectfic conductance: Maximum dally, 19,800 micromhos Dec. 5, 1960; mintmum daily, 60 micromhos July 1 , 1961 , Witer temperatures: Maximum, $34.0^{\circ} \mathrm{C}$ July 31,1961 ; minimum, $1.0^{\circ} \mathrm{C}$ Dec. $14,1960$.

REMARKS, - The second of two samples collected at the same time is a field determination.

CHEMICAL ANALYSES, WATER YEAR OCTOBER 1969 TO SEPTEMBER 1970

\begin{tabular}{|c|c|c|c|c|c|c|c|c|c|}
\hline DATE & $\begin{array}{l}Z I N C \\
(L N) \\
(U G / L)\end{array}$ & $\begin{array}{l}\text { CAD- } \\
\text { MIUM } \\
\text { (CD) } \\
\text { (UG/L) }\end{array}$ & $\begin{array}{l}\text { OIS- } \\
\text { SOLVED } \\
\text { OXYGEN } \\
\text { (MG/L) }\end{array}$ & $\begin{array}{l}\text { TOTAL } \\
\text { BETA } \\
\text { (B) } \\
\text { (PC/L) }\end{array}$ & $\begin{array}{l}\text { FECAL } \\
\text { COLI- } \\
\text { FORM } \\
\text { (COL. } \\
\text { PER } \\
100 \mathrm{ML} \text { ) }\end{array}$ & $\begin{array}{l}\text { SPECI- } \\
\text { FIC } \\
\text { CONO- } \\
\text { UCTANCE } \\
\text { (MICRO- } \\
\text { MHOSI }\end{array}$ & $\begin{array}{c}P H \\
\text { (UNITS) }\end{array}$ & $\begin{array}{l}\text { TE MP- } \\
\text { ERATURE } \\
\text { (DEG C) }\end{array}$ & $\begin{array}{l}\text { COLOR } \\
\text { (PLAT- } \\
\text { INUM- } \\
\text { COAALI } \\
\text { UNIIS) }\end{array}$ \\
\hline${ }_{28}^{0 C T} . .$. & - & - & 8.5 & -- & 4900 & 15800 & 7.6 & 18.0 & -- \\
\hline $\begin{array}{l}\text { NaV. } \\
25 . . \\
\text { DEC. }\end{array}$ & -+ & $-\infty$ & 7.7 & -- & 400 & 8300 & 8.2 & 10.5 & -- \\
\hline $\begin{array}{l}17 \ldots . . \\
27 \ldots \\
\text { JAN. }\end{array}$ & $=-$ & $=$ & $11 . \overline{3}$ & $\overline{-}$ & $-\overline{60}$ & $\begin{array}{l}12900 \\
10100\end{array}$ & $\begin{array}{l}6.9 \\
5.8\end{array}$ & $\begin{array}{l}8.0 \\
8.0\end{array}$ & 50 \\
\hline $\begin{array}{c}27 \ldots \\
F E B .\end{array}$ & -- & -- & 10.8 & -- & -- & 12050 & 6.4 & 8.0 & -- \\
\hline $\begin{array}{l}24 \ldots \\
24 \ldots\end{array}$ & $=$ & $=$ & 6.8 & $=-$ & 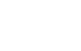 & $\begin{array}{l}15900 \\
10000\end{array}$ & $\begin{array}{l}6.7 \\
6.7\end{array}$ & $\begin{array}{l}9.0 \\
9.0\end{array}$ & 45 \\
\hline $\begin{array}{l}24 \ldots \\
A P R\end{array}$ & - & -- & 10.4 & -- & 3000 & 508 & 6.9 & $14 \% 0$ & - \\
\hline $\begin{array}{l}21 \ldots \\
21 \ldots\end{array}$ & $\overline{-}$ & $=$ & $10 \overline{8}$ & $=$ & $\overrightarrow{36}$ & $\begin{array}{l}707 \\
760\end{array}$ & $\begin{array}{l}6.7 \\
8.2\end{array}$ & $\begin{array}{l}23.0 \\
23.0\end{array}$ & 70 \\
\hline $\begin{array}{l}\text { MAY } \\
26 . . .\end{array}$ & $\pi$ & -7 & 7.0 & -. & - & 16000 & 7.5 & 75.5 & - \\
\hline JUNE & & & 1.0 & & 7000 & 10000 & 1.0 & 200 & \\
\hline $\begin{array}{l}16 \ldots . . \\
\text { JULY }\end{array}$ & -- & -- & 7.2 & - & 200 & 20500 & 7.1 & 27.0 & -- \\
\hline $\begin{array}{l}22 \ldots \\
22 \ldots\end{array}$ & 30 & 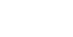 & 6.4 & $\begin{array}{r}160 \\
--\end{array}$ & $40 \overline{0}$ & $\begin{array}{l}19200 \\
19000\end{array}$ & $\begin{array}{l}7.1 \\
6.9\end{array}$ & $\begin{array}{l}30.0 \\
30.0\end{array}$ & 30 \\
\hline $\begin{array}{l}\text { AUG. } \\
18 . . \\
\text { SEPT. }\end{array}$ & -- & - & 6.5 & -- & 2440 & 11500 & 6.4 & 29.0 & -- \\
\hline $22 \ldots$ & -- & -- & 6.3 & - & 240 & 10100 & 6.9 & 28.0 & -- \\
\hline
\end{tabular}

\begin{tabular}{|c|c|c|c|c|c|c|c|}
\hline DATE & $\begin{array}{l}\text { DOT } \\
\text { (UG/() }\end{array}$ & $\begin{array}{l}\text { DDE } \\
\text { (UG/L) }\end{array}$ & $\begin{array}{l}\text { DDO } \\
\text { (UG/L) }\end{array}$ & $\begin{array}{l}\text { CHL OR- } \\
\text { OANE } \\
\text { (UGLL) }\end{array}$ & $\begin{array}{l}\text { DI - } \\
\text { ELDRIN } \\
\text { (UG/L) }\end{array}$ & $\begin{array}{l}\text { ENOR IN } \\
\text { (UG/L) }\end{array}$ & $\begin{array}{l}\text { HEP IA- } \\
\text { CHLOR }\end{array}$ \\
\hline $\begin{array}{l}\text { HULY } \\
20 \ldots\end{array}$ & $<.01$ & .00 & .00 & $<.01$ & .00 & $<.01$ & .00 \\
\hline
\end{tabular}

\begin{tabular}{|c|c|c|c|c|c|c|}
\hline DATE & $\begin{array}{l}\text { HEPTA- } \\
\text { CHLCR } \\
\text { EPOX IDE } \\
\text { (UG /L) }\end{array}$ & ALDR IN & $\begin{array}{l}\text { LINDANE } \\
\text { IUG/L) }\end{array}$ & $\begin{array}{l}\text { ENDO- } \\
\text { SULFAN } \\
\text { (UG/L) }\end{array}$ & $\begin{array}{l}\text { TOX- } \\
\text { APHENE } \\
\text { (UG/L) }\end{array}$ & $\begin{array}{c}\text { METH- } \\
\text { OXY - } \\
\text { CHLOR } \\
\text { (UG/L) }\end{array}$ \\
\hline $\begin{array}{l}\text { ULY } \\
20 \ldots . .\end{array}$ & .00 & .00 & .00 & .00 & $<.25$ & $<.02$ \\
\hline
\end{tabular}


LOCATION (revised).--Lat $35^{\circ} 37^{\prime} 48^{\prime \prime}$, long $79^{\circ} 03^{\prime} 36^{\prime \prime}$, Chatham County, at bridge on U.S. Highway $1,1.1$ miles northeast of Moncure, 1.3 miles downstream from gaging station, and 2.6 mtles upstream from confiuence with Deep R1ver.

DRA INAGE AREA. $-1,700 \mathrm{sq} \mathrm{m}$, approximately.

PERIOD OF RECORD,--Chemical analyses: October 1960 to September 1961, July 1969 to September 1970.

REMARKS.--Prior to October 1961 samples collected at site, 02098208 Haw River at Moncure, at old U.S. Highway 1 bridge, 1.1 miles downstream. Records of discharge are given for 02098200 Haw River near Haywood. The second of two samples collected at the same time is a field determination.

CHEMICAL ANALYSES, WATER YEAR OCTOBER 1969 TO SEPTEMBER 1970

\begin{tabular}{|c|c|c|c|c|c|c|c|c|c|c|}
\hline DATE & TIME & $\begin{array}{l}\text { OHS- } \\
\text { CHARGE } \\
\text { ICFSS }\end{array}$ & 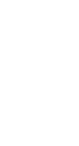 & $\begin{array}{l}\text { O1S- } \\
\text { SOL VED } \\
\text { IREN } \\
\text { IRE } \\
\text { I } \\
\text { UG }\end{array}$ & $\begin{array}{l}\text { OIS- } \\
\text { SCLVED } \\
\text { CAL } \\
\text { CIUA } \\
\text { ICA1 } \\
\text { IMGAL }\end{array}$ & $\begin{array}{l}\text { DIS- } \\
\text { SOLVED } \\
\text { MAG- } \\
\text { NE- } \\
\text { SIUH } \\
\text { IMGI } \\
\text { IMG LI I }\end{array}$ & $\begin{array}{c}500104 \\
\text { SNAI } \\
\text { (NAG/L) }\end{array}$ & $\begin{array}{l}P- \\
\text { TAS- } \\
\text { SIUM } \\
\text { IKI } \\
(M G / L 1\end{array}$ & $\begin{array}{l}\text { BICAR- } \\
\text { BONATE } \\
\text { CHCO3I } \\
\text { IMG/LI }\end{array}$ & $\begin{array}{l}\text { CAR- } \\
\text { BONATE } \\
\text { (COB31 } \\
\text { (MG/LI) }\end{array}$ \\
\hline 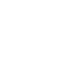 & $\begin{array}{l}1030 \\
1030\end{array}$ & $22 R^{--}$ & $\because$ & $\because$ & 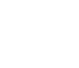 & $\because$ & $=-$ & $=$ & $\overline{72}$ & $\because$ \\
\hline $\begin{array}{c}213 . \\
21\end{array} 2 \ldots$ & $\begin{array}{l}0900 \\
0900\end{array}$ & $300^{--}$ & $=$ & $\because$ & -- & $\because$ & $=$ & $=$ & $\because$ & $=$ \\
\hline $\begin{array}{c}\text { DEC. } \\
19 . . \\
19 . .\end{array}$ & $\begin{array}{l}1915 \\
1015\end{array}$ & $\begin{array}{l}1360 \\
1360\end{array}$ & 11 & $\begin{array}{l}72 \\
--\end{array}$ & 5.8 & 2.9 & ${ }^{16}$ & 4.2 & 33 & $\therefore$ \\
\hline $\begin{array}{r}15 \% \\
15 \%\end{array}$ & $\begin{array}{l}1000 \\
1000\end{array}$ & ${ }_{680}^{--}$ & $=$ & $\because$ & $=$ & -- & $=$ & -- & $\because$ & $=$ \\
\hline $\begin{array}{r}27 . . . \\
27\end{array}$ & $\begin{array}{l}0940 \\
3940\end{array}$ & $=$ & $=$ & $=$ & $=-$ & -- & $=-$ & $=-$ & $=$ & $=$ \\
\hline 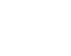 & $\begin{array}{l}3955 \\
3955\end{array}$ & $\begin{array}{l}2340 \\
2340\end{array}$ & 11 & $\underline{52}$ & 6.4 & 2.4 & ${ }^{10}$ & 1.8 & 25 & $\therefore$ \\
\hline 20 & $\begin{array}{l}0330 \\
3430\end{array}$ & $1050^{--}$ & $14^{--}$ & BO & 7.3 & $3 .-4$ & $13^{--}$ & 2.3 & 34 & $\because$ \\
\hline $25 .$. & $\begin{array}{l}0830 \\
J 930\end{array}$ & $\begin{array}{l}360 \\
360\end{array}$ & -- & $=$ & $=$ & -- & $=$ & $=$ & $=$ & $=$ \\
\hline $\begin{array}{c}15 . . \\
15 \ldots\end{array}$ & $\begin{array}{l}0715 \\
0915\end{array}$ & $\begin{array}{l}240 \\
240\end{array}$ & $\because$ & $\because$ & -- & $=$ & $=$ & $=$ & $\because$ & $\because$ \\
\hline $29 \ldots$ & $\begin{array}{l}0945 \\
3945\end{array}$ & $\begin{array}{l}228 \\
228\end{array}$ & 15 & $\begin{array}{l}107 \\
--\end{array}$ & 11 & 4.8 & ${ }^{63}-$ & 6.4 & 88 & $\therefore$ \\
\hline $\begin{array}{r}\text { All } 6 . \ldots \\
17 \ldots \\
17 \ldots\end{array}$ & $\begin{array}{l}1030 \\
1030\end{array}$ & $700^{--}$ & -- & $\because$ & $\because$ & $=$ & $=$ & $=$ & $\because$ & $=$ \\
\hline $21 \ldots$ & $\begin{array}{l}1050 \\
1050\end{array}$ & $118^{--}$ & -- & $\because$ & -- & z- & -- & $\because$ & $\because$ & $=$ \\
\hline JATE & 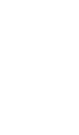 & $\begin{array}{l}\text { CHLC- } \\
\text { PLEE } \\
I C 11 \\
\text { I MG/LI }\end{array}$ & $\begin{array}{l}\text { DIS- } \\
\text { SOLVED } \\
\text { FUC } \\
\text { RIDE } \\
\text { IFI } \\
\text { IFI I I } \\
\text { (WG/LI }\end{array}$ & $\begin{array}{c}\text { NITRATE } \\
\text { (NO3) } \\
\text { (MG/LI) }\end{array}$ & 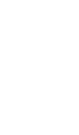 & 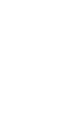 & $\begin{array}{l}\text { OIS- } \\
\text { SOLVED } \\
\text { SOLLDS } \\
\text { TOLNS } \\
\text { PER } \\
\text { AC-FTI }\end{array}$ & $\begin{array}{l}\text { OIS- } \\
\text { SOLVD } \\
\text { SOL IDS } \\
\text { TONS } \\
\text { PER } \\
\text { OAYI }\end{array}$ & $\begin{array}{l}\text { HARO- } \\
\text { NESS } \\
\text { IIAAGI } \\
\text { (MGAL) }\end{array}$ & $\begin{array}{l}\text { NON- } \\
\text { CAR- } \\
\text { BOAA TE } \\
\text { HARDO- } \\
\text { NESS } \\
\text { NESTL }\end{array}$ \\
\hline $\begin{array}{c}\text { סct. } \\
23 . \\
{ }_{23} 3 \ldots\end{array}$ & $\because$ & -- & -- & $=$ & $\because$ & $\because$ & $\because$ & $\because-$ & $\because$ & $=$ \\
\hline $\begin{array}{r}\text { Nov. } \\
21 . \ldots \\
31\end{array}$ & - & $\because$ & $\because$ & $\because$ & $\because$ & $\because$ & $\because$ & $\because-$ & $\because$ & $\because$ \\
\hline 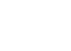 & 15 & 13 & -4 & 4.5 & .ro & 101 & .14 & $371 \ldots$ & 27 & $\therefore$ \\
\hline $\begin{array}{l}\text { JAN. } \\
15 . . \\
15 . .\end{array}$ & -- & $=$ & $=$ & -- & $=$ & $\because$ & $=$ & $\because$ & $\because$ & $=$ \\
\hline 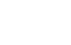 & $\because$ & $=-$ & -- & -- & $\because$ & $=$ & $\because$ & $\because$ & $=$ & $\because$ \\
\hline $\begin{array}{r}4 A K \\
20 . \ldots \\
22 \ldots\end{array}$ & ${ }^{14}$ & 9.7 & $\therefore 2$ & 1.7 & .29 & 11 & .10 & $449 \ldots$ & 26 & 6 \\
\hline $\begin{array}{r}\text { APP. } \\
20 \ldots \\
20 \ldots\end{array}$ & $15^{--}$ & $12^{--}$ & .3 & 2.7 &.$\overline{38}$ & 86 & .12 & $244^{--}$ & $\overline{32}$ & 4 \\
\hline $\begin{array}{l}\frac{M}{M A Y} \\
25 \ldots \\
25\end{array}$ & $=$ & $=$ & $\because$ & $\because$ & $\overline{-}$ & $\ddot{-}$ & -- & $\because$ & $=$ & 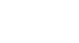 \\
\hline 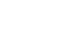 & -- & $=$ & -- & -z & $\because$ & $\because$ & -: & $\because$ & $\because$ & $\because$ \\
\hline
\end{tabular}


02098206 HAW RIVER NEAR MONCURE, N. C.--Continued

CHEMICAL ANALYSES, WATER YEAR OCTOBER 1969 TO SEPTEMBER 1970

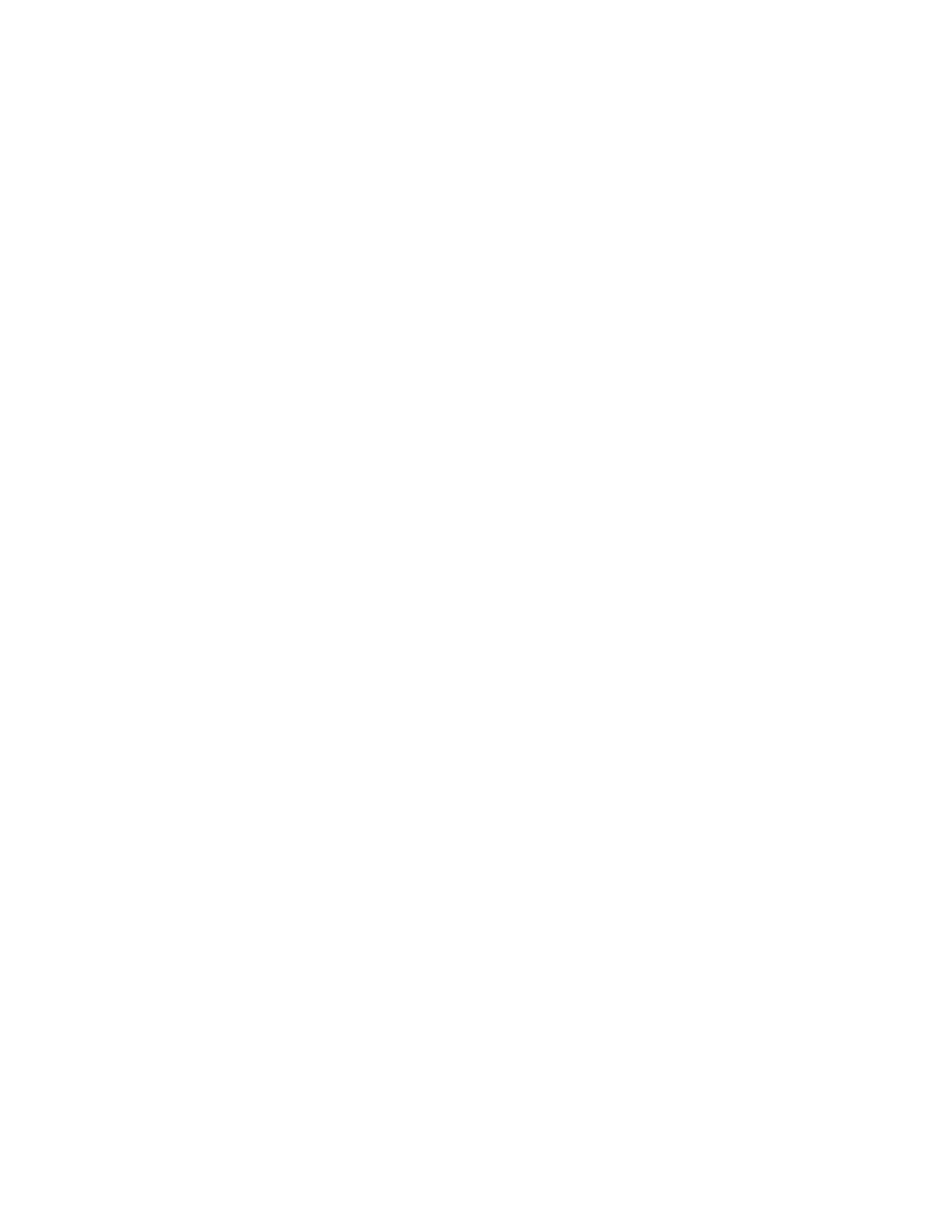

\begin{tabular}{|c|c|c|c|c|c|c|c|c|c|}
\hline 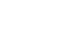 & $=$ & $\because$ & $=$ & $\because-$ & $\because$ & $\because$ & $\because$ & 59 & $=$ \\
\hline $\begin{aligned} \text { vov. } \\
2 \mathrm{I}\end{aligned}$ & $\because$ & $=$ & $=$ & $=$ & -- & $\because$ & $\because$ & -- & $=$ \\
\hline${ }_{D E C}^{21} \cdots$ & -- & -- & -- & -- & -- & - & -- & -- & -- \\
\hline $\begin{array}{l}17 \ldots \\
17 \ldots\end{array}$ & 1.4 & $\begin{array}{l}52 \\
-2\end{array}$ & $\because$ & $=$ & .10 & $\because$ & $\because$ & 27 & $\because-$ \\
\hline $\begin{array}{l}\text { JAN. } \\
15 \ldots\end{array}$ & -- & -- & -- & -- & -- & - & $\because$ & -- & $\because$ \\
\hline FEG & & & & & & & & & \\
\hline $27 \cdots$ & - & -- & $\because$ & 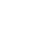 & 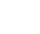 & - & $=$ & $\because$ & $=$ \\
\hline $28 \ldots$ & $\therefore$ & 44 & $\because$ & $\because-$ & . 17 & $=$ & $=$ & 21 & $=$ \\
\hline $\begin{array}{c}\text { AOC: } \\
\\
\\
20\end{array}$ & & & -- & & & -- & -- & & \\
\hline MAY & $1 . c$ & 45 & -- & -- & .11 & -- & - & 28 & -- \\
\hline$\frac{25}{25} \ldots$ & $=-$ & $\because$ & 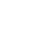 & $\because$ & $\because$ & $\because-$ & - & $\because-$ & $=$ \\
\hline $\begin{array}{l}\text { JUNE } \\
15 \ldots .\end{array}$ & -- & -- & -- & -- & -- & -- & -- & -- & -- \\
\hline JuL & & & & & & & -. & & \\
\hline $\begin{array}{l}29 \ldots \\
29 \ldots\end{array}$ & $\begin{array}{l}4.0 \\
--\end{array}$ & $\stackrel{71}{-1}$ & $\therefore$ & $\therefore$ & -31 & -1 & 16 & $\begin{array}{l}72 \\
64\end{array}$ & $\begin{array}{l}10 \\
-\end{array}$ \\
\hline $17 \ldots$ & -- & -- & -- & -- & -- & - & - & -- & -- \\
\hline SEP. & & $\cdots$ & & & & $\cdots$ & & & \\
\hline $21 \ldots$ & - & $\because$ & 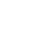 & $\because$ & $\because$ & $\because$ & $\because$ & -- & $\because$ \\
\hline
\end{tabular}


02102049 DEEP RIVER AT U.S. HIGHAY 1, AT MONCURE, N. C.

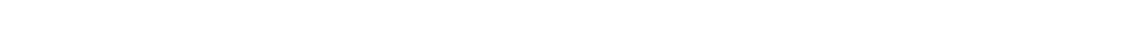
1.2 miles downtream from gaging station, and 3 miles upstream from Haw River.

DRA INAGE AREA, --1,420 sq mi, approximately.

PERIOD OF RECORD.--Chepmical analyses: October 1943 to September 1944, October 1955 to September 1956, Octo-

ber 1961 to September 1967 , October 1967 to September 1969 (partial-record), October 1969 to September 1970.

Prior to October 1965, pubilshed as 02102000 Deep River at Moncure.

water temperatures: October 1943 to September 1944, October 1955 to September 1956, October 1961 to September 1967.

EXTREMES. $-1943-44,1955-56,1961-67$ :

Dissolved solids: Maximum, $114 \mathrm{mg} / \mathrm{l}$ Oct. 1-7, 1962 ; minimum, $35 \mathrm{mg} / 1$ (calculated) Feb. 25-27, 1966. CHEMICAL ANALYSES, WATER YEAR OCTOBER 1969 TO SEPTEMBER 1970

\begin{tabular}{|c|c|c|c|c|c|c|c|c|c|c|c|}
\hline DATE & TIME & $\begin{array}{l}\text { OIS- } \\
\text { CHARGE } \\
\text { (CFS) }\end{array}$ & $\begin{array}{l}\text { SILICA } \\
\text { ISIOLI } \\
\text { IMGILI }\end{array}$ & $\begin{array}{l}\text { OIS- } \\
\text { SOLVED } \\
\text { IHON } \\
\text { (FE) } \\
\text { (UG/L) }\end{array}$ & $\begin{array}{l}\text { CAL- } \\
\text { CIUM } \\
(C A) \\
(M G / L)\end{array}$ & $\begin{array}{c}\text { MAG- } \\
\text { NE- } \\
\text { SIUM } \\
\text { (MG) } \\
(M G / L)\end{array}$ & $\begin{array}{l}\text { SOD [UM } \\
(N A) \\
(M G / L)\end{array}$ & $\begin{array}{l}\text { PO- } \\
\text { TAS- } \\
\text { SIUM } \\
\text { (K) } \\
\text { (MG/L) }\end{array}$ & $\begin{array}{l}\text { BICAR- } \\
\text { BONAIE } \\
\text { (HCO3) } \\
\text { (MG/L) }\end{array}$ & $\begin{array}{l}\text { CAR- } \\
\text { BONATE } \\
\text { (CO3) } \\
\text { (MG/L) }\end{array}$ & $\begin{array}{l}\text { SULFATE } \\
\text { (SO4) } \\
\text { (MG/L) }\end{array}$ \\
\hline $\begin{array}{l}\text { वC. } \\
23 . . . \\
\text { NOV. }\end{array}$ & 1345 & 209 & -- & -- & - & -- & - & -- & 28 & -- & -- \\
\hline DEC... & 1100 & 200 & -- & -- & -- & -- & - & - & - & - & - \\
\hline $\begin{array}{l}19 \ldots \\
19 \ldots \\
\text { JAN. }\end{array}$ & $\begin{array}{l}1340 \\
1340\end{array}$ & $\begin{array}{l}313 \\
313\end{array}$ & 11 & $\begin{array}{r}0 \\
--\end{array}$ & $\begin{array}{r}6.7 \\
--\end{array}$ & $\begin{array}{r}2.7 \\
--\end{array}$ & 15 & $\begin{array}{r}3.9 \\
--\end{array}$ & 34 & - & 11 \\
\hline $\begin{array}{l}15 . . . \\
\text { FEB. }\end{array}$ & 1100 & 675 & -- & -- & - & -- & -- & - & -- & -- & - \\
\hline $\begin{array}{r}27 \ldots . . \\
27 \ldots \\
\text { MAR. }\end{array}$ & $\begin{array}{l}1130 \\
1150\end{array}$ & $\begin{array}{l}2550 \\
2550\end{array}$ & 12 & 150 & $\begin{array}{r}4.3 \\
--\end{array}$ & 2.0 & 6.7 & 1.4 & 18 & $\begin{array}{r}0 \\
--\end{array}$ & $\begin{array}{r}7.8 \\
-2\end{array}$ \\
\hline $\begin{array}{l}28 \ldots . \\
28 \ldots \\
A P R .\end{array}$ & $\begin{array}{l}1215 \\
1215\end{array}$ & $\begin{array}{l}1980 \\
1980\end{array}$ & II & 56 & 4.4 & 2.0 & 5.5 & 2.2 & 17 & $\begin{array}{r}0 \\
--\end{array}$ & 11 \\
\hline $\begin{array}{l}20 \ldots . . \\
20 \ldots \\
\text { MAY }\end{array}$ & $\begin{array}{l}0900 \\
0900\end{array}$ & $\begin{array}{l}2430 \\
2430\end{array}$ & 11 & 124 & $\begin{array}{r}4.5 \\
--\end{array}$ & $\begin{array}{l}1.6 \\
--\end{array}$ & $\begin{array}{r}5.9 \\
--\end{array}$ & 1.2 & 19 & - & 6.4 \\
\hline JUNE & 0905 & 316 & -- & $=-$ & - & $\rightarrow$ & - & -- & -- & $\cdots$ & -- \\
\hline JuLY $15 .$. & 0845 & 176 & -- & -- & -- & -- & - & -- & -- & -- & - \\
\hline $\begin{array}{l}29 \ldots . . \\
29 . . \\
\text { AUG. }\end{array}$ & $\begin{array}{l}1100 \\
1100\end{array}$ & $\begin{array}{l}246 \\
246\end{array}$ & 10 & $\begin{array}{r}107 \\
--\end{array}$ & 7.4 & 2.7 & 16 & 3.3 & 41 & $\begin{array}{r}0 \\
--\end{array}$ & 11 \\
\hline SEPT. & 1100 & $6 B O$ & -- & -- & - & -- & - & - & -- & -- & - \\
\hline $21 \ldots$ & 1130 & 70 & -- & $\cdots$ & - & -- & - & $\rightarrow-$ & $\cdots$ & $=$ & - \\
\hline
\end{tabular}

\begin{tabular}{|c|c|c|c|c|c|c|c|c|c|}
\hline $\begin{array}{l}\text { CHLO- } \\
\text { RIDE } \\
\text { [CLI } \\
\text { [MG/L] }\end{array}$ & $\begin{array}{l}\text { FLUO- } \\
\text { KIDE } \\
\text { (F) } \\
\text { (AG/L) }\end{array}$ & $\begin{array}{l}\text { N I TRATE } \\
\text { (NO3) } \\
\text { (MG/L) }\end{array}$ & $\begin{array}{l}\text { ORTHO } \\
\text { PHOS- } \\
\text { PHATE } \\
\text { (PO4) } \\
\text { (MG/L) }\end{array}$ & $\begin{array}{l}\text { SOLVED } \\
\text { SOLIOS } \\
\text { (RESI- } \\
\text { OUE AT } \\
\text { IBO C) } \\
\text { (MGAL) }\end{array}$ & $\begin{array}{l}\text { OLS- } \\
\text { SOLVEO } \\
\text { SOLIOS } \\
\text { ITONS } \\
\text { PER } \\
\text { AC-FII }\end{array}$ & $\begin{array}{l}\text { DIS- } \\
\text { SOLVED } \\
\text { SOLIDS } \\
\text { ITONS } \\
\text { PER } \\
\text { DAYI }\end{array}$ & $\begin{array}{l}\text { HARO- } \\
\text { NESS } \\
\text { (CA,MG) } \\
(M G / L)\end{array}$ & $\begin{array}{l}\text { NIJN- } \\
\text { CAR- } \\
\text { BONATE } \\
\text { HARD- } \\
\text { NFSS } \\
\text { (MG/L) }\end{array}$ & $\begin{array}{l}\text { SOUIUM } \\
\text { AD- } \\
\text { SORP- } \\
\text { TION } \\
\text { KATIO }\end{array}$ \\
\hline $23 \ldots$ & -- & -- & -- & -- & - & - & -- & - & - \\
\hline $21 \ldots$ & -- & -- & -- & -- & -- & -- & -- & -- & -- \\
\hline $\begin{array}{l}19 \ldots \\
19 \ldots \\
\text { IAN. }\end{array}$ & -3 & 1.3 & 1.1 & 97 & .13 & 82.0 & $\begin{array}{l}2 B \\
--\end{array}$ & - & 1.2 \\
\hline $\begin{array}{l}15 \ldots \\
=E B .\end{array}$ & - & -- & -- & - & -- & - & -- & -- & - \\
\hline $\begin{array}{l}27 \ldots \\
27 \ldots \\
\text { AAR. }\end{array}$ & -1 & 1.2 & .89 & $\begin{array}{l}63 \\
--\end{array}$ & .09 & ${ }^{434}$-- & 18 & $\begin{array}{r}4 \\
--\end{array}$ & $\begin{array}{l}-7 \\
-2\end{array}$ \\
\hline $\begin{array}{l}28 \ldots . . \\
28 \ldots \\
P R .\end{array}$ & $\frac{-1}{--}$ & 1.7 & .00 & -5 & .07 & $294 \ldots$ & $\begin{array}{l}19 \\
--\end{array}$ & $\begin{array}{r}5 \\
--\end{array}$ & $\therefore 5$ \\
\hline $\begin{array}{l}20 \ldots . \\
20 \ldots \\
1 A Y\end{array}$ & $\because 0$ & 1.4 & .00 & 63 & .09 & ${ }^{413} \ldots$ & $\begin{array}{l}18 \\
--\end{array}$ & -2 & $\therefore 6$ \\
\hline IUNE & - & - & -- & -- & -- & -- & -- & -- & - \\
\hline $15 \ldots$ & - & - & - & -- & $\cdots$ & -- & $\cdots$ & -- & -- \\
\hline $\begin{array}{l}29 \ldots . . \\
29 \ldots \\
U_{G G} . .\end{array}$ & $\because 2$ & 1.0 & $=-$ & 87 & +12 & 57.8 & $\begin{array}{l}30 \\
--\end{array}$ & - & 1.3 \\
\hline $17 \ldots$ & -- & - & - & -- & -- & -- & -- & -- & - \\
\hline $21 \ldots$ & -- & $=$ & - & -- & -- & -- & -- & -- & -- \\
\hline
\end{tabular}


02102049 DEEP RIVER AT U.S. HIGHWAY 1, AT MONCURE, N. C.-COntinued

EXTREMES, 1943-44, 1955 56, 1961-67.--Cont 1nued

Hardness: Maximum, $35 \mathrm{mg} / 1$ Nov, 1-30, 1961; minimum, $12 \mathrm{mg} / 1$ on many days 1n 1944 and 1956 .

Specific conductance (1955-56, 1961-67): Yaximum da11y, 443 micromhos Feb. 1, 1966; min1mum daily, 25 micromhos

Water temperatures: Maximum, $34.5^{\circ} \mathrm{C}$ July 3,1956 ; min1mum, freezing point Jan. 29, 1963, Jan. 15, 1964, and Jan. $29,1966$.

REMARKS. - No apprectable inflow between sampling point and gaging station at Moncure except during periods of heavy local runoff. Records of discharge are given for 02102000 Deep River at Moncure. The second of two samples collected at the same time is a field determination.

CHEMICAL ANALYSES, WATER YEAR OCTOBER 1969 IO SEPTEMBER 1970

\begin{tabular}{|c|c|c|c|c|c|c|c|c|c|c|}
\hline DATE & $\begin{array}{l}\text { PERCENT } \\
\text { SODIUM }\end{array}$ & $\begin{array}{l}\text { B10- } \\
\text { CHEM- } \\
\text { ICAL } \\
\text { OXYGEN } \\
\text { DEMAND } \\
\text { IMG/L) }\end{array}$ & $\begin{array}{c}\text { PHENOLS } \\
\text { (UG/L) }\end{array}$ & $\begin{array}{l}\text { METHY- } \\
\text { LENE } \\
\text { BLUE } \\
\text { ACVIVE } \\
\text { SUB- } \\
\text { STANCE } \\
\text { (MG/L) }\end{array}$ & $\begin{array}{l}\text { TUR- } \\
\text { B1D- } \\
\text { ITY } \\
\text { I JTUI }\end{array}$ & $\begin{array}{l}\text { SUS- } \\
\text { PENDED } \\
\text { SOL IDS } \\
\text { (MG/L) }\end{array}$ & $\begin{array}{l}\text { ALKA- } \\
\text { LINITY } \\
\text { AS } \\
\text { CACO3 } \\
\text { IMG/L) }\end{array}$ & $\begin{array}{l}\text { TOIAL } \\
\text { CHRO- } \\
\text { MIUM } \\
\text { (CR) } \\
\text { (UG/L) }\end{array}$ & $\begin{array}{l}\text { COPPER } \\
\text { ICU) } \\
\{\cup G / L\}\end{array}$ & $\begin{array}{l}\text { LEAD } \\
\text { (PBI } \\
\text { (UG/L) }\end{array}$ \\
\hline $\begin{array}{c}\text { ocr. } \\
23 . . \\
\text { NOV. }\end{array}$ & - & -- & -- & -- & -- & -- & 23 & -- & -- & -- \\
\hline $21 .$. & $\cdots$ & -- & -- & -- & - & -- & -- & -- & -- & -- \\
\hline i9.... & 50 & -- & -- & .20 & -- & - & 28 & -- & -- & -- \\
\hline${ }_{J A N}^{19}$. & - & -- & -- & - & -- & -- & - & -- & -- & -- \\
\hline $\begin{array}{l}15 . . \\
F E B\end{array}$ & - & -- & -- & -- & - & -- & -- & -- & -- & -- \\
\hline $\begin{array}{l}\text { FEB. } \\
27 \ldots\end{array}$ & 41 & -- & -- & .06 & -- & -- & 15 & -- & -- & -- \\
\hline $\begin{array}{r}27 \ldots . . \\
\text { MAR. }\end{array}$ & $\therefore$ & -- & -- & - & - & -- & 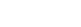 & -- & -- & - \\
\hline $\begin{array}{r}28 . . . \\
28 . . .\end{array}$ & 37 & $=$ & $\overline{-}$ & .15 & -- & $=$ & 14 & -- & -- & $=-$ \\
\hline $\begin{array}{l}\text { APR. } \\
20 . . .\end{array}$ & 40 & -- & -- & .11 & -- & -- & 16 & -- & -- & -- \\
\hline$\underset{\text { MAY }}{20 . \cdots}$ & -- & -- & - & - & - & -- & - & -- & -- & - \\
\hline $25 \ldots$ & - & - & -- & - & -- & -- & -- & -- & -- & -- \\
\hline $\begin{array}{l}\text { JUNE } \\
15 \ldots . .\end{array}$ & $\cdots$ & -- & -- & -- & -- & - & - & -- & -- & -- \\
\hline $\begin{array}{l}\text { JULY. } \\
29 . . .\end{array}$ & - & -- & - & - & - & 17 & - & -- & -- & -- \\
\hline $\begin{array}{l}29 . \ldots \\
29 . \ldots\end{array}$ & 51 & 2.8 & 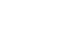 & .11 & 15 & 17 & $\begin{array}{l}34 \\
31\end{array}$ & - & - & 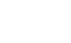 \\
\hline $\begin{array}{l}\text { AugG. } \\
17 \ldots . . .\end{array}$ & $\ldots$ & -- & - & -- & - & -- & - & -- & - & -- \\
\hline SEPT. & & & & & & & & & & \\
\hline $21 \ldots$ & - & -- & - & -- & - & -- & - & -- & - & -- \\
\hline & & & & & & $\begin{array}{l}\text { FECAL } \\
\text { COL I- } \\
\text { FORM }\end{array}$ & $\begin{array}{l}\text { SPECI- } \\
\text { FIC } \\
\text { CONO- }\end{array}$ & & & $\begin{array}{l}\text { COLOR } \\
\text { (PLAT- }\end{array}$ \\
\hline & $\begin{array}{l}2 \text { INC } \\
(2 N)\end{array}$ & $\begin{array}{l}\text { CrANI DE } \\
\text { (CN) }\end{array}$ & $\begin{array}{l}\text { MIUM } \\
\text { (CD) }\end{array}$ & $\begin{array}{l}\text { SOLVED } \\
\text { OXYGEEN }\end{array}$ & $\begin{array}{l}\text { BETA } \\
\text { (B) }\end{array}$ & $\begin{array}{c}\text { ICOL. } \\
\text { PER }\end{array}$ & $\begin{array}{l}\text { UCTANCE } \\
\text { IMICRD- }\end{array}$ & PH & $\begin{array}{c}\text { IEMP- } \\
\text { ERATURE }\end{array}$ & $\begin{array}{l}\text { INUM- } \\
\text { COBALT }\end{array}$ \\
\hline OA TE & $G / L 1$ & $(M G / L)$ & $(U G / L)$ & $(M G / L)$ & $(P C / L)$ & $100 \mathrm{MLI}$ & & (UNI IS) & (OEG C) & UNIIS: \\
\hline
\end{tabular}

\begin{tabular}{|c|c|c|c|c|c|c|c|c|c|c|}
\hline $\begin{array}{l}\text { ocr. } \\
23 . . .\end{array}$ & - & -- & - & 11.0 & -- & -- & 91 & 7.2 & 16.0 & -- \\
\hline $21 . .$. & - & -- & -- & 13.0 & - & 18 & 143 & 7.0 & 8.0 & -- \\
\hline DEC. & $\sim$ & -- & -- & -- & - & -- & 113 & 6.4 & 6.0 & 12 \\
\hline $19 .$. & - & - & $=$ & 11.8 & - & - & 102 & 6.4 & 6.0 & -2 \\
\hline $15 \ldots$ & -- & -- & -- & 13.3 & - & 168 & 105 & 7.4 & 1.0 & - \\
\hline 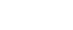 & - & -- & -- & - & - & -- & 68 & 6.4 & 6.0 & 60 \\
\hline $27 \ldots$ & - & -- & -- & 11.5 & - & - & 85 & 7.2 & 6.0 & -- \\
\hline $\begin{array}{l}\text { MAR. } \\
28 . . .\end{array}$ & - & -- & - & - & -- & -- & 71 & 6.3 & 12.0 & 30 \\
\hline $28 \ldots$ & $\cdots$ & -- & - & 10.5 & - & 248 & 77 & 7.2 & 12.0 & - \\
\hline $\begin{array}{c}\text { APR } \\
20 \ldots\end{array}$ & $\ldots$ & $\ldots$ & -- & -- & 4.0 & -- & 70 & 6.2 & 18.0 & 35 \\
\hline $20 \ldots$ & - & -- & -- & 9.8 & $=$ & 84 & 72 & 6.7 & 18.0 & - \\
\hline $25 . .$. & - & -- & -- & 8.7 & -- & 12 & 97 & 7.5 & 24.2 & -- \\
\hline 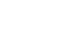 & - & -- & -- & 7.8 & -- & 22 & 120 & 7.6 & 25,0 & -- \\
\hline JULY & - & -- & - & - & - & $\ldots$ & $\ldots$ & -- & -- & -- \\
\hline $29 .$. & 13 & .00 & 0 & - & 9.0 & -- & 139 & 7.0 & 26.5 & 25 \\
\hline $29 \ldots$ & - & -- & -- & 7.2 & - & 20 & 160 & 7.4 & 26.5 & -- \\
\hline $17 \ldots$ & 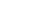 & -- & -- & 7.8 & -- & 132 & Bo & 6.6 & 24,0 & -- \\
\hline SEP T. & & & & 70 & & 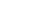 & & $6 \mathrm{cos}$ & 28 & \\
\hline $21 \ldots$ & - & $=-$ & - & 7.9 & - & 62 & 120 & 6.6 & 26.5 & -- \\
\hline
\end{tabular}


02102500 CAPE FEAR RIVER AT LILLINGTON, $N$. C.

LOCATION,--Lat $35^{\circ} 24^{\prime} 30^{\prime \prime}$, long $78^{\circ} 48^{\prime} 48^{\prime \prime}$, Harnett County, at gaging station near right bank of downstream bridge on U.S. Highway 401, 1, $800 \mathrm{ft}$ downstream from Norfolk Southern Railway bridge, $0.5 \mathrm{mjle}$ north of Lillington, $1 \mathrm{mile}$ downstream from Neal Creek, and at mile 178 .

DRAINAGE AREA, $--3,440 \mathrm{sq} \mathrm{mi}$, approximately.

PERIOD OF RECORD.--Chemical analyses: November 1944 to October 1945, October 1954 to September 1955 , November 1960 to September 1967, October 1967 to September 1969 (partial-record), October 1969 to September 1970.

Water temperatures: 'November 1944 to October 1945, October 1954 to September 1955, June 1959 to September 1967.

EXTREMES. - 1944-45, 1954-55, 1959-67

Dissolved solids (1944-45, 1954-55): Maximum, $176 \mathrm{mg} / 1 \mathrm{Oct}, 11-15,1954$; minimum, 48 mg/1 Feb. 20-28, Mar. 1-10, 1945 .

Hardness (1944-45, 1954-55): Haximum, $34 \mathrm{mg} / 1$ Oct. 11-15, 1954; minimum, $10 \mathrm{mg} / 1$ Oct. 21-31, 1954.

Speciflc conductance (1954-55): Maximum daily, 272 micromhos Oct. 11, 1954 (figures for Oct. 1-10, Oct. 11-15, 1954 , of 279 and 300 micromhos, respectively, are in error and should be 1 ess than 272); minimum daily,

41.1 micromhos Sept. 4,1955

Water temperatures: Maximum, $35.5^{\circ} \mathrm{C}$ June 30,$1959 ;$ minimum, $0.5^{\circ} \mathrm{C}$ on severa 1 days in January and February 1966.

REMARKS.--The second of two samples collected at the same time is a field determination.

CHEMICAL ANALYSES, WATER YEAR OCTOBER 1969 TO SEPTEMBER 1970

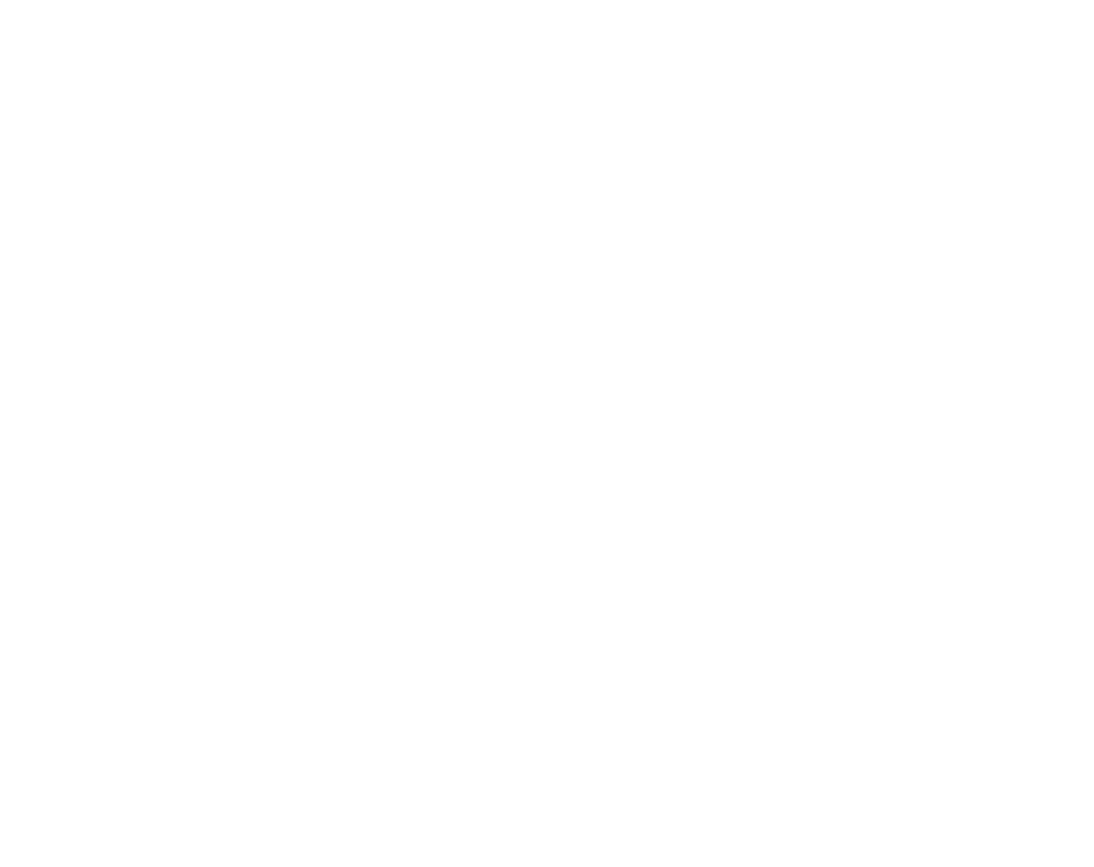

\begin{tabular}{|c|c|c|c|c|c|c|c|c|c|c|}
\hline${ }_{23}^{23} \ldots$ & $\bar{z}$ & -- & $=$ & $=$ & $=$ & $=$ & -- & - & $=$ & $=$ \\
\hline $\begin{array}{l}21 \\
21\end{array}$ & $=$ & $=$ & $=$ & $=$ & $\bar{z}$ & $=$ & -- & 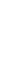 & -- & $\because$ \\
\hline $24 \ldots$. & $24 \ldots$ & .4 & 3.0 & 1.0 & 122 & .17 & GB5 & 2 & $\therefore$ & 1.8 \\
\hline $\begin{array}{l}\text { Jan. } \\
15 . . .\end{array}$ & - & -- & -- & - & - & -- & $=$ & - & - & $=$ \\
\hline $\begin{array}{lll} \\
F E B]\end{array}$ & -- & -- & -- & - & . & - & - & - & $\ldots$ & -- \\
\hline $27 . .:$ & -- & - & -- & - & - & -- & -- & - & -- & -- \\
\hline 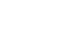 & 5.8 & .1 & 3.0 & .53 & 72 & .10 & 4060 & 2 & $\therefore$ & .7 \\
\hline APR & _. & - & - & & - & - & - & & -- & \\
\hline $20 \ldots$ & 8.3 & .2 & 2.4 & . & 72 & .10 & 474 & 2 & 4 & .7 \\
\hline 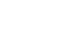 & - & -- & -- & -- & - & -- & - & - & -. & -- \\
\hline JUNE. & -- & -- & -- & -- & - & - & -. & & - & -- \\
\hline${ }_{15}^{15 \ldots}$ & -- & $\because$ & $\overline{-}$ & $=$ & $=$ & $=$ & $=$ & $=$ & $=$ & $=$ \\
\hline$\cdots$ & 16 & .3 & 2.4 & -- & 83 & .11 & 162 & 2 & 1 & 1.4 \\
\hline $\begin{array}{l}\text { AUG. } \\
17 . \ldots\end{array}$ & - & - & -- & - & - & -- & $\cdots$ & & -- & - \\
\hline$\dddot{\pi}$ & & & & & - & - & & & - & 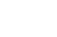 \\
\hline & $\overline{--}$ & $\bar{z}$ & $\overline{--}$ & $=$ & $=$ & $=-$ & $=$ & & 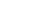 & $=$ \\
\hline
\end{tabular}


02102500 CAPE FEAR RIVER AT LILLINGTON, N. C.--Cont Inued

CHEMICAL ANALYSES, WATER YEAR OCTOBER 1969 TO SEPTEMBER 1970

\begin{tabular}{|c|c|c|c|c|c|c|c|c|c|c|c|}
\hline DATE & $\begin{array}{l}\text { PERCENT } \\
\text { SOOIUM }\end{array}$ & 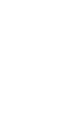 & $\begin{array}{c}\text { PHENOLS } \\
\text { IUG/L) }\end{array}$ & $\begin{array}{l}\text { IOTAL } \\
\text { KJELL } \\
\text { OAHL } \\
\text { NIIRD- } \\
\text { GEN } \\
\text { INI } \\
(M G / L)\end{array}$ & $\begin{array}{l}\text { METHY- } \\
\text { LENE } \\
\text { BLUE } \\
\text { ACTIVE } \\
\text { SUB } \\
\text { SIANCE } \\
\text { IMG } / L)\end{array}$ & $\begin{array}{l}\text { rUR- } \\
\text { BIDO- } \\
\text { IIYY } \\
\text { IJTUI }\end{array}$ & $\begin{array}{l}\text { SUS- } \\
\text { PENDED } \\
\text { SOL IDS } \\
\text { IMG L }\end{array}$ & $\begin{array}{l}\text { ALKA- } \\
\text { ALITY } \\
\text { AS } \\
\text { ACD3 } \\
\text { CAGOL } \\
\text { MG/L }\end{array}$ & $\begin{array}{l}\text { IOTAL } \\
\text { CHRDO } \\
\text { MIUM } \\
\text { ICR } \\
\text { IUGA }\end{array}$ & $\begin{array}{l}\text { COPPER } \\
\text { ICUI } \\
\text { (UG/L) }\end{array}$ & $\begin{array}{l}\text { EAD } \\
\text { IPBD } \\
\text { I U }\end{array}$ \\
\hline 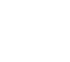 & $=$ & $=$ & $=$ & 1.8 & -- & 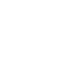 & -- & $\overline{33}$ & $=$ & $=$ & -- \\
\hline $\begin{array}{r}\text { Nov. } \\
21 . \\
21 \ldots\end{array}$ & $=$ & -- & $\because$ & .55 & $=$ & $=$ & $=$ & $=$ & $=$ & $=$ & $=$ \\
\hline $\begin{array}{l}\text { DEC. } \\
24 . . \\
24 \ldots .\end{array}$ & 58 & -- & $=$ & 1.1 & .00 & $=$ & -- & 33 & $=$ & -- & -- \\
\hline $\begin{array}{l}\text { JAN. } \\
15 . . .\end{array}$ & - & -- & -- & .68 & -- & - & -- & -- & -- & - & - \\
\hline 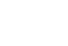 & & -- & -- & & -- & -- & -- & & -- & - & \\
\hline $\begin{array}{l}27 \ldots \\
27 \ldots\end{array}$ & $\because$ & $=$ & - & $\cdot .40$ & $\bar{z}$ & $\bar{z}$ & $=$ & "-- & $\overline{-}$ & -- & 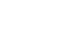 \\
\hline 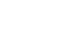 & 41 & -- & $=$ & .33 & .09 & $\tilde{z}$ & $=$ & 15 & $\because$ & $=$ & -- \\
\hline $\begin{array}{l}\text { APR } \\
200\end{array}$ & & & & & & & & & & - & \\
\hline${ }_{20 \%}^{20.0}$ & 42 & -- & - & -10 & .11 & - & -- & 18 & - & $=$ & $\because$ \\
\hline $25 \ldots$ & -- & -- & - & .29 & - & - & - & -- & -- & - & -- \\
\hline JUNE. & & & & & & & & & & - & \\
\hline $\begin{array}{l}155 . . \\
15 \%\end{array}$ & $\overline{-}$ & "- & $\overline{-}$ & .24 & $\overline{-}$ & $\because$ & -- & -- & $\overline{-}$ & $\overline{-}$ & $\overline{-}$ \\
\hline $\begin{array}{l}233 \\
23 \ldots \\
23 . .\end{array}$ & 54 & .7 & $\stackrel{0}{-}$ & .14 & .10 & 15 & 52 & $\begin{array}{l}25 \\
23\end{array}$ & - & - & - \\
\hline $\begin{array}{l}\text { AUG. } \\
177 . . \\
17 \ldots . .\end{array}$ & $=$ & $=$ & $=$ & .18 & $=$ & $\overline{-}$ & =- & -- & $=$ & $=-$ & $=$ \\
\hline $\begin{array}{c}\text { SEPT. } \\
21 . . .\end{array}$ & -- & -- & - & .60 & -- & - & -- & -- & -- & -- & -- \\
\hline & & -- & & & & & & -- & & & \\
\hline
\end{tabular}

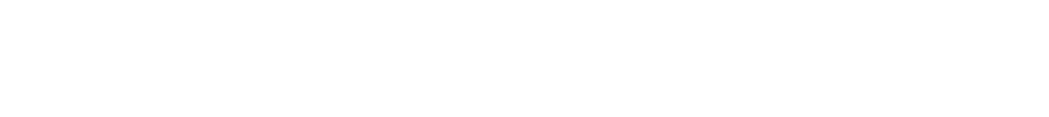

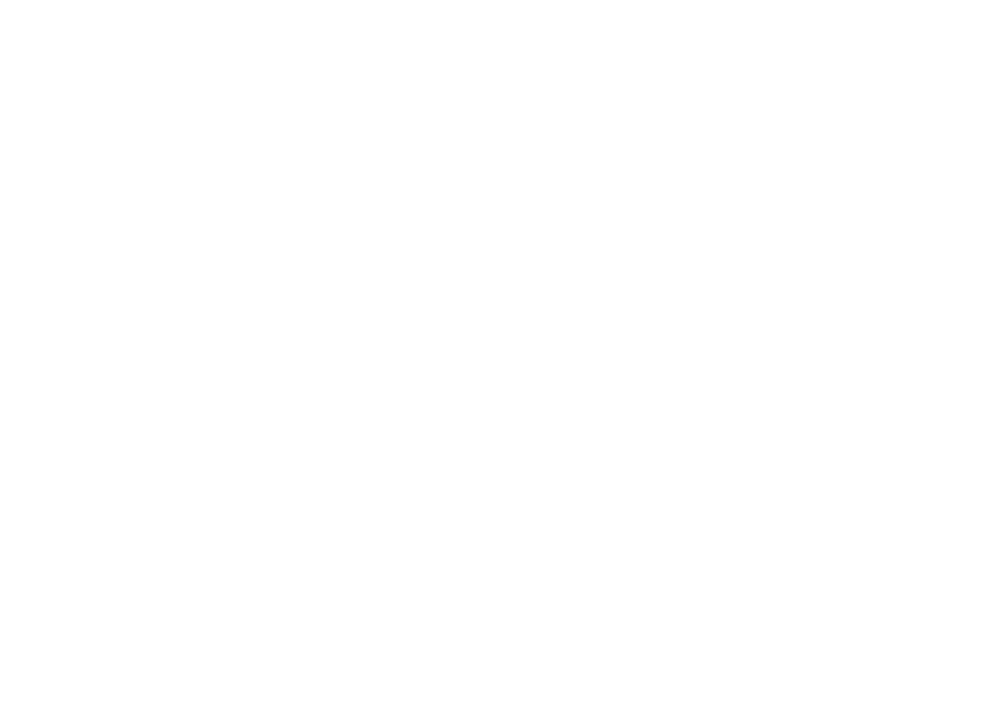

$\begin{array}{llllllll}\text { JULY } & <.01 & .00 & .00 & <.01 & .00 & <.01 & .00\end{array}$

\begin{tabular}{|c|c|c|c|c|c|c|}
\hline & $\begin{array}{l}\text { HEPTA- } \\
\text { CHLOK } \\
\text { EPOXIDE }\end{array}$ & & LINOANE & $\begin{array}{l}\text { ENDO- } \\
\text { SUL FAN }\end{array}$ & $\begin{array}{l}\text { IOX- } \\
\text { APHENE }\end{array}$ & $\begin{array}{l}\text { METH- } \\
\text { OXY- } \\
\text { CHLOR }\end{array}$ \\
\hline ATTE & IUG/L) & $(\cup G / L)$ & (UG/L) & (UG/L) & $(11 \mathrm{G} / \mathrm{L})$ & (UG/L) \\
\hline
\end{tabular}

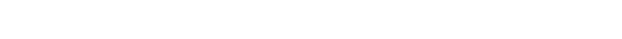


02105544 CAPE FEAR RIVER AT LOCK 2 , NEAR ELIZABETHTOHN, N. C.

LOCATION.--Lat $34^{\circ} 37^{\prime} 37^{\prime \prime}$, long $78^{\circ} 34^{\prime} 44^{\prime \prime}$, Bladen County, at Lock No. 2, 1 mile upstream from Turnbull Creek and 1.75 miles east of Eilzabethtown.

DRAINACE AREA. $-4,980 \mathrm{sq} \mathrm{m} 1$.

PERIOD OF RECORD.--Chemical analyses: July 1969 to September 1970.

REXARKS. - The second of two samples collected at the same time is a field determination.

CHEMICAL ANALYSES, WATER YEAR OCTDBER 1969 TO SEPTEMAER 1970

\begin{tabular}{|c|c|c|c|c|c|c|c|c|c|c|}
\hline DATE & TIME & $\begin{array}{l}\text { SILICA } \\
\text { (SID2) } \\
\text { (MG/L) }\end{array}$ & $\begin{array}{l}\text { DIS- } \\
\text { SOLVED } \\
\text { IRDN } \\
\text { (FE) } \\
\text { (UG/L) }\end{array}$ & $\begin{array}{l}\text { CAL- } \\
\text { CIUM } \\
(C A) \\
(M G / L)\end{array}$ & $\begin{array}{l}\text { MAG- } \\
\text { NE- } \\
\text { SIUM } \\
\text { IMGI } \\
(M G / L)\end{array}$ & $\begin{array}{l}\text { SODIUM } \\
(N A) \\
(M G / L)\end{array}$ & $\begin{array}{l}P O- \\
\text { TAS- } \\
\text { SIUM } \\
(K) \\
(M G / L)\end{array}$ & $\begin{array}{l}\text { BIC } \triangle R- \\
\text { BONATE } \\
(H C \cap 3) \\
(M G / L)\end{array}$ & $\begin{array}{l}\text { CAR- } \\
\text { AONATE } \\
\text { (Cח3) } \\
\text { (MG/L) }\end{array}$ & $\begin{array}{l}\text { SULFAT } \\
\text { (SOA) } \\
\text { (MG/L }\end{array}$ \\
\hline $\begin{array}{l}\mathrm{OCT} . \\
27 \ldots . . \\
\mathrm{DEC} .\end{array}$ & 1300 & -- & $\cdots$ & -- & $\rightarrow$ & -- & - & 16 & -- & $\cdots$ \\
\hline MAR... & 1600 & 11 & 160 & 6.6 & 1.9 & 20 & 3.6 & 33 & 0 & 12 \\
\hline $\begin{array}{c}23 . . \\
A O R .\end{array}$ & 1740 & 9.8 & 38 & 4.9 & 2.0 & 10 & 1.6 & 21 & 0 & 11 \\
\hline Jut $21 \ldots$ & 1130 & 8.8 & 237 & 4.0 & 1.5 & 6.6 & 1.4 & 14 & 0 & 10 \\
\hline $23 \ldots$ & 0945 & 7.6 & 7 & 6.1 & 2.9 & 17 & 3.0 & 34 & 0 & 22 \\
\hline DATE & $\begin{array}{l}\text { CHLO- } \\
\text { RIDE } \\
\text { (CL) } \\
\text { ( } M G / L)\end{array}$ & $\begin{array}{l}\text { FLUD- } \\
\text { RIOE } \\
\text { (F) } \\
\text { (MG/L) }\end{array}$ & $\begin{array}{l}\text { NI TRATE } \\
\text { (NO3) } \\
\text { (MG/L) }\end{array}$ & $\begin{array}{l}\text { CRTHD } \\
\text { PHOS- } \\
\text { PHATE } \\
\text { (PO4) } \\
\text { (MG/L) }\end{array}$ & $\begin{array}{l}\text { DIS- } \\
\text { SDLVED } \\
\text { SOLI OS } \\
\text { (RESI } \\
\text { OUE AT } \\
180 \text { CI } \\
\text { (MG/LI) }\end{array}$ & $\begin{array}{l}\text { DIS- } \\
\text { SOLVED } \\
\text { SOLIOS } \\
\text { ITONS } \\
\text { PER } \\
\text { AC-FTI }\end{array}$ & $\begin{array}{l}\text { HARD- } \\
\text { NESS } \\
\text { (CA, MG) } \\
\text { (MGILI) }\end{array}$ & $\begin{array}{l}\text { NON- } \\
\text { CAR- } \\
\text { BNNATE } \\
\text { HARO- } \\
\text { NESS } \\
\text { IMG/LI }\end{array}$ & $\begin{array}{l}\text { SOOIL } \\
\text { AD- } \\
\text { SOKP } \\
\text { TIUH } \\
\text { RAII }\end{array}$ & $\begin{array}{l}\text { IUM } \\
- \\
- \\
-\end{array}$ \\
\hline
\end{tabular}

OCT.

DEC...

$\begin{array}{lll}\text { MAR. } & \\ 23 . . . & 11\end{array}$

APR.
$21 . .$.$\quad 7.8$

JULY

$\begin{array}{rcr}-- & - & - \\ 4.7 & 1.5 & 10 \\ .2 & .39 & 12 \\ 2.2 & .08 & 64 \\ 2.6 & -- & 96\end{array}$

--
102
72
96

$\begin{array}{ll}-- & -- \\ .14 & 24 \\ .10 & 20 \\ .09 & 16 \\ .13 & 27\end{array}$

$-$

1.0

96

METHY-

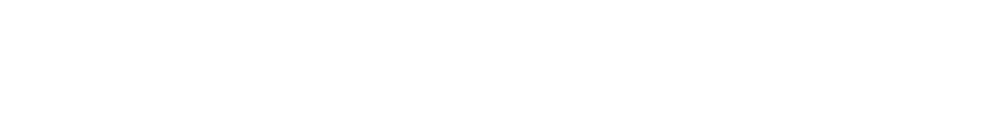

\begin{tabular}{|c|c|c|c|c|c|c|c|c|c|c|}
\hline${ }_{27}^{27 .}$. & - & -- & - & -- & - & -- & -- & -- & 35 & -- \\
\hline $\begin{array}{l}\text { NOV.:. } \\
24 \ldots\end{array}$ & -- & -- & -- & -- & - & -- & -- & -- & 25 & -- \\
\hline $\begin{array}{c}24 \cdots, \cdots \\
D E C .\end{array}$ & & & & & - & -- & & & & \\
\hline $\begin{array}{l}16 \ldots \\
16 \ldots\end{array}$ & 60 & $\because$ & $=$ & .15 & -- & $\because-$ & 27 & -- & $\stackrel{45}{\longrightarrow}$ & $=-$ \\
\hline $\begin{array}{l}\text { JAN. } \\
26 . . .\end{array}$ & - & -- & - & -- & - & -- & -- & -- & 48 & -- \\
\hline FEB & 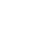 & & & & 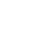 & & 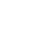 & 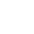 & & 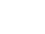 \\
\hline${ }_{23}^{23} \ldots$ & - & $\overline{--}$ & - & - & - & $\because$ & - & -- & - & 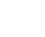 \\
\hline 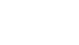 & 49 & $=$ & $=$ & .12 & $=$ & -- & 17 & $=$ & م & $=$ \\
\hline $\begin{array}{l}\text { APR. } \\
21 . .\end{array}$ & -- & -- & -- & - & -- & -- & -- & -- & -- & -- \\
\hline $\operatorname{MAY} \cdots$ & 44 & -- & -- & .10 & -- & -- & 11 & -- & 30 & $\cdots$ \\
\hline $\begin{array}{l}26 . \ldots \\
26 . \ldots\end{array}$ & $\bar{z}$ & $=$ & $=$ & $=$ & $=$ & $=-$ & $=$ & $=-$ & 23 & $=-$ \\
\hline $16 \ldots$ & - & - & - & -- & - & -- & -- & -- & 35 & -- \\
\hline${ }_{\text {JuLY }}^{\text {jo. }}$ & -- & -- & & & -- & -- & -- & -- & & -- \\
\hline${ }_{23}^{23} \ldots$ & 54 & 1.5 & $\stackrel{0}{-}$ & .12 & 2.0 & 28 & 28 & $\therefore$ & $\therefore$ & - \\
\hline $\begin{array}{l}\text { AUG. } \\
18 . .\end{array}$ & -- & -- & -- & -- & - & -- & -- & -. & 10 & -. \\
\hline $\begin{array}{l}18 \ldots, \\
\text { SEPT. }\end{array}$ & - & & -- & -- & - & -- & -- & -- & & -- \\
\hline $\begin{array}{l}21 \ldots \\
211 \ldots\end{array}$ & $=$ & $\because$ & $=$ & $\bar{z}$ & $=$ & $=$ & $=$ & $=$ & 85 & -- \\
\hline
\end{tabular}


02105544 CAPE FEAR RIVER AT LOCK 2, 'NEAR ELIZABETHTOWN, N. C.--Cont Inued

CHEMICAL ANALYSES, WATER YEAR OCTOBER 1969 TO SEPTEMBER 1970

\begin{tabular}{|c|c|c|c|c|c|c|c|c|c|c|}
\hline DATE & $\begin{array}{c}\text { ZINC } \\
\text { (2N) } \\
\text { (UG/L) }\end{array}$ & $\begin{array}{c}\text { CYANIDE } \\
\text { (CN) } \\
\text { (MG/L) }\end{array}$ & $\begin{array}{l}\text { CAO- } \\
\text { MIUM } \\
\text { (CDI } \\
\text { (UG/L) }\end{array}$ & $\begin{array}{l}\text { DIS- } \\
\text { SOLVEO } \\
\text { OXYGEN } \\
\text { (MG/L) }\end{array}$ & $\begin{array}{l}\text { TOTAL } \\
\text { BETA } \\
\text { (B) } \\
(P C / L)\end{array}$ & $\begin{array}{l}\text { FECAL } \\
\text { COLI- } \\
\text { FORM } \\
\text { ICOL. } \\
\text { PER } \\
\text { OOO MLI) }\end{array}$ & $\begin{array}{l}\text { SPECI- } \\
\text { FIC } \\
\text { COND- } \\
\text { UCTANCE } \\
\text { (MICRO- } \\
\text { MHOS) }\end{array}$ & $\begin{array}{c}\text { PH } \\
\text { [UNITSI }\end{array}$ & $\begin{array}{l}\text { TEMP- } \\
\text { ERATURE } \\
\text { (OEG C) }\end{array}$ & $\begin{array}{l}\text { COL DR } \\
\text { IPLAT- } \\
\text { INUM- } \\
\text { COBALT } \\
\text { UNITSI }\end{array}$ \\
\hline $\begin{array}{r}\text { OCT. } \\
27 \ldots\end{array}$ & - & 00 & -- & -- & -- & -- & 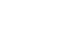 & $\pi-$ & -- & $-\pi$ \\
\hline $27 \ldots$ & -- & - & -- & B. 3 & - & $B 20$ & 84 & 6.7 & 18.0 & $=$ \\
\hline $\begin{array}{l}\text { NOV. } \\
24 \ldots . .\end{array}$ & -- & .00 & - & - & - & -- & - & -- & - & -- \\
\hline$\underset{D E C .}{24 \ldots}$ & -- & - & -- & 10.0 & -- & 960 & 122 & 7.0 & 10.0 & -- \\
\hline $16 \ldots$ & - & .00 & -- & - & -- & - & 129 & 6.5 & 7.0 & 30 \\
\hline $\begin{array}{l}16 \ldots . . \\
\text { JAN. }\end{array}$ & -- & -- & -- & 14.6 & -- & 1680 & 185 & 5.2 & 7.0 & -- \\
\hline $26 \ldots$ & -- & .00 & -- & -- & -- & -- & - & -- & 6.0 & -- \\
\hline $\begin{array}{c}26 \ldots . . \\
\text { FEB. }\end{array}$ & -- & -- & - & 10.8 & - & -- & 130 & 6.4 & 6.0 & -- \\
\hline $23 \ldots$ & -- & .00 & $=$ & - & - & -- & - & - & -- & $\rightarrow$ \\
\hline MAR... & - & -- & - & 10.9 & - & -- & 70 & 6.3 & 9.0 & -- \\
\hline $\begin{array}{l}23 \ldots \\
23 \ldots\end{array}$ & $=$ & .00 & $=$ & $11 \overline{-8}$ & $\because$ & $28 \overline{0}$ & $\begin{array}{r}95 \\
105\end{array}$ & $\begin{array}{l}6.1 \\
6.6\end{array}$ & $\begin{array}{l}12.0 \\
12.0\end{array}$ & 20 \\
\hline $\begin{array}{l}A P R . \\
21 \ldots\end{array}$ & -- & 00 & -- & $=$ & 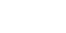 & -- & - & -- & -- & -- \\
\hline $\operatorname{MAY}_{\operatorname{Ma}}^{21}$ & - & -- & - & 8.2 & - & 980 & 80 & 6.3 & 20.0 & 60 \\
\hline $26 \ldots$ & -- & .00 & -- & - & $\rightarrow$ & -- & - & -- & - & -- \\
\hline $26 \ldots$ & $=$ & -- & -- & 7.8 & -- & 640 & 120 & 7.0 & 24.5 & -- \\
\hline $16 \ldots$ & - & .00 & - & - & - & -- & - & -- & 26.0 & -. \\
\hline JuL 16 & - & -- & - & 7.3 & - & 920 & 119 & 6.6 & 26.0 & -- \\
\hline $23 \ldots$ & 3 & .00 & 0 & 5.5 & 7.4 & 160 & 138 & 6.7 & 26.5 & 20 \\
\hline $\begin{array}{l}23 . . . \\
\text { AUG. }\end{array}$ & -- & -- & -- & -- & -- & -- & 138 & -- & - & -- \\
\hline $18 \ldots$ & -- & .00 & -- & - & -- & -- & - & $\rightarrow$ & 25.5 & $-\rightarrow$ \\
\hline $\begin{array}{l}18 \ldots . . \\
\text { SEPT. }\end{array}$ & -- & -+ & -- & 6.0 & $\rightarrow$ & 3200 & 75 & 6.8 & 25.5 & -- \\
\hline $21 \ldots$ & -- & .01 & -- & $\overline{5}$ & - & -- & - & -- & 28.5 & -- \\
\hline $21 \ldots$ & -- & $=$ & -- & 5.6 & $\cdots$ & 480 & 98 & 7.6 & 28.5 & -- \\
\hline
\end{tabular}

02107571 CAPE FEAR RIVER NEAR NAVASSA, N. C.

LOCATION,--Lat $34^{\circ} 17^{\circ} 00^{\prime \prime}$, long $77^{\circ} 59^{\prime} 50^{\prime \prime}$, New Hanover County, water-qual1ty recorder on left bank at bost pier, at Caroitna Power and Light Company Sutton Steam-Electric Generating Plant, 1.5 miles downstream from Catfiah Creek, 2 miles northeast of Navassa, 6 miles upstream from Market Street in wilmington, and at mile 34.0.

DRAINAGE AREA, - 7, $050 \mathrm{sq} m i$, approximately.

PERIOD OF RECORD. - Chemical analyses: October 1960 to September 1961, October 1966 to September 1967, December 196?

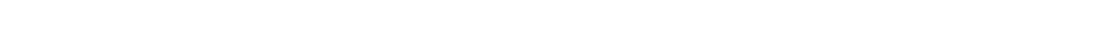
Royster." Water temperatures: October 1960 to September 1961, October 1966 to September 1967, December 1967 to September
1970.

EXTREMES, $-1969-70$ :

Dissolved oxygen: Laximum recorded, $13,0 \mathrm{mg} / 1$ Dec. 30; minimum recorded, $2.2 \mathrm{mg} / 1$ Sept. 26.

Water temperatures: Yaximum recorded, $31.5^{\circ} \mathrm{C}$ Aug. 1 ; minimum, $1.5^{\circ} \mathrm{C}$ Jan. 24 .

Period of record:

Chloride (1960-61): Maximum, 1,700 mg/l Sept. 23, 1960; minimum, 4.6 mg/1 May 1, 1961

Specific conductance $(1960-61$, 1966-69): Maximum dally, 29,000 micromhos Oct. 10, 1968; minimum daily, 48 micromhos Apr. 17, July 5, Sept. 8 , 1961

Water temperatures: Kaximum, 35.0 $\mathrm{C}$ Aug. 20, 1968; minimum, $1.0^{\circ} \mathrm{C}$ Feb. 15, $16,1969$.

REMARKS.--Recorder not operating during part of December and April to July. Prior to October 1961, values of specific conductance and chloride were determined from individual samples. The recorder intake location is 1 foot below mean low-water surface and 6 feet off left bank. Hecorder not sensitive to very
ances. The second of two samples collected at the same time is a field determination.

CHEMICAL ANALYSES, WATER YeAR OCTOBER 1969 to SEPTEMBER 1970

\begin{tabular}{|c|c|c|c|c|c|c|c|c|c|c|}
\hline DATE & TIME & $\begin{array}{l}\text { SILICA } \\
\text { (S102) } \\
\text { (MG/L) }\end{array}$ & $\begin{array}{l}\text { DIS- } \\
\text { SOLVED } \\
\text { IRON } \\
\text { (FE) } \\
\text { (UG/L) }\end{array}$ & $\begin{array}{l}\text { CAL- } \\
\text { CIUM } \\
\text { (CA) } \\
\text { (MG/L) }\end{array}$ & $\begin{array}{c}\text { MAG- } \\
\text { NE- } \\
\text { SIUM } \\
(M G) \\
(M G / L)\end{array}$ & $\begin{array}{l}\text { SOOIUM } \\
\text { (NA) } \\
\text { (MG/L) }\end{array}$ & $\begin{array}{l}\text { Pח- } \\
\text { IAS- } \\
\text { SIUM } \\
\text { (K) } \\
\text { (MG/L) }\end{array}$ & $\begin{array}{l}\text { BICAR- } \\
\text { BONATE } \\
\text { (HCO3) } \\
\text { (MG/L) }\end{array}$ & $\begin{array}{l}\text { CAR- } \\
\text { SONATE } \\
\text { (COB) } \\
\text { (MG/L) }\end{array}$ & $\begin{array}{l}\text { SULFATE } \\
\text { (SO4) } \\
\text { (MG/L) }\end{array}$ \\
\hline $\begin{array}{l}\text { OCT. } \\
27 . . . \\
\text { DEC. }\end{array}$ & 1530 & -- & - & -- & - & -- & -- & 28 & -- & - \\
\hline & 0800 & 8.0 & 260 & 4.2 & 2.3 & 20 & 2.8 & 26 & 0 & 26 \\
\hline $24 \ldots$ & 0945 & 6.1 & 119 & 4.0 & 1.3 & 8.8 & 1.2 & 12 & 0 & 8.4 \\
\hline
\end{tabular}

\begin{tabular}{|c|c|c|c|c|c|c|c|c|c|}
\hline DATE & $\begin{array}{l}\text { CHLO- } \\
\text { RIDE } \\
(C L) \\
(M G / L)\end{array}$ & $\begin{array}{l}\text { FLUO- } \\
\text { RIDE } \\
\text { (F) } \\
(\mathrm{MG} / \mathrm{L})\end{array}$ & $\begin{array}{c}\text { NI TRATE } \\
\text { (NO3) } \\
\text { (MG/L) }\end{array}$ & $\begin{array}{l}\text { ORTHD } \\
\text { PHOS- } \\
\text { PHAIE } \\
\text { (PO }) \\
\text { (MG/L) }\end{array}$ & $\begin{array}{l}\text { OIS- } \\
\text { SOLVEO } \\
\text { SOLIDS } \\
\text { (RESI- } \\
\text { OUE AI } \\
\text { IBOCI) } \\
\text { (MG/L) }\end{array}$ & $\begin{array}{l}\text { DIS- } \\
\text { SOLVEO } \\
\text { SOLIDS } \\
\text { ITONS } \\
\text { PER } \\
\text { AC-FT) }\end{array}$ & $\begin{array}{l}\text { HARD- } \\
\text { NESS } \\
\text { (CA, MG) } \\
\text { (MG/L) }\end{array}$ & $\begin{array}{l}\text { NON- } \\
\text { CAR- } \\
\text { BONATE } \\
\text { HARD- } \\
\text { NESS } \\
\text { IMG/LI }\end{array}$ & $\begin{array}{l}\text { SDOIUM } \\
\text { AD- } \\
\text { SORP- } \\
\text { TION } \\
\text { RATIO }\end{array}$ \\
\hline $\begin{array}{c}\text { OCI. } \\
27 \ldots . . \\
\text { DEC. }\end{array}$ & -- & - & $=-$ & $\cdots$ & $\cdots$ & -- & -- & -- & -- \\
\hline $\begin{array}{l}17 \ldots \\
\text { MAR... }\end{array}$ & 12 & .3 & 2.7 & .50 & 100 & .14 & 20 & 2 & 1.9 \\
\hline $24 \ldots$ & 10 & .1 & 1.2 & .27 & 58 & .08 & 16 & 6 & 1.0 \\
\hline
\end{tabular}


02107571 CAPE FEAR RIVER NEAR NAVASSA, N. C.--Continued CHEMICAL ANALYSES, WATER YEAR OCTOBER 1969 TO SEPTEMBER 1970

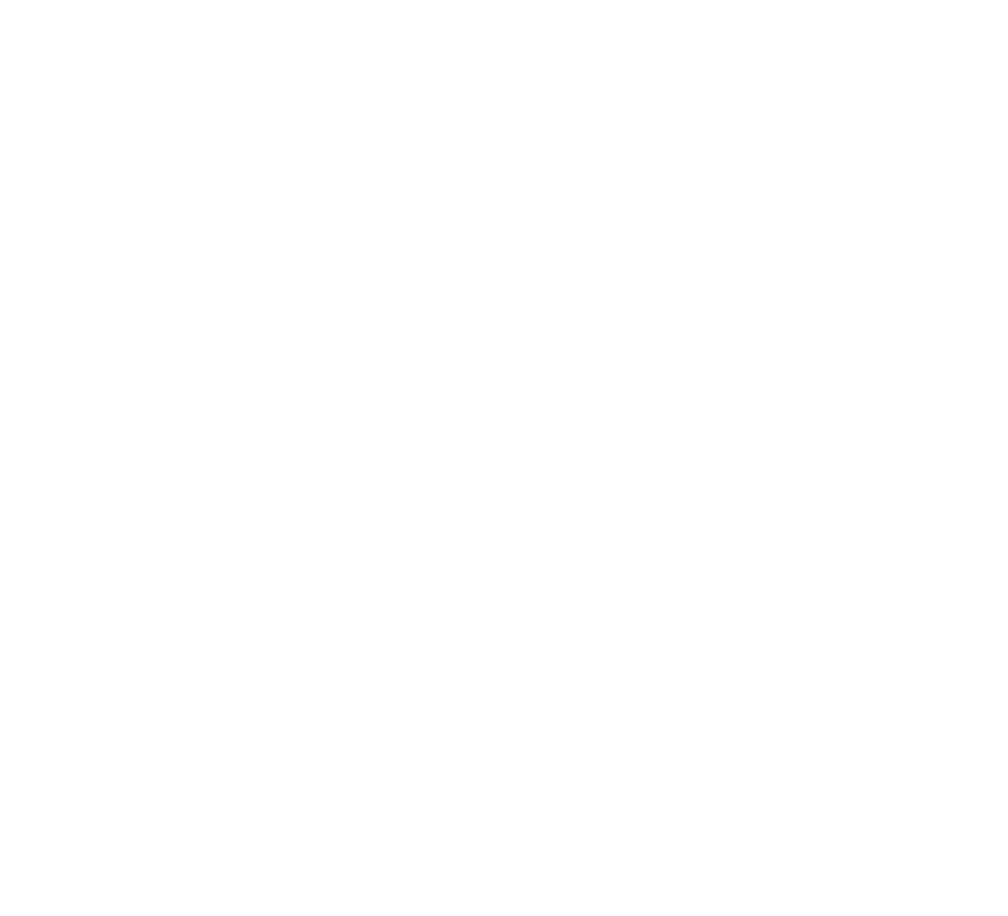

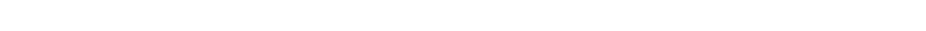
OCTOBER
NOVEMBER
DECEMBER
JANUARY
FEBRUARY
MARCH

Dar

1 $2 \ldots$

3.0 .0

$5 \ldots \ldots$

$6 \ldots$

$7 \ldots \ldots$

$10 \ldots . . . .$.

$11 \ldots . .$.

$12 \ldots \ldots$

$13 \ldots \ldots$

150000

$16 . \ldots$

$17 . . .$.

$18 \ldots \ldots$

1000

$21 \ldots$

$22 \ldots$

$23 \ldots . .0$

$24 \ldots . .0$

$26 . . .0$

$27 \ldots \ldots$

$28 \ldots . .$.

$29 . \cdots$

$30 \ldots . . .$.

MONTH
MAXIMUM MINIMUM MAX

$\begin{array}{ll}5.9 & 5.5 \\ 6.1 & 5.6 \\ 6.2 & 5.6 \\ 6.7 & 5.7 \\ 7.3 & 6.5\end{array}$

8.0
8.0
8.0
8.0

7.0
7.0
7.0
7.0

6.6

5.7

$5.4 \quad 5.3$

5.6
5.4
5.3
5.1
5.0

5.3

$\begin{array}{ll}5.5 & 5.1 \\ 5.3 & 5.2 \\ 5.5 & 5.0\end{array}$

$5.5 \quad 5.0$

5.4

$5.4 \quad 5.0$

$4.9 \quad 4.4$

5.2

6.0

7.0

4.8
4.7
5.0
5.0
6.0

1.0

8.7

8.0

8.0

8. 7

6.0

7.0
6.0
6.0

6.0
6.0

$\therefore: 0$

8.0
8.0
8.0
8.0
8.0
8.0
7.6
7.5
7.4
7.5
7.5
7.6
7.0
8.5
8.
8.0
7.55
7.5
8.1
8.3
8.5
7.6
8.5
8.5
8.5
7

7.1

7.0
7.0
7.0
7.0

7.0
7.0
7.0

$\begin{array}{llll}7.0 & - & - & 12.1 \\ 7.2 & = & = & 12.1 \\ 7.2 & - & - & 12.2\end{array}$

$7.2 \quad=\quad=\quad \begin{aligned} & 12.2 \\ & 12.2\end{aligned}$

$-$

$\bar{z}=$

12.2

12.4
12.5
-.2

$12 \overline{2}$

12.0
11.9
11.9

$\begin{array}{rr}- & - \\ 12.2 & 11.9 \\ 12.3 & 11.9\end{array}$

\begin{tabular}{llll}
8.3 & 7.6 & 12.3 & 11.7 \\
7.6 & 7.0 & 12.4 & 11.9 \\
8.5 & 7.0 & 12.3 & 11.9 \\
8.5 & 7.0 & 12.7 & 12.0 \\
8.5 & 7.0 & 13.0 & 12.0 \\
\hline- &. & 12.6 & 12.0
\end{tabular}

10.8
10.7

12.3

12.0

12.4
10.6
10.7

10.7
10.8
10.8

12.5

$2=1$

11.9

12.0

2.1
2.0
2.0

$11.6 \quad 10.4$

$11.9 \quad 10.4$

$\begin{array}{ll}11.8 & 10.4 \\ 11.8 & 10.7\end{array}$

$\begin{array}{ll}11.8 & 10.7 \\ 11.8 & 10.6\end{array}$

$\begin{array}{ll}11.9 & 10.4 \\ 12.0 & 10.4\end{array}$

$\begin{array}{ll}12.0 & 10.5 \\ -1 & 10.7\end{array}$

$\begin{array}{lll}11.8 & 10.6 & 10.3\end{array}$

11.610 .1

$\begin{array}{ll}11.6 & 10.0 \\ 11.6 & 10.0\end{array}$

$\begin{array}{rr}11.7 & 10.0 \\ 11.8 & 9.9\end{array}$

$\begin{array}{ll}10.4 & 10.0 \\ 10.3 & 10.2 \\ 10.2 & 10.7\end{array}$

$\begin{array}{lll}10.3 & 10.2 & 9.7 \\ 10.2 & 10.7 & 10.0\end{array}$

10.3

10.2

10.9 minum maximum minimun

$\begin{array}{lll}10.3 & 10.8 & 10.3\end{array}$

$\begin{array}{lll}10.6 & 11.0 & 10.3\end{array}$

$\begin{array}{llr}10.1 & 10.6 & 10.2 \\ 10.3 & 11.0 & 6.5\end{array}$

10.2 -

10.1

10.1

$10.1=$

$10.1 \quad 7.0 \quad 6.8$

$\begin{array}{lll}10.0 & 7.3 & 6.6 \\ 10.1 & 7.0 & 6.5\end{array}$

$\begin{array}{lll}10.2 & 7.3 & 6.9 \\ 10.2 & 7.2 & 6.8\end{array}$

$10.2 \quad 7.3 \quad 6.9$

$\begin{array}{lll}0.1 & 7.5 & 7.0 \\ 0.6 & 7.2\end{array}$

$\begin{array}{lll}0.1 & 7.4 & 7.1\end{array}$

$\begin{array}{lll}9.9 & 7.4 & 7.1 \\ 9.8 & 7.5 & 7.2\end{array}$

$\begin{array}{lll}9.7 & 7.3 & 7.2 \\ 9.6 & 7.3 & 7.0\end{array}$

$9.6 \quad 7.1 \quad 6.9$

$\begin{array}{lll}9.4 & 6.9 & 6.8 \\ 9.7 & 6.8 & 6.5\end{array}$

$\begin{array}{lll}0.0 & 6.8 & 6.5 \\ - & 6.9 & 6.6\end{array}$

$6.9 \quad 6.6$

$11.0 \quad 6.4$ 
02107571 CAPE FEAR RIVER NEAR NAVASSA, N. C.- COnt InUeC

DISSOLVED OXYGEN (DO), IN MILLIGRAMS PER LITER, WATER YEAR OCTOBER 1969 TO SEPTEMBER 1970
APRIL
MAY
JUNE
JuLY
AUGUST
SEPTEMBER

dar maximum minimum maximum minimun maximum mintmum maximum minimum maximum minimum maximum minimum

\begin{tabular}{|c|c|c|c|c|c|c|c|c|c|c|c|c|}
\hline $\begin{array}{l}1 \ldots \ldots \\
2 \ldots \ldots \\
3 \ldots \ldots \\
4 \ldots \ldots \\
5 \ldots \ldots\end{array}$ & $\begin{array}{l}7.0 \\
7.4 \\
7.2 \\
7.3 \\
7.1\end{array}$ & $\begin{array}{l}6.6 \\
6.9 \\
6.9 \\
6.9 \\
6.8\end{array}$ & $\begin{array}{l}= \\
= \\
=\end{array}$ & $\begin{array}{l}\overline{-} \\
\bar{z}\end{array}$ & $=$ & $\begin{array}{l}= \\
=\end{array}$ & $=$ & $=$ & $\begin{array}{l}7 \\
5.9 \\
5.2 \\
5.2\end{array}$ & $\begin{array}{l}- \\
4.2 \\
4.6 \\
4.6\end{array}$ & $\begin{array}{l}5.7 \\
5.5 \\
5.7 \\
5.8 \\
5.9\end{array}$ & $\begin{array}{l}5.2 \\
4.9 \\
4.7 \\
4.9 \\
4.8\end{array}$ \\
\hline $\begin{array}{c}6 \ldots \ldots \\
7 \ldots \ldots \\
8 \ldots \ldots \\
10 \ldots \ldots\end{array}$ & $\begin{array}{l}6.9 \\
6.7 \\
6.7 \\
6.8 \\
6.9\end{array}$ & $\begin{array}{l}6.7 \\
6.5 \\
6.4 \\
6.6 \\
6.6\end{array}$ & $=$ & $\begin{array}{l}\overline{-} \\
= \\
=\end{array}$ & $\begin{array}{l}= \\
= \\
=\end{array}$ & $=$ & $=$ & $=$ & $\begin{array}{l}4.9 \\
4.7 \\
4.7 \\
4.8 \\
4.9\end{array}$ & $\begin{array}{l}4.5 \\
4.4 \\
4.2 \\
4.2 \\
4.4\end{array}$ & $\begin{array}{l}5.2 \\
-.- \\
5.1 \\
5.6 \\
5.4\end{array}$ & $\begin{array}{l}4.6 \\
4.4 \\
4.6\end{array}$ \\
\hline $\begin{array}{l}11 \ldots \ldots \\
12 \ldots \ldots \\
13 \ldots \ldots \\
14 \ldots \ldots \\
15 \ldots \ldots\end{array}$ & $\begin{array}{l}7.0 \\
6.8 \\
6.9 \\
6.9 \\
6.8\end{array}$ & $\begin{array}{l}6.5 \\
6.5 \\
6.5 \\
6.5 \\
6.5\end{array}$ & $\begin{array}{l}= \\
=\end{array}$ & $\bar{z}$ & $\bar{z}$ & $=$ & $=$ & $=$ & $\begin{array}{l}5.1 \\
5.1 \\
6.4 \\
6.2 \\
5.3\end{array}$ & $\begin{array}{l}4.6 \\
4.6 \\
4.8 \\
5.1 \\
4.9\end{array}$ & $\begin{array}{l}6.4 \\
5.8 \\
6.0 \\
5.6 \\
5.4\end{array}$ & $\begin{array}{l}4.4 \\
4.3 \\
4.2 \\
4.2 \\
4.5\end{array}$ \\
\hline $\begin{array}{l}16 \ldots \ldots \\
17 \ldots \ldots \\
18 \ldots \ldots \\
19 \ldots \ldots \\
20 \ldots \ldots\end{array}$ & $\begin{array}{l}7.3 \\
7.4 \\
6.9 \\
6.7 \\
6.5\end{array}$ & $\begin{array}{l}6.5 \\
6.7 \\
6.3 \\
6.2 \\
6.1\end{array}$ & $\begin{array}{l}= \\
=\end{array}$ & $\begin{array}{l}\bar{z} \\
=\end{array}$ & $=$ & $=$ & $\begin{array}{l}= \\
-\end{array}$ & $=$ & $\begin{array}{l}5.3 \\
6.0 \\
5.9 \\
5.5 \\
5.7\end{array}$ & $\begin{array}{l}4.8 \\
5.0 \\
5.0 \\
5.0 \\
4.9\end{array}$ & $\begin{array}{l}5.1 \\
5.0 \\
4.8 \\
5.5 \\
5.1\end{array}$ & $\begin{array}{l}4.3 \\
4.1 \\
3.6 \\
3.9 \\
4.3\end{array}$ \\
\hline $\begin{array}{l}21 \ldots \ldots \\
22 \ldots \ldots \\
23 \ldots \ldots \ldots \\
24 \ldots \ldots \\
25 \ldots \ldots\end{array}$ & $\begin{array}{l}6.4 \\
6.2 \\
6.0 \\
6.3 \\
-.3\end{array}$ & $\begin{array}{r}6.0 \\
5.8 \\
5.6 \\
5.7 \\
-.\end{array}$ & $=$ & $\begin{array}{l}\bar{z} \\
\bar{z}\end{array}$ & $=$ & $=$ & $=$ & $=$ & $\begin{array}{l}5.8 \\
6.1 \\
6.4 \\
6.2 \\
5.5\end{array}$ & $\begin{array}{l}5.2 \\
5.4 \\
5.5 \\
4.9 \\
4.8\end{array}$ & $\begin{array}{l}4.9 \\
4.3 \\
3.9 \\
3.5 \\
3.3\end{array}$ & $\begin{array}{l}3.7 \\
3.2 \\
2.9 \\
2.5 \\
2.3\end{array}$ \\
\hline $\begin{array}{l}26 \ldots \ldots \\
27 \ldots \ldots \\
28 \ldots \ldots \\
29 \ldots \ldots \\
30 \ldots \ldots \\
31 \ldots \ldots\end{array}$ & $\begin{array}{l}= \\
= \\
=\end{array}$ & $\begin{array}{l}= \\
= \\
=\end{array}$ & $\begin{array}{l}= \\
= \\
=\end{array}$ & $\begin{array}{l}\bar{z} \\
\overline{=}\end{array}$ & $=$ & $=$ & $\begin{array}{r}-5 \\
4.9 \\
5.1 \\
5.3 \\
-- \\
--\end{array}$ & $\begin{array}{l}3.5 \\
3.4 \\
4.6 \\
-. \\
-\end{array}$ & $\begin{array}{l}5.2 \\
5.9 \\
5.8 \\
5.5 \\
4.9 \\
6.0\end{array}$ & $\begin{array}{l}4.6 \\
4.7 \\
5.0 \\
4.7 \\
4.2 \\
4.0\end{array}$ & $\begin{array}{l}3.3 \\
3.7 \\
3.7 \\
3.8 \\
4.0 \\
-\end{array}$ & $\begin{array}{l}2.2 \\
2.3 \\
2.7 \\
3.1 \\
3.3 \\
\end{array}$ \\
\hline MONTH & 7.4 & 5.6 & -- & - & -- & - & - & $\sim$ & 6.4 & 4.0 & 6.4 & 2.2 \\
\hline
\end{tabular}

TEMPERATURE $\left({ }^{\circ} \mathrm{C}\right)$ OF WATER, WATER YEAR OCTOBER 1969 TO SEPTEMBER 1970

\begin{tabular}{|c|c|c|c|c|c|c|c|c|c|c|c|c|}
\hline \multirow[t]{2}{*}{ DAY } & \multicolumn{2}{|c|}{$\mathrm{OCT}$} & \multicolumn{2}{|c|}{ ACV } & \multicolumn{2}{|c|}{ OEC } & \multicolumn{2}{|c|}{ JAN } & \multicolumn{2}{|c|}{ FEB } & \multicolumn{2}{|c|}{ MAR } \\
\hline & MAX & MIN & MAX & MIN & MAX & MI N & $\operatorname{MAX}$ & MIN & $\operatorname{MAX}$ & MIN & $\operatorname{mAX}$ & MIN \\
\hline $\begin{array}{l}1 \\
2 \\
3 \\
4 \\
5\end{array}$ & $\begin{array}{l}20.5 \\
22.0 \\
23.0 \\
22.0 \\
22.0\end{array}$ & $\begin{array}{l}20.0 \\
20.5 \\
20.5 \\
20.0 \\
19.5\end{array}$ & $\begin{array}{l}18.5 \\
19.0 \\
20.0 \\
19.0 \\
17.0\end{array}$ & $\begin{array}{l}17.0 \\
17.0 \\
18.0 \\
17.0 \\
15.0\end{array}$ & $=$ & $\begin{array}{l}= \\
=- \\
=-\end{array}$ & $\begin{array}{r}10.0 \\
9.5 \\
9.5 \\
8.5 \\
8.0\end{array}$ & $\begin{array}{l}8.0 \\
8.0 \\
8.0 \\
7.0 \\
4.5\end{array}$ & $\begin{array}{r}10.0 \\
8.5 \\
9.5 \\
9.0 \\
9.0\end{array}$ & $\begin{array}{l}6.5 \\
6.5 \\
8.5 \\
8.5 \\
7.0\end{array}$ & $\begin{array}{r}9.5 \\
14.0 \\
11.0 \\
10.5 \\
--\end{array}$ & $\begin{array}{r}7.0 \\
8.0 \\
9.5 \\
10.0 \\
--\end{array}$ \\
\hline $\begin{array}{r}6 \\
7 \\
8 \\
9 \\
10\end{array}$ & $\begin{array}{l}21.5 \\
21.0 \\
21.0 \\
21.5 \\
21.0\end{array}$ & $\begin{array}{l}19.5 \\
19.0 \\
19.5 \\
20.0 \\
20.5\end{array}$ & $\begin{array}{l}16.0 \\
15.0 \\
14.5 \\
14.0 \\
14.0\end{array}$ & $\begin{array}{l}14.0 \\
13.0 \\
13.0 \\
12.0 \\
11.5\end{array}$ & $=$ & $\begin{array}{l}=- \\
=- \\
=-\end{array}$ & $\begin{array}{l}8.0 \\
8.0 \\
7.0 \\
5.5 \\
5.0\end{array}$ & $\begin{array}{l}6.5 \\
5.5 \\
5.0 \\
4.0 \\
3.5\end{array}$ & $\begin{array}{l}8.0 \\
7.0 \\
7.0 \\
8.5 \\
9.0\end{array}$ & $\begin{array}{l}6.5 \\
6.5 \\
6.0 \\
6.0 \\
6.5\end{array}$ & $\begin{array}{l}= \\
= \\
=\end{array}$ & $\begin{array}{l}=- \\
\overline{--} \\
=-\end{array}$ \\
\hline $\begin{array}{l}11 \\
12 \\
13 \\
14 \\
15\end{array}$ & $\begin{array}{l}21.0 \\
21.0 \\
21.0 \\
21.5 \\
21.5\end{array}$ & $\begin{array}{l}20.0 \\
20.0 \\
20.0 \\
20.5 \\
20.5\end{array}$ & $\begin{array}{l}14.0 \\
14.5 \\
14.0 \\
15.5 \\
14.0\end{array}$ & $\begin{array}{l}11.5 \\
12.0 \\
12.0 \\
11.5 \\
10.0\end{array}$ & $\begin{array}{l}= \\
\bar{z} \\
=\end{array}$ & $\begin{array}{l}=- \\
=- \\
=-\end{array}$ & $\begin{array}{l}4.5 \\
4.0 \\
4.5 \\
4.5 \\
4.0\end{array}$ & $\begin{array}{l}3.0 \\
3.0 \\
3.0 \\
2.0 \\
3.0\end{array}$ & $\begin{array}{r}9.5 \\
9.5 \\
8.5 \\
9.5 \\
11.0\end{array}$ & $\begin{array}{l}6.5 \\
6.5 \\
6.5 \\
6.5 \\
7.0\end{array}$ & $\begin{array}{l}11.0 \\
16.5 \\
17.0 \\
15.5 \\
17.0\end{array}$ & $\begin{array}{l}10.0 \\
13.5 \\
14.0 \\
14.0 \\
13.0\end{array}$ \\
\hline $\begin{array}{l}16 \\
17 \\
18 \\
19 \\
20\end{array}$ & $\begin{array}{l}21.5 \\
23.0 \\
21.0 \\
23.5 \\
24.0\end{array}$ & $\begin{array}{l}20.0 \\
20.0 \\
20.0 \\
19.5 \\
18.5\end{array}$ & $\begin{array}{l}12.0 \\
11.5 \\
11.5 \\
13.0 \\
12.0\end{array}$ & $\begin{array}{r}10.0 \\
9.5 \\
8.5 \\
10.0 \\
10.0\end{array}$ & $\bar{E}$ & $\begin{array}{l}=- \\
=- \\
=- \\
=-\end{array}$ & $\begin{array}{l}4.5 \\
4.5 \\
4.5 \\
5.5 \\
6.0\end{array}$ & $\begin{array}{l}3.0 \\
3.0 \\
3.5 \\
4.0 \\
4.5\end{array}$ & $\begin{array}{r}9.0 \\
9.5 \\
10.5 \\
9.0 \\
9.0\end{array}$ & $\begin{array}{l}8.5 \\
8.5 \\
8.5 \\
8.5 \\
7.0\end{array}$ & $\begin{array}{l}14.0 \\
13.0 \\
15.5 \\
13.0 \\
15.0\end{array}$ & $\begin{array}{l}12.0 \\
11.5 \\
10.5 \\
11.5 \\
11.5\end{array}$ \\
\hline $\begin{array}{l}21 \\
22 \\
23 \\
24 \\
25\end{array}$ & $\begin{array}{l}22.0 \\
21.0 \\
20.5 \\
20.0 \\
19.5\end{array}$ & $\begin{array}{l}20.5 \\
19.5 \\
19.5 \\
18.5 \\
18.0\end{array}$ & $\begin{array}{l}11.5 \\
11.5 \\
13.0 \\
13.0 \\
12.0\end{array}$ & $\begin{array}{r}10.0 \\
10.0 \\
10.0 \\
10.0 \\
9.5\end{array}$ & $\begin{array}{l}\overline{-} \\
7.0 \\
7.0 \\
6.5\end{array}$ & $\begin{array}{r}-- \\
-\overline{-0} \\
5.5 \\
6.0\end{array}$ & $\begin{array}{l}5.5 \\
5.0 \\
4.5 \\
4.0 \\
4.0\end{array}$ & $\begin{array}{l}4.5 \\
3.0 \\
3.0 \\
1.5 \\
2.0\end{array}$ & $\begin{array}{l}7.0 \\
7.0 \\
8.0 \\
9.0 \\
9.0\end{array}$ & $\begin{array}{l}4.5 \\
6.5 \\
6.5 \\
7.0 \\
8.5\end{array}$ & $\begin{array}{l}14.0 \\
14.0 \\
13.5 \\
13.0 \\
12.0\end{array}$ & $\begin{array}{l}12.0 \\
12.0 \\
12.0 \\
11.5 \\
11.0\end{array}$ \\
\hline $\begin{array}{l}26 \\
27 \\
28 \\
29 \\
30 \\
31\end{array}$ & $\begin{array}{l}20.0 \\
20.0 \\
20.0 \\
19.0 \\
19.0 \\
18.5\end{array}$ & $\begin{array}{l}18.0 \\
18.0 \\
17.0 \\
15.5 \\
16.0 \\
16.5\end{array}$ & $\begin{array}{r}12.0 \\
11.5 \\
=- \\
=- \\
=\end{array}$ & $\begin{array}{r}10.0 \\
10.0 \\
=- \\
= \\
=\end{array}$ & $\begin{array}{r}7.0 \\
8.5 \\
8.5 \\
9.0 \\
10.5 \\
8.0\end{array}$ & $\begin{array}{l}6.0 \\
5.5 \\
5.0 \\
5.0 \\
5.5 \\
6.5\end{array}$ & $\begin{array}{r}5.0 \\
5.5 \\
6.0 \\
10.0 \\
8.5 \\
9.0\end{array}$ & $\begin{array}{l}3.5 \\
4.0 \\
3.0 \\
5.5 \\
6.5 \\
6.5\end{array}$ & $\begin{array}{r}9.5 \\
10.0 \\
9.5 \\
=- \\
=-\end{array}$ & $\begin{array}{r}8.5 \\
8.0 \\
5.5 \\
=- \\
=- \\
=-\end{array}$ & $\begin{array}{l}13.0 \\
13.0 \\
13.0 \\
14.5 \\
14.0 \\
14.0\end{array}$ & $\begin{array}{l}11.5 \\
12.0 \\
11.5 \\
13.0 \\
13.5 \\
13.0\end{array}$ \\
\hline AVG & 21.0 & 19.0 & 14.0 & 12.0 & - & -- & 6.0 & 4.5 & 9.0 & 7.0 & 13.5 & 11.5 \\
\hline
\end{tabular}


CAPE FEAR RIVER BASIN

02107571 CAPE FEAR RIVER NEAR NAVASSA, N. C.--ContInued TEMPERATURE $\left({ }^{\circ} \mathrm{C}\right)$ OF WATER, WATER YEAR OCTOBER 1969 TO SEPTEMBER 1970

\begin{tabular}{|c|c|c|c|c|c|c|c|c|c|c|c|c|}
\hline \multirow[t]{2}{*}{ DAY } & \multicolumn{2}{|c|}{$A P R$} & \multicolumn{2}{|c|}{ MAY } & \multicolumn{2}{|c|}{ JUN } & \multicolumn{2}{|c|}{ JUL } & \multicolumn{2}{|c|}{ AUG } & \multicolumn{2}{|c|}{ SEP } \\
\hline & $\operatorname{MAX}$ & MIN N & $\operatorname{MAX}$ & MIN & $\operatorname{MAX}$ & MIN & $\operatorname{MAX}$ & MI N & $\operatorname{MAX}$ & MIN & MAX & MIN \\
\hline $\begin{array}{l}1 \\
2 \\
3 \\
4 \\
5\end{array}$ & $\begin{array}{l}14.0 \\
14.5 \\
14.0 \\
14.0 \\
13.5\end{array}$ & $\begin{array}{l}13.0 \\
14.0 \\
11.5 \\
13.0 \\
12.0\end{array}$ & $\begin{array}{l}=- \\
=- \\
=\end{array}$ & $\begin{array}{l}-- \\
=- \\
-\square\end{array}$ & $\begin{array}{l}= \\
\bar{z} \\
=\end{array}$ & $\begin{array}{l}-- \\
-- \\
-- \\
--\end{array}$ & $\begin{array}{l}=- \\
=- \\
=-\end{array}$ & $\begin{array}{l}=- \\
= \\
= \\
=\end{array}$ & $\begin{array}{l}31.5 \\
30.5 \\
31.0 \\
30.0 \\
30.0\end{array}$ & $\begin{array}{r}=- \\
29.0 \\
29.0 \\
29.0\end{array}$ & $\begin{array}{l}28.0 \\
28.5 \\
30.0 \\
30.0 \\
30.5\end{array}$ & $\begin{array}{l}26.5 \\
26.5 \\
26.5 \\
26.5 \\
26.5\end{array}$ \\
\hline $\begin{array}{r}6 \\
7 \\
8 \\
9 \\
10\end{array}$ & $\begin{array}{l}13.5 \\
13.5 \\
14.0 \\
16.5 \\
16.5\end{array}$ & $\begin{array}{l}11.0 \\
12.0 \\
12.0 \\
13: 5 \\
14.5\end{array}$ & $\begin{array}{l}=- \\
=- \\
=-\end{array}$ & $\begin{array}{l}-- \\
\ddot{--} \\
--\end{array}$ & $\begin{array}{l}= \\
= \\
=\end{array}$ & $\begin{array}{l}\ddot{-} \\
z- \\
--\end{array}$ & $\begin{array}{l}\because- \\
= \\
=\end{array}$ & $\begin{array}{l}= \\
=- \\
=-\end{array}$ & $\begin{array}{l}29.5 \\
29.5 \\
29.0 \\
28.5 \\
28.0\end{array}$ & $\begin{array}{l}28.5 \\
28.5 \\
28.0 \\
28.0 \\
28.0\end{array}$ & $\begin{array}{r}29.5 \\
29.5 \\
30.5 \\
30.5\end{array}$ & $\begin{array}{l}27.0 \\
27.0 \\
27.0 \\
28.0\end{array}$ \\
\hline $\begin{array}{l}11 \\
12 \\
13 \\
14 \\
15\end{array}$ & $\begin{array}{l}16.5 \\
18.5 \\
19.5 \\
20.0 \\
18.5\end{array}$ & $\begin{array}{l}15.0 \\
15.5 \\
15.5 \\
15.5 \\
16.5\end{array}$ & $\begin{array}{l}= \\
z \\
z \\
-\end{array}$ & $\begin{array}{l}= \\
=- \\
=\end{array}$ & $\begin{array}{l}= \\
= \\
=\end{array}$ & $\begin{array}{l}=- \\
=- \\
=- \\
--\end{array}$ & $\begin{array}{l}= \\
= \\
=\end{array}$ & $\begin{array}{l}= \\
=- \\
=-\end{array}$ & $\begin{array}{l}30.0 \\
28.0 \\
26.0 \\
26.5 \\
27.0\end{array}$ & $\begin{array}{l}27.0 \\
26.5 \\
26.5 \\
25.5 \\
24.5\end{array}$ & $\begin{array}{l}30.0 \\
28.0 \\
23.0 \\
28.0 \\
28.0\end{array}$ & $\begin{array}{l}26.5 \\
26.5 \\
26.5 \\
26.0 \\
25.5\end{array}$ \\
\hline $\begin{array}{l}16 \\
17 \\
18 \\
19 \\
20\end{array}$ & $\begin{array}{l}18.5 \\
18.5 \\
18.5 \\
18.5 \\
20.5\end{array}$ & $\begin{array}{l}15.5 \\
16.0 \\
16.0 \\
16.5 \\
18.0\end{array}$ & $\begin{array}{l}=- \\
=- \\
=-\end{array}$ & $\begin{array}{l}=- \\
=- \\
=-\end{array}$ & $\begin{array}{l}= \\
= \\
=\end{array}$ & 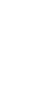 & $\begin{array}{l}=- \\
=- \\
=-\end{array}$ & $\begin{array}{l}= \\
=- \\
=- \\
=\end{array}$ & $\begin{array}{l}26.5 \\
27.0 \\
28.5 \\
28.5 \\
28.5\end{array}$ & $\begin{array}{l}24.5 \\
25.0 \\
25.5 \\
25.5 \\
26.0\end{array}$ & $\begin{array}{l}28.0 \\
28.0 \\
29.0 \\
30.0 \\
28.5\end{array}$ & $\begin{array}{l}25.5 \\
26.0 \\
26.0 \\
26.5 \\
26.0\end{array}$ \\
\hline $\begin{array}{l}21 \\
22 \\
23 \\
24 \\
25\end{array}$ & $\begin{array}{r}20.5 \\
20.5 \\
22.0 \\
23.5 \\
-.-\end{array}$ & $\begin{array}{r}18.0 \\
19.0 \\
19.5 \\
20.0 \\
-.-\end{array}$ & $\begin{array}{l}\square \\
\because- \\
--\end{array}$ & 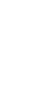 & 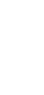 & $\begin{array}{l}\because- \\
-- \\
--\end{array}$ & $\begin{array}{l}=- \\
=- \\
=-\end{array}$ & $\begin{array}{l}=- \\
=- \\
=\end{array}$ & $\begin{array}{l}29.5 \\
29.0 \\
29.5 \\
29.5 \\
28.0\end{array}$ & $\begin{array}{l}26.5 \\
26.5 \\
27.0 \\
26.5 \\
26.5\end{array}$ & $\begin{array}{l}29.0 \\
30.0 \\
29.5 \\
30.0 \\
30.5\end{array}$ & $\begin{array}{l}26.0 \\
26.5 \\
26.5 \\
26.5 \\
26.5\end{array}$ \\
\hline $\begin{array}{l}26 \\
27 \\
28 \\
29 \\
30 \\
31\end{array}$ & $\begin{array}{l}=- \\
=- \\
=- \\
=- \\
--\end{array}$ & $\begin{array}{l}=- \\
z- \\
=- \\
=-\end{array}$ & $\begin{array}{l}-- \\
=- \\
=- \\
=-\end{array}$ & $\begin{array}{l}=- \\
=- \\
=- \\
=-\end{array}$ & $\begin{array}{l}= \\
= \\
= \\
=\end{array}$ & $\begin{array}{l}=- \\
=- \\
=- \\
=\end{array}$ & $\begin{array}{r}--5 \\
31.0 \\
31.0 \\
30.5 \\
29.5 \\
--\end{array}$ & $\begin{array}{r}-0 \\
29.0 \\
29.0 \\
28.5 \\
28.5 \\
--\end{array}$ & $\begin{array}{l}28.0 \\
28.5 \\
29.5 \\
29.5 \\
28.5 \\
30.0\end{array}$ & $\begin{array}{l}26.0 \\
26.0 \\
26.5 \\
26.5 \\
26.5 \\
26.5\end{array}$ & $\begin{array}{r}30.0 \\
30.0 \\
28.0 \\
27.0 \\
26.5 \\
.-\end{array}$ & $\begin{array}{r}26.5 \\
27.0 \\
26.0 \\
25.5 \\
25.0 \\
-.\end{array}$ \\
\hline A VG & 17.5 & 15.0 & -- & - & -- & -- & $\cdots$ & -- & 29.0 & 27.0 & 29.0 & 26.5 \\
\hline
\end{tabular}

02107572 CAPE FEAR RIVER AT ROYSTER, N. C.

LOCATION.--Lat $34^{\circ} 16^{\prime} 15^{\prime \prime}$, I long $78^{\circ} 00^{\prime} 00^{\prime \prime}$, Brunswlck County, water-quality recorder on right bank at Royster Fertilizer plant pumping station at Royster, and 2.5 miles downstream from Indian Creek.

DRA INAGE AREA, -7, $060 \mathrm{sq} \mathrm{mi}$, approximately.

PERIOD OF RECORD.--Chemical analyses: November 1961 to September 1970.

Water temperatures: November 1961 to September 1970.

EXTREMES.--1969-70:

Specific conductance: Waximum recorded, 18,000 micromhos June 18; minimum recorded, 200 micromhos on many days, Water temperatures: Maximum recorded, 33.0 ${ }^{\circ} \mathrm{C}$ June $30 ;$ minimum, $2.0^{\circ} \mathrm{C}$ Jan. 13.

Perlod of record:

Specific conductance: Yaximum dally, 20,000 micromhos on many days in 1966, 1968 and 1969; minimum daily, 43 micromhos Oct. 16, 1964 .

water temperatures: Maximum, $35.0^{\circ} \mathrm{C}$ Aug. 23, 1968; minimum, 2.0 $0^{\circ} \mathrm{C} \mathrm{Jan.} \mathrm{13,} 1970$.

REMARKs, - Records of specific conductance are fragmentary, with records for several months missing or incomplete. Specific conductance and temperature shown in tables are recorder values, Recorder intake about 1 foot below
water surface.

IC CONDUCTANCE (MICROMHOS/CM AT $25^{\circ} \mathrm{C}$ ), WATER YEA: OCTOBER 1969 TO SEPTEMBER 1970
OC, TOBER
NOVEMBER
DECEMBER
JANUARY
FEBRUARY
MARCH

\begin{tabular}{|c|c|c|c|c|c|c|c|c|c|c|c|c|}
\hline DAY & MAX IMUM & MINIMUM & $\begin{array}{l}\text { MAXIMUM } \\
14000\end{array}$ & MINIMUM & MAXIMUM & MINIMUM & MAXIMUM & MINIMUN & MAXI MUM & MINI MUM & MAXIMUM & MINIMUM \\
\hline 2 & - & - & 14000 & - & 470 & - & $\ldots$ & $\overline{-}$ & $=$ & $=$ & - & $=$ \\
\hline $3 . \ldots$ & - & - & - & - & -- & - & - & -- & - & - & - & - \\
\hline $4 \ldots \ldots$ & - & - & -- & - & - & - & $\rightarrow$ & -- & - & - & - & - \\
\hline $5 \ldots \ldots$ & $\cdots$ & - & - & -- & $=$ & - & $\rightarrow$ & - & $\cdots$ & - & - & - \\
\hline $6 \ldots$. & - & -- & - & - & - & - & - & -- & -- & - & -- & - \\
\hline T..... & - & - & -- & - & - & - & - & -- & -- & - & $\sim$ & -- \\
\hline B...... & $=$ & - & - & $=-$ & -- & - & $=$ & $=$ & $=$ & - & -- & - \\
\hline $9 \ldots \ldots$ & - & - & -- & - & $=-$ & - & $m$ & $=$ & - & - & - & - \\
\hline $10 \ldots \ldots$ & -- & - & - & - & - & - & -- & -- & - & - & - & - \\
\hline $11 \ldots \ldots$ & $\rightarrow$ & - & -- & -- & -- & - & - & - & - & -- & $\ldots$ & - \\
\hline $12 \ldots$ & 280 & - & - & $\cdots$ & 400 & 200 & - & - & - & - & - & - \\
\hline $13 \ldots \ldots$ & 3100 & $\rightarrow$ & -- & - & 220 & 200 & -- & -- & - & - & - & -- \\
\hline $14 \ldots \ldots$ & 3700 & - & - & $=$ & 220 & - & -- & - & - & - & - & - \\
\hline $15 \ldots \ldots$ & 4800 & - & - & -- & 200 & - & - & - & - & - & - & - \\
\hline $16 \ldots \ldots$ & 6600 & -- & - & - & - & - & - & $=-$ & - & - & - & - \\
\hline $17 \ldots \ldots$ & 2900 & - & -- & - & 200 & $m$ & 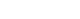 & $=$ & -- & $=$ & -- & - \\
\hline $18 \ldots .$. & 4600 & - & - & - & 200 & - & - & - & $\rightarrow$ & - & - & -- \\
\hline $19 \ldots .$. & 3700 & $-\rightarrow$ & - & - & 200 & - & -- & -- & -- & - & -- & $=$ \\
\hline $20 \ldots \ldots$ & 3900 & - & - & -- & 210 & 200 & -- & -- & -- & - & -- & - \\
\hline $21 \ldots \ldots$ & 2900 & - & 220 & - & 220 & - & $\cdots$ & -- & - & - & - & - \\
\hline $22 \ldots \ldots$ & 4000 & -- & 480 & - & 220 & -- & -- & - & - & - & - & - \\
\hline $23 \ldots \ldots$ & 4100 & -- & 400 & -- & 200 & - & - & $=-$ & - & - & -- & - \\
\hline $24 \ldots \ldots$ & 4500 & - & 300 & - & 200 & - & - & -- & - & - & -- & $\ldots$ \\
\hline $25 \ldots \ldots$ & 8400 & - & 440 & - & 200 & $\cdots$ & - & - & - & - & - & - \\
\hline $26 \ldots \ldots$ & 7200 & 200 & 680 & $m$ & 200 & - & - & -- & - & - & -- & - \\
\hline $27 \ldots \ldots$ & 7800 & $\cdots$ & 720 & - & - & - & - & -- & - & - & - & -- \\
\hline $28 \ldots \ldots$ & 3400 & - & 1680 & -- & -- & - & - & 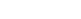 & - & - & - & - \\
\hline $29 \ldots \ldots$ & 7600 & - & 2600 & - & - & - & - & - & - & -- & - & - \\
\hline $30 \ldots \ldots$ & 10000 & 200 & 3300 & - & - & - & - & -- & - & - & -- & $\ldots$ \\
\hline $31 \ldots . .$. & 14000 & 200 & - & - & - & - & -- & -- & -- & - & - & - \\
\hline AVERAGE & - & - & - & - & -- & - & -- & - & -- & - & -- & - \\
\hline
\end{tabular}


02107572 CAPE FEAR RIVER AT ROYSTER, N. C.--Continued

SPECIFIC CONDUCTANCE (MICROMHOS/CM AT $25^{\circ} \mathrm{C}$ ), WATER YEAR OCTORER 1969 TO SEPTEMBER 1970

APRIL

MaY

JUNE

JULY

AUGUST

SEPTEMEER

DA maximua minimum maximum minimum maximum hinimum maximum nimimum haximum minimum maximum minimum

\begin{tabular}{|c|c|c|c|c|c|c|c|c|c|c|c|c|}
\hline $\begin{array}{l}1 \ldots \ldots \\
2 \ldots \ldots \\
3 \ldots \ldots \\
4 \ldots \ldots\end{array}$ & $=$ & $\begin{array}{l}= \\
= \\
=\end{array}$ & $=$ & $=$ & $\begin{array}{l}4600 \\
4000 \\
5400 \\
5100 \\
5600\end{array}$ & $\begin{array}{l}\bar{z} \\
=\end{array}$ & $\begin{array}{l}= \\
=\end{array}$ & $\begin{array}{l}= \\
= \\
=\end{array}$ & $\begin{array}{r}2200 \\
2100 \\
500 \\
510 \\
780\end{array}$ & $\begin{array}{l}450 \\
450 \\
300 \\
275 \\
275\end{array}$ & $\begin{array}{l}z \\
=\end{array}$ & $\begin{array}{l}\bar{z} \\
\bar{z}\end{array}$ \\
\hline $\begin{array}{r}6 \ldots \ldots \\
7 \ldots \ldots \\
8 \ldots \ldots \\
9 \ldots \ldots \\
10 \ldots \ldots\end{array}$ & $\begin{array}{l}\overline{-} \\
\overline{--} \\
-\end{array}$ & $\begin{array}{l}= \\
= \\
=\end{array}$ & $\begin{array}{l}= \\
= \\
=\end{array}$ & $=$ & $\begin{array}{l}6500 \\
6500 \\
6300 \\
5500 \\
9000\end{array}$ & $\begin{array}{l}= \\
= \\
=\end{array}$ & $\begin{array}{l}-- \\
= \\
--\end{array}$ & $=$ & $\begin{array}{r}700 \\
530 \\
2200 \\
4600 \\
1800\end{array}$ & $\begin{array}{l}300 \\
300 \\
300 \\
350 \\
350\end{array}$ & $\begin{array}{r}\overline{-1} \\
400 \\
1200 \\
2200\end{array}$ & $\bar{I}$ \\
\hline $\begin{array}{l}11 \ldots \ldots \\
12 \ldots \ldots \\
13 \ldots \ldots \\
14 \ldots \ldots \\
15 \ldots \ldots\end{array}$ & $\begin{array}{l}\overline{-} \\
\overline{-}\end{array}$ & $\begin{array}{l}= \\
= \\
= \\
=\end{array}$ & $\begin{array}{l}= \\
= \\
=\end{array}$ & $=$ & $\begin{array}{r}8900 \\
10400 \\
8600 \\
13500 \\
14300\end{array}$ & $\begin{array}{l}= \\
= \\
=\end{array}$ & $\begin{array}{l}= \\
= \\
=\end{array}$ & $=$ & $\begin{array}{r}6575 \\
4000 \\
500 \\
500 \\
500\end{array}$ & $\begin{array}{l}400 \\
400 \\
400 \\
350 \\
300\end{array}$ & $\begin{array}{l}2850 \\
2000 \\
1750 \\
1350 \\
1750\end{array}$ & $\begin{array}{l}- \\
200 \\
250 \\
-\end{array}$ \\
\hline $\begin{array}{l}16 \ldots \ldots \\
17 \ldots \ldots \\
18 \ldots \ldots \\
19 \ldots \ldots \\
20 \ldots \ldots\end{array}$ & $=$ & $\begin{array}{l}\overline{-} \\
=\end{array}$ & $\begin{array}{r}600 \\
3000 \\
2300 \\
1700\end{array}$ & $\bar{z}$ & $\begin{array}{l}17000 \\
17500 \\
18000 \\
17000 \\
17200\end{array}$ & $=$ & $\begin{array}{l}= \\
= \\
=\end{array}$ & $=$ & $\begin{array}{l}400 \\
450 \\
510 \\
400 \\
400\end{array}$ & $\begin{array}{l}300 \\
300 \\
300 \\
300 \\
300\end{array}$ & $\begin{array}{l}580 \\
1200 \\
1650 \\
1100 \\
1280\end{array}$ & $\begin{array}{l}7 \\
200 \\
200\end{array}$ \\
\hline $\begin{array}{l}21 \ldots \ldots \\
22 \ldots \ldots \\
23 \ldots \ldots \\
24 \ldots \ldots \\
25 \ldots \ldots\end{array}$ & $=$ & $\bar{z}$ & $\begin{array}{l}2000 \\
2600 \\
4300 \\
4800 \\
4000\end{array}$ & $\begin{array}{l}= \\
= \\
\end{array}$ & $\begin{array}{l}17600 \\
16200 \\
15000 \\
15000 \\
13200\end{array}$ & $=$ & $\begin{array}{l}\overline{-} \\
=\end{array}$ & $\begin{array}{l}= \\
= \\
=\end{array}$ & $\begin{array}{l}400 \\
400 \\
400 \\
400 \\
400\end{array}$ & $\begin{array}{l}300 \\
300 \\
300 \\
300 \\
300\end{array}$ & $\begin{array}{r}600 \\
650 \\
990 \\
1250 \\
6900\end{array}$ & $\begin{array}{l}\bar{Z} \\
200 \\
200\end{array}$ \\
\hline $\begin{array}{l}26 \ldots \ldots \\
27 \ldots \ldots \\
28 \ldots \ldots \\
29 \ldots \ldots \\
30 \ldots \ldots \\
31 \ldots \ldots\end{array}$ & $\begin{array}{l}= \\
= \\
=\end{array}$ & $\begin{array}{l}-- \\
-- \\
-- \\
--\end{array}$ & $\begin{array}{r}5400 \\
800 \\
2800 \\
2000 \\
4800 \\
4900\end{array}$ & $\begin{array}{l}= \\
= \\
=\end{array}$ & $\begin{array}{r}7600 \\
8800 \\
12000 \\
7300 \\
12200 \\
-2\end{array}$ & $\begin{array}{l}= \\
= \\
=\end{array}$ & $\begin{array}{l}= \\
= \\
=\end{array}$ & $\begin{array}{l}- \\
=- \\
= \\
=-\end{array}$ & $\begin{array}{l}\bar{z} \\
= \\
=\end{array}$ & $\begin{array}{l}\bar{z} \\
= \\
=\end{array}$ & $\begin{array}{r}9000 \\
10000 \\
7000 \\
9500 \\
9600 \\
-\end{array}$ & $\begin{array}{l}200 \\
200 \\
200 \\
200 \\
200 \\
--\end{array}$ \\
\hline AVERAGE & -- & - & - & -- & 10860 & - & - & $=$ & 1370 & 328 & $\ldots$ & - \\
\hline
\end{tabular}

TEMPERATURE $\left({ }^{\circ} \mathrm{C}\right)$ OF HATER, WATER YEAR OCTOBER 1969 TO SEPTEMBER 1970

\begin{tabular}{|c|c|c|c|c|c|c|c|c|c|c|c|c|}
\hline \multirow[t]{2}{*}{ DAY } & \multicolumn{2}{|c|}{ OCT } & \multicolumn{2}{|c|}{ NOV } & \multicolumn{2}{|c|}{ DEC } & \multicolumn{2}{|c|}{ JAN } & \multicolumn{2}{|c|}{ FEB } & \multicolumn{2}{|c|}{ MAR } \\
\hline & MAX & MI N & MAX & MIN & $\operatorname{MAX}$ & MIN & MAX & MIN & MAX & MIN & MAX & MIN \\
\hline $\begin{array}{l}1 \\
2 \\
3 \\
4 \\
5\end{array}$ & $\begin{array}{l}21.5 \\
23.5 \\
23.5 \\
23.5 \\
22.0\end{array}$ & $\begin{array}{l}20.5 \\
21.0 \\
21.0 \\
21.5 \\
21.0\end{array}$ & $\begin{array}{r}19.5 \\
=- \\
=-\end{array}$ & $\begin{array}{l}= \\
= \\
=\end{array}$ & $\begin{array}{r}12.0 \\
= \\
=\end{array}$ & $\begin{array}{r}10.5 \\
=- \\
=- \\
=-\end{array}$ & $\begin{array}{r}12.0 \\
9.0 \\
8.5 \\
7.0 \\
7.0\end{array}$ & $\begin{array}{l}7.0 \\
7.0 \\
7.0 \\
6.5 \\
6.5\end{array}$ & $\begin{array}{r}9.0 \\
9.5 \\
12.0 \\
12.0 \\
10.5\end{array}$ & $\begin{array}{l}7.0 \\
7.0 \\
8.5 \\
9.0 \\
0.0\end{array}$ & $\begin{array}{l}11.0 \\
11.0 \\
11.0 \\
11.5 \\
12.0\end{array}$ & $\begin{array}{r}8.5 \\
9.0 \\
9.5 \\
10.0 \\
10.5\end{array}$ \\
\hline $\begin{array}{r}6 \\
7 \\
8 \\
9 \\
10\end{array}$ & $\begin{array}{l}22.0 \\
22.0 \\
23.5 \\
23.5 \\
23.0\end{array}$ & $\begin{array}{l}20.5 \\
20.5 \\
20.0 \\
20.0 \\
20.0\end{array}$ & $\begin{array}{l}= \\
=- \\
=\end{array}$ & $\begin{array}{l}=- \\
=- \\
=-\end{array}$ & $\begin{array}{l}= \\
=\end{array}$ & $\begin{array}{l}- \\
- \\
--\end{array}$ & $\begin{array}{l}8.0 \\
7.0 \\
7.0 \\
7.0 \\
4.0\end{array}$ & $\begin{array}{l}6.0 \\
6.5 \\
5.5 \\
4.0 \\
3.5\end{array}$ & $\begin{array}{r}10.5 \\
9.5 \\
8.5 \\
9.0 \\
9.5\end{array}$ & $\begin{array}{l}7.0 \\
6.5 \\
6.0 \\
6.5 \\
6.5\end{array}$ & $\begin{array}{l}12.0 \\
13.0 \\
12.0 \\
13.5 \\
13.5\end{array}$ & $\begin{array}{l}11.0 \\
11.0 \\
11.0 \\
11.5 \\
11.5\end{array}$ \\
\hline $\begin{array}{l}11 \\
12 \\
13 \\
14 \\
15\end{array}$ & $\begin{array}{l}22.0 \\
21.5 \\
23.0 \\
23.5 \\
23.5\end{array}$ & $\begin{array}{l}20.5 \\
20.5 \\
20.5 \\
20.5 \\
20.5\end{array}$ & $\begin{array}{l}\because- \\
\because- \\
--\end{array}$ & $\begin{array}{l}= \\
= \\
=-\end{array}$ & $\begin{array}{r}10.5 \\
10.5 \\
9.5 \\
9.5\end{array}$ & $\begin{array}{l}--5 \\
9.5 \\
9.0 \\
8.5 \\
8.0\end{array}$ & $\begin{array}{l}4.0 \\
4.0 \\
3.5 \\
3.5 \\
4.0\end{array}$ & $\begin{array}{l}3.0 \\
3.0 \\
2.0 \\
3.0 \\
3.0\end{array}$ & $\begin{array}{r}9.5 \\
10.5 \\
10.0 \\
10.0 \\
9.0\end{array}$ & $\begin{array}{l}6.5 \\
6.5 \\
6.5 \\
6.5 \\
7.0\end{array}$ & $\begin{array}{l}15.5 \\
15.5 \\
18.5 \\
16.0 \\
14.5\end{array}$ & $\begin{array}{l}13.0 \\
13.5 \\
14.5 \\
14.0 \\
13.5\end{array}$ \\
\hline $\begin{array}{l}16 \\
17 \\
18 \\
19 \\
20\end{array}$ & $\begin{array}{l}23.5 \\
22.0 \\
23.0 \\
21.5 \\
23.5\end{array}$ & $\begin{array}{l}20.5 \\
20.5 \\
18.5 \\
20.0 \\
20.5\end{array}$ & $\begin{array}{r}\because \\
= \\
13.0\end{array}$ & $\begin{array}{l}=- \\
= \\
=\end{array}$ & $\begin{array}{l}9.0 \\
9.0 \\
8.5 \\
8.5 \\
8.0\end{array}$ & $\begin{array}{l}8.0 \\
8.0 \\
7.0 \\
7.0 \\
6.0\end{array}$ & $\begin{array}{l}4.0 \\
4.5 \\
4.0 \\
5.0 \\
5.5\end{array}$ & $\begin{array}{l}3.0 \\
3.0 \\
3.5 \\
4.0 \\
4.5\end{array}$ & $\begin{array}{r}10.0 \\
10.5 \\
10.0 \\
10.5\end{array}$ & $\begin{array}{r}0.0 \\
0.5 \\
8.0 \\
7.0\end{array}$ & $\begin{array}{l}17.0 \\
14.5 \\
14.5 \\
14.5 \\
14.0\end{array}$ & $\begin{array}{l}12.0 \\
12.0 \\
13.0 \\
13.0 \\
12.0\end{array}$ \\
\hline $\begin{array}{l}21 \\
22 \\
23 \\
24 \\
25\end{array}$ & $\begin{array}{l}23.5 \\
22.0 \\
21.5 \\
21.0 \\
21.0\end{array}$ & $\begin{array}{r}20.0 \\
20.5 \\
=- \\
28.0\end{array}$ & $\begin{array}{l}13.0 \\
12.0 \\
13.0 \\
14.0 \\
13.0\end{array}$ & $\begin{array}{r}10.5 \\
10.0 \\
9.5 \\
--\end{array}$ & $\begin{array}{l}7.0 \\
8.0 \\
8.0 \\
8.0 \\
6.5\end{array}$ & $\begin{array}{l}5.5 \\
6.5 \\
6.0 \\
6.0 \\
6.0\end{array}$ & $\begin{array}{l}7.0 \\
5.5 \\
5.0 \\
4.5 \\
4.0\end{array}$ & $\begin{array}{l}5.0 \\
4.0 \\
4.0 \\
3.0 \\
3.0\end{array}$ & $\begin{array}{r}-- \\
\overline{z .5} \\
9.0\end{array}$ & $\begin{array}{l}=- \\
=- \\
8.0 \\
8.5\end{array}$ & $\begin{array}{l}14.5 \\
15.5 \\
16.5 \\
14.5 \\
14.5\end{array}$ & $\begin{array}{l}13.0 \\
13.0 \\
13.0 \\
10.5 \\
11.5\end{array}$ \\
\hline $\begin{array}{l}26 \\
27 \\
28 \\
29 \\
30 \\
31\end{array}$ & $\begin{array}{l}20.5 \\
21.0 \\
20.5 \\
20.5 \\
19.0 \\
19.5\end{array}$ & $\begin{array}{r}17.0 \\
\ldots \\
0 \\
17.0 \\
17.0\end{array}$ & $\begin{array}{r}13.5 \\
13.0 \\
13.0 \\
12.0 \\
11.5 \\
=-\end{array}$ & $\begin{array}{c}10.5 \\
10.5 \\
10.5 \\
10.5 \\
10.5 \\
=-\end{array}$ & $\begin{array}{l}7.0 \\
7.0 \\
6.0 \\
6.0 \\
8.0 \\
8.0\end{array}$ & $\begin{array}{l}6.5 \\
5.5 \\
5.0 \\
5.5 \\
5.5 \\
6.5\end{array}$ & $\begin{array}{r}4.5 \\
5.5 \\
6.0 \\
7.0 \\
13.5 \\
9.0\end{array}$ & $\begin{array}{l}3.5 \\
4.0 \\
4.5 \\
5.5 \\
6.5 \\
7.0\end{array}$ & $\begin{array}{r}11.5 \\
9.5 \\
10.0 \\
- \\
=-\end{array}$ & $\begin{array}{r}8.5 \\
8.5 \\
8.0 \\
=- \\
=-\end{array}$ & $\begin{array}{l}14.0 \\
14.5 \\
14.0 \\
14.0 \\
15.5 \\
18.0\end{array}$ & $\begin{array}{l}11.5 \\
12.0 \\
13.0 \\
13.0 \\
14.0 \\
14.0\end{array}$ \\
\hline AYG & 22.0 & 20.0 & - & -- & -- & -- & 6.0 & 4.5 & 10.0 & 7.5 & 14.0 & 12.0 \\
\hline
\end{tabular}


02107572 CAPE FEAR RIVER AT ROYSTER, N. C.--Continued

TEMPERATURE $\left({ }^{\circ} \mathrm{C}\right)$ OF WATER, WATER YEAR OCTOBER 1969 TO SEPJEMBER 1970

\begin{tabular}{|c|c|c|c|c|c|c|c|c|c|c|c|c|}
\hline \multirow[t]{2}{*}{ DAY } & \multicolumn{2}{|c|}{$\triangle P R$} & \multicolumn{2}{|c|}{ MAY } & \multicolumn{2}{|c|}{ JUN } & \multicolumn{2}{|c|}{ Jur } & \multicolumn{2}{|c|}{ AUG } & \multicolumn{2}{|c|}{ SEP } \\
\hline & MAX & MI N & MAX & MIN & $\max$ & MIN & $\max$ & MIN & $\max$ & MtN & $\operatorname{MAX}$ & MIN \\
\hline $\begin{array}{l}1 \\
2 \\
3 \\
4 \\
5\end{array}$ & $\begin{array}{l}17.0 \\
15.5 \\
16.5 \\
15.5 \\
15.5\end{array}$ & $\begin{array}{l}13.5 \\
13.5 \\
13.5 \\
14.0 \\
14.5\end{array}$ & $\begin{array}{l}-= \\
- \\
- \\
-\end{array}$ & $\begin{array}{l}=- \\
=- \\
=-\end{array}$ & $\begin{array}{l}27.0 \\
27.0 \\
27.0 \\
27.0 \\
27.0\end{array}$ & $\begin{array}{l}25.0 \\
25.5 \\
25.5 \\
25.0 \\
25.0\end{array}$ & $\begin{array}{l}= \\
-- \\
-\end{array}$ & $\begin{array}{l}= \\
= \\
--\end{array}$ & $\begin{array}{l}31.0 \\
32.0 \\
31.0 \\
31.0 \\
30.5\end{array}$ & $\begin{array}{l}27.0 \\
27.0 \\
28.0 \\
28.0 \\
28.0\end{array}$ & $\begin{array}{l}29.0 \\
28.5 \\
29.0 \\
29.0 \\
29.5\end{array}$ & $\begin{array}{l}26.5 \\
26.5 \\
26.5 \\
26.5 \\
26.5\end{array}$ \\
\hline $\begin{array}{r}6 \\
7 \\
8 \\
9 \\
10\end{array}$ & $\begin{array}{r}20.0 \\
18.0 \\
=- \\
=-\end{array}$ & $\begin{array}{r}15.0 \\
15.5 \\
=- \\
=- \\
--\end{array}$ & $\begin{array}{l}= \\
\ddot{-} \\
-\end{array}$ & 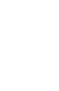 & $\begin{array}{l}28.0 \\
26.5 \\
26.0 \\
28.0 \\
28.5\end{array}$ & $\begin{array}{l}25.5 \\
25.5 \\
25.5 \\
25.0 \\
25.5\end{array}$ & $\begin{array}{l}= \\
= \\
- \\
-\end{array}$ & $\begin{array}{l}= \\
- \\
-\end{array}$ & $\begin{array}{l}29.5 \\
30.0 \\
30.0 \\
28.0 \\
28.5\end{array}$ & $\begin{array}{l}28.0 \\
28.0 \\
27.0 \\
27.0 \\
27.0\end{array}$ & $\begin{array}{l}30.5 \\
29.5 \\
29.0 \\
29.5 \\
29.5\end{array}$ & $\begin{array}{l}26.5 \\
27.0 \\
27.0 \\
27.0 \\
27.0\end{array}$ \\
\hline $\begin{array}{l}11 \\
12 \\
13 \\
14 \\
15\end{array}$ & $\begin{array}{r}=- \\
=- \\
20.5\end{array}$ & $=-$ & $\begin{array}{l}- \\
= \\
-\end{array}$ & $\begin{array}{l}=- \\
=- \\
=-\end{array}$ & $\begin{array}{l}29.5 \\
30.0 \\
29.0 \\
27.0 \\
27.0\end{array}$ & $\begin{array}{l}26.0 \\
26.0 \\
26.0 \\
26.0 \\
26.0\end{array}$ & $=$ & $\begin{array}{l}= \\
=- \\
=-\end{array}$ & $\begin{array}{l}26.5 \\
26.5 \\
26.5 \\
26.0 \\
26.0\end{array}$ & $\begin{array}{l}26.5 \\
26.0 \\
25.5 \\
25.0 \\
24.0\end{array}$ & $\begin{array}{l}29.0 \\
28.0 \\
27.0 \\
27.0 \\
28.0\end{array}$ & $\begin{array}{l}27.0 \\
26.0 \\
26.0 \\
25.5 \\
25.5\end{array}$ \\
\hline $\begin{array}{l}16 \\
17 \\
18 \\
19 \\
20\end{array}$ & $\begin{array}{l}20.5 \\
22.0 \\
21.0 \\
19.5 \\
20.5\end{array}$ & $\begin{array}{l}18.0 \\
18.0 \\
18.0 \\
17.0 \\
18.5\end{array}$ & $\begin{array}{l}24.5 \\
24.5 \\
24.0 \\
27.0 \\
26.5\end{array}$ & $\begin{array}{l}23.0 \\
23.5 \\
23.0 \\
23.0 \\
23.0\end{array}$ & $\begin{array}{l}28.0 \\
29.0 \\
29.5 \\
30.0 \\
31.0\end{array}$ & $\begin{array}{l}26.0 \\
26.5 \\
27.0 \\
27.0 \\
28.0\end{array}$ & $\begin{array}{l}=- \\
- \\
-\end{array}$ & $\begin{array}{l}=- \\
=- \\
=-\end{array}$ & $\begin{array}{l}26.0 \\
27.0 \\
28.0 \\
28.0 \\
27.0\end{array}$ & $\begin{array}{l}24.0 \\
24.0 \\
24.5 \\
30.5 \\
25.5\end{array}$ & $\begin{array}{l}29.0 \\
29.0 \\
28.0 \\
30.0 \\
28.0\end{array}$ & $\begin{array}{l}25.5 \\
25.5 \\
26.0 \\
26.0 \\
26.0\end{array}$ \\
\hline $\begin{array}{l}21 \\
22 \\
23 \\
24 \\
25\end{array}$ & $\begin{array}{l}21.5 \\
23.5 \\
23.5 \\
23.5 \\
22.0\end{array}$ & $\begin{array}{l}19.0 \\
19.5 \\
20.0 \\
20.5 \\
21.0\end{array}$ & $\begin{array}{l}25.0 \\
25.5 \\
27.0 \\
28.0 \\
28.5\end{array}$ & $\begin{array}{l}23.5 \\
24.0 \\
24.5 \\
25.0 \\
25.0\end{array}$ & $\begin{array}{l}31.0 \\
31.5 \\
30.5 \\
30.5 \\
32.0\end{array}$ & $\begin{array}{l}28.5 \\
28.5 \\
29.0 \\
29.0 \\
29.5\end{array}$ & $\begin{array}{l}= \\
= \\
=\end{array}$ & $\begin{array}{l}= \\
= \\
= \\
=\end{array}$ & $\begin{array}{l}28.0 \\
28.5 \\
28.0 \\
28.0 \\
28.0\end{array}$ & $\begin{array}{l}25.5 \\
26.0 \\
26.5 \\
26.5 \\
26.0\end{array}$ & $\begin{array}{l}28.5 \\
28.0 \\
29.0 \\
30.0 \\
30.0\end{array}$ & $\begin{array}{l}26.0 \\
26.0 \\
26.5 \\
26.5 \\
26.5\end{array}$ \\
\hline $\begin{array}{l}26 \\
27 \\
28 \\
29 \\
30 \\
31\end{array}$ & $\begin{array}{l}=- \\
-- \\
-- \\
--\end{array}$ & $\begin{array}{l}=- \\
=- \\
=- \\
=-\end{array}$ & $\begin{array}{l}28.5 \\
27.0 \\
27.0 \\
27.0 \\
26.5 \\
26.5\end{array}$ & $\begin{array}{l}25.5 \\
26.0 \\
26.0 \\
26.0 \\
25.5 \\
25.0\end{array}$ & $\begin{array}{r}31.5 \\
31.5 \\
29.5 \\
29.0 \\
33.0 \\
=-\end{array}$ & $\begin{array}{r}29.0 \\
29.0 \\
28.5 \\
28.0 \\
27.0 \\
-0\end{array}$ & $\begin{array}{l}= \\
=- \\
-- \\
-\end{array}$ & $\begin{array}{l}=- \\
=- \\
=- \\
=\end{array}$ & $\begin{array}{l}28.0 \\
28.0 \\
28.5 \\
28.0 \\
30.0 \\
30.5\end{array}$ & $\begin{array}{l}25.5 \\
25.5 \\
26.0 \\
25.5 \\
26.0 \\
26.0\end{array}$ & $\begin{array}{r}30.0 \\
29.5 \\
29.0 \\
28.5 \\
26.5 \\
. .\end{array}$ & $\begin{array}{r}27.0 \\
27.0 \\
25.5 \\
25.5 \\
24.5 \\
.-\end{array}$ \\
\hline AVG & -- & - & - & - & 29.0 & 27.0 & -- & $=$ & 28.5 & 26.5 & 29.0 & 26.5 \\
\hline
\end{tabular}

02108692 NORTHEAST CAPE FEAR RIVER AT WILMINGTON, N. C.

LOCATION,--Lat $34^{\circ} 15^{\prime} 10^{\prime \prime}$, Iong $77^{\circ} 57^{\prime}$ O0", New Hanover County, at bridge on U.s. Highway 17 at wilmington, and 1 mile downstream from Smith Creek.

DRA INAGE AREA. $-1,740$ sq $\mathrm{m} 1$.

PERIOD OF RECORD.--Chemical analyses: Ju1y 1969 to September 1970.

REMARKS.--The second of two samples collected at the same time is a field determination. CHEMICAL ANALYSES, hateR YEAR OCTOBER 1969 TO SEPTEMBFR 1970

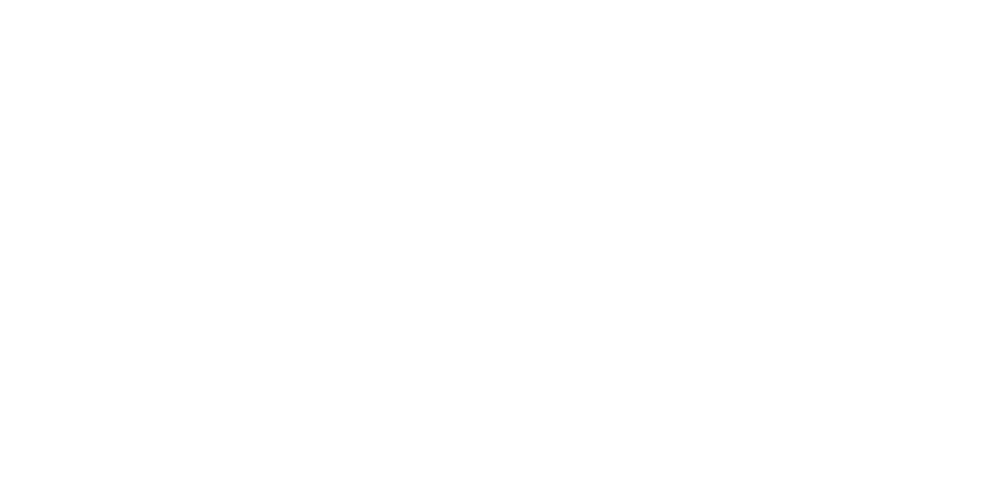

\begin{tabular}{|c|c|c|c|c|c|c|c|c|c|c|}
\hline $\begin{array}{l}27 . . \\
\text { NOV. }\end{array}$ & - & -- & -- & -- & - & -- & -- & -- & -- & -- \\
\hline $\begin{array}{l}24 \ldots . \\
D E C .\end{array}$ & -- & -- & -- & - & -- & - & -- & -- & -- & - \\
\hline $\begin{array}{l}17 \ldots \\
17 \ldots \\
\text { FEB... }\end{array}$ & 39 & $\because 4$ & 2.2 & .07 & 150 & .20 & 2.71 & $\begin{array}{l}48 \\
--\end{array}$ & 14 & 1.5 \\
\hline $\begin{array}{l}23 \ldots \\
A P R .\end{array}$ & 8.9 & .1 & 1.0 & .04 & 67 & .09 & -- & 17 & 0 & .8 \\
\hline $\begin{array}{c}21 \\
\text { JULY }\end{array}$ & 34 & .2 & 2.8 & .00 & 113 & .15 & -- & 30 & 16 & 1.8 \\
\hline $22 \ldots$ & 4340 & .6 & 1.3 & .35 & 8090 & 11.0 & -- & 1470 & 1410 & 27 \\
\hline
\end{tabular}


CAPE FEAR RIVER BASIN

02108692 NORTHEAST CAPE FEAR RIVER AT WILNINGTON, N. C.--Continued

CHEMICAL ANALYSES, WATER YEAH OCTOBER 1969 TO SEPTEMBER 1970

PEIHY-
PENE
DATE

\begin{tabular}{|c|c|c|c|c|c|c|c|c|c|}
\hline DATE & $\begin{array}{c}\text { CrantDE } \\
\text { (CN) } \\
(M G / L)\end{array}$ & $\begin{array}{l}\text { CAD- } \\
\text { MIUM } \\
\text { ICDI } \\
\text { I UG }\end{array}$ & $\begin{array}{l}\text { D15- } \\
\text { SOLVED } \\
\text { OXYGEN } \\
(M G / L)\end{array}$ & $\begin{array}{c}\text { TOTAL } \\
B E T A \\
\text { (B) } \\
(\mathrm{PC} / \mathrm{L},\end{array}$ & $\begin{array}{c}\text { FECAL } \\
\text { CODLI- } \\
\text { FORM } \\
\text { CORD. } \\
\text { PDE } \\
100 \mathrm{MLI}\end{array}$ & $\begin{array}{l}\text { SPECI- } \\
\text { FIC } \\
\text { COND- } \\
\text { UCANCE } \\
\text { CMICRO- } \\
\text { MHOSI }\end{array}$ & $\begin{array}{c}\text { PH } \\
\text { (UNITS) }\end{array}$ & $\begin{array}{l}\text { TEMP- } \\
\text { ERATURE } \\
\text { OAEG CI }\end{array}$ & $\begin{array}{l}\text { COLOR } \\
\text { IPLAT- } \\
\text { INUYM- } \\
\text { COBAL } \\
\text { UNITS }\end{array}$ \\
\hline$\therefore$ & -- & -- & 7.4 & -- & 2000 & 10000 & 7.1 & 20.0 & -- \\
\hline $\begin{array}{l}v . \\
4 . \ldots .\end{array}$ & - & -- & 5.7 & -- & 180 & 2000 & 5.8 & 13.0 & -- \\
\hline $\begin{array}{l}17 . \\
17 \ldots\end{array}$ & $=$ & $=$ & $11 \overline{-8}$ & $=$ & 300 & $\begin{array}{l}206 \\
230\end{array}$ & $\begin{array}{l}6.5 \\
5.5\end{array}$ & $\begin{array}{l}8.0 \\
8.0\end{array}$ & Bo \\
\hline JaA. & -- & -- & 10.2 & -- & -- & 135 & 6.7 & 8.0 & -- \\
\hline FEB. & $=$ & $=$ & $\overline{2}$ & $=$ & $=$ & $\begin{array}{l}71 \\
90\end{array}$ & $\begin{array}{l}6.1 \\
6.3\end{array}$ & $\begin{array}{r}\mathbf{y} .0 \\
9.0\end{array}$ & 75 \\
\hline $\begin{array}{l}\text { MAR: } \\
24 \ldots .\end{array}$ & -- & -- & 11.0 & -- & 400 & 120 & 6.9 & 12.0 & -- \\
\hline $\begin{array}{c}\text { APR: } \\
21 \ldots . \\
21\end{array}$ & $=$ & $=$ & $7 . \overline{8}$ & $\because$ & $4 \overline{440}$ & $\begin{array}{l}172 \\
170\end{array}$ & $\begin{array}{l}0.3 \\
0.6\end{array}$ & $\begin{array}{l}211.0 \\
21.0\end{array}$ & 盟 \\
\hline & -- & -- & 5.5 & -- & 1460 & 7300 & 6.8 & 24.5 & -- \\
\hline & -- & -- & 6.4 & -- & 680 & 20000 & 7.0 & 27.0 & -- \\
\hline & .00 & $\therefore$ & 4.5 & 149 & $=$ & $\begin{array}{r}10400 \\
8000\end{array}$ & $\begin{array}{l}7.1 \\
6.7\end{array}$ & $\begin{array}{l}29.0 \\
29.0\end{array}$ & 35 \\
\hline & -- & - & -- & - & 1480 & 300 & 6.8 & 26.5 & -- \\
\hline $22 \ldots$ & -. & -. & 5.7 & -- & 2220 & 6000 & 0.2 & 270 & \\
\hline
\end{tabular}


02110750 WACCAMAW RIVER AT CONWAY, S. C.

LOCATION, --Lat $33^{\circ} 49^{\prime} 53^{\prime \prime}$, long $79^{\circ} 02^{\prime} 37^{\prime \prime}$, Horry County, at bridge on U.S. Highway 501 bypass, 1 mile southeast of Conway, 2.2 miles downstream from Kingston Lake, and at mile 45.8 .

PERIOD OF RECORD.--Chemical analyses: July 1969 to September 1970.

REMARKS.--The second of two samples collected at the same time is a field determination.

CHEMICAL ANALYSES, JULY 1969 TO SEPTEMBER 1970

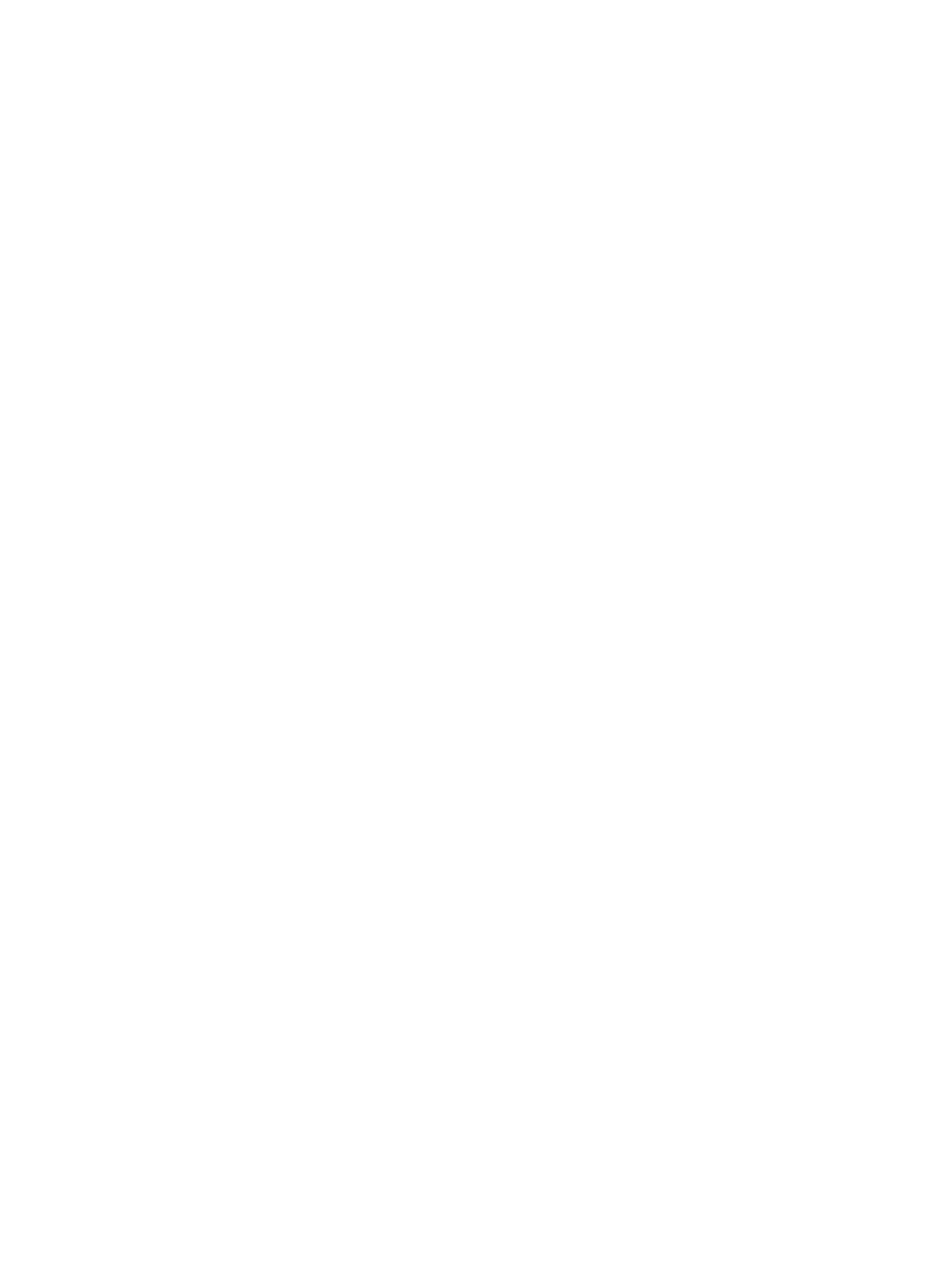


02112000 YADKIN RIVER. AT WILKESBORO, N, C.

LOCATION.--Lat $36^{\circ} \mathrm{ng} 9^{\prime} 09^{\prime \prime}$, long $81^{\circ} 08^{\prime} 45^{\prime \prime}$, wilkes County, temperature recorder at gaging station on right bank 150 ft upstream from bridge on U.S. Highway $421 \mathrm{~A}$ between North Wilkesboro and Wilkesboro, 150 ft downstream from Reddies River, 0.5 mile northeast of Wilkesboro, and 382 miles upstream from mouth of pee Dee River in Winyah Bay.

DRAINAGE AREA. - $493 \mathrm{sq} \mathrm{mi}$.

PERIOD OF RECORD.--Chemical analyses: October 1947 to September 1948, October 1961 to September 1962 , October 1967

to September 1970. October 1947 to September 1948, October 1957 to September 1970.
Water temperatures:

EXTREMES. - -1967-70:

Water temperatures $1967-68$ : Maximum, $23.5^{\circ} \mathrm{C}$ Aug. $21,22,24$; minimum, $2.0^{\circ} \mathrm{C}$ Jan. 13.

Water temperatures 1968m69: Maximum, $24.0^{\circ} \mathrm{C}$ Aug. 10, 11 ; minimum, $1.5^{\circ} \mathrm{C}$ Jan. $8,11-16$.

Fater temperatures $1969-70$ : Maximum, $23.0^{\circ} \mathrm{C}$ July 29 , Aug. $1,2,4,5 ;$ min1mum, $3.0^{\circ} \mathrm{C}$ Jan. $9-11,22,23$.

Period of record:

Dissolved solids (1947-48): Maximum, $37 \mathrm{mg} / 1$ May 1-10, July 1-10, Aug. 21-31, 1948; minimum, 27 mg/1 Mar. $21-31$, 1948 .

Hardness (1947-48): Maximum, $14 \mathrm{mg} / 1$ Aug. 21-31, 1948; minimum, $6 \mathrm{mg} / 1$ July 11-20, 1948. hater temperatures $(1947-48,1957-70)$ : Maximum, 28.5 ${ }^{\circ} \mathrm{C}$ June 24, 25, 1948; minimum, freezing point on several
days in $1958,1960,1962$.

REMARKS.--The second of two samples collected at the same time is a field determination.

CHEMICAL ANALYSES, WATER YEAR OCTOBER 1969 TO SEPTEMBER 1970

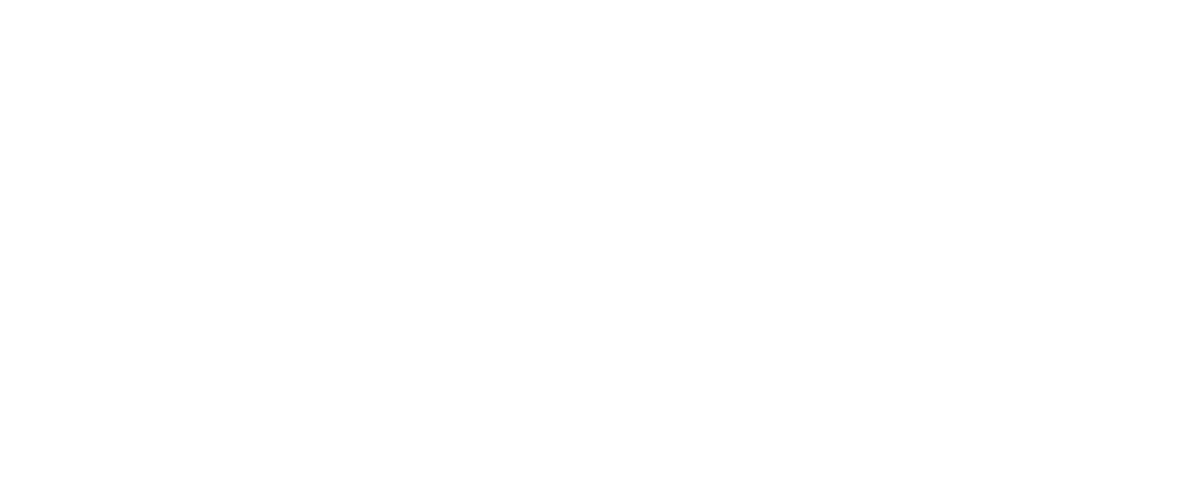

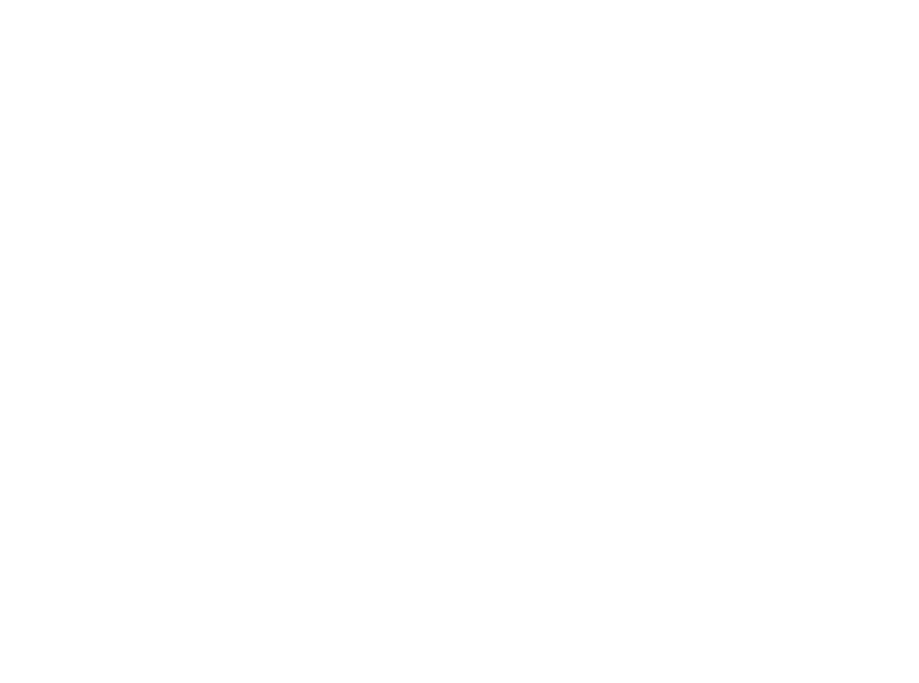


02112000 YADKIN RIVER AT WILKESBORO, N. C.--Cont1nued

TEMPERATURE $\left({ }^{\circ} \mathrm{C}\right)$ OF WATER, WATER YEAR OCTOBER 1967 TO SEPTEMBER 1968

\begin{tabular}{|c|c|c|c|c|c|c|c|c|c|c|c|c|}
\hline \multirow[t]{2}{*}{ DAY } & \multicolumn{2}{|c|}{$\mathrm{OCT}$} & \multicolumn{2}{|c|}{ Nov } & \multicolumn{2}{|c|}{ DEC } & \multicolumn{2}{|c|}{ JAN } & \multicolumn{2}{|c|}{ FEB } & \multicolumn{2}{|c|}{ MAR } \\
\hline & MAX & MIN & $\operatorname{MAX}$ & MIN & $\operatorname{MAX}$ & MIN & $\operatorname{MAX}$ & MIN & $\max$ & MIN & $\max$ & MIN \\
\hline $\begin{array}{l}1 \\
2 \\
3 \\
4 \\
5\end{array}$ & $\begin{array}{l}19.5 \\
18.5 \\
18.5 \\
18.5 \\
19.0\end{array}$ & $\begin{array}{l}16.5 \\
10.5 \\
16.0 \\
16.0 \\
15.5\end{array}$ & $\begin{array}{l}13.5 \\
13.5 \\
13.5 \\
13.5 \\
13.0\end{array}$ & $\begin{array}{l}11.5 \\
12.0 \\
12.0 \\
12.0 \\
11.5\end{array}$ & $\begin{array}{l}9.5 \\
9.0 \\
9.5 \\
9.5 \\
9.0\end{array}$ & $\begin{array}{l}9.0 \\
9.5 \\
8.0 \\
8.5 \\
7.0\end{array}$ & $\begin{array}{l}7.0 \\
6.5 \\
6.0 \\
6.5 \\
6.0\end{array}$ & $\begin{array}{l}6.5 \\
6.0 \\
6.0 \\
6.0 \\
5.5\end{array}$ & $\begin{array}{l}5.0 \\
5.0 \\
5.0 \\
5.5 \\
5.5\end{array}$ & $\begin{array}{l}5.0 \\
4.5 \\
4.5 \\
4.5 \\
4.0\end{array}$ & $\begin{array}{l}5.0 \\
6.0 \\
6.0 \\
6.0 \\
6.5\end{array}$ & $\begin{array}{l}3.5 \\
4.0 \\
4.0 \\
3.5 \\
4.0\end{array}$ \\
\hline $\begin{array}{r}6 \\
7 \\
8 \\
9 \\
10\end{array}$ & $\begin{array}{l}18.5 \\
17.0 \\
17.0 \\
18.0 \\
19.0\end{array}$ & $\begin{array}{l}16.0 \\
16.5 \\
16.5 \\
17.0 \\
17.0\end{array}$ & $\begin{array}{l}12.0 \\
11.5 \\
11.5 \\
11.5 \\
11.5\end{array}$ & $\begin{array}{l}10.5 \\
10.5 \\
10.5 \\
10.0 \\
10.0\end{array}$ & $\begin{array}{l}9.0 \\
9.0 \\
9.5 \\
8.5 \\
8.5\end{array}$ & $\begin{array}{l}8.0 \\
7.0 \\
8.0 \\
8.0 \\
8.5\end{array}$ & $\begin{array}{l}5.5 \\
5.5 \\
5.5 \\
5.0 \\
5.0\end{array}$ & $\begin{array}{l}5.5 \\
5.0 \\
4.5 \\
5.0 \\
5.0\end{array}$ & $\begin{array}{l}5.5 \\
5.5 \\
5.5 \\
5.5 \\
5.0\end{array}$ & $\begin{array}{l}4.5 \\
4.0 \\
4.5 \\
4.5 \\
4.0\end{array}$ & $\begin{array}{l}6.0 \\
7.0 \\
7.0 \\
7.0 \\
7.0\end{array}$ & $\begin{array}{l}4.5 \\
4.5 \\
4.5 \\
5.5 \\
6.0\end{array}$ \\
\hline $\begin{array}{l}11 \\
12 \\
13 \\
14 \\
15\end{array}$ & $\begin{array}{l}18.5 \\
17.0 \\
18.0 \\
18.0 \\
18.5\end{array}$ & $\begin{array}{l}16.5 \\
16.0 \\
16.0 \\
16.5 \\
17.0\end{array}$ & $\begin{array}{l}10.5 \\
11.0 \\
10.5 \\
10.5 \\
10.5\end{array}$ & $\begin{array}{r}9.5 \\
9.5 \\
10.0 \\
9.5 \\
9.5\end{array}$ & $\begin{array}{l}9.5 \\
9.0 \\
9.0 \\
9.0 \\
9.0\end{array}$ & $\begin{array}{l}8.5 \\
8.5 \\
8.5 \\
8.0 \\
8.5\end{array}$ & $\begin{array}{l}5.0 \\
4.5 \\
4.0 \\
4.5 \\
4.5\end{array}$ & $\begin{array}{l}4.5 \\
4.0 \\
2.0 \\
4.0 \\
4.0\end{array}$ & $\begin{array}{l}5.0 \\
5.0 \\
5.0 \\
5.0 \\
5.0\end{array}$ & $\begin{array}{l}4.0 \\
3.5 \\
3.5 \\
3.5 \\
4.0\end{array}$ & $\begin{array}{l}7.0 \\
6.5 \\
6.0 \\
6.5 \\
7.0\end{array}$ & $\begin{array}{l}6.0 \\
6.0 \\
6.0 \\
5.5 \\
6.0\end{array}$ \\
\hline $\begin{array}{l}16 \\
17 \\
18 \\
19 \\
20\end{array}$ & $\begin{array}{l}18.5 \\
18.0 \\
18.5 \\
18.5 \\
18.0\end{array}$ & $\begin{array}{l}16.5 \\
16.5 \\
16.5 \\
16.5 \\
16.0\end{array}$ & $\begin{array}{l}10.0 \\
10.5 \\
10.5 \\
10.5 \\
10.0\end{array}$ & $\begin{array}{l}8.5 \\
9.0 \\
9.5 \\
9.5 \\
9.0\end{array}$ & $\begin{array}{l}8.5 \\
9.0 \\
9.0 \\
9.5 \\
9.5\end{array}$ & $\begin{array}{l}7.0 \\
8.0 \\
8.0 \\
9.0 \\
9.0\end{array}$ & $\begin{array}{l}4.5 \\
4.5 \\
4.5 \\
4.5 \\
4.5\end{array}$ & $\begin{array}{l}3.5 \\
3.5 \\
3.5 \\
3.5 \\
3.5\end{array}$ & $\begin{array}{l}5.0 \\
5.5 \\
4.5 \\
5.0 \\
5.5\end{array}$ & $\begin{array}{l}3.5 \\
4.0 \\
3.5 \\
3.0 \\
4.0\end{array}$ & $\begin{array}{l}7.0 \\
7.0 \\
9.5 \\
8.5 \\
9.0\end{array}$ & $\begin{array}{l}6.5 \\
6.5 \\
6.5 \\
7.0 \\
6.5\end{array}$ \\
\hline $\begin{array}{l}21 \\
22 \\
23 \\
24 \\
25\end{array}$ & $\begin{array}{l}16.5 \\
15.5 \\
15.5 \\
14.5 \\
15.5\end{array}$ & $\begin{array}{l}15.0 \\
14.5 \\
13.5 \\
13.5 \\
14.0\end{array}$ & $\begin{array}{r}9.5 \\
10.0 \\
10.0 \\
9.5 \\
10.5\end{array}$ & $\begin{array}{l}9.5 \\
9.0 \\
9.5 \\
9.0 \\
9.5\end{array}$ & $\begin{array}{l}9.0 \\
9.5 \\
9.0 \\
8.5 \\
8.5\end{array}$ & $\begin{array}{l}9.0 \\
9.0 \\
8.0 \\
8.0 \\
8.0\end{array}$ & $\begin{array}{l}4.5 \\
4.5 \\
4.5 \\
4.5 \\
4.5\end{array}$ & $\begin{array}{l}4.0 \\
4.0 \\
4.0 \\
4.0 \\
4.0\end{array}$ & $\begin{array}{l}5.0 \\
5.0 \\
4.5 \\
5.0 \\
5.0\end{array}$ & $\begin{array}{l}4.0 \\
3.0 \\
3.5 \\
3.5 \\
3.5\end{array}$ & $\begin{array}{r}9.0 \\
9.5 \\
10.0 \\
11.0 \\
10.5\end{array}$ & $\begin{array}{l}7.0 \\
7.0 \\
8.0 \\
9.0 \\
8.5\end{array}$ \\
\hline $\begin{array}{l}26 \\
27 \\
28 \\
29 \\
30 \\
31\end{array}$ & $\begin{array}{l}15.5 \\
14.5 \\
14.0 \\
13.5 \\
13.5 \\
13.0\end{array}$ & $\begin{array}{l}14.0 \\
13.0 \\
13.0 \\
11.5 \\
11.5 \\
12.0\end{array}$ & $\begin{array}{r}10.5 \\
9.5 \\
9.5 \\
9.5 \\
9.5 \\
-.\end{array}$ & $\begin{array}{r}9.0 \\
9.0 \\
8.5 \\
7.0 \\
8.5 \\
-.\end{array}$ & $\begin{array}{l}9.0 \\
8.0 \\
9.0 \\
8.0 \\
7.0 \\
7.0\end{array}$ & $\begin{array}{l}8.0 \\
8.0 \\
6.5 \\
6.5 \\
6.5 \\
7.0\end{array}$ & $\begin{array}{l}4.5 \\
4.5 \\
4.5 \\
5.0 \\
5.0 \\
5.0\end{array}$ & $\begin{array}{l}3.5 \\
3.5 \\
4.0 \\
4.0 \\
4.5 \\
4.5\end{array}$ & $\begin{array}{r}5.0 \\
5.5 \\
5.5 \\
4.5 \\
-.\end{array}$ & $\begin{array}{l}3.5 \\
3.5 \\
4.0 \\
4.0 \\
-- \\
--\end{array}$ & $\begin{array}{l}10.5 \\
11.0 \\
10.5 \\
10.5 \\
10.5 \\
10.5\end{array}$ & $\begin{array}{l}8.0 \\
8.5 \\
8.5 \\
8.5 \\
8.5 \\
9.0\end{array}$ \\
\hline$\Delta V G$ & 17.0 & 15.0 & 11.0 & 9.5 & 8.5 & 8.0 & 5.0 & 4.5 & 5.0 & 4.0 & 8.0 & 6.5 \\
\hline
\end{tabular}

\begin{tabular}{|c|c|c|c|c|c|c|c|c|c|c|c|c|}
\hline \multirow[t]{2}{*}{ DAY } & \multicolumn{2}{|c|}{$A P R$} & \multicolumn{2}{|c|}{ MAY } & \multicolumn{2}{|c|}{ JUN } & \multicolumn{2}{|c|}{ JUL } & \multicolumn{2}{|c|}{ AUG } & \multicolumn{2}{|c|}{ SEP } \\
\hline & $\operatorname{MAX}$ & MI N & MAX & MIN & $\operatorname{MAX}$ & MIN & $\operatorname{MAX}$ & $\operatorname{MIN}$ & $\max$ & MIN & MAX & MIN \\
\hline $\begin{array}{l}1 \\
2 \\
3 \\
4 \\
5\end{array}$ & $\begin{array}{r}11.0 \\
10.0 \\
9.0 \\
10.0 \\
10.0\end{array}$ & $\begin{array}{l}9.5 \\
8.5 \\
9.0 \\
9.0 \\
9.5\end{array}$ & $\begin{array}{l}15.0 \\
14.5 \\
14.5 \\
14.0 \\
14.5\end{array}$ & $\begin{array}{l}12.0 \\
13.0 \\
12.0 \\
13.0 \\
13.0\end{array}$ & $\begin{array}{l}18.5 \\
17.0 \\
18.5 \\
18.5 \\
18.5\end{array}$ & $\begin{array}{l}15.0 \\
15.5 \\
16.0 \\
15.5 \\
15.5\end{array}$ & $\begin{array}{l}22.0 \\
22.0 \\
20.0 \\
21.5 \\
21.0\end{array}$ & $\begin{array}{l}18.5 \\
19.0 \\
19.5 \\
19.0 \\
19.0\end{array}$ & $\begin{array}{l}21.5 \\
21.5 \\
21.5 \\
21.5 \\
22.0\end{array}$ & $\begin{array}{l}20.0 \\
20.0 \\
20.5 \\
20.5 \\
21.0\end{array}$ & $\begin{array}{l}19.5 \\
21.0 \\
21.0 \\
20.5 \\
20.0\end{array}$ & $\begin{array}{l}19.0 \\
18.5 \\
18.5 \\
18.0 \\
19.0\end{array}$ \\
\hline $\begin{array}{r}6 \\
7 \\
8 \\
9 \\
10\end{array}$ & $\begin{array}{l}10.0 \\
11.0 \\
10.5 \\
11.0 \\
10.0\end{array}$ & $\begin{array}{l}9.0 \\
9.5 \\
9.5 \\
9.5 \\
9.5\end{array}$ & $\begin{array}{l}15.0 \\
14.5 \\
15.0 \\
15.0 \\
14.5\end{array}$ & $\begin{array}{l}11.5 \\
12.0 \\
13.0 \\
13.0 \\
13.5\end{array}$ & $\begin{array}{l}18.5 \\
17.0 \\
18.0 \\
18.5 \\
18.5\end{array}$ & $\begin{array}{l}15.5 \\
15.5 \\
16.5 \\
17.0 \\
17.0\end{array}$ & $\begin{array}{l}21.5 \\
21.5 \\
21.0 \\
20.5 \\
20.0\end{array}$ & $\begin{array}{l}19.0 \\
19.5 \\
19.5 \\
19.0 \\
19.5\end{array}$ & $\begin{array}{l}23.0 \\
23.0 \\
23.0 \\
21.5 \\
21.5\end{array}$ & $\begin{array}{l}20.0 \\
20.0 \\
20.5 \\
20.0 \\
20.0\end{array}$ & $\begin{array}{l}20.5 \\
21.0 \\
20.5 \\
20.0 \\
20.0\end{array}$ & $\begin{array}{l}19.5 \\
19.0 \\
19.0 \\
18.5 \\
18.0\end{array}$ \\
\hline $\begin{array}{l}11 \\
12 \\
13 \\
14 \\
15\end{array}$ & $\begin{array}{l}11.0 \\
12.0 \\
11.5 \\
11.5 \\
12.0\end{array}$ & $\begin{array}{r}9.0 \\
9.0 \\
9.5 \\
10.0 \\
10.0\end{array}$ & $\begin{array}{l}14.5 \\
15.5 \\
15.5 \\
14.5 \\
16.0\end{array}$ & $\begin{array}{l}13.5 \\
14.0 \\
14.0 \\
14.0 \\
14.5\end{array}$ & $\begin{array}{l}19.0 \\
19.0 \\
19.0 \\
19.5 \\
20.0\end{array}$ & $\begin{array}{l}17.0 \\
16.5 \\
16.5 \\
16.5 \\
16.5\end{array}$ & $\begin{array}{l}20.5 \\
21.0 \\
21.0 \\
21.5 \\
22.0\end{array}$ & $\begin{array}{l}19.5 \\
20.0 \\
19.5 \\
20.0 \\
19.5\end{array}$ & $\begin{array}{l}21.0 \\
21.5 \\
21.0 \\
21.5 \\
21.5\end{array}$ & $\begin{array}{l}20.0 \\
20.0 \\
20.0 \\
20.0 \\
20.5\end{array}$ & $\begin{array}{l}20.0 \\
20.5 \\
20.0 \\
20.0 \\
20.0\end{array}$ & $\begin{array}{l}19.0 \\
18.5 \\
16.5 \\
17.0 \\
16.5\end{array}$ \\
\hline $\begin{array}{l}16 \\
17 \\
18 \\
19 \\
20\end{array}$ & $\begin{array}{l}12.0 \\
11.5 \\
12.0 \\
12.0 \\
13.0\end{array}$ & $\begin{array}{r}9.5 \\
9.5 \\
10.0 \\
10.5 \\
10.5\end{array}$ & $\begin{array}{l}16.0 \\
15.0 \\
16.0 \\
16.0 \\
16.0\end{array}$ & $\begin{array}{l}14.5 \\
14.5 \\
14.5 \\
14.0 \\
14.0\end{array}$ & $\begin{array}{l}20.0 \\
18.5 \\
18.0 \\
19.5 \\
19.5\end{array}$ & $\begin{array}{l}16.5 \\
17.0 \\
17.0 \\
17.0 \\
17.0\end{array}$ & $\begin{array}{l}22.0 \\
21.5 \\
21.5 \\
21.5 \\
22.0\end{array}$ & $\begin{array}{l}19.5 \\
20.0 \\
19.5 \\
20.0 \\
20.0\end{array}$ & $\begin{array}{l}22.0 \\
23.0 \\
23.0 \\
22.0 \\
23.0\end{array}$ & $\begin{array}{l}20.0 \\
20.5 \\
20.5 \\
20.5 \\
20.5\end{array}$ & $\begin{array}{l}19.5 \\
19.5 \\
19.0 \\
19.0 \\
19.5\end{array}$ & $\begin{array}{l}16.5 \\
17.0 \\
17.0 \\
17.0 \\
18.0\end{array}$ \\
\hline $\begin{array}{l}21 \\
22 \\
23 \\
24 \\
25\end{array}$ & $\begin{array}{l}13.5 \\
13.0 \\
11.5 \\
14.0 \\
12.0\end{array}$ & $\begin{array}{l}10.5 \\
10.5 \\
111.0 \\
11.0 \\
11.5\end{array}$ & $\begin{array}{l}15.5 \\
16.5 \\
18.0 \\
19.5 \\
16.5\end{array}$ & $\begin{array}{l}14.0 \\
14.0 \\
14.5 \\
15.0 \\
15.0\end{array}$ & $\begin{array}{l}20.0 \\
20.0 \\
20.5 \\
19.0 \\
20.5\end{array}$ & $\begin{array}{l}17.0 \\
18.0 \\
18.0 \\
18.5 \\
18.5\end{array}$ & $\begin{array}{l}23.0 \\
22.0 \\
23.0 \\
23.0 \\
22.0\end{array}$ & $\begin{array}{l}19.5 \\
20.0 \\
20.0 \\
19.5 \\
19.5\end{array}$ & $\begin{array}{l}23.5 \\
23.5 \\
23.0 \\
23.5 \\
23.0\end{array}$ & $\begin{array}{l}20.5 \\
20.0 \\
20.5 \\
20.5 \\
20.5\end{array}$ & $\begin{array}{l}20.0 \\
19.5 \\
19.5 \\
20.0 \\
19.5\end{array}$ & $\begin{array}{l}18.0 \\
17.0 \\
16.5 \\
16.5 \\
16.5\end{array}$ \\
\hline $\begin{array}{l}26 \\
27 \\
28 \\
29 \\
30 \\
31\end{array}$ & $\begin{array}{r}13.5 \\
12.0 \\
13.0 \\
11.5 \\
15.0 \\
=-\end{array}$ & $\begin{array}{r}10.5 \\
11.0 \\
11.5 \\
11.5 \\
11.5 \\
-.-5\end{array}$ & $\begin{array}{l}15.5 \\
16.0 \\
16.5 \\
17.0 \\
17.0 \\
17.0\end{array}$ & $\begin{array}{l}15.0 \\
15.0 \\
16.0 \\
15.5 \\
15.5 \\
15.5\end{array}$ & $\begin{array}{r}21.0 \\
20.5 \\
20.5 \\
21.5 \\
21.5 \\
--5\end{array}$ & $\begin{array}{r}18.5 \\
18.5 \\
18.5 \\
18.0 \\
18.0 \\
--\end{array}$ & $\begin{array}{l}21.0 \\
22.0 \\
22.0 \\
22.0 \\
20.5 \\
21.5\end{array}$ & $\begin{array}{l}20.0 \\
20.0 \\
20.0 \\
20.0 \\
20.0 \\
20.0\end{array}$ & $\begin{array}{l}23.0 \\
21.5 \\
21.0 \\
21.0 \\
21.0 \\
20.5\end{array}$ & $\begin{array}{l}20.0 \\
19.0 \\
18.0 \\
18.0 \\
18.0 \\
18.0\end{array}$ & $\begin{array}{r}19.5 \\
19.5 \\
19.5 \\
19.5 \\
19.0 \\
-0\end{array}$ & $\begin{array}{r}18.0 \\
17.0 \\
17.0 \\
16.5 \\
16.5 \\
-\end{array}$ \\
\hline AVG & 11.5 & 10.0 & 15.5 & 14.0 & 19.0 & 17.0 & 21.5 & 19.5 & 22.0 & 20.0 & 20.0 & 17.5 \\
\hline
\end{tabular}


PEE DEE RIYER BASIN

02112000 YADKIN RIVER AT WILKESBORO, N, C.-Continued

TEMPERATURE ('O) OF WATER, WATER YEAR OCTOBER 1968 TO SEPTEMBER 1969

\begin{tabular}{|c|c|c|c|c|c|c|c|c|c|c|c|c|}
\hline \multirow{3}{*}{ DAY } & \multicolumn{12}{|c|}{ Livi liv } \\
\hline & \multicolumn{2}{|c|}{$O C T$} & \multicolumn{2}{|c|}{ NOV } & \multicolumn{2}{|c|}{ DEC } & \multicolumn{2}{|c|}{ JAN } & \multicolumn{2}{|c|}{ FEB } & \multicolumn{2}{|c|}{ MAR } \\
\hline & $\operatorname{MAX}$ & MI N & MAX & MIN & MAX & MIN & MAX & MIN & $\max$ & MI N & $\operatorname{MAX}$ & MIN \\
\hline $\begin{array}{l}1 \\
2 \\
3 \\
4 \\
5\end{array}$ & $\begin{array}{l}19.5 \\
18.5 \\
18.5 \\
18.5 \\
16.5\end{array}$ & $\begin{array}{l}15.5 \\
16.0 \\
16.5 \\
15.5 \\
14.0\end{array}$ & $\begin{array}{l}13.0 \\
13.0 \\
13.0 \\
11.5 \\
12.0\end{array}$ & $\begin{array}{l}10.5 \\
11.0 \\
11.0 \\
11.0 \\
11.0\end{array}$ & $\begin{array}{l}8.0 \\
8.5 \\
8.0 \\
8.0 \\
8.5\end{array}$ & $\begin{array}{l}7.0 \\
8.0 \\
8.0 \\
9.0 \\
7.0\end{array}$ & $\begin{array}{l}4.5 \\
4.0 \\
4.5 \\
4.0 \\
3.5\end{array}$ & $\begin{array}{l}3.5 \\
3.5 \\
3.5 \\
3.0 \\
3.0\end{array}$ & $\begin{array}{l}4.5 \\
5.0 \\
4.5 \\
4.5 \\
5.0\end{array}$ & $\begin{array}{l}4.5 \\
4.5 \\
4.0 \\
4.0 \\
4.0\end{array}$ & $\begin{array}{l}4.5 \\
6.0 \\
6.0 \\
6.0 \\
6.5\end{array}$ & $\begin{array}{l}3.5 \\
4.0 \\
4.0 \\
5.0 \\
5.0\end{array}$ \\
\hline $\begin{array}{r}6 \\
7 \\
9 \\
9 \\
10\end{array}$ & $\begin{array}{l}16.0 \\
18.5 \\
17.0 \\
15.0 \\
15.5\end{array}$ & $\begin{array}{l}14.0 \\
15.0 \\
16.0 \\
15.0 \\
15.0\end{array}$ & $\begin{array}{l}12.0 \\
13.0 \\
13.0 \\
11.5 \\
11.5\end{array}$ & $\begin{array}{l}11.5 \\
11.5 \\
11.5 \\
11.0 \\
10.5\end{array}$ & $\begin{array}{l}8.5 \\
8.0 \\
6.5 \\
6.5 \\
6.5\end{array}$ & $\begin{array}{l}7.0 \\
6.5 \\
6.0 \\
6.0 \\
5.5\end{array}$ & $\begin{array}{l}3.0 \\
3.0 \\
3.5 \\
4.0 \\
3.5\end{array}$ & $\begin{array}{l}2.0 \\
2.0 \\
1.5 \\
3.0 \\
2.0\end{array}$ & $\begin{array}{l}5.0 \\
5.0 \\
5.0 \\
5.0 \\
5.5\end{array}$ & $\begin{array}{l}4.5 \\
4.5 \\
5.0 \\
4.5 \\
4.5\end{array}$ & $\begin{array}{l}6.0 \\
6.5 \\
6.5 \\
7.0 \\
7.0\end{array}$ & $\begin{array}{l}5.5 \\
5.5 \\
5.5 \\
6.0 \\
5.5\end{array}$ \\
\hline $\begin{array}{l}11 \\
12 \\
13 \\
14 \\
15\end{array}$ & $\begin{array}{l}16.5 \\
17.0 \\
17.0 \\
17.0 \\
17.0\end{array}$ & $\begin{array}{l}15.0 \\
15.5 \\
16.0 \\
15.5 \\
15.0\end{array}$ & $\begin{array}{l}11.0 \\
10.5 \\
10.5 \\
10.5 \\
10.5\end{array}$ & $\begin{array}{r}10.0 \\
9.5 \\
9.5 \\
9.0 \\
9.0\end{array}$ & $\begin{array}{l}6.0 \\
6.0 \\
6.0 \\
6.0 \\
5.5\end{array}$ & $\begin{array}{l}5.0 \\
4.5 \\
5.0 \\
5.0 \\
5.0\end{array}$ & $\begin{array}{l}3.5 \\
3.0 \\
3.5 \\
3.5 \\
3.5\end{array}$ & $\begin{array}{l}1.5 \\
1.5 \\
1.5 \\
1.5 \\
1.5\end{array}$ & $\begin{array}{l}5.5 \\
5.5 \\
5.5 \\
5.5 \\
5.0\end{array}$ & $\begin{array}{l}4.5 \\
4.5 \\
4.5 \\
4.0 \\
3.5\end{array}$ & $\begin{array}{l}6.0 \\
7.0 \\
8.0 \\
9.0 \\
8.0\end{array}$ & $\begin{array}{l}5.5 \\
5.0 \\
5.5 \\
5.0 \\
5.5\end{array}$ \\
\hline $\begin{array}{l}16 \\
17 \\
18 \\
19 \\
20\end{array}$ & $\begin{array}{l}16.5 \\
18.0 \\
17.0 \\
18.0 \\
18.0\end{array}$ & $\begin{array}{l}16.0 \\
16.5 \\
17.0 \\
17.0 \\
16.5\end{array}$ & $\begin{array}{r}9.5 \\
9.5 \\
10.0 \\
10.0 \\
10.0\end{array}$ & $\begin{array}{l}9.0 \\
9.5 \\
9.5 \\
9.5 \\
8.5\end{array}$ & $\begin{array}{l}5.5 \\
5.5 \\
6.0 \\
5.5 \\
5.5\end{array}$ & $\begin{array}{l}5.0 \\
4.5 \\
4.5 \\
5.0 \\
5.0\end{array}$ & $\begin{array}{l}3.5 \\
3.5 \\
4.0 \\
4.0 \\
3.5\end{array}$ & $\begin{array}{l}1.5 \\
2.0 \\
3.5 \\
3.5 \\
2.0\end{array}$ & $\begin{array}{l}4.0 \\
5.0 \\
5.0 \\
5.5 \\
5.5\end{array}$ & $\begin{array}{l}3.5 \\
4.0 \\
4.5 \\
4.0 \\
4.0\end{array}$ & $\begin{array}{l}8.0 \\
3.5 \\
6.5 \\
8.0 \\
8.5\end{array}$ & $\begin{array}{l}5.5 \\
5.5 \\
6.0 \\
6.0 \\
6.0\end{array}$ \\
\hline $\begin{array}{l}21 \\
22 \\
23 \\
24 \\
25\end{array}$ & $\begin{array}{l}17.0 \\
16.0 \\
16.0 \\
15.5 \\
14.5\end{array}$ & $\begin{array}{l}16.0 \\
15.0 \\
14.5 \\
14.0 \\
14.0\end{array}$ & $\begin{array}{r}9.5 \\
10.0 \\
9.5 \\
9.0 \\
8.5\end{array}$ & $\begin{array}{l}8.5 \\
8.5 \\
9.0 \\
8.0 \\
7.0\end{array}$ & $\begin{array}{l}6.0 \\
5.5 \\
5.5 \\
5.0 \\
4.5\end{array}$ & $\begin{array}{l}4.5 \\
5.5 \\
5.0 \\
4.5 \\
4.0\end{array}$ & $\begin{array}{l}3.5 \\
4.5 \\
4.0 \\
4.5 \\
4.5\end{array}$ & $\begin{array}{l}3.5 \\
3.5 \\
4.0 \\
4.0 \\
3.5\end{array}$ & $\begin{array}{l}5.5 \\
4.5 \\
5.5 \\
5.0 \\
5.5\end{array}$ & $\begin{array}{l}4.0 \\
4.0 \\
4.0 \\
4.5 \\
4.5\end{array}$ & $\begin{array}{l}9.5 \\
8.0 \\
9.0 \\
8.0 \\
8.5\end{array}$ & $\begin{array}{l}7.0 \\
7.0 \\
6.5 \\
8.0 \\
8.0\end{array}$ \\
\hline $\begin{array}{l}26 \\
27 \\
28 \\
29 \\
30 \\
31\end{array}$ & $\begin{array}{l}14.5 \\
14.5 \\
14.0 \\
13.0 \\
13.0 \\
13.0\end{array}$ & $\begin{array}{l}13.5 \\
13.0 \\
13.0 \\
11.5 \\
10.5 \\
10.5\end{array}$ & $\begin{array}{r}8.5 \\
9.5 \\
9.0 \\
9.0 \\
8.5 \\
-.-\end{array}$ & $\begin{array}{l}6.5 \\
6.5 \\
8.0 \\
9.0 \\
8.0 \\
-.-\end{array}$ & $\begin{array}{l}5.0 \\
5.0 \\
6.0 \\
5.0 \\
5.0 \\
4.5\end{array}$ & $\begin{array}{l}4.0 \\
4.0 \\
5.0 \\
4.5 \\
4.5 \\
4.5\end{array}$ & $\begin{array}{l}4.0 \\
4.0 \\
3.5 \\
4.0 \\
4.5 \\
5.0\end{array}$ & $\begin{array}{l}3.0 \\
3.5 \\
3.5 \\
3.5 \\
4.0 \\
4.0\end{array}$ & $\begin{array}{r}6.0 \\
6.0 \\
5.0 \\
=- \\
=-\end{array}$ & $\begin{array}{r}4.5 \\
4.0 \\
4.0 \\
=- \\
=-\end{array}$ & $\begin{array}{r}9.0 \\
9.5 \\
10.0 \\
9.5 \\
10.5 \\
10.5\end{array}$ & $\begin{array}{l}8.5 \\
8.0 \\
8.0 \\
8.0 \\
8.5 \\
9.5\end{array}$ \\
\hline AVG & 16.5 & 15.0 & 10.5 & 9.5 & 6.0 & 5.5 & 3.5 & 3.0 & 5.0 & 4.0 & 7.5 & 6.0 \\
\hline
\end{tabular}

\begin{tabular}{|c|c|c|c|c|c|c|c|c|c|c|c|c|}
\hline \multirow[t]{2}{*}{ DAY } & \multicolumn{2}{|c|}{$\triangle P R$} & \multicolumn{2}{|c|}{ MAY } & \multicolumn{2}{|c|}{ JUN } & \multicolumn{2}{|c|}{ JUL } & \multicolumn{2}{|c|}{ AUG } & \multicolumn{2}{|c|}{ SEP } \\
\hline & $\operatorname{MAX}$ & MIN & MAX & MIN & $\operatorname{MAX}$ & MIN & $\max$ & MIN & $\max$ & MI N & $\max$ & MIN \\
\hline $\begin{array}{l}1 \\
2 \\
3 \\
4 \\
5\end{array}$ & $\begin{array}{l}10.5 \\
11.0 \\
11.5 \\
10.0 \\
10.0\end{array}$ & $\begin{array}{l}8.5 \\
8.5 \\
9.5 \\
9.5 \\
9.5\end{array}$ & $\begin{array}{l}14.5 \\
15.0 \\
15.0 \\
15.0 \\
15.5\end{array}$ & $\begin{array}{l}13.0 \\
12.0 \\
13.0 \\
13.0 \\
13.0\end{array}$ & $\begin{array}{l}18.5 \\
18.5 \\
17.0 \\
17.0 \\
17.0\end{array}$ & $\begin{array}{l}15.5 \\
16.5 \\
16.0 \\
15.5 \\
16.0\end{array}$ & $\begin{array}{l}20.0 \\
20.5 \\
20.5 \\
20.5 \\
20.5\end{array}$ & $\begin{array}{l}18.5 \\
18.5 \\
18.5 \\
18.5 \\
19.5\end{array}$ & $\begin{array}{l}22.0 \\
21.5 \\
21.5 \\
21.5 \\
23.0\end{array}$ & $\begin{array}{l}20.5 \\
20.5 \\
20.5 \\
20.5 \\
21.0\end{array}$ & $\begin{array}{l}21.5 \\
21.5 \\
21.0 \\
21.5 \\
23.0\end{array}$ & $\begin{array}{l}20.5 \\
21.0 \\
21.0 \\
21.0 \\
21.5\end{array}$ \\
\hline $\begin{array}{r}6 \\
7 \\
8 \\
9 \\
10\end{array}$ & $\begin{array}{l}11.5 \\
11.5 \\
11.5 \\
12.0 \\
10.0\end{array}$ & $\begin{array}{l}9.5 \\
8.5 \\
9.0 \\
9.0 \\
9.5\end{array}$ & $\begin{array}{l}15.5 \\
16.0 \\
15.0 \\
15.5 \\
15.5\end{array}$ & $\begin{array}{l}13.0 \\
13.5 \\
14.0 \\
14.0 \\
13.5\end{array}$ & $\begin{array}{l}18.5 \\
19.0 \\
19.0 \\
18.5 \\
17.0\end{array}$ & $\begin{array}{l}16.0 \\
16.5 \\
16.5 \\
16.5 \\
17.0\end{array}$ & $\begin{array}{l}20.5 \\
20.5 \\
21.5 \\
21.5 \\
20.5\end{array}$ & $\begin{array}{l}18.5 \\
18.5 \\
19.0 \\
20.0 \\
19.0\end{array}$ & $\begin{array}{l}23.5 \\
23.5 \\
23.5 \\
23.5 \\
24.0\end{array}$ & $\begin{array}{l}21.5 \\
21.0 \\
21.0 \\
21.5 \\
22.0\end{array}$ & $\begin{array}{l}22.0 \\
22.0 \\
21.5 \\
21.5 \\
21.5\end{array}$ & $\begin{array}{l}21.5 \\
20.5 \\
20.5 \\
20.5 \\
20.0\end{array}$ \\
\hline $\begin{array}{l}11 \\
12 \\
13 \\
14 \\
15\end{array}$ & $\begin{array}{l}11.5 \\
11.5 \\
11.5 \\
10.0 \\
10.5\end{array}$ & $\begin{array}{r}9.5 \\
9.5 \\
9.5 \\
10.0 \\
9.5\end{array}$ & $\begin{array}{l}15.5 \\
15.5 \\
16.0 \\
15.0 \\
15.5\end{array}$ & $\begin{array}{l}13.5 \\
13.5 \\
13.5 \\
13.5 \\
14.0\end{array}$ & $\begin{array}{l}18.5 \\
18.5 \\
19.0 \\
19.0 \\
19.5\end{array}$ & $\begin{array}{l}16.5 \\
17.0 \\
17.0 \\
17.0 \\
18.0\end{array}$ & $\begin{array}{l}19.5 \\
21.0 \\
21.0 \\
21.0 \\
21.0\end{array}$ & $\begin{array}{l}19.0 \\
19.0 \\
19.0 \\
18.5 \\
19.0\end{array}$ & $\begin{array}{l}24.0 \\
23.5 \\
23.0 \\
23.0 \\
22.0\end{array}$ & $\begin{array}{l}21.0 \\
21.5 \\
22.0 \\
21.5 \\
21.5\end{array}$ & $\begin{array}{l}21.5 \\
21.5 \\
21.5 \\
21.5 \\
21.5\end{array}$ & $\begin{array}{l}19.5 \\
20.0 \\
20.0 \\
19.5 \\
19.5\end{array}$ \\
\hline $\begin{array}{l}16 \\
17 \\
18 \\
10 \\
20\end{array}$ & $\begin{array}{l}12.0 \\
13.0 \\
12.0 \\
13.5 \\
13.0\end{array}$ & $\begin{array}{l}10.5 \\
11.0 \\
11.5 \\
11.5 \\
12.0\end{array}$ & $\begin{array}{l}15.5 \\
15.5 \\
15.0 \\
16.0 \\
18.0\end{array}$ & $\begin{array}{l}14.5 \\
14.0 \\
14.5 \\
15.0 \\
10.5\end{array}$ & $\begin{array}{l}19.0 \\
19.0 \\
19.0 \\
19.0 \\
18.5\end{array}$ & $\begin{array}{l}18.5 \\
18.5 \\
18.5 \\
18.0 \\
18.0\end{array}$ & $\begin{array}{l}21.5 \\
21.5 \\
21.5 \\
22.0 \\
21.5\end{array}$ & $\begin{array}{l}19.0 \\
19.0 \\
19.5 \\
19.5 \\
19.5\end{array}$ & $\begin{array}{l}23.0 \\
23.5 \\
23.5 \\
23.0 \\
23.0\end{array}$ & $\begin{array}{l}21.5 \\
22.0 \\
22.0 \\
23.0 \\
22.0\end{array}$ & $\begin{array}{l}21.5 \\
21.0 \\
21.5 \\
20.5 \\
20.5\end{array}$ & $\begin{array}{l}19.5 \\
20.0 \\
20.0 \\
19.5 \\
20.0\end{array}$ \\
\hline $\begin{array}{l}21 \\
22 \\
23 \\
24 \\
25\end{array}$ & $\begin{array}{l}13.0 \\
14.0 \\
13.0 \\
14.0 \\
14.0\end{array}$ & $\begin{array}{l}11.5 \\
12.0 \\
11.5 \\
11.5 \\
11.5\end{array}$ & $\begin{array}{l}19.0 \\
16.0 \\
16.5 \\
11.5 \\
11.0\end{array}$ & $\begin{array}{r}9.0 \\
15.0 \\
9.5 \\
10.0 \\
9.5\end{array}$ & $\begin{array}{l}19.0 \\
18.5 \\
18.5 \\
19.5 \\
21.5\end{array}$ & $\begin{array}{l}18.0 \\
18.0 \\
18.0 \\
18.0 \\
18.5\end{array}$ & $\begin{array}{l}21.5 \\
21.5 \\
21.5 \\
21.0 \\
22.0\end{array}$ & $\begin{array}{l}20.0 \\
20.5 \\
20.0 \\
20.0 \\
20.0\end{array}$ & $\begin{array}{l}23.0 \\
22.0 \\
22.0 \\
23.0 \\
23.0\end{array}$ & $\begin{array}{l}21.5 \\
21.5 \\
21.0 \\
21.0 \\
20.5\end{array}$ & $\begin{array}{l}20.5 \\
19.5 \\
19.5 \\
19.5 \\
20.0\end{array}$ & $\begin{array}{l}19.5 \\
19.0 \\
18.5 \\
19.0 \\
19.0\end{array}$ \\
\hline $\begin{array}{l}26 \\
27 \\
28 \\
29 \\
30 \\
31\end{array}$ & $\begin{array}{r}14.5 \\
15.0 \\
14.5 \\
14.0 \\
15.0 \\
-.0\end{array}$ & $\begin{array}{c}11.5 \\
12.0 \\
13.0 \\
13.0 \\
13.0 \\
.\end{array}$ & $\begin{array}{l}16.5 \\
16.0 \\
18.0 \\
18.5 \\
18.5 \\
18.0\end{array}$ & $\begin{array}{r}9.5 \\
15.5 \\
15.0 \\
9.5 \\
10.0 \\
15.5\end{array}$ & $\begin{array}{c}20.0 \\
20.0 \\
19.5 \\
20.0 \\
20.5 \\
-.\end{array}$ & $\begin{array}{r}18.0 \\
18.5 \\
18.5 \\
18.5 \\
18.5 \\
.\end{array}$ & $\begin{array}{l}22.0 \\
22.0 \\
22.0 \\
22.0 \\
23.0 \\
23.0\end{array}$ & $\begin{array}{l}20.5 \\
20.5 \\
20.5 \\
21.0 \\
20.5 \\
20.5\end{array}$ & $\begin{array}{l}23.0 \\
23.0 \\
23.0 \\
23.0 \\
23.0 \\
22.0\end{array}$ & $\begin{array}{l}20.5 \\
20.5 \\
20.5 \\
20.0 \\
20.5 \\
20.5\end{array}$ & $\begin{array}{r}20.0 \\
20.0 \\
20.0 \\
19.5 \\
19.5 \\
. .\end{array}$ & $\begin{array}{r}19.0 \\
18.5 \\
18.5 \\
18.0 \\
18.0 \\
-0\end{array}$ \\
\hline$\Delta \vee G$ & 12.5 & 10.5 & 16.0 & 12.5 & 19.0 & 17.5 & 21.5 & 19.5 & 23.0 & 21.5 & 21.0 & 19.5 \\
\hline
\end{tabular}


02112000 YADKIN RIVER AT WILKESBORO, N. C. - Continued TEMPERATURE $\left({ }^{\circ} \mathrm{C}\right)$ OF WATER, WATER YEAR OCTOBER 1969 TO SEPTEMBER 1970

\begin{tabular}{|c|c|c|c|c|c|c|c|c|c|c|c|c|}
\hline & & & & ONTIN & $S$ ETHY & DHOL & UATEI & RMUE & & & & \\
\hline DAY & & & & & & & & & & & & \\
\hline & MAX & MI N & MAX & MIN & $\operatorname{MAX}$ & MIN & MAX & MIN & $\operatorname{MAX}$ & MIN & $\max$ & MIN \\
\hline $\begin{array}{l}1 \\
2 \\
3 \\
4 \\
5\end{array}$ & $\begin{array}{l}18.5 \\
20.0 \\
20.0 \\
19.0 \\
18.5\end{array}$ & $\begin{array}{l}17.0 \\
18.0 \\
18.5 \\
19.0 \\
18.0\end{array}$ & $\begin{array}{l}14.0 \\
15.0 \\
14.5 \\
14.0 \\
13.5\end{array}$ & $\begin{array}{l}13.5 \\
14.0 \\
14.0 \\
13.5 \\
13.0\end{array}$ & $\begin{array}{r}10.0 \\
10.0 \\
10.0 \\
9.5 \\
9.0\end{array}$ & $\begin{array}{l}5.0 \\
8.5 \\
9.0 \\
8.5 \\
8.0\end{array}$ & $\begin{array}{l}6.0 \\
6.0 \\
6.0 \\
5.5 \\
5.5\end{array}$ & $\begin{array}{l}5.5 \\
5.5 \\
5.0 \\
5.0 \\
5.0\end{array}$ & $\begin{array}{l}5.0 \\
5.5 \\
5.0 \\
4.5 \\
4.5\end{array}$ & $\begin{array}{l}4.0 \\
4.5 \\
4.0 \\
3.5 \\
3.5\end{array}$ & $\begin{array}{l}8.5 \\
8.5 \\
8.5 \\
7.0 \\
8.0\end{array}$ & $\begin{array}{l}6.5 \\
6.5 \\
6.5 \\
6.5 \\
6.5\end{array}$ \\
\hline $\begin{array}{r}6 \\
7 \\
8 \\
9 \\
10\end{array}$ & $\begin{array}{l}18.5 \\
18.5 \\
18.5 \\
18.5 \\
18.5\end{array}$ & $\begin{array}{l}18.0 \\
16.5 \\
17.0 \\
17.0 \\
16.5\end{array}$ & $\begin{array}{l}14.0 \\
14.0 \\
13.5 \\
13.0 \\
13.0\end{array}$ & $\begin{array}{l}13.0 \\
12.0 \\
11.5 \\
11.5 \\
11.0\end{array}$ & $\begin{array}{l}8.5 \\
8.0 \\
8.5 \\
8.5 \\
8.0\end{array}$ & $\begin{array}{l}8.0 \\
7.0 \\
8.0 \\
8.0 \\
7.0\end{array}$ & $\begin{array}{l}5.0 \\
5.5 \\
4.5 \\
4.0 \\
4.0\end{array}$ & $\begin{array}{l}5.0 \\
4.5 \\
4.0 \\
3.0 \\
3.0\end{array}$ & $\begin{array}{l}4.5 \\
5.0 \\
5.5 \\
5.0 \\
5.5\end{array}$ & $\begin{array}{l}4.0 \\
4.0 \\
4.5 \\
4.5 \\
4.5\end{array}$ & $\begin{array}{l}9.0 \\
8.5 \\
9.5 \\
9.5 \\
9.0\end{array}$ & $\begin{array}{l}6.0 \\
6.0 \\
6.5 \\
6.5 \\
6.5\end{array}$ \\
\hline $\begin{array}{l}11 \\
12 \\
13 \\
14 \\
15\end{array}$ & $\begin{array}{l}18.5 \\
18.5 \\
18.5 \\
18.5 \\
17.0\end{array}$ & $\begin{array}{l}17.0 \\
17.0 \\
17.0 \\
17.0 \\
16.5\end{array}$ & $\begin{array}{l}13.0 \\
13.0 \\
13.0 \\
11.5 \\
11.5\end{array}$ & $\begin{array}{l}11.5 \\
11.5 \\
11.0 \\
11.0 \\
10.5\end{array}$ & $\begin{array}{l}8.0 \\
8.5 \\
8.0 \\
8.5 \\
8.0\end{array}$ & $\begin{array}{l}8.0 \\
8.0 \\
7.0 \\
7.0 \\
7.0\end{array}$ & $\begin{array}{l}4.0 \\
4.0 \\
4.5 \\
4.5 \\
5.0\end{array}$ & $\begin{array}{l}3.0 \\
3.5 \\
3.5 \\
3.5 \\
4.0\end{array}$ & $\begin{array}{l}5.5 \\
5.5 \\
6.0 \\
5.0 \\
5.5\end{array}$ & $\begin{array}{l}4.5 \\
4.5 \\
4.5 \\
5.0 \\
5.0\end{array}$ & $\begin{array}{l}9.5 \\
8.0 \\
8.5 \\
9.5 \\
9.5\end{array}$ & $\begin{array}{l}7.0 \\
7.0 \\
7.0 \\
8.0 \\
8.5\end{array}$ \\
\hline $\begin{array}{l}16 \\
17 \\
18 \\
19 \\
20\end{array}$ & $\begin{array}{l}18.0 \\
17.0 \\
17.0 \\
18.0 \\
17.0\end{array}$ & $\begin{array}{l}16.5 \\
16.0 \\
16.0 \\
15.5 \\
16.0\end{array}$ & $\begin{array}{l}12.0 \\
11.5 \\
11.0 \\
11.0 \\
11.0\end{array}$ & $\begin{array}{l}10.5 \\
10.0 \\
10.5 \\
10.5 \\
10.5\end{array}$ & $\begin{array}{l}8.0 \\
8.0 \\
7.0 \\
7.0 \\
7.0\end{array}$ & $\begin{array}{l}6.5 \\
6.5 \\
6.5 \\
6.5 \\
6.0\end{array}$ & $\begin{array}{l}5.0 \\
4.5 \\
5.0 \\
4.5 \\
4.5\end{array}$ & $\begin{array}{l}3.5 \\
4.0 \\
4.5 \\
4.5 \\
4.0\end{array}$ & $\begin{array}{l}5.5 \\
5.5 \\
6.5 \\
7.0 \\
6.5\end{array}$ & $\begin{array}{l}5.0 \\
5.0 \\
5.0 \\
5.5 \\
5.5\end{array}$ & $\begin{array}{r}10.0 \\
9.5 \\
10.0 \\
8.5 \\
8.5\end{array}$ & $\begin{array}{l}8.0 \\
8.0 \\
8.5 \\
8.5 \\
8.0\end{array}$ \\
\hline $\begin{array}{l}21 \\
22 \\
23 \\
24 \\
25\end{array}$ & $\begin{array}{l}16.5 \\
16.5 \\
15.5 \\
15.5 \\
14.5\end{array}$ & $\begin{array}{l}16.0 \\
15.0 \\
14.5 \\
14.0 \\
14.5\end{array}$ & $\begin{array}{r}11.0 \\
10.5 \\
10.5 \\
10.5 \\
9.5\end{array}$ & $\begin{array}{r}10.0 \\
9.5 \\
9.5 \\
9.0 \\
9.0\end{array}$ & $\begin{array}{l}6.5 \\
7.0 \\
6.5 \\
6.5 \\
6.0\end{array}$ & $\begin{array}{l}6.0 \\
6.0 \\
6.0 \\
6.0 \\
4.5\end{array}$ & $\begin{array}{l}4.0 \\
4.0 \\
4.0 \\
4.5 \\
4.5\end{array}$ & $\begin{array}{l}3.5 \\
3.0 \\
3.0 \\
3.5 \\
4.0\end{array}$ & $\begin{array}{l}6.5 \\
7.0 \\
7.0 \\
8.0 \\
7.0\end{array}$ & $\begin{array}{l}5.0 \\
5.0 \\
6.0 \\
5.5 \\
6.5\end{array}$ & $\begin{array}{r}9.0 \\
9.0 \\
9.5 \\
9.5 \\
10.5\end{array}$ & $\begin{array}{l}8.0 \\
8.5 \\
9.0 \\
8.5 \\
9.0\end{array}$ \\
\hline $\begin{array}{l}26 \\
27 \\
28 \\
29 \\
30 \\
31\end{array}$ & $\begin{array}{l}15.5 \\
15.0 \\
14.5 \\
14.0 \\
14.0 \\
14.0\end{array}$ & $\begin{array}{l}14.5 \\
13.5 \\
13.0 \\
13.0 \\
12.0 \\
13.5\end{array}$ & $\begin{array}{r}10.0 \\
9.5 \\
9.5 \\
10.0 \\
9.0 \\
.-.\end{array}$ & $\begin{array}{r}8.5 \\
8.5 \\
9.0 \\
9.0 \\
8.5 \\
. .\end{array}$ & $\begin{array}{l}6.0 \\
6.0 \\
6.5 \\
6.5 \\
6.0 \\
6.0\end{array}$ & $\begin{array}{l}4.5 \\
5.5 \\
5.5 \\
6.0 \\
6.0 \\
6.0\end{array}$ & $\begin{array}{l}5.5 \\
6.0 \\
5.0 \\
5.5 \\
5.0 \\
5.0\end{array}$ & $\begin{array}{l}4.0 \\
4.0 \\
4.0 \\
4.5 \\
4.5 \\
4.0\end{array}$ & $\begin{array}{l}7.0 \\
8.0 \\
\theta .0 \\
-- \\
=-\end{array}$ & $\begin{array}{r}5.5 \\
6.0 \\
6.0 \\
-- \\
-.\end{array}$ & $\begin{array}{r}9.5 \\
11.0 \\
10.5 \\
11.0 \\
10.0 \\
11.0\end{array}$ & $\begin{array}{l}9.0 \\
9.0 \\
8.5 \\
9.5 \\
9.0 \\
9.0\end{array}$ \\
\hline AVG & 17.0 & 16.0 & 12.0 & 11.0 & 7.5 & 1.0 & 5.0 & 4.0 & 6.0 & 5.0 & 9.0 & 7.5 \\
\hline
\end{tabular}

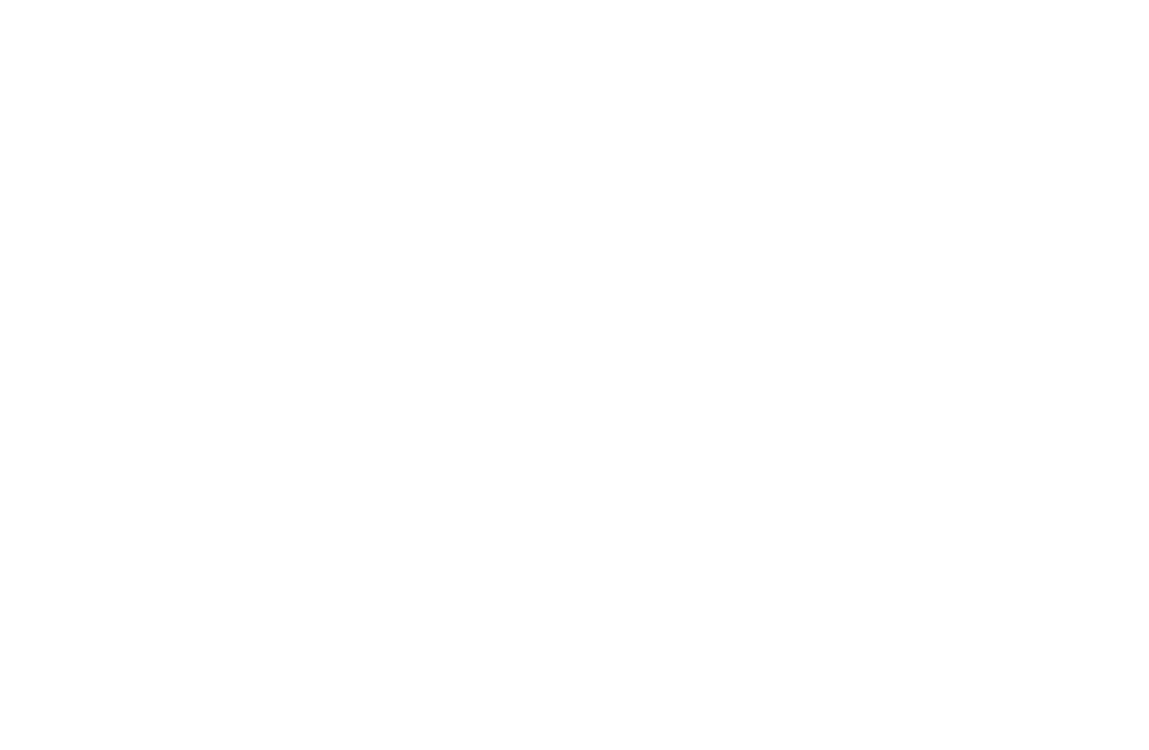


O2116500 YADKIN RIVER AT YADKIN COLLEGE, N. C.

LOCATION. -Lat $35^{\circ} 51^{\prime} 24^{\prime \prime}$, long $80^{\circ} 23^{\prime} 10^{\prime \prime}$, Davidson County, at gaging station near left bank on downstream end of pier of bridge on U.S. H1ghway $64,1.5$ miles south of Yadkin College, 6.2 miles downstream from Reedy Creek, and 295 miles upstream from mouth of pee Dee Hiver in winyah Bay.

DRA INAGE AREA.--2,280 sq mi, approximately.

PERIOD OF REC RD.--Chemical analyses: October 1943 to September 1944, October 1950 to September 1951 , October 1955 to September 1970 .

Water temperatures: October 1943 to September 1944, October 1950 to September 1951 , October 1955 to September 1967 .

Sediment records: January 1951 to September 1970

EXTREMES. - 1969-70:

Sediment concentrations: Maximum daily, $1,810 \mathrm{mg} / 1$ June $14 ;$ minimum daily, $17 \mathrm{mg} / 1 \mathrm{Dec} .7$.
Sediment discharge: Maximum daily, 108,900 tons Aug. $11 ;$ minimum daily, 70 tons Dec. 6,7 .

Period of record:

Dissolved solids (1943-44, 1950-51, 1955-67): Maximum, $85 \mathrm{mg} / 1$ Nov. 1-10, 1950; minimum, $32 \mathrm{mg} / 1 \mathrm{Mar}$. 21-31, 1944

Hardness (1943-44, 1950-51, 1955-67): Maximum, $26 \mathrm{mg} / 1 \mathrm{Mar} .6,1959 ; \mathrm{minimum}, 8 \mathrm{mg} / 1 \mathrm{Dec}, 25,1962$.

Specific conductance (1955-67): Haximum daily, 136 micromhos Aug. 17, 1956; minimum da1ly, 26 micromhos

Sept, 1, 1964

Water temperatures $(1943-44,1950-51,1955-67)$ : Maximum, $31.0^{\circ} \mathrm{C}$ Aug. 24,1959 ; minimum, freezing point on many

days during winter periods.

Sediment concentrations: Maximum daily, 2,970 $\mathrm{mg} / 1$ May 26, 1952; minimum daily, $1 \mathrm{mg} / 1 \mathrm{Dec}, 3,1953$.

Sediment discharge: Maximum daily, 126,000 tons Mar, 13, 1963; minimum daily, 3 tons Dec. 3 , 1953.

REMARKS. -The second of two samples collected at the same time is a field determination.

CHEMICAL ANALYSES, WATER YEAR OCTOBER 1969 TO SEPIEMBER 1970

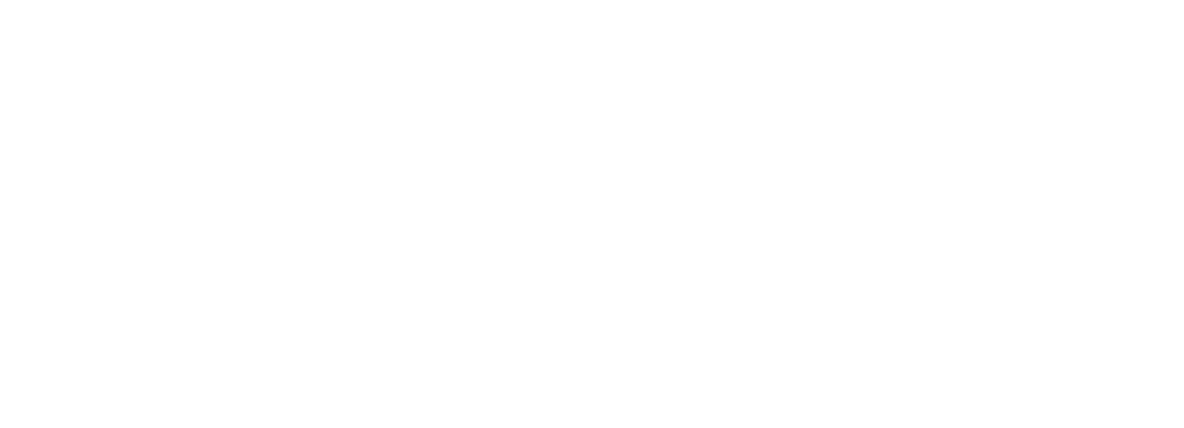

\begin{tabular}{|c|c|c|c|c|c|}
\hline DATE & $\begin{array}{l}\text { DIS- } \\
\text { SOLVED } \\
\text { DXYGEN } \\
\left(M T_{s} / L\right)\end{array}$ & $\begin{array}{l}\text { SPECI - } \\
\text { FIC } \\
\text { COND- } \\
\text { UCTANCE } \\
\text { (MICRO- } \\
\text { MHOSI }\end{array}$ & $\begin{array}{c}\text { PH } \\
\text { IUNITSI }\end{array}$ & $\begin{array}{l}\text { TEMP- } \\
\text { ERATURE } \\
\text { IDEG CI }\end{array}$ & $\begin{array}{l}\text { COLOR } \\
\text { (PLAT- } \\
\text { INUM- } \\
\text { COBAL I } \\
\text { UNITS) }\end{array}$ \\
\hline \multicolumn{6}{|l|}{ MAY } \\
\hline $22 \ldots$ & $\because$ & 77 & 6.1 & 22.0 & 5 \\
\hline $22 \ldots$ & 2.1 & $\cdots$ & 6.7 & 22.0 & -- \\
\hline
\end{tabular}


PEE DEE RIVER BASIN

02116500 YADKIN RIVER AT YADKIN COLLEGE, N. C.-mContinued

SUSPENDED-SEOIMENT CISCHARGE, WATER YEAR OCTOBER 1969 TO SEPTEMBER 1970

OCTOBFR

NOVEMBER

DECEMBER

MEAN MEAN

CONCEN- SEDIMENT

DEDIMENT

MEAN
DISCHARGE

MEAN

$\begin{array}{cll}\text { OISCHARGE } & \text { TRATIDN } & \text { DISCHARGE } \\ \text { (CFS) } & \text { (MG/L) } & \text { ITCNSIDAY) }\end{array}$

(CFS)

SEDIMENT

(MGIL) (TONSIDAY)
(ISHARE

MEAN

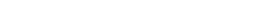

$\begin{array}{rr}43 & 160 \\ 68 & 295 \\ 248 & 2405 \\ 169 & 1350 \\ 47 & 367\end{array}$

3590

1430

4540

$\begin{array}{rr}46 & 166 \\ 77 & 297 \\ 490 & 4110 \\ 608 & 7450 \\ 250 & 1610\end{array}$

$\begin{array}{rr}129 & 644 \\ 72 & 338 \\ 150 & 075 \\ 189 & 1200 \\ 64 & 351\end{array}$

2030

1780
1630

1740

2160
2360

2360
1970

189
Ah

1640

1613
530

1740

1490

1470

$60 \quad 282$

$\begin{array}{ll}50 & 265 \\ 53 & 253 \\ 50 & 199\end{array}$

1490

1490
1510

1510

1490
.520

1480

1410

1410
2350

1310
.380

$50 \quad 190$

$\begin{array}{ll}45 & 271 \\ 39 & 138\end{array}$

$\begin{array}{ll}30 & 106 \\ 30 & 112\end{array}$

1430

1410
1480

$48 \quad 231$

$\begin{array}{ll}30 & 132 \\ 39 & 173 \\ 55 & 239 \\ 35 & 145\end{array}$

31
32
73
239
45

$45 \quad 191$

$\begin{array}{ll}48 & 196 \\ 39 & 159\end{array}$

$\begin{array}{ll}40 & 161 \\ 62 & 254\end{array}$

$\begin{array}{ll}25 & 100 \\ 35 & 135\end{array}$

135
145
180

․․․

3170
2140

1320

1320
1300

1300
1300

$\begin{array}{rr}30 & 111 \\ 39 & \$ 35 \\ 27 & 96\end{array}$

111
35
96
211
98

1830
1700

1700
1640

1340

1400

1340

1360
1350

TOTAL $523^{\circ}$

$\begin{array}{rr}25 & 90 \\ 22 & 84 \\ 51 & 192 \\ 61 & 221 \\ 37 & 140 \\ 59 & 211 \\ -- & 206 \div !\end{array}$

$\substack{1,500 \\ \text { isto } \\ 1,200}$

1510

1540

707

133

1970

$\begin{array}{ll}230 & 1979 \\ 125 & 722\end{array}$

$\begin{array}{rr}68 & 336 \\ 92 & 422 \\ 51 & 226\end{array}$

53360

$\begin{array}{ll}46 & 194 \\ 39 & 164\end{array}$

$\begin{array}{ll}38 & 164 \\ 38 & 157\end{array}$

28

122
177

$-$

12190

(CFS)

MEAN

CONCEN- SEDIMENT

TRATION DISCHARGE

$\begin{array}{lll}1530 & 22 & 90\end{array}$

1420

1460
1430

1430

1430
1520

1520

2330
3090
3250

3250

10700

8440

3950
2950

2410

2190

2090

1990
1010
1780

1780

1790

2330

2810

2100

2740
2720

2340

2140

2370
4750

85840

$\begin{array}{rr}22 & 90 \\ 38 & 146 \\ 52 & 205 \\ 70 & 270 \\ 25 & 97\end{array}$

$\begin{array}{ll}18 & 70 \\ 17 & 70\end{array}$

$\begin{array}{rr}17 & 70 \\ 130 & 818 \\ 185 & 1540\end{array}$

$263 \quad 1540$

$940 \quad 27200$

$638 \quad 14500$

312
202
1510

125813

$\begin{array}{ll}72 & 426 \\ 40 & 226\end{array}$

$\begin{array}{ll}38 & 204 \\ 52 & 268\end{array}$

$95 \quad 457$

$\begin{array}{ll}85 & 411 \\ 55 & 346\end{array}$

$\begin{array}{ll}10 B & 319 \\ 90 & 595\end{array}$

1220

$\begin{array}{ll}165 & 1220 \\ 105 & 771\end{array}$

44
56

85
145

-.

62145

\begin{tabular}{|c|c|c|c|c|c|c|c|c|c|}
\hline & & JANUARY & & & $F E B R U A R Y$ & & & MARCH & \\
\hline CAY & $\begin{array}{l}\text { MEAN } \\
\text { OI SCHAPGE } \\
\text { (CFS) }\end{array}$ & $\begin{array}{l}\text { MFAN } \\
\text { CONCEN- } \\
\text { TRATI GN } \\
(M G / L)\end{array}$ & $\begin{array}{l}\text { SEDIMENT } \\
\text { DISCHARGE } \\
\text { (TONS/DAY) }\end{array}$ & $\begin{array}{l}\text { MEAN } \\
\text { OISCHARGE } \\
\text { (CFS) }\end{array}$ & $\begin{array}{l}\text { MEAN } \\
\text { CONCEN- } \\
\text { TRATION } \\
\text { (MG /L) }\end{array}$ & $\begin{array}{l}\text { SEOIMENT } \\
\text { DISCHARGE } \\
\text { (TONS/OAY) }\end{array}$ & $\begin{array}{l}\text { MEAN } \\
\text { DISCHARGE } \\
\text { (CFS) }\end{array}$ & $\begin{array}{l}\text { MEAN } \\
\text { CONCEN- } \\
\text { TRATION } \\
\text { (MG/L) }\end{array}$ & $\begin{array}{l}\text { SEDIMENT } \\
\text { DI SCHARGE } \\
\text { (TONS / DAY) }\end{array}$ \\
\hline$i$ & 9530 & 558 & 14400 & 2420 & 130 & $B 40$ & 2060 & 31 & 172 \\
\hline$?$ & 6500 & 413 & 7400 & 2800 & 150 & 1210 & 2010 & 60 & 326 \\
\hline 3 & 3330 & 121 & 1630 & 6910 & 492 & 9180 & 1920 & 85 & 413 \\
\hline 4 & 7302 & ino & 756 & 6090 & 434 & 7140 & 1810 & 48 & 235 \\
\hline a & 2550 & 95 & 354 & 3660 & 255 & 2523 & 2030 & 67 & 367 \\
\hline 6 & 2450 & 87 & 576 & 2800 & 165 & 1250 & 2050 & 60 & 332 \\
\hline 7 & 2280 & 72 & 443 & 2560 & 103 & 712 & 2030 & 75 & 411 \\
\hline 8 & 2000 & 89 & 491 & 2530 & 95 & 649 & 1880 & 83 & $42 !$ \\
\hline o & 1850 & 80 & 400 & 2360 & 90 & 573 & 1930 & 87 & 430 \\
\hline 10 & 1730 & 80 & 374 & 2480 & 129 & 864 & 1900 & 118 & 573 \\
\hline 11 & 1700 & 70 & 321 & 2710 & 111 & 812 & 1840 & 62 & 308 \\
\hline 12 & 1900 & 40 & 194 & 2540 & 97 & 665 & 1930 & $5 B$ & 354 \\
\hline 13 & $20 \times 0$ & 21 & 315 & 2270 & $B 8$ & 429 & 2030 & 35 & 466 \\
\hline 14 & 2230 & 35 & 211 & 2170 & 70 & 410 & 2380 & 68 & 437 \\
\hline is & 2020 & 64 & $34^{\circ}$ & 2110 & $t 9$ & 387 & 2440 & 82 & 540 \\
\hline 16 & 2100 & 90 & 454 & 2210 & 220 & 1310 & 2140 & 103 & 595 \\
\hline 17 & 1930 & 78 & 406 & 7520 & 635 & 12000 & 1900 & 80 & 410 \\
\hline I 8 & 2350 & 92 & 584 & 5480 & 371 & 5490 & 1990 & 99 & 531 \\
\hline 19 & 3050 & 135 & 1110 & 3620 & 239 & 2340 & 2430 & 85 & 558 \\
\hline $2 \mathrm{C}$ & 2510 & 140 & 087 & 2820 & 278 & 1350 & 2700 & ${ }^{2} 2$ & 598 \\
\hline 21 & 2220 & 20 & 539 & 2650 & 107 & 766 & 2770 & 80 & 598 \\
\hline 22 & 1910 & $A ?$ & 346 & 2340 & 55 & 347 & 3340 & 175 & 2580 \\
\hline 23 & 1500 & 40 & 171 & 2170 & 53 & 340 & 3780 & 165 & 1680 \\
\hline 24 & 1750 & 60 & 295 & 2170 & 108 & 633 & 3310 & 125 & 1120 \\
\hline 25 & 2050 & S8 & 376 & $2: 50$ & 55 & 321 & 2820 & 105 & 799 \\
\hline $2 t$ & 22RT & 100 & 516 & 2200 & 27 & 160 & 2530 & 70 & 479 \\
\hline 27 & $2 \div 60$ & $\operatorname{lan}$ & 816 & 2060 & 70 & 389 & 2410 & 58 & 377 \\
\hline 28 & 2060 & 120 & 667 & 2070 & 60 & 335 & 2310 & 60 & 374 \\
\hline $2^{\circ}$ & 1770 & 115 & 312 & - & $=$ & - & 2290 & 79 & 488 \\
\hline 30 & 3990 & 435 & 4570 & -- & -- & -- & 2310 & 83 & $51 \%$ \\
\hline 31 & 2090 & 300 & 2340 & -- & - & $=$ & 2460 & 97 & 644 \\
\hline TOTAL & 81680 & -- & 43183 & 85970 & -- & 54331 & 71430 & - & 17138 \\
\hline
\end{tabular}


PEE DEE RIVER BASIN

02116500 YADKIN RIVER AT YADKIN COLLEGE, $N$, C,--Continued

SUSPENDED-SEOIMENT OISCHARGE, WATER YEAR OCTOBFR 1969 TO SEPTEMBER 1970

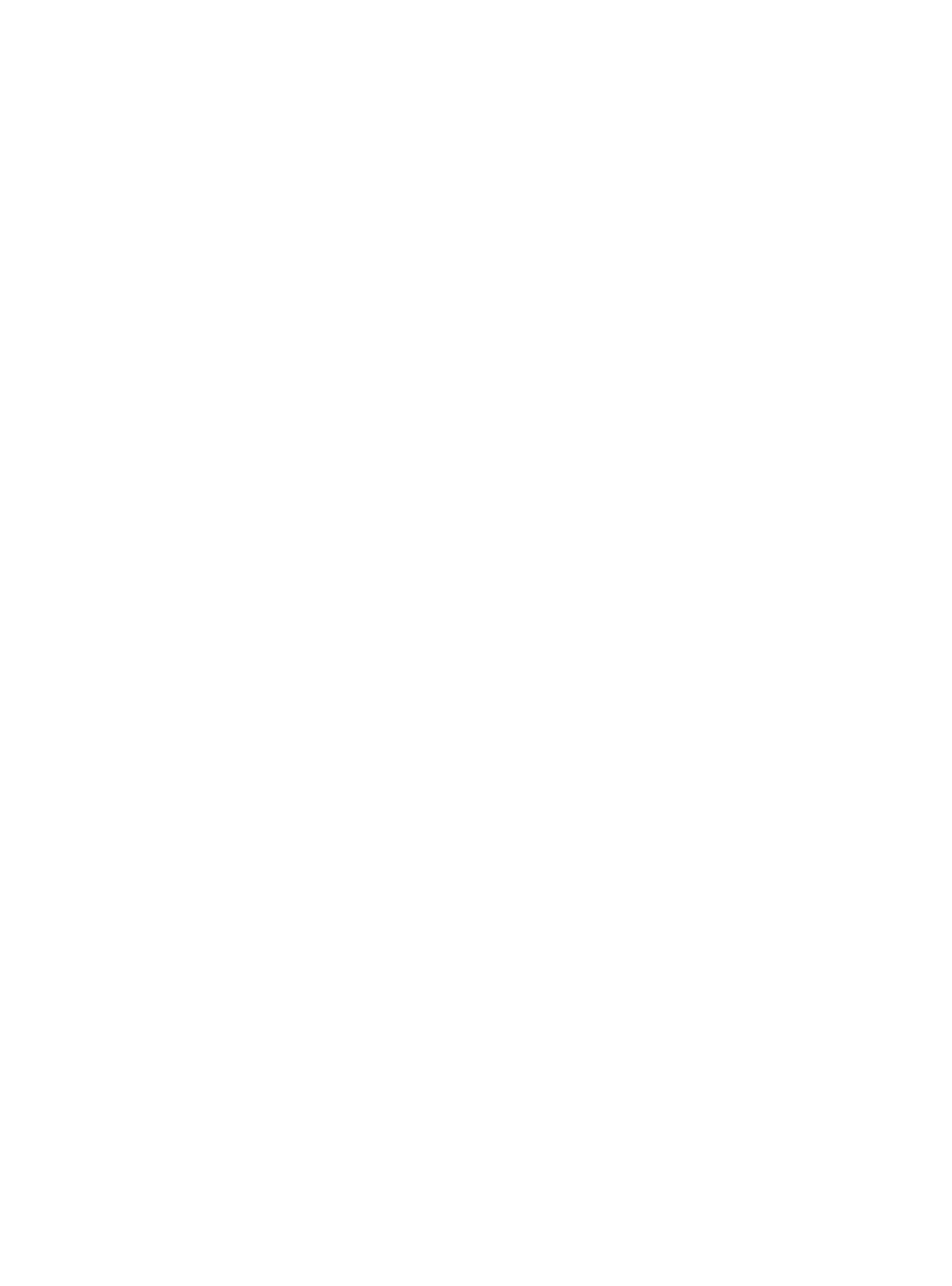


02118000 SOUTH YADKIN RIVER NEAR YOCKSVILLE, N. C.

LOCATION.--Lat $35^{\circ} 50^{\prime} 39^{\prime \prime}$, long $80^{\circ} 39^{\prime} 38^{\prime \prime}$, Rowan County, temperature recorder at gaging station on right bank at downstream side of bridge on Secondary Road 1972, 1 mile upstream from Little Creek, 4 miles downstream from Fifth Creek, 4.5 miles upstream from Hunting Creek, and 6.5 miles southwest of Mocksville.

DRAINAGE AREA. --313 sq mi.

PERIOD OF RECORD,--Chemical analyses: October 1953 to September 1954, October 1960 to August 1967.

Water temperatures: October 1980 to September 1969 (discontinued).

Sediment records: January 1958 to December 1967.

EXTRE MES. - - 1967-69:

Water temperatures 1967-68: Yaximum, $26.5^{\circ} \mathrm{C}$ Aug. 24,25 ; minimum, $3.5^{\circ} \mathrm{C}$ Jan. $13,14, F e b, 14,15,26$

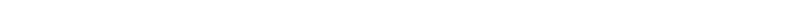

TEMPERATURE ( $\left.{ }^{\circ} \mathrm{C}\right)$ OF WATER, WATER YEAR OCTOBER 1967 TO SEPTEMBER 1968

MAX MIN

14.

16.0

18.0

13.0

12.0
15.5

16.0

18.0

16.5

16.0

15.5
16.5

15.0

15.0

15.5

16.0
15.5

15.5
16.0

15.0

15.5

15.5
15.0
14.0

13.5

15.0

$16.5 \quad 15.0$

16.5

16.0

15.0

15.5
15.0
13.0
11.5

13.0
11.5

$11.5 \quad 10.5$

11.5
11.5
11.5

11.5
12.0

10.5
10.5
10.5
11.0
11.5

11.5

$12.0 \quad 11.0$

$\begin{array}{ll}11.5 & 10.5 \\ 11.5 & 10.5\end{array}$

10.5

9.5

9.0

$14.5 \quad 13.0$

DAY

APR

$\operatorname{MAX}$

17.0

16.5
14.0

14.0
12.0

14.0

15.5
14.0
11.5

14.0
11.5
11.5
12.0

MAX
11.5
12.0
12.0
11.5
10.5
8.5
7.0
6.0
6.0
7.0

NOV

OEC

MIN

\section{MIN}

$\begin{array}{ll}5.5 & 5.0 \\ 6.0 & 5.5 \\ 6.5 & 5.5 \\ 6.5 & 6.5 \\ 6.5 & 5.5\end{array}$

6.0

6.0
6.5
8.0
9.0

9.0

9.0

9.5

9.5

9.0

6.0

7.0

6.0

6.5
8.0

8.0
9.0
9.0

9.5

8.5
8.5
8.5
6.0

6.0
5.0

3.5

MAY

13.5
14.0

15.0

15.5
16.5

16.5

14.5

15.0
15.5

15.5

$14.5 \quad 16.5$

15.5

16.5

14.0

16.5

18.0
15.5

15.5
15.5

$15.5 \quad 16.5$

$14.0 \quad 17.0$

16.5

14. 5

19.0

18.0
18.0
17.0

17.0

18.0
17.0
16.0
14.5

16.0

14.5

14.5

14.0

13.5
14.0

14.0

12.0

16.0

14.5

$\begin{array}{ll}16.0 & 14.0 \\ 17.0 & 16.0\end{array}$

17.0
17.0

$\begin{array}{ll}18.0 & 17.0 \\ 17.0 & 16.5\end{array}$

15.0

14.0

14.0

16.5
16.5

17.0
16.5

15.5

16.0

16.5

16.5
17.0

18.0
19.0

17.0

16.5
15.0

15.0
15.5

15.5
17.0

17.0

16.5
15.5

15.5
15.0

15.5
16.0

16.0

17.0

5.0
5.5
5.5
6.5
5.5
5.5
6.0
6.5
8.0
9.0

$\begin{array}{ll}9.0 & 9.0 \\ 9.0 & 9.5\end{array}$

.5

$10.5 \quad 8.5$

12.0
13.0

$9.5 \quad 7.0$

$\begin{array}{ll}7.0 & 6.5 \\ 6.5 & 6.5 \\ 6.5 & 6.5\end{array}$

6.5
6.5

8.07 .5

JUN

$\begin{array}{ll}19.0 & 18.0 \\ 19.5 & 19.0\end{array}$

19.5

$\begin{array}{ll}19.5 & 19.0\end{array}$

$\begin{array}{ll}19.0 & 19.0 \\ 19.5 & 19.0\end{array}$

20.020 .0

$\begin{array}{ll}20.5 & 20.0 \\ 20.5 & 20.5 \\ 20.5 & 19.5\end{array}$

$20.0 \quad 19.5$

$\begin{array}{ll}20.5 & 20.0 \\ 20.5 & 20.5\end{array}$

$\begin{array}{ll}20.5 & 20.5 \\ 20.5 & 20.0 \\ 20.0 & 19.5\end{array}$

$20.5 \quad 19.5$

$20.5 \quad 20.0$

$=0$

$26.0 \quad 22.0$

$\begin{array}{ll}24.0 & 23.5 \\ 23.5 & 22.0\end{array}$

$22.0 \quad 20.5$

(RMOGRAPH)

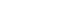

MAR

MAX MIN MAX MIN MAX MIN

$\begin{array}{lll}6.5 & 6.5 & 9.0 \\ 6.5 & 6.5 & 9.0 \\ 7.0 & 6.5 & 9.0 \\ 9.0 & 7.0 & 9.5\end{array}$

$\begin{array}{lll}9.0 & 5.0 & 4.5 \\ 9.0 & 5.5 & 4.5 \\ 8.5 & 6.5 & 5.5 \\ 7.0 & 6.5 & 6.0 \\ 6.5 & 6.5 & 6.0\end{array}$

9.0

$\begin{array}{lll}7.0 & 6.0 & 6.5 \\ 6.0 & 6.0 & 6.0 \\ 6.0 & 5.0 & 6.0 \\ 5.0 & 4.5 & 6.0 \\ 4.5 & 4.5 & 6.0 \\ 4.5 & 4.5 & 5.5\end{array}$

$6.5 \quad 6.5$

$6.0 \quad 7.0 \quad 6.5$

$\begin{array}{rrr}5.5 & 8.0 & 6.5 \\ 5.5 & 8.5 & 7.0 \\ 5.5 & 10.0 & 8.5\end{array}$

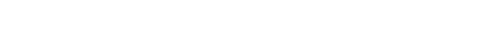

$\begin{array}{lll}4.5 & 4.5 & 5.5 \\ 4.5 & 4.0 & 5.0 \\ 4.0 & 3.5 & 4.0 \\ 4.0 & 3.5 & 4.0\end{array}$

$\begin{array}{lll}5.0 & 12.0 & 11.0 \\ 4.0 & 12.0 & 11.5 \\ 4.0 & 11.5 & 10.0\end{array}$

4.0

4.5

$10.0 \quad 9.0$

$\begin{array}{lll}4.5 & 4.0 & 5.0 \\ 4.5 & 4.5 & 5.5 \\ 4.5 & 4.5 & 5.5\end{array}$

$\begin{array}{lll}4.5 & 4.5 & 5.5 \\ 5.0 & 4.5 & 5.0 \\ 5.5 & 5.0 & 5.0\end{array}$

4.

$\begin{array}{rr}9.5 & 8.0 \\ 10.5 & 9.5 \\ 10.5 & 10.0 \\ 10.5 & 10.0\end{array}$

$11.0 \quad 10.5$

5.0

$10.5 \quad 10.0$

$\begin{array}{lll}6.0 & 5.0 & 5.5 \\ 6.0 & 5.5 & 5.5 \\ 7.0 & 6.0 & 5.0\end{array}$

7.0
6.5

6.5

6.0
5.0
6.0

6.0

7.0

8.5
9.0

6.0

sul

$17.0 \quad 16.5 \quad 23.5$

$\begin{array}{lll}17.0 & 16.5 & 23.5 \\ 19.0 & 17.0 & 24.5\end{array}$

24.5
24.0
22.0

21.5
23.5

$23.5 \quad 24.0 \quad 23.0$

$24.0 \quad 24.0 \quad 23.5$

$22.0 \quad 24.5$

22.0

23.0
23.0

23.0
23.0

$21.5 \quad 24.5$

24.0

24.5
24.5

24.5

25.0

21.5

22.0

22.0
22.0

25.5

$21.5 \quad 24.5$

23.5
21.5

23.0

23.0

$\begin{array}{lll}23.0 & 22.0 & 25.0 \\ 23.0 & 23.0 & 25.0\end{array}$

23.0

$23.0 \quad 24.0$

23.5

23.0

25.0
25.5

24.0

$\begin{array}{ll}23.0 & 25.5 \\ 23.0 & 26.0\end{array}$

24.5

24.0

26.0
26.5

24.5

24.5
24.5
24.5

$24 \cdot 5$

24.5
24.5

$24.0 \quad 25.5$

26.5

21.5
21.5

21.5
21.5

23.0

24.0

24.5
24.5

24.5

25.0

25.0

25.5
25.5

$24.0 \quad 25.0$

$24.5 \quad 22.0$

$\begin{array}{ll}24.5 & 20.0 \\ 23.5 & 19.5 \\ 23.5 & 20.0\end{array}$

24.5

22.0

18.5

18.0
17.0

$\begin{array}{ll}13.0 & 11.5 \\ 14.5 & 13.0\end{array}$

$\begin{array}{ll}14.5 & 13.0 \\ 14.5 & 13.0\end{array}$

$\begin{array}{ll}3.0 & 10.5\end{array}$

$\begin{array}{rr}10.5 & 9.5 \\ 12.0 & 10.5\end{array}$

$13.0 \quad 12.0$

$\begin{array}{ll}14.5 & 13.0 \\ 14.5 & 14.0 \\ 16.0 & 14.5\end{array}$

23.5

22.5

24.0

23.0

$10.5 \quad 9.5$

SEP 
02118000 SOUTH YADKIN RIVER NEAR MOCKSVILLE, N. C.--Cont InUed

Pertod of record

Dissolved solids (1960-67): Maximum, $158 \mathrm{mg} / 1$ June $3-11,1961 ;$ mintmum, 34 mg/1 Mky 1-31, 1965 ,

Hardness (1960-67): Maximum, $103 \mathrm{mg} / 1$ June $3-11,1961$; minimum, $12 \mathrm{mg} / 1$ Mar. 1-31, 1962 and Mar. 1-31, 1965 . Specific conductance (1960-67): Haximum daily, 239 micromhos June 7, 1961; minimum da11y, 23 micromhos Oct. 15, 1964 .

Water temperatures: Maximum, $26.5^{\circ} \mathrm{C}$ Aug. 24, 25, 1968, July 6, 7, 1969; minimum, freezing point on many days during 1961, 1963-64.

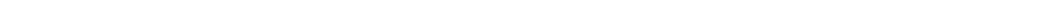

REMARKS.--Temperature data collected at this site October 1969 to September 1970 are unreliable and are not published.

TEMPERATURE $\left({ }^{\circ} \mathrm{C}\right)$ OF WATER, HATER YEAR DCTOBER 1968 TO SEPTEMBER 1969 (CONTINUOUS ETHYL ALCOHOL-ACTUATED THERMOGRAPH)

\begin{tabular}{|c|c|c|c|c|c|c|c|c|c|c|c|c|}
\hline \multirow[t]{2}{*}{ DAY } & \multicolumn{2}{|c|}{ OCT } & \multicolumn{2}{|c|}{ NOV } & \multicolumn{2}{|c|}{ DEC } & \multicolumn{2}{|c|}{ JAN } & \multicolumn{2}{|c|}{ FE8 } & \multicolumn{2}{|c|}{ MAR } \\
\hline & MAX & MI N & MAX & MIN & $\max$ & MIN & $\operatorname{MAX}$ & MIN & MAX & MIN & MAX & MIN \\
\hline $\begin{array}{l}1 \\
2 \\
3 \\
4 \\
5\end{array}$ & $\begin{array}{l}18.0 \\
18.0 \\
18.5 \\
18.5 \\
16.5\end{array}$ & $\begin{array}{l}16.0 \\
16.0 \\
17.0 \\
16.5 \\
13.0\end{array}$ & $\begin{array}{l}11.0 \\
12.0 \\
13.0 \\
13.0 \\
13.0\end{array}$ & $\begin{array}{r}9.0 \\
10.5 \\
11.5 \\
12.0 \\
12.0\end{array}$ & $\begin{array}{l}9.0 \\
8.0 \\
8.0 \\
8.0 \\
8.0\end{array}$ & $\begin{array}{l}8.0 \\
7.0 \\
7.0 \\
8.0 \\
6.5\end{array}$ & $\begin{array}{l}5.0 \\
4.0 \\
3.0 \\
3.0 \\
3.0\end{array}$ & $\begin{array}{l}3.5 \\
3.0 \\
3.0 \\
3.0 \\
2.0\end{array}$ & $\begin{array}{l}8.0 \\
8.0 \\
8.0 \\
8.0 \\
6.5\end{array}$ & $\begin{array}{l}8.0 \\
8.0 \\
8.0 \\
6.5 \\
5.5\end{array}$ & $\begin{array}{l}5.5 \\
5.0 \\
5.0 \\
5.5 \\
5.5\end{array}$ & $\begin{array}{l}4.0 \\
4.0 \\
5.0 \\
5.0 \\
5.0\end{array}$ \\
\hline $\begin{array}{r}6 \\
7 \\
6 \\
9 \\
10\end{array}$ & $\begin{array}{l}13.5 \\
14.5 \\
15.0 \\
15.0 \\
15.5\end{array}$ & $\begin{array}{l}12.5 \\
12.0 \\
14.5 \\
14.5 \\
14.5\end{array}$ & $\begin{array}{r}13.5 \\
14.5 \\
14.5 \\
12.0 \\
9.5\end{array}$ & $\begin{array}{r}13.0 \\
13.5 \\
12.0 \\
9.5 \\
9.0\end{array}$ & $\begin{array}{l}6.5 \\
6.0 \\
5.5 \\
4.0 \\
3.0\end{array}$ & $\begin{array}{l}6.0 \\
5.5 \\
4.0 \\
3.0 \\
2.0\end{array}$ & $\begin{array}{l}2.0 \\
2.0 \\
2.0 \\
3.0 \\
3.0\end{array}$ & $\begin{array}{l}2.0 \\
2.0 \\
2.0 \\
2.0 \\
2.0\end{array}$ & $\begin{array}{l}6.0 \\
7.0 \\
7.0 \\
7.0 \\
7.0\end{array}$ & $\begin{array}{l}5.5 \\
6.0 \\
7.0 \\
7.0 \\
0.0\end{array}$ & $\begin{array}{l}5.5 \\
6.0 \\
6.0 \\
6.5 \\
7.0\end{array}$ & $\begin{array}{l}5.5 \\
5.5 \\
5.5 \\
6.0 \\
6.0\end{array}$ \\
\hline $\begin{array}{l}11 \\
12 \\
13 \\
14 \\
15\end{array}$ & $\begin{array}{l}16.0 \\
17.0 \\
18.5 \\
19.0 \\
19.5\end{array}$ & $\begin{array}{l}15.0 \\
16.0 \\
17.0 \\
17.0 \\
18.0\end{array}$ & $\begin{array}{l}9.0 \\
8.0 \\
7.0 \\
7.0 \\
8.0\end{array}$ & $\begin{array}{l}8.0 \\
6.5 \\
6.5 \\
6.5 \\
6.5\end{array}$ & $\begin{array}{l}2.0 \\
2.0 \\
3.5 \\
5.5 \\
5.5\end{array}$ & $\begin{array}{l}2.0 \\
2.0 \\
2.0 \\
3.5 \\
3.5\end{array}$ & $\begin{array}{l}3.0 \\
2.0 \\
2.0 \\
2.0 \\
2.0\end{array}$ & $\begin{array}{l}2.0 \\
2.0 \\
2.0 \\
2.0 \\
1.5\end{array}$ & $\begin{array}{l}6.0 \\
5.5 \\
5.5 \\
4.5 \\
3.5\end{array}$ & $\begin{array}{r}3.0 \\
5.0 \\
3.5 \\
3.5\end{array}$ & $\begin{array}{l}7.0 \\
6.0 \\
6.0 \\
6.5 \\
6.5\end{array}$ & $\begin{array}{l}6.0 \\
5.0 \\
5.0 \\
5.5 \\
6.0\end{array}$ \\
\hline $\begin{array}{l}16 \\
17 \\
18 \\
19 \\
20\end{array}$ & $\begin{array}{l}18.5 \\
19.0 \\
19.0 \\
19.0 \\
19.0\end{array}$ & $\begin{array}{l}18.5 \\
18.5 \\
29.0 \\
19.0 \\
18.0\end{array}$ & $\begin{array}{r}9.0 \\
11.0 \\
13.0 \\
13.0 \\
10.5\end{array}$ & $\begin{array}{r}7.0 \\
9.0 \\
11.0 \\
10.5 \\
8.0\end{array}$ & $\begin{array}{l}3.5 \\
2.0 \\
2.0 \\
3.5 \\
4.5\end{array}$ & $\begin{array}{l}2.0 \\
2.0 \\
2.0 \\
2.0 \\
3.5\end{array}$ & $\begin{array}{l}1.5 \\
2.0 \\
3.5 \\
5.5 \\
5.5\end{array}$ & $\begin{array}{l}1.5 \\
1.5 \\
2.0 \\
3.5 \\
5.0\end{array}$ & $\begin{array}{l}3.0 \\
1.5 \\
3.5 \\
4.5 \\
4.5\end{array}$ & $\begin{array}{l}1.5 \\
1.0 \\
1.5 \\
3.5 \\
3.5\end{array}$ & $\begin{array}{r}6.5 \\
7.0 \\
7.0 \\
8.5 \\
10.0\end{array}$ & $\begin{array}{l}6.5 \\
6.0 \\
7.0 \\
7.0 \\
8.5\end{array}$ \\
\hline $\begin{array}{l}21 \\
22 \\
23 \\
24 \\
25\end{array}$ & $\begin{array}{l}18.5 \\
16.0 \\
15.0 \\
15.0 \\
15.0\end{array}$ & $\begin{array}{l}16.0 \\
14.5 \\
14.5 \\
14.5 \\
14.0\end{array}$ & $\begin{array}{l}8.0 \\
6.5 \\
6.5 \\
7.0 \\
7.0\end{array}$ & $\begin{array}{l}6.5 \\
6.0 \\
6.0 \\
6.0 \\
6.5\end{array}$ & $\begin{array}{l}4.5 \\
4.5 \\
5.5 \\
5.5 \\
4.0\end{array}$ & $\begin{array}{l}4.5 \\
4.5 \\
4.5 \\
4.0 \\
3.5\end{array}$ & $\begin{array}{l}5.0 \\
5.5 \\
6.0 \\
6.5 \\
6.5\end{array}$ & $\begin{array}{l}5.0 \\
5.0 \\
5.5 \\
6.0 \\
6.0\end{array}$ & $\begin{array}{l}4.0 \\
4.0 \\
3.5 \\
3.5 \\
5.5\end{array}$ & $\begin{array}{l}3.5 \\
3.5 \\
3.5 \\
3.5 \\
4.0\end{array}$ & $\begin{array}{l}11.0 \\
11.0 \\
11.0 \\
10.0 \\
10.0\end{array}$ & $\begin{array}{r}10.0 \\
10.5 \\
8.5 \\
9.5 \\
9.5\end{array}$ \\
\hline $\begin{array}{l}26 \\
27 \\
28 \\
29 \\
30 \\
31\end{array}$ & $\begin{array}{l}14.0 \\
12.0 \\
11.0 \\
10.5 \\
10.0 \\
10.0\end{array}$ & $\begin{array}{r}11.5 \\
10.0 \\
10.0 \\
10.0 \\
9.0 \\
9.0\end{array}$ & $\begin{array}{r}7.0 \\
7.0 \\
9.5 \\
10.0 \\
10.0 \\
--\end{array}$ & $\begin{array}{l}6.5 \\
6.5 \\
7.0 \\
9.5 \\
9.0 \\
-.-\end{array}$ & $\begin{array}{l}3.5 \\
3.5 \\
6.0 \\
6.0 \\
6.0 \\
5.0\end{array}$ & $\begin{array}{l}2.0 \\
2.0 \\
3.5 \\
5.5 \\
5.0 \\
5.0\end{array}$ & $\begin{array}{l}6.0 \\
5.0 \\
4.5 \\
4.5 \\
6.0 \\
8.0\end{array}$ & $\begin{array}{l}5.0 \\
4.0 \\
4.5 \\
4.5 \\
4.5 \\
6.0\end{array}$ & $\begin{array}{r}6.0 \\
6.0 \\
6.0 \\
=- \\
=-\end{array}$ & $\begin{array}{r}5.5 \\
5.5 \\
5.5 \\
-5 \\
=- \\
--\end{array}$ & $\begin{array}{l}10.5 \\
10.0 \\
10.5 \\
10.0 \\
11.5 \\
11.5\end{array}$ & $\begin{array}{r}10.0 \\
9.5 \\
8.5 \\
9.0 \\
10.0 \\
8.5\end{array}$ \\
\hline AVG & 16.0 & 14.5 & 10.0 & 9.0 & 5.0 & 4.0 & 4.0 & 3.5 & 5.5 & 5.0 & 8.0 & 7.0 \\
\hline \multirow[t]{2}{*}{ DAY } & \multicolumn{2}{|c|}{$A P R$} & \multicolumn{2}{|c|}{ MAY } & \multicolumn{2}{|c|}{ JUN } & \multicolumn{2}{|c|}{ JUL } & \multicolumn{2}{|c|}{ AUG } & \multicolumn{2}{|c|}{ SEP } \\
\hline & MAX & MI N & $\operatorname{MAX}$ & MIN & $\max$ & MIN & MAX & MIN & $\operatorname{MAx}$ & MI N & $\max$ & MIN \\
\hline $\begin{array}{l}1 \\
2 \\
3 \\
4 \\
5\end{array}$ & $\begin{array}{l}11.0 \\
12.0 \\
14.0 \\
14.0 \\
14.0\end{array}$ & $\begin{array}{l}10.0 \\
10.5 \\
12.0 \\
14.0 \\
14.0\end{array}$ & $\begin{array}{l}18.0 \\
16.5 \\
16.5 \\
18.0 \\
18.5\end{array}$ & $\begin{array}{l}16.0 \\
15.5 \\
15.5 \\
16.0 \\
17.0\end{array}$ & $\begin{array}{l}22.0 \\
22.0 \\
22.0 \\
20.5 \\
19.5\end{array}$ & $\begin{array}{l}21.0 \\
22.0 \\
20.0 \\
19.5 \\
19.0\end{array}$ & $\begin{array}{l}26.0 \\
25.0 \\
24.5 \\
25.0 \\
25.5\end{array}$ & $\begin{array}{l}25.0 \\
23.0 \\
24.0 \\
24.5 \\
24.0\end{array}$ & $\begin{array}{l}23.5 \\
23.5 \\
23.0 \\
21.5 \\
21.0\end{array}$ & $\begin{array}{l}23.0 \\
23.0 \\
21.5 \\
21.0 \\
20.0\end{array}$ & $\begin{array}{l}19.0 \\
18.0 \\
18.5 \\
18.5 \\
18.5\end{array}$ & $\begin{array}{l}18.0 \\
18.0 \\
18.0 \\
18.0 \\
18.0\end{array}$ \\
\hline $\begin{array}{r}6 \\
7 \\
8 \\
9 \\
10\end{array}$ & $\begin{array}{l}15.0 \\
15.0 \\
15.0 \\
15.0 \\
15.0\end{array}$ & $\begin{array}{l}14.0 \\
14.0 \\
13.5 \\
14.0 \\
15.0\end{array}$ & $\begin{array}{l}19.0 \\
19.5 \\
19.0 \\
20.0 \\
20.0\end{array}$ & $\begin{array}{l}18.0 \\
18.0 \\
19.0 \\
19.0 \\
18.0\end{array}$ & $\begin{array}{l}20.5 \\
21.5 \\
23.5 \\
23.5 \\
23.0\end{array}$ & $\begin{array}{l}19.0 \\
20.0 \\
21.5 \\
23.0 \\
21.0\end{array}$ & $\begin{array}{l}26.5 \\
26.5 \\
26.0 \\
25.5 \\
24.0\end{array}$ & $\begin{array}{l}25.5 \\
25.5 \\
25.5 \\
24.0 \\
23.5\end{array}$ & $\begin{array}{l}21.5 \\
22.0 \\
22.0 \\
23.0 \\
23.0\end{array}$ & $\begin{array}{l}20.5 \\
20.5 \\
20.5 \\
21.0 \\
22.0\end{array}$ & $\begin{array}{l}19.0 \\
20.0 \\
19.5 \\
19.0 \\
19.0\end{array}$ & $\begin{array}{l}18.5 \\
19.0 \\
19.0 \\
18.5 \\
17.0\end{array}$ \\
\hline $\begin{array}{l}11 \\
12 \\
13 \\
14 \\
15\end{array}$ & $\begin{array}{l}16.0 \\
16.0 \\
15.5 \\
15.5 \\
14.5\end{array}$ & $\begin{array}{l}14.5 \\
15.0 \\
15.0 \\
14.5 \\
13.5\end{array}$ & $\begin{array}{l}18.0 \\
17.0 \\
15.5 \\
15.5 \\
16.5\end{array}$ & $\begin{array}{l}17.0 \\
14.5 \\
14.5 \\
15.0 \\
15.5\end{array}$ & $\begin{array}{l}21.0 \\
21.5 \\
23.5 \\
23.5 \\
23.5\end{array}$ & $\begin{array}{l}20.5 \\
21.0 \\
21.5 \\
21.5 \\
21.5\end{array}$ & $\begin{array}{l}23.5 \\
24.0 \\
24.0 \\
24.0 \\
24.0\end{array}$ & $\begin{array}{l}23.5 \\
23.5 \\
23.0 \\
23.0 \\
23.0\end{array}$ & $\begin{array}{l}22.0 \\
21.5 \\
21.0 \\
20.0 \\
20.0\end{array}$ & $\begin{array}{l}20.5 \\
20.0 \\
19.5 \\
19.5 \\
19.5\end{array}$ & $\begin{array}{l}17.0 \\
15.5 \\
15.5 \\
15.5 \\
15.5\end{array}$ & $\begin{array}{l}15.0 \\
14.5 \\
14.5 \\
14.0 \\
14.5\end{array}$ \\
\hline $\begin{array}{l}16 \\
17 \\
18 \\
19 \\
20\end{array}$ & $\begin{array}{l}14.5 \\
15.5 \\
15.5 \\
15.5 \\
15.0\end{array}$ & $\begin{array}{l}13.5 \\
14.0 \\
15.0 \\
15.0 \\
14.0\end{array}$ & $\begin{array}{l}18.0 \\
18.5 \\
18.5 \\
18.0 \\
19.0\end{array}$ & $\begin{array}{l}16.5 \\
18.0 \\
18.0 \\
18.0 \\
18.0\end{array}$ & $\begin{array}{l}23.5 \\
23.5 \\
22.0 \\
23.5 \\
23.5\end{array}$ & $\begin{array}{l}23.5 \\
22.0 \\
21.5 \\
22.0 \\
22.0\end{array}$ & $\begin{array}{l}24.0 \\
24.5 \\
25.5 \\
25.0 \\
25.5\end{array}$ & $\begin{array}{l}23.0 \\
23.0 \\
23.5 \\
24.0 \\
24.5\end{array}$ & $\begin{array}{l}20.0 \\
20.0 \\
21.0 \\
21.0 \\
21.5\end{array}$ & $\begin{array}{l}19.5 \\
19.5 \\
20.0 \\
21.0 \\
21.0\end{array}$ & $\begin{array}{l}15.5 \\
16.0 \\
17.0 \\
17.0 \\
15.5\end{array}$ & $\begin{array}{l}14.5 \\
15.5 \\
16.0 \\
15.0 \\
15.0\end{array}$ \\
\hline $\begin{array}{l}21 \\
22 \\
23 \\
24 \\
25\end{array}$ & $\begin{array}{l}14.0 \\
13.5 \\
13.5 \\
13.0 \\
12.0\end{array}$ & $\begin{array}{l}13.0 \\
13.0 \\
13.0 \\
11.0 \\
11.0\end{array}$ & $\begin{array}{l}20.0 \\
20.0 \\
20.5 \\
21.0 \\
21.0\end{array}$ & $\begin{array}{l}19.0 \\
20.0 \\
20.0 \\
20.0 \\
20.0\end{array}$ & $\begin{array}{l}22.0 \\
22.0 \\
21.5 \\
22.0 \\
24.5\end{array}$ & $\begin{array}{l}21.0 \\
21.5 \\
21.0 \\
21.0 \\
22.0\end{array}$ & $\begin{array}{l}25.5 \\
25.5 \\
24.5 \\
24.5 \\
24.5\end{array}$ & $\begin{array}{l}24.5 \\
24.5 \\
24.5 \\
23.5 \\
23.5\end{array}$ & $\begin{array}{l}21.0 \\
20.0 \\
18.5 \\
18.0 \\
19.0\end{array}$ & $\begin{array}{l}20.0 \\
18.5 \\
16.5 \\
16.5 \\
17.0\end{array}$ & $\begin{array}{l}15.5 \\
15.5 \\
15.5 \\
16.0 \\
17.0\end{array}$ & $\begin{array}{l}16.5 \\
15.5 \\
15.5 \\
16.0 \\
16.0\end{array}$ \\
\hline $\begin{array}{l}26 \\
27 \\
28 \\
29 \\
30 \\
31\end{array}$ & $\begin{array}{c}14.0 \\
15.5 \\
18.0 \\
19.0 \\
19.0 \\
.0\end{array}$ & $\begin{array}{r}11.5 \\
13.5 \\
15.5 \\
13.0 \\
17.0 \\
. \ldots\end{array}$ & $\begin{array}{l}21.0 \\
21.0 \\
20.0 \\
20.0 \\
21.0 \\
22.0\end{array}$ & $\begin{array}{l}20.0 \\
20.0 \\
18.5 \\
19.0 \\
20.0 \\
20.5\end{array}$ & $\begin{array}{r}24.5 \\
25.0 \\
26.0 \\
26.0 \\
25.5 \\
.-\end{array}$ & $\begin{array}{r}23.0 \\
24.5 \\
24.5 \\
25.0 \\
24.5 \\
.--\end{array}$ & $\begin{array}{l}24.5 \\
25.5 \\
25.5 \\
25.0 \\
24.5 \\
24.5\end{array}$ & $\begin{array}{l}23.5 \\
24.0 \\
24.5 \\
24.0 \\
23.5 \\
22.0\end{array}$ & $\begin{array}{l}19.5 \\
19.5 \\
19.0 \\
18.5 \\
18.5 \\
19.0\end{array}$ & $\begin{array}{l}18.0 \\
18.5 \\
16.5 \\
16.5 \\
16.5 \\
17.0\end{array}$ & $\begin{array}{r}18.0 \\
18.0 \\
18.5 \\
16.0 \\
16.0 \\
.-0\end{array}$ & $\begin{array}{r}17.0 \\
17.0 \\
16.0 \\
16.0 \\
15.0 \\
.\end{array}$ \\
\hline AVG & 15.0 & 13.5 & 19.0 & 18.0 & 23.0 & 22.0 & 25.0 & 24.0 & 20.5 & 19.5 & 17.0 & 16.5 \\
\hline
\end{tabular}


02129000 PEE DEE RIVER NEAR ROCKINGHAM, N. C.

LOCATION.--Lat $34^{\circ} 56^{\prime} 46^{\prime \prime}$, long $79^{\circ} 52^{\prime} 11^{\prime \prime}$, Richmond County, at gaging station on left bank at bridge on U.S. H1ghway $74,2.5$ miles upstream from Falling Creek, 3.3 miles downstream from Blewett Falis hydroelectric plant, 6 miles west of Rockingham, and 192 miles upstream from mouth in Winyah Bay.

DRAINAGE AREA.--6,870 sq $\mathrm{m} 1$, approximately.

PERIOD OF RECORD.-Chemical analyses: October 1946 to September 1946, October 1957 to September 1967, October 1967 to September 1969 (partial-record), October 1969 to September 1970.

Water temperatures: October 1946 to September 1948, October 1957 to September 1967.

EXTREMES. $-1946-48,1957-67$ :

Dissolved solids: Maximum, $84 \mathrm{mg} / 1 \mathrm{Jan} .1-31,1966 ;$ minimum, $38 \mathrm{mg} / 1$ Mar. 1-10, 1948.

Hardness: Max1mum, $27 \mathrm{mg} / \mathrm{i}$ Mar. 1-14, 1963; min1mum, $11 \mathrm{mg} / 1 \mathrm{Feb} .1-10$, 1958.

Specific conductance (1957-67): Maximum daily, 152 micromhos Nov. 17, 1959; minimum da11y, 41 micromhos Mar. 17, 1964

Wa ter temperatures: Maximum, $29.5^{\circ} \mathrm{C}$ Sept. 1, 2, 1962; minimum, rreezing point on many days during 1961-62. REMARKS.--The second of two samples collected at the same time is a field determination.

CHEMICAL analyses, hater Year octoBer 1969 to SEPTEMBER 1970

\begin{tabular}{|c|c|c|c|c|c|c|c|c|c|c|c|}
\hline DATE & TIME & $\begin{array}{l}\text { OIS- } \\
\text { CHARGE } \\
\text { ICFSI }\end{array}$ & $\begin{array}{l}\text { SILICA } \\
\text { (SIOL) } \\
\text { ( } M G / L \text { ) }\end{array}$ & $\begin{array}{l}\text { DIS- } \\
\text { SOLVED } \\
\text { IRDN } \\
\text { IFE I } \\
\text { IUG/LI }\end{array}$ & $\begin{array}{l}\text { CAL- } \\
\text { CIUM } \\
(C A) \\
(M G / L)\end{array}$ & $\begin{array}{l}\text { MAG- } \\
\text { NEE- } \\
\text { SIUM } \\
\text { (MG } \\
\text { IMG/L) }\end{array}$ & $\begin{array}{c}\text { SOBIUM } \\
\text { INAI } \\
\text { (MG/LI }\end{array}$ & $\begin{array}{l}\text { PO- } \\
\text { TAS- } \\
\text { SIUM } \\
\text { (K) } \\
\text { IMG/L) }\end{array}$ & $\begin{array}{l}\text { BICAR- } \\
\text { BONATE } \\
\text { (HCOZ) } \\
\text { IMG/LI }\end{array}$ & $\begin{array}{l}\text { CAR- } \\
\text { BDNATE } \\
\text { (CO3) } \\
\text { (MG/L) }\end{array}$ & $\begin{array}{c}\text { SULFATE } \\
\text { ISO4 I } \\
\text { IMG/LI }\end{array}$ \\
\hline $\begin{array}{c}O C_{T} T_{0} \\
28 . \ldots\end{array}$ & 1145 & 7300 & -- & - & -- & -- & -- & -- & - & -- & - \\
\hline $\begin{array}{l}\text { Nov. } \\
25 . . \\
\text { DEC. }\end{array}$ & 1215 & 7010 & -- & -- & -- & - & - & -- & -- & -- & $\cdots$ \\
\hline $22 \ldots$ & 1330 & 7390 & 10 & 0 & 5.1 & 1.6 & 11 & 2.5 & 30 & 0 & 8.4 \\
\hline JAN. & 1330 & 7390 & -- & -- & -- & - & - & -- & 32 & 0 & -- \\
\hline $\begin{array}{l}26 . . \\
F E B .\end{array}$ & 1645 & 7640 & $-\pi$ & -- & -- & -- & - & - & - & - & -- \\
\hline $\begin{array}{l}24 \ldots \\
\text { MAR.. }\end{array}$ & 1545 & 7640 & - & -- & -- & -- & -- & - & -- & - & -- \\
\hline $\begin{array}{l}25 \ldots \\
25 \ldots\end{array}$ & $\begin{array}{l}1615 \\
1615\end{array}$ & $\begin{array}{l}10200 \\
10200\end{array}$ & 10 & 161 & 4.8 & 2.0 & 6.4 & $\begin{array}{l}4.1 \\
--\end{array}$ & 18 & -0 & 11 \\
\hline${ }_{\text {MAY }}^{27}$ & 1430 & 6560 & -- & 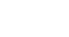 & $-\infty$ & -- & -- & -- & -- & - & -- \\
\hline $25 \ldots$ & 1150 & 7300 & - & - & - & -. & -- & $-\infty$ & -- & - & -- \\
\hline $26 \ldots$ & 1430 & 7560 & 10 & 5 & 3.6 & 2.8 & 9.0 & 2.1 & 30 & 0 & 6.6 \\
\hline $26 \ldots$ & 1430 & 7560 & - & -- & - & - & - & -- & -- & $\cdots$ & - \\
\hline AUG. & & & & & & & & & & & \\
\hline $\begin{array}{l}05 \ldots \\
05 \ldots\end{array}$ & $\begin{array}{l}1345 \\
1345\end{array}$ & $\begin{array}{l}7640 \\
7640\end{array}$ & 12 & 114 & $\begin{array}{r}4.0 \\
-.-\end{array}$ & $\begin{array}{l}2.5 \\
--.\end{array}$ & 10 & $\begin{array}{r}2.7 \\
--\end{array}$ & $2 B$ & 0 & B.0 \\
\hline $25 \ldots$ & 1415 & 13300 & -- & -- & - & -- & -- & -- & -- & + & -- \\
\hline 2 В... & 1500 & 7860 & 9.2 & 0 & 3.4 & 1.5 & 5.7 & 2.6 & 20 & 0 & 6.0 \\
\hline $28 \ldots$ & 1500 & 7860 & $\omega$ & $\ldots$ & - & - & - & - & - & -- & - \\
\hline
\end{tabular}

\begin{tabular}{|c|c|c|c|c|c|c|c|c|c|c|}
\hline DATE & $\begin{array}{l}\text { CHLO- } \\
\text { RIOE } \\
\text { ICLI) } \\
\text { IMG/LI }\end{array}$ & $\begin{array}{l}\text { FlUO- } \\
\text { RIOE } \\
\text { IFI } \\
\text { I MG ILI I }\end{array}$ & $\begin{array}{l}\text { NITRATE } \\
\text { INO31) } \\
\text { IMG/L) }\end{array}$ & $\begin{array}{l}\text { ORTHO } \\
\text { PHOS- } \\
\text { PHATE } \\
\text { POO4 } \\
\text { IPOALLI }\end{array}$ & 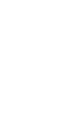 & $\begin{array}{l}\text { DIS- } \\
\text { SOLVED } \\
\text { SOL IDS } \\
\text { TIONS } \\
\text { PER } \\
\text { AC-FT }\end{array}$ & $\begin{array}{l}\text { DIS- } \\
\text { SOLVED } \\
\text { SOL IDS } \\
\text { TTONS } \\
\text { PER } \\
\text { DAYY }\end{array}$ & $\begin{array}{c}\text { HARD- } \\
\text { NESS } \\
\text { ICA MGG } \\
\text { IMG I I }\end{array}$ & $\begin{array}{l}\text { NON- } \\
\text { CAR- } \\
\text { BONATE } \\
\text { HARD- } \\
\text { NESS } \\
\text { CMG/L) }\end{array}$ & $\begin{array}{l}\text { SOOTUM } \\
\text { AD- } \\
\text { SORP- } \\
\text { TION } \\
\text { RATIOT }\end{array}$ \\
\hline OCF. & -- & -- & -- & -- & -- & -- & -- & -- & -- & -. \\
\hline $\begin{array}{l}25 . \\
D E C\end{array}$ & -- & - & -- & -- & -- & -- & -. & -- & -- & -- \\
\hline${ }_{22}^{22} \ldots$ & 7.2 & $\therefore 2$ & 2.5 & .05 & 67 & .09 & 1340 & 20 & $\therefore$ & 1.1 \\
\hline $\begin{array}{l}\text { JAN. } \\
28 . .\end{array}$ & -- & -- & - & - & -- & -- & - & .- & .. & ... \\
\hline FEB & -- & $\ldots$ & -- & -- & -- & ... & $\ldots$ & -- & -- & -- \\
\hline & 6.5 & .1 & 2.7 & .00 & 71 & .10 & 1960 & 20 & 5 & 0 \\
\hline $\begin{array}{l}\text { APR: } \\
27 \ldots \ldots\end{array}$ & -- & -- & - & - & -- & -- & -- & -- & -- & -- \\
\hline MAY & - & -- & -- & -- & -- & -- & -- & -- & -- & -- \\
\hline & 7.6 & $\therefore$ & 1.1 & .00 & 69 & .09 & 1410 & 20 & 0 & 9 \\
\hline & 7.6 & & & & & & 1100 & & & \\
\hline & $\cdots$ & - & $\because$ & -- & 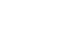 & -- & - & - & - & $\because 0$ \\
\hline SEPT. & . & & & & 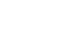 & & & 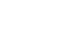 & & \\
\hline$\because$ & 3.0 & $\therefore$ & 10 & $\because-0$ & 51 & $\stackrel{-01}{-0}$ & 1080 & 13 & - - & -6 \\
\hline
\end{tabular}


PEE DEE RIVER BASIN

02129000 PEE DEE RIVER NEAR ROCKINGHAM, N. C. --Cont1nued CHEMICAL ANALYSES, WAIER YEAR OCTOBER 1969 TO SEPTEMBER 1970

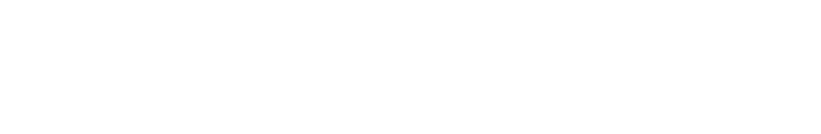

\begin{tabular}{|c|c|c|c|c|c|c|c|c|c|}
\hline $\begin{array}{l}\text { OCT. } \\
28 . . . \\
\text { NOV. }\end{array}$ & -- & - & $=$ & - & $=$ & -- & -- & - & - \\
\hline $\begin{array}{l}25 \ldots \\
\text { DEC. }\end{array}$ & -- & -- & -- & 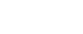 & -- & - & -- & -- & - \\
\hline $22 \ldots$ & 52 & -- & -. & .15 & -- & - & 25 & -- & $\ldots$ \\
\hline $\begin{array}{l}22 \ldots \\
\text { JAN. }\end{array}$ & - & -- & -- & - & -- & - & 26 & -- & - \\
\hline $\begin{array}{l}26 \ldots \\
\text { FEB. }\end{array}$ & $-\infty$ & -- & -- & -- & -- & -- & -- & -- & -- \\
\hline $24 \ldots$ & -- & -- & -- & -- & $\rightarrow-$ & -- & -- & +- & -- \\
\hline $25 \ldots$ & 35 & - & -- & .02 & -- & -- & 15 & -- & - \\
\hline APR: & -7 & -- & -- & -- & & $-\infty$ & 16 & -- & -- \\
\hline $\operatorname{MAY}_{\text {MAY }}^{27}$ & -- & -- & -- & -- & -- & -- & -- & -- & -- \\
\hline $\begin{array}{l}25 \ldots \\
\text { JUNE }\end{array}$ & -- & -- & -- & -- & -- & - & -- & -- & -- \\
\hline $26 \ldots$ & 46 & -- & -- & .05 & -- & -- & 25 & -- & -- \\
\hline $26 \ldots$ & -- & -- & -- & -- & -- & -- & -- & -- & -- \\
\hline $05 \ldots$ & 48 & 1.7 & 0 & .04 & 5.0 & 52 & 23 & 0 & 5 \\
\hline $05 \ldots$ & -- & - & - & - & - & - & 22 & $=$ & -- \\
\hline $25 \ldots$ & -- & $=-$ & -- & $=-$ & $\cdots$ & -- & - & $\sim$ & -- \\
\hline $\begin{array}{l}\text { SEP T. } \\
28 . . .\end{array}$ & 41 & -- & -- & .02 & -- & -- & 16 & -- & -- \\
\hline $28 \ldots$ & -- & -- & - & - & -- & -- & 20 & -- & - \\
\hline & $\begin{array}{l}\text { LEAU } \\
\text { (PB) }\end{array}$ & $\begin{array}{l}\text { ZINC } \\
\text { I ZNI }\end{array}$ & $\begin{array}{l}\text { CAD- } \\
\text { MIUM } \\
\text { ICOI }\end{array}$ & $\begin{array}{l}\text { DIS- } \\
\text { SOLVED } \\
\text { OXYGEN }\end{array}$ & $\begin{array}{l}\text { FECAL } \\
\text { COLI- } \\
\text { FDRM } \\
\text { (COL. } \\
\text { PER }\end{array}$ & $\begin{array}{l}\text { SPECI- } \\
\text { FIC } \\
\text { COND- } \\
\text { UCTANCE } \\
\text { IMICKO- }\end{array}$ & PH & $\begin{array}{l}\text { TEMP- } \\
\text { ERATURE }\end{array}$ & $\begin{array}{l}\text { COLUR } \\
\text { IPLAT } \\
\text { INUM- } \\
\text { COBAL }\end{array}$ \\
\hline DA TE & $(U G / L)$ & IUG/L) & $(U G / L)$ & {$[M G / L)$} & $100 \mathrm{~mL}$ & MHOSI & (UNITS) & $(D E G C)$ & UNITS \\
\hline $\begin{array}{l}C T . \\
28 . \ldots\end{array}$ & -- & - & - & 5.8 & -- & -- & 6.4 & 16.5 & -- \\
\hline $\begin{array}{l}25 \ldots \\
E C .\end{array}$ & -- & -- & -- & 7.3 & -- & 110 & 7.4 & 11.5 & - \\
\hline $22 \ldots$ & - & -- & - & $\rightarrow$ & -- & 81 & 6.8 & 7.5 & 5 \\
\hline $\begin{array}{l}22 \ldots \\
A N .\end{array}$ & -- & -- & -- & 7.9 & $\cdots$ & 91 & 6.9 & 7.5 & - \\
\hline $\begin{array}{l}26 \ldots \\
E 8 . .\end{array}$ & -- & -- & -- & 8.1 & -- & 110 & 7.1 & 5.0 & -- \\
\hline $\begin{array}{l}24 \ldots \\
A R .\end{array}$ & $=$ & -- & -- & 9.0 & - & 90 & 6.8 & 8.5 & - \\
\hline $25 \ldots$ & -- & - & -- & -- & -- & 85 & 6.2 & 12.0 & 75 \\
\hline $\begin{array}{l}25 \ldots . . \\
P R .\end{array}$ & - & -- & -- & 9.3 & -- & 85 & 6.6 & 12.0 & - \\
\hline${ }_{A Y}^{27} \cdots$ & -- & -- & -- & 7.3 & - & 105 & 6.7 & 21.0 & - \\
\hline $\begin{array}{l}25 \ldots \\
\text { UNE }\end{array}$ & -- & -- & -- & 6.5 & 108 & 105 & 6.9 & 22.5 & -- \\
\hline $26 \ldots$ & -- & -- & -- & -- & -- & 80 & 6.3 & 26.0 & 0 \\
\hline $26 \ldots$ & -- & -- & $=$ & 5.0 & 20 & 120 & 7.4 & 2.5 & -- \\
\hline $05 \ldots$ & 0 & 14 & 0 & -- & -- & 90 & 6.7 & 28.5 & 8 \\
\hline $05 \ldots$ & -- & - & -- & 4.1 & 40 & 94 & 6.9 & 28.5 & - \\
\hline $\begin{array}{l}25 \ldots . . \\
\text { EPT. }\end{array}$ & - & -- & -- & 6.5 & 196 & 63 & 6.5 & 25.5 & -- \\
\hline $28 \ldots$ & $=-$ & $=$ & $=-$ & -- & -- & 61 & 6.7 & 26.5 & 5 \\
\hline & -- & -- & -- & $7 \cdot 4$ & - & 74 & 7.0 & 26.5 & - \\
\hline
\end{tabular}

\begin{tabular}{|c|c|c|c|c|c|c|c|}
\hline & DOT & TDE & 000 & $\underset{\text { DANF }}{\text { CHL OF- }}$ & $\underset{\text { ELDRIN }}{D I-}$ & FNDR IN & $\begin{array}{l}\text { HEPTA- } \\
\text { CHLOR }\end{array}$ \\
\hline OATE & (UG/L) & $(U G / L)$ & (UG/L) & (UGA) & $(U G / L)$ & IUG/L) & $\mid U G / L)$ \\
\hline $\begin{array}{l}\text { AUG. } \\
05 . . .\end{array}$ & $<.01$ & .00 & .00 & $<.01$ & .00 & $\angle . D t$ & .00 \\
\hline
\end{tabular}

\begin{tabular}{|c|c|c|c|c|c|c|}
\hline & $\begin{array}{l}\text { HEPTA- } \\
\text { CHLCR } \\
\text { EP'JXIOE }\end{array}$ & AL DRIN & LINOANE & $\begin{array}{l}\text { ENDO- } \\
\text { SULFAN }\end{array}$ & $\begin{array}{c}\text { TIX- } \\
\text { APHENE }\end{array}$ & $\begin{array}{l}\text { METH- } \\
\text { UXY- }\end{array}$ \\
\hline DATE & (UG $/ L)$ & $(U G / L)$ & (UG/L) & (UG $/ \mathrm{L})$ & $(U G / L)$ & (UG/L) \\
\hline
\end{tabular}

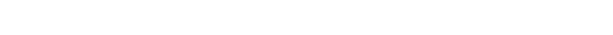


02130000 PEE DEE RIVER AT CHERAw, S. C.

LOCATION.-Lat $34^{\circ} \mathbf{4 2}^{\prime} 28^{\prime \prime}$, long $79^{\circ} 52^{\prime} 26^{\prime \prime}$, Chesterfield County, at bridge on U.S. H1ghway 1 , $0.1 \mathrm{mile}$ upstream from Seaboard Coast Line Rallroad bridge and Huckleberry Creek, 0.5 mile downstream from discontinued gaging station, $0.6 \mathrm{mile}$ northeast of Cheraw, and at mile 160.8 .

DRAINAGE AREA. $-7,320$ sq $\mathrm{ml}$ (at gaging station).

PERIOD OF RECORD.--Chemlcal analyses: July 1969 to September 1970.

REMARKS.--The second of two samples collected at the same time is a fleld determination. CHEMICAL ANALYSES, JULY 1969 TO SEPTEMBER 1970

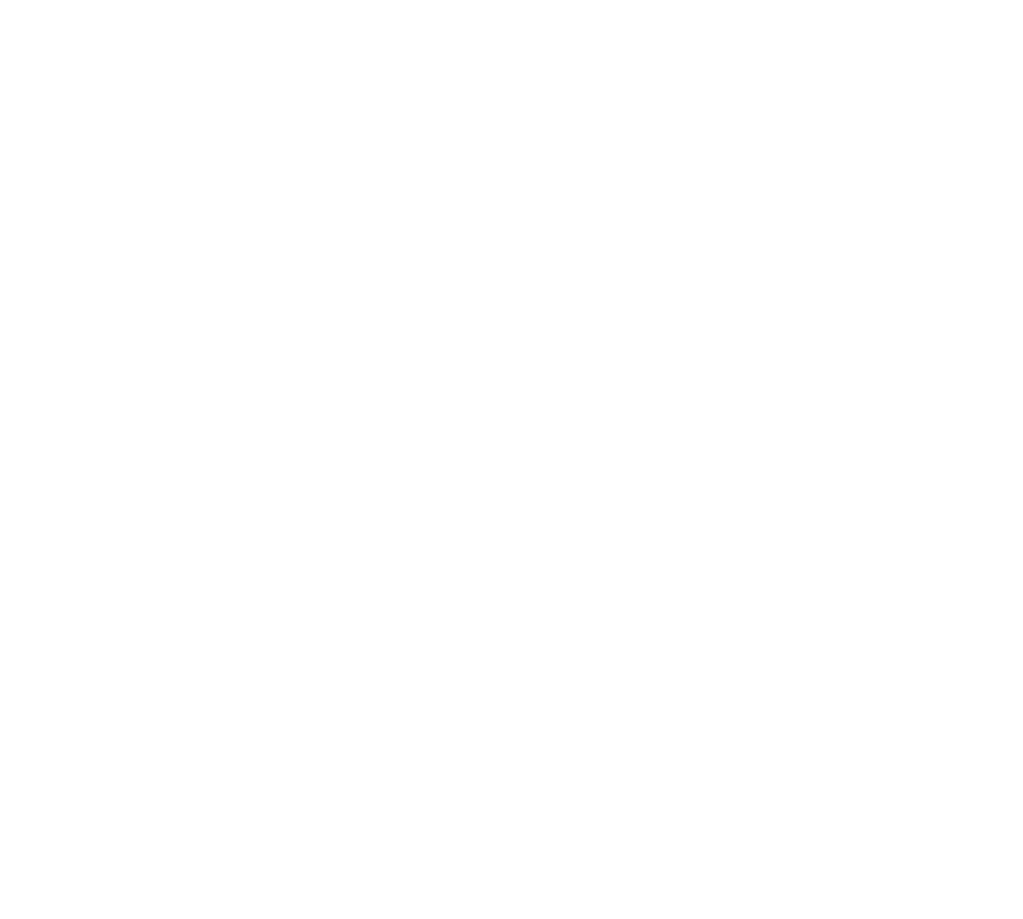

\begin{tabular}{|c|c|c|c|c|c|c|c|c|c|c|c|c|}
\hline DATE & TIME & $\begin{array}{l}\text { TEMP- } \\
\text { ERATURE } \\
\text { ( OEG C) }\end{array}$ & $\begin{array}{l}\text { CIS- } \\
\text { CHARGE } \\
\text { (CFS) }\end{array}$ & $\begin{array}{l}\text { TUR- } \\
\text { BIO- } \\
\text { ITY } \\
\text { (JTU) }\end{array}$ & $\begin{array}{l}\text { COLOR } \\
\text { (PLAT- } \\
\text { INUM- } \\
\text { COBALT } \\
\text { UNITS) }\end{array}$ & $\begin{array}{l}\text { SPECI- } \\
\text { FIC } \\
\text { CONO- } \\
\text { UCTANCE } \\
\text { (MICRO- } \\
\text { MHOSI }\end{array}$ & $\begin{array}{l}\text { OIS- } \\
\text { SOL VEO } \\
\text { OXYGEN } \\
\text { (MG/L) }\end{array}$ & $\begin{array}{l}\text { BIC- } \\
\text { CHEM- } \\
\text { ICAL } \\
\text { OXYGEN } \\
\text { OEMAND } \\
\text { (MGIL I }\end{array}$ & $\begin{array}{c}\text { PH } \\
\text { (UNITS) }\end{array}$ & $\begin{array}{l}\text { ALKA- } \\
\text { LINITY } \\
\text { AS } \\
\text { CACDS } \\
\text { IMGILI }\end{array}$ & $\begin{array}{l}\text { BICAR- } \\
\text { BCNATE } \\
\text { (HCD3) } \\
\text { (MG/L) }\end{array}$ & $\begin{array}{r}\text { TJTAL } \\
\text { NON- } \\
\text { FILT- } \\
\text { RABLE } \\
\text { RESIDUE } \\
\text { IMGILI }\end{array}$ \\
\hline $\begin{array}{l}\text { ост. } \\
30 \ldots . . \\
30 . .\end{array}$ & $\begin{array}{l}1430 \\
1430\end{array}$ & $\begin{array}{l}15.5 \\
15.5\end{array}$ & $\begin{array}{l}1210 \\
1210\end{array}$ & - & 20 & $\begin{array}{l}74 \\
80\end{array}$ & $7 . \overline{4}$ & 1.0 & $\begin{array}{l}6.7 \\
7.4\end{array}$ & 21 & 26 & -4 \\
\hline DATE & $\begin{array}{l}\text { TOTAL } \\
\text { PHOS- } \\
\text { PHORUS } \\
\text { (P) } \\
\text { (MG/L) }\end{array}$ & $\begin{array}{l}\text { HARD- } \\
\text { NESS } \\
\text { (CA,MG) } \\
\text { (MG/L) }\end{array}$ & $\begin{array}{l}\text { NON- } \\
\text { CAR- } \\
\text { BONATE } \\
\text { HARO- } \\
\text { NESS } \\
\text { (NGILI I }\end{array}$ & $\begin{array}{l}\text { CHLO- } \\
\text { RIDE } \\
\text { (CL) } \\
\text { (MG/L) }\end{array}$ & $\begin{array}{l}\text { SULFATE } \\
\text { (SOL) } \\
\text { (MG/L) }\end{array}$ & $\begin{array}{l}\text { OIS- } \\
\text { SULVSO } \\
\text { FLUD- } \\
\text { RIOE } \\
\text { (F) } \\
\text { (MGIL) }\end{array}$ & $\begin{array}{l}\text { TOTAL } \\
\text { CHRD- } \\
M I J M \\
\text { (CR) } \\
\text { (UG/L) }\end{array}$ & $\begin{array}{l}\text { OIS- } \\
\text { SOLVEO } \\
\text { COPPER } \\
\text { (CU) } \\
\text { (UG/L) }\end{array}$ & $\begin{array}{l}\text { TOTAL } \\
\text { IRON } \\
\text { (FE) } \\
\text { (UG/L) }\end{array}$ & $\begin{array}{l}\text { OIS- } \\
\text { SCLVED } \\
\text { LEAD } \\
\text { (PB) } \\
\text { (UG/L) }\end{array}$ & $\begin{array}{l}\text { TOT AL } \\
\text { MAN- } \\
\text { G } \triangle N E S E \\
\text { (MN) } \\
\text { (UG /L) }\end{array}$ & $\begin{array}{l}\text { DIS- } \\
\text { SOLVEO } \\
\text { NICKEL } \\
\text { (NI) } \\
\text { (UG/L) }\end{array}$ \\
\hline
\end{tabular}

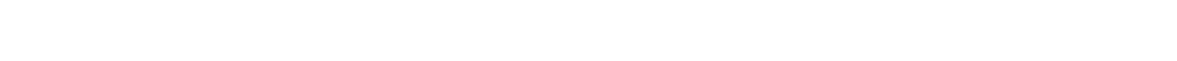


02131000 PEE DEE RIVER AT PEEDEE, S.C.

(International Hydrological Decade River Station)

LOCATION,--Lat $34^{\circ} 12^{\prime} 15^{\prime \prime}$, long $79^{\circ} 32^{\prime} 55^{\prime \prime}$, Narion County, at gaging station in pier of bridge on U.S. Highway 76 at peedee, 0.2 mile downstream from Seaboard Coast Line Railroad bridge, 8,5 miles downstream from Black Creek, Peedee, 0,2 mile dow

DRAINAGE AREA, $--8,830 \mathrm{sq} \mathrm{ml}$, approximate1y.

PERIOD OF RECORD.--Chemical analyses: October 1948 to September 1949, October 1961 to September 1970. Water temperatures: February 1967 to September 1969 (discontinued). Sediment records: February 1967 to september 1970.

EXTRENES, $-1969-70$ :

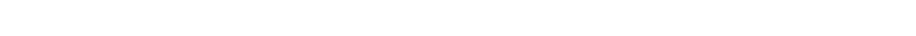

Period of record:

Specific conductance: Maximum daily, 140 micromhos Dec. 3, 1967; minimum dally, 52 micromhos July 16, 1968, Water temperatures: Naximum, $32.0^{\circ} \mathrm{C}$ Aug. 8, 1968; minimum, $2.0^{\circ} \mathrm{C} \mathrm{Jan} .18,1968$

Sediment concentrations: Maximum daily, $294 \mathrm{mg} / 1$ Aug. 12,1970 ; minimum daily, $11 \mathrm{mg} / 1 \mathrm{Nov} .8,1969$

Sediment discharge: Maximum daily, 11,000 tons Aug, 12, 1970; minimum daily, 73 tons Sept. 30, 1968 .

CHEMICAL ANALYSES, WATER YEAR DCTOBER 1969 TO SEPTEMBER 1970

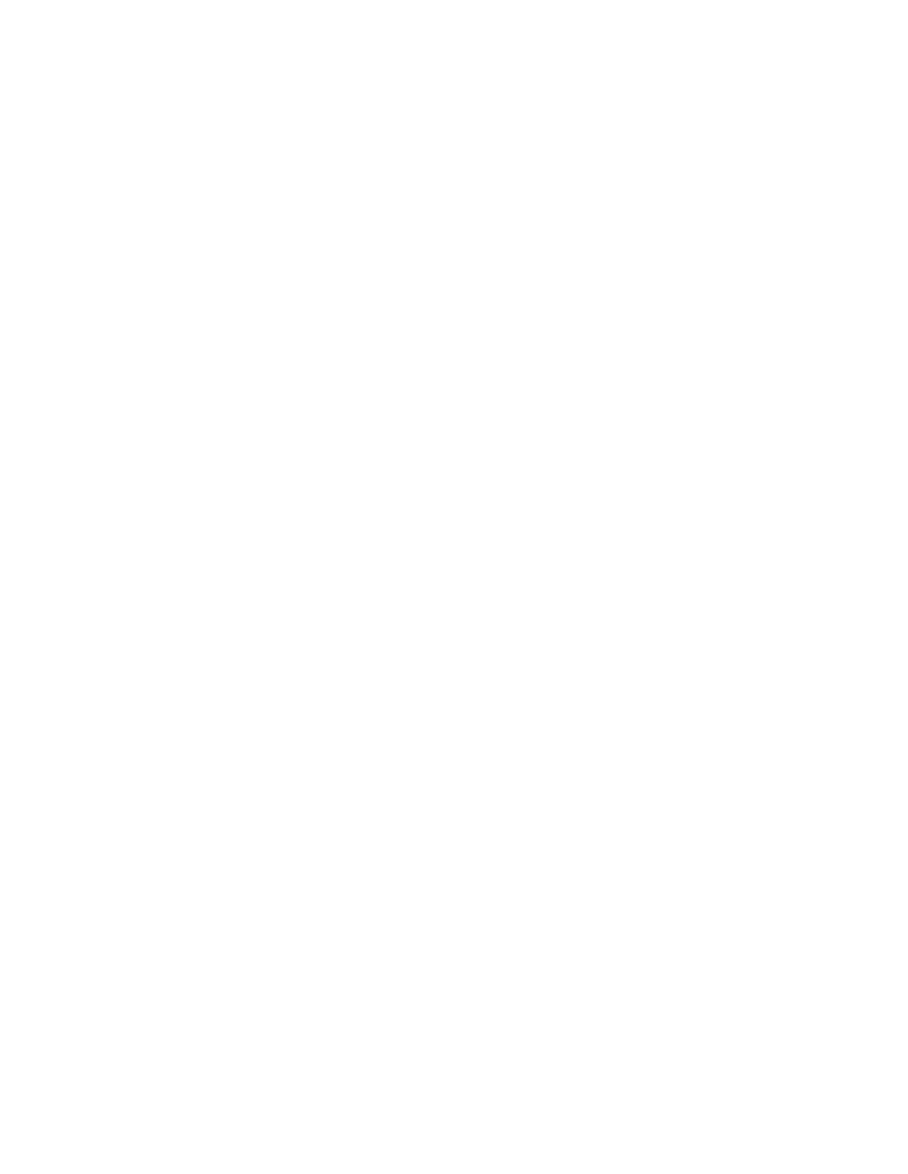


PEE DEE RIVER BASIN

02131000 PEE DEE RIVER AT PEEDEE, S.C.--Cont1nued SUSPENDED-SEDIMENT DISCHARGE, WATER YEAR OCTOBER 1969 TO SEPTEMBER 1970

\begin{tabular}{|c|c|c|c|c|c|c|c|c|c|}
\hline & & OCTOBER & & & NOVEMBER & & & DECEMBER & \\
\hline DAY & $\begin{array}{c}\text { MEAN } \\
\text { DISCHARGE } \\
\text { (CFS) }\end{array}$ & $\begin{array}{l}\text { MEAN } \\
\text { CONCEN- } \\
\text { TRATION } \\
\text { (MG/L) }\end{array}$ & $\begin{array}{l}\text { SEDIMENT } \\
\text { DI SCHARGE } \\
\text { (TONS/DAY) }\end{array}$ & $\begin{array}{l}\text { MEAN } \\
\text { DISCHARGE } \\
\text { (CFS) }\end{array}$ & $\begin{array}{l}\text { MEAN } \\
\text { CONCEN- } \\
\text { TRATION } \\
\text { (MG/L) }\end{array}$ & $\begin{array}{l}\text { SEDIMENT } \\
\text { DISCHARGE } \\
\text { (TONS / DAY) }\end{array}$ & $\begin{array}{c}\text { MEAN } \\
\text { DISCHARGE } \\
\text { (CFS) }\end{array}$ & $\begin{array}{l}\text { MEAN } \\
\text { CDNCEN- } \\
\text { TRATIDN } \\
\text { (MG/L) }\end{array}$ & $\begin{array}{l}\text { SEDIMENT } \\
\text { DISCHARGE } \\
\text { (TONS/DAY) }\end{array}$ \\
\hline $\begin{array}{l}1 \\
2 \\
3 \\
4 \\
5\end{array}$ & $\begin{array}{r}4830 \\
4510 \\
7660 \\
10300 \\
10500\end{array}$ & $\begin{array}{l}65 \\
42 \\
83 \\
91 \\
55\end{array}$ & $\begin{array}{r}848 \\
511 \\
1720 \\
2530 \\
1560\end{array}$ & $\begin{array}{l}3810 \\
3490 \\
2200 \\
1860 \\
2520\end{array}$ & $\begin{array}{l}44 \\
35 \\
19 \\
38 \\
15\end{array}$ & $\begin{array}{l}453 \\
330 \\
113 \\
191 \\
102\end{array}$ & $\begin{array}{l}2500 \\
2500 \\
4110 \\
3830 \\
3710\end{array}$ & $\begin{array}{l}19 \\
18 \\
41 \\
40 \\
34\end{array}$ & $\begin{array}{l}128 \\
122 \\
455 \\
414 \\
341\end{array}$ \\
\hline $\begin{array}{r}6 \\
7 \\
8 \\
9 \\
10\end{array}$ & $\begin{array}{l}8020 \\
5660 \\
6390 \\
7150 \\
7250\end{array}$ & $\begin{array}{l}47 \\
27 \\
59 \\
65 \\
75\end{array}$ & $\begin{array}{r}1020 \\
413 \\
1020 \\
1250 \\
1470\end{array}$ & $\begin{array}{l}2820 \\
3610 \\
4370 \\
4930 \\
3680\end{array}$ & $\begin{array}{l}15 \\
42 \\
11 \\
51 \\
32\end{array}$ & $\begin{array}{l}114 \\
409 \\
130 \\
679 \\
318\end{array}$ & $\begin{array}{l}4050 \\
3690 \\
3090 \\
3580 \\
4970\end{array}$ & $\begin{array}{l}24 \\
26 \\
17 \\
14 \\
31\end{array}$ & $\begin{array}{l}262 \\
259 \\
142 \\
135 \\
416\end{array}$ \\
\hline $\begin{array}{l}11 \\
12 \\
13 \\
14 \\
15\end{array}$ & $\begin{array}{l}7230 \\
6410 \\
4670 \\
3830 \\
5830\end{array}$ & $\begin{array}{l}87 \\
61 \\
34 \\
45 \\
78\end{array}$ & $\begin{array}{r}1700 \\
1060 \\
429 \\
465 \\
1230\end{array}$ & $\begin{array}{l}2360 \\
2650 \\
1990 \\
3440 \\
4800\end{array}$ & $\begin{array}{l}14 \\
21 \\
31 \\
31 \\
44\end{array}$ & $\begin{array}{r}89 \\
150 \\
167 \\
288 \\
570\end{array}$ & $\begin{array}{r}6180 \\
8680 \\
9670 \\
10200 \\
10300\end{array}$ & $\begin{array}{l}36 \\
85 \\
59 \\
46 \\
50\end{array}$ & $\begin{array}{r}601 \\
1990 \\
1540 \\
1270 \\
1390\end{array}$ \\
\hline $\begin{array}{l}16 \\
17 \\
18 \\
19 \\
20\end{array}$ & $\begin{array}{l}5950 \\
5670 \\
5740 \\
5230 \\
3360\end{array}$ & $\begin{array}{l}56 \\
50 \\
57 \\
57 \\
32\end{array}$ & $\begin{array}{l}900 \\
765 \\
883 \\
805 \\
290\end{array}$ & $\begin{array}{l}5450 \\
4710 \\
2940 \\
3370 \\
2390\end{array}$ & $\begin{array}{l}59 \\
30 \\
22 \\
19 \\
25\end{array}$ & $\begin{array}{l}868 \\
382 \\
175 \\
173 \\
161\end{array}$ & $\begin{array}{l}9440 \\
8370 \\
8470 \\
8220 \\
7750\end{array}$ & $\begin{array}{l}43 \\
36 \\
94 \\
45 \\
43\end{array}$ & $\begin{array}{r}1100 \\
814 \\
2150 \\
999 \\
900\end{array}$ \\
\hline $\begin{array}{l}21 \\
22 \\
23 \\
24 \\
25\end{array}$ & $\begin{array}{l}3080 \\
4190 \\
4200 \\
3900 \\
5100\end{array}$ & $\begin{array}{l}27 \\
55 \\
42 \\
58 \\
53\end{array}$ & $\begin{array}{l}225 \\
622 \\
476 \\
611 \\
730\end{array}$ & $\begin{array}{l}2490 \\
4040 \\
4730 \\
3040 \\
2670\end{array}$ & $\begin{array}{l}19 \\
29 \\
39 \\
21 \\
28\end{array}$ & $\begin{array}{l}128 \\
316 \\
498 \\
172 \\
202\end{array}$ & $\begin{array}{l}6550 \\
4700 \\
3470 \\
6130 \\
7550\end{array}$ & $\begin{array}{l}33 \\
43 \\
27 \\
35 \\
37\end{array}$ & $\begin{array}{l}584 \\
546 \\
253 \\
579 \\
754\end{array}$ \\
\hline $\begin{array}{l}26 \\
27 \\
28 \\
29 \\
30 \\
31\end{array}$ & $\begin{array}{l}5400 \\
5200 \\
3800 \\
4420 \\
5160 \\
4270\end{array}$ & $\begin{array}{l}59 \\
29 \\
-- \\
55 \\
55 \\
40\end{array}$ & $\begin{array}{l}860 \\
407 \\
410 \\
656 \\
766 \\
461\end{array}$ & $\begin{array}{l}4630 \\
4480 \\
4420 \\
3230 \\
3180 \\
-\end{array}$ & $\begin{array}{l}51 \\
52 \\
42 \\
22 \\
29 \\
--\end{array}$ & $\begin{array}{l}638 \\
629 \\
501 \\
192 \\
249 \\
-\end{array}$ & $\begin{array}{r}7700 \\
6890 \\
9070 \\
10400 \\
10500 \\
9680\end{array}$ & $\begin{array}{l}52 \\
24 \\
48 \\
41 \\
41 \\
37\end{array}$ & $\begin{array}{r}1080 \\
446 \\
1180 \\
1150 \\
1160 \\
967\end{array}$ \\
\hline TOTAL & 174910 & -- & 27093 & 104300 & - & 9387 & 205950 & -- & 24127 \\
\hline & & JANUARY & & & FEBRUARY & & & MARCH & \\
\hline DAY & $\begin{array}{l}\text { MEAN } \\
\text { DISCHARGE } \\
\text { (CFS) }\end{array}$ & $\begin{array}{l}\text { MEAN } \\
\text { CONCEN- } \\
\text { TRATION } \\
\text { (MG/L) }\end{array}$ & $\begin{array}{l}\text { SEDIMENT } \\
\text { DISCHARGE } \\
\text { (TONS/DAY) }\end{array}$ & $\begin{array}{l}\text { MEAN } \\
\text { DISCHARGE } \\
\text { (CFS) }\end{array}$ & $\begin{array}{l}\text { MEAN } \\
\text { CONCEN- } \\
\text { TRATION } \\
\text { (MG /L) }\end{array}$ & $\begin{array}{l}\text { SEDIMENT } \\
\text { DISCHARGE } \\
\text { (TONS/DAY) }\end{array}$ & $\begin{array}{c}\text { MEAN } \\
\text { DISCHARGE } \\
\text { (CFS) }\end{array}$ & $\begin{array}{l}\text { MEAN } \\
\text { CONCEN- } \\
\text { TRATIDN } \\
\text { (MG/L) }\end{array}$ & $\begin{array}{l}\text { SEDIMENT } \\
\text { DISCHARGE } \\
\text { (TONS/DAY) }\end{array}$ \\
\hline $\begin{array}{l}1 \\
2 \\
3 \\
4 \\
5\end{array}$ & $\begin{array}{l}9640 \\
9730 \\
9510 \\
9180 \\
9110\end{array}$ & $\begin{array}{l}67 \\
71 \\
55 \\
44 \\
48\end{array}$ & $\begin{array}{l}1740 \\
1870 \\
1410 \\
1090 \\
1180\end{array}$ & $\begin{array}{r}8910 \\
7360 \\
7680 \\
9430 \\
12000\end{array}$ & $\begin{array}{l}49 \\
41 \\
32 \\
53 \\
70\end{array}$ & $\begin{array}{r}1180 \\
815 \\
664 \\
1350 \\
2270\end{array}$ & $\begin{array}{r}12900 \\
12500 \\
10800 \\
9440 \\
8620\end{array}$ & $\begin{array}{l}68 \\
778 \\
98 \\
75\end{array}$ & $\begin{array}{l}2370 \\
2360 \\
2270 \\
2500 \\
1750\end{array}$ \\
\hline $\begin{array}{r}6 \\
7 \\
8 \\
9 \\
10\end{array}$ & $\begin{array}{r}9540 \\
10100 \\
10600 \\
10900 \\
11000\end{array}$ & $\begin{array}{l}28 \\
25 \\
33 \\
35 \\
--\end{array}$ & $\begin{array}{r}721 \\
682 \\
944 \\
1030 \\
1040\end{array}$ & $\begin{array}{l}14100 \\
14500 \\
14100 \\
13500 \\
12100\end{array}$ & $\begin{array}{r}124 \\
57 \\
58 \\
79 \\
34\end{array}$ & $\begin{array}{l}4720 \\
2230 \\
2210 \\
2880 \\
1110\end{array}$ & $\begin{array}{l}8140 \\
7980 \\
8270 \\
7570 \\
6900\end{array}$ & $\begin{array}{l}80 \\
31 \\
59 \\
77 \\
31\end{array}$ & $\begin{array}{r}1760 \\
668 \\
1320 \\
1570 \\
578\end{array}$ \\
\hline $\begin{array}{l}11 \\
12 \\
13 \\
14 \\
15\end{array}$ & $\begin{array}{r}10900 \\
9520 \\
7160 \\
7180 \\
7430\end{array}$ & $\begin{array}{l}23 \\
28 \\
17 \\
20 \\
15\end{array}$ & $\begin{array}{l}677 \\
720 \\
329 \\
388 \\
301\end{array}$ & $\begin{array}{l}9760 \\
9920 \\
9980 \\
9880 \\
9660\end{array}$ & $\begin{array}{l}27 \\
36 \\
56 \\
44 \\
42\end{array}$ & $\begin{array}{r}712 \\
964 \\
1510 \\
1170 \\
1100\end{array}$ & $\begin{array}{l}7020 \\
6820 \\
6650 \\
6860 \\
6280\end{array}$ & $\begin{array}{l}46 \\
49 \\
57 \\
60 \\
59\end{array}$ & $\begin{array}{r}872 \\
902 \\
1020 \\
1110 \\
1000\end{array}$ \\
\hline $\begin{array}{l}16 \\
17 \\
18 \\
19 \\
20\end{array}$ & $\begin{array}{l}8120 \\
8000 \\
7130 \\
5310 \\
4810\end{array}$ & $\begin{array}{l}23 \\
35 \\
38 \\
23 \\
27\end{array}$ & $\begin{array}{l}504 \\
756 \\
732 \\
330 \\
351\end{array}$ & $\begin{array}{r}7760 \\
6000 \\
11200 \\
17300 \\
19500\end{array}$ & $\begin{array}{r}47 \\
85 \\
-\overline{161}\end{array}$ & $\begin{array}{r}985 \\
972 \\
2570 \\
5610 \\
8480\end{array}$ & $\begin{array}{l}4870 \\
4180 \\
6310 \\
7770 \\
8510\end{array}$ & $\begin{array}{l}39 \\
31 \\
59 \\
69 \\
72\end{array}$ & $\begin{array}{r}513 \\
350 \\
1010 \\
1450 \\
1650\end{array}$ \\
\hline $\begin{array}{l}21 \\
22 \\
23 \\
24 \\
25\end{array}$ & $\begin{array}{l}6870 \\
8120 \\
8550 \\
7800 \\
6980\end{array}$ & $\begin{array}{l}34 \\
-- \\
-- \\
--\end{array}$ & $\begin{array}{l}631 \\
877 \\
808 \\
632 \\
471\end{array}$ & $\begin{array}{l}20100 \\
20500 \\
20200 \\
17500 \\
14500\end{array}$ & $\begin{array}{l}91 \\
62 \\
66 \\
37 \\
36\end{array}$ & $\begin{array}{l}4940 \\
3430 \\
3600 \\
1750 \\
1410\end{array}$ & $\begin{array}{r}9840 \\
11300 \\
14300 \\
18200 \\
19600\end{array}$ & $\begin{array}{r}72 \\
52 \\
68 \\
104 \\
79\end{array}$ & $\begin{array}{l}1910 \\
1590 \\
2630 \\
5110 \\
4180\end{array}$ \\
\hline $\begin{array}{l}26 \\
27 \\
28 \\
29 \\
30 \\
31\end{array}$ & $\begin{array}{l}5410 \\
4330 \\
6010 \\
6500 \\
7340 \\
8640\end{array}$ & $\begin{array}{l}14 \\
14 \\
18 \\
22 \\
39 \\
49\end{array}$ & $\begin{array}{r}204 \\
164 \\
292 \\
386 \\
773 \\
1140\end{array}$ & $\begin{array}{r}13300 \\
12900 \\
12700 \\
= \\
= \\
-\end{array}$ & $\begin{array}{l}55 \\
37 \\
46 \\
-- \\
-- \\
--\end{array}$ & $\begin{array}{r}1980 \\
1290 \\
1580 \\
=- \\
=-\end{array}$ & $\begin{array}{l}20300 \\
20400 \\
19600 \\
18400 \\
17000 \\
14500\end{array}$ & $\begin{array}{l}55 \\
50 \\
46 \\
45 \\
58 \\
29\end{array}$ & $\begin{array}{l}3010 \\
2750 \\
2430 \\
2240 \\
1660 \\
1140\end{array}$ \\
\hline TOTAL & 251420 & -- & 23173 & 356340 & - & 63482 & 341830 & - & 56673 \\
\hline
\end{tabular}


PEE DEE RIVER BASIN

02131000 PEE DEE RIVER AT PEEDEE, S.C.--Cont \pm nued

SUSPENDED-SEDIMENT DISCHARGE, WATER YEAR OCTOBER 1969 TO SEPTEMBER 1970

\begin{tabular}{|c|c|}
\hline DAY & $\begin{array}{c}\text { MEAN } \\
\text { DISCHARGE } \\
\text { (CFS) }\end{array}$ \\
\hline $\begin{array}{l}1 \\
2 \\
3 \\
4 \\
5\end{array}$ & $\begin{array}{l}14000 \\
14700 \\
17400 \\
19500 \\
20900\end{array}$ \\
\hline $\begin{array}{r}6 \\
7 \\
8 \\
9 \\
10\end{array}$ & $\begin{array}{l}21900 \\
22100 \\
21100 \\
19900 \\
18100\end{array}$ \\
\hline $\begin{array}{l}11 \\
12 \\
13 \\
14 \\
15\end{array}$ & $\begin{array}{r}16300 \\
14700 \\
12300 \\
9610 \\
9450\end{array}$ \\
\hline $\begin{array}{l}16 \\
17 \\
18 \\
19 \\
20\end{array}$ & $\begin{array}{r}10300 \\
10900 \\
10300 \\
9270 \\
7920\end{array}$ \\
\hline $\begin{array}{l}21 \\
22 \\
23 \\
24 \\
25\end{array}$ & $\begin{array}{l}6200 \\
6810 \\
6700 \\
7350 \\
7200\end{array}$ \\
\hline $\begin{array}{l}26 \\
27 \\
28 \\
29 \\
30 \\
31\end{array}$ & $\begin{array}{l}6240 \\
4060 \\
3790 \\
6170 \\
7770 \\
-\end{array}$ \\
\hline
\end{tabular}

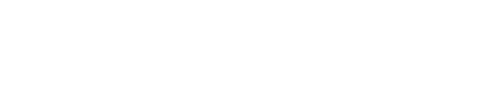

$\begin{array}{lccc} & \text { JUNE } \\ \text { SEDIMENT } & \text { MEAN } & \text { MEAN } & \\ \text { CONCEN- } & \text { SEDIMENT } \\ \text { DISCHARGE } & \text { DISCHARGE } & \text { TRATION } & \text { DISCHARGE } \\ \text { (TONS/DAY) } & \text { (CFS) } & \text { (MG/L) } & \text { (TONS/DAY) }\end{array}$

$\begin{array}{rlll}37 & 1400 & 7210 & 5 \\ 52 & 2060 & 6450 & 41 \\ 52 & 2440 & 6000 & 5 \\ 113 & 5950 & 5200 & 4 \\ 104 & 5870 & 4870 & 3\end{array}$

59
41
56
49
34

1150
714
907
688
447
2570
2310
1720
1420

2510
1920
3440

5330

$\begin{array}{ll}-- & 271 \\ -- & 156\end{array}$

$\begin{array}{rrr}68 & 4020 & 8560 \\ 48 & 2860 & 10700\end{array}$

$\begin{array}{lll}48 & 2860 & 10700 \\ 44 & 2510 & 11400\end{array}$

$\begin{array}{lll}43 & 2310 & 11200 \\ 44 & 2150 & 10800\end{array}$

$44 \quad 1940$

$\begin{array}{rr}46 & 1830 \\ 62 & 2060 \\ 28 & 727\end{array}$

9190

$\begin{array}{rr}2060 & 6600 \\ 727 & 7050\end{array}$

111

111
80
56
47
51

1810

2030

1530
1800

7460

7040

7040
5840

5840
4510
5830

5830
$1540 \quad 5910$

5910

$\begin{array}{rrr}41 & 686 & 6040 \\ 73 & 1340 & 6180 \\ 54 & 977 & 6180 \\ 76 & 1510 & 5650\end{array}$

1510
1420

5650
3620

943
395
256

1280
1870

2830
5440
5800
4930
4330

59074

203500

4750

4330
3330

3330
2000

2010

1190

1190
696

1410
1410

3130
3160

3160
4070

4070
3550

1390

2050

893
1010
377

2080

4650

6120
5920

5920
6600

$\overline{91}$

91
51

TOTAL 362940

11

1280
957

5270

5270
2660
1930

1930
3670
4770

4840
4870

4870
4460
2320

2320
1830

112830

$\begin{array}{ll}48 & 616 \\ 45 & 526 \\ 32 & 288 \\ -- & 135\end{array}$

TuLY

\begin{tabular}{|c|c|}
\hline DAY & $\begin{array}{c}\text { MEAN } \\
\text { DISCHARGE } \\
\text { (CFS) }\end{array}$ \\
\hline $\begin{array}{l}1 \\
2 \\
3 \\
4 \\
5\end{array}$ & $\begin{array}{l}1830 \\
2600 \\
4250 \\
4620 \\
4220\end{array}$ \\
\hline $\begin{array}{r}6 \\
7 \\
8 \\
9 \\
10\end{array}$ & $\begin{array}{l}2210 \\
1830 \\
2500 \\
3870 \\
4640\end{array}$ \\
\hline $\begin{array}{l}11 \\
12 \\
13 \\
14 \\
15\end{array}$ & $\begin{array}{l}5360 \\
4770 \\
2350 \\
1850 \\
1940\end{array}$ \\
\hline $\begin{array}{l}16 \\
17 \\
18 \\
19 \\
20\end{array}$ & $\begin{array}{l}3030 \\
4650 \\
4600 \\
3190 \\
1930\end{array}$ \\
\hline $\begin{array}{l}21 \\
22 \\
23 \\
24 \\
25\end{array}$ & $\begin{array}{l}1890 \\
3540 \\
5550 \\
5810 \\
3600\end{array}$ \\
\hline $\begin{array}{l}26 \\
27 \\
28 \\
29 \\
300 \\
31\end{array}$ & $\begin{array}{l}2630 \\
3500 \\
3880 \\
5870 \\
6250 \\
6790\end{array}$ \\
\hline
\end{tabular}

MEAN

SEDIMENT
MEAN
DISCHARGE
(TONS/DAY)

AUGUST

32603

SEPTEMBER

MEAN

CONCEN-
TRATION

SED IMENT

DISCHARGE
(TONS/DAY)

MEAN MEAN

CONCEN- SEDIMENT

$\begin{array}{cl}\text { DISCHARGE } & \text { TRATION } \\ \text { (CFS) } & \text { DISCHARGE } \\ & \end{array}$

990790

$\begin{array}{lr}87 & 1860 \\ 67 & 1220 \\ 40 & \\ 40 & \\ 53 & \\ & \\ 61 & \\ 48 & \\ 67 & 107 \\ 77 & 11 \\ 42 & \end{array}$

186
122
52
454
743
875
709
107
111
41

10000

9830

9250
8570
9020

$32 \quad 864$

$\begin{array}{ll}211 & 6750 \\ 528 & 4880 \\ 686 & 4200\end{array}$

661

5310
5470
5890
5360

3680

42

11000

13800

18000
19700

20800

54
294
30
141

11000

1460
7500
5340

9020

7720

4720
3890

3890
3720
5890

6510

6510
7380

7000

5110
4980

4000

3070

2400
2540

6660

6660
6740

6670

6670
6360
5480

2510

3190

3190
2830

5680
6370

6370
6380

2670
3300
4280

5910

3930
3290

3290
2840

2510
2210

4710
2780
2910

2910
4260

1640

TOTAL 115550

-- 14236

499320

82616

180520

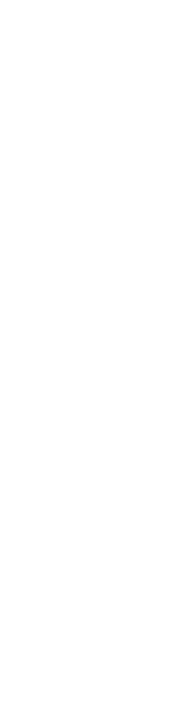

TOTAL DISCHARGE FOR YEAR (CFS-DAYS)
TOTAL SUSPENDED-SEDIMENT DISCHARGE FOR YEAR (TONS)

438133 
02131250 LYNCHES RIVER NEAR PAGELAND, S. C. LOCATION. -Lat $34^{\circ} 45^{\prime} 00^{\prime \prime}$, long $80^{\circ} 30^{\prime} 31^{\prime \prime}$, Chesterfield County, at bridge on State Highway $9,1.5$ miles upstream
from wildcat Creek, 7 miles west of Pageland, and at mile 133.0.

PERIOD OF RECORD.--Chemical analyses: July 1969 to September 1970.

REMARKS. --The second of two samples collected at the same time is a field determination.

CHEMICAL ANALYSES, JULY 1969 TO SEPTEMBER 1970

\begin{tabular}{|c|c|c|c|c|c|c|c|c|c|c|}
\hline DATE & TIME & $\begin{array}{l}\text { TEMP- } \\
\text { ERATUREE } \\
\text { IOEG CI }\end{array}$ & $\begin{array}{l}\text { DIS- } \\
\text { CHARGE } \\
\text { (CFS) }\end{array}$ & $\begin{array}{l}\text { SPECI- } \\
\text { FIC } \\
\text { CONO- } \\
\text { UCTANCE } \\
\text { (MICRO- } \\
\text { MHOS) }\end{array}$ & $\begin{array}{l}\text { DIS- } \\
\text { SOL VEO } \\
\text { OXYGEN } \\
\text { (MG/L) }\end{array}$ & $\begin{array}{c}P H \\
\text { (UNITS) }\end{array}$ & $\begin{array}{l}\text { TOYAL } \\
\text { PHOS- } \\
\text { PHDRUS } \\
\text { (P) } \\
\text { (MG/L) }\end{array}$ & $\begin{array}{l}\text { NITRATE } \\
\text { (NO3) } \\
\text { (MGAL) }\end{array}$ & $\begin{array}{c}\text { FECAL } \\
\text { COLI- } \\
\text { FORM } \\
\text { ICOL. } \\
\text { PER } \\
100 \mathrm{ML}\end{array}$ & $\begin{array}{c}\text { IMME- } \\
\text { DIAIE } \\
\text { COLI- } \\
\text { FDMM } \\
\text { ICRD. } \\
\text { PER } \\
100 \text { MLI) }\end{array}$ \\
\hline $\begin{array}{c}\text { JuLY } \\
23 \ldots . .\end{array}$ & 0815 & - & 2.7 & - & -- & - & .01 & .2 & -- & -- \\
\hline $\begin{array}{r}23 \ldots \\
\text { AUG. }\end{array}$ & 0915 & 26.0 & -- & 90 & 6.9 & 7.0 & - & - & -- & -- \\
\hline $\begin{array}{l}26 \ldots . \\
26 . .\end{array}$ & $\begin{array}{l}1120 \\
1120\end{array}$ & $21 . \overline{5}$ & $0 . \overline{6}$ & $\overline{80}$ & 7.4 & $\overrightarrow{7.4}$ & .00 & .6 & $=$ & $=$ \\
\hline $\begin{array}{l}\text { SEP. } \\
26 . . .\end{array}$ & 0855 & - & . & ( & 17 & 107 & .02 & 1.4 & -- & 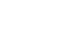 \\
\hline $26 \ldots$ & 0855 & 19.5 & 36 & 70 & 9.1 & 7.0 & - & - & 4700 & $=$ \\
\hline $23 \ldots$ & 1645 & 14.0 & 5.6 & 73 & - & 6.7 & .02 & .5 & - & $\because$ \\
\hline NOV." & & & 300 & & 10.0 & 7.6 & & & -- & 137 \\
\hline $18 \ldots$ & 1615 & 10.5 & 6.9 & - & - & $\because$ & .02 & -6 & -- & $=$ \\
\hline OEC. & & & & & 200 & & & & & - \\
\hline $16 \ldots$ & 1540 & 4.0 & 9.3 & -- & -- & -- & .05 & .0 & -- & -- \\
\hline $16 \ldots$ & 1540 & 4.0 & 9.3 & 85 & 10.6 & 7.5 & - & - & -- & 53 \\
\hline $21 \ldots$ & 1725 & 2.0 & 32 & -- & -- & -- & .01 & 1.0 & -- & - \\
\hline FEB... & 1725 & 2.0 & 32 & 100 & 11.0 & 7.7 & & -- & $\cdots$ & 62 \\
\hline $20 \ldots$ & 1210 & 7.5 & 60 & -- & -- & $=$ & $.04^{\prime}$ & 1.5 & -- & - \\
\hline MAR. & 1210 & & & 80 & 19.0 & 1.1 & & & & - \\
\hline $18 \ldots$ & 1000 & 9.5 & 19 & - & -- & -- & .01 & 1.4 & -- & -- \\
\hline $\begin{array}{l}18 \\
A P R\end{array}$ & 1000 & 9.5 & 1.9 & 88 & 11.0 & 6.8 & -- & - & -- & - \\
\hline $21 \ldots$ & 1007 & 19.0 & 20 & -- & -- & -- & .01 & .1 & - & -- \\
\hline $\operatorname{MAY}_{\operatorname{Ma}}^{21}$ & 1007 & 19.0 & 20 & 94 & 10.1 & 7.8 & & & 65 & - \\
\hline $20 \ldots$ & 1300 & 22.5 & 8.0 & -- & $=$ & - & .02 & .2 & - & - \\
\hline JUNE... & 1300 & 22.5 & 8.0 & 84 & 7.8 & 7.6 & & & -- & - \\
\hline $17 \ldots$ & 1225 & 25.5 & 2.5 & $\overline{0}$ & -- & $\because$ & .01 & .1 & -- & -- \\
\hline JULY & & & & 91 & & 1.5 & & & & - \\
\hline $08 \ldots$ & 1015 & 24.5 & 14 & -- & -- & - & .01 & .1 & -- & - \\
\hline $\begin{array}{l}08 . . . \\
\text { AUG. }\end{array}$ & 1015 & 24.5 & 14 & 105 & 7.4 & 7.4 & $\pi$ & - & 63 & -- \\
\hline $18 \ldots$ & 0945 & 25.0 & 6.7 & - & -- & -- & .02 & .9 & - & -- \\
\hline SEP... & & & 6.7 & 89 & 7.3 & 7.5 & & - & 800 & - \\
\hline $22 \ldots$ & 1240 & 25.5 & 4.9 & $\overline{90}$ & $\overline{-}$ & -- & .00 & $=$ & $\overline{-}$ & - \\
\hline & 1240 & 25.5 & 4.9 & 80 & 7.9 & 7.1 & & & 153 & $\cdots$ \\
\hline
\end{tabular}

\begin{tabular}{|c|c|c|c|c|c|c|c|c|c|c|}
\hline DATE & TIME & $\begin{array}{l}\text { TEMP- } \\
\text { ERATURE } \\
\text { IDEG CI }\end{array}$ & $\begin{array}{l}\text { DIS- } \\
\text { CHARGE } \\
\text { (CFS) }\end{array}$ & $\begin{array}{l}\text { TUR- } \\
\text { BID- } \\
\text { ITY } \\
\text { (JTU) }\end{array}$ & $\begin{array}{l}\text { COLOR } \\
\text { IPLAT- } \\
\text { INUM- } \\
\text { COBALT } \\
\text { UNITSI }\end{array}$ & $\begin{array}{l}\text { SPECI- } \\
\text { FIC } \\
\text { CONOD } \\
\text { UCANCE } \\
\text { (MICRD- } \\
\text { MHOSI }\end{array}$ & $\begin{array}{l}\text { DIS- } \\
\text { SOLVED } \\
\text { OXYGEN } \\
\text { (MGAL) }\end{array}$ & $\begin{array}{l}\text { BIO- } \\
\text { CHEM- } \\
\text { ICAL } \\
\text { OXYGEN } \\
\text { DEMAND } \\
\text { (MG/L) }\end{array}$ & $\begin{array}{c}P H \\
\text { (UNI IS) }\end{array}$ & $\begin{array}{l}\text { ALKA- } \\
\text { LINITY } \\
\text { AS } \\
\text { CACOI } \\
\text { (MG IL) }\end{array}$ \\
\hline $\begin{array}{l}\text { OCT. } \\
23 . . \\
23 . . .\end{array}$ & $\begin{array}{l}1645 \\
1645\end{array}$ & $\begin{array}{l}14.0 \\
14.0\end{array}$ & $\begin{array}{l}5.6 \\
5.6\end{array}$ & $\therefore$ & 15 & $\begin{array}{l}73 \\
76\end{array}$ & 10.0 & 1.7 & $\begin{array}{l}6.7 \\
7.6\end{array}$ & 25 \\
\hline DATE & $\begin{array}{l}\text { BICAR- } \\
\text { BONATE } \\
\text { (HCOB) } \\
\text { (MGILI) }\end{array}$ & $\begin{array}{l}\text { TOTAL } \\
\text { PHOS- } \\
\text { PHORUS } \\
\text { (P) } \\
\text { (MG /L) }\end{array}$ & $\begin{array}{l}\text { HARO- } \\
\text { NESS } \\
\text { (CA,MG) } \\
\text { (MG/L) }\end{array}$ & $\begin{array}{l}\text { NON- } \\
\text { CAR- } \\
\text { BONATE } \\
\text { HARO- } \\
\text { NESS } \\
\text { IMG/LI) }\end{array}$ & $\begin{array}{l}\text { CHLD- } \\
\text { RIOE } \\
\text { (CL) } \\
\text { (MG/L) }\end{array}$ & $\begin{array}{c}\text { SULFATE } \\
\text { (SO4) } \\
(\mathrm{MG} / \mathrm{L})\end{array}$ & $\begin{array}{l}\text { DIS- } \\
\text { SDLVED } \\
\text { FLUD- } \\
\text { RIDE } \\
\text { IFI } \\
\text { (MG/L) }\end{array}$ & $\begin{array}{l}\text { TOTAL } \\
\text { CHRD- } \\
\text { MIUM } \\
\text { ICR) } \\
\text { (UGLI) }\end{array}$ & $\begin{array}{l}\text { DIS- } \\
\text { SOL VFD } \\
\text { CDPPER } \\
\text { 'CU) } \\
\text { (UG IL) }\end{array}$ & $\begin{array}{l}\text { TOTAL } \\
\text { IRON } \\
\text { IFEI } \\
\text { (UG/L) }\end{array}$ \\
\hline $\begin{array}{l}\text { DCT. } \\
23 \ldots . . \\
23 \ldots\end{array}$ & 30 & .02 & 26 & 1 & 7.0 & 44 & $\therefore$ & $\stackrel{0}{--}$ & $\stackrel{0}{--}$ & 344 \\
\hline DATE & $\begin{array}{l}\text { OIS- } \\
\text { SOLVED } \\
\text { LEAD } \\
\text { IPB) } \\
\text { IUG/L) }\end{array}$ & $\begin{array}{l}\text { TOTAL } \\
\text { MAN- } \\
\text { GANESE } \\
\text { (MN) } \\
\text { (UG/L) }\end{array}$ & $\begin{array}{l}\text { DIS- } \\
\text { SOL VED } \\
\text { NICKEL } \\
\text { INI) } \\
\text { (UG LL) }\end{array}$ & $\begin{array}{c}\text { COLI- } \\
\text { FORM } \\
\text { ICOL- } \\
\text { ONIES } \\
\text { PER } \\
100 \mathrm{MLI}\end{array}$ & $\begin{array}{l}\text { FECAL } \\
\text { COLI- } \\
\text { FORM } \\
\text { ICOL. } \\
\text { PER } \\
100 \mathrm{MLI}\end{array}$ & $\begin{array}{l}\text { METHY- } \\
\text { LENE } \\
\text { BLUE } \\
\text { ACTIVE } \\
\text { SUB- } \\
\text { STANCE } \\
\text { (MGAL) }\end{array}$ & $\begin{array}{l}\text { DIS- } \\
\text { SOL VED } \\
\text { SOLIDS } \\
\text { IRES1- } \\
\text { OUE AT } \\
\text { ISO CI } \\
\text { CMGALI) }\end{array}$ & $\begin{array}{l}\text { OIS- } \\
\text { SOLVED } \\
\text { SOLIDS } \\
\text { (TONS } \\
\text { PER } \\
\text { DAY }\end{array}$ & $\begin{array}{l}\text { OIS- } \\
\text { SOLVED } \\
\text { SOLIDS } \\
\text { ITDNS } \\
\text { PER } \\
\text { AC-FTI }\end{array}$ & $\begin{array}{l}\text { NI TRA TE } \\
\text { (ND 3) } \\
\text { (MG } / 4 \text { ) }\end{array}$ \\
\hline $\begin{array}{r}\text { OCT. } \\
23 \ldots \\
23 . .\end{array}$ & 11 & 10 & 5 & 237 & $=$ & .05 & 50 & .76 & .07 & $\therefore 5$ \\
\hline
\end{tabular}


02131500 LYNCHES RIVER N'EAR BISHOPVILLE, S. C)

LOCATION.--Lat $34^{\circ} 15^{\circ} 0^{\prime \prime}$, Long $80^{\circ} 12^{\prime} 50^{\prime \prime}$, Lee County, at gaging station near center of span on downstream side of bridge on U.S. Highway 15, 1 mile upstream from Seaboard Coast Line Railroad bridge, 2.9 miles northeast of Bishopville, 3.3 miles downstream from Beils Branch, and at mile 89.5.

DRA INAGE AREA. - $675 \mathrm{sq} \mathrm{ml}$.

PERIOD OF RECORD.--Chemical analyses: October 1945 to September 1946, October 1957 to September 1958 , July 1969 to

September 1970.
Water temperatures: October 1945 to September 1946.

EXTREMES. -1945-46:

Dissolved solids: Maximum, $41 \mathrm{mg} / 1$ oct. 1-10, Dec. 1-10; minimum, $26 \mathrm{mg} / 1 \mathrm{sept}, 1-10$.

Water tempera tures: Maximum, $25.5{ }^{\circ} \mathrm{C}$ June 23 , July 11, 12, 14, 17; minimum, $2.0{ }^{1-10}$ Dec. $20-22$.

REKARKS.-The second of two samples collected at the same time is a field determination.

CHEMICAL ANALYSES, JULY 1969 TO SEPTEMBER 1970

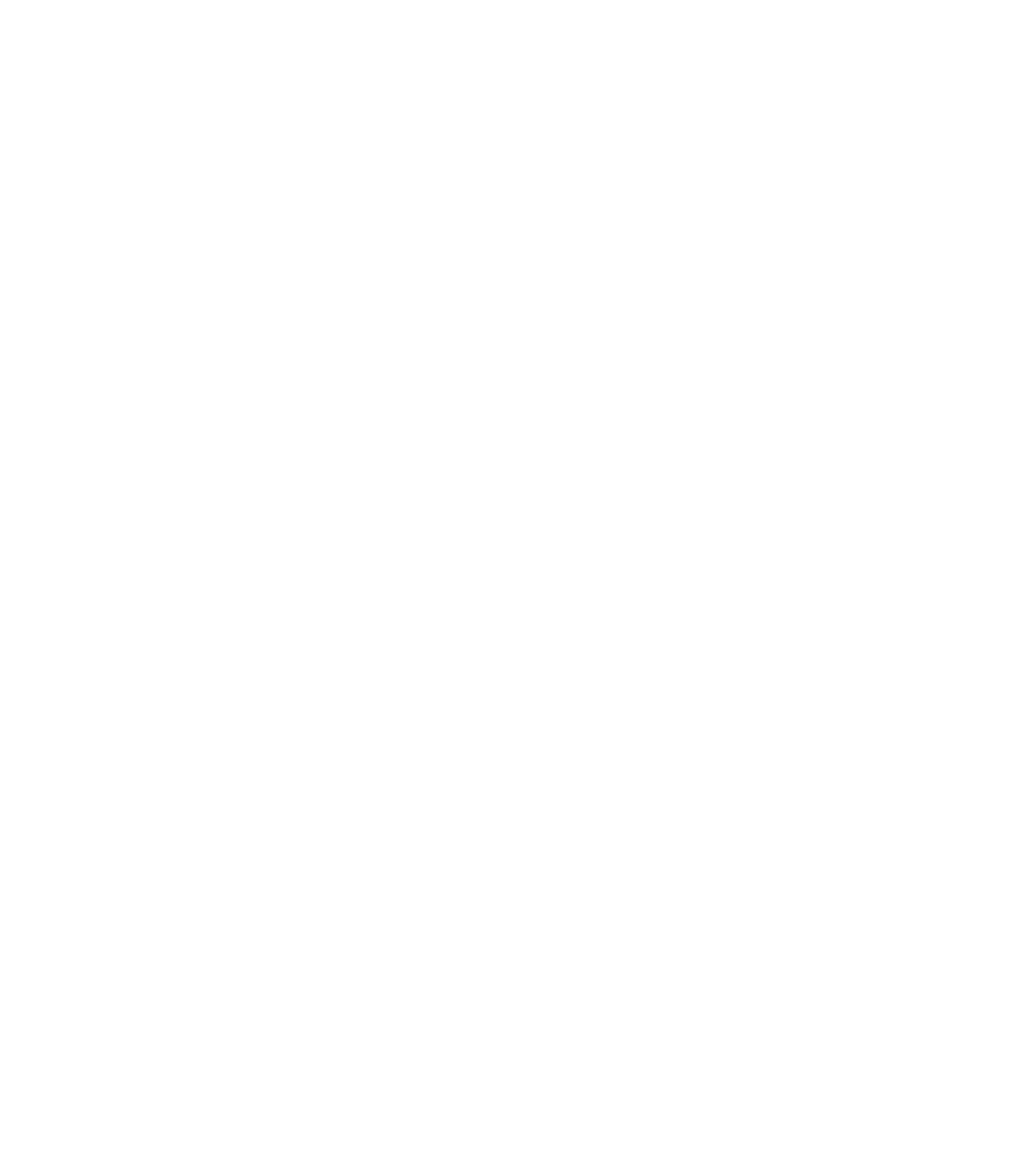


02132000 LYNCHES RIVER AT EFFINGHAM, S. C.

LOCATION,--Lat $34^{\circ} 03^{\prime} 05^{\prime \prime}$, long $79^{\circ} 45^{\circ} 15^{\prime \prime}$, Florence County, at gaging station on left bank at downstream side of bridge on U.S. Highway $52,75 \mathrm{ft}$ upstream from Seaboard Coast line Railroad bridge, 1 mile south of Effingham,
and at mile 43.4 .

DRAINAGE AREA.--1,030 sq mi, approximately.

PERIOD OF RECORD.-Chemical analyses: October 1951 to September 1952, October 1960 to April 1966 , July 1969 to September 1970

Water temperatures: October 1954 to September 1970.

EXTRENES. - 1969-70:

Water temperatures: Maximum, $30.5^{\circ} \mathrm{C}$ June $20-22$, July $3-5$; minimum, $0.5^{\circ} \mathrm{C}$ Jan. $10,11,24$.

Period of record:

Water temperatures: Maximum, $32.0^{\circ} \mathrm{C}$ on several days in $1960,1961,1963$; minimum, $0.5^{\circ} \mathrm{C} \mathrm{Jan.} 10,11,24,1970$.

REMARKS.-The second of two samples collected at the same time is a field determination. Recorder malfunctioned, Jan. $2-10,1969$.

CHEMICAL ANALYSES, JULY 1969 TO SEPTEMBER 1970

\begin{tabular}{|c|c|c|c|c|c|c|c|c|}
\hline DATE & TIME & $\begin{array}{l}\text { TEMP- } \\
\text { ERATURE } \\
\text { (DEG C) }\end{array}$ & $\begin{array}{l}\text { DIS- } \\
\text { CHARGE } \\
\text { (CFSI }\end{array}$ & $\begin{array}{l}\text { SPECI- } \\
\text { FIC } \\
\text { CONO- } \\
\text { UCT ANCE } \\
\text { (MICRO- } \\
\text { MHOS) }\end{array}$ & $\begin{array}{l}\text { OIS- } \\
\text { SOLVED } \\
\text { OXYGEN } \\
\text { (MG/L) }\end{array}$ & $\begin{array}{c}\text { PH } \\
\text { |UNITS }\end{array}$ & $\begin{array}{l}\text { TOTAL } \\
\text { PHOS- } \\
\text { PHDRUS } \\
\text { (P) } \\
\text { (MG/L) }\end{array}$ & $\begin{array}{l}\text { NITRATE } \\
\text { (NO3) } \\
\text { (MGAL) }\end{array}$ \\
\hline JuLY & & & & & & & & \\
\hline $\begin{array}{l}23 \ldots \\
23 \ldots\end{array}$ & $\begin{array}{l}1505 \\
1505\end{array}$ & $27 \overline{.5}$ & 315 & Bo & $\overline{6 . \overline{2}}$ & 6.6 & .05 & 1.0 \\
\hline AUG. & & & & & & & & \\
\hline $\begin{array}{l}26 \ldots . \\
26 \ldots \\
\text { SEP. }\end{array}$ & $\begin{array}{l}1720 \\
1720\end{array}$ & $23 . \overline{0}$ & $827^{-}$ & 46 & $6 . \overline{2}$ & $5 . \overline{9}$ & .05 & $\because 7$ \\
\hline $\begin{array}{l}26 \ldots . . \\
26 . .\end{array}$ & $\begin{array}{l}1140 \\
1140\end{array}$ & $21 . \overline{0}$ & $916^{--}$ & 55 & $\overline{7.5}$ & $\overline{6.6}$ & .02 & 1.0 \\
\hline $30 \ldots$ & $\begin{array}{l}0845 \\
0845\end{array}$ & $\begin{array}{l}13.0 \\
13.0\end{array}$ & $\begin{array}{l}344 \\
344\end{array}$ & $\begin{array}{l}73 \\
75\end{array}$ & $11 . \overline{0}$ & $\begin{array}{l}6.7 \\
7.4\end{array}$ & .06 & 1.5 \\
\hline $\begin{array}{l}19 \ldots \\
19 \ldots\end{array}$ & $\begin{array}{l}1250 \\
1250\end{array}$ & $\begin{array}{l}11.0 \\
11.0\end{array}$ & $\begin{array}{l}A 425 \\
A 425\end{array}$ & $\overline{12}$ & $9 . \overline{0}$ & 7.0 & .07 & $\because 9$ \\
\hline $\begin{array}{l}17 \ldots . . \\
177 \ldots \\
\text { JAN. }\end{array}$ & $\begin{array}{l}1245 \\
1245\end{array}$ & $\begin{array}{l}5.5 \\
5.5\end{array}$ & $\begin{array}{l}930 \\
930\end{array}$ & $\overline{60}$ & $10 . \overline{-}$ & $\overline{7.1}$ & .06 & $\therefore 0$ \\
\hline $\begin{array}{c}22 \ldots \\
22 . \ldots \\
F E B .\end{array}$ & $\begin{array}{l}1420 \\
1420\end{array}$ & $\begin{array}{l}2.5 \\
2.5\end{array}$ & $\begin{array}{l}1020 \\
1020\end{array}$ & $\overline{58}$ & $11 . \overline{2}$ & $\overline{7.7}$ & .01 & 1.1 \\
\hline $\begin{array}{l}18 \ldots . \\
18 . .\end{array}$ & $\begin{array}{l}1010 \\
1010\end{array}$ & $\begin{array}{l}8.0 \\
8.0\end{array}$ & $\begin{array}{l}1160 \\
1160\end{array}$ & -- & $12 . \overline{4}$ & 7.7 & .03 & $\therefore 6$ \\
\hline $\begin{array}{l}18 \ldots \\
18 . . \\
A P R .\end{array}$ & $\begin{array}{l}1445 \\
1445\end{array}$ & $\begin{array}{l}12.0 \\
12.0\end{array}$ & $\begin{array}{l}740 \\
740\end{array}$ & $\overline{76}$ & 9.9 & $\overline{7.3}$ & .02 & 2.7 \\
\hline $\begin{array}{l}21 \ldots \ldots \\
21 \ldots \ldots\end{array}$ & $\begin{array}{l}1420 \\
1420\end{array}$ & $\begin{array}{l}21.5 \\
21.5\end{array}$ & $\begin{array}{l}825 \\
825\end{array}$ & $-\overline{60}$ & $\overline{7.2}$ & $\overline{6.9}$ & .03 & -3 \\
\hline $\begin{array}{l}20 \ldots . . . \\
20 . .\end{array}$ & $\begin{array}{l}0925 \\
0925\end{array}$ & $\begin{array}{l}21.5 \\
21.5\end{array}$ & $\begin{array}{l}A 301 \\
A 301\end{array}$ & $\overline{94}$ & $\overline{8.8}$ & $\overline{7.5}$ & .02 & -6 \\
\hline $\begin{array}{l}18 \ldots . \\
18 . . \\
\text { JUtY }\end{array}$ & $\begin{array}{l}1030 \\
1030\end{array}$ & $\begin{array}{l}26.5 \\
26.5\end{array}$ & $\begin{array}{l}201 \\
201\end{array}$ & $\overrightarrow{102}$ & $\overline{1.2}$ & 7.2 & .02 & .5 \\
\hline $\begin{array}{l}08 . . . \\
08 . . \\
\text { AUG. }\end{array}$ & $\begin{array}{l}1310 \\
1310\end{array}$ & $\begin{array}{l}28.0 \\
28.0\end{array}$ & $\begin{array}{l}\text { A } 146 \\
\text { A } 146\end{array}$ & $\overline{56}$ & $8 \overline{3}$ & 7.5 & .03 & -7 \\
\hline $\begin{array}{l}24 \ldots . \\
24 \ldots \\
\text { SEP. }\end{array}$ & $\begin{array}{l}1015 \\
1015\end{array}$ & $\begin{array}{l}25.5 \\
25.5\end{array}$ & $\begin{array}{l}490 \\
490\end{array}$ & $\overrightarrow{19}$ & $\overline{T .0}$ & $\overline{7.3}$ & .03 & 1.6 \\
\hline $\begin{array}{l}22 \ldots \\
22 \ldots\end{array}$ & $\begin{array}{l}1600 \\
1600\end{array}$ & $\begin{array}{l}27.0 \\
27.0\end{array}$ & $\begin{array}{l}221 \\
221\end{array}$ & $\overline{90}$ & $\overline{7.1}$ & $\overline{6.9}$ & .04 & 1.0 \\
\hline
\end{tabular}

A DAILY MEAN DISCHARGE.

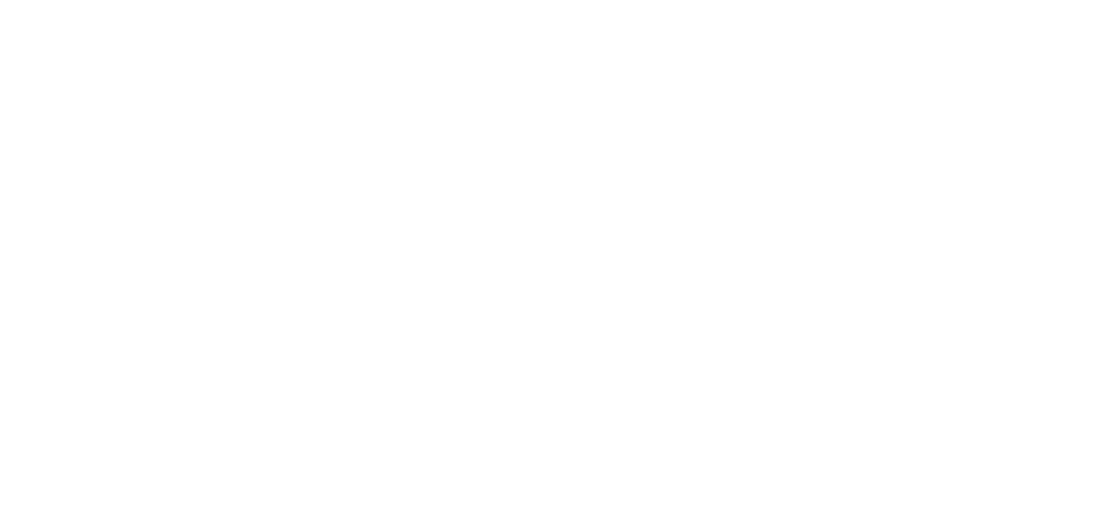

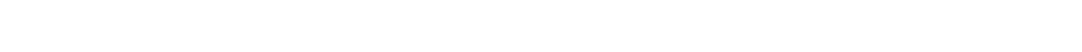


PEE DEE RIVER BASIN

02132000 LYNCHES RIVER AT EFFINGHAM, S. C.--Continued

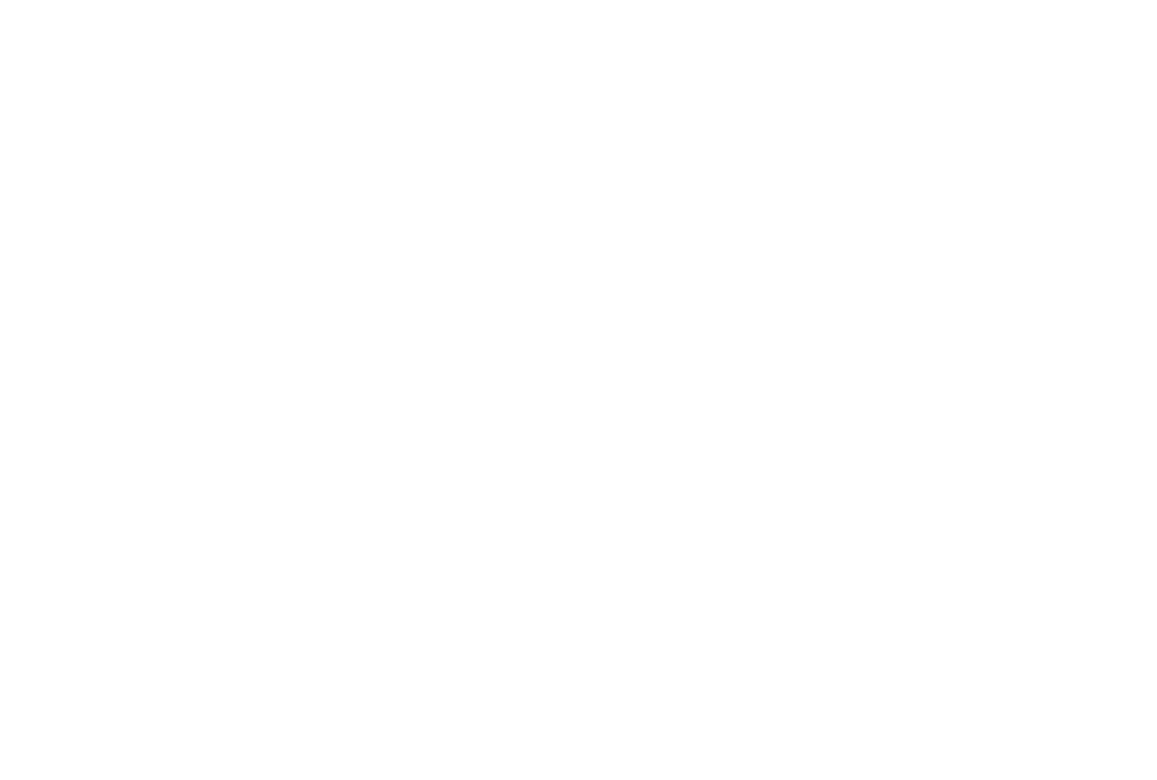

\begin{tabular}{|c|c|c|c|c|c|c|c|c|c|c|c|c|}
\hline \multirow[t]{2}{*}{ DAY } & \multicolumn{2}{|c|}{$\triangle P R$} & \multicolumn{2}{|c|}{ MaY } & \multicolumn{2}{|c|}{ Jun } & \multicolumn{2}{|c|}{ JuL } & \multicolumn{2}{|c|}{ AUG } & \multicolumn{2}{|c|}{ SEP } \\
\hline & MAX & MIN & $\max$ & MIN & $\max$ & MIN & $M \Delta X$ & MIN & $\operatorname{MAX}$ & MIN & $\operatorname{MAX}$ & MIN \\
\hline $\begin{array}{l}1 \\
2 \\
3 \\
4 \\
5\end{array}$ & $\begin{array}{l}13.5 \\
15.5 \\
15.5 \\
16.0 \\
16.0\end{array}$ & $\begin{array}{l}13.0 \\
13.5 \\
14.0 \\
14.0 \\
15.0\end{array}$ & $\begin{array}{l}23.5 \\
22.5 \\
21.5 \\
20.5 \\
18.0\end{array}$ & $\begin{array}{l}21.5 \\
20.5 \\
20.5 \\
17.0 \\
15.5\end{array}$ & $\begin{array}{l}22.5 \\
24.0 \\
24.5 \\
24.5 \\
26.0\end{array}$ & $\begin{array}{l}22.0 \\
22.0 \\
22.5 \\
23.5 \\
23.5\end{array}$ & $\begin{array}{l}29.0 \\
29.5 \\
30.5 \\
30.5 \\
30.5\end{array}$ & $\begin{array}{l}25.0 \\
27.0 \\
28.0 \\
29.0 \\
29.0\end{array}$ & $\begin{array}{l}30.0 \\
29.5 \\
29.0 \\
30.0 \\
29.5\end{array}$ & $\begin{array}{l}27.5 \\
28.0 \\
27.5 \\
28.0 \\
27.5\end{array}$ & $\begin{array}{l}27.5 \\
27.0 \\
26.5 \\
25.5 \\
26.5\end{array}$ & $\begin{array}{l}26.0 \\
25.5 \\
25.0 \\
24.5 \\
25.5\end{array}$ \\
\hline $\begin{array}{r}\epsilon \\
7 \\
8 \\
5 \\
1 C\end{array}$ & $\begin{array}{l}15.0 \\
16.0 \\
16.5 \\
18.0 \\
19.0\end{array}$ & $\begin{array}{l}14.0 \\
14.0 \\
14.0 \\
16.0 \\
18.0\end{array}$ & $\begin{array}{l}19.5 \\
19.0 \\
20.0 \\
21.0 \\
21.0\end{array}$ & $\begin{array}{l}16.5 \\
16.5 \\
16.5 \\
18.0 \\
19.5\end{array}$ & $\begin{array}{l}26.0 \\
25.0 \\
25.0 \\
25.5 \\
25.5\end{array}$ & $\begin{array}{l}24.0 \\
23.5 \\
23.5 \\
22.0 \\
22.0\end{array}$ & $\begin{array}{l}29.0 \\
29.0 \\
28.5 \\
28.5 \\
29.0\end{array}$ & $\begin{array}{l}26.5 \\
26.0 \\
26.5 \\
26.5 \\
26.5\end{array}$ & $\begin{array}{l}28.5 \\
27.5 \\
26.5 \\
26.5 \\
25.5\end{array}$ & $\begin{array}{l}26.5 \\
24.5 \\
25.5 \\
25.5 \\
24.5\end{array}$ & $\begin{array}{l}27.0 \\
26.5 \\
25.5 \\
25.5 \\
26.0\end{array}$ & $\begin{array}{l}25.0 \\
25.0 \\
24.5 \\
23.5 \\
23.5\end{array}$ \\
\hline $\begin{array}{l}11 \\
12 \\
13 \\
14 \\
15\end{array}$ & $\begin{array}{l}19.0 \\
19.0 \\
19.0 \\
20.5 \\
20.5\end{array}$ & $\begin{array}{l}17.5 \\
17.5 \\
17.0 \\
19.0 \\
18.0\end{array}$ & $\begin{array}{l}21.5 \\
22.0 \\
24.0 \\
25.0 \\
25.0\end{array}$ & $\begin{array}{l}19.5 \\
20.0 \\
21.0 \\
22.0 \\
22.5\end{array}$ & $\begin{array}{l}25.0 \\
25.0 \\
28.0 \\
26.0 \\
25.5\end{array}$ & $\begin{array}{l}23.5 \\
22.0 \\
24.0 \\
24.5 \\
23.5\end{array}$ & $\begin{array}{l}29.5 \\
29.5 \\
29.0 \\
28.0 \\
29.5\end{array}$ & $\begin{array}{l}26.5 \\
27.0 \\
27.0 \\
26.0 \\
26.0\end{array}$ & $\begin{array}{l}24.5 \\
23.5 \\
23.5 \\
25.0 \\
25.5\end{array}$ & $\begin{array}{l}23.5 \\
23.5 \\
23.0 \\
23.0 \\
24.0\end{array}$ & $\begin{array}{l}26.5 \\
25.5 \\
25.5 \\
26.0 \\
26 . C\end{array}$ & $\begin{array}{l}25.5 \\
24.0 \\
23.5 \\
23.5 \\
24.0\end{array}$ \\
\hline $\begin{array}{l}16 \\
17 \\
18 \\
19 \\
20\end{array}$ & $\begin{array}{l}19.5 \\
19.5 \\
20.5 \\
21.0 \\
23.5\end{array}$ & $\begin{array}{l}17.5 \\
17.5 \\
17.5 \\
19.5 \\
21.0\end{array}$ & $\begin{array}{l}24.0 \\
23.5 \\
22.0 \\
22.5 \\
24.0\end{array}$ & $\begin{array}{l}22.5 \\
21.5 \\
19.5 \\
19.5 \\
20.0\end{array}$ & $\begin{array}{l}26.0 \\
28.0 \\
28.5 \\
30.5 \\
30.5\end{array}$ & $\begin{array}{l}23.5 \\
24.5 \\
25.0 \\
27.5 \\
28.0\end{array}$ & $\begin{array}{l}30.0 \\
29.5 \\
29.0 \\
29.5 \\
29.5\end{array}$ & $\begin{array}{l}26.5 \\
26.5 \\
26.0 \\
26.5 \\
27.0\end{array}$ & $\begin{array}{l}26.0 \\
27.0 \\
27.5 \\
26.5 \\
25.5\end{array}$ & $\begin{array}{l}24.0 \\
24.5 \\
25.5 \\
25.0 \\
24.0\end{array}$ & $\begin{array}{l}26.5 \\
27.0 \\
28.0 \\
28.5 \\
28.0\end{array}$ & $\begin{array}{l}24.5 \\
26.0 \\
26.0 \\
26.5 \\
26.5\end{array}$ \\
\hline $\begin{array}{l}21 \\
22 \\
23 \\
24 \\
25\end{array}$ & $\begin{array}{l}24.0 \\
24.0 \\
24.0 \\
24.5 \\
24.5\end{array}$ & $\begin{array}{l}21.5 \\
21.0 \\
21.5 \\
22.5 \\
22.5\end{array}$ & $\begin{array}{l}24.5 \\
25.0 \\
25.0 \\
25.5 \\
25.0\end{array}$ & $\begin{array}{l}21.0 \\
22.0 \\
22.0 \\
22.5 \\
21.0\end{array}$ & $\begin{array}{l}30.5 \\
29.5 \\
28.5 \\
28.5 \\
29 . C\end{array}$ & $\begin{array}{l}28.5 \\
26.5 \\
26.5 \\
26.5 \\
26.5\end{array}$ & $\begin{array}{l}29.0 \\
28.5 \\
26.0 \\
26.5 \\
27.0\end{array}$ & $\begin{array}{l}26.5 \\
25.5 \\
25.0 \\
25.0 \\
25.5\end{array}$ & $\begin{array}{l}26.5 \\
26.5 \\
27.0 \\
27.0 \\
25.5\end{array}$ & $\begin{array}{l}24.5 \\
25.5 \\
25.5 \\
25.5 \\
24.5\end{array}$ & $\begin{array}{l}27.5 \\
27.5 \\
28.0 \\
27.5 \\
27.5\end{array}$ & $\begin{array}{l}25.5 \\
26.0 \\
26.0 \\
25.5 \\
25.5\end{array}$ \\
\hline $\begin{array}{l}26 \\
27 \\
28 \\
29 \\
30 \\
31\end{array}$ & $\begin{array}{r}24.0 \\
23.5 \\
24.0 \\
23.5 \\
23.5 \\
.0\end{array}$ & $\begin{array}{r}21.5 \\
22.0 \\
22.5 \\
21.0 \\
21.5 \\
-.-\end{array}$ & $\begin{array}{l}24.0 \\
25.5 \\
25.0 \\
24.5 \\
23.5 \\
23.5\end{array}$ & $\begin{array}{l}21.5 \\
22.5 \\
22.5 \\
23.5 \\
22.0 \\
21.5\end{array}$ & $\begin{array}{c}28.0 \\
29.0 \\
28.0 \\
26.0 \\
26.5 \\
.-\end{array}$ & $\begin{array}{r}26.0 \\
26.5 \\
25.5 \\
24.0 \\
23.5 \\
-.-\end{array}$ & $\begin{array}{l}28.5 \\
28.5 \\
28.0 \\
29.0 \\
28.5 \\
29.0\end{array}$ & $\begin{array}{l}25.5 \\
26.5 \\
26.0 \\
26.0 \\
26.0 \\
26.0\end{array}$ & $\begin{array}{l}25.0 \\
25.5 \\
26.0 \\
27.0 \\
27.0 \\
28.0\end{array}$ & $\begin{array}{l}24.0 \\
24.5 \\
24.5 \\
25.0 \\
26.0 \\
25.5\end{array}$ & $\begin{array}{r}28.0 \\
27.5 \\
26.0 \\
21.5 \\
20.5 \\
. .5\end{array}$ & $\begin{array}{r}25.5 \\
25.5 \\
21.5 \\
15.5 \\
18.5 \\
=.\end{array}$ \\
\hline AYC & 20. & 18,2 & 22,9 & 20.4 & 26.8 & 24.5 & 28.9 & 26.4 & 26.7 & 25.2 & 26.4 & 24.5 \\
\hline
\end{tabular}


02134500 LUMBER RIVER AT BOARDMAN, N. C.

LOCATION.--Lat $34^{\circ} 26^{\prime} 32^{\prime \prime}$, long $78^{\circ} 57^{\prime} 38^{\prime \prime}$, Robeson County, at gaging station on right bank 50 ft downstream from bridge on U.S. Highway 74,1 mile downstream from Seaboard Coast Line Railroad bridge at Boardman, 1.5 miles downstream from Big Swamp, and 40.5 miles upstream from mouth.

DRAINAGE AREA.--1,220 sq $\mathrm{m} 1$, approximately.

PERIOD OF RECORD,--Chęrtcal analyses: October 1946 to September 1947, October 1956 to September 1957, October 1967 to September 1969 (partial-record), October 1969 to September 1970.

Water temperatures: October 1946 to September 1947

EXTREMES, $-1946-47$ :

Dissolved solids: Maximum, $59 \mathrm{mg} / 1$ Sept. 21-30, 1947, minimum, $28 \mathrm{mg} / 1$ Mar. 1-10, 1947.

Hardness: Maximum, $11 \mathrm{mg} / 1$ Nov. $21-30$, i946, Aug. 21-31, 1947; min1mum, $6 \mathrm{mg} / 1$ on many days in 1947.

Wa ter temperatures: Maximum, $28.0^{\circ} \mathrm{C}$ June 11,1947 ; minimum, $2.0^{\circ} \mathrm{C}$ Feb. 11,1947 .

REMARKS.-The second of two samples collected at the same time is a field determination.

CHEMICAL ANALYSES, WATER YEAR OCTOBER 1969 TO SEPTEMBER 1970

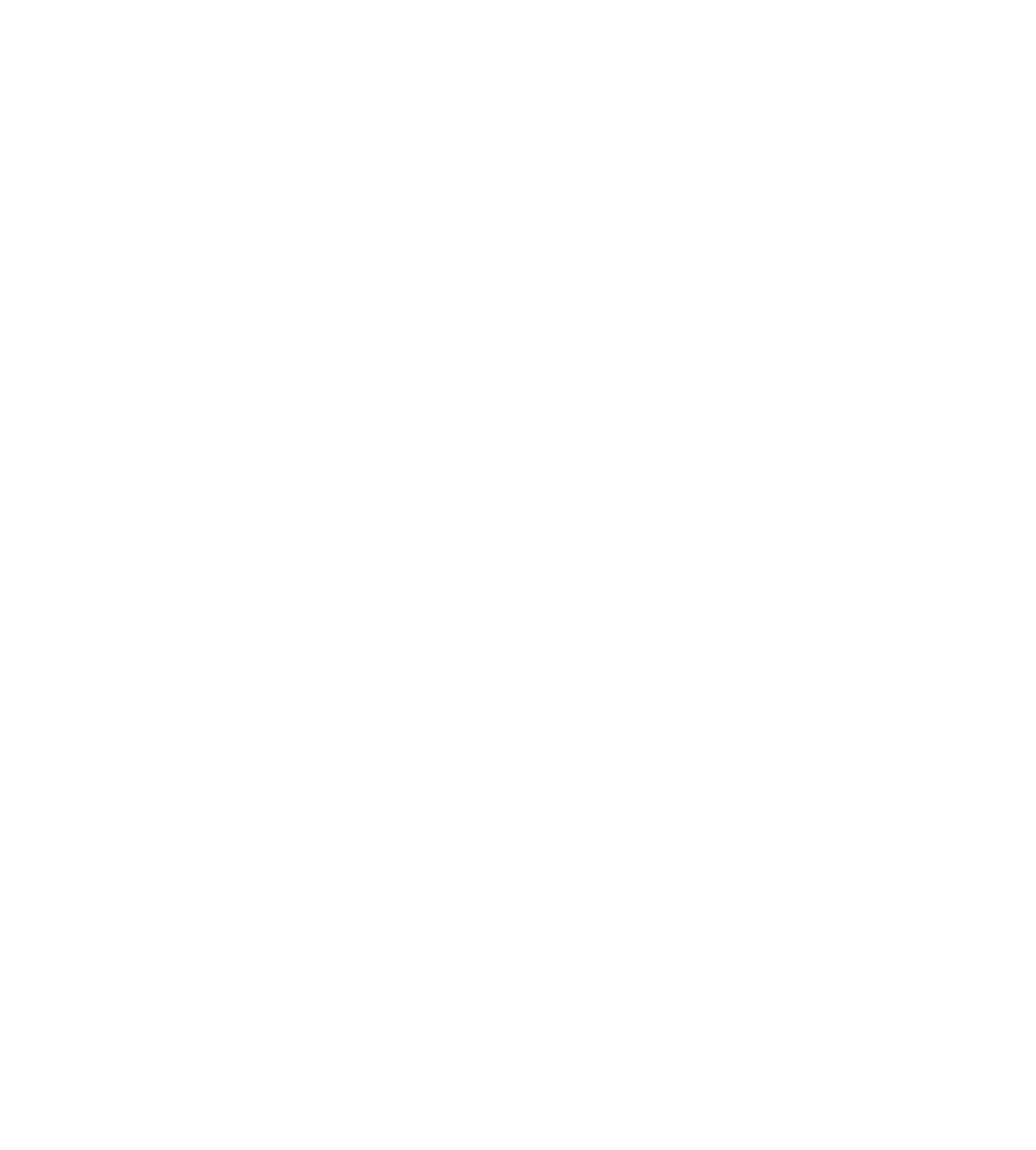


02134500 LUMBER RIVER AT BOARDMAN, N. C.-COntinued

CHEMICAL ANALYSES, WATER YEAR OCTOBER 1969 TO SEPTEMBER 1970

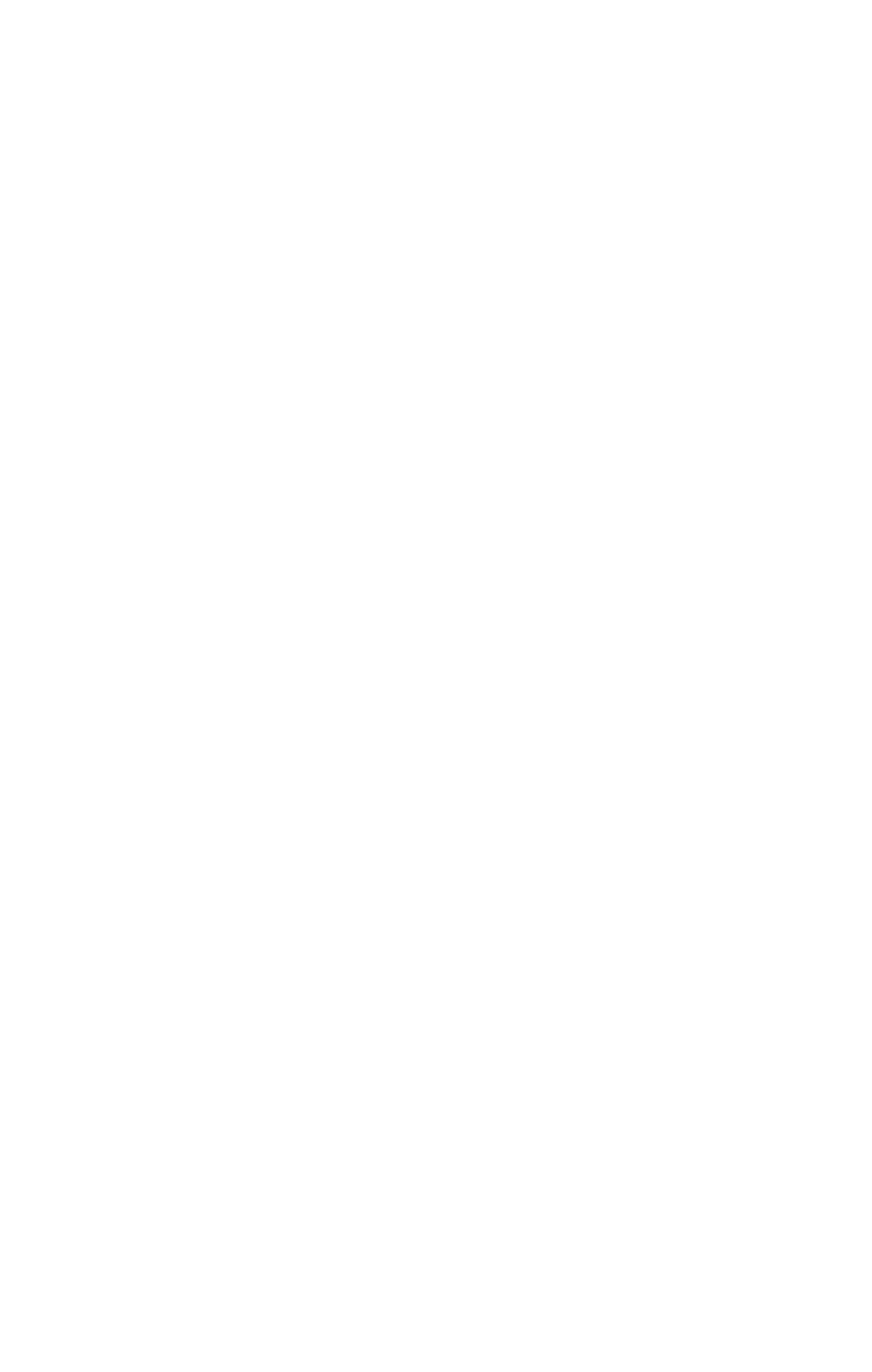


02135200 PEE DEE RIVER NEAR CONWAY, S. C.

LOCATION.--Lat $33^{\circ} 39^{\prime} 39^{\prime \prime}$, long $79^{\circ} 09^{\circ} 17^{\prime \prime}$, Horry County, at bridge on U,S, Highway $701,0.5 \mathrm{mile}$ upstream from Bull Creek, 2.4 miles downstream from Conch Creek, 13.7 miles southwest of Conway, and at mile 28.3.

PERIOD OF RECORD.--Chemical analyses: July 1969 to September 1970.

REMARKS.--The second of two samples collected at the same time is a fleld determination.

CHEMICAL ANALYSES, JULY 1969 TO SEPTEMBER 1970

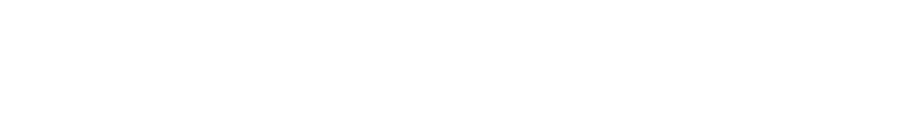

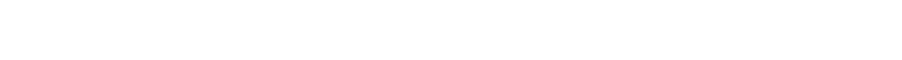

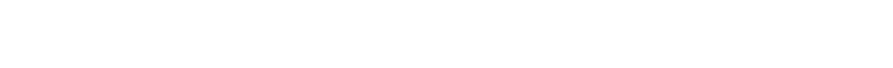

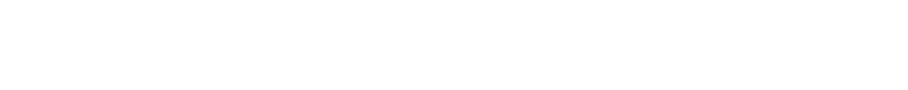

$\begin{array}{ccccccccc}29 . \ldots & 1200 & 16.5 & 73 & -5 & 6.5 & .06 & 1.6 & = \\ 29 . . . & 1200 & 16.5 & 75 & 8.0 & 7.0 & -5 & -5 & -\end{array}$

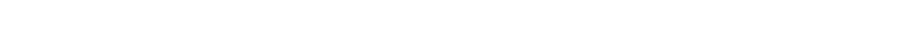

$\begin{array}{lllllllll}20 . \cdots & 0835 & 10.5 & \overline{75} & 10.0 & 7.0 & .05 & 1.7 & -\end{array}$

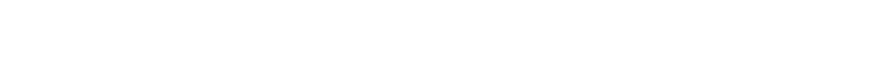

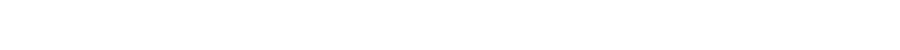

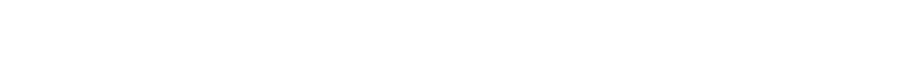

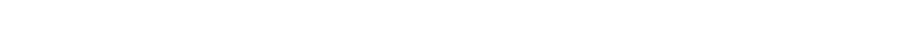

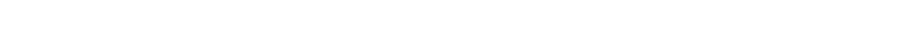

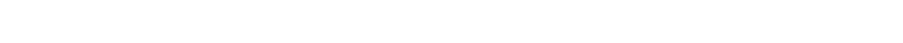

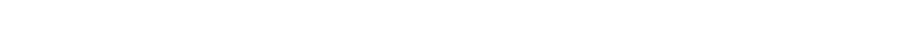

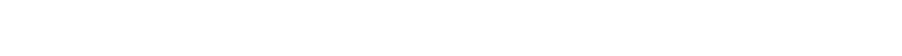

$05 . . .0900$

$05 . . .090$

$25 \ldots .0830$

$23, \ldots \quad 1015$

28.5

$\begin{array}{ll}28.5 & 105 \\ 25.0 & -\end{array}$

$-1$

$-$

$.09 \quad 1.8$

25.0 $80 \quad 6.2$

6.5

.05

$6.5 \quad .08$

SPECI-

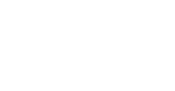

SOIS-

BIO-

CHEM-

ICAL

OXYGEN

(MGL) (UNITS)

$\begin{array}{ccc}\text { LINITY BICAR- } & \text { FILT- } \\ \text { RABLE } & \\ \text { AS } & \text { BONATE RESIDUE }\end{array}$

CACO3 (HCO3)

( $M G / L)$ (NG/L) (MG/L)

\begin{tabular}{|c|c|c|c|c|c|c|c|c|c|c|c|}
\hline $\begin{array}{l}29 \ldots \\
29 . \ldots\end{array}$ & $\begin{array}{l}1200 \\
1200\end{array}$ & $\begin{array}{l}16.5 \\
16.5\end{array}$ & $\begin{array}{r}3 \\
--\end{array}$ & 100 & $\begin{array}{l}73 \\
75\end{array}$ & $\overrightarrow{8.0}$ & 1.6 & $\begin{array}{l}6.5 \\
7.0\end{array}$ & 16 & 20 & 13 \\
\hline & TOTAL & & $\begin{array}{l}\text { NON- } \\
\text { CAR- }\end{array}$ & & & $\begin{array}{l}\text { DIS- } \\
\text { SOL } V=0\end{array}$ & TOTAL & DIS- & & OI S- & \\
\hline & PHOS - & HAKD- & BONATE & CHLO- & & FLUO- & CHRO- & SOLVEO & TOTAL & SOLVFD & MAN- \\
\hline & $\begin{array}{l}\text { PHCRUS } \\
\text { (P) }\end{array}$ & $\begin{array}{l}\text { NESS } \\
(C A, M G)\end{array}$ & $\begin{array}{l}\text { HARC- } \\
\text { NESS }\end{array}$ & $\begin{array}{l}\text { RIDE } \\
\text { (CL) }\end{array}$ & $\begin{array}{l}\text { SULFATE } \\
\text { (SO4) }\end{array}$ & $\begin{array}{l}\text { RIOE } \\
\text { (F) }\end{array}$ & $\begin{array}{l}M I U M \\
(C R)\end{array}$ & $\begin{array}{l}\text { COPPER } \\
\text { (CU) }\end{array}$ & $\begin{array}{l}\text { IRON } \\
\text { (FE) }\end{array}$ & $\begin{array}{l}\text { LEAD } \\
\text { (PB) }\end{array}$ & $\begin{array}{l}\text { GANESE } \\
\text { (MN) }\end{array}$ \\
\hline$D \Delta T \check{C}$ & $(M G / L)$ & (MG/L) & $(M G / L)$ & $(M G / L)$ & $(M G / L)$ & $(M G / L)$ & $(U G / L)$ & $(\cup G / L)$ & (UG，L) & $(U G / L)$ & (UG/L) \\
\hline
\end{tabular}

\begin{tabular}{|c|c|c|c|c|c|c|c|c|c|c|c|}
\hline $29 .$. & .00 & 18 & 2 & 9.4 & 6.8 & .2 & 0 & 0 & 439 & 14 & 0 \\
\hline $29 .$. & - & -- & -- & -- & -- & -- & -- & METHY- & ors-- & -- & - \\
\hline & $\begin{array}{l}\text { Dis- } \\
\text { SotVto }\end{array}$ & $\begin{array}{c}\text { DIS- } \\
\text { SOLVE-D }\end{array}$ & $\begin{array}{c}\text { SUS- } \\
\text { PENDFO }\end{array}$ & $\begin{array}{l}\text { DIS- } \\
\text { SOLVEO }\end{array}$ & $\begin{array}{l}\text { SUS- } \\
\text { PINDED }\end{array}$ & $\begin{array}{l}\text { COLI- } \\
\text { FORM } \\
\text { ICOL- }\end{array}$ & $\begin{array}{l}\text { FECAL } \\
\text { COLI- } \\
\text { FORM }\end{array}$ & $\begin{array}{l}\text { LENE } \\
\text { BLUE } \\
\text { ACTIVE }\end{array}$ & $\begin{array}{l}\text { SOL VED } \\
\text { SOLIOS } \\
\text { (RESI- }\end{array}$ & $\begin{array}{l}\text { DI S- } \\
\text { SOLVED } \\
\text { SOL IOS }\end{array}$ & \\
\hline & $\begin{array}{l}\text { NICKEL } \\
\text { (NI) }\end{array}$ & ALPHA & ALPHA & BETA & BETA & $\begin{array}{c}\text { ONIES } \\
\text { PER }\end{array}$ & $\begin{array}{l}\text { ICOL. } \\
\text { PER }\end{array}$ & $\begin{array}{l}\text { SUB- } \\
\text { STANCE }\end{array}$ & $\begin{array}{l}\text { DUE AT } \\
\text { I } 80 \text { CI }\end{array}$ & $\begin{array}{l}\text { ITONS } \\
\text { PER }\end{array}$ & $\begin{array}{l}\text { NITRATE } \\
\text { (NO3) }\end{array}$ \\
\hline DATE & $(U G / L)$ & $(P C / L)$ & $(P C / L)$ & $(P C / L)$ & $(P C / L)$ & $100 \mathrm{ML})$ & $100 \mathrm{ML})$ & $(M G / L)$ & $(M G / L)$ & $A(-F T)$ & (MG/L) \\
\hline
\end{tabular}

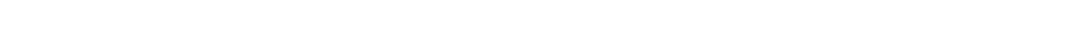


02143500 INDI AN CREEK NEAR LABORATORY, N. C.

LOCATION.--Lat $35^{\circ} 25^{\prime} 20^{\prime \prime}$, long $81^{\circ} 15^{\prime} 52^{\prime \prime}$, Lincoln County, temperature recorder at gaging station on left bank 250 ft upstream from remains of Rudisill Mili dam, 0.5 mile upstream from bridge on Secondary Road $1252,1.5$ miles upupstream from remains of Rudisill Mill dam, 0.5 mile upstream from bridge on Seconda
stream from mouth, 1.5 miles south of Laboratory, and 3.5 miles south of Lincolnton.

DRA INAGE AREA, $--68.4 \mathrm{sq} \mathrm{mi}$.

PERIOD OF RECORD.--Chemical analyses: October 1951 to September 1952.

Water temperatures: January 1953 to September 1970.

EXTREMES, --1967-70:

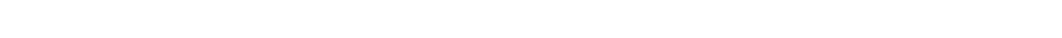

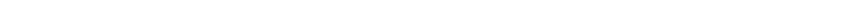

period of record:

Water temperatures: Haximum, $29.0^{\circ} \mathrm{C}$ Aug. $1,2,5,1953$; minimum, freezing point on several days in 1962 and 1966 .

TEMPERATURE $\left({ }^{\circ} \mathrm{C}\right)$ OF WATER, HATER YEAR OCTOBER 1967 TO SEPTEMBER 1968 CONTINUOUS ETHYL ALCOHOL-ACTUATED THERMOGRAPH)

\begin{tabular}{|c|c|c|c|c|c|c|c|c|c|c|c|c|}
\hline \multirow[t]{2}{*}{ DAY } & \multicolumn{2}{|c|}{$\mathrm{OCT}$} & \multicolumn{2}{|c|}{ NOV } & \multicolumn{2}{|c|}{ DEC } & \multicolumn{2}{|c|}{ JAN } & \multicolumn{2}{|c|}{ FE8 } & \multicolumn{2}{|c|}{ MAR } \\
\hline & $\operatorname{MAX}$ & MIN & $\operatorname{MAX}$ & MIN & $\operatorname{MAX}$ & $\operatorname{MIN}$ & MAX & MIN & MAX & MIN & $\operatorname{MAX}$ & MIN \\
\hline $\begin{array}{l}1 \\
2 \\
3 \\
4 \\
5\end{array}$ & $\begin{array}{l}14.0 \\
14.5 \\
15.5 \\
16.0 \\
16.5\end{array}$ & $\begin{array}{l}13.0 \\
13.5 \\
14.5 \\
15.0 \\
15.5\end{array}$ & $\begin{array}{l}= \\
=- \\
=\end{array}$ & $\begin{array}{l}=- \\
=- \\
=- \\
=-\end{array}$ & $\begin{array}{l}6.5 \\
6.5 \\
7.0 \\
7.0 \\
6.5\end{array}$ & $\begin{array}{l}6.0 \\
6.5 \\
6.5 \\
6.0 \\
5.5\end{array}$ & $\begin{array}{l}7.0 \\
7.0 \\
7.0 \\
9.0 \\
8.5\end{array}$ & $\begin{array}{l}6.5 \\
6.5 \\
6.5 \\
7.0 \\
5.5\end{array}$ & $\begin{array}{l}9.5 \\
9.0 \\
8.5 \\
7.0 \\
6.0\end{array}$ & $\begin{array}{l}9.0 \\
8.5 \\
6.5 \\
5.5 \\
5.0\end{array}$ & $\begin{array}{l}4.5 \\
6.0 \\
8.0 \\
7.0 \\
7.0\end{array}$ & $\begin{array}{l}3.5 \\
4.0 \\
6.0 \\
5.5 \\
5.5\end{array}$ \\
\hline $\begin{array}{r}6 \\
7 \\
8 \\
9 \\
10\end{array}$ & $\begin{array}{l}16.5 \\
16.5 \\
15.5 \\
15.5 \\
17.0\end{array}$ & $\begin{array}{l}15.5 \\
15.5 \\
15.0 \\
15.5 \\
15.5\end{array}$ & $\begin{array}{l}8.0 \\
7.0 \\
8.5 \\
6.5 \\
8.0\end{array}$ & $\begin{array}{l}6.5 \\
5.5 \\
5.0 \\
5.0 \\
6.0\end{array}$ & $\begin{array}{r}6.5 \\
8.0 \\
9.5 \\
11.0 \\
11.0\end{array}$ & $\begin{array}{r}5.5 \\
6.0 \\
8.0 \\
10.0 \\
10.0\end{array}$ & $\begin{array}{l}5.5 \\
5.5 \\
5.5 \\
4.0 \\
4.0\end{array}$ & $\begin{array}{l}5.0 \\
5.5 \\
4.0 \\
4.0 \\
4.0\end{array}$ & $\begin{array}{l}5.5 \\
5.5 \\
6.5 \\
6.5 \\
6.0\end{array}$ & $\begin{array}{l}5.0 \\
5.0 \\
5.5 \\
5.5 \\
5.5\end{array}$ & $\begin{array}{r}8.5 \\
8.5 \\
3.5 \\
11.0 \\
11.5\end{array}$ & $\begin{array}{r}6.5 \\
6.5 \\
6.5 \\
8.0 \\
11.0\end{array}$ \\
\hline $\begin{array}{l}11 \\
12 \\
13 \\
14 \\
15\end{array}$ & $\begin{array}{l}16.5 \\
15.5 \\
15.0 \\
15.0 \\
16.0\end{array}$ & $\begin{array}{l}15.5 \\
14.5 \\
14.5 \\
14.0 \\
15.0\end{array}$ & $\begin{array}{r}9.0 \\
10.5 \\
10.5 \\
10.0 \\
9.5\end{array}$ & $\begin{array}{r}7.0 \\
9.0 \\
10.0 \\
9.0 \\
8.0\end{array}$ & $\begin{array}{r}10.0 \\
9.5 \\
9.5 \\
9.0 \\
11.0\end{array}$ & $\begin{array}{l}9.0 \\
9.0 \\
9.0 \\
8.0 \\
9.0\end{array}$ & $\begin{array}{l}4.0 \\
4.0 \\
3.5 \\
3.5 \\
3.5\end{array}$ & $\begin{array}{l}4.0 \\
3.5 \\
2.0 \\
2.0 \\
3.5\end{array}$ & $\begin{array}{l}5.5 \\
5.0 \\
4.5 \\
4.5 \\
5.0\end{array}$ & $\begin{array}{l}5.0 \\
3.5 \\
4.0 \\
3.5 \\
4.0\end{array}$ & $\begin{array}{r}11.5 \\
11.5 \\
10.5 \\
9.0 \\
3.5\end{array}$ & $\begin{array}{r}10.5 \\
10.5 \\
9.0 \\
6.5 \\
6.5\end{array}$ \\
\hline $\begin{array}{l}18 \\
17 \\
18 \\
19 \\
20\end{array}$ & $\begin{array}{l}16.0 \\
16.5 \\
16.0 \\
15.0 \\
13.0\end{array}$ & $\begin{array}{l}15.5 \\
15.5 \\
14.5 \\
13.0 \\
11.0\end{array}$ & $\begin{array}{l}9.5 \\
6.5 \\
3.0 \\
9.0 \\
8.0\end{array}$ & $\begin{array}{l}6.0 \\
5.5 \\
6.0 \\
6.5 \\
6.0\end{array}$ & $\begin{array}{r}11.0 \\
8.0 \\
11.0 \\
12.0 \\
12.0\end{array}$ & $\begin{array}{r}9.0 \\
6.5 \\
7.0 \\
11.0 \\
12.0\end{array}$ & $\begin{array}{l}4.0 \\
4.0 \\
4.5 \\
4.5 \\
5.5\end{array}$ & $\begin{array}{l}3.5 \\
3.5 \\
4.0 \\
4.0 \\
4.5\end{array}$ & $\begin{array}{l}5.5 \\
5.5 \\
5.5 \\
5.0 \\
5.5\end{array}$ & $\begin{array}{l}4.5 \\
4.5 \\
5.0 \\
3.5 \\
4.0\end{array}$ & $\begin{array}{l}10.0 \\
11.0 \\
11.0 \\
11.0 \\
11.0\end{array}$ & $\begin{array}{r}9.5 \\
9.5 \\
9.0 \\
9.0 \\
10.0\end{array}$ \\
\hline $\begin{array}{l}21 \\
22 \\
23 \\
24 \\
25\end{array}$ & $\begin{array}{l}11.5 \\
12.0 \\
12.0 \\
12.0 \\
13.5\end{array}$ & $\begin{array}{l}10.5 \\
11.0 \\
11.0 \\
11.0 \\
12.0\end{array}$ & $\begin{array}{r}7.0 \\
9.0 \\
10.0 \\
9.5 \\
9.0\end{array}$ & $\begin{array}{l}6.5 \\
7.0 \\
9.0 \\
9.0 \\
8.5\end{array}$ & $\begin{array}{r}12.0 \\
13.5 \\
13.0 \\
8.0 \\
7.0\end{array}$ & $\begin{array}{r}12.0 \\
12.0 \\
8.0 \\
6.5 \\
6.5\end{array}$ & $\begin{array}{l}6.0 \\
6.0 \\
8.0 \\
8.0 \\
5.5\end{array}$ & $\begin{array}{l}5.0 \\
5.0 \\
6.0 \\
5.0 \\
4.5\end{array}$ & $\begin{array}{l}5.5 \\
5.5 \\
4.5 \\
4.5 \\
4.5\end{array}$ & $\begin{array}{l}5.0 \\
4.0 \\
3.5 \\
3.5 \\
3.5\end{array}$ & $\begin{array}{r}13.5 \\
14.0 \\
14.0 \\
10.0 \\
9.0\end{array}$ & $\begin{array}{r}11.0 \\
12.0 \\
10.0 \\
7.0 \\
7.0\end{array}$ \\
\hline $\begin{array}{l}26 \\
27 \\
28 \\
29 \\
30 \\
31\end{array}$ & $\begin{array}{l}13.5 \\
12.0 \\
11.5 \\
11.0 \\
10.0 \\
11.0\end{array}$ & $\begin{array}{r}11.5 \\
10.5 \\
10.5 \\
9.0 \\
9.0 \\
10.0\end{array}$ & $\begin{array}{l}9.0 \\
9.0 \\
9.0 \\
6.5 \\
6.5 \\
-.-\end{array}$ & $\begin{array}{r}8.0 \\
9.0 \\
6.5 \\
5.0 \\
5.5 \\
-.\end{array}$ & $\begin{array}{l}7.0 \\
7.0 \\
6.5 \\
6.5 \\
6.5 \\
6.0\end{array}$ & $\begin{array}{l}7.0 \\
6.5 \\
5.5 \\
5.5 \\
6.0 \\
6.0\end{array}$ & $\begin{array}{l}5.0 \\
5.0 \\
6.0 \\
7.0 \\
8.5 \\
9.5\end{array}$ & $\begin{array}{l}4.0 \\
4.5 \\
5.0 \\
6.0 \\
7.0 \\
8.5\end{array}$ & $\begin{array}{r}4.5 \\
4.5 \\
4.5 \\
4.5 \\
-.- \\
--\end{array}$ & $\begin{array}{l}3.5 \\
3.5 \\
4.0 \\
4.0 \\
.- \\
.-\end{array}$ & $\begin{array}{l}10.0 \\
11.0 \\
12.0 \\
13.5 \\
13.5 \\
14.5\end{array}$ & $\begin{array}{r}7.0 \\
9.0 \\
10.0 \\
11.0 \\
12.0 \\
13.0\end{array}$ \\
\hline AVG & 14.5 & 13.0 & 8.5 & 7.0 & 9.0 & 8.0 & 5.5 & 5.0 & 5.5 & 4.5 & 10.5 & 8.5 \\
\hline \multirow[t]{2}{*}{ DAY } & \multicolumn{2}{|c|}{$\triangle P R$} & \multicolumn{2}{|c|}{ MAY } & \multicolumn{2}{|c|}{ JUN } & \multicolumn{2}{|c|}{ JUL } & \multicolumn{2}{|c|}{ AUG } & \multicolumn{2}{|c|}{ SEP } \\
\hline & MAX & MI N & $\max$ & MIN & MAX & MIN & MAX & MIN & $\operatorname{MAX}$ & MtN & MAX & MIN \\
\hline $\begin{array}{l}1 \\
2 \\
3 \\
4 \\
5\end{array}$ & $\begin{array}{l}15.5 \\
15.0 \\
12.0 \\
12.0 \\
13.5\end{array}$ & $\begin{array}{r}14.0 \\
11.5 \\
10.0 \\
9.5 \\
11.5\end{array}$ & $\begin{array}{l}14.0 \\
14.0 \\
14.5 \\
14.5 \\
14.5\end{array}$ & $\begin{array}{l}11.5 \\
13.0 \\
13.0 \\
14.0 \\
13.5\end{array}$ & $\begin{array}{l}16.5 \\
17.0 \\
18.0 \\
18.0 \\
18.0\end{array}$ & $\begin{array}{l}14.5 \\
16.0 \\
16.5 \\
16.5 \\
16.5\end{array}$ & $\begin{array}{l}21.0 \\
22.0 \\
22.0 \\
20.5 \\
18.5\end{array}$ & $\begin{array}{l}19.0 \\
20.0 \\
20.5 \\
18.5 \\
18.0\end{array}$ & $\begin{array}{l}21.5 \\
22.0 \\
23.0 \\
23.0 \\
24.0\end{array}$ & $\begin{array}{l}20.0 \\
21.0 \\
21.5 \\
21.5 \\
22.0\end{array}$ & $\begin{array}{l}18.0 \\
19.0 \\
20.0 \\
19.5 \\
20.0\end{array}$ & $\begin{array}{l}18.0 \\
18.0 \\
18.0 \\
18.5 \\
19.0\end{array}$ \\
\hline $\begin{array}{r}6 \\
7 \\
8 \\
9 \\
10\end{array}$ & $\begin{array}{l}13.5 \\
13.5 \\
14.0 \\
14.5 \\
14.5\end{array}$ & $\begin{array}{l}11.5 \\
11.5 \\
12.0 \\
13.5 \\
12.0\end{array}$ & $\begin{array}{l}13.5 \\
12.0 \\
13.0 \\
13.0 \\
14.5\end{array}$ & $\begin{array}{l}11.0 \\
10.5 \\
11.0 \\
11.5 \\
12.0\end{array}$ & $\begin{array}{l}18.0 \\
18.0 \\
18.0 \\
18.5 \\
18.5\end{array}$ & $\begin{array}{l}16.0 \\
16.0 \\
18.0 \\
18.0 \\
17.0\end{array}$ & $\begin{array}{l}19.0 \\
20.0 \\
20.0 \\
19.0 \\
18.0\end{array}$ & $\begin{array}{l}18.0 \\
18.0 \\
18.5 \\
18.0 \\
18.0\end{array}$ & $\begin{array}{l}24.0 \\
24.5 \\
24.5 \\
24.5 \\
24.5\end{array}$ & $\begin{array}{l}22.0 \\
23.0 \\
23.5 \\
23.5 \\
24.0\end{array}$ & $\begin{array}{l}20.5 \\
20.5 \\
19.5 \\
19.0 \\
19.0\end{array}$ & $\begin{array}{l}20.0 \\
19.0 \\
18.0 \\
18.5 \\
18.5\end{array}$ \\
\hline $\begin{array}{l}11 \\
12 \\
13 \\
14 \\
15\end{array}$ & $\begin{array}{l}13.0 \\
13.0 \\
13.5 \\
15.0 \\
16.0\end{array}$ & $\begin{array}{l}11.0 \\
10.5 \\
11.0 \\
13.0 \\
14.5\end{array}$ & $\begin{array}{l}14.5 \\
15.5 \\
16.5 \\
16.5 \\
14.0\end{array}$ & $\begin{array}{l}14.0 \\
14.5 \\
15.0 \\
14.0 \\
13.0\end{array}$ & $\begin{array}{l}20.0 \\
20.0 \\
19.5 \\
18.5 \\
18.5\end{array}$ & $\begin{array}{l}18.5 \\
19.0 \\
18.0 \\
16.0 \\
16.0\end{array}$ & $\begin{array}{l}19.0 \\
19.5 \\
19.5 \\
20.0 \\
20.5\end{array}$ & $\begin{array}{l}18.0 \\
19.0 \\
18.5 \\
19.0 \\
19.0\end{array}$ & $\begin{array}{l}24.5 \\
23.0 \\
20.5 \\
22.0 \\
23.0\end{array}$ & $\begin{array}{l}23.0 \\
20.5 \\
20.0 \\
20.5 \\
21.0\end{array}$ & $\begin{array}{l}19.0 \\
19.0 \\
18.0 \\
16.5 \\
18.0\end{array}$ & $\begin{array}{l}18.5 \\
16.5 \\
16.0 \\
16.0 \\
16.5\end{array}$ \\
\hline $\begin{array}{l}16 \\
17 \\
18 \\
19 \\
20\end{array}$ & $\begin{array}{l}15.5 \\
13.5 \\
15.0 \\
15.0 \\
16.5\end{array}$ & $\begin{array}{l}12.0 \\
11.0 \\
13.0 \\
13.5 \\
14.5\end{array}$ & $\begin{array}{l}15.5 \\
15.5 \\
15.5 \\
15.5 \\
15.5\end{array}$ & $\begin{array}{l}14.0 \\
14.5 \\
14.5 \\
15.0 \\
14.0\end{array}$ & $\begin{array}{l}19.0 \\
19.0 \\
19.0 \\
18.0 \\
19.0\end{array}$ & $\begin{array}{l}17.0 \\
18.5 \\
18.0 \\
17.0 \\
17.0\end{array}$ & $\begin{array}{l}21.0 \\
21.0 \\
21.0 \\
20.0 \\
20.0\end{array}$ & $\begin{array}{l}19.0 \\
20.0 \\
20.0 \\
19.5 \\
19.0\end{array}$ & $\begin{array}{l}23.5 \\
24.5 \\
24.5 \\
24.5 \\
24.5\end{array}$ & $\begin{array}{l}22.0 \\
22.0 \\
23.5 \\
24.0 \\
23.5\end{array}$ & $\begin{array}{l}18.0 \\
18.0 \\
18.0 \\
18.5 \\
19.0\end{array}$ & $\begin{array}{l}16.5 \\
17.0 \\
17.0 \\
17.0 \\
18.5\end{array}$ \\
\hline $\begin{array}{l}21 \\
22 \\
23 \\
24 \\
25\end{array}$ & $\begin{array}{l}16.5 \\
16.5 \\
15.5 \\
13.5 \\
13.5\end{array}$ & $\begin{array}{l}15.0 \\
14.5 \\
13.5 \\
13.0 \\
11.0\end{array}$ & $\begin{array}{l}14.5 \\
14.0 \\
15.5 \\
18.0 \\
18.0\end{array}$ & $\begin{array}{l}13.5 \\
13.0 \\
13.5 \\
15.5 \\
16.5\end{array}$ & $\begin{array}{l}19.0 \\
19.0 \\
20.0 \\
20.0 \\
20.0\end{array}$ & $\begin{array}{l}17.0 \\
18.0 \\
18.5 \\
19.0 \\
18.5\end{array}$ & $\begin{array}{l}20.5 \\
21.0 \\
21.0 \\
21.0 \\
21.5\end{array}$ & $\begin{array}{l}19.0 \\
19.5 \\
20.0 \\
20.0 \\
20.0\end{array}$ & $\begin{array}{l}25.0 \\
25.0 \\
25.0 \\
25.5 \\
25.5\end{array}$ & $\begin{array}{l}23.5 \\
24.0 \\
24.0 \\
24.5 \\
24.0\end{array}$ & $\begin{array}{l}19.0 \\
18.5 \\
18.0 \\
18.0 \\
18.0\end{array}$ & $\begin{array}{l}18.0 \\
17.0 \\
16.5 \\
16.5 \\
16.5\end{array}$ \\
\hline $\begin{array}{l}26 \\
27 \\
28 \\
29 \\
30 \\
31\end{array}$ & $\begin{array}{r}12.0 \\
12.0 \\
11.5 \\
11.5 \\
12.0 \\
.--\end{array}$ & $\begin{array}{c}10.5 \\
11.0 \\
11.0 \\
10.0 \\
10.0 \\
.-0\end{array}$ & $\begin{array}{l}17.0 \\
15.5 \\
15.5 \\
15.0 \\
15.0 \\
15.5\end{array}$ & $\begin{array}{l}15.5 \\
15.0 \\
13.5 \\
13.5 \\
14.5 \\
14.0\end{array}$ & $\begin{array}{r}21.0 \\
21.00 \\
21.0 \\
19.0 \\
20.0 \\
-.\end{array}$ & $\begin{array}{r}20.0 \\
20.0 \\
18.0 \\
16.5 \\
18.0 \\
--\end{array}$ & $\begin{array}{l}21.5 \\
21.0 \\
21.0 \\
21.0 \\
20.5 \\
20.5\end{array}$ & $\begin{array}{l}21.0 \\
20.0 \\
20.0 \\
20.0 \\
20.0 \\
19.5\end{array}$ & $\begin{array}{l}24.5 \\
23.5 \\
21.0 \\
19.0 \\
18.5 \\
18.0\end{array}$ & $\begin{array}{l}23.5 \\
21.0 \\
19.0 \\
17.0 \\
16.5 \\
16.5\end{array}$ & $\begin{array}{r}19.0 \\
19.0 \\
18.5 \\
18.0 \\
17.0 \\
.0\end{array}$ & $\begin{array}{r}18.0 \\
18.0 \\
16.5 \\
16.5 \\
16.0 \\
.-\end{array}$ \\
\hline AVG & 14.0 & 12.0 & 15.0 & 13.5 & 19.0 & 17.5 & 20.5 & 19.0 & 23.0 & 22.0 & 18.5 & 17.5 \\
\hline
\end{tabular}


02143500 INDIAN CREEK NEAR LABORATORY, N. C.--Continued

TEMPERATURE $\left({ }^{\circ} \mathrm{C}\right)$ OF WATER, WATER YEAR OCTOBER 1968 TO SEPTEMBER 1969 (CONTINUOUS ETHYL ALCOHOL-ACTUATED THERMOGRAPH)

\begin{tabular}{|c|c|c|c|c|c|c|c|c|c|c|c|c|}
\hline \multirow[t]{2}{*}{ DAY } & \multicolumn{2}{|c|}{$\mathrm{OCT}$} & \multicolumn{2}{|c|}{ Nov } & \multicolumn{2}{|c|}{ DEC } & \multicolumn{2}{|c|}{ JAN } & \multicolumn{2}{|c|}{ FEB } & \multicolumn{2}{|c|}{ MAR } \\
\hline & $\operatorname{MAX}$ & MIN & $\operatorname{MAX}$ & MIN & MAX & $M I N$ & MAX & MIN & $\max$ & MIN & $\operatorname{MAX}$ & MIN \\
\hline $\begin{array}{l}1 \\
2 \\
3 \\
4 \\
5\end{array}$ & $\begin{array}{l}17.0 \\
16.5 \\
17.0 \\
17.0 \\
15.0\end{array}$ & $\begin{array}{l}15.5 \\
15.5 \\
16.0 \\
15.0 \\
12.0\end{array}$ & $\begin{array}{r}9.5 \\
10.5 \\
11.0 \\
11.0 \\
11.5\end{array}$ & $\begin{array}{r}8.0 \\
9.5 \\
10.5 \\
11.0 \\
11.0\end{array}$ & $\begin{array}{l}9.0 \\
7.0 \\
8.5 \\
9.0 \\
8.5\end{array}$ & $\begin{array}{l}6.5 \\
6.5 \\
7.0 \\
8.5 \\
6.0\end{array}$ & $\begin{array}{l}5.5 \\
4.0 \\
3.5 \\
3.5 \\
3.0\end{array}$ & $\begin{array}{l}4.0 \\
2.0 \\
2.0 \\
3.0 \\
1.5\end{array}$ & $\begin{array}{l}9.5 \\
9.0 \\
9.0 \\
9.0 \\
6.0\end{array}$ & $\begin{array}{l}8.5 \\
8.5 \\
8.0 \\
5.5 \\
5.5\end{array}$ & $\begin{array}{l}5.0 \\
6.0 \\
6.0 \\
6.0 \\
6.0\end{array}$ & $\begin{array}{l}4.0 \\
4.0 \\
5.0 \\
5.0 \\
5.0\end{array}$ \\
\hline $\begin{array}{r}6 \\
7 \\
8 \\
9 \\
10\end{array}$ & $\begin{array}{l}13.0 \\
14.5 \\
14.5 \\
15.0 \\
15.0\end{array}$ & $\begin{array}{l}11.5 \\
11.5 \\
14.5 \\
14.5 \\
14.5\end{array}$ & $\begin{array}{r}12.0 \\
13.5 \\
13.0 \\
10.5 \\
8.5\end{array}$ & $\begin{array}{r}11.5 \\
12.0 \\
10.5 \\
9.5 \\
7.0\end{array}$ & $\begin{array}{l}6.5 \\
5.0 \\
5.0 \\
3.5 \\
2.0\end{array}$ & $\begin{array}{l}5.0 \\
4.5 \\
3.5 \\
2.0 \\
2.0\end{array}$ & $\begin{array}{l}1.5 \\
0.5 \\
1.0 \\
3.5 \\
3.5\end{array}$ & $\begin{array}{l}0.5 \\
0.5 \\
0.5 \\
1.0 \\
2.0\end{array}$ & $\begin{array}{l}6.5 \\
8.0 \\
7.0 \\
7.0 \\
7.0\end{array}$ & $\begin{array}{l}6.0 \\
6.5 \\
7.0 \\
6.5 \\
5.5\end{array}$ & $\begin{array}{l}6.0 \\
6.5 \\
7.0 \\
8.5 \\
8.0\end{array}$ & $\begin{array}{l}5.5 \\
5.0 \\
5.5 \\
7.0 \\
6.5\end{array}$ \\
\hline $\begin{array}{l}11 \\
12 \\
13 \\
14 \\
15\end{array}$ & $\begin{array}{l}15.5 \\
16.5 \\
17.0 \\
18.0 \\
17.0\end{array}$ & $\begin{array}{l}15.0 \\
15.5 \\
16.5 \\
16.5 \\
16.5\end{array}$ & $\begin{array}{l}7.0 \\
6.5 \\
6.0 \\
5.5 \\
7.0\end{array}$ & $\begin{array}{l}6.5 \\
5.5 \\
5.5 \\
4.5 \\
5.0\end{array}$ & $\begin{array}{l}2.0 \\
2.0 \\
4.5 \\
6.0 \\
6.0\end{array}$ & $\begin{array}{l}1.5 \\
1.5 \\
2.0 \\
4.5 \\
3.5\end{array}$ & $\begin{array}{l}2.0 \\
1.5 \\
1.0 \\
1.0 \\
1.0\end{array}$ & $\begin{array}{l}1.0 \\
1.0 \\
1.0 \\
1.0 \\
1.0\end{array}$ & $\begin{array}{l}6.0 \\
6.0 \\
6.0 \\
5.0 \\
4.0\end{array}$ & $\begin{array}{l}5.0 \\
6.0 \\
5.0 \\
4.0 \\
4.0\end{array}$ & $\begin{array}{l}6.5 \\
5.5 \\
6.0 \\
7.0 \\
7.0\end{array}$ & $\begin{array}{l}5.0 \\
5.0 \\
5.0 \\
5.0 \\
6.0\end{array}$ \\
\hline $\begin{array}{l}16 \\
17 \\
18 \\
19 \\
20\end{array}$ & $\begin{array}{l}17.0 \\
18.5 \\
19.0 \\
19.0 \\
19.0\end{array}$ & $\begin{array}{l}17.0 \\
17.0 \\
18.5 \\
19.0 \\
16.5\end{array}$ & $\begin{array}{r}9.5 \\
11.0 \\
12.0 \\
12.0 \\
8.5\end{array}$ & $\begin{array}{r}7.0 \\
9.5 \\
12.0 \\
7.0 \\
6.0\end{array}$ & $\begin{array}{l}3.5 \\
2.0 \\
2.0 \\
4.0 \\
5.0\end{array}$ & $\begin{array}{l}1.5 \\
1.5 \\
1.5 \\
2.0 \\
4.0\end{array}$ & $\begin{array}{l}1.0 \\
2.0 \\
4.0 \\
6.5 \\
6.5\end{array}$ & $\begin{array}{l}0.5 \\
1.0 \\
1.0 \\
4.0 \\
5.0\end{array}$ & $\begin{array}{l}4.0 \\
2.0 \\
4.5 \\
5.0 \\
5.0\end{array}$ & $\begin{array}{l}1.5 \\
1.5 \\
2.0 \\
4.0 \\
4.0\end{array}$ & $\begin{array}{r}7.0 \\
8.0 \\
8.0 \\
10.0 \\
10.5\end{array}$ & $\begin{array}{l}6.0 \\
6.0 \\
8.0 \\
7.0 \\
9.0\end{array}$ \\
\hline $\begin{array}{l}21 \\
22 \\
23 \\
24 \\
25\end{array}$ & $\begin{array}{l}16.5 \\
15.0 \\
14.5 \\
14.5 \\
14.5\end{array}$ & $\begin{array}{l}14.5 \\
13.0 \\
24.0 \\
14.0 \\
13.0\end{array}$ & $\begin{array}{l}6.0 \\
5.5 \\
6.0 \\
7.0 \\
7.0\end{array}$ & $\begin{array}{l}4.5 \\
4.5 \\
5.0 \\
6.0 \\
6.0\end{array}$ & $\begin{array}{l}5.0 \\
5.5 \\
6.0 \\
6.0 \\
4.0\end{array}$ & $\begin{array}{l}4.5 \\
5.0 \\
5.5 \\
4.0 \\
3.5\end{array}$ & $\begin{array}{l}6.0 \\
6.5 \\
7.0 \\
8.0 \\
8.0\end{array}$ & $\begin{array}{l}5.0 \\
6.0 \\
6.5 \\
1.0 \\
6.0\end{array}$ & $\begin{array}{l}5.0 \\
5.0 \\
6.0 \\
6.0 \\
6.0\end{array}$ & $\begin{array}{l}4.0 \\
4.5 \\
4.5 \\
5.5 \\
5.0\end{array}$ & $\begin{array}{l}11.5 \\
11.5 \\
10.5 \\
11.0 \\
11.0\end{array}$ & $\begin{array}{r}10.5 \\
10.0 \\
8.5 \\
9.5 \\
10.5\end{array}$ \\
\hline $\begin{array}{l}26 \\
27 \\
28 \\
29 \\
30 \\
31\end{array}$ & $\begin{array}{r}13.0 \\
10.5 \\
10.5 \\
10.5 \\
9.0 \\
8.0\end{array}$ & $\begin{array}{r}10.5 \\
9.0 \\
9.5 \\
9.0 \\
7.0 \\
7.0\end{array}$ & $\begin{array}{r}7.0 \\
7.0 \\
10.5 \\
11.0 \\
10.5 \\
.0\end{array}$ & $\begin{array}{r}5.0 \\
5.5 \\
7.0 \\
10.5 \\
9.0 \\
-.-\end{array}$ & $\begin{array}{l}3.5 \\
4.5 \\
8.0 \\
8.0 \\
6.0 \\
5.5\end{array}$ & $\begin{array}{l}3.0 \\
3.0 \\
4.5 \\
6.0 \\
4.5 \\
4.5\end{array}$ & $\begin{array}{l}6.0 \\
4.5 \\
4.5 \\
4.0 \\
7.0 \\
9.5\end{array}$ & $\begin{array}{l}4.5 \\
4.5 \\
4.0 \\
4.0 \\
4.0 \\
7.0\end{array}$ & $\begin{array}{r}6.0 \\
6.0 \\
6.0 \\
=- \\
=-\end{array}$ & $\begin{array}{r}5.0 \\
5.0 \\
5.0 \\
-- \\
-- \\
--\end{array}$ & $\begin{array}{r}11.0 \\
9.5 \\
9.5 \\
11.0 \\
13.0 \\
12.0\end{array}$ & $\begin{array}{r}9.0 \\
8.0 \\
7.0 \\
9.0 \\
10.5 \\
10.5\end{array}$ \\
\hline AVG & 15.0 & 14.0 & 9.0 & 7.5 & 5.5 & 4.0 & 4.0 & 3.0 & 6.0 & 5.0 & B. 5 & 7.0 \\
\hline \multirow[t]{2}{*}{ DAY } & \multicolumn{2}{|c|}{$A P R$} & \multicolumn{2}{|c|}{ MAY } & \multicolumn{2}{|c|}{ JUN } & \multicolumn{2}{|c|}{ JUL } & \multicolumn{2}{|c|}{ AUG } & \multicolumn{2}{|c|}{ SEP } \\
\hline & $\operatorname{MAX}$ & MI N & $\operatorname{MAX}$ & MIN & $\max$ & MIN & MAX & MIN & MAX & MIN & $\max$ & MIN \\
\hline $\begin{array}{l}1 \\
2 \\
3 \\
4 \\
5\end{array}$ & $\begin{array}{l}11.5 \\
13.5 \\
15.5 \\
15.5 \\
14.5\end{array}$ & $\begin{array}{r}9.5 \\
11.0 \\
13.5 \\
14.5 \\
14.0\end{array}$ & $\begin{array}{l}16.0 \\
15.0 \\
15.5 \\
16.5 \\
17.0\end{array}$ & $\begin{array}{l}14.5 \\
14.0 \\
14.0 \\
14.5 \\
15.0\end{array}$ & $\begin{array}{l}20.5 \\
20.5 \\
20.0 \\
18.5 \\
18.0\end{array}$ & $\begin{array}{l}19.5 \\
20.0 \\
18.5 \\
16.5 \\
16.5\end{array}$ & $\begin{array}{l}25.0 \\
24.0 \\
24.0 \\
24.0 \\
24.5\end{array}$ & $\begin{array}{l}23.5 \\
22.0 \\
22.0 \\
22.0 \\
23.0\end{array}$ & $\begin{array}{l}23.0 \\
22.0 \\
21.5 \\
20.5 \\
20.5\end{array}$ & $\begin{array}{l}21.0 \\
21.5 \\
20.5 \\
20.0 \\
19.0\end{array}$ & $\begin{array}{l}20.5 \\
20.5 \\
21.0 \\
20.5 \\
20.5\end{array}$ & $\begin{array}{l}20.5 \\
20.5 \\
20.5 \\
20.0 \\
20.0\end{array}$ \\
\hline $\begin{array}{r}6 \\
7 \\
8 \\
9 \\
10\end{array}$ & $\begin{array}{l}15.0 \\
15.0 \\
15.0 \\
15.0 \\
15.0\end{array}$ & $\begin{array}{l}14.0 \\
13.0 \\
13.0 \\
13.5 \\
14.5\end{array}$ & $\begin{array}{l}17.0 \\
18.5 \\
18.5 \\
18.5 \\
18.5\end{array}$ & $\begin{array}{l}15.5 \\
16.0 \\
17.0 \\
17.0 \\
15.5\end{array}$ & $\begin{array}{l}19.0 \\
20.0 \\
21.0 \\
20.5 \\
20.5\end{array}$ & $\begin{array}{l}17.0 \\
18.5 \\
19.5 \\
20.0 \\
19.5\end{array}$ & $\begin{array}{l}24.5 \\
24.5 \\
24.0 \\
24.0 \\
23.5\end{array}$ & $\begin{array}{l}23.5 \\
23.5 \\
23.0 \\
22.0 \\
21.5\end{array}$ & $\begin{array}{l}21.0 \\
21.0 \\
22.0 \\
23.0 \\
24.0\end{array}$ & $\begin{array}{l}20.0 \\
20.0 \\
20.5 \\
21.5 \\
22.0\end{array}$ & $\begin{array}{l}21.0 \\
21.0 \\
21.0 \\
20.5 \\
20.5\end{array}$ & $\begin{array}{l}20.5 \\
20.0 \\
20.5 \\
20.5 \\
19.5\end{array}$ \\
\hline $\begin{array}{l}11 \\
12 \\
13 \\
14 \\
15\end{array}$ & $\begin{array}{l}17.0 \\
16.5 \\
16.0 \\
15.5 \\
13.5\end{array}$ & $\begin{array}{l}14.0 \\
15.0 \\
15.0 \\
13.5 \\
13.0\end{array}$ & $\begin{array}{l}16.0 \\
15.5 \\
15.0 \\
16.0 \\
16.5\end{array}$ & $\begin{array}{l}15.0 \\
13.5 \\
13.0 \\
14.5 \\
16.0\end{array}$ & $\begin{array}{l}20.5 \\
21.00 \\
21.0 \\
21.0 \\
21.0\end{array}$ & $\begin{array}{l}19.0 \\
20.0 \\
20.0 \\
20.0 \\
20.5\end{array}$ & $\begin{array}{l}23.5 \\
24.0 \\
24.0 \\
23.5 \\
23.5\end{array}$ & $\begin{array}{l}22.0 \\
22.0 \\
21.5 \\
21.5 \\
21.5\end{array}$ & $\begin{array}{l}23.5 \\
21.5 \\
21.5 \\
21.0 \\
21.0\end{array}$ & $\begin{array}{l}21.0 \\
20.5 \\
20.5 \\
20.5 \\
20.5\end{array}$ & $\begin{array}{l}19.5 \\
18.0 \\
18.0 \\
18.0 \\
18.5\end{array}$ & $\begin{array}{l}17.0 \\
17.0 \\
16.5 \\
16.5 \\
16.5\end{array}$ \\
\hline $\begin{array}{l}16 \\
17 \\
18 \\
19 \\
20\end{array}$ & $\begin{array}{l}15.5 \\
16.0 \\
16.0 \\
16.0 \\
15.0\end{array}$ & $\begin{array}{l}13.0 \\
14.0 \\
15.5 \\
14.5 \\
13.0\end{array}$ & $\begin{array}{l}16.5 \\
16.0 \\
16.0 \\
16.5 \\
18.5\end{array}$ & $\begin{array}{l}15.5 \\
15.5 \\
15.5 \\
16.0 \\
16.5\end{array}$ & $\begin{array}{l}21.0 \\
21.0 \\
20.5 \\
21.5 \\
21.5\end{array}$ & $\begin{array}{l}20.5 \\
20.0 \\
19.5 \\
20.5 \\
20.0\end{array}$ & $\begin{array}{l}23.0 \\
23.0 \\
24.0 \\
24.5 \\
24.5\end{array}$ & $\begin{array}{l}21.5 \\
21.5 \\
23.0 \\
23.5 \\
24.0\end{array}$ & $\begin{array}{l}21.5 \\
22.0 \\
23.5 \\
24.0 \\
24.0\end{array}$ & $\begin{array}{l}20.5 \\
21.5 \\
21.5 \\
23.0 \\
23.0\end{array}$ & $\begin{array}{l}19.0 \\
19.5 \\
20.5 \\
20.5 \\
18.0\end{array}$ & $\begin{array}{l}18.0 \\
18.5 \\
19.5 \\
18.0 \\
16.5\end{array}$ \\
\hline $\begin{array}{l}21 \\
22 \\
23 \\
24 \\
25\end{array}$ & $\begin{array}{l}14.0 \\
14.0 \\
14.0 \\
12.0 \\
13.5\end{array}$ & $\begin{array}{l}12.0 \\
13.5 \\
11.5 \\
11.0 \\
11.0\end{array}$ & $\begin{array}{l}19.0 \\
19.0 \\
19.0 \\
19.0 \\
19.0\end{array}$ & $\begin{array}{l}18.0 \\
18.5 \\
18.0 \\
18.5 \\
18.0\end{array}$ & $\begin{array}{l}20.5 \\
20.5 \\
20.5 \\
21.0 \\
23.0\end{array}$ & $\begin{array}{l}19.0 \\
20.0 \\
20.0 \\
19.5 \\
20.5\end{array}$ & $\begin{array}{l}24.5 \\
24.5 \\
24.0 \\
23.5 \\
23.0\end{array}$ & $\begin{array}{l}23.5 \\
23.5 \\
23.5 \\
22.0 \\
21.5\end{array}$ & $\begin{array}{l}23.5 \\
22.0 \\
20.0 \\
19.5 \\
20.0\end{array}$ & $\begin{array}{l}21.5 \\
20.0 \\
18.5 \\
18.5 \\
18.5\end{array}$ & $\begin{array}{l}16.5 \\
17.0 \\
18.0 \\
18.0 \\
18.5\end{array}$ & $\begin{array}{l}16.0 \\
16.0 \\
17.0 \\
18.0 \\
17.0\end{array}$ \\
\hline $\begin{array}{l}26 \\
27 \\
28 \\
29 \\
30 \\
31\end{array}$ & $\begin{array}{r}15.0 \\
16.0 \\
16.5 \\
17.0 \\
17.0 \\
=-\end{array}$ & $\begin{array}{r}13.0 \\
14.0 \\
15.5 \\
16.0 \\
15.0 \\
=-\end{array}$ & $\begin{array}{l}19.5 \\
19.5 \\
18.0 \\
19.5 \\
20.0 \\
20.5\end{array}$ & $\begin{array}{l}18.5 \\
18.0 \\
16.5 \\
17.0 \\
18.5 \\
19.5\end{array}$ & $\begin{array}{r}23.5 \\
24.5 \\
25.0 \\
25.0 \\
25.0 \\
\ldots\end{array}$ & $\begin{array}{r}21.5 \\
23.0 \\
23.5 \\
23.5 \\
23.5 \\
--\end{array}$ & $\begin{array}{l}23.5 \\
24.5 \\
25.0 \\
25.0 \\
23.5 \\
23.5\end{array}$ & $\begin{array}{l}21.5 \\
23.0 \\
24.0 \\
23.0 \\
21.5 \\
21.5\end{array}$ & $\begin{array}{l}20.5 \\
21.0 \\
20.5 \\
20.0 \\
20.0 \\
20.5\end{array}$ & $\begin{array}{l}19.0 \\
19.5 \\
19.5 \\
19.0 \\
19.0 \\
20.0\end{array}$ & $\begin{array}{r}18.5 \\
19.0 \\
19.0 \\
18.5 \\
16.5 \\
-.\end{array}$ & $\begin{array}{r}18.0 \\
18.0 \\
18.0 \\
16.5 \\
15.0 \\
--\end{array}$ \\
\hline AVG & 15.0 & 13.5 & 17.5 & 16.0 & 21.5 & 20.0 & 24.0 & 22.5 & 21.5 & 20.5 & 19.0 & 18.0 \\
\hline
\end{tabular}


SANTEE RIVER "BASIN

02143500 INDIAN CREEK NEAR LABORATORY, N. C.--COntinued

TEMPERATURE ( $\left.{ }^{\circ} \mathrm{C}\right)$ OF WATER, WATER YEAR OCTOBER 1969 TO SEPTEMBER 1970

\begin{tabular}{|c|c|c|c|c|c|c|c|c|c|c|c|c|}
\hline \multirow[t]{2}{*}{ DAY } & \multicolumn{2}{|c|}{$O C T$} & \multicolumn{2}{|c|}{ NOV } & \multicolumn{2}{|c|}{ DEC } & \multicolumn{2}{|c|}{ JAN } & \multicolumn{2}{|c|}{ FEB } & \multicolumn{2}{|c|}{ MAR } \\
\hline & $\max$ & MIN & $\max$ & MIN & $\operatorname{MÁx}$ & MIN & $\max$ & MIN & $\max$ & MIN & $\max$ & MIN \\
\hline $\begin{array}{l}1 \\
2 \\
3 \\
4 \\
5\end{array}$ & $\begin{array}{l}16.0 \\
19.0 \\
19.0 \\
18.5 \\
18.0\end{array}$ & $\begin{array}{l}15.5 \\
16.0 \\
18.0 \\
17.0 \\
16.5\end{array}$ & $\begin{array}{l}=- \\
=- \\
=-\end{array}$ & $=$ & $\begin{array}{l}6.0 \\
5.5 \\
5.0 \\
4.5 \\
4.0\end{array}$ & $\begin{array}{l}5.0 \\
4.5 \\
4.5 \\
4.0 \\
3.0\end{array}$ & $\begin{array}{l}9.5 \\
7.0 \\
5.5 \\
5.0 \\
4.0\end{array}$ & $\begin{array}{l}7.0 \\
5.5 \\
5.0 \\
4.0 \\
3.0\end{array}$ & $\begin{array}{l}5.0 \\
8.5 \\
8.5 \\
6.0 \\
4.0\end{array}$ & $\begin{array}{l}4.0 \\
4.5 \\
6.0 \\
4.0 \\
3.5\end{array}$ & $\begin{array}{r}8.5 \\
10.5 \\
10.5 \\
10.5 \\
11.0\end{array}$ & $\begin{array}{r}7.0 \\
8.5 \\
9.5 \\
10.5 \\
10.5\end{array}$ \\
\hline $\begin{array}{r}6 \\
7 \\
8 \\
9 \\
10\end{array}$ & $\begin{array}{r}16.5 \\
17.0 \\
18.0 \\
17.0 \\
--\end{array}$ & $\begin{array}{r}16.0 \\
16.0 \\
17.0 \\
16.0 \\
-.-\end{array}$ & $\begin{array}{l}= \\
=- \\
=-\end{array}$ & $\begin{array}{l}= \\
= \\
=\end{array}$ & $\begin{array}{l}4.0 \\
4.5 \\
6.0 \\
7.0 \\
7.0\end{array}$ & $\begin{array}{l}3.0 \\
4.0 \\
4.5 \\
6.0 \\
6.5\end{array}$ & $\begin{array}{l}3.5 \\
4.0 \\
4.0 \\
1.5 \\
1.5\end{array}$ & $\begin{array}{l}3.0 \\
3.0 \\
1.5 \\
1.5 \\
1.5\end{array}$ & $\begin{array}{l}4.0 \\
5.0 \\
6.0 \\
7.0 \\
7.0\end{array}$ & $\begin{array}{l}3.0 \\
4.0 \\
5.0 \\
6.0 \\
6.0\end{array}$ & $\begin{array}{l}11.0 \\
10.5 \\
10.0 \\
10.5 \\
10.5\end{array}$ & $\begin{array}{r}10.0 \\
9.0 \\
8.5 \\
9.0 \\
9.0\end{array}$ \\
\hline $\begin{array}{l}11 \\
12 \\
13 \\
14 \\
15\end{array}$ & $\begin{array}{l}=- \\
=- \\
=- \\
--\end{array}$ & $\begin{array}{l}=- \\
\ddot{-} \\
= \\
--\end{array}$ & $\begin{array}{l}= \\
=- \\
=-\end{array}$ & $\begin{array}{l}= \\
= \\
=\end{array}$ & $\begin{array}{l}8.5 \\
8.5 \\
6.5 \\
6.5 \\
6.5\end{array}$ & $\begin{array}{l}6.5 \\
6.5 \\
6.0 \\
6.0 \\
5.5\end{array}$ & $\begin{array}{l}1.5 \\
1.5 \\
1.5 \\
2.0 \\
3.0\end{array}$ & $\begin{array}{l}1.5 \\
1.5 \\
1.0 \\
1.5 \\
1.0\end{array}$ & $\begin{array}{l}6.0 \\
5.5 \\
5.0 \\
5.5 \\
6.0\end{array}$ & $\begin{array}{l}4.5 \\
4.5 \\
4.0 \\
4.5 \\
5.0\end{array}$ & $\begin{array}{r}11.0 \\
11.0 \\
10.5 \\
9.5 \\
8.5\end{array}$ & $\begin{array}{r}9.5 \\
10.5 \\
9.5 \\
6.5 \\
6.0\end{array}$ \\
\hline $\begin{array}{l}16 \\
17 \\
18 \\
19 \\
20\end{array}$ & $\begin{array}{l}= \\
=- \\
=- \\
=-\end{array}$ & $\begin{array}{l}=- \\
=- \\
=-\end{array}$ & $\begin{array}{r}-5 \\
6.0 \\
8.5 \\
10.5 \\
10.0\end{array}$ & $\begin{array}{l}-.5 \\
4.5 \\
6.0 \\
8.5 \\
8.0\end{array}$ & $\begin{array}{l}5.5 \\
4.5 \\
4.0 \\
4.5 \\
4.5\end{array}$ & $\begin{array}{l}4.5 \\
4.0 \\
3.5 \\
4.0 \\
4.0\end{array}$ & $\begin{array}{l}3.5 \\
4.0 \\
6.5 \\
6.5 \\
6.0\end{array}$ & $\begin{array}{l}3.0 \\
3.5 \\
4.5 \\
6.0 \\
5.0\end{array}$ & $\begin{array}{l}6.0 \\
6.0 \\
8.5 \\
8.5 \\
8.5\end{array}$ & $\begin{array}{l}6.0 \\
5.5 \\
6.0 \\
7.0 \\
6.0\end{array}$ & $\begin{array}{l}6.0 \\
6.5 \\
9.0 \\
9.0 \\
9.0\end{array}$ & $\begin{array}{l}5.0 \\
5.0 \\
6.5 \\
9.0 \\
9.0\end{array}$ \\
\hline $\begin{array}{l}21 \\
22 \\
23 \\
24 \\
25\end{array}$ & $\begin{array}{r}21.0 \\
=- \\
=-\end{array}$ & $\begin{array}{r}10.0 \\
=- \\
--\end{array}$ & $\begin{array}{l}9.0 \\
6.0 \\
7.0 \\
9.5 \\
9.0\end{array}$ & $\begin{array}{l}6.0 \\
5.0 \\
5.5 \\
7.0 \\
8.0\end{array}$ & $\begin{array}{l}4.0 \\
5.0 \\
5.0 \\
5.0 \\
5.0\end{array}$ & $\begin{array}{r}4.0 \\
4.0 \\
4.5 \\
4.5 \\
3.5\end{array}$ & $\begin{array}{l}5.0 \\
2.0 \\
1.5 \\
1.5 \\
3.5\end{array}$ & $\begin{array}{l}2.0 \\
1.5 \\
1.5 \\
1.5 \\
1.5\end{array}$ & $\begin{array}{l}6.0 \\
6.0 \\
8.5 \\
8.5 \\
7.0\end{array}$ & $\begin{array}{l}4.5 \\
4.5 \\
6.0 \\
6.5 \\
7.0\end{array}$ & $\begin{array}{r}9.0 \\
9.0 \\
8.5 \\
8.5 \\
10.5\end{array}$ & $\begin{array}{l}9.0 \\
8.5 \\
7.0 \\
7.0 \\
8.0\end{array}$ \\
\hline $\begin{array}{l}26 \\
27 \\
28 \\
29 \\
30 \\
31\end{array}$ & $\begin{array}{l}=- \\
=- \\
=- \\
=-\end{array}$ & $\begin{array}{l}=- \\
=- \\
=- \\
-=\end{array}$ & $\begin{array}{l}9.0 \\
8.5 \\
8.5 \\
6.5 \\
8.0 \\
-.\end{array}$ & $\begin{array}{r}7.0 \\
7.0 \\
8.0 \\
7.0 \\
6.0 \\
-0\end{array}$ & $\begin{array}{l}4.0 \\
4.0 \\
5.0 \\
6.5 \\
8.5 \\
9.5\end{array}$ & $\begin{array}{l}3.0 \\
3.5 \\
3.5 \\
5.0 \\
6.5 \\
8.5\end{array}$ & $\begin{array}{l}6.0 \\
6.0 \\
6.0 \\
9.5 \\
9.5 \\
7.0\end{array}$ & $\begin{array}{l}3.5 \\
5.5 \\
5.0 \\
6.0 \\
7.0 \\
5.0\end{array}$ & $\begin{array}{l}7.0 \\
5.5 \\
7.0 \\
-= \\
=-\end{array}$ & $\begin{array}{r}5.0 \\
4.5 \\
5.5 \\
-- \\
--\end{array}$ & $\begin{array}{l}10.5 \\
10.5 \\
10.5 \\
13.5 \\
13.5 \\
10.5\end{array}$ & $\begin{array}{r}10.5 \\
8.5 \\
8.5 \\
10.5 \\
9.0 \\
8.0\end{array}$ \\
\hline AVG & -- & - & -- & + & 5.5 & 4.5 & 4.5 & 3.5 & 6.5 & 5.0 & 10.0 & 8.5 \\
\hline \multirow[t]{2}{*}{ DAY } & \multicolumn{2}{|c|}{$\triangle P R$} & \multicolumn{2}{|c|}{ MAY } & \multicolumn{2}{|c|}{ JUN } & \multicolumn{2}{|c|}{ JUL } & \multicolumn{2}{|c|}{ AUG } & \multicolumn{2}{|c|}{ SEP } \\
\hline & MAX & MIN & $\max$ & MIN & MAX & MIN & $\max$ & MIN & $\operatorname{MAX}$ & MIN & $\max$ & $\operatorname{MrN}$ \\
\hline $\begin{array}{l}1 \\
2 \\
3 \\
4 \\
5\end{array}$ & $\begin{array}{l}10.5 \\
12.0 \\
12.0 \\
10.5 \\
10.5\end{array}$ & $\begin{array}{l}9.5 \\
9.5 \\
9.0 \\
9.0 \\
9.5\end{array}$ & $\begin{array}{l}19.0 \\
18.5 \\
18.0 \\
15.5 \\
15.0\end{array}$ & $\begin{array}{l}17.0 \\
17.0 \\
15.5 \\
14.0 \\
13.0\end{array}$ & $\begin{array}{l}19.5 \\
20.5 \\
20.5 \\
20.5 \\
20.0\end{array}$ & $\begin{array}{l}18.5 \\
19.5 \\
19.5 \\
19.5 \\
19.0\end{array}$ & $\begin{array}{l}23.0 \\
23.0 \\
23.5 \\
23.5 \\
23.0\end{array}$ & $\begin{array}{l}20.5 \\
21.5 \\
21.5 \\
22.0 \\
21.5\end{array}$ & $\begin{array}{l}24.5 \\
24.0 \\
24.0 \\
24.0 \\
24.0\end{array}$ & $\begin{array}{l}23.0 \\
23.0 \\
22.0 \\
23.0 \\
22.0\end{array}$ & $\begin{array}{l}23.5 \\
23.0 \\
23.0 \\
23.5 \\
23.5\end{array}$ & $\begin{array}{l}23.0 \\
22.0 \\
22.0 \\
22.0 \\
23.0\end{array}$ \\
\hline $\begin{array}{r}6 \\
7 \\
8 \\
9 \\
10\end{array}$ & $\begin{array}{l}10.5 \\
11.0 \\
11.5 \\
14.0 \\
14.0\end{array}$ & $\begin{array}{r}9.5 \\
9.0 \\
9.5 \\
11.0 \\
12.0\end{array}$ & $\begin{array}{l}16.0 \\
16.0 \\
16.0 \\
17.0 \\
18.0\end{array}$ & $\begin{array}{l}14.5 \\
13.5 \\
13.5 \\
15.5 \\
16.5\end{array}$ & $\begin{array}{l}19.5 \\
19.5 \\
19.5 \\
19.5 \\
20.0\end{array}$ & $\begin{array}{l}18.5 \\
18.5 \\
18.0 \\
18.0 \\
18.5\end{array}$ & $\begin{array}{l}21.5 \\
21.5 \\
21.0 \\
22.0 \\
22.0\end{array}$ & $\begin{array}{l}20.0 \\
20.0 \\
20.0 \\
21.0 \\
21.5\end{array}$ & $\begin{array}{l}23.0 \\
22.0 \\
22.0 \\
21.5 \\
21.0\end{array}$ & $\begin{array}{l}22.0 \\
21.5 \\
21.5 \\
21.0 \\
20.5\end{array}$ & $\begin{array}{l}23.0 \\
22.0 \\
20.5 \\
21.5 \\
22.0\end{array}$ & $\begin{array}{l}21.5 \\
20.5 \\
19.5 \\
20.5 \\
21.0\end{array}$ \\
\hline $\begin{array}{l}11 \\
12 \\
13 \\
14 \\
15\end{array}$ & $\begin{array}{l}14.0 \\
14.0 \\
14.0 \\
14.5 \\
15.0\end{array}$ & $\begin{array}{l}11.0 \\
12.0 \\
14.0 \\
13.0 \\
11.5\end{array}$ & $\begin{array}{l}18.0 \\
17.0 \\
19.5 \\
19.5 \\
20.0\end{array}$ & $\begin{array}{l}17.0 \\
16.0 \\
17.0 \\
18.5 \\
19.0\end{array}$ & $\begin{array}{l}20.0 \\
20.0 \\
20.5 \\
20.5 \\
19.5\end{array}$ & $\begin{array}{l}19.0 \\
19.0 \\
19.5 \\
19.5 \\
19.0\end{array}$ & $\begin{array}{l}22.0 \\
23.0 \\
23.0 \\
23.0 \\
23.5\end{array}$ & $\begin{array}{l}21.5 \\
21.0 \\
21.5 \\
22.0 \\
21.5\end{array}$ & $\begin{array}{l}20.5 \\
20.0 \\
19.5 \\
20.5 \\
21.0\end{array}$ & $\begin{array}{l}19.5 \\
19.5 \\
19.5 \\
19.5 \\
20.0\end{array}$ & $\begin{array}{l}22.0 \\
22.0 \\
20.5 \\
20.5 \\
21.0\end{array}$ & $\begin{array}{l}21.5 \\
20.0 \\
19.5 \\
20.0 \\
20.0\end{array}$ \\
\hline $\begin{array}{l}16 \\
17 \\
18 \\
19 \\
20\end{array}$ & $\begin{array}{l}15.0 \\
15.0 \\
17.0 \\
17.0 \\
17.0\end{array}$ & $\begin{array}{l}13.0 \\
14.0 \\
14.0 \\
15.0 \\
14.5\end{array}$ & $\begin{array}{l}20.0 \\
19.0 \\
18.0 \\
17.0 \\
18.0\end{array}$ & $\begin{array}{l}19.0 \\
16.5 \\
15.5 \\
15.5 \\
16.0\end{array}$ & $\begin{array}{l}20.5 \\
21.5 \\
23.0 \\
23.5 \\
23.5\end{array}$ & $\begin{array}{l}19.0 \\
20.0 \\
21.0 \\
21.5 \\
21.5\end{array}$ & $\begin{array}{l}24.0 \\
23.5 \\
22.0 \\
23.5 \\
23.5\end{array}$ & $\begin{array}{l}22.0 \\
21.0 \\
21.0 \\
21.5 \\
22.0\end{array}$ & $\begin{array}{l}21.5 \\
21.5 \\
22.0 \\
22.0 \\
22.0\end{array}$ & $\begin{array}{l}20.5 \\
21.0 \\
21.0 \\
21.0 \\
21.0\end{array}$ & $\begin{array}{l}21.0 \\
21.0 \\
21.5 \\
22.0 \\
22.0\end{array}$ & $\begin{array}{l}20.5 \\
20.0 \\
20.5 \\
21.0 \\
21.0\end{array}$ \\
\hline $\begin{array}{l}21 \\
22 \\
23 \\
24 \\
25\end{array}$ & $\begin{array}{l}18.0 \\
17.0 \\
18.5 \\
19.0 \\
18.5\end{array}$ & $\begin{array}{l}15.5 \\
15.0 \\
16.0 \\
18.5 \\
16.0\end{array}$ & $\begin{array}{l}19.5 \\
20.5 \\
21.0 \\
21.0 \\
21.0\end{array}$ & $\begin{array}{l}16.5 \\
19.0 \\
19.5 \\
19.5 \\
19.5\end{array}$ & $\begin{array}{l}22.0 \\
22.0 \\
21.5 \\
22.0 \\
22.0\end{array}$ & $\begin{array}{l}20.5 \\
21.0 \\
21.0 \\
20.5 \\
21.0\end{array}$ & $\begin{array}{l}23.5 \\
21.5 \\
21.0 \\
22.0 \\
23.0\end{array}$ & $\begin{array}{l}21.5 \\
19.5 \\
19.5 \\
21.0 \\
21.5\end{array}$ & $\begin{array}{l}22.0 \\
22.0 \\
21.5 \\
21.5 \\
21.5\end{array}$ & $\begin{array}{l}21.5 \\
21.5 \\
21.0 \\
21.0 \\
20.5\end{array}$ & $\begin{array}{l}21.5 \\
22.0 \\
22.0 \\
22.0 \\
21.5\end{array}$ & $\begin{array}{l}20.5 \\
21.0 \\
21.0 \\
21.0 \\
21.0\end{array}$ \\
\hline $\begin{array}{l}26 \\
27 \\
28 \\
29 \\
3 c \\
31\end{array}$ & $\begin{array}{r}16.5 \\
16.5 \\
17.0 \\
18.5 \\
19.0 \\
--\end{array}$ & $\begin{array}{r}16.0 \\
15.5 \\
16.5 \\
15.0 \\
19.0 \\
.--\end{array}$ & $\begin{array}{l}19.5 \\
19.5 \\
19.5 \\
19.5 \\
19.0 \\
18.5\end{array}$ & $\begin{array}{l}19.0 \\
18.5 \\
18.5 \\
19.0 \\
18.5 \\
18.0\end{array}$ & $\begin{array}{r}22.0 \\
23.0 \\
21.5 \\
19.5 \\
20.5 \\
.-\end{array}$ & $\begin{array}{r}20.5 \\
21.5 \\
19.5 \\
18.5 \\
18.5 \\
.--\end{array}$ & $\begin{array}{l}23.0 \\
23.0 \\
23.0 \\
23.5 \\
23.5 \\
24.0\end{array}$ & $\begin{array}{l}21.5 \\
22.0 \\
21.5 \\
22.0 \\
23.0 \\
22.0\end{array}$ & $\begin{array}{l}21.0 \\
21.0 \\
21.5 \\
21.5 \\
23.0 \\
23.5\end{array}$ & $\begin{array}{l}20.5 \\
20.5 \\
20.5 \\
20.5 \\
21.5 \\
21.5\end{array}$ & $\begin{array}{r}21.5 \\
21.5 \\
21.0 \\
19.0 \\
16.5 \\
-.-\end{array}$ & $\begin{array}{r}21.0 \\
21.0 \\
19.0 \\
16.5 \\
16.0 \\
\\
. .0\end{array}$ \\
\hline$A \vee G$ & 15.0 & 13.0 & 18.5 & 17.0 & 21.0 & 19.5 & 22.5 & 21.5 & 22.0 & 21.0 & 21.5 & 20.5 \\
\hline
\end{tabular}


02145442 SOUTH FORK CATAFBA RIVER NEAR ELMORES CROSSROADS, N. C.

LOCATION,--Lat $35^{\circ} 10^{\prime} 00^{\prime \prime}$, long $81^{\circ} 02^{\prime} 18^{\prime \prime}$, Gaston County, water-quality recorder at Lower Armstrong Bridge on Secondary Road $2524,1.0$ mile above mouth, and 5.2 miles southeast of Elmores Crossroads.

DRA INAGE AREA. $--660 \mathrm{sq} \mathrm{mi}$.

PERIOD OF RECORD. --Water temperatures: November 1969 to September 1970.

EXTREMES, - - 1969-70:

Water temperatures: Maximum, $37.0^{\circ} \mathrm{C}$ Aug. 3 ; minimum, $6.5^{\circ} \mathrm{C}$ Jan, 11.

TEMPERATURE $\left({ }^{\circ} \mathrm{C}\right)$ OF NATER, NOVEMBER 1969 TO SEPTEMBER 1970

\begin{tabular}{|c|c|c|c|c|c|c|c|c|c|c|c|c|}
\hline \multirow[t]{2}{*}{ DAY } & \multicolumn{2}{|c|}{ OCT } & \multicolumn{2}{|c|}{ NOV } & \multicolumn{2}{|c|}{ DEC } & \multicolumn{2}{|c|}{ JAN } & \multicolumn{2}{|c|}{ FEB } & \multicolumn{2}{|c|}{ MAR } \\
\hline & MAX & MI N & $\operatorname{MAX}$ & MIN & MAX & $\mathrm{MIN}$ & $\max$ & MIN & $\operatorname{Max}$ & MIN & MAX & MIN \\
\hline $\begin{array}{l}1 \\
2 \\
3 \\
4 \\
5\end{array}$ & $\begin{array}{l}= \\
\ddot{-} \\
=\end{array}$ & $\begin{array}{l}=- \\
=- \\
=-\end{array}$ & $\begin{array}{l}= \\
= \\
=\end{array}$ & 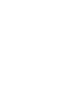 & $\begin{array}{r}16.0 \\
16.0 \\
16.0 \\
15.0 \\
15.0\end{array}$ & $\begin{array}{l}13.0 \\
12.0 \\
12.0 \\
12.0 \\
12.0\end{array}$ & $\begin{array}{l}15.5 \\
14.5 \\
14.5 \\
13.5 \\
13.5\end{array}$ & $\begin{array}{l}13.5 \\
13.0 \\
13.5 \\
11.5 \\
12.0\end{array}$ & $\begin{array}{l}14.0 \\
16.5 \\
17.0 \\
15.0 \\
16.0\end{array}$ & $\begin{array}{l}12.0 \\
11.0 \\
14.5 \\
12.0 \\
10.0\end{array}$ & $\begin{array}{l}18.5 \\
19.5 \\
19.5 \\
20.0 \\
21.5\end{array}$ & $\begin{array}{l}16.0 \\
16.0 \\
17.0 \\
17.0 \\
19.5\end{array}$ \\
\hline $\begin{array}{r}6 \\
7 \\
8 \\
9 \\
10\end{array}$ & $\begin{array}{l}= \\
=- \\
=\end{array}$ & $\begin{array}{l}=- \\
=- \\
=-\end{array}$ & $\begin{array}{r}=- \\
20.5 \\
20.0 \\
20.0 \\
20.0\end{array}$ & $\begin{array}{r}-0 \\
20.0 \\
18.0 \\
18.5 \\
18.0\end{array}$ & $\begin{array}{l}14.5 \\
14.5 \\
16.5 \\
16.5 \\
16.0\end{array}$ & $\begin{array}{l}13.5 \\
13.0 \\
13.5 \\
15.0 \\
12.0\end{array}$ & $\begin{array}{l}12.0 \\
11.5 \\
11.0 \\
10.0 \\
10.5\end{array}$ & $\begin{array}{r}11.0 \\
11.0 \\
9.0 \\
8.0 \\
8.5\end{array}$ & $\begin{array}{l}15.5 \\
15.5 \\
15.5 \\
15.0 \\
15.5\end{array}$ & $\begin{array}{l}13.0 \\
14.5 \\
13.0 \\
12.0 \\
13.5\end{array}$ & $\begin{array}{l}21.0 \\
20.5 \\
20.0 \\
20.5 \\
21.0\end{array}$ & $\begin{array}{l}19.0 \\
18.0 \\
18.5 \\
18.0 \\
18.5\end{array}$ \\
\hline $\begin{array}{l}11 \\
12 \\
13 \\
14 \\
15\end{array}$ & $\begin{array}{l}= \\
\ddot{-} \\
=\end{array}$ & $\begin{array}{l}= \\
=- \\
=\end{array}$ & $\begin{array}{l}20.0 \\
20.5 \\
20.0 \\
19.5 \\
18.0\end{array}$ & $\begin{array}{l}18.5 \\
18.5 \\
19.0 \\
16.0 \\
16.0\end{array}$ & $\begin{array}{l}14.0 \\
13.5 \\
13.5 \\
13.0 \\
13.5\end{array}$ & $\begin{array}{r}10.0 \\
10.5 \\
9.5 \\
9.5 \\
11.0\end{array}$ & $\begin{array}{r}10.0 \\
11.5 \\
12.0 \\
12.0 \\
-\end{array}$ & $\begin{array}{r}6.5 \\
7.0 \\
10.5 \\
10.0 \\
=-\end{array}$ & $\begin{array}{l}15.5 \\
16.0 \\
16.0 \\
16.0 \\
15.5\end{array}$ & $\begin{array}{l}12.0 \\
14.5 \\
14.0 \\
15.0 \\
14.0\end{array}$ & $\begin{array}{l}22.0 \\
21.5 \\
20.5 \\
19.5 \\
18.5\end{array}$ & $\begin{array}{l}19.5 \\
20.0 \\
19.0 \\
18.0 \\
16.0\end{array}$ \\
\hline $\begin{array}{l}16 \\
17 \\
18 \\
19 \\
20\end{array}$ & $\begin{array}{l}= \\
=- \\
=-\end{array}$ & $\begin{array}{l}=- \\
=- \\
=\end{array}$ & $\begin{array}{l}18.0 \\
18.5 \\
19.5 \\
19.5 \\
19.5\end{array}$ & $\begin{array}{l}15.5 \\
15.0 \\
17.0 \\
17.0 \\
16.5\end{array}$ & $\begin{array}{l}13.5 \\
14.5 \\
14.5 \\
15.5 \\
14.5\end{array}$ & $\begin{array}{l}12.0 \\
12.0 \\
11.5 \\
12.0 \\
13.5\end{array}$ & $\begin{array}{l}= \\
= \\
=\end{array}$ & $\begin{array}{l}= \\
= \\
=\end{array}$ & $\begin{array}{l}15.5 \\
13.0 \\
14.5 \\
15.5 \\
15.0\end{array}$ & $\begin{array}{r}12.0 \\
9.5 \\
8.0 \\
10.0 \\
13.5\end{array}$ & $\begin{array}{l}19.0 \\
18.5 \\
19.5 \\
19.5 \\
18.5\end{array}$ & $\begin{array}{l}16.0 \\
17.0 \\
18.5 \\
18.0 \\
18.0\end{array}$ \\
\hline $\begin{array}{l}21 \\
22 \\
23 \\
24 \\
25\end{array}$ & $\begin{array}{l}=- \\
=- \\
=-\end{array}$ & $\begin{array}{l}=- \\
=- \\
=-\end{array}$ & $\begin{array}{l}18.5 \\
19.0 \\
19.0 \\
19.5 \\
19.0\end{array}$ & $\begin{array}{l}16.0 \\
16.5 \\
16.0 \\
18.0 \\
16.0\end{array}$ & $\begin{array}{l}14.0 \\
13.5 \\
13.5 \\
12.0 \\
11.5\end{array}$ & $\begin{array}{r}11.5 \\
11.0 \\
9.0 \\
10.0 \\
9.0\end{array}$ & $\begin{array}{l}= \\
= \\
=\end{array}$ & $\begin{array}{l}\ddot{-} \\
\ddot{z} \\
\ddot{-}\end{array}$ & $\begin{array}{l}15.5 \\
15.5 \\
18.0 \\
18.0 \\
18.0\end{array}$ & $\begin{array}{l}12.0 \\
12.0 \\
14.5 \\
14.5 \\
15.5\end{array}$ & $\begin{array}{l}18.5 \\
18.5 \\
17.0 \\
18.0 \\
19.0\end{array}$ & $\begin{array}{l}18.0 \\
16.5 \\
15.0 \\
14.5 \\
15.5\end{array}$ \\
\hline $\begin{array}{l}26 \\
27 \\
28 \\
29 \\
30 \\
31\end{array}$ & $\begin{array}{l}=- \\
=- \\
=- \\
--\end{array}$ & $\begin{array}{l}=- \\
=- \\
=- \\
=-\end{array}$ & $\begin{array}{r}19.5 \\
18.5 \\
17.0 \\
16.5 \\
15.0 \\
. .\end{array}$ & $\begin{array}{r}16.0 \\
15.5 \\
15.5 \\
14.0 \\
13.5 \\
-.\end{array}$ & $\begin{array}{l}10.5 \\
10.0 \\
11.0 \\
13.0 \\
13.5 \\
15.0\end{array}$ & $\begin{array}{r}-5.5 \\
8.5 \\
10.0 \\
10.5 \\
10.0\end{array}$ & $\begin{array}{r}=- \\
15.0 \\
14.0 \\
15.5 \\
15.5\end{array}$ & $\begin{array}{r}-- \\
8.5 \\
11.5 \\
14.0 \\
12.0\end{array}$ & $\begin{array}{r}16.0 \\
15.0 \\
19.0 \\
=- \\
=\end{array}$ & $\begin{array}{r}13.5 \\
11.5 \\
14.0 \\
= \\
=-\end{array}$ & $\begin{array}{r}18.5 \\
=- \\
=- \\
=- \\
=-\end{array}$ & $\begin{array}{r}16.5 \\
=- \\
=- \\
=-\end{array}$ \\
\hline AVG & -- & - & 19.0 & 16.5 & 14.0 & 11.5 & -- & - & 16.0 & 12.5 & 19.5 & 17.5 \\
\hline \multirow[t]{2}{*}{ DAY } & \multicolumn{2}{|c|}{ APR } & \multicolumn{2}{|c|}{ mar } & \multicolumn{2}{|c|}{ JUN } & \multicolumn{2}{|c|}{ JUL } & \multicolumn{2}{|c|}{ AUG } & \multicolumn{2}{|c|}{ SEP } \\
\hline & $\max$ & MI N & $\operatorname{MAX}$ & MIN & MAX & MIN & $\operatorname{MAX}$ & MIN & MAX & MI N & MAX & $\operatorname{MIN}$ \\
\hline $\begin{array}{l}1 \\
2 \\
3 \\
4 \\
5\end{array}$ & $\begin{array}{l}= \\
=- \\
=\end{array}$ & $\begin{array}{l}=- \\
=- \\
= \\
-\end{array}$ & $\begin{array}{r}=- \\
-- \\
24.5 \\
26.5\end{array}$ & $\begin{array}{r}=- \\
24.0 \\
24.0\end{array}$ & $\begin{array}{l}30.0 \\
30.5 \\
30.5 \\
30.5 \\
31.5\end{array}$ & $\begin{array}{l}27.0 \\
29.0 \\
29.0 \\
29.5 \\
29.5\end{array}$ & $\begin{array}{l}34.0 \\
35.0 \\
35.0 \\
34.5 \\
34.0\end{array}$ & $\begin{array}{l}31.5 \\
33.5 \\
33.0 \\
31.5 \\
33.0\end{array}$ & $\begin{array}{l}36.0 \\
35.0 \\
37.0 \\
35.5 \\
35.5\end{array}$ & $\begin{array}{l}33.5 \\
33.5 \\
33.0 \\
33.5 \\
34.0\end{array}$ & $\begin{array}{l}35.0 \\
35.0 \\
34.0 \\
34.0 \\
34.0\end{array}$ & $\begin{array}{l}34.0 \\
33.5 \\
33.0 \\
33.0 \\
33.0\end{array}$ \\
\hline $\begin{array}{r}6 \\
7 \\
8 \\
9 \\
10\end{array}$ & $\begin{array}{l}=- \\
=- \\
=\end{array}$ & $\begin{array}{l}=- \\
=- \\
=-\end{array}$ & $\begin{array}{l}26.0 \\
26.5 \\
28.0 \\
28.0 \\
29.5\end{array}$ & $\begin{array}{l}24.5 \\
24.0 \\
25.0 \\
25.0 \\
26.5\end{array}$ & $\begin{array}{r}30.5 \\
29.5 \\
30.5 \\
30.0 \\
-\end{array}$ & $\begin{array}{r}28.5 \\
28.0 \\
28.0 \\
29.5 \\
-.-\end{array}$ & $\begin{array}{l}33.5 \\
33.5 \\
33.0 \\
32.0 \\
33.5\end{array}$ & $\begin{array}{l}30.5 \\
30.5 \\
31.0 \\
31.0 \\
32.0\end{array}$ & $\begin{array}{l}34.0 \\
34.0 \\
33.5 \\
32.0 \\
31.0\end{array}$ & $\begin{array}{l}32.0 \\
33.0 \\
32.0 \\
31.0 \\
25.0\end{array}$ & $\begin{array}{l}34.0 \\
33.5 \\
35.5 \\
33.5 \\
34.5\end{array}$ & $\begin{array}{l}33.5 \\
32.0 \\
32.0 \\
31.5 \\
32.0\end{array}$ \\
\hline $\begin{array}{l}11 \\
12 \\
13 \\
14 \\
15\end{array}$ & $\begin{array}{l}= \\
\because- \\
= \\
=\end{array}$ & $\begin{array}{l}=- \\
=- \\
=-\end{array}$ & $\begin{array}{l}30.0 \\
29.5 \\
30.0 \\
30.0 \\
29.5\end{array}$ & $\begin{array}{l}26.5 \\
27.0 \\
26.5 \\
27.0 \\
27.0\end{array}$ & $\begin{array}{l}= \\
= \\
=\end{array}$ & $\begin{array}{l}= \\
=- \\
\because-\end{array}$ & $\begin{array}{l}35.5 \\
34.5 \\
36.0 \\
35.5 \\
36.5\end{array}$ & $\begin{array}{l}33.0 \\
33.0 \\
33.0 \\
33.0 \\
34.0\end{array}$ & $\begin{array}{l}25.0 \\
22.0 \\
28.0 \\
30.0 \\
33.0\end{array}$ & $\begin{array}{l}21.5 \\
21.0 \\
21.5 \\
25.5 \\
28.0\end{array}$ & $\begin{array}{l}34.0 \\
33.0 \\
32.0 \\
34.5 \\
33.5\end{array}$ & $\begin{array}{l}33.0 \\
31.0 \\
30.5 \\
29.0 \\
31.5\end{array}$ \\
\hline $\begin{array}{l}16 \\
17 \\
18 \\
19 \\
20\end{array}$ & $\begin{array}{l}=- \\
=- \\
=- \\
=-\end{array}$ & $\begin{array}{l}=- \\
=- \\
=-\end{array}$ & $\begin{array}{l}28.5 \\
28.0 \\
28.5 \\
30.5 \\
31.5\end{array}$ & $\begin{array}{l}26.0 \\
26.0 \\
25.5 \\
27.0 \\
28.0\end{array}$ & $\begin{array}{l}= \\
= \\
= \\
=\end{array}$ & $\begin{array}{l}= \\
= \\
= \\
=\end{array}$ & $\begin{array}{l}36.0 \\
35.0 \\
35.0 \\
34.0 \\
33.5\end{array}$ & $\begin{array}{l}33.5 \\
33.0 \\
33.0 \\
33.0 \\
32.0\end{array}$ & $\begin{array}{l}33.0 \\
33.5 \\
34.5 \\
34.0 \\
35.5\end{array}$ & $\begin{array}{l}29.5 \\
30.0 \\
31.5 \\
32.0 \\
32.0\end{array}$ & $\begin{array}{l}33.5 \\
34.0 \\
33.5 \\
34.0 \\
33.5\end{array}$ & $\begin{array}{l}31.5 \\
32.0 \\
32.0 \\
32.0 \\
30.5\end{array}$ \\
\hline $\begin{array}{l}21 \\
22 \\
23 \\
24 \\
25\end{array}$ & $\begin{array}{l}=- \\
=- \\
= \\
--\end{array}$ & $\begin{array}{l}= \\
= \\
= \\
=\end{array}$ & $\begin{array}{l}32.0 \\
31.5 \\
31.5 \\
31.5 \\
31.0\end{array}$ & $\begin{array}{l}28.5 \\
29.0 \\
29.0 \\
29.0 \\
29.5\end{array}$ & $\begin{array}{r}= \\
= \\
34.5 \\
33.0\end{array}$ & $\begin{array}{r}=- \\
=- \\
32.0 \\
31.5\end{array}$ & $\begin{array}{l}35.0 \\
33.5 \\
33.5 \\
35.5 \\
35.0\end{array}$ & $\begin{array}{l}32.0 \\
31.5 \\
31.5 \\
31.5 \\
23.5\end{array}$ & $\begin{array}{l}34.0 \\
33.0 \\
32.0 \\
32.0 \\
32.0\end{array}$ & $\begin{array}{l}33.0 \\
31.5 \\
31.0 \\
30.5 \\
31.5\end{array}$ & $\begin{array}{l}33.0 \\
33.0 \\
34.0 \\
33.5 \\
33.5\end{array}$ & $\begin{array}{l}30.5 \\
31.0 \\
32.0 \\
31.5 \\
32.0\end{array}$ \\
\hline $\begin{array}{l}26 \\
27 \\
28 \\
29 \\
30 \\
31\end{array}$ & $\begin{array}{l}= \\
=- \\
=- \\
--\end{array}$ & $\begin{array}{l}=- \\
=- \\
=- \\
=-\end{array}$ & $\begin{array}{l}31.5 \\
31.5 \\
30.5 \\
30.0 \\
29.5 \\
28.5\end{array}$ & $\begin{array}{l}29.5 \\
29.5 \\
29.0 \\
29.0 \\
28.0 \\
27.0\end{array}$ & $\begin{array}{r}34.0 \\
33.0 \\
31.5 \\
31.5 \\
33.5 \\
-\end{array}$ & $\begin{array}{r}31.5 \\
31.5 \\
30.0 \\
29.5 \\
30.0 \\
.-\end{array}$ & $\begin{array}{l}33.0 \\
33.5 \\
36.5 \\
35.5 \\
36.0 \\
36.0\end{array}$ & $\begin{array}{l}24.0 \\
26.5 \\
25.5 \\
28.5 \\
34.0 \\
33.5\end{array}$ & $\begin{array}{l}33.5 \\
34.5 \\
35.5 \\
34.5 \\
35.5 \\
36.0\end{array}$ & $\begin{array}{l}31.5 \\
31.5 \\
32.0 \\
32.0 \\
33.5 \\
33.5\end{array}$ & $\begin{array}{r}33.5 \\
32.0 \\
30.5 \\
30.5 \\
30.0 \\
.-\end{array}$ & $\begin{array}{r}31.5 \\
30.5 \\
29.5 \\
29.5 \\
29.0 \\
.-\end{array}$ \\
\hline AVG & -- & - & 29.5 & 27.0 & - & - & 34.5 & 31.5 & 33.0 & 30.5 & 33.5 & 31.5 \\
\hline
\end{tabular}


O2145531 CATAWBa RiVER AT STATE high\%AY 49, NEAR PINEVILLE, N. C.

LOCATION.--Lat $35^{\circ} 06^{\prime} 06^{\prime \prime}$, long $81^{\circ} 02^{\prime} 23^{\prime \prime}$, Mecklenburg County, at bridge on State Highway $49,0.5$ mile downstream from Porters Branch, 10 miles west of Pineville.

DRA INAGE AREA, $--2,810 \mathrm{sq} \mathrm{mi}$.

PERIOD OF RECORD.--Chemical analyses: July 1969 to September 1970.

REMARKS. - The second of two samples collected at the same time is a field determination.

CHEMICAL ANALYSES, WATER yeAR OCTOBER 1969 TO SEPTEMBER 1970

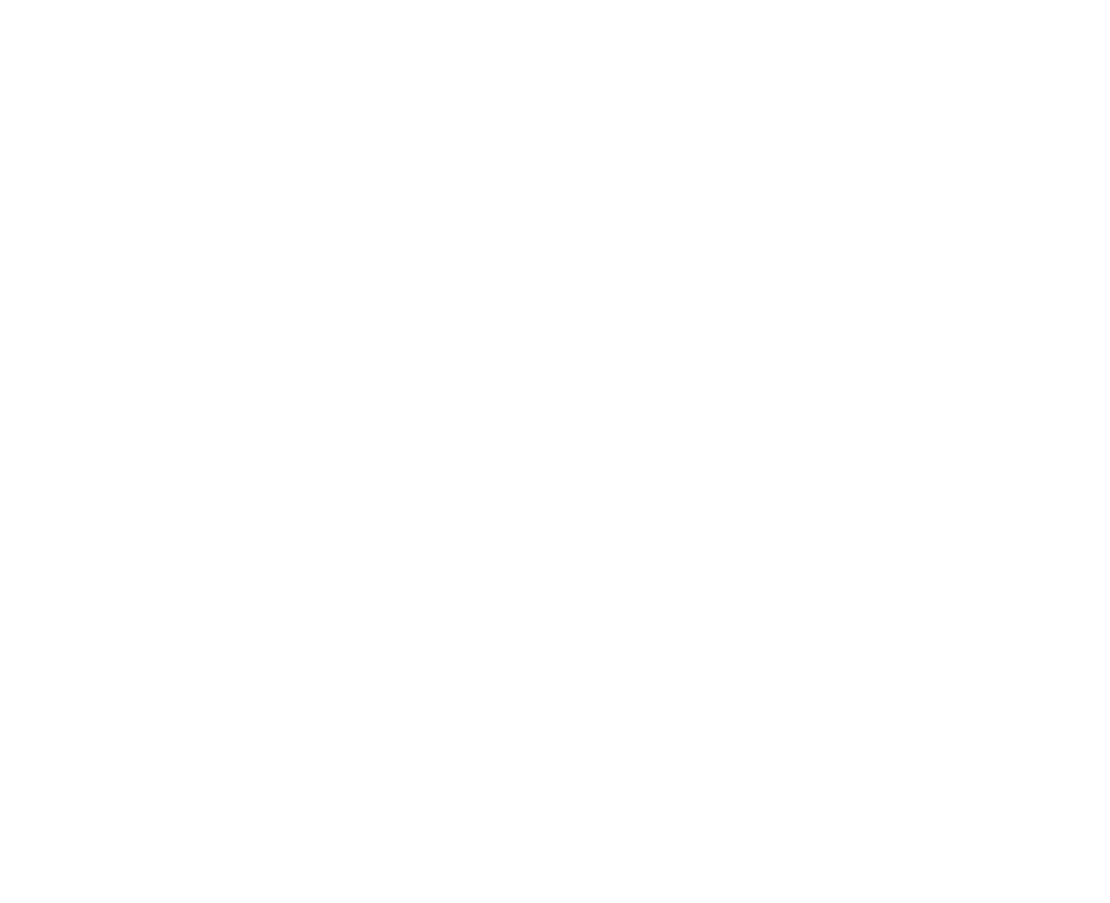
$M G / L) \quad I U G / L$

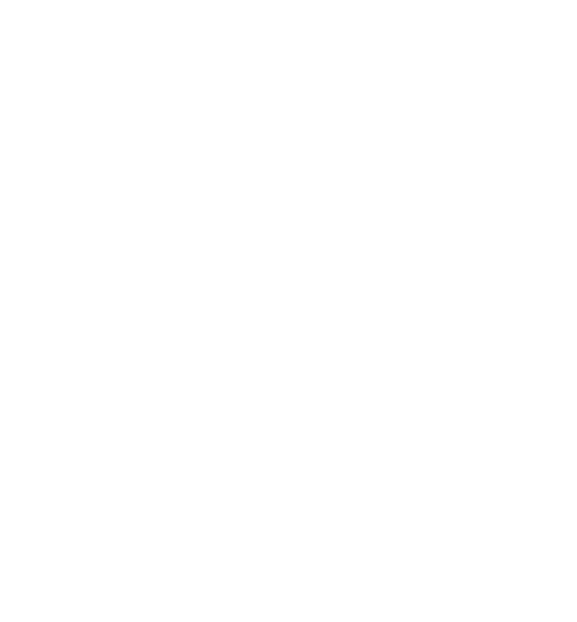

\begin{tabular}{|c|c|c|c|c|}
\hline-- & -- & - & 35 & -- \\
\hline- & 26 & -- & - & $\cdots$ \\
\hline- & -- & - & 25 & -. \\
\hline -- & 59 & -- & $\cdots$ & -- \\
\hline$\cdots$ & 16 & -- & 43 & -- \\
\hline- & 16 & -- & -- & -- \\
\hline-- & - & -- & 60 & -- \\
\hline-- & 17 & - & -- & - \\
\hline-- & - & $\sim$ & 24 & - \\
\hline- & 16 & -- & -- & -- \\
\hline- & 16 & -- & 35 & - \\
\hline$\rightarrow$ & 16 & -- & -- & $\cdots$ \\
\hline- & -- & -- & 30 & $\cdots$ \\
\hline-- & 20 & -- & -- & -- \\
\hline-- & -- & -- & 25 & -- \\
\hline- & 16 & 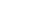 & -- & -- \\
\hline -- & 16 & -- & 45 & - \\
\hline-- & -- & - & -- & $\cdots$ \\
\hline 4 & 21 & 0 & 0 & 0 \\
\hline-- & 23 & $\rightarrow$ & - & -- \\
\hline-- & - & -- & 5 & - \\
\hline-- & 18 & -- & -- & -- \\
\hline$=$ & 16 & -- & 6 & -- \\
\hline- & 16 & -- & -- & - \\
\hline
\end{tabular}


02145531 CATAWBa RIVER AT STATE highWAY 49, NEAR PINEVILLE, N. C.--Continued

CHEMICAL ANALYSES, hATER YEAR OCTMBER 1969 TO SEPTEMBER 1970

\begin{tabular}{|c|c|c|c|c|c|c|c|c|c|c|}
\hline DATE & $\begin{array}{l}\text { ZINC } \\
(2 N) \\
\{U G / 1)\end{array}$ & $\begin{array}{c}\text { CYANIDE } \\
\text { (MG) } \\
(M G / L)\end{array}$ & 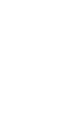 & $\begin{array}{l}\text { DIS- } \\
\text { SOLVD } \\
\text { XIVGEN } \\
\text { IMG/L) }\end{array}$ & $\begin{array}{l}\text { TDTAL } \\
\text { BETA } \\
\text { (PCAL) }\end{array}$ & 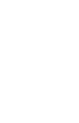 & $\begin{array}{l}\text { SPECI- } \\
\text { FIC } \\
\text { CDND- } \\
\text { UCTANCE } \\
\text { IMICRIT- } \\
\text { MHDSI }\end{array}$ & $\begin{array}{c}\mathrm{PH} \\
\text { (unstrs) }\end{array}$ & $\begin{array}{l}\text { TEMP- } \\
\text { FEATURE } \\
\text { IOEG C }\end{array}$ & $\begin{array}{l}\text { CULOR } \\
\text { CPLAT } \\
\text { INUM- } \\
\text { CORAL } \\
\text { UNI IS }\end{array}$ \\
\hline $\begin{array}{l}\text { ocr. } \\
29 . . . \\
29 . . .\end{array}$ & $=$ & $\because$ & $=$ & $8 .-3$ & $=$ & $=$ & $\overline{95}$ & $0 .-0$ & $\sqrt[17.5]{-5}$ & $=$ \\
\hline $\begin{array}{l}\text { Nov. } \\
26 . . .\end{array}$ & -- & -- & -- & -- & -- & - & -- & -- & -5 & -- \\
\hline$\underset{D E C .}{26 \%}$ & - & - & -- & 8.0 & - & -- & 89 & 7.2 & 13.5 & -- \\
\hline $\begin{array}{l}17 \ldots . \\
17 \ldots\end{array}$ & $=$ & $=$ & $\overline{-}$ & $\overline{9.4}$ & $=$ & $=$ & $\begin{array}{r}85 \\
130\end{array}$ & $\begin{array}{l}6.99 \\
5.3\end{array}$ & $\begin{array}{r}9.0 \\
10.5\end{array}$ & 10 \\
\hline UAN. & - & -- & - & -- & - & - & 7 & $\because$ & 6.0 & 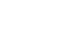 \\
\hline FEB. & - & $\cdots$ & -- & 9.0 & -- & -- & 93 & 7.2 & 6.0 & \\
\hline $\begin{array}{l}19 . . . \\
19 . . .\end{array}$ & $=$ & $=$ & $=$ & $\overline{8.8}$ & $=$ & $=$ & $\overline{103}$ & 6.9 & $\begin{array}{l}9.0 \\
9.0\end{array}$ & $=$ \\
\hline $\begin{array}{r}\text { MAR: } \\
26 . \cdots\end{array}$ & - & -- & -- & -- & -- & -- & 85 & & & \\
\hline${ }_{260}^{26 \cdots}$ & - & -- & - & 8.1 & -- & -- & 89 & 5.6 & 14.5 & -- \\
\hline 29. & $=$ & $\because$ & - & 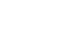 & - & - & $-\overline{0}$ & $\because$ & 22.5 & - \\
\hline MAY & & & & 0.0 & & 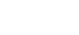 & & & & \\
\hline $\begin{array}{c}20 \ldots \ldots \\
\text { JUNEE }\end{array}$ & -- & - & - & 8.7 & - & 0 & 99 & 7.7 & 25.0 & $=$ \\
\hline${ }_{23}^{23} \cdots$ & 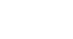 & $\because$ & $\overline{-}$ & 8.4 & $=$ & 278 & $\begin{array}{r}84 \\
110\end{array}$ & $\begin{array}{l}6.1 \\
7: 0\end{array}$ & $\begin{array}{l}28.5 \\
28.5\end{array}$ & $\begin{array}{c}5 \\
--\end{array}$ \\
\hline & 19 & .00 & $\therefore$ & $-\overline{7.2}$ & 3.0 & $\overline{120}$ & 102 & $\begin{array}{l}6.8 \\
8.2\end{array}$ & $\begin{array}{l}31.0 \\
31.0\end{array}$ & 10 \\
\hline $\begin{array}{l}\text { AUG. } \\
26 .\end{array}$ & -- & -- & -- & -- & -.. & -- & & .. & & \\
\hline & -- & -- & -- & 6.3 & -- & 8 & $\begin{array}{l}110 \\
110\end{array}$ & 7.5 & 20.0 & \\
\hline${ }_{25}^{25} \ldots$ & $=$ & $=$ & $=$ & $\overline{8.5}$ & $=$ & $\overline{10}$ & $\begin{array}{l}61 \\
64\end{array}$ & 6.3 & $\begin{array}{l}27.5 \\
775\end{array}$ & -. \\
\hline
\end{tabular}
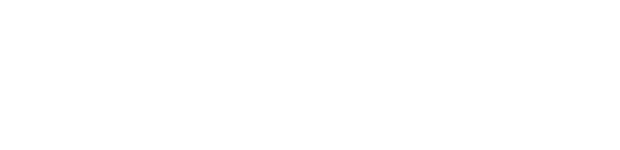

\begin{tabular}{|c|c|c|c|c|c|c|c|}
\hline DATE & $\begin{array}{c}\text { DDI } \\
\text { (UG/L) }\end{array}$ & $\begin{array}{l}\text { DDE } \\
\text { (UG/L) }\end{array}$ & $\begin{array}{l}\text { DDD } \\
\text { (UG/L) }\end{array}$ & $\begin{array}{l}\text { CHLDR- } \\
\text { DANE } \\
\text { (UG/L) }\end{array}$ & $\begin{array}{l}\text { DI- } \\
\text { ELDRIN } \\
\text { (UG/L) }\end{array}$ & $\begin{array}{l}\text { ENOR IN } \\
\text { (UG/L) }\end{array}$ & $\begin{array}{l}\text { HEPTA- } \\
\text { CHLDR } \\
\text { (UG/L) }\end{array}$ \\
\hline $\begin{array}{l}\text { JULY } \\
28 . .\end{array}$ & $<.01$ & .00 & .00 & $<.01$ & .00 & $<.01$ & .00 \\
\hline
\end{tabular}


02146800 SUGAR CREEK NEAR FORT MILL, S. C. LOCATION,-Lat $35^{\circ} 00^{\prime} 21^{\prime \prime}$, long $80^{\circ} 54^{\prime} 09^{\prime \prime}$, York County, at bridge on State Highway $160,0.7$ mile downstream from Clems
Branch, and 2.6 miles east of Fort Mill.

DRAINAGE AREA. $\rightarrow 262$ sq $\mathrm{m} 1$.

PERIOD OF RECORD,--Chemical analyses: July 1969 to September 1970.

REMARKS.--The second of two samples collected at the same time is a fleld determination.

CHEMICAL ANALYSES, WATER YEAR OCTOBER 1969 TO SEPTEMBER 1970

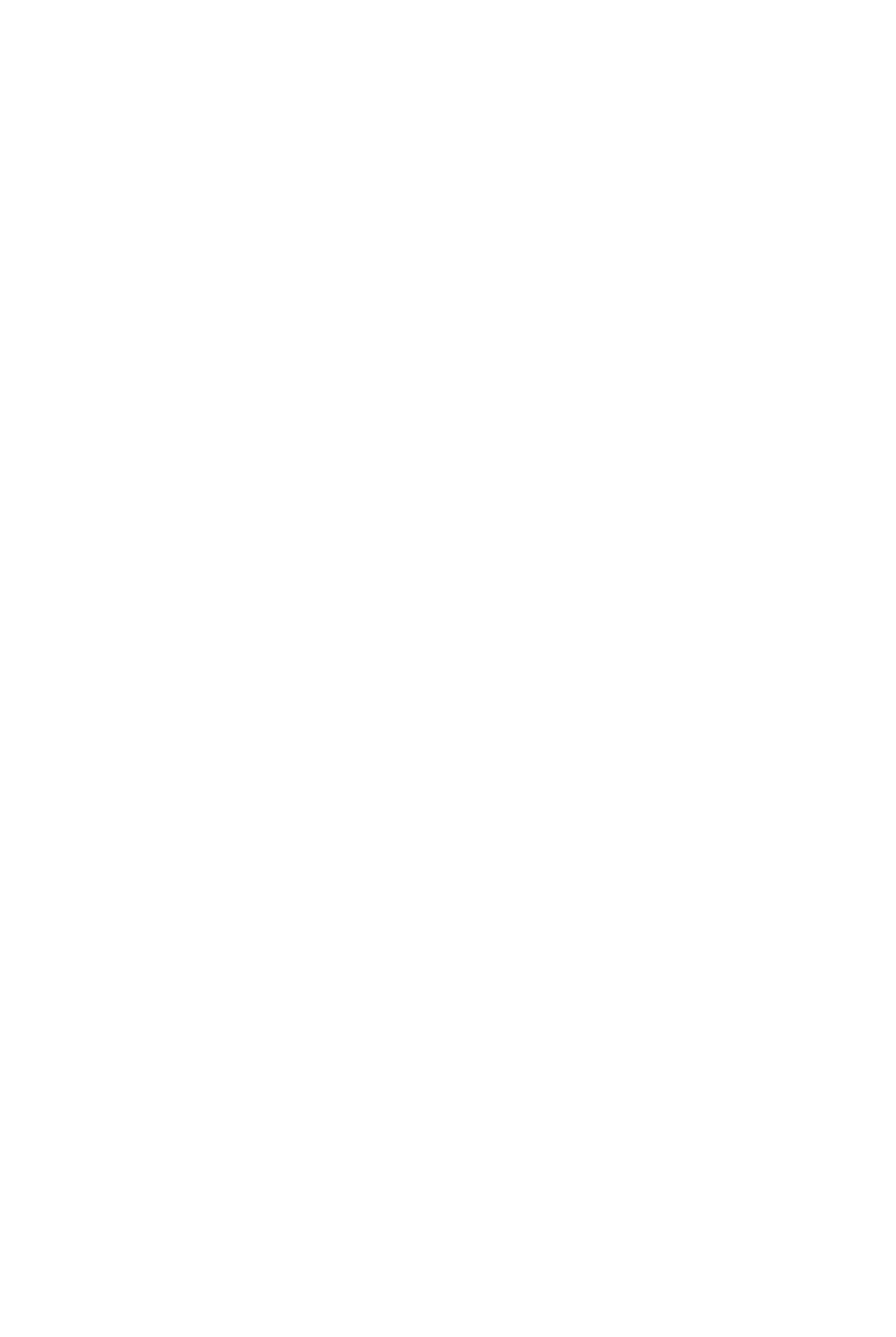


02146800 SUGAR CREEK NEAR FORT MILL, S. C.--Cont1nued

CHEMICAL ANALYSES, WATER YEAR OCTOBER 1969 TO SEPTEMBER 1970

\begin{tabular}{|c|c|c|c|c|c|c|c|c|c|c|}
\hline DATE & $\begin{array}{l}\text { SOOLUM } \\
\text { AD- } \\
\text { SORP- } \\
\text { TION } \\
\text { RAT IO }\end{array}$ & $\begin{array}{l}\text { PERCENT } \\
\text { SUOIUM }\end{array}$ & $\begin{array}{l}\text { BIO- } \\
\text { CHEM- } \\
\text { ICAL } \\
\text { OXYGEN } \\
\text { OEYANU } \\
\text { (MG/LI }\end{array}$ & $\begin{array}{l}\text { PHENOLS } \\
\text { (UG/L) }\end{array}$ & $\begin{array}{l}\text { ME THY- } \\
\text { LENE } \\
\text { BLUE } \\
\text { ALTIVE } \\
\text { SUB- } \\
\text { STANCE } \\
\text { IMG/LI }\end{array}$ & $\begin{array}{l}\text { TUR- } \\
\text { BID- } \\
\text { ITY } \\
\text { IJTUI }\end{array}$ & $\begin{array}{l}\text { TOTAL } \\
\text { NON- } \\
\text { FILT- } \\
\text { RABLE } \\
\text { RES IDUE } \\
\text { IMGIL) }\end{array}$ & $\begin{array}{l}\text { ALKA- } \\
\text { LINI TY } \\
\text { AS } \\
\text { CACO3 } \\
\text { (MGIL) }\end{array}$ & $\begin{array}{l}\text { DIS- } \\
\text { SOLVED } \\
\text { COPPER } \\
\text { (CU) } \\
\text { (UG L ) }\end{array}$ & $\begin{array}{l}\text { DIS- } \\
\text { SOLVED } \\
\text { LEAD } \\
\text { (PB) } \\
\text { (UGIL) }\end{array}$ \\
\hline 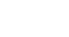 & -- & -- & 3.8 & -- & -- & - & -- & -- & -- & $=$ \\
\hline Nov. & -- & -- & -- & -- & -- & -- & -- & 115 & -- & -- \\
\hline $20 \ldots$ & -- & - & 7.5 & -- & -- & -- & -- & -- & -- & - \\
\hline UEC... & - & - & -- & - & $\therefore-$ & $\cdots$ & -- & -- & -- & -- \\
\hline $17 \ldots$ & 1.6 & $\begin{array}{l}48 \\
--\end{array}$ & 7.8 & $=$ & .17 & $=$ & $\overline{--}$ & $\begin{array}{l}65 \\
66\end{array}$ & $=$ & - \\
\hline JAN. & & & & & & & & & & \\
\hline $29 \ldots$ & -- & -- & 5.6 & -- & -- & -- & - & -- & -- & - \\
\hline $\begin{array}{r}29 . . \\
F E B .\end{array}$ & -- & -- & -- & - & -- & -- & -- & 80 & -- & - \\
\hline $19 \ldots$ & -- & -- & 7.5 & -- & -- & -- & $\cdots$ & -- & -- & - \\
\hline$\underset{M A R}{19} \ldots$ & -- & -- & -- & -- & -- & -- & -- & 48 & $\cdots$ & $\cdots$ \\
\hline $26 \ldots$ & 1.0 & 39 & 3.7 & -- & .26 & - & -- & 39 & $=-$ & -- \\
\hline $\begin{array}{r}26 \ldots \\
A P R .\end{array}$ & -- & -- & -- & -- & -- & -- & -- & $5 B$ & $-\infty$ & - \\
\hline $29 \ldots$ & -- & -- & 3.2 & -- & - & -- & -- & 72 & - & - \\
\hline$\underset{\operatorname{MaY}}{29} \cdot$ & -- & -- & -- & - & -- & - & -- & 72 & -- & - \\
\hline $\begin{array}{l}\text { MAY } \\
20 . .\end{array}$ & - & $=$ & 7.9 & -- & -- & 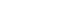 & -- & - & -- & - \\
\hline $20 \ldots$ & -- & $\cdots$ & - & -- & -- & -- & -- & 102 & - & $\ldots$ \\
\hline JUNE & & & & & & & & & & \\
\hline $23 \ldots$ & 1.6 & 49 & 4.9 & -- & .16 & -- & -- & 70 & -- & - \\
\hline $23 \ldots$ & -- & -- & -- & -- & - & - & -- & 121 & -- & \\
\hline $28 \ldots$ & 1.8 & 50 & 3.3 & 0 & .30 & 17 & 317 & 29 & 0 & 0 \\
\hline $28 \ldots$ & - & -- & -- & -- & -- & $\cdots$ & -- & 88 & -- & -- \\
\hline AUG. & & & & & & & & & & \\
\hline $20 \ldots$ & -- & -- & 6.2 & $\cdots$ & - & -- & -- & -- & -- & $\cdots$ \\
\hline $26 \ldots$ & -- & -- & -- & -- & -- & -- & -- & 111 & - & \\
\hline $25 \ldots$ & 3.7 & 66 & 7.4 & - & .33 & -- & - & 49 & -- & - \\
\hline $25 \ldots$ & -- & -- & -- & - & - & -- & -- & 109 & -- & \\
\hline
\end{tabular}

\begin{tabular}{|c|c|c|c|c|c|c|c|c|c|}
\hline DATE & $\begin{array}{l}\text { Dis- } 5- \\
\text { SOLVED } \\
\text { LINC } \\
\text { INN } \\
\text { (UG }\end{array}$ & $\begin{array}{c}\text { CYANDEE } \\
(\text { CNN) } \\
(M G / L)\end{array}$ & $\begin{array}{l}\text { DIS- } \\
\text { SOLVLD } \\
\text { CAD- } \\
\text { MIUM } \\
\text { (UO) } \\
\text { (UG/L) }\end{array}$ & $\begin{array}{l}\text { OIS- } \\
\text { SOLVED } \\
\text { OXYG GEN } \\
\text { MG/L }\end{array}$ & $\begin{array}{l}\text { TOTALL } \\
\text { BEA } \\
(\mathrm{PC} / L)\end{array}$ & $\begin{array}{l}\text { SPECI- } \\
\text { FIC } \\
\text { CUND- } \\
\text { UCTAVCE } \\
\text { (MICRDD- } \\
\text { MHOS) }\end{array}$ & $\begin{array}{c}\text { PH } \\
\text { (UNIIS) }\end{array}$ & $\begin{array}{l}\text { TEMP } \\
\text { ERAYRE } \\
\text { IOEG C }\end{array}$ & $\begin{array}{l}\text { COLOR } \\
\text { COLAT- } \\
\text { PLUMA- } \\
\text { COBALT } \\
\text { UNI TSI }\end{array}$ \\
\hline $\begin{array}{l}\text { Oct. } \\
29 . . \\
29 . \ldots\end{array}$ & -- & -- & $\because-$ & 4.2 & $\because$ & 425 & 5.1 & 13.0 & $=$ \\
\hline $\begin{array}{c}\text { Nov. } \\
26 . .\end{array}$ & -- & $=$ & $=$ & $5 \overline{8}$ & $=-$ & $\overline{300}$ & 7. & 10.5 & -- \\
\hline $\begin{array}{l}26 \ldots \ldots \\
\text { UEC }\end{array}$ & & & & 3.8 & 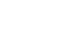 & 380 & & 10.5 & - \\
\hline${ }_{17}^{17 \ldots} \ldots$ & -- & -- & $=$ & 8.5 & $=$ & 350 & 0.5 & 6.0 & - \\
\hline $29 \ldots$ & z- & $\because$ & $=$ & $\overline{5}$ & $\because$ & 200 & 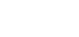 & $\begin{array}{l}10.0 \\
10.0\end{array}$ & $=$ \\
\hline & -- & -- & -- & -- & - & -- &.- & 9.0 & -- \\
\hline & -- & -- & - & 8.1 & - & 170 & 7.1 & 9.0 & -- \\
\hline$\ldots$ & $\because$ & $\because$ & $\because$ & 0.0 & $\because$ & $\begin{array}{l}210 \\
220\end{array}$ & $\begin{array}{l}6.3 \\
6.6\end{array}$ & $\begin{array}{l}12.5 \\
12.5\end{array}$ & 15 \\
\hline & $=-$ & $=$ & $\because-$ & 3.8 & $\because-$ & $\begin{array}{l}340 \\
3400\end{array}$ & 6.4 & $\begin{array}{r}20.5 \\
20.5\end{array}$ & $=$ \\
\hline & -- & -- & & & & & - & & -- \\
\hline & -- & -- & - & 3.8 & - & 265 & 6.6 & 23.5 & - \\
\hline & $=$ & --- & $\because$ & $\begin{array}{l}3.6 \\
3.6\end{array}$ & $\therefore$ & 260 & $\begin{array}{l}6.6 \\
7.1\end{array}$ & $\begin{array}{l}26.5 \\
26.5\end{array}$ & 15 \\
\hline & $\begin{array}{l}34 \\
--.\end{array}$ & .00 & $\therefore$ & 4.0 & 10 & $\begin{array}{l}315 \\
320\end{array}$ & 6.8 & $\begin{array}{r}29.0 \\
29.0\end{array}$ & - \\
\hline & -- & -- & -- & -. & - &.- & - & 26.5 & -- \\
\hline & -- & $\cdots$ & $\cdots$ & 3.2 & - & 400 & 7.3 & 26.5 & -- \\
\hline${ }_{25}^{25} \ldots$ & $\because$ & $=$ & $=$ & $\overline{-0}$ & - & $\begin{array}{r}480 \\
490\end{array}$ & $\begin{array}{l}6.8 \\
7: 6\end{array}$ & $\begin{array}{r}24.5 \\
24.5\end{array}$ & 40 \\
\hline
\end{tabular}


02152622 BROAD RIVER NEAR EARL, N. C.

LOCATION.--Lat $35^{\circ} 10^{\circ} 48^{\prime \prime}$, long $81^{\circ} 37^{\circ} 06^{\prime \prime}$, Cleveland County, at E1lis Ferry, 2 miles downstream from First Broad River, and 5 miles west of Earl.

DRA INAGE AREA.--1,270 sq mi, approximately.

PERIOD OF RECORD.--Chemical analyses: October 1967 to September 1969 (partial-record), October 1969 to September 1970 .

REMARKS. - The second of two samples collected at the same time is a field determination. CHEMICAL ANALYSES, WATER YEAR OCTOBER 1969 TO SEPTEMBER 1970

\begin{tabular}{|c|c|c|c|c|c|c|c|c|c|c|c|}
\hline DATE & TI ME & $\begin{array}{l}\text { DIS- } \\
\text { CHARGE } \\
\text { (CFS) }\end{array}$ & $\begin{array}{l}\text { SILICA } \\
\text { (SIOL) } \\
\text { (MG/L) }\end{array}$ & $\begin{array}{l}\text { OIS- } \\
\text { SOLVEO } \\
\text { IRON } \\
\text { (FE) } \\
\text { (UG/L) }\end{array}$ & $\begin{array}{l}\text { YOTAL } \\
\text { MAN- } \\
\text { GANFSE } \\
\text { (MN) } \\
\text { (UG/L) }\end{array}$ & $\begin{array}{l}\text { CAL- } \\
\text { CIUM } \\
(C A) \\
(M G / L)\end{array}$ & $\begin{array}{l}\text { MAG- } \\
\text { NE- } \\
\text { SIUM } \\
\text { (MG) } \\
(+\triangle G / L)\end{array}$ & $\begin{array}{l}\text { SHOIUM } \\
\text { (NA) } \\
\text { (MG/L) }\end{array}$ & $\begin{array}{l}P \cap- \\
\text { YAS- } \\
\text { SIUM } \\
\text { (K) } \\
\text { (MG/L) }\end{array}$ & $\begin{array}{l}\text { BICAR- } \\
\text { BONATE } \\
\text { (HCO3) } \\
\text { (MG/L) }\end{array}$ & $\begin{array}{l}\text { CAR- } \\
\text { BONATE } \\
\text { (COB) } \\
\text { (MG/L) }\end{array}$ \\
\hline ocr. & 1215 & 1650 & -- & - & -- & - & - & -- & $\cdots$ & $=-$ & - \\
\hline $\begin{array}{l}24 . . . \\
O E C .\end{array}$ & 1015 & 1750 & -- & -- & -- & -- & - & -- & -- & -- & -- \\
\hline $\begin{array}{l}15 \ldots . \\
15 \ldots . \\
\text { JAN. }\end{array}$ & $\begin{array}{l}1125 \\
1125\end{array}$ & $\begin{array}{l}2450 \\
2450\end{array}$ & 11 & $\begin{array}{l}50 \\
--\end{array}$ & $=$ & 2.9 & 1.0 & 3.0 & 1.6 & 14 & $\begin{array}{r}0 \\
--\end{array}$ \\
\hline $\begin{array}{l}28 . . \\
F E B .\end{array}$ & 1140 & 2030 & -- & $\rightarrow$ & - & -- & -- & -- & $\cdots$ & -- & -- \\
\hline MAR... & 1145 & 2210 & -- & -- & - & -- & - & - & $\cdots$ & -- & - \\
\hline $\begin{array}{l}24 \ldots \\
24 \ldots \\
A P R .\end{array}$ & $\begin{array}{l}1200 \\
1200\end{array}$ & $\begin{array}{l}2630 \\
2630\end{array}$ & 11 & 14 & $=$ & 2.7 & 1.0 & 3.7 & 1.3 & 14 & 0 \\
\hline $28 . \cdots$ & 0945 & 2410 & -- & -- & - & -- & -- & -- & -- & -- & -- \\
\hline JUNE & 1300 & 1730 & -- & -- & -- & -- & - & -- & -- & 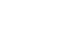 & - \\
\hline $\begin{array}{l}24 \ldots \\
24 \ldots \\
\text { JuLY }\end{array}$ & $\begin{array}{l}1100 \\
1100\end{array}$ & $\begin{array}{l}1040 \\
1040\end{array}$ & 13 & $\begin{array}{r}5 \\
---\end{array}$ & $=$ & 3.4 & 1.2 & 6.0 & 1.6 & 19 & $\begin{array}{c}0 \\
--\end{array}$ \\
\hline $\begin{array}{l}29 \ldots . . \\
29 \ldots . . \\
\text { SEPT. }\end{array}$ & $\begin{array}{l}1030 \\
1030\end{array}$ & $\begin{array}{l}1520 \\
1520\end{array}$ & 11 & 154 & 20 & 1.6 & .6 & 6.2 & 2.3 & 12 & $\begin{array}{r}0 \\
--\end{array}$ \\
\hline $\begin{array}{l}24 \ldots \\
24 \ldots\end{array}$ & $\begin{array}{l}1230 \\
1230\end{array}$ & $\begin{array}{l}1010 \\
1010\end{array}$ & 14 & 17 & $=-$ & 3.1 & 1.1 & 5.2 & 1.5 & 20 & -0 \\
\hline
\end{tabular}

\begin{tabular}{|c|c|c|c|c|c|c|c|c|c|c|c|}
\hline DATE & $\begin{array}{c}\text { SULFATE } \\
(5041 \\
(19 G / 21\end{array}$ & $\begin{array}{l}\text { CHLO- } \\
\text { RLOE } \\
\text { (IL) } \\
\text { (ML/L) }\end{array}$ & 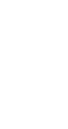 & $\begin{array}{c}\text { NITRATE } \\
\text { (NMB) } \\
\text { NMG } / L, 1\end{array}$ & $\begin{array}{l}\text { ORTHO } \\
\text { PHOS- } \\
\text { PHATE } \\
\text { POA4I } \\
\text { PMG I I }\end{array}$ & $\begin{array}{l}\text { DIS- } \\
\text { SOLVED } \\
\text { SNLI IDS } \\
\text { RRES } \\
\text { OUE AY } \\
\text { IBO C } \\
\text { IMG/L }\end{array}$ & $\begin{array}{l}\text { DIS- } \\
\text { SOLVED } \\
\text { SOL IIDS } \\
\text { TroNS } \\
\text { PER } \\
\text { AC-FT, }\end{array}$ & $\begin{array}{l}\text { DIS- } \\
\text { SOLVED } \\
\text { SOL IOS } \\
\text { TONS } \\
\text { PER } \\
\text { DAY }\end{array}$ & 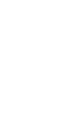 & $\begin{array}{l}\text { NUN- } \\
\text { CAK- } \\
\text { GONATE } \\
\text { MARD- } \\
\text { MESS } \\
\text { NESS } \\
\text { MSG/LI }\end{array}$ & 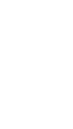 \\
\hline act. & -- & -- & -- & -- & -- & -- & -- & -. & -- & -- & -. \\
\hline $\begin{array}{l}14 . \\
24 . . .\end{array}$ & -- & -- & -- & -- & - & -- & -- & - & -- & -- & -- \\
\hline${ }_{15 .}^{15 .}$ & 2.4 & 4.0 & $\therefore$ & 1.6 & .05 & 33 & $\begin{array}{r}.04 \\
-\end{array}$ & $\begin{array}{r}218 \\
--\end{array}$ & 11 & $\begin{array}{r}0 \\
-\end{array}$ & $: 4$ \\
\hline $\begin{array}{l}\text { JAN. } \\
28 \%\end{array}$ & - & - & .. & -- & -- & -- & -- & ... & -- & -- & -- \\
\hline $\begin{array}{c}27 . \\
27 .\end{array}$ & -- & -- & -- & -- & -- & -- & -- & -- & -- & -- & -- \\
\hline$\ldots$ & 2.8 & 4.7 & .2 & 1.4 & .00 & 35 & .05 & 249 & 11 & 0 & .5 \\
\hline $\begin{array}{l}A, 0 R . \\
28 \ldots . .\end{array}$ & -- & -- & -- & -- & - & -- & -- & -- & -- & -- & -- \\
\hline $\operatorname{ar} \operatorname{Mar}_{21}$ & -- & -- & .. & -- & -- & -- & _- & .. & -.- & -. & -- \\
\hline & 4.0 & 7.0 & .1 & 1.4 & .26 & 50 & .07. & 140 & 14 & 0 & .7 \\
\hline $\begin{array}{l}J U L Y \\
{ }_{29}{ }_{2} . . .\end{array}$ & 3.6 & 5.0 & .2 & 2.2 & -- & 39 & .05 & 160 & 6 & 0 & 1.1 \\
\hline $\begin{array}{c}\text { SET } \\
24 \ldots\end{array}$ & 3.2 & 5.0 & .0 & .4 & .09 & 45 & 00 & 123 & 12 & 0 & 0 \\
\hline $24 \ldots: 0$ & - & - & $\because-$ & $\because$ & -1 & 3 & - & -1 & -1 & -- & $\because$ \\
\hline
\end{tabular}


02152622 BROAD RIVER NEAR EARL, N. C.--Continued CHEMICAL ANALYSES, HATER YEAR OCTIBFR 1969 TO SEPIEMBER 1970

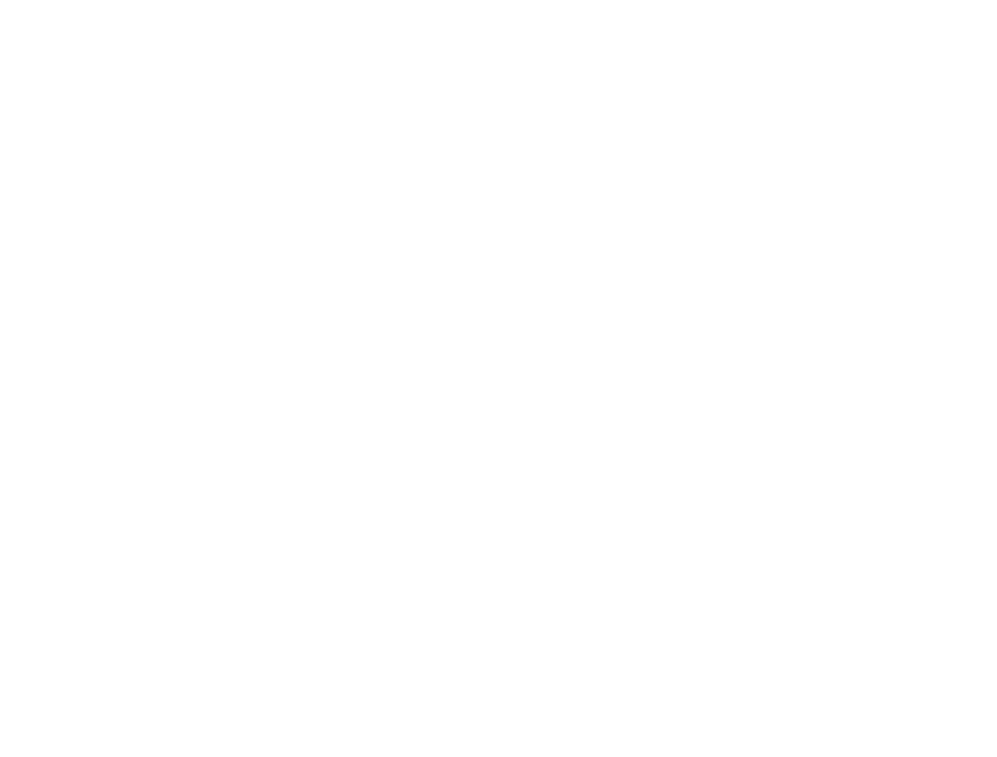

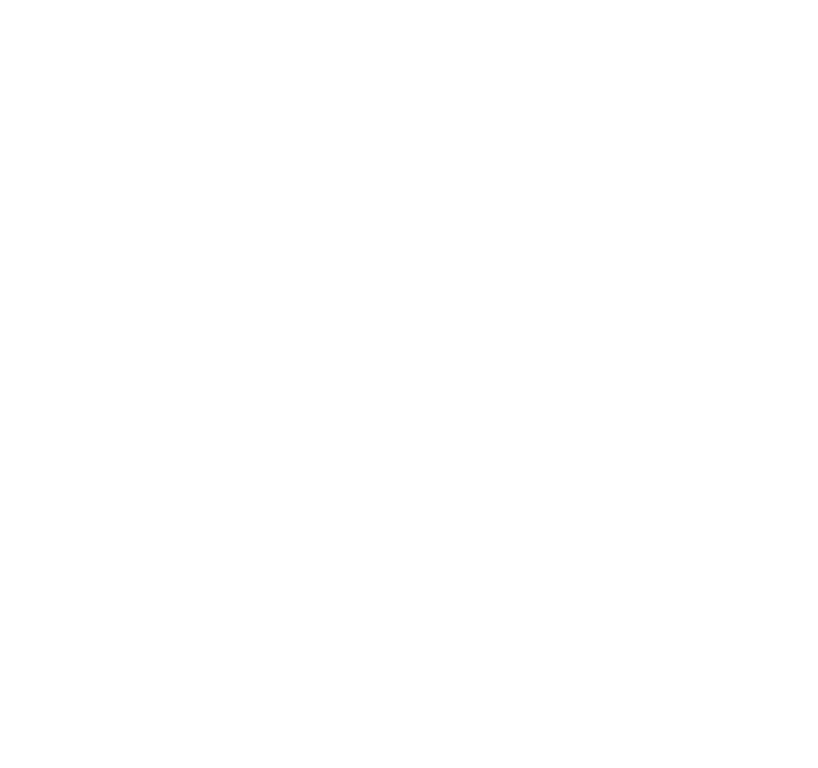

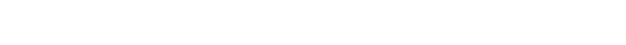


02153456 BUFFALO CREEK NEAR GROVER, H. C.

LOCATION,--Lat $35^{\circ} 10^{\prime} 16^{\prime \prime}$, Iong $81^{\circ} 31^{\prime} 04^{\prime \prime}$, Cleveland County, at bridge on State H1ghway 198, 0.1 mile upstream from North Carolina-South Carolina State iline, and 4 miles west of Grover.

DRA INAGE AREA, --170 sq mi, approximately.

PERIOD OF RECORD.-Chemical analyses: October 1967 to September 1969 (partial-record), October 1969 to September 1970 .

REMARKS.--The second of two samples collected at the same time is a field determination.

CHEMICAL ANALYSES, WATER YEAR OCTOBER 1969 TO SEPTEMBER 1970

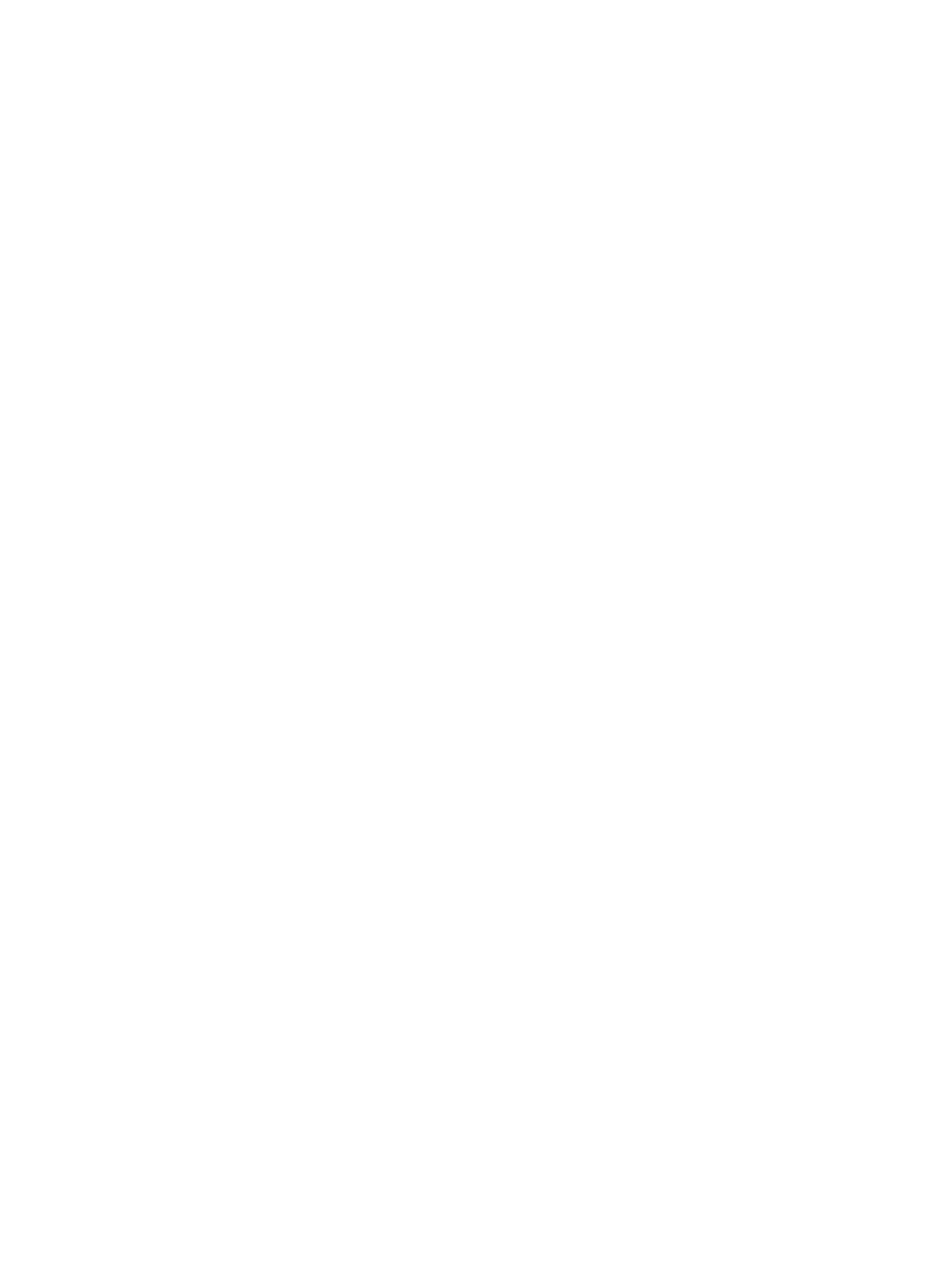


SANTEE RIVER BASIN

02153456 BUFFALO CREEK NEAR GROVER, N. C.-COntinued

CHEMICAL ANALYSES, WATER YEAR OCTOBER 1969 TO SEPTEMBER 1970

\begin{tabular}{|c|c|c|c|c|c|c|c|c|c|c|c|}
\hline DATE & $\begin{array}{l}\text { PERC ENT } \\
\text { SOOIUM }\end{array}$ & 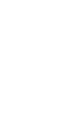 & $\begin{array}{l}\text { PHENOLS } \\
\text { (UGG/L) }\end{array}$ & $\begin{array}{l}\text { METHY- } \\
\text { LENE } \\
\text { BLUE } \\
\text { ACIIVE } \\
\text { SUA } \\
\text { SIANCE } \\
\text { IMG/LI }\end{array}$ & $\begin{array}{l}\text { YuR- } \\
\text { UID- } \\
\text { IITY } \\
\text { IJTU }\end{array}$ & $\begin{array}{l}\text { SUS- } \\
\text { PENOED } \\
\text { SOLIIDS } \\
\text { MGG/LI) }\end{array}$ & $\begin{array}{l}\text { ALKA- } \\
\text { LNITY } \\
\text { AS } \\
\text { CACCO } \\
\text { IMGAL }\end{array}$ & 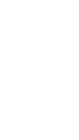 & $\begin{array}{l}\text { TOTAL } \\
\text { CHRR- } \\
\text { MIUM } \\
\text { ICR I } \\
\text { IUG/L }\end{array}$ & $\begin{array}{l}\text { COPPER R } \\
\text { ICU) } \\
\text { (UG/L) }\end{array}$ & 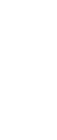 \\
\hline $\begin{array}{r}\text { वст. } \\
30 . . . \\
30 . .\end{array}$ & $=-$ & $=$ & - & $=$ & $=$ & $=$ & 30 & $\because-$ & $=$ & $=$ & $=$ \\
\hline $\begin{array}{l}\text { NOV. } \\
24 \ldots . . \\
24 \ldots\end{array}$ & -- & $\overline{-}$ & $\stackrel{0}{-}$ & $\bar{z}$ & -- & $=$ & $\overline{57}$ & -- & -- & $=$ & $=$ \\
\hline $\begin{array}{c}0.6 . \\
15 . . .\end{array}$ & 56 & -- & 0 & & -- & -- & & -- & -- & - & -- \\
\hline $\begin{array}{c}15 \ldots . . \\
\text { JAN." }\end{array}$ & $\therefore$ & -- & -- & - & -- & - & 23 & -- & -- & -- & -- \\
\hline $\begin{array}{r}28 . . . \\
28 . . .\end{array}$ & $\because$ & $=$ & $\therefore$ & $=$ & -- & $=$ & 20 & -- & -- & $=$ & -- \\
\hline FEB. & & & & & -- & - & -- & _- & -- & $\ldots$ & -- \\
\hline $27 \ldots$ & -- & - & -- & - & - & - & 18 & -- & - & -- & - \\
\hline $\begin{aligned} 24 . & \\
24 \ldots & \end{aligned}$ & 52 & $=$ & - -0 & .04 & $=$ & $=$ & $\begin{array}{r}5 \\
16\end{array}$ & -- & $=$ & $\overline{-}$ & -- \\
\hline APR. & & & & & -- & - & -- & -- & -- & -- & - \\
\hline $\begin{array}{r}28.0 \\
\end{array}$ & $=$ & $\because$ & -0 & 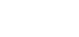 & - & $=$ & 20 & - & - & - & - \\
\hline $\begin{array}{c}\operatorname{Mar} \\
21 \ldots . . .\end{array}$ & -- & -- & 5 & $=$ & -- & $=$ & - & $=$ & -- & $=$ & -- \\
\hline JUNE & $\cdots$ & -- & . & & & & 22 & & & & \\
\hline $\begin{array}{l}24 \ldots \\
24 \ldots\end{array}$ & 59 & $\overline{--}$ & $\therefore$ & $=$ & $=-$ & $=$ & $\begin{array}{l}21 \\
21\end{array}$ & $=$ & $=$ & $=$ & $=$ \\
\hline $\begin{array}{r}29 . \ldots \\
29 . \ldots\end{array}$ & $\stackrel{61}{-}$ & 3.5 & $=$ & .05 & 25 & $\therefore$ & $\begin{array}{l}22 \\
21\end{array}$ & 324 & _o & - & $\therefore$ \\
\hline $\begin{array}{c}\text { AUG. } \\
27 . .\end{array}$ & -- & -- & 0 & - & -- & -- & -- & -- & -- & -- & -- \\
\hline${ }_{S E P T}^{27.0}$ & -- & - & -- & -- & -- & -- & & -- & -- & - & -- \\
\hline $\begin{array}{l}24 \ldots \ldots \\
24 \ldots\end{array}$ & 67 & $=$ & - & .05 & -- & $\tilde{z}$ & $\begin{array}{l}22 \\
21\end{array}$ & -- & $=-$ & $=$ & {[} \\
\hline
\end{tabular}

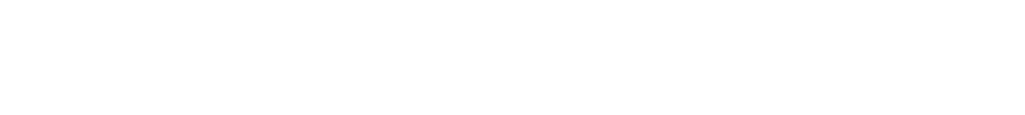

OC T

\begin{tabular}{|c|c|c|c|c|c|c|c|c|c|c|}
\hline $\begin{array}{c}30 . \\
{ }_{30} 0 \%\end{array}$ & $\overline{--}$ & $\because$ & $\overline{-}$ & 8.0 & $\bar{z}$ & $\overline{-z}$ & $11 \overline{9}$ & 6.8 & $\begin{array}{l}10.5 \\
10.5\end{array}$ & -- \\
\hline $24 \%$ & $\bar{z}$ & $=$ & $=$ & 8.7 & -- & -- & 119 & $0 . \overline{4}$ & $\begin{array}{l}8.0 \\
8.0\end{array}$ & $=$ \\
\hline $\begin{array}{l}\mathrm{DEC} \\
15 .\end{array}$ & -- & -- & - & -- & - & -- & 97 & 5.8 & 5.0 & 5 \\
\hline${ }_{\text {ANA... }}^{15}$ & -- & -- & -- & 10.4 & - & -- & 102 & 6.4 & 5.0 & \\
\hline $28 \ldots$ & -- & $=$ & -- & $\overline{9.4}$ & $=$ & - & $\overrightarrow{100}$ & $\therefore$ & 4.0 & $=-$ \\
\hline $27 \ldots$ & -- & -- & -- & - & - & - & - & -- & 5.0 & -- \\
\hline $\begin{array}{l}27 \% \\
\text { MaR: }\end{array}$ & - & -- & -- & 8.9 & $\cdots$ & -- & 100 & 6.5 & 5.0 & $\cdots$ \\
\hline $\begin{array}{l}24 \ldots . . \\
24\end{array}$ & $\overline{-}$ & -- & $=$ & $10 . \overline{9}$ & - & $=$ & $\begin{array}{l}86 \\
85 \\
85\end{array}$ & $\begin{array}{l}5.6 \\
6.5\end{array}$ & $\begin{array}{l}8.0 \\
8.0\end{array}$ & -5 \\
\hline $28 \%$ & - & $\because$ & - & -- & - & - & $\bar{m}$ & $\because$ & 17.5 & -- \\
\hline${ }_{4 A Y}^{28} \cdots$ & & & & 7.8 & & 340 & 95 & & & - \\
\hline $21 \ldots$ & $\overline{--}$ & $\overline{--}$ & $\overline{\sigma-}$ & 7.9 & $\overline{-\sigma}$ & $\overline{-}$ & $1 \overline{130}$ & 6.8 & $\begin{array}{l}18.5 \\
18.5\end{array}$ & $=$ \\
\hline $24 \ldots$ & $\overline{-}$ & $\bar{z}$ & $=$ & $\overline{8}$ & -- & 912 & $\begin{array}{l}110 \\
135\end{array}$ & 6.2 & 21.0 & 5 \\
\hline (29) & 20 & .00 & 0 & $\cdots$ & 5.0 & -- & 120 & 6.5 & 20.5 & 8 \\
\hline AUG:" & & & & & & & & & & \\
\hline $27 \ldots$ & $\overline{-}$ & -- & - & 0.3 & $\overline{-\sigma}$ & 240 & $\overline{89}$ & 6.9 & $\begin{array}{l}22.5 \\
22.5\end{array}$ & $\overline{-}$ \\
\hline $24 \ldots \ldots$ & 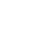 & -- & $\overline{--}$ & $7-2$ & 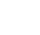 & -730 & $\begin{array}{l}165 \\
168\end{array}$ & 6.4 & $\begin{array}{r}22.5 \\
22.5\end{array}$ & 5 \\
\hline
\end{tabular}


02153500 BROAD RIVER NEAR GAFFNEY, S. C,

LOCATION,--Lat $35^{\circ} 05^{\prime} 20^{\prime \prime}$, long $81^{\circ} 34^{\prime} 20^{\prime \prime}$, Cherokee County, at gaging station on right bank at downstream side of bridge on U.S. Highwa $29,0.3 \mathrm{mile}$ upstream from Cheroke Creek, 4.4 miles downstream from Gaston Shoals Dam, and 4.5 miles east of Gafiney.

DRAINAGE AREA.--1, $490 \mathrm{sq} \mathrm{m1}$, approximately.

PERIOD OF RECORD.-Chemical analyses: October 1949 to September 1950, August 1969 to September 1970.

REMARKS. - The second of two samples collected at the same time is a field determination.

CHEMICAL ANALYSES, AUGUST 1969 TO SEPTEMBER 1970

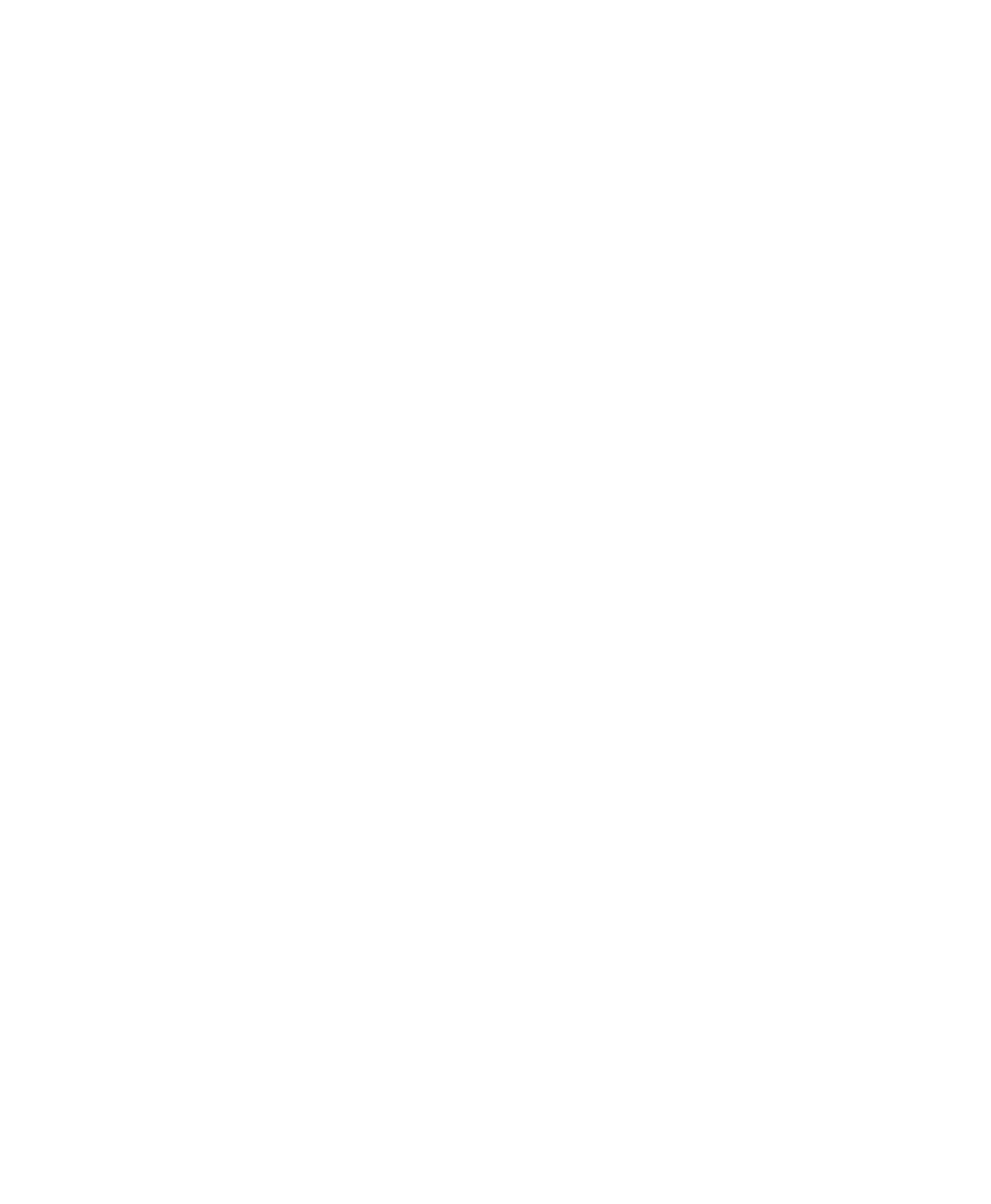


02154020 NORTH PACOLET RIVER NEAR SANDY PLAINS, N. C.

LOCATION,--Lat $35^{\circ} 12^{\prime} 58^{\prime \prime}$, long $82^{\circ} 10^{\prime} 52^{\prime \prime}$, Polk County, at bridge on Secondary Road $1517,1.2$ miles downstream from Horse Creek, and 5.6 miles southwest of Sandy Plains.

DRA INAGE AREA. --44.8 sq $\mathrm{mi}$.

CHEMICAL ANALYSES, WATER YEAR OCTOBER 1969 TO SEPTEMBER 1970

\begin{tabular}{|c|c|c|c|c|c|c|c|c|c|c|}
\hline & & CHEMICAL & ANALYSES & S, WATER & YEAR OCTC & ER 1969 & TO SEPTEM & ER 1970 & & \\
\hline UATE & TIME & $\begin{array}{l}\text { DIS- } \\
\text { CHARGE } \\
\text { (CFS) }\end{array}$ & $\begin{array}{l}\text { SILICA } \\
\text { (SICZ) } \\
\text { (MG/L) }\end{array}$ & $\begin{array}{l}\text { UIS- } \\
\text { SOL VED } \\
\text { IRCN } \\
\text { (FE) } \\
\text { (UG/L) }\end{array}$ & $\begin{array}{c}\text { DIS- } \\
\text { SCLVEO } \\
\text { CAL- } \\
\text { CIUM } \\
\text { (CA) } \\
(N G / L)\end{array}$ & $\begin{array}{l}\text { DIS- } \\
\text { SOL VFD } \\
M A G- \\
\text { NF- } \\
\text { SIUM } \\
(M G) \\
(M G / L)\end{array}$ & $\begin{array}{l}\text { SUEIUM } \\
\text { (NA) } \\
(M G / L)\end{array}$ & $\begin{array}{l}P O- \\
\text { TAS- } \\
\text { SIUM } \\
(K) \\
(M G / L)\end{array}$ & $\begin{array}{l}\text { BICAR - } \\
\text { BONA TE } \\
\text { (HCO3) } \\
(M G / L)\end{array}$ & $\begin{array}{l}\text { CAR- } \\
\text { BUNATE } \\
\text { (CO3) } \\
\text { (MG/L) }\end{array}$ \\
\hline $\begin{array}{c}\text { OC T. } \\
30 . . .\end{array}$ & 0930 & -- & -- & -- & -- & -- & -- & -- & - & \\
\hline $\begin{array}{l}30 . . \\
\text { NuV. }\end{array}$ & 0930 & 59 & -- & -- & -- & -- & - & - & 28 & \\
\hline $24 \ldots$ & 1330 & $97^{--}$ & -- & $=$ & -- & -- & -- & -- & $-\overline{56}$ & \\
\hline DEC. & & 41 & & - & - & -- & & 7. & 56 & \\
\hline $\begin{array}{l}15 \ldots \\
15 \ldots\end{array}$ & $\begin{array}{l}1435 \\
1435\end{array}$ & $\begin{array}{l}120 \\
120\end{array}$ & 13 & 11 & 3.0 & 1.1 & 7.5 & 1.4 & $\begin{array}{l}28 \\
20\end{array}$ & \\
\hline JAN. & & & & & & & & & & \\
\hline $\begin{array}{l}28 \ldots \\
2 \varepsilon \ldots\end{array}$ & $\begin{array}{l}1345 \\
1415\end{array}$ & ${ }^{85}$ & $=$ & -- & $-\infty$ & -- & $=$ & $=$ & $=$ & \\
\hline $\begin{array}{l}\text { FEts. } \\
27 \ldots \\
\text { MAK... }\end{array}$ & 0900 & 91 & $\cdots$ & -- & -- & -- & -- & -- & -- & \\
\hline $\begin{array}{l}24 \ldots \\
24 \ldots \\
A P R .\end{array}$ & $\begin{array}{l}1000 \\
1000\end{array}$ & $\begin{array}{l}118 \\
118\end{array}$ & 13 & 17 & 3.1 & $1 . ?$ & $10 \ldots$ & $1 . I$ & $\begin{array}{l}33 \\
--\end{array}$ & \\
\hline $\begin{array}{l}28 \ldots \\
28 \ldots\end{array}$ & $\begin{array}{l}1230 \\
1230\end{array}$ & 81 & $\because$ & -- & -- & -- & $=$ & $=$ & $=$ & \\
\hline MAY & & & & & & & & & & \\
\hline $21 \ldots$ & $\begin{array}{l}1630 \\
1530\end{array}$ & 50 & -- & -- & - & -- & -- & $=$ & + & \\
\hline JUNE & & & & & & - & & - & & \\
\hline $16 \ldots$ & $\begin{array}{l}1420 \\
1420\end{array}$ & -- & 15 & 100 & 4.0 & 1.9 & 7.5 & 1.8 & 220 & \\
\hline $16 \ldots$ & $\begin{array}{l}1420 \\
1400\end{array}$ & $44^{--}$ & $15^{--}$ & $\overline{27}$ & $-\overline{7}$ & - & -- & -- & -- & \\
\hline $\begin{array}{l}24 \ldots \\
24 \ldots\end{array}$ & $\begin{array}{l}1400 \\
1400\end{array}$ & $\begin{array}{l}44 \\
44\end{array}$ & 15 & 27 & 3.7 & 1.3 & 23 & 2.1 & 58 & \\
\hline$\Delta u r_{3}$. & & & & & & & & & & \\
\hline $04 \ldots$ & 1330 & 45 & 13 & 466 & 3.4 & I. 2 & 12 & 1.7 & 34 & \\
\hline & 1330 & 45 & -- & -- & -- & -- & - & -- & -- & \\
\hline $\begin{array}{l}27 \ldots \\
27 \ldots\end{array}$ & 1530 & -- & -- & -- & -- & $\overline{-}$ & - & $=$ & $\overline{-}$ & \\
\hline SEP. & 1530 & & 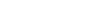 & . & - & 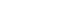 & & & & \\
\hline $\begin{array}{l}24 \ldots \\
24 \ldots\end{array}$ & $\begin{array}{l}1730 \\
1730\end{array}$ & $\begin{array}{l}34 \\
34\end{array}$ & 16 & 69 & 4.3 & $1: 9$ & 25 & 2.4 & 56 & \\
\hline UATE & $\begin{array}{l}\text { SULFATE } \\
\text { (SO4) } \\
\text { (MU/L) }\end{array}$ & $\begin{array}{l}\text { CHLD- } \\
\text { KIDE } \\
(C L) \\
(\$ S / L)\end{array}$ & $\begin{array}{l}\text { OIS- } \\
\text { SOLVED } \\
\text { FLUC- } \\
\text { RICE } \\
\text { (F) } \\
\text { (MG/L) }\end{array}$ & $\begin{array}{l}\text { NITRATE } \\
\text { (NC3) } \\
\text { I YG/L) }\end{array}$ & $\begin{array}{l}\text { CIS- } \\
\text { SOLVEO } \\
\text { CRTHD } \\
\text { PHOS- } \\
\text { PHATE } \\
\text { (POU) } \\
\text { (MG/L) }\end{array}$ & $\begin{array}{l}\text { DIS- } \\
\text { SOLVED } \\
\text { SOLIOS } \\
\text { (RESI- } \\
\text { DUE AT } \\
\text { LBO C) } \\
\text { (MG/L) }\end{array}$ & $\begin{array}{l}\text { UIS- } \\
\text { SALVED } \\
\text { SOLIDS } \\
\text { ITONS } \\
\text { PER } \\
\text { AC }-F T \text { I I }\end{array}$ & $\begin{array}{l}\text { DIS- } \\
\text { SOLVEO } \\
\text { SOLIDS } \\
\text { ITUNS } \\
\text { PER } \\
\text { DAYI }\end{array}$ & $\begin{array}{l}\text { HARD- } \\
\text { NESS } \\
(C A, M C) \\
(M G / L)\end{array}$ & $\begin{array}{l}\text { NON- } \\
\text { CAR- } \\
\text { BONATE } \\
\text { HARO- } \\
\text { NESS } \\
\text { (MG/L) }\end{array}$ \\
\hline $\begin{array}{l}\text { UCT. } \\
30 .\end{array}$ & -- & -- & -- & - & -- & -- & -- & $=$ & -- & \\
\hline
\end{tabular}
aC T

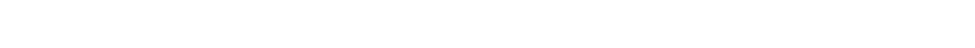

Nov.

$\begin{array}{lllll}24.6 & -- & -- & -- & --\end{array}$

$\begin{array}{cccccc}15 \ldots . & 3.2 & 4.7 & .0 & .9 & .00 \\ 15 \ldots & -. & -. & -0 & -0 & --\end{array}$

AN.

28.

$27 .$.

$24 \ldots 3.6$

$\triangle P R$

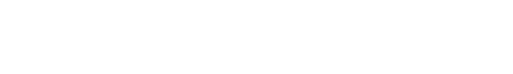

MAY

$5 \mathrm{I}$. .

JU.

16... 4.8

$16 \ldots . . \quad 4.9$

$24,$.

$\triangle U G$.

$\begin{array}{lllll}\text { J } 4 \ldots . . & 1.6 & 8.6 & -1 & 1\end{array}$

$27 \ldots \ldots$

SEP.

$24 \ldots \ldots \quad 1 n$

4

$47 \quad .06$

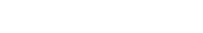

$\because \quad=$

15.2

15.2

$--$

$--\quad--$

$51 \quad .07$

$07 \quad 16$.

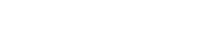

$\begin{array}{lll}-- & - & - \\ - & -\end{array}$

$.1 \quad .9 \quad .30$

$+-$

52

93

.07

11.0

$\begin{array}{lll}-1 & 1.1 & - \\ -- & -\end{array}$

$64 \quad .09$

7.78 
02154020 NORTH PACOLET RIVER NEAR SANDY PLAINS, N. C.--Continued

PERIOD OF RECORD. -Chemical analyses: October 1967 to September 1969 (partial-record), October 1969 to September 1970 .

REMARXS.--The second of two samples collected at the same time is a field determination.

CHEMICAL ANALYSES, WATER YEAR OCTOBER 1969 TO SEPTEMBER 1970

\begin{tabular}{|c|c|c|c|c|c|c|c|c|c|}
\hline UA TE & $\begin{array}{l}\text { SODIUM } \\
\text { AO- } \\
\text { SORP- } \\
\text { TION } \\
\text { RATIO }\end{array}$ & $\begin{array}{l}\text { PERCENT } \\
\text { SOOIUM }\end{array}$ & $\begin{array}{l}\text { BIC- } \\
\text { CHEM- } \\
\text { ICAL } \\
\text { OXYGEN } \\
\text { OEMAND } \\
\text { (MG/L) }\end{array}$ & $\begin{array}{l}\text { METHY- } \\
\text { LENE } \\
\text { BLUE } \\
\text { ACIIVE } \\
\text { SUB- } \\
\text { STANCE } \\
\text { IMG LII }\end{array}$ & $\begin{array}{l}\text { TUR- } \\
\text { BIO- } \\
\text { ITY } \\
\text { (JTU) }\end{array}$ & $\begin{array}{l}\text { TUTAL } \\
\text { NON- } \\
\text { FILT- } \\
\text { RABLE. } \\
\text { RESIDUE } \\
\text { IMG/LI }\end{array}$ & $\begin{array}{l}\text { ALKA- } \\
\text { LINITY } \\
\text { AS } \\
\text { CACO3 } \\
\text { (MGILI) }\end{array}$ & $\begin{array}{l}\text { DIS- } \\
\text { SOLVED } \\
\text { COPPER } \\
\text { ICUI } \\
\text { IUG/L) }\end{array}$ & $\begin{array}{l}\text { DIS- } \\
\text { SOL VED } \\
\text { LEAD } \\
\text { (PB) } \\
\text { (UG/LI }\end{array}$ \\
\hline $\begin{array}{l}\text { 1CT. } \\
30 \ldots . .\end{array}$ & -- & -- & -- & -- & -- & -- & + & $\cdots$ & - \\
\hline Nov... & -- & - & -- & -- & - & -- & 23 & - & - \\
\hline $24 \ldots$ & -- & -- & -- & -- & -- & -- & - & - & -- \\
\hline $\begin{array}{l}24 \ldots . \\
O E C .\end{array}$ & -- & -- & -- & -- & -- & -- & 46 & -- & -- \\
\hline $15 \ldots$ & .9 & 54 & -- & .03 & -- & -- & 23 & -- & -- \\
\hline $\begin{array}{l}15 \ldots . . \\
\text { JAN. }\end{array}$ & -- & -- & -- & -- & -- & -- & 20 & $\cdots$ & - \\
\hline $28 \ldots$ & - & -- & -- & -- & -- & -- & 27 & - & $\cdots$ \\
\hline $\begin{array}{l}28, \cdots \\
F E B .\end{array}$ & -- & -- & - & - & $\cdots$ & $\cdots$ & $\cdots$ & -- & -- \\
\hline $27 \ldots$ & -- & -- & -- & -- & -- & -- & 30 & -- & -- \\
\hline MAR. & & & & & & & & & \\
\hline $24 \ldots$ & 1.2 & 61 & -- & .10 & -- & -- & 27 & $\cdots$ & $\cdots$ \\
\hline $24 \ldots$ & -- & -- & $=$ & -- & -- & -- & 26 & -- & - \\
\hline $\begin{array}{l}A P R . \\
28 . .\end{array}$ & -- & -- & - & -- & - & $=$ & $=$ & -- & -- \\
\hline $28 .$. & -- & -- & -- & -- & -- & -- & 33 & - & $m$ \\
\hline MAY & & & & & & & & & \\
\hline $21 \ldots$ & -- & -- & -- & -- & - & -- & $=$ & $\cdots$ & -- \\
\hline $21 \ldots$ & $=$ & -- & -- & -- & -- & -- & 29 & $\cdots$ & $\cdots$ \\
\hline JUAE & & & & & & & & & \\
\hline $16 \ldots$ & .8 & 45 & -- & .04 & -- & -- & 180 & $\cdots$ & - \\
\hline $16 \ldots$ & -- & $\bar{x}$ & -- & $\overline{-}$ & -- & $=-$ & - & $\cdots$ & $=$ \\
\hline $24 \ldots$ & 2.6 & 74 & -- & .08 & -- & $=-$ & 48 & $\cdots$ & - \\
\hline $24 \ldots$ & -- & -- & $\cdots$ & -- & -- & -- & 49 & $\cdots$ & -- \\
\hline AUG. & & & & & & & & & \\
\hline $04 \ldots$ & 1.4 & 63 & 1.2 & .09 & 28 & 84 & 28 & 5 & 0 \\
\hline $04 \ldots$ & -- & -- & -- & -- & $\cdots$ & $\cdots$ & 28 & $\cdots$ & -- \\
\hline $27 \ldots$ & - & -- & - & - & - & $\cdots$ & - & - & -- \\
\hline $27 \ldots$ & $\cdots$ & -- & -- & -- & $=-$ & -- & 44 & $\cdots$ & - \\
\hline $\begin{array}{l}\text { SEP. } \\
24 \ldots\end{array}$ & 2.5 & 72 & $=$ & .11 & -- & -- & 46 & -- & -- \\
\hline $24 \ldots$ & -- & - & -- & -- & 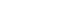 & - & 43 & - & -- \\
\hline & $\begin{array}{l}\text { OIS- } \\
\text { SOLVED }\end{array}$ & & $\begin{array}{l}\text { DIS- } \\
\text { SOL VED } \\
\text { CAD- }\end{array}$ & DIS= & TOTAL & $\begin{array}{l}\text { SPECI- } \\
\text { FIC } \\
\text { COND- }\end{array}$ & & & $\begin{array}{l}\text { COLOR } \\
\text { PPLAT- }\end{array}$ \\
\hline & $\begin{array}{l}21 N C \\
(2 N)\end{array}$ & $\begin{array}{c}\text { CYANIDE } \\
\text { (CN) }\end{array}$ & $\begin{array}{l}\text { MIUM } \\
\text { (CDI }\end{array}$ & $\begin{array}{l}\text { SOLVED } \\
\text { OXYGEN }\end{array}$ & BETA & $\begin{array}{l}\text { UCTANCE } \\
\text { IMICRO- }\end{array}$ & PH & $\begin{array}{l}\text { TEMP- } \\
\text { ERATURE }\end{array}$ & $\begin{array}{l}\text { INUM- } \\
\text { COBAL T }\end{array}$ \\
\hline DATE & $(U G / L)$ & $(M G / L)$ & IUG/L) & $(M G / L)$ & $(P C / L)$ & MHOSI & IUNITSI & (DEG C I & UNITSI \\
\hline$O C T$ & & & & & & & & & \\
\hline $30 \ldots$ & $\cdots$ & $\cdots$ & -- & $-\overline{-}$ & 2.0 & -- & $\cdots$ & $\cdots$ & $\cdots$ \\
\hline $30 . \cdots$ & -- & -- & -- & 12.0 & -- & 101 & 5.9 & 8.0 & $=$ \\
\hline $24 \ldots$ & -- & -- & -- & $=-$ & 1.8 & $\rightarrow$ & -- & -- & $=-$ \\
\hline $24 \ldots$ & -- & -. & -- & 9.0 & - & 79 & 0.2 & 11.0 & - \\
\hline DEC. & & & & & & & & & \\
\hline $15 \ldots$ & - & -- & -- & $=$ & 5.1 & 68 & 6.0 & 6.5 & 5 \\
\hline $15 \ldots$ & -- & -- & $-\infty$ & 10.7 & $\cdots$ & 66 & 6.8 & 6.5 & -- \\
\hline $\begin{array}{l}\text { JAN. } \\
28 . . .\end{array}$ & $=-$ & $\ldots$ & -- & 10,7 & -- & 110 & 7.2 & & -- \\
\hline $28 \ldots$ & - & $\ldots$ & $=$ & 20. & 3,4 & 110 & 1.2 & 6.5 & - \\
\hline FE8. & ( & & . & $\cdots$ & 3.4 & 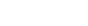 & - & 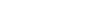 & ( \\
\hline $27 \ldots$ & -- & -- & -- & 12.3 & -- & 111 & 8.0 & 3.5 & $=-$ \\
\hline MAR. & & & & & & & & & \\
\hline $24 \ldots$ & -- & -- & -- & - & -- & 70 & 6.6 & 7.0 & 5 \\
\hline $24 \ldots$ & $-\cdot$ & $=$ & -- & 12.0 & $\cdots$ & 95 & 8.1 & 7.0 & -- \\
\hline $2 B \ldots$ & -- & -- & - & -- & 3.5 & -- & -- & 17.0 & -- \\
\hline $28 \ldots$ & -- & -- & -- & 8.5 & - & 111 & 8.0 & 17.0 & $=-$ \\
\hline MAY & & & & & & & & & \\
\hline $21 \ldots$ & $=-$ & -- & $-\infty$ & $\cdots$ & 3.1 & $=-$ & $\cdots$ & 22.5 & -- \\
\hline $21 \ldots$ & -- & -- & -- & 7.6 & -- & 121 & 7.5 & 22.5 & -- \\
\hline JUNE & & & & & & & & & \\
\hline $16 \ldots$ & -- & -- & -- & -- & 1.6 & 83 & 6.8 & -- & 17 \\
\hline $16 \ldots$ & -- & -- & -- & $\rightarrow$ & 1.6 & 83 & 6.8 & -- & 17 \\
\hline $24 \ldots$ & -- & -- & -- & -- & 1.4 & 130 & 6.6 & 20.0 & 5 \\
\hline $24 \ldots$ & - & -- & -- & 6.7 & -- & 153 & 9.7 & 20.0 & - \\
\hline AUG. & & & & & & & & & \\
\hline $04 \ldots$ & 8 & .00 & 0 & 7.4 & 6.0 & 90 & 6.9 & 25.0 & 5 \\
\hline $04 \ldots$ & -- & -- & -- & 7.4 & -- & 90 & 7.9 & 25.0 & $=-$ \\
\hline $27 \ldots$ & -- & -- & -- & -- & 4.0 & $\overline{--}$ & -- & $=-$ & - \\
\hline $27 \ldots$ & -- & -- & $\cdots$ & 7.6 & + & 138 & 8.5 & 23.5 & -- \\
\hline SEP. & & & & & & & & & \\
\hline $24 \ldots$ & $=$ & $=$ & $=$ & $-\overline{5}$ & 2.7 & 145 & 7.5 & 24.0 & 5 \\
\hline & -- & $=-$ & $=-$ & 8.5 & -- & 171 & 2 & 24.0 & - \\
\hline
\end{tabular}


02156350 PACOLET RIVER AT PACOLET MILLS, S. C.

LOCATION.--Lat $34^{\circ} 55^{\prime} 16^{\prime \prime}$, long $81^{\circ} 45^{\prime} 29^{\prime \prime}$, Spartanburg County, at bridge on State Highway 150 at Pacolet Mtlls,

0.1 mile downstream from dam at Pacolet Mill, and 3.4 miles downstream from Lawsons Fork Creek.

PERIOD OF RECORD,--Chemical analyses: July 1969 to September 1970.

REMARKS.--The second of two samples collected at the same time is a field determination.

CHEMICAL ANALYSES, JULY 1969 TO SEPTEMBER 1970

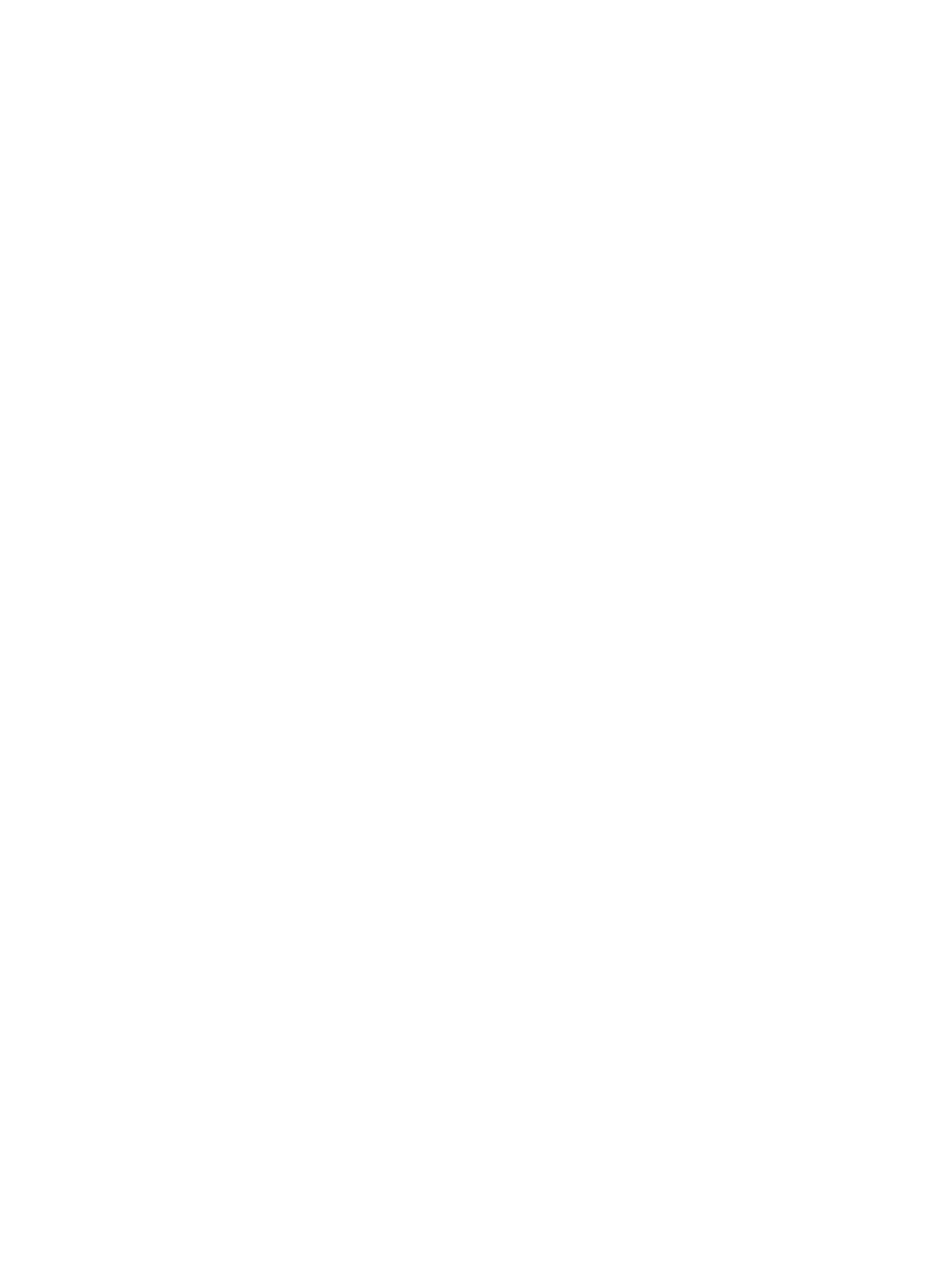


02156500 BROAD RIVER NEAR CARLISLE, S. C.

LOCATION.--Lat $34^{\circ} 35^{\prime} 46^{\prime \prime}$, long $81^{\circ} 25^{\prime} 20^{\prime \prime}$, Union County, at gaging station on right bank at downstream side of bridge on State Highway 72,2 miles upstream from Sandy River, 2 miles downstream from Seaboard Coast Line Ra1lroad bridge, 2.5 m1les east of Carlisle, and 5 miles downstream from Neal Shoals Dam.

DRAINAGE AREA, $--2,790 \mathrm{sq} \mathrm{m} 1$, approximately.

PERIOD OF RECORD.--Chem1cal analyses: October 1947 to September 1948, October 1962 to September 1964 , September 1969 to September 1970 .

REMARKS.-The second of two samples collected at the same time is a field determination.

CHEMICAL ANALYSES, SEPTEMBER 1969 TO SEPTEMBER 1970

\begin{tabular}{|c|c|c|c|c|c|c|c|c|c|c|}
\hline DATE & TIME & $\begin{array}{l}\text { TEMP- } \\
\text { ERATURE } \\
\text { (DEG C) }\end{array}$ & $\begin{array}{l}\text { DIS- } \\
\text { CHAPGE } \\
\text { (CFS) }\end{array}$ & $\begin{array}{l}\text { SPECI- } \\
\text { FIC } \\
\text { CONO- } \\
\text { UCTANCE } \\
\text { IMICRO- } \\
\text { MHOSI }\end{array}$ & $\begin{array}{l}\text { DIS- } \\
\text { SOLVED } \\
\text { OXYGEN } \\
\text { (MG/L) }\end{array}$ & $\begin{array}{c}\text { PH } \\
\text { (UNITS) }\end{array}$ & $\begin{array}{l}\text { TOTAL } \\
\text { PHOS- } \\
\text { PHORUS } \\
\text { \{P\} } \\
\text { (MG/L) }\end{array}$ & $\begin{array}{l}\text { NITRATE } \\
\text { (NO3) } \\
\text { (MG/L) }\end{array}$ & $\begin{array}{l}\text { FECAL } \\
\text { COLI- } \\
\text { FORM } \\
\text { (COL. } \\
\text { PER } \\
\text { IDO ML) }\end{array}$ & $\begin{array}{c}\text { IMAE- } \\
\text { DIATE } \\
\text { COLI- } \\
\text { FORM } \\
\text { ICOL. } \\
\text { PER } \\
100 \mathrm{MLI}\end{array}$ \\
\hline SEP. & & & & & & & & & & \\
\hline $\begin{array}{l}25 \ldots . \\
25 \ldots \\
0 C T:\end{array}$ & $\begin{array}{l}1415 \\
1415\end{array}$ & $22 . \overline{0}$ & $3710^{--}$ & $\overline{64}$ & $\overline{7.7}$ & 7.4 & .01 & 1.0 & $27 \overline{0}$ & $\overline{-}$ \\
\hline $\begin{array}{l}23 . . . \\
23 . . \\
\text { nov. }\end{array}$ & $\begin{array}{l}1300 \\
1300\end{array}$ & $\begin{array}{l}17.0 \\
17.0\end{array}$ & $\begin{array}{l}2430 \\
2430\end{array}$ & $\begin{array}{l}66 \\
72\end{array}$ & 9.6 & $\begin{array}{l}6.5 \\
7.1\end{array}$ & $\stackrel{.02}{--}$ & $\stackrel{3}{-}$ & $=$ & 750 \\
\hline $\begin{array}{l}18 \ldots \\
18 . . \\
\text { ogc... }\end{array}$ & $\begin{array}{l}1420 \\
1420\end{array}$ & $\begin{array}{l}9.5 \\
9.5\end{array}$ & $\begin{array}{l}2270 \\
2270\end{array}$ & $\overline{80}$ & $10 \overline{0}$ & $8 \overline{1}$ & .16 & -9 & $=$ & $=$ \\
\hline $\begin{array}{l}16 \ldots \\
16 \ldots\end{array}$ & $\begin{array}{l}1345 \\
1345\end{array}$ & $\begin{array}{l}6.0 \\
6.0\end{array}$ & $\begin{array}{l}3130 \\
3130\end{array}$ & 53 & $10 . \overline{3}$ & $7 .-3$ & .05 & .0 & $=$ & 560 \\
\hline $\begin{array}{r}21 \ldots \\
21 \ldots\end{array}$ & $\begin{array}{l}1525 \\
1525\end{array}$ & $\begin{array}{l}4.5 \\
4.5\end{array}$ & $\begin{array}{l}3510 \\
3510\end{array}$ & 64 & 10.8 & $8 . \overline{3}$ & .02 & 1.0 & $=$ & 7400 \\
\hline $\begin{array}{l}\text { FEB. } \\
20 . \ldots \\
20 . . . \\
\text { MAR. }\end{array}$ & $\begin{array}{l}1030 \\
1030\end{array}$ & $\begin{array}{l}8.5 \\
8.5\end{array}$ & $\begin{array}{l}5340 \\
5340\end{array}$ & $\overline{55}$ & 13.0 & 7.6 & .05 & 1.4 & $\overline{--}$ & - \\
\hline $\begin{array}{l}24 \ldots . \\
24 \ldots \\
A P R .\end{array}$ & $\begin{array}{l}1310 \\
1310\end{array}$ & $\begin{array}{l}10.0 \\
10.0\end{array}$ & $\begin{array}{l}5200 \\
5200\end{array}$ & 60 & 12.0 & 7.5 & .01 & $=3$ & $=$ & $\because$ \\
\hline $\begin{array}{c}27 \ldots . . \\
27 . \cdots\end{array}$ & $\begin{array}{l}0945 \\
0945\end{array}$ & $\begin{array}{l}20.0 \\
20.0\end{array}$ & $\begin{array}{l}3210 \\
3210\end{array}$ & $\overline{67}$ & $\overline{9.8}$ & 6.8 & .01 & $=9$ & $\overline{76}$ & - \\
\hline $\begin{array}{l}22 \ldots . . \\
22 \ldots \\
\text { JUNE }\end{array}$ & $\begin{array}{l}0805 \\
0805\end{array}$ & $\begin{array}{l}24.0 \\
24.0\end{array}$ & $\begin{array}{l}\text { A2450 } \\
A 2450\end{array}$ & $\overrightarrow{88}$ & $\overline{8.6}$ & $8 . \overline{4}$ & .03 & 1.4 & 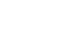 & $=$ \\
\hline $\begin{array}{l}17 \ldots . . \\
\text { July }\end{array}$ & $\begin{array}{l}1020 \\
1010\end{array}$ & $\begin{array}{l}25.0 \\
25.0\end{array}$ & $\begin{array}{l}\text { A23 } 300 \\
\text { A2300 }\end{array}$ & $\overline{92}$ & $\overline{7.3}$ & 7.6 & .03 & -4 & 1100 & $=$ \\
\hline $\begin{array}{l}08 \ldots . . \\
08 . . \\
\text { AUG. }\end{array}$ & $\begin{array}{l}0840 \\
0840\end{array}$ & $\begin{array}{l}26.5 \\
26.5\end{array}$ & $\begin{array}{l}470 \\
470\end{array}$ & $\overrightarrow{90}$ & $8 . \overline{4}$ & 8.6 & .03 & .6 & $11 \overline{00}$ & $=$ \\
\hline $\begin{array}{l}19 . . . \\
\text { SEP. }\end{array}$ & $\begin{array}{l}1200 \\
1100\end{array}$ & $\begin{array}{l}27.0 \\
27.0\end{array}$ & $\begin{array}{l}2860 \\
2860\end{array}$ & $\overline{64}$ & $\overline{8.0}$ & $7 . \overline{4}$ & .03 & .6 & $2 \overline{17}$ & $=$ \\
\hline $\begin{array}{l}22 \ldots \\
22 \ldots\end{array}$ & $\begin{array}{l}1115 \\
1115\end{array}$ & $\begin{array}{l}27.0 \\
27.0\end{array}$ & $\begin{array}{l}1300 \\
1300\end{array}$ & $2 \overline{100}$ & $\overline{8.7}$ & $\overline{7.1}$ & .03 & -3 & 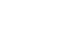 & $=$ \\
\hline
\end{tabular}

A DAILY MEAN DISCHARGE.

\begin{tabular}{|c|c|c|c|c|c|c|c|c|c|c|c|c|}
\hline JATE & TIME & $\begin{array}{l}\text { TEMP- } \\
\text { EFATURE } \\
\text { (OEG C) }\end{array}$ & $\begin{array}{l}\text { OIS- } \\
\text { CHARGF } \\
\text { (CFS) }\end{array}$ & $\begin{array}{l}\text { TUR- } \\
\text { EIO- } \\
\text { ITY } \\
\text { (JTU) }\end{array}$ & $\begin{array}{l}\text { COLOZ } \\
\text { IPLAT- } \\
\text { INUM- } \\
\text { CTBALT } \\
\text { UNITSI }\end{array}$ & $\begin{array}{l}\text { SPECI- } \\
\text { FIC } \\
\text { COND- } \\
\text { UCTANCE } \\
\text { (MICRO- } \\
\text { MHOS) }\end{array}$ & $\begin{array}{l}\text { DIS- } \\
\text { SOL VE O } \\
\text { CXYGEN } \\
\text { (MG/L) }\end{array}$ & $\begin{array}{l}\text { BIO- } \\
\text { CHEM- } \\
\text { ICAL } \\
\text { OXYGEN } \\
\text { OFMAND } \\
\text { (MG/L) }\end{array}$ & $\begin{array}{c}P H \\
\text { (UNITS) }\end{array}$ & $\begin{array}{l}\text { ALKA- } \\
\text { LINITY } \\
\text { AS } \\
\text { CACO3 } \\
\text { (MG/L) }\end{array}$ & $\begin{array}{l}\text { BICAR = } \\
\text { BCNATE } \\
(H C \cap 3) \\
(M G / L)\end{array}$ & $\begin{array}{r}\text { TOTAL } \\
\text { NON- } \\
\text { EILT- } \\
\text { RABLE } \\
\text { RESIDUE } \\
\text { (MG/L) }\end{array}$ \\
\hline $\begin{array}{l}\text { ocr. } \\
23 \ldots . . \\
23 \ldots\end{array}$ & $\begin{array}{l}1300 \\
1300\end{array}$ & $\begin{array}{l}17.0 \\
17.0\end{array}$ & $\begin{array}{l}2430 \\
2430\end{array}$ & -1 & $\begin{array}{r}5 \\
--\end{array}$ & $\begin{array}{l}66 \\
72\end{array}$ & 9.6 & 4.1 & $\begin{array}{l}6.5 \\
7.1\end{array}$ & 24 & $\begin{array}{l}29 \\
--\end{array}$ & 17 \\
\hline ATE & $\begin{array}{l}\text { TOTAL } \\
\text { PHOS- } \\
\text { PHORUS } \\
\text { (P) } \\
\text { (MG/L) }\end{array}$ & $\begin{array}{l}\text { HAKO- } \\
\text { NESS } \\
\text { (CA,MG) } \\
\text { (MG/L) }\end{array}$ & $\begin{array}{l}\text { NON- } \\
\text { CAR-- } \\
\text { SONATF } \\
\text { HARD- } \\
\text { NESS } \\
(M G / L)\end{array}$ & $\begin{array}{l}\text { CHLO- } \\
\text { RIOE } \\
\text { (CL) } \\
\text { (MG }\end{array}$ & $\begin{array}{l}\text { SULFATE } \\
\text { (SO4) } \\
\text { (MG/L) }\end{array}$ & $\begin{array}{l}\text { OIS- } \\
\text { SOLVFD } \\
\text { FLUD- } \\
\text { RIDE } \\
\text { (F) } \\
\text { (MS/L) }\end{array}$ & $\begin{array}{l}\text { TOTAL } \\
\text { CHRO- } \\
\text { MIUM } \\
\text { (CQ) } \\
\text { (UG/L) }\end{array}$ & $\begin{array}{l}\text { OIS- } \\
\text { SOLVEO } \\
\text { COPPER } \\
\text { (CU) } \\
\text { (UG/L) }\end{array}$ & $\begin{array}{l}\text { TOTAL } \\
\text { IRON } \\
\text { ( } F E \text { ) } \\
\text { (UG/L) }\end{array}$ & $\begin{array}{l}\text { DIS- } \\
\text { SOLVFD } \\
\text { LFAD } \\
\text { (PB) } \\
\text { (UG / I) }\end{array}$ & $\begin{array}{l}\text { TOTAL } \\
\text { MAN- } \\
\text { GANESE } \\
\text { (YN) } \\
\text { (UG/L) }\end{array}$ & $\begin{array}{l}\text { DIS- } \\
\text { SOLVED } \\
\text { NICKEL } \\
\text { INII) } \\
\text { (UGILI) }\end{array}$ \\
\hline
\end{tabular}

\begin{tabular}{|c|c|c|c|c|c|c|c|c|c|c|c|c|}
\hline $\begin{array}{l}0 \text { OCT. } \\
23 . . .\end{array}$ & .02 & 18 & $n$ & 5.2 & 6.4 & .1 & 0 & 0 & 73 & 14 & 0 & 8 \\
\hline $23 \ldots$ & - & -- & -- & -- & -- & - & $=$ & - & $\cdots$ & -- & $\cdots$ & - \\
\hline & $\begin{array}{l}\text { OIS- } \\
\text { SULVF=? }\end{array}$ & $\begin{array}{c}S U 5- \\
P \in A D E D\end{array}$ & $\begin{array}{l}\text { OIS- } \\
\text { SOL VED }\end{array}$ & $\begin{array}{l}\text { SUS- } \\
\text { PENOEO }\end{array}$ & $\begin{array}{l}\text { COLI- } \\
\text { FORM } \\
\text { COL- }\end{array}$ & $\begin{array}{l}\text { FECAL } \\
\text { COLI- } \\
\text { FORM }\end{array}$ & $\begin{array}{l}\text { METHY- } \\
\text { LEVE } \\
\text { BLUE } \\
\text { ACT IVE }\end{array}$ & $\begin{array}{l}\text { OIS- } \\
\text { SOLVFO } \\
\text { SOLIDS } \\
\text { IREST- }\end{array}$ & $\begin{array}{l}\text { OIS- } \\
\text { SOLVED } \\
\text { SOLIDS }\end{array}$ & $\begin{array}{l}\text { OIS- } \\
\text { SCLVEO } \\
\text { SOLIDS }\end{array}$ & & \\
\hline & ALPHA & ALPHA & BETA & BETA & $\begin{array}{c}\text { DNIES } \\
\text { PER }\end{array}$ & ICOL. & $\begin{array}{l}\text { SUA- } \\
\text { STANCE }\end{array}$ & $\begin{array}{l}\text { DUE AT } \\
\text { IBC CI }\end{array}$ & (TCNS & $\begin{array}{l}\text { ITCNS } \\
\text { PER } \\
A C-F Y\end{array}$ & $\begin{array}{l}\text { NITRATE } \\
\text { (NO3) } \\
\text { (MG/L) }\end{array}$ & \\
\hline UATE & $(P C / L)$ & $(P C / L)$ & $(P C / L)$ & $(P C / L)$ & $100 \mathrm{MLS}$ & $100 \mathrm{MLI}$ & $(M G / L)$ & $(M G / L)$ & & & & \\
\hline
\end{tabular}

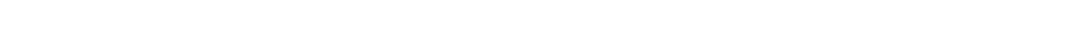


02157000 NORTH TYGER RIVER NEAR FAIRMONT, s. C.

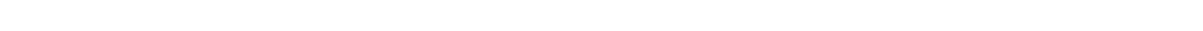
from Frey Creek and 2.2 miles north of Falrmont.

DRA INAGE AREA, $--44 \oplus q \pi 1$.

PERIOD OF RBCORD.-Chem1Cul anulyen: February 1951 to May 2986 (mincelinneoun),

Fater temperaturen: October 1968 to september 1970.

EXTREMES, $-1969-70$ :

Fater temperatures: Laximum, $24.0^{\circ} \mathrm{C}$ July $14-17 ;$ minimum, $3.8^{\circ} \mathrm{C}$ Feb. 1.

Perlod of record:

Water tompernturea: Maximum, $24.5^{\circ} \mathrm{C} J u 1 y ~ 28,29,1969 ;$ minimum, 3.6 ${ }^{\circ} \mathrm{C}$ Feb. 26, 1987, Dec, 16, 1968, Feb. 16, 17, TEMPERATURE ('O) OF WATER, WATER YEAR DCTOBER 1969 TO SEPTEMBER 1970

NOV OEC

JAR

FE 8

MAR MaX OCT

$\begin{array}{ll}16.5 & 16.3 \\ 19.0 & 16.5 \\ 19.0 & 17.5 \\ 18.0 & 17.5 \\ 18.0 & 17.0\end{array}$

$\begin{array}{ll}14.0 & 13.5 \\ 14.5 & 14.0 \\ 14.5 & 14.0 \\ 14.0 & 13.0 \\ 13.0 & 11.5\end{array}$

0.5
8.5
6.5
0.0
6.5

:

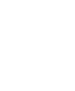

3.5
5.0
5.0
4.0

11.5

$\begin{array}{lll}7.0 & 6.3 & = \\ 7.0 & 7.0 & = \\ 8.0 & 7.0 & = \\ 0.0 & 0.0 & =\end{array}$

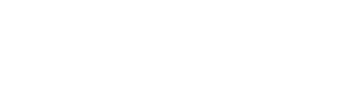

17.5

17.0

$11.5 \quad 11.5$

0.5

0.0

$9.0 \quad 0.0$

$\begin{array}{llll}17.0 & 16.5 & 11.5 & 11.0 \\ 17.5 & 17.0 & 13.5 & 11.5 \\ 18.5 & 17.0 & 13.5 & 11.5 \\ 19.0 & 17.5 & 11.5 & 10.5 \\ 18.0 & 16.0 & 10.5 & 9.0\end{array}$

10.0

16.0

16.0
15.5
14.0

14.0
15.0

15.3
14.0
13.5
13.0

9.0
9.5
11.5
12.0

8.0
8.5
9.5

0.5
0.5

0.5
0.5
0.5
8.5
0.0

0.0

$\begin{array}{lll}17.5 & 15.0 & 10.0 \\ 16.0 & 14.0 & 9.5 \\ 14.0 & 11.0 & 10.0\end{array}$

11.5

int:o

14.5
15.0
14.0
12.0

1220
iti:
io:
i.:

$\begin{array}{ll}2.0 & 10.5 \\ 4.0 & 10.0 \\ 1.5 & 10.5 \\ 0.5 & 10.5 \\ 0.5 & 9.5\end{array}$

14.0

11.5

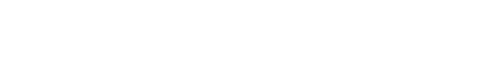

${ }_{10.5}^{10.0} \quad \because \quad=-\quad-$

10.0

$\begin{array}{lll}-- & - & -\end{array}$

9.5
10.0

10.0
9.5
0.5

16.0

14.8

11.5

10.7

car

MAX $A P R$

MAY

MIN

$\max$

MIN

$\because \quad: \quad 3: 90$

$\begin{array}{rrr}4.5 & 4.0 & 10.6 \\ 5.5 & 4.5 & 9.5 \\ 6.0 & 5.5 & 9.5\end{array}$

$6.3 \quad 6.0$

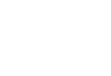

3.5
6.0
5.5
6.0

4.5

5.5
5.0
5.0
5.5

13.0

19.0
19.0
18.5
17.5

\section{0}

\section{8}

\section{5}

\section{5.}

23.5
23.5
23.5
23.5

$21.5 \quad 20.5$

$\begin{array}{lll}16.5 & 20.5 & 20.5 \\ 16.5 & 20.5 & 20.0\end{array}$

$\begin{array}{ll}13.5 & 13.0 \\ 13.5 & 13.5\end{array}$

16.5

20.0

13.5.

$$
\begin{aligned}
& 16.5 \\
& 16.5 \\
& 17.0 \\
& 17.0
\end{aligned}
$$

$\begin{array}{lll}13.5 & 13.5 & 17.0 \\ 14.5 & 13.5 & 17.0 \\ 14.5 & 14.0 & 17.5\end{array}$

16.5
16.0
16.5
17.0

20.0

20.0
20.0
20.0

\section{9.}

$$
\begin{aligned}
& 19.3 \\
& 19.0 \\
& 19.0 \\
& 19.3
\end{aligned}
$$

$17.0 \quad 20.5 \quad 19.3$

19.5

17.5
18.5
19.5
19.5

辛:

20.5

$\begin{array}{lll}14.5 & 14.5 & 19.5 \\ 15.0 & 14.5 & 19.5\end{array}$

15.0

$14.5 \quad 19.5$

16

$13.0 \quad 15.0$

$15.0 \quad 19$.

$\begin{array}{lll}16.0 & 13.0 & 19.5\end{array}$

$\begin{array}{lll}16.5 & 16.0 & 18.0\end{array}$

19.5

21::0

sion

永2:3

(3.0

23.0

17.0

$\begin{array}{lll}17.0 & 16.3 & 20.5 \\ 17.0 & 16.5 & 21.0\end{array}$

$17.5 \quad 17.0 \quad 21.0$

$\begin{array}{lll}17.5 & 17.5 & 21.0 \\ 17.5 & 17.5 & 21.0\end{array}$

18.0
19.5
20.0
20.0
20.0

23.3
23.5

23.522 .5

$\begin{array}{ll}23.5 & 22.0 \\ 23.5 & 22.5\end{array}$

$20.0 \quad 23.5 \quad 22.5$

$\begin{array}{lll}17.5 & 17.5 & 20.5 \\ 17.5 & 17.5 & 20.0\end{array}$

$17.5 \quad 17.5 \quad 20.0$

$10.0 \quad 17.5 \quad 20.0$

20.0

$\begin{array}{ll}22.5 & 22.5 \\ 22.5 & 22.5 \\ 22.5 & 21.5 \\ 21.5 & 20.5 \\ 21.5 & 20.5\end{array}$

ii

25.5

15.2

19.1

18.5

21.7

20.9

$\begin{array}{ll}23.0 & 22.0 \\ 22.5 & 21.5 \\ 22.0 & 21.5\end{array}$

21.5
22.5
22.5
22.5
22.5
22.5
21.5
21.5
21.5

6.5
0.5
$7: 0$
7.5
6.0
6.5
700
7.00

6.0

$\begin{array}{ll}14 . c & 12.0 \\ 15.0 & 14.0\end{array}$

$\begin{array}{rr}14.0 & 14.0 \\ 13.0 & 13.5 \\ 11.5 & 9.5\end{array}$

Av

$\begin{array}{ll}23.5 & 22.5 \\ 22.5 & 22.5 \\ 23.5 & 22.5\end{array}$

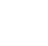

24.0

$24.0 \quad 23.5$

$\begin{array}{ll}24.0 & 22.5 \\ 22.5 & 22.0 \\ 22.5 & 22.0\end{array}$

$22.3 \quad 22.0$

$23.5 \quad 23.0$

$\begin{array}{ll}23.0 & 22.0 \\ 22.0 & 21.5 \\ 22.0 & 21.5\end{array}$

22.5

22.5

$22.5 \quad 22.5$

$22:$
22
22
22
22
2

$\begin{array}{ll}- & 6.5 \\ 0 & 6.0 \\ 0 & 7.0 \\ -.5\end{array}$

$\begin{array}{ll}6.0 & 6.0 \\ 7.0 & 6.0\end{array}$

$\begin{array}{lll}5.5 & --\end{array}$ 
02159700 TYGER RIVER NEAR* UNION, S. C.

LOCATION,--Lat $34^{\circ} 40^{\circ} 00^{\prime \prime}$, Long $81^{\circ} 44^{\prime} 23^{\prime \prime}$, Union County, at bridge on state Highway $49,1.2$ miles upstream from Issac Creek, 4.0 miles downstream from Dutchmans Creek, and 7.4 miles southwest of Union.

PERIOD OF RECORD.--Chemichl analyses: Auguat 1889 to September 1870.

REMARKS,--The second of two samples collected at the same time is a field determination.

CHEMICAL ANALYSES, AUSUST 1969 TO SEPTEMBER 1970

\begin{tabular}{|c|c|c|c|c|c|c|c|c|c|c|}
\hline DATE & TIME & $\begin{array}{l}\text { TEAP- } \\
\text { ERATURE } \\
\text { IOEG CI }\end{array}$ & $\begin{array}{l}\text { ODS- } \\
\text { CHARGE } \\
\text { CHASI }\end{array}$ & $\begin{array}{l}\text { SPECI- } \\
\text { FIC } \\
\text { CONO- } \\
\text { UCFAMEE } \\
\text { UMICRO- } \\
\text { MHOSI }\end{array}$ & $\begin{array}{l}\text { OOIS- } \\
\text { SOLVD } \\
\text { OXYGEEN } \\
\text { IMG/LI I }\end{array}$ & $\begin{array}{c}\text { PH } \\
\text { (UNITS) }\end{array}$ & $\begin{array}{l}\text { TOTAL } \\
\text { PHOS- } \\
\text { PHORUS } \\
\text { IPI } \\
\text { IMG/L }\end{array}$ & $\begin{array}{c}\text { MITRATE } \\
\text { (NOB) } \\
\text { (MG/L) }\end{array}$ & $\begin{array}{c}\text { FECAL } \\
\text { COLI- } \\
\text { FORM } \\
\text { ICQL. } \\
\text { PER } \\
100 \mathrm{MLI}\end{array}$ & $\begin{array}{c}\text { IMME- } \\
\text { OIATE } \\
\text { COLL } \\
\text { POR } \\
\text { PCDL. } \\
\text { PCER } \\
100 \mathrm{MLI}\end{array}$ \\
\hline $\begin{array}{l}\text { UG. } \\
25 . . . \\
25 . \ldots . \\
59\end{array}$ & $\begin{array}{l}1500 \\
1500\end{array}$ & 22.5 & 482 & $\overline{80}$ & 7.0 & 7.0 & .01 & 1.1 & $=$ & $=$ \\
\hline $\begin{array}{r}25 \ldots \\
25.0 \\
\text { oct: }\end{array}$ & $\begin{array}{l}1205 \\
1205\end{array}$ & 19.5 & $640^{--}$ & 140 & $\overrightarrow{7 . A}$ & 7.6 & .03 & 1.0 & 3800 & $=$ \\
\hline $\begin{array}{c}23 \ldots . \\
23 .: \\
\text { Nov. }\end{array}$ & $\begin{array}{l}0930 \\
0930\end{array}$ & $13 \overline{3}$ & 343 & $\begin{array}{l}148 \\
170\end{array}$ & 11.0 & 8.8 & .21 & $\because 9$ & $=$ & 270 \\
\hline${ }_{18}^{18 . .}$ & $\begin{array}{l}1150 \\
1150\end{array}$ & $\begin{array}{l}9.0 \\
9.0\end{array}$ & $\begin{array}{l}399 \\
399\end{array}$ & 90 & $10 . \overline{0}$ & 7.7 & $\cdot{ }^{-13}$ & 1.1 & $=$ & $\because$ \\
\hline $160 .$. & $\begin{array}{l}1053 \\
1059\end{array}$ & $\begin{array}{l}4.0 \\
4.0\end{array}$ & $\begin{array}{l}617 \\
617\end{array}$ & 70 & 10.7 & $7 .-7$ & .08 & $\therefore$ & $=$ & $\overline{10}$ \\
\hline $\begin{array}{l}21 \ldots . \\
21 \ldots \\
k \in \in B\end{array}$ & $\begin{array}{l}1250 \\
1230\end{array}$ & $\begin{array}{l}2.5 \\
2.5\end{array}$ & $\begin{array}{l}507 \\
907\end{array}$ & $\overrightarrow{100}$ & $12 . \overline{2}$ & 7.8 & .04 & 1.3 & $=$ & $\sqrt[128]{28}$ \\
\hline $19 \%:$ & $\begin{array}{l}1515 \\
1519\end{array}$ & $\begin{array}{l}11.0 \\
11: 0\end{array}$ & $\begin{array}{l}1140 \\
1140\end{array}$ & 83 & 11.0 & 8.0 & .05 & 1.4 & $=$ & $\bar{z}$ \\
\hline${ }_{24}^{24 \ldots}$ & $\begin{array}{l}1010 \\
1010\end{array}$ & $\begin{array}{l}8.5 \\
8.5\end{array}$ & $\begin{array}{l}1160 \\
1160\end{array}$ & 37 & $10 . \overline{2}$ & 7.1 & .04 & $\therefore$ & $=$ & $\approx$ \\
\hline $27 \ldots$ & $\begin{array}{l}1310 \\
1310\end{array}$ & $\begin{array}{l}18.0 \\
18.0\end{array}$ & $\begin{array}{l}570 \\
370\end{array}$ & 129 & $8 \overline{8.6}$ & 7.3 & .07 & 1.8 & $\because$ & $=$ \\
\hline $\begin{array}{l}22 \ldots . . \\
2 U N E\end{array}$ & $\begin{array}{l}0855 \\
0855\end{array}$ & $\begin{array}{l}21.5 \\
21.5\end{array}$ & $\begin{array}{l}370 \\
370\end{array}$ & $\overline{185}$ & $\overrightarrow{8.5}$ & $\overrightarrow{T, B}$ & $\stackrel{.08}{-}$ & 1.7 & $\because$ & $=$ \\
\hline $\begin{array}{l}17 \ldots \\
17 \ldots\end{array}$ & $\begin{array}{l}0800 \\
0800\end{array}$ & $\begin{array}{l}23.5 \\
23.5\end{array}$ & $\begin{array}{l}330 \\
330\end{array}$ & 115 & 8.8 & 7.5 & .03 & $\therefore 4$ & $\overline{86}$ & $=$ \\
\hline $\begin{array}{r}07 . . \\
07 \ldots\end{array}$ & $\begin{array}{l}1430 \\
1430\end{array}$ & $\begin{array}{l}26.5 \\
26.5\end{array}$ & $\begin{array}{l}250 \\
250\end{array}$ & 100 & 1.5 & 7.8 & .02 & .5 & $\overline{39}$ & $=$ \\
\hline & $\begin{array}{l}1330 \\
1330\end{array}$ & $\begin{array}{l}27.0 \\
27: 0\end{array}$ & $\begin{array}{l}315 \\
315\end{array}$ & 119 & $\overline{7.7}$ & 7.7 & ${ }^{.04}$ & 1.4 & 207 & $\because$ \\
\hline $\begin{array}{l}22 \ldots . . \\
22 \ldots\end{array}$ & $\begin{array}{l}09455 \\
0945\end{array}$ & $\begin{array}{l}\begin{array}{l}4.0 \\
24: 0\end{array}\end{array}$ & $\begin{array}{l}179 \\
179\end{array}$ & 240 & 8.1 & $7 .-6$ & .15 & 1.2 & $=$ & $z$ \\
\hline
\end{tabular}

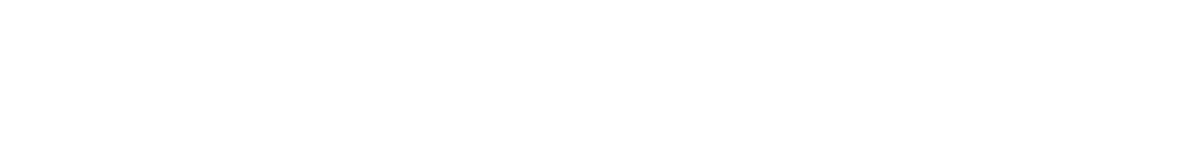
OCT.

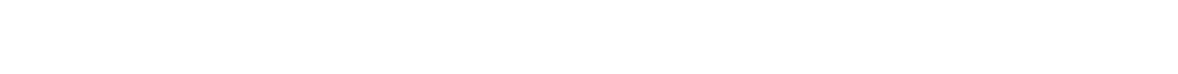

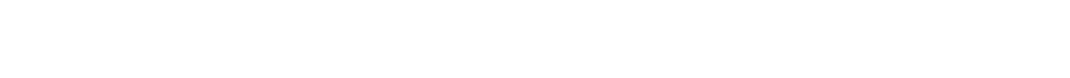

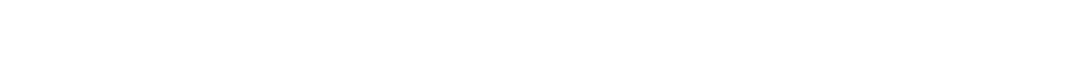

\begin{tabular}{|c|c|c|c|c|c|c|c|c|c|c|c|}
\hline $\begin{array}{l}67 . \\
231 \ldots . \\
23 . .0\end{array}$ & . 21 & $\ddot{20}$ & $\ddot{0}$ & $12^{-0}$ & A. & $=1$ & $\ddot{13}$ & - & 238 & $=$ & 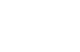 \\
\hline DAFE & $\begin{array}{c}\text { OIS } \\
\text { SQLVED } \\
\text { NIEKEL } \\
\text { (NI) } \\
\text { (UG/LI) }\end{array}$ & $\begin{array}{c}A 15= \\
\text { SULVFo } \\
\text { ALPHA } \\
(B C / L)\end{array}$ & $\begin{array}{l}5 U 5= \\
\text { PENOEO } \\
\text { ALPHA } \\
\text { TEE/LI }\end{array}$ & $\begin{array}{c}\text { OIS= } \\
\text { SOLVEO } \\
\text { OEFA } \\
\text { (PC/L) }\end{array}$ & $\begin{array}{c}\text { SUSE } \\
\text { PENEO } \\
\text { BEFA } \\
\text { (ACルL) }\end{array}$ & $\begin{array}{c}\text { COLI= } \\
\text { PERM } \\
\text { PCOLE } \\
\text { ONIES } \\
\text { PER } \\
100^{\circ} \text { MLI }\end{array}$ & $\begin{array}{l}\text { FEEAL } \\
\text { CALI } \\
\text { FORM } \\
\text { (EQL. } \\
\text { PER } \\
\text { 100 ML) }\end{array}$ & $\begin{array}{l}\text { LENE } \\
\text { SLUE } \\
\text { ACFIVE } \\
\text { SUGE } \\
\text { SFANCE } \\
\text { (MGIL) }\end{array}$ & 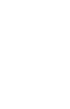 & 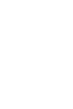 & $\begin{array}{l}\text { NIfAATE } \\
\text { INQ3) } \\
\text { (NO/L) }\end{array}$ \\
\hline
\end{tabular}

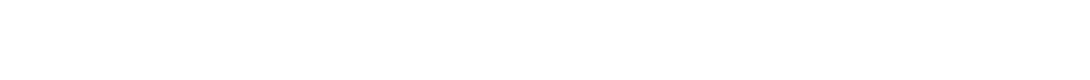


LOCATION.--lat $34^{\circ} 36^{\prime} 38^{\prime \prime}$, long $81^{\circ} 54^{\prime} 35^{\prime \prime}$, Spartanburg County, at bridge on State Highway 49 , 60 ft downstream from gaging station, 0.8 inlle upstream from Warrior Creek, and 4 miles southeast of Enoree.

DRAINAGE AREA. - -307 sq mi (at gaging station).

PERIOD OF RBCORD,--Chemical analyses: October 1947 to September 1948, July 1969 to September 1970. Water temperatures: October 1966 to September 1970 .

EXTREMES. $-1969-70$ :

Water temperatures: Kaximum, $28.0^{\circ} \mathrm{C}$ June 19,$22 ;$ minimum, $2.0^{\circ} \mathrm{C} \mathrm{Jan.} 12,13$.

Period of record:

Water temperatures: Kaximum, $28.0^{\circ} \mathrm{C}$ Aug, 22-24, 1968, June 19, 22, 1970 ; minimum, $1.5^{\circ} \mathrm{C} \mathrm{Dec.} 17,1969$.

REMARKS. - The second of two samples collected at the same time is a field determination. Temperature recorder at gaging station $60 \mathrm{ft}$ unstream from sampling site. Recorder malfunctioned Oct. 1-29, 1968, Nov. 4-30, 1969,

CHEMICAL ANALYSES, JULY, 1969 TO SEDTEMBER 1970

\begin{tabular}{|c|c|c|c|c|c|c|c|c|c|c|}
\hline DATE & TIME & $\begin{array}{l}\text { TEMP } \\
\text { ERATURE } \\
\text { IDEG C) }\end{array}$ & $\begin{array}{l}\text { OHS- } \\
\text { CHAPGE } \\
\text { (CFS) }\end{array}$ & $\begin{array}{l}\text { SPECI- } \\
\text { FIC } \\
\text { COND } \\
\text { UCYANEE } \\
\text { IMICRO- } \\
\text { MHOS I }\end{array}$ & $\begin{array}{l}\text { OIS- } \\
\text { SOLVED } \\
\text { OXYGEN } \\
\text { IMG/L) }\end{array}$ & $\begin{array}{c}\text { PH } \\
\text { (UNITS) }\end{array}$ & $\begin{array}{l}\text { TORAL } \\
\text { PHOS- } \\
\text { PHOR US } \\
\text { IO) } \\
\text { (MG/L) }\end{array}$ & $\begin{array}{c}\text { NITRATE } \\
\text { (NO3) } \\
\text { (NG/L) }\end{array}$ & $\begin{array}{c}\text { FECAL } \\
C O L 1- \\
F O R H \\
F O R \\
\text { ICOL. } \\
\text { PER } \\
100 \mathrm{MLI}\end{array}$ & $\begin{array}{c}\text { TMME- } \\
\text { OATE } \\
\text { COLI } \\
\text { FORM } \\
\text { ICOL. } \\
\text { PER } \\
\text { IOO MLI }\end{array}$ \\
\hline $\begin{array}{l}\text { JuLY } \\
21 \ldots . . \\
211 \ldots\end{array}$ & $\begin{array}{l}1725 \\
1725\end{array}$ & 27.0 & 268 & $\overline{95}$ & 7.0 & $\overline{6.6}$ & ${ }^{.03}$ & $\because 6$ & $=$ & $\because$ \\
\hline 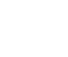 & $\begin{array}{l}1405 \\
1405\end{array}$ & $22 . \overline{5}$ & $186^{--}$ & $\overline{85}$ & 7.4 & 7.2 & .00 & 1.0 & $=$ & $\because$ \\
\hline 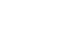 & $\begin{array}{l}0945 \\
0945\end{array}$ & 19.0 & $341^{--}$ & 100 & 8.2 & 7.0 & .03 & $\therefore$ & $4 \overline{460}$ & $=$ \\
\hline $\begin{array}{r}23 \ldots \\
23 \ldots \\
\text { Nov. }\end{array}$ & $\begin{array}{l}1115 \\
1115\end{array}$ & $\begin{array}{l}13.5 \\
13.5\end{array}$ & $\begin{array}{l}218 \\
218\end{array}$ & $\begin{array}{r}89 \\
100\end{array}$ & $11 . \overline{0}$ & $\begin{array}{l}6.5 \\
7.3\end{array}$ & .09 & $\therefore$ & $=$ & $=$ \\
\hline $\begin{array}{l}18 . . \\
18 . .\end{array}$ & $\begin{array}{l}315 \\
1315\end{array}$ & $\begin{array}{l}9.0 \\
9.0\end{array}$ & $\begin{array}{l}213 \\
213\end{array}$ & 30 & $10 . \overline{0}$ & $\overline{7.2}$ & ${ }^{.06}$ & 1.2 & $=$ & $=$ \\
\hline $\begin{array}{r}16 \ldots . . \\
16 \ldots \\
\text { JAN... }\end{array}$ & $\begin{array}{l}1230 \\
1230\end{array}$ & $\begin{array}{l}5.0 \\
5.0\end{array}$ & $\begin{array}{l}332 \\
312\end{array}$ & $\overline{56}$ & 11.5 & 7.4 & .02 & 1.4 & $=$ & $=$ \\
\hline $\begin{array}{r}21 \ldots . . \\
21 \ldots\end{array}$ & $\begin{array}{l}1420 \\
1420\end{array}$ & $\begin{array}{r}4.0 \\
4.0\end{array}$ & $\begin{array}{l}314 \\
314\end{array}$ & 72 & $11 . \overline{7}$ & 8.1 & .01 & 1.3 & $=$ & 250 \\
\hline $20 \ldots$ & $\begin{array}{l}0925 \\
0925\end{array}$ & $\begin{array}{l}8.5 \\
8.5\end{array}$ & $\begin{array}{l}523 \\
523\end{array}$ & 72 & $12 . \overline{6}$ & 7.1 & .04 & 2.0 & $=$ & $=$ \\
\hline $\begin{aligned} 24: . . \\
24: 0 \\
A P R .\end{aligned}$ & $\begin{array}{l}0935 \\
0935\end{array}$ & $\begin{array}{l}9.0 \\
9.0\end{array}$ & $\begin{array}{l}753 \\
753\end{array}$ & 48 & 11.6 & $7 .-6$ & .03 & 1.1 & $=$ & $=$ \\
\hline 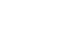 & $\begin{array}{l}1345 \\
1345\end{array}$ & $\begin{array}{l}21: 0 \\
21: 0\end{array}$ & $\begin{array}{l}358 \\
358\end{array}$ & $\overline{78}$ & $9 . \overline{1}$ & 0.8 & .03 & 2.1 & $12 \overline{30}$ & $=$ \\
\hline $\begin{array}{r}22 \ldots \\
22 \ldots \\
J U N E\end{array}$ & $\begin{array}{l}0930 \\
0930\end{array}$ & $\begin{array}{l}20.5 \\
20.5\end{array}$ & $\begin{array}{l}230 \\
230\end{array}$ & $\overline{90}$ & 8.7 & $7 .-$ & .01 & 1.7 & $=$ & $=$ \\
\hline $\begin{array}{c}17 \ldots \\
\text { juL } \ddot{Y}\end{array}$ & $\begin{array}{l}0850 \\
0850\end{array}$ & $\begin{array}{l}22.5 \\
22.5\end{array}$ & $\begin{array}{l}216 \\
216\end{array}$ & 57 & 9.0 & 7.3 & .01 & 1.6 & $\overline{155}$ & $=$ \\
\hline $\begin{array}{r}08 \ldots \\
08 . . . \\
\text { AUG. }\end{array}$ & $\begin{array}{l}7045 \\
0745\end{array}$ & $\begin{array}{l}22.0 \\
22.0\end{array}$ & $\begin{array}{l}202 \\
202\end{array}$ & $\overline{64}$ & $8 . \overline{9}$ & $\overline{7.1}$ & .02 & 1.0 & $\overline{220}$ & $=$ \\
\hline & $\begin{array}{l}1410 \\
1410\end{array}$ & $\begin{array}{l}26.5 \\
26.5\end{array}$ & $\begin{array}{l}160 \\
160\end{array}$ & 72 & $\overline{8.0}$ & 7.3 & .04 & 1.3 & $\overline{220}$ & $=$ \\
\hline${ }_{15}^{15 \ldots .}$ & $\begin{array}{l}1440 \\
1440\end{array}$ & $\begin{array}{l}24.0 \\
24.0\end{array}$ & $\begin{array}{l}136 \\
136\end{array}$ & $\ddot{84}$ & $8 . \overline{0}$ & 7.0 & .01 & 2.0 & 407 & $\because$ \\
\hline
\end{tabular}

\begin{tabular}{|c|c|c|c|c|c|c|c|c|c|c|c|c|}
\hline CATE & TIMF & $\begin{array}{l}\text { TFMP- } \\
\text { LPATIPE } \\
\text { (OFG C) }\end{array}$ & $\begin{array}{l}\text { OIS- } \\
\text { CHARF: } \\
\text { (CFS) }\end{array}$ & $\begin{array}{l}\text { TUJP- } \\
\text { BID- } \\
\text { ITY } \\
\text { (JTU) }\end{array}$ & $\begin{array}{l}\text { COLOR } \\
\text { (PLAT- } \\
\text { INUM- } \\
\text { COBALT } \\
\text { UNITS I }\end{array}$ & $\begin{array}{l}\text { SPECI- } \\
\text { FIC } \\
\text { COND- } \\
\text { UCIANCE } \\
\text { (MICRO- } \\
\text { MHOS) }\end{array}$ & $\begin{array}{l}\text { OIS- } \\
\text { SOLVED } \\
\text { OXYGEN } \\
\text { (YGLL) }\end{array}$ & $\begin{array}{l}\text { BIO- } \\
\text { CHFM- } \\
\text { ICAL } \\
\text { OXYGEN } \\
\text { DEMAND } \\
\text { (MG/L) }\end{array}$ & $\begin{array}{c}\text { PH } \\
\text { (UNITS) }\end{array}$ & $\begin{array}{l}\text { ALKA- } \\
\text { LINI IY } \\
\text { AS } \\
\text { CACO3 } \\
\text { (MG/L) }\end{array}$ & $\begin{array}{l}\text { 8ICAR- } \\
\text { BONATE } \\
\text { (HCO3) } \\
\text { (MG/L) }\end{array}$ & $\begin{array}{r}\text { TOTAL } \\
\text { NON- } \\
\text { FILT- } \\
\text { RABLE } \\
\text { RESIOUE } \\
\text { (MG/L) }\end{array}$ \\
\hline $\begin{array}{l}0 . \\
23 \ldots\end{array}$ & 111 & 13.5 & 218 & 1 & 5 & 8 & -- & 2.2 & & 19 & 23 & 48 \\
\hline
\end{tabular}

GCT.
$23 .$.
$23 .$.

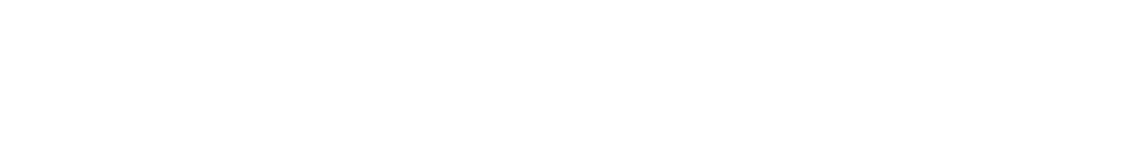
DCT.
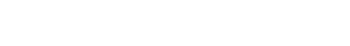

.13

68

40.0

$.09 \quad .7$ 
SANTEE RIVER BASIN

02160500 ENOREE RIVER NEAR ENOREE, S. C.--COntinued

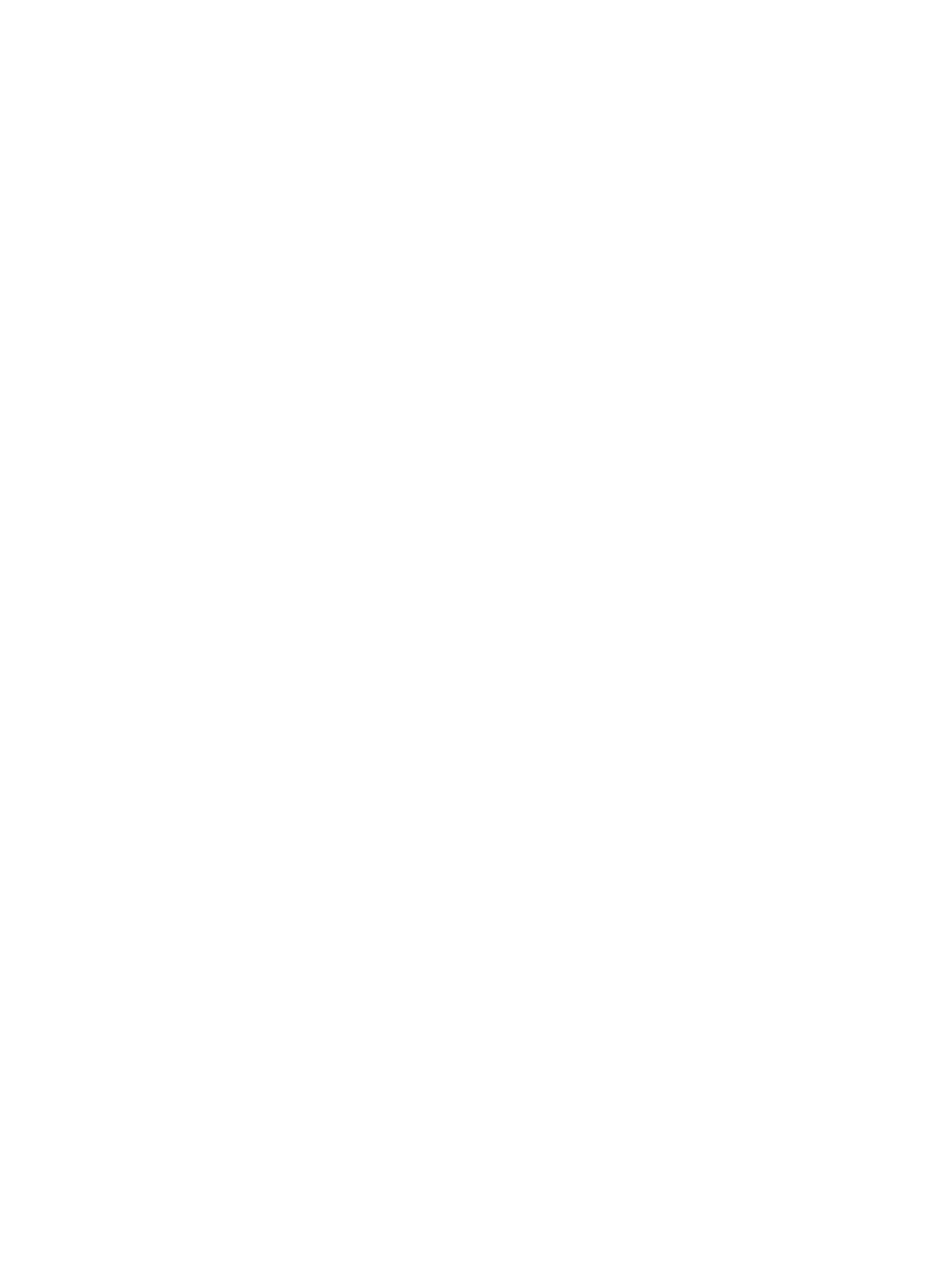


02169500 SALUDA RIVER NEAR TARE SHOALS, $\mathbf{s}$. c.

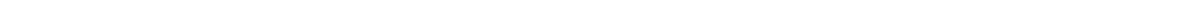
from Fare Shouls Dam, 1.3 miles upstream from gaging stution, 1.4 ailes southeast of Ware Shouls, and $6.3 \mathrm{miles}$ upstream Irom Turkey Creek.

DRAINAGE AREA.--569 sq m1 (at gaging station).

PIR IOD OF RECORD.--Chemlcal analyses: July 1969 to September 1970.

REuRxs,--The second of two samples collected at the same time 1s a field determination.

CHEMICAL ANALYSES, JULY 1969 TO SEPTEMBER 1970

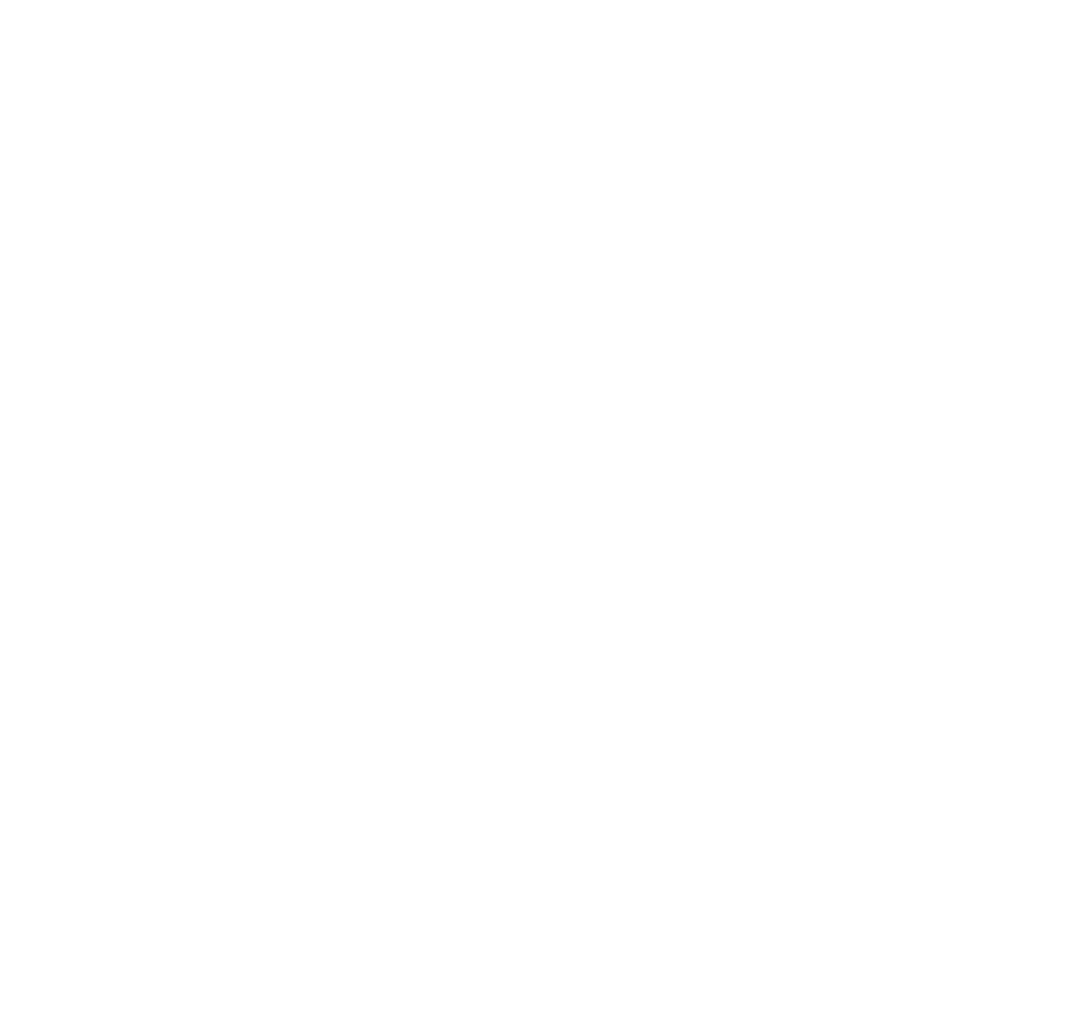

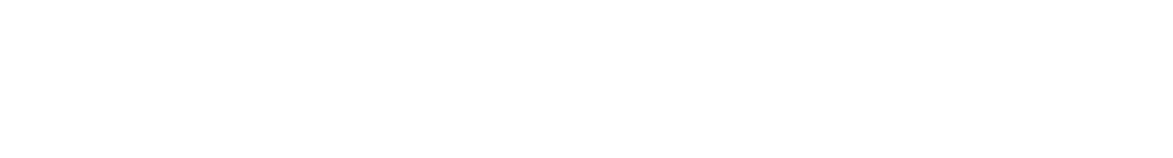

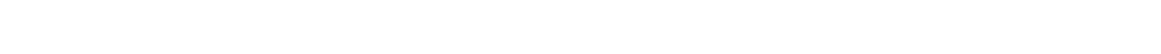
$\underset{20}{20}$

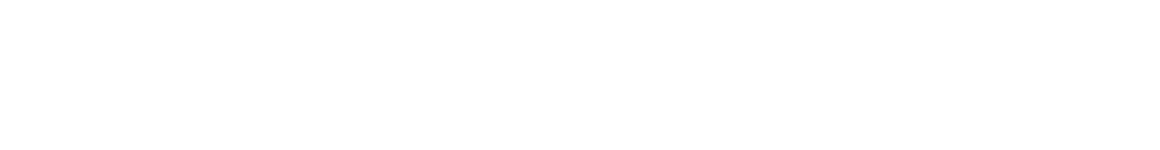

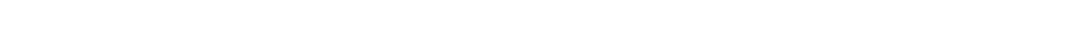


O2264000 REEDY RIVER NEAR GREYVVILLE, S. C.

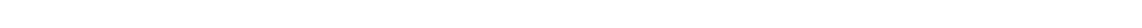
from bridge on Interetme Highway 85, 0,5 m1le upetroum from Bruehy Creek, 2.8 mileo upetream from dam at Conentee, and 3,8 miles southenet of city hall in Greenvilie.

DRAINAGK ARKA, $--48.6 \mathrm{eq}$. 1 .

PERIOD OP RECORD.--ChemiCal analyoee: July 1868 to September 1870.

REMARKS.-The eccond of two enples collected at the wame time io a fleld determination.

CHEMICAL ANALYSES, JULY 1969 TO SEPTEMBER 1970

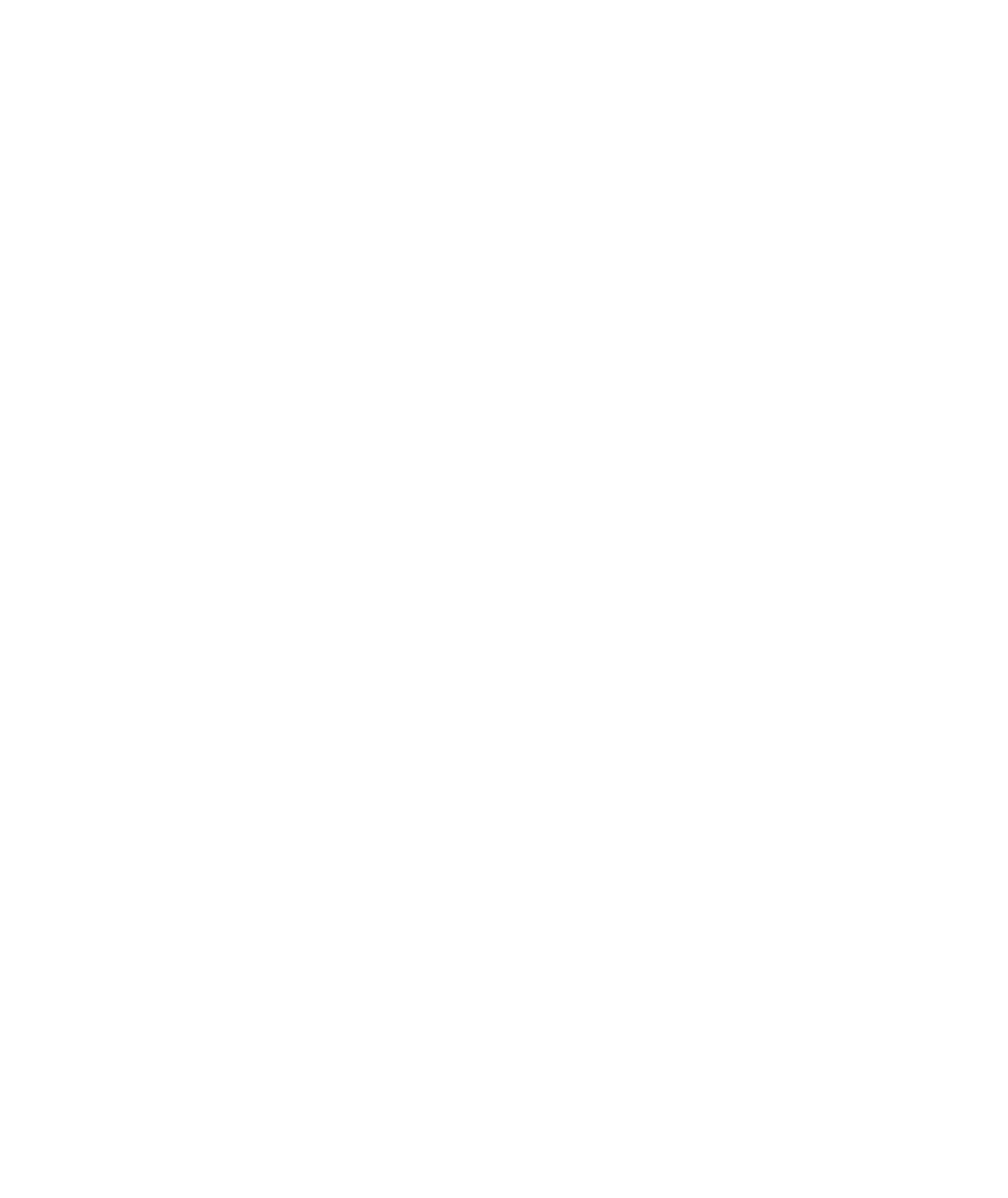


02165000 REEDY RIVER NEAR WARE SHOALS, S. C.

LOCATION,--Lat $34^{\circ} 27^{\prime} 43^{\prime \prime}$, long $82^{\circ} 11^{\prime} 50^{\prime \prime}$, Laurens County, at bridge on state Highway 252 , 200 ft downstream from dam at Boyds $111,1.7 \mathrm{miles} u p s t r e a m$ from gaging station, 4.5 miles northeast of Ware shoals, and 12 miles upstream
from Rabon Creek.

DRAINAGE AREA.--228 sq $\mathrm{m} 1$ (at gaging station).

PERIOD OF RECORD,--Chemical analyses: July 1969 to September 1970.

REMARKS.--The second of two samples collected at the same time is a field determination.

CHEMICAL ANALYSES, JULY 1969 TO SEPTEMBER 1970

\begin{tabular}{|c|c|c|c|c|c|c|c|c|}
\hline DATE & TIME & $\begin{array}{l}\text { TEMP- } \\
\text { ERATURE } \\
\text { (DEG C) }\end{array}$ & $\begin{array}{l}\text { OIS- } \\
\text { CHARGE } \\
\text { (CFS) }\end{array}$ & $\begin{array}{l}\text { SPECI- } \\
\text { FIC } \\
\text { CONO- } \\
\text { UCTANCE } \\
\text { (MICRO- } \\
\text { MHOSI }\end{array}$ & $\begin{array}{l}\text { OIS- } \\
\text { SOLVEO } \\
\text { OXYGEN } \\
\text { (MG/L) }\end{array}$ & $\begin{array}{c}\text { PH } \\
\text { (UNI TS) }\end{array}$ & $\begin{array}{l}\text { TDTAL } \\
\text { PHOS- } \\
\text { PHORUS } \\
\text { (P) } \\
\text { (MG/L) }\end{array}$ & $\begin{array}{l}\text { NITRAT } \\
\text { (NO3) } \\
\text { (MG/L }\end{array}$ \\
\hline
\end{tabular}

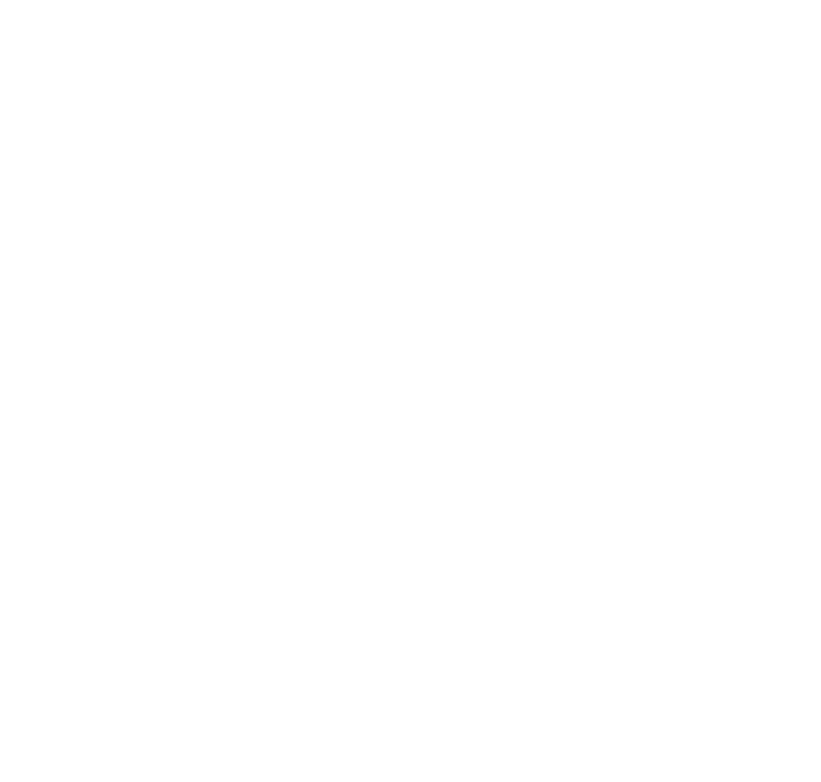

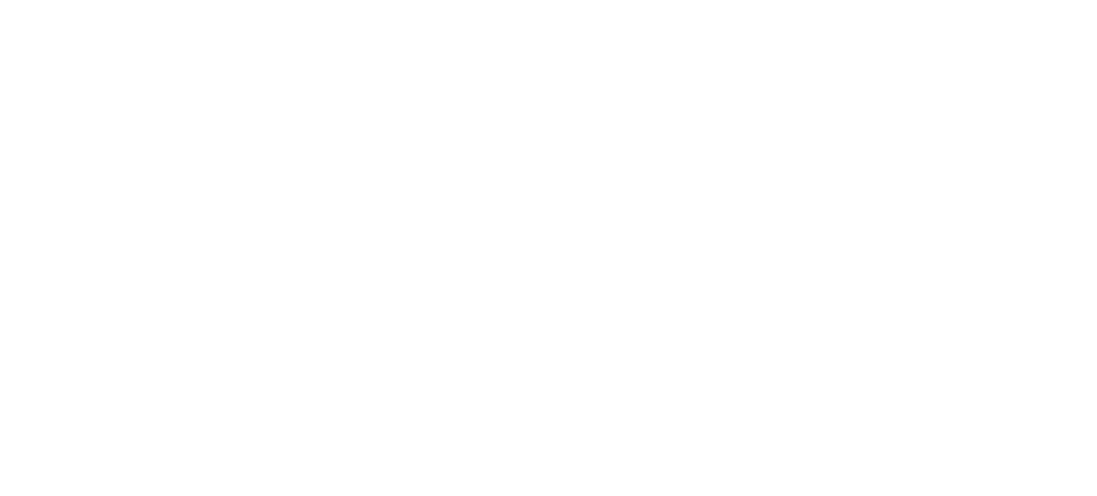

OCT

$21 . . \quad 35$

$\begin{array}{lll}150 & .20 & 6.2\end{array}$ 
02167500 SALUDA RIVER NEAR SILVERSTREET, S, C.

LOCATION.--Lat $34^{\circ} 10^{\prime} 58^{\prime \prime}$, long $81^{\circ} 43^{\prime} 37^{\prime \prime}$, Newberry County, at bridge on State Highwa 121, 200 ft downstream from discontinued ga

DRA INAGE AREA. $-1,620 \mathrm{sq} \mathrm{mi}$ (at gaging station).

PERIOD OF RECORD.--Chemical analyses: July 1969 to September 1970.

REMARKS. - The second of two samples collected at the same time is a field determination.

CHEMICAL ANALYSES, JULY 1969 TO SEPTEMBER 1970

\begin{tabular}{|c|c|c|c|c|c|c|c|c|c|c|}
\hline DATE & TIME & $\begin{array}{l}\text { TEMP- } \\
\text { ERATURE } \\
\text { DEEG } \quad \text { C) }\end{array}$ & $\begin{array}{l}\text { DIS- } \\
\text { CHARGE } \\
\text { (CFS) }\end{array}$ & $\begin{array}{l}\text { SPECI- } \\
\text { FIC } \\
\text { CONO- } \\
\text { UCTANCE } \\
\text { (MICRO- } \\
\text { MHOSI) }\end{array}$ & $\begin{array}{l}\text { DIS- SOLD } \\
\text { SOLVEN } \\
\text { XYYGEN } \\
\text { MGG/L }\end{array}$ & $\begin{array}{c}\text { PH } \\
\text { (UNITS) }\end{array}$ & $\begin{array}{l}\text { TOTAL } \\
\text { PHOS- } \\
\text { PHOR SOS } \\
\text { IP) } \\
\text { IMG/L) }\end{array}$ & $\begin{array}{l}\text { NI TRATE } \\
\text { (NO3) } \\
\text { (MG / I ) }\end{array}$ & $\begin{array}{c}\text { FECAL } \\
\text { CGLI- } \\
\text { FORM } \\
\text { (COL. } \\
\text { PER } \\
100 \mathrm{ML})\end{array}$ & $\begin{array}{c}\text { I MME- } \\
\text { OIATE } \\
\text { COLI- } \\
\text { FORM } \\
\text { FOLL. } \\
\text { PER } \\
100 \text { MLI }\end{array}$ \\
\hline $\begin{array}{l}\text { UuLr } \\
21 . . .\end{array}$ & -- & - & 377 & 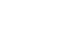 & - & - & .02 & .0 & -- & - \\
\hline$\frac{1 \ldots}{5.0}$ & & 27.5 & & 70 & 5.8 & 7.2 & -- & -- & -- & \\
\hline $5 \%$ & $\begin{array}{l}0815 \\
0815\end{array}$ & 23.5 & 759 & $\overrightarrow{72}$ & 0.4 & $\overline{7.2}$ & .02 & $\therefore$ & 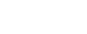 & -- \\
\hline $3 \ldots$ & $\begin{array}{l}1135 \\
1135\end{array}$ & $22 . \overline{5}$ & $1800^{--}$ & $\overline{78}$ & 6 & $\overrightarrow{7}$ & .00 & .6 & $-\overline{0}$ & - \\
\hline${ }_{21}^{c r} \cdot \ldots$ & 0930 & 21.0 & 956 & 71 & $\because$ & 6.7 & .06 & 1.3 & -- & -- \\
\hline iv. & & & & & & & & & & \\
\hline 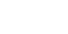 & $\begin{array}{l}1100 \\
1100\end{array}$ & $\begin{array}{l}10.0 \\
10.0\end{array}$ & $\begin{array}{l}274 \\
274\end{array}$ & 85 & 8.8 & 6.3 & 105 & 1.5 & -- & $\overline{-}$ \\
\hline $\begin{array}{l}15 \% \\
15 \%\end{array}$ & $\begin{array}{l}1050 \\
1050\end{array}$ & $\begin{array}{l}8.5 \\
8.5\end{array}$ & $\begin{array}{l}1920 \\
1920\end{array}$ & $\overline{78}$ & 10.1 & $\overline{7.5}$ & .06 & 8 & $\because$ & 640 \\
\hline o.... & & 5.5 & 1100 & & - & -- & .01 & 1.3 & -- & \\
\hline$\ldots$ & 1015 & 5.5 & 1100 & 81 & 10.3 & 7.6 & - & $\ldots$ & -- & 117 \\
\hline 9 & $\begin{array}{l}9925 \\
0925\end{array}$ & $\begin{array}{l}9: 0 \\
9: 0\end{array}$ & $\begin{array}{l}4200 \\
4400\end{array}$ & $\overline{74}$ & 8.7 & $\overline{7 . \overline{8}}$ & .04 & 1.9 & $z$ & $\because$ \\
\hline 20.... & 135 & 12.0 & 3400 & & - & $\cdots$ & .09 & 1.9 & -- & - \\
\hline$A P R=$ & & & 3400 & 61 & 10.4 & & & & & \\
\hline & 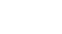 & $\begin{array}{l}19.5 \\
19.5\end{array}$ & $\begin{array}{l}39000 \\
3900\end{array}$ & $\overline{85}$ & 9.0 & $T .2$ & $\cdot 02$ & $\therefore$ & 255 & $=$ \\
\hline${ }_{21}^{21} \ldots$ & $\begin{array}{l}0835 \\
0835\end{array}$ & $\begin{array}{l}22.0 \\
22.0\end{array}$ & $\begin{array}{l}1050 \\
1050\end{array}$ & $\overrightarrow{67}$ & 8.7 & 7.- & .02 & .5 & $=$ & $\overline{-}$ \\
\hline $\begin{array}{c}\text { JUNE. } \\
16 . . .\end{array}$ & 0830 & 24.0 & 300 & - & - & -- & .02 & .1 & -- & -- \\
\hline & & & & & & & & & & \\
\hline & 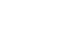 & 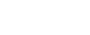 & $\begin{array}{l}200 \\
200 \\
200\end{array}$ & 70 & 7.4 & 7.1 & .02 & $\therefore$ & 97 & 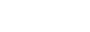 \\
\hline & $\begin{array}{l}2215 \\
1215\end{array}$ & $\begin{array}{l}26.5 \\
26.5\end{array}$ & $\begin{array}{l}3900 \\
3900\end{array}$ & $\overline{80}$ & $\overline{6.6}$ & $T-\overline{1.1}$ & .01 & $\therefore$ & $\sqrt{123}$ & -- \\
\hline $15 \ldots$ & 0830 & 24.0 & 3000 & -- & 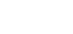 & $\therefore$ & .00 & .1 & - & -- \\
\hline
\end{tabular}

\begin{tabular}{|c|c|c|c|c|c|c|c|c|c|c|c|c|}
\hline DATE & TIM & $\begin{array}{l}\text { TEMP- } \\
\text { CKATURE } \\
\text { (DEG C I }\end{array}$ & $\begin{array}{l}\text { CIS- } \\
\text { CHARGF } \\
\text { (CFS) }\end{array}$ & $\begin{array}{l}\text { TUR- } \\
\text { BIO- } \\
\text { ITY } \\
\text { IJTUI }\end{array}$ & $\begin{array}{l}\text { CULOR } \\
\text { (PLAT- } \\
\text { INUM- } \\
\text { COBALT } \\
\text { UNITSI }\end{array}$ & $\begin{array}{l}\text { SPFCI- } \\
\text { FIC } \\
\text { COND- } \\
\text { UCTANCE } \\
\text { YICAJ- } \\
\text { MHISI }\end{array}$ & $\begin{array}{c}\text { DIS- } \\
S \cap L V E O \\
\text { OXYGEN } \\
(M G / L)\end{array}$ & $\begin{array}{l}\text { BIO- } \\
\text { CHEM- } \\
\text { ICAL } \\
\text { OXYGEN } \\
\text { OENAND } \\
\text { IMG/LI }\end{array}$ & $\begin{array}{c}P H \\
\text { (UNITS) }\end{array}$ & $\begin{array}{l}\text { ALKA- } \\
\text { LINITY } \\
\text { AS } \\
\text { CACD3 } \\
\text { (MG/L) }\end{array}$ & $\begin{array}{l}\text { BICAR- } \\
\text { BINATF } \\
\text { (HCD3) } \\
\text { (MG/L) }\end{array}$ & $\begin{array}{l}\text { TOTAL } \\
\text { NON- } \\
\text { FILT- } \\
\text { RABLF } \\
\text { RESIDUE } \\
\text { TMGILI }\end{array}$ \\
\hline \multirow{7}{*}{$\begin{array}{r}\text { DCT. } \\
21 \ldots . \\
21 \ldots \\
21 \ldots\end{array}$} & & & & & & & & & & & & \\
\hline & 0855 & $=$ & - & -- & -- & - & -- & 1.3 & -- & 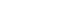 & -- & -- \\
\hline & 0930 & 21.0 & 956 & I & 5 & 71 & -- & -- & 6.7 & 25 & $3 !$ & 3 \\
\hline & 0930 & 21.0 & $\begin{array}{l}956 \\
\text { NuN- }\end{array}$ & $\cdots$ & -- & $015^{76}$ & 7.2 & -- & 6.5 & -- & -- & -- \\
\hline & TOTAL & & $C A R=$ & & & SOLVEO & TOTAL & DIS- & & DIS- & TOTAL & DIS- \\
\hline & $\begin{array}{l}\text { PHOS- } \\
\text { PHDRUS }\end{array}$ & $\begin{array}{l}\text { HARD- } \\
\text { NESS }\end{array}$ & BONATE & CHL ?- & & FLUn- & CHQO- & SOLVED & TOTAL & SOLVEO & MAIN- & SOLVFD \\
\hline & (P) & (CA,MG) & NE SS & (CL) & (S) 4$)^{\circ}$ & (F) & $(C 2)$ & $\begin{array}{c}\text { COPPER } \\
\text { (CU) }\end{array}$ & SFE & $\begin{array}{l}\text { LEAD } \\
\text { |PB| }\end{array}$ & $\begin{array}{l}\text { GANESE } \\
\text { (MNI }\end{array}$ & $\begin{array}{l}\text { NICKEL } \\
\text { (NI) }\end{array}$ \\
\hline$O \Delta T E$ & (MG/L) & $(M G / L)$ & $(M G / L)$ & $(M G / L)$ & $\mid M G / L)$ & $(M G / L)$ & $(U G / L)$ & $(U G / L)$ & $(U G / L)$ & $(U G / L)$ & $(U G / L)$ & (UG/L) \\
\hline \multirow{2}{*}{\multicolumn{13}{|c|}{-}} \\
\hline & & & & & & & & & $\overline{8}$ & $\bar{s}$ & $\overline{10}$ & - \\
\hline $21 \ldots$ & .06 & 14 & $n$ & 4.1 & 4.0 & .3 & 0 & 0 & 84 & 5 & 10 & 8 \\
\hline
\end{tabular}


02169000 BALUDA RIVER NEAR COLUMBIA, s. C.

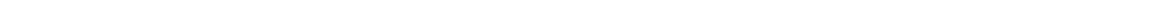

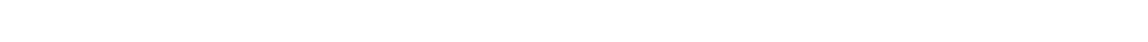

DRA IKAGE AREA. $-2,010 \div \mathrm{m1}$, approximately.

PEAIOD OF RECORD.--Chemical analywen: October 1960 to Beptember 1962, October 1969 to Beptember 1870. REMARKs.--The wecond of two mamplen collected at the wame time 1. a fleld determination.

CHEMICAL ANALYSES, JULY 1969 TO SEPTEMBER 1970

\begin{tabular}{|c|c|c|c|c|c|c|c|c|c|c|}
\hline DATE & TIME & $\begin{array}{l}\text { TEAP- } \\
\text { ERTURE } \\
\text { IOEG CI }\end{array}$ & $\begin{array}{l}\text { OIS- } \\
\text { CHARGE } \\
\text { iCFSI }\end{array}$ & $\begin{array}{l}\text { SPECI- } \\
\text { EIC } \\
\text { EOND- } \\
\text { UCTANE } \\
\text { YMICRO- } \\
\text { MHOSI }\end{array}$ & 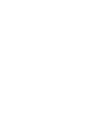 & $\begin{array}{c}\text { PH } \\
\text { (UNITS) }\end{array}$ & $\begin{array}{l}\text { TOTAL } \\
\text { PHOS- } \\
\text { PHORUS } \\
\text { PQ1 } \\
\text { (MG/U) }\end{array}$ & $\begin{array}{l}\text { NirRATE } \\
\text { (NO3) } \\
\text { IMG/L) }\end{array}$ & $\begin{array}{c}\text { FECAL } \\
\text { COA } \\
\text { FORH. } \\
\text { FOR. } \\
\text { ICOL. } \\
100 \mathrm{MLI} \\
100 \mathrm{ML}\end{array}$ & $\begin{array}{c}\text { IMME- } \\
\text { OIAIE } \\
\text { OOLI } \\
\text { CORM } \\
\text { ICOL. } \\
\text { PDER } \\
100 \mathrm{MLI}\end{array}$ \\
\hline $\begin{array}{c}\text { ост. } \\
02 . . . \\
02 . . .\end{array}$ & $\begin{array}{r}0730 \\
0730\end{array}$ & $\begin{array}{l}17.5 \\
17.5\end{array}$ & $\begin{array}{l}704 \\
704\end{array}$ & $\bar{\pi}$ & 3.7 & 6.7 & .00 & $\stackrel{1.0}{-}$ & $=$ & $\bar{z}$ \\
\hline $\begin{array}{r}\text { rov. } \\
03 . . . \\
03 . . . \\
21 . . . \\
21 . .\end{array}$ & $\begin{array}{l}1430 \\
1430 \\
1450 \\
1450\end{array}$ & $\begin{array}{l}18.0 \\
18.0 \\
14.0 \\
14.0\end{array}$ & $\begin{array}{l}3580 \\
3580 \\
3640 \\
3640\end{array}$ & $\frac{63}{62}$ & $\begin{array}{r}\overline{4.9} \\
10.0\end{array}$ & $\begin{array}{l}0.3 \\
8.9 \\
7.6\end{array}$ & .06 & $\therefore$ & $\begin{array}{l}= \\
=\end{array}$ & $\ddot{70}$ \\
\hline $\begin{array}{r}12 . . . \\
12 . . .\end{array}$ & $\begin{array}{l}1230 \\
1230\end{array}$ & $\begin{array}{l}12.0 \\
12.0\end{array}$ & $\begin{array}{l}7300 \\
7300\end{array}$ & $\overline{66}$ & $\ddot{9.8}$ & $\pi$ & .05 & $\because$ & $=$ & 208 \\
\hline $\begin{array}{l}28 . . . \\
28 . . .\end{array}$ & $\begin{array}{l}1230 \\
1230\end{array}$ & $\begin{array}{l}10.0 \\
10.0\end{array}$ & $\begin{array}{l}405 \\
405\end{array}$ & 100 & $u \overline{. z}$ & 7.5 & .02 & 1.2 & $=$ & 690 \\
\hline re.... & $\begin{array}{l}1600 \\
1600\end{array}$ & $\begin{array}{l}9.5 \\
9.3\end{array}$ & $\begin{array}{l}3700 \\
3700\end{array}$ & $\overline{73}$ & 10.3 & 8.2 & .03 & $\therefore$ & $=$ & $=$ \\
\hline $\begin{array}{r}17 . . . \\
17 \% \\
A P R_{0}\end{array}$ & $\begin{array}{l}1350 \\
1350\end{array}$ & $\begin{array}{l}10.0 \\
10: 0\end{array}$ & $\begin{array}{l}2200 \\
2200\end{array}$ & $\overline{76}$ & $12 . \overline{6}$ & 7.8 & .02 & $\therefore$ & $=$ & $=$ \\
\hline $\begin{array}{l}20 \%: .: \\
20 \%\end{array}$ & $\begin{array}{l}1515 \\
1515\end{array}$ & $17: 0$ & $\begin{array}{l}1910 \\
1910\end{array}$ & $\overline{34}$ & $\because 0$ & 8.4 & .02 & $\because 4$ & $\overline{83}$ & $\because$ \\
\hline $\begin{array}{l}22 . . . \\
22 . . .\end{array}$ & $\begin{array}{l}1150 \\
1150\end{array}$ & $\begin{array}{l}14.5 \\
14.5\end{array}$ & $\begin{array}{l}2160 \\
2160\end{array}$ & $\overline{71}$ & 10.0 & 7.7 & .01 & .3 & $=$ & $=$ \\
\hline 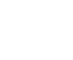 & $\begin{array}{l}1300 \\
1300\end{array}$ & $\begin{array}{l}20.5 \\
20.5\end{array}$ & $\begin{array}{l}378 \\
378\end{array}$ & $\overrightarrow{92}$ & $9 . \overline{0}$ & 7.6 & .02 & 1.7 & $\ddot{14}$ & $=$ \\
\hline 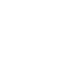 & $\begin{array}{l}1340 \\
1340\end{array}$ & $\begin{array}{l}177: 0 \\
17: 0\end{array}$ & $\begin{array}{l}8780 \\
6780\end{array}$ & 75 & 9.7 & 7.3 & .01 & $\therefore$ & -7 & $=$ \\
\hline $\begin{array}{l}190 .: \\
19 .: .\end{array}$ & $\begin{array}{l}1330 \\
1330\end{array}$ & $\begin{array}{ll}17 \\
17: 0\end{array}$ & $\begin{array}{l}2530 \\
2530\end{array}$ & $\overline{79}$ & 9.0 & $\because \ddot{3}$ & .01 & $\therefore$ & 43 & $\because$ \\
\hline $\begin{array}{r}240 . . . \\
24 \ldots . .\end{array}$ & $\begin{array}{l}1315 \\
1315\end{array}$ & $\begin{array}{l}19.5 \\
19.5\end{array}$ & $\begin{array}{l}10000 \\
10000\end{array}$ & 72 & 6.2 & 7.2 & .00 & 1.0 & $\ddot{3 i}$ & $=$ \\
\hline DATE & TIME & 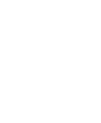 & $\begin{array}{l}\text { OIS- } \\
\text { CHARG: } \\
\text { ICASI }\end{array}$ & 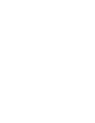 & $\begin{array}{l}\text { COLOR } \\
\text { TPLAT- } \\
\text { INUM- } \\
\text { CuAALT } \\
\text { UNITSI }\end{array}$ & $\begin{array}{l}\text { SPECI- } \\
\text { EIC } \\
\text { CUND- } \\
\text { UCFANCE } \\
\text { IMICRO- } \\
\text { MHOSI }\end{array}$ & $\begin{array}{l}\text { O1S- } \\
\text { SDLVED } \\
\text { OXYGEN } \\
\text { IMG/LI }\end{array}$ & $\begin{array}{l}\text { BIOE } \\
\text { CHEM- } \\
\text { ICAL } \\
\text { OXYGEN } \\
\text { OEMAND } \\
\text { (MGLI) }\end{array}$ & $\begin{array}{c}\text { PH } \\
\text { IUNITSI }\end{array}$ & $\begin{array}{l}\text { ALKA- } \\
\text { LINITY } \\
\text { AS } \\
\text { CACD } \\
\text { IMGIL) }\end{array}$ \\
\hline 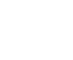 & $\begin{array}{l}1430 \\
1436\end{array}$ & 18.00 & $\begin{array}{l}3380 \\
3380\end{array}$ & $\therefore$ & so & $\begin{array}{l}53 \\
72\end{array}$ & 4 & $\because 8$ & $\begin{array}{l}6.5 \\
6.9\end{array}$ & 22 \\
\hline $\begin{array}{l}\text { DATE } \\
\text { YyoY, }\end{array}$ & 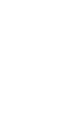 & 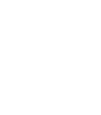 & $\begin{array}{l}\text { NARC- } \\
\text { NESS } \\
\text { ISA,MOI) } \\
\text { (MG/L) }\end{array}$ & $\begin{array}{l}\text { NON- } \\
\text { CARE } \\
\text { BDNATE } \\
\text { HARO- } \\
\text { NESS } \\
\text { I MG/L) }\end{array}$ & 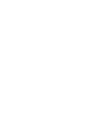 & $\begin{array}{c}\text { SULFATF } \\
\text { (SOQ) } \\
\text { (MG/L) }\end{array}$ & 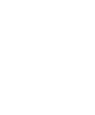 & 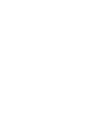 & 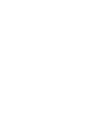 & 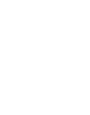 \\
\hline $\begin{array}{c}\text { Nov: } \\
03 . . . \\
03 . . .\end{array}$ & 2? & $\because 06$ & 18 & $\therefore$ & $4: 3$ & 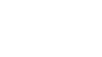 & $\therefore$ & $\therefore$ & $\therefore$ & $\stackrel{172}{-=}$ \\
\hline & 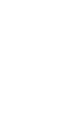 & $\begin{array}{l}\text { TOTAL } \\
\text { MAN } \\
\text { GANES } \\
\text { MANA } \\
\text { IUG/LI }\end{array}$ & $\begin{array}{l}\text { OIS- } \\
\text { SOLVED } \\
\text { Nickel } \\
\text { INII } \\
\text { IUOLLI }\end{array}$ & $\begin{array}{c}\text { COLI: } \\
\text { FDR } \\
\text { ICOL: } \\
\text { ONIES } \\
\text { PER } \\
100 \quad * 4,\end{array}$ & 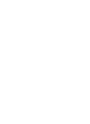 & $\begin{array}{l}\text { LENE } \\
\text { BLUE } \\
\text { ACTIVE } \\
\text { SUG- } \\
\text { STANCE } \\
\text { IMG LLI }\end{array}$ & $\begin{array}{l}\text { SOLVEO } \\
\text { SOL IDS } \\
\text { IRES I } \\
\text { DUE AT } \\
\text { IBE CL } \\
\text { IMG L }\end{array}$ & $\begin{array}{c}\text { DIS- } \\
\text { SOLVED } \\
\text { SOLIDS } \\
\text { ITONS } \\
\text { PER } \\
\text { OAYI }\end{array}$ & 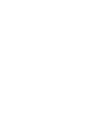 & $\begin{array}{l}\text { Nitrate } \\
\text { (NOB) } \\
\text { (MOA) }\end{array}$ \\
\hline $\begin{array}{c}010 . . .8 \\
03\end{array}$ & $\therefore 8$ & 1006 & $\therefore$ & $\ddot{70}$ & $\because$ & $\because 8$ & $\because$ & 434 & $\because 06$ & $\therefore$ \\
\hline
\end{tabular}


02169603 CONGAREE RIVER NEAR CAYCE, S. C.

LOCATION. - Lat 33'52'45", long $81^{\circ} 00^{\prime} 48^{\prime \prime}$, Lexington County, at Carolina Eastman Company water intake, 1 mile downstream from Toms Branch, 7.2 miles south of Cayce, and 8.7 miles downstream from gaging station.

PER IOD OF RECORD.-Chemical analyses: July 1969 to September 1970.

REYARKS.--The second of two samplea collected at the same time is a field determination.

CHEMICAL ANALYSES, JULY 1969 TO SEPIEMBER 1970

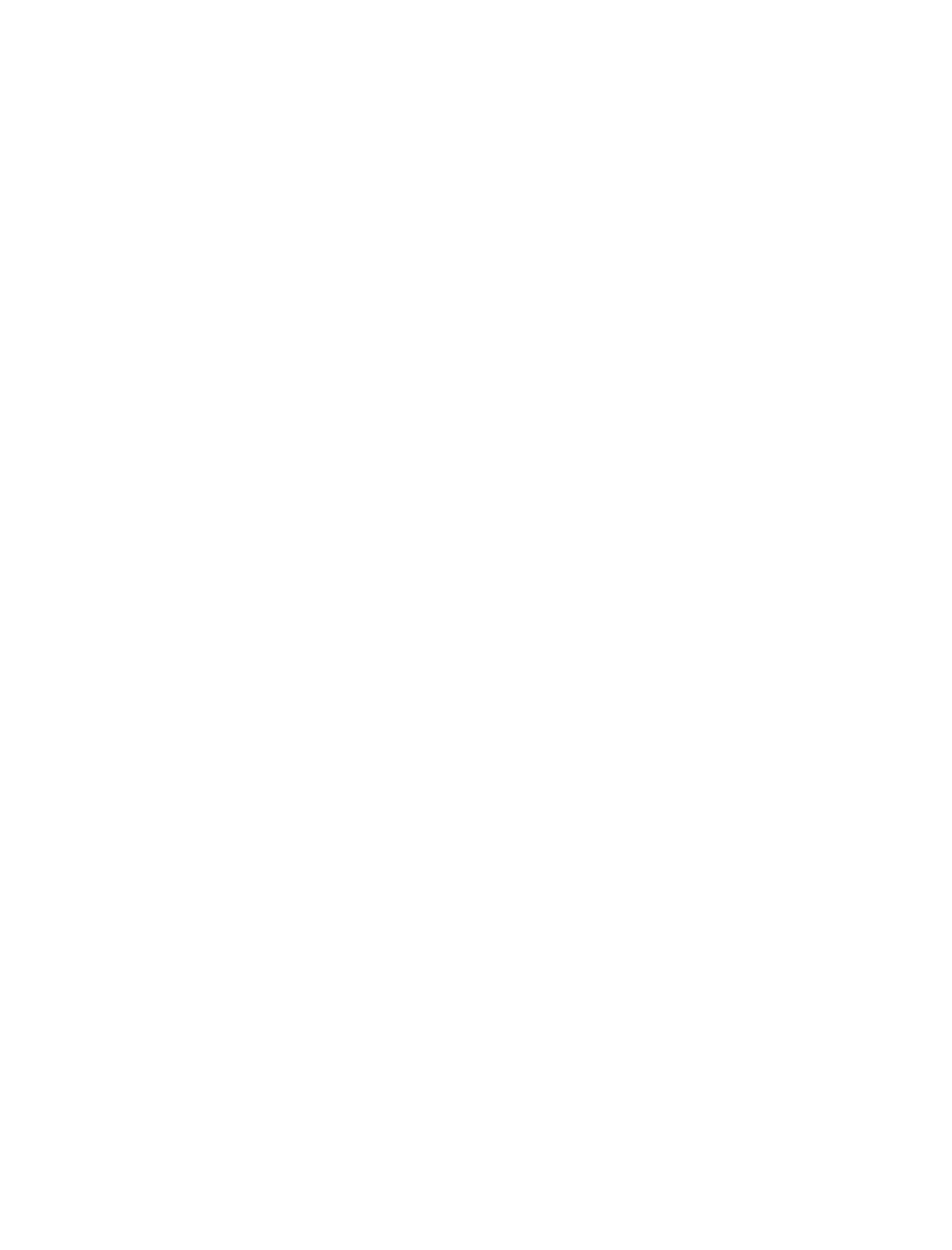

oc

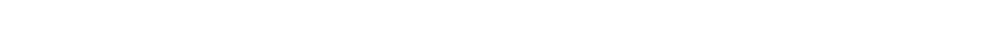


02169750 CONGAREE RIVER NEAR FT. MOTTE, S. C.

LOCATION.--Lat $33^{\circ} 45^{\prime} 10^{\prime \prime}$, long $80^{\circ} 38^{\prime} 43^{\prime \prime}$, Calhoun County, at bridge on U.S. Highway $601,0.8$ mile downstream from Buckhead Creek, 1.5 miles upstream from confluence with Wateree River, $3.0 \mathrm{miles}$ northeast of Ft. Motte, 3.0 miles downstream from Southern Rallway bridge, and 20.2 miles downstream from gaging station.

PERION OF RECORD.--Chemical analyses: July 1969 to September 1970.

REMARKS. - The second of two samples collected at the same time is a field determination.

CHEMICAL ANALYSES, JULY 1969 TO SEPTEMBER 1970

\begin{tabular}{|c|c|c|c|c|c|c|c|c|c|c|}
\hline DATE & TIME & $\begin{array}{l}\text { TEMP- } \\
\text { ERATURE } \\
\text { (OEG C) }\end{array}$ & $\begin{array}{l}\text { OIS- } \\
\text { CHARGE } \\
\text { (CFS) }\end{array}$ & $\begin{array}{l}\text { SPECI- } \\
\text { FIC } \\
\text { COND- } \\
\text { UCT ANCE } \\
\text { (MICRO- } \\
\text { MHOS) }\end{array}$ & $\begin{array}{l}\text { DIS- } \\
\text { SOLVEO } \\
\text { OXYGEN } \\
\text { IMG/LI }\end{array}$ & $\begin{array}{c}\text { PH } \\
\text { (UNITS) }\end{array}$ & $\begin{array}{l}\text { TOTAL } \\
\text { PHOS- } \\
\text { PHORUS } \\
\text { (P) } \\
\text { (MG LI) }\end{array}$ & $\begin{array}{l}\text { NITRATE } \\
\text { (NO3) } \\
\text { (MG/L) }\end{array}$ & $\begin{array}{c}\text { FECAL } \\
\text { COLII- } \\
\text { FORM } \\
\text { COLL. } \\
\text { PER } \\
100 \mathrm{MLI}\end{array}$ & $\begin{array}{c}\text { IMME- } \\
\text { OIATE } \\
\text { COLI- } \\
\text { FoRM } \\
\text { ICOL. } \\
\text { PER } \\
100 \text { MLI }\end{array}$ \\
\hline $\begin{array}{l}\text { JULY } \\
25\end{array}$ & & & & & & & & & & \\
\hline $\begin{array}{l}25 \ldots . \\
25 . \ldots\end{array}$ & $\begin{array}{l}1510 \\
1510\end{array}$ & $27 \overline{5}$ & ${ }^{6510}-$ & $\overline{70}$ & $6 . \overline{6}$ & $\overline{7.2}$ & .06 & $\because 9$ & $=$ & $=$ \\
\hline $\begin{array}{l}\text { AUG. } \\
2 B . . .\end{array}$ & & - & - & & 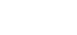 & 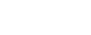 & .01 & .5 & 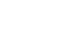 & 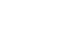 \\
\hline 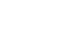 & 1400 & 23.0 & 9680 & 75 & 7.2 & 7.2 & -- & $\because$ & - & $=$ \\
\hline $\begin{array}{l}01 \ldots . \\
01 \ldots\end{array}$ & 1340 & 20.5 & 4630 & $\overline{78}$ & $\because$ & $\rightarrow$ & .02 & 1.0 & $=$ & -- \\
\hline Nov. & & 20.5 & 4630 & & 7.0 & & & & & - \\
\hline $\begin{array}{l}03 \ldots \\
03 . . .\end{array}$ & $\begin{array}{l}1206 \\
1200\end{array}$ & $\begin{array}{l}16.5 \\
16.5\end{array}$ & $\begin{array}{l}6270 \\
6270\end{array}$ & $\begin{array}{l}68 \\
75\end{array}$ & 7.9 & $\begin{array}{l}7.0 \\
6.6\end{array}$ & .11 & 1.7 & $=$ & 22000 \\
\hline $21 \ldots$ & 1200 & 11.5 & 7660 & 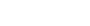 & 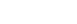 & - & .13 & .6 & $=$ & - \\
\hline 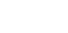 & 1200 & 11.5 & 7660 & 78 & 10.0 & 1.4 & -- & +- & - & - \\
\hline $12 \ldots$ & 1000 & 8.0 & 13600 & - & $\cdots$ & -- & .07 & 1.0 & - & $\cdots$ \\
\hline $\begin{array}{c}12 \ldots . \\
\text { JAN. }\end{array}$ & 1000 & 8.0 & 13620 & 70 & 10.0 & 7.3 & - & - & -- & 9000 \\
\hline $19 \ldots$ & 1325 & 6.5 & 6650 & -- & -- & -. & .03 & 1.3 & - & -- \\
\hline $\begin{array}{l}19 \ldots . \\
\text { FEB. }\end{array}$ & 1325 & 6.5 & 6650 & 72 & 10.4 & 7.2 & - & -- & -- & 12600 \\
\hline $\begin{array}{l}27 \ldots \\
27 \ldots\end{array}$ & 0930 & 8.0 & 12000 & -- & -- & -- & .03 & 1.1 & -- & -- \\
\hline MAR." & 0937 & 8.0 & 12000 & 11 & 10.2 & 7.4 & & & -- & - \\
\hline $\begin{array}{l}19 \ldots . . \\
19 . . .\end{array}$ & 1520 & 13.0 & 7500 & - & -- & $=$ & .04 & .8 & - & - \\
\hline APR. & & 13.0 & 7500 & 80 & 9.9 & 6.9 & & -- & - & - \\
\hline $\begin{array}{l}20 \ldots \\
20 \ldots\end{array}$ & 1400 & 20.0 & 5800 & -- & -- & -- & .02 & .5 & - & - \\
\hline MAY & 1400 & 20.0 & 5800 & 78 & 10.1 & 7.2 & -- & & 776 & - \\
\hline $\begin{array}{l}18 \ldots \\
18 . \ldots\end{array}$ & 1000 & 24.0 & 6000 & -- & - & - & .02 & .2 & - & - \\
\hline JUNE & 1000 & 24.0 & 6000 & 19 & 9.6 & 6.6 & -- & & - & -- \\
\hline $\begin{array}{l}22 \ldots \\
22 \ldots\end{array}$ & 1105 & 24.5 & 12500 & - & -- & 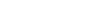 & .03 & 1.3 & -- & - \\
\hline JULY & & & & 72 & 7.4 & 7.2 & & & 4800 & - \\
\hline $\begin{array}{l}17 \ldots \\
17 \ldots\end{array}$ & 1315 & 26.0 & 6000 & - & -- & - & .05 & 1.1 & -- & -- \\
\hline AUG. & 1315 & 26.0 & 6000 & 90 & 8.4 & 7.4 & & & 1700 & - \\
\hline $\begin{array}{l}27 \ldots \\
27 \ldots\end{array}$ & 1145 & 27.0 & 6900 & -. & -- & -- & .01 & 2.2 & -- & - \\
\hline SEP. & 1145 & 27.0 & 6900 & 90 & 7.4 & 7.3 & -- & & 7000 & - \\
\hline $\begin{array}{l}14 \ldots . \\
14 \ldots\end{array}$ & $\begin{array}{l}0945 \\
0945\end{array}$ & $\begin{array}{r}25.0 \\
25.0\end{array}$ & $\begin{array}{r}4800 \\
4800\end{array}$ & $\overline{105}$ & - & $\because$ & .08 & 1.1 & -- & -- \\
\hline & & 2300 & 4800 & 105 & 7.4 & 7.4 & -- & & 6100 & - \\
\hline
\end{tabular}

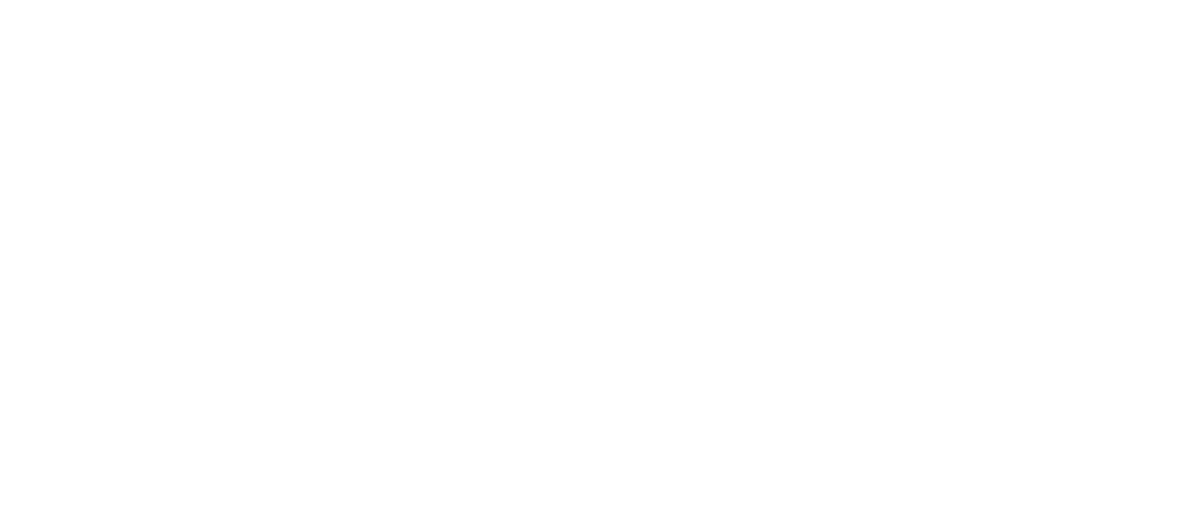


02171500 SANTEE RIVER NEAR PINEVILLE, $S, C$.

(International Hydrological Decade River Station and radiochemical station)

LOCATION.--Lat $33^{\circ} 27^{\prime} 15^{\prime \prime}$, long $80^{\circ} 09^{\prime} 25^{\prime \prime}$, Berkeley County, at gaging station on right bank, 2.4 miles downstream from Lake Marion Dam, 3 miles upstream from Dead River, 6.7 miles west of pineville, and at mile 85.0 .

DRA INAGE AREA, --14,700 sq mi, approximately.

PER IOD OF RECORD.--Chem1Cal analyses: October 1951 to September 1952, January 1966 to September 1970.

REMARKS. - The second of two samples collected at the same time is a field determination.

CHEMICAL ANALYSES, WATER YEAR OCTOBER 1969 TO SEPTEMBER 1970

\begin{tabular}{|c|c|c|c|c|c|c|c|c|c|}
\hline DATE & TI ME & $\begin{array}{l}\text { TEMP- } \\
\text { ERATURE } \\
\text { (OEG C) }\end{array}$ & $\begin{array}{l}\text { COLOR } \\
\text { (PLAT- } \\
\text { INUM- } \\
\text { CUBALT } \\
\text { UNITS }\end{array}$ & $\begin{array}{l}\text { SPECI- } \\
\text { FIC } \\
\text { CJND- } \\
\text { UCTANCE } \\
\text { (MICRO- } \\
\text { MHOS) }\end{array}$ & $\begin{array}{l}\text { DIS- } \\
\text { SDLVED } \\
\text { OLYGEEN } \\
\text { (MGLLL) }\end{array}$ & $\begin{array}{c}\text { PH } \\
\text { (UNITS) }\end{array}$ & $\begin{array}{l}\text { ALKA- } \\
\text { LINITY } \\
\text { AS } \\
\text { CACOS } \\
(Y G / L)\end{array}$ & $\begin{array}{l}\text { BICAR- } \\
\text { BDNATE } \\
\text { (HCO3) } \\
\text { (MGLL) }\end{array}$ & $\begin{array}{l}\text { CAR- } \\
\text { BONATE } \\
\text { (CNO3) } \\
\text { (MG L L }\end{array}$ \\
\hline $\begin{array}{l}\text { XCT. } \\
15 . \ldots\end{array}$ & $\begin{array}{l}c 820 \\
n 820\end{array}$ & $\begin{array}{r}21.5 \\
21.5\end{array}$ & -5 & $\begin{array}{l}71 \\
83\end{array}$ & $9 . \overline{4}$ & $\begin{array}{l}6.6 \\
7.3\end{array}$ & 22 & 27 & $\begin{array}{r}0 \\
--\end{array}$ \\
\hline $\begin{array}{c}15 \ldots . \\
\text { งอง. }\end{array}$ & $n 220$ & 21.5 & -- & 93 & 9.4 & 7.3 & -- & -- & -- \\
\hline $13 \ldots$ & $(845$ & 14.5 & -- & $\bar{a}$ & -- & 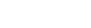 & -- & -- & -- \\
\hline DEC. & 0345 & 14.5 & $\cdots$ & 88 & 17.3 & 7.2 & -- & & -- \\
\hline $23 .$. & 1520 & 9.5 & 10 & 98 & $\overline{-}$ & 6.5 & 25 & 30 & 0 \\
\hline JAN. & 1520 & 9.5 & -- & 97 & 13.4 & 7.9 & - & $\cdots$ & $\cdots$ \\
\hline $\begin{array}{l}15 \ldots \\
15 \ldots\end{array}$ & $\begin{array}{l}0920 \\
6920\end{array}$ & $\begin{array}{l}4.5 \\
4.5\end{array}$ & $=$ & $\overline{80}$ & $10 \overline{-4}$ & $\overline{7.7}$ & $=$ & $=$ & $=$ \\
\hline FEB. & & & & & . & & & & \\
\hline $\begin{array}{l}12 \ldots \\
12 \ldots\end{array}$ & $\begin{array}{l}1440 \\
1440\end{array}$ & $\begin{array}{l}9.5 \\
9.5\end{array}$ & $\because$ & 99 & $14 . \overline{1}$ & 7.7 & $=$ & $\ddot{z}$ & $=$ \\
\hline $\begin{array}{l}\text { MAY } \\
15 \ldots\end{array}$ & OBLC & 24.5 & -- & -- & -- & -- & -- & -- & -- \\
\hline $15 \ldots$ & $c 81 c$ & 24.5 & -- & 80 & 3.3 & 7.5 & -- & -- & - \\
\hline $11 \ldots$ & 1305 & 26.5 & -- & $\cdots$ & -- & -- & 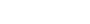 & - & -- \\
\hline $11 \ldots$ & 1365 & 26.5 & -- & 38 & 3.6 & 7.5 & -- & - & -. \\
\hline AUG. & & & -- & - & - & -. & -- & -- & $=$ \\
\hline $\begin{array}{l}84 \ldots . \\
04 \ldots\end{array}$ & $\begin{array}{l}13135 \\
1335\end{array}$ & 30.5 & $=$ & 90 & 3.6 & 7.5 & - & - & $\overline{--}$ \\
\hline $25 \ldots$ & 1030 & 28.7 & -- & - & - & -- & -- & -- & -- \\
\hline $25 \ldots$ & $103 r$ & $23 . ?$ & -- & 95 & 5.2 & -- & -- & -- & -- \\
\hline SEP. & 1125 & 27.5 & 5 & 101 & -- & 6.6 & 24 & 29 & 0 \\
\hline $21 \ldots$ & 1125 & 27.5 & -- & 270 & 5.9 & 7.2 & - & $\because$ & -- \\
\hline & & $\begin{array}{l}\text { CIS- } \\
\text { SOLVED } \\
\text { ORTHT }\end{array}$ & & $\begin{array}{l}\text { NON- } \\
\text { CAR- }\end{array}$ & $\begin{array}{l}\text { DIS- } \\
\text { SOLVEO }\end{array}$ & $\begin{array}{l}\text { DIS- } \\
\text { SOLVED } \\
\text { MAL- }\end{array}$ & & $\begin{array}{c}\text { SODIUM } \\
\text { AD- }\end{array}$ & \\
\hline & & pHos- & HARD- & B CNATE & CAL- & $\mathrm{NE}-$ & & SORP- & \\
\hline & $\begin{array}{l}\text { PHATE } \\
\text { (PDG) }\end{array}$ & PHATE & NESS & HAR O- & 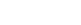 & SIUM & Sonium & TION & PERCENT \\
\hline DATE & $(M G / L)$ & $\begin{array}{l}(P O 4) \\
(M G /)\end{array}$ & $\begin{array}{c}(C A, M G) \\
(M G / L)\end{array}$ & $\begin{array}{l}\text { NESS } \\
(M G / L)\end{array}$ & $\begin{array}{l}(C A) \\
(M G / L)\end{array}$ & $\begin{array}{l}(M G) \\
(M G G L)\end{array}$ & $\begin{array}{l}(N A) \\
(M G / L)\end{array}$ & RATIO & SODIUM \\
\hline $\begin{array}{l}\text { OCT. } \\
15 \ldots . .\end{array}$ & $=$ & .00 & $\because 7$ & ? & 4.3 & 1.5 & 8.0 & $=8$ & 47 \\
\hline $\begin{array}{r}15 \ldots \\
\text { NCV. }\end{array}$ & - & & $\cdots$ & -- & -- & & & & $=-$ \\
\hline $13 \ldots$ & -- & -- & -- & -- & -- & -- & -- & -- & -- \\
\hline $\begin{array}{l}13 \ldots \\
\text { CEC.... }\end{array}$ & - & -- & -- & -- & -- & -- & -- & -- & -- \\
\hline $23 \ldots$ &.$c 0$ & .00 & 20 & s & 5.0 & 1.6 & 11 & 1.1 & 52 \\
\hline $23 \ldots$ & -- & -- & - & -- & -- & -- & -- & -- & - \\
\hline $\begin{array}{l}\text { JAR. } \\
\text { 15... }\end{array}$ & -- & -- & $\cdots$ & -- & -- & $\cdots$ & -- & -- & -- \\
\hline $15 \ldots$ & -- & -- & -- & -- & -- & -- & -- & -- & -- \\
\hline FER. & & & & & & & & & \\
\hline $12 \ldots$ & $=$ & $=$ & $=$ & $\overline{-}$ & $=$ & $\bar{z}$ & $\bar{z}$ & $=$ & $=$ \\
\hline NAY & & & & & & & & & \\
\hline $15 \ldots$ & $=$ & $=$ & $=$ & $=$ & $=$ & $=$ & $=$ & $\therefore$ & 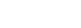 \\
\hline JUNE & & & & & & & & & \\
\hline${ }_{11}^{11} \ldots$. & $=$ & $=$ & $=$ & - & $=$ & 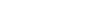 & $=$ & $=$ & $=$ \\
\hline$\triangle$ UUG. & $\because$ & - & -- & -- & $\ldots$ & -- & -- & -- & -- \\
\hline $\begin{array}{l}04 \ldots \\
34 \ldots\end{array}$ & -- & $\ldots$ & - & -- & - & - & - & - & - \\
\hline $25 \ldots$ & -- & -- & -- & -- & -- & -- & $\cdots$ & -- & 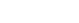 \\
\hline $\begin{array}{l}25 \cdots \\
\text { SEP. }\end{array}$ & - & -- & -- & -- & - & $\cdots$ & - & -- & $\sigma$ \\
\hline $2 ! \cdots$ & $\because$ & .00 & 23 & $\therefore$ & 5.1 & 2.0 & 11 & 1.0 & 50 \\
\hline & & & & & & & & & - \\
\hline
\end{tabular}


02171500 SANTEE RIVER NEAR PINEVILLE, S. C.--Cont inued

CHEMICAL ANALYSES, WATER YEAR OCTOBER 1969 TO SEPTEMBER 1970

\begin{tabular}{|c|c|c|c|c|c|c|c|c|c|}
\hline DATE & $\begin{array}{l}\text { PO- } \\
\text { TAS- } \\
\text { SIUM } \\
(K) \\
(M G / L)\end{array}$ & $\begin{array}{l}\text { CHLO- } \\
\text { RIOE } \\
\text { (Ct) } \\
(M G / L)\end{array}$ & $\begin{array}{l}\text { SULFATE } \\
\text { (SO4) } \\
\text { (MG/L) }\end{array}$ & $\begin{array}{l}\text { DIS- } \\
\text { SOL VFD } \\
\text { FLUO- } \\
\text { RIDE } \\
\text { (F) } \\
\text { (MGIL) }\end{array}$ & $\begin{array}{l}\text { SILICA } \\
\text { (SIOL) } \\
\text { (MG/L) }\end{array}$ & $\begin{array}{l}\text { DIS- } \\
\text { SOLVED } \\
\text { IRON } \\
\text { (FE) } \\
\text { (UG/L) }\end{array}$ & $\begin{array}{l}\text { OIS- } \\
\text { SOLVFD } \\
\text { RADIUM } \\
226 \\
\text { (RA) } \\
\text { (PC } C L)\end{array}$ & $\begin{array}{c}\text { COLI - } \\
\text { FORM } \\
\text { (COL- } \\
\text { ONIES } \\
\text { PER } \\
100 \text { ML) }\end{array}$ & $\begin{array}{l}\text { OIS- } \\
\text { SOLVED } \\
\text { SOL IOS } \\
\text { IRESI- } \\
\text { OUE AT } \\
\text { ISC C) } \\
\text { (MG/L) }\end{array}$ \\
\hline$C \mathrm{CT}$ & & & & & & & & & \\
\hline $\begin{array}{l}15 \ldots \\
15 \ldots\end{array}$ & 2.2 & 8.0 & 6.8 & $\because 1$ & 11 & -0 & $=$ & $\overline{50}$ & 61 \\
\hline Nov. & & & & & & & . & 30 & - \\
\hline $13 \ldots$ & $=$ & -- & - & $=-$ & -- & -- & .0 & - & -- \\
\hline $\begin{array}{l}13 \ldots . . \\
O E C .\end{array}$ & - & -- & -- & -- & -- & -- & -- & 107 & -- \\
\hline $23 \ldots$ & 2.3 & 9.5 & 9.6 & .1 & 7.1 & 17 & .0 & $=$ & 61 \\
\hline $23 \ldots$ & - & -- & -- & -- & - & $\cdots$ & -- & 67 & -- \\
\hline $15 \ldots$ & - & -- & - & -- & -- & -- & .0 & $\cdots$ & -- \\
\hline $\begin{array}{l}15 \ldots \\
F E B .\end{array}$ & -- & -- & -- & -- & -- & -- & -- & 53 & -- \\
\hline $12 \ldots$ & -- & -- & -- & -- & -- & -- & -- & - & -- \\
\hline $12 \ldots$ & -- & -- & -- & -- & -- & -- & -- & -- & -- \\
\hline $\begin{array}{r}\text { MAY } \\
15 . . .\end{array}$ & - & - & - & - & - & $=$ & .0 & $=$ & $=$ \\
\hline $\begin{array}{l}15 \ldots \\
\text { JUNE }\end{array}$ & -- & -- & -- & -- & -- & -- & -- & $\cdots$ & -- \\
\hline $11 \ldots$ & -- & -- & - & $\cdots$ & -- & -- & .0 & - & -- \\
\hline $11 \ldots$ & -- & -- & - & $m$ & -- & -- & $=-$ & $\cdots$ & - \\
\hline AUG. & & & & & & & & & \\
\hline $04 \ldots$ & $\overline{-}$ & -- & $=$ & $\overline{--}$ & $\because$ & -- & $\because 0$ & 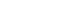 & -- \\
\hline $25 \ldots$ & -- & -- & - & $\rightarrow$ & - & -- & .0 & - & - \\
\hline $25 \ldots$ & - & -- & -- & $\cdots$ & -- & -- & -- & -- & -- \\
\hline $21 \ldots$ & 2.3 & 10 & 9.8 & .2 & 9.2 & 0 & .0 & -- & 70 \\
\hline $21 \ldots$ & -- & - & - & - & -- & -- & $\cdots$ & 220 & $=$ \\
\hline
\end{tabular}

\begin{tabular}{|c|c|c|c|c|c|c|c|c|c|}
\hline DATE & 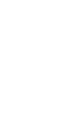 & $\begin{array}{l}\text { OrS- } \\
\text { SRLVEC } \\
\text { SOLVINS } \\
\text { TONS } \\
\text { PER } \\
\text { DAYI }\end{array}$ & $\begin{array}{l}\text { O1S- } \\
\text { SOLVED } \\
\text { SOL IDS } \\
\text { TONS } \\
\text { PER } \\
\text { AE-FY, }\end{array}$ & $\begin{array}{c}\text { NI TRATE } \\
\text { (NOB) } \\
\text { (MGOLOL) }\end{array}$ & $\begin{array}{c}\text { OIS- } \\
\text { SOLVED } \\
\text { NATURAL } \\
\text { URANU UM } \\
\text { (UU) } \\
\text { (UG LL) }\end{array}$ & 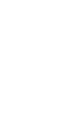 & 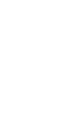 & $\begin{array}{c}\text { OIS- } \\
\text { SOLVED } \\
\text { GROSS } \\
\text { BETA } \\
\text { AS SRRC } \\
\text { SYOO } \\
\text { IPCLL) }\end{array}$ & 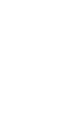 \\
\hline $15 \%$ & 55 & 52.7 & .03 & $\therefore$ & $=$ & $\because$ & $\because$ & $\because$ & $=$ \\
\hline $\begin{array}{l}\text { cv. } \\
13 \\
13\end{array}$ & -- & -- & $\because=$ & $=$ & .08 & .5 & $: 4$ & 3.1 & $\therefore 4$ \\
\hline $23 \ldots$ & 62 & 51.7 & $\because 9$ & .5 & . & $\therefore$ & -.5 & 3.0 & $\therefore 4$ \\
\hline & -- & -- & -- & -- & .01 & .5 & .4 & 3.0 & $\therefore 4$ \\
\hline$\ldots$ & -- & -- & -- & -- & -- & -- & -- & -- & -- \\
\hline & & & -- & -- & $\cdots$ & -- & - & -- & - \\
\hline & $\ddot{z}$ & $=$ & $=$ & $=$ & .02 & $\therefore$ & $\therefore$ & $\begin{array}{l}3.4 \\
--\end{array}$ & $\therefore$ \\
\hline & - & $\because$ & $\because$ & $=$ & .93 & $\because 7$ & $\therefore 4$ & 3.4 & $\therefore 6$ \\
\hline & -- & -- & -- & -- & .05 & .5 & .5 & 3.6 & .4 \\
\hline & $=$ & $\bar{Z}$ & $=$ & $=$ &.$\overline{01}$ & 9 &.$\overline{.4}$ & 4.8 & .6 \\
\hline & & & & & & & -- & -- & - \\
\hline & 65 & 78.6 & $\begin{array}{r}10 \\
-10\end{array}$ & - 1.6 & .09 & $\therefore$ & $\because 7$ & $\begin{array}{l}3.6 \\
3\end{array}$ & $\therefore$ \\
\hline
\end{tabular}


02171600 BANTEE RIVER NEAR ST. STEPHENB, S, C.

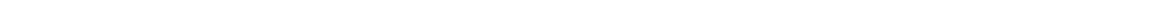
Compli. Brat phens, and 6.8 miles upetrenm from gaglng etation near Jamentown.

PERIOD OF RECORD,--Chemical analyees: July 1968 to september 1970.

REuARS.--The second of two amples collected at the eame time is a fleld deternination.

CHEMICAL ANALYSES, JULY 1969 TO SEPTEMBER 1970

\begin{tabular}{|c|c|c|c|c|c|c|c|c|}
\hline OATE & TIME & $\begin{array}{l}\text { TEAP- } \\
\text { ERAFURE } \\
\text { (DEG C) }\end{array}$ & $\begin{array}{l}\text { OTS- } \\
\text { CHARGE } \\
\text { (CFS) }\end{array}$ & $\begin{array}{l}\text { SPECI- } \\
\text { FIC } \\
\text { COND- } \\
\text { UCTANCE } \\
\text { I MICRO- } \\
\text { MHOSI }\end{array}$ & $\begin{array}{l}\text { OIS- } \\
\text { SOLVED } \\
\text { OXYGEN } \\
\text { (MO/L) }\end{array}$ & $\begin{array}{c}\text { PH } \\
\text { (UNITS) }\end{array}$ & $\begin{array}{l}\text { TOTAL } \\
\text { PHOS- } \\
\text { PHORUS } \\
\text { (P) } \\
\text { (MG/L) }\end{array}$ & $\begin{array}{c}\text { NITRATE } \\
\text { (NOS) } \\
\text { (MG/L) }\end{array}$ \\
\hline $\begin{array}{l}\text { JULY } \\
25 . . . \\
25 . . \\
\text { AUG. }\end{array}$ & $\begin{array}{l}1050 \\
1050\end{array}$ & 28.5 & 765 & $\overline{80}$ & 6.8 & 6.8 & .02 & $\because 0$ \\
\hline $27 \ldots$ & $\begin{array}{l}1710 \\
1710\end{array}$ & 27.5 & $763^{-}$ & $\overline{90}$ & $\overline{B . T}$ & $\overline{7.4}$ & .00 & $\because 6$ \\
\hline $\begin{array}{l}30 . \ldots \\
30 \ldots . . . \\
\text { oct. }\end{array}$ & $\begin{array}{l}1210 \\
1210\end{array}$ & $21 . \overline{5}$ & $704^{-}$ & $\overline{92}$ & $8 . \overline{0}$ & $\overrightarrow{7.1}$ & .00 & 1.0 \\
\hline $\begin{array}{l}28 \ldots . . . \\
28 . \ldots \\
\text { NoV. }\end{array}$ & $\begin{array}{l}1600 \\
1600\end{array}$ & $\begin{array}{l}19.0 \\
19.0\end{array}$ & 712 & $\begin{array}{l}10 \\
90\end{array}$ & $9 . \overline{1}$ & $\begin{array}{l}7.6 \\
7.2\end{array}$ & .03 & $\because 9$ \\
\hline $\begin{array}{l}20 \ldots \\
20 \ldots \ldots \\
\text { OEC.... }\end{array}$ & $\begin{array}{l}1245 \\
1245\end{array}$ & $\begin{array}{l}23.5 \\
13.5\end{array}$ & $\begin{array}{l}610 \\
610\end{array}$ & $\overline{90}$ & $10 . \overline{0}$ & 7.3 & .04 & $\because 6$ \\
\hline $\begin{array}{l}18 . . . \\
\text { JAN... }\end{array}$ & $\begin{array}{l}1320 \\
1320\end{array}$ & $\begin{array}{l}6.0 \\
8.0\end{array}$ & $\begin{array}{l}685 \\
685\end{array}$ & 100 & $10 . \overline{0}$ & 7.5 & .09 & $\because 0$ \\
\hline $\begin{array}{l}27 \ldots \ldots \\
27 \ldots \cdots \\
F \in B .\end{array}$ & $\begin{array}{l}1215 \\
1215\end{array}$ & $\begin{array}{l}8.0 \\
8.0\end{array}$ & $\begin{array}{l}709 \\
709\end{array}$ & 97 & 12.3 & $\overline{7.4}$ & .01 & $\because 9$ \\
\hline $\begin{array}{l}18 \ldots . . . \\
\text { MAR. }\end{array}$ & $\begin{array}{l}0735 \\
0735\end{array}$ & $\begin{array}{l}6.0 \\
8.0\end{array}$ & $\begin{array}{l}826 \\
026\end{array}$ & 86 & $14 . \overline{3}$ & $\overline{7.3}$ & .03 & 13 \\
\hline $\begin{array}{l}25 \ldots . . . \\
25 . . . \\
\text { APR. }\end{array}$ & $\begin{array}{l}1030 \\
1030\end{array}$ & $\begin{array}{l}23.5 \\
13.5\end{array}$ & $\begin{array}{l}31800 \\
31800\end{array}$ & $\overline{00}$ & $9 . \overline{-0}$ & 7.5 & .30 & $\because 1$ \\
\hline $\begin{array}{l}22 . \\
22 .\end{array}$ & $\begin{array}{l}1410 \\
1410\end{array}$ & $\begin{array}{l}22.0 \\
22.0\end{array}$ & $\begin{array}{l}783 \\
783\end{array}$ & 110 & $8 \overrightarrow{5}$ & 7.1 & .01 & .3 \\
\hline $\begin{array}{l}18 \ldots . . . \\
\text { JUNE }\end{array}$ & $\begin{array}{l}1550 \\
1550\end{array}$ & $\begin{array}{l}24.5 \\
24.5\end{array}$ & $\begin{array}{l}630 \\
630\end{array}$ & $2 \overline{10}$ & $6 . \overline{0}$ & 7.1 & .01 & $\because 1$ \\
\hline $\begin{array}{l}19 . \\
19.0 \\
\text { AUG. }\end{array}$ & $\begin{array}{l}1100 \\
1100\end{array}$ & $\begin{array}{l}29.0 \\
29.0\end{array}$ & $\begin{array}{l}764 \\
764\end{array}$ & $\ddot{90}$ & $\overline{7.7}$ & 7.2 & .01 & $\therefore$ \\
\hline $\begin{array}{l}04 . \\
04 . \\
25 . \\
25 . \\
\text { SEP. }\end{array}$ & $\begin{array}{l}1250 \\
1250 \\
1100 \\
1100\end{array}$ & $\begin{array}{l}31.0 \\
31.0 \\
27.0 \\
27.0\end{array}$ & $\begin{array}{l}600 \\
600 \\
690 \\
690\end{array}$ & $\frac{90}{105}$ & $\begin{array}{r}-\overline{2} \\
7.4\end{array}$ & $\frac{7.5}{6.8}$ & .03 & $\frac{.5}{.2}$ \\
\hline & $\begin{array}{l}1155 \\
1155\end{array}$ & $\begin{array}{l}26.5 \\
26.5\end{array}$ & $\begin{array}{l}600 \\
600\end{array}$ & as & $\overline{7.0}$ & $\overline{7.1}$ & .00 & -3 \\
\hline
\end{tabular}

\begin{tabular}{|c|c|c|c|c|c|c|c|c|c|c|c|}
\hline DATE & TI ME & $\begin{array}{l}\text { TEMP- } \\
\text { ERATURE } \\
\text { IOEO C.I }\end{array}$ & $\begin{array}{l}\text { DIS- } \\
\text { CHARGE } \\
\text { (CFS) }\end{array}$ & 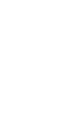 & $\begin{array}{l}\text { COLOR } \\
\text { (PLAT- } \\
\text { INUM- } \\
\text { COSALT } \\
\text { UNITSI) }\end{array}$ & $\begin{array}{l}\text { SPECI- } \\
\text { FIC } \\
\text { COND- } \\
\text { UCTANCE } \\
\text { (MICRO- } \\
\text { MHDSI }\end{array}$ & $\begin{array}{l}\text { OIS- } \\
\text { SOLVED } \\
\text { OXYGEN } \\
\text { (MG/L) }\end{array}$ & $\begin{array}{l}\text { DTO- } \\
\text { CHEM- } \\
\text { ICAL } \\
\text { OXYGEN } \\
\text { DEMAND } \\
\text { IMG/LI }\end{array}$ & $\begin{array}{c}\text { PH } \\
\text { (UNITSI }\end{array}$ & $\begin{array}{l}\text { ALKA- } \\
\text { LINI TV } \\
\text { AS } \\
\text { CACOB } \\
\text { IMG/LI) }\end{array}$ & $\begin{array}{l}\text { BICAR- } \\
\text { BONATE } \\
\text { (HEOS) } \\
\text { (MG/L) }\end{array}$ \\
\hline $\begin{array}{l}0,7 . \\
28 \ldots . . . \\
28 . . .\end{array}$ & $\begin{array}{r}1000 \\
1600 \\
\text { roTAL }\end{array}$ & $\begin{array}{l}19.0 \\
19.0\end{array}$ & $\begin{array}{l}712 \\
712\end{array}$ & 2 & 20 & 90 & 9.1 & 1.2 & $\begin{array}{l}7.6 \\
7.2\end{array}$ & 25 & 30 \\
\hline DATE & $\begin{array}{r}\text { NONE } \\
\text { FILTE } \\
\text { RABLE } \\
\text { RESIOUE } \\
\text { (MG IL) }\end{array}$ & $\begin{array}{l}\text { TATAL } \\
\text { PHOS - } \\
\text { PHORUS } \\
(P) \\
(M O L)\end{array}$ & $\begin{array}{l}\text { HARQ- } \\
\text { NESS } \\
(C A, M G) \\
(M G / L)\end{array}$ & $\begin{array}{l}\text { NON- } \\
\text { CAR- } \\
\text { GONATE } \\
\text { HARO- } \\
\text { NESS } \\
\text { (MG/L) }\end{array}$ & $\begin{array}{l}\text { CHLO- } \\
\text { RIOE } \\
\text { (CLI } \\
(M G / L)\end{array}$ & $\begin{array}{l}\text { SULFATE } \\
\text { (SOA) } \\
\text { (MGAL) }\end{array}$ & $\begin{array}{l}\text { OISE } \\
\text { SOL VEO } \\
\text { LUOW } \\
\text { RIDE } \\
\text { (F) } \\
\text { (MO/L) }\end{array}$ & $\begin{array}{l}\text { TOTAL } \\
\text { CHMO- } \\
\text { MIUM } \\
\text { ICRI } \\
(U G / L)\end{array}$ & $\begin{array}{l}\text { OIS- } \\
\text { SOLVED } \\
\text { COPPER } \\
\text { (CU) } \\
\text { (UG/L) }\end{array}$ & $\begin{array}{l}\text { TETAL } \\
\text { IRON } \\
\text { (FE) } \\
\text { (UG/L) }\end{array}$ & $\begin{array}{l}\text { OIS- } \\
\text { SOLVED } \\
\text { LEAAD } \\
\text { (PB) } \\
\text { (UG/L) }\end{array}$ \\
\hline $\begin{array}{l}\text { ocr. } \\
28 \ldots . . \\
26 \ldots\end{array}$ & -3 & $\because 3$ & 21 & $\therefore$ & 28 & 10 & $\because 2$ & $\stackrel{0}{-1}$ & 10 & $\begin{array}{r}183 \\
-.-7\end{array}$ & 18 \\
\hline DATE & $\begin{array}{l}\text { TOTAL } \\
\text { MAN- } \\
\text { GANESE } \\
\text { (MN) } \\
\text { (UGIL) }\end{array}$ & $\begin{array}{l}\text { OIS- } \\
\text { SOLVFO } \\
\text { NICKEL } \\
\text { INI) } \\
\text { (UGLL) }\end{array}$ & $\begin{array}{l}\text { DI S- } \\
\text { SOLVED } \\
\text { ALPHA } \\
\text { (PCLL) }\end{array}$ & $\begin{array}{l}\text { SUS- } \\
\text { PENOED } \\
\text { ALPHA } \\
\text { (PC/L) }\end{array}$ & $\begin{array}{l}\text { DIS- } \\
\text { SavEo } \\
\text { BETA } \\
\text { (PCAL) }\end{array}$ & $\begin{array}{l}\text { SUS- } \\
\text { PENDED } \\
\text { GETA } \\
\text { (PCM) }\end{array}$ & $\begin{array}{l}\text { LENE } \\
\text { GLUE } \\
\text { ACTIVE } \\
\text { SUBE } \\
\text { STANCE } \\
\text { IMGLL }\end{array}$ & $\begin{array}{l}\text { SOLVED } \\
\text { SOLIDS } \\
\text { IRESI- } \\
\text { DUE AT } \\
\text { IGO C) } \\
\text { (MGIL) }\end{array}$ & $\begin{array}{l}\text { DI S- } \\
\text { SOLVED } \\
\text { SOL IOS } \\
\text { ITONS } \\
\text { PER } \\
\text { DAYI }\end{array}$ & $\begin{array}{l}\text { OIS- } \\
\text { SOL VEO } \\
\text { SOLIDS } \\
\text { ITONS } \\
\text { PER } \\
\text { AC-FTI }\end{array}$ & $\begin{array}{l}\text { NITRATE } \\
\text { (NO3) } \\
\text { (MG/L) }\end{array}$ \\
\hline $\begin{array}{l}\text { ост. } \\
28 . . . \\
28 . .\end{array}$ & 20 & - & $\therefore$ & $\therefore$ & 3.8 & $\because$ & $\because 00$ & $\begin{array}{l}60 \\
=-\end{array}$ & $115 \ldots$ & $\because 08$ & $\because 9$ \\
\hline
\end{tabular}


02172090 ASHLEY RIVER AT CHARLESTON, S. C.

LOCATION, - Lat $32^{\circ} 47^{\prime} 00^{\prime \prime}$, long $79^{\circ} 57^{\prime} 39^{\prime \prime}$, Charleston County, at bridge on U.S. H1ghway 17 , at Charleston, 0.9 mile upstream from Wappoo' Creek, and at mile 2.2 .

PERIOD OF RECORD,--Chemical analyses: July 1969 to September 1970.

REKARKS.--The second of two samples collected at the same time is a fleld determination.

CHEMICAL ANALYSES, JULY 1969 TO SEPTEMBER 1970

\begin{tabular}{|c|c|c|c|c|c|c|c|c|c|}
\hline DATE & TIME & $\begin{array}{l}\text { TEMP- } \\
\text { ERATURE } \\
\text { IDEG CI }\end{array}$ & $\begin{array}{l}\text { SPECI- } \\
\text { FIC } \\
\text { COND- } \\
\text { UCTANCE } \\
\text { (MICRO- } \\
\text { MHOS) }\end{array}$ & $\begin{array}{l}\text { DIS- } \\
\text { SOLVED } \\
\text { OXYGEN } \\
\text { (MG/L) }\end{array}$ & $\begin{array}{c}\text { PH } \\
\text { (UNITS) }\end{array}$ & $\begin{array}{l}\text { TORAL } \\
\text { PHOS- } \\
\text { PHORUS } \\
\text { (P) } \\
\text { (MG/L) }\end{array}$ & $\begin{array}{c}\text { NITRATE } \\
\text { (NO3) } \\
\text { (MG/L) }\end{array}$ & $\begin{array}{l}\text { FECAL } \\
\text { COLL- } \\
\text { FORM } \\
\text { ICOL. } \\
\text { PER } \\
100 \mathrm{MLI}\end{array}$ & $\begin{array}{c}\text { TMME- } \\
\text { DIATE } \\
\text { COLI- } \\
\text { FORM } \\
\text { ICOL. } \\
\text { PER - } \\
\text { POO MLL) }\end{array}$ \\
\hline
\end{tabular}

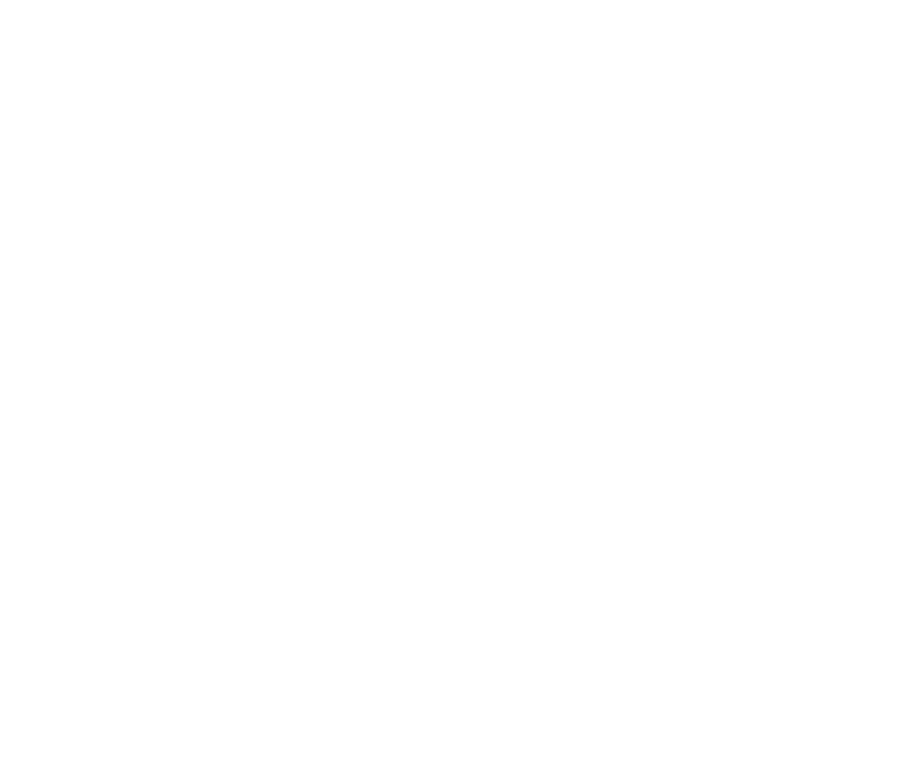

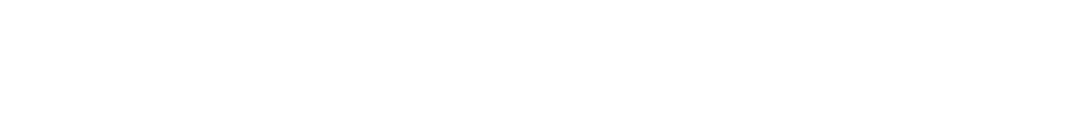
OCT

\begin{tabular}{|c|c|c|c|c|c|c|c|c|c|c|c|}
\hline $\begin{array}{l}28 \ldots \\
28 \ldots\end{array}$ & $\begin{array}{l}1300 \\
1300\end{array}$ & $\begin{array}{l}18.5 \\
18.5\end{array}$ & -1 & 10 & $\begin{array}{l}19700 \\
26000\end{array}$ & $8 . \overline{7}$ & 1.0 & $\begin{array}{l}7.8 \\
7.8\end{array}$ & 88 & 107 & $\overline{-}$ \\
\hline $39 . .$. & 1300 & - & $\mathrm{ACN}-$ & $\cdots$ & -- & DIS=- & - & - & - & -- & 15 \\
\hline & $\begin{array}{l}\text { TOTAL } \\
\text { PHOS- } \\
\text { PHORUS } \\
\text { (P) }\end{array}$ & $\begin{array}{l}\text { HAPD- } \\
\text { NESS } \\
(C A, M G)\end{array}$ & $\begin{array}{l}\text { CAR- } \\
\text { BONATE } \\
\text { HAR L- } \\
\text { NESS }\end{array}$ & $\begin{array}{l}\text { CHLO- } \\
\text { RICE } \\
\text { (CL) }\end{array}$ & $\begin{array}{l}\text { SULFATE } \\
\left(\mathrm{SO}_{4}\right)\end{array}$ & $\begin{array}{l}\text { SOLVED } \\
\text { FLUO- } \\
\text { RIDE } \\
\text { IF) }\end{array}$ & $\begin{array}{l}\text { TOTAL } \\
\text { CHRO- } \\
\text { MIUM } \\
\text { (CR) }\end{array}$ & $\begin{array}{l}\text { DIS- } \\
\text { SOLVED } \\
\text { COPPER } \\
\text { (CUI) }\end{array}$ & $\begin{array}{l}\text { TOTAL } \\
\text { IRON } \\
\text { (FE) }\end{array}$ & $\begin{array}{l}\text { DIS- } \\
\text { S OLVED } \\
\text { LEAD } \\
\text { (P8) }\end{array}$ & $\begin{array}{l}\text { TOTAL } \\
\text { MAN- } \\
\text { GANESE } \\
\text { (MN) }\end{array}$ \\
\hline
\end{tabular}

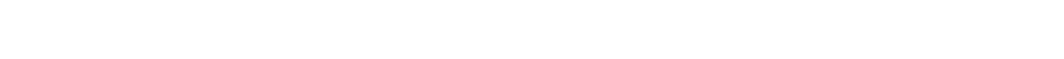
OCT

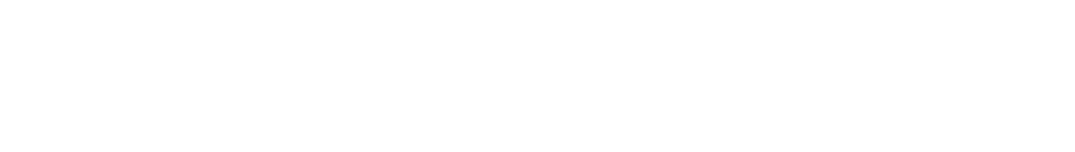

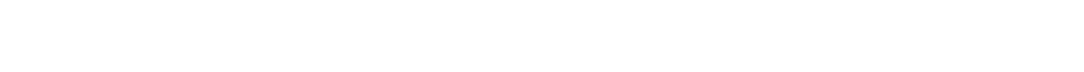


02175000 EDISTO RIVER NEAR GIVHANS, S, C

(International Hydrological Decade River station)

LOCATION.--Lat $33^{\circ} 01^{\prime} 40^{\prime \prime}$, long $80^{\circ} 23^{\prime} 30^{\prime \prime}$, Dorchester County, at gaging station on left bank at downstream side of bridge on State Highway $61,2.3$ miles downstream from Four Hole Swamp, 2.8 miles west of Givhans, and at mile 59,9 DRAINAGE AREA. - 2,730 sq $m 1$, approximately.

PERIOD OF RECORD. --Chemical analyses: March 1967 to September 1969

Water temperatures: March 1967 to September 1969

Sediment records: Marci. 1967 to September 1970.

EXTREMES. $--1967-69$ :

Specific conductance: Maximum da1Iy, 92 micromhos oct. 25-27, 1968 ; min1mum da1ly, 37 micromhos Nov, 10, 17, 1967 , May 10, 1968

Water temperatures: Maximum da1ly, 32. $0^{\circ} \mathrm{C}$ Aug. 1, 1968 , July 23, 26, 1969; minimum da1ly, 3.0 $0^{\circ} \mathrm{C}$ Jan. $13-19,1968$, Sediment concentration: Naximum dal1y, $85 \mathrm{mg} / \mathrm{i}$ June 10,1969 ; minimum daliy, $2 \mathrm{mg} / 1 \mathrm{Feb}$. 23, Mar. 5 , 17, Dec. 18,

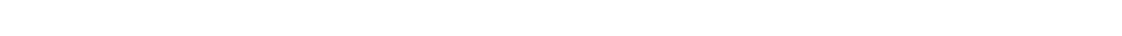
SUSPENDED-SEDIMENT DISCHARGE, WATER YEAR OCTOBER 1969 TO SEPTEMBER 1970

\begin{tabular}{|c|c|c|c|c|c|c|c|c|c|}
\hline & & OCTOBER & & & NCVEMBER & & & DECEMBER & \\
\hline DAY & $\begin{array}{c}\text { MEAN } \\
\text { DISCHARGE } \\
\text { (CFS) }\end{array}$ & $\begin{array}{l}\text { MEAN } \\
\text { CONCEN- } \\
\text { TRATION } \\
\text { (MG/L) }\end{array}$ & $\begin{array}{l}\text { SEDIMENT } \\
\text { DI SCHARGE } \\
\text { (TONS/DAY) }\end{array}$ & $\begin{array}{l}\text { MEAN } \\
\text { DISCHARGE } \\
\text { (CFS) }\end{array}$ & $\begin{array}{l}\text { MEAN } \\
\text { CONCEN- } \\
\text { TRATION } \\
\text { (MG/L) }\end{array}$ & $\begin{array}{l}\text { SEDIMENT } \\
\text { DI ICHARGE } \\
\text { (TONS /DAY) }\end{array}$ & $\begin{array}{l}\text { MEAN } \\
\text { DISCHARGE } \\
\text { (CFS) }\end{array}$ & $\begin{array}{l}\text { MEAN } \\
\text { CONCEN- } \\
\text { TRATION } \\
\text { (MG/L) }\end{array}$ & $\begin{array}{l}\text { SEDIMENT } \\
\text { DI SCHARGE } \\
\text { (TONS/DAY) }\end{array}$ \\
\hline $\begin{array}{l}1 \\
2 \\
3 \\
4 \\
5\end{array}$ & $\begin{array}{l}2400 \\
2360 \\
2400 \\
2460 \\
2400\end{array}$ & $\begin{array}{l}36 \\
21 \\
18 \\
18 \\
24\end{array}$ & $\begin{array}{l}233 \\
134 \\
117 \\
120 \\
156\end{array}$ & $\begin{array}{l}1100 \\
1810 \\
2400 \\
2520 \\
2540\end{array}$ & $\begin{array}{r}6 \\
12 \\
12 \\
6 \\
7\end{array}$ & $\begin{array}{l}18 \\
59 \\
78 \\
41 \\
48\end{array}$ & $\begin{array}{l}1260 \\
1240 \\
1240 \\
1230 \\
1220\end{array}$ & $\begin{array}{l}7 \\
9 \\
6 \\
5 \\
4\end{array}$ & $\begin{array}{l}24 \\
30 \\
20 \\
17 \\
13\end{array}$ \\
\hline $\begin{array}{r}6 \\
7 \\
8 \\
9 \\
10\end{array}$ & $\begin{array}{l}2400 \\
2340 \\
2260 \\
2300 \\
2280\end{array}$ & $\begin{array}{l}14 \\
19 \\
19 \\
18 \\
23\end{array}$ & $\begin{array}{r}91 \\
120 \\
116 \\
112 \\
142\end{array}$ & $\begin{array}{l}2490 \\
2400 \\
2300 \\
2210 \\
2100\end{array}$ & $\begin{array}{r}9 \\
9 \\
10 \\
10 \\
8\end{array}$ & $\begin{array}{l}61 \\
58 \\
62 \\
60 \\
45\end{array}$ & $\begin{array}{l}1210 \\
1220 \\
1280 \\
1330 \\
1410\end{array}$ & $\begin{array}{r}6 \\
3 \\
3 \\
8 \\
14\end{array}$ & $\begin{array}{l}20 \\
9.9 \\
10 \\
29 \\
53\end{array}$ \\
\hline $\begin{array}{l}11 \\
12 \\
13 \\
14 \\
15\end{array}$ & $\begin{array}{l}2500 \\
2700 \\
2270 \\
1790 \\
1620\end{array}$ & $\begin{array}{l}23 \\
18 \\
11 \\
26 \\
-2\end{array}$ & $\begin{array}{r}155 \\
131 \\
67 \\
77 \\
44\end{array}$ & $\begin{array}{l}1970 \\
1870 \\
1780 \\
1700 \\
1600\end{array}$ & $\begin{array}{l}8 \\
6 \\
4 \\
7 \\
3\end{array}$ & $\begin{array}{l}43 \\
30 \\
19 \\
32 \\
13\end{array}$ & $\begin{array}{l}1720 \\
2000 \\
2160 \\
2260 \\
2340\end{array}$ & $\begin{array}{l}8 \\
9 \\
9 \\
8 \\
9\end{array}$ & $\begin{array}{l}37 \\
49 \\
52 \\
49 \\
57\end{array}$ \\
\hline $\begin{array}{l}16 \\
17 \\
18 \\
19 \\
20\end{array}$ & $\begin{array}{l}1500 \\
1350 \\
1200 \\
1190 \\
1180\end{array}$ & $\begin{array}{r}7 \\
9 \\
10 \\
13 \\
12\end{array}$ & $\begin{array}{l}28 \\
33 \\
32 \\
42 \\
38\end{array}$ & $\begin{array}{l}1560 \\
1490 \\
1440 \\
1380 \\
1350\end{array}$ & $\begin{array}{l}5 \\
6 \\
3 \\
5 \\
3\end{array}$ & $\begin{array}{l}21 \\
24 \\
12 \\
19 \\
11\end{array}$ & $\begin{array}{l}2400 \\
2460 \\
2500 \\
2560 \\
2620\end{array}$ & $\begin{array}{l}9 \\
6 \\
8 \\
7 \\
6\end{array}$ & $\begin{array}{l}58 \\
40 \\
54 \\
48 \\
42\end{array}$ \\
\hline $\begin{array}{l}21 \\
22 \\
23 \\
24 \\
25\end{array}$ & $\begin{array}{l}1250 \\
1260 \\
1200 \\
1160 \\
1100\end{array}$ & $\begin{array}{r}9 \\
10 \\
16 \\
6 \\
12\end{array}$ & $\begin{array}{l}30 \\
34 \\
52 \\
19 \\
36\end{array}$ & $\begin{array}{l}1300 \\
1300 \\
1300 \\
1310 \\
1290\end{array}$ & $\begin{array}{l}6 \\
7 \\
7 \\
7 \\
1\end{array}$ & $\begin{array}{l}21 \\
25 \\
25 \\
25 \\
3.5\end{array}$ & $\begin{array}{l}2670 \\
2720 \\
2760 \\
2770 \\
2740\end{array}$ & $\begin{array}{l}6 \\
6 \\
5 \\
4 \\
5\end{array}$ & $\begin{array}{l}43 \\
44 \\
37 \\
30 \\
37\end{array}$ \\
\hline $\begin{array}{l}26 \\
27 \\
28 \\
29 \\
30 \\
31\end{array}$ & $\begin{array}{r}1070 \\
1050 \\
1040 \\
1020 \\
988 \\
964\end{array}$ & $\begin{array}{r}14 \\
5 \\
11 \\
10 \\
5 \\
7\end{array}$ & $\begin{array}{l}40 \\
14 \\
31 \\
28 \\
13 \\
18\end{array}$ & $\begin{array}{r}1280 \\
1270 \\
1260 \\
1260 \\
1250 \\
-\end{array}$ & $\begin{array}{r}8 \\
6 \\
7 \\
4 \\
4 \\
--\end{array}$ & $\begin{array}{l}28 \\
21 \\
24 \\
14 \\
14 \\
--\end{array}$ & $\begin{array}{l}2720 \\
2730 \\
2730 \\
2710 \\
2700 \\
2680\end{array}$ & $\begin{array}{l}9 \\
6 \\
4 \\
8 \\
7 \\
6\end{array}$ & $\begin{array}{l}66 \\
44 \\
29 \\
59 \\
51 \\
43\end{array}$ \\
\hline TOTAL & 53002 & JANUARY & 2303 & 50830 & FEBRUARY & 954.5 & 65590 & MARCH & 1194.9 \\
\hline DAY & $\begin{array}{l}\text { MEAN } \\
\text { DISCHARGE } \\
\text { (CFS) }\end{array}$ & $\begin{array}{l}\text { MEAN } \\
\text { CONCEN- } \\
\text { TRATION } \\
\text { (MG/L) }\end{array}$ & $\begin{array}{l}\text { SEDIMENT } \\
\text { DISCHARGE } \\
\text { (TONS/DAY) }\end{array}$ & $\begin{array}{l}\text { MEAN } \\
\text { DISCHARGE } \\
\text { (CFS) }\end{array}$ & $\begin{array}{l}\text { MEAN } \\
\text { CONCEN- } \\
\text { TRATION } \\
\text { (MG/L) }\end{array}$ & $\begin{array}{l}\text { SEDIMENT } \\
\text { DISCHARGE } \\
\text { (TONS/DAY) }\end{array}$ & $\begin{array}{c}\text { MEAN } \\
\text { DISCHARGE } \\
\text { (CFS) }\end{array}$ & $\begin{array}{l}\text { MEAN } \\
\text { CONCEN- } \\
\text { TRATION } \\
\text { (MG/L) }\end{array}$ & $\begin{array}{l}\text { SEDIMENT } \\
\text { DISCHARGE } \\
\text { (TONS/DAY) }\end{array}$ \\
\hline $\begin{array}{l}1 \\
2 \\
3 \\
4 \\
5\end{array}$ & $\begin{array}{l}2680 \\
2690 \\
2720 \\
2750 \\
2760\end{array}$ & $\begin{array}{l}7 \\
4 \\
4 \\
5 \\
4\end{array}$ & $\begin{array}{l}51 \\
29 \\
29 \\
37 \\
30\end{array}$ & $\begin{array}{l}2520 \\
2520 \\
2860 \\
3570 \\
4400\end{array}$ & $\begin{array}{r}7 \\
8 \\
10 \\
10 \\
15\end{array}$ & $\begin{array}{r}48 \\
54 \\
77 \\
96 \\
178\end{array}$ & $\begin{array}{l}3360 \\
3230 \\
3140 \\
3040 \\
2970\end{array}$ & $\begin{array}{r}3 \\
5 \\
4 \\
-5 \\
5\end{array}$ & $\begin{array}{l}27 \\
44 \\
34 \\
41 \\
40\end{array}$ \\
\hline $\begin{array}{r}6 \\
7 \\
8 \\
9 \\
10\end{array}$ & $\begin{array}{l}2800 \\
2970 \\
3220 \\
3410 \\
3460\end{array}$ & $\begin{array}{l}8 \\
6 \\
6 \\
6 \\
6\end{array}$ & $\begin{array}{l}80 \\
48 \\
52 \\
55 \\
56\end{array}$ & $\begin{array}{l}4710 \\
4720 \\
4720 \\
4690 \\
4580\end{array}$ & $\begin{array}{r}17 \\
10 \\
9 \\
6 \\
5\end{array}$ & $\begin{array}{r}216 \\
127 \\
115 \\
76 \\
62\end{array}$ & $\begin{array}{l}2950 \\
2970 \\
3040 \\
3240 \\
3500\end{array}$ & $\begin{array}{r}4 \\
8 \\
9 \\
12 \\
9\end{array}$ & $\begin{array}{r}32 \\
64 \\
74 \\
165 \\
85\end{array}$ \\
\hline $\begin{array}{l}11 \\
12 \\
13 \\
14 \\
15\end{array}$ & $\begin{array}{l}3420 \\
3430 \\
3460 \\
3520 \\
3610\end{array}$ & $\begin{array}{l}7 \\
4 \\
5 \\
4 \\
6\end{array}$ & $\begin{array}{l}65 \\
37 \\
47 \\
38 \\
58\end{array}$ & $\begin{array}{l}4370 \\
4120 \\
3840 \\
3570 \\
3340\end{array}$ & $\begin{array}{l}7 \\
5 \\
6 \\
4 \\
4\end{array}$ & $\begin{array}{l}83 \\
56 \\
62 \\
39 \\
36\end{array}$ & $\begin{array}{l}3770 \\
3940 \\
4010 \\
4030 \\
3920\end{array}$ & $\begin{array}{r}10 \\
6 \\
6 \\
7 \\
5\end{array}$ & $\begin{array}{r}102 \\
64 \\
65 \\
76 \\
53\end{array}$ \\
\hline $\begin{array}{l}16 \\
17 \\
18 \\
19 \\
20\end{array}$ & $\begin{array}{l}3650 \\
3650 \\
3620 \\
3590 \\
3530\end{array}$ & $\begin{array}{l}7 \\
5 \\
5 \\
7 \\
7\end{array}$ & $\begin{array}{l}69 \\
49 \\
49 \\
68 \\
67\end{array}$ & $\begin{array}{l}3140 \\
3060 \\
3070 \\
3160 \\
3280\end{array}$ & $\begin{array}{l}7 \\
9 \\
6 \\
9 \\
7\end{array}$ & $\begin{array}{l}59 \\
74 \\
50 \\
77 \\
62\end{array}$ & $\begin{array}{l}3700 \\
3420 \\
3150 \\
2910 \\
2800\end{array}$ & $\begin{array}{l}5 \\
7 \\
7 \\
6 \\
6\end{array}$ & $\begin{array}{l}50 \\
65 \\
60 \\
47 \\
45\end{array}$ \\
\hline $\begin{array}{l}21 \\
22 \\
23 \\
24 \\
25\end{array}$ & $\begin{array}{l}3450 \\
3320 \\
3180 \\
3040 \\
2920\end{array}$ & $\begin{array}{l}7 \\
3 \\
5 \\
5 \\
6\end{array}$ & $\begin{array}{l}65 \\
27 \\
43 \\
41 \\
47\end{array}$ & $\begin{array}{l}3380 \\
3470 \\
3530 \\
3550 \\
3550\end{array}$ & $\begin{array}{c}-- \\
-- \\
9 \\
5 \\
6\end{array}$ & $\begin{array}{l}73 \\
75 \\
86 \\
48 \\
58\end{array}$ & $\begin{array}{l}2870 \\
3320 \\
4190 \\
5180 \\
5680\end{array}$ & \begin{tabular}{r}
6 \\
13 \\
\hdashline- \\
-7
\end{tabular} & $\begin{array}{r}46 \\
117 \\
113 \\
140 \\
107\end{array}$ \\
\hline $\begin{array}{l}26 \\
27 \\
28 \\
29 \\
30 \\
31\end{array}$ & $\begin{array}{l}2840 \\
2760 \\
2690 \\
2680 \\
2590 \\
2560\end{array}$ & $\begin{array}{r}4 \\
5 \\
4 \\
5 \\
14 \\
6\end{array}$ & $\begin{array}{l}31 \\
37 \\
29 \\
36 \\
98 \\
41\end{array}$ & $\begin{array}{r}3590 \\
3570 \\
3490 \\
=- \\
=-\end{array}$ & $\begin{array}{r}5 \\
4 \\
4 \\
-- \\
-- \\
--\end{array}$ & $\begin{array}{l}48 \\
39 \\
38 \\
-- \\
-- \\
--\end{array}$ & $\begin{array}{l}6080 \\
6610 \\
7250 \\
7640 \\
7240 \\
8060\end{array}$ & $\begin{array}{r}4 \\
54 \\
44 \\
24 \\
28 \\
46\end{array}$ & $\begin{array}{r}66 \\
964 \\
861 \\
495 \\
547 \\
1000\end{array}$ \\
\hline TOTAL & 96970 & - & 1489 & 102370 & $=$ & 2112 & 131210 & - & 5629 \\
\hline
\end{tabular}


02175000 EDISTO RIVER NEAR GIVHANS, S. C...-Continued SUSPENDED-SEDIMENT DISCHARGE, WATER YEAR OCTOBER 1969 TO SEPTEMBER 1970

\begin{tabular}{|c|c|c|c|c|c|c|c|c|c|}
\hline & & APRIL & & & MAY & & & JUNE & \\
\hline DAY & $\begin{array}{c}\text { MEAN } \\
\text { DI SCHARGE } \\
\text { (CFS) }\end{array}$ & $\begin{array}{l}\text { MEAN } \\
\text { CONCEN- } \\
\text { TRATION } \\
\text { (MG/L) }\end{array}$ & $\begin{array}{l}\text { SEDIMENT } \\
\text { DISCHARGE } \\
\text { (TONS/DAY) }\end{array}$ & $\begin{array}{l}\text { MEAN } \\
\text { DISCHARGE } \\
\text { (CFS) }\end{array}$ & $\begin{array}{l}\text { MEAN } \\
\text { CONCEN- } \\
\text { TRATION } \\
\text { (MG/L) }\end{array}$ & $\begin{array}{l}\text { SEDIMENT } \\
\text { DISCHARGE } \\
\text { (TONS/DAY) }\end{array}$ & $\begin{array}{l}\text { MEAN } \\
\text { DISCHARGE } \\
\text { (CFS) }\end{array}$ & $\begin{array}{l}\text { MEAN } \\
\text { CONCEN- } \\
\text { TRATION } \\
\text { (MG/L) }\end{array}$ & $\begin{array}{l}\text { SEDIMENT } \\
\text { DISCHARGE } \\
\text { (TONS/DAY) }\end{array}$ \\
\hline $\begin{array}{l}1 \\
2 \\
3 \\
4 \\
5\end{array}$ & $\begin{array}{r}8940 \\
9950 \\
10300 \\
10400 \\
10800\end{array}$ & $\begin{array}{r}19 \\
8 \\
-2 \\
12\end{array}$ & $\begin{array}{l}459 \\
215 \\
417 \\
421 \\
350\end{array}$ & $\begin{array}{l}2120 \\
2070 \\
1960 \\
1850 \\
1760\end{array}$ & $\begin{array}{l}6 \\
15 \\
14 \\
16 \\
12\end{array}$ & $\begin{array}{l}34 \\
84 \\
74 \\
80 \\
57\end{array}$ & $\begin{array}{l}1300 \\
1550 \\
1580 \\
1600 \\
1500\end{array}$ & $\begin{array}{l}13 \\
-21 \\
10 \\
12\end{array}$ & $\begin{array}{l}53 \\
63 \\
90 \\
43 \\
49\end{array}$ \\
\hline $\begin{array}{r}6 \\
7 \\
8 \\
9 \\
10\end{array}$ & $\begin{array}{r}11200 \\
10900 \\
10100 \\
8970 \\
8060\end{array}$ & $\begin{array}{r}34 \\
4 \\
24 \\
6\end{array}$ & $\begin{array}{r}454 \\
1590 \\
109 \\
581 \\
131\end{array}$ & $\begin{array}{l}1670 \\
1380 \\
1520 \\
1489 \\
1400\end{array}$ & $\begin{array}{l}8 \\
15 \\
26 \\
14 \\
16\end{array}$ & $\begin{array}{r}36 \\
64 \\
107 \\
56 \\
60\end{array}$ & $\begin{array}{l}1400 \\
1300 \\
1190 \\
1100 \\
1040\end{array}$ & $\begin{array}{r}10 \\
9 \\
11 \\
10 \\
7\end{array}$ & $\begin{array}{l}38 \\
32 \\
35 \\
30 \\
20\end{array}$ \\
\hline $\begin{array}{l}11 \\
12 \\
13 \\
14 \\
15\end{array}$ & $\begin{array}{l}7300 \\
6600 \\
5910 \\
5240 \\
4680\end{array}$ & $\begin{array}{r}4 \\
5 \\
9 \\
3 \\
--\end{array}$ & $\begin{array}{r}79 \\
89 \\
144 \\
42 \\
63\end{array}$ & $\begin{array}{l}1400 \\
1300 \\
1300 \\
1250 \\
1200\end{array}$ & $\begin{array}{r}19 \\
15 \\
8 \\
8 \\
19\end{array}$ & $\begin{array}{l}72 \\
53 \\
28 \\
27 \\
62\end{array}$ & $\begin{array}{r}1000 \\
942 \\
900 \\
813 \\
780\end{array}$ & $\begin{array}{r}10 \\
7 \\
12 \\
6 \\
4\end{array}$ & $\begin{array}{l}27 \\
18 \\
29 \\
13 \\
8.4\end{array}$ \\
\hline $\begin{array}{l}21 \\
22 \\
23 \\
24 \\
25\end{array}$ & $\begin{array}{l}2970 \\
2840 \\
2720 \\
2610 \\
2500\end{array}$ & $\begin{array}{r}14 \\
27 \\
16 \\
14 \\
8\end{array}$ & $\begin{array}{r}112 \\
207 \\
118 \\
99 \\
54\end{array}$ & $\begin{array}{l}1160 \\
1240 \\
1320 \\
1400 \\
1420\end{array}$ & $\begin{array}{l}34 \\
21 \\
25 \\
20\end{array}$ & $\begin{array}{r}106 \\
84 \\
75 \\
95 \\
77\end{array}$ & $\begin{array}{l}650 \\
640 \\
636 \\
675 \\
800\end{array}$ & $\begin{array}{r}3 \\
4 \\
7 \\
8 \\
10\end{array}$ & $\begin{array}{l}5.3 \\
6.9 \\
12 \\
15 \\
22\end{array}$ \\
\hline $\begin{array}{l}26 \\
27 \\
28 \\
29 \\
30 \\
31\end{array}$ & $\begin{array}{r}2400 \\
2310 \\
2260 \\
2210 \\
2150 \\
--\end{array}$ & $\begin{array}{r}13 \\
12 \\
-9 \\
15 \\
-2\end{array}$ & $\begin{array}{l}84 \\
75 \\
61 \\
54 \\
87 \\
--\end{array}$ & $\begin{array}{l}1320 \\
1200 \\
1300 \\
1400 \\
1500 \\
1520\end{array}$ & $\begin{array}{r}22 \\
22 \\
16 \\
12 \\
11 \\
6\end{array}$ & $\begin{array}{l}78 \\
71 \\
56 \\
45 \\
45 \\
25\end{array}$ & $\begin{array}{r}908 \\
980 \\
1060 \\
1140 \\
1150 \\
=-\end{array}$ & $\begin{array}{r}8 \\
12 \\
11 \\
11 \\
11 \\
-=\end{array}$ & $\begin{array}{l}20 \\
32 \\
31 \\
34 \\
34 \\
--\end{array}$ \\
\hline $\begin{array}{l}1 \\
2 \\
3 \\
4 \\
5\end{array}$ & $\begin{array}{r}1120 \\
1050 \\
950 \\
860 \\
800\end{array}$ & $\begin{array}{r}6 \\
13 \\
6 \\
9 \\
10\end{array}$ & $\begin{array}{l}18 \\
37 \\
15 \\
21 \\
22\end{array}$ & $\begin{array}{l}910 \\
900 \\
900 \\
890 \\
855\end{array}$ & $\begin{array}{r}\overline{18} \\
3 \\
9 \\
9\end{array}$ & $\begin{array}{l}25 \\
44 \\
7.3 \\
22 \\
21\end{array}$ & $\begin{array}{l}1500 \\
1310 \\
1200 \\
1120 \\
1050\end{array}$ & $\begin{array}{r}13 \\
11 \\
9 \\
7 \\
10\end{array}$ & $\begin{array}{l}53 \\
39 \\
29 \\
21 \\
28\end{array}$ \\
\hline $\begin{array}{r}6 \\
7 \\
9 \\
10\end{array}$ & $\begin{array}{l}720 \\
672 \\
630 \\
630 \\
627\end{array}$ & $\begin{array}{r}12 \\
9 \\
5 \\
20 \\
19\end{array}$ & $\begin{array}{l}21 \\
16 \\
8.5 \\
34 \\
32\end{array}$ & $\begin{array}{l}820 \\
820 \\
800 \\
800 \\
796\end{array}$ & $\begin{array}{r}3 \\
9 \\
9 \\
12 \\
12\end{array}$ & $\begin{array}{l}6.6 \\
20 \\
19 \\
17 \\
26\end{array}$ & $\begin{array}{r}1000 \\
960 \\
932 \\
922 \\
890\end{array}$ & $\begin{array}{r}11 \\
6 \\
8 \\
8 \\
8\end{array}$ & $\begin{array}{l}30 \\
16 \\
20 \\
20 \\
19\end{array}$ \\
\hline $\begin{array}{l}12 \\
12 \\
13 \\
14 \\
13\end{array}$ & $\begin{array}{l}600 \\
600 \\
597 \\
620 \\
640\end{array}$ & $\begin{array}{r}5 \\
12 \\
8 \\
14 \\
5\end{array}$ & $\begin{array}{c}8.1 \\
19 \\
13 \\
23 \\
8.6\end{array}$ & $\begin{array}{r}827 \\
956 \\
1320 \\
1640 \\
1800\end{array}$ & $\begin{array}{r}6 \\
13 \\
6 \\
13 \\
13\end{array}$ & $\begin{array}{l}13 \\
34 \\
21 \\
58 \\
63\end{array}$ & $\begin{array}{l}880 \\
880 \\
894 \\
886 \\
855\end{array}$ & $\begin{array}{r}7 \\
11 \\
8 \\
9 \\
7\end{array}$ & $\begin{array}{l}17 \\
26 \\
19 \\
22 \\
16\end{array}$ \\
\hline $\begin{array}{l}16 \\
17 \\
18 \\
19 \\
20\end{array}$ & $\begin{array}{l}660 \\
690 \\
670 \\
660 \\
640\end{array}$ & $\begin{array}{r}11 \\
8 \\
7 \\
10 \\
6\end{array}$ & $\begin{array}{l}20 \\
15 \\
13 \\
28 \\
10\end{array}$ & $\begin{array}{l}2060 \\
2130 \\
2200 \\
2200 \\
2200\end{array}$ & $\begin{array}{l}6 \\
20 \\
13 \\
26 \\
14\end{array}$ & $\begin{array}{r}33 \\
115 \\
77 \\
95 \\
83\end{array}$ & $\begin{array}{l}848 \\
866 \\
908 \\
921 \\
880\end{array}$ & $\begin{array}{r}9 \\
9 \\
5 \\
14\end{array}$ & $\begin{array}{l}21 \\
21 \\
12 \\
9.8 \\
33\end{array}$ \\
\hline $\begin{array}{l}21 \\
22 \\
23 \\
24 \\
25\end{array}$ & $\begin{array}{l}633 \\
672 \\
720 \\
760 \\
000\end{array}$ & $\begin{array}{r}6 \\
4 \\
9 \\
10\end{array}$ & $\begin{array}{l}10 \\
7.3 \\
17 \\
21 \\
21\end{array}$ & $\begin{array}{l}2200 \\
2200 \\
2200 \\
2160 \\
2130\end{array}$ & $\begin{array}{l}11 \\
20 \\
23 \\
26 \\
24\end{array}$ & $\begin{array}{l}65 \\
59 \\
70 \\
93 \\
81\end{array}$ & $\begin{array}{l}834 \\
826 \\
785 \\
747 \\
741\end{array}$ & $\begin{array}{r}29 \\
20 \\
8 \\
4\end{array}$ & $\begin{array}{l}20 \\
44 \\
42 \\
16 \\
8.0\end{array}$ \\
\hline $\begin{array}{l}26 \\
27 \\
29 \\
29 \\
30 \\
31\end{array}$ & $\begin{array}{l}962 \\
997 \\
900 \\
925 \\
925 \\
925\end{array}$ & $\begin{array}{r}10 \\
10 \\
10 \\
4 \\
5 \\
9\end{array}$ & $\begin{array}{l}23 \\
24 \\
24 \\
10 \\
12 \\
22\end{array}$ & $\begin{array}{l}2200 \\
2200 \\
2240 \\
2100 \\
1930 \\
1800\end{array}$ & $\begin{array}{r}11 \\
10 \\
15 \\
12 \\
6 \\
12\end{array}$ & $\begin{array}{l}65 \\
59 \\
91 \\
68 \\
31 \\
58\end{array}$ & $\begin{array}{l}711 \\
690 \\
684 \\
687 \\
639 \\
-2\end{array}$ & $\begin{array}{r}7 \\
4 \\
5 \\
8 \\
6 \\
-2\end{array}$ & $\begin{array}{l}13 \\
7.5 \\
9.2 \\
15 \\
10 \\
-0\end{array}$ \\
\hline
\end{tabular}


02175020 EDISTO RIVER AT JACKSONBORO, $s$. $C$.

LOCATION.--Lat $32^{\circ} 45^{\prime} 55^{\prime \prime}$, long $80^{\circ} 26^{\prime} 45^{\prime \prime}$, Colleton County, at bridge on U.S, Highway $17,0.2$ mile upstream erom Seaboard Coast Line Railroad bridge, 0.6 mile southeast of Jacksonboro, 2.3 miles downstream from Green Meadow Creek, and at mile 33.0 .

PERIOD OF RECORD.--Chemical analyses: July 1969 to September 1970.

REMARKS. --The second of two samples collected at the same time is a fleld determination.

CHEMICAL ANALYSES, JULY 1969 TO SEPTEMBER 1970

\begin{tabular}{|c|c|c|c|c|c|c|c|c|c|c|c|}
\hline & DATE & TIME & $\begin{array}{l}\text { TEMP- } \\
\text { ERATURE } \\
\text { IOEG C) }\end{array}$ & $\begin{array}{l}\text { SPECI- } \\
\text { FIC } \\
\text { CONO- } \\
\text { UCYANCE } \\
\text { (MICRO- } \\
\text { MHOSI) }\end{array}$ & $\begin{array}{l}\text { DIS- } \\
\text { SOL VED } \\
\text { OXYGEN } \\
\text { (MG/L) }\end{array}$ & $\begin{array}{c}\text { PH } \\
\text { (UNITSI }\end{array}$ & $\begin{array}{l}\text { TOTAL } \\
\text { PHOS- } \\
\text { PHORUS } \\
\text { (P) } \\
\text { (MG/L) }\end{array}$ & $\begin{array}{c}\text { NITRATE } \\
\text { INOB) } \\
\text { (MG/L) }\end{array}$ & $\begin{array}{c}\text { FECAL } \\
\text { COLI- } \\
\text { FORM } \\
\text { TCOL. } \\
\text { PER } \\
100 \mathrm{MLI}\end{array}$ & $\begin{array}{c}\text { IMME- } \\
\text { OIATE } \\
\text { COLI- } \\
\text { FORM } \\
\text { ICOL. } \\
\text { PER } \\
\text { IOO MLI }\end{array}$ & \\
\hline & $\begin{array}{l}\text { JULY } \\
24 \ldots . . \\
24 \ldots\end{array}$ & $\begin{array}{l}1310 \\
1310\end{array}$ & $30 . \overline{5}$ & $\overline{75}$ & $\overline{0.7}$ & $\overline{r .3}$ & .10 & 1.0 & $=$ & $=-$ & - \\
\hline & $\begin{array}{c}\text { AUG. } \\
28 . . .\end{array}$ & 0920 & 30.3 & $=$ & 6.7 & 1.3 & .06 & 1.1 & - & -- & .. \\
\hline & $\begin{array}{l}28 . . . \\
\text { SEP. }\end{array}$ & 0920 & 23.55 & 65 & 5.6 & 6.7 & .06 & 1.1 & $\overline{-}$ & $\overline{-}$ & E \\
\hline & $30 . .$. & 1600 & $21 \overline{0}$ & - & $=$ & -- & .04 & 1.4 & $\bar{a}$ & -- & - \\
\hline & ост... & 1600 & $21 . n$ & 50 & 7.3 & 6.5 & - & & 60 & - & - \\
\hline & $\begin{array}{r}28 \ldots \\
28 \ldots\end{array}$ & $\begin{array}{l}1100 \\
1100\end{array}$ & $\begin{array}{l}19.0 \\
19.0\end{array}$ & $\begin{array}{l}53 \\
60\end{array}$ & $\overline{8.6}$ & 6.4 & .05 & $\therefore 9$ & $=$ & $\overline{73}$ & 3 \\
\hline & $\begin{array}{l}\text { Nov. } \\
20 . . .\end{array}$ & 1630 & 12.5 & -- & - & - & .14 & 1.1 & - & -- & - \\
\hline & $\begin{array}{l}20 . . . \\
D E C\end{array}$ & 1630 & 12.5 & 65 & 9.2 & 6.9 & - & $\underline{-1}$ & - & - & - \\
\hline & $\begin{array}{r}19 \ldots \\
19 . \ldots\end{array}$ & $\begin{array}{l}0835 \\
0835\end{array}$ & $\begin{array}{l}7: 0 \\
7: 0\end{array}$ & $\overline{75}$ & $10 \overline{1}$ & .5 & .10 & 1.4 & $=$ & $350 \overline{00}$ & \\
\hline & $\begin{array}{l}\text { JAN. } \\
27 . \ldots\end{array}$ & 1515 & 7.5 & - & - & -- & .05 & 1.1 & - & - & \\
\hline & $27 \ldots$ & 1515 & 7.5 & 68 & 10.4 & 7.1 & -03 & 10 & $=$ & 270 & \\
\hline & FES... & 1120 & 10.5 & - & - & - & .03 & .1 & - & - & \\
\hline & $\begin{array}{l}26 . . \\
\text { MAR. }\end{array}$ & 1120 & 10.5 & 61 & 10.0 & 6.9 & 3 & $\because$ & - & $=$ & 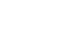 \\
\hline & $19 . .$. & 1100 & 15.0 & - & - & - & .04 & .3 & - & - & \\
\hline & $\begin{array}{l}19 \ldots \\
A P R_{0}\end{array}$ & 1100 & 15.0 & 76 & 10.2 & 7.2 & - & - & - & - & \\
\hline & $23 \ldots$ & 2245 & 23.5 & - & - & - & .04 & .4 & -- & - & \\
\hline & $\underset{\operatorname{MAY}}{23} \cdot \cdots$ & 1245 & 23.5 & 60 & 7.6 & 6.8 & -- & - & 32 & - & \\
\hline & $18 \ldots$ & 1335 & 26.0 & - & - & $=$ & .04 & .2 & - & - & \\
\hline & $\underset{\text { JUNE }}{18 \ldots .}$ & 1335 & 26.0 & 119 & 0.2 & T.O & -- & & - & - & \\
\hline & $23 \ldots$ & 1030 & 29.0 & - & - & -- & .05 & .7 & - & -- & \\
\hline & $23 \ldots$ & 1030 & 29.0 & 58 & 7.1 & r. 1 & - & $\because$ & 58 & - & \\
\hline & $17 \ldots$ & 1005 & 30.0 & - & - & -- & .06 & 1.4 & - & -- & \\
\hline & $17 \ldots$ & 1005 & 30.0 & 72 & 7.4 & T. 2 & - & $=$ & 60 & - & \\
\hline & $25 \ldots$ & 1410 & 28.0 & - & - & - & .08 & 2.0 & - & -- & \\
\hline & SEP... & 1410 & 28.0 & 175 & 7.5 & 6.7 & - & & 47 & - & \\
\hline & $28 .$. & 1245 & 24.5 & $\overline{30}$ & - & 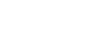 & .07 & 1.1 & $\bar{F}$ & - & \\
\hline DATE & TIME & $\begin{array}{l}\text { TEMP- } \\
\text { ERATURE } \\
\text { (DEG C) }\end{array}$ & $\begin{array}{l}\text { TUR- } \\
\text { BIO- } \\
\text { ITY } \\
\text { (JTU) }\end{array}$ & $\begin{array}{l}\text { COLOR } \\
\text { (PLAT- } \\
\text { INUM- } \\
\text { COBALT } \\
\text { UNITS) }\end{array}$ & $\begin{array}{l}\text { SPECI- } \\
\text { FIC } \\
\text { COND- } \\
\text { UCTANCE } \\
\text { (MICRC- } \\
\text { MHOSI }\end{array}$ & $\begin{array}{l}\text { DIS- } \\
\text { SOLVED } \\
\text { OXYGEN } \\
\text { (MG/L) }\end{array}$ & $\begin{array}{l}\text { BIO- } \\
\text { CHEM- } \\
\text { ICAL } \\
\text { OXYGEN } \\
\text { DEMAND } \\
\text { (MG/L) }\end{array}$ & $\begin{array}{c}\text { PH } \\
\text { (UNITS) }\end{array}$ & $\begin{array}{l}\text { ALKA- } \\
\text { LINITY } \\
\text { AS } \\
\text { CACOB }\end{array}$ & $\begin{array}{l}\text { BICAR- } \\
\text { BDNATE } \\
\text { MCOB) }\end{array}$ & $\begin{array}{l}\text { TOTAL } \\
\text { NON- } \\
\text { FILT- } \\
\text { RABLE } \\
\text { RESIOUE }\end{array}$ \\
\hline OCT. & & & & & & & & & & & \\
\hline $28 \ldots$ & 1100 & 18.8 & 1 & 50 & 53 & -- & -- & 6.4 & 13 & 16 & 4 \\
\hline & 1100 & 18.8 & -- & - & 60 & 8.6 & -- & 7.1 & $\because$ & - & $=$ \\
\hline $28 \ldots$ & 1130 & $\cdots$ & -- & -- & - & $015=$ & 1.2 & -- & - & -. & -- \\
\hline & $\begin{array}{l}\text { TCTAL } \\
\text { PHOS- } \\
\text { PHORUS } \\
\text { (P) }\end{array}$ & $\begin{array}{l}\text { HARD- } \\
\text { NESS } \\
(C A, M G)\end{array}$ & $\begin{array}{l}\text { CAR- } \\
\text { BONATE } \\
\text { HARD- } \\
\text { NESS }\end{array}$ & $\begin{array}{l}\text { CHLO- } \\
\text { RIOE } \\
\text { (CL) }\end{array}$ & $\begin{array}{l}\text { SULFATE } \\
\left(\mathrm{SO}_{4}\right)\end{array}$ & $\begin{array}{l}\text { SOLVED } \\
\text { FLUD- } \\
\text { RIDE } \\
\text { (F) }\end{array}$ & $\begin{array}{l}\text { TOTAL } \\
\text { CHRO- } \\
\text { MIUM } \\
\text { (CR) }\end{array}$ & $\begin{array}{l}\text { OIS- } \\
\text { SOLVED } \\
\text { COPPER } \\
\text { (CU) }\end{array}$ & $\begin{array}{l}\text { TOTAL } \\
\text { IRON } \\
\text { (FE) }\end{array}$ & $\begin{array}{l}\text { DIS- } \\
\text { SCLVED } \\
\text { LEAD } \\
\text { (PB) }\end{array}$ & $\begin{array}{l}\text { TOTAL } \\
\text { MAN- } \\
\text { GANESE } \\
\text { (MN) }\end{array}$ \\
\hline DATE & (MG/L) & $(M G / L)$ & $(M G / L)$ & $(M G / L)$ & (MG/L) & $(M G / L)$ & (UG/L) & (UG/L) & (UGｉ） & $($ UG $/ L)$ & $(\cup G / L)$ \\
\hline${ }_{29}^{\mathrm{OCr} .} .$. & .05 & 15 & 2 & 7.9 & 5.2 & .1 & 0 & 5 & 432 & 5 & 10 \\
\hline & & & & & & & & $\begin{array}{l}\text { METHY- } \\
\text { LENE }\end{array}$ & $\begin{array}{l}\text { D15- } \\
\text { SOLVED }\end{array}$ & & \\
\hline & oIs- & ots- & sus- & DIS- & sus- & FORM & COLI- & BLUE & Solios & SOLVED & \\
\hline & SOLVED & SOLVEO & PENCED & SOLVFD & PENOED & ICOL- & FORM & ACTIVE & (RESI- & SOLIOS & \\
\hline & (NI) & & & & & PER & PER & STANCE & $\begin{array}{lll} & 180 & 4\end{array}$ & PER & (NO3) \\
\hline DATE & (UG/L) & $(P C / L)$ & $(P C / L)$ & $(P C / L)$ & $(P C / L)$ & $100 \mathrm{~mL})$ & $100 \mathrm{ML}$ & (MG/L) & (MGＬ) & $A C-F T I$ & (MG/L) \\
\hline & & & & & & & & & & & \\
\hline $\begin{array}{l}28 \ldots \\
28 . \ldots\end{array}$ & -8 & $\therefore$ & $\therefore 2$ & 6.2 & .7 & $\overline{73}$ & $=$ & $13 \ldots$ & 50 & .07 & 9 \\
\hline $28 \ldots$ & -. & $\cdots$ & & & & & & & & & $\cdots$ \\
\hline
\end{tabular}


02176150 COMBAHEE RIVER NEAR GREENPOND, S. C.

LOCATION, - Lat $32^{\circ} 49^{\circ} \mathrm{OB} "$, long $80^{\circ} 41^{\prime} 00^{\prime \prime}$, Colleton County, at bridge on U.S. Highway $17,3.0 \mathrm{mtles}$ downstream from Cuckolds Creek, $6.8 \mathrm{miles}$ southwest of Greenpond, $8.5 \mathrm{miles}$ upstream from Seaboard Coast Line Ra1lroad bridge, and at mile 24.0 .

PERIOD OF RECORD.--Chemical analyses: July 1969 to September 1970.

REMARKS,-The second of two samples collected at the same time is a fleld determination.

CHEMICAL ANALYSES, JULY 1969 TO SEPTEMBER 1970

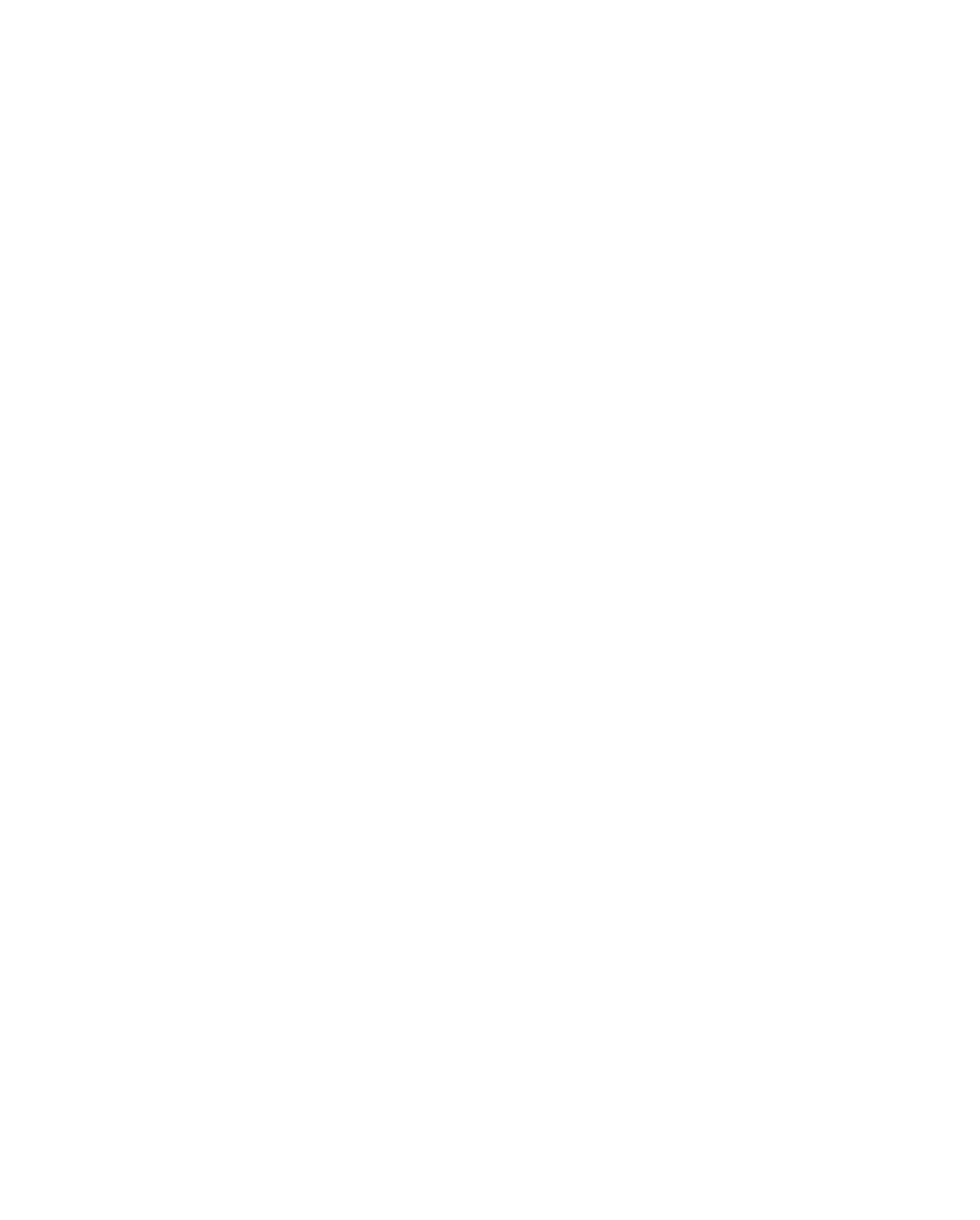


02176600 BEAUFORT RIVER AT BEAUFORT, S, C.

LOCATION. - Lat $32^{\circ} 25^{\prime} 40^{\prime \prime}$, long $80^{\circ} 40^{\prime} 1^{\prime \prime}$, Beaufort County, at bridge on U.S. Highway 21 , at Beaufort, and at mile 10.7.

PERIOD OF RECORD.--Chemical analyses: July 1969 to September 1970.

REMARKS. -The second of two samples collected at the same time is a field determination.

CHEMICAL ANALYSES, JULY 1969 TO SEPTEMBER 1970

\begin{tabular}{|c|c|c|c|c|c|c|c|c|c|c|c|}
\hline & DATE & TIME & $\begin{array}{c}\text { TEMP- } \\
\text { ERATURE } \\
\text { (DEG C) }\end{array}$ & $\begin{array}{l}\text { SPECI- } \\
\text { FIC } \\
\text { COND- } \\
\text { UCTANCE } \\
\text { (MICRO- } \\
\text { MHOSI }\end{array}$ & $\begin{array}{l}\text { DIS- } \\
\text { SOLVED } \\
\text { OXYGEN } \\
\text { (MG/L) }\end{array}$ & $\begin{array}{c}\text { HH } \\
\text { (UNITSI }\end{array}$ & $\begin{array}{l}\text { TOTAL } \\
\text { PHOS- } \\
\text { PHORUS } \\
\text { (P) } \\
\text { (MG/L) }\end{array}$ & $\begin{array}{c}\text { NITRATE } \\
\text { (NO3) } \\
\text { (MGLL) }\end{array}$ & $\begin{array}{c}\text { FECAL } \\
\text { COLI- } \\
\text { FORM } \\
\text { (COL. } \\
\text { PER } \\
100 \mathrm{ML} \text { ) }\end{array}$ & $\begin{array}{c}\text { TMME- } \\
\text { DIATE } \\
\text { COLI- } \\
\text { FORM } \\
\text { ICOL- } \\
\text { PER } \\
100 \mathrm{MLI}\end{array}$ & \\
\hline & $\begin{array}{l}\text { JULY } \\
24 \ldots . \\
24 \ldots .\end{array}$ & $\begin{array}{l}1110 \\
1110\end{array}$ & $29 . \overline{5}$ & 50000 & 5.9 & $\overrightarrow{7.7}$ & .06 & $=$ & $\overline{-}$ & $\overline{-}$ & \\
\hline & $\begin{array}{l}\text { AUG. } \\
28 \ldots . \\
288 . .\end{array}$ & $\begin{array}{l}1050 \\
1050\end{array}$ & $26 . \overline{0}$ & 34000 & $\overline{6.6}$ & $\overline{7.8}$ & .05 & $\therefore$ & $\overline{-}$ & $=$ & \\
\hline & $\begin{array}{l}01 . . . \\
01 \ldots . \\
27 \ldots \\
27 \ldots \\
\text { nov. }\end{array}$ & $\begin{array}{l}0850 \\
0850 \\
1600 \\
1600\end{array}$ & $\begin{array}{l}22.0 \\
22.0 \\
20.5 \\
20.5\end{array}$ & $\begin{array}{r}34000 \\
21300 \\
--\end{array}$ & $\begin{array}{r}7.8 \\
10.0\end{array}$ & $\begin{array}{l}7.7 \\
7.8 \\
7.8\end{array}$ & .04 & $\frac{-3}{-}$ & $\begin{array}{l}-- \\
220 \\
--\end{array}$ & $\begin{array}{l}=- \\
\overline{-z} \\
6300\end{array}$ & \\
\hline & $\begin{array}{l}\text { Nov. } \\
21 \ldots . \\
21 \ldots\end{array}$ & $\begin{array}{l}0910 \\
0910\end{array}$ & $\begin{array}{l}12.5 \\
12.5\end{array}$ & 31000 & $10 . \overline{0}$ & $\overline{7.8}$ & -13 & $\overline{-}$ & $=$ & $\overline{-}$ & \\
\hline & $\begin{array}{l}\text { DEC. } \\
19 . .\end{array}$ & $\begin{array}{l}1040 \\
1040\end{array}$ & $\begin{array}{r}9.5 \\
9.5\end{array}$ & $3900 \overline{0}$ & $10 \overline{\overline{2}}$ & 7.8 & .15 & $\overline{-}$ & $=$ & $21 \overline{00}$ & \\
\hline & $\begin{array}{l}19 . . . \\
\text { JAN. } \\
28 . .\end{array}$ & 0910 & 8.0 & 30000 & 1002 & - & .03 & $\cdots$ & - & - & \\
\hline & $\begin{array}{r}28 . . . \\
\text { FEB. }\end{array}$ & 0910 & 8.0 & 34000 & 14.4 & 8.1 & - & - & - & 610 & \\
\hline & $\begin{array}{r}26 \ldots \\
26 \ldots\end{array}$ & $\begin{array}{l}1245 \\
1245\end{array}$ & $\begin{array}{l}10.5 \\
10.5\end{array}$ & 39000 & $10 . \overline{8}$ & $\overrightarrow{8.1}$ & .02 & $\because 0$ & $\overline{-}$ & $\overline{-}$ & \\
\hline & $\begin{array}{l}19 . . . \\
19 . .\end{array}$ & $\begin{array}{l}1215 \\
1215\end{array}$ & $\begin{array}{l}16.0 \\
16.0\end{array}$ & $380 \overline{0}$ & $10 \overline{.2}$ & $\overline{7.9}$ & .02 & $\because 0$ & $\overline{-}$ & $\because$ & \\
\hline & $\begin{array}{l}\text { APR. } \\
23 . \ldots\end{array}$ & 1100 & 20.5 & -- & - & - & .03 & .1 & $\cdots$ & $\cdots$ & \\
\hline & $\underset{\text { MAY }}{23 . \cdots}$ & 1100 & 20.5 & 30000 & 9.8 & 7.8 & - & - & 10 & -- & \\
\hline & $\begin{array}{l}18 \ldots . . \\
18 \%\end{array}$ & $\begin{array}{l}1230 \\
1230\end{array}$ & $\begin{array}{l}25.0 \\
25.0\end{array}$ & 34000 & $8 . \overline{5}$ & $\overline{7.6}$ & .05 & -1 & $=$ & $=$ & \\
\hline & $23 \ldots$ & $\begin{array}{l}1320 \\
1320\end{array}$ & $\begin{array}{l}29.5 \\
29.5\end{array}$ & $3600 \overline{0}$ & $\overline{7.0}$ & 7.8 & .04 & $\therefore$ & 220 & $=$ & \\
\hline & $\begin{array}{l}\text { JULY } \\
17 \ldots . . \\
17 \ldots\end{array}$ & $\begin{array}{l}0810 \\
0810\end{array}$ & $\begin{array}{l}28.0 \\
28.0\end{array}$ & 35000 & $\overline{6.5}$ & 7.7 & .07 & 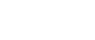 & $\overline{110}$ & $=$ & \\
\hline & $\begin{array}{l}\text { AUG. } \\
27 . . .\end{array}$ & 0900 & 28.0 & - & 5 & $\overline{7.5}$ & .07 & -3 & $\overline{200}$ & $=$ & \\
\hline & $\begin{array}{l}27 . . \\
\text { SFP. }\end{array}$ & 0900 & 28.0 & 33000 & 5.5 & 7.5 & & - & 200 & & \\
\hline & $\begin{array}{l}28 \ldots \\
28 . . .\end{array}$ & $\begin{array}{l}1100 \\
1100\end{array}$ & $\begin{array}{r}27.5 \\
27.5\end{array}$ & 36000 & $7 . \overline{6}$ & $\overrightarrow{7.4}$ & .09 & $\ddot{2}$ & $\overline{140}$ & $=$ & \\
\hline $\begin{array}{l}\text { DATE } \\
\text { OCT. }\end{array}$ & TIME & $\begin{array}{l}\text { TEMP- } \\
\text { ERATURE } \\
\text { CDEG C) }\end{array}$ & $\begin{array}{l}\text { TUR- } \\
\text { BIC- } \\
\text { ITY } \\
\text { (JTU) }\end{array}$ & $\begin{array}{l}\text { COLOR } \\
\text { IPLAT- } \\
\text { INUM- } \\
\text { COBALT } \\
\text { UNITSI }\end{array}$ & $\begin{array}{l}\text { SPFCI - } \\
\text { FIC } \\
\text { COND- } \\
\text { UCTANCE } \\
\text { (MICRO- } \\
\text { MHOSI }\end{array}$ & $\begin{array}{l}\text { DIS- } \\
\text { SnLVED } \\
\text { OXYGEN } \\
\text { IMGLLI }\end{array}$ & $\begin{array}{l}\text { BIJ- } \\
\text { CHEM- } \\
\text { ICAL } \\
\text { OXYGEN } \\
\text { DEMAND } \\
\text { IMG/L) }\end{array}$ & $\begin{array}{c}\text { PH } \\
\text { (UNITSI }\end{array}$ & $\begin{array}{l}\text { ALKA- } \\
\text { LINITY } \\
\text { AS } \\
\text { CACDB } \\
(M G / L)\end{array}$ & $\begin{array}{l}\text { BICAR- } \\
\text { BONATF } \\
\text { HCCCI } \\
\text { CMGSLI }\end{array}$ & $\begin{array}{l}\text { NONA- } \\
\text { FILT- } \\
\text { RABLF } \\
\text { RES IDUE } \\
\text { CMG/LI }\end{array}$ \\
\hline $27 \ldots$ & 1600 & 20.6 & 5 & 20 & 21300 & $\because$ & -- & -- & $10 !$ & 123 & 27 \\
\hline $\begin{array}{l}27 \ldots \\
27 \ldots\end{array}$ & $\begin{array}{l}1620 \\
1650\end{array}$ & 20.6 & $\overline{-}$ & $=$ & $=$ & 10.0 & $\bar{a}$ & 7.8 & $=-$ & $\bar{z}$ & $=$ \\
\hline $\begin{array}{l}\text { DATE } \\
\text { OCT. }\end{array}$ & $\begin{array}{l}\text { TOTAL } \\
\text { PHOS- } \\
\text { PHGRUS } \\
\text { (P) } \\
\text { (MG/L) }\end{array}$ & $\begin{array}{l}\text { HARD- } \\
\text { NESS } \\
(C A, M G) \\
(M G / L)\end{array}$ & $\begin{array}{l}\text { NON- } \\
\text { CAR- } \\
\text { BONATE } \\
\text { HARD- } \\
\text { NFSS } \\
\text { IMG/LI }\end{array}$ & $\begin{array}{l}\text { CHLO- } \\
\text { RIDE } \\
\text { ICLI } \\
\text { CMG/LI }\end{array}$ & $\begin{array}{l}\text { SULFATE } \\
\text { (SO4) } \\
\text { (MG/L) }\end{array}$ & $\begin{array}{l}\text { DIS- } \\
\text { SOLV=D } \\
\text { FLUD- } \\
\text { RIDE } \\
\text { (F) } \\
\text { (MG } / L)\end{array}$ & $\begin{array}{l}\text { TOTAL } \\
\text { CHRO- } \\
\text { MUM } \\
\text { (CR) } \\
(U G / L)\end{array}$ & $\begin{array}{l}\text { OIS- } \\
\text { SOLVED } \\
\text { COPPER } \\
\text { (CU) } \\
\text { (UG/L) }\end{array}$ & $\begin{array}{l}\text { TOTAL } \\
\text { IRON } \\
\text { (FEE } \\
\text { (UG/L) }\end{array}$ & $\begin{array}{l}\text { DIS- } \\
\text { SCLVED } \\
\text { LEAC } \\
(P B) \\
\text { IUG } \\
\text { UG }\end{array}$ & $\begin{array}{l}\text { TOTAL } \\
\text { MAN- } \\
\text { GANESE } \\
\text { (MN) } \\
\text { (UG/L) }\end{array}$ \\
\hline & .10 & 4080 & 3980 & 13100 & 1750 & 1.1 & c & $\begin{array}{r}70 \\
\text { METHY- }\end{array}$ & ${ }^{18}{ }^{18}$ & 18 & 10 \\
\hline & $\begin{array}{l}\text { OIS- } \\
\text { SOLVED } \\
\text { NICKEL } \\
\text { (NI) }\end{array}$ & $\begin{array}{l}\text { DIS- } \\
\text { SOLVED } \\
\text { ALPHA }\end{array}$ & $\begin{array}{l}\text { SUS- } \\
\text { PENDED } \\
\text { ALPHA }\end{array}$ & $\begin{array}{l}\text { DIS- } \\
\text { SOLVED } \\
\text { BETA }\end{array}$ & $\begin{array}{l}\text { SUS- } \\
\text { PENDED } \\
\text { BETA }\end{array}$ & $\begin{array}{l}\text { COLI - } \\
\text { FORY } \\
\text { ICNL- } \\
\text { ONIES } \\
\text { PER } \\
\text { PER }\end{array}$ & $\begin{array}{l}\text { FECAL } \\
\text { COLI- } \\
\text { CORM } \\
\text { ICOL. } \\
\text { PER }\end{array}$ & $\begin{array}{l}\text { LENE } \\
\text { BLUE } \\
\text { ACTIVE } \\
\text { SUB- } \\
\text { STANCE }\end{array}$ & $\begin{array}{l}\text { SOL VED } \\
\text { SOLIDS } \\
\text { (RESI- } \\
\text { DUE AT } \\
190 \text { C) }\end{array}$ & $\begin{array}{l}\text { DIS- } \\
\text { SOLVED } \\
\text { SOLIDS } \\
\text { ITONS } \\
\text { DER }\end{array}$ & $\begin{array}{l}\text { NITRATE } \\
\text { (NO3) }\end{array}$ \\
\hline & (UG/L) & $(P C / L)$ & $(P C / L)$ & $(P C / L)$ & (PC/L) & $100 \mathrm{ML}$ ) & $100 \mathrm{mLI}$ & IMG $/ L)$ & $\left(M_{G} / L\right)$ & $A C-F T)$ & $(M G / L)$ \\
\hline $27 \ldots$ & -- & ${ }^{51}-$ & $\because 4$ & 200 & $1: 4$ & $630 \overline{0}$ & $=$ & 1.1 & 24000 & 32.5 & $=$ \\
\hline
\end{tabular}


02177000 CHATTOOGA RIVER NEAR CLAYTON, GA.

LOCATION, --Lat $34^{\circ} 48^{\prime} 50^{\prime \prime}$, long $83^{\circ} 18^{\prime} 22^{\prime \prime}$, Rabun County, $s$. C. at gaging station on left bank $150 \mathrm{ft}$ downstream from bridge on U.S. H1ghway $76,2.8$ mlles upstream from Stekoa Creek, 7 miles southeast of Clayton, 9 miles downstream from War Woman Creek, and' 9 miles upstream from confluence with Tallulah River.

DRAINAGE AREA, $--207 \mathrm{sq} \cdot \mathrm{mi}$.

PERIOD OF RFCORD.--Chemlcal analyses: February 1988 to September 1970 .

REMARKS.--Field determination of temperature, alkalinity, pH and dissolved oxygen by U.S. Geological Survey. Laboratory chemical analyses by Georgla Water Quality Control Board.

CHEMICAL ANALYSES, WATER YEAR OCTOEEP 1969 TO SEPTEMBER 1970

\begin{tabular}{|c|c|c|c|c|c|}
\hline DATE & TIME & $\begin{array}{l}\text { DIS- } \\
\text { CHARGE } \\
\text { (CFS) }\end{array}$ & $\begin{array}{c}P H \\
\text { (UNITS) }\end{array}$ & $\begin{array}{l}\text { TEMP- } \\
\text { FHATUHE } \\
\text { COEG C }\end{array}$ & $\begin{array}{l}\text { DIS- } \\
\text { SDLVED } \\
\text { OXYGEN } \\
\text { (MG/L) }\end{array}$ \\
\hline $\begin{array}{l}\text { Ute. } \\
\text { 22... } \\
\text { nak. }\end{array}$ & 1715 & An 4 & 7.2 & $3 . n$ & 13.0 \\
\hline$\underset{\text { JUNE }}{24 \ldots}$ & 1630 & 820 & 5.8 & 9.0 & 9.8 \\
\hline $\begin{array}{l}24 \ldots . . \\
\text { StFT. }\end{array}$ & 1715 & $34 n$ & 6.3 & 25.0 & 8.0 \\
\hline $29 \ldots$ & 11140 & 194 & $7.1)$ & 17.0 & 10.0 \\
\hline
\end{tabular}

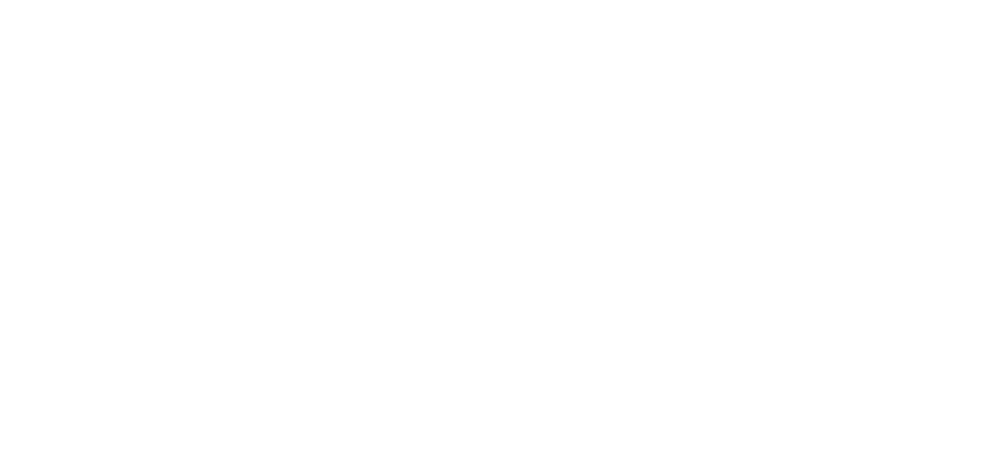

OEC.

OEC. $22 .$.

(MG/L) (MG/L) MHOS)

$\begin{array}{rrr}2.5 & . ? & 91 \\ 2.0 & -. & 36 \\ 3.0 & .4 & <30 \\ 5.0 & .3 & 150\end{array}$


02178400 TALLULAH RIVER NEAR CLAYTON, GA.
(HYdrolog 10 bench-mark otht1ON)

LOCATION, -LLt 34"53'25", long $83^{\circ} 32^{\prime} 50^{\prime \prime}$, Rabun County, temperature recorder at gaging wtatton on right benk 100 tt downitream from bridge on county roed, 220 st downetream from Pereimon Creok, 8 miles uputream from Burton Dam, and 10.3 milen weet of ciayton.

DRAINAGR AREA.--66.6 $\mathrm{mq}$.

PERIOD OR RECORD, -Chemical analyes: October 1987 to September 1970.

Water temperatures: Beptember 1964 to September 1070.

EXTREKES, $-106 \theta-70$ :

Weter temperaturee: Kaximum, $25.0^{\circ} \mathrm{C}$ July 3,4, 18, 16, Aug. 2, 5; minimum, freening point on eeveral dayn durlag January.

Pertod of record:

water temperatures: keximum, $28.0^{\circ} \mathrm{C}$ July 28,1968 ; minimum, freezing point on several daye during winter perlodv.

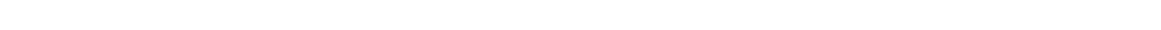
water temperature, pH, and dimolved oxven by U.B, Geological Burvey.

CHEMICAL ANALYSES. WATER YEAN OCTOEEL IYSO TO SEPTEMEER 1970

\begin{tabular}{|c|c|c|c|c|c|}
\hline DATE & FIME & $\begin{array}{l}\text { OTS- } \\
\text { CHALGE } \\
\text { (CFS) }\end{array}$ & $\begin{array}{c}\text { PH } \\
\text { (UNITS) }\end{array}$ & $\begin{array}{l}\text { TEMP- } \\
\text { EKAYURE } \\
\text { (DEG C) }\end{array}$ & $\begin{array}{l}\text { DIS= } \\
\text { SOLVED } \\
\text { OXYOEN } \\
\text { (MG/L) }\end{array}$ \\
\hline $\begin{array}{l}\text { UEC. } \\
\text { JUEE } \\
\text { JUNE }\end{array}$ & 1530 & 148 & 0.0 & 4.0 & 10.0 \\
\hline $\begin{array}{l}24 . . . \\
\text { SEPT. }\end{array}$ & 1600 & 121 & 6.1 & 21.0 & 7.4 \\
\hline $24 \ldots$ & 1130 & 67 & 7.0 & 13.0 & 10.0 \\
\hline
\end{tabular}

\begin{tabular}{|c|c|c|c|c|c|c|c|c|c|c|}
\hline DATE & $\begin{array}{l}\text { SILICA } \\
\text { (SIOZ) } \\
\text { (MG/L) }\end{array}$ & $\begin{array}{l}\text { TOTAL } \\
\text { IHON } \\
\text { (FE) } \\
\text { (UG/L) }\end{array}$ & $\begin{array}{l}\text { TOTAL } \\
\text { MAN- } \\
\text { GANESE } \\
\text { (MN) } \\
\text { (UG/L) }\end{array}$ & $\begin{array}{l}\text { DIS- } \\
\text { SOLVEO } \\
\text { CAL= } \\
\text { CIUM } \\
\text { (CA) } \\
\text { (MG/L) }\end{array}$ & $\begin{array}{l}\text { UIS- } \\
\text { SOLVED } \\
\text { MAG- } \\
\text { NE- } \\
\text { SIUM } \\
\text { (MG) } \\
\text { (MG/L) }\end{array}$ & $\begin{array}{l}\text { SODJUM } \\
\text { (NA) } \\
\text { (MG/L) }\end{array}$ & $\begin{array}{l}\text { PO- } \\
\text { TAS- } \\
\text { SIUM } \\
(K) \\
\text { (MG/L) }\end{array}$ & $\begin{array}{l}\text { ALKA- } \\
\text { LINITY } \\
\text { AS } \\
\text { CACO3 } \\
\text { (MG } L L)\end{array}$ & $\begin{array}{l}\text { SULFATE } \\
(S O 4) \\
(M G / L)\end{array}$ & $\begin{array}{l}\text { CHLD- } \\
\text { RIDE } \\
\text { (CL) } \\
(M G / L)\end{array}$ \\
\hline $\begin{array}{l}\text { IYEC. } \\
22 . . . \\
\text { JUNE }\end{array}$ & 1.7 & 150 & $<50$ & 1.8 & .5 & .8 & .4 & 7 & $<2,0$ & .8 \\
\hline & $\forall .0$ & 150 & sso & 2.6 & .6 & 1.3 & .6 & 9 & $<2,0$ & .7 \\
\hline $29 . \ldots$ & 9.5 & 100 & $<50$ & 1.4 & .6 & 1.3 & .5 & 8 & $<2,0$ & .7 \\
\hline DATE & $\begin{array}{l}\text { NITHATH } \\
(N) \\
(M(, / L)\end{array}$ & $\begin{array}{l}\text { PHOS- } \\
\text { PMATE } \\
\text { (POL) } \\
\text { (MG/L) }\end{array}$ & $\begin{array}{c}\text { TUTAL } \\
\text { FILTE } \\
\text { RAGLE } \\
\text { RESIOUE } \\
\text { (MG/L) }\end{array}$ & $\begin{array}{l}\text { TOTAL } \\
\text { NON- } \\
\text { FILTE } \\
\text { RAELE } \\
\text { RESIDUE } \\
\text { (MG/L) }\end{array}$ & $\begin{array}{l}\text { HARD- } \\
\text { NESS } \\
\text { (CA,MG) } \\
(M G / L)\end{array}$ & $\begin{array}{l}\text { SPECI- } \\
\text { FIC } \\
\text { COND- } \\
\text { UCTANCE } \\
\text { IMICRO- } \\
\text { MHOSI }\end{array}$ & $\begin{array}{l}\text { COLOR } \\
\text { (PLAT= } \\
\text { INUM= } \\
\text { CORALT } \\
\text { UNITS) }\end{array}$ & $\begin{array}{l}\text { TUR- } \\
\text { BID= } \\
\text { ITY } \\
\text { (JTU) }\end{array}$ & $\begin{array}{l}\text { BIO- } \\
\text { CHEM- } \\
\text { ICAL } \\
\text { OXYGEN } \\
\text { DEMAND } \\
\text { (MG/L) }\end{array}$ & $\begin{array}{c}\text { FECAL } \\
\text { COLI- } \\
\text { FORM } \\
\text { (COL. } \\
\text { PER } \\
100 \mathrm{ML}) \\
\text { (MPN) }\end{array}$ \\
\hline
\end{tabular}

UEC.

UEC.
JUNE.

$24 \ldots . .0 \quad .0 \quad<05$

26

MHOSI

UNITS)

(MG/L)

MPNI

$<05$

19

4
6
6

16
16
18

$\begin{array}{rrrr}7 & 3.0 & .1 & <30 \\ - & 4.0 & .5 & 210 \\ 5 & 3.0 & .4 & 430\end{array}$


02178400 TALLULAH RIVER NEAR CLAYTON, GA.--Continued TEMPERATURE ('०) OF WATER, WATER YEAR OCTOBER 1969 TO SEPTEMBER 1970

\begin{tabular}{|c|c|c|c|c|c|c|c|c|c|c|c|c|}
\hline \multirow[b]{2}{*}{ isty } & \multicolumn{2}{|c|}{ DCTOSAEN } & \multicolumn{2}{|c|}{ WWEMRET } & \multicolumn{2}{|c|}{ IDECEMLEH } & \multicolumn{2}{|c|}{ JANUAQY } & \multicolumn{2}{|c|}{ FFHKUARRY } & \multicolumn{2}{|c|}{ MARCH } \\
\hline & $N \Delta x$ & $A \mathrm{I}$ & $\because a x$ & 1.151 & $1 \pm x$ & MIM & $\max$ & YIN & $\operatorname{MAX}$ & $M I^{N}$ & MAX & MIN \\
\hline $\begin{array}{l}1 \\
? \\
3 \\
4 \\
4\end{array}$ & $\begin{array}{l}14.5 \\
17.5 \\
16.5 \\
17.0 \\
17.1\end{array}$ & $\begin{array}{l}14.11 \\
14.03 \\
14.0 \\
14.11 \\
1+.5\end{array}$ & $\begin{array}{r}12.4 \\
14.5 \\
13.5 \\
10.5 \\
4.5\end{array}$ & $\begin{array}{l}11.3 \\
12.0 \\
10.3 \\
3.3 \\
9.5\end{array}$ & $\begin{array}{l}0.0 \\
4.5 \\
3.5 \\
4.5 \\
3.5\end{array}$ & $\begin{array}{l}4.5 \\
4.0 \\
4.5 \\
3.0 \\
1.0\end{array}$ & $\begin{array}{l}8.0 \\
5.5 \\
5.0 \\
4.0 \\
3.5\end{array}$ & $\begin{array}{l}5.5 \\
3.5 \\
4.0 \\
2.0 \\
1.5\end{array}$ & $\begin{array}{l}5.0 \\
4.0 \\
8.0 \\
3.0 \\
4.5\end{array}$ & $\begin{array}{l}3.0 \\
5.0 \\
3.5 \\
1.0 \\
? .0\end{array}$ & $\begin{array}{r}9.0 \\
11.5 \\
10.0 \\
11.0 \\
13.5\end{array}$ & $\begin{array}{r}6.5 \\
6.5 \\
7.0 \\
17.0 \\
10.0\end{array}$ \\
\hline $\begin{array}{r}3 \\
7 \\
4 \\
4 \\
111\end{array}$ & $\begin{array}{l}15.5 \\
14.5 \\
14.5 \\
15.0 \\
19.5\end{array}$ & $\begin{array}{l}1.3 .7 \\
14.11 \\
14.0 \\
13.0 \\
13.0\end{array}$ & $\begin{array}{r}y .3 \\
4.3 \\
10.11 \\
111.01 \\
11.01\end{array}$ & $\begin{array}{l}0.5 \\
7.0 \\
7.0 \\
i .0 \\
7.0\end{array}$ & $\begin{array}{l}4.0 \\
5.5 \\
9.5 \\
3.5 \\
7.0\end{array}$ & $\begin{array}{l}5 . n \\
3.5 \\
6.0 \\
5.0 \\
5.5\end{array}$ & $\begin{array}{l}4.0 \\
4.0 \\
0.5 \\
0.5 \\
0.5\end{array}$ & $\begin{array}{l}3.0 \\
0.0 \\
0.5 \\
0.0 \\
0.0\end{array}$ & $\begin{array}{l}5.5 \\
5.5 \\
8.0 \\
9.0 \\
6.0\end{array}$ & $\begin{array}{l}4.5 \\
5.0 \\
5.5 \\
5.0 \\
5.0\end{array}$ & $\begin{array}{r}11.5 \\
9.5 \\
9.5 \\
11.5 \\
12.0\end{array}$ & $\begin{array}{l}9.0 \\
9.0 \\
6.5 \\
6.5 \\
7.0\end{array}$ \\
\hline $\begin{array}{l}11 \\
12 \\
13 \\
14 \\
14\end{array}$ & $\begin{array}{l}16.5 \\
16.5 \\
17.11 \\
1 \mathrm{H.b} \\
10.61\end{array}$ & $\begin{array}{l}14.7 \\
14.11 \\
14.7 \\
14.7 \\
1+\infty\end{array}$ & $\begin{array}{l}1, .01 \\
1 ? .01 \\
1,0.1 \\
4.7 \\
4.01\end{array}$ & $\begin{array}{r}7.0 \\
10.0 \\
\times .11 \\
4.0 \\
1.01\end{array}$ & $\begin{array}{l}7.0 \\
4.01 \\
4.0 \\
7.01 \\
n .0\end{array}$ & $\begin{array}{l}7.0 \\
5.01 \\
3.01 \\
4.5 \\
4.011\end{array}$ & $\begin{array}{l}0.0 \\
1.11 \\
3.5 \\
2.0 \\
4.5\end{array}$ & $\begin{array}{l}0.0 \\
0.0 \\
1.0 \\
1.0 \\
2.0\end{array}$ & $\begin{array}{l}5.5 \\
5.5 \\
7.0 \\
4.0 \\
9.0\end{array}$ & $\begin{array}{l}4.0 \\
4.5 \\
3.5 \\
5.5 \\
3.0\end{array}$ & $\begin{array}{r}11.5 \\
1 ? .0 \\
11.0 \\
5.5 \\
7.0\end{array}$ & $\begin{array}{r}8.0 \\
11.0 \\
7.0 \\
4.5 \\
3.5\end{array}$ \\
\hline $\begin{array}{l}1 \mathrm{H} \\
17 \\
17 \\
14 \\
61\end{array}$ & $\begin{array}{l}15.5 \\
14.5 \\
11.01 \\
1 \geqslant .11 \\
17.5\end{array}$ & $\begin{array}{l}11.4 \\
1104 \\
10 \\
110 \\
110\end{array}$ & $\begin{array}{c}4.3 \\
3.0 \\
40.1 \\
140 \\
n, 3\end{array}$ & $\begin{array}{l}1.1 r \\
1.3 \\
n .01 \\
n .0 \\
4.4\end{array}$ & $\begin{array}{l}4.3 \\
1.5 \\
4.5 \\
\because .3 \\
+.0\end{array}$ & $\begin{array}{l}2.0 \\
1.5 \\
1.5 \\
4.0 \\
1.5\end{array}$ & $\begin{array}{l}7.0 \\
2.0 \\
6.5 \\
6.0 \\
3.5\end{array}$ & $\begin{array}{l}2.0 \\
4.5 \\
5.0 \\
3.0 \\
2.0\end{array}$ & $\begin{array}{r}9.5 \\
11.5 \\
11.5 \\
11.5 \\
2.0\end{array}$ & $\begin{array}{l}9.0 \\
9.5 \\
9.5 \\
8.0 \\
5.0\end{array}$ & $\begin{array}{r}6.5 \\
5.5 \\
9.5 \\
8.5 \\
17.0\end{array}$ & $\begin{array}{l}1.5 \\
2.0 \\
5.5 \\
6.5 \\
8.0\end{array}$ \\
\hline $\begin{array}{l}-1 \\
2 ? \\
33 \\
24 \\
25\end{array}$ & $\begin{array}{r}1+.0 \\
14.5 \\
11.5 \\
4.5 \\
4.5\end{array}$ & 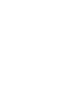 & $\begin{array}{c}2.11 \\
\because 03 \\
11.11 \\
11.11 \\
\because .7\end{array}$ & $\begin{array}{r}4.3 \\
4.3 \\
4.3 \\
1.11 \\
.01\end{array}$ & $\begin{array}{l}4.0 \\
4.0 \\
4.0 \\
4.0 \\
4.01\end{array}$ & $\begin{array}{l}0 \cdot b \\
11 \cdot 3 \\
3.0 \\
2.0\end{array}$ & $\begin{array}{l}2.0 \\
n .5 \\
2.5 \\
2.7 \\
4.7\end{array}$ & $\begin{array}{l}0.0 \\
0.0 \\
0.0 \\
0.0 \\
2.0\end{array}$ & $\begin{array}{r}6.5 \\
8.0 \\
10.5 \\
H .0 \\
8.0\end{array}$ & $\begin{array}{l}3.0 \\
3.5 \\
4.0 \\
5.0 \\
6.0\end{array}$ & $\begin{array}{r}9.5 \\
4.5 \\
7.0 \\
7.0 \\
10.5\end{array}$ & $\begin{array}{l}8.5 \\
4.5 \\
5.5 \\
5.0 \\
6.0\end{array}$ \\
\hline $\begin{array}{l}2 n \\
+7 \\
+8 \\
34 \\
x 17\end{array}$ & $\begin{array}{l}13.0 \\
14.0 \\
13.0 \\
111.01 \\
4.5 \\
11.5\end{array}$ & 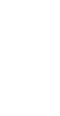 & 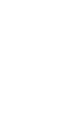 & 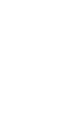 & $\begin{array}{l}4.01 \\
1.01 \\
4.0 \\
2.0 \\
4.3 \\
4.5\end{array}$ & $\begin{array}{l}2.0 \\
1.11 \\
3.0 \\
4.0 \\
3.4 \\
0.0\end{array}$ & $\begin{array}{r}4.5 \\
4.0 \\
7.0 \\
10.0 \\
10.11 \\
5.5\end{array}$ & $\begin{array}{l}4.11 \\
5.5 \\
5.0 \\
4.5 \\
5.11 \\
3.5\end{array}$ & \begin{tabular}{l}
6.0 \\
4.5 \\
2.5 \\
\hdashline.. \\
\hdashline.-
\end{tabular} & \begin{tabular}{l}
2.0 \\
1.5 \\
4.0 \\
\hdashline-2 \\
-2.
\end{tabular} & $\begin{array}{r}10.0 \\
0.5 \\
10.0 \\
13.5 \\
10.5 \\
14.0\end{array}$ & $\begin{array}{l}9.0 \\
5.0 \\
5.0 \\
9.5 \\
8.5 \\
9.0\end{array}$ \\
\hline \multirow[t]{2}{*}{ MONTH } & 17.0 & 6.0 & 14.5 & 1.0 & 8.5 & 0.5 & 10.0 & 0.0 & 11.5 & 1.0 & 14.0 & 1.5 \\
\hline & \multicolumn{2}{|c|}{$A H+I L$} & \multicolumn{2}{|c|}{ MAY } & \multicolumn{2}{|c|}{ JuNE } & \multicolumn{2}{|c|}{ JuLr } & \multicolumn{2}{|c|}{ A.JGUST } & \multicolumn{2}{|c|}{ SEPIEMTER } \\
\hline$H Y$ & $\sin x$ & $v_{1} 1$ & $4 \Delta x$ & $\cdot[$ & $\operatorname{cis} x$ & $\mathrm{u}_{\mathrm{I}} \mathrm{s}$ & $M \Delta x$ & MIN & $* \Delta x$ & MIN & MAX & MIN \\
\hline $\begin{array}{l}1 \\
? \\
3 \\
4 \\
5\end{array}$ & $\begin{array}{l}12.0 \\
12.0 \\
10.5 \\
11.5 \\
11.5\end{array}$ & $\begin{array}{c}19.11 \\
4.11 \\
3.11 \\
4.3 \\
1.11\end{array}$ & $\begin{array}{l}14.5 \\
17.11 \\
17.11 \\
1 \%, 0 \\
10.3\end{array}$ & $\begin{array}{l}12.11 \\
13.01 \\
1300 \\
1700 \\
11.0\end{array}$ & $\begin{array}{l}14.0 \\
17.0 \\
1000 \\
1 \% 0 \\
1 \rightarrow 0\end{array}$ & $\begin{array}{l}17.0 \\
16.5 \\
15.0 \\
14.5 \\
14.0\end{array}$ & $\begin{array}{l}23.5 \\
24.0 \\
25.0 \\
25.0 \\
23.5\end{array}$ & $\begin{array}{l}17.0 \\
19.5 \\
14.5 \\
14.5 \\
18.5\end{array}$ & $\begin{array}{l}24.0 \\
25.0 \\
24.5 \\
24.5 \\
25.0\end{array}$ & $\begin{array}{l}18.5 \\
19.0 \\
20.0 \\
20.0 \\
19.5\end{array}$ & $\begin{array}{l}24.5 \\
24.0 \\
23.5 \\
24.0 \\
23.0\end{array}$ & $\begin{array}{l}19.0 \\
19.5 \\
19.0 \\
19.5 \\
19.0\end{array}$ \\
\hline $\begin{array}{r}6 \\
7 \\
4 \\
4 \\
10\end{array}$ & $\begin{array}{l}11.03 \\
12.01 \\
11.3 \\
1303 \\
10.11\end{array}$ & $\begin{array}{l}07 \\
30 \\
40 \\
40\end{array}$ & $\begin{array}{l}17.01 \\
1701 \\
17.0 \\
1 \% 0 \\
14.0\end{array}$ & $\begin{array}{l}12.01 \\
10.2 \\
11.0 \\
19.0 \\
14.0\end{array}$ & $\begin{array}{l}1 \mathrm{1m} 0 \\
17.0 \\
1 \% .0 \\
1 \mathrm{1} .5 \\
11.0\end{array}$ & $\begin{array}{l}13.0 \\
18.0 \\
1801 \\
13.0 \\
14.0\end{array}$ & $\begin{array}{l}21.0 \\
21.5 \\
29.0 \\
21.5 \\
23.5\end{array}$ & $\begin{array}{l}16.5 \\
15.4 \\
16.0 \\
17.0 \\
18.0\end{array}$ & $\begin{array}{l}24.0 \\
24.0 \\
21.5 \\
27.0 \\
17.01\end{array}$ & $\begin{array}{l}20.0 \\
20.0 \\
17.5 \\
19.0 \\
14.5\end{array}$ & $\begin{array}{l}22.0 \\
19.5 \\
21.5 \\
20.5 \\
21.5\end{array}$ & $\begin{array}{l}18.5 \\
18.0 \\
19.5 \\
18.5 \\
18.5\end{array}$ \\
\hline $\begin{array}{l}11 \\
12 \\
13 \\
14 \\
15\end{array}$ & $\begin{array}{l}13.5 \\
18.0 \\
1300 \\
15.0 \\
15.0\end{array}$ & $\begin{array}{r}4: 1 \\
11: 11 \\
11: 11 \\
1103 \\
+0\end{array}$ & $\begin{array}{l}10.0 \\
1407 \\
1107 \\
11010 \\
1.01\end{array}$ & $\begin{array}{l}14.4 \\
13.5 \\
19.5 \\
15.5 \\
10.0\end{array}$ & $\begin{array}{l}14.0 \\
14.0 \\
17.0 \\
16.0 \\
14.0\end{array}$ & $\begin{array}{l}14.4 \\
14.5 \\
13.0 \\
15.0 \\
14.5\end{array}$ & $\begin{array}{l}22.01 \\
22.0 \\
22.0 \\
22.0 \\
20.0\end{array}$ & $\begin{array}{l}17.0 \\
10.5 \\
18.0 \\
14.5 \\
14.5\end{array}$ & $\begin{array}{l}12.5 \\
12.0 \\
21.4 \\
21.5 \\
20.4\end{array}$ & $\begin{array}{l}17.0 \\
17.0 \\
16.5 \\
17.0 \\
16.5\end{array}$ & $\begin{array}{l}21.0 \\
21.5 \\
21.5 \\
22.0 \\
21.5\end{array}$ & $\begin{array}{l}13.5 \\
19.0 \\
19.5 \\
18.0 \\
19.0\end{array}$ \\
\hline $\begin{array}{l}14 \\
17 \\
14 \\
19 \\
20\end{array}$ & 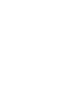 & 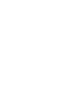 & $\begin{array}{l}14 . n \\
010.1 \\
1+0 \\
2.1011 \\
1.10\end{array}$ & $\begin{array}{l}10.4 \\
12.11 \\
16.0 \\
13.11 \\
14.01\end{array}$ & $\begin{array}{l}14.5 \\
14.5 \\
28.0 \\
2 \% .0 \\
1 \% 0\end{array}$ & $\begin{array}{l}10.0 \\
15.0 \\
13.0 \\
11.0 \\
1 \mathrm{n} . n\end{array}$ & $\begin{array}{l}25.0 \\
23.5 \\
23.5 \\
23.0 \\
23.0\end{array}$ & $\begin{array}{l}19.5 \\
14.0 \\
14.5 \\
14.0 \\
18.5\end{array}$ & $\begin{array}{l}20.5 \\
21.0 \\
20.0 \\
19.5 \\
23.0\end{array}$ & $\begin{array}{l}17.0 \\
17.0 \\
19.0 \\
17.0 \\
17.0\end{array}$ & $\begin{array}{l}21.5 \\
22.0 \\
22.0 \\
23.5 \\
22.0\end{array}$ & $\begin{array}{l}16.5 \\
17.0 \\
19.5 \\
18.5 \\
19.0\end{array}$ \\
\hline $\begin{array}{l}21 \\
? 2 \\
+3 \\
+4 \\
-5\end{array}$ & $\begin{array}{l}14.0 \\
19.61 \\
1700 \\
17.11 \\
14.0\end{array}$ & $\begin{array}{l}15.1 \\
11 \\
1301 \\
140 \\
13.7\end{array}$ & $\begin{array}{l}3.7 \\
37.61 \\
33.4 \\
31.4 \\
36.7\end{array}$ & $\begin{array}{l}14.5 \\
13.5 \\
12.011 \\
19.5 \\
13.5\end{array}$ & $\begin{array}{l}11.5 \\
21.5 \\
20.0 \\
11.0 \\
14.4\end{array}$ & $\begin{array}{l}10.5 \\
17.0 \\
10.5 \\
17.0 \\
17.0\end{array}$ & $\begin{array}{l}21.5 \\
14.5 \\
19.5 \\
19.5 \\
21.0\end{array}$ & $\begin{array}{l}19.5 \\
14.0 \\
19.5 \\
17.0 \\
17.0\end{array}$ & $\begin{array}{l}22.0 \\
20.5 \\
2100 \\
20.0 \\
22,0\end{array}$ & $\begin{array}{l}18.5 \\
18.5 \\
19.0 \\
17.0 \\
18.5\end{array}$ & $\begin{array}{l}22.0 \\
21.5 \\
21.5 \\
21.0 \\
21.5\end{array}$ & $\begin{array}{l}19.5 \\
19.0 \\
19.0 \\
19.5 \\
13.0\end{array}$ \\
\hline $\begin{array}{l}26 \\
37 \\
24 \\
14 \\
90 \\
11\end{array}$ & $\begin{array}{l}14.0 \\
14.5 \\
14.07 \\
14.5 \\
14.5 \\
-.0\end{array}$ & $\begin{array}{l}15.11 \\
1201 \\
11.3 \\
14.01 \\
170 \\
-0 .\end{array}$ & $\begin{array}{l}23.7 \\
31.11 \\
14.01 \\
19.1 \\
17.11 \\
14.01\end{array}$ & $\begin{array}{l}17.01 \\
12.5 \\
12.0 \\
1 \% .01 \\
17.3 \\
17.4\end{array}$ & 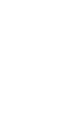 & $\begin{array}{l}15.0 \\
14.0 \\
14.0 \\
14.5 \\
15.0 \\
-.-0\end{array}$ & $\begin{array}{l}24.0 \\
19.5 \\
23.0 \\
24.0 \\
23.0 \\
23.1\end{array}$ & $\begin{array}{l}17.0 \\
17.0 \\
17.0 \\
14.0 \\
14.0 \\
14.5\end{array}$ & $\begin{array}{l}21.5 \\
21.5 \\
22.0 \\
22.0 \\
24.5 \\
24.5\end{array}$ & $\begin{array}{l}18.0 \\
18.0 \\
18.0 \\
18.0 \\
19.0 \\
19.0\end{array}$ & $\begin{array}{l}21.0 \\
19.0 \\
12.5 \\
15.5 \\
15.5 \\
-.2\end{array}$ & $\begin{array}{r}19.0 \\
17.0 \\
15.0 \\
11.0 \\
9.5 \\
\ldots\end{array}$ \\
\hline MONTH & 19.5 & 6.0 & 23.5 & 10.5 & 22.0 & 12.0 & 25.0 & 15.5 & 25.0 & 16.5 & 24.5 & 9.5 \\
\hline
\end{tabular}


02187500 SAVANNAH RIVER NEAR IVA, S. C.

LOCATION.--Lat $34^{\circ} 15^{\prime} 20^{\prime \prime}$, long $82^{\circ} 44^{\prime} 42^{\prime \prime}$, Anderson County, on left bank at downstream g1de of bridge on State H1ghway $184,0.5$ mile ups tream from Littie Generostee Creek, $5.8 \mathrm{mlles}$ gouthwest of Iva, and at mile 296.5 .

DRAINAGE AREA. --2,231 $\mathrm{ml}$,

PERIOD OF RECORD.--Chem1Cal analyges: February 1968 to September 1970.

Water temperatures: October 1962 to September 1987 , October 1968 to September 1970.

REMARKS.--Field determination of discharge, water temperature, pH, and dissolved oxygen by U.S. Geological Survey. Laboratory chemical analyges by Georgla Water Quality Control Board.

CHEMICAL ANALYSES. NATEH YEAH UCTOHER 1969 TO SEPTEMBER 1970

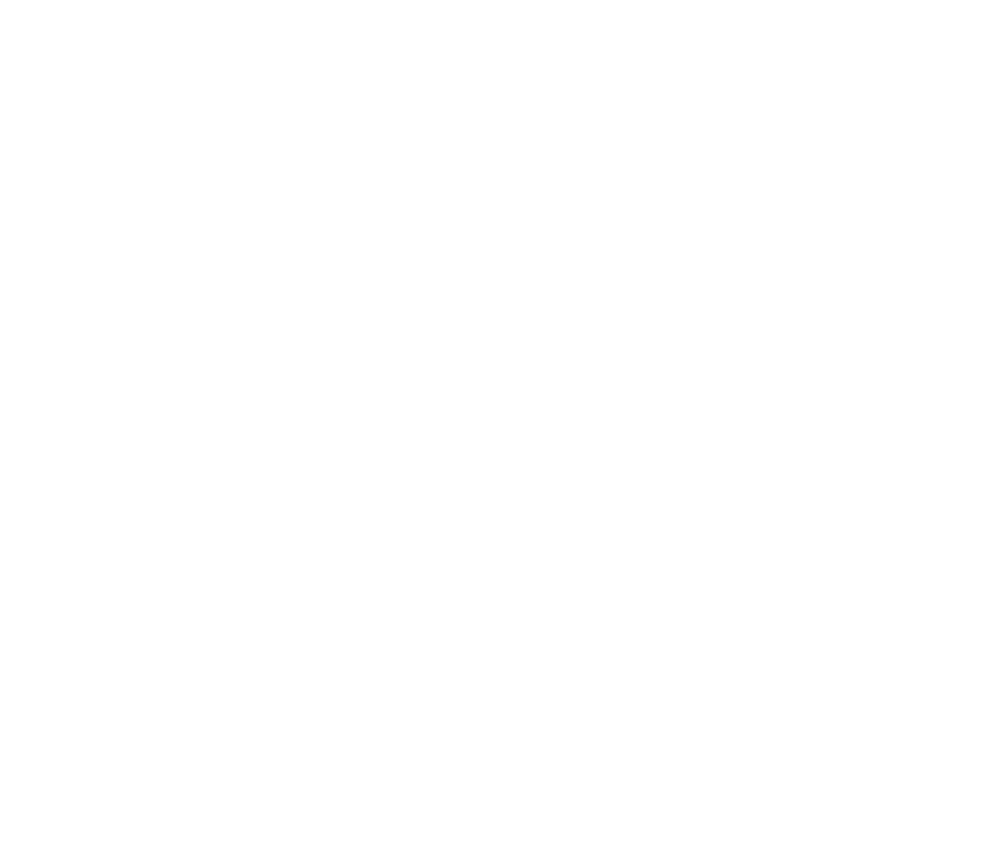


SAVANNAH RIVER BASIN

02187500 SAVANAAH RIVER NEAR IVA, S, C,-.COntinued

TEMPERATURE ( $\left.{ }^{\circ} \mathrm{C}\right)$ OF WATER, WATER YEAR DCTOBER 1969 TO SEPTEMBER 1970

\begin{tabular}{|c|c|c|c|c|c|c|c|c|c|c|c|c|}
\hline \multirow[b]{2}{*}{ DAY } & \multicolumn{2}{|c|}{ OCTOEER } & \multicolumn{2}{|c|}{ NOVEMEER } & \multicolumn{2}{|c|}{ DECEMBER } & \multicolumn{2}{|c|}{ JANUARY } & \multicolumn{2}{|c|}{ FEBRUARY } & \multicolumn{2}{|c|}{ MARCH } \\
\hline & $\max$ & MIN & $\max$ & MIN & $\max$ & MIN & $\max$ & MIN & $\max$ & MIN & $\max$ & MIN \\
\hline $\begin{array}{l}1 \\
2 \\
3 \\
4 \\
5\end{array}$ & $\begin{array}{r}15.5 \\
15.5 \\
16.0 \\
17.0 \\
17.0\end{array}$ & $\begin{array}{l}15.0 \\
15.0 \\
15.5 \\
15.5 \\
16.5\end{array}$ & $\begin{array}{l}15.5 \\
15.5 \\
15.5 \\
15.5 \\
15.5\end{array}$ & $\begin{array}{l}15.5 \\
15.5 \\
15.5 \\
15.0 \\
15.0\end{array}$ & $\begin{array}{l}13.5 \\
12.0 \\
13.0 \\
13.0 \\
13.0\end{array}$ & $\begin{array}{l}12.0 \\
12.0 \\
13.0 \\
13.0 \\
13.0\end{array}$ & $\begin{array}{l}10.5 \\
10.0 \\
10.0 \\
10.0 \\
10.0\end{array}$ & $\begin{array}{l}10.0 \\
10.0 \\
10.0 \\
10.0 \\
9.0\end{array}$ & $\begin{array}{l}8.0 \\
8.0 \\
8.0 \\
8.0 \\
8.0\end{array}$ & $\begin{array}{l}8.0 \\
8.0 \\
8.0 \\
8.0 \\
8.0\end{array}$ & $\begin{array}{l}8.0 \\
8.0 \\
8.0 \\
8.0 \\
7.0\end{array}$ & $\begin{array}{l}7.0 \\
8.0 \\
7.0 \\
7.0 \\
7.0\end{array}$ \\
\hline $\begin{array}{r}6 \\
7 \\
8 \\
9 \\
10\end{array}$ & $\begin{array}{l}17.0 \\
16.5 \\
16.5 \\
16.0 \\
16.0\end{array}$ & $\begin{array}{l}16.5 \\
16.5 \\
16.0 \\
16.0 \\
16.0\end{array}$ & $\begin{array}{l}15.0 \\
15.0 \\
15.0 \\
15.0 \\
15.0\end{array}$ & $\begin{array}{l}15.0 \\
15.0 \\
14.5 \\
14.5 \\
14.5\end{array}$ & $\begin{array}{l}13.0 \\
13.0 \\
13.0 \\
12.0 \\
12.0\end{array}$ & $\begin{array}{l}13.0 \\
13.0 \\
11.5 \\
11.5 \\
12.0\end{array}$ & $\begin{array}{l}9.0 \\
9.0 \\
9.0 \\
9.0 \\
8.5\end{array}$ & $\begin{array}{l}9.0 \\
9.0 \\
8.5 \\
8.5 \\
8.5\end{array}$ & $\begin{array}{l}8.0 \\
8.0 \\
8.0 \\
8.0 \\
8.0\end{array}$ & $\begin{array}{l}8.0 \\
8.0 \\
8.0 \\
8.0 \\
8.0\end{array}$ & $\begin{array}{l}8.0 \\
7.0 \\
7.0 \\
8.0 \\
8.0\end{array}$ & $\begin{array}{l}7.0 \\
7.0 \\
7.0 \\
7.0 \\
7.0\end{array}$ \\
\hline $\begin{array}{l}11 \\
12 \\
13 \\
14 \\
15\end{array}$ & $\begin{array}{l}16.5 \\
18.0 \\
18.0 \\
16.5 \\
16.5\end{array}$ & $\begin{array}{l}16.0 \\
16.5 \\
16.5 \\
16.5 \\
16.5\end{array}$ & $\begin{array}{l}14.5 \\
14.5 \\
15.0 \\
15.0 \\
15.0\end{array}$ & $\begin{array}{l}24.5 \\
14.5 \\
15.0 \\
15.0 \\
14.5\end{array}$ & $\begin{array}{l}12.0 \\
12.0 \\
12.0 \\
12.0 \\
11.5\end{array}$ & $\begin{array}{l}12.0 \\
12.0 \\
12.0 \\
11.5 \\
11.5\end{array}$ & $\begin{array}{l}8.5 \\
8.5 \\
8.0 \\
8.0 \\
8.0\end{array}$ & $\begin{array}{l}8.5 \\
8.0 \\
8.0 \\
8.0 \\
8.0\end{array}$ & $\begin{array}{l}8.0 \\
8.0 \\
8.0 \\
8.0 \\
8.0\end{array}$ & $\begin{array}{l}8.0 \\
8.0 \\
8.0 \\
8.0 \\
7.0\end{array}$ & $\begin{array}{l}7.0 \\
7.0 \\
7.0 \\
7.0 \\
6.5\end{array}$ & $\begin{array}{l}0.5 \\
6.5 \\
6.5 \\
0.5 \\
0.5\end{array}$ \\
\hline $\begin{array}{l}16 \\
17 \\
19 \\
19 \\
20\end{array}$ & $\begin{array}{l}16.5 \\
16.5 \\
16.0 \\
16.0 \\
15.5\end{array}$ & $\begin{array}{l}16.5 \\
16.0 \\
15.5 \\
15.5 \\
15.5\end{array}$ & $\begin{array}{l}14.5 \\
12.0 \\
13.5 \\
13.5 \\
14.0\end{array}$ & $\begin{array}{l}12.0 \\
11.5 \\
12.0 \\
13.5 \\
13.5\end{array}$ & $\begin{array}{l}11.5 \\
11.5 \\
11.5 \\
11.5 \\
11.5\end{array}$ & $\begin{array}{l}11.5 \\
11.5 \\
11.5 \\
11.5 \\
11.5\end{array}$ & $\begin{array}{l}8.0 \\
8.0 \\
8.5 \\
8.5 \\
8.5\end{array}$ & $\begin{array}{l}8.0 \\
8.0 \\
8.0 \\
8.5 \\
8.5\end{array}$ & $\begin{array}{l}8.0 \\
8.0 \\
8.0 \\
8.0 \\
8.0\end{array}$ & $\begin{array}{l}8.0 \\
8.0 \\
8.0 \\
8.0 \\
8.0\end{array}$ & $\begin{array}{l}6.5 \\
6.5 \\
6.0 \\
6.0 \\
5.5\end{array}$ & $\begin{array}{l}6.5 \\
6.0 \\
6.0 \\
5.5 \\
5.5\end{array}$ \\
\hline $\begin{array}{l}21 \\
22 \\
23 \\
24 \\
25\end{array}$ & $\begin{array}{l}16.0 \\
16.0 \\
16.0 \\
16.0 \\
15.5\end{array}$ & $\begin{array}{l}15.5 \\
16.0 \\
16.0 \\
15.5 \\
15.5\end{array}$ & $\begin{array}{l}14.0 \\
14.0 \\
14.0 \\
14.0 \\
14.0\end{array}$ & $\begin{array}{l}14.0 \\
14.0 \\
14.0 \\
13.5 \\
14.0\end{array}$ & $\begin{array}{l}11.5 \\
10.5 \\
10.5 \\
10.5 \\
10.5\end{array}$ & $\begin{array}{l}10.5 \\
10.0 \\
10.5 \\
10.5 \\
10.5\end{array}$ & $\begin{array}{l}8.5 \\
8.5 \\
8.0 \\
8.0 \\
8.0\end{array}$ & $\begin{array}{l}8.5 \\
8.0 \\
8.0 \\
8.0 \\
8.0\end{array}$ & $\begin{array}{l}8.0 \\
8.0 \\
8.0 \\
8.0 \\
8.0\end{array}$ & $\begin{array}{l}8.0 \\
8.0 \\
8.0 \\
8.0 \\
8.0\end{array}$ & $\begin{array}{l}5.5 \\
6.5 \\
6.5 \\
6.5 \\
6.0\end{array}$ & $\begin{array}{l}5.5 \\
5.5 \\
6.5 \\
6.0 \\
6.0\end{array}$ \\
\hline $\begin{array}{l}26 \\
27 \\
26 \\
29 \\
30 \\
31\end{array}$ & $\begin{array}{l}16.0 \\
16.5 \\
16.5 \\
15.5 \\
15.5 \\
15.5\end{array}$ & $\begin{array}{l}15.5 \\
16.0 \\
15.5 \\
15.0 \\
15.0 \\
15.5\end{array}$ & $\begin{array}{l}14.0 \\
14.0 \\
14.0 \\
14.0 \\
14.0 \\
\end{array}$ & $\begin{array}{l}14.0 \\
14.0 \\
14.0 \\
14.0 \\
13.5 \\
.\end{array}$ & $\begin{array}{l}10.5 \\
10.0 \\
10.0 \\
10.0 \\
10.5 \\
10.5\end{array}$ & $\begin{array}{r}9.5 \\
10.0 \\
10.0 \\
10.0 \\
10.0 \\
10.5\end{array}$ & $\begin{array}{l}8.0 \\
8.0 \\
8.0 \\
8.0 \\
8.0 \\
8.0\end{array}$ & $\begin{array}{l}7.0 \\
8.0 \\
8.0 \\
8.0 \\
8.0 \\
8.0\end{array}$ & $\begin{array}{l}8.0 \\
7.0 \\
7.0 \\
-\infty . \\
\cdots \\
-\infty\end{array}$ & $\begin{array}{l}7.0 \\
7.0 \\
7.0 \\
\ldots-\infty \\
-\infty\end{array}$ & $\begin{array}{l}6.0 \\
6.0 \\
6.5 \\
9.0 \\
9.5 \\
8.0\end{array}$ & $\begin{array}{l}6.0 \\
6.0 \\
6.0 \\
6.5 \\
8.0 \\
7.0\end{array}$ \\
\hline \multirow[t]{2}{*}{ MONTH } & 18.0 & 15.0 & 15.5 & 11.5 & 13.5 & 9.5 & 10.5 & 7.0 & 8.0 & 7.0 & 9.5 & 5,5 \\
\hline & \multicolumn{2}{|c|}{ APRIL } & \multicolumn{2}{|c|}{ MAY } & \multicolumn{2}{|c|}{ JUNE } & \multicolumn{2}{|c|}{ JULY } & \multicolumn{2}{|c|}{ AUGUST } & \multicolumn{2}{|c|}{ SEPTEMBER } \\
\hline DAY & MAX & MIN & $\max$ & MIN & $\max$ & MIN & $\max$ & MIN & $\max$ & MIN & $\max$ & MIN \\
\hline $\begin{array}{l}1 \\
2 \\
3 \\
4 \\
5\end{array}$ & $\begin{array}{l}7.0 \\
6.5 \\
6.5 \\
7.0 \\
8.5\end{array}$ & $\begin{array}{l}6.0 \\
6.5 \\
6.5 \\
6.5 \\
7.0\end{array}$ & $\begin{array}{r}8.5 \\
9.0 \\
9.5 \\
10.0 \\
9.5\end{array}$ & $\begin{array}{l}8.0 \\
8.0 \\
9.0 \\
9.5 \\
9.5\end{array}$ & 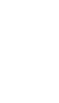 & 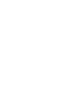 & 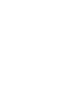 & 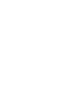 & $\begin{array}{l}24.0 \\
27.0 \\
27.0 \\
23.5 \\
22.5\end{array}$ & $\begin{array}{l}21.0 \\
24.0 \\
22.5 \\
22.5 \\
21.0\end{array}$ & $\begin{array}{l}25.0 \\
24.0 \\
23.5 \\
23.5 \\
24.0\end{array}$ & $\begin{array}{l}24.0 \\
23.5 \\
22.5 \\
22.5 \\
22.5\end{array}$ \\
\hline $\begin{array}{r}6 \\
7 \\
8 \\
9 \\
10\end{array}$ & $\begin{array}{l}8.5 \\
8.0 \\
7.0 \\
6.5 \\
6.5\end{array}$ & $\begin{array}{l}8.0 \\
7.0 \\
6.5 \\
6.5 \\
6.5\end{array}$ & $\begin{array}{r}9.5 \\
9.5 \\
9.0 \\
9.5 \\
12.0\end{array}$ & $\begin{array}{l}9.5 \\
9.0 \\
8.5 \\
8.5 \\
9.5\end{array}$ & $\ddot{a}$ & $\begin{array}{l}a \\
\because-\infty \\
\because-\end{array}$ & $\begin{array}{l}=-\infty \\
\because-\infty \\
\because-\infty\end{array}$ & 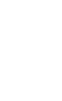 & $\begin{array}{l}22.5 \\
22.0 \\
22.5 \\
24.5 \\
24.5\end{array}$ & $\begin{array}{l}21.5 \\
22.0 \\
21.5 \\
22.5 \\
23.5\end{array}$ & $\begin{array}{l}26.0 \\
26.0 \\
26.0 \\
22.5 \\
22.0\end{array}$ & $\begin{array}{l}22.5 \\
26.0 \\
22.5 \\
22.0 \\
22.0\end{array}$ \\
\hline $\begin{array}{l}11 \\
12 \\
13 \\
14 \\
15\end{array}$ & $\begin{array}{l}7.0 \\
8.0 \\
8.5 \\
8.0 \\
8.0\end{array}$ & $\begin{array}{l}6.5 \\
7.0 \\
8.0 \\
8.0 \\
8.0\end{array}$ & $\begin{array}{r}13.0 \\
\ldots \\
\cdots\end{array}$ & \begin{tabular}{l}
9.5 \\
$\because-\infty$ \\
\hdashline$-\infty$ \\
$-\infty$
\end{tabular} & $\ddot{y}$ & $\ddot{-\infty}$ & $\begin{array}{l}\ldots \\
\because \ldots \\
\because \ldots \\
\because-\infty\end{array}$ & $\ddot{a}$ & $\begin{array}{l}24.5 \\
25.5 \\
23.5 \\
22.5 \\
24.5\end{array}$ & $\begin{array}{l}23.5 \\
23.5 \\
22.5 \\
22.0 \\
22.5\end{array}$ & $\begin{array}{l}22.0 \\
22.0 \\
23.5 \\
24.0 \\
21.5\end{array}$ & $\begin{array}{l}22.0 \\
21.5 \\
21.5 \\
21.5 \\
21.0\end{array}$ \\
\hline $\begin{array}{l}16 \\
17 \\
18 \\
19 \\
20\end{array}$ & $\begin{array}{r}8.0 \\
8.0 \\
8.0 \\
11.0 \\
11.5\end{array}$ & $\begin{array}{r}8.0 \\
7.0 \\
7.0 \\
8.0 \\
10.5\end{array}$ & $\begin{array}{r}\ldots- \\
20.0 \\
20.0\end{array}$ & $\begin{array}{l}=- \\
17.5 \\
16.5\end{array}$ & 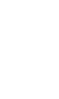 & $\ddot{m}$ & $\begin{array}{l}21.0 \\
21.5 \\
22.0 \\
25.5 \\
25.5\end{array}$ & $\begin{array}{l}20.0 \\
20.5 \\
20.5 \\
22.0 \\
22.0\end{array}$ & $\begin{array}{l}27.0 \\
27.0 \\
23.5 \\
23.5 \\
24.0\end{array}$ & $\begin{array}{l}24.5 \\
23.5 \\
23.5 \\
22.5 \\
22.5\end{array}$ & $\begin{array}{l}21.0 \\
21.0 \\
20.5 \\
21.0 \\
22.5\end{array}$ & $\begin{array}{l}20.5 \\
20.5 \\
20.5 \\
19.5 \\
21.0\end{array}$ \\
\hline $\begin{array}{l}21 \\
22 \\
23 \\
24 \\
25\end{array}$ & $\begin{array}{r}10.5 \\
8.5 \\
8.5 \\
8.5 \\
8.5\end{array}$ & $\begin{array}{l}8.5 \\
8.5 \\
8.5 \\
8.5 \\
8.0\end{array}$ & $\begin{array}{l}16.5 \\
14.5 \\
15.5 \\
19.5 \\
19.5\end{array}$ & $\begin{array}{l}34.0 \\
33.5 \\
33.0 \\
15.5 \\
34.5\end{array}$ & 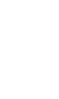 & 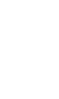 & $\begin{array}{l}22.0 \\
22.0 \\
24.5 \\
21.5 \\
23.5\end{array}$ & $\begin{array}{l}22.0 \\
21.5 \\
22.0 \\
21.0 \\
21.00\end{array}$ & $\begin{array}{l}23.5 \\
24.5 \\
27.0 \\
28.0 \\
24.5\end{array}$ & $\begin{array}{l}22.5 \\
22.5 \\
24.5 \\
24.5 \\
24.5\end{array}$ & $\begin{array}{l}23.5 \\
20.0 \\
20.0 \\
19.0 \\
19.0\end{array}$ & $\begin{array}{l}20.0 \\
19.5 \\
19.5 \\
19.0 \\
18.0\end{array}$ \\
\hline $\begin{array}{l}26 \\
27 \\
28 \\
29 \\
30 \\
31\end{array}$ & $\begin{array}{l}9.5 \\
9.5 \\
9.0 \\
8.5 \\
8.5 \\
. .-\end{array}$ & $\begin{array}{l}8.0 \\
9.0 \\
8.5 \\
8.5 \\
8.5 \\
-. .\end{array}$ & $\begin{array}{l}14.5 \\
14.5 \\
13.0 \\
12.0 \\
14.0 \\
16.0\end{array}$ & $\begin{array}{l}13.5 \\
13.5 \\
12.0 \\
12.0 \\
12.0 \\
14.0\end{array}$ & 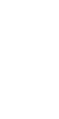 & 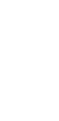 & $\begin{array}{l}26.0 \\
26.0 \\
22.5 \\
21.5 \\
21.5 \\
21.5\end{array}$ & $\begin{array}{l}23.5 \\
22.5 \\
21.5 \\
21.0 \\
21.0 \\
=.0\end{array}$ & $\begin{array}{l}24.0 \\
25.5 \\
27.0 \\
25.0 \\
28.0 \\
28.0\end{array}$ & $\begin{array}{l}23.5 \\
23.5 \\
25.5 \\
24.0 \\
24.0 \\
24.0\end{array}$ & $\begin{array}{r}21.0 \\
22.5 \\
21.0 \\
17.0 \\
18.0 \\
\ldots-\end{array}$ & $\begin{array}{l}19.0 \\
21.0 \\
17.5 \\
17.5 \\
17.5 \\
-\end{array}$ \\
\hline MONTH & 11.5 & 6.0 & $-\infty$ & $\infty$ & -- & $\cdots$ & $-\infty$ & $\infty$ & 28.0 & 21.0 & 26.0 & 17.5 \\
\hline
\end{tabular}


02197300 UPPER THREE RUNS NEAR. NEW ELLENTON, S. C.

(Hydrologic bench-mark station)

LOCATION,-Lat $33^{\circ} 23^{\prime} 05^{\prime \prime}$, long $81^{\circ} 37^{\prime} 00^{\prime \prime}$, Alken County, at gaging station on downstream side of bridge on U, S. High-

way 278, 0.4 mile upstream from Johnson Fork Creek, and 4.8 m1les southeast of New Ellenton.

DRA INAGE AREA, $-87.0 \mathrm{~Bq} \mathrm{mi}$.

PERIOD OF RECORD.--Chemicul analymes: July 1986 to September 1970

Sed1ment records.--October 1867 to september 1870 (poriod1c).

CHEMICAL ANALYSES, HATER YEAR OCTOBER 1969 TO SEPTEMBER 1970

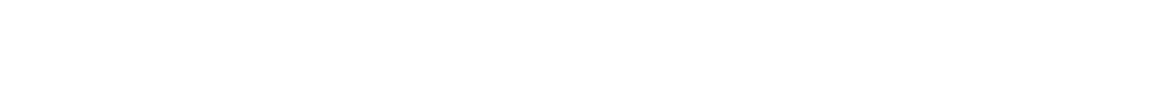

$$
\begin{aligned}
& \text { SPECI- } \\
& \text { COLOR FIC }
\end{aligned}
$$

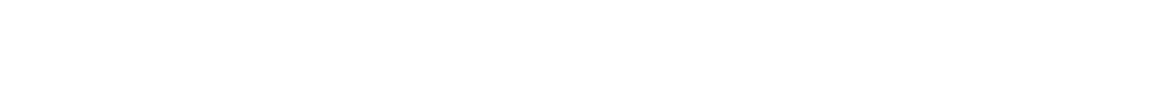

XT. $\begin{array}{lllll}\text { ERATURE } & \text { CHARGE } & \text { CCBALT } & \text { (MICRO- } & \text { OXYGEN } \\ \text { (DFG C) } & \text { (CFSI } & \text { UNITSI MHOS) } & \text { (MGL) } & \text { (UNITSI }\end{array}$

PHORUS

$\begin{array}{ll}08 \ldots & 1035 \\ 0 . \ldots 1 & 1035\end{array}$

$\begin{array}{ll}18.5 & 89 \\ 18.5 & 99\end{array}$

$\begin{array}{rrr}5 & 13 & -5 \\ -- & 14 & 8.0\end{array}$

$\begin{array}{llllll}6.0 & 2 & 3 & 0 & .00 & .00 \\ 5.8 & -2 & -- & -0 & -0 & -\end{array}$

D6... 1100

$10.0 \quad 96$

14
--5

5.3

DEC.

$01 \ldots .2 \quad 1335$

10 is 10.1

5.2

$05 . . . \quad 1145$

$\begin{array}{ll}12.5 & 98 \\ 12.3 & 98\end{array}$

$9.5 \quad 99$

$\begin{array}{rrr}3 & 13 & = \\ -5 & 16 & 11.6\end{array}$

$\begin{array}{ll}12.5 & 107 \\ 12.5 & 107\end{array}$

$\begin{array}{rr}5 & 13 \\ - & 17\end{array}$

15.5100

$14 . . .1400$

D5... 1145

$05 \ldots .1145$

1... 0905

$01 \ldots .0905$

ULY

1... $\quad 1130$

$01 \ldots .1130$

11... 0945

$11 \ldots$ 2945

ग1... 1036

$19.0 \quad 43$

$\begin{array}{ll}10 & 14 \\ \cdots & 18\end{array}$

11.8

5.5

19.0

20.0 28

19.5100

19.5100

$\begin{array}{ll}20.0 & 92 \\ 20.6 & 92\end{array}$

$10 \quad 13$

2
-2

$\begin{array}{ll}10 & 13 \\ -0 \quad 16\end{array}$

$\begin{array}{rr}5 & 14 \\ -- & 19\end{array}$

11.2

3.4

$\begin{array}{lllllll}-- & 5.4 & 2 & 2 & 0 & .01 & -\end{array}$

$\begin{array}{lllllll}-- & 5.6 & 3 & 4 & 0 & .11 & -\end{array}$

$\begin{array}{rrrrrrr}-- & 5.7 & 2 & 3 & 0 & -- & .00\end{array}$

$01 \ldots 1030$

(2)

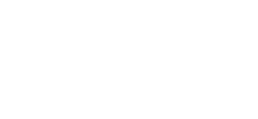

SUSPENDED-SEDIMENT DISCHARGE, WATER YEAR DCTOBER 1969 TO SEPTEMBER 1970

\begin{tabular}{|c|c|c|c|c|c|c|c|c|c|}
\hline DATE & TIME & $\begin{array}{l}\text { DISCHARGE } \\
\text { (CFS) }\end{array}$ & $\begin{array}{l}\text { CONCEN- } \\
\text { TRAT!ON } \\
\text { (MG/L) }\end{array}$ & $\begin{array}{l}\text { SUSPENDED } \\
\text { SEDIMENT } \\
\text { DISCHARGE } \\
\text { (TONS/DAY) }\end{array}$ & DATE & TIME & $\begin{array}{l}\text { DISCHARGE } \\
\text { (CFS) }\end{array}$ & $\begin{array}{l}\text { CONCEN- } \\
\text { TRATION } \\
\text { (MG/L) }\end{array}$ & $\begin{array}{l}\text { SUSPENDED } \\
\text { SED IMENT } \\
\text { DI SCHARGE } \\
\text { (TONS/DAY) }\end{array}$ \\
\hline$O C T \quad 08$ & 1015 & 80 & 6 & 1.3 & MAY 05 & 1200 & 91 & 5 & 1.2 \\
\hline NOV OG & 1115 & 87 & 5 & 1.2 & JUN 01 & 0905 & 84 & 7 & 1.6 \\
\hline DEC 01 & 1350 & 89 & 5 & 1.2 & JUL OI & 1130 & 78 & 6 & 1.3 \\
\hline JAN O5 & 1150 & 90 & 6 & 1.5 & AUG 08 & 0945 & 91 & 5 & 1.2 \\
\hline FEB 14 & 1415 & 107 & $\begin{array}{l}8 \\
6\end{array}$ & $\begin{array}{l}1.3 \\
1.7\end{array}$ & SEP 01 & $\begin{array}{l}1045 \\
\text { 10 }\end{array}$ & 83 & 5 & 1.1 \\
\hline
\end{tabular}


SAVANNAH RIVER BASIN

02197300 UPPER THREE RUNS NEAR NEW ELLENTON, S. C.--Continued

CHEMICAL ANALYSES, WATER YEAR OCTOBER 1969 TO SEPTEMBER 1970

\begin{tabular}{|c|c|c|c|c|c|c|c|c|c|c|c|c|}
\hline DATF & $\begin{array}{l}\text { HARQ- } \\
\text { NESS } \\
(C A, M G) \\
(M G) L)\end{array}$ & $\begin{array}{l}\text { NCN- } \\
\text { CAR- } \\
\text { RONATF } \\
\text { HARD- } \\
\text { NESS } \\
\text { (MGIL) }\end{array}$ & $\begin{array}{l}\text { DIS- } \\
\text { SOLVED } \\
\text { CAL- } \\
\text { CIUM } \\
\text { (CA) } \\
\text { (MG } / L)\end{array}$ & $\begin{array}{l}\text { DIS- } \\
\text { SOLVED } \\
\text { MAG- } \\
\text { NE- } \\
\text { SIUM } \\
\text { (MG) } \\
\text { (MG/L) }\end{array}$ & $\begin{array}{l}\text { SODIUM } \\
\text { (NA) } \\
\text { (MGIL) }\end{array}$ & $\begin{array}{l}\text { SOOIUM } \\
\text { AD- } \\
\text { SORP- } \\
\text { TION } \\
\text { RATIO }\end{array}$ & $\begin{array}{l}\text { PERCENT } \\
\text { SOOIUM }\end{array}$ & $\begin{array}{l}\text { PO- } \\
\text { TAS- } \\
\text { SIUM } \\
\text { (K) } \\
\text { (MG/L) }\end{array}$ & $\begin{array}{l}\text { CHLO- } \\
\text { RIDE } \\
(C L) \\
(M G / L)\end{array}$ & $\begin{array}{l}\text { SULFATE } \\
\text { (SO4) } \\
\text { (MG/L) }\end{array}$ & $\begin{array}{l}\text { DIS- } \\
\text { SOLVED } \\
\text { FLUO- } \\
\text { RICE } \\
\text { (F) } \\
\text { (MG/L) }\end{array}$ & $\begin{array}{l}\text { SILICA } \\
\text { (SIO2) } \\
\text { (MG/L) }\end{array}$ \\
\hline OCT. & 2 & 0 & .4 & .3 & 1.2 & $\cdot 3$ & 51 & .2 & 2.3 & .8 & .0 & 7.7 \\
\hline $\begin{array}{l}\text { OB. } \\
\text { NOV. }\end{array}$ & -- & - & - & $\cdots$ & $\cdots$ & - & - & $=$ & $\rightarrow$ & $\rightarrow$ & -- & - \\
\hline $\begin{array}{l}\text { O6.... } \\
\text { OS... } \\
\text { OEC. }\end{array}$ & -2 & $\therefore$ & $\therefore$ & $\therefore 3$ & 1.2 & $\therefore 3$ & $5 !$ & $\therefore 2$ & 2.3 & -8 & $\therefore$ & 7.7 \\
\hline $01 \ldots$ & 2 & 0 & .4 & .3 & 1.2 & .3 & 51 & .2 & 2.6 & .8 & .0 & 7.6 \\
\hline JAN." & - & -- & $=$ & $=$ & $=$ & $=$ & $=$ & $=$ & - & -- & -- & - \\
\hline $\begin{array}{l}05 \ldots . \\
05 \ldots\end{array}$ & -2 & $\begin{array}{r}0 \\
--\end{array}$ & $\because 4$ & -3 & 1.2 & $\because 3$ & 51 & $\therefore 2$ & 2.0 & $\because 8$ & $\therefore$ & 7.3 \\
\hline $\begin{array}{l}F E B . \\
14 \ldots . \\
14 \ldots .\end{array}$ & -4 & 2 & 1.4 & $\therefore 2$ & 1.4 & $\therefore 3$ & $\begin{array}{l}41 \\
--\end{array}$ & $\because 1$ & 3.2 & 1.2 & $\therefore$ & 7.0 \\
\hline MAY & & & & & & & & & & & & \\
\hline $05 \ldots$ & 2 & 1 & .4 & .4 & 1.3 & .3 & 51 & .1 & 3.1 & .2 & 0 & 6.8 \\
\hline JUNE & - & 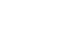 & $=$ & - & - & - & $\cdots$ & 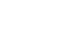 & 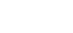 & $\ldots$ & - & - \\
\hline $01 \ldots$ & 4 & 1 & .5 & .3 & 1.2 & .3 & 49 & .2 & 2.4 & 1.2 & .0 & 6.9 \\
\hline $01 . .$. & -- & -- & -- & -- & $=-$ & - & -- & -- & - & - & -- & -- \\
\hline $01 \ldots$ & 4 & 0 & .4 & .3 & 1.5 & .4 & 57 & .2 & 3.4 & 1.2 & .0 & 7.2 \\
\hline $\begin{array}{l}\text { n1... } \\
\text { Aug. }\end{array}$ & - & -- & -- & -- & - & -- & $\cdots$ & -. & -- & -- & - & - \\
\hline $11 \ldots$ & 2 & 0 & .5 & .2 & 1.3 & .4 & 52 & .4 & 2.2 & .0 & .0 & 7.4 \\
\hline $11 \ldots$ & - & -- & -- & - & - & - & -- & -- & -- & -- & -- & - \\
\hline $01 \ldots$ & 2 & $n$ & .8 & .1 & 1.3 & .4 & 51 & .2 & 2.3 & .6 & .0 & 7.4 \\
\hline $01 \ldots$ & - & -- & -- & -- & $=-$ & - & -- & -- & -- & -- & -- & -- \\
\hline DATE & $\begin{array}{l}\text { DIS- } \\
\text { SOLVEO } \\
\text { CAD- } \\
\text { MIUM } \\
\text { (CD) } \\
\text { (UG/L) }\end{array}$ & $\begin{array}{l}\text { TOTAL } \\
\text { CHRO- } \\
\text { MIUM } \\
\text { (CR) } \\
\text { (UG/L) }\end{array}$ & $\begin{array}{l}\text { OIS- } \\
\text { SOLVEC } \\
\text { COPPER } \\
\text { (CU) } \\
\text { (UG } L \text { ) }\end{array}$ & $\begin{array}{l}\text { TOTAL } \\
\text { IRON } \\
\text { IFE } \\
\text { CUG/L I }\end{array}$ & $\begin{array}{l}\text { DIS- } \\
\text { SOLEO } \\
\text { IROV } \\
\text { (FE) } \\
\text { (UG/L) }\end{array}$ & $\begin{array}{l}\text { DIS- } \\
\text { SJLVEO } \\
L \in A O \\
\text { (PB) } \\
\text { (UG/L) }\end{array}$ & $\begin{array}{l}\text { TOTAL } \\
\text { MAN- } \\
\text { GANFSE } \\
\text { (MN) } \\
\text { (UG/L) }\end{array}$ & $\begin{array}{l}\text { DIS- } \\
\text { SOLVED } \\
\text { MAN- } \\
\text { GANESE } \\
\text { (MN) } \\
\text { (UGIL) }\end{array}$ & $\begin{array}{l}\text { OIS- } \\
\text { SOL VED } \\
\text { NICKEL } \\
\text { (NI) } \\
\text { (UG/L) }\end{array}$ & $\begin{array}{l}\text { DIS- } \\
\text { SCL VED } \\
\text { STRDN- } \\
\text { TIUM } \\
\text { (SRI } \\
\text { (UG IL) }\end{array}$ & $\begin{array}{l}\text { OIS- } \\
\text { SCLVED } \\
\text { IINC } \\
\text { (ZN) } \\
\text { (UGIL) }\end{array}$ & $\begin{array}{l}\text { POTAL } \\
\text { ALUM- } \\
\text { [NUM } \\
\text { (AL) } \\
\text { (UG/L) }\end{array}$ \\
\hline OCT. & -- & - & - & $r$ & & & & & & & & \\
\hline $\begin{array}{l}\text { OB... } \\
\text { Nov. }\end{array}$ & - & 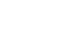 & $\cdots$ & $=-$ & - & $=$ & $\begin{array}{l}10 \\
--\end{array}$ & $\because$ & $\because$ & $\overline{--}$ & $\because$ & $=$ \\
\hline $06 . .$. & - & - & $\cdots$ & 0 & -- & -- & -- & - & -- & -- & -- & - \\
\hline OS... & - & -- & -- & - & $=-$ & -- & $\cdots$ & - & - & -- & -- & - \\
\hline $01 \ldots$ & -- & -- & - & 0 & -- & -- & - & -. & -- & -- & -- & -- \\
\hline JA... & -- & -- & - & -- & -- & - & -- & - & -- & - & - & $\cdots$ \\
\hline $05 \ldots$ & 0 & -- & ? & 483 & -- & 0 & 65 & -- & 0 & 0 & 0 & 200 \\
\hline $\begin{array}{r}05 \ldots \\
F\end{array}$ & -- & -- & $\cdots$ & -- & -- & - & $\cdots$ & $\cdots$ & -- & -- & -- & - \\
\hline $14 \ldots$ & - & - & -- & 3 & -- & - & 0 & -- & -- & -- & $=$ & - \\
\hline $14 \ldots$ & -- & -- & -- & -- & -- & -- & -- & -- & - & - & -- & $=$ \\
\hline $05 \ldots$ & 0 & 0 & $3 c$ & 510 & $=$ & 0 & 60 & $\cdots$ & 0 & 0 & 0 & 200 \\
\hline $05 \ldots$ & $\rightarrow$ & -- & - & -- & -- & -- & -- & -- & - & -- & -- & - \\
\hline $01 .$. & -- & 0 & $c$ & 334 & - & 0 & 0 & - & -- & 0 & 0 & 95 \\
\hline $01 \ldots$ & -- & - & $-\cdots$ & -- & - & - & -- & - & -- & -- & -- & - \\
\hline $01 \ldots$ & -- & -- & $-\infty$ & 320 & - & -- & $: 7$ & - & -- & -- & -- & 47 \\
\hline $01 \ldots$ & -- & -- & -- & -- & -- & -- & $\because$ & - & -- & $-\infty$ & - & $=$ \\
\hline $\begin{array}{l}\text { AUG } \\
\text { II.... }\end{array}$ & -- & -- & -. & $m$ & 32 & -- & $-m$ & 0 & -- & -- & -- & $-\pi$ \\
\hline $11 \ldots$ & -- & - & -- & -- & - & - & $\therefore$ & - & -- & $\ldots$ & $\overline{-}$ & $\rightarrow$ \\
\hline SEP. & $=$ & 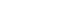 & -- & $\Omega$ & 35 & -- & - & 0 & & - & - & - \\
\hline $01 .$. & -- & - & $-\ldots$ & $\ldots$ & 33 & $=$ & 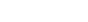 & -- & $=$ & - & $=$ & $=$ \\
\hline
\end{tabular}


SAVANNAH RIVER BASIN

02197300 UPPER THREE RUNS NEAR NEW ELLENTON, S. C.--Continued

CHEMICAL ANALYSES, WATER YEAR OCTOBER 1969 TO SEPTEMBER 1970

\begin{tabular}{|c|c|c|c|c|c|c|c|c|c|c|c|}
\hline DATE & $\begin{array}{l}\text { DIS- } \\
\text { SOLLEC } \\
\text { ALPHA }\end{array}$ & $\begin{array}{l}\text { SUS- } \\
\text { PENDEO } \\
\text { ALPHA } \\
\text { PPCMLI }\end{array}$ & $\begin{array}{l}\text { DIS- } \\
\text { SOLVED } \\
\text { BETA } \\
\text { (PC/L) }\end{array}$ & $\begin{array}{l}\text { SUS- } \\
\text { PENOD } \\
\text { BSTA } \\
\text { (PC/L) }\end{array}$ & $\begin{array}{l}\text { DIS- } \\
\text { SCLEE } \\
\text { RAD IUY } \\
226 \\
\text { (RA) } \\
(P C / L)\end{array}$ & $\begin{array}{l}\text { OIS- } \\
\text { SOLVED } \\
\text { NATURAL } \\
\text { URANI UM } \\
\text { UU) } \\
\text { (UG/L) }\end{array}$ & $\begin{array}{c}\text { COLI- } \\
\text { FORM } \\
\text { (COLM } \\
\text { ONIES } \\
\text { PER } \\
100 \mathrm{ML})\end{array}$ & $\begin{array}{l}\text { ALDRIN } \\
(\text { UGI })\end{array}$ & $\begin{array}{l}\text { LINDANE } \\
\text { (UG/L) }\end{array}$ & $\begin{array}{l}200 \\
(4 r, h),\end{array}$ & DDE \\
\hline 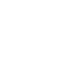 & $\because: 2$ & 1.2 & $2: 4$ & $\therefore$ & $\therefore$ & $\therefore 0$ & 380 & .00 & .00 & $\because 1$ & .00 \\
\hline 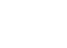 & $\because$ & $\because$ & $\because$ & $\because$ & $z$ & $\because=$ & $\overline{70}$ & $\because$ & 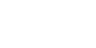 & $\because$ & $\because$ \\
\hline OEC. & -- & -- & -- & -- & -- & -- & $\ddot{-}$ & -- & $\because$ & -- & - \\
\hline JAN.". & -- & -- & -- & - & -- & -- & 100 & -- & -- & - & - \\
\hline 年 & -: & $\because$ & -: & $=$ & $\because$ & $=$ & 150 & $\because$ & -- & $=$ & $\because$ \\
\hline $\begin{array}{l}14 \ldots . . \\
14 \ldots\end{array}$ & $=$ & $=$ & $\because$ & $\because$ & $\because$ & $\because$ & $\because$ & $\because$ & $\because$ & $=$ & $\because$ \\
\hline 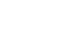 & 3.5 & 1.2 & 1.7 & $\therefore$ & $\therefore$ & $\therefore$ & $\because$ & $\because$ & $=$ & $\because$ & $\because$ \\
\hline $\begin{array}{l}\text { JuNE. } \\
\text { Gi..... }\end{array}$ & $\cdots$ & -- & $\cdots$ & -- & -- & -- & -- & -- & -- & -- & -- \\
\hline נüLY & -- & - & -- & -- & -- & -- & -- & -- & -- & -- & $\cdots$ \\
\hline $\begin{array}{l}01 \ldots \\
01 \ldots . . .\end{array}$ & $\because$ & $\because$ & $\because$ & $\because$ & $\because$ & $\because$ & $\because$ & $\because$ & $\because$ & $\because-$ & $\because$ \\
\hline Augs.... & -- & -- & -- & -- & -- & -- & -- & -- & -- & -- & -- \\
\hline$\underset{S E P .}{111}$ & -- & -- & -- & -- & -- & -- & -- & -- & -- & -- & -- \\
\hline $\begin{array}{l}f_{1}^{1} \ldots \ldots \\
0 \\
0\end{array}$ & $\because$ & $=$ & $\because$ & $\because$ & $\because$ & $\because$ & 100 & $\because$ & $\because$ & $\because$ & $\because-$ \\
\hline & ODT & $\begin{array}{l}01- \\
\text { ELORIN }\end{array}$ & ENDRIN & $\begin{array}{l}\text { HEPTA- } \\
\text { CHLJPF }\end{array}$ & $2,4,5-T$ & SILVEX & 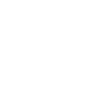 & $\begin{array}{l}\text { DIS- } \\
\text { SOLVED } \\
\text { SDLIDS } \\
\text { (SUM OF } \\
\text { CONSTI- } \\
\text { TUENTS) }\end{array}$ & 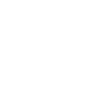 & 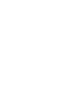 & $\begin{array}{l}\text { NI TRATE } \\
\text { (NO31) }\end{array}$ \\
\hline DATE & (UGM) & (UG/L) & (UG/L) & (UG/L) & rug/h & $(U G / L)$ & imGMi & (mG/Li & & $A C-F T)$ & \\
\hline 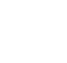 & $\stackrel{x}{-x}$ & $\stackrel{. \angle C}{--}$ & .00 &.$c c$ & .00 & .00 & 14 & 15 & 3.36 & .02 & $:^{5}$ \\
\hline $\begin{array}{l}\text { Nov. } \\
\text { of.... } \\
0.6 \%\end{array}$ & $\because$ & $\because$ & $\because-$ & -- & $=$ & $\because$ & 14 & 15 & $\begin{array}{r}3.63 \\
-.-\end{array}$ & $\because 02$ & 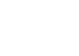 \\
\hline $\begin{array}{l}01 . . \\
01 \ldots\end{array}$ & $=$ & $\because-$ & $\because$ & -- & $=$ & $=$ & 16 & 17 & 4.23 & .02 & $\therefore$ \\
\hline 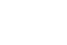 & $\because$ & $\because$ & $\because$ & -- & $=$ & $=$ & 16 & 14 & 4.28 & .02 & .7 \\
\hline $\begin{aligned} F[8 . \\
14 . .\end{aligned}$ & -- & -- & -- & -- & -- & -- & 11 & 16 & 3.18 & .01 & .4 \\
\hline mar & -- & -- & -- & & -. & -- & 14 & 14 & 3.78 & .02 & \\
\hline 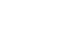 & - & -- & - & -- & -- & -- & $\ldots$ & -2 & ... & $\because$. & $\because 3$ \\
\hline $\begin{array}{lll}0 & 1 & \ldots \\
0 & 1 \ldots\end{array}$ & $\because-$ & $=$ & $=$ & $\because$ & $=$ & $=$ & 23 & 15 & 5.78 & .03 & i.: \\
\hline $\begin{array}{l}\text { r. } \\
\text { ril: } \\
01\end{array}$ & $\because-$ & $\because$ & $\because$ & $=$ & $\because$ & $\because$ & 20 & 17 & 4. 75 & .03 & $\therefore 2$ \\
\hline $\begin{array}{l}\text { AUg } \\
11 . .\end{array}$ & $\cdots$ & -- & -- & -- & - & -- & 16 & 13 & 4.32 & .02 & .3 \\
\hline $\begin{array}{c}17 . \\
s \in p .\end{array}$ & -- & -- & & -- & -- & $-\infty$ & & - & & -- & \\
\hline $01 \ldots$ & -- & $=$ & $\because-$ & $\because=$ & $=$ & $\because-$ & 24 & 16 & 5.98 & .03 & $\because 1$ \\
\hline
\end{tabular}


02197500 SAVANNAH RIVER AT BURTONS FERRY RIDGE, NEAR MILLLAVEN, GA.

LOCATION. --Lat $32^{\circ} 56^{\prime} 20^{\prime \prime}$, Long $81^{\circ} 30^{\prime} 10^{\prime \prime}$, Screven County, temperature recorder at gaging station on downstream side of left pler of drawspan of bridge on U.S. H1ghway 301,2 miles downstream from Rocky Creek, $9 \mathrm{~m} 11$ es east of
Mil lhaven, and at mile 129, 2 .

DRAINAGE AREA. $--8,650 \mathrm{sq} \mathrm{m}$, approximately.

PERIOD OF RBCORD. --Chemical anal yses: February 1968 to current year,

Water temperatyren: January 1956 to September 1970 (discontinued).

EXTR ENES. - $-1969-70$ :

Fater tomperatures: Maximum, $26.0^{\circ} \mathrm{C}$ Aug. $1,3-8 ;$ mintmum, $4.5^{\circ} \mathrm{C}$ Jan. $11,12$.

Perlod of record:

Water temperaturea: Maximum, $30.0^{\circ} \mathrm{C}$ Aug. 25, $1958 ;$ mintmum, 4.0 $0^{\circ} \mathrm{C}$ Feb. 19, $20,1058$.

REMAKs, - Field determination of dincharge, whter temperature, pH, and disaolved oxygen by U.s. Geological survey. Laboratory chemical analyoes by Georgia Fater Quality Control Board.

CHEMICAL ANALYSES, WATER YEAK OCTOHER I969 TD SEPTEMHFH 1970

\begin{tabular}{|c|c|c|c|c|c|}
\hline UATE & rIMF & $\begin{array}{l}\text { UIS- } \\
\text { CHAN(TE } \\
\text { lCFS) }\end{array}$ & $\begin{array}{c}\text { PH } \\
\text { (UNITS) }\end{array}$ & $\begin{array}{l}\text { TEMP- } \\
\text { ENATUHF } \\
\text { (DEG C) }\end{array}$ & $\begin{array}{l}\text { DIS- } \\
\text { SOLVED } \\
\text { OXYGEN } \\
\text { (MG/L) }\end{array}$ \\
\hline $\begin{array}{l}\text { JAN. } \\
\text { INS... }\end{array}$ & IAIS & 7700 & 0.19 & $A, n$ & 13.0 \\
\hline MAH. & 1630 & GRMOD & 7.1 & $4 . n$ & 4.7 \\
\hline dunf... & 1315 & $\angle A B O 0$ & 6.8 & 12,1 & A.? \\
\hline sut... & 1545 & 755 ! & 7.1 & $21 . n$ & 7.4 \\
\hline $\begin{array}{l}14 \ldots . . \\
\text { ster. }\end{array}$ & $075 n$ & 7900 & 7.0 & 74.0 & A.? \\
\hline 13... & 1610 & hall & 7.3 & 24.0 & 7.1 \\
\hline
\end{tabular}

\begin{tabular}{|c|c|c|c|c|c|c|c|c|c|c|}
\hline UATE & $\begin{array}{l}\text { SILICL } \\
\text { (SIOZ) } \\
(N G / L)\end{array}$ & $\begin{array}{l}\text { TOTAL } \\
\text { IRON } \\
\text { (F+) } \\
(\cup G / L)\end{array}$ & $\begin{array}{l}\text { TOTAL } \\
\text { MAN- } \\
\text { GANESE } \\
\text { (MNV) } \\
(J O / L)\end{array}$ & $\begin{array}{l}\text { OIS- } \\
\text { SOLVEO } \\
\text { CAL- } \\
\text { CIUM } \\
\text { (CA) } \\
\text { (MG/L) }\end{array}$ & $\begin{array}{l}\text { DIS- } \\
\text { SOLVED } \\
\text { MAG- } \\
\text { NE- } \\
\text { SIUM } \\
\text { (MG) } \\
\text { (MEIL) }\end{array}$ & $\begin{array}{l}\text { SODIUM } \\
\text { (NA) } \\
\text { (MG/L) }\end{array}$ & $\begin{array}{l}\text { PO- } \\
\text { YAS- } \\
\text { SIUM } \\
\text { (K) } \\
\text { (MG/L) }\end{array}$ & $\begin{array}{l}\text { ALKA- } \\
\text { LI'UITY } \\
\text { AS } \\
\text { CACO3 } \\
\text { (MG/I.) }\end{array}$ & $\begin{array}{l}\text { SULFATE } \\
\text { (SO4) } \\
\text { (MG/L) }\end{array}$ & $\begin{array}{l}\text { CHLO- } \\
\text { PIOE } \\
\text { (CL) } \\
\text { (MG/L) }\end{array}$ \\
\hline $\begin{array}{l}\text { JAIV. } \\
06 \ldots . .\end{array}$ & 10 & bou & $<50$ & 4.5 & 1.3 & 5.4 & 1.4 & -- & 4.0 & 4.7 \\
\hline $\begin{array}{l}\text { FER. } \\
16 . . .\end{array}$ & 9.9 & 550 & $<50$ & 4.2 & 1.2 & 8.0 & $1 . A$ & 21 & 4.0 & 6.2 \\
\hline${ }_{\text {Jutive }}^{24}$ & $4 . n$ & 3000 & 50 & 4.1 & 1.3 & 5.4 & 2.0 & 14 & 0.0 & 4.4 \\
\hline "uL. & $7 .-$ & 400 & $<b u$ & 4.2 & $1 \cdot 2$ & 8.5 & 1.5 & 20 & 6.0 & 6.7 \\
\hline SEPT. & $4 \cdot \rightarrow$ & 11110 & $<50$ & 3.6 & 1.2 & 6.3 & 1.5 & 19 & 10 & 5.0 \\
\hline $15 \ldots$ & 4. 1 & $37 \cdot j$ & $<5 u$ & 3.3 & 1.1 & 7.6 & 1.6 & 21 & 5.0 & 6.7 \\
\hline & & & $\begin{array}{l}\text { TOTAL } \\
\text { FILT- }\end{array}$ & $\begin{array}{l}\text { TOTAL. } \\
\text { NON- } \\
\text { FILT- }\end{array}$ & & $\begin{array}{l}\text { SPECI- } \\
\text { FIC }\end{array}$ & COLOR & & $\begin{array}{l}\text { BIO- } \\
\text { CHEM- }\end{array}$ & $\begin{array}{l}\text { FECA:- } \\
\text { COLI- } \\
\text { FORM }\end{array}$ \\
\hline UATE & $\begin{array}{c}\text { NITHATt } \\
(N)) \\
(M, J L)\end{array}$ & $\begin{array}{l}\text { PHOS- } \\
\text { PHATE } \\
\text { (PO4) } \\
(M G / L)\end{array}$ & $\begin{array}{l}\text { NABLE } \\
\text { RESIDUE } \\
\text { (MG }\end{array}$ & $\begin{array}{l}\text { HABLE } \\
\text { RESIUUE } \\
\text { (MG/L) }\end{array}$ & $\begin{array}{l}\text { HAHS - } \\
\text { NESS } \\
\text { (CA.MG) } \\
\text { (MC, /L) }\end{array}$ & $\begin{array}{l}\text { COND- } \\
\text { UCTANCE } \\
\text { (MICRO- } \\
\text { MHOS) }\end{array}$ & $\begin{array}{l}\text { (PLAT- } \\
\text { INUM- } \\
\text { COBALT } \\
\text { UNITS) }\end{array}$ & $\begin{array}{l}\text { TUP- } \\
\text { AIO- } \\
\text { ITY } \\
\text { (JTUI }\end{array}$ & $\begin{array}{l}\text { ICAL } \\
\text { OXYGFN } \\
\text { DEMANO } \\
\text { (MG/L) }\end{array}$ & $\begin{array}{c}\text { ICOL. } \\
\text { PER } \\
100 \mathrm{MLI} \\
\text { (MPN) }\end{array}$ \\
\hline $\begin{array}{l}\text { JAN. } \\
\text { HAE... }\end{array}$ & $\cdot 2$ & .38 & 54 & 13 & 17 & 69 & 25 & 11 & 1.4 & $\tilde{2} \mathbf{3}$ \\
\hline 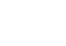 & - 2 & . 55 & 44 & 2 & 14 & 78 & 20 & 11 & 1.3 & \\
\hline JUNE". & $\cdot \hat{z}$ & .26 & 113 & 04 & 16 & 95 & 140 & 68 & 2.5 & 750 \\
\hline JULY" & .4 & .17 & 73 & 9 & 16 & 70 & 40 & 15 & 1.2 & 4300 \\
\hline $\begin{array}{l}14 \ldots . . \\
S E F, "\end{array}$ & . & . 25 & $=$ & $n=$ & 14 & 65 & $=$ & 19 & 1.0 & $=0$ \\
\hline $15, \ldots$ & .3 & 1.0 & 60 & 1月 & 14 & 74 & 25 & A. 0 & .6 & 4300 \\
\hline
\end{tabular}


SAVANNAH RIVER GASIN

O2107600 SAYANAAH RIVER AT BURTONS FERRY RIDGE, KEAR MILLHAVEN, GA, --COntInUed

TEMPERATURE ('0) OF WATER, WATER YEAR OCTOBER 1969 TO SEPTEMBER 1970

\begin{tabular}{|c|c|c|c|c|c|c|c|c|c|c|c|c|}
\hline \multirow[b]{2}{*}{ DAY } & \multicolumn{2}{|c|}{ OCTOEER } & \multicolumn{2}{|c|}{ NOVEMBER } & \multicolumn{2}{|c|}{ OECEMBER } & \multicolumn{2}{|c|}{ JANUARY } & \multicolumn{2}{|c|}{ FEBRUARY } & \multicolumn{2}{|c|}{ MARCH } \\
\hline & $\operatorname{MAX}$ & MIN & $\operatorname{mAX}$ & MIN & $\operatorname{MAX}$ & MIN & MAX & MIN & $\operatorname{MAX}$ & MIN & MAX & MIN \\
\hline $\begin{array}{l}1 \\
2 \\
3 \\
4 \\
5\end{array}$ & $\begin{array}{l}21.00 \\
21.00 \\
211.0 \\
21.00 \\
21.0\end{array}$ & $\begin{array}{l}21.0 \\
21.0 \\
21.0 \\
21.0 \\
21.0\end{array}$ & $\begin{array}{l}17.0 \\
17.0 \\
17.0 \\
17.0 \\
17.0\end{array}$ & $\begin{array}{l}17.0 \\
17.0 \\
17.0 \\
17.0 \\
16.0\end{array}$ & $\begin{array}{r}10.5 \\
10.0 \\
9.5 \\
9.0 \\
8.0\end{array}$ & $\begin{array}{r}10.0 \\
9.5 \\
9.0 \\
8.0 \\
7.0\end{array}$ & $\begin{array}{l}9.0 \\
9.0 \\
9.0 \\
9.0 \\
0.5\end{array}$ & $\begin{array}{l}9.0 \\
9.0 \\
9.0 \\
8.5 \\
8.0\end{array}$ & $\begin{array}{l}9.5 \\
9.5 \\
9.5 \\
9.5 \\
9.0\end{array}$ & $\begin{array}{l}9.5 \\
9.5 \\
9.5 \\
9.0 \\
8.5\end{array}$ & $\begin{array}{l}10.0 \\
10.5 \\
11.5 \\
11.5 \\
11.5\end{array}$ & $\begin{array}{l}9.5 \\
10.0 \\
10.5 \\
11.5 \\
11.5\end{array}$ \\
\hline $\begin{array}{r}6 \\
7 \\
9 \\
10\end{array}$ & $\begin{array}{l}21.00 \\
21.00 \\
21.00 \\
21.0 \\
21.00\end{array}$ & $\begin{array}{l}21.0 \\
21.0 \\
21.0 \\
21.0 \\
21.0\end{array}$ & $\begin{array}{l}16.0 \\
15.5 \\
15.0 \\
15.0 \\
15.0\end{array}$ & $\begin{array}{l}15.5 \\
15.0 \\
14.5 \\
14.5 \\
15.0\end{array}$ & $\begin{array}{l}7.0 \\
8.0 \\
8.5 \\
8.5 \\
8.0\end{array}$ & $\begin{array}{l}7.0 \\
7.0 \\
8.0 \\
8.0 \\
8.0\end{array}$ & $\begin{array}{l}8.5 \\
8.5 \\
8.0 \\
6.0 \\
6.0\end{array}$ & $\begin{array}{l}8.0 \\
8.0 \\
6.0 \\
6.0 \\
5.0\end{array}$ & $\begin{array}{l}9.0 \\
8.5 \\
9.0 \\
9.0 \\
9.0\end{array}$ & $\begin{array}{l}8.5 \\
8.5 \\
8.5 \\
9.0 \\
9.0\end{array}$ & $\begin{array}{l}11.5 \\
12.0 \\
12.0 \\
12.0 \\
12.0\end{array}$ & $\begin{array}{l}11.5 \\
11.5 \\
12.0 \\
12.0 \\
12.0\end{array}$ \\
\hline $\begin{array}{l}11 \\
12 \\
13 \\
14 \\
15\end{array}$ & $\begin{array}{l}21.0 \\
21.00 \\
21.00 \\
21.0 \\
21.0\end{array}$ & $\begin{array}{l}21.0 \\
21.0 \\
21.0 \\
21.0 \\
21.0\end{array}$ & $\begin{array}{l}15.0 \\
15.0 \\
14.5 \\
14.5 \\
14.0\end{array}$ & $\begin{array}{l}15.0 \\
14.5 \\
14.5 \\
14.0 \\
13.0\end{array}$ & $\begin{array}{l}8.0 \\
8.0 \\
8.5 \\
8.5 \\
8.0\end{array}$ & $\begin{array}{l}8.0 \\
8.0 \\
8.0 \\
8.0 \\
8.0\end{array}$ & $\begin{array}{l}5.0 \\
5.0 \\
5.0 \\
5.5 \\
5.5\end{array}$ & $\begin{array}{l}4.5 \\
4.5 \\
5.8 \\
5.5 \\
5.5\end{array}$ & $\begin{array}{l}9.0 \\
8.5 \\
8.5 \\
6.5 \\
9.0\end{array}$ & $\begin{array}{l}8.5 \\
8.5 \\
8.5 \\
8.5 \\
8.5\end{array}$ & $\begin{array}{l}12.0 \\
13.5 \\
14.0 \\
14.0 \\
14.0\end{array}$ & $\begin{array}{l}12.0 \\
12.0 \\
13.5 \\
14.0 \\
14.0\end{array}$ \\
\hline $\begin{array}{l}16 \\
17 \\
18 \\
19 \\
20\end{array}$ & $\begin{array}{r}21.0 \\
0 \\
0\end{array}$ & $\begin{array}{r}21.0 \\
\ldots \\
0\end{array}$ & $\begin{array}{l}13.0 \\
11.5 \\
11.5 \\
11.5 \\
11.5\end{array}$ & $\begin{array}{l}11.5 \\
11.5 \\
11.5 \\
11.0 \\
11.5\end{array}$ & $\begin{array}{l}8.0 \\
8.0 \\
8.0 \\
8.0 \\
8.0\end{array}$ & $\begin{array}{l}8.0 \\
8.0 \\
7.0 \\
6.5 \\
8.0\end{array}$ & $\begin{array}{l}6.0 \\
6.0 \\
8.0 \\
8.5 \\
8.5\end{array}$ & $\begin{array}{l}5.5 \\
6.0 \\
6.5 \\
8.0 \\
8.5\end{array}$ & $\begin{array}{l}9.0 \\
9.0 \\
9.0 \\
9.0 \\
9.0\end{array}$ & $\begin{array}{l}9.0 \\
9.0 \\
9.0 \\
9.0 \\
9.0\end{array}$ & $\begin{array}{l}14.0 \\
13.5 \\
13.0 \\
13.0 \\
13.5\end{array}$ & $\begin{array}{l}13.5 \\
13.0 \\
13.0 \\
13.0 \\
13.0\end{array}$ \\
\hline $\begin{array}{l}21 \\
22 \\
23 \\
24 \\
25\end{array}$ & 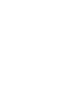 & $m$ & $\begin{array}{l}11.5 \\
11.0 \\
11.0 \\
11.0 \\
11.0\end{array}$ & $\begin{array}{l}11.5 \\
10.5 \\
10.5 \\
11.0 \\
10.5\end{array}$ & $\begin{array}{l}8.0 \\
7.0 \\
7.0 \\
8.0 \\
8.0\end{array}$ & $\begin{array}{l}7.0 \\
7.0 \\
7.0 \\
7.0 \\
7.0\end{array}$ & $\begin{array}{l}0.5 \\
8.5 \\
7.0 \\
6.5 \\
6.5\end{array}$ & $\begin{array}{l}8.5 \\
6.0 \\
6.5 \\
6.5 \\
6.5\end{array}$ & $\begin{array}{l}9.0 \\
9.0 \\
9.5 \\
9.5 \\
9.5\end{array}$ & $\begin{array}{l}9.0 \\
9.0 \\
9.5 \\
9.5 \\
9.5\end{array}$ & $\begin{array}{l}13.5 \\
13.5 \\
13.5 \\
13.5 \\
13.5\end{array}$ & $\begin{array}{l}13.5 \\
13.5 \\
13.5 \\
13.0 \\
13.5\end{array}$ \\
\hline $\begin{array}{l}26 \\
27 \\
28 \\
29 \\
30 \\
31\end{array}$ & $\begin{array}{r}\ldots 0 \\
18.0 \\
18.0 \\
18.0 \\
17.5\end{array}$ & $\begin{array}{l}\ldots 0 \\
20.0 \\
18.0 \\
18.0 \\
17.5 \\
17.0\end{array}$ & $\begin{array}{l}11.0 \\
11: 0 \\
1100 \\
11.0 \\
11.0\end{array}$ & $\begin{array}{l}30.0 \\
30.5 \\
11.0 \\
10.5 \\
10.5 \\
\ldots\end{array}$ & $\begin{array}{l}9.0 \\
8.0 \\
8.0 \\
7.0 \\
7.0 \\
9.0\end{array}$ & $\begin{array}{l}8.0 \\
8.0 \\
7.0 \\
7.0 \\
7.0 \\
8.0\end{array}$ & $\begin{array}{l}8.0 \\
8.0 \\
8.0 \\
9.5 \\
9.5 \\
9.5\end{array}$ & $\begin{array}{l}7.0 \\
8.0 \\
8.0 \\
8.0 \\
9.5 \\
9.5\end{array}$ & $\begin{array}{l}9.5 \\
9.5 \\
9.5 \\
=-\infty \\
-\ldots-\infty\end{array}$ & $\begin{array}{l}9.5 \\
9.0 \\
9.5 \\
0.5 \\
0.0\end{array}$ & $\begin{array}{l}13.5 \\
14.0 \\
14.0 \\
14.0 \\
14.0 \\
14.0\end{array}$ & $\begin{array}{l}13.5 \\
13.5 \\
14.0 \\
14.0 \\
14.0 \\
14.0\end{array}$ \\
\hline \multirow[t]{2}{*}{ MONTH } & $-\infty$ & $\infty$ & 27.0 & 30.0 & 10.5 & 6.5 & 9.5 & 4.5 & 9.5 & 0.5 & Lwo & Or \\
\hline & \multicolumn{2}{|c|}{ APRIL } & \multicolumn{2}{|c|}{ MaY } & \multicolumn{2}{|c|}{ JUNE } & \multicolumn{2}{|c|}{ MHYY } & \multicolumn{2}{|c|}{ AUOUST } & \multicolumn{2}{|c|}{ SEPTEMBER } \\
\hline DAY & $\max$ & MIN & $\operatorname{MAX}$ & MIN & MAX & MIN & $\operatorname{mAX}$ & MIN & MAX & MIN & MAX & MIN \\
\hline $\begin{array}{l}1 \\
2 \\
3 \\
4 \\
5\end{array}$ & $\begin{array}{l}14.0 \\
14.0 \\
14.0 \\
14.0 \\
14.0\end{array}$ & $\begin{array}{l}14.0 \\
14.0 \\
14.0 \\
14.0 \\
14.0\end{array}$ & $\begin{array}{l}20.5 \\
20.0 \\
20.0 \\
20.0 \\
19.0\end{array}$ & $\begin{array}{l}20.0 \\
20.0 \\
20.0 \\
19.0 \\
18.0\end{array}$ & $\begin{array}{l}21.5 \\
21.5 \\
21.5 \\
21.5 \\
21.5\end{array}$ & $\begin{array}{l}21.5 \\
21.5 \\
21.5 \\
21.5 \\
21.5\end{array}$ & $\begin{array}{l}24.0 \\
24.5 \\
24.5 \\
24.5 \\
24.0\end{array}$ & $\begin{array}{l}23.5 \\
24.0 \\
24.0 \\
24.0 \\
24.0\end{array}$ & $\begin{array}{l}26.0 \\
25.5 \\
26.0 \\
26.0 \\
26.0\end{array}$ & $\begin{array}{l}25.5 \\
25.0 \\
25.0 \\
25.5 \\
26.0\end{array}$ & $\begin{array}{l}25.5 \\
25.5 \\
25.0 \\
25.0 \\
25.0\end{array}$ & $\begin{array}{l}25.0 \\
25.0 \\
25.0 \\
25.0 \\
25.0\end{array}$ \\
\hline $\begin{array}{r}6 \\
7 \\
8 \\
9 \\
10\end{array}$ & $\begin{array}{l}14.0 \\
15.0 \\
15.0 \\
15.5 \\
16.0\end{array}$ & $\begin{array}{l}14.0 \\
14.0 \\
15.0 \\
15.0 \\
15.5\end{array}$ & $\begin{array}{l}18.0 \\
18.0 \\
19.0 \\
20.0 \\
20.0\end{array}$ & $\begin{array}{l}18.0 \\
18.0 \\
18.0 \\
19.0 \\
20.0\end{array}$ & $\begin{array}{l}21.5 \\
21.5 \\
21.5 \\
21.5 \\
21.5\end{array}$ & $\begin{array}{l}21.5 \\
21.55 \\
21.5 \\
21.5 \\
21.5\end{array}$ & $\begin{array}{l}24.0 \\
24.00 \\
24.0 \\
24.0 \\
24.0\end{array}$ & $\begin{array}{l}24.0 \\
24.0 \\
24.0 \\
24.0 \\
24.0\end{array}$ & $\begin{array}{l}26.0 \\
26.0 \\
26.0 \\
25.5 \\
25.5\end{array}$ & $\begin{array}{l}26.0 \\
25.5 \\
25.5 \\
25.0 \\
25.0\end{array}$ & $\begin{array}{l}25.0 \\
25.0 \\
25.0 \\
25.0 \\
25.0\end{array}$ & $\begin{array}{l}25.0 \\
25.0 \\
25.0 \\
25.0 \\
25.0\end{array}$ \\
\hline $\begin{array}{l}11 \\
12 \\
13 \\
14 \\
15\end{array}$ & $\begin{array}{l}16.0 \\
16.0 \\
16.0 \\
16.0 \\
16.5\end{array}$ & $\begin{array}{l}15.5 \\
15.5 \\
15.5 \\
16.0 \\
16.5\end{array}$ & $\begin{array}{l}20.0 \\
20.0 \\
20.5 \\
20.5 \\
20.5\end{array}$ & $\begin{array}{l}20.0 \\
20.0 \\
20.0 \\
20.5 \\
20.5\end{array}$ & $\begin{array}{l}21.5 \\
21.5 \\
21.5 \\
21.5 \\
21.5\end{array}$ & $\begin{array}{l}21.5 \\
21.0 \\
21.5 \\
21.5 \\
21.5\end{array}$ & $\begin{array}{l}24.0 \\
24.0 \\
24.0 \\
25.0 \\
25.0\end{array}$ & $\begin{array}{l}24.0 \\
24.0 \\
24.0 \\
24.5 \\
24.5\end{array}$ & $\begin{array}{l}25.5 \\
25.5 \\
25.0 \\
24.5 \\
24.0\end{array}$ & $\begin{array}{l}25.0 \\
24.5 \\
24.5 \\
24.0 \\
23.5\end{array}$ & $\begin{array}{l}25.0 \\
25.0 \\
25.0 \\
24.0 \\
24.5\end{array}$ & $\begin{array}{l}25.0 \\
24.5 \\
24.5 \\
24.5 \\
24.5\end{array}$ \\
\hline $\begin{array}{l}16 \\
17 \\
18 \\
19 \\
20\end{array}$ & $\begin{array}{l}16.5 \\
16.5 \\
16.5 \\
17.0 \\
17.5\end{array}$ & $\begin{array}{l}16.5 \\
16.5 \\
16.5 \\
16.5 \\
17.0\end{array}$ & $\begin{array}{l}20.5 \\
20.5 \\
20.5 \\
20.5 \\
20.5\end{array}$ & $\begin{array}{l}20.5 \\
20.5 \\
20.5 \\
20.5 \\
20.5\end{array}$ & $\begin{array}{l}22.0 \\
22.5 \\
23.5 \\
24.0 \\
24.0\end{array}$ & $\begin{array}{l}21.5 \\
22.0 \\
22.5 \\
23.5 \\
24.0\end{array}$ & $\begin{array}{l}25.0 \\
24.5 \\
24.5 \\
24.5 \\
24.5\end{array}$ & $\begin{array}{l}24.5 \\
24.5 \\
24.5 \\
24.5 \\
24.5\end{array}$ & $\begin{array}{l}24.0 \\
24.5 \\
25.0 \\
25.5 \\
25.5\end{array}$ & $\begin{array}{l}23.5 \\
24.0 \\
24.5 \\
25.0 \\
25.0\end{array}$ & $\begin{array}{l}24.5 \\
24.5 \\
24.00 \\
24.00 \\
24.00\end{array}$ & $\begin{array}{l}24.0 \\
24.0 \\
24.0 \\
24.0 \\
24.0\end{array}$ \\
\hline $\begin{array}{l}21 \\
22 \\
23 \\
24 \\
25\end{array}$ & $\begin{array}{l}19.0 \\
19.5 \\
20.0 \\
20.5 \\
20.5\end{array}$ & $\begin{array}{l}17.5 \\
19.0 \\
19.5 \\
20.0 \\
20.5\end{array}$ & $\begin{array}{l}21.0 \\
21.5 \\
21.5 \\
21.5 \\
21.5\end{array}$ & $\begin{array}{l}20.5 \\
21.0 \\
21.5 \\
21.5 \\
21.5\end{array}$ & $\begin{array}{l}24.5 \\
24.5 \\
24.0 \\
24.5 \\
24.5\end{array}$ & $\begin{array}{l}24.0 \\
24.5 \\
24.0 \\
24.0 \\
24.5\end{array}$ & $\begin{array}{l}25.0 \\
24.5 \\
24.5 \\
24.5 \\
24.5\end{array}$ & $\begin{array}{l}24.5 \\
24.5 \\
24.5 \\
24.0 \\
24.0\end{array}$ & $\begin{array}{l}25.5 \\
25.0 \\
25.0 \\
25.0 \\
25.0\end{array}$ & $\begin{array}{l}25.0 \\
25.0 \\
25.0 \\
25.0 \\
25.0\end{array}$ & $\begin{array}{l}24.5 \\
24.5 \\
24.5 \\
24.5 \\
24.5\end{array}$ & $\begin{array}{l}24.0 \\
24.0 \\
24.0 \\
24.0 \\
24.0\end{array}$ \\
\hline $\begin{array}{l}26 \\
27 \\
28 \\
29 \\
30 \\
31\end{array}$ & $\begin{array}{r}20.5 \\
20.5 \\
20.5 \\
20.5 \\
20.5 \\
\end{array}$ & $\begin{array}{l}20.5 \\
20.5 \\
20.5 \\
20.5 \\
20.5 \\
\ldots\end{array}$ & $\begin{array}{l}21.5 \\
21.5 \\
21.5 \\
21.5 \\
21.5 \\
21.5\end{array}$ & $\begin{array}{l}21 \cdot 5 \\
21 \cdot 5 \\
21.5 \\
21.5 \\
21 \cdot 5 \\
21.5\end{array}$ & $\begin{array}{r}24.0 \\
24.0 \\
24.0 \\
24.0 \\
23.0 \\
=0\end{array}$ & $\begin{array}{r}24.0 \\
24.0 \\
24.0 \\
23.5 \\
23.5 \\
=0\end{array}$ & $\begin{array}{l}25.0 \\
25.0 \\
25.0 \\
25.5 \\
25.5 \\
25.5\end{array}$ & $\begin{array}{l}24.0 \\
24.5 \\
24.5 \\
25.0 \\
25.5 \\
25.5\end{array}$ & $\begin{array}{l}25.0 \\
25.0 \\
25.0 \\
25.0 \\
25.5 \\
25.5\end{array}$ & $\begin{array}{l}25.0 \\
25.0 \\
25.0 \\
25.0 \\
25.0 \\
25.0\end{array}$ & $\begin{array}{r}24.5 \\
24.5 \\
24.5 \\
24.5 \\
23.5 \\
.00\end{array}$ & $\begin{array}{r}24.5 \\
24.5 \\
24.5 \\
23.5 \\
22.0 \\
=\ldots\end{array}$ \\
\hline MONTK & eors & 24.0 & 21.5 & 18.0 & 24.5 & 21.0 & 25.5 & 23.5 & 26.0 & 23.5 & 25.5 & 22.0 \\
\hline
\end{tabular}


02212600 FALLING CREEK NEAR JULIETTE, GA.

(Hydrologic bench-mark station)

LOCATION.--Lat $33^{\circ} 05^{\prime} 59^{\prime \prime}$, long $83^{\circ} 43^{\prime} 25^{\prime \prime}$, Jones County, at gaging station on left bank $100 \mathrm{ft}$ upstream from highway brtdge, 4 miles upstream from Caney Creek, and 5.1 miles east of Juliette.

DRAINAGE AREA. --72.2 sq $\mathrm{mi}$.

PERIOD OF RECORD,--Chemical analyses: October 1967 to September 1970.

Water temperatures: August 1965 to September 1970.

EXTREMES, --1969-70:

Water temperatures: Maximum, $31.5^{\circ} \mathrm{C}$ Aug. 3 ; minimum, freezing point Jan, 9, 10.

Pertod of record:

Water temperatures: Maximum, $31.5^{\circ} \mathrm{C}$ Aug. 3, 1970; minimum, freezing point Jan. 9, $10,1970$.

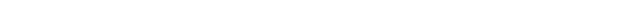

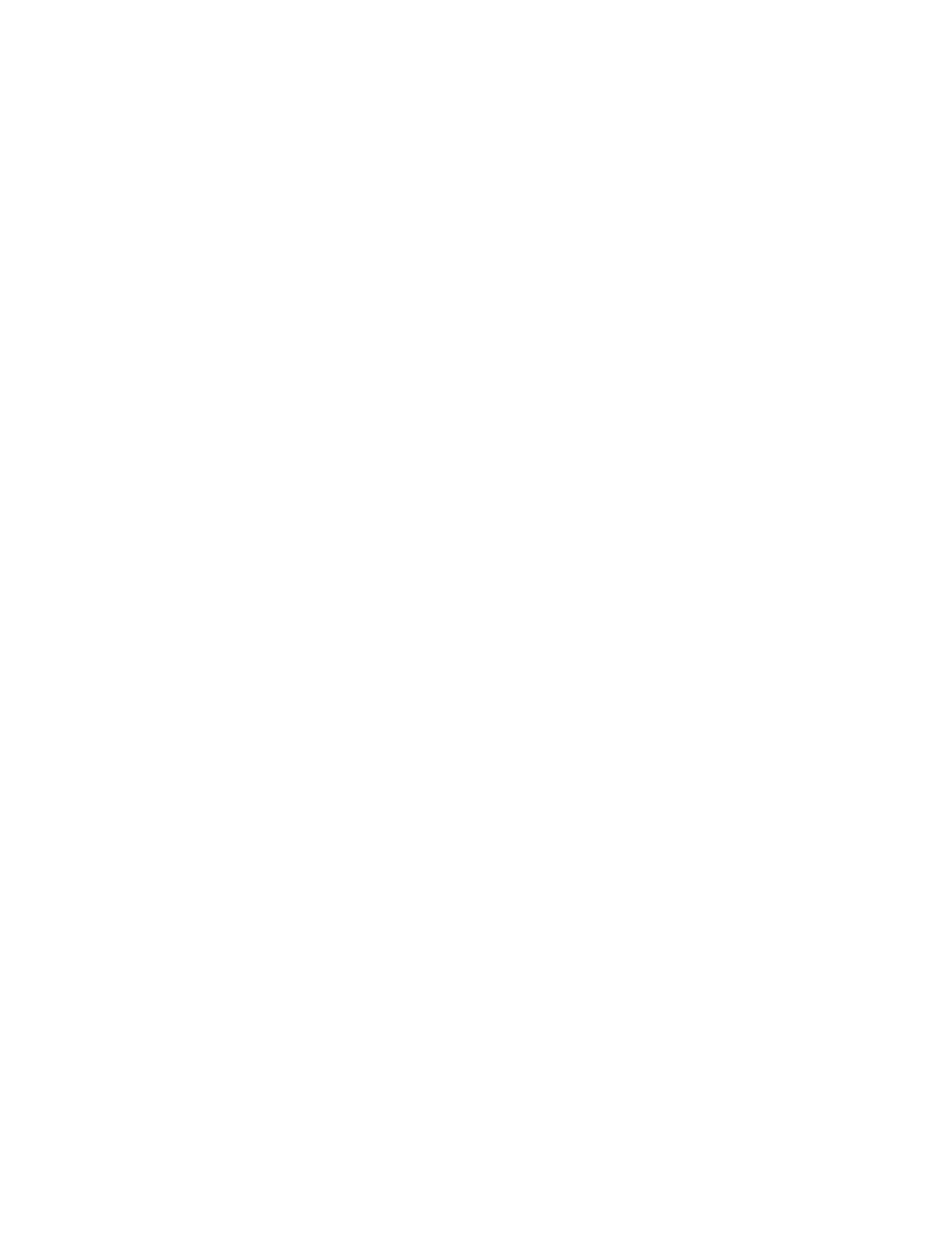


02212600 FALLING CREEK NEAR JULIETTE, GA.--Continued

CHEMICAL ANALYSES, WATER YEAR OCTOBER 1969 TO SEPTEMBER 1970

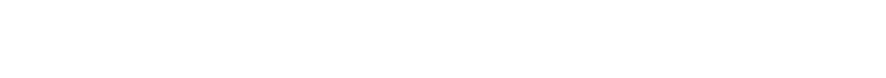

$$
\begin{aligned}
& \text { AINALYSIS IJF OIMITIIJNAL SAMPLE }
\end{aligned}
$$

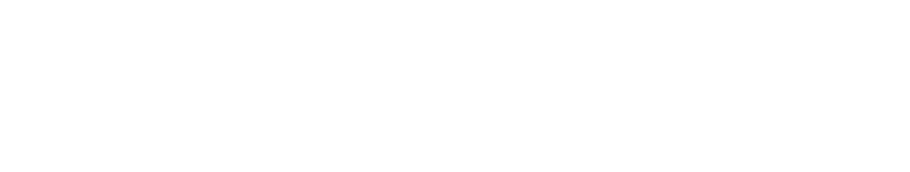

$$
\begin{aligned}
& \text { SHT. }
\end{aligned}
$$

TEMPERATURE ( $\left.{ }^{\circ} \mathrm{C}\right)$ OF WATER, hATER YEAR OCTOBER 1969 TO SEPTEMBER 1970

OCTIHEH NOVEMHEH DH.CFMGFK JANIAARY FEBPUARY

MARCH

\begin{tabular}{|c|c|c|c|c|c|c|c|c|c|c|c|c|}
\hline HaY & $\max$ & 410 & $\operatorname{Max}$ & YIN & $\operatorname{MAX}$ & $M I^{M !}$ & $M \triangle x$ & MIN & $M \Delta x$ & MIN & $\operatorname{MAX}$ & MIN \\
\hline $\begin{array}{l}1 \\
\dot{c} \\
3 \\
4 \\
3\end{array}$ & $\begin{array}{l}19.0 \\
19.0 \\
14.0 \\
19.5 \\
19.0\end{array}$ & $\begin{array}{l}17.11 \\
17.11 \\
19.5 \\
17.11 \\
17.0\end{array}$ & $\begin{array}{l}15.01 \\
16.0 \\
10.0 \\
14.0 \\
11.0\end{array}$ & $\begin{array}{l}14.5 \\
10.0 \\
14.0 \\
11.0 \\
4.5\end{array}$ & $\begin{array}{l}4.0 \\
4.0 \\
7.0 \\
0.5 \\
2.0\end{array}$ & $\begin{array}{l}3.5 \\
5.5 \\
5.0 \\
5.11 \\
3.5\end{array}$ & $\begin{array}{l}9.0 \\
6.5 \\
5.0 \\
4.0 \\
4.0\end{array}$ & $\begin{array}{l}0.5 \\
4.5 \\
4.0 \\
3.0 \\
2.0\end{array}$ & $\begin{array}{l}6.0 \\
9.0 \\
9.0 \\
5.0 \\
4.5\end{array}$ & $\begin{array}{l}4.0 \\
6.0 \\
6.0 \\
3.5 \\
3.0\end{array}$ & $\begin{array}{l}13.5 \\
14.5 \\
15.0 \\
15.0 \\
16.5\end{array}$ & $\begin{array}{l}10.5 \\
10.5 \\
11.5 \\
14.0 \\
14.5\end{array}$ \\
\hline $\begin{array}{r}6 \\
7 \\
4 \\
4 \\
10\end{array}$ & $\begin{array}{l}14.5 \\
14.0 \\
14.5 \\
14.5 \\
14.5\end{array}$ & $\begin{array}{l}17.9 \\
19.4 \\
14.01 \\
14.1 \\
13.11\end{array}$ & $\begin{array}{l}11104 \\
1103 \\
1105 \\
110 \\
11.8\end{array}$ & $\begin{array}{l}4.5 \\
9.5 \\
4.5 \\
4.0 \\
4.0\end{array}$ & $\begin{array}{l}5.5 \\
9.0 \\
4.0 \\
.00 \\
7.0\end{array}$ & $\begin{array}{l}5.0 \\
5.5 \\
4.0 \\
6.5 \\
0.5\end{array}$ & $\begin{array}{l}4.5 \\
4.5 \\
2.0 \\
0.5 \\
0.5\end{array}$ & $\begin{array}{l}4.0 \\
2.0 \\
0.0 \\
0 \\
0\end{array}$ & $\begin{array}{l}5.5 \\
4.5 \\
7.0 \\
8.0 \\
6.5\end{array}$ & $\begin{array}{l}3.5 \\
4.0 \\
4.5 \\
6.5 \\
5.0\end{array}$ & $\begin{array}{l}16.0 \\
14.0 \\
13.5 \\
15.5 \\
16.0\end{array}$ & $\begin{array}{l}12.0 \\
13.0 \\
12.0 \\
11.0 \\
11.0\end{array}$ \\
\hline $\begin{array}{l}11 \\
12 \\
13 \\
14 \\
15\end{array}$ & $\begin{array}{l}14.5 \\
10.5 \\
20.0 \\
20.0 \\
10.4\end{array}$ & $\begin{array}{l}17.01 \\
17.0 \\
17.01 \\
170 \\
17.11\end{array}$ & 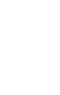 & $\begin{array}{r}4.0 \\
11.0 \\
11.0 \\
0.0 \\
4.3\end{array}$ & $\begin{array}{l}4.5 \\
4.0 \\
0.0 \\
7.0 \\
0.5\end{array}$ & $\begin{array}{l}7.0 \\
6.0 \\
4.5 \\
5.0 \\
5.0\end{array}$ & $\begin{array}{l}0.5 \\
2.0 \\
3.0 \\
3.5 \\
4.5\end{array}$ & $\begin{array}{l}0.5 \\
0.5 \\
1.5 \\
0.5 \\
3.0\end{array}$ & $\begin{array}{r}8.0 \\
8.0 \\
7.0 \\
8.5 \\
10.5\end{array}$ & $\begin{array}{l}4.0 \\
5.5 \\
4.0 \\
4.5 \\
0.0\end{array}$ & $\begin{array}{l}15.0 \\
18.0 \\
16.0 \\
13.0 \\
12.0\end{array}$ & $\begin{array}{r}11.5 \\
14.5 \\
10.5 \\
9.0 \\
8.0\end{array}$ \\
\hline $\begin{array}{l}16 \\
17 \\
14 \\
14 \\
20\end{array}$ & $\begin{array}{l}18.5 \\
17.0 \\
15.0 \\
14.0 \\
14.5\end{array}$ & $\begin{array}{l}15.0 \\
15.41 \\
12.01 \\
1+, " 11 \\
16.01\end{array}$ & $\begin{array}{l}6.7 \\
4.11 \\
11.0 \\
12.01 \\
111.01\end{array}$ & $\begin{array}{r}4.5 \\
3.0 \\
4.0 \\
1100 \\
\rightarrow .0\end{array}$ & $\begin{array}{l}5.5 \\
4.5 \\
4.0 \\
0.0 \\
5.0\end{array}$ & $\begin{array}{l}4.0 \\
3.0 \\
2.0 \\
4.0 \\
4 \cdot 0\end{array}$ & $\begin{array}{l}6.0 \\
0.5 \\
9.0 \\
8.5 \\
7.5\end{array}$ & $\begin{array}{l}4.0 \\
6.0 \\
5.5 \\
7.0 \\
5.0\end{array}$ & $\begin{array}{l}10.5 \\
10.5 \\
11.5 \\
12.0 \\
11.5\end{array}$ & $\begin{array}{r}10.0 \\
9.5 \\
10.0 \\
9.0 \\
9.0\end{array}$ & $\begin{array}{l}12.0 \\
11.5 \\
15.5 \\
14.5 \\
15.0\end{array}$ & $\begin{array}{r}7.0 \\
7.0 \\
11.5 \\
13.0 \\
14.0\end{array}$ \\
\hline $\begin{array}{l}21 \\
22 \\
23 \\
24 \\
45\end{array}$ & $\begin{array}{l}14.5 \\
14.5 \\
15.0 \\
13.5 \\
14.5\end{array}$ & $\begin{array}{l}14,3 \\
15,01 \\
13,01 \\
11,3 \\
13,1\end{array}$ & $\begin{array}{l}3.4 \\
401 \\
11011 \\
11011\end{array}$ & $\begin{array}{l}n \cdot 0 \\
2.5 \\
n \cdot 5 \\
0.5 \\
4.5\end{array}$ & $\begin{array}{l}4.0 \\
4.5 \\
4.5 \\
4.5 \\
4.0\end{array}$ & $\begin{array}{l}3.5 \\
4.5 \\
4.0 \\
3.5 \\
3.5\end{array}$ & $\begin{array}{l}5.0 \\
2.0 \\
3.0 \\
4.0 \\
5.0\end{array}$ & $\begin{array}{l}3.0 \\
1.0 \\
1.5 \\
2.0 \\
2.0\end{array}$ & $\begin{array}{l}10.0 \\
10.0 \\
11.5 \\
12.0 \\
11.5\end{array}$ & $\begin{array}{r}9.0 \\
5.5 \\
9.0 \\
10.0 \\
10.5\end{array}$ & $\begin{array}{l}15.0 \\
13.0 \\
11.5 \\
12.0 \\
14.5\end{array}$ & $\begin{array}{l}13.0 \\
11.5 \\
10.0 \\
10.5 \\
11.5\end{array}$ \\
\hline $\begin{array}{l}36 \\
37 \\
34 \\
24 \\
30 \\
31\end{array}$ & $\begin{array}{l}16.11 \\
10.0 \\
16.0 \\
14.5 \\
13.0 \\
14.5\end{array}$ & $\begin{array}{l}15.11 \\
13.5 \\
14.11 \\
11.5 \\
11.5 \\
11.01\end{array}$ & $\begin{array}{c}13.11 \\
11.11 \\
11.3 \\
11.01 \\
\ldots .3\end{array}$ & $\begin{array}{r}11.0 \\
y .0 \\
16.5 \\
y .0 \\
7.0 \\
0 .-0\end{array}$ & $\begin{array}{r}3.0 \\
4.5 \\
5.0 \\
7.0 \\
10.5 \\
110.5\end{array}$ & $\begin{array}{l}4.5 \\
4.0 \\
3.5 \\
4.5 \\
7.0 \\
9.0\end{array}$ & $\begin{array}{r}9.0 \\
4.5 \\
8.5 \\
10.5 \\
10.5 \\
6.5\end{array}$ & $\begin{array}{l}5.5 \\
6.0 \\
5.5 \\
4.0 \\
6.5 \\
4.5\end{array}$ & $\begin{array}{r}10.5 \\
9.5 \\
11.5 \\
-0.5 \\
\ldots . .0\end{array}$ & $\begin{array}{l}8.0 \\
6.5 \\
8.5 \\
\cdots-\end{array}$ & $\begin{array}{l}15.0 \\
15.0 \\
15.0 \\
19.0 \\
16.5 \\
14.5\end{array}$ & $\begin{array}{l}13.5 \\
11.5 \\
12.0 \\
14.5 \\
12.0 \\
11.5\end{array}$ \\
\hline iN. (WH & -4.0 & l.1." & $1 n \cdot 4$ & 4.5 & $11+3$ & $2 \cdot n$ & 10.5 & 0 & 13.0 & 3.0 & 19.0 & 7.0 \\
\hline & \multicolumn{2}{|c|}{ APHIL } & \multicolumn{2}{|c|}{ MAY } & \multicolumn{2}{|c|}{ Juvt } & \multicolumn{2}{|c|}{ JULY } & \multicolumn{2}{|c|}{ AUGUST } & \multicolumn{2}{|c|}{ SEPTEMHER } \\
\hline I AY & $\operatorname{MAX}$ & IN & $\ln \Delta x$ & $14[\mathrm{~N}$ & $m \Delta x$ & ${ }^{M} I^{N}$ & $\max$ & $M[N$ & MAX & MIN & $\max$ & MIN \\
\hline $\begin{array}{l}1 \\
2 \\
3 \\
4 \\
5\end{array}$ & $\begin{array}{l}1 \mathrm{~h} .5 \\
1 \mathrm{H} .5 \\
1 \mathrm{~h} .5 \\
1 \mathrm{~h} .5 \\
15.5\end{array}$ & $\begin{array}{l}14.5 \\
15.5 \\
14.5 \\
13.5 \\
14.5\end{array}$ & $\begin{array}{l}25,01 \\
21.0 \\
21.01 \\
19.3 \\
19.11\end{array}$ & $\begin{array}{l}21.0 \\
20.0 \\
14.0 \\
10.0 \\
10.0\end{array}$ & $\begin{array}{l}23.0 \\
23.5 \\
23.5 \\
21.0 \\
23.5\end{array}$ & $\begin{array}{l}? 1.0 \\
2 ? .11 \\
2 ? .0 \\
2 ? .0 \\
? 2.0\end{array}$ & $\begin{array}{l}2 \mu .5 \\
311.5 \\
24.5 \\
25.0 \\
23.5\end{array}$ & $\begin{array}{c}25.5 \\
- \\
-- \\
---\end{array}$ & $\begin{array}{l}29.5 \\
30.0 \\
31.5 \\
31.0 \\
30.0\end{array}$ & $\begin{array}{l}27.5 \\
27.5 \\
28.0 \\
27.0 \\
28.5\end{array}$ & $\begin{array}{l}26.5 \\
26.5 \\
26.5 \\
26.5 \\
25.5\end{array}$ & $\begin{array}{l}24.5 \\
24.5 \\
24.5 \\
24.5 \\
24.5\end{array}$ \\
\hline $\begin{array}{r}0 \\
7 \\
y \\
y \\
10\end{array}$ & $\begin{array}{l}19.0 \\
18.5 \\
14.5 \\
14.0 \\
14.0\end{array}$ & $\begin{array}{l}16.5 \\
14.11 \\
13.7 \\
14.01 \\
10.5\end{array}$ & $\begin{array}{l}21100 \\
1903 \\
20.0 \\
20.11 \\
21.01\end{array}$ & $\begin{array}{l}16.0 \\
1500 \\
10.5 \\
17.0 \\
19.0\end{array}$ & $\begin{array}{l}22.0 \\
20.5 \\
21.5 \\
24.5 \\
24.0\end{array}$ & $\begin{array}{l}20.0 \\
19.0 \\
19.0 \\
19.0 \\
21.0\end{array}$ & $\begin{array}{l}27.0 \\
20.5 \\
27.5 \\
29.0 \\
30.0\end{array}$ & $\begin{array}{l}-0 . \\
26.0 \\
26.5 \\
26.0\end{array}$ & $\begin{array}{l}30.0 \\
28.5 \\
27.5 \\
27.0 \\
25.5\end{array}$ & $\begin{array}{l}2 R .0 \\
27.5 \\
26.5 \\
26.0 \\
24.5\end{array}$ & $\begin{array}{l}26.0 \\
25.5 \\
25.5 \\
25.0 \\
25.5\end{array}$ & $\begin{array}{l}24.0 \\
24.0 \\
23.0 \\
23.0 \\
23.5\end{array}$ \\
\hline $\begin{array}{l}11 \\
12 \\
13 \\
14 \\
15\end{array}$ & $\begin{array}{l}16.01 \\
16.5 \\
20.0 \\
211.5 \\
19.5\end{array}$ & $\begin{array}{l}15.11 \\
15.11 \\
10.5 \\
15.3 \\
15.4\end{array}$ & $\begin{array}{l}21.0 \\
21.0 \\
22.0 \\
22.0 \\
23.0\end{array}$ & $\begin{array}{l}14.5 \\
17.0 \\
17.0 \\
17.5 \\
17.5\end{array}$ & $\begin{array}{l}23.0 \\
23.5 \\
23.5 \\
23.0 \\
23.0\end{array}$ & $\begin{array}{l}21.0 \\
21.0 \\
21.0 \\
21.0 \\
21.0\end{array}$ & $\begin{array}{l}30.5 \\
29.0 \\
27.0 \\
27.5 \\
27.0\end{array}$ & $\begin{array}{r}30.0 \\
-0 . \\
26.0 \\
25.0\end{array}$ & $\begin{array}{l}24.5 \\
23.5 \\
24.5 \\
25.5 \\
25.5\end{array}$ & $\begin{array}{l}23.5 \\
23.0 \\
23.5 \\
23.0 \\
23.5\end{array}$ & $\begin{array}{l}25.5 \\
24.5 \\
24.5 \\
25.0 \\
24.0\end{array}$ & $\begin{array}{l}24.0 \\
23.5 \\
21.0 \\
22.0 \\
21.0\end{array}$ \\
\hline $\begin{array}{l}10 \\
17 \\
19 \\
19 \\
20\end{array}$ & $\begin{array}{l}1 \mathrm{H} .5 \\
12.0 \\
19.5 \\
21.5 \\
22.0\end{array}$ & $\begin{array}{l}10.11 \\
10.1 \\
16.5 \\
19.01 \\
14.11\end{array}$ & $\begin{array}{l}21.3 \\
21.3 \\
21.3 \\
21.3 \\
24.0\end{array}$ & $\begin{array}{l}20.0 \\
20.5 \\
19.0 \\
17.0 \\
19.0\end{array}$ & $\begin{array}{l}24.0 \\
24.5 \\
25.5 \\
25.5 \\
26.0\end{array}$ & $\begin{array}{l}21.5 \\
22.0 \\
23.0 \\
23.4 \\
23.5\end{array}$ & $\begin{array}{l}27.5 \\
2 H .5 \\
2 H .0 \\
2 M .0 \\
2 B .0\end{array}$ & $\begin{array}{l}25.0 \\
25.0 \\
25.0 \\
26.0 \\
25.5\end{array}$ & $\begin{array}{l}26.5 \\
26.5 \\
27.0 \\
26.5 \\
25.5\end{array}$ & $\begin{array}{l}24.0 \\
24.0 \\
24.5 \\
24.5 \\
25.0\end{array}$ & $\begin{array}{r}25.0 \\
25.0 \\
\ldots-0 \\
\ldots-0\end{array}$ & $\begin{array}{r}23.0 \\
22.0 \\
-0 . \\
-\cdots\end{array}$ \\
\hline $\begin{array}{l}21 \\
2 ? \\
33 \\
24 \\
+3\end{array}$ & $\begin{array}{l}21.5 \\
21.5 \\
23.0 \\
22.0 \\
210.0\end{array}$ & $\begin{array}{l}1 \mathrm{~lm} .10 \\
18.01 \\
19.4 \\
70.0 \\
14.1\end{array}$ & $\begin{array}{l}23.0 \\
2 ? .0 \\
23.5 \\
20.0 \\
21.5\end{array}$ & $\begin{array}{l}1 y .5 \\
1 y .5 \\
20.0 \\
20.0 \\
20.0\end{array}$ & $\begin{array}{l}27.0 \\
24.0 \\
25.5 \\
25.0 \\
24.0\end{array}$ & $\begin{array}{l}24.5 \\
24.5 \\
23.5 \\
24.0 \\
24.0\end{array}$ & $\begin{array}{l}24.0 \\
20.0 \\
27.0 \\
24.5 \\
29.5\end{array}$ & $\begin{array}{l}25.0 \\
24.0 \\
24.0 \\
25.5 \\
25.5\end{array}$ & $\begin{array}{l}25.0 \\
25.0 \\
25.0 \\
26.5 \\
25.5\end{array}$ & $\begin{array}{l}24.5 \\
24.0 \\
24.5 \\
25.0 \\
25.0\end{array}$ & $\begin{array}{l}0.5 \\
26.5 \\
25.5 \\
25.5\end{array}$ & $\begin{array}{l}24.5 \\
23.0 \\
22.0\end{array}$ \\
\hline $\begin{array}{l}26 \\
27 \\
23 \\
24 \\
90 \\
31\end{array}$ & $\begin{array}{l}20.0 \\
20.0 \\
21.5 \\
22.0 \\
23.5 \\
-. .\end{array}$ & $\begin{array}{l}14.0 \\
17.0 \\
21.0 \\
20.0 \\
21.0 \\
\ldots .0\end{array}$ & $\begin{array}{l}23.0 \\
23.0 \\
22.0 \\
21.4 \\
21.5 \\
21.0\end{array}$ & $\begin{array}{l}20.0 \\
20.0 \\
21.0 \\
20.0 \\
20.0 \\
21.0\end{array}$ & $\begin{array}{c}c b .5 \\
25.0 \\
>4.0 \\
21.0 \\
23.5 \\
-. .0\end{array}$ & $\begin{array}{r}23.5 \\
24.5 \\
21.5 \\
20.0 \\
20.0 \\
-\ldots\end{array}$ & $\begin{array}{l}39.0 \\
24.5 \\
34.0 \\
24.5 \\
30.5 \\
30.0\end{array}$ & $\begin{array}{l}24.5 \\
25.0 \\
27.0 \\
26.5 \\
26.5 \\
27.0\end{array}$ & $\begin{array}{l}25.0 \\
25.0 \\
25.5 \\
26.0 \\
26.5 \\
26.5\end{array}$ & $\begin{array}{l}24.5 \\
24.5 \\
24.0 \\
24.5 \\
24.5 \\
24.5\end{array}$ & $\begin{array}{l}25.5 \\
24.0 \\
22.0 \\
19.5 \\
19.0 \\
\ldots . .0\end{array}$ & $\begin{array}{l}21.5 \\
22.0 \\
20.5 \\
18.0 \\
15.5 \\
\ldots\end{array}$ \\
\hline MONTH & 23.5 & 13.5 & 24.0 & 16.0 & 27.0 & 19.0 & 30.5 & -- & 31.5 & 23.0 & 26.5 & 15.5 \\
\hline
\end{tabular}


02226000 ALTAMAHA RIVER AT DOCTORTOWN, GA

O2226000 ALTAMAKA RIVER AT DOCTORTOWN, GA,
(International Hydrological Decade River Station)

LOCATION,--lat $31^{\circ} 39^{\prime} 16^{\prime \prime}$, long $81^{\circ} 49^{\prime} 41^{\prime \prime}$, wayne County, at gaging station on right bank 60 ft downstream from Seaboard Coast Line Railroad bridge at Doctortown, 4.5 miles northeast of Jesup, and at mile 59.4 .

DRAINAGE AREA. $+13,600 \mathrm{sq} \mathrm{mi}$, approximately.

PER IOD OF RECORD,--Chemical analyses: September 1967 to September 1970.

Water temperatures: November 1967 to September 1970.

CHFMICAL ANALYSES. WATER YEAH UCTOAER IU6Y TO SEPTEMASEL 1970

\begin{tabular}{|c|c|c|c|c|c|}
\hline UATE & TIRE & $\begin{array}{l}\text { DIS- } \\
\text { CHANGE } \\
\text { (CFS) }\end{array}$ & $\begin{array}{c}P_{H} \\
\text { (UNITS) }\end{array}$ & $\begin{array}{l}\text { TEMP- } \\
\text { ERATUNE- } \\
\text { (DEG C) }\end{array}$ & $\begin{array}{l}\text { DIS- } \\
\text { SOLVFD } \\
\text { OXYGES } \\
\left(M r_{3}, L\right)\end{array}$ \\
\hline 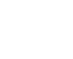 & $u \rightarrow, \pi$ & $5 ? 111$ & 7.4 & $\gg . n$ & 6.4 \\
\hline $\begin{array}{ll}20 & \ldots \\
b_{t} & 0 .\end{array}$ & $130 n$ & 5730 & 7.9 & $12 . n$ & 4.7 \\
\hline Jan... & SLl & $y+4=9$ & 7.4 & $\vec{A}, n$ & 4.8 \\
\hline $\begin{array}{c}c \in 0 . \\
F+0 .\end{array}$ & 1130 & 10400 & 7.2 & $7 . n$ & $1 \mathrm{~h} .1)$ \\
\hline $\begin{array}{r}04 \ldots \\
24 \ldots \\
a+24 .\end{array}$ & $4+311$ & $\begin{array}{l}\text { lanon } \\
\text { lantion }\end{array}$ & $\begin{array}{l}7 . ? \\
7 . ?\end{array}$ & $\begin{array}{r}4.11 \\
11.0\end{array}$ & $\begin{array}{l}7.3 \\
\text { H. }\end{array}$ \\
\hline $\begin{array}{l}27 \ldots \\
\operatorname{mar}\end{array}$ & 1100 & $131 \mathrm{no}$ & 7.3 & 23.11 & 6.1 \\
\hline velinfe... & $\| \sin$ & 11400 & 7.4 & $21 . n$ & 5.8 \\
\hline $\int_{J i L Y}^{C 3} \not$ & 1030 & 5490 & 7.3 & $3 n \cdot 0$ & 4.0 \\
\hline Stri:.. & 11100 & 35kit & 7.2 & 24.0 & 0.4 \\
\hline $22 \ldots$ & 10011 & 4130 & 7.4 & 27.11 & $7 .>$ \\
\hline
\end{tabular}

\begin{tabular}{|c|c|c|c|c|c|c|c|c|c|c|}
\hline WATt & 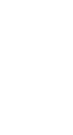 & 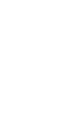 & 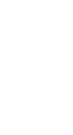 & 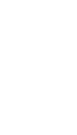 & 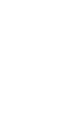 & 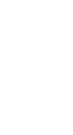 & 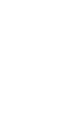 & $\begin{array}{l}\text { ALKA- } \\
\text { LINITY } \\
\text { OS } \\
\text { CACOS } \\
(A G, L)\end{array}$ & $\begin{array}{l}\text { SULFATF } \\
\text { (SO4) } \\
(M+1) L L)\end{array}$ & $\begin{array}{l}\text { CHLOU- } \\
\text { HIDE } \\
\text { (CL) } \\
\text { (ME, L ) }\end{array}$ \\
\hline 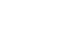 & 14 & $y-14$ & 3,1 & $m=1$ & 1.6 & is & r.n & 34 & 11 & 12 \\
\hline $211 \ldots$ & -- & -- & -- & -- & -- & -- & - & -- & -- & $\ldots$ \\
\hline נ2.... & 13 & $x+1$ & 31 & 7.1 & 1.0 & !t & 1.4 & in & 11 & 4.0 \\
\hline fre... & -- & $\cdots$ & -- & -- & -- & -- & -- & - & - & -- \\
\hline $114 \ldots$ & -- & -- & -- & -- & -. & -- & -- & -- & -. & \\
\hline$e^{4} \ldots$ & -- & $t=11$ & $x$ & 5.4 & 1.2 & $7 . n$ & 1.1 & 11 & 9.0 & 7.8 \\
\hline $7, \cdots$ & -- & -- & -- & $\cdots$ & -- & - & -- & -- & -- & -- \\
\hline whot... & te & 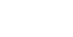 & $\because$ & 1. & 1.4 & 11 & $1 . n$ & 311 & $R \cdot n$ & R. 0 \\
\hline Jull... & -- & -- & -- & -- & -- & $\cdots$ & -- & -- & -- & $\cdots$ \\
\hline siq. & -- & $\cdots$ & -- & -- & -- & -- & -- & -- & -- & 9.3 \\
\hline ¿е... & ir & $-\infty, 1$ & $?$ & -.4 & 1.7 & $1 n$ & 1.. & 34 & 4.11 & n. \\
\hline
\end{tabular}


ALTAMAHA RIVER BASIN

02226000 ALTAMAHA RIVER AT DOCTORTONA, GA.--Contınued

EXTREUES.--1969-70:

Water temperatures: Maximum, $30.5^{\circ} \mathrm{C}$ June 21,22 , Aug. 2-9; minimum, $5.5^{\circ} \mathrm{C}$ Jan. $11-16$.

Period of record:

Water temperatures: Maximum, $33.0^{\circ} \mathrm{C}$ Aug. $22-26,1968$; minimum, $5.5^{\circ} \mathrm{C}$ Jan. 11-16, 1970.

CHEMICAL ANALYSES, WATER YEAR OCTOBER 1969 TO SEPTEMBER 1970

\begin{tabular}{|c|c|c|c|c|c|c|c|c|c|c|}
\hline 1) $\Delta \mathrm{Tt}$ & 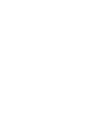 & 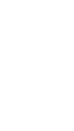 & $\begin{array}{l}\text { TUTAL } \\
\text { FILTE } \\
\text { RAMLE } \\
\text { PESIFHIH } \\
\text { (MG/L) }\end{array}$ & 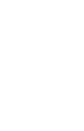 & $\begin{array}{l}\text { HART)- } \\
\text { INESS } \\
\text { (CA,MG) } \\
\text { (MG/L) }\end{array}$ & $\begin{array}{l}\text { SPECI- } \\
\text { FIC } \\
\text { CONI)- } \\
\text { UCTANCE } \\
\text { (MICRO- } \\
\text { MHOS) }\end{array}$ & $\begin{array}{l}\text { COLOR } \\
\text { (PLAT- } \\
\text { INIJM- } \\
\text { COHALT } \\
\text { UNITS) }\end{array}$ & $\begin{array}{l}\text { TUR- } \\
\text { BID- } \\
\text { ITY } \\
\text { (JTU) }\end{array}$ & $\begin{array}{l}\text { BIO- } \\
\text { CHEM- } \\
\text { ICAL } \\
\text { OXYGEN } \\
\text { DEMAND } \\
\text { (MG/L) }\end{array}$ & $\begin{array}{c}\text { FECAL } \\
\text { COLI- } \\
\text { FORM } \\
\text { (COL. } \\
\text { PER } \\
\text { 100 ML) } \\
\text { (MPN) }\end{array}$ \\
\hline 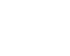 & .11 & $\cdot x^{4}$ & l"y & לי & 26 & 145 & לS & 17 & $2 . A$ & 4300 \\
\hline 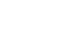 & $\cdots$ & - & -- & -- & -- & -- & - & -- & 3.6 & 15000 \\
\hline $\begin{array}{l}22 . \cdots \\
\text { jari. }\end{array}$ & .1 & $\cdot c^{* 1}$ & sil & $1 \times$ & 22 & 110 & $4 n$ & 18 & 2.4 & 930 \\
\hline $\begin{aligned} 26 . . . \\
r+m .\end{aligned}$ & -- & $m$ & - & -- & -- & -- & -- & -- & 1.4 & 1500 \\
\hline $114 \ldots$ & -- & -- & $\cdots$ & -- & - & -- & $=$ & -- & 1.9 & 4300 \\
\hline nt. & ."1 & - 20 & $a c$ & le & in & 83 & $6 n$ & 15 & 11.2 & 91 \\
\hline${ }_{m, \Delta Y}+\cdots$ & -- & -- & -- & -- & -- & -- & - & -- & 1.8 & 30 \\
\hline Jisit... & $\cdot 2$ & .13 & (1.) & 317 & 22 & 99 & 90 & 35 & 1.8 & 230 \\
\hline H从Y & -- & $\cdots$ & -- & -- & - & -- & 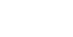 & -- & 3.6 & 36 \\
\hline C7... & -- & - & -- & -- & - & - & $-\infty$ & - & 3.1 & 150 \\
\hline cर... & $\cdots$ & - 10 & 14 & ל & 30 & 115 & 35 & 4.0 & 1.0 & 9 I \\
\hline
\end{tabular}

\begin{tabular}{|c|c|c|c|c|c|c|}
\hline $1, \Delta 1 t$ & 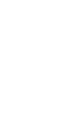 & $\begin{array}{c}\text { SUS- } \\
\text { PFNIEE } \\
\text { GNOSE } \\
\text { ALPHA } \\
\text { AS } \\
\text { UIANAT } \\
\text { OUG/L) }\end{array}$ & $\begin{array}{c}\text { DIS- } \\
\text { SOLVED } \\
\text { GHOSS } \\
\text { HETA } \\
\text { AS SHYO } \\
\text { IYYO } \\
\text { (PC/LI }\end{array}$ & $\begin{array}{c}\text { SUS- } \\
\text { PENHEE } \\
\text { CROSS } \\
\text { HFTA } \\
\text { AS SPYO } \\
\text { PY9O } \\
\text { (PCAL) }\end{array}$ & $\begin{array}{l}\text { UIS- } \\
\text { SOLVED } \\
\text { RADIIM } \\
\text { 2LS } \\
\text { (RA) } \\
\text { (PC/L) }\end{array}$ & $\begin{array}{l}\text { DIS- } \\
\text { SOLVEO } \\
\text { NATURAL } \\
\text { URANIUM } \\
\text { (U) } \\
\text { (UG/L) }\end{array}$ \\
\hline $\begin{array}{c}\text { uct. } \\
\text { es... }\end{array}$ & 1.1 & 1.7 & 3.1 & .80 & .0 & .01 \\
\hline 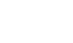 & $1 \cdot 1$ & 1.1 & 3.3 & .40 & .0 & .02 \\
\hline $\begin{array}{l}22 . . . \\
j u i l .\end{array}$ & 1.3 & 1.1 & 2.4 & .50 & .0 & .04 \\
\hline & $1 . ?$ & 1.0 & 6.0 & 1.0 & . 0 & .06 \\
\hline $24 \ldots$ & $\Rightarrow 1$ & .40 & 2.4 & .70 & .0 & .05 \\
\hline 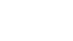 & 1.1 & 1.4 & 3.4 & 1.8 & .0 & .06 \\
\hline${ }_{J_{j} j^{n+1}}^{27} \cdots$ & 1.4 & 1.4 & 3.6 & 1.5 & .0 & .03 \\
\hline JuL ${ }_{\text {Ju }} 3 .$. & 1.4 & .617 & 3.1 & . 80 & .0 & .04 \\
\hline 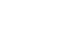 & 1.0 & $1 . \bar{A}$ & 4.1 & 1.9 & .0 & .08 \\
\hline $\begin{array}{l}24 \ldots \\
s+31\end{array}$ & 1.6 & 1.4 & 3.4 & 1.4 & .0 & .07 \\
\hline 82.1 & 1.1 & 1.0 & 3.3 & 1.3 & $\cdot n$ & .03 \\
\hline
\end{tabular}


02226000 ALTAMAHA RIVER AT DOCTORTOHN, GA.--Continued TEMPERATURE $\left({ }^{\circ} \mathrm{C}\right)$ OF WATER, WATER YEAR OCTOBER 1969 TO SEPTEMBER 1970

\begin{tabular}{|c|c|c|c|c|c|c|c|c|c|c|c|}
\hline \multicolumn{2}{|c|}{ OCT MHEN } & \multicolumn{2}{|c|}{ NI) VE IABE R } & \multicolumn{2}{|c|}{ UECEEMMFK } & \multicolumn{2}{|c|}{ JANUSARY } & \multicolumn{2}{|c|}{ FERRUARY } & \multicolumn{2}{|c|}{ MARCH } \\
\hline$v \Delta x$ & II V & 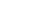 & $\Rightarrow I N$ & $M \Delta x$ & $M I N$ & $\operatorname{MAX}$ & MIN & $\operatorname{MAX}$ & $M I N$ & MAX & MIN \\
\hline $\begin{array}{l}21.5 \\
21.5 \\
21.5 \\
20.11 \\
26.0\end{array}$ & $\begin{array}{l}21.3 \\
? 1.3 \\
21.5 \\
21.5 \\
2.01\end{array}$ & $\begin{array}{l}1+.11 \\
1+00 \\
14.01 \\
14011 \\
14.0\end{array}$ & $\begin{array}{l}14.01 \\
14.0 \\
14.0 \\
1400 \\
14.0\end{array}$ & $\begin{array}{l}14.5 \\
14.0 \\
13.5 \\
13.5 \\
12.0\end{array}$ & $\begin{array}{l}14.0 \\
13.5 \\
13.5 \\
12.0 \\
11.5\end{array}$ & $\begin{array}{l}11.0 \\
\text { II.0 } \\
\text { I1.0 } \\
\text { I1.0 } \\
10.5\end{array}$ & $\begin{array}{l}10.5 \\
11.0 \\
11.0 \\
10.5 \\
10.0\end{array}$ & $\begin{array}{l}11.0 \\
11.0 \\
11.0 \\
11.0 \\
10.5\end{array}$ & $\begin{array}{l}11.0 \\
11.0 \\
11.0 \\
10.5 \\
10.0\end{array}$ & $\begin{array}{l}11.0 \\
11.5 \\
12.0 \\
13.0 \\
13.5\end{array}$ & $\begin{array}{l}11.0 \\
11.0 \\
11.5 \\
12.0 \\
13.0\end{array}$ \\
\hline $\begin{array}{l}22.0 \\
3.0 \\
23.0 \\
23.0 \\
31.5\end{array}$ & $\begin{array}{l}32.11 \\
32011 \\
3201 \\
33.11 \\
3.11\end{array}$ & $\begin{array}{l}15.01 \\
1500 \\
1500 \\
150 \\
1500\end{array}$ & $\begin{array}{l}I 0.5 \\
1 n .0 \\
I 0.0 \\
I n .0 \\
I n .0\end{array}$ & 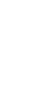 & $\begin{array}{l}11.0 \\
111.0 \\
111.0 \\
11.00 \\
11.0\end{array}$ & $\begin{array}{r}10.0 \\
10.0 \\
4.0 \\
8.5 \\
7.0\end{array}$ & $\begin{array}{r}10.0 \\
9.5 \\
8.5 \\
7.0 \\
6.0\end{array}$ & $\begin{array}{l}10.0 \\
10.0 \\
10.0 \\
10.0 \\
10.0\end{array}$ & $\begin{array}{r}10.0 \\
10.0 \\
10.0 \\
10.0 \\
9.5\end{array}$ & $\begin{array}{l}14.0 \\
14.0 \\
14.0 \\
14.0 \\
14.5\end{array}$ & $\begin{array}{l}13.5 \\
14.0 \\
14.0 \\
14.0 \\
14.0\end{array}$ \\
\hline $\begin{array}{r}3.5 \\
27.5 \\
23.5 \\
2.5 \\
2.5 \\
4.0\end{array}$ & 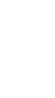 & $\begin{array}{l}16.0 \\
16.01 \\
120.11 \\
10.01 \\
12.0\end{array}$ & $\begin{array}{l}\text { In.0 } \\
\text { I } 0.0 \\
\text { In.0 } \\
I n=0 \\
I \supset 00\end{array}$ & $\begin{array}{l}\text { I I. } 00 \\
\text { I } 1.00 \\
\text { I } 1.00 \\
11.0 \\
11.00\end{array}$ & $\begin{array}{l}11.0 \\
11.00 \\
11.0 \\
11.0 \\
11.0\end{array}$ & $\begin{array}{l}6.0 \\
5.5 \\
5.5 \\
5.5 \\
5.5\end{array}$ & $\begin{array}{l}5.5 \\
5.5 \\
5.5 \\
5.5 \\
5.5\end{array}$ & $\begin{array}{r}9.5 \\
9.5 \\
9.5 \\
9.5 \\
10.0\end{array}$ & $\begin{array}{l}9.5 \\
9.5 \\
9.5 \\
9.5 \\
9.5\end{array}$ & $\begin{array}{l}14.5 \\
14.5 \\
14.5 \\
14.5 \\
14.5\end{array}$ & $\begin{array}{l}14.0 \\
14.0 \\
14.5 \\
14.5 \\
14.5\end{array}$ \\
\hline $\begin{array}{l}24.0 \\
24.11 \\
3.5 \\
34.5 \\
23.5\end{array}$ & $\begin{array}{l}34.1 \\
24.1 \\
23.7 \\
23.7 \\
33.11\end{array}$ & $\begin{array}{l}14,11 \\
14,5 \\
1403 \\
14.5 \\
1201\end{array}$ & $\begin{array}{l}14.5 \\
14.5 \\
14.5 \\
14.5 \\
14.5\end{array}$ & $\begin{array}{l}\text { II.0 } \\
11.0 \\
10.5 \\
10.5 \\
10.5\end{array}$ & $\begin{array}{l}11.0 \\
10.5 \\
10.5 \\
10.5 \\
10.5\end{array}$ & $\begin{array}{l}6.0 \\
5.5 \\
7.0 \\
8.0 \\
8.5\end{array}$ & $\begin{array}{l}5.5 \\
6.0 \\
6.5 \\
7.0 \\
8.0\end{array}$ & $\begin{array}{l}10.0 \\
10.5 \\
10.5 \\
11.0 \\
11.0\end{array}$ & $\begin{array}{l}10.0 \\
10.0 \\
10.5 \\
10.5 \\
11.0\end{array}$ & $\begin{array}{l}14.5 \\
14.5 \\
14.0 \\
14.5 \\
15.0\end{array}$ & $\begin{array}{l}14.5 \\
14.0 \\
14.0 \\
14.0 \\
14.5\end{array}$ \\
\hline $\begin{array}{l}27.11 \\
29.0 \\
23.0 \\
22.0 \\
20.0\end{array}$ & $\begin{array}{l}23.01 \\
23.01 \\
22.11 \\
211.4 \\
211.1\end{array}$ & $\begin{array}{l}14.7 \\
14.7 \\
14.71 \\
I 4.11 \\
I 4.01\end{array}$ & $\begin{array}{l}14.0 \\
14.0 \\
14.0 \\
14.01 \\
14.01\end{array}$ & $\begin{array}{r}10.5 \\
10.5 \\
4.5 \\
4.0 \\
4.0\end{array}$ & $\begin{array}{r}10.5 \\
9.5 \\
9.0 \\
4.0 \\
4.10\end{array}$ & $\begin{array}{l}4.5 \\
8.5 \\
8.5 \\
8.5 \\
8.5\end{array}$ & $\begin{array}{l}9.5 \\
7.0 \\
8.5 \\
8.5 \\
4.5\end{array}$ & $\begin{array}{l}11.0 \\
11.0 \\
11.0 \\
11.0 \\
11.0\end{array}$ & $\begin{array}{l}11.0 \\
11.0 \\
11.0 \\
11.0 \\
11.0\end{array}$ & $\begin{array}{l}15.5 \\
16.0 \\
16.0 \\
15.5 \\
15.5\end{array}$ & $\begin{array}{l}15.0 \\
15.5 \\
15.5 \\
15.5 \\
15.5\end{array}$ \\
\hline $\begin{array}{l}211.01 \\
0.0 \\
0.01 \\
0.01 \\
14.0 \\
-\cdots .0\end{array}$ & $\begin{array}{l}211 \cdot 11 \\
20 \cdot 0 \\
211 \cdot 11 \\
2(1.011 \\
1+011 \\
1+\ldots 11\end{array}$ & $\begin{array}{l}14.0 \\
14.11 \\
1403 \\
14.5 \\
1+05 \\
-0.5\end{array}$ & $\begin{array}{l}\mathrm{I} 4.0 \\
\mathrm{I} 4.0 \\
\mathrm{I} 4.01 \\
\mathrm{I} 4.5 \\
14.5 \\
-\end{array}$ & $\begin{array}{r}4.5 \\
4.5 \\
10.0 \\
10.0 \\
10.0 \\
10.0\end{array}$ & $\begin{array}{r}4.0 \\
4.5 \\
9.5 \\
10.0 \\
10.0 \\
10.0\end{array}$ & $\begin{array}{r}5.5 \\
3.5 \\
9.0 \\
10.0 \\
11.0 \\
11.0\end{array}$ & $\begin{array}{r}9.0 \\
8.0 \\
8.5 \\
9.0 \\
10.0 \\
11.0\end{array}$ & $\begin{array}{r}11.0 \\
11.0 \\
11.0 \\
-0- \\
-\ldots\end{array}$ & $\begin{array}{r}11.0 \\
11 \\
11.0 \\
0 \\
\ldots-0\end{array}$ & $\begin{array}{l}15.5 \\
15.0 \\
15.0 \\
15.0 \\
15.0 \\
15.5\end{array}$ & $\begin{array}{l}15.5 \\
15.0 \\
15.0 \\
15.0 \\
15.0 \\
15.5\end{array}$ \\
\hline$(4.1)$ & $1+01$ & $I+0,1$ & $14 \cdot 01$ & 14.5 & 9.0 & $1 \mathrm{I} \cdot 0$ & 5.5 & $1 \mathrm{I} \cdot 0$ & 9.5 & 16.0 & 11.0 \\
\hline
\end{tabular}

\begin{tabular}{|c|c|c|c|c|c|c|c|c|c|c|c|}
\hline \multicolumn{2}{|c|}{ ANRIL } & \multicolumn{2}{|c|}{$1 \times 4 Y$} & \multicolumn{2}{|c|}{ JUNF } & \multicolumn{2}{|c|}{ JUEYY } & \multicolumn{2}{|c|}{ AUGUST } & \multicolumn{2}{|c|}{ SEPTEMBER } \\
\hline$\because A x$ & 1 & $\Delta x$ & $4 a^{r}$ & $\ln 1 x$ & ma & $M \Delta X$ & MIN & $\operatorname{MAX}$ & $M I N$ & $\operatorname{MAX}$ & MIN \\
\hline 10.5 & 17.7 & 2307 & 24,3 & 10.0 & 25.0 & 74.0 & 29.0 & $3 n .0$ & 29.5 & 26.5 & 26.5 \\
\hline in." & $1\urcorner .7$ & is. & 25.5 & 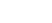 & $>5.14$ & 24.5 & 24.0 & 30.0 & 30.0 & 27.0 & 26.5 \\
\hline $1 n . n$ & $\ln ^{n}$ & 3.4 & 23.3 & 23.13 & 2.0 & 30.0 & 24.5 & $3 n .5$ & 30.0 & 28.0 & 27.0 \\
\hline $1+.01$ & ln..1 & 3.4 & 23.11 & xhen & $23 . n$ & 30.0 & 30.0 & 30.5 & 30.5 & 28.0 & 28.0 \\
\hline $1^{n}, 0$ & 15.13 & $23 . n_{4}$ & $c e .0$ & P.0 & 24.5 & $311 \cdot 0$ & 30.0 & 30.5 & 30.5 & 28.5 & 28.0 \\
\hline 1 h. $n$ & $1 \mathrm{h.1}$ & 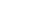 & 2,0 & 24.6 & 24.4 & 30.0 & 30.0 & 30.5 & 30.5 & 29.5 & 28.5 \\
\hline ith.h & 15.1 & 20.11 & $2^{3} \cdot 11$ & 24.5 & 74.5 & $30 . n$ & 30.0 & 30.5 & 30.5 & 28.5 & 28.5 \\
\hline $\ln .6$ & 10.7 & (द.1) & $2>0$ & 24.5 & 24.5 & 30.0 & 30.0 & $3 n .5$ & 30.5 & 28.5 & 28.5 \\
\hline lan.b & 1n.? & cen & $2 r \cdot 11$ & 24.3 & 24.5 & 30.0 & 30.0 & 30.5 & 30.0 & $2 \mathrm{H} .5$ & 28.0 \\
\hline in.n & 1h.? & 31.11 & 2.0 & $8 n .0$ & 24.5 & 30.0 & 29.5 & 30.0 & 29.0 & 28.0 & $2 \mathrm{B.O}$ \\
\hline 17.0 & 16.7 & +3.5 & 25.01 & 24.5 & 25.0 & 24.5 & 29.0 & 29.0 & 28.5 & 28.0 & 28.0 \\
\hline 17.01 & 17.11 & 2303 & 23.5 & $2 n .0$ & 20.5 & 29.0 & 24.0 & 29.5 & 28.5 & 28.0 & 28.0 \\
\hline 17.6 & 17.11 & 24.3 & $24 \cdot 11$ & $2 n \cdot b$ & 20.0 & 24.5 & 29.0 & 28.5 & 28.5 & 28.0 & $2 B .0$ \\
\hline 17.0 & 17.1 & 24.2 & 24.0 & $<n \cdot b$ & 26.5 & $30 . n$ & 20.5 & 28.5 & 28.5 & 28.0 & 28.0 \\
\hline 18.0 & 11.12 & $\dot{c} s .0$ & 74.5 & 26.5 & 26.5 & 30.0 & 30.0 & 24.5 & 28.5 & 28.0 & 28.0 \\
\hline $1 \mu \cdot n$ & 14.1 & 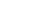 & 25.0 & 37.10 & 26.5 & 30.0 & $3 n .0$ & 28.5 & 28.5 & 28.0 & $2 B .0$ \\
\hline $\ln .0$ & 1 1." & לירי & 20.5 & $\therefore .0$ & 27.0 & 30.0 & 30.0 & 28.5 & 28.5 & 28.5 & 28.0 \\
\hline 14.5 & $1 . .1$ & en. & 23.0 & 4.0 & $\mathrm{PM}_{0} \mathrm{OA}$ & $30 . n$ & 30.0 & $2 \mathrm{H} .5$ & 28.5 & $2 R .5$ & 28.5 \\
\hline 14.5 & $1 \ldots$ & en. & ל ל & 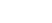 & 29.0 & 30.0 & $3 n .0$ & 28.5 & 28.5 & 28.5 & $2 \mathrm{H} .5$ \\
\hline 11.0 & $1+. h$ & m." & 20.4 & $31 . \cdot 0$ & 24.5 & 30.0 & 30.0 & 28.5 & 28.5 & 28.5 & 28.5 \\
\hline ל. & - & ל. מי & ל.5. & S11. & 30.0 & 30.0 & 30.0 & 29.5 & 28.5 & 28.5 & 28.5 \\
\hline+1.0 & - & & 7h. & 311.0 & 30.4 & 10.0 & 30.0 & 29.5 & $2 A .5$ & 28.5 & 28.5 \\
\hline ל. & +1. & n, n & 70.11 & 311.0 & 24.4 & 310.0 & 30.0 & 24.5 & 28.5 & 28.5 & 28.5 \\
\hline$r=0.11$ & 3. & -5.7 & 26.0 & 24.5 & 29.5 & 30.0 & $30 . n$ & 28.5 & $2 B .0$ & 28.5 & 28.5 \\
\hline $2 \pi \cdot n$ & $3+1$ & Ph. & $2 h \cdot b$ & $\mathrm{c}^{4} \cdot 4$ & 24.5 & 30.0 & 29.5 & 29.0 & 27.0 & 28.5 & 28.5 \\
\hline$\therefore e \cdot 1$ & +1 & - th. & 250.1 & ל. & 24.11 & 24.5 & 24.5 & 27.0 & 26.5 & 28.5 & 28.5 \\
\hline 3.14 & ג & sh. 1 & $2 n .11$ & 240 & $+y=0$ & 24.5 & 24.0 & 26.5 & 26.5 & 28.5 & 28.5 \\
\hline$=4.11$ & $r \$ 1$ & 100.1 & $2 m .0$ & d4. & $\Rightarrow 4 . n$ & $2 y .0$ & 29.0 & 26.5 & 26.5 & 28.5 & 28.0 \\
\hline 2.s. & \pm 3.1 & r. & 20.4 & 24.11 & 24.11 & >⿻. & 24.0 & 26.5 & 26.5 & 28.0 & 26.5 \\
\hline 7.4 & כ.3. & I & כ. כ2 & 34.0 & 34.0 & 29.5 & 29.5 & 75.5 & 26.5 & 26.5 & 26.0 \\
\hline & 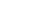 & ג.ר & $2 \cdot \cdot 13$ & -.- & -- & $2+.5$ & 24.5 & 25.5 & 26.5 & $\cdots$ & - \\
\hline$>7.4$ & $1 \%$ ? & en.'s & $2 \pi \cdot n$ & 311.4 & C.4. & $30 . n$ & $<9.0$ & 30.5 & 26.5 & 28.5 & 26.0 \\
\hline
\end{tabular}


ST. WARYS RIVER BASIN

02231000 ST, MARYS RIVER NEAR YACCLENNY, FLA.

LOCATION, Lat $30^{\circ} 21^{\prime} 31$, long $82^{\circ} 04^{\prime} 54$, in NW 1 sec.2, T.2 S., R.22 E., Baker County, at gaging station on r 1 ght bank $200 \mathrm{ft}$ downstream from si te of former Stokes Bridge, 1 mile downstream from confluence of North and South prongs, $6 \mathrm{mlles}$ nor theast of lacclenny, and 100 miles upstream from mouth.

DRAI NAGE AREA. $700 \mathrm{sq} \mathrm{mi}$, approximately (1ncludes part of watershed in Okefenokee Swamp, which is 1 ndeterminate).

PERIOD OF RECORD. Chemical analyses: March 1965 to September 1970.

Water temperatures: Warch 1965 to October 1969.

EXTREMES.--Period of record:

Specific conductance (1965-69): Maximum da11y, 97 micromhos Oct. 30, Nov. 28, 29, 1968; mi nimum da1ly, 26 m1cromhos Mar. 15, July $2,1966$.

pH (1965-68): Maximum daily, 7.8 Nov, 1, 1966; m1nimum da11y, 4.2 Sept. 4, 21, 1967, Apri1 1966; min1mum

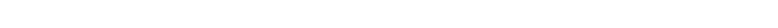

daily, 50 units several days during Hay, June, November and December 1967.
water tempera tures: Haximum, $31.0^{\circ} \mathrm{C}$ July 28,1966 ; minimum, 6. $0^{\circ} \mathrm{C}$ Jan. 21, 1966, Jan. 17, $19.21,1968$.

CHEMICAL ANALYSES, WATER YEAR OCTOBER 1969 TO SEPTEMBER 1970

\begin{tabular}{|c|c|c|c|c|c|c|c|c|c|c|c|c|}
\hline DATE & $\begin{array}{l}\text { DIS- } \\
\text { CHARGE } \\
\text { (CFS) }\end{array}$ & $\begin{array}{l}\text { TEMP- } \\
\text { ERATURE } \\
\text { (DEG C) }\end{array}$ & $\begin{array}{l}\text { SILICA } \\
\text { (SIO2) } \\
\text { (MG/L) }\end{array}$ & $\begin{array}{l}\text { DIS- } \\
\text { SOLVED } \\
\text { CAL- } \\
\text { CIUM } \\
\text { (CA) } \\
\text { (MG/L) }\end{array}$ & $\begin{array}{l}\text { DIS- } \\
\text { SOLVED } \\
\text { MAG- } \\
\text { NE- } \\
\text { SIUM } \\
\text { (MG) } \\
\text { (MG/L) }\end{array}$ & $\begin{array}{l}\text { SODIUM } \\
\text { (NA) } \\
\text { (MG/L) }\end{array}$ & $\begin{array}{l}\text { PO- } \\
\text { TAS- } \\
\text { SIUM } \\
\text { (K) } \\
\text { (MG/L) }\end{array}$ & $\begin{array}{c}\text { PH } \\
\text { (UNITS) }\end{array}$ & $\begin{array}{l}\text { GICAR- } \\
\text { GONATE } \\
\text { (HCO3) } \\
\text { (MG/L) }\end{array}$ & $\begin{array}{l}\text { CAR- } \\
\text { GONATE } \\
\text { (CO3) } \\
\text { (MG/L) }\end{array}$ & $\begin{array}{l}\text { SULFATE } \\
\text { (S04) } \\
\text { (MG/L) }\end{array}$ & $\begin{array}{l}\text { CHLO- } \\
\text { RIDE } \\
\text { (CLI) } \\
\text { (MG/L) }\end{array}$ \\
\hline $\begin{array}{l}0 c r . \\
07 \ldots . . . \\
31 \ldots \\
\text { vov... }\end{array}$ & 2920 & 23.0 & 4.4 & 1.7 & $\because$ & 3.5 & $\because 3$ & 4.4 & - & $=$ & 1.6 & 6.1 \\
\hline $\begin{array}{l}15 . . . \\
\text { aUG. }\end{array}$ & 1750 & 25.0 & 7.7 & 3.5 & 1.8 & 3.9 & .3 & 6.6 & 12 & 0 & .4 & 9.5 \\
\hline $06 \ldots$ & 671 & 27.5 & 4.0 & 1.4 & .7 & 2.4 & .2 & 4.6 & 0 & 0 & .2 & 5.5 \\
\hline ATE & $\begin{array}{l}\text { DIS- } \\
\text { SOLVED } \\
\text { FLUO- } \\
\text { RIDE } \\
\text { (F) } \\
\text { (MG/L) }\end{array}$ & $\begin{array}{l}\text { HARD- } \\
\text { NESS } \\
(C A, M G) \\
(M G / L)\end{array}$ & $\begin{array}{l}\text { NON- } \\
\text { CAR- } \\
\text { BONATE } \\
\text { HARD- } \\
\text { NESS } \\
\text { (MG/L) }\end{array}$ & $\begin{array}{l}\text { ALKA- } \\
\text { LINITY } \\
\text { AS } \\
\text { CACO3 } \\
\text { (MG/L) }\end{array}$ & $\begin{array}{l}\text { DIS- } \\
\text { SOLVED } \\
\text { SOLIDS } \\
\text { (RESI- } \\
\text { DUE AT } \\
180 \text { C) } \\
\text { (MG/L) }\end{array}$ & $\begin{array}{l}\text { DIS- } \\
\text { SOLVED } \\
\text { SOLIDS } \\
\text { (SUM OF } \\
\text { CONSTI- } \\
\text { TUENTS) } \\
\text { (MG/L) }\end{array}$ & $\begin{array}{l}\text { SPECI- } \\
\text { FIC } \\
\text { COND- } \\
\text { UCTANCE } \\
\text { (MICRO- } \\
\text { MHOS) }\end{array}$ & $\begin{array}{l}\text { COLOR } \\
\text { (PLAT- } \\
\text { INUM- } \\
\text { COBALT } \\
\text { UNITS) }\end{array}$ & $\begin{array}{l}\text { TUR- } \\
\text { OID- } \\
\text { ITY } \\
\text { (JTU) }\end{array}$ & $\begin{array}{l}\text { DIS- } \\
\text { SOLVED } \\
\text { ORTHO } \\
\text { PHOS- } \\
\text { PHATE } \\
\text { (POA) } \\
\text { (MG/L) }\end{array}$ & $\begin{array}{l}\text { PHOS- } \\
\text { PHATE } \\
\text { (PO4) } \\
\text { (MG/L) }\end{array}$ & $\begin{array}{l}\text { NITRATE } \\
\text { (NO3) } \\
\text { (MG/L) }\end{array}$ \\
\hline
\end{tabular}

$\begin{array}{rrr}\text { OCT. } & & \\ 07 \ldots . . & .1 & \\ 31 \ldots . . & -. & \\ \text { NOV. } & .2 & 10 \\ 25 . \ldots & .2 & 16 \\ \text { MAY } 15 . . . & .1 & 16 \\ \text { AUG.... } & .2 & \end{array}$

$\begin{array}{rrrr}8 & 8 & 0 & 83 \\ -- & -- & -- & -- \\ 10 & 10 & 0 & 83 \\ 16 & 6 & 10 & 78 \\ 7 & 7 & 0 & 84\end{array}$

19
24
34
15

$\begin{array}{ll}47 & 200 \\ 46 & 20 \\ 50 & 240 \\ 36 & 240\end{array}$

200

$\begin{array}{cccc}-- & -\overline{15} & . \overline{15} & .2 \\ -- & -.2 & -. & .0 \\ 10 & .14 & .15 & .2 \\ -- & -- & -. & .0\end{array}$

\begin{tabular}{|c|c|c|c|c|c|c|c|c|c|c|c|}
\hline DATE & $\begin{array}{l}\text { NITRITE } \\
\text { (NO2) } \\
\text { (MG/L) }\end{array}$ & $\begin{array}{l}\text { AMMONIA } \\
\text { (NHL) } \\
\text { (MG/L) }\end{array}$ & $\begin{array}{l}\text { ORGANIC } \\
\text { NITRO- } \\
\text { GEN } \\
\text { (N) } \\
\text { (MG/L) }\end{array}$ & $\begin{array}{l}\text { DIS- } \\
\text { SOLVED } \\
\text { ARSENIC } \\
\text { (ASS) } \\
\text { (UG/L) }\end{array}$ & $\begin{array}{l}\text { DIS- } \\
\text { SOLVED } \\
\text { COPPER } \\
\text { (CU) } \\
\text { (UG/L) }\end{array}$ & $\begin{array}{l}\text { DIS- } \\
\text { SOLVEO } \\
\text { IRON } \\
\text { (FE) } \\
\text { (UG/L) }\end{array}$ & $\begin{array}{l}\text { DIS- } \\
\text { SOLVED } \\
\text { LEAD } \\
(P B) \\
(U G / L)\end{array}$ & $\begin{array}{l}\text { SOLVED } \\
\text { MAN- } \\
\text { GANESE } \\
\text { (MN) } \\
\text { (UGAL) }\end{array}$ & $\begin{array}{l}\text { SOLVED } \\
\text { STRON- } \\
\text { TIUM } \\
\text { (SR) } \\
\text { (UG/L) }\end{array}$ & $\begin{array}{l}\text { OIS- } \\
\text { SOLVEO } \\
\text { ZINC } \\
\text { (ZN) } \\
\text { (UG/L) }\end{array}$ & $\begin{array}{l}\text { DIS- } \\
\text { SOLVED } \\
\text { OXYGEN } \\
\text { (MGLL) }\end{array}$ \\
\hline OCT. & .03 & -- & -- & - & - & 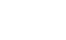 & -- & $=$ & - & - & $\ldots$ \\
\hline $\begin{array}{l}31 . . . \\
\text { nov. }\end{array}$ & .05 & $\cdots$ & $\cdots$ & -- & -- & -- & -- & -- & - & - & - \\
\hline$\underset{\text { MAY }}{25 . . .}$ & .03 & - & $\cdots$ & - & - & - & - & $\cdots$ & -- & 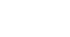 & -- \\
\hline $\begin{array}{l}15 . . . \\
\text { aug. }\end{array}$ & .04 & .09 & .52 & 10 & 0 & 490 & 0 & 0 & 100 & 200 & 5.6 \\
\hline & .04 & -- & - & $\cdots$ & - & -- & -- & - & - & $\cdots$ & -- \\
\hline
\end{tabular}

(MAJUR CONSTITUENTS)

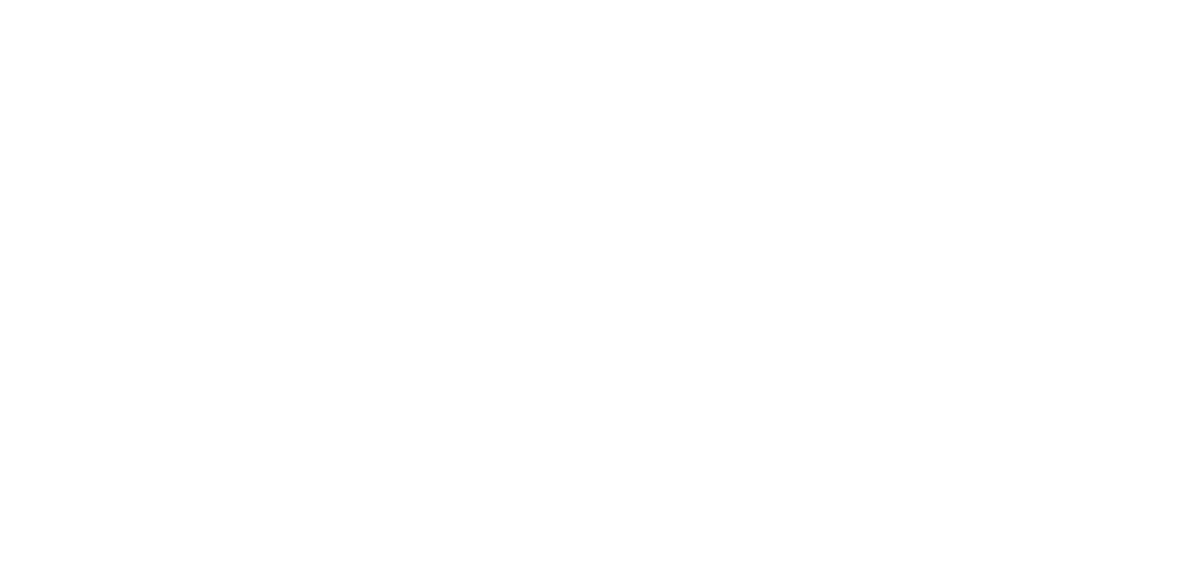


02231000 ST, MARYS RIVER NEAR MACCLENNY, FLA,--Continued

CHEMICAL ANALYSES, WATER YEAR OCTOBER 1969 TO SEPTEMBER 1970

(MACRONUTRIENTS AND OTHER RELATED CONSTITUENTS)

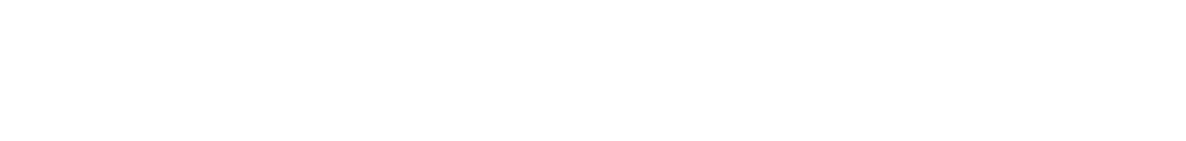

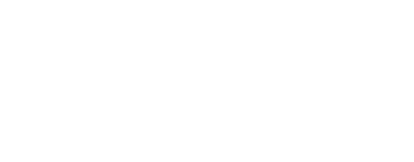

MAY $\quad .04 \quad 0.04$

(FIELD MEASUREMENTS)

\begin{tabular}{|c|c|c|c|c|c|c|c|c|c|c|c|c|}
\hline DATE & TIME & $\begin{array}{l}\text { STAGE } \\
\text { (FT } \\
\text { ABOVE } \\
\text { DATUM) }\end{array}$ & $\begin{array}{l}\text { DIS- } \\
\text { CHARGE } \\
\text { (CFS) }\end{array}$ & $\begin{array}{l}\text { TEMPER- } \\
\text { ATURE } \\
\text { (DEG C) }\end{array}$ & $\begin{array}{l}\text { D1S- } \\
\text { SOLVED } \\
\text { OXYGEN } \\
\text { (MG/L) }\end{array}$ & $\begin{array}{l}\text { PER- } \\
\text { CENT } \\
\text { SATUR- } \\
\text { ATION }\end{array}$ & $\begin{array}{l}\text { SPE- } \\
\text { CIFIC } \\
\text { CON- } \\
\text { DUCT- } \\
\text { ANCE } \\
\text { (MICRO- } \\
\text { MHOS) }\end{array}$ & $\begin{array}{c}\text { PH } \\
\text { (UNITS) }\end{array}$ & $\begin{array}{l}\text { BICAR- } \\
\text { BONATE } \\
\text { IHCO3) } \\
\text { (MG/L) }\end{array}$ & $\begin{array}{l}\text { CAR- } \\
\text { BONATE } \\
\text { (CO3) } \\
\text { (MG/L) }\end{array}$ & $\begin{array}{l}\text { TRANS- } \\
\text { PAR- } \\
\text { ENCY } \\
\text { SECCHI } \\
\text { OISK } \\
\text { (IN) }\end{array}$ & $\begin{array}{c}D E \geqslant T H \\
(=T)\end{array}$ \\
\hline $\begin{array}{c}\text { MAY } \\
15 . .\end{array}$ & 1230 & 2.45 & 89 & 25.0 & 5.6 & 67 & -- & 6.5 & - & -- & -- & - \\
\hline
\end{tabular}

SPECIFIC CONDUCTANCE (MICROMHDS/CM AT $25^{\circ} \mathrm{C}$ ), OCTOBER 1969

DAY

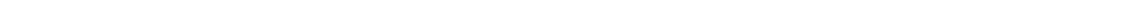

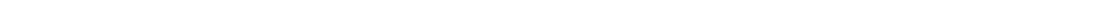

(TRACE METALS)

\begin{tabular}{|c|c|c|c|c|c|c|c|c|c|c|c|c|}
\hline DATE & $\begin{array}{l}\text { OIS- } \\
\text { SOLVED } \\
\text { ALUN- } \\
\text { INUM } \\
\text { (AL) } \\
\text { (UG/I, }\end{array}$ & $\begin{array}{c}\text { DIS- } \\
\text { SOLVFU } \\
\text { ARSENIC } \\
\text { (AS) } \\
\text { (UG/L) }\end{array}$ & $\begin{array}{c}\text { DIS- } \\
\text { SOLVED } \\
\text { GORON } \\
\text { (B) } \\
\text { (UG/L) }\end{array}$ & $\begin{array}{l}\text { UIS- } \\
\text { SOLVFD } \\
\text { CAO- } \\
\text { MIUM } \\
\text { (CD) } \\
\text { (UG/L) }\end{array}$ & $\begin{array}{l}\text { HEXA- } \\
\text { VALENT } \\
\text { CHPO- } \\
\text { MIUM } \\
\text { (CRG) } \\
\text { (UG/L) }\end{array}$ & $\begin{array}{l}\text { OIS- } \\
\text { SOLVED } \\
\text { CHKO- } \\
\text { MIUM } \\
\text { (CK) } \\
\text { (UG/L) }\end{array}$ & $\begin{array}{l}\text { OIS- } \\
\text { SOLVED } \\
\text { COPPEK } \\
\text { (CU) } \\
\text { (UG/L) }\end{array}$ & $\begin{array}{l}\text { DIC- } \\
\text { SOLVEN } \\
\text { IRON } \\
\text { (FE) } \\
\text { (UG/L) }\end{array}$ & $\begin{array}{l}\text { DIS- } \\
\text { SOLVED } \\
\text { LEAD } \\
\text { (PR) } \\
\text { (UG/L) }\end{array}$ & $\begin{array}{l}\text { DIS- } \\
\text { SDLVED } \\
\text { MAN- } \\
\text { GANESE } \\
\text { (MN) } \\
\text { (UG/L) }\end{array}$ & $\begin{array}{l}\text { TOTAL } \\
\text { MERCURY } \\
\text { (H(,) } \\
\text { (UG/L) }\end{array}$ & $\begin{array}{l}\text { CIS- } \\
\text { SCLVEO } \\
\text { ZIVC } \\
\text { (ZN) } \\
((I G / L)\end{array}$ \\
\hline $\begin{array}{l}4 Y \\
5 .\end{array}$ & 350 & 10 & -- & -- & -- & - & 0 & 490 & 0 & 0 & -- & 200 \\
\hline
\end{tabular}

WATER TEMPERATURE $\left({ }^{\circ} \mathrm{C}\right)$, DCTOBER 1969

DAY

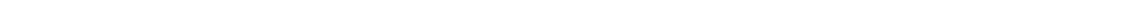

OCT $\quad \begin{array}{llllllllllllllllllllllllllllllll}22 & 23 & 23 & 23 & 23 & 24 & 23 & 22 & 23 & 23 & 23 & 22 & 21 & 20 & 22 & 22 & 23 & 22 & 24 & 23 & 23 & 23 & 21 & 19 & 19 & 20 & 20 & 20 & 19 & 19 & 19 & 21.5\end{array}$

ST, JOHNS RIVER BASIN

02232000 ST. JOHNS RIVER NEAR MELBOURNE, FLA.

LOCATION, --Lat $28^{\circ} 05^{\prime} 03^{\prime \prime}$, long $80^{\circ} 45^{\prime} 11^{\prime \prime}$, In NE $\frac{1}{4}$ sec.6, T.28 S., R.36 E., Brevard County, at gaging station on left bank 300 (revised) $f t$ upstream from b́ridge on U.S. Highway 192,1 mile downtream from Samgrass Lake, 1.8 miles upstream from Lake washington, 9.2 miles west of Melbourne, and 262 miles upstream from mouth.

DRA INAGE AREA. .-968 sq mi.

PERIOD OF RECORD,--Chemical analyses: October 1954 to September 1969 (miscellaneous), October 1969 to September 1970. Fater temperatures: August 1969 to September 1970.

EXTREMES. $-1969-70$ :

Specific conductance: Maximum daily, 359 micromhos July 19; minimum daily, 68 micromhos Oct. 7.

Water temperatures: Maximum, $31.0^{\circ} \mathrm{C}$ Aug. 7 ; minimum, $7.0^{\circ} \mathrm{C}$ Jan. 10. 
ST. JOHNS RIVER BASIN

02232000 ST, JOHNS RIVER NEAR MELBOURNE, FLA.--Continued

CHEMICAL ANALYSES, WATER YEAR,OCTOBER 1969 TO SEPTEMBER 1970

(MAJOR CONSTITUENTS)

\begin{tabular}{|c|c|c|c|c|c|c|c|c|c|c|c|c|}
\hline DATE & $\begin{array}{l}\text { DIS- } \\
\text { CHARGE } \\
\text { (CFS) }\end{array}$ & $\begin{array}{l}\text { TEMPER- } \\
\text { ATURE } \\
\text { (DEG C) }\end{array}$ & $\begin{array}{l}\text { SPE- } \\
\text { CIFIC } \\
\text { CON- } \\
\text { DUCT- } \\
\text { ANCE } \\
\text { (MICRO- } \\
\text { MHOS) }\end{array}$ & $\begin{array}{l}\text { DIS- } \\
\text { SDL VED } \\
\text { IRON } \\
\text { (FE) } \\
(U G / L)\end{array}$ & $\begin{array}{l}\text { UIS- } \\
\text { SOLVED } \\
\text { CAL- } \\
\text { CIUM } \\
\text { (CA) } \\
(M G / L)\end{array}$ & $\begin{array}{l}\text { DIS- } \\
\text { SOLVED } \\
\text { MAG- } \\
\text { NE- } \\
\text { SIUM } \\
\text { (MG) } \\
\text { (MGLL) }\end{array}$ & $\begin{array}{l}\text { OIS- } \\
\text { SOLVED } \\
\text { STRON- } \\
\text { TIUM } \\
\text { (SR) } \\
\text { (UG/L) }\end{array}$ & $\begin{array}{l}\text { DIS- } \\
\text { SOLVED } \\
\text { SODIUM } \\
\text { (NA) } \\
\text { (MG/L) }\end{array}$ & $\begin{array}{l}\text { DIS- } \\
\text { SOLVEO } \\
\text { PO- } \\
\text { TAS- } \\
\text { SIJM } \\
\text { (K) } \\
\text { (MG/L) }\end{array}$ & $\begin{array}{l}\text { BICAR- } \\
\text { BONATE } \\
\text { (HCO3) } \\
\text { (MG/L) }\end{array}$ & $\begin{array}{l}\text { CAR- } \\
\text { BONATE } \\
\text { (CO3) } \\
\text { (MG/L) }\end{array}$ & $\begin{array}{r}\text { PH } \\
\text { (UNITS }\end{array}$ \\
\hline ост., & 1969 & & & & & & & & & & & \\
\hline $\begin{array}{l}01 . . . \\
23 . . \\
\text { Nov. }\end{array}$ & $\begin{array}{l}1690 \\
2750\end{array}$ & $\begin{array}{l}26.0 \\
26.5\end{array}$ & $\begin{array}{l}144 \\
111\end{array}$ & $\begin{array}{l}150 \\
410\end{array}$ & $\begin{array}{l}13 \\
11\end{array}$ & $\begin{array}{l}2.2 \\
1.8\end{array}$ & $\overrightarrow{180}$ & $\begin{array}{l}12 \\
7.7\end{array}$ & $\begin{array}{l}3.6 \\
1.0\end{array}$ & $\begin{array}{l}32 \\
32\end{array}$ & 0 & \\
\hline JAN.". & $\begin{array}{l}1960 \\
1970\end{array}$ & 19.5 & 125 & - & 12 & 2.0 & -- & 20 & .6 & 28 & 0 & \\
\hline $\begin{array}{l}07 . . \\
\text { FEB. }\end{array}$ & 895 & 13.5 & 170 & - & 14 & 2.5 & $-\infty$ & 15 & 1.2 & 36 & 0 & \\
\hline $\begin{array}{l}03 . . . \\
\text { MAR. }\end{array}$ & 1500 & 16.0 & 170 & 120 & 15 & 2.6 & 180 & 16 & 1.7 & 36 & 0 & \\
\hline MAY $05 . .$. & 686 & 20.0 & 219 & - & 18 & 3.4 & 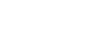 & 20 & 1.1 & 44 & 0 & \\
\hline JULY & 208 & 27.0 & 223 & 130 & 19 & 3.2 & 360 & 20 & .2 & 46 & -- & \\
\hline $\begin{array}{l}27 . . . \\
\text { AUG. }\end{array}$ & 93 & 31.0 & 315 & 160 & 28 & 5.2 & 610 & 25 & 1.7 & 68 & $n$ & \\
\hline & 89 & 32.5 & 280 & -- & 26 & 4.8 & - & 20 & 1.1 & 68 & 0 & \\
\hline DATE & $\begin{array}{l}\text { DIS- } \\
\text { SOLVED } \\
\text { SULFATE } \\
\text { (SO4) } \\
\text { (MG/L) }\end{array}$ & $\begin{array}{l}\text { OIS- } \\
\text { SOLVED } \\
\text { CHLO- } \\
\text { RTOE } \\
\text { (CL) } \\
\text { (MG/L) }\end{array}$ & $\begin{array}{l}\text { OIS- } \\
\text { SOLVFD } \\
\text { FLUU- } \\
\text { RIDE } \\
\text { (F) } \\
(M G / L)\end{array}$ & $\begin{array}{l}\text { HARD- } \\
\text { NESS } \\
(C A, M G) \\
(M G / L)\end{array}$ & $\begin{array}{l}\text { NON- } \\
\text { CAR- } \\
\text { BONATE } \\
\text { HARD- } \\
\text { NESS } \\
\text { (MG/L) }\end{array}$ & $\begin{array}{l}\text { ALKA- } \\
\text { LINITY } \\
\text { AS } \\
\text { CACO3 } \\
(M G / L)\end{array}$ & $\begin{array}{l}\text { DIS- } \\
\text { SOLVED } \\
\text { SOLIDS } \\
\text { (RESI- } \\
\text { DUE AT } \\
\text { I\&O C) } \\
\text { (MG/L) }\end{array}$ & $\begin{array}{l}\text { CIS- } \\
\text { SOLVED } \\
\text { SOLIDS } \\
\text { (SUM OF } \\
\text { CONSTI- } \\
\text { TUENTS) } \\
\text { (MG/L) }\end{array}$ & $\begin{array}{l}\text { DIS- } \\
\text { SOLVED } \\
\text { SOLIDS } \\
\text { (TONS } \\
\text { PER } \\
\text { DAY) }\end{array}$ & $\begin{array}{l}\text { OIS- } \\
\text { SOLVFD } \\
\text { SOLIDS } \\
\text { (TONS } \\
\text { PER } \\
\text { AC-FT) }\end{array}$ & $\begin{array}{l}\text { TANNIN } \\
\text { AND } \\
\text { LIGNIN } \\
\text { (MG/LI }\end{array}$ & $\begin{array}{l}\text { DEPTH } \\
\text { (FT) }\end{array}$ \\
\hline
\end{tabular}

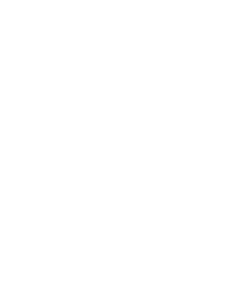

22
16
21
28
32
37
38
52
45

$\begin{array}{ll}.2 & 4 \\ .2 & 3 \\ .2 & 3 \\ .2 & 46 \\ .3 & 4 \\ .2 & 5 \\ .2 & 6 \\ .3 & 92 \\ .3 & 85\end{array}$

$2 \quad 16 \quad 26$

(MG/L)

DAYI AC-FTI

AND
LIGNIN DEPTH

\section{(MACRONUTRIENTS AND OTHER RELATED CONSTITUENTS)}

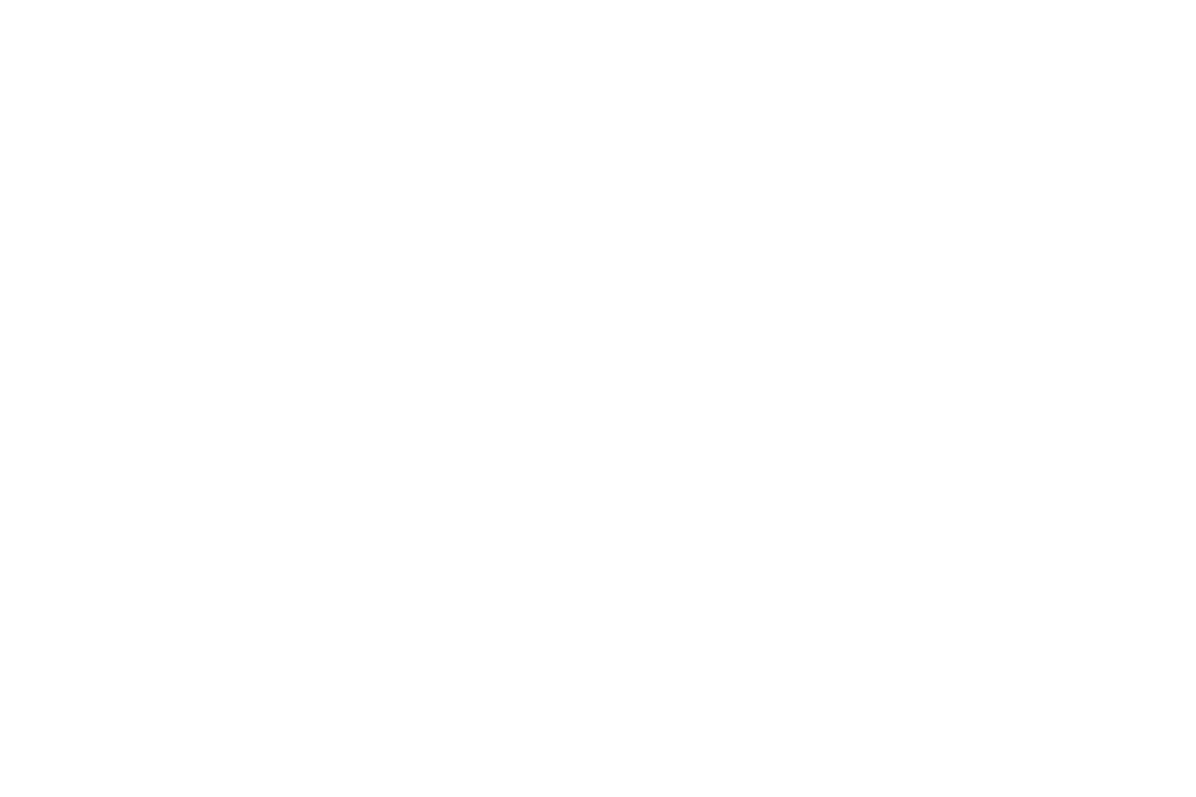

\begin{tabular}{|c|c|c|c|}
\hline $\begin{array}{l}\text { OCT..' } \\
23 \ldots \\
\text { FEB... }\end{array}$ & ${ }_{70}^{69} 1300$ & & 2750 \\
\hline $\begin{array}{l}03 \ldots \\
\text { MAY }\end{array}$ & 1330 & 4.39 & 1500 \\
\hline $\begin{array}{l}04 \ldots . . . \\
\text { JuLYY }\end{array}$ & 1230 & 2.72 & 208 \\
\hline $27 \ldots$ & 1410 & 2.16 & 93 \\
\hline
\end{tabular}

$\begin{array}{rrr}26.5 & .9 & 1 \\ 16.0 & -- & - \\ 27.0 & 5.9 & 73 \\ 30.0 & 5.0 & 67\end{array}$

90
175
229
318

$\begin{array}{rrrrr}6.3 & 33 & 0 & -- & -- \\ 7.1 & 36 & -- & -- & 1.0 \\ 7.2 & 47 & -- & -- & -- \\ 7.5 & 68 & 0 & -- & --\end{array}$


02232000 ST. JOHNS RIVER NEAR MELBOURNE, FLA.--ContInued SPECIFIC CONDUCTANCE (MICROMHOS/CM AT $25^{\circ} \mathrm{C}$ ), WATER YEAR OCTOBER 1969 TO SEPTEMBER 1970

\begin{tabular}{|c|c|c|c|c|c|c|c|c|c|c|c|c|}
\hline DAY & DCT & NOV & DEC & JAN & FEB & MAR & APR & MAY & JUN & JUL & AUG & SEP \\
\hline $\begin{array}{l}1 \\
2 \\
3 \\
4 \\
5\end{array}$ & $\begin{array}{r}135 \\
139 \\
136 \\
134 \\
96\end{array}$ & $\begin{array}{l}110 \\
110 \\
113 \\
116 \\
112\end{array}$ & $\begin{array}{l}130 \\
133 \\
134 \\
136 \\
140\end{array}$ & $\begin{array}{l}160 \\
150 \\
170 \\
160 \\
165\end{array}$ & $\begin{array}{l}169 \\
169 \\
171 \\
189 \\
170\end{array}$ & $\begin{array}{l}215 \\
214 \\
215 \\
215 \\
212\end{array}$ & $\begin{array}{l}188 \\
170 \\
170 \\
165 \\
162\end{array}$ & $\begin{array}{l}212 \\
218 \\
218 \\
219 \\
219\end{array}$ & $\begin{array}{l}240 \\
232 \\
229 \\
232 \\
231\end{array}$ & $\begin{array}{l}298 \\
301 \\
308 \\
307 \\
298\end{array}$ & $\begin{array}{l}326 \\
323 \\
332 \\
337 \\
332\end{array}$ & $\begin{array}{l}298 \\
279 \\
235 \\
218 \\
190\end{array}$ \\
\hline $\begin{array}{r}6 \\
7 \\
8 \\
9 \\
10\end{array}$ & $\begin{array}{l}85 \\
68 \\
74 \\
78 \\
73\end{array}$ & $\begin{array}{l}123 \\
125 \\
123 \\
125 \\
130\end{array}$ & $\begin{array}{l}136 \\
141 \\
145 \\
143 \\
141\end{array}$ & $\begin{array}{l}159 \\
165 \\
170 \\
170 \\
165\end{array}$ & $\begin{array}{l}180 \\
179 \\
175 \\
180 \\
182\end{array}$ & $\begin{array}{l}213 \\
216 \\
215 \\
215 \\
215\end{array}$ & $\begin{array}{l}-10 \\
160 \\
174 \\
172\end{array}$ & $\begin{array}{l}222 \\
220 \\
220 \\
228 \\
220\end{array}$ & $\begin{array}{l}230 \\
230 \\
230 \\
230 \\
240\end{array}$ & $\begin{array}{l}379 \\
277 \\
273 \\
275 \\
280\end{array}$ & $\begin{array}{l}336 \\
325 \\
311 \\
306 \\
297\end{array}$ & $\begin{array}{l}179 \\
175 \\
171 \\
174 \\
169\end{array}$ \\
\hline $\begin{array}{l}11 \\
12 \\
13 \\
14 \\
15\end{array}$ & $\begin{array}{l}74 \\
80 \\
80 \\
88 \\
95\end{array}$ & $\begin{array}{l}128 \\
127 \\
123 \\
122 \\
121\end{array}$ & $\begin{array}{l}144 \\
141 \\
160 \\
145 \\
130\end{array}$ & $\begin{array}{l}160 \\
160 \\
160 \\
151 \\
160\end{array}$ & $\begin{array}{l}179 \\
189 \\
180 \\
184 \\
190\end{array}$ & $\begin{array}{l}214 \\
209 \\
212 \\
216 \\
212\end{array}$ & $\begin{array}{l}170 \\
170 \\
175 \\
172 \\
175\end{array}$ & $\begin{array}{l}223 \\
225 \\
226 \\
227\end{array}$ & $\begin{array}{l}238 \\
239 \\
245 \\
243 \\
245\end{array}$ & $\begin{array}{l}280 \\
271 \\
270 \\
292 \\
311\end{array}$ & $\begin{array}{l}286 \\
278 \\
277 \\
276 \\
274\end{array}$ & $\begin{array}{l}-.- \\
176 \\
179 \\
179\end{array}$ \\
\hline $\begin{array}{l}16 \\
17 \\
18 \\
19 \\
20\end{array}$ & $\begin{array}{l}97 \\
92 \\
98 \\
92 \\
95\end{array}$ & $\begin{array}{l}122 \\
120 \\
118 \\
120 \\
115\end{array}$ & $\begin{array}{l}127 \\
126 \\
122 \\
124 \\
127\end{array}$ & $\begin{array}{l}155 \\
160 \\
170 \\
178 \\
181\end{array}$ & $\begin{array}{l}179 \\
184 \\
180 \\
180 \\
181\end{array}$ & $\begin{array}{l}211 \\
212 \\
207 \\
204 \\
205\end{array}$ & $\begin{array}{l}175 \\
180 \\
181 \\
185 \\
190\end{array}$ & $\begin{array}{l}228 \\
229 \\
230 \\
230 \\
230\end{array}$ & $\begin{array}{l}250 \\
255 \\
262 \\
270 \\
280\end{array}$ & $\begin{array}{l}311 \\
318 \\
342 \\
359 \\
351\end{array}$ & $\begin{array}{l}275 \\
277 \\
276 \\
275 \\
277\end{array}$ & $\begin{array}{l}186 \\
191 \\
204 \\
229 \\
222\end{array}$ \\
\hline $\begin{array}{l}26 \\
27 \\
28 \\
29 \\
30 \\
31\end{array}$ & $\begin{array}{r}95 \\
100 \\
106 \\
100 \\
109 \\
113\end{array}$ & $\begin{array}{l}119 \\
121 \\
121 \\
123 \\
126 \\
0-\end{array}$ & $\begin{array}{l}170 \\
140 \\
150 \\
152 \\
155 \\
160\end{array}$ & $\begin{array}{l}168 \\
162 \\
168 \\
170 \\
169 \\
175\end{array}$ & $\begin{array}{l}199 \\
200 \\
209 \\
- \\
-\end{array}$ & $\begin{array}{l}195 \\
195 \\
187 \\
184 \\
178 \\
182\end{array}$ & $\begin{array}{l}205 \\
210 \\
215 \\
218 \\
220 \\
-\end{array}$ & $\begin{array}{l}223 \\
222 \\
223 \\
223 \\
222 \\
221\end{array}$ & $\begin{array}{l}292 \\
290 \\
291 \\
300 \\
300 \\
-\end{array}$ & $\begin{array}{l}302 \\
303 \\
303 \\
303 \\
300 \\
309\end{array}$ & $\begin{array}{l}288 \\
299 \\
306 \\
301 \\
304 \\
297\end{array}$ & $\begin{array}{l}248 \\
250 \\
243 \\
242 \\
--\end{array}$ \\
\hline ERAGE & 97 & 121 & 139 & 165 & 184 & 205 & 186 & 224 & 258 & 309 & 297 & 217 \\
\hline
\end{tabular}

(TRACE METALS)

\begin{tabular}{|c|c|c|c|c|c|c|c|c|c|c|c|c|}
\hline & $\begin{array}{l}\text { OIS- } \\
\text { SOLVED }\end{array}$ & D15- & DIS- & $\begin{array}{l}\text { OIS- } \\
\text { SOLVFO }\end{array}$ & $\begin{array}{r}\text { HEXA- } \\
\text { VALENT }\end{array}$ & $\begin{array}{l}\text { OIS- } \\
\text { SULVED }\end{array}$ & DIS- & DIS- & $015-$ & $\begin{array}{c}\text { OIS- } \\
\text { SOLVED }\end{array}$ & & DI \\
\hline & ALUN=- & SOLVFO & SOLVEO & $C A D=$ & CHRO- & CHKO- & SOLVED & SOLVEn & SOLVEO & MAN- & TOTAL & SCL \\
\hline & InUM & $\begin{array}{c}\text { APSENIC } \\
\text { (AS) }\end{array}$ & $\begin{array}{l}\text { DORON } \\
\text { (B) }\end{array}$ & $\begin{array}{l}\text { MIUM } \\
\text { (CD) }\end{array}$ & MIUM & MIUM & COPPER & $\begin{array}{l}\text { IRON } \\
\text { (FE) }\end{array}$ & LEAD & GANESE & $\begin{array}{l}\text { MERCURY } \\
\text { (HG }\end{array}$ & $\begin{array}{l}Z \text { I YC } \\
(Z N)\end{array}$ \\
\hline & $(U G / L)$ & (Uis/L) & $(\cup G / L)$ & $(U G / L)$ & $(U G / L)$ & (UG/L) & (UG/L) & (UG/L) & (UG/L) & $(U G / L)$ & $(U G / L)$ & (US/L) \\
\hline
\end{tabular}

OCT., 1969

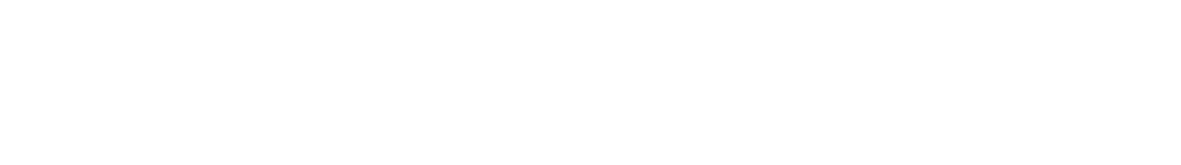

(OTHER DATA)

\begin{tabular}{|c|c|c|c|c|c|c|c|c|c|c|c|c|}
\hline & $\begin{array}{l}\text { IMME- } \\
\text { DIATE } \\
\text { COLI- } \\
\text { FORM } \\
\text { ICOL. } \\
\text { PER }\end{array}$ & $\begin{array}{l}\text { DELAYED } \\
\text { COLI - } \\
\text { FORM } \\
\text { ICQL- } \\
\text { ONIES } \\
\text { PER }\end{array}$ & $\begin{array}{l}\text { OIL } \\
\text { AND } \\
\text { GREASE }\end{array}$ & $\begin{array}{l}\text { METHY- } \\
\text { LENE } \\
\text { BLUE } \\
\text { ACTIVE } \\
\text { SUB- } \\
\text { STANCE }\end{array}$ & $\begin{array}{l}\text { DIS- } \\
\text { SOLVED } \\
\text { ORGANIC } \\
\text { NITRO- } \\
\text { GEN } \\
\text { (N) }\end{array}$ & & $\begin{array}{l}\text { IODIDE } \\
\text { (I) }\end{array}$ & $\begin{array}{l}\text { TOTAL } \\
\text { ALUM- } \\
\text { INUM } \\
\text { (AL) }\end{array}$ & $\begin{array}{l}\text { DIS- } \\
\text { SOLVED } \\
\text { COBALT } \\
\text { (CD) }\end{array}$ & $\begin{array}{l}\text { TOTAL } \\
\text { IRON } \\
\text { (FE) }\end{array}$ & $\begin{array}{l}\text { DIS- } \\
\text { SOLVED } \\
\text { LITHIUM } \\
\text { (LII) }\end{array}$ & $\begin{array}{l}\text { DIS- } \\
\text { SOLVED } \\
\text { MERCURY } \\
\text { (HG) }\end{array}$ \\
\hline ITE & $100 \mathrm{ML}\}$ & $100 \mathrm{ML})$ & $(M G / L)$ & $(M G / L)$ & $(M G / L)$ & (UG/L) & (MG/L) & $(U G / L)$ & (UG/L) & $(U G / L)$ & (UG /L) & $(U G / L)$ \\
\hline
\end{tabular}

OCT., 1y+a

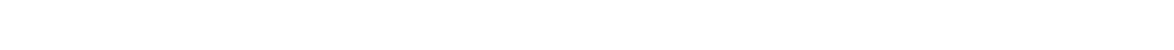

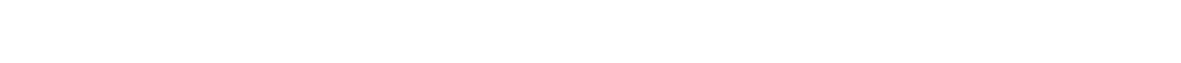

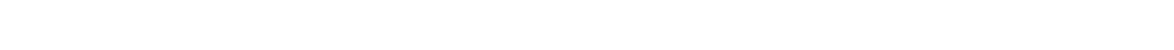

$? 7 .$. 
ST. JOHNS RIVER BASIN

02232000 ST. JOHNS RIVER NEAR MELBOURNE, FLA.--COnt1 Inued

TEMPERATURE $\left({ }^{\circ} \mathrm{C}\right)$ OF WATER, WATER YEAR OCTOBER 1969 TO SEPTEMBER 1970

\begin{tabular}{|c|c|c|c|c|c|c|c|c|c|c|c|c|}
\hline DAY & OCT & NOV & DEC & JAN & FEB & MAR & $A P R$ & MAY & JUN & JUL & AUG & SEP \\
\hline $\begin{array}{l}1 \\
2 \\
3 \\
4 \\
5\end{array}$ & $\begin{array}{l}26.0 \\
27.0 \\
26.0 \\
26.0 \\
28.0\end{array}$ & $\begin{array}{l}23.0 \\
23.0 \\
23.0 \\
22.0 \\
19.0\end{array}$ & $\begin{array}{l}16.5 \\
16.0 \\
15.5 \\
15.5 \\
14.5\end{array}$ & $\begin{array}{l}17.5 \\
16.5 \\
16.0 \\
14.0 \\
14.0\end{array}$ & $\begin{array}{l}14.5 \\
16.0 \\
17.5 \\
13.0 \\
11.5\end{array}$ & $\begin{array}{l}17.0 \\
16.0 \\
19.0 \\
19.0 \\
20.0\end{array}$ & $\begin{array}{l}22.5 \\
25.0 \\
23.0 \\
23.0 \\
22.5\end{array}$ & $\begin{array}{l}26.0 \\
25.0 \\
25.0 \\
27.0 \\
26.0\end{array}$ & $\begin{array}{l}25.0 \\
25.0 \\
25.0 \\
25.0 \\
28.0\end{array}$ & $\begin{array}{l}26.5 \\
29.0 \\
30.0 \\
30.0 \\
28.0\end{array}$ & $\begin{array}{l}30.0 \\
30.0 \\
30.0 \\
30.0 \\
30.0\end{array}$ & $\begin{array}{l}28.0 \\
29.0 \\
30.0 \\
30.0 \\
30.0\end{array}$ \\
\hline $\begin{array}{r}6 \\
7 \\
8 \\
9 \\
10\end{array}$ & $\begin{array}{l}25.0 \\
25.0 \\
25.0 \\
26.0 \\
26.0\end{array}$ & $\begin{array}{l}18.0 \\
17.0 \\
17.0 \\
18.0 \\
18.0\end{array}$ & $\begin{array}{l}15.0 \\
15.5 \\
16.0 \\
17.0 \\
17.5\end{array}$ & $\begin{array}{r}16.0 \\
14.0 \\
11.0 \\
8.0 \\
7.0\end{array}$ & $\begin{array}{l}13.0 \\
15.0 \\
15.0 \\
15.0 \\
14.5\end{array}$ & $\begin{array}{l}19.0 \\
20.0 \\
20.0 \\
18.0 \\
19.0\end{array}$ & $\begin{array}{l}-0- \\
21.0 \\
21.0 \\
22.0\end{array}$ & $\begin{array}{l}27.0 \\
24.0 \\
25.0 \\
26.0 \\
26.0\end{array}$ & $\begin{array}{l}26.0 \\
26.0 \\
25.0 \\
24.0 \\
26.0\end{array}$ & $\begin{array}{l}27.0 \\
28.0 \\
29.0 \\
29.0 \\
28.0\end{array}$ & $\begin{array}{l}30.0 \\
31.0 \\
28.0 \\
29.0 \\
28.0\end{array}$ & $\begin{array}{l}30.0 \\
28.0 \\
28.0 \\
28.0 \\
29.0\end{array}$ \\
\hline $\begin{array}{l}11 \\
12 \\
13 \\
14 \\
15\end{array}$ & $\begin{array}{l}26.0 \\
28.0 \\
26.0 \\
25.0 \\
25.0\end{array}$ & $\begin{array}{l}18.0 \\
18.0 \\
18.5 \\
19.0 \\
17.0\end{array}$ & $\begin{array}{l}18.0 \\
17.5 \\
15.0 \\
14.5 \\
14.0\end{array}$ & $\begin{array}{r}9.0 \\
10.0 \\
11.0 \\
12.0 \\
13.0\end{array}$ & $\begin{array}{l}14.0 \\
14.0 \\
15.0 \\
18.0 \\
16.0\end{array}$ & $\begin{array}{l}20.0 \\
20.0 \\
20.0 \\
17.0 \\
15.0\end{array}$ & $\begin{array}{l}23.0 \\
23.0 \\
23.0 \\
25.0 \\
25.0\end{array}$ & $\begin{array}{r}25.0 \\
25.0 \\
25.0 \\
26.0\end{array}$ & $\begin{array}{l}25.0 \\
25.0 \\
29.0 \\
29.0 \\
29.0\end{array}$ & $\begin{array}{l}28.0 \\
28.0 \\
27.0 \\
28.0 \\
29.0\end{array}$ & $\begin{array}{r}28.0 \\
28.0 \\
28.0 \\
28.0\end{array}$ & $\begin{array}{r}29.0 \\
29.0 \\
28.0\end{array}$ \\
\hline $\begin{array}{l}16 \\
17 \\
18 \\
19 \\
20\end{array}$ & $\begin{array}{l}26.0 \\
26.0 \\
26.0 \\
26.0 \\
26.0\end{array}$ & $\begin{array}{l}15.0 \\
22.0 \\
16.0 \\
20.0 \\
18.0\end{array}$ & $\begin{array}{l}14.0 \\
15.0 \\
14.5 \\
15.0 \\
15.0\end{array}$ & $\begin{array}{l}16.0 \\
16.0 \\
17.0 \\
17.0 \\
16.0\end{array}$ & $\begin{array}{l}19.0 \\
20.0 \\
18.0 \\
18.0 \\
17.5\end{array}$ & $\begin{array}{l}15.0 \\
10.0 \\
17.5 \\
20.0 \\
21.0\end{array}$ & $\begin{array}{l}25.0 \\
24.5 \\
25.0 \\
24.0 \\
25.0\end{array}$ & $\begin{array}{l}25.0 \\
26.0 \\
26.0 \\
26.5 \\
26.0\end{array}$ & $\begin{array}{l}28.5 \\
29.0 \\
30.0 \\
29.0 \\
30.0\end{array}$ & $\begin{array}{l}29.0 \\
28.0 \\
30.0 \\
29.0 \\
29.0\end{array}$ & $\begin{array}{l}29.0 \\
30.0 \\
29.0 \\
30.0 \\
30.0\end{array}$ & $\begin{array}{l}28.0 \\
29.0 \\
29.0 \\
30.0 \\
29.0\end{array}$ \\
\hline $\begin{array}{l}21 \\
22 \\
23 \\
24 \\
25\end{array}$ & $\begin{array}{l}26.0 \\
26.0 \\
26.0 \\
25.5 \\
24.0\end{array}$ & $\begin{array}{l}18.0 \\
17.0 \\
17.0 \\
17.0 \\
17.5\end{array}$ & $\begin{array}{l}15.0 \\
15.0 \\
15.0 \\
15.0 \\
15.5\end{array}$ & $\begin{array}{l}15.0 \\
13.5 \\
13.0 \\
13.0 \\
13.5\end{array}$ & $\begin{array}{l}15.0 \\
16.0 \\
15.0 \\
15.0 \\
17.0\end{array}$ & $\begin{array}{l}22.0 \\
23.0 \\
20.0 \\
18.0 \\
19.0\end{array}$ & $\begin{array}{l}25.0 \\
27.0 \\
27.0 \\
27.0 \\
27.0\end{array}$ & $\begin{array}{l}25.0 \\
26.0 \\
26.0 \\
26.0 \\
25.0\end{array}$ & $\begin{array}{l}29.0 \\
30.0 \\
28.5 \\
28.0 \\
30.0\end{array}$ & $\begin{array}{l}29.0 \\
28.0 \\
27.0 \\
28.0 \\
28.0\end{array}$ & $\begin{array}{l}30.0 \\
30.0 \\
30.0 \\
30.0 \\
28.0\end{array}$ & $\begin{array}{l}29.0 \\
28.5 \\
29.0 \\
29.0 \\
29.0\end{array}$ \\
\hline $\begin{array}{l}26 \\
27 \\
28 \\
29 \\
30 \\
31\end{array}$ & $\begin{array}{l}24.0 \\
24.0 \\
24.0 \\
24.0 \\
23.0 \\
23.5\end{array}$ & $\begin{array}{r}18.0 \\
18.0 \\
19.0 \\
19.0 \\
18.0 \\
-\end{array}$ & $\begin{array}{l}16.0 \\
15.0 \\
15.0 \\
15.0 \\
15.5 \\
16.0\end{array}$ & $\begin{array}{l}14.0 \\
15.0 \\
15.0 \\
17.0 \\
18.0 \\
15.0\end{array}$ & $\begin{array}{r}16.0 \\
16.0 \\
15.0 \\
-0 . \\
-\end{array}$ & $\begin{array}{l}20.0 \\
20.0 \\
21.0 \\
17.0 \\
18.0 \\
25.0\end{array}$ & $\begin{array}{r}26.0 \\
28.0 \\
26.0 \\
29.0 \\
28.0 \\
-. .-\end{array}$ & $\begin{array}{l}24.5 \\
27.0 \\
28.0 \\
26.0 \\
26.0 \\
27.0\end{array}$ & $\begin{array}{r}30.0 \\
28.5 \\
28.5 \\
28.0 \\
28.0 \\
\ldots .-\end{array}$ & $\begin{array}{l}27.0 \\
29.0 \\
27.0 \\
30.0 \\
30.0 \\
-.-0\end{array}$ & $\begin{array}{l}30.0 \\
30.0 \\
30.0 \\
30.0 \\
29.0 \\
30.0\end{array}$ & $\begin{array}{r}28.0 \\
29.0 \\
28.0 \\
28.0 \\
- \\
-0\end{array}$ \\
\hline AVERAGE & 25.5 & 18.5 & 15.5 & 14.0 & 15.5 & 19.0 & 24.5 & 26.0 & 27.5 & 28.5 & 29.5 & 29.0 \\
\hline
\end{tabular}

02232400 ST. JOHNS RIVER NEAR COCOA, FLA.

LOCAT ION.--Lat $28^{\circ} 22^{\prime} 10^{\prime \prime}$, long $80^{\circ} 52^{\prime} 2^{\prime \prime}$, in SE $\frac{1}{4}$ sec.25, T.24 S., R.34 E., Brevard County, at gaging station near right bank on downtream side of bridge on State Highway $520,0.7$ mile downstream from outlet of Lake poinsett and 8.8 miles west of Cocoa, and 232 miles upstream from mouth.

DRAINAGE AREA.--1, $331 \mathrm{sq}$ mi.

PERIOD OF RECORD,--Chemical analyses: October 1953 to September 1970.

Water temperatures: October 1953 to September 1960, July 1964 to September 1970.

EXTREMES. -1969-70:

Specific conductance: Maximum daily, 1,350 micromhos July 23; minimum daily, 210 mteromhos Dec. 3.

water temperatures: Maximum, $33.5^{\circ} \mathrm{C}$ Sept. 2 ; minimum, $9.0^{\circ} \mathrm{C}$ Jan. 10.

Period of record:

Dissolved solids (1953-60): Maximum, $998 \mathrm{mg} / 1 \mathrm{July} 11-20,1956 ; \mathrm{minimum}, 68 \mathrm{mg} / 1 \mathrm{Mar}, 17,18,1960$.

Hardness (1953-60): Maximum, $194 \mathrm{mg} / 1$ June 11-20, 1956; minimum, $16 \mathrm{mg} / 1$ Var. 17, $18,1960$.

Specific conductance: Naximum daily, 3,500 micromos June 27, 30, July 2, 1962; minimum daily, 40 micromhos

Aug. 27, 1964.

Water temperatures: Maximum, $35.0^{\circ} \mathrm{C}$ Aug. 9,$1956 ;$ minqmum, 8. $0^{\circ} \mathrm{C} \mathrm{Jan.} \mathrm{9-12,} 1956$, Feb. $5,1966$.

\begin{tabular}{|c|c|c|c|c|c|c|c|c|c|c|c|c|}
\hline & & & CHEMICAL & ANALYSES & $\begin{array}{l}\text {, WATER } \\
\text { (MAJ }\end{array}$ & $\begin{array}{l}\text { EAR OCTL } \\
\text { CONSTI }\end{array}$ & $\begin{array}{l}\text { BER } 1969 \\
\text { JENTS) }\end{array}$ & TO SEPTEM & BER 1970 & & & \\
\hline DATE & $\begin{array}{l}\text { DIS- } \\
\text { CHARGE } \\
\text { (CFS) }\end{array}$ & $\begin{array}{l}\text { TEMPER- } \\
\text { ATURE } \\
\text { (OEG C) }\end{array}$ & $\begin{array}{l}\text { SPE- } \\
\text { CIFIC } \\
\text { CON- } \\
\text { DUCT- } \\
\text { ANCE } \\
\text { (MICRO- } \\
\text { MHOS) }\end{array}$ & $\begin{array}{l}\text { DIS- } \\
\text { SOLVED } \\
\text { IRON } \\
\text { (FE) } \\
\text { (UG/L) }\end{array}$ & $\begin{array}{l}\text { UIS- } \\
\text { SOLVED } \\
\text { CAL- } \\
\text { CIUM } \\
\text { (CA) } \\
(M G / L)\end{array}$ & $\begin{array}{l}\text { OIS- } \\
\text { SOLVEO } \\
\text { MAG- } \\
\text { NE- } \\
\text { SIUM } \\
\text { (MG) } \\
\text { SMG/LI }\end{array}$ & $\begin{array}{l}\text { OIS- } \\
\text { SOLVED } \\
\text { STRON- } \\
\text { TIUM } \\
\text { (SR) } \\
\text { (UG/L) }\end{array}$ & $\begin{array}{l}\text { DIS- } \\
\text { SOLVED } \\
\text { SODIUY } \\
\text { (NA) } \\
\text { (MG/L) }\end{array}$ & $\begin{array}{l}\text { DIS- } \\
\text { SOLVED } \\
\text { PO- } \\
\text { TAS- } \\
\text { SIIJM } \\
\text { (K) } \\
\text { (MG/L) }\end{array}$ & $\begin{array}{l}\text { BICAR= } \\
\text { BONATE } \\
\text { (HCO3) } \\
\text { (MGIL) }\end{array}$ & $\begin{array}{l}\text { CAR- } \\
\text { BONATE } \\
\text { (CO3) } \\
\text { (MG/L) }\end{array}$ & $\begin{array}{c}\text { PH } \\
\text { (UNITS) }\end{array}$ \\
\hline ост... & $\begin{array}{l}969 \\
1890\end{array}$ & 27.5 & 309 & -- & 23 & 4.6 & - & 30 & .6 & 52 & -- & 7.1 \\
\hline $\begin{array}{l}29 . . . \\
\text { Nov. }\end{array}$ & 4880 & 23.0 & 253 & -- & - & -- & -- & - & -- & -- & - & -- \\
\hline JAN... & $\begin{array}{l}4100 \\
970\end{array}$ & 18.5 & 222 & 230 & 15 & 3.4 & 420 & 21 & 1.2 & 37 & 0 & 7.4 \\
\hline $\begin{array}{l}13 . . . \\
\text { FER. }\end{array}$ & 1620 & 11.0 & 289 & -- & 19 & 4.3 & -- & 29 & 1.0 & 36 & $n$ & 6.4 \\
\hline $\begin{array}{l}\text { O4.... } \\
\text { MAR. }\end{array}$ & 1580 & 12.0 & 320 & 70 & 21 & 5.1 & 540 & 34 & 2.1 & 40 & $n$ & 7.2 \\
\hline MAY & 1190 & 20.5 & 358 & -- & 22 & 5.2 & - & 36 & 2.3 & $4 n$ & 0 & 6.5 \\
\hline juLY... & 591 & 23.0 & 410 & 160 & 26 & 5.4 & 700 & 42 & .9 & 50 & -- & 7.3 \\
\hline $\begin{array}{l}01 \ldots . . \\
30 . . \\
\text { AUG. }\end{array}$ & $\begin{array}{l}121 \\
292\end{array}$ & $\begin{array}{l}30.5 \\
30.0\end{array}$ & $\begin{array}{l}1700 \\
1160\end{array}$ & $\overrightarrow{80}$ & $\begin{array}{l}68 \\
58\end{array}$ & $\begin{array}{l}30 \\
20\end{array}$ & 3700 & $\begin{array}{l}236 \\
140\end{array}$ & $\begin{array}{l}5.0 \\
4.1\end{array}$ & $\begin{array}{l}76 \\
64\end{array}$ & $\stackrel{n}{n}$ & $\begin{array}{l}7.2 \\
7.3\end{array}$ \\
\hline $19 .$. & 379 & 32.0 & 1150 & - & 56 & 20 & -- & 132 & 4.7 & 64 & 0 & 7.4 \\
\hline
\end{tabular}


02232400 ST, JOHNS RIVER NEAR COCOA, FLA.--CONtinued

CHEMICAL ANALYSES, WATER YEAR OCTOBER 1969 TO SEPTEMBER 1970 IMAJOR CONSTITUENTS)

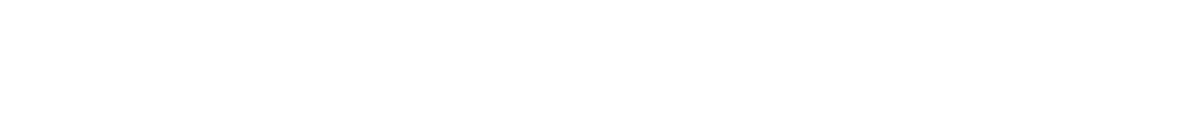

OCT., 1969

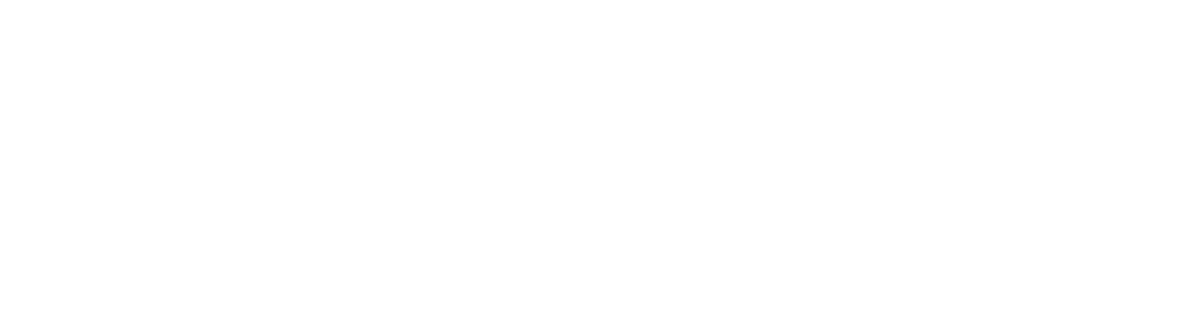

(MACRONUTRIENTS AND OTHER RELATED CONSTITUENTS)

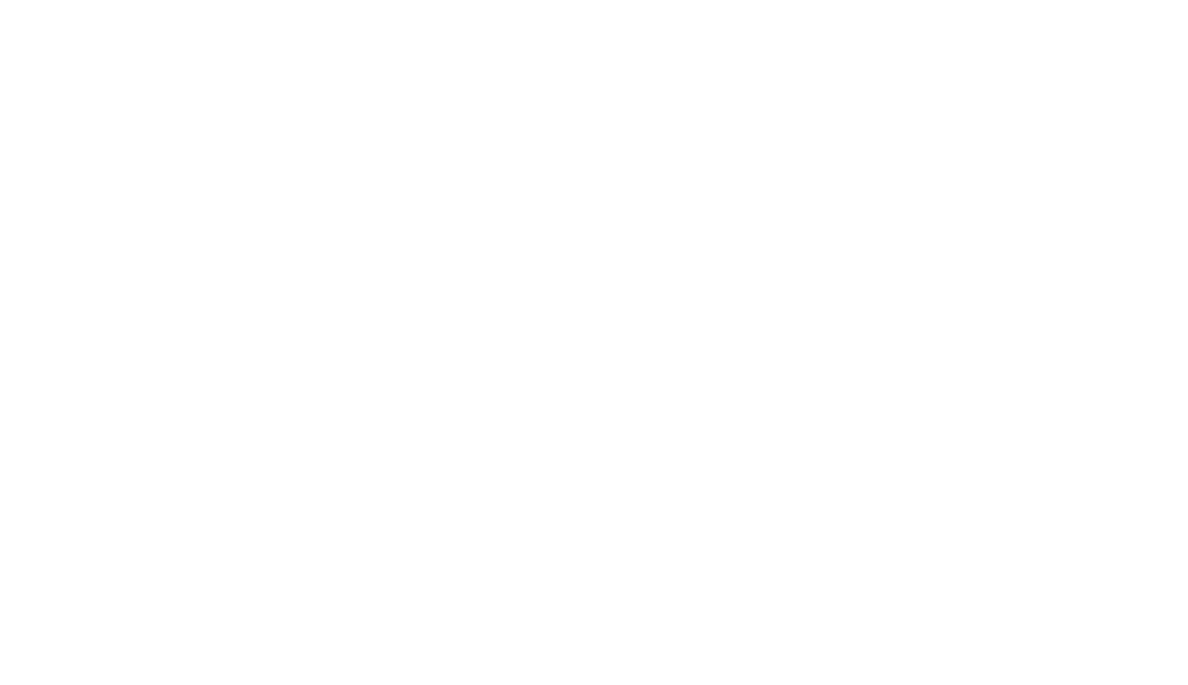

(FIELD MEASUREMENTS)

\begin{tabular}{|c|c|c|c|c|c|c|c|c|c|c|c|c|}
\hline DATE & TIME & $\begin{array}{l}\text { STAGE } \\
\text { (FT } \\
\text { ABOVE } \\
\text { DATUM) }\end{array}$ & $\begin{array}{l}\text { DIS- } \\
\text { CHARGE } \\
\text { (CFS) }\end{array}$ & $\begin{array}{l}\text { TEMPER- } \\
\text { ATURE } \\
\text { (DEG C) }\end{array}$ & $\begin{array}{l}\text { DIS- } \\
\text { SOLVED } \\
\text { OXYGEN } \\
(M G / L)\end{array}$ & $\begin{array}{l}\text { PER- } \\
\text { CENT } \\
\text { SATUR- } \\
\text { ATION }\end{array}$ & $\begin{array}{l}\text { SPE- } \\
\text { CIF IC } \\
\text { CON- } \\
\text { DUCT- } \\
\text { ANCE } \\
\text { (MICRO- } \\
\text { MHOS) }\end{array}$ & $\begin{array}{c}\mathrm{PH} \\
\text { (UNITS) }\end{array}$ & $\begin{array}{l}\text { BICAR- } \\
\text { BONATE } \\
\text { (HCOZ) } \\
(M G / L)\end{array}$ & $\begin{array}{l}\text { CAR- } \\
\text { BDNATE } \\
\text { (CO3) } \\
\text { (MG/L) }\end{array}$ & $\begin{array}{l}\text { TRANS- } \\
\text { PAR- } \\
\text { ENCY } \\
\text { SECCHI } \\
\text { OISK } \\
\text { (IN) }\end{array}$ & $\begin{array}{l}\text { OEPTH } \\
\text { (FT) }\end{array}$ \\
\hline ост.. 1969 & 6800 & 16.39 & 4880 & 23.0 & 5.1 & 59 & 253 & $\cdots$ & $\cdots$ & $=$ & 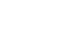 & 1.0 \\
\hline FEB... 1970 & 0945 & 15.96 & 4100 & 18.5 & 8.3 & 90 & 213 & 7.4 & 38 & 0 & $=$ & -- \\
\hline MAY & 1645 & 13.92 & 1560 & 12.0 & 10.0 & 93 & 340 & 7.7 & 40 & - & -- & $\cdots$ \\
\hline JuLY... & 0930 & 12.06 & 591 & 23.0 & 7.7 & 88 & 412 & 7.7 & $-\infty$ & -- & - & $\cdots$ \\
\hline $30 \ldots$ & 0900 & 10.88 & 292 & 30.0 & 5.8 & 76 & 1190 & 7.7 & 66 & 0 & -- & -- \\
\hline
\end{tabular}


ST, JOHNS RIVER BASIN

169

02232400 ST. JOHNS RIVER NEAR COCOA, FLA.-_CODT1nued

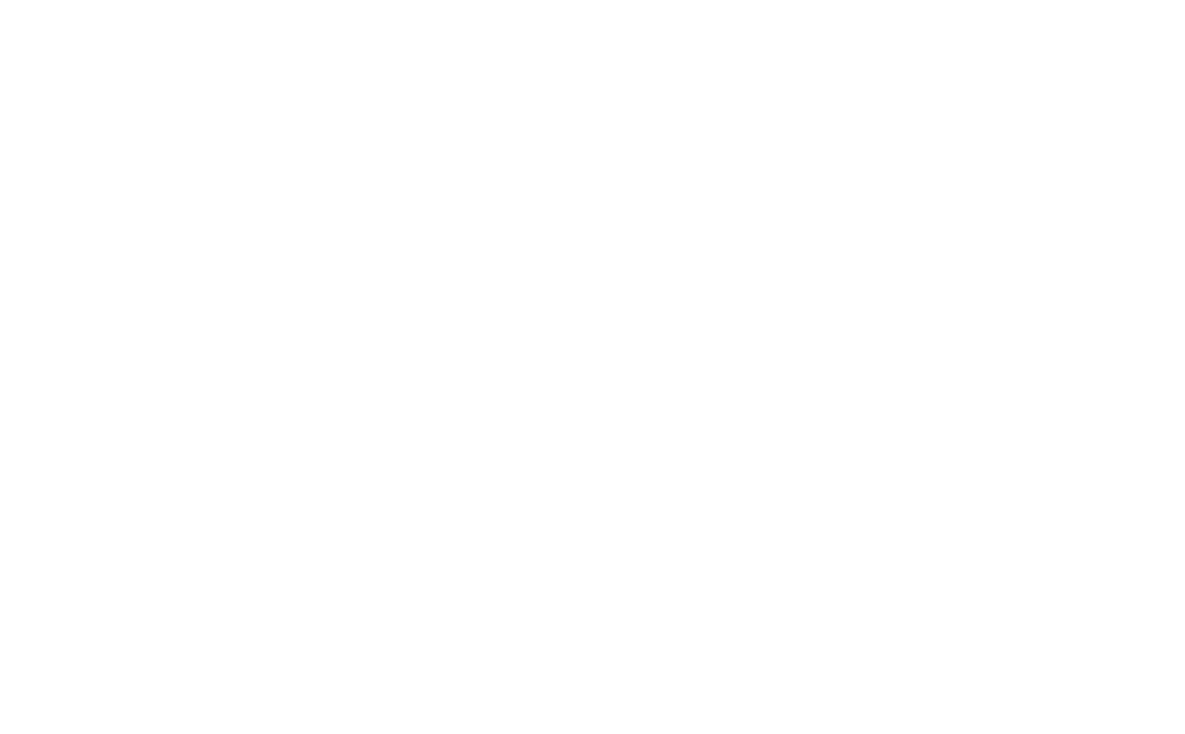

(ORGANOCHLORIDE COMPOUNDS IN WATER)

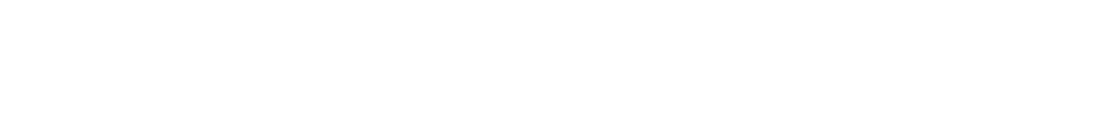

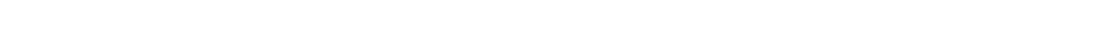

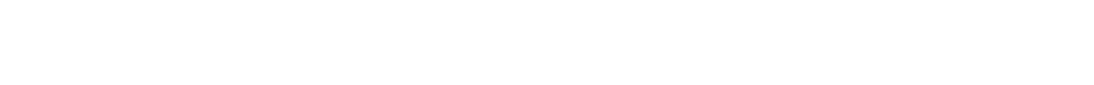

(ORGANOCHLORIDE COMPOUNDS IN SEDIMFNTS)

\begin{tabular}{|c|c|c|c|c|c|c|c|c|}
\hline & $A L D R$ & ODO & DDE & DOT & $\begin{array}{l}\text { DI- } \\
\text { ELDRIN }\end{array}$ & ENDP IN & $\begin{array}{l}\text { HEPTA- } \\
\text { CHLOR }\end{array}$ & LINDANE \\
\hline & & IN & IN & IN & IN & IN & IN & IN \\
\hline & ROTTOM & BOT TOM & BOTIOM & ВОТтом & ROTIOM & BOTTOM & BOITOM & BOTTOM \\
\hline & & $\begin{array}{c}\text { DE- } \\
\text { POSITS }\end{array}$ & $\begin{array}{l}\text { DE- } \\
\text { POSIIS }\end{array}$ & $\begin{array}{l}\text { UE- } \\
\text { POSIIS }\end{array}$ & & $\begin{array}{l}\text { DE- } \\
\text { POSITS }\end{array}$ & $\begin{array}{l}\text { DE- } \\
\text { POSIIS }\end{array}$ & $\begin{array}{l}\text { DE- } \\
\text { POSITS }\end{array}$ \\
\hline & (UG,KG) & (UG/KG) & $(U G / K G)$ & $(11 G / K G)$ & $(1 / G / K G)$ & (UG/KG) & (UG/KG) & $(U G / K G)$ \\
\hline
\end{tabular}

MAY 1970

JUL

30 ...

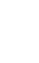

.0
3.1
3.1

1.5

5

iTRACE METALS

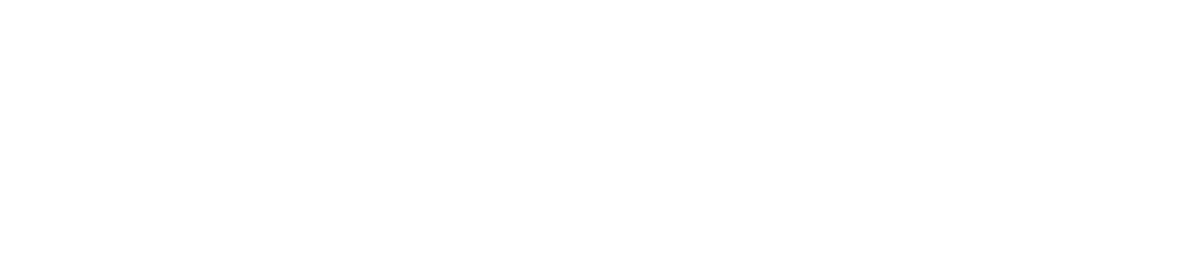

(HERBICIDES AND ORGANOPHORUS INSECTIDES IN WATER AND SEDIMENT)

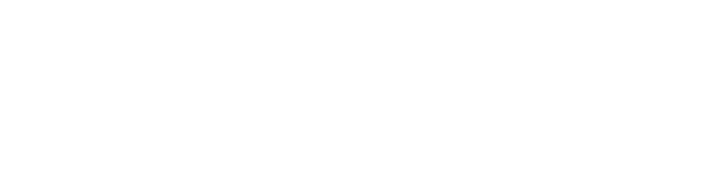


02232400 ST. JOHNS RIVER NFAR COCOA, FLA.--Continued

CHEMICAL ANALYSES, WATER YEAR OCTOBER 1969 TO SEPTEMBER 1970
(OTHER DATA)

\begin{tabular}{|c|c|c|c|c|c|c|c|c|c|c|c|c|}
\hline JJATE & $\begin{array}{c}\text { IMME- } \\
\text { DIATE } \\
\text { COLI- } \\
\text { FORM } \\
\text { \{COL. } \\
\text { PER } \\
100 \mathrm{MLI}\end{array}$ & $\begin{array}{c}\text { DELAYED } \\
\text { COLI- } \\
\text { FORM } \\
\text { (COL- } \\
\text { ONIES } \\
\text { PER } \\
100 \mathrm{ML} \text { ) }\end{array}$ & $\begin{array}{l}\text { OIL } \\
\text { AND } \\
\text { GREASE } \\
\text { (MG/L) }\end{array}$ & $\begin{array}{l}\text { METHY } \\
\text { LENE } \\
\text { BLUE } \\
\text { ACTIVE } \\
\text { SUB- } \\
\text { STANCE } \\
\text { (MG/L }\end{array}$ & $\begin{array}{l}\text { DIS. } \\
\text { SOLVED } \\
\text { ORGANIC } \\
\text { NITRO- } \\
\text { GEN } \\
\text { (N) } \\
\text { (MG/L) }\end{array}$ & $\begin{array}{l}\text { PHENOLS } \\
\text { IUG/L }\end{array}$ & $\begin{array}{l}\text { IODIDE } \\
\text { (I) } \\
\text { (MG/L) }\end{array}$ & $\begin{array}{l}\text { TOTAL } \\
\text { ALUM- } \\
\text { INUM } \\
\text { (AL) } \\
\text { (UG/L) }\end{array}$ & $\begin{array}{l}\text { DIS- } \\
\text { SOLVED } \\
\text { COBALT } \\
\text { (CO) } \\
\text { (UG/L) }\end{array}$ & $\begin{array}{l}\text { TOTAL } \\
\text { IRON } \\
\text { (FE) } \\
\text { (UG/L) }\end{array}$ & $\begin{array}{l}\text { DIS- } \\
\text { SOLVED } \\
\text { LITHIUM } \\
\text { (LI) } \\
\text { (UG/L) }\end{array}$ & $\begin{array}{c}\text { DIS- } \\
\text { SOLVED } \\
\text { MERCURY } \\
\text { (HG) } \\
\text { (UG/L) }\end{array}$ \\
\hline \multicolumn{13}{|c|}{ Nov., $19+9$} \\
\hline MAY $\because \cdot$ & $47 \pi^{1231}$ & -- & -- & - & -- & -- & -- & $-\infty$ & -- & $\sim$ & - & -- \\
\hline JUL 07. & $\infty$ & -- & -- & ." & -- & f] & -- & $n$ & -- & $\cdots$ & -- & -- \\
\hline $30 \ldots$ & -- & - & -- & -- & $.5 ?$ & -- & $-\infty$ & 100 & -- & -- & $n$ & - \\
\hline \multicolumn{13}{|c|}{ TEMPERATURE } \\
\hline DAY & OCT & NOV & DEC & JAN & FEB & MAR & APR & Mar & JUN & HUL & AUG & SEP \\
\hline $\begin{array}{l}1 \\
2 \\
3 \\
4 \\
5\end{array}$ & $\begin{array}{l}27.0 \\
28.0 \\
27.0 \\
27.0 \\
27.0\end{array}$ & $\begin{array}{l}23.5 \\
25.0 \\
23.5 \\
22.0 \\
19.0\end{array}$ & $\begin{array}{l}19.0 \\
17.0 \\
17.0 \\
15.0 \\
15.0\end{array}$ & $\begin{array}{l}16.0 \\
15.5 \\
15.0 \\
14.5 \\
14.0\end{array}$ & $\begin{array}{l}15.0 \\
16.0 \\
16.0 \\
12.0 \\
12.0\end{array}$ & $\begin{array}{l}18.0 \\
19.0 \\
18.0 \\
19.0 \\
19.5\end{array}$ & $\begin{array}{l}21.0 \\
23.5 \\
20.0 \\
21.5 \\
22.0\end{array}$ & $\begin{array}{l}24.5 \\
25.0 \\
26.0 \\
25.5 \\
25.0\end{array}$ & $\begin{array}{l}26.5 \\
27.0 \\
28.0 \\
28.0 \\
25.5\end{array}$ & $\begin{array}{l}30.0 \\
30.0 \\
29.5 \\
28.5 \\
29.0\end{array}$ & $\begin{array}{l}29.0 \\
30.0 \\
33.0 \\
30.0 \\
29.0\end{array}$ & $\begin{array}{l}28.5 \\
33.5 \\
28.5 \\
28.0 \\
31.0\end{array}$ \\
\hline $\begin{array}{r}6 \\
7 \\
8 \\
9 \\
10\end{array}$ & $\begin{array}{l}26.0 \\
26.0 \\
26.0 \\
26.0 \\
26.0\end{array}$ & $\begin{array}{l}18.0 \\
17.0 \\
18.0 \\
19.0 \\
19.0\end{array}$ & $\begin{array}{l}15.5 \\
16.0 \\
17.5 \\
17.0 \\
17.0\end{array}$ & $\begin{array}{r}16.0 \\
14.0 \\
12.5 \\
12.0 \\
9.0\end{array}$ & $\begin{array}{l}12.0 \\
14.0 \\
15.0 \\
15.0 \\
13.5\end{array}$ & $\begin{array}{l}19.5 \\
20.0 \\
19.0 \\
19.0 \\
17.5\end{array}$ & $\begin{array}{l}23.0 \\
22.5 \\
25.0 \\
26.0 \\
24.0\end{array}$ & $\begin{array}{l}26.0 \\
26.5 \\
25.0 \\
27.5 \\
25.0\end{array}$ & $\begin{array}{l}26.0 \\
27.5 \\
28.0 \\
28.5 \\
29.0\end{array}$ & $\begin{array}{l}30.0 \\
-. .2 \\
30.5 \\
29.0 \\
29.0\end{array}$ & $\begin{array}{l}32.0 \\
29.0 \\
30.0 \\
29.0 \\
28.0\end{array}$ & $\begin{array}{l}29.0 \\
28.0 \\
27.5 \\
27.0 \\
28.5\end{array}$ \\
\hline $\begin{array}{l}11 \\
12 \\
13 \\
14 \\
15\end{array}$ & $\begin{array}{l}26.0 \\
25.0 \\
27.0 \\
26.0 \\
27.0\end{array}$ & $\begin{array}{l}18.5 \\
18.0 \\
20.0 \\
16.0 \\
18.0\end{array}$ & $\begin{array}{l}17.5 \\
17.0 \\
15.0 \\
14.0 \\
15.0\end{array}$ & $\begin{array}{r}9.5 \\
10.0 \\
10.5 \\
11.0 \\
13.0\end{array}$ & $\begin{array}{l}14.0 \\
16.0 \\
15.0 \\
16.0 \\
16.5\end{array}$ & $\begin{array}{l}19.0 \\
22.0 \\
19.0 \\
16.0 \\
15.0\end{array}$ & $\begin{array}{l}22.5 \\
25.0 \\
26.0 \\
26.5 \\
25.0\end{array}$ & $\begin{array}{l}26.0 \\
26.0 \\
25.0 \\
28.0 \\
27.0\end{array}$ & $\begin{array}{l}28.0 \\
27.0 \\
29.0 \\
31.0 \\
29.0\end{array}$ & $\begin{array}{l}31.0 \\
27.5 \\
29.0 \\
29.5 \\
28.5\end{array}$ & $\begin{array}{l}28.0 \\
27.0 \\
26.0 \\
27.5 \\
29.5\end{array}$ & $\begin{array}{l}28.0 \\
28.5 \\
28.5 \\
28.0 \\
26.5\end{array}$ \\
\hline $\begin{array}{l}16 \\
17 \\
18 \\
19 \\
20\end{array}$ & $\begin{array}{l}28.0 \\
26.0 \\
26.0 \\
26.0 \\
28.0\end{array}$ & $\begin{array}{l}15.0 \\
18.0 \\
18.0 \\
17.0 \\
18.0\end{array}$ & $\begin{array}{l}15.0 \\
15.0 \\
16.0 \\
15.0 \\
15.5\end{array}$ & $\begin{array}{l}14.0 \\
15.0 \\
15.5 \\
15.5 \\
15.0\end{array}$ & $\begin{array}{l}17.0 \\
18.0 \\
17.5 \\
19.0 \\
17.0\end{array}$ & $\begin{array}{l}15.5 \\
19.0 \\
20.0 \\
21.5 \\
21.0\end{array}$ & $\begin{array}{l}25.5 \\
26.0 \\
26.0 \\
24.0 \\
25.0\end{array}$ & $\begin{array}{l}26.5 \\
25.5 \\
26.5 \\
26.0 \\
24.0\end{array}$ & $\begin{array}{l}29.0 \\
28.0 \\
28.0 \\
28.0 \\
28.0\end{array}$ & $\begin{array}{l}28.5 \\
30.0 \\
30.0 \\
27.5 \\
29.0\end{array}$ & $\begin{array}{l}30.5 \\
31.5 \\
32.0 \\
31.0 \\
28.5\end{array}$ & $\begin{array}{l}26.5 \\
28.0 \\
27.0 \\
28.0 \\
28.5\end{array}$ \\
\hline $\begin{array}{l}21 \\
22 \\
23 \\
24 \\
25\end{array}$ & $\begin{array}{l}28.0 \\
28.0 \\
28.0 \\
24.0 \\
24.0\end{array}$ & $\begin{array}{l}18.0 \\
17.0 \\
18.0 \\
17.0 \\
18.0\end{array}$ & $\begin{array}{l}15.0 \\
16.0 \\
16.0 \\
17.0 \\
17.0\end{array}$ & $\begin{array}{l}15.5 \\
15.0 \\
13.5 \\
16.0 \\
14.5\end{array}$ & $\begin{array}{l}14.5 \\
15.0 \\
18.0 \\
18.5 \\
18.0\end{array}$ & $\begin{array}{l}22.0 \\
19.0 \\
21.0 \\
21.5 \\
22.0\end{array}$ & $\begin{array}{l}24.5 \\
26.0 \\
27.0 \\
27.5 \\
26.0\end{array}$ & $\begin{array}{l}26.0 \\
25.5 \\
26.0 \\
25.0 \\
25.0\end{array}$ & $\begin{array}{l}33.0 \\
27.5 \\
27.0 \\
29.0 \\
27.5\end{array}$ & $\begin{array}{l}26.0 \\
26.5 \\
30.0 \\
28.0 \\
28.5\end{array}$ & $\begin{array}{r}30.0 \\
29.0 \\
28.5 \\
29.0 \\
-\ldots\end{array}$ & $\begin{array}{l}29.0 \\
28.5 \\
29.5 \\
30.0 \\
29.0\end{array}$ \\
\hline $\begin{array}{l}26 \\
27 \\
28 \\
29 \\
30 \\
31\end{array}$ & $\begin{array}{l}24.0 \\
23.0 \\
24.0 \\
24.0 \\
22.0 \\
=-0\end{array}$ & $\begin{array}{l}18.0 \\
19.0 \\
20.0 \\
19.5 \\
19.0 \\
----\end{array}$ & $\begin{array}{l}16.5 \\
16.5 \\
15.0 \\
16.5 \\
16.5 \\
17.0\end{array}$ & $\begin{array}{l}15.0 \\
15.5 \\
17.0 \\
20.0 \\
16.0 \\
18.5\end{array}$ & $\begin{array}{r}17.0 \\
16.0 \\
16.0 \\
-0 . \\
--.-\end{array}$ & $\begin{array}{l}20.0 \\
21.0 \\
23.0 \\
24.0 \\
22.0 \\
22.0\end{array}$ & $\begin{array}{r}24.5 \\
25.5 \\
22.0 \\
-.0 \\
26.5 \\
-.-\end{array}$ & $\begin{array}{l}25.0 \\
26.5 \\
26.0 \\
25.5 \\
25.0 \\
25.5\end{array}$ & $\begin{array}{l}28.0 \\
27.0 \\
28.0 \\
28.5 \\
28.0 \\
-. .\end{array}$ & $\begin{array}{l}29.5 \\
29.0 \\
29.0 \\
29.5 \\
31.5 \\
28.5\end{array}$ & $\begin{array}{l}31.5 \\
29.0 \\
28.5 \\
28.5 \\
29.0 \\
30.5\end{array}$ & $\begin{array}{l}26.5 \\
26.0 \\
28.5 \\
26.0 \\
25.0 \\
-.-2\end{array}$ \\
\hline IERAGE & 26.0 & 19.0 & 16.0 & 14.5 & 15.5 & 20.0 & 24.5 & 25.5 & 28.0 & 29.0 & 29.5 & 28.0 \\
\hline
\end{tabular}

02232500 ST, JOHNS RIVER NEAR CHRISTMAS, FLA

LOCATION, --Lat $28^{\circ} 32^{\prime} 35^{\prime \prime}$, long B $0^{\circ} 56^{\prime} 40^{\prime \prime}$, In SW/ sec.29, T.22 S., R.34 E., Orange County, at gaging station on left bank about $150 \mathrm{ft}$ downstream from bridge on State Highway $50,0.3$ miles upstream (revised) from Tootoosahatchee Creek, 2 miles upstream from Lake Cone, 4.5 miles east of Christmas, and 209 miles upstream from mouth.

DRA INAGE AREA $=-1,539 \mathrm{sq} \mathrm{mi}$ (revised), includes that of Tootoosahatchee Creek.

PER IOD OF RECORD,--Chemical analyses: October 1954 to September 1958, June 1962 to March 1963, October 1964 to September 1970 .

Water temperatures: June 1965 to September 1970

EXTREMES. - -1969-70:

Specific conductance: Maximum da $12 y, 1,800$ micromos July 14, 15; mintmum dal1y, 300 micromhos Oct. $28,29$.

Water temperatures: Maximum, $37.0^{\circ} \mathrm{C}$ Oct. 1 ; minimum, $8.5^{\circ} \mathrm{C}$ Jan. 10.

Period of record:

Specific conductance (1962-70): Waximum dally, 4,800 micromhos July 1, 1962; minimum datly, 112 micromhos

July $1,1966$.

Water temperatures $(1965-70)$ : Maximun, $39.0^{\circ} \mathrm{C}$ July 9 , Aug. 30 , Sept. 15,$1969 ;$ mintmum, $3.0^{\circ} \mathrm{C} \mathrm{Jan}, 30,1967$.

CHEMICAL ANALYSES, WATER YEAR OCTOBER 1969 TO SEPTEMBER 1970 (MAJOR CONSTITUENTS)

SPE-

SPE-
CIFIC
CON-
DUCT-
AVCE
(MICRO-
CHARGE ATURE AVCE (MICRO-

DATE (CFS)

NoV., 1969

$05 . .19800$

$12 \ldots .04240$

13... 1970

$30 \ldots .2400$

MAR.

$04 \ldots 1640$

MAY

$08 \ldots .593$

JULY

$\begin{array}{ll}01 \ldots . . \quad & 136 \\ 23 \ldots & 595\end{array}$

AUG.

$19 \ldots \ldots$

22... 412

$\begin{array}{rrrr}17.5 & 371 & 310 & 18 \\ 17.0 & 352 & -- & 20 \\ 11.0 & 500 & -- & 23 \\ 18.5 & 492 & 160 & 25 \\ 20.0 & 562 & -- & 27 \\ 23.5 & 670 & 170 & 31 \\ 30.0 & 1490 & -- & 6 \\ 28.0 & 1780 & 380 & 7 \\ 30.5 & 1500 & -- & 69 \\ 31.5 & 1170 & -- & 49\end{array}$

UIS-
OIS- SOLVEO
SOLVED

$\begin{array}{lllc} & \text { OIS- } & \text { SOLVEO } & \text { OIS- } \\ \text { DIS- } & \text { SOLVED } & \text { MAG- } & \text { SOLVED } \\ \text { SOLVEO } & \text { CAL- } & \text { NE- } & \text { STRON- } \\ \text { IRON } & \text { CIUM } & \text { SIUM } & \text { TIUM } \\ \text { (FE) } & \text { (CA) } & \text { (MG) } & \text { (SR) }\end{array}$

(MG/L) (MGL) (SR)

$\begin{array}{lrrrrrrr}18 & 5.3 & 580 & 42 & 1.4 & 38 & 0 & 7.5 \\ 20 & 5.6 & -- & 39 & 1.5 & 40 & - & 6.9 \\ 23 & 7.8 & -- & 60 & 2.0 & 38 & -- & 6.9 \\ 25 & 8.1 & 690 & 60 & 2.7 & 44 & 0 & 7.1 \\ 27 & 8.5 & -- & 67 & 7.8 & 44 & -- & 6.6 \\ 31 & 9.2 & 890 & 61 & 1.2 & 50 & -- & 7.2 \\ 60 & 25 & -- & 189 & 4.9 & 68 & 0 & 7.4 \\ 76 & 24 & 2600 & 229 & 5.4 & 42 & 0 & 6.8 \\ 69 & 29 & -- & 190 & 5.3 & 68 & -- & 7.6 \\ 49 & 20 & -- & 145 & 4.3 & 66 & 0 & 7.3\end{array}$

CAR-

BONATE PH

$\begin{array}{lllll}(N A) & (K) & (H C O 3) & (C O 3) \\ (M G / L) & (M G / L) & (M G / L) & (M G / L) & \text { (UNITS) }\end{array}$ 
ST. JOHNS RIVER BASIN

02232500 ST. JOHNS RIVER NEAR CHRISTMAS, FLA.--COnt inued

CHEMICAL ANALYSES, WATER YEAR OCTOBER 1969 TO SEPTEMBER 1970

(MAJOR CONSTITUENTS)

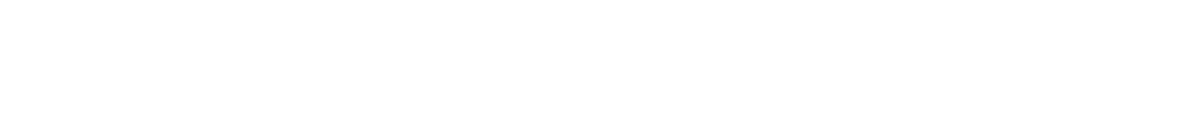

NOV.. 1969

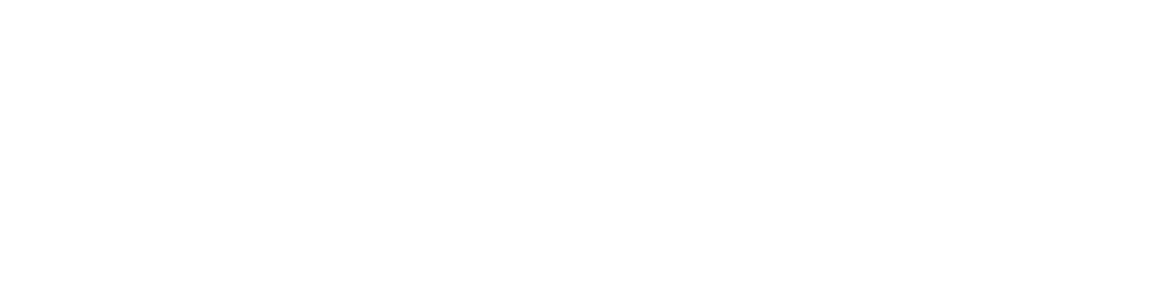

(MACRONUTRIENTS AND OTHER RELATED CONSTITUENTS)

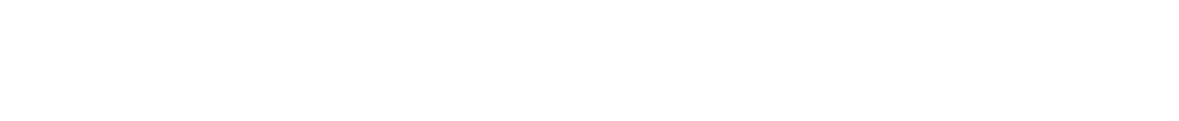

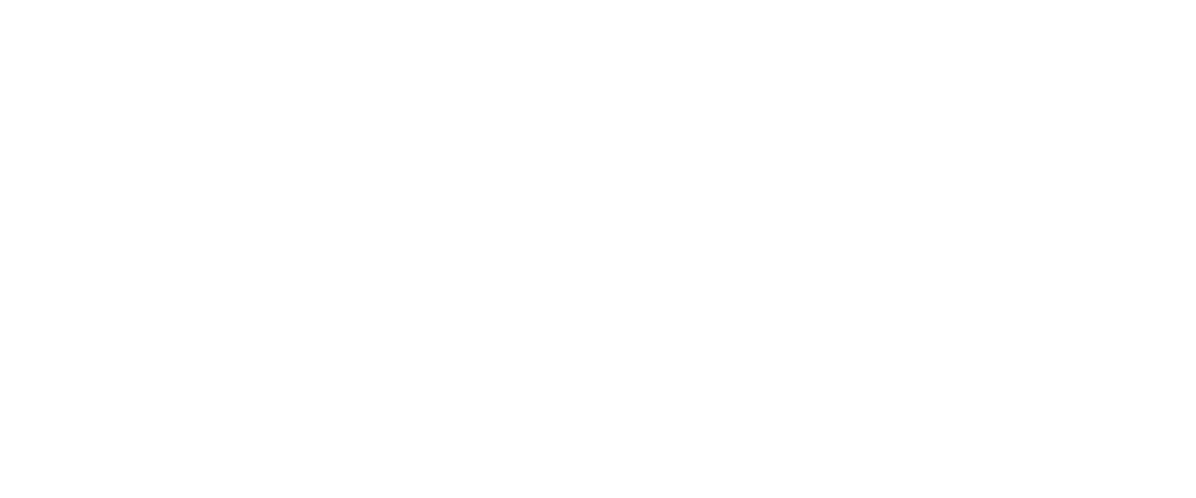

(FIELD MEASUREMENTS)

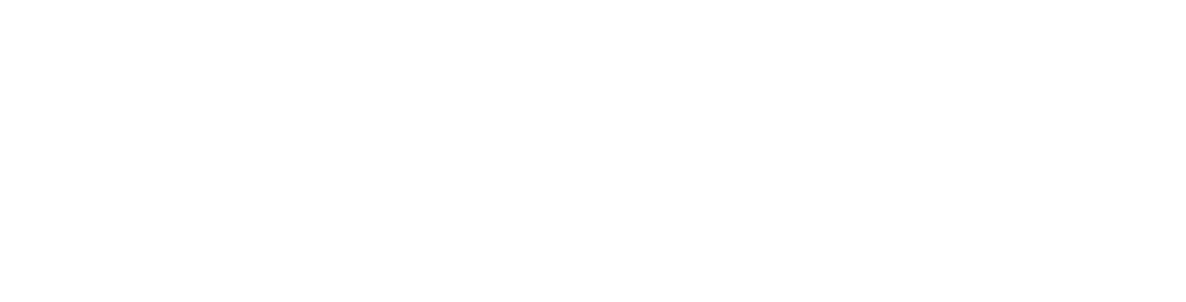

(TRACE IAETALS)

\begin{tabular}{|c|c|c|c|c|c|c|c|c|c|c|c|c|}
\hline & $\begin{array}{l}\text { OIS- } \\
\text { SULLVED } \\
\text { ALUM- }\end{array}$ & $\begin{array}{l}\text { DIS- } \\
\text { SOLVED }\end{array}$ & $\begin{array}{l}\text { DIS- } \\
\text { SOLVEO }\end{array}$ & $\begin{array}{l}\text { DIS- } \\
\text { SOLVEO } \\
\text { CAI- }\end{array}$ & $\begin{array}{r}\text { HEXA- } \\
\text { VALENT } \\
\text { CHP.)- }\end{array}$ & $\begin{array}{l}\text { DOS- } \\
\text { SULVED } \\
\text { CHRO- }\end{array}$ & DIS- & $\begin{array}{l}\text { UI } c_{-} \\
\text {SOLVEO }\end{array}$ & DIS- & $\begin{array}{l}\text { OIS- } \\
\text { SOLVEO }\end{array}$ & & LIS- \\
\hline & I vurs & APSENIC & WORON. & MIUM & NiUM & CHRO- & $\begin{array}{l}\text { SULVED } \\
\text { COPPER }\end{array}$ & COLVEN & SOLVER & MAN- & TOTAL. & SOLVEO \\
\hline & (AL) & (AS) & (8) & $(C D)$ & (CR6) & (CK) & $\begin{array}{l}\text { COPPER } \\
\text { (CU) }\end{array}$ & $\begin{array}{l}\text { IRON } \\
\text { (FE) }\end{array}$ & $\begin{array}{l}\text { LEAD } \\
\text { (PR) }\end{array}$ & $\begin{array}{l}\text { GANESE } \\
\text { (MN) }\end{array}$ & $\begin{array}{c}\text { MERCURY } \\
\text { (HE) }\end{array}$ & $\begin{array}{l}\text { ZIVC } \\
(Z N)\end{array}$ \\
\hline DATE & $(U G / L)$ & $(U G / L)$ & $(U G / L)$ & (UG/L) & $(U G / L)$ & $(U G / L)$ & $(U G / L)$ & (UG/L) & $(16 G / L)$ & $(U G / L)$ & $(U G / L)$ & $(U g / L)$ \\
\hline
\end{tabular}

\begin{tabular}{|c|c|c|c|c|c|c|c|c|c|c|c|c|}
\hline $\begin{array}{l}\text { NOV.. } 1969 \\
06 . . .1970 \\
\text { JAN.. } 1970\end{array}$ & -- & 10 & 0 & $n$ & -- & -- & 1 & $31 n$ & 0 & 10 & -- & 20 \\
\hline$\underset{M A Y}{30} \cdots$ & -- & - & - & -- & -- & $=$ & 0 & $1<0$ & -- & 0 & $=$ & 10 \\
\hline JIJLY... & -- & - & -- & -- & - & -- & 0 & 170 & - & I0 & -- & 40 \\
\hline $23 \ldots$ & -- & -- & -- & 10 & -- & -- & 0 & 380 & - & 30 & - & 30 \\
\hline
\end{tabular}


02232500 ST, JOHNS RIVER NEAR CHRISTMAS, FLA.--Continued

CHEMICAL ANALYSES, WATER YEAR DCTOBER 1969 TO SEPTEMBER 19TO (OTHER DATA)

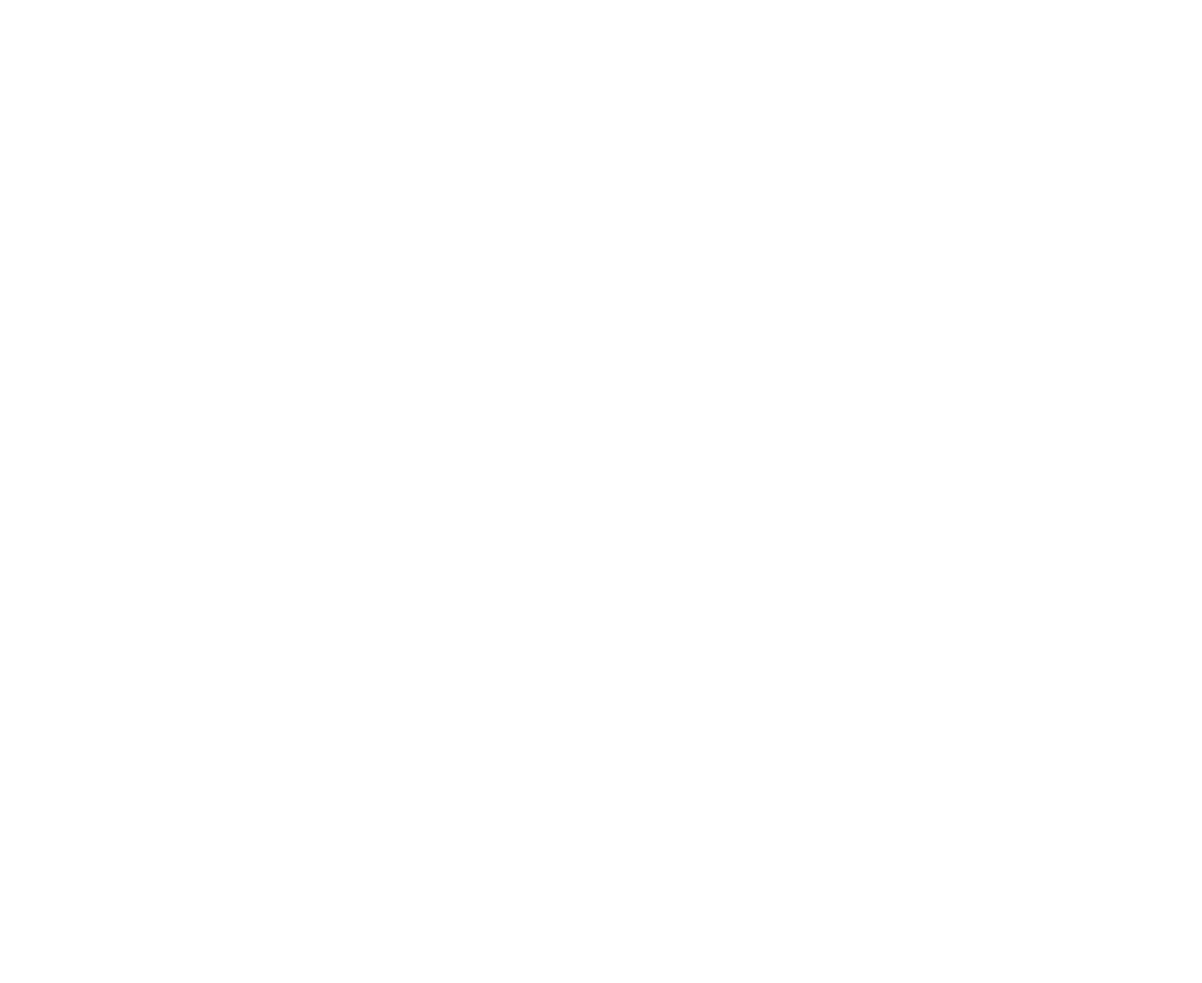

SPECIFIC CONDUCTANCE (MICROMHOS/CM AT $25^{\circ} \mathrm{C}$ ), WATER YEAR OCTOBER 1969 TO SEPTEMBER 1970

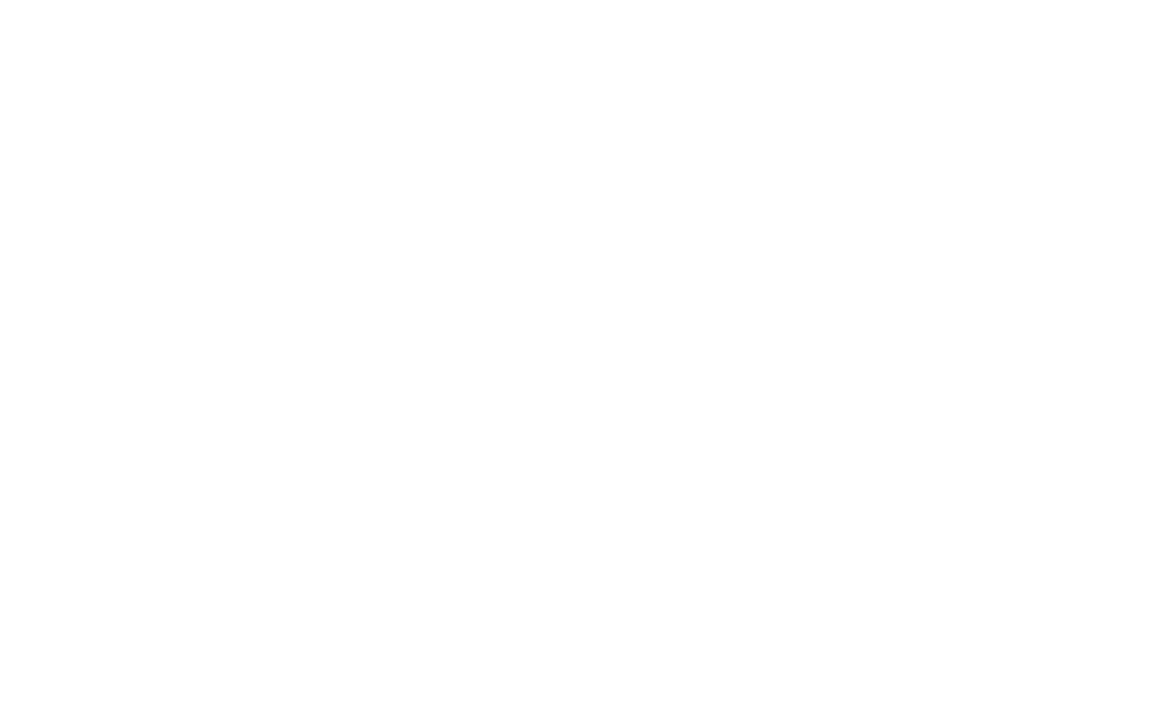


02238500 OKLAWAHA RIVER AT MOSS BLUFF, FLA.

LOCATION,--Lat $29^{\circ} 04^{\prime} 52^{\prime \prime}$, I Ing $81^{\circ} 52^{\prime} 51^{\prime \prime}$, In SWl sec.23, T.16 S., R.24 E., Marion County, at gaging station at downstream side of spillway structure of Moss Bluff Dam, 0,3 mile upstream from bridge on State Highway 464 , 0.4 mile southwest of Moss Bluff, and 3.9 miles northeast of Okiawaha. Prior to Oct. 1, 1969, at site $0.3 \mathrm{mile}$ downstream.

DRAINAGE AREA.--910 sq mi, approximately.

PERIOD OF RECORD, --Chemical analyses: November 1963 to September 1970.

Water temperatures: November 1963 to September 1970.

EXTREMES. $-1969-70$ :

Specific conductance: Maximum daily, 303 micromhos Sept, 15; minimum dä1ly, 219 micromhos Apr. $6,7$.

water temperatures: Maximum, $31.5^{\circ} \mathrm{C}$ Aug. 2 , Sept, 6 ; minimum, $8.0^{\circ} \mathrm{C}$ Jan. $10,11$.

period of record:

Specific conductance: Maximum dally, 535 micromhos Aug. 8, 1967; minimum daily, 60 micromhos July $21,1964$.

Water temperatures: Maximum, $34.0^{\circ} \mathrm{C}$ June 25,$1969 ;$ minimum, $9.0^{6} \mathrm{C}$ on several days during January and Febru-

arv 1966.

CHEMICAL ANALYSES, WATER YEAR OCTOBER 1969 TO SEPTEMBER 1970 IMAJOR CONSTITUENTSI

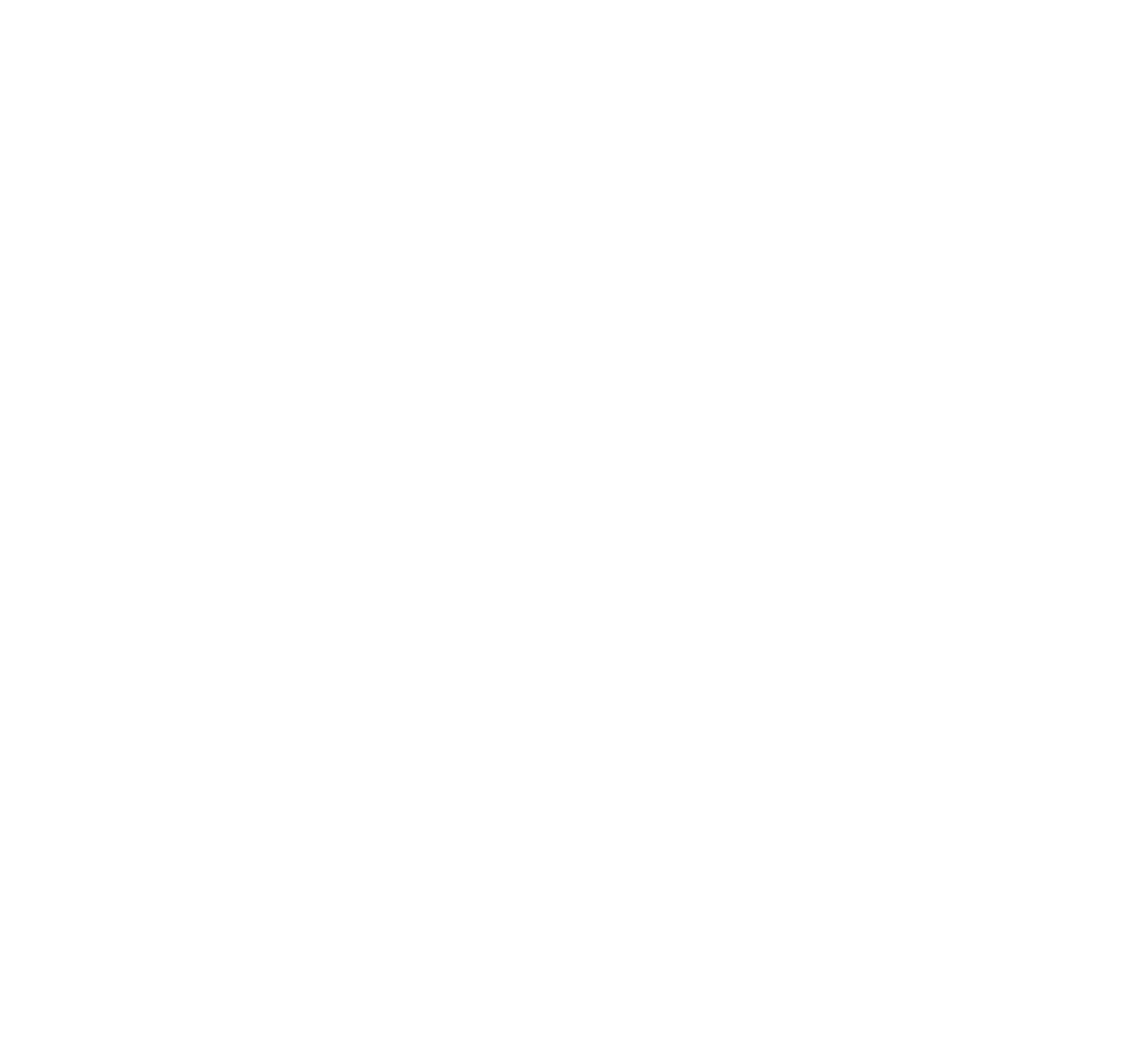


CHEMICAL ANALYSES, WATER YEAR OCTOBER 1969 TO SEPTEMBER 1970 (MACRONUTRIENTS AND OTHER RELATED CONSTITUENTS)

\begin{tabular}{|c|c|c|c|c|c|c|c|c|c|c|c|c|}
\hline ATH & $\begin{array}{c}\text { TOTAL } \\
\left.\text { A MONIA }^{2} \text { (NM } 4\right) \\
(M G / L)\end{array}$ & $\begin{array}{l}\text { TOTAL } \\
\text { NITYITL } \\
\text { (NOZ) } \\
\text { (MG/L) }\end{array}$ & $\begin{array}{l}\text { TOTAL } \\
\text { NITHATE } \\
\text { (NOB) } \\
\text { (MG/L) }\end{array}$ & $\begin{array}{c}\text { OHGANIC } \\
\text { NITRO- } \\
\text { GEN } \\
\text { (N) } \\
\text { (NG/L) }\end{array}$ & $\begin{array}{l}\text { UIS- } \\
\text { SOLVEA } \\
\text { OPIHO } \\
\text { PHUS- } \\
\text { PHATE } \\
\text { (POIL) } \\
\text { (MG/L) }\end{array}$ & $\begin{array}{l}\text { PHOS- } \\
\text { PHATE } \\
\text { (PO4) } \\
\text { (MOILL) }\end{array}$ & $\begin{array}{l}\text { DIS- } \\
\text { SOLVEO } \\
\text { SILICA } \\
\text { (SIOZ) } \\
\text { (MG/L) }\end{array}$ & $\begin{array}{l}\text { TUR- } \\
\text { BID- } \\
\text { ITY } \\
\text { (JTU) }\end{array}$ & $\begin{array}{l}\text { COLOR } \\
\text { (PLAT- } \\
\text { INUM- } \\
\text { COBALT } \\
\text { UNITS) }\end{array}$ & $\begin{array}{l}\text { TOTAL } \\
\text { ORGANIC } \\
\text { CARAON } \\
\text { (C) } \\
\text { (MG/L) }\end{array}$ & $\begin{array}{l}\text { PIO- } \\
\text { CHEM- } \\
\text { ICAL } \\
\text { OXYGEN } \\
\text { DEMAND } \\
\text { (MG/L) }\end{array}$ & $\begin{array}{l}\text { DEPTH } \\
\text { (FT) }\end{array}$ \\
\hline
\end{tabular}

OCT., 1969

\begin{tabular}{|c|c|c|c|c|c|c|c|c|c|c|c|c|}
\hline $06 \ldots$ & - & .01 & 3.0 & -- & - & -- & 3.4 & -- & 40 & $\cdots$ & -- & $\cdots$ \\
\hline $\begin{array}{l}31 . . . \\
\text { Nov. }\end{array}$ & -- & .02 & 1.8 & - & .08 & .11 & - & - & -- & $\cdots$ & -- & $-\infty$ \\
\hline $19 .$. & .00 & .01 & .6 & 1.0 & .03 & .08 & -- & 11 & 40 & - & 1.0 & - \\
\hline $20 \ldots$ & $\overline{-}$ & .01 & 3.4 & 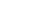 & $\overline{10}$ & $\overline{-}$ & 2.0 & -- & 40 & $=$ & - & $\cdots$ \\
\hline $\begin{array}{l}30 \ldots \\
\text { DEC. }\end{array}$ & $\cdots$ & .00 & 2.2 & - & .10 & .16 & - & -- & -- & -- & -- & - \\
\hline JAN...'1970 & -- & .02 & $1.0^{\circ}$ & 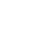 & .16 & .19 & -- & -- & -- & - & -- & $=$ \\
\hline $09 \ldots$ & $=$ & .02 & 4.8 & -- & - & - & 1.9 & -- & 50 & -- & $=$ & - \\
\hline $20 \ldots$ & .14 & .02 & 1.2 & 1.6 & .07 & .12 & - & 10 & 40 & -- & 2.7 & \\
\hline FER... & - & .10 & 2.3 & - & .18 & .26 & -- & - & - & $\cdots$ & - & . \\
\hline $20 \ldots$ & - & .02 & 1.7 & $=-$ & - & - & .8 & -- & 40 & -- & - & - \\
\hline $28 \ldots$ & $=$ & .02 & 2.6 & - & .28 & .33 & - & - & -- & -- & -- & 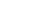 \\
\hline $19 \ldots$ & .09 & .02 & .3 & 2.0 & .09 & .14 & $m$ & 12 & 50 & -- & 3.4 & 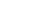 \\
\hline $31 \ldots$ & -- & .56 & 2.7 & - & .23 & .29 & - & $=$ & - & -- & - & \\
\hline APR. & & & & & & & & & & & & \\
\hline$n 6 . .$. & -- & .02 & 1.9 & -- & - & $\bar{a}$ & 1.4 & -- & 60 & -- & $=$ & - \\
\hline MAY & - & .18 & 3.1 & $\cdots$ & .18 & .25 & - & -- & $=-$ & $\rightarrow$ & -- & \\
\hline $04 \ldots$ & .12 & .07 & .8 & 1.4 & .12 & .26 & 1.6 & 23 & 45 & -- & 3.8 & $=$ \\
\hline JUNE & - & .02 & 2.1 & - & .22 & .30 & - & -- & -- & - & -- & \\
\hline $29 .$. & - & - & - & $=$ & - & - & 2.8 & - & 50 & -- & - & \\
\hline $30 \ldots$ & -- & .03 & 1.9 & $\cdots$ & .17 & .24 & - & -- & $=$ & $=-$ & -- & \\
\hline JULY & & & & & & & & & & & & \\
\hline $24 \ldots$ & .09 & .02 & $\cdot 1$ & 1.4 & .06 & .20 & -- & 14 & 50 & $=$ & 3.4 & \\
\hline & .05 & .01 & $\bullet 0$ & 1.0 & .11 & .23 & 1.9 & 10 & 20 & -- & - & \\
\hline $31 \ldots$ & - & .90 & .3 & $=-$ & .11 & .18 & - & - & -- & -- & -- & \\
\hline $03 \ldots$ & .07 & .02 & .0 & .60 & .104 & .19 & 1.3 & 20 & 20 & -- & -- & \\
\hline & .08 & .03 & .0 & .95 & .07 & .11 & 2.0 & 11 & 80 & - & 5.9 & \\
\hline
\end{tabular}

SPECIFIC CONDUCTANCE (MICROMHOS/CM AT 25ㅇ), WATER YEAR OCTOBER 1969 TO SEPTEMBER 1970

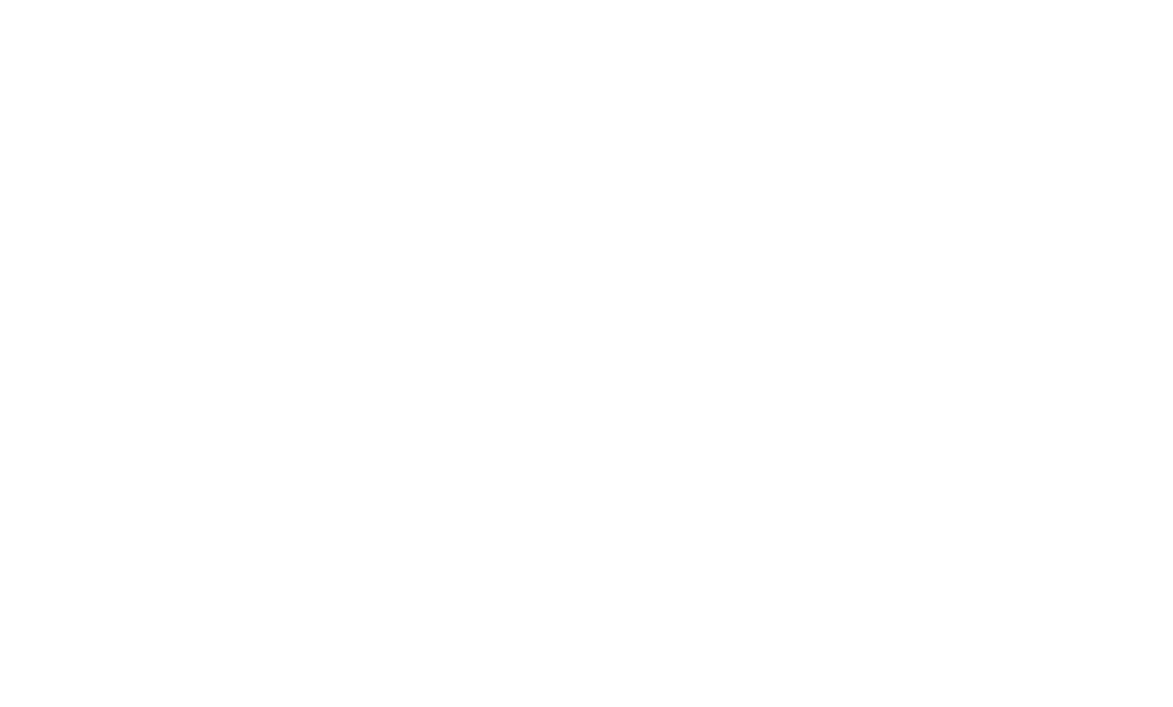

(TRACE METALS)

\begin{tabular}{|c|c|c|c|c|c|c|c|c|c|c|c|c|}
\hline & $\begin{array}{c}\text { DIS- } \\
\text { SOL VED }\end{array}$ & DIS & & $\begin{array}{l}\text { DIS- } \\
\text { SOLVED }\end{array}$ & $\begin{array}{r}\text { HEXA- } \\
\text { VALENTT }\end{array}$ & $\begin{array}{l}\text { DIS- } \\
\text { SOLVED }\end{array}$ & & & & $\begin{array}{c}\text { OIS- } \\
\text { SOLVED }\end{array}$ & & cis \\
\hline & ALUK- & SOLVFO & SOLVEU & $C A D-$ & CHRO- & CHNO- & SOLVED & SDLVEN & SOL VEO & MAN- & TOTAL & SCLVEO \\
\hline & I vu: & ARSENIC & GORON & MIUM & MIUM & MIUM & COPPER & $\begin{array}{l}\text { IRON } \\
\text { (FE) }\end{array}$ & LEAD & GANESE & MERCURY & $\begin{array}{l}21 V C \\
(Z N)\end{array}$ \\
\hline & $\begin{array}{l}(A L) \\
(U G / L)\end{array}$ & $\begin{array}{c}(A S) \\
(U G / L)\end{array}$ & $\begin{array}{c}(15) \\
(U G / L)\end{array}$ & $\begin{array}{c}(C D) \\
(U G / L)\end{array}$ & $\begin{array}{l}\text { (CR6) } \\
(\cup G / L\end{array}$ & $\begin{array}{c}(C K) \\
(U G / L)\end{array}$ & $\begin{array}{c}\text { (CU) } \\
\text { (UG/L) }\end{array}$ & $\begin{array}{c}(F E) \\
\left(U G / L_{-}\right)\end{array}$ & $\begin{array}{c}(P A) \\
(U G / L)\end{array}$ & $\begin{array}{c}(M N) \\
(U G / L)\end{array}$ & $\begin{array}{c}(H(S) \\
(U G / L)\end{array}$ & $(L G / L)$ \\
\hline
\end{tabular}
$04 . .$. $+$ $\begin{array}{lllll}0 & - & - & - & -\end{array}$ SEP. 
02238500 OKLAWAHA RIVER AT MOSS BLUFF, FLA.--Continued

CHEMICAL ANALYSES, WATER YEAR OCTOBER 1969 TO SEPTEMBER 1970 OTHER DATA

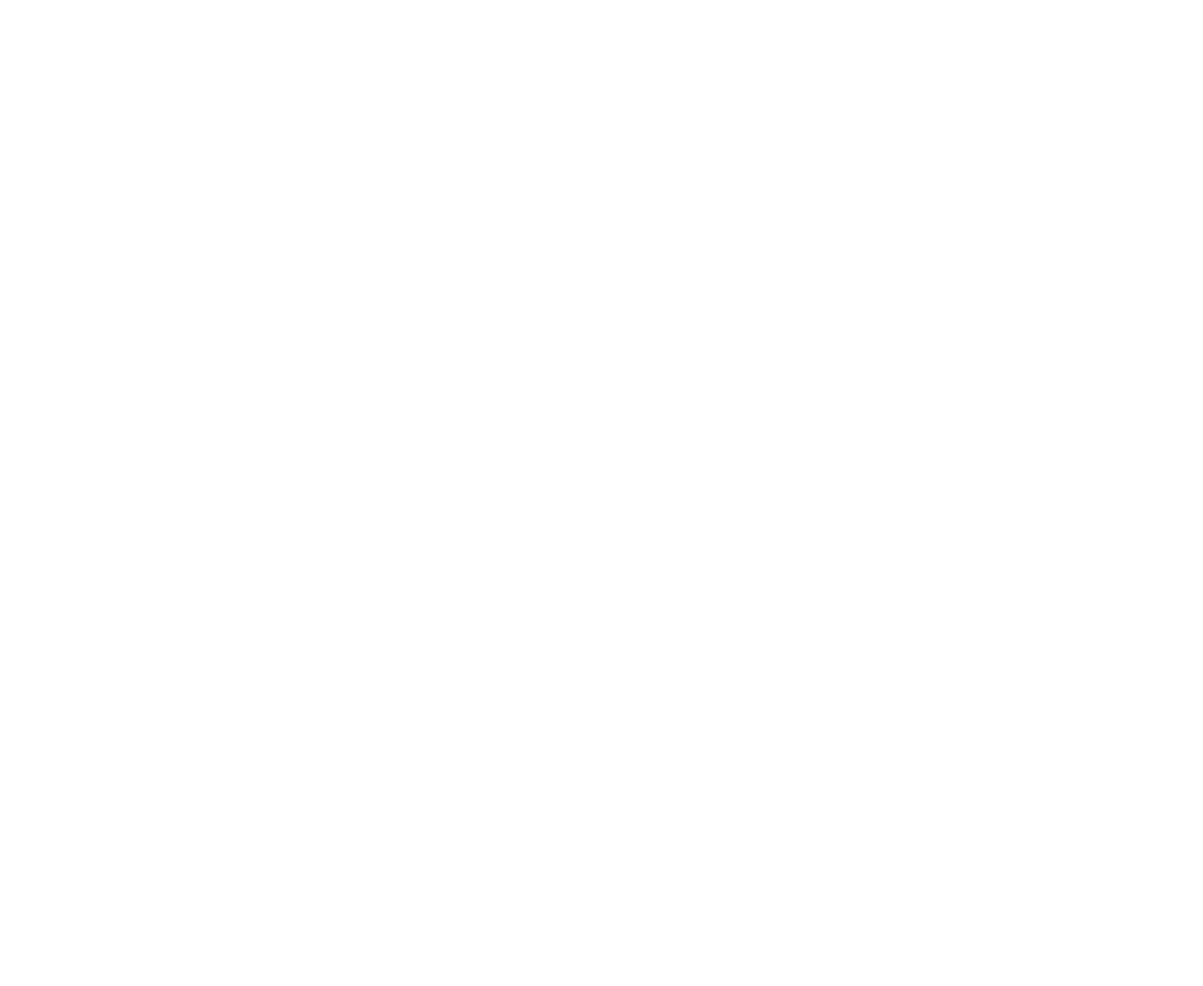

02244005 OKLAWAHA RIVER AT STATE HIGHWAY 19, NEAR SALT SPRINGS, FLA,

LOCATION,--Lat $29^{\circ} 28^{\circ} 43^{\prime \prime}$, long $81^{\circ} 44^{\circ} 00^{\prime \prime}$ (revised), Putnam County, at center of stream at bridge on State Highway 19 , 4.8 miles upstream from mouth, and 8.7 miles north of Salt Springs.

DRAINAGE AREA.--2,950 sq m1, approximately.

PERIOD OF RECORD,--Chemical analyses: October 1962 to September 1970.

Water temperatures: Octaber 1962 to September 1970.

EXTREMES.--1969-70:

Specific conductance: Maximum daily, 439 micromhos Aug. 5 ; minimum daily, 142 micromhos Feb. 11.

Color: Maximum daily, 300 units Aug. 27; minimum daily, 30 units July 3,9 Water temperatures: Maximum, $30.0^{\circ} \mathrm{C}$ on several days during June, July, and August; min1mum, 12.0 ${ }^{\circ} \mathrm{C} \mathrm{Feb.} \mathrm{4-6,}$
10, 11.

Period of record:

Spec1fic conductance: Maximum daily, 800 micromos June 7,1968 ; minimum daily, 122 micromhos July 4, 17, 19,

Color (1966-70): Maximum da1ly, 300 units Aug. 27, 1970; minimum da1ly, 5 units on many days during June and April 1968 Hater temperatures: Haximum, $32.0^{\circ} \mathrm{C}$ on several days during July and August 1965, and June and July 1969; minCHEMICAL ANALYSES, WATER YEAR OCTOBER 1969 TO SEPTEMBER 1970 (MAJOR CONSTIITUENTS)

\begin{tabular}{|c|c|c|c|c|c|c|c|c|c|c|c|c|}
\hline $\begin{array}{ll}\mathrm{C} \\
\mathrm{CH}\end{array}$ & $\begin{array}{l}S=- \\
\text { SI }\end{array}$ & $\begin{array}{l}\text { TEMPER- } \\
\text { ATURE } \\
\text { (DEG C) }\end{array}$ & $\begin{array}{l}\text { SPE- } \\
\text { CIFIC } \\
\text { CON- } \\
\text { DUCT- } \\
\triangle \cup C E \\
\text { (MICRO- } \\
\text { MHOSI }\end{array}$ & $\begin{array}{l}\text { DIS- } \\
\text { SOLVED } \\
\text { IRON } \\
\text { (FE) } \\
\text { (UG/L) }\end{array}$ & $\begin{array}{l}\text { UIS- } \\
\text { SOLVED } \\
\text { CAL- } \\
\text { CIUM } \\
\text { (CA) } \\
\text { (MG/L) }\end{array}$ & $\begin{array}{l}\text { O1S- } \\
\text { SOLVED } \\
\text { MAG- } \\
\text { NE- } \\
\text { SIUM } \\
\text { (MG) } \\
\text { (MG/L) }\end{array}$ & $\begin{array}{l}\text { DIS- } \\
\text { SOLVED } \\
\text { SIRON- } \\
\text { TIUM } \\
\text { (SR) } \\
\text { (UG/L) }\end{array}$ & $\begin{array}{l}\text { DIS- } \\
\text { SOLVED } \\
\text { SODIUM } \\
\text { (NA) } \\
\text { (MG/L) }\end{array}$ & $\begin{array}{l}\text { DIS- } \\
\text { SOLVED } \\
\text { PO- } \\
\text { TAS- } \\
\text { SIIJM } \\
\text { (K) } \\
\text { (MG/L) }\end{array}$ & $\begin{array}{l}\text { BICAR- } \\
\text { BONATE } \\
\text { (HCO3) } \\
\text { (MG/L) }\end{array}$ & $\begin{array}{l}\text { CAR- } \\
\text { BON } 1 \text { TE. } \\
\text { (CO3) } \\
\text { (MG/L) }\end{array}$ & $\begin{array}{c}P H \\
\text { (UNITS) }\end{array}$ \\
\hline $\begin{array}{l}\text { OCT.., } \\
07 . . .\end{array}$ & -- & 26.0 & 310 & -- & 36 & 7.6 & -- & 15 & 2.3 & 112 & 0 & 7.1 \\
\hline $\begin{array}{l}\text { DEC. } \\
\text { O1.... } \\
\text { FEB..'1970 }\end{array}$ & -- & 17.0 & 340 & -- & 40 & 8.4 & -- & 19 & 2.1 & 118 & $n$ & 6.7 \\
\hline MAY $26 .$. & - & 15.5 & 255 & 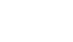 & 28 & 6.0 & $\cdots$ & 15 & 2.1 & 91 & -- & 6.7 \\
\hline JUNE & -- & 25.0 & 357 & -- & 38 & 8.4 & 330 & 20 & 1.7 & 116 & 0 & 7.4 \\
\hline $\begin{array}{l}02 \ldots \\
30 \ldots\end{array}$ & $=$ & $\begin{array}{l}26.5 \\
28.0\end{array}$ & $\begin{array}{l}420 \\
415\end{array}$ & $\ddot{--}$ & $\begin{array}{l}46 \\
46\end{array}$ & $\begin{array}{l}9.7 \\
9.4\end{array}$ & $=$ & $\begin{array}{l}27 \\
26\end{array}$ & $\begin{array}{l}1.7 \\
1.5\end{array}$ & $\begin{array}{l}132 \\
136\end{array}$ & $\overline{--}$ & $\begin{array}{l}8.0 \\
8.2\end{array}$ \\
\hline $\begin{array}{l}\text { AUG. } \\
\text { O3... } \\
\text { SEP. }\end{array}$ & -- & 29.0 & 420 & - & 48 & 9.1 & -- & 21 & 1.5 & 140 & 0 & 7.8 \\
\hline $04 \ldots$ & $=$ & $\begin{array}{l}28.5 \\
28.5\end{array}$ & $\begin{array}{l}352 \\
335\end{array}$ & 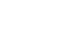 & ${ }^{40} \ldots$ & 7.2 & $=$ & ${ }^{18}$ & 1.4 & 112 & -0 & $\begin{array}{l}7.8 \\
7.8\end{array}$ \\
\hline
\end{tabular}




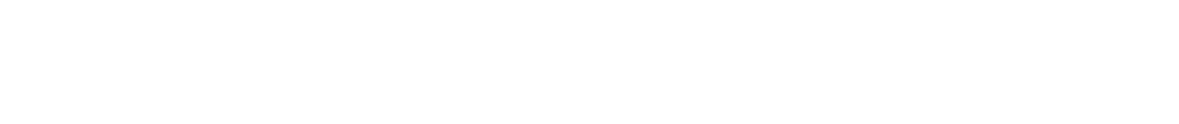

OCT., 1969

\begin{tabular}{|c|c|c|c|c|c|c|c|c|c|c|c|c|}
\hline O7:... & 22 & 25 & .4 & 122 & 30 & 92 & 217 & 172 & - & .30 & - & $=$ \\
\hline FEB... 1970 & 26 & 30 & .4 & 135 & 38 & 97 & 241 & $19 n$ & -- & .33 & - & $=$ \\
\hline MAY 26 & 20 & 24 & .3 & 95 & 28 & 66 & 169 & 137 & -- & .23 & 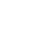 & - \\
\hline JUNE & 28 & 33 & .3 & 130 & 35 & 95 & 236 & 193 & -- & .32 & - & -- \\
\hline $\begin{array}{l}02 \ldots \\
30 \cdots \\
\text { AUG. }\end{array}$ & $\begin{array}{l}37 \\
33\end{array}$ & $\begin{array}{l}47 \\
47\end{array}$ & .3 & $\begin{array}{l}155 \\
154\end{array}$ & $\begin{array}{l}47 \\
42\end{array}$ & $\begin{array}{l}108 \\
112\end{array}$ & $\begin{array}{l}292 \\
290\end{array}$ & $\begin{array}{l}240 \\
237\end{array}$ & $=$ & $\begin{array}{r}.40 \\
.39\end{array}$ & $=$ & $=$ \\
\hline $\begin{array}{l}\text { 03... } \\
\text { SEP. }\end{array}$ & 32 & 41 & $\cdot 3$ & 158 & 43 & 115 & 252 & $22^{8}$ & -- & .34 & - & - \\
\hline $\begin{array}{l}04 \ldots \\
22 \ldots\end{array}$ & 32 & $\begin{array}{l}32 \\
38\end{array}$ & $\therefore 2$ & 130 & $\begin{array}{l}38 \\
--\end{array}$ & 92 & 262 & 105 & $=$ & .36 & 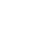 & $=$ \\
\hline
\end{tabular}

(MACRONUTRIENTS AND OTHER RELATED CONSTITUENTS)

\begin{tabular}{|c|c|c|c|c|c|c|c|c|c|c|c|c|}
\hline A TE & $\begin{array}{l}\text { TOTAL } \\
\text { ANMONIA } \\
\text { (Nत4) } \\
\text { (MG/L) }\end{array}$ & $\begin{array}{l}\text { TOTAL } \\
\text { NITHITE } \\
\text { (NOZ) } \\
\text { (MG/L) }\end{array}$ & $\begin{array}{l}\text { TOTAL } \\
\text { NITHATE } \\
\text { (NO3) } \\
\text { (MG/L) }\end{array}$ & $\begin{array}{l}\text { OPGANIC } \\
\text { NITRO- } \\
\text { GEN } \\
\text { (N) } \\
\text { (NG/L) }\end{array}$ & $\begin{array}{l}\text { UIS- } \\
\text { SOLVEN } \\
\text { ORTHO } \\
\text { PHUS- } \\
\text { PHATE } \\
\text { (POL) } \\
\text { (MG/L) }\end{array}$ & $\begin{array}{l}\text { PHOS- } \\
\text { PHATE } \\
\text { (PO4) } \\
\text { (MO/L) }\end{array}$ & $\begin{array}{l}\text { DIS- } \\
\text { SOLVED } \\
\text { SILICA } \\
\text { (SIOZ) } \\
\text { (MG/L) }\end{array}$ & $\begin{array}{l}\text { TUR- } \\
\text { BID- } \\
\text { ITY } \\
\text { (JTU) }\end{array}$ & $\begin{array}{l}\text { COLOR } \\
\text { (PLAT- } \\
\text { INUM- } \\
\text { COBALT } \\
\text { UNITS) }\end{array}$ & $\begin{array}{l}\text { TOTAL } \\
\text { ORGAMIC } \\
\text { CARBON } \\
\text { (C) } \\
\text { (MG/L) }\end{array}$ & $\begin{array}{l}\text { AIO- } \\
\text { CHEM- } \\
\text { ICAL } \\
\text { OXYCEN } \\
\text { DEMANND } \\
\text { (MG/L) }\end{array}$ & $\begin{array}{l}\text { DEPTH } \\
\text { (FT) }\end{array}$ \\
\hline A & & & & & & & & & & & & \\
\hline
\end{tabular}

\begin{tabular}{|c|c|c|c|c|c|c|c|c|c|c|c|c|}
\hline $07 \ldots .$. & $=$ & .01 & 1.2 & -- & -- & -- & 7.2 & -- & 100 & $=$ & -- & 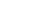 \\
\hline $31 \ldots$ & -- & .02 & .2 & -- & .13 & .14 & - & -- & - & $=$ & $\Rightarrow$ & $\ldots$ \\
\hline NOV. & -- & . 1 & ? & -- & & . & - & - & - & $=$ & -- & $=$ \\
\hline DEC. & & 8 & 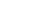 & & 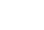 & . & 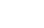 & & 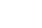 & & & 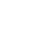 \\
\hline $\begin{array}{l}01 \ldots \\
31 \ldots\end{array}$ & - & .01 & .3 & - & - & 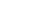 & 6.3 & -- & 50 & -- & -- & - \\
\hline FEB.:. 1970 & -- & .04 & .2 & - & .06 & .08 & -- & -- & $\cdots$ & - & - & $-\infty$ \\
\hline $\begin{array}{l}26 \ldots \\
28 . . .\end{array}$ & - & .02 & .3 & -- & -- & -- & 1.3 & -- & BO & -- & - & - \\
\hline MAR." & - & .02 & .5 & -- & .11 & .13 & -- & -- & -- & -- & $=$ & $\cdots$ \\
\hline APR... & -- & .03 & .8 & -- & .18 & .21 & - & -- & -- & - & - & -- \\
\hline MAY $29 .$. & -- & .10 & .2 & $=$ & .20 & .24 & - & $=$ & - & - & -- & - \\
\hline $18 \ldots$ & .11 & .02 & .4 & .60 & .16 & .17 & 5.5 & 4 & 55 & -- & 1.2 & $\because$ \\
\hline $31 \ldots$ & - & .03 & .6 & - & .13 & .15 & $\cdots$ & - & -- & $=$ & $=$ & \\
\hline JUNE & & & & & & & & & & & & \\
\hline $30 \ldots$ & $\overline{--}$ & .02 & .0 & $=$ & 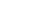 & $=-$ & $\begin{array}{l}6.0 \\
6.4\end{array}$ & $=$ & $\begin{array}{l}50 \\
50\end{array}$ & $=$ & $=$ & $-\infty$ \\
\hline $30 \ldots$ & - & .02 & .7 & -- & .11 & $.16 \backslash$ & - & -- & -- & -- & -- & \\
\hline JULY & & & & & & & & & & & & \\
\hline $\begin{array}{l}31 . . . \\
\text { AUG. }\end{array}$ & - & .08 & .4 & -- & .13 & .17 & -- & -- & -- & -- & -- & -- \\
\hline AUG. & .04 & .01 & .2 & .47 & .11 & .21 & 6.2 & 4 & $3 n$ & -- & - & $=$ \\
\hline SEP. & & & & & & & & & 70 & 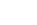 & - & \\
\hline $\begin{array}{l}04 \ldots . . \\
22 . .\end{array}$ & $\begin{array}{l}.09 \\
.07\end{array}$ & .03 & .2 & $\begin{array}{l}.31 \\
.45\end{array}$ & $\begin{array}{r}.13 \\
.13\end{array}$ & $\begin{array}{l}.19 \\
.15\end{array}$ & $\begin{array}{l}8.8 \\
6.7\end{array}$ & $\begin{array}{l}7 \\
7\end{array}$ & $\begin{array}{l}m \\
3 n\end{array}$ & - & .2 & \\
\hline
\end{tabular}

COLOR (UNITS), WATER YEAR OCTOBER 1969 TD SEPTEMBER 1970

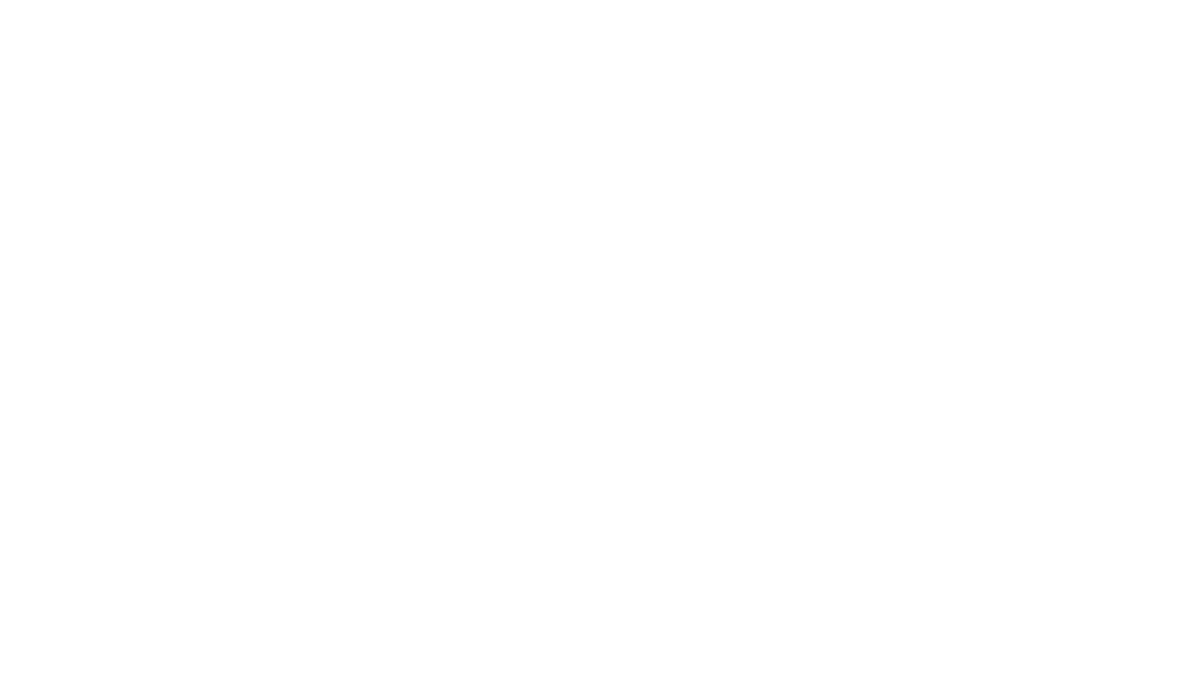


ST, JOHNS RIVER BASIN

02244005 OKLAWAHA RIVER AT STATE HIGHWAY 19; NGAR SALT SPRINGS, FLA.--COnt1nUed

SPECIFIC CONDUCTANCE (MICROMHOS/CM AT $25^{\circ} \mathrm{C}$ ), HATER YEAR OCTOBER 1969 TO SEPTEMBER 1970

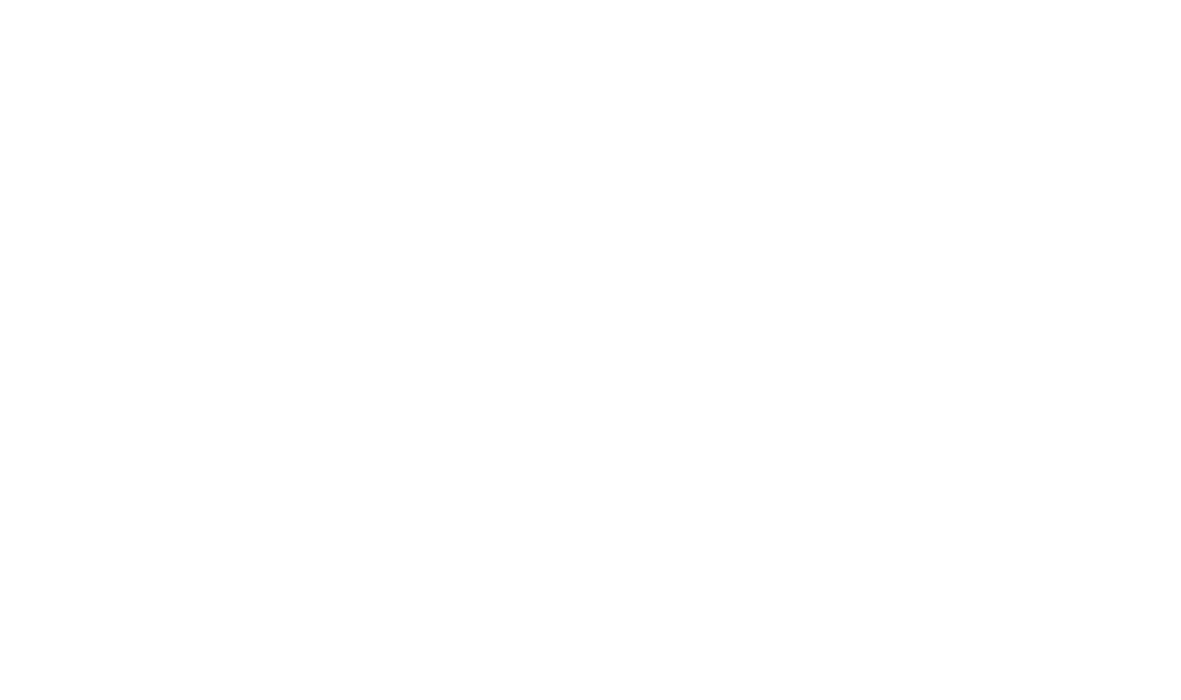

IORGANOCHLORIDE COMPOUNDS IN HATER I

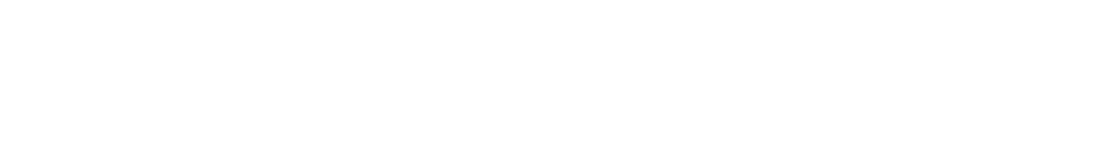

TEMPERATURE ( ${ }^{\circ} \mathrm{C}$ ) OF WATER, WATER YEAR OCTOBER 1969 TO SEPTEMBER 1970

\begin{tabular}{|c|c|c|c|c|c|c|c|c|c|c|c|c|}
\hline DAY & $\mathrm{OCT}$ & NoV & DEC & JAN & FEB & MAR & $A P R$ & MAY & JUN & UL & AUG & SEP \\
\hline $\begin{array}{l}1 \\
2 \\
3 \\
4 \\
5\end{array}$ & $\begin{array}{r}25.5 \\
26.0 \\
26.0 \\
26.0\end{array}$ & $\begin{array}{r}22.5 \\
22.0 \\
20.0 \\
18.0\end{array}$ & $\begin{array}{l}15.0 \\
15.0 \\
14.0 \\
14.0 \\
13.0\end{array}$ & $\begin{array}{l}m- \\
m- \\
-\cdots\end{array}$ & $\begin{array}{l}14.0 \\
14.0 \\
12.0 \\
12.0\end{array}$ & $\begin{array}{l}15.0 \\
16.0 \\
15.0 \\
16.0 \\
-.0\end{array}$ & $\begin{array}{r}22.0 \\
22.0 \\
20.0 \\
20.0\end{array}$ & $\begin{array}{r}26.0 \\
24.0 \\
25.0 \\
23.0\end{array}$ & $\begin{array}{l}26.0 \\
25.0 \\
26.0 \\
25.0 \\
25.0\end{array}$ & $\begin{array}{r}29.0 \\
29.0 \\
29.0 \\
-\end{array}$ & $\begin{array}{l}28.0 \\
30.0 \\
30.0 \\
30.0 \\
30.0\end{array}$ & $\begin{array}{r}28.0 \\
28.0 \\
28.0 \\
28.0 \\
-\end{array}$ \\
\hline $\begin{array}{r}6 \\
7 \\
8 \\
9 \\
10\end{array}$ & $\begin{array}{l}25.5 \\
25.5 \\
25.5 \\
25.5 \\
25.5\end{array}$ & $\begin{array}{l}17.0 \\
17.0 \\
18.0 \\
19.0 \\
18.0\end{array}$ & $\begin{array}{r}19.0 \\
15.0 \\
14.0 \\
16.0\end{array}$ & 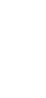 & $\begin{array}{r}12.0 \\
13.0 \\
13.0 \\
12.0\end{array}$ & $\begin{array}{l}17.0 \\
17.0 \\
16.0 \\
18.0\end{array}$ & $\begin{array}{r}20.0 \\
20.0 \\
20.0 \\
21.0\end{array}$ & $\begin{array}{r}23.0 \\
24.0 \\
24.0 \\
24.0\end{array}$ & $\begin{array}{l}26.0 \\
26.0 \\
25.0 \\
26.0\end{array}$ & $\begin{array}{l}28.0 \\
30.0 \\
28.0 \\
28.0 \\
27.0\end{array}$ & $\begin{array}{r}30.0 \\
29.0 \\
28.0\end{array}$ & $\begin{array}{l}---0 \\
29.0 \\
29.0 \\
28.0 \\
28.0\end{array}$ \\
\hline $\begin{array}{l}11 \\
12 \\
13 \\
14 \\
15\end{array}$ & $\begin{array}{l}25.5 \\
25.0 \\
23.5 \\
25.0 \\
25.0\end{array}$ & $\begin{array}{r}18.0 \\
18.5 \\
18.5 \\
15.0\end{array}$ & $\begin{array}{l}1 \overline{15.0} \\
13.0 \\
13.0 \\
14.0\end{array}$ & 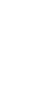 & $\begin{array}{r}12.0 \\
13.0 \\
12.0 \\
15.0\end{array}$ & $\begin{array}{r}19.0 \\
20.0 \\
15.5\end{array}$ & $\begin{array}{r}22.0 \\
22.0 \\
23.0 \\
22.0\end{array}$ & $\begin{array}{l}24.0 \\
24.0 \\
25.0 \\
25.0 \\
25.0\end{array}$ & $\begin{array}{r}--0 \\
27.0 \\
28.0 \\
26.0 \\
26.0\end{array}$ & $\begin{array}{l}27.0 \\
27.0 \\
27.0 \\
28.0\end{array}$ & $\begin{array}{l}27.0 \\
27.0 \\
27.0 \\
27.0 \\
28.0\end{array}$ & $\begin{array}{r}30.0 \\
28.0 \\
28.0 \\
27.0 \\
-\end{array}$ \\
\hline $\begin{array}{l}16 \\
17 \\
18 \\
19 \\
20\end{array}$ & $\begin{array}{r}25.0 \\
21.5 \\
25.0 \\
25.0\end{array}$ & $\begin{array}{l}-0 . \\
15.5 \\
16.5 \\
17.0 \\
15.5\end{array}$ & $\begin{array}{r}13.0 \\
13.0 \\
14.0 \\
14.0\end{array}$ & $=$ & $\begin{array}{l}16.0 \\
15.0 \\
15.0 \\
16.0 \\
15.0\end{array}$ & $\begin{array}{l}15.5 \\
15.5 \\
16.0 \\
19.0 \\
19.0\end{array}$ & $\begin{array}{r}22.0 \\
22.0 \\
22.0 \\
24.0\end{array}$ & $\begin{array}{l}25.0 \\
25.0 \\
25.0 \\
25.0\end{array}$ & $\begin{array}{l}27.0 \\
28.0 \\
29.0 \\
29.0\end{array}$ & $\begin{array}{l}29.0 \\
28.0 \\
28.0 \\
29.0 \\
28.0\end{array}$ & $\begin{array}{r}28.0 \\
27.0 \\
27.0 \\
27.0\end{array}$ & $\begin{array}{l}28.0 \\
28.0 \\
28.0 \\
28.0 \\
28.0\end{array}$ \\
\hline $\begin{array}{l}21 \\
22 \\
23 \\
24 \\
25\end{array}$ & $\begin{array}{r}25.5 \\
25.5 \\
22.5 \\
22.5\end{array}$ & $\begin{array}{l}14.5 \\
15.0 \\
16.0 \\
15.5 \\
16.0\end{array}$ & $\begin{array}{r}14.0 \\
13.0 \\
14.0 \\
14.0\end{array}$ & $=$ & $\begin{array}{l}15.0 \\
15.0 \\
15.0 \\
16.0\end{array}$ & $\begin{array}{r}20.0 \\
17.0 \\
18.0 \\
18.0\end{array}$ & $\begin{array}{r}25.0 \\
25.0 \\
25.0\end{array}$ & $\begin{array}{l}26.0 \\
26.0 \\
27.0 \\
26.0\end{array}$ & $\begin{array}{r}29.0 \\
28.0 \\
30.0 \\
30.0 \\
-.-\end{array}$ & $\begin{array}{r}28.0 \\
28.0 \\
28.0 \\
28.0\end{array}$ & $\begin{array}{r}--- \\
28.0 \\
28.0 \\
28.0 \\
28.0\end{array}$ & $\begin{array}{r}28.0 \\
29.0 \\
28.0 \\
28.0 \\
-. .\end{array}$ \\
\hline $\begin{array}{l}26 \\
27 \\
28 \\
29 \\
30 \\
31\end{array}$ & $\begin{array}{r}22.5 \\
22.5 \\
23.0 \\
22.5 \\
=0.0 \\
22.0\end{array}$ & $\begin{array}{r}17.0 \\
17.0 \\
16.5 \\
15.5 \\
-\ldots\end{array}$ & $\begin{array}{l}14.0 \\
13.0 \\
13.0 \\
14.0 \\
15.0 \\
15.0\end{array}$ & $\begin{array}{l}--- \\
=- \\
=- \\
=-\end{array}$ & $\begin{array}{r}14.0 \\
15.0 \\
15.0 \\
=-0 \\
0-\end{array}$ & $\begin{array}{r}18.0 \\
18.0 \\
20.0 \\
21.0\end{array}$ & $\begin{array}{r}25.0 \\
25.0 \\
26.0 \\
26.0 \\
\ldots \ldots\end{array}$ & $\begin{array}{r}24.0 \\
26.0 \\
25.0 \\
25.0 \\
26.0\end{array}$ & $\begin{array}{r}28.0 \\
28.0 \\
28.0 \\
28.0 \\
29.0 \\
. .0\end{array}$ & $\begin{array}{r}=-0 \\
28.0 \\
28.0 \\
28.0 \\
28.0 \\
29.0\end{array}$ & $\begin{array}{r}28.0 \\
28.0 \\
27.0 \\
28.0 \\
28.0\end{array}$ & $\begin{array}{r}28.0 \\
27.0 \\
27.0 \\
26.0 \\
25.0 \\
-. .\end{array}$ \\
\hline VERAGE & 24.5 & 17.5 & 14.0 & -.- & 14.0 & -- & -.. & 25.0 & 27.0 & 28.0 & 28.0 & 28.0 \\
\hline
\end{tabular}


LOCATION,--Lat $26^{\circ} 55^{\prime} 56^{\prime \prime}$, long $81^{\circ} 18^{\prime} 54^{\prime \prime}$, In SW' sec.3, T.41 S., R.30 E., Glades County, at gaging station near right bank on downstream side of bridge on U.S. Highway 27, 1 mile south of Palmdale, and 16 miles upstream from Lake Okeechobee.

DRA INAGE AREA, --311 sq mi.

PER IOD OF RECORD.-mChemical analyses: July 1964 to September 1970.

Water temperatures: July 1964 to September 1970 .

EXTREMES. $-1969-70$ :

Speclfic conductance: Maximum daily, 540 micromhos May 24; minimum daily, 37 micromhos Mar. 21.

Hater temperatures: Meximum, $30.0^{\circ} \mathrm{C}$ June $7,13,19,28$; minimum, $8.0^{\circ} \mathrm{C}$ Jan. 8 .

period of record:

Specific conductance: Maximum daily, 860 micromhos July 21, 1964; minimum daily, 38 micromhos Aug. $31,1965$.

Hater temperatures: Maximum, $32.0^{\circ} \mathrm{C}$ July 20, 1964; minimum, 8.0 $\mathrm{C}$ Jan, 8, 1970 .

CHEMICAL ANALYSES, WATER YEAR OCTOBER 1969 TO SEPTEMBER 1970

SPE-

CON-

(MAJOR CONSTITUENTS)

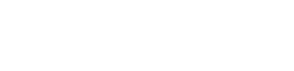

DUCT-

ANCE

OIS- SOLVED
OIS-

DIS-
DIS-

OCT. 1969

I6... 3967

DEC. 25.5

MHOS)

SOLVEO
IRON

SOLVED
CAL-

NEG- SOLVEO

$\begin{array}{llll}\text { IRON } & \text { CIUM } & \text { SIUM } & \text { TIUM } \\ \text { (FE) } & \text { (CA) } & \text { (MG) } & \text { (SR) }\end{array}$

DIS- PO-
SOLVED TAS-

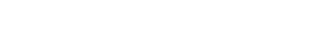

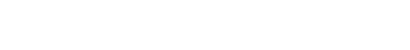

01... 134

JAN.: 1970

MAR.

16.5

4.7

(CO3)
(MG/L) (UNITS)

04 ... 68

14.0

116

-- 4

$2.2 \quad-2$

.7

-- 6.3

$06 \ldots 2.9$

21.0

102

$-$

6.2

3.0

-2 13

2.9

12

$-$

6.4

JUNE

26.5

135

-.

4.4

$2.3 \quad-\quad 11$

1.4

.912

6.0

$24 \ldots 118$

AUG. 204

$26.0 \quad 110$

200

5.9

3.1

$-15$

27.0229

24... 280

27.0

27.0

83

-- 9.0

$\begin{array}{ccc}2.4 & 200 & 12 \\ 2.6 & -0 & 12\end{array}$

.9

6.2

4.6

.8

12
14

0

7.0
6.8

$1.5 \quad 24$

.510

7.0

5.4

$2.2 \quad--\quad 8.0$

1.2

6.2

DIS- DIS-

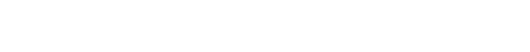

DIS- SOLVED SOLV-

SOLVEO CHLO- FLUO-

SULFATE RIDE PIOE

HARO-

BONATE ALKA- SOLIDS SOLIOS

HONATE LINITY TREI- (SUM OF SOLIDS

CACO3 DUE AT CONSTI-

SOLIOS SOL.IOS

TTONS TTONS ANNIN

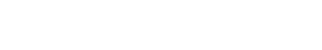

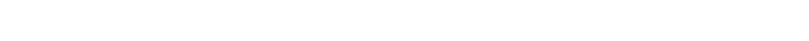

OCT. 1969

$16.01969-14$

OEC. $1.6 \quad 24$

JAN.:1970 $1.6 \quad 24$

22... $\quad 1.6$

$04 \ldots 203.229$

O6... $\quad .9 \quad 21$

$\begin{array}{lll}14 \ldots . .0 & 4.0 & 21 \\ \text { JUNE } & & \end{array}$

24... $15 \quad 50$

AUG. $14 \ldots 1.6 \quad 1.6 \quad 14$

$\begin{array}{lll}\text { SEP. } & 1.6 & 14 \\ 24 \ldots & .6 & 20\end{array}$

.3
.2
.2
.2
.2
.3
.3
.3

$\begin{array}{rrrrrrrrr}21 & 11 & 11 & 97 & 41 & 104 & .13 & -- & - \\ 28 & 18 & 11 & 114 & 59 & 41.2 & .16 & -- & - \\ 21 & 13 & 8 & 86 & 50 & 166 & .12 & - & - \\ 28 & 18 & 10 & 114 & 65 & 21.1 & .16 & -- & - \\ 25 & 15 & 10 & 96 & 51 & .75 & .13 & - & - \\ 26 & 14 & 11 & 100 & 57 & -. & .14 & - & - \\ 42 & 22 & 20 & 156 & 116 & 49.7 & .21 & - & - \\ 22 & 14 & 8 & 84 & 39 & 46.3 & .11 & - & - \\ 24 & \text { I1 } & 12 & 114 & 51 & 86.2 & .16 & -- & --\end{array}$

(MACRONUTRIENTS AND OTHER RELATED CONSTITUENTS)

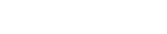

SOLVÉO

OPGANIC OPTHO

PHOS-

PHOS- DIS-

SOLVEO TUR-

SILICA BIO-

$\begin{array}{lll}\text { COLOR } & \text { TOTAL } & \text { RIO- } \\ \text { CHEM- } \\ \text { (PLAT- } & \text { ORGANIC } & \text { ICAL } \\ \text { INUM- } & \text { CARBON } & \text { OXYGEN } \\ \text { COBALT } & \text { (C) } & \text { OEMAND } \\ \text { UNITS) } & \text { (MG/L) } & \text { (MG/L) }\end{array}$

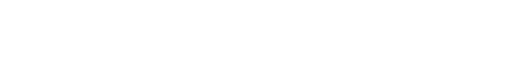

$\begin{array}{lll}(P O A) & \text { (SIOZ) ITY } \\ \text { (MGAL) } & \text { (MG/L) (JTI) }\end{array}$

$\begin{array}{ll}\text { OEMAND } & \text { DEPTH } \\ \text { (MGLL) } & \text { (FT) }\end{array}$

\begin{tabular}{|c|c|c|}
\hline \multicolumn{3}{|l|}{ OCТ.. 1969} \\
\hline $16 \ldots$ & - & .04 \\
\hline Nov... & -- & .03 \\
\hline $30 \ldots$ & -- & .03 \\
\hline $\begin{array}{l}\text { OEC. } \\
\text { O1.... }\end{array}$ & - & \\
\hline $01 \ldots$ & $\overline{-}$ & .03 \\
\hline JAN., 1970 & 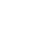 & .03 \\
\hline $\begin{array}{l}22 \ldots \\
31 \ldots\end{array}$ & -- & $\begin{array}{l}.02 \\
.02\end{array}$ \\
\hline FER. & & \\
\hline $\begin{array}{l}10 \ldots \\
28 \ldots\end{array}$ & .05 & $\begin{array}{l}.03 \\
.02\end{array}$ \\
\hline MAR. & & \\
\hline $\begin{array}{l}04 \ldots \\
31 \ldots\end{array}$ & $\cdots$ & .01 \\
\hline APR. & -- & .03 \\
\hline$\underset{\text { MAY }}{30 . . .}$ & -- & .04 \\
\hline $06 \ldots$ & .10 & .03 \\
\hline $14 \ldots$ & - & .02 \\
\hline JUNE & - & .03 \\
\hline $24 \ldots$ & -- & .02 \\
\hline $30 \ldots$ & -- & .03 \\
\hline AUG. & & \\
\hline SEP. & -- & .02 \\
\hline & .07 & .06 \\
\hline
\end{tabular}

\begin{tabular}{|c|c|c|}
\hline .7 & $=$ & .28 \\
\hline .0 & -- & .18 \\
\hline $\begin{array}{l}0 \\
.1\end{array}$ & $=$ & .19 \\
\hline .0 & $=$ &.$\overline{18}$ \\
\hline $\begin{array}{l}.0 \\
.0\end{array}$ & .61 & $\begin{array}{l}.15 \\
.28\end{array}$ \\
\hline $\begin{array}{l}.0 \\
.0\end{array}$ & $=$ & .54 \\
\hline$n$ & $m$ & .43 \\
\hline .0 & I.? & .34 \\
\hline .2 & $=$ & $\begin{array}{l}.41 \\
.36\end{array}$ \\
\hline . & -- & $=-$ \\
\hline - 0 & -- & .36 \\
\hline .0 & -- & .36 \\
\hline .0 & .64 & . 39 \\
\hline
\end{tabular}

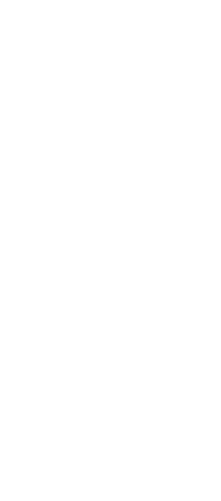

\begin{tabular}{|c|c|c|}
\hline 200 & $=$ & $\because$ \\
\hline -- & -- & -- \\
\hline 140 & 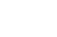 & $\because$ \\
\hline 120 & $\because$ & -: \\
\hline$=$ & $\because$ & $\because$ \\
\hline 160 & $\because-$ & :- \\
\hline & -- & -- \\
\hline $\begin{array}{l}120 \\
140\end{array}$ & 22 & 2.0 \\
\hline & & \\
\hline 120 & $\overline{-}$ & 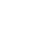 \\
\hline 160 & -- & -- \\
\hline & -- & -- \\
\hline
\end{tabular}



(FIELD MEASUREMENTS)

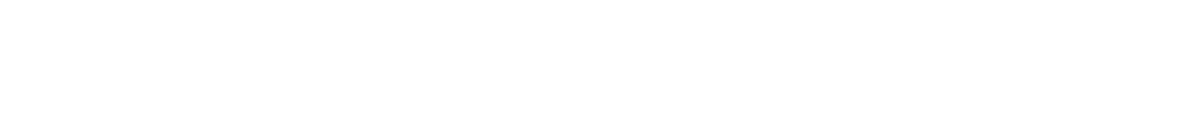
JAN., 1970

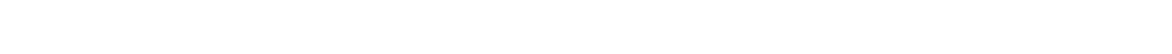
SPECIFIC CONDUCTANCE (MICROMHOS/CM AT $25^{\circ} \mathrm{C}$ ), WATER YEAR OCTOBER 1969 TO SEPTEMBER 1970

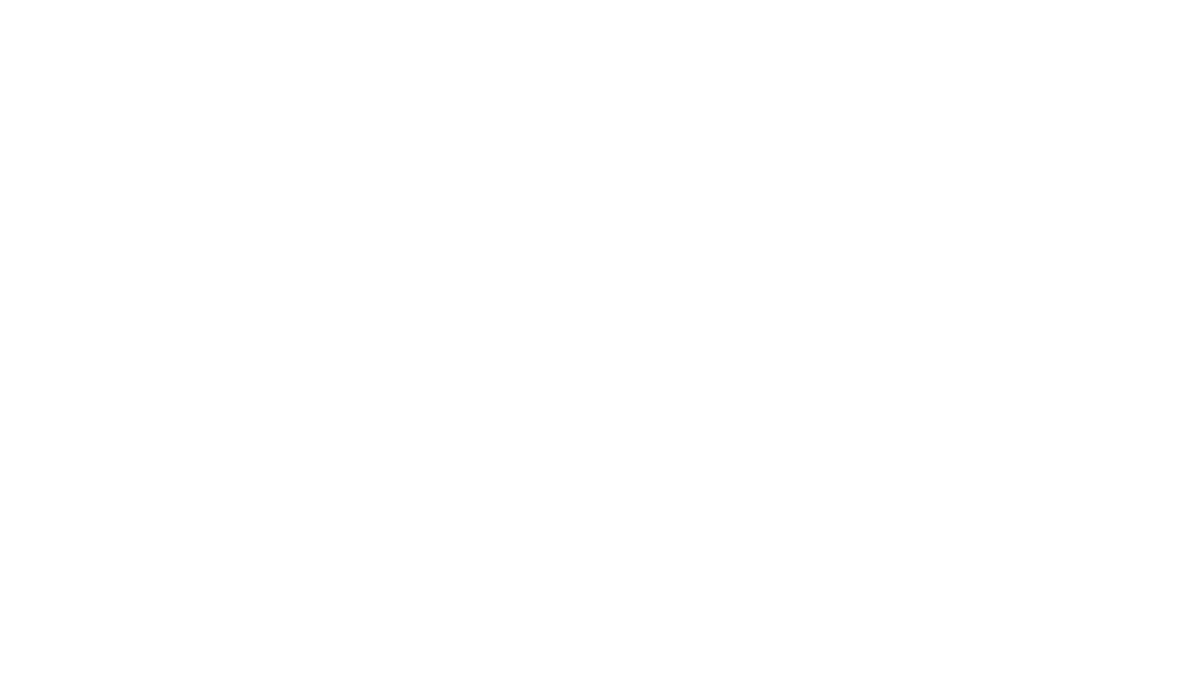

(TRACE METALS)

\begin{tabular}{|c|c|c|c|c|c|c|c|c|c|c|c|c|}
\hline DATE & $\begin{array}{l}\text { DIS- } \\
\text { SOLVED } \\
\text { ALUM- } \\
\text { INUM } \\
\text { (AL) } \\
\text { (UG/L) }\end{array}$ & $\begin{array}{c}\text { OIS- } \\
\text { SOLVFD } \\
\text { ARGENIC } \\
\text { (AS) } \\
\text { (UG/L) }\end{array}$ & $\begin{array}{c}\text { DIS- } \\
\text { SOLVEU } \\
\text { BORON } \\
(B) \\
(U G / L)\end{array}$ & $\begin{array}{l}\text { OIS- } \\
\text { SOLVEO } \\
\text { CAD- } \\
\text { NIUM } \\
\text { (CD) } \\
\text { (UG/L) }\end{array}$ & $\begin{array}{l}\text { MEXA- } \\
\text { VALEVT } \\
\text { CHRO- } \\
\text { MIUM } \\
\text { (CRG) } \\
\text { (UG/L) }\end{array}$ & $\begin{array}{l}\text { DIS- } \\
\text { SOLVEO } \\
\text { CHHO- } \\
\text { MIUM } \\
\text { (CH) } \\
\text { (UG/L) }\end{array}$ & $\begin{array}{l}\text { DIS- } \\
\text { SOLVED } \\
\text { COPPER } \\
\text { (CU) } \\
\text { (UG/L) }\end{array}$ & $\begin{array}{l}\text { DIC- } \\
\text { SOLVEN } \\
\text { IRON } \\
\text { (FE) } \\
\text { (UGAL) }\end{array}$ & $\begin{array}{l}\text { OIS- } \\
\text { SOLVEO } \\
\text { LEAD } \\
\text { (PR) } \\
(\mathrm{UG} / \mathrm{L})\end{array}$ & $\begin{array}{l}\text { DIS- } \\
\text { SOLVED } \\
\text { MAN- } \\
\text { GANESE } \\
\text { (MN) } \\
\text { (UG/L) }\end{array}$ & $\begin{array}{l}\text { TOTAL } \\
\text { MERCURY } \\
\text { (HG) } \\
\text { (UGLL) }\end{array}$ & $\begin{array}{l}\text { DIS- } \\
\text { SNLVED } \\
\text { ZIVC } \\
\text { (ZN) } \\
(U G / L)\end{array}$ \\
\hline $\begin{array}{l}\operatorname{MAY}, 1970 \\
06 . . .\end{array}$ & -- & $>0$ & -- & -- & -- & -- & $2 n$ & 200 & 0 & 10 & $=$ & 40 \\
\hline & & & TEMPERATURE & $\left({ }^{\circ} \mathrm{C}\right)$ OF & WATER, & WATER YEAR & OCTOBER & 1969 TO & SEPTEMBER & 1970 & & \\
\hline $\begin{array}{r}\text { DAY } \\
1 \\
2 \\
3 \\
4 \\
5\end{array}$ & $\begin{array}{l}001 \\
26.0 \\
26.0 \\
26.0 \\
26.0 \\
26.5\end{array}$ & $\begin{array}{r}\text { NOV } \\
23.0 \\
25.5 \\
23.0 \\
23.0 \\
23.0\end{array}$ & $\begin{array}{r}\text { OEC } \\
13.5 \\
13.5 \\
14.0 \\
14.0 \\
16.5\end{array}$ & $\begin{array}{r}\text { JAN } \\
18.0 \\
18.0 \\
17.0 \\
15.0 \\
11.0\end{array}$ & $\begin{array}{l}\text { FEB } \\
17.0 \\
17.0 \\
18.0 \\
17.0 \\
17.0\end{array}$ & $\begin{array}{l}\text { MAR } \\
18.0 \\
18.0 \\
19.0 \\
19.5 \\
19.5\end{array}$ & $\begin{array}{r}A P R \\
22.0 \\
22.0 \\
23.5 \\
23.5 \\
23.5\end{array}$ & $\begin{array}{r}\text { MAY } \\
27.0 \\
27.0 \\
27.0 \\
27.0 \\
27.0\end{array}$ & $\begin{array}{l}\text { JUN } \\
29.0 \\
28.0 \\
27.0 \\
26.0 \\
26.0\end{array}$ & \begin{tabular}{l} 
Ju \\
\hdashline-- \\
\hdashline-- \\
\hdashline--
\end{tabular} & $\begin{array}{l}\text { AUG } \\
27.0 \\
27.0 \\
27.0 \\
27.0 \\
27.0\end{array}$ & $\begin{array}{l}\text { SEP } \\
26.0 \\
26.0 \\
26.0 \\
26.0 \\
27.0\end{array}$ \\
\hline $\begin{array}{r}6 \\
7 \\
8 \\
9 \\
10\end{array}$ & $\begin{array}{l}26.0 \\
26.0 \\
26.0 \\
26.0 \\
26.0\end{array}$ & $\begin{array}{l}23.0 \\
23.5 \\
25.5 \\
25.5 \\
25.5\end{array}$ & $\begin{array}{l}17.0 \\
17.0 \\
17.0 \\
17.5 \\
17.5\end{array}$ & $\begin{array}{r}15.0 \\
15.0 \\
10.0 \\
9.0 \\
8.0\end{array}$ & $\begin{array}{l}17.0 \\
18.0 \\
17.0 \\
16.5 \\
16.0\end{array}$ & $\begin{array}{l}19.5 \\
19.5 \\
21.0 \\
21.0 \\
20.5\end{array}$ & $\begin{array}{l}20.0 \\
20.0 \\
20.5 \\
20.5 \\
21.0\end{array}$ & $\begin{array}{l}27.0 \\
28.0 \\
27.0 \\
27.0 \\
28.0\end{array}$ & $\begin{array}{l}29.0 \\
30.0 \\
27.0 \\
29.0 \\
27.0\end{array}$ & $\begin{array}{l}--- \\
--- \\
---\end{array}$ & $\begin{array}{l}27.5 \\
27.0 \\
27.5 \\
27.5 \\
27.5\end{array}$ & $\begin{array}{l}26.0 \\
26.0 \\
26.0 \\
26.0 \\
26.0\end{array}$ \\
\hline $\begin{array}{l}11 \\
12 \\
13 \\
14 \\
15\end{array}$ & $\begin{array}{l}26.5 \\
26.5 \\
26.0 \\
26.0 \\
26.0\end{array}$ & $\begin{array}{l}23.5 \\
23.0 \\
23.0 \\
25.0 \\
23.5\end{array}$ & $\begin{array}{l}14.0 \\
14.0 \\
17.0 \\
17.0 \\
14.0\end{array}$ & $\begin{array}{r}9.0 \\
9.0 \\
11.0 \\
15.5 \\
16.0\end{array}$ & $\begin{array}{l}17.0 \\
17.0 \\
17.0 \\
17.0 \\
17.0\end{array}$ & $\begin{array}{l}18.0 \\
18.5 \\
18.0 \\
18.0 \\
18.0\end{array}$ & $\begin{array}{l}22.5 \\
23.0 \\
24.0 \\
23.5 \\
23.5\end{array}$ & $\begin{array}{l}27.0 \\
27.0 \\
27.0 \\
28.0 \\
28.0\end{array}$ & $\begin{array}{l}27.0 \\
29.0 \\
30.0 \\
29.0 \\
27.0\end{array}$ & $\begin{array}{l}m \\
\cdots-- \\
---\end{array}$ & $\begin{array}{l}27.0 \\
27.5 \\
27.0 \\
27.0 \\
27.5\end{array}$ & $\begin{array}{l}27.0 \\
27.0 \\
27.0 \\
26.0 \\
26.0\end{array}$ \\
\hline $\begin{array}{l}16 \\
17 \\
18 \\
19 \\
20\end{array}$ & $\begin{array}{l}26.0 \\
26.5 \\
26.5 \\
26.0 \\
26.0\end{array}$ & $\begin{array}{l}23.5 \\
23.0 \\
19.0 \\
19.0 \\
19.5\end{array}$ & $\begin{array}{l}15.0 \\
17.0 \\
17.0 \\
17.0 \\
17.0\end{array}$ & $\begin{array}{l}16.0 \\
17.0 \\
20.0 \\
16.0 \\
16.0\end{array}$ & $\begin{array}{l}18.0 \\
18.0 \\
19.0 \\
19.0 \\
19.0\end{array}$ & $\begin{array}{l}18.0 \\
19.5 \\
19.5 \\
20.0 \\
20.0\end{array}$ & $\begin{array}{l}23.5 \\
23.5 \\
24.0 \\
25.0 \\
24.5\end{array}$ & $\begin{array}{l}26.5 \\
28.0 \\
27.0 \\
27.0 \\
27.0\end{array}$ & $\begin{array}{l}27.0 \\
29.0 \\
27.0 \\
30.0 \\
29.0\end{array}$ & $\begin{array}{l}\cdots- \\
\cdots \\
\cdots-\end{array}$ & $\begin{array}{l}27.0 \\
27.5 \\
27.5 \\
27.0 \\
27.5\end{array}$ & $\begin{array}{l}26.0 \\
27.0 \\
27.0 \\
27.0 \\
27.0\end{array}$ \\
\hline $\begin{array}{l}21 \\
22 \\
23 \\
24 \\
25\end{array}$ & $\begin{array}{l}26.0 \\
26.0 \\
26.5 \\
25.5 \\
26.0\end{array}$ & $\begin{array}{l}21.5 \\
23.5 \\
23.0 \\
20.0 \\
19.5\end{array}$ & $\begin{array}{l}17.0 \\
17.0 \\
18.5 \\
18.5 \\
-2 .\end{array}$ & $\begin{array}{l}14.0 \\
1400 \\
14.0 \\
13.0 \\
13.0\end{array}$ & $\begin{array}{l}19.0 \\
18.0 \\
18.0 \\
18.0 \\
17.0\end{array}$ & $\begin{array}{l}20.0 \\
17.0 \\
16.5 \\
16.0 \\
17.0\end{array}$ & $\begin{array}{l}25.0 \\
24.5 \\
24.5 \\
25.5 \\
26.0\end{array}$ & $\begin{array}{l}27.0 \\
28.0 \\
28.0 \\
27.5 \\
26.0\end{array}$ & $\begin{array}{l}29.0 \\
26.0 \\
27.0 \\
27.0 \\
29.5\end{array}$ & $\begin{array}{l}--- \\
\cdots \\
\cdots-\end{array}$ & $\begin{array}{l}27.0 \\
27.0 \\
26.5 \\
27.0 \\
27.5\end{array}$ & $\begin{array}{l}26.0 \\
26.0 \\
27.0 \\
26.5 \\
26.0\end{array}$ \\
\hline $\begin{array}{l}26 \\
27 \\
28 \\
29 \\
30 \\
31\end{array}$ & $\begin{array}{l}26.5 \\
26.0 \\
25.5 \\
24.0 \\
23.0 \\
23.0\end{array}$ & $\begin{array}{r}19.5 \\
20.5 \\
20.5 \\
20.0 \\
20.5 \\
. . .\end{array}$ & $\begin{array}{l}16.0 \\
17.0 \\
19.0 \\
19.0 \\
19.0 \\
17.0\end{array}$ & $\begin{array}{l}13.0 \\
14.0 \\
17.0 \\
17.0 \\
17.0 \\
16.0\end{array}$ & $\begin{array}{r}17.0 \\
17.0 \\
17.0 \\
\ldots-0 \\
\ldots-0\end{array}$ & $\begin{array}{l}20.0 \\
22.5 \\
22.5 \\
22.0 \\
22.0 \\
22.0\end{array}$ & $\begin{array}{l}26.0 \\
27.0 \\
27.0 \\
27.0 \\
27.0 \\
.0 .0\end{array}$ & $\begin{array}{l}26.0 \\
26.0 \\
26.0 \\
25.5 \\
26.0 \\
26.0\end{array}$ & $\begin{array}{l}29.5 \\
26.5 \\
30.0 \\
27.0 \\
27.0 \\
-. .-\end{array}$ & $\begin{array}{l}--- \\
\cdots-- \\
--- \\
-\cdots\end{array}$ & $\begin{array}{l}28.0 \\
26.5 \\
26.5 \\
27.0 \\
27.5 \\
27.5\end{array}$ & $\begin{array}{l}26.0 \\
26.5 \\
26.0 \\
27.0 \\
27.0 \\
-.-\end{array}$ \\
\hline AVERAGE & 26.0 & 22.5 & 16.5 & 14.5 & 17.5 & 19.5 & 24.0 & 27.0 & 28.0 & $\cdots$ & 27.0 & 26.5 \\
\hline
\end{tabular}


LOCATION.--(revised) Lat $27^{\circ} 13^{\prime} 32^{\prime \prime}$, LOAg $80^{\circ} 57^{\prime} 46^{\prime \prime}$, In NEł sec.30, T. $37 \mathrm{~S}$, , R.34 E., Okeechobee County, at gaging station on left bank in downstream lock control house at lock and control structure 65E, $1.8 \mathrm{miles}$ downstream from State Highway 70 , about 8.5 miles west of okeechobee, and 8.2 miles upstream from mouth.

DRAINAGE AREA.--Indeterminate.

PER IOD OF RECORD,--Chemical analyses: October 1967 to September 1970.

Water temperatures: October 1967 to September 1970 CHEMICAL ANALYSES, WATER YEAR OCTOBER 1969 TO SEPTEMBER 1970
(MAJOR CONSTITUENTS)

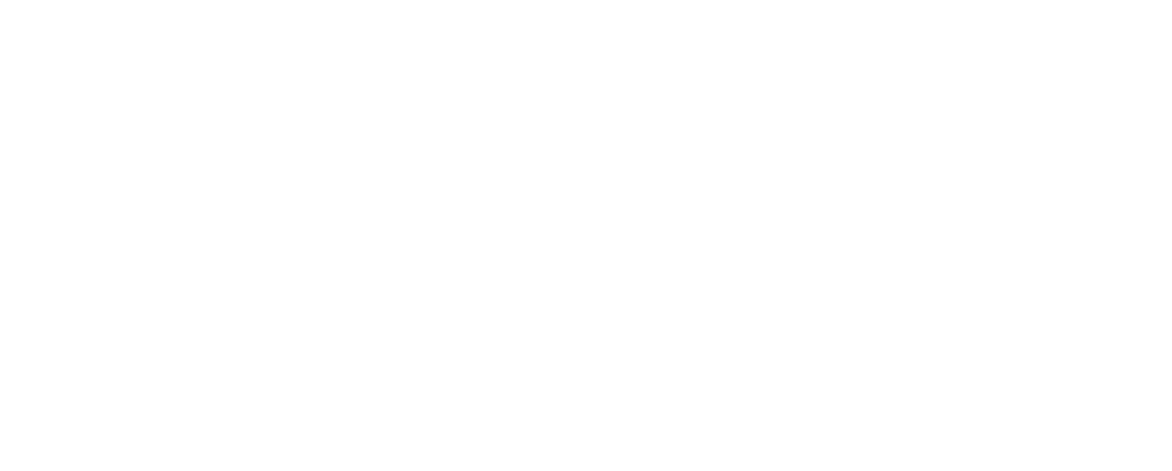

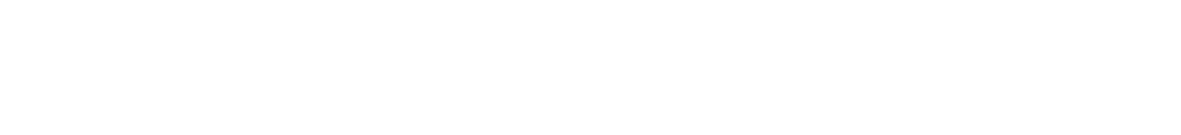
OCT. 1969

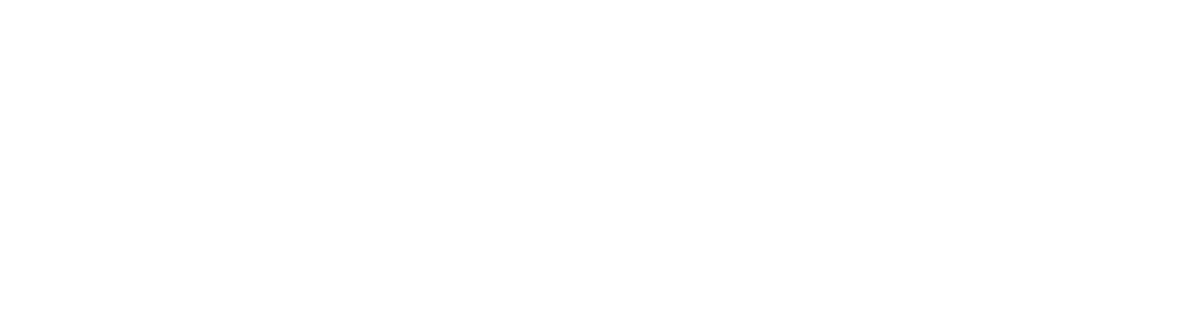
(MACRONUTRIENTS AND OTHER RELATED CONSTITUENTS)

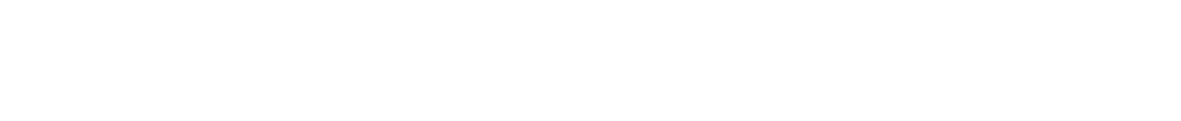
OCT., 1969

\begin{tabular}{|c|c|c|c|c|c|c|c|c|c|c|c|c|}
\hline $\begin{array}{l}\text { OCT.1 } 1969 \\
01 . . .\end{array}$ & $=$ & - & .1 & $\cdots$ & $=-$ & $=$ & 2.4 & - & A0 & $=$ & 1.1 & $=$ \\
\hline $31 \ldots$ & $=-$ & .02 & .0 & - & .10 & .12 & - & -- & - & -- & -- & -- \\
\hline NOV. & & & & & & & & & & & & \\
\hline $\begin{array}{l}30 . \cdots \\
\text { DEC. }\end{array}$ & - & .01 & .0 & -- & .07 & .14 & -- & $-\infty$ & -- & -- & $\cdots$ & $\cdots$ \\
\hline $03 \ldots$ & -- & - & .2 & $\approx$ & - & 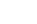 & 2.3 & $\cdots$ & 80 & -- & .6 & $\rightarrow$ \\
\hline $\begin{array}{l}31 \ldots . \cdots 1970 \\
\text { JAN.: } 1970\end{array}$ & - & .01 & $\bullet 0$ & $\cdots$ & .07 & .10 & $\cdots$ & $\cdots$ & $-\infty$ & -- & $\cdots$ & $\cdots$ \\
\hline FEB. & $-\infty$ & -- & - & $\cdots$ & .21 & .24 & - & -- & -- & -- & -- & $=$ \\
\hline $04 \ldots$ & -- & $=$ & .0 & $=$ & $\bar{x}$ & $=$ & 2.2 & - & 110 & -- & .5 & $=$ \\
\hline MAR." & - & .10 & $\cdot 8$ & $-\infty$ & .71 & .78 & $\infty$ & $\infty$ & - & $=$ & $\cdots$ & $=$ \\
\hline $03 \ldots$ & $\cdots$ & .03 & .2 & $\rightarrow$ & $=-$ & $=$ & 1.1 & - & 100 & $=$ & 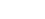 & - \\
\hline $\begin{array}{l}31 \cdots \\
A P R .\end{array}$ & $m$ & .24 & 1.3 & - & .28 & .31 & $\cdots$ & $\cdots$ & - & $\cdots$ & $\cdots$ & - \\
\hline $03 \ldots$ & - & .02 & $\cdot 0$ & $=-$ & $m$ & $=$ & 1.2 & $\cdots$ & 110 & $\cdots$ & 1.5 & $\cdots$ \\
\hline MAY & . & 30 & 4.4 & & .30 & .34 & 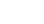 & 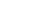 & $=-$ & $\cdots$ & . & \\
\hline $06 \ldots$ & .10 & .07 & 2.2 & .87 & .19 & .23 & 3.2 & $\cdots$ & 70 & 16 & 1.2 & - \\
\hline JUNE & 20 & .03 & & & $\cdot 27$ & . 31 & $\cdots$ & 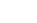 & - & - & $\cdots$ & \\
\hline $03 \ldots$ & $-\infty$ & .02 & 2.0 & $\ldots$ & $\cdots$ & $=$ & 3,3 & $\cdots$ & 100 & 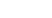 & 1.0 & \\
\hline JULY & $\cdots$ & .02 & .8 & $-\infty$ & .11 & .17 & - & $\cdots$ & - & - & - & \\
\hline $01 \ldots$ & $\because$ & .02 & .9 & 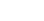 & $=$ & $=$ & 3.3 & $\cdots$ & 70 & $\cdots$ & $\ldots$ & \\
\hline 02. & .16 & .01 & -9 & .30 & .18 & .23 & 6.4 & 6 & in & $\cdots$ & $=$ & \\
\hline & & .01 & .8 & $\cdots$ & .12 & .15 & $\cdots$ & $\cdots$ & $\ldots$ & 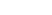 & $=$ & \\
\hline
\end{tabular}


EXTREMES. $-1969-70$ :

Specific conductance: Maximum daily, 300 micromhos July 10, 11, 12; minimum daily, 105 micromhos Oct, 10.

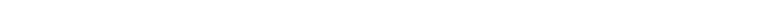

Period of record:

Specific conductance: Maximum daily, 411 micromhos Dec, 21, 1968; minimum dally, 77 micromhos July 14, 1968,

Water temperatures: Maximum, $31.0^{\circ} \mathrm{C}$ July 29, 30, 1968, July 12, 13, 14, 1969; minimum, 5.0 ${ }^{\circ} \mathrm{C}$ Dec. 14, 15,

$16,1970$.

CHEMICAL ANALYSES, WATER YEAR OCTOBER 1969 TO SEPTEMBER 1970

IFIELD MEASUREMENTS

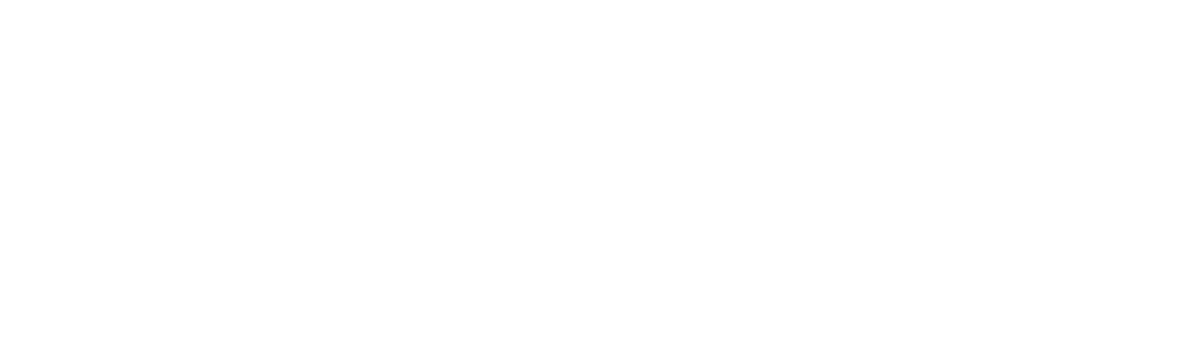

\begin{tabular}{|c|c|c|c|c|c|c|c|c|c|c|c|c|}
\hline DAY & $D C \mathbf{T}$ & NOV & DEC & JAN & FEB & MAR & APR & MAY & JUN & JUL & AUG & SEP \\
\hline $\begin{array}{l}1 \\
2 \\
4 \\
5\end{array}$ & $\begin{array}{l}127 \\
236 \\
170 \\
140\end{array}$ & $\begin{array}{l}170 \\
180 \\
195 \\
195\end{array}$ & $\begin{array}{l}145 \\
158 \\
160 \\
165\end{array}$ & $\begin{array}{l}170 \\
180 \\
200 \\
175\end{array}$ & $\begin{array}{l}172 \\
180 \\
165 \\
150\end{array}$ & $\begin{array}{l}190 \\
183 \\
177 \\
173\end{array}$ & $\begin{array}{l}117 \\
115 \\
115 \\
120\end{array}$ & $\begin{array}{l}142 \\
158 \\
142 \\
143\end{array}$ & $\begin{array}{l}200 \\
200 \\
215 \\
220\end{array}$ & $\begin{array}{l}285 \\
286 \\
286 \\
295\end{array}$ & $\begin{array}{l}240 \\
238 \\
233 \\
234\end{array}$ & $\begin{array}{l}255 \\
253 \\
253 \\
253\end{array}$ \\
\hline $\begin{array}{r}6 \\
7 \\
8 \\
9 \\
10\end{array}$ & $\begin{array}{l}130 \\
130 \\
125 \\
135 \\
105\end{array}$ & $\begin{array}{l}170 \\
190 \\
185 \\
190 \\
192\end{array}$ & $\begin{array}{l}169 \\
171 \\
175 \\
170 \\
199\end{array}$ & $\begin{array}{l}175 \\
225 \\
190 \\
165 \\
155\end{array}$ & $\begin{array}{l}170 \\
165 \\
160 \\
155 \\
170\end{array}$ & $\begin{array}{l}156 \\
152 \\
147 \\
140 \\
135\end{array}$ & $\begin{array}{l}115 \\
114 \\
114 \\
114 \\
113\end{array}$ & $\begin{array}{l}158 \\
155 \\
153 \\
150 \\
160\end{array}$ & $\begin{array}{l}218 \\
248 \\
250 \\
258 \\
260\end{array}$ & $\begin{array}{l}285 \\
290 \\
288 \\
292 \\
300\end{array}$ & $\begin{array}{l}232 \\
234 \\
234 \\
229 \\
235\end{array}$ & $\begin{array}{l}252 \\
252 \\
253 \\
254 \\
256\end{array}$ \\
\hline $\begin{array}{l}11 \\
12 \\
13 \\
14 \\
15\end{array}$ & $\begin{array}{l}160 \\
155 \\
170 \\
165 \\
150\end{array}$ & $\begin{array}{l}182 \\
179 \\
185 \\
189 \\
170\end{array}$ & $\begin{array}{l}169 \\
169 \\
165 \\
141 \\
130\end{array}$ & $\begin{array}{l}150 \\
130 \\
115 \\
140 \\
140\end{array}$ & $\begin{array}{l}185 \\
160 \\
155 \\
160 \\
162\end{array}$ & $\begin{array}{l}134 \\
130 \\
135 \\
137 \\
144\end{array}$ & $\begin{array}{l}124 \\
123 \\
130 \\
132 \\
125\end{array}$ & $\begin{array}{l}169 \\
165 \\
168 \\
168 \\
172\end{array}$ & $\begin{array}{l}235 \\
240 \\
255 \\
294 \\
298\end{array}$ & $\begin{array}{l}300 \\
300 \\
295 \\
290 \\
288\end{array}$ & $\begin{array}{l}235 \\
242 \\
240 \\
257 \\
249\end{array}$ & $\begin{array}{l}257 \\
256 \\
256 \\
257 \\
258\end{array}$ \\
\hline $\begin{array}{l}16 \\
17 \\
18 \\
19 \\
20\end{array}$ & $\begin{array}{l}150 \\
150 \\
130 \\
130 \\
-\end{array}$ & \begin{tabular}{l}
189 \\
\hdashline 159 \\
125
\end{tabular} & $\begin{array}{l}122 \\
115 \\
109 \\
117 \\
-\end{array}$ & $\begin{array}{l}123 \\
131 \\
120 \\
117 \\
117\end{array}$ & $\begin{array}{l}160 \\
180 \\
165 \\
162 \\
160\end{array}$ & $\begin{array}{l}137 \\
135 \\
132 \\
131 \\
129\end{array}$ & $\begin{array}{l}117 \\
117 \\
122 \\
140 \\
120\end{array}$ & $\begin{array}{l}183 \\
178 \\
176 \\
176 \\
180\end{array}$ & $\begin{array}{l}290 \\
280 \\
260 \\
265 \\
268\end{array}$ & $\begin{array}{l}285 \\
280 \\
288 \\
285 \\
290\end{array}$ & $\begin{array}{l}236 \\
237 \\
243 \\
244 \\
240\end{array}$ & $\begin{array}{l}259 \\
259 \\
259 \\
262 \\
262\end{array}$ \\
\hline $\begin{array}{l}21 \\
22 \\
23 \\
24 \\
25\end{array}$ & $\begin{array}{l}160 \\
155 \\
150 \\
155 \\
150\end{array}$ & $\begin{array}{l}118 \\
119 \\
118 \\
123 \\
124\end{array}$ & $\begin{array}{l}130 \\
133 \\
142 \\
132\end{array}$ & $\begin{array}{l}115 \\
114 \\
128 \\
132 \\
162\end{array}$ & $\begin{array}{l}200 \\
175 \\
162 \\
170 \\
170\end{array}$ & $\begin{array}{l}124 \\
131 \\
123 \\
121 \\
124\end{array}$ & $\begin{array}{l}123 \\
130 \\
124 \\
127 \\
134\end{array}$ & $\begin{array}{l}186 \\
186 \\
185 \\
188 \\
187\end{array}$ & $\begin{array}{l}285 \\
270 \\
279 \\
278 \\
270\end{array}$ & $\begin{array}{l}295 \\
285 \\
285 \\
285 \\
280\end{array}$ & $\begin{array}{l}240 \\
240 \\
243 \\
247 \\
255\end{array}$ & $\begin{array}{l}262 \\
263 \\
263 \\
264 \\
267\end{array}$ \\
\hline $\begin{array}{l}26 \\
27 \\
28 \\
29 \\
30 \\
31\end{array}$ & $\begin{array}{l}140 \\
145 \\
1150 \\
160 \\
160\end{array}$ & $\begin{array}{r}125 \\
138 \\
135 \\
135 \\
138 \\
\end{array}$ & $\begin{array}{l}130 \\
135 \\
138 \\
145 \\
140 \\
127\end{array}$ & $\begin{array}{l}165 \\
171 \\
170 \\
185 \\
190 \\
175\end{array}$ & $\begin{array}{l}165 \\
175 \\
165 \\
-- \\
---\end{array}$ & $\begin{array}{l}123 \\
137 \\
133 \\
131 \\
124 \\
126\end{array}$ & $\begin{array}{l}130 \\
132 \\
132 \\
140 \\
140 \\
-\end{array}$ & $\begin{array}{l}201 \\
213 \\
195 \\
237 \\
195 \\
194\end{array}$ & $\begin{array}{l}280 \\
280 \\
280 \\
280 \\
280 \\
-\end{array}$ & $\begin{array}{l}275 \\
260 \\
260 \\
260 \\
255 \\
246\end{array}$ & $\begin{array}{l}251 \\
255 \\
252 \\
254 \\
250 \\
251\end{array}$ & $\begin{array}{l}272 \\
268 \\
264 \\
268 \\
268 \\
-\end{array}$ \\
\hline IERAGE & 149 & 161 & 146 & 155 & 167 & 141 & 124 & 174 & 258 & 283 & 242 & 250 \\
\hline
\end{tabular}

(ORGANOCHLORIDE COMPOUNDS IN WATER)

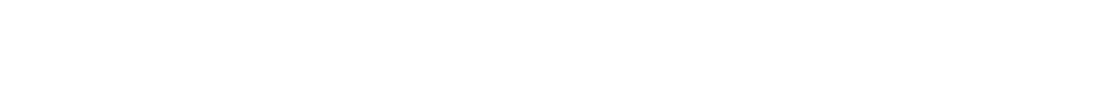

.00

.00

(TRACE METALS)

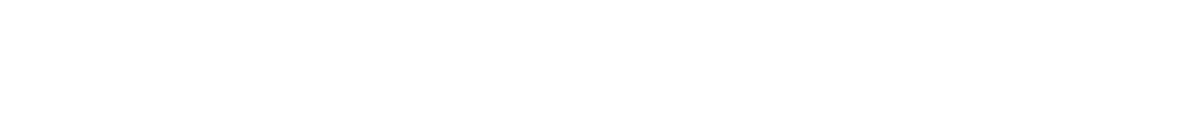

OCT..

\begin{tabular}{|c|c|c|c|c|c|c|c|c|c|c|c|c|}
\hline $\begin{array}{l}\text { OI... } \\
\text { OEC. }\end{array}$ & -- & + & -- & $=$ & $=$ & - & 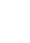 & I 20 & - & - & $\cdots$ & - \\
\hline FEB.:. ${ }_{1970}$ & $\cdots$ & - & -- & $=$ & -- & -- & - & $12 n$ & -- & -- & -- & - \\
\hline APR... & -- & -- & $=$ & $=$ & -- & -- & - & 70 & $m$ & -- & -- & - \\
\hline MAY 03 & $=$ & - & -- & -- & $\cdots$ & -- & - & Ian & - & $\cdots$ & $\cdots$ & - \\
\hline JUNE & - & 10 & -- & -- & -- & 10 & 0 & 280 & 10 & 10 & - & 30 \\
\hline JULY... & -- & - & $=$ & $=$ & -- & -- & - & $24 n$ & - & -- & -- & -- \\
\hline $\begin{array}{l}01 \ldots . \\
02 \ldots\end{array}$ & $=$ & $\overline{10}$ & $=$ & $\because$ & $=$ & $\ddot{0}$ & 10 & $12 n$ & $\overline{0}$ & $\ddot{i n}$ & $=$ & $=$ \\
\hline
\end{tabular}


CHEMICAL ANALYSES, WATER YEAR OCTOBER 1969 TO SÉPTEMBER 1970
(OTHER DATA)

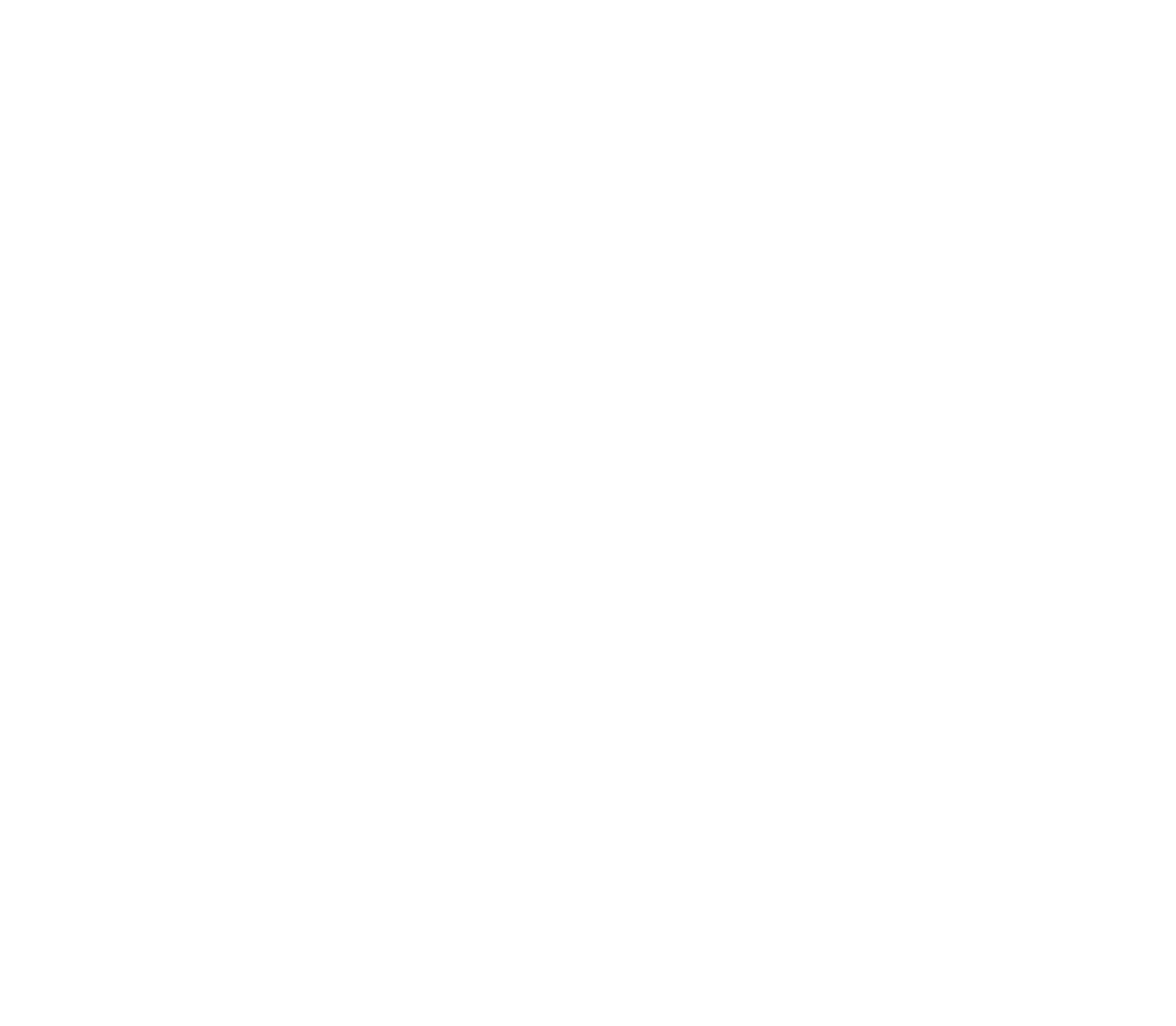

02273200 CANAL 41A AT S-68 AT LAKE istokPOGa, NEAR LAKE PLACID, FLA.

LOCATION,--Lat $27^{\circ} 19^{\prime} 55^{\prime \prime}$, long $81^{\circ} 15^{\prime} 05^{\prime \prime}$, in sec.19 or 20 , T.36 S., R.31 E., Highlands County, at gaging station $33 \mathrm{ft}$ from right bank, $350 \mathrm{ft}$ upstream from control structure 68 at Lake Istokpoga, and $7.5 \mathrm{miles}$ northeast of town of Lake placid.

DRA INAGE AREA. - Inde terminate.

PERIOD OF RECORD.--Chemical analyses: September 1963 to September 1970.

Water temperatures: October 1963 to September 1970.

EXTRENES, - -1969m-70:

Speciftc conductance: Kaxtmum da1ly, 97 micromhos July 16; mintmum dat1y, 51 micromhos Oct. 31.

Water temperatures: Maximum, $30.5^{\circ} \mathrm{C}$ Apr, 16 and Jun. $27 ;$ minimum, $9.0^{\circ} \mathrm{C}$ Jan. 10.

Pertod of record:

Spectfic conductance: Maximum dat1y, 182 micromhos June 1, 1968; minimum datly, 51 micromhos oct. $31,1970$.
Water temperatures: Maximum, 34.0 CHEMICAL ANALYSES, WATER YEAR OCTOBER 1969 TO SEPTEMBER 1970 WATER YEAR OCTOBER 1969
(MAJOR CONSTITUENTS)

\begin{tabular}{|c|c|c|c|c|c|c|c|c|c|c|c|c|}
\hline DATE & $\begin{array}{l}\text { DIS- } \\
\text { CHARGE } \\
\text { (CFS) }\end{array}$ & $\begin{array}{l}\text { TEMPER- } \\
\text { ATURE } \\
\text { (OEG C) }\end{array}$ & $\begin{array}{l}\text { SPE- } \\
\text { CIFIC } \\
\text { CON- } \\
\text { DUCT- } \\
\text { ANCE } \\
\text { (MICRO- } \\
\text { MHOS) }\end{array}$ & $\begin{array}{l}\text { OIS- } \\
\text { SOLVED } \\
\text { IRON } \\
\text { (FE) } \\
\left(U_{G} / L\right)\end{array}$ & $\begin{array}{l}\text { OIS- } \\
\text { SOLVED } \\
\text { CAL- } \\
\text { CIUM } \\
\text { (CA) } \\
\text { (MG/L) }\end{array}$ & $\begin{array}{l}\text { DIS- } \\
\text { SOLVED } \\
\text { MAG- } \\
\text { NE- } \\
\text { SIUM } \\
\text { (MG) } \\
\text { (MG/L) }\end{array}$ & $\begin{array}{l}\text { OIS- } \\
\text { SOLVED } \\
\text { STRON- } \\
\text { TIUM } \\
\text { (SR) } \\
\text { (UG/L) }\end{array}$ & $\begin{array}{l}\text { OIS- } \\
\text { SOLVED } \\
\text { SODIUM } \\
\text { (NA) } \\
\text { (MG/L) }\end{array}$ & $\begin{array}{l}\text { DIS- } \\
\text { SOL VED } \\
\text { PO- } \\
\text { TAS- } \\
\text { SIUM } \\
\text { (K) } \\
\text { (MG/L) }\end{array}$ & $\begin{array}{l}\text { BICAR- } \\
\text { BONATE } \\
\text { (HCO3) } \\
\text { (MG/L) }\end{array}$ & $\begin{array}{l}\text { CAR- } \\
\text { BONATE } \\
\text { (CO3) } \\
\text { (MG/L) }\end{array}$ & $\begin{array}{c}\text { PH } \\
\text { (UNITS) }\end{array}$ \\
\hline $\begin{array}{l}\text { OCT., } \\
\text { I6... } \\
\text { DEC. }\end{array}$ & $\begin{array}{l}1969 \\
715\end{array}$ & 27.5 & 58 & -- & 3.0 & 1.7 & -- & 4.4 & [ . I & Imor & -- & 6.3 \\
\hline JAN., & $1970^{320}$ & 18.0 & 62 & $\rightarrow$ & 3.5 & 1.7 & - & 4.5 & 1.2 & 6 & $B$ & 6.0 \\
\hline $\begin{array}{l}22 . . \\
\text { MAR. }\end{array}$ & 160 & 14.0 & 67 & $\cdots$ & 3.6 & I.P & $=$ & 5.3 & 1.3 & 6 & 0 & 5.9 \\
\hline MAY $26 .$. & 1670 & 19.5 & 75 & - & 4.0 & 2.0 & - & 5.5 & 1.3 & A & - & 6.0 \\
\hline JUNE & 195 & 28.0 & 89 & - & 4.3 & 2.5 & - & 6.5 & 1.6 & 5 & $n$ & 6.5 \\
\hline $\begin{array}{l}19 . . . \\
19 . . \\
\text { AUG. }\end{array}$ & $\begin{array}{l}.00 \\
.00\end{array}$ & $\begin{array}{l}29.0 \\
29.0\end{array}$ & $\begin{array}{l}94 \\
95\end{array}$ & $=$ & $\begin{array}{l}5.1 \\
4.8\end{array}$ & $\begin{array}{l}2.7 \\
2.5\end{array}$ & $\therefore$ & $\begin{array}{l}7.0 \\
7.2\end{array}$ & $\begin{array}{l}1.7 \\
1.9\end{array}$ & $\begin{array}{l}6 \\
4\end{array}$ & $\overline{0}$ & $\begin{array}{l}6.2 \\
6.4\end{array}$ \\
\hline $\begin{array}{l}13 \ldots . . \\
\text { SEP. }\end{array}$ & 165 & 29.5 & 90 & -- & 4.6 & 2.5 & - & 6.7 & 1.5 & 6 & 0 & 6.0 \\
\hline $24 \ldots$ & 30 & 28.0 & 94 & - & 4.3 & 2.6 & - & 7.1 & 1.5 & 4 & 0 & 5.7 \\
\hline
\end{tabular}


02273200 CANAL 41A AT S-68 AT LAKE ISTOKPOGA, NEAR LAKE PLACID, FLA.--Continued CHEMICAL ANALYSES, WATER YEAR OCTOBER 1969 TO SEPTEMBER 1970

\begin{tabular}{|c|c|c|c|c|c|c|c|c|c|c|c|c|}
\hline su & $\begin{array}{l}\text { DIS- } \\
\text { SOLVED } \\
\text { SULFATF- } \\
\text { (SO } 4) \\
\text { (MG/L) }\end{array}$ & $\begin{array}{l}\text { DIS- } \\
\text { SOLVED } \\
\text { CHLO- } \\
\text { RIDE } \\
\text { (CL) } \\
\text { (MG/L) }\end{array}$ & $\begin{array}{l}\text { OIS- } \\
\text { SOLVFD } \\
\text { FLUO- } \\
\text { RIDE } \\
\text { (F) } \\
\text { (MG/L) }\end{array}$ & $\begin{array}{l}\text { HARD- } \\
\text { NESS } \\
\text { (CA,MG) } \\
\text { (MG/L) }\end{array}$ & $\begin{array}{l}\text { NON- } \\
\text { CAR- } \\
\text { AONATE } \\
\text { HAPD- } \\
\text { NESS } \\
\text { (MG/L) }\end{array}$ & $\begin{array}{l}\text { ALKA- } \\
\text { LINITY } \\
\text { AS } \\
\text { CACO3 } \\
(M G / L)\end{array}$ & $\begin{array}{l}\text { DIS- } \\
\text { SOLVED } \\
\text { SOLIDS } \\
\text { (RESI- } \\
\text { OUE AT } \\
180 \text { C) } \\
\text { (MG/L) }\end{array}$ & $\begin{array}{l}\text { DIS- } \\
\text { SULVFO) } \\
\text { SOLIOS } \\
\text { (SUM OF } \\
\text { CONSTI- } \\
\text { TUENTS) } \\
\text { (MG/L) }\end{array}$ & $\begin{array}{l}\text { DIS- } \\
\text { SOLVED } \\
\text { SOLIDS } \\
\text { (TONS } \\
\text { PER } \\
\text { DAY) }\end{array}$ & $\begin{array}{l}\text { DIS- } \\
\text { SOLVE) } \\
\text { SOLINS } \\
\text { (TONS } \\
\text { PFR } \\
\text { AC-FT) }\end{array}$ & $\begin{array}{l}\text { TANNIN } \\
\text { AND } \\
\text { LIGNIN } \\
\text { (MG/L) }\end{array}$ & $\begin{array}{l}\text { DENTH } \\
\text { (FT) }\end{array}$ \\
\hline \multirow{3}{*}{$\begin{array}{l}\text { OCT.. } 1969 \\
16 \ldots \\
\text { OEC... } \\
\text { O2... } \\
\text { JAN.. } 1970 \\
22 \ldots . . \\
\text { MAR. }\end{array}$} & 9.2 & 7.5 & .2 & 15 & 10 & 5 & 60 & 30 & 116 & .08 & $m$ & -- \\
\hline & 2.4 & 8.8 & .2 & 16 & 11 & 5 & 55 & 29 & 47.5 & .07 & - & - \\
\hline & 4.4 & 9.5 & .1 & 17 & 12 & 5 & 55 & 30 & 23.8 & .07 & -- & - \\
\hline MAY 26 & 12 & 9.0 & .1 & 18 & 12 & 7 & 80 & 44 & 361 & .11 & -- & - \\
\hline JUNE & 14 & 11 & .2 & 21 & 17 & 4 & 79 & 44 & 41.6 & .11 & -- & -- \\
\hline $\begin{array}{l}19 \ldots . . \\
19 . \ldots \\
A U G .\end{array}$ & $\begin{array}{l}17 \\
15\end{array}$ & $\begin{array}{l}12 \\
12\end{array}$ & .12 & $\begin{array}{l}24 \\
23\end{array}$ & $\begin{array}{l}19 \\
19\end{array}$ & $\begin{array}{l}5 \\
3\end{array}$ & $\begin{array}{l}84 \\
67\end{array}$ & $\begin{array}{l}52 \\
46\end{array}$ & $\begin{array}{l}.00 \\
.00\end{array}$ & .111 & $=$ & $=$ \\
\hline SEP... & 15 & 14 & .2 & 22 & 17 & 5 & 78 & 50 & 34.7 & .11 & -- & - \\
\hline $24 \ldots$ & 16 & 12 & .2 & 21 & 18 & 3 & 71 & 51 & 5.75 & .10 & -- & - \\
\hline & & & & AACRONUTR & NTS AND & OTHER RE & TED CON & TI TUENTS : & & & & \\
\hline
\end{tabular}

\begin{tabular}{|c|c|c|c|c|c|c|c|c|c|c|c|c|}
\hline OATF & $\begin{array}{l}\text { TOTAL } \\
\text { AMMONTA } \\
\text { (Nint) } \\
\text { (MG/L) }\end{array}$ & 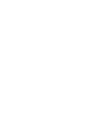 & 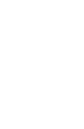 & $\begin{array}{l}\text { OHGANIC } \\
\text { NITRND- } \\
\text { GEN } \\
\text { (N) } \\
\text { (NG/L) }\end{array}$ & 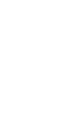 & $\begin{array}{l}\text { PHCS- } \\
\text { PHATE } \\
\text { PPO4) } \\
\text { (MGSL) }\end{array}$ & $\begin{array}{l}\text { DIS- } \\
\text { soLveg } \\
\text { SILICA } \\
\text { (S102) } \\
(M G / L)\end{array}$ & $\begin{array}{l}\text { TUR- } \\
\text { BIDD } \\
\text { ITY } \\
\text { (JTU) }\end{array}$ & $\begin{array}{l}\text { COLOR } \\
\text { PLLAT- } \\
\text { INUM- } \\
\text { COBALT } \\
\text { UNITS }\end{array}$ & $\begin{array}{c}\text { TNTAL } \\
\text { ORGANIC } \\
\text { CARRON } \\
\text { IC) } \\
\text { (MG }\end{array}$ & 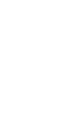 & $\begin{array}{c}\text { DEPTH } \\
(F T)\end{array}$ \\
\hline 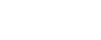 & 9 & & & & & & & & & (2) & & -- \\
\hline 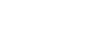 & -- & 然 & : & $=$ & .14 & .17 & 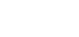 & -- & -. & -- & - & -- \\
\hline $\begin{array}{l}02 \ldots . . \\
31 \ldots\end{array}$ & $=$ & $\begin{array}{l}.01 \\
: 01\end{array}$ & $\begin{array}{l}.8 \\
.0\end{array}$ & $=$ &.$\ddot{06}$ &.$\overline{08}$ & 3.3 & $=$ & 100 & $=$ & $=$ & $\because$ \\
\hline 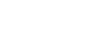 & $=$ & . & $: 0$ & $=$ &.$\overline{06}$ & - & 1.5 & $=$ & nn & $=$ & $=$ & -: \\
\hline FEH.: & & & & $\ldots$ & 09 & & & & & - & -9 & -. \\
\hline MAR:". & -- & .03 & ${ }^{\circ} 3$ & -- & .09 & . & 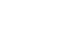 & -- & -- & $\cdots$ & -- & 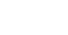 \\
\hline $\begin{array}{l}26 \ldots \\
31 \ldots .\end{array}$ & 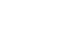 & $\begin{array}{l}.03 \\
.02\end{array}$ & : $: 2$ & $\because$ & $\ddot{0 B}$ &.$\overline{10}$ & 6.5 & $\ddot{z}$ & 100 & $\because$ & $\because$ & -- \\
\hline $30 . \cdots$ & -- & .04 &.$n$ & $\cdots$ & $.1 n$ & .18 & -- & -- & -- & -- & -- & -- \\
\hline $\begin{array}{l}13 . . . \\
31 \ldots\end{array}$ & .05 & : & $:_{5}^{0}$ & .70 & $\begin{array}{l}.08 \\
.06\end{array}$ & $\begin{array}{l}.12 \\
.08\end{array}$ & 1.3 & 10 & 120 & $\because$ & $=$ & -- \\
\hline JUNE & $\because$ & .00 & 1.3 & $\because$ & $=$ & $\because$ & 2.3 & $=$ & 70 & $\because-$ & $=$ & $=$ \\
\hline $\begin{array}{l}19 . \ldots \\
300 .\end{array}$ & $\because$ & $\begin{array}{l}.02 \\
.02\end{array}$ & $::_{0}^{4}$ & $=$ & .02 &.$\overline{09}$ & $\therefore$ & $=$ & 50 & $=$ & "- & $\because$ \\
\hline $31 \ldots$ & -- & .01 & .0 & -- & .02 & .09 & -- & -- & -- & -- & -- & -- \\
\hline AUG... & .07 & 2.4 & .5 & .34 & .08 & .17 & 2.4 & 5 & $5 n$ & -- & -- & $\cdots$ \\
\hline 24.... & .00 & .02 & .0 & .29 & .06 & .08 & 5.5 & 4 & 50 & -- & -- & -. \\
\hline
\end{tabular}

\begin{tabular}{|c|c|c|c|c|c|c|c|c|c|c|c|c|}
\hline DAY & OCT & Nov & $\begin{array}{l}\text { COLOR } \\
\text { OEC }\end{array}$ & $\begin{array}{l}\text { (UNITS), } \\
\text { JAN }\end{array}$ & $\begin{array}{l}\text { WATER YEAR } \\
\text { FEB }\end{array}$ & $\begin{array}{l}\text { OC TOBER } \\
\text { MAR }\end{array}$ & $\begin{array}{c}1969 \text { TO } \\
\text { APR }\end{array}$ & $\begin{array}{l}\text { SEPTEMBER } \\
\text { MAY }\end{array}$ & $\begin{array}{c}1970 \\
\text { JUN }\end{array}$ & JUL & AUG & SEP \\
\hline $\begin{array}{l}1 \\
2 \\
3 \\
4 \\
5\end{array}$ & $\begin{array}{l}73 \\
71 \\
69 \\
67 \\
68\end{array}$ & \begin{tabular}{l}
-- \\
$\cdots$ \\
$\because-$ \\
\hdashline
\end{tabular} & $\begin{array}{l}58 \\
59 \\
59 \\
60 \\
62\end{array}$ & $\begin{array}{l}65 \\
63 \\
63 \\
63 \\
62 \\
63\end{array}$ & $\begin{array}{l}68 \\
67 \\
68 \\
68 \\
68\end{array}$ & $\begin{array}{l}72 \\
72 \\
73 \\
74 \\
75\end{array}$ & $\begin{array}{l}78 \\
80 \\
79 \\
72 \\
77\end{array}$ & $\begin{array}{l}85 \\
82 \\
84 \\
82 \\
84\end{array}$ & $\begin{array}{l}89 \\
89 \\
76 \\
86 \\
87\end{array}$ & $\begin{array}{l}94 \\
93 \\
94 \\
94 \\
91 \\
95\end{array}$ & $\begin{array}{l}95 \\
89 \\
88 \\
87 \\
90\end{array}$ & 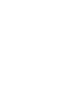 \\
\hline $\begin{array}{r}6 \\
7 \\
8 \\
9 \\
10\end{array}$ & $\begin{array}{l}67 \\
65 \\
64 \\
65 \\
64 \\
64\end{array}$ & $\begin{array}{l}--- \\
-- \\
-- \\
-\end{array}$ & $\begin{array}{l}59 \\
59 \\
59 \\
58 \\
50\end{array}$ & $\begin{array}{l}87 \\
66 \\
64 \\
69 \\
64\end{array}$ & $\begin{array}{l}70 \\
69 \\
70 \\
70 \\
71\end{array}$ & $\begin{array}{l}73 \\
72 \\
73 \\
74 \\
73\end{array}$ & $\begin{array}{l}76 \\
79 \\
78 \\
77 \\
75\end{array}$ & $\begin{array}{l}87 \\
90 \\
87 \\
92 \\
86\end{array}$ & $\begin{array}{l}92 \\
87 \\
90 \\
89 \\
98\end{array}$ & $\begin{array}{l}92 \\
91 \\
91 \\
92 \\
95\end{array}$ & $\begin{array}{l}91 \\
90 \\
88 \\
88 \\
86\end{array}$ & $\begin{array}{l}-- \\
\square \\
\because \because \\
-\end{array}$ \\
\hline $\begin{array}{l}11 \\
12 \\
13 \\
14 \\
15\end{array}$ & $\begin{array}{l}60 \\
60 \\
62 \\
60 \\
59\end{array}$ & \begin{tabular}{l}
- \\
\hdashline- \\
$-\cdots$
\end{tabular} & $\begin{array}{l}58 \\
60 \\
61 \\
60 \\
60\end{array}$ & $\begin{array}{l}65 \\
65 \\
66 \\
65 \\
63\end{array}$ & $\begin{array}{l}71 \\
71 \\
70 \\
70 \\
70\end{array}$ & $\begin{array}{l}75 \\
74 \\
72 \\
75 \\
76\end{array}$ & $\begin{array}{l}82 \\
80 \\
82 \\
79 \\
80\end{array}$ & $\begin{array}{l}86 \\
87 \\
87 \\
88 \\
89\end{array}$ & $\begin{array}{l}89 \\
92 \\
90 \\
88 \\
88\end{array}$ & $\begin{array}{l}93 \\
93 \\
89 \\
90 \\
90\end{array}$ & $\begin{array}{l}90 \\
87 \\
87 \\
88 \\
88\end{array}$ & $\begin{array}{l}--- \\
-\because- \\
-\cdots\end{array}$ \\
\hline $\begin{array}{l}16 \\
17 \\
18 \\
19 \\
20\end{array}$ & $\begin{array}{l}59 \\
50 \\
58 \\
56 \\
55\end{array}$ & \begin{tabular}{l}
.-- \\
\hdashline- \\
$-\cdots$ \\
--
\end{tabular} & $\begin{array}{l}64 \\
64 \\
62 \\
62 \\
62 \\
61\end{array}$ & $\begin{array}{l}64 \\
66 \\
64 \\
64 \\
64\end{array}$ & $\begin{array}{l}72 \\
72 \\
72 \\
71 \\
73\end{array}$ & $\begin{array}{l}75 \\
76 \\
75 \\
75 \\
78\end{array}$ & $\begin{array}{l}80 \\
80 \\
81 \\
80 \\
80\end{array}$ & $\begin{array}{l}89 \\
87 \\
87 \\
88 \\
88\end{array}$ & $\begin{array}{l}87 \\
89 \\
90 \\
89 \\
86\end{array}$ & $\begin{array}{l}97 \\
92 \\
95 \\
89 \\
89\end{array}$ & $\begin{array}{l}88 \\
89 \\
88 \\
89 \\
87\end{array}$ & $\begin{array}{l}\because- \\
\cdots \\
\cdots \\
-\cdots\end{array}$ \\
\hline $\begin{array}{l}21 \\
22 \\
23 \\
24 \\
25\end{array}$ & $\begin{array}{l}55 \\
55 \\
55 \\
55 \\
52\end{array}$ & $\begin{array}{l}- \\
\because- \\
\cdots \\
-\cdots\end{array}$ & $\begin{array}{l}60 \\
61 \\
63 \\
64 \\
62 \\
62\end{array}$ & $\begin{array}{l}65 \\
67 \\
67 \\
66 \\
66\end{array}$ & $\begin{array}{l}73 \\
71 \\
73 \\
73 \\
72 \\
73\end{array}$ & $\begin{array}{l}77 \\
75 \\
75 \\
73 \\
72\end{array}$ & $\begin{array}{l}82 \\
83 \\
82 \\
82 \\
82\end{array}$ & $\begin{array}{l}89 \\
89 \\
89 \\
85 \\
86\end{array}$ & $\begin{array}{l}89 \\
90 \\
92 \\
93 \\
92\end{array}$ & $\begin{array}{l}89 \\
87 \\
87 \\
86 \\
88\end{array}$ & $\begin{array}{l}86 \\
88 \\
89 \\
89 \\
91\end{array}$ & $\begin{array}{l}--- \\
\cdots \\
-\cdots\end{array}$ \\
\hline $\begin{array}{l}26 \\
27 \\
28 \\
29 \\
30 \\
31\end{array}$ & $\begin{array}{l}52 \\
54 \\
54 \\
52 \\
53 \\
51\end{array}$ & 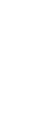 & $\begin{array}{l}63 \\
64 \\
61 \\
61 \\
61 \\
62\end{array}$ & $\begin{array}{l}65 \\
67 \\
67 \\
66 \\
67 \\
72\end{array}$ & $\begin{array}{r}72 \\
72 \\
73 \\
7- \\
\hdashline- \\
\hdashline-\end{array}$ & $\begin{array}{l}71 \\
72 \\
73 \\
74 \\
73 \\
72\end{array}$ & $\begin{array}{r}83 \\
85 \\
85 \\
80 \\
86 \\
-8\end{array}$ & $\begin{array}{l}87 \\
87 \\
87 \\
88 \\
88 \\
87\end{array}$ & $\begin{array}{r}90 \\
93 \\
90 \\
94 \\
90 \\
-90\end{array}$ & $\begin{array}{l}85 \\
86 \\
85 \\
88 \\
87 \\
90\end{array}$ & $\begin{array}{l}89 \\
90 \\
89 \\
87 \\
88 \\
87\end{array}$ & 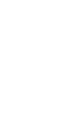 \\
\hline ERAGE & 80 & -- & 61 & 05 & 11 & 74 & 80 & 87 & 89 & 90 & 89 & --- \\
\hline
\end{tabular}


02274500 TAYLOR CREEK ABOVE OKEECHOBEE, FLA.--CONTINUed

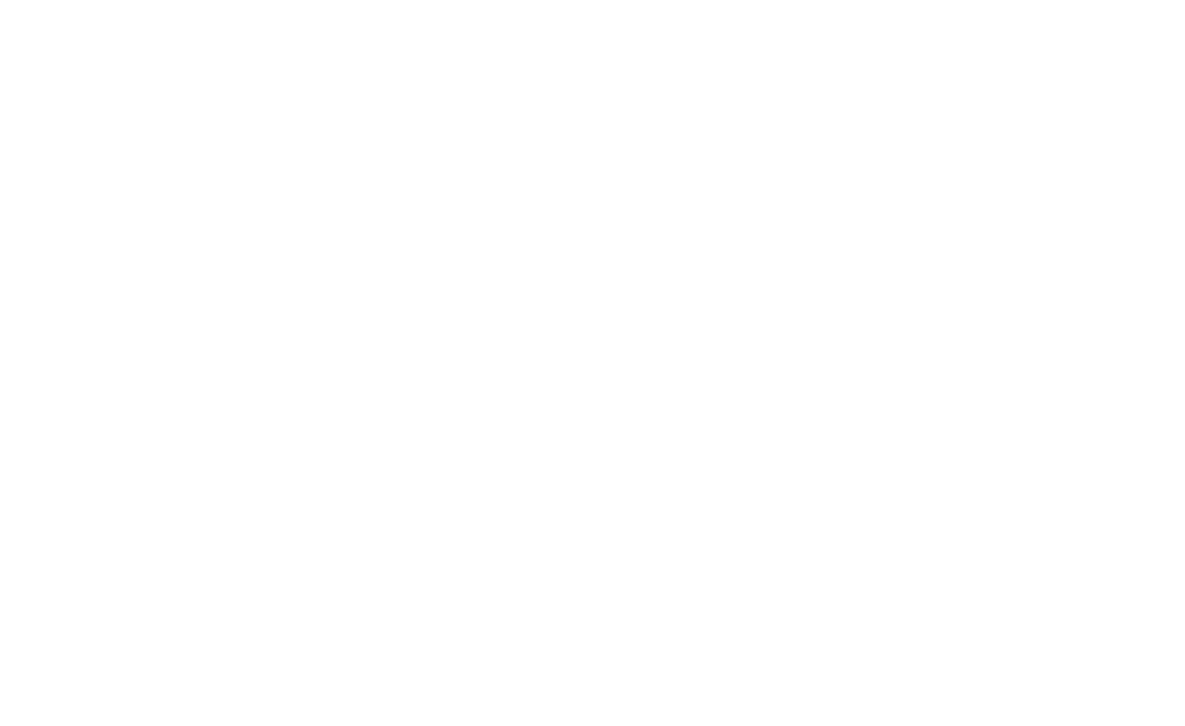

02274500 TAYLOR CREEK ABOVE OKEECHOBEE, FLA.

LOCATION,--Lat $27^{\circ} 17^{\prime} 03^{\prime \prime}$, long $80^{\circ} 49^{\prime} 20^{\prime \prime}$, In NWt sec.3, T.37 S, , R.35 E., Okeechobee County, at gaging station near center of channel, on downstream side of county bridge, 0.8 mile downstream from small tributary canal, 2.8 miles north of okeechobee, and 7.6 miles upstream from mouth.

DRAINAGE AREA, --98.7 sq $\mathrm{m} 1$.

PERIOD OF RECORD.--Chemical analyses: July 1964 to September 1970

Water temperatures: July 1964 to September 1970.

EXTREMES. - 1969-70:

Speciflc conductance: Maximum da1ly, 2,990 micromhos May 11; minimum da1ly, 84 micromhos Oct. 3

Water temperatures: Maximum, $32.0^{\circ} \mathrm{C}$ June $20 ;$ minimum, $8.0^{\circ} \mathrm{C}$ Jan. 10.

Period of record:

Specific conductance: Maximum da1ly, 3,200 micromhos Feb. 12, 1968; minimum daily, 83 micromhos Aug. 11, 1969, Water temperatures: Maximum, $34.0^{\circ} \mathrm{C}$ July 12,1964 , Aug. 1,1967 ; minimum, $8.0^{\circ} \mathrm{C}$ Jan. 10,1970

\begin{tabular}{|c|c|c|c|c|c|c|c|c|c|c|c|c|}
\hline & & & CHEMICAL & L ANALYSE & $\begin{array}{l}\text { - WATER } \\
\text { CMAJO }\end{array}$ & $\begin{array}{l}\text { EAR OCTO } \\
\text { CONSTIT }\end{array}$ & $\begin{array}{l}\text { ER } 1969 \\
\text { ENTS? }\end{array}$ & TO SEPTE & IER 1970 & & & \\
\hline DATE & $\begin{array}{l}\text { DIS- } \\
\text { CHARGE } \\
\text { (CFS) }\end{array}$ & $\begin{array}{l}\text { TEMPER- } \\
\text { ATURE } \\
\text { (OEG C) }\end{array}$ & $\begin{array}{l}\text { SPE- } \\
\text { CIFIC } \\
\text { CON- } \\
\text { DUCT- } \\
\text { ANCE } \\
\text { (MICRO- } \\
\text { MHOS) }\end{array}$ & $\begin{array}{l}\text { DIS- } \\
\text { SOLVED } \\
\text { IRON } \\
\text { (FE) } \\
\text { (UG/L) }\end{array}$ & $\begin{array}{l}\text { UIS- } \\
\text { SOLVED } \\
\text { CAL- } \\
\text { CIUM } \\
\text { (CA) } \\
\text { (MG/L) }\end{array}$ & $\begin{array}{l}\text { DIS- } \\
\text { SOLVED } \\
\text { MAG- } \\
\text { NE- } \\
\text { SIUM } \\
\text { (MG) } \\
\text { (MG/L) }\end{array}$ & $\begin{array}{l}\text { DIS- } \\
\text { SOLVED } \\
\text { STRON- } \\
\text { TIUM } \\
\text { (SR) } \\
\text { (UGA) }\end{array}$ & $\begin{array}{l}\text { DIS- } \\
\text { SOLVEO } \\
\text { SODIUY } \\
\text { (NA) } \\
\text { (MG/L) }\end{array}$ & $\begin{array}{l}\text { DIS- } \\
\text { SOLVED } \\
\text { PO- } \\
\text { TAS- } \\
\text { SIIMM } \\
\text { (K) } \\
\text { (MG/L) }\end{array}$ & $\begin{array}{l}\text { BICAR- } \\
\text { BחNATE } \\
\text { (HCO3) } \\
\text { (MG/L) }\end{array}$ & $\begin{array}{l}\text { CAR- } \\
\text { BON2TE } \\
\text { (CO3) } \\
\text { (MG/L) }\end{array}$ & $\begin{array}{c}\text { PH } \\
\text { (UNITS) }\end{array}$ \\
\hline $\begin{array}{l}\text { NOV., } \\
\text { O4... } \\
\text { JAN.: }\end{array}$ & $\begin{array}{c}969 \\
291 \\
970\end{array}$ & 23.0 & 210 & -- & 16 & 3.4 & -- & 18 & 3.9 & 40 & - & 7.0 \\
\hline & 353 & 9.0 & 190 & -- & 13 & 3.0 & - & 17 & 3.5 & 28 & $=$ & 0.4 \\
\hline MAY 03 & 25 & 20.0 & 1200 & - & 66 & 23 & $=$ & 132 & 7.0 & 120 & 0 & 6.9 \\
\hline JUNE... & 10 & 28.0 & 1600 & 40 & 88 & 31 & 7600 & 184 & 8.8 & 164 & 0 & 8.2 \\
\hline $30 \ldots$ & 171 & - & 452 & $\cdots$ & 33 & 7.7 & $m$ & 41 & 3.5 & 72 & $n$ & 7.7 \\
\hline & $\begin{array}{l}\text { DIS- } \\
\text { SOLVED } \\
\text { SULFATE } \\
\text { (\$O } 4 \text { ) } \\
\text { (MG/L) }\end{array}$ & $\begin{array}{l}\text { DIS- } \\
\text { SOLVED } \\
\text { CHLO- } \\
\text { RIDE } \\
\text { (CL) } \\
(M G / L)\end{array}$ & $\begin{array}{l}\text { DIS- } \\
\text { SOLVFD } \\
\text { FL, IO) } \\
\text { RIDE } \\
(F) \\
(M G / L)\end{array}$ & $\begin{array}{l}\text { HARD- } \\
\text { NESS } \\
\text { (CA,MG) } \\
\text { (MG/L) }\end{array}$ & $\begin{array}{l}\text { NON- } \\
\text { CAR- } \\
\text { RONATE } \\
\text { HARO- } \\
\text { NESS } \\
\text { (MG/L) }\end{array}$ & $\begin{array}{l}\text { ALKA- } \\
\text { LINITY } \\
\text { AS } \\
\text { CACO3 } \\
\text { (MG/L) }\end{array}$ & $\begin{array}{l}\text { DIS- } \\
\text { SOL VEO } \\
\text { SOLIDS } \\
\text { (RESI- } \\
\text { DUE AT } \\
\text { I } 80 \text { C) } \\
\text { (MG L) }\end{array}$ & $\begin{array}{l}\text { DIS- } \\
\text { SULVED } \\
\text { SOL IOS } \\
\text { (SUM OF } \\
\text { CONSTI- } \\
\text { TUENTS) } \\
\text { (MG/L) }\end{array}$ & $\begin{array}{l}\text { DIS- } \\
\text { SOLVED } \\
\text { SOLINS } \\
\text { (TDNS } \\
\text { PER } \\
\text { DAY) }\end{array}$ & $\begin{array}{l}\text { DIS- } \\
\text { SOLVFD } \\
\text { SOL IOS } \\
\text { (TONS } \\
\text { PER } \\
\text { AC-FT) }\end{array}$ & $\begin{array}{l}\text { TANININ } \\
\text { AND } \\
\text { LIGNIN } \\
\text { (MG/L) }\end{array}$ & $\begin{array}{c}D E-2 T H \\
(F T)\end{array}$ \\
\hline
\end{tabular}

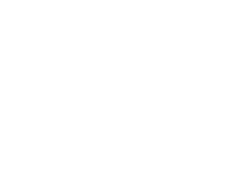

$\begin{array}{rrrr}.2 & 54 & 21 & 33 \\ .2 & 45 & 22 & 23 \\ .4 & 259 & 161 & 98 \\ .4 & 356 & 221 & 135 \\ .4 & 114 & 55 & 59\end{array}$

$\begin{array}{ccc}151 & 114 & 119 \\ 138 & 99 & 132 \\ 743 & 644 & 51.8 \\ 903 & 862 & 24.4 \\ 303 & 247 & 140\end{array}$

$\begin{array}{rrr}.21 & -- & - \\ .19 & - & - \\ 1.01 & -- & - \\ 1.23 & -- & - \\ .41 & -- & -\end{array}$


LAKE OKEECHOBEE AND THE EVERGLADES BASINS

02274500 TAYLOR CREEK ABOVE OKEECHOBEE, FLA.--ContInued

CHEMICAL ANALYSES, MATER YEAR OCTOBER 1969 10 SEPTEMBER 1970
(MACRONUTRIENTS AND OTHER RELATED CONSTI I TUENTS)

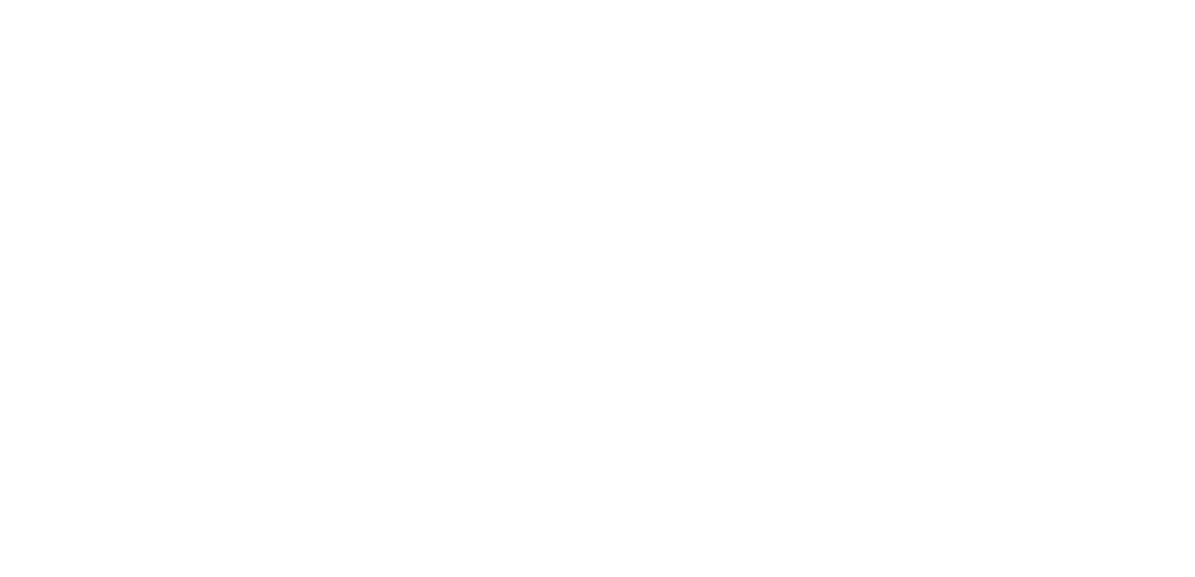

SPECIFIC CONDUCTANCE (MICROMHOS/CM AT $25^{\circ} \mathrm{C}$ ). WATER YEAR OCTOBER 1969 TO SEPTEMBER 1970

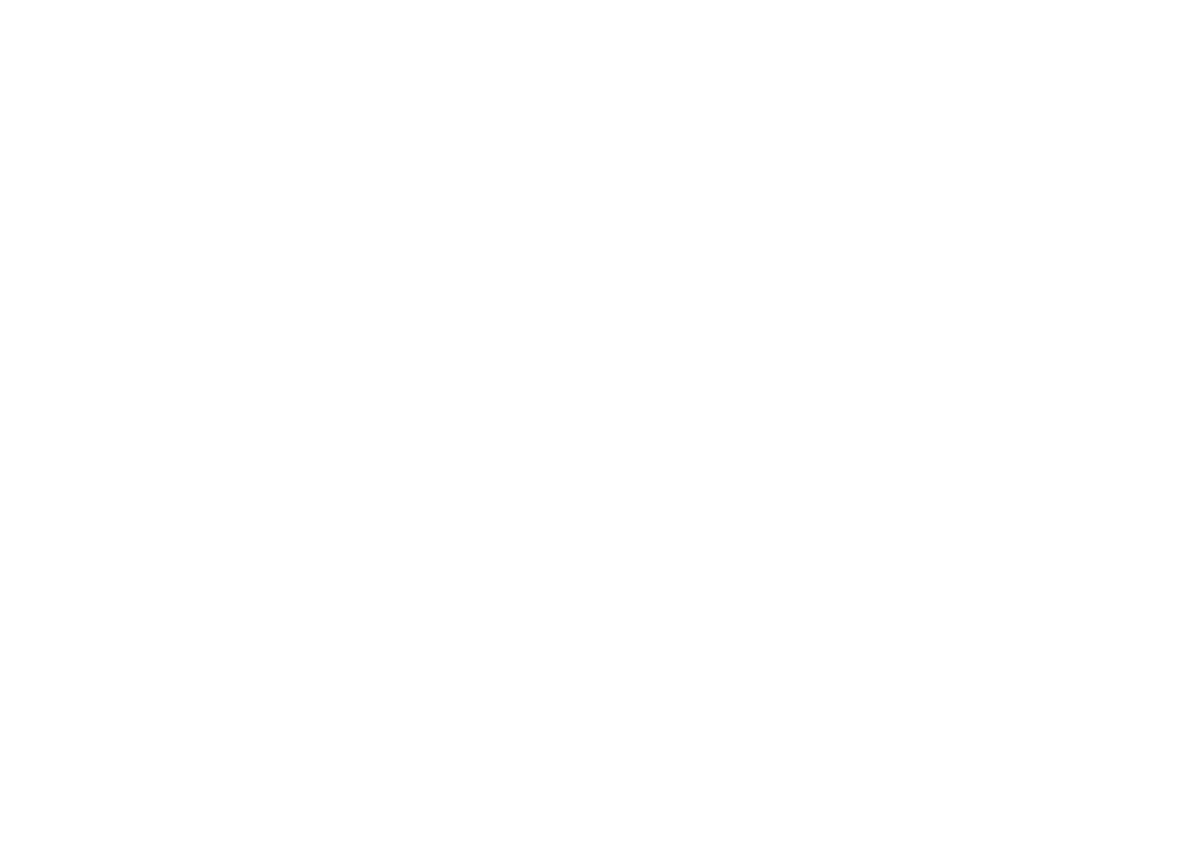

MAY, 1970

05.0

20

$40 \quad 10$

70 
02274500 TAYLOR CREEK ABOVE OKEECHOBEE, PLA.--Continued

TEMPERATURE ('०) DF HATER, HATER YEAR OCTOBER 1969 TO SEPTEMBER 1970

\begin{tabular}{|c|c|c|c|c|c|c|c|c|c|c|c|c|}
\hline DAY & $\mathrm{OCT}$ & NOV & OEC & JAN & FEB & MAR & $A P R$ & MAY & JUN & JUL & AUG & SEP \\
\hline $\begin{array}{l}1 \\
2 \\
3 \\
4 \\
5\end{array}$ & $\begin{array}{l}28.0 \\
28.0 \\
27.0 \\
29.0 \\
27.0\end{array}$ & $\begin{array}{l}23.0 \\
23.0 \\
23.5 \\
22.5 \\
19.5\end{array}$ & $\begin{array}{l}16.0 \\
16.0 \\
16.5 \\
16.5 \\
15.0\end{array}$ & $\begin{array}{l}19.0 \\
19.5 \\
15.0 \\
14.0 \\
14.0\end{array}$ & $\begin{array}{l}17.0 \\
18.5 \\
19.0 \\
12.0 \\
11.0\end{array}$ & $\begin{array}{l}18.0 \\
20.0 \\
18.0 \\
19.0 \\
20.0\end{array}$ & $\begin{array}{l}26.0 \\
27.0 \\
25.0 \\
25.0 \\
27.0\end{array}$ & $\begin{array}{l}28.0 \\
27.0 \\
27.0 \\
27.0 \\
27.0\end{array}$ & $\begin{array}{r}27.0 \\
26.5 \\
27.0 \\
27.0\end{array}$ & $\begin{array}{l}28.0 \\
28.5 \\
31.5 \\
30.5 \\
28.0\end{array}$ & $\begin{array}{r}29.5 \\
30.0 \\
0.0\end{array}$ & $\overrightarrow{=}$ \\
\hline $\begin{array}{r}6 \\
7 \\
8 \\
9 \\
10\end{array}$ & $\begin{array}{l}28.0 \\
26.0 \\
26.0 \\
27.0 \\
26.0\end{array}$ & $\begin{array}{l}18.0 \\
17.0 \\
18.0 \\
19.0 \\
20.0\end{array}$ & $\begin{array}{l}16.0 \\
17.5 \\
19.0 \\
19.0 \\
20.0\end{array}$ & $\begin{array}{r}14.0 \\
13.0 \\
9.0 \\
11.0 \\
8.0\end{array}$ & $\begin{array}{l}13.0 \\
15.0 \\
18.0 \\
17.5 \\
17.0\end{array}$ & $\begin{array}{l}22.0 \\
21.0 \\
21.0 \\
19.0 \\
21.0\end{array}$ & $\begin{array}{l}26.0 \\
25.0 \\
24.0 \\
24.0 \\
23.0\end{array}$ & $\begin{array}{l}28.0 \\
27.0 \\
26.0 \\
27.0 \\
26.5\end{array}$ & $\begin{array}{l}27.0 \\
27.5 \\
26.0 \\
28.0 \\
29.5\end{array}$ & $\begin{array}{l}27.0 \\
27.5 \\
26.5 \\
29.0 \\
30.0\end{array}$ & $\begin{array}{r}-10 \\
22.0 \\
27.0 \\
26.5\end{array}$ & $\begin{array}{l}-- \\
-- \\
--\end{array}$ \\
\hline $\begin{array}{l}11 \\
12 \\
13 \\
14 \\
15\end{array}$ & 28.0 & $\begin{array}{l}20.5 \\
20.5 \\
22.0 \\
20.0 \\
14.5\end{array}$ & $\begin{array}{r}20.0 \\
17.0 \\
17.0 \\
15.0\end{array}$ & $\begin{array}{r}9.0 \\
10.0 \\
15.0 \\
16.5 \\
18.0\end{array}$ & $\begin{array}{l}15.5 \\
16.0 \\
16.0 \\
17.0 \\
20.0\end{array}$ & $\begin{array}{l}21.0 \\
20.0 \\
19.5 \\
16.5 \\
17.0\end{array}$ & $\begin{array}{l}27.0 \\
24.0 \\
24.0 \\
26.5 \\
21.0\end{array}$ & $\begin{array}{l}26.5 \\
27.0 \\
27.0 \\
27.0 \\
27.0\end{array}$ & $\begin{array}{l}29.5 \\
26.0 \\
29.0 \\
30.0 \\
29.0\end{array}$ & $\begin{array}{l}30.0 \\
29.0 \\
27.5 \\
31.5 \\
31.5\end{array}$ & $\begin{array}{l}28.0 \\
27.0 \\
30.0 \\
28.5 \\
31.0\end{array}$ & 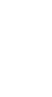 \\
\hline $\begin{array}{l}16 \\
17 \\
18 \\
19 \\
20\end{array}$ & $\begin{array}{r}\cdots \\
26.0 \\
26.0\end{array}$ & $\begin{array}{l}15.0 \\
17.5 \\
20.0 \\
21.0 \\
20.0\end{array}$ & $\begin{array}{l}16.0 \\
16.0 \\
17.0 \\
18.0 \\
20.0\end{array}$ & $\begin{array}{l}17.0 \\
19.0 \\
19.0 \\
18.0 \\
18.5\end{array}$ & $\begin{array}{r}21.5 \\
21.0 \\
20.0 \\
19.0\end{array}$ & $\begin{array}{l}16.0 \\
18.0 \\
19.0 \\
19.0 \\
18.0\end{array}$ & $\begin{array}{r}25.0 \\
27.0 \\
25.0 \\
27.0\end{array}$ & $\begin{array}{l}27.0 \\
25.0 \\
26.0 \\
20.0 \\
28.0\end{array}$ & $\begin{array}{l}29.0 \\
29.0 \\
29.5 \\
21.0 \\
32.0\end{array}$ & $\begin{array}{l}28.5 \\
30.0 \\
29.5 \\
31.0 \\
30.0\end{array}$ & $\begin{array}{l}31.0 \\
28.5 \\
29.5 \\
30.0 \\
30.5\end{array}$ & $\begin{array}{l}\because- \\
\because \therefore \\
\because-\end{array}$ \\
\hline $\begin{array}{l}21 \\
22 \\
23 \\
24 \\
25\end{array}$ & $\begin{array}{l}27.0 \\
26.0 \\
26.0 \\
24.0 \\
23.0\end{array}$ & $\begin{array}{l}19.0 \\
18.0 \\
18.0 \\
19.5 \\
20.0\end{array}$ & $\begin{array}{l}23.0 \\
18.0 \\
17.0 \\
18.0 \\
18.0\end{array}$ & $\begin{array}{l}17.0 \\
19.0 \\
16.0 \\
16.5 \\
17.0\end{array}$ & $\begin{array}{l}17.0 \\
18.0 \\
19.0 \\
20.0 \\
17.0\end{array}$ & $\begin{array}{l}21.0 \\
21.0 \\
19.0 \\
22.0 \\
20.0\end{array}$ & $\begin{array}{l}29.0 \\
25.0 \\
27.0 \\
26.0 \\
24.0\end{array}$ & $\begin{array}{l}28.5 \\
28.0 \\
27.0 \\
27.0 \\
24.0\end{array}$ & $\begin{array}{l}30.0 \\
31.0 \\
30.0 \\
29.5 \\
27.5\end{array}$ & $\begin{array}{l}32.0 \\
27.0 \\
26.5 \\
26.5 \\
30.0\end{array}$ & $\begin{array}{r}26.5 \\
=-0 \\
0 .\end{array}$ & $\begin{array}{l}29.0 \\
29.0 \\
29.0 \\
28.0 \\
28.0\end{array}$ \\
\hline $\begin{array}{l}26 \\
27 \\
28 \\
29 \\
30 \\
31\end{array}$ & $\begin{array}{l}23.0 \\
24.0 \\
24.0 \\
24.0 \\
22.0 \\
23.0\end{array}$ & $\begin{array}{l}20.5 \\
19.0 \\
21.0 \\
20.0 \\
17.0 \\
\end{array}$ & $\begin{array}{l}16.0 \\
18.0 \\
15.0 \\
18.0 \\
17.0 \\
20.0\end{array}$ & $\begin{array}{l}18.0 \\
17.0 \\
20.5 \\
20.0 \\
19.0 \\
19.0\end{array}$ & $\begin{array}{r}17.5 \\
17.0 \\
18.5 \\
- \\
- \\
-\end{array}$ & $\begin{array}{r}19.5 \\
19.0 \\
-0.0 \\
28.0 \\
27.0 \\
26.5\end{array}$ & $\begin{array}{l}26.0 \\
26.0 \\
28.0 \\
27.0 \\
28.0 \\
\end{array}$ & $\begin{array}{l}=- \\
=- \\
\square- \\
-- \\
-\end{array}$ & $\begin{array}{r}28.0 \\
29.0 \\
31.0 \\
30.0 \\
28.0 \\
\ldots-0\end{array}$ & $\begin{array}{l}30.0 \\
30.0 \\
29.0 \\
28.0 \\
28.5 \\
30.0\end{array}$ & $\begin{array}{l}=- \\
-\cdots \\
--\end{array}$ & $\begin{array}{r}29.0 \\
30.0 \\
28.0 \\
27.0 \\
-\end{array}$ \\
\hline VERAGE & $-\ldots$ & 19.5 & 17.5 & 16.0 & 17.5 & 20.0 & 25.5 & 26.5 & 28.5 & 29.0 & - & $-\infty$ \\
\hline
\end{tabular}

02276416 LAKE OKEECHOBEE AT PAHOKEE, FLA.

(Formerly published as 02277901 Lake Okeechobee at Canai point, Fla.)

LOCATION,--Lat $26^{\circ} 49^{\prime} 30^{\prime \prime}$, long $80^{\circ} 53^{\prime} 23^{\prime \prime}$, Palm Beach County, on southeast side of lake at end of fishing pier 600 ft from shore in pahokee, Fla.

DRAINAGE AREA. $--5,650 \mathrm{sq} \mathrm{mi}$.

PERIOD OF RECORD. - Chemical analyses: September 1963 to September 1967, January 1969 to September 1970.

Water temperatures: September 1963 to September 1987, January 1969 to January 1970 (Discontinued).

EXTREKES. - - October 1969 to January 1970:

Specific conductance: Maximum dally, 800 micromhos Dec, 2 ; minimum dally, 460 micromhos Jan. 19.

Water temperatures: Maximum, $29.0^{\circ} \mathrm{C}$ Oct, 4,22 ; minimum, $9.0^{\circ} \mathrm{C}$ Jan, 11

period of record:

Specific conductance: Maximum daily, 1,080 micromhos Mar. 12, 1969; minimum daily, 425 micromhos Aug. $15,1969$.

Vater temperatures: Maximum, $31.0^{\circ} \mathrm{C}$ July $6,10,1969$; minimum, $9.0^{\circ} \mathrm{C}$ Jan, 11,1970

Turbidity (October 1969 to January 1970): Maximum daily, 60 JTU Nov. 5, ig69; minimum daily, 5 JTU Oct. $23,1969$.

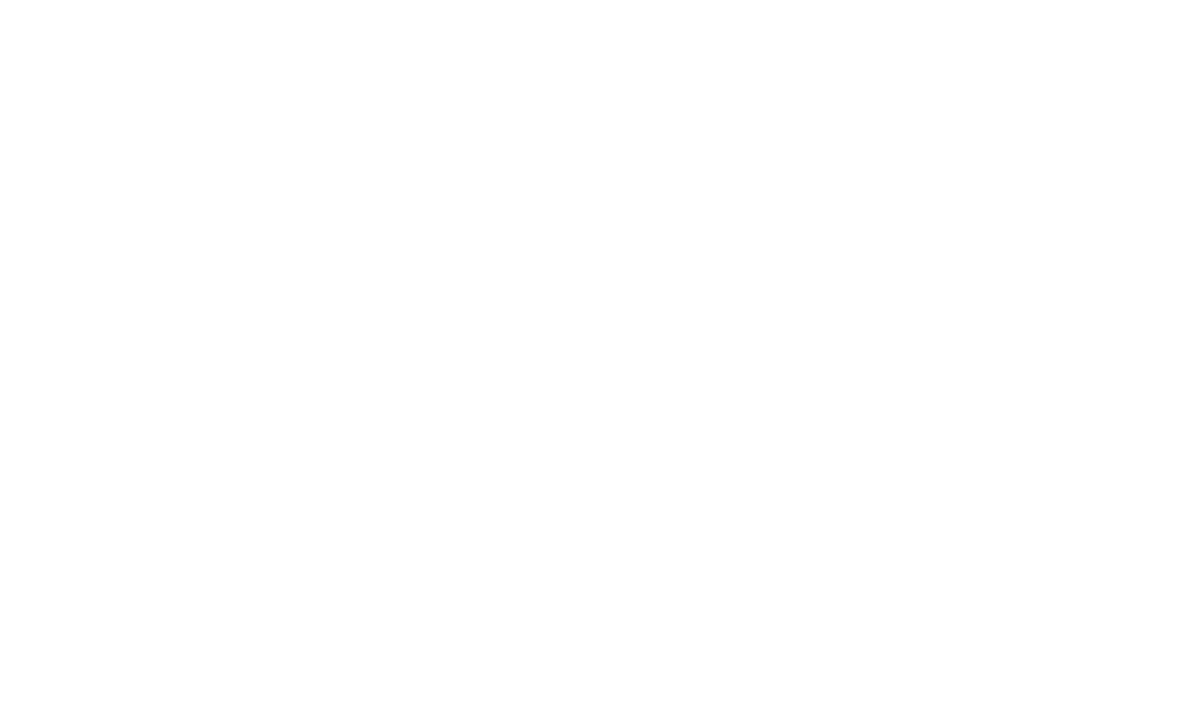


02276416 LAKE OKEECHOBEE AT PAHOKEE, FLA.--Cont1 nued

(MACRONUTRIENTS AND OTHER RELATED CONSTITUENTS)

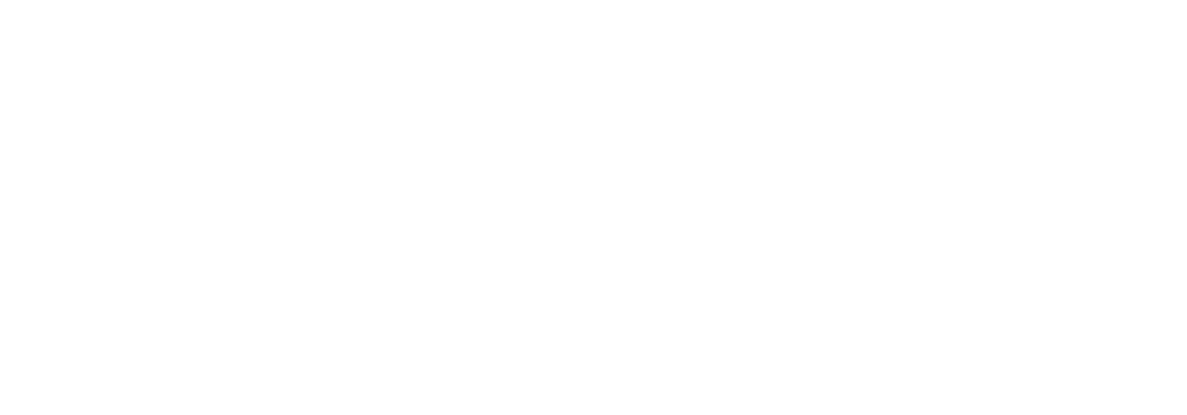

SPECIFIC CONDUCTANCE (MICROMHOS/CM AT $25^{\circ} \mathrm{C}$ ), OCTOBER 1969 TO JANUARY 1970

\begin{tabular}{|c|c|c|c|c|c|c|c|c|c|c|c|c|c|c|}
\hline DAY & OCT & NOV & DEC & JAN & DAY & OCT & Nov & DEC & JAN & DAY & $O C_{T}$ & NOV & DEC & JAN \\
\hline $\begin{array}{l}1 \\
2\end{array}$ & $\begin{array}{l}725 \\
600\end{array}$ & $\begin{array}{l}615 \\
560\end{array}$ & $\begin{array}{l}775 \\
800\end{array}$ & $\begin{array}{l}550 \\
540\end{array}$ & $\begin{array}{l}12 \\
13\end{array}$ & $\begin{array}{l}750 \\
725\end{array}$ & $\begin{array}{l}630 \\
615\end{array}$ & $\begin{array}{l}590 \\
600\end{array}$ & $\begin{array}{l}500 \\
500\end{array}$ & $\begin{array}{l}23 \\
24\end{array}$ & $\overline{560}$ & $\begin{array}{l}685 \\
665\end{array}$ & $\begin{array}{l}610 \\
600\end{array}$ & $\begin{array}{l}600 \\
540\end{array}$ \\
\hline 3 & 560 & 620 & 640 & 510 & 14 & 700 & 600 & 625 & 475 & 25 & 600 & 670 & 575 & -2 \\
\hline 4 & 485 & 660 & 640 & 525 & 15 & 690 & 590 & 560 & 495 & 26 & 560 & 630 & 540 & 590 \\
\hline 5 & 480 & 730 & 590 & 645 & 16 & 650 & 665 & 650 & 498 & 27 & 550 & 660 & 560 & 565 \\
\hline 6 & 540 & 665 & 640 & 680 & 17 & 650 & 650 & 650 & 490 & 28 & $-m$ & 640 & 590 & 580 \\
\hline 7 & 600 & 630 & 640 & 750 & 18 & 640 & 620 & 630 & 485 & 29 & 710 & 600 & 560 & 510 \\
\hline 8 & 625 & 635 & 650 & 590 & 19 & 610 & 620 & 610 & 460 & 30 & 650 & -- & 560 & 480 \\
\hline 9 & 715 & 620 & 550 & 550 & 20 & 710 & 675 & 610 & 550 & 31 & 710 & -- & 550 & 550 \\
\hline 10 & 640 & 610 & 575 & 540 & 21 & 610 & 750 & 625 & 550 & & & & & \\
\hline 11 & 690 & 625 & 565 & 510 & 22 & - & 685 & 575 & 540 & AVG & 633 & 642 & 611 & 545 \\
\hline
\end{tabular}

TURBIDITY, IN JACKSON TURBIDITY UNITS, OCTOBER 1969 TO JANUARY 1970

\begin{tabular}{|c|c|c|c|c|c|c|c|c|c|c|c|c|c|c|}
\hline DAY & OCT & NOV & DEC & JAN & DAY & OCT & NOV & DEC & JAN & DAY & OCT & NOV & DEC & JAN \\
\hline 1 & 35 & 20 & 25 & 10 & 12 & 20 & 15 & 20 & 15 & 23 & 5 & 15 & 10 & 15 \\
\hline$\frac{1}{2}$ & 25 & 20 & 30 & 15 & 13 & 20 & 15 & 35 & 15 & 24 & 6 & 10 & 15 & 20 \\
\hline 3 & 25 & 30 & 15 & 15 & 14 & 20 & 50 & 30 & 10 & 25 & 6 & 10 & 15 & - \\
\hline 4 & 15 & 30 & 15 & 25 & 15 & 20 & 35 & 6 & 10 & 26 & 6 & 15 & 15 & 15 \\
\hline 5 & 15 & 60 & 15 & 20 & 16 & 15 & 20 & 15 & 10 & 27 & 6 & 20 & 20 & 15 \\
\hline 6 & 20 & 50 & 15 & 15 & $\begin{array}{l}10 \\
17\end{array}$ & 15 & 20 & 15 & 15 & 28 & 6 & 9 & 20 & 15 \\
\hline 7 & 20 & 40 & 15 & 35 & 18 & 20 & 30 & 20 & 20 & 29 & 15 & 10 & 15 & 10 \\
\hline 8 & 20 & 35 & 15 & 30 & 19 & 15 & 20 & 15 & 15 & 30 & 10 & 20 & 10 & 15 \\
\hline 9 & 25 & 30 & 15 & 30 & 20 & 15 & 35 & 15 & 20 & 31 & 10 & - & 10 & 35 \\
\hline 10 & 25 & 25 & 15 & 30 & 21 & 7 & 40 & 15 & 20 & & & & & \\
\hline 11 & 20 & $\begin{array}{l}25 \\
25\end{array}$ & $\begin{array}{l}13 \\
15\end{array}$ & 15 & 22 & 10 & 10 & 15 & 20 & AVG & 15 & 25 & 15 & 20 \\
\hline
\end{tabular}

(TRACE METALS)

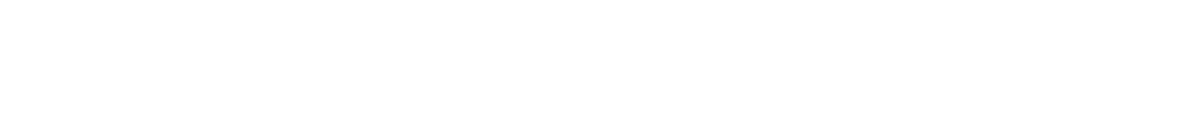
02276416 - LAKE OKEECMOHEE AT PAHOKFE FLA (LAT 264930 LONG OBO 40 05)

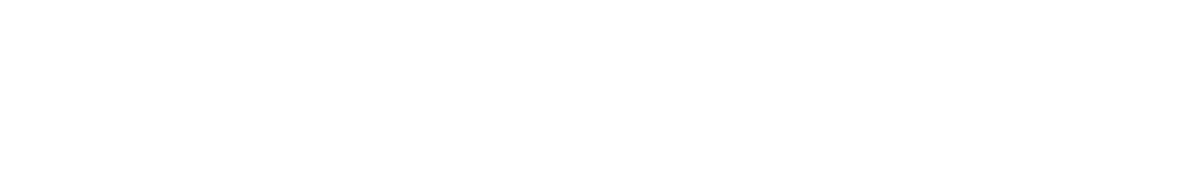

TEMPERATURE ('OC) OF WATER, OCTOBER 1969 TO JANUARY 1970

\begin{tabular}{|c|c|c|c|c|c|c|c|c|c|c|c|c|c|c|}
\hline DAY & $\mathrm{OCT}$ & NOV & DEC & JAN & DAY & OCT & NOV & DEC & SAN & DAY & OCT & NOV & DEC & JAN \\
\hline $\begin{array}{r}1 \\
2 \\
3 \\
4 \\
5 \\
6 \\
7 \\
8 \\
9 \\
10 \\
11\end{array}$ & $\begin{array}{l}28.0 \\
28.0 \\
27.0 \\
29.0 \\
28.0 \\
27.0 \\
27.0 \\
27.0 \\
27.0 \\
27.0 \\
26.0\end{array}$ & $\begin{array}{l}25.0 \\
25.0 \\
25.0 \\
25.0 \\
21.0 \\
20.0 \\
20.0 \\
21.0 \\
20.0 \\
21.0 \\
20.0\end{array}$ & $\begin{array}{l}19.0 \\
19.0 \\
18.0 \\
18.0 \\
17.0 \\
18.0 \\
19.0 \\
19.0 \\
20.0 \\
20.0 \\
20.0\end{array}$ & $\begin{array}{r}19.0 \\
19.0 \\
20.0 \\
17.0 \\
16.0 \\
18.0 \\
16.0 \\
13.0 \\
12.0 \\
10.0 \\
9.0\end{array}$ & $\begin{array}{l}12 \\
13 \\
14 \\
15 \\
16 \\
17 \\
18 \\
19 \\
20 \\
21 \\
22\end{array}$ & $\begin{array}{r}27.0 \\
27.0 \\
26.0 \\
27.0 \\
28.0 \\
28.0 \\
27.0 \\
25.0 \\
28.0 \\
29.0\end{array}$ & $\begin{array}{l}21.0 \\
22.0 \\
22.0 \\
19.0 \\
19.0 \\
19.0 \\
19.0 \\
20.0 \\
20.0 \\
18.0 \\
19.0\end{array}$ & $\begin{array}{l}19.0 \\
17.0 \\
16.0 \\
16.0 \\
18.0 \\
18.0 \\
18.0 \\
18.0 \\
19.0 \\
19.0\end{array}$ & $\begin{array}{l}10.0 \\
12.0 \\
12.0 \\
14.0 \\
13.0 \\
15.0 \\
15.0 \\
17.0 \\
16.0 \\
17.0\end{array}$ & $\begin{array}{l}23 \\
24 \\
25 \\
26 \\
27 \\
28 \\
29 \\
30 \\
31\end{array}$ & $\begin{array}{l}28.0 \\
24.0 \\
28.0 \\
26.0 \\
25.0 \\
26.0 \\
26.0 \\
25.0 \\
25.0\end{array}$ & $\begin{array}{l}19.0 \\
19.0 \\
20.0 \\
19.0 \\
20.0 \\
21.0 \\
21.0 \\
20.0\end{array}$ & $\begin{array}{l}18.0 \\
18.0 \\
19.0 \\
18.0 \\
16.0 \\
17.0 \\
18.0 \\
19.0 \\
19.0\end{array}$ & $\begin{array}{r}16.0 \\
16.0 \\
18.0 \\
18.0 \\
19.0 \\
19.0 \\
19.0 \\
18.0\end{array}$ \\
\hline
\end{tabular}


LOCATION,.-.Lat $27^{\circ} 06^{\prime} 39^{\prime \prime}$, long $80^{\circ} 17^{\prime} 06^{\prime \prime}$, 1n Hanson Grant, T.39 S., R.41 E., Martin County, at gaging station at upstream end of right lock all, 6.3 miles southwest of stuart.

DRAINAGE AREA...-Indeterminate.

PERIOD OF RECORD, --Chemical analyses: Detober 1960 to September 1962, July 1964 to September 1970.

Water temperatures: July 1964 to September 1970.

EXTREMES. $-1969-70$ :

Specific conductance: Maximum da11y, 600 micromhos Nov, 28 ; minimum da1ly, 160 micromhos Mar. 27.

Fater temperatures: Maximum; 36.0 C Aug. 31; minimum, i2.0 $\mathrm{C}$ Jan. $10, \mathrm{~F} \theta \mathrm{b}$. 4.

Perlod of record:

Specific conductuce (1964-70): Maximum da1ly, 5,040 micromhos June 10, 1967; minimum dally, 180 micromhos

Mar. $27,1970$.

Water temperatures: Maximum, $36.0^{\circ} \mathrm{C}$ Aug. 31,$1970 ;$ minimum, $12.0^{\circ} \mathrm{C} \mathrm{Jan} .10$, Feb. $4,1970$.

CHEMICAL ANALYSES, WATER YEAR OCTOBER 1969 TO SEPTEMBER 1970

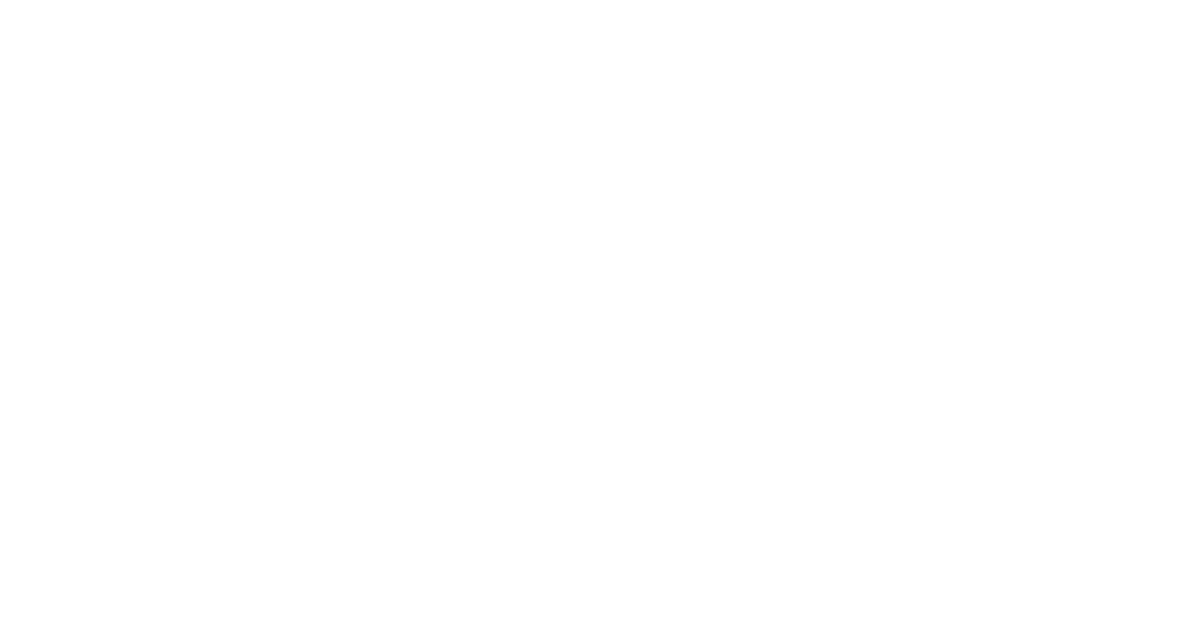

(MACRONUTRIENTS AND OTHER RELATED CONSTITUENTS)

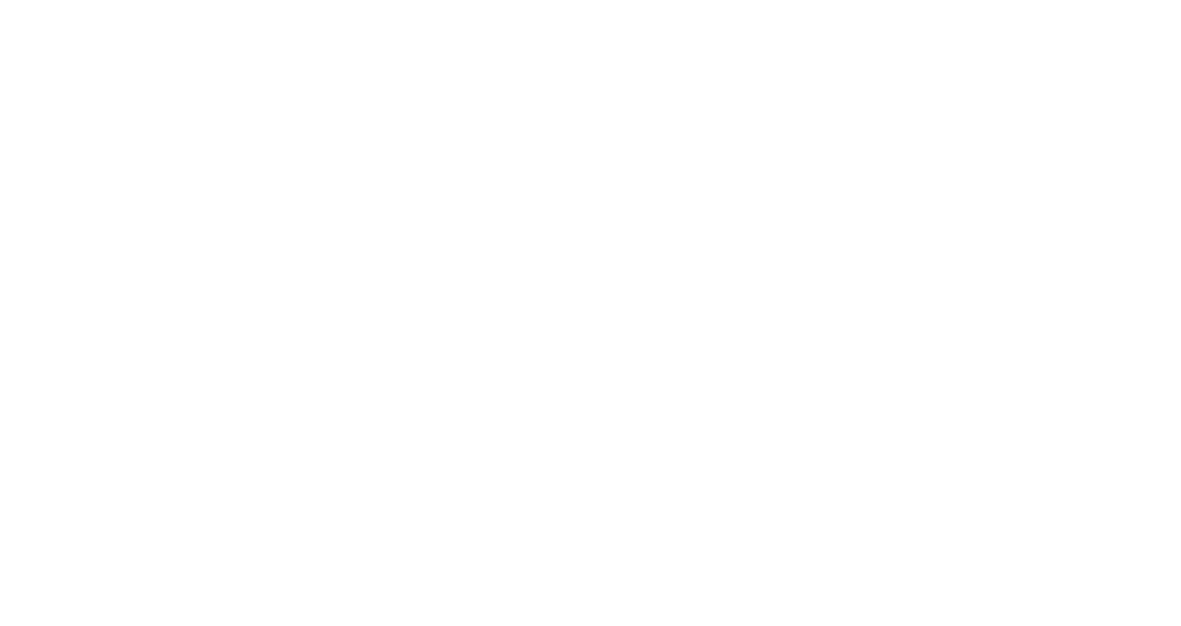

(FIELD MEASUREMENTS)

\begin{tabular}{|c|c|c|c|c|c|c|c|c|c|c|c|c|}
\hline DATE & TIME & $\begin{array}{l}\text { STAGE } \\
\text { (FT } \\
\text { ABOVE } \\
\text { DATUM) }\end{array}$ & $\begin{array}{l}\text { DIS- } \\
\text { CHARGE } \\
\text { (CFS) }\end{array}$ & $\begin{array}{l}\text { TEMPER- } \\
\text { ATURE } \\
\text { (DEG C) }\end{array}$ & $\begin{array}{l}\text { OIS- } \\
\text { SOLVED } \\
\text { OXYGEN } \\
\text { (MG/L) }\end{array}$ & $\begin{array}{l}\text { PER- } \\
\text { CENT } \\
\text { SATUR- } \\
\text { ATION }\end{array}$ & $\begin{array}{l}\text { CON- } \\
\text { DUCT- } \\
\text { ANCE } \\
\text { (MICRO- } \\
\text { MHOS) }\end{array}$ & $\begin{array}{c}P H \\
\text { (UNITS) }\end{array}$ & $\begin{array}{l}\text { BICAR- } \\
\text { BONATE } \\
\text { (HCO3) } \\
\text { (MG/L) }\end{array}$ & $\begin{array}{l}\text { CAR- } \\
\text { BONATE } \\
\text { (CO3) } \\
(\mathrm{MG} / \mathrm{L})\end{array}$ & $\begin{array}{l}\text { PAR- } \\
\text { ENCY } \\
\text { SECCHI } \\
\text { DISK } \\
\text { (IN) }\end{array}$ & $\begin{array}{c}O E>T H \\
(=T)\end{array}$ \\
\hline & & & & & & & & & & & & \\
\hline 29. & 1050 & $=$ & .00 & 25.5 & 6.7 & 81 & 450 & 7.7 & - & -- & -- & -- \\
\hline
\end{tabular}


LAKE OKEECHOBEE AND THE EVERGLADES BASINS

02277000 ST. LUCIE CANAL AT LOCK, NEAR STUART, FLA.--Cont1nued

SPECIFIC CONDUCTANCE (MICROMHOS/CM AT $25^{\circ} \mathrm{C}$ ), WATER YEAR OCTOBER 1969 TO SEPTEMBER 1970

\begin{tabular}{|c|c|c|c|c|c|c|c|c|c|c|c|c|}
\hline OAY & OCT & NOV & $\mathrm{DEC}$ & JAN & FEB & $M A R$ & $A P R$ & may & JUN & Jur & AUG & SEP \\
\hline $\begin{array}{l}1 \\
2 \\
3 \\
4 \\
5\end{array}$ & $\begin{array}{l}480 \\
470 \\
470 \\
470 \\
410\end{array}$ & $\begin{array}{l}440 \\
450 \\
460 \\
470 \\
490\end{array}$ & $\begin{array}{l}520 \\
565 \\
520 \\
505 \\
500\end{array}$ & $\begin{array}{l}410 \\
410 \\
405 \\
408 \\
420\end{array}$ & $\begin{array}{l}500 \\
490 \\
490 \\
475 \\
460\end{array}$ & $\begin{array}{l}510 \\
510 \\
510 \\
\end{array}$ & $\begin{array}{l}435 \\
430 \\
440 \\
440\end{array}$ & $\begin{array}{l}339 \\
359 \\
365 \\
375 \\
379\end{array}$ & $\begin{array}{l}470 \\
470 \\
480 \\
480 \\
480\end{array}$ & $\begin{array}{l}450 \\
456 \\
474 \\
489 \\
500\end{array}$ & $\begin{array}{l}365 \\
365 \\
365 \\
365 \\
365\end{array}$ & $\begin{array}{l}420 \\
410 \\
400 \\
397 \\
398\end{array}$ \\
\hline $\begin{array}{r}6 \\
7 \\
8 \\
9 \\
10\end{array}$ & $\begin{array}{l}395 \\
455 \\
470 \\
470 \\
480\end{array}$ & $\begin{array}{l}480 \\
450 \\
350 \\
290 \\
320\end{array}$ & $\begin{array}{l}480 \\
480 \\
485 \\
468 \\
460\end{array}$ & $\begin{array}{l}411 \\
415 \\
420 \\
420 \\
422\end{array}$ & $\begin{array}{l}470 \\
470 \\
460 \\
460 \\
460\end{array}$ & $\begin{array}{l}510 \\
510 \\
500 \\
510 \\
510\end{array}$ & $\begin{array}{l}445 \\
445 \\
430 \\
440 \\
425\end{array}$ & $\begin{array}{l}375 \\
374 \\
377 \\
378 \\
378\end{array}$ & $\begin{array}{l}460 \\
470 \\
450 \\
450 \\
430\end{array}$ & $\begin{array}{l}500 \\
510 \\
540 \\
540 \\
540\end{array}$ & $\begin{array}{l}369 \\
373 \\
380 \\
377 \\
382\end{array}$ & $\begin{array}{l}399 \\
395 \\
395 \\
393 \\
395\end{array}$ \\
\hline $\begin{array}{l}11 \\
12 \\
13 \\
14 \\
15\end{array}$ & $\begin{array}{l}485 \\
500 \\
500 \\
500 \\
500\end{array}$ & $\begin{array}{l}320 \\
310 \\
310 \\
340 \\
370\end{array}$ & $\begin{array}{l}450 \\
450 \\
440 \\
440 \\
440\end{array}$ & $\begin{array}{l}420 \\
435 \\
441 \\
439 \\
450\end{array}$ & $\begin{array}{l}465 \\
470 \\
470 \\
465 \\
465\end{array}$ & $\begin{array}{l}510 \\
510 \\
550 \\
440 \\
475\end{array}$ & $\begin{array}{l}405 \\
390 \\
370 \\
360 \\
350\end{array}$ & $\begin{array}{l}380 \\
385 \\
385 \\
388 \\
381\end{array}$ & $\begin{array}{l}430 \\
420 \\
420 \\
410 \\
400\end{array}$ & $\begin{array}{l}540 \\
540 \\
530 \\
500 \\
490\end{array}$ & $\begin{array}{l}408 \\
397 \\
396 \\
397 \\
403\end{array}$ & $\begin{array}{l}395 \\
400 \\
400 \\
405 \\
400\end{array}$ \\
\hline $\begin{array}{l}16 \\
17 \\
18 \\
19 \\
20\end{array}$ & $\begin{array}{l}490 \\
490 \\
480 \\
450 \\
400\end{array}$ & $\begin{array}{l}335 \\
345 \\
360 \\
390 \\
390\end{array}$ & $\begin{array}{l}435 \\
430 \\
420 \\
410 \\
400\end{array}$ & $\begin{array}{l}480 \\
490 \\
450 \\
480 \\
488\end{array}$ & $\begin{array}{l}475 \\
470 \\
470 \\
475 \\
470\end{array}$ & $\begin{array}{l}470 \\
430 \\
455 \\
448 \\
460\end{array}$ & $\begin{array}{l}345 \\
330 \\
335 \\
325 \\
320\end{array}$ & $\begin{array}{l}393 \\
393 \\
411 \\
409 \\
415\end{array}$ & $\begin{array}{l}410 \\
400 \\
400 \\
400 \\
400\end{array}$ & $\begin{array}{l}450 \\
450 \\
450 \\
430 \\
430\end{array}$ & $\begin{array}{l}415 \\
414 \\
416 \\
416 \\
426\end{array}$ & $\begin{array}{l}408 \\
415 \\
415 \\
420 \\
428\end{array}$ \\
\hline $\begin{array}{l}21 \\
22 \\
23 \\
24 \\
25\end{array}$ & $\begin{array}{l}400 \\
410 \\
400 \\
370 \\
410\end{array}$ & $\begin{array}{l}410 \\
525 \\
530 \\
550 \\
550\end{array}$ & $\begin{array}{l}390 \\
390 \\
390 \\
390 \\
400\end{array}$ & $\begin{array}{l}492 \\
455 \\
435 \\
471 \\
485\end{array}$ & $\begin{array}{l}470 \\
472 \\
480 \\
490 \\
500\end{array}$ & $\begin{array}{l}460 \\
470 \\
472 \\
470 \\
450\end{array}$ & $\begin{array}{l}325 \\
315 \\
320 \\
335 \\
325\end{array}$ & $\begin{array}{l}424 \\
435 \\
445 \\
450 \\
452\end{array}$ & $\begin{array}{l}405 \\
405 \\
405 \\
410 \\
415\end{array}$ & $\begin{array}{l}425 \\
411 \\
410 \\
409 \\
398\end{array}$ & $\begin{array}{l}430 \\
432 \\
430 \\
435 \\
431\end{array}$ & $\begin{array}{l}429 \\
430 \\
433 \\
440 \\
447\end{array}$ \\
\hline $\begin{array}{l}26 \\
27 \\
28 \\
29 \\
30 \\
31\end{array}$ & $\begin{array}{l}450 \\
440 \\
430 \\
340 \\
350 \\
-2\end{array}$ & $\begin{array}{l}550 \\
590 \\
600 \\
540 \\
540 \\
-\end{array}$ & $\begin{array}{l}400 \\
405 \\
410 \\
410 \\
415 \\
415\end{array}$ & $\begin{array}{l}490 \\
485 \\
472 \\
479 \\
472 \\
481\end{array}$ & $\begin{array}{l}500 \\
500 \\
510 \\
\cdots \\
\cdots\end{array}$ & $\begin{array}{l}265 \\
180 \\
270 \\
355 \\
412\end{array}$ & $\begin{array}{l}300 \\
280 \\
270 \\
285 \\
310 \\
-\end{array}$ & $\begin{array}{l}495 \\
470 \\
470 \\
480 \\
490 \\
495\end{array}$ & $\begin{array}{l}415 \\
425 \\
430 \\
440 \\
430 \\
---\end{array}$ & $\begin{array}{l}382 \\
380 \\
377 \\
375 \\
362 \\
359\end{array}$ & $\begin{array}{l}436 \\
438 \\
446 \\
446 \\
446 \\
438\end{array}$ & $\begin{array}{l}443 \\
443 \\
448 \\
445 \\
447 \\
--7\end{array}$ \\
\hline AVERAGE & 446 & 435 & 442 & 449 & 477 & 451 & 363 & 411 & 430 & 455 & 407 & 416 \\
\hline
\end{tabular}

(TRACE METALS)

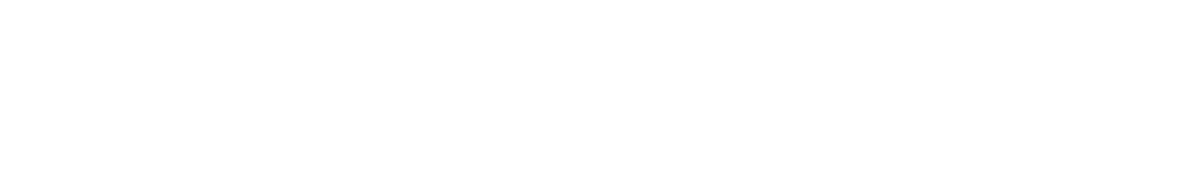

TEMPERATURE (OC) OF HATER, WATER YEAR OCTOBER 1969 TO SEPTEMBER 1970

\begin{tabular}{|c|c|c|c|c|c|c|c|c|c|c|c|c|}
\hline DAY & OCT & NOV & DEC & JAN & FEB & MAR & $A P R$ & mar & JUN & $\mathrm{NL}$ & NUG & SEP \\
\hline $\begin{array}{l}1 \\
2 \\
3 \\
4 \\
5\end{array}$ & $\begin{array}{l}28.0 \\
28.0 \\
29.0 \\
28.0 \\
28.0\end{array}$ & $\begin{array}{l}24.0 \\
24.0 \\
24.0 \\
25.0 \\
22.0\end{array}$ & $\begin{array}{r}17.0 \\
18.0 \\
17.0 \\
17.0 \\
\end{array}$ & $\begin{array}{l}18.0 \\
18.0 \\
20.0 \\
18.0 \\
17.0\end{array}$ & $\begin{array}{l}16.0 \\
17.0 \\
19.0 \\
12.0 \\
14.0\end{array}$ & $\begin{array}{r}18.0 \\
18.0 \\
19.0 \\
-0 .\end{array}$ & $\begin{array}{l}25.0 \\
24.0 \\
24.0 \\
25.0\end{array}$ & $\begin{array}{l}26.0 \\
25.0 \\
24.0 \\
25.0 \\
26.0\end{array}$ & $\begin{array}{l}25.0 \\
26.0 \\
26.0 \\
26.0 \\
27.0\end{array}$ & $\begin{array}{l}28.0 \\
28.0 \\
29.0 \\
29.0 \\
29.0\end{array}$ & $\begin{array}{l}30.0 \\
29.0 \\
29.0 \\
29.0 \\
28.0\end{array}$ & $\begin{array}{l}28.0 \\
29.0 \\
29.0 \\
29.0 \\
29.0\end{array}$ \\
\hline $\begin{array}{r}6 \\
7 \\
8 \\
9 \\
10\end{array}$ & $\begin{array}{l}28.0 \\
28.0 \\
27.0 \\
28.0 \\
25.0\end{array}$ & $\begin{array}{l}20.0 \\
18.0 \\
18.0 \\
19.0 \\
19.0\end{array}$ & $\begin{array}{l}17.5 \\
18.0 \\
19.0 \\
20.0 \\
20.0\end{array}$ & $\begin{array}{l}18.0 \\
16.0 \\
1400 \\
14.0 \\
12.0\end{array}$ & $\begin{array}{l}15.0 \\
15.0 \\
15.0 \\
15.0 \\
14.0\end{array}$ & $\begin{array}{l}19.0 \\
20.0 \\
20.0 \\
19.0 \\
19.0\end{array}$ & $\begin{array}{l}25.0 \\
24.0 \\
24.0 \\
22.0 \\
22.0\end{array}$ & $\begin{array}{l}25.0 \\
24.0 \\
25.0 \\
25.0 \\
25.0\end{array}$ & $\begin{array}{l}26.0 \\
27.0 \\
27.0 \\
27.0 \\
27.0\end{array}$ & $\begin{array}{l}28.0 \\
29.0 \\
29.0 \\
29.0\end{array}$ & $\begin{array}{l}27.0 \\
29.0 \\
30.0 \\
30.0 \\
29.0\end{array}$ & $\begin{array}{l}29.0 \\
29.0 \\
29.0 \\
29.0\end{array}$ \\
\hline $\begin{array}{l}11 \\
12 \\
13 \\
14 \\
15\end{array}$ & $\begin{array}{l}25.0 \\
26.0 \\
26.0 \\
25.0 \\
25.0\end{array}$ & $\begin{array}{l}19.0 \\
19.0 \\
20.0 \\
21.0 \\
18.0\end{array}$ & $\begin{array}{l}19.0 \\
17.0 \\
16.0 \\
16.0 \\
17.0\end{array}$ & $\begin{array}{l}13.0 \\
14.0 \\
14.0 \\
14.0 \\
16.0\end{array}$ & $\begin{array}{l}14.0 \\
15.0 \\
15.0 \\
15.0 \\
17.0\end{array}$ & $\begin{array}{l}20.0 \\
20.0 \\
20.0 \\
14.0 \\
16.0\end{array}$ & $\begin{array}{l}24.0 \\
24.0 \\
24.0 \\
24.0 \\
24.0\end{array}$ & $\begin{array}{l}25.0 \\
25.0 \\
25.0 \\
25.0 \\
25.0\end{array}$ & $\begin{array}{l}27.0 \\
27.0 \\
27.0 \\
27.0 \\
27.0\end{array}$ & $\begin{array}{l}29.0 \\
29.0 \\
29.0 \\
29.0 \\
28.0\end{array}$ & $\begin{array}{l}29.0 \\
29.0 \\
29.0 \\
29.0 \\
29.0\end{array}$ & $\begin{array}{l}29.0 \\
28.0 \\
28.0 \\
28.0 \\
29.0\end{array}$ \\
\hline $\begin{array}{l}16 \\
17 \\
18 \\
19 \\
20\end{array}$ & $\begin{array}{l}26.0 \\
25.0 \\
26.0 \\
26.0 \\
25.0\end{array}$ & $\begin{array}{l}17.0 \\
18.0 \\
19.0 \\
20.0 \\
20.0\end{array}$ & $\begin{array}{l}17.0 \\
17.0 \\
17.0 \\
17.0 \\
17.0\end{array}$ & $\begin{array}{l}15.0 \\
16.0 \\
16.0 \\
16.0 \\
16.0\end{array}$ & $\begin{array}{l}17.0 \\
19.0 \\
18.0 \\
18.0 \\
17.0\end{array}$ & $\begin{array}{l}16.0 \\
17.0 \\
18.0 \\
20.0 \\
20.0\end{array}$ & $\begin{array}{l}25.0 \\
24.0 \\
24.0 \\
25.0 \\
25.0\end{array}$ & $\begin{array}{l}25.0 \\
25.0 \\
26.0 \\
26.0 \\
26.0\end{array}$ & $\begin{array}{l}27.0 \\
27.0 \\
27.0 \\
27.0 \\
28.0\end{array}$ & $\begin{array}{l}28.0 \\
29.0 \\
30.0 \\
30.0 \\
30.0\end{array}$ & $\begin{array}{l}29.0 \\
29.0 \\
29.0 \\
29.0 \\
29.0\end{array}$ & $\begin{array}{l}29.0 \\
28.0 \\
28.0 \\
28.0 \\
29.0\end{array}$ \\
\hline $\begin{array}{l}21 \\
22 \\
23 \\
24 \\
25\end{array}$ & $\begin{array}{l}25.0 \\
26.0 \\
26.0 \\
26.0 \\
25.0\end{array}$ & $\begin{array}{l}18.0 \\
17.0 \\
18.0 \\
19.0 \\
19.0\end{array}$ & $\begin{array}{l}17.0 \\
17.0 \\
16.0 \\
17.0 \\
17.0\end{array}$ & $\begin{array}{l}15.0 \\
15.0 \\
14.0 \\
15.0 \\
15.0\end{array}$ & $\begin{array}{l}17.0 \\
18.0 \\
18.0 \\
18.0 \\
18.0\end{array}$ & $\begin{array}{l}21.0 \\
22.0 \\
20.0 \\
20.0 \\
20.0\end{array}$ & $\begin{array}{l}25.0 \\
26.0 \\
26.0 \\
26.0 \\
26.0\end{array}$ & $\begin{array}{l}26.0 \\
25.0 \\
25.0 \\
25.0 \\
25.0\end{array}$ & $\begin{array}{l}28.0 \\
28.0 \\
28.0 \\
27.0 \\
28.0\end{array}$ & $\begin{array}{l}29.0 \\
29.0 \\
28.0 \\
29.0 \\
28.0\end{array}$ & $\begin{array}{l}29.0 \\
29.0 \\
29.0 \\
29.0\end{array}$ & $\begin{array}{l}28.0 \\
28.0 \\
28.0 \\
28.0 \\
28.0\end{array}$ \\
\hline $\begin{array}{l}26 \\
27 \\
28 \\
29 \\
30 \\
31\end{array}$ & $\begin{array}{l}24.0 \\
25.0 \\
25.0 \\
25.0 \\
23.0 \\
-\ldots\end{array}$ & $\begin{array}{l}19.0 \\
19.0 \\
19.0 \\
20.0 \\
19.0 \\
\end{array}$ & $\begin{array}{l}18.0 \\
16.0 \\
16.0 \\
17.0 \\
19.0 \\
19.0\end{array}$ & $\begin{array}{l}15.0 \\
16.0 \\
16.0 \\
17.0 \\
18.0 \\
15.0\end{array}$ & $\begin{array}{r}18.0 \\
16.0 \\
17.0 \\
- \\
=-\end{array}$ & $\begin{array}{l}19.0 \\
20.0 \\
21.0 \\
23.0 \\
25.0\end{array}$ & $\begin{array}{l}26.0 \\
25.5 \\
25.0 \\
26.0 \\
26.0 \\
\end{array}$ & $\begin{array}{l}26.0 \\
26.0 \\
25.0 \\
26.0\end{array}$ & $\begin{array}{l}28.0 \\
29.0 \\
29.0 \\
28.0 \\
28.0 \\
-\end{array}$ & $\begin{array}{l}28.0 \\
28.0 \\
29.0 \\
29.0 \\
28.0 \\
29.0\end{array}$ & $\begin{array}{l}29.0 \\
29.0 \\
28.0 \\
28.0 \\
29.0 \\
36.0\end{array}$ & $\begin{array}{r}28.0 \\
28.0 \\
27.0 \\
28.0 \\
28.0 \\
-\ldots .0\end{array}$ \\
\hline AVERAGE & 26.0 & 19.5 & 17.5 & 15.5 & 16.5 & 19.5 & 24.5 & 25.0 & 27.0 & 29.0 & 29.0 & 28.5 \\
\hline
\end{tabular}


02278000 West palm Beach Canal at HGS-5, at CaNal pOINT, Fla.

LOCATION.--Lat $26^{\circ} 51^{\prime} 50^{\prime \prime}$, long $80^{\circ} 37^{\prime} 55^{\prime \prime}$, in NEł sec.33, T.41 S., R.37 E., Paim Beach County, at gaging station, on right bank in hurricane gate structure 5 at Lake Okeechobee, $200 \mathrm{ft}$ upstream from brtdge on U.S. Highway 441 at Canal point.

DRAINAGE AREA. --Indeterminate.

PER IOD OF AECORD.--Chemical analyses: October 1953 to September 1954, October 1957 to September 1958 , October 1960 to September 1961, July 1964 to September 1970.

Water temperatures:' July 1964 to September 1970.

EXTREMES, $-1969-70$ :

Specific conductance: Maximum daily, 2,400 micromhos Nov. 9; minimum daily, 302 micromhos May $2,3$.

water temperatures: Maximum, $31.0^{\circ} \mathrm{C}$ July 22 , Sept. 1 ; minimum, $10.0^{\circ} \mathrm{C}$ Jan. 11 .

period of record:

Specific conductance (1964-70): Haximum da1ly, 2,800 micromhos Oct, 24, 1964; minimum da1ly, 300 micromhos

Water temperatures: Maximum, $33.0^{\circ} \mathrm{C}$ July $27,28,1969$; mintmum, $10.0^{\circ} \mathrm{C} \mathrm{Jan.} 11,1970$. CHEMICAL ANALYSES, WATER YEAR OCTOBER 1969 TO SEPTEMBER 1970 (MAJOR CONSTITUENTS)

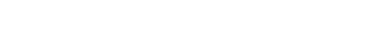

CON-

$\begin{array}{cc}\text { OIS- } & \text { TEMPER- } \\ \text { CHARGE } & \text { ATURE } \\ \text { DATE (CFS) } & \text { (DEG C) }\end{array}$

DUCT-

DIS-

UIS- SOLVED

CAL- NE- SOLVED

IRON CIUM SIUM
(FE) (CA) IMG)

MHOS) (UG/L)

(MG/L) (MG/L)

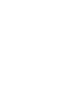

$\begin{array}{cc}\text { DIS- } \\ \text { SOLVED } \\ \text { DIS- } \\ \text { PO- } \\ \text { SOLVED } \\ \text { SODIUM } & \text { TAS- } \\ \text { SIIMM }\end{array}$

BONATE PH

OCT., 1969

MAY: 1970

MAY 1970

01.0

AUG.

SEP.

22...

$$
25.0
$$

540

50

$48 \quad 15$

44

68

46

NON-
CAR-
RONATE
HARD-
NESS
GMG

ALKA-
LINITY
AS
CACD 3
(MG

$-$

$43 \quad 3.4$

(MGLL) (UNITS)

$\begin{array}{llll}\text { DIS- } & \text { SOLVEO } & \text { SOLVFD } & \\ \text { SOLVED } & \text { CHLO- } & \text { FLUU- } & \text { HARD- } \\ \text { SULFOTE } & \text { RIDE } & \text { RIDE } & \text { NESS } \\ \text { (SOL) } & \text { (CL) } & \text { (F) } & \text { (CA MG }) \\ (M G / L) & (M G / L) & \text { (MG/L) } & \text { (MG/L) }\end{array}$

DCT., 196943

MAY 1970

JULY

$01 \ldots 44$

AUG.

11...

I1... $31 \quad 51$

$.3 \quad 182$

57

125

DIS-

$\begin{array}{ll}\text { SOLVEO SOLVED } & \text { DIS- } \\ \text { SOLIOS SOLIDS } & \text { SOLVED SOLVED }\end{array}$

IRESI- ISUM OF SOLIOS SOLIDS TANNIN

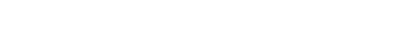

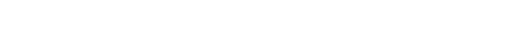

22... $39 \quad 50$

$.5 \quad 110$

.4164

$.3 \quad 194$

161

$\begin{array}{rr}57 & 125 \\ 21 & 89\end{array}$

342

311

$M G / L) \quad(F T)$

MACRONUTRIENTS AND OTHER RELATED CONSTITUENTS

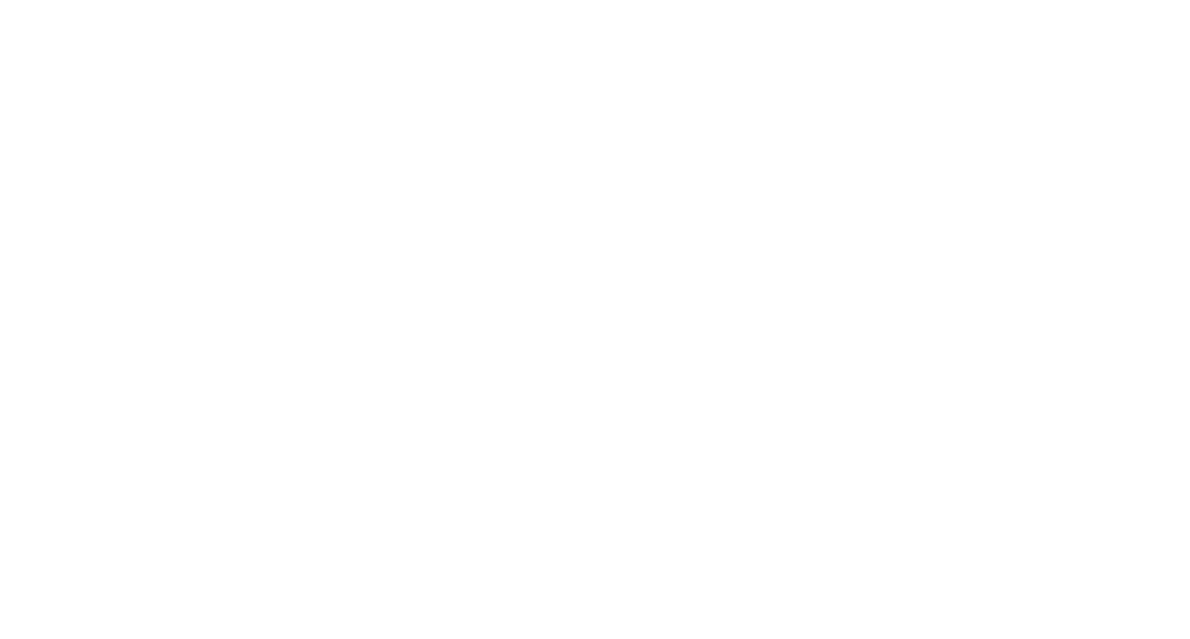


LAKE OKEECHOBEE AND THE EVERGLADES BASINS

02278000 WEST PALM BEACH CANAL AT HGS-5, AT CANAL POINT, FLA.--Continued

SPECIFIC CONDUCTANCE (MICROMHOS/CM AT $25^{\circ} \mathrm{C}$ ), WATER YEAR OCTOBER 1969 TO SEPTEMBER 1970

\begin{tabular}{|c|c|c|c|c|c|c|c|c|c|c|c|c|}
\hline $\begin{array}{r}\text { DAY } \\
\text { I }\end{array}$ & $\begin{array}{l}O C T \\
\text { OOC }\end{array}$ & $\begin{array}{r}\text { NOV } \\
1280\end{array}$ & $\begin{array}{r}\text { DEC } \\
1820\end{array}$ & $\begin{array}{l}\text { JAN } \\
540\end{array}$ & $\begin{array}{l}\text { FEB } \\
4 B 5\end{array}$ & $\begin{array}{l}\text { MAR } \\
475\end{array}$ & $\begin{array}{r}\text { APR } \\
1250\end{array}$ & $\begin{array}{l}\text { MAY } \\
305\end{array}$ & $\begin{array}{l}\text { JUN } \\
445\end{array}$ & $\begin{array}{l}\text { JUL } \\
510\end{array}$ & AUG & $\begin{array}{l}\text { SEP } \\
630\end{array}$ \\
\hline 2 & 625 & 1020 & 2320 & 565 & 475 & 480 & 1250 & 302 & 460 & 500 & $\cdots$ & 570 \\
\hline 3 & 690 & 1250 & 2300 & 545 & 470 & 475 & 1250 & 302 & 440 & 450 & $\cdots$ & 520 \\
\hline 4 & 650 & 1240 & 2350 & 520 & 475 & 480 & 1250 & 308 & 440 & 420 & --. & 510 \\
\hline 5 & 1290 & 1290 & 1600 & 525 & 510 & 475 & 1220 & 335 & 550 & 410 & --- & 510 \\
\hline 6 & 500 & 2000 & 1620 & 520 & 1250 & 480 & 1280 & 352 & 520 & 400 & $\cdots$ & 510 \\
\hline 7 & 560 & 2240 & 1700 & 525 & 1430 & 676 & 1350 & 345 & 880 & 400 & $\cdots$ & 530 \\
\hline 8 & 575 & 2200 & 1400 & 510 & 1500 & 670 & 1400 & 360 & 930 & 410 & -- & 725 \\
\hline 9 & 1350 & 2400 & 1300 & 520 & 1600 & 642 & $14 \mathrm{CO}$ & 360 & 620 & 410 & $\cdots$ & 422 \\
\hline 10 & 1390 & 2250 & 1380 & 525 & 1620 & 678 & 1170 & 359 & 510 & 410 & $\cdots$ & 418 \\
\hline $\begin{array}{l}11 \\
12\end{array}$ & $\begin{array}{l}1120 \\
1210\end{array}$ & $\begin{array}{l}2250 \\
23 \mathrm{CC}\end{array}$ & $\begin{array}{l}1220 \\
1850\end{array}$ & $\begin{array}{l}515 \\
540\end{array}$ & $\begin{array}{l}650 \\
640\end{array}$ & $\begin{array}{l}687 \\
696\end{array}$ & $\begin{array}{l}1160 \\
1150\end{array}$ & $\begin{array}{l}374 \\
372\end{array}$ & $\begin{array}{l}470 \\
460\end{array}$ & $\begin{array}{l}540 \\
490\end{array}$ & $=-$ & $\begin{array}{l}438 \\
434\end{array}$ \\
\hline 13 & $14 \mathrm{CO}$ & 2160 & 1890 & 815 & 560 & 690 & I 800 & 370 & 640 & 520 & -- & 428 \\
\hline 14 & 510 & 2200 & 1800 & 940 & 550 & 1350 & 460 & 370 & 550 & 410 & $\cdots$ & 440 \\
\hline is & 510 & 1850 & 2000 & $66 \mathrm{C}$ & 565 & 1340 & 430 & 370 & 505 & 420 & $\cdots$ & 570 \\
\hline 16 & 525 & 1600 & 2110 & 900 & 560 & 1350 & 460 & 382 & 485 & 430 & -- & 460 \\
\hline 17 & 500 & 1750 & 2080 & 650 & 1300 & 1360 & 460 & 382 & 500 & 620 & $\cdots$ & 430 \\
\hline 18 & 500 & 1700 & 2000 & 800 & 1100 & 1350 & 430 & 383 & 435 & 560 & -- & 445 \\
\hline 19 & 540 & 1 A B 0 & 2100 & 1150 & 1280 & 1330 & 410 & 389 & 465 & 590 & -- & 445 \\
\hline 20 & 540 & 2000 & 1950 & 1410 & 1250 & 1360 & $\cdots$ & 395 & 595 & 540 & -- & 445 \\
\hline 21 & 480 & 1940 & 2080 & 1600 & 1350 & 1360 & 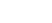 & 399 & 475 & 450 & $m$ & 450 \\
\hline 22 & 480 & 1920 & 2100 & 540 & 550 & 1360 & 340 & 408 & 420 & 450 & -- & 445 \\
\hline 23 & 480 & 1910 & 2090 & 510 & 540 & 1350 & 338 & 400 & 425 & 500 & $\cdots$ & 445 \\
\hline 24 & 550 & 1800 & 1810 & 510 & $54 \mathrm{C}$ & 1350 & 329 & 415 & 495 & 540 & --- & 445 \\
\hline 25 & 550 & 2000 & 1610 & 510 & 550 & 1370 & 329 & 429 & 450 & 440 & $\cdots$ & 440 \\
\hline 26 & 550 & 1990 & 1800 & 480 & 475 & 485 & 329 & 620 & 450 & 460 & $\cdots$ & 450 \\
\hline 27 & 550 & 1950 & 1650 & 450 & 475 & 480 & 317 & 620 & 510 & 860 & $=-$ & 440 \\
\hline 28 & 540 & 2000 & 740 & 455 & 480 & 485 & 280 & 570 & 530 & 770 & $\cdots$ & 445 \\
\hline 29 & 675 & 1990 & 560 & 458 & -- & 480 & 285 & 540 & 510 & 970 & $\cdots$ & 450 \\
\hline 30 & 680 & 1820 & 540 & 460 & -- & 480 & 288 & 460 & 495 & 470 & - & 450 \\
\hline 31 & 680 & - & 540 & $45 \mathrm{C}$ & -- & 480 & $\cdots$ & 465 & -- & 470 & $m$ & -- \\
\hline VERAGE & 705 & $I B T C$ & 1690 & 648 & 829 & 862 & 800 & 401 & 522 & 510 & $\cdots$ & 478 \\
\hline
\end{tabular}

(TRACE METALS) OCT.P 1969

$$
\begin{aligned}
& \text { OCT... } 1969 \\
& \text { 2A... } \\
& \text { MAY } 1970 \\
& \text { 05... } \\
& \text { SUG. } \\
& \text { I1... } \\
& \text { SEP.: } \\
& 22 \ldots
\end{aligned}
$$


LOCATIOY 年 $15 \mathrm{ft}$ from south bank, $200 \mathrm{ft}$ downstream from North New River Canas north of South Bay.

DRAINAGE AREA.---Indeterminate.

PER IOD OF RECORD.--Chemical analyses: October 1957 to September 1958, October 1959 to September 1962 , and Au-

Wust 1964 to September 1970.64 to September 1970.

EXTREMES. - 1969-70:

Maximum daily, 2,100 micromhos Nov. 14-16; minimum daily, 360 micromhos Apr. 28.

Saximum, 38.0 $0^{\circ}$ ' on several days during August; mintmum, $24,0^{\circ} \mathrm{C}$ Jan. $8,10$.

Period of record:

pecific conductance (1964-70): Maximum daily, 2,310 micromos Jan. 27, 1969; minimum da11y, 118 micromhos Dec. 19,1965

Haximum, $38.0^{\circ} \mathrm{C}$ on several days during dugust 1970 ; minimum, $14.0^{\circ} \mathrm{C}$ on several days during January 1965 and January to Warch 1968.

CHEMICAL ANALYSES, WATER YEAR OCTOBER 1969 TO SEPTEMBER $19 T 0$ (MAJOR CONSTITUENTS)

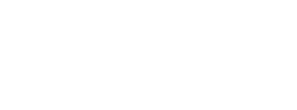

SPE-
CIFIC
CON-
DUCT-
ANCE
(MICRO-
MHOS)

$\begin{array}{ccc} & \text { OIS- } & \text { OIS- } \\ \text { DOLVED } \\ \text { DIS- } & \text { SOLVEO } & \text { MAG- } \\ \text { SOLVED } & \text { CAL- } & \text { NVE- } \\ \text { IRON } & \text { CIUM } & \text { SIUM } \\ \text { (FE) } & \text { (CA) } & \text { (MG) } \\ \text { (UG/L) } & \text { (MGAL) } & \text { (MG/L) }\end{array}$

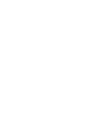

(UGR),

DIS-
SOLVEO
SODIUM
(NA)
(MG/L)

SIS-

SOLVED

PAS-

TAS- BICAR$(M G / L) \quad(M G / L)$

CAR-

BONATE PH

(CO3)
(MG/L) (UNITS)

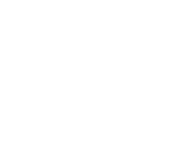

$\begin{array}{rr}27.0 & 680 \\ 27.0 & 1160 \\ 28.0 & 1620\end{array}$

10
$--\quad 46$

19
12

$1200 \quad 4$

48
35

$\begin{array}{ll}3.6 & 196 \\ 2.7 & 162\end{array}$

$12 \quad 8.6$

120

40

$\begin{array}{rr}-- & 89 \\ 4200 & 155\end{array}$

$4.4 \quad 424$

$7.8 \quad 5 n 9$

26

26

A. 6

7.9

\begin{tabular}{|c|c|c|c|c|c|c|c|c|}
\hline & DIS- & $\begin{array}{l}\text { D1S- } \\
\text { SOLVED }\end{array}$ & $\begin{array}{l}\text { DIS- } \\
\text { SOLVFD }\end{array}$ & & $\begin{array}{l}\text { NON- } \\
\text { CAR- }\end{array}$ & ALKA $=$ & $\begin{array}{l}\text { DIS- } \\
\text { SOLVED } \\
\text { SOLIDS }\end{array}$ & $\begin{array}{l}\text { OIS- } \\
\text { SULVEN } \\
\text { SOLIOS }\end{array}$ \\
\hline & $\begin{array}{l}\text { SOLVED } \\
\text { SULF ATE }\end{array}$ & CHLO- & FL'10- & HARD- & RONATE & LINITY & (RESI - & I SUM OF \\
\hline ATE & $\begin{array}{l}\text { (SO4) } \\
\text { (MG/L) }\end{array}$ & $\begin{array}{l}(C L) \\
(M G / L)\end{array}$ & $\begin{array}{l}\text { (F) } \\
(M G / L)\end{array}$ & $\begin{array}{l}\text { NESS } \\
(C A, M G) \\
(M G / L)\end{array}$ & $\begin{array}{l}\text { HAPD- } \\
\text { NESS } \\
(M G / L)\end{array}$ & $\begin{array}{c}A S \\
\text { CACO3 } \\
\text { (MG/L) }\end{array}$ & $\begin{array}{l}\text { DUE AT } \\
180 \text { C) } \\
\text { (MG LL) }\end{array}$ & $\begin{array}{l}\text { CONST T- } \\
\text { TUENTS) } \\
\text { (MG/L) }\end{array}$ \\
\hline
\end{tabular}

DIS-
SCLVED
SOLIDS
(TONS
PER
OAY)

DIS-
SOLVFD

SOLVFD

SOLIDS TANNIN

STONS AND

$\begin{array}{ccc}\text { PER } & \text { LIGNIN } & \text { DEPTH } \\ \triangle C-F T) & \text { (MG/L) } & \text { (FT) }\end{array}$

MAY 1970

$\begin{array}{llr}\text { MAY. } 1970 \\ 05 . . . & 50 & 76 \\ 19 . . . & 43 & 50 \\ \text { JULY } & & \\ \text { O1... } & 92 & 12 \\ \text { SEP. } & & \end{array}$

76
50
122

$\begin{array}{ll}.5 & 239 \\ .4 & 165\end{array}$

79
32

$180 \quad 445$

445
223

380 --

.51

$391 \quad 779$

721

$365^{--}$

$\begin{array}{lll}.51 & =-\end{array}$

$417 \quad 1150$

1050

1.2575

158

(MACRONUTRIENTS AND OTHER RELATED CONSTITUENTS)

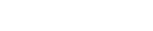

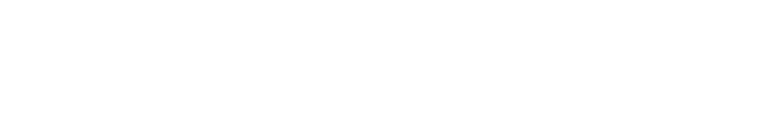

$\begin{array}{lll}\text { OCT.. } 1969 \quad \text {-. } & .02\end{array}$

$30 . . . \quad$ -

DEC.

31....

JAN...

MAR.

APR:

MAY

MAY

$05 \ldots$

JUNE

JUNE

JUL $\dot{3}$ Y

$01 \ldots$

$31 \ldots$

SEP.

(MG/

$(N / L)$

(MG/L) (M(i/L)

(MG/L)

TUR-
BID-
ITY
(JTU)

$\begin{array}{lcc}\text { COLOR } & \text { TOTAL } & \text { QIO- } \\ \text { CHEM- } \\ \text { IPLAT- } & \text { ORGANIC } & \text { ICAL } \\ \text { INUM- } & \text { CARHON } & \text { OXYGEN } \\ \text { COBALT } & \text { (C) } & \text { DEMAND }\end{array}$

UNITS)

$(M G / L)$

DEPTH

$22 . . .2 .0$

$$
\begin{aligned}
& 7.9 \\
& 5.1
\end{aligned}
$$

$-.40$

.43

$\begin{array}{ll}-- & - \\ - & -\end{array}$

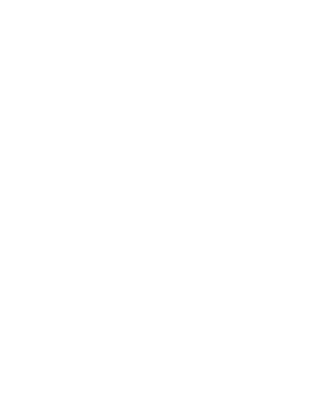

(FIELD MEASUREMENTS)

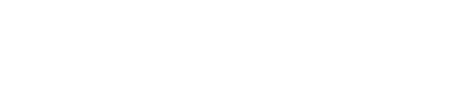

SPE-

$\begin{array}{lll} & \text { CIFIC } \\ \text { PIS- } & \text { CENT } & \text { CON- } \\ \text { CUCT- }\end{array}$

SOLVED SATUR- ANCE

DXYGEN

ATION

(MICRO-

MHOS)
PH BICAR-

$(H C \cap 3)$
$(M G / L)$

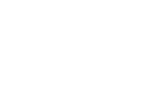

$\begin{array}{ll}\text { BONATE } & \text { SECCH } \\ \text { (CO3) } & \text { DISK } \\ \text { (MG/L) } & \text { (IN) }\end{array}$ 
LAKE OKEECHOBEE AND THE EVERGLADES BASINS

02280500 HILLSBORO CANAL BELOW HGS-4, NEAR SOUTH BAY, FLA.--Continued

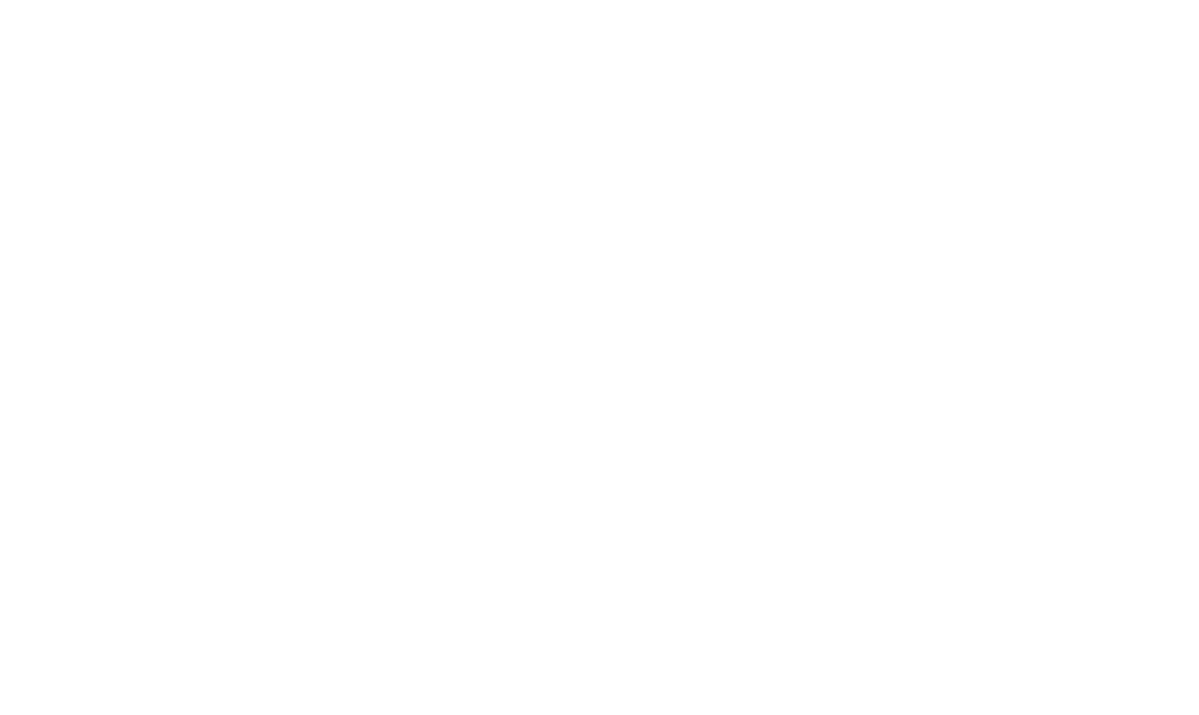

(TRACE METALS)

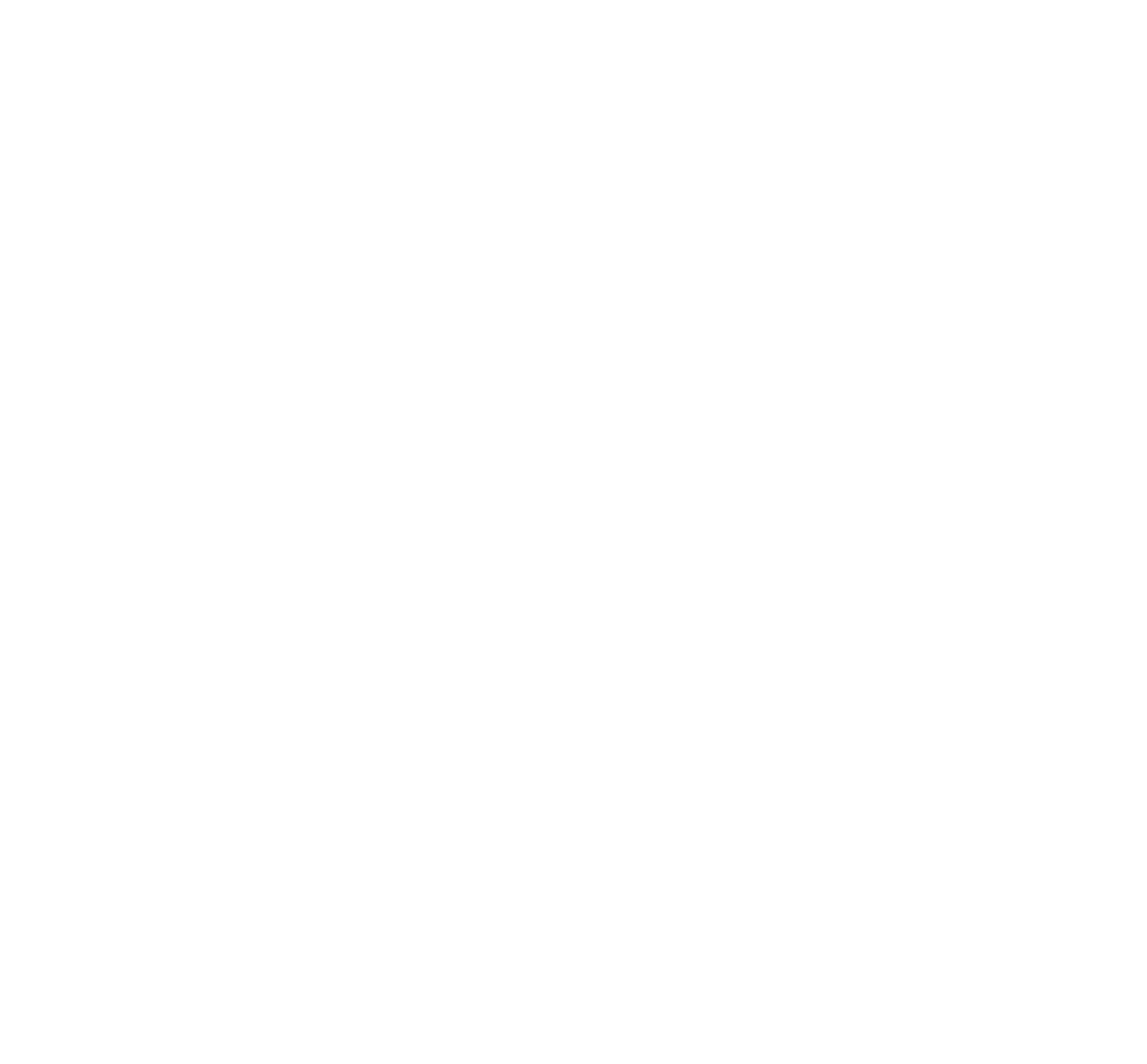


02283500 NORTH NEW RIVER CANAL BELOW HGS-4, NEAR SOUTH BAY, FLA.

LOCATION,--Lat $26^{\circ} 41^{\prime} 50^{\prime \prime}$, long $80^{\circ} 42^{\prime} 50^{\prime \prime}$, in SWł sec.35, T.43 S., R. 36 E., Palm Beach County, at gaging station $30 \mathrm{ft}$ from west bank, $800 \mathrm{ft}$ downstream from Hilisboro Canai, $1,600 \mathrm{ft}$ downstream from hurricane gate structure 4 $30 \mathrm{ft}$ from west bank, $800 \mathrm{ft}$ downstream from Hilisboro Canal, $1,600 \mathrm{ft}$ dow
and pump station 2 at Lake Okeechobee, and 2.5 miles north of South Bay.

DRAINAGE AREA.--Indeterminate.

PERIOD OF RECORD. --Chemical analyses: October 1957 to August 1962, August 1964 to September 1970.

Water temperatures: October 1964 to September 1969.

EXTREHES. $-1969-70$

Specific conductance: Maximum daily, 2,100 micromhos Aug. 1; minimum daily, 450 micromhos Apr. 30.

Period of record:

Specific conductance (1964-70): Naximum dally, 2,100 micromhos Aug. 1, 1970; min1mum da1ly, 450 micromhos

Apr. 30,1970 .

Water temperatures (1964-69): Maximum, 33. $0^{\circ} \mathrm{C}$ on several days during June to August 1967, and August to September 1969; minimum, $14.0^{\circ} \mathrm{C}$ on several days during January 1965 and January to March 1968. CHEMICAL ANALYSES, WATER YEAR DCTOBER 1969 TO SEPTEMBER 1970 (MAJOR CONSTITUENTS)

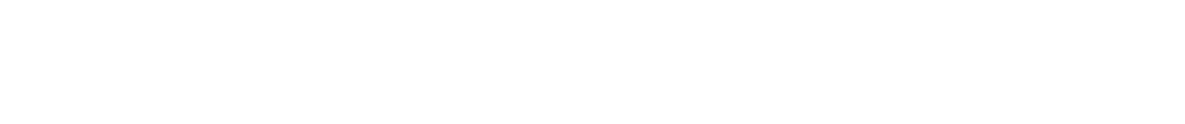

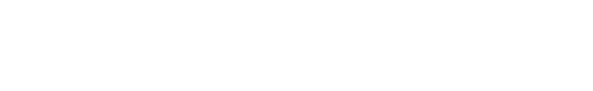

\section{$19 \quad 1200$}

$\begin{array}{rrrr}3.6 & 196 & 12 & 8.6 \\ 2.7 & 160 & 0 & 8.2 \\ 4.8 & 352 & 32 & 8.7\end{array}$

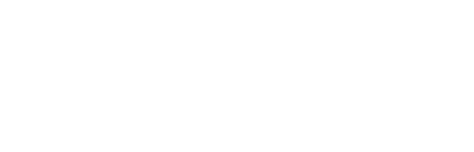

$\begin{array}{ll} & \\ \text { NOH- } & \\ \text { CAR- } & \text { ALKA- } \\ \text { BONATE } & \text { LINITY } \\ \text { HARD- } & \text { AS } \\ \text { NESS } & \text { CACD3 } \\ \text { (MGLL) } & \text { (MG/L) }\end{array}$

\section{SOLESI- ISUM OF}

$\begin{array}{lll}\text { DIS- } & \text { DIS- } \\ \text { SOLVED SULVED OIS- } & \\ \text { SOLIS- } & \text { SOL }\end{array}$ DUE AT CONST DO CI TUENTS (MG/L) (MG/L)

$\begin{array}{rrr}.5 & 239 & 79 \\ .4 & 170 & 39 \\ 1.1 & 446 & 104\end{array}$

$\begin{array}{ll}180 & 445 \\ 131 & 32 \\ 342 & 851\end{array}$

(MACRONUTRIENTS AND DTHER RELATED CONSTITUENTS)

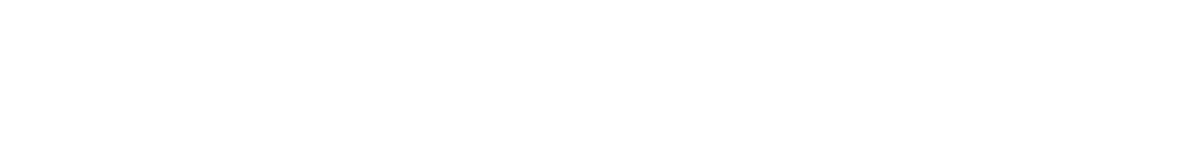

OCT.. 1969

\begin{tabular}{|c|c|c|c|c|}
\hline $\begin{array}{l}\text { oct... } 1969 \\
\text { 31.... } \\
\text { Nov. }\end{array}$ & -- & .02 & 13 & $\cdots$ \\
\hline $30 \ldots$ & $=$ & .00 & 5.9 & - \\
\hline JAN...'1970 & - & .00 & 1.2 & - \\
\hline $\begin{array}{l}31 \ldots \\
\text { MAR... }\end{array}$ & - &.$\cap 1$ & 3.4 & -- \\
\hline $\begin{array}{l}31 \ldots \\
A P R\end{array}$ & - & - & -- & - \\
\hline $\begin{array}{l}30 \\
\text { MAY }\end{array}$ & -- & . 84 & 6.9 & -- \\
\hline $\begin{array}{c}05 \ldots \\
19 \ldots \\
31 \ldots \\
\text { JUNE }\end{array}$ & $\begin{array}{r}.08 \\
.15 \\
--\end{array}$ & $\begin{array}{l}.03 \\
.02 \\
.12\end{array}$ & $13^{.0}$ & $\begin{array}{r}1.9 \\
1.4 \\
-0\end{array}$ \\
\hline JUL & -- & .02 & 11 & - \\
\hline $\begin{array}{l}01 \ldots . . \\
31 \ldots\end{array}$ & .77 & $\begin{array}{l}.18 \\
.02\end{array}$ & $\begin{array}{l}1.2 \\
4.3\end{array}$ & 1.? \\
\hline
\end{tabular}

$\begin{array}{lll}.99 & 1.0 & - \\ .35 & .35 & -- \\ .07 & .08 & -- \\ .07 & .13 & -- \\ .38 & .39 & -- \\ .22 & .26 & -- \\ .06 & .11 & 8.9 \\ .07 & .09 & 6.4 \\ .10 & .19 & -- \\ .41 & .49 & -- \\ .24 & .26 & 18 \\ .32 & .34 & -.\end{array}$

$\begin{array}{lllll}-- & -- & -- & - & - \\ -- & -- & -- & -- & - \\ -- & -- & -- & -- & -- \\ -- & -- & -- & -- & - \\ -- & -- & -- & -- & - \\ -- & -- & -- & -- & - \\ 36 & 80 & -- & 302 & - \\ 22 & 5 n & -- & -- & - \\ -- & -- & - & - & - \\ 3 n & -- & -- & -- & - \\ -- & 240 & -- & -- & -\end{array}$

(TRACE METALS)

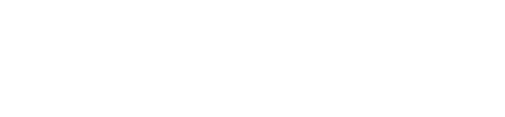
MAY, 1970 
LAKE OKEECHOBEE AND THE EVERGLADES BASINS

02283500 NORTH NEW RIVER CANAL BELOW HGS-4, NEAR SOUTH BAY, FLA.--Continued

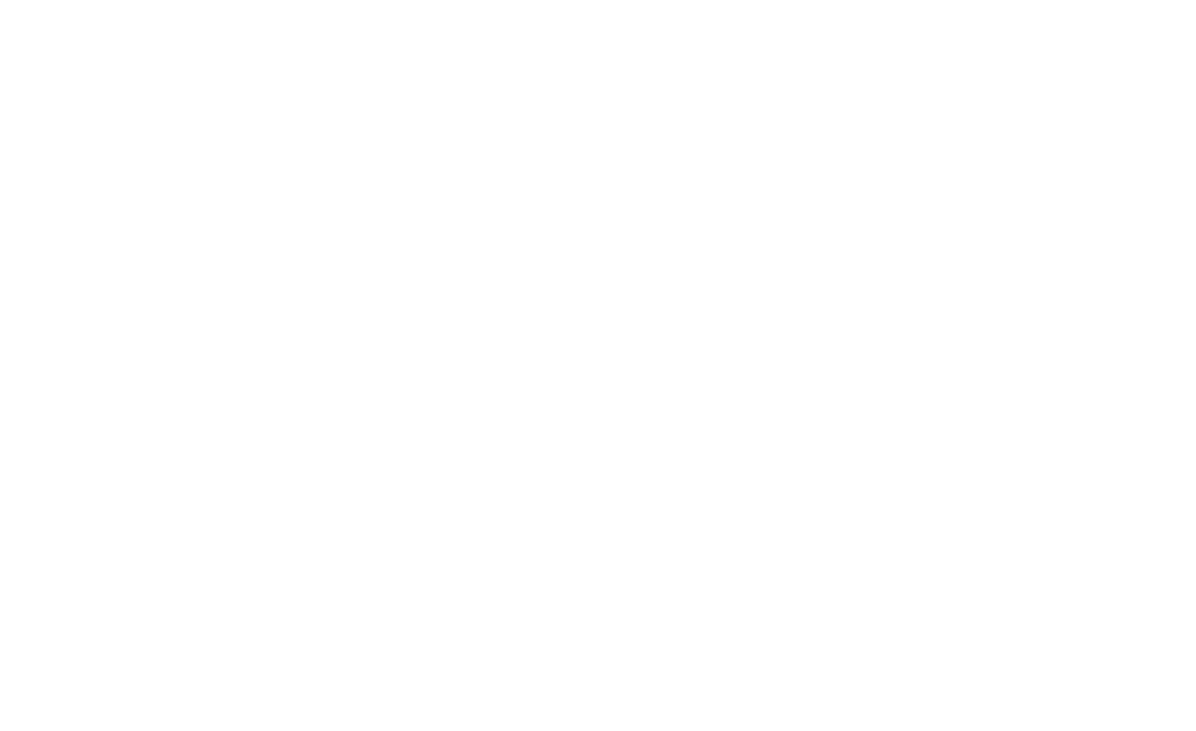

02283000 NORTH NEW RIVER CANAL MEAR FORT LAUDERDALE, FLA,

LOCATION. - Lat $26^{\circ} 05^{\prime} 39^{\prime \prime}$, long $80^{\circ} 13^{\prime} 48^{\prime \prime}$, in SW $\frac{1}{2}$ sec.14, T.50 S., R. 41 E., Broward County, at gaging station on right bank $20 \mathrm{ft}$ upstream from lock and salinity-control structure' on State' H1ghway 84 , and 6 miles southwest of Fort Lauderdale.

DRAINAGE AREA, -- Indeterminate.

PERIOD OF RECORD.--Chemical analyses: August 1964 to September 1970.

Water temperatures: August 1964 to September 1970.

EXTREYES. - - 1969-70:

Specific conductance: Maximum daily, 950 micromhos Apr. 26-28; minimum daily, 540 micromhos Feb. 5, Mar. 5,

Water temperatures: Naximum, $31.0^{\circ} \mathrm{C}$ Aug. 4, 9; minimum, 15. $0^{\circ} \mathrm{C}$ Jan. 10, Feb. 4, 5

perlod of record:

Specific conductance: Maximum daily, 995 mlcromhos Nay 29-31, 1967; minimum daily, 332 micromhos June 20,

Water temperatures: Maximum, $31.0^{\circ} \mathrm{C}$ July 7,1965 , July 11, 13, 1969, Aug. 4, 9, 1970; minimum, $13.0^{\circ} \mathrm{C} \mathrm{Jan} .31$,

1966 .

CHEMICAL ANALYSES, WATER YEAR OCTOBER 1969 TO SEPTEMBER 1970 (MAJOR CONSTITUENTS)

\begin{tabular}{|c|c|c|c|c|c|c|c|c|c|c|c|c|}
\hline DATE & $\begin{array}{l}\text { DIS- } \\
\text { CHARGE } \\
\text { (CFS) }\end{array}$ & $\begin{array}{l}\text { TEMPER- } \\
\text { ATUPE } \\
\text { (DEG C) }\end{array}$ & $\begin{array}{l}\text { SPE- } \\
\text { CIFIC } \\
\text { COIN- } \\
\text { DUCT- } \\
\text { ANCE } \\
\text { (MICRO- } \\
\text { MHUS) }\end{array}$ & $\begin{array}{l}\text { DIS- } \\
\text { SOLVED } \\
\text { IRON } \\
\text { (FE) } \\
\left(U_{U} / L\right)\end{array}$ & $\begin{array}{l}\text { UIS- } \\
\text { SOLVED } \\
\text { CAL- } \\
\text { CIUM } \\
\text { (CA) } \\
\text { (MG/L) }\end{array}$ & $\begin{array}{l}\text { DIS- } \\
\text { SOLVED } \\
\text { NAG- } \\
\text { NE- } \\
\text { SIUM } \\
\text { (MG) } \\
\text { (MG/L) }\end{array}$ & $\begin{array}{l}\text { OLS- } \\
\text { SOLVEO } \\
\text { STRON- } \\
\text { TIUM } \\
\text { (SR) } \\
\text { (UG/L) }\end{array}$ & $\begin{array}{l}\text { DIS- } \\
\text { SOLVEN } \\
\text { SOOIUM } \\
\text { (NA) } \\
\text { (MG/L) }\end{array}$ & $\begin{array}{l}\text { DIS- } \\
\text { SOLVED } \\
\text { PO- } \\
\text { TAC- } \\
\text { SIIJM } \\
\text { (K) } \\
\text { (NG/L) }\end{array}$ & $\begin{array}{l}\text { BICAR - } \\
\text { BONATE } \\
\text { (HCO3) } \\
\text { (MG LL) }\end{array}$ & $\begin{array}{l}\text { CAR- } \\
\text { BONATE } \\
\text { (CO3) } \\
\text { (MG/L) }\end{array}$ & $\begin{array}{l}\text { PH } \\
\text { (UNITS }\end{array}$ \\
\hline $\begin{array}{l}\text { FER... } \\
17 . .\end{array}$ & 970 & 21.0 & 610 & 330 & 72 & 9.0 & 810 & 41 & 1.3 & 258 & $n$ & 7.7 \\
\hline DATE & $\begin{array}{l}\text { DIS- } \\
\text { SOLVED } \\
\text { SULFATE } \\
\text { (SO4) } \\
(\mathrm{MG} / L)\end{array}$ & $\begin{array}{l}\text { DIS- } \\
\text { SOLVED } \\
\text { CHLO- } \\
\text { RIDE } \\
\text { (CLI } \\
\text { (MG/L) }\end{array}$ & $\begin{array}{l}\text { DIS- } \\
\text { SOLVFD } \\
\text { FLIIU- } \\
\text { RIOE } \\
\text { (F) } \\
(\mathrm{MG} / \mathrm{L})\end{array}$ & $\begin{array}{l}\text { HARD- } \\
\text { NESS } \\
\text { (CA, } A+G) \\
(M G / L)\end{array}$ & $\begin{array}{l}\text { DON- } \\
\text { CAR- } \\
\text { RONATE } \\
\text { HARD- } \\
\text { NESS } \\
\text { (NGGLL) }\end{array}$ & $\begin{array}{l}\text { ALKA- } \\
\text { LINITY } \\
\text { AS } \\
\text { CACO } 3 \\
\text { (MG/L) }\end{array}$ & $\begin{array}{l}\text { DIS- } \\
\text { SOLVED } \\
\text { SOL.IOS } \\
\text { (RESI- } \\
\text { DUE AT } \\
1 \text { CO C) } \\
\text { (MG/L) }\end{array}$ & $\begin{array}{l}\text { OIS- } \\
\text { SULVFD } \\
\text { SULIOS } \\
\text { ISUM OF } \\
\text { CONSTI- } \\
\text { TUENTS) } \\
\text { (MG/L) }\end{array}$ & $\begin{array}{l}\text { OIS- } \\
\text { SOL VED } \\
\text { SOL INS } \\
\text { (TONS } \\
\text { PER } \\
\text { DAY) }\end{array}$ & $\begin{array}{l}\text { DIS- } \\
\text { SOLVFF } \\
\text { SOLIOS } \\
\text { (TONS } \\
\text { PER } \\
\text { AC-FT) }\end{array}$ & $\begin{array}{l}\text { TAYIN IN } \\
\text { AND } \\
\text { LIGNIN } \\
(1 G / L)\end{array}$ & $\begin{array}{c}\text { DE 'TH } \\
(4) T\end{array}$ \\
\hline
\end{tabular}

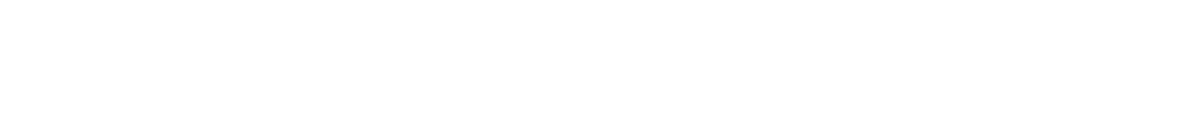


CHEMICAL ANALYSES, WATER YEAR OCTOBER 1969 TO SEPTEMBER 1970 [MACRONUTRIENTS AND OTHER RELATED CONSTITUENTS

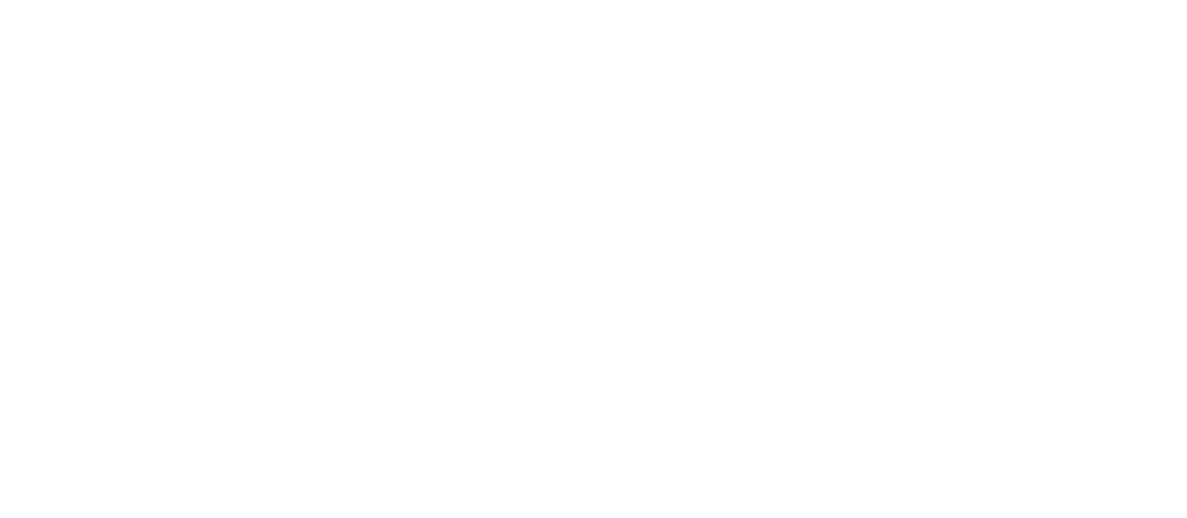

SPECIFIC CONDUCTANCE (MICROMHOS/CM AT $25^{\circ} \mathrm{C}$ ), WATER YEAR OCTOBER 1969 TO SEPTEMBER 1970

\begin{tabular}{|c|c|c|c|c|c|c|c|c|c|c|c|c|}
\hline DAY & OCT & NOV & $D E C$ & JAN & FEB & MAR & APR & MAY & JUN & JUL & AUG & SEP \\
\hline $\begin{array}{l}1 \\
2 \\
3 \\
4 \\
5\end{array}$ & $\begin{array}{l}--- \\
--- \\
--- \\
---\end{array}$ & $\begin{array}{l}-- \\
-- \\
-- \\
--\end{array}$ & $\begin{array}{l}700 \\
700 \\
690 \\
710 \\
715\end{array}$ & $\begin{array}{l}700 \\
690 \\
690 \\
570 \\
575\end{array}$ & $\begin{array}{l}550 \\
550 \\
550 \\
550 \\
540\end{array}$ & $\begin{array}{l}570 \\
550 \\
550 \\
575 \\
540\end{array}$ & $\begin{array}{l}698 \\
620 \\
700 \\
780 \\
700\end{array}$ & $\begin{array}{l}880 \\
770 \\
885 \\
760 \\
640\end{array}$ & $\begin{array}{l}m \\
\cdots \\
\cdots \\
\cdots\end{array}$ & $\begin{array}{l}600 \\
620 \\
720 \\
620 \\
600\end{array}$ & $\begin{array}{l}740 \\
730 \\
750 \\
760 \\
710\end{array}$ & $\begin{array}{l}610 \\
620 \\
605 \\
590 \\
620\end{array}$ \\
\hline $\begin{array}{r}6 \\
7 \\
8 \\
9 \\
10\end{array}$ & $\begin{array}{l}--- \\
--- \\
--- \\
--- \\
--\end{array}$ & $\begin{array}{l}--- \\
--- \\
---\end{array}$ & $\begin{array}{l}720 \\
725 \\
690 \\
690 \\
690\end{array}$ & $\begin{array}{l}570 \\
575 \\
570 \\
575 \\
580\end{array}$ & $\begin{array}{l}549 \\
550 \\
549 \\
551 \\
560\end{array}$ & $\begin{array}{l}560 \\
480 \\
475 \\
480 \\
480\end{array}$ & $\begin{array}{l}680 \\
690 \\
700 \\
700 \\
750\end{array}$ & $\begin{array}{l}625 \\
635 \\
650 \\
649 \\
645\end{array}$ & $\begin{array}{l}520 \\
580 \\
640 \\
630 \\
630\end{array}$ & $\begin{array}{l}600 \\
620 \\
630 \\
660 \\
670\end{array}$ & $\begin{array}{l}710 \\
650 \\
650 \\
630 \\
620\end{array}$ & $\begin{array}{l}620 \\
635 \\
625 \\
630\end{array}$ \\
\hline $\begin{array}{l}11 \\
12 \\
13 \\
14 \\
15\end{array}$ & $\begin{array}{l}--- \\
--- \\
\cdots- \\
\cdots \\
\cdots-\end{array}$ & $\begin{array}{l}--- \\
--- \\
--- \\
--\end{array}$ & $\begin{array}{l}650 \\
650 \\
650 \\
670 \\
660\end{array}$ & $\begin{array}{l}565 \\
560 \\
560 \\
570 \\
565\end{array}$ & $\begin{array}{l}550 \\
550 \\
550 \\
551 \\
550\end{array}$ & $\begin{array}{l}580 \\
550 \\
550 \\
650 \\
660\end{array}$ & $\begin{array}{l}750 \\
750 \\
750 \\
750 \\
750\end{array}$ & $\begin{array}{l}705 \\
725 \\
730 \\
730 \\
725\end{array}$ & $\begin{array}{l}860 \\
860 \\
860 \\
850 \\
860\end{array}$ & $\begin{array}{l}660 \\
570 \\
580 \\
570 \\
600\end{array}$ & $\begin{array}{l}625 \\
600 \\
570 \\
600 \\
605\end{array}$ & $\begin{array}{l}550 \\
535 \\
630 \\
615 \\
640\end{array}$ \\
\hline $\begin{array}{l}16 \\
17 \\
18 \\
19 \\
20\end{array}$ & $\begin{array}{l}--- \\
-- \\
-- \\
-- \\
--\end{array}$ & $\begin{array}{l}-- \\
-- \\
-- \\
--\end{array}$ & $\begin{array}{l}675 \\
660 \\
680 \\
680 \\
690\end{array}$ & $\begin{array}{l}575 \\
565 \\
550 \\
590 \\
580\end{array}$ & $\begin{array}{l}560 \\
550 \\
550 \\
550 \\
551\end{array}$ & $\begin{array}{l}660 \\
620 \\
675 \\
680 \\
750\end{array}$ & $\begin{array}{l}750 \\
780 \\
800 \\
750 \\
810\end{array}$ & $\begin{array}{l}675 \\
680 \\
680 \\
680 \\
670\end{array}$ & $\begin{array}{l}850 \\
870 \\
590 \\
850 \\
850\end{array}$ & $\begin{array}{l}610 \\
600 \\
660 \\
660 \\
690\end{array}$ & $\begin{array}{l}620 \\
620 \\
615 \\
650 \\
670\end{array}$ & $\begin{array}{l}600 \\
630 \\
630 \\
620\end{array}$ \\
\hline $\begin{array}{l}21 \\
22 \\
23 \\
24 \\
25\end{array}$ & $\begin{array}{l}--- \\
--- \\
--- \\
---\end{array}$ & $\begin{array}{l}-- \\
-- \\
-\cdots \\
---\end{array}$ & $\begin{array}{l}690 \\
690 \\
710 \\
690 \\
710\end{array}$ & $\begin{array}{l}575 \\
580 \\
590 \\
590 \\
580\end{array}$ & $\begin{array}{l}555 \\
575 \\
560 \\
560 \\
600\end{array}$ & $\begin{array}{l}750 \\
750 \\
750 \\
740 \\
730\end{array}$ & $\begin{array}{l}760 \\
880 \\
860 \\
890 \\
900\end{array}$ & $\begin{array}{l}645 \\
698 \\
698 \\
547 \\
645\end{array}$ & \begin{tabular}{l}
-- \\
$\overline{640}$ \\
\hdashline-
\end{tabular} & $\begin{array}{l}700 \\
690 \\
720 \\
660 \\
660\end{array}$ & $\begin{array}{l}680 \\
670 \\
660 \\
630 \\
655\end{array}$ & $\begin{array}{l}625 \\
645 \\
580 \\
610 \\
595\end{array}$ \\
\hline $\begin{array}{l}26 \\
27 \\
28 \\
29 \\
30 \\
31\end{array}$ & \begin{tabular}{l}
-- \\
-- \\
\hdashline-- \\
--- \\
--
\end{tabular} & $\begin{array}{l}-- \\
-- \\
\cdots- \\
-- \\
--\end{array}$ & $\begin{array}{l}700 \\
700 \\
700 \\
710 \\
710 \\
715\end{array}$ & $\begin{array}{l}580 \\
590 \\
575 \\
575 \\
590 \\
590\end{array}$ & $\begin{array}{l}600 \\
600 \\
599 \\
-- \\
--\end{array}$ & $\begin{array}{l}725 \\
740 \\
750 \\
765 \\
720 \\
720\end{array}$ & $\begin{array}{l}950 \\
950 \\
950 \\
900 \\
900 \\
-\ldots\end{array}$ & $\begin{array}{l}550 \\
550 \\
545 \\
545 \\
525 \\
545\end{array}$ & $\begin{array}{l}600 \\
640 \\
640 \\
640 \\
640 \\
-\end{array}$ & $\begin{array}{l}720 \\
720 \\
710 \\
710 \\
710 \\
720\end{array}$ & $\begin{array}{l}660 \\
645 \\
620 \\
630 \\
630 \\
620\end{array}$ & $\begin{array}{l}610 \\
630 \\
630 \\
640 \\
620 \\
\end{array}$ \\
\hline VERAGE & -- & $\cdots$ & 691 & 587 & 559 & 638 & 787 & 666 & -- & 654 & 652 & 614 \\
\hline
\end{tabular}

(ORGANOCHLORIDE COMPOUNDS IN WATER )

\begin{tabular}{|c|c|c|c|c|c|c|c|c|c|c|c|}
\hline & & $\begin{array}{l}\text { CHLOR- } \\
\text { OAINE }\end{array}$ & & & & $\begin{array}{l}\text { DI- } \\
\text { ELDRIN }\end{array}$ & & $\begin{array}{l}\text { HFPTA- } \\
\text { CHLOR }\end{array}$ & $\begin{array}{l}\text { HEPTA= } \\
\text { CHLOR } \\
\text { EPOXIDE }\end{array}$ & LINIDANE & $\begin{array}{l}\text { TOS- } \\
\triangle P H E N E\end{array}$ \\
\hline & $(1) G / L)$ & (UG/L) & $(U G / L)$ & $(U G / L)$ & $\left(1 U_{G} / L\right)$ & $(U G / L)$ & (UG/L) & $(U G / L)$ & $(U G / L)$ & $(U G / L)$ & $(U G / L)$ \\
\hline
\end{tabular}

OCT., 1968

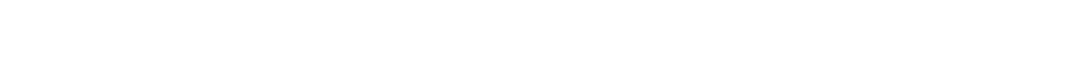

(TRACE METALS)

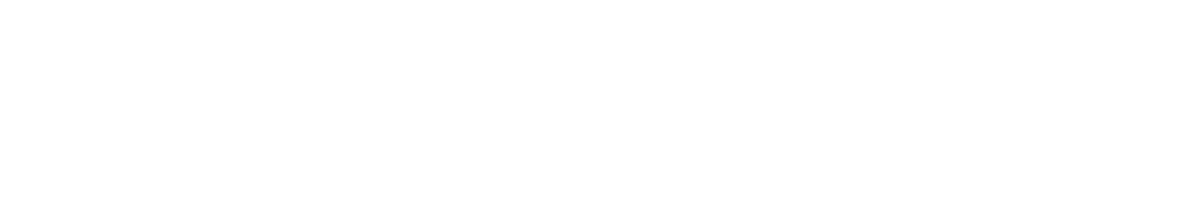


LAKE OKEECHOBEE AND THE EVERGLADES BASINS

02285000 NORTH NEW RIVER CANAL NEAR FORT LAUDERDALE, FLA, --Continued

TEMPERATURE $\left({ }^{\circ} \mathrm{C}\right)$ OF WATER, WATER YEAR OCTOBER 1969 TO SEPTEMBER 1970

\begin{tabular}{|c|c|c|c|c|c|c|c|c|c|c|c|c|}
\hline DAY & $O C \top$ & NOV & DEC & JAN & FEB & MAR & APR & MAY & JUN & JUL & AUG & SEP \\
\hline $\begin{array}{l}1 \\
2 \\
3 \\
4 \\
5\end{array}$ & $\begin{array}{l}28.0 \\
28.0 \\
29.0 \\
28.0 \\
27.0\end{array}$ & $\begin{array}{l}28.0 \\
28.0 \\
26.0 \\
27.0 \\
25.0\end{array}$ & $\begin{array}{l}19.0 \\
20.0 \\
20.0 \\
20.0 \\
20.0\end{array}$ & $\begin{array}{l}20.0 \\
20.0 \\
20.0 \\
19.0 \\
20.0\end{array}$ & $\begin{array}{l}20.0 \\
19.0 \\
16.0 \\
15.0 \\
15.0\end{array}$ & $\begin{array}{l}21.0 \\
21.0 \\
19.0 \\
19.0 \\
20.0\end{array}$ & $\begin{array}{l}24.0 \\
26.0 \\
24.0 \\
25.0 \\
24.0\end{array}$ & $\begin{array}{l}27.0 \\
27.0 \\
27.0 \\
27.0 \\
25.0\end{array}$ & $\overline{-}$ & $\begin{array}{l}28.0 \\
26.0 \\
27.0 \\
27.0 \\
29.0\end{array}$ & $\begin{array}{l}28.0 \\
26.0 \\
30.0 \\
31.0 \\
30.0\end{array}$ & $\begin{array}{l}26.0 \\
26.0 \\
26.0 \\
26.0 \\
26.0\end{array}$ \\
\hline $\begin{array}{r}6 \\
7 \\
8 \\
9 \\
10\end{array}$ & $\begin{array}{l}28.0 \\
27.0 \\
27.0 \\
26.0 \\
27.0\end{array}$ & $\begin{array}{l}23.0 \\
24.0 \\
24.0 \\
25.0 \\
25.0\end{array}$ & $\begin{array}{l}20.0 \\
20.0 \\
20.0 \\
21.0 \\
20.0\end{array}$ & $\begin{array}{l}19.0 \\
17.0 \\
16.0 \\
16.0 \\
15.0\end{array}$ & $\begin{array}{l}16.0 \\
17.0 \\
19.0 \\
18.0 \\
16.0\end{array}$ & $\begin{array}{l}20.0 \\
20.0 \\
19.0 \\
19.0 \\
20.0\end{array}$ & $\begin{array}{l}25.0 \\
23.0 \\
20.0 \\
25.0 \\
26.0\end{array}$ & $\begin{array}{l}27.0 \\
26: 0 \\
28.0 \\
27.0 \\
27.0\end{array}$ & $\begin{array}{l}26.0 \\
27.0 \\
27.0 \\
26.0 \\
26.0\end{array}$ & $\begin{array}{l}27.0 \\
25.0 \\
28.0 \\
26.0 \\
27.0\end{array}$ & $\begin{array}{l}26.0 \\
28.0 \\
30.0 \\
31.0 \\
29.0\end{array}$ & $\begin{array}{l}28.0 \\
30.0 \\
26.0 \\
-29.0\end{array}$ \\
\hline $\begin{array}{l}11 \\
12 \\
13 \\
14 \\
15\end{array}$ & $\begin{array}{l}27.0 \\
28.0 \\
28.0 \\
28.0 \\
28.0\end{array}$ & $\begin{array}{l}24.0 \\
26.0 \\
24.0 \\
24.0 \\
20.0\end{array}$ & $\begin{array}{l}21.0 \\
19.0 \\
19.0 \\
19.0 \\
18.0\end{array}$ & $\begin{array}{l}17.0 \\
19.0 \\
19.0 \\
26.0 \\
24.0\end{array}$ & $\begin{array}{l}18.0 \\
18.0 \\
20.0 \\
20.0 \\
21.0\end{array}$ & $\begin{array}{l}21.0 \\
19.0 \\
19.0 \\
19.0 \\
18.0\end{array}$ & $\begin{array}{l}26.0 \\
25.0 \\
26.0 \\
28.0 \\
26.0\end{array}$ & $\begin{array}{l}28.0 \\
28.0 \\
27.0 \\
27.0 \\
27.0\end{array}$ & $\begin{array}{r}26.0 \\
27.0 \\
26.0 \\
26.0\end{array}$ & $\begin{array}{l}27.0 \\
27.0 \\
26.0 \\
25.0 \\
26.0\end{array}$ & $\begin{array}{l}29.0 \\
28.0 \\
26.0 \\
28.0 \\
26.0\end{array}$ & $\begin{array}{l}28.0 \\
26.0 \\
28.0 \\
26.0 \\
26.0\end{array}$ \\
\hline $\begin{array}{l}16 \\
17 \\
18 \\
19 \\
20\end{array}$ & $\begin{array}{l}27.0 \\
26.0 \\
28.0 \\
28.0 \\
28.0\end{array}$ & $\begin{array}{l}20.0 \\
22.0 \\
22.0 \\
22.0 \\
21.0\end{array}$ & $\begin{array}{l}19.0 \\
19.0 \\
20.0 \\
19.0 \\
19.0\end{array}$ & $\begin{array}{l}21.0 \\
19.0 \\
20.0 \\
18.0 \\
19.0\end{array}$ & $\begin{array}{l}22.0 \\
21.0 \\
20.0 \\
21.0 \\
19.0\end{array}$ & $\begin{array}{l}19.0 \\
19.0 \\
19.0 \\
20.0 \\
19.0\end{array}$ & $\begin{array}{l}27.0 \\
27.0 \\
27.0 \\
27.0 \\
26.0\end{array}$ & $\begin{array}{l}26.0 \\
27.0 \\
28.0 \\
27.0 \\
26.0\end{array}$ & $\begin{array}{l}27.0 \\
25.0 \\
27.0 \\
26.0 \\
29.0\end{array}$ & $\begin{array}{l}28.0 \\
26.0 \\
29.0 \\
26.0 \\
28.0\end{array}$ & $\begin{array}{l}26.0 \\
26.0 \\
30.0 \\
28.0 \\
26.0\end{array}$ & $\begin{array}{r}26.0 \\
20.0 \\
-27.0 \\
30.0\end{array}$ \\
\hline $\begin{array}{l}21 \\
22 \\
23 \\
24 \\
25\end{array}$ & $\begin{array}{l}28.0 \\
28.0 \\
28.0 \\
28.0 \\
27.0\end{array}$ & $\begin{array}{l}22.0 \\
22.0 \\
21.0 \\
22.0 \\
22.0\end{array}$ & $\begin{array}{l}19.0 \\
19.0 \\
19.0 \\
20.0 \\
20.0\end{array}$ & $\begin{array}{l}18.0 \\
18.0 \\
19.0 \\
19.0 \\
20.0\end{array}$ & $\begin{array}{l}18.0 \\
19.0 \\
19.0 \\
18.0 \\
18.0\end{array}$ & $\begin{array}{l}20.0 \\
20.0 \\
19.0 \\
21.0 \\
20.0\end{array}$ & $\begin{array}{l}26.0 \\
27.0 \\
26.0 \\
27.0 \\
27.0\end{array}$ & $\begin{array}{l}26.0 \\
27.0 \\
26.0 \\
26.0 \\
27.0\end{array}$ & $\frac{-}{26.0}$ & $\begin{array}{l}24.0 \\
28.0 \\
25.0 \\
28.0 \\
29.0\end{array}$ & $\begin{array}{l}26.0 \\
26.0 \\
26.0 \\
28.0\end{array}$ & $\begin{array}{l}28.0 \\
29.0 \\
27.0 \\
30.0 \\
26.0\end{array}$ \\
\hline $\begin{array}{l}26 \\
27 \\
28 \\
29 \\
30 \\
31\end{array}$ & $\begin{array}{l}27.0 \\
27.0 \\
27.0 \\
26.0 \\
27.0 \\
27.0\end{array}$ & $\begin{array}{l}21.0 \\
22.0 \\
21.0 \\
20.0 \\
20.0 \\
\end{array}$ & $\begin{array}{l}20.0 \\
19.0 \\
20.0 \\
20.0 \\
21.0 \\
20.0\end{array}$ & $\begin{array}{l}20.0 \\
20.0 \\
21.0 \\
21.0 \\
20.0 \\
20.0\end{array}$ & $\begin{array}{r}19.0 \\
20.0 \\
\ldots \\
\ldots\end{array}$ & $\begin{array}{l}20.0 \\
24.0 \\
25.0 \\
25.0 \\
26.0 \\
26.0\end{array}$ & $\begin{array}{l}28.0 \\
29.0 \\
30.0 \\
28.0 \\
27.0 \\
\end{array}$ & $\begin{array}{l}26.0 \\
26.0 \\
24.0 \\
25.0 \\
25.0 \\
26.0\end{array}$ & $\begin{array}{l}26.0 \\
29.0 \\
25.0 \\
26.0 \\
25.0 \\
\end{array}$ & $\begin{array}{l}29.0 \\
30.0 \\
28.0 \\
30.0 \\
28.0 \\
29.0\end{array}$ & $\begin{array}{l}26.0 \\
29.0 \\
28.0 \\
29.0 \\
26.0 \\
26.0\end{array}$ & $\begin{array}{r}26.0 \\
30.0 \\
29.0 \\
28.0 \\
29.0 \\
-\end{array}$ \\
\hline AVERAGE & 27.5 & 23.0 & 19.5 & 19.5 & 18.5 & 20.5 & 26.0 & 26.5 & -- & 27.5 & 27.5 & 27.0 \\
\hline
\end{tabular}

02286400 MIAMI CANAL AT HGS-3 and S-3, AT LAKE HARBOR, FLA.

LOCATION.--Lat $26^{\circ} 41^{\prime} 55^{\prime \prime}$, long $80^{\circ} 48^{\prime} 25^{\prime \prime}$, in SE $\frac{1}{4}$ sec.35, T.43 S., R.35 E., Palm Beach County, at gaging station at hurricane gate structure 3 and pump station 3 at Lake Okeechobee, 0.4 mile upstream from U. S. Highway 27 , in Lake Harbor.

DRAINAGE AREA.--Indeterminate.

PERIOD OF RECORD.--Chemical analyses: October 1953 to September 1970.

Water temperatures: January 1968 to September 1970.

EXTREMES. $-1969-70$ :

Specific conductance: Maximum daily, 1,470 micromhos Oct. 12; minimum daily, 445 micromhos May 13.

water temperatures: Haximum, $29.0^{\circ} \mathrm{C}$ on several days during June, July and September; minimum, $10.0^{\circ} \mathrm{C}$ Jan. 10.

Period of record:

Specific conductance (1965-70): Maximum daily, 1,630 micromhos Oct. 28, 1968; minimum da11y, 445 micromhos

Way 13, 1970. to September 1970; minimum, $7.0^{\circ} \mathrm{C}$ Feb. 15,1968 .

CHEMICAL ANALYSES, WATER YEAR OCTOBER 1969 TO SEPTEMBER 1970 (MAJOR CONSTITUENTS)

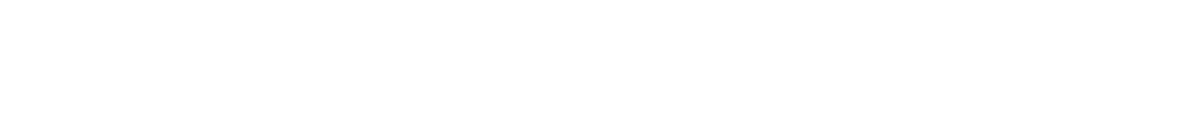

\begin{tabular}{|c|c|c|c|c|c|c|c|c|c|c|c|c|}
\hline OCT., & 1969 & -- & 840 & 70 & 80 & 26 & -- & 66 & 4.3 & 252 & 0 & 7.7 \\
\hline $19 .$. & 476 & 26.5 & 490 & -- & 45 & 12 & 700 & 33 & 2.7 & 154 & 0 & 8.1 \\
\hline Ol... & .00 & 28.5 & 1100 & -- & 124 & 32 & -- & 80 & 4.8 & 424 & 20 & 8.5 \\
\hline $22 \ldots$ & .00 & 28.0 & 940 & -- & 78 & 28 & -- & 82 & 4.2 & 278 & 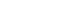 & 8.2 \\
\hline DATE & $\begin{array}{l}\text { D1S- } \\
\text { SOLVED } \\
\text { SULFATE } \\
\text { (SO4) } \\
\text { (MG/L) }\end{array}$ & $\begin{array}{l}\text { OIS- } \\
\text { SOLVED } \\
\text { CHLO- } \\
\text { RIDE } \\
\text { (CL) } \\
\text { (MG/L) }\end{array}$ & $\begin{array}{c}\text { DIS- } \\
\text { SOLVFO } \\
\text { FL:JU- } \\
\text { RIDE } \\
\text { (F) } \\
\text { (MG/L) }\end{array}$ & $\begin{array}{l}\text { HARD- } \\
\text { NESS } \\
\text { (CA,MG) } \\
\text { (MG/L) }\end{array}$ & $\begin{array}{l}\text { NON- } \\
\text { CAR- } \\
\text { RONATE } \\
\text { HARD- } \\
\text { NESS } \\
\text { (MG/L) }\end{array}$ & $\begin{array}{l}\text { ALKA- } \\
\text { LINITY } \\
\text { AS } \\
\text { CACO3 } \\
\text { (MG/L) }\end{array}$ & $\begin{array}{l}\text { OIS- } \\
\text { SOLVED } \\
\text { SOLIDS } \\
\text { (QESI- } \\
\text { DUE AT } \\
\text { I\&O C) } \\
\text { (MG/L) }\end{array}$ & $\begin{array}{l}\text { DIS- } \\
\text { SULVED } \\
\text { SOLIDS } \\
\text { (SUM OF } \\
\text { CONST T- } \\
\text { TUENTS) } \\
\text { (MG/L) }\end{array}$ & $\begin{array}{l}\text { DIS- } \\
\text { SOLVED } \\
\text { SOL IDS } \\
\text { (TONS } \\
\text { PER } \\
\text { DAY) }\end{array}$ & $\begin{array}{l}\text { DIS- } \\
\text { SOL VFD } \\
\text { SOL IDS } \\
\text { ITONS } \\
\text { PER } \\
\text { AC-FT I }\end{array}$ & $\begin{array}{l}\text { TANNIN } \\
\text { AND } \\
\text { LIGNIN } \\
\text { (MG/L) }\end{array}$ & $\begin{array}{l}\text { DEPTH } \\
\text { (FT) }\end{array}$ \\
\hline $\begin{array}{l}\text { OCT., } \\
24 \ldots . . \\
\text { MAY }\end{array}$ & $\begin{array}{ll}1969 & \\
19070\end{array}$ & 98 & .6 & 307 & 100 & 20 & 569 & 498 & - & .77 & -- & - \\
\hline JULY & 41 & 48 & .4 & 163 & 37 & 126 & 327 & 265 & 420 & .44 & -- & -- \\
\hline $\begin{array}{l}01 . . \\
\text { SEP. }\end{array}$ & 100 & 110 & .8 & 441 & 60 & 381 & 792 & 700 & .00 & 1.08 & -- & - \\
\hline $22 \ldots$ & 96 & 112 & .6 & 310 & 82 & 228 & 638 & 555 & .00 & .87 & -- & -- \\
\hline
\end{tabular}




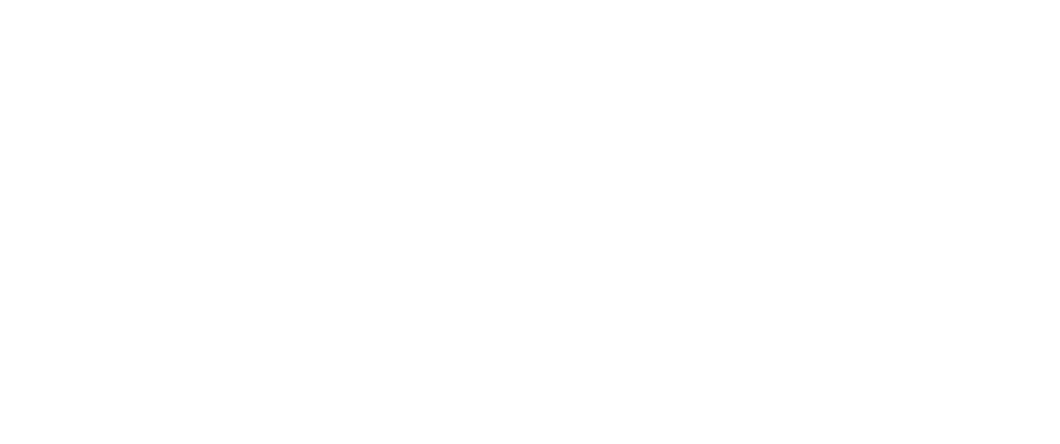

SPECIFIC CONDUCTANCE (MICROMHOS/CM AT $25^{\circ} \mathrm{C}$ ), WATER YEAR OCTOBER 1969 TO SEPTEMBER 1970

\begin{tabular}{|c|c|c|c|c|c|c|c|c|c|c|c|c|}
\hline DAY & OCT & NOV & DEC & JAN & FEB & MAR & APR & MAY & JUN & JUL & AUG & SEP \\
\hline $\begin{array}{l}1 \\
2 \\
3 \\
4 \\
5\end{array}$ & $\begin{array}{l}1200 \\
1150 \\
1200 \\
1150 \\
1270\end{array}$ & $\begin{array}{r}1080 \\
990 \\
1050 \\
1100 \\
1020\end{array}$ & $\begin{array}{l}940 \\
890 \\
750 \\
815 \\
840\end{array}$ & $\begin{array}{r}830 \\
830 \\
820 \\
1100 \\
1100\end{array}$ & $\begin{array}{r}670 \\
525 \\
615 \\
1200 \\
675\end{array}$ & $\begin{array}{l}495 \\
495 \\
505 \\
465 \\
495\end{array}$ & $\begin{array}{l}550 \\
750 \\
800 \\
850 \\
750\end{array}$ & $\begin{array}{l}605 \\
648 \\
652 \\
658 \\
750\end{array}$ & $\begin{array}{r}1040 \\
1000 \\
980 \\
920 \\
1020\end{array}$ & $\begin{array}{r}1050 \\
1050 \\
1000 \\
1000 \\
990\end{array}$ & $\ddot{--}$ & $\begin{array}{l}1030 \\
1050 \\
1050 \\
1070 \\
1000\end{array}$ \\
\hline $\begin{array}{r}6 \\
7 \\
8 \\
9 \\
10\end{array}$ & $\begin{array}{r}1150 \\
1150 \\
1150 \\
820 \\
1350\end{array}$ & $\begin{array}{l}960 \\
950 \\
500 \\
900 \\
930\end{array}$ & $\begin{array}{l}825 \\
850 \\
900 \\
870 \\
850\end{array}$ & $\begin{array}{l}490 \\
480 \\
495 \\
460 \\
500\end{array}$ & $\begin{array}{l}--- \\
690 \\
640 \\
025 \\
540\end{array}$ & $\begin{array}{l}548 \\
520 \\
790 \\
935 \\
900\end{array}$ & $\begin{array}{l}950 \\
780 \\
900 \\
960 \\
980\end{array}$ & $\begin{array}{l}700 \\
595 \\
680 \\
495 \\
451\end{array}$ & $\begin{array}{r}880 \\
1050 \\
1030 \\
1060 \\
1100\end{array}$ & $\begin{array}{r}940 \\
1040 \\
1030 \\
1230 \\
970\end{array}$ & 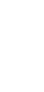 & $\begin{array}{l}1000 \\
1010 \\
1010 \\
1020 \\
1000\end{array}$ \\
\hline $\begin{array}{l}11 \\
12 \\
13 \\
14 \\
15\end{array}$ & $\begin{array}{r}890 \\
1470 \\
1370 \\
890 \\
870\end{array}$ & $\begin{array}{r}910 \\
850 \\
880 \\
1110 \\
1150\end{array}$ & $\begin{array}{r}1000 \\
1050 \\
940 \\
940 \\
900\end{array}$ & $\begin{array}{l}620 \\
490 \\
525 \\
550 \\
760\end{array}$ & $\begin{array}{l}540 \\
540 \\
540 \\
540 \\
825\end{array}$ & $\begin{array}{l}930 \\
775 \\
755 \\
874 \\
875\end{array}$ & $\begin{array}{r}940 \\
930 \\
1000 \\
960 \\
970\end{array}$ & $\begin{array}{l}455 \\
455 \\
445 \\
460 \\
470\end{array}$ & $\begin{array}{l}1080 \\
1050 \\
1030 \\
1130 \\
1000\end{array}$ & $\begin{array}{l}900 \\
910 \\
850 \\
850 \\
850\end{array}$ & 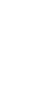 & $\begin{array}{r}980 \\
1000 \\
990 \\
1020 \\
980\end{array}$ \\
\hline $\begin{array}{l}16 \\
17 \\
18 \\
19 \\
20\end{array}$ & $\begin{array}{r}980 \\
1390 \\
700 \\
970 \\
660\end{array}$ & $\begin{array}{r}950 \\
1000 \\
1000 \\
975 \\
970\end{array}$ & $\begin{array}{l}850 \\
860 \\
920 \\
990 \\
910\end{array}$ & $\begin{array}{r}1080 \\
570 \\
710 \\
620 \\
560\end{array}$ & $\begin{array}{l}540 \\
560 \\
550 \\
570 \\
525\end{array}$ & $\begin{array}{r}884 \\
965 \\
985 \\
1040 \\
910\end{array}$ & $\begin{array}{l}800 \\
760 \\
760 \\
730 \\
740\end{array}$ & $\begin{array}{l}490 \\
490 \\
460 \\
470 \\
450\end{array}$ & $\begin{array}{l}1020 \\
1050 \\
1300 \\
1000 \\
1070\end{array}$ & $\begin{array}{l}860 \\
910 \\
980 \\
960 \\
850\end{array}$ & $\ddot{--}$ & $\begin{array}{r}1070 \\
1020 \\
980 \\
980 \\
1010\end{array}$ \\
\hline $\begin{array}{l}21 \\
22 \\
23 \\
24 \\
25\end{array}$ & $\begin{array}{r}650 \\
820 \\
1010 \\
840 \\
660\end{array}$ & $\begin{array}{l}950 \\
950 \\
950 \\
920 \\
890\end{array}$ & $\begin{array}{l}925 \\
840 \\
860 \\
880 \\
800\end{array}$ & $\begin{array}{l}510 \\
490 \\
460 \\
495 \\
530\end{array}$ & $\begin{array}{l}525 \\
490 \\
480 \\
490 \\
495\end{array}$ & $\begin{array}{r}860 \\
935 \\
775 \\
1190 \\
580\end{array}$ & $\begin{array}{l}700 \\
710 \\
700 \\
750 \\
760\end{array}$ & $\begin{array}{l}560 \\
547 \\
452 \\
655 \\
655\end{array}$ & $\begin{array}{r}1040 \\
1030 \\
1040 \\
950 \\
940\end{array}$ & $\begin{array}{r}950 \\
920 \\
970 \\
1040 \\
830\end{array}$ & $\begin{array}{l}=- \\
=- \\
=-\end{array}$ & $\begin{array}{l}930 \\
900 \\
870 \\
910 \\
940\end{array}$ \\
\hline $\begin{array}{l}26 \\
27 \\
28 \\
29 \\
30 \\
31\end{array}$ & $\begin{array}{r}980 \\
800 \\
850 \\
950 \\
1010 \\
1350\end{array}$ & $\begin{array}{r}890 \\
950 \\
1100 \\
970 \\
940 \\
---\end{array}$ & $\begin{array}{l}900 \\
850 \\
800 \\
930 \\
875 \\
850\end{array}$ & $\begin{array}{r}500 \\
535 \\
540 \\
500 \\
550 \\
1100\end{array}$ & $\begin{array}{l}480 \\
530 \\
510 \\
-\cdots \\
--. \\
--\end{array}$ & $\begin{array}{r}1070 \\
530 \\
590 \\
765 \\
760 \\
800\end{array}$ & $\begin{array}{r}800 \\
1120 \\
710 \\
720 \\
100 \\
-\end{array}$ & $\begin{array}{l}790 \\
795 \\
795 \\
910 \\
880 \\
660\end{array}$ & $\begin{array}{r}950 \\
950 \\
1000 \\
1100 \\
1030 \\
\end{array}$ & $\begin{array}{r}910 \\
1130 \\
1010 \\
940 \\
1070 \\
1110\end{array}$ & $\begin{array}{l}=- \\
=-- \\
=-- \\
=-\end{array}$ & $\begin{array}{r}990 \\
1180 \\
1150 \\
990 \\
950 \\
-\end{array}$ \\
\hline IVERAGE & 1020 & 974 & 884 & 639 & 589 & 774 & 818 & 599 & 1030 & 971 & -- & 1000 \\
\hline
\end{tabular}

(TRACE METALS)

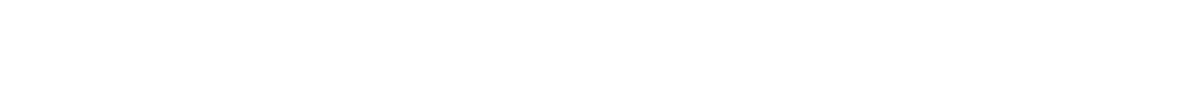


02286400 MIAMI CANAL AT HGS-3 and S-3, AT LAKE HARBOR, FLA.--Cont Inued

TEMPERATURE $\left({ }^{\circ} \mathrm{C}\right)$ OF WATER, WATER YEAR OCTOBER 1969 TO SEPTEMBER 1970

\begin{tabular}{|c|c|c|c|c|c|c|c|c|c|c|c|c|}
\hline DAY & $\mathrm{OCT}$ & NOV & DEC & JAN & FEB & MAR & $\triangle P R$ & MAY & JUN & JUL & AUG & SEP \\
\hline $\begin{array}{l}1 \\
2 \\
3 \\
4 \\
5\end{array}$ & $\begin{array}{l}28.0 \\
27.0 \\
27.0 \\
27.0 \\
28.0\end{array}$ & $\begin{array}{l}24.0 \\
24.0 \\
24.0 \\
23.0 \\
26.0\end{array}$ & $\begin{array}{l}19.0 \\
18.0 \\
18.0 \\
18.0 \\
18.0\end{array}$ & $\begin{array}{l}21.0 \\
21.0 \\
20.0 \\
17.0 \\
19.0\end{array}$ & $\begin{array}{l}19.0 \\
19.0 \\
20.0 \\
17.0 \\
17.0\end{array}$ & $\begin{array}{l}20.0 \\
20.0 \\
21.0 \\
21.0 \\
21.0\end{array}$ & $\begin{array}{l}27.0 \\
26.0 \\
26.0 \\
27.0 \\
25.0\end{array}$ & $\begin{array}{l}28.0 \\
27.0 \\
26.0 \\
27.0 \\
26.0\end{array}$ & $\begin{array}{l}27.0 \\
27.0 \\
27.0 \\
28.0 \\
27.0\end{array}$ & $\begin{array}{l}27.0 \\
28.0 \\
27.0 \\
29.0 \\
28.0\end{array}$ & $\begin{array}{l}-\infty \\
\cdots- \\
\cdots-\end{array}$ & $\begin{array}{l}28.0 \\
28.0 \\
27.0 \\
28.0 \\
28.0\end{array}$ \\
\hline $\begin{array}{r}6 \\
7 \\
8 \\
9 \\
10\end{array}$ & $\begin{array}{l}26.0 \\
26.0 \\
27.0 \\
26.0 \\
25.0\end{array}$ & $\begin{array}{l}21.0 \\
24.0 \\
20.0 \\
19.0 \\
21.0\end{array}$ & $\begin{array}{l}18.0 \\
19.0 \\
19.0 \\
20.0 \\
20.0\end{array}$ & $\begin{array}{l}18.0 \\
15.0 \\
14.0 \\
11.0 \\
10.0\end{array}$ & $\begin{array}{l}--- \\
16.0 \\
17.0 \\
17.0 \\
17.0\end{array}$ & $\begin{array}{l}22.0 \\
22.0 \\
22.0 \\
21.0 \\
22.0\end{array}$ & $\begin{array}{l}26.0 \\
20.0 \\
25.0 \\
25.0 \\
25.0\end{array}$ & $\begin{array}{l}26.0 \\
26.0 \\
28.0 \\
26.0 \\
25.0\end{array}$ & $\begin{array}{l}26.0 \\
27.0 \\
28.0 \\
27.0 \\
27.0\end{array}$ & $\begin{array}{l}28.0 \\
29.0 \\
28.0 \\
27.0 \\
28.0\end{array}$ & $\begin{array}{l}m \\
-- \\
-- \\
m\end{array}$ & $\begin{array}{l}28.0 \\
29.0 \\
28.0 \\
28.0 \\
28.0\end{array}$ \\
\hline $\begin{array}{l}11 \\
12 \\
13 \\
14 \\
15\end{array}$ & $\begin{array}{l}26.0 \\
26.0 \\
26.0 \\
26.0 \\
27.0\end{array}$ & $\begin{array}{l}20.0 \\
20.0 \\
22.0 \\
19.0 \\
19.0\end{array}$ & $\begin{array}{l}21.0 \\
19.0 \\
18.0 \\
16.0 \\
18.0\end{array}$ & $\begin{array}{l}11.0 \\
13.0 \\
12.0 \\
14.0 \\
15.0\end{array}$ & $\begin{array}{l}17.0 \\
17.0 \\
18.0 \\
18.0 \\
18.0\end{array}$ & $\begin{array}{l}22.0 \\
22.0 \\
22.0 \\
20.0 \\
20.0\end{array}$ & $\begin{array}{l}26.0 \\
27.0 \\
28.0 \\
27.0 \\
27.0\end{array}$ & $\begin{array}{r}27.0 \\
26.0 \\
27.0 \\
27.0\end{array}$ & $\begin{array}{l}27.0 \\
27.0 \\
26.0 \\
29.0 \\
27.0\end{array}$ & $\begin{array}{l}28.0 \\
28.0 \\
27.0 \\
27.0 \\
28.0\end{array}$ & $\begin{array}{l}-- \\
\cdots- \\
-- \\
--\end{array}$ & $\begin{array}{l}27.0 \\
27.0 \\
28.0 \\
27.0 \\
28.0\end{array}$ \\
\hline $\begin{array}{l}16 \\
17 \\
18 \\
19 \\
20\end{array}$ & $\begin{array}{l}27.0 \\
27.0 \\
26.0 \\
26.0 \\
26.0\end{array}$ & $\begin{array}{l}19.0 \\
19.0 \\
20.0 \\
20.0 \\
19.0\end{array}$ & $\begin{array}{l}17.0 \\
17.0 \\
18.0 \\
18.0 \\
19.0\end{array}$ & $\begin{array}{l}17.0 \\
19.0 \\
17.0 \\
18.0 \\
17.0\end{array}$ & $\begin{array}{l}21.0 \\
20.0 \\
21.0 \\
20.0 \\
20.0\end{array}$ & $\begin{array}{l}21.0 \\
19.0 \\
22.0 \\
25.0 \\
25.0\end{array}$ & $\begin{array}{l}27.0 \\
27.0 \\
26.0 \\
27.0 \\
27.0\end{array}$ & $\begin{array}{l}27.0 \\
28.0 \\
27.0 \\
27.0 \\
27.0\end{array}$ & $\begin{array}{l}27.0 \\
26.0 \\
28.0 \\
27.0 \\
28.0\end{array}$ & $\begin{array}{l}27.0 \\
29.0 \\
28.0 \\
29.0 \\
28.0\end{array}$ & 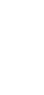 & $\begin{array}{l}27.0 \\
27.0 \\
27.0 \\
27.0 \\
27.0\end{array}$ \\
\hline $\begin{array}{l}21 \\
22 \\
23 \\
24 \\
25\end{array}$ & $\begin{array}{l}26.0 \\
26.0 \\
25.0 \\
25.0 \\
25.0\end{array}$ & $\begin{array}{r}19.0 \\
19.0 \\
20.0 \\
20.0\end{array}$ & $\begin{array}{l}19.0 \\
19.0 \\
18.0 \\
17.0 \\
21.0\end{array}$ & $\begin{array}{l}18.0 \\
17.0 \\
17.0 \\
17.0 \\
17.0\end{array}$ & $\begin{array}{l}19.0 \\
19.0 \\
20.0 \\
19.0 \\
\end{array}$ & $\begin{array}{l}24.0 \\
25.0 \\
23.0 \\
23.0 \\
22.0\end{array}$ & $\begin{array}{l}28.0 \\
28.0 \\
28.0 \\
28.0 \\
27.0\end{array}$ & $\begin{array}{l}26.0 \\
26.0 \\
25.0 \\
25.0 \\
25.0\end{array}$ & $\begin{array}{l}29.0 \\
28.0 \\
28.0 \\
28.0 \\
28.0\end{array}$ & $\begin{array}{l}28.0 \\
27.0 \\
28.0 \\
29.0 \\
28.0\end{array}$ & $\begin{array}{l}-\cdots \\
-- \\
\cdots- \\
-\cdots\end{array}$ & $\begin{array}{l}27.0 \\
28.0 \\
28.0 \\
27.0 \\
27.0\end{array}$ \\
\hline $\begin{array}{l}26 \\
27 \\
28 \\
29 \\
30 \\
31\end{array}$ & $\begin{array}{l}24.0 \\
24.0 \\
24.0 \\
25.0 \\
24.0 \\
24.0\end{array}$ & $\begin{array}{c}21.0 \\
21.0 \\
22.0 \\
20.0 \\
21.0 \\
\ldots .-\end{array}$ & $\begin{array}{l}20.0 \\
17.0 \\
18.0 \\
18.0 \\
18.0 \\
19.0\end{array}$ & $\begin{array}{l}19.0 \\
19.0 \\
20.0 \\
20.0 \\
21.0 \\
19.0\end{array}$ & $\begin{array}{r}19.0 \\
20.0 \\
19.0 \\
-0- \\
---\end{array}$ & $\begin{array}{l}24.0 \\
23.0 \\
24.0 \\
26.0 \\
27.0 \\
27.0\end{array}$ & $\begin{array}{l}28.0 \\
27.0 \\
27.0 \\
28.0 \\
28.0 \\
-.-\end{array}$ & $\begin{array}{c}27.0 \\
27.0 \\
26.0 \\
27.0 \\
26.0 \\
\ldots\end{array}$ & $\begin{array}{r}28.0 \\
28.0 \\
28.0 \\
29.0 \\
28.0 \\
-\end{array}$ & $\begin{array}{l}28.0 \\
29.0 \\
28.0 \\
28.0 \\
28.0 \\
28.0\end{array}$ & $\begin{array}{l}--- \\
--- \\
-- \\
-- \\
--\end{array}$ & $\begin{array}{r}27.0 \\
27.0 \\
26.0 \\
27.0 \\
27.0 \\
\ldots-\end{array}$ \\
\hline VERAGE & 26.0 & 21.0 & 18.5 & 17.0 & 18.5 & 22.5 & 27.0 & 26.5 & 27.5 & 28.0 & $\cdots$ & 27.5 \\
\hline
\end{tabular}

02287395 MIAMI CANAL EAST OF LEVEE 30, NEAR MIAMI, FLA.

LOCATION.--Lat $25^{\circ} 56^{\prime} 28^{\prime \prime}$, long $80^{\circ} 26^{\prime} 23^{\prime \prime}$, In NEt sec.9, T.52 S., R. 39 E., Dade County, at gaglng stat1on near center of span on upstream side of bridge on State Highway 27,200 ' $\mathrm{ft}$ downstream from control structure $32,14.1$ miles upstream from salinity control structure, 19.5 miles northwest of Mlams, and 19.8 miles upstream from mouth.

DRAINAGE AREA, - - Indeterminate.

PERIOD OF RECORD...-Chemical analyses: November 1958 to September 1970.

Water temperatures: November 1958 to September 1970.

EXTREMES. - - 1969-70:

Specific conductance: Maximum da1ly, 860 micromhos April 23; minimum da1ly, 218 micromhos Mar. 26, 27.

Water temperatures: Maximum, $34.5^{\circ} \mathrm{C} \mathrm{Apr}$. 3; minimum, 15, $0^{\circ} \mathrm{C} \mathrm{Mar}, 16$.

Period of record:

D1ssolved solids (1958-67): Naximum, $469 \mathrm{mg} / 1 \mathrm{Jan}, 21-31,1961 ; \mathrm{mln} 1 \mathrm{mum}, 258 \mathrm{mg} / 1 \mathrm{Jan}, 1-10,1965$.

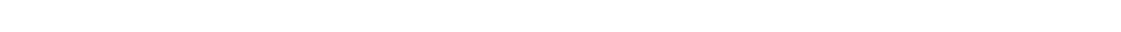

Spectifc 1970 .

Water temperatures: Maximum, $37.0^{\circ} \mathrm{C}$ June 24,1963 , Aug. 6, 27, 1967 ; min1mum, $15.0^{\circ} \mathrm{C} \mathrm{Mar.} 16,1970$.

\begin{tabular}{|c|c|c|c|c|c|c|c|c|c|c|c|c|}
\hline & & & CHEMICAL & ANALYSES & $\begin{array}{l}\text { - WATER } \\
\text { (MAJOF }\end{array}$ & $\begin{array}{l}\text { EAR OCTOID } \\
\text { CONSTITL }\end{array}$ & $\begin{array}{l}\text { ER } 1969 \\
\text { ENTSI }\end{array}$ & TO SEPTEM & IBER 1970 & & & \\
\hline JATE & $\begin{array}{l}\text { DIS- } \\
\text { CHARGE } \\
\text { (CFS) }\end{array}$ & $\begin{array}{l}\text { TEMPER- } \\
\text { ATURE } \\
\text { (DEG C) }\end{array}$ & $\begin{array}{l}\text { SPE- } \\
\text { CIFIC } \\
\text { CON- } \\
\text { DUCT- } \\
\text { ANCE } \\
\text { (MICRO- } \\
\text { MHOS) }\end{array}$ & $\begin{array}{l}\text { DIS- } \\
\text { SULVED } \\
\text { IRON } \\
(F E) \\
(U G / L)\end{array}$ & $\begin{array}{l}\text { UIS- } \\
\text { SOLVED } \\
\text { CAL- } \\
\text { CIUM } \\
(C A) \\
(M G / L)\end{array}$ & $\begin{array}{l}\text { DIS- } \\
\text { SOL VED } \\
\text { MAG- } \\
\text { NE- } \\
\text { SIUM } \\
\text { (MG) } \\
\text { (MG/L) }\end{array}$ & $\begin{array}{l}\text { DIS- } \\
\text { SOLVED } \\
\text { STRON- } \\
\text { TIUM } \\
\text { (SR) } \\
(U G / L)\end{array}$ & $\begin{array}{l}\text { OIS- } \\
\text { SOLVED } \\
\text { SODIUM } \\
\text { (NA) } \\
\text { (MG/L) }\end{array}$ & $\begin{array}{l}\text { DIC- } \\
\text { SOLVEO } \\
\text { PO- } \\
\text { TAS- } \\
\text { SI'IM } \\
\text { (K) } \\
\text { (MG/L) }\end{array}$ & $\begin{array}{l}\text { BICAR- } \\
\text { BONATE } \\
\text { (HCOZ) } \\
\text { (MG/L) }\end{array}$ & $\begin{array}{l}\text { CAR- } \\
\text { BONATE } \\
(C O 3) \\
\text { (MG/L) }\end{array}$ & $\begin{array}{c}\text { PH } \\
\text { (UNITS) }\end{array}$ \\
\hline $\begin{array}{l}\text { JAN., } \\
13 . . . \\
\text { MAY }\end{array}$ & -- & 19.0 & 590 & - & 71 & 11 & - & 38 & 1.2 & 258 & -- & 7.8 \\
\hline $\begin{array}{l}06 \ldots \\
15 \ldots\end{array}$ & $B 70$ & $\begin{array}{l}25.0 \\
25.0\end{array}$ & $\begin{array}{l}750 \\
730\end{array}$ & $=$ & $\begin{array}{l}67 \\
60\end{array}$ & $\begin{array}{l}17 \\
17\end{array}$ & $120 \overline{0}$ & $\begin{array}{l}63 \\
71\end{array}$ & $\begin{array}{l}1.9 \\
1.9\end{array}$ & $\begin{array}{l}268 \\
248\end{array}$ & $\overline{16}$ & $\begin{array}{l}7.7 \\
8.6\end{array}$ \\
\hline DATE & $\begin{array}{l}\text { DIS- } \\
\text { SOLVED } \\
\text { SULFATE } \\
\text { (SO\&) } \\
\text { (MG/L) }\end{array}$ & $\begin{array}{l}\text { DIS- } \\
\text { SOLVED } \\
\text { CHLO- } \\
\text { RIDE } \\
\text { (CL) } \\
\text { (MG/L) }\end{array}$ & $\begin{array}{l}\text { DIS- } \\
\text { SOLVFD } \\
\text { FLUO- } \\
\text { RIDE } \\
\text { (F) } \\
\text { (MG/L) }\end{array}$ & $\begin{array}{l}\text { HARO- } \\
\text { NESS } \\
\text { (CA,MG) } \\
(M G / L)\end{array}$ & $\begin{array}{l}\text { NON- } \\
\text { CAR- } \\
\text { RONATE } \\
\text { HARD- } \\
\text { NESS } \\
\text { (MG/L) }\end{array}$ & $\begin{array}{l}\text { ALKA- } \\
\text { LINITY } \\
\text { AS } \\
\text { CACO3 } \\
\text { (MG/L) }\end{array}$ & $\begin{array}{l}\text { IIS- } \\
\text { SOLVED } \\
\text { SOLIOS } \\
\text { RRESI- } \\
\text { DUE AT } \\
\text { ICO C) } \\
\text { (MG/L) }\end{array}$ & $\begin{array}{l}\text { DIS- } \\
\text { CULVEN } \\
\text { SOLIOS } \\
\text { (SUM OF } \\
\text { CONSTI- } \\
\text { TUENTS) } \\
\text { (MG/L) }\end{array}$ & $\begin{array}{l}\text { DIS- } \\
\text { SOLVED } \\
\text { SDLIDS } \\
\text { (TONS } \\
\text { PER } \\
\text { OAY) }\end{array}$ & $\begin{array}{l}\text { OIS- } \\
\text { SOLVFD } \\
\text { SOLIDS } \\
\text { (TONS } \\
\text { PER } \\
\text { AC-FT) }\end{array}$ & $\begin{array}{l}\text { TANNIN } \\
\text { AND } \\
\text { LIGNIN } \\
\text { (MG/L) }\end{array}$ & $\begin{array}{c}\text { DE. TH } \\
(F T)\end{array}$ \\
\hline $\begin{array}{l}\text { JAN., } \\
13 . . . \\
\text { MAY }\end{array}$ & $\cdot 4$ & 58 & .3 & 222 & 3 & 220 & 356 & $3>0$ & -- & .48 & -- & -- \\
\hline $\begin{array}{l}06 \ldots \\
15 \ldots\end{array}$ & $\begin{array}{l}17 \\
16\end{array}$ & $\begin{array}{l}93 \\
92\end{array}$ & .5 & $\begin{array}{l}237 \\
221\end{array}$ & $\begin{array}{r}18 \\
0\end{array}$ & $\begin{array}{l}22 n \\
230\end{array}$ & $\begin{array}{l}457 \\
442\end{array}$ & $\begin{array}{l}401 \\
409\end{array}$ & $1070 \ldots$ & $\begin{array}{l}.62 \\
.60\end{array}$ & $=$ & $=$ \\
\hline
\end{tabular}


02287395 MIAMI CANAL EAST OF LEVEE 30, NEAR MIAMI, FLA.--Continued

(MACRONUTRIENTS AND OTHER RELATED CONSTITUENTS)

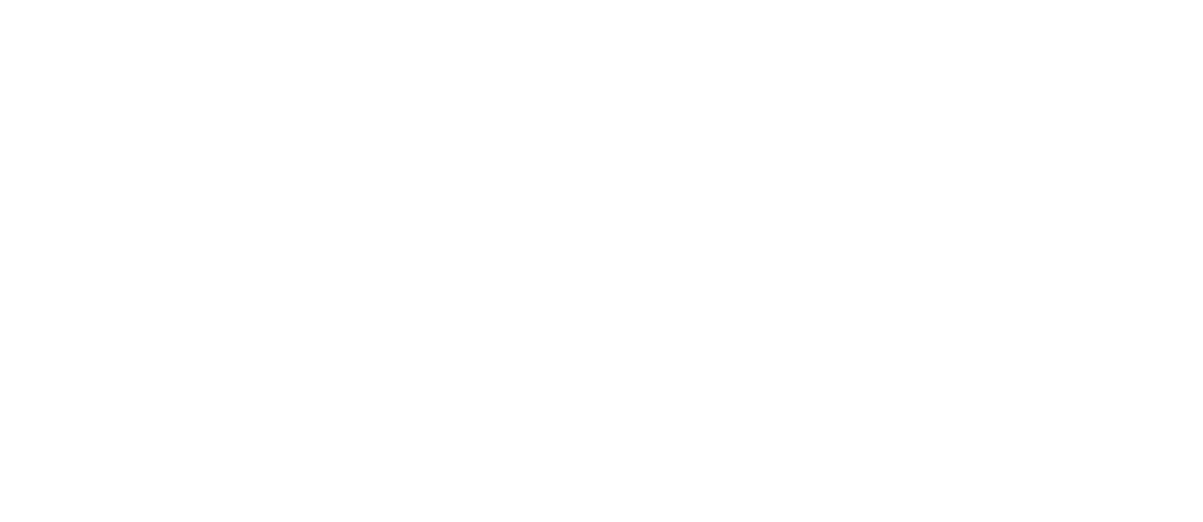

SPECIFIC CONDUCTANCE IMICROMHOS/CM AT $25^{\circ} \mathrm{C}$, WATER YEAR OCTOBER 1969 TO SEPTEMBER 1970

\begin{tabular}{|c|c|c|c|c|c|c|c|c|c|c|c|c|}
\hline OAY & DCT & NOV & DEC & $J A_{L}$. & FEB & MAR & APR & HAY & JUN & JUL & $A \cup G$ & SEP \\
\hline 1 & 603 & 550 & 550 & 600 & 580 & 575 & 750 & 750 & 651 & 590 & 625 & 565 \\
\hline 2 & 580 & 550 & 550 & 580 & 580 & 590 & 750 & 750 & 625 & 590 & 600 & 525 \\
\hline 3 & 590 & 540 & 550 & 575 & $\cdots$ & 590 & 760 & 680 & 610 & 590 & 620 & 565 \\
\hline 4 & 590 & 540 & 550 & 580 & -- & 600 & 760 & 680 & 600 & 600 & 610 & 565 \\
\hline 5 & 590 & 530 & 550 & 580 & 580 & 380 & 760 & 675 & 600 & 600 & 610 & 555 \\
\hline 6 & 560 & 550 & 550 & 580 & 580 & 375 & 760 & 680 & 610 & 600 & 615 & $57 \mathrm{C}$ \\
\hline 7 & 553 & 580 & 550 & 580 & 580 & 375 & 760 & 670 & 600 & 600 & 615 & 575 \\
\hline 8 & $-\cdots$ & 540 & 550 & 585 & 580 & 375 & 750 & 670 & 625 & 590 & 610 & 565 \\
\hline 9 & 564 & 540 & 550 & 585 & 575 & 378 & 160 & 650 & 610 & 600 & 615 & 575 \\
\hline 10 & $\cdots$ & 550 & 500 & 575 & 575 & 450 & 760 & 675 & 625 & 600 & 615 & 565 \\
\hline 11 & 587 & 550 & 550 & 570 & 580 & 450 & $-\ldots$ & 070 & 620 & 590 & 600 & 570 \\
\hline 12 & $\cdots$ & 550 & 550 & 580 & 590 & 255 & 790 & 675 & $\cdots$ & 600 & 620 & $\cdots$ \\
\hline 13 & $\cdots$ & 540 & 550 & 580 & 585 & 255 & 790 & 670 & $-\cdots$ & 600 & 615 & 565 \\
\hline 14 & 591 & 550 & 550 & 580 & 580 & 350 & 800 & 675 & -- & 600 & 620 & 565 \\
\hline I5 & 592 & 550 & 550 & 580 & 575 & 380 & 800 & 675 & -- & 590 & 590 & 555 \\
\hline 16 & 594 & $\cdots$ & 550 & 580 & 580 & 420 & 800 & 670 & $m$ & 600 & 595 & 560 \\
\hline 17 & 594 & 550 & 550 & 580 & 580 & 450 & Boo & 670 & -- & 600 & 615 & 545 \\
\hline 18 & $\cdots$ & 550 & 560 & 570 & 585 & 450 & 750 & 630 & $\ldots$ & $\ldots$ & 615 & 565 \\
\hline 19 & 569 & 550 & 550 & 575 & 590 & 450 & 850 & 630 & -- & $\cdots$ & 610 & 575 \\
\hline 20 & 564 & 550 & 550 & 580 & 580 & 455 & 850 & 640 & $-\infty$ & $\cdots$ & 610 & 565 \\
\hline 21 & 589 & 550 & 560 & 575 & 585 & 490 & -- & 635 & $-\cdots$ & -- & 610 & 565 \\
\hline 22 & 580 & 560 & 560 & $\cdots$ & 580 & 490 & 850 & 640 & -- & -- & 605 & 555 \\
\hline 23 & $\cdots$ & 560 & 560 & -- & 590 & 475 & 860 & -- & 650 & 810 & 605 & 565 \\
\hline 24 & 574 & 550 & 560 & -- & 590 & 490 & 800 & $=$ & 650 & 740 & 600 & 565 \\
\hline 25 & 580 & 550 & 560 & --- & 590 & 510 & 800 & - & 600 & 740 & 605 & 560 \\
\hline 26 & 590 & 550 & 520 & -- & 550 & 218 & -- & $\cdots$ & 610 & 590 & 610 & 565 \\
\hline 27 & 584 & 540 & 560 & $\cdots$ & 590 & 218 & -- & -- & 649 & 590 & 605 & 555 \\
\hline 28 & 579 & 550 & 550 & -- & 550 & 230 & 760 & -- & 600 & 570 & 605 & 565 \\
\hline 29 & 556 & 550 & 570 & - & $\cdots$ & 330 & 800 & -- & 640 & 600 & 600 & 555 \\
\hline 30 & 555 & 550 & 570 & 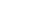 & - & 350 & 800 & -- & 625 & 580 & 585 & 565 \\
\hline 31 & $\cdots$ & -- & 675 & $\cdots$ & --- & -- & -- & $-\ldots$ & $\cdots$ & $\cdots$ & 600 & $\cdots$ \\
\hline VERAGE & -- & 549 & 557 & -- & 582 & 413 & $7 B 7$ & $m$ & $m$ & 614 & 608 & 562 \\
\hline
\end{tabular}

(ORGANOCHLORIDE COMPOUNDS IN WATER,

\begin{tabular}{|c|c|c|c|c|c|c|c|c|c|c|c|}
\hline & & $\begin{array}{l}\text { CHLOR- } \\
\text { DAINE }\end{array}$ & & & DDT & ELORIN & & $\begin{array}{l}\text { HFPTA- } \\
\text { CHLOR }\end{array}$ & $\begin{array}{l}\text { HEPTA- } \\
\text { CHLOR } \\
\text { EPOXIDE }\end{array}$ & LINDANE & $\begin{array}{l}\text { TOX- } \\
\text { APH :NE }\end{array}$ \\
\hline DATE & $(U G / L)$ & $(\cup G / L)$ & (UG/L) & $(U G / L)$ & (UG/L) & $(U ⿱ 一 ⿻ / 丨)$ & $(U G / L)$ & $(U G / L)$ & $(\mathrm{UG} / \mathrm{L})$ & (UG/L) & (UG.LL) \\
\hline
\end{tabular}

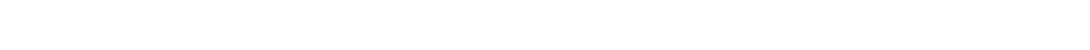

HERBICIDES AND ORGANOPHORUS INSECTIDES IN WATER AND SEDIMENT

\begin{tabular}{|c|c|c|c|c|c|c|c|}
\hline & & $2,4,5-1$ & SILVEX & $\begin{array}{l}O I- \\
A Z I N O N\end{array}$ & & $\begin{array}{l}\text { METHYL } \\
\text { PARA- }\end{array}$ & \\
\hline ATE & & $(U G / L)$ & & $(U G / L)$ & $\begin{array}{l}\text { THION } \\
\text { (UG/L) }\end{array}$ & $\begin{array}{l}\text { THION } \\
\text { (UG/L) }\end{array}$ & $\begin{array}{l}\text { THION } \\
\text { (UG/L) }\end{array}$ \\
\hline
\end{tabular}

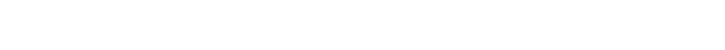


LAKE OKEECHOBEE AND THE EVERGLADES BASINS

02287395 MIAMI CANAL EAST OF LEVEE 30, NEAR YIAMI, FLA.--Continued

TEMPERATURE ( $\left.{ }^{\circ} \mathrm{C}\right)$ OF HATER, HATER YEAR OCTOBER 1969 TO SEPTEMBER 1970

\begin{tabular}{|c|c|c|c|c|c|c|c|c|c|c|c|c|}
\hline DAY & $\mathrm{CCT}$ & NOV & DEC & JAN & $F E B$ & $M A R$ & $A P R$ & MAY & JUN & NL & $A \cup G$ & SEP \\
\hline $\begin{array}{l}1 \\
2 \\
3 \\
4 \\
5\end{array}$ & $\begin{array}{l}31.0 \\
31.0 \\
24.0 \\
30.0 \\
29.0\end{array}$ & $\begin{array}{l}22.0 \\
22.0 \\
24.0 \\
24.0 \\
22.0\end{array}$ & $\begin{array}{l}19.0 \\
19.0 \\
19.0 \\
24.0 \\
24.0\end{array}$ & $\begin{array}{l}22.0 \\
20.0 \\
18.0 \\
19.0 \\
22.0\end{array}$ & $\begin{array}{r}18.0 \\
18.0 \\
-19.0 \\
19.0\end{array}$ & $\begin{array}{l}17.0 \\
16.0 \\
17.0 \\
18.0 \\
18.0\end{array}$ & $\begin{array}{l}30.0 \\
30.0 \\
34.5 \\
30.0 \\
25.0\end{array}$ & $\begin{array}{l}30.0 \\
28.0 \\
24.0 \\
25.0 \\
28.0\end{array}$ & $\begin{array}{l}26.0 \\
28.0 \\
28.0 \\
25.0 \\
25.0\end{array}$ & $\begin{array}{l}29.0 \\
28.0 \\
29.0 \\
29.0 \\
30.0\end{array}$ & $\begin{array}{l}26.5 \\
25.5 \\
25.5 \\
26.0 \\
26.0\end{array}$ & $\begin{array}{l}26.0 \\
26.0 \\
28.0 \\
28.0 \\
28.0\end{array}$ \\
\hline $\begin{array}{r}6 \\
7 \\
8 \\
9 \\
10\end{array}$ & $\begin{array}{r}30.0 \\
23.0 \\
28.0 \\
-. .\end{array}$ & $\begin{array}{l}22.0 \\
30.0 \\
24.0 \\
25.0 \\
24.0\end{array}$ & $\begin{array}{r}27.0 \\
27.0 \\
22.0 \\
23.0\end{array}$ & $\begin{array}{r}24.0 \\
-0.0 \\
25.0 \\
25.0 \\
25.0\end{array}$ & $\begin{array}{l}19.0 \\
23.0 \\
23.0 \\
21.0 \\
23.0\end{array}$ & $\begin{array}{l}19.0 \\
18.0 \\
19.0 \\
18.0 \\
18.0\end{array}$ & $\begin{array}{l}30.0 \\
31.0 \\
31.0 \\
32.0 \\
32.0\end{array}$ & $\begin{array}{l}28.0 \\
26.0 \\
25.0 \\
30.0 \\
25.0\end{array}$ & $\begin{array}{l}27.0 \\
26.0 \\
29.0 \\
29.0 \\
23.0\end{array}$ & $\begin{array}{l}30.0 \\
29.0 \\
30.0 \\
30.0 \\
27.0\end{array}$ & $\begin{array}{l}25.5 \\
25.5 \\
25.5 \\
26.5 \\
28.0\end{array}$ & $\begin{array}{l}28.0 \\
26.5 \\
30.0 \\
29.5 \\
27.0\end{array}$ \\
\hline $\begin{array}{l}11 \\
12 \\
13 \\
14 \\
15\end{array}$ & \begin{tabular}{r}
29.0 \\
\hdashline-2 \\
30.0 \\
30.0
\end{tabular} & $\begin{array}{l}26.0 \\
24.0 \\
24.0 \\
24.0 \\
24.0\end{array}$ & $\begin{array}{l}22.0 \\
18.0 \\
18.0 \\
24.0 \\
23.0\end{array}$ & $\begin{array}{l}20.0 \\
21.0 \\
20.0 \\
21.0 \\
22.0\end{array}$ & $\begin{array}{l}19.0 \\
23.0 \\
23.0 \\
21.0 \\
23.0\end{array}$ & $\begin{array}{l}18.0 \\
19.0 \\
19.0 \\
17.0 \\
16.0\end{array}$ & $\begin{array}{l}29.0 \\
30.0 \\
30.0 \\
29.0\end{array}$ & $\begin{array}{l}25.0 \\
23.0 \\
24.0 \\
26.0 \\
26.0\end{array}$ & $\begin{array}{c}24.0 \\
- \\
--- \\
---\end{array}$ & $\begin{array}{l}27.0 \\
29.0 \\
29.0 \\
28.0 \\
28.0\end{array}$ & $\begin{array}{l}26.5 \\
26.5 \\
27.0 \\
27.0 \\
26.0\end{array}$ & $\begin{array}{r}26.5 \\
26.5 \\
26.0 \\
26.5\end{array}$ \\
\hline $\begin{array}{l}16 \\
17 \\
18 \\
19 \\
20\end{array}$ & $\begin{array}{r}29.0 \\
28.0 \\
-1.0 \\
27.0 \\
27.0\end{array}$ & $\begin{array}{r}-13.0 \\
24.0 \\
24.0 \\
-\end{array}$ & $\begin{array}{r}23.0 \\
24.0 \\
24.0 \\
22.0 \\
-.-\end{array}$ & $\begin{array}{l}19.0 \\
19.0 \\
19.0 \\
19.0 \\
19.0\end{array}$ & $\begin{array}{l}23.0 \\
19.0 \\
19.0 \\
21.0 \\
20.0\end{array}$ & $\begin{array}{l}15.0 \\
18.0 \\
19.0 \\
20.0 \\
20.0\end{array}$ & $\begin{array}{l}29.0 \\
28.0 \\
29.0 \\
28.0 \\
29.0\end{array}$ & $\begin{array}{l}26.0 \\
25.0 \\
28.0 \\
28.0 \\
25.0\end{array}$ & $\begin{array}{l}-- \\
-\cdots \\
-\cdots \\
--\end{array}$ & $\begin{array}{r}29.0 \\
28.0 \\
\hdashline--\end{array}$ & $\begin{array}{l}26.5 \\
28.0 \\
28.0 \\
27.5 \\
28.0\end{array}$ & $\begin{array}{l}29.0 \\
26.5 \\
28.0 \\
27.0 \\
27.0\end{array}$ \\
\hline $\begin{array}{l}21 \\
22 \\
23 \\
24 \\
25\end{array}$ & $\begin{array}{r}24.0 \\
27.0 \\
29.0 \\
29.0\end{array}$ & $\begin{array}{r}--- \\
29.0 \\
29.0 \\
23.0 \\
23.0\end{array}$ & $\begin{array}{l}25.0 \\
22.0 \\
27.0 \\
27.0 \\
21.0\end{array}$ & \begin{tabular}{r}
19.0 \\
\hdashline- \\
\hdashline- \\
-
\end{tabular} & $\begin{array}{l}19.0 \\
19.0 \\
19.0 \\
19.0 \\
20.0\end{array}$ & $\begin{array}{l}22.0 \\
22.0 \\
18.0 \\
19.0 \\
18.0\end{array}$ & $\begin{array}{l}--.0 \\
29.0 \\
30.0 \\
30.0 \\
27.0\end{array}$ & $\begin{array}{r}25.0 \\
29.0 \\
- \\
-\end{array}$ & $\begin{array}{r}25.0 \\
25.0 \\
29.0\end{array}$ & $\begin{array}{r}--0 \\
29.0 \\
29.0 \\
29.0\end{array}$ & $\begin{array}{l}28.0 \\
28.0 \\
27.0 \\
27.0 \\
27.5\end{array}$ & $\begin{array}{l}25.5 \\
28.0 \\
26.5 \\
25.0 \\
27.0\end{array}$ \\
\hline $\begin{array}{l}26 \\
27 \\
28 \\
29 \\
30 \\
31\end{array}$ & $\begin{array}{r}29.0 \\
30.0 \\
30.0 \\
26.0 \\
26.0 \\
-.-\end{array}$ & $\begin{array}{r}24.0 \\
23.0 \\
18.0 \\
22.0 \\
22.0 \\
\ldots\end{array}$ & $\begin{array}{l}24.0 \\
25.0 \\
25.0 \\
28.0 \\
29.0 \\
26.5\end{array}$ & $\begin{array}{l}--- \\
-- \\
-- \\
-- \\
--\end{array}$ & $\begin{array}{r}20.0 \\
19.0 \\
19.0 \\
\\
- \\
-\end{array}$ & $\begin{array}{r}18.0 \\
18.0 \\
21.0 \\
22.0 \\
23.0 \\
\ldots .0\end{array}$ & $\begin{array}{l}-.- \\
30.0 \\
20.0 \\
24.0 \\
-\ldots\end{array}$ & 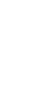 & $\begin{array}{r}28.0 \\
25.0 \\
25.0 \\
28.0 \\
27.0 \\
. .-\end{array}$ & $\begin{array}{r}30.0 \\
29.0 \\
30.0 \\
38.0 \\
38.0 \\
-.0\end{array}$ & $\begin{array}{l}29.0 \\
29.0 \\
25.5 \\
25.5 \\
26.5 \\
26.5\end{array}$ & $\begin{array}{r}28.0 \\
28.0 \\
28.0 \\
26.5 \\
26.5 \\
-.-\end{array}$ \\
\hline IVERAGE & --- & 24.0 & 23.5 & -- & 20.5 & 18.5 & 29.0 & -- & $-\cdots$ & 29.5 & 27.0 & 27.0 \\
\hline
\end{tabular}

02292000 CALOOSAHATChEE CANAL AT MOORE HAVEN, FLA.

LOCATION, - Lat $26^{\circ} 50^{\prime} 30^{\prime \prime}$, long $81^{\circ} 05^{\prime} 20^{\prime \prime}$, in sec, 12, T.42 S., R.32 E., Glades County, at gaging station in control house of control structure 77 at Lake Okeechobee outlet, and 15 miles upstream from 1 ock 2 .

DRAI NAGE AREA.--Indeterminate.

PERIOD OF RECORD.--Chemical analyses: July 1964 to September 1970.

Water temperatures: July 1964 to September 1970.

EXTREMES, - -1969-70:

Specific conductance: Maximum daily, 570 micromhos July 1; minimum daily, 200 micromhos Oct. 4.

Specific conductance: Maximum daily, 570 micromhos July 1 ; minimum daily, 200 micromhos Oct. 4 .
water temperatures: Maximum, $31.0^{\circ} \mathrm{C}$ on several days during June and July; minimum, 9.0 $0^{\circ} \mathrm{Can}$. io, 11.

Period of record:

Specific conductance: Maximum daily, 1,390 micromhos Feb. 12, 1969 ; minimum daily, 150 micromhos Sept. $28,1964$. Hater temperatures: baximum, $32.0^{\circ} \mathrm{C}$ on several days during July 1969; minimum, 9.0\% Jan. 10 , 11,1970 . CHEMICAL ANALYSES, WATER YEAR OCTOBER 1969 TO SEPTEMBER 1970

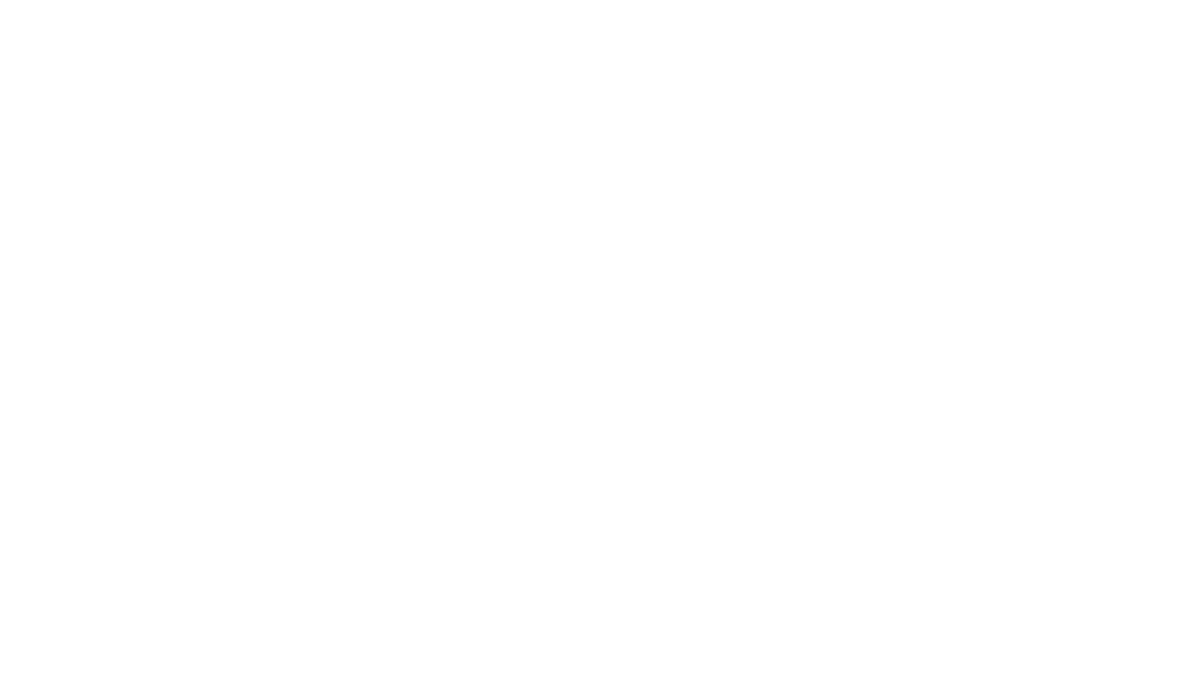




\begin{tabular}{|c|c|c|c|c|c|c|c|c|c|c|c|c|}
\hline & 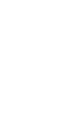 & $\begin{array}{l}\text { TOTAL } \\
\text { NITHT) } \\
\text { (NDO2) } \\
\text { (MG, })\end{array}$ & $\begin{array}{l}\text { TOTAL } \\
\text { NITHATE } \\
\text { (NOB) } \\
\text { (MG/L) }\end{array}$ & 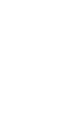 & 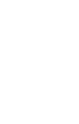 & $\begin{array}{l}\text { PHCS } \\
\text { PHATE } \\
\text { (PO4) } \\
\text { (MGILL) }\end{array}$ & $\begin{array}{l}\text { DIS- } \\
\text { SOLVED } \\
\text { SIICA } \\
\text { (S1OZI) } \\
\text { (SM/L) }\end{array}$ & $\begin{array}{l}\text { TUR- } \\
\text { HID } \\
\text { ITY } \\
\text { (JTU) }\end{array}$ & $\begin{array}{l}\text { COLOR } \\
\text { PPLAT- } \\
\text { INUM- } \\
\text { COBALT } \\
\text { ONITSI }\end{array}$ & 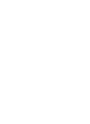 & 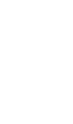 & $\begin{array}{c}\text { DEPTH } \\
\text { (FT) }\end{array}$ \\
\hline${ }^{c T .},{ }^{1969}$ & .16 & . & ${ }^{-n}$ & .98 & .07 & .10 & 8.8 & -- & 60 & - & -- & $=$ \\
\hline i.... & .06 & .06 & .3 & .83 & . 16 & .09 & 6.1 & $\cdots$ & $6 n$ & -- & -- & -- \\
\hline$\cdots$ & $\therefore$ & .n1 & .3 & - & . & . $\cap R$ & - & -- & -- & -- & -- & -- \\
\hline $\begin{array}{lll}31 \\
J N_{0}\end{array}$ & -- &.$n 1$ & .3 & -- & .04 & .09 & -- & -- & -- & -- & -- & -- \\
\hline $\begin{array}{l}14 \ldots \\
31 \ldots:\end{array}$ & $.1 \mathrm{I}$ & $: 01$ & $\stackrel{0}{:}$ & .85 & $\begin{array}{l}15 \\
: 0\end{array}$ & $: 11^{18}$ & 3.7 & $=$ & 80 & $\because$ & $=$ & $\therefore$ \\
\hline $28 . .$. & $=$ & $\begin{array}{l}: 06 \\
.07\end{array}$ & $: 5$ & $=$ & $\begin{array}{l}.01 \\
: 11\end{array}$ & $\begin{array}{r}.04 \\
: 14\end{array}$ & $\because$ & $=$ & $\because$ & $\because$ & $=$ & $\because$ \\
\hline & -- & .09 & 1.5 & -- & .26 & .28 & -- & -- & -- & -. & -- & -- \\
\hline 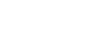 & .11 & 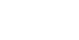 & $\stackrel{2}{2}$ & 1.2 & $\begin{array}{l}.05 \\
.02\end{array}$ & $\begin{array}{l}.09 \\
.11\end{array}$ & 6.1 & 22 & 60 & 20 & 2.4 & $=$ \\
\hline$\ldots$ & -- &.$n 2$ & 2.8 & -- & .11 & .16 & -- & -- & -- & -- & -- & -- \\
\hline & .80 & .03 & $\stackrel{.1}{1.4}$ & 1.2 & $\begin{array}{l}.09 \\
.10\end{array}$ & $\begin{array}{l}.21 \\
.15\end{array}$ & 7.7 & $\begin{array}{l}15 \\
--\end{array}$ & $=$ & $=$ & $=$ & $=$ \\
\hline SE, 22 & .14 & .05 & .4 & .45 & .1 & .18 & 3.8 & -- & 60 & -- & -- & -- \\
\hline
\end{tabular}

SPECIFIC CONDUCTANCE (MICROMHOS/CM AT $25^{\circ} \mathrm{C}$ ), WATER YEAR OCTOBER 1969 TO SEPTEMBER 1970

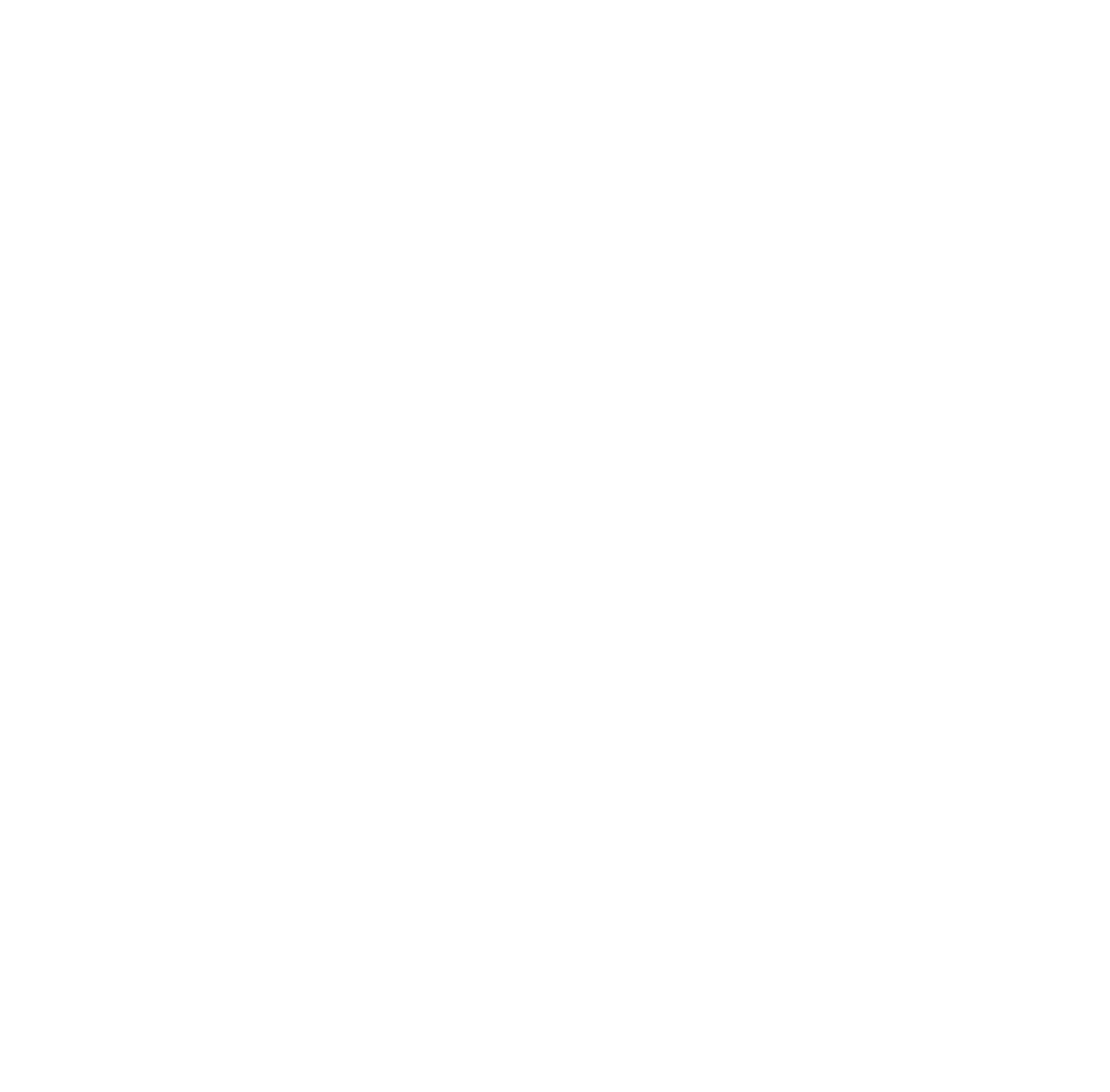


LAKE OKEECHOBEE AND THE EVERGLADES BASINS

02292000 CALOOSAHATCHEE CANAL AT MOORE HAVEN, FLA.---Continued

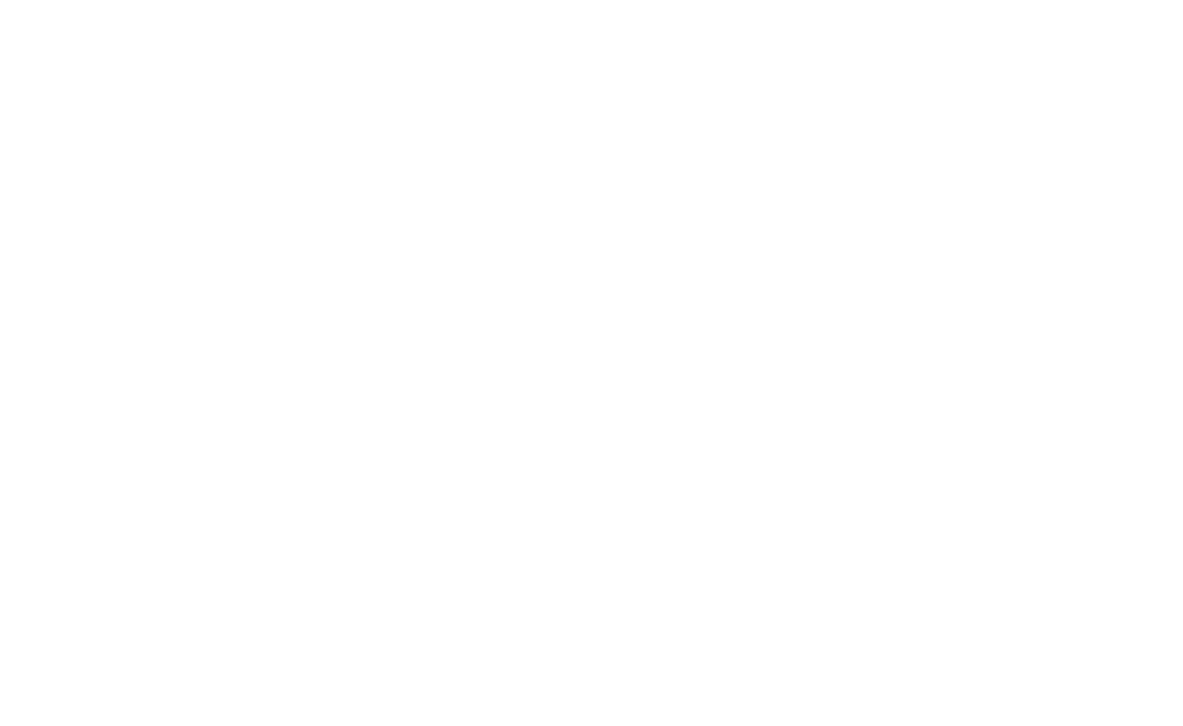

02295637 PEACE RIVER AT ZOLFO SPRINGS, FLA.

LOCATION.--Lat $27^{\circ} 30^{\prime} 15^{\prime \prime}$, Iong $81^{\circ} 48^{\prime} 04^{\prime \prime}$, in St sec.22, T.34 S., R.25 E., Hardee County, at gaging station near right bank on downstream side of bridge on U.S. Highway $17,0.8$ mile north of Zolfo Springs, and 69 miles upstream from
mouth.

DRA INAGE AREA. --826 sq $\mathrm{ml}$.

PERIOD OF RECORD.--Chemical analyses: September 1964 to September 1970.

Nater temperatures: September 1964 to September 1970.

EXTREMES. $--1969-70$ :

Fluoride: Maximum dally, $3.3 \mathrm{mg} / 1$ May 8 ; minimum daily, $0.9 \mathrm{mg} / 1$ Oct, 3, Jan. 7, Mar. 12, 27-29.

Phosphate: Maximum daily, $12 \mathrm{mg} / 1$ Hay 8 ; minimum daily, .63 mg/1 Apr, 13

Specific conductance: Maximum daily, 640 micromhos Apr. 12, 23; minimum dally, 115 micromhos Oct. 3.

pH: Maximum daily, 8.0 May $3,5,7$; minimum daily, 5.9 Jan. 8

Turbidity: Maximum da1ly, 25 JTU June 24 ; minimum daily, 0.0 JTU Feb, 17

Water temperatures: Maximum, $30.0^{\circ} \mathrm{C}$ on many days during June to August; minimum, $9.0^{\circ} \mathrm{C} \mathrm{Jan} .10$.

Period of record:

Fluortde: Kaximum daily, $5.3 \mathrm{mg} / 1$ Feb. 12, 13, 21, 1966; minimum daily, 0.1 June 14, 1968

Phosphate: Maximum daily, $32 \mathrm{mg} / 1$ Oct. 29,1968 ; minimum daily, $63 \mathrm{mg} / 1 \mathrm{Apr} .13,1970$.

Specific conductance: Maximum daily, 640 micromhos Apr. 12, 13, 1970; minimum daily, 68 micromhos Aug. $11,1965$.

Turbidty: Kaximum daily, $700 \mathrm{mg} / 1$ as silica Dec. 30, 1969; minimum daily, $0.0 \mathrm{mg} / 1$ as silica on many days during December and March 1968.

Water temperatures: Maximum, $31.0^{\circ} \mathrm{C}$ June 1,1965 , July 6,1966 , July $8,9,12,1969 ;$ minimum, $9.0^{\circ} \mathrm{C}$ Feb. 1 , 1966 , Jan, 10,1970 . CHEMICAL ANALYSES, WATER YEAR OCTOBER 1969 TO SEPTEMBER 1970

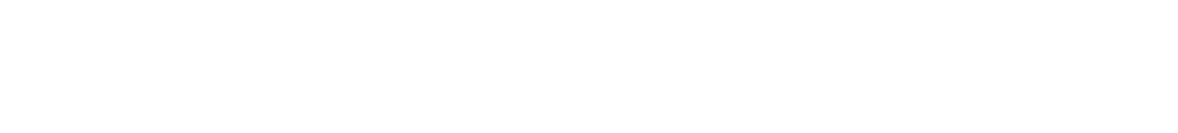

\begin{tabular}{|c|c|c|}
\hline $\begin{array}{r}\text { OCT. } \\
08 . \\
31 .\end{array}$ & $\begin{array}{r}1969 \\
18\end{array}$ & $=-$ \\
\hline nav. & & \\
\hline $21 \ldots$ & 812 & \\
\hline JAN., & 1970 & \\
\hline $\begin{array}{r}08 . . \\
\text { FEF. }\end{array}$ & 1400 & \\
\hline $\begin{array}{l}\text { FEF. } \\
17 . .\end{array}$ & & \\
\hline $\begin{array}{l}17 \ldots \\
\triangle P R\end{array}$ & 580 & \\
\hline $\begin{array}{r}\text { APR } \\
08 . .\end{array}$ & 937 & \\
\hline MAY & & \\
\hline 14. & 171 & \\
\hline
\end{tabular}

$\begin{array}{lllllll}25.0 & 188 & - & 18 & 6.4 & -. & 10 \\ 24.0 & 249 & - & - & - & - & 15 \\ 17.0 & 277 & - & 26 & 9.5 & - & 15 \\ 13.0 & 275 & -- & 26 & 11 & -- & 12 \\ 19.0 & 330 & -- & 33 & 11 & -- & 17 \\ 22.0 & 270 & -- & 25 & 8.5 & -- & 15 \\ 24.0 & 504 & -- & 52 & 18 & -- & 25\end{array}$

$\begin{array}{rrrr}1.9 & 38 & n & 7.1 \\ -. & -0 & -- & 7.2 \\ 7.2 & 56 & -- & 7.0 \\ 7.0 & 64 & 0 & 7.4 \\ 7.3 & \text { Bn } & -- & 7.8 \\ 2.1 & \text { 39 } & -- & 7.5 \\ 1.1 & 92 & 0 & 7.5\end{array}$


02295637 PEACE RIVER AT ZOLFO SPRINGS, FLA.--Cont1nued

CHEMICAL ANALYSES, WATER YEAR OCTOBER 1969 TO SEPTEMBER 1970 (MAJUR CONSTITUENTS)

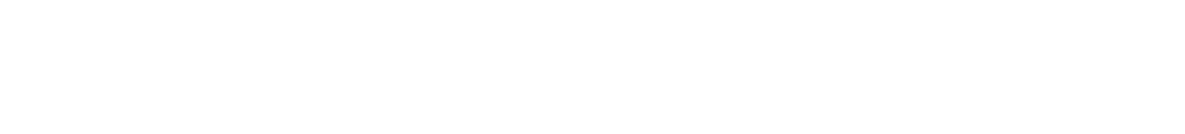

\begin{tabular}{|c|c|c|c|c|}
\hline $\begin{array}{l}0 \mathrm{0} r \ldots 1969 \\
08 \ldots . . \\
31 . \ldots\end{array}$ & 34 & ${ }^{10}$ & $\begin{array}{l}1.0 \\
1.4\end{array}$ & $\begin{array}{l}72 \\
--\end{array}$ \\
\hline NOV. & 53 & 16 & 1,1 & 104 \\
\hline JAN.. 1970 & & & & \\
\hline $\begin{array}{l}08 . . . \\
\text { FEB. }\end{array}$ & 52 & 16 & 1.1 & 110 \\
\hline $\begin{array}{l}17 \ldots . . \\
\text { APR. }\end{array}$ & 68 & 15 & 1.5 & 128 \\
\hline$\underset{\text { MAY }}{08 * \cdots}$ & 52 & 16 & 1.0 & 98 \\
\hline $14 \ldots$ & 150 & 13 & 2.5 & $2 \cap 4$ \\
\hline
\end{tabular}

$\begin{array}{rrrrrrrrr}40 & 31 & 153 & 115 & 7.56 & .21 & -- & -- \\ -- & -- & -- & -2 & -- & -- & - & - \\ 59 & 46 & 197 & 166 & 432 & .27 & -- & -- \\ 58 & 52 & 198 & 167 & 748 & .27 & -- & -- \\ 62 & 66 & 223 & 194 & 349 & .30 & -- & -- \\ 50 & 48 & 189 & 159 & 476 & .26 & -- & -- \\ 128 & 75 & 373 & 316 & 172 & .51 & -- & --\end{array}$

(FIELD MEASUREMENTS)

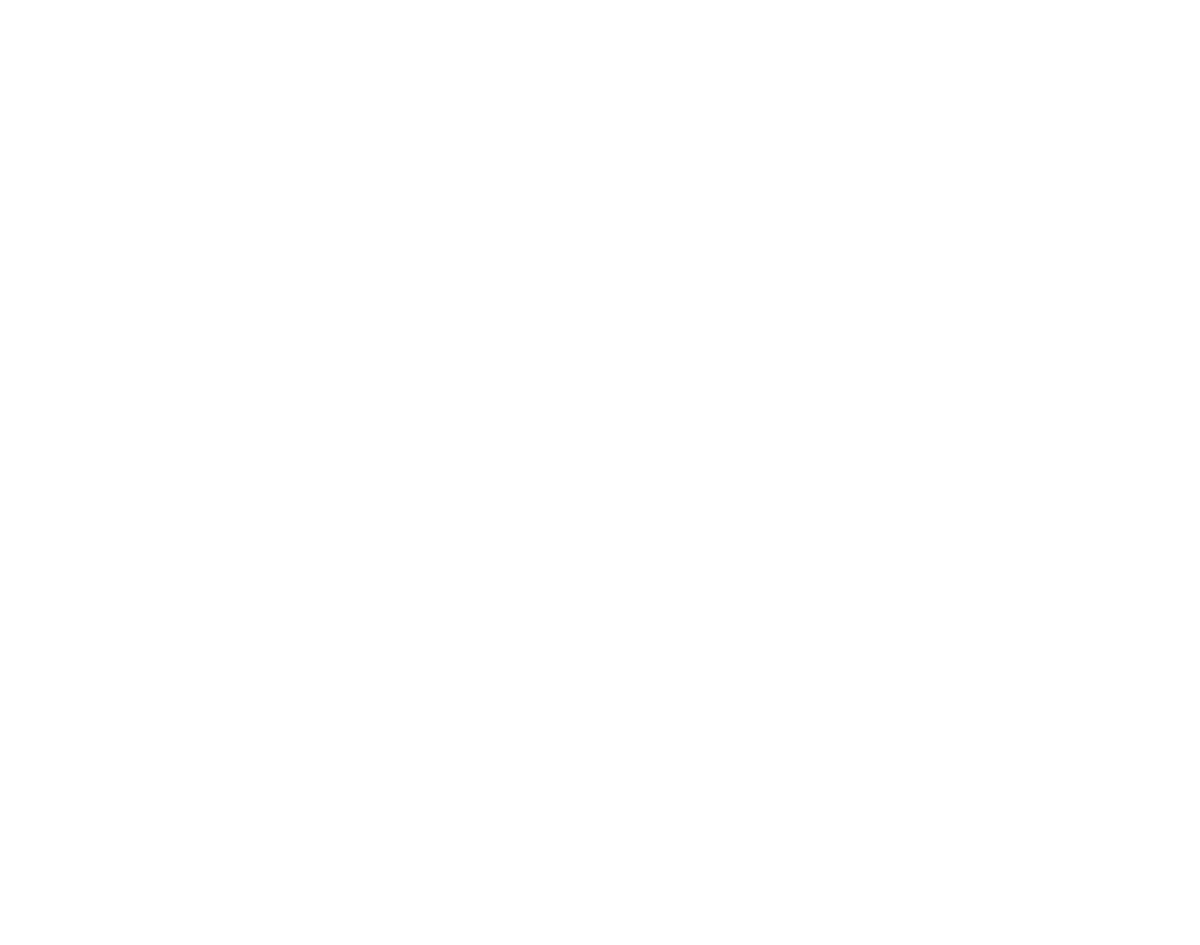


PEACE RI VER BASIN

02295637 PEACE RIVER AT ZOLFO SPRINGS, FLA.--Continued

PHOSPHATE, IN MILLIGRAMS PER LITER, OCTOBER 1969 TO SEPTEMBER 1970

\begin{tabular}{|c|c|c|c|c|c|c|c|c|c|c|c|c|}
\hline DAY & OCT & NoV & DEC & JAN & FEB & MAR & APR & MAY & JUN & JUt & AUG & SEP \\
\hline $\begin{array}{l}1 \\
2 \\
3 \\
4 \\
5\end{array}$ & $\begin{array}{l}5.5 \\
4.6 \\
4.6 \\
4.1 \\
4.1\end{array}$ & $\begin{array}{l}4.9 \\
5.1 \\
5.7 \\
7.0 \\
7.0\end{array}$ & $\begin{array}{l}9.3 \\
9.5 \\
9.3 \\
8.9 \\
9.0\end{array}$ & $\begin{array}{l}9.5 \\
7.3 \\
7.1 \\
7.1 \\
7.0\end{array}$ & $\begin{array}{l}10 \\
6.3 \\
4.4 \\
4.2 \\
6.1\end{array}$ & $\begin{array}{l}6.6 \\
8.1 \\
8.2 \\
8.0 \\
7.0\end{array}$ & $\begin{array}{l}5.6 \\
5.7 \\
6.5 \\
6.7 \\
5.9\end{array}$ & $\begin{array}{l}9.3 \\
8.8 \\
11 \\
10 \\
11\end{array}$ & $\begin{array}{l}5.4 \\
5.4 \\
5.9 \\
6.5 \\
4.3\end{array}$ & 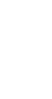 & 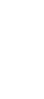 & $=$ \\
\hline $\begin{array}{r}6 \\
7 \\
8 \\
9 \\
10\end{array}$ & $\begin{array}{l}4.1 \\
4.1 \\
4.3 \\
4.4 \\
4.4\end{array}$ & $\begin{array}{l}7.0 \\
6.7 \\
6.1 \\
6.4 \\
5.6\end{array}$ & $\begin{array}{l}8.6 \\
8.1 \\
8.1 \\
7.2 \\
5.7\end{array}$ & $\begin{array}{l}6.3 \\
4.2 \\
4.8 \\
4.1 \\
4.1\end{array}$ & $\begin{array}{l}5.7 \\
3.7 \\
3.8 \\
3.8 \\
4.1\end{array}$ & $\begin{array}{l}7.0 \\
6.6 \\
5.7 \\
5.1 \\
6.3\end{array}$ & $\begin{array}{l}5.8 \\
5.6 \\
6.0 \\
6.6 \\
8.2\end{array}$ & $\begin{array}{l}11 \\
11 \\
12 \\
10 \\
9.2\end{array}$ & $\begin{array}{l}6.1 \\
5.9 \\
5.4 \\
6.5 \\
6.8\end{array}$ & $\begin{array}{l}=- \\
=- \\
=-\end{array}$ & $=$ & $=$ \\
\hline $\begin{array}{l}11 \\
12 \\
13 \\
14 \\
15\end{array}$ & $\begin{array}{l}4.6 \\
4.5 \\
5.2 \\
5.2 \\
5.6\end{array}$ & $\begin{array}{l}6.2 \\
6.4 \\
6.4 \\
4.2 \\
5.7\end{array}$ & $\begin{array}{l}4.6 \\
5.0 \\
4.8 \\
4.3 \\
4.4\end{array}$ & $\begin{array}{l}4.3 \\
4.4 \\
4.6 \\
4.4 \\
4.7\end{array}$ & $\begin{array}{l}4.2 \\
5.2 \\
6.3 \\
6.8 \\
6.8\end{array}$ & $\begin{array}{l}5.2 \\
3.8 \\
4.4 \\
4.5 \\
4.6\end{array}$ & $\begin{array}{c}7.6 \\
.72 \\
.63 \\
7.4 \\
7.4\end{array}$ & $\begin{array}{c}9.1 \\
9.7 \\
9.5 \\
10 \\
10\end{array}$ & $\begin{array}{l}6.8 \\
6.4 \\
7.5 \\
6.8 \\
6.5\end{array}$ & $\begin{array}{l}-- \\
-- \\
--\end{array}$ & $=$ & $\ddot{\cdots}$ \\
\hline $\begin{array}{l}16 \\
17 \\
18 \\
19 \\
20\end{array}$ & $\begin{array}{l}5.6 \\
4.9 \\
6.1 \\
4.8 \\
4.8\end{array}$ & $\begin{array}{l}5.7 \\
5.2 \\
4.4 \\
5.1 \\
4.1\end{array}$ & $\begin{array}{l}4.5 \\
5.4 \\
5.6 \\
5.1 \\
4.4\end{array}$ & $\begin{array}{l}4.7 \\
5.1 \\
5.8 \\
5.9 \\
5.6\end{array}$ & $\begin{array}{l}7.1 \\
7.6 \\
6.8 \\
9.0 \\
8.0\end{array}$ & $\begin{array}{l}4.6 \\
4.9 \\
5.2 \\
4.9 \\
4.9\end{array}$ & $\begin{array}{l}8.3 \\
8.2 \\
5.7 \\
6.9 \\
8.3\end{array}$ & $\begin{array}{l}9.8 \\
8.0 \\
4.1 \\
5.9 \\
7.7\end{array}$ & $\begin{array}{l}6.1 \\
7.1 \\
7.1 \\
6.6 \\
7.4\end{array}$ & $\begin{array}{l}=- \\
\ddot{--} \\
\square-\end{array}$ & $=$ & 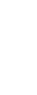 \\
\hline $\begin{array}{l}21 \\
22 \\
23 \\
24 \\
25\end{array}$ & $\begin{array}{l}5.6 \\
5.9 \\
5.4 \\
6.1 \\
5.6\end{array}$ & $\begin{array}{l}5.0 \\
4.9 \\
4.9 \\
5.9 \\
5.6\end{array}$ & $\begin{array}{l}4.8 \\
4.7 \\
4.6 \\
5.5 \\
5.8\end{array}$ & $\begin{array}{l}6.1 \\
5.7 \\
6.1 \\
7.0 \\
7.0\end{array}$ & $\begin{array}{l}7.1 \\
7.5 \\
7.1 \\
6.9 \\
1.1\end{array}$ & $\begin{array}{l}5.6 \\
6.3 \\
5.6 \\
6.0 \\
6.4\end{array}$ & $\begin{array}{c}9.5 \\
11 \\
9.5 \\
10 \\
9.0\end{array}$ & $\begin{array}{l}8.5 \\
9.3 \\
9.3 \\
9.5 \\
9.2\end{array}$ & $\begin{array}{l}8.1 \\
8.1 \\
8.5 \\
6.2 \\
6.1\end{array}$ & $\begin{array}{l}a- \\
m \\
m\end{array}$ & $\begin{array}{l}= \\
=- \\
=\end{array}$ & $=$ \\
\hline $\begin{array}{l}26 \\
27 \\
28 \\
29 \\
30 \\
31\end{array}$ & $\begin{array}{l}5.1 \\
6.5 \\
6.9 \\
6.4 \\
5.6 \\
5.4\end{array}$ & $\begin{array}{l}5.6 \\
7.1 \\
6.1 \\
6.5 \\
6.5 \\
-\ldots\end{array}$ & $\begin{array}{l}5.4 \\
4.8 \\
5.3 \\
5.4 \\
5.4 \\
5.5\end{array}$ & $\begin{array}{l}6.9 \\
7.0 \\
7.7 \\
6.6 \\
8.0 \\
6.4\end{array}$ & $\begin{array}{c}6.7 \\
7.8 \\
7.4 \\
- \\
- \\
-\end{array}$ & $\begin{array}{l}3.4 \\
3.9 \\
4.4 \\
5.2 \\
4.6 \\
5.1\end{array}$ & $\begin{array}{r}9.7 \\
8.4 \\
7.8 \\
7.9 \\
9.6 \\
-\end{array}$ & $\begin{array}{l}9.0 \\
9.1 \\
9.1 \\
6.7 \\
4.8 \\
5.9\end{array}$ & $\begin{array}{l}5.1 \\
5.1 \\
6.1 \\
6.6 \\
7.0 \\
\end{array}$ & 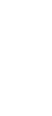 & $\ddot{=}$ & $=$ \\
\hline AVERAGE & 5.2 & 5.8 & 6.1 & 6.0 & 6.1 & 5.6 & 7.2 & 9.0 & 6.4 & $-\infty$ & $m$ & \\
\hline
\end{tabular}

SPECIFIC CONDUCTANCE (MICROMHOS/CM AT $25^{\circ} \mathrm{C}$ ), OCTOBER 1969 TO AUGUST 1970

\begin{tabular}{|c|c|c|c|c|c|c|c|c|c|c|c|c|}
\hline DAY & OCT & NoV & DEC & JAN & FEB & MAR & $A P R$ & MAY & JUN & JUL & AUE & SEP \\
\hline $\begin{array}{l}1 \\
2 \\
3 \\
4 \\
5\end{array}$ & $\begin{array}{l}200 \\
175 \\
115 \\
120 \\
135\end{array}$ & $\begin{array}{l}210 \\
240 \\
250 \\
250 \\
265\end{array}$ & $\begin{array}{l}335 \\
325 \\
325 \\
320 \\
310\end{array}$ & $\begin{array}{l}295 \\
305 \\
285 \\
285 \\
285\end{array}$ & $\begin{array}{l}335 \\
335 \\
235 \\
240 \\
265\end{array}$ & $\begin{array}{l}343 \\
364 \\
374 \\
385 \\
343\end{array}$ & $\begin{array}{l}215 \\
215 \\
221 \\
240 \\
249\end{array}$ & $\begin{array}{l}410 \\
405 \\
430 \\
430 \\
445\end{array}$ & $\begin{array}{l}275 \\
270 \\
260 \\
280 \\
178\end{array}$ & $\begin{array}{l}318 \\
309 \\
320 \\
230 \\
252\end{array}$ & $\begin{array}{l}203 \\
210 \\
235 \\
242 \\
245\end{array}$ & $\ddot{m}$ \\
\hline $\begin{array}{r}6 \\
7 \\
8 \\
9 \\
10\end{array}$ & $\begin{array}{l}145 \\
145 \\
175 \\
175 \\
179\end{array}$ & $\begin{array}{l}270 \\
275 \\
275 \\
275 \\
275\end{array}$ & $\begin{array}{l}315 \\
340 \\
340 \\
340 \\
280\end{array}$ & $\begin{array}{l}260 \\
205 \\
240 \\
235 \\
235\end{array}$ & $\begin{array}{l}265 \\
265 \\
275 \\
280 \\
345\end{array}$ & $\begin{array}{l}343 \\
311 \\
254 \\
250 \\
270\end{array}$ & $\begin{array}{l}250 \\
255 \\
269 \\
270 \\
280\end{array}$ & $\begin{array}{l}470 \\
470 \\
485 \\
485 \\
465\end{array}$ & $\begin{array}{l}242 \\
245 \\
280 \\
295 \\
310\end{array}$ & $\begin{array}{l}279 \\
273 \\
278 \\
273 \\
252\end{array}$ & $\begin{array}{l}253 \\
270 \\
273 \\
269 \\
270\end{array}$ & $\bar{m}$ \\
\hline $\begin{array}{l}11 \\
12 \\
13 \\
14 \\
15\end{array}$ & $\begin{array}{l}180 \\
225 \\
225 \\
220 \\
220\end{array}$ & $\begin{array}{l}279 \\
289 \\
300 \\
250 \\
230\end{array}$ & $\begin{array}{l}240 \\
240 \\
220 \\
220 \\
220\end{array}$ & $\begin{array}{l}250 \\
250 \\
252 \\
260 \\
270\end{array}$ & $\begin{array}{l}375 \\
320 \\
330 \\
335 \\
335\end{array}$ & $\begin{array}{l}281 \\
197 \\
203 \\
218 \\
234\end{array}$ & $\begin{array}{l}298 \\
640 \\
640 \\
321 \\
325\end{array}$ & $\begin{array}{l}465 \\
470 \\
485 \\
490 \\
480\end{array}$ & $\begin{array}{l}312 \\
325 \\
345 \\
340 \\
38 C\end{array}$ & $\begin{array}{l}200 \\
201 \\
190 \\
165 \\
179\end{array}$ & $\begin{array}{l}324 \\
337 \\
339 \\
286 \\
396\end{array}$ & $\begin{array}{l}\cdots \\
\square \\
\cdots\end{array}$ \\
\hline $\begin{array}{l}16 \\
17 \\
18 \\
19 \\
20\end{array}$ & $\begin{array}{l}220 \\
220 \\
245 \\
230 \\
230\end{array}$ & $\begin{array}{l}235 \\
245 \\
245 \\
245 \\
245\end{array}$ & $\begin{array}{l}235 \\
265 \\
260 \\
260 \\
265\end{array}$ & $\begin{array}{l}270 \\
270 \\
285 \\
285 \\
285\end{array}$ & $\begin{array}{l}355 \\
325 \\
340 \\
340 \\
355\end{array}$ & $\begin{array}{l}270 \\
250 \\
255 \\
260 \\
260\end{array}$ & $\begin{array}{l}335 \\
338 \\
390 \\
322 \\
360\end{array}$ & $\begin{array}{l}475 \\
485 \\
485 \\
500 \\
500\end{array}$ & $\begin{array}{l}346 \\
335 \\
310 \\
335 \\
34 i\end{array}$ & $\begin{array}{l}185 \\
198 \\
198 \\
209 \\
220\end{array}$ & $\begin{array}{l}284 \\
286 \\
277 \\
296 \\
305\end{array}$ & 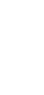 \\
\hline $\begin{array}{l}21 \\
22 \\
23 \\
24 \\
25\end{array}$ & $\begin{array}{l}230 \\
250 \\
250 \\
280 \\
270\end{array}$ & $\begin{array}{l}245 \\
255 \\
262 \\
262 \\
285\end{array}$ & $\begin{array}{l}265 \\
265 \\
240 \\
250 \\
270\end{array}$ & $\begin{array}{l}285 \\
290 \\
295 \\
310 \\
310\end{array}$ & $\begin{array}{l}360 \\
360 \\
365 \\
365 \\
395\end{array}$ & $\begin{array}{l}281 \\
281 \\
259 \\
280 \\
302\end{array}$ & $\begin{array}{l}375 \\
382 \\
395 \\
380 \\
\mathbf{3 8 5}\end{array}$ & $\begin{array}{l}510 \\
510 \\
495 \\
480 \\
465\end{array}$ & $\begin{array}{l}355 \\
374 \\
370 \\
295 \\
300\end{array}$ & $\begin{array}{l}239 \\
222 \\
161 \\
141 \\
160\end{array}$ & $\begin{array}{l}337 \\
286 \\
317 \\
249 \\
245\end{array}$ & $\ddot{m}$ \\
\hline $\begin{array}{l}26 \\
27 \\
28 \\
29 \\
30 \\
31\end{array}$ & $\begin{array}{l}245 \\
245 \\
245 \\
249 \\
249 \\
249\end{array}$ & $\begin{array}{l}279 \\
290 \\
290 \\
300 \\
300 \\
--\end{array}$ & $\begin{array}{l}270 \\
270 \\
260 \\
255 \\
255 \\
275\end{array}$ & $\begin{array}{l}315 \\
325 \\
332 \\
315 \\
317 \\
322\end{array}$ & \begin{tabular}{l}
315 \\
340 \\
345 \\
-- \\
\hdashline-
\end{tabular} & $\begin{array}{l}156 \\
166 \\
166 \\
177 \\
187 \\
198\end{array}$ & $\begin{array}{l}405 \\
385 \\
385 \\
410 \\
415 \\
-\end{array}$ & $\begin{array}{l}420 \\
415 \\
415 \\
355 \\
405 \\
300\end{array}$ & $\begin{array}{l}250 \\
230 \\
249 \\
270 \\
275 \\
-\end{array}$ & $\begin{array}{l}150 \\
150 \\
127 \\
143 \\
161 \\
185\end{array}$ & $\begin{array}{l}243 \\
246 \\
307 \\
198 \\
244 \\
241\end{array}$ & $\begin{array}{l}a \\
\cdots \\
\cdots \\
\cdots\end{array}$ \\
\hline AVERAGF & 211 & 264 & 275 & 281 & 325 & 262 & 345 & 455 & 299 & 212 & 275 & $-\infty$ \\
\hline
\end{tabular}


PEACE RIVER BASIN

02295637 PEACE RIVER AT ZOLFO SPRINGS, FLA.--Cont1nued

PH (UNITS), OCTOBER 1969 TO JUNE 1970

\begin{tabular}{|c|c|c|c|c|c|c|c|c|c|c|c|c|}
\hline DAY & OCT & NOV & DEC & JAN & FEB & MAR & $A P R$ & MAY & JUN & JUL & AUG & SEP \\
\hline $\begin{array}{l}1 \\
2 \\
3 \\
4 \\
5\end{array}$ & $\begin{array}{l}6.9 \\
6.9 \\
6.7 \\
6.6 \\
6.7\end{array}$ & $\begin{array}{l}7.4 \\
7.4 \\
7.3 \\
7.5 \\
7.7\end{array}$ & $\begin{array}{l}7.3 \\
7.4 \\
7.5 \\
7.6 \\
7.7\end{array}$ & $\begin{array}{l}8.0 \\
8.0 \\
7.9 \\
7.7 \\
7.7\end{array}$ & $\begin{array}{l}7.6 \\
7.5 \\
7.4 \\
7.4 \\
7.4\end{array}$ & $\begin{array}{l}7.2 \\
7.3 \\
7.6 \\
7.6 \\
7.5\end{array}$ & $\begin{array}{l}6.9 \\
7.0 \\
7.2 \\
7.1 \\
7.1\end{array}$ & $\begin{array}{l}7.5 \\
7.5 \\
8.0 \\
7.7 \\
8.0\end{array}$ & $\begin{array}{l}7.4 \\
7.3 \\
7.3 \\
7.1 \\
6.9\end{array}$ & $\overline{=-}$ & $\overline{-ב}$ & 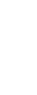 \\
\hline $\begin{array}{r}6 \\
7 \\
8 \\
9 \\
10\end{array}$ & $\begin{array}{l}6.8 \\
6.8 \\
6.8 \\
6.9 \\
6.9\end{array}$ & $\begin{array}{l}7.4 \\
7.6 \\
7.4 \\
7.4 \\
7.6\end{array}$ & $\begin{array}{l}7.4 \\
7.5 \\
7.5 \\
7.7 \\
7.6\end{array}$ & $\begin{array}{l}7.7 \\
7.6 \\
5.9 \\
6.7 \\
7.0\end{array}$ & $\begin{array}{l}7.5 \\
7.6 \\
7.5 \\
7.6 \\
7.6\end{array}$ & $\begin{array}{l}7.4 \\
7.3 \\
7.3 \\
7.3 \\
7.3\end{array}$ & $\begin{array}{l}7.1 \\
7.2 \\
7.3 \\
7.4 \\
7.5\end{array}$ & $\begin{array}{l}7.8 \\
8.0 \\
7.9 \\
7.8 \\
7.8\end{array}$ & $\begin{array}{l}7.0 \\
7.0 \\
7.2 \\
7.1 \\
7.5\end{array}$ & 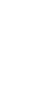 & 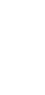 & 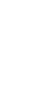 \\
\hline $\begin{array}{l}11 \\
12 \\
13 \\
14 \\
15\end{array}$ & $\begin{array}{l}6.9 \\
7.0 \\
7.0 \\
7.0 \\
7.1\end{array}$ & $\begin{array}{l}7.5 \\
7.4 \\
7.6 \\
7.2 \\
7.4\end{array}$ & $\begin{array}{l}7.6 \\
7.2 \\
7.4 \\
7.4 \\
7.1\end{array}$ & $\begin{array}{l}7.4 \\
7.5 \\
7.7 \\
7.7 \\
7.8\end{array}$ & $\begin{array}{l}7.7 \\
7.7 \\
7.6 \\
7.4 \\
7.5\end{array}$ & $\begin{array}{l}7.2 \\
7.1 \\
7.1 \\
7.0 \\
7.0\end{array}$ & $\begin{array}{l}7.6 \\
7.8 \\
7.7 \\
7.8 \\
7.6\end{array}$ & $\begin{array}{l}7.5 \\
7.5 \\
7.8 \\
7.6 \\
7.8\end{array}$ & $\begin{array}{l}7.4 \\
7.2 \\
7.2 \\
7.5 \\
7.7\end{array}$ & בים & $\ddot{\cdots}$ & $\ddot{=-}$ \\
\hline $\begin{array}{l}16 \\
17 \\
18 \\
19 \\
20\end{array}$ & $\begin{array}{l}7.1 \\
7.1 \\
7.1 \\
6.9 \\
6.9\end{array}$ & $\begin{array}{l}7.3 \\
7.2 \\
7.3 \\
7.3 \\
7.3\end{array}$ & $\begin{array}{l}7.3 \\
7.4 \\
7.3 \\
7.3 \\
7.4\end{array}$ & $\begin{array}{l}7.6 \\
7.7 \\
7.8 \\
7.8 \\
7.8\end{array}$ & $\begin{array}{l}7.6 \\
7.5 \\
7.5 \\
7.5 \\
7.5\end{array}$ & $\begin{array}{l}7.2 \\
7.3 \\
7.2 \\
7.2 \\
7.2\end{array}$ & $\begin{array}{l}7.5 \\
7.4 \\
7.3 \\
7.4 \\
7.3\end{array}$ & $\begin{array}{l}7.9 \\
7.6 \\
7.6 \\
7.6 \\
7.9\end{array}$ & $\begin{array}{l}6.6 \\
7.5 \\
7.2 \\
7.2 \\
7.2\end{array}$ & 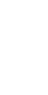 & 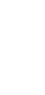 & $=$ \\
\hline $\begin{array}{l}21 \\
22 \\
23 \\
24 \\
25\end{array}$ & $\begin{array}{l}6.9 \\
6.9 \\
7.1 \\
7.1 \\
7.1\end{array}$ & $\begin{array}{l}7.3 \\
7.4 \\
7.4 \\
7.4 \\
7.4\end{array}$ & $\begin{array}{l}7.4 \\
7.4 \\
7.3 \\
7.4 \\
7.4\end{array}$ & $\begin{array}{l}7.6 \\
7.8 \\
7.7 \\
7.8 \\
7.8\end{array}$ & $\begin{array}{l}7.6 \\
7.6 \\
7.5 \\
7.6 \\
7.6\end{array}$ & $\begin{array}{l}7.2 \\
7.1 \\
7.1 \\
7.3 \\
7.0\end{array}$ & $\begin{array}{l}7.4 \\
7.3 \\
7.3 \\
7.2 \\
7.3\end{array}$ & $\begin{array}{l}7.8 \\
7.3 \\
7.7 \\
7.5 \\
7.6\end{array}$ & $\begin{array}{l}7.2 \\
7.3 \\
7.3 \\
7.1 \\
7.1\end{array}$ & ב- & ב- & $\ddot{m}$ \\
\hline $\begin{array}{l}26 \\
27 \\
28 \\
29 \\
30 \\
31\end{array}$ & $\begin{array}{l}7.1 \\
7.1 \\
7.1 \\
7.1 \\
7.2 \\
7.2\end{array}$ & $\begin{array}{l}7.5 \\
7.5 \\
7.4 \\
7.5 \\
7.5 \\
-.-0\end{array}$ & $\begin{array}{l}7.4 \\
7.4 \\
7.4 \\
7.4 \\
7.4 \\
7.4\end{array}$ & $\begin{array}{l}7.8 \\
7.8 \\
7.8 \\
7.9 \\
7.9 \\
7.9\end{array}$ & $\begin{array}{l}7.4 \\
7.4 \\
7.4 \\
-.- \\
-- \\
---\end{array}$ & $\begin{array}{l}6.8 \\
6.8 \\
6.6 \\
6.9 \\
6.9 \\
6.9\end{array}$ & $\begin{array}{l}7.2 \\
7.3 \\
7.3 \\
7.4 \\
7.4 \\
-\end{array}$ & $\begin{array}{l}7.6 \\
7.7 \\
7.7 \\
7.4 \\
7.4 \\
7.5\end{array}$ & $\begin{array}{l}7.0 \\
7.0 \\
7.0 \\
7.1 \\
7.1 \\
-.-\end{array}$ & 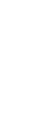 & 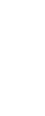 & 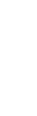 \\
\hline AVERAGE & 7.0 & 7.4 & 7.4 & 7.7 & 7.5 & 7.2 & 7.3 & 7.7 & 7.2 & $\ldots$ & $m$ & - \\
\hline
\end{tabular}

TURBIDITY, IN JACKSON TURBIDITY UNITS, OCTOBER 1969 TO JUNE 1970

\begin{tabular}{|c|c|c|c|c|c|c|c|c|c|c|c|c|}
\hline DAY & OCT & NOV & DEC & JAN & FEB & MAR & APR & MAY & JUN & JUL & AUG & SEP \\
\hline $\begin{array}{l}1 \\
2 \\
3 \\
4 \\
5\end{array}$ & $\begin{array}{l}6 \\
6 \\
6 \\
6 \\
3\end{array}$ & $\begin{array}{l}5 \\
4 \\
5 \\
5 \\
6\end{array}$ & $\begin{array}{r}5 \\
6 \\
6 \\
15 \\
10\end{array}$ & $\begin{array}{l}7 \\
3 \\
5 \\
4 \\
3\end{array}$ & $\begin{array}{l}5 \\
5 \\
6 \\
4 \\
5\end{array}$ & $\begin{array}{l}6 \\
6 \\
6 \\
5 \\
6\end{array}$ & $\begin{array}{l}6 \\
4 \\
4 \\
5 \\
4\end{array}$ & $\begin{array}{l}7 \\
7 \\
7 \\
6 \\
7\end{array}$ & $\begin{array}{l}15 \\
10 \\
15 \\
15 \\
10\end{array}$ & $\bar{m}$ & 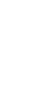 & $=$ \\
\hline $\begin{array}{r}6 \\
7 \\
8 \\
9 \\
10\end{array}$ & $\begin{array}{l}3 \\
4 \\
2 \\
4 \\
4\end{array}$ & $\begin{array}{l}4 \\
4 \\
4 \\
4 \\
4\end{array}$ & $\begin{array}{l}6 \\
4 \\
5 \\
5 \\
5\end{array}$ & $\begin{array}{l}4 \\
5 \\
1 \\
4 \\
3\end{array}$ & $\begin{array}{l}5 \\
5 \\
5 \\
4 \\
4\end{array}$ & $\begin{array}{l}5 \\
7 \\
6 \\
6 \\
5\end{array}$ & $\begin{array}{l}4 \\
0 \\
5 \\
5 \\
7\end{array}$ & $\begin{array}{r}7 \\
6 \\
2 \\
10 \\
6\end{array}$ & $\begin{array}{l}20 \\
20 \\
20 \\
15 \\
20\end{array}$ & $=$ & 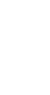 & $\ddot{\square}$ \\
\hline $\begin{array}{l}11 \\
12 \\
13 \\
14 \\
15\end{array}$ & $\begin{array}{l}4 \\
3 \\
4 \\
3 \\
4\end{array}$ & $\begin{array}{l}6 \\
4 \\
4 \\
7 \\
5\end{array}$ & $\begin{array}{l}7 \\
5 \\
7 \\
5 \\
4\end{array}$ & $\begin{array}{l}4 \\
2 \\
3 \\
2 \\
2\end{array}$ & $\begin{array}{l}5 \\
4 \\
4 \\
4 \\
5\end{array}$ & $\begin{array}{l}6 \\
5 \\
6 \\
4 \\
5\end{array}$ & $\begin{array}{l}6 \\
5 \\
1 \\
5 \\
6\end{array}$ & $\begin{array}{l}8 \\
7 \\
6 \\
7 \\
5\end{array}$ & $\begin{array}{r}20 \\
15 \\
9 \\
20 \\
20\end{array}$ & ב- & $\ddot{-\infty}$ & $\begin{array}{l}\because-0 \\
\because-0 \\
\because-\end{array}$ \\
\hline $\begin{array}{l}16 \\
17 \\
18 \\
19 \\
20\end{array}$ & $\begin{array}{l}4 \\
4 \\
4 \\
4 \\
4\end{array}$ & $\begin{array}{l}5 \\
6 \\
5 \\
6 \\
4\end{array}$ & $\begin{array}{l}3 \\
5 \\
3 \\
4 \\
5\end{array}$ & $\begin{array}{l}2 \\
3 \\
2 \\
3 \\
3\end{array}$ & $\begin{array}{l}4 \\
0 \\
5 \\
5 \\
5\end{array}$ & $\begin{array}{l}5 \\
4 \\
5 \\
4 \\
4\end{array}$ & $\begin{array}{l}5 \\
5 \\
5 \\
4 \\
6\end{array}$ & $\begin{array}{l}2 \\
5 \\
5 \\
6 \\
5\end{array}$ & $\begin{array}{l}20 \\
20 \\
20 \\
20 \\
20\end{array}$ & $\ddot{-\infty}$ & $=$ & $\overline{-}$ \\
\hline $\begin{array}{l}21 \\
22 \\
23 \\
24 \\
25\end{array}$ & $\begin{array}{l}5 \\
4 \\
5 \\
4 \\
5\end{array}$ & $\begin{array}{l}6 \\
4 \\
5 \\
4 \\
5\end{array}$ & $\begin{array}{l}3 \\
4 \\
3 \\
4 \\
3\end{array}$ & $\begin{array}{l}4 \\
3 \\
3 \\
3 \\
3\end{array}$ & $\begin{array}{l}4 \\
5 \\
4 \\
5 \\
4\end{array}$ & $\begin{array}{l}7 \\
0 \\
4 \\
3 \\
5\end{array}$ & $\begin{array}{l}6 \\
5 \\
4 \\
3 \\
4\end{array}$ & $\begin{array}{l}5 \\
6 \\
5 \\
5 \\
6\end{array}$ & $\begin{array}{l}15 \\
15 \\
15 \\
25 \\
20\end{array}$ & 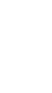 & $\bar{m}$ & $\begin{array}{l}\square- \\
\square=- \\
=-\end{array}$ \\
\hline $\begin{array}{l}26 \\
27 \\
28 \\
29 \\
30 \\
31\end{array}$ & $\begin{array}{l}4 \\
5 \\
4 \\
5 \\
6 \\
4\end{array}$ & $\begin{array}{r}3 \\
4 \\
5 \\
6 \\
3 \\
-\end{array}$ & $\begin{array}{l}4 \\
3 \\
4 \\
5 \\
5 \\
4\end{array}$ & $\begin{array}{l}1 \\
3 \\
2 \\
3 \\
3 \\
3\end{array}$ & $\begin{array}{r}6 \\
5 \\
5 \\
-- \\
--\end{array}$ & $\begin{array}{l}5 \\
6 \\
4 \\
4 \\
3 \\
4\end{array}$ & $\begin{array}{r}3 \\
3 \\
3 \\
4 \\
3 \\
- \\
\end{array}$ & $\begin{array}{l}9 \\
7 \\
6 \\
7 \\
8 \\
5\end{array}$ & $\begin{array}{r}20 \\
15 \\
15 \\
15 \\
20 \\
-\end{array}$ & $\ddot{\square}$ & $\overline{-\infty}$ & 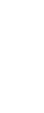 \\
\hline AVERAGE & 4 & 5 & 5 & 3 & 4 & 5 & 4 & 6 & 15 & -- & $-\infty$ & -- \\
\hline YEAR & 6 & & & & & & & & & & & \\
\hline
\end{tabular}


PEACE RIVER BASIN

02295637 PEACE RIVER AT ZOLFO SPRINGS, FLA,--Cont1nued

TEMPERATURE ('C) OF WATER, WATER YEAR OCTOBER 1969 TO SEPTEMBER 1970

\begin{tabular}{|c|c|c|c|c|c|c|c|c|c|c|c|c|}
\hline DAY & $O C T$ & NOV & DEC & JAN & FEB & MAR & $A P R$ & MAY & JUN & JUL & AUG & SEP \\
\hline $\begin{array}{l}1 \\
2 \\
3 \\
4 \\
5\end{array}$ & $\begin{array}{l}27.0 \\
27.0 \\
26.0 \\
27.0 \\
26.0\end{array}$ & $\begin{array}{l}24.0 \\
24.0 \\
24.0 \\
22.0 \\
19.0\end{array}$ & $\begin{array}{l}19.0 \\
16.0 \\
16.0 \\
16.0 \\
15.0\end{array}$ & $\begin{array}{l}18.0 \\
17.0 \\
17.0 \\
16.0 \\
16.0\end{array}$ & $\begin{array}{l}18.0 \\
19.0 \\
17.0 \\
12.0 \\
13.0\end{array}$ & $\begin{array}{l}19.0 \\
19.0 \\
20.0 \\
21.0 \\
20.0\end{array}$ & $\begin{array}{l}25.0 \\
25.0 \\
23.0 \\
24.0 \\
24.0\end{array}$ & $\begin{array}{l}28.0 \\
27.0 \\
26.0 \\
25.0 \\
25.0\end{array}$ & $\begin{array}{l}25.0 \\
26.0 \\
26.0 \\
26.0 \\
25.0\end{array}$ & $\begin{array}{l}28.0 \\
29.0 \\
29.0 \\
29.0 \\
30.0\end{array}$ & $\begin{array}{l}29.0 \\
29.0 \\
29.0 \\
30.0 \\
30.0\end{array}$ & $\ddot{m} \bar{m}$ \\
\hline $\begin{array}{r}6 \\
7 \\
8 \\
9 \\
10\end{array}$ & $\begin{array}{l}26.0 \\
26.0 \\
25.0 \\
25.0 \\
25.0\end{array}$ & $\begin{array}{l}19.0 \\
18.0 \\
19.0 \\
20.0 \\
20.0\end{array}$ & $\begin{array}{l}16.0 \\
17.0 \\
18.0 \\
17.0 \\
20.0\end{array}$ & $\begin{array}{r}18.0 \\
14.0 \\
11.0 \\
10.0 \\
9.0\end{array}$ & $\begin{array}{l}14.0 \\
17.0 \\
17.0 \\
18.0 \\
16.0\end{array}$ & $\begin{array}{l}21.0 \\
20.0 \\
21.0 \\
20.0 \\
20.0\end{array}$ & $\begin{array}{l}24.0 \\
24.0 \\
23.0 \\
23.0 \\
24.0\end{array}$ & $\begin{array}{l}26.0 \\
25.0 \\
25.0 \\
25.0 \\
25.0\end{array}$ & $\begin{array}{l}26.0 \\
25.0 \\
26.0 \\
27.0 \\
28.0\end{array}$ & $\begin{array}{l}27.0 \\
28.0 \\
28.0 \\
28.0 \\
28.0\end{array}$ & $\begin{array}{l}30.0 \\
30.0 \\
28.0 \\
28.0 \\
27.0\end{array}$ & $\bar{\square}=$ \\
\hline $\begin{array}{l}11 \\
12 \\
13 \\
14 \\
15\end{array}$ & $\begin{array}{l}26.0 \\
26.0 \\
25.0 \\
25.0 \\
25.0\end{array}$ & $\begin{array}{l}20.0 \\
21.0 \\
20.0 \\
19.0 \\
17.0\end{array}$ & $\begin{array}{l}20.0 \\
18.0 \\
15.0 \\
16.0 \\
15.0\end{array}$ & $\begin{array}{l}10.0 \\
12.0 \\
12.0 \\
13.0 \\
16.0\end{array}$ & $\begin{array}{l}15.0 \\
15.0 \\
17.0 \\
17.0 \\
20.0\end{array}$ & $\begin{array}{l}20.0 \\
21.0 \\
20.0 \\
19.0 \\
17.0\end{array}$ & $\begin{array}{l}24.0 \\
24.0 \\
25.0 \\
26.0 \\
25.0\end{array}$ & $\begin{array}{l}26.0 \\
25.0 \\
26.0 \\
26.0 \\
26.0\end{array}$ & $\begin{array}{l}28.0 \\
28.0 \\
28.0 \\
28.0 \\
28.0\end{array}$ & $\begin{array}{l}28.0 \\
28.0 \\
29.0 \\
28.0 \\
29.0\end{array}$ & $\begin{array}{l}27.0 \\
28.0 \\
27.0 \\
29.0 \\
29.0\end{array}$ & $\ddot{\square}=$ \\
\hline $\begin{array}{l}16 \\
17 \\
18 \\
19 \\
20\end{array}$ & $\begin{array}{l}26.0 \\
25.0 \\
25.0 \\
25.0 \\
26.0\end{array}$ & $\begin{array}{l}15.0 \\
17.0 \\
19.0 \\
20.0 \\
19.0\end{array}$ & $\begin{array}{l}16.0 \\
17.0 \\
17.0 \\
16.0 \\
16.0\end{array}$ & $\begin{array}{l}17.0 \\
18.0 \\
18.0 \\
18.0 \\
18.0\end{array}$ & $\begin{array}{l}20.0 \\
20.0 \\
19.0 \\
20.0 \\
18.0\end{array}$ & $\begin{array}{l}17.0 \\
19.0 \\
20.0 \\
21.0 \\
22.0\end{array}$ & $\begin{array}{l}25.0 \\
26.0 \\
26.0 \\
26.0 \\
26.0\end{array}$ & $\begin{array}{l}27.0 \\
27.0 \\
28.0 \\
28.0 \\
27.0\end{array}$ & $\begin{array}{l}28.0 \\
29.0 \\
29.0 \\
29.0 \\
29.0\end{array}$ & $\begin{array}{l}30.0 \\
30.0 \\
30.0 \\
30.0 \\
28.0\end{array}$ & $\begin{array}{l}29.0 \\
30.0 \\
30.0 \\
30.0 \\
30.0\end{array}$ & $\begin{array}{l}29.0 \\
29.0 \\
29.0 \\
29.0 \\
28.0\end{array}$ \\
\hline $\begin{array}{l}21 \\
22 \\
23 \\
24 \\
25\end{array}$ & $\begin{array}{l}26.0 \\
25.0 \\
27.0 \\
25.0 \\
24.0\end{array}$ & $\begin{array}{l}17.0 \\
17.0 \\
17.0 \\
18.0 \\
20.0\end{array}$ & $\begin{array}{l}17.0 \\
18.0 \\
16.0 \\
16.0 \\
18.0\end{array}$ & $\begin{array}{l}17.0 \\
16.0 \\
15.0 \\
15.0 \\
16.0\end{array}$ & $\begin{array}{l}17.0 \\
17.0 \\
18.0 \\
18.0 \\
20.0\end{array}$ & $\begin{array}{l}23.0 \\
21.0 \\
20.0 \\
19.0 \\
19.0\end{array}$ & $\begin{array}{l}27.0 \\
27.0 \\
28.0 \\
26.0 \\
25.0\end{array}$ & $\begin{array}{l}27.0 \\
27.0 \\
27.0 \\
25.0 \\
25.0\end{array}$ & $\begin{array}{l}30.0 \\
39.0 \\
30.0 \\
30.0 \\
30.0\end{array}$ & $\begin{array}{l}27.0 \\
28.0 \\
26.0 \\
28.0 \\
29.0\end{array}$ & $\begin{array}{l}30.0 \\
29.0 \\
29.0 \\
27.0 \\
30.0\end{array}$ & $\begin{array}{l}28.0 \\
28.0 \\
27.0 \\
28.0 \\
27.0\end{array}$ \\
\hline $\begin{array}{l}26 \\
27 \\
28 \\
29 \\
30 \\
31\end{array}$ & $\begin{array}{l}25.0 \\
25.0 \\
25.0 \\
24.0 \\
25.0 \\
24.0\end{array}$ & $\begin{array}{l}20.0 \\
20.0 \\
20.0 \\
19.0 \\
20.0 \\
\ldots\end{array}$ & $\begin{array}{l}18.0 \\
16.0 \\
15.0 \\
17.0 \\
19.0 \\
19.0\end{array}$ & $\begin{array}{l}17.0 \\
18.0 \\
19.0 \\
20.0 \\
19.0 \\
18.0\end{array}$ & $\begin{array}{r}17.0 \\
17.0 \\
18.0 \\
-\square- \\
-\end{array}$ & $\begin{array}{l}20.0 \\
20.0 \\
22.0 \\
24.0 \\
25.0 \\
24.0\end{array}$ & $\begin{array}{r}26.0 \\
27.0 \\
27.0 \\
28.0 \\
28.0 \\
-\end{array}$ & $\begin{array}{l}25.0 \\
27.0 \\
27.0 \\
24.0 \\
25.0 \\
26.0\end{array}$ & $\begin{array}{l}29.0 \\
29.0 \\
29.0 \\
30.0 \\
27.0 \\
-\end{array}$ & $\begin{array}{l}28.0 \\
29.0 \\
27.0 \\
29.0 \\
29.0 \\
29.0\end{array}$ & $\begin{array}{l}29.0 \\
28.0 \\
29.0 \\
30.0 \\
28.0 \\
29.0\end{array}$ & $\begin{array}{l}27.0 \\
27.0 \\
27.0 \\
27.0 \\
26.0 \\
-\end{array}$ \\
\hline AVERAGE & 25.5 & 19.5 & 17.0 & 15.5 & 17.5 & 20.5 & 25.5 & 26.0 & 28.0 & 28.5 & 29.0 & $-\infty$ \\
\hline
\end{tabular}

02296750 PEACE RIVER AT ARCADIA, FLA.

LOCATION.--Lat $27^{\circ} 13^{\prime} 19^{\prime \prime}$, long $81^{\circ} 52^{\prime} 34^{\prime \prime}$, In SE sec.26, T.37 S., R.24 E., DeSoto County, at gaging station, on left bank $500 \mathrm{ft}$ upstream' from bridge on State Highway 70, $i$ mile west of post office in Arcadia, 6.1 miles upstream bank 500 ft upstream from bridge on State Highway 70,
from Joshua Creek, and 36 miles upstream from mouth.

DRAINAGE AREA.--1,367 sq $\mathrm{ml}$.

PERIOD OF RECORD.--Chemical analyses: October 1961 to September 1970.

Water temperatures: February 1962 to September 1970.

EXTREMES. - - 1969-70

Fluoride: Maximum dally, $3.1 \mathrm{mg} / 1$ May $19 ; \mathrm{min} 1 \mathrm{mum}$ dally, $0.5 \mathrm{mg} / 1$ July $15,16$.

phosphate: Maximum daliy, $11 \mathrm{mg} / 1$ May $19 ;$ minimum dally, $1.9 \mathrm{mg} / 1$ Dec. 14.

Specific conductance: Maximum dally, 495 micromhos May 23; min1mum daily, 100 micromhos oct. 3, July $15,16$.

$\mathrm{pH}$ : Maximum dally, 7.8 May 10 ; minimum daily, 6.4 July 17

pH: Maximum daily, 7.8 May 10 ; minlmum dally, 6.4 July 17 .

Water temperatures: Maximum, $31.0^{\circ} \mathrm{C}$ Aug. 5 ; min1mum, freezing point Jan. 10.

Period of record:

D1ssolved solids (1961-67): Maximum, $335 \mathrm{mg} / 1$ May 11-20, 1967; min1mum, $50 \mathrm{mg} / 1 \mathrm{Aug}$. 21-25, 1963 ,

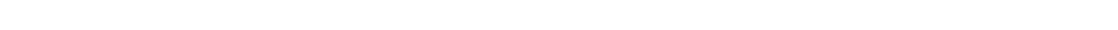
June 11,1968

Phosphate'(1963-70): Maximum da1ly, $29 \mathrm{mg} / 1$ May 27, 1967; minimum da1ly, $1 \mathrm{mg} / 1$ May $19,1970$.

Speciflc conductance: Maximun dally, 1,750 micromhos Feb. 3, 1963; minimum da1ly, 45 micromhos Sept. 23, 1962. pH (1962-70): Maximum dally, 8.3 Mar. 31, 1968; minimum da1ly, 5.1 Mar. 1, 1963.

Turbid1ty (1962-70): Maximun dally, 350 mg/1 as slica Jan. 1, 1969; minimum daily, 0 mg/las silica on several days in october 1965, August 1966, many days during November, December 1967 and September 1968

Water temperatures: Maximum, $35.0^{\circ} \mathrm{C}$ on several days during Juiy and August 1968; min1mum, freezing polnt Jan. 10, 1970 .

CHEMICAL ANALYSES, WATER YEAR DCTOBER 1969 TO SEPTEMBER 1970 (MAJOR CONSTITUENTS)

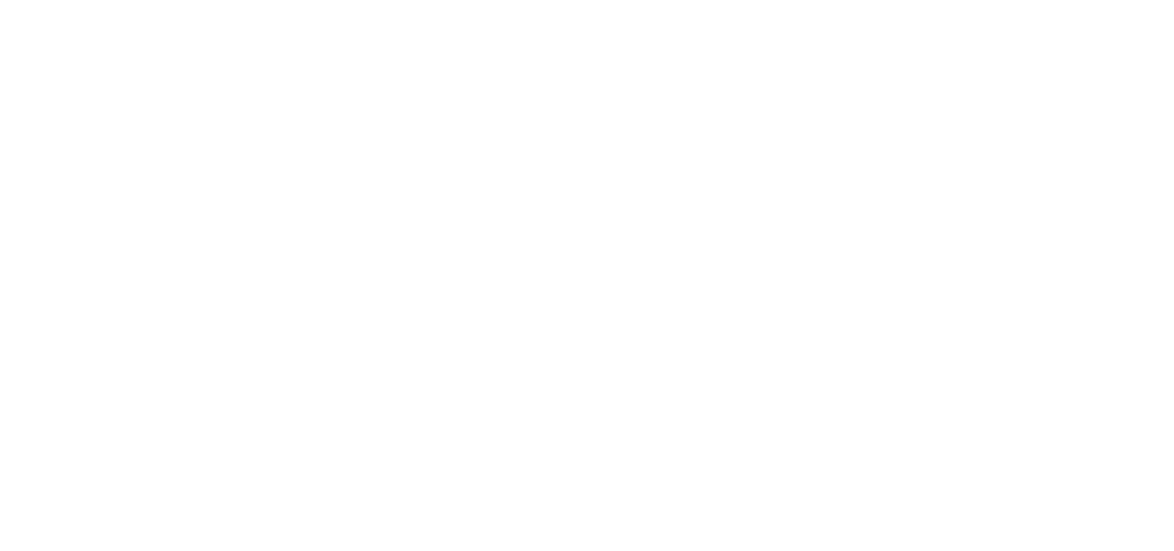


02296750 PEACE RIVER AT ARCADIA, FLA, --Continued

CHEMICAL ANALYSES, WATER YEAR OCTOBER 1969 TO SEPTEMBER 1970 (MAJOR CONSTI IUENTS)

OIS-
SOLVED
OCT., 1969

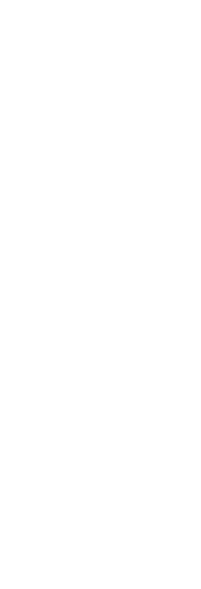

$\begin{array}{lrll}12 & .8 & 50 & 27 \\ 11 & .7 & 46 & 23 \\ 14 & 1.3 & 69 & 33 \\ 16 & 1.1 & 82 & 39 \\ 17 & .1 & 73 & 39\end{array}$

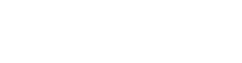

$813^{--} \quad .17 \quad 000$ 17
18
14

$\begin{array}{ll}.1 & 73 \\ .0 & 99 \\ .7 & 73 \\ .9 & 66\end{array}$

$\begin{array}{ll}39 & 3 \\ 55 & 4 \\ 37 & 36 \\ 34 & 32\end{array}$

$\begin{array}{ll}34 & 166 \\ 43 & 181 \\ 36 & 165 \\ 32 & 139\end{array}$

166
181
165
139

109
152
126
108

$\because=: 14$

$\bar{z} \quad \bar{z}$

$\begin{array}{rrr}15 & 1.0 & 103 \\ 13 & .6 & 49 \\ 14 & .7 & 57 \\ 16 & 1.0 & 90\end{array}$

$\begin{array}{lll}56 & 48 & =- \\ 11 & 20 & =- \\ 33 & 24 & 116 \\ 61 & 29 & =-\end{array}$

148
78
95
123

$610^{--} \quad .23$

.23
.25
.22
.19

$=\overline{-}=$

$\begin{array}{rrr}16 & 1.0 & 99 \\ 17 & .9 & 106\end{array}$

$17 \quad 1.2 \quad 123$

58

$59 \quad 47$

$42 \quad 183$

156

$661=$

$491 \quad .29$

.70
.11
.16
.17
.25
.25

$73 \quad 50 \quad 201$

183 --

$\begin{array}{lll}17 & 1.0 & 42 \\ 12 & 1.0 & 41\end{array}$

$15 \quad 1.4 \quad 130$

51
25

$\begin{array}{ll}31 & 172 \\ 16 & 100\end{array}$

134
72

$200 \quad 212$

$16 \quad 2.5 \quad 201$

62

$68 \quad 221$

200

$\begin{array}{rrr}12 & 1.2 & 98 \\ 15 & 1.3 & 108\end{array}$

$124 \quad 76 \quad 302$

29

$161 \quad 346-$ 7

$\begin{array}{ll}41 & 182 \\ 37 & 197 \\ 36 & 181\end{array}$

161

848

MACRONUTRIENTS AND OTHER RELATED CDNSTITUENTS

\begin{tabular}{|c|c|c|c|c|c|c|c|c|c|c|c|c|}
\hline DATE & $\begin{array}{l}\text { TOTAL } \\
\text { A.NMONIA } \\
\text { (Nr:4) } \\
(M G / L)\end{array}$ & $\begin{array}{l}\text { TOTAL } \\
\text { NITRITE } \\
\text { (NOZ) } \\
\text { (MG/L) }\end{array}$ & $\begin{array}{l}\text { TOTAL } \\
\text { NITKATE } \\
\text { (NO3) } \\
\text { (MG/L) }\end{array}$ & $\begin{array}{c}\text { OHGANIC } \\
\text { NITRO- } \\
\text { GEN } \\
\text { (N) } \\
\text { (NG/L) }\end{array}$ & $\begin{array}{l}\text { UIS- } \\
\text { SOLVE? } \\
\text { ORTHO } \\
\text { PHUS- } \\
\text { PHATE } \\
(P() 4) \\
\text { (MG/L) }\end{array}$ & $\begin{array}{l}\text { PHOS- } \\
\text { PHATE } \\
(P O 4) \\
(M G / L)\end{array}$ & $\begin{array}{l}\text { OIS- } \\
\text { SOL VEO } \\
\text { SILICA } \\
\text { (SIOL) } \\
\text { (MG/L) }\end{array}$ & $\begin{array}{l}\text { TUR- } \\
\text { BID- } \\
\text { IIY } \\
\text { (JTU) }\end{array}$ & $\begin{array}{l}\text { COLOR } \\
\text { (PLAI- } \\
\text { INUM- } \\
\text { COBALI } \\
\text { UNITS) }\end{array}$ & $\begin{array}{c}\text { TOTAL } \\
\text { ORGANIC } \\
\text { CARBON } \\
\text { (C) } \\
\text { (MG/L) }\end{array}$ & $\begin{array}{l}\text { AIO- } \\
\text { CHEM- } \\
\text { ICAL } \\
\text { OXYrFN } \\
\text { DEMA.DD } \\
\text { (MG/L) }\end{array}$ & $\begin{array}{c}\text { DEPTH } \\
(F T)\end{array}$ \\
\hline \multirow{5}{*}{\multicolumn{2}{|c|}{$\begin{array}{l}\text { JULY, } 1970 \\
16 \ldots . . \\
31 \ldots \\
\text { AUG... } \\
\text { 27... } \\
\text { SEP. } \\
30 \ldots . .\end{array}$}} & & & & & & & & & & & \\
\hline & & .03 & 1.0 & $=$ & 2.1 & 2.3 & 5.3 & $=$ & 120 & -- & - & -- \\
\hline & & & & & & & -- & - & $=$ & -- & $=-$ & - \\
\hline & & .06 & 1.5 & -- & 2.5 & 2.7 & $=-$ & 10 & $\rightarrow$ & - & -- & $=$ \\
\hline & & .03 & 4.7 & -- & 3.3 & 3.3 & - & 3 & -- & $\rightarrow$ & -- & -- \\
\hline
\end{tabular}


PEACE RIVER BASIN

02296750 PEACE RIVER AT ARCADIA, FLA,--Continued

FLUORIDE, IN MILLIGRAMS PER LITER, WATER YEAR OCTOBER 1969 TO JULY 1970

\begin{tabular}{|c|c|c|c|c|c|c|c|c|c|c|c|c|}
\hline OAY & OC $T$ & NOV & DEC & JAA & FEB & M AR & $A P R$ & HAY & JUN & JUL & AU6 & SEP \\
\hline $\begin{array}{l}1 \\
2 \\
3 \\
4 \\
5 \\
1\end{array}$ & $\begin{array}{l}.8 \\
.8 \\
.8 \\
.7 \\
.7\end{array}$ & $\begin{array}{l}.7 \\
.7 \\
.8 \\
.7 \\
.7\end{array}$ & $\begin{array}{l}1.0 \\
1.1 \\
1.1 \\
1.1 \\
1.1\end{array}$ & $\begin{array}{r}1.0 \\
.8 \\
.8 \\
.8 \\
.7\end{array}$ & $\begin{array}{l}1.1 \\
1.1 \\
1.1 \\
1.0 \\
.8\end{array}$ & $\begin{array}{r}.99 \\
1.0 \\
1.0 \\
1.1\end{array}$ & $\begin{array}{l}.6 \\
.9 \\
.8 \\
.8\end{array}$ & $\begin{array}{l}1.9 \\
2.0 \\
2.1 \\
2.1 \\
2.1\end{array}$ & $\begin{array}{l}1.1 \\
1.1 \\
1.1 \\
1.1 \\
1.1\end{array}$ & $\begin{array}{l}1.1 \\
1.1 \\
1.3 \\
1.4 \\
1.4\end{array}$ & $=-$ & $\begin{array}{l}=- \\
\square- \\
=-\end{array}$ \\
\hline $\begin{array}{r}6 \\
7 \\
8 \\
9 \\
10\end{array}$ & $\begin{array}{l}.7 \\
.8 \\
.8 \\
.8 \\
.8\end{array}$ & $\begin{array}{l}.8 \\
.8 \\
.8 \\
.9 \\
.8\end{array}$ & $\begin{array}{l}1.1 \\
1.1 \\
1.1 \\
1.1 \\
.9\end{array}$ & $\begin{array}{l}.7 \\
.7 \\
.4 \\
.5 \\
.5\end{array}$ & $\begin{array}{r}1.0 \\
1.0 \\
.9 \\
.8 \\
.9\end{array}$ & $\begin{array}{r}1.3 \\
1.1 \\
1.0 \\
1.0 \\
.9\end{array}$ & $\begin{array}{r}.9 \\
.9 \\
.9 \\
1.9\end{array}$ & $\begin{array}{l}2.2 \\
2.4 \\
2.5 \\
2.6 \\
2.7\end{array}$ & $\begin{array}{l}.9 \\
1.1 \\
1.0 \\
1.1 \\
1.1\end{array}$ & $\begin{array}{l}1.3 \\
1.4 \\
1.3 \\
1.3 \\
1.1\end{array}$ & $\begin{array}{l}\square \\
=- \\
\square\end{array}$ & $=$ \\
\hline $\begin{array}{l}11 \\
12 \\
13 \\
14 \\
15\end{array}$ & $\begin{array}{r}.9 \\
.9 \\
1.9 \\
1.0\end{array}$ & $\begin{array}{r}.9 \\
1.0 \\
1.0 \\
.9 \\
.9\end{array}$ & $\begin{array}{l}.7 \\
.7 \\
.6 \\
.6 \\
.6\end{array}$ & $\begin{array}{l}.5 \\
.6 \\
.6 \\
.5 \\
.6\end{array}$ & $\begin{array}{l}.9 \\
1.0 \\
1.0 \\
1.1 \\
1.1\end{array}$ & $\begin{array}{l}.8 \\
.9 \\
.9 \\
.7 \\
.8\end{array}$ & $\begin{array}{l}1.0 \\
1.2 \\
1.1 \\
1.2 \\
1.2\end{array}$ & $\begin{array}{l}2.7 \\
2.8 \\
2.7 \\
2.4 \\
2.4\end{array}$ & $\begin{array}{l}1.2 \\
1.2 \\
1.3 \\
1.1 \\
1.1\end{array}$ & $\begin{array}{r}.9 \\
.6 \\
.5 \\
1.0 \\
.5\end{array}$ & $\begin{array}{l}=- \\
=- \\
=- \\
=-\end{array}$ & 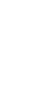 \\
\hline $\begin{array}{l}16 \\
17 \\
18 \\
19 \\
20\end{array}$ & $\begin{array}{l}1.3 \\
1.0 \\
1.1 \\
1.1 \\
1.1\end{array}$ & $\begin{array}{l}.7 \\
.7 \\
.7 \\
.7 \\
.7\end{array}$ & $\begin{array}{l}.6 \\
.6 \\
.6 \\
.7 \\
.7\end{array}$ & $\begin{array}{l}.6 \\
.7 \\
.6 \\
.6 \\
.6\end{array}$ & $\begin{array}{l}1.1 \\
1.1 \\
1.2 \\
1.2 \\
1.4\end{array}$ & $\begin{array}{l}.8 \\
.8 \\
.9 \\
.9 \\
.9\end{array}$ & $\begin{array}{l}1.4 \\
1.5 \\
1.4 \\
1.3 \\
1.3\end{array}$ & $\begin{array}{l}2.4 \\
2.8 \\
2.8 \\
3.1 \\
2.8\end{array}$ & $\begin{array}{l}1.0 \\
1.0 \\
1.0 \\
1.1 \\
1.2\end{array}$ & $\begin{array}{l}.5 \\
.6 \\
.6 \\
.6 \\
.6\end{array}$ & $\begin{array}{c}-- \\
m \\
--\end{array}$ & 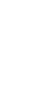 \\
\hline $\begin{array}{l}21 \\
22 \\
23 \\
24 \\
25\end{array}$ & $\begin{array}{l}1.1 \\
1.2 \\
1.3 \\
1.2 \\
1.0\end{array}$ & $\begin{array}{l}.8 \\
.7 \\
.8 \\
.8 \\
.8\end{array}$ & $\begin{array}{l}1.0 \\
1.0 \\
.8 \\
.9 \\
.9\end{array}$ & $\begin{array}{l}.7 \\
.7 \\
.8 \\
.8 \\
.8\end{array}$ & $\begin{array}{l}1.2 \\
1.2 \\
1.2 \\
1.2 \\
1.2\end{array}$ & $\begin{array}{r}1.0 \\
.9 \\
1.0 \\
1.0 \\
0.9\end{array}$ & $\begin{array}{l}1.3 \\
1.4 \\
1.4 \\
1.6 \\
1.7\end{array}$ & $\begin{array}{l}2.3 \\
2.3 \\
2.4 \\
2.2 \\
2.2\end{array}$ & $\begin{array}{l}1.4 \\
1.4 \\
1.4 \\
1.4 \\
1.4\end{array}$ & $\begin{array}{r}.6 \\
.7 \\
\because .8 \\
.6\end{array}$ & $\begin{array}{l}=- \\
=- \\
=-\end{array}$ & \begin{tabular}{l}
$a-$ \\
$\because-$ \\
\hdashline- \\
$-\cdots$
\end{tabular} \\
\hline $\begin{array}{l}26 \\
27 \\
28 \\
29 \\
30 \\
31\end{array}$ & $\begin{array}{l}1.0 \\
1.0 \\
1.0 \\
1.1 \\
1.1 \\
1.0\end{array}$ & $\begin{array}{r}1.0 \\
.9 \\
1.0 \\
1.0 \\
1.0 \\
-.0\end{array}$ & $\begin{array}{l}1.0 \\
1.0 \\
1.0 \\
1.0 \\
1.0 \\
1.0\end{array}$ & $\begin{array}{r}.8 \\
.8 \\
.9 \\
.9 \\
.9 \\
1.0\end{array}$ & $\begin{array}{r}1.1 \\
0.9 \\
1.1 \\
\hdashline-- \\
\hdashline-\end{array}$ & $\begin{array}{l}.6 \\
.5 \\
.5 \\
.6 \\
.6 \\
.6\end{array}$ & $\begin{array}{l}1.9 \\
1.9 \\
1.9 \\
1.9 \\
1.8 \\
-9\end{array}$ & $\begin{array}{l}2.3 \\
1.8 \\
2.0 \\
1.6 \\
1.4 \\
1.2\end{array}$ & $\begin{array}{l}1.4 \\
1.2 \\
1.1 \\
1.1 \\
1.0 \\
-\end{array}$ & $\begin{array}{l}.7 \\
.6 \\
.6 \\
.6 \\
.6 \\
.7\end{array}$ & $\begin{array}{l}--- \\
=- \\
=- \\
---\end{array}$ & $\begin{array}{l}a- \\
\cdots \\
\cdots-\end{array}$ \\
\hline AVERAGE & 1.0 & $\begin{array}{l}\text { - } \\
\text { PHOS }\end{array}$ & $\stackrel{.9}{E, ~ I N ~}$ & $\begin{array}{c}.7 \\
\text { LLIGR }\end{array}$ & $\begin{array}{c}1.1 \\
\text { PER LI }\end{array}$ & .9 & $\begin{array}{c}1.3 \\
\text { YEAR OC }\end{array}$ & $\begin{array}{l}2.3 \\
\text { ER } 19\end{array}$ & $\begin{array}{c}1.2 \\
\text { TO JULY }\end{array}$ & $70^{.8}$ & -- & -- \\
\hline DAY & OCT & NOV & DEC & JAN & FEB & MAR & APR & MAY & JUN & JUL & AUG & SEP \\
\hline $\begin{array}{l}1 \\
2 \\
3 \\
4 \\
5\end{array}$ & $\begin{array}{l}3.1 \\
2.7 \\
2.2 \\
2.6 \\
2.5\end{array}$ & $\begin{array}{l}2.9 \\
3.5 \\
3.7 \\
3.0 \\
3.7\end{array}$ & $\begin{array}{l}4.6 \\
4.9 \\
5.3 \\
6.3 \\
6.2\end{array}$ & $\begin{array}{l}4.3 \\
4.2 \\
5.1 \\
4.5 \\
4.5\end{array}$ & $\begin{array}{l}5.4 \\
5.7 \\
5.1 \\
4.5 \\
3.1\end{array}$ & $\begin{array}{l}3.9 \\
4.2 \\
4.2 \\
4.5 \\
5.5\end{array}$ & $\begin{array}{l}3.0 \\
3.5 \\
3.8 \\
4.0 \\
4.0\end{array}$ & $\begin{array}{l}7.4 \\
7.9 \\
8.7 \\
8.1 \\
8.3\end{array}$ & $\begin{array}{l}5.1 \\
5.0 \\
5.0 \\
5.0 \\
4.6\end{array}$ & $\begin{array}{l}4.6 \\
4.8 \\
5.6 \\
7.1 \\
6.5\end{array}$ & $\ddot{z-}$ & $\ddot{m}$ \\
\hline $\begin{array}{r}6 \\
7 \\
8 \\
9 \\
10\end{array}$ & $\begin{array}{l}2.8 \\
2.9 \\
2.7 \\
2.8 \\
2.8\end{array}$ & $\begin{array}{l}4.3 \\
4.2 \\
4.0 \\
4.0 \\
4.0\end{array}$ & $\begin{array}{l}6.5 \\
5.3 \\
5.6 \\
5.8 \\
4.0\end{array}$ & $\begin{array}{l}4.7 \\
3.9 \\
2.3 \\
2.6 \\
2.7\end{array}$ & $\begin{array}{l}4.1 \\
4.3 \\
3.1 \\
3.0 \\
3.0\end{array}$ & $\begin{array}{l}5.4 \\
4.1 \\
4.2 \\
4.5 \\
3.4\end{array}$ & $\begin{array}{l}4.1 \\
4.2 \\
4.1 \\
4.3 \\
5.2\end{array}$ & $\begin{array}{r}8.8 \\
9.6 \\
9.6 \\
10 \\
8.6\end{array}$ & $\begin{array}{l}4.1 \\
4.7 \\
4.7 \\
5.0 \\
5.2\end{array}$ & $\begin{array}{l}5.0 \\
6.5 \\
5.1 \\
5.5 \\
4.9\end{array}$ & $\ddot{=}$ & $\ddot{m}$ \\
\hline $\begin{array}{l}11 \\
12 \\
13 \\
14 \\
15\end{array}$ & $\begin{array}{l}2.8 \\
3.2 \\
3.2 \\
3.3 \\
3.6\end{array}$ & $\begin{array}{l}4.1 \\
4.1 \\
4.4 \\
4.0 \\
2.6\end{array}$ & $\begin{array}{l}2.3 \\
2.3 \\
2.2 \\
1.9 \\
2.0\end{array}$ & $\begin{array}{l}2.6 \\
2.7 \\
2.9 \\
2.7 \\
2.9\end{array}$ & $\begin{array}{l}3.2 \\
3.8 \\
4.0 \\
4.0 \\
4.8\end{array}$ & $\begin{array}{l}3.6 \\
3.8 \\
3.2 \\
2.7 \\
3.2\end{array}$ & $\begin{array}{l}6.2 \\
5.7 \\
5.7 \\
5.4 \\
5.6\end{array}$ & $\begin{array}{l}8.1 \\
7.6 \\
8.3 \\
8.7 \\
8.9\end{array}$ & $\begin{array}{l}5.3 \\
5.5 \\
5.6 \\
4.9 \\
4.8\end{array}$ & $\begin{array}{l}4.1 \\
2.1 \\
2.1 \\
4.2 \\
2.1\end{array}$ & $\ddot{=}$ & $=$ \\
\hline $\begin{array}{l}16 \\
17 \\
18 \\
19 \\
20\end{array}$ & $\begin{array}{l}4.0 \\
3.8 \\
3.8 \\
3.9 \\
3.7\end{array}$ & $\begin{array}{l}3.0 \\
3.1 \\
3.3 \\
3.2 \\
3.0\end{array}$ & $\begin{array}{l}2.0 \\
2.1 \\
2.3 \\
2.5 \\
2.8\end{array}$ & $\begin{array}{l}2.9 \\
2.7 \\
3.6 \\
3.6 \\
3.9\end{array}$ & $\begin{array}{l}5.2 \\
5.2 \\
5.3 \\
5.3 \\
7.1\end{array}$ & $\begin{array}{l}3.1 \\
3.4 \\
3.4 \\
3.4 \\
3.7\end{array}$ & $\begin{array}{l}6.2 \\
6.1 \\
6.3 \\
6.2 \\
6.2\end{array}$ & $\begin{array}{c}9.1 \\
10 \\
9.9 \\
11 \\
9.1\end{array}$ & $\begin{array}{l}4.6 \\
4.4 \\
4.1 \\
4.8 \\
5.8\end{array}$ & $\begin{array}{l}2.1 \\
2.1 \\
2.2 \\
2.2 \\
2.3\end{array}$ & $\ddot{-a}$ & $=$ \\
\hline $\begin{array}{l}21 \\
22 \\
23 \\
24 \\
25\end{array}$ & $\begin{array}{l}3.8 \\
4.1 \\
4.3 \\
4.1 \\
3.6\end{array}$ & $\begin{array}{l}3.1 \\
3.0 \\
3.6 \\
3.6 \\
3.7\end{array}$ & $\begin{array}{l}3.1 \\
3.1 \\
3.2 \\
3.1 \\
3.8\end{array}$ & $\begin{array}{l}4.0 \\
4.0 \\
4.1 \\
4.4 \\
4.9\end{array}$ & $\begin{array}{l}5.3 \\
6.8 \\
6.2 \\
5.7 \\
5.3\end{array}$ & $\begin{array}{l}3.8 \\
3.7 \\
4.2 \\
4.1 \\
3.8\end{array}$ & $\begin{array}{l}6.1 \\
7.2 \\
6.7 \\
7.5 \\
\text { A.2 }\end{array}$ & $\begin{array}{l}5.8 \\
6.1 \\
7.5 \\
7.4 \\
7.5\end{array}$ & $\begin{array}{l}6.5 \\
6.6 \\
7.0 \\
7.0 \\
7.1\end{array}$ & $\begin{array}{l}2.5 \\
3.2 \\
3.1 \\
2.5 \\
2.3\end{array}$ & $=$ & $\begin{array}{l}=- \\
=- \\
=-\end{array}$ \\
\hline $\begin{array}{l}26 \\
27 \\
28 \\
29 \\
30 \\
31\end{array}$ & $\begin{array}{l}4.0 \\
3.4 \\
3.5 \\
3.8 \\
4.3 \\
3.4\end{array}$ & $\begin{array}{l}4.0 \\
4.1 \\
4.2 \\
4.6 \\
4.6 \\
-. .-\end{array}$ & $\begin{array}{l}3.9 \\
4.1 \\
4.2 \\
4.2 \\
4.1 \\
4.1\end{array}$ & $\begin{array}{l}4.9 \\
5.1 \\
5.1 \\
5.1 \\
5.3 \\
6.1\end{array}$ & $\begin{array}{l}4.6 \\
3.6 \\
4.3 \\
-.- \\
-\end{array}$ & $\begin{array}{l}3.5 \\
2.9 \\
2.0 \\
2.6 \\
2.7 \\
2.7\end{array}$ & $\begin{array}{l}8.6 \\
8.6 \\
8.7 \\
8.0 \\
7.3 \\
-\end{array}$ & $\begin{array}{l}7.6 \\
8.1 \\
7.9 \\
7.2 \\
5.4 \\
4.0\end{array}$ & $\begin{array}{l}6.5 \\
5.7 \\
5.1 \\
5.3 \\
4.8 \\
-.-\end{array}$ & $\begin{array}{l}2.6 \\
2.4 \\
2.6 \\
2.4 \\
2.5 \\
2.9\end{array}$ & $\begin{array}{l}m \\
\cdots \\
-\infty \\
=-\end{array}$ & $\begin{array}{l}=- \\
=- \\
=- \\
--\end{array}$ \\
\hline AVERAGE & 3.4 & 3.7 & 3.8 & 3.9 & 4.7 & 3.7 & 5.9 & 8.1 & 5.3 & 3.6 & $\cdots$ & $\cdots$ \\
\hline
\end{tabular}


02296750 PEACE RIVER AT'ARCADIA, FLA.--Cont1nued

SPECIFIC CONDUCTANCE (MICROMHOS AT $25^{\circ} \mathrm{C}$ ), WATER YEAR OCTOBER 1969 TO SEPTEMBER 1970

\begin{tabular}{|c|c|c|c|c|c|c|c|c|c|c|c|c|}
\hline DAY & OCT & NOV & DEC & JAN & FEB & MAR & APR & MAY & JUN & JUL & AUG & SEP \\
\hline $\begin{array}{l}1 \\
2 \\
3 \\
4 \\
5\end{array}$ & $\begin{array}{l}130 \\
125 \\
100 \\
120 \\
115\end{array}$ & $\begin{array}{l}180 \\
195 \\
195 \\
195 \\
190\end{array}$ & $\begin{array}{l}235 \\
235 \\
255 \\
285 \\
260\end{array}$ & $\begin{array}{l}250 \\
250 \\
250 \\
220 \\
215\end{array}$ & $\begin{array}{l}290 \\
298 \\
291 \\
259 \\
192\end{array}$ & $\begin{array}{l}245 \\
250 \\
260 \\
265 \\
291\end{array}$ & $\begin{array}{l}150 \\
160 \\
160 \\
171 \\
191\end{array}$ & $\begin{array}{l}370 \\
380 \\
395 \\
380 \\
390\end{array}$ & $\begin{array}{l}315 \\
285 \\
285 \\
261 \\
240\end{array}$ & $\begin{array}{l}225 \\
228 \\
240 \\
250 \\
241\end{array}$ & $\begin{array}{l}135 \\
140 \\
135 \\
158 \\
173\end{array}$ & $\begin{array}{l}171 \\
195 \\
206 \\
224 \\
233\end{array}$ \\
\hline $\begin{array}{r}6 \\
7 \\
8 \\
9 \\
10\end{array}$ & $\begin{array}{l}115 \\
115 \\
120 \\
125 \\
125\end{array}$ & $\begin{array}{l}190 \\
210 \\
210 \\
219 \\
219\end{array}$ & $\begin{array}{l}260 \\
255 \\
260 \\
260 \\
225\end{array}$ & $\begin{array}{l}215 \\
200 \\
230 \\
130 \\
165\end{array}$ & $\begin{array}{l}221 \\
224 \\
215 \\
220 \\
225\end{array}$ & $\begin{array}{l}306 \\
300 \\
245 \\
255 \\
220\end{array}$ & $\begin{array}{l}190 \\
201 \\
210 \\
220 \\
229\end{array}$ & $\begin{array}{l}400 \\
420 \\
430 \\
450 \\
455\end{array}$ & $\begin{array}{l}200 \\
240 \\
245 \\
261 \\
270\end{array}$ & $\begin{array}{l}229 \\
239 \\
230 \\
239 \\
221\end{array}$ & $\begin{array}{l}175 \\
189 \\
186 \\
197 \\
214\end{array}$ & $\ddot{-\infty}$ \\
\hline $\begin{array}{l}11 \\
12 \\
13 \\
14 \\
15\end{array}$ & $\begin{array}{l}140 \\
165 \\
145 \\
175 \\
170\end{array}$ & $\begin{array}{l}219 \\
230 \\
230 \\
210 \\
165\end{array}$ & $\begin{array}{l}155 \\
145 \\
130 \\
130 \\
130\end{array}$ & $\begin{array}{l}170 \\
180 \\
160 \\
180 \\
185\end{array}$ & $\begin{array}{l}235 \\
249 \\
258 \\
269 \\
279\end{array}$ & $\begin{array}{l}220 \\
220 \\
194 \\
165 \\
185\end{array}$ & $\begin{array}{l}240 \\
255 \\
259 \\
265 \\
279\end{array}$ & $\begin{array}{l}460 \\
460 \\
460 \\
460 \\
460\end{array}$ & $\begin{array}{l}285 \\
285 \\
290 \\
280 \\
278\end{array}$ & $\begin{array}{l}198 \\
110 \\
110 \\
200 \\
100\end{array}$ & $\begin{array}{l}184 \\
216 \\
222 \\
228 \\
211\end{array}$ & 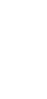 \\
\hline $\begin{array}{l}16 \\
17 \\
18 \\
19 \\
20\end{array}$ & $\begin{array}{l}170 \\
189 \\
185 \\
185 \\
205\end{array}$ & $\begin{array}{l}185 \\
185 \\
200 \\
180 \\
180\end{array}$ & $\begin{array}{l}130 \\
130 \\
145 \\
150 \\
165\end{array}$ & $\begin{array}{l}190 \\
190 \\
210 \\
210 \\
220\end{array}$ & $\begin{array}{l}280 \\
285 \\
280 \\
275 \\
279\end{array}$ & $\begin{array}{l}190 \\
200 \\
202 \\
210 \\
210\end{array}$ & $\begin{array}{l}295 \\
295 \\
300 \\
300 \\
305\end{array}$ & $\begin{array}{l}475 \\
475 \\
475 \\
475 \\
475\end{array}$ & $\begin{array}{l}271 \\
265 \\
258 \\
270 \\
289\end{array}$ & $\begin{array}{l}100 \\
110 \\
119 \\
117 \\
118\end{array}$ & $\begin{array}{l}222 \\
214 \\
212 \\
220 \\
227\end{array}$ & 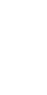 \\
\hline $\begin{array}{l}21 \\
22 \\
23 \\
24 \\
25\end{array}$ & $\begin{array}{l}190 \\
205 \\
215 \\
205 \\
180\end{array}$ & $\begin{array}{l}200 \\
190 \\
205 \\
205 \\
225\end{array}$ & $\begin{array}{l}185 \\
189 \\
200 \\
200 \\
210\end{array}$ & $\begin{array}{l}230 \\
225 \\
230 \\
230 \\
230\end{array}$ & $\begin{array}{l}290 \\
275 \\
285 \\
299 \\
289\end{array}$ & $\begin{array}{l}220 \\
225 \\
225 \\
225 \\
220\end{array}$ & $\begin{array}{l}305 \\
325 \\
320 \\
339 \\
370\end{array}$ & $\begin{array}{l}475 \\
480 \\
495 \\
465 \\
455\end{array}$ & $\begin{array}{l}320 \\
325 \\
340 \\
335 \\
330\end{array}$ & $\begin{array}{l}122 \\
150 \\
147 \\
128 \\
114\end{array}$ & $\begin{array}{l}227 \\
236 \\
188 \\
156 \\
162\end{array}$ & $\ddot{m}$ \\
\hline $\begin{array}{l}26 \\
27 \\
28 \\
29 \\
30 \\
31\end{array}$ & $\begin{array}{l}185 \\
185 \\
190 \\
190 \\
215 \\
210\end{array}$ & $\begin{array}{l}235 \\
235 \\
235 \\
235 \\
235 \\
---\end{array}$ & $\begin{array}{l}215 \\
220 \\
220 \\
220 \\
220 \\
225\end{array}$ & $\begin{array}{l}250 \\
245 \\
240 \\
265 \\
245 \\
280\end{array}$ & $\begin{array}{l}269 \\
270 \\
250 \\
-\ldots \\
-\infty\end{array}$ & $\begin{array}{l}200 \\
165 \\
120 \\
135 \\
135 \\
145\end{array}$ & $\begin{array}{l}370 \\
370 \\
370 \\
370 \\
365 \\
---\end{array}$ & $\begin{array}{l}440 \\
400 \\
425 \\
375 \\
320 \\
260\end{array}$ & $\begin{array}{l}320 \\
295 \\
245 \\
240 \\
225 \\
-\end{array}$ & $\begin{array}{l}125 \\
119 \\
116 \\
112 \\
125 \\
130\end{array}$ & $\begin{array}{l}149 \\
151 \\
161 \\
163 \\
148 \\
153\end{array}$ & $=$ \\
\hline AVERAGE & 164 & 206 & 201 & 216 & 263 & 214 & 273 & 430 & 278 & 162 & 186 & $\cdots$ \\
\hline & & & & (UNITS), & WATER YEAR & OCTOBER & 1969 TO & JULY 1970 & & & & \\
\hline DAY & OCT & Nov & DEC & JAN & FEB & MAR & APR & MAY & JUN & JUL & AUG & SEP \\
\hline $\begin{array}{l}1 \\
2 \\
3 \\
4 \\
5\end{array}$ & $\begin{array}{l}6.6 \\
6.6 \\
7.1 \\
7.0 \\
6.9\end{array}$ & $\begin{array}{l}6.9 \\
6.9 \\
6.8 \\
6.8 \\
6.9\end{array}$ & $\begin{array}{l}7.1 \\
7.4 \\
7.2 \\
7.2 \\
7.1\end{array}$ & $\begin{array}{l}7.3 \\
7.2 \\
7.4 \\
7.2 \\
7.1\end{array}$ & $\begin{array}{l}7.0 \\
7.2 \\
7.1 \\
7.0 \\
7.1\end{array}$ & $\begin{array}{l}7.3 \\
7.2 \\
7.4 \\
7.4 \\
7.2\end{array}$ & $\begin{array}{l}6.9 \\
6.8 \\
6.8 \\
6.7 \\
6.8\end{array}$ & $\begin{array}{l}7.1 \\
7.6 \\
7.2 \\
7.1 \\
7.7\end{array}$ & $\begin{array}{l}7.1 \\
7.0 \\
7.0 \\
7.0 \\
7.0\end{array}$ & $\begin{array}{l}7.0 \\
7.4 \\
7.2 \\
7.2 \\
7.3\end{array}$ & $\begin{array}{l}=- \\
=-- \\
=-\end{array}$ & $\ddot{m}$ \\
\hline $\begin{array}{r}6 \\
7 \\
8 \\
9 \\
10\end{array}$ & $\begin{array}{l}6.6 \\
7.3 \\
6.7 \\
6.7 \\
6.9\end{array}$ & $\begin{array}{l}7.3 \\
7.3 \\
7.3 \\
7.3 \\
7.2\end{array}$ & $\begin{array}{l}7.2 \\
7.3 \\
7.2 \\
7.3 \\
7.3\end{array}$ & $\begin{array}{l}7.0 \\
7.1 \\
7.1 \\
7.2 \\
7.0\end{array}$ & $\begin{array}{l}7.1 \\
7.3 \\
7.3 \\
7.3 \\
7.3\end{array}$ & $\begin{array}{l}7.2 \\
7.0 \\
6.9 \\
7.0 \\
6.9\end{array}$ & $\begin{array}{l}6.9 \\
6.9 \\
6.9 \\
6.9 \\
6.9\end{array}$ & $\begin{array}{l}7.6 \\
7.2 \\
7.6 \\
7.3 \\
7.8\end{array}$ & $\begin{array}{l}7.0 \\
6.8 \\
6.8 \\
6.8 \\
6.8\end{array}$ & $\begin{array}{l}7.1 \\
6.9 \\
7.0 \\
7.1 \\
7.0\end{array}$ & 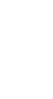 & $=$ \\
\hline $\begin{array}{l}11 \\
12 \\
13 \\
14 \\
15\end{array}$ & $\begin{array}{l}6.8 \\
7.2 \\
6.9 \\
6.8 \\
6.8\end{array}$ & $\begin{array}{l}7.3 \\
7.1 \\
7.1 \\
7.1 \\
7.1\end{array}$ & $\begin{array}{l}7.1 \\
7.0 \\
7.0 \\
6.9 \\
6.9\end{array}$ & $\begin{array}{l}7.0 \\
7.3 \\
7.1 \\
7.1 \\
7.4\end{array}$ & $\begin{array}{l}7.2 \\
7.3 \\
7.4 \\
7.4 \\
7.4\end{array}$ & $\begin{array}{l}6.8 \\
7.0 \\
7.0 \\
6.7 \\
6.8\end{array}$ & $\begin{array}{l}6.9 \\
6.9 \\
6.9 \\
7.0 \\
7.0\end{array}$ & $\begin{array}{l}7.4 \\
7.4 \\
7.2 \\
7.7 \\
7.7\end{array}$ & $\begin{array}{l}6.8 \\
7.0 \\
7.1 \\
7.2 \\
7.2\end{array}$ & $\begin{array}{l}6.9 \\
6.7 \\
6.5 \\
7.1 \\
6.9\end{array}$ & $=$ & $\overline{-}$ \\
\hline $\begin{array}{l}16 \\
17 \\
18 \\
19 \\
20\end{array}$ & $\begin{array}{l}6.9 \\
7.0 \\
6.8 \\
6.9 \\
6.9\end{array}$ & $\begin{array}{l}7.0 \\
7.0 \\
7.0 \\
7.1 \\
7.4\end{array}$ & $\begin{array}{l}6.9 \\
6.9 \\
6.9 \\
6.9 \\
6.9\end{array}$ & $\begin{array}{l}7.4 \\
7.4 \\
7.4 \\
7.4 \\
7.4\end{array}$ & $\begin{array}{l}7.4 \\
7.4 \\
7.4 \\
7.4 \\
7.4\end{array}$ & $\begin{array}{l}6.7 \\
6.8 \\
6.9 \\
7.1 \\
6.8\end{array}$ & $\begin{array}{l}7.0 \\
7.0 \\
7.1 \\
7.1 \\
7.2\end{array}$ & $\begin{array}{l}7.4 \\
7.6 \\
7.3 \\
7.5 \\
7.4\end{array}$ & $\begin{array}{l}7.1 \\
7.1 \\
7.0 \\
7.1 \\
7.2\end{array}$ & $\begin{array}{l}6.5 \\
6.4 \\
6.7 \\
6.6 \\
6.8\end{array}$ & $\begin{array}{l}=- \\
=- \\
=-\end{array}$ & $\overline{-}$ \\
\hline $\begin{array}{l}21 \\
22 \\
23 \\
24 \\
25\end{array}$ & $\begin{array}{l}6.9 \\
6.9 \\
6.9 \\
7.0 \\
7.0\end{array}$ & $\begin{array}{l}7.4 \\
7.1 \\
7.1 \\
7.3 \\
7.3\end{array}$ & $\begin{array}{l}6.9 \\
6.9 \\
6.9 \\
7.0 \\
7.2\end{array}$ & $\begin{array}{l}7.4 \\
7.4 \\
7.4 \\
7.5 \\
7.5\end{array}$ & $\begin{array}{l}7.4 \\
7.4 \\
7.3 \\
7.3 \\
7.2\end{array}$ & $\begin{array}{l}6.8 \\
6.8 \\
6.8 \\
6.9 \\
6.9\end{array}$ & $\begin{array}{l}7.1 \\
7.1 \\
7.2 \\
7.1 \\
7.1\end{array}$ & $\begin{array}{l}7.5 \\
7.5 \\
7.6 \\
7.2 \\
7.3\end{array}$ & $\begin{array}{l}7.3 \\
7.3 \\
7.3 \\
7.3 \\
7.0\end{array}$ & $\begin{array}{l}6.9 \\
6.9 \\
7.0 \\
7.0 \\
6.9\end{array}$ & $\begin{array}{l}=- \\
\overline{-} \\
\overline{-}\end{array}$ & $\overline{--}$ \\
\hline $\begin{array}{l}26 \\
27 \\
28 \\
29 \\
30 \\
31\end{array}$ & $\begin{array}{l}7.0 \\
7.0 \\
7.0 \\
7.0 \\
7.0 \\
7.0\end{array}$ & $\begin{array}{l}7.4 \\
7.4 \\
7.3 \\
7.3 \\
7.4 \\
-.-\end{array}$ & $\begin{array}{l}7.4 \\
7.4 \\
7.4 \\
7.3 \\
7.4 \\
7.4\end{array}$ & $\begin{array}{l}7.5 \\
7.5 \\
7.6 \\
7.6 \\
7.5 \\
7.5\end{array}$ & \begin{tabular}{l}
7.2 \\
7.1 \\
7.1 \\
\hdashline.- \\
$-\therefore$
\end{tabular} & $\begin{array}{l}6.9 \\
6.8 \\
6.7 \\
6.6 \\
6.5 \\
6.7\end{array}$ & $\begin{array}{l}7.1 \\
7.1 \\
7.2 \\
7.2 \\
7.2 \\
-. .-\end{array}$ & $\begin{array}{l}7.4 \\
7.4 \\
7.2 \\
7.0 \\
6.9 \\
6.7\end{array}$ & $\begin{array}{l}7.1 \\
6.9 \\
6.8 \\
6.9 \\
6.8 \\
-\cdots-\end{array}$ & $\begin{array}{l}6.8 \\
6.7 \\
6.7 \\
6.5 \\
6.7 \\
6.7\end{array}$ & $\begin{array}{l}=- \\
\overline{-} \\
\overline{-} \\
\square\end{array}$ & $=$ \\
\hline AVERAGE & 6.9 & 7.2 & 7.1 & 7.3 & 7.3 & 6.9 & 7.0 & 7.4 & 7.0 & 6.9 & -- & - \\
\hline
\end{tabular}


PEACE RIVER BASIN

211

02296750 PEACE RIVER AT ARCADIA, FLA.--Continued

TURBIDITY, IN JACKSON TURBIDITY UNITS, WATER YEAR OCTOBER 1969 TO SEPTEMBER 1970

\begin{tabular}{|c|c|c|c|c|c|c|c|c|c|c|c|c|}
\hline DAY & OCT & NOV & OEC & JAN & FEB & MAR & $A P R$ & MAY & JUN & JUL & AUG & SEP \\
\hline $\begin{array}{l}1 \\
2 \\
3 \\
4 \\
5\end{array}$ & $\begin{array}{l}4 \\
3 \\
5 \\
3 \\
7\end{array}$ & $\begin{array}{l}4 \\
2 \\
2 \\
4 \\
3\end{array}$ & $\begin{array}{l}3 \\
3 \\
3 \\
4 \\
4\end{array}$ & $\begin{array}{l}2 \\
3 \\
3 \\
4 \\
3\end{array}$ & $\begin{array}{l}3 \\
3 \\
4 \\
5 \\
6\end{array}$ & $\begin{array}{l}5 \\
3 \\
4 \\
2 \\
3\end{array}$ & $\begin{array}{l}2 \\
2 \\
3 \\
2 \\
3\end{array}$ & $\begin{array}{l}6 \\
6 \\
6 \\
5 \\
6\end{array}$ & $\begin{array}{l}15 \\
15 \\
10 \\
15 \\
10\end{array}$ & $\begin{array}{r}15 \\
15 \\
10 \\
10 \\
9\end{array}$ & $\ddot{=}$ & $=$ \\
\hline $\begin{array}{r}6 \\
7 \\
8 \\
9 \\
10\end{array}$ & $\begin{array}{l}3 \\
3 \\
2 \\
4 \\
3\end{array}$ & $\begin{array}{r}3 \\
3 \\
4 \\
-3\end{array}$ & $\begin{array}{l}6 \\
5 \\
4 \\
6 \\
3\end{array}$ & $\begin{array}{l}4 \\
5 \\
6 \\
3 \\
6\end{array}$ & $\begin{array}{l}5 \\
5 \\
3 \\
5 \\
2\end{array}$ & $\begin{array}{l}4 \\
3 \\
3 \\
3 \\
3\end{array}$ & $\begin{array}{l}3 \\
3 \\
4 \\
4 \\
4\end{array}$ & $\begin{array}{l}5 \\
7 \\
4 \\
4 \\
8\end{array}$ & $\begin{array}{l}20 \\
20 \\
10 \\
20 \\
15\end{array}$ & $\begin{array}{r}10 \\
9 \\
9 \\
6 \\
4\end{array}$ & $\overline{=}$ & $\begin{array}{l}= \\
=- \\
=-\end{array}$ \\
\hline $\begin{array}{l}11 \\
12 \\
13 \\
14 \\
15\end{array}$ & $\begin{array}{l}5 \\
3 \\
3 \\
3 \\
2\end{array}$ & $\begin{array}{r}--5 \\
3 \\
4 \\
2\end{array}$ & $\begin{array}{l}3 \\
1 \\
3 \\
2 \\
2\end{array}$ & $\begin{array}{l}3 \\
2 \\
4 \\
3 \\
3\end{array}$ & $\begin{array}{l}2 \\
3 \\
4 \\
4 \\
4\end{array}$ & $\begin{array}{l}4 \\
3 \\
3 \\
2 \\
4\end{array}$ & $\begin{array}{r}6 \\
5 \\
-5 \\
6\end{array}$ & $\begin{array}{l}5 \\
7 \\
4 \\
5 \\
4\end{array}$ & $\begin{array}{l}15 \\
15 \\
15 \\
15 \\
15\end{array}$ & $\begin{array}{l}5 \\
3 \\
7 \\
5 \\
6\end{array}$ & $\ddot{m}$ & $\begin{array}{l}=- \\
=- \\
=-\end{array}$ \\
\hline $\begin{array}{l}16 \\
17 \\
18 \\
19 \\
20\end{array}$ & $\begin{array}{l}4 \\
3 \\
3 \\
3 \\
2\end{array}$ & $\begin{array}{l}5 \\
4 \\
4 \\
4 \\
3\end{array}$ & $\begin{array}{l}2 \\
2 \\
2 \\
2 \\
3\end{array}$ & $\begin{array}{l}2 \\
\mathbf{3} \\
\mathbf{3} \\
\mathbf{3} \\
\mathbf{3}\end{array}$ & $\begin{array}{l}2 \\
3 \\
2 \\
3 \\
3\end{array}$ & $\begin{array}{l}3 \\
4 \\
2 \\
3 \\
3\end{array}$ & $\begin{array}{l}6 \\
5 \\
5 \\
5 \\
8\end{array}$ & $\begin{array}{l}7 \\
5 \\
5 \\
6 \\
6\end{array}$ & $\begin{array}{r}20 \\
15 \\
9 \\
10 \\
15\end{array}$ & $\begin{array}{l}3 \\
5 \\
4 \\
6 \\
6\end{array}$ & $\ddot{m}$ & $\begin{array}{l}-- \\
-- \\
--\end{array}$ \\
\hline $\begin{array}{l}21 \\
22 \\
23 \\
24 \\
25\end{array}$ & $\begin{array}{l}4 \\
3 \\
2 \\
3 \\
3\end{array}$ & $\begin{array}{r}-. \\
5 \\
3 \\
4\end{array}$ & $\begin{array}{l}2 \\
1 \\
3 \\
3 \\
3\end{array}$ & $\begin{array}{l}3 \\
2 \\
3 \\
2 \\
3\end{array}$ & $\begin{array}{l}5 \\
4 \\
3 \\
4 \\
4\end{array}$ & $\begin{array}{l}3 \\
1 \\
3 \\
2 \\
3\end{array}$ & $\begin{array}{r}-7 \\
6 \\
7 \\
8\end{array}$ & $\begin{array}{l}6 \\
4 \\
4 \\
4 \\
4\end{array}$ & $\begin{array}{l}15 \\
15 \\
15 \\
15 \\
20\end{array}$ & $\begin{array}{l}7 \\
6 \\
6 \\
7 \\
7\end{array}$ & $\ddot{m}$ & $\ddot{z}=$ \\
\hline $\begin{array}{l}26 \\
27 \\
28 \\
29 \\
30 \\
31\end{array}$ & $\begin{array}{l}2 \\
2 \\
2 \\
3 \\
2 \\
3\end{array}$ & $\begin{array}{r}4 \\
3 \\
3 \\
4 \\
3 \\
-3\end{array}$ & $\begin{array}{l}2 \\
3 \\
3 \\
2 \\
3 \\
3\end{array}$ & $\begin{array}{l}3 \\
3 \\
2 \\
3 \\
2 \\
3\end{array}$ & $\begin{array}{r}4 \\
3 \\
3 \\
-\infty \\
\hdashline--\end{array}$ & $\begin{array}{l}3 \\
3 \\
2 \\
2 \\
2 \\
2\end{array}$ & $\begin{array}{r}6 \\
5 \\
4 \\
4 \\
4 \\
-\end{array}$ & $\begin{array}{l}6 \\
4 \\
5 \\
4 \\
6 \\
6\end{array}$ & $\begin{array}{r}15 \\
15 \\
10 \\
10 \\
10 \\
\end{array}$ & $\begin{array}{l}6 \\
4 \\
4 \\
4 \\
4 \\
4\end{array}$ & $\bar{m}$ & $=$ \\
\hline AVERAGE & 3 & 3 & 3 & 3 & 3 & 3 & 5 & 5 & 15 & 6 & -- & $\cdots$ \\
\hline
\end{tabular}

(TRACE METALS)

\begin{tabular}{|c|c|c|c|c|c|c|c|c|c|c|c|c|}
\hline & $\begin{array}{l}\text { UIS- } \\
\text { SULVED }\end{array}$ & DIS- & OIS- & $\begin{array}{l}\text { UIS- } \\
\text { SOLVFO }\end{array}$ & $\begin{array}{r}\text { HEXA- } \\
\text { VALENT }\end{array}$ & UIS- & & & & $\begin{array}{l}\text { OIS- } \\
\text { SOLVED }\end{array}$ & & LIS- \\
\hline & ALUA $=$ & Solvfo & SOLVEL & $C A D-$ & Chen- & $\mathrm{CH}+\mathrm{O}-$ & SCLVED & SOL VEO & SOLVEO & MAN- & TOTAL & SCLVEO \\
\hline & INUM & ARGENIC & BOHON" & MIUM & MIUM & MIUM & COPPEK & IRON & LEAD & GANESE & MERCURY & 2 I VC \\
\hline DATE & $\begin{array}{l}(A L) \\
(U G / L)\end{array}$ & $\begin{array}{l}\text { (AS) } \\
\text { (UG/L) }\end{array}$ & $\begin{array}{c}(3) \\
(16)\end{array}$ & $\begin{array}{c}(\mathrm{CD}) \\
(\cup G / L)\end{array}$ & $\begin{array}{l}\left(C R_{6}\right) \\
\left(U G_{1}\right)\end{array}$ & $\begin{array}{c}(C K) \\
(U G)\end{array}$ & $\begin{array}{l}\text { (CU) } \\
\text { (UG }\end{array}$ & $\begin{array}{l}\text { (FE) } \\
(U G) \text { ( }\end{array}$ & (PR) & $\begin{array}{c}\text { (MN) } \\
\text { (UGG) }\end{array}$ & $(H G)$ & $\begin{array}{l}(Z N) \\
\left(U_{G}\right)\end{array}$ \\
\hline
\end{tabular}
JUNE, 1970

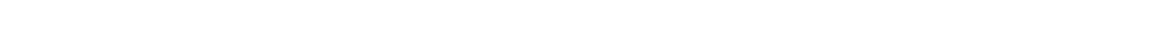

TEMPERATURE ( $\left.{ }^{\circ} \mathrm{C}\right)$ OF WATER, WATER YEAR DCTOBER 1969 TO SEPTEMBER 1970

\begin{tabular}{|c|c|c|c|c|c|c|c|c|c|c|c|c|}
\hline DAY & OCT & Nov & $D E C$ & JAN & FEB & MAR & $A P R$ & MAY & JUN & JUL & $A \cup G$ & SEP \\
\hline $\begin{array}{l}1 \\
2 \\
3 \\
4 \\
5\end{array}$ & $\begin{array}{l}29.0 \\
24.0 \\
24.0 \\
26.0 \\
24.0\end{array}$ & $\begin{array}{r}23.0 \\
21.0 \\
19.0 \\
18.0 \\
9.0\end{array}$ & $\begin{array}{l}15.0 \\
15.0 \\
12.0 \\
15.0 \\
14.0\end{array}$ & $\begin{array}{l}16.0 \\
15.0 \\
16.0 \\
15.0 \\
16.0\end{array}$ & $\begin{array}{r}15.0 \\
18.0 \\
23.0 \\
8.0 \\
6.0\end{array}$ & $\begin{array}{l}18.0 \\
17.0 \\
18.0 \\
20.0 \\
19.0\end{array}$ & $\begin{array}{l}24.0 \\
25.0 \\
20.0 \\
20.0 \\
18.0\end{array}$ & $\begin{array}{l}25.0 \\
22.0 \\
24.0 \\
22.0 \\
20.0\end{array}$ & $\begin{array}{l}22.0 \\
23.0 \\
25.0 \\
25.0 \\
23.0\end{array}$ & $\begin{array}{l}27.0 \\
27.0 \\
24.0 \\
28.0 \\
27.0\end{array}$ & $\begin{array}{l}28.0 \\
29.0 \\
29.0 \\
29.0 \\
31.0\end{array}$ & $\begin{array}{l}27.0 \\
29.0 \\
29.0 \\
29.0 \\
29.0\end{array}$ \\
\hline $\begin{array}{r}6 \\
7 \\
8 \\
9 \\
10\end{array}$ & $\begin{array}{l}25.0 \\
24.0 \\
22.0 \\
24.0 \\
24.0\end{array}$ & $\begin{array}{l}10.0 \\
15.0 \\
14.0 \\
16.0 \\
15.0\end{array}$ & $\begin{array}{l}13.0 \\
18.0 \\
18.0 \\
18.0 \\
15.0\end{array}$ & $\begin{array}{r}17.0 \\
16.0 \\
4.0 \\
2.0 \\
0.0\end{array}$ & $\begin{array}{l}18.0 \\
12.0 \\
10.0 \\
12.0 \\
14.0\end{array}$ & $\begin{array}{l}18.0 \\
18.0 \\
19.0 \\
16.0 \\
14.0\end{array}$ & $\begin{array}{l}18.0 \\
18.0 \\
18.0 \\
18.0 \\
20.0\end{array}$ & $\begin{array}{l}19.0 \\
19.0 \\
22.0 \\
23.0 \\
22.0\end{array}$ & $\begin{array}{l}23.0 \\
25.0 \\
24.0 \\
28.0 \\
25.0\end{array}$ & $\begin{array}{l}28.0 \\
25.0 \\
24.0 \\
25.0 \\
25.0\end{array}$ & $\begin{array}{l}29.0 \\
29.0 \\
28.0 \\
27.0 \\
27.0\end{array}$ & $\begin{array}{l}\cdots \\
-\cdots \\
-\cdots\end{array}$ \\
\hline $\begin{array}{l}11 \\
12 \\
13 \\
14 \\
15\end{array}$ & $\begin{array}{l}25.0 \\
24.0 \\
23.0 \\
22.0 \\
24.0\end{array}$ & $\begin{array}{l}14.0 \\
19.0 \\
20.0 \\
14.0 \\
10.0\end{array}$ & $\begin{array}{r}16.0 \\
8.0 \\
8.0 \\
14.0 \\
15.0\end{array}$ & $\begin{array}{r}8.0 \\
11.0 \\
18.0 \\
16.0 \\
16.0\end{array}$ & $\begin{array}{l}15.0 \\
13.0 \\
13.0 \\
14.0 \\
19.0\end{array}$ & $\begin{array}{l}19.0 \\
20.0 \\
14.0 \\
10.0 \\
16.0\end{array}$ & $\begin{array}{l}20.0 \\
21.0 \\
21.0 \\
22.0 \\
20.0\end{array}$ & $\begin{array}{l}22.0 \\
23.0 \\
22.0 \\
23.0 \\
22.0\end{array}$ & $\begin{array}{l}24.0 \\
24.0 \\
23.0 \\
25.0 \\
24.0\end{array}$ & $\begin{array}{l}24.0 \\
28.0 \\
29.0 \\
26.0 \\
27.0\end{array}$ & $\begin{array}{l}27.0 \\
28.0 \\
27.0 \\
30.0 \\
27.0\end{array}$ & 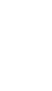 \\
\hline $\begin{array}{l}16 \\
17 \\
18 \\
19 \\
20\end{array}$ & $\begin{array}{l}22.0 \\
23.0 \\
23.0 \\
23.0 \\
24.0\end{array}$ & $\begin{array}{l}12.0 \\
15.0 \\
18.0 \\
20.0 \\
15.0\end{array}$ & $\begin{array}{l}14.0 \\
13.0 \\
12.0 \\
14.0 \\
15.0\end{array}$ & $\begin{array}{r}17.0 \\
10.0 \\
8.0 \\
12.0 \\
15.0\end{array}$ & $\begin{array}{l}20.0 \\
20.0 \\
14.0 \\
15.0 \\
12.0\end{array}$ & $\begin{array}{l}14.0 \\
15.0 \\
22.0 \\
20.0 \\
21.0\end{array}$ & $\begin{array}{l}20.0 \\
23.0 \\
24.0 \\
24.0 \\
24.0\end{array}$ & $\begin{array}{l}22.0 \\
22.0 \\
25.0 \\
25.0 \\
24.0\end{array}$ & $\begin{array}{l}26.0 \\
26.0 \\
26.0 \\
28.0 \\
28.0\end{array}$ & $\begin{array}{l}26.0 \\
29.0 \\
27.0 \\
29.0 \\
27.0\end{array}$ & $\begin{array}{l}30.0 \\
29.0 \\
28.0 \\
30.0 \\
29.0\end{array}$ & $\ddot{-a}$ \\
\hline $\begin{array}{l}21 \\
22 \\
23 \\
24 \\
25\end{array}$ & $\begin{array}{l}25.0 \\
26.0 \\
26.0 \\
22.0 \\
23.0\end{array}$ & $\begin{array}{l}23.0 \\
24.0 \\
17.0 \\
17.0 \\
17.0\end{array}$ & $\begin{array}{l}11.0 \\
10.0 \\
12.0 \\
23.0 \\
10.0\end{array}$ & $\begin{array}{l}15.0 \\
15.0 \\
14.0 \\
16.0 \\
19.0\end{array}$ & $\begin{array}{l}16.0 \\
14.0 \\
15.0 \\
15.0 \\
12.0\end{array}$ & $\begin{array}{l}22.0 \\
16.0 \\
17.0 \\
14.0 \\
17.0\end{array}$ & $\begin{array}{l}25.0 \\
24.0 \\
25.0 \\
25.0 \\
25.0\end{array}$ & $\begin{array}{l}25.0 \\
24.0 \\
25.0 \\
22.0 \\
21.0\end{array}$ & $\begin{array}{l}26.0 \\
26.0 \\
28.0 \\
26.0 \\
25.0\end{array}$ & $\begin{array}{l}27.0 \\
28.0 \\
26.0 \\
28.0 \\
27.0\end{array}$ & $\begin{array}{l}28.0 \\
26.0 \\
28.0 \\
27.0 \\
27.0\end{array}$ & $\overline{--}$ \\
\hline $\begin{array}{l}26 \\
27 \\
28 \\
29 \\
30 \\
31\end{array}$ & $\begin{array}{l}23.0 \\
23.0 \\
22.0 \\
22.0 \\
19.0 \\
23.0\end{array}$ & $\begin{array}{c}19.0 \\
19.0 \\
20.0 \\
18.0 \\
16.0 \\
-\end{array}$ & $\begin{array}{r}12.0 \\
9.0 \\
14.0 \\
14.0 \\
19.0 \\
17.0\end{array}$ & $\begin{array}{l}15.0 \\
14.0 \\
16.0 \\
19.0 \\
15.0 \\
10.0\end{array}$ & $\begin{array}{r}12.0 \\
13.0 \\
14.0 \\
\ldots \\
\ldots-\end{array}$ & $\begin{array}{l}18.0 \\
19.0 \\
22.0 \\
19.0 \\
20.0 \\
22.0\end{array}$ & $\begin{array}{l}26.0 \\
33.0 \\
25.0 \\
25.0 \\
25.0 \\
-\end{array}$ & $\begin{array}{l}22.0 \\
25.0 \\
26.0 \\
23.0 \\
24.0 \\
23.0\end{array}$ & $\begin{array}{r}28.0 \\
28.0 \\
23.0 \\
25.0 \\
22.0 \\
\ldots\end{array}$ & $\begin{array}{l}28.0 \\
29.0 \\
27.0 \\
28.0 \\
27.0 \\
29.0\end{array}$ & $\begin{array}{l}29.0 \\
28.0 \\
28.0 \\
26.0 \\
22.0 \\
28.0\end{array}$ & 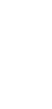 \\
\hline ERAGE & 23.5 & 17.0 & 14.0 & 13.5 & 14.5 & 18.0 & 22.5 & 23.0 & 25.0 & 27.0 & 28.0 & -- \\
\hline
\end{tabular}


LOCATION.--Lat $27^{\circ} 40^{\prime} 15^{\prime \prime}$, long $82^{\circ} 21^{\prime} 10^{\prime \prime}$, in NE sec.25, T.32 S, R.19 E., H111sborough County, at gaging station, on left bank $25 \mathrm{ft}$ downstream from bridge on U.S. Highway $301,1.6$ miles upstream from Cypress Creek, 4 miles southwest of w1mauma, and $15 \mathrm{miles}$ upstream from mouth.

DRAINAGE AREA. - - $149 \mathrm{sq} \mathrm{m} 1$.

PERIOD OF RECORD. - -Chemical ana Iyses: October 1956 to September 1970.

water temperatures: October 1956 to September 1957, October 1968 to september 1970.

EXTREMES. - 1969-70:

Specific conductance: Maximum da1ly, 250 micromhos May $255_{j}$ minimum da11y, 51 micromhos oct. 3,5 ,

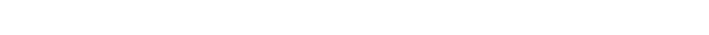

Perlod of record:

Dissolved solids (1956-57): Maximum, $88 \mathrm{mg} / \mathrm{l}$ Mar, 1-10, 1957; minimum, $36 \mathrm{mg} / 1 \mathrm{Dec}, 1-10,1956$.

Hardness (1956-57): Maximum, $24 \mathrm{mg} / 1$ Jan. 11-20, 21-31; Feb. 1-10, 11-20, 1957; m1nimum, 9 mg/i Aug. 1-10,

1957.

Specific conductance (1956-57, 1967-70): Maximum datly, 259 micromhos May 25, 1970; mintmum datly, 31 micromhos

Aug. 22,1968 .

water temperatures: Maximum, $32.0^{\circ} \mathrm{C}$ June 22,$1970 ;$ min1mum, $7.0^{\circ} \mathrm{C}$ Jan. 10,1970,

CHEMICAL ANALYSES, WATER YEAR OCTOBER 1969 TO SEPTEMBER 1970 ATER YEAR OCTOBER 1969
(MAJOR CONSTITUENTS)

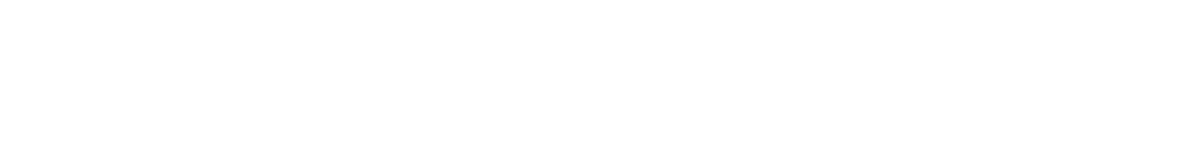

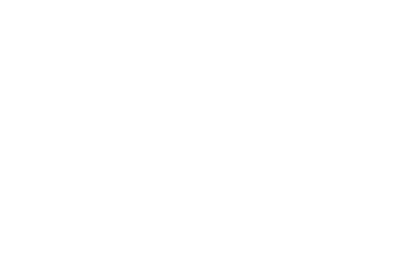

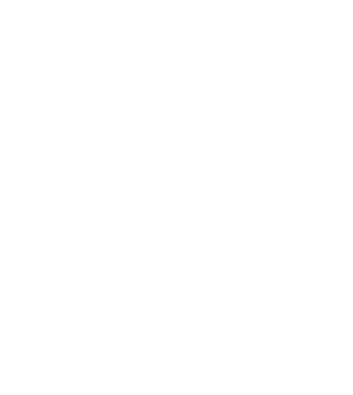

$\begin{array}{ll}5.9 & 1.2 \\ 6.1 & 1.2 \\ 5.2 & 1.0 \\ 6.0 & 1.5 \\ 5.2 & .9 \\ 5.6 & 1.5 \\ 5.4 & 2.0\end{array}$

$\begin{array}{rrr}11 & -- & 6.0 \\ 9 & -- & 6.2 \\ 14 & 0 & 6.4 \\ 4 & 0 & 5.4 \\ 21 & -- & 7.2 \\ 9 & 0 & 6.7 \\ 9 & 0 & 65.0\end{array}$

\begin{tabular}{|c|c|c|c|c|}
\hline & & DIS- & DIS- & \\
\hline & $\begin{array}{l}\text { DIS- } \\
\text { SOLVED }\end{array}$ & $\begin{array}{l}\text { SOLVED } \\
\text { CHLO- }\end{array}$ & $\begin{array}{l}\text { SOLVFD } \\
\text { FLUO- }\end{array}$ & HARD- \\
\hline & & & & \\
\hline DATE & $(M G / L)$ & (MG/L) & $(M G / L)$ & $(M G / L)$ \\
\hline
\end{tabular}

\begin{tabular}{|c|c|c|c|c|}
\hline $\begin{array}{l}\text { NOV... } 1969 \\
\text { O3.... } \\
\text { DEC. }\end{array}$ & 7.2 & 12 & .4 & 24 \\
\hline JAN... 1970 & 8.8 & 12 & .4 & 23 \\
\hline MAR... & 10 & 12 & .3 & 27 \\
\hline $\begin{array}{l}11 \ldots . . . \\
A P R .\end{array}$ & 10 & 12 & .4 & 20 \\
\hline JUNE & 11 & 9.6 & .3 & 32 \\
\hline JULY... & 11 & 10 & .4 & 26 \\
\hline $13 . .$. & 15 & 12 & .4 & 30 \\
\hline
\end{tabular}

\begin{tabular}{|c|c|c|c|c|c|c|c|}
\hline 15 & 9 & 75 & $4 A$ & 18.2 & .10 & $=$ & -- \\
\hline 16 & 7 & 64 & 43 & 42.9 & .79 & - & - \\
\hline 15 & 11 & 70 & 51 & 14.7 & 1n & -- & -- \\
\hline 17 & 3 & 89 & 4? & 98.5 & .12 & $-\cdot$ & -- \\
\hline 15 & 17 & 72 & 55 & 6.14 & .10 & -- & - \\
\hline 19 & 7 & 76 & 50 & -- & .10 & -- & + \\
\hline 22 & 7 & 102 & 55 & 20.4 & .14 & $=$ & -- \\
\hline
\end{tabular}

(FIELD MEASUREMENTS)

\begin{tabular}{|c|c|c|c|c|c|c|c|}
\hline DIS- & $\begin{array}{l}\text { PER- } \\
\text { CENY }\end{array}$ & $\begin{array}{l}\text { SPE- } \\
\text { CIFIC } \\
\text { CON- } \\
\text { DUCT- }\end{array}$ & & $B I C A R=$ & CAR - & $\begin{array}{l}\text { TRANS- } \\
\text { PAR- } \\
\text { ENCY }\end{array}$ & \\
\hline SOLVED & SATUR- & ANCE & PH & BONATE & BDNATE & SECCHI & \\
\hline $\begin{array}{l}\text { OXYGEN } \\
\text { (MGLL) }\end{array}$ & ATION & $\begin{array}{l}\text { (MICRO- } \\
\text { MHOS) }\end{array}$ & (UNITS) & $(\mathrm{HCO} 3)$ & $(\cos )$ & DISK & DEPTH \\
\hline
\end{tabular}

JUNE, 1970 
02300500 LITTLE MANATEE RIVER, NEAR WIMAUMA, FLA.--Cont1nued

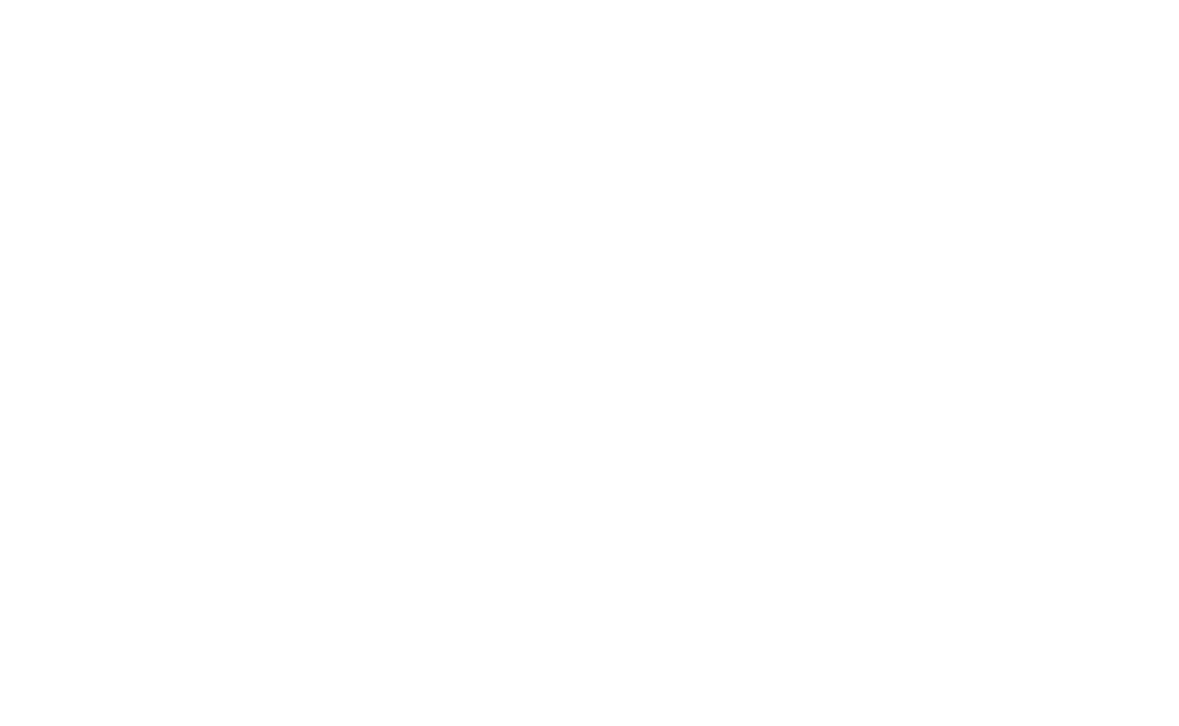

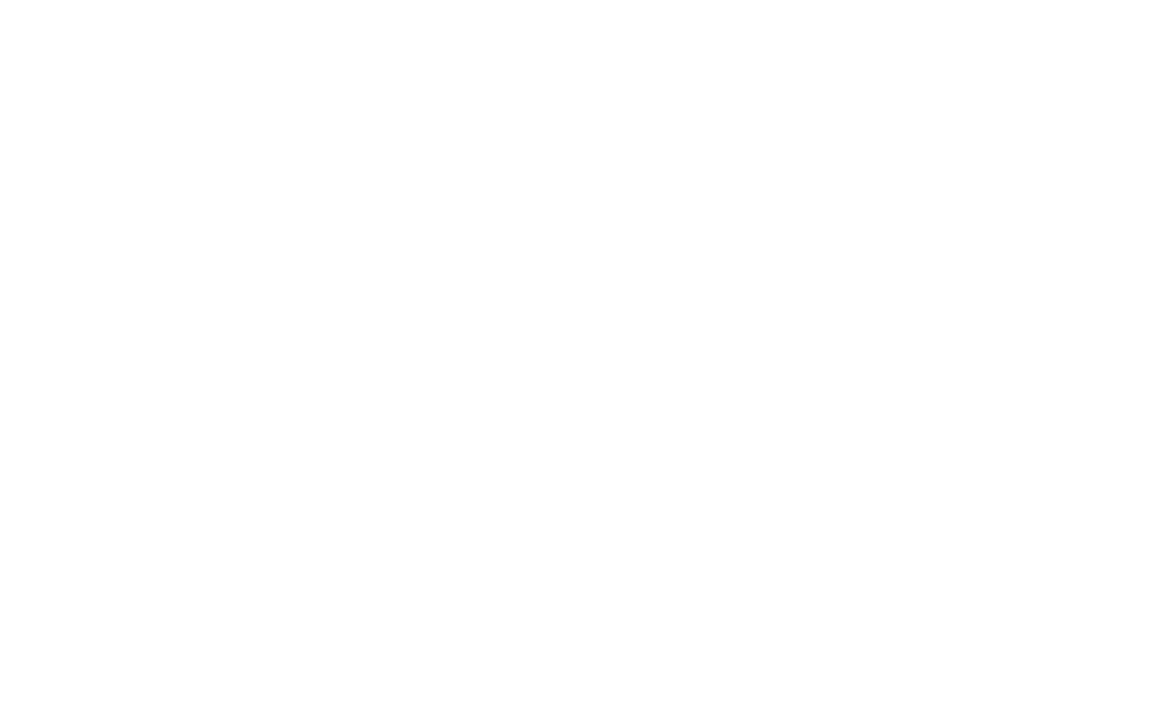


LOCATION, - -Lat $27^{\circ} 53^{\circ} 01^{\prime \prime}$, long $82^{\circ} 06^{\prime} 01^{\prime \prime}$, In SW 1 sec.10, T.30 S., R.22 E., H111sborough County, at gag1ng station, near center of span at downstream side of highway bridge, 1.2 miles north of Keysville, 4 miles upstream from
confluence with South Prong Alafia River, and 29 miles upstream from mouth of Alafia River at Hilisborough Bay. DRAINAGE AREA.--135 sq mi, approximately.

PERIOD OF RECORD.--Chemical analyses; October 1965 to September 1970.

CHEMICAL ANALYSES, WATER YEAR OCTOBER 1969 TO SEPTEMBER 1970 CHEMICAL ANALYSES, WATER YEAR OCTOBER
(MAJOR CONSTITUENTS)

\begin{tabular}{|c|c|c|c|c|c|c|c|c|c|c|c|c|}
\hline DATE & $\begin{array}{l}\text { OIS- } \\
\text { CHARGE } \\
\text { (CFS) }\end{array}$ & $\begin{array}{l}\text { TEMPER- } \\
\text { ATURE } \\
\text { (OEG C) }\end{array}$ & $\begin{array}{l}\text { SPE- } \\
\text { CIFIC } \\
\text { CON- } \\
\text { DUCT- } \\
\text { A.VCE } \\
\text { (MICRD- } \\
\text { MHOS) }\end{array}$ & $\begin{array}{l}\text { OIS- } \\
\text { SOLVED } \\
\text { IRON } \\
\text { (FE') } \\
\text { (UG/L) }\end{array}$ & $\begin{array}{l}\text { OIS- } \\
\text { SOLVED } \\
\text { CAL- } \\
\text { CIUM } \\
\text { (CA) } \\
\text { (MG/L) }\end{array}$ & $\begin{array}{l}\text { OIS- } \\
\text { SOLVED } \\
\text { MAG- } \\
\text { NE- } \\
\text { SIUM } \\
\text { (MG) } \\
\text { (MG/L) }\end{array}$ & $\begin{array}{l}\text { DIS- } \\
\text { SOLVED } \\
\text { STRON- } \\
\text { TIUM } \\
\text { (SR) } \\
\text { (UGLL) }\end{array}$ & $\begin{array}{l}\text { DIS- } \\
\text { SOLVED } \\
\text { SODIUM } \\
\text { (NA) } \\
\text { (MG/L) }\end{array}$ & $\begin{array}{l}\text { OIS- } \\
\text { SOLVEO } \\
\text { PO- } \\
\text { TAS- } \\
\text { SIUJM } \\
\text { (K) } \\
\text { (MG/L) }\end{array}$ & $\begin{array}{l}\text { BICAR- } \\
\text { BONATE } \\
\text { (HCO3) } \\
\text { (MG/L) }\end{array}$ & $\begin{array}{l}\text { CAR- } \\
\text { BONATE } \\
\text { (CO3) } \\
\text { (MG/L) }\end{array}$ & $\begin{array}{c}\text { PH } \\
\text { (UNITS) }\end{array}$ \\
\hline $\begin{array}{r}\text { MAY }, \\
19 . .\end{array}$ & 1970 & 25.0 & 870 & 110 & 92 & 15 & 200 & 64 & 2.6 & 2 & 0 & 4.8 \\
\hline$D \triangle T E$ & $\begin{array}{c}\text { DIS- } \\
\text { SOLVED } \\
\text { SULF ATE } \\
(\$ 04) \\
(M G / L)\end{array}$ & $\begin{array}{l}\text { DIS- } \\
\text { SOLVED } \\
\text { CHLO- } \\
\text { RIOE } \\
\text { (CL) } \\
\text { (MG/L) }\end{array}$ & $\begin{array}{l}\text { DIS- } \\
\text { SOLVEO } \\
\text { FLUU- } \\
\text { RIDE } \\
\text { (F) } \\
(M G / L)\end{array}$ & $\begin{array}{l}\text { HARD- } \\
\text { NESS } \\
\text { (CA,MG) } \\
\text { (MG/L) }\end{array}$ & $\begin{array}{l}\text { NON- } \\
\text { CAR- } \\
\text { BONATE } \\
\text { HARD- } \\
\text { NESS } \\
\text { (MG/L) }\end{array}$ & $\begin{array}{l}\text { ALKA- } \\
\text { LINITY } \\
\text { AS } \\
\text { CACO3 } \\
\text { (MG/L) }\end{array}$ & $\begin{array}{l}\text { OIS- } \\
\text { SOL VED } \\
\text { SOL IOS } \\
\text { (RESI - } \\
\text { DUE AT } \\
\text { I RO C) } \\
\text { (MG/L) }\end{array}$ & $\begin{array}{l}\text { DIS- } \\
\text { SULVEO } \\
\text { SOLIOS } \\
\text { (SUM OF } \\
\text { CONSTI- } \\
\text { TUENTS) } \\
\text { (MGLL) }\end{array}$ & $\begin{array}{l}\text { DIS- } \\
\text { SOLVED } \\
\text { SOLIDS } \\
\text { (TONS } \\
\text { PER } \\
\text { DAY) }\end{array}$ & $\begin{array}{l}\text { DIS- } \\
\text { SOLVFD } \\
\text { SOL IOS } \\
\text { (TONS } \\
\text { PER } \\
\text { AC-FT) }\end{array}$ & $\begin{array}{l}\text { TANNIN } \\
\text { AND } \\
\text { LIGNIN } \\
\text { (MG/L) }\end{array}$ & $\begin{array}{c}\text { OEPTH } \\
\text { (FT) }\end{array}$ \\
\hline
\end{tabular}

MAY, 1970

75

13

$291 \quad 289$

$\begin{array}{lll}2 & 581 & 627\end{array}$

$-.79$

(MACRONUTRIENTS AND OTHER RELATED CONSTITUENTS)

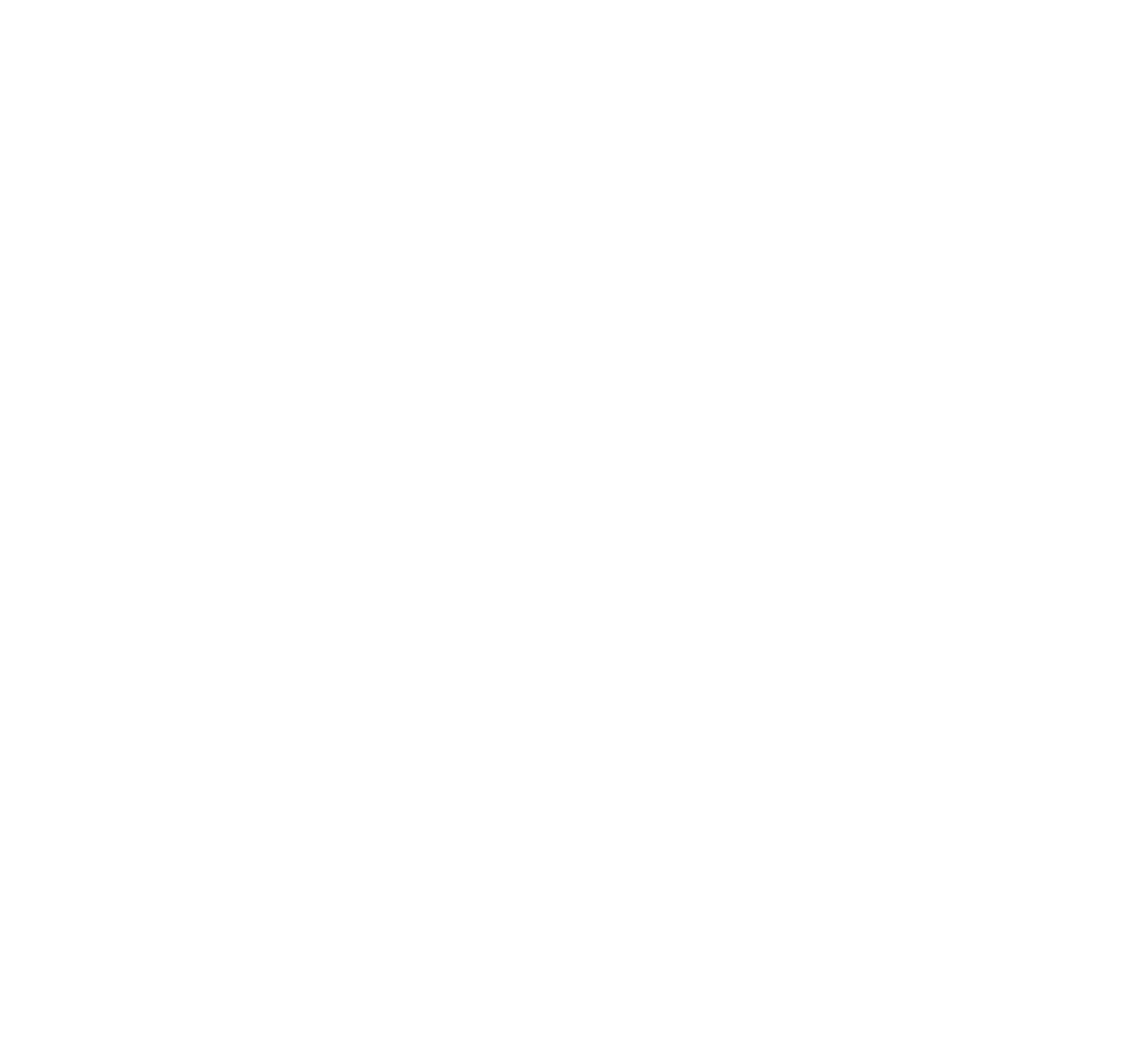


02301300 SOUTH PRONG ALAFIA RIVER NEAR LITHIA, FLA.

LOCATION.--Lat $27^{\circ} 47^{\prime} 47^{\prime \prime}$, long $82^{\circ} 07^{\prime} 04^{\prime \prime}$, in Sw sec.9, T.31 S., R.22 E., Hillsborough County, at gaging station at right bank on downstream side of bridge on count

DRAI NAGE AREA, --107 sq mi.

PERIOD OF RECORD.--Chemical analyses: October 1965 to September 1970.

CHEMICAL ANALYSES, WATER YEAR OCTOBER 1969 TO SEPTEMBER 1970 (MAJOR CONSTITUENTS)

\begin{tabular}{|c|c|c|c|c|c|c|c|c|c|c|c|c|}
\hline & $\begin{array}{l}\text { OIS- } \\
\text { CHAHGE } \\
\text { (CFS) }\end{array}$ & $\begin{array}{l}\text { TEMPER- } \\
\text { ATURE } \\
\text { ADEG CI }\end{array}$ & $\begin{array}{l}\text { SPE- } \\
\text { CIFIC } \\
\text { CDN- } \\
\text { OUCT- } \\
\text { AUCE } \\
\text { (MICRO- } \\
\text { MHOS) }\end{array}$ & $\begin{array}{l}\text { OIS- } \\
\text { SOLVEO } \\
\text { IRON } \\
\text { (FE) } \\
\text { (UU/L) }\end{array}$ & $\begin{array}{l}\text { UIS- } \\
\text { SOLVEO } \\
\text { CAL- } \\
\text { CIUM } \\
\text { (CA) } \\
\text { (MGLL) }\end{array}$ & $\begin{array}{l}\text { OIS- } \\
\text { SOLVED } \\
\text { MAG- } \\
\text { NE- } \\
\text { SIUIM } \\
\text { (MG) } \\
\text { (MG/L) }\end{array}$ & $\begin{array}{l}\text { OIS- } \\
\text { SOLVED } \\
\text { STRON- } \\
\text { TIUM } \\
\text { (SR) } \\
\text { (UG/L) }\end{array}$ & $\begin{array}{l}\text { OIS- } \\
\text { SOLVE) } \\
\text { SODIUM } \\
\text { (NA) } \\
\text { (MG/L) }\end{array}$ & $\begin{array}{l}\text { DIS- } \\
\text { SOL VED } \\
\text { PO- } \\
\text { TAS- } \\
\text { SIIJM } \\
\text { (K) } \\
(M G / L)\end{array}$ & $\begin{array}{l}\text { BICAR- } \\
\text { BONATE } \\
\text { (HCO3) } \\
\text { (MG/L) }\end{array}$ & $\begin{array}{l}\text { CAR- } \\
\text { BONATK } \\
\text { (CO3) } \\
\text { (MG/L) }\end{array}$ & $\begin{array}{c}\text { PH } \\
\text { (UNITS) }\end{array}$ \\
\hline$A T E$ & (CFS) & $(D E G \quad C)$ & MHOSI & (UG/L) & (MG/L) & $(M G / L)$ & (UG/L) & (MG/L) & $(M G / L)$ & (MG/L) & & (UNITS) \\
\hline
\end{tabular}

MAY 1970

$25.0 \quad 380$

$-34 \quad 12$

$-29$

$\begin{array}{llll}. ? & 26 & 0 & 7.4\end{array}$

\begin{tabular}{|c|c|c|c|c|c|c|c|c|c|c|c|c|}
\hline DATE & $\begin{array}{l}\text { OIS- } \\
\text { SOLVED } \\
\text { SULFATE } \\
\text { (SO4) } \\
\text { (MGLL) }\end{array}$ & $\begin{array}{l}\text { DLS- } \\
\text { SOLVEO } \\
\text { CHLO- } \\
\text { RIOE } \\
\text { (CL) } \\
\text { (MG/L) }\end{array}$ & $\begin{array}{l}\text { DIS- } \\
\text { SOLVFD } \\
\text { FLUO= } \\
\text { RIOE } \\
\text { (F) } \\
\text { (MG/L) }\end{array}$ & $\begin{array}{l}\text { HARD- } \\
\text { NESS } \\
\text { (CA,MG) } \\
\text { (MG/L) }\end{array}$ & $\begin{array}{l}\text { NON- } \\
\text { CAR- } \\
\text { BONATE } \\
\text { HARO- } \\
\text { NESS } \\
\text { (MG/L) }\end{array}$ & $\begin{array}{l}\text { ALKA- } \\
\text { LINITY } \\
\text { AS } \\
\text { CACO3 } \\
\text { (MG/L) }\end{array}$ & $\begin{array}{l}\text { DIS- } \\
\text { SOLVEO } \\
\text { SOLIDS } \\
\text { (RESI - } \\
\text { DUE AT } \\
\text { JEO C) } \\
\text { (MGIL) }\end{array}$ & $\begin{array}{l}\text { DIS- } \\
\text { SULVFI } \\
\text { SOLIOS } \\
\text { ISUM OF } \\
\text { CONSTI- } \\
\text { TUEMTS) } \\
\text { (MG/L) }\end{array}$ & $\begin{array}{l}\text { OIS- } \\
\text { SOLYED } \\
\text { SOL. IDS } \\
\text { (TONS } \\
\text { PER } \\
\text { OAY) }\end{array}$ & $\begin{array}{l}\text { NIS- } \\
\text { SOLVFD } \\
\text { SOLIOS } \\
\text { ITONS } \\
\text { PER } \\
\text { AC-FTI }\end{array}$ & $\begin{array}{l}\text { TANNIN } \\
\text { AND } \\
\text { LIGNIN } \\
\text { (MG/L) }\end{array}$ & $\begin{array}{c}\text { DE 'TH } \\
(f T)\end{array}$ \\
\hline $\begin{array}{l}\text { AYY } \\
19 .:\end{array}$ & ${ }^{0} \neq 10$ & 14 & 3.1 & 135 & 114 & 21 & 266 & 251 & 16.1 & . 36 & 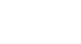 & 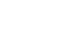 \\
\hline
\end{tabular}

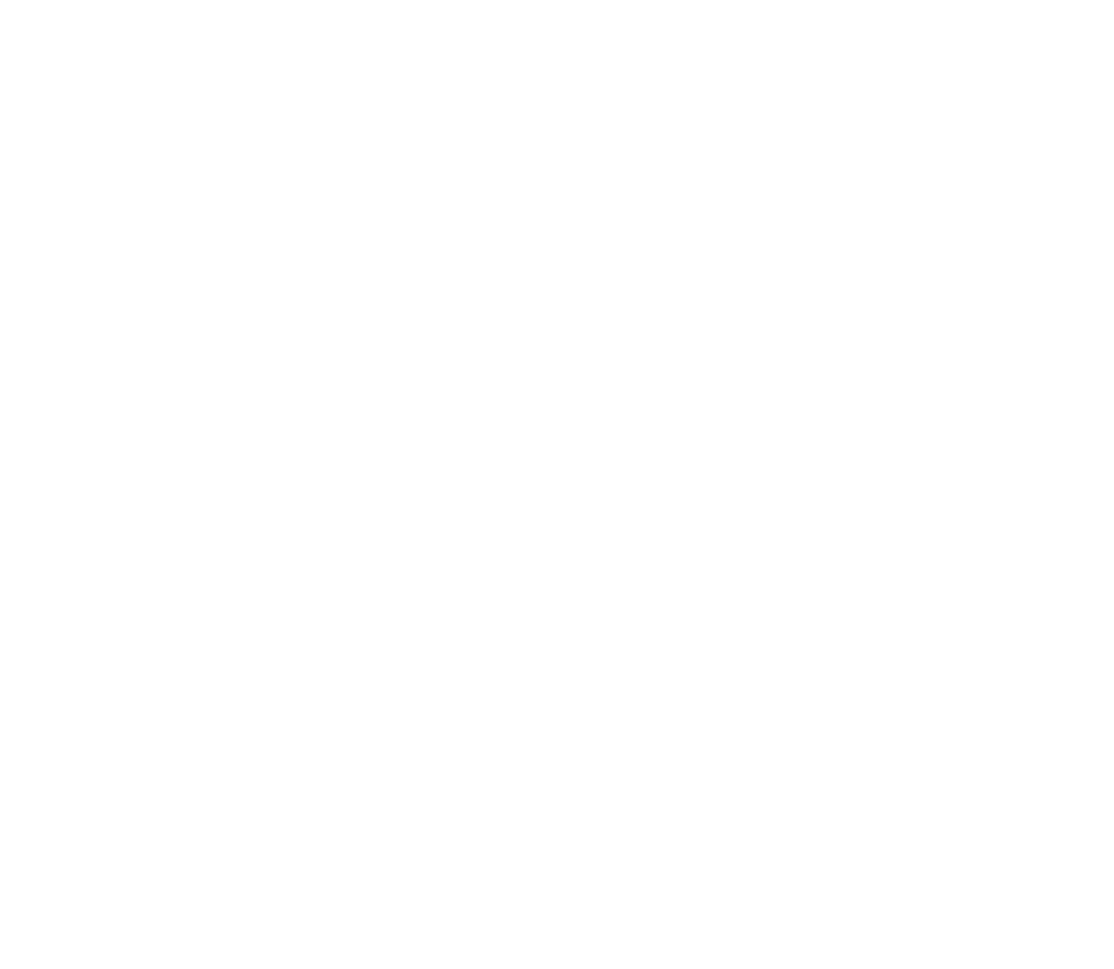


LOCATION.--Lat $27^{\circ} 52^{\prime} 19^{\prime \prime}$, long $82^{\circ} 12^{\prime} 41^{\prime \prime}$, in NE $\frac{1}{4}$ sec.16, T.30 S., R.21 E., Hillsborough County, at gaging station

near center of span on downstream side of bridge on Marvina Road, 1.1 miles northeast of Lithia (Station),
4.3 miles west of Lithia, 2.0 miles upstream from Little Fishhawk Creek, and 16 miles upstream from mouth.

DRAINAGE AREA.--335 sq mi, approximately.

PERIOD OF RECORD,--Chemical analyses: November 1956 to September 1958, October 1963 to September 1970.

Mater temperatures: October 1957 to September 1958 , October 1963 to september 1970.

EXTREKES - - 1969-70:

Specific conductance: Maximum dally, 1,490 micromhos Sept. 27, 29, 30; minimum da1ly, 170 micromhos oct. 3

pater temperatures: Maximum, $30.0^{\circ} \mathrm{C}$ on several days during June to August; minimum, 6.0 ${ }^{\circ} \mathrm{C} \mathrm{Jan.} 10$.

Period of record:

Dissolved solids (1957-58): Maximum, $659 \mathrm{mg} / 1$ June 11-22, 1958; minimum, $134 \mathrm{mg} / 1$ Oct. 1-10, 1957.

Hardness (1957-58): Maximum, $370 \mathrm{mg} / 1$ June 11-22, 1958; minimum, $66 \mathrm{mg} / 1$ Oct. 1-10, 1957

Fluoride (1964-69): Maximum daily, $30 \mathrm{mg} / 1$ Aug, 16,1265 ; minimu dally 2.3 mg/1 sept. 3,1969

Specific conductance (1957-58, 1963-70): Maximum daily, 1,490 micromhos Sept. 27, 29, 30, 1970; minimum

datly, 150 micromhos Jan 12,1964 , Sept, $3,1969$.

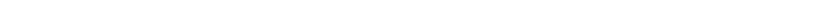

Turbidity (1964-69): Maximum daily, $108 \mathrm{mg} / 1$ as silica June 23, 1967; minimum daily, 0 mg/1 as silica June 7 ,

1967

water temperatures: Maximum, $31.0^{\circ} \mathrm{C}$ June 13,1964 ; minimum, $6.0^{\circ} \mathrm{C} \mathrm{Jan} .10,1970$.

CHEMICAL ANALYSES, WATER YEAR OCTOBER 1969 TO SEPTEMBER 1970 (MAJOR CONSTITUENTS)

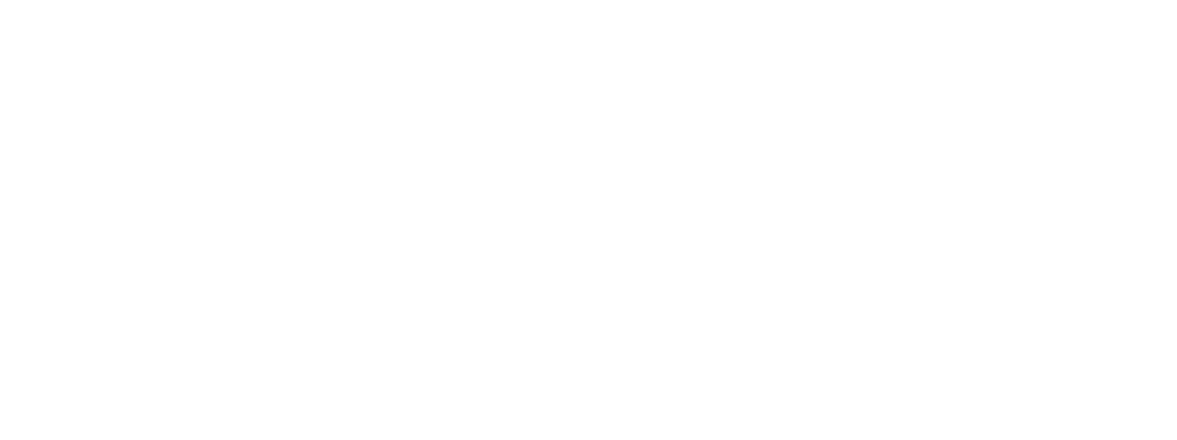

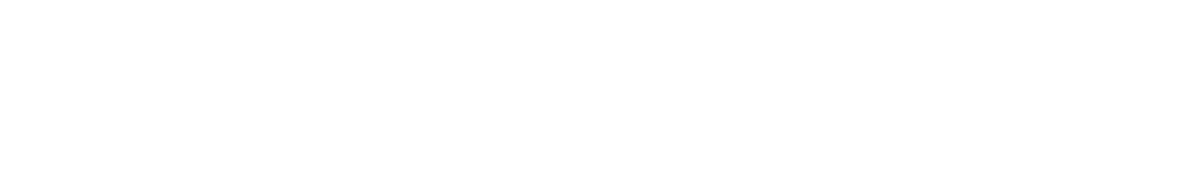

(MACRONUTRIENTS AND OTHER RELATED CONSTITUENTS) UIS-

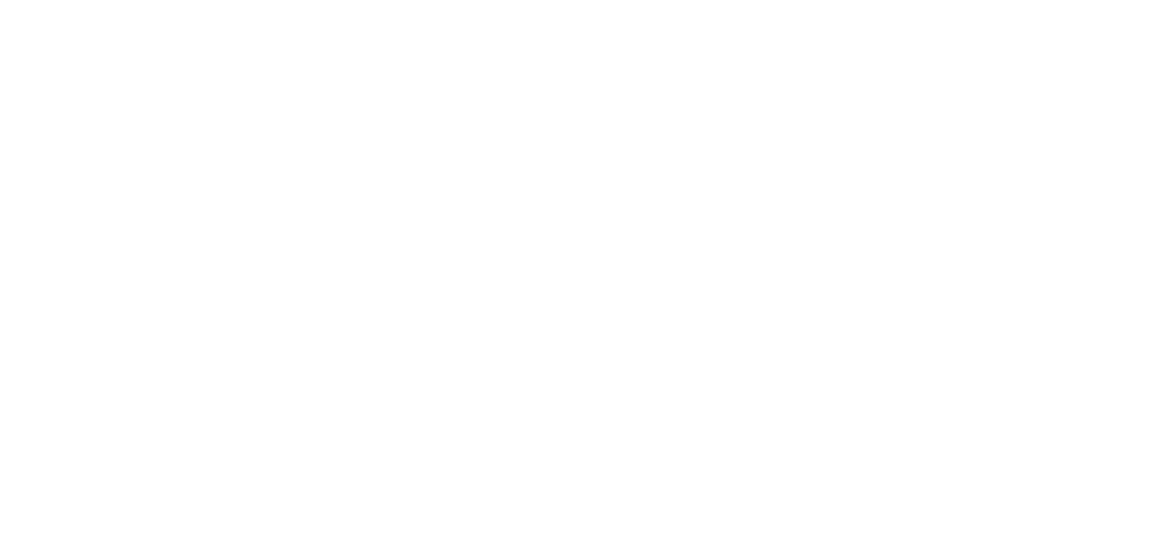


COASTAL BASINS BETWEEN MYAKKA RIVER AND HILLSBOROUGH RIVER 02301500 ALAFIA RIVER AT LITHIA, FLA.,-Continued

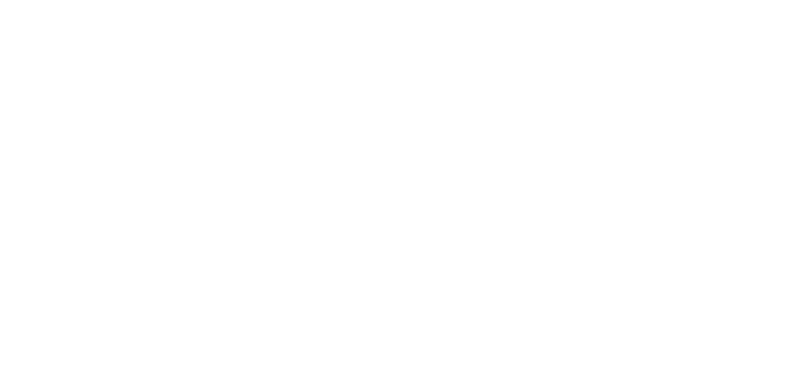

PHOSPHATE (AS PO4), IN MILLIGRAMS PER LITER, WATER YEAR OCTOBER 1969 TO SEPTEMBER 1970

$\begin{array}{rrrrrrrrrr}\text { DAY } & \text { OCT } & \text { NOV } & \text { DEC } & \text { JAN } & \text { DAY } & \text { OCT } & \text { NOV } & \text { DEC } & \text { JAN } \\ 1 & 36 & 24 & 67 & 68 & 18 & 36 & 38 & 47 & 71 \\ 2 & 36 & 31 & 73 & 68 & 19 & 36 & 39 & 52 & 75 \\ 3 & 16 & 35 & 78 & 44 & 20 & 35 & 48 & 56 & 76 \\ 4 & 20 & 34 & 84 & 39 & 21 & 34 & 47 & 57 & 76 \\ 5 & -- & 34 & 90 & 44 & 22 & 35 & 49 & 58 & 77 \\ 6 & 23 & 35 & 93 & 46 & 23 & 34 & 50 & 60 & 75 \\ 7 & 27 & 34 & 72 & 54 & 24 & 38 & 52 & 65 & 75 \\ 8 & 30 & 35 & 78 & 44 & 25 & 38 & 53 & 66 & 79 \\ 9 & 30 & 37 & 72 & 35 & 26 & 31 & 54 & 52 & 87 \\ 10 & 31 & 37 & 27 & 51 & 27 & 28 & 60 & 52 & 80 \\ 11 & -- & -- & 22 & 51 & 28 & 29 & 60 & 61 & 80 \\ 12 & 32 & -- & 32 & 61 & 29 & 41 & 61 & 62 & 81 \\ 13 & 31 & -- & 38 & 62 & 30 & 39 & 64 & 60 & 81 \\ 14 & 32 & -- & 42 & 68 & 31 & 34 & -- & -- & 81 \\ 15 & 33 & -- & 43 & 70 & \text { AVER- } & & & & \\ 16 & 34 & 46 & 45 & 66 & \text { AGE } & 32 & 44 & 58 & 66 \\ 17 & -- & 34 & 45 & 70 & & & & & \end{array}$

SPECIFIC CONDUCTANCE (MICROMHOS/CM AT $25^{\circ} \mathrm{C}$ ), WATER YEAR OCTOBER 1969 TO SEPTEMBER 1970

\begin{tabular}{|c|c|c|c|c|c|c|c|c|c|c|c|c|}
\hline DAY & OCT & NOV & DEC & JAN & FEB & MAR & APR & MAY & JUN & JUL & AUG & SEP \\
\hline $\begin{array}{l}1 \\
2 \\
3 \\
4 \\
5\end{array}$ & $\begin{array}{r}345 \\
360 \\
170 \\
195 \\
--\end{array}$ & $\begin{array}{l}340 \\
350 \\
390 \\
360 \\
475\end{array}$ & $\begin{array}{l}505 \\
510 \\
520 \\
570 \\
580\end{array}$ & $\begin{array}{l}610 \\
610 \\
415 \\
380 \\
420\end{array}$ & $\begin{array}{l}600 \\
600 \\
400 \\
350 \\
449\end{array}$ & $\begin{array}{l}-- \\
=- \\
=- \\
--\end{array}$ & $\begin{array}{l}410 \\
450 \\
450 \\
460 \\
460\end{array}$ & $\begin{array}{l}555 \\
630 \\
580 \\
580 \\
570\end{array}$ & $\begin{array}{l}475 \\
415 \\
415 \\
440 \\
428\end{array}$ & $\begin{array}{l}430 \\
450 \\
480 \\
490 \\
530\end{array}$ & $\begin{array}{l}660 \\
680 \\
700 \\
710 \\
650\end{array}$ & $\begin{array}{l}390 \\
396 \\
418 \\
419 \\
423\end{array}$ \\
\hline $\begin{array}{r}6 \\
7 \\
8 \\
9 \\
10\end{array}$ & $\begin{array}{l}270 \\
280 \\
290 \\
325 \\
325\end{array}$ & $\begin{array}{l}475 \\
475 \\
475 \\
475 \\
475\end{array}$ & $\begin{array}{l}805 \\
580 \\
550 \\
500 \\
285\end{array}$ & $\begin{array}{l}495 \\
310 \\
355 \\
420 \\
460\end{array}$ & $\begin{array}{l}600 \\
640 \\
648 \\
625 \\
610\end{array}$ & $\begin{array}{l}-- \\
-- \\
-- \\
--\end{array}$ & $\begin{array}{l}470 \\
480 \\
490 \\
500 \\
490\end{array}$ & $\begin{array}{l}570 \\
565 \\
550 \\
553 \\
548\end{array}$ & $\begin{array}{l}450 \\
560 \\
600 \\
590 \\
590\end{array}$ & $\begin{array}{l}530 \\
500 \\
460 \\
460 \\
400\end{array}$ & $\begin{array}{l}620 \\
550 \\
500 \\
500 \\
450\end{array}$ & $\begin{array}{l}423 \\
426 \\
357 \\
359 \\
396\end{array}$ \\
\hline $\begin{array}{l}11 \\
12 \\
13 \\
14 \\
15\end{array}$ & $\begin{array}{l}-- \\
355 \\
325 \\
340 \\
335\end{array}$ & $\begin{array}{l}-- \\
-- \\
-- \\
--\end{array}$ & $\begin{array}{l}240 \\
320 \\
480 \\
480 \\
480\end{array}$ & $\begin{array}{r}461 \\
485 \\
495 \\
530 \\
530\end{array}$ & $\begin{array}{l}610 \\
648 \\
650 \\
680 \\
685\end{array}$ & $\begin{array}{l}-- \\
-- \\
-- \\
--\end{array}$ & $\begin{array}{l}480 \\
480 \\
490 \\
485 \\
520\end{array}$ & $\begin{array}{l}600 \\
610 \\
620 \\
608 \\
615\end{array}$ & $\begin{array}{l}580 \\
580 \\
540 \\
550 \\
270\end{array}$ & $\begin{array}{l}400 \\
400 \\
410 \\
560 \\
610\end{array}$ & $\begin{array}{l}450 \\
450 \\
450 \\
490 \\
530\end{array}$ & $\begin{array}{l}394 \\
392 \\
392 \\
366 \\
377\end{array}$ \\
\hline $\begin{array}{l}16 \\
17 \\
18 \\
19 \\
20\end{array}$ & $\begin{array}{r}370 \\
-- \\
390 \\
390 \\
390\end{array}$ & $\begin{array}{l}430 \\
430 \\
430 \\
470 \\
470\end{array}$ & $\begin{array}{l}440 \\
440 \\
465 \\
510 \\
485\end{array}$ & $\begin{array}{l}500 \\
580 \\
580 \\
580 \\
590\end{array}$ & $\begin{array}{l}660 \\
560 \\
540 \\
600 \\
640\end{array}$ & $\begin{array}{l}-- \\
-- \\
-- \\
--\end{array}$ & $\begin{array}{l}515 \\
530 \\
575 \\
575 \\
585\end{array}$ & $\begin{array}{l}600 \\
620 \\
620 \\
580 \\
630\end{array}$ & $\begin{array}{l}410 \\
470 \\
500 \\
475 \\
450\end{array}$ & $\begin{array}{l}680 \\
690 \\
560 \\
640 \\
640\end{array}$ & $\begin{array}{l}600 \\
600 \\
850 \\
850 \\
760\end{array}$ & $\begin{array}{l}377 \\
442 \\
488 \\
491 \\
492\end{array}$ \\
\hline $\begin{array}{l}26 \\
27 \\
28 \\
29 \\
30 \\
31\end{array}$ & $\begin{array}{l}365 \\
335 \\
355 \\
475 \\
480 \\
440\end{array}$ & $\begin{array}{c}465 \\
510 \\
510 \\
510 \\
520 \\
--\end{array}$ & $\begin{array}{r}460 \\
440 \\
550 \\
540 \\
500 \\
--\end{array}$ & $\begin{array}{l}630 \\
620 \\
620 \\
620 \\
620 \\
620\end{array}$ & $\begin{array}{r}550 \\
510 \\
-- \\
-- \\
-- \\
--\end{array}$ & $\begin{array}{l}+- \\
=- \\
=- \\
--\end{array}$ & $\begin{array}{c}575 \\
575 \\
575 \\
560 \\
565 \\
--\end{array}$ & $\begin{array}{r}445 \\
-- \\
-- \\
280 \\
300 \\
285\end{array}$ & $\begin{array}{r}470 \\
415 \\
-2 \\
420 \\
425 \\
-0\end{array}$ & $\begin{array}{l}510 \\
560 \\
560 \\
570 \\
600 \\
620\end{array}$ & $\begin{array}{l}520 \\
360 \\
360 \\
250 \\
350 \\
400\end{array}$ & $\begin{array}{r}357 \\
1490 \\
-- \\
1490 \\
1490 \\
--\end{array}$ \\
\hline AVERAGE & 356 & 459 & 485 & 532 & 594 & -- & 521 & 548 & 479 & 506 & 532 & 533 \\
\hline
\end{tabular}


02301500 ALAFIA RIVER AT LITHIA, FLA.--Continued

PH (UNITS), OCTOBER 1969 TO SEPTEMBER 1970

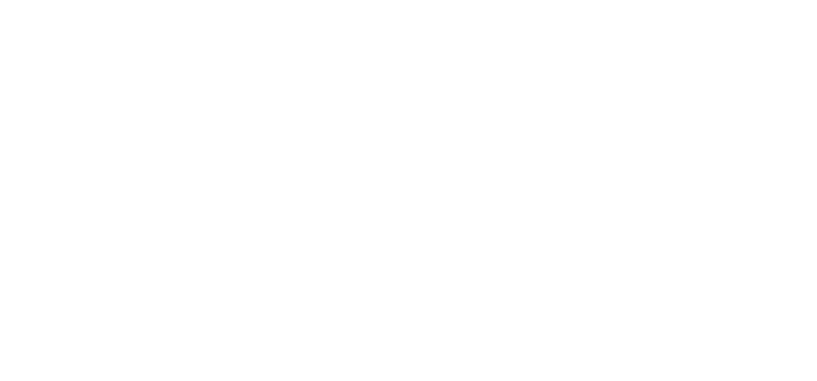

$\begin{array}{rrrrrrrrrr}\text { DAY } & \text { OCT } & \text { NOV } & \text { DEC } & \text { JAN } & \text { DAY } & \text { OCT } & \text { NOV } & \text { DEC } & \text { JAN } \\ 1 & 30 & 25 & 15 & 10 & 18 & 6 & 10 & 15 & 5 \\ 2 & 10 & 15 & 10 & 10 & 19 & 4 & 10 & 15 & 5 \\ 3 & 60 & 20 & 15 & 15 & 20 & 10 & 10 & 10 & 7 \\ 4 & 15 & 10 & 10 & 10 & 21 & 10 & 10 & 10 & 6 \\ 5 & -- & 10 & 10 & 10 & 22 & 4 & 10 & 7 & 7 \\ 6 & 25 & 10 & 10 & 10 & 23 & 25 & 10 & 8 & 8 \\ 7 & 30 & 10 & 15 & 10 & 24 & 10 & 10 & 15 & 9 \\ 5 & 20 & 10 & 10 & 10 & 25 & 6 & 10 & 10 & 8 \\ 9 & 4 & 10 & 10 & 10 & 26 & 5 & 10 & 10 & 4 \\ 10 & B & 10 & 35 & 10 & 27 & 25 & 10 & 10 & 8 \\ 11 & -- & - & 25 & 10 & 28 & 10 & 10 & 15 & 6 \\ 12 & 25 & - & 20 & 10 & 29 & 10 & 10 & 10 & 9 \\ 13 & 10 & -- & 15 & 10 & 30 & 10 & 10 & 15 & 9 \\ 14 & 20 & -- & 25 & 10 & 31 & 10 & -- & -1 & 9 \\ 15 & 6 & -- & 20 & 10 & \text { AVER- } & & & \\ 16 & 4 & 15 & 20 & 10 & \text { AGE } & 15 & 10 & 15 & 9 \\ 17 & -- & 10 & 15 & 5 & & & & & \end{array}$

TEMPERATURE $\left({ }^{\circ} \mathrm{C}\right)$ OF WATER, WATER YEAR OCTOBER 1969 TO SEPTEMBER 1970

\begin{tabular}{|c|c|c|c|c|c|c|c|c|c|c|c|c|}
\hline DAY & $\mathrm{OCT}$ & NOV & DEC & JAN & FEB & MAR & APR & MAY & JUN & JUL & AUG & SEP \\
\hline $\begin{array}{l}1 \\
2 \\
3 \\
4 \\
5\end{array}$ & $\begin{array}{r}26.0 \\
26.0 \\
25.0 \\
26.0 \\
--\end{array}$ & $\begin{array}{l}23.0 \\
24.0 \\
23.0 \\
21.0 \\
18.0\end{array}$ & $\begin{array}{l}16.0 \\
15.0 \\
14.0 \\
14.0 \\
13.0\end{array}$ & $\begin{array}{l}15.0 \\
15.0 \\
15.0 \\
13.0 \\
12.0\end{array}$ & $\begin{array}{l}15.0 \\
15.0 \\
17.0 \\
14.0 \\
12.0\end{array}$ & $\begin{array}{l}-- \\
-- \\
-- \\
--\end{array}$ & $\begin{array}{l}23.0 \\
23.0 \\
22.0 \\
22.0 \\
23.0\end{array}$ & $\begin{array}{l}25.0 \\
27.0 \\
25.0 \\
24.0 \\
23.0\end{array}$ & $\begin{array}{l}26.0 \\
25.0 \\
27.0 \\
26.0 \\
26.0\end{array}$ & $\begin{array}{l}28.0 \\
29.0 \\
30.0 \\
30.0 \\
30.0\end{array}$ & $\begin{array}{l}29.0 \\
30.0 \\
29.0 \\
29.0 \\
30.0\end{array}$ & $\begin{array}{l}28.0 \\
29.0 \\
29.0 \\
29.0 \\
29.0\end{array}$ \\
\hline $\begin{array}{r}6 \\
7 \\
8 \\
9 \\
10\end{array}$ & $\begin{array}{l}25.0 \\
25.0 \\
25.0 \\
25.0 \\
25.0\end{array}$ & $\begin{array}{l}17.0 \\
16.0 \\
17.0 \\
18.0 \\
18.0\end{array}$ & $\begin{array}{l}14.0 \\
15.0 \\
15.0 \\
16.0 \\
18.0\end{array}$ & $\begin{array}{r}12.0 \\
15.0 \\
15.0 \\
14.0 \\
6.0\end{array}$ & $\begin{array}{l}14.0 \\
15.0 \\
16.0 \\
15.0 \\
13.0\end{array}$ & $\begin{array}{l}-- \\
-- \\
-- \\
-- \\
--\end{array}$ & $\begin{array}{l}22.0 \\
22.0 \\
21.0 \\
21.0 \\
21.0\end{array}$ & $\begin{array}{l}23.0 \\
23.0 \\
22.0 \\
26.0 \\
26.0\end{array}$ & $\begin{array}{l}27.0 \\
27.0 \\
27.0 \\
27.0 \\
27.0\end{array}$ & $\begin{array}{l}30.0 \\
30.0 \\
29.0 \\
29.0 \\
27.0\end{array}$ & $\begin{array}{l}29.0 \\
29.0 \\
27.0 \\
27.0 \\
27.0\end{array}$ & $\begin{array}{l}29.0 \\
29.0 \\
28.0 \\
29.0 \\
29.0\end{array}$ \\
\hline $\begin{array}{l}11 \\
12 \\
13 \\
14 \\
15\end{array}$ & $\begin{array}{l}25.0 \\
26.0 \\
24.0 \\
24.0 \\
23.0\end{array}$ & $\begin{array}{l}-- \\
-- \\
-- \\
--\end{array}$ & $\begin{array}{l}17.0 \\
16.0 \\
15.0 \\
13.0 \\
13.0\end{array}$ & $\begin{array}{r}8.0 \\
12.0 \\
11.0 \\
12.0 \\
13.0\end{array}$ & $\begin{array}{l}14.0 \\
14.0 \\
15.0 \\
15.0 \\
16.0\end{array}$ & $\begin{array}{l}-- \\
-- \\
-- \\
-- \\
--\end{array}$ & $\begin{array}{l}23.0 \\
23.0 \\
23.0 \\
23.0 \\
24.0\end{array}$ & $\begin{array}{r}23.0 \\
=- \\
=-\end{array}$ & $\begin{array}{l}26.0 \\
26.0 \\
28.0 \\
28.0 \\
25.0\end{array}$ & $\begin{array}{l}27.0 \\
27.0 \\
27.0 \\
29.0 \\
30.0\end{array}$ & $\begin{array}{l}27.0 \\
27.0 \\
27.0 \\
28.0 \\
29.0\end{array}$ & $\begin{array}{l}29.0 \\
29.0 \\
29.0 \\
27.0 \\
28.0\end{array}$ \\
\hline $\begin{array}{l}16 \\
17 \\
18 \\
19 \\
20\end{array}$ & $\begin{array}{r}24.0 \\
-- \\
26.0 \\
25.0 \\
25.0\end{array}$ & $\begin{array}{l}15.0 \\
14.0 \\
16.0 \\
17.0 \\
17.0\end{array}$ & $\begin{array}{l}14.0 \\
15.0 \\
14.0 \\
14.0 \\
14.0\end{array}$ & $\begin{array}{l}15.0 \\
22.0 \\
23.0 \\
15.0 \\
16.0\end{array}$ & $\begin{array}{l}18.0 \\
18.0 \\
18.0 \\
17.0 \\
16.0\end{array}$ & $\begin{array}{l}-- \\
=- \\
=- \\
--\end{array}$ & $\begin{array}{l}24.0 \\
23.0 \\
25.0 \\
25.0 \\
24.0\end{array}$ & $\begin{array}{l}26.0 \\
25.0 \\
26.0 \\
26.0 \\
27.0\end{array}$ & $\begin{array}{l}28.0 \\
28.0 \\
27.0 \\
29.0 \\
30.0\end{array}$ & $\begin{array}{l}29.0 \\
29.0 \\
28.0 \\
2 B .0 \\
2 B .0\end{array}$ & $\begin{array}{l}29.0 \\
29.0 \\
29.0 \\
29.0 \\
29.0\end{array}$ & $\begin{array}{l}28.0 \\
29.0 \\
29.0 \\
29.0 \\
29.0\end{array}$ \\
\hline $\begin{array}{l}21 \\
22 \\
23 \\
24 \\
25\end{array}$ & $\begin{array}{l}24.0 \\
25.0 \\
25.0 \\
25.0 \\
24.0\end{array}$ & $\begin{array}{l}15.0 \\
17.0 \\
11.0 \\
11.0 \\
18.0\end{array}$ & $\begin{array}{l}15.0 \\
15.0 \\
15.0 \\
15.0 \\
17.0\end{array}$ & $\begin{array}{l}17.0 \\
14.0 \\
15.0 \\
14.0 \\
15.0\end{array}$ & $\begin{array}{l}15.0 \\
15.0 \\
15.0 \\
15.0 \\
17.0\end{array}$ & $\begin{array}{l}-- \\
-- \\
-- \\
--\end{array}$ & $\begin{array}{l}24.0 \\
25.0 \\
27.0 \\
26.0 \\
25.0\end{array}$ & $\begin{array}{l}26.0 \\
27.0 \\
27.0 \\
25.0 \\
25.0\end{array}$ & $\begin{array}{l}30.0 \\
30.0 \\
30.0 \\
29.0 \\
29.0\end{array}$ & $\begin{array}{l}27.0 \\
26.0 \\
26.0 \\
26.0 \\
29.0\end{array}$ & $\begin{array}{l}29.0 \\
28.0 \\
27.0 \\
27.0 \\
27.0\end{array}$ & $\begin{array}{l}29.0 \\
28.0 \\
28.0 \\
27.0 \\
26.0\end{array}$ \\
\hline $\begin{array}{l}26 \\
27 \\
28 \\
29 \\
30 \\
31\end{array}$ & $\begin{array}{l}23.0 \\
22.0 \\
23.0 \\
23.0 \\
23.0 \\
23.0\end{array}$ & $\begin{array}{l}18.0 \\
20.0 \\
20.0 \\
18.0 \\
17.0 \\
\end{array}$ & $\begin{array}{r}17.0 \\
15.0 \\
14.0 \\
14.0 \\
15.0 \\
--\end{array}$ & $\begin{array}{l}13.0 \\
14.0 \\
14.0 \\
14.0 \\
18.0 \\
15.0\end{array}$ & $\begin{array}{r}16.0 \\
15.0 \\
-- \\
-- \\
-- \\
--\end{array}$ & $\begin{array}{l}-- \\
-- \\
-- \\
-- \\
--\end{array}$ & $\begin{array}{r}25.0 \\
24.0 \\
25.0 \\
25.0 \\
25.0 \\
\end{array}$ & $\begin{array}{r}25.0 \\
-0 \\
- \\
25.0 \\
26.0\end{array}$ & $\begin{array}{r}29.0 \\
29.0 \\
-- \\
29.0 \\
29.0 \\
--\end{array}$ & $\begin{array}{l}29.0 \\
29.0 \\
29.0 \\
28.0 \\
29.0 \\
29.0\end{array}$ & $\begin{array}{l}28.0 \\
28.0 \\
28.0 \\
28.0 \\
28.0 \\
28.0\end{array}$ & $\begin{array}{r}26.0 \\
27.0 \\
-0 \\
27.0 \\
26.0 \\
--\end{array}$ \\
\hline AVERAGE & 24.5 & 17.5 & 15.0 & 14.5 & 15.5 & - & 23.5 & 25.0 & 27.5 & 28.5 & 28.0 & 28.0 \\
\hline
\end{tabular}


02301600 LITHIA SPRINGS NEAR LITHIA, FLA.

LOCATION.--Lat $27^{\circ} 52^{\prime} 00^{\prime \prime}$, Iong $82^{\circ} 13^{\prime} 50^{\prime \prime}$, in SW sec.17, T.30 S., R.21 E., Hillsborough County, at gaging station, 500 it upstream from Alafia River and 5.3 miles northwest of Lithia.

PERIOD OF RECORD...-Chemical analyses: October 1956 to September 1970.

\begin{tabular}{|c|c|c|c|c|c|c|c|c|c|c|c|c|}
\hline & & & CHEMIC & AL ANALYS & $\begin{array}{r}\text { 5, WATER } \\
\text { (MAJ }\end{array}$ & $\begin{array}{l}\text { EAR OCTO } \\
\text { CONSTIIT }\end{array}$ & $\begin{array}{l}\text { ER } 1969 \\
\text { ENTSI }\end{array}$ & TO SEPTEM & ER 1970 & & & \\
\hline DATE & $\begin{array}{l}\text { DIS- } \\
\text { CHARGE } \\
\text { (CFS) }\end{array}$ & $\begin{array}{l}\text { TEMPER- } \\
\text { ATURE } \\
\text { (DEG C) }\end{array}$ & $\begin{array}{l}\text { SPE- } \\
\text { CIFIC } \\
\text { CDN- } \\
\text { DUCI- } \\
\text { ANCE } \\
\text { (MICPO- } \\
\text { MHOS) }\end{array}$ & $\begin{array}{l}\text { DIS- } \\
\text { SOLVED } \\
\text { IRDN } \\
\text { (FE) } \\
\text { (UELL) }\end{array}$ & $\begin{array}{l}\text { UIS- } \\
\text { SOLVED } \\
\text { CAL- } \\
\text { CIUM } \\
\text { (CA) } \\
(M G / L)\end{array}$ & $\begin{array}{l}\text { DIS- } \\
\text { SOLVED } \\
\text { MAG- } \\
\text { NE- } \\
\text { SIUM } \\
\text { (MG) } \\
\text { (MG/L) }\end{array}$ & $\begin{array}{l}\text { DIS- } \\
\text { SOLVED } \\
\text { STLON- } \\
\text { TIUM } \\
\text { (SR) } \\
\text { (UG/L) }\end{array}$ & $\begin{array}{l}\text { OIS- } \\
\text { SOLVEN } \\
\text { SODIUY } \\
\text { (NA) } \\
\text { (MG/L) }\end{array}$ & $\begin{array}{l}D I C- \\
\text { SOLVED } \\
\text { PO- } \\
T A C- \\
\text { SI IJM } \\
(K) \\
(M G / L)\end{array}$ & $\begin{array}{l}\text { BICAR- } \\
\text { BONATE } \\
\text { (HCO3) } \\
\text { (MG/L) }\end{array}$ & $\begin{array}{l}\text { CAR- } \\
\text { BONATH } \\
(C O 3) \\
(M G / L)\end{array}$ & $\begin{array}{c}\text { PH } \\
\text { (UNITS) }\end{array}$ \\
\hline $\begin{array}{l}\text { OCT.. } 1968 \\
21 \ldots \\
\text { JAN.: } 1970\end{array}$ & $70^{64}$ & 25.5 & 458 & -- & 62 & 11 & -- & 14 & .7 & 124 & -- & 7.2 \\
\hline FER.. & 39 & 24.0 & 420 & -- & 60 & 11 & - & 12 & .7 & -- & -- & - \\
\hline & 47 & 25.0 & 440 & -- & $6 n$ & 11 & -- & 13 & 3.1 & 124 & $n$ & 7.8 \\
\hline$\underset{\text { MAY }}{07 . . .}$ & 41 & 25.0 & $37 n$ & -- & 54 & 10 & -- & 13 & .8 & 83 & $n$ & 8.1 \\
\hline $21 \ldots$ & 30 & 24.0 & 411 & $=$ & 49 & 9.4 & - & 12 & .7 & 120 & 0 & 8.2 \\
\hline su & $\begin{array}{l}\text { DIS- } \\
\text { SOL VED } \\
\text { SULF LTE } \\
\text { (\$O4) } \\
\text { (MG/L) }\end{array}$ & $\begin{array}{l}\text { DIS- } \\
\text { SOLVEO } \\
\text { CHLD- } \\
\text { RIDE } \\
\text { (CL) } \\
(M G / L)\end{array}$ & $\begin{array}{l}\text { DIS- } \\
\text { SOLVFD } \\
\text { FLIIO- } \\
\text { RIDE } \\
(F) \\
(M G / L)\end{array}$ & $\begin{array}{l}\text { HADD- } \\
\text { NESS } \\
(C A \cdot M G) \\
(M G / L)\end{array}$ & $\begin{array}{l}\text { NON- } \\
\text { CAR- } \\
\text { RONATE } \\
\text { HARD- } \\
\text { NESS } \\
\text { (MG/L) }\end{array}$ & $\begin{array}{l}\text { ALKA- } \\
\text { LINITY } \\
\text { AS } \\
\text { CACO3 } \\
\text { (MG/L) }\end{array}$ & $\begin{array}{l}\text { DIS- } \\
\text { SOLVED } \\
\text { SOLIDS } \\
\text { (QESI- } \\
\text { DUE AT } \\
\text { IRO C) } \\
(M G / L)\end{array}$ & $\begin{array}{l}\text { DIS- } \\
\text { SULVEN } \\
\text { SULIOS } \\
\text { (SUM OF } \\
\text { CONSTI- } \\
\text { TUENTS) } \\
\text { (MGIL) }\end{array}$ & $\begin{array}{l}\text { DIS- } \\
\text { SCLVED } \\
\text { SOLIOS } \\
\text { (TONS } \\
\text { PER } \\
\text { DAY) }\end{array}$ & $\begin{array}{l}\text { NIS- } \\
\text { SOLVFD } \\
\text { SOLIOS } \\
\text { ITONS } \\
\text { PER } \\
\triangle C-F T \text { T) }\end{array}$ & $\begin{array}{l}\text { TANNIN } \\
\text { AND } \\
\text { LIGNIN } \\
\text { (MG/L) }\end{array}$ & $\begin{array}{l}\text { DE 'TH } \\
(t+1)\end{array}$ \\
\hline $\begin{array}{l}\text { OCT.\#1969 } \\
\text { 21... } \\
\text { JAN..1970 }\end{array}$ & 56 & 23 & .5 & 200 & 97 & 102 & 310 & 249 & 36.8 & .42 & -- & -- \\
\hline IE... & 78 & 24 & .6 & 195 & -- & - & $>78$ & - & 29.3 & .38 & - & - \\
\hline${ }_{A P R}^{16 . .}$ & 81 & 25 & .5 & 195 & 93 & $1 \cap 2$ & 284 & 277 & 30.3 & .39 & - & $=$ \\
\hline$\underset{\text { MAY }}{07} \cdots$ & 80 & 22 & .4 & 176 & 108 & 68 & 239 & 240 & 26.6 & .33 & 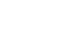 & -- \\
\hline $21 \ldots$ & 65 & 21 & .3 & 161 & 63 & 98 & 258 & 233 & 21.1 & .35 & -- & -- \\
\hline
\end{tabular}

(MACRONUTRIENTS AND OTHER RELATED CONSTITUENTS)

\begin{tabular}{|c|c|c|c|c|c|c|c|c|c|c|c|c|}
\hline OATR & $\begin{array}{l}\text { TOTAL } \\
\text { WMONIA } \\
\text { (NAS) } \\
\text { (MG/L) }\end{array}$ & $\begin{array}{l}\text { TOTAL } \\
\text { NITLITE } \\
\text { (NOP) } \\
\text { (MG/L) }\end{array}$ & $\begin{array}{l}\text { TOTAL } \\
\text { NITHATE } \\
\text { (NO3) } \\
\text { (MG/L) }\end{array}$ & $\begin{array}{l}\text { OHGANIC } \\
\text { NITRO- } \\
\text { GEN } \\
\text { (IV) } \\
\text { (NGLL) }\end{array}$ & $\begin{array}{l}\text { UIS- } \\
\text { SOLVES } \\
\text { ORTHO } \\
\text { PHUS- } \\
\text { PHATE } \\
(P(14) \\
\text { (MG/L) }\end{array}$ & $\begin{array}{l}\text { PHOS- } \\
\text { PHATE } \\
(P O 4) \\
(M O / L)\end{array}$ & $\begin{array}{l}\text { OIS- } \\
\text { SOLVED } \\
\text { SILICA } \\
\text { (SIOZ) } \\
\text { (MG/L) }\end{array}$ & $\begin{array}{l}\text { TUR- } \\
\text { BID- } \\
\text { ITY } \\
\text { (JTU) }\end{array}$ & $\begin{array}{l}\text { COLOR } \\
\text { (PLAT- } \\
\text { INUM- } \\
\text { COBALT } \\
\text { UNITS) }\end{array}$ & $\begin{array}{l}\text { TOTAL } \\
\text { ORGANIC } \\
\text { CARAON } \\
\text { (C) } \\
\text { (MG/L) }\end{array}$ & $\begin{array}{l}\text { RIO)- } \\
\text { CHEHA- } \\
\text { ICAL } \\
\text { OXYGEN } \\
\text { DEMAIND } \\
\text { (MG/L) }\end{array}$ & $\begin{array}{l}\text { DEPIH } \\
\text { (FT) }\end{array}$ \\
\hline OCT., 1969 & & & & & & & & & & & & \\
\hline $19 \ldots$ & -- & .01 & 8.5 & -- & . la & .22 & -- & $=$ & 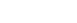 & - & $\cdots$ & $\cdots$ \\
\hline $\begin{array}{l}2 \mathrm{I} \ldots \\
\text { nov... }\end{array}$ & -- & .01 & 6.6 & -- & -- & -- & 14 & -- & 5 & -- & -- & -- \\
\hline $\begin{array}{l}29 \ldots . . . \\
\text { DEC. }\end{array}$ & -- & .04 & 7.9 & -- & $.1 A$ & .20 & -- & -- & -- & -- & -- & -- \\
\hline JAN.:. & - & .02 & 7.7 & - & .98 & 1.1 & $\cdots$ & -- & - & $-\infty$ & 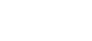 & - \\
\hline $\begin{array}{l}12 \ldots \\
25 \ldots\end{array}$ & $\overline{-}$ & .06 & 6.2 & $=$ & $\begin{array}{r}.60 \\
.37\end{array}$ & $\begin{array}{r}.60 \\
.40\end{array}$ & $\begin{array}{r}7.5 \\
-.-\end{array}$ & $=$ & $\begin{array}{l}n \\
--\end{array}$ & $=$ & $=$ & $=$ \\
\hline FEQ. & & & & & & & & $-\infty$ & & - & $\cdots$ & $=$ \\
\hline $\begin{array}{l}16 \ldots . . \\
22 \ldots\end{array}$ & $m$ & .01 & $\begin{array}{l}9.4 \\
8.8\end{array}$ & $=$ & $\begin{array}{l}.16 \\
.25\end{array}$ & $\begin{array}{r}.16 \\
.26\end{array}$ & 15 & $\because$ & -0 & $\overline{--}$ & $\ddot{-}$ & $\overline{-}$ \\
\hline MAR. & & & & & & & & & - & $=$ & $=$ & $-\infty$ \\
\hline $\begin{array}{l}22 \ldots \\
A P R .\end{array}$ & -- & .02 & 9.6 & - & .36 & .60 & - & -- & - & $=-$ & -- & -- \\
\hline $07 \ldots$ & - & .00 & 6.1 & -- & -- & -- & 13 & -- & 10 & -- & -- & -- \\
\hline$\underset{\text { MAY }}{29 . \ldots}$ & $=-$ & .03 & 6.4 & -- & 7.0 & - & $=$ & -- & -- & -- & -- & -- \\
\hline $21 \ldots$ & .06 & .01 & 1.1 & .15 & .21 & .31 & 15 & -- & n & -- & -- & -- \\
\hline$\underset{\text { JUNE }}{31 \ldots}$ & -- & .04 & 5.2 & - & n.1 & $n .2$ & $=-$ & -- & - & -- & -- & -- \\
\hline JULY & -- & .03 & 9.5 & -- & .18 & .27 & -- & -- & - & -- & -- & -- \\
\hline $\begin{array}{l}25 \ldots \\
\Delta \cup G .\end{array}$ & - & .01 & 8.9 & - & .04 & - & -- & -- & - & -- & -- & -- \\
\hline $18 \ldots$ & 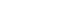 & .02 & 9.7 & - & .16 & .17 & $\cdots$ & 1 & - & -- & -- & -- \\
\hline & & $\begin{array}{l}\text { DIS- } \\
\text { SDLVED } \\
\text { FLUD- } \\
\text { RIDE } \\
\text { (F) }\end{array}$ & $\begin{array}{l}\text { PHDS- } \\
\text { PHATE } \\
\text { (PD4) }\end{array}$ & $\begin{array}{l}\text { SPE- } \\
\text { CIFIC } \\
\text { CON- } \\
\text { DUCT- } \\
\text { ANCE } \\
\text { IMICRD- }\end{array}$ & $\begin{array}{l}\text { TEMPER- } \\
\text { ATURE }\end{array}$ & & & $\begin{array}{l}\text { DIS- } \\
\text { SOLVED } \\
\text { FLUD- } \\
\text { RIDE } \\
\text { (F) }\end{array}$ & $\begin{array}{l}\text { PHDS- } \\
\text { PHATE } \\
\text { (PD4) }\end{array}$ & $\begin{array}{l}\text { SPE- } \\
\text { CIFIC } \\
\text { CON- } \\
\text { DUCT- } \\
\text { ANCE } \\
\text { IMICRD- }\end{array}$ & $\begin{array}{l}\text { TEMPER- } \\
\text { ATURE }\end{array}$ & \\
\hline DAT & TE & (MG/L) & $(M G / L)$ & MHOS) & $(D E G C)$ & & DATE & $(M G / L)$ & $(M G / L)$ & MHDS ) & (DEG C) & \\
\hline OCT & 12 & .4 & .12 & 385 & 26.0 & & APR 12 & .4 & .33 & 460 & 25.0 & \\
\hline & 19 & .5 & .18 & 402 & 25.0 & & 18 & .4 & .52 & 449 & 27.0 & \\
\hline NOV & 01 & .4 & .18 & 460 & 25.0 & & 26 & .4 & .14 & 445 & 26.0 & \\
\hline & 08 & .3 & .18 & 440 & 24.0 & & 29 & 1.5 & 7.0 & 400 & 24.0 & \\
\hline & 16 & .6 & 1.6 & 450 & 20.0 & & MAY 09 & .4 & .06 & 432 & 26.0 & \\
\hline & 23 & .3 & .18 & 440 & 23.0 & & 17 & .4 & .12 & 420 & 27.0 & \\
\hline & 29 & .3 & .18 & 410 & 22.0 & & 25 & .5 & .34 & 415 & 26.0 & \\
\hline DEC & 06 & .4 & 21 & 425 & 24.0 & & 31 & 1.3 & 6.1 & 355 & 27.0 & \\
\hline & 14 & .8 & 3.7 & 425 & 24.0 & & JUN 07 & .3 & .21 & 420 & 27.0 & \\
\hline & 20 & .4 & .21 & 415 & 24.0 & & 14 & .4 & .02 & 530 & 27.0 & \\
\hline & 27 & .5 & .98 & 415 & 25.0 & & 23 & .4 & .30 & 430 & 28.0 & \\
\hline JAN & 04 & .8 & 3.8 & 440 & - & & 29 & .3 & .18 & 430 & 27.0 & \\
\hline & 11 & .5 & 2.1 & 440 & 23.0 & & JUL 07 & .4 & .22 & 431 & 27.0 & \\
\hline & 18 & .4 & .31 & 445 & 25.0 & & 14 & .4 & .36 & 429 & 27.0 & \\
\hline & 25 & .4 & .37 & 445 & 25.0 & & 19 & .4 & .28 & 429 & 26.0 & \\
\hline$F E B$ & 01 & .4 & .30 & 450 & 25.0 & & 25 & .4 & .64 & 429 & 26.0 & \\
\hline & 08 & .4 & .26 & 440 & 25.0 & & AUG 03 & .4 & .18 & 440 & 28.0 & \\
\hline & 15 & .4 & .20 & 450 & 24.0 & & 11 & .4 & .37 & 440 & 27.0 & \\
\hline & 22 & .4 & .25 & 445 & 25.0 & & 17 & .4 & .24 & 415 & 29.0 & \\
\hline MAR & 01 & .3 & .31 & 447 & 25.0 & & SEP OI & .5 & .09 & 434 & 25.0 & \\
\hline & 08 & 1.4 & & 437 & 22.0 & & 13 & .4 & .24 & 441 & 27.0 & \\
\hline & 15 & 1.0 & 3.1 & 426 & 22.0 & & 20 & .4 & .52 & 450 & 27.0 & \\
\hline & 22 & .4 & .36 & 439 & 24.0 & & 26 & .4 & .15 & 445 & 27.0 & \\
\hline$A P R$ & 05 & .4 & .14 & 442 & 25.0 & & & & & & & \\
\hline
\end{tabular}


LOCATION..-Lat $28^{\circ} 09^{\prime} 30^{\prime \prime}$, long $82^{\circ} 09^{\prime} 10^{\prime \prime}$, In SW 1 sec.6, T.27 S, R. 22 E., Hillsborough County, at gaging station near right bank in pool above Seaboard Coastline Railroad trestle and

DRAINAGE AREA. - $1.6 \mathrm{sq} \mathrm{m1}$, approximately.

PERIOD OF RECORD..-Chemical analyses: March 1965 to September 1970.

CHEMICAL ANALYSES, WATER YEAR OCTOBER 1969 TO SEPTEMBER 1970 (MAJOR CONSTITUENTS)

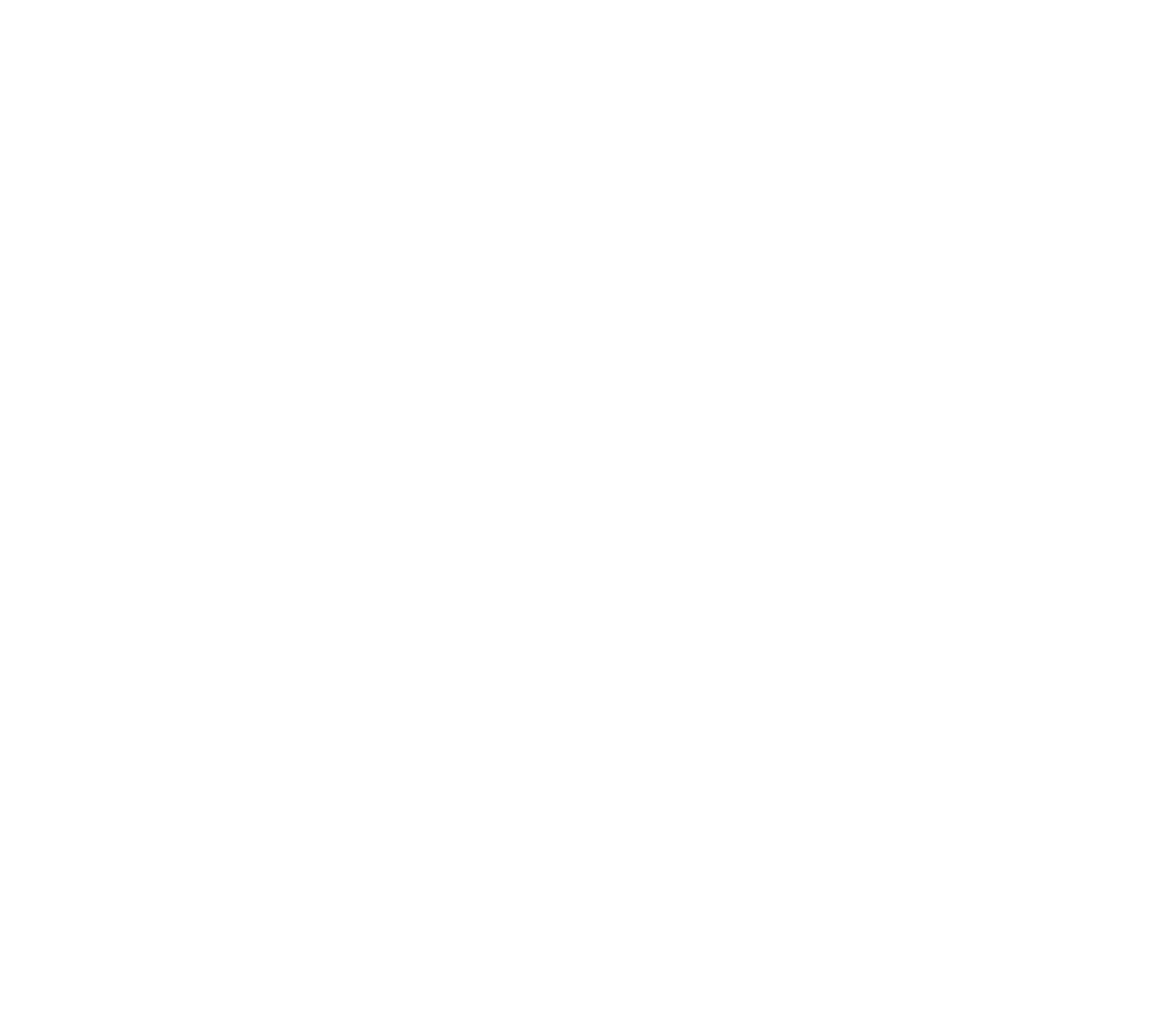

JUNE, 1970

\begin{tabular}{|c|c|c|c|c|c|c|}
\hline $04 \ldots$ & 1525 & 72. & & 1 & 29.0 & 5.9 \\
\hline & & $\begin{array}{l}\text { DIS- } \\
\text { SOLVED }\end{array}$ & & $\begin{array}{l}\text { SPE- } \\
\text { CIFIC } \\
\text { CON- }\end{array}$ & & \\
\hline & $\begin{array}{l}\text { CHLO- } \\
\text { RIDE } \\
\text { (CL) }\end{array}$ & $\begin{array}{l}\text { FLUO- } \\
\text { RIDE } \\
\text { (F) }\end{array}$ & $\begin{array}{l}\text { PHOS- } \\
\text { PHATE } \\
\text { (PO4) }\end{array}$ & $\begin{array}{l}\text { DUCT- } \\
\text { ANCE } \\
\text { IMICRO- }\end{array}$ & $\mathrm{PH}$ & $\begin{array}{l}\text { TEMPER- } \\
\text { ATURE }\end{array}$ \\
\hline $\begin{array}{l}\text { DATE } \\
\text { CT } 10\end{array}$ & $(M G / L)$ & $(M G / L)$ & $(M G / L)$ & MHOS) & (UNITS) & $\begin{array}{l}\text { ATURE } \\
\text { (DEG C) }\end{array}$ \\
\hline 14 & 43 & $\begin{array}{l}1.9 \\
2.0\end{array}$ & $\begin{array}{l}5.6 \\
6.5\end{array}$ & 225 & 6.1 & 30.0 \\
\hline 21 & $\begin{array}{l}43 \\
57\end{array}$ & $\begin{array}{l}2.0 \\
2.0\end{array}$ & $\begin{array}{l}6.5 \\
7.6\end{array}$ & $\begin{array}{l}610 \\
670\end{array}$ & $\begin{array}{l}7.1 \\
7.0\end{array}$ & $\begin{array}{l}30.0 \\
30.0\end{array}$ \\
\hline 31 & 49 & 3.7 & 13 & 715 & 6.8 & $\begin{array}{l}30.0 \\
31.0\end{array}$ \\
\hline ov 04 & 59 & 1.8 & 6.0 & 690 & 6.8 & 32.0 \\
\hline 11 & 73 & 1.1 & 3.9 & 670 & 7.4 & 30.0 \\
\hline 18 & 64 & .9 & 5.0 & 660 & 7.4 & 29.0 \\
\hline 25 & 78 & .6 & 1.2 & 660 & 7.5 & 27.0 \\
\hline DEC 02 & 96 & .6 & .20 & 780 & 7.3 & 28.0 \\
\hline 09 & 60 & .6 & .27 & 580 & 7.7 & 29.0 \\
\hline 16 & 30 & 1.6 & 8.6 & 325 & 7.2 & 26.0 \\
\hline 23 & 12 & 2.0 & 11 & 360 & 7.2 & 26.0 \\
\hline 30 & 54 & 1.4 & 6.0 & 540 & 7.5 & 26.0 \\
\hline IAN OG & 26 & 1.9 & 17 & 265 & 6.6 & 19.0 \\
\hline 13 & 30 & 1.6 & 8.1 & 289 & 6.9 & 26.0 \\
\hline 20 & 60 & 1.7 & 9.4 & 490 & 6.9 & 22.0 \\
\hline 27 & 60 & 1.8 & 9.9 & 545 & 7.2 & 31.0 \\
\hline EB 02 & 29 & 1.5 & 12 & 290 & 7.5 & 31.0 \\
\hline 10 & 39 & 1.3 & 9.1 & 345 & 7.2 & 24.0 \\
\hline 17 & 36 & 4.5 & 76 & 470 & 7.5 & 28.0 \\
\hline 24 & 46 & 1.3 & 8.0 & 470 & 7.1 & 29.0 \\
\hline R 03 & 67 & 1.4 & 8.3 & 624 & 7.0 & 29.0 \\
\hline 10 & 48 & 3.0 & 19 & 468 & 6.9 & 31.0 \\
\hline 17 & 38 & 1.9 & 7.2 & 364 & 6.9 & 29.0 \\
\hline 24 & 59 & 1.4 & 4.2 & 567 & 7.1 & 33.0 \\
\hline 31 & 30 & 2.4 & 14 & 364 & 7.1 & 34.0 \\
\hline
\end{tabular}

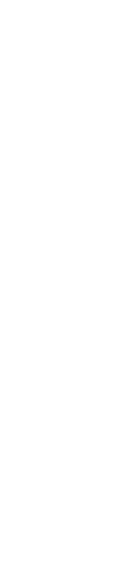

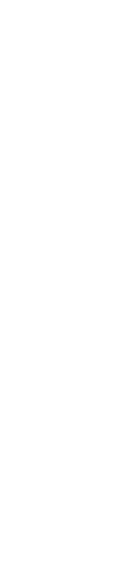

DIS-
SOLVED
FLUD-
RIDE
(F)
(MG/L)
3.1
1.3
.6
.6
.7
.5
.8
.8
1.0
.9
1.3
3.4
1.2
1.4
1.7
4.4
3.6
2.4
2.5
1.4
1.4
2.0
.7
1.0
.8
.9

\begin{tabular}{|c|c|c|}
\hline $\begin{array}{l}\text { SPE- } \\
\text { CIFIC } \\
\text { CON- } \\
\text { DUCT- } \\
\text { ANCE }\end{array}$ & & TEMPER \\
\hline MICRO- & PH & ATURE \\
\hline $\begin{array}{c}\text { Mitos) } \\
500\end{array}$ & $\begin{array}{c}\text { (UNITS) } \\
7.2\end{array}$ & $\begin{array}{r}\text { (DEG C } \\
27.0\end{array}$ \\
\hline $\begin{array}{l}545 \\
555\end{array}$ & $\begin{array}{l}7.4 \\
7.5\end{array}$ & $\begin{array}{l}32.0 \\
31.0\end{array}$ \\
\hline $\begin{array}{l}615 \\
660\end{array}$ & 7.6 & $\begin{array}{l}34.0 \\
29.0\end{array}$ \\
\hline 520 & 7.8 & 29.0 \\
\hline 530 & 7.7 & 32.0 \\
\hline 630 & 6.9 & 29.0 \\
\hline 710 & 7.3 & 31.0 \\
\hline 660 & 7.8 & 34.0 \\
\hline 590 & 7.4 & 34.0 \\
\hline 660 & 7.0 & 31.0 \\
\hline 640 & 7.0 & 31.0 \\
\hline 600 & 7.8 & 31.0 \\
\hline 510 & 7.8 & 31.0 \\
\hline 695 & 7.3 & 31.0 \\
\hline 620 & 7.5 & 31.0 \\
\hline 645 & - & 32.0 \\
\hline 680 & -- & 31.0 \\
\hline 545 & -- & 34.0 \\
\hline 565 & -- & 34.0 \\
\hline 715 & -- & 30.0 \\
\hline 555 & -- & 31.0 \\
\hline 610 & -- & 33.0 \\
\hline 510 & -- & 34.0 \\
\hline 720 & -- & \\
\hline
\end{tabular}


02303400 CYPRESS CREEK NEAR SAN ANTONIO, FLA.

LOCATION. - Lat $28^{\circ} 19^{\prime} 25^{\prime \prime}$, long $82^{\circ} 23^{\prime} 03^{\prime \prime}$, in SWl sec.11, T.25 S., R.19 E., Pasco County, at center on downstream side of box culverts on State Highway 52, 3.3 miles downstream from Bee Tree Branch, 6.8 miles west of San Antonio, 12 miles west of Dade City, and 25 miles upstream from mouth.

DRAINAGE AREA. - 56 sq $\mathrm{mi}$.

PERIOD OF RECORD.--Chemical analyses: October 1963 to September 1970.

Water temperatures: October 1963 to September 1970.

EXTRENES. - 1969-70:

Specific conductance: Maximum daily, 269 micrombos May 17; minimum daily, 53 micromhos Dec. 14

Water temperatures: Maximum, $31.0^{\circ} \mathrm{C}$ on many days during July to November; minimura, $18.0^{\circ} \mathrm{C}$ on several days during December to February.

period of record:

Specific conductance: Maximum da11y, 341 micromhos Apr, 5, 1967; minimum da1ly, 43 micromhos Sept. $12,1966$.

water temperatures: Maximum, $36.0^{\circ} \mathrm{C}$ June $25,29,1969 ;$ mínimum, $7.0^{\circ} \mathrm{C}$ Dec. $18,1963$.

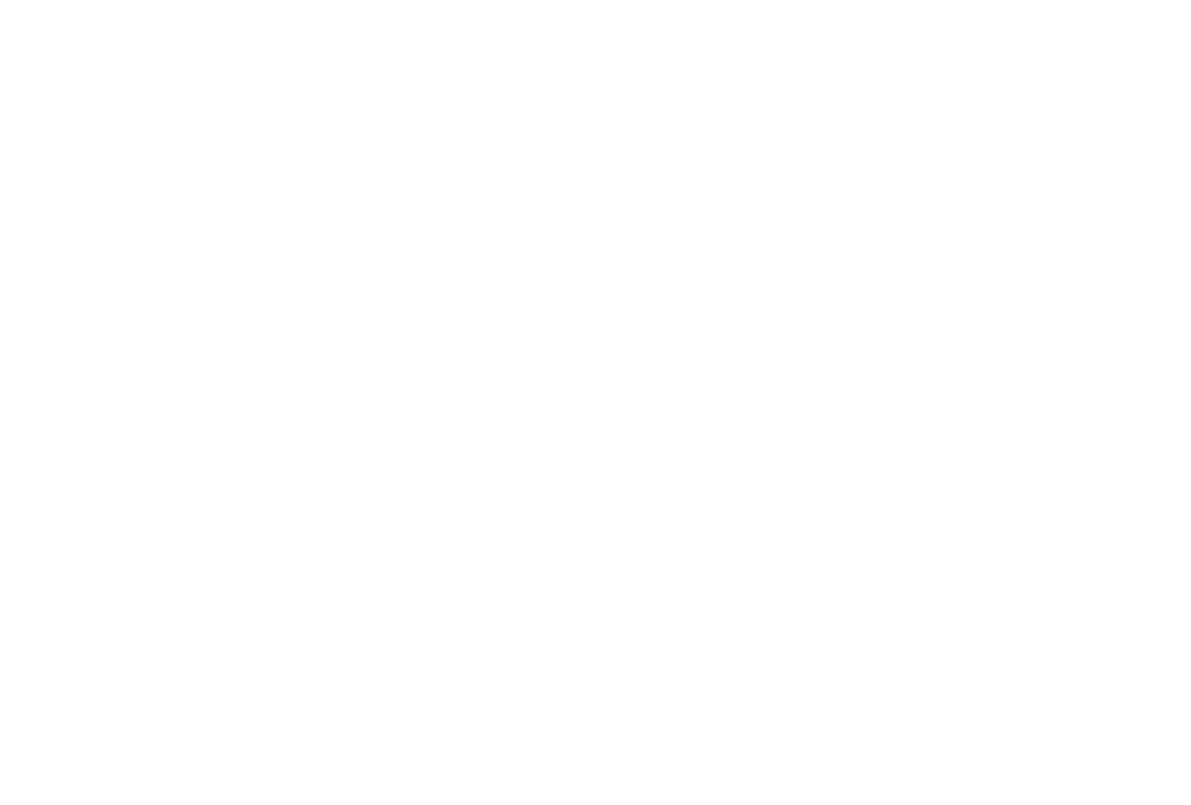

(FIELD MEASUREMENTS)

\begin{tabular}{|c|c|c|c|c|c|c|c|c|c|c|c|c|}
\hline DATE & TIME & $\begin{array}{l}\text { STAGE } \\
\text { (FT } \\
\text { A8OVE } \\
\text { DATUM) }\end{array}$ & $\begin{array}{l}\text { DIS- } \\
\text { CHARGE } \\
\text { (CFS) }\end{array}$ & $\begin{array}{l}\text { TEMPER- } \\
\text { ATURE } \\
\text { (DEG C) }\end{array}$ & $\begin{array}{l}\text { DIS- } \\
\text { SOLVEO } \\
\text { OXYGEN } \\
(M G / L)\end{array}$ & $\begin{array}{l}\text { PER- } \\
\text { CENT } \\
\text { SATUR- } \\
\text { ATION }\end{array}$ & $\begin{array}{l}\text { CIFIC } \\
\text { CON- } \\
\text { DUCT- } \\
\text { ANCE } \\
\text { (MICRO- } \\
\text { MHOS) }\end{array}$ & $\begin{array}{c}\text { PH } \\
\text { (UNITS) }\end{array}$ & $\begin{array}{l}\text { BICAR- } \\
\text { BONATE } \\
\text { (HCO3) } \\
(H G / L)\end{array}$ & $\begin{array}{l}\text { CAR- } \\
\text { BONATE } \\
\text { (CO3) } \\
\text { (MG/L) }\end{array}$ & $\begin{array}{l}\text { TAANS- } \\
\text { PAR- } \\
\text { ENCY } \\
\text { SECCHI } \\
\text { DISK } \\
\text { (IN) }\end{array}$ & $\begin{array}{c}\text { DENTH } \\
(=T)\end{array}$ \\
\hline
\end{tabular}

JUNE, 1970

$2.87 \quad 20$

25.0

3.6

43

139 
HILLSBOROUGH RIVER BASIN

02303400 CYPRESS CREEK NEAR SAN ANTONIO, FLA.---Cont1nued

SPECIFIC CONDUCTANCE (MICROMHOS/CM AT 250 C), WATER YEAR OCTOBER 1969 TO SEPTEMBER 1970

\begin{tabular}{|c|c|c|c|c|c|c|c|c|c|c|c|c|}
\hline DAY & $\mathrm{OCT}$ & Nov & DEC & JAN & FEB & MAR & APR & MAY & JUN & JUL & AU G & SEP \\
\hline $\begin{array}{l}1 \\
2 \\
3 \\
4 \\
5\end{array}$ & $\begin{array}{l}67 \\
60 \\
67 \\
70 \\
73\end{array}$ & $\begin{array}{l}104 \\
104 \\
105 \\
105 \\
115\end{array}$ & $\begin{array}{l}170 \\
170 \\
175 \\
175 \\
175\end{array}$ & $\begin{array}{l}87 \\
84 \\
87 \\
84 \\
63\end{array}$ & $\begin{array}{l}71 \\
65 \\
64 \\
63 \\
72\end{array}$ & $\begin{array}{r}124 \\
125 \\
124 \\
124 \\
78\end{array}$ & $\begin{array}{r}100 \\
99 \\
100 \\
98 \\
109\end{array}$ & $\begin{array}{l}200 \\
200 \\
225 \\
225 \\
225\end{array}$ & $\begin{array}{l}124 \\
125 \\
124 \\
124 \\
125\end{array}$ & $\begin{array}{l}240 \\
240 \\
240 \\
238 \\
238\end{array}$ & $\begin{array}{l}-- \\
-- \\
-- \\
--\end{array}$ & $\begin{array}{l}111 \\
148 \\
147 \\
148 \\
147\end{array}$ \\
\hline $\begin{array}{r}6 \\
7 \\
8 \\
9 \\
10\end{array}$ & $\begin{array}{l}73 \\
73 \\
73 \\
75 \\
75\end{array}$ & $\begin{array}{l}115 \\
125 \\
124 \\
133 \\
133\end{array}$ & $\begin{array}{r}175 \\
87 \\
86 \\
87 \\
87\end{array}$ & $\begin{array}{l}63 \\
63 \\
63 \\
76 \\
76\end{array}$ & $\begin{array}{l}74 \\
73 \\
74 \\
88 \\
88\end{array}$ & $\begin{array}{l}77 \\
76 \\
78 \\
80 \\
79\end{array}$ & \begin{tabular}{l}
110 \\
108 \\
108 \\
\hdashline$\cdots$
\end{tabular} & $\begin{array}{l}225 \\
225 \\
220 \\
250 \\
248\end{array}$ & $\begin{array}{l}125 \\
124 \\
175 \\
175 \\
172\end{array}$ & $\begin{array}{l}235 \\
265 \\
265 \\
265 \\
265\end{array}$ & $=$ & $\begin{array}{l}147 \\
146 \\
146 \\
146 \\
149\end{array}$ \\
\hline $\begin{array}{l}11 \\
12 \\
13 \\
14 \\
15\end{array}$ & $\begin{array}{r}75 \\
75 \\
100 \\
80 \\
91\end{array}$ & $\begin{array}{r}125 \\
124 \\
113 \\
107 \\
57\end{array}$ & $\begin{array}{l}54 \\
54 \\
55 \\
53 \\
70\end{array}$ & $\begin{array}{l}76 \\
76 \\
89 \\
89 \\
89\end{array}$ & $\begin{array}{l}87 \\
89 \\
57 \\
96 \\
97\end{array}$ & $\begin{array}{l}80 \\
81 \\
79 \\
80 \\
77\end{array}$ & $\begin{array}{l}--- \\
135 \\
135 \\
135\end{array}$ & $\begin{array}{l}247 \\
250 \\
249 \\
250 \\
268\end{array}$ & $\begin{array}{l}170 \\
173 \\
175 \\
220 \\
218\end{array}$ & $\begin{array}{l}265 \\
265 \\
200 \\
200 \\
200\end{array}$ & $\begin{array}{l}=- \\
=- \\
=-\end{array}$ & $\begin{array}{l}149 \\
149 \\
150 \\
149 \\
149\end{array}$ \\
\hline $\begin{array}{l}16 \\
17 \\
18 \\
19 \\
20\end{array}$ & $\begin{array}{r}94 \\
93 \\
92 \\
98 \\
102\end{array}$ & $\begin{array}{r}96 \\
96 \\
97 \\
115 \\
116\end{array}$ & $\begin{array}{l}71 \\
85 \\
84 \\
34 \\
84\end{array}$ & $\begin{array}{l}89 \\
95 \\
95 \\
95 \\
95\end{array}$ & $\begin{array}{l}9 B \\
100 \\
100 \\
101 \\
102\end{array}$ & $\begin{array}{c}78 \\
89 \\
91 \\
92 \\
50\end{array}$ & $\begin{array}{l}135 \\
135 \\
135 \\
137 \\
170\end{array}$ & $\begin{array}{l}265 \\
269 \\
267 \\
268 \\
268\end{array}$ & $\begin{array}{l}218 \\
219 \\
215 \\
215 \\
248\end{array}$ & $\begin{array}{l}200 \\
200 \\
200 \\
205 \\
205\end{array}$ & 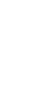 & $\begin{array}{l}149 \\
149 \\
180 \\
179 \\
181\end{array}$ \\
\hline $\begin{array}{l}21 \\
22 \\
23 \\
24 \\
25\end{array}$ & $\begin{array}{l}110 \\
112 \\
107 \\
106 \\
100\end{array}$ & $\begin{array}{l}106 \\
130 \\
130 \\
129 \\
129\end{array}$ & $\begin{array}{l}93 \\
94 \\
94 \\
94 \\
97\end{array}$ & $\begin{array}{l}101 \\
101 \\
101 \\
101 \\
116\end{array}$ & $\begin{array}{l}105 \\
105 \\
105 \\
105 \\
109\end{array}$ & $\begin{array}{l}98 \\
97 \\
99 \\
98 \\
97\end{array}$ & $\overline{170}$ & $\begin{array}{l}251 \\
251 \\
251 \\
252 \\
252\end{array}$ & $\begin{array}{l}240 \\
240 \\
240 \\
240 \\
240\end{array}$ & $\begin{array}{l}206 \\
205 \\
203 \\
208 \\
205\end{array}$ & \begin{tabular}{l}
--- \\
\hdashline- \\
\hdashline-
\end{tabular} & $\begin{array}{l}179 \\
179 \\
179 \\
179 \\
180\end{array}$ \\
\hline $\begin{array}{l}26 \\
27 \\
28 \\
29 \\
30 \\
31\end{array}$ & $\begin{array}{l}100 \\
120 \\
120 \\
120 \\
120 \\
120\end{array}$ & $\begin{array}{l}116 \\
115 \\
132 \\
161 \\
162 \\
---\end{array}$ & $\begin{array}{r}99 \\
100 \\
99 \\
84 \\
84 \\
83\end{array}$ & $\begin{array}{l}118 \\
115 \\
115 \\
129 \\
129 \\
130\end{array}$ & \begin{tabular}{l}
110 \\
110 \\
110 \\
\hdashline-0
\end{tabular} & $\begin{array}{l}97 \\
83 \\
83 \\
82 \\
83 \\
82\end{array}$ & $\begin{array}{l}190 \\
200 \\
200 \\
200 \\
200 \\
\end{array}$ & $\begin{array}{l}252 \\
124 \\
123 \\
122 \\
122 \\
122\end{array}$ & $\begin{array}{l}170 \\
170 \\
170 \\
170 \\
170 \\
\end{array}$ & $\begin{array}{l}205 \\
208 \\
205 \\
205 \\
205 \\
205\end{array}$ & \begin{tabular}{l}
$\square-$ \\
$\square-$ \\
\hdashline- \\
--
\end{tabular} & $\begin{array}{l}163 \\
163 \\
159 \\
159 \\
162 \\
\end{array}$ \\
\hline AVER AGE & 92 & 119 & 100 & 93 & 91 & 90 & $\rightarrow-$ & 225 & 184 & 222 & $\ldots$ & 157 \\
\hline
\end{tabular}

TEMPERATURE $\left({ }^{\circ} \mathrm{C}\right)$ OF WATER, WATER YEAR OCTOBER 1969 TO SEPTEMBER 1970

\begin{tabular}{|c|c|c|c|c|c|c|c|c|c|c|c|c|}
\hline DAY & $\propto \subset T$ & NOV & DEC & $J A N$ & FEG & MAR & $A P R$ & MAY & JUN & $\boldsymbol{U} \mathrm{L}$ & AUG & SEP \\
\hline $\begin{array}{l}1 \\
2 \\
3 \\
4 \\
5\end{array}$ & $\begin{array}{l}31.0 \\
31.0 \\
31.0 \\
31.0 \\
30.0\end{array}$ & $\begin{array}{l}29.0 \\
28.0 \\
26.0 \\
24.0 \\
25.0\end{array}$ & $\begin{array}{l}20.0 \\
20.0 \\
20.0 \\
19.0 \\
19.0\end{array}$ & $\begin{array}{l}19.0 \\
19.0 \\
19.0 \\
18.0 \\
20.0\end{array}$ & $\begin{array}{l}19.0 \\
19.0 \\
19.0 \\
18.0 \\
18.0\end{array}$ & $\begin{array}{l}21.0 \\
22.0 \\
23.0 \\
23.0 \\
22.0\end{array}$ & $\begin{array}{l}23.0 \\
23.0 \\
24.0 \\
24.0 \\
24.0\end{array}$ & $\begin{array}{l}30.0 \\
30.0 \\
29.0 \\
28.0 \\
27.0\end{array}$ & $\begin{array}{l}30.0 \\
29.0 \\
29.0 \\
29.0 \\
29.0\end{array}$ & $\begin{array}{l}30.0 \\
30.0 \\
30.0 \\
30.0 \\
31.0\end{array}$ & 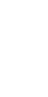 & $\begin{array}{l}31.0 \\
31.0 \\
31.0 \\
31.0 \\
31.0\end{array}$ \\
\hline $\begin{array}{r}6 \\
7 \\
8 \\
9 \\
10\end{array}$ & $\begin{array}{l}31.0 \\
30.0 \\
30.0 \\
30.0 \\
30.0\end{array}$ & $\begin{array}{l}24.0 \\
23.0 \\
22.0 \\
23.0 \\
23.0\end{array}$ & $\begin{array}{l}19.0 \\
19.0 \\
19.0 \\
19.0 \\
20.0\end{array}$ & $\begin{array}{l}19.0 \\
19.0 \\
18.0 \\
18.0 \\
18.0\end{array}$ & $\begin{array}{l}19.0 \\
20.0 \\
19.0 \\
19.0 \\
19.0\end{array}$ & $\begin{array}{l}22.0 \\
23.0 \\
23.0 \\
22.0 \\
22.0\end{array}$ & $\begin{array}{r}24.0 \\
25.0 \\
25.0 \\
\ldots .0 \\
-\end{array}$ & $\begin{array}{l}27.0 \\
26.0 \\
26.0 \\
30.0 \\
29.0\end{array}$ & $\begin{array}{l}29.0 \\
29.0 \\
30.0 \\
30.0 \\
30.0\end{array}$ & $\begin{array}{l}31.0 \\
30.0 \\
30.0 \\
30.0 \\
31.0\end{array}$ & $=$ & $\begin{array}{l}31.0 \\
31.0 \\
31.0 \\
31.0 \\
31.0\end{array}$ \\
\hline $\begin{array}{l}11 \\
12 \\
13 \\
14 \\
15\end{array}$ & $\begin{array}{l}30.0 \\
30.0 \\
29.0 \\
30.0 \\
30.0\end{array}$ & $\begin{array}{l}23.0 \\
23.0 \\
23.0 \\
23.0 \\
21.0\end{array}$ & $\begin{array}{l}20.0 \\
20.0 \\
20.0 \\
20.0 \\
19.0\end{array}$ & $\begin{array}{l}19.0 \\
19.0 \\
19.0 \\
19.0 \\
19.0\end{array}$ & $\begin{array}{l}19.0 \\
19.0 \\
19.0 \\
20.0 \\
20.0\end{array}$ & $\begin{array}{l}22.0 \\
22.0 \\
21.0 \\
20.0 \\
19.0\end{array}$ & $\begin{array}{l}25.0 \\
25.0 \\
25.0\end{array}$ & $\begin{array}{l}30.0 \\
30.0 \\
30.0 \\
30.0 \\
30.0\end{array}$ & $\begin{array}{l}29.0 \\
29.0 \\
30.0 \\
30.0 \\
30.0\end{array}$ & $\begin{array}{l}31.0 \\
31.0 \\
31.0 \\
31.0 \\
31.0\end{array}$ & $\ddot{-\infty}$ & $\begin{array}{l}31.0 \\
31.0 \\
31.0 \\
31.0 \\
30.0\end{array}$ \\
\hline $\begin{array}{l}16 \\
17 \\
18 \\
19 \\
20\end{array}$ & $\begin{array}{l}30.0 \\
30.0 \\
29.0 \\
30.0 \\
29.0\end{array}$ & $\begin{array}{l}21.0 \\
20.0 \\
20.0 \\
20.0 \\
20.0\end{array}$ & $\begin{array}{l}19.0 \\
19.0 \\
20.0 \\
19.0 \\
20.0\end{array}$ & $\begin{array}{l}20.0 \\
19.0 \\
19.0 \\
20.0 \\
20.0\end{array}$ & $\begin{array}{l}21.0 \\
21.0 \\
21.0 \\
21.0 \\
21.0\end{array}$ & $\begin{array}{l}19.0 \\
22.0 \\
24.0 \\
25.0 \\
26.0\end{array}$ & $\begin{array}{l}25.0 \\
26.0 \\
26.0 \\
28.0 \\
29.0\end{array}$ & $\begin{array}{l}30.0 \\
30.0 \\
29.0 \\
29.0 \\
30.0\end{array}$ & $\begin{array}{l}30.0 \\
29.0 \\
30.0 \\
30.0 \\
29.0\end{array}$ & $\begin{array}{l}31.0 \\
31.0 \\
31.0 \\
31.0 \\
31.0\end{array}$ & $\begin{array}{l}--- \\
m-- \\
---\end{array}$ & $\begin{array}{l}30.0 \\
30.0 \\
31.0 \\
31.0 \\
30.0\end{array}$ \\
\hline $\begin{array}{l}21 \\
22 \\
23 \\
24 \\
25\end{array}$ & $\begin{array}{l}29.0 \\
29.0 \\
28.0 \\
28.0 \\
29.0\end{array}$ & $\begin{array}{l}29.0 \\
22.0 \\
21.0 \\
22.0 \\
21.0\end{array}$ & $\begin{array}{l}19.0 \\
19.0 \\
20.0 \\
20.0 \\
18.0\end{array}$ & $\begin{array}{l}19.0 \\
19.0 \\
19.0 \\
19.0 \\
19.0\end{array}$ & $\begin{array}{l}21.0 \\
21.0 \\
21.0 \\
21.0 \\
21.0\end{array}$ & $\begin{array}{l}22.0 \\
22.0 \\
23.0 \\
24.0 \\
24.0\end{array}$ & $\begin{array}{c}=- \\
\overline{3} \\
\overline{30.0}\end{array}$ & $\begin{array}{l}30.0 \\
30.0 \\
30.0 \\
29.0 \\
29.0\end{array}$ & $\begin{array}{l}30.0 \\
30.0 \\
30.0 \\
30.0 \\
30.0\end{array}$ & $\begin{array}{l}31.0 \\
31.0 \\
31.0 \\
31.0 \\
31.0\end{array}$ & 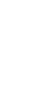 & $\begin{array}{l}31.0 \\
31.0 \\
30.0 \\
30.0 \\
30.0\end{array}$ \\
\hline $\begin{array}{l}26 \\
27 \\
28 \\
29 \\
30 \\
31\end{array}$ & $\begin{array}{l}29.0 \\
29.0 \\
29.0 \\
28.0 \\
28.0 \\
28.0\end{array}$ & $\begin{array}{c}20.0 \\
20.0 \\
31.0 \\
20.0 \\
20.0 \\
\ldots\end{array}$ & $\begin{array}{l}18.0 \\
19.0 \\
19.0 \\
20.0 \\
20.0 \\
20.0\end{array}$ & $\begin{array}{l}19.0 \\
21.0 \\
21.0 \\
19.0 \\
19.0 \\
19.0\end{array}$ & $\begin{array}{r}21.0 \\
21.0 \\
21.0 \\
\ldots \\
\ldots\end{array}$ & $\begin{array}{l}24.0 \\
22.0 \\
23.0 \\
23.0 \\
23.0 \\
23.0\end{array}$ & $\begin{array}{r}30.0 \\
30.0 \\
30.0 \\
30.0 \\
30.0 \\
\ldots . .\end{array}$ & $\begin{array}{l}29.0 \\
30.0 \\
29.0 \\
29.0 \\
29.0 \\
29.0\end{array}$ & $\begin{array}{r}30.0 \\
30.0 \\
30.0 \\
30.0 \\
30.0 \\
-.\end{array}$ & $\begin{array}{l}31.0 \\
31.0 \\
31.0 \\
31.0 \\
31.0 \\
31.0\end{array}$ & $\begin{array}{l}=- \\
-- \\
--- \\
--- \\
--\end{array}$ & $\begin{array}{l}30.0 \\
30.0 \\
30.0 \\
30.0 \\
30.0 \\
-\end{array}$ \\
\hline VERAGE & 29.5 & 23.0 & 29.5 & 19.0 & 20.0 & 22.5 & $\cdots$ & 29.0 & 29.5 & 31.0 & -- & 30.5 \\
\hline
\end{tabular}


LOCATION..-Lat $28^{\circ} 02 \cdot 23^{\prime \prime}$, long $82^{\circ} 34^{\prime} 31^{\prime \prime}$, in $\mathrm{N}_{2} \mathrm{sec} .23, \mathrm{~T} .28 \mathrm{~S}$, , R. $17 \mathrm{E}$, , Hillsborough County, gaging station on left bank $100 \mathrm{ft}$ upstream from Seaboárd Railway bridge, 1,600 ft upstream from concrete control, $2.5 \mathrm{mi}$ les downstream from Brushy Creek, 6.1 miles upstream from mouth, and 7.7 miles northwest of Sulphur Springs post office.

DRAINAGE AREA.--35 sq mi, approximately.

PERIOD OF RECORD.--Chemical analyses: March 1965 to September 1970

Hater temperatures: October 1967 to September 1970 .

EXTREMES, - -1969-70:

Specific conductance: Maximum daily, 203 micromhos Sept. 1 ; minimum daily, 67 micromhos Dec. 10.

water temperatures: Maximum, $35.0^{\circ} \mathrm{C}$ May 27 ; minimum, 11.0 $0^{\circ} \mathrm{C} \mathrm{Jan} .8$, Feb. 3 .

Period of record:

Specific conductance (1967-70): Maximum daily, 240 micromhos Oct. 16, 1967; minimum daily, 61 micromhos Aug. 4,

Water temperatures: Maximum, $35.0^{\circ} \mathrm{C}$ May 27,$1970 ;$ minimum, $11.0^{\circ} \mathrm{C} \mathrm{Jan.} \mathrm{8,} \mathrm{Feb.} 3,1970$.

CHEMICAL ANALYSES, WATER YEAR DCTOBER 1969 TO SEPTEMBER 1970

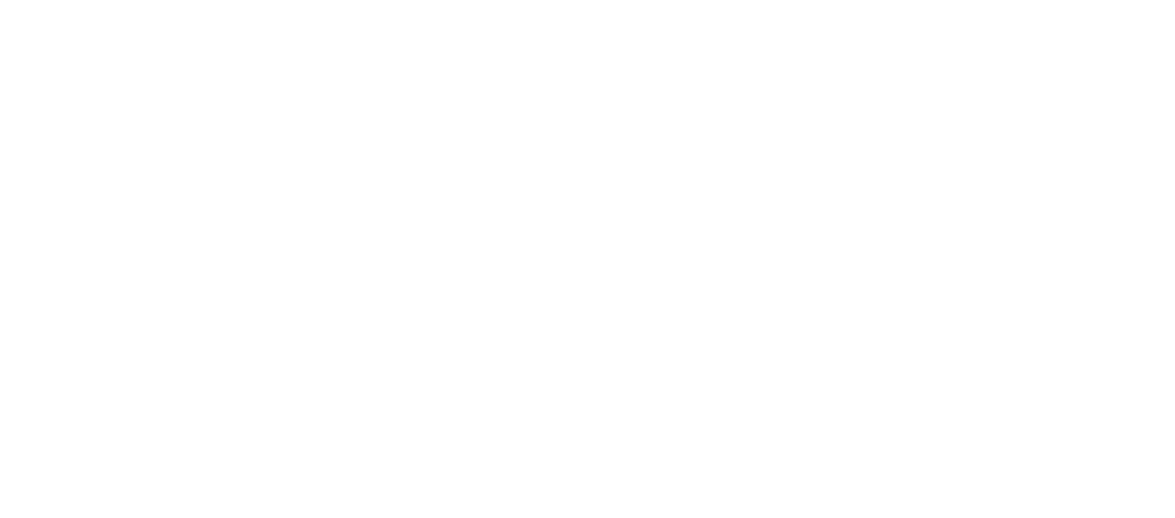

\begin{tabular}{|c|c|c|c|c|c|c|c|c|c|c|c|c|}
\hline $13 \ldots{ }^{1969}$ & 7.2 & 11 & .2 & 29 & 12 & 16 & 78 & 47 & 6.11 & .11 & $m$ & - \\
\hline $\begin{array}{l}20 \ldots . . \\
\text { JAN... }\end{array}$ & 7.6 & 14 & .2 & 33 & 16 & 17 & 98 & 60 & 5.29 & .13 & -- & -- \\
\hline FEY. & 6.6 & 9.8 & .1 & 16 & $1 \mathrm{t}$ & 6 & 66 & 37 & 53.5 & .09 & - & - \\
\hline $\begin{array}{l}09 . . . \\
\text { MAP. }\end{array}$ & 11 & 12 & .2 & 21 & 13 & 7 & 79 & 47 & 13.5 & .11 & - & - \\
\hline MAY & 9.8 & 12 & .3 & 22 & 14 & 7 & 63 & 44 & 9.90 & .09 & - & - \\
\hline JUNF... & 8.6 & 12 & .1 & 39 & $1 \mathrm{t}$ & 28 & 82 & 66 & 1.05 & .11 & - & \\
\hline
\end{tabular}

SPECIFIC CONDUCTANCE (MICROMHOS/CM AT $25^{\circ} \mathrm{C}$ ), WATER YEAR OCTOBER 1969 TO SEPTEMBER 1970

\begin{tabular}{|c|c|c|c|c|c|c|c|c|c|c|c|c|}
\hline \multirow{2}{*}{ DAY } & & \multicolumn{2}{|c|}{ EY EEA } & \multirow{2}{*}{\multicolumn{2}{|c|}{ MAR APR }} & & \multirow[b]{2}{*}{ SEP } \\
\hline & $\mathrm{DCT}$ & NOV & $D E C$ & $J \Delta N$ & FEB & & & MAY & JUN & JUL & $A \cup G$ & \\
\hline 1 & 95 & -- & 118 & -- & 100 & 120 & 84 & 148 & 150 & $-\infty$ & 152 & 203 \\
\hline 2 & 95 & 107 & 130 & -- & 103 & 80 & -- & 115 & 155 & - & 131 & -- \\
\hline 3 & 100 & $-\bar{c}+2+x$ & 124 & 104 & 110 & 105 & 89 & 138 & 190 & -- & 183 & 139 \\
\hline 4 & -- & 105 & --- & 106 & --- & 105 & 98 & 95 & 155 & -- & -- & 117 \\
\hline 5 & 85 & 101 & 118 & 114 & 94 & 95 & 89 & 131 & $\cdots$ & -- & $\cdots$ & $\cdots$ \\
\hline 6 & -- & 120 & 120 & 92 & 89 & 65 & 100 & 123 & --- & -- & 142 & -- \\
\hline 7 & 90 & 100 & 118 & 78 & 88 & 77 & 83 & 123 & 180 & -- & 153 & $-\cdots$ \\
\hline 8 & 90 & 110 & 121 & 120 & 91 & $8 \mathrm{~L}$ & 85 & 105 & $\cdots$ & -- & 125 & 114 \\
\hline 9 & 92 & 103 & 113 & $-\infty$ & st & 96 & 87 & 134 & - & $m$ & 168 & 110 \\
\hline to & 91 & 111 & 57 & B I & Q7 & 82 & 87 & 162 & 148 & -- & 127 & 98 \\
\hline 11 & --- & 103 & $-\infty$ & 83 & 85 & $8 t$ & 98 & 120 & 140 & -- & 135 & 113 \\
\hline 12 & 85 & 104 & 77 & -- & 89 & $-\overline{-3}$ & 100 & 118 & 150 & --- & $\cdots$ & -- \\
\hline 13 & 87 & 101 & 79 & 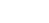 & 96 & 77 & 90 & 136 & 130 & -- & -- & $-\bar{x}$ \\
\hline 14 & 88 & 102 & 92 & 85 & 90 & 77 & 97 & 120 & $-\cdots$ & -- & 168 & 106 \\
\hline 15 & 85 & 108 & 84 & $-\cdots$ & 96 & $\cdots$ & 105 & 144 & 160 & $m$ & 129 & 111 \\
\hline 16 & 90 & 111 & 83 & -- & -- & 80 & -- & $-\infty$ & -- & --- & -- & $-\infty$ \\
\hline 17 & 90 & 110 & 80 & 89 & 95 & 80 & 92 & -- & 131 & -- & 151 & --- \\
\hline 18 & 90 & 110 & 99 & 94 & -- & 87 & $-\overline{2}$ & 120 & $-\infty$ & $\rightarrow$ & 152 & 110 \\
\hline 19 & 90 & 107 & 80 & 90 & 100 & 80 & 97 & 125 & $\cdots$ & 131 & 143 & - \\
\hline 20 & $-\rightarrow$ & $\cdots$ & 94 & 109 & 98 & -- & 105 & -- & $\rightarrow$ & --- & -- & $\cdots$ \\
\hline 21 & 95 & 107 & 103 & 89 & too & 90 & -- & 149 & - & 155 & 158 & -5 \\
\hline 22 & 105 & 106 & $\cdots$ & 104 & 96 & 80 & 101 & $\cdots$ & 161 & $m$ & 135 & 115 \\
\hline 23 & 105 & I C4 & 93 & 101 & 89 & 82 & 114 & 150 & -- & -.. & 116 & 116 \\
\hline 24 & 110 & -3 & 106 & 89 & 88 & 94 & -- & 155 & 150 & $\cdots$ & $-\overline{-}$ & $\overline{128}$ \\
\hline 25 & 120 & 105 & 94 & 103 & 91 & 85 & 110 & $\cdots$ & -- & $\cdots$ & 135 & 128 \\
\hline 26 & 110 & 100 & 97 & 100 & 100 & 95 & $m$ & $-\bar{x}$ & $m$ & -- & 158 & 127 \\
\hline 27 & 105 & 115 & -- & 94 & 97 &.- & 111 & 159 & -- & $m$ & -- & 110 \\
\hline 28 & -- & --- & 106 & 109 & 96 & $\cdots$ & --- & - & 155 & $\cdots$ & 147 & 129 \\
\hline 29 & 105 & ILI & 99 & -- & $-\infty$ & 80 & -- & 160 & 140 & -- & -- & 137 \\
\hline 30 & 105 & -- & 94 & $10 \mathrm{t}$ & $\cdots$ & 102 & 108 & -- & 165 & --- & $\cdots$ & -- \\
\hline 31 & 105 & - & 102 & $\rightarrow$ & -- & -- & -- & $m$ & $\cdots$ & $\cdots$ & $\cdots$ & -- \\
\hline AVERAGE & 96 & 107 & 100 & -- & 94 & 87 & $m$ & -- & -- & $-\cdots$ & $\cdots$ & $\cdots$ \\
\hline
\end{tabular}


02307000 ROCKY CREEK NEAR SULHHUR SPRINGS, FLA.--Continued

TEMPERATURE $\left({ }^{\circ} \mathrm{C}\right)$ OF WATER, WATER YEAR OCTOBER 1969 TO SEPTEMBER 1970

\begin{tabular}{|c|c|c|c|c|c|c|c|c|c|c|c|c|}
\hline DAY & $O C T$ & NoV & DEC & JAA & FEB & MAR & $\triangle P R$ & MAY & JUN & Jut & AUG & SEP \\
\hline $\begin{array}{l}1 \\
2 \\
3 \\
4 \\
5\end{array}$ & $\begin{array}{r}29.0 \\
26.0 \\
26.0 \\
25.0\end{array}$ & $\begin{array}{r}24.0 \\
-1.0 \\
21.0\end{array}$ & $\begin{array}{r}18.0 \\
18.0 \\
19.0 \\
18.0\end{array}$ & $\begin{array}{l}--- \\
15.0 \\
13.0 \\
16.0\end{array}$ & $\begin{array}{l}15.0 \\
15.0 \\
11.0 \\
14.0\end{array}$ & $\begin{array}{l}15.0 \\
19.0 \\
16.0 \\
16.0 \\
15.0\end{array}$ & $\begin{array}{l}26.0 \\
25.0 \\
23.0 \\
23.0\end{array}$ & $\begin{array}{l}34.0 \\
29.0 \\
32.0 \\
29.0 \\
30.0\end{array}$ & $\begin{array}{r}33.0 \\
31.0 \\
34.0 \\
33.0 \\
-.0\end{array}$ & $\begin{array}{l}m-- \\
\cdots- \\
\cdots-\end{array}$ & $\ddot{--}$ & $\begin{array}{l}-- \\
--- \\
-\infty \\
--\end{array}$ \\
\hline $\begin{array}{r}6 \\
7 \\
8 \\
9 \\
10\end{array}$ & $\begin{array}{r}--- \\
29.0 \\
26.0 \\
26.0 \\
26.0\end{array}$ & $\begin{array}{l}23.0 \\
21.0 \\
23.0 \\
22.0 \\
22.0\end{array}$ & $\begin{array}{l}19.0 \\
19.0 \\
20.0 \\
18.0 \\
18.0\end{array}$ & $\frac{15.0}{11.0}$ & $\begin{array}{l}14.0 \\
14.0 \\
14.0 \\
15.0 \\
13.0\end{array}$ & $\begin{array}{l}17.0 \\
16.0 \\
15.0 \\
16.0 \\
18.0\end{array}$ & $\begin{array}{l}27.0 \\
24.0 \\
25.0 \\
24.0 \\
25.0\end{array}$ & $\begin{array}{l}30.0 \\
29.0 \\
29.0 \\
29.0 \\
32.0\end{array}$ & $\begin{array}{r}30.0 \\
34.0\end{array}$ & $\begin{array}{l}\cdots- \\
\cdots- \\
\cdots- \\
\cdots-\end{array}$ & $\begin{array}{l}=- \\
=- \\
--- \\
--\end{array}$ & $\begin{array}{l}-m \\
\cdots \\
\cdots \\
m-\end{array}$ \\
\hline $\begin{array}{l}11 \\
12 \\
13 \\
14 \\
15\end{array}$ & $\begin{array}{r}26.0 \\
27.0 \\
26.0 \\
-\ldots\end{array}$ & $\begin{array}{l}21.0 \\
23.0 \\
22.0 \\
21.0 \\
20.0\end{array}$ & $\begin{array}{l}13.0 \\
17.0 \\
15.0 \\
16.0\end{array}$ & $\begin{array}{r}13.0 \\
\hdashline 14.0 \\
\hdashline-\end{array}$ & $\begin{array}{l}15.0 \\
14.0 \\
15.0 \\
15.0 \\
14.0\end{array}$ & $\begin{array}{r}15.0 \\
13.0 \\
13.0 \\
\ldots\end{array}$ & $\begin{array}{l}24.0 \\
26.0 \\
25.0 \\
27.0 \\
27.0\end{array}$ & $\begin{array}{l}34.0 \\
28.0 \\
30.0 \\
30.0 \\
33.0\end{array}$ & $\begin{array}{r}33.0 \\
35.0 \\
34.0 \\
--\end{array}$ & $\begin{array}{l}\cdots \\
\cdots \\
\cdots\end{array}$ & $\begin{array}{l}--- \\
--- \\
--- \\
--\end{array}$ & 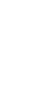 \\
\hline $\begin{array}{l}16 \\
17 \\
18 \\
19 \\
20\end{array}$ & $\begin{array}{l}26.0 \\
26.0 \\
26.0 \\
25.0 \\
\end{array}$ & $\begin{array}{l}20.0 \\
22.0 \\
21.0 \\
21.0 \\
-\end{array}$ & $\begin{array}{l}16.0 \\
16.0 \\
17.0 \\
17.0 \\
16.0\end{array}$ & $\begin{array}{l}14.0 \\
14.0 \\
15.0 \\
14.0 \\
16.0\end{array}$ & $\begin{array}{r}13.0 \\
15.0 \\
15.0\end{array}$ & $\begin{array}{l}16.0 \\
15.0 \\
17.0 \\
17.0 \\
-\end{array}$ & $\begin{array}{r}28.0 \\
25.0 \\
25.0\end{array}$ & $\begin{array}{r}7-2 \\
30.0 \\
31.0\end{array}$ & $\begin{array}{r}30.0 \\
-- \\
--\end{array}$ & 33.0 & $\begin{array}{l}m \\
-- \\
-\infty \\
-\infty\end{array}$ & $\begin{array}{l}-- \\
-- \\
-- \\
--\end{array}$ \\
\hline $\begin{array}{l}21 \\
22 \\
23 \\
24 \\
25\end{array}$ & $\begin{array}{l}27.0 \\
26.0 \\
27.0 \\
26.0 \\
26.0\end{array}$ & $\begin{array}{r}20.0 \\
16.0 \\
-19.0\end{array}$ & $\begin{array}{l}17.0 \\
17.0 \\
18.0 \\
18.0\end{array}$ & $\begin{array}{l}16.0 \\
16.0 \\
14.0 \\
13.0 \\
15.0\end{array}$ & $\begin{array}{l}13.0 \\
15.0 \\
17.0 \\
16.0 \\
17.0\end{array}$ & $\begin{array}{l}22.0 \\
19.0 \\
24.0 \\
19.0 \\
18.0\end{array}$ & $\begin{array}{r}2 \overline{28.0} \\
28.0 \\
28.0\end{array}$ & $\begin{array}{r}34.0 \\
-0.0 \\
34.0 \\
34.0\end{array}$ & $\begin{array}{r}33.0 \\
29.0 \\
-0\end{array}$ & $\begin{array}{c}32.0 \\
\cdots \\
\cdots-\end{array}$ & $\begin{array}{l}m \\
m-- \\
--\end{array}$ & $\begin{array}{l}--- \\
--- \\
-- \\
--\end{array}$ \\
\hline $\begin{array}{l}26 \\
27 \\
28 \\
29 \\
30 \\
31\end{array}$ & $\begin{array}{r}26.0 \\
26.0 \\
-0.0 \\
25.0 \\
23.0 \\
25.0\end{array}$ & $\begin{array}{r}19.0 \\
19.0 \\
19.0 \\
-0.0\end{array}$ & $\begin{array}{l}16.0 \\
16.0 \\
17.0 \\
16.0 \\
16.0\end{array}$ & $\begin{array}{r}15.0 \\
14.0 \\
16.0 \\
14.0 \\
14.0\end{array}$ & $\begin{array}{r}15.0 \\
15.0 \\
15.0 \\
-\ldots \\
-\ldots\end{array}$ & $\begin{array}{r}19.0 \\
-0 . \\
21.0 \\
24.0 \\
=-0\end{array}$ & $\begin{array}{r}29.0 \\
29.0 \\
--0\end{array}$ & $\begin{array}{r}-0- \\
35.0 \\
34.0 \\
-.0 \\
---\end{array}$ & $\begin{array}{r}-0 . \\
33.0 \\
32.0 \\
34.0 \\
-\end{array}$ & $\begin{array}{l}m \\
\cdots- \\
\cdots \\
\cdots\end{array}$ & $\begin{array}{l}-= \\
--- \\
--- \\
--\end{array}$ & $\begin{array}{l}--- \\
-- \\
-- \\
-- \\
--\end{array}$ \\
\hline JERAGE & 26.0 & --- & 17.5 & -- & 14.5 & 17.5 & $\cdots$ & $\cdots$ & $\cdots$ & $m$ & $\cdots$ & $\cdots$ \\
\hline
\end{tabular}

02307479 LAKE TARPON NEAR TARPON SPRINGS, FLA.

LOCATION.--Lat $28^{\circ} 05^{\prime} 35^{\prime \prime}$, Iong $82^{\circ} 43^{\prime} 20^{\prime \prime}$, in sec.32, T.27 S., R.16 E., Pinellas County, at gaging station on west shore of lake, on dock at Cobb Acres, 4.2 miles southeast of Tarpon Springs.

DRAINAGE AREA.--60 sq mi, approximately.

PERIOD OF RECORD.--Chemical analyses: September 1952 to September 1970.

Water temperatures: October 1963 to September 1970.

EXTREMES. . - 1969-70:

Specific conductance: Maximum daily, 3,700 micromhos Oct. 3; minimum daily, 1,020 micromhos Feb. 7

water temperatures: Maximum, $33.0^{\circ} \mathrm{C}$ Juil 7 ; minimum, $9.0^{\circ} \mathrm{C}$ Jan. $11,12,14$,

period of record:

Specific conductance: Maximum daily, 19,900 micromhos May 31, June 18, 19, 1968; minimun daily, 871 micromhos Sept. 27, 1964 Wa ter temperatures: Maximum, $33.0^{\circ} \mathrm{C}$ July 29,30 , Aug. 14, 21, 1968, July 7,$1970 ;$ minimum, 9. $0^{\circ} \mathrm{C}$ Feb. 6,1966 ,
Jan. 11, 12, 14, 1970.

CHEMICAL ANALYSES, WATER YEAR OCTOBER 1969 TO SEPTEMBER 1970 (MAJOR CONSTITUENTS)

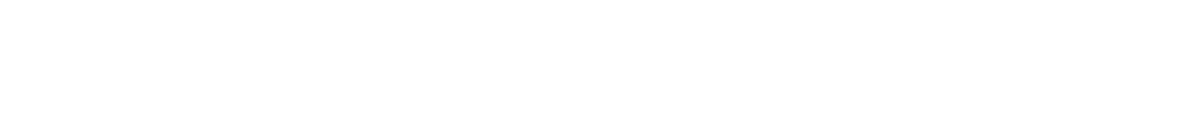
OCT.P 1969

\begin{tabular}{|c|c|c|c|c|c|c|c|c|c|c|c|c|}
\hline $15 \ldots$ & - & 27.0 & 3430 & 230 & 33 & 65 & - & $54 ?$ & 20 & 6 & 0 & 5.9 \\
\hline $15 \ldots$ & - & 28.0 & 3350 & 210 & 32 & 64 & -- & 540 & $2 n$ & 10 & 0 & A. 0 \\
\hline $15 \ldots$ & -- & 27.5 & 7280 & 70 & 111 & 142 & -- & 1180 & 41 & 128 & 0 & 7.3 \\
\hline NOV. & $<.01$ & 28.0 & 2990 & -- & 31 & 56 & -- & 462 & 17 & 9 & n & 5.9 \\
\hline JAN.:.'1970 & $<.01$ & 20.5 & 7000 & - & 112 & 139 & - & 1170 & 42 & 105 & 0 & 7.0 \\
\hline $12 \ldots$ & $<.0:$ & 10.0 & 2540 & - & 30 & $4 B$ & - & 405 & 15 & 8 & $=$ & 6.9 \\
\hline FEB. & $<.01$ & 12.5 & 2600 & -- & 38 & 50 & - & 415 & 15 & 19 & -- & 7.2 \\
\hline $10 \ldots$ & $=$ & 14.0 & 1620 & - & 25 & 30 & - & 256 & 9.5 & 1? & -- & 8.2 \\
\hline$\underset{\text { MAY }}{10}$ & -- & 14.5 & 2320 & -- & 28 & 42 & -- & 376 & 14 & 16 & -- & 7.1 \\
\hline $07 \ldots$ & $-\infty$ & 26.2 & 2200 & $=-$ & 24 & 30 & $=$ & 261 & 9.4 & 16 & $=$ & 6.2 \\
\hline $\begin{array}{l}27 . \\
\text { JUNE }\end{array}$ & $-\infty$ & 22.0 & 1550 & - & 21 & 27 & - & 234 & 9.2 & 12 & D & 6.5 \\
\hline & $\cdots$ & 31.4 & 1700 & - & 30 & 30 & -- & 260 & 9.6 & 21 & -- & 6.9 \\
\hline
\end{tabular}



(MAJOR CONSTITUENTS)

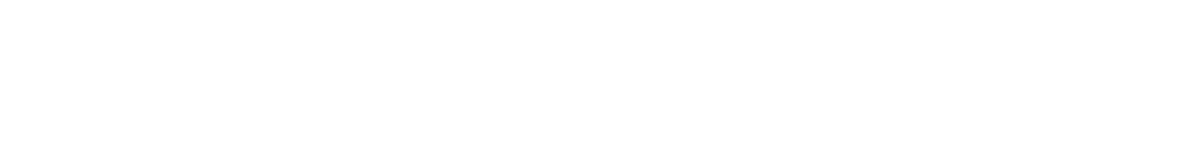

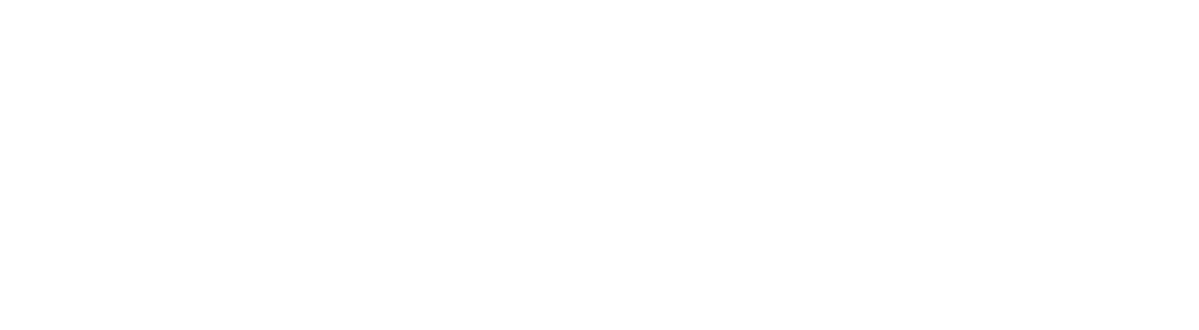

(MACRONUTRIENTS AND OTHER RELATED CONSTITUENTS)

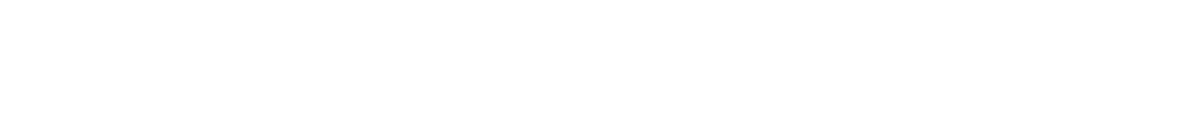

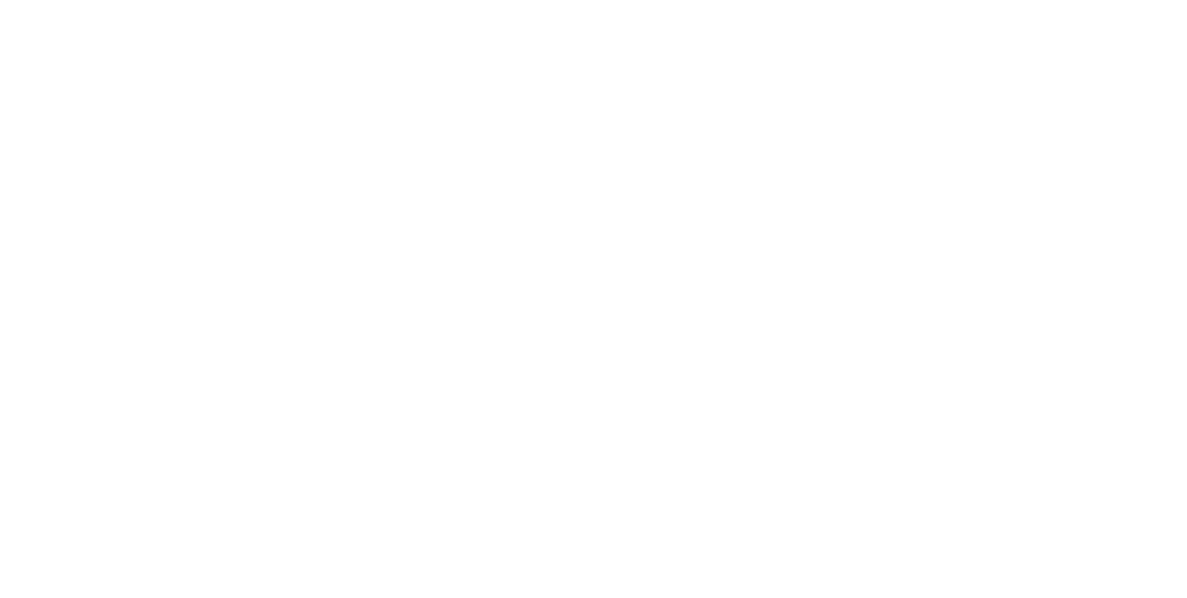

(TRACE METALS)

\begin{tabular}{|c|c|c|c|c|c|c|c|c|c|c|c|c|}
\hline & $\begin{array}{l}\text { DIS= } \\
\text { SOLVEO }\end{array}$ & DIS- & OIS - & $\begin{array}{l}\text { UIS- } \\
\text { SOLVEO }\end{array}$ & $\begin{array}{r}\text { HEXA- } \\
\text { VALENT }\end{array}$ & $\begin{array}{l}\text { DIS- } \\
\text { SOLVED }\end{array}$ & OIS- & DIS- & & $\begin{array}{l}\text { DIS- } \\
\text { SOLVED }\end{array}$ & & OIS- \\
\hline & ALUM- & SOLVFO & SOLVED & CAD- & CHPO- & CHKO- & SOLV & SOLVEn & SOLVEO & MAN- & TOTAL & SOLVED \\
\hline & $\begin{array}{l}\text { INUM } \\
\text { (AL) }\end{array}$ & $\begin{array}{l}\text { APSENIC } \\
\text { (AS) }\end{array}$ & $\begin{array}{c}G O N O N \\
(\theta)\end{array}$ & $\begin{array}{l}\text { MIU'A } \\
\text { ICO) }\end{array}$ & $\begin{array}{l}\text { MIUM } \\
\text { (CRG) }\end{array}$ & $\begin{array}{l}\text { MIUM } \\
\text { (CK) }\end{array}$ & $\begin{array}{l}\text { COPPER } \\
\text { (CU) }\end{array}$ & $\begin{array}{l}\text { IRON } \\
\text { (FE) }\end{array}$ & $\begin{array}{l}\text { LEAD } \\
\text { (PR) }\end{array}$ & $\begin{array}{l}\text { GANESEE } \\
\text { (MN) }\end{array}$ & $\begin{array}{c}\text { MERCURY } \\
\text { (H(G) }\end{array}$ & $\begin{array}{l}Z I V C \\
(Z N)\end{array}$ \\
\hline & (UG/L) & (UG/L) & (UG/L) & (UG/L) & (UG/L. & (UG/L) & (UG/L) & (UG/L) & (UG/L) & $(U G / L)$ & $(U G / L)$ & $(L G / L)$ \\
\hline
\end{tabular}
OCT.. 1969

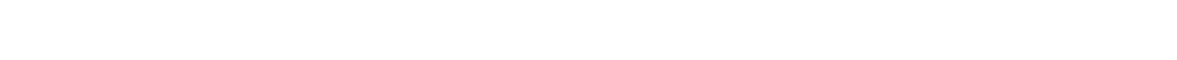


02307479 LAKE TARPON NEAR TARPON SPRINGS, FLA,.-COnt1nued

SPECIFIC CONDUCTANCE (MICROMHOS/CM AT 25ㄷ), WATER YEAR OCTOBER 1969 TO SEPTEMBER 1970

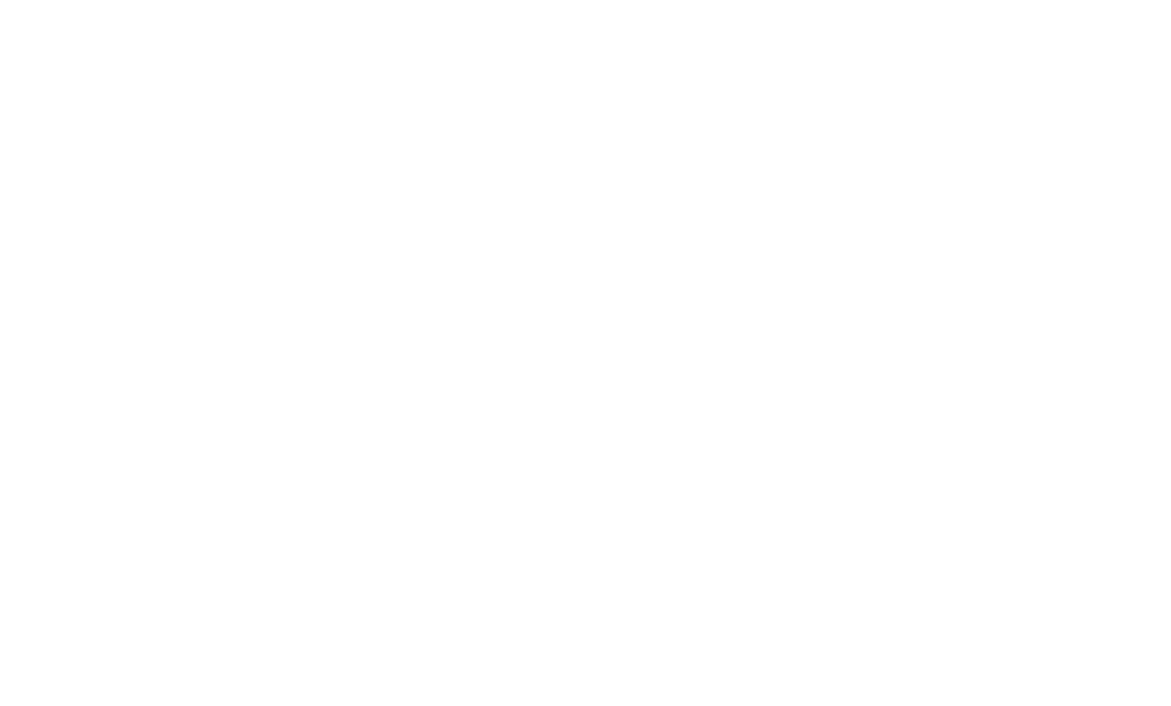

TEMPERATURE ('O C) OF WATER, WATER YEAR OCTOBER 1969 TD SEPTEMBER 1970

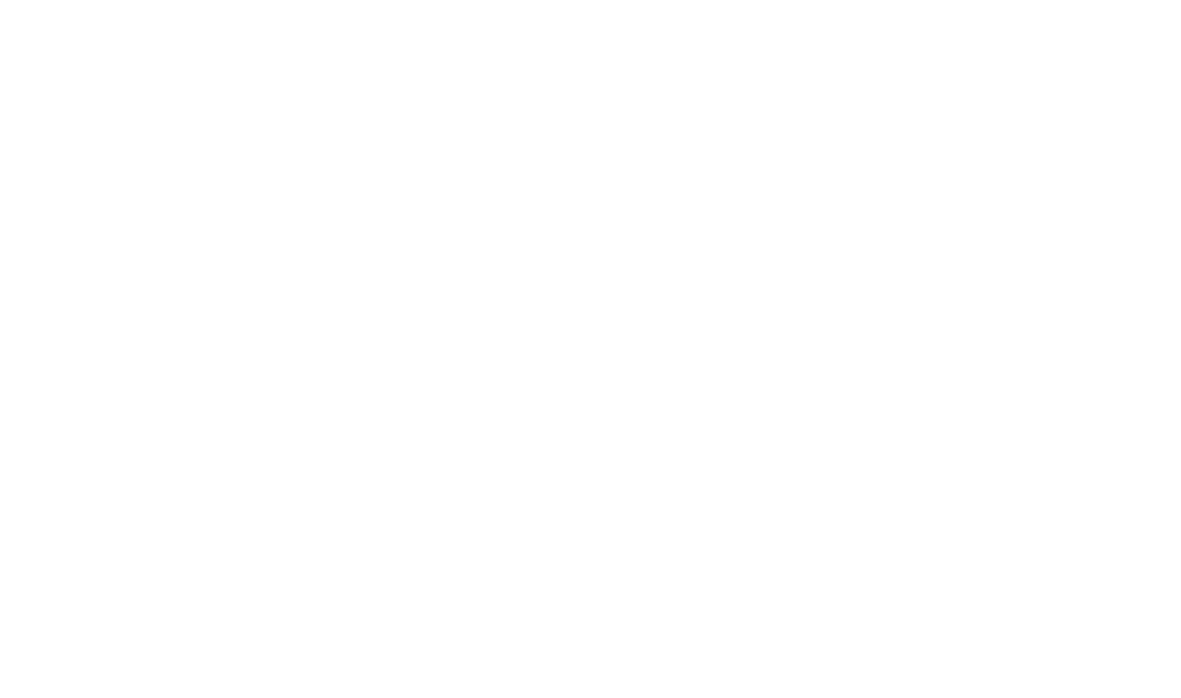


02310000 aNCLOTE RIVER NEAR ELFERS, FLA.

LOCATION, --Lat $28^{\circ} 12 \cdot 50^{\prime \prime}$, long $82^{\circ} 40^{\prime} 00^{\prime \prime}$, in NE sec, 23, T. 26 S, R.16 E, Pasco County, at gaging station on left bank $40 \mathrm{ft}$ downstream from bridge on 'state Highway $54,3.5$ miles east of Elfers, and 16 miles upstream from mouth.

DRAINAGE AREA. - - $72.5 \mathrm{sq}$ mi.

PERIOD OF RECORD. .. Chemical analyses: October 1962 to September 1970.

Water temperatures: October 1962 to September 1970.

EXTRELES, $--1969-70$ :

Specific conductance: Maximum daily, 400 micromhos May $20 ;$ minimum daily, 54 micromhos Feb.5.
water temperatures: Haximum, $27.0^{\circ} \mathrm{C}$ on many days during June to September; minimum, 7.0 $0^{\circ} \mathrm{C}$ Jan. $10,11$.

Period of record:

Specific conductance: Maximum daily, 440 micromhos July 2, 4, 1968; minlmum daily, 16 micromhos Dec. $31,1963$. pH (1967-68): Maximum dally, 7.5 Dec. 8, 1967; minimum daily, 4.5 July 29, 1968.

Water temperatures: Maximum, $29.0^{\circ} \mathrm{C}$ on severai days from May to October 1968 ; minimum, $7.0^{\circ} \mathrm{C} \mathrm{Jan} .16,1964$, Feb. 1, 2, 1966, Jan. 10, i1, 1970 . CHEMICAL ANALYSES, WATER YEAR OCTOBER 1969 TO SEPTEMBER 1970 (MAJOR CONSTI TUENTS)

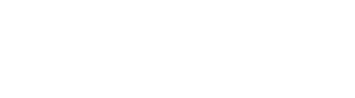
SPE-
CIFIC
CON-
DUCT-
ANCE
(MICRO-
MHOS) OCT., 1969

NOV.

$18 \ldots 623$

AN.: 1970

$12 \ldots 260$

EH.

$12 \ldots 168$

MAR.
26... 107

MAY

06...

JUNE

$10 \ldots .$.

$18 .$.

SEP.

$03 . .0$ 22.0

$22.0 \quad 102$

16.5

117

10.0

14.0

17.8

23.0

25.0
28.0

28.0

31.0

\begin{abstract}
21.0
\end{abstract}

$\begin{array}{cl} & \text { DIS- } \\ \text { DIS- } & \text { SOLVED } \\ \text { SOLVED } & \text { CHLO- } \\ \text { SULFATE } & \text { RIDE } \\ \text { (SOL) } & \text { (CLI) } \\ \text { (MG/L) } & \text { (MG/L) }\end{array}$

( $\mathrm{NL}$ (L)

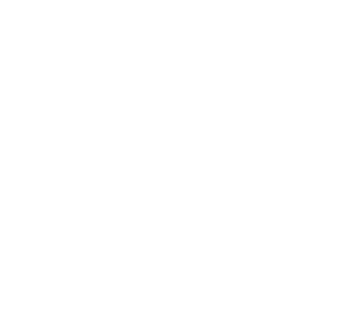

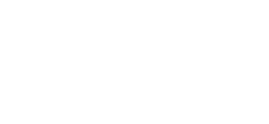

DIS-
SOLVEO
STRON-
TIUM
(SR)
(UG/L)

OIS-
SOLVEN
SODIUM
(NA)
(MGLL)

DIS-
SOLVEO
PO-
TAS-
SIUMM
(K)
(MG/L)

BICAR-

BONATE
(HCO3)
(MG LL)

CAR-

BONATE PH (CO3)
(MG/L) (UNITS) IMG

(U)

$\begin{array}{rrrrrr}-- & 5.5 & 1.2 & 34 & n & 6.5 \\ -- & 5.3 & 1.2 & 37 & -- & 5.8 \\ 60 & 4.9 & .9 & 12 & 0 & 7.0 \\ -- & 5.4 & 1.0 & 30 & -- & 7.4 \\ -- & 5.0 & 1.0 & 74 & 0 & 6.4 \\ 300 & 6.3 & .8 & 208 & 4 & 8.4 \\ -- & 5.3 & .7 & 88 & 0 & 8.2 \\ -- & 5.8 & .8 & 174 & -- & 0.0 \\ -- & 5.7 & .9 & 124 & 0 & 7.9 \\ 80 & 4.6 & 1.3 & 23 & 0 & 0.6\end{array}$

34

0.5
$n$

$\begin{array}{ccc}\text { DIS- } & & \text { NON- } \\ \text { SOLVEO } & & \text { CAR- } \\ \text { FLIU)- } & \text { HARD- } & \text { HONATE } \\ \text { RIDE } & \text { NESS } & \text { HARO- } \\ \text { (F) } & (C A, M G) & \text { NESS } \\ \text { (MG/L) } & \text { (MG/L) } & \text { (MG/L) }\end{array}$

$\begin{array}{ll} & \text { DIS- } \\ \text { SOLVED } & \\ \text { ALKA- } & \text { SOLIDS } \\ \text { LINITY } & \text { RESIT } \\ \text { AS } & \text { OUE AT } \\ \text { CACO3 CON } & 180 \text { C) TUEN }\end{array}$

SIS-

DIS- nIS-

$\begin{array}{lll}\text { SOLIDS } & \text { SOLVED } & \text { SOLVFD } \\ \text { (SUM OF } & \text { SOLIDS } & \text { SOLIITS } \\ \text { TANNIN }\end{array}$

SOL.IDS SOLINS TANNIN
ITONS TONS

$\begin{array}{llll}\text { (TONS } & \text { (TONS } & \text { AND } \\ \text { PER } & \text { PER } & \text { LIGNIN } & \text { DEPTH } \\ \text { DAY) } & \text { AC-FT) } & \text { (MG LL) } & \text { (FT) }\end{array}$

(MUENSI

DAY)

(MG/L) (MG/L)

$\begin{array}{rrrr}.2 & 39 & 11 & 2 \\ .1 & 46 & 15 & 3 \\ .1 & 20 & 10 & 1 \\ .2 & 33 & 9 & 2 \\ .3 & 31 & 11 & 2 \\ .2 & 197 & 20 & 17 \\ .2 & 105 & 33 & 7 \\ .2 & 159 & 16 & 14 \\ .3 & 131 & 29 & 10 \\ .2 & 31 & 12 & 1\end{array}$

91
100
54
71
94
244
171
266
187
98

$\begin{array}{ll}53 & 159 \\ 61 & 168 \\ 35 & 37.9 \\ 49 & 32.2 \\ 45 & 27.2 \\ 229 & 2.19 \\ 128 & 3.28 \\ 190 & 3.29 \\ 153 & 3.29 \\ 42 & 47.1\end{array}$

$\begin{array}{lll}.12 & - & - \\ .14 & -- & - \\ .07 & -- & - \\ .10 & -- & - \\ .13 & -- & - \\ .33 & -- & - \\ .23 & -- & - \\ .36 & -- & - \\ .25 & -- & - \\ .13 & -- & --\end{array}$

(MACRONUTRIENTS AND OTHER RELATED CONSTITUENTS)

\begin{tabular}{|c|c|c|c|c|c|c|c|c|c|c|c|c|}
\hline A & $\begin{array}{l}\text { TOTAL } \\
\text { AMONONIA } \\
\text { (NTI) } \\
\text { (MG/L) }\end{array}$ & $\begin{array}{c}\text { TOTAL } \\
\text { NIYLIT } \\
\text { (NOZL) } \\
\text { (MG/L) }\end{array}$ & $\begin{array}{c}\text { TOTAL } \\
\text { NITKATE } \\
\text { (NO3) } \\
\text { (MG/L) }\end{array}$ & $\begin{array}{c}\text { OHGANIC } \\
\text { NITRO- } \\
G E N) \\
\text { GEN) } \\
(N G / L)\end{array}$ & 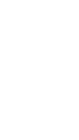 & $\begin{array}{l}\text { PHCS- } \\
\text { PPATE } \\
\text { POOA } \\
\text { (MG/L) }\end{array}$ & $\begin{array}{l}\text { DIS- } \\
\text { SOLVEDD } \\
\text { SILICA } \\
\text { ISIOCL) } \\
\text { SMG/L) }\end{array}$ & $\begin{array}{c}\text { TUR- } \\
\text { BID- } \\
\text { IIY } \\
\text { (JTU) }\end{array}$ & $\begin{array}{l}\text { COLOR } \\
\text { PLAT- } \\
\text { INUM- } \\
\text { COBALT } \\
\text { UNITS }\end{array}$ & $\begin{array}{c}\text { TOTAL } \\
\text { ORGALIC } \\
\text { CARHON } \\
(C) \\
\text { (MG/L) }\end{array}$ & 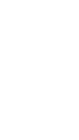 & $\underset{(F T)}{\text { DEPTH }}$ \\
\hline${ }^{\text {OCT..: }}{ }_{15}^{1969}$ & 9 & & .0 & -- & & & 3.6 & -- & 120 & -- & -- & -- \\
\hline${ }_{31 \ldots}$ & - & .03 & ס & -- & .07 & .08 & $\because$ & -- & - & -- & -- & -- \\
\hline $\begin{array}{l}180 . . \\
30\end{array}$ & $\because$ & $\begin{array}{l}n 2 \\
.01\end{array}$ & $: 3$ & $=$ & $\overline{. \overline{D E}}$ &.$\overline{0}$ & 4.7 & $=$ & 10n & $=$ & $=$ & $\because$ \\
\hline $\begin{array}{l}\text { DECC. } \\
{ }_{3}\end{array}$ & -- & .00 & . & -- & .07 & .07 & -- & -- & -. & -- & -- & -- \\
\hline 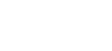 & $\because$ & $\begin{array}{l}.02 \\
.02\end{array}$ & : & $=$ & $\begin{array}{l}.02 \\
.02\end{array}$ & .07 & 2.4 & $\because$ & 55 & $=$ & $=$ & $=$ \\
\hline Fin & $=$ & $\begin{array}{l}.03 \\
.03\end{array}$ & .2 & $\because$ & .03 & .05 & $\therefore$ & $=$ & $\begin{array}{l}Q_{11} \\
--\end{array}$ & $=$ & $=$ & $\because$ \\
\hline $\begin{array}{l}\text { MAR: } \\
26 . . . \\
31\end{array}$ & $\because$ & $\begin{array}{l}.02 \\
003\end{array}$ & 0 & $=$ & $\overline{0}$ & $\overline{10}$ & $\therefore$ & $\because$ & 120 & $=$ & $\because$ & $\because$ \\
\hline
\end{tabular}




\begin{tabular}{|c|c|c|c|c|c|c|c|c|c|c|c|c|}
\hline DATE & 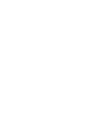 & $\begin{array}{c}\text { TOTAL } \\
\text { NITRITE } \\
\text { (NOZI) } \\
\text { (MG/L) }\end{array}$ & $\begin{array}{c}\text { TOTAL } \\
\text { NITAATE } \\
\text { (NOB) } \\
\text { (MG/L) }\end{array}$ & $\begin{array}{l}\text { OPGANIC } \\
\text { NITRO- } \\
\text { GEN } \\
\text { (N) } \\
(N G / L)\end{array}$ & $\begin{array}{l}\text { UIS- } \\
\text { SOLVED } \\
\text { OPTHO } \\
\text { PHOS- } \\
\text { PHATE } \\
\text { PHA4 } \\
\text { (PA) } \\
\text { (MGLL) }\end{array}$ & $\begin{array}{l}\text { PHOS- } \\
\text { PHATE } \\
\text { PHOA) } \\
\text { (MOG,L) }\end{array}$ & 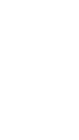 & $\begin{array}{l}\text { TUR- } \\
\text { BID- } \\
\text { ITY } \\
\text { (JTU) }\end{array}$ & $\begin{array}{l}\text { COLOR } \\
\text { (PP LT- } \\
\text { INUM- } \\
\text { COBAL T T } \\
\text { UNITS }\end{array}$ & $\begin{array}{l}\text { TOTAL } \\
\text { ORGANIC } \\
\text { CARPON } \\
\text { IC } \\
\text { (MG }\end{array}$ & 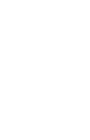 & $\begin{array}{c}\text { DEPTH } \\
(F T)\end{array}$ \\
\hline $\begin{array}{l}\text { APR. } \\
\text { MAY.... }\end{array}$ & -- & .06 & .2 & -- & .14 & .16 & -- & -- & -- & -- & -- & -- \\
\hline JU... & .09 & $\begin{array}{l}.01 \\
.15\end{array}$ & $: 11$ & .15 & $\begin{array}{r}.13 \\
.13\end{array}$ & $\begin{array}{r}15 \\
: 14\end{array}$ & ${ }^{10}$ & $\begin{array}{c}5 \\
--\end{array}$ & 10 & $=$ & .5 & $=$ \\
\hline $\begin{array}{l}10 . . \\
18 \ldots\end{array}$ & $=-$ & $\begin{array}{l}.01 \\
.02\end{array}$ & : & $=$ & .07 & .11 & $\begin{array}{l}6.4 \\
6.6\end{array}$ & $=$ & $\begin{array}{l}40 \\
40\end{array}$ & $=$ & $=$ & $=$ \\
\hline${ }_{J U L Y}^{30} \cdots$ & -. & .03 & 9 & -- & .09 & .13 & $\because$ & $\because$ & -2 & $\overline{-}$ & $=$ & $=$ \\
\hline $\begin{array}{c}31 \ldots . \\
31\end{array}$ & $\because$ & $\begin{array}{l}: 00 \\
: 01\end{array}$ & : & $=$ & $\begin{array}{l}.04 \\
.12\end{array}$ &.$\overline{13}$ & 6.4 & $=$ & $\underline{60}$ & $=$ & -- & $=$ \\
\hline $03 .$. & -- & .07 & .0 & -- & .11 & .11 & 3.8 & 22 & 160 & -- & -- & -- \\
\hline & $\begin{array}{l}\text { U15- } \\
\text { SOLVED } \\
\text { AL VUM- } \\
\text { INUM } \\
\text { YULI } \\
\text { IUG/L) }\end{array}$ & $\begin{array}{l}\text { DIS- } \\
\text { SOLVED } \\
\text { APSENIC } \\
\text { IASI } \\
\text { IUGAL) }\end{array}$ & 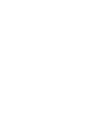 & $\begin{array}{l}\text { DIS- } \\
\text { SOLVED } \\
\text { CAD- } \\
\text { MIUM } \\
\text { ICDI } \\
\text { (UG/L) } \\
\text { USG }\end{array}$ & $\begin{array}{l}\text { HEXA- IT } \\
\text { VALEVI } \\
\text { CHRO- } \\
\text { MIIUM } \\
\text { (CFG) } \\
\text { IUGAL) }\end{array}$ & $\begin{array}{l}\text { ICE METALS) } \\
\text { OOSS- } \\
\text { SOLVED } \\
\text { CHHD- } \\
\text { MIUM } \\
\text { (CH) } \\
\text { (UG }\end{array}$ & $\begin{array}{l}\text { DIS- } \\
\text { SOLVDED } \\
\text { COPEER } \\
\text { ICUI } \\
\text { CUG/L) }\end{array}$ & 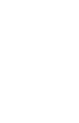 & $\begin{array}{l}\text { OrS- } \\
\text { SOLVED } \\
\text { LEAD } \\
\text { IPA) } \\
\text { IUG/L) }\end{array}$ & $\begin{array}{l}\text { OIS- } \\
\text { SOLVED } \\
\text { MAN- } \\
\text { GANESE } \\
\text { MEN } \\
\text { (MG) } \\
(U G / L)\end{array}$ & $\begin{array}{l}\text { TOTAL } \\
\text { MERCQRY } \\
\text { (UGS) } \\
\text { (UG/L) }\end{array}$ & $\begin{array}{l}\text { OIS- } \\
\text { SLVED } \\
\text { ZINC } \\
\text { (ZN) } \\
(U G / L)\end{array}$ \\
\hline $\operatorname{Mar}, \ldots$ & $70 \quad--$ & 20 & -. & -. & -- & -. & 0 & 130 & 0 & 60 & -- & 10 \\
\hline
\end{tabular}

SPECIFIC CONDUCTANCE (MICROMHOS/CM AT 250 C), WATER YEAR OCTOBER 1969 TO SEPTEMBER 1970

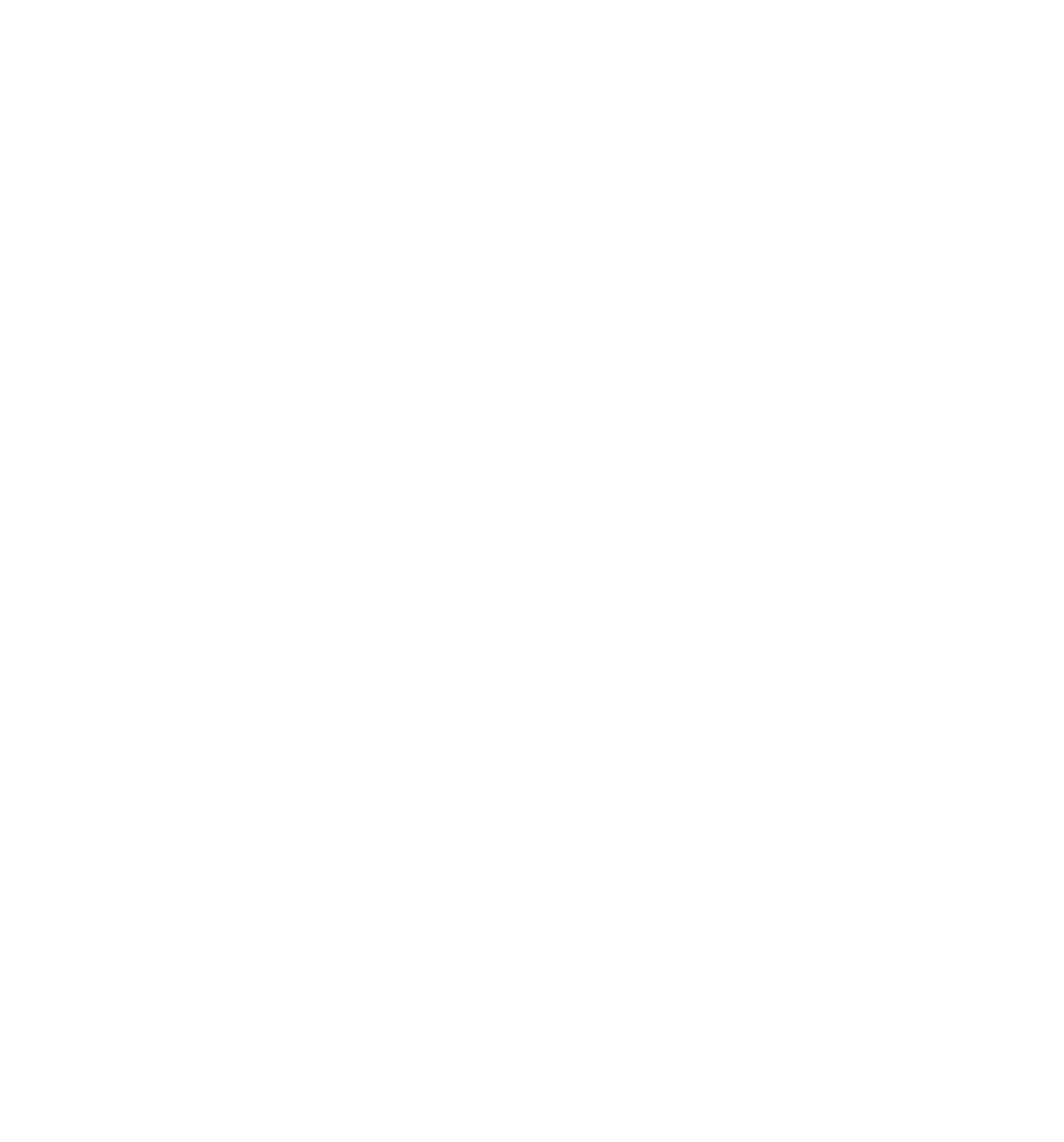


02310305 PITHLACHASCOTEE RIVER NEAR RICHEY LAKES, FLA.

LOCATION, --Lat $28^{\circ} 14^{\prime} 14^{\prime \prime}$, long $82^{\circ} 41^{\prime} 38^{\prime \prime}$, Pasco County, in center of stream, 0.5 mile downstream from bridge on Trouble Creek Road, and $0.5 \mathrm{mile}$ southeast of New Port Richey.

PERIOD OF RECORD.--Chemical analyses: January 1963 to September 1970.

Water temperatures: January 1963 to September 1970 .

EXTREKES. - - 1969-70:

Specific conductance: Maximum daily, 945 micromhos May 21; minimum da1ly, 69 micromhos Feb. 5.

water temperatures: Maximum, $29.0^{\circ} \mathrm{C}$ May 27,$28 ;$ minimum, $7.0^{\circ} \mathrm{C}$ Jan. 10,11 .

Period of record:

Specific conductance: Maximum daily, 1,400 micromhos June 2, 1967; minimum da1ly, 58 micrombos Aug. 2, 1965. water temperatures: Maximum, $29.0^{\circ} \mathrm{C}$ May $27,28,1970 ; \mathrm{m} 1 \mathrm{n} 1 \mathrm{mum}, 7.0^{\circ} \mathrm{C} \mathrm{Jan.10,11,1970.}$

\section{CHEMICAL ANALYSES, WATER YEAR OCTOBER 1969 TO SEPTEMBER 1970} (MAJOR CONSTITUENTS)

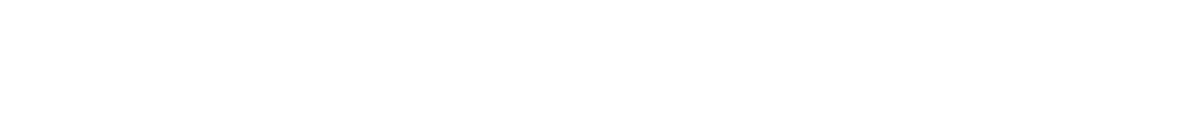

\begin{tabular}{|c|c|c|c|c|}
\hline $\begin{array}{l}\text { JAN.. } 1970 \\
12 \ldots . . \\
\text { FEB. }\end{array}$ & $\cdots$ & 10.0 & 97 & $\cdots$ \\
\hline MAR... & -- & 17.1 & 96 & -- \\
\hline$\underset{\text { MAY }}{30 \cdots}$ & $\cdots$ & 23.0 & 120 & -- \\
\hline JUNE & - & 22.0 & 420 & - \\
\hline $\begin{array}{l}10 \ldots \\
19 \ldots\end{array}$ & $=$ & $\begin{array}{l}23.5 \\
24.7\end{array}$ & $\begin{array}{l}382 \\
415\end{array}$ & -- \\
\hline
\end{tabular}

$\begin{array}{cccccc} & & \text { DIS- } & \text { DIS- } & & \text { NON- } \\ \text { OIS- } & \text { SOLVED } & \text { SOLVFD } & & \text { CAR- } \\ \text { SOLVED } & \text { CHLO- } & \text { FLIO- } & \text { HARD- } & \text { BONATE } \\ \text { SULFATE } & \text { PIOE } & \text { RIDE } & \text { NESS } & \text { HARD- } \\ & \text { (SOL) } & \text { (CL) } & \text { (F) } & \text { (CA,MG) } & \text { NESS } \\ \text { DATE } & (M G / L) & (M G / L) & (M G / L) & (M G / L) & (M G / L)\end{array}$

\begin{tabular}{|c|c|c|c|c|c|c|}
\hline 1.2 & 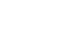 & 5.6 & .5 & 29 & $-\infty$ & 7.4 \\
\hline 1.2 & -- & 5.5 & .5 & 30 & - & 7.4 \\
\hline 1.5 & $=$ & 5.6 & .5 & 38 & 0 & 6.7 \\
\hline 5.1 & - & 22 & .9 & 148 & 0 & 8.0 \\
\hline $\begin{array}{l}4.7 \\
5.1\end{array}$ & $=$ & $\begin{array}{l}19 \\
20\end{array}$ & 1.9 & $\begin{array}{l}141 \\
151\end{array}$ & $\begin{array}{r}4 \\
--\end{array}$ & $\begin{array}{l}8.3 \\
7.5\end{array}$ \\
\hline $\begin{array}{l}\text { ALKA- } \\
\text { LINITY } \\
\text { AS } \\
\text { CACO3 } \\
(M G / L)\end{array}$ & $\begin{array}{l}\text { DIS- } \\
\text { SOLVED } \\
\text { SOLIDS } \\
\text { (RESI- } \\
\text { OUE AT } \\
180 \text { C) } \\
\text { (MG/L) }\end{array}$ & $\begin{array}{c}\text { DIS- } \\
\text { SUL VED } \\
\text { SOL IOS } \\
\text { (SUM OF } \\
\text { CONSTI- } \\
\text { TUENTS) } \\
\text { (MG L) }\end{array}$ & $\begin{array}{l}\text { DIS- } \\
\text { SOLVED } \\
\text { SOLIDS } \\
\text { (TONS } \\
\text { PER } \\
\text { DAY) }\end{array}$ & $\begin{array}{l}\text { NIS- } \\
\text { SOLVFD } \\
\text { SOLIDS } \\
\text { (TONS } \\
\text { PER } \\
\text { AC-FT) }\end{array}$ & $\begin{array}{l}\text { TANNIN } \\
\text { AND } \\
\text { LIGNIN } \\
\text { (MG/L) }\end{array}$ & $\begin{array}{c}\mathrm{DE} \triangle T \mathrm{H} \\
(\boldsymbol{H} T)\end{array}$ \\
\hline
\end{tabular}

\begin{tabular}{|c|c|}
\hline $\begin{array}{l}\text { JAN., } 1970 \\
12 \ldots .\end{array}$ & 3.7 \\
\hline $\begin{array}{l}\text { FEB. } \\
16 . . .\end{array}$ & 2.6 \\
\hline $\begin{array}{l}\text { MAR. } \\
30 . . . \\
\text { MAY }\end{array}$ & 3.2 \\
\hline $05 \ldots$ & 30 \\
\hline $\begin{array}{l}\text { JUNE } \\
10 \ldots \ldots \\
19 \ldots\end{array}$ & $\begin{array}{l}33 \\
34\end{array}$ \\
\hline
\end{tabular}

$\begin{array}{lrl}.1 & 35 \\ .1 & 38 & \\ .2 & 44 & 113 \\ .2 & 163 & 4 \\ .2 & 157 & 35 \\ .2 & 171\end{array}$

$\begin{array}{rrr}24 & 80 & 53 \\ 25 & 75 & 49 \\ 31 & 99 & 58 \\ 121 & 265 & 238 \\ 122 & 267 & 232 \\ 124 & 277 & 240\end{array}$

(MACRDNUTRIENTS AND OTHER RELATED CONSTITUENTS)

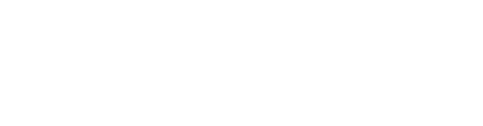

UIS-
SOI VER

OCT.. 1969 -- .02

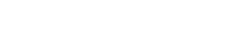

31 ...

JAN., 1970

$12 . .$.

$31 .$.

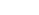

$28 \ldots$

MAR.

MAR...

$31 \ldots$

MAY...

MAY

$05 \ldots .$.
$31 \ldots$
JUNE

JUNE

$10 \ldots$

$19 . .$.

JULY

$31 .$.

SEP.

$\begin{array}{ll}-. & .02 \\ - & .02\end{array}$

$$
\text { (Mor }
$$

$$
\text { (MG/L) (MG/L }
$$

SOLVEN
ORIHO
PHOS-

PHATE
(PO4)
(MG/L)

PHOS-

DIS-
SOLVED (SIOZ)
(MGAL) BID-
ITY
(JTU)

3
9
8
8

$\begin{array}{cccc}-- & .11 & - & - \\ -- & .10 & -- & - \\ - & .13 & -- & - \\ -- & .36 & -- & -- \\ -- & .36 & -- & - \\ 2.36 & .38 & -- & -\end{array}$
(MG/L) $\begin{array}{lcc} & & \\ \text { COLOR } & \text { TOTAL } & \text { CHEM- } \\ \text { (PLAT- ORGANIC } & \text { ICAL } \\ \text { INUM- } & \text { CAHBON } & \text { OXYGEN } \\ \text { COBALT } & \text { (C) } & \text { OEMAND } \\ \text { UNITS) } & \text { (MG/L) } & \text { (MGNL) }\end{array}$

(FIELD MEASUREMENTS)

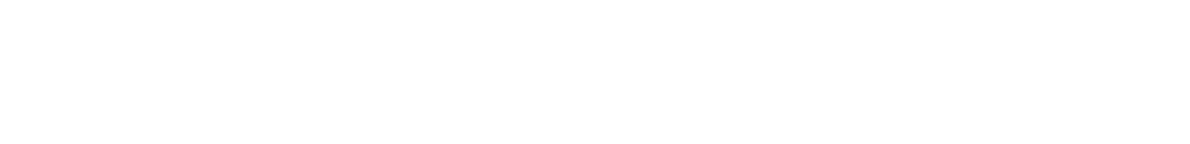
MAR.. 1970 
02310305 PITHLACHASCOTEE RIVER NEAR RICHEY LAKES, FLA.--Continued

SPECIFIC CONDUCTANCE (MICROMHOS/CM AT $25^{\circ} \mathrm{C}$ ), WATER YEAR OCTOBER 1969 TO SEPTEMBER 1970

\begin{tabular}{|c|c|c|c|c|c|c|c|c|c|c|c|c|}
\hline DAY & $\mathrm{OCT}$ & NOV & $D E C$ & JAN & $F \in B$ & MAR & APR & MAY & JUN & JUL & AUG & SEP \\
\hline $\begin{array}{l}1 \\
2 \\
3 \\
4 \\
5\end{array}$ & $\begin{array}{l}124 \\
107 \\
103 \\
104 \\
103\end{array}$ & $\begin{array}{l}150 \\
155 \\
160 \\
158 \\
168\end{array}$ & $\begin{array}{l}230 \\
230 \\
235 \\
245 \\
274\end{array}$ & $\begin{array}{l}121 \\
126 \\
119 \\
109 \\
102\end{array}$ & $\begin{array}{r}145 \\
150 \\
75 \\
75 \\
69\end{array}$ & $\begin{array}{l}116 \\
118 \\
120 \\
125 \\
130\end{array}$ & $\begin{array}{l}120 \\
124 \\
128 \\
126 \\
129\end{array}$ & $\begin{array}{l}370 \\
410 \\
405 \\
390 \\
405\end{array}$ & $\begin{array}{l}255 \\
260 \\
258 \\
270 \\
295\end{array}$ & $\begin{array}{l}338 \\
335 \\
350 \\
369 \\
405\end{array}$ & $\begin{array}{l}492 \\
359 \\
347 \\
369 \\
369\end{array}$ & $\begin{array}{l}102 \\
100 \\
103 \\
110 \\
117\end{array}$ \\
\hline $\begin{array}{r}6 \\
7 \\
8 \\
9 \\
10\end{array}$ & $\begin{array}{l}105 \\
106 \\
106 \\
109 \\
115\end{array}$ & $\begin{array}{l}170 \\
178 \\
190 \\
190 \\
195\end{array}$ & $\begin{array}{l}255 \\
280 \\
250 \\
250 \\
115\end{array}$ & $\begin{array}{r}102 \\
93 \\
90 \\
87 \\
89\end{array}$ & $\begin{array}{l}71 \\
75 \\
77 \\
80 \\
83\end{array}$ & $\begin{array}{r}140 \\
88 \\
89 \\
90 \\
90\end{array}$ & $\begin{array}{l}136 \\
139 \\
146 \\
160 \\
160\end{array}$ & $\begin{array}{l}425 \\
432 \\
425 \\
480 \\
445\end{array}$ & $\begin{array}{l}300 \\
318 \\
332 \\
380 \\
415\end{array}$ & $\begin{array}{l}450 \\
420 \\
460 \\
340 \\
220\end{array}$ & $\begin{array}{l}400 \\
416 \\
410 \\
426 \\
332\end{array}$ & $\begin{array}{l}112 \\
114 \\
119 \\
125 \\
134\end{array}$ \\
\hline $\begin{array}{l}11 \\
12 \\
13 \\
14 \\
15\end{array}$ & $\begin{array}{l}121 \\
127 \\
132 \\
140 \\
145\end{array}$ & $\begin{array}{l}200 \\
200 \\
2 C 8 \\
170 \\
151\end{array}$ & $\begin{array}{l}77 \\
71 \\
75 \\
81 \\
85\end{array}$ & $\begin{array}{r}90 \\
92 \\
97 \\
100 \\
102\end{array}$ & $\begin{array}{l}85 \\
87 \\
90 \\
94 \\
95\end{array}$ & $\begin{array}{l}93 \\
87 \\
86 \\
85 \\
85\end{array}$ & $\begin{array}{l}162 \\
170 \\
172 \\
180 \\
200\end{array}$ & $\begin{array}{l}450 \\
450 \\
452 \\
845 \\
725\end{array}$ & $\begin{array}{l}420 \\
382 \\
430 \\
435 \\
430\end{array}$ & $\begin{array}{l}215 \\
260 \\
284 \\
278 \\
319\end{array}$ & $\begin{array}{l}259 \\
257 \\
243 \\
272 \\
204\end{array}$ & $\begin{array}{l}137 \\
146 \\
159 \\
170 \\
171\end{array}$ \\
\hline $\begin{array}{l}16 \\
17 \\
18 \\
19 \\
20\end{array}$ & $\begin{array}{l}152 \\
163 \\
163 \\
171 \\
180\end{array}$ & $\begin{array}{l}145 \\
143 \\
148 \\
150 \\
161\end{array}$ & $\begin{array}{r}90 \\
93 \\
98 \\
101 \\
105\end{array}$ & $\begin{array}{l}105 \\
107 \\
106 \\
109 \\
113\end{array}$ & $\begin{array}{r}97 \\
102 \\
100 \\
99 \\
100\end{array}$ & $\begin{array}{r}88 \\
87 \\
95 \\
57 \\
100\end{array}$ & $\begin{array}{l}190 \\
210 \\
230 \\
225 \\
230\end{array}$ & $\begin{array}{l}845 \\
750 \\
550 \\
560 \\
900\end{array}$ & $\begin{array}{l}425 \\
410 \\
420 \\
422 \\
415\end{array}$ & $\begin{array}{l}280 \\
310 \\
319 \\
349 \\
382\end{array}$ & $\begin{array}{l}190 \\
177 \\
171 \\
168 \\
171\end{array}$ & $\begin{array}{l}172 \\
172 \\
177 \\
182 \\
186\end{array}$ \\
\hline $\begin{array}{l}26 \\
27 \\
28 \\
29 \\
30 \\
31\end{array}$ & $\begin{array}{l}161 \\
151 \\
145 \\
140 \\
149 \\
150\end{array}$ & $\begin{array}{l}200 \\
210 \\
215 \\
218 \\
220 \\
-\end{array}$ & $\begin{array}{l}122 \\
118 \\
115 \\
115 \\
118 \\
122\end{array}$ & $\begin{array}{l}125 \\
127 \\
133 \\
134 \\
140 \\
144\end{array}$ & $\begin{array}{l}112 \\
114 \\
114 \\
--- \\
-\cdots\end{array}$ & $\begin{array}{l}113 \\
108 \\
108 \\
108 \\
111 \\
113\end{array}$ & $\begin{array}{l}315 \\
325 \\
345 \\
355 \\
370 \\
-\end{array}$ & $\begin{array}{l}445 \\
450 \\
480 \\
380 \\
235 \\
760\end{array}$ & $\begin{array}{l}286 \\
260 \\
290 \\
325 \\
375 \\
-\end{array}$ & $\begin{array}{l}328 \\
365 \\
385 \\
441 \\
775 \\
416\end{array}$ & $\begin{array}{r}143 \\
137 \\
138 \\
127 \\
105 \\
99\end{array}$ & $\begin{array}{l}283 \\
238 \\
237 \\
240 \\
246 \\
-\end{array}$ \\
\hline VERAGE & 141 & 179 & 146 & 111 & 97 & 104 & 213 & 529 & 355 & 355 & 245 & 170 \\
\hline
\end{tabular}

TEMPERATURE ( $\left.{ }^{\circ} \mathrm{C}\right)$ OF WATER, WATER YEAR OCTOBER 1969 TO SEPTEMBER 1970

\begin{tabular}{|c|c|c|c|c|c|c|c|c|c|c|c|c|}
\hline DAY & OCT & NOV & DEC & JAN & FEB & MAR & $A P R$ & MAY & JUN & JUL & AUG & SEP \\
\hline $\begin{array}{l}1 \\
2 \\
3 \\
4 \\
5\end{array}$ & $\begin{array}{l}24.0 \\
25.0 \\
25.0 \\
25.0 \\
25.0\end{array}$ & $\begin{array}{l}23.0 \\
23.0 \\
22.0 \\
21.0 \\
18.0\end{array}$ & $\begin{array}{l}17.0 \\
16.0 \\
16.0 \\
16.0 \\
15.0\end{array}$ & $\begin{array}{l}18.0 \\
15.0 \\
14.0 \\
12.0 \\
11.0\end{array}$ & $\begin{array}{l}14.0 \\
15.0 \\
16.0 \\
12.0 \\
11.0\end{array}$ & $\begin{array}{l}18.0 \\
18.0 \\
19.0 \\
19.0 \\
18.0\end{array}$ & $\begin{array}{l}23.0 \\
23.0 \\
21.0 \\
20.0 \\
21.0\end{array}$ & $\begin{array}{l}24.0 \\
24.0 \\
23.0 \\
23.0 \\
23.0\end{array}$ & $\begin{array}{l}24.0 \\
24.0 \\
24.0 \\
24.0 \\
25.0\end{array}$ & $\begin{array}{l}26.0 \\
26.0 \\
26.0 \\
26.0 \\
26.0\end{array}$ & $\begin{array}{l}26.0 \\
26.0 \\
26.0 \\
26.0 \\
26.0\end{array}$ & $\begin{array}{l}27.0 \\
27.0 \\
27.0 \\
27.0 \\
27.0\end{array}$ \\
\hline $\begin{array}{r}6 \\
7 \\
8 \\
9 \\
10\end{array}$ & $\begin{array}{l}25.0 \\
25.0 \\
25.0 \\
25.0 \\
25.0\end{array}$ & $\begin{array}{l}17.0 \\
17.0 \\
18.0 \\
18.0 \\
19.0\end{array}$ & $\begin{array}{l}16.0 \\
17.0 \\
18.0 \\
17.0 \\
17.0\end{array}$ & $\begin{array}{r}14.0 \\
14.0 \\
10.0 \\
8.0 \\
7.0\end{array}$ & $\begin{array}{l}10.0 \\
14.0 \\
15.0 \\
11.0 \\
14.0\end{array}$ & $\begin{array}{l}19.0 \\
19.0 \\
19.0 \\
18.0 \\
18.0\end{array}$ & $\begin{array}{l}21.0 \\
20.0 \\
19.0 \\
20.0 \\
20.0\end{array}$ & $\begin{array}{l}21.0 \\
22.0 \\
22.0 \\
22.0 \\
22.0\end{array}$ & $\begin{array}{l}25.0 \\
24.0 \\
24.0 \\
24.0 \\
24.0\end{array}$ & $\begin{array}{l}27.0 \\
27.0 \\
27.0 \\
26.0 \\
26.0\end{array}$ & $\begin{array}{l}26.0 \\
27.0 \\
27.0 \\
25.0 \\
25.0\end{array}$ & $\begin{array}{l}26.0 \\
26.0 \\
26.0 \\
26.0 \\
26.0\end{array}$ \\
\hline $\begin{array}{l}11 \\
12 \\
13 \\
14 \\
15\end{array}$ & $\begin{array}{l}25.0 \\
25.0 \\
24.0 \\
24.0 \\
24.0\end{array}$ & $\begin{array}{l}19.0 \\
19.0 \\
19.0 \\
19.0 \\
16.0\end{array}$ & $\begin{array}{l}17.0 \\
17.0 \\
14.0 \\
13.0 \\
14.0\end{array}$ & $\begin{array}{r}7.0 \\
9.0 \\
11.0 \\
11.0 \\
14.0\end{array}$ & $\begin{array}{l}14.0 \\
14.0 \\
16.0 \\
15.0 \\
15.0\end{array}$ & $\begin{array}{l}19.0 \\
20.0 \\
19.0 \\
17.0 \\
15.0\end{array}$ & $\begin{array}{l}20.0 \\
20.0 \\
21.0 \\
22.0 \\
21.0\end{array}$ & $\begin{array}{r}23.0 \\
23.0 \\
23.0 \\
23.0 \\
-\end{array}$ & $\begin{array}{l}24.0 \\
25.0 \\
24.0 \\
25.0 \\
25.0\end{array}$ & $\begin{array}{l}26.0 \\
26.0 \\
26.0 \\
26.0 \\
26.0\end{array}$ & $\begin{array}{l}25.0 \\
26.0 \\
26.0 \\
26.0 \\
26.0\end{array}$ & $\begin{array}{l}27.0 \\
27.0 \\
26.0 \\
27.0 \\
26.0\end{array}$ \\
\hline $\begin{array}{l}16 \\
17 \\
18 \\
19 \\
20\end{array}$ & $\begin{array}{l}24.0 \\
24.0 \\
23.0 \\
24.0 \\
24.0\end{array}$ & $\begin{array}{l}13.0 \\
16.0 \\
17.0 \\
18.0 \\
17.0\end{array}$ & $\begin{array}{l}15.0 \\
15.0 \\
15.0 \\
15.0 \\
14.0\end{array}$ & $\begin{array}{l}15.0 \\
17.0 \\
18.0 \\
17.0 \\
16.0\end{array}$ & $\begin{array}{l}16.0 \\
18.0 \\
17.0 \\
13.0 \\
16.0\end{array}$ & $\begin{array}{l}15.0 \\
16.0 \\
17.0 \\
19.0 \\
20.0\end{array}$ & $\begin{array}{l}21.0 \\
21.0 \\
22.0 \\
23.0 \\
23.0\end{array}$ & $\begin{array}{l}23.0 \\
23.0 \\
23.0 \\
23.0 \\
22.0\end{array}$ & $\begin{array}{l}25.0 \\
26.0 \\
26.0 \\
26.0 \\
27.0\end{array}$ & $\begin{array}{l}26.0 \\
27.0 \\
27.0 \\
27.0 \\
26.0\end{array}$ & $\begin{array}{l}26.0 \\
26.0 \\
26.0 \\
26.0 \\
27.0\end{array}$ & $\begin{array}{l}26.0 \\
26.0 \\
26.0 \\
26.0 \\
26.0\end{array}$ \\
\hline $\begin{array}{l}21 \\
22 \\
23 \\
24 \\
25\end{array}$ & $\begin{array}{l}24.0 \\
24.0 \\
25.0 \\
24.0 \\
23.0\end{array}$ & $\begin{array}{l}15.0 \\
15.0 \\
17.0 \\
17.0 \\
18.0\end{array}$ & $\begin{array}{l}15.0 \\
15.0 \\
15.0 \\
16.0 \\
17.0\end{array}$ & $\begin{array}{l}13.0 \\
15.0 \\
12.0 \\
13.0 \\
13.0\end{array}$ & $\begin{array}{l}19.0 \\
17.0 \\
17.0 \\
16.0 \\
17.0\end{array}$ & $\begin{array}{l}21.0 \\
20.0 \\
17.0 \\
16.0 \\
16.0\end{array}$ & $\begin{array}{l}25.0 \\
25.0 \\
25.0 \\
24.0 \\
23.0\end{array}$ & $\begin{array}{l}24.0 \\
26.0 \\
24.0 \\
23.0 \\
24.0\end{array}$ & $\begin{array}{l}22.0 \\
27.0 \\
26.0 \\
26.0 \\
26.0\end{array}$ & $\begin{array}{l}25.0 \\
25.0 \\
26.0 \\
26.0 \\
26.0\end{array}$ & $\begin{array}{l}26.0 \\
25.0 \\
26.0 \\
26.0 \\
26.0\end{array}$ & $\begin{array}{l}26.0 \\
26.0 \\
26.0 \\
26.0 \\
25.0\end{array}$ \\
\hline $\begin{array}{l}26 \\
27 \\
28 \\
29 \\
30 \\
31\end{array}$ & $\begin{array}{l}22.0 \\
23.0 \\
24.0 \\
23.0 \\
22.0 \\
23.0\end{array}$ & $\begin{array}{l}19.0 \\
20.0 \\
20.0 \\
20.0 \\
18.0 \\
-\end{array}$ & $\begin{array}{l}17.0 \\
17.0 \\
14.0 \\
19.0 \\
16.0 \\
18.0\end{array}$ & $\begin{array}{l}14.0 \\
17.0 \\
18.0 \\
18.0 \\
19.0 \\
17.0\end{array}$ & $\begin{array}{r}17.0 \\
18.0 \\
16.0 \\
-2 . \\
-\end{array}$ & $\begin{array}{l}17.0 \\
17.0 \\
19.0 \\
21.0 \\
23.0 \\
23.0\end{array}$ & $\begin{array}{r}23.0 \\
23.0 \\
24.0 \\
24.0 \\
24.0 \\
-0 .\end{array}$ & $\begin{array}{l}24.0 \\
29.0 \\
29.0 \\
24.0 \\
23.0 \\
24.0\end{array}$ & $\begin{array}{c}26.0 \\
26.0 \\
26.0 \\
26.0 \\
26.0 \\
-. .0\end{array}$ & $\begin{array}{l}26.0 \\
26.0 \\
26.0 \\
26.0 \\
27.0 \\
26.0\end{array}$ & $\begin{array}{l}26.0 \\
26.0 \\
26.0 \\
26.0 \\
26.0 \\
27.0\end{array}$ & $\begin{array}{l}25.0 \\
26.0 \\
26.0 \\
25.0 \\
24.0 \\
-\end{array}$ \\
\hline VERAGE & $24 . \mathrm{C}$ & 18.5 & 16.0 & 14.0 & 15.0 & 18.5 & 22.0 & 23.5 & 25.0 & 26.0 & 26.0 & 26.0 \\
\hline
\end{tabular}



02310649 CHASSAHOWITZKa SPRINGS NEAR hONOSASSA, FLA.

LOCATION.--Lat $28^{\circ} 42^{\prime} 55^{\prime \prime}$, long $82^{\circ} 34^{\prime} 32^{\prime \prime}$, Citrus County, at gage 1.7 miles west of U.S. Highway $19,6.0$ miles southeast of town of Homasassa Springs.

PERIOD OF RECORD.--Chemical analyses: October 1968 to September 1970. Water temperatures: October 1968 to September 1970.

EXTREMES, $--1969-70$ :

Specific conductance: Maximum daily, 3,700 micromhos Nov. 17, 18; minimum da1ly, 370 micromhos Feb. 2 Water temperatures: Waximum, $22.0^{\circ} \mathrm{C}$ Dec. 18, Jan. 30, Apr. 3, June 12,28 ; minimum, $18.0^{\circ} \mathrm{C}$ on many days during
December to July and September.

period of record

Specific conductance: Maximum daily, 5,600 micromhos Aug. 31, 1969; minimum datly, 370 micromhos Feb. 2, 1970 , Water temperatures: Maximum, $25.0^{\circ} \mathrm{C}$ Apr. 2, 1969; minimum, $15.0^{\circ} \mathrm{C} \mathrm{Feb.18,} 1969$.

CHEMICAL ANALYSES, WATER YEAR OCTOBER 1969 TO SEPTEMBER 1970

MACRONUTRIENTS AND OTHER RELATED CONSTITUENTS

\begin{tabular}{|c|c|c|c|c|c|c|c|c|c|c|c|}
\hline DATE & $\begin{array}{l}\text { POTAL } \\
\text { ANMONIA } \\
(N-4) \\
\text { (MGLL) }\end{array}$ & $\begin{array}{l}\text { TOTAL } \\
\text { NITQITE } \\
\text { (:NOZ) } \\
\text { (MG/L) }\end{array}$ & $\begin{array}{l}\text { TOTAL } \\
\text { NITRATE } \\
\text { (NO3) } \\
\text { (MG/L) }\end{array}$ & $\begin{array}{l}\text { OPGANIC } \\
\text { NITRTO } \\
\text { GEN } \\
\text { (N) } \\
\text { (NG/L) }\end{array}$ & $\begin{array}{l}\text { UIS- } \\
\text { SOLVER } \\
\text { OHTHO } \\
\text { PHUS- } \\
\text { PHATE } \\
\text { (POL) } \\
(\text { MGIL) }\end{array}$ & $\begin{array}{l}\text { PHCS- } \\
\text { PHATE } \\
(P() 4) \\
(M G / L)\end{array}$ & $\begin{array}{l}\text { DIS- } \\
\text { SOLVED } \\
\text { SILICA } \\
\text { (SIOZ) } \\
\text { (MG/L) }\end{array}$ & $\begin{array}{l}\text { TUR- } \\
\text { BID- } \\
\text { ITY } \\
\text { (JTU) }\end{array}$ & $\begin{array}{l}\text { COLOR } \\
\text { (PL LT- } \\
\text { INUM- } \\
\text { COBALT } \\
\text { UNITS) }\end{array}$ & $\begin{array}{l}\text { TOTAL } \\
\text { ORGANIC } \\
\text { CARAON } \\
\text { (C) } \\
\text { (MG/L) }\end{array}$ & $\begin{array}{l}\text { HIO- } \\
\text { CHEM- } \\
\text { ICAL } \\
\text { OXYGEN } \\
\text { DENA } \\
\text { (MG/LD) }\end{array}$ \\
\hline
\end{tabular}

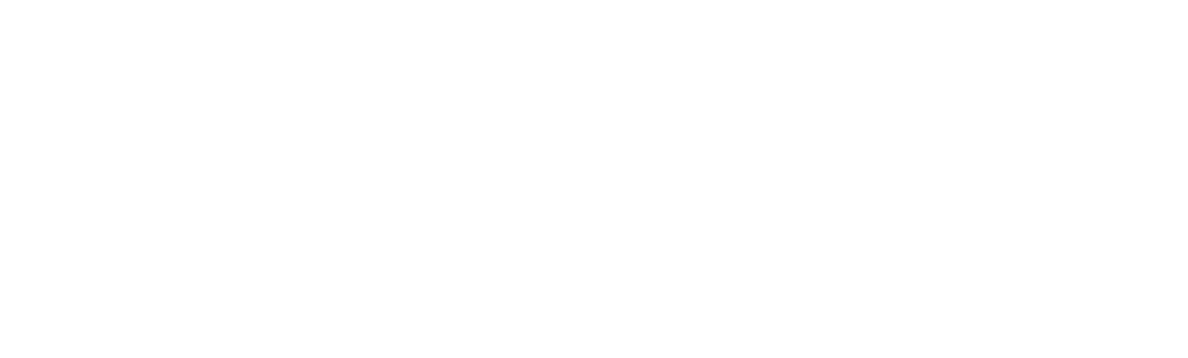

SPECIFIC CONDUCTANCE (MICROMHOS/CM AT $25^{\circ} \mathrm{C}$ ), WATER YEAR OCTOBER 1969 TO SEPTEMBER 1970

\begin{tabular}{|c|c|c|c|c|c|c|c|c|c|c|c|c|}
\hline OAY & UCT & NOV & DEC & JAN & FE 8 & MAR & $\triangle P R$ & MAY & JUN & JUL & $A \cup G$ & SEP \\
\hline $\begin{array}{l}\text { I } \\
2 \\
3 \\
4 \\
5\end{array}$ & $\begin{array}{l}550 \\
540 \\
550 \\
550 \\
540\end{array}$ & $\begin{array}{r}1900 \\
1010 \\
1240 \\
1500 \\
500\end{array}$ & $\begin{array}{l}--0 \\
\overline{--0} \\
\overline{520}\end{array}$ & $\begin{array}{l}510 \\
510 \\
520 \\
500 \\
510\end{array}$ & $\begin{array}{l}465 \\
370 \\
420 \\
550 \\
470\end{array}$ & $\begin{array}{l}450 \\
450 \\
440 \\
440 \\
440\end{array}$ & $\begin{array}{l}495 \\
400 \\
452 \\
450 \\
454\end{array}$ & $\begin{array}{l}425 \\
400 \\
395 \\
445 \\
500\end{array}$ & $\begin{array}{l}425 \\
440 \\
460 \\
490 \\
500\end{array}$ & $\begin{array}{l}780 \\
570 \\
500 \\
515 \\
490\end{array}$ & $\begin{array}{l}\cdots \\
\cdots \\
\cdots \\
\cdots\end{array}$ & $\begin{array}{l}660 \\
715 \\
640 \\
625\end{array}$ \\
\hline $\begin{array}{r}6 \\
7 \\
8 \\
9 \\
10\end{array}$ & $\begin{array}{l}540 \\
540 \\
455 \\
450 \\
450\end{array}$ & $\begin{array}{l}--- \\
525 \\
520 \\
520 \\
525\end{array}$ & $\begin{array}{l}490 \\
525 \\
600 \\
540 \\
525\end{array}$ & $\begin{array}{l}440 \\
530 \\
540 \\
525 \\
510\end{array}$ & $\begin{array}{l}480 \\
480 \\
465 \\
485 \\
470\end{array}$ & $\begin{array}{l}420 \\
4 \in C \\
430 \\
440 \\
450\end{array}$ & $\begin{array}{l}455 \\
452 \\
452 \\
450 \\
452\end{array}$ & $\begin{array}{l}420 \\
497 \\
403 \\
495 \\
450\end{array}$ & $\begin{array}{l}445 \\
450 \\
470 \\
475 \\
450\end{array}$ & $\begin{array}{l}460 \\
560 \\
550 \\
550 \\
820\end{array}$ & $\ddot{m}$ & $\begin{array}{l}605 \\
610 \\
615 \\
675 \\
695\end{array}$ \\
\hline $\begin{array}{l}11 \\
12 \\
13 \\
14 \\
15\end{array}$ & $\begin{array}{r}560 \\
1960 \\
540 \\
580 \\
570\end{array}$ & $\begin{array}{l}680 \\
680 \\
580 \\
580 \\
610\end{array}$ & $\begin{array}{l}580 \\
540 \\
530 \\
520 \\
500\end{array}$ & $\begin{array}{l}500 \\
485 \\
480 \\
480 \\
470\end{array}$ & $\begin{array}{l}455 \\
460 \\
455 \\
470 \\
480\end{array}$ & $\begin{array}{l}480 \\
500 \\
435 \\
430 \\
445\end{array}$ & $\begin{array}{l}450 \\
454 \\
450 \\
455 \\
452\end{array}$ & $\begin{array}{l}490 \\
490 \\
430 \\
495 \\
420\end{array}$ & $\begin{array}{l}480 \\
450 \\
480 \\
520 \\
490\end{array}$ & $\begin{array}{l}660 \\
610 \\
660 \\
660 \\
850\end{array}$ & $=$ & $\begin{array}{l}675 \\
680 \\
700 \\
695 \\
640\end{array}$ \\
\hline $\begin{array}{l}16 \\
17 \\
18 \\
19 \\
20\end{array}$ & $\begin{array}{l}570 \\
540 \\
530 \\
525 \\
510\end{array}$ & $\begin{array}{r}500 \\
3700 \\
3700 \\
560 \\
565\end{array}$ & $\begin{array}{l}540 \\
510 \\
540 \\
520 \\
530\end{array}$ & $\begin{array}{l}490 \\
455 \\
455 \\
470 \\
470\end{array}$ & $\begin{array}{l}440 \\
460 \\
435 \\
460 \\
475\end{array}$ & $\begin{array}{l}440 \\
445 \\
480 \\
440 \\
445\end{array}$ & $\begin{array}{l}450 \\
449 \\
425 \\
448 \\
455\end{array}$ & $\begin{array}{l}460 \\
455 \\
465 \\
430 \\
452\end{array}$ & $\begin{array}{l}430 \\
430 \\
460 \\
525 \\
-\end{array}$ & $\begin{array}{r}710 \\
850 \\
690 \\
1050 \\
1150\end{array}$ & $\ddot{m}$ & $\begin{array}{l}640 \\
665 \\
650 \\
675 \\
655\end{array}$ \\
\hline $\begin{array}{l}21 \\
22 \\
23 \\
24 \\
25\end{array}$ & $\begin{array}{l}550 \\
550 \\
525 \\
550 \\
520\end{array}$ & $\begin{array}{l}570 \\
565 \\
565 \\
560 \\
560\end{array}$ & $\begin{array}{l}540 \\
530 \\
525 \\
580 \\
540\end{array}$ & $\begin{array}{l}490 \\
485 \\
470 \\
480 \\
470\end{array}$ & $\begin{array}{l}470 \\
440 \\
450 \\
445 \\
470\end{array}$ & $\begin{array}{l}440 \\
440 \\
440 \\
450 \\
450\end{array}$ & $\begin{array}{l}450 \\
490 \\
450 \\
425 \\
450\end{array}$ & $\begin{array}{l}415 \\
420 \\
475 \\
455 \\
430\end{array}$ & $\begin{array}{l}500 \\
460 \\
550 \\
580 \\
520\end{array}$ & $\begin{array}{r}1090 \\
1140 \\
700 \\
1040 \\
850\end{array}$ & $\bar{m}$ & $\begin{array}{l}665 \\
630 \\
665 \\
610 \\
650\end{array}$ \\
\hline $\begin{array}{l}26 \\
27 \\
28 \\
29 \\
30 \\
11\end{array}$ & $\begin{array}{l}540 \\
540 \\
775 \\
775 \\
770 \\
775\end{array}$ & $\begin{array}{l}540 \\
540 \\
560 \\
575 \\
570 \\
-\end{array}$ & $\begin{array}{l}590 \\
580 \\
540 \\
525 \\
500 \\
575\end{array}$ & $\begin{array}{l}490 \\
495 \\
500 \\
470 \\
550 \\
550\end{array}$ & $\begin{array}{l}475 \\
475 \\
480 \\
-- \\
---\end{array}$ & $\begin{array}{l}450 \\
450 \\
455 \\
445 \\
450 \\
450\end{array}$ & $\begin{array}{l}450 \\
470 \\
450 \\
449 \\
450 \\
-\end{array}$ & $\begin{array}{l}480 \\
485 \\
445 \\
455 \\
430 \\
448\end{array}$ & $\begin{array}{l}520 \\
580 \\
510 \\
500 \\
550 \\
-\end{array}$ & $\begin{array}{r}970 \\
1030 \\
1050 \\
620 \\
790 \\
720\end{array}$ & 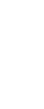 & $\begin{array}{l}625 \\
645 \\
645 \\
630 \\
640\end{array}$ \\
\hline VERAGE & 609 & 897 & 538 & 494 & 462 & 448 & 451 & 450 & 488 & 764 & $\cdots$ & 652 \\
\hline
\end{tabular}


02310649 CHASSAHOWITZKA SPRINGS NEAR HOHOSASSA, FLA.--Continued

TEMPERATURE ( $\left.{ }^{\circ} \mathrm{C}\right)$ OF WATER, WATER YEAR OCTOBER 1969 TO SEPTEMBER 1970

\begin{tabular}{|c|c|c|c|c|c|c|c|c|c|c|c|c|}
\hline DAY & $\mathrm{CCT}$ & NOV & DEC & JAN & FEB & MAR & $A P R$ & MAY & JUN & $\boldsymbol{M L}$ & AUG & SEP \\
\hline $\begin{array}{l}2 \\
2 \\
3 \\
4 \\
5\end{array}$ & $\begin{array}{l}21.0 \\
21.0 \\
21.0 \\
21.0 \\
22.0\end{array}$ & $\begin{array}{l}21.0 \\
21.0 \\
20.0 \\
20.0 \\
21.0\end{array}$ & $\begin{array}{c}-0 \\
\overline{-} \\
18.0\end{array}$ & $\begin{array}{l}18.0 \\
19.0 \\
19.0 \\
20.0 \\
18.0\end{array}$ & $\begin{array}{l}20.0 \\
29.0 \\
19.0 \\
19.0 \\
19.0\end{array}$ & $\begin{array}{l}21.0 \\
19.0 \\
19.0 \\
19.0 \\
18.0\end{array}$ & $\begin{array}{l}19.0 \\
18.0 \\
22.0 \\
19.0 \\
19.0\end{array}$ & $\begin{array}{l}19.0 \\
18.0 \\
18.0 \\
19.0 \\
18.0\end{array}$ & $\begin{array}{l}19.0 \\
19.0 \\
19.0 \\
19.0 \\
18.0\end{array}$ & $\begin{array}{l}19.0 \\
19.0 \\
19.0 \\
18.0 \\
18.0\end{array}$ & 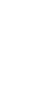 & $\begin{array}{r}18.0 \\
19.0 \\
18.0 \\
19.0\end{array}$ \\
\hline $\begin{array}{r}6 \\
7 \\
8 \\
9 \\
10\end{array}$ & $\begin{array}{l}21.0 \\
21.0 \\
21.0 \\
21.0 \\
21.0\end{array}$ & $\begin{array}{l}21.0 \\
21.0 \\
21.0 \\
21.0\end{array}$ & $\begin{array}{l}20.0 \\
20.0 \\
29.0 \\
20.0 \\
20.0\end{array}$ & $\begin{array}{l}19.0 \\
19.0 \\
18.0 \\
18.0 \\
18.0\end{array}$ & $\begin{array}{l}19.0 \\
20.0 \\
15.0 \\
19.0 \\
19.0\end{array}$ & $\begin{array}{r}19.0 \\
19.0 \\
19.0 \\
19.0 \\
18.0\end{array}$ & $\begin{array}{l}19.0 \\
19.0 \\
18.0 \\
19.0 \\
19.0\end{array}$ & $\begin{array}{l}19.0 \\
19.0 \\
19.0 \\
18.0 \\
18.0\end{array}$ & $\begin{array}{l}19.0 \\
19.0 \\
18.0 \\
18.0 \\
18.0\end{array}$ & $\begin{array}{l}19.0 \\
18.0 \\
19.0 \\
18.0 \\
18.0\end{array}$ & $\begin{array}{l}--- \\
--- \\
---\end{array}$ & $\begin{array}{l}19.0 \\
18.0 \\
18.0 \\
19.0 \\
19.0\end{array}$ \\
\hline $\begin{array}{l}11 \\
12 \\
13 \\
14 \\
15\end{array}$ & $\begin{array}{l}21.0 \\
21.0 \\
22.0 \\
21.0 \\
21.0\end{array}$ & $\begin{array}{l}21.0 \\
21.0 \\
21.0 \\
21.0 \\
21.0\end{array}$ & $\begin{array}{l}19.0 \\
29.0 \\
19.0 \\
29.0 \\
19.0\end{array}$ & $\begin{array}{l}19.0 \\
19.0 \\
19.0 \\
19.0 \\
19.0\end{array}$ & $\begin{array}{l}18.0 \\
19.0 \\
19.0 \\
18.0 \\
19.0\end{array}$ & $\begin{array}{l}19.0 \\
18.0 \\
19.0 \\
21.0 \\
19.0\end{array}$ & $\begin{array}{l}18.0 \\
19.0 \\
19.0 \\
19.0 \\
18.0\end{array}$ & $\begin{array}{l}19.0 \\
20.0 \\
18.0 \\
19.0 \\
18.0\end{array}$ & $\begin{array}{l}19.0 \\
22.0 \\
18.0 \\
19.0 \\
18.0\end{array}$ & $\begin{array}{l}18.0 \\
19.0 \\
19.0 \\
18.0 \\
19.0\end{array}$ & $\begin{array}{l}-- \\
-- \\
--\end{array}$ & $\begin{array}{l}18.0 \\
18.0 \\
18.0 \\
19.0 \\
19.0\end{array}$ \\
\hline $\begin{array}{l}16 \\
17 \\
18 \\
19 \\
20\end{array}$ & $\begin{array}{l}21.0 \\
21.0 \\
21.0 \\
21.0 \\
211.0\end{array}$ & $\begin{array}{l}21.0 \\
21.0 \\
21.0 \\
21.0 \\
21.0\end{array}$ & $\begin{array}{l}19.0 \\
19.0 \\
22.0 \\
18.0 \\
19.0\end{array}$ & $\begin{array}{l}20.0 \\
19.0 \\
19.0 \\
20.0 \\
19.0\end{array}$ & $\begin{array}{l}19.0 \\
19.0 \\
18.0 \\
19.0 \\
29.0\end{array}$ & $\begin{array}{l}19.0 \\
15.0 \\
19.0 \\
18.0 \\
19.0\end{array}$ & $\begin{array}{l}18.0 \\
19.0 \\
19.0 \\
18.0 \\
18.0\end{array}$ & $\begin{array}{l}19.0 \\
19.0 \\
18.0 \\
18.0 \\
19.0\end{array}$ & $\begin{array}{l}19.0 \\
18.0 \\
18.0 \\
19.0 \\
19.0\end{array}$ & $\begin{array}{l}18.0 \\
19.0 \\
18.0 \\
19.0 \\
19.0\end{array}$ & 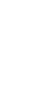 & $\begin{array}{l}18.0 \\
19.0 \\
18.0 \\
19.0 \\
19.0\end{array}$ \\
\hline $\begin{array}{l}21 \\
22 \\
23 \\
24 \\
25\end{array}$ & $\begin{array}{l}22.0 \\
21.0 \\
21.0 \\
21.0 \\
21.0\end{array}$ & $\begin{array}{l}21.0 \\
21.0 \\
21.0 \\
21.0 \\
21.0\end{array}$ & $\begin{array}{l}20.0 \\
20.0 \\
20.0 \\
19.0 \\
19.0\end{array}$ & $\begin{array}{l}19.0 \\
19.0 \\
19.0 \\
19.0 \\
19.0\end{array}$ & $\begin{array}{l}18.0 \\
19.0 \\
18.0 \\
19.0 \\
19.0\end{array}$ & $\begin{array}{l}19.0 \\
19.0 \\
18.0 \\
19.0 \\
19.0\end{array}$ & $\begin{array}{l}18.0 \\
19.0 \\
18.0 \\
19.0 \\
19.0\end{array}$ & $\begin{array}{l}19.0 \\
18.0 \\
19.0 \\
18.0 \\
18.0\end{array}$ & $\begin{array}{l}18.0 \\
19.0 \\
19.0 \\
19.0 \\
18.0\end{array}$ & $\begin{array}{l}19.0 \\
18.0 \\
18.0 \\
18.0 \\
19.0\end{array}$ & $\overline{--}$ & $\begin{array}{l}18.0 \\
18.0 \\
18.6 \\
18.0 \\
19.0\end{array}$ \\
\hline $\begin{array}{l}26 \\
27 \\
28 \\
29 \\
30 \\
31\end{array}$ & $\begin{array}{l}21.0 \\
22.0 \\
21.0 \\
22.0 \\
21.0 \\
21.0\end{array}$ & $\begin{array}{l}21.0 \\
21.0 \\
21.0 \\
21.0 \\
21.0 \\
-\end{array}$ & $\begin{array}{l}19.0 \\
20.0 \\
18.0 \\
20.0 \\
20.0 \\
20.0\end{array}$ & $\begin{array}{l}19.0 \\
19.0 \\
19.0 \\
20.0 \\
22.0 \\
21.0\end{array}$ & $\begin{array}{r}18.0 \\
18.0 \\
19.0 \\
- \\
- \\
-\end{array}$ & $\begin{array}{l}19.0 \\
18.0 \\
18.0 \\
18.0 \\
19.0 \\
18.0\end{array}$ & $\begin{array}{r}18.0 \\
21.0 \\
19.0 \\
18.0 \\
18.0 \\
\end{array}$ & $\begin{array}{l}19.0 \\
19.0 \\
19.0 \\
20.0 \\
18.0 \\
19.0\end{array}$ & $\begin{array}{l}18.0 \\
18.0 \\
22.0 \\
19.0 \\
18.0 \\
-\end{array}$ & $\begin{array}{l}18.0 \\
19.0 \\
19.0 \\
18.0 \\
18.0 \\
19.0\end{array}$ & $\begin{array}{l}--- \\
--- \\
--- \\
--\end{array}$ & $\begin{array}{r}19.0 \\
18.0 \\
19.0 \\
18.0 \\
18.0 \\
-. .\end{array}$ \\
\hline AVERAGE & 21.0 & 21.0 & 20.0 & 19.0 & 19.0 & 29.0 & 19.0 & 18.5 & 19.0 & 18.5 & -- & 18.5 \\
\hline
\end{tabular}

02310650 CHASSAHOWITZKA RIVER NEAR HOMOSASSA, FLA,

LOCATION.--Lat $28^{\circ} 42^{\prime} 54^{\prime \prime}$, long $82^{\circ} 34^{\prime} 38^{\prime \prime}$, In SW sec.26, T. 20 S., R.17 E., Citrus County, at gaging station, near left bank just downstream from head of springs, 0.5 mile upstream from Baird creek, $4.9 \mathrm{miles}$ upstream from mouth, and 5.1 miles southeast of Homosassa.

PERIOD OF RECORD.--Chemical analyses: January 1964 to September 1967, October 1968 to September 1970. Water temperatures: August 1964 to July 1965 , October 1968 to September 1970.

EXTREMES. - - 1969-7D:

Specific conductance: Maximum da1ly, 1,900 micromhos Oct. 12 ; minimum daily, 430 micromhos Mar, $11,19$.

Period of record:

Epectfic conductance: Yaximum da1ly, 4,680 micromhos oct. 20, 1968; mintmum datly, 385 micromhos Dec. 18 , 1968 . water temperatures: (August 1964 to Juiy 1965, 1968-70): Haximum, 26.0 ${ }^{\circ} \mathrm{C}$ Aug. 5,$1969 ; \mathrm{min} 1 \mathrm{mum}, 19.0^{\circ} \mathrm{C}$ on several days during February. CHEMICAL ANALYSES, WATER YEAR OCTOBER 1969 TO SEPTEMBER 1970
(MAJOR CONSTITUENTS)

SPE- DIS- DIS-

\begin{tabular}{|c|c|c|c|c|c|c|c|c|}
\hline $\begin{array}{l}\text { SPE- } \\
\text { CIFIC } \\
\text { CON- } \\
\text { DUCI- } \\
\text { ANCE } \\
\text { CMICRO- } \\
\text { MHOSI }\end{array}$ & $\begin{array}{l} \\
\text { DIS- } \\
\text { SOLVED } \\
\text { IRON } \\
(F E) \\
\left(U_{G} / L\right)\end{array}$ & $\begin{array}{l}\text { OIS- } \\
\text { SOLVED } \\
\text { CAL- } \\
\text { CIUM } \\
\text { (CA) } \\
\text { (MG/L) }\end{array}$ & $\begin{array}{l}\text { DIS- } \\
\text { SOLVED } \\
\text { MAG- } \\
\text { NE- } \\
\text { SIUM } \\
\text { (MG) } \\
\text { (MG/L) }\end{array}$ & $\begin{array}{l}\text { DIS- } \\
\text { SOLVEO } \\
\text { STRON- } \\
\text { TIUM } \\
\text { (SR) } \\
\text { (UG/L) }\end{array}$ & & $\begin{array}{l}\text { BICAR- } \\
\text { BNNATE } \\
\text { (HCO3) } \\
\text { (MG/L) }\end{array}$ & $\begin{array}{r}\text { PH } \\
\text { (UNIT }\end{array}$ \\
\hline
\end{tabular}

\begin{tabular}{|c|c|c|c|c|c|c|c|c|c|c|c|c|}
\hline $\begin{array}{c}\text { OCT... } \\
27 . . .\end{array}$ & 1969 & 24.0 & 545 & -- & 50 & 13 & -- & 43 & 1.7 & 170 & -- & 7.7 \\
\hline JAN.. & $\begin{array}{l}1970 \\
172\end{array}$ & 23.5 & $63 n$ & - & 50 & 14 & - & 60 & 2.1 & 172 & $\cdots$ & 8. 2 \\
\hline $\begin{array}{l}\text { MAR. } \\
\text { O3... } \\
\text { APR. }\end{array}$ & 158 & 23.0 & 480 & - & 45 & 12 & -- & 37 & 1.5 & 159 & 0 & 7.6 \\
\hline JUNE & 163 & 24.97 & 550 & -- & 48 & 12 & - & 43 & 1.6 & 168 & 2 & 8.3 \\
\hline $02 \ldots$ & - & 26.5 & 500 & so & 46 & 11 & 200 & 36 & 1.6 & 172 & 0 & H.? \\
\hline OG... & 125 & -- & 468 & -- & - & -- & - & - & -- & -- & $=$ & -- \\
\hline $30 \ldots$ & -- & 24.0 & 735 & 20 & 48 & 16 & 220 & 76 & 3.0 & 170 & 0 & 8.2 \\
\hline DATE & $\begin{array}{l}\text { DIS- } \\
\text { SOLVED } \\
\text { SULFATE } \\
\text { (SOL) } \\
\text { (MG/L) }\end{array}$ & $\begin{array}{l}\text { DIS- } \\
\text { SOLVEO } \\
\text { CHLO- } \\
\text { RIDE } \\
\text { (CL) } \\
\text { (MG/L) }\end{array}$ & $\begin{array}{l}\text { DIS- } \\
\text { SOLVFD } \\
\text { FLIIU- } \\
\text { RIOE } \\
\text { (F) } \\
\text { (HGLL) }\end{array}$ & $\begin{array}{l}\text { HARD- } \\
\text { NESS } \\
\text { (CA,MG) } \\
\text { (MGLL) }\end{array}$ & $\begin{array}{l}\text { NON- } \\
\text { CAR- } \\
\text { BONATE } \\
\text { HARD- } \\
\text { NESS } \\
\text { (MG/L) }\end{array}$ & $\begin{array}{l}\text { ALKA- } \\
\text { LINITY } \\
\text { AS } \\
\text { CACO3 } \\
\text { (MG/L) }\end{array}$ & $\begin{array}{l}\text { OIS- } \\
\text { SOLVED } \\
\text { SOLIDS } \\
\text { (QESI- } \\
\text { OUE AT } \\
\text { IRO C) } \\
\text { (MG/L) }\end{array}$ & $\begin{array}{l}\text { DIS- } \\
\text { SULVFO } \\
\text { SOLIDS } \\
\text { (SUM OF } \\
\text { CONSTI- } \\
\text { TUENTS) } \\
\text { (MGII.) }\end{array}$ & $\begin{array}{l}\text { DIS- } \\
\text { SOLVED } \\
\text { SOLIDS } \\
\text { (TONS } \\
\text { PER } \\
\text { OAY) }\end{array}$ & $\begin{array}{l}\text { NIS- } \\
\text { SOLVFD } \\
\text { SOLIDS } \\
\text { (TONS } \\
\text { PER } \\
\text { AC-FT) }\end{array}$ & $\begin{array}{l}\text { TANNIN } \\
\text { AND } \\
\text { LIGNIN } \\
\text { (MG/L) }\end{array}$ & $\begin{array}{l}\text { DE'TH } \\
\text { (IT) }\end{array}$ \\
\hline $\begin{array}{l}\text { OCT. } \\
27 \ldots\end{array}$ & $1969 \quad 14$ & 75 & .2 & 179 & 39 & 139 & 313 & $29 n$ & 161 & .43 & -- & - \\
\hline $\begin{array}{l}\text { JAN." } \\
19 . . \\
\text { MAR. }\end{array}$ & 197021 & 106 & .1 & 183 & 42 & 141 & 365 & 347 & 170 & .50 & + & - \\
\hline $\begin{array}{l}03 \ldots \\
\text { APR. }\end{array}$ & 14 & 68 & .3 & 162 & 32 & 130 & 271 & $26 n$ & 116 & .37 & -- & $\cdots$ \\
\hline $\begin{array}{l}14 \ldots \\
\text { JUNE }\end{array}$ & 17 & 74 & .2 & 170 & 32 & 141 & 336 & 287 & 148 & .46 & -- & $=$ \\
\hline $\begin{array}{l}02 \ldots \\
\text { JULY }\end{array}$ & 13 & 70 & .2 & 160 & 19 & 141 & 289 & $27 ?$ & -- & .39 & -- & $\cdots$ \\
\hline SE. & -- & 86 & - & $=$ & -- & - & - & $=$ & -- & - & - & - \\
\hline $30 \ldots$ & 23 & 135 & .2 & 189 & 49 & 139 & 414 & 394 & -- & .56 & -- & -- \\
\hline
\end{tabular}




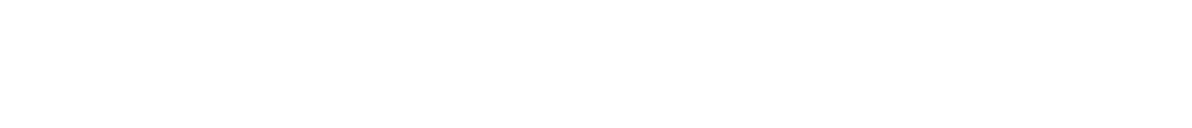
octo.

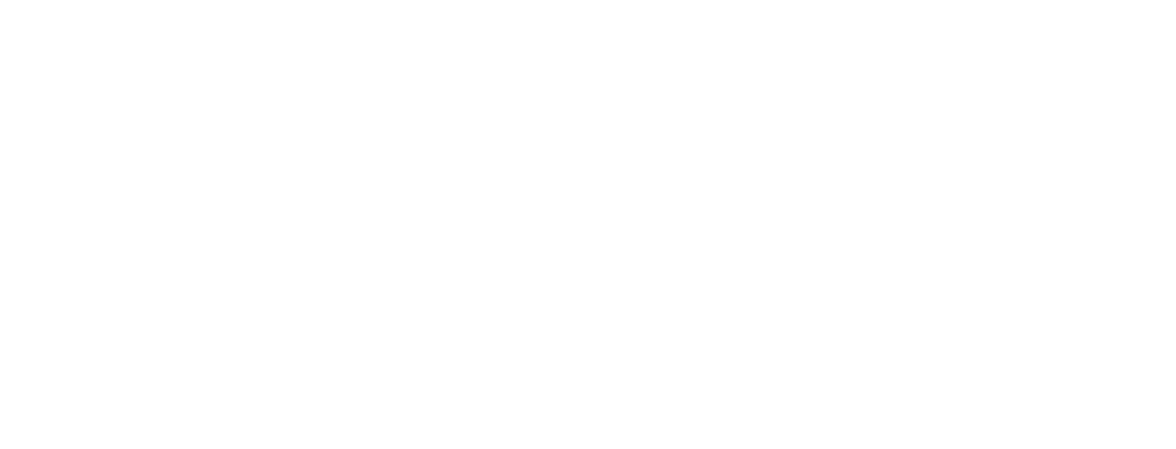

SPECIFIC CONDUCTANCE (MICROMHOS/CM AT $25^{\circ} \mathrm{C}$ ), WATER YEAR OCTOBER 1969 TO SEPTEMBER 1970

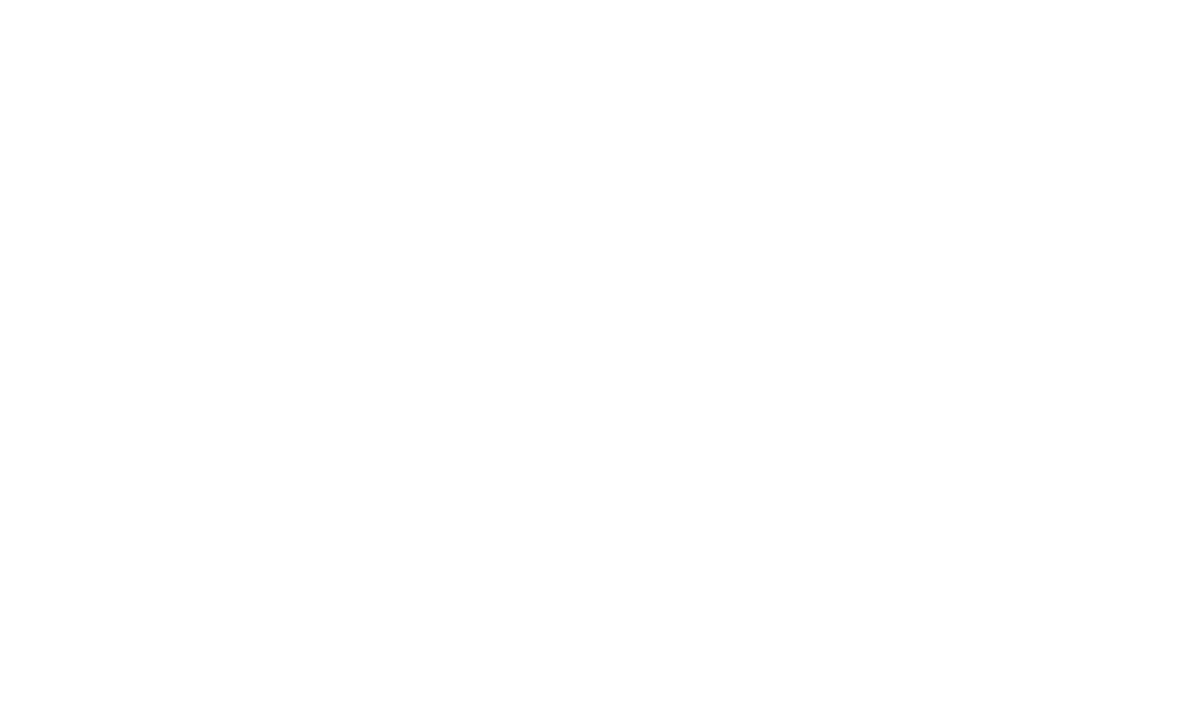

(TRACE METALS)

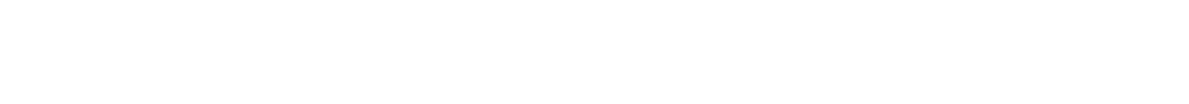
JUNE SEP. (2) 30 $-$ $=$ 
02310650 CHASSAHOWITZKA RIVER NEAR HONOSASSA, FLA.--Cont1 nued

\begin{tabular}{|c|c|c|c|c|c|c|c|c|c|c|c|c|}
\hline OAY & $\mathrm{OCT}$ & NOV & OEC & JAN & FEB & MAR & $A P R$ & MAY & JUN & JUL & AUG & SEP \\
\hline $\begin{array}{l}1 \\
2 \\
3 \\
4 \\
5\end{array}$ & $\begin{array}{l}24.0 \\
24.0 \\
24.0 \\
24.0 \\
24.0\end{array}$ & $\begin{array}{l}24.0 \\
24.0 \\
23.0 \\
24.0 \\
24.0\end{array}$ & $\begin{array}{c}\cdots \\
21.0 \\
\cdots\end{array}$ & $\begin{array}{l}21.0 \\
21.0 \\
21.0 \\
23.0 \\
21.0\end{array}$ & $\begin{array}{l}23.0 \\
21.0 \\
22.0 \\
21.0 \\
22.0\end{array}$ & $\begin{array}{l}1 B .0 \\
22.0 \\
21.0 \\
21.0 \\
21.0\end{array}$ & $\begin{array}{l}22.0 \\
21.0 \\
19.0 \\
21.0 \\
22.0\end{array}$ & $\begin{array}{l}21.0 \\
22.0 \\
20.0 \\
21.0 \\
22.0\end{array}$ & $\begin{array}{l}22.0 \\
21.0 \\
20.0 \\
21.0 \\
21.0\end{array}$ & $\begin{array}{l}21.0 \\
22.0 \\
21.0 \\
21.0 \\
22.0\end{array}$ & $\begin{array}{l}21.0 \\
22.0 \\
21.0 \\
21.0 \\
21.0\end{array}$ & $\begin{array}{l}22.0 \\
21.0 \\
21.0 \\
21.0 \\
22.0\end{array}$ \\
\hline $\begin{array}{r}6 \\
7 \\
8 \\
9 \\
10\end{array}$ & $\begin{array}{l}24.0 \\
24.0 \\
24.0 \\
24.0 \\
24.0\end{array}$ & $\begin{array}{l}24.0 \\
24.0 \\
24.0 \\
24.0\end{array}$ & $\begin{array}{l}28.0 \\
22.0 \\
22.0 \\
22.0 \\
23.0\end{array}$ & $\begin{array}{l}22.0 \\
21.0 \\
21.0 \\
20.0 \\
21.0\end{array}$ & $\begin{array}{l}21.0 \\
23.0 \\
22.0 \\
21.0 \\
22.0\end{array}$ & $\begin{array}{l}22.0 \\
22.0 \\
22.0 \\
21.0 \\
21.0\end{array}$ & $\begin{array}{l}21.0 \\
22.0 \\
21.0 \\
22.0 \\
21.0\end{array}$ & $\begin{array}{l}21.0 \\
21.0 \\
21.0 \\
22.0 \\
21.0\end{array}$ & $\begin{array}{l}22.0 \\
21.0 \\
21.0 \\
21.0 \\
21.0\end{array}$ & $\begin{array}{l}21.0 \\
21.0 \\
22.0 \\
21.0 \\
22.0\end{array}$ & $\begin{array}{l}21.0 \\
22.0 \\
22.0 \\
22.0 \\
21.0\end{array}$ & $\begin{array}{l}21.0 \\
21.0 \\
21.0 \\
22.0 \\
21.0\end{array}$ \\
\hline $\begin{array}{l}11 \\
12 \\
13 \\
14 \\
15\end{array}$ & $\begin{array}{l}24.0 \\
24.0 \\
24.0 \\
24.0 \\
24.0\end{array}$ & $\begin{array}{l}24.0 \\
24.0 \\
24.0 \\
24.0 \\
24.0\end{array}$ & $\begin{array}{l}21.0 \\
21.0 \\
21.0 \\
21.0 \\
21.0\end{array}$ & $\begin{array}{l}21.0 \\
22.0 \\
21.0 \\
22.0 \\
22.0\end{array}$ & $\begin{array}{l}21.0 \\
21.0 \\
22.0 \\
21.0 \\
21.0\end{array}$ & $\begin{array}{l}21.0 \\
21.0 \\
21.0 \\
22.0 \\
21.0\end{array}$ & $\begin{array}{l}21.0 \\
22.0 \\
21.0 \\
21.0 \\
22.0\end{array}$ & $\begin{array}{l}21.0 \\
22.0 \\
21.0 \\
21.0 \\
21.0\end{array}$ & $\begin{array}{l}21.0 \\
18.0 \\
21.0 \\
21.0 \\
21.0\end{array}$ & $\begin{array}{l}21.0 \\
21.0 \\
22.0 \\
21.0 \\
21.0\end{array}$ & $\begin{array}{l}21.0 \\
22.0 \\
21.0 \\
21.0 \\
22.0\end{array}$ & $\begin{array}{l}21.0 \\
21.0 \\
22.0 \\
22.0 \\
21.0\end{array}$ \\
\hline $\begin{array}{l}16 \\
17 \\
18 \\
19 \\
20\end{array}$ & $\begin{array}{l}24.0 \\
24.0 \\
24.0 \\
24.0 \\
24.0\end{array}$ & $\begin{array}{l}24.0 \\
24.0 \\
24.0 \\
24.0 \\
24.0\end{array}$ & $\begin{array}{l}20.0 \\
21.0 \\
20.0 \\
21.0 \\
21.0\end{array}$ & $\begin{array}{l}22.0 \\
21.0 \\
22.0 \\
23.0 \\
21.0\end{array}$ & $\begin{array}{l}21.0 \\
21.0 \\
21.0 \\
22.0 \\
21.0\end{array}$ & $\begin{array}{l}21.0 \\
22.0 \\
21.0 \\
21.0 \\
22.0\end{array}$ & $\begin{array}{l}21.0 \\
21.0 \\
22.0 \\
21.0 \\
21.0\end{array}$ & $\begin{array}{l}21.0 \\
21.0 \\
22.0 \\
21.0 \\
22.0\end{array}$ & $\begin{array}{l}21.0 \\
21.0 \\
22.0 \\
22.0 \\
21.0\end{array}$ & $\begin{array}{l}20.0 \\
21.0 \\
21.0 \\
22.0 \\
22.0\end{array}$ & $\begin{array}{l}21.0 \\
21.0 \\
22.0 \\
22.0 \\
21.0\end{array}$ & $\begin{array}{l}21.00 \\
21.0 \\
21.0 \\
21.0 \\
22.0\end{array}$ \\
\hline $\begin{array}{l}26 \\
27 \\
28 \\
29 \\
30 \\
31\end{array}$ & $\begin{array}{l}23.0 \\
24.0 \\
24.0 \\
24.0 \\
21.0 \\
24.0\end{array}$ & $\begin{array}{l}24.0 \\
24.0 \\
24.0 \\
24.0 \\
24.0 \\
-. .\end{array}$ & $\begin{array}{l}21.0 \\
22.0 \\
21.0 \\
23.0 \\
23.0 \\
23.0\end{array}$ & $\begin{array}{l}21.0 \\
22.0 \\
21.0 \\
22.0 \\
19.0 \\
19.0\end{array}$ & $\begin{array}{l}21.0 \\
21.0 \\
22.0 \\
-0 . \\
-0\end{array}$ & $\begin{array}{l}22.0 \\
21.0 \\
22.0 \\
21.0 \\
21.0 \\
21.0\end{array}$ & $\begin{array}{l}21.0 \\
19.0 \\
22.0 \\
21.0 \\
22.0 \\
-\end{array}$ & $\begin{array}{l}21.0 \\
22.0 \\
21.0 \\
22.0 \\
22.0 \\
21.0\end{array}$ & $\begin{array}{l}21.0 \\
22.0 \\
19.0 \\
21.0 \\
21.0 \\
-0\end{array}$ & $\begin{array}{l}21.0 \\
22.0 \\
21.0 \\
21.0 \\
21.0 \\
22.0\end{array}$ & $\begin{array}{l}22.0 \\
21.0 \\
21.0 \\
22.0 \\
21.0 \\
22.0\end{array}$ & $\begin{array}{l}21.0 \\
21.0 \\
22.0 \\
22.0 \\
21.0 \\
\ldots .-0\end{array}$ \\
\hline AVERAGE & 24.0 & 24.0 & 21.5 & 21.5 & 21.5 & 21.5 & 21.5 & 21.5 & 21.0 & 21.5 & 21.5 & 21.5 \\
\hline
\end{tabular}

WITHLACOOCHEE RIVER BASIN

O2310800 WITHLACOOCHEE RIVER NEAR EVA, FLA.

LOCATION, --Lat $28^{\circ} 21^{\prime} 38^{\prime \prime}$, long $81^{\circ} 49^{\circ} 08^{\prime \prime}$, in NW $\frac{1}{4}$ sec.33, T.24 S., R.25 E., Polk County, at gaging station near center of span on upstream side of bridge on State Highway $33,2.5$ miles north of Eva, 6.5 miles upstream from small tributary, and 138 miles upstream from mouth.

DRAINAGE AREA, --130 sq mi, approximately.

PERIOD OF RECORD,--.Chemical analyses: October 1963 to September 1970

Water temperatures: October 1963 to September 1970.

EXTREMES, - - 1969-70:

Specific conductance: Naximum daily, 87 micromhos Nov. 23 ; minimum daily, 51 micromhos Sept. 12, Oct. 3 . water temperatures: Maximum, $27.0^{\circ} \mathrm{C}$ Aug. $19,20,22 ;$ minimum, $6.0^{\circ} \mathrm{C}$ Jan. 10

Period of record:

Specific conductance: Maximum daily, 264 micromhos June 9, 1967; minimum daily, 39 micromhos Sept. 22, 1969. Water temperatures: Maximum, $33.0^{\circ} \mathrm{C}$ Aug. 3, 1964 ; minimum, 5. $0^{\circ} \mathrm{C}$ Jan. 31 , Feb. $1,1966$.

CHEMICAL ANALYSES, NATER YEAR OCTOBER 1969 TO SEPTEMBER 1970 (MAJOR CONSTI TUENTS)

\begin{tabular}{|c|c|c|c|c|c|c|c|c|c|c|c|c|}
\hline DATE & $\begin{array}{l}\text { OIS- } \\
\text { CHAF̂GE } \\
\text { (CFS) }\end{array}$ & $\begin{array}{l}\text { TEMPEP- } \\
\text { ATUKE } \\
(D E G \quad C)\end{array}$ & $\begin{array}{l}\text { SPE- } \\
\text { CIFIC } \\
\text { CON- } \\
\text { DUCF- } \\
\text { ANCE } \\
\text { (MICRO- } \\
\text { MHOS) }\end{array}$ & $\begin{array}{l}\text { DIS- } \\
\text { SOLVED } \\
\text { IRON } \\
\text { (FE) } \\
\left(U_{G} / L\right)\end{array}$ & $\begin{array}{l}\text { UIS- } \\
\text { SOLVEO } \\
\text { CAL- } \\
\text { CIUM } \\
\text { (CA) } \\
\text { (MG/L) }\end{array}$ & $\begin{array}{l}\text { OIS- } \\
\text { SOLVED } \\
\text { MAG- } \\
\text { NE- } \\
\text { SIUM } \\
\text { (MG) } \\
\text { (MG/L) }\end{array}$ & $\begin{array}{l}\text { DIS- } \\
\text { SOLVED } \\
\text { STRON- } \\
\text { TIUM } \\
\text { (SR) } \\
(U G / L)\end{array}$ & $\begin{array}{l}\text { DIS- } \\
\text { SOLVEN } \\
\text { SODIUM } \\
\text { (NA) } \\
\text { (MG/L) }\end{array}$ & $\begin{array}{l}\text { DIS- } \\
\text { SOLVED } \\
\text { PO- } \\
\text { TAS- } \\
\text { SIUM } \\
\text { (K) } \\
\text { (MG/L) }\end{array}$ & $\begin{array}{l}\text { B ICAR- } \\
\text { BONATE } \\
\text { (HCO3) } \\
\text { (MG/L) }\end{array}$ & $\begin{array}{l}\text { CAR- } \\
\text { BONATI: } \\
\text { (CO3) } \\
\text { (MG/L) }\end{array}$ & $\begin{array}{c}\text { PH } \\
\text { (UNITS) }\end{array}$ \\
\hline $\begin{array}{l}\text { OCT. } \\
\text { nl.... } \\
\text { NOV. }\end{array}$ & 88 & 25.5 & 69 & -. & 2.3 & 1.1 & - & 5.0 & .3 & 0 & 0 & 4.3 \\
\hline $\begin{array}{l}18 \ldots . . . \\
\text { JAN. }\end{array}$ & 76 & 17.0 & 78 & -. & 2.4 & 1.3 & - & 6.4 & .2 & 0 & 0 & 4.3 \\
\hline O8... & 252 & 8.0 & 65 & -- & 1.7 & 1.0 & -- & 5.5 & .2 & 0 & - & 4.4 \\
\hline $\begin{array}{l}24 \ldots \\
\text { MAY }\end{array}$ & 113 & 12.5 & 68 & - & 2.1 & .9 & - & 6.0 & .2 & 0 & $=$ & 4.4 \\
\hline JUNE & $=$ & 22.0 & 75 & 770 & 2.4 & 1.4 & 100 & B. 2 & 1.9 & 4 & -- & 6.4 \\
\hline AUS... & 1.5 & 29.0 & 69 & $\cdots$ & 4.4 & 1.3 & - & 6.4 & .2 & 0 & 0 & 4.7 \\
\hline $\begin{array}{l}05 . . . \\
\text { SEP... } \\
29 . . .\end{array}$ & 10 & 23.5 & 65 & $-\infty$ & 2.3 & 1.0 & - & 5.0 & .7 & 0 & 0 & 4.3 \\
\hline $29 . .$. & 115 & 24.0 & 55 & 510 & 2.8 & .2 & 60 & 4.5 & .6 & 0 & 0 & 4.5 \\
\hline
\end{tabular}


02310800 WITHLACOOCHEE. RI VER NEAR EVA, FLA. .- Continued

CHEMICAL ANALYSES, WATER YEAR OCTOBER 1969 TO SEPTEMBER 1970

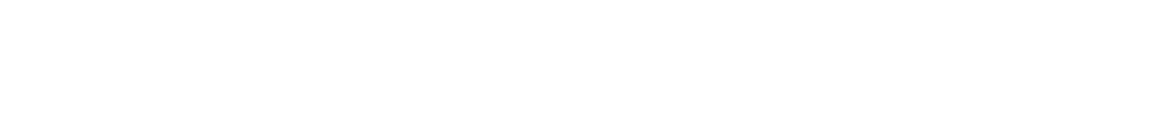

OCT. 1969

\begin{tabular}{|c|c|c|c|c|c|c|c|c|c|c|c|c|}
\hline $\begin{array}{l}\text { 01... } \\
\text { Nov. }\end{array}$ & 1.6 & 10 & .3 & 10 & 10 & $n$ & 126 & 25 & 29.9 & .17 & -- & - \\
\hline JAN... 1970 & 1.6 & 12 & .3 & 12 & 12 & 0 & 116 & 30 & 23.8 & .16 & 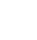 & - \\
\hline $\begin{array}{l}08 . . . \\
\text { FEB. }\end{array}$ & 1.5 & 10 & .2 & 8 & 8 & $n$ & $=$ & 23 & 15.6 & .03 & -- & $\cdots$ \\
\hline$\underset{M A Y}{24 \ldots}$ & .8 & 11 & .2 & 9 & 9 & 0 & 84 & 22 & 25.6 & .11 & -- & -- \\
\hline JUNE & .4 & 14 & .2 & 12 & 9 & 3 & 113 & 32 & $=-$ & .15 & - & -- \\
\hline AUG... & .8 & 13 & .3 & 17 & 17 & $n$ & 70 & 29 & .28 & $\cdot 10$ & - & $=$ \\
\hline $\begin{array}{l}05 . . \\
\text { SEP. }\end{array}$ & .8 & 9.5 & $\cdot 2$ & 10 & 10 & 0 & 96 & 23 & 2.59 & .13 & -- & -- \\
\hline $29 . \ldots$ & 1.2 & 8.0 & .1 & 11 & 11 & 0 & 38 & 22 & 11.8 & .05 & - & \\
\hline
\end{tabular}

(MACRONUTRIENTS AND OTHER RELATED CONSTITUENTS)

\begin{tabular}{|c|c|c|c|c|c|c|c|c|c|c|c|c|}
\hline DATE & $\begin{array}{c}\text { TOTAL } \\
A^{*} N O N I A \\
(N \cap 4) \\
(M G / L)\end{array}$ & $\begin{array}{l}\text { TOTAL } \\
\text { NITYITE } \\
\text { (NOZ) } \\
\text { (MG/L) }\end{array}$ & $\begin{array}{l}\text { TOTAL } \\
\text { NITHATE } \\
\text { (NU3) } \\
\text { (MG/L) }\end{array}$ & $\begin{array}{l}\text { OHGANIC } \\
\text { NITROD- } \\
\text { GEN } \\
\text { (N) } \\
\text { (NG/L) }\end{array}$ & $\begin{array}{l}\text { UIS- } \\
\text { SULVE } \\
\text { OHTHO } \\
\text { PHUS- } \\
\text { PHATE } \\
\text { (PISU) } \\
\text { (MGILI) }\end{array}$ & $\begin{array}{l}\text { PHCS- } \\
\text { PHATE } \\
\text { (PO4) } \\
\text { (MIIL) }\end{array}$ & $\begin{array}{l}\text { DIS- } \\
\text { SOLVED } \\
\text { SILICA } \\
\text { (SIOZI } \\
\text { (MG/L) }\end{array}$ & $\begin{array}{l}\text { TUR- } \\
\text { BID- } \\
\text { ITY } \\
\text { (JTU) }\end{array}$ & $\begin{array}{l}\text { COLOR } \\
\text { (PLAT- } \\
\text { INUM- } \\
\text { COSALT } \\
\text { UNITS) }\end{array}$ & $\begin{array}{l}\text { TOT LL } \\
\text { ORGANIIC } \\
\text { CARRON } \\
\text { ICI } \\
\text { (MEAL) }\end{array}$ & $\begin{array}{l}\text { HIO- } \\
\text { CHEM- } \\
\text { ICAL } \\
\text { OXYGEN } \\
\text { DENAHI } \\
\text { (MG LL) }\end{array}$ & $\begin{array}{c}\text { DEPTH } \\
\text { (FT) }\end{array}$ \\
\hline \multicolumn{13}{|c|}{ OCT, 1969} \\
\hline $01 \ldots$ & -- & .05 & .5 & 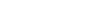 & -- & -- & 3.6 & -- & $40 n$ & -- & -- & -- \\
\hline $31 \ldots$ & -- & .07 & .0 & -- & .07 & .06 & - & -- & - & - & - & - \\
\hline $18 \ldots$ & - & .04 & .2 & -- & - & -- & $5 . ?$ & - & 280 & -- & -- & -- \\
\hline $\begin{array}{r}30 . . \\
\text { OEC. }\end{array}$ & -- & .03 & .1 & -- & -- & .05 & - & -- & -- & -- & - & -- \\
\hline $\begin{array}{r}31 \ldots . . \\
\text { JAN... }\end{array}$ & 1970 & .03 & .2 & $\cdots$ & .06 & .06 & -- & -- & - & -- & -- & -- \\
\hline $08 \ldots$ & $=-$ & .03 & . n & -- & -- & 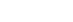 & 2.5 & - & $24 \pi$ & - & -- & - \\
\hline $\begin{array}{l}31 . . . \\
F E B .\end{array}$ & -- & .04 & .7 & -- & .04 & .06 & - & - & -- & -- & -- & -- \\
\hline $24 \ldots$ & - & .04 & .0 & -- & -- & -. & .8 & - & 290 & -- & - & $\cdots$ \\
\hline MAR... & -- & .05 & .0 & - & .04 & .04 & - & -- & - & $=$ & $-\infty$ & -- \\
\hline $\begin{array}{r}31 \ldots \\
A P R .\end{array}$ & -- & .05 & .0 & -- & - & .07 & -- & -- & -- & -- & -- & - \\
\hline$\underset{\operatorname{MAY}}{30} \cdots$ & $\cdots$ & .07 & .0 & -- & .11 & .11 & - & - & - & - & - & -- \\
\hline $\begin{array}{l}02 \ldots \\
31 \ldots \\
\text { JUNE }\end{array}$ & .23 & $\begin{array}{r}.07 \\
.05\end{array}$ & .0 & 1.3 & $\begin{array}{l}.09 \\
.08\end{array}$ & $\begin{array}{l}.12 \\
.08\end{array}$ & 1.8 & $=$ & 400 & $=$ & 1.5 & $=$ \\
\hline $22 \ldots$ & -- & .02 & .1 & - & .07 & -- & 2.0 & -- & 400 & -- & -- & -- \\
\hline JULY & -- & .04 & .0 & -- & .10 & .13 & -- & - & -- & -- & $=$ & - \\
\hline AUG... & -- & .06 & .0 & -- & .10 & .10 & -- & -- & -- & -- & -- & -- \\
\hline $\begin{array}{l}05 . \cdots \\
\text { SEP. }\end{array}$ & .20 & .08 & 0 & .51 & .13 & .14 & 3.5 & 2 & $40 n$ & - & -- & - \\
\hline $29 \ldots$ & .15 & .08 & .0 & .47 & .10 & .11 & 3.5 & 1 & $32 \pi$ & 124 & 1.11 & - \\
\hline
\end{tabular}

(FIELD MEASUREMENTS)

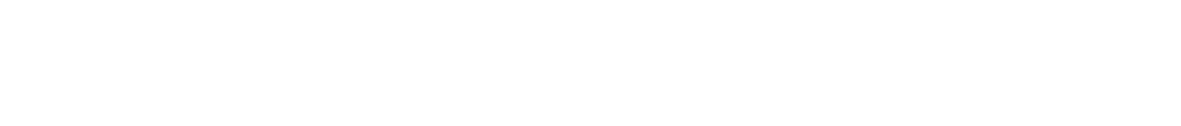
$\begin{array}{cccccc}\text { SEP.. } 1970 & & & & & \end{array}$

(TRACE METALS)

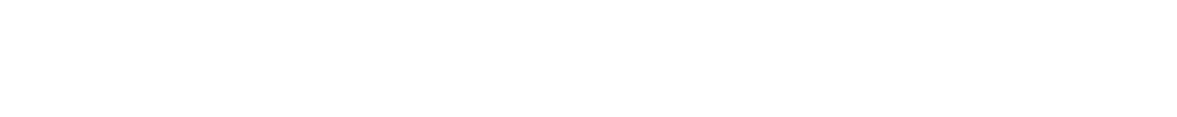
$02 . .$.

SEP. -(1) $\begin{array}{lll}(U G / L) & (U G / L) & (U G / L) \text { (UG/L) }\end{array}$

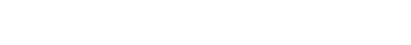

$29 . . \quad 340$

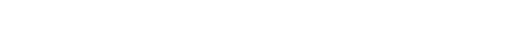
$\begin{array}{rrrrr}770 & 20 & 3 n & -- & -- \\ 510 & 0 & 10 & -- & 130\end{array}$ 
02310800 HITHLACOOCHEE RIVER NEAR EVA, FLA SPECIFIC CONDUCTANCE (MICROMHOS/CM AT $25^{\circ} \mathrm{C}$ ), WATER YEAR OCTOBER 1969 TO SEPTEMBER 1970

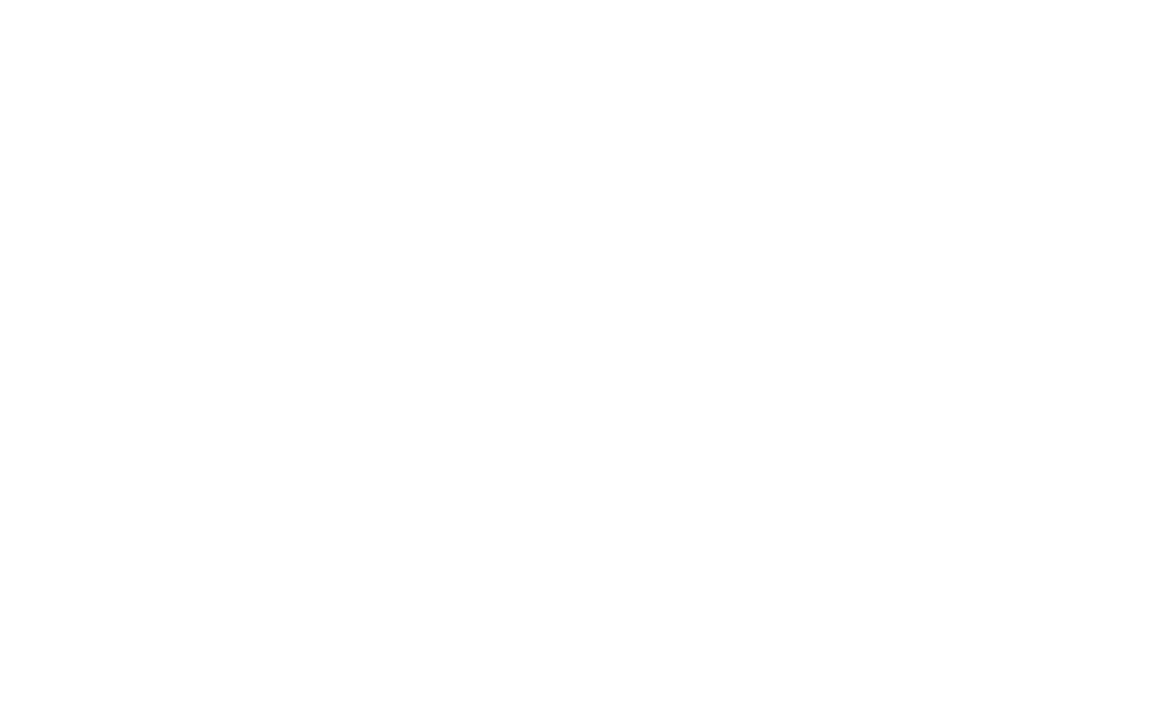

TEMPERATURE ('0) OF WATER, WATER YEAR OCTOBER 1969 TO SEPTEMBER 1970

\begin{tabular}{|c|c|c|c|c|c|c|c|c|c|c|c|c|}
\hline DAY & GCT & NOV & DEC & JAN & FEB & MAR & $\triangle P R$ & MAY & JUN & $\boldsymbol{U} \mathbf{L}$ & AUG & SEP \\
\hline $\begin{array}{l}1 \\
2 \\
3 \\
4 \\
5\end{array}$ & $\begin{array}{l}25.0 \\
25.0 \\
24.0 \\
25.0 \\
25.0\end{array}$ & $\begin{array}{l}22.0 \\
21.0 \\
21.0 \\
20.0 \\
16.0\end{array}$ & $\begin{array}{l}13.0 \\
13.0 \\
12.0 \\
12.0 \\
11.0\end{array}$ & $\begin{array}{l}16.0 \\
14.0 \\
13.0 \\
11.0 \\
10.0\end{array}$ & $\begin{array}{l}13.0 \\
13.0 \\
18.0 \\
11.0 \\
14.0\end{array}$ & $\begin{array}{l}14.0 \\
15.0 \\
15.0 \\
14.0 \\
17.0\end{array}$ & $\begin{array}{l}22.0 \\
22.0 \\
19.0 \\
18.0 \\
19.0\end{array}$ & $\begin{array}{l}23.0 \\
23.0 \\
21.0 \\
21.0 \\
20.0\end{array}$ & $\begin{array}{r}25.0 \\
25.0 \\
24.0 \\
24.0 \\
-\end{array}$ & $\begin{array}{l}24.0 \\
24.0 \\
24.0 \\
25.0 \\
25.0\end{array}$ & $\begin{array}{l}25.0 \\
25.0 \\
24.0 \\
25.0 \\
26.0\end{array}$ & $\begin{array}{r}24.0 \\
26.0 \\
25.0 \\
25.0\end{array}$ \\
\hline $\begin{array}{r}6 \\
7 \\
8 \\
9 \\
10\end{array}$ & $\begin{array}{l}26.0 \\
24.0 \\
23.0 \\
23.0 \\
24.0\end{array}$ & $\begin{array}{l}15.0 \\
15.0 \\
18.0 \\
16.0 \\
14.0\end{array}$ & $\begin{array}{l}17.0 \\
15.0 \\
14.0 \\
14.0 \\
16.0\end{array}$ & $\begin{array}{r}17.0 \\
13.0 \\
8.0 \\
7.0 \\
6.0\end{array}$ & $\begin{array}{l}12.0 \\
12.0 \\
13.0 \\
13.0 \\
12.0\end{array}$ & $\begin{array}{r}16.0 \\
18.0 \\
16.0 \\
18.0\end{array}$ & $\begin{array}{l}20.0 \\
20.0 \\
19.0 \\
20.0 \\
20.0\end{array}$ & $\begin{array}{l}21.0 \\
21.0 \\
21.0 \\
21.0 \\
21.0\end{array}$ & $\begin{array}{l}23.0 \\
23.0 \\
23.0 \\
23.0 \\
24.0\end{array}$ & $\begin{array}{l}25.0 \\
25.0 \\
24.0 \\
24.0 \\
26.0\end{array}$ & $\begin{array}{l}26.0 \\
26.0 \\
26.0 \\
26.0 \\
26.0\end{array}$ & $\begin{array}{r}25.0 \\
25.0 \\
25.0 \\
25.0\end{array}$ \\
\hline $\begin{array}{l}11 \\
12 \\
13 \\
14 \\
15\end{array}$ & $\begin{array}{l}23.0 \\
23.0 \\
23.0 \\
23.0 \\
22.0\end{array}$ & $\begin{array}{l}15.0 \\
16.0 \\
17.0 \\
17.0 \\
13.0\end{array}$ & $\begin{array}{l}16.0 \\
14.0 \\
13.0 \\
14.0 \\
13.0\end{array}$ & $\begin{array}{l}--- \\
--- \\
--- \\
--\end{array}$ & $\begin{array}{l}12.0 \\
12.0 \\
12.0 \\
12.0 \\
14.0\end{array}$ & $\begin{array}{r}17.0 \\
18.0 \\
14.0 \\
14.0\end{array}$ & $\begin{array}{r}19.0 \\
19.0 \\
20.0 \\
20.0\end{array}$ & $\begin{array}{l}22.0 \\
21.0 \\
24.0 \\
22.0 \\
23.0\end{array}$ & $\begin{array}{l}24.0 \\
24.0 \\
24.0 \\
25.0 \\
24.0\end{array}$ & $\begin{array}{l}26.0 \\
26.0 \\
25.0 \\
24.0 \\
25.0\end{array}$ & $\begin{array}{l}26.0 \\
26.0 \\
25.0 \\
25.0 \\
25.0\end{array}$ & $\begin{array}{r}25.0 \\
25.0 \\
25.0 \\
24.0\end{array}$ \\
\hline $\begin{array}{l}16 \\
17 \\
10 \\
19 \\
20\end{array}$ & $\begin{array}{l}23.0 \\
22.5 \\
23.0 \\
23.0 \\
23.0\end{array}$ & $\begin{array}{l}12.0 \\
15.0 \\
15.0 \\
16.0 \\
15.0\end{array}$ & $\begin{array}{l}13.0 \\
12.0 \\
11.0 \\
12.0 \\
15.0\end{array}$ & $\begin{array}{r}\ldots-0 \\
12.0 \\
15.0 \\
13.0\end{array}$ & $\begin{array}{l}17.0 \\
17.0 \\
16.0 \\
14.0 \\
15.0\end{array}$ & $\begin{array}{l}13.0 \\
15.0 \\
15.0 \\
18.0 \\
19.0\end{array}$ & $\begin{array}{l}20.0 \\
20.0 \\
21.0 \\
21.0 \\
22.0\end{array}$ & $\begin{array}{l}23.0 \\
24.0 \\
24.0 \\
25.0 \\
24.0\end{array}$ & $\begin{array}{l}24.0 \\
24.0 \\
25.0 \\
24.0\end{array}$ & $\begin{array}{l}25.0 \\
25.0 \\
25.0 \\
25.0 \\
25.0\end{array}$ & $\begin{array}{l}26.0 \\
26.0 \\
26.0 \\
27.0 \\
27.0\end{array}$ & $\begin{array}{r}25.0 \\
24.0 \\
24.0 \\
25.0 \\
24.0\end{array}$ \\
\hline $\begin{array}{l}26 \\
27 \\
28 \\
29 \\
30 \\
31\end{array}$ & $\begin{array}{r}22.0 \\
22.0 \\
22.0 \\
23.0 \\
23.0\end{array}$ & $\begin{array}{l}17.0 \\
17.0 \\
17.0 \\
16.0 \\
15.0 \\
-0.0\end{array}$ & $\begin{array}{l}14.0 \\
16.0 \\
12.0 \\
12.0 \\
14.0 \\
15.0\end{array}$ & $\begin{array}{l}12.0 \\
14.0 \\
14.0 \\
16.0 \\
17.0 \\
12.0\end{array}$ & $\begin{array}{r}13.0 \\
15.0 \\
13.0 \\
-0 . \\
-\end{array}$ & $\begin{array}{l}18.0 \\
16.0 \\
19.0 \\
21.0 \\
21.0 \\
22.0\end{array}$ & $\begin{array}{r}23.0 \\
22.0 \\
24.0 \\
24.0 \\
\\
. .0\end{array}$ & $\begin{array}{r}23.0 \\
24.0 \\
24.0 \\
23.0 \\
24.0\end{array}$ & $\begin{array}{r}25.0 \\
25.0 \\
26.0 \\
25.0 \\
26.0 \\
-\end{array}$ & $\begin{array}{l}25.0 \\
25.0 \\
25.0 \\
24.0 \\
26.0 \\
26.0\end{array}$ & $\begin{array}{l}25.0 \\
25.0 \\
24.0 \\
26.0 \\
26.0 \\
25.0\end{array}$ & $\begin{array}{l}24.0 \\
25.0 \\
24.0 \\
24.0 \\
23.0 \\
\end{array}$ \\
\hline AVERAGE & 23.5 & 16.0 & 13.5 & -- & 13.5 & 17.0 & 21.0 & 23.0 & 24.5 & 25.0 & 25.5 & 24.5 \\
\hline
\end{tabular}


02311500 WITHLACOOCHEE RIVER NEAR DADE CITY, FLA,

LOCATION. --Lat $28^{\circ} 21^{\prime} 08^{\prime \prime}$, long $82^{\circ} 07^{\circ} 34^{\prime \prime}$, in SE $\frac{1}{4}$ sec.32, T.24 S., R.22 E., Pasco County, at gaging station near left bank on downstream side of Lanier Bridge on River Road, 4 miles east of Dade City, and 110 miles upstream from mouth.

DRAINAGE AREA.--390 sq mi, approximately.

PERIOD OF RECORD.--Chemical analyses: July 1966 to september 1970.

Water temperatures: July 1966 to September 1970.

EXTREMES, - -1969-70

Specific conductance: Maximum daily, 230 micromhos May $22 ;$ minimum daily, 55 micromhos oct. $5,6$.

water temperatures: Maximum, $29.0^{\circ} \mathrm{C}$ June 21 ; minimum, $7.5^{\circ} \mathrm{C}$ Jan. 10.

period of record:

Specific conductance: Naximum daily, 259 micromhos May 31,1967 ; minimum daily, 45 micromhos Sept. 17, 18, 1968. Water temperatures: Maximum, $32.0^{\circ} \mathrm{C}$ July 10, 1969; minimum, 7.0 ${ }^{\circ} \mathrm{C}$ Dec. $18,1968$. CHEMICAL ANALYSES, WATER YEAR OCTOBER 1969 TO SEPTEMBER 1970
(MAJOR CONSTITUENTS?

\begin{tabular}{|c|c|c|c|c|c|c|c|c|c|c|c|c|}
\hline & $\begin{array}{l}\text { DIS- } \\
\text { CHARGE } \\
\text { (CFS) }\end{array}$ & $\begin{array}{l}\text { TEMPER- } \\
\text { ATURE } \\
\text { (DEG }\end{array}$ & $\begin{array}{l}\text { CON- } \\
\text { DUCT- } \\
\text { ANCE } \\
\text { (MICRO- } \\
\text { MHOS) }\end{array}$ & $\begin{array}{l}\text { DIS- } \\
\text { SOLVED } \\
\text { IRON } \\
\text { (FE) } \\
\text { (UG/L) }\end{array}$ & $\begin{array}{l}\text { SOLVEO } \\
\text { CAL- } \\
\text { CIUM } \\
\text { (CA) } \\
\text { (MG/L) }\end{array}$ & $\begin{array}{l}\text { MAG- } \\
\text { NE- } \\
\text { SIUM } \\
\text { (MG) } \\
\text { (MG/L) }\end{array}$ & $\begin{array}{l}\text { SOLVED } \\
\text { STRON- } \\
\text { TIUM } \\
\text { (SR) } \\
\text { (UG/L) }\end{array}$ & $\begin{array}{l}\text { OIS- } \\
\text { SOLVED } \\
\text { SODIUM } \\
\text { (NA) } \\
\text { (MG/L) }\end{array}$ & $\begin{array}{l}\text { PO- } \\
\text { TAS- } \\
\text { SIIJM } \\
(K) \\
(M G / L)\end{array}$ & $\begin{array}{l}\text { 8ICAR- } \\
\text { BNNATE } \\
\text { (HCO3) } \\
\text { (MG/L) }\end{array}$ & $\begin{array}{l}\text { CAR- } \\
\text { BONATE } \\
\text { (CO3) } \\
\text { (MG/L) }\end{array}$ & $P H$ \\
\hline & (CFS) & $(D F G C)$ & MHOSI & $\left(U_{G} / L\right)$ & (MG/L) & $(M G / L)$ & (UG $/ L)$ & (MG/L) & $M G / L)$ & $(M G / L)$ & $(M G / L)$ & \\
\hline
\end{tabular}

\begin{tabular}{|c|c|c|c|c|c|c|c|c|c|c|c|c|}
\hline $\begin{array}{l}\text { NOV.: } \\
19 . . . \\
\text { JAN.:" }\end{array}$ & $\begin{array}{l}969 \\
970\end{array}$ & 15.5 & 93 & - & 12 & 1.7 & -- & 6.6 & .6 & 25 & $=$ & 7.0 \\
\hline $\begin{array}{l}05 . . . \\
\text { FEB. }\end{array}$ & 528 & 11.0 & 82. & -- & 8.6 & 1.5 & - & 6.4 & .5 & 15 & -- & 0.4 \\
\hline${ }_{\text {MAY }}^{26 . . .}$ & 451 & 14.0 & 68 & - & 7.1 & 1.3 & -- & 6.0 & .7 & 16 & - & 6.4 \\
\hline JU.... & -- & 25.5 & 111 & -- & 14 & 1.8 & -- & 7.2 & .1 & 34 & 0 & 7.0 \\
\hline $\begin{array}{l}23 . \cdots \\
\text { AUG. }\end{array}$ & 16 & 29.0 & 155 & -- & 22 & 2.5 & $=$ & 8.0 & .3 & 66 & - & 7.0 \\
\hline SEP. & 33 & 26.0 & 118 & -- & 16 & 2.1 & -- & 6.4 & .6 & 42 & 0 & 7.4 \\
\hline $24 \ldots$ & 85 & 26.0 & 115 & - & 16 & 2.0 & -- & 6.3 & .6 & 40 & 0 & 7.2 \\
\hline DATE & $\begin{array}{l}\text { DIS- } \\
\text { SOL VED } \\
\text { SULFATE } \\
\text { (SO4) } \\
\text { (MG/L) }\end{array}$ & $\begin{array}{l}\text { DIS- } \\
\text { SOLVED } \\
\text { CHLO- } \\
\text { RIDE } \\
\text { (CL) } \\
(M G / L)\end{array}$ & $\begin{array}{l}\text { DIS- } \\
\text { SOLVFD } \\
\text { FL:HU- } \\
\text { RIDE } \\
\text { (F) } \\
(M G / L)\end{array}$ & $\begin{array}{l}\text { HARD- } \\
\text { NESS } \\
\text { (CA,MG) } \\
(M G / L)\end{array}$ & $\begin{array}{l}\text { NON- } \\
\text { CAR- } \\
\text { BONATE } \\
\text { HARO- } \\
\text { NESS } \\
\text { (MG/L) }\end{array}$ & $\begin{array}{l}\text { ALKA- } \\
\text { LINITY } \\
\text { AS } \\
\text { CACO3 } \\
\text { (MG } L \text { L) }\end{array}$ & $\begin{array}{l}\text { DIS- } \\
\text { SOL VED } \\
\text { SOL IDS } \\
\text { (RESI- } \\
\text { DUE AT } \\
180 \quad \mathrm{C}) \\
\text { (MG/L) }\end{array}$ & $\begin{array}{l}\text { DIS- } \\
\text { SOLVEO } \\
\text { SOLIOS } \\
\text { (SUM OF } \\
\text { CONSTI- } \\
\text { TUENTS) } \\
\text { (MGLL) }\end{array}$ & $\begin{array}{l}\text { DIS- } \\
\text { SOLVED } \\
\text { SOLIDS } \\
\text { (TONS } \\
\text { PER } \\
\text { DAY) }\end{array}$ & $\begin{array}{l}\text { DIS- } \\
\text { SOLVFD } \\
\text { SOLIDS } \\
\text { (TONS } \\
\text { PER } \\
\text { AC-FT) }\end{array}$ & $\begin{array}{l}\text { TANNIN } \\
\text { AND } \\
\text { LIGNIN } \\
\text { (MG/L) }\end{array}$ & $\begin{array}{l}\text { DEPTH } \\
(F T)\end{array}$ \\
\hline
\end{tabular}

\begin{tabular}{|c|c|}
\hline $\begin{array}{l}\text { NOV.: } 1969 \\
19 . . . \\
\text { JAN., } 1970\end{array}$ & 1.6 \\
\hline FEB... & .8 \\
\hline$\underset{\operatorname{MAY}}{26} \ldots$ & 1.0 \\
\hline JUNE & 2.0 \\
\hline $\begin{array}{l}23 \ldots . . \\
\text { AUG. }\end{array}$ & 1.4 \\
\hline$\underset{\text { SEP. }}{13 \ldots}$ & .8 \\
\hline & .8 \\
\hline
\end{tabular}

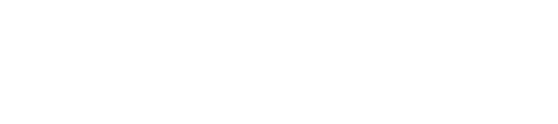

MACRONUTRIENTS AND DTHER RELATFD CDNSTITUENTS

$\begin{array}{lll} & \text { DIS- } & \\ \text { PHOS- } & \text { SOLVED } & \text { TUR- } \\ \text { PHATE } & \text { SILICA } & \text { BID } \\ \text { PO4) } & \text { (SIOZ) } & \text { ITY }\end{array}$

\begin{tabular}{|c|c|c|c|c|c|c|c|c|c|}
\hline .3 & 37 & 17 & 21 & 123 & 52 & 1.07 & .17 & - & -- \\
\hline .3 & 28 & 15 & 12 & 90 & 42 & 128 & .12 & $=$ & -- \\
\hline .3 & 23 & 10 & 13 & $8 n$ & 36 & 97.4 & .11 & -- & -- \\
\hline .3 & 43 & 15 & 28 & 119 & 59 & -- & .16 & -- & - \\
\hline .2 & 66 & 12 & 54 & 131 & 85 & 5.60 & $.1^{A}$ & $\cdots$ & - \\
\hline .2 & 49 & 14 & 34 & 114 & 65 & 10.2 & .16 & - & \\
\hline .3 & 48 & 15 & 33 & 120 & 63 & 27.8 & .16 & $=$ & \\
\hline
\end{tabular}

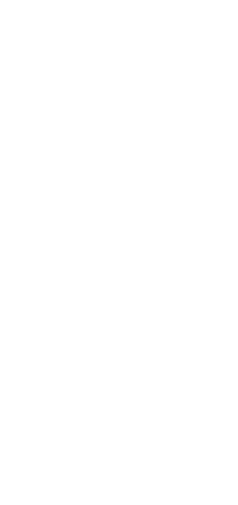

\begin{tabular}{|c|c|c|c|}
\hline .03 & .0 & - & .10 \\
\hline $\begin{array}{r}.03 \\
.03\end{array}$ & $\begin{array}{l}.6 \\
.2\end{array}$ & $=$ & .07 \\
\hline . 12 & .1 & -- & .06 \\
\hline $\begin{array}{r}.03 \\
.03\end{array}$ & $\begin{array}{r}3.6 \\
.0\end{array}$ & $=$ & .08 \\
\hline $\begin{array}{l}.04 \\
.04\end{array}$ & .4 & $=$ & .08 \\
\hline .04 & .0 & $\cdots$ & .14 \\
\hline .05 & .1 & -- & .10 \\
\hline $\begin{array}{l}.04 \\
.04\end{array}$ & $\begin{array}{l}1 \\
.0\end{array}$ & .72 & $\begin{array}{r}.10 \\
.05\end{array}$ \\
\hline $\begin{array}{l}.02 \\
.02\end{array}$ & $\begin{array}{l}0 \\
.0\end{array}$ & 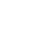 &.$\overline{40}$ \\
\hline .03 & .0 & -- & .09 \\
\hline .04 & .0 & .50 & .12 \\
\hline .95 & .0 & .47 & .06 \\
\hline
\end{tabular}


WI THLACOOCHEE RIVER BASIN

02311500 WITHLACOOCHEE RIVER NEAR DADE CITY, FLA,.-Continued

SPECIFIC CONDUCTANCE (MICROMHOS/CM AT $25^{\circ} \mathrm{C}$ ), WATER YEAR OCTOBER 1969 TO SEPTEMBER 1970

\begin{tabular}{|c|c|c|c|c|c|c|c|c|c|c|c|c|}
\hline DAY & OCT & NOV & $D E C$ & JAiv & FES & MAK & $A P R$ & MAY & JUN & $J \mathbf{U L}$ & AUG & SEP \\
\hline $\begin{array}{l}1 \\
2 \\
3 \\
4 \\
5\end{array}$ & $\begin{array}{l}64 \\
60 \\
60 \\
61 \\
55\end{array}$ & $\begin{array}{l}75 \\
76 \\
76 \\
80 \\
79\end{array}$ & $\begin{array}{l}99 \\
95 \\
98 \\
98 \\
98\end{array}$ & $\begin{array}{r}85 \\
-75 \\
-75 \\
---\end{array}$ & $\begin{array}{l}80 \\
73 \\
76 \\
73 \\
75\end{array}$ & $\begin{array}{r}72 \\
71 \\
70 \\
73 \\
-\end{array}$ & $\begin{array}{l}73 \\
73 \\
74 \\
74 \\
72\end{array}$ & $\begin{array}{r}95 \\
96 \\
97 \\
100 \\
\end{array}$ & $\begin{array}{l}135 \\
140 \\
144 \\
134\end{array}$ & $\begin{array}{l}148 \\
155 \\
144 \\
141 \\
142\end{array}$ & $\begin{array}{l}117 \\
119 \\
--\end{array}$ & 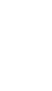 \\
\hline $\begin{array}{r}6 \\
7 \\
8 \\
9 \\
10\end{array}$ & $\begin{array}{l}55 \\
57 \\
60 \\
60 \\
60\end{array}$ & $\begin{array}{l}80 \\
81 \\
81 \\
80 \\
81\end{array}$ & $\begin{array}{r}-0- \\
102 \\
88 \\
137\end{array}$ & $\begin{array}{r}-72 \\
70 \\
71 \\
70\end{array}$ & $\begin{array}{l}67 \\
65 \\
64 \\
65 \\
64\end{array}$ & $\begin{array}{l}72 \\
75 \\
77 \\
75 \\
76\end{array}$ & $\begin{array}{l}73 \\
74 \\
76 \\
76 \\
75\end{array}$ & $\begin{array}{l}104 \\
107 \\
-\end{array}$ & $\begin{array}{l}133 \\
132 \\
134 \\
135 \\
136\end{array}$ & $\begin{array}{l}145 \\
1149 \\
150 \\
-\end{array}$ & $\begin{array}{l}121 \\
120 \\
118 \\
115 \\
119\end{array}$ & $\begin{array}{l}109 \\
112 \\
110 \\
119 \\
120\end{array}$ \\
\hline $\begin{array}{l}11 \\
12 \\
13 \\
14 \\
15\end{array}$ & $\begin{array}{l}60 \\
60 \\
60 \\
60 \\
61\end{array}$ & $\begin{array}{l}81 \\
81 \\
80 \\
80 \\
81\end{array}$ & $\begin{array}{r}138 \\
86 \\
71 \\
-65\end{array}$ & $\begin{array}{r}72 \\
70 \\
67 \\
68 \\
-2\end{array}$ & $\begin{array}{l}60 \\
60 \\
60 \\
61 \\
61\end{array}$ & $\begin{array}{l}75 \\
75 \\
71 \\
72 \\
71\end{array}$ & $\begin{array}{l}75 \\
75 \\
76 \\
77 \\
78\end{array}$ & $\begin{array}{l}115 \\
115 \\
120 \\
120 \\
125\end{array}$ & $\begin{array}{l}140 \\
140 \\
145 \\
145 \\
155\end{array}$ & $\begin{array}{l}-100 \\
160 \\
160 \\
159\end{array}$ & \begin{tabular}{l}
117 \\
119 \\
117 \\
\hdashline-
\end{tabular} & $\begin{array}{l}122 \\
122 \\
-128 \\
-2\end{array}$ \\
\hline $\begin{array}{l}16 \\
17 \\
18 \\
19 \\
20\end{array}$ & $\begin{array}{l}63 \\
63 \\
65 \\
65 \\
60\end{array}$ & $\begin{array}{l}85 \\
85 \\
86 \\
86 \\
87\end{array}$ & $\begin{array}{l}65 \\
64 \\
65 \\
64 \\
73\end{array}$ & $\begin{array}{r}69 \\
70 \\
70 \\
69 \\
\end{array}$ & $\begin{array}{l}60 \\
63 \\
64 \\
65 \\
65\end{array}$ & $\begin{array}{r}70 \\
72 \\
72 \\
\end{array}$ & $\begin{array}{l}78 \\
80 \\
80 \\
81 \\
82\end{array}$ & $\begin{array}{l}130 \\
165 \\
155 \\
145 \\
165\end{array}$ & $\begin{array}{l}150 \\
155 \\
155 \\
175 \\
-\end{array}$ & $\begin{array}{l}140 \\
138 \\
140 \\
135 \\
125\end{array}$ & $\begin{array}{l}127 \\
129 \\
124 \\
126\end{array}$ & \begin{tabular}{l}
123 \\
\hdashline-2 \\
128 \\
127
\end{tabular} \\
\hline $\begin{array}{l}21 \\
22 \\
23 \\
24 \\
25\end{array}$ & $\begin{array}{r}68 \\
70 \\
71 \\
-0-\end{array}$ & $\begin{array}{l}93 \\
88 \\
91 \\
89 \\
89\end{array}$ & $\begin{array}{l}66 \\
69 \\
68 \\
70 \\
70\end{array}$ & $\begin{array}{l}73 \\
73 \\
73 \\
76 \\
75\end{array}$ & $\begin{array}{l}65 \\
66 \\
66 \\
66 \\
67\end{array}$ & $\begin{array}{r}10 \\
-79 \\
69 \\
70 \\
\end{array}$ & $\begin{array}{l}84 \\
85 \\
86 \\
87 \\
90\end{array}$ & $\begin{array}{r}185 \\
230 \\
220 \\
-150\end{array}$ & $\begin{array}{l}170 \\
155 \\
160 \\
155\end{array}$ & $\begin{array}{l}127 \\
128 \\
125 \\
115 \\
\end{array}$ & $\begin{array}{l}120 \\
109 \\
116 \\
114 \\
115\end{array}$ & \begin{tabular}{l}
127 \\
\hdashline 111 \\
111 \\
104
\end{tabular} \\
\hline $\begin{array}{l}26 \\
27 \\
28 \\
29 \\
30 \\
31\end{array}$ & $\begin{array}{r}--- \\
80 \\
78 \\
77 \\
77 \\
75\end{array}$ & $\begin{array}{r}92 \\
91 \\
92 \\
94 \\
94 \\
-\end{array}$ & $\begin{array}{r}74 \\
71 \\
79 \\
72 \\
72\end{array}$ & $\begin{array}{l}76 \\
78 \\
84 \\
78 \\
78 \\
8 \mathrm{C}\end{array}$ & $\begin{array}{r}69 \\
69 \\
70 \\
-- \\
-\end{array}$ & $\begin{array}{r}-19 \\
-72 \\
73\end{array}$ & $\begin{array}{r}91 \\
92 \\
101 \\
99 \\
106 \\
-\end{array}$ & $\begin{array}{l}150 \\
155 \\
200 \\
140 \\
1-2 \\
130\end{array}$ & $\begin{array}{l}150 \\
145 \\
145 \\
150 \\
195 \\
-\end{array}$ & $\begin{array}{l}118 \\
-119 \\
115 \\
115 \\
115\end{array}$ & \begin{tabular}{l}
116 \\
116 \\
\hdashline-2 \\
0
\end{tabular} & $\begin{array}{l}108 \\
103 \\
121 \\
0- \\
-\end{array}$ \\
\hline IERAGE & 65 & 84 & 82 & 74 & 66 & $-\infty$ & 81 & 141 & 148 & 136 & -- & -- \\
\hline
\end{tabular}

TEMPERATURE $\left({ }^{\circ} \mathrm{C}\right)$ OF WATER, WATER YEAR OCTOBER 1969 TO SEPTEMBER 1970

\begin{tabular}{|c|c|c|c|c|c|c|c|c|c|c|c|c|}
\hline DAY & $\mathrm{OCr}$ & NOV & OEC & JAN & FEB & MAR & $A P R$ & MAY & JUN & $\mathbf{J U}$ & AUG & SEP \\
\hline $\begin{array}{l}1 \\
2 \\
3 \\
4 \\
5\end{array}$ & $\begin{array}{l}25.0 \\
25.0 \\
26.0 \\
25.0 \\
25.5\end{array}$ & $\begin{array}{l}25.5 \\
23.0 \\
21.5 \\
20.0 \\
19.0\end{array}$ & $\begin{array}{l}14.0 \\
15.0 \\
13.0 \\
12.0 \\
13.5\end{array}$ & $\begin{array}{r}16.0 \\
13.5 \\
-\ldots\end{array}$ & $\begin{array}{l}14.0 \\
15.5 \\
16.0 \\
11.5 \\
10.5\end{array}$ & $\begin{array}{r}15.0 \\
15.0 \\
16.0 \\
17.0 \\
\ldots\end{array}$ & $\begin{array}{l}22.5 \\
23.5 \\
21.5 \\
20.5 \\
20.0\end{array}$ & 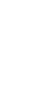 & $\begin{array}{r}24.5 \\
25.0 \\
25.0 \\
24.0\end{array}$ & $\begin{array}{l}26.5 \\
25.0 \\
26.0 \\
26.5 \\
28.0\end{array}$ & $\begin{array}{r}29.0 \\
26.5 \\
-. . \\
-.\end{array}$ & $\begin{array}{l}25.0 \\
25.5 \\
26.0 \\
26.5 \\
25.5\end{array}$ \\
\hline $\begin{array}{r}0 \\
7 \\
8 \\
9 \\
10\end{array}$ & $\begin{array}{l}25.0 \\
25.0 \\
25.5 \\
25.0 \\
24.5\end{array}$ & $\begin{array}{r}17.0 \\
17.5 \\
18.0 \\
18.5 \\
17.0\end{array}$ & $\begin{array}{r}--- \\
14.0 \\
13.5 \\
14.0\end{array}$ & $\begin{array}{r}--.5 \\
12.5 \\
10.5 \\
9.0 \\
7.5\end{array}$ & $\begin{array}{l}11.5 \\
14.0 \\
13.0 \\
13.0 \\
13.0\end{array}$ & $\begin{array}{l}17.5 \\
19.0 \\
18.0 \\
19.0 \\
17.5\end{array}$ & $\begin{array}{l}20.5 \\
19.5 \\
18.5 \\
18.5 \\
19.0\end{array}$ & $\overline{-}$ & $\begin{array}{l}24.0 \\
24.5 \\
24.5 \\
25.0 \\
25.0\end{array}$ & $\begin{array}{r}27.0 \\
26.5 \\
27.0 \\
-\end{array}$ & $\begin{array}{l}26.0 \\
25.5 \\
26.0 \\
26.0 \\
26.5\end{array}$ & $\begin{array}{r}25.0 \\
28.0 \\
26.5 \\
26.0 \\
25.0\end{array}$ \\
\hline $\begin{array}{l}11 \\
12 \\
13 \\
14 \\
15\end{array}$ & $\begin{array}{l}24.5 \\
25.5 \\
23.5 \\
24.0 \\
24.5\end{array}$ & $\begin{array}{l}18.5 \\
18.0 \\
18.5 \\
18.0 \\
15.0\end{array}$ & $\begin{array}{r}12.5 \\
14.5 \\
12.5 \\
-13.5 \\
13.5\end{array}$ & $\begin{array}{l}8.0 \\
8.0 \\
9.0 \\
9.5 \\
-.-\end{array}$ & $\begin{array}{l}12.5 \\
13.0 \\
13.5 \\
13.5 \\
17.0\end{array}$ & $\begin{array}{l}17.5 \\
18.0 \\
19.0 \\
17.0 \\
15.0\end{array}$ & $\begin{array}{l}21.0 \\
21.5 \\
20.5 \\
18.0 \\
18.0\end{array}$ & $\begin{array}{l}24.0 \\
25.0 \\
23.5 \\
24.5 \\
24.0\end{array}$ & $\begin{array}{l}25.0 \\
24.5 \\
25.5 \\
26.0 \\
25.5\end{array}$ & $\begin{array}{r}-0 . \\
25.0 \\
27.0 \\
25.0\end{array}$ & $\begin{array}{r}26.0 \\
26.5 \\
25.5 \\
-.- \\
-\end{array}$ & $\begin{array}{r}27.5 \\
27.5 \\
-.5 \\
25.5 \\
-.-\end{array}$ \\
\hline $\begin{array}{l}16 \\
17 \\
18 \\
19 \\
20\end{array}$ & $\begin{array}{l}24.5 \\
23.0 \\
23.5 \\
24.0 \\
24.5\end{array}$ & $\begin{array}{l}13.0 \\
13.5 \\
17.5 \\
18.5 \\
16.5\end{array}$ & $\begin{array}{l}15.0 \\
14.5 \\
12.5 \\
14.5 \\
13.5\end{array}$ & $\begin{array}{r}11.0 \\
15.0 \\
16.5 \\
16.0 \\
\end{array}$ & $\begin{array}{l}16.5 \\
17.0 \\
16.0 \\
17.0 \\
16.0\end{array}$ & $\begin{array}{r}14.5 \\
15.0 \\
16.5 \\
--\end{array}$ & $\begin{array}{l}17.5 \\
17.5 \\
21.0 \\
21.5 \\
20.0\end{array}$ & $\begin{array}{l}25.0 \\
25.0 \\
25.0 \\
25.5 \\
24.0\end{array}$ & $\begin{array}{r}26.0 \\
26.5 \\
28.0 \\
25.5 \\
-.-\end{array}$ & $\begin{array}{l}26.0 \\
25.5 \\
26.0 \\
28.5 \\
24.5\end{array}$ & $\begin{array}{r}25.5 \\
26.0 \\
--0 \\
26.0 \\
27.0\end{array}$ & $\begin{array}{r}25.5 \\
26.5 \\
28.0\end{array}$ \\
\hline $\begin{array}{l}21 \\
22 \\
23 \\
24 \\
25\end{array}$ & $\begin{array}{r}24.5 \\
26.0 \\
25.0 \\
-\ldots \\
-\cdots\end{array}$ & $\begin{array}{l}13.0 \\
14.0 \\
14.0 \\
16.5 \\
16.0\end{array}$ & $\begin{array}{l}14.0 \\
13.5 \\
14.5 \\
15.5 \\
15.0\end{array}$ & $\begin{array}{l}14.0 \\
12.0 \\
11.0 \\
12.0 \\
13.5\end{array}$ & $\begin{array}{l}14.5 \\
15.5 \\
14.0 \\
14.5 \\
14.5\end{array}$ & $\begin{array}{r}20.0 \\
- \\
18.0 \\
16.5 \\
\ldots-.5\end{array}$ & $\begin{array}{l}--- \\
--- \\
---\end{array}$ & $\begin{array}{r}24.0 \\
23.5 \\
24.0 \\
-23.5 \\
23.5\end{array}$ & $\begin{array}{r}29.0 \\
27.5 \\
27.0 \\
26.5\end{array}$ & $\begin{array}{r}25.5 \\
24.5 \\
25.5 \\
28.0 \\
\ldots . .\end{array}$ & $\begin{array}{l}26.0 \\
25.5 \\
24.5 \\
25.0 \\
25.5\end{array}$ & $\begin{array}{r}26.0 \\
26.5 \\
27.0 \\
27.0\end{array}$ \\
\hline $\begin{array}{l}26 \\
27 \\
28 \\
29 \\
30 \\
31\end{array}$ & $\begin{array}{r}--- \\
24.0 \\
24.0 \\
23.5 \\
22.0 \\
22.0\end{array}$ & $\begin{array}{r}17.5 \\
18.5 \\
18.0 \\
18.0 \\
17.0 \\
-\end{array}$ & $\begin{array}{l}15.0 \\
13.0 \\
12.5 \\
14.0 \\
15.5\end{array}$ & $\begin{array}{l}13.0 \\
15.5 \\
15.0 \\
17.5 \\
18.0 \\
14.5\end{array}$ & $\begin{array}{r}14.0 \\
13.0 \\
14.0 \\
\ldots-0 \\
-0 .\end{array}$ & $\begin{array}{r}18.0 \\
-00 \\
21.0 \\
22.0\end{array}$ & \begin{tabular}{l}
--- \\
\hdashline- \\
\hdashline- \\
---
\end{tabular} & $\begin{array}{r}23.5 \\
24.0 \\
23.5 \\
24.5 \\
25.0\end{array}$ & $\begin{array}{l}25.5 \\
28.0 \\
25.5 \\
26.5 \\
24.5 \\
-\end{array}$ & $\begin{array}{r}27.0 \\
-.0 \\
26.5 \\
27.5 \\
26.0 \\
26.5\end{array}$ & $\begin{array}{r}26.0 \\
26.5 \\
-.- \\
-. \\
--\end{array}$ & $\begin{array}{r}26.0 \\
26.5 \\
25.5 \\
\ldots- \\
-.- \\
-\end{array}$ \\
\hline VERAGE & 24.5 & 17.5 & 14.0 & 12.5 & 14.0 & - & -- & $\cdots$ & 25.5 & 26.5 & -- & $\cdots$ \\
\hline
\end{tabular}


02313000 WITHLACOOCHEE RIVER NEAR HOLDER, FLA.

LOCATION, - - Lat $28^{\circ} 59^{\prime} 19^{\prime \prime}$, long $82^{\circ} 20^{\prime} 59^{\prime \prime}$, in NWł sec,30, T.17 S, , R.20 E, Marion County, at gaging station, near right bank on downstream side of bridge on State Highway $200,4.5$ miles northeast of Holder, and 38 miles up-
stream from mouth.

DRAINAGE AREA.--1,710 sq mi, approximately. PERIOD OF RECORD.-Chemical analyses: January 1950 to December 1951, September 1954 to October 1955 , October 1962
to September 1970.

Water temperatures: January 1950 to December 1951, October 1962 to September 1970.

EXTREMES.--1969-70:

Specific conductance: Maximum dally, 298 micromhos Aug. 17; minimum daily, 150 micromhos Jan. 7.

Water temperatures: Maximum, $30.0^{\circ} \mathrm{C}$ Aug. 5 ; minimum, $5.0^{\circ} \mathrm{C}$ Jan. 10.

period of record:

Dissolved solids (1950-51): Kaximum, $275 \mathrm{mg} / 1$ July 11-20, 1950; minimum, $119 \mathrm{mg} / 1$ Sept. 21-30, 1950

Hardness $(1950-51)$ : Maximum, $191 \mathrm{mg} / 1$ July 11-20, 1950; minimum, $63 \mathrm{mg} / 1$ Sept. 21-30, 1950 .

Specific conductance (1950-51, 1962-68): Maximum datly, 575 micromhos Aug. 9, 1963; ninimum daily, 120 micro.

mhos Aug. 29,1968 ,
Water temperatures: Maximum, $33.0^{\circ} \mathrm{C}$ July 17, $1950 ;$ minimum, $5.0^{\circ} \mathrm{C}$ Jan. $10,1970$. CHEMICAL ANALYSES, WATER YEAR OCTOBER $1969^{\circ}$ TO SEPTEMBER 1970

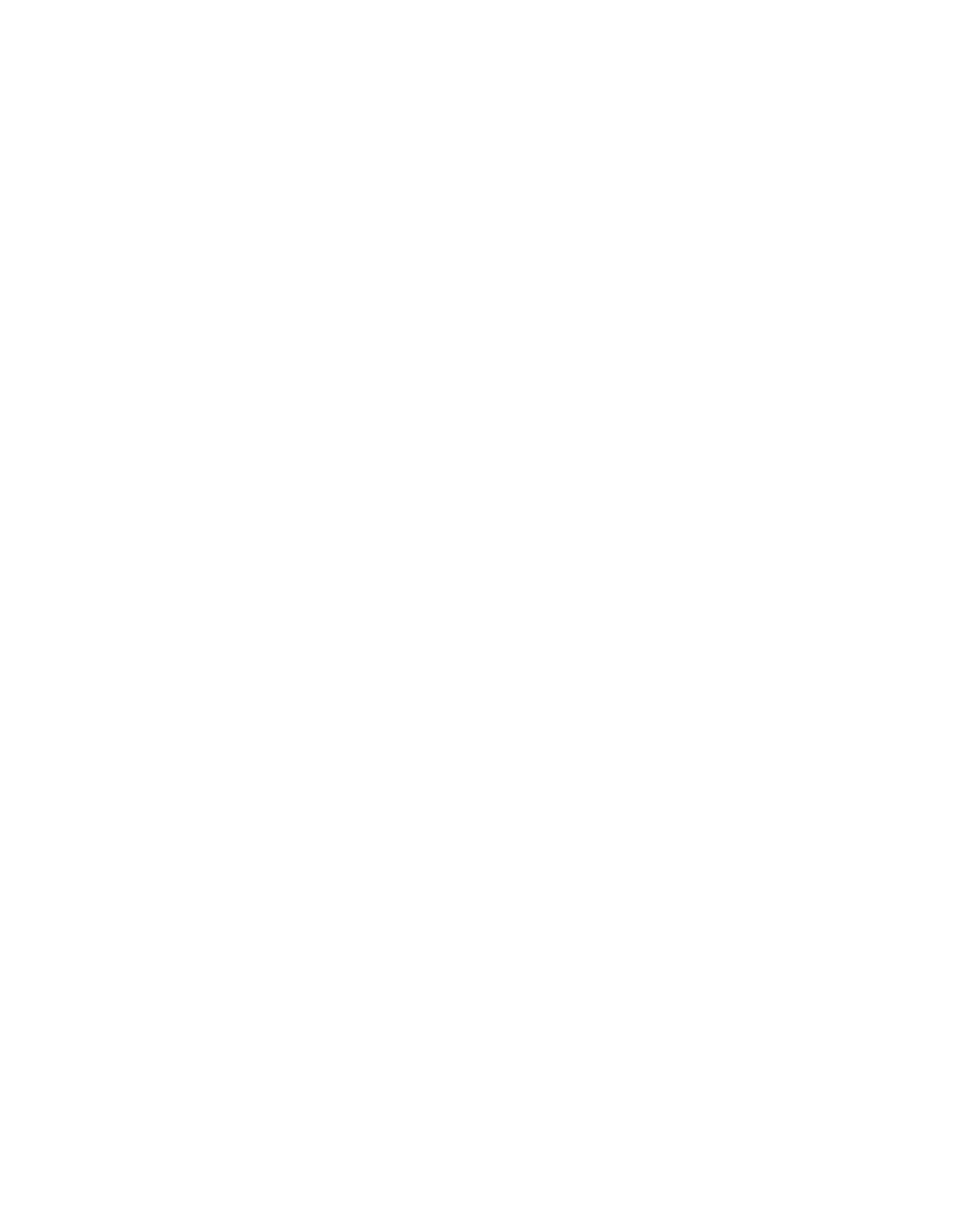


02313000 WITHLACOOCHEE RIVER NEAR HOLDER, FLA, - COntinued

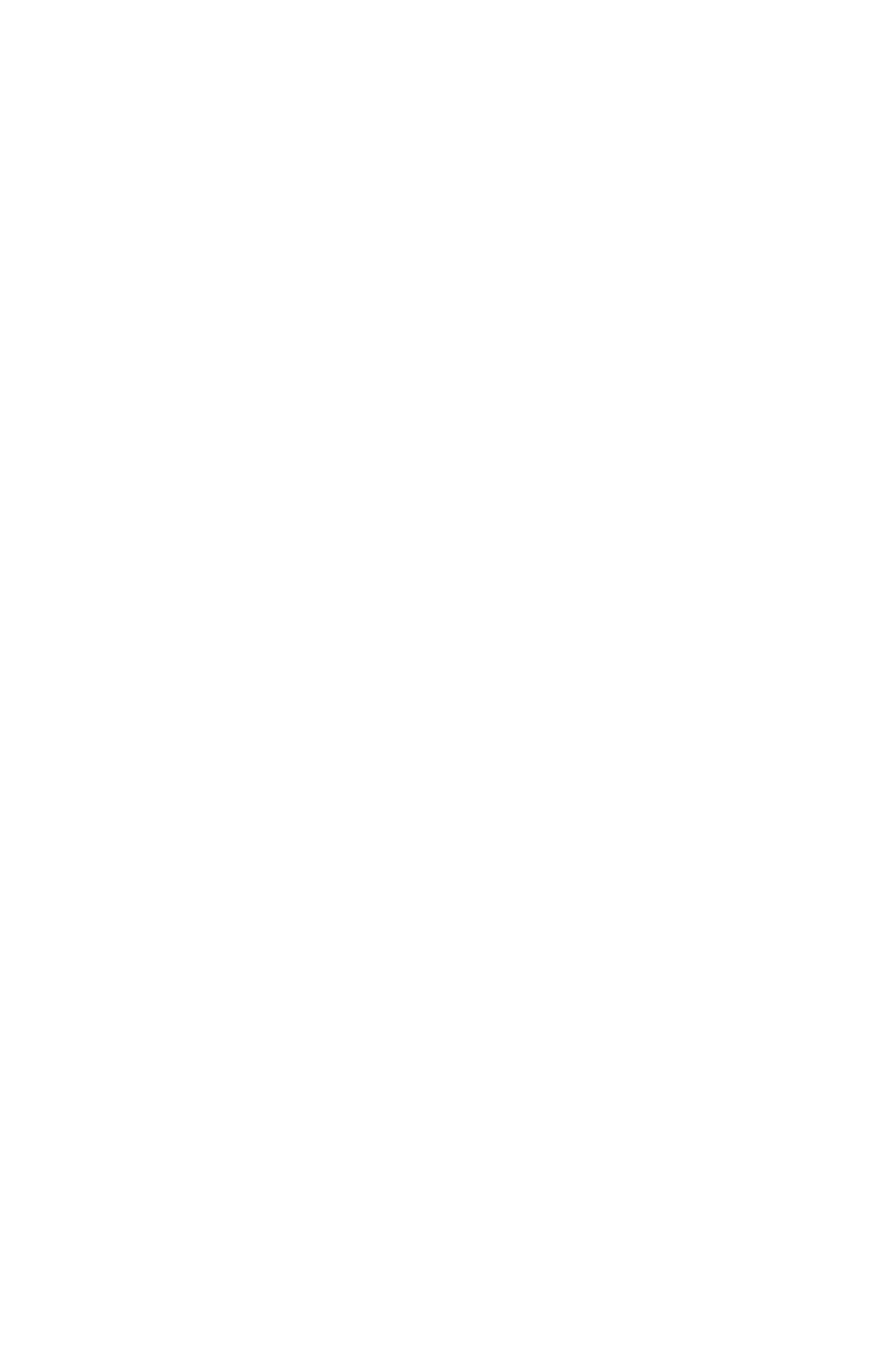


02313100 RAINBOW SPRINGS NEAR DUNNELLON, FLA.

LOCATION, - - Lat $29^{\circ} 06^{\circ} 08^{\prime \prime}$, long $82^{\circ} 26^{\prime} 16^{\prime \prime}$, in SE 1 sec.12, T.16 S., R.18 E., Karion County, at gaging station, at head of springs, 3.9 miles north of Dunneilon, and 5.6 miles upstream from mouth.

PERIOD OF RECORD...Chemlcal analyses: August 1964 to September 1970.

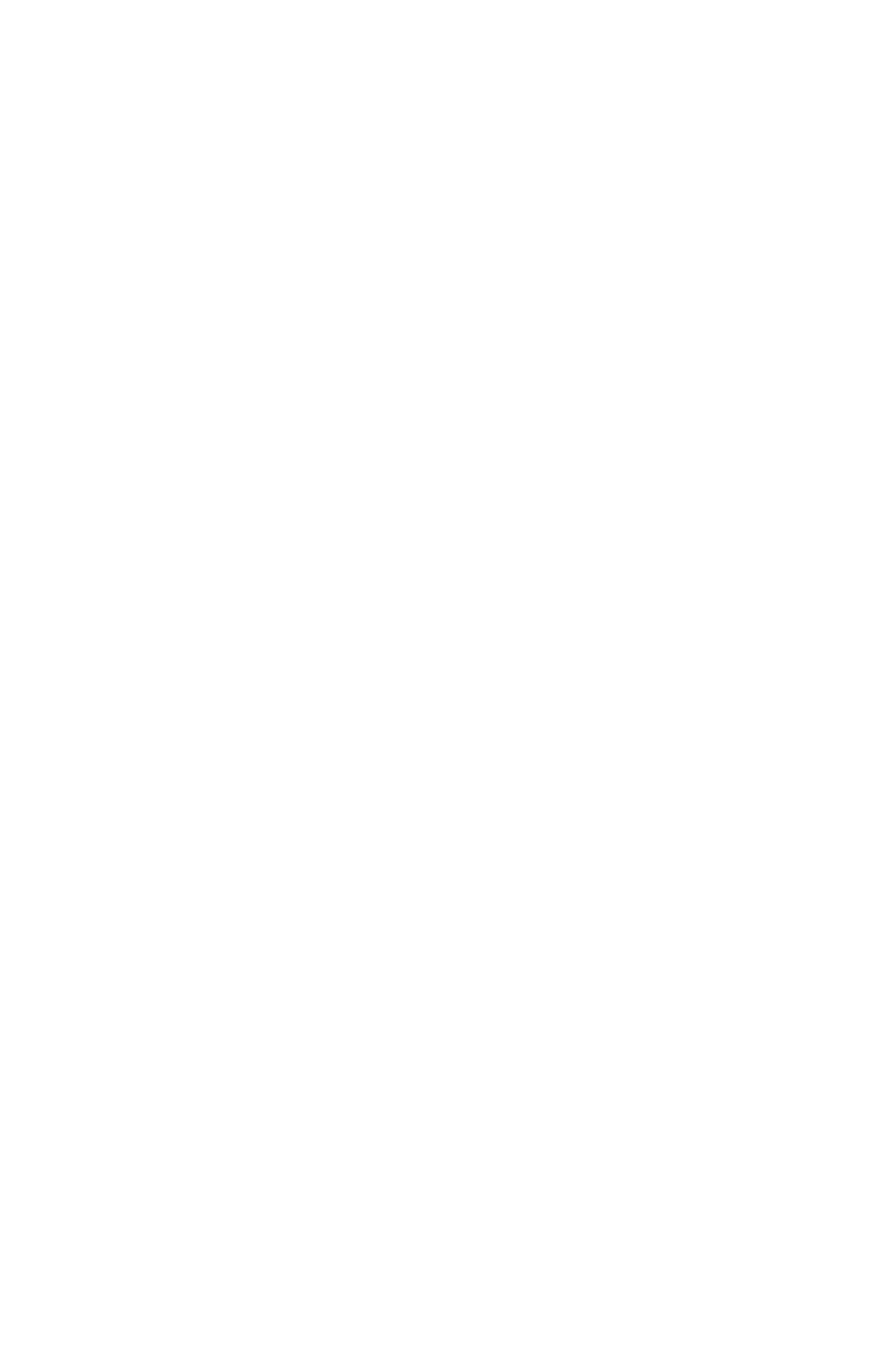


WITHALOOCHEE RIVER BASIN

02313100 RAINBOW SPRINGS NEAR DUNNELLON, FLA.--Cont1nued

CHEMICAL ANALYSES, HATER YEAR OCTOBER 1969 TO SEPTEMBER 1970 (ORGANOCHLORIDE COMPOUNDS IN WATER)

ALDRIN CHLOR- DDD DOE DDT ELDRIN ENDRIN CHLOR EPOXIOE LINDANE APHENE

DAYE (UG/L) (UGL) (UG/L) (UG/L) (UG/L) (UG/L) (UG/L) (UG/L) (UG/L) (UJG/L) (UG/L)

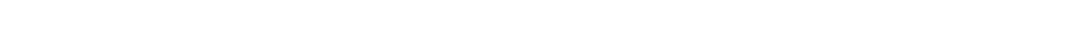

(TRACE METALS)

\begin{tabular}{|c|c|c|c|c|c|c|c|c|c|c|c|c|}
\hline & UIS- & & & DIS- & HEXA- & 0I5- & & & & DIS- & & \\
\hline & SOLVED & DIS- & 015- & SOLVED & VALENT & SOLVED & DIS- & DIS- & OIS- & SOLVEO & & CIs- \\
\hline & $\begin{array}{l}\text { ALUM- } \\
\text { INU }\end{array}$ & $\begin{array}{l}\text { SOLVFU } \\
\text { APSENIC }\end{array}$ & $\begin{array}{l}\text { SOLVE? } \\
\text { GORON }\end{array}$ & $\begin{array}{l}\text { CAD- } \\
\text { MIUHA }\end{array}$ & $\begin{array}{l}C_{\text {ChPO- }} \\
\text { MIUM }\end{array}$ & MIUSM & $\begin{array}{l}\text { SOLVED } \\
\text { COPPER }\end{array}$ & $\begin{array}{l}\text { SOLVED } \\
\text { IRON }\end{array}$ & $\begin{array}{l}\text { SOLVED } \\
\text { LEAD }\end{array}$ & $\begin{array}{l}\text { MAN- } \\
\text { GANESE }\end{array}$ & $\begin{array}{l}\text { IORAL } \\
\text { MERCURY }\end{array}$ & ZIVC \\
\hline & (AL) & (AS) & (B) & (CD) & $\left(\mathrm{CP}_{6}\right)$ & (CK) & (cu) & (FE) & (PR) & (MN) & (HG) & $\begin{array}{c}(Z N) \\
(Z G / L)\end{array}$ \\
\hline DATE & (UG/) & $(U G / L)$ & $(\mathrm{JG} / \mathrm{L})$ & (UG/L) & (UG/L) & (UG/L) & (UG/L) & (UG/L) & $(U G / L)$ & (UG/L) & (UG/L) & $\pi(s)$ \\
\hline
\end{tabular}

MAY I 1970 --

SEP.

$\begin{array}{lll}-- & -- \\ -- & --\end{array}$

(OTHER DATA)

\begin{tabular}{|c|c|c|c|c|c|c|c|c|c|c|c|c|c|}
\hline BATE & $\begin{array}{r}\text { IMM } \\
D I \\
C D \\
B \\
P C \\
P D\end{array}$ & $\begin{array}{l}\text { ME- } \\
\text { IATE } \\
\text { OLI- } \\
\text { FORM } \\
\text { COL. } \\
\text { ER } \\
\text { ML. }\end{array}$ & $\begin{array}{c}\text { DELAYED } \\
\text { COLI- } \\
\text { FDRM } \\
\text { (COL- } \\
\text { ONIES } \\
\text { PER } \\
100 \mathrm{ML} \text { ) }\end{array}$ & $\begin{array}{l}\text { OIL } \\
\text { AND } \\
\text { GREASE } \\
\text { (MG/L) }\end{array}$ & $\begin{array}{l}\text { METHY- } \\
\text { LENE } \\
\text { BLUE } \\
\text { ACTIVE } \\
\text { SUB- } \\
\text { STANCE } \\
\text { (MG/L) }\end{array}$ & $\begin{array}{l}\text { DIS- } \\
\text { SOLVED } \\
\text { ORGANIC } \\
\text { NITRO- } \\
\text { GEN } \\
\text { (N) } \\
\text { (MG/L) }\end{array}$ & $\begin{array}{l}\text { PHENOLS } \\
\text { (UG/L) }\end{array}$ & $\begin{array}{l}\text { IODIDE } \\
\text { (I) } \\
\text { (MG/L) }\end{array}$ & $\begin{array}{l}\text { TOTAL } \\
\text { ALUM- } \\
\text { INUM } \\
\text { (AL) } \\
\text { (UG/L) }\end{array}$ & $\begin{array}{l}\text { DIS- } \\
\text { SOLVED } \\
\text { COBALT } \\
\text { (CO) } \\
\text { (UG/L) }\end{array}$ & $\begin{array}{l}\text { TOTAL } \\
\text { IRON } \\
\text { (FE) } \\
\text { (UG/L) }\end{array}$ & $\begin{array}{l}\text { DIS- } \\
\text { SDLVED } \\
\text { LITHIUM } \\
\text { (LI) } \\
\text { (UG/L) }\end{array}$ & $\begin{array}{c}\text { DIS- } \\
\text { SOLVED } \\
\text { MERCURY } \\
\text { (HG) } \\
\text { (UG/L) }\end{array}$ \\
\hline \multicolumn{14}{|c|}{ MAY, $147 "$} \\
\hline $\begin{array}{l}\text { B.... } \\
S F D .\end{array}$ & & 110 & -- & 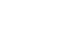 & -- & $\cdots$ & 10 & -- & 0 & $\rightarrow$ & -- & -- & - \\
\hline $17 \ldots$ & & 110 & -- & -- & $\cdots$ & -- & -- & -- & -- & -- & -- & -- & .0 \\
\hline
\end{tabular}

\section{SUWANNEE RIVER BASIN}

D2319000 WI THLACOOCHEE RI VER NEAR PINETTA, FLA.

LOCATION.--Lat $30^{\circ} 35^{\prime} 43^{\prime \prime}$, long $83^{\circ} 15^{\prime} 35^{\prime \prime}$, in NW sec.7, T. 2 N., R.11 E., Nadison County, at gaging station on right bank $30 \mathrm{ft}$ downstream from highway bridge, 0.1 mile downstream from small tributary, 0.3 mile west of Bellville, 5.6 miles east of Pinetta, and 22 miles upstream from mouth.

DRAINAGE AREA. - 2,120 sq mi, approximately.

PERIOD OF RECORD.--Chemical analyses: November 1962 to September 1970.

Water temperatures: October 1963 to September 1970.

EXTREMES. - - 1969-70:

Specific conductance: Maximum daily, 370 micromhos Dec. 6, 7; minimum daily, 40 micromhos Apr. $5,6$.

water temperatures: Maximum, $27.0^{\circ} \mathrm{C}$ on several days during June, July, September; minimum, $2.0^{\circ} \mathrm{C}$ Mar. 29.

period of record:

Specific conductance: Maximum daily, 510 micromhos Nov, 27, 28, 30, 1968; minimum daily, 18 micromhos Dec. 10 , 1964.

water temperatures: Maximum, $34.0^{\circ} \mathrm{C}$ Aug. 17,1968 ; minimum, $2.0^{\circ} \mathrm{C} \mathrm{Mar} .29,1970$. CHEMICAL ANALYSES, WATER YEAR OCTOBER 1969 TO SEPTEMBER 1970
(MAJOR CONSTITUENTS)

\begin{tabular}{|c|c|c|c|c|c|c|c|c|c|c|c|c|}
\hline DATE & $\begin{array}{l}\text { DIS- } \\
\text { CHAKGE } \\
\text { (CFS) }\end{array}$ & $\begin{array}{l}\text { TEMPER- } \\
\text { ATURE } \\
\text { (DEG C) }\end{array}$ & $\begin{array}{l}\text { SPE- } \\
\text { CIF IC } \\
\text { CON- } \\
\text { DUCT- } \\
\text { ANCE } \\
\text { (MICRO- } \\
\text { MHOS) }\end{array}$ & $\begin{array}{l}\text { OIS- } \\
\text { SOLVED } \\
\text { IRON } \\
\text { (FE) } \\
\text { (UG/L) }\end{array}$ & $\begin{array}{l}\text { UIS- } \\
\text { SGLVED } \\
\text { CAL- } \\
\text { CIUM } \\
\text { (CA) } \\
\text { (MG/L) }\end{array}$ & $\begin{array}{l}\text { DIS- } \\
\text { SOLVED } \\
\text { MAG- } \\
\text { NE- } \\
\text { SIUM } \\
\text { (MG) } \\
\text { (MG/L) }\end{array}$ & $\begin{array}{l}\text { UIS- } \\
\text { SDLVED } \\
\text { STRON- } \\
\text { IIUM } \\
\text { (SR) } \\
\text { (UG/L) }\end{array}$ & $\begin{array}{l}\text { DIS- } \\
\text { SOLVED } \\
\text { SODIUM } \\
\text { (NA) } \\
\text { (MG/L) }\end{array}$ & $\begin{array}{l}\text { DIS- } \\
\text { SOL VEO } \\
\text { PO- } \\
\text { TAS- } \\
\text { SIIJM } \\
\text { (K) } \\
\text { (MG/L) }\end{array}$ & $\begin{array}{l}\text { BICAR- } \\
\text { BONATE } \\
\text { (HCO3) } \\
\text { (MG/L) }\end{array}$ & $\begin{array}{l}\text { CAR- } \\
\text { BONATE } \\
\text { (CO3) } \\
\text { (MG/L) }\end{array}$ & $\begin{array}{c}\text { PH } \\
\text { (UNITS) }\end{array}$ \\
\hline $\begin{array}{r}\text { OCT. } \\
01 . . .\end{array}$ & $\begin{array}{l}969 \\
2180\end{array}$ & & & & & & & & & & & \\
\hline $\begin{array}{l}15 . . \\
\text { Nov. }\end{array}$ & $\begin{array}{r}2180 \\
370\end{array}$ & $\begin{array}{l}23.0 \\
23.0\end{array}$ & $\begin{array}{r}72 \\
224\end{array}$ & $\because$ & $\begin{array}{r}3.2 \\
--\end{array}$ & 1.2 & $=$ & 9.0 & 1.5 & 18 & $=$ & $\begin{array}{l}6.3 \\
7.3\end{array}$ \\
\hline $\begin{array}{l}19 . . . \\
\text { OEC.. }\end{array}$ & 140 & 17.0 & 340 & -- & 30 & 5.2 & -- & 40 & 1.8 & 176 & $=$ & 6.9 \\
\hline $\begin{array}{l}11 \ldots . \\
31 \ldots \\
F E A_{0}\end{array}$ & $\begin{array}{l}1010^{--} \\
970^{--}\end{array}$ & $11 . \overline{5}$ & $\overrightarrow{9 H}$ & 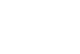 & $\begin{array}{r}24 \\
4.9\end{array}$ & 3.8 & $=$ & $\begin{array}{l}15 \\
11\end{array}$ & $\begin{array}{l}1.6 \\
1.6\end{array}$ & $\overline{22}$ & $=$ & 0.4 \\
\hline APR. & 3750 & 8.5 & 65 & $\cdots$ & - & - & -- & -- & - & -- & -- & - \\
\hline MAY & -- & - & 67 & -- & $\cdots$ & - & -- & - & - & $\cdots$ & -- & + \\
\hline JULY.". & 274 & 24.5 & 268 & $23 t$ & 32 & 4.2 & 120 & 21 & $\mathrm{I} \cdot 3$ & 139 & 0 & 7.4 \\
\hline $\begin{array}{l}01 \ldots . . . \\
\text { AUG. }\end{array}$ & 865 & 28.0 & 108 & -- & 9.6 & 1.7 & -- & $1 n$ & 1.1 & 42 & $n$ & 7.7 \\
\hline $\begin{array}{l}13 \ldots \\
20 \ldots\end{array}$ & $\begin{array}{l}3100 \\
8670\end{array}$ & 26.5 & 35 & $=$ & $\overline{--}$ & 7 & $=$ & $\begin{array}{l}10 \\
2.5\end{array}$ & $\overline{1}$ & $-\bar{z}$ & $\overline{0}$ & $5 \overline{5}$ \\
\hline
\end{tabular}

A INCLUDES 3.1 MG/L DISSOLVED OXYGEN COMPUTING AS 36 PERCENT SATURATION. 
SUTANNEE RIVER BASIN

02319000 WITHLACOOCHEE RIVER NEAR PINETTA, FLA.--Continued

CHEMICAL ANALYSES, NATER YEAR OCTOBER 1969 TO SEPTEMBER 1970 (MAJOR CONSTITUENTS)

\begin{tabular}{|c|c|c|c|c|c|c|c|c|c|c|c|c|}
\hline DATE & $\begin{array}{l}\text { DIS- } \\
\text { SOLVED } \\
\text { SULFATE } \\
(S O 4) \\
(N G / L)\end{array}$ & $\begin{array}{l}\text { OIS- } \\
\text { SOLVED } \\
\text { CHLO- } \\
\text { RIDE } \\
(C L) \\
(M G / L)\end{array}$ & $\begin{array}{l}\text { DIS- } \\
\text { SOLVFD } \\
\text { FLUO- } \\
\text { RIDE } \\
\text { (F) } \\
(M G / L)\end{array}$ & $\begin{array}{l}\text { HARD- } \\
\text { NESS } \\
(C A, M G) \\
(M G / L)\end{array}$ & $\begin{array}{l}\text { NON- } \\
\text { CAR- } \\
\text { RONATE } \\
\text { HARD- } \\
\text { NESS } \\
\text { (MG/L) }\end{array}$ & $\begin{array}{l}\text { ALKA- } \\
\text { LINITY } \\
\text { AS } \\
\text { CACO3 } \\
(M G / L)\end{array}$ & $\begin{array}{l}\text { DIS- } \\
\text { SOLVED } \\
\text { SOLIDS } \\
\text { REESI- } \\
\text { OUE AT } \\
\text { 1RO CI } \\
\text { (MG/L) }\end{array}$ & $\begin{array}{l}\text { DIS- } \\
\text { SULVEO } \\
\text { SOLIOS } \\
\text { (SUM OF } \\
\text { CONSTT- } \\
\text { TUENTS) } \\
\text { (MGAL) }\end{array}$ & $\begin{array}{l}\text { DIS- } \\
\text { SOLVED } \\
\text { SOLIOS } \\
\text { (TONS } \\
\text { PER } \\
\text { DAY) }\end{array}$ & $\begin{array}{l}\text { OIS- } \\
\text { SOLVFD } \\
\text { SOLIDS } \\
\text { (TONS } \\
\text { PER } \\
\text { AC-FT) }\end{array}$ & $\begin{array}{l}\text { TANNIN } \\
\text { AND } \\
\text { LIGNIN } \\
\text { (MG/L) }\end{array}$ & $\begin{array}{c}D E: P T H \\
(N T)\end{array}$ \\
\hline \multicolumn{13}{|c|}{ OCT. 1969} \\
\hline $15 \ldots$ & $\begin{array}{r}3.4 \\
--\end{array}$ & 8.5 & .4 & 13 & $-?$ & 15 & 81 & 44 & 47 & 11 & $\overline{-}$ & -- \\
\hline $\begin{array}{c}\text { NOV. } \\
18 . . . \\
\text { DEC. }\end{array}$ & 19 & 9.0 & .9 & 97 & 0 & 144 & 239 & $2 n g$ & 90.3 & .33 & -- & $=-$ \\
\hline $\begin{array}{r}11 \ldots \\
31 \ldots \\
\text { FEB... }\end{array}$ & $8 . \overline{8}$ & $9 . \overline{5}$ & $\begin{array}{r}1.2 \\
.5\end{array}$ & $\begin{array}{l}17 \\
20\end{array}$ & $-\overline{2}$ & $\overline{18}$ & 81 & 60 & $221^{--}$ &.$\overline{11}$ & $=$ & $=$ \\
\hline${ }_{A P R}^{11} \cdot$. & - & -- & .4 & - & -- & - & - & -- & -- & - & -- & -- \\
\hline MAY & -- & -- & .4 & -- & $\cdots$ & - & $-\infty$ & 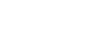 & -- & -- & $-\infty$ & -- \\
\hline$\underset{\text { JULY }}{26 . . .}$ & 14 & 6.0 & .5 & 98 & 0 & 114 & 172 & 159 & $-\infty$ & .73 & - & - \\
\hline $\begin{array}{l}01 . . . \\
\text { AUG. }\end{array}$ & 7.3 & 7.0 & .4 & 31 & 0 & 34 & $10 ?$ & 67 & 238 & .14 & $=-$ & -- \\
\hline $20 \ldots$ & .6 & 5.0 & $: 3$ & $\overline{8}$ & $-\overline{7}$ & $-\overline{2}$ & 60 & $\overline{19}$ & $1410^{--}$ & . & $\because$ & $=$ \\
\hline DATE & $\begin{array}{c}\text { TOTAL } \\
\text { A MONIA } \\
\text { (Mr;4) } \\
(M G / L)\end{array}$ & $\begin{array}{l}\text { TOTAL } \\
\text { NITRITL } \\
\text { (NOL) } \\
\text { (MG/L) }\end{array}$ & $\begin{array}{l}\text { TOTAL } \\
\text { NITKATE } \\
\text { (NO3) } \\
\text { (MG/L) }\end{array}$ & $\begin{array}{c}\text { OHGANIC } \\
\text { NITRT- } \\
\text { GEN } \\
\text { (N) } \\
\text { (NG/L) }\end{array}$ & $\begin{array}{l}\text { IENTS AND } \\
\text { UIS- } \\
\text { SOL VED } \\
\text { OHTHO } \\
\text { PHUS- } \\
\text { FHATE } \\
\text { (PO4) } \\
\text { (MG/L) }\end{array}$ & $\begin{array}{l}\text { PHOS- } \\
\text { PHATE } \\
\text { (PO } 4) \\
\text { (MG/L) }\end{array}$ & $\begin{array}{l}\text { OIS- } \\
\text { SOLVEA } \\
\text { SILICA } \\
\text { (SIOZ) } \\
\text { (MG/L) }\end{array}$ & $\begin{array}{l}\text { TUR- } \\
\text { HID- } \\
\text { ITY } \\
\text { (JTU) }\end{array}$ & $\begin{array}{l}\text { COLOR } \\
\text { (PLAT- } \\
\text { INUM- } \\
\text { COBALT } \\
\text { UNITS) }\end{array}$ & $\begin{array}{l}\text { TOTAL } \\
\text { ORGANIC } \\
\text { CAHAON } \\
\text { (C) } \\
\text { (MG/L) }\end{array}$ & $\begin{array}{l}\text { HIO- } \\
\text { CHEM- } \\
\text { ICAL } \\
\text { OXYGEN } \\
\text { DEMANSD } \\
\text { (MG/L) }\end{array}$ & $\begin{array}{l}\text { DEPTH } \\
\text { (FT) }\end{array}$ \\
\hline $\begin{array}{l}\text { OCT.. } 19 \\
01 \ldots . .\end{array}$ & 969 & .02 & - & - & 1. & (1) & 8.7 & 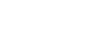 & $10 n$ & - & - & -- \\
\hline $15 \ldots$ & -- & .03 & .4 & -- & .92 & 1.0 & $=-$ & 25 & -- & $\sim$ & 3.0 & -- \\
\hline $\begin{array}{l}31 . . . \\
\text { Nov. }\end{array}$ & -- & .07 & .5 & -- & .64 & .75 & -- & -- & -- & $\cdots$ & -- & -- \\
\hline $\begin{array}{l}18 \ldots \\
30 \ldots\end{array}$ & $=$ & $\begin{array}{l}.04 \\
.03\end{array}$ & .7 & $=$ &.$\overline{76}$ & . & 15 & $=$ & $\begin{array}{l}16 n \\
--\end{array}$ & $=$ & $=$ & $=$ \\
\hline & -- & .01 & .9 & -- & 1.2 & 1.2 & - & 10 & 100 & -- & $2 . n$ & -- \\
\hline $31 \ldots$ & -. & .03 & .6 & -- & .57 & .51 & -- & - & - & -- & -- & - \\
\hline $\begin{array}{l}31 \ldots . . \\
\text { JAN.. } 19\end{array}$ & - & .01 & .4 & -- & -- & -- & 10 & -- & 70 & -- & -- & -- \\
\hline $\begin{array}{l}31 \ldots \\
\text { FEH. }\end{array}$ & -- & .06 & .3 & -- & .38 & .43 & -- & -- & -- & -- & -- & -- \\
\hline $\begin{array}{l}11 \ldots \\
28 \ldots\end{array}$ & $=$ & .04 & .0 & 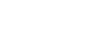 & .22 & .23 & - & $3 R$ & -- & - & 1.4 & $=$ \\
\hline $\begin{array}{l}28 . . . \\
\text { MAR. }\end{array}$ & $\cdots$ & .04 & $\bullet$ & $\cdots$ & .21 & .24 & $-\infty$ & -- & $\cdots$ & -- & $\cdots$ & $-\infty$ \\
\hline $\begin{array}{c}31 \ldots \\
A P R . .\end{array}$ & -- & .04 & .2 & -- & .28 & .34 & -- & - & - & - & -- & -- \\
\hline $\begin{array}{l}09 \ldots \\
30 \ldots\end{array}$ & $\ddot{-a}$ & $\begin{array}{l}.03 \\
.05\end{array}$ & $\because 0$ & $=$ & $\begin{array}{r}.25 \\
.54\end{array}$ & .30 & -- & 7 & - & -- & 1.6 & $\cdots$ \\
\hline MAY & & & & & & .59 & -- & -- & $\cdots$ & - & $\cdots$ & -2 \\
\hline $\begin{array}{l}26 . . . \\
31 \ldots .\end{array}$ & .02 & $\begin{array}{l}.06 \\
.03\end{array}$ & 3.6 & .27 & $\begin{array}{l}.47 \\
1.2\end{array}$ & $\begin{array}{l}.48 \\
1.2\end{array}$ & 11 & 12 & $\begin{array}{l}90 \\
--\end{array}$ & 13 & 2.8 & 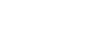 \\
\hline JUNE & & & & & & & & & & & & \\
\hline $\begin{aligned} & 30 \ldots \\
& J U L Y\end{aligned}$ & -- & .03 & 1.9 & -- & .41 & .47 & - & -- & -- & -- & -- & -- \\
\hline $01 \ldots$ & $=$ & .02 & 1.4 & - & - & -- & 7.8 & -- & 120 & -- & -- & -- \\
\hline $31 \ldots$ & -- & .03 & 1.3 & -- & .43 & .47 & -- & -- & $=$ & -- & $\cdots$ & $=$ \\
\hline AUG. & & & & & & & & & & & & \\
\hline $\begin{array}{l}13 \ldots \\
20 \ldots\end{array}$ &.$\overline{07}$ &.$\overline{03}$ &. & .36 & $\begin{array}{l}.28 \\
.25\end{array}$ & $\begin{array}{r}.35 \\
.35\end{array}$ & $\begin{array}{l}5.5 \\
5.4\end{array}$ & $\begin{array}{l}7 \\
5\end{array}$ & 100 & 34 & $2 \cdot ?$ & - \\
\hline & $S P E$ & ECIFIC CON & JNDUCTANCE & (MICROMH & $\mathrm{SS} / \mathrm{CM}$ AT 2 & $25^{\circ} \mathrm{Cl}$, WATE & ER YEAR D & CTOBER 196 & 69 TO SEF & PTEMBER 19 & 70 & \\
\hline DAY & OCTOBER & NOVEMBER & CECEMBER & JANUARY & FEBRUARY & MARCH & APRIL & MAY & JUNE & JULY & AUGUST & SEPTEMBER \\
\hline $\begin{array}{l}1 \ldots \ldots \\
2 \ldots \ldots \\
3 \ldots \ldots \\
4 \ldots \ldots \\
5 \ldots \ldots\end{array}$ & $\begin{array}{r}69 \\
67 \\
74 \\
74 \\
103\end{array}$ & $\begin{array}{l}300 \\
300 \\
300 \\
305 \\
305\end{array}$ & $\begin{array}{l}340 \\
345 \\
345 \\
350 \\
350\end{array}$ & $\begin{array}{l}95 \\
89 \\
91 \\
90 \\
90\end{array}$ & $\begin{array}{l}123 \\
116 \\
102 \\
104 \\
124\end{array}$ & $\begin{array}{l}54 \\
69 \\
68 \\
79 \\
77\end{array}$ & $\begin{array}{l}43 \\
42 \\
41 \\
41 \\
40\end{array}$ & $\begin{array}{l}178 \\
175 \\
188 \\
185 \\
198\end{array}$ & $\begin{array}{r}175 \\
128 \\
127 \\
68 \\
69\end{array}$ & $\begin{array}{l}110 \\
139 \\
137 \\
148 \\
148\end{array}$ & $\begin{array}{l}\because- \\
-- \\
--\end{array}$ & $\begin{array}{l}56 \\
54 \\
48 \\
50 \\
47\end{array}$ \\
\hline $\begin{array}{r}8 \ldots \ldots \\
7 \ldots \ldots \\
8 \ldots \ldots \\
10 \ldots \ldots\end{array}$ & $\begin{array}{l}105 \\
134 \\
135 \\
165 \\
160\end{array}$ & $\begin{array}{l}305 \\
305 \\
310 \\
315 \\
325\end{array}$ & $\begin{array}{l}370 \\
370 \\
355 \\
360 \\
350\end{array}$ & $\begin{array}{l}84 \\
85 \\
83 \\
67 \\
68\end{array}$ & $\begin{array}{l}72 \\
64 \\
64 \\
64 \\
62\end{array}$ & $\begin{array}{l}88 \\
87 \\
88 \\
89 \\
76\end{array}$ & $\begin{array}{l}40 \\
44 \\
43 \\
43 \\
44\end{array}$ & $\begin{array}{l}199 \\
210 \\
210 \\
205 \\
203\end{array}$ & $\begin{array}{l}53 \\
53 \\
45 \\
44 \\
45\end{array}$ & $\begin{array}{l}148 \\
177 \\
189 \\
185 \\
170\end{array}$ & $\begin{array}{l}=- \\
=- \\
=\end{array}$ & $\begin{array}{l}47 \\
59 \\
55 \\
85 \\
84\end{array}$ \\
\hline $\begin{array}{l}11 \ldots \ldots \\
12 \ldots \ldots \\
13 \ldots \ldots \\
14 \ldots \ldots \\
15 \ldots \ldots\end{array}$ & $\begin{array}{l}180 \\
180 \\
205 \\
205 \\
220\end{array}$ & $\begin{array}{l}322 \\
331 \\
330 \\
329 \\
328\end{array}$ & $\begin{array}{l}320 \\
320 \\
170 \\
165 \\
125\end{array}$ & $\begin{array}{l}67 \\
66 \\
70 \\
65 \\
65\end{array}$ & $\begin{array}{l}62 \\
60 \\
66 \\
62 \\
63\end{array}$ & $\begin{array}{l}77 \\
68 \\
67 \\
61 \\
63\end{array}$ & $\begin{array}{l}45 \\
45 \\
53 \\
50 \\
75\end{array}$ & $\begin{array}{l}220 \\
220 \\
231 \\
230 \\
248\end{array}$ & $\begin{array}{l}46 \\
52 \\
50 \\
48 \\
47\end{array}$ & $\begin{array}{l}171 \\
170 \\
171 \\
150 \\
151\end{array}$ & $\begin{array}{l}=- \\
\ddot{-} \\
=-\end{array}$ & $\begin{array}{r}103 \\
105 \\
92 \\
93 \\
124\end{array}$ \\
\hline $\begin{array}{l}16 \ldots \ldots \\
17 \ldots \ldots \\
18 \ldots \ldots \\
19 \ldots \ldots \\
20 \ldots \ldots\end{array}$ & $\begin{array}{l}220 \\
235 \\
235 \\
250 \\
250\end{array}$ & $\begin{array}{l}325 \\
329 \\
338 \\
340 \\
337\end{array}$ & $\begin{array}{l}120 \\
122 \\
121 \\
137 \\
139\end{array}$ & $\begin{array}{l}67 \\
69 \\
68 \\
68 \\
71\end{array}$ & $\begin{array}{l}80 \\
60 \\
60 \\
57 \\
56\end{array}$ & $\begin{array}{l}64 \\
64 \\
63 \\
65 \\
62\end{array}$ & $\begin{array}{r}74 \\
99 \\
97 \\
114 \\
114\end{array}$ & $\begin{array}{l}247 \\
220 \\
222 \\
223 \\
222\end{array}$ & $\begin{array}{r}63 \\
62 \\
104 \\
104 \\
131\end{array}$ & $\begin{array}{l}170 \\
169 \\
162 \\
169 \\
152\end{array}$ & $\begin{array}{l}-- \\
-- \\
--\end{array}$ & $\begin{array}{l}125 \\
162 \\
160 \\
182 \\
183\end{array}$ \\
\hline $\begin{array}{l}21 \ldots \ldots \\
22 \ldots \ldots \\
23 \ldots \ldots \\
24 \ldots \ldots \\
25 \ldots \ldots\end{array}$ & $\begin{array}{l}250 \\
250 \\
250 \\
250 \\
265\end{array}$ & $\begin{array}{l}335 \\
349 \\
349 \\
350 \\
350\end{array}$ & $\begin{array}{l}145 \\
145 \\
160 \\
160 \\
130\end{array}$ & $\begin{array}{l}68 \\
74 \\
72 \\
79 \\
77\end{array}$ & $\begin{array}{l}58 \\
58 \\
55 \\
55 \\
56\end{array}$ & $\begin{array}{l}63 \\
80 \\
80 \\
79 \\
80\end{array}$ & $\begin{array}{l}122 \\
120 \\
135 \\
135 \\
150\end{array}$ & $\begin{array}{l}224 \\
223 \\
243 \\
243 \\
260\end{array}$ & $\begin{array}{l}133 \\
135 \\
135 \\
135 \\
135\end{array}$ & $\begin{array}{l}152 \\
180 \\
182 \\
170 \\
168\end{array}$ & $\begin{array}{l}=- \\
z- \\
--\end{array}$ & $\begin{array}{l}200 \\
200 \\
214 \\
213 \\
213\end{array}$ \\
\hline $\begin{array}{l}26 \ldots \ldots \\
27 \ldots \ldots \\
28 \ldots \ldots \\
29 \ldots \ldots \\
30 \ldots \ldots \\
31 \ldots \ldots\end{array}$ & $\begin{array}{l}261 \\
270 \\
270 \\
280 \\
280 \\
290\end{array}$ & $\begin{array}{r}359 \\
359 \\
361 \\
360 \\
345 \\
-0\end{array}$ & $\begin{array}{r}130 \\
128 \\
115 \\
108 \\
95 \\
94\end{array}$ & $\begin{array}{r}93 \\
92 \\
200 \\
102 \\
112 \\
110\end{array}$ & $\begin{array}{l}57 \\
54 \\
55 \\
-- \\
--\end{array}$ & $\begin{array}{r}67 \\
65 \\
67 \\
64 \\
42 \\
134\end{array}$ & $\begin{array}{l}150 \\
160 \\
158 \\
161 \\
160 \\
-0\end{array}$ & $\begin{array}{l}259 \\
263 \\
263 \\
228 \\
229 \\
178\end{array}$ & $\begin{array}{r}138 \\
137 \\
135 \\
134 \\
96 \\
--\end{array}$ & $\begin{array}{l}111 \\
111 \\
109 \\
109 \\
128 \\
130\end{array}$ & $\begin{array}{l}=- \\
=- \\
-- \\
--\end{array}$ & $\begin{array}{l}210 \\
212 \\
210 \\
231 \\
234 \\
-2\end{array}$ \\
\hline AVERAGE & 199 & 329 & 215 & 80 & 70 & 72 & 87 & 220 & 94 & 152 & -- & 135 \\
\hline
\end{tabular}


02319000 WITHLACOOCHEE RIVER NEAR PINETTA, FLA.--Continued

CHEMICAL ANALYSES, WATER YEAR OCTOBER 1969 TO SEPTEMBER 1970 (TRACE METALS)

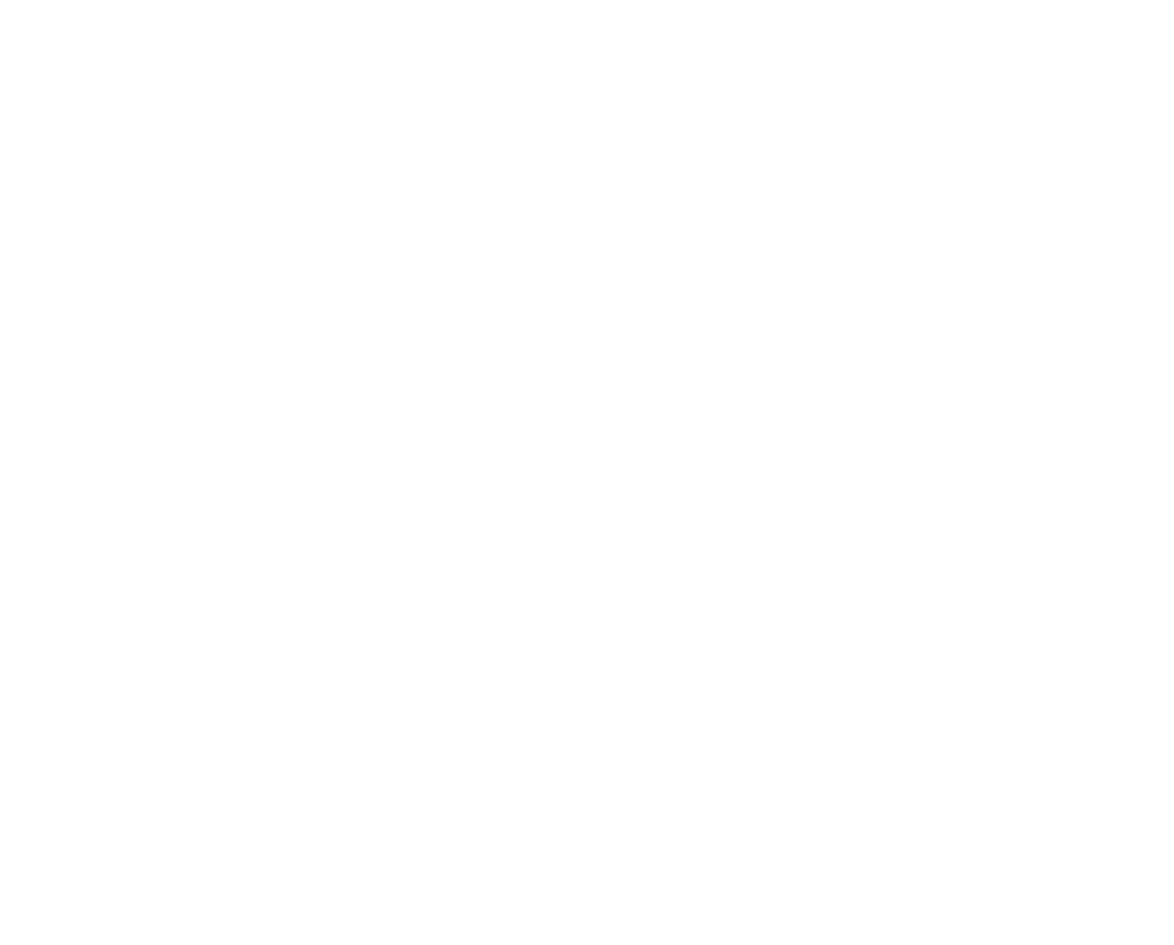

02320500 SUYANNEE RIVER AT BRANFORD, FLA.

LOCATION.--Lat $29^{\circ} 57^{\prime} 20^{\prime \prime}$, long $82^{\circ} 55^{\prime} 40^{\prime \prime}$, in NE $\frac{1}{4}$ sec. 20 , T. 6 S., R.14 E., Suwannee County, at gaging station near left bank on upstream side of bridge on U.S. Highways 27 and 129 at Branford, 10.8 miles upstream from Santa Fe left bank

DRAINAGE AREA.--7,740 sq mi, approximately, includes part of water shed in Okefenokee Swamp which is indeterminate. PERIOD OF RECORD.--Chemical analyses: January 1954 to September 1957, October 1962 to September 1970.

Yater temperatures: January 1954 to September 1957, October 1962 to September 1970.

EXTRBYES $-1969-70$ :

Specific conductance: Maximum daily, 286 micromhos May 27 ; minimum daily, 38 micrombos Aug. 18, 19, 21, 25.
Color: Yaximum daily, 320 units on several days during August and September; minimum daily, 40 units May 26-28.

Color: Maximum dally, 320 units on several days during August and Septem

Period of record:

Dissolved solids (1954-57): Maximum, $224 \mathrm{mg} / 1 \mathrm{Aug} .11-20$, Dec. 11-20, 1954; minimum, $74 \mathrm{mg} / 1 \mathrm{kay} 11-20,1956$, Apr $1-10,1957$

Hardness (1954-57): Maximum, $177 \mathrm{mg} / 1 \mathrm{Dec} .11-20,1954$, Jan. 1-10, 11-20, 1955; minimum, $18 \mathrm{mg} / 1 \mathrm{June} 11-20$, 1957.

Specific conductance: Maximum daily, 435 micromhos Dec. 13, 1954; minimum dally, 25 micromhos Dec. 13, 1964. Color (1967-70): Maximum daily, 320 units on several days during September 1969, August and September 1970;

minimum, 5 units Nov. $5,14,1968$

Water temperatures: Maximum, $30.0^{\circ} \mathrm{C}$ on several days during July and August $1968 ;$ minimum, $7,0^{\circ} \mathrm{C} \mathrm{Jan} .30, \mathrm{Feb}, 3$, 4,1966 . 
02320500 SUWANNEE RIVER AT BRANFORD, FLA.--Continued

CHEMICAL ANALYSES, WATER YEAR OCTOBER 1969 TO SEPTEMBER 1970

$$
\text { (MAJOR CONSTITUENTS) }
$$

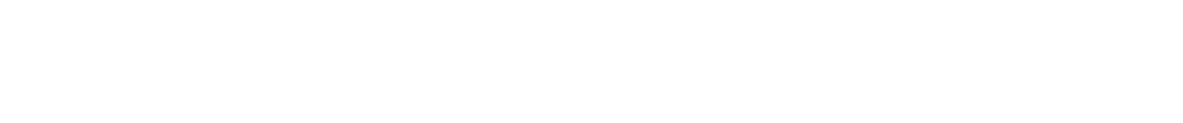
NOV.. 1969

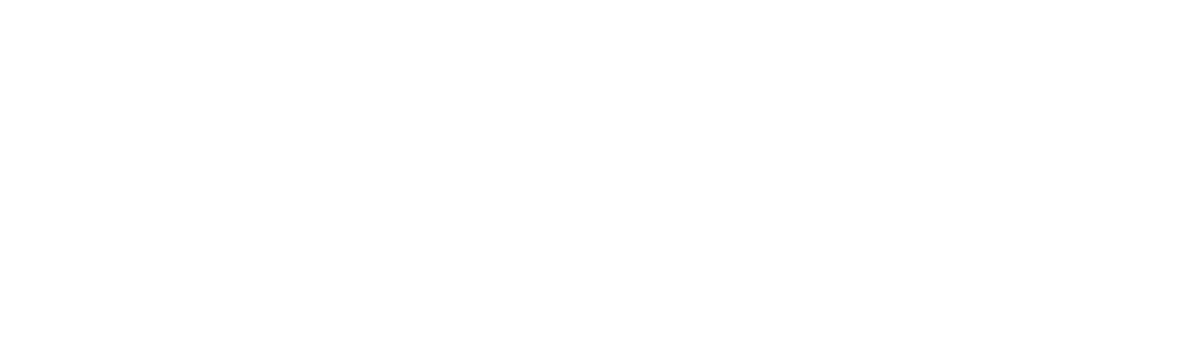

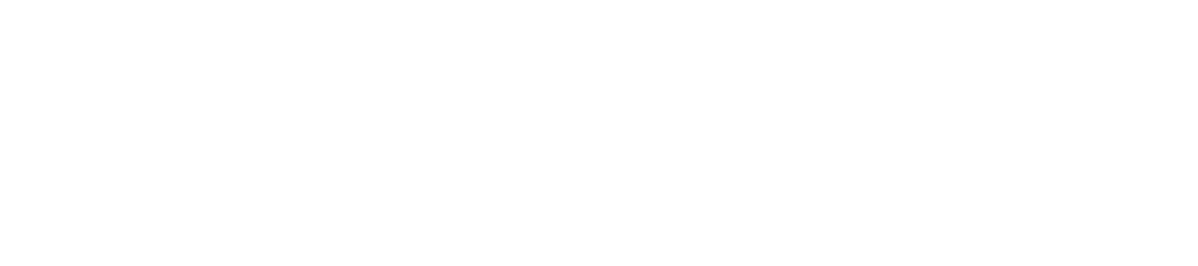

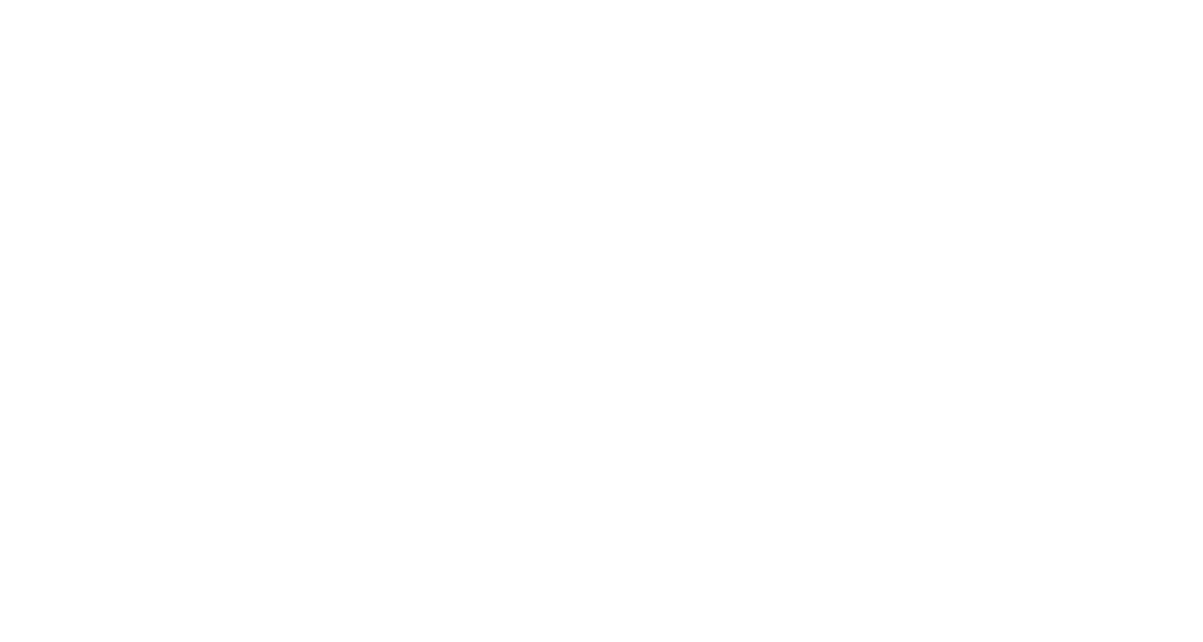

\begin{tabular}{|c|c|c|c|c|c|c|c|c|c|c|c|c|}
\hline DATE & 7 佂 & $\begin{array}{l}\text { STAGE } \\
\text { (FT } \\
\text { ABOVE } \\
\text { DATUM) }\end{array}$ & $\begin{array}{l}\text { DIS- } \\
\text { CHARGE } \\
\text { (CFS) }\end{array}$ & $\begin{array}{l}\text { TEMPER- } \\
\text { ATURE } \\
\text { (DEG C) }\end{array}$ & $\begin{array}{l}\text { DIS- } \\
\text { SOLVED } \\
\text { OXYGEN } \\
\text { (MG L ) }\end{array}$ & $\begin{array}{l}\text { PER- } \\
\text { CENT } \\
\text { SATUR- } \\
\text { ATION }\end{array}$ & $\begin{array}{l}\text { SPE- } \\
\text { CIFIC } \\
\text { CON- } \\
\text { DUCT- } \\
\text { ANCE } \\
\text { (AICRO- } \\
\text { MHOS) }\end{array}$ & $\begin{array}{c}\text { PH } \\
\text { (UNITS) }\end{array}$ & $\begin{array}{l}\text { BICAP- } \\
\text { BONATE } \\
\text { (HCN3) } \\
\text { (MG } / L)\end{array}$ & $\begin{array}{l}\text { CAR- } \\
\text { BONATE } \\
\text { (CO3) } \\
\text { (MG/L) }\end{array}$ & $\begin{array}{l}\text { TRANS- } \\
\text { PAR- } \\
\text { ENCY } \\
\text { SECCHI } \\
\text { DISK } \\
\text { (IN) }\end{array}$ & $\begin{array}{l}\text { DEOTH } \\
\text { (r } F T)\end{array}$ \\
\hline $\begin{array}{l}\text { DEC., } \\
03 . . . \\
\text { FEB., }\end{array}$ & 1030 & 7.65 & - & 16.0 & 7.0 & 70 & 203 & 7.3 & 108 & 0 & $\cdots$ & $\cdots$ \\
\hline $\begin{array}{l}02 . . . \\
04 \ldots \\
\text { MAR. }\end{array}$ & $\begin{array}{l}1030 \\
1200\end{array}$ & $\begin{array}{r}7.95 \\
11.81\end{array}$ & $\begin{array}{l}5400 \\
8750\end{array}$ & $\begin{array}{l}14.5 \\
14.0\end{array}$ & $\begin{array}{l}8.4 \\
7.4\end{array}$ & $\begin{array}{l}82 \\
71\end{array}$ & $\begin{array}{r}185 \\
81\end{array}$ & $\begin{array}{l}7.0 \\
7.5\end{array}$ & $\overline{62}$ & $\overline{0}$ & $\because$ & $\overline{-}$ \\
\hline $\begin{array}{c}30 \ldots \\
\text { MAY } \\
26 \ldots\end{array}$ & 1300 & 16.14 & 12800 & 18.5 & 6.2 & $\cdots$ & 284 & 6.5 & 148 & $\cdots$ & $\cdots$ & - \\
\hline
\end{tabular}


SUWANNEE RIVER BASIN

02320500 SUWANNEE RIVER AT BRANFORD, FLA.--Continued SPECIFIC CONDUCTANCE (MICROMHOS/CM AT $25^{\circ} \mathrm{C}$ ), WATER YEAR OCTOBER 1969 TO SEPTEMBER 1970

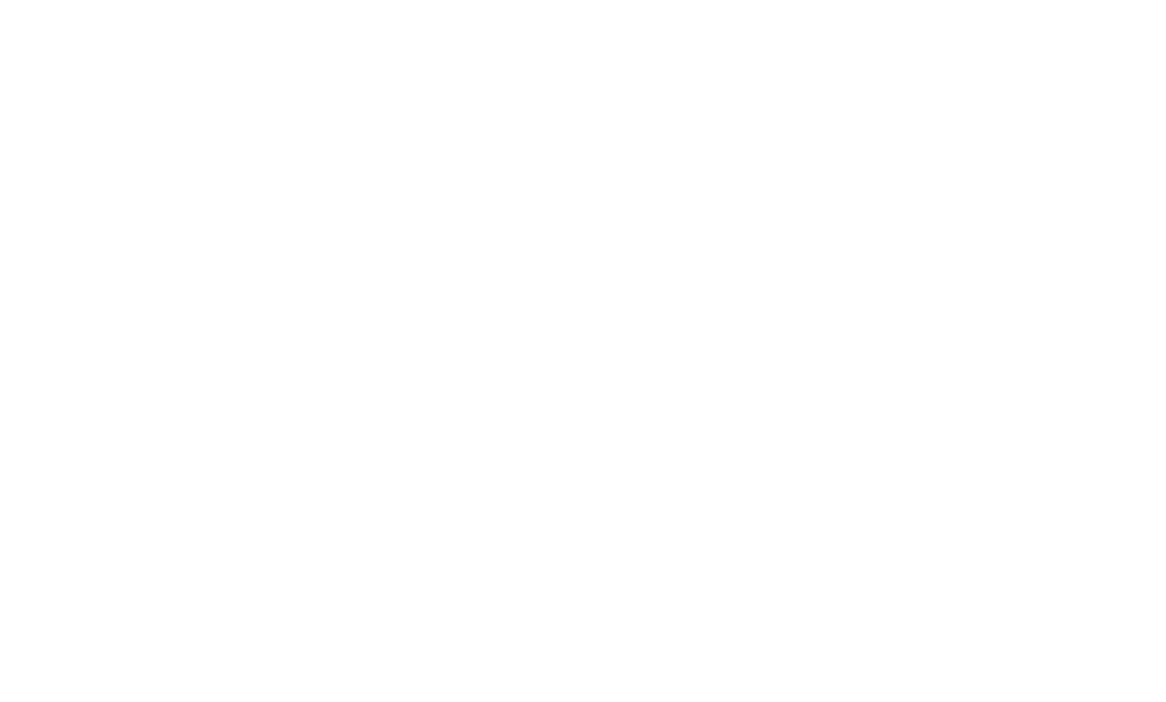

COLOR (UNITS), WATER YEAR OCTOBER 1969 TO SEPTEMBER 1970

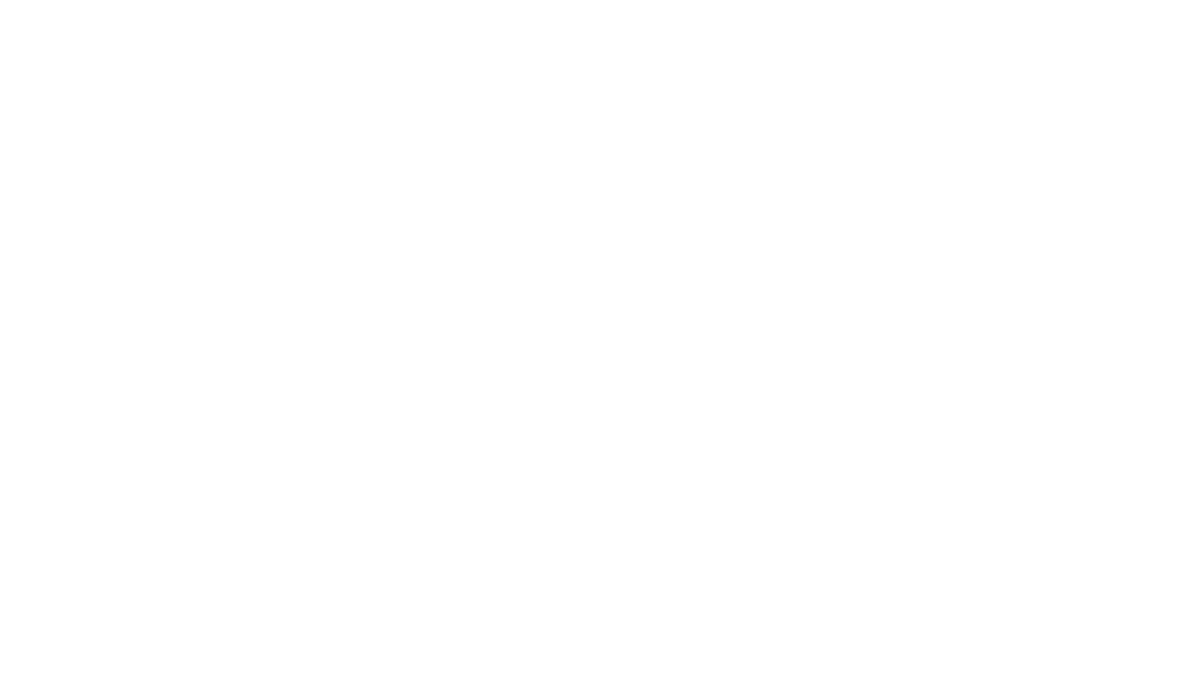

(TRACE METALS)

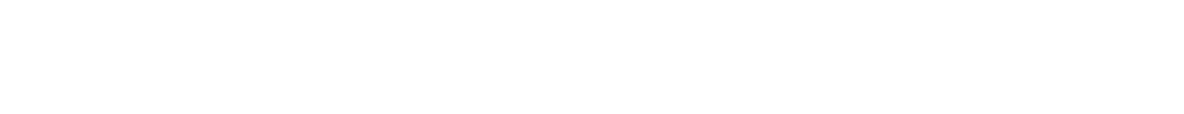

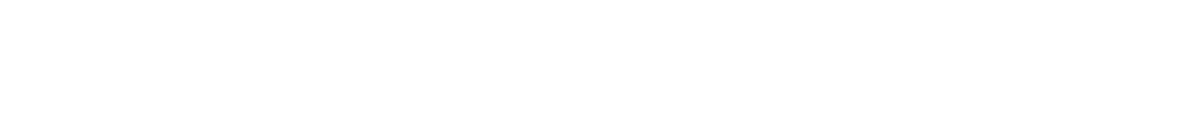


02320500 SUWANNEE RIVER AT BRANFORD, FLA.--Continued CHEMICAL ANALYSES, WATER YEAR OCTOBER 1969 TO SEPTEMBER 1970

\begin{tabular}{|c|c|c|c|c|c|c|c|c|c|c|c|c|}
\hline $\begin{array}{r}\text { IM } \\
\mathrm{D} \\
\text { DATE } 100 \\
\text { DEC., } 1969\end{array}$ & $\begin{array}{l}\text { ME- } \\
\text { IATE } \\
\text { OLI I } \\
\text { FORM } \\
\text { COLL. } \\
\text { ER } \\
\text { MLI }\end{array}$ & $\begin{array}{l}\text { DELAYED } \\
\text { COLI- } \\
\text { FORM } \\
\text { ICO'- } \\
\text { ONIES } \\
\text { PER } \\
100 \mathrm{ML} \text { ) }\end{array}$ & $\begin{array}{c}\text { DIL } \\
\text { AND } \\
\text { GREASE } \\
\text { (MG/L) }\end{array}$ & $\begin{array}{l}\text { METHY- } \\
\text { LENE } \\
\text { BLUE } \\
\text { ACTIVE } \\
\text { SUB- } \\
\text { STANCE } \\
\text { (MG/L) }\end{array}$ & $\begin{array}{l}\text { DIS- } \\
\text { SOLVED } \\
\text { ORGANIC } \\
\text { NITRD- } \\
\text { GEN } \\
\text { (N) } \\
\text { (MG/L) }\end{array}$ & $\begin{array}{l}\text { PHENOLS } \\
\text { (UG/L) }\end{array}$ & $\begin{array}{l}\text { IODIDE } \\
(I) \\
(M G / L)\end{array}$ & $\begin{array}{l}\text { TOTAL } \\
\text { ALUM- } \\
\text { INUM } \\
\text { (AL) } \\
\text { (UG/L) }\end{array}$ & $\begin{array}{l}\text { DIS- } \\
\text { SOLVED } \\
\text { COBALT } \\
\text { (CO) } \\
\text { (UG/L) }\end{array}$ & $\begin{array}{l}\text { TOTAL } \\
\text { IRON } \\
\text { (FE) } \\
\text { (UG/L) }\end{array}$ & $\begin{array}{l}\text { DIS- } \\
\text { SOLVED } \\
\text { LITHIUM } \\
\text { (LI) } \\
\text { (UG/L) }\end{array}$ & $\begin{array}{c}\text { DIS- } \\
\text { SOLVED } \\
\text { MERCURY } \\
\text { (HG) } \\
\text { (UG/L) }\end{array}$ \\
\hline FF:.: I I & 1411 & -- & $\sim$ & -- & - & -- & - & -- & -- & - & -- & -- \\
\hline MAR... & sen & -- & - & $\cdots$ & $\sim$ & -- & -- & -- & -- & - & - & $\cdots$ \\
\hline${ }_{\operatorname{moy}}^{30} \cdots$ & 3माका & - & +- & -- & -- & - & -- & - & - & - & -- & -- \\
\hline sh.... & $5 m a$ & - & -- & -- & -- & -- & -- & מल"I & -- & -- & -- & -- \\
\hline
\end{tabular}

TEMPERATURE $\left({ }^{\circ} \mathrm{C}\right)$ OF WATER, WATER YEAR OCTOBER 1969 TO SEPTEMBER 1970

\begin{tabular}{|c|c|c|c|c|c|c|c|c|c|c|c|c|}
\hline . IAY & $x T$ & $\mathrm{NOSV}$ & ot $c$ & JA A & FES & MAK & $A P R$ & YAY & JUN & $\mathrm{JUL}$ & AUG & SEP \\
\hline i & 24.5 & $2 ? .4$ & 17.0 & 15.5 & 14.5 & 14.0 & 20.0 & 24.0 & 24.0 & 25.0 & 27.0 & 27.5 \\
\hline 6 & $2+.2$ & $\angle 2.3$ & 17.0 & 15.0 & 15.2 & 14.5 & 21.0 & 23.3 & 24.5 & 26.0 & 27.0 & 28.0 \\
\hline 3 & 24.5 & 22.5 & 17.0 & 15.0 & 16.0 & 14.5 & 20.5 & 23.0 & 25.0 & 26.0 & 27.0 & 28.0 \\
\hline 4 & 74.3 & 21.1 & 16.0 & 14.0 & 13.0 & 16.0 & 21.0 & 23.5 & 25.0 & 26.0 & 27.0 & 28.0 \\
\hline 5 & 24.5 & 19.0 & 10.0 & 14.0 & 13.0 & 17.0 & 21.0 & $2 ? .0$ & 25.0 & 26.0 & 29.0 & 28.0 \\
\hline u & 240 & 100 & 10.5 & 14.5 & 13.0 & 17.5 & 20.0 & 21.5 & 24.5 & 20.5 & 28.0 & 28.5 \\
\hline ? & 24.0 & $1+.0$ & $1=.5$ & 12.0 & 13.0 & iR,o & 20.0 & 22.5 & 24.0 & 26.0 & 27.5 & - \\
\hline a & 24.0 & 170 & 12.0 & 10.0 & 12.0 & 19.0 & 20.0 & 22.5 & 24.5 & 26.0 & 27.5 & 23.0 \\
\hline O & 24.5 & 19.0 & $\ldots$ & 10.0 & 12.0 & 18.0 & 20.0 & 23.0 & 25.0 & 26.0 & 27.0 & 28.0 \\
\hline ir & $2+.5$ & $1=.0$ & 17.0 & 9.5 & 11.0 & 10.0 & 17.5 & 23.0 & 25.0 & 26.0 & 27.0 & 27.5 \\
\hline 16 & 24.7 & 17.5 & [R. & 3.0 & 12.0 & 10.0 & $2 \mathrm{~J} .0$ & 23.0 & 25.0 & 26.0 & 26.0 & 27.5 \\
\hline 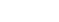 & 24.0 & 18.5 & 19.0 & 10.6 & 12.5 & 18.5 & 20.0 & 23.5 & 25.0 & 25.5 & 26.0 & 27.0 \\
\hline is & 21.2 & 14.5 & 14.5 & $1 ;, 1]$ & 12.5 & $12 . ?$ & 20.5 & 24.5 & 25.0 & 25.5 & 26.0 & 27.0 \\
\hline 14 & $2+.11$ & 12.0 & 14.5 & 7.6 & 12.5 & 16.0 & 21.0 & 24.0 & 25.0 & 25.0 & 26.0 & 27.0 \\
\hline is & $2+0$ & $1 \mathrm{~A} .5$ & 15.0 & 10.7 & 13.0 & 16.5 & 21.0 & 24.0 & 25.0 & 27.0 & 26.0 & 20.5 \\
\hline in & 24.3 & 17.0 & $1=0$ & 11.6 & 14.5 & 17.0 & 21.0 & 23.5 & 25.0 & 26.0 & 26.0 & 26.0 \\
\hline 17 & 23.0 & 16.0 & 15.0 & 11.3 & 15.0 & 17.0 & 22.0 & 23.0 & 26.5 & 26.0 & 27.0 & 26.0 \\
\hline i. & $\because \therefore$ & 16. & 14.0 & 12.0 & 15.0 & 17.0 & 22.0 & $? 3.5$ & 26.0 & 27.0 & 27.0 & 26.0 \\
\hline i) & 11.3 & 14.5 & $\ldots$ & 12.0 & 15.0 & 17.5 & 22.0 & 23.0 & 26.0 & 26.5 & 27.0 & 26.0 \\
\hline$\therefore$ & $240^{7}$ & 15.5 & 14.0 & 12.5 & 14.5 & 12.5 & 22.0 & 23.0 & 26.0 & 26.0 & 27.0 & 26.0 \\
\hline$<1$ & 34.0 & 15.5 & 14.0 & 12.0 & 14.0 & 10.0 & 23.0 & 24.0 & 26.0 & 26.5 & 27.0 & 26.0 \\
\hline 72 & $(4)$, & $150=$ & 14.9 & 12.0 & 14.0 & 18.0 & 22.5 & 23.0 & 26.0 & 26.0 & 27.0 & 26.5 \\
\hline$\therefore$ & 23.11 & $1+.5$ & 14.0 & 12.0 & 14.0 & 17.5 & 23.0 & 24.0 & 25.5 & $26 . c$ & 27.0 & 26.5 \\
\hline 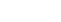 & 22.0 & 17.0 & 14.6 & 12,3 & $15 . ?$ & 19.7 & 23.0 & 24.0 & 25.5 & 26.0 & 27.0 & 26.0 \\
\hline 3 & 22.0 & 10.5 & 15.5 & $12 . \mathrm{C}$ & 15.0 & 19.5 & 23.0 & 24.0 & $2 n .0$ & 26.0 & 27.0 & 25.5 \\
\hline 2 & $22 \cdot 5$ & 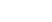 & 14.5 & 13.6 & 14.0 & 20.0 & 23.5 & 24.0 & 25.0 & 27.0 & 28.0 & 25.0 \\
\hline 27 & $27 \cdot 3$ & $1 \% .0$ & 15.0 & 14.0 & 12.5 & 19.0 & 23.0 & 24.0 & 25.0 & 26.0 & 27.0 & 25.0 \\
\hline in & $? \therefore .5$ & $i=0$ & $1 \supset . ?$ & 13.5 & 14.0 & 20.0 & 23.5 & 24.0 & 25.0 & 26.0 & 27.0 & 25.0 \\
\hline$\leftrightarrow$ & 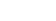 & 18.5 & 14.3 & 14.5 & - & 20.0 & 23.5 & 24.0 & 25.5 & 27.0 & 27.0 & 24.0 \\
\hline 10 & 71.1 & 17.11 & $1 \mathrm{b.c}$ & 19.0 & -- & 19.0 & 24.3 & 24.0 & 25.0 & 27.0 & 27.0 & 23.0 \\
\hline 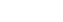 & 21.7 & -- & $1 t \cdot C$ & 14.5 & -- & 12.0 & -- & 24.0 & $=-$ & 27.0 & 27.0 & $-\infty$ \\
\hline AVERAGE & 23.5 & $1 \mathrm{H} \cdot 0$ & 15.5 & 12.5 & 13.5 & 19.1 & 21.5 & 23.5 & 25.0 & 26.0 & $2 \top .0$ & 26.5 \\
\hline
\end{tabular}

02321500 SANTA FE RIVER AT WORTHINGTON SPRINGS, FLA.

LOCATION, - - Lat $29^{\circ} 55^{\prime} 18^{\prime \prime}$, long $82^{\circ} 25^{\prime} 35^{\prime \prime}$, in SE sec.32, T.6 S., R.19 E., Alachua County, at gaging station near center of span on downstream side of bridge on State Highway 121, 0.5 mile south of worthington springs, and center of span on downstream side
$0.8 \mathrm{mile}$ downstream from New River.

DRAINAGE AREA,--582 sq $\mathrm{mi}$.

PERIOD OF RECORD.--Chemical analyses: July 1957 to September 1960, October 1963 to September 1970.

EXTREMES, - - 1969-70:

Specteic conductance: Kaximum daily, 110 micromhos July 4; minimum datly, 31 micromhos Feb. 5, Mar. 30, 31.

Water temperatures: Laximum, $27.5^{\circ} \mathrm{C}$ Aug. 17,$31 ;$ minimum, $11.0^{\circ} \mathrm{C}$ on several days during December.

period of record:

Dissolved solids (1957-60): Maximum, $124 \mathrm{mg} / 1$ July $21 \mathrm{m1}, 1960 ;$ minimum, $53 \mathrm{mg} / 1$ Mar. 18 22, 1960 .

Specific conductance: Maximum daily, 210 micromhos May 29, 1965; minimum daily, 31 micromhos Aug. 3i, 1968,

Feb. 5, Mar. 30, 3i, 1970 .

pater temperatures: Haximum, $32.0^{\circ} \mathrm{C} \mathrm{July} 7,1962$; minimura $4.0^{\circ} \mathrm{C} \mathrm{Feb}, 19,1958$.

\begin{tabular}{|c|c|c|c|c|c|c|c|c|c|c|c|c|}
\hline & & & CHEMICAL & ANALYSE & $\begin{array}{l}\text { WATER } \\
\text { IMAJO }\end{array}$ & $\begin{array}{l}\text { EAR OCTL } \\
\text { CONSTI }\end{array}$ & $\begin{array}{l}\text { R } 1969 \\
\text { ENS : }\end{array}$ & O SEPTE & IER 1970 & & & \\
\hline DATE & $\begin{array}{l}\text { DIS- } \\
\text { CHARGE } \\
\text { (CFS) }\end{array}$ & $\begin{array}{l}\text { TEMPER- } \\
\text { ATURE } \\
\text { (DEG C) }\end{array}$ & $\begin{array}{l}\text { SFE- } \\
\text { CIFIC } \\
\text { CON- } \\
\text { DUCT- } \\
\text { AUCE } \\
\text { (MICRO- } \\
\text { MHOS) }\end{array}$ & $\begin{array}{l}\text { OIS- } \\
\text { SOLVED } \\
\text { IRON } \\
\text { (FE) } \\
(U G / L)\end{array}$ & $\begin{array}{l}\text { UIS- } \\
\text { SOLVEO } \\
\text { CAL- } \\
\text { CIUM } \\
\text { (CA) } \\
(M G / L)\end{array}$ & $\begin{array}{l}\text { DIS- } \\
\text { SOLVEO } \\
\text { MAG- } \\
\text { NE- } \\
\text { SIUM } \\
\text { (MG) } \\
\text { (MG/L) }\end{array}$ & $\begin{array}{l}\text { DIS- } \\
\text { SOLVED } \\
\text { STRONF } \\
\text { TIUM } \\
\text { (SR) } \\
\text { (UG/L) }\end{array}$ & $\begin{array}{l}\text { OIS- } \\
\text { SOLVEA } \\
\text { SOOIUY } \\
\text { (NA) } \\
\text { (MG/L) }\end{array}$ & $\begin{array}{l}\text { DIC- } \\
\text { SOLVEO } \\
\text { PO- } \\
\text { TAC- } \\
\text { SIIJM } \\
\text { (K) } \\
\text { (MG/L) }\end{array}$ & $\begin{array}{l}\text { BICAR- } \\
\text { BONATE } \\
\text { (HCO3) } \\
\text { (MG/L) }\end{array}$ & $\begin{array}{l}\text { CAR- } \\
\text { BON } 1 T E \\
(\mathrm{CO} 3) \\
(\mathrm{MG} / \mathrm{L})\end{array}$ & $\begin{array}{c}\mathrm{PH} \\
\text { (UNITS) }\end{array}$ \\
\hline $\begin{array}{l}\text { OCT. } \\
02 \ldots \\
13 \ldots\end{array}$ & $\begin{array}{l}1969 \\
772 \\
900\end{array}$ & 25.0 & $6 B$ & -- & $\begin{array}{r}5.7 \\
-.\end{array}$ & 2.0 & -- & 4.0 & $\therefore 9$ & 14 & $=$ & 6.1 \\
\hline $\begin{array}{l}\text { NOV. } \\
\text { PR.... } \\
\text { DEC. }\end{array}$ & 500 & 13.5 & 80 & -- & 5.6 & 2.0 & -. & 6.7 & .8 & 9 & -- & 6.0 \\
\hline $\begin{array}{l}08 \ldots . . \\
\text { JAN.. }\end{array}$ & $1970^{510}$ & 13.5 & -- & -- & 6.1 & $2 . ?$ & - & 6.4 & 1.4 & -- & - & - \\
\hline $\begin{array}{l}O B . . \\
\text { FEB. }\end{array}$ & 3450 & 7.0 & 42 & -- & 3.2 & 1.2 & -- & 3.7 & .9 & 6 & - & 6.0 \\
\hline $\begin{array}{l}09 . . \\
\text { MAR. }\end{array}$ & 3800 & 11.5 & 47 & $=$ & - & - & - & -- & -- & - & $-\infty$ & -- \\
\hline $10 .$. & 1080 & 26.0 & 62 & - & 4.9 & 1.8 & -- & 4.8 & .9 & in & -- & 6.2 \\
\hline Mar... & 2900 & 17.5 & 43 & -- & $-\infty$ & - & -- & $=$ & - & -- & - & -- \\
\hline $\begin{array}{l}23 \ldots . . \\
\text { JUNE. }\end{array}$ & 64 & 25.0 & 79 & 260 & 6.1 & $2 \cdot ?$ & 310 & 6.7 & .5 & 14 & 0 & 0.4 \\
\hline $\begin{array}{l}30 \ldots \\
\text { AUG. }\end{array}$ & 307 & 23.5 & 85 & -- & R. 0 & $3 . n$ & -- & 5.6 & 1.0 & 19 & -- & 7.3 \\
\hline $17 \ldots$ & 2100 & 27.0 & 52 & - & 4.5 & 1.5 & - & 3.3 & 1.1 & s & 0 & 6.1 \\
\hline
\end{tabular}


02321500 SANTA FE RIVER AT WORTHINGTON SPRINGS, FLA.--Continued

CHEMICAL ANALYSES, WATER YEAR OCTOBER 1969 TO SEPTEMBER 1970

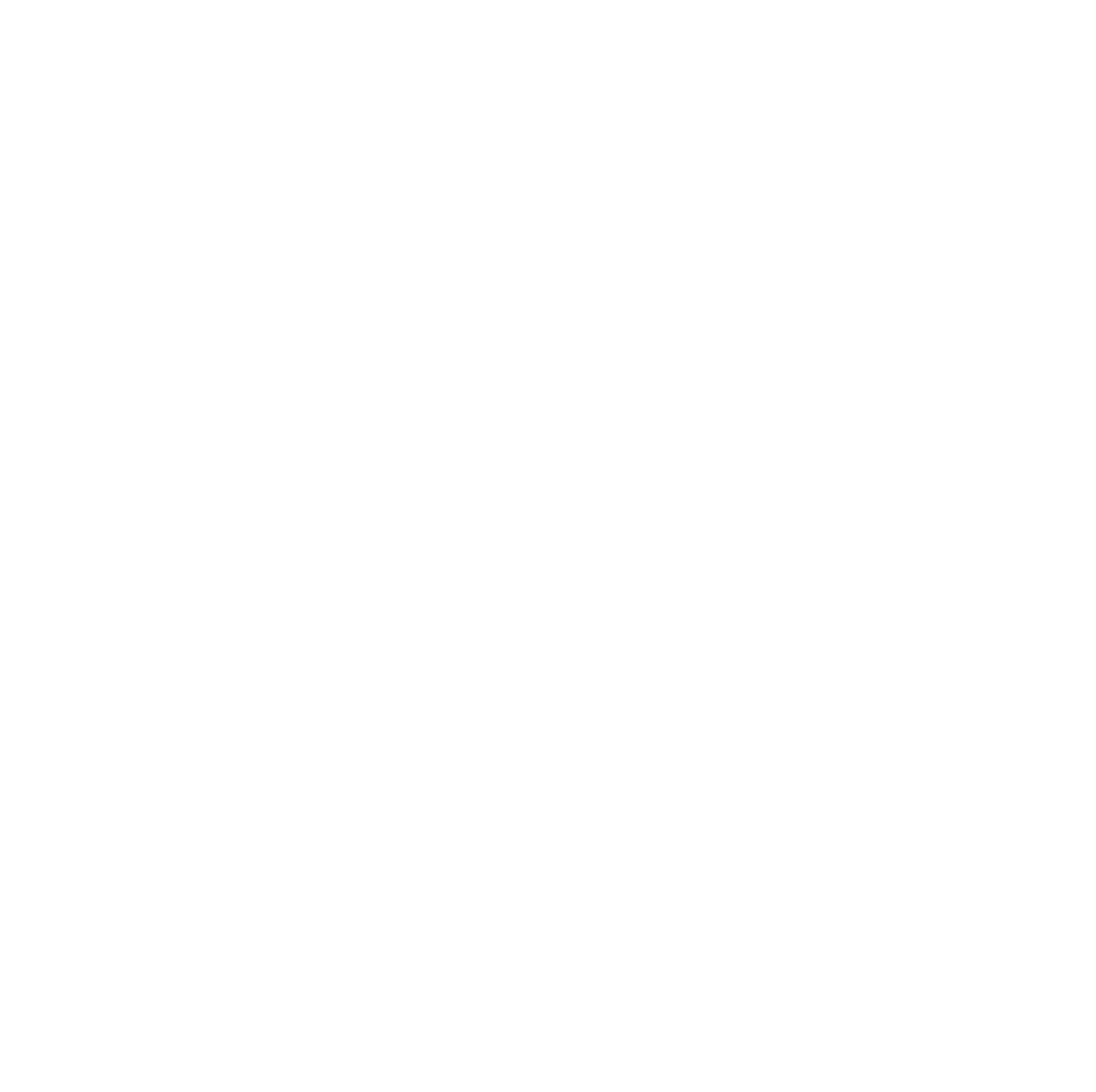

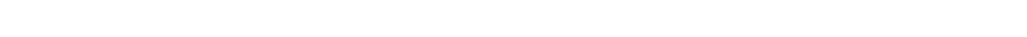

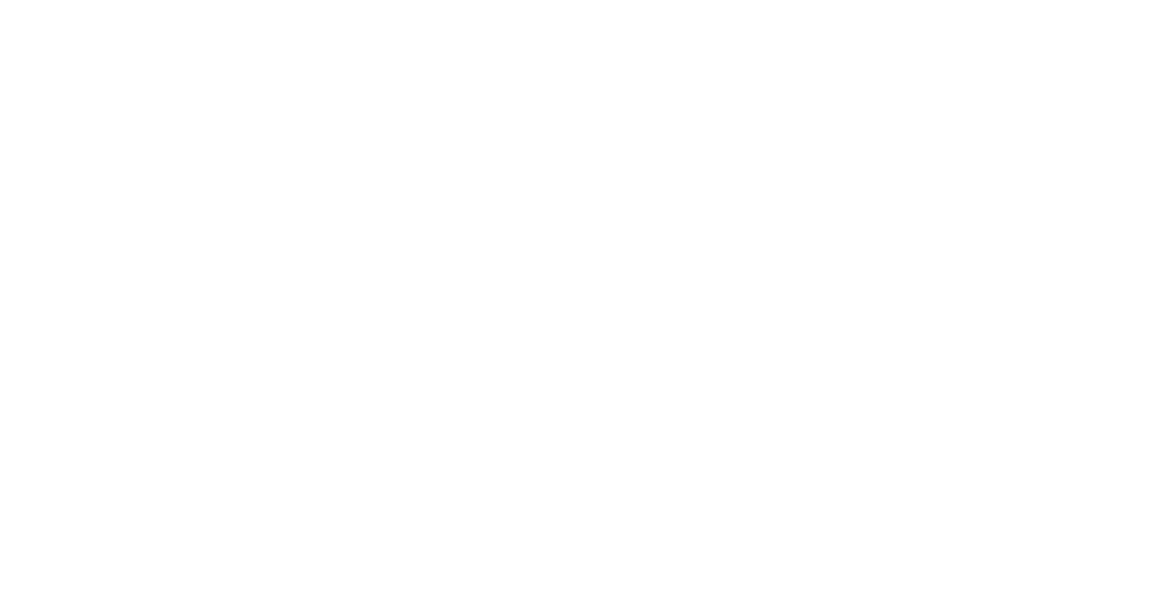


SUWANNEE RIVER BASIN

02321500 SANTA FE RIVER AT WORTHINGTON SPRINGS, FLA.--Continued CHEMICAL ANALYSES, HATER YEAR OCTOBER 1969 TO SEPTEMBER 1970 (TRACE METALS)

\begin{tabular}{|c|c|c|c|c|c|c|c|c|c|c|c|c|}
\hline & $\begin{array}{c}\text { UIS- } \\
\text { SOLVEO }\end{array}$ & ols- & DIS- & $\begin{array}{l}\text { DIS- } \\
\text { SOLVEO }\end{array}$ & $\begin{array}{r}\text { HEXA } \\
\text { VALENT }\end{array}$ & $\begin{array}{l}\text { DIS- } \\
\text { SOLLVED }\end{array}$ & DIS- & DIS- & DIS- & $\begin{array}{l}\text { DIS- } \\
\text { SOLVED }\end{array}$ & & QIs \\
\hline & ALUM & SOLVFU & SOL VEO & CAD- & ChPO- & CHRO- & SOLVED & SOLVEN & SOLVẼD & MAN- & TOTAL & SOLVEO \\
\hline & $\begin{array}{l}\text { I VuM } \\
\text { (AL) }\end{array}$ & $\begin{array}{l}\text { APSENIC } \\
\text { (AS) }\end{array}$ & $\begin{array}{c}\text { BORON } \\
(\theta)\end{array}$ & $\begin{array}{l}\text { MIUM } \\
\text { (CD) }\end{array}$ & $\begin{array}{l}\text { MIUM } \\
\text { (CR6) }\end{array}$ & $\begin{array}{l}\text { MIUM } \\
\text { (CH) }\end{array}$ & $\begin{array}{l}\text { COPHER } \\
\text { (CU) }\end{array}$ & $\begin{array}{l}\text { IRON } \\
\text { (FE) }\end{array}$ & $\begin{array}{l}\text { LEAQ } \\
(P R)\end{array}$ & $\begin{array}{l}\text { GANESE } \\
\text { (MN) }\end{array}$ & $\begin{array}{l}\text { MERCURY } \\
\text { (HG) }\end{array}$ & $\begin{array}{l}\text { ZIVC } \\
\text { (ZN) }\end{array}$ \\
\hline$A T E$ & $(U G / L)$ & $(U G / L)$ & $(U G / L)$ & (UG/L) & (UGG) & $(U G / L)$ & $(U G / L)$ & $\left(U{ }_{3} / \mathrm{L}\right)$ & (UG/L) & $(U G / L)$ & (UG/L) & IUS/L) \\
\hline
\end{tabular}

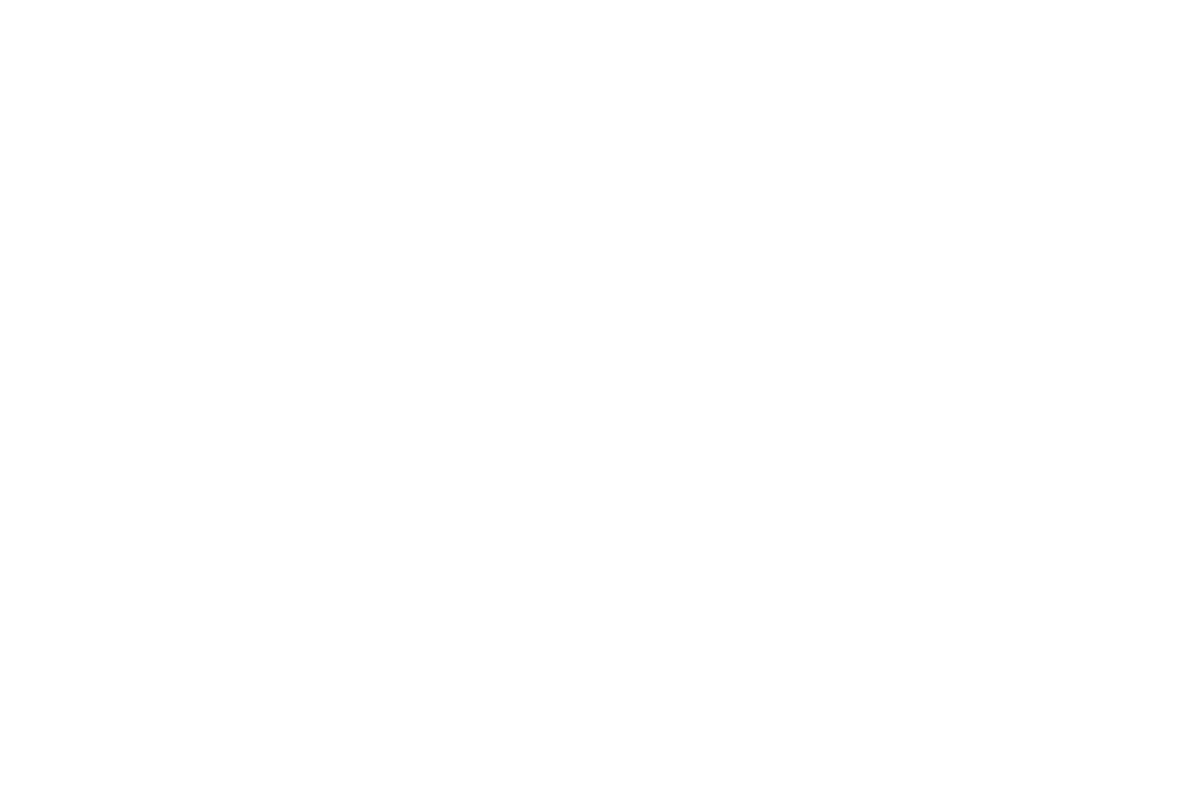

COASTAL BASINS BETWEEN AUCILLA RI VER AND OCHLOCKONEE RIVER 02327100 SOPCHOPPY RIVER NEAR SOPCHOPPY, FLA, (Hydrologic bench-mark station)

LOCATION, - Lat $30^{\circ} 07^{\prime} 45^{\prime \prime}$, long $84^{\circ} 29^{\prime} 40^{\prime \prime}$, In NW $\frac{1}{4}$ sec.24, T.4 S., R.3 W., Wakulla County, Apalachicola National Forest, at gaging station near left bank on downstream side of bridge on U.S. Forest Road 346-A, 4.7 m1les north of Sopchoppy, 5.2 miles upstream from Duval Branch, and 24 miles upstream from mouth.

DRAI NAGE AREA.--97.9 sq $\mathrm{ml}$.

PERIOD OF RECORD. - Water temperatures: June 1964 to September 1970.

EXTREMES. - 1964-69:

Water temperatures: Maximum, $32.0^{\circ} \mathrm{C}$ June 3,$1965 ;$ minimum, 4. $0^{\circ} \mathrm{C}$ Jan. 31, Feb. 1, 1966.

CHEMICAL ANALYSES, WATER YEAR DCTOBER 1969 TO SEPTEMBER 1970 (MAJOR CONSTITUENTS

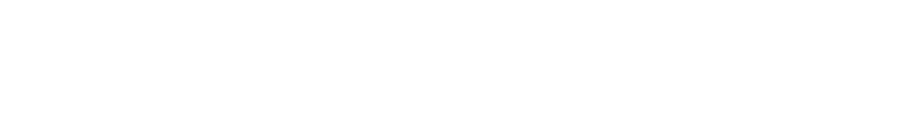

\begin{tabular}{|c|c|c|c|c|c|c|}
\hline $\begin{array}{r}\mathrm{OCT}, \mathrm{B} \\
13 \ldots\end{array}$ & ${ }_{46}^{69}$ & 21.2 & 36 & 230 & 5.2 & .7 \\
\hline $\begin{array}{l}\text { NOV. } \\
12 . . \\
\text { DEC. }\end{array}$ & 3.0 & 17.0 & 192 & 190 & 34 & 3.4 \\
\hline $\begin{array}{l}17 . . \\
\text { JAN." }\end{array}$ & $70^{33}$ & 9.2 & 42 & 250 & 5.4 & 1.0 \\
\hline $\begin{array}{l}15 . \\
\text { FEE. }\end{array}$ & 365 & 6.8 & 42 & - & 1.1 & .4 \\
\hline $\begin{array}{l}18 \ldots \\
\text { APR. }\end{array}$ & 264 & 12.5 & 41 & 250 & 1.2 & .3 \\
\hline${ }_{\text {MAY }} 15 \cdots$ & 331 & 18.0 & 40 & -- & 1.2 & .3 \\
\hline $\begin{array}{l}13 \ldots \\
18 . \\
\text { JUNE }\end{array}$ & $\begin{array}{l}2.7 \\
2.1\end{array}$ & $\begin{array}{l}21.5 \\
13.5\end{array}$ & $\begin{array}{r}192 \\
38\end{array}$ & $\begin{array}{r}320 \\
--\end{array}$ & $\stackrel{34}{1.2}$ & $\begin{array}{r}3.5 \\
.3\end{array}$ \\
\hline 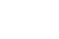 & 6.0 & 26.5 & 175 & -- & 30 & 3.2 \\
\hline $\begin{array}{l}15 . . \\
\text { AUG. }\end{array}$ & 25 & $\cdots$ & 42 & $=$ & 6.4 & .7 \\
\hline SEP.. & 853 & $24 . n$ & 46 & 630 & 1.1 & .3 \\
\hline
\end{tabular}

$\begin{array}{rrrrrr}\ldots & 1.8 & .2 & 6 & 0 & 5.7 \\ \ldots & 2.7 & .3 & 108 & 0 & 7.5 \\ \ldots & 2.1 & .1 & 7 & 0 & 5.7 \\ \ldots & 2.0 & .0 & 0 & 0 & 4.3 \\ - & 1.9 & .0 & 0 & 0 & 4.3 \\ 50 & 1.8 & .0 & 0 & 0 & 4.2 \\ -. & 3.0 & .4 & 115 & 0 & 7.9 \\ - & 2.8 & .0 & 0 & 0 & 4.3 \\ 20 & 2.0 & .3 & 102 & 0 & 7.3 \\ - & 2.0 & .1 & 0 & 0 & 4.0 \\ & 2.0 & .2 & 5 & 0 & 5.5\end{array}$




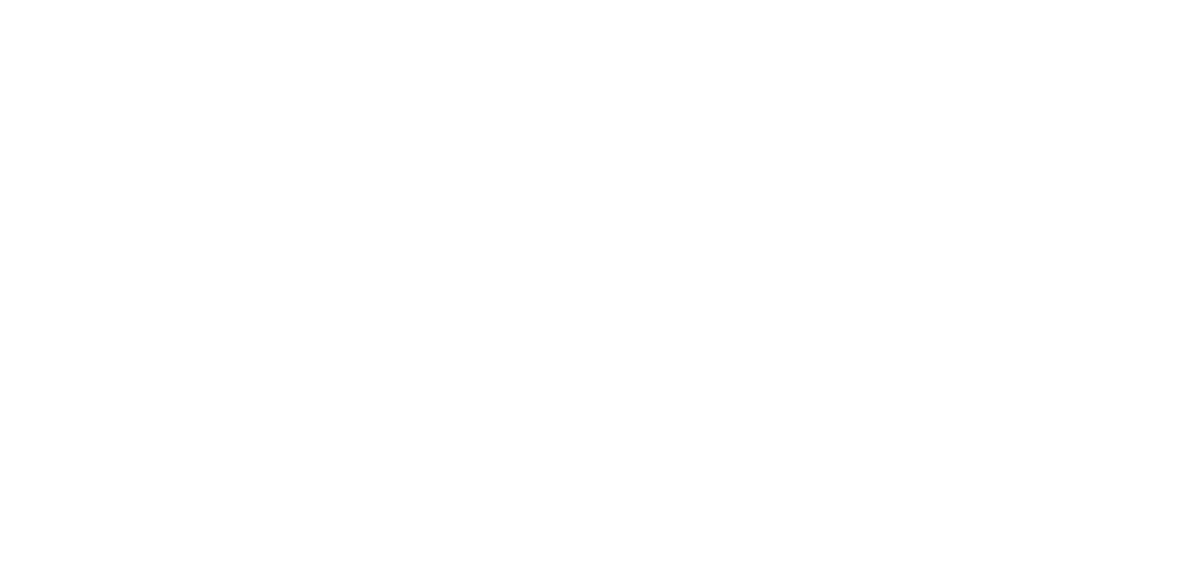

(MACRONUTRIENTS AND OTHER RELATED CONSTITUENTS)

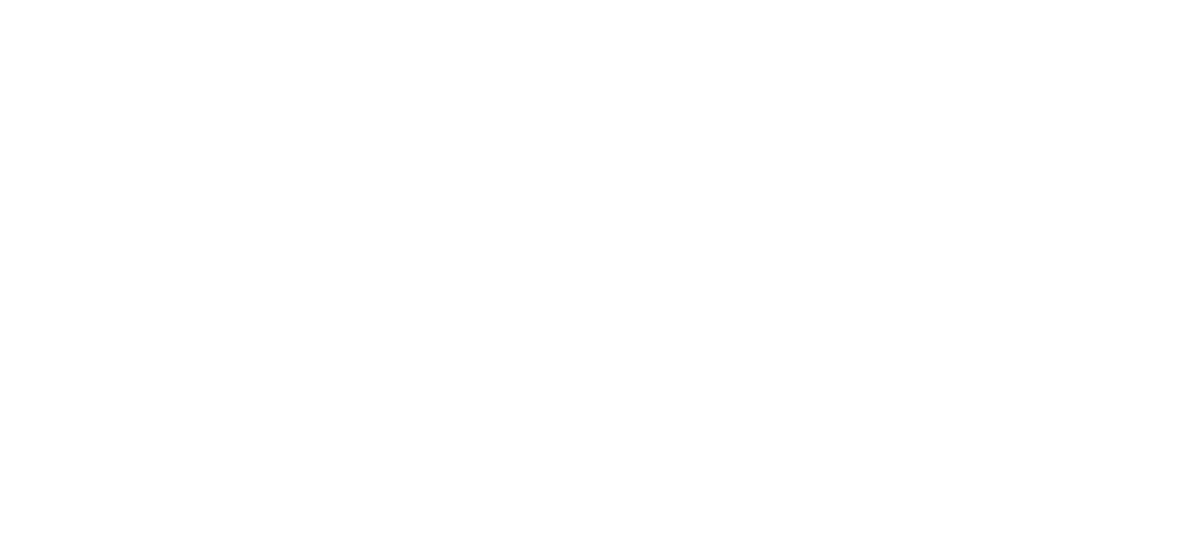

(ORGANOCHLORIDE COMPOUNDS IN WATERI

\begin{tabular}{|c|c|c|c|c|c|c|c|c|c|c|c|}
\hline UATE & $\begin{array}{l}\text { ALOR IN } \\
(H G / L)\end{array}$ & $\begin{array}{l}\text { CHLOR- } \\
\text { OANE } \\
\text { (UG/L) }\end{array}$ & $\begin{array}{l}\text { DOD } \\
(U G / L)\end{array}$ & $\begin{array}{c}\text { ODE } \\
(U G / \mathrm{L})\end{array}$ & $\begin{array}{l}\text { DOT } \\
(U G / L)\end{array}$ & $\begin{array}{c}\text { DI- } \\
\text { ELDRIN } \\
(U G / L)\end{array}$ & $\begin{array}{l}\text { ENDFIN } \\
\text { (UG/L) }\end{array}$ & $\begin{array}{l}\text { HEPTA- } \\
\text { CHLOR } \\
\text { (UG/L) }\end{array}$ & $\begin{array}{c}\text { HEPTA- } \\
\text { CHLOR } \\
\text { EPOXIDE } \\
\text { (UG/L) }\end{array}$ & $\begin{array}{l}\text { LINDANE } \\
\text { (UG/L) }\end{array}$ & $\begin{array}{c}\text { TOX- } \\
\text { APHENE } \\
\text { (UG/L) }\end{array}$ \\
\hline \multicolumn{12}{|c|}{ FEB., 1968} \\
\hline OUNE & .00 & -- & .00 & .00 & .00 & .00 & - nn & .00 & - & .00 & -- \\
\hline 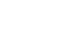 & .00 & - & .00 & .00 & .00 & .00 & .00 & .00 & + & .00 & - \\
\hline $13 \ldots$ & .00 & $\cdots$ & .00 & .00 & - & -- & -- & - & -- & -- & -- \\
\hline
\end{tabular}


02327100 SOPCHOPPY RIVER NEAR SOPCHOPPY, FLA,--Continued

CHEMICAL ANALYSES, WATER YEAR OCTOBER 1969 TO SEPTEMBER 1970 IORGANDCHLORIDE COMPOUNDS IN SEDIMENT?

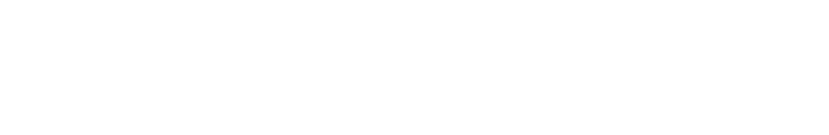

OCT., 1969

$13 \ldots$

$.0 \quad .0$

$.0 \quad .0$

.0 .0

$.0 \quad .0 \quad .0$

(TRACE METALS)

\begin{tabular}{|c|c|c|c|c|c|c|c|c|c|c|c|c|}
\hline & $\begin{array}{l}\text { UIS- } \\
\text { SOLVEO }\end{array}$ & ols- & DIS- & $\begin{array}{l}\text { UIS- } \\
\text { SOL VEO }\end{array}$ & $\begin{array}{l}\text { HEXA- } \\
\text { VALENT }\end{array}$ & $\begin{array}{l}\text { DIS- } \\
\text { SOLVEDO }\end{array}$ & OIS- & DIS- & DI5 - & $\begin{array}{c}\text { OIS- } \\
\text { SOLVËD }\end{array}$ & & CIS- \\
\hline & ALU1'- & SOLVFO & SOLVEL & $\mathrm{CAO}^{-}$ & CHPO- & (HRS)- & SCLVEN & SOLVEn & SOL & MAN- & TOTAL & SRLVEO \\
\hline & I vu:4 & $\triangle P C E N I C$ & BORON & NIUM & Mivu & MIUM & COPHER & IRON & LEAD & GANESE & MERCURY & ZIVC \\
\hline ATE & $\begin{array}{c}(A L) \\
(\cup G / L)\end{array}$ & $\begin{array}{c}(A S) \\
(\cup G / L)\end{array}$ & $\begin{array}{c}(B) \\
(U G / L)\end{array}$ & $\begin{array}{c}(C D) \\
(U G / L)\end{array}$ & $\begin{array}{l}\text { (CRG) } \\
\text { (UG/L) }\end{array}$ & $\begin{array}{c}(C H) \\
(U G / L)\end{array}$ & $\begin{array}{l}(C U) \\
(U G / L)\end{array}$ & $\begin{array}{c}(F E) \\
(U F / L)\end{array}$ & $\begin{array}{c}(P R) \\
(U G / L)\end{array}$ & $\begin{array}{c}(M N) \\
(U G / L)\end{array}$ & $\begin{array}{l}(H(t) \\
(U G / L)\end{array}$ & $\left(\begin{array}{l}(<N) \\
([G / L)\end{array}\right.$ \\
\hline
\end{tabular}

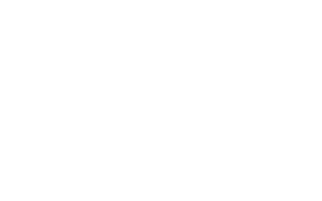

--
-
-
-
-
-

$\begin{array}{lll}-- & -- & - \\ -- & - & - \\ -- & -- & - \\ -- & -- & - \\ -- & -- & -\end{array}$

(RADIOCHEMICAL DATA)

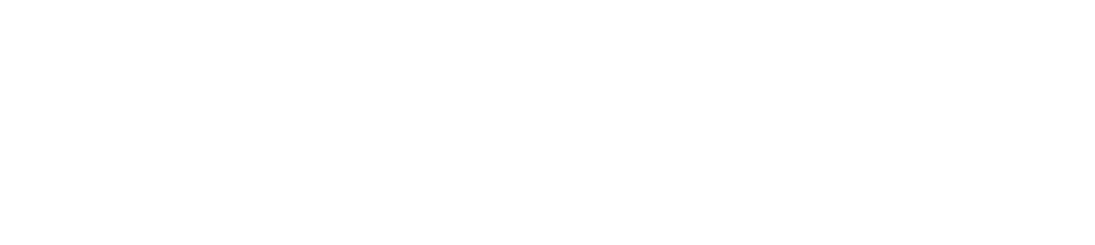

(OTHER DATA
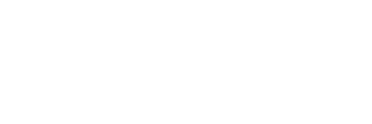

METHY - DIS-
LENE SOLVED

BLUE ORGANIC

ACTIVE NITRD-

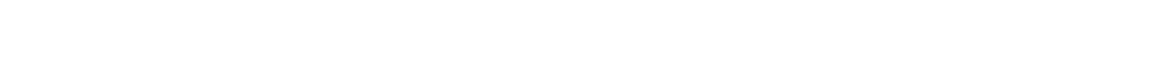

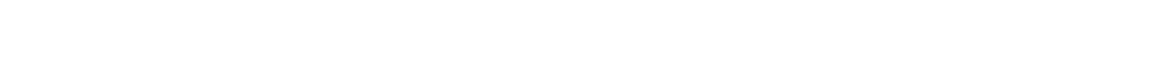

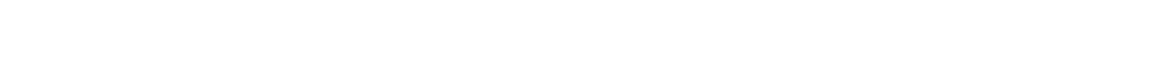

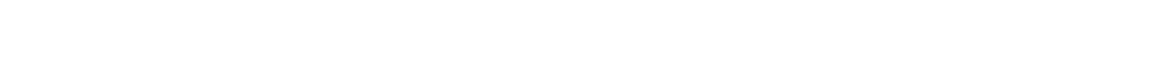

$\begin{array}{llll}\text { TOTAL } & \text { DIS- } & \text { DIS- } & \text { DIS- } \\ \text { ALUM- } & \text { SOLVED } & \text { TOTAL SOLVED } & \text { SOLVED } \\ \text { SOLVE }\end{array}$

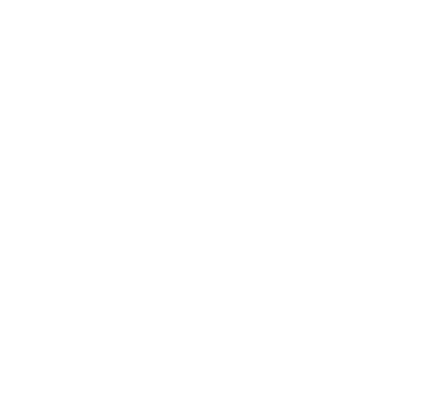




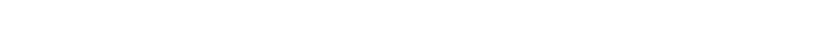

\begin{tabular}{|c|c|c|c|c|c|c|c|c|c|c|c|c|}
\hline DAY & Mas & Alt & $\therefore \Delta x$ & $.1]^{4}$ & $\Delta x$ & AI & Ane & ${ }^{*}{ }_{T}$ & $n a x$ & $W\left[I^{N 1}\right.$ & MAX & MIN \\
\hline 1 & 21.0 & 20.9 & -- & -.- & --- & -- & -. &.- & $1 \cdot 0$ & 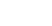 & --- & -- \\
\hline 2 & $21 . r$ & $21 .$. & - & -- & $\ldots$ & $\ldots$ & -- & -. & 1.11 & $\because$ & -- & -. \\
\hline 3 & 21.0 & 20.5 & $\rightarrow$ & $\cdots$ & - & -- & -- & $=$ & 111.0 & 10.9 & $1 ? .1$ & 11.0 \\
\hline 4 & 21.0 & 20.5 & -.- & -.. & -.- & -- & $\ldots$ & -- & 11.0 & +11 & 12.0 & $12 . n$ \\
\hline 5 & 22.0 & 21.0 & $\ldots$ & $\ldots$ & $-\ldots$ & -.. & $\ldots$ & -- & +.5 & $\because ?$ & 13.0 & 12.0 \\
\hline 6 & 21.5 & 21.4 & -- & -- & -.- &.- & --- & -- & 1.1 & r. & 13.5 & 13.7 \\
\hline 7 & $=$ & $\ldots$ & -- & -- & -. &.- & -- & -- & - & $\cdots$ & 13.2 & 13.5 \\
\hline 8 & --- & -. & $\ldots$ & $\ldots$ & -- & -- & -- & $\ldots$ & -- & $\cdots$ & 15.4 & 13.0 \\
\hline 9 & -. & - & $\ldots$ & -. & -.- & $\ldots$ & -. & -.. & 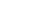 & $\cdots$ & 17.1 & 12.5 \\
\hline 10 & -- & -- & -- & $\cdots$ & -- & $\cdots$ & -- & $\cdots$ & -- & -- & 17.11 & $13 . n$ \\
\hline 11 & -.- & --. & -.. & $\ldots$ & -.. & --. & -.. & -.- & -.. & - & 150 & 13.11 \\
\hline 12 & $\ldots$ & -- & -- & -- & $\ldots$ & -- & $\ldots$ & $\ldots$ & - & $\cdots$ & 13.1 & $13.1^{1}$ \\
\hline 13 & $\cdots$ & -- & -- & --- & -- & -- & -- & --- & -- & -- & 17.5 & 13.5 \\
\hline 14 & $\ldots$ & --- & -- & $\ldots$ & -- & -- & $\ldots$ & $\ldots$ & -.. & -- & 14.1 & 13.0 \\
\hline 15 & $\cdots$ & -- & $-\ldots$ & -- & -- & -- & -- & -- & -- &.- & 13.5 & 12.5 \\
\hline 16 & $\ldots$ & $\ldots$ & $-\infty$ & $\ldots$ & -- & --- & - & -- & $\ldots$ & $\ldots$ & $13 . n$ & 12.7 \\
\hline 17 & -.. & -- & ... & -- & - & -- & -.- & - - & 12.0 & $k \cdot 1$ & 13.7 & 13.3 \\
\hline is & -- & $\ldots$ & -- & $\ldots$ & - - & --- & $\cdots$ & -- & $1>0$ & 17 & 14.0 & 14.0 \\
\hline 19 & 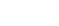 & 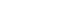 & --- & -- & -- & --- & $-\infty$ & -- & $12=0$ & in & $1+$. & 14.0 \\
\hline 20 & $\ldots$ & $\cdots$ & $\cdots$ & -- & -- & $\cdots$ & $-\infty$ & $=-$ & 13 & 11.1 & 17.11 & $1 \mathrm{~m} . \mathrm{n}$ \\
\hline 21 & $\ldots$ & -- & $\ldots$ & $\ldots$ & -- & $\cdots$ & 4.1 & -- & 11.01 & 10.7 & $1 H_{0}{ }^{\prime}$ & 17.0 \\
\hline 22 & -. & -- & -- & -- & -.. & 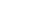 & $\therefore$ & +- & $\ldots$ & $\ldots$ & $1 \cdots$ & 14.0 \\
\hline 23 & -. & - & -- & -- & -- & -- & l. n & -- & $\ldots$ & - & $1^{H .11}$ & $i t . n$ \\
\hline 24 & -.- & --. & --- & -.- & --- & -.. & 7. & --- & -- &.- & $\ln .1$ & 15.5 \\
\hline 25 & $\ldots$ & $-\infty$ & -- & $+\cdots$ & - & -. & 1.4 & ?. & -- & --- & 15.1 & in.en \\
\hline 26 & --- & --- & -.. & - & -- & --. & H.h & ?.h & -.- & -.. & 16.11 & $15, n$ \\
\hline 27 & -.. & -- & -- & $\ldots$ & -- & $\ldots$ & 101 & $\because$ & -. & - & 16.5 & $15 .: 1$ \\
\hline 28 & $\cdots$ & $\ldots$ & -. & $-\ldots$ & -- & -.. & 11.0 & 10.1 & -- & - & $1+4.4$ & 15.0 \\
\hline $2 y$ & -.. & $-\ldots$ & -- & -.. & -- & -- & $11 . r$ & 17.0 & --- & - & 16.1 & $16, n$ \\
\hline 30 & -- & -.- & -- & $-\infty$ & $-\cdots$ & -. & $1 \geq$. & 11. & -. & -- & $\therefore$ & $\ldots$ \\
\hline 31 & --- & $\cdots$ & $\ldots$ & $\ldots$ & -- & -- & $1<$. & 10. & $-\infty$ & -- & 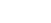 & -- \\
\hline \multirow[t]{2}{*}{ AVERAGE } & --- & -- & $\cdots$ & -. & $\cdots$ & -- & $\ldots$ & $\ldots$ & -- & -- & 17.11 & 11.1 \\
\hline & \multicolumn{2}{|c|}{ APKIL } & \multicolumn{2}{|c|}{$\therefore i y$} & \multicolumn{2}{|c|}{1110} & \multicolumn{2}{|c|}{ SH Y Y } & \multicolumn{2}{|c|}{ H. } & \multicolumn{2}{|c|}{ SE UTE MFN } \\
\hline DAY & $\operatorname{MAX}$ & "Ian & $\therefore \Delta x$ & $\therefore 1 \%$ & $n A x$ & $\cdot 1 r$ & $\ln x$ & 'I' & $13 x$ & $\therefore$ I & $\alpha A x$ & +11 \\
\hline 1 & -+ & 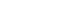 & 24.6 & 24.0 & $=-$ & $\ldots$ & 2.4 .7 & $>4 . n$ & Pn.et & $2+.1$ & $>4.5$ & $<4.5$ \\
\hline 2 & -- & -- & $14 . ?$ & $230^{2}$ & -- & -.. & -4 & 4.4 & $A_{0}>$ & $+t$ & 25.11 & 24.4 \\
\hline 3 & -- & -- & 3.5 & 23.0 & $\ldots$ & $\cdots$ & re. & 25.5 & $=4.5$ & it: & 25.1 & $24: 4$ \\
\hline 4 & $\ldots$ &.- & 13.1 & 21.5 & --- & $\cdots$ & +... & $3 x^{\prime}$. & 27.1 & st. & $x$ & in..1 \\
\hline 5 & $\cdots$ & -- & 21.4 & 14.1 & $\ldots$ & $\ldots$ & $3 m$ & $2 n .1$ & -7.5 & -7. & 27.0 & $c 4.5$ \\
\hline 6 & -. & -- & 21.0 & $1+.1$ & --- & -.. & st. 1 & $c^{n} \cdot n$ & -7.2 & $\therefore 1$ & "מכ" & 24.4 \\
\hline 7 & $\ldots$ & -- & 22.11 & $20 \cdot 1$ & -. & $\ldots$ & - & $\therefore$ & 87.3 & 27. & $>4.0$ & 24.5 \\
\hline a & -- & --- & - & $\cdots$ & -- & --- & -- & -- & -2.5 & $\therefore t$ & 24.4 & 24.1 \\
\hline 9 & --- & -- & --- & $-\cdots$ & -- & - & -- & -- & $x_{n} \cdot 1$. & $\therefore$. & 24.1 & 24.5 \\
\hline 10 &.- & -- & -- & -- & -- & - & ?a. & 24. & in. 1 & 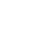 & 25.11 & חילי \\
\hline 11 & $-\infty$ & - & $\ldots$ & $\ldots$ &.- & 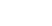 & $\therefore$ & $\Rightarrow+0^{\circ}$ & 3.11 & $\therefore$. & $=5$. & 24.0 \\
\hline 12 & 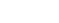 & -.- & 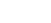 & $\cdots$ & $\ldots$ & $\cdots$ & 24.11 & 74.11 & $(5)$. & $x_{0}$ & -. & -.. \\
\hline 13 & -- & -- & $c^{n}$. & 21.11 & $=4.5$ & 3.1 & 4. & 24.1 & $-4,3$ & , & $\cdots$ & -- \\
\hline 14 & -. & --- & 26.0 & C? & $=0.5$ & 3. & $-4,4$ & 3.5 & 24,4 & $=4$, & -.- & - \\
\hline is & $1+.5$ & 13.0 & $2 n=0$ & $\gg \cdot v$ & $=.1$ & 23.1 & 3 & ל.לי & -4.5 & $\therefore 4$ & -- & --- \\
\hline 10 & 14.5 & Im. & 29.5 & C... & $74 .=$ & $c_{2}^{2} 1$ & th & in. & , a.h & 4.7 & 24.5 & Zu. \\
\hline 17 & 14.0 & 12.11 & य." & $<4$ & 75.4 & 23.1 & $=0.1$ & $\therefore$ & $4 e^{h}$ & $-A_{0}$, & $>5.4$ & 25.5 \\
\hline is & ?ri.n & $1 \mathrm{mo}=$ & $\cdots$ & $\cdots$ & n. & 1 & $A_{0} 1$ & $3 c_{12}$ & 3,11 & $\Rightarrow$ & eti. & $c^{h} \cdot 5$ \\
\hline 19 & 20.0 & $1+1$ & -- & -. & , th & 24.1 & $2 F^{\prime \prime}$ & $\therefore 0^{n}$ & $\therefore 4$ & 24 & $\rightarrow n$. & $\pi h .0$ \\
\hline 20 & 21.6 & -11.0 & $\cdots$ & -- & $2+.11$ & 24.5 & A. & 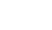 & -- & $\cdots$ & $2 \ldots .1$ & $2 t .0$ \\
\hline 21 & $? 1.0$ & $\bar{c} 0 . \bar{L}$ & --- & -- & 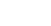 & $=-1$ & 2..." & $e^{n} \cdot 1$ & -- & -.- & $2=0$ & $c^{f} .1$ \\
\hline 22 & $?<\cdot n$ & $>1.0$ & -- & -- & $24=1$ & & $e_{+}=1$ & & -- & -- & $r_{0} \cdot 1$ & $F_{A} \cdot 1$ \\
\hline 23 & 22.5 & $\gg>0$ & $\ldots$ & -.- & $m_{01}$ & $x^{\prime}$ & -4.4 & i4. 1 & - & --- & $2+.11$ & 0.11 \\
\hline 24 & 22.5 & $c e-6$ & $\ldots$ & 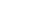 & $=n . r$ & $c .1$ & $24 .-7$ & 24.4 & -- & -- & Sh.W & 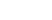 \\
\hline 25 & 22.0 & ?2. & --- & -- & H. 19 & 14. & $2 x . c$ & 2ר.". & $\ldots$ & $\cdots$ & $2 n .1$ & 25.5 \\
\hline 26 & 22.0 & C?.11 & - & -. & ל. & 34.11 &, 5.5 & ל. & 24.6 & 34.11 & 25. & 2৬." \\
\hline 27 & 24.0 & $\Rightarrow>0$ & $\ldots$ & $\ldots$ & $7^{3} \cdot 4$ & 34.1 & in in & $x, .1$ & $=4.11$ & $<4$ & 74.5 & 24.5 \\
\hline $2 A$ & $24 . c$ & $23 . n$ & --- & - & is. & 34.11 & 3.1 & י & 34.1 & $>4.3$ & $>5.1$ & $=4.5$ \\
\hline 29 & 24.0 & 5.3. & -- & -- & 14.11 & 24.11 & $25.1+$ & 3.n & ↔" & 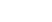 & 25.11 & 34.11 \\
\hline 30 & $(4,01)$ & $<3.5$ & 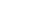 & -- & 4.1 & त. & She & shol & $=4,1$ & $a_{0}$ & $=4.4$ & 23.11 \\
\hline וד & $-\infty$ & $=$ & -- & -- & -- & -- & $c^{n}$. & -- & 4.7 & 4. & - & - \\
\hline AVERAGE & -- & -- & -- & -- & -- & $=-$ & $2 h$. & $=9.9$ & .7 .3 & 24. & $2 \mathrm{~N}_{0} 1$ & 23.4 \\
\hline
\end{tabular}


02329000 OCHLOCKONEE RIVER NEAR HAVANA, FLA.

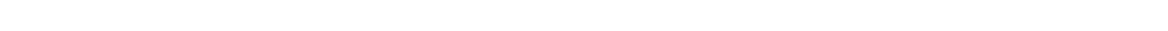
bank on downstream side of downstream bridge on divided U.S. Highway 27, 0.8 mile upstream from Seaboard Rail road bridge, 4 miles downstream Highway $27,0.8$ mile upstream from Seaboard Airline Ra1lroad bridge, 4 miles downstream from ki11 Creek, 5 miles southeast of Havana, and 94 miles upstream from mouth.

DRAINAGE AREA.--1,140 sq mi, approximately, at site used prior to January 1929, 1,220 sq mi, approximately.

PERIOD OF RECORD.--Chemical analyses: October 1962 to September 1970.

water temperatures: October 1962 to September 1970.

EXTREMES , - - 1969-70

Speciflc conductance: Maximum dally, 265 micromhos June 30; minimum daily, 36 micromhos Mar. 30.

pH: yaximum, 7.6 Aug. 7, 9; minimum, 5.9 Mar, 30, 31,

water temperatures: Maximum, $27.0^{\circ} \mathrm{C}$ on several days during June, July, August; min1mum, $5.0^{\circ} \mathrm{C} \mathrm{Jan,} 10,11$.

period of record:

Specific conductance: Maximum daily, 775 micromhos Nov. 15, 1962; minimum daily, 16 micromhos Sept, 22, 23, 1968 .

$\mathrm{pH}(1966-60)$ : Maximum daily, 7.9 Nov, 24, 1967; minimum da1ly, 5.7 Sept. 23, 1969.

Water temperatures: Haximum, $29.0^{\circ} \mathrm{C}$ Aug. 11,1963 , June 21,$1964 ;$ minimum, $1.0^{\circ} \mathrm{C}$ Dec. 26,1963,

CHEMICAL ANALYSES, WATER YEAR OCTOBER 1969 TO SEPTEMBER 1970

IMAJOR CONSTITUENTS)

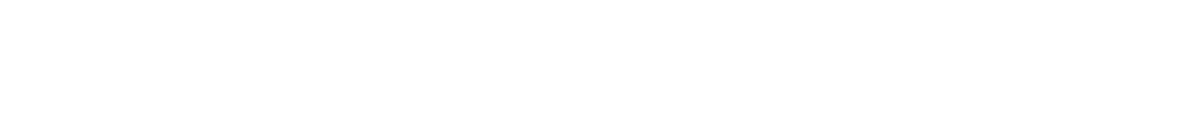
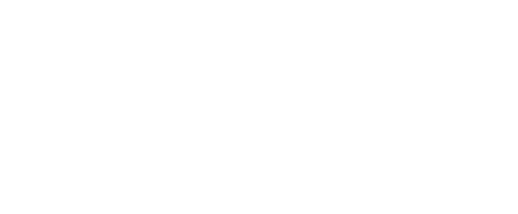

7.1

UG/L) (MG/L)

(MG/L) (MG/L)

(UNTTS)

$\begin{array}{rr}12.0 & 165 \\ 4.5 & 88 \\ 15.0 & 45 \\ 23.5 & 50 \\ 25.0 & 195 \\ 26.0 & 57\end{array}$

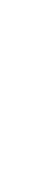

7.1
3.1
2.9
6.4
4.8
3.0
NON-
CAR-
ONATE
NOPO-
ESS

3.2
1.4
1.2
2.6
2.1
1.2

ALKA-
INITY
AS
CACO3
(MGG, ,

$\begin{array}{cc}- & 19 \\ -- & 11 \\ -- & 4.3 \\ 0 & 2.7 \\ -- & 28 \\ 30 & 5.6\end{array}$

$$
1.5
$$$$
28
$$$$
--\quad 6.8
$$

DIS-
SOLSE
SULVEN
SOLIDS SOLIOS

SOLIOS SOLIOS
IRESI- ISUM OF

IRESI- ISUM OF

IAO C) TUENTS)

$\begin{array}{ll}\text { OIS- } & \text { NIS- } \\ \text { SOLVED } & \text { SDLVFD } \\ \text { SOLIDS } & \text { SOLIDS }\end{array}$

SOLIDS SOLIDS TANNIN

TRONS ITONS AND

PER LIGNIN DEPTH

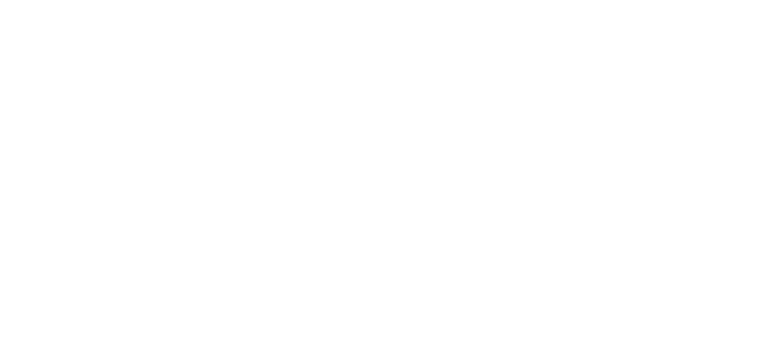

$\begin{array}{rllll}86 & 44.8 & .14 & -- & -- \\ 58 & 377 & .12 & -- & -- \\ 25 & 225 & .05 & -- & -- \\ 54 & 83.1 & .11 & -- & -- \\ 108 & 101 & .15 & -- & -- \\ 35 & 188 & .06 & -- & --\end{array}$

(MACRONUTRIENTS AND OTHER RELATED CONSTITUENTS)

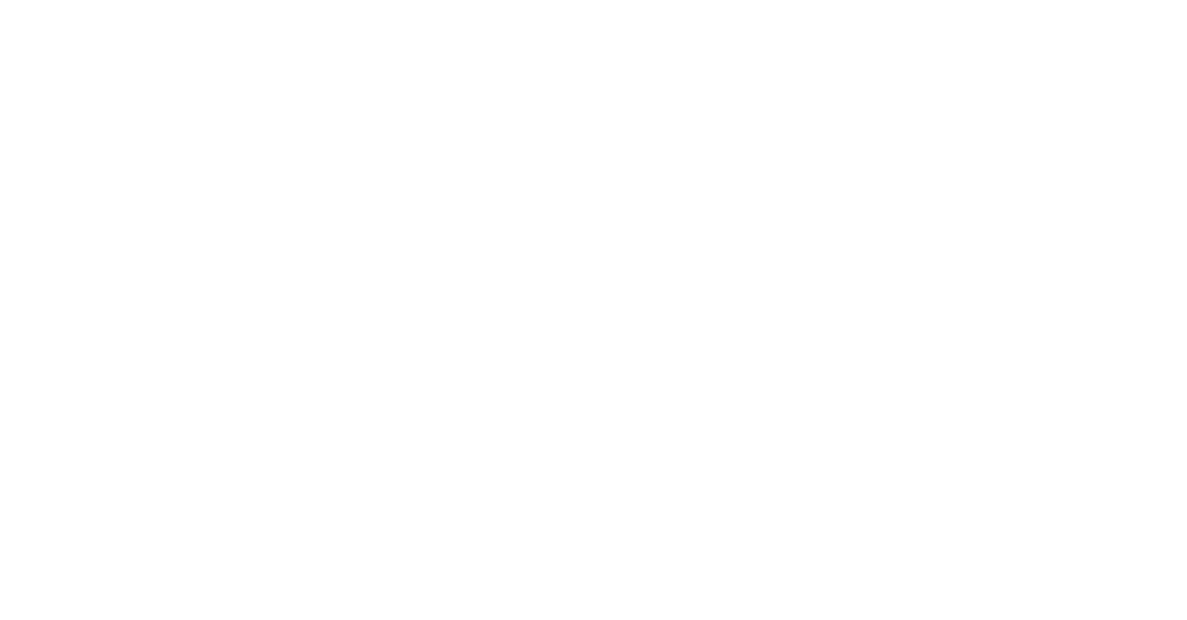


O2329000 OCHLOCKONEE RIVER NEAR HAVANA, FLA.--CONTInUEd

SPECIFIC CONDUCTANCE (MICROMHOS/CM AT $25^{\circ} \mathrm{C}$ ), WATER YEAR OCTOBER 1969 TO SEPTEMBER 1970

DAY OCTOBER NOVEMBER DECEMBER JANUARY FEBRUARY MARCH APRIL MAY JUNE JULY AUGUST SEPTEMBER

\begin{tabular}{|c|c|c|c|c|c|c|c|c|c|c|c|c|}
\hline $\begin{array}{l}1 \ldots \ldots \\
2 \ldots \ldots \\
3 \ldots \ldots \\
4 \ldots \ldots \\
5 \ldots \ldots\end{array}$ & $\begin{array}{l}73 \\
70 \\
72 \\
82 \\
95\end{array}$ & $\begin{array}{l}135 \\
125 \\
115 \\
135 \\
138\end{array}$ & $\begin{array}{l}142 \\
135 \\
144 \\
160 \\
152\end{array}$ & $\begin{array}{r}160 \\
87 \\
84 \\
95 \\
84\end{array}$ & $\begin{array}{l}89 \\
83 \\
54 \\
52 \\
60\end{array}$ & $\begin{array}{l}66 \\
60 \\
62 \\
64 \\
62\end{array}$ & $\begin{array}{l}39 \\
41 \\
42 \\
44 \\
43\end{array}$ & $\begin{array}{l}96 \\
92 \\
90 \\
98 \\
96\end{array}$ & $\begin{array}{r}170 \\
125 \\
110 \\
85 \\
65\end{array}$ & $\begin{array}{r}87 \\
134 \\
135 \\
99 \\
85\end{array}$ & $\begin{array}{r}99 \\
100 \\
94 \\
76 \\
75\end{array}$ & $\begin{array}{l}59 \\
58 \\
59 \\
65 \\
70\end{array}$ \\
\hline $\begin{array}{c}6 \ldots \ldots \\
7 \ldots \ldots \\
8 \ldots \ldots \\
9 \ldots \ldots \\
10 \ldots \ldots\end{array}$ & $\begin{array}{l}90 \\
90 \\
93 \\
95 \\
94\end{array}$ & $\begin{array}{l}132 \\
144 \\
141 \\
138 \\
130\end{array}$ & $\begin{array}{l}150 \\
144 \\
130 \\
124 \\
128\end{array}$ & $\begin{array}{r}83 \\
65 \\
66 \\
131 \\
133\end{array}$ & $\begin{array}{l}62 \\
57 \\
55 \\
56 \\
55\end{array}$ & $\begin{array}{l}60 \\
63 \\
69 \\
76 \\
46\end{array}$ & $\begin{array}{l}44 \\
46 \\
45 \\
45 \\
47\end{array}$ & $\begin{array}{r}100 \\
97 \\
100 \\
96 \\
100\end{array}$ & $\begin{array}{l}80 \\
89 \\
66 \\
64 \\
60\end{array}$ & $\begin{array}{r}89 \\
141 \\
153 \\
170 \\
170\end{array}$ & $\begin{array}{l}82 \\
87 \\
91 \\
90 \\
72\end{array}$ & $\begin{array}{l}71 \\
72 \\
78 \\
87 \\
96\end{array}$ \\
\hline $\begin{array}{l}11 \ldots \ldots \\
12 \ldots \ldots \\
13 \ldots \ldots \\
14 \ldots \ldots \\
15 \ldots \ldots\end{array}$ & $\begin{array}{l}100 \\
108 \\
110 \\
110 \\
111\end{array}$ & $\begin{array}{l}138 \\
150 \\
146 \\
150 \\
133\end{array}$ & $\begin{array}{r}108 \\
82 \\
213 \\
242 \\
205\end{array}$ & $\begin{array}{r}92 \\
79 \\
85 \\
98 \\
128\end{array}$ & $\begin{array}{l}53 \\
54 \\
61 \\
62 \\
66\end{array}$ & $\begin{array}{l}49 \\
63 \\
62 \\
56 \\
53\end{array}$ & $\begin{array}{l}48 \\
52 \\
55 \\
57 \\
60\end{array}$ & $\begin{array}{l}120 \\
110 \\
110 \\
110 \\
114\end{array}$ & $\begin{array}{l}57 \\
52 \\
50 \\
55 \\
63\end{array}$ & $\begin{array}{l}119 \\
221 \\
168 \\
167 \\
142\end{array}$ & $\begin{array}{l}65 \\
39 \\
42 \\
52 \\
55\end{array}$ & $\begin{array}{r}94 \\
80 \\
-- \\
-- \\
103\end{array}$ \\
\hline $\begin{array}{l}16 \ldots \ldots \\
17 \ldots \ldots \\
18 \ldots \ldots \\
19 \ldots \ldots \\
20 \ldots \ldots\end{array}$ & $\begin{array}{l}117 \\
117 \\
114 \\
122 \\
122\end{array}$ & $\begin{array}{l}135 \\
150 \\
150 \\
171 \\
141\end{array}$ & $\begin{array}{l}134 \\
110 \\
110 \\
114 \\
125\end{array}$ & $\begin{array}{r}126 \\
127 \\
128 \\
73 \\
77\end{array}$ & $\begin{array}{l}70 \\
56 \\
62 \\
78 \\
84\end{array}$ & $\begin{array}{l}53 \\
52 \\
53 \\
54 \\
56\end{array}$ & $\begin{array}{l}67 \\
60 \\
68 \\
72 \\
76\end{array}$ & $\begin{array}{l}115 \\
105 \\
110 \\
125 \\
115\end{array}$ & $\begin{array}{r}75 \\
160 \\
90 \\
92 \\
90\end{array}$ & $\begin{array}{r}98 \\
95 \\
100 \\
87 \\
133\end{array}$ & $\begin{array}{l}55 \\
65 \\
60 \\
61 \\
55\end{array}$ & $\begin{array}{r}106 \\
96 \\
103 \\
99 \\
102\end{array}$ \\
\hline $\begin{array}{l}22 \ldots \ldots \\
22 \ldots \ldots \\
23 \ldots \ldots \\
24 \ldots \ldots \\
25 \ldots \ldots\end{array}$ & $\begin{array}{l}117 \\
110 \\
145 \\
110 \\
114\end{array}$ & $\begin{array}{l}141 \\
128 \\
126 \\
131 \\
118\end{array}$ & $\begin{array}{l}128 \\
103 \\
110 \\
115 \\
175\end{array}$ & $\begin{array}{l}74 \\
69 \\
72 \\
80 \\
89\end{array}$ & $\begin{array}{l}64 \\
55 \\
52 \\
52 \\
52\end{array}$ & $\begin{array}{l}67 \\
62 \\
59 \\
67 \\
73\end{array}$ & $\begin{array}{l}75 \\
76 \\
75 \\
75 \\
78\end{array}$ & $\begin{array}{r}130 \\
85 \\
75 \\
84 \\
95\end{array}$ & $\begin{array}{l}104 \\
102 \\
103 \\
110 \\
120\end{array}$ & $\begin{array}{r}171 \\
103 \\
48 \\
45 \\
125\end{array}$ & $\begin{array}{l}47 \\
43 \\
44 \\
48 \\
47\end{array}$ & $\begin{array}{l}102 \\
110 \\
116 \\
119 \\
123\end{array}$ \\
\hline $\begin{array}{l}26 \ldots \ldots \\
27 \ldots \ldots \\
28 \ldots \ldots \\
29 \ldots \ldots \\
30 \ldots \ldots \\
31 \ldots \ldots\end{array}$ & $\begin{array}{l}112 \\
127 \\
124 \\
131 \\
125 \\
134\end{array}$ & $\begin{array}{r}138 \\
139 \\
131 \\
129 \\
127 \\
--\end{array}$ & $\begin{array}{r}230 \\
95 \\
122 \\
190 \\
200 \\
155\end{array}$ & $\begin{array}{l}93 \\
87 \\
77 \\
76 \\
86 \\
89\end{array}$ & $\begin{array}{l}52 \\
54 \\
61 \\
-- \\
-- \\
--\end{array}$ & $\begin{array}{l}98 \\
70 \\
50 \\
42 \\
36 \\
39\end{array}$ & $\begin{array}{r}82 \\
87 \\
95 \\
104 \\
100 \\
-7\end{array}$ & $\begin{array}{l}105 \\
110 \\
120 \\
120 \\
120 \\
120\end{array}$ & $\begin{array}{r}126 \\
86 \\
92 \\
95 \\
265 \\
--\end{array}$ & $\begin{array}{r}155 \\
95 \\
76 \\
80 \\
89 \\
71\end{array}$ & $\begin{array}{l}49 \\
56 \\
82 \\
85 \\
69 \\
61\end{array}$ & $\begin{array}{l}119 \\
117 \\
125 \\
160 \\
157 \\
--\end{array}$ \\
\hline AVERAGE & 107 & 136 & 144 & .3 & 61 & 59 & 63 & 105 & 96 & 117 & 66 & 98 \\
\hline
\end{tabular}

PH (UNITS), WATER YEAR OCTOBER 1969 TO SEPTEMBER 1970

DAY CCTCBER NOVEMBER CECEMBER JANUARY FEBRUARY MARCH APRIL MAY JUNE JULY AUGUST SEPTEMBER

\begin{tabular}{|c|c|c|c|c|c|c|c|c|c|c|c|c|}
\hline $\begin{array}{l}1 \ldots \ldots \\
2 \ldots \ldots \\
4 \ldots \ldots \\
5 \ldots \ldots\end{array}$ & $\begin{array}{l}6.2 \\
6.5 \\
7.0 \\
6.7 \\
6.7\end{array}$ & $\begin{array}{l}7.1 \\
7.3 \\
7.3 \\
7.0 \\
7.0\end{array}$ & $\begin{array}{l}7.5 \\
7.4 \\
7.2 \\
7.2 \\
7.2\end{array}$ & $\begin{array}{l}6.4 \\
6.4 \\
6.7 \\
6.5 \\
6.5\end{array}$ & $\begin{array}{l}6.2 \\
6.4 \\
6.3 \\
6.4 \\
6.3\end{array}$ & $\begin{array}{l}6.2 \\
6.2 \\
6.4 \\
6.5 \\
6.6\end{array}$ & $\begin{array}{l}6.0 \\
6.1 \\
6.2 \\
6.3 \\
6.4\end{array}$ & $\begin{array}{l}6.9 \\
6.9 \\
6.9 \\
6.8 \\
6.8\end{array}$ & $\begin{array}{l}6.6 \\
7.0 \\
6.8 \\
6.8 \\
6.7\end{array}$ & $\begin{array}{l}7.0 \\
6.9 \\
7.0 \\
6.9 \\
6.8\end{array}$ & $\begin{array}{l}7.3 \\
7.2 \\
7.2 \\
7.3 \\
7.4\end{array}$ & $\begin{array}{l}6.9 \\
6.8 \\
6.9 \\
7.0 \\
6.8\end{array}$ \\
\hline $\begin{array}{c}6 \ldots \ldots \\
7 \ldots \ldots \\
8 \ldots \ldots \\
9 \ldots \ldots \\
10 \ldots \ldots\end{array}$ & $\begin{array}{l}6.9 \\
6.8 \\
6.9 \\
6.8 \\
6.8\end{array}$ & $\begin{array}{l}7.1 \\
7.0 \\
7.4 \\
7.2 \\
7.2\end{array}$ & $\begin{array}{l}7.3 \\
7.1 \\
7.2 \\
7.1 \\
7.0\end{array}$ & $\begin{array}{l}6.6 \\
6.7 \\
6.4 \\
7.1 \\
7.1\end{array}$ & $\begin{array}{l}6.5 \\
6.3 \\
6.5 \\
6.8 \\
6.7\end{array}$ & $\begin{array}{l}6.7 \\
6.6 \\
6.7 \\
6.4 \\
6.3\end{array}$ & $\begin{array}{l}6.4 \\
6.2 \\
6.2 \\
6.1 \\
6.1\end{array}$ & $\begin{array}{l}6.9 \\
7.2 \\
7.0 \\
7.0 \\
7.0\end{array}$ & $\begin{array}{l}6.7 \\
6.5 \\
6.4 \\
6.5 \\
6.3\end{array}$ & $\begin{array}{l}6.8 \\
6.5 \\
6.5 \\
6.9 \\
7.0\end{array}$ & $\begin{array}{l}7.5 \\
7.6 \\
7.3 \\
7.6 \\
7.2\end{array}$ & $\begin{array}{l}6.8 \\
6.9 \\
6.8 \\
7.1 \\
7.0\end{array}$ \\
\hline $\begin{array}{l}11 \ldots \ldots \\
12 \ldots \ldots \\
13 \ldots \ldots \\
14 \ldots \ldots \\
15 \ldots \ldots\end{array}$ & $\begin{array}{l}6.9 \\
6.9 \\
6.9 \\
7.0 \\
7.0\end{array}$ & $\begin{array}{l}7.1 \\
7.1 \\
7.4 \\
7.0 \\
7.1\end{array}$ & $\begin{array}{l}6.8 \\
6.8 \\
6.7 \\
6.7 \\
6.8\end{array}$ & $\begin{array}{l}6.2 \\
6.3 \\
6.2 \\
6.2 \\
7.1\end{array}$ & $\begin{array}{l}6.2 \\
6.2 \\
6.3 \\
6.2 \\
6.7\end{array}$ & $\begin{array}{l}6.3 \\
6.2 \\
6.2 \\
6.2 \\
6.4\end{array}$ & $\begin{array}{l}6.3 \\
6.3 \\
6.1 \\
6.2 \\
6.3\end{array}$ & $\begin{array}{l}7.1 \\
7.1 \\
7.1 \\
7.0 \\
7.0\end{array}$ & $\begin{array}{l}6.3 \\
6.2 \\
6.2 \\
6.2 \\
6.4\end{array}$ & $\begin{array}{l}7.0 \\
7.0 \\
6.7 \\
6.7 \\
7.0\end{array}$ & $\begin{array}{l}6.9 \\
6.7 \\
6.4 \\
6.7 \\
6.7\end{array}$ & $\begin{array}{r}7.2 \\
7.0 \\
0 .- \\
7.2\end{array}$ \\
\hline $\begin{array}{l}16 \ldots \ldots \\
17 \ldots \ldots \\
18 \ldots \ldots \\
19 \ldots \ldots \\
20 \ldots \ldots\end{array}$ & $\begin{array}{l}6.9 \\
7.1 \\
6.9 \\
7.0 \\
7.0\end{array}$ & $\begin{array}{l}7.1 \\
7.0 \\
7.0 \\
7.2 \\
7.2\end{array}$ & $\begin{array}{l}6.7 \\
6.7 \\
6.7 \\
6.7 \\
6.7\end{array}$ & $\begin{array}{l}6.3 \\
7.1 \\
6.3 \\
6.4 \\
6.3\end{array}$ & $\begin{array}{l}6.5 \\
6.5 \\
6.4 \\
6.2 \\
6.7\end{array}$ & $\begin{array}{l}6.2 \\
6.3 \\
6.3 \\
6.3 \\
6.2\end{array}$ & $\begin{array}{l}6.3 \\
6.5 \\
6.4 \\
6.4 \\
6.4\end{array}$ & $\begin{array}{l}7.0 \\
7.0 \\
7.0 \\
7.1 \\
7.2\end{array}$ & $\begin{array}{l}6.8 \\
6.7 \\
6.7 \\
6.7 \\
6.8\end{array}$ & $\begin{array}{l}6.7 \\
6.8 \\
6.9 \\
6.8 \\
6.8\end{array}$ & $\begin{array}{l}6.8 \\
6.7 \\
6.5 \\
6.7 \\
6.7\end{array}$ & $\begin{array}{l}7.3 \\
7.2 \\
7.3 \\
7.2 \\
7.2\end{array}$ \\
\hline $\begin{array}{l}21 \ldots \ldots \\
22 \ldots \ldots \\
23 \ldots \ldots \\
24 \ldots \ldots \\
25 \ldots \ldots\end{array}$ & $\begin{array}{l}7.0 \\
6.9 \\
6.8 \\
6.9 \\
6.9\end{array}$ & $\begin{array}{l}7.0 \\
7.1 \\
7.3 \\
7.0 \\
7.1\end{array}$ & $\begin{array}{l}6.7 \\
6.7 \\
6.7 \\
6.6 \\
6.5\end{array}$ & $\begin{array}{l}6.2 \\
6.3 \\
6.4 \\
6.4 \\
6.5\end{array}$ & $\begin{array}{l}6.4 \\
6.4 \\
6.4 \\
6.7 \\
6.2\end{array}$ & $\begin{array}{l}6.2 \\
6.3 \\
6.3 \\
6.7 \\
6.3\end{array}$ & $\begin{array}{l}6.4 \\
6.4 \\
6.5 \\
6.5 \\
6.5\end{array}$ & $\begin{array}{l}6.8 \\
6.8 \\
6.9 \\
6.9 \\
7.2\end{array}$ & $\begin{array}{l}6.8 \\
6.8 \\
6.8 \\
6.9 \\
6.9\end{array}$ & $\begin{array}{l}6.7 \\
6.8 \\
6.3 \\
6.0 \\
6.0\end{array}$ & $\begin{array}{l}7.0 \\
6.8 \\
6.8 \\
6.8 \\
7.0\end{array}$ & $\begin{array}{l}7.2 \\
7.3 \\
7.4 \\
7.5 \\
7.4\end{array}$ \\
\hline $\begin{array}{l}26 \ldots \ldots \\
27 \ldots \ldots \\
28 \ldots \ldots \\
29 \ldots \ldots \\
30 \ldots \ldots \\
31 \ldots \ldots\end{array}$ & $\begin{array}{l}6.9 \\
6.7 \\
6.7 \\
7.0 \\
7.0 \\
7.0\end{array}$ & $\begin{array}{l}7.5 \\
7.2 \\
7.1 \\
7.0 \\
7.2 \\
-.\end{array}$ & $\begin{array}{l}6.6 \\
6.6 \\
6.5 \\
6.4 \\
6.4 \\
6.7\end{array}$ & $\begin{array}{l}6.6 \\
6.5 \\
6.6 \\
6.6 \\
6.7 \\
6.8\end{array}$ & $\begin{array}{l}6.2 \\
6.1 \\
6.4 \\
=- \\
=\end{array}$ & $\begin{array}{l}6.3 \\
6.3 \\
6.7 \\
6.7 \\
5.9 \\
5.9\end{array}$ & $\begin{array}{l}6.5 \\
6.5 \\
6.7 \\
6.7 \\
6.7 \\
-.7\end{array}$ & $\begin{array}{l}7.1 \\
7.1 \\
7.0 \\
7.0 \\
7.0 \\
6.9\end{array}$ & $\begin{array}{l}6.9 \\
6.8 \\
6.8 \\
6.9 \\
6.9 \\
-.\end{array}$ & $\begin{array}{l}6.2 \\
6.4 \\
6.5 \\
6.5 \\
6.6 \\
6.6\end{array}$ & $\begin{array}{l}6.5 \\
7.0 \\
6.8 \\
7.0 \\
7.0 \\
6.7\end{array}$ & $\begin{array}{l}7.3 \\
7.2 \\
7.2 \\
7.4 \\
7.4 \\
-.\end{array}$ \\
\hline$\triangle V E R$ AGE & 6.8 & 7.1 & 6.8 & 6.5 & 6.3 & 6.3 & 6.3 & 6.9 & 6.6 & 6.6 & 6.9 & 7.1 \\
\hline
\end{tabular}

(TRACE METALS)

\begin{tabular}{|c|c|c|c|c|c|c|c|c|c|c|c|c|}
\hline DATE & $\begin{array}{l}\text { TOTAL } \\
\text { ALUM- } \\
\text { INUHA } \\
\text { (AL) } \\
\text { (UGLL) }\end{array}$ & $\begin{array}{l}\text { DIS- } \\
\text { SOLVED } \\
\text { APGENIC } \\
\text { (AS) } \\
\text { (UG/L) }\end{array}$ & $\begin{array}{c}\text { OIS- } \\
\text { SOLVEU } \\
\text { GORON } \\
\text { (B) } \\
\text { (UG/L) }\end{array}$ & $\begin{array}{l}\text { DIS- } \\
\text { SOLVED } \\
\text { CAD- } \\
\text { MIUM } \\
\text { (CD) } \\
\text { (UG/L) }\end{array}$ & $\begin{array}{l}\text { MEXA- } \\
\text { VALENT } \\
\text { CHPO- } \\
\text { MIUM } \\
\text { (CRG) } \\
\text { (UG/L) }\end{array}$ & $\begin{array}{l}\text { DIS- } \\
\text { SOLVEO } \\
\text { CHKD- } \\
\text { MIUM } \\
\text { (CR) } \\
\text { (UG/L) }\end{array}$ & $\begin{array}{l}\text { OIS- } \\
\text { SOLVED } \\
\text { COPPER } \\
\text { (CU) } \\
\text { (UG/L) }\end{array}$ & $\begin{array}{l}\text { DIS- } \\
\text { SOLVEN } \\
\text { IRON } \\
\text { (FE) } \\
\text { (UG/L) }\end{array}$ & $\begin{array}{l}\text { DIS- } \\
\text { SOLVEN } \\
\text { LEAO } \\
\text { (PR) } \\
\text { (UG/L) }\end{array}$ & $\begin{array}{l}\text { OIS- } \\
\text { SOLVEO } \\
\text { MAN- } \\
\text { GANESE } \\
\text { (MN) } \\
\text { (UG/L) }\end{array}$ & $\begin{array}{l}\text { TOYAL } \\
\text { MERCURY } \\
\text { (HG) } \\
\text { (UG/L) }\end{array}$ & $\begin{array}{l}\text { OIS- } \\
\text { SILVEO } \\
\text { ZIVC } \\
\text { (ZN) } \\
\text { (UG/L) }\end{array}$ \\
\hline \multirow{3}{*}{$\begin{array}{l}\text { MAY . } 1970 \\
04 \ldots . . \\
\text { SEP. } \\
02 \ldots .\end{array}$} & & & & & & & & & & & & \\
\hline & . & 10 & $-\cdot$ & -- & $-\cdot$ & -- & $n$ & 1400 & 0 & 90 & $-\infty$ & 170 \\
\hline & -- & 10 & -- & -- & -- & -- & I0 & 1100 & 10 & 80 & - & 60 \\
\hline
\end{tabular}


OCHLOCKONEE RIVER BASIN

02329000 OCHLOCKONEE RIVER NEAR HAVANA, FLA.--CONtInued

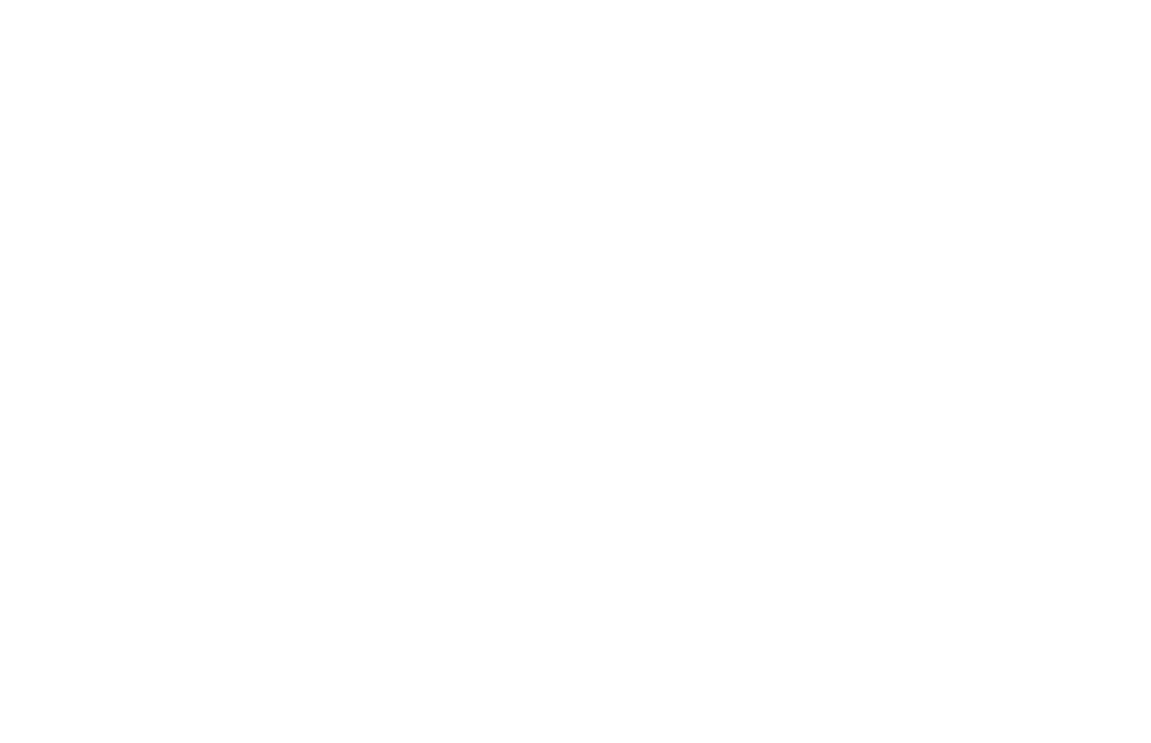

APALACHICOLA RIVER BASIN

02335500 CHATTAHOOCHEE RIVER NEAR ROSWELL, GA.

LOCATION, - -Lat $34^{\circ} 00^{+} 20^{\prime \prime}$, long $84^{\circ} 19^{\prime} 53^{\prime \prime}$, Fulton County, temperature recorder on right bank $1.5 \mathrm{miles}$ upstream from Big Creek and bridge on U.S. Highway 19,2 miles southeast of Roswell, and at mile 318.8 .

DRAINAGE AREA.--1,230 sq mi, approximately.

PERIOD OF RECORD.--Water temperatures: July 1967 to September 1970.

EXTREYES, - - 1969-70:

Water temperatures: Maximum, $20.0^{\circ} \mathrm{C}$ July 23,27 ; minimum, freezing point Jan. 10.

Period of record:

Water temperatures: Maximum, $21,0^{\circ} \mathrm{C}$ June 10,1968 , July 6,$1969 ;$ minimum, freezing point Jan. $10,1970$. REMARKS, - - Flow regulated by Lake Sidney Lanter since January 1956 (see sta. 2-3344).

TEMPERATURE ( $\left.{ }^{\circ} \mathrm{C}\right)$ OF WATER, WATER YEAR OCTOBER 1969 TO SEPTEMBER 1970

DCTOBER

NOVEMBER

DECEMBER

JANUARY

FEBRUARY

MARCH

\begin{tabular}{|c|c|c|c|c|c|c|c|c|c|c|c|c|}
\hline \multirow[b]{2}{*}{ DAY } & & \multicolumn{2}{|c|}{ (6) } & & & & \\
\hline & $\operatorname{MAX}$ & MIN & $\operatorname{MAX}$ & MIN & MAX & MIN & MAX & MIN & $\operatorname{MAX}$ & MIN & $M A X$ & MIN \\
\hline $\begin{array}{l}1 \\
2 \\
3 \\
4 \\
5\end{array}$ & $\begin{array}{l}11.0 \\
11.0 \\
11.5 \\
22.0 \\
15.0\end{array}$ & $\begin{array}{l}10.0 \\
10.5 \\
11.0 \\
11.6 \\
11.5\end{array}$ & $\begin{array}{l}12.0 \\
11.5 \\
11.0 \\
10.5 \\
10.5\end{array}$ & $\begin{array}{r}10.5 \\
10.5 \\
9.0 \\
9.0 \\
9.0\end{array}$ & $\begin{array}{l}9.5 \\
9.5 \\
9.5 \\
9.0 \\
9.0\end{array}$ & $\begin{array}{l}7.0 \\
8.5 \\
8.5 \\
8.5 \\
8.5\end{array}$ & $\begin{array}{l}6.5 \\
4.5 \\
5.0 \\
4.0 \\
3.5\end{array}$ & $\begin{array}{l}4.5 \\
3.0 \\
4.0 \\
2.0 \\
2.0\end{array}$ & $\begin{array}{l}4.0 \\
4.5 \\
8.0 \\
5.5 \\
5.5\end{array}$ & $\begin{array}{l}2.0 \\
3.5 \\
5.5 \\
4.5 \\
5.0\end{array}$ & $\begin{array}{r}9.5 \\
10.5 \\
10.0 \\
9.5 \\
10.0\end{array}$ & $\begin{array}{l}8.0 \\
8.5 \\
9.0 \\
9.0 \\
9.0\end{array}$ \\
\hline $\begin{array}{r}6 \\
7 \\
8 \\
9 \\
10\end{array}$ & $\begin{array}{l}14.0 \\
11.5 \\
11.0 \\
11.0 \\
11.0\end{array}$ & $\begin{array}{l}11.5 \\
10.5 \\
10.0 \\
10.5 \\
10.5\end{array}$ & $\begin{array}{l}10.5 \\
10.5 \\
11.0 \\
10.5 \\
10.5\end{array}$ & $\begin{array}{r}9.0 \\
9.5 \\
10.0 \\
9.0 \\
8.5\end{array}$ & $\begin{array}{l}9.0 \\
8.0 \\
8.5 \\
8.5 \\
8.5\end{array}$ & $\begin{array}{l}8.0 \\
6.5 \\
6.5 \\
8.5 \\
8.5\end{array}$ & $\begin{array}{l}4.5 \\
4.0 \\
3.0 \\
3.0 \\
2.0\end{array}$ & $\begin{array}{l}3.0 \\
1.5 \\
1.0 \\
0.5 \\
0.0\end{array}$ & $\begin{array}{l}6.5 \\
8.0 \\
8.5 \\
8.5 \\
8.0\end{array}$ & $\begin{array}{l}5.0 \\
6.0 \\
6.5 \\
7.0 \\
6.0\end{array}$ & $\begin{array}{r}10.0 \\
9.5 \\
9.5 \\
11.0 \\
10.5\end{array}$ & $\begin{array}{l}9.5 \\
8.5 \\
8.5 \\
8.0 \\
9.0\end{array}$ \\
\hline $\begin{array}{l}11 \\
12 \\
13 \\
14 \\
15\end{array}$ & $\begin{array}{l}11.0 \\
14.5 \\
14.0 \\
13.0 \\
10.5\end{array}$ & $\begin{array}{r}10.5 \\
11.0 \\
11.0 \\
10.5 \\
9.5\end{array}$ & $\begin{array}{l}11.0 \\
11.5 \\
10.5 \\
10.5 \\
10.0\end{array}$ & $\begin{array}{r}9.5 \\
10.0 \\
9.5 \\
9.0 \\
0.5\end{array}$ & $\begin{array}{l}8.5 \\
8.5 \\
8.0 \\
8.5 \\
8.0\end{array}$ & $\begin{array}{l}8.5 \\
9.0 \\
6.5 \\
6.5 \\
6.5\end{array}$ & $\begin{array}{l}1.5 \\
1.5 \\
4.0 \\
3.5 \\
3.5\end{array}$ & $\begin{array}{l}1.0 \\
1.0 \\
1.5 \\
1.5 \\
2.0\end{array}$ & $\begin{array}{l}7.0 \\
8.0 \\
7.0 \\
7.0 \\
8.5\end{array}$ & $\begin{array}{l}5.5 \\
6.0 \\
6.0 \\
6.0 \\
7.0\end{array}$ & $\begin{array}{l}9.5 \\
9.5 \\
9.5 \\
8.5 \\
9.5\end{array}$ & $\begin{array}{l}9.0 \\
9.0 \\
8.0 \\
6.5 \\
7.0\end{array}$ \\
\hline $\begin{array}{l}16 \\
17 \\
19 \\
19 \\
20\end{array}$ & $\begin{array}{l}10.5 \\
10.5 \\
10.0 \\
10.0 \\
11.0\end{array}$ & $\begin{array}{r}9.5 \\
9.5 \\
9.0 \\
9.5 \\
10.0\end{array}$ & $\begin{array}{r}8.5 \\
10.0 \\
10.5 \\
10.5 \\
10.0\end{array}$ & $\begin{array}{r}6.5 \\
5.5 \\
10.0 \\
9.5 \\
9.0\end{array}$ & $\begin{array}{l}8.0 \\
8.0 \\
8.0 \\
8.5 \\
8.0\end{array}$ & $\begin{array}{l}6.0 \\
6.0 \\
6.0 \\
6.5 \\
7.0\end{array}$ & $\begin{array}{l}4.0 \\
4.0 \\
5.5 \\
4.5 \\
4.0\end{array}$ & $\begin{array}{l}2.0 \\
3.5 \\
4.0 \\
3.5 \\
3.0\end{array}$ & $\begin{array}{l}8.5 \\
8.5 \\
9.5 \\
9.0 \\
8.0\end{array}$ & $\begin{array}{l}8.5 \\
B .0 \\
8.0 \\
8.0 \\
6.5\end{array}$ & $\begin{array}{r}9.5 \\
9.0 \\
10.0 \\
10.0 \\
11.0\end{array}$ & $\begin{array}{r}6.5 \\
7.0 \\
8.0 \\
9.0 \\
10.0\end{array}$ \\
\hline $\begin{array}{l}21 \\
22 \\
23 \\
24 \\
25\end{array}$ & $\begin{array}{l}11.0 \\
10.5 \\
10.0 \\
10.9 \\
11.0\end{array}$ & $\begin{array}{l}9.5 \\
9.5 \\
8.5 \\
8.5 \\
9.0\end{array}$ & $\begin{array}{r}10.0 \\
10.0 \\
9.5 \\
10.0 \\
10.0\end{array}$ & $\begin{array}{l}9.0 \\
9.0 \\
9.0 \\
9.0 \\
9.5\end{array}$ & $\begin{array}{l}7.0 \\
5.5 \\
6.5 \\
5.5 \\
5.0\end{array}$ & $\begin{array}{l}5.0 \\
5.0 \\
5.0 \\
5.0 \\
4.0\end{array}$ & $\begin{array}{l}3.0 \\
2.0 \\
1.5 \\
3.0 \\
3.0\end{array}$ & $\begin{array}{l}1.5 \\
1.0 \\
1.0 \\
1.0 \\
1.5\end{array}$ & $\begin{array}{l}8.0 \\
8.5 \\
9.0 \\
9.0 \\
8.0\end{array}$ & $\begin{array}{l}6.0 \\
5.5 \\
7.0 \\
8.0 \\
7.0\end{array}$ & $\begin{array}{r}10.5 \\
9.5 \\
9.5 \\
8.5 \\
10.5\end{array}$ & $\begin{array}{l}9.5 \\
9.5 \\
8.5 \\
8.5 \\
8.5\end{array}$ \\
\hline $\begin{array}{l}76 \\
27 \\
28 \\
29 \\
30 \\
31\end{array}$ & $\begin{array}{l}11.5 \\
11.5 \\
11.0 \\
11.0 \\
11.5 \\
11.5\end{array}$ & $\begin{array}{r}10.5 \\
9.0 \\
9.5 \\
9.5 \\
10.0 \\
10.5\end{array}$ & $\begin{array}{r}10.5 \\
10.0 \\
9.5 \\
10.0 \\
9.0 \\
-\end{array}$ & $\begin{array}{l}9.5 \\
9.5 \\
8.5 \\
9.5 \\
8.5 \\
\end{array}$ & $\begin{array}{l}4.0 \\
4.5 \\
4.5 \\
6.0 \\
8.0 \\
8.0\end{array}$ & $\begin{array}{l}3.0 \\
2.0 \\
3.0 \\
4.5 \\
0.0 \\
0.5\end{array}$ & $\begin{array}{l}6.0 \\
5.5 \\
4.5 \\
6.0 \\
6.0 \\
4.0\end{array}$ & $\begin{array}{l}1.5 \\
4.5 \\
4.0 \\
4.5 \\
4.0 \\
3.5\end{array}$ & $\begin{array}{l}8.0 \\
8.5 \\
8.0 \\
--- \\
--.-\end{array}$ & \begin{tabular}{l}
6.5 \\
6.0 \\
7.0 \\
\hdashline.- \\
\hdashline-0
\end{tabular} & $\begin{array}{l}11.0 \\
11.5 \\
12.0 \\
15.0 \\
14.0 \\
11.5\end{array}$ & $\begin{array}{r}10.0 \\
9.0 \\
9.0 \\
10.5 \\
11.0 \\
9.5\end{array}$ \\
\hline AVERAGE & 15.0 & 8.5 & 12.0 & 5.5 & 9.5 & 2.0 & 6.5 & 0 & 9.5 & 2.0 & 15.0 & 6.5 \\
\hline
\end{tabular}


02335500 CHATTAHOOCHEE RIVER NEAR ROSWELL, GA.--Cont1 nued

TEMPERATURE ( $\left.{ }^{\circ} \mathrm{C}\right)$ OF WATER, NATER YEAR OCTOBER 1969 TO SEPTEMBER 1970

\begin{tabular}{|c|c|c|c|c|c|c|c|c|c|c|c|c|}
\hline \multirow[b]{2}{*}{ DAY } & \multicolumn{2}{|c|}{ APRIL } & \multicolumn{2}{|c|}{ MAY } & \multicolumn{2}{|c|}{ JUNE } & \multicolumn{2}{|c|}{ JULY } & \multicolumn{2}{|c|}{ A UG UST } & \multicolumn{2}{|c|}{ SEPTEMBER } \\
\hline & MAX & MIN & MAX & MIN & MAX & MIN & MAX & MIN & $\operatorname{MAX}$ & MIN & MAX & $\operatorname{MIN}$ \\
\hline $\begin{array}{l}1 \\
2 \\
3 \\
4 \\
5\end{array}$ & $\begin{array}{l}11.5 \\
13.0 \\
13.5 \\
13.5 \\
13.5\end{array}$ & $\begin{array}{l}10.5 \\
10.5 \\
10.5 \\
10.0 \\
10.5\end{array}$ & $\begin{array}{l}16.5 \\
15.0 \\
14.5 \\
15.0 \\
16.5\end{array}$ & $\begin{array}{l}14.5 \\
14.0 \\
13.0 \\
12.0 \\
13.5\end{array}$ & $\begin{array}{l}18.0 \\
17.0 \\
15.0 \\
15.5 \\
15.5\end{array}$ & $\begin{array}{l}14.0 \\
10.0 \\
10.5 \\
20.5 \\
10.5\end{array}$ & $\begin{array}{l}19.0 \\
15.0 \\
15.0 \\
15.5 \\
19.0\end{array}$ & $\begin{array}{l}13.5 \\
11.0 \\
12.0 \\
13.5 \\
15.0\end{array}$ & $\begin{array}{l}15.5 \\
19.5 \\
19.5 \\
15.0 \\
15.0\end{array}$ & $\begin{array}{l}10.5 \\
15.5 \\
11.5 \\
20.5 \\
10.5\end{array}$ & $\begin{array}{l}14.5 \\
14.5 \\
14.5 \\
15.0 \\
14.5\end{array}$ & $\begin{array}{l}11.9 \\
11.5 \\
11.5 \\
11.5 \\
11.5\end{array}$ \\
\hline $\begin{array}{r}6 \\
7 \\
B \\
9 \\
10\end{array}$ & $\begin{array}{l}14.5 \\
15.0 \\
14.5 \\
14.5 \\
14.5\end{array}$ & $\begin{array}{l}11.0 \\
11.0 \\
10.5 \\
11.0 \\
12.0\end{array}$ & $\begin{array}{l}17.0 \\
17.0 \\
18.0 \\
18.0 \\
18.0\end{array}$ & $\begin{array}{l}14.0 \\
13.5 \\
13.5 \\
14.0 \\
14.5\end{array}$ & $\begin{array}{l}14.5 \\
16.5 \\
18.5 \\
18.5 \\
14.0\end{array}$ & $\begin{array}{l}10.0 \\
12.0 \\
14.5 \\
10.0 \\
10.0\end{array}$ & $\begin{array}{l}18.5 \\
18.0 \\
14.0 \\
14.0 \\
14.5\end{array}$ & $\begin{array}{l}10.0 \\
10.5 \\
10.5 \\
10.5 \\
10.5\end{array}$ & $\begin{array}{l}14.5 \\
14.0 \\
15.0 \\
16.0 \\
17.0\end{array}$ & $\begin{array}{l}10.5 \\
10.5 \\
10.5 \\
15.0 \\
14.5\end{array}$ & $\begin{array}{l}18.0 \\
18.0 \\
17.0 \\
16.0 \\
15.0\end{array}$ & $\begin{array}{l}15.0 \\
15.5 \\
15.0 \\
11.5 \\
11.5\end{array}$ \\
\hline $\begin{array}{l}11 \\
12 \\
13 \\
14 \\
15\end{array}$ & $\begin{array}{l}13.5 \\
13.5 \\
14.5 \\
14.5 \\
14.0\end{array}$ & $\begin{array}{l}11.0 \\
11.0 \\
11.5 \\
12.0 \\
11.5\end{array}$ & $\begin{array}{l}18.5 \\
18.0 \\
14.5 \\
15.0 \\
15.0\end{array}$ & $\begin{array}{l}14.5 \\
13.5 \\
13.5 \\
13.5 \\
14.0\end{array}$ & $\begin{array}{l}13.5 \\
14.0 \\
13.5 \\
15.5 \\
16.0\end{array}$ & $\begin{array}{l}10.0 \\
10.0 \\
10.0 \\
13.5 \\
13.5\end{array}$ & $\begin{array}{l}14.5 \\
19.0 \\
19.0 \\
16.5 \\
14.5\end{array}$ & $\begin{array}{l}10.5 \\
14.5 \\
15.5 \\
10.5 \\
10.5\end{array}$ & $\begin{array}{l}14.0 \\
14.5 \\
16.0 \\
18.5 \\
15.5\end{array}$ & $\begin{array}{l}11.0 \\
13.5 \\
14.0 \\
13.0 \\
10.5\end{array}$ & $\begin{array}{l}15.0 \\
14.5 \\
18.0 \\
18.5 \\
15.0\end{array}$ & $\begin{array}{l}11.5 \\
11.5 \\
15.0 \\
18.0 \\
11.0\end{array}$ \\
\hline $\begin{array}{l}21 \\
22 \\
23 \\
24 \\
25\end{array}$ & $\begin{array}{l}17.0 \\
15.5 \\
16.0 \\
15.5 \\
13.5\end{array}$ & $\begin{array}{l}14.0 \\
13.5 \\
13.5 \\
12.0 \\
11.5\end{array}$ & $\begin{array}{l}16.0 \\
15.0 \\
14.5 \\
19.0 \\
19.0\end{array}$ & $\begin{array}{l}13.5 \\
13.5 \\
13.5 \\
14.5 \\
15.0\end{array}$ & $\begin{array}{l}18.0 \\
19.5 \\
19.0 \\
15.0 \\
15.0\end{array}$ & $\begin{array}{l}13.5 \\
15.5 \\
10.5 \\
13.0 \\
13.5\end{array}$ & $\begin{array}{l}13.0 \\
17.0 \\
19.0 \\
20.0 \\
15.5\end{array}$ & $\begin{array}{l}10.5 \\
16.0 \\
16.5 \\
16.5 \\
11.0\end{array}$ & $\begin{array}{l}14.5 \\
15.5 \\
18.0 \\
18.5 \\
14.0\end{array}$ & $\begin{array}{l}10.5 \\
11.0 \\
13.0 \\
11.5 \\
11.0\end{array}$ & $\begin{array}{l}18.0 \\
14.5 \\
15.0 \\
14.5 \\
15.0\end{array}$ & $\begin{array}{l}12.0 \\
12.0 \\
11.5 \\
12.0 \\
12.0\end{array}$ \\
\hline $\begin{array}{l}26 \\
27 \\
29 \\
29 \\
30 \\
31\end{array}$ & $\begin{array}{r}13.5 \\
14.0 \\
17.0 \\
18.0 \\
17.0 \\
-. .0\end{array}$ & $\begin{array}{r}12.0 \\
12.0 \\
13.0 \\
14.5 \\
14.5 \\
-. .\end{array}$ & $\begin{array}{l}17.0 \\
15.0 \\
15.0 \\
14.0 \\
13.5 \\
15.0\end{array}$ & $\begin{array}{l}12.0 \\
13.5 \\
13.0 \\
111.5 \\
11.0 \\
12.0\end{array}$ & $\begin{array}{c}18.0 \\
17.0 \\
18.0 \\
18.0 \\
19.5 \\
\ldots .-\end{array}$ & $\begin{array}{r}13.5 \\
11.0 \\
14.5 \\
14.5 \\
15.0 \\
-. .-\end{array}$ & $\begin{array}{l}19.5 \\
20.0 \\
16.5 \\
15.0 \\
15.0 \\
15.0\end{array}$ & $\begin{array}{l}15.5 \\
16.5 \\
10.5 \\
10.5 \\
10.5 \\
10.5\end{array}$ & $\begin{array}{l}14.0 \\
14.0 \\
13.5 \\
14.5 \\
19.5 \\
19.0\end{array}$ & $\begin{array}{l}11.0 \\
10.5 \\
11.0 \\
11.0 \\
14.5 \\
11.5\end{array}$ & $\begin{array}{r}14.5 \\
15.0 \\
15.5 \\
14.5 \\
14.5 \\
-. .5\end{array}$ & $\begin{array}{l}12.0 \\
14.5 \\
11.5 \\
12.5 \\
11.5 \\
\end{array}$ \\
\hline VERAGE & 18.0 & 10.0 & 19.0 & 11.0 & 19.5 & 10.0 & 20.0 & 10.0 & 19.5 & 10.5 & 18.5 & 11.0 \\
\hline
\end{tabular}

02358000 APALACHICOLA RIVER AT CHATTAHOOCHEE, FLA.

LOCATION, -- Lat $30^{\circ} 42^{\prime} 03^{\prime \prime}$, long $84^{\circ} 51^{\prime} 33^{\prime \prime}$, 1n NW $\frac{1}{4}$ sec.32, T.4 N, , R.6 W., Jackson County, at gaging station on down-

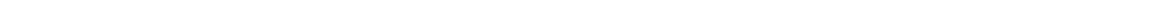
downstream from Mosquito creek, 1 mile west of Chattahoochee, and 106 miles upstream from mouth.

DRAINAGE AREA. --17,200 sq mi, approximately.

PERIOD OF RECORD.--Chemlcal analyses: November 1962 to September 1970.

Water temperatures: November 1962 to September 1970.

EXTRENES. - - 1969-70

Specific conductance: Maximum dal1y, 128 micromhos May 26 ; minimum da1ly, 57 micromhos Apr. 2

water temperatures: Maximum, $31.0^{\circ} \mathrm{C}$ Aug. 4, 5 ; minimum, $6.0^{\circ} \mathrm{C} \mathrm{Jan} .9,10$.

perlod of record:

Spec1f1c conductance: Maximum da1ly, 220 m1cromhos Nov. 10, 1962; min1mum da1ly, 41 micromhos Mar. $10,12,1966$. Fater temperatures: Max1mum, $32.0^{\circ} \mathrm{C}$ Aug. 8, 1963 ; m1n1mum, $5,0^{\circ} \mathrm{C}$ Dec. $15,1968$. CHEMICAL ANALYSES, WATER YEAR OCTOBER 1969 TO SEPTEMBER 1970 (MAJOR CONSTITUENTS)

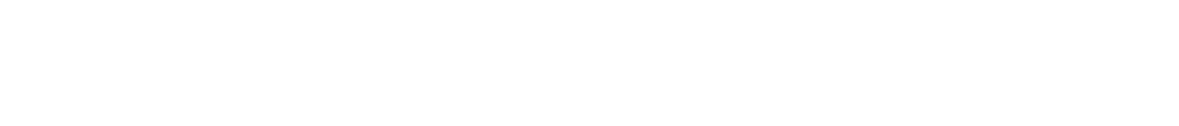

\begin{tabular}{|c|c|c|c|c|c|c|c|c|c|c|c|c|}
\hline \multicolumn{13}{|c|}{ OCT., 1969} \\
\hline $07 . .$. & 12100 & 29.0 & 103 & -- & 15 & 1.0 & -- & 4.1 & 1.0 & $4 \pi$ & -- & 5.5 \\
\hline 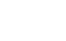 & $70^{11200}$ & 13.0 & 102 & 0 & 12 & 1.2 & -- & 7.0 & 1.8 & 45 & $n$ & 6.7 \\
\hline $\begin{array}{l}02 \ldots B \\
\text { MAR. }\end{array}$ & 19800 & 13.4 & 107 & -- & 15 & $1 . n$ & - & 4.0 & 1.2 & 51 & -- & 6.6 \\
\hline${ }_{\text {MAY }}^{24 \ldots C}$ & 102000 & 15.0 & 65 & - & 4.8 & $1 . n$ & -- & 5.6 & 1.5 & 22 & $n$ & 6.6 \\
\hline JULY & 15500 & 25.0 & 110 & 220 & 12 & 1.2 & 0 & 4.2 & 1.3 & 46 & -- & 7.7 \\
\hline $\begin{array}{l}01 . . E \\
\text { SEP. }\end{array}$ & 11800 & 28.5 & 110 & -- & 12 & 1.2 & 90 & 6.1 & 1.6 & 46 & $n$ & 7.0 \\
\hline $02 . . F$ & 15400 & 29.0 & 110 & 60 & 14 & 1.2 & $3 n$ & 6.0 & 1.4 & $5 ?$ & $n$ & 7.4 \\
\hline
\end{tabular}


02358000 APALACHICOLA RIVER AT CHATTAHOOCHER, FLA.--Continued CHEMICAL ANALYSES, WATER YEAR OCTOBER 1969 TO SEPTEMBER 1970 (MAJOR CONSTI TUENTS)

\begin{tabular}{|c|c|c|c|c|c|c|c|c|c|c|c|c|}
\hline & $\begin{array}{l}\text { OIS- } \\
\text { SOLVED } \\
\text { SULFATE } \\
(S O 4) \\
(M G / L)\end{array}$ & $\begin{array}{l}\text { OIS- } \\
\text { SOLVEO } \\
\text { CHLO- } \\
\text { RIDE } \\
\text { (CL) } \\
\text { (MG/L) }\end{array}$ & $\begin{array}{l}\text { DIS- } \\
\text { SOLVFD } \\
\text { FLUO- } \\
\text { RIDE } \\
\text { (F) } \\
\text { (MG/L) }\end{array}$ & $\begin{array}{l}\text { HARU- } \\
\text { NESS } \\
\text { (CA,MG) } \\
\text { (MG/L) }\end{array}$ & $\begin{array}{l}\text { NON- } \\
\text { CAR- } \\
\text { RONATE } \\
\text { HARD- } \\
\text { NESS } \\
\text { (MG L) }\end{array}$ & $\begin{array}{l}\text { ALKA- } \\
\text { LINITY } \\
\text { AS } \\
\text { CACO3 } \\
\text { (MG } L \text { ) }\end{array}$ & $\begin{array}{l}\text { DIS- } \\
\text { SOLVED } \\
\text { SOLIDS } \\
\text { (RESI - } \\
\text { DUE AT } \\
\text { IDO C) } \\
\text { (MG L) }\end{array}$ & $\begin{array}{l}\text { NIS- } \\
\text { SULVED } \\
\text { SOLIDS } \\
\text { (SUM OF } \\
\text { CONSTI- } \\
\text { TUENTS) } \\
\text { (MG/L) }\end{array}$ & $\begin{array}{l}\text { DIS- } \\
\text { SOLVED } \\
\text { SOLIDS } \\
\text { (TONS } \\
\text { PER } \\
\text { OAY) }\end{array}$ & $\begin{array}{l}\text { DIS- } \\
\text { SOLVFD } \\
\text { SOLIDS } \\
\text { (TONS } \\
\text { PER } \\
\text { AC-FI) }\end{array}$ & $\begin{array}{l}\text { TANNIN } \\
\text { AND } \\
\text { LIGNIN } \\
\text { (MGIL) }\end{array}$ & DE'TH \\
\hline
\end{tabular}

\begin{tabular}{|c|c|c|c|c|c|c|c|c|c|c|}
\hline $07 .$. & & 8.8 & 3. & .2 & & 42 & 2 & & 39 & 70 \\
\hline $\begin{array}{r}20 . . \\
\text { FEB., }\end{array}$ & ${ }^{A} 1970$ & 6.8 & 5. & .1 & & 35 & 1 & & 37 & 57 \\
\hline MAR. & & 4.8 & 40 & .1 & & 42 & 0 & & 42 & 65 \\
\hline & & 8.0 & 3. & .1 & & 16 & 0 & & 18 & 45 \\
\hline JULY & & 4.8 & 3. & .2 & & 35 & 0 & & 39 & 60 \\
\hline SEP.. & & 4.8 & 4. & .1 & & 35 & 0 & & 38 & 72 \\
\hline $02 \ldots$ & & 1.6 & 6. & .3 & & 40 & 0 & & 43 & 83 \\
\hline $\begin{array}{l}A \\
B \\
C \\
D \\
E \\
F\end{array}$ & $\begin{array}{l}\text { INCLUD } \\
\text { INCLUD } \\
\text { INCLUD } \\
\text { INCLUD } \\
\text { INCLUD } \\
\text { INCLUD }\end{array}$ & $\begin{array}{ll}\text { ES } & 9.4 \\
\text { ES } & 8.5 \\
\text { ES } & 7.8 \\
\text { ES } & 7.6 \\
\text { ES } & 7.7 \\
\text { ES } & 7.5\end{array}$ & $\begin{array}{l}M G / L \\
M G / L \\
M G / L \\
M G / L \\
M G / L \\
M G / L\end{array}$ & $\begin{array}{l}\text { DISSOLYED } \\
\text { DISSOLYED } \\
\text { DISSOLYED } \\
\text { DISSOLVED } \\
\text { DISSOLYED } \\
\text { DISSOLYED }\end{array}$ & $\begin{array}{l}\text { OXYGEN } \\
\text { OXYGEN } \\
\text { OXYGEN } \\
\text { OXYGEN } \\
\text { OXYGEN } \\
\text { OXYGEN }\end{array}$ & $\begin{array}{l}\text { COMPUTING } \\
\text { COMPUTING } \\
\text { COMPUTING } \\
\text { COMPUTING } \\
\text { COMPUTING } \\
\text { COMPUTING }\end{array}$ & $\begin{array}{l}\text { AS } \\
A S \\
\text { AS } \\
\text { AS } \\
\text { AS }\end{array}$ & $\begin{array}{l}89 \\
81 \\
76 \\
90 \\
97 \\
96\end{array}$ & $\begin{array}{l}\text { PERCENT } \\
\text { PERCENT } \\
\text { PERCENT } \\
\text { PERCENT } \\
\text { PERCENT } \\
\text { PERCENT }\end{array}$ & $\begin{array}{l}\text { SATURATION. } \\
\text { SATURATIDN. } \\
\text { SATURATION. } \\
\text { SATURATION. } \\
\text { SATURATION. } \\
\text { SATURATION. }\end{array}$ \\
\hline
\end{tabular}

(MACRONUTRIENTS AND DTHER RELATED CONSTITUENTS)

\begin{tabular}{|c|c|c|c|c|c|c|c|c|c|c|c|}
\hline ATH & $\begin{array}{l}\text { TOTAL } \\
\text { ANMONIA } \\
\text { (M!M4) } \\
(M G / L)\end{array}$ & $\begin{array}{l}\text { TOTAL } \\
\text { NITQITL } \\
\text { (NOZ) } \\
\text { (MG/L) }\end{array}$ & $\begin{array}{l}\text { TOTAL } \\
\text { NITHATE } \\
\text { (NO3) } \\
\text { (MG/L) }\end{array}$ & $\begin{array}{l}\text { ONG ANIC } \\
\text { NITRD- } \\
\text { GEN } \\
\text { (N) } \\
\text { (NG/L) }\end{array}$ & $\begin{array}{l}\text { UIS- } \\
\text { SOLVEN } \\
\text { ORTHO } \\
\text { PHUS- } \\
\text { FHATE } \\
\text { (POH) } \\
(M G / L)\end{array}$ & $\begin{array}{l}\text { PHCS- } \\
\text { PHATE } \\
\text { (PO4) } \\
\text { (MG/L) }\end{array}$ & $\begin{array}{l}\text { DIS- } \\
\text { SOLVES } \\
\text { SILICA } \\
\text { (SIOZ) } \\
(M G / L)\end{array}$ & $\begin{array}{l}\text { TUR- } \\
\text { BID- } \\
\text { ITY } \\
\text { (JTU) }\end{array}$ & $\begin{array}{l}\text { COLOR } \\
\text { (PLAT- } \\
\text { INUM- } \\
\text { COBALT } \\
\text { UNITS) }\end{array}$ & $\begin{array}{c}\text { TOTAL } \\
\text { ORGANIC } \\
\text { CARBON } \\
\text { (C) } \\
\text { (MG/L) }\end{array}$ & $\begin{array}{l}\text { RIO- } \\
\text { CHEM- } \\
\text { ICAL } \\
\text { OXYGEN } \\
\text { OEMAND } \\
\text { (MG/L) }\end{array}$ \\
\hline
\end{tabular}

\begin{tabular}{|c|c|c|c|c|c|c|c|c|c|c|c|c|}
\hline $\begin{array}{l}\text { OCT.” } 1969 \\
\text { O7.... } \\
\text { NOV. }\end{array}$ & $=$ & .00 & l.h & -- & $-\infty$ & - & B. 0 & -- & 5 & $=$ & -+ & $\cdots$ \\
\hline $20 \ldots 1970$ & - & -- & .2 & - & - & .29 & 5.2 & - & 5 & - & $=$ & $\cdots$ \\
\hline MAR. & - & .01 & .0 & - & $=$ & -- & 4.2 & - & 9 & -- & - & $\cdots$ \\
\hline $24 \ldots$ & $=$ & .00 & .0 & - & -- & $=$ & 4.0 & $\because$ & 5 & -- & - & $=$ \\
\hline JULY... & .09 & .06 & .8 & . 38 & 1.3 & 1.5 & 5.7 & 14 & 10 & 2.0 & 2.3 & - \\
\hline SEP. & .04 & .03 & .5 & $\cdots$ & .02 & .06 & $5 . H$ & 20 & 5 & -- & -- & $\cdots$ \\
\hline $02 \ldots$ & .01 & .01 & 1.4 & .31 & .06 & .11 & 7.8 & 6 & 0 & - & .8 & \\
\hline
\end{tabular}

(TRACE METALS)

\begin{tabular}{|c|c|c|c|c|c|c|c|c|c|c|c|c|}
\hline DATE & $\begin{array}{l}\text { IIS- } \\
\text { SULVED } \\
\text { AL UNM- } \\
\text { IVUM } \\
(A L L) \\
(U G / L)\end{array}$ & $\begin{array}{c}\text { DIS- } \\
\text { SOLVFU } \\
\text { ARSENIC } \\
\text { (AS) } \\
(U G / L)\end{array}$ & $\begin{array}{c}\text { OIS- } \\
\text { SOLVED } \\
\text { BORON } \\
\text { (A) } \\
\text { (UG/L) }\end{array}$ & $\begin{array}{l}\text { UIS- } \\
\text { SOLVFO } \\
\text { CAD- } \\
\text { MIUM } \\
\text { (CO) } \\
\text { (UG/L) }\end{array}$ & $\begin{array}{l}\text { HEXA- } \\
\text { VALENT } \\
\text { CHRO- } \\
\text { MIUM } \\
\text { (CRG) } \\
\text { (UG/L) }\end{array}$ & $\begin{array}{l}\text { DIS- } \\
\text { SOLVED } \\
\text { CHKO- } \\
\text { MIUM } \\
\text { (CK) } \\
\text { (UG/L) }\end{array}$ & $\begin{array}{l}\text { DIS- } \\
\text { SOLVED } \\
\text { COPPER } \\
\text { (EU) } \\
\text { (UG/L) }\end{array}$ & $\begin{array}{l}\text { UIS- } \\
\text { SOLVEN } \\
\text { IRON } \\
\text { (FE) } \\
\text { (UF/L) }\end{array}$ & $\begin{array}{l}\text { DIS- } \\
\text { SOLVEO } \\
\text { LEAD } \\
\text { (PA) } \\
(1 \mathrm{G} / L)\end{array}$ & $\begin{array}{l}\text { DIS- } \\
\text { SOLVED } \\
\text { MAN- } \\
\text { GANESE } \\
\text { (MN) } \\
\text { (UG/L) }\end{array}$ & $\begin{array}{l}\text { TOTAL } \\
\text { MERCURY } \\
\text { (HO) } \\
\text { (UG/L) }\end{array}$ & $\begin{array}{l}\text { UIS- } \\
\text { SI LVEO } \\
\text { ZIVC } \\
\text { (ZN) } \\
(U G / L)\end{array}$ \\
\hline NOV.: 1969 & -- & - & -- & -- & - & -- & -- & 0 & -- & -- & - & - \\
\hline SEP. & 0 & 0 & -- & -- & - & - & 0 & 220 & 10 & 20 & -- & 270 \\
\hline $02 \ldots$ & - & 0 & $\ldots$ & - & -- & - & 20 & ho & 20 & 30 & -- & 70 \\
\hline
\end{tabular}

RADIOCHEMICAL DATA

\begin{tabular}{|c|c|c|c|c|c|c|c|c|c|c|c|}
\hline & & & & $\begin{array}{l}\text { DIS- } \\
\text { SOLVED }\end{array}$ & $\begin{array}{l}\text { UIS- } \\
\text { SOLVED }\end{array}$ & $\begin{array}{l}\text { DIS- } \\
\text { SOLVED }\end{array}$ & $\begin{array}{c}\text { DIS- } \\
\text { SOLVED }\end{array}$ & $\begin{array}{l}\text { SUS- } \\
\text { PENDED }\end{array}$ & $\begin{array}{l}\text { SIIS- } \\
\text { PENOEDD }\end{array}$ & $\begin{array}{c}\text { SIIS- } \\
\text { DENDFD }\end{array}$ & $\begin{array}{l}\text { SUC- } \\
\text { PENDED }\end{array}$ \\
\hline & SOLVED & COLVED & SOLVE.D & GROSS & Gross & GROSS & GPOSS & GPOSS & GROSS & GROSS & GROSS \\
\hline & FA -226 & NATURAL & NATURAL & $A L P H A$ & ALPHA & FFTA & RETA & ALPHA & ALPHA & RETA & RE TA \\
\hline & $\begin{array}{l}\text { (RAUON) } \\
\text { METHOD) } \\
\text { (PC/L) }\end{array}$ & $\begin{array}{l}\text { URANIUM } \\
\text { (U) } \\
\text { (UG/L) }\end{array}$ & $\begin{array}{c}\text { URANIUM } \\
\text { (U) } \\
\text { (UG/L) }\end{array}$ & $\begin{array}{c}A S \\
U-N A T \\
(U G / L)\end{array}$ & $\begin{array}{c}\text { AS } \\
U \text {-NAT } \\
\text { (PC/L) }\end{array}$ & $\begin{array}{c}\text { AS } \$ P 90 \\
\angle Y 90 \\
(P C / L)\end{array}$ & $\begin{array}{c}\text { AS } \\
C S-137 \\
(P C / L)\end{array}$ & $\begin{array}{c}A S \\
U-N A T \text {. } \\
\text { (UG/L) }\end{array}$ & $\begin{array}{c}\Delta S \\
U-N A T \text {. } \\
(P C / L)\end{array}$ & $\begin{array}{c}\text { AS SR90 } \\
\text { SY90 } \\
(P C / L)\end{array}$ & $\begin{array}{c}\text { AS } \\
\operatorname{CS}-137 \\
(P C / L)\end{array}$ \\
\hline
\end{tabular}

\begin{tabular}{|c|c|c|c|c|c|c|c|c|c|c|c|}
\hline $\begin{array}{l}\text { OCT.. } 1967 \\
03 . . .\end{array}$ & - & $<.4$ & -- & $<.6$ & $<.2$ & 2.2 & 2.7 & .9 & .3 & 1.1 & 1.3 \\
\hline $\begin{array}{l}\text { MAR.. 1968 } \\
15 \ldots .\end{array}$ & -- & $<.4$ & $\cdots$ & .5 & .2 & 2.0 & 2.5 & 2.6 & .9 & 2.0 & 2.4 \\
\hline $\begin{array}{l}\text { OCT. } \\
23 \ldots . .1969 \\
\text { APR.. } 1969\end{array}$ & .03 & $<.4$ & -- & 1.5 & .5 & 2.4 & 3.1 & $<.4$ & $<.1$ & .9 & 1.0 \\
\hline $\begin{array}{l}22 \ldots \\
\text { MAR., } 1970\end{array}$ & .07 & $<.4$ & - & $<.4$ & $<.1$ & 2.2 & 2.8 & 1.4 & .5 & $<.4$ & $<.4$ \\
\hline $\begin{array}{l}24 \ldots \\
\text { SEP. }\end{array}$ & .02 & - & .09 & $<.4$ & $<1$ & 3.2 & 4.0 & 2.6 & .9 & 2.0 & 2.3 \\
\hline 02. & .04 & - & .07 & 1.3 & .4 & 2.7 & 3.5 & .6 & .2 & 1.0 & 1.1 \\
\hline
\end{tabular}


02358000 APALACHICOLA RIVER AT CHATTAHOOCHEE, FLA. - Continued

SPECIFIC CONDUCTANCE (MICROMHOS/CM AT 250 C), WATER YEAR OCTOBER 1969 TO SEPTEMBER 1970

DAY OCTOBER NOVEMBER DECEMBER JANUARY FEBRUARY MARCH APRIL MAY JUNE JULY AUGUST SEPTEMBER

\begin{tabular}{|c|c|c|c|c|c|c|c|c|c|c|c|c|}
\hline $\begin{array}{l}1 \ldots \ldots \\
2 \ldots \ldots \\
3 \ldots \ldots \\
4 \ldots \ldots \\
5 \ldots \ldots\end{array}$ & $\begin{array}{l}98 \\
78 \\
87 \\
86 \\
86\end{array}$ & $\begin{array}{l}97 \\
103 \\
103 \\
120 \\
116\end{array}$ & $\begin{array}{r}120 \\
108 \\
105 \\
92 \\
87\end{array}$ & $\begin{array}{l}90 \\
93 \\
72 \\
83 \\
98\end{array}$ & $\begin{array}{l}90 \\
97 \\
92 \\
90 \\
88\end{array}$ & $\begin{array}{l}88 \\
92 \\
87 \\
85 \\
86\end{array}$ & $\begin{array}{l}58 \\
57 \\
59 \\
50 \\
63\end{array}$ & $\begin{array}{r}88 \\
95 \\
95 \\
88 \\
103\end{array}$ & $\begin{array}{l}112 \\
115 \\
120 \\
116 \\
118\end{array}$ & $\begin{array}{l}99 \\
104 \\
103 \\
112 \\
114\end{array}$ & $\begin{array}{r}105 \\
108 \\
102 \\
102 \\
97\end{array}$ & $\begin{array}{r}113 \\
110 \\
102 \\
102 \\
99\end{array}$ \\
\hline $\begin{array}{r}6 \ldots \ldots \\
7 \ldots \ldots \\
8 \ldots \ldots \\
10 \ldots \ldots\end{array}$ & $\begin{array}{l}94 \\
97 \\
92 \\
97 \\
93\end{array}$ & $\begin{array}{l}120 \\
116 \\
119 \\
114 \\
111\end{array}$ & $\begin{array}{r}98 \\
116 \\
100 \\
88 \\
86\end{array}$ & $\begin{array}{l}90 \\
82 \\
91 \\
85 \\
84\end{array}$ & $\begin{array}{r}88 \\
90 \\
94 \\
100 \\
95\end{array}$ & $\begin{array}{l}86 \\
89 \\
89 \\
92 \\
86\end{array}$ & $\begin{array}{l}63 \\
62 \\
70 \\
68 \\
67\end{array}$ & $\begin{array}{r}102 \\
98 \\
90 \\
100 \\
100\end{array}$ & $\begin{array}{l}94 \\
90 \\
83 \\
87 \\
88\end{array}$ & $\begin{array}{l}104 \\
104 \\
111 \\
114 \\
111\end{array}$ & $\begin{array}{l}93 \\
97 \\
92 \\
95 \\
94\end{array}$ & $\begin{array}{r}99 \\
102 \\
96 \\
94 \\
99\end{array}$ \\
\hline $\begin{array}{l}11 \ldots \ldots \\
12 \ldots \ldots \\
13 \ldots \ldots \\
14 \ldots \ldots \\
15 \ldots \ldots\end{array}$ & $\begin{array}{l}94 \\
95 \\
95 \\
97 \\
90\end{array}$ & $\begin{array}{r}113 \\
110 \\
113 \\
110 \\
98\end{array}$ & $\begin{array}{r}109 \\
86 \\
114 \\
115 \\
120\end{array}$ & $\begin{array}{l}93 \\
85 \\
80 \\
77 \\
78\end{array}$ & $\begin{array}{l}83 \\
78 \\
79 \\
83 \\
84\end{array}$ & $\begin{array}{l}82 \\
80 \\
78 \\
92 \\
90\end{array}$ & $\begin{array}{l}66 \\
75 \\
83 \\
82 \\
80\end{array}$ & $\begin{array}{l}108 \\
106 \\
115 \\
109 \\
108\end{array}$ & $\begin{array}{l}86 \\
80 \\
79 \\
83 \\
84\end{array}$ & 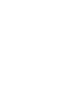 & $\begin{array}{l}94 \\
92 \\
93 \\
90 \\
91\end{array}$ & $\begin{array}{r}100 \\
97 \\
93 \\
105 \\
108\end{array}$ \\
\hline $\begin{array}{l}16 \ldots \ldots \\
17 \ldots \ldots \\
18 \ldots \ldots \\
19 \ldots \ldots \\
20 \ldots \ldots\end{array}$ & $\begin{array}{r}94 \\
100 \\
101 \\
100 \\
100\end{array}$ & $\begin{array}{r}99 \\
95 \\
100 \\
95 \\
88\end{array}$ & $\begin{array}{l}90 \\
90 \\
95 \\
93 \\
88\end{array}$ & $\begin{array}{l}88 \\
82 \\
82 \\
84 \\
79\end{array}$ & $\begin{array}{l}88 \\
78 \\
77 \\
78 \\
80\end{array}$ & $\begin{array}{r}100 \\
90 \\
100 \\
93 \\
95\end{array}$ & $\begin{array}{r}82 \\
81 \\
88 \\
118 \\
118\end{array}$ & $\begin{array}{l}105 \\
113 \\
104 \\
110 \\
107\end{array}$ & $\begin{array}{l}87 \\
87 \\
90 \\
93 \\
95\end{array}$ & $\begin{array}{l}112 \\
110 \\
115 \\
122 \\
120\end{array}$ & $\begin{array}{r}101 \\
107 \\
102 \\
96 \\
94\end{array}$ & $\begin{array}{l}105 \\
105 \\
105 \\
104 \\
109\end{array}$ \\
\hline $\begin{array}{l}21 \ldots \ldots \\
22 \ldots \ldots \\
23 \ldots \ldots \\
24 \ldots \ldots \\
25 \ldots \ldots\end{array}$ & $\begin{array}{r}100 \\
94 \\
95 \\
93 \\
105\end{array}$ & $\begin{array}{l}100 \\
100 \\
121 \\
121 \\
118\end{array}$ & $\begin{array}{r}125 \\
113 \\
98 \\
104 \\
100\end{array}$ & $\begin{array}{r}78 \\
85 \\
87 \\
82 \\
102\end{array}$ & $\begin{array}{r}87 \\
101 \\
107 \\
94 \\
87\end{array}$ & $\begin{array}{l}79 \\
78 \\
69 \\
69 \\
77\end{array}$ & $\begin{array}{r}88 \\
87 \\
89 \\
105 \\
94\end{array}$ & $\begin{array}{l}104 \\
107 \\
111 \\
110 \\
123\end{array}$ & $\begin{array}{l}100 \\
105 \\
100 \\
104 \\
105\end{array}$ & $\begin{array}{l}115 \\
110 \\
115 \\
105 \\
104\end{array}$ & $\begin{array}{l}93 \\
93 \\
99 \\
98 \\
94\end{array}$ & $\begin{array}{l}113 \\
118 \\
113 \\
110 \\
100\end{array}$ \\
\hline $\begin{array}{l}26 \ldots \ldots \\
27 \ldots \ldots \\
28 \ldots \ldots \\
29 \ldots \ldots \\
30 \ldots \ldots \\
31 \ldots \ldots\end{array}$ & $\begin{array}{r}107 \\
108 \\
102 \\
90 \\
89 \\
94\end{array}$ & $\begin{array}{r}105 \\
95 \\
103 \\
96 \\
96 \\
--\end{array}$ & $\begin{array}{r}88 \\
96 \\
99 \\
100 \\
104 \\
87\end{array}$ & $\begin{array}{r}99 \\
96 \\
94 \\
100 \\
85 \\
96\end{array}$ & $\begin{array}{l}95 \\
95 \\
89 \\
-- \\
-- \\
--\end{array}$ & $\begin{array}{l}75 \\
77 \\
75 \\
84 \\
69 \\
72\end{array}$ & $\begin{array}{r}98 \\
107 \\
93 \\
88 \\
89 \\
--\end{array}$ & $\begin{array}{l}128 \\
122 \\
100 \\
107 \\
100 \\
107\end{array}$ & $\begin{array}{r}98 \\
110 \\
100 \\
98 \\
100 \\
--\end{array}$ & $\begin{array}{ll}1113 \\
1110 \\
110 \\
110 \\
114 \\
105\end{array}$ & $\begin{array}{l}95 \\
98 \\
106 \\
101 \\
101 \\
106\end{array}$ & $\begin{array}{r}101 \\
101 \\
107 \\
125 \\
125 \\
--\end{array}$ \\
\hline AVERAGE & 95 & 106 & 100 & 87 & 88 & 84 & 81 & 105 & 96 & 110 & 97 & 105 \\
\hline \multicolumn{4}{|c|}{ TEMPERATURE } & $\left({ }^{\circ} \mathrm{C}\right) \mathrm{OF}$ & WATER, WA & YEAR & OCTOBER I & 1969 TO SE & MBER & & & \\
\hline DAY & OCT & Nov & OEC & JAN & FEB & MAR & $A P R$ & MAY & JUN & JUL & AUG & SEP \\
\hline $\begin{array}{l}1 \\
2 \\
3 \\
4 \\
5\end{array}$ & $\begin{array}{l}22.0 \\
22.0 \\
23.0 \\
22.0 \\
22.0\end{array}$ & $\begin{array}{l}18.0 \\
18.0 \\
16.0 \\
18.5 \\
18.0\end{array}$ & $\begin{array}{l}13.5 \\
13.5 \\
13.5 \\
12.0 \\
11.0\end{array}$ & $\begin{array}{r}10.0 \\
10.0 \\
10.0 \\
10.0 \\
9.0\end{array}$ & $\begin{array}{r}12.0 \\
13.0 \\
11.0 \\
9.0 \\
10.0\end{array}$ & $\begin{array}{l}14.0 \\
15.0 \\
15.0 \\
15.0 \\
16.0\end{array}$ & $\begin{array}{l}20.0 \\
18.0 \\
18.0 \\
18.0 \\
19.0\end{array}$ & $\begin{array}{l}25.0 \\
25.0 \\
25.0 \\
23.0 \\
24.0\end{array}$ & $\begin{array}{l}26.0 \\
26.0 \\
25.5 \\
26.0 \\
26.0\end{array}$ & $\begin{array}{l}28.0 \\
29.0 \\
29.0 \\
28.0 \\
28.0\end{array}$ & $\begin{array}{l}29.0 \\
30.0 \\
30.0 \\
31.0 \\
31.0\end{array}$ & $\begin{array}{l}30.0 \\
30.0 \\
30.0 \\
30.0 \\
30.0\end{array}$ \\
\hline $\begin{array}{r}6 \\
7 \\
8 \\
9 \\
10\end{array}$ & $\begin{array}{l}22.0 \\
22.0 \\
22.0 \\
23.0 \\
22.0\end{array}$ & $\begin{array}{l}15.5 \\
16.5 \\
16.5 \\
17.0 \\
16.5\end{array}$ & $\begin{array}{l}11.5 \\
12.0 \\
12.0 \\
11.0 \\
11.0\end{array}$ & $\begin{array}{l}9.0 \\
7.0 \\
7.0 \\
6.0 \\
6.0\end{array}$ & $\begin{array}{l}10.0 \\
11.0 \\
12.0 \\
12.0 \\
10.0\end{array}$ & $\begin{array}{l}17.0 \\
15.0 \\
15.0 \\
16.0 \\
16.0\end{array}$ & $\begin{array}{l}19.0 \\
19.0 \\
20.0 \\
20.0 \\
20.0\end{array}$ & $\begin{array}{l}24.0 \\
25.0 \\
25.0 \\
25.0 \\
25.0\end{array}$ & $\begin{array}{l}26.0 \\
26.0 \\
26.5 \\
26.0 \\
26.0\end{array}$ & $\begin{array}{l}28.0 \\
28.0 \\
28.0 \\
28.0 \\
28.0\end{array}$ & $\begin{array}{l}30.0 \\
30.0 \\
30.0 \\
30.0 \\
30.0\end{array}$ & $\begin{array}{l}30.0 \\
30.0 \\
30.0 \\
29.0 \\
29.0\end{array}$ \\
\hline $\begin{array}{l}11 \\
12 \\
13 \\
14 \\
15\end{array}$ & $\begin{array}{l}22.0 \\
22.0 \\
23.0 \\
22.0 \\
21.0\end{array}$ & $\begin{array}{l}17.0 \\
18.0 \\
16.5 \\
15.5 \\
13.5\end{array}$ & $\begin{array}{l}11.0 \\
10.5 \\
11.5 \\
12.0 \\
11.0\end{array}$ & $\begin{array}{l}6.5 \\
7.0 \\
8.0 \\
8.0 \\
8.0\end{array}$ & $\begin{array}{l}11.5 \\
12.0 \\
11.0 \\
12.0 \\
13.0\end{array}$ & $\begin{array}{l}16.0 \\
17.0 \\
14.0 \\
15.0 \\
15.0\end{array}$ & $\begin{array}{l}20.0 \\
21.0 \\
21.0 \\
22.0 \\
21.0\end{array}$ & $\begin{array}{l}25.0 \\
25.0 \\
25.5 \\
26.0 \\
26.0\end{array}$ & $\begin{array}{l}26.0 \\
26.0 \\
27.0 \\
27.0 \\
28.0\end{array}$ & $\begin{array}{l}28.0 \\
28.0 \\
28.0 \\
28.0 \\
29.0\end{array}$ & $\begin{array}{l}29.0 \\
28.0 \\
28.0 \\
28.0 \\
28.0\end{array}$ & $\begin{array}{l}29.0 \\
30.0 \\
29.0 \\
29.0 \\
29.0\end{array}$ \\
\hline $\begin{array}{l}16 \\
17 \\
18 \\
19 \\
20\end{array}$ & $\begin{array}{l}21.0 \\
20.0 \\
19.0 \\
20.0 \\
21.0\end{array}$ & $\begin{array}{l}13.5 \\
14.5 \\
15.0 \\
13.5 \\
12.0\end{array}$ & $\begin{array}{l}11.0 \\
10.5 \\
11.0 \\
11.0 \\
11.0\end{array}$ & $\begin{array}{r}8.5 \\
10.0 \\
10.0 \\
9.0 \\
8.5\end{array}$ & $\begin{array}{l}14.0 \\
13.0 \\
13.5 \\
14.0 \\
13.0\end{array}$ & $\begin{array}{l}15.0 \\
15.0 \\
17.0 \\
17.0 \\
18.0\end{array}$ & $\begin{array}{l}21.0 \\
22.0 \\
22.0 \\
23.0 \\
23.0\end{array}$ & $\begin{array}{l}25.0 \\
25.0 \\
26.0 \\
25.0 \\
25.0\end{array}$ & $\begin{array}{l}28.0 \\
28.0 \\
29.0 \\
30.0 \\
29.0\end{array}$ & $\begin{array}{l}29.0 \\
29.0 \\
29.0 \\
29.0 \\
29.0\end{array}$ & $\begin{array}{l}29.0 \\
29.0 \\
28.0 \\
29.0 \\
29.0\end{array}$ & $\begin{array}{l}29.0 \\
29.0 \\
29.0 \\
29.0 \\
29.0\end{array}$ \\
\hline $\begin{array}{l}21 \\
22 \\
23 \\
24 \\
25\end{array}$ & $\begin{array}{l}21.0 \\
21.0 \\
20.0 \\
18.0 \\
19.0\end{array}$ & $\begin{array}{l}13.0 \\
13.5 \\
14.0 \\
14.0 \\
14.5\end{array}$ & $\begin{array}{r}11.0 \\
9.5 \\
10.5 \\
10.5 \\
11.0\end{array}$ & $\begin{array}{r}8.0 \\
7.0 \\
8.0 \\
B .5 \\
10.0\end{array}$ & $\begin{array}{l}12.0 \\
12.0 \\
13.0 \\
14.0 \\
14.0\end{array}$ & $\begin{array}{l}17.0 \\
16.0 \\
15.0 \\
15.0 \\
16.0\end{array}$ & $\begin{array}{l}23.0 \\
23.0 \\
23.5 \\
24.0 \\
25.0\end{array}$ & $\begin{array}{l}26.0 \\
26.0 \\
26.0 \\
27.0 \\
27.0\end{array}$ & $\begin{array}{l}29.0 \\
29.0 \\
29.0 \\
29.0 \\
28.0\end{array}$ & $\begin{array}{l}29.0 \\
28.0 \\
28.0 \\
29.0 \\
29.0\end{array}$ & $\begin{array}{l}29.0 \\
29.0 \\
29.0 \\
29.0 \\
20.0\end{array}$ & $\begin{array}{l}29.0 \\
29.0 \\
29.0 \\
29.0 \\
29.0\end{array}$ \\
\hline $\begin{array}{l}26 \\
27 \\
28 \\
29 \\
30 \\
31\end{array}$ & $\begin{array}{l}20.0 \\
20.0 \\
19.0 \\
18.0 \\
19.0 \\
19.0\end{array}$ & $\begin{array}{r}14.5 \\
14.5 \\
14.5 \\
15.0 \\
13.5 \\
.-\end{array}$ & $\begin{array}{l}11.0 \\
11.0 \\
11.5 \\
11.0 \\
12.0 \\
11.0\end{array}$ & $\begin{array}{l}12.0 \\
11.0 \\
12.0 \\
12.0 \\
11.0 \\
11.0\end{array}$ & $\begin{array}{r}14.0 \\
13.0 \\
13.0 \\
\approx . \\
=\end{array}$ & $\begin{array}{l}17.0 \\
17.0 \\
17.0 \\
19.0 \\
20.0 \\
20.0\end{array}$ & $\begin{array}{l}24.0 \\
25.0 \\
25.0 \\
25.0 \\
25.0 \\
. .\end{array}$ & $\begin{array}{l}26.0 \\
27.0 \\
27.0 \\
26.0 \\
26.0 \\
26.0\end{array}$ & $\begin{array}{r}28.0 \\
29.0 \\
28.0 \\
28.0 \\
28.0 \\
.-\end{array}$ & $\begin{array}{l}29.0 \\
29.0 \\
30.0 \\
30.0 \\
30.0 \\
30.0\end{array}$ & $\begin{array}{l}29.0 \\
29.0 \\
29.0 \\
29.0 \\
29.0 \\
30.0\end{array}$ & $\begin{array}{l}29.0 \\
29.0 \\
29.0 \\
27.0 \\
26.0 \\
-0\end{array}$ \\
\hline AVG & 20.8 & 15.3 & 11.3 & 8.9 & 12.2 & 16.1 & 21.6 & 25.4 & 27.4 & 28.6 & 28.9 & 29.1 \\
\hline
\end{tabular}

02359000 CHIPOLA RIVER NEAR ALTHA, FLA.

LOCATION. - Lat $30^{\circ} 32^{\prime} 02^{\prime \prime}$, long $85^{\circ} 09^{\circ} 55^{\prime \prime}$, In NW $\frac{1}{4}$ sec. 32, T. 2 N., R. 9 w., Calhoun County, at gaging station, on right bank on downstream side of bridge on' State Highway $274,0.9$ mile downstream from Hoiliman Branch, $3.5 \mathrm{miles}$
southwest of Altha, and 54 miles upstream from mouth.

DRAINAGE AREA. - 781 sq mi.

PERIOD OF RECORD.--Chemical analyses: October 1962 to September 1970.

Water temperatures: October 1962 to september 1970.

EXTRENES $-1969-70$ :

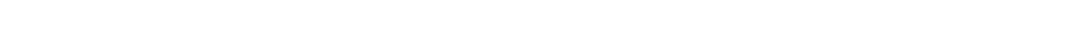

Period of record:

Speciftc conductance: Maximum daily, 258 micromhos June 1,1966 ; minimum daily, 52 micromhos May $6,1964$.

Water temperatures: Maximum, $29.0^{\circ} \mathrm{C}$ June 24, 1969; minimum, 7.0 ${ }^{\circ} \mathrm{C} \mathrm{Jan} .16,1984$. 
02359000 CHIPOLA RIVER NEAR ALTHIA, FLA.--Cont $₫$ nued

CHEMICAL ANALYSES, WATER YEAR OCTOBER 1969 TO SEPTEMBER 1970

$$
\text { (MAJOR CONSTITUENTS) }
$$

\begin{tabular}{|c|c|c|c|c|c|c|c|c|c|c|c|c|}
\hline DATE & $\begin{array}{l}\text { OIS- } \\
\text { CHARGE } \\
\text { (CFS) }\end{array}$ & $\begin{array}{l}\text { TEMPER- } \\
\text { ATURE } \\
\text { (DEG C) }\end{array}$ & $\begin{array}{l}\text { SPE- } \\
\text { CIFIC } \\
\text { CON- } \\
\text { DUCI- } \\
\text { ANCE } \\
\text { (MICRO- } \\
\text { MHOS) }\end{array}$ & $\begin{array}{l}\text { OIS- } \\
\text { SOLVED } \\
\text { IRCN } \\
\text { (FE) } \\
\text { (UGLL) }\end{array}$ & $\begin{array}{l}\text { OIS- } \\
\text { SOLVED } \\
\text { CAL- } \\
\text { CIUM } \\
\text { (CA) } \\
\text { (MG/L) }\end{array}$ & $\begin{array}{l}\text { OIS- } \\
\text { SOL VED } \\
\text { MAG- } \\
\text { NE- } \\
\text { SIUM } \\
\text { (MG) } \\
(M G / L)\end{array}$ & $\begin{array}{l}\text { OIS- } \\
\text { SOLVED } \\
\text { STRON- } \\
\text { I IUM } \\
\text { (SR) } \\
\text { (UG/L) }\end{array}$ & $\begin{array}{l}\text { DIS- } \\
\text { SOLVEN } \\
\text { SODIUM } \\
\text { (NA) } \\
\text { (MG L ) }\end{array}$ & $\begin{array}{l}\text { DIS- } \\
\text { SOLVED } \\
\text { PO- } \\
\text { TAS- } \\
\text { SIUM } \\
\text { (K) } \\
\text { (MG/L) }\end{array}$ & $\begin{array}{l}\text { BICAR- } \\
\text { BONATE } \\
\text { (HCO3) } \\
\text { (MG/L) }\end{array}$ & $\begin{array}{l}\text { CAR- } \\
\text { BONATE } \\
\text { (CO3) } \\
\text { (MG/L) }\end{array}$ & $\begin{array}{c}\mathrm{PH} \\
\text { (UNIIS) }\end{array}$ \\
\hline $\begin{array}{l}\text { NOV..: } \\
20 \ldots . . \\
\text { FEB.., }\end{array}$ & $\begin{array}{l}1969 \\
679 \\
1970\end{array}$ & 14.0 & 201 & $=$ & 33 & 4.4 & -- & $3 . n$ & .6 & 114 & -- & 7.4 \\
\hline $\begin{array}{l}02 . . . \\
\text { MAR. }\end{array}$ & 2010 & 12.8 & 150 & -- & 24 & 3.0 & -- & 3.3 & .5 & 80 & - & 7.0 \\
\hline$\underset{\text { MAY }}{23 . \cdots}$ & 2660 & 16.0 & 140 & -- & 22 & 2.6 & -- & 3.1 & .7 & 80 & - & 7.3 \\
\hline JULY & 1170 & 21.5 & 205 & 100 & 26 & 4.2 & 0 & 11 & .5 & $17 n$ & $n$ & 8.2 \\
\hline SEP... & 863 & 24.2 & 200 & -- & 32 & 4.0 & -- & 2.4 & .5 & 119 & 0 & 7.8 \\
\hline $02 \ldots$ & 960 & 25.0 & 188 & 60 & 30 & 4.5 & $3 n$ & 2.9 & .4 & I 10 & 0 & 7.9 \\
\hline DATE & $\begin{array}{l}\text { OIS- } \\
\text { SOLVED } \\
\text { SULFATE } \\
\text { (SO4) } \\
\text { (MGLL) }\end{array}$ & $\begin{array}{l}\text { DIS- } \\
\text { SOLVED } \\
\text { CHLO- } \\
\text { RIDE } \\
\text { (CL) } \\
\text { (MG/L) }\end{array}$ & $\begin{array}{l}\text { DIS- } \\
\text { SOLVFO } \\
\text { FL UO- } \\
\text { RIOE } \\
(F) \\
(M G / L)\end{array}$ & $\begin{array}{l}\text { HARD- } \\
\text { NESS } \\
\text { (CA, } \$ G G) \\
\text { (MG/L) }\end{array}$ & $\begin{array}{l}\text { NON- } \\
\text { CAR- } \\
\text { RONATE } \\
\text { HARD- } \\
\text { NESS } \\
\text { (MG/L) }\end{array}$ & $\begin{array}{l}\text { ALKA- } \\
\text { LINITY } \\
\text { AS } \\
\text { CACO3 } \\
\text { (MG/L) }\end{array}$ & $\begin{array}{l}\text { DIS- } \\
\text { SOLVED } \\
\text { SOLIDS } \\
\text { (RESI- } \\
\text { DUE AT } \\
\text { I CO C) } \\
\text { (MG L) }\end{array}$ & $\begin{array}{l}\text { NIS- } \\
\text { SULVEA } \\
\text { SOLIOS } \\
\text { ISUM OF } \\
\text { CONSTY- } \\
\text { TUENTS) } \\
\text { (MG/L) }\end{array}$ & $\begin{array}{l}\text { DIS- } \\
\text { SOLVED } \\
\text { SOLIDS } \\
\text { (TONS } \\
\text { PER } \\
\text { DAY) }\end{array}$ & $\begin{array}{l}\text { DIS- } \\
\text { SOLVFD } \\
\text { SOLINS } \\
\text { (TONS } \\
\text { PEA } \\
\text { AC-FT) }\end{array}$ & $\begin{array}{l}\text { TANN IN } \\
\text { AND } \\
\text { LISNIN } \\
\text { (MG/L) }\end{array}$ & $\begin{array}{l}\text { ME }>T H \\
\text { (FT) }\end{array}$ \\
\hline
\end{tabular}

Nov., 1969

\begin{tabular}{|c|c|c|c|c|c|c|c|c|c|c|c|c|}
\hline FEB.. 1970 & .8 & 4.8 & .1 & 101 & 7 & 94 & 120 & 111 & 220 & .16 & -- & -- \\
\hline MLR... & .6 & 5.5 & .1 & 73 & 7 & 66 & 92 & 8? & $49 y$ & .13 & -- & -- \\
\hline MAY $23 .$. & .6 & 5.0 & 1 & 66 & 0 & 66 & 90 & 77 & 646 & .12 & -- & -- \\
\hline JULY... & .8 & 4.0 & .2 & 83 & $n$ & $9 A$ & 120 & 115 & 379 & .15 & -- & $\rightarrow$ \\
\hline SEP... & .7 & 4.0 & .1 & 97 & 0 & 97 & 112 & $\ln 9$ & 261 & .15 & -- & $\cdots$ \\
\hline $02 \ldots$ & .0 & 5.5 & .1 & 94 & 4 & 90 & $1:$ ? & $1 \cap 6$ & 288 & .15 & -- & - \\
\hline
\end{tabular}

MACRONUTRIENTS AND OTHER RELATED CONSTITUENTS

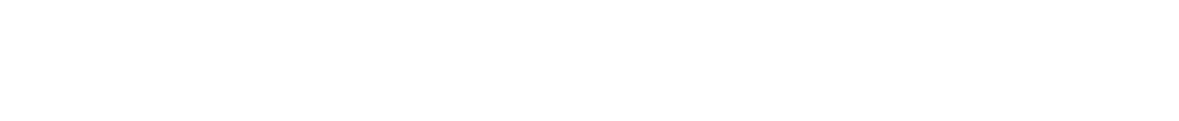

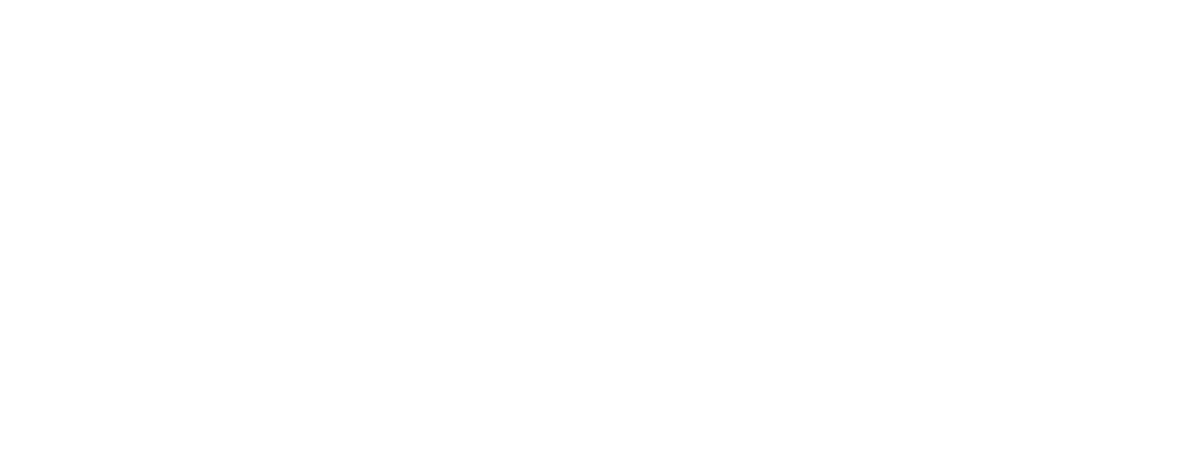

(FIELD MEASUREMENTS)

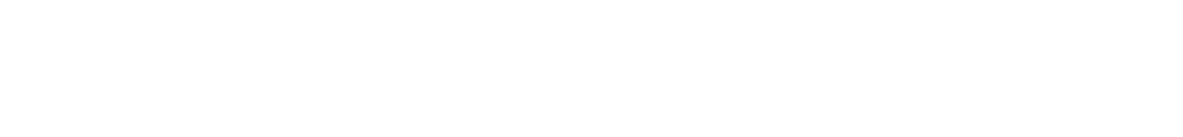

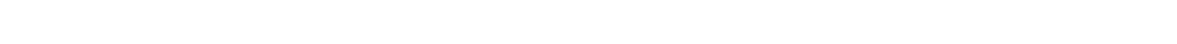

(TRACE METALS)

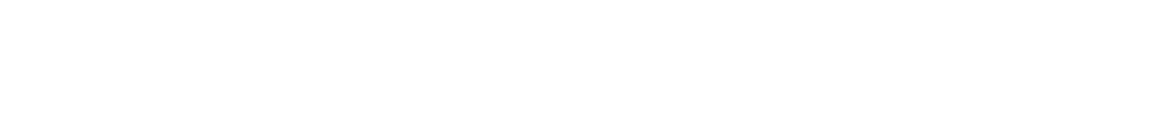
DATE MAY . 1970
O7...
SEP.
$02 . .$. 
02359000 CHIPOLA RIVER NEAR ALTHIA, FLA,--Continued

SPECIFIC CONDUCTANCE (MICROMHOS/CM AT $25^{\circ} \mathrm{C}$ ), WATER YEAR OCTOBER 1969 TO SEPTEMBER 1970

\begin{tabular}{|c|c|c|c|c|c|c|c|c|c|c|c|c|}
\hline DAY & OCT & NOV & DeC & $J \Delta A$ & FEd & NAR & $\triangle P R$ & MAY & JUN & JUL & AUG & SEP \\
\hline 1 & 163 & 205 & $2 x$ & $\cdots$ & $-\cdots$ & -- & 144 & 205 & 203 & $\ldots$ & $\cdots$ & 183 \\
\hline 2 & 165 & -- & 205 & 170 & 150 & Iso & 135 & 210 & 205 & $\cdots$ & $\cdots$ & 188 \\
\hline 3 & 173 & 2000 & 208 & $\cdots$ & 131 & 163 & 128 & $\cdots$ & 205 & -- & 194 & 191 \\
\hline 4 & $-\cdots$ & 200 & 209 & $-\cdots$ & 131 & $i \in 0$ & 120 & 205 & 209 & $\cdots$ & $19 B$ & 194 \\
\hline$b$ & $\cdots$ & 200 & 210 & 175 & 132 & 147 & $\cdots$ & 207 & 192 & $\cdots$ & 201 & 196 \\
\hline 6 & $\ldots$ & 200 &.- & 265 & $13^{\circ}$ & 140 & 130 & 200 & -- & 201 & 200 & $\cdots$ \\
\hline 7 & --- & 200 & $\cdots$ & 155 & 132 & 150 & 138 & 211 & -- & 198 & 198 & $\cdots$ \\
\hline$R$ & 1203 & -- & 190 & $1+0$ & $\cdots$ & $\cdots$ & 150 & 209 & 188 & 210 & $\cdots$ & 198 \\
\hline a & 1 Яอ & -- & 200 & 165 & 141 & so & 160 & $\cdots$ & 180 & 209 & -- & --- \\
\hline 10 & $1+45$ & 205 & 190 & 105 & $\cdots$ & 113 & 166 & -- & 180 & 208 & $-\cdots$ & 200 \\
\hline 11 & $\cdots$ & -- & 195 & -- & 155 & 121 & $-\infty$ & 210 & 194 & 210 & -- & 199 \\
\hline 12 & $\cdots$ & $2: 0$ & 190 & 150 & $1<0$ & $1>2$ & $\cdots$ & $21 ?$ & 200 & $\cdots$ & $\cdots$ & -- \\
\hline 13 & $1>0$ & $2 \mathrm{cs}$ & 125 & 250 & 162 & 125 & 169 & 205 & 204 & 211 & $\cdots$ & $\cdots$ \\
\hline 14 & 100 & 205 & 1 त2 & $1 \neq 0$ & $\cdots$ & -- & 170 & 209 & $\cdots$ & 198 & $\cdots$ & 201 \\
\hline 15 & $1 \rightarrow 3$ & 200 & 180 & 160 & -- & -- & $1>0$ & 207 & 208 & 197 & $\cdots$ & 201 \\
\hline 10 & 150 & $\cdots$ & 127 & 155 & 132 & 147 & 169 & 205 & 204 & 200 & $\cdots$ & 206 \\
\hline 17 & 1 a J & $20 \%$ & $i \times 0$ & -- & 80 & 148 & 170 & $\cdots$ & $2 \mathrm{C9}$ & 204 & 163 & 199 \\
\hline 18 & 100 & 200 & 190 & $\cdots$ & 80 & 140 & 175 & $20 \mathrm{~A}$ & $2 \mathrm{CA}$ & $\cdots$ & 172 & 198 \\
\hline 14 & $\cdots$ & 203 & 172 & 155 & $\therefore 1$ & 149 & $\cdots$ & 205 & 209 & --- & 173 & 202 \\
\hline 20 & 185 & 207 & $\cdots$ & 170 & 101 & $15 \mathrm{~s}$ & 192 & $20 R$ & -- & 208 & 173 & $\cdots$ \\
\hline 21 & $1+3$ & 202 & $\cdots$ & 170 & 42 & $16 ?$ & 139 & 203 & $\cdots$ & 201 & 173 & 204 \\
\hline 22 & in, & -- & 100 & 170 & $-\infty$ & $=$ & 190 & 205 & 205 & 200 & $\cdots$ & 203 \\
\hline 23 & $i+p$ & $\cdots$ & 125 & 175 & --- & 140 & 192 & $\cdots$ & 209 & 209 & $\cdots$ & 204 \\
\hline 24 & Lu) & zuL & 180 & 175 & $12^{\circ}$ & 132 & 192 & --- & 205 & 202 & $\cdots$ & 204 \\
\hline$\angle 5$ & -- & 2317 & $\cdots$ & $\cdots$ & 140 & 114 & 195 & 205 & 205 & 197 & 150 & 205 \\
\hline $2 n$ & -. & 200 & -- & 100 & (5) & $1: 9$ & -.- & $20)$ & - & -- & 148 & 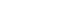 \\
\hline 27 & $1=1$ & $\ldots$ & $1 \mathrm{aJ}$ & 130 & 155 & 110 & 230 & 205 & -- & 191 & 158 & $\cdots$ \\
\hline $2 x$ & $1 \times 1$ & $\cdots$ & $\cdots$ & $\cdots$ & $\ldots$ & $\because$ & $? 03$ & 202 & --- & $1 O B$ & 168 & 205 \\
\hline 25 & 101 & -- & 175 & 100 & - & $\cdots$ & 204 & 202 & -- & 191 & 172 & 204 \\
\hline su & 135 & $\cdots$ & 170 & $1 \times 0$ & $\cdots$ & 137 & 205 & $\ldots-$ & $-\cdots$ & 195 & 182 & 205 \\
\hline 31 & $1+5$ & --- & 170 & $\cdots$ & -- & 142 & $\cdots$ & $\cdots$ & -- & 203 & $\cdots$ & -- \\
\hline AVERAGE & -- & -- & $m-$ & --- & --- & --- & 170 & --- & --- & --- & --- & -- \\
\hline \multicolumn{13}{|c|}{ (OTHER DATA) } \\
\hline & $\begin{array}{l}\text { IMME- } \\
\text { DIATE }\end{array}$ & $\begin{array}{l}\text { DELAYED } \\
\text { CDLI- }\end{array}$ & & $\begin{array}{l}\text { METHY- } \\
\text { LENE }\end{array}$ & $\begin{array}{l}\text { DIS- } \\
\text { SOLVED }\end{array}$ & & & & & & & \\
\hline & COLI- & $\begin{array}{l}\text { FORM } \\
\text { (COL- }\end{array}$ & & $\begin{array}{l}\text { BLUE } \\
\text { ACTIVE }\end{array}$ & $\begin{array}{l}\text { ORGANIC } \\
\text { NIRO- }\end{array}$ & & & TOTAL & DIS- & & DIS- & DIS- \\
\hline & ICOL. & ONIES & AND & SUB- & $\begin{array}{l}\text { NITUN } \\
\text { GEN }\end{array}$ & PHENOLS & IODIDE & $\begin{array}{l}\text { ALUM- } \\
\text { INUM }\end{array}$ & $\begin{array}{l}\text { SOLVED } \\
\text { COBALT }\end{array}$ & $\begin{array}{l}\text { TOTAL } \\
\text { IRON }\end{array}$ & $\begin{array}{l}\text { SOLVED } \\
\text { LITHIUM }\end{array}$ & $\begin{array}{l}\text { SOLVED } \\
\text { MERCURY }\end{array}$ \\
\hline JATE & $\begin{array}{c}\text { PER } \\
100 \mathrm{ML}\}\end{array}$ & $\begin{array}{c}P E R \\
100 \mathrm{MLI}\end{array}$ & $\begin{array}{l}\text { GREASE } \\
\text { (MG/L) }\end{array}$ & $\begin{array}{l}\text { STANCE } \\
(M G / L)\end{array}$ & $\begin{array}{c}(N) \\
\{M G / L)\end{array}$ & (UG/L) & $\begin{array}{c}(I) \\
(M G / L)\end{array}$ & $\begin{array}{l}(A L) \\
(U G / L)\end{array}$ & $\begin{array}{c}(C O) \\
(U G / L)\end{array}$ & $\begin{array}{c}(F E) \\
(U G / L)\end{array}$ & $\begin{array}{l}\text { (LI) } \\
\text { (UG/L) }\end{array}$ & $\begin{array}{l}\text { (HG) } \\
(U G / L)\end{array}$ \\
\hline
\end{tabular}

TEMPERATURE $\left.1^{\circ} \mathrm{C}\right)$ OF WATER, WATER YEAR OCTOBER 1969 TO SEPTEMBER 1970

\begin{tabular}{|c|c|c|c|c|c|c|c|c|c|c|c|c|}
\hline UAY & $1 k \mathrm{~T}$ & נח V & ure & $J A N$ & rEs & YAR & Ath & MAY & JUN & JUL & $A \cup G$ & SEP \\
\hline 1 & 23)$. & $1^{+4}+1$ & 15.0 & $\cdots$ & -- & $=-$ & 2100 & 24.0 & 25.0 & -- & --- & $2 b .0$ \\
\hline 2 & $2+. .0$ & -.- & 15.0 & 13.0 & 14.3 & $\cdots$ & $? 1.0$ & 24.0 & 24.0 & $\cdots$ & $\cdots$ & 26.0 \\
\hline 3 & $\ldots$ & $1 \ldots 1$ & $1 b .0$ & -. & $1 x \cdot 3$ & --- & 20.0 & $\cdots$ & 24.0 & $\cdots$ & 24.0 & 26.0 \\
\hline 4 & $\cdots$ & $1=0$ & 15.11 & $\cdots$ & 11.0 & $\cdots$ & 21.0 & 24.0 & 24.0 & $\cdots$ & 24.0 & 27.0 \\
\hline$"$ & $\cdots$ & $2+.1$ & $(4)$. & 11.1 & 10.0 & -- & -- & 22.0 & 24.0 & $\ldots$ & 24.0 & 27.0 \\
\hline '3 & $\cdots$ & 17.2 & -.- & 11.0 & 10.0 & $\cdots$ & 13.0 & 32.0 & $\cdots$ & 22.0 & 24.0 & +- \\
\hline T & $\cdots$ & $1=0$ & -- & $19^{\rho} \cdot 0$ & 17.3 & --- & $1^{2} \cdot 3$ & 22.3 & -- & 22.0 & 24.0 & $\cdots$ \\
\hline$"$ & $2 \cdot$ & -.. & 13.1 & 10.0 & -- & -.- & 19.0 & 22.0 & 23.0 & 23.0 & -.. & 27.0 \\
\hline${ }^{7}$ & 37.17 & $=$ & 10. & 3 & $1^{2} \cdot 7$ & $\cdots$ & $19 ?$ & -.. & 23.0 & 23.0 & $\cdots$ & $\cdots$ \\
\hline 117 & $2 \geq .3$ & 17.5 & 14.3 & 4.9 & $-\cdot$ & $\cdots$ & 13.0 & -- & 23.0 & 23.0 & $\cdots$ & 26.0 \\
\hline 11 & $\cdots$ & $\ldots$ & 17.11 & -- & 13.11 & $\cdots$ & --- & 23.0 & 24.0 & 23.0 & $\cdots$ & 27.0 \\
\hline 12 & $\ldots$ & 10.9 & 15.0 & 3.1 & 13.0 & $\cdots$ & -- & 29.0 & 24.0 & -- & -- & $-\cdots$ \\
\hline 13 & $2 \cdot 1$ & 17.0 & 15,1 & $\because$ & 12.1 & $\ldots$ & 21.0 & 23.0 & 25.0 & $23 . c$ & -- & -- \\
\hline 14 & 22.1 & $1 \%$ & $\cdots$ & 110 & --- & -.- & 21.0 & 24.2 & $\cdots$ & 23.0 & $\cdots$ & 26.0 \\
\hline Is & $\therefore 1.1$ & $1 \%$ & $15 . u$ & 10.1 & -- & --- & $21 . c$ & 24.0 & 25.0 & 24.0 & -- & 26.0 \\
\hline 15 & 21.1 & $\cdots$ & 14.0 & 12.0 & 13.1 & $-\ldots$ & 21.0 & 24.0 & $? 5.0$ & 24.0 & -- & 26.0 \\
\hline 17 & 21.1 & 15.1 & 14.1 & $\cdots$ & 15,13 & -- & 21.0 & $\cdots$ & 25.0 & 24.0 & 34.0 & 26.0 \\
\hline 10 & 20.5 & 14.7 & 14.7 & -- & 13.0 & $\cdots$ & 22.0 & $24 \cdot 1)$ & 25.7 & --- & $25 . n$ & 27.0 \\
\hline 19 & $\cdots$ & 16.2 & 15.2 & 14.0 & 14.0 & -- & -- & $24 . J$ & 25.0 & $-\cdots$ & 25.0 & 27.0 \\
\hline $2 J$ & 21.0 & $1^{5} \ldots 1$ & -.. & 13.0 & 14.3 & $\cdots$ & 21.0 & 74.0 & -- & 24.0 & 26.0 & --- \\
\hline$\because 1$ & 3.1 & 14 & $\cdots$ & $1^{2} \cdot 0$ & 12.0 & $\cdots$ & 23.0 & 24.1 & $\cdots$ & 23.0 & 26.0 & 27.0 \\
\hline 23 & 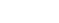 & $-\cdot-$ & 13.7 & 12.3 & -- & $\cdots$ & 24.9 & 24.0 & 26.0 & 24.0 & $\cdots$ & 26.0 \\
\hline 23 & 3.1 & -- & 19.0 & $12 . c$ & -- & 13.0 & 24.0 & -- & 25.0 & 23.0 & $\cdots$ & 27.0 \\
\hline 34 & 20. & 16. & 14.6 & 13.0 & 13.0 & $1 \epsilon .5$ & 24.0 & -- & 26.0 & 22.0 & -- & 26.0 \\
\hline 25 & -+ & $l^{4}=11$ & $\cdots$ & $\ldots$ & {$[5 \cdot 3$} & 10.5 & 24.7 & 24.3 & 25.0 & $22 . n$ & 26.0 & 26.0 \\
\hline 26 & --- & 17.0 & -.- & 15.0 & 15.0 & $1 t .5$ & $\ldots$ & 24.0 & -- & $\cdots$ & 26.0 & -- \\
\hline 27 & $\geq 3.1$ & $\cdots$ & 13.4 & lh, I & $1 \ldots)$ & 16.5 & 24.0 & 24.0 & $\cdots$ & 23.0 & 25.0 & -- \\
\hline 29 & $\because 2 \ldots$ & $\cdots$ & --- & $=$ & $\cdots$ & $\cdots$ & 24.0 & 25.0 & $\cdots$ & 23.0 & 25.0 & 26.0 \\
\hline 30 & $\therefore \ldots$ & $\cdots$ & 12.1 & 17.0 & $\cdots$ & $\cdots$ & 24.0 & 25.0 & $-\cdots$ & 24.0 & 20.0 & 25.0 \\
\hline 3) & 30.3 & -- & 15.0 & 17.0 & $\cdots$ & -.. & 25.0 & -. & $\cdots$ & 24.0 & 26.0 & 25.0 \\
\hline 31 & 23 & $\cdots$ & $15 . J$ & $\cdots$ & $\cdots$ & -- & $-\cdots$ & -- & $\cdots$ & 24.0 & $\cdots$ & $\cdots$ \\
\hline ERAGE & $\cdots$ & $\cdots$ & $\cdots$ & $\ldots$ & $\cdots$ & -- & 21.4 & -- & $\cdots$ & -- & -- & -- \\
\hline
\end{tabular}


02361000 CHOCTAWHATCHEE RIVER NEAR NEWTON, ALA.

LOCATION.--Lat $31^{\circ} 20^{\prime} 30^{\prime \prime}$, long $85^{\circ} 36^{\prime} 43^{\prime \prime}$, in SE $\frac{1}{4}$ sec. 2, T.4 N., R. 24 E., Dale County, temperature recorder at gaging station on left bank' at downstream side on bridge on State Highway i23, 200 ft downstream from abandoned millam, $1,500 \mathrm{ft}$ upstream from Hurricane Creek, 0.8 mile north of Newton, 1 mile downstream from Atlantic Coast Line Rail road bridge, and at mile 133.0 .

DRAI NAGE AREA. - -683 sq $\mathrm{mi}$.

PERIOD OF RECORD.-.-Chem1cal analyses: March 1964 to september 1966.

water temperatures: March 1964 to september 1970.

EXTAENES, - - 1969-70:

Chemical analyses: March 1964 to September 1966, October 1968 to September 1969 (m1scellaneous).

Water temperatures: Ninimum, freezing point Jan. 9-11.

period of record:

Pater temperatures: Naximum, $36.0^{\circ} \mathrm{C}$ July 31, 1968; minimum, freezing point Jan. 30, 31, 1966, Jan. 9-11, 1970. REMARKS. --Temperature recorder malfunctioned Feb. 21-23, 26-28, May 28-June 20, June 24-July 3, and July 12-Sept. 30. TEMPERATURE $\left({ }^{\circ} \mathrm{C}\right)$ OF WATER, WATER YEAR OCTOBER 1969 TO SEPTEMBER 1970

\begin{tabular}{|c|c|c|c|c|c|c|c|c|c|c|c|c|}
\hline \multirow[t]{2}{*}{ DAY } & \multicolumn{2}{|c|}{ DCT } & \multicolumn{2}{|c|}{ NOV } & \multicolumn{2}{|c|}{$D E C$} & \multicolumn{2}{|c|}{$J A N$} & \multicolumn{2}{|c|}{ FFA } & \multicolumn{2}{|c|}{ MAR } \\
\hline & $M A X$ & MIN & $\operatorname{MAX}$ & $M I N$ & $\operatorname{MAX}$ & $M I N$ & $\operatorname{MAX}$ & MIN & $\operatorname{MAX}$ & $M I N$ & $\operatorname{M\Delta x}$ & MIN \\
\hline $\begin{array}{l}1 \\
2 \\
3 \\
4 \\
5\end{array}$ & $\begin{array}{l}22.5 \\
27.5 \\
22.5 \\
23.0 \\
27.5\end{array}$ & $\begin{array}{l}20.5 \\
21.5 \\
19.5 \\
20.0 \\
22.0\end{array}$ & $\begin{array}{l}17.5 \\
17.0 \\
15.0 \\
17.5 \\
11.0\end{array}$ & $\begin{array}{r}15.5 \\
15.0 \\
12.5 \\
10.4 \\
1.0\end{array}$ & $\begin{array}{r}10.0 \\
10.0 \\
4.5 \\
8.0 \\
7.0\end{array}$ & $\begin{array}{l}7.0 \\
7.5 \\
6.5 \\
6.5 \\
5.0\end{array}$ & $\begin{array}{r}11.5 \\
9.0 \\
7.0 \\
5.5 \\
5.0\end{array}$ & $\begin{array}{l}9.0 \\
6.5 \\
5.5 \\
3.5 \\
4.0\end{array}$ & $\begin{array}{r}8.5 \\
10.0 \\
10.0 \\
7.0 \\
4.5\end{array}$ & $\begin{array}{l}6.5 \\
8.0 \\
7.0 \\
4.0 \\
2.5\end{array}$ & $\begin{array}{l}11.4 \\
13.0 \\
14.0 \\
14.0 \\
15.0\end{array}$ & $\begin{array}{r}9.5 \\
10.0 \\
11.5 \\
13.0 \\
14.0\end{array}$ \\
\hline $\begin{array}{r}6 \\
7 \\
8 \\
9 \\
10\end{array}$ & $\begin{array}{l}24.0 \\
24.0 \\
24.0 \\
24.0 \\
24.0\end{array}$ & $\begin{array}{l}22.0 \\
22.0 \\
22.5 \\
22.0 \\
22.5\end{array}$ & $\begin{array}{l}10.5 \\
12.5 \\
14.5 \\
14.0 \\
13.0\end{array}$ & $\begin{array}{r}7.0 \\
8.5 \\
11.5 \\
11.0 \\
0.5\end{array}$ & $\begin{array}{r}8.5 \\
11.5 \\
12.0 \\
10.0 \\
0.5\end{array}$ & $\begin{array}{r}7.0 \\
8.5 \\
10.0 \\
9.0 \\
9.0\end{array}$ & $\begin{array}{l}5.5 \\
5.5 \\
3.0 \\
2.0 \\
0.0\end{array}$ & $\begin{array}{r}5.0 \\
3.0 \\
1.5 \\
0.0 \\
-0.0\end{array}$ & $\begin{array}{l}6.0 \\
6.5 \\
8.0 \\
8.0 \\
8.0\end{array}$ & $\begin{array}{l}3.5 \\
4.0 \\
5.0 \\
7.5 \\
7.0\end{array}$ & $\begin{array}{l}15.0 \\
14.5 \\
12.0 \\
12.0 \\
13.5\end{array}$ & $\begin{array}{r}13.5 \\
12.0 \\
11.0 \\
9.5 \\
10.0\end{array}$ \\
\hline $\begin{array}{l}11 \\
12 \\
13 \\
14 \\
15\end{array}$ & $\begin{array}{l}24.0 \\
24.0 \\
27.5 \\
22.5 \\
20.5\end{array}$ & $\begin{array}{l}22.5 \\
22.5 \\
21.5 \\
20.5 \\
19.0\end{array}$ & $\begin{array}{r}12.5 \\
15.0 \\
13.5 \\
11.5 \\
8.0\end{array}$ & $\begin{array}{r}9.0 \\
12.0 \\
11.5 \\
8.0 \\
5.5\end{array}$ & $\begin{array}{r}11.0 \\
10.0 \\
0.0 \\
0.5 \\
0.0\end{array}$ & $\begin{array}{l}9.5 \\
9.0 \\
6.0 \\
7.0 \\
4.0\end{array}$ & $\begin{array}{l}1.5 \\
3.5 \\
4.5 \\
5.0 \\
5.5\end{array}$ & $\begin{array}{l}0.0 \\
1.5 \\
3.5 \\
3.0 \\
4.5\end{array}$ & $\begin{array}{r}7.5 \\
7.5 \\
7.0 \\
8.5 \\
11.0\end{array}$ & $\begin{array}{l}5.5 \\
6.5 \\
4.5 \\
5.0 \\
8.5\end{array}$ & $\begin{array}{r}13.0 \\
14.5 \\
14.0 \\
10.0 \\
0.5\end{array}$ & $\begin{array}{r}11.0 \\
12.5 \\
10.0 \\
0.0 \\
9.0\end{array}$ \\
\hline $\begin{array}{l}16 \\
17 \\
19 \\
19 \\
20\end{array}$ & $\begin{array}{l}20.5 \\
19.5 \\
19.5 \\
19.5 \\
21.5\end{array}$ & $\begin{array}{l}18.5 \\
17.5 \\
15.5 \\
17.0 \\
19.5\end{array}$ & $\begin{array}{r}7.0 \\
9.0 \\
12.0 \\
12.0 \\
9.5\end{array}$ & $\begin{array}{l}4.0 \\
4.5 \\
9.0 \\
9.0 \\
7.5\end{array}$ & $\begin{array}{l}8.0 \\
7.0 \\
7.0 \\
8.5 \\
8.0\end{array}$ & $\begin{array}{l}4.0 \\
5.0 \\
4.5 \\
6.0 \\
5.5\end{array}$ & $\begin{array}{r}7.0 \\
9.0 \\
10.0 \\
10.0 \\
9.5\end{array}$ & $\begin{array}{l}5.5 \\
7.0 \\
9.0 \\
9.0 \\
7.0\end{array}$ & $\begin{array}{l}17.5 \\
12.0 \\
11.0 \\
12.5 \\
11.5\end{array}$ & $\begin{array}{l}11.0 \\
10.5 \\
10.0 \\
10.5 \\
10.5\end{array}$ & $\begin{array}{r}9.5 \\
111.0 \\
13.0 \\
16.0 \\
17.0\end{array}$ & $\begin{array}{r}R .5 \\
8.5 \\
10.0 \\
13.0 \\
1 R .0\end{array}$ \\
\hline $\begin{array}{l}21 \\
27 \\
23 \\
74 \\
25\end{array}$ & $\begin{array}{l}22.5 \\
22.0 \\
20.0 \\
17.5 \\
18.0\end{array}$ & $\begin{array}{l}21.5 \\
20.0 \\
17.0 \\
16.0 \\
16.0\end{array}$ & $\begin{array}{r}8.5 \\
8.5 \\
10.0 \\
12.5 \\
13.0\end{array}$ & $\begin{array}{r}6.5 \\
6.0 \\
7.5 \\
10.0 \\
11.5\end{array}$ & $\begin{array}{l}8.0 \\
8.0 \\
R .0 \\
8.0 \\
0.0\end{array}$ & $\begin{array}{l}6.0 \\
6.5 \\
5.0 \\
6.0 \\
7.0\end{array}$ & $\begin{array}{l}7.0 \\
5.0 \\
5.5 \\
5.5 \\
7.5\end{array}$ & $\begin{array}{l}5.0 \\
3.5 \\
4.5 \\
4.0 \\
4.0\end{array}$ & $\begin{array}{r}=- \\
10.5 \\
11.0\end{array}$ & $\begin{array}{r}=- \\
10.0 \\
10.5\end{array}$ & $\begin{array}{l}17.0 \\
15.0 \\
11.5 \\
13.0 \\
14.0\end{array}$ & $\begin{array}{r}15.0 \\
11.5 \\
9.0 \\
9.0 \\
10.5\end{array}$ \\
\hline $\begin{array}{l}26 \\
27 \\
28 \\
29 \\
30 \\
31\end{array}$ & $\begin{array}{l}19.0 \\
19.0 \\
18.0 \\
16.0 \\
15.0 \\
15.5\end{array}$ & $\begin{array}{l}17.0 \\
16.0 \\
16.0 \\
14.0 \\
12.5 \\
14.0\end{array}$ & $\begin{array}{r}14.0 \\
14.0 \\
15.0 \\
13.5 \\
10.5 \\
=-\end{array}$ & $\begin{array}{r}11.5 \\
11.5 \\
13.0 \\
10.5 \\
9.5 \\
--\end{array}$ & $\begin{array}{r}9.0 \\
8.0 \\
7.5 \\
11.0 \\
14.0 \\
14.0\end{array}$ & $\begin{array}{r}\text { R.0 } \\
6.0 \\
5.0 \\
7.0 \\
11.0 \\
11.5\end{array}$ & $\begin{array}{l}11.5 \\
10.5 \\
12.0 \\
14.5 \\
14.5 \\
11.0\end{array}$ & $\begin{array}{r}7.5 \\
9.0 \\
9.5 \\
12.0 \\
11.0 \\
R .5\end{array}$ & $\begin{array}{l}=- \\
-- \\
-- \\
--\end{array}$ & $\begin{array}{l}-- \\
=- \\
=- \\
=- \\
--\end{array}$ & $\begin{array}{r}14.5 \\
14.0 \\
14.0 \\
16.0 \\
16.0 \\
15.0\end{array}$ & $\begin{array}{l}12.5 \\
11.5 \\
12.0 \\
17.5 \\
14.0 \\
14.0\end{array}$ \\
\hline$\Delta \vee G$ & 20.9 & 18.9 & 12.2 & 9.5 & a. 2 & 7.0 & 7.2 & 5.2 & 9.0 & 7.1 & 13.5 & 11.4 \\
\hline
\end{tabular}

\begin{tabular}{|c|c|c|c|c|c|c|c|c|c|c|c|c|}
\hline \multirow[t]{2}{*}{ DAY } & \multicolumn{2}{|c|}{$\triangle P R$} & \multicolumn{2}{|c|}{$M \Delta Y$} & \multicolumn{2}{|c|}{ JUN } & \multicolumn{2}{|c|}{ JUL } & \multicolumn{2}{|c|}{ AllG, } & \multicolumn{2}{|c|}{ SEP } \\
\hline & $\operatorname{MAx}$ & MIN & $\operatorname{M\Delta x}$ & MIN & $\operatorname{MAX}$ & $M ! N$ & $\max$ & $M I N$ & MAX & MIN & $M \Delta X$ & $M I^{A M}$ \\
\hline 1 & 17.0 & 15.0 & 24.5 & $2 x .5$ & -- & -- & -- & -- & -- & -- & $\cdots$ & -- \\
\hline 2 & 17.0 & 16.0 & 24.5 & 22.5 & -- & -- & $=$ & -- & - & -- & -- & -- \\
\hline 3 & 17.0 & 15.0 & 23.5 & 20.5 & $\cdots$ & -- & -- & -- & -- & - & -- & -- \\
\hline 4 & $1 \mathrm{~A}, 0$ & 13.5 & 20.5 & 20.5 & -- & -- & 30.0 & 27.5 & -- & -- & -- & $\cdots$ \\
\hline 5 & 16.5 & 14.5 & 21.0 & 21.0 & -- & -- & 29.0 & 25.0 & -- & -- & -- & -- \\
\hline 0 & 17.0 & 14.5 & 22.0 & $>1.0$ & -- & -- & 28.5 & $2^{2} .5$ & -- & -- & - & - \\
\hline 7 & 17.0 & 14.0 & 22.0 & 18.5 & -- & -- & 28.5 & 24.0 & -- & -- & -- & - \\
\hline R & 16.0 & 12.5 & 22.0 & 18.5 & -- & -- & 27.0 & 24.0 & -- & -- & -- & -- \\
\hline 9 & $1 \kappa .5$ & 13.5 & 22.0 & 19.5 & -- & -- & 26.5 & 23.0 & - & -- & -- & -- \\
\hline 10 & 16.5 & 15.5 & 22.0 & 19.5 & - & -- & 27.0 & 24.0 & -- & -- & -- & -- \\
\hline 11 & 16.5 & 15.0 & 22.0 & 20.0 & -- & - & 24.0 & 22.0 & +- & -- & -- & -- \\
\hline 12 & $1 \mathrm{H.5}$ & 15.5 & 24.5 & 21.0 & -- & -- & -- & -- & -- & -- & -- & -- \\
\hline 13 & 17.5 & 14.5 & 25.0 & 22.0 & -- & -- & -- & -- & -- & -- & -- & -- \\
\hline 14 & 10.0 & 16.5 & 75.0 & 21.5 & -- & -- & -- & -- & -- & -- & -- & -- \\
\hline 15 & 19.5 & 15.5 & 25.0 & 22.5 & -- & -- & - & -- & -- & -- & -- & -- \\
\hline $1 \mathrm{~h}$ & $1^{8} .5$ & 17.0 & 25,0 & 23.0 & -- & -- & - & -- & -- & -- & -- & -- \\
\hline 17 & 19.5 & 16.5 & 25.0 & 23.0 & - & - & -- & -- & -- & -- & -- & -- \\
\hline 18 & 21.0 & 18.5 & 25.0 & 21.0 & -- & -- & -- & -- & -- & -- & -- & -- \\
\hline 19 & 21.5 & $>0.0$ & 25.0 & 22.0 & -- & -- & -- & -- & -- & -- & -- & -- \\
\hline 20 & 21.0 & 18.5 & 25.0 & 21.0 & -- & -- & -- & -- & -- & -- & -- & -- \\
\hline 21 & 21.5 & 18.5 & 25.0 & 21.0 & 30.0 & 26.5 & -- & -- & - & -- & -- & -- \\
\hline 22 & 22.5 & 20.0 & 25.0 & $? 1.5$ & 30.5 & 27.0 & - & -- & -- & -- & -- & -- \\
\hline 23 & 22.0 & 20.5 & 25.0 & 23.0 & 28.5 & 25.5 & -- & -- & -- & -- & -- & -- \\
\hline 24 & 22.5 & 21.5 & 25.0 & 23.0 & - & -- & -- & -- & -- & -- & -- & -- \\
\hline 25 & 22.5 & 21.5 & 25.0 & 23.0 & -- & -- & -- & -- & -- & -- & -+ & $-\infty$ \\
\hline 26 & 22.5 & 21.5 & 24.5 & 23.0 & - & -- & -- & -- & -- & -- & -- & -- \\
\hline 27 & 22.5 & $? 2.5$ & 24.5 & 23.0 & -- & -- & -- & -- & -- & -- & -- & -- \\
\hline ? & 24.5 & 22.5 & - & - & $\cdots$ & $\cdots$ & -- & -- & - & -- & -- & -- \\
\hline 29 & 24.5 & 24.0 & -- & -- & - & -- & -- & -- & -- & -- & -- & -- \\
\hline 30 & 24.5 & 23.5 & -- & -- & -- & -- & -- & -- & -- & -- & - & -- \\
\hline 31 & - & - & -- & -- & - & -- & -- & -- & $=$ & -- & -- & -- \\
\hline$\triangle \vee V G$ & 19.5 & 17.5 & 23.8 & 21.4 & -- & $\sim$ & -- & -- & -- & -- & -- & $=$ \\
\hline
\end{tabular}


02365500 CHOCTAMHATCHEE RIVER AT CARYVILLE, FLA.

LOCATION,--Lat $30^{\circ} 46^{\prime} 32^{\prime \prime}$, long $85^{\circ} 49^{\prime} 40^{\prime \prime}$, in $\mathrm{NW}^{\frac{1}{4}}$ sec.10, T.4 N., R.16 W., Holmes County, at gaging station near right bank on downstream side of bridge on U.S. Highway $90,300 \mathrm{ft}$ downstream from Louisville and Nashville Railroad bridge, $0.8 \mathrm{mile}$ west of Caryville, 1.8 miles downstream from Wrights Creek, and 64 miles upstream AINAGE AREA, - -3,499 sq mi.

PERIOD OF RECORD.-.Chemical analyses: October 1962 to September 1970.

Water temperatures: October 1962 to September 1970.

EXTRENES, - -1969-70:

Specific conductance: Naximum dally, 108 micromhos May $30 ;$ minimum daily, 28 micromhos June $1,3,5$.
water temperatures: Naximum, $28.0^{\circ} \mathrm{C}$ on several days during July to September; min1mum, 4.0 ${ }^{\circ} \mathrm{C}$ Jan. 8.10 .

Period of record:

Specific conductance: Maximum da1ly, 266 micromhos Apr, 14, 1963; minimum daily, 22 micromhos Dec, 1 , 1962 ,

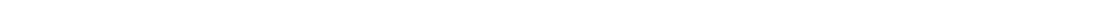

SPECIFIC CONDUCTANCE (MICROMHOS/CM AT $25^{\circ} \mathrm{C}$ ), WATER YEAR OCTOBER 1969 TO SEPTEMBER 1970

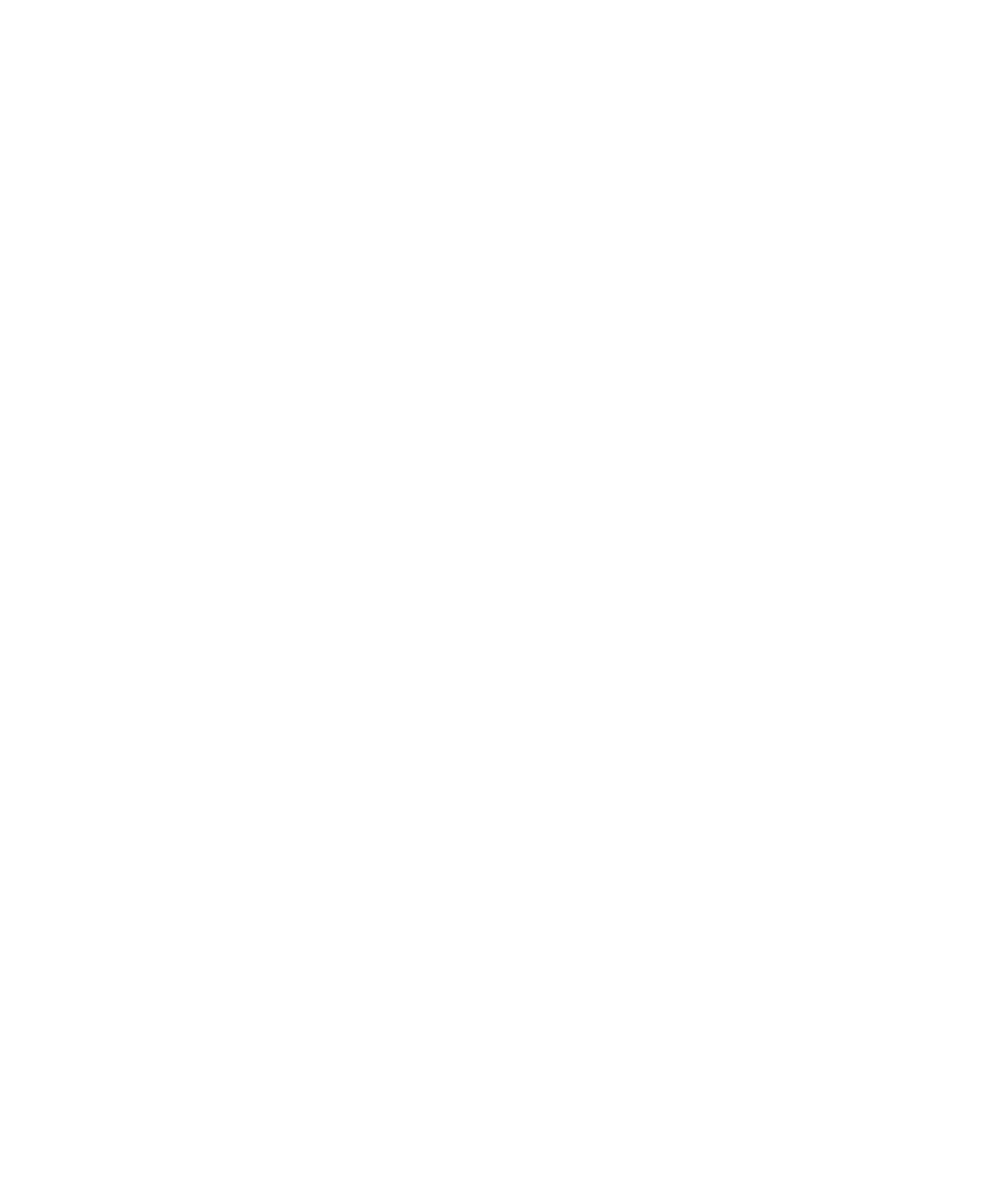


02368000 YELLON RIVER AT MILLIGAN, FLA.

LOCATION.--Lat $30^{\circ} 45^{\prime} 10^{\prime \prime}$, long $86^{\circ} 37^{\prime} 45^{\prime \prime}$, in sec.15, T.3 N., R.24 W., Okaloosa County, at gaging station near right bank on upstream side of old bridge on U.S. Highway $90,0.5 \mathrm{mile}$ east of Milligan, $0.5 \mathrm{mile}$ upstream from Trammel Creek, 6.7 miles upstream from Shoal River, and 40 miles upstream from mouth.

DRAINAGE AREA,.$-624 \mathrm{sq} \mathrm{mi}$.

PERIOD OF RECORD. ..-Chemical analyses: October 1962 to September 1970.

Water temperatures: October 1962 to September 1970.

EXTREMES. - -1969-70:

Specific conductance: Maximum daily, 74 micromhos May 1; minimum daily, 26 micromhos Mar. 30.

Water temperatures: $\operatorname{Max} 1 \mathrm{mum}, 28.0^{\circ} \mathrm{C}$ on several days during July, August, September; minımum, $9.0^{\circ} \mathrm{C} \mathrm{Jan} .21$.

Period of record:

Specific conductance: Maximum daily, 96 micromhos Feb. 8, 1968; minimum daily, 13 micromhos Apr. $28,1964$.

water temperatures: Maximum, $30.0^{\circ} \mathrm{C}$ on several days during June to August, 1968, July 11, 14, 15, 1969; minimum; $3.0^{\circ} \mathrm{C}$ Dec. 14,1962 .

CHEMICAL ANALYSES, WATER YEAR DCTOBER 1969 TO SEPTEMBER 1970 (MAJOR CONSTITUENTS)

$\begin{array}{cc}\text { DIS- } & \text { TEMPER- } \\ \text { CHARGE } & \text { ATURE } \\ \text { DATE (CFS) } & \text { (DEG C) }\end{array}$

\begin{tabular}{|c|c|c|c|c|c|c|c|}
\hline $\begin{array}{l}\text { SPE- } \\
\text { CIFIC }\end{array}$ & & UIS- & $\begin{array}{l}\text { DIS- } \\
\text { SOLVED }\end{array}$ & DIS- & & $\begin{array}{l}\text { DIC- } \\
\text { SOLVED }\end{array}$ & \\
\hline $\mathrm{CON}^{-}$ & DIS- & SOLVED & MAG $=$ & SOLVED & DIS- & PO- & \\
\hline DUCT- & SOLVED & $C A L=$ & $N E-$ & STRON- & SOLVEN & TAS- & BICAR - \\
\hline ANCE & IRON & cium & SIUM & I IUM & SODIU4 & SIIJM & BONATE \\
\hline MICRO- & $(F E)$ & (CA) & (MG) & (SR) & (NA) & $(K)$ & $(\mathrm{HCO} 3)$ \\
\hline MHOSI & $\left(U_{G} / L\right)$ & $(M G / L)$ & $(M G / L)$ & (UG/L\}) & & $(\mathrm{MG} / \mathrm{L})$ & $(M G / L)$ \\
\hline
\end{tabular}

CAR-

BONATE PH NOV.. 1969

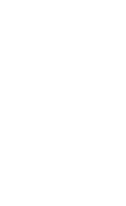

14.5
4.0
16.0
23.0
28.0
26.5
DIS-
SOLVED
CHLD-
RIOE
(CL)
(MG/L)
Uis/L)

(MG/L) (UG/L) (MG/L)

$(M G / L) \quad(M G / L)$

(MG/L) (UNITS)

\begin{tabular}{|c|c|c|c|c|c|c|}
\hline & DIS- & $\begin{array}{c}\text { DIS- } \\
\text { SOLVED }\end{array}$ & $\begin{array}{c}\text { DIS- } \\
\text { SOLVFD }\end{array}$ & & $\begin{array}{l}\text { NON- } \\
\text { CAR- }\end{array}$ & ALKA = \\
\hline & SOLVEO & CHLO- & FL(1)- & HARD- & RONATE & LINITY \\
\hline & SULFATE & RIDE & RIOE & NESS & HARD - & AS \\
\hline & $(\$ 04)$ & $(C L)$ & $(F)$ & $(C A, M G)$ & NESS & $\mathrm{CACO} 3$ \\
\hline$A T E$ & $(M G / L)$ & $(M G / L)$ & $(M G / L)$ & $(N G / L)$ & $(M G / L)$ & $(M G / L)$ \\
\hline
\end{tabular}

\begin{tabular}{|c|c|c|}
\hline NOV., 1969 & 1.2 & 3.5 \\
\hline MAR... & 8 & 3.5 \\
\hline MAY 05 & 2.0 & 3.0 \\
\hline $\begin{array}{l}19 . . . \\
\text { AUG. }\end{array}$ & .8 & 3.0 \\
\hline IY... & $\cdot 6$ & 3.5 \\
\hline $22 \ldots$ & .8 & 3.2 \\
\hline
\end{tabular}

$\begin{array}{ll}.1 & 24 \\ .0 & 12 \\ .1 & 10 \\ .1 & 30 \\ .1 & 18 \\ .1 & 23\end{array}$

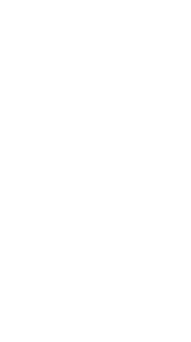

.5
.5
.5
.4
.4
.5
DIS-
SOLVED SOL
SOLINS SOL
ITONS
PER
DAY

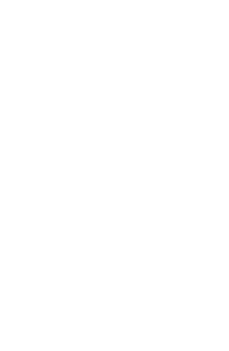

MACRONUTRIENTS AND OTHER RELATED CONSTITUENTS

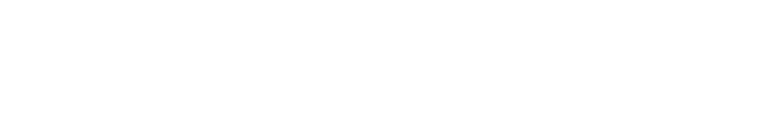

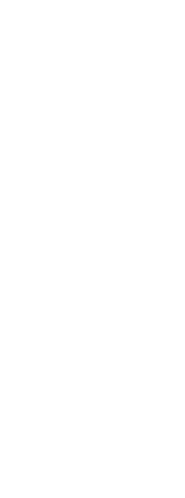

.02
.01
.02
.01
.01
.02
.03
.00
.03
.08
.03
.02
.02
.01
.01
.02

$\begin{array}{ll}.2 & \\ .6 & \\ .2 & \\ .3 & \\ .0 & - \\ .1 & - \\ .0 & - \\ .1 & - \\ .4 & - \\ .4 & .1 \\ .5 & - \\ .3 & - \\ .4 & - \\ .0 & - \\ .3 & .23\end{array}$

$\begin{array}{ll}-. & . \\ - & \\ -- & .04 \\ -- & .04 \\ -- & .02 \\ -- & .04 \\ -- & .00 \\ 14 & .05 \\ - & .01 \\ -- & .02 \\ -- & .02 \\ -- & - \\ 23 & .05\end{array}$

$03 \quad .04$

$--$

$\begin{array}{ll}36 & 52.2 \\ 21 & 159 \\ 29 & 189 \\ 40 & 42.6 \\ 29 & 46.8 \\ 36 & 54.2\end{array}$

$$
\begin{array}{r}
.06 \\
.04 \\
.04 \\
.07 \\
.15
\end{array}
$$

(IT) 
02368000 YELLOW RIVER AT MYLLIGAN, FLA.-.-Continued SPECIFIC CONDUCTANCE (MICROMHOS/CM AT $25^{\circ} \mathrm{C}$ ), WATER YEAR OCTOBER 1969 TO SEPTEMBER 1970

\begin{tabular}{|c|c|c|c|c|c|c|c|c|c|c|c|c|}
\hline uar & $\begin{array}{l}101 \\
50\end{array}$ & $\begin{array}{l}4 . v \\
6,5\end{array}$ & $\begin{array}{c}1 \mathrm{JiC} \\
64\end{array}$ & J A B & FEn & $\begin{array}{r}M A R \\
41\end{array}$ & $\begin{array}{r}\triangle D P \\
53\end{array}$ & $\begin{array}{c}\text { YAY } \\
74\end{array}$ & $\begin{array}{r}\text { JUN } \\
50\end{array}$ & $J_{51}$ & $\begin{array}{r}\text { AUG } \\
65\end{array}$ & $\begin{array}{r}\text { SEP } \\
65\end{array}$ \\
\hline ; & on & 44 & no & 44 & $4 R$ & 24 & 26 & $4 \mathrm{H}$ & 73 & 50 & 52 & 45 \\
\hline 3 & 55 & C. & $\therefore 2$ & 37 & +3 & 41 & (1) & 40 & 19 & 52 & 36 & 58 \\
\hline 4 & $\therefore 5$ & $n_{4}$ & 43 & 79 & 11 & 30 & 33 & 67 & 55 & 58 & 52 & 62 \\
\hline 5 & 35 & 64 & 42 & 44 & 43 & $2^{\circ}$ & 50 & 64 & S6 & 55 & 44 & 59 \\
\hline$t$ & 53 & 63 & 4) & 47 & 43 & 27 & 64 & 73 & 64 & 52 & 47 & 67 \\
\hline 7 & 35 & 4 & 42 & 44 & 47 & 32 & 33 & 04 & 17 & 55 & 57 & 58 \\
\hline ה & 5, & 49 & $4 ?$ & 55 & 43 & 32 & 50 & 56 & 51 & 55 & 37 & 63 \\
\hline 7 & 65 & 4. & 42 & 44 & 43 & 3.) & 64 & 73 & 23 & 55 & 65 & 64 \\
\hline 1) & 1,0 & 44 & 4 & 44 & 52 & 79 & 64 & 63 & 25 & 55 & 64 & 63 \\
\hline 11 & 5 & 4. & 43 & 45 & 34 & 20 & 50 & 63 & $2^{2}$ & 56 & 42 & 65 \\
\hline 12 & in & 40 & 42 & $4 i$ & 47 & 21 & 50 & 73 & 43 & 50 & 44 & 58 \\
\hline 13 & 54 & 4. & 42 & 30 & 31 & 30 & 43 & 64 & 48 & 50 & 37 & 59 \\
\hline 14 & 55 & 42 & 42 & 46 & 47 & 32 & 64 & 63 & 53 & 51 & 47 & 60 \\
\hline is & 3 & $4 \mathrm{~F}$ & 42 & $3 t$ & 43 & 3? & 32 & 73 & 48 & 58 & 64 & 59 \\
\hline 10 & 59 & 44 & 42 & $4 t$ & 43 & 57 & 32 & h2 & 44 & 51 & 43 & 37 \\
\hline 17 &, 5 & $4 a$ & 42 & 43 & 50 & 31 & 29 & 49 & 73 & 54 & 64 & 52 \\
\hline $1^{2}$ & 5 & 4 & 47 & 47 & 34 & 48 & 04 & 73 & 65 & so & 68 & 48 \\
\hline 14 & of & $\therefore 3$ & 44 & 42 & 42 & 30 & 50 & .3 & 47 & 59 & 48 & 52 \\
\hline i) & ho & $\therefore$ & 44 & 43 & 43 & 42 & bo & 00 & 43 & 53 & 52 & 54 \\
\hline$\therefore 1$ & $a$ & $\mathrm{~A}, 2$ & 44 & 45 & 43 & 36 & 51 & 73 & 65 & 53 & 48 & 53 \\
\hline 22 & $\because 3$ & $5=$ & 44 & 45 & 32 & 32 & 04 & 63 & 47 & 45 & 37 & 56 \\
\hline \& & 65 & +2 & 44 & $4 H$ & 31 & 30 & 50 & 74 & 52 & 43 & 36 & 52 \\
\hline 14 & $t, 4$ & $\theta ?$ & 44 & 44 & 31 & 47 & 52 & 62 & 37 & 42 & 57 & 36 \\
\hline En & $E \rightarrow$ & $\mathrm{B}^{5}$ & 44 & $4 k$ & 34 & 20 & 63 & 42 & 40 & 50 & 42 & 36 \\
\hline 26 & 05 & 6 & .4 & 44 & ${ }^{23}$ & 12 & 31 & 65 & 50 & 52 & 46 & 43 \\
\hline 27 & of & $\epsilon^{2}$ & 44 & 45 & 43 & 12 & 50 & 48 & 22 & 53 & 63 & $5 ?$ \\
\hline m & $\rightarrow b$ & +2 & 44 & 45 & 37 & 27 & 48 & 51 & 0.2 & 26 & 42 & 35 \\
\hline 74 & 55 & hi2 & +4 & 52 & $\cdots$ & 32 & द? & 73 & 17 & $6 C$ & 36 & 57 \\
\hline s) & bo & $0<$ & 4.4 & 45 & $\ldots$ & $\therefore$ & 64 & 50 & 50 & 51 & 36 & 60 \\
\hline 11 & 25 & -- & 44 & 44 & $\cdots$ & 27 & -- & 65 & $\cdots$ & 52 & $4 A$ & $\ldots$ \\
\hline AVERAGE & 61 & 47 & 45 & 44 & 40 & 33 & 50 & 53 & 46 & 53 & 49 & 54 \\
\hline
\end{tabular}

(TRACE METALS)

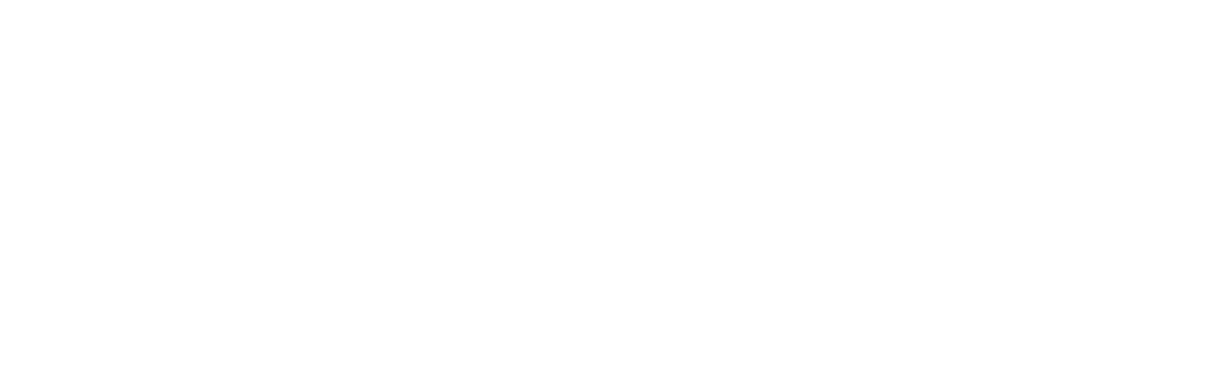
MAY 14

TEMPERATURE ('०) OF WATER, WATER YEAR OCTOBER 1969 TO SEPTEMBER 1970

\begin{tabular}{|c|c|c|c|c|c|c|c|c|c|c|c|c|}
\hline 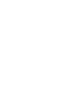 & $\begin{array}{l}1.5 \\
1+.0 \\
3.1 \\
21.3 \\
14.0 \\
2.01\end{array}$ & 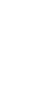 & $\begin{array}{r}J \in C \\
12.3 \\
10.3 \\
0.3 \\
14.0 \\
1403\end{array}$ & $\begin{array}{r}14 V \\
27.0 \\
10.0 \\
1 \% .8 \\
15.0 \\
1\end{array}$ & $\begin{array}{l}F \in \cdot 5 \\
20.0 \\
12.0 \\
13.0 \\
1,1) .0 \\
1.0\end{array}$ & $\begin{array}{r}\text { YAR } \\
12.0 \\
15.0 \\
15.0 \\
18.0 \\
17.0\end{array}$ & $\begin{array}{r}A P R \\
13.0 \\
20.0 \\
20.0 \\
19.0 \\
20.0\end{array}$ & $\begin{array}{l}\text { MAY } \\
24.0 \\
21.0 \\
21.0 \\
19.0 \\
19.3\end{array}$ & $\begin{array}{r}\text { SUY } \\
19.0 \\
19.0 \\
19.0 \\
29.0 \\
21.0\end{array}$ & $\begin{array}{r}\text { Jut } \\
26.0 \\
27.0 \\
27.0 \\
25.0 \\
27.0\end{array}$ & $\begin{array}{r}\text { AUG } \\
25.0 \\
24.0 \\
21.0 \\
21.0 \\
27.0\end{array}$ & $\begin{array}{r}\text { SEP } \\
27.0 \\
27.0 \\
26.0 \\
29.0 \\
27.0\end{array}$ \\
\hline $\begin{array}{r}6 \\
7 \\
3 \\
7 \\
13\end{array}$ & $\begin{array}{ll}1 & 7.11 \\
1 & 7 \\
2 & 01 \\
2 & 1 \\
1 & =1\end{array}$ & 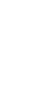 & $\begin{array}{l}11.0 \\
1203 \\
19,13 \\
? 703 \\
10.1\end{array}$ & $\begin{array}{l}15.0 \\
10.0 \\
10.0 \\
12.0 \\
12.0\end{array}$ & $\begin{array}{l}1.9 .0 \\
12.0 \\
12.0 \\
15.0 \\
13.0\end{array}$ & $\begin{array}{l}19.9 \\
1 ? .2 \\
19.12 \\
16.0 \\
16.0\end{array}$ & $\begin{array}{l}10.0 \\
19.0 \\
20.0 \\
17.0 \\
70.0\end{array}$ & $\begin{array}{l}20.0 \\
21.0 \\
21.0 \\
21.0 \\
21.0\end{array}$ & $\begin{array}{l}21.0 \\
12.0 \\
22.0 \\
21.0 \\
21.0\end{array}$ & $\begin{array}{l}25.0 \\
25.0 \\
27.0 \\
28.0 \\
27.0\end{array}$ & $\begin{array}{l}75.0 \\
21.0 \\
75.0 \\
26.0 \\
21.0\end{array}$ & $\begin{array}{l}26.0 \\
21.0 \\
26.0 \\
26.0 \\
26.0\end{array}$ \\
\hline $\begin{array}{l}11 \\
12 \\
13 \\
14 \\
13\end{array}$ & $\begin{array}{ll}1 & 1 \\
21 & 1 \\
21 & 1 \\
20.11 \\
1 & 1\end{array}$ & $\begin{array}{l}19.1 \\
130 \\
23.5 \\
19.5 \\
19.3\end{array}$ & $\begin{array}{l}17.0 \\
10.0 \\
20.0 \\
2110 \\
21.0\end{array}$ & $\begin{array}{l}10.0 \\
15.0 \\
11.0 \\
12.0 \\
10.0\end{array}$ & $\begin{array}{l}10.0 \\
12.0 \\
12.0 \\
12.0 \\
15.0\end{array}$ & $\begin{array}{l}17.0 \\
12.0 \\
12.0 \\
10.2 \\
12.0\end{array}$ & $\begin{array}{l}21.0 \\
21.0 \\
21.0 \\
21.0 \\
21.0\end{array}$ & $\begin{array}{l}25.0 \\
25.0 \\
21.0 \\
21.0 \\
25.0\end{array}$ & $\begin{array}{l}21.0 \\
20.0 \\
23.0 \\
21.0 \\
13.0\end{array}$ & $\begin{array}{l}29.0 \\
21.0 \\
25.0 \\
21.0 \\
21.0\end{array}$ & $\begin{array}{l}19.0 \\
21.0 \\
20.0 \\
24.0 \\
75.0\end{array}$ & $\begin{array}{l}27.0 \\
21.0 \\
26.0 \\
26.0 \\
25.0\end{array}$ \\
\hline $\begin{array}{l}15 \\
17 \\
13 \\
15 \\
23\end{array}$ & $\begin{array}{l}1.0 \\
11.1 \\
17 \\
1 \div 3 \\
17.3\end{array}$ & $\begin{array}{l}20.0 \\
19.0 \\
19.0 \\
20.0 \\
15.0\end{array}$ & $\begin{array}{l}14.3 \\
13.0 \\
17.4 \\
23.11 \\
15.0\end{array}$ & $\begin{array}{ll}12 & 0 \\
12 & 0 \\
11 & 0 \\
12.0 \\
1 & 0.0\end{array}$ & $\begin{array}{l}15.0 \\
12.9 \\
15.3 \\
15.0 \\
15.2\end{array}$ & $\begin{array}{l}10.13 \\
12.0 \\
15.0 \\
15.0 \\
16.0\end{array}$ & $\begin{array}{l}20.0 \\
20.0 \\
10.0 \\
10.2 \\
70.0\end{array}$ & $\begin{array}{l}21.0 \\
21.0 \\
21.0 \\
21.0 \\
20.0\end{array}$ & $\begin{array}{l}23.0 \\
23.0 \\
25.0 \\
21.0 \\
22.0\end{array}$ & $\begin{array}{l}26.0 \\
26.0 \\
26.0 \\
27.0 \\
26.0\end{array}$ & $\begin{array}{l}24.0 \\
26.0 \\
27.0 \\
26.0 \\
20.0\end{array}$ & $\begin{array}{l}21.0 \\
22.0 \\
23.0 \\
21.0 \\
25.0\end{array}$ \\
\hline $\begin{array}{l}21 \\
22 \\
23 \\
24 \\
25\end{array}$ & 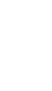 & $\begin{array}{l}14.0 \\
10.0 \\
18.0 \\
1 \% .0 \\
1 \% .0\end{array}$ & 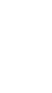 & $\begin{array}{r}4.0 \\
12.7 \\
11.5 \\
13.01 \\
13.0\end{array}$ & $\begin{array}{l}12.0 \\
10.0 \\
17.0 \\
15.0 \\
15.0\end{array}$ & $\begin{array}{l}12.0 \\
15.0 \\
15.0 \\
15.0 \\
14.1\end{array}$ & $\begin{array}{l}25.0 \\
21.0 \\
21.0 \\
24.0 \\
23.0\end{array}$ & $\begin{array}{l}21.0 \\
20.0 \\
21.0 \\
21.0 \\
20.0\end{array}$ & $\begin{array}{l}22.0 \\
21.0 \\
21.0 \\
21.0 \\
20.0\end{array}$ & $\begin{array}{l}21.0 \\
2.00 \\
21.0 \\
21.0 \\
20.0\end{array}$ & $\begin{array}{l}26.0 \\
27.0 \\
75.0 \\
27.0 \\
27.0\end{array}$ & $\begin{array}{l}26.0 \\
26.0 \\
25.0 \\
21.0 \\
24.0\end{array}$ \\
\hline $\begin{array}{l}20 \\
27 \\
24 \\
20 \\
30 \\
41\end{array}$ & 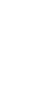 & $\begin{array}{l}16.0 \\
17.3 \\
18.3 \\
26.3 \\
17.0\end{array}$ & $\begin{array}{l}1301 \\
\because 0 \\
1703 \\
100 \\
140 \\
20.0\end{array}$ & $\begin{array}{l}12.0 \\
11.0 \\
30.0 \\
15.0 \\
15.0 \\
15.3\end{array}$ & $\begin{array}{r}12.0 \\
12.0 \\
12.0 \\
0.0 \\
0 .\end{array}$ & $\begin{array}{l}15.0 \\
19.0 \\
15.0 \\
19.0 \\
20.0 \\
20.0\end{array}$ & $\begin{array}{r}21.0 \\
21.0 \\
23.0 \\
22.0 \\
25.0 \\
-\end{array}$ & $\begin{array}{l}21.0 \\
21.0 \\
21.0 \\
20.0 \\
19.0 \\
19.0\end{array}$ & $\begin{array}{l}25.0 \\
23.0 \\
22.0 \\
22.0 \\
22.0 \\
-\end{array}$ & $\begin{array}{l}21.0 \\
25.0 \\
27.0 \\
26.0 \\
29.0 \\
29.0\end{array}$ & $\begin{array}{l}26.0 \\
25.0 \\
26.0 \\
26.0 \\
27.0 \\
28.0\end{array}$ & $\begin{array}{l}25.0 \\
23.0 \\
22.0 \\
21.0 \\
21.0 \\
\end{array}$ \\
\hline AVERAGE & 12.5 & 13.5 & 14.0 & 13.0 & 12.3 & 15.0 & 21.0 & 21.0 & 21.5 & 25.0 & $? 4.5$ & 24.5 \\
\hline
\end{tabular}


02371500 CONECUH RIVER AT BRANTLEY, ALA.

LOCATION, --Lat $31^{\circ} 34^{\prime} 24^{\prime \prime}$, long $86^{\circ} 15^{\prime} 06^{\prime \prime}$, 1n SEł sec.16, T.7 N., R.18 E., Crenshaw County, temperature recorder at gaging station on left bank at downtream side of bridge on U.S. H1ghway 331 and State Highway 52 , 0.5 mile downstream from loody Mill Creek, 0.8 mile southeast of Brantley, and at mile 112.3.

DRAINAGE AREA, - -492 sq $\mathrm{mi}$.

PERIOD OF RECORD. --Chemical analyses: March 1964 to September 1968, October 1968 to September 1969 (miscellaneous). Water temperatures: March 1964 to September 1970.

EXTREMES, --1969-70:

Water temperatures: Maximum, $27.0^{\circ} \mathrm{C}$ on several days during July and August; manimum, $2.0^{\circ} \mathrm{C}$ Jan, $9-11$.

Period of record:

Dissolved solids: Maximum, $99 \mathrm{mg} / 1$ Sept. 1-30, 1968; minimum, $19 \mathrm{mg} / 1$ Mar. 1-10, 1966.

Hardness: Maximum, $80 \mathrm{mg} / 1$ June 11-20, 1968; minimum, $9 \mathrm{mg} / \mathrm{I}$ Mar. $1-10,1966$

Specific conductance: Maximum daily, 206 micromhos Sept. 13, 1968; minimum daily, 25 micromhos kar. 5 , 1966.

Water temperatures: Maximum, 29.0 $0^{\circ} \mathrm{C}$ June $20,21,1964$, Aug. 24,1968 , June 27-30, July $7-9,1969 ;$ minimum, $2.0^{\circ} \mathrm{C}$ Jan. 31, Feb. 1, 1966, Jan. 9-11, 1970.

TEMPERATURE $\left({ }^{\circ} \mathrm{C}\right)$ OF WATER, WATER YEAR OCTOBER 1969 TO SEPTEMBER 1970

\begin{tabular}{|c|c|c|c|c|c|c|c|c|c|c|c|c|}
\hline \multirow[t]{2}{*}{ DAY } & \multicolumn{2}{|c|}{$\cap C T$} & \multicolumn{2}{|c|}{ NOV } & \multicolumn{2}{|c|}{ DEC } & \multicolumn{2}{|c|}{ JAN } & \multicolumn{2}{|c|}{ FFA } & \multicolumn{2}{|c|}{ MAR } \\
\hline & $M \Delta X$ & MIN & $M A X$ & MIN & MAX & $N$ IN & $M \Delta X$ & MIN & $\operatorname{M\Delta X}$ & $M I N$ & $M \Delta x$ & MIN \\
\hline 1 & 19.0 & $1^{R} .0$ & 16.0 & 15.0 & 10.0 & 9.0 & 10.0 & 9.0 & 9.0 & 9.0 & 10.0 & 0.0 \\
\hline 2 & 19.0 & 19.0 & 16.0 & 15.0 & 9.0 & 9.0 & 9.0 & R. 0 & 9.0 & 9.0 & 11.0 & 10.0 \\
\hline 3 & 19.0 & 19.0 & 15.0 & 14.0 & 9.0 & $R .0$ & 2.0 & 7.0 & 9.0 & $R .0$ & 12.0 & 11.0 \\
\hline 4 & 19.0 & 18.0 & 14.0 & 13.0 & R. 0 & 8.0 & 7.0 & h. & 8.0 & h. 0 & 13.0 & 12.0 \\
\hline 5 & 19.0 & 19.0 & 13.0 & 12.0 & 9.0 & 7.0 & 6.0 & 6.0 & 6.0 & h. 0 & 14.0 & 12.0 \\
\hline G & 20.0 & 19.0 & 12.0 & 11.0 & a. 0 & 8.0 & 7.0 & 6.0 & 6.0 & 6.0 & 14.0 & 14.0 \\
\hline 7 & 20.0 & 19.0 & 12.0 & 11.0 & 9.0 & 2.0 & $t .0$ & 5.0 & f.o & f. 0 & 14.0 & 13.0 \\
\hline A & 21.0 & 20.0 & 14.0 & 12.0 & 9.0 & 9.0 & 5.0 & 3.0 & 7.0 & 6.0 & 13.0 & $1 ? .0$ \\
\hline 9 & 21.0 & 20.0 & 14.0 & 13.0 & 9.0 & 9.0 & 3.0 & 2.0 & 9.0 & 7.0 & 12.0 & 11.0 \\
\hline 10 & 21.0 & 20.0 & 13.0 & 12.0 & 0.0 & 9.0 & 2.0 & 7.0 & 8.0 & 8,0 & $1 ? .0$ & 12.0 \\
\hline 11 & $>1.0$ & 20.0 & 13.0 & 12.0 & 9.0 & 9.0 & 3.0 & 2.0 & 8.0 & R. 0 & 13.0 & 12.0 \\
\hline 12 & 21.0 & 20.0 & 14.0 & 13.0 & 0.0 & 9.0 & 3.0 & 3.0 & 8.0 & R. 0 & 13.0 & 13.0 \\
\hline 13 & 21.0 & 20.0 & 13.0 & 13.0 & $R .0$ & R. 0 & 3.0 & 3.0 & 9.0 & r.o & 13.0 & 12.0 \\
\hline 14 & 21.0 & 19.0 & 13.0 & 11.0 & 9.0 & 2.0 & 4.0 & 3.0 & R. 0 & R. 0 & 12.0 & 11.0 \\
\hline 15 & 10.0 & 18.0 & 11.0 & 9.0 & 8.0 & 8.0 & 4.0 & 4.0 & 10.0 & 8.0 & 11.0 & 10.0 \\
\hline 16 & 19.0 & 17.0 & 9.0 & 2.0 & 8.0 & 9.0 & 5.0 & 4.0 & 11.0 & 10.0 & 11.0 & 10.0 \\
\hline 17 & 17.0 & 16.0 & .0 & 8.0 & 8.0 & 7.0 & 7.0 & 5.0 & 11.0 & 10.0 & 11.0 & 10.0 \\
\hline 18 & 17.0 & $1 h .0$ & 11.0 & 0.0 & 7.0 & 7.0 & 8.0 & 7.0 & 10.0 & 10.0 & 12.0 & 11.0 \\
\hline 18 & 17.0 & 16.0 & 12.0 & 11.0 & Q. 0 & 7.0 & 4.0 & 8.0 & 11.0 & 10.0 & 14.0 & 12.0 \\
\hline 20 & 14.0 & 17.0 & 11.0 & 10.0 & 口. 0 & 7.0 & $R .0$ & 7.0 & 11.0 & 10.0 & 15.0 & 14.0 \\
\hline 21 & 10.0 & $1 \mathrm{H} .0$ & 10.0 & $9 . n$ & 8.0 & 7.0 & 7.0 & 6.0 & 10.0 & 9.0 & 15.0 & 14.0 \\
\hline 22 & 10.0 & 19.0 & 9.0 & 9.0 & 2.0 & 7.0 & t. 0 & $A .0$ & 9.0 & 8.0 & 14.0 & 12.0 \\
\hline 23 & ${ }^{1 R} .0$ & 17.0 & 10.0 & 4.0 & 7.0 & 7.0 & 0.0 & 6.0 & 9.0 & 9.0 & 12.0 & 11.0 \\
\hline 24 & 17.0 & $1 \mathrm{~K} .0$ & 10.0 & 10.0 & 7.0 & h. 0 & h.o & 5.0 & 10.0 & 0.0 & 13.0 & 11.0 \\
\hline $2^{5}$ & 17.0 & $1+.0$ & 11.0 & 10.0 & R. 0 & h.o & $h=0$ & h. 0 & 10.0 & 10.0 & 14.0 & 13.0 \\
\hline $2^{h}$ & 17.0 & 16.0 & 12.0 & 11.0 & 8.0 & 7.0 & R. 0 & 6.0 & 10.0 & 10.0 & 14.0 & 14.0 \\
\hline 27 & 17.0 & 1 h. 0 & 12.0 & 11.0 & 7.0 & h.o & 9.0 & 2.0 & 10.0 & 9.0 & 14.0 & 13.0 \\
\hline $2^{8}$ & 17.0 & 16.0 & 12.0 & 12.0 & $A=0$ & $A .0$ & $1 n .0$ & R. 0 & 9.0 & 9.0 & 14.0 & 11.0 \\
\hline $2^{\circ}$ & 16.0 & 15.0 & 12.0 & 11.0 & R. 0 & $R .0$ & 12.0 & 10.0 & - & -- & $1^{5} .0$ & 14.0 \\
\hline 30 & 16.0 & 14.0 & 11.0 & 10.0 & 10.0 & R. 0 & 12.0 & 11.0 & -- & -- & is.o & 14.0 \\
\hline 21 & 15.0 & 15.0 & - & - & 10.0 & 10.0 & 11.0 & 9.0 & -- & -- & 15.0 & 14.0 \\
\hline$\triangle \vee G$ & 19.5 & 17.5 & 12.1 & 11.1 & A. 2 & 7.5 & 4.7 & $5 . R$ & R. $A$ & R. 3 & 13.0 & 12.0 \\
\hline \multirow[t]{2}{*}{ IIAY } & \multicolumn{2}{|c|}{$A P R$} & & & & & & & & & & \\
\hline & $M A X$ & MIN & $M \Delta x$ & $M I N$ & $M \Delta x$ & $M ! N$ & MAX & $M ! N$ & MAX & MIN & $M \Delta X$ & $M I M$ \\
\hline 1 & 17.0 & 15.0 & 24.0 & 23.0 & 23.0 & 22.0 & 25.0 & 23.0 & 27.0 & 25.0 & 25.0 & 24.0 \\
\hline 2 & 19.0 & 17.0 & $2^{x} \cdot 0$ & 22.0 & 23.0 & 22.0 & $2 h .0$ & 24.0 & 27.0 & 26.0 & 25.0 & 24.0 \\
\hline$x$ & 17.0 & 16.0 & 22.0 & 20.0 & 22.0 & 19.0 & 27.0 & 25.0 & 27.0 & $2 k .0$ & 26.0 & 25.0 \\
\hline 4 & 1 h. 0 & 15.0 & 20.0 & 10.0 & 19.0 & 19.0 & 27.0 & 26.0 & 27.0 & 26.0 & 26.0 & 25.0 \\
\hline 5 & 14.0 & $1 \mathrm{~h} .0$ & 19.0 & 18.0 & 19.0 & 19.0 & 28.0 & 24.0 & $2 k .0$ & 25.0 & 26.0 & 25.0 \\
\hline B & 14.0 & 16.0 & 10.0 & 18.0 & 19.0 & 19.0 & 26.0 & 24.0 & 75.0 & 29.0 & 76.0 & 24.0 \\
\hline 7 & 16.0 & 16.0 & 20.0 & 10.0 & 19.0 & 19.0 & 25.0 & 24.0 & 26.0 & 75.0 & 25.0 & 25.0 \\
\hline a & 16.0 & 15.0 & 20.0 & 10.0 & 19.0 & 19.0 & 25.0 & 24.0 & $2 h=0$ & 25.0 & 25.0 & 24.0 \\
\hline c & 16.0 & 16.0 & 20.0 & 19.0 & 20.0 & 19.0 & 26.0 & 24.0 & 25.0 & 24.0 & 25.0 & 24.0 \\
\hline 10 & 17.0 & 16.0 & 21.0 & 20.0 & 20.0 & 20.0 & 26.0 & 24.0 & $2^{5} .0$ & 24.0 & 25.0 & 24.0 \\
\hline 11 & 16.0 & 16.0 & 22.0 & 20.0 & 21.0 & 20.0 & 20.0 & 25.0 & 24.0 & $2^{\prime}+0$ & 25.0 & 24.0 \\
\hline 12 & 16.0 & 16.0 & 22.0 & 20.0 & 21.0 & 21.0 & 26.0 & 24.0 & 24.0 & 24.0 & 25.0 & 24.0 \\
\hline 13 & 17.0 & 16.0 & 23.0 & 21.0 & 22.0 & 21.0 & 25.0 & 24.0 & 25.0 & 24.0 & 24.0 & 24.0 \\
\hline 14 & 12.0 & 17.0 & 23.0 & 21.0 & 23.0 & 22.0 & 25.0 & 24.0 & 25.0 & 24.0 & 24.0 & 23.0 \\
\hline is & 18.0 & 17.0 & 23.0 & 21.0 & 23.0 & 22.0 & 25.0 & $2^{2} \cdot 0$ & 25.0 & 25.0 & 25.0 & 24.0 \\
\hline $1 \mathrm{f}$ & $1^{R} .0$ & 17.0 & 23.0 & 22.0 & 24.0 & 23.0 & $2 h .0$ & 24.0 & 25.0 & 25.0 & 25.0 & 24.0 \\
\hline 17 & $1 R .0$ & 17.0 & 23.0 & 22.0 & 24.0 & 23.0 & $26 . n$ & 25.0 & 26.0 & 25.0 & 25.0 & 24.0 \\
\hline$i^{A}$ & 19.0 & $1 R \cdot 0$ & 23.0 & 21.0 & 25.0 & 24.0 & 26.0 & 25.0 & 26.0 & 25.0 & 25.0 & 24.0 \\
\hline 19 & 19.0 & 19.0 & 23.0 & 21.0 & 25.0 & 24.0 & 26.0 & 25.0 & $2 \hbar .0$ & 24.0 & 25.0 & 24.0 \\
\hline 20 & 20.0 & 19.0 & $2^{2} \cdot 0$ & 21.0 & 26.0 & 25.0 & 26.0 & 25.0 & $2^{5} .0$ & 24.0 & 25.0 & 24.0 \\
\hline$? 1$ & 20.0 & 19.0 & 23.0 & 20.0 & $2 h .0$ & 25.0 & 26.0 & 25.0 & 25.0 & 24.0 & 25.0 & 24.0 \\
\hline 22 & 21.0 & 20.0 & 24.0 & 21.0 & 26.0 & 25.0 & 26.0 & 25.0 & 25.0 & 24.0 & 25.0 & 24.0 \\
\hline 23 & 21.0 & 71.0 & 24.0 & 22.0 & 26.0 & 75.0 & 25.0 & 24.0 & $2^{5} .0$ & 24.0 & 24.0 & 23.0 \\
\hline 24 & 22.0 & 21.0 & 24.0 & 22.0 & $2 t .0$ & 25.0 & 25.0 & 24.0 & 25.0 & 24.0 & 25.0 & 23.0 \\
\hline 25 & 27.0 & $>1.0$ & $2 x .0$ & 22.0 & $2=0$ & 24.0 & 25.0 & 24.0 & 24.0 & 24.0 & 24.0 & 23.0 \\
\hline 26 & 22.0 & 21.0 & 24.0 & 22.0 & 24.0 & 24.0 & 26.0 & 24.0 & 24.0 & 22.0 & 24.0 & $2 x .0$ \\
\hline$? 7$ & 22.0 & 22.0 & 25.0 & 22.0 & 24.0 & 23.0 & 26.0 & 25.0 & 22.0 & $2 x \cdot 0$ & 24.0 & 23.0 \\
\hline 2 月 & 23.0 & 22.0 & 25.0 & 23.0 & $>5.0$ & 24.0 & $2 \hbar .0$ & $2^{5} .0$ & 23.0 & 23.0 & 23.0 & $22 . n$ \\
\hline 29 & 24.0 & 23.0 & 25.0 & 23.0 & 25.0 & 24.0 & $2+.0$ & $>5.0$ & 24.0 & $2^{x} \cdot 0$ & 22.0 & 20.0 \\
\hline 10 & 24.0 & 23.0 & 24.0 & $2^{2} \cdot 0$ & 25.0 & $2^{2} .0$ & 27.0 & 25.0 & 25.0 & 24.0 & 20.0 & 19.0 \\
\hline 31 & $\ldots$ & - & 27.0 & 22.0 & - & - & 27.0 & 25.0 & 75.0 & 24.0 & $=$ & - \\
\hline Avr: & 18.8 & 19.1 & $2 ? .5$ & 20.4 & 22.4 & 22.1 & $25 . R$ & 24.4 & 25.1 & 24.3 & 24.6 & 23.5 \\
\hline
\end{tabular}


02374796 LITTLE ESCAMBIA CREEK BELOW CHAVERS CREEK, ALA.

LOCATION. - Lat $31^{\circ} 04^{\prime} 23^{\prime \prime}$, long $87^{\circ} 12^{\prime} 57^{\prime \prime}$, in SE $\mathrm{SE}_{\frac{1}{4}}$ sec.1, T.1 N., R, 8 E., Escambia County, at left bank 0.1 mile downstream from Chavers Creek, 4 milés northwest of Pollard, Ala., and 4.3 miles upstream from U.S. Highway 31. DRAINAGE AREA.--126 sq mi.

PERIOD OF RECORD.--Chemical analyses: October 1962 to September 1963, October 1964 to September 1965 (miscellaneous), February 1970 to september 1970.

\begin{tabular}{|c|c|c|c|c|c|c|c|c|c|c|}
\hline & & CHEMICA & ANALYSE & - WATER & EAR OCTC & BER 1969 & $\begin{array}{l}0 \text { SEPTEN } \\
\text { NDN- }\end{array}$ & $\begin{array}{l}\text { BER } 1970 \\
\text { SPECI - }\end{array}$ & & \\
\hline VATE & IIME & $\begin{array}{l}\text { DIS- } \\
\text { CHARGE } \\
\text { (CFS) }\end{array}$ & $\begin{array}{l}\text { BICAR- } \\
\text { BONATE } \\
\text { \{HCO3\} } \\
\text { (MG/L) }\end{array}$ & $\begin{array}{l}\text { CAK- } \\
\text { BONATE } \\
\text { (CO3) } \\
(\mathrm{MG} / \mathrm{L})\end{array}$ & $\begin{array}{l}\text { CHLL- } \\
\text { RIDE } \\
\text { ICLI } \\
\text { IMGILI }\end{array}$ & $\begin{array}{l}\text { HARU- } \\
\text { NESS } \\
\text { (CA,MG) } \\
\text { (MG/L) }\end{array}$ & $\begin{array}{l}\text { CAR- } \\
\text { BDNATE } \\
\text { HARD- } \\
\text { NESS } \\
\text { (MG/L) }\end{array}$ & $\begin{array}{l}\text { FIC } \\
\text { COND- } \\
\text { UCTANCE } \\
\text { IMICRU- } \\
\text { MHOSI }\end{array}$ & $\begin{array}{c}\text { PH } \\
\text { (UNITS) }\end{array}$ & $\begin{array}{l}\text { IEMP- } \\
\text { ERATURE } \\
\text { IDEG CI }\end{array}$ \\
\hline $\begin{array}{l}\text { FEB.,. } 1970 \\
\text { O2... } \\
\text { MAR. }\end{array}$ & 1520 & -- & 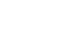 & 0 & 5.4 & 5 & 3 & 31 & 5.2 & 11.0 \\
\hline APR. & 1135 & 22 & 4 & 0 & 4.4 & 7 & 4 & 30 & 5.7 & 13.0 \\
\hline $\begin{array}{l}01 \ldots \\
27 \ldots\end{array}$ & $\begin{array}{l}1100 \\
1325\end{array}$ & $\begin{array}{l}50 \\
12\end{array}$ & $\begin{array}{l}2 \\
5\end{array}$ & $\begin{array}{l}0 \\
0\end{array}$ & $\begin{array}{l}2.8 \\
2.6\end{array}$ & $\begin{array}{l}4 \\
4\end{array}$ & $\begin{array}{l}2 \\
0\end{array}$ & $\begin{array}{l}22 \\
23\end{array}$ & $\begin{array}{l}5.0 \\
6.7\end{array}$ & $\begin{array}{l}17.0 \\
23.0\end{array}$ \\
\hline JUNE & & & & & & & & & & \\
\hline${ }_{\text {JULY }}^{30}$ & 1550 & 12 & 2 & 0 & 28 & 14 & 12 & 108 & 5.5 & 24.0 \\
\hline SEP. & 1430 & 15 & 2 & 0 & 8.4 & 5 & 3 & 42 & 5.4 & 25.0 \\
\hline $29 \ldots$ & 1400 & 26 & 8 & 0 & 9.8 & 6 & 0 & 49 & 6.2 & 20.5 \\
\hline
\end{tabular}

02374798 LITTLE ESCANBIA CREEK BELOW POLLARD OIL FIELD, ALA.

LOCATION.--Lat $31^{\circ} 02^{\prime} 42^{\prime \prime}$, long $87^{\circ} 13^{\prime} 06^{\prime \prime}$, in SE $\frac{1}{4} \mathrm{SW}-\mathrm{l}$ sec.13, T.1 N., R.8 E., Escambia County, at left bank at bridge nor county road, 2.1 miles upstream from U.S. Highway $31,2.2$ miles downstream from Chauers Creek, and 2.8 miles
northwest of pollard.

DRAI NAGE AREA. $--129 \mathrm{sq} \mathrm{mi}$.

PERIOD OF RECORD. --Chemical analyses: October 1962 to September 1963, October 1966 to September 1968 (miscellaneous), October 1969 to September 1970 .

CHEMICAL ANALYSES, WATER YEAR OCTOBER 1969 TO SEPTEMBER 1970

\begin{tabular}{|c|c|c|c|}
\hline $\begin{array}{l}\text { NON- } \\
\text { CAR- } \\
\text { BONATE } \\
\text { HARD- } \\
\text { NESS } \\
\text { (MG/L) }\end{array}$ & $\begin{array}{l}\text { SPECI- } \\
\text { FIC } \\
\text { CONO- } \\
\text { UCIANCE } \\
\text { IMICRO- } \\
\text { MHOS) }\end{array}$ & $\begin{array}{c}\text { PH } \\
\{\text { UNITS }\end{array}$ & $\begin{array}{l}\text { TEMP- } \\
\text { ERATURE } \\
\text { (DFG C) }\end{array}$ \\
\hline 4 & 88 & 5.7 & 25.0 \\
\hline 7 & 97 & 6.0 & 13.0 \\
\hline $\begin{array}{r}10 \\
8\end{array}$ & $\begin{array}{r}101 \\
82\end{array}$ & $\begin{array}{l}6.2 \\
5.5\end{array}$ & $\begin{array}{l}10.0 \\
12.0\end{array}$ \\
\hline 5 & 43 & 5.5 & 10.0 \\
\hline 9 & 76 & 5.5 & 14.0 \\
\hline $\begin{array}{r}2 \\
12\end{array}$ & $\begin{array}{l}29 \\
19\end{array}$ & $\begin{array}{l}5.0 \\
6.2\end{array}$ & $\begin{array}{l}17.0 \\
23.0\end{array}$ \\
\hline $\begin{array}{l}4 \\
6\end{array}$ & $\begin{array}{l}21 \\
76\end{array}$ & $\begin{array}{l}4.4 \\
7.2\end{array}$ & $\begin{array}{l}20.0 \\
23.0\end{array}$ \\
\hline 9 & 103 & 6.0 & 25.0 \\
\hline 4 & 41 & 5.2 & 21.0 \\
\hline 10 & 93 & & \\
\hline
\end{tabular}

02374800 LITTLE ESCAMBIA CREEK NEAR POLLARD, ALA. LOCATION.--Lat $31^{\circ} 01^{\prime} 14^{\prime \prime}$, long $87^{\circ} 12^{\prime} 25^{\prime \prime}$, in SW $\frac{1}{4}$ NW $\frac{1}{2} \mathrm{sec}, 30, \mathrm{~T} .1$ N., R.9 E., Escambia County, at left bank at bridge
on U.S. Highway 31,2 miles west of pollard, and at mile 3.1 .

DRAINAGE AREA.--138 sq mi.

PERIOD OF RECORD.--Chemical analyses: October 1967 to September 1969 (miscellaneous), October 1969 to September 1970. CHEMICAL ANALYSES, WATER YEAR OCTOBER 1969 TO SEPTEMBER 1970

\begin{tabular}{|c|c|c|c|c|c|c|c|c|c|c|}
\hline $\begin{array}{l}\text { DATE } \\
\text { OCT., } 1969\end{array}$ & TIME & $\begin{array}{l}\text { DIS- } \\
\text { CHARGE } \\
\text { (CFS) }\end{array}$ & $\begin{array}{l}\text { 8ICAR- } \\
\text { BONATE } \\
\text { (HCD3) } \\
(M G / L)\end{array}$ & $\begin{array}{l}\text { CAR- } \\
\text { BONAIE } \\
\text { (CO3) } \\
(* G / L)\end{array}$ & $\begin{array}{l}\text { CHLO- } \\
\text { RIOE } \\
\text { (CL) } \\
\text { (MG/L) }\end{array}$ & $\begin{array}{l}\text { HARD- } \\
\text { NESS } \\
(C A, M G) \\
(M G / L)\end{array}$ & $\begin{array}{l}\text { NON- } \\
\text { CAR- } \\
\text { BONATE } \\
\text { HARO- } \\
\text { NESS } \\
\text { (MG/L) }\end{array}$ & $\begin{array}{l}\text { SPECI- } \\
\text { FIC } \\
\text { COND- } \\
\text { UCTANCE } \\
\text { (MICRO- } \\
\text { MHOSI }\end{array}$ & $\begin{array}{c}P H \\
\text { (UNITS) }\end{array}$ & $\begin{array}{l}\text { TEMP- } \\
\text { ERATURE } \\
\text { IOEG C I }\end{array}$ \\
\hline $\begin{array}{l}03 . . . \\
\text { nOV. }\end{array}$ & 1610 & $=-$ & 2 & 0 & 8.0 & 6 & 4 & 45 & 5.2 & 25.0 \\
\hline O5... & 1520 & - & 6 & 0 & 27 & 11 & 6 & 92 & 6.2 & 13.0 \\
\hline 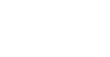 & $\begin{array}{l}1230 \\
1325\end{array}$ & -- & $\begin{array}{l}4 \\
3\end{array}$ & $\begin{array}{l}0 \\
0\end{array}$ & $\begin{array}{l}22 \\
19\end{array}$ & $\begin{array}{l}11 \\
10\end{array}$ & $\begin{array}{l}B \\
B\end{array}$ & $\begin{array}{l}90 \\
78\end{array}$ & $\begin{array}{l}6.1 \\
5.4\end{array}$ & $\begin{array}{l}10.0 \\
12.0\end{array}$ \\
\hline MAR. & 1325 & -- & 2 & 0 & 7.6 & 8 & 6 & 41 & 5.4 & 10.0 \\
\hline APR.: 1970 & 1230 & 27 & 2 & 0 & 17 & 9 & 7 & 72 & 5.4 & 13.0 \\
\hline $\begin{array}{l}O 1 \ldots . . \\
27 \ldots \\
\text { JUNE }\end{array}$ & $\begin{array}{l}0920 \\
1215\end{array}$ & $\begin{array}{l}50 \\
16\end{array}$ & $\begin{array}{l}2 \\
6\end{array}$ & $\begin{array}{l}0 \\
0\end{array}$ & $19^{4 \cdot 8}$ & 14 & $\begin{array}{l}2 \\
6\end{array}$ & $\begin{array}{l}30 \\
79\end{array}$ & $\begin{array}{l}5.0 \\
6.3\end{array}$ & $\begin{array}{l}17.0 \\
23.0\end{array}$ \\
\hline $\begin{array}{l}01 \ldots . . \\
\text { sul. }\end{array}$ & $\begin{array}{l}1215 \\
1340\end{array}$ & $\begin{array}{r}100 \\
20\end{array}$ & $\begin{array}{l}0 \\
4\end{array}$ & $\begin{array}{l}0 \\
0\end{array}$ & $19^{2 \cdot B}$ & $11^{4}$ & $\begin{array}{l}4 \\
8\end{array}$ & $\begin{array}{l}24 \\
80\end{array}$ & $\begin{array}{l}4.3 \\
5.7\end{array}$ & $\begin{array}{l}20.0 \\
23.0\end{array}$ \\
\hline $\begin{array}{l}29 . . . \\
\text { AUG. }\end{array}$ & 1300 & 18 & 2 & 0 & 25 & 11 & 9 & 99 & 5.2 & 26.0 \\
\hline SEP. & 1030 & 50 & 4 & 0 & 7.4 & 6 & 3 & 40 & 5.4 & 20.0 \\
\hline $29 \ldots$ & 1015 & 28 & 3 & 0 & 22 & 11 & 9 & 89 & 5.8 & 19.5 \\
\hline
\end{tabular}


02387500 OOSTANAUla RIVER AT RESACA, Ga.

LOCATION.--Lat $34^{\circ} 34^{\prime} 42^{\prime \prime}$, long $84^{\circ} 56^{\prime} 29^{\prime \prime}$, Gordon County, at gaging station near left bank on downstream side of pier of bridge on U.S. Highway 41 at Resaca, $200 \mathrm{ft}$ downstream from Nashville, Chattanooga and St. Louis Railway bridge, $0.8 \mathrm{mile}$ upstream from camp Creek, and $3.5 \mathrm{miles}$ domstream from confluence of Conasauga and coosawattee
Rivers.

DRAINAGE AREA.--1,610 sq mi, approximately.

PERIOD OF RECORD.--Chemical analyses: November 1969 to September 1970 ,

Water temperatures: July 1967 to September 1970.

EXTREMES. - - 1969-70:

Water temperatures: Maximum, $26.0^{\circ} \mathrm{C}$ Aug. $5-8 ;$ minimum, $1.0^{\circ} \mathrm{C}$ Jan. $9-14$.

period of record:

Water temperatures: Maximum recorded, $28.0^{\circ} \mathrm{C}$ several days in June and July, $1969 ;$ mini inum, $1.0^{\circ} \mathrm{C} \mathrm{Jan} .9-14$, 1970.

REMARKS.--Laboratory chemical analyses by Georgia water Quality Control Board. Field determination of discharge, water temperature, $\mathrm{pH}$, and dissolved oxygen by U.S. Geological Survey.

CHEMICAL ANALYSES, WATER YEAR DCTOBER 1969 TO SEPTEMBER 1970

\begin{tabular}{|c|c|c|c|c|c|}
\hline $141 E$ & II I ' & $\begin{array}{l}\text { गIS- } \\
\text { (Hritge } \\
\text { (Cts) }\end{array}$ & $\begin{array}{c}\text { (WN } \\
\text { (Jis) }\end{array}$ & $\begin{array}{l}\text { IFME- } \\
\text { FAATHET } \\
\text { (UFG C) }\end{array}$ & $\begin{array}{l}\text { DIS- } \\
\text { GULVEI } \\
\text { WXYGE } \\
\text { (MG,L) }\end{array}$ \\
\hline${ }_{1+\infty}+\infty$ & $1 / 3 ; k$ & 104,1 & 1.4 & 13.4 & 4.4 \\
\hline $\begin{array}{ll}15 . . \\
13 \\
1.0\end{array}$ & 113. & 1.1511 & $7 . ?$ & $5 . n$ & $10 . n$ \\
\hline $77 \ldots$ & $11 u r$ & $\$ 146$ & 7.4 & 3.11 & 11.0 \\
\hline 11"... & 1111, & 14711 & $h .4$ & $10 . n$ & $\ln . n$ \\
\hline , & $11 \ldots, 1$ & 3141 & 1.6 & $1 \mathrm{H.} .1$ & 6.4 \\
\hline "1⿴囗火 & $1 m_{4 h}$ & 11140 & 1.2 & 14.5 & h. 3 \\
\hline $\begin{array}{c}1+\ldots \\
41+6\end{array}$ & $1+310$ & n4h & 7.7 & 25.0 & n.h \\
\hline$\lambda \ldots$ & 1142 & $44 ?$ & 7.4 & 73.1 & b.t. \\
\hline
\end{tabular}

\begin{tabular}{|c|c|c|c|c|c|c|c|c|c|c|}
\hline WATt & $\begin{array}{l}111(L) \\
(4 I 11) \\
(1, L)\end{array}$ & 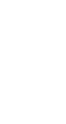 & 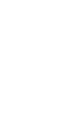 & $\begin{array}{l}\text { PIS- } \\
\text { SULVU) } \\
\text { LAI - } \\
(1) \text { IA } \\
(C A) \\
(A[G / L)\end{array}$ & $\begin{array}{l}\text { IIS } \\
\text { SOLVE- } \\
\text { MAG- } \\
\text { IF- } \\
\text { SI IMM } \\
\text { (MG) } \\
\text { (MC/L) }\end{array}$ & $\begin{array}{c}\text { SOOI UM } \\
(\mathrm{NA}) \\
(\mathrm{MG} / \mathrm{L})\end{array}$ & $\begin{array}{l}\text { PO- } \\
\text { TAS- } \\
\text { SIUM } \\
\text { (K) } \\
\text { (MG/L) }\end{array}$ & $\begin{array}{l}\text { ALKA- } \\
\text { LINITY } \\
\text { AS } \\
\text { CACO3 } \\
\text { (MG LL) }\end{array}$ & $\begin{array}{l}\text { SULFATE } \\
(S O 4) \\
(M G / L)\end{array}$ & $\begin{array}{l}\text { CHLO- } \\
\text { RIDE } \\
\text { (CL) } \\
\text { (MG/L }\end{array}$ \\
\hline risv. & & & & & & & & & & \\
\hline $\begin{array}{l}1+\ldots \\
1+c\end{array}$ & $r .3$ & 450 & $<b 0$ & 13 & 3.4 & 10 & 1.5 & 45 & 8.0 & 18 \\
\hline $\begin{array}{ll}1 & \\
J A & \ldots\end{array}$ & $\leadsto 1$ & $\sin 0$ & $<$ iu & 16 & 2.4 & h.s & $1 \cdot 3$ & 39 & 6.0 & 7. \\
\hline 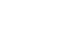 & $m \cdot 1$ & $s(r)$ & sol & 11 & P. & 3.2 & -- & 44 & 7.0 & 3. \\
\hline 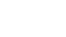 & $n .7$ & (-5) & <bi & 14 & 3.0 & 3.2 & $1 . n$ & 4? & 6.0 & 3. \\
\hline$\left\{\begin{array}{l}1 \\
j \mid f ; \beta\end{array}\right.$ & $\lambda . e$ & $3<41$ & < <is & 14 & 3.5 & 2.0 & 1.4 & 47 & $B .0$ & 2. \\
\hline${ }_{H L Y}^{1)} \cdots$ & +1 & $b>6$ & $<>11$ & 12 & 3.0 & 5.0 & 1.3 & 37 & 8.0 & \\
\hline $\begin{array}{c}14 \ldots . . \\
4110.0\end{array}$ & 7.1 & $\langle 1,1, b]$ & <su & 13 & $\cdot{ }^{H}$ & 4.6 & 1.3 & 43 & 10 & 14 \\
\hline ch... & ל. & 13186 & <bil & $\forall \Rightarrow$ & 3.2 & 9.4 & 2.1 & $4 n$ & 11 & 10 \\
\hline
\end{tabular}

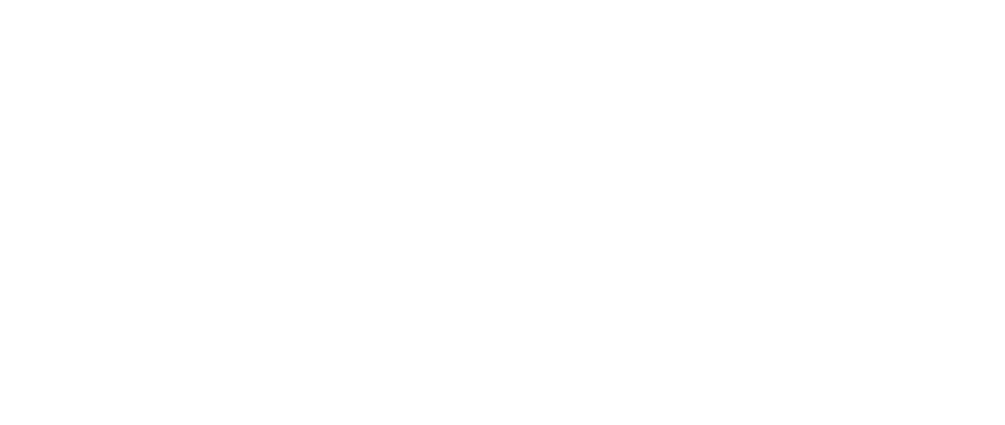


02387500 OOSTANAULA RIVER AT RESACA, GA,--Continued

TEMPERATURE ('०) OF WATER, WATER YEAR OCTOBER 1969 TO SEPTEMBER 1970

OECEMBER JANUARY

FEBRUARY MARCH

\begin{tabular}{|c|c|c|c|c|c|c|c|c|c|c|c|c|}
\hline \multirow[b]{2}{*}{ DAY } & & & & & & \\
\hline & $\max$ & MIN & MAX & MIN & $\operatorname{MAX}$ & MIN & $\operatorname{MAX}$ & MIN & $\operatorname{MAX}$ & MIV & MAX & MIN \\
\hline $\begin{array}{l}1 \\
2 \\
3 \\
4 \\
5\end{array}$ & $\begin{array}{l}18.5 \\
18.5 \\
19.0 \\
19.0 \\
19.5\end{array}$ & $\begin{array}{l}18.0 \\
18.5 \\
18.5 \\
18.5 \\
28.5\end{array}$ & $\begin{array}{l}13.5 \\
14.0 \\
14.0 \\
14.0 \\
12.0\end{array}$ & $\begin{array}{l}12.0 \\
13.5 \\
13.5 \\
12.0 \\
10.5\end{array}$ & $\begin{array}{l}6.5 \\
6.0 \\
5.5 \\
5.0 \\
5.0\end{array}$ & $\begin{array}{l}5.5 \\
5.0 \\
5.0 \\
4.5 \\
4.0\end{array}$ & $\begin{array}{r}10.5 \\
9.0 \\
6.5 \\
5.5 \\
4.5\end{array}$ & $\begin{array}{l}9.0 \\
6.5 \\
5.5 \\
4.5 \\
4.0\end{array}$ & $\begin{array}{l}6.5 \\
5.5 \\
6.0 \\
6.0 \\
4.0\end{array}$ & $\begin{array}{l}5.0 \\
5.0 \\
5.5 \\
4.0 \\
3.5\end{array}$ & $\begin{array}{r}0.0 \\
9.0 \\
10.5 \\
12.0 \\
13.0\end{array}$ & $\begin{array}{r}6.5 \\
B .0 \\
9.0 \\
10.5 \\
12.0\end{array}$ \\
\hline $\begin{array}{r}6 \\
7 \\
8 \\
9 \\
10\end{array}$ & $\begin{array}{l}19.0 \\
19.0 \\
18.5 \\
18.5 \\
18.0\end{array}$ & $\begin{array}{l}18.5 \\
18.5 \\
18.5 \\
17.0 \\
17.0\end{array}$ & $\begin{array}{l}10.5 \\
10.0 \\
10.0 \\
10.5 \\
10.5\end{array}$ & $\begin{array}{r}9.5 \\
9.5 \\
9.5 \\
9.5 \\
10.0\end{array}$ & $\begin{array}{l}4.5 \\
5.5 \\
6.0 \\
6.5 \\
6.5\end{array}$ & $\begin{array}{l}4.5 \\
4.5 \\
5.5 \\
6.0 \\
6.5\end{array}$ & $\begin{array}{l}4.0 \\
4.0 \\
3.5 \\
1.5 \\
1.5\end{array}$ & $\begin{array}{l}4.0 \\
3.5 \\
1.5 \\
1.0 \\
1.0\end{array}$ & $\begin{array}{l}4.5 \\
5.5 \\
6.5 \\
6.5 \\
6.5\end{array}$ & $\begin{array}{l}3.5 \\
4.5 \\
5.5 \\
6.5 \\
6.5\end{array}$ & $\begin{array}{l}13.0 \\
13.0 \\
11.5 \\
11.0 \\
11.5\end{array}$ & $\begin{array}{l}12.0 \\
11.5 \\
10.5 \\
10.0 \\
10.0\end{array}$ \\
\hline $\begin{array}{l}11 \\
12 \\
13 \\
14 \\
15\end{array}$ & $\begin{array}{l}18.5 \\
19.0 \\
19.5 \\
19.5 \\
19.0\end{array}$ & $\begin{array}{l}18.0 \\
18.5 \\
19.0 \\
18.0 \\
16.5\end{array}$ & $\begin{array}{r}10.5 \\
11.0 \\
11.0 \\
11.0 \\
9.0\end{array}$ & $\begin{array}{r}10.0 \\
10.5 \\
10.5 \\
9.0 \\
7.0\end{array}$ & $\begin{array}{l}7.0 \\
7.0 \\
7.0 \\
6.0 \\
6.0\end{array}$ & $\begin{array}{l}6.5 \\
7.0 \\
6.0 \\
5.5 \\
6.0\end{array}$ & $\begin{array}{l}1.0 \\
1.0 \\
1.0 \\
1.5 \\
2.0\end{array}$ & $\begin{array}{l}1.0 \\
1.0 \\
1.0 \\
1.0 \\
1.5\end{array}$ & $\begin{array}{l}6.5 \\
6.0 \\
6.0 \\
6.0 \\
6.5\end{array}$ & $\begin{array}{l}5.5 \\
5.5 \\
5.5 \\
5.5 \\
5.0\end{array}$ & $\begin{array}{l}12.0 \\
13.0 \\
13.0 \\
11.5 \\
10.0\end{array}$ & $\begin{array}{r}11.0 \\
12.0 \\
11.5 \\
10.0 \\
9.0\end{array}$ \\
\hline $\begin{array}{l}16 \\
17 \\
18 \\
19 \\
20\end{array}$ & $\begin{array}{l}16.5 \\
16.5 \\
15.5 \\
14.5 \\
15.5\end{array}$ & $\begin{array}{l}16.5 \\
15.5 \\
14.5 \\
14.0 \\
14.5\end{array}$ & $\begin{array}{l}7.0 \\
6.0 \\
8.5 \\
9.5 \\
9.5\end{array}$ & $\begin{array}{l}5.5 \\
5.5 \\
6.0 \\
3.5 \\
9.0\end{array}$ & $\begin{array}{l}6.0 \\
5.0 \\
4.5 \\
4.0 \\
4.0\end{array}$ & $\begin{array}{l}5.0 \\
4.5 \\
4.0 \\
4.0 \\
4.0\end{array}$ & $\begin{array}{l}3.0 \\
4.5 \\
5.5 \\
5.5 \\
5.5\end{array}$ & $\begin{array}{l}2.0 \\
3.0 \\
4.5 \\
5.5 \\
5.0\end{array}$ & $\begin{array}{l}8.0 \\
8.5 \\
8.5 \\
9.0 \\
9.0\end{array}$ & $\begin{array}{l}6.5 \\
B .0 \\
8.5 \\
8.5 \\
8.0\end{array}$ & $\begin{array}{c}=- \\
=- \\
0.5\end{array}$ & 10.0 \\
\hline $\begin{array}{l}21 \\
22 \\
23 \\
24 \\
25\end{array}$ & $\begin{array}{l}16.0 \\
16.0 \\
15.5 \\
14.0 \\
13.0\end{array}$ & $\begin{array}{l}15.5 \\
15.0 \\
14.0 \\
13.0 \\
13.0\end{array}$ & $\begin{array}{l}9.0 \\
7.0 \\
6.5 \\
8.0 \\
8.5\end{array}$ & $\begin{array}{l}7.0 \\
6.0 \\
6.5 \\
6.5 \\
8.0\end{array}$ & $\begin{array}{l}4.0 \\
4.0 \\
4.0 \\
3.5 \\
3.5\end{array}$ & $\begin{array}{l}4.0 \\
4.0 \\
3.5 \\
3.5 \\
3.5\end{array}$ & $\begin{array}{l}5.0 \\
3.5 \\
2.0 \\
2.0 \\
2.0\end{array}$ & $\begin{array}{l}3.5 \\
2.0 \\
1.5 \\
1.5 \\
2.0\end{array}$ & $\begin{array}{l}8.0 \\
6.5 \\
6.5 \\
6.5 \\
7.0\end{array}$ & $\begin{array}{l}6.5 \\
5.5 \\
6.0 \\
6.5 \\
6.5\end{array}$ & $\begin{array}{r}11.0 \\
11.0 \\
10.0 \\
9.0 \\
9.5\end{array}$ & $\begin{array}{r}10.5 \\
10.0 \\
9.0 \\
9.0 \\
9.0\end{array}$ \\
\hline $\begin{array}{l}26 \\
27 \\
28 \\
29 \\
30 \\
31\end{array}$ & $\begin{array}{l}13.5 \\
13.5 \\
13.5 \\
13.0 \\
12.0 \\
12.0\end{array}$ & $\begin{array}{l}13.0 \\
13.0 \\
13.0 \\
12.0 \\
11.0 \\
11.5\end{array}$ & $\begin{array}{l}9.0 \\
9.0 \\
8.5 \\
9.5 \\
8.0 \\
-. .\end{array}$ & $\begin{array}{l}8.5 \\
8.5 \\
2.5 \\
8.0 \\
6.5 \\
-.-\end{array}$ & $\begin{array}{r}3.5 \\
3.5 \\
3.5 \\
4.5 \\
10.5 \\
11.0\end{array}$ & $\begin{array}{r}3.5 \\
3.5 \\
3.5 \\
3.5 \\
4.5 \\
10.5\end{array}$ & $\begin{array}{l}4.0 \\
5.5 \\
5.5 \\
8.0 \\
8.5 \\
8.0\end{array}$ & $\begin{array}{l}2.0 \\
4.0 \\
5.5 \\
5.5 \\
8.0 \\
6.5\end{array}$ & $\begin{array}{l}6.5 \\
6.0 \\
8.5 \\
-.- \\
-.- \\
-.-\end{array}$ & $\begin{array}{l}6.0 \\
5.5 \\
5.5 \\
-. . \\
-.- \\
-.-\end{array}$ & $\begin{array}{l}11.0 \\
11.0 \\
11.0 \\
12.0 \\
12.0 \\
12.0\end{array}$ & $\begin{array}{r}9.5 \\
11.0 \\
10.5 \\
11.0 \\
12.0 \\
12.0\end{array}$ \\
\hline DNTH & 19.5 & 11.0 & 14.0 & 5.5 & 11.0 & 3.5 & 10.5 & 1.0 & 9.0 & 3.5 & 13.0 & 6.5 \\
\hline
\end{tabular}

\begin{tabular}{|c|c|c|c|c|c|c|c|c|c|c|c|c|}
\hline \multirow[b]{2}{*}{ DAY } & \multicolumn{2}{|c|}{ APRIL } & \multicolumn{2}{|c|}{ MAY } & \multicolumn{2}{|c|}{ JUNE } & \multicolumn{2}{|c|}{ JUtY } & \multicolumn{2}{|c|}{ AUGUST } & \multicolumn{2}{|c|}{ SEPTEMBER } \\
\hline & $\operatorname{MAx}$ & $M I N$ & MAX & MIN & $\operatorname{Max}$ & $\operatorname{MIN}$ & MAX & M $1 N$ & MAX & MIN & $\operatorname{MAX}$ & MIN \\
\hline $\begin{array}{l}1 \\
2 \\
3 \\
4 \\
5\end{array}$ & $\begin{array}{l}13.0 \\
13.0 \\
13.0 \\
13.0 \\
13.0\end{array}$ & $\begin{array}{l}12.0 \\
13.0 \\
13.0 \\
12.0 \\
13.0\end{array}$ & $\begin{array}{r}19.5 \\
19.5 \\
=- \\
=-\end{array}$ & $\begin{array}{r}19.0 \\
18.5 \\
-0 . \\
-0\end{array}$ & $\begin{array}{l}19.0 \\
19.5 \\
19.5 \\
19.5 \\
19.0\end{array}$ & $\begin{array}{l}19.0 \\
19.0 \\
19.5 \\
19.0 \\
18.5\end{array}$ & $\begin{array}{l}23.5 \\
24.5 \\
25.5 \\
25.5 \\
25.5\end{array}$ & $\begin{array}{l}22.0 \\
23.5 \\
24.5 \\
25.0 \\
24.5\end{array}$ & $\begin{array}{l}25.5 \\
25.5 \\
25.5 \\
25.5 \\
26.0\end{array}$ & $\begin{array}{l}24.5 \\
25.0 \\
25.0 \\
25.0 \\
25.0\end{array}$ & $\begin{array}{l}25.0 \\
25.0 \\
25.0 \\
25.0 \\
24.5\end{array}$ & $\begin{array}{l}24.5 \\
24.5 \\
24.5 \\
24.5 \\
24.5\end{array}$ \\
\hline $\begin{array}{r}6 \\
7 \\
8 \\
9 \\
10\end{array}$ & $\begin{array}{l}13.0 \\
13.5 \\
13.5 \\
13.5 \\
14.0\end{array}$ & $\begin{array}{l}13.0 \\
13.0 \\
13.0 \\
13.0 \\
13.5\end{array}$ & $=$ & $\bar{m}$ & $\begin{array}{l}18.5 \\
18.0 \\
19.0 \\
20.0 \\
20.0\end{array}$ & $\begin{array}{l}18.0 \\
18.0 \\
18.0 \\
18.5 \\
19.5\end{array}$ & $\begin{array}{l}24.5 \\
24.0 \\
23.5 \\
23.5 \\
23.5\end{array}$ & $\begin{array}{l}23.5 \\
23.0 \\
23.0 \\
23.0 \\
23.0\end{array}$ & $\begin{array}{c}26.0 \\
26.0 \\
26.0 \\
25.5 \\
-.-\end{array}$ & $\begin{array}{r}25.5 \\
25.5 \\
25.5 \\
25.0 \\
-.-\end{array}$ & $\begin{array}{l}24.5 \\
24.0 \\
23.5 \\
23.5 \\
23.5\end{array}$ & $\begin{array}{l}24.0 \\
23.5 \\
23.0 \\
23.0 \\
23.0\end{array}$ \\
\hline $\begin{array}{l}11 \\
12 \\
13 \\
14 \\
15\end{array}$ & $\begin{array}{l}14.0 \\
14.0 \\
14.0 \\
14.5 \\
14.5\end{array}$ & $\begin{array}{l}13.5 \\
14.0 \\
14.0 \\
14.0 \\
14.5\end{array}$ & $\bar{m}$ & 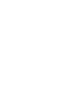 & $\begin{array}{l}20.0 \\
20.5 \\
20.5 \\
20.0 \\
20.5\end{array}$ & $\begin{array}{l}19.5 \\
20.0 \\
20.0 \\
19.5 \\
19.5\end{array}$ & $\begin{array}{l}23.5 \\
24.0 \\
24.5 \\
24.5 \\
25.0\end{array}$ & $\begin{array}{l}23.0 \\
23.5 \\
23.5 \\
24.0 \\
24.5\end{array}$ & $\begin{array}{l}\cdots- \\
\cdots- \\
--\end{array}$ & $\begin{array}{l}-- \\
-- \\
--\end{array}$ & $\begin{array}{l}24.0 \\
24.0 \\
23.5 \\
23.5 \\
23.5\end{array}$ & $\begin{array}{l}23.5 \\
23.5 \\
23.0 \\
23.0 \\
23.0\end{array}$ \\
\hline $\begin{array}{l}16 \\
17 \\
18 \\
19 \\
20\end{array}$ & $\begin{array}{l}14.5 \\
14.5 \\
15.0 \\
16.0 \\
17.0\end{array}$ & $\begin{array}{l}14.5 \\
14.5 \\
14.5 \\
15.0 \\
16.0\end{array}$ & $\vec{m}$ & 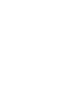 & $\begin{array}{l}21.0 \\
21.5 \\
23.5 \\
23.5 \\
23.5\end{array}$ & $\begin{array}{l}20.5 \\
20.5 \\
21.5 \\
22.0 \\
23.0\end{array}$ & $\begin{array}{l}25.5 \\
25.0 \\
25.0 \\
24.5 \\
24.5\end{array}$ & $\begin{array}{l}24.5 \\
24.0 \\
24.0 \\
24.0 \\
24.0\end{array}$ & $\overline{-\cdots}$ & $\begin{array}{l}=- \\
\overline{-} \\
\overline{-}\end{array}$ & $\begin{array}{l}23.5 \\
23.5 \\
23.5 \\
24.0 \\
24.5\end{array}$ & $\begin{array}{l}23.0 \\
23.5 \\
23.0 \\
23.5 \\
24.0\end{array}$ \\
\hline $\begin{array}{l}21 \\
22 \\
23 \\
24 \\
25\end{array}$ & $\begin{array}{l}18.0 \\
18.0 \\
17.0 \\
18.0 \\
19.0\end{array}$ & $\begin{array}{l}17.0 \\
16.5 \\
16.5 \\
17.0 \\
18.0\end{array}$ & 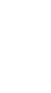 & 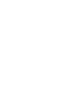 & $\begin{array}{l}23.5 \\
23.5 \\
23.0 \\
23.5 \\
23.5\end{array}$ & $\begin{array}{l}23.0 \\
23.0 \\
22.0 \\
22.0 \\
22.0\end{array}$ & -- & $\begin{array}{l}--- \\
=- \\
=-\end{array}$ & 24.0 & $\begin{array}{r}--0 \\
24.0 \\
23.0\end{array}$ & $\begin{array}{l}24.5 \\
24.5 \\
24.0 \\
23.5 \\
23.5\end{array}$ & $\begin{array}{l}24.5 \\
24.0 \\
23.0 \\
23.5 \\
23.5\end{array}$ \\
\hline $\begin{array}{l}26 \\
27 \\
28 \\
29 \\
30 \\
31\end{array}$ & $\begin{array}{c}18.0 \\
16.0 \\
17.0 \\
18.5 \\
19.0 \\
\ldots-0\end{array}$ & $\begin{array}{c}16.0 \\
16.0 \\
16.0 \\
17.0 \\
18.5 \\
-.0\end{array}$ & $\begin{array}{l}19.5 \\
19.5 \\
19.5 \\
19.5 \\
19.5 \\
19.5\end{array}$ & $\begin{array}{l}19.5 \\
19.5 \\
19.5 \\
19.5 \\
19.0 \\
19.0\end{array}$ & $\begin{array}{l}23.0 \\
23.0 \\
23.0 \\
23.0 \\
22.0 \\
-\end{array}$ & $\begin{array}{l}22.0 \\
22.0 \\
22.0 \\
21.0 \\
21.0 \\
-\end{array}$ & $\begin{array}{r}--. \\
24.5 \\
24.5 \\
24.5 \\
25.0 \\
25.5\end{array}$ & $\begin{array}{r}23.5 \\
24.0 \\
24.0 \\
24.0 \\
75.0\end{array}$ & $\begin{array}{l}24.0 \\
24.0 \\
24.0 \\
24.0 \\
24.5 \\
25.0\end{array}$ & $\begin{array}{l}23.5 \\
23.5 \\
23.5 \\
24.0 \\
24.0 \\
24.5\end{array}$ & $\begin{array}{r}23.5 \\
23.5 \\
21.5 \\
20.5 \\
19.5 \\
-. .\end{array}$ & $\begin{array}{r}23.0 \\
21.0 \\
20.5 \\
19.5 \\
19.5 \\
\end{array}$ \\
\hline DNTH & 19.0 & 12.0 & -- & -- & 23.5 & 18.0 & 25.5 & 22.0 & -- & -- & 25.0 & 18.5 \\
\hline
\end{tabular}


02388500 OOSTANaUla RiVER NEAR ROME, GA.

LOCATION.--Lat $34^{\circ} 18^{\circ} 02^{\prime \prime}$, long $85^{\circ} 08^{\circ} 30^{\prime \prime}$, Floyd County, at gaging station on left bank 1.2 miles upstream from Dry Creek, 4,5 miles north of Rome, 4.5 miles upstream from confluence with Etowah River, and 6.5 miles downstream from Armuchee Creek.

DRAINAGE AREA. $--2,120 \mathrm{sq} \mathrm{mi}$, approximately.

PERIOD OF RECORD..--Chemical analyses: March 1968 to September 1970.

RFMARKS, --Laboratory chemical analyses by Georgia water quality Control Board. Field determination of discharge, water temperature, $\mathrm{pH}$, and dissolved oxygen by U.S. Geological Survey.

CHEMICAL ANALYSES, WATER YEAR DCTOBER 1969 TÓ SEPTEMBER 1970

\begin{tabular}{|c|c|c|c|c|c|}
\hline$\triangle A T E$ & TIME & $\begin{array}{l}\text { UIS- } \\
\text { CHALISE } \\
\text { (CFSI }\end{array}$ & $\begin{array}{c}\mathrm{PH} \\
\text { (UNITS) }\end{array}$ & $\begin{array}{l}\text { TEMH- } \\
\text { FNATUFE } \\
\text { (DET CI }\end{array}$ & $\begin{array}{l}\text { DIS- } \\
\text { SOLVED } \\
\text { OXYGEN } \\
\text { (MG/L) }\end{array}$ \\
\hline Uet. & $172^{n}$ & 850 & 7.8 & 21.0 & 5.1 \\
\hline 1... & 1045 & 796 & 7.9 & 7.5 & 8.6 \\
\hline $\begin{array}{c}13 . . \\
F+\cdots\end{array}$ & $175 \pi$ & 540 & 7.3 & 2.0 & -- \\
\hline $15 \ldots$ & 1135 & 2nso & -- & 8.0 & 10.4 \\
\hline $\sin _{1 \rightarrow Y} \cdot$. & 13.40 & 3550 & 0.8 & 13.0 & B. 3 \\
\hline JUNt... & 1730 & 2100 & 0.5 & 20.5 & 5.5 \\
\hline $\begin{array}{c}23 \\
a, \cdots\end{array}$ & 1 sun & 1720 & 6.6 & 25.0 & 4.7 \\
\hline 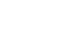 & $1>44$ & 94 & 7.5 & 27.5 & 5.0 \\
\hline $14 \ldots$ & 1445 & sil 1 & 7.3 & $2 h .5$ & 4.6 \\
\hline
\end{tabular}

\begin{tabular}{|c|c|c|c|c|c|c|c|c|c|c|}
\hline VATE & 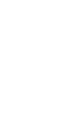 & $\begin{array}{l}\text { TOTAL } \\
\text { IHI) } \\
(F E) \\
(U G / L)\end{array}$ & $\begin{array}{l}\text { TOTAL } \\
\text { WAN- } \\
\text { GAINE SE } \\
\text { (MN) } \\
\text { (UG/L) }\end{array}$ & $\begin{array}{l}\text { UIS- } \\
\text { SOLVEO } \\
\text { CAL- } \\
\text { CIUM } \\
\text { (CA) } \\
\text { (MG/L) }\end{array}$ & $\begin{array}{l}\text { UIS- } \\
\text { SOLVED } \\
\text { MAG- } \\
\text { NF- } \\
\text { SIUM } \\
\text { (MG) } \\
\text { (MG/L) }\end{array}$ & $\begin{array}{c}\text { SODIUM } \\
\text { (NA) } \\
(M G / L)\end{array}$ & $\begin{array}{l}\text { PO- } \\
\text { TAS- } \\
\text { SIUM } \\
\text { (K) } \\
\text { (MG/L) }\end{array}$ & $\begin{array}{l}\text { ALKA- } \\
\text { LINITY } \\
\text { AS } \\
\text { CACO3 } \\
\text { (MG } / \text { L) }\end{array}$ & $\begin{array}{l}\text { SULFATE } \\
\text { (SO4) } \\
\text { (MG/L) }\end{array}$ & $\begin{array}{l}\text { CHLO- } \\
\text { RIDE } \\
\text { (CL) } \\
(M G / L)\end{array}$ \\
\hline $\begin{array}{l}\text { मCT. } \\
13 . . . \\
\text { DEC. }\end{array}$ & $\theta .0$ & bno & $<s 0$ & 16 & 3.8 & 12 & 1.9 & 51 & 8.0 & 16 \\
\hline JAN. & H.L & $3>0$ & $<50$ & 10 & 3.2 & 12 & 1.3 & 51 & 6.0 & 14 \\
\hline $\begin{array}{l}13 . . \\
\text { FEH. }\end{array}$ & $M . H$ & טלי & $<50$ & 14 & 3.1 & 4.1 & 2.0 & 48 & 4.0 & 6.7 \\
\hline $\begin{array}{l}12 \ldots \\
M A K\end{array}$ & 7.5 & 350 & <su & 15 & 3.1 & 4.2 & 9 & 48 & 5.0 & 5.3 \\
\hline $\begin{array}{l}30 \ldots \\
\text { raY }\end{array}$ & 5.5 & obo & $<50$ & 14 & 3.0 & 2.4 & 1.1 & 45 & 6.0 & 2.9 \\
\hline $\operatorname{JUNF}_{11}$ & 4.5 & 430 & $<50$ & 14 & 3.4 & 4.0 & 1.1 & 45 & 6.0 & 4.3 \\
\hline ats $33 . \cdots$ & 7.11 & 500 & $<50$ & 14 & 3.4 & 7.0 & 1.5 & 46 & 8.0 & 8.1 \\
\hline 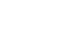 & 4.11 & 450 & $<50$ & 15 & 3.2 & 7.8 & 1.1 & 44 & 8,0 & 8.4 \\
\hline $14 \ldots$ & A. & 470 & $<50$ & 15 & 3.9 & 11 & 2.2 & 51 & 9.0 & 14 \\
\hline
\end{tabular}

\begin{tabular}{|c|c|c|c|c|c|c|c|c|c|c|}
\hline GATE & 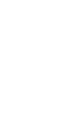 & $\begin{array}{l}\text { PHOS- } \\
\text { PHATE } \\
(P O 4) \\
(M C / L)\end{array}$ & $\begin{array}{l}\text { TOTAL } \\
\text { FILT- } \\
\text { RABLE } \\
\text { RESIUUE } \\
\text { (MG/L) }\end{array}$ & $\begin{array}{l}\text { TOTAL } \\
\text { NON- } \\
\text { FILT- } \\
\text { RABLE } \\
\text { WF SIUUE } \\
\text { (MG/L) }\end{array}$ & $\begin{array}{l}\text { HARU- } \\
\text { NESS } \\
\text { (CA,MG) } \\
\text { (MG/L) }\end{array}$ & $\begin{array}{l}\text { SPECI - } \\
\text { FIC } \\
\text { COND- } \\
\text { UCTANCE } \\
\text { (MICHO- } \\
\text { MHOS) }\end{array}$ & $\begin{array}{l}\text { COLOR } \\
\text { (PLAT- } \\
\text { INUM- } \\
\text { COBAL.T } \\
\text { UNITS) }\end{array}$ & $\begin{array}{l}\text { TUR- } \\
\text { RIO- } \\
\text { ITY } \\
\text { (JTU) }\end{array}$ & $\begin{array}{l}\text { OIO- } \\
\text { CHEM- } \\
\text { ICAL } \\
\text { OXYGEN } \\
\text { DEMAND } \\
\text { IMG/L }\end{array}$ & $\begin{array}{l}\text { FECAL } \\
\text { COLI- } \\
\text { FORM } \\
\text { (CQL. } \\
\text { PER } \\
\text { 100 ML) } \\
\text { (MPN) }\end{array}$ \\
\hline OCT. & & & & & & & & & & \\
\hline$\underset{\text { DeC. }}{13}$ & . 1 & .40 & 123 & $\cdots$ & 53 & 1 но & 15 & $2 ?$ & 1.5 & 2300 \\
\hline JAN... & . 11 & 1.6 & 90 & 1 & 48 & 155 & 30 & 14 & 2.0 & 23000 \\
\hline $\begin{array}{l}13 \ldots \\
+1+4 .\end{array}$ & $\cdot c$ & . 39 & In & 13 & 49 & 134 & 20 & -- & 3.0 & 4300 \\
\hline $\begin{array}{l}15 . . . \\
\text { Makn. }\end{array}$ & .1 & .50 & n. 3 & 5 & 44 & 130 & 15 & 10 & 1.2 & 93000 \\
\hline${ }_{M A Y}^{46} \cdots$ & .3 & .30 & 14 & so & 45 & 105 & 30 & 25 & .5 & 9300 \\
\hline JUNA & -- & .47 & 113 & 32 & 44 & 114 & 25 & 15 & -- & $\cdots$ \\
\hline$\underset{\Delta 11 \in}{23} \ldots$ & .3 & 1.2 & 54 & 20 & 61 & 132 & 30 & 15 & 1,1 & 2300 \\
\hline 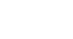 & .3 & 1.3 & तe & 31 & 48 & 138 & 15 & 18 & .8 & 2400000 \\
\hline $14 \ldots$ & .2 & 1.6 & os & b4 & 48 & 179 & 40 & 15 & 1.4 & 430 \\
\hline
\end{tabular}


LOCATION.--Lat $34^{\circ} 14^{\prime} 23^{\prime \prime}$, long $84^{\circ} 29^{\prime} 47^{\prime \prime}$, Cherokee County, at gaging station on left bank 100 ft downstream from bridge on State Highway 5 spur and 140 at Canton, 0.8 mile upstream from Canton Creek, and 1.8 miles downstream
from Hickory Log Creek.

DRAINAGE AREA. $--605 \mathrm{sq} \mathrm{mi}$.

PERIOD OF RECORD.--Chemical analyses: March 1968 to September 1970.

REMARKS. - - Laboratory chemical analyses by Georgla water Quality Control Board. Field determination of discharge, water temperature, $\mathrm{pH}$, and dissolved oxygen by U.S. Geological Survey.

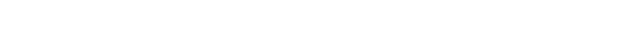

\begin{tabular}{|c|c|c|c|c|c|}
\hline$\lrcorner \Delta T F$ & f linf & $\begin{array}{l}\text { lIIS- } \\
\text { Cra-gt } \\
\text { (CF S) }\end{array}$ & $\begin{array}{c}\text { Fh } \\
\text { (1)IITS) }\end{array}$ & $\begin{array}{l}\text { TEMP- } \\
\text { FRATIJHF } \\
\text { (UtG C) }\end{array}$ & $\begin{array}{l}\text { DIS- } \\
\text { SOLVE') } \\
\text { OXYGEN } \\
\text { (MG/L) }\end{array}$ \\
\hline $\begin{array}{l}\text { viv. } \\
11 \ldots . . \\
\text { itce. }\end{array}$ & 160013 & $64 \mathrm{~L}$ & h.th & 9.9 & 10. \\
\hline$<2 \ldots$ & $\ln 15$ & 435 & 0.4 & 4.11 & 13.0 \\
\hline "1i. & $111 \mathrm{~h}$ & 1200 & 6.7 & 5.0 & 12.0 \\
\hline $\begin{array}{l}17 \ldots \\
\text { and. }\end{array}$ & $11{ }^{\prime \prime}$ & 710 & 0.2 & 4.91 & 9.6 \\
\hline$\underset{\text { juilut }}{e+\ldots}$ & 12014 & $1 b>0$ & 0.2 & 19.0 & 8.9 \\
\hline${ }_{J \cdot L_{r}} \cdots$ & lnon? & 1240 & 6.5 & 20.0 & 6.3 \\
\hline$c_{111} \ldots$ & & 420 & 7.4 & 21.0 & 7.8 \\
\hline $11 \ldots$ & lesn & 434 & 7.4 & 23.0 & 6.6 \\
\hline
\end{tabular}

\begin{tabular}{|c|c|c|c|c|c|c|c|c|c|c|}
\hline (IAT) & $\begin{array}{l}\rightarrow I L I C \\
1>J 1, p 1 \\
11,0 / 1-1\end{array}$ & 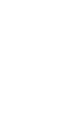 & $\begin{array}{l}\text { TUTAL. } \\
\text { TALI- } \\
\text { UANF SE } \\
\text { (NII) } \\
\text { (UU/L) }\end{array}$ & $\begin{array}{c}\text { (JIS- } \\
\text { SOLVE) } \\
\text { CAL- } \\
\text { CIUjM } \\
\text { (CA) } \\
\text { (AOG/L) }\end{array}$ & $\begin{array}{l}\text { UIS- } \\
\text { SOLVEU } \\
\text { MAG- } \\
\text { NE- } \\
\text { SIUMA } \\
\text { (MG) } \\
\text { (MGIL) }\end{array}$ & $\begin{array}{l}\text { SODIUM } \\
\text { (NA) } \\
\text { (MG/L) }\end{array}$ & $\begin{array}{l}P O- \\
\text { TAS- } \\
\text { SIUM } \\
\text { (K) } \\
\text { (MG/L) }\end{array}$ & $\begin{array}{l}\text { ALKA- } \\
\text { LINITY } \\
\text { AS } \\
\text { CACO3 } \\
\text { (MG/L) }\end{array}$ & $\begin{array}{l}\text { SULFATE } \\
\text { (SO4) } \\
\text { (MG/L) }\end{array}$ & $\begin{array}{l}\text { CHLO- } \\
\text { RIDE } \\
\text { ICL } \\
\text { (MG/L) }\end{array}$ \\
\hline $\begin{array}{l}\text { IUV. } \\
\text { J1... } \\
\text { IEC. }\end{array}$ & 7.11 & ino & $<\infty$ & 3.2 & .3 & 1.5 & .9 & 15 & $<2.0$ & 1.3 \\
\hline 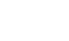 & 4.4 & 370 & <su & 3.5 & .9 & 1.5 & .8 & 13 & 2.0 & 1.6 \\
\hline वट्土 & 7.4 & 450 & $<b$ & 1.3 & .9 & 1.4 & .8 & 12 & 2.0 & 2.1 \\
\hline $\begin{array}{l}17 \ldots \\
\Delta+K\end{array}$ & 10 & חה & $<s u$ & 3.5 & .8 & 1.6 & .6 & 14 & $<2.0$ & 1.2 \\
\hline JUNA... & $\pi .4$ & $\ln 10$ & $<50$ & 4.5 & .8 & 1.2 & 1.0 & 17 & 3.0 & 1.0 \\
\hline $\operatorname{sic}^{150}$ &.+- & $4(1)$ & $<54$ & 0.2 & $\cdot n$ & 1.4 & 1.0 & 20 & 2.0 & 1.5 \\
\hline 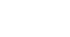 & 10 & $2>1 i$ & $\Leftrightarrow 0$ & 3.7 & .8 & 1.7 & 1.0 & 15 & $<2 . n$ & 3.2 \\
\hline $31 \ldots$ & M. $\mathrm{T}$ & $3+11$ & $<b u$ & 3.5 & .9 & 1.8 & 1.0 & 17 & $<2.0$ & 1.0 \\
\hline
\end{tabular}

\begin{tabular}{|c|c|c|c|c|c|c|c|c|c|c|}
\hline WATE & $\begin{array}{c}\text { IIT }\{A T H \\
(\cup) \\
(, A G / L)\end{array}$ & $\begin{array}{l}\text { HHUS } \\
\text { HHATE } \\
(P(1) 4) \\
(41, / L)\end{array}$ & $\begin{array}{l}\text { TUTAL } \\
\text { FILT- } \\
\text { RAMLE } \\
\text { RESIUAT. } \\
(1910 / L)\end{array}$ & $\begin{array}{l}\text { TOTAL } \\
\text { NOIY- } \\
F 1 L T- \\
\text { KAHLE } \\
\text { HESIONJE } \\
\text { (ML/L) }\end{array}$ & $\begin{array}{l}\text { HARU- } \\
\text { NESS } \\
(C A, M G) \\
(M G / L)\end{array}$ & $\begin{array}{l}\text { SOECI- } \\
\text { FIC } \\
\text { CONI- } \\
\text { UCTANCE- } \\
\text { (MICRO- } \\
\text { MHOSI) }\end{array}$ & $\begin{array}{l}\text { COLOR } \\
\text { (PLAT- } \\
\text { INUM- } \\
\text { COBALT } \\
\text { UNITS) }\end{array}$ & $\begin{array}{l}\text { TUR- } \\
\text { BID- } \\
\text { ITY } \\
\text { (JTU) }\end{array}$ & $\begin{array}{l}\text { BIO- } \\
\text { CHEM- } \\
\text { ICAL } \\
\text { OXYGEN } \\
\text { DEMAND } \\
\text { (MG L ) }\end{array}$ & $\begin{array}{l}\text { FECAL } \\
\text { CDLI- } \\
\text { FORM } \\
\text { (CDL. } \\
\text { PER } \\
100 \text { ML) } \\
\text { (MPN) }\end{array}$ \\
\hline $\begin{array}{l}\text { ruv. } \\
11 \ldots . . . \\
\text { ate. }\end{array}$ & .1 & .15 & 37 & 2 & 11 & 34 & 25 & 6.0 & .4 & 36 \\
\hline Le... & .11 & (1) & 31 & b & 11 & 34 & 15 & 9.0 & 1.4 & 2300 \\
\hline WAK... & .1 & .10 & $4 \pi$ & 10 & 11 & 32 & 10 & 12 & 1.2 & 2300 \\
\hline 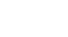 & $\cdot 1$ & - & 47 & $A$ & 11 & 37 & 1n & 4.0 & .7 & 36 \\
\hline $\sin _{\sin } \cdots$ & $\cdot r$ & .40 & 44 & 52 & ל & 40 & 30 & 28 & 1.1 & 2300 \\
\hline 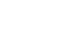 & .2 & .14 & $1 y$ & 45 & 18 & 42 & 25 & 28 & 1.9 & 3900 \\
\hline 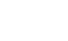 & .1 & .19d & 51 & 16 & 12 & 34 & 10 & 6.0 & .8 & 21000 \\
\hline $31 \ldots$ & .1 & .04 & ל3 & 22 & 14 & 35 & 20 & 8. 0 & .6 & 430 \\
\hline
\end{tabular}


02396000 ETOWAH RIVER AT ROME, GA.

LOCATION.--Lat $34^{\circ} 15^{\prime} 26^{\prime \prime}$, long $85^{\circ} 09^{\prime} 30^{\prime \prime}$, Floyd County, at gaging station downstream side of center pler of Southern Ratlway bridge in Rome, 2 miles upstream from confiuence with Oostanaula River.

DRAINAGE AREA, - - 1,810 sq mi, approximately.

PERIOD OF RECORD.--Chemical analyses: March 1968 to September 1970.

REMARKS.--Laboratory chemical analyses by Georgia Water Quality Control Board. Field determination of discharge, water temperature, $\mathrm{pH}$, and dissolved oxygen by U.S. Geological Survey.

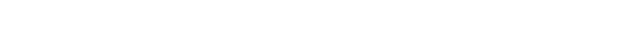

\begin{tabular}{|c|c|c|c|c|c|}
\hline$\triangle \triangle T E$ & $1 \mathrm{IIt}$ & $\begin{array}{l}\text { JES- } \\
\text { CHAPlut } \\
\text { (CFS) }\end{array}$ & $\begin{array}{c}\text { HH } \\
(\text { IINITS) }\end{array}$ & $\begin{array}{l}\text { TEMP- } \\
\text { FHATUPF } \\
\text { (GH, C C }\end{array}$ & $\begin{array}{l}\text { OIS- } \\
\text { SOLVEI) } \\
\text { OXYGFY) } \\
\text { (MG/L) }\end{array}$ \\
\hline $\begin{array}{l}x_{1} \\
13 . .\end{array}$ & $120 n$ & 534 & 7.5 & $21 . n$ & R. 0 \\
\hline נin. & $110 \mathrm{r}$ & $n>n$ & 7.17 & k.n & 11.0 \\
\hline $13 \ldots$ & 15bt & 1440 & 7.7 & 5.0 & 13.0 \\
\hline 120. & म小 & 405 & 6.6 & $7.1 t$ & 11,7 \\
\hline sin $\cdots$ & 113.4 & $14 h(1$ & h. H & 14.0 & 9.9 \\
\hline 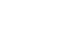 & 11111 & thit & 7.1 & $1 \mathrm{H} .0$ & 1.1 \\
\hline$+3 \ldots$ & l man & 2130 & $\theta . \rightarrow$ & 25.7 & 6.4 \\
\hline $\begin{array}{l}194 \ldots \\
s+w 7\end{array}$ & $1+4 b$ & 35011 & 7.3 & 21.0 & 7.7 \\
\hline $14 \ldots$ & 1036 & has & 1.4 & 23.5 & 7.2 \\
\hline
\end{tabular}

\begin{tabular}{|c|c|c|c|c|c|c|c|c|c|c|}
\hline IATE & $\begin{array}{l}\text { SILIS } \\
\text { (SIUS) } \\
\text { (No/L) }\end{array}$ & $\begin{array}{l}\text { TOTAL } \\
\text { INOA } \\
\text { (FH) } \\
\text { (UDAL) }\end{array}$ & 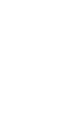 & $\begin{array}{l}\text { UIS- } \\
\text { SOLVEO) } \\
\text { CAL- } \\
\text { CIIUM } \\
\text { (CA) } \\
\text { (MG/L) }\end{array}$ & $\begin{array}{l}\text { DIS- } \\
\text { SOLVEU } \\
\text { MAG- } \\
\text { NEE- } \\
\text { SIUM } \\
\text { (MG) } \\
(M G / L)\end{array}$ & $\begin{array}{l}\text { SOOIUM } \\
\text { (NA) } \\
\text { (M(J/L) }\end{array}$ & $\begin{array}{l}P O= \\
\text { TAS- } \\
\text { SIUM } \\
(K) \\
(M G / L)\end{array}$ & $\begin{array}{l}\text { ALKA- } \\
\text { LINITY } \\
\text { AS } \\
\text { CACO } 3 \\
\text { (MG/L) }\end{array}$ & $\begin{array}{c}\text { SULFATE } \\
\text { (SO4) } \\
\text { (MG/L) }\end{array}$ & $\begin{array}{l}\text { CHLO- } \\
\text { RIOE } \\
\text { (CL) } \\
(M G / L\end{array}$ \\
\hline 19... & $n .$. & $10 n$ & $<b 0$ & 16 & 4.4 & 2.1 & 1.7 & 49 & 3.0 & 1.9 \\
\hline JA1... & M. & $\sin$ & $\langle b|$ & 10 & 3.6 & 2.0 & 1.0 & 47 & 3.0 & 1.8 \\
\hline $\begin{array}{c}110 . \\
r+40\end{array}$ & $1 ?$ & 4110 & $<0$ & 11 & 4.85 & 2.5 & 1.6 & 57 & 3.0 & 2.5 \\
\hline מל... & 4.11 & 40,1 & <bi & 12 & 4.3 & 1.4 & 1.1 & 50 & 4.0 & 1.6 \\
\hline $\begin{array}{l}30 . . \\
\text { NaY }\end{array}$ & 7.11 & Buis & $<y$ & $1 b$ & 5.0 & 1.9 & 1.4 & 61 & 6.0 & 2.8 \\
\hline$\underset{f(1) \mid t}{11} \ldots$ & $m .1$ & $4 m 11$ & 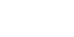 & 14 & $t .2$ & 2.0 & 1.2 & 62 & 4.0 & 1.6 \\
\hline $\begin{array}{l}23 . . . \\
\Delta 16 .\end{array}$ & y.' & 400 & $<50$ & its & 6.0 & 2.9 & 1.7 & 63 & 6.0 & 2.1 \\
\hline 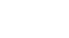 & 111 & 1000 & 511 & н.ટ & 2.2 & 2.2 & 1.4 & 31 & 6.0 & .8 \\
\hline $14 \ldots$ & n. & C10 & $<0$ & 11 & 4.1 & 1.4 & 1.2 & 49 & 4.0 & 2.8 \\
\hline
\end{tabular}

\begin{tabular}{|c|c|c|c|c|c|c|c|c|c|c|}
\hline $11 \mathrm{TE}$ & $\begin{array}{c}\text { IITSir } \\
61) \\
(a, L / L)\end{array}$ & $\begin{array}{l}\text { Hecis- } \\
\text { HASTE } \\
(10114) \\
(140 / L)\end{array}$ & $\begin{array}{l}\text { TUTAL } \\
\text { FILI- } \\
\text { RAOLE } \\
\text { RESIUUE } \\
\left(M T_{Y} / L\right)\end{array}$ & $\begin{array}{l}\text { TOTAL } \\
\text { INOIN- } \\
\text { PILT- } \\
\text { HABLE } \\
\text { MESIOUE } \\
\text { (MG/L) }\end{array}$ & $\begin{array}{l}\text { HARU- } \\
\text { NESS } \\
\text { \{CA.MG) } \\
\text { (MGAL) }\end{array}$ & $\begin{array}{l}\text { SPECI- } \\
\text { FIC } \\
\text { CONO- } \\
\text { UCTANCE } \\
\text { (MICRO- } \\
\text { MHOS) }\end{array}$ & $\begin{array}{l}\text { COLOR } \\
\text { IPLAT- } \\
\text { INUM- } \\
\text { COHALT } \\
\text { UNITS) }\end{array}$ & $\begin{array}{l}\text { TUR- } \\
\text { PIU- } \\
\text { ITY } \\
\text { (JTU) }\end{array}$ & $\begin{array}{l}\text { BIO- } \\
\text { CHEM- } \\
\text { ICAL } \\
\text { OXYGEN } \\
\text { DEMANN } \\
\text { (MG/L) }\end{array}$ & $\begin{array}{l}\text { FECAL } \\
\text { CDLI- } \\
\text { FORM } \\
\text { (CDL. } \\
\text { PER } \\
\text { (OOOML) } \\
\text { (MPN) }\end{array}$ \\
\hline $\mathrm{C} T$. & & & & & & & & & & \\
\hline $\begin{array}{ll}13 . . \\
n+c\end{array}$ & .1 & ל5 & $M 1$ & 4 & 46 & 112 & 5 & 4.0 & 1.5 & 150000 \\
\hline joil... & $\cdot 1$ & .11 & be & 7 & 42 & Yn & 20 & 10 & 1.1 & 4300 \\
\hline $13 \ldots$ & r. & .14 & 77 & 10 & 50 & 134 & 10 & -- & 1.4 & 4300 \\
\hline $15 \ldots$ & .2 & $.1 \mathrm{H}$ & sy & 1 & 44 & 212 & 15 & 20 & .9 & 4300 \\
\hline $3_{A Y} \cdots$ & .4 & .12 & כצ & 20 & 63 & 136 & -- & 19 & 1.1 & 9300 \\
\hline Juist & -- & .14 & 121 & 11 & 59 & $1>4$ & 25 & 12 & -- & \\
\hline abs... & .1 & . 16 & +1 & 29 & 48 & 136 & 30 & 19 & .5 & \\
\hline 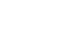 & .c & .17 & os & 64 & $3 n$ & 73 & 30 & 32 & .7 & \\
\hline $14 \ldots$ & .2 & .12 & 1 & $\angle 0$ & 44 & 102 & 15 & 6.0 & .4 & 9300 \\
\hline
\end{tabular}


02400500 COOSA RIVER AT GADSDEN, ALA.

LOCAIION..-Lat $34^{\circ} 00^{\prime} 37^{\prime \prime}$, long $85^{\circ} 59^{\prime} 52^{\prime \prime}$ (revised), in NEł sec.10, T.12 S., R.6 F., Etowah County, temperature recorder at gaging station near midstream pier of Etowah County Memorial Bridge on U.S. Highway 431 in Gadsden,

$450 \mathrm{ft}$ downstream from Louisville and Nashville Hailroad bridge, 1.5 miles upstream from Big Wilis Creek, and at

AINAGE AREA. $--5,800 \mathrm{sq} \mathrm{mi}$, approximately.

PERIOD OF RECORD.--Chemical analyses: October 1965 to September 1967, August 1969 to september 1970.

Water temperatures: October 1962 to September 1970 .

EXTREMES, $--1969-70$ :

Water temperatures: Maximum, $31.5 \mathrm{July} 11,12$; minimum, $2.0^{\circ} \mathrm{C}$ Jan. 12,13 .

Period of record:

Water temperatures: Maximum, $31.5^{\circ} \mathrm{C}$ July 11, 12, 1970; mintmum, 2. $0^{\circ} \mathrm{C} \mathrm{DeC.} \mathrm{27,} \mathrm{28,} \mathrm{1963,} \mathrm{Jan.} \mathrm{1-4,} \mathrm{1964,} \mathrm{Jan.} \mathrm{12,}$ 13,1970 .

CHEMICAL ANALYSES, WATER YEAR OCTOBER 1969 TO SEPTEMBER 1970

\begin{tabular}{|c|c|c|c|c|c|c|c|c|c|c|c|}
\hline OATE & TIME & $\begin{array}{l}\text { OIS- } \\
\text { CHARGE } \\
\text { (CFS) }\end{array}$ & $\begin{array}{l}\text { SILICA } \\
\text { (SIO2) } \\
\text { (MGLL) }\end{array}$ & $\begin{array}{l}\text { DIS- } \\
\text { SOLVED } \\
\text { IRON } \\
\text { (FE) } \\
\text { (UG/L) }\end{array}$ & $\begin{array}{l}\text { DIS- } \\
\text { SOLVED } \\
\text { MAN- } \\
\text { GANESE } \\
\text { (MN) } \\
\text { (UG/LI) }\end{array}$ & $\begin{array}{l}\text { CAL- } \\
\text { CIUM } \\
\text { (CA) } \\
\text { (MG/LI }\end{array}$ & $\begin{array}{l}\text { MAG- } \\
\text { NE- } \\
\text { SIUM } \\
\text { (MGI } \\
\text { (MG/L) }\end{array}$ & $\begin{array}{l}\text { SO0LUM } \\
\text { (NA) } \\
(M G / L)\end{array}$ & $\begin{array}{l}\text { PO- } \\
\text { TAS- } \\
\text { SIUM } \\
\text { (KI) } \\
\text { (NG/L) }\end{array}$ & $\begin{array}{l}\text { BICAR- } \\
\text { BONATE } \\
\text { (HCD } 3) \\
(\backsim G / L)\end{array}$ & $\begin{array}{l}\text { CAR- } \\
\text { BONATE } \\
\text { (CD3) } \\
\text { (MG/L) }\end{array}$ \\
\hline $\begin{array}{l}\text { NOV. } \\
04 . . \\
\text { JAN. }\end{array}$ & 1400 & 6870 & 3.2 & 20 & -- & 13 & 4.2 & 7.6 & 1.6 & 66 & 0 \\
\hline $\begin{array}{c}13 \ldots \\
\text { FEA. }\end{array}$ & 1430 & 5300 & 5.5 & 90 & $\cdots$ & 11 & 2.7 & 3.8 & 1.2 & 43 & 0 \\
\hline MAR:. & 1430 & 9200 & 7.2 & 70 & -- & 14 & 3.5 & 5.2 & 1.3 & 56 & 0 \\
\hline $\begin{array}{l}25 \ldots \\
\triangle P R .\end{array}$ & 1400 & 31700 & 4.3 & 40 & 20 & 8.4 & 2.3 & 3.0 & 1.2 & 34 & 0 \\
\hline $\begin{array}{l}28 \ldots . . \\
\text { JUNE }\end{array}$ & 1245 & 34100 & 4.8 & 40 & 20 & 12 & 3.1 & 4.4 & .7 & 54 & 0 \\
\hline JuLY.. & 1500 & 13000 & 5.0 & 10 & 7 & 13 & 3.5 & 3.7 & 1.4 & 56 & 0 \\
\hline $\begin{array}{l}15 . . \\
\text { AUG. }\end{array}$ & 1600 & 3960 & 5.2 & 20 & 25 & 14 & 3.9 & 4.7 & 1.0 & 62 & 0 \\
\hline$\underset{\text { SEPT. }}{20 . .}$ & 1330 & 4480 & 5.5 & 12 & 15 & 14 & 4.2 & 6.6 & 1.7 & 68 & 0 \\
\hline $18 \ldots$ & 0830 & 5780 & 4.7 & 60 & 11 & 14 & 4.2 & 8.4 & 2.0 & 70 & 0 \\
\hline DATE & $\begin{array}{l}\text { SULFATE } \\
\text { (SO4) } \\
\text { (MG/L) }\end{array}$ & $\begin{array}{l}\text { CHLO- } \\
\text { RIDE } \\
(\mathrm{CL}) \\
(\mathrm{MG} / \mathrm{L})\end{array}$ & $\begin{array}{l}\text { FLUD- } \\
\text { RIDE } \\
\text { (F) } \\
\text { (MG/L) }\end{array}$ & $\begin{array}{l}\text { NITRAIE } \\
\text { (NO3) } \\
\text { (MG/L) }\end{array}$ & $\begin{array}{l}\text { DIS- } \\
\text { SOLVED } \\
\text { SOLIOS } \\
\text { (RESI- } \\
\text { DUE AT } \\
\text { I } 80 \text { C) } \\
(M G / L)\end{array}$ & $\begin{array}{l}\text { DIS- } \\
\text { SOLVEO } \\
\text { SOLIDS } \\
\text { ISUM OF } \\
\text { CONSTI- } \\
\text { TUENIS) } \\
\text { (MGIL) }\end{array}$ & $\begin{array}{l}\text { DIS- } \\
\text { SOLVEO } \\
\text { SOLIDS } \\
\text { (TONS } \\
\text { PER } \\
\text { AC-FI) }\end{array}$ & $\begin{array}{l}\text { HARD- } \\
\text { NESS } \\
\text { (CA,MG) } \\
(M G / L)\end{array}$ & $\begin{array}{l}\text { NON- } \\
\text { CAR- } \\
\text { BDNATE } \\
\text { HARD- } \\
\text { NESS } \\
\text { IMG ILI }\end{array}$ & $\begin{array}{l}\text { SPECI- } \\
\text { FIC } \\
\text { CONO- } \\
\text { UCTANCE } \\
\text { (MICRD- } \\
\text { MHOS) }\end{array}$ & (UNITS) \\
\hline
\end{tabular}

NOV.

\begin{tabular}{|c|c|c|c|c|c|c|c|c|c|c|c|}
\hline $\begin{array}{l}\text { OA... } \\
\text { JAN. }\end{array}$ & 5.0 & 5.5 & .1 & .3 & 75 & 74 & .10 & 50 & 0 & 136 & 7.9 \\
\hline $\begin{array}{c}13 \ldots \\
F \in B .\end{array}$ & 7.2 & 2.9 & .1 & 1.4 & 60 & 57 & .08 & 39 & 4 & 91 & 7.2 \\
\hline MAR... & 8.2 & 3.6 & .0 & .8 & 65 & 72 & .09 & 49 & 3 & 116 & 7.2 \\
\hline $\begin{array}{l}25 \ldots \\
\triangle P R .\end{array}$ & 6.8 & 2.4 & .1 & 1.0 & 55 & 46 & .07 & 30 & 2 & 76 & 7.0 \\
\hline JUNE & 5.8 & 3.1 & .1 & .4 & 63 & 61 & .09 & 43 & 0 & 107 & 6.9 \\
\hline JuLY... & 5.8 & 2.9 & .1 & 1.0 & 60 & 64 & .08 & 47 & 1 & 112 & 7.3 \\
\hline $\begin{array}{l}15 \ldots . . \\
\text { AUG. }\end{array}$ & 6.6 & 3.8 & - 1 & $\cdot 1$ & 69 & 70 & .09 & 51 & 0 & 124 & 7.2 \\
\hline$\underset{\text { SEPT. }}{20}$ & 7.2 & 4.7 & $\cdot 1$ & .1 & 8.4 & 77 & .11 & 52 & 0 & 136 & 7.2 \\
\hline $18 \ldots$ & 8.4 & 5.4 & .2 & .2 & 94 & 82 & .13 & 52 & 0 & 140 & 7.3 \\
\hline
\end{tabular}

FIELD ANALYSES

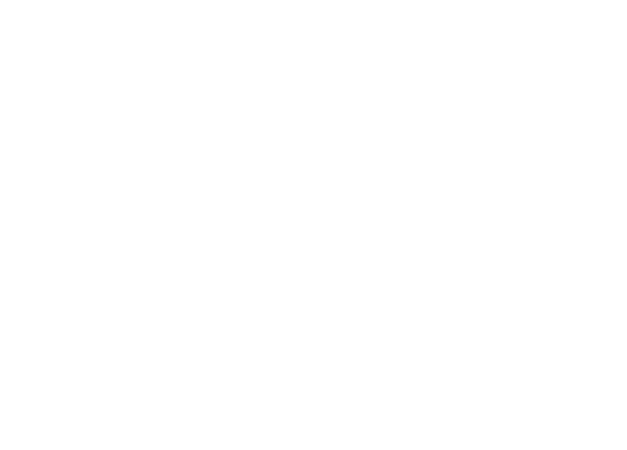


MOBILE RIVER BASIN

02400500 COOSA RIVER AT GADSDEN, ALA.--Continued

TEMPERATURE ( $\left.{ }^{\circ} \mathrm{C}\right)$ OF WATER, WATER YEAR OCTOBER 1969 TO SEPTEMBER 1970

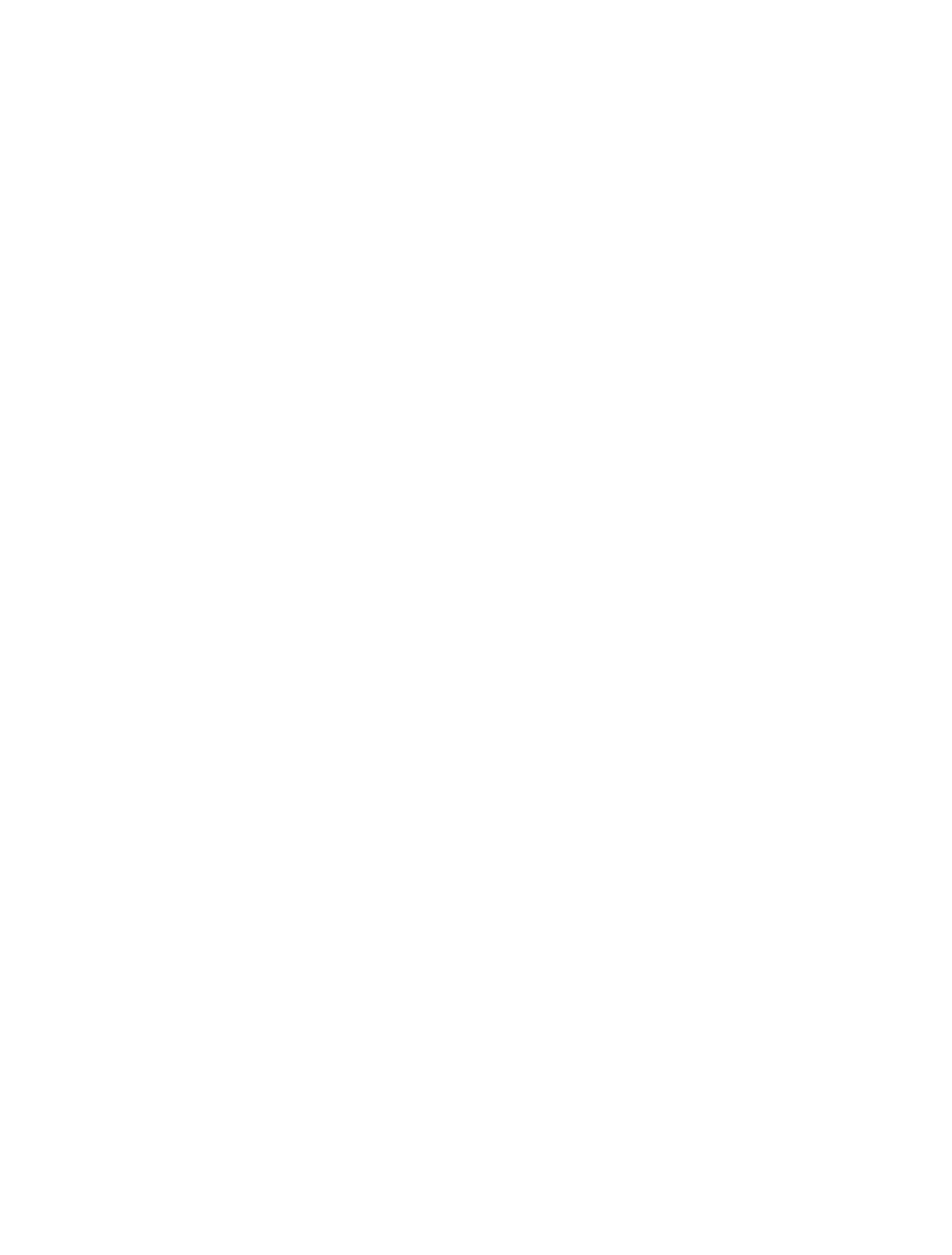


02407000 COOSA RIVER AT CHILDERSBURG, ALA.

LOCATION.--Lat $33^{\circ} 17^{\prime} 30^{\prime \prime}$, long $86^{\circ} 21^{\prime} 50^{\prime \prime}$ (revised), in NEt sec.18, T.20 S., R.3 E., Shelby County, at gaging station near right bank on downstream side of pier of Central of Georgia Railway bridge, $700 \mathrm{ft}$ upstream from bridge on State Highway $38,0.5$ mile downstream from Tallasseehatchee Creek, 1 mile northwest of childersburg, and at mile $\mathbf{8 6 . 3}$.

DRAINAGE AREA, $--8,390 \mathrm{sq} \mathrm{mi}$, approximately.

PERIOD OF RECORD,--Chemical analyses: November 1965 to September 1968, August 1969 to September 1970.

Water temperatures: October 1962 to September 1970.

EXTRENES. - - 1969-70:

Water temperatures: Maximum, $28.5^{\circ} \mathrm{C}$ on several days during July and August; minimum, $7.0^{\circ} \mathrm{C}$ Jan. $9-25,27$.

Period of record:

Water temperatures: Maximum, $36.0^{\circ} \mathrm{C}$ July 6, 1969; minimum, 3. $0^{\circ} \mathrm{C} \mathrm{Jan.} \mathrm{26-30,} 1963$.

RENARKS. - - Streamflow regulated by upstream reservoirs and hydroelectric plants,

CHEMICAL ANALYSES, HATER YEAR OCTOBER 1969 TO SEPTEMBER 1970

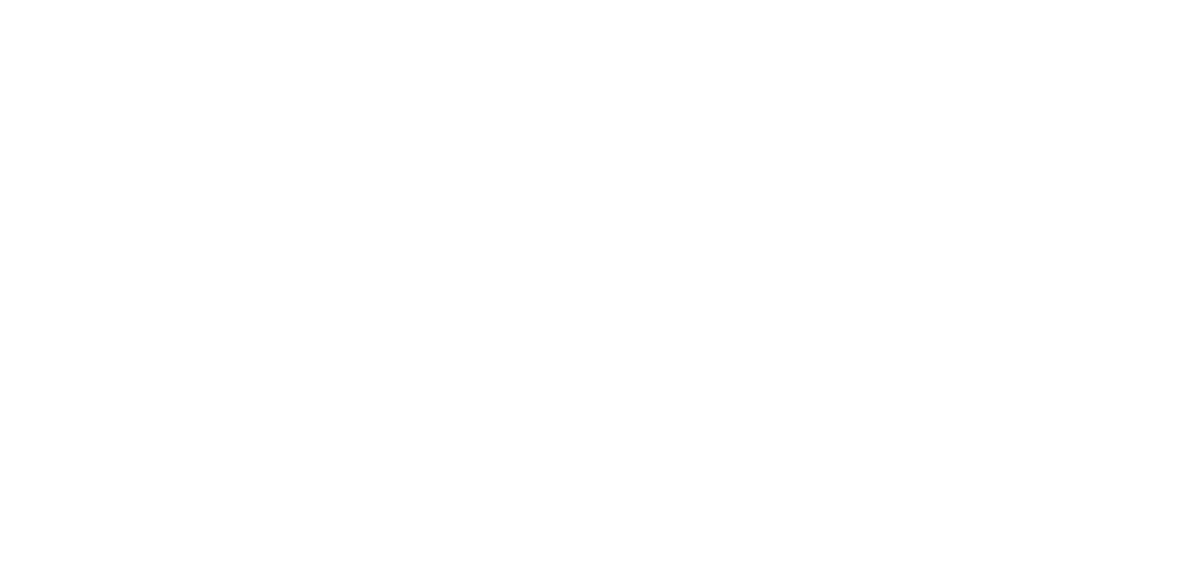

\begin{tabular}{|c|c|c|c|}
\hline $\begin{array}{l}\text { NOV. } \\
\text { O4.... }\end{array}$ & 12 & 8.5 & .1 \\
\hline JAN. & & . & \\
\hline $\begin{array}{l}13 \ldots \\
\text { FEB. }\end{array}$ & 10 & 5.6 & .1 \\
\hline MAR... & 12 & 5.2 & $\cdot 1$ \\
\hline $\begin{array}{l}25 \ldots \\
\text { APR... }\end{array}$ & 7.2 & 3.1 & .1 \\
\hline JUNE & 6.2 & 2.8 & $\cdot 1$ \\
\hline Juty & 7.0 & 4.5 & .1 \\
\hline $\begin{array}{l}14 \ldots . \\
\text { AUG. }\end{array}$ & 10 & 5.4 & .1 \\
\hline SEPY. & 9.6 & 6.3 & .1 \\
\hline $19 \ldots$ & 8.9 & 7.2 & .2 \\
\hline
\end{tabular}

\begin{tabular}{|c|c|c|c|c|c|c|}
\hline & & & ELD ANAL & SSES & & \\
\hline DAJE & TIME & $\begin{array}{l}\text { DIS- } \\
\text { CHARGE } \\
\text { (CFS) }\end{array}$ & $\begin{array}{l}\text { SPECI- } \\
\text { FIC } \\
\text { CONO- } \\
\text { UCTANCE } \\
\text { (MICRO- } \\
\text { MHDSI }\end{array}$ & $\begin{array}{c}\text { PH } \\
\text { IUNITSI }\end{array}$ & $\begin{array}{l}\text { DISS- } \\
\text { CLVED } \\
\text { OXYGEN } \\
\text { (MGIL) }\end{array}$ & $\begin{array}{l}\text { TEMP- } \\
\text { ERATURE } \\
\text { (DEG C) }\end{array}$ \\
\hline NDY, 1969 & & & & & & \\
\hline $\begin{array}{l}04 . . . \\
\text { JAN., } 1970\end{array}$ & 1040 & 12300 & 152 & 7.1 & 7.5 & 17.5 \\
\hline $\begin{array}{l}13 \ldots \\
\text { FEB. }\end{array}$ & 1035 & 9600 & 148 & 7.0 & 10.5 & 6.0 \\
\hline & 1020 & 33000 & 143 & 7.2 & 10.5 & 7.5 \\
\hline $\begin{array}{l}25 \ldots . . \\
\text { APR. }\end{array}$ & 0900 & 60400 & 90 & 7.1 & 10.5 & 12.0 \\
\hline JUNE & 0830 & 53800 & 93 & 7.2 & 7.8 & 19.0 \\
\hline JuLY... & 0930 & 11400 & 130 & 7.2 & 5.5 & 23.0 \\
\hline $\begin{array}{l}14 \ldots . \\
\text { AUG. }\end{array}$ & 1400 & 4140 & 154 & 7.3 & 4.3 & 28.0 \\
\hline $20 \ldots$ & 0940 & 1500 & 164 & 7.2 & 4.6 & 27.0 \\
\hline $\begin{array}{l}\text { SEP. } 1970 \\
19 \ldots\end{array}$ & 1100 & 11700 & 178 & 7.2 & 5.5 & 28.0 \\
\hline
\end{tabular}


MOBILE RIVER BASIN

02407000 COOSA RIVER AT CHILDERSBURG, ALA.--Continued

TEMPERATURE ( ${ }^{\circ} \mathrm{C}$ ) OF WATER, WATER YEAR OCTOBER 1969 TO SEPTEMBER 1970

\begin{tabular}{|c|c|c|c|c|c|c|c|c|c|c|c|c|}
\hline \multirow[t]{2}{*}{ DAY } & \multicolumn{2}{|c|}{$\mathrm{nC} \mathrm{T}$} & \multicolumn{2}{|c|}{ Nov } & \multicolumn{2}{|c|}{ DEC } & \multicolumn{2}{|c|}{ JAN } & \multicolumn{2}{|c|}{ FFR } & \multicolumn{2}{|c|}{ MAR } \\
\hline & MAX & MIN & $\operatorname{MAX}$ & $M 1 N$ & $\operatorname{MAX}$ & MIN & MAX & MIN & MAX & MIN & MAX & $M 1 N$ \\
\hline $\begin{array}{l}1 \\
2 \\
3 \\
4 \\
5\end{array}$ & $\begin{array}{l}23.0 \\
22.0 \\
22.0 \\
22.0 \\
23.0\end{array}$ & $\begin{array}{l}22.0 \\
21.5 \\
22.0 \\
22.0 \\
22.0\end{array}$ & $\begin{array}{l}19.0 \\
19.0 \\
19.5 \\
18.0 \\
17.0\end{array}$ & $\begin{array}{l}1 R .5 \\
18.5 \\
18.0 \\
17.0 \\
12.5\end{array}$ & $\begin{array}{l}13.0 \\
13.0 \\
13.0 \\
17.5 \\
1>.5\end{array}$ & $\begin{array}{l}13.0 \\
13.0 \\
12.5 \\
12.5 \\
12.0\end{array}$ & $\begin{array}{l}R .0 \\
R .0 \\
R .0 \\
R .0 \\
R .0\end{array}$ & $\begin{array}{l}R .0 \\
R .0 \\
R .0 \\
R .0 \\
R .0\end{array}$ & $\begin{array}{l}7.5 \\
R .0 \\
R .0 \\
R .0 \\
R .0\end{array}$ & $\begin{array}{l}7.5 \\
7.5 \\
8.0 \\
8.0 \\
8.0\end{array}$ & $\begin{array}{r}9.0 \\
10.0 \\
10.0 \\
10.0 \\
10.0\end{array}$ & $\begin{array}{r}9.0 \\
9.0 \\
10.0 \\
10.0 \\
10.0\end{array}$ \\
\hline $\begin{array}{r}6 \\
7 \\
8 \\
9 \\
10\end{array}$ & $\begin{array}{l}23.0 \\
23.0 \\
23.0 \\
>3.0 \\
>3.0\end{array}$ & $\begin{array}{l}22.0 \\
23.0 \\
23.0 \\
23.0 \\
73.0\end{array}$ & $\begin{array}{l}16.5 \\
16.5 \\
16.5 \\
16.5 \\
16.5\end{array}$ & $\begin{array}{l}16.5 \\
16.5 \\
16.5 \\
16.5 \\
16.5\end{array}$ & $\begin{array}{l}12.0 \\
12.0 \\
12.0 \\
11.5 \\
11.5\end{array}$ & $\begin{array}{l}12.0 \\
12.0 \\
11.0 \\
11.0 \\
11.0\end{array}$ & $\begin{array}{l}R .0 \\
0.0 \\
R .0 \\
7.5 \\
7.0\end{array}$ & $\begin{array}{l}8.0 \\
8.0 \\
7.5 \\
7.0 \\
7.0\end{array}$ & $\begin{array}{l}R=0 \\
R=0 \\
R=0 \\
R=0 \\
R=0\end{array}$ & $\begin{array}{l}R .0 \\
R .0 \\
R .0 \\
R .0 \\
R .0\end{array}$ & $\begin{array}{l}10.0 \\
10.0 \\
10.0 \\
10.0 \\
10.5\end{array}$ & $\begin{array}{l}10.0 \\
10.0 \\
10.0 \\
10.0 \\
10.0\end{array}$ \\
\hline $\begin{array}{l}11 \\
12 \\
13 \\
14 \\
15\end{array}$ & $\begin{array}{l}23.0 \\
23.5 \\
24.0 \\
23.5 \\
23.0\end{array}$ & $\begin{array}{l}22.0 \\
23.0 \\
23.0 \\
22.0 \\
22.0\end{array}$ & $\begin{array}{l}16.5 \\
16.5 \\
16.5 \\
16.0 \\
16.0\end{array}$ & $\begin{array}{l}16.5 \\
1 \mathrm{~h} .5 \\
1 \mathrm{~h} .0 \\
1 \mathrm{~h} .0 \\
15.5\end{array}$ & $\begin{array}{l}11.5 \\
11.0 \\
10.5 \\
10.5 \\
10.5\end{array}$ & $\begin{array}{l}11.0 \\
10.5 \\
10.5 \\
10.5 \\
10.5\end{array}$ & $\begin{array}{l}7.0 \\
7.0 \\
7.0 \\
7.0 \\
7.0\end{array}$ & $\begin{array}{l}7.0 \\
7.0 \\
7.0 \\
7.0 \\
7.0\end{array}$ & $\begin{array}{l}8.0 \\
R .0 \\
R .0 \\
R .0 \\
R .5\end{array}$ & $\begin{array}{l}R .0 \\
R .0 \\
R .0 \\
R .0 \\
R .0\end{array}$ & $\begin{array}{l}11.0 \\
11.0 \\
11.0 \\
10.5 \\
10.5\end{array}$ & $\begin{array}{l}10.0 \\
10.5 \\
10.5 \\
10.5 \\
10.5\end{array}$ \\
\hline $\begin{array}{l}16 \\
17 \\
18 \\
19 \\
70\end{array}$ & $\begin{array}{l}22.0 \\
21.5 \\
21.5 \\
21.5 \\
21.5\end{array}$ & $\begin{array}{l}21.5 \\
>1.5 \\
>1.5 \\
>1.5 \\
20.0\end{array}$ & $\begin{array}{l}15.5 \\
15.0 \\
15.0 \\
15.0 \\
15.0\end{array}$ & $\begin{array}{l}14.5 \\
14.5 \\
15.0 \\
15.0 \\
14.5\end{array}$ & $\begin{array}{l}10.5 \\
10.5 \\
10.5 \\
10.5 \\
10.5\end{array}$ & $\begin{array}{l}10.5 \\
10.0 \\
10.5 \\
10.5 \\
10.0\end{array}$ & $\begin{array}{l}7.0 \\
7.5 \\
7.5 \\
7.5 \\
7.0\end{array}$ & $\begin{array}{l}7.0 \\
7.0 \\
7.0 \\
7.0 \\
7.0\end{array}$ & $\begin{array}{l}R .5 \\
R .5 \\
R .0 \\
R .0 \\
R .0\end{array}$ & $\begin{array}{l}R .0 \\
R .0 \\
R .0 \\
R .0 \\
R .0\end{array}$ & $\begin{array}{l}10.5 \\
10.5 \\
11.0 \\
11.5 \\
11.5\end{array}$ & $\begin{array}{l}10.5 \\
10.5 \\
10.5 \\
11.0 \\
11.5\end{array}$ \\
\hline $\begin{array}{l}21 \\
22 \\
23 \\
24 \\
25\end{array}$ & $\begin{array}{l}21.0 \\
21.0 \\
21.0 \\
20.0 \\
10.5\end{array}$ & $\begin{array}{l}21.0 \\
>1.0 \\
20.0 \\
14.5 \\
19.5\end{array}$ & $\begin{array}{l}14.5 \\
14.5 \\
14.0 \\
14.0 \\
14.0\end{array}$ & $\begin{array}{l}14.5 \\
14.0 \\
14.0 \\
14.0 \\
14.0\end{array}$ & $\begin{array}{r}10.0 \\
10.0 \\
0.5 \\
9.0 \\
0.0\end{array}$ & $\begin{array}{r}10.0 \\
9.5 \\
9.0 \\
9.0 \\
9.0\end{array}$ & $\begin{array}{l}7.0 \\
7.0 \\
7.0 \\
7.0 \\
7.5\end{array}$ & $\begin{array}{l}7.0 \\
7.0 \\
7.0 \\
7.0 \\
7.0\end{array}$ & $\begin{array}{l}8.0 \\
9.0 \\
4.0 \\
9.0 \\
9.5\end{array}$ & $\begin{array}{l}R .0 \\
R .0 \\
9.0 \\
90 \\
0.0\end{array}$ & $\begin{array}{l}11.5 \\
11.5 \\
11.5 \\
11.5 \\
11.0\end{array}$ & $\begin{array}{l}11.5 \\
11.5 \\
11.5 \\
11.0 \\
10.5\end{array}$ \\
\hline $\begin{array}{l}26 \\
27 \\
29 \\
29 \\
30 \\
31\end{array}$ & $\begin{array}{l}19.5 \\
19.5 \\
19.5 \\
19.0 \\
19.0 \\
10.0\end{array}$ & $\begin{array}{l}19.0 \\
19.0 \\
19.0 \\
19.0 \\
19.0 \\
19.0\end{array}$ & $\begin{array}{r}14.0 \\
14.0 \\
14.0 \\
14.0 \\
14.0 \\
=-0\end{array}$ & $\begin{array}{r}14.0 \\
14.0 \\
14.0 \\
14.0 \\
13.0 \\
--\end{array}$ & $\begin{array}{l}0.0 \\
8.5 \\
R .5 \\
8.5 \\
8.5 \\
R .5\end{array}$ & $\begin{array}{l}R .5 \\
8.5 \\
R .5 \\
R .5 \\
8.5 \\
R .0\end{array}$ & $\begin{array}{l}8.0 \\
R .0 \\
8.0 \\
R .0 \\
R .0 \\
R .0\end{array}$ & $\begin{array}{l}7.5 \\
7.0 \\
7.5 \\
7.5 \\
7.5 \\
7.5\end{array}$ & $\begin{array}{r}9.0 \\
8.5 \\
9.0 \\
=- \\
-- \\
--\end{array}$ & $\begin{array}{r}R .5 \\
\text { A. } 5 \\
8.5 \\
-- \\
=-\end{array}$ & $\begin{array}{l}11.0 \\
11.0 \\
11.5 \\
11.5 \\
11.5 \\
12.0\end{array}$ & $\begin{array}{l}11.0 \\
11.0 \\
11.0 \\
11.5 \\
11.5 \\
11.5\end{array}$ \\
\hline AVG, & $21 . h$ & 21.1 & 15.7 & 15.4 & 10.5 & 10.3 & 7.5 & 7.3 & R.? & R.I & 10.7 & 10.5 \\
\hline \multirow[t]{2}{*}{ DAY } & \multicolumn{2}{|c|}{$\triangle P R$} & \multicolumn{2}{|c|}{ MAY } & \multicolumn{2}{|c|}{ JIIN } & \multicolumn{2}{|c|}{ JUL. } & \multicolumn{2}{|c|}{$\Delta \notin 1 F$} & \multicolumn{2}{|c|}{ SFP } \\
\hline & MAX & MIN & $\max$ & MIN & $\max$ & MIN & MAX & MIN & MAX & MIN & $\max$ & MIN \\
\hline 1 & 12.0 & 12.0 & 20.0 & 10.5 & 23.0 & 23.0 & 27.0 & 26.0 & $7 R .0$ & $2 \mathrm{R} .0$ & 27.5 & 27.0 \\
\hline $\begin{array}{l}2 \\
3 \\
4 \\
5 \\
6\end{array}$ & $\begin{array}{l}12.5 \\
12.5 \\
13.0 \\
13.0 \\
13.5\end{array}$ & $\begin{array}{l}12.0 \\
12.5 \\
12.5 \\
13.0 \\
13.0\end{array}$ & $\begin{array}{l}20.0 \\
20.0 \\
20.0 \\
20.0 \\
21.0\end{array}$ & $\begin{array}{l}20.0 \\
19.5 \\
19.0 \\
29.5 \\
20.0\end{array}$ & $\begin{array}{l}23.0 \\
23.0 \\
23.0 \\
23.0 \\
23.5\end{array}$ & $\begin{array}{l}23.0 \\
23.0 \\
23.0 \\
23.0 \\
23.0\end{array}$ & $\begin{array}{l}27.0 \\
27.5 \\
27.5 \\
2 R .0 \\
2 R .0\end{array}$ & $\begin{array}{l}26.5 \\
27.0 \\
27.5 \\
27.5 \\
27.5\end{array}$ & $\begin{array}{l}2 R .0 \\
2 R .5 \\
28.5 \\
29.5 \\
2 H .5\end{array}$ & $\begin{array}{l}2 R .0 \\
2 R .0 \\
2 B .0 \\
2 R .0 \\
28.0\end{array}$ & $\begin{array}{l}27.5 \\
27.5 \\
27.0 \\
27.5 \\
27.5\end{array}$ & $\begin{array}{l}27.0 \\
27.0 \\
27.0 \\
27.0 \\
27.5\end{array}$ \\
\hline $\begin{array}{r}7 \\
R \\
0 \\
10 \\
11\end{array}$ & $\begin{array}{l}14.0 \\
14.0 \\
14.5 \\
14.5 \\
14.5\end{array}$ & $\begin{array}{l}13.5 \\
14.0 \\
14.0 \\
14.5 \\
14.5\end{array}$ & $\begin{array}{l}21.0 \\
21.0 \\
21.0 \\
21.0 \\
21.0\end{array}$ & $\begin{array}{l}20.5 \\
21.0 \\
21.0 \\
21.0 \\
21.0\end{array}$ & $\begin{array}{l}24.0 \\
24.0 \\
24.0 \\
24.0 \\
24.0\end{array}$ & $\begin{array}{l}23.5 \\
23.0 \\
23.5 \\
23.5 \\
23.5\end{array}$ & $\begin{array}{l}27.5 \\
27.5 \\
27.0 \\
27.0 \\
28.0\end{array}$ & $\begin{array}{l}27.5 \\
27.0 \\
77.0 \\
27.0 \\
27.0\end{array}$ & $\begin{array}{l}2 R .5 \\
2 R .0 \\
2 R .0 \\
2 R .0 \\
27.0\end{array}$ & $\begin{array}{l}28.0 \\
27.5 \\
27.5 \\
27.0 \\
25.5\end{array}$ & $\begin{array}{l}27.5 \\
27.0 \\
27.5 \\
27.5 \\
2 R .0\end{array}$ & $\begin{array}{l}27.0 \\
26.5 \\
27.0 \\
27.0 \\
27.5\end{array}$ \\
\hline $\begin{array}{l}12 \\
13 \\
14 \\
15 \\
16\end{array}$ & $\begin{array}{l}14.5 \\
15.0 \\
15.5 \\
15.5 \\
16.5\end{array}$ & $\begin{array}{l}14.5 \\
14.5 \\
15.0 \\
15.5 \\
15.5\end{array}$ & $\begin{array}{l}22.0 \\
22.0 \\
27.0 \\
22.5 \\
23.0\end{array}$ & $\begin{array}{l}21.5 \\
22.0 \\
21.5 \\
22.0 \\
22.5\end{array}$ & $\begin{array}{l}24.5 \\
24.5 \\
24.5 \\
25.0 \\
25.0\end{array}$ & $\begin{array}{l}23.5 \\
24.0 \\
24.0 \\
24.5 \\
24.5\end{array}$ & $\begin{array}{l}2 R .0 \\
2 R .5 \\
2 R .5 \\
2 R .0 \\
2 R .0\end{array}$ & $\begin{array}{l}2 R .0 \\
21.0 \\
2 R .0 \\
27.5 \\
2 R .0\end{array}$ & $\begin{array}{l}27.0 \\
27.5 \\
28.0 \\
27.5 \\
27.5\end{array}$ & $\begin{array}{l}26.0 \\
26.5 \\
27.0 \\
27.5 \\
27.5\end{array}$ & $\begin{array}{l}2 R .0 \\
2 R .0 \\
2 R .0 \\
2 R .0 \\
27.5\end{array}$ & $\begin{array}{l}27.5 \\
27.5 \\
27.5 \\
27.5 \\
27.5\end{array}$ \\
\hline $\begin{array}{l}17 \\
18 \\
19 \\
20 \\
21\end{array}$ & $\begin{array}{l}16.0 \\
18.5 \\
17.0 \\
17.0 \\
17.0\end{array}$ & $\begin{array}{l}16.0 \\
16.0 \\
16.5 \\
17.0 \\
17.0\end{array}$ & $\begin{array}{l}23.0 \\
23.0 \\
23.0 \\
23.5 \\
23.5\end{array}$ & $\begin{array}{l}22.5 \\
22.5 \\
22.5 \\
23.0 \\
23.0\end{array}$ & $\begin{array}{l}25.0 \\
25.0 \\
25.0 \\
25.5 \\
26.0\end{array}$ & $\begin{array}{l}24.5 \\
25.0 \\
25.0 \\
25.0 \\
25.5\end{array}$ & $\begin{array}{l}2 R .0 \\
2 R .0 \\
28.0 \\
2 R .5 \\
2 R .0\end{array}$ & $\begin{array}{l}27.5 \\
2 R .0 \\
28.0 \\
28.0 \\
28.0\end{array}$ & $\begin{array}{l}28.0 \\
27.5 \\
27.5 \\
27.0 \\
27.5\end{array}$ & $\begin{array}{l}27.5 \\
27.0 \\
27.0 \\
26.5 \\
27.0\end{array}$ & $\begin{array}{l}27.5 \\
27.5 \\
27.5 \\
27.5 \\
28.0\end{array}$ & $\begin{array}{l}27.5 \\
27.5 \\
27.5 \\
27.0 \\
27.5\end{array}$ \\
\hline $\begin{array}{l}22 \\
23 \\
24 \\
25 \\
26\end{array}$ & $\begin{array}{l}17.5 \\
17.5 \\
17.5 \\
18.0 \\
18.5\end{array}$ & $\begin{array}{l}17.0 \\
17.5 \\
17.5 \\
17.5 \\
18.0\end{array}$ & $\begin{array}{l}23.5 \\
23.5 \\
23.5 \\
23.5 \\
24.0\end{array}$ & $\begin{array}{l}23.0 \\
23.0 \\
23.5 \\
23.0 \\
23.0\end{array}$ & $\begin{array}{l}26.0 \\
26.0 \\
26.0 \\
26.0 \\
26.5\end{array}$ & $\begin{array}{l}25.5 \\
25.5 \\
25.5 \\
25.5 \\
25.5\end{array}$ & $\begin{array}{l}2 R .0 \\
27.5 \\
2 R .0 \\
2 R .0 \\
2 R .5\end{array}$ & $\begin{array}{l}27.5 \\
27.0 \\
27.0 \\
28.0 \\
78.0\end{array}$ & $\begin{array}{l}27.5 \\
27.5 \\
27.5 \\
27.5 \\
27.5\end{array}$ & $\begin{array}{l}27.0 \\
27.0 \\
27.0 \\
27.0 \\
77.0\end{array}$ & $\begin{array}{l}2 R .0 \\
27.5 \\
27.0 \\
77.0 \\
27.5\end{array}$ & $\begin{array}{l}27.5 \\
27.0 \\
27.0 \\
27.0 \\
26.5\end{array}$ \\
\hline $\begin{array}{l}27 \\
2 R \\
29 \\
30 \\
31\end{array}$ & $\begin{array}{r}18.5 \\
19.0 \\
19.5 \\
19.5 \\
-.\end{array}$ & $\begin{array}{r}18.5 \\
18.5 \\
19.0 \\
19.0 \\
=-\end{array}$ & $\begin{array}{l}23.5 \\
24.0 \\
24.0 \\
23.5 \\
23.5\end{array}$ & $\begin{array}{l}23.0 \\
23.0 \\
23.5 \\
23.0 \\
23.0\end{array}$ & $\begin{array}{r}27.0 \\
27.0 \\
27.0 \\
26.5 \\
-. .\end{array}$ & $\begin{array}{r}26.5 \\
2 h .5 \\
26.0 \\
26.0 \\
0 .\end{array}$ & $\begin{array}{l}2 R .5 \\
2 R .5 \\
2 R .5 \\
2 R .0 \\
2 R .5\end{array}$ & $\begin{array}{l}2 R .0 \\
2 R .0 \\
2 R .0 \\
2 R .0 \\
2 R .0\end{array}$ & $\begin{array}{l}27.0 \\
26.5 \\
76.5 \\
27.0 \\
27.0\end{array}$ & $\begin{array}{l}26.0 \\
26.0 \\
26.0 \\
26.0 \\
26.5\end{array}$ & $\begin{array}{r}27.5 \\
27.0 \\
2 h .5 \\
24.0 \\
-.\end{array}$ & $\begin{array}{l}27.0 \\
26.0 \\
26.0 \\
25.0\end{array}$ \\
\hline
\end{tabular}


LOCATION。--Lat $33^{\circ} 37^{\prime} 22^{\prime \prime}$, Iong $85^{\circ} 31 \cdot 20^{\prime \prime}$, in NW sec, 20, T.16 S., R.11 E., Cleburne County, at gaging station on right bank $5 \mathrm{ft}$ dowstream from county road bridge, 2.2 miles upstream from Cane creek, 4 miles southeast of Heflin, and at mile 186.6 .

DRAINAGE AREA.--444 sq mi.

PERIOD OF RECORD.--ChemicaI analyses: October 1964 to September 1966, October 1967 to September 1969 (miscellaneous), October 1969 to September 1970.

CHEMICAL ANALYSES, WATER YEAR OCTOBER 1969 TO SEPTEMBER 1970

\begin{tabular}{|c|c|c|c|c|c|c|c|c|c|c|c|c|}
\hline $\begin{array}{l}\text { DATE } \\
\text { OCT. }\end{array}$ & TIME & $\begin{array}{l}\text { OIS- } \\
\text { CHARGE } \\
\text { (CFS) }\end{array}$ & $\begin{array}{l}\text { SILICA } \\
\text { (SIOZI) } \\
\text { (MGIL) }\end{array}$ & $\begin{array}{l}\text { OIS- } \\
\text { SOLVED } \\
\text { IRON } \\
\text { IFE) } \\
\text { (UG/L) }\end{array}$ & $\begin{array}{l}\text { SOLVED } \\
\text { MAN- } \\
\text { GANESE } \\
\text { (MN) } \\
\text { (UG } / L \text {, }\end{array}$ & $\begin{array}{l}\text { CAL- } \\
\text { CIIJM } \\
(C A) \\
(M G / L)\end{array}$ & $\begin{array}{c}M A G- \\
N E- \\
\text { SIUM } \\
(M G) \\
(M G / L)\end{array}$ & $\begin{array}{l}\text { SODIUM } \\
\text { (NA) } \\
\text { (MGIL) }\end{array}$ & $\begin{array}{l}\text { PO- } \\
\text { TAS- } \\
\text { SIUM } \\
\text { (K) } \\
(\mathrm{MG} / \mathrm{L})\end{array}$ & $\begin{array}{l}\text { BICAR - } \\
\text { BONATE } \\
\text { (HCOBI } \\
\text { I MGILI) }\end{array}$ & $\begin{array}{l}\text { CAR- } \\
\text { BONATE } \\
\text { (CO3) } \\
\text { (MG } / L)\end{array}$ & $\begin{array}{c}\text { SULFATE } \\
(504) \\
(\$ G / L)\end{array}$ \\
\hline $\begin{array}{l}14 \ldots . \\
\text { Nov. }\end{array}$ & 1300 & 137 & -- & $m$ & -- & -- & -- & -- & -- & 19 & 0 & -- \\
\hline $\begin{array}{l}05 \ldots \\
25 \ldots \\
\text { JAN. }\end{array}$ & $\begin{array}{l}0820 \\
0945\end{array}$ & $\begin{array}{l}179 \\
177\end{array}$ & 9.8 & 180 & $=$ & 3.2 & 1.4 & 2.5 & 1.2 & $\begin{array}{l}21 \\
18\end{array}$ & $\begin{array}{l}0 \\
0\end{array}$ & 1.2 \\
\hline $07 . .$. & 1015 & 883 & $\rightarrow$ & $\overline{50}$ & -- & -- & - & - & -- & 11 & 1 & -- \\
\hline$\underset{F E B}{14, .}$ & 0845 & 510 & 9.8 & 50 & -- & 2.8 & 1.2 & 1.9 & 1.1 & 15 & 0 & 2.0 \\
\hline $\begin{array}{l}18 \ldots \\
19 . . . \\
\text { MAR. }\end{array}$ & $\begin{array}{l}0810 \\
0950\end{array}$ & $\begin{array}{l}700 \\
886\end{array}$ & 12 & 240 & $=$ & 2.5 & 1.3 & 2.2 & 1.0 & $\begin{array}{l}15 \\
14\end{array}$ & $\begin{array}{l}0 \\
0\end{array}$ & 2.0 \\
\hline APR.. & 0910 & 900 & 7.9 & 190 & 30 & 1.8 & .9 & 1.8 & .6 & 10 & 0 & 3.2 \\
\hline JUNE & 1540 & 1030 & 11 & 370 & 30 & 2.2 & 1.2 & 1.6 & .3 & 14 & 0 & 1.6. \\
\hline $\begin{array}{l}04 \ldots \\
17 \ldots \\
\text { JuL }\end{array}$ & $\begin{array}{l}0900 \\
0900\end{array}$ & $\begin{array}{r}1850 \\
334\end{array}$ & $\begin{array}{r}7.5 \\
--\end{array}$ & 130 & $=$ & 2.8 & 1.1 & 1.9 & 1.0 & $\begin{array}{l}12 \\
12\end{array}$ & $\begin{array}{l}0 \\
0\end{array}$ & 2.2 \\
\hline $\begin{array}{l}16 . . . \\
\text { AUG. }\end{array}$ & 0930 & 196 & 12 & 230 & 48 & 2.7 & 1.2 & 2.3 & .7 & 16 & 0 & .6 \\
\hline SEPT. & 1645 & 340 & 4.6 & 97 & 23 & 2.1 & .8 & 1.8 & 1.7 & 10 & 0 & $2 \cdot 2$ \\
\hline $\begin{array}{l}15 \ldots \\
16 \ldots\end{array}$ & $\begin{array}{l}0845 \\
1605\end{array}$ & $\begin{array}{l}178 \\
121\end{array}$ & 10 & $\begin{array}{r}610 \\
015-\end{array}$ & $\begin{array}{c}78 \\
015-\end{array}$ & 2.8 & 1.1 & 2.3 & $\because 8$ & $\begin{array}{l}18 \\
15\end{array}$ & $\begin{array}{l}0 \\
0\end{array}$ & $\because 2$ \\
\hline & & & & $\begin{array}{l}\text { SCLVEO } \\
\text { SDLIOS }\end{array}$ & $\begin{array}{l}\text { SOLVED } \\
\text { SOLIDS }\end{array}$ & $\begin{array}{l}\text { OIS- } \\
\text { SOLVED }\end{array}$ & & $\begin{array}{l}\text { NON- } \\
\text { CAR- }\end{array}$ & $\begin{array}{l}\text { SPECI - } \\
\text { FIC }\end{array}$ & & $\begin{array}{l}\text { COLI- } \\
\text { FORM }\end{array}$ & $\begin{array}{l}\text { FECAL } \\
\text { COLI- }\end{array}$ \\
\hline & $\begin{array}{l}\text { CHLO- } \\
\text { RIOE } \\
\text { (CL) }\end{array}$ & $\begin{array}{l}\text { FLUD- } \\
\text { RIDE } \\
\text { (F) }\end{array}$ & $\begin{array}{l}\text { NITRATE } \\
\text { (ND3) }\end{array}$ & $\begin{array}{l}\text { (RESI- } \\
\text { DUE AT } \\
\text { IBO C) }\end{array}$ & $\begin{array}{l}\text { I SUM DF } \\
\text { CONSTI - } \\
\text { TUENTSI }\end{array}$ & $\begin{array}{l}\text { SOLIOS } \\
\text { ITONS } \\
\text { PER }\end{array}$ & $\begin{array}{l}\text { HARD- } \\
\text { NESS } \\
\text { (CA,MG) }\end{array}$ & $\begin{array}{l}\text { BONATE } \\
\text { HARD- } \\
\text { NESS }\end{array}$ & $\begin{array}{l}\text { COND- } \\
\text { UCTANCE } \\
\text { IMICRO- }\end{array}$ & $P H$ & $\begin{array}{l}\text { COOL- } \\
\text { ONIES } \\
\text { PER }\end{array}$ & $\begin{array}{l}\text { FORM } \\
\text { ICOL. } \\
\text { PER }\end{array}$ \\
\hline $\begin{array}{l}\text { DATE } \\
\text { OCT. }\end{array}$ & (MG/L) & (MG/L) & $(M G / L)$ & (MG/L) & IMG/L) & $A C-F T I$ & $(M G / L)$ & $(M G / L)$ & MHOSI & (UNITS) & $100 \mathrm{~mL})$ & $100 \mathrm{ML})$ \\
\hline $\begin{array}{l}14 \ldots . . \\
\text { NOV. }\end{array}$ & 2.6 & -- & -- & -- & -- & -- & 16 & 1 & 43 & 7.5 & -- & -- \\
\hline $\begin{array}{l}05 \ldots . \\
25 \ldots \\
\text { JAN. }\end{array}$ & $\begin{array}{l}2.1 \\
2.2\end{array}$ & $\div 0$ & $\because 3$ & 31 & 32 & .04 & $\begin{array}{l}14 \\
12\end{array}$ & $\begin{array}{l}0 \\
0\end{array}$ & $\begin{array}{l}40 \\
43\end{array}$ & $\begin{array}{l}7.3 \\
7.3\end{array}$ & 570 & $=$ \\
\hline $\begin{array}{l}07 \ldots \\
14 \ldots \\
F \in B .\end{array}$ & $\begin{array}{l}2.2 \\
1.8\end{array}$ & $\overline{-1}$ & .4 & $\overline{2 B}$ & $\overline{28}$ & .04 & $\begin{array}{l}12 \\
12\end{array}$ & $\begin{array}{l}\text { I } \\
0\end{array}$ & $\begin{array}{l}31 \\
34\end{array}$ & $\begin{array}{l}8.4 \\
7.2\end{array}$ & $7 \overrightarrow{30}$ & $=$ \\
\hline $\begin{array}{l}1 B \ldots \\
19 . . . \\
\text { MAR. }\end{array}$ & $\begin{array}{l}2.1 \\
2.4\end{array}$ & $\therefore$ & $\therefore 3$ & 23 & 30 & .03 & $\begin{array}{l}12 \\
10\end{array}$ & $\begin{array}{l}0 \\
0\end{array}$ & $\begin{array}{l}32 \\
36\end{array}$ & $\begin{array}{l}7.1 \\
7.1\end{array}$ & $\begin{array}{r}1800 \\
--\end{array}$ & $=$ \\
\hline $\begin{array}{l}26 \ldots . . \\
\text { APR. }\end{array}$ & 1.5 & .1 & .3 & 23 & 23 & $.0 x$ & 8 & D & 29 & 6.5 & 1400 & -- \\
\hline JUNE & 1.4 & .1 & .2 & 29 & 27 & .04 & 10 & 0 & 30 & 7.0 & 3600 & 350 \\
\hline $\begin{array}{l}04 \ldots \\
17 \ldots \\
\text { JuLY }\end{array}$ & $\begin{array}{l}1.5 \\
2.4\end{array}$ & $=1$ & 1.1 & 23 & 25 & .03 & $\begin{array}{r}12 \\
9\end{array}$ & $\begin{array}{l}2 \\
0\end{array}$ & $\begin{array}{l}29 \\
34\end{array}$ & $\begin{array}{l}7.0 \\
7.4\end{array}$ & $\begin{array}{r}32000 \\
--\end{array}$ & $\begin{array}{r}3500 \\
--\end{array}$ \\
\hline $\begin{array}{l}16 . . . \\
\text { AUG. }\end{array}$ & 1.6 & +1 & .2 & 29 & 29 & .04 & 12 & 0 & 37 & 1.0 & 670 & 130 \\
\hline $\begin{array}{l}20 \ldots . . \\
\text { SEPT. }\end{array}$ & 1.8 & .1 & 1.0 & 30 & 21 & .04 & 9 & 1 & 30 & 6.4 & 5000 & 1170 \\
\hline $\begin{array}{l}15 \ldots \\
16 \ldots\end{array}$ & $\begin{array}{l}2.2 \\
1.6\end{array}$ & $\therefore$ & $\therefore 2$ & 29 & 29 & .04 & $\begin{array}{r}12 \\
5\end{array}$ & $\begin{array}{l}0 \\
0\end{array}$ & $\begin{array}{l}36 \\
32\end{array}$ & $\begin{array}{l}6.6 \\
7.0\end{array}$ & $\begin{array}{r}1500 \\
-.\end{array}$ & 120 \\
\hline
\end{tabular}

\begin{tabular}{|c|c|c|c|c|c|c|}
\hline DATE & TIME & $\begin{array}{l}\text { DIS- } \\
\text { CHARGE } \\
\text { (CFS) }\end{array}$ & $\begin{array}{l}\text { 5PECI- } \\
\text { FIC } \\
\text { COND- } \\
\text { UCTANCE } \\
\text { IMICRR- } \\
\text { MHOSI }\end{array}$ & $\begin{array}{c}P H \\
\text { |UNITS }\end{array}$ & $\begin{array}{l}\text { DIS- } \\
\text { SOLVED } \\
\text { OXYGEN } \\
\text { (MG/L) }\end{array}$ & $\begin{array}{l}\text { TEMP- } \\
\text { ERATURE } \\
\text { (DEG C) }\end{array}$ \\
\hline $\begin{array}{l}\text { OCT. } \\
14 . . . \\
\text { NoV. }\end{array}$ & 1305 & 137 & -- & -- & -- & 19.0 \\
\hline $\begin{array}{l}05 \ldots \\
25 \ldots\end{array}$ & $\begin{array}{l}0820 \\
0840\end{array}$ & $\begin{array}{l}179 \\
177\end{array}$ & $\begin{array}{l}38 \\
--\end{array}$ & 7.1 & 10.3 & $\begin{array}{r}10.0 \\
3.0\end{array}$ \\
\hline $\begin{array}{l}\text { JAN. } \\
07 \ldots . . \\
14 \ldots\end{array}$ & $\begin{array}{l}0850 \\
0845\end{array}$ & $\begin{array}{l}882 \\
510\end{array}$ & $\overline{35}$ & 7.1 & 14.9 & $\begin{array}{r}4.0 \\
.0\end{array}$ \\
\hline $\begin{array}{l}18 \ldots \\
19 . .\end{array}$ & $\begin{array}{l}0810 \\
0950\end{array}$ & $\begin{array}{l}700 \\
520\end{array}$ & 30 & 7.3 & 11.8 & $\begin{array}{l}8.0 \\
9.0\end{array}$ \\
\hline $\begin{array}{l}\text { MAR. } \\
26 . . \\
\text { APR. }\end{array}$ & 0910 & 900 & -- & 6.4 & 10.5 & 11.5 \\
\hline $\begin{array}{l}01 \ldots . . \\
28 .\end{array}$ & $\begin{array}{l}0930 \\
1540\end{array}$ & $\begin{array}{r}627 \\
1030\end{array}$ & $=$ & 6.9 & $8 . \overline{7}$ & $\begin{array}{l}14.0 \\
19.0\end{array}$ \\
\hline JUNE & 1015 & 292 & 40 & -- & -- & 19.0 \\
\hline $\begin{array}{l}04 \ldots \\
\text { JuLY }\end{array}$ & $\begin{array}{l}0900 \\
0825\end{array}$ & $\begin{array}{r}1850 \\
334\end{array}$ & $=$ & 6.9 & $\begin{array}{l}8.6 \\
--\end{array}$ & $\begin{array}{l}19.0 \\
21.0\end{array}$ \\
\hline $16 \ldots$ & 0930 & 196 & 38 & 6.9 & 7.8 & 24.0 \\
\hline $\begin{array}{l}20 \ldots . . \\
\text { SEPT. }\end{array}$ & 1645 & 340 & 30 & 6.6 & 7.4 & 23.0 \\
\hline $\begin{array}{l}15 \ldots \\
17 \ldots\end{array}$ & $\begin{array}{l}0845 \\
1535\end{array}$ & $\begin{array}{l}17 a \\
121\end{array}$ & $\begin{array}{l}38 \\
40\end{array}$ & $\begin{array}{r}7.1 \\
-.2\end{array}$ & $\begin{array}{l}8.2 \\
--.\end{array}$ & $\begin{array}{l}22.0 \\
24.0\end{array}$ \\
\hline
\end{tabular}


02414500 TALLAPOOSA RIVER AT WADLEY, ALA ,

LOCATION.--Lat $33^{\circ} 07^{\prime} 00^{\prime \prime}$, long $85^{\circ} 33^{\prime} 39^{\prime \prime}$, in Sw sec.12, T.22 S., R.10 E., Randolph County, at gaging station near center of channel on' downstream side of bridge on State Highway 22 , $i$ 'mile downstream from Beaver Dam Creek, and at mile 125.3 .

DRAINAGE AREA, . $1,660 \mathrm{sq} \mathrm{mi}$, approximate $1 \mathrm{y}$.

pERIOD OF RECORD.--Chemical analyses: October 1964 to September 1965, October 1967 to September 1969 (miscellaneous), October 1969 to September 1970 .

CHEMICAL ANALYSES, WATER YEAR OCTOBER 1969 TO SEPTEMBER 1970

\begin{tabular}{|c|c|c|c|c|c|c|c|c|c|c|c|c|}
\hline DATE & TIME & $\begin{array}{l}\text { DIS- } \\
\text { CHARGE } \\
\text { (CFS) }\end{array}$ & $\begin{array}{l}\text { SILICA } \\
\text { (SIOL) } \\
\text { (MG/L) }\end{array}$ & $\begin{array}{l}\text { OIS- } \\
\text { SOLVEO } \\
\text { IQON } \\
\text { (FE) } \\
\text { (UG/L) }\end{array}$ & $\begin{array}{l}\text { DIS- } \\
\text { SDLVED } \\
\text { MAN- } \\
\text { GANESE } \\
\text { (MN) } \\
\text { (UGILI) }\end{array}$ & $\begin{array}{l}\text { CAL- } \\
\text { CIUM } \\
(C A) \\
(M G / L)\end{array}$ & $\begin{array}{l}\text { MAG- } \\
\text { NE- } \\
\text { SIUM } \\
\text { (MG) } \\
\text { (MG/L) }\end{array}$ & $\begin{array}{l}\text { SDD I UM } \\
\text { (NA) } \\
(M G / L)\end{array}$ & $\begin{array}{l}\text { PD- } \\
\text { TAS- } \\
\text { SIUM } \\
\text { (K) } \\
\text { (MG/L) }\end{array}$ & $\begin{array}{l}\text { BICAR- } \\
\text { BDNATE } \\
\text { (HCD } 3 \text { ) } \\
\text { (MG/L) }\end{array}$ & $\begin{array}{l}\text { CAR- } \\
\text { BDNATE } \\
\text { (CD3) } \\
\text { (MG/LL) }\end{array}$ & $\begin{array}{l}\text { SULFATE } \\
\text { (SO4) } \\
\text { (MG/L) }\end{array}$ \\
\hline $\begin{array}{l}\text { NOV. } \\
\text { O5... } \\
\text { JAN. }\end{array}$ & 1215 & 794 & 8.5 & 60 & -- & $2 \cdot 0$ & 1.2 & 2.7 & 1.2 & 16 & 0 & 1.6 \\
\hline FEB. & 1210 & 2020 & 10 & 40 & -- & 2.2 & 1.2 & 2.3 & 1.7 & 13 & 0 & 2.8 \\
\hline $\begin{array}{c}18 \ldots . . \\
\text { MAR. }\end{array}$ & 1110 & 2750 & 11 & 100 & -- & 2.2 & 1.3 & 2.3 & - B & 14 & 0 & 2.4 \\
\hline $\begin{array}{c}26 . . \\
\triangle P P R .\end{array}$ & 1235 & 4690 & 7.4 & 70 & 20 & 1.5 & .8 & $1 \cdot B$ & .7 & 8 & 0 & 2.2 \\
\hline JUNE & 1045 & 3600 & 9.9 & 260 & 20 & 2.0 & 1.1 & 1.8 & .4 & 12 & 0 & 1.8 \\
\hline juLY & 1245 & 8210 & 7.6 & 120 & 9 & 1.8 & 1.1 & 1.8 & 1.2 & 11 & 0 & 2.0 \\
\hline $\begin{array}{l}14 \ldots . \\
\text { AUG. }\end{array}$ & 1000 & 582 & 9.6 & 80 & 29 & 1.7 & 1.1 & 2.4 & 1.0 & 13 & 0 & .4 \\
\hline SEPT. & 1030 & 1280 & 11 & 400 & 20 & 2.1 & $1 . t$ & $2 \cdot 3$ & 1.1 & 14 & 0 & 1.0 \\
\hline $15 \ldots$ & 1300 & 521 & 9.2 & 480 & 28 & 1.5 & 1.0 & 2.4 & 1.3 & 14 & 0 & .2 \\
\hline & $\begin{array}{l}\text { CHLO- } \\
\text { RIDE } \\
\text { (CL) }\end{array}$ & $\begin{array}{l}\text { FLUO- } \\
\text { RIDE } \\
\text { (F) }\end{array}$ & $\begin{array}{l}\text { NITRAYE } \\
\text { (NO3) }\end{array}$ & $\begin{array}{l}\text { DIS- } \\
\text { SOLVED } \\
\text { SOLIDS } \\
\text { IRESI- } \\
\text { DUE AT } \\
\text { IBO CI }\end{array}$ & $\begin{array}{l}\text { DIS- } \\
\text { SOLVED } \\
\text { SOLIDS } \\
\text { ISUM OF } \\
\text { CONSTI- } \\
\text { TUFNTSI }\end{array}$ & $\begin{array}{l}\text { DIS- } \\
\text { SOLVEO } \\
\text { SOLIOS } \\
\text { ITONS } \\
\text { PER }\end{array}$ & $\begin{array}{l}\text { HARO- } \\
\text { NESS } \\
\text { (CA,MG) }\end{array}$ & $\begin{array}{l}\text { NON- } \\
\text { CAR- } \\
\text { BONATE } \\
\text { HARD- } \\
\text { NESS }\end{array}$ & $\begin{array}{l}\text { SPEC1- } \\
\text { FIC } \\
\text { COND- } \\
\text { UCTANCE } \\
\text { IMICRO- }\end{array}$ & $\mathrm{PH}$ & $\begin{array}{l}\text { COLI- } \\
\text { FORM } \\
\text { ICOL- } \\
\text { ONIES } \\
\text { PER }\end{array}$ & $\begin{array}{l}\text { FECAL } \\
\text { COL 1- } \\
\text { FORM } \\
\text { ICOL. } \\
\text { PER }\end{array}$ \\
\hline DATE & (MG/L) & $(M G / L)$ & (MG/L) & $(M G / L)$ & ( $M G / L)$ & $A C-F T$ & (MG/L) & $(M G / L)$ & мHOSI & (UN1TS) & $100 \mathrm{ML})$ & $100 \mathrm{MLI}$ \\
\hline $\begin{array}{l}\text { NOV. } \\
\text { O5.... } \\
\text { JAN. }\end{array}$ & 1.6 & .1 & $\cdot 3$ & 27 & 27 & .04 & 10 & 0 & 37 & 7.4 & 7300 & $-\infty$ \\
\hline $\begin{array}{l}14 \ldots \\
\text { FEB. }\end{array}$ & 2.0 & .1 & .5 & 28 & 29 & .04 & 10 & 0 & 35 & 7.0 & 1500 & $\cdots$ \\
\hline $\begin{array}{l}1 B . . . \\
\text { MAR. }\end{array}$ & 2.2 & $\cdot 1$ & .6 & 19 & 30 & .03 & 11 & 0 & 33 & 6.8 & 2100 & - \\
\hline $\begin{array}{l}26 . . \\
A P R .\end{array}$ & 1.7 & .1 & . B & 25 & 21 & .03 & 7 & 0 & 28 & 6.7 & 1200 & - \\
\hline JUNE & 1.6 & .1 & .9 & 26 & 26 & .04 & 10 & 0 & 30 & 6.8 & 5300 & 420 \\
\hline JuLr & 1.6 & .1 & 1.7 & 19 & 24 & .03 & 9 & 0 & 29 & 6.8 & 20000 & 3700 \\
\hline AUG. & 2.3 & .1 & .2 & 32 & 25 & .04 & 9 & 0 & 33 & 6.7 & 1000 & 170 \\
\hline SEPT. & 1.7 & $\cdot 1$ & .9 & 29 & 29 & .04 & 10 & 0 & 33 & 6.4 & 600 & 140 \\
\hline $15 \ldots$ & 2.2 & .1 & .2 & 32 & 25 & .04 & 8 & 0 & 32 & 6.2 & 5500 & - \\
\hline
\end{tabular}

FIELD ANALYSES

\begin{tabular}{|c|c|c|c|c|c|c|}
\hline DATE & TIME & $\begin{array}{l}\text { DIS- } \\
\text { CHARGE } \\
\text { ICFSI }\end{array}$ & $\begin{array}{l}\text { SPEC I- } \\
\text { FIC } \\
\text { COND- } \\
\text { UCTANCE } \\
\text { IMICRO- } \\
\text { MHOSI }\end{array}$ & $\begin{array}{c}\text { PH } \\
\text { (UNITSI }\end{array}$ & $\begin{array}{l}\text { DIS- } \\
\text { SOLVED } \\
\text { OXYGEN } \\
\text { (MG/L) }\end{array}$ & $\begin{array}{l}\text { TEMP- } \\
\text { ERATURE } \\
\text { (DEG CI I }\end{array}$ \\
\hline $\begin{array}{l}\text { NDV. } \\
\text { O5... } \\
25 \ldots \\
\text { JAN. }\end{array}$ & $\begin{array}{l}1215 \\
0955\end{array}$ & $\begin{array}{l}794 \\
829\end{array}$ & $\begin{array}{l}32 \\
40\end{array}$ & 7.2 & 11.4 & $\begin{array}{l}12.0 \\
10.0\end{array}$ \\
\hline $\begin{array}{l}06 \ldots \\
14 \ldots \\
F E B .\end{array}$ & $\begin{array}{l}1100 \\
1210\end{array}$ & $\begin{array}{l}1880 \\
2020\end{array}$ & $\begin{array}{l}40 \\
39\end{array}$ & $\overline{7.4}$ & $14 . \overline{5}$ & $\begin{array}{l}5.0 \\
2.5\end{array}$ \\
\hline $\begin{array}{l}18 \ldots \\
18 . . \\
\text { MAR. }\end{array}$ & $\begin{array}{l}1110 \\
1410\end{array}$ & $\begin{array}{l}2750 \\
2850\end{array}$ & $\begin{array}{l}32 \\
45\end{array}$ & 7.3 & 11.8 & $\begin{array}{r}9.5 \\
10.5\end{array}$ \\
\hline $\begin{array}{c}26 \ldots . . \\
A P R .\end{array}$ & 1235 & 4690 & -- & 6.8 & 10.3 & 13.0 \\
\hline${ }_{\text {JUNE }}^{29} \ldots$ & 1045 & 3600 & -- & 7.0 & 8.9 & 19.5 \\
\hline $\begin{array}{l}04 \ldots \\
\text { JuLY }\end{array}$ & 1245 & 8210 & -- & 6.9 & 8.5 & 20.0 \\
\hline $\begin{array}{l}14 \ldots \\
\text { AUG. }\end{array}$ & 1000 & 582 & 35 & 7.0 & 8.0 & 27.0 \\
\hline SEP $21 .$. & 1030 & 1280 & 35 & 6.8 & B.1 & 25.5 \\
\hline $\begin{array}{l}15 \ldots \\
18 \ldots\end{array}$ & $\begin{array}{l}1300 \\
1315\end{array}$ & $\begin{array}{l}521 \\
547\end{array}$ & $\begin{array}{l}34 \\
40\end{array}$ & $\begin{array}{l}7.0 \\
--\end{array}$ & B.8 & $\begin{array}{l}25.5 \\
29.0\end{array}$ \\
\hline
\end{tabular}


02418500 TALLAPOOSA RIVER BELO TALLASSEE, ALA.

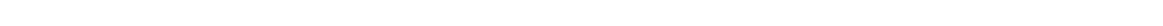
left bank, 1.5 miles downstream from Benjamin Fitzpatrick Highway bridge and Thurlow Dam at Tallassee, 3.5 miles upstream from Uphapee Creek, and at mile 48,1 .

DRAINAGE AREA, $--3,320$ sq $\mathrm{m} 1$, approximately.

PERIOD OF RECORD.--Chemical analyses: October 1967 to September 1969 (miscellaneous), October 1969 to September 1970 .

CHEMICAL ANALYSES, WATER YEAR OCTOBER 1969 TO SEPTEMBER 1970

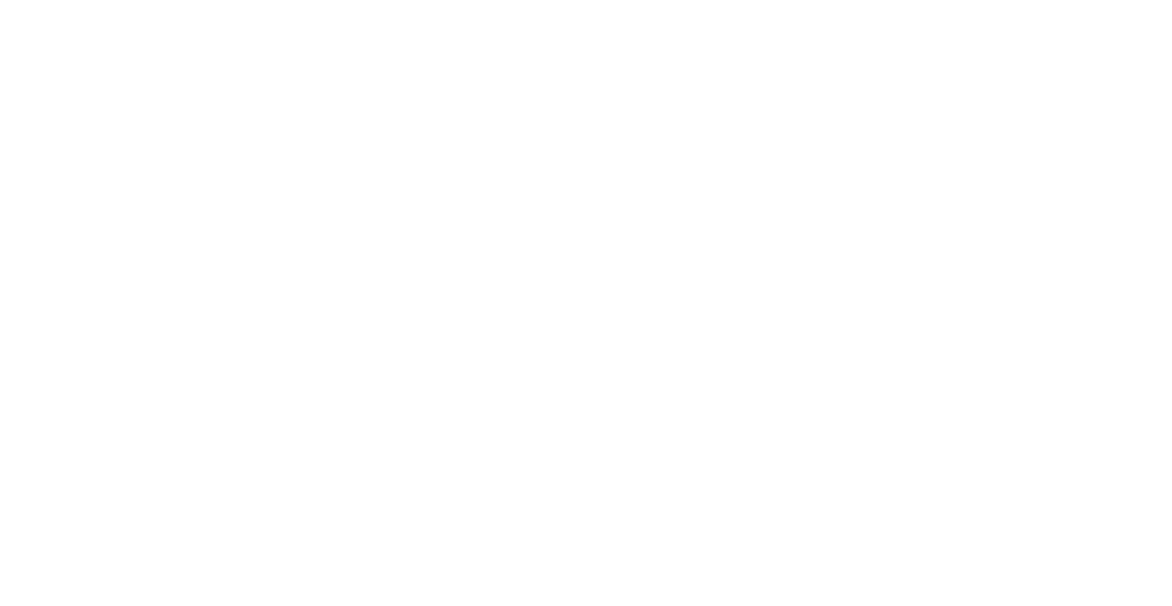

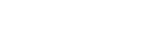

\begin{tabular}{|c|c|c|c|c|}
\hline $\begin{array}{c}\text { OCT. } \\
\text { OL.... }\end{array}$ & 2.1 & . 1 & .3 & 35 \\
\hline NOV. & & & & \\
\hline $\begin{array}{l}\text { O3... } \\
\text { JAN. }\end{array}$ & 2.0 & .0 & .2 & 28 \\
\hline $\begin{array}{l}12 \ldots \\
\text { FFB. }\end{array}$ & 2.4 & .1 & .5 & 28 \\
\hline $\begin{array}{l}16 \ldots . . . \\
\text { MAR. }\end{array}$ & 2.9 & .1 & .3 & 28 \\
\hline $\begin{array}{l}24 \ldots . . \\
A P R \text {. }\end{array}$ & 2.1 & .1 & .3 & 32 \\
\hline JUNE & 2.4 & .1 & .1 & 28 \\
\hline juL ${ }_{\text {ju }}$ & 2.2 & .1 & .8 & 25 \\
\hline $\begin{array}{l}14 \ldots . . \\
\text { AUG. }\end{array}$ & 1.9 & .1 & .4 & 29 \\
\hline & 2.2 & .1 & 1.3 & 28 \\
\hline $14 \ldots$ & 2.0 & - 1 & .1 & 32 \\
\hline
\end{tabular}

$\begin{array}{lrrr}26 & .05 & 12 & 0 \\ 30 & .04 & 9 & 0 \\ 31 & .04 & 9 & 0 \\ 36 & .04 & 12 & 0 \\ 26 & .04 & 9 & 0 \\ 31 & .04 & 10 & 0 \\ 33 & .03 & 11 & 0 \\ 29 & .04 & 10 & 0 \\ 24 & .04 & 11 & 0 \\ 27 & .04 & 11 & 0\end{array}$

$\begin{array}{rrrr}41 & 6.9 & 770 & - \\ 42 & 7.2 & 130 & - \\ 38 & 7.0 & 200 & - \\ 43 & 6.8 & 250 & - \\ 37 & 6.9 & 330 & - \\ 40 & 6.8 & 700 & 33 \\ 39 & 7.0 & 78 & 37 \\ 39 & 6.8 & 290 & 55 \\ 37 & 6.5 & 90 & -- \\ 40 & 6.7 & 120 & 7\end{array}$

\begin{tabular}{|c|c|c|c|c|c|c|}
\hline DATE & TIME & $\begin{array}{l}\text { DIS- } \\
\text { CHARGE } \\
\text { (CFS) }\end{array}$ & $\begin{array}{l}\text { SPECI- } \\
\text { FIC } \\
\text { COND- } \\
\text { UCTANCE } \\
\text { (MICRO- } \\
\text { MHOSI }\end{array}$ & $\begin{array}{c}\text { PH } \\
\text { (UNITS) }\end{array}$ & $\begin{array}{l}\text { DISS- } \\
\text { OLVED } \\
\text { OXYGEN } \\
\text { (MG/L) }\end{array}$ & $\begin{array}{l}\text { TEMP- } \\
\text { ERATURE } \\
\text { (DEG C) }\end{array}$ \\
\hline $\begin{array}{l}\text { OCT. } \\
\text { O1.... } \\
\text { Nov. }\end{array}$ & 0815 & 7500 & 30 & 7.0 & 7.5 & 20.5 \\
\hline JAN... & 1400 & $4 R 60$ & 38 & 7.0 & 9.0 & 18.5 \\
\hline $\begin{array}{l}12 . . \\
\text { FEB. }\end{array}$ & 1400 & 17800 & 42 & 7.3 & 12.6 & 7.0 \\
\hline MAR... & 1340 & 4430 & 42 & 7.1 & 12.2 & 9.0 \\
\hline${ }_{\triangle P R}^{24} \ldots$ & 1315 & 15000 & 35 & 6.8 & 11.9 & 10.5 \\
\hline JUNE & 1250 & 9320 & 44 & 7.1 & 10.0 & 22.0 \\
\hline JuLY & 1255 & 8900 & 40 & 6.9 & 9.0 & 17.0 \\
\hline AUG. & 1100 & 713 & 39 & 6.9 & 8.9 & 21.0 \\
\hline SEPY: & 1330 & 7190 & 39 & 6.7 & 7.4 & 19.5 \\
\hline $14 \ldots$ & 1330 & 7630 & 42 & 6.5 & 7.6 & 21.0 \\
\hline
\end{tabular}


02420000 ALABAMA RIVER NEAR MONTGONERY, ALA.

LOCATION. - Lat $32^{\circ} 24^{\prime} 41^{\prime \prime}$, long $86^{\circ} 24^{\prime} 30^{\prime \prime}$, In NW 1 sec. $31, \mathrm{~T} .17 \mathrm{~N}$, , R.17 E., Montgomery County, at gaging station in pier near midstream of bridge on U.S. Highway 31,4 miles upstream from Autauga Creek, 6 miles northwest of e 287.6

DRAINAGE AREA.--15,100 sq mi, approximately. PERIOD OF RECORD.--Chemical analyses: October 1967 to September 1969 (miscellaneous), October 1969 to September

CHEMICAL ANALYSES, WATER YEAR OCTOBER 1969 TO SEPTEMBER 1970

\begin{tabular}{|c|c|c|c|c|c|c|c|c|c|c|c|}
\hline DATE & TIME & $\begin{array}{l}\text { DIS- } \\
\text { CHARGE } \\
\text { (CFS) }\end{array}$ & $\begin{array}{l}\text { SILICA } \\
\text { (SIOL2) } \\
(\mathrm{MG} / \mathrm{L})\end{array}$ & $\begin{array}{l}\text { DIS- } \\
\text { SOLVED } \\
\text { IRON } \\
\text { (FE) } \\
\text { IUG/L) }\end{array}$ & $\begin{array}{l}\text { DIS- } \\
\text { SOLVED } \\
\text { MAN- } \\
\text { GANESE } \\
\text { (MN) } \\
\text { (UG/L) }\end{array}$ & $\begin{array}{l}C A L- \\
C I \cup M \\
(C A) \\
(M G / L)\end{array}$ & $\begin{array}{c}\text { MAG- } \\
\text { NE- } \\
\text { SIUM } \\
\text { (MG) } \\
(M G / L)\end{array}$ & $\begin{array}{l}\text { SODIUM } \\
\text { (NA) } \\
\text { (MG/L) }\end{array}$ & $\begin{array}{l}\text { PO- } \\
\text { IAS- } \\
\text { SIUM } \\
\text { (K) } \\
\text { (MG/L) }\end{array}$ & $\begin{array}{l}\text { B ICAR- } \\
\text { BONATE } \\
\text { (HCD } \\
(M G / L)\end{array}$ & $\begin{array}{l}\text { CAR- } \\
\text { BONATE } \\
\text { (CO3) } \\
\text { (MG/L) }\end{array}$ \\
\hline $\begin{array}{l}\mathrm{OCT} . \\
07 . . .\end{array}$ & 1000 & 14900 & -- & -- & - & -- & - & -- & $=-$ & 48 & 0 \\
\hline $\begin{array}{l}\text { NOV. } \\
\text { O3... } \\
\text { JAN. }\end{array}$ & 1010 & 5350 & 4.7 & 50 & -- & 12 & 4.2 & 8.1 & 1.7 & 55 & 0 \\
\hline $\begin{array}{c}12 \ldots \\
\text { FEB. }\end{array}$ & 1010 & 1760 & 5.7 & 50 & -- & 6.5 & 2.6 & 6.1 & 1.0 & 37 & 0 \\
\hline MAR... & 0955 & 8500 & 7.0 & 110 & -- & 10 & 3.1 & 6.0 & 1.7 & 40 & 0 \\
\hline${ }_{A P R}^{24 \ldots}$ & 1000 & 114000 & 4.2 & 80 & 20 & 7.6 & 2.2 & 3.4 & 1.1 & 32 & 0 \\
\hline JUNE & 0940 & 40400 & 5.3 & 80 & 20 & 10 & 3.0 & 3.6 & .7 & 41 & 0 \\
\hline $\operatorname{dut}_{\text {Ju }}$ & 0955 & 12600 & 5.7 & 60 & 8 & 10 & 3.2 & 3.8 & 1.5 & 44 & 0 \\
\hline $\begin{array}{l}13 . . \\
\text { AUG. }\end{array}$ & 1600 & 3740 & 6.1 & 30 & 42 & 10 & 3.6 & 4.8 & 1.4 & 44 & 0 \\
\hline $\begin{array}{l}19 . . \\
\text { SEPT. }\end{array}$ & 1100 & 8540 & 6.1 & 2 & 34 & 9.3 & 2.9 & 4.9 & 1.5 & 41 & 0 \\
\hline $14 \ldots$ & 0915 & 6980 & 8.7 & 140 & 20 & 3.9 & 1.3 & 3.4 & 1.2 & 22 & 0 \\
\hline DATE & $\begin{array}{l}\text { SULFATE } \\
\text { (504) } \\
\text { (MG/L) }\end{array}$ & $\begin{array}{l}\text { CHLO- } \\
\text { RIDE } \\
\text { (CL) } \\
\text { (MG/L) }\end{array}$ & $\begin{array}{l}\text { FLUO- } \\
\text { RIDE } \\
\text { (F) } \\
\text { (HG/L) }\end{array}$ & $\begin{array}{l}\text { NITRATF } \\
\text { (NO3) } \\
\text { (MG/L) }\end{array}$ & $\begin{array}{l}\text { DIS- } \\
\text { SOLVED } \\
\text { SOLIDS } \\
\text { IRESI- } \\
\text { DUE AT } \\
\text { I80 CI } \\
\text { IMG IL) }\end{array}$ & $\begin{array}{l}\text { DIS- } \\
\text { SOLVED } \\
\text { SOLIOS } \\
\text { ISUM OF } \\
\text { CONSTI- } \\
\text { TUENIS) } \\
\text { (MGLL) }\end{array}$ & $\begin{array}{l}\text { OIS- } \\
\text { SOLVED } \\
\text { SOLIDS } \\
\text { (TONS } \\
\text { PER } \\
\text { AC-FT) }\end{array}$ & $\begin{array}{l}\text { HARD- } \\
\text { NESS } \\
\text { (CA,MG) } \\
\text { (MG/1) }\end{array}$ & $\begin{array}{l}\text { NON- } \\
\text { CAR- } \\
\text { BONATE } \\
\text { HARD- } \\
\text { NESS } \\
\text { (MG/L) }\end{array}$ & $\begin{array}{l}\text { SPECI- } \\
\text { FIC } \\
\text { CONO- } \\
\text { UCTANCF } \\
\text { (MICRO- } \\
\text { MHOS) }\end{array}$ & (UNITS) \\
\hline
\end{tabular}

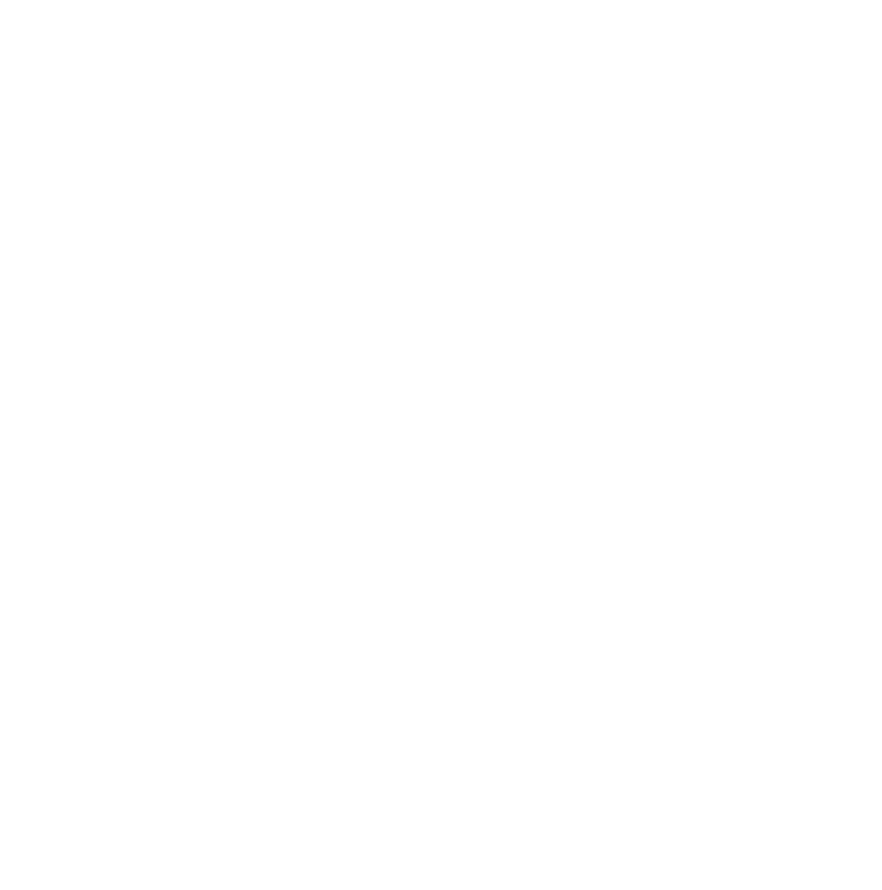


02423000 alabama river at selma, ala.

LOCATION.-- Lat $32^{\circ} 24^{\prime} 20^{\prime \prime}$, long $87^{\circ} 01^{\circ} 07^{\prime \prime}$, in $\mathrm{SE} \frac{1}{4}$ sec.36, T.17 N., R.10 E., Dallas County, temperature recorder at gaging station in first pler from right bank of Edmund pettus Bridge on U.S. Highway $80,1 \mathrm{n}$ Selma, $1 \mathrm{mile}$ up-
stream from Valley Creek, and at mile 214.8 .

DRAINAGE AREA.--17,000 sq mi, approximately.

PERIOD OF RECORD.--Chemical analyses: October 1965 to September 1967, October 1967 to September 1968 (miscellane-

ous), August 1969 to September 1970 .
Water temperatures: October 1955 to November 1956, June 1962 to september 1970.

EXTRENES, - -1969-70:

Water temperatures: Minimum, $8.0^{\circ} \mathrm{C}$ Jan. $24-27$.

Period of record:

Water temperatures: Maximum, $30.0^{\circ} \mathrm{C}$ Aug. 6,1963 , Aug. 16-19, 1966, July $7-9,1969 ;$ minimum, $6.0^{\circ} \mathrm{C}$ Jan, 29 to Feb. 1, 1963, Jan, 2-5, 16-20, 1964

REMARKS.--Recorder malfunction June 11 to sept. 30.

CHEMICAL ANALYSES, WATER YEAR OCTOBER 1969 TO SEPTEMBER 1970

\begin{tabular}{|c|c|c|c|c|c|c|c|c|c|c|c|}
\hline DATE & TIME & $\begin{array}{l}\text { DIS- } \\
\text { CHARGE } \\
\text { (CFS) }\end{array}$ & $\begin{array}{l}\text { SILICA } \\
\text { (SIDZ) } \\
\text { (MG/L) }\end{array}$ & $\begin{array}{l}\text { OIS- } \\
\text { SOLVED } \\
\text { IRON } \\
\text { (FE) } \\
\text { (UG/L) }\end{array}$ & $\begin{array}{l}\text { DIS- } \\
\text { SOLVED } \\
\text { MAN- } \\
\text { GANESE } \\
\text { (MN) } \\
\text { (UG/L) }\end{array}$ & $\begin{array}{l}\text { CAL- } \\
\text { CIUM } \\
\text { (CA) } \\
\text { (MGIL) }\end{array}$ & $\begin{array}{l}\text { MAG- } \\
\text { NE- } \\
\text { SIUM } \\
\text { (MG) } \\
\text { (MG/L) }\end{array}$ & $\begin{array}{l}\text { SOOIUM } \\
\text { (NA) } \\
(N G / L)\end{array}$ & $\begin{array}{l}\text { PO- } \\
\text { TAS- } \\
\text { SIUM } \\
(\mathrm{K}) \\
(M G / L)\end{array}$ & $\begin{array}{l}\text { BICAR- } \\
\text { BDNATE } \\
\text { (HCD3) } \\
(M G / L)\end{array}$ & $\begin{array}{l}\text { CAR- } \\
\text { BDNATE } \\
\text { (CO3) } \\
\text { (MG/L I }\end{array}$ \\
\hline OCT. & & & & & & & & & & & \\
\hline & 0945 & 6320 & 4.4 & 80 & - & 13 & 3.0 & 10 & 1.5 & 54 & 0 \\
\hline $\begin{array}{l}\text { OA... } \\
\text { JAN. }\end{array}$ & 1035 & 13400 & 5.6 & 150 & -- & 12 & 3.3 & 10 & 2.0 & 53 & 0 \\
\hline MAR... & 1025 & 22900 & 3.8 & 100 & $\cdots$ & 12 & 3.2 & 6.1 & 1.6 & 47 & 0 \\
\hline $\begin{array}{l}03 \ldots \\
\triangle P R .\end{array}$ & 0800 & 13200 & 5.3 & $12 \mathrm{c}$ & -- & 13 & 3.2 & 5.7 & 1.4 & 47 & 0 \\
\hline$\underset{\text { MAY }}{07 . .}$ & 0930 & 44700 & 7.2 & 130 & 20 & 9.5 & 2.3 & 3.4 & 1.3 & 34 & 0 \\
\hline$\underset{\text { JUNE }}{12 \ldots}$ & 0910 & 13700 & 6.9 & 120 & 30 & 9.4 & 3.0 & 4.2 & 1.2 & 39 & 0 \\
\hline $\operatorname{suc}_{\text {jur }}^{10}$ & 0830 & 17700 & 6.6 & $14 \mathrm{C}$ & 42 & 8.7 & 2.5 & 4.6 & 1.3 & 34 & 0 \\
\hline $\begin{array}{l}13 \ldots . . \\
\text { AUG. }\end{array}$ & 1045 & 11900 & 7.8 & 90 & 33 & 8.8 & 3.1 & 7.3 & 1.5 & 40 & 0 \\
\hline $31 \ldots$ & 0930 & 13400 & 6.5 & 108 & 40 & 8.6 & 2.6 & 6.0 & 1.8 & 38 & 0 \\
\hline & & CHLO- & FLUO- & & $\begin{array}{l}\text { OIS- } \\
\text { SDLVED } \\
\text { SOL IDS } \\
\text { GRESI- }\end{array}$ & $\begin{array}{l}\text { OIS- } \\
\text { SOLVEO } \\
\text { SOLIOS } \\
\text { SUM OF }\end{array}$ & $\begin{array}{l}\text { DIS- } \\
\text { SOLVEO }\end{array}$ & HARD- & $\begin{array}{l}\text { NON- } \\
\text { CAR- } \\
\text { BONAIE }\end{array}$ & $\begin{array}{l}\text { SPFCI- } \\
\text { FIC } \\
\text { COND- }\end{array}$ & \\
\hline & $\begin{array}{l}\text { SULFATE } \\
\text { (SD4) }\end{array}$ & $\begin{array}{l}\text { RIOE } \\
\text { (CL) }\end{array}$ & $\begin{array}{l}\text { RIDE } \\
\text { (F) }\end{array}$ & $\begin{array}{l}\text { NITRATE } \\
\text { (NO3) }\end{array}$ & $\begin{array}{ll}\text { DUE AT } \\
180 \mathrm{Cl}\end{array}$ & $\begin{array}{l}\text { CONST I- } \\
\text { TUENTSI }\end{array}$ & $\begin{array}{l}\text { ITONS } \\
\text { PER }\end{array}$ & $\begin{array}{l}\text { NESS } \\
\text { (CA, MG) }\end{array}$ & $\begin{array}{l}\text { HAR D- } \\
\text { NESS }\end{array}$ & $\begin{array}{l}\text { UCTANCE } \\
\text { (MICRO- }\end{array}$ & PH \\
\hline DATE & $(M G / L)$ & $(M G / L)$ & $(M G / L)$ & (MG/L) & $(M G / L)$ & $(M G / L)$ & $A(-F T)$ & $(M G / L)$ & $(M G / L)$ & MHOSI & IUNITSI \\
\hline
\end{tabular}

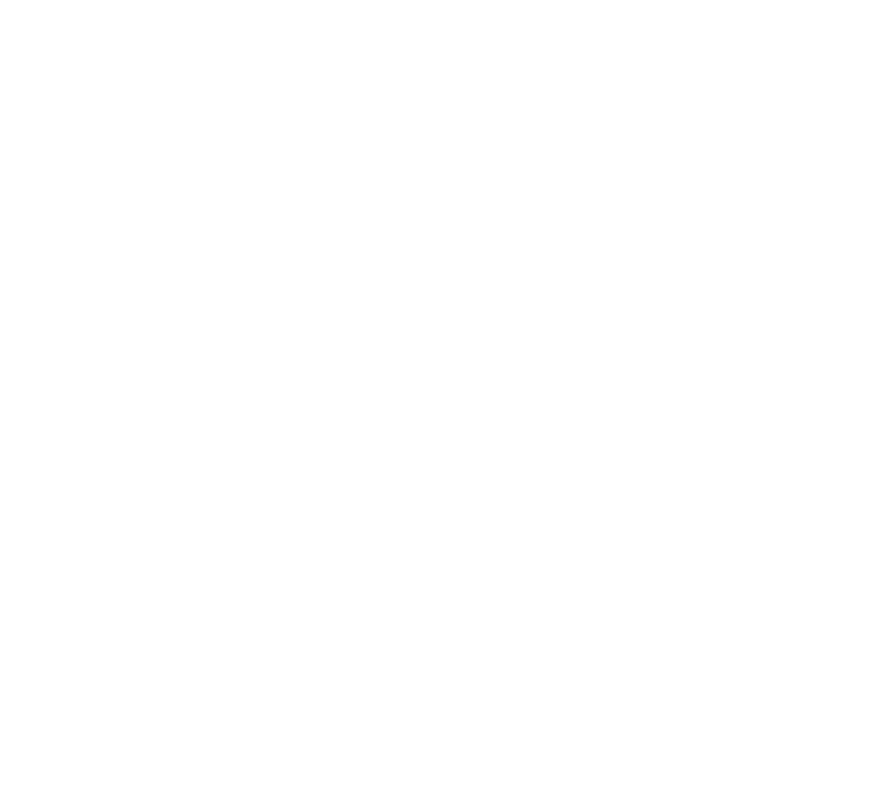


MOBILE RIVER BASIN

02423000 aLABAMA RIVER AT SELMA, ALA.--Continued

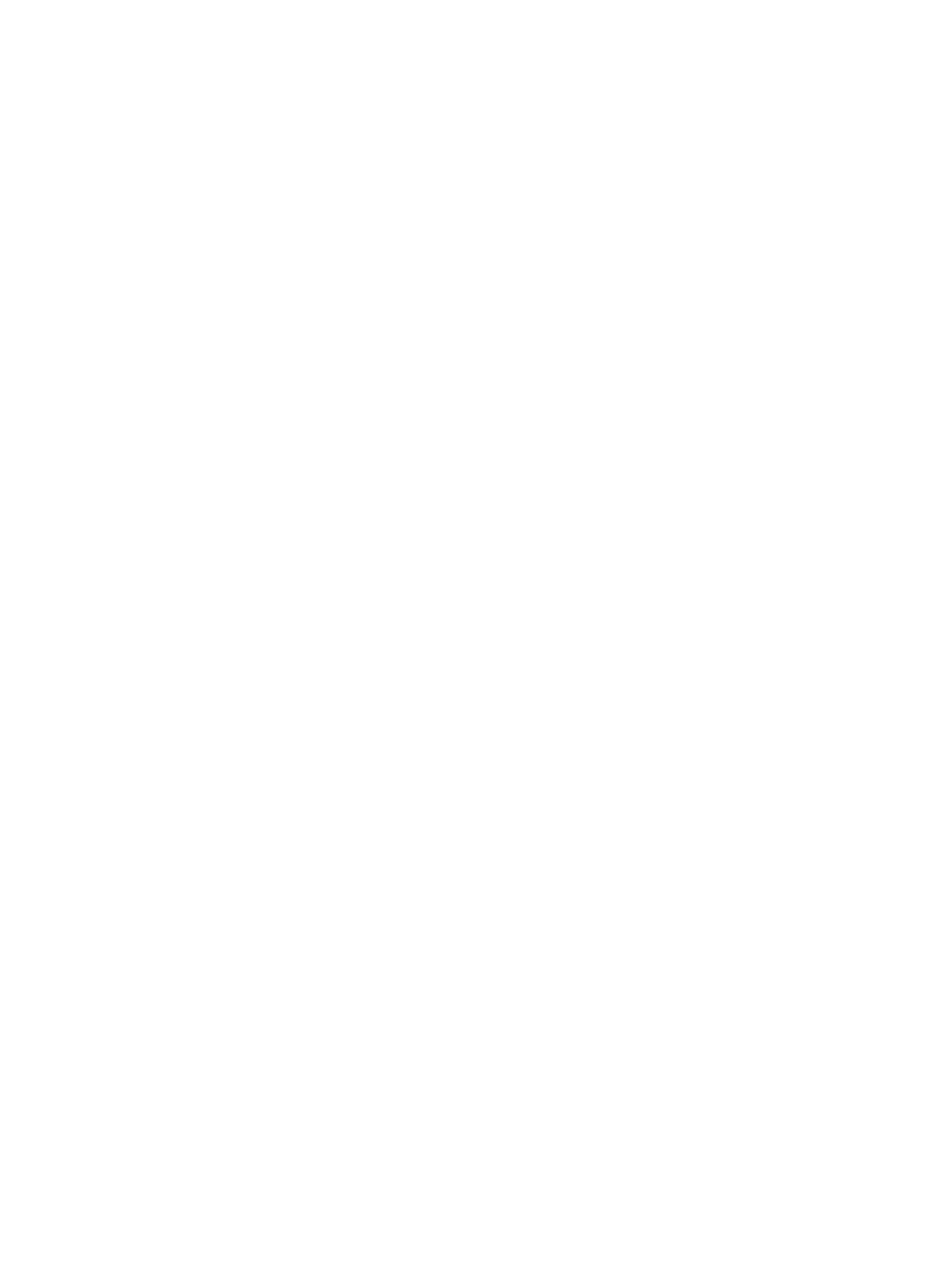


LOCATION, .- Lat $33^{\circ} 19^{\prime} 34^{\prime \prime}$, long $86^{\circ} 56^{\prime} 59^{\prime \prime}$, in wec.3, T.20 S., R.4 W., Jefferson County, at gaglng station near left bank on downstréam side of bridge on county road, 1.4 miles southwest of Greenwood, and 5.5 miles south of Bessemer.

DRAINAGE AREA, -- $72.4 \mathrm{sq} \mathrm{ml}$.

PERIOD OF RECORD.--Chem1cal analyses: October 1966 to September 1967, October 1968 to September 1970 (m1scellane.

water temperatures: October 1969 to september 1970.

EXTREMES. - - 1969-70:

water temperatures: Maximum, $27.0^{\circ} \mathrm{C}$ Aug. 4-7; min1mum, $2.5^{\circ} \mathrm{C} \operatorname{Jan}, 9,10$.

CHEMICAL ANALYSES, WATER YEAR OCTOBER 1969 TO SEPTEMBER 1970

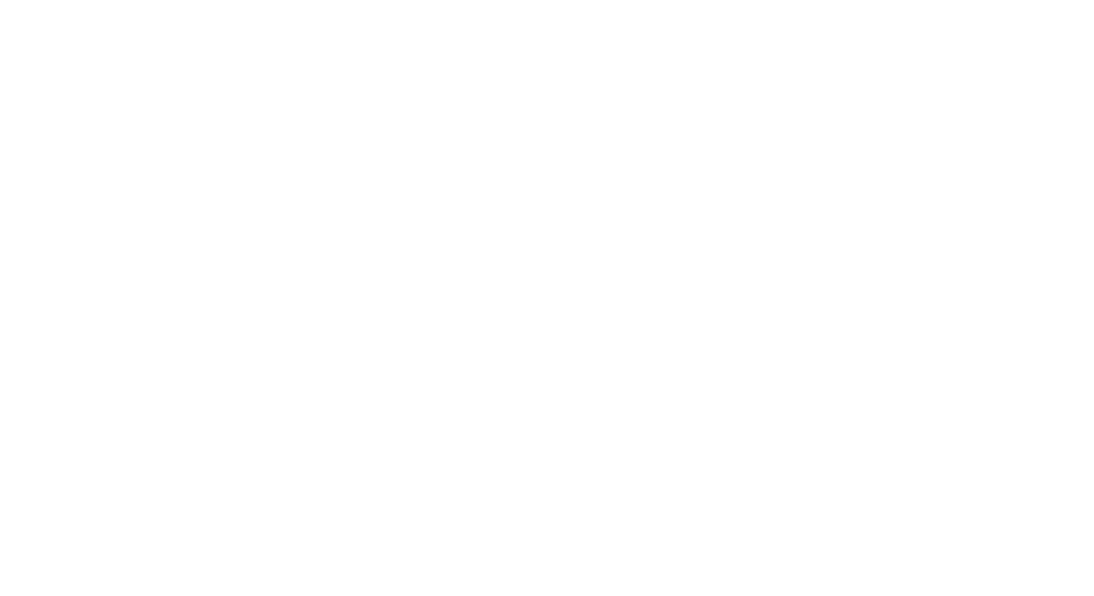


02423630 SHADES CREEK NEAR GREENWOOD, ALA...-Continued

TEMPERATURE $\left({ }^{\circ} \mathrm{C}\right)$ OF WATER, WATER YEAR OCTOBER 1969 TO SEPTEMBER 1970

NEC

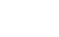


02429000 LIMESTONE CREEK NEAR MONROEVILLE, ALA.

LOCATION, .-Lat $31^{\circ} 34^{\prime} 45^{\prime \prime}$, long $87^{\circ} 21^{\prime} 06^{\prime \prime}$, In NE $\frac{1}{4}$ sec.22, T.7 N., R.7 E., Monroe County, temperature recorder at gaglag station near left bank on downstream side of pier of bridge on State Highway 41,3 miles northwest of
uonroeville, and 10 miles upstream from mouth.

DRAINAGE AREA. $--117 \mathrm{sq} \mathrm{mi}$. PERIOD OF RECORD.--Chemical analyses: October 1968 to September 1969 (miscellaneous), October 1965 to September 1967.
Water temperatures: February 1963 to September 1970 .

EXTREMES, --1969-70:

Water temperatures: Maximum, $25.0^{\circ} \mathrm{C}$ July 20, 21, Sept. 7, 8; min1mum, 1. $0^{\circ} \mathrm{C}$ Jan, 10.

Perlod of record:

Water temperatures: Maximum, $27.0^{\circ} \mathrm{C}$ June 15,1963 , June $23-25,1969$; minimum, $1.0^{\circ} \mathrm{C} \mathrm{Jan}, 10,1970$.

TEMPERATURE ( ${ }^{\circ} \mathrm{C}$ ) OF WATER, WATER YEAR OCTOBER 1969 TO SEPTEMBER 1970

\begin{tabular}{|c|c|c|c|c|c|c|c|c|c|c|c|c|}
\hline \multirow[t]{2}{*}{ nAY } & \multicolumn{2}{|c|}{$n \in T$} & \multicolumn{2}{|c|}{ NTW } & \multicolumn{2}{|c|}{$13+1$} & \multicolumn{2}{|c|}{$1 \Delta W$} & \multicolumn{2}{|c|}{ rRR } & \multicolumn{2}{|c|}{$M A R$} \\
\hline & $M \Delta X$ & MIN. & Ni $\Delta x$ & MIN & $M A X$ & $M_{1} I N$ & $M \Delta x$ & HIN & $M \Delta x$ & $N_{1} \mid A_{l}$ & $\max$ & $M T M$ \\
\hline 1 & 19.5 & 18.0 & $1 \% .0$ & 15.0 & 7.5 & 5.5 & 10.5 & a.h & A. 5 & 7.5 & 17.0 & 0.5 \\
\hline ? & 19.0 & 18.0 & $1 \mathrm{~A} .0$ & $15 . n$ & 7.0 & 6.5 & R. 5 & 4.5 & 11.0 & A. 5 & 12.5 & 11.0 \\
\hline 3 & 19.5 & 18.5 & 15.0 & 13.0 & 7.0 & 0.0 & 7.0 & $7 . n$ & 11.0 & $7 . \overline{5}$ & $1+0$ & 12.0 \\
\hline 4 & 19.5 & 19. ก & 13.0 & 11.5 & 7.0 & 5.5 & 7.0 & 5.0 & 7.5 & $n .0$ & 13.0 & $12 . n$ \\
\hline 5 & 19.5 & 19.5 & 11.5 & 10.0 & h. 0 & $4 \cdot 5$ & 6.0 & 9.5 & 7.0 & 9.0 & 14.0 & $1 ?$. \\
\hline A & $2 n .0$ & 20.0 & 10.5 & 9.5 & 7.0 & 5.0 & 7.0 & $n \cdot n$ & 7.5 & 4.5 & 14.0 & 17.5 \\
\hline 7 & 20.5 & 20.0 & 17.11 & 10.5 & $a . n$ & 7.0 & 7.0 & 4.5 & 8.0 & +.5 & 14.0 & $11 . n$ \\
\hline a & 20.5 & 20.4 & 14.5 & 12.0 & 9.0 & 8.0 & 4.5 & 2.5 & +.5 & 7.5 & 11.0 & 11.01 \\
\hline 9 & 20.5 & 20.0 & 14.0 & 12.5 & R. त & 7.0 & 2.5 & 3.5 & 9.4 & 4.0 & 12.0 & 10.0 \\
\hline 10 & $>1.0$ & 20.5 & 13.5 & 11.0 & a. 5 & 2.0 & 2.0 & $1 . n$ & 9.5 & n. & 12.0 & 11.0 \\
\hline 11 & 21.0 & 21.0 & 11.0 & 10,0 & 9.5 & R. & 4.0 & 2.0 & 9.5 & 7.5 & 12.0 & 12.51 \\
\hline $1 ?$ & 22.0 & $21 . n$ & 13.4 & 11.0 & 0.5 & 7.0 & $A \cdot b$ & 4.0 & a.h & 8.5 & 12.4 & $1 \because 11$ \\
\hline 13 & 22.0 & 21.5 & 27.5 & 12.7 & 7.0 & 5.5 & 7.0 & 4.5 & R. 5 & $x .5$ & 12.0 & 0.4 \\
\hline 14 & 22.01 & 18.0 & 12.5 & 9.5 & 7.5 & 5.5 & 7.0 & 5.5 & 4.5 & 7.5 & 9.5 & 7.4 \\
\hline 15 & 19.0 & $1+.0$ & 9.5 & 7.0 & 7.5 & h. 0 & 2.0 & $n .5$ & $1 \cdot 0$ & 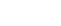 & 11.6 & 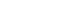 \\
\hline $1 \mathrm{~A}$ & 16.0 & 15.0 & 7.5 & $h .5$ & A. 5 & h. 5 & 9.0 & a. & 12.4 & 10.5 & $10 . n$ & 8.0 \\
\hline 17 & 15.5 & 15.0 & 9.0 & 7.0 & $x .5$ & 5.0 & 10.0 & $9 . \pi$ & $100^{2}$ & 4.5 & 11.0 & 4.5 \\
\hline $1^{\text {R }}$ & 15.0 & 14.0 & $1>n$ & 9.5 & $h .0$ & 5.0 & 10.5 & $10 . n$ & 11.0 & 4.5 & 14.0 & 11.0 \\
\hline 10 & 15.5 & 14.5 & 13.5 & 10.5 & 0.0 & +.0 & 10.5 & . 0 & 17.0 & 11.5 & ln.on & 14.6 \\
\hline 20 & 18.5 & 15.5 & 10.5 & ${ }^{R} \cdot n$ & 0.0 & $R .0$ & 9.0 & $7 . n$ & 12.0 & 10.0 & $1+.0$ & 15.1 \\
\hline 21 & 19.5 & 18.5 & 2.5 & 0.5 & 9.5 & $r .0$ & 7.0 & 5.5 & $1 \cap .0$ & 7.5 & 14.01 & 12.0 \\
\hline $2 ?$ & 10.5 & $1 R \cdot 5$ & 8.0 & $n .5$ & 9.5 & 8.5 & 5.5 & 4.5 & a.n & $7 . n$ & 12.14 & 11. \\
\hline 23 & $1^{R} \cdot 5$ & $1 \mathrm{~h} .0$ & 0.9 & 7.5 & 8.5 & 7.0 & 7.0 & h. 5 & 10.0 & 0.0 & 11.4 & u. \\
\hline$? 4$ & ik.n & 15.0 & 10.5 & 9.5 & 7.0 & 6.5 & 7.0 & $h . n$ & 10.5 & $10 . n$ & 14.0 & 11.0 \\
\hline 25 & 14.5 & 15.0 & 11.5 & $\ln \cdot 4$ & 4.0 & 7.0 & 9.5 & 7.0 & 11.0 & 10.5 & 14.5 & 17.0 \\
\hline $2 h$ & 16.5 & $1 \mathrm{~A} \cdot \mathrm{n}$ & 11.5 & 11.5 & 0.0 & x.5 & $1=n$ & 0. & 30.5 & a.h & $1+.4$ & 14.6 \\
\hline 27 & $1 \mathrm{~h} \cdot \mathrm{h}$ & $1 \kappa .0$ & 11.5 & 11.5 & 8.5 & $n .5$ & 12.0 & 11.4 & a. - & 7.4 & $1, n$ & $1+.11$ \\
\hline 28 & 26.5 & 15.5 & 11.5 & 11.5 & 10.0 & 7.5 & 13.2 & 11.5 & 30.0 & a. 0 & 14.0 & 12.1 \\
\hline$? 0$ & 15.5 & 14.5 & 11.5 & 9.5 & $1 ?$ & 10.0 & 14.5 & 13.4 & - & -- & 14.5 & $1+.11$ \\
\hline 30 & 15.0 & 14.5 & 7.5 & 7.0 & 15.0 & 12.5 & 34.4 & 10.5 & -+ & -- & 15.5 & $14 . n$ \\
\hline 31 & 15.0 & 14.5 & -- & -- & 14.0 & 10.5 & 10.5 & 7.5 & -- & -- & $3 \cap .5$ & 11.5 \\
\hline$\Delta \vee f_{1}$ & $1^{8} .3$ & 17.4 & 11.7 & 10.1 & 8.5 & 7.0 & 8.7 & 3. 7 & 4.7 & 8.1 & 13.3 & 11.4 \\
\hline \multirow[t]{2}{*}{ TAY } & \multicolumn{2}{|c|}{$\triangle P R$} & & & & & & & & & & \\
\hline & $M A X$ & $M I N$ & MAS & $M I N$ & $M A X$ & MTN & $M A X$ & MT & $x+x$ & $M T H$ & $M A X$ & $\cdots$ \\
\hline 1 & 34.5 & $1 \mathrm{k} .5$ & 73.5 & 21.0 & 20.5 & 10.5 & $27 \cdot 5$ & 20.0 & $74 . n$ & 24.0 & 24.0 & $\because x^{5}$ \\
\hline$\frac{7}{3}$ & 17.5 & 16.5 & 20 & 20.5 & 30.4 & 20.0 & 27.5 & $p \cdot n$ & 34.13 & 34.0 & 24.17 & 27.11 \\
\hline 3 & 16.5 & 13.5 & 20.7 & 19.4 & $>0.0$ & 14.7 & $x .4$ & $>4.5$ & 24.0 & $x \cdot n$ & 24.13 & 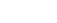 \\
\hline $\begin{array}{l}4 \\
5\end{array}$ & $1 \mathrm{~h} .0$ & $2^{7} .5$ & 18.5 & $1 \mathrm{Hoh}$ & 10.5 & $1 R_{0}=5$ & $2 n \cdot n$ & $=2.0$ & $x_{i}+n$ & $2 \cdot 0$ & 24.11 & 34.6 \\
\hline $\begin{array}{l}5 \\
h\end{array}$ & $1 \mathrm{~K} .5$ & in. 0 & 17.5 & $1 \mathrm{sec}$ & 14.5 & 19.0 & $23 . n$ & 21.5 & 24.0 & J"r. & $2 / 4 \cdot h$ & $\because$. . \\
\hline h & 15.5 & 15.0 & 17.4 & 17.0 & 19. & 18.4 & 22.5 & 330 & 24.0 & 34.11 & $74 .-$ & 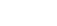 \\
\hline 7 & 17.5 & 15.0 & 1 . .5 & 17.5 & 18.5 & 18.0 & $2+00$ & 37.0 & 24.7 & 24.16 & in. & 24.4 \\
\hline R & 17.0 & 15.0 & 10.0 & $1 \times \cdot b$ & 19.4 & 18.5 & 24.17 & 13. & 24.11 & 24.5 & $=5.0$ & 24061 \\
\hline 9 & 17.5 & $1 \mathrm{k}=0$ & 19.5 & 14.0 & $19 . n$ & 19.5 & 23.4 & 73.0 & 34.8 & 22.5 & 34.0 & $2=0$ \\
\hline 10 & 17.5 & 17.0 & 19.5 & 10.5 & 14.5 & 14.0 & 24.0 & 33.0 & 24.4 & 22.4 & 34.11 & 74. \\
\hline 11 & 17.0 & Ifan & 20.0 & 10.5 & 19.5 & $19 . n$ & $?+.5$ & 74.0 & 34.7 & 3.5 & $7 a,{ }^{2}$ & $2+.0$ \\
\hline $\begin{array}{l}1 ? \\
13\end{array}$ & 18.0 & $1+.5$ & 20.0 & 20.0 & 20.0 & 19.5 & 24.5 & 23.0 & $2^{2} \cdot 5$ & $\therefore e^{6}$ & $x a^{n}$ & $x$ \\
\hline 13 & $I^{8} \cdot 5$ & 17.0 & $>r .4$ & $20.0^{\circ}$ & 20.5 & $>7.0$ & 24.0 & $>2 . n$ & 27.4 & 22.4 & 30.4 & $>4.5$ \\
\hline 14 & 10.0 & TA.O & $20 .{ }^{\circ}$ & 70.5 & 21.0 & 70.5 & $2+.0$ & $22 . n$ & 34.5 & $27 .=$ & 24.6 & 20.4 \\
\hline 15 & 18.5 & 17.0 & 20.5 & $>0.4$ & 21.5 & 21.0 & $2^{2} \cdot 4$ & 24.0 & 23. & 3.4 & $34 . h$ & $?^{x} \cdot 0$ \\
\hline is & 17.0 & 17.0 & 20.5 & 20.0 & 21.5 & 21.5 & 24.2 & 73.01 & 3.5 & 13.5 & -4.2 & $2+5$ \\
\hline $\begin{array}{l}17 \\
18\end{array}$ & 17.5 & 17.0 & 20.0 & 14.5 & 22.0 & 21.4 & $24 \cdot 0$ & 23.5 & 24.7 & 27.5 & 24.1 & $?+9$ \\
\hline 19 & $\begin{array}{l}18.5 \\
14.5\end{array}$ & 17.5 & 20.0 & 10.0 & 27.4 & 22.0 & 24.0 & $>2.0$ & 34.11 & 74.0 & 14.5 & 34.0 \\
\hline 20 & $\begin{array}{l}14.5 \\
20.0\end{array}$ & 17.5 & $19 \cdot 5$ & 14.5 & $? ? \cdot h$ & 27.4 & 34.5 & 22.5 & 34.7 & 24.0 & $24 . h$ & 24.11 \\
\hline 21 & 20.0 & $\begin{array}{l}19.5 \\
19.0\end{array}$ & $\begin{array}{l}20.0 \\
20.0\end{array}$ & $\begin{array}{l}19 \cdot 5 \\
20.0\end{array}$ & $\begin{array}{l}?^{2} .0 \\
24.0\end{array}$ & $\begin{array}{l}22.5 \\
2 i .0\end{array}$ & 25.0 & $\begin{array}{l}34.0 \\
24.0\end{array}$ & $\begin{array}{l}24.11 \\
32 .\end{array}$ & $\begin{array}{ll}3: \bar{n} \\
31.5\end{array}$ & $\begin{array}{l}74 . \\
24.0\end{array}$ & $\begin{array}{l}24.0 \\
4.01\end{array}$ \\
\hline 22 & 21.0 & 20.0 & 20.5 & 20.0 & 24.0 & 23.0 & 74.5 & 22.5 & $>2.5$ & 32.4 & $x$ & 94.1 \\
\hline 23 & 21.5 & 21.0 & 23.0 & 20.5 & 74.0 & $2^{2} .5$ & $2+$. & $=2.0$ & 73.4 & 72.5 & $24_{0} \cdot h$ & 34.0 \\
\hline 24 & 21.0 & 21.0 & $>1.0$ & 21.0 & 24.0 & 24.0 & $\because: 0$ & 22.0 & $\because x_{1}$ & $2 \% 5$ & 24.0 & 31.5 \\
\hline 25 & 21.0 & 20.5 & 21.0 & 21.0 & 24.0 & 23.0 & 23.0 & $2 \pi .0$ & $22 \cdot h$ & 23.0 & 24. & $\because$. \\
\hline 24 & 20.5 & 20.5 & 21.0 & 21.0 & 27.0 & 22.5 & $? \cdot 0$ & 3.0 & $\because .0$ & 20.5 & 22.0 & 22.5 \\
\hline$? 7$ & $20 .=$ & 20.5 & 21.0 & 21.0 & 23.0 & 22.4 & 24.5 & $\because 2.0$ & 27.5 & 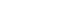 & $23 . n$ & 3 \\
\hline$P R$ & 21.0 & $? 0.5$ & 21.0 & $>1.0$ & 23.5 & 23.0 & 24.0 & 32.4 & 7.5 & $7 ? .1$ & $\Rightarrow 9.5$ & 20.5 \\
\hline$>0$ & 21.4 & 21.0 & $>1.0$ & 21.0 & $? \div .5$ & $\gg 2.4$ & 24.0 & 74.0 & 22.5 & $>20$ & $2 n \cdot h$ & 14.0 \\
\hline 30 & $2 ? \cdot n$ & 31.5 & 21.0 & 21.0 & 22.4 & 22.0 & 24.0 & 24.01 & 24.0 & 23.9 & 10.0 & 11.6 \\
\hline 21 & -- & + & 21.0 & 20.5 & -- & - & 24.01 & 74.0 & $24.7 t$ & 2.0 & & - \\
\hline Ave, & 12.7 & 17.7 & 20.1 & 14.6 & 21.4 & 20.9 & 23.8 & 23.1 & $\therefore \cdot f$ & 23.4 & 73.2 & $?=1$ \\
\hline
\end{tabular}


O242950o ALABANA RIVER AT CLAIBORNE, ALA.
(International Hydrological Decade River Station)

LOCATION,--Lat $31^{\circ} 32^{\prime} 48^{\prime \prime}$, long $87^{\circ} 30^{\prime} 45^{\prime \prime}$, in sec. 25, T.7 N., R.5 E., Monroe County, at gaging station near left bank on downstream side of pier of bridge on U.S. Highway 84 at Claiborne, 0.5 mile downstream from Limestone Creek, 12 miles west of Monroevilie, and at mile 76.1 .

DRAINAGE AREA.--22,000 sq mi, approximate1y.

PERIOD OF RECORD.--Chemical analyses: March 1967 to September 1970. Water temperatures: March 1967 to September 1968.

CHEMICAL ANALYSES, WATER YEAR OCTOBER 1969 TO SEPTEMBER 1970

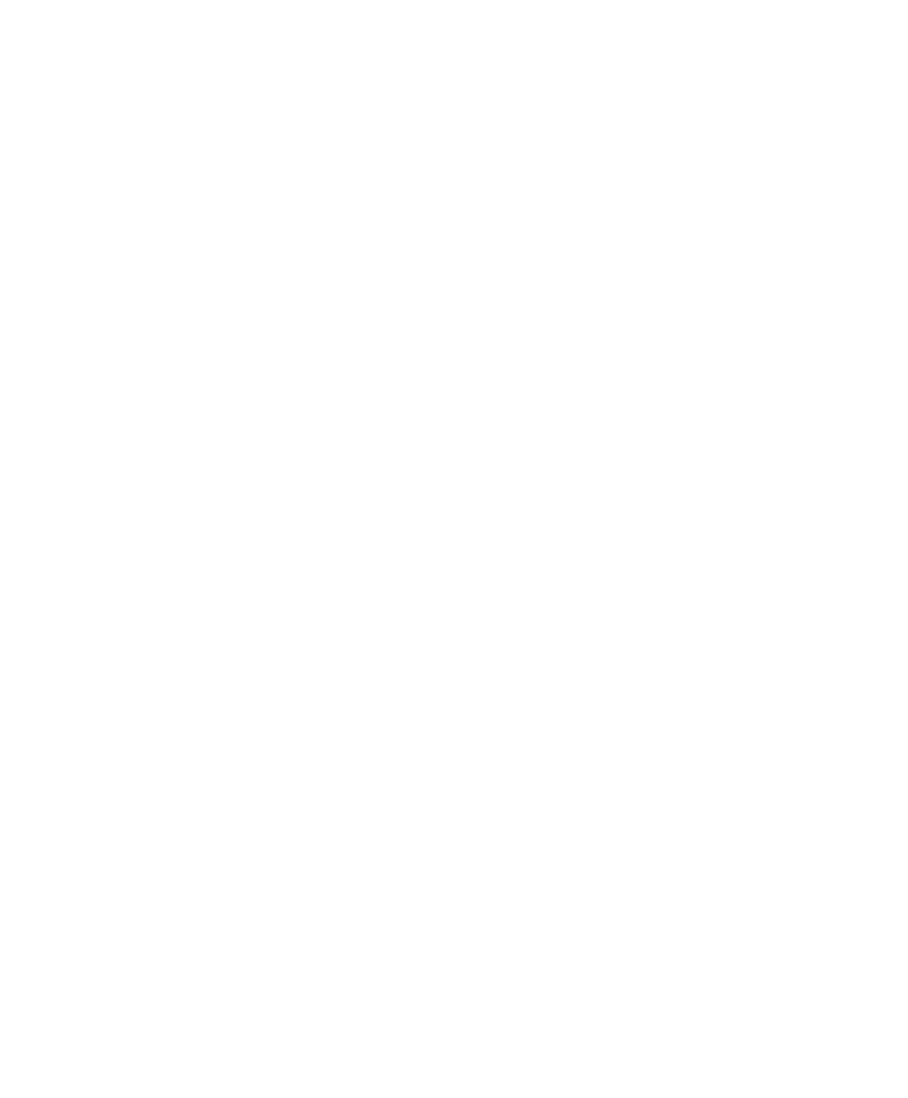


02429500 ALABAHA RIVER AT CLAIBORNE, ALA.--Cont1 nued CHEMICAL ANALYSES, WATER YEAR OCTOBER 1969 TO SEPTEMBER 1970

\begin{tabular}{|c|c|c|c|c|c|c|c|}
\hline & $\begin{array}{l}\text { OIS- } \\
\text { SOLVED } \\
\text { SOLIDS } \\
\text { ITONS } \\
\text { PER }\end{array}$ & $\begin{array}{l}\text { HARO- } \\
\text { NESS } \\
\text { (CA, MG) }\end{array}$ & $\begin{array}{l}\text { NON- } \\
\text { CAR- } \\
\text { BONATE } \\
\text { HARD- } \\
\text { NESS }\end{array}$ & $\begin{array}{l}\text { SPECI- } \\
\text { FIC } \\
\text { CONO- } \\
\text { UCTANCE } \\
\text { IMICRO- }\end{array}$ & $P H$ & $\begin{array}{l}\text { COLI- } \\
\text { FORM } \\
\text { ICOL- } \\
\text { ONIES } \\
\text { PER }\end{array}$ & $\begin{array}{l}\text { FECAL } \\
\text { COLI- } \\
\text { FORM } \\
\text { ICOL. } \\
\text { PER }\end{array}$ \\
\hline DATE & & & & & (UNITS) & $100 \mathrm{~mL} /$ & $100 \mathrm{~mL} J$ \\
\hline $\begin{array}{l}\text { तCT. } \\
22 \ldots . . \\
\text { DEC. }\end{array}$ & .10 & 48 & 0 & 142 & 7.8 & 330 & - \\
\hline $\begin{array}{l}11 \ldots \\
11 \ldots\end{array}$ & $\begin{array}{l}.12 \\
.12\end{array}$ & $\begin{array}{l}51 \\
51\end{array}$ & $\begin{array}{l}0 \\
0\end{array}$ & $\begin{array}{l}148 \\
148\end{array}$ & $\begin{array}{l}7.7 \\
7.7\end{array}$ & 570 & $\because$ \\
\hline $\begin{array}{l}28 \ldots \\
28 \ldots\end{array}$ & .11 & $\begin{array}{l}49 \\
48\end{array}$ & $\begin{array}{l}6 \\
5\end{array}$ & $\begin{array}{l}116 \\
119\end{array}$ & $\begin{array}{l}7.6 \\
7.5\end{array}$ & 570 & 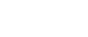 \\
\hline $\begin{array}{l}\text { MAR. } \\
04 \ldots . . \\
04 \ldots \\
\text { APR. }\end{array}$ & .09 & 41 & -1 & 96 & $\begin{array}{r}7.2 \\
-.2\end{array}$ & $50 \overline{0}$ & $=$ \\
\hline $08 \ldots$ & .07 & 39 & $\begin{array}{r}7 \\
--\end{array}$ & $8 B$ & 7.3 & 1600 & $=$ \\
\hline MAY & & & & & & & \\
\hline $\begin{array}{l}13 \ldots \\
\begin{array}{l}13 \ldots \\
\text { JUNE }\end{array}\end{array}$ & $\begin{array}{l}.10 \\
.10\end{array}$ & $\begin{array}{l}41 \\
42\end{array}$ & $\begin{array}{l}2 \\
3\end{array}$ & $\begin{array}{l}103 \\
104\end{array}$ & $\begin{array}{l}7.2 \\
7.1\end{array}$ & 300 & $=$ \\
\hline $11 \ldots$ & .09 & 36 & 6 & 95 & 7.4 & -- & $\sim$ \\
\hline JuLY & $=$ & $\cdots$ & - & -- & -- & -- & - \\
\hline $\begin{array}{l}23 \ldots \\
23 \ldots \\
\text { SEPT. }\end{array}$ & $\begin{array}{l}.10 \\
.10\end{array}$ & $\begin{array}{l}41 \\
41\end{array}$ & $\frac{1}{1}$ & $\begin{array}{l}102 \\
115\end{array}$ & $\begin{array}{l}7.3 \\
7.0\end{array}$ & $\overline{30}$ & $2 \overline{16}$ \\
\hline $02 \ldots$ & .09 & 35 & 1 & 100 & 7.0 & 350 & 10 \\
\hline \multicolumn{8}{|c|}{ FIELD ANALYSES } \\
\hline & DATE & TIME & $\begin{array}{l}\text { OIS- } \\
\text { CHARGE } \\
\text { (CFS) }\end{array}$ & $\begin{array}{l}\text { SPECI- } \\
\text { FIC } \\
\text { COND- } \\
\text { UCTANCE } \\
\text { IMICRO- } \\
\text { MHOSI }\end{array}$ & $\begin{array}{c}\text { PH } \\
\text { [UNITS ] }\end{array}$ & $\begin{array}{l}\text { DIS- } \\
\text { SOLVED } \\
\text { OXYGEN } \\
\text { (MG/L) }\end{array}$ & $\begin{array}{l}\text { TEMP- } \\
\text { ERATURE } \\
\text { (DEG C) }\end{array}$ \\
\hline & $\begin{array}{l}\text { OCT. } \\
22 . . \\
\text { OEC. }\end{array}$ & 1145 & 9540 & 122 & 7.4 & 9.0 & 22.0 \\
\hline & JAN. & 1135 & 22000 & 150 & 7.2 & 12.0 & 11.0 \\
\hline & $\begin{array}{l}28 \ldots \\
28 \ldots \\
\text { MAR. }\end{array}$ & $\begin{array}{l}1125 \\
1230\end{array}$ & $\begin{array}{l}10000 \\
10000\end{array}$ & $\begin{array}{l}119 \\
119\end{array}$ & 7.1 & $\begin{array}{l}14.3 \\
14.3\end{array}$ & $\begin{array}{l}9.0 \\
9.0\end{array}$ \\
\hline & $\begin{array}{l}04 \ldots \\
04 \ldots \\
A P R .\end{array}$ & $\begin{array}{l}1145 \\
1245\end{array}$ & $\begin{array}{l}41000 \\
41000\end{array}$ & $\begin{array}{l}98 \\
98\end{array}$ & $=$ & $\begin{array}{l}11.1 \\
11.1\end{array}$ & $\begin{array}{l}12.5 \\
12.5\end{array}$ \\
\hline & $\begin{array}{l}O B \ldots \\
O B . \ldots\end{array}$ & $\begin{array}{l}0900 \\
1000\end{array}$ & $\begin{array}{l}46700 \\
46700\end{array}$ & $\begin{array}{l}85 \\
85\end{array}$ & $\begin{array}{l}7.0 \\
7.0\end{array}$ & $\begin{array}{l}11.0 \\
11.0\end{array}$ & $\begin{array}{l}15.0 \\
15.0\end{array}$ \\
\hline & $\begin{array}{l}13 \ldots \ldots \\
\text { JUNE }\end{array}$ & $\begin{array}{l}0900 \\
1000\end{array}$ & $\begin{array}{l}15600 \\
15600\end{array}$ & $\begin{array}{l}106 \\
106\end{array}$ & $\begin{array}{l}7.2 \\
7.2\end{array}$ & $\begin{array}{l}10.5 \\
10.5\end{array}$ & $\begin{array}{l}22.5 \\
22.5\end{array}$ \\
\hline & $\begin{array}{l}11 \ldots \\
\text { Juty }\end{array}$ & $\begin{array}{l}1015 \\
1115\end{array}$ & $\begin{array}{l}33900 \\
33600\end{array}$ & $\begin{array}{l}93 \\
93\end{array}$ & $\begin{array}{l}7.2 \\
7.2\end{array}$ & $\begin{array}{l}7.1 \\
7.1\end{array}$ & $\begin{array}{l}23.0 \\
23.0\end{array}$ \\
\hline & $\begin{array}{l}23 \ldots \\
23 \ldots \\
23 \ldots\end{array}$ & $\begin{array}{l}1023 \\
1600 \\
1700\end{array}$ & $\begin{array}{l}16500 \\
16400 \\
16400\end{array}$ & $\begin{array}{l}-\overline{-} \\
113\end{array}$ & $\begin{array}{l}-\overline{-} \\
7.2 \\
7.2\end{array}$ & $\begin{array}{l}8 . \overline{8} \\
8.8\end{array}$ & $\begin{array}{l}28.0 \\
29.0 \\
29.0\end{array}$ \\
\hline & $\begin{array}{l}\text { SEPT. } \\
02 \ldots \\
26 \ldots\end{array}$ & $\begin{array}{l}0830 \\
1455\end{array}$ & 8930 & 106 & 7.0 & 9.2 & $\begin{array}{l}26.0 \\
24.0\end{array}$ \\
\hline
\end{tabular}


02444500 TOMBIGBEE RIVER NEAR COCHRANE, ALA.

LOCATION.--Lat $33^{\circ} 04^{\prime} 45^{\prime \prime}$, long $88^{\circ} 44^{\prime} 18^{\prime \prime}$, in sec.7, T. 24 N., R. 2 W., Pickens County, at gaging station near left bank on downstream side of bridge on State Highway $17,200 \mathrm{ft}$ upstream from Alabama, Tennessee and Northern Railroad bridge, 1.2 mtles northeast of Cochrane, 2.2 miles downstream from Boguechitto Creek, 7 miles southwest of Aliceville, and at mile 271.4 .

DRAINAGE AREA.--5,990 sq mi, approximately.

PERIOD OF RECORD.--Chemical analyses: October 1966 to September 1969 (miscellaneous), October 1969 to September 1970.

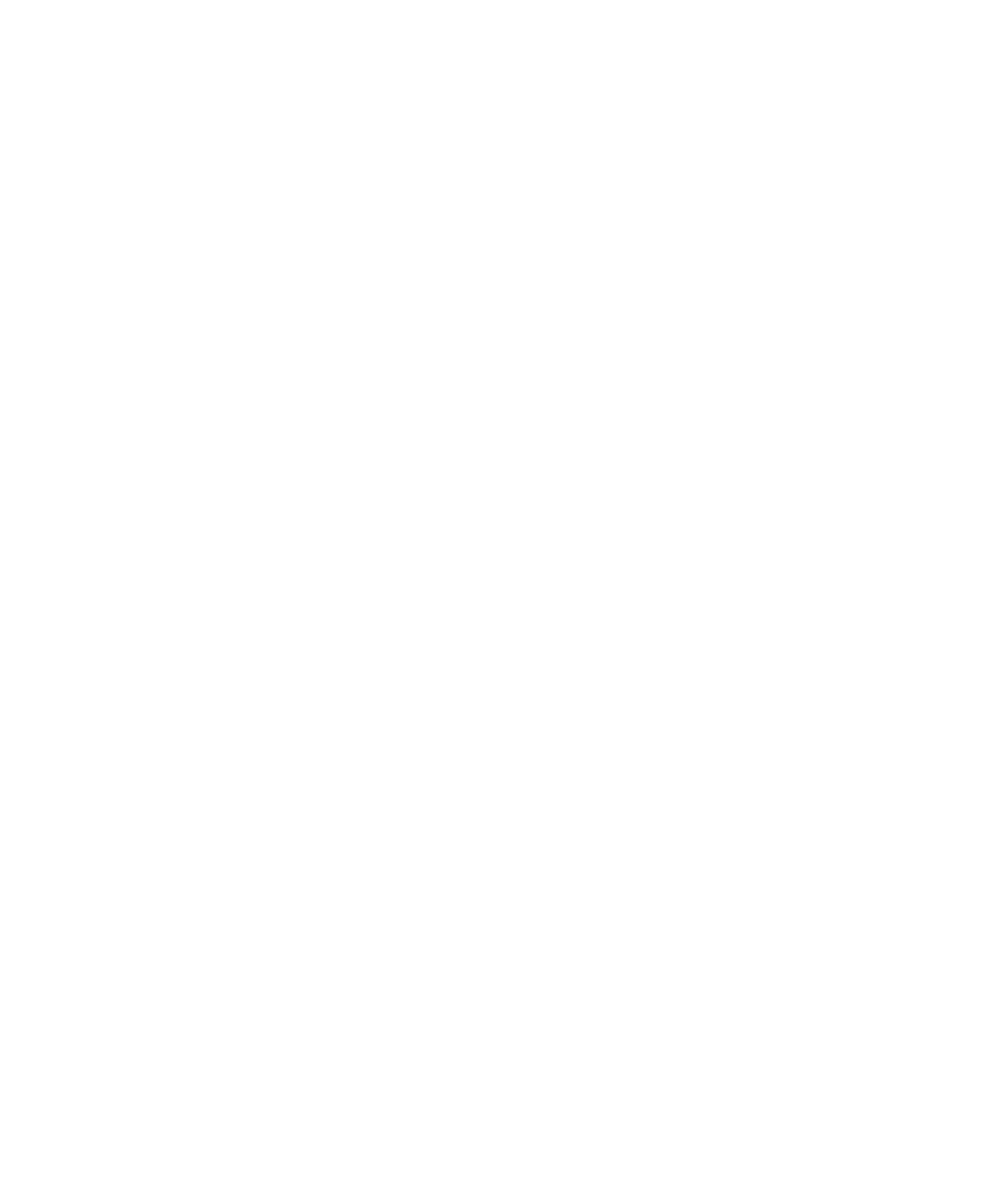


02449000 TONBIGBEE RIVER AT GAINESVILLE, ALA.

LOCATION, .. Lat $32^{\circ} 49^{\circ} 30^{\prime \prime}$, long $88^{\circ} 09^{\prime} 24^{\prime \prime}$, in SE $\frac{1}{4}$ sec.2, T.21 N., R.2 w., Sumter County, temperature recorder at gaging station on downstream side of right bank pier of bridge on State Highway 39 at Gainesville, 2 miles downstream from Noxubee River, and at mile 234.4 .

DRAI NAGE AREA. - - 8,700 sq $\mathrm{m} t$, approximately.

PERIOD OF RSCORD.--Chemical analyses: October 1966 to September 1967, October 1967 to September 1968 (miscellane. ous).

Water temperatures: October 1962 to September 1970.

\section{EXTREMES. - - 1969-70}

Water temperatures: Minimum, $2.5^{\circ} \mathrm{C}$ Jan. $13-15$.

Period of record:

Water temperatures: Maximum, $34.0^{\circ} \mathrm{C} \mathrm{July} \mathrm{11,} 1969 ;$ minimum, $2.0^{\circ} \mathrm{C}$ Feb. $1,1966$.

REMARKS,.--Recorder malfunction April 1-20, May 12-June 1, July 23-Sept. 5, Sept. 10-14.

TEMPERATURE $\left({ }^{\circ} \mathrm{C}\right)$ OF WATER, HATER YEAR OCTOBER 1969 TO SEPTEMBER 1970

\begin{tabular}{|c|c|c|c|c|c|c|c|c|c|c|c|c|}
\hline \multirow{3}{*}{ DAY } & \multirow{2}{*}{\multicolumn{2}{|c|}{ ח T }} & \multirow{2}{*}{\multicolumn{2}{|c|}{$\begin{array}{l}\text { NORATURE } \\
\text { NOT }\end{array}$}} & \multirow{2}{*}{\multicolumn{2}{|c|}{$\begin{array}{l}\text { HER, WATE } \\
\text { UIFr }\end{array}$}} & \multirow{2}{*}{\multicolumn{2}{|c|}{$\begin{array}{c}\text { IOSER } 1989 \text { TOM } \\
\text { IAi, }\end{array}$}} & \multirow{2}{*}{\multicolumn{2}{|c|}{ FFE }} & \multirow{2}{*}{\multicolumn{2}{|c|}{ MAF }} \\
\hline & & & & & & & & & & & & \\
\hline & $M \Delta X$ & $M I N$ & $M \Delta x$ & $M I N$ & $M \Delta X$ & MIN & $m \angle x$ & MIIS & $M \Delta X$ & 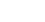 & $M A x$ & MTII \\
\hline 1 & 23.5 & 22.0 & 15.5 & 15.5 & 9.0 & 0.0 & 6.0 & 6.0 & 4.5 & 9.5 & 4.5 & $a . r$ \\
\hline$?$ & $? ? .0$ & 21.5 & 15.5 & 15.0 & 9.0 & 0.0 & n. & h. & 9.5 & +0 & 10.2 & 9.4 \\
\hline 3 & 23.0 & 21.5 & 15.0 & 14.0 & 9.0 & 8. 5 & 6.0 & 5.5 & 4.5 & a. 5 & 17.0 & 10.5 \\
\hline 4 & $33 . n$ & 21.5 & 14.0 & 13.0 & g.h & 9.0 & $n .5$ & $\therefore n$ & 2.5 & $1 . n$ & 13.5 & $110 \Rightarrow$ \\
\hline 5 & 23.0 & 23.0 & 13.0 & 17.5 & $R \cdot 0$ & 7.0 & $n$ & 5.0 & 1.0 & $n$ & $1>4$ & 10. \\
\hline h & $23 . n$ & 22.0 & 12.5 & 12.0 & 7.0 & 4.0 & 5.0 &.$- n$ & A. & $4 . h$ & $1<.0$ & 12.4 \\
\hline 7 & 27.0 & $?>0$ & $17 . n$ & 17.0 & h. 0 & R. 0 & .0 & 4.4 & 5.5 & h. & 12.0 & $i ? .7$ \\
\hline a & 27.0 & 21.5 & 12.5 & 12.0 & $n .0$ & 6. 0 & 5.0 & $4 . n$ & h. & n. & 12.5 & 13.4 \\
\hline 9 & 31.5 & $>1.0$ & $1=0$ & 12.5 & 6.3 & A. 0 & 4.0 & 3.5 & $\ldots h$ & n. 5 & 130 & 11.7 \\
\hline 10 & 21.5 & $>3,0$ & 13.0 & 13.61 & t. & A.u & $3 . F_{5}$ & 1.0 & 7.0 & $A=5$ & 31.5 & 11.2 \\
\hline 11 & 21.0 & 21.0 & 13.0 & 13.0 & 6.0 & 6.0 & 3.0 & 2.0 & 7.1 & 7.0 & 12.4 & 11.5 \\
\hline 1) & 21.5 & 21.0 & 13.0 & 13.0 & h. 0 & +.0 & $3 . n$ & 3.0 & 8.0 & 7.0 & 17.0 & $1<0$ \\
\hline 13 & 71.5 & 21.0 & 12.5 & 19.0 & 5.0 & 6.0 & 3.1 & 25 & 40 & $7.6^{4}$ & 12.1 & 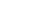 \\
\hline 14 & 21.0 & 19.5 & 17.5 & 12.0 & 6.3 & R. 0 & $=n$ & 2.5 & $x \cdot n$ & 7.5 & 17.4 & $1 \ldots h$ \\
\hline 15 & 19.5 & $1 R .0$ & 12.0 & 10.5 & h. 0 & 6. 0 & $x \cdot n$ & 2.5 & 4.0 & $8 . n$ & $1>0$ & 11.5 \\
\hline 16 & 19.0 & 18.0 & 10.5 & 10.0 & $\kappa .0$ & 6.0 & 2.5 & x.? & 4.0 & a. n & 11.4 & 11.4 \\
\hline 17 & $1 \% .0$ & 17.5 & 10.0 & 10.0 & $n .0$ & h. 0 & 4.4 & 3.5 & $0 . r$ & . 1 & 11.7 & 11.7 \\
\hline $1 R$ & 17.4 & 17.0 & 11.0 & 10.0 & n. 0 & R.O & . & 4.5 & 9.0 & 9.0 & 11.5 & 11.2 \\
\hline 19 & 17.0 & 17.0 & 11.0 & 11.0 & t. .3 & +.5 & $+\cap 0$ & $\Rightarrow h$ & 4.5 & $a^{\prime}$ & 13.4 & 11.3 \\
\hline 20 & 17.0 & 17.0 & 11.0 & 10.0 & 0.0 & $\circ .0$ & R. II & h. & 4.0 & 9.11 & $1<.0$ & 17.4 \\
\hline 21 & $1^{A} .0$ & 17.0 & 10.0 & 9.5 & 6. 0 & 5.5 & 0.0 & h.n & 9.0 & 9.0 & 14.0 & 14.0 \\
\hline 22 & 18.0 & 17.5 & 4.5 & 9.5 & 5.5 & 5.5 & $n .0$ & 5.5 & +0 & 4.0 & 14.0 & 13.4 \\
\hline 73 & 18.0 & 17.0 & 9.5 & 9.0 & 5.5 & 4.0 & 5.5 & 5.5 & 9.0 & 8.5 & 17.6 & 12.5 \\
\hline 24 & 17.0 & 1 h. 5 & 9.0 & 9.0 & 5.0 & 5.0 & n. 5 & $5 . n$ & 4.5 & r. & 12.4 & $1 ? . h$ \\
\hline 25 & $1 \mathrm{k} .5$ & 14.5 & 9.0 & 9.0 & 5.0 & 4.0 & 4.5 & 5.0 & 10.0 & 4.4 & 17.4 & 17.4 \\
\hline $2 h$ & 16.5 & 16.0 & 9.0 & 9.0 & 5.0 & 5.0 & 4.5 & 5.5 & 17.0 & 9.4 & 13.2 & 17.5 \\
\hline$? 7$ & $1 h .5$ & 16.0 & $4 \cdot 5$ & 9.0 & 5.0 & 4.0 & 7.5 & h. 5 & 4.5 & 0.0 & 13.4 & $1+.4$ \\
\hline 29 & $1 h .5$ & $1 \mathrm{~A} .3$ & 10.0 & 9.5 & 4.0 & 4.0 & $x .5$ & $7 . h$ & $a \cdot n$ & 9.0 & $13^{2} \cdot 4$ & $1+, n$ \\
\hline 29 & $1 \mathrm{h.5}$ & 16.0 & 10.0 & 9.5 & 4.5 & 4.0 & 4.5 & 9.5 & - & -- & 14.0 & 12 \\
\hline 30 & $1+.0$ & 15.5 & 10.0 & $0 . n$ & - .0 & 4.4 & $\theta$ & 9.5 & -- & -- & 34.0 & 14.0 \\
\hline 31 & 15.5 & 15.5 & $\cdots$ & -- & h. 0 & h. 0 & 4.4 & 4.5 & -- & -- & 14.0 & $1<n$ \\
\hline$\Delta V \sigma_{0}$ & 19.4 & 18.8 & 11.6 & 11.2 & h. $\}$ & 5.0 & 5.4 & 5.0 & 8.4 & 7.4 & 12.5 & $1>.1$ \\
\hline \multirow[t]{2}{*}{ TAY } & & & & & & & & & & & & \\
\hline & $M \Delta x$ & MIN & $M \Delta x$ & MIN & $M A X$ & $M 1 \mathrm{~N}$ & $\operatorname{Max}$ & MIN & $M \Delta x$ & $\times 1$. & $M A X$ & M1म \\
\hline 1 & -- & -- & 22.0 & 21.5 & -- & -- & 24.5 & $>8.0$ & - & $\ldots$ & -- & - \\
\hline 2 & -- & -- & 21.4 & 21.5 & 24.0 & $2+.5$ & 79.5 & $2 R .5$ & -- & -- & -- & - \\
\hline 3 & -- & -- & $? 1.5$ & 21.0 & 23.5 & 24.0 & $2 n .0$ & 24.5 & -- & -- & -- & -- \\
\hline 4 & -- & -- & 21.0 & $2 n .5$ & 23.0 & 23.0 & 30.5 & $3 n .0$ & -- & -- & - & -- \\
\hline 5 & -- & -- & 20.5 & 20.0 & 73.5 & 23.5 & in. 5 & 20.5 & -- & -- & - & -- \\
\hline 6 & -- & -- & 20.0 & 19.5 & 23.5 & 27.5 & 79.5 & $>8.5$ & -- & -- & 17.0 & 35.6 \\
\hline 7 & -- & -- & 19.5 & 10.0 & $? ? .5$ & 22.5 & 29.5 & $>A .5$ & $\cdots$ & -- & 30.11 & $3(1.0)$ \\
\hline के & -- & -- & 14.0 & 19.0 & 27.5 & 22,5 & $29 . n$ & 78.5 & -- & -- & 30.0 & $30 . n$ \\
\hline 9 & -- & -- & 19.5 & 19.0 & 23.0 & 22.5 & 28.5 & PR. O & -- & -- & $3 n . n$ & 20.0 \\
\hline 10 & -- & -- & $>0.0$ & 19.5 & 27.5 & 27.5 & 79.0 & 28.5 & -- & -- & -- & -- \\
\hline 11 & -- & -- & $>1.0$ & $>0.0$ & 79.4 & 22.5 & 29.5 & 29.0 & -- & -- & -- & -- \\
\hline 17 & -- & -- & -- & -- & 22.5 & 23.5 & 79.5 & 20.4 & -- & -+ & -- & $-\infty$ \\
\hline 13 & -- & -- & -- & -- & $><.5$ & 27.3 & 20.0 & 24.4 & -- & -- & - & $\cdots$ \\
\hline 14 & -- & -- & -- & -- & 25.5 & 24.5 & 30.0 & 30.0 & -- & -- & -- & -- \\
\hline 15 & -- & -- & -- & -- & 25.5 & 25.5 & 30.0 & 79.4 & -- & -- & 70.7 & $=4.5$ \\
\hline is & -- & -- & -- & -- & 26.0 & $2 n .5$ & $3 n \cdot n$ & 30.0 & -- & -- & 74.0 & 28.4 \\
\hline 17 & -- & -- & -- & -- & 27.0 & $2 h .0$ & 30.0 & 30.0 & - & - & 29.0 & 70.0 \\
\hline 19 & -- & -- & -- & - & $2 R \cdot 0$ & 27.0 & 30.0 & $70 . n$ & - & -- & 34.0 & 30.0 \\
\hline 19 & - & -- & -- & -- & $2 R .0$ & $2^{R} \cdot 0$ & 30.0 & 24.5 & -- & -- & 20.0 & 20.0 \\
\hline 20 & -- & -- & -- & -- & 29.0 & 27.5 & 70.5 & 74.5 & -- & -- & 79.0 & 20.01 \\
\hline 21 & 20.0 & 20.0 & -- & -- & 28.0 & 28.0 & 29.5 & 27.0 & -- & -- & 29.0 & $>0.0$ \\
\hline 22 & 20.0 & 20.0 & -- & - & $2^{a} .0$ & $2 A .0$ & $27 . n$ & 24.5 & -- & -- & 20.0 & 79.0 \\
\hline 23 & 20.0 & 20.0 & - & - & 20.0 & $29 . b$ & -- & -- & -- & -- & 34.0 & 70.0 \\
\hline 24 & 20.5 & 20.0 & -- & -- & 29.0 & 29.0 & - & -- & -- & -- & $3 n .0$ & 20.0 \\
\hline 25 & 20.5 & 20.5 & $\cdots$ & -- & 29.0 & $2^{A} \cdot 5$ & -- & -- & -- & -- & 29.0 & 240.0 \\
\hline 26 & 20.5 & 20.5 & -- & -- & $P R .5$ & 28.0 & -- & -- & - & -- & 28.0 & 3.0 \\
\hline 27 & 20.5 & 20.5 & -- & -- & $28 . h$ & $2^{R} .5$ & -- & -- & -- & -- & $2 x \cdot n$ & 2,0 \\
\hline$? 8$ & 30.5 & 20.5 & -- & -- & 29.5 & $2^{R} .0$ & -- & -- & -- & -- & 37.0 & 24.0 \\
\hline 79 & 21.0 & 20.5 & -- & -- & $2^{\mu} \cdot 5$ & 28.0 & -- & - & -- & -- & 24.0 & 24.0 \\
\hline 30 & 21.5 & 21.0 & -- & -- & 28.5 & 29.0 & -- & -- & -- & $-\infty$ & $>4 . n$ & 21.11 \\
\hline 31 & $\sim$ & -- & -- & -- & - & - & -- & -- & -- & -- & -. & -- \\
\hline AVG & -- & -- & -- & -- & $2 h .0$ & 25.5 & -- & -- & -- & -- & -- & -- \\
\hline
\end{tabular}


02450250 SIPSEY FORK NEAR GRAYSON, ALA.

(Hydrolog1c bench-mark station)

LOCATION.--Lat $34^{\circ} 17^{\prime} 07^{\prime \prime}$, long $87^{\circ} 23^{\prime} 56^{\prime \prime}$, in N $\frac{1}{2}$ sec.8, T.9 S., R. 8 W., winston County, at gaging stat1on 0.1 m1le downstream from bridge on Cranal Road, 0.5 mile downstream from Borden Creek, $4.5 \mathrm{~m} 1 \mathrm{les}$ west of $\mathrm{Grayson}$, and 14 m1les nor theast of Hayleville.

DRAI NAGE AREA. $--91.3 \mathrm{sq} \mathrm{m} 1$.

PERIOD OF RECORD...-Chemical analyses: October 1966 to september 1970.

CHEMICAL ANALYSES, WATER YEAR OCTOBER 1969 TO SEPTEMBER 1970

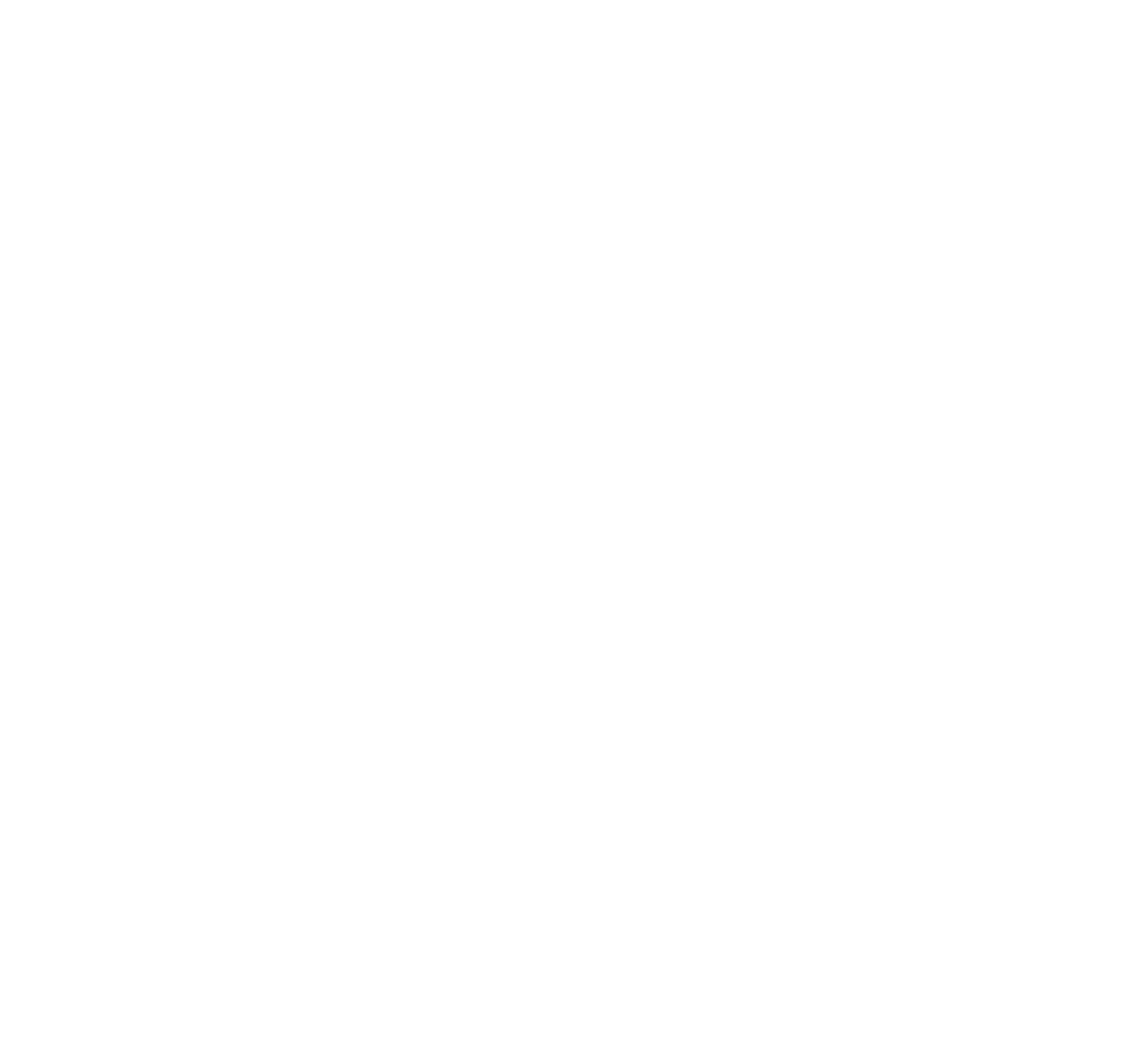

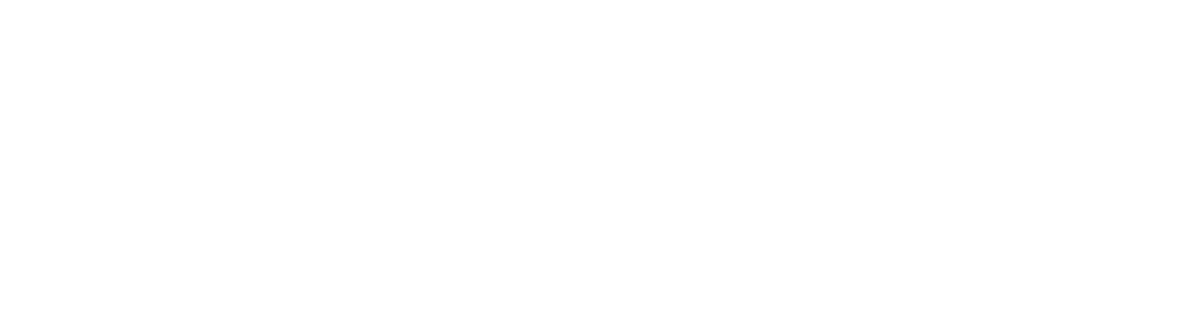

SUSPENDED-SEDIMENT DISCHARGE MEASUREMENTS, WATER YEAR OCTOBER 1969 TO SEPTEMBER 1970

\begin{tabular}{|c|c|c|c|c|c|c|c|c|c|c|c|}
\hline & & & & CONCEN- & $\begin{array}{l}\text { SUSPENDED } \\
\text { SEDIMENT }\end{array}$ & & & & & CONCFN- & $\begin{array}{l}\text { SUSPENDED } \\
\text { SEDIMENT }\end{array}$ \\
\hline & & & DISCHARGE & TRAT I DN & DISCHARGE & & & & DISCHARGE & TRATION & DISCHARGE \\
\hline$D C T$ & ${ }_{8,1969}$ & $\begin{array}{l}\text { TIMEE } \\
\text { IIOO }\end{array}$ & $\begin{array}{c}\text { (CFS) } \\
67\end{array}$ & (MG/L) & (TONSIDAY) & FEB & $\begin{array}{l}\text { DATE } \\
11 . . .\end{array}$ & $\begin{array}{l}\text { TIME } \\
1000\end{array}$ & $\begin{array}{l}\text { (CFS) } \\
105\end{array}$ & IMG/L) & (TONS I DAY ) \\
\hline NOV & $12 \ldots \ldots$ & 1055 & 118 & 15 & 4.8 & MAR & $11 \ldots .$. & 1000 & 106 & 1 & .29 \\
\hline OEC & $3 \ldots \ldots$ & 1000 & 22 & 0 & 0 & $A P R$ & $15 \ldots \ldots$ & 1000 & 85 & 20 & 4.6 \\
\hline$O E C$ & $30 \ldots \ldots$ & 1152 & 12200 & 345 & 11400 & MAY & $20 \ldots \ldots$ & 0925 & 29 & 1 &.$O R$ \\
\hline $\begin{array}{l}n \in C \\
D E C\end{array}$ & $30 \ldots \ldots$ & 1330 & 10900 & 424 & 12500 & JUN & $17 \ldots \ldots$ & 1030 & 24 & $\therefore$ & 0 \\
\hline $\begin{array}{l}\text { DEC } \\
\text { DEC }\end{array}$ & $\begin{array}{l}30 \ldots \ldots \\
30 . \ldots .\end{array}$ & $\begin{array}{l}1500 \\
1600\end{array}$ & $\begin{array}{l}10600 \\
10300\end{array}$ & $\begin{array}{l}273 \\
193\end{array}$ & $\begin{array}{l}7810 \\
5370\end{array}$ & $\begin{array}{l}\text { JIIL } \\
\text { AUG }\end{array}$ & $\begin{array}{r}8 \ldots \ldots \\
12 \ldots \ldots\end{array}$ & $\begin{array}{l}1030 \\
0955\end{array}$ & $49^{5 \cdot 3}$ & $\begin{array}{r}0 \\
22\end{array}$ & $\begin{array}{l}0 \\
2.9\end{array}$ \\
\hline$D E C$ & $30 \ldots \ldots$ & 1700 & 9950 & 113 & 3040 & SEP & $10 . \ldots \ldots$ & 1030 & 7.7 & 1 & .02 \\
\hline JAN & $1 \mathrm{~A}, 1970$ & 1040 & 164 & 0 & 0 & & & & & & \\
\hline
\end{tabular}


LOCATION. - Lat $33^{\circ} 12^{\prime} 50^{\prime \prime}$, long $87^{\circ} 34^{\prime} 25^{\prime \prime}$, In SW $\frac{1}{4}$ sec.15, T. 21 S., R. 10 W., Tuscaloosa County, at gaging station near rlght bank on downstream side of pler cf bridge on U.S. Highway 82, in Tuscaloosa, 0.2 mile upstream from Gulf, River, and 127.05 miles upstream from mouth.

DRAINAGE AREA, $-4,828$ sq $\mathrm{m} 1$.

PERIOD OF RECORD, --Chemlcal analyses: October 1965 to September 1970.

water temperatures: November 1960 to September 1970.

EXTREMES, $--1969-70$

Dissolved solids: Maximum, $156 \mathrm{mg} / \mathrm{l}$ Dec. 1-31; minimum, $63 \mathrm{mg} / \mathrm{I}$ May 1-24, 26, 29.

CHEMICAL ANALYSES, WATER YEAR OCTOBER I969 TO SEPTEMBER 1970

\begin{tabular}{|c|c|c|c|c|c|c|c|c|c|c|c|}
\hline OATE & $\begin{array}{l}\text { DIS- } \\
\text { CHARGE } \\
\text { (CFS) }\end{array}$ & $\begin{array}{l}\text { SILICA } \\
\text { ISIO2I } \\
\text { (MGIL) }\end{array}$ & $\begin{array}{l}\text { DIS- } \\
\text { SOLVED } \\
\text { MAN- } \\
\text { GANESE } \\
\text { (MN) } \\
\text { (UGAL) }\end{array}$ & $\begin{array}{l}\text { CAL- } \\
\text { CIUM } \\
\text { (CA) } \\
\text { (MG/L) }\end{array}$ & $\begin{array}{l}\text { MAG- } \\
\text { NF- } \\
\text { SIUM } \\
\text { (MG) } \\
\text { (MG } / L)\end{array}$ & $\begin{array}{l}\text { SODIUM } \\
\text { (NA) } \\
\text { (MG/L) }\end{array}$ & $\begin{array}{l}\text { PO- } \\
\text { TAS- } \\
\text { SIUM } \\
(K) \\
(M G / L)\end{array}$ & $\begin{array}{l}21 N C \\
(Z N) \\
(U G / L)\end{array}$ & $\begin{array}{l}\text { BICAR- } \\
\text { BONATE } \\
\text { (HCD3) } \\
\text { (MG/L) }\end{array}$ & $\begin{array}{l}\text { CAR- } \\
\text { BONATE } \\
\text { (CO3) } \\
\text { (MG/L) }\end{array}$ & $\begin{array}{l}\text { SULFATE } \\
\text { (SO4) } \\
\text { (MG/L) }\end{array}$ \\
\hline${ }_{01-31}^{O C T}$ & 1470 & 4.6 & $\cdots$ & 14 & 6.9 & 20 & 3.0 & -- & 34 & 0 & 69 \\
\hline NOV. & 1510 & 5.7 & - & 11 & 7.3 & 21 & 3.8 & - & 34 & 0 & 68 \\
\hline $\begin{array}{l}01-31 \\
\text { JAN. }\end{array}$ & 5430 & 3.8 & -- & 13 & 6.0 & 24 & 4.2 & -- & 31 & 0 & 77 \\
\hline $012-03$ & $\begin{array}{r}14500 \\
9650\end{array}$ & $\begin{array}{l}7.0 \\
7.7\end{array}$ & $=$ & $\begin{array}{l}13 \\
12\end{array}$ & $\begin{array}{l}7.2 \\
6.4\end{array}$ & $\begin{array}{l}17 \\
13\end{array}$ & $\begin{array}{l}3.8 \\
3.3\end{array}$ & $=-$ & $\begin{array}{l}26 \\
26\end{array}$ & : & $\begin{array}{l}64 \\
53\end{array}$ \\
\hline $04-12$ & 8570 & 7.0 & -- & 13 & 7.2 & 17 & 3.8 & -- & 26 & 0 & 64 \\
\hline $\begin{array}{r}13-21 \\
22-31\end{array}$ & 7700 & 7.7 & -- & 12 & 6.4 & 13 & 3.3 & $=$ & 26 & 0 & 53 \\
\hline $\begin{array}{c}22-31 \\
F E B .\end{array}$ & 12000 & 7.6 & -- & 11 & 5.3 & 9.5 & 2.8 & - & 23 & 0 & 46 \\
\hline $\begin{array}{l}01-07 \\
08-19 \\
20-28\end{array}$ & $\begin{array}{l}8230 \\
3940 \\
4070\end{array}$ & $\begin{array}{l}7.5 \\
7.9 \\
8.3\end{array}$ & $=$ & $\begin{array}{l}9.8 \\
13 \\
14\end{array}$ & $\begin{array}{l}5.2 \\
6.6 \\
7.4\end{array}$ & $\begin{array}{l}10 \\
14 \\
18\end{array}$ & $\begin{array}{l}2.6 \\
2.7 \\
3.1\end{array}$ & $=$ & $\begin{array}{l}18 \\
23 \\
29\end{array}$ & $\begin{array}{l}0 \\
0 \\
0\end{array}$ & $\begin{array}{l}42 \\
63 \\
67\end{array}$ \\
\hline MAR. & & & & & & & & & & & \\
\hline $01-04$ & 8860 & 7.2 & - & 11 & 6.1 & 15 & 1.7 & -- & 21 & 0 & 58 \\
\hline $05-08$ & 11400 & 4.7 & - & 11 & 5.7 & 12 & 1.4 & -- & 20 & 0 & 48 \\
\hline $10 .$. & 5920 & 7.2 & - & 11 & 6.1 & 15 & 1.7 & $\cdots$ & 21 & 0 & 58 \\
\hline $11 \ldots$ & 4790 & 4.7 & - & 11 & 5.7 & 12 & 1.4 & $=$ & 20 & 0 & 48 \\
\hline $12-16$ & 3440 & 7.2 & - & 11 & 6.1 & 15 & 1.7 & -- & 21 & 0 & 58 \\
\hline $17 \ldots$ & 3580 & 5.1 & -- & 14 & 5.5 & 17 & 1.8 & -- & 20 & 0 & 66 \\
\hline $18 \ldots$ & 4470 & 7.2 & -- & 11 & 6.1 & 15 & 1.7 & -- & 21 & 0 & 58 \\
\hline $19 \ldots$ & 87800 & 5.1 & -- & 14 & 5.5 & 17 & 1.8 & -- & 20 & 0 & 66 \\
\hline $20 \ldots$ & 188000 & 5.2 & -- & 9.0 & 4.5 & 4.5 & 1.0 & -- & 18 & 0 & 34 \\
\hline $\begin{array}{l}24-31 \\
\text { APR. }\end{array}$ & 16800 & 5.2 & $\cdots$ & 9.0 & 4.5 & 4.5 & 1.0 & -- & 19 & 0 & 34 \\
\hline $01 \ldots$ & 9510 & 5.2 & -- & 9.0 & 4.5 & 4.5 & 1.0 & -- & 18 & 0 & 34 \\
\hline $02-03$ & 24300 & 7.8 & -- & 7.9 & 4.1 & 6.4 & 1.6 & -- & 18 & 0 & 32 \\
\hline $04-10$ & 12000 & a.1 & -- & 8.0 & 5.0 & 8.9 & 1.8 & -- & 20 & 0 & 38 \\
\hline $11 \ldots$ & 3420 & 9.2 & -- & 11 & 5.5 & 12 & 1.8 & - & 22 & 0 & 53 \\
\hline $12 \ldots$ & 4500 & 8.1 & -- & 8.0 & 5.0 & 9.8 & 1.8 & -- & 20 & 0 & 38 \\
\hline $13 \ldots$ & 3880 & 9.2 & -- & 11 & 5.5 & 12 & 1.8 & -- & 22 & 0 & 53 \\
\hline $14 \ldots$ & $\begin{array}{r}6530 \\
6150\end{array}$ & 8.1 & $=$ & 8.0 & 5.0 & ${ }_{12}^{8.8}$ & 1.8 & $=$ & 20 & $\therefore$ & 38 \\
\hline $\begin{array}{l}15-17 \\
18-19\end{array}$ & $\begin{array}{r}6150 \\
21500\end{array}$ & $\begin{array}{l}9.2 \\
8.1\end{array}$ & $\overline{-}$ & & 5.5 & 12 & 1.8 & -- & 22 & 0 & 53 \\
\hline $\begin{array}{l}18-19 \\
20 .\end{array}$ & 40400 & 8.1 & $\overline{-}$ & 8.0 & 5.0 & 8.8 & 1.8 & -- & 20 & 0 & 38 \\
\hline $20 \ldots$ & $\begin{array}{l}40400 \\
\end{array}$ & 88 & -- & 7.9 & 4.1 & 6.4 & 1.6 & -- & 18 & 0 & 32 \\
\hline $21 \ldots$ & 34900 & 8.1 & -- & 8.0 & 5.0 & 8.8 & 1.8 & - & 20 & 0 & 38 \\
\hline $22-25$ & 19000 & 9.2 & -- & 11 & 5.5 & 12 & 1.8 & -- & 22 & 0 & 53 \\
\hline $26 \ldots$ & 47300 & 8.1 & -- & 8.0 & 5.0 & 8.8 & 1.8 & -- & 20 & 0 & 38 \\
\hline $27 \ldots$ & 74700 & 7.5 & -- & & 3.4 & 5.0 & 1.6 & -- & 16 & 0 & - \\
\hline MAY 280 & 34500 & 7.8 & -- & 7.9 & 4.1 & 6.4 & 1.6 & -- & 18 & 0 & 32 \\
\hline ol-24 & 7190 & 8. 1 & -. & 0.6 & 3.3 & 5.6 & 1.3 & -- & 18 & 0 & 25 \\
\hline $25 \ldots$ & 1380 & 7.4 & -- & 7.5 & 3.4 & 7.8 & 1.6 & -- & 22 & 0 & 28 \\
\hline $26 \ldots$ & 1840 & 8.1 & -- & 6.6 & 3.3 & 5.6 & 1.3 & - & 18 & 0 & 25 \\
\hline $27-28$ & 1580 & 7.4 & -- & 7.5 & 3.4 & 7.8 & 1.6 & -- & 22 & 0 & 28 \\
\hline $29 \ldots$ & 2160 & 8.1 & -- & 0.6 & 3.3 & 5.6 & 1.3 & -- & 18 & 0 & 25 \\
\hline $\begin{array}{l}30-31 \\
\text { JUNE }\end{array}$ & 2600 & & $\cdots$ & & 3.4 & 7.8 & 1.6 & -- & 22 & 0 & 28 \\
\hline $01-06$ & 12700 & 11 & -- & 7.2 & 3.2 & 7.0 & 1.4 & -- & 29 & 0 & 19 \\
\hline $07-10$ & & & -- & 8.4 & 3.8 & 0.5 & 1.8 & -- & 24 & 0 & 35 \\
\hline $11 \ldots$ & 3290 & 7.7 & -- & 8.5 & 4.4 & 14 & 2.2 & -- & 24 & 0 & - \\
\hline $12-16$ & 3280 & 7.0 & -- & 13 & 6.0 & 18 & 2.8 & - & 30 & 0 & 63 \\
\hline $17-29$ & 3110 & 8.6 & -- & 12 & 5.9 & 20 & 3.1 & -- & 34 & 0 & 63 \\
\hline $\begin{array}{l}30 \\
\text { JULY }\end{array}$ & 2240 & 7.0 & -- & 13 & 6.0 & 18 & 2.8 & -- & 30 & 0 & 63 \\
\hline $01-02$ & 4920 & 7.0 & -- & 13 & 0.0 & 18 & 2.8 & -. & 30 & 0 & 63 \\
\hline $03-31$ & 2320 & 8.4 & -- & 13 & 6.4 & 16 & 2.7 & -- & 35 & 0 & 59 \\
\hline AUG, & & & & & & & & .- & & & \\
\hline $1 I-20$ & $\begin{array}{l}4110 \\
2450\end{array}$ & $\begin{array}{l}5.1 \\
5.3\end{array}$ & $\begin{array}{r}50 \\
4\end{array}$ & $\begin{array}{l}13 \\
12\end{array}$ & $\begin{array}{l}6.9 \\
6.3\end{array}$ & $\begin{array}{l}16 \\
13\end{array}$ & $\begin{array}{l}3.1 \\
3.0\end{array}$ & $\overline{-}$ & $\begin{array}{l}33 \\
30\end{array}$ & 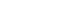 & $\begin{array}{l}63 \\
53\end{array}$ \\
\hline $21-29$ & 2100 & 6.1 & -- & 12 & 0.6 & 13 & 3.2 & - & 22 & 0 & $\begin{array}{l}53 \\
59\end{array}$ \\
\hline $30-31$ & 3370 & 8.6 & 120 & 8.9 & 4.5 & 8.0 & 2.4 & - & 30 & 0 & $\begin{array}{l}59 \\
27\end{array}$ \\
\hline SEPT. & & & & & & & & & & & \\
\hline $\begin{array}{l}01-02 \\
03-30\end{array}$ & $\begin{array}{l}3660 \\
1670\end{array}$ & $\begin{array}{l}7.8 \\
6.1\end{array}$ & 20 & 11 & 6.2 & 12 & 3.0 & 50 & 27 & 0 & 54 \\
\hline & 1070 & 0.1 & 20 & 14 & 7.7 & 16 & 3.9 & 30 & 35 & 0 & 64 \\
\hline IME & -- & 6.8 & -- & 9.6 & 4.8 & 9.1 & 1.7 & -- & 20 & 0 & 43 \\
\hline ONS & 7206 & 6.7 & -- & 12 & 6.0 & 15 & 2.8 & -- & 28 & 0 & 56 \\
\hline R OAY & -- & 125 & -- & 184 & 94 & 204 & 40 & -- & 416 & 0 & 828 \\
\hline
\end{tabular}


EXTREMES, 1969-70,--Continued

Hardaess: Maximum, $67 \mathrm{mg} / 1$ Sept. 3-30; minimum, $30 \mathrm{mg} / 1 \mathrm{Apr} .27$, May 1-24, $26,29$.

Specific conductance: Maximum dally, 267 micromhos Dec. 16; minimum daily, 93 micromhos May 6.

, $31.0^{\circ} \mathrm{C}$ Aus, $16, \mathrm{minimum}, 5.5^{\circ} \mathrm{C} \mathrm{Feb}, 5$

Period of record:

Dissolved Solids (1966-70): Maximum, $150 \mathrm{mg} / 1 \mathrm{Dec} .1-31,1969 ;$ minimum, $49 \mathrm{mg} / 1 \mathrm{Jan} .13-17,1968$.

Hardness (1966-70): Maximum, $8 \mathrm{mg} / 1$ July 14-15, 1969; minimum, $24 \mathrm{mg} / 1$ Jgh, 13-17, 1968

Specific conductance (1966-70): Kaximum daily, 277 micromhos July 15, 1969; minimum daily, 78 micromhos Jan. 14,

2ter temperatures: Maximum, $35.0^{\circ} \mathrm{C}$ Aug. 6, 1963; minimum, 5. $0^{\circ} \mathrm{C}$ Jan. 30, 31, Dec, 25, 1963, Jan, 31, Feb, 1,

CHEMICAL ANALYSES, hATER YEAR OCTOBER 1969 TO SEPTEMBER 1970

\begin{tabular}{|c|c|c|c|c|c|c|c|c|c|c|}
\hline DATE & $\begin{array}{l}\text { CHLO- } \\
\text { R(DE } \\
(\mathrm{CL}) \\
(\mathrm{MG} / \mathrm{L})\end{array}$ & $\begin{array}{l}\text { FLUD- } \\
\text { RIDE } \\
\text { (F) } \\
\text { (MG/L) }\end{array}$ & $\begin{array}{l}\text { NITRATE } \\
\text { (ND3) } \\
\text { (MGIL) }\end{array}$ & $\begin{array}{l}\text { DIS- } \\
\text { SDLVED } \\
\text { SOLIDS } \\
\text { (RESI- } \\
\text { DUE AT } \\
\text { IBOC) } \\
\text { (MG IL) }\end{array}$ & $\begin{array}{l}\text { DIS- } \\
\text { SOLVED } \\
\text { SDLIDS } \\
\text { (SUM OF } \\
\text { CONSTI- } \\
\text { TUENTS) } \\
\text { (MGNL) }\end{array}$ & $\begin{array}{l}\text { DIS- } \\
\text { SOLVED } \\
\text { SOLIDS } \\
\text { (TONS } \\
\text { PER } \\
\text { AC-FT) }\end{array}$ & $\begin{array}{l}\text { HARD- } \\
\text { NESS } \\
\text { (CA,MG) } \\
\text { (MG/L) }\end{array}$ & $\begin{array}{l}\text { NON- } \\
\text { CAR- } \\
\text { BONATE } \\
\text { HARD- } \\
\text { NESS } \\
\text { IMG LLI }\end{array}$ & $\begin{array}{l}\text { SPECI- } \\
\text { FIC } \\
\text { COND- } \\
\text { UCTANCE } \\
\text { (MICRD- } \\
\text { MHOSI }\end{array}$ & $\begin{array}{c}\text { PH } \\
\text { IUNITSI }\end{array}$ \\
\hline $\begin{array}{c}O C T \\
01-31\end{array}$ & 4.6 & .3 & 3.1 & -- & 143 & .19 & 61 & 33 & 235 & 6.8 \\
\hline $\begin{array}{l}\text { NOV. } \\
\text { Ol-30 } \\
\text { DEC. }\end{array}$ & 5.2 & .3 & 4.4 & -- & 144 & .20 & 58 & 30 & 255 & 7.1 \\
\hline $\begin{array}{l}\text { O1-31 } \\
\text { JAN. }\end{array}$ & 5.2 & .5 & 1.4 & 156 & 150 & .21 & 57 & 32 & 247 & 6.7 \\
\hline $\begin{array}{l}01 . . . \\
02-03 \\
04-12 \\
13-21 \\
22-31 \\
F E B .\end{array}$ & $\begin{array}{l}5.0 \\
4.8 \\
5.0 \\
4.8 \\
4.0\end{array}$ & $\begin{array}{l}.2 \\
.3 \\
.2 \\
.3 \\
.2\end{array}$ & $\begin{array}{l}8.0 \\
5.6 \\
8.0 \\
5.6 \\
1.5\end{array}$ & $\begin{array}{l}= \\
z \\
=\end{array}$ & $\begin{array}{r}138 \\
119 \\
138 \\
119 \\
99\end{array}$ & $\begin{array}{l}.19 \\
.16 \\
.19 \\
.16 \\
.13\end{array}$ & $\begin{array}{l}62 \\
56 \\
62 \\
56 \\
49\end{array}$ & $\begin{array}{l}41 \\
35 \\
41 \\
35 \\
30\end{array}$ & $\begin{array}{l}218 \\
187 \\
218 \\
187 \\
154\end{array}$ & $\begin{array}{l}6.7 \\
6.5 \\
6.7 \\
6.5 \\
6.4\end{array}$ \\
\hline $\begin{array}{l}01-07 \\
08-19 \\
20-28 \\
\text { MAR. }\end{array}$ & $\begin{array}{l}4.0 \\
3.2 \\
5.2\end{array}$ & $\begin{array}{r}.2 \\
.3 \\
.3\end{array}$ & $\begin{array}{l}4.5 \\
5.6 \\
6.6\end{array}$ & $=$ & $\begin{array}{r}95 \\
127 \\
144\end{array}$ & $\begin{array}{r}.13 \\
.17 \\
.20\end{array}$ & $\begin{array}{l}46 \\
60 \\
65\end{array}$ & $\begin{array}{l}31 \\
41 \\
41\end{array}$ & $\begin{array}{l}145 \\
187 \\
225\end{array}$ & $\begin{array}{l}6.8 \\
6.6 \\
6.8\end{array}$ \\
\hline $\begin{array}{l}01-04 \\
05-08 \\
10 \ldots \\
11 \ldots . . \\
12-16 \\
17 \ldots \\
18 \ldots . \\
19 \ldots \\
20 \ldots \\
24-31 \\
\text { APR. }\end{array}$ & $\begin{array}{l}4.4 . \\
3.6 \\
4.4 \\
3.6 \\
4.4 \\
4.8 \\
4.4 \\
4.8 \\
2.0 \\
2.0\end{array}$ & $\begin{array}{l}.3 \\
.2 \\
.3 \\
.2 \\
.3 \\
.2 \\
.3 \\
.2 \\
.2 \\
.2\end{array}$ & $\begin{array}{l}4.6 \\
3.6 \\
4.6 \\
3.6 \\
4.6 \\
7.0 \\
4.6 \\
7.0 \\
1.9 \\
1.9\end{array}$ & $\begin{array}{l}119 \\
100 \\
119 \\
100 \\
119 \\
119 \\
-19 \\
69\end{array}$ & $\begin{array}{l}119 \\
100 \\
119 \\
100 \\
119 \\
131 \\
119 \\
131 \\
71 \\
71\end{array}$ & $\begin{array}{l}.16 \\
.14 \\
.16 \\
.14 \\
.16 \\
.18 \\
.16 \\
.18 \\
.09 \\
.09\end{array}$ & $\begin{array}{l}53 \\
48 \\
53 \\
48 \\
53 \\
58 \\
53 \\
58 \\
41 \\
41\end{array}$ & $\begin{array}{l}36 \\
32 \\
36 \\
32 \\
36 \\
42 \\
36 \\
42 \\
26 \\
26\end{array}$ & $\begin{array}{l}204 \\
172 \\
204 \\
172 \\
204 \\
222 \\
204 \\
222 \\
117 \\
117\end{array}$ & $\begin{array}{l}6.9 \\
6.1 \\
6.9 \\
6.1 \\
6.9 \\
7.3 \\
6.9 \\
7.9 \\
5.7 \\
5.7\end{array}$ \\
\hline $\begin{array}{l}01 \ldots . \\
02-03 \\
04-10 \\
11 \ldots \\
12 \ldots \\
13 \ldots \\
14 \ldots \\
15-17 \\
18-19 \\
20 \ldots \\
21 \ldots \\
22-25 \\
26 \ldots \\
27 \ldots \\
28-30 \\
\text { MAY }\end{array}$ & $\begin{array}{l}2.0 \\
2.4 \\
2.6 \\
3.0 \\
2.6 \\
3.0 \\
2.6 \\
3.0 \\
2.6 \\
2.4 \\
2.6 \\
3.0 \\
2.6 \\
2.0 \\
2.4\end{array}$ & $\begin{array}{l}.2 \\
.1 \\
.1 \\
.1 \\
.1 \\
11 \\
.1 \\
11 \\
.1 \\
.1 \\
.1 \\
11 \\
11 \\
.1 \\
.1\end{array}$ & $\begin{array}{l}1.9 \\
2.0 \\
3.1 \\
3.3 \\
3.1 \\
3.3 \\
3.1 \\
3.3 \\
3.1 \\
2.0 \\
3.1 \\
3.3 \\
3.1 \\
2.0 \\
2.0\end{array}$ & $\begin{array}{r}69 \\
74 \\
78 \\
106 \\
78 \\
106 \\
78 \\
106 \\
78 \\
74 \\
78 \\
106 \\
78 \\
74\end{array}$ & $\begin{array}{r}71 \\
73 \\
86 \\
110 \\
86 \\
110 \\
86 \\
110 \\
86 \\
73 \\
86 \\
110 \\
86 \\
7- \\
73\end{array}$ & $\begin{array}{l}.09 \\
.110 \\
.11 \\
.114 \\
.11 \\
.114 \\
.11 \\
.114 \\
.11 \\
.10 \\
.11 \\
.114 \\
.11 \\
.10\end{array}$ & $\begin{array}{l}41 \\
37 \\
41 \\
50 \\
41 \\
50 \\
41 \\
50 \\
41 \\
37 \\
41 \\
50 \\
41 \\
30 \\
37\end{array}$ & $\begin{array}{l}26 \\
22 \\
25 \\
32 \\
25 \\
32 \\
25 \\
32 \\
25 \\
22 \\
25 \\
32 \\
25 \\
17 \\
22\end{array}$ & $\begin{array}{l}117 \\
120 \\
147 \\
168 \\
147 \\
168 \\
147 \\
168 \\
147 \\
120 \\
147 \\
168 \\
147 \\
97 \\
120\end{array}$ & $\begin{array}{l}5.7 \\
6.7 \\
6.7 \\
6.9 \\
6.7 \\
6.9 \\
6.7 \\
6.9 \\
6.7 \\
6.7 \\
6.7 \\
6.9 \\
6.7 \\
6.9 \\
6.7\end{array}$ \\
\hline $\begin{array}{c}\text { MAY } \\
01-24 \\
25 \ldots . . \\
26 \ldots . \\
27-28 \\
29 . \ldots \\
30-3 i\end{array}$ & $\begin{array}{l}2.2 \\
2.8 \\
2.2 \\
2.8 \\
2.2 \\
2.8\end{array}$ & $\begin{array}{l}.1 \\
.2 \\
.1 \\
.2 \\
.1 \\
.2\end{array}$ & $\begin{array}{l}1.6 \\
1.6 \\
1.6 \\
1.6 \\
1.6 \\
1.6\end{array}$ & $\begin{array}{l}63 \\
73 \\
63 \\
73 \\
63 \\
73\end{array}$ & $\begin{array}{l}63 \\
71 \\
63 \\
71 \\
63 \\
71\end{array}$ & $\begin{array}{l}.09 \\
.10 \\
.09 \\
.10 \\
.09 \\
.10\end{array}$ & $\begin{array}{l}30 \\
33 \\
30 \\
33 \\
30 \\
33\end{array}$ & $\begin{array}{l}15 \\
15 \\
15 \\
15 \\
15 \\
15\end{array}$ & $\begin{array}{l}100 \\
115 \\
100 \\
115 \\
100 \\
115\end{array}$ & $\begin{array}{l}6.7 \\
6.7 \\
6.7 \\
6.7 \\
6.7 \\
6.7\end{array}$ \\
\hline $\begin{array}{l}\text { JUNE } \\
01-06 \\
07-10 \\
11-2 . \\
12-16 \\
17-29 \\
30 . . . \\
\text { JULY }\end{array}$ & $\begin{array}{l}2.2 \\
2.4 \\
3.2 \\
3.4 \\
3.8 \\
3.4\end{array}$ & $\begin{array}{l}.1 \\
11 \\
11 \\
11 \\
.2\end{array}$ & $\begin{array}{l}1.2 \\
2.1 \\
3.9 \\
4.1 \\
3.7 \\
4.1\end{array}$ & $\begin{array}{r}76 \\
91 \\
129 \\
145 \\
129\end{array}$ & $\begin{array}{r}66 \\
85 \\
-7 \\
132 \\
137 \\
132\end{array}$ & $\begin{array}{r}.10 \\
.12 \\
.12 \\
.18 \\
.20 \\
.19\end{array}$ & $\begin{array}{l}31 \\
37 \\
39 \\
57 \\
54 \\
57\end{array}$ & $\begin{array}{l}7 \\
17 \\
19 \\
32 \\
26 \\
32\end{array}$ & $\begin{array}{l}114 \\
136 \\
169 \\
213 \\
234 \\
213\end{array}$ & $\begin{array}{l}6.7 \\
7.0 \\
7.2 \\
7.0 \\
6.6 \\
7.0\end{array}$ \\
\hline $\begin{array}{l}01-02 \\
03-31\end{array}$ & $\begin{array}{l}3.4 \\
3.8\end{array}$ & .1 & $\begin{array}{r}4.1 \\
.2\end{array}$ & $\begin{array}{l}129 \\
119\end{array}$ & $\begin{array}{l}132 \\
127\end{array}$ & $\begin{array}{r}.18 \\
.16\end{array}$ & $\begin{array}{l}57 \\
59\end{array}$ & $\begin{array}{l}32 \\
30\end{array}$ & $\begin{array}{l}213 \\
206\end{array}$ & $\begin{array}{l}7.0 \\
6.9\end{array}$ \\
\hline $\begin{array}{l}\text { AUG. } \\
O I-10 \\
11-20 \\
2 I-29 \\
3 O-31 \\
\text { SEPT. }\end{array}$ & $\begin{array}{l}3.6 \\
3.6 \\
3.2 \\
4.0\end{array}$ & $\begin{array}{l}.1 \\
.2 \\
.1 \\
.1\end{array}$ & $\begin{array}{l}2.4 \\
2.0 \\
2.4 \\
1.2\end{array}$ & $\begin{array}{l}131 \\
107 \\
112 \\
--\end{array}$ & $\begin{array}{r}130 \\
113 \\
117 \\
78\end{array}$ & $\begin{array}{l}.18 \\
.15 \\
.15 \\
.11\end{array}$ & $\begin{array}{l}61 \\
56 \\
57 \\
41\end{array}$ & $\begin{array}{l}34 \\
31 \\
39 \\
16\end{array}$ & $\begin{array}{l}196 \\
180 \\
189 \\
132\end{array}$ & $\begin{array}{l}7.2 \\
6.9 \\
6.8 \\
6.8\end{array}$ \\
\hline $\begin{array}{l}01-02 \\
03-30\end{array}$ & $\begin{array}{l}3.6 \\
4.4\end{array}$ & .2 & 2.17 & $\begin{array}{r}85 \\
126\end{array}$ & $\begin{array}{l}111 \\
136\end{array}$ & $\begin{array}{r}.12 \\
.17\end{array}$ & $\begin{array}{l}53 \\
67\end{array}$ & $\begin{array}{l}31 \\
38\end{array}$ & $\begin{array}{l}169 \\
210\end{array}$ & $\begin{array}{l}7.1 \\
7.0\end{array}$ \\
\hline IIME & 2.9 & .2 & 3.2 & -- & 93 & .12 & 44 & 27 & 148 & 6.5 \\
\hline $\begin{array}{l}\text { D. AVG. } \\
\text { TONS } \\
\text { ER DAY }\end{array}$ & $\begin{array}{l}3.9 \\
60\end{array}$ & $\begin{array}{r}.2 \\
3.5\end{array}$ & 3.0 & - & 119 & .16 & 53 & 30 & 193 & 6.8 \\
\hline
\end{tabular}


MOBILE RIVER BASIN

02465000 BLACK WARRIOR RIVER AT TUSCALOOSA, ALA.--Continued

CHEMICAL ANALYSES, WATER YEAR OCTOBER 1969 TO SEPTEMBER 1970

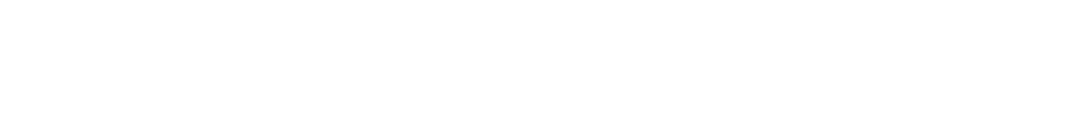
ANALYSIS OF ADOTTIONAL SAMPLE

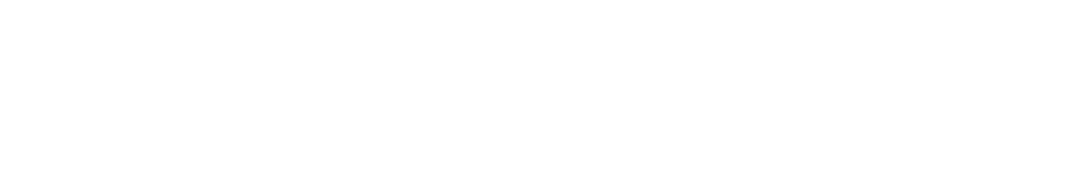

ANALYSIS OF ADDITIONAL SAMPLE

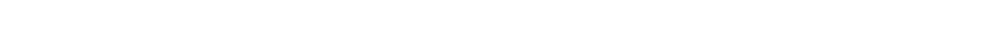

SPECIFIC CONDUCTANCE (MICROMHOS/CM AT $25^{\circ} \mathrm{C}$ ), WATER YEAR OCTOBER 1969 TO SEPTEMBER 1970

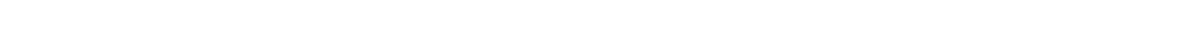

\begin{tabular}{|c|c|c|c|c|c|c|c|c|c|c|c|c|}
\hline $1 \ldots \ldots$ & 238 & 213 & 243 & 204 & $14 ?$ & 198 & 112 & 107 & 112 & $>14$ & 199 & 1 ha \\
\hline $2, \cdots$ & $2 x h$ & 204 & 248 & $19 \mathrm{n}$ & 140 & $19 \mathrm{n}$ & $1 \geqslant 0$ & 44 & $1 \geqslant 1$ & 214 & 197 & 170 \\
\hline $3 \ldots \ldots$ & 234 & 217 & 747 & 196 & 135 & 144 & 123 & in & 114 & 212 & 2014 & I4] \\
\hline $4 \ldots \ldots$ & 250 & 217 & 242 & 201 & $1 \div 8$ & $1 \mathrm{gAt}$ & 13 & $4 i$ & $17>$ & $20 \mathrm{H}$ & 370 & 244 \\
\hline $5 \ldots \ldots$ & 251 & 207 & 240 & 203 & 15.7 & 167 & 131 & 93 & in & 2012 & 214 & $20 n$ \\
\hline A...... & 251 & 211 & 241 & 208 & 161 & 165 & 175 & 42 & 116 & 704 & 195 & -- \\
\hline $7 \ldots \ldots$ & $24 R$ & 215 & 247 & 210 & IAG & 162 & 140 & an & $1>4$ & 217 & 196 & -- \\
\hline $8 \ldots \ldots$ & 240 & 216 & 241 & 226 & 179 & 163 & 144 & पh & 141 & $31 \mathrm{~A}$ & 194 & - \\
\hline$q \ldots$ & 243 & 225 & 239 & 217 & $17 \mathrm{~h}$ & -- & 151 & ath & 141 & 712 & 204 & $>617$ \\
\hline $10 \ldots \ldots$ & 247 & 222 & 245 & 274 & 180 & 190 & $15 x$ & $9 \mathrm{H}$ & $1<7$ & 214 & 144 & 203 \\
\hline $11 \ldots$. & 239 & 226 & 247 & 733 & -- & 175 & $1+4$ & ao & $I+7$ & 11 & 144 & thr \\
\hline $12 \ldots$ & 241 & 233 & 240 & $21 t$ & $1 \times 3$ & I मЯ & 157 & 98 & $? n_{n}$ & 716 & $1 \% \mathrm{~K}$ & $>11$ \\
\hline $13 \ldots \ldots$ & 243 & 229 & 249 & $19 \mathrm{~A}$ & 197 & $19 \%$ & 154 & 100 & $20 n$ & $>13$ & iun & 200 \\
\hline $14 \ldots \ldots$ & 746 & 227 & 254 & 184 & 191 & $10 R$ & 152 & 97 & 207 & 15 & Ins & 2011 \\
\hline $15 . . .$. & $24 h$ & $22 ?$ & 253 & 1 虾 & 190 & $20 \mathrm{~s}$ & $\ln 5$ & 49 & inci & ;1) & 171 & 210 \\
\hline $16 \ldots .$. & 247 & 221 & 267 & 181 & 205 & 2614 & I 64 & 101 & 316 & 7134 & 178 & 719 \\
\hline $17 \ldots$ & 244 & 214 & 257 & $1 \times 0$ & $2 n h$ & 213 & is? & 95 & 202 & 200 & 100 & 211 \\
\hline $18 \ldots \ldots$ & 247 & 225 & $25 \%$ & 197 & $2 \cap 6$ & 204 & $15 \mathrm{~s}$ & $10 \%$ & 330 & 200 & 184 & 31. \\
\hline $19 \ldots \ldots$ & 237 & 225 & $7 A 3$ & 177 & 211 & 223 & 133 & $10 \mathrm{~A}$ & 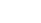 & $10-$ & 184 & 221 \\
\hline $20 \ldots \ldots$ & 241 & 227 & 245 & 171 & $2>8$ & 107 & 107 & -. & $24 \mathrm{~h}$ & $>013$ & $>n$ & $>18$ \\
\hline $21 \ldots$. & 234 & 220 & 244 & 16,0 & 257 & -- & 144 & 106 & 744 & $2 \sqcap 3$ & Iut & 210 \\
\hline $22 \ldots \ldots$ & 240 & 221 & $35 ?$ & $15 R$ & $2 \geqslant 4$ & -- & $17 \Omega$ & 100 & 735 & 199 & 141 & 317 \\
\hline $23 \ldots \ldots$ & 245 & $? ? h$ & - & $1+7$ & $? ? 9$ & -- & 175 & - & $2=4$ & $20 ?$ & 147 & 210 \\
\hline $24 \ldots \ldots$ & 235 & $2>8$ & 257 & 140 & $7>0$ & $12 k$ & $1 \cap 7$ & 112 & $? 77$ & 200 & 100 & 200 \\
\hline $24 \ldots \ldots$ & - & 220 & 250 & 150 & $23 c$ & 114 & 144 & 114 & 797 & 207 & 197 & 11 \\
\hline $2 \hbar \ldots .$. & 243 & $>30$ & 343 & $15 t$ & $P>h$ & $11 \mathrm{~h}$ & $1 \%, 6$ & 111 & 794 & $? 11$ & 107 & $31 \%$ \\
\hline $27 \ldots$. & 233 & 242 & $? 40$ & 157 & 214 & 114 & 111 & 1 in & 270 & 221 & ?ni & 10 \\
\hline $24 \ldots \ldots$ & 236 & 233 & 239 & $1] \mathrm{h}$ & 215 & 111 & 111 & 114 & 200 & $21^{4}$ & 187 & 210 \\
\hline$? 9 \ldots$. & $22^{9}$ & 240 & $? 4 ?$ & $14 h$ & - & in & $11^{\mathrm{R}}$ & 112 & $\sin$ & 215 & $1 \in 2$ & 214 \\
\hline $30 \ldots .$. & 234 & 240 & 245 & $14 \mathrm{~h}$ & - & $10 \mathrm{H}$ & 112 & 114 & $>1$. & Jrin & $13 \alpha_{4}$ & $\therefore>$ \\
\hline $31 \ldots$ & 231 & -- & 243 & 145 & -- & 110 & -- & 13 & -- & 205 & $1<7$ & -- \\
\hline AVERAT.E & 241 & 233 & 242 & 192 & 142 & 16.4 & 142 & $10^{2}$ & 149 & 204 & 129 & $\pi \mathrm{o}$ \\
\hline
\end{tabular}


MOBILE RIVER BASIN

02465000 BLACK WARRIOR RIVER AT TUSCALOOSA, ALA.--Cont Inued

TEMPERATURE (OC) OF WATER, WATER YEAR OCTOBER 1969 TO SEPTEMBER 1970

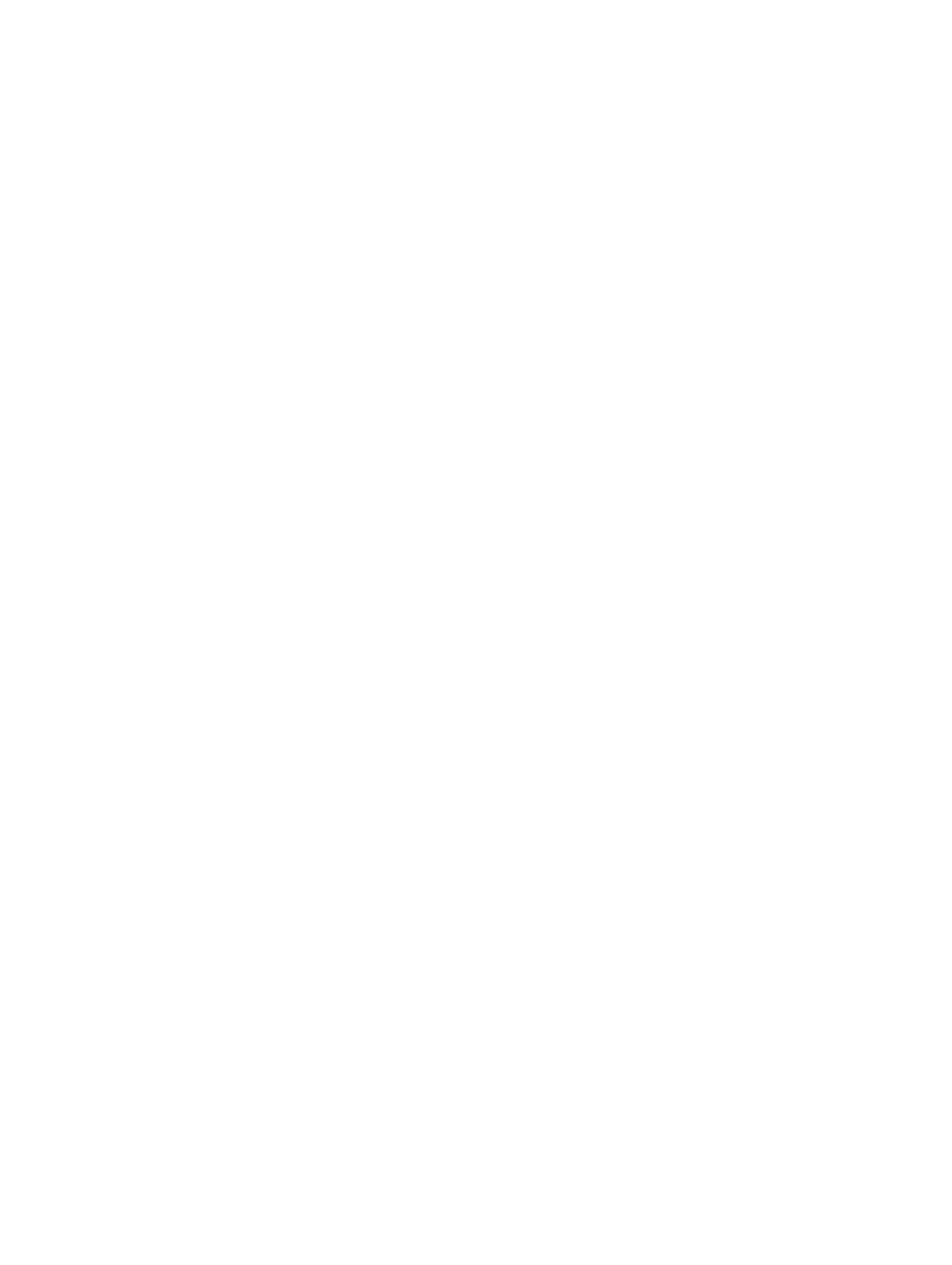


02467001 (revised) TOMBIGBEE RIVER AT DEMOPOLIS LOCK AND DAM, NEAR COATOPA, ALA. (LOWER POOL)

LOCATION,--Lat $32^{\circ} 31^{\prime} 15^{\prime \prime}$, long $87^{\circ} 52^{\prime} 39^{\prime \prime}$, In NWl sec.22, T.18 N., R.2 E., Marengo County, at gaging station (lower pool) on left bank $100 \mathrm{ft}$ upstream from lock and dam, $0.5 \mathrm{mile}$ downstream from Boscue Creek, $2.5 \mathrm{miles}$ west of Demopolis, 3,5 miles upstream from Hall Creek, 13 miles east of Coatopa, and at mile 171.2.

DRAINAGE AREA. - - 15,400 sq mi, approximately.

PERIOD OF RECORD, --Chemical analyses: October 1965 to September 1969 (misce1laneous, as station no, 02467000), Oc tober 1969 to september 1970 .

CHEMICAL ANALYSES, WATER YEAR OCTOBER 1969 TO SEPTEMBER 1970

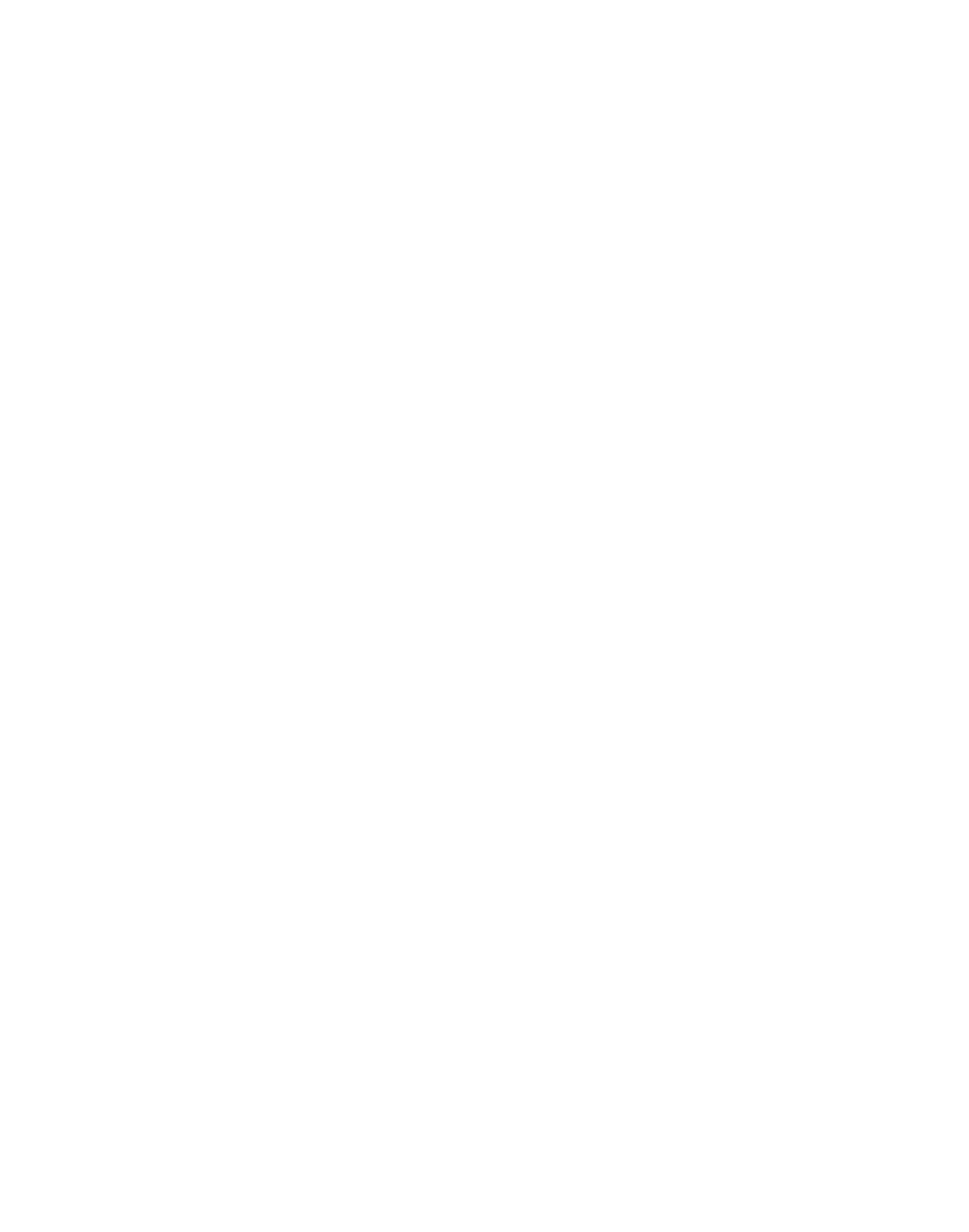


02469694 PUSS CUSS CREEK NEAR GILBERTOWN, ALA.

LOCATION. --Lat $31^{\circ} 53^{\prime} 44^{\prime \prime}$, long $88^{\circ} 23^{\prime} 19^{\prime \prime}$, In NTiłsE $\frac{1}{4}$ sec.28, T.11 N., R.4 W., Choctaw County, at bridge on County Road $14,0.9$ mile upstream from mouth, 1.6 miles downstream from James Ćreek, and 4 miles west of Gilbertown. DRAINAGE AREA. $--52.7 \mathrm{sq} \mathrm{md}$.

PERIOD OF RECORD.--Chemical analyses: October 1966 to September 1969 (miscellaneous), October 1969 to September 1970. CHEMICAL ANALYSES, WATER YEAR OCTOBER 1969 TO SEPTEMBER 1970

\begin{tabular}{|c|c|c|c|c|c|c|c|c|c|c|}
\hline OATE & TIME & $\begin{array}{l}\text { DIS- } \\
\text { CHARGE } \\
\text { (CFS) }\end{array}$ & $\begin{array}{l}\text { BICAR- } \\
\text { RONATE } \\
\text { (HCD3) } \\
\text { (MG/L) }\end{array}$ & $\begin{array}{l}\text { CAR- } \\
\text { BONATE } \\
\text { (CO3) } \\
\text { (MG/L) }\end{array}$ & $\begin{array}{l}\text { CHLO- } \\
\text { RIDE } \\
(C L) \\
(M G / L)\end{array}$ & $\begin{array}{l}\text { HARD- } \\
\text { NESS } \\
\text { (CA,MG) } \\
\text { (MG/L) }\end{array}$ & $\begin{array}{l}\text { NON- } \\
\text { CAR- } \\
\text { RONATE } \\
\text { HARD- } \\
\text { NESS } \\
\text { (MG/L) }\end{array}$ & $\begin{array}{l}\text { SPECI- } \\
\text { FIC } \\
\text { COND- } \\
\text { UCTANCE } \\
\text { (MICRN- } \\
\text { MHOS) }\end{array}$ & $\begin{array}{c}\mathrm{PH} \\
\text { (UNETSI }\end{array}$ & $\begin{array}{l}\text { TFMP- } \\
\text { FRATURE } \\
\text { (DEG C) }\end{array}$ \\
\hline $\begin{array}{l}\text { OCI., } 1969 \\
\text { O1... }\end{array}$ & 1220 & -- & 139 & 0 & 772 & 282 & 168 & 2470 & 7.3 & 24.0 \\
\hline $\begin{array}{l}\text { NOV. } \\
\text { O7... } \\
\text { OEC. }\end{array}$ & 1115 & - & 126 & 0 & 1820 & 538 & 435 & 5590 & 7.3 & 20.0 \\
\hline $\begin{array}{l}03 \ldots \ldots \\
29 \ldots\end{array}$ & $\begin{array}{l}0730 \\
1340\end{array}$ & $=$ & $\begin{array}{l}138 \\
139\end{array}$ & $\begin{array}{l}0 \\
0\end{array}$ & $\begin{array}{l}960 \\
556\end{array}$ & $\begin{array}{l}350 \\
250\end{array}$ & $\begin{array}{l}237 \\
136\end{array}$ & $\begin{array}{l}3190 \\
1910\end{array}$ & $\begin{array}{l}7.5 \\
7.9\end{array}$ & $\begin{array}{r}5.0 \\
12.0\end{array}$ \\
\hline $\begin{array}{l}\text { FEB.. } 1970 \\
05 \ldots \ldots \\
\text { MAR.. }\end{array}$ & 1030 & - & 125 & 0 & 349 & 194 & 92 & 1320 & 7.4 & 6.0 \\
\hline $\begin{array}{l}04 \ldots \\
30 . \ldots\end{array}$ & $\begin{array}{l}0915 \\
0830\end{array}$ & 20 & $\begin{array}{r}48 \\
129\end{array}$ & $\begin{array}{l}0 \\
0\end{array}$ & $\begin{array}{r}16 \\
268\end{array}$ & $\begin{array}{r}52 \\
175\end{array}$ & $\begin{array}{l}13 \\
70\end{array}$ & $\begin{array}{r}133 \\
1080\end{array}$ & $\begin{array}{l}6.8 \\
7.4\end{array}$ & $\begin{array}{l}13.0 \\
14.0\end{array}$ \\
\hline $\begin{array}{l}\text { APR. } \\
\text { JUNE }\end{array}$ & 0900 & 5.0 & 150 & 0 & 664 & 288 & 165 & 2540 & 7.5 & 23.0 \\
\hline JuL 04 . & 0900 & 6.0 & 106 & 0 & 660 & 250 & 163 & 2290 & 8.2 & 21.5 \\
\hline $\begin{array}{l}03 . . . \\
\text { Jutr, } 1970\end{array}$ & 1110 & 6.0 & 170 & 0 & 1760 & 500 & 360 & 5420 & 7.8 & 25.0 \\
\hline $\begin{array}{l}07 \ldots \\
31 \ldots \\
\text { SEP. }\end{array}$ & $\begin{array}{l}1300 \\
1100\end{array}$ & $\begin{array}{l}5.0 \\
9.0\end{array}$ & $\begin{array}{l}142 \\
120\end{array}$ & $\begin{array}{l}0 \\
0\end{array}$ & $\begin{array}{r}1600 \\
313\end{array}$ & $\begin{array}{l}500 \\
188\end{array}$ & $\begin{array}{r}383 \\
90\end{array}$ & $\begin{array}{l}4710 \\
1210\end{array}$ & $\begin{array}{l}8.1 \\
7.4\end{array}$ & $\begin{array}{l}33.0 \\
28.0\end{array}$ \\
\hline $\begin{array}{l}01 \ldots \\
28 \ldots\end{array}$ & $\begin{array}{l}1030 \\
1040\end{array}$ & $\begin{array}{l}5.0 \\
4.0\end{array}$ & $\begin{array}{l}149 \\
150\end{array}$ & $\begin{array}{l}0 \\
0\end{array}$ & $\begin{array}{r}660 \\
1050\end{array}$ & $\begin{array}{l}281 \\
388\end{array}$ & $\begin{array}{l}159 \\
165\end{array}$ & $\begin{array}{l}2360 \\
3490\end{array}$ & $\begin{array}{l}7.6 \\
7.3\end{array}$ & $\begin{array}{l}25.0 \\
16.5\end{array}$ \\
\hline
\end{tabular}

02469710 LITTLE MILL CREEK AT GILBERTOWN, ALA.

LOCATION.--Lat $31^{\circ} 52 \cdot 20^{\prime \prime}$, long $88^{\circ} 19^{\prime} 16^{\prime \prime}$, in $N^{\prime} \frac{1}{4}$ sec.6, T.10 N., R.3 W., Choctaw County, at left bank, 20 ft downstream from

DRAINAGE AREA. - - -3.50 sq $\mathrm{mi}$.

PERIOD OF RECORD. --Chemtcal analyses: December 1969 to September 1970.

CHEMICAL ANALYSES, WATER YEAR DCTOBER 1969 TO SEPTEMBER 1970

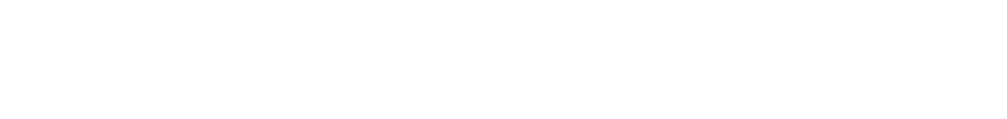

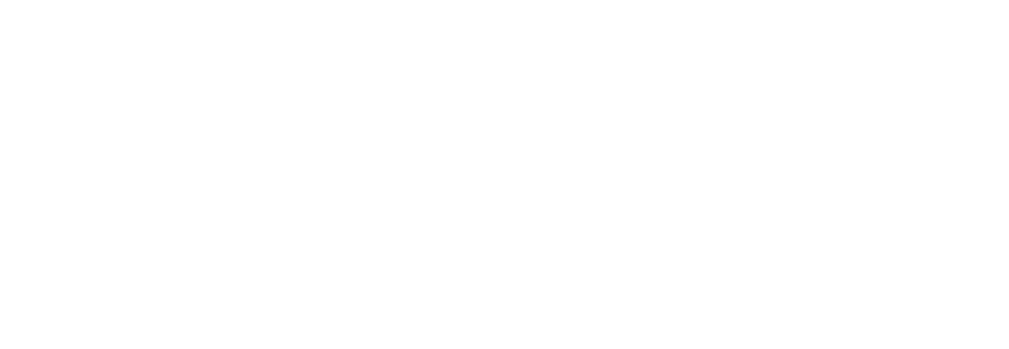


02469711 LitTLE MiLl CREEK AT MOUTH NEAR GILBERTOWN, ALA.

LOCATION,--Lat $31^{\circ} 51^{\prime} 40^{\prime \prime}$, long $88^{\circ} 17^{\prime} 20^{\prime \prime}$, in SE $\frac{1}{4}$ SE east of Gilbertown, and at the mouth.

DRAI NAGE AREA, - -5.21 sq mi.

PERIOD OF RECORD.--Chemtcal analyses: October 1964 to September 1969 (miscellaneous), October 1969 to September 1970 .

CHEMICAL ANALYSES, WATER YEAR OCTOBER 1969 TO SEPTEMBER 1970

\begin{tabular}{|c|c|c|c|c|c|c|c|c|c|c|}
\hline & & & BICAK- & CAR- & CHLC- & HARO- & $\begin{array}{l}\text { NON- } \\
\text { CAR- } \\
\text { BONATE }\end{array}$ & $\begin{array}{l}\text { SPECI- } \\
\text { FIC } \\
\text { COND- }\end{array}$ & & \\
\hline$\Delta \mathrm{T} \varepsilon$ & TIME & $\begin{array}{l}\text { DIS- } \\
\text { CHARGE } \\
\text { (CFS) }\end{array}$ & $\begin{array}{l}\text { BONATE } \\
\text { (HCD S } \\
\text { (MG/L) }\end{array}$ & $\begin{array}{l}\text { BONATE } \\
\text { (CO3) } \\
\text { (MG/L) }\end{array}$ & $\begin{array}{l}\text { RIDE } \\
\text { (CLI } \\
\text { IMG/LI) }\end{array}$ & $\begin{array}{l}\text { NESS } \\
(C A, M G) \\
(M G / L)\end{array}$ & $\begin{array}{l}\text { HARD- } \\
\text { NESS } \\
\text { (MG/L) }\end{array}$ & $\begin{array}{l}\text { UCTANCE } \\
\text { IMICRO- } \\
\text { MHOSI }\end{array}$ & $\begin{array}{c}\text { PH } \\
\text { (UNIIS }\end{array}$ & $\begin{array}{l}\text { TEMP- } \\
\text { 'ERATURE } \\
\text { IDEG C C }\end{array}$ \\
\hline
\end{tabular}

\begin{tabular}{|c|c|c|c|c|c|c|c|c|c|c|}
\hline $\begin{array}{l}\text { OCT...1969 } \\
\text { 01... } \\
\text { Nov. }\end{array}$ & 1330 & -- & 44 & 0 & 1130 & 305 & 269 & 3520 & 6.6 & 23.0 \\
\hline OT... & 0925 & - & 36 & 0 & 2610 & 812 & 782 & 8700 & 6.9 & 10.0 \\
\hline $\begin{array}{l}03 \ldots \ldots \\
29 \ldots \ldots 1970\end{array}$ & $\begin{array}{l}0900 \\
1425\end{array}$ & -- & $\begin{array}{l}30 \\
21\end{array}$ & $\begin{array}{l}0 \\
0\end{array}$ & $\begin{array}{r}2520 \\
754\end{array}$ & $\begin{array}{l}712 \\
206\end{array}$ & $\begin{array}{l}688 \\
189\end{array}$ & $\begin{array}{l}7360 \\
2380\end{array}$ & $\begin{array}{l}6.8 \\
6.6\end{array}$ & $\begin{array}{r}7.0 \\
12.0\end{array}$ \\
\hline $\begin{array}{l}05 . . \\
\text { MAR. }\end{array}$ & 0950 & -- & 20 & 0 & 780 & 250 & 234 & 2400 & 6.7 & 3.0 \\
\hline $\begin{array}{l}04 \ldots \\
30 \ldots \\
A P Q \ldots\end{array}$ & $\begin{array}{l}1030 \\
0900\end{array}$ & $\begin{array}{l}8.0 \\
2.0\end{array}$ & $\begin{array}{l}13 \\
28\end{array}$ & $\begin{array}{l}0 \\
0\end{array}$ & $\begin{array}{r}88 \\
488\end{array}$ & $\begin{array}{r}38 \\
150\end{array}$ & $\begin{array}{r}27 \\
127\end{array}$ & $\begin{array}{r}328 \\
1580\end{array}$ & $\begin{array}{l}6.1 \\
6.4\end{array}$ & $\begin{array}{l}15.0 \\
13.0\end{array}$ \\
\hline JUNE & 1030 & 1.5 & 32 & 0 & 1340 & 438 & 412 & 4360 & 6.7 & 22.0 \\
\hline JuLY & 1020 & 1.5 & 16 & 0 & 1520 & 420 & 407 & 4670 & 6.5 & 21.0 \\
\hline $\begin{array}{l}02 \ldots \\
07 \ldots \\
31 \ldots \\
\text { SEP. }\end{array}$ & $\begin{array}{l}1300 \\
1245 \\
0915\end{array}$ & $\begin{array}{l}.10 \\
2.0^{10} \\
1.5\end{array}$ & $\begin{array}{l}59 \\
62 \\
14\end{array}$ & $\begin{array}{l}0 \\
0 \\
0\end{array}$ & $\begin{array}{r}1680 \\
920 \\
1600\end{array}$ & $\begin{array}{l}475 \\
189 \\
425\end{array}$ & $\begin{array}{l}426 \\
137 \\
413\end{array}$ & $\begin{array}{l}5180 \\
2800 \\
4850\end{array}$ & $\begin{array}{l}6.9 \\
6.6 \\
t .5\end{array}$ & $\begin{array}{l}24.0 \\
29.0 \\
24.0\end{array}$ \\
\hline $\begin{array}{l}01 \ldots \\
28 \ldots\end{array}$ & $\begin{array}{l}0930 \\
1140\end{array}$ & $\begin{array}{l}1.0 \\
1.0\end{array}$ & $\begin{array}{l}43 \\
62\end{array}$ & $\begin{array}{l}0 \\
0\end{array}$ & $\begin{array}{r}1500 \\
980\end{array}$ & $\begin{array}{l}38 I \\
288\end{array}$ & $\begin{array}{l}346 \\
237\end{array}$ & $\begin{array}{l}4800 \\
3420\end{array}$ & $\begin{array}{l}6.8 \\
7.1\end{array}$ & $\begin{array}{l}24.0 \\
20.0\end{array}$ \\
\hline
\end{tabular}

02469727 SURVEYORS CREEK NEAR BARRYTOWN, ALA.

LOCATION. - - Iat $31^{\circ} 51^{\circ} 50^{\prime \prime}$, long $88^{\circ} 13^{\prime} 20^{\prime \prime}$, in SE $\frac{1}{\mathrm{SE}}$ sec.12, T.10 N., R.3 W., Choctaw County, at left bank, 1.2 miles west of Barrytown, and 0.1 mile upstream from mouth.

DRAINAGE AREA. $-\mathbf{- 2 4 . 6} \mathrm{sq} \mathrm{mi}$.

PERIOD OF RECORD.--Chemical analyses: October 1964 to September 1969 (miscellaneous), October 1969 to September 1970.

CHEMICAL ANALYSES, WATER YEAR OCTOBER 1969 TO SEPTEMBER 1970

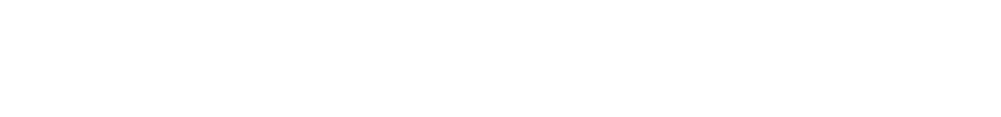

\begin{tabular}{|c|c|c|c|c|c|c|c|c|c|c|}
\hline $\begin{array}{l}\text { OCT. . } 1969 \\
01 \ldots\end{array}$ & 1350 & -- & 57 & D & 854 & 225 & 178 & 2670 & 7.1 & 23.0 \\
\hline $\begin{array}{l}\text { NOV. } \\
\text { O7... } \\
\text { OEC. }\end{array}$ & 0940 & -- & 27 & 0 & $25 B$ & 88 & 66 & 969 & 6.9 & 11.0 \\
\hline $\begin{array}{l}03 \ldots \\
29 \ldots \\
\text { FE } \ldots 1970\end{array}$ & $\begin{array}{l}0915 \\
1440\end{array}$ & $=$ & $\begin{array}{l}30 \\
42\end{array}$ & $\begin{array}{l}0 \\
0\end{array}$ & $\begin{array}{r}99 \\
221\end{array}$ & $\begin{array}{l}41 \\
90\end{array}$ & $\begin{array}{l}16 \\
56\end{array}$ & $\begin{array}{l}405 \\
800\end{array}$ & $\begin{array}{l}7.0 \\
7.3\end{array}$ & $\begin{array}{r}7.0 \\
11.0\end{array}$ \\
\hline $\begin{array}{l}05 \ldots \\
\text { MAR... }\end{array}$ & 0950 & -- & 16 & 0 & 51 & 32 & 19 & 218 & 6.6 & 3.0 \\
\hline $\begin{array}{r}04 \ldots \\
30 \ldots \\
A P R .\end{array}$ & $\begin{array}{l}1100 \\
0925\end{array}$ & ${ }^{40}-$ & $\begin{array}{r}B \\
20\end{array}$ & $\begin{array}{l}0 \\
0\end{array}$ & $23^{5.2}$ & $\begin{array}{l}13 \\
41\end{array}$ & $\begin{array}{r}6 \\
25\end{array}$ & $\begin{array}{r}46 \\
151\end{array}$ & $\begin{array}{l}6.0 \\
6.3\end{array}$ & $\begin{array}{l}16.0 \\
13.0\end{array}$ \\
\hline JUNE & 1045 & 8.0 & 32 & 0 & 85 & 46 & 20 & 403 & 7.1 & 23.0 \\
\hline JULY... & 1115 & 10 & 19 & 0 & 56 & 32 & 16 & 242 & 7.4 & 22.0 \\
\hline $02 \ldots$ & $\begin{array}{l}1415 \\
0900\end{array}$ & $\begin{array}{l}7.0 \\
-0\end{array}$ & $\begin{array}{l}51 \\
39\end{array}$ & $\begin{array}{l}0 \\
0\end{array}$ & $\begin{array}{l}880 \\
519\end{array}$ & $\begin{array}{l}250 \\
175\end{array}$ & $\begin{array}{l}208 \\
143\end{array}$ & $\begin{array}{l}2640 \\
1730\end{array}$ & $\begin{array}{l}7.2 \\
6.8\end{array}$ & 24.0 \\
\hline $\begin{array}{l}\text { SEP. } \\
01 \ldots . \\
28 . . .\end{array}$ & $\begin{array}{l}0900 \\
1230\end{array}$ & $\begin{array}{l}6.0 \\
5.0\end{array}$ & $\begin{array}{l}40 \\
88\end{array}$ & $\begin{array}{l}0 \\
0\end{array}$ & $\begin{array}{l}280 \\
595\end{array}$ & $\begin{array}{r}88 \\
206\end{array}$ & $\begin{array}{r}55 \\
134\end{array}$ & $\begin{array}{r}990 \\
2040\end{array}$ & $\begin{array}{l}6.9 \\
7.4\end{array}$ & $\begin{array}{l}26.0 \\
20.0\end{array}$ \\
\hline
\end{tabular}


02469730 OKATUPPA CREEK NEAR BARRYTOWN, ALA.

LOCATION.--Lat $31^{\circ} 50^{\prime} 50^{\prime \prime}$, long $88^{\circ} 13^{\prime} 58^{\prime \prime}$, in SE $\mathrm{S}_{4} \mathrm{SE} \frac{1}{4}$ sec.12, T.10 N., R. 3 w., Choctaw County, near left bank on down stream side of bridge on Choctaw County Highway 14,1 mile east' of Barrytown, and 2 miles southwest of womack
Hill. DRAINAGE AREA.--260 sq mi, approximately.

PERIOD OF RECORD. - Chemical analyses: October 1964 to september 1965 , October 1967 to September 1969 (miscellaneous), October 1965 to September 1967 , October 1969 to September 1970.

CHEMICAL ANALYSES, WATER YEAR OCTOBER 1969 TO SEPTEMBER 1970

\begin{tabular}{|c|c|c|c|c|c|c|c|c|c|c|}
\hline DATE & TIME & $\begin{array}{l}\text { DIS- } \\
\text { CHARGE } \\
\text { (CFS) }\end{array}$ & $\begin{array}{l}\text { BICAR- } \\
\text { BONATE } \\
\text { (HCO3) } \\
\text { (MGIL) }\end{array}$ & $\begin{array}{l}\text { CAR- } \\
\text { BONATE } \\
\text { (CO3) } \\
\text { (MG/L) }\end{array}$ & $\begin{array}{l}\text { CHLOO- } \\
\text { RIOE } \\
\text { (CL) } \\
\text { (MG/L) }\end{array}$ & $\begin{array}{l}\text { HARD- } \\
\text { NESS } \\
\text { (CA,MG) } \\
\text { (MG/L) }\end{array}$ & $\begin{array}{l}\text { NON- } \\
\text { CAR- } \\
\text { BONATE } \\
\text { HARD- } \\
\text { NESS } \\
\text { (MG/L) }\end{array}$ & $\begin{array}{l}\text { SPECI- } \\
\text { FIC } \\
\text { COND- } \\
\text { UCTANCE } \\
\text { (MICRO- } \\
\text { MHOS) }\end{array}$ & $\begin{array}{c}\text { PH } \\
\text { (UNITS) }\end{array}$ & $\begin{array}{l}\text { TEMP- } \\
\text { ERATURE } \\
\text { IOEG CI }\end{array}$ \\
\hline \multicolumn{11}{|l|}{ NOV., 1969} \\
\hline OЕC... & 0930 & -- & 33 & 0 & 334 & 125 & 98 & 1190 & 3.9 & 11.0 \\
\hline $\begin{array}{l}03 . . . \\
F E B . .1970\end{array}$ & 0920 & - & 42 & 0 & 342 & 106 & 72 & 1190 & 6.9 & 6.0 \\
\hline MAR... & 0900 & -- & 36 & 0 & 100 & 62 & 32 & 412 & 7.3 & 4.0 \\
\hline $\begin{array}{l}04 \ldots \ldots \\
\begin{array}{l}30 \ldots \\
A P R\end{array}\end{array}$ & $\begin{array}{l}1045 \\
0915\end{array}$ & 750 & $\begin{array}{l}47 \\
38\end{array}$ & $\begin{array}{l}0 \\
0\end{array}$ & $\begin{array}{l}17 \\
90\end{array}$ & $\begin{array}{l}52 \\
61\end{array}$ & $\begin{array}{l}13 \\
30\end{array}$ & $\begin{array}{l}143 \\
386\end{array}$ & $\begin{array}{l}7.0 \\
6.8\end{array}$ & $\begin{array}{l}15.0 \\
16.0\end{array}$ \\
\hline $\begin{array}{l}30 \ldots \\
\text { JUNE, } 1970\end{array}$ & 1100 & 40 & 50 & 0 & 239 & 99 & 58 & 902 & 7.2 & 26.0 \\
\hline JuLY & 1100 & 40 & 41 & 0 & 258 & 99 & 66 & 939 & 7.2 & 23.0 \\
\hline $\begin{array}{l}02 \ldots \\
07 \ldots \\
31 \ldots\end{array}$ & $\begin{array}{l}1400 \\
1100 \\
1000\end{array}$ & $\begin{array}{l}10 \\
10 \\
30\end{array}$ & $\begin{array}{l}50 \\
55 \\
57\end{array}$ & $\begin{array}{l}0 \\
0 \\
0\end{array}$ & $\begin{array}{r}1040 \\
1920 \\
179\end{array}$ & $\begin{array}{r}250 \\
500 \\
88\end{array}$ & $\begin{array}{r}209 \\
455 \\
42\end{array}$ & $\begin{array}{r}2990 \\
5870 \\
708\end{array}$ & $\begin{array}{l}7.1 \\
6.6 \\
7.2\end{array}$ & $\begin{array}{l}24.0 \\
27.0 \\
28.0\end{array}$ \\
\hline SEP. & 1000 & & . & . & 179 & Do & 48 & 708 & 1.2 & 28.0 \\
\hline $\begin{array}{l}01 \ldots \\
28 \ldots\end{array}$ & $\begin{array}{l}0830 \\
1200\end{array}$ & $\begin{array}{l}30 \\
25\end{array}$ & $\begin{array}{l}80 \\
88\end{array}$ & $\begin{array}{l}0 \\
0\end{array}$ & $\begin{array}{l}384 \\
600\end{array}$ & $\begin{array}{l}156 \\
200\end{array}$ & $\begin{array}{r}91 \\
123\end{array}$ & $\begin{array}{l}1310 \\
2050\end{array}$ & $\begin{array}{l}7.4 \\
7.1\end{array}$ & $\begin{array}{l}27.0 \\
20.0\end{array}$ \\
\hline
\end{tabular}

02469762 TOMBIGBEE RIVER AT COFFEEVILLE LOCK AND DAM, NEAR COFFEEVILLE, ALA. (LOWER POOL)

02469762 TONBIGBEE RIVER AT COFFEEVILLE LOCK AND DAM, NEAR COFFEEVILLE, ALA, (LOWER POOL)
(Formerly published as 02469761 Tombigbee River at Jackson lock and dam near Coffeeville, Ala,)

LOCATION.--Lat $31^{\circ} 45^{\prime} 30^{\prime \prime}$, long $88^{\circ} 07^{\prime} 45^{\prime \prime}$, in sec.12, T.9 N., R.2 W. , Choctaw County, at gaging station (lower pool) near right bank at Jackson lock and dam, 4 miles downstream from Turkey creek, 2 miles west of Coffeeville, and

DRAINAGE AREA.--18,500 sq mi (approximately).

PERIOD OF RECORD, -.-Chemical analyses: October 1966 to September 1967, October 1968 to September 1969 (miscelianeous), as 02469761 Tombigbee River at Jackson lock and dam, Coffeeville, Ala,), October 1969 to September 1970 . CHEMICAL ANALYSES, HATER YEAR OCTOBER 1969 TO SEPTEMBER 1970

\begin{tabular}{|c|c|c|c|c|c|c|c|c|c|c|c|}
\hline DATE & TI ME & $\begin{array}{l}\text { DIS- } \\
\text { CHARGE } \\
\text { (CFS) }\end{array}$ & $\begin{array}{l}\text { SILICA } \\
\text { (SIOL) } \\
\text { (MG/L) }\end{array}$ & $\begin{array}{l}\text { DIS- } \\
\text { SOLVED } \\
\text { IRON } \\
\text { (FE) } \\
\text { (UG/L) }\end{array}$ & $\begin{array}{l}\text { DI S- } \\
\text { SOL VED } \\
\text { MAN- } \\
\text { GANESE } \\
\text { (MN) } \\
\text { (UG/L) }\end{array}$ & $\begin{array}{l}\text { CAL- } \\
\text { CIUM } \\
(C A) \\
(M G / L)\end{array}$ & $\begin{array}{c}\text { MAG- } \\
\text { NE- } \\
\text { SIUM } \\
\text { (MG) } \\
\text { (MG/L) }\end{array}$ & $\begin{array}{l}\text { SOOIUM } \\
\text { (NA) } \\
\text { (MG/L) }\end{array}$ & $\begin{array}{l}\text { PO- } \\
\text { TAS- } \\
\text { SIUM } \\
\text { (K) } \\
\text { (MG/L) }\end{array}$ & $\begin{array}{l}\text { BICAR - } \\
\text { BONATE } \\
\text { (HCO3) } \\
\text { (MG/L) }\end{array}$ & $\begin{array}{l}\text { CAR- } \\
\text { BONATE } \\
\text { (C03) } \\
\text { (MG/L) }\end{array}$ \\
\hline $\begin{array}{r}\text { OCT. } \\
21 \ldots \\
22 \ldots\end{array}$ & $\begin{array}{l}1345 \\
1345\end{array}$ & $\begin{array}{r}2670 \\
24800\end{array}$ & $\begin{array}{l}5.2 \\
6.2\end{array}$ & $\begin{array}{r}40 \\
100\end{array}$ & $=$ & $\begin{array}{l}16 \\
14\end{array}$ & $\begin{array}{l}3.7 \\
3.3\end{array}$ & $\begin{array}{l}20 \\
15\end{array}$ & $\begin{array}{l}2.3 \\
3.0\end{array}$ & $\begin{array}{l}42 \\
40\end{array}$ & $\begin{array}{l}0 \\
0\end{array}$ \\
\hline $\begin{array}{l}\text { JAN. } \\
27 \ldots . . \\
\text { MAR. }\end{array}$ & 1430 & 14700 & 6.6 & 40 & - & 17 & 3.7 & 9.6 & 2.4 & 39 & 0 \\
\hline $\begin{array}{l}03 \ldots \\
A P R .\end{array}$ & 1300 & 22300 & 7.7 & 90 & -- & 18 & 2.7 & 7.1 & 1.7 & 50 & 0 \\
\hline$\underset{\text { MAY }}{07 .}$ & 1300 & 86200 & 7.8 & 150 & 50 & 14 & 2.3 & 4.2 & 1.5 & 36 & 0 \\
\hline JUNE & 1340 & 65900 & 7.9 & 350 & 30 & 12 & 1.9 & 5.5 & 1.5 & 40 & 0 \\
\hline juty & 1400 & 13800 & 6.5 & 130 & 24 & 11 & 2.2 & 6.2 & 1.6 & 32 & 0 \\
\hline SEPT. & 1030 & 9660 & 7.3 & 130 & 54 & 19 & 3.9 & 30 & 3.0 & 49 & 0 \\
\hline $01 \ldots$ & 1130 & 6150 & 7.5 & 67 & 20 & 14 & 3.4 & 14 & 2.5 & 44 & 0 \\
\hline OATE & $\begin{array}{l}\text { SULFATE } \\
\text { (SO4) } \\
\text { (MG/L) }\end{array}$ & $\begin{array}{l}\text { CHLO- } \\
\text { RIOE } \\
\text { (CL) } \\
\text { (MG/L) }\end{array}$ & $\begin{array}{l}\text { FLUD- } \\
\text { RIDE } \\
\text { (F) } \\
(\text { MG } / L)\end{array}$ & $\begin{array}{l}\text { NITRATE } \\
\text { (NO3) } \\
\text { (MG /L) }\end{array}$ & $\begin{array}{l}\text { DIS- } \\
\text { SOL VED } \\
\text { SOLIDS } \\
\text { IRESI- } \\
\text { OUE AT } \\
\text { IBO C) } \\
\text { (HG IL) }\end{array}$ & $\begin{array}{l}\text { OIS- } \\
\text { SOLVEO } \\
\text { SOLIDS } \\
\text { I SUM OF } \\
\text { CONSTI- } \\
\text { TUENTS) } \\
\text { (MGIL) }\end{array}$ & $\begin{array}{l}\text { DIS- } \\
\text { SOLVED } \\
\text { SOLIDS } \\
\text { ITONS } \\
\text { PER } \\
\text { AC-FTI }\end{array}$ & $\begin{array}{l}\text { HARD- } \\
\text { NESS } \\
\text { (CA, MG) } \\
\text { (MG/L) }\end{array}$ & $\begin{array}{l}\text { NON- } \\
\text { CAR- } \\
\text { BONATE } \\
\text { HARD- } \\
\text { NESS } \\
\text { (MG/L) }\end{array}$ & $\begin{array}{l}\text { SPECI- } \\
\text { FIC } \\
\text { CONO- } \\
\text { UCTANCE } \\
\text { (MICRO- } \\
\text { MHOSI }\end{array}$ & $\begin{array}{c}\text { PH } \\
\text { (UNITS) }\end{array}$ \\
\hline${ }_{21}^{\mathrm{ocT}} .$. & 38 & 18 & .2 & 1,4 & 132 & 126 & .18 & 55 & 21 & 226 & 7.3 \\
\hline JAN. & 30 & 13 & .2 & 1.7 & 110 & 106 & .15 & 49 & 16 & 178 & 7.2 \\
\hline MAR... & $2 B$ & 10 & .1 & 1.2 & 96 & 98 & .13 & 58 & 26 & 158 & 7.2 \\
\hline $\begin{array}{l}03 . . \\
\text { APR. }\end{array}$ & 22 & 7.1 & .2 & .9 & 101 & 92 & .14 & 56 & 15 & $15 T$ & 7.1 \\
\hline MAY 07 & $1 \mathrm{~B}$ & 4.2 & .1 & 1.0 & 72 & 71 & .10 & 44 & 14 & 108 & 7.0 \\
\hline $\begin{array}{l}12 \ldots . . \\
\text { JUNE }\end{array}$ & 10 & 6.0 & .1 & .9 & 72 & 66 & .10 & 38 & 5 & 108 & 6.9 \\
\hline$\underset{\text { JuLY }}{10 . .}$ & 15 & 5.8 & .1 & 1.6 & 74 & 66 & .10 & 37 & 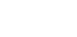 & 116 & 7.5 \\
\hline SEPT... & 28 & 45 & .2 & .9 & 174 & 161 & .24 & 64 & 24 & 297 & 7.0 \\
\hline $01 . .$. & 28 & 13 & .3 & 1.2 & 104 & 106 & .14 & 49 & 13 & 176 & 6.9 \\
\hline
\end{tabular}


02469762 TOMBIGBEE RIVER AT COFFEEVILE LOCK AND DAM, NEAR COFFEEVILLE, ALA. (LOWER POOL)--CONT1 nued CHEMICAL ANALYSES, WATER YEAR OCTOBER 1969 TO SEPTEMBER 1970

\begin{tabular}{|c|c|c|c|c|c|c|}
\hline \multirow[b]{2}{*}{ DATE } & \multicolumn{6}{|c|}{ FIELD ANALYSES } \\
\hline & TIME & $\begin{array}{l}\text { DIS- } \\
\text { CHARGE } \\
\text { (CFS) }\end{array}$ & $\begin{array}{l}\text { SPECI- } \\
\text { FIC } \\
\text { COND- } \\
\text { UCTANCE } \\
\text { (MICRD- } \\
\text { WHOSI }\end{array}$ & $\begin{array}{c}\text { PH } \\
\text { CUNITSI }\end{array}$ & $\begin{array}{l}\text { DIS- } \\
\text { SOLVED } \\
\text { OXYGEN } \\
\text { (MG/L) }\end{array}$ & $\begin{array}{l}\text { TEMP- } \\
\text { ERATURE } \\
\text { (DEG C) }\end{array}$ \\
\hline ост. & 1345 & 2670 & 189 & 7.2 & 8.3 & 23.5 \\
\hline & 1600 & 24800 & 175 & 6.9 & 11.6 & 10.5 \\
\hline MAR: & 1430 & 14700 & 160 & 6.8 & 13.4 & 7.5 \\
\hline $\begin{array}{l}03 \ldots \\
\text { APR. }\end{array}$ & 1300 & 22300 & 158 & 6.9 & 12.0 & 11.5 \\
\hline$\underset{\text { MAY }}{07} \cdots$ & 1300 & 86200 & 102 & 6.9 & 8.0 & 15.0 \\
\hline $\begin{array}{l}12 \ldots . . \\
\text { JUNE }\end{array}$ & 1340 & 65900 & 110 & 7.0 & 6.8 & 20.5 \\
\hline $10 . \cdots$ & 1400 & 13800 & 115 & 7.3 & 9.0 & 24.0 \\
\hline SEPT. & 1030 & 9660 & 295 & 7.3 & 8.1 & 29.5 \\
\hline $01 . .$. & 1130 & 6150 & 189 & 7.4 & 7.9 & 29.5 \\
\hline
\end{tabular}

LOCATION.--Lat $31^{\circ} 31^{\prime}$, long $87^{\circ} 56^{\prime}$, in sec.1, T.6 N., R.1 E., Clarke County, on domstream side of bridge, near midstream, on U.S. Highway 43,1 mile west of Jackson, 2.5 miles upstream from Southern Railroad bridge, 5 miles upstream from Bassett Creek, and 8.3 miles downstream from lock 1.

DRAINAGE AREA.--19,000 sq mi, approximately, downstream from former gaging station.

PER IOD OF RECORD.-_Chemical analyses: March 1966 to September 1970.

Water temperatures: October 1962 to September 1970.

EXTREMES - $1969-70$ :

Nater temperatures: Waximum, $31.0^{\circ} \mathrm{C}$ on several days $1 \mathrm{n}$ August; minimum, $5.0^{\circ} \mathrm{C}$ on several days $1 \mathrm{n}$ January.

period of record:

Dissolved solids (1966-69): Maximum, $136 \mathrm{mg} / 1 \mathrm{Sept} .14,15,25,1966$; mintmum, 49 mg/1 Har. 21, 24, 28-31, 1968 .

( Maximum, $68 \mathrm{mg} / 1$ Sept. 14, 15, 25, 1966 and Aug, 5, 1967;

pecific conductance (1966-68): Maximum daily, 240 micromhos Sept. 26, 1968; minimum da1ly, 77 micromhos Jan, 23,

vater tem

ruary 1966 . CHEMICAL ANALYSES, WATER YEAR OCTOBER 1969 TO SEPTEMBER 1970

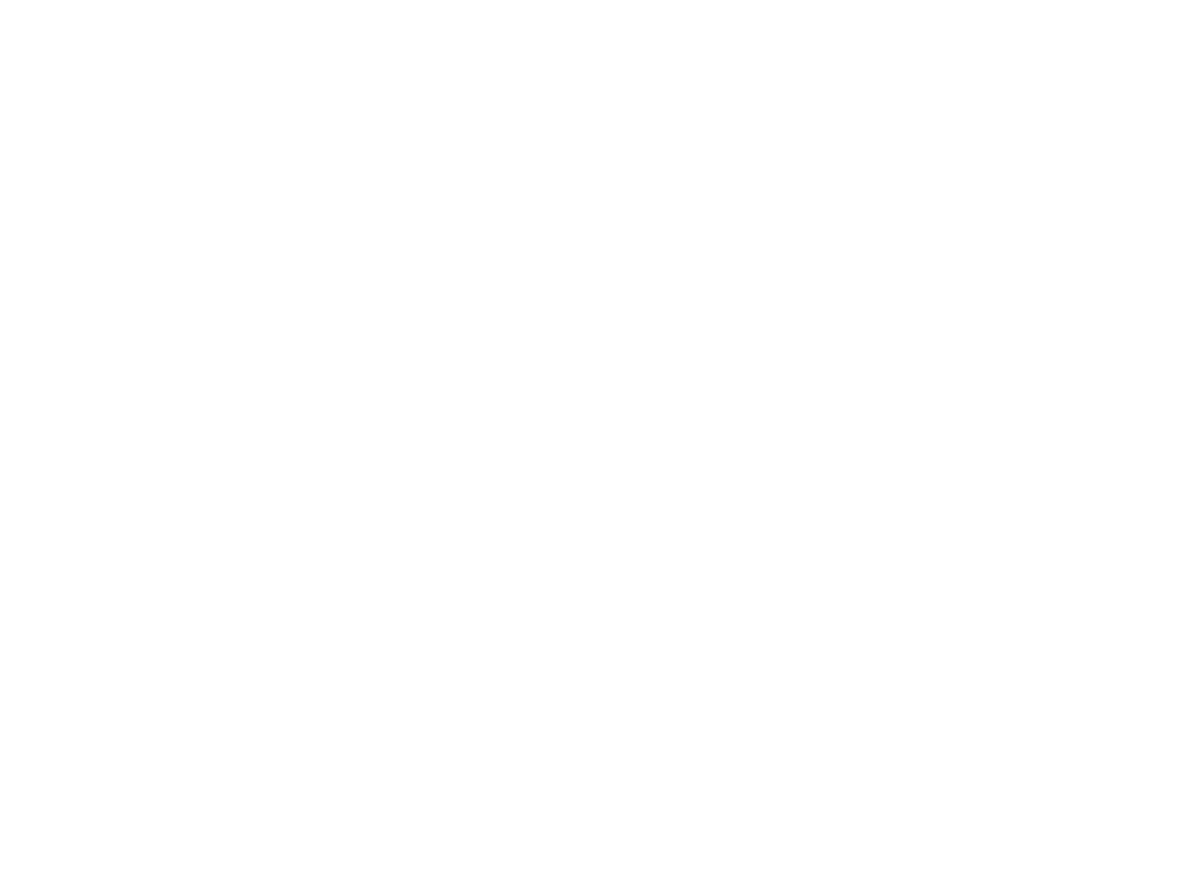


NOBILE RIVER BASIN

02470040 TOMBIGBEE RIVER NEAR JACKSON, ALA.--Continued CHEMICAL ANALYSES, WATER YEAR OCTOBER 1969 TO SEPTEMBER 1970

\begin{tabular}{|c|c|c|c|c|c|c|}
\hline DATE & I I ME & $\begin{array}{l}\text { DIS- } \\
\text { CHARGE } \\
\text { (CFS) }\end{array}$ & $\begin{array}{l}\text { SPECI- } \\
\text { FIC } \\
\text { COND- } \\
\text { UCTANCE } \\
\text { (MICRD- } \\
\text { MHOS I }\end{array}$ & $\begin{array}{c}P H \\
\text { (UNITS) }\end{array}$ & $\begin{array}{l}\text { DIS- } \\
\text { SOLVED } \\
\text { OXYGEN } \\
\text { (MG/L) }\end{array}$ & $\begin{array}{l}\text { TEMP- } \\
\text { ERATURE } \\
\text { (DEG C) }\end{array}$ \\
\hline $\begin{array}{l}\text { OCT. } \\
22 \ldots \\
\text { DEC. }\end{array}$ & 0845 & 2770 & 192 & 7.2 & 8.2 & 22.5 \\
\hline JAN. & 0845 & 24800 & 181 & 6.9 & 11.6 & 10.5 \\
\hline $\begin{array}{l}28 . \cdots \\
\text { MAR. }\end{array}$ & 0835 & 14700 & 159 & 6.9 & 13.0 & 7.5 \\
\hline $\begin{array}{l}04 \ldots . \\
A P R \text {. }\end{array}$ & 0800 & 47500 & 141 & -- & 11.3 & 12.0 \\
\hline${ }_{\operatorname{MAY}}^{07 . .}$ & 1530 & 86200 & 100 & 6.7 & 7.8 & 15.5 \\
\hline JUNE & 1600 & 65900 & 105 & 7.3 & 6.5 & 20.5 \\
\hline $10 \ldots$ & 1600 & 13800 & 115 & 7.2 & 8.7 & 24.0 \\
\hline $\begin{array}{l}23 \ldots \\
23 \ldots . . \\
\text { SEPT. }\end{array}$ & $\begin{array}{l}1300 \\
1330\end{array}$ & $\begin{array}{l}9660 \\
9660\end{array}$ & $\begin{array}{l}195 \\
195\end{array}$ & $\begin{array}{l}7.3 \\
7.3\end{array}$ & $\begin{array}{l}7.4 \\
7.4\end{array}$ & $\begin{array}{l}29.0 \\
29.0\end{array}$ \\
\hline $01 \ldots$ & 1600 & 6150 & 193 & 7.2 & 7.7 & 30.5 \\
\hline
\end{tabular}

TEMPERATURE $\left({ }^{\circ} \mathrm{C}\right)$ OF WATER, WAIER YEAR OCTOBER 1969 TO SEPTEMBER 1970

\begin{tabular}{|c|c|c|c|c|c|c|c|c|c|c|c|c|}
\hline nAY & & & & & & & & & & & & \\
\hline 1 & $\begin{array}{r}\text { MAX } \\
2 h .0\end{array}$ & $\begin{array}{r}M 1 N \\
25.0\end{array}$ & $\begin{array}{r}M \Delta x \\
21.0\end{array}$ & $\begin{array}{r}M I N \\
21.0\end{array}$ & $\begin{array}{r}\text { MAX } \\
14.0\end{array}$ & $\begin{array}{r}\text { MIN } \\
13.0\end{array}$ & $\begin{array}{l}\text { MAX } \\
\text { G. }\end{array}$ & $\begin{array}{l}M 1 M \\
R .0\end{array}$ & $\begin{array}{l}M A x \\
\text { R.n }\end{array}$ & $\begin{array}{l}M \mp N \\
R .01\end{array}$ & $\begin{array}{r}N A x \\
10 .\end{array}$ & $\begin{array}{r}\text { MIN" } \\
10.0\end{array}$ \\
\hline ; & $24 . n$ & 74.0 & 21.0 & 21.0 & 17.0 & 13.0 & प. 0 & 9. त & 0.0 & 0 & $\begin{array}{l}10.11 \\
10.0\end{array}$ & 10.0 \\
\hline 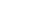 & 24.0 & 24.0 & 21.0 & 70.0 & 13.0 & 13.0 & R.n & 8.0 & $n$ & K. O & 11.0 & 10.0 \\
\hline 4 & 25.0 & 24.0 & 20.0 & 14.0 & $j=.0$ & 12.0 & 40 & $9 . n$ & $R .0$ & a. & $1>0$ & 11.0 \\
\hline 5 & 25.0 & 25.0 & 19.0 & 19.0 & 12.0 & 12.0 & $\because n$ & $\because n$ & . 0 & $n .0$ & 17.0 & 13.0 \\
\hline a & 25.0 & 75.0 & 19.0 & 19.0 & $12 . n$ & 1200 & $\because n$ & $\therefore . n$ & 8.0 & $\therefore$ & $1>0$ & $1>0$ \\
\hline 7 & 25.0 & $>5.0$ & 18.0 & 15.0 & $12 . ?$ & $1>0$ & $r . n$ & 7.0 & 20 & 20 & 17.17 & $1>0$ \\
\hline a & 75.0 & 25.0 & 18.0 & 18.0 & $1>0$ & 17.0 & $7 . n$ & 7.0 & $\therefore$. & $8 . \overline{11}$ & 12011 & $1 ;$ \\
\hline a & 25.0 & $25 . n$ & 19.0 & 18.0 & 12.0 & 11.0 & $? .0$ & $n=0$ & a. &.$n$ & 17.0 & $1>1$ \\
\hline 10 & 25.0 & 25.0 & 10.0 & 18.0 & 11.0 & 11.0 & h.n & 4.0 & $2 . n$ & r. 0 & 17.0 & $1 . .1$ \\
\hline 11 & 25.0 & 25.0 & 19.0 & 18.0 & 11.0 & 11.0 & 5.0 & 5.0 & H.n & ค. . & 17.0 & 1 . \\
\hline 1) & 25.0 & $2 n . n$ & $1 A .0$ & 18.0 & 11.0 & 10.6 & $\because n$ & 5.0 & $R .0$ & $H=n$ & 12.0 & 17.0 \\
\hline 12 & $25 . n$ & 24.0 & $1 \% .0$ & $1 \% \cdot n$ & 16.0 & 10.0 & $n . n$ & h. & $\cdot 0$ & 7.0 & 17.0 & $1 \geqslant 0$ \\
\hline 14 & ס. מיד & 24.0 & 18.0 & 17.5 & 10.0 & 9.0 & .0 & 5.0 & 1.0 & 7.6 & 17.11 & 1. \\
\hline 15 & $>4 . n$ & $2+. n$ & 11.0 & $1 h \cdot n$ & 9. & 0.0 & 4.0 & 5.0 & $7 . n$ & 7.0 & $1 ?=\pi$ & 120 \\
\hline in & $>2 . n$ & 22.0 & $1 h .0$ & $1 \mathrm{f} . \mathrm{n}$ & $\therefore$ & 0.0 & 5.0 & $5 . n$ & an & $\because n$ & 120 & $1 \%$ \\
\hline 17 & $2 \geqslant .0$ & $22 . n$ & $1 \leftarrow .0$ & $1 \mathrm{mon}$ & 0 & 4.0 & 5.0 & n. & 2.0 & a. $n$ & $1>0$ & $17 . n$ \\
\hline$t^{R}$ & $\gg \geqslant 0$ & 22.0 & 16.0 & 16.0 & .0 & 4.0 & 5.0 & 5.0 & 4.0 & A.n & 1200 & 17. \\
\hline 19 & 22.0 & 27.0 & $1 \mathrm{~A} .0$ & $1 \mathrm{~h} . \mathrm{n}$ & 9.0 & 9.0 & 5.0 & $4 . \pi$ & $\operatorname{tin}$ & 4.0 & 12.11 & 1.11 \\
\hline 20 & $\gg . n$ & 22.0 & $1 \mathrm{H} .0$ & 15.0 & 0.0 & 9.0 & $5 . n$ & 5.0 & . n & +.7 & 12.0 & $t^{2} \cdot 11$ \\
\hline 21 & $2^{2} .0$ & 22.0 & 15.0 & 15.0 & 0.0 & $a, c$ & 4.0 & $n . n$ & 4.0 & 4.0 & 12.0 & $1, .0$ \\
\hline$? 7$ & 23.0 & 23,0 & 15,0 & 15.0 & 4.0 & 0.0 & 5.0 & 5.7 & 4.0 & 4.0 & $1+.4$ & 12.1 \\
\hline 73 & 23.0 & 73.0 & 15,0 & 15.0 & $a . n$ & 9.0 & 5.0 & 5.0 & a.n & 4.0 & 12.0 & 12.6 \\
\hline 24 & $23 . n$ & 20.0 & 15.0 & 15.0 & 0 & 0.0 & 5.0 & . & $\ln , n$ & $4 . n$ & $i 3.0$ & 120 \\
\hline 25 & $\gg . n$ & $22 . n$ & 15.0 & 15.0 & 0.0 & $0 . a$ & B. & .0 & $1 n .0$ & 10.0 & 12.0 & $1 ? .0$ \\
\hline $2 h$ & $\Rightarrow 7 . n$ & $\gg 20$ & 15.0 & 15.0 & 0.0 & 4.0 & t.n & b. & 10,0 & 10.0 & $1>0$ & $12 \cdot n$ \\
\hline 27 & 27.0 & 37.0 & 15.0 & $15 . r$ & .0 & R. 0 & 7.0 & $A=n$ & $2 \pi 0$ & 10.0 & 12.0 & $1=0$ \\
\hline 28 & 72.0 & 27.0 & 15.0 & 15.0 & . & R. 0 & 7.8 & 7.1 & 10.0 & 16.0 & $i^{2} .0$ & 1. \\
\hline 20 & 37.0 & $>70$ & 15.0 & 14.0 & 2.0 & a. 0 & $\pi \cdot 0$ & 7.0 & -- & $\ldots$ & 12.0 & 12.0 \\
\hline 30 & $22 . n$ & $>1.0$ & 14.0 & 14.0 & 0.0 & R.O & a.n & A. 0 & -- & -- & 13.0 & 14.0 \\
\hline 31 & 21.0 & 21.0 & - & - & 0 & 9.0 & A. 0 & 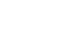 & -- & -- & 13.0 & $i^{2} .0$ \\
\hline$\triangle V F$ & 23.5 & $2 x .2$ & 17.1 & $1 \mathrm{~h} . \mathrm{R}$ & 10.2 & 10.0 & 6.2 & A. 1 & R. 5 & R. 3 & 12.1 & $1^{2} .0$ \\
\hline max & $\operatorname{MAX}$ & MIN & $M A X$ & $M I N$ & $\operatorname{tax}$ & MTMI & $M \Delta x$ & MIN & $\operatorname{mar}$ & $M J^{N}$ & Des & UIV \\
\hline 1 & $14 . n$ & $I^{3} .0$ & 20.0 & 20.0 & 25.0 & 25.0 & 24.0 & 39.0 & $2 n .0$ & $3 \pi, 0$ & $>0 . n$ & 20.17 \\
\hline ? & $14 . n$ & 14.0 & $2 n .0$ & 20.0 & 25.0 & 25.0 & 20.0 & 39.0 & 3]. 0 & $3 n .0$ & 20.0 & 20.11 \\
\hline 3 & 14.0 & 14.0 & 20.0 & 20.0 & $75 . n$ & 25.0 & $30 . n$ & $20 . n$ & ח. II & 71.0 & 39.0 & 70.1 \\
\hline 4 & 14.0 & 14.0 & $>n .0$ & 20.0 & 75.0 & 25.0 & 20.0 & in. & $\because 10$ & 31.0 & $2 a . n$ & Da. \\
\hline 5 & $15 . n$ & 14.0 & 20.0 & 20.0 & 25.0 & $2^{c} .0$ & $x \cap .0$ & $30 . n$ & झा. & 20.0 & 20.0 & 34.0 \\
\hline A & $15 . n$ & 15.0 & 20.0 & 20.? & 25.0 & 24.0 & 40.0 & 20.0 & 31.7 & $3 n .0$ & 29.0 & 20.0 \\
\hline 7 & 15.0 & 15.0 & 20.0 & 20.0 & 24.0 & 24.0 & 20.0 & 29.0 & 21.1 & an. $n$ & $=0,0$ & 4.6 \\
\hline \& & 15,0 & 15.0 & 20.0 & 19.0 & 74.0 & 24.0 & $20 . n$ & $2+. n$ & 31.0 & $3 n .0$ & 29.0 & $>0.0$ \\
\hline 9 & 16.0 & 15.0 & 10.0 & 19.0 & 24.0 & 27.0 & 20.0 & 20.0 & 31.0 & 30.0 & 33.0 & 30.0 \\
\hline 10 & 16,0 & $1 \mathrm{~h} .0$ & 10.0 & 10.0 & 72.0 & 22.0 & 30.0 & 20.0 & al. & $x$ non & 30.0 & 24.0 \\
\hline 11 & 16.0 & 16.0 & 19.0 & 19.7 & 24.0 & 23.0 & 70.0 & $27 . n$ & $3 n .0$ & $36) .0$ & 30.01 & 29.6 \\
\hline 1? & 16.0 & 16.0 & 20.0 & 19.0 & 24.0 & 24.0 & 24.0 & so.n & $3 n . n$ & 30.0 & 30.0 & 70.0 \\
\hline 12 & 16.0 & 16.0 & 30.0 & 20.0 & 25,0 & 24.0 & 24.0 & 29.0 & $30 . n$ & 30. & 40.0 & . \\
\hline 34 & $1 \mathrm{~h} .0$ & 16.0 & 21.0 & 20.0 & 25.0 & 75.0 & 20.0 & $>0 . n$ & ${ }^{2} 1.0$ & $3 n, n$ & $2 n . n$ & $x .0$ \\
\hline 15 & 17.0 & 16.0 & 21.0 & 21.0 & 25.0 & 24.0 & 74.0 & 74.0 & 31.0 & $3 \pi \cdot \pi$ & 30.0 & 24.0 \\
\hline in & 17.0 & 17.0 & 27.0 & 21.0 & 26.0 & 25.0 & 29.0 & $>0.11$ & $\begin{array}{ll}30.0 \\
0\end{array}$ & 10.17 & an. & 0.0 \\
\hline 17 & 17.0 & 17.0 & 22.0 & $22 . n$ & $2 h .0$ & 26.0 & 24.0 & $>0.0$ & $3 n . n$ & $3 n . n$ & 30.0 & .9 .0 \\
\hline is & $1 \times .0$ & 17.0 & 27.0 & 22.0 & 27.0 & 26.0 & 30.0 & 30.0 & $3 n .0$ & $x \pi .0$ & 70.0 & $30 . r$ \\
\hline 19 & $1^{R} \cdot n$ & $l^{R} .0$ & 23.0 & 27.0 & 27.0 & 27.0 & in. 0 & $2 n .0$ & $3 \pi .0$ & 10.0 & 29.0 & 20.0 \\
\hline 30 & $i^{\circ} .0$ & 19.0 & 27.0 & $>3 . n$ & $>8, n$ & 27.0 & $=1 . n$ & 20.0 & $\operatorname{an} . n$ & 30.0 & 30.0 & 70.1 \\
\hline 21 & ia.n & 12.0 & 23.0 & 23.0 & $2 R .0$ & 25.0 & $+n \cdot n$ & 31.0 & $=0$ & $3 n . n$ & $2 \pi . n$ & $3 n .0$ \\
\hline 77 & 14.0 & $l^{R} .0$ & 23.0 & 23.0 & $\therefore .0$ & $2 R .0$ & $30 . n$ & $20 . n$ & $3 n .0$ & 30.0 & $3 n \cdot n$ & ₹n. 0 \\
\hline $7^{7}$ & $1^{9} .0$ & lis. & 24.0 & 24.0 & $3 R=0$ & 39.0 & 24.0 & 29.0 & $2 n . n$ & 1n.n & $30 . n$ & $-a .0$ \\
\hline$x$ & 19.0 & 19.0 & $>4,0$ & 24.0 & 29.0 & 78.0 & 20,0 & 34.0 & $2 n, n$ & , & 29.0 & $30 . n$ \\
\hline 25 & 19.0 & 10.0 & 34.0 & 34.0 & $3 x . n$ & 8.0 & 20.0 & $2 a .0$ & 30.0 & 20.0 & $29 . n$ & 20.3 \\
\hline Ph & 19.0 & 10.0 & 25.0 & 34.0 & 29.0 & 29.0 & 34.0 & $>2.0$ & 30.0 & 20.0 & 30.0 & 20.0 \\
\hline 27 & $2 n . n$ & 19.0 & 25.0 & 25.0 & 29.0 & 32.0 & x & $28 . n$ & 20.0 & $2 \pi, n$ & 29.7 & 22.01 \\
\hline 78 & 20.0 & 20.0 & 25.0 & 25.0 & $>a .0$ & 28.0 & $=0.0$ & 24.0 & 29.0 & $\rightarrow 9.0$ & 28.0 & $\Rightarrow$. in \\
\hline 20 & $2 n . n$ & $>0.0$ & 25.0 & 25.0 & 28.0 & 28.0 & $2 n .0$ & an. & 38.0 & 24.0 & 38.0 & 27.0 \\
\hline 30 & $>0 . n$ & 20.0 & 25.0 & $2+., n$ & 9.0 & 29.0 & $20 . n$ & $30 . n$ & $P R \cdot \cap$ & 24.0 & 37.0 & $7+0$ \\
\hline 31 & -- & .. & man & $p=.0$ & - & -- & $2 n, n$ & on & 70.0 & 28.0 & -- & 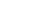 \\
\hline Avr. & 17.0 & $1 \mathrm{~h} .7$ & 21.0 & 21.6 & 26.1 & 75.8 & 20.4 & 79.1 & $3 n . n$ & "A. & 20.3 & -9.4 \\
\hline
\end{tabular}


O2470520 CEDAR CREEK BELOW BRANCH, NEAR CITRONELLE, ALA.

LOCATION.--Lat $31^{\circ} 07^{\prime} 10^{\prime \prime}$, long $88^{\circ} 12^{\prime} 28^{\prime \prime}$, In NW $\frac{1}{4} \mathrm{SW} \frac{1}{4}$ sec. 20, T.2 N., R. 2 w., Mobile County, at left bank, 1.8 miles upstream from Hector Branch, 2.5 milés northeast of Citronelle, and 3 miles upstream from County Road 96 crossing

DRAINAGE AREA. $--3.59 \mathrm{sq} \mathrm{ml}$.

PERIOD OF RECORD.--Chemical analyses: October 1967 to September 1969 (miscellaneous), October 1969 to September 1970.

CHEMICAL ANALYSES, WATER YEAR OCTOBER 1969 TO SEPTEMBER 1970

\begin{tabular}{|c|c|c|c|c|c|c|c|c|c|c|}
\hline DATE & TIME & $\begin{array}{l}\text { OIS- } \\
\text { CHARGE } \\
\text { ICFSI }\end{array}$ & $\begin{array}{l}\text { BICAR- } \\
\text { BONATE } \\
\text { (HCOZ) } \\
\text { (MG/L) }\end{array}$ & $\begin{array}{l}\text { CAR- } \\
\text { RONATE } \\
\text { (CO3) } \\
\text { (MG/L) }\end{array}$ & $\begin{array}{l}\text { CHLO- } \\
\text { RIOE } \\
(C L) \\
(M G / L)\end{array}$ & $\begin{array}{l}\text { HARD- } \\
\text { NESS } \\
(C A, M G) \\
(M G / L)\end{array}$ & $\begin{array}{l}\text { NON- } \\
\text { CAR- } \\
\text { BCNATE } \\
\text { HARD- } \\
\text { NESS } \\
\text { (MG/L) }\end{array}$ & $\begin{array}{l}\text { SPECI- } \\
\text { FIC } \\
\text { COND- } \\
\text { UCTANCE } \\
\text { (MICRO- } \\
\text { MHNSI }\end{array}$ & $\begin{array}{c}P H \\
\text { (UNITS) }\end{array}$ & $\begin{array}{l}\text { TEMP- } \\
\text { FRATURE } \\
\text { (DEG C) }\end{array}$ \\
\hline $\begin{array}{l}\text { OCT., } 1969 \\
02 \ldots . .\end{array}$ & 1220 & -- & 6 & 0 & 34 & 18 & 13 & 125 & 5.9 & 24.0 \\
\hline $\begin{array}{l}\text { NOV. } \\
\text { O6.... } \\
\text { DEC. }\end{array}$ & 1210 & - & 3 & 0 & 33 & 19 & 17 & 123 & 6.0 & 14.0 \\
\hline $\begin{array}{l}02 \ldots \\
30 \ldots \ldots\end{array}$ & $\begin{array}{l}0920 \\
1020\end{array}$ & $\ddot{-}$ & $\begin{array}{l}3 \\
3\end{array}$ & $\begin{array}{l}0 \\
0\end{array}$ & $\begin{array}{l}32 \\
24\end{array}$ & $\begin{array}{l}18 \\
18\end{array}$ & $\begin{array}{l}16 \\
16\end{array}$ & $\begin{array}{l}122 \\
119\end{array}$ & $\begin{array}{l}5.7 \\
5.4\end{array}$ & $\begin{array}{r}8.0 \\
12.0\end{array}$ \\
\hline $\begin{array}{l}\text { FE8... } 1970 \\
\text { M4... } \\
\text { MAR. }\end{array}$ & 1320 & -- & 2 & D & 24 & 15 & 13 & 119 & 5.2 & 6.0 \\
\hline $\begin{array}{l}03 \ldots \\
31 \ldots \\
A P R . \cdots\end{array}$ & $\begin{array}{l}1250 \\
0920\end{array}$ & $\begin{array}{l}1.0 \\
2.0\end{array}$ & $\begin{array}{l}3 \\
1\end{array}$ & $\begin{array}{l}0 \\
0\end{array}$ & $\begin{array}{l}25 \\
17\end{array}$ & $\begin{array}{l}19 \\
12\end{array}$ & $\begin{array}{l}17 \\
11\end{array}$ & $\begin{array}{r}120 \\
77\end{array}$ & $\begin{array}{l}5.7 \\
5.0\end{array}$ & $\begin{array}{l}14.0 \\
13.0\end{array}$ \\
\hline JUNE & 1300 & .22 & 2 & D & 27 & 19 & 17 & 113 & 6.0 & 24.0 \\
\hline JULY... & 1130 & 1.0 & 0 & D & 14 & 11 & 11 & 67 & 4.2 & 20.0 \\
\hline $\begin{array}{l}03 \ldots \\
30 \ldots \\
\text { SEP. }\end{array}$ & $\begin{array}{l}1530 \\
1215\end{array}$ & $\begin{array}{l}.50 \\
1.0^{\circ}\end{array}$ & $\begin{array}{l}5 \\
2\end{array}$ & $\begin{array}{l}0 \\
0\end{array}$ & $14^{6.8}$ & $\begin{array}{l}15 \\
10\end{array}$ & $\begin{array}{r}11 \\
B\end{array}$ & $\begin{array}{r}100 \\
76\end{array}$ & $\begin{array}{l}6.6 \\
5.2\end{array}$ & $\begin{array}{l}23.0 \\
25.0\end{array}$ \\
\hline $\begin{array}{l}01 \ldots \\
30 . .\end{array}$ & $\begin{array}{l}0830 \\
1015\end{array}$ & $\begin{array}{l}1.0 \\
1.0\end{array}$ & $\begin{array}{l}4 \\
4\end{array}$ & $\begin{array}{l}0 \\
0\end{array}$ & $\begin{array}{l}27 \\
23\end{array}$ & $\begin{array}{l}16 \\
14\end{array}$ & $\begin{array}{l}13 \\
11\end{array}$ & $\begin{array}{r}107 \\
97\end{array}$ & $\begin{array}{l}6.0 \\
5.7\end{array}$ & $\begin{array}{l}25.0 \\
19.0\end{array}$ \\
\hline
\end{tabular}

02470910 CHICKASAW CREEK A COUNTY BRIDGE, NEAR GULFCREST, ALA.

LOCATION,.-Lat $31^{\circ} 00^{\circ} 28^{\prime \prime}$, long $88^{\circ} 13^{\prime} 30^{\prime \prime}$, in SW $\frac{1}{4} W_{1}$ sec.31, T.1 N., R.2 W., Mobile County, at bridge on untmproved

road, 1.0 mile northeast of Gulfcrest, 2.2 miles upstream from Sand Hili Creek, and 3.9 miles upstrogm from Sand

DRAI NAGE AREA. - - 9.03 sq $\mathrm{ml}$.

PERIOD OF RECORD,.-Chemical analyses: October 1966 to September 1969 (miscellaneous), October 1969 to September 1970. CHEMICAL ANALYSES, WATER YEAR OCTOBER 1969 TO SEPTEMBER 1970

\begin{tabular}{|c|c|c|c|c|c|c|c|c|c|c|}
\hline DATE & TIME & $\begin{array}{l}\text { O1S- } \\
\text { CHARGE } \\
\text { (CFS) }\end{array}$ & $\begin{array}{l}\text { 8ICAR- } \\
\text { BDNATE } \\
\text { (HCO3) } \\
\text { (MG/L) }\end{array}$ & $\begin{array}{l}\text { CAR- } \\
\text { BONATE } \\
\text { (CO3) } \\
\text { (MG/L) }\end{array}$ & $\begin{array}{l}\text { CHLO- } \\
\text { RIDE } \\
\text { (CL) } \\
(M G / L)\end{array}$ & $\begin{array}{l}\text { HARD- } \\
\text { NESS } \\
(C A, M G) \\
(M G / L)\end{array}$ & $\begin{array}{l}\text { NON- } \\
\text { CAR- } \\
\text { BONATE } \\
\text { HARD- } \\
\text { NESS } \\
\text { (MG/L) }\end{array}$ & $\begin{array}{l}\text { SPECI- } \\
\text { FIC } \\
\text { COND- } \\
\text { UCTANCE } \\
\text { (WICRO- } \\
\text { MHOSI }\end{array}$ & $\begin{array}{c}\text { PH } \\
\text { (UNITS) }\end{array}$ & $\begin{array}{l}\text { TEMP- } \\
\text { ERATURE } \\
\text { (DEG C) }\end{array}$ \\
\hline${ }_{02 \ldots 1 . .1969}$ & 1020 & -- & 6 & 0 & 4.4 & 5 & 0 & 35 & 6.1 & 24.0 \\
\hline $\begin{array}{l}\text { NOV. } \\
\text { O6.... } \\
\text { DEC. }\end{array}$ & D810 & -- & 6 & 0 & 2.8 & 4 & 0 & 24 & 6.1 & 9.0 \\
\hline $\begin{array}{l}02 \ldots \ldots \\
30 \ldots 1970\end{array}$ & $\begin{array}{l}0745 \\
0900 \\
\end{array}$ & 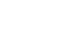 & $\begin{array}{l}5 \\
4\end{array}$ & $\begin{array}{l}0 \\
0\end{array}$ & $\begin{array}{l}3.6 \\
4.9\end{array}$ & $\begin{array}{l}5 \\
8\end{array}$ & $\begin{array}{l}1 \\
5\end{array}$ & $\begin{array}{l}26 \\
33\end{array}$ & $\begin{array}{l}6.1 \\
5.7\end{array}$ & $\begin{array}{r}8.0 \\
12.0\end{array}$ \\
\hline $\begin{array}{l}04 . . . \\
\text { MAR. }\end{array}$ & 0745 & -- & 4 & 0 & 3.8 & 8 & 5 & 29 & 5.6 & 4.0 \\
\hline $03 \ldots$ & $\begin{array}{l}0730 \\
0700\end{array}$ & $\begin{array}{l}8.0 \\
6.0\end{array}$ & $\begin{array}{l}5 \\
3\end{array}$ & $\begin{array}{l}0 \\
0\end{array}$ & $\begin{array}{l}3.0 \\
2.4\end{array}$ & $\begin{array}{l}6 \\
5\end{array}$ & 3 & $\begin{array}{l}30 \\
27\end{array}$ & $\begin{array}{l}5.9 \\
5.4\end{array}$ & $\begin{array}{l}15.0 \\
14.0\end{array}$ \\
\hline JUNE & 0740 & 4.0 & 7 & 0 & 3.6 & 8 & 2 & 29 & 6.1 & 22.0 \\
\hline JuLY, 1970 & 0730 & 12 & 1 & 0 & 2.6 & 5 & 4 & 27 & 5.1 & 20.0 \\
\hline $\begin{array}{l}03 \ldots \\
30 \ldots\end{array}$ & $\begin{array}{l}1440 \\
0745\end{array}$ & $\begin{array}{l}3.0 \\
5.0\end{array}$ & $\begin{array}{l}7 \\
5\end{array}$ & $\begin{array}{l}0 \\
0\end{array}$ & $\begin{array}{l}6.0 \\
4.2\end{array}$ & $\begin{array}{l}8 \\
6\end{array}$ & $\begin{array}{l}2 \\
2\end{array}$ & $\begin{array}{r}35 \\
31\end{array}$ & $\begin{array}{l}6.6 \\
6.6\end{array}$ & $\begin{array}{l}24.0 \\
23.0\end{array}$ \\
\hline $01 \ldots$ & $\begin{array}{l}1600 \\
0840\end{array}$ & $\begin{array}{l}3.0 \\
3.0\end{array}$ & $\begin{array}{l}5 \\
4\end{array}$ & $\begin{array}{l}0 \\
0\end{array}$ & $\begin{array}{l}3.8 \\
3.2\end{array}$ & $\begin{array}{l}5 \\
5\end{array}$ & $\frac{1}{2}$ & $\begin{array}{l}26 \\
24\end{array}$ & $\begin{array}{l}6.1 \\
6.3\end{array}$ & $\begin{array}{l}25.0 \\
18.0\end{array}$ \\
\hline
\end{tabular}


02473360 LEAF RIVER NEAR UAHNED, MISS.

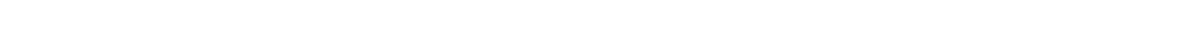
bridge on county road, 0.5 mile north of Mahned, and 0.5 mile upstream from Tallahala Creek.

DRAINAGE AREA.--1,880 sq mi, approximately.

PERIOD OF RECORD.--Chemical analyses: October 1969 to September 1970.

CHEMICAL ANALYSES, FEBRUARY TO SEPTEMBER 1970

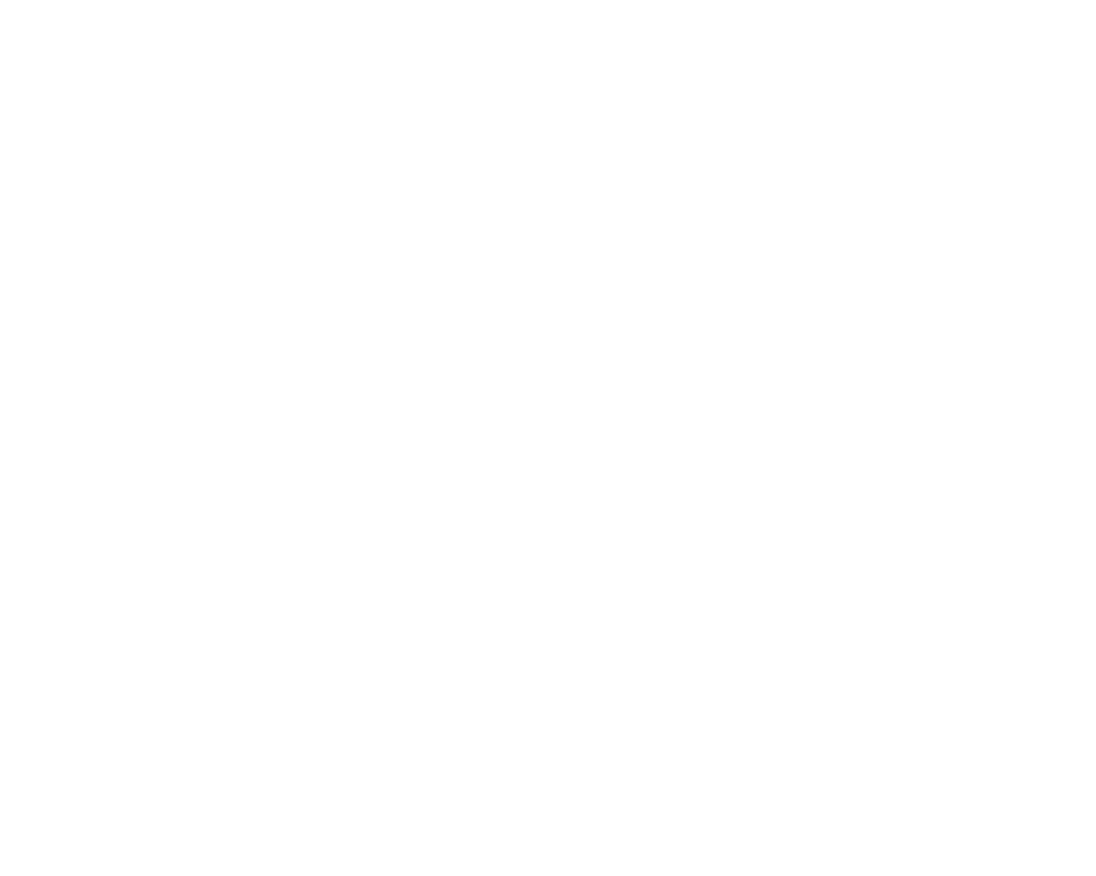


02473360 LEAF RIVER NEAR MAFNED, MISS,--Continued

SPECIFIC CONDUCTANCE (MICROMHOS/CM AT $25^{\circ} \mathrm{C}$ ), APRIL TO SEPTEMBER 1970

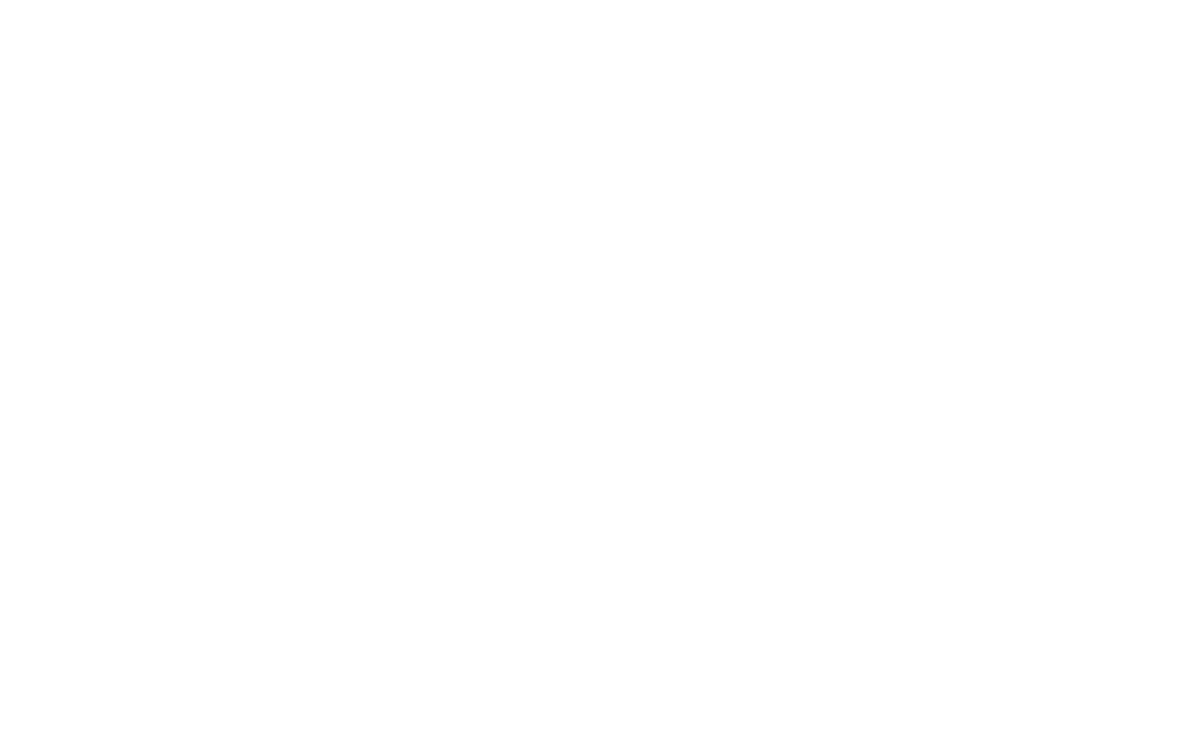

TEMPERATURE $\left({ }^{\circ} \mathrm{C}\right)$ OF WATER, APRIL TO SEPTEMBER 1970

APRIL

DAY
2


6
8
10
1
12
13
14
15
16
17
18
19
20
2
2
2
24
25
26
27
28
29
30
31

JUNE

JULY

MIN

29.0

29.0

30.0
31.0

29.0

29.0

29.0

29.0

29.0
28.0

29.0

29.0

28.0
28.0

28.0
29.0

28.0
28.0

28.0

29.0
29.0

28.0
27.0

27.0
27.0

27.0
27.0

27.0

27.0
28.0

29.0
29.0

29.0
29.0

30.0

29.0

AUGUST

MAX MIN

$\begin{array}{ll}33.0 & 30.0 \\ 33.0 & 30.0\end{array}$

$\begin{array}{ll}29.0 & 28.0 \\ 29.0 & 28.0\end{array}$

$\begin{array}{llll}32.0 & 30.0 & 29.0 & 28.0 \\ 33.0 & 30.0 & 30.0 & 28.0\end{array}$

$\begin{array}{llll}32.0 & 30.0 & 30.0 & 29.0\end{array}$

$\begin{array}{llll}31.0 & 29.0 & 31.0 & 29.0\end{array}$

$\begin{array}{llll}31.0 & 29.0 & 31.0 & 29.0 \\ 30.0 & 28.0 & 29.0 & 27.0\end{array}$

$\begin{array}{llll}30.0 & 29.0 & 29.0 & 29.0\end{array}$

$\begin{array}{llll}30.0 & 29.0 & 29.0 & 28.0\end{array}$

$\begin{array}{llll}30.0 & 29.0 & 29.0 & 29.0\end{array}$

$\begin{array}{llll}30.0 & 29.0 & 29.0 & 28.0\end{array}$

$\begin{array}{llll}30.0 & 29.0 & 29.0 & 28.0\end{array}$

$\begin{array}{llll}30.0 & 28.0 & 29.0 & 28.0 \\ 30.0 & 29.0 & 29.0 & 28.0\end{array}$

$\begin{array}{llll}31.0 & 29.0 & 29.0 & 28.0\end{array}$

$\begin{array}{llll}30.0 & 29.0 & 29.0 & 28.0\end{array}$

$\begin{array}{llll}30.0 & 29.0 & 30.0 & 29.0\end{array}$

$\begin{array}{llll}30.0 & 29.0 & 30.0 & 29.0 \\ 29.0 & 29.0 & 30.0 & 29.0\end{array}$

$29.0 \quad 28.0 \quad 30.0 \quad 29.0$

$\begin{array}{llll}29.0 & 28.0 & 30.0 & 29.0\end{array}$

$\begin{array}{llll}28.0 & 28.0 & 30.0 & 29.0 \\ 28.0 & 27.0 & 29.0 & 28.0\end{array}$

$\begin{array}{llll}28.0 & 27.0 & 29.0 & 28.0 \\ 28.0 & 28.0 & 29.0 & 28.0\end{array}$

$28.0 \quad 27.0 \quad 29.0 \quad 28.0$

$\begin{array}{llll}27.0 & 26.0 & 29.0 & 28.0\end{array}$

$26.026 .0 \quad 27.0 \quad 25.0$

$\begin{array}{llll}28.0 & 27.0 & 26.0 & 25.0\end{array}$

$30.0 \quad 28.0 \quad 29.0 \quad 28.0$ 
02474500 TALLAHALA CREEK NEAR RUNNELSTOWN, MISS.

LOCATION, --Lat $31^{\circ} 19^{\prime} 57^{\prime \prime}$, long $89^{\circ} 06^{\prime} 46^{\prime \prime}$, in SEłSE gaging station at bridge on county highway between Sunrise and Runnelstown, 3 miles south of Runnelstown, and gaging station at bridge on
9 miles upstream from mouth.

DRAINAGE AREA. $--612 \mathrm{sq} \mathrm{m} 1$.

PERIOD OF RECORD,--Chemical analyses: October 1969 to September 1970.

CHEMICAL ANALYSES, WATER YEAR OCTOBER 1969 TO SEPTEMBER 1970

\begin{tabular}{|c|c|c|c|c|c|c|c|c|c|c|c|}
\hline DATE & $\begin{array}{l}\text { DIS- } \\
\text { CHARGF } \\
\text { ICFSI }\end{array}$ & $\begin{array}{l}\text { TUR- } \\
\text { BID- } \\
\text { ITY } \\
\text { (MG/L) }\end{array}$ & $\begin{array}{c}\text { COLDR } \\
\text { (PLATI- } \\
\text { NUM- } \\
\text { COBALT } \\
\text { UNITS) }\end{array}$ & $\begin{array}{l}\text { SPECI- } \\
\text { FIC } \\
\text { CON?- } \\
\text { UCTANCE } \\
\text { (MICRO- } \\
\text { MHOSI }\end{array}$ & $\begin{array}{c}\text { BI3- } \\
\text { CHEM- } \\
\text { ICAL } \\
\text { OXYGEN } \\
\text { DEMAVD } \\
\text { (YTIL) }\end{array}$ & $\begin{array}{l}\text { CHEM- } \\
\text { ICAL } \\
\text { OXYGEN } \\
\text { DEMANO } \\
\text { (MG/L) }\end{array}$ & $\begin{array}{c}\text { PH } \\
\text { (uvirs) }\end{array}$ & $\begin{array}{l}\text { ALKA- } \\
\text { LINITY } \\
\text { AS } \\
\text { CACOB } \\
\text { (MS/L) }\end{array}$ & $\begin{array}{c}\text { ORGANIC } \\
\text { NITQI- } \\
\text { GEN } \\
\text { (NI } \\
\text { (MG/L) }\end{array}$ & $\begin{array}{c}\text { NI TRI TE } \\
\text { (N) } \\
\text { (MG/LI }\end{array}$ & $\begin{array}{l}\text { PHIS- } \\
\text { PHATE } \\
\text { (PR4) } \\
\text { (MG/L) }\end{array}$ \\
\hline $\begin{array}{l}\text { OCT. } \\
\text { O1... } \\
\text { Nov. }\end{array}$ & 68 & 25 & 40 & 190 & -- & 16 & 6.7 & 21 & 1.1 & .01 & .25 \\
\hline $\begin{array}{l}2 n . . . \\
\text { JAN. }\end{array}$ & 98 & 25 & 50 & 250 & 15 & 42 & 7.0 & 167 & 4.5 & .00 & 1.5 \\
\hline $\begin{array}{l}98 . . . \\
\text { FEB. }\end{array}$ & 959 & 52 & 95 & 92 & 100 & 112 & 5.6 & 10 & 2.1 & .03 & .38 \\
\hline $\begin{array}{l}19 \ldots . . \\
A P R .\end{array}$ & 802 & 34 & 40 & 110 & $3 n$ & 96 & 6.2 & 12 & 1.1 & .03 & .16 \\
\hline MAY & 940 & 30 & 100 & 100 & -- & 75 & 6.1 & 19 & .80 & .00 & .13 \\
\hline $\begin{array}{l}13 . . . \\
\text { AUG. }\end{array}$ & 160 & 25 & 100 & 115 & 20 & 42 & 6.4 & 32 & 2.1 & .10 & .21 \\
\hline $\begin{array}{l}\text { LEPT. } \\
\text { SET }\end{array}$ & 927 & 27 & 40 & 100 & 3.9 & 27 & 6.6 & 24 & 1.5 & .40 & .27 \\
\hline $73 \ldots$ & 8.0 & 27 & 50 & 200 & 5.0 & 37 & 7.1 & 79 & 2.0 & .10 & 1.1 \\
\hline
\end{tabular}

\begin{tabular}{|c|c|c|c|c|c|c|c|c|}
\hline DATE & $\begin{array}{l}\text { HARD- } \\
\text { NESS } \\
(C A, M G) \\
(M G / L)\end{array}$ & $\begin{array}{l}\text { CAL- } \\
\text { (IUMM } \\
\text { (CA) } \\
\text { (MG/L) }\end{array}$ & $\begin{array}{l}\text { MAG- } \\
\text { NE- } \\
\text { SIUM } \\
\text { (MG) } \\
(M G / L)\end{array}$ & $\begin{array}{l}\text { SINIUM } \\
\text { (NA) } \\
\text { (MGIL) }\end{array}$ & $\begin{array}{c}\text { SODIUM } \\
\text { AD- } \\
\text { SORP- } \\
\text { TION } \\
\text { RATIO }\end{array}$ & $\begin{array}{l}\text { PERCENT } \\
\text { SODIUM }\end{array}$ & $\begin{array}{l}\text { PO- } \\
\text { TAS- } \\
\text { SIUM } \\
\text { (K) } \\
(M G / L I\end{array}$ & $\begin{array}{l}\text { SJLFATE } \\
\text { (SD4) } \\
\text { ( MG/L) }\end{array}$ \\
\hline $\begin{array}{l}\text { nC. } \\
01 . . . \\
\text { Nnv. }\end{array}$ & 26 & 21 & 5.0 & 35 & 1.8 & 50 & 2.1 & 4.4 \\
\hline$\underset{\text { JAN. }}{20 . .}$ & 23 & 15 & -- & 71 & 5.0 & 79 & 3.6 & 4.0 \\
\hline $\begin{array}{l}09 . . . \\
F F B .\end{array}$ & 122 & 111 & 11 & 20 & .5 & 12 & 2.3 & 6.8 \\
\hline APR:.. & 25 & 18 & $7 . n$ & 21 & 1.1 & 38 & 1.8 & 4.9 \\
\hline MAY 2. & 26 & 20 & 6.0 & 22 & 1.1 & 38 & 1.6 & 17 \\
\hline AUG... & 28 & 20 & 8.0 & 26 & 1.2 & 40 & 2.2 & 9.2 \\
\hline$s=p$ & 20 & 3. 0 & 14 & 25 & 1.3 & 42 & 2.0 & 5.2 \\
\hline $23 \ldots$ & 33 & 22 & - & -- & - & - & - & 4.6 \\
\hline & DATF & $\begin{array}{l}\text { DISS- } \\
\text { OLVED } \\
\text { DXYGEN } \\
\text { IMG/LI }\end{array}$ & $\begin{array}{l}\text { TATAL } \\
\text { RESI- } \\
\text { nIIF } \\
(M(; / L)\end{array}$ & $\begin{array}{l}\text { LOSS } \\
\text { DN } \\
\text { IGNI- } \\
\text { TION } \\
\text { IMGILI I }\end{array}$ & $\begin{array}{l}\text { DIS- } \\
\text { SOLVED } \\
\text { SOLIDS } \\
\text { (MG/L) }\end{array}$ & $\begin{array}{l}\text { SUS- } \\
\text { PENDE) } \\
\text { STLIOS } \\
\text { (MG /L) }\end{array}$ & $\begin{array}{l}\text { NI TRITE } \\
\text { (Nח2) } \\
\text { (MG/L) }\end{array}$ & $\begin{array}{l}\text { NI TRATE } \\
\text { (NJ3) } \\
\text { ( } 4 G / L)\end{array}$ \\
\hline & $\begin{array}{l}\text { OCT. } \\
\text { D1.... } \\
\text { NOV. }\end{array}$ & 7.4 & 170 & 106 & -- & 7 & .00 & .0 \\
\hline & $\begin{array}{l}20 \ldots \\
\text { JAN. }\end{array}$ & 1.8 & 413 & 93 & -- & 7 & .39 & -- \\
\hline & $\begin{array}{l}\text { O9... } \\
F E B .\end{array}$ & .0 & 233 & 163 & - & 17 & .00 & -- \\
\hline & APR. & 5.2 & 210 & 136 & -- & 32 & $\cdot 20$ & - \\
\hline & MAY & 0.2 & -- & -- & - & - & .10 & -- \\
\hline & AUG: & 0.0 & 167 & 117 & 142 & 25 & .00 & - \\
\hline & SFPT. & 4.0 & 230 & 13 & 99 & 31 & .00 & -- \\
\hline & 130. & $\cdot 2$ & 190 & 127 & -- & 20 & .00 & - \\
\hline
\end{tabular}


ATION.--Lat $34^{\circ} 42^{\prime} 20^{\prime \prime}$, long $89^{\circ} 01^{\prime} 40^{\prime \prime}$, in Sw $\frac{1}{4}$ sec. 32, T.9 N., R.10 W., St. Stephens meridian, Jones County, at bridge on U.S. Highway $84,0.7 \mathrm{mile}$ east of Cleo, and 5.2 miles east of Laurel.

TRIOD OF RECORD.--Chemical analyses: October 1969 to September 1970.

CHEMICAL ANALYSES, OCTOBER 1969 TO JULY 1970

\begin{tabular}{|c|c|c|c|c|c|c|c|c|c|c|}
\hline DATE & $\begin{array}{l}\text { CAL- } \\
\text { CIUM } \\
\text { ICAI } \\
\text { (MG/LI }\end{array}$ & $\begin{array}{c}\text { MAS- } \\
\text { NE- } \\
\text { SIUM } \\
\text { I YSI } \\
\text { (MG/LI }\end{array}$ & $\begin{array}{l}\text { SODIUM } \\
\text { (NA) } \\
\text { IMG/L) }\end{array}$ & $\begin{array}{l}\text { SnDIIIM } \\
\text { An- } \\
\text { SORP- } \\
\text { RIONN } \\
\text { RTIO }\end{array}$ & $\begin{array}{l}\text { PERCENT } \\
\text { SNIIUM }\end{array}$ & $\begin{array}{l}P O- \\
T A S- \\
S I U M \\
(K) \\
(M G / L)\end{array}$ & $\begin{array}{l}\text { SULFATE } \\
\text { (SO4) } \\
\text { (MG/LI) }\end{array}$ & $\begin{array}{c}\text { TOLI- } \\
\text { FORM } \\
\text { ICOL- } \\
\text { JNIES } \\
\text { PFR } \\
100 \mathrm{MLI}\end{array}$ & $\begin{array}{l}\text { DIS- } \\
\text { SALVED } \\
\text { SOLINS } \\
\text { IRESI- } \\
\text { DUE AT } \\
\text { ISO CI } \\
\text { IMG/L) }\end{array}$ & $\begin{array}{l}\text { DIS- } \\
\text { SOLVED } \\
\text { SOLINS } \\
\text { I TONS } \\
\text { PFR } \\
\text { AC-FTI }\end{array}$ \\
\hline $\begin{array}{c}\mathrm{CCT} \\
01 . . \\
\text { DEC. }\end{array}$ & 74 & 19 & -- & -- & -- & -- & 11 & -- & 474 & .64 \\
\hline JAN... & 112 & 36 & $12 ?$ & 2.6 & $3 B$ & 4.3 & 8.7 & 5000 & 1031 & $1.4 n$ \\
\hline MAR. & 82 & 22 & 97 & 2.5 & 42 & 1.7 & 12 & -- & 484 & .66 \\
\hline $\begin{array}{l}\text { O5... } \\
A P R .\end{array}$ & 66 & 19 & 59 & 1.6 & 34 & 1.8 & 4.8 & 600 & - & -- \\
\hline $\begin{array}{r}15, \ldots \\
\text { MAY } \\
27 \ldots\end{array}$ & 55 & 14 & 112 & 3.5 & 55 & 1.4 & 2.0 & 80 & -- & - \\
\hline $\begin{array}{l}27 . . . \\
\text { JuLY }\end{array}$ & 12 & -- & 80 & 2.6 & 49 & .6 & 7.7 & 120 & - & -- \\
\hline $14 \ldots$ & 59 & 14 & 74 & 2.2 & 44 & 1.6 & 6.0 & 500 & $-\pi$ & -- \\
\hline
\end{tabular}

\begin{tabular}{|c|c|c|c|c|c|c|c|c|c|c|c|}
\hline DATE & $\begin{array}{l}\text { TUR- } \\
\text { BID- } \\
\text { ITY } \\
\text { IMG/LI }\end{array}$ & $\begin{array}{l}\text { COLIJR } \\
\text { IPLATI- } \\
\text { INUM- } \\
\text { COBALT } \\
\text { UNITSI }\end{array}$ & $\begin{array}{l}\text { SPECI- } \\
\text { FIC } \\
\text { COND- } \\
\text { UCTANCE } \\
\text { (MICRO- } \\
\text { MHDSI }\end{array}$ & $\begin{array}{l}\text { BIO- } \\
\text { CHEM- } \\
\text { ICAL } \\
\text { OXYGEN } \\
\text { DEMANO } \\
\text { (MG/L) }\end{array}$ & $\begin{array}{l}\text { CHEY- } \\
\text { ICAL } \\
\text { OXYGEN } \\
\text { OEMAN } \\
\text { (MGSL ) }\end{array}$ & $\begin{array}{c}\text { PH } \\
\text { (UNITS) }\end{array}$ & $\begin{array}{l}\text { ALKA- } \\
\text { LENITY } \\
\text { AS } \\
\text { CACOB } \\
\text { IMGILI) }\end{array}$ & $\begin{array}{l}\text { JRFAVI: } \\
\text { NETRT- } \\
\text { GEV } \\
\text { (N) } \\
\text { IMG/LI }\end{array}$ & $\begin{array}{l}\text { NITRITE } \\
\text { IVI) } \\
\text { (MG/L) }\end{array}$ & $\begin{array}{l}\text { PHOS- } \\
\text { PHATE } \\
\text { (PO4) } \\
\text { (MG/L) }\end{array}$ & $\begin{array}{l}\text { HARO- } \\
\text { NESS } \\
\text { (CA, } 4 ; 1 \\
\text { (MGIL) }\end{array}$ \\
\hline $\begin{array}{l}\text { nCr. } \\
\text { O1... } \\
\text { DEC. }\end{array}$ & 25 & 20 & 600 & -- & 11 & 6.8 & 17 & .62 & .01 & .00 & 93 \\
\hline $\begin{array}{l}\text { O4... } \\
\text { JAN. }\end{array}$ & 25 & 10 & 810 & 3.4 & 21 & 6.6 & 34 & 1.5 & .00 & Iח. & 148 \\
\hline $\begin{array}{l}22 . . \\
\text { MAR. }\end{array}$ & 15 & 15 & 620 & 4.1 & 7.4 & 7.0 & 27 & 1.0 & .00 & .06 & 104 \\
\hline $\begin{array}{l}05 \ldots . . \\
A P R .\end{array}$ & 10 & 20 & 550 & .8 & 15 & 6.5 & 13 & .67 & .20 & .03 & -- \\
\hline $\begin{array}{l}15 \ldots . . \\
\text { MAY } \\
27 \ldots . .\end{array}$ & $5 . n$ & 45 & $39 n$ & 1.5 & 17 & 6.7 & 15 & .71 & .0n & .03 & 69 \\
\hline $\operatorname{JuLY}_{14}^{27 \ldots}$ & 5.0 & 10 & 460 & 2.4 & 15 & 7.5 & IB & .73 & .12 & .04 & 97 \\
\hline $14 \ldots\}$ & 10 & 35 & 330 & 1.3 & 16 & 7.2 & 18 & 1.7 & 1.0 & .01 & 73 \\
\hline
\end{tabular}

\begin{tabular}{|c|c|c|c|c|c|c|c|}
\hline DATE & $\begin{array}{l}\text { YOTAL } \\
\text { RESI- } \\
\text { DUE } \\
\text { (MG/L) }\end{array}$ & $\begin{array}{l}\text { LOSS } \\
\text { SN } \\
\text { IGNT- } \\
\text { TYON } \\
\text { IMG/LI }\end{array}$ & $\begin{array}{l}\text { DIS- } \\
\text { SOLVEO } \\
\text { SOL. IDS } \\
\text { (MG/L) }\end{array}$ & $\begin{array}{l}\text { SUS- } \\
\text { PENDEO } \\
\text { SOLIDS } \\
\text { IMGILI }\end{array}$ & $\begin{array}{c}\text { NITRITE } \\
\text { (NOZI } \\
\text { IMG/LI }\end{array}$ & $\begin{array}{l}\text { CHLD- } \\
\text { RIOE } \\
\text { (CLI) } \\
\text { (YGIL) }\end{array}$ & $\begin{array}{l}\text { VITRATE } \\
\text { (NO3) } \\
\text { (ME/L) }\end{array}$ \\
\hline $\begin{array}{l}\text { OCT. } \\
\text { OI }\end{array}$ & -- & -- & -- & -- & -- & -- & .0 \\
\hline $\begin{array}{l}\text { DEC. } \\
\text { O4.... }\end{array}$ & $m$ & -- & -- & $=$ & - & 317 & -- \\
\hline $\begin{array}{l}\text { D5... } \\
\text { APR. }\end{array}$ & 390 & 257 & 371 & 9 & סח. & 140 & -- \\
\hline $\operatorname{maY}_{\text {MAY }}^{15 . . .}$ & 357 & 240 & 347 & 10 & .00 & $\cdots$ & -- \\
\hline juLY $^{27}$ & 373 & 227 & 371 & 2 & .00 & -- & -- \\
\hline $14 \ldots$ & 383 & 320 & 378 & 5 & .00 & - & -- \\
\hline
\end{tabular}

02477000 CHICKASAWHAY RIVER AT ENTERPRISE, YISS.

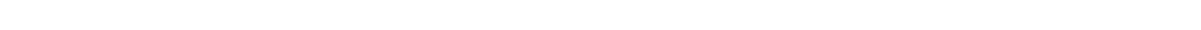
ing station at bridge on State Highway 513 in Enterprise, 0.5 mile downstream from confluence of Chunky River and Oka tibbee Creek, and at mile 158.2 .

DRA INAGE AREA.--913 sq $\mathrm{mi}$.

PERIOD OF RECORD, - Chemical analyses: October 1969 to September 1970.

CHEMICAL ANALYSES, WATER YEAR OCTOBER 1969 TO SEPTEMBER 1970

\begin{tabular}{|c|c|c|c|c|c|c|c|c|c|c|c|c|}
\hline DATE & $\begin{array}{l}\text { OIS- } \\
\text { CHARGE } \\
\text { ICFSI }\end{array}$ & $\begin{array}{l}\text { TIJR- } \\
\text { BIN- } \\
\text { ITY } \\
\text { (MG/L) }\end{array}$ & $\begin{array}{l}\text { CDLOR } \\
\text { IPLATI- } \\
\text { INUM- } \\
\text { COBALT } \\
\text { UNIYSI }\end{array}$ & $\begin{array}{l}\text { SPECI- } \\
\text { FIC } \\
\text { COND- } \\
\text { UCTANCF } \\
\text { IMICRI- } \\
\text { MHOSI }\end{array}$ & $\begin{array}{l}\text { RID- } \\
\text { CHEM- } \\
\text { ICAL } \\
\text { OXYGFN } \\
\text { DEMAND } \\
\text { (MG/L) }\end{array}$ & $\begin{array}{l}\text { CHEM- } \\
\text { ICAL } \\
\text { OXYGEN } \\
\text { DEMAND } \\
\text { (MG/L) }\end{array}$ & $\begin{array}{c}\text { PH } \\
\text { (UNITS) }\end{array}$ & $\begin{array}{l}\text { ALKA- } \\
\text { LINITY } \\
\text { AS } \\
\text { CACDB } \\
\text { (MGILI) }\end{array}$ & $\begin{array}{l}\text { ORGANIC } \\
\text { NITOJ- } \\
\text { GFN } \\
\text { (N) } \\
\text { (MF/L) }\end{array}$ & $\begin{array}{c}\text { NITRITE } \\
\text { (N) } \\
\text { (MIS/L) }\end{array}$ & $\begin{array}{l}\text { PHOS- } \\
\text { PHATE } \\
\text { (POL) } \\
\text { (MGIL) }\end{array}$ & $\begin{array}{l}\text { IART) } \\
\text { NESS } \\
(C A, M G) \\
(M G / L)\end{array}$ \\
\hline $\begin{array}{l}\text { oct. } \\
\text { ol.... } \\
\text { OEC. }\end{array}$ & 88 & 25 & 20 & 120 & -- & 16 & 1.2 & 29 & 2.0 & .11 & .71 & 27 \\
\hline $\begin{array}{l}04 . . \\
\text { JAN. }\end{array}$ & 145 & 25 & 30 & 90 & 3.7 & 16 & 7.1 & 49 & 3.1 & .04 & 1.0 & 30 \\
\hline $\begin{array}{l}21 \ldots \\
{ }_{A P R}\end{array}$ & 554 & 20 & 15 & 70 & 3.6 & 9.3 & 7.1 & 30 & 1.3 & .00 & .15 & 21 \\
\hline$\underset{\text { MAY }}{15} \cdots$ & 162 & 15 & 45 & 68 & 1.1 & 13 & 6.8 & 15 & .70 & .13 & .21 & 22 \\
\hline $\begin{array}{l}27 . . . \\
\text { AUG. }\end{array}$ & -- & 5.0 & 15 & 98 & 2.4 & 11 & 7.0 & 26 & .73 & .60 & .42 & 30 \\
\hline $26 \ldots$ & 946 & 32 & 80 & 54 & 2.1 & 21 & 7.1 & 22 & 2.5 & .10 & .26 & 24 \\
\hline
\end{tabular}


02477000 CHICKASAWHAY RIVER AT ENTERPRISE, yISS.--Continued CHEMICAL ANALYSES, WATER YEAR OCTOBER 1969 TO SEPTEMBER 1970

\begin{tabular}{|c|c|c|c|c|c|c|c|c|c|c|c|}
\hline SATE & $\begin{array}{l}\text { CAL- } \\
\text { CIUM } \\
\text { (CA) } \\
\text { (MGILI) }\end{array}$ & $\begin{array}{l}\text { MAG- } \\
\text { NE- } \\
\text { SIUM } \\
\text { (MG) } \\
\text { (MG/L) }\end{array}$ & $\begin{array}{l}\text { SODIUM } \\
\text { (NA) } \\
\text { (MG/L) }\end{array}$ & $\begin{array}{c}\text { SHOIUM } \\
\text { AR- } \\
\text { SORP- } \\
\text { TION } \\
\text { RATIO }\end{array}$ & $\begin{array}{l}\text { PERCENT } \\
\text { SNDIUM }\end{array}$ & $\begin{array}{l}\text { PO- } \\
\text { YAS- } \\
\text { SIUM } \\
\text { (K) } \\
\text { (MG/L) }\end{array}$ & $\begin{array}{l}\text { SIULFATE } \\
(504) \\
\text { (MG/L) }\end{array}$ & $\begin{array}{c}\text { COLI- } \\
\text { FORY } \\
\text { ICOL- } \\
\text { ONIES } \\
\text { PER } \\
\text { 10O ML, }\end{array}$ & $\begin{array}{l}\text { I DIS- } \\
\text { SOL VED } \\
\text { SOLINS } \\
\text { IRESI- } \\
\text { OUE AT } \\
\text { ISO C) } \\
\text { (MGIL) }\end{array}$ & $\begin{array}{l}\text { DIS- } \\
\text { SDLYFS } \\
\text { SOLIDS } \\
\text { (TONS } \\
\text { PER } \\
\text { DAY) }\end{array}$ & $\begin{array}{l}\text { DIS- } \\
\text { SOLVED } \\
\text { SDLIDS } \\
\text { (TONS } \\
\text { PER } \\
\text { AC-FTI }\end{array}$ \\
\hline \multicolumn{12}{|l|}{ oct. } \\
\hline $\begin{array}{c}01 \ldots . . \\
\text { DEC. }\end{array}$ & 21 & 6.0 & 19 & .9 & 34 & 3.2 & 14 & $m$ & 102 & 24.2 & .14 \\
\hline $\begin{array}{l}04 . . \\
\text { JAN. }\end{array}$ & 27 & 3.0 & 17 & .8 & 31 & 2.7 & 13 & 1500 & 98 & 38.4 & .13 \\
\hline $\begin{array}{l}21 \ldots \\
A P R\end{array}$ & 15 & 6.0 & 11 & .6 & 27 & 1.3 & 15 & 5000 & 80 & 120 & .11 \\
\hline MAY $15 \ldots$ & 16 & 6.0 & 9.0 & .5 & 23 & 1.2 & 3.0 & 740 & -- & -- & - \\
\hline & 22 & $\cdots$ & 18 & 1.1 & 41 & 2.0 & 15 & 460 & - & -- & -- \\
\hline \multirow{6}{*}{$\begin{array}{l}\text { AUG. } \\
26 . .\end{array}$} & 14 & 10 & 7.8 & .4 & 18 & 1.8 & 8.6 & 41400 & -- & -- & -- \\
\hline & & & DATE & $\begin{array}{l}\text { TOTAL } \\
\text { RESI- } \\
\text { DUE } \\
\text { (MGIL) }\end{array}$ & $\begin{array}{c}\text { LOSS } \\
\text { ON } \\
\text { IGNI- } \\
\text { TION } \\
\text { ( MG/L) }\end{array}$ & $\begin{array}{l}\text { OIS- } \\
\text { SOLVED } \\
\text { SOLIDS } \\
\text { IMG/LI }\end{array}$ & $\begin{array}{l}\text { SUS- } \\
\text { PENDED } \\
\text { SOLIOS } \\
\text { (MG/L) }\end{array}$ & $\begin{array}{l}\text { NI TRITE } \\
\text { (ND2) } \\
\text { (MG/L) }\end{array}$ & $\begin{array}{l}\text { NI YRATE } \\
\text { (NJ3) } \\
\text { (MG/L) }\end{array}$ & & \\
\hline & & & $\begin{array}{l}\text { OCT. } \\
\text { OI... } \\
\text { ADR. }\end{array}$ & -- & - & -- & -- & -- & .5 & & \\
\hline & & & $\operatorname{MAY}_{15}^{15}$ & 113 & 53 & 106 & 7 & .01 & $-\overline{1}$ & & \\
\hline & & & $\begin{array}{l}27 \ldots \\
\text { Aug. }\end{array}$ & 93 & 43 & $B 5$ & A & .18 & -- & & \\
\hline & & & $26 \ldots$ & 143 & 70 & 107 & 36 & .02 & -- & & \\
\hline
\end{tabular}

LOCATION.--Lat $30^{\circ} 58^{\prime} 40^{\prime \prime}$, long $88^{\circ} 43^{\prime} 35^{\prime \prime}$, in SW子 sec.18, T.1 S., R.7 w., St. Stephens meridian, George County, at brtdge on highway between Merrill and Avent, 0.5 mile downstream from confluence, of Leaf and Chickasawhay rivers, $0.5 \mathrm{mile}$ west of Merrill, and at mile 80.8 .

DRAINAGE AREA. $-6,600 \mathrm{sq} \mathrm{mi}$, approximately.

PERIOD OF RECORD. - Chemical analyses: January 1966 to September 1970. Water temperatures: April to September 1970

CHEMICAL ANALYSES, NOVEMBER 1969 TO JUNE 1970

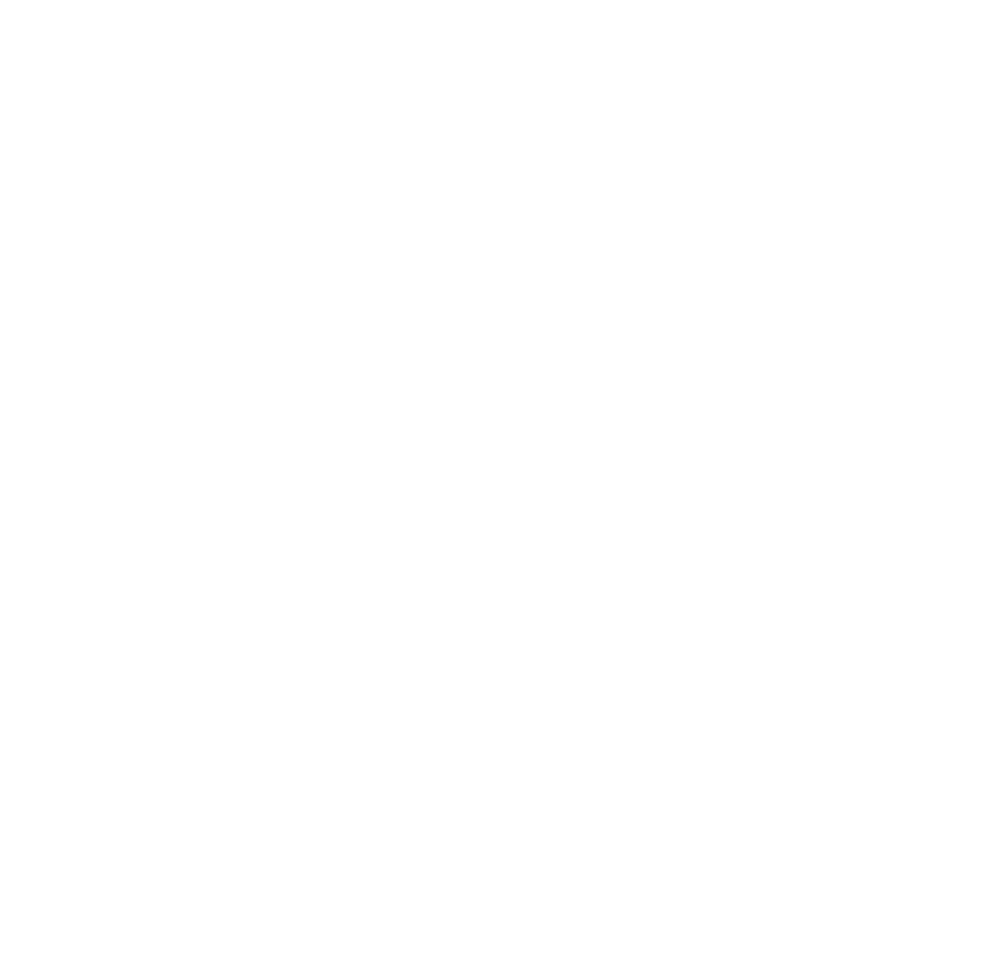


SPECIFIC CONDUCTANCE (MICROMHOS/CM AT $25^{\circ} \mathrm{C}$ ), APRIL TO SEPTEMBER 1970

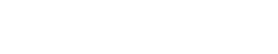

MAX MIN

105

11
12
13
14
15

$\begin{array}{rr}225 & 105 \\ 171 & 105 \\ 185 & 95 \\ 110 & 95\end{array}$

$\begin{array}{ll}16 & 200 \\ 17 & 300 \\ 18 & -- \\ 19 & --\end{array}$

19
20

$21 \quad 260 \quad 210 \quad 200$

$\begin{array}{ll}21 & 26 \\ 22 & \\ 23 & \\ 24 & 26 \\ 25 & \end{array}$

$\begin{array}{ll}26 & \\ 27 & \\ 28 & 26 \\ 29 & 280 \\ 30 & \end{array}$

31

AVERAGE
MAY

\begin{tabular}{cccc}
\multicolumn{2}{c}{ MAY } & \multicolumn{3}{c}{ JUNE } \\
MAX & MIN & MAX & MIN \\
-- & -- & 575 & 400 \\
-- & -- & 675 & 270 \\
-- & -- & 550 & 280 \\
-- & -- & 600 & 240 \\
-- & -- & 750 & 470 \\
-- & -- & 575 & 300 \\
-- & -- & 460 & 250 \\
-- & -- & 490 & 310 \\
-- & -- & 360 & 210 \\
-- & -- & 210 & 150 \\
-- & -- & 420 & 150 \\
\hline- & -- & 700 & 420
\end{tabular}

\begin{tabular}{rl}
\multicolumn{2}{c}{ JULY } \\
MAX & M \\
700 & 2 \\
850 & 2 \\
875 & 7 \\
800 & 7 \\
800 & 6 \\
750 & 5 \\
750 & 5 \\
900 & 5 \\
700 & 2 \\
850 & 2 \\
900 & \\
900 & 3 \\
950 & 3 \\
950 & 6 \\
1050 & 7 \\
700 & 4 \\
& \\
675 & 3 \\
1400 & 2 \\
1300 & 770 \\
1050 & 6 \\
950 & 600
\end{tabular}

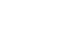

AUGUST

SEPTEMBER

$\begin{array}{rrrr}\text { MAX } & \text { MIN } & \text { MAX } & \text { MIN } \\ -- & -- & 120 & 108 \\ -- & -- & -- & -- \\ -- & -- & -- & -- \\ -- & -- & -- & -- \\ -- & -- & -- & -- \\ 700 & 360 & -- & -- \\ 700 & 580 & -- & -- \\ 550 & 320 & -- & - \\ 470 & 220 & 240 & 100 \\ 440 & 220 & 480 & 150 \\ 380 & 230 & 335 & 150 \\ 230 & 120 & 440 & 150 \\ 280 & 130 & 195 & 185 \\ 400 & 160 & 240 & 185 \\ 400 & 190 & 330 & 240 \\ 330 & 210 & 260 & 165 \\ 340 & 140 & 165 & 130 \\ 320 & 155 & 130 & 120 \\ 170 & 125 & 120 & 120 \\ 190 & 120 & 575 & 120 \\ 125 & 120 & 600 & 320 \\ 122 & 120 & 440 & 240 \\ 500 & 120 & 240 & 190 \\ 390 & 140 & 190 & 160 \\ 280 & 130 & 460 & 160 \\ 390 & 130 & 320 & 140 \\ 360 & 140 & 140 & 130 \\ 140 & 115 & 130 & 85 \\ 115 & 110 & 120 & 85 \\ 115 & 110 & 120 & 105 \\ 120 & 110 & -- & -- \\ 329 & 177 & -- & --\end{array}$

TEMPERATURE (०) OF WATER, APRIL TO SEPTEMBER 1970

\begin{tabular}{|c|c|c|c|c|c|c|c|c|c|c|c|c|}
\hline DAY & \multicolumn{2}{|c|}{ APRIL } & \multicolumn{2}{|c|}{ MAY } & \multicolumn{2}{|c|}{ JUNE } & \multicolumn{2}{|c|}{ JULYY } & \multicolumn{2}{|c|}{ AUGUST } & \multicolumn{2}{|c|}{ SEPTEMBER } \\
\hline $\begin{array}{l}1 \\
2 \\
3 \\
4 \\
5\end{array}$ & $\begin{array}{l}=- \\
=- \\
=-\end{array}$ & $\begin{array}{l}=- \\
=- \\
=- \\
--\end{array}$ & $\begin{array}{l}=- \\
=- \\
=-\end{array}$ & $\begin{array}{l}-- \\
-- \\
-- \\
--\end{array}$ & $\begin{array}{l}27.0 \\
26.0 \\
26.0 \\
26.0 \\
26.0\end{array}$ & $\begin{array}{l}26.0 \\
25.0 \\
25.0 \\
25.0 \\
25.0\end{array}$ & $\begin{array}{l}31.0 \\
31.0 \\
32.0 \\
32.0 \\
31.0\end{array}$ & $\begin{array}{l}29.0 \\
29.0 \\
30.0 \\
30.0 \\
29.0\end{array}$ & $\begin{array}{l}32.0 \\
32.0 \\
31.0 \\
31.0 \\
31.0\end{array}$ & $\begin{array}{l}30.0 \\
30.0 \\
30.0 \\
29.0 \\
29.0\end{array}$ & $\begin{array}{l}28.0 \\
29.0 \\
29.0 \\
30.0 \\
30.0\end{array}$ & $\begin{array}{l}27.0 \\
28.0 \\
28.0 \\
28.0 \\
28.0\end{array}$ \\
\hline $\begin{array}{r}6 \\
7 \\
8 \\
9 \\
10\end{array}$ & $\begin{array}{r}=- \\
\overline{-} \\
19.0\end{array}$ & $\begin{array}{r}-- \\
=- \\
19.0\end{array}$ & $\begin{array}{l}-- \\
-- \\
-- \\
--\end{array}$ & $\begin{array}{l}-- \\
=- \\
=- \\
--\end{array}$ & $\begin{array}{l}26.0 \\
26.0 \\
27.0 \\
27.0 \\
27.0\end{array}$ & $\begin{array}{l}25.0 \\
25.0 \\
25.0 \\
25.0 \\
26.0\end{array}$ & $\begin{array}{l}31.0 \\
31.0 \\
30.0 \\
30.0 \\
30.0\end{array}$ & $\begin{array}{l}29.0 \\
29.0 \\
29.0 \\
28.0 \\
28.0\end{array}$ & $\begin{array}{l}30.0 \\
30.0 \\
29.0 \\
29.0 \\
29.0\end{array}$ & $\begin{array}{l}28.0 \\
28.0 \\
28.0 \\
28.0 \\
28.0\end{array}$ & $\begin{array}{l}31.0 \\
31.0 \\
29.0 \\
29.0 \\
29.0\end{array}$ & $\begin{array}{l}29.0 \\
29.0 \\
27.0 \\
27.0 \\
28.0\end{array}$ \\
\hline $\begin{array}{l}11 \\
12 \\
13 \\
14 \\
15\end{array}$ & $\begin{array}{l}19.0 \\
20.0 \\
20.0 \\
20.0 \\
20.0\end{array}$ & $\begin{array}{l}19.0 \\
19.0 \\
19.0 \\
20.0 \\
19.0\end{array}$ & $\begin{array}{r}-- \\
-- \\
23.0 \\
24.0 \\
25.0\end{array}$ & $\begin{array}{r}-- \\
23.0 \\
23.0 \\
23.0\end{array}$ & $\begin{array}{l}28.0 \\
28.0 \\
29.0 \\
30.0 \\
30.0\end{array}$ & $\begin{array}{l}26.0 \\
26.0 \\
27.0 \\
28.0 \\
29.0\end{array}$ & $\begin{array}{l}30.0 \\
30.0 \\
30.0 \\
29.0 \\
29.0\end{array}$ & $\begin{array}{l}29.0 \\
28.0 \\
28.0 \\
28.0 \\
28.0\end{array}$ & $\begin{array}{l}28.0 \\
28.0 \\
29.0 \\
29.0 \\
29.0\end{array}$ & $\begin{array}{l}28.0 \\
27.0 \\
27.0 \\
28.0 \\
28.0\end{array}$ & $\begin{array}{l}29.0 \\
29.0 \\
30.0 \\
29.0 \\
29.0\end{array}$ & $\begin{array}{l}28.0 \\
28.0 \\
28.0 \\
28.0 \\
28.0\end{array}$ \\
\hline $\begin{array}{l}21 \\
22 \\
23 \\
24 \\
25\end{array}$ & $\begin{array}{l}=- \\
=- \\
=-\end{array}$ & $\begin{array}{l}=- \\
=- \\
=- \\
--\end{array}$ & $\begin{array}{l}=- \\
=- \\
=-\end{array}$ & $\begin{array}{l}-- \\
z- \\
z- \\
--\end{array}$ & $\begin{array}{l}31.0 \\
31.0 \\
31.0 \\
30.0 \\
28.0\end{array}$ & $\begin{array}{l}30.0 \\
29.0 \\
30.0 \\
28.0 \\
27.0\end{array}$ & $\begin{array}{l}30.0 \\
29.0 \\
28.0 \\
27.0 \\
27.0\end{array}$ & $\begin{array}{l}29.0 \\
27.0 \\
27.0 \\
26.0 \\
26.0\end{array}$ & $\begin{array}{l}28.0 \\
28.0 \\
28.0 \\
27.0 \\
27.0\end{array}$ & $\begin{array}{l}27.0 \\
27.0 \\
27.0 \\
27.0 \\
26.0\end{array}$ & $\begin{array}{l}29.0 \\
29.0 \\
28.0 \\
27.0 \\
27.0\end{array}$ & $\begin{array}{l}28.0 \\
28.0 \\
27.0 \\
26.0 \\
26.0\end{array}$ \\
\hline $\begin{array}{l}26 \\
27 \\
28 \\
29 \\
30 \\
31\end{array}$ & $\begin{array}{l}-- \\
-- \\
-- \\
-- \\
--\end{array}$ & $\begin{array}{l}-- \\
=- \\
-- \\
-- \\
--\end{array}$ & $\begin{array}{r}-- \\
-- \\
29.0 \\
28.0 \\
27.0 \\
27.0\end{array}$ & $\begin{array}{r}-- \\
-- \\
27.0 \\
27.0 \\
26.0 \\
26.0\end{array}$ & $\begin{array}{r}28.0 \\
29.0 \\
30.0 \\
30.0 \\
31.0 \\
--\end{array}$ & $\begin{array}{r}27.0 \\
27.0 \\
28.0 \\
28.0 \\
29.0 \\
---\end{array}$ & $\begin{array}{l}27.0 \\
29.0 \\
29.0 \\
30.0 \\
31.0 \\
31.0\end{array}$ & $\begin{array}{l}26.0 \\
27.0 \\
28.0 \\
28.0 \\
29.0 \\
29.0\end{array}$ & $\begin{array}{l}27.0 \\
27.0 \\
26.0 \\
26.0 \\
27.0 \\
28.0\end{array}$ & $\begin{array}{l}27.0 \\
26.0 \\
26.0 \\
26.0 \\
26.0 \\
27.0\end{array}$ & $\begin{array}{r}27.0 \\
27.0 \\
26.0 \\
25.0 \\
25.0 \\
\ldots\end{array}$ & $\begin{array}{r}26.0 \\
26.0 \\
25.0 \\
24.0 \\
23.0 \\
-.\end{array}$ \\
\hline AVERAGE & -- & -- & -- & -- & 29.0 & 27.0 & 30.0 & 28.0 & 29.0 & 28.0 & 29.0 & 27.0 \\
\hline
\end{tabular}


02479020 PASCAGOULA RIVER NEAR BENNDALE, MISS.

LOCATION.--Lat $30^{\circ} 52^{\prime} 45^{\prime \prime}$, Long $88^{\circ} 46^{\prime} 22^{\prime \prime}$, on line between sec.15 and 22 , T.2 S., R.8 W., St. Stephens meridian, George County, at bridge on' State Highway 26, 0.4 mile upstream from Bates Creek, 2.1 miles east of Benndale, and 11.7 miles southwest of Lucedale.

DRAINAGE AREA, $--6,690 \mathrm{sp} \mathrm{mi}$, approximately.

CHEMICAL ANALYSES, WATER YEAR OCTOBER 1969 TO SEPTEMBER 1970

\begin{tabular}{|c|c|c|c|c|c|c|c|c|c|c|c|}
\hline NAFE & $\begin{array}{l}\text { DIS- } \\
\text { CHARTEC } \\
\text { (CFS) }\end{array}$ & $\begin{array}{l}\text { CAL- } \\
\text { CIUH } \\
\text { (CA) } \\
\text { ( } 4 G / L)\end{array}$ & $\begin{array}{l}\text { MAF- } \\
\text { NE- } \\
\text { SIUM } \\
\text { ( } 4 F) \\
\text { (MGIL) }\end{array}$ & $\begin{array}{c}\text { Sanf IU* } \\
\text { (NA) } \\
\text { (UG/L) }\end{array}$ & $\begin{array}{l}\text { P)- } \\
\text { TAS- } \\
\text { SIIJM } \\
\text { (K) } \\
\text { I YG/L) }\end{array}$ & $\begin{array}{l}\text { ALKA- } \\
\text { LINITY } \\
\text { AS } \\
\text { CAC }]_{3} \\
(M G / L)\end{array}$ & $\begin{array}{l}\text { SHLFATC } \\
(S \cap 4) \\
\left(4 R_{*} / L\right)\end{array}$ & $\begin{array}{l}\text { PHIS - } \\
\text { PłAT } \\
(P 74) \\
(45 / L)\end{array}$ & $\begin{array}{l}\text { HARD- } \\
\text { VFSS } \\
\text { IrA, } A G) \\
(4,11)\end{array}$ & $\begin{array}{c}\text { SJI UM } \\
\text { A T- } \\
\text { STRP- } \\
\text { TITN } \\
\text { RATI }\end{array}$ & 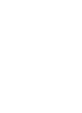 \\
\hline 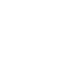 & 1310 & 27 & a. & $4 h$ & 2.0 & o & 14 & .94 & $3 n$ & $? 1$ & 300 \\
\hline & 1400 & 18 & -- & 31 & $1 \cdot 3$ & $3 n$ & 1.5 & .19 & 21 & 2.0 & 145 \\
\hline FER. & $738 n$ & 21 & 1.0 & 22 & 1.4 & 11 & 3.5 & . & 72 & 1.3 & $9 k$ \\
\hline $\begin{array}{l}19 . . . \\
A P R .\end{array}$ & 8680 & $1 R$ & 6.0 & 24 & 1.0 & 13 & 3.7 & .05 & 24 & 1.3 & 117 \\
\hline MAY & AORO & 13 & 1.0 & 16 & .8 & 17 &.$?$ & .04 & 14 & 1.2 & 50 \\
\hline AIJ5... & 2490 & 19 & 9.0 & 39 & 1.5 & 16 & 8.2 & .94 & $\times 7$ & 1.9 & 197 \\
\hline$\underset{\varsigma \in P T .}{12}$ & 2910 & 15 & 7.0 & 33 & 1.3 & 11 & 5.1 & . ns & $? ?$ & 1.9 & 145 \\
\hline $23 \ldots$ & 1400 & 14 & - & -- & -- & 12 & 11 & .17 & $>3$ & -- & ?חn \\
\hline
\end{tabular}

\begin{tabular}{|c|c|c|c|c|c|c|c|c|c|c|}
\hline DATF & (INTS & $\begin{array}{l}\text { COLAP } \\
\text { IOLATI- } \\
\text { NIM- } \\
\text { CORALT } \\
\text { UVITSI }\end{array}$ & $\begin{array}{l}\text { TIJP- } \\
\text { BID- } \\
\text { ITY } \\
\text { I MG./LI I I }\end{array}$ & $\begin{array}{l}\text { RFY- } \\
\text { CHFM- } \\
\text { ICAL } \\
\text { OKYGFN } \\
\text { FFMAN } \\
\text { (YC,LI) }\end{array}$ & $\begin{array}{l}\text { CHEM- } \\
\text { CHEAL } \\
\text { OXYGEN } \\
\text { DEGAND } \\
\text { IMG/LI }\end{array}$ & $\begin{array}{l}\text { TRGANET } \\
\text { NITRT- } \\
\text { GFN } \\
\text { (N) } \\
\text { IMr/L) }\end{array}$ & $\begin{array}{c}\text { TFMP- } \\
\text { ERATURE } \\
\text { ITES II }\end{array}$ & $\begin{array}{l}\text { DIS- } \\
\text { SOLVED } \\
\text { OXYGEN } \\
\text { MGG/LI }\end{array}$ & $\begin{array}{l}\text { MITPITT } \\
\text { (U) } \\
\text { (MG/L) }\end{array}$ & $\begin{array}{c}\text { COL1- } \\
\text { CTRM } \\
\text { ICTE- } \\
\text { ONIFS } \\
\text { PFQ } \\
\text { INO MLJ }\end{array}$ \\
\hline $\begin{array}{c}\text { חCT. } \\
\text { n?:... } \\
\text { NกV. }\end{array}$ & $7 . n$ & 25 & -- & -- & 81 & -- & 31.3 & $7 . n$ & .19 & \\
\hline $20 \ldots$ & 6.7 & 25 & 25 & 7.4 & 7.9 & 1.1 & $13 . n$ & 7.7 & $.3 n$ & \\
\hline $\begin{array}{l}\text { FAN. } \\
\text { OQ... }\end{array}$ & 6.1 & 50 & 67 & 6.6 & $3 n$ & I. $\mathrm{S}$ & $5 . n$ & 10.7 & . $n 1$ & \\
\hline${ }_{A D R}^{19}, \ldots$ & 0.3 & 40 & 78 & 1.7 & 21 & .79 & 13.0 & 8.3 & .04 & \\
\hline YAY & 6.4 & 40 & 30 & .5 & 15 & -- & 17.0 & 7.3 & -- & 127 \\
\hline $\begin{array}{l}12 \ldots . . \\
\text { Autr.: }\end{array}$ & b. 5 & 47 & 25 & 1.1 & 15 & .78 & 24.0 & 6.4 & $\cdot>n$ & \\
\hline${ }_{S F}^{12} \%$ & 6.3 & 45 & $2 n$ & 1.3 & 18 & 1.1 & 29.0 & 6.7 & .60 & 390 \\
\hline $33 .$. & 6.4 & 25 & 10 & $? \cdot n$ & 9.1 & .87 & 30.0 & 5.8 & .3 & \\
\hline
\end{tabular}

LOCATION. --Lat $31^{\circ} 01^{\prime} 30^{\prime \prime}$, long 89 $01^{\circ} 00^{\prime \prime}$, in NW gaging station at bridge on State Highway $29,1.2$ miles east of Janice, and 5.5 miles upstream from mouth.

DRA INAGE AREA. - - $52.2 \mathrm{sq} \mathrm{mi}$.

PERIOD OF RECORD.--Chemical analyses: December 1966 to September 1970.

CHEMICAL ANALYSF, WATER YFAR NCTMBER 1969 TI SFPTEMRER 197T

\begin{tabular}{|c|c|c|c|c|c|c|c|c|c|c|c|}
\hline DATF & $\begin{array}{l}\text { NIS- } \\
\text { CHARCF } \\
\text { (CFSI }\end{array}$ & $\begin{array}{l}\text { SILICA } \\
\text { (SID?) } \\
(4, / 1)\end{array}$ & 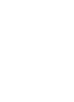 & $\begin{array}{l}\text { CAL- } \\
(I) M \\
(C A) \\
(\forall G / L)\end{array}$ & $\begin{array}{c}M \Delta G- \\
N F- \\
\text { SIUM } \\
(Y F) \\
(M r, L)\end{array}$ & $\begin{array}{l}\text { Snnf IJM } \\
\text { (NA) } \\
\text { (Mr, LL) }\end{array}$ & $\begin{array}{l}P D- \\
\text { PAS- } \\
S(1 / M \\
(K) \\
(H S / L)\end{array}$ & $\begin{array}{l}\text { B ICAQ - } \\
\text { ЯาVATE } \\
\text { (HCJ } H \text { ) } \\
(M T / L)\end{array}$ & $\begin{array}{l}\text { SIILFATF } \\
\text { (S74) } \\
\text { (MS/L) }\end{array}$ & $\begin{array}{l}C H L T- \\
R[)= \\
(\because L) \\
(M S / L)\end{array}$ & $\begin{array}{l}\text { FLUก- } \\
\text { RIOF } \\
(\subset) \\
(M C / L)\end{array}$ \\
\hline $\begin{array}{l}r C, . \\
0 ? . .\end{array}$ & A1? & 9.7 & 10 & .3 & .5 & 2.3 & .5 & 5 & . $n$ & 3.0 & $\cdot ?$ \\
\hline $\begin{array}{l}\text { Niv. } \\
\text { n5... } \\
\text { DEC. }\end{array}$ & 10 & 17 & 0 & .8 & .5 & 3.0 & .5 & 3 & $1 . n$ & $3 . n$ & $\cdot ?$ \\
\hline JAN... & $A 14$ & 9.0 & 40 & .0 & .2 & 2.1 & .4 & 4 & . $n$ & 3.9 &.$>$ \\
\hline & 87 & $1 n$ & 70 & 1.3 & .2 & 2.2 & .7 & 3 & 2.6 & 3.7 & -1 \\
\hline $\begin{array}{l}11 \ldots \\
M A R=\end{array}$ & 39 & 11 & 40 & .9 & .4 & 1.0 & .5 & 3 & 1.8 & 2.7 & . \\
\hline nO4... & 1900 & $4 .^{9}$ & 50 & $1 . n$ & .4 & 1.7 & 1,7 & 4 & -n & 2.0 & - 1 \\
\hline $\begin{array}{l}16 . \cdots \\
\text { MAY }\end{array}$ & $4 T$ & 10 & -- & .7 & .3 & 3.0 & .6 & 7 & 3.0 & 9.7 & .1 \\
\hline JUNF & 10 & 9.9 & $\cdots$ & .7 & .3 & 2.5 & .6 & 4 & $\cdot 3$ & $x .5$ & 1.7 \\
\hline $\begin{array}{l}0_{4}^{4} . . \\
\text { Aus }\end{array}$ & $3 \overrightarrow{7}$ & 11 & -- & 1.4 & .4 & 2.4 & .5 & 3 & L. R & 3.3 & .1 \\
\hline$\underset{S \in p}{17 .}$ & 184 & 9.4 & $4 n$ & 7.0 & .0 & - $n$ & .0 & 3 & $\cdot 0$ & 2.1 & $\cdot 7$ \\
\hline OR... & 92 & -- & 80 & 1.1 & .9 & .9 &.$T$ & 5 &.$?$ & $? .8$ & -1 \\
\hline
\end{tabular}

A DAILY MEAN DISCHARge. 
02479155 CYPRESS CREEK NEAR JANICE, MISS,--COntinued

CHEMICAL ANALYSES, WATER YEAR OCTOBER 1969 TO SEPTEMBER 1970

\begin{tabular}{|c|c|c|c|c|c|c|c|c|c|c|c|c|}
\hline DATE & $\begin{array}{l}\text { DIS- } \\
\text { SCLVED } \\
\text { IRQN } \\
\text { (FE) } \\
\text { IUG/L, }\end{array}$ & $\begin{array}{l}\text { DIS- } \\
\text { SOLVED } \\
\text { SOLIDS } \\
\text { IRESI- } \\
\text { OUE AT } \\
\text { ISO C) } \\
\text { (MG/L). }\end{array}$ & $\begin{array}{l}\text { DIS- } \\
\text { SOLVED } \\
\text { SOLICS } \\
\text { ISUM DF } \\
\text { CONSII- } \\
\text { TUENIS) } \\
\text { (MTIL) }\end{array}$ & $\begin{array}{l}\text { DIS- } \\
\text { SOLVEO } \\
\text { SOLIDS } \\
\text { ITONS } \\
\text { PER } \\
\text { DAY) }\end{array}$ & $\begin{array}{l}\text { DIS- } \\
\text { SOLVED } \\
\text { SOLIDS } \\
\text { (IONS } \\
\text { PER } \\
\text { AC-FT) }\end{array}$ & $\begin{array}{l}\text { NITRATE } \\
\text { (NO3) } \\
\text { (MG/L) }\end{array}$ & $\begin{array}{l}\text { TEMP- } \\
\text { EPATURE } \\
\text { IDEG C) }\end{array}$ & $\begin{array}{c}\text { IRON } \\
\text { (FE) } \\
\text { (UG/L) }\end{array}$ & ALDR IN & $\begin{array}{l}\text { CHLOR- } \\
\text { DANE } \\
\text { (UG/L) }\end{array}$ & (UG $L$ ) & (UG/L) \\
\hline $\begin{array}{l}\text { OCT. } \\
02 . . .\end{array}$ & 10 & 30 & 19 & 0.97 & 0.04 & 0.4 & - & -- & -- & -- & - & - \\
\hline $29 \ldots$ & - & - & $=$ & - & - & - & 17.0 & - & - & -- & -- & - \\
\hline $\begin{array}{c}05 \\
D E C . . .\end{array}$ & 0 & 47 & 22 & 2.41 & 0.06 & 0.6 & -- & - & -- & -- & -- & - \\
\hline $03 .$. & 40 & 31 & 19 & 1.17 & 0.04 & 0.4 & $\overline{0}$ & - & $=$ & -- & - & - \\
\hline $\begin{array}{l}\text { O9... } \\
\text { JAN. }\end{array}$ & -- & -- & -- & - & $\cdots$ & -- & 8.0 & -- & -- & 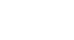 & $=$ & - \\
\hline $\begin{array}{l}08 \ldots \\
26 \ldots \\
\text { FER... }\end{array}$ & 20 & 52 & 21 & 12.2 & 0.07 & 0.4 & 12.0 & 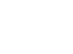 & $=$ & - & $=$ & $=$ \\
\hline MAR. & 40 & 44 & 20 & 4.63 & 0.06 & 0.3 & -- & -- & -- & - & -- & -- \\
\hline $\begin{array}{l}04 \ldots \\
10 \ldots \\
\triangle P R . .\end{array}$ & 60 & 54 & 13 & $262 \ldots$ & 0.07 & 0.4 & $13 . \overline{0}$ & $\because$ & - & $=$ & $=$ & $\overline{-}$ \\
\hline $\begin{array}{l}16 \ldots \\
23 \ldots \\
\operatorname{MAY}\end{array}$ & $=$ & 43 & 23 & $\begin{array}{r}5.46 \\
--\end{array}$ & 0.05 & 0.3 & $\begin{array}{l}20.0 \\
23.0\end{array}$ & 30 & $=$ & $=$ & -- & $=$ \\
\hline $\begin{array}{l}27 . . \\
\text { JUNE }\end{array}$ & -- & 34 & 20 & 0.92 & 0.05 & 0.3 & 25.0 & 50 & - & -- & -- & - \\
\hline $02 \ldots$ & -- & $\cdots$ & $=$ & - & $\rightarrow$ & -- & 22.0 & -- & -- & -- & -- & -- \\
\hline SEPT. & 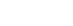 & 43 & 27 & 4.30 & 0.06 & 0.6 & $\cdots$ & 160 & + & 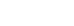 & -- & - \\
\hline $08 \ldots$ & -- & $\cdots$ & -- & - & - & -- & -- & -- & .00 & .00 & .00 & .00 \\
\hline $\begin{array}{l}\text { SEPT. } \\
08 \ldots \text {. A }\end{array}$ & - & - & -- & -- & -. & -- & -- & -- & .00 & .00 & .00 & .00 \\
\hline
\end{tabular}

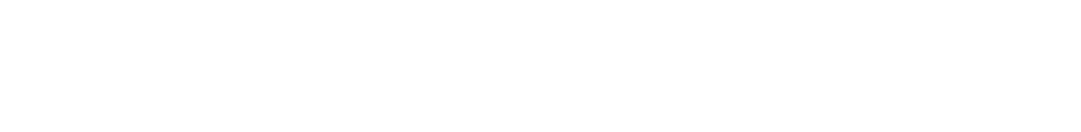

\begin{tabular}{|c|c|c|c|c|c|c|c|c|c|c|c|}
\hline 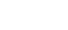 & .4 & $3 n$ & 10 & .74 & .07 & 4 & 0 & 20 & 6.1 & -- & $3 n$ \\
\hline Nov. & .6 & 47 & 27 & .05 & 2.41 & 4 & 2 & 75 & 5.5 & -- & $3 n$ \\
\hline $\begin{array}{l}\text { DFC. } \\
\text { J3... } \\
\text { JAN. }\end{array}$ & .4 & ${ }^{2} 1$ & 19 & .04 & 1.17 & 3 & 0 & 19 & 5.7 & - & 37 \\
\hline or... & .4 & 52 & 21 &.$n 7$ & 12.7 & 4 & , & 29 & 5.4 & -- & 25 \\
\hline MAR: & .3 & 44 & 20 & .06 & 4.63 & 4 & $?$ & 74 & 5.4 & - & 25 \\
\hline $\begin{array}{l}04 \ldots \\
A D R \text {. }\end{array}$ & .4 & 54 & 13 & .07 & $26 ?$ & 4 & 1 & 25 & 5.4 & -- & 9า \\
\hline${ }_{{ }_{A Y Y}}^{16} \cdots$ & .3 & 43 & 27 & . n6 & 5.46 & 3 & 1 & 27 & 5.1 & $2 n \cdot n$ & 49 \\
\hline$\underset{\text { JUNE }}{27 \ldots}$ &.$^{2}$ & 24 & $>n$ & .05 & .9 & 3 & ก & 33 & $5 .=$ & 26.0 & $4 n$ \\
\hline $\begin{array}{r}04 \ldots . \\
\text { A HGG. }\end{array}$ & - & 43 & 27 & .06 & 4.30 & 5 & 3 & 75 & 5.4 & -- & 67 \\
\hline$\underset{\text { СFPT. }}{12 \ldots}$ & .5 & 58 & 15 & . 08 & $29 . A$ & 5 & 3 & 76 & 5.1 & -- & an \\
\hline $09 . .$. & .4 & 45 & $?$ & .06 & 9.95 & 5 & 1 & 20 & 5.5 & 25.0 & 57 \\
\hline
\end{tabular}

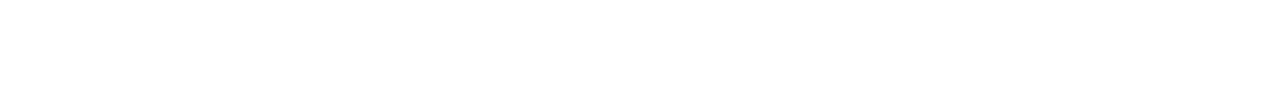
SEPT

$\begin{array}{lllllllllllllllllllll}0 \text { C.. } & .00 & .00 & .00 & .00 & .00 & .00 & .00 & .00 & .00 & .00 & .00 & .00 & .00 & .00\end{array}$

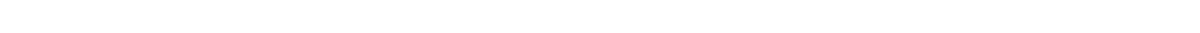

A BOTTOM DEPOSIT SAMPLE. 
02479170 BLACK CREEK NEAR BENNDALE, MISS.

LOCATION. --Lat $30^{\circ} 46^{\prime} 50^{\prime \prime}$, long $88^{\circ} 45^{\prime} 40^{\prime \prime}$, In SWl $_{4}$ sec.14, T.3 S, , R. 8 F., St. Stephens mer1d1an, George County, at bridge on State H1ghway 57, 0.7 mile north of Broome School, and 7.6 miles south of Benndale.

DRAINAGE AREA, --760 sq $\mathrm{m} 1$, approximately.

CHFMICAL ANALYSES, WATER YFAR GCIOBER 1969 TO SFPTEMBFR 1970

\begin{tabular}{|c|c|c|c|c|c|c|c|c|c|c|c|c|}
\hline DATF & $\begin{array}{l}\text { NIS- } \\
\text { CHARGE } \\
\text { (TFS) }\end{array}$ & $\begin{array}{c}C A L- \\
C I \cup M \\
(C A) \\
(M Z I E)\end{array}$ & $\begin{array}{c}\text { MAG- } \\
\text { NF- } \\
\text { SIUM } \\
\text { IMGI } \\
\text { (MF/L) }\end{array}$ & $\begin{array}{l}\text { SחDIUM } \\
(V A) \\
(M \cap / L)\end{array}$ & $\begin{array}{l}\text { P)- } \\
\text { TAS- } \\
\text { SIIA4 } \\
\text { IK) } \\
\text { (4T/L) }\end{array}$ & $\begin{array}{l}\text { ALKA- } \\
\text { LINITY } \\
\text { AS } \\
\text { CACO3 } \\
\text { (YSILI) }\end{array}$ & $\begin{array}{l}\text { SULFATE- } \\
\text { I SN4) } \\
\text { (4जIL) }\end{array}$ & $\begin{array}{l}\text { DHOS- } \\
\text { PHATE } \\
\text { (P)4) } \\
\text { (MF/L) }\end{array}$ & $\begin{array}{l}\text { ATS- } \\
\text { SOLVED } \\
\text { STLINS } \\
\text { (RESI- } \\
\text { NUF Ar } \\
190 \text { C) } \\
\text { (4FIL) }\end{array}$ & $\begin{array}{l}\text { DIS- } \\
\text { SOLVEN } \\
\text { SMLIDS } \\
\text { ITONS } \\
\text { DFR } \\
\text { AC-FTI }\end{array}$ & $\begin{array}{l}\text { OIS- } \\
\text { SOLVEN } \\
\text { SJLIDS } \\
\text { ITONS } \\
\text { PFR } \\
\text { TAYI }\end{array}$ & $\begin{array}{l}\text { HAQD- } \\
\text { NESS } \\
\text { ICA, } 4 \text {; } \\
\text { (4S/L }\end{array}$ \\
\hline $\begin{array}{l}n c r . \\
\text { nz:... } \\
\text { Nav. }\end{array}$ & 250 & $3 . n$ & 1.0 & 9.6 & .4 & 4 & 3.7 & .04 & 202 & .27 & 141 & 4 \\
\hline $\begin{array}{l}\text { PO... } \\
\text { JAN. }\end{array}$ & 472 & $2 . n$ & -- & 7.7 & .6 & 9 & 9.3 & .11 & 257 & .35 & 294 & 4 \\
\hline $\begin{array}{l}08 . . . \\
F F R .\end{array}$ & 2500 & in & 2.0 & 7.8 & .7 & 3 & 1.8 & .04 & 77 & .11 & $5 ? ?$ & 12 \\
\hline $\begin{array}{l}19 . . \\
A D R .\end{array}$ & 2450 & $3 . n$ & 3.7 & 5. 2 & .6 & 5 & 1.6 & .04 & 171 & .14 & 669 & -- \\
\hline${ }_{\text {MAY }}^{2} \cdots$ & - & 4.0 & $3 . n$ & -- & - & 7 & 1.3 & $\cdot n 3$ & - & -- & -- & 7 \\
\hline $\begin{array}{l}13 . . . \\
\text { Aur.. }\end{array}$ & $4>7$ & 4.17 & 1.0 & $A \cdot A$ & .6 & 5 & 4.3 & .04 & - & -- & - & 5 \\
\hline $\begin{array}{l}17 . . \\
\text { SEPT. }\end{array}$ & >०ค? & $x=0$ & 3.0 & 1. ? & .7 & 6 & 4. $A$ & .01 & $\cdots$ & -- & -- & 6 \\
\hline $21 \ldots$ & 325 & $5 . n$ & -- & -. & $\cdots$ & 6 & 3.8 & ค?? & -- & -- & -- & 7 \\
\hline
\end{tabular}

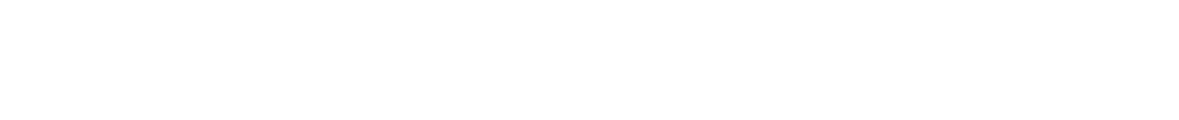

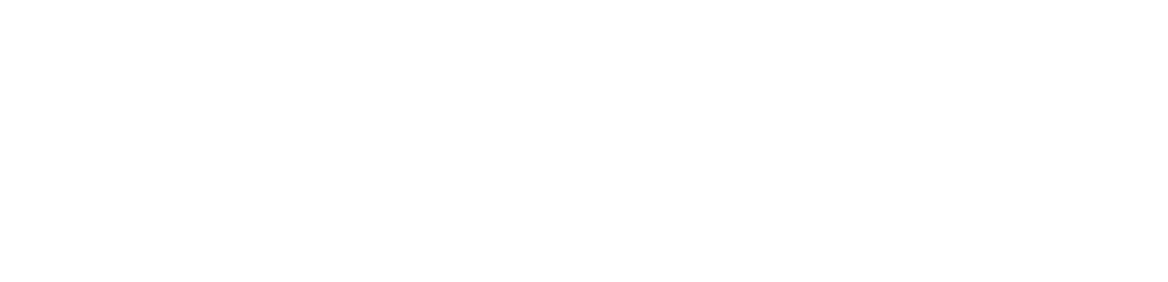

O2479438 BEAVER POND BRANCH NEAR CITRONELLE, ALA.

LOCATION.--Lat $31^{\circ} 06^{\prime} 45^{\prime \prime}$, Iong $88^{\circ} 14^{\prime} 47^{\prime \prime}$, In NBłNEł sec.26, T.2 N., R.3 w., Mobile County, at left bank at private bridge, 2.1 miles upstrean from Sandy Fork Branch, and 1.4 miles north of Citronelle.

DRAINAGE AREA, $--0.56 \mathrm{sq} \mathrm{m} 1$.

PERIOD OF RECORD.--Chem1cal analyses: October 1968 to September 1969 (miscellaneous), October 1969 to September 1970. CHEMICAL ANALYSES, WATER YEAR OCTOBER 1969 TO SEPTEMBER 1970

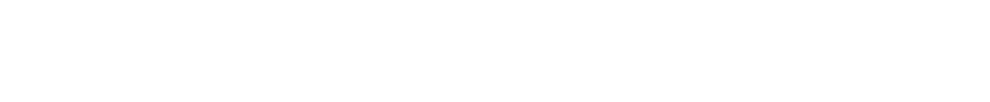

\begin{tabular}{|c|c|c|c|c|c|c|c|c|c|c|}
\hline $06 . . .1904$ & 1545 & -- & 8 & D & 168 & 100 & 93 & 579 & 5.7 & 14.0 \\
\hline $\begin{array}{l}\text { DEC. } \\
\text { O2... } \\
\text { FEQ.11970 }\end{array}$ & 1220 & -- & 7 & 0 & 164 & 88 & 82 & 565 & 6.0 & 13.0 \\
\hline MAR. & 0900 & -- & 9 & 0 & 155 & 85 & 78 & 550 & 5.7 & 6.0 \\
\hline $\begin{array}{l}03 \ldots \\
30 \ldots \\
\text { APR... }\end{array}$ & $\begin{array}{l}0910 \\
1205\end{array}$ & $\begin{array}{l}2.0 \\
2.0\end{array}$ & $\begin{array}{r}8 \\
26\end{array}$ & $\begin{array}{l}0 \\
0\end{array}$ & $\begin{array}{r}176 \\
70\end{array}$ & $\begin{array}{r}100 \\
60\end{array}$ & $\begin{array}{l}94 \\
39\end{array}$ & $\begin{array}{l}590 \\
291\end{array}$ & $\begin{array}{l}5.6 \\
6.3\end{array}$ & $\begin{array}{l}14.0 \\
13.0\end{array}$ \\
\hline JUNE & 0900 & 1.0 & 7 & 0 & 190 & 101 & 95 & 654 & 5.8 & 22.0 \\
\hline JULY & 0900 & 1.5 & 27 & 0 & 122 & 80 & 58 & 462 & 5.9 & 20.0 \\
\hline $\begin{array}{l}03 \ldots \\
30 \ldots \\
\text { SEP. }\end{array}$ & $\begin{array}{l}0945 \\
0930\end{array}$ & $1.0^{10}$ & $\begin{array}{l}11 \\
29\end{array}$ & $\begin{array}{l}0 \\
0\end{array}$ & $\begin{array}{l}176 \\
172\end{array}$ & $\begin{array}{l}94 \\
96\end{array}$ & $\begin{array}{l}85 \\
72\end{array}$ & $\begin{array}{l}616 \\
622\end{array}$ & $\begin{array}{l}6.6 \\
6.2\end{array}$ & $\begin{array}{l}22.0 \\
24.0\end{array}$ \\
\hline $\begin{array}{l}01 \ldots . \\
30 \ldots\end{array}$ & $\begin{array}{l}1245 \\
1320\end{array}$ & $\begin{array}{l}1.0 \\
1.0\end{array}$ & $\begin{array}{l}13 \\
12\end{array}$ & $\begin{array}{l}0 \\
0\end{array}$ & $\begin{array}{l}184 \\
191\end{array}$ & $\begin{array}{l}95 \\
98\end{array}$ & $\begin{array}{l}85 \\
88\end{array}$ & $\begin{array}{l}650 \\
659\end{array}$ & $\begin{array}{l}6.1 \\
5.9\end{array}$ & $\begin{array}{l}25.0 \\
19.5\end{array}$ \\
\hline
\end{tabular}




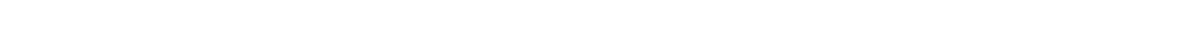

DRAINAGE AREA. $-0.46 \mathrm{sq} \mathrm{mi}$.

PERIOD OF RECORD.--Chemical analyses: October 1966 to September 1969 (miscellaneous), October 1969 to September 1970, CHEMICAL ANAI.YSES, WATER YEAR OCTOBER 1969 TO SEPTEMBER 1970

\begin{tabular}{|c|c|c|c|c|c|c|c|c|c|c|}
\hline & & & & & & & $\begin{array}{l}\text { NON- } \\
\text { CAR- }\end{array}$ & $\begin{array}{l}\text { SPECI - } \\
\text { FIC }\end{array}$ & & \\
\hline DATE & TIME & $\begin{array}{l}\text { OIS- } \\
\text { CHARGE } \\
\text { (CFS) }\end{array}$ & $\begin{array}{l}\text { BICAR- } \\
\text { BONATE } \\
\text { (HCOZ) } \\
\text { (MG/L) }\end{array}$ & $\begin{array}{l}\text { CAR- } \\
\text { BONATE } \\
\text { (CO3) } \\
\text { (MG/L) }\end{array}$ & $\begin{array}{l}\text { CHLO- } \\
\text { RIDE } \\
\text { (CL) } \\
\text { (MG/L) }\end{array}$ & $\begin{array}{l}\text { HARD- } \\
\text { NESS } \\
\text { (CA,MG) } \\
\text { (MG/L) }\end{array}$ & $\begin{array}{l}\text { BQNATE } \\
\text { HARD- } \\
\text { NESS } \\
\text { (MG/L) }\end{array}$ & $\begin{array}{l}\text { COND- } \\
\text { UCTANCE } \\
\text { (MICRO- } \\
\text { MHOS) }\end{array}$ & $\begin{array}{c}\text { PH } \\
\text { (UNITS) }\end{array}$ & $\begin{array}{l}\text { TEMP- } \\
\text { ERATURE } \\
\text { (DEG C) }\end{array}$ \\
\hline
\end{tabular}

\begin{tabular}{|c|c|c|c|c|c|c|c|c|c|c|}
\hline OCT.'1969 & 1600 & -- & 12 & 0 & 21 & 18 & 8 & 95 & 6.9 & 24.0 \\
\hline $\begin{array}{l}\text { NOV. } \\
\text { OS.... } \\
\text { DEC. }\end{array}$ & 1350 & - & 7 & 0 & 23 & 18 & 12 & 100 & 5.8 & 15.0 \\
\hline $\begin{array}{l}02 \ldots \ldots \\
30 \ldots 1970\end{array}$ & $\begin{array}{l}1215 \\
1200\end{array}$ & $=$ & $\begin{array}{l}7 \\
5\end{array}$ & $\begin{array}{l}0 \\
0\end{array}$ & $\begin{array}{l}21 \\
15\end{array}$ & $\begin{array}{l}15 \\
12\end{array}$ & $\begin{array}{l}9 \\
8\end{array}$ & $\begin{array}{l}94 \\
69\end{array}$ & $\begin{array}{l}6.1 \\
6.1\end{array}$ & $\begin{array}{l}11.0 \\
12.0\end{array}$ \\
\hline $\begin{array}{l}04 \ldots . . \\
\text { MAR. }\end{array}$ & 0850 & -- & 6 & 0 & 11 & 10 & 5 & 65 & 5.8 & 4.0 \\
\hline $\begin{array}{l}03 \ldots \\
30 \ldots \\
\triangle P R . .\end{array}$ & $\begin{array}{l}0900 \\
1210\end{array}$ & $\begin{array}{l}150 \\
2.0\end{array}$ & $\begin{array}{l}8 \\
5\end{array}$ & $\begin{array}{l}0 \\
0\end{array}$ & $\begin{array}{l}13 \\
6.4\end{array}$ & $\begin{array}{r}14 \\
9\end{array}$ & $\begin{array}{l}7 \\
5\end{array}$ & $\begin{array}{l}75 \\
45\end{array}$ & $\begin{array}{l}5.9 \\
5.9\end{array}$ & $\begin{array}{l}14.0 \\
14.0\end{array}$ \\
\hline $\begin{array}{l}29 \ldots . . \\
\text { JUNE }\end{array}$ & 1000 & .56 & 11 & 0 & 16 & 16 & 7 & 88 & 6.1 & 23.0 \\
\hline JULY & 0845 & 1.0 & 6 & 0 & 8.0 & 11 & 6 & 53 & 5.7 & 20.0 \\
\hline $\begin{array}{l}03 \ldots . . \\
30 \ldots \\
\text { SEP. }\end{array}$ & $\begin{array}{l}0930 \\
0915\end{array}$ & 1.0 & $\begin{array}{r}11 \\
8\end{array}$ & $\begin{array}{l}0 \\
0\end{array}$ & $\begin{array}{l}20 \\
11\end{array}$ & $\begin{array}{l}19 \\
12\end{array}$ & $\begin{array}{r}10 \\
5\end{array}$ & $\begin{array}{l}97 \\
64\end{array}$ & $\begin{array}{l}6.8 \\
6.1\end{array}$ & $\begin{array}{l}22.0 \\
23.0\end{array}$ \\
\hline $\begin{array}{l}01 \ldots \\
30 \ldots\end{array}$ & $\begin{array}{l}1230 \\
1300\end{array}$ & $\begin{array}{l}.60 \\
.50\end{array}$ & $\begin{array}{l}11 \\
10\end{array}$ & $\begin{array}{l}0 \\
0\end{array}$ & $\begin{array}{l}16 \\
15\end{array}$ & $\begin{array}{l}15 \\
16\end{array}$ & $\begin{array}{l}6 \\
8\end{array}$ & $\begin{array}{l}81 \\
76\end{array}$ & $\begin{array}{l}6.0 \\
6.4\end{array}$ & $\begin{array}{l}25.0 \\
19.0\end{array}$ \\
\hline
\end{tabular}

02479447 BEAVER POND BRANCH AT YOUTH, NEAR CITRONELLE, ALA.

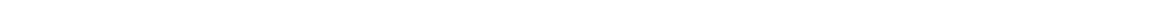
downstream from Mill Branch, 4 miles' west of Citronelle, and D.1 mile upstream from mouth.

DRA INAGE AREA. $---8.53 \mathrm{sq} \mathrm{mi}$

PERIOD OF RECORD. --Chemical analyses: October 1966 to September 1969 (miscellaneous), October 1969 to September 1970. CHEMICAL ANALYSES, WATER YEAR OCTOBER 1969 TO SEPTEMBER 1970

BICAR-
OATE


02479466 PUPPY CREEK ON RUSSELL ROAD, NEAR CITRONELLE, ALA.

LOCATION,--Lat $31^{\circ} 03^{\prime} 21^{\prime \prime}$, long $88^{\circ} 15^{\prime} 00^{\prime \prime}$, In Sw $\frac{1}{4} \mathrm{SE} \frac{1}{4}$ sec.11, T.1 N., R.3 w., Mob1le County, at bridge on Russell Road, and 2.6 miles southwest of Citronelle.

DRA INAGE AREA. $--4.30 \mathrm{sq}$. 1 .

PERIOD OF RECORD,--Chemlcal analyses: October 1969 to September 1970.

CHEMICAL ANALYSES, WATER YEAR OCTOBER 1969 TO SEPTEMBER 1970

\begin{tabular}{|c|c|c|c|c|c|c|c|c|c|c|}
\hline OATF & IIME & $\begin{array}{l}\text { DIS- } \\
\text { CHARGE } \\
\text { (CFS) }\end{array}$ & $\begin{array}{l}\text { BICAR- } \\
\text { BONATE } \\
\text { (HCO3) } \\
\text { (MG/L) }\end{array}$ & $\begin{array}{l}\text { C.AR- } \\
\text { BONATE } \\
\text { (CO3) } \\
\text { (MG/L) }\end{array}$ & $\begin{array}{l}\text { CHLO- } \\
R I O E \\
(\mathrm{CL}) \\
(\mathrm{MG} / \mathrm{C})\end{array}$ & $\begin{array}{l}\text { HARD- } \\
\text { NESS } \\
\text { (CA,MG) } \\
\text { (MG/L) }\end{array}$ & $\begin{array}{l}\text { NON- } \\
\text { CAR- } \\
\text { BONATE } \\
\text { HARD- } \\
\text { NESS } \\
\text { (MG/L) }\end{array}$ & $\begin{array}{l}\text { SPECI- } \\
\text { FIC } \\
\text { COND- } \\
\text { UCTANCE } \\
\text { (MICRC- } \\
\text { MHOSI }\end{array}$ & $\begin{array}{c}\text { PH } \\
\text { (UNTTS) }\end{array}$ & $\begin{array}{l}\text { TEMP- } \\
\text { ERATIJREE } \\
\text { (DEG C) }\end{array}$ \\
\hline $\begin{array}{l}\text { Nov., } 1969 \\
06 . . .\end{array}$ & 0815 & -- & 0 & D & 4800 & 2340 & 2340 & 12700 & 3.5 & 10.0 \\
\hline $\begin{array}{l}\text { OEC. } \\
\text { O2... } \\
\text { FEB., } 1970\end{array}$ & 1105 & -- & 0 & 0 & 1240 & & 650 & 3890 & 4.0 & 10.0 \\
\hline MAR.. & 1130 & -- & 2 & 0 & 324 & 158 & 157 & 1050 & 4.9 & 4.0 \\
\hline $03 \ldots$ & $\begin{array}{l}0750 \\
0715\end{array}$ & 0.0 & $\begin{array}{l}3 \\
5\end{array}$ & $\begin{array}{l}0 \\
0\end{array}$ & $\begin{array}{r}224 \\
84\end{array}$ & $\begin{array}{r}125 \\
44\end{array}$ & $\begin{array}{r}123 \\
40\end{array}$ & $\begin{array}{l}767 \\
301\end{array}$ & $\begin{array}{l}5.4 \\
5.9\end{array}$ & $\begin{array}{l}13.0 \\
24.0\end{array}$ \\
\hline $\begin{array}{l}\text { APR . } \\
29 \ldots . . \\
\text { JUNE }\end{array}$ & 0750 & 3.0 & 17 & 0 & 211 & 116 & 102 & 728 & 5.8 & 22.0 \\
\hline JuLy & 0745 & 10 & 4 & 0 & 75 & 40 & 37 & 277 & 5.2 & 20.0 \\
\hline $\begin{array}{l}03 \ldots \\
30 \ldots \\
\text { SEP. }\end{array}$ & $\begin{array}{l}1525 \\
0800\end{array}$ & $\begin{array}{l}4.0 \\
7.0\end{array}$ & $\begin{array}{r}16 \\
0\end{array}$ & $\begin{array}{l}0 \\
0\end{array}$ & $\begin{array}{l}198 \\
474\end{array}$ & $\begin{array}{l}103 \\
231\end{array}$ & $\begin{array}{r}90 \\
231\end{array}$ & $\begin{array}{r}669 \\
1580\end{array}$ & $\begin{array}{l}6.6 \\
3.7\end{array}$ & $\begin{array}{l}24.0 \\
22.0\end{array}$ \\
\hline $01 \ldots$ & $\begin{array}{l}1520 \\
0920\end{array}$ & $\begin{array}{l}3.0 \\
2.0\end{array}$ & 9 & $\begin{array}{l}0 \\
0\end{array}$ & $\begin{array}{r}750 \\
17\end{array}$ & $\begin{array}{r}381 \\
18\end{array}$ & $\begin{array}{r}381 \\
11\end{array}$ & $\begin{array}{r}2550 \\
101\end{array}$ & $\begin{array}{l}3.5 \\
6.0\end{array}$ & $\begin{array}{l}27.0 \\
18.5\end{array}$ \\
\hline
\end{tabular}

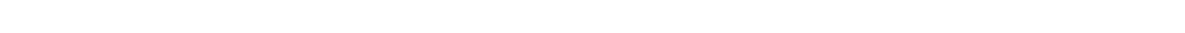
way $217,4.8$ miles upstream from mouth, 8.3 m1les southwest of citroneile.

DRAINAGE AREA. - -28.8 sq $\mathrm{ml}$.

PERIOD OF RECORD.--Chemlcal analyses: October 1965 to September 1969 (m1scellaneous), October 1969 to September 1970. CHEMICAL ANALYSES, WATER YEAR OCTOBER 1969 TO SEPTEMBER 1970

\begin{tabular}{|c|c|c|c|c|c|c|c|c|c|c|}
\hline DATE & TIME & $\begin{array}{l}\text { OIS- } \\
\text { CHARGE } \\
\text { (CFS) }\end{array}$ & $\begin{array}{l}\text { B I CAR- } \\
\text { 8DNATE } \\
\text { (HCO3) } \\
\text { (MG/L) }\end{array}$ & $\begin{array}{l}\text { CAR- } \\
\text { BONATF } \\
\text { (CO3) } \\
\text { (MG/L) }\end{array}$ & $\begin{array}{l}\text { CHL O- } \\
\text { RIOE } \\
\text { (CL) } \\
\text { (MGIL) }\end{array}$ & $\begin{array}{l}\text { HARO- } \\
\text { NFSS } \\
\text { (CA,MG) } \\
\text { (MG/L) }\end{array}$ & $\begin{array}{l}\text { NON- } \\
\text { CAR- } \\
\text { BONATE } \\
\text { HARD- } \\
\text { NESS } \\
\text { (MG/L) }\end{array}$ & $\begin{array}{l}\text { SPECI- } \\
\text { FIC } \\
\text { COND- } \\
\text { UCTANCE } \\
\text { (MICRO- } \\
\text { MHOS) }\end{array}$ & $\begin{array}{c}\text { PH } \\
\text { IUNITSI }\end{array}$ & $\begin{array}{l}\text { TEMP- } \\
\text { ERATURF } \\
\text { (DEG C) }\end{array}$ \\
\hline $\begin{array}{l}\text { ocr.,. } 1969 \\
\text { O2... }\end{array}$ & 91210 & -- & 2 & 0 & 302 & 150 & 148 & 979 & 4.7 & 24.0 \\
\hline $\begin{array}{l}\text { NOV. } \\
\text { O6... } \\
\text { DEC. }\end{array}$ & 0835 & -- & 1 & 0 & 460 & 225 & 224 & 1470 & 4.6 & 10.0 \\
\hline $\begin{array}{l}02 \ldots \\
30 \ldots \\
F E B . .1970\end{array}$ & $\begin{array}{r}0950 \\
1545 \\
0\end{array}$ & 15 & I & $\begin{array}{l}0 \\
0\end{array}$ & $\begin{array}{r}212 \\
59\end{array}$ & $\begin{array}{r}108 \\
32\end{array}$ & $\begin{array}{r}107 \\
30\end{array}$ & $\begin{array}{l}733 \\
219\end{array}$ & $\begin{array}{l}4.8 \\
5.0\end{array}$ & $\begin{array}{r}9.0 \\
12.0\end{array}$ \\
\hline $\begin{array}{l}04 \ldots \\
\text { MAR. }\end{array}$ & 1100 & -- & 1 & 0 & 58 & 35 & 34 & 220 & 4.9 & 4.0 \\
\hline $\begin{array}{l}03 \ldots \\
30 \ldots \\
\text { APR... }\end{array}$ & $\begin{array}{l}1205 \\
1300\end{array}$ & $15^{9.0}$ & I & $\begin{array}{l}0 \\
0\end{array}$ & $\begin{array}{c}43 \\
6.4\end{array}$ & $\begin{array}{l}26 \\
10\end{array}$ & $\begin{array}{r}25 \\
8\end{array}$ & $\begin{array}{r}1 / 3 \\
41\end{array}$ & $\begin{array}{l}5.1 \\
5.0\end{array}$ & $\begin{array}{l}15.0 \\
13.0\end{array}$ \\
\hline JUNE & 1130 & 8.0 & 3 & 0 & 39 & 23 & 21 & 175 & 5.4 & 23.0 \\
\hline JuLY... & 1045 & 40 & 0 & 0 & 11 & 9 & 9 & 58 & 3.8 & 20.0 \\
\hline $\begin{array}{r}03 . \ldots \\
30 . . \\
\text { SEP. }\end{array}$ & $\begin{array}{l}1330 \\
1045\end{array}$ & $20^{3.0}$ & $\begin{array}{l}4 \\
1\end{array}$ & $\begin{array}{l}0 \\
0\end{array}$ & $\begin{array}{l}48 \\
44\end{array}$ & $\begin{array}{l}26 \\
24\end{array}$ & $\begin{array}{l}23 \\
23\end{array}$ & $\begin{array}{l}181 \\
176\end{array}$ & $\begin{array}{l}6.1 \\
4.7\end{array}$ & $\begin{array}{l}24.0 \\
25.0\end{array}$ \\
\hline $01 \ldots$ & $\begin{array}{l}1500 \\
1600\end{array}$ & $\begin{array}{l}7.0 \\
7.0\end{array}$ & 1 & $\begin{array}{l}0 \\
0\end{array}$ & $\begin{array}{r}101 \\
99\end{array}$ & $\begin{array}{l}51 \\
52\end{array}$ & $\begin{array}{l}50 \\
51\end{array}$ & $\begin{array}{l}369 \\
349\end{array}$ & $\begin{array}{l}4.6 \\
4.7\end{array}$ & $\begin{array}{l}26.0 \\
19.5\end{array}$ \\
\hline
\end{tabular}

02480207 ESCATAWPA RIVER AT WOSS POINT, MISS.

LOCATION,--Lat $30^{\circ} 25^{\prime} 35^{\prime \prime}$, long $88^{\circ} 32^{\prime} 40^{\prime \prime}$, in sec.24, T.7 S., R.6 w., St. Stephens meridian, Jackson County, at bridge on State H1ghway 63, in Moss Point.

PERIOD OF RECORD.--Chemical analyses: October 1969 to September 1970.

CHEMICAL ANALYSES, WATER YEAR DCTMBFR IOKO IT SEDTFMRTR 1979

\begin{tabular}{|c|c|c|c|c|c|c|c|c|c|c|}
\hline OATF & 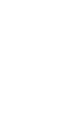 & $\begin{array}{l}\text { MAF- } \\
\text { NF- } \\
\text { SIIIM } \\
\text { IMGS } \\
\text { IMG/LI }\end{array}$ & $\begin{array}{c}\text { CMIUM } \\
\text { (NA) } \\
\text { (MALL) }\end{array}$ & $\begin{array}{l}P \cap- \\
\text { TAC- } \\
\text { SrJu } \\
\text { (K) } \\
\text { (Mr, }\end{array}$ & $\begin{array}{l}\text { ALKA- } \\
\text { LINITY } \\
\text { AS } \\
\text { CACAB } \\
\text { IMFIL, }\end{array}$ & $\begin{array}{l}\text { SILFATE } \\
\text { (ST4) } \\
(4 S, I L)\end{array}$ & 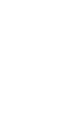 & 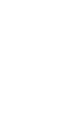 & $\begin{array}{l}\text { STIIIM } \\
\text { AR- } \\
\text { STRD- } \\
\text { TI IN } \\
\text { RATIT }\end{array}$ & $\begin{array}{l}\text { SPECI- } \\
\text { FIT } \\
\text { OTVD- } \\
\text { UCTANTF } \\
\text { (MICRT- } \\
\text { MHTSI }\end{array}$ \\
\hline 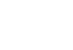 & llan & $10>n$ & I 21 & on & 47 & 390 & $\cdot n x$ & 737 & .6 & $160 n \pi$ \\
\hline $\begin{array}{l}\text { NOV. } \\
\text { JNA... } \\
\text { JAN. }\end{array}$ & $37 n$ & -- & $56 \cap 7$ & 244 & 69 & 412 & .10 & $180 n$ & 90 & $14 \mathrm{nnn}$ \\
\hline $\begin{array}{l}O O^{2} . . \\
F E R \text {. }\end{array}$ & 230 & $30 n$ & 700 & 47 & 23 & $6 \mathrm{~B}$ & .04 & 53? & 7.7 & $500 n$ \\
\hline${ }_{\text {APO. }}^{\text {IO }}$ & Q म & $4 n 2$ & fon & 34 & 15 & 20 & $\cdot n 2$ & 497 & 6.5 & $4>000$ \\
\hline MAY & 12 & 52 & $16 n$ & 5.5 & A & 53 & + & $7 n$ & 4.3 & $45 \pi$ \\
\hline $\begin{array}{l}13 . . . \\
\text { Aur.: }\end{array}$ & $4 h$ & 29 & 755 & in & 10 & 111 & .01 & 135 & 5.1 & $1>n n$ \\
\hline & $10 n$ & 396 & 960 & 29 & 13 & 136 & .03 & $4 R h$ & ค. 7 & $33 n 7$ \\
\hline $23 \ldots$ & 410 & -- & -- & -- & 59 & $11 n n$ & 15 & $>6 \cap n$. & $\cdots$ & 10500 \\
\hline
\end{tabular}


02480207 ESCATAWPA RIVER AT MOSS POINT, MISS.--Continued CHEMICAL ANALYSES, WATER YEAR OCTOBER 1969 TO SEPTEMBER 1970

\begin{tabular}{|c|c|c|c|c|c|c|c|c|c|c|}
\hline DATE & $\begin{array}{c}\text { PH } \\
\text { (UNITS) }\end{array}$ & $\begin{array}{l}\text { COLOP } \\
\text { IPLATI- } \\
\text { NIM- } \\
\text { PNBALT } \\
\text { IJITSI }\end{array}$ & $\begin{array}{l}\text { TUR- } \\
\text { FIn- } \\
\text { ITV } \\
\text { (UG/LI }\end{array}$ & $\begin{array}{c}917- \\
\text { CHFM- } \\
\text { ICAL } \\
\text { OXYCFN } \\
\text { OFMANO } \\
\text { IMrILI }\end{array}$ & 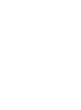 & $\begin{array}{l}\text { ORPANIS } \\
\text { NITRר- } \\
\text { FFN } \\
\text { IVI } \\
\text { (MSAL) }\end{array}$ & $\begin{array}{l}\text { YFMO- } \\
\text { OAATISE } \\
\text { TOFO C }\end{array}$ & $\begin{array}{l}\text { DIS- } \\
\text { SOLVED } \\
\text { OXYGEN } \\
\text { (MG/L) }\end{array}$ & $\begin{array}{c}\text { VITRITS } \\
(N) \\
(M-/ L)\end{array}$ & $\begin{array}{c}\text { CULI- } \\
\text { FARY } \\
\text { ICAL- } \\
\text { TVIFS } \\
\text { OFR } \\
\text { ION ML, }\end{array}$ \\
\hline $\begin{array}{c}n C^{\top} . \\
n 2 . . \\
N \cap v .\end{array}$ & 6.5 & $5 n$ & -- & -- & 51 & 1.4 & 24.7 & 0.5 & . & $\sim$ \\
\hline $\begin{array}{l}20 . . \\
\text { JAN. }\end{array}$ & 6.3 & 45 & 75 & in & 71 & 1.7 & 12.2 & .4 &.$n 1$ & 14800 \\
\hline $\begin{array}{c}n R_{.} . . \\
F \in R_{.}\end{array}$ & h. 1 & 45 & 35 & 5.7 & 17 & 1.1 & 6.7 & א. 5 & $-n 1$ & $96 \pi 0 n$ \\
\hline${ }_{\triangle R R}^{10} \cdots$ & $t .3$ & 50 & 10 & 7.6 & 31 & .55 & 13.0 & 6.2 & .24 & -- \\
\hline MAY & 6.0 & $5 n$ & 15 & 2.1 & 27 & -- & 17.0 & 5.0 & -- & -- \\
\hline 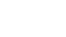 & 5.7 & 100 & 37 & 3.4 & Th & 1.7 & 23.0 & 0.0 & .nn & 192กn \\
\hline $\begin{array}{c}12 \ldots \\
\text { SEP }\end{array}$ & $6 . n$ & 70 & $1^{n}$ & 6.7 & 3' & $.7 n$ & 27.0 & 1.2 & $4 . n$ & $700 n$ \\
\hline $22 \ldots$ & 6.9 & 50 & 15 & $10^{9}$ & 73 & $.4 n$ & 28.0 & 3.1 & 17 & Pח \\
\hline
\end{tabular}

PEARL RIVER BASIN

02482550 PEARL RIVER NEAR CARTHAGE, MISS.

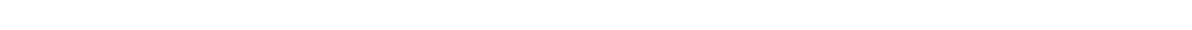
ing station at bridge on State Highway $35,2.1$ miles south of Carthage, 4.0 miles downstream from Lobutcha Creek, and 10.8 miles upstream from Tuscolameta Creek.

DRAINAGE AREA. $--1,347 \mathrm{sq} \mathrm{mi}$.

REMARKS.--Continuous specific conductance record discontinued. CHEMICAL ANALYSES, WATER YEAR OCTOBER 1969 TO SEPTEMBER 1970

\begin{tabular}{|c|c|c|c|c|c|c|c|c|c|c|c|}
\hline חATE & $\begin{array}{l}\text { DIS- } \\
\text { PHARGF } \\
\text { (CFS) }\end{array}$ & $\begin{array}{l}\text { CAL- } \\
\text { rIIJA } \\
(C A \mid \\
(M G / L)\end{array}$ & $\begin{array}{l}\text { MAr:- } \\
\text { NF- } \\
\text { SIUM } \\
\text { IMSOI } \\
\text { IMF, }\end{array}$ & $\begin{array}{l}\text { SOก II:M } \\
(4 A) \\
(4 C, L)\end{array}$ & $\begin{array}{l}\text { D)- } \\
\text { TAS- } \\
\text { SIUM } \\
\text { (K) } \\
\text { (MT, /L) }\end{array}$ & $\begin{array}{l}\text { ALKA- } \\
\text { LIVITY } \\
\text { AC } \\
\text { CACT3 } \\
\text { IMRIL) }\end{array}$ & $\begin{array}{l}\text { SULFATE } \\
(C 74) \\
(A 5 / L)\end{array}$ & $\begin{array}{l}\text { PपतS- } \\
\text { गमATE } \\
\text { (गत4) } \\
(45 / 2)\end{array}$ & $\begin{array}{l}\text { पART- } \\
\text { VFSS } \\
(r A, 4 ;) \\
(15 / L)\end{array}$ & 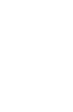 & 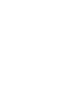 \\
\hline Der. & & & & & & & & & & & \\
\hline & 117 & 12 & $2 . n$ & 9.5 & 1.5 & 34 & 17 & $\cdot \cap b$ & 14 & .7 & 5.4 \\
\hline $\begin{array}{l}23 . . \\
\text { MAR. }\end{array}$ & 1260 & 7.2 & in & 0.5 & 1.1 & 13 & 2.5 & $.7 ?$ & 17 & .5 & 35 \\
\hline${ }_{A P Q}^{n 4}$ & $314 n$ & 7.0 & 8. 0 & -- & $\cdots$ & a &.$?$ & .09 & 15 & -- & 45 \\
\hline$\underset{\text { MYY }}{15 \cdots}$ & 975 & a. & 6.7 & 7.9 & 1.0 & $1 ?$ &.$?$ & .13 & 15 & .5 & 47 \\
\hline $\begin{array}{l}P 7 . . \\
\sin y\end{array}$ & 126 & 13 & -- & 10 & 1.2 & 10 & 9.2 & $\cdot 7 x$ & $2 n$ & $\cdot{ }^{2}$ & 53 \\
\hline $\begin{array}{l}14 \ldots . \\
\text { Allsi: }\end{array}$ & 147 & $7 . n$ & $7 . n$ & 6.9 & h. 2 & 17 & 4.4 & .15 & 14 & .4 & 41 \\
\hline $25 \ldots$ & $7 \mathrm{An}$ & 5.0 & c.n & 5.2 & 1.5 & 1? & 4.6 & .14 & 14 & .3 & $>R$ \\
\hline
\end{tabular}

\begin{tabular}{|c|c|c|c|c|c|c|c|c|c|c|}
\hline DATF & $\begin{array}{c}P H \\
\text { ('JNITS) }\end{array}$ & $\begin{array}{c}\text { COLAR } \\
\text { IDLATI- } \\
\text { NIYM- } \\
\text { CORALT } \\
\text { UNITCI }\end{array}$ & $\begin{array}{l}\text { ride- } \\
919- \\
\text { Irr } \\
\text { IMfIL) }\end{array}$ & 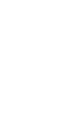 & $\begin{array}{l}\text { CHEM- } \\
\text { ICAL } \\
\text { OXYSON } \\
\text { OEMANO } \\
\text { IWGILI }\end{array}$ & 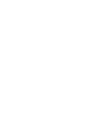 & $\begin{array}{l}T=\text { YO- } \\
\text { FRATUPF } \\
\text { DFF } T \text { I }\end{array}$ & $\begin{array}{l}\text { TICS- } \\
\text { ALVEA } \\
\text { TXYGFN } \\
\text { IUEALI }\end{array}$ & $\begin{array}{l}\text { VITRITE } \\
(N) \\
(4=/ L)\end{array}$ & $\begin{array}{c}\text { EOLI- } \\
\text { FORM } \\
\text { ICOL- } \\
\text { ONIFS } \\
\text { OFR } \\
\text { IOT MLI }\end{array}$ \\
\hline $\begin{array}{c}\mathrm{nEr} . \\
n_{2}, \ldots\end{array}$ & 6.4 & 15 & 25 & 3.7 & 2.4 & 1.1 & a. 0 & $1 n^{2} 2$ &.$\cap 7$ & $5 \cap n$ \\
\hline $\begin{array}{l}\text { JAN. } \\
23 . . . \\
\text { WAR. }\end{array}$ & 6.5 & 40 & 75 & $x .5$ & 12 & .78 & $4 \cdot n$ & 11.8 & . ni & $12 n$ \\
\hline n००... & $7 . ?$ & 45 & 25 & 1.4 & 17 & .95 & $14 . n$ & 8.1 & .10 & $77 \mathrm{nn}$ \\
\hline MAY $15 . \cdots$ & 4.4 & 75 & 10 & .7 & 15 & $.7 n$ & 18.0 & 7.3 & . nr & $12 n$ \\
\hline $27 \ldots$ & R. 5 & 10 & 10 & 3.1 & 11 & $A^{-}$ & 24.0 & 7.0 & $\cdot \ln$ & son \\
\hline $\begin{array}{l}14 \ldots \\
\text { aivs: }\end{array}$ & 6.3 & 90 & 34 & 1.4 & 15 & .90 & 29.0 & 5.1 & .20 & $26 ?$ \\
\hline $26 \ldots$ & 6.6 & $5 n$ & 59 & .9 & $2 n$ & 1.7 & 27.0 & 7.1 & .17 & $1 R \cap 0$ \\
\hline
\end{tabular}


PEARL RIVER BASIN

02482550 PEARL RIVER NEAR CARTHAGE, MISS.--Cont1nued

SPECIFIC CONDUCTANCE (MICROMHOS/CM AT $25^{\circ} \mathrm{C}$ ), OCTOBER 1969 TO MARCH 1970

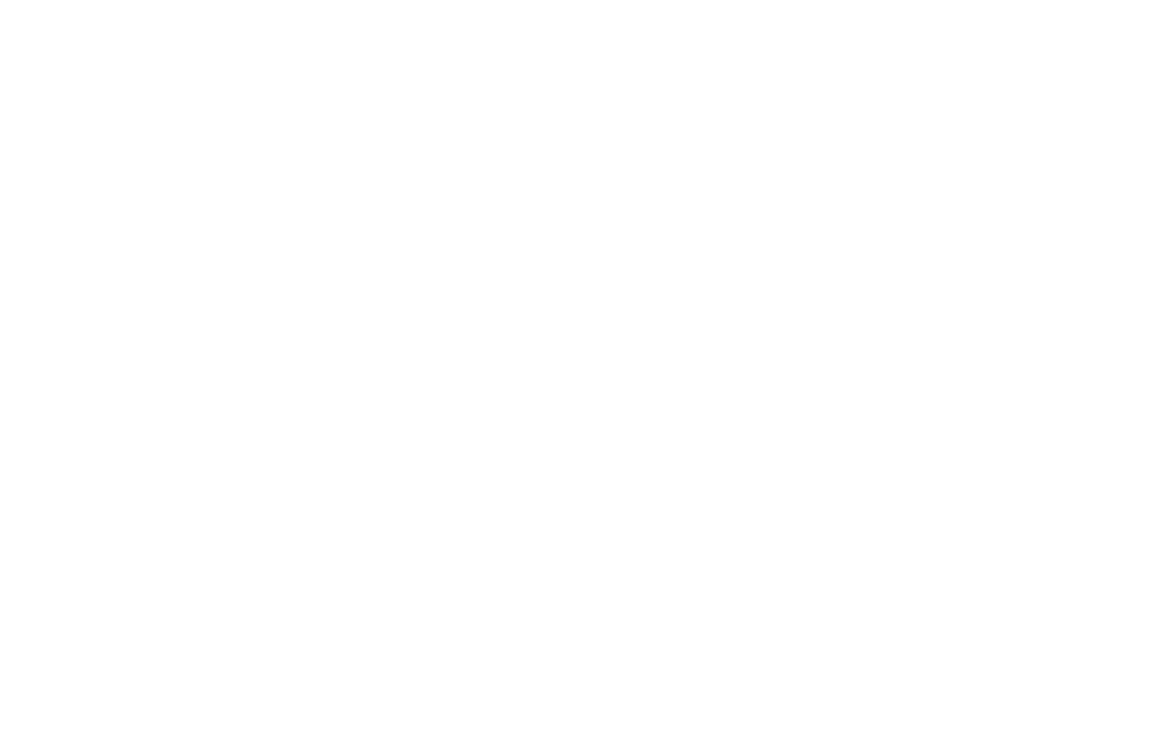

02484500 YOCKANOOKANY RIVER NEAR OFAHOMA, MISS.

LOCATION, --Lat $32^{\circ} 42^{\prime} 20^{\prime \prime}$, long $89^{\circ} 40^{\prime} 20^{\prime \prime}$, In NE 1 NEt sec, 22 , T. 10 N., R.6 E., Choctaw meridian, Leake County, at gaging station at bridge on State Highwa $16,1.5$ miles east of ofahoma, 3 miles upstream from mouth, and 8.5 miles southwest of Carthage.

DRAINAGE AREA, $-\mathbf{- 4 8 4} \mathrm{sq} \mathrm{m} 1$.

PERIOD OF RECORD.--Chemical analyses: November 1969 to September 1970.

REMARKS. --Continuous specific conductance record discontinued. CHEMICAL ANALYSES, DECEMBER 1969 TO AUGUST 1970

\begin{tabular}{|c|c|c|c|c|c|c|c|c|c|c|c|}
\hline NATE & $\begin{array}{l}\text { DIS- } \\
\text { CHARSFF } \\
\text { (CFSI }\end{array}$ & $\begin{array}{l}\text { CAL- } \\
\text { CIUYY } \\
(C A) \\
(M S / L)\end{array}$ & $\begin{array}{l}\text { MAG- } \\
\text { NF- } \\
\text { SIUM } \\
\text { (MG) } \\
(M G / L)\end{array}$ & $\begin{array}{l}\text { SODIUU } \\
\text { (NA) } \\
\text { I MEIL) }\end{array}$ & $\begin{array}{l}\text { PN- } \\
\text { TAS- } \\
\text { STUM } \\
\text { (X) } \\
\text { (MVIL) }\end{array}$ & $\begin{array}{l}\text { ALKA- } \\
\text { LINITY } \\
\text { AS } \\
\text { CACר3 } \\
\text { IMSILI }\end{array}$ & $\begin{array}{c}\text { SULFATF } \\
(5 \cap 4) \\
(4 G / L)\end{array}$ & $\begin{array}{l}\text { PHIS- } \\
\text { PHATE } \\
(P \cap 4) \\
(M S / L)\end{array}$ & 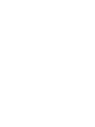 & $\begin{array}{l}\text { OIS- } \\
\text { SOLVFD } \\
\text { SOLIOS } \\
\text { ITONS } \\
\text { OFO } \\
\text { AC-FFI }\end{array}$ & $\begin{array}{l}\text { DIS- } \\
\text { SOLVED } \\
\text { SOLIDS } \\
\text { ITONS } \\
\text { PER } \\
\text { MAYI }\end{array}$ \\
\hline $\begin{array}{c}\text { DEC. } \\
\text { O?... } \\
\text { JAN. }\end{array}$ & 41 & 13 & 7. C & 11 & 2.3 & 77 & 17 & .41 & 101 & .14 & 11.7 \\
\hline MAR. & $2 B_{4}$ & 10 & 17 & 12 & 2.7 & 17 & 5.1 & .17 & 77 & .10 & 54.9 \\
\hline APQ. & 1010 & 7.0 & 5.0 & 8.0 & 1.2 & 9 & 1.8 & .06 & -- & -- & -- \\
\hline MAY & 231 & 10 & 9.0 & 9.0 & .9 & 11 & 2.0 & .22 & -- & -- & -- \\
\hline 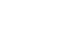 & 27 & 11 & -- & 11 & 1.1 & in & 5.9 & .06 & -- & -- & -- \\
\hline $\begin{array}{l}14 \ldots . \\
\text { 4ug. }\end{array}$ & 26 & a. $n$ & 3. 0 & 7.5 & 1.5 & - & 7.2 & .26 & - & -- & -. \\
\hline ’h... & 362 & 5.0 & 9.0 & 5.5 & 1.5 & 9 & $4 \cdot 9$ & .19 & -- & - & - \\
\hline DATF & $\begin{array}{l}\text { HAQO- } \\
\text { NESS } \\
\text { (CA,MCS) } \\
\text { (MG/L) }\end{array}$ & $\begin{array}{c}\text { SOOIUM } \\
\text { AO- } \\
\text { SORP- } \\
\text { TION } \\
\text { RATIO }\end{array}$ & $\begin{array}{l}\text { SPECI- } \\
\text { FIC } \\
\text { CONO- } \\
\text { UCTANCE } \\
\text { (MICRO- } \\
\text { MHISI }\end{array}$ & $\begin{array}{l}\text { PH } \\
\text { \{INITS }\end{array}$ & $\begin{array}{l}\text { COLAR } \\
\text { IPLATT- } \\
\text { NIIM- } \\
\text { COBALT } \\
\text { UNITS }\end{array}$ & $\begin{array}{l}\text { TUR- } \\
\text { BID- } \\
\text { ITY } \\
\{M G / L\}\end{array}$ & $\begin{array}{c}\text { RI9- } \\
\text { CHE M- } \\
\text { ICAL } \\
\text { OXYGEV } \\
\text { DEMAN) } \\
\text { (MG/L) }\end{array}$ & 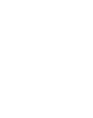 & 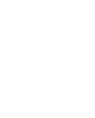 & $\begin{array}{l}\text { NITRITF } \\
\text { IN] } \\
\text { [MGIL] }\end{array}$ & $\begin{array}{c}\text { COLY- } \\
\text { FJRY } \\
\text { ICOL- } \\
\text { ONIFS } \\
\text { PER } \\
\text { IOO ML, }\end{array}$ \\
\hline $\begin{array}{l}\text { DFC. } \\
\eta ? . .\end{array}$ & & & & & & & & & & & \\
\hline JAN. & $2^{n}$ & .6 & 58 & 6.5 & 20 & 25 & 1.9 & $1 ?$ & 1.6 & .00 & 100 \\
\hline $\begin{array}{l}27 . . \\
\text { MAR: } \\
\text { nS... }\end{array}$ & 22 & .6 & 42 & 6.7 & 25 & 25 & 2.7 & A. $?$ & .05 & 50 & 140 \\
\hline $\begin{array}{c}n 5 \\
\text { ApR... }\end{array}$ & 12 & .6 & 44 & 7.1 & 45 & 35 & 1.5 & 19 & .73 & $.0 t$ & 9900 \\
\hline $15 \ldots$ & 18 & .5 & 49 & 6.5 & 50 & 10 & 1.8 & 11 & .60 & - an & 20 \\
\hline $\operatorname{sul} \ddot{x}$ & 22 & .9 & 6? & 6.7 & 15 & 10 & 1.5 & $9 . ?$ & .67 & . & $15 n$ \\
\hline $\begin{array}{l}14 \ldots \\
\text { sug. }\end{array}$ & 14 & .5 & 47 & 6.4 & 90 & 37 & 1.6 & 13 & - BO & .40 & 104 \\
\hline $26 \ldots$ & 14 & $\cdot 2$ & 30 & 6.7 & 50 & 59 & 1.0 & 20 & 1.3 & .20 & 2000 \\
\hline
\end{tabular}


PEARL RIVER BASIN

02484500 YOCKANOOKANY RIVER NEAR OFAHOMA, MISS.--ContInued

SPECIFIC CONDUCTANCE (MICROMHOS/CM AT $25^{\circ} \mathrm{C}$ ), NOVEMBER 1969 TO SEPTEMBER 1970

NOVEMBER

DECEMBER

JANUARY

FEBRUARY

MARCH

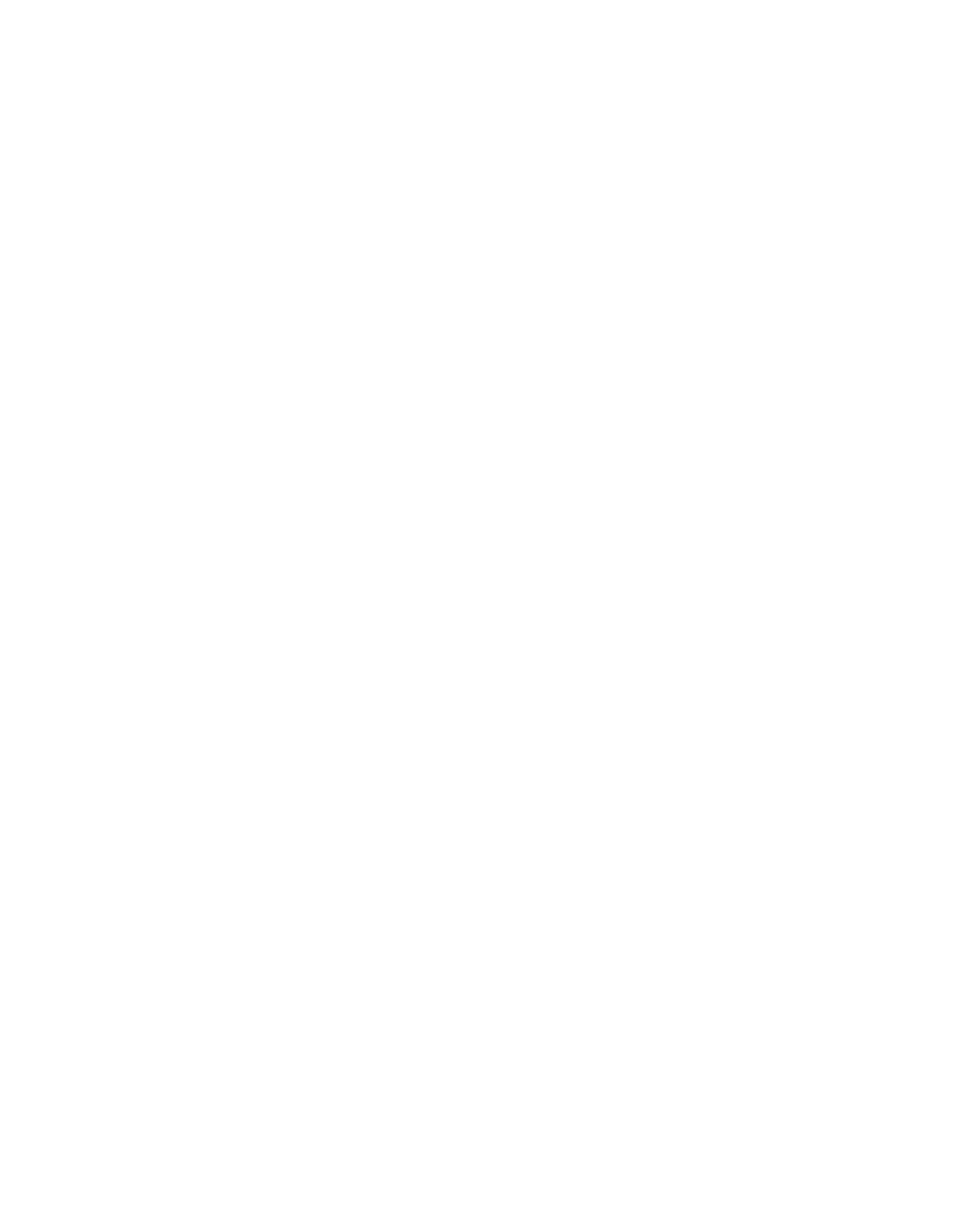


02486450 PEARL RIVER ABOVE BYRAM, MISS.

LOCATION,--Lat $32^{\circ} 10^{\prime} 30^{\prime \prime}$, long $90^{\circ} 12^{\prime} 00^{\prime \prime}$, In sec.19, T.4 N., R.1 E., Choctaw meridian, Rankin County, 0.5 mile upstream from bridge on county road, and 0.7 mile southeast of Byram.

DRAINAGE AREA, --3,430 sq $\mathrm{m} 1$, approximately.

PER IOD OF RECORD,--Chem1cal analyses: February 1969 to September 1970.

REMARKS.--Type 2 denotes laboratory analyses; type 3 denotes fleld analyses.

CHEMICAL ANALYSES, WATER YEAR OCTOBER 1969 TO SEPTEMBER 1970

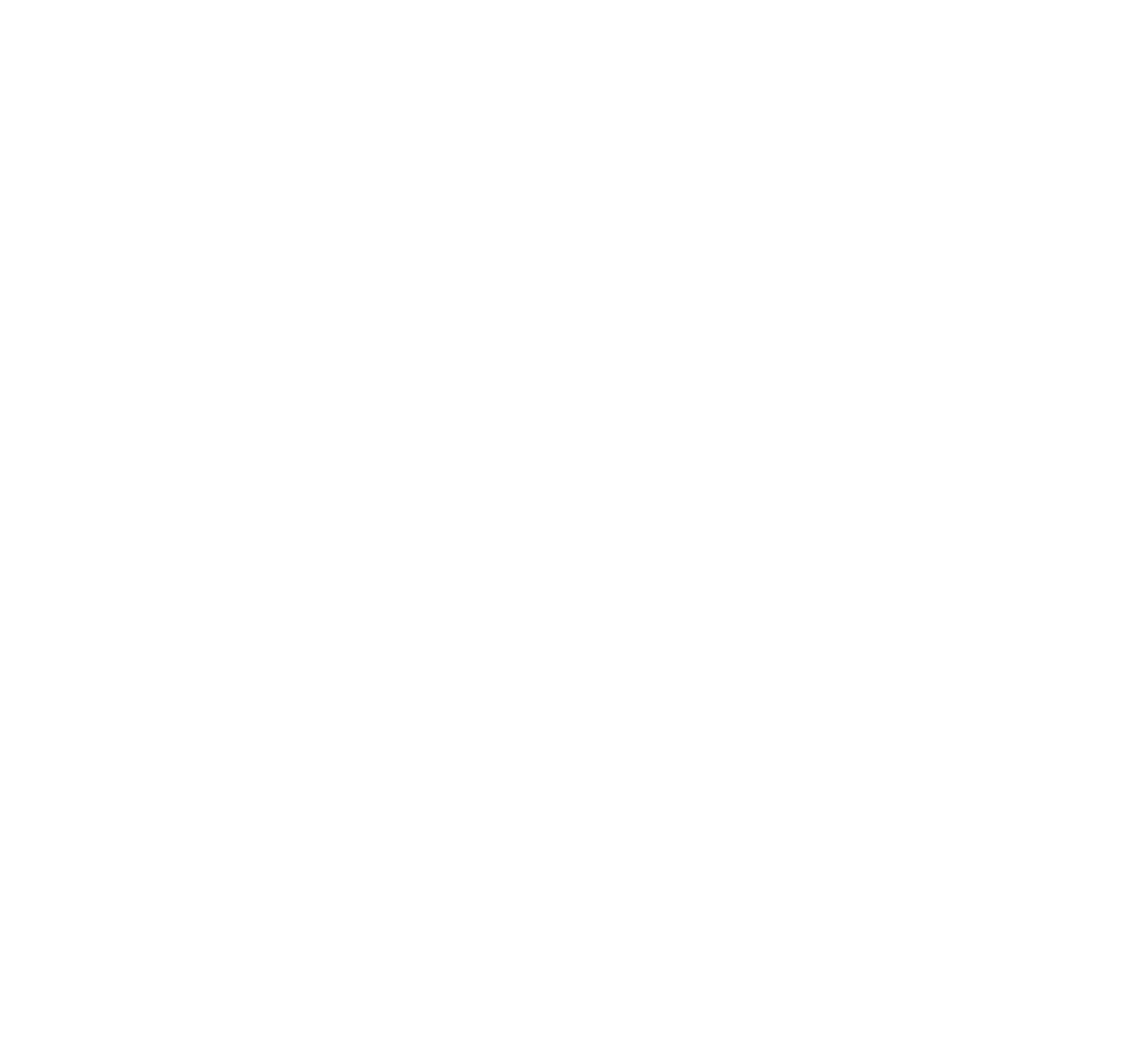

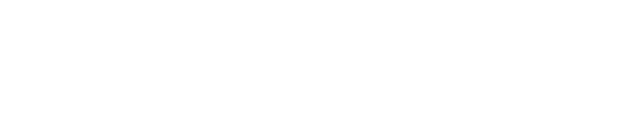

\begin{tabular}{|c|c|c|c|c|c|c|}
\hline $\begin{array}{c}\text { OCT. } \\
\text { ОЯ... }\end{array}$ & 2.3 & 6.1 & 6000 & .01 & -- & -- \\
\hline og... & - & -. & -- & - & -- & -- \\
\hline $06 . .$. & 2.2 & 7.8 & -- & .00 & 6.4 & -- \\
\hline OS... & -- & -- & -- & - & - & - \\
\hline $\begin{array}{l}05 \ldots \\
20 . \ldots\end{array}$ & $\begin{array}{l}1.7 \\
1.6\end{array}$ & $\begin{array}{l}17 \\
16\end{array}$ & $\begin{array}{r}2600 \\
39000\end{array}$ & $\begin{array}{l}.00 \\
.00\end{array}$ & $\begin{array}{l}1.2 \\
2.2\end{array}$ & $\begin{array}{r}42 \\
104\end{array}$ \\
\hline APR. & & & & & & \\
\hline МАY... & - & .5 & 4400 & .00 & -- & 82 \\
\hline${ }_{\text {JUNE }}^{27} \cdots$ & 1.8 & 11 & 1050 & .00 & 3.4 & 86 \\
\hline $\begin{array}{l}10 \ldots \\
\text { JULY }\end{array}$ & 2.0 & 29 & 20000 & .01 & 4.6 & 114 \\
\hline $29 \ldots$ & $\cdots$ & 17 & 130000 & .00 & 1.4 & 115 \\
\hline SEPT. & -- & - & -- & & & \\
\hline $09 \ldots$ & 2.2 & 14 & -- & .00 & -- & 100 \\
\hline
\end{tabular}


PEARL RIVER BASIN

02486450 PEARL RIVER ABOVE BYRAK, MISS.--Continued

SPECIFIC CONDUCTANCE (MICROMHOS/CM AT $25^{\circ} \mathrm{C}$ ), WATER YEAR OCTOBER 1969 TO SEPTEMBER 1970 NOVEMBER

$$
\text { DECEMBER }
$$

$$
\text { : }
$$

MAX MIN

160
160
130
135
140

125
125
110
125
130

MAX$$
100 \quad 100
$$

160

$\begin{array}{ll}160 & 140 \\ 153 & 13 \\ 145 & 13 \\ 150 & 12 \\ 150 & 12\end{array}$

$165 \quad 145$

145

135
135

118
120
115

130

130
133
125

120

$\begin{array}{lll}135 & 110 & 165 \\ & \end{array}$

175
160
160
150
140

113
150
145
130
130

175
205
205
140
150

$\begin{array}{lll}140 & 120 & 170 \\ 130 & 115 & 165\end{array}$

$\begin{array}{lll}130 & 115 & 165 \\ 140 & 115 & 150\end{array}$

$123 \quad 140 \quad 140$

$\begin{array}{lll}140 & 115 & 140 \\ 140 & 125\end{array}$

$153 \quad 13$

$144 \quad 122$

$\begin{array}{lll}108 & 95 & 85 \\ 110 & 95 & 85 \\ 117 & 95 & 80 \\ 118 & 85 & 70 \\ 113 & 80 & 75\end{array}$

108

105 $\begin{array}{lr}105 & 85 \\ 115 & 105 \\ 140 & 11\end{array}$

$\begin{array}{rrr}150 & 155 & 85 \\ 155 & 145 & 80 \\ 130 & 80 & 65 \\ 125 & 70 & 60 \\ 125 & 60 & 45\end{array}$

12

135
140

140
130
130

130

---

$\begin{array}{rr}75 & 70 \\ 85 & 7 \\ 70 & 65 \\ 75 & 70 \\ 80 & 75 \\ 130 & 110 \\ 104 & 85\end{array}$

$$
\begin{array}{ll}
135 & 125 \\
158 & 130 \\
160 & 140 \\
160 & 150 \\
160 & 145 \\
- & -- \\
--- & -- \\
--- & -- \\
\hline 100 & -\overline{65}
\end{array}
$$

104 JUNE

JUNE

JANUARY

FEBRUARY

MARCH

\begin{tabular}{rrrrrr} 
MAX & MIN & MAX & MIN & MAX & MIN \\
85 & 80 & --- & --- & -- & -- \\
80 & 75 & -- & -- & -- & $-\cdots$ \\
-130 & -110 & 112 & 75 & 75 & 67 \\
--- & --- & 74 & 73 & 102 & 75 \\
\hline & & 75 & 85 & 57
\end{tabular}

$\begin{array}{llllll}80 & 75 & 66 & 63 & 73 & 50 \\ 80 & 75 & 70 & 65 & 75 & 70 \\ 85 & 80 & 70 & 69 & 70 & 61 \\ 85 & 80 & 73 & 69 & 61 & 49\end{array}$

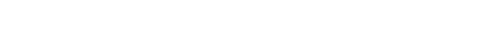

$\begin{array}{rrrrrrr}85 & --- & --- & 80 & 70 & 80 & 78 \\ 85 & 80 & 75 & 85 & 80 & 85 & 78 \\ 80 & 77 & 77 & 87 & 80 & 88 & 85 \\ 70 & 77 & 77 & -- & -- & 87 & 78 \\ 75 & 77 & 73 & -- & -- & 86 & 77\end{array}$

$\begin{array}{llllllll}85 & 60 & 73 & 58 & \ldots- & \ldots & 90 & 70 \\ 75 & 70 & 67 & 59 & -\cdots & \ldots & 90 & 78\end{array}$

$\begin{array}{llllll}60 & 57 & -- & - & 90 & 78 \\ 68 & 53 & -- & -- & 110 & 87 \\ 78 & 67 & -- & -- & 108 & 87\end{array}$

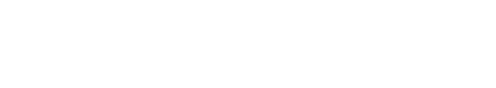

$131 \quad 69$

$\begin{array}{llllll}75 & 72 & -- & -- & 68 & 66 \\ 82 & 73 & -- & -- & 67 & 65 \\ 90 & 75 & - & -- & 66 & 65\end{array}$

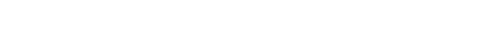

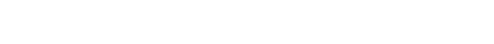

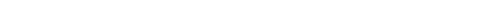

AUGUST SEPTEMBER

DAY MAX MIN MAX MIN MAX MIN MAX MIN MAX MIN MAX MIN

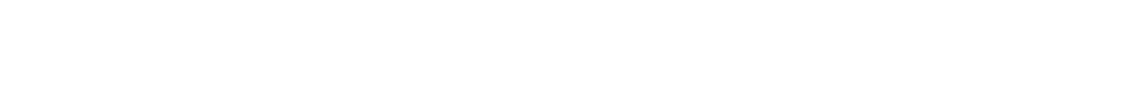

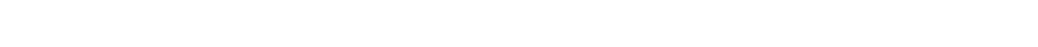

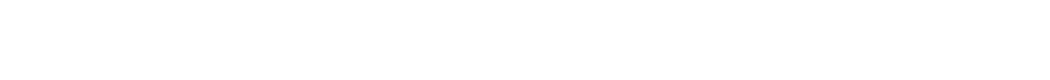

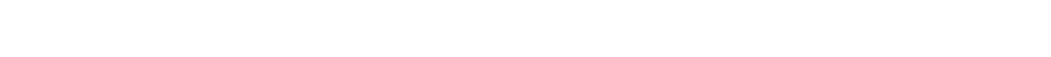

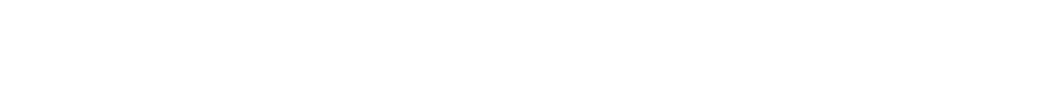

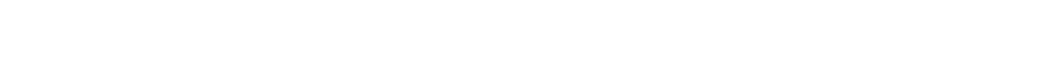

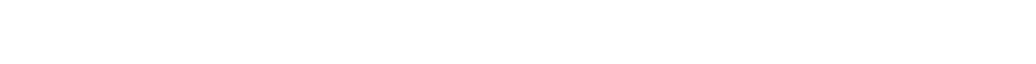

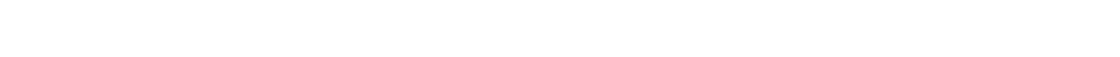

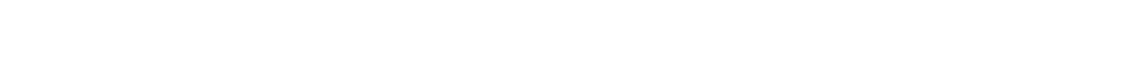

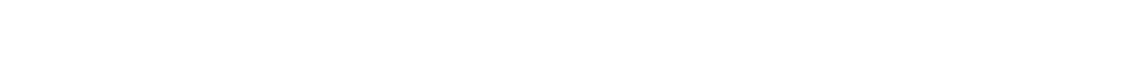

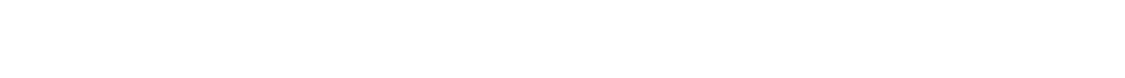

AVG

"... -..

- ... - -

$155 \quad 131$ 
02487000 PEARL RIVER AT GEORGETOWN, MISS.

LOCATION,--Lat $31^{\circ} 52^{\prime} 30^{\prime \prime}$, long $90^{\circ} 08^{\prime} 25^{\prime \prime}$, In Sw $\frac{1}{4}$ sec.31, T.1 N., R.2 E., Choctaw meridian, Copiah County, at bridge on State Highway 28,2 miles east of Georgetown.

DRAINAGE AREA. $--3,790 \mathrm{sq} \mathrm{mi}$, approximately.

PERIOD OF RECORD,--Chemical analyses: November 1969 to September 1970.

CHEMICAL ANALYSES, NOVEMBER 1969 TO SEPTEMBER 1970

\begin{tabular}{|c|c|c|c|c|c|c|c|c|c|c|c|}
\hline RATF & $\begin{array}{l}\text { DIS- } \\
\text { CHARCF } \\
\text { ICFSI }\end{array}$ & $\begin{array}{l}\text { CAL- } \\
\text { CILM } \\
(C A) \\
(M G / L)\end{array}$ & $\begin{array}{c}\text { MAG- } \\
\text { NF- } \\
\text { SIUM } \\
\text { (MG) } \\
\text { (MEILI) }\end{array}$ & $\begin{array}{l}\text { SODIUM } \\
\text { (NA) } \\
\text { IMG/LI }\end{array}$ & $\begin{array}{l}\text { P)- } \\
\text { TAS- } \\
\text { SI IM } \\
(K) \\
(M G / L)\end{array}$ & $\begin{array}{l}\text { ALKA- } \\
\text { LINI TY } \\
\text { AS } \\
\text { CACJ3 } \\
\text { IMG ILI }\end{array}$ & $\begin{array}{l}\text { SIFLFATF } \\
(5 \cap 4) \\
(M G / L)\end{array}$ & $\begin{array}{l}\text { PHOS- } \\
\text { PHATE } \\
\text { (PO4) } \\
\text { (MG/L) }\end{array}$ & $\begin{array}{l}\text { HARD- } \\
\text { NFSS } \\
\text { (CA, YG) } \\
\text { (MG/L) }\end{array}$ & $\begin{array}{l}\text { SODI UM } \\
\text { AD- } \\
\text { SORP- } \\
\text { TINN } \\
\text { RATIO }\end{array}$ & $\begin{array}{l}\text { SPFCI- } \\
\text { FIE } \\
\text { CNND- } \\
\text { UCTANCF } \\
\text { IMICRT- } \\
\text { MHDSI }\end{array}$ \\
\hline $\begin{array}{l}\text { Nov. } \\
\text { D6... } \\
\text { DEC. }\end{array}$ & 960 & 21 & 1.0 & 22 & 2.1 & 31 & 7.7 & 1.4 & 22 & 1.3 & inn \\
\hline $\begin{array}{c}17 \ldots \\
F \in B .\end{array}$ & $10 \cap 0$ & 16 & 8.0 & 14 & 1.8 & 37 & 1.6 & .71 & 24 & .7 & S.5 \\
\hline $\begin{array}{l}05 \ldots \\
\text { MAR. }\end{array}$ & $415 n$ & 12 & 4.0 & -- & - & -- & 46 & .03 & 14 & -- & hก \\
\hline $\begin{array}{l}19 \ldots . . \\
\text { APR. }\end{array}$ & 3907 & 17 & 9.0 & 12 & 1.6 & 5 & 15 & 1.0 & 21 & .3 & 70 \\
\hline JUNE & 5700 & 12 & -- & - & -- & 9 & $\cdot{ }^{B}$ & .23 & 23 & -- & 51 \\
\hline $\begin{array}{l}10 . . . \\
\text { Jutr }\end{array}$ & $66 n$ & 14 & 9.0 & 11 & 2.0 & 11 & 3.6 & - 08 & 23 & .6 & 3) \\
\hline $\begin{array}{l}29 \ldots . . \\
\text { SFPT. }\end{array}$ & $? 25$ & 27 & 9.0 & 70 & 2.0 & 33 & 0.2 & .75 & 76 & .0 & 130 \\
\hline ग9... & 170 & 23 & 9.0 & 20 & 2.3 & 27 & 14 & .24 & 31 & .9 & 109 \\
\hline
\end{tabular}

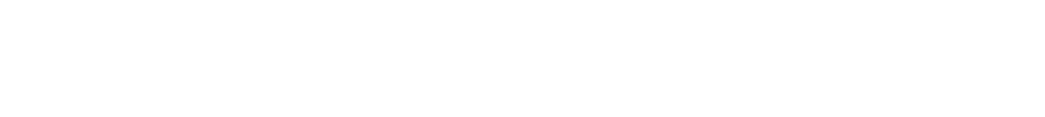

\begin{tabular}{|c|c|c|c|c|c|c|c|c|c|c|}
\hline OS... & 7.0 & 20 & 25 & 1.8 & 11 & 1.7 & 15.0 & 6.7 & .55 & 1770 \\
\hline $\begin{aligned} & 17 \ldots \\
&=F B .\end{aligned}$ & 6.6 & 5 & 25 & 2.6 & 9.2 & 1.8 & 20.0 & 9. 0 & .17 & 1250 \\
\hline NS... & 5.4 & 10 & 85 & -- & 19 & 1.6 & 7.0 & 12.1 & $\cdot 2 n$ & 2hno \\
\hline $\begin{array}{l}19 \ldots . \\
\triangle P R .\end{array}$ & 6.0 & 20 & 37 & 1.8 & 14 & .70 & 15.0 & -- & .20 & $15 n n$ \\
\hline $\begin{array}{l}\text { PQ... } \\
\text { JUNF }\end{array}$ & 6.1 & 50 & 47 & -- & 19 & - & 24.0 & 6.8 & .10 & 3100 \\
\hline $\begin{array}{l}10 . . . \\
\text { JuLY }\end{array}$ & h. 5 & 30 & 75 & $? .0$ & 17 & 1.0 & 26.0 & 5.7 & .02 & 1000 \\
\hline $\begin{array}{l}29 \ldots \\
\text { SFPT. }\end{array}$ & 7.2 & 35 & 29 & 4.3 & 19 & 1.8 & 31.0 & 8.1 & .60 & $2 n$ \\
\hline $09 . .$. & 6.7 & 20 & 78 & 1.3 & 14 & 2.0 & 31.0 & 8.3 & .70 & 483 \\
\hline
\end{tabular}

02488500 PEARL RIVER NEAR MONTICELLO, MISS.

LOCATION.--Lat $31^{\circ} 33^{\prime}$, long $90^{\circ} 05^{\prime}$, in Sw $\$$ sec. 23, T.7 N., R. 21 w., St. Stephens meridian, Lawrence County, at gaging station at bridge on U,S, Highway 84,1 mile east of Monticelio, 2.5 miles upstream from Halls Creek, 3 miles up-
stream from Silver Creek, and at mile 190.8 .

DRAINAGE AREA. $--5,040 \mathrm{sq} \mathrm{mi}$, approximately.

PERIOD OF RECORD.--Chemical analyses: April 1965 to September 1970.

Water temperatures: November 1965 to September 1969 (discontinued).

EXTREMES. - -1965-69:

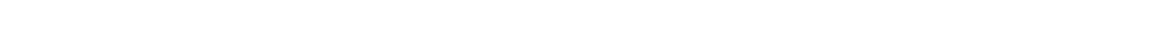
rater 1969 . CHEMICAL ANALYSES, NOVEMBER 1969 TO SEPTEMBER 1970

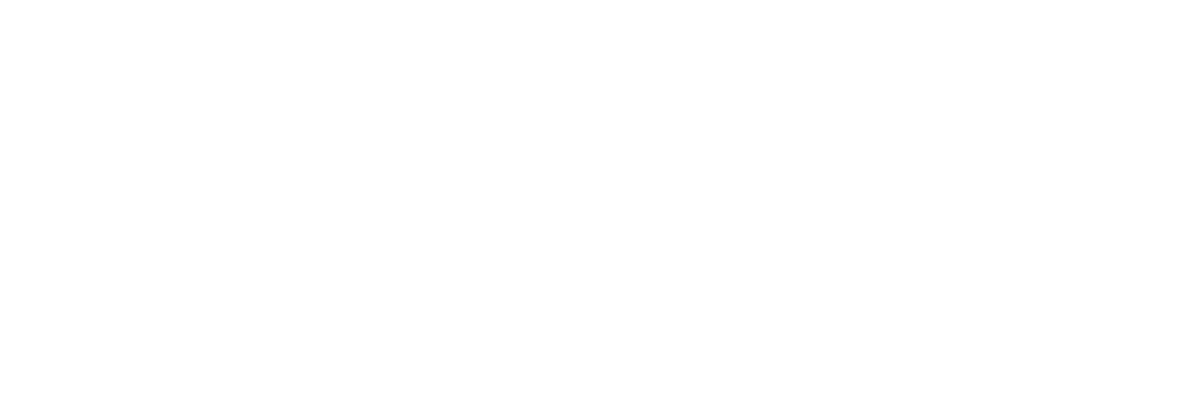


PEARL RIVER BASIN

02488500 PEARL RIVER NEAR MONTICELLO, YISS.--CONt Inued

CHEMICAL ANALYSES, NOVEMBER 1969 TO SEPTEMBER 1970

\begin{tabular}{|c|c|c|c|c|c|c|c|c|c|c|c|}
\hline DATF & $\begin{array}{l}\text { SPECI- } \\
\text { FIC } \\
\text { CONA- } \\
\text { HCTANCF } \\
\text { (MICPN- } \\
\text { MHOSI }\end{array}$ & $\begin{array}{c}\text { Pu } \\
\text { (UVITS) }\end{array}$ & $\begin{array}{c}\text { COLRQ } \\
\text { (PLATI- } \\
\text { NIIM- } \\
\text { COAALT } \\
\text { INITSI }\end{array}$ & $\begin{array}{l}\text { TUR- } \\
\text { A IO- } \\
\text { ITY } \\
\text { IMCILI }\end{array}$ & $\begin{array}{l}\text { AI?- } \\
\text { CHFM- } \\
\text { ICAL } \\
\text { AXYGFN } \\
\text { DFMAND } \\
\text { (MFIL) }\end{array}$ & $\begin{array}{l}\text { CHEM- } \\
\text { ICAL } \\
\text { OXYGEN } \\
\text { DEMAND } \\
\text { (MG/L) }\end{array}$ & $\begin{array}{l}\text { ORGANIC } \\
\text { NITRT- } \\
\text { SFN } \\
\text { (N) } \\
\text { IYSILI }\end{array}$ & $\begin{array}{l}\text { TЕYP- } \\
\text { ERATIIRE } \\
\text { I } \cap F \text { CI }\end{array}$ & $\begin{array}{l}\text { OISS- } \\
\text { TLVE? } \\
\text { OXYGEN } \\
\text { (YG/LI }\end{array}$ & $\begin{array}{c}\text { NITRIT } \\
\text { (N) } \\
\text { (MI/L) }\end{array}$ & $\begin{array}{c}\text { COLI- } \\
\text { FORM } \\
\text { ICOL- } \\
\text { TNIES } \\
\text { OER } \\
\text { ION YLI }\end{array}$ \\
\hline $\begin{array}{l}\text { Nnv. } \\
\text { a6... }\end{array}$ & 120 & 7.7 & 30 & 25 & 3.7 & ?n & 1.2 & 16.0 & 9.6 & $.0 ?$ & 4510 \\
\hline $\begin{array}{l}\text { nFC. } \\
17 . .\end{array}$ & 99 & 6.6 & 20 & 25 & 2.5 & 16 & 1.8 & $11 . n$ & 9.0 & .30 & 2040 \\
\hline $\begin{array}{l}05 . . \\
M A R\end{array}$ & 85 & 6.6 & $3 n$ & 250 & - & 78 & 7.7 & 3.3 & -- & .75 & 930 \\
\hline${ }_{\triangle P R}^{10} \ldots$ & 70 & 6.4 & 35 & 30 & 2.3 & 19 & .50 & 16.0 & 8.9 & .20 & $17 n n$ \\
\hline JINA.." & 48 & h. 1 & 50 & 40 & -- & 20 & -- & 23.0 & 7.1 & חח & $\operatorname{san} 0$ \\
\hline $\begin{array}{l}17 \ldots . . \\
\text { JULY }\end{array}$ & 91 & 6.4 & 25 & $? 5$ & .4 & 15 & .84 & 26.0 & 5.7 & .00 & 1900 \\
\hline 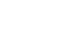 & 140 & $h .4$ & 40 & 32 & 2.4 & 16 & - & 31.0 & 6.2 & .60 & 9830 \\
\hline & 47 & 6.2 & 30 & 10 & 1.2 & 10 & 1.0 & 31.0 & 7.1 & .50 & 12900 \\
\hline
\end{tabular}

02489000 PEARL RIVER NEAR COLUMBIA, MISS.

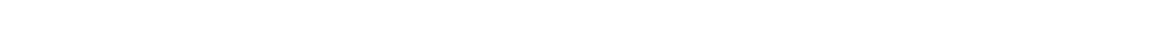

station at bridge on U.S. Highway $98,1,5$ miles southwest of Columbia, 2 miles downstream from Fernwood, Colum-
bta, and Gulf Railroad bridge, 2.2 miles upstream from Silver Creek, and 2.8 miles downstream from Jones Creek.

DRA INAGE AREA. $--5,690 \mathrm{sq} \mathrm{mi}$, approximately.

PERIOD OF RECORD.--ChemiCRI analyses: November 1969 to September 1970.

CHEMICAL ANALYSES, NOVEMBER 1969 TO SEPTEMBER 1970

\begin{tabular}{|c|c|c|c|c|c|c|c|c|c|c|c|}
\hline TATF & $\begin{array}{l}\text { OIS- } \\
\text { CHARSFF } \\
\text { (CFS) }\end{array}$ & $\begin{array}{l}\text { CAL- } \\
\text { CIUUA } \\
(C A) \\
(A G / L)\end{array}$ & $\begin{array}{c}\text { MAF- } \\
N E- \\
\text { SIIIM } \\
(M G I \\
\text { IMG IL) }\end{array}$ & $\begin{array}{l}\text { SUNIUM } \\
\text { (NA) } \\
\text { (MC./L) }\end{array}$ & $\begin{array}{l}\text { p)- } \\
\text { TAS- } \\
\text { SIJM } \\
\text { (K) } \\
\text { (HG/L) }\end{array}$ & $\begin{array}{l}\text { ALKA- } \\
\text { LINITY } \\
\text { AS } \\
\text { CACTIS } \\
\text { (YSILI) }\end{array}$ & $\begin{array}{l}\text { SULFATE } \\
\text { (Sח4) } \\
\text { (MG/L) }\end{array}$ & $\begin{array}{l}\text { PपDS- } \\
\text { PपATE } \\
(P \cap 4) \\
(4 G / L)\end{array}$ & $\begin{array}{l}\text { HARO- } \\
\text { VESS } \\
\text { (CA,MG) } \\
\text { (MG/L) }\end{array}$ & $\begin{array}{l}\text { SOOIUM } \\
\text { AN- } \\
\text { SORD- } \\
\text { TIJN } \\
\text { RATIO }\end{array}$ & $\begin{array}{l}\text { SPFCI- } \\
\text { FIC } \\
\text { CONO- } \\
\text { UCTANCE } \\
\text { IMICRT- } \\
\text { MHOSI }\end{array}$ \\
\hline Nov. & 91ก & 12 & 3.0 & 25 & 1.6 & 24 & 14 & .27 & 15 & 1.7 & $\circ 0$ \\
\hline $\begin{array}{l}D E C . \\
17 . . \\
F F B .\end{array}$ & 1520 & 15 & 5.7 & 22 & 2.1 & 40 & 14 & .41 & Oי & 1.3 & BA \\
\hline 75... & 5000 & 11 & 4.0 & -- & -- & -- & 15 & .17 & 15 & $\cdots$ & 59 \\
\hline $\begin{array}{l}19 \\
\triangle P D_{0}\end{array}$ & 5150 & 12 & 7.0 & 14 & 1.7 & 12 & 14 & .15 & 10 & .9 & 70 \\
\hline$\underset{\text { JUNF }}{29 . .}$ & 8170 & $1 n$ & -- & -- & -- & 7 & .7 & .05 & 16 & -- & 43 \\
\hline${ }_{\text {JULY }}^{19}$ & $250^{n}$ & 13 & n. 0 & 18 & 2.1 & 24 & 5.0 & -- & 19 & 1.0 & 99 \\
\hline $29 \ldots$ & QDO & 5.0 & 3.0 & 19 & 1.7 & 21 & 15 & .34 & B & 1.6 & 100 \\
\hline $09 .$. & 975 & 7.0 & $5 . ?$ & 16 & 1.4 & $Q$ & 9.1 & .19 & 12 & 1.1 & 68 \\
\hline
\end{tabular}

\begin{tabular}{|c|c|c|c|c|c|c|c|c|c|c|}
\hline DATF & $\begin{array}{c}\text { OH } \\
\text { (ujurs) }\end{array}$ & $\begin{array}{c}\text { COL OR } \\
\text { PLATI- } \\
\text { NUM- } \\
\text { CORALT } \\
\text { UNITSI }\end{array}$ & $\begin{array}{l}\text { TUR- } \\
\text { RIN- } \\
\text { ITY } \\
\text { ( YG/L) }\end{array}$ & $\begin{array}{l}\text { BID- } \\
\text { CHEM- } \\
\text { ICAL } \\
\text { TXYGEN } \\
\text { OEMANO } \\
\text { (MG/L) }\end{array}$ & $\begin{array}{l}\text { CHFM- } \\
\text { ICAL } \\
\text { OXYTEN } \\
\text { OFMANO } \\
\text { IMG/LI }\end{array}$ & $\begin{array}{l}\text { TRGANIE } \\
\text { NITRT- } \\
\text { GEN } \\
\text { IN) } \\
\text { (MG/L) }\end{array}$ & $\begin{array}{l}\text { TEMP- } \\
\text { FRATURE } \\
\text { (DEG C) }\end{array}$ & $\begin{array}{l}\text { TISS- } \\
\text { OLVEO } \\
\text { IXYSFFV } \\
\text { (MG/L) }\end{array}$ & $\begin{array}{l}\text { NI TRI TE } \\
\text { (N) } \\
\text { (MG/L) }\end{array}$ & $\begin{array}{c}\text { COLI- } \\
\text { CORY } \\
\text { ICOL- } \\
\text { ONFES } \\
\text { PER } \\
100 \text { ML) }\end{array}$ \\
\hline $\begin{array}{l}\text { Nov. } \\
\text { OS... } \\
\text { DEC. }\end{array}$ & 7.7 & 70 & 25 & 1.7 & $1 n$ & .67 & $15 . ?$ & 9.7 & .32 & RA50 \\
\hline $\begin{array}{l}17 . . \\
F \in R .\end{array}$ & 6.5 & 45 & 25 & 2.3 & 12 & 1.0 & $11 . n$ & 0.5 & .38 & 2350 \\
\hline $\begin{array}{l}05 \ldots . . \\
\text { YAR. }\end{array}$ & 6.6 & 30 & 120 & -- & 22 & 1.5 & 2. 0 & 10.7 & .10 & 3000 \\
\hline $\begin{array}{l}19 . . \\
A P R\end{array}$ & 6.6 & 45 & 27 & 1.7 & 16 & .70 & 16.0 & -- & $.2 n$ & $110 n$ \\
\hline$\underset{\text { JUNF }^{\circ} \ldots}{ }$ & 6.1 & 35 & 39 & -- & 17 & -- & 24.0 & 7.1 & .10 & 1600 \\
\hline $\begin{array}{l}10 . . \\
\text { JULY }\end{array}$ & 6.9 & 35 & 20 & .3 & 13 & - RO & 25.0 & 5.5 & .10 & 1100 \\
\hline SFP 29. & 6.3 & 45 & $1 n$ & $\cdot 3$ & B.1 & .60 & 29.0 & 5.8 & .50 & 3400 \\
\hline $00 . .$. & 6.3 & 30 & 10 & .9 & A.? & 1.1 & 29.0 & 7.2 & .60 & 100 \\
\hline
\end{tabular}


02489500 PEARL RIVER NEAR BOGALUSA, LA.

LOCATION.--Lat $30^{\circ} 47^{\prime} 35^{\prime \prime}$, long $89^{\circ} 49^{\prime} 15^{\prime \prime}$, on line between secs.17 and $08, T .3$ S., R. 14 E., Washington Parish, at gaging station at bridge on State Highway 10,2 miles east of Bogalusa, and 2 miles upstream from Bogue Lusa Creek. DRAINAGE AREA. - 6,630 sq $\mathrm{mz}$, approximately.

PERIOD OF RECORD.--Chemical analyses: November 1962 to Seplember 1970. Water temperatures: November 1962 to September 1970.

Sediment records: Apri1 1967 to September 1970.

EXTREMES. --1969-70:

Sediment concentratıons: Maxımum daily, $266 \mathrm{mg} / 1 \mathrm{Jan}, 5 ; \mathrm{minsmum}$ daIly, $2 \mathrm{mg} / 1$ Nov. $11-13$

Sediment discharge: Maximum daily, 11,700 tons March 7 ; minimum daily, 7 tons Nov. 11-13.

Period of record:

Dissolved solıds (1962-67): Maximum, $117 \mathrm{mg} / 1$ Sept. 9-12, 1965; m1n1mum, $32 \mathrm{mg} / 1 \mathrm{Apr}, 21-30$, May 1-10, 1963,

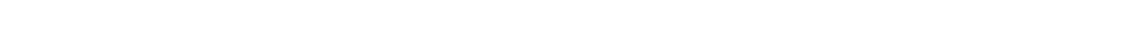
Specific conductance: Maximum daily, 180 micromhos Sept. 10, 1965; minimum dally, 31 micromhos Feb. 15-17, 1966

Water temperatures: Maximum, $34.0^{\circ} \mathrm{C}$ July 14, 1967; minimum, $2,0^{\circ} \mathrm{C} \mathrm{Dec,} \mathrm{21,} 1963$.

Sediment concentrations (1967-70): Maximum da11v, $522 \mathrm{mg} / 1 \mathrm{Dec}$. 17, 1967; manimum daily, $2 \mathrm{mg} / 1 \mathrm{Nov} .11-13$,

Sediment discharge (1967-70): Maximum da11y, 32,700 tons May 7, 1967; mmamum da11y, 7 tons Nov. 11-13, 1969.

REMARKS. - When discharge is greater than $11,300 \mathrm{cfs}$, there are 5 overflow channels. On these days sediment concentrations in the overflon channels are computed as 10 percent of the concentration in the main channel. This is used as a basis for computing total concentration and load.

CHEMICAL ANALYSES, WATER YEAR OCTODER 1969 TO SEPTEMBER 1970

\begin{tabular}{|c|c|c|c|c|c|c|c|c|c|c|}
\hline UATE. & $\begin{array}{l}\text { DISCHAKGE } \\
\text { (CFS) }\end{array}$ & $\begin{array}{l}\text { SILICA } \\
\text { (SIO2) } \\
\text { (MG/L) }\end{array}$ & $\begin{array}{l}\text { IRON } \\
\text { (FE) } \\
\text { (UG/L) }\end{array}$ & $\begin{array}{c}\text { CALCIUM } \\
\text { (CA) } \\
\text { (MG/L) }\end{array}$ & $\begin{array}{l}\text { MAGNESIUM } \\
\text { (MG) } \\
(M G / L)\end{array}$ & $\begin{array}{l}\text { SODIUM } \\
\text { (NA) } \\
\text { (MG/L) }\end{array}$ & $\begin{array}{c}\text { POTASSIUM } \\
(K) \\
(M G / L)\end{array}$ & $\begin{array}{l}\text { BICARBONATE } \\
\text { (HCO3) } \\
\text { (MG/L) }\end{array}$ & $\begin{array}{l}\text { SULFATE } \\
\text { (SO4) } \\
\text { (MG/L) }\end{array}$ & $\begin{array}{c}\text { CHLORID } \\
\text { (CL) } \\
\text { (MG/L) }\end{array}$ \\
\hline $\begin{array}{l}16 \\
15 \\
16\end{array}$ & $\begin{array}{r}1210 \\
10700 \\
9000\end{array}$ & $\begin{array}{l}11 \\
0.6 \\
6.0\end{array}$ & $\begin{array}{r}10 \\
290 \\
20\end{array}$ & $\begin{array}{l}5.0 \\
6.0 \\
4.5\end{array}$ & $\begin{array}{r}1.8 \\
.5 \\
.9\end{array}$ & $\begin{array}{l}12 \\
5.6 \\
6.7\end{array}$ & $\begin{array}{l}1.8 \\
2.0 \\
2.1\end{array}$ & $\begin{array}{r}20 \\
4 \\
12\end{array}$ & $\begin{array}{l}9.6 \\
18 \\
10\end{array}$ & $\begin{array}{l}12 \\
6.1 \\
7.9\end{array}$ \\
\hline $\begin{array}{l}27 \\
15 \\
T .3 U\end{array}$ & $\begin{array}{l}2050 \\
1750\end{array}$ & $\begin{array}{l}0.0 \\
8.0 \\
8.1\end{array}$ & $\begin{array}{r}220 \\
10 \\
200\end{array}$ & $\begin{array}{l}3.0 \\
3.1 \\
2.9\end{array}$ & $\begin{array}{l}1.8 \\
1.0 \\
1.2\end{array}$ & $\begin{array}{r}9.6 \\
9.4 \\
10\end{array}$ & $\begin{array}{l}1.5 \\
2.2 \\
2.3\end{array}$ & $\begin{array}{l}16 \\
13 \\
15\end{array}$ & $\begin{array}{c}9.4 \\
12 \\
8.0\end{array}$ & $\begin{array}{l}9.0 \\
11 \\
11\end{array}$ \\
\hline
\end{tabular}

DATE

FLUOKIUE
(F)
$(M G / L)$

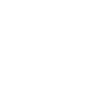

$$
\begin{aligned}
& \text { UISSOLVED DISSOLVED } \\
& \text { SOLIUS SOLIUS }
\end{aligned}
$$

MG/L

SOLIUS
(RESIDUE.

SOLIUS

1.220

180 C) STITUENTS) (CA, MG)
(MG/L) (MG/L) (MG/L)

NON-CAK-

SPECIFIC

$\begin{array}{lccc}\text { CON- } & \text { COLOR } & \\ \text { OUCTANCE } & \text { TEM- } & \text { (PLATINUM- } & \\ \text { (MICRO- } & \text { PERATURE } & \text { COBALT } & \text { PH } \\ \text { MHOS) } & \text { (DEG C) } & \text { UNITS) } & \text { (UNITS) }\end{array}$

NUV. 16

$\begin{array}{rrr}0.1 & 0.4 & 62 \\ .3 & 1.2 & 72 \\ .1 & .7 & 71\end{array}$

$\begin{array}{ll}62 & 1 \\ 49 & 1 \\ 46 & 1\end{array}$

$\begin{array}{ll}17 & 17 \\ 17 & 14\end{array}$

95
75
79

$\begin{array}{rl}16.0 & \\ 7.5 & 30\end{array}$

MAY 27

$\begin{array}{lll}.1 & 0 & 50 \\ 11 & 11 & 72 \\ 112 & 71\end{array}$

49
52

12
12
12

1
14
5
0

78

$\begin{array}{ll}b & 7.2 \\ 30 & 6.1\end{array}$

SEPT, SU

.1

52

27.5
28.0

20

6.7

$\begin{array}{llr}85 & 28.0 & 0 \\ 85 & 23.0 & 30\end{array}$

6.4
6.2
6.7

DATE

DISSULVEU
OXYGEN
(DU)
$(M G / L)$

QI0-

CHEMICAL

OXYGEN

DEMANO

(MG/L)

CHEMICAL
OXYGEN

DEMANU

(COO)

(MG/L)

AMMONIA

NITHOGEN PHOSPHATE SUSPENDED

(N)

(MG/L)

(POH)

SOLIDS

(MG/L)

COLIFORM
COLONIES

$200 \mathrm{ML})$

$\begin{array}{cc}\text { STHEP- } & \text { FECAL } \\ \text { TOCOCCI } & \text { COLIFORM } \\ \text { (COLONIES } & \text { (COLONIES } \\ \text { PEK } & \text { PER } \\ 100 \mathrm{ML}) & 100 \mathrm{ML} \text { ) }\end{array}$

NOV. 18

MAN. IS

9.4
12.0

0.0
.70

39

$\because$

$\because \quad \because$

0.1

MAY 27

JULY is

$-\frac{0.1}{7.9}$

1.9

$U$
$2 y$

$=$

$=\overline{-}$

$\begin{array}{lll}\because & \because & \because \\ \because & \because & = \\ \because & \because & \because\end{array}$


02489500 PEARL RIVER NEAR BOGALUSA, LA.--Continued

SPECIFIC CONDUCTANCE (MICROMHOS/CM AT $25^{\circ} \mathrm{C}$ ), WATER YEAR OCTOBER 1969 TO SEPTEMBER 1970

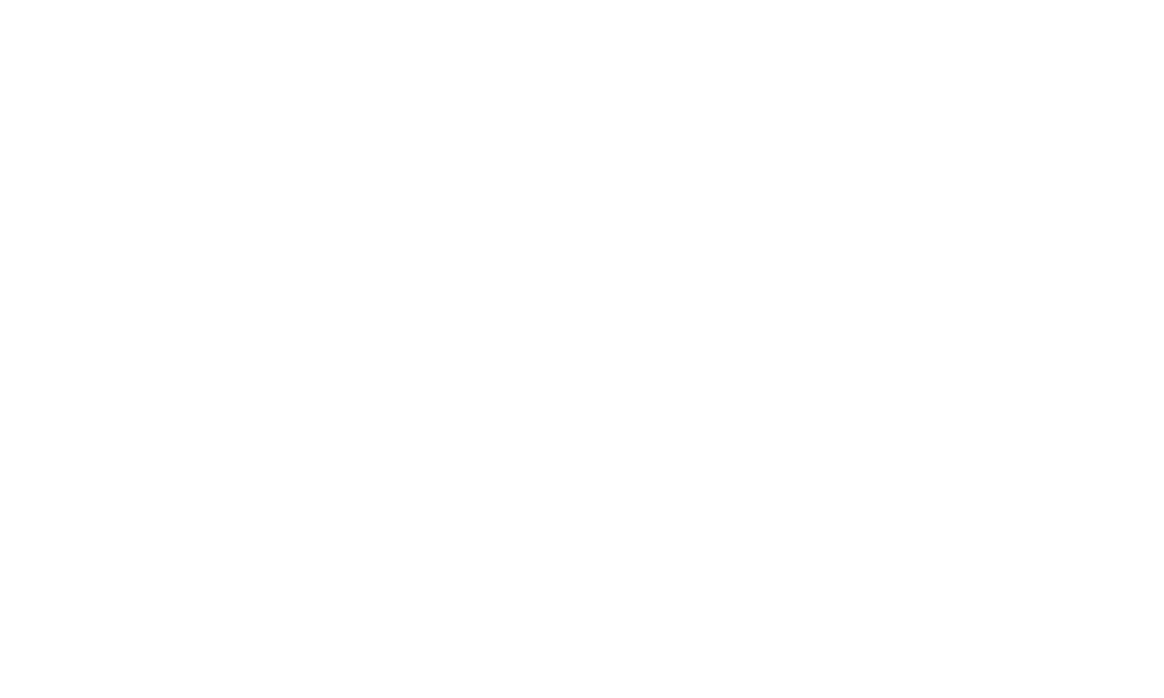

TEMPERATURE ( $\left.{ }^{\circ} \mathrm{C}\right)$ OF WATER, WATER YEAR OCTOBER 1969 TO SEPTEMBER 1970

\begin{tabular}{|c|c|c|c|c|c|c|c|c|c|c|c|c|}
\hline DAY & OCT & NOV & DEC & JAN & $F E B$ & MAR & APR & MAY & JUN & JUL & AUG & SEP \\
\hline $\begin{array}{l}1 \\
2 \\
3 \\
4 \\
5\end{array}$ & $\begin{array}{r}21.0 \\
23.0 \\
-\cdots\end{array}$ & $\begin{array}{l}-- \\
-- \\
-\cdots \\
m-\end{array}$ & $\begin{array}{r}-0 \\
13.0 \\
10.0 \\
---\end{array}$ & $\begin{array}{l}9.0 \\
8.0 \\
8.0 \\
-.-\end{array}$ & $\begin{array}{l}--- \\
-0.0 \\
9.0\end{array}$ & $\begin{array}{r}15.0 \\
15.0 \\
16.0\end{array}$ & 16.0 & $\begin{array}{r}25.0 \\
21.0 \\
20.0 \\
21.0\end{array}$ & $\begin{array}{r}24.0 \\
-24.0 \\
25.0\end{array}$ & $\begin{array}{r}30.0 \\
-13.0 \\
30.0 \\
-\end{array}$ & $\begin{array}{r}--- \\
30.0 \\
32.0 \\
29.0\end{array}$ & $\begin{array}{l}28.0 \\
28.0 \\
28.0 \\
29.0 \\
29.0\end{array}$ \\
\hline $\begin{array}{r}6 \\
7 \\
8 \\
9 \\
10\end{array}$ & $\begin{array}{l}-\cdots \\
-\cdots \\
-\cdots\end{array}$ & $\begin{array}{r}17.0 \\
\hdashline- \\
\hdashline\end{array}$ & \begin{tabular}{c}
10.0 \\
\hdashline- \\
$\cdots$
\end{tabular} & $\begin{array}{l}4.0 \\
5.0 \\
-.0\end{array}$ & $\begin{array}{r}--- \\
10.0 \\
10.0\end{array}$ & $\begin{array}{r}13.0 \\
14.0 \\
16.0\end{array}$ & $\begin{array}{l}17.0 \\
17.0 \\
19.0 \\
19.0\end{array}$ & $\begin{array}{r}23.0 \\
24.0 \\
23.0\end{array}$ & $\begin{array}{r}26.0 \\
26.0 \\
28.0 \\
26.0\end{array}$ & $\begin{array}{l}29.0 \\
30.0 \\
30.0 \\
30.0 \\
30.0\end{array}$ & $\begin{array}{r}30.0 \\
31.0 \\
- \\
-\end{array}$ & $\begin{array}{r}30.0 \\
29.0 \\
30.0 \\
29.0\end{array}$ \\
\hline $\begin{array}{l}11 \\
12 \\
13 \\
14 \\
15\end{array}$ & 28.0 & $\begin{array}{r}17.0 \\
0.0 \\
14.0 \\
15.0\end{array}$ & $\begin{array}{r}11.0 \\
12.0 \\
12.0 \\
14.0\end{array}$ & $\begin{array}{l}-1.0 \\
7.0 \\
--2\end{array}$ & $\begin{array}{l}11.0 \\
10.0 \\
12.0 \\
12.0 \\
13.0\end{array}$ & $\begin{array}{r}15.0 \\
13.0 \\
11.0 \\
12.0\end{array}$ & $\begin{array}{l}19.0 \\
20.0 \\
20.0 \\
19.0\end{array}$ & $\begin{array}{r}24.0 \\
24.0 \\
24.0 \\
- \\
-\end{array}$ & $\begin{array}{l}26.0 \\
28.0 \\
30.0 \\
30.0 \\
29.0\end{array}$ & $\begin{array}{r}28.0 \\
28.0 \\
28.0 \\
29.0\end{array}$ & $\begin{array}{l}28.0 \\
29.0 \\
30.0 \\
31.0 \\
29.0\end{array}$ & $\begin{array}{r}29.0 \\
29.0 \\
29.0 \\
28.0\end{array}$ \\
\hline $\begin{array}{l}16 \\
17 \\
18 \\
19 \\
20\end{array}$ & $\begin{array}{c}-- \\
-- \\
22.0\end{array}$ & $\begin{array}{l}-- \\
m- \\
-- \\
--\end{array}$ & $\begin{array}{l}-\overline{-} \\
-\cdots \\
-\square \\
-\square\end{array}$ & $\begin{array}{c}7.0 \\
9.0 \\
-- \\
6.0\end{array}$ & $\begin{array}{l}11.0 \\
11.0 \\
11.0 \\
12.0 \\
\end{array}$ & $\begin{array}{r}14.0 \\
14.0 \\
16.0 \\
-\overline{15.0}\end{array}$ & $\begin{array}{r}20.0 \\
-0 \\
\hdashline \overline{21.0}\end{array}$ & $\begin{array}{l}-- \\
--- \\
--- \\
--\end{array}$ & $\begin{array}{l}31.0 \\
31.0 \\
30.0 \\
28.0 \\
30.0\end{array}$ & $\begin{array}{l}30.0 \\
30.0 \\
30.0 \\
29.0 \\
30.0\end{array}$ & $\begin{array}{l}30.0 \\
29.0 \\
30.0 \\
28.0 \\
30.0\end{array}$ & $\begin{array}{l}29.0 \\
29.0 \\
29.0 \\
29.0 \\
29.0\end{array}$ \\
\hline $\begin{array}{l}21 \\
22 \\
23 \\
24 \\
25\end{array}$ & $\begin{array}{r}23.0 \\
22.0 \\
22.0 \\
20.0\end{array}$ & $\begin{array}{r}-15.0 \\
15.0 \\
14.0\end{array}$ & $\begin{array}{r}12.0 \\
12.0 \\
11.0\end{array}$ & $\begin{array}{l}6.0 \\
-- \\
--\end{array}$ & $\begin{array}{r}--- \\
13.0 \\
12.0 \\
12.0\end{array}$ & $\begin{array}{r}-0 \\
15.0 \\
16.0 \\
16.0\end{array}$ & $\begin{array}{r}21.0 \\
22.0 \\
24.0 \\
24.0\end{array}$ & 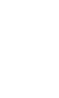 & $\begin{array}{l}31.0 \\
30.0 \\
28.0 \\
28.0 \\
29.0\end{array}$ & $\begin{array}{l}27.0 \\
27.0 \\
27.0 \\
27.0 \\
25.0\end{array}$ & $\begin{array}{l}29.0 \\
28.0 \\
27.0 \\
27.0 \\
27.0\end{array}$ & $\begin{array}{l}29.0 \\
29.0 \\
26.0 \\
29.0 \\
27.0\end{array}$ \\
\hline $\begin{array}{l}26 \\
27 \\
28 \\
29 \\
30 \\
31\end{array}$ & $\begin{array}{r}19.0 \\
21.0 \\
20.0 \\
0.0 \\
18.0\end{array}$ & $\begin{array}{r}13.0 \\
13.0 \\
11.0 \\
12.0 \\
\end{array}$ & $\begin{array}{r}--- \\
11.0 \\
13.0 \\
14.0 \\
\ldots-\end{array}$ & $\begin{array}{r}13.0 \\
11.0 \\
12.0\end{array}$ & $\begin{array}{r}10.0 \\
11.0 \\
14.0 \\
- \\
-\end{array}$ & $\begin{array}{r}14.0 \\
15.0 \\
15.0 \\
15.0 \\
\end{array}$ & $\begin{array}{r}--- \\
25.0 \\
25.0 \\
25.0 \\
--- \\
--\end{array}$ & $\begin{array}{l}--- \\
--- \\
-- \\
--- \\
--\end{array}$ & $\begin{array}{r}29.0 \\
29.0 \\
28.0 \\
30.0 \\
29.0 \\
\end{array}$ & $\begin{array}{r}27.0 \\
26.0 \\
30.0 \\
29.0 \\
- \\
-\end{array}$ & $\begin{array}{r}27.0 \\
27.0 \\
27.0 \\
28.0\end{array}$ & $\begin{array}{l}28.0 \\
25.0 \\
24.0 \\
23.0 \\
23.0\end{array}$ \\
\hline AVERAGE & $\cdots$ & $\cdots$ & $\cdots$ & $\cdots$ & -- & $\cdots$ & $-\cdots$ & -- & 28.0 & 29.0 & 29.0 & 28.0 \\
\hline
\end{tabular}


PEARL RIVEP BASIN

02489500 PEARL RIVER NEAR BOGALUSA, LA,--Continued

SUSPENDED-SEDIMENT DISCHARGE, WATER YEAR OCTOBER 1969 TO SEPTEMBER 1970

OCTOBER

NOVEMBER

DECEMBER

MEAN
DISCHARGE
(CFS)

CONCEN- SEDIMENT

SEDIMENT MEAN CONCEN- SEDIMENT

MEAN CONCEN-

CONCEN- SEDIMENT

$\begin{array}{ll}E & 10 \\ E & 10 \\ E & 14 \\ E & 14 \\ E & 14\end{array}$

E 14

E 36

1320

1330
1680
1900

1900

1660
1580
1460

1370

1300
1290

1290
1280

1260

1280

1290
1290

1350

1390

1340

1240

1240

TOTAL $\quad 43110$

DAY

1
10
1
12
14
15
16
17
19
19
20
21
22
23
24
25
26
27
29
30
31

$\begin{array}{rrr}5120 & 62 & 857 \\ 6750 & 118 & 2150\end{array}$

8170

8630
8940

9540

10700

11600

12700
13000

13200

13100

11700
10600

84
7930

$9600 \quad 72 \quad 1870$

8800

8170
7580

6930

6330

5910
5370

5370

4030

3740
3520

3520
3180

2930

2970

TOTAL 244310

E ESTIMATED.

256 E 5970

256 E 6590

242 E 7000

$200 \quad 6860$

6230

5330

3840

2730
2390

1470
1170

1170
921
711

3030
3940
5660

5660
6270

19

19
30
36
50

6790

6570
6510
6510

6510
6350

6350
6080

5710

5160

4390
3680

3180

3080
3790

4320
3860

3860
3480

3270

2810

2530

2560
2690

543
449
361
294

3040
3060

3360

--

233
$E \quad 217$

82734

121680

1530
1350

E 141

114
96
97
102
TRATION DISCHARGE DISCHARGE TRATION DISCHARGE DISCHARGE

\begin{tabular}{|c|c|c|c|}
\hline $\begin{array}{l}1250 \\
1250 \\
1260 \\
1260 \\
1250\end{array}$ & $\begin{array}{l}3 \\
3 \\
4 \\
4 \\
4\end{array}$ & $\begin{array}{l}E \\
E \\
E \\
E \\
E\end{array}$ & $\begin{array}{l}10 \\
10 \\
14 \\
14 \\
14\end{array}$ \\
\hline $\begin{array}{l}1270 \\
1280 \\
1250 \\
1240 \\
1250\end{array}$ & $\begin{array}{r}4 \\
4 \\
5 \\
6 \\
4\end{array}$ & $E$ & $\begin{array}{l}14 \\
14 \\
17 \\
20 \\
14\end{array}$ \\
\hline $\begin{array}{l}1270 \\
1260 \\
1250 \\
1220 \\
1210\end{array}$ & $\begin{array}{l}2 \\
2 \\
2 \\
3 \\
4\end{array}$ & & $\begin{array}{r}7 \\
7 \\
7 \\
10 \\
13\end{array}$ \\
\hline $\begin{array}{l}1200 \\
1200 \\
1200 \\
1270 \\
1370\end{array}$ & $\begin{array}{r}4 \\
3 \\
3 \\
5 \\
10\end{array}$ & $E$ & $\begin{array}{l}13 \\
10 \\
10 \\
17 \\
37\end{array}$ \\
\hline $\begin{array}{l}1500 \\
1540 \\
1540 \\
1560 \\
1440\end{array}$ & $\begin{array}{l}14 \\
20 \\
32 \\
26 \\
13\end{array}$ & $\stackrel{E}{E}$ & $\begin{array}{r}57 \\
83 \\
133 \\
110 \\
50\end{array}$ \\
\hline $\begin{array}{l}1330 \\
1270 \\
1260 \\
1260 \\
1240\end{array}$ & $\begin{array}{l}7 \\
6 \\
4 \\
4 \\
4\end{array}$ & & $\begin{array}{l}25 \\
21 \\
14 \\
14 \\
13\end{array}$ \\
\hline & & & \\
\hline 38950 & -- & & 792 \\
\hline
\end{tabular}

\section{0} $\begin{array}{ll}\text { TRATION) } & \text { DISCHARGE } \\ \text { (TONS/DAY) }\end{array}$

155
319
550
846

1670
1530

1350
$\mathbf{1} 321$

586

432
273

219
189

175
287
303
208
169

E 169

1240
1230
1240
1240

1240
1220

1270

1680

2740
3360

3360

3300

2750
2240

2020

1940

1860

1800

1780
1780

4
3
3
3
3
3

$\begin{array}{ll}E & 13 \\ E & 10 \\ E & 10 \\ E & 10 \\ E & 10\end{array}$

E $\quad 14$

E 259

$\begin{array}{ll}E & 490 \\ E & 472\end{array}$

49 E 437

$\begin{array}{rrr}49 & \text { E } & 437 \\ 35 & & 260 \\ 25 & & 151 \\ 16 & & 87 \\ 12 & & 63\end{array}$

12

12
14
14

60

1820

2940

2060

2140
2210

2680

2960

3380

3720

4110
4390

74090

58
67
67

14

$16 \quad 89$

92
107
217

E 271

283

422
766

69

$\begin{array}{ll}72 & 853 \\ 63 & 788\end{array}$

$--$

6613

MARCH

$\begin{array}{rrr}5160 & 33 & 460 \\ 6550 & 54 & 955 \\ 7220 & 68 & 1330 \\ 9090 & 94 & 2310\end{array}$

$\begin{array}{rrr}9090 & 94 & 2310 \\ 13200 & 139 & 4960\end{array}$

15400

17000
17300

16200

$209 \quad 8690$

$\begin{array}{rr}255 & 11700 \\ 212 & 9930\end{array}$

$\begin{array}{lr}247 & 10800 \\ 124 & 4800\end{array}$

,2woo

12900

11700

12900

$102 \quad 3570$

$82 \quad 2630$

$\begin{array}{rr}94 & 2980 \\ 117 & 4070\end{array}$

13200

112

12100
10300

9020
8140

$95 \quad 3120$

$69 \quad 2220$

1680
1230

1090

56
52

9170
13700

16800

17600

$\begin{array}{rrr}114 & E & 2820 \\ 213 & \text { E } & 7890 \\ 226 & & 10300\end{array}$

8300
8140
6750

17300

171

$25 \quad 5740$

$\begin{array}{ll}140 & 17000 \\ 132 & 16700\end{array}$

132
163
--
--

16700
16800

17100

17600

17600
18200

$\begin{array}{ll}125 & 5740 \\ 118 & 5340 \\ 118 & 5360 \\ 118 & 5430\end{array}$

6270
6530

$409340 \quad \ldots \quad 153085$ 
02489500 PEARL RIVER NEAR BOGALUSA, LA.--Cont1nued SUSPENDED-SEDIMENT DISCHARGE, WATER YEAR OCTOBER 1969 TO SEPTEMBER 1970

\begin{tabular}{|c|c|c|c|c|c|c|c|c|c|c|c|}
\hline \multirow[b]{2}{*}{ DAY } & \multicolumn{4}{|c|}{ APRIL } & \multicolumn{4}{|c|}{ MAY } & \multicolumn{3}{|c|}{ JUNE } \\
\hline & $\begin{array}{c}\text { MEAN } \\
\text { DI SCHARGE } \\
\text { (CFS) }\end{array}$ & $\begin{array}{l}\text { MEAN } \\
\text { CDNCEN- } \\
\text { TRATI ON } \\
(M G / L)\end{array}$ & \multicolumn{2}{|c|}{$\begin{array}{l}\text { SEDIMENT } \\
\text { DISCHARGE } \\
\text { (TONS/DAY) }\end{array}$} & \multicolumn{2}{|r|}{$\begin{array}{l}\text { MEAN } \\
\text { CONCEN- } \\
\text { TRATION } \\
(M G / L)\end{array}$} & \multicolumn{2}{|c|}{$\begin{array}{l}\text { SEDIMENT } \\
\text { DI SCHARGE } \\
\text { (TONS/DAY) }\end{array}$} & \multicolumn{3}{|c|}{$\begin{array}{l}\text { MEAN } \\
\text { CONCEN- } \\
\text { TRATION } \\
\text { (MG/L) }\end{array}$} \\
\hline $\begin{array}{l}1 \\
2 \\
3 \\
4 \\
5\end{array}$ & $\begin{array}{l}19000 \\
19400 \\
19500 \\
19400 \\
19300\end{array}$ & $\begin{array}{r}149 \\
104 \\
91 \\
83 \\
79\end{array}$ & $\begin{array}{l}E \\
E \\
E \\
E\end{array}$ & $\begin{array}{l}7640 \\
5440 \\
4800 \\
4360 \\
3890\end{array}$ & $\begin{array}{r}9520 \\
8700 \\
9380 \\
14100 \\
18200\end{array}$ & $\begin{array}{r}75 \\
66 \\
132 \\
216 \\
194\end{array}$ & & $\begin{array}{l}1930 \\
1550 \\
3340 \\
8230 \\
9560\end{array}$ & $\begin{array}{l}2630 \\
3070 \\
3430 \\
3940 \\
4400\end{array}$ & $\begin{array}{l}16 \\
25 \\
32 \\
38 \\
41\end{array}$ & $\begin{array}{l}114 \\
207 \\
296 \\
404 \\
487\end{array}$ \\
\hline $\begin{array}{r}6 \\
7 \\
8 \\
9 \\
10\end{array}$ & $\begin{array}{r}14800 \\
10100 \\
7360 \\
5950 \\
5440\end{array}$ & $\begin{array}{l}78 \\
77 \\
68 \\
66 \\
62\end{array}$ & & $\begin{array}{r}3130 \\
2100 \\
1350 \\
1060 \\
911\end{array}$ & $\begin{array}{l}19800 \\
20400 \\
20400 \\
20200 \\
19700\end{array}$ & $\begin{array}{l}170 \\
136 \\
123 \\
114 \\
111\end{array}$ & $\begin{array}{l}E \\
E\end{array}$ & $\begin{array}{l}9040 \\
7510 \\
6770 \\
6220 \\
5880\end{array}$ & $\begin{array}{l}4500 \\
4080 \\
3750 \\
3840 \\
3740\end{array}$ & $\begin{array}{l}45 \\
38 \\
35 \\
34 \\
35\end{array}$ & $\begin{array}{l}547 \\
419 \\
354 \\
353 \\
353\end{array}$ \\
\hline $\begin{array}{l}11 \\
12 \\
13 \\
14 \\
15\end{array}$ & $\begin{array}{r}5740 \\
6730 \\
8250 \\
10100 \\
11300\end{array}$ & $\begin{array}{r}60 \\
57 \\
69 \\
118 \\
113\end{array}$ & & $\begin{array}{r}930 \\
1040 \\
1540 \\
3210 \\
3440\end{array}$ & $\begin{array}{l}18800 \\
18100 \\
16500 \\
15100 \\
13100\end{array}$ & $\begin{array}{r}100 \\
90 \\
91 \\
87 \\
82\end{array}$ & E & $\begin{array}{l}5060 \\
4420 \\
4050 \\
3550 \\
2880\end{array}$ & $\begin{array}{l}3580 \\
3420 \\
3020 \\
2640 \\
2420\end{array}$ & $\begin{array}{l}34 \\
30 \\
25 \\
20 \\
15\end{array}$ & $\begin{array}{r}329 \\
277 \\
204 \\
143 \\
98\end{array}$ \\
\hline $\begin{array}{l}16 \\
17 \\
18 \\
19 \\
20\end{array}$ & $\begin{array}{r}10000 \\
8340 \\
6950 \\
6380 \\
6570\end{array}$ & $\begin{array}{l}64 \\
42 \\
39 \\
40 \\
47\end{array}$ & $\begin{array}{l}E \\
E \\
E\end{array}$ & $\begin{array}{r}1730 \\
946 \\
732 \\
689 \\
834\end{array}$ & $\begin{array}{r}10200 \\
7330 \\
5360 \\
4540 \\
4210\end{array}$ & $\begin{array}{l}60 \\
45 \\
37 \\
34 \\
32\end{array}$ & $\begin{array}{l}E \\
E \\
E \\
E \\
E\end{array}$ & $\begin{array}{r}1650 \\
891 \\
535 \\
417 \\
364\end{array}$ & $\begin{array}{l}2270 \\
2150 \\
2090 \\
2010 \\
1920\end{array}$ & $\begin{array}{r}12 \\
9 \\
7 \\
7 \\
8\end{array}$ & $\begin{array}{l}74 \\
52 \\
40 \\
38 \\
41\end{array}$ \\
\hline $\begin{array}{l}21 \\
22 \\
23 \\
24 \\
25\end{array}$ & $\begin{array}{l}6900 \\
7920 \\
8920 \\
9000 \\
8790\end{array}$ & $\begin{array}{l}47 \\
65 \\
92 \\
84 \\
70\end{array}$ & & $\begin{array}{r}876 \\
1390 \\
2220 \\
2040 \\
1660\end{array}$ & $\begin{array}{l}3980 \\
3780 \\
3520 \\
3260 \\
2990\end{array}$ & $\begin{array}{l}30 \\
28 \\
26 \\
26 \\
22\end{array}$ & $\begin{array}{l}E \\
E \\
E \\
E \\
E\end{array}$ & $\begin{array}{l}322 \\
286 \\
247 \\
229 \\
178\end{array}$ & $\begin{array}{l}1870 \\
1810 \\
1760 \\
1820 \\
2090\end{array}$ & $\begin{array}{r}6 \\
5 \\
5 \\
6 \\
14\end{array}$ & $\begin{array}{l}30 \\
24 \\
24 \\
29 \\
79\end{array}$ \\
\hline $\begin{array}{l}26 \\
27 \\
28 \\
29 \\
30 \\
31\end{array}$ & $\begin{array}{r}8910 \\
9270 \\
9680 \\
9900 \\
9860 \\
--\end{array}$ & $\begin{array}{l}72 \\
72 \\
69 \\
74 \\
80 \\
--\end{array}$ & & $\begin{array}{r}1730 \\
1800 \\
1800 \\
1980 \\
2130 \\
-\end{array}$ & $\begin{array}{l}2800 \\
2670 \\
2620 \\
2630 \\
2630 \\
2520\end{array}$ & $\begin{array}{l}19 \\
18 \\
18 \\
17 \\
16 \\
15\end{array}$ & $\begin{array}{l}E \\
E \\
E \\
E \\
E \\
E\end{array}$ & $\begin{array}{l}144 \\
130 \\
127 \\
121 \\
114 \\
102\end{array}$ & $\begin{array}{r}2620 \\
2850 \\
2900 \\
2620 \\
2270 \\
\ldots\end{array}$ & $\begin{array}{l}22 \\
24 \\
22 \\
16 \\
16 \\
--\end{array}$ & $\begin{array}{r}156 \\
185 \\
172 \\
113 \\
98 \\
--\end{array}$ \\
\hline TOTAL & 308760 & -- & & 67398 & 307040 & -- & & 85847 & 85510 & -- & 5740 \\
\hline DAY & & JULY & & & & AUGUST & & & & SEPTEMBER & \\
\hline $\begin{array}{l}1 \\
2 \\
3 \\
4 \\
5\end{array}$ & $\begin{array}{l}2000 \\
1840 \\
1740 \\
1670 \\
1590\end{array}$ & $\begin{array}{l}21 \\
20 \\
17 \\
13 \\
10\end{array}$ & & $\begin{array}{r}113 \\
99 \\
80 \\
59 \\
43\end{array}$ & $\begin{array}{l}2050 \\
2220 \\
2020 \\
1860 \\
1770\end{array}$ & $\begin{array}{r}12 \\
16 \\
9 \\
7 \\
5\end{array}$ & & $\begin{array}{l}66 \\
96 \\
49 \\
35 \\
24\end{array}$ & $\begin{array}{l}3140 \\
2680 \\
2420 \\
2250 \\
2250\end{array}$ & $\begin{array}{l}27 \\
25 \\
20 \\
18 \\
18\end{array}$ & $\begin{array}{l}229 \\
181 \\
131 \\
109 \\
109\end{array}$ \\
\hline $\begin{array}{r}6 \\
7 \\
8 \\
9 \\
10\end{array}$ & $\begin{array}{l}1590 \\
1580 \\
1580 \\
1580 \\
1660\end{array}$ & $\begin{array}{r}14 \\
21 \\
22 \\
16 \\
7\end{array}$ & & $\begin{array}{l}60 \\
90 \\
94 \\
68 \\
31\end{array}$ & $\begin{array}{l}1920 \\
2040 \\
2290 \\
3120 \\
3260\end{array}$ & $\begin{array}{r}7 \\
13 \\
31 \\
53 \\
43\end{array}$ & $\begin{array}{l}E \\
E \\
E\end{array}$ & $\begin{array}{r}36 \\
72 \\
192 \\
446 \\
378\end{array}$ & $\begin{array}{l}2210 \\
1970 \\
1790 \\
1720 \\
1850\end{array}$ & $\begin{array}{l}18 \\
16 \\
12 \\
10 \\
12\end{array}$ & $\begin{array}{r}107 \\
85 \\
58 \\
46 \\
60\end{array}$ \\
\hline $\begin{array}{l}11 \\
12 \\
13 \\
14 \\
15\end{array}$ & $\begin{array}{l}1870 \\
2450 \\
2310 \\
2190 \\
2400\end{array}$ & $\begin{array}{l}16 \\
36 \\
24 \\
27 \\
31\end{array}$ & $E$ & $\begin{array}{r}81 \\
2.38 \\
150 \\
160 \\
201\end{array}$ & $\begin{array}{l}2750 \\
2660 \\
3040 \\
2610 \\
2190\end{array}$ & $\begin{array}{l}31 \\
28 \\
34 \\
23 \\
13\end{array}$ & & $\begin{array}{r}230 \\
201 \\
279 \\
162 \\
77\end{array}$ & $\begin{array}{l}1810 \\
1860 \\
1980 \\
1850 \\
1870\end{array}$ & $\begin{array}{l}12 \\
17 \\
17 \\
14 \\
14\end{array}$ & $\begin{array}{l}59 \\
85 \\
91 \\
70 \\
71\end{array}$ \\
\hline $\begin{array}{l}16 \\
17 \\
18 \\
19 \\
20\end{array}$ & $\begin{array}{l}2340 \\
2070 \\
2070 \\
2060 \\
2180\end{array}$ & $\begin{array}{r}22 \\
14 \\
10 \\
12 \\
7\end{array}$ & & $\begin{array}{r}139 \\
78 \\
56 \\
67 \\
41\end{array}$ & $\begin{array}{l}2120 \\
2180 \\
2450 \\
2590 \\
2480\end{array}$ & $\begin{array}{r}8 \\
8 \\
17 \\
14 \\
14\end{array}$ & & $\begin{array}{r}46 \\
47 \\
112 \\
98 \\
94\end{array}$ & $\begin{array}{l}1950 \\
1800 \\
1720 \\
1650 \\
1560\end{array}$ & $\begin{array}{r}12 \\
8 \\
8 \\
8 \\
10\end{array}$ & $\begin{array}{l}63 \\
39 \\
37 \\
36 \\
42\end{array}$ \\
\hline $\begin{array}{l}21 \\
22 \\
23 \\
24 \\
25\end{array}$ & $\begin{array}{l}2330 \\
2390 \\
2620 \\
2570 \\
2570\end{array}$ & $\begin{array}{l}13 \\
22 \\
29 \\
21 \\
17\end{array}$ & & $\begin{array}{r}82 \\
142 \\
205 \\
146 \\
118\end{array}$ & $\begin{array}{l}2380 \\
2440 \\
2480 \\
2460 \\
2870\end{array}$ & $\begin{array}{l}23 \\
21 \\
19 \\
12 \\
30\end{array}$ & & $\begin{array}{r}148 \\
138 \\
127 \\
80 \\
232\end{array}$ & $\begin{array}{l}1510 \\
1490 \\
1490 \\
1520 \\
1640\end{array}$ & $\begin{array}{l}8 \\
6 \\
3 \\
6 \\
9\end{array}$ & $\begin{array}{l}33 \\
24 \\
12 \\
25 \\
40\end{array}$ \\
\hline $\begin{array}{l}26 \\
27 \\
28 \\
29 \\
30 \\
31\end{array}$ & $\begin{array}{l}2510 \\
2400 \\
2200 \\
1980 \\
2020 \\
2000\end{array}$ & $\begin{array}{r}15 \\
9 \\
6 \\
6 \\
5 \\
6\end{array}$ & & $\begin{array}{r}102 \\
58 \\
36 \\
32 \\
27 \\
32\end{array}$ & $\begin{array}{l}3450 \\
3400 \\
3650 \\
4020 \\
4000 \\
3610\end{array}$ & $\begin{array}{l}48 \\
45 \\
57 \\
62 \\
53 \\
31\end{array}$ & & $\begin{array}{l}447 \\
413 \\
562 \\
673 \\
572 \\
302\end{array}$ & $\begin{array}{r}1920 \\
2380 \\
2200 \\
1950 \\
1920 \\
--\end{array}$ & $\begin{array}{l}10 \\
22 \\
18 \\
12 \\
10 \\
--\end{array}$ & $\begin{array}{r}52 \\
141 \\
107 \\
63 \\
52 \\
--\end{array}$ \\
\hline TOTAL & 64300 & -- & & 2928 & 82380 & -- & & 6434 & 58350 & -- & 2257 \\
\hline $\begin{array}{l}\text { TOTAL } \\
\text { TOTAL }\end{array}$ & $\begin{array}{l}\text { DISCHARGE } \\
\text { SUSPENDED- }\end{array}$ & $\begin{array}{l}\text { FOR YEAR } \\
\text { SEDIMENT }\end{array}$ & $\begin{array}{l}\text { ICFS } \\
\text { DISC }\end{array}$ & $\begin{array}{l}\text { S-DAYS ) } \\
\text { CHARGE FOR }\end{array}$ & YEAR (TONS) & & & & & & $\begin{array}{r}1837880 \\
428797\end{array}$ \\
\hline
\end{tabular}


02490900 BOGUE CHITTO NEAR LEHR, MISS,

LOCATION. . - Lat $31^{\circ} 01^{\prime} 20^{\prime \prime}$, long $90^{\circ} 12^{\prime} 20^{\prime \prime}$, on line between secs.28 and $29, T .1$ N, , R. 10 W., St. Stephens meridian, Walthall County, at bridge on county highway between Lehr and Dillion, and 0.9 mile southwest of Lehr.

PERIOD OF RECORD...-Chemical analyses: November 1969 to Sentember $197 \mathrm{c}$ CHEMICAL ANALYSES, NOVEMBER 1969 TO SEPTEMBER 1970

\begin{tabular}{|c|c|c|c|c|c|c|c|c|c|c|}
\hline DATE & $\begin{array}{l}C A L- \\
C I U M \\
(C A) \\
(M C / L I\end{array}$ & $\begin{array}{l}\text { MAG- } \\
\text { NE- } \\
S I U M \\
I Y G \mid \\
(M G / L)\end{array}$ & $\begin{array}{l}\text { SDIIUM } \\
\text { (NA) } \\
\text { IYG/L) }\end{array}$ & $\begin{array}{l}\text { PO- } \\
\text { TAS- } \\
\text { SIUM } \\
(K)^{-} \\
\left(M C^{\prime} / L\right)\end{array}$ & $\begin{array}{l}\text { ALKA- } \\
\text { LINITY } \\
\text { AS } \\
\text { CACIB3 } \\
\text { (MPILI) }\end{array}$ & $\begin{array}{l}\text { SULFATE } \\
(504) \\
(M=1 L)\end{array}$ & $\begin{array}{l}\text { PHOC- } \\
\text { PUATF } \\
\text { (PN4) } \\
\text { (YG/L) }\end{array}$ & $\begin{array}{l}\text { AQT- } \\
\text { VFSE } \\
\text { (CA, MF) } \\
(M F, L)\end{array}$ & 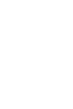 & $\begin{array}{l}\text { SPECI- } \\
\text { FIC } \\
\text {-TVT- } \\
\text { UCTANCF } \\
\text { (NICRO- } \\
\text { MHTSI }\end{array}$ \\
\hline $\begin{array}{c}\text { Nov. } \\
\text { OK... } \\
\text { ner. }\end{array}$ & 5.0 & $4 . n$ & in & .6 & 5 & 4.0 & .05 & 9 & - ค & 75 \\
\hline $17 \ldots$ & 11 & 7.0 & 29 & $1 . ?$ & 15 & 1.6 & .00 & 19 & 1.5 & $\ln$ \\
\hline MAO... & 7.0 & $3 . n$ & -- & -. & -- & S.? & .10 & in & -- & 47 \\
\hline $\begin{array}{ll}10 & 10 . \\
A O R\end{array}$ & 5.0 & 5.0 & 11 & .9 & 7 & $1 \cdot n$ & .07 & in & .9 & 46 \\
\hline $\begin{array}{l}20 \ldots . . \\
\text { JIJNF }\end{array}$ & 9.0 & - & -- & -- & 7 & .3 & 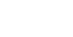 & 17 & -- & 38 \\
\hline $\operatorname{SEP}_{\text {SE. }}^{1 \cap . .}$ & $5 . n$ & 4.0 & 17 & I. $n$ & ค & ? & .04 & 21 & .5 & 46 \\
\hline na... & 6.0 & $4 . n$ & $9 . n$ & 1.2 & 10 & 4.8 & .17 & $1 n$ & .7 & 41 \\
\hline
\end{tabular}

\begin{tabular}{|c|c|c|c|c|c|c|c|c|c|c|}
\hline OATE & $\begin{array}{c}\mathrm{PH} \\
(I N I T S)\end{array}$ & $\begin{array}{l}\text { COLLAP } \\
\text { IPLATI- } \\
\text { NIJU- } \\
\text { CORALT } \\
\text { INNTSI }\end{array}$ & $\begin{array}{l}\text { TIIR- } \\
\text { AIN- } \\
\text { ISY } \\
\text { (MF,LS }\end{array}$ & 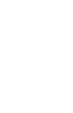 & $\begin{array}{l}\text { CHEM- } \\
\text { ICAL } \\
\text { OXYGFN } \\
\text { DEMANO } \\
\text { (MGIL) }\end{array}$ & $\begin{array}{l}\text { TRTAVIE } \\
\text { NITQ7) } \\
\text { GFY } \\
\text { (VII } \\
\text { IMILL) }\end{array}$ & $\begin{array}{l}\text { TEMD- } \\
\text { FRATIJRE } \\
\text { (TFS C) }\end{array}$ & 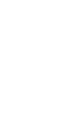 & $\begin{array}{l}\text { NITRITT } \\
\text { INI } \\
\text { IURILI }\end{array}$ & $\begin{array}{c}\text { COLI- } \\
\text { FORA } \\
\text { IOAL- } \\
\text { TNIES } \\
\text { PFR } \\
\text { ION YL }\end{array}$ \\
\hline $\begin{array}{l}\text { Nav. } \\
\text { Of.... } \\
\text { DFr.. }\end{array}$ & 6.8 & 5 & 25 & 1.8 & 3.4 & . 5 ? & 13.0 & 10.5 & .71 & $4 ! h$ \\
\hline $17 \ldots$ & A. 2 & 5 & 25 & 1.4 & 2.0 & .32 & $7 . n$ & 10.7 & .13 & Pq \\
\hline WAR.. & 6.4 & 35 & 54 & -- & 14 & 1.3 & ค. ก & 10.7 &.$\gg 7$ & I $\mathrm{kmn}$ \\
\hline $\begin{array}{l}17 . . . \\
\text { ADR. }\end{array}$ & A. 5 & 30 & 10 & 1.9 & $5 . A$ & 4.0 & 18.7 & 9.7 & .70 & 360 \\
\hline $\begin{array}{c}20 \\
\text { JUNजF }\end{array}$ & 6.1 & 10 & 5.0 & -- & 4.0 & -- & 24.0 & 7.6 & .20 & $I^{n} \cap$ \\
\hline SFPT. & 6.5 & 15 & $1 n$ & .4 & 14 & .40 & 22.0 & 6.4 & .10 & $20 n$ \\
\hline n.... & $B . n$ & 35 & 17 & .7 & -- & .70 & 26.0 & 8.1 & .05 & n \\
\hline
\end{tabular}

02492502 HOBOLOCHITTO CREEK NEAR PICAYUNE, MISS.

LOCATION..-Lat $30^{\circ} 32^{\prime} 30^{\prime \prime}$, long $89^{\circ} 44^{\prime} 22^{\prime \prime}$, in sec.28, T.6 S., R.17 w., St. Stephens meridian, Pearl Rzver County, at bridge on county highway, $2.0 \mathrm{miles}$ west of Picayune.

PERIOD OF RECORD.--Cherical analyses: January to September 1970.

CHEMICAL ANALYSES, NOVEMBER 1969 TO SEPTEMBER 1970

\begin{tabular}{|c|c|c|c|c|c|c|c|c|c|c|c|}
\hline$n \Delta T F$ & $\begin{array}{l}\text { DIS- } \\
\text { CHARCE } \\
\text { TCFCI }\end{array}$ & $\begin{array}{l}\text { CAL- } \\
\text { CIIIM } \\
\left(C_{A}\right) \\
(M, I L)\end{array}$ & $\begin{array}{c}\text { MAR- } \\
N E- \\
S T U M \\
\text { INFI } \\
\text { IMrOLI }\end{array}$ & $\begin{array}{l}\text { SnIUH } \\
\text { (NA) } \\
\text { (MG/L) }\end{array}$ & $\begin{array}{l}\text { P)- } \\
\text { TAS- } \\
\text { SIIM } \\
\text { (K) } \\
\text { (M?/L। }\end{array}$ & $\begin{array}{l}\text { ALKA- } \\
\text { LIVITY } \\
\text { AS } \\
\text { CAC, A } \\
\text { (MF, LLI }\end{array}$ & $\begin{array}{l}\text { SIfLATr } \\
(5,14) \\
(43 / L)\end{array}$ & $\begin{array}{l}\text { PHनS- } \\
34 \triangle T E \\
\text { (ग) } \\
(4 \div / 1\end{array}$ & 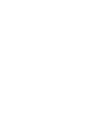 & 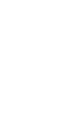 & 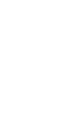 \\
\hline $\begin{array}{l}\text { JAN. } \\
\text { NA ... } \\
F F{ }^{\circ} .\end{array}$ & fan & 17 & $1 . n$ & 13 & 1.9 & 7 & 3.4 & .12 & 95 & .13 & 151 \\
\hline $\begin{array}{l}10 . . \\
A D R\end{array}$ & 245 & 7.0 & $4 . ?$ & 7.5 & 1.4 & 4 & 1.6 & .72 & 54 &.$n 7$ & $47 . x$ \\
\hline $\operatorname{Mar} \cdots$ & ann & 4.7 & 4.9 & 7.5 & $1 . n$ & 7 & 7.0 & .05 & -- & -- & $=-$ \\
\hline $\begin{array}{l}13 \ldots \\
\text { JIINE }\end{array}$ & 175 & $5 . n$ & $5 . n$ & 15 & $1 . n$ & $1^{R}$ & 6.6 & . na & -- & -- & -. \\
\hline $\begin{array}{l}24 \ldots \\
\text { ayr... }\end{array}$ & $\ln 7$ & 11 & . & -- & -- & $>5$ & 5.3 & .77 & $\cdots$ & -- & -- \\
\hline 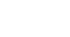 & $x 20$ & 6.0 & $3 . n$ & 13 & 1.2 & 13 & $? .9$ & $\cdot \cap 7$ & -- & & -- \\
\hline x... & 132 & 5.0 & -- & - & - & 30 & $x, n$ & .15 & $\cdots$ & $\cdots$ & -- \\
\hline OATF & $\begin{array}{l}\text { HAPD- } \\
\text { NFSS } \\
(C A, N S) \\
(M G / L)\end{array}$ & 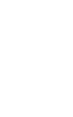 & $\begin{array}{l}\text { SPECI- } \\
\text { FIR } \\
\text { CIND- } \\
\text { URTANCF } \\
\text { GMTCRר- } \\
\text { MHNCI }\end{array}$ & 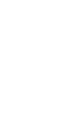 & $\begin{array}{l}\text { CALTR } \\
\text { (PLAYI- } \\
\text { NIIM- } \\
\text { CORALT } \\
\text { INNITSI }\end{array}$ & $\begin{array}{l}\text { YYS- } \\
\text { BID- } \\
\text { ITY } \\
\text { (WISL) }\end{array}$ & $\begin{array}{c}\text { AI ר- } \\
\text { CHFH- } \\
\text { ICAL } \\
\text { OXYFFV } \\
\text { TEMANO } \\
\text { (XG/L) }\end{array}$ & $\begin{array}{l}\text { CHFY- } \\
\text { ITAL } \\
\text { TXYJFV } \\
\text { OEYANT } \\
\text { TWFILI }\end{array}$ & $\begin{array}{c}\text { RSAVIC. } \\
\text { VITRT- } \\
\text { SEV } \\
\text { IVI } \\
\text { (*:L) }\end{array}$ & $\begin{array}{c}V I T 21 T= \\
1 N i) \\
\text { MFILI }\end{array}$ & 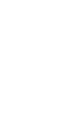 \\
\hline $\begin{array}{l}\text { JAN. } \\
\text { NR... } \\
\text { FEA... }\end{array}$ & 13 & $1 . n$ & $4 n$ & 5.7 & -- & 25 & $3 . ?$ & 32 & 3.4 & $\cdot m$ & 5279 \\
\hline $\begin{array}{c}10 \\
\triangle D P \\
n ? .\end{array}$ & 11 & .5 & 15 & 5.7 & 50 & in & $\begin{array}{l}1.7 \\
1.9\end{array}$ & $\begin{array}{l}25 \\
24\end{array}$ & 3 & - & 4क口ר \\
\hline 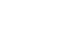 & $1 n$ & 1.1 & 54 & h.? & $5 n$ & 25 & ?. & 34 & $1 . n$ & . $7 n$ & 1407 \\
\hline $\begin{array}{l}34 \ldots . . \\
\text { A ris.. }\end{array}$ & 11 & -- & $14^{n}$ & $h .9$ & 25 & 25 & 7.9 & 29 & $1 . n$ & n & $10 \div 9$ \\
\hline 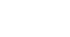 & $=-$ & $1 \cdot 1$ & $4 \pi$ & 6.4 & so & 75 & $? .5$ & 35 & 5.' & $.7 n$ & וברדי \\
\hline$\geq 3 \ldots$ & -- & -- & sn & 6.4 & 50 & 15 & 4.5 & 28 & 1.3 & . nn & 212 \\
\hline
\end{tabular}


02043862 PASQUOTANK RIVER AT ELIZABETH CITY, N,C.

LOCATION.-. Lat $36^{\circ} 18^{\prime} 00^{\prime \prime}$, long $79^{\circ} 13^{\prime} 00^{\prime \prime}$, Pasquotank County, at bridge on U.S. H1ghway 158, in El1zabeth City and 0.5 miles below Knobbs Creek.

DRAINAGE AREA.--300 sq mi, approximately.

PERIOD OF RECORD.--Chemical analyses: October 1957 to september 1967 (da1ly), October 1968 to September 1970 (partial records).

1957 to September 1967

EXTREMES. --.Period of record:

Chloride: Maximum, 8,020 mg/1 oct. 30 (B), 1958; minlmum, 4.5 mg/1 Mar. 6 (T), 1961 .

Specific conductance: Naximum daily, 20,600 micromhos Oct, 29 (B), 1958; minimum daily, 58 micrombos July 21 , (T), 21 (T), 1966.

ater temperatures: Maximum, $31.5^{\circ} \mathrm{C}$ July 29, 30 (T), 1959, Sept, 1 (T), 1960, July 13 (T), 1966; m1n1mum,

freezing point on several days in 1958, 1966.

REMARKs, - Salinity station prior to 1968; top $(T)$ and bottom (B) samples were collected once daily, The second of two samples collected at the same time is a field determination.

CHEMICAL ANALYSES, WATER YEAR OCTOBER 1969 TO SEPTEMBER 1970

\begin{tabular}{|c|c|c|c|c|c|c|c|c|c|c|c|}
\hline DATE & T I ME & $\begin{array}{l}\text { SILICA } \\
\text { (SIO2) } \\
\text { (HG/L) }\end{array}$ & $\begin{array}{l}\text { OIS- } \\
\text { SOAVEO } \\
\text { IRON } \\
\text { (FE) } \\
\text { (UG/L) }\end{array}$ & $\begin{array}{c}\text { CAL- } \\
\text { CIUM } \\
\text { (CA) } \\
(M G / L)\end{array}$ & $\begin{array}{l}\text { MAG- } \\
\text { NE- } \\
\text { SIUM } \\
\text { (MG) } \\
(M G / L)\end{array}$ & $\begin{array}{l}\text { SOOIUM } \\
\text { (NA) } \\
\text { (MG/L) }\end{array}$ & $\begin{array}{l}\text { PO- } \\
\text { IAS- } \\
\text { SI UM } \\
\text { (K) } \\
\text { (HG/L) }\end{array}$ & $\begin{array}{l}\text { BICAR- } \\
\text { BONATE } \\
\text { (HCO3) } \\
\text { (HG/L) }\end{array}$ & $\begin{array}{l}\text { CAR- } \\
\text { BONATE } \\
\text { (COB) } \\
\text { (MGIL) }\end{array}$ & $\begin{array}{l}\text { SULFATE } \\
\text { (SOL) } \\
\text { (MG/L) }\end{array}$ & $\begin{array}{l}\text { CHLO- } \\
\text { RIOE } \\
\text { (CL) } \\
\text { (MG/L) }\end{array}$ \\
\hline $\begin{array}{l}\text { OCT. } \\
\text { JUAE } \\
\text { JUNE }\end{array}$ & 0910 & 7.8 & 90 & 12 & 23 & 180 & 15 & 14 & D & 52 & 340 \\
\hline $25 .$. & 0940 & 4.0 & 114 & 14 & 24 & 198 & 13 & 18 & 0 & 62 & 362 \\
\hline DATE & $\begin{array}{l}\text { FLUO- } \\
\text { RLOE } \\
\text { (F) } \\
\text { (MG/L) }\end{array}$ & $\begin{array}{l}\text { NITRATE } \\
\text { (NO3) } \\
\text { (MG/L) }\end{array}$ & $\begin{array}{l}\text { ORTHO } \\
\text { PHOS- } \\
\text { PHATE } \\
\text { (PO4) } \\
\text { (MG/L) }\end{array}$ & $\begin{array}{l}\text { OIS- } \\
\text { SOLVED } \\
\text { SOLIDS } \\
\text { IRESI- } \\
\text { DUE AT } \\
\text { IBO C) } \\
\text { (MG/L) }\end{array}$ & $\begin{array}{l}\text { DIS- } \\
\text { SOLVEO } \\
\text { SOLIDS } \\
\text { (TONS } \\
\text { PER } \\
\text { AC-FT) }\end{array}$ & $\begin{array}{l}\text { HARD- } \\
\text { NESS } \\
\text { (CA, MG) } \\
\text { (MG/L) }\end{array}$ & $\begin{array}{l}\text { NON- } \\
\text { CAR- } \\
\text { BONATE } \\
\text { HARO- } \\
\text { NESS } \\
\text { (MG/L) }\end{array}$ & $\begin{array}{l}\text { SOOIUM } \\
\text { AD- } \\
\text { SORP- } \\
\text { TION } \\
\text { RATIO }\end{array}$ & $\begin{array}{l}\text { PERCENT } \\
\text { SODIUM }\end{array}$ & $\begin{array}{l}\text { METHY- } \\
\text { LENE } \\
\text { BLUE } \\
\text { ACTIVE } \\
\text { SUB- } \\
\text { STANCE } \\
\text { (MG/LI) }\end{array}$ & $\begin{array}{l}\text { ALKA- } \\
\text { LINITY } \\
\text { AS } \\
\text { CACO3 } \\
\text { (MG/L) }\end{array}$ \\
\hline
\end{tabular}

\begin{tabular}{|c|c|c|c|c|c|c|c|c|c|c|c|}
\hline $\begin{array}{l}\text { OC7. } \\
14 \ldots . . \\
\text { JUNE }\end{array}$ & .4 & 3.3 & .02 & 736 & 1.00 & 124 & 113 & 7.0 & 73 & .18 & 11 \\
\hline $25 \ldots$ & .3 & 2.7 & .02 & 753 & 1.02 & 133 & 118 & 7.5 & 74 & .04 & 15 \\
\hline & & & & $\begin{array}{l}\text { OIS- } \\
\text { SOLVED } \\
\text { CXYGEN }\end{array}$ & $\begin{array}{l}\text { SPECI- } \\
\text { FIC } \\
\text { CONO- } \\
\text { UCTANCE } \\
\text { IMICRO- }\end{array}$ & PH & $\begin{array}{l}\text { TEMP- } \\
\text { ERATURE }\end{array}$ & $\begin{array}{l}\text { COLDR } \\
\text { IPLAT- } \\
\text { INUM- } \\
\text { COBALT }\end{array}$ & & & \\
\hline
\end{tabular}

\begin{tabular}{|c|c|c|c|c|c|}
\hline DATE & $(M G / L)$ & MHOSI & (UNITS) & IDEG CI & UNITS \\
\hline DCT. & & & & & \\
\hline $14 \ldots$ & - & $100 n$ & 4.0 & $\overline{-}$ & 150 \\
\hline JUNF & 5.6 & -- & -- & 22.0 & -- \\
\hline $25 \ldots$ & $\cdots$ & $12<0$ & 6.4 & $26 . n$ & $10 n$ \\
\hline $25 \ldots$ & 9.6 & -. & 7.0 & 26.0 & - \\
\hline
\end{tabular}

02043892 PERQUIXANS RIVER AT U,S. HIGHWAY 17, AT HERTFORD, N.C.

LOCATION.--Lat $36^{\circ} 11^{\prime} 40^{\prime \prime}$, long $76^{\circ} 28^{\prime} 00^{\prime \prime}$, Perquimans County, at bridge on U.S. Highway 17 at Hertford and 0.75 mile above M1li creek.

DRAINAGE AREA. --94 sq mi, approximately.

PERIOD OF RECORD.--Chemical analyses: October 1957 to September 1960 (daily), October 1968 to September 1970

water temperatures: October 1957 to September 1960.

EXTREMES, -. Period of record

Chloride: Maximum, 1,290 mg/1 Dec, 25, 1958; minimum, $8.0 \mathrm{mg} / 1 \mathrm{Feb} .1-15,1960$

Specific conductance: Maximum da1iy, 4,290 micromhos Dec. 25, 1958; minimum daily, 53 micromhos Feb. $2,1960$. water temperatures: Maximum, $30.5^{\circ} \mathrm{C}$ Aug. 7,1958 ; mintmum, freezing point Feb. 18, 1958, Mar. 12-14, 1960.

REMARKS.--Operated as a salinity station dur1ng water years 1958-60. Records of specific conductance (unpublished) of samples collected once dally October 1957 to September 1959 are avallable in district office in Rale1gh, N.C. The second of two samples collected at the same time is a fleld determination.

$$
\text { CHEMical analyses, hater year october } 1969 \text { to SEPTEMBER } 1970
$$

\begin{tabular}{|c|c|c|c|c|c|c|c|c|c|c|c|}
\hline DATE & I I ME & $\begin{array}{l}\text { SILICA } \\
\text { (SIOZ) } \\
\text { (MG/L) }\end{array}$ & $\begin{array}{l}\text { OIS- } \\
\text { SOLVEO } \\
\text { IRON } \\
\text { (FE) } \\
\text { (UG/L) }\end{array}$ & $\begin{array}{l}\text { CAL- } \\
\text { CIUM } \\
(C A) \\
(M G / L)\end{array}$ & $\begin{array}{l}\text { MAG- } \\
\text { NE- } \\
\text { SIUM } \\
\text { (MG) } \\
(M G / L)\end{array}$ & $\begin{array}{l}\text { SODIUM } \\
\text { (NA) } \\
\text { (MG/L) }\end{array}$ & $\begin{array}{l}\text { PO- } \\
\text { TAS- } \\
\text { SIUM } \\
\text { (K) } \\
(M G / L)\end{array}$ & $\begin{array}{l}\text { BICAR- } \\
\text { BONATE } \\
\text { (HCO3) } \\
\text { (MG/L) }\end{array}$ & $\begin{array}{l}\text { CAR- } \\
\text { BONATE } \\
\text { (CD3) } \\
\text { (MG/L) }\end{array}$ & $\begin{array}{l}\text { SUL FATE } \\
\text { (SO4) } \\
\text { (MG/L) }\end{array}$ & $\begin{array}{l}\text { CHLO- } \\
\text { RIDE } \\
\text { (CLI) } \\
\text { (HG/L) }\end{array}$ \\
\hline $\begin{array}{l}\text { OCT. } \\
13 . . . \\
\text { JAN. }\end{array}$ & 1850 & 10 & 300 & 10 & 93 & 75 & 7.8 & 18 & 0 & 30 & 134 \\
\hline $\begin{array}{l}27 \ldots . . \\
27 \ldots \\
\text { JUNE }\end{array}$ & $\begin{array}{l}1445 \\
1445\end{array}$ & 8.1 & 242 & 22 & 20 & 380 & 18 & 23 & $\begin{array}{r}0 \\
--\end{array}$ & 96 & 652 \\
\hline $25 \ldots$ & 1340 & 3.7 & 0 & 7.3 & 11 & 73 & 6.7 & 20 & 0 & 30 & 126 \\
\hline
\end{tabular}



PERQUIMANS RIVER BASIN

02043892 PERQUIMANS RIVER AT U.S. HIGHWAY 17, AT HERTFORD, N.C.--Cont1nued CHEMICAL ANALYSES, HATER YEAR OCTOBER 1969 TO SEPTEMBER 1970

\begin{tabular}{|c|c|c|c|c|c|c|c|c|c|c|c|}
\hline DAIE & $\begin{array}{l}\text { FLUO- } \\
\text { RIDE } \\
\text { (F) } \\
\text { (MG/L) }\end{array}$ & $\begin{array}{l}\text { NITRATE } \\
\text { (ND3) } \\
\text { (MG/L) }\end{array}$ & $\begin{array}{l}\text { ORTHO } \\
\text { PHOS- } \\
\text { PHATE } \\
\text { (PO4) } \\
\text { (MG/L) }\end{array}$ & $\begin{array}{l}\text { DIS- } \\
\text { SOLVED } \\
\text { SOLI DS } \\
\text { (RES I- } \\
\text { DUE AI } \\
\text { IBO C) } \\
\text { ( MGIL) }\end{array}$ & $\begin{array}{l}\text { DIS- } \\
\text { SDL VED } \\
\text { SOL IDS } \\
\text { (TONS } \\
\text { PER } \\
\text { AC-FT) }\end{array}$ & $\begin{array}{l}\text { HARD- } \\
\text { NESS } \\
\text { (CA,MG) } \\
(M G / L)\end{array}$ & $\begin{array}{l}\text { NON- } \\
\text { CAR- } \\
\text { BONATE } \\
\text { HARD- } \\
\text { NESS } \\
\text { (MG/L) }\end{array}$ & $\begin{array}{l}\text { SODIUA } \\
\text { AD- } \\
\text { SORP- } \\
\text { TION } \\
\text { RATIO }\end{array}$ & $\begin{array}{l}\text { PERCENT } \\
\text { SODIUH }\end{array}$ & $\begin{array}{l}\text { ME THY- } \\
\text { LENE } \\
\text { BLUE } \\
\text { ACTIVE } \\
\text { SUB- } \\
\text { STANCE } \\
\text { IMGILI }\end{array}$ & $\begin{array}{l}\text { ALKA- } \\
\text { LINITY } \\
\text { AS } \\
\text { CACQ3 } \\
\text { (MG IL) }\end{array}$ \\
\hline $\begin{array}{l}\text { OCT. } \\
13 \ldots . . \\
\text { JAN. }\end{array}$ & .3 & 2.9 & .07 & 352 & .48 & 64 & 49 & 1.6 & $2 B$ & .10 & 15 \\
\hline $\begin{array}{l}27 \ldots . . \\
\text { JUNE }\end{array}$ & $\therefore 2$ & -8 & .04 & $\begin{array}{l}1440 \\
--\end{array}$ & 1.96 & 136 & 117 & 14 & B4 & $14 \ldots$ & $\begin{array}{l}19 \\
16\end{array}$ \\
\hline $25 \ldots$ & .3 & 3.2 & .08 & 303 & .41 & 62 & 45 & 4.0 & 69 & .12 & 16 \\
\hline
\end{tabular}

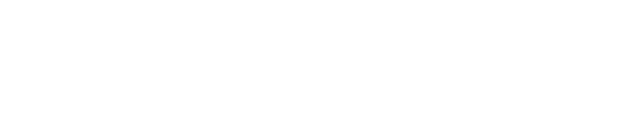

\begin{tabular}{|c|c|c|c|c|c|c|}
\hline $13 \ldots$ & - & 500 & 6.7 & -- & -- & 150 \\
\hline $13 \ldots$ & 7.2 & -- & -- & 22.0 & -- & -- \\
\hline IAN. & & & & & & \\
\hline $\begin{array}{l}27 \ldots \ldots \\
27 \ldots\end{array}$ & $12 \overline{5}$ & 2100 & $\begin{array}{l}6.4 \\
6.3\end{array}$ & 3.0 & $\because$ & 110 \\
\hline JUNE & & & & & & \\
\hline $25 \ldots$ & $\overline{-}$ & 500 & 6.1 & 29.3 & $\because 7$ & 110 \\
\hline
\end{tabular}

02043902 PERQUIMANS RIVER ABOVE SUTTON CREEK, NEAR HERTFORD, N.C.

LOCATION.--Lat $36^{\circ} 10^{\prime} 00^{\prime \prime}$, long $76^{\circ} 25^{\prime} 10^{\prime \prime}$, Perquimans County, 1.8 miles upstream from Sutton Creek and 3.2 miles southeast of Hertford.

DRAINAGE AREA...130 sq m1, approximately.

PERIOD OF RECORD.--Chemical analyses: October 1967 to September 1970 (partial record).

REMARKS.--The second of two samples collected at the same time is a field determination. CHEMICAL ANALYSES, WATER YEAR OCTOBER 1969 TO SEPTEMBER 1970

\begin{tabular}{|c|c|c|c|c|c|c|c|c|c|}
\hline DATE & TIME & $\begin{array}{l}\text { SILICA } \\
\text { (SIO2) } \\
\text { (MG/L) }\end{array}$ & $\begin{array}{l}\text { DIS- } \\
\text { SOLVED } \\
\text { IRON } \\
\text { (FE) } \\
\text { (UG/L) }\end{array}$ & $\begin{array}{l}\text { OIS- } \\
\text { SOLVEO } \\
\text { CAL- } \\
\text { CIUM } \\
\text { (CA) } \\
\text { (MGLL) }\end{array}$ & $\begin{array}{l}\text { DIS- } \\
\text { SOLVED } \\
\text { MAG- } \\
\text { NE- } \\
\text { SIUM } \\
\text { (MG) } \\
\text { IMG/L) }\end{array}$ & $\begin{array}{l}\text { SODIUM } \\
\text { (NA) } \\
\text { (MG/L) }\end{array}$ & $\begin{array}{l}\text { PO- } \\
\text { TAS- } \\
\text { SIUM } \\
\text { (K) } \\
\text { (MG/L) }\end{array}$ & $\begin{array}{l}\text { BICAR- } \\
\text { 3ONATE } \\
\text { ( HCO3) } \\
\text { ( MG/L) }\end{array}$ & $\begin{array}{l}\text { CAR- } \\
\text { BONATE } \\
\text { (COB) } \\
\text { (MG/L) }\end{array}$ \\
\hline $\begin{array}{l}\text { OCT - } \\
13 \ldots \\
\text { JUNE }\end{array}$ & 1830 & 8.2 & 340 & 9.0 & 14 & 119 & 23 & 16 & 0 \\
\hline $\begin{array}{l}25 \ldots \\
25 \ldots\end{array}$ & $\begin{array}{l}1300 \\
1300\end{array}$ & 3.2 & $\therefore$ & 24 & 1.7 & 91 & $\begin{array}{r}7.5 \\
-\end{array}$ & 18 & - \\
\hline DATE & $\begin{array}{l}\text { SULFATE } \\
\text { (SDG) } \\
\text { (MGIL) }\end{array}$ & $\begin{array}{l}\text { CHLO- } \\
\text { RIOE } \\
\text { (CL) } \\
\text { (MG/L) }\end{array}$ & $\begin{array}{l}\text { DIS- } \\
\text { SOLVED } \\
\text { FLUO- } \\
\text { RIDE } \\
\text { (F) } \\
\text { (MG/L) }\end{array}$ & $\begin{array}{c}\text { NI TRATE } \\
\text { (NO3) } \\
(\text { MG/L) }\end{array}$ & $\begin{array}{l}\text { DIS- } \\
\text { SOLVEO } \\
\text { ORIHO } \\
\text { PHOS- } \\
\text { PHAIE } \\
\text { (PO4) } \\
\text { (MG/L) }\end{array}$ & $\begin{array}{l}\text { DIS- } \\
\text { SOLVED } \\
\text { SOLIOS } \\
\text { IRESI- } \\
\text { OUE AT } \\
\text { IBO Cl } \\
\text { IHG/LI }\end{array}$ & $\begin{array}{l}\text { DIS- } \\
\text { SOLVED } \\
\text { SOLIDS } \\
\text { (TONS } \\
\text { PER } \\
\text { AC-FT) }\end{array}$ & $\begin{array}{l}\text { HARD- } \\
\text { VESS } \\
\text { (CA, MG) } \\
\text { ( } M G / L)\end{array}$ & $\begin{array}{l}\text { NON- } \\
\text { CAR- } \\
\text { BONATE } \\
\text { HARO- } \\
\text { NESS } \\
\text { (MG/L) }\end{array}$ \\
\hline $\begin{array}{l}\text { OCT. } \\
13 \ldots . . \\
\text { JUNE }\end{array}$ & 38 & 228 & .3 & 2.0 & .05 & 487 & .66 & 80 & 67 \\
\hline $\begin{array}{l}25 . \ldots \\
25 \ldots\end{array}$ & ${ }^{25}-$ & ${ }^{156}=$ & -2 & 2.4 & .06 & $\begin{array}{r}350 \\
--\end{array}$ & .48 & 67 & 52 \\
\hline DATE & $\begin{array}{l}\text { SODIUM } \\
\text { AD- } \\
\text { SORP- } \\
\text { TIDN } \\
\text { RATIO }\end{array}$ & $\begin{array}{c}\text { PERCENT } \\
\text { SODIUH }\end{array}$ & $\begin{array}{l}\text { MEIHY - } \\
\text { LENE } \\
\text { BLUE } \\
\text { ACT IVE } \\
\text { SUB- } \\
\text { ST ANCE } \\
\text { (MG/L) }\end{array}$ & $\begin{array}{l}\text { ALKA- } \\
\text { LINITY } \\
\text { AS } \\
\text { CACO3 } \\
\text { (MG/L) }\end{array}$ & $\begin{array}{l}\text { DIS- } \\
\text { SOLVED } \\
\text { OXYGEN } \\
\text { (MG/LI) }\end{array}$ & $\begin{array}{l}\text { SPECI- } \\
\text { FIC } \\
\text { COND- } \\
\text { UCIANCE } \\
\text { (MIERO- } \\
\text { MHOSI }\end{array}$ & $\begin{array}{c}\text { PH } \\
\text { (UNITS) }\end{array}$ & $\begin{array}{l}\text { TEMP- } \\
\text { ERATURE } \\
\text { (DEG C ) }\end{array}$ & $\begin{array}{l}\text { COLOR } \\
\text { (PLAT- } \\
\text { INUM- } \\
\text { COBALT } \\
\text { UNITSI }\end{array}$ \\
\hline $\begin{array}{l}\text { OCT. } \\
\text { JUNE }\end{array}$ & 5.8 & 70 & .10 & 13 & - & 726 & 6.7 & 22.0 & 120 \\
\hline $\begin{array}{l}25 \ldots \\
25 \ldots\end{array}$ & 4.8 & $\begin{array}{l}72 \\
---\end{array}$ & .09 & 15 & 9.0 & $\begin{array}{r}570 \\
--\end{array}$ & $\begin{array}{l}6.2 \\
7.0\end{array}$ & $\begin{array}{l}28.0 \\
28.0\end{array}$ & 60 \\
\hline
\end{tabular}


LOCATION,--Lat $36^{\circ} 24^{\prime} 00^{\prime \prime}$, long $76^{\circ} 55^{\prime} 50^{\prime \prime}$, Hertford County, at bridge draw section on U, S, Highway 158 and State Highway 97 at Winton and 2.7 miles downstream from Meherrin River.

DRAINAGE AREA, . 4,200 sq $\mathrm{mi}$, approximately.

PERI OD OF RECORD.--Chemlcal analyses: October 1954 to September 1967 (daily), October 1968 to September 1970 (partial record).

October 1954 to September 1967.

EXTREMES, --period of record:

Chloride: Naximum, $398 \mathrm{mg} / 1$ Dec, 15, 1958 ; minimum, $2.9 \mathrm{mg} / 1 \mathrm{Apr}, 1-30,1958$

Specific conductance: Maximum da12y, 1,400 micromhos Dec. 13, 15, 1958; minimum daily, 36 micromhos May 12,

Water temperatures: Maximum, $30.5^{\circ} \mathrm{C}$ Aug, 5, 7, 8, 1955, JuIy 27, 1957; minimum, freezing point Feb. 12 , 1960 . RENARKS.-. The second of two samples collected at the same time is a field determination.

CHEMICAL ANALYSES, hateR YEAR OCTOBER 1969 TO SEPTEMBER 1970

\begin{tabular}{|c|c|c|c|c|c|c|c|c|c|c|c|}
\hline DATE & II ME & $\begin{array}{l}\text { SILICA } \\
\text { (SIOL) } \\
\text { (MG/L) }\end{array}$ & $\begin{array}{l}\text { DIS- } \\
\text { SOLVEO } \\
\text { IRON } \\
\text { (FE) } \\
\text { (UG/L) }\end{array}$ & $\begin{array}{l}\text { CAL- } \\
\text { CIUM } \\
\text { (CA) } \\
\text { (MG/L) }\end{array}$ & $\begin{array}{l}\text { MAG- } \\
\text { NE- } \\
\text { SIUM } \\
\text { (MG) } \\
(N G / L)\end{array}$ & $\begin{array}{l}\text { SOOIUM } \\
\text { (NA) } \\
\text { (MG/L) }\end{array}$ & $\begin{array}{l}\text { PO- } \\
\text { TAS- } \\
\text { SI UM } \\
\text { (K) } \\
\text { (MG/L) }\end{array}$ & $\begin{array}{l}\text { BICAR- } \\
\text { BONATE } \\
\text { (HCO3) } \\
\text { (MG/L) }\end{array}$ & $\begin{array}{l}\text { CAR- } \\
\text { BONATE } \\
\text { (CO3) } \\
\text { (NG/L) }\end{array}$ & $\begin{array}{l}\text { SULFATE } \\
\text { (SOG) } \\
(M G / L)\end{array}$ & $\begin{array}{l}\text { CHLO- } \\
\text { RIOE } \\
\text { (CL) } \\
\text { (MG/L) }\end{array}$ \\
\hline $\begin{array}{l}\text { OCT. } \\
14 \ldots . . . \\
\text { JAN. }\end{array}$ & 1600 & 11 & 170 & 5.8 & 1.3 & 6.0 & 2.0 & 19 & 0 & 7.6 & 7.7 \\
\hline JUNE & 1340 & 12 & 91 & 5.7 & 1.5 & 12 & 1,8 & 22 & 0 & 12 & 13 \\
\hline $29 \ldots$ & 1740 & 9.0 & $\cdots$ & 7.0 & 3.2 & 14 & 2.4 & 39 & 0 & 8.4 & 13 \\
\hline $\begin{array}{l}29 . . . \\
\text { SEPT. }\end{array}$ & 1740 & -- & - & -- & - & $\rightarrow-$ & - & - & -- & - & - \\
\hline $\begin{array}{l}21 \ldots \\
21 \ldots\end{array}$ & $\begin{array}{l}1530 \\
1530\end{array}$ & 8.0 & 13 & 0.4 & 1.8 & 9.0 & 2.3 & 29 & 0 & 6.4 & B. 0 \\
\hline DATE & $\begin{array}{l}\text { FLUO- } \\
\text { RIDE } \\
\text { IFI } \\
\text { IMG /L) }\end{array}$ & $\begin{array}{l}\text { NI TRATE } \\
\text { (NG3) } \\
\text { (MG/L) }\end{array}$ & $\begin{array}{l}\text { ORTHO } \\
\text { PHOS- } \\
\text { PHATE } \\
\text { (POA) } \\
\text { (MGIL) }\end{array}$ & $\begin{array}{l}\text { DIS- } \\
\text { SOLVED } \\
\text { SOLI DS } \\
\text { (RESI- } \\
\text { DUE AT } \\
\text { I BO CI } \\
\text { (MGIL) }\end{array}$ & $\begin{array}{l}\text { DIS- } \\
\text { SOL VED } \\
\text { SOL IDS } \\
\text { (TONS } \\
\text { PER } \\
\text { AC-FT) }\end{array}$ & $\begin{array}{l}\text { HARD- } \\
\text { NESS } \\
\text { (CA,MG) } \\
\text { (MG/L) }\end{array}$ & $\begin{array}{l}\text { NON- } \\
\text { CAR- } \\
\text { BONATE } \\
\text { HARD- } \\
\text { NESS } \\
\text { (MG/L) }\end{array}$ & $\begin{array}{l}\text { SODIUM } \\
\text { AO- } \\
\text { SORP- } \\
\text { TION } \\
\text { RATIO }\end{array}$ & $\begin{array}{l}\text { PERCENT } \\
\text { SBOIUM }\end{array}$ & $\begin{array}{l}\text { MEIHY- } \\
\text { LENE } \\
\text { BLUE } \\
\text { ACTIVE } \\
\text { SUB- } \\
\text { STANCE } \\
\text { (MGIL) }\end{array}$ & $\begin{array}{l}\text { ALKA- } \\
\text { LINITY } \\
\text { AS } \\
\text { CACO3 } \\
\text { (MG/L) }\end{array}$ \\
\hline $\begin{array}{c}\text { OCr. } \\
14 \ldots . .\end{array}$ & .0 & 1.9 & .06 & 70 & .10 & 20 & 4 & .6 & 37 & .04 & 16 \\
\hline $\begin{array}{l}\text { JAN. } \\
27 \ldots\end{array}$ & .2 & 1 & .00 & 83 & 11 & 20 & 2 & 1.2 & 53 & 17 & 0 \\
\hline JUNE & 3 & 20 & 00 & RT & 22 & 20 & 2 & 20.2 & 33 & .12 & 18 \\
\hline $\begin{array}{l}29 . . \\
29 . .\end{array}$ & $\div 3$ & 2.0 & .36 & 87 & .12 & 30 & 0 & 1.1 & 47 & .09 & 32 \\
\hline SEPT. & & & & & 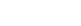 & . & 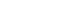 & 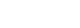 & 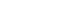 & - & 37 \\
\hline $\begin{array}{l}21 \ldots \\
21 \ldots\end{array}$ & $\because 2$ & 1.1 & .03 & 78 & 11 & 23 & - & -8 & 43 & $\overline{-}$ & $\begin{array}{l}24 \\
25\end{array}$ \\
\hline & & & UATF & $\begin{array}{l}\text { DIS- } \\
\text { SOLVED } \\
\text { OXYGEN } \\
\text { (MG/L) }\end{array}$ & $\begin{array}{l}\text { SPECI- } \\
\text { FIC } \\
\text { COND- } \\
\text { UCTANCE } \\
\text { (MICRO- } \\
\text { MHOSI) }\end{array}$ & $\begin{array}{c}\text { PH } \\
\text { (UNITS) }\end{array}$ & $\begin{array}{l}\text { TEMP- } \\
\text { ERATURE } \\
\text { IDEG C) }\end{array}$ & $\begin{array}{l}\text { COLCR } \\
\text { (PLAT- } \\
\text { INUM- } \\
\text { COBAL T } \\
\text { UNITSI }\end{array}$ & & & \\
\hline & & & DCT. & & & & & & & & \\
\hline & & & $\begin{array}{l}14 \ldots \\
14 \ldots \\
J \Delta N .\end{array}$ & $6 . \overline{0}$ & 63 & 6.3 & $\begin{array}{l}26.0 \\
26.0\end{array}$ & $\begin{array}{l}70 \\
--\end{array}$ & & & \\
\hline & & & $\underset{\text { JUNF }}{27 \ldots . .}$ & $12 . \overrightarrow{0}$ & 97 & $\begin{array}{l}6.3 \\
6.5\end{array}$ & $\begin{array}{l}3.0 \\
3.0\end{array}$ & 50 & & & \\
\hline & & & 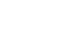 & 9. & 116 & $\begin{array}{l}6.6 \\
7.3\end{array}$ & $\begin{array}{l}28.0 \\
28.0\end{array}$ & $5 \mathrm{C}$ & & & \\
\hline & & & $? 1 \ldots$ & 7.2 & 91 & $\begin{array}{l}6.5 \\
6.5\end{array}$ & $\begin{array}{l}30.0 \\
30.0\end{array}$ & 50 & & & \\
\hline
\end{tabular}


CHOWAN RIVER BASIN

02053652 CHOWAN RIVER NEAR EDENHOUSE, N.C.

LOCATION.--Lat $36^{\circ} 02 \cdot 48^{\prime \prime}$, long $76^{\circ} 41^{\prime} 48^{\prime \prime}$, Bertie County, at bridge on U. 3 . Highway 17 , 1 mile northeast of Edenhouse and 3.8 miles downstream from Rockyhock creek.

DRAINAGE AREA, --4,871 sq mi.

PERIOD OF RECORD.--Chemical analyses: October 1957 to September 1967 (daily), Octaber 1967 to September 1970

Water temperatures: October 1957 to september 1967.

EXTREMES, -. period of record:

Chloride: Maximum, 9,140 mg/1 Nov, 11 (B), 1958; minımum, $3.0 \mathrm{mg} / 1$ June $1-30,1961$.

Specific conductance: Maximum daily, 23,500 micromhos Nov. 11 (B), 1958; minimum dally, 43 micromhos

Sept. 22 (B), 1960

water temperatures: Maximum, $33.0^{\circ} \mathrm{C}$ June 11 (T), 1959; minimum, freezing point Jan, 24, 25, 1961, Jan. 31 (T), 1966.

REMARKS.--Salinity station prior to 1968; top ( $T$ ) and bottom (B) samples were collected once dally. The second of two samples collected at the same time is a field determination.

$$
\text { CHEMICAL ANALYSES, WATER YEAR OCTOBER } 1969 \text { TO SEPTEMBER } 1970
$$

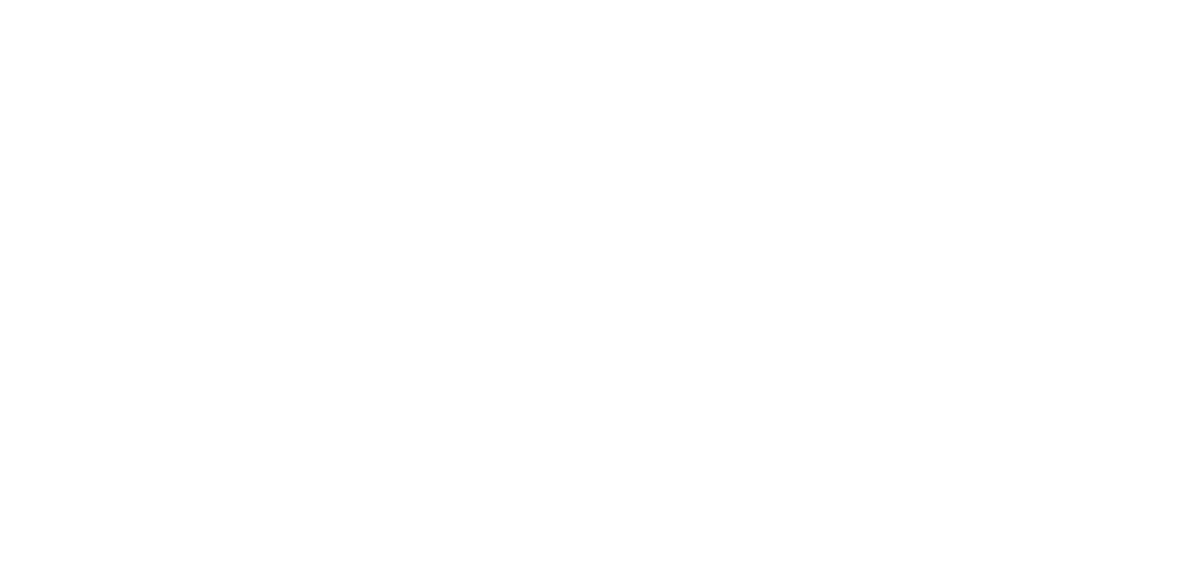

\begin{tabular}{|c|c|}
\hline $16 . .$. & 1.3 \\
\hline Juty & 1.0 \\
\hline $01 \ldots A$ & 1.4 \\
\hline $\begin{array}{l}01 \ldots \\
01 \ldots . .8\end{array}$ & $\overline{1.4}$ \\
\hline $01 \ldots$ & - \\
\hline $01 \ldots c$ & 1.8 \\
\hline SEPY. & \\
\hline $23 \ldots A$ & .5 \\
\hline $\begin{array}{l}23 \ldots \ldots \\
23 \ldots \ldots B\end{array}$ & $\overline{6}$ \\
\hline $23 \ldots$ & - \\
\hline $23 \ldots c$ & .5 \\
\hline & - \\
\hline
\end{tabular}

\begin{tabular}{|c|c|c|c|c|c|}
\hline 62 & .08 & - & 20 & 6 & .7 \\
\hline 168 & .23 & -- & 28 & 0 & 2.8 \\
\hline 86 & .12 & .28 & 26 & 9 & 1.4 \\
\hline 86 & .12 & - & $\overline{26}$ & $\overline{0}$ & 1.5 \\
\hline-- & - & -- & - & -- & - \\
\hline 103 & .14 & -- & 28 & 11 & 1.9 \\
\hline-- & - & - & 一 & -- & -- \\
\hline 77 & .10 & - & 23 & 6 & 1.0 \\
\hline$m$ & $\overrightarrow{10}$ & - & - & $\bar{i}$ & $-\overline{3}$ \\
\hline$\overline{--}$ & .10 & $=$ & -2 & -1 & $\begin{array}{l}1.3 \\
-.\end{array}$ \\
\hline 90 & .12 & -- & 28 & 2 & 1.2 \\
\hline \multirow[t]{4}{*}{-} & - & - & - & -- & - \\
\hline & & $\begin{array}{l}\text { SOECI - } \\
\text { FIC }\end{array}$ & & & COLOR \\
\hline & oIs- & CONO- & & & IPLAT- \\
\hline & $\begin{array}{l}\text { SOLVED } \\
\text { CXYGEN }\end{array}$ & $\begin{array}{l}\text { UCTANCE } \\
\text { INICRO- }\end{array}$ & $\mathrm{PH}$ & $\begin{array}{l}\text { TEMP- } \\
\text { ERATURE }\end{array}$ & $\begin{array}{l}\text { INUM- } \\
\text { CORALT }\end{array}$ \\
\hline DATE & (MG/L) & MHDSI & (UNITS) & IDEG C) & UNITS \\
\hline \multicolumn{6}{|l|}{ DCT. } \\
\hline $16 . .$. & - & 66 & 6.3 & -- & 80 \\
\hline JAN... & 7.5 & - & R. 1 & 22.0 & -- \\
\hline \multicolumn{6}{|l|}{ JAN. } \\
\hline $\begin{array}{l}27 \ldots . . \\
27 \ldots\end{array}$ & -- & $22 \mathrm{k}$ & 0.5 & $3 . r$ & $14 n$ \\
\hline JUL $^{27} \ddot{Y}$ & 13.7 & -- & $\cdots$ & 3.0 & -- \\
\hline \multicolumn{6}{|l|}{ JULY } \\
\hline $11 \ldots$ & A.n & $\cdots$ & 7.4 & 28.0 & - \\
\hline$\cap 1 \ldots$ B & -- & 135 & 6.3 & $28 . n$ & 5 \\
\hline$p 1 \ldots$ & ค.? & $-\bar{x}$ & 6.8 & 38.0 & $-\overline{-}$ \\
\hline $21 \ldots c$ & -- & 1 त & 5.4 & 27.0 & $3 n$ \\
\hline $\begin{array}{l}\text { PI... } \\
\text { SEPT. }\end{array}$ & 7.5 & \multicolumn{3}{|c|}{ SEPT. } & \\
\hline $23 \ldots A$ & -- & $1: 1$ & 6.5 & 28.0 & 15 \\
\hline $23 \ldots$ & 4.0 & -- & 7.4 & 28.0 & -- \\
\hline $23 \ldots$ B & -- & 131 & B. ${ }^{R}$ & 28.0 & 15 \\
\hline $23 \ldots$ & 4.0 & -- & 7.2 & 28.0 & -- \\
\hline $23 \ldots c$ & - & 141 & 6.5 & $28 . ?$ & 15 \\
\hline & 3.9 & 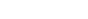 & 7.1 & $28 . c$ & -- \\
\hline
\end{tabular}

A SAMPLE COLLECTED AT OUARTER-POINT NEAREST LEFT RANK, LOOKING UPSTREAM.

B SAMPLE COLLECTED AT MIDPOINT OF STREAM. 
02080482 ROANOKE RIVER NEAR ROANOKE RAPIDS, N.C.

LOCATION (revised), - Lat $36^{\circ} 29^{\prime} 10^{\prime \prime}$, long $77^{\circ} 37^{\prime} 40^{\prime \prime}$, Halifax County, at bridge on State Highway 48 at Roanoke Rapids, 1.2 miles upstream from gaging station, 1.6 miles downstream from Roanoke Rapids Dam, and 3.7 miles upstrean from Chockoyotte Creek.

DRAINAGE AREA.-.8,410 sq $m 1$, approximately.

PERIOD OF RECORD.--Chenical analyses: October 1948 to September 1949 (daily), October 1967 to September 1970

water temperatures: october 1948 to september 1949.

EXTRENES.--Pertod of record:

Dissolved solids: Maxtmum, $74 \mathrm{mg} / 1$ Nov. 11-20, 1948; minimum, $46 \mathrm{mg} / 1$ Dec. 1-10, 1948, Jan. 1-10, 1949.

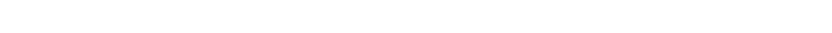

REMARX. - Miscellaneous samples of chemical data collected at described site and/or at gaging station 1.2 miles downstream are published for water years 1946-47, 1955-67. Records of discharge are given for 02080500 Roanoke River at Roanoke Rapids. The second of two samples collected at the same time is a fleld determination. CHEMICAL ANALYSES, WATER YEAR OCTOBER 1969 TO SEPTEMBER 1970

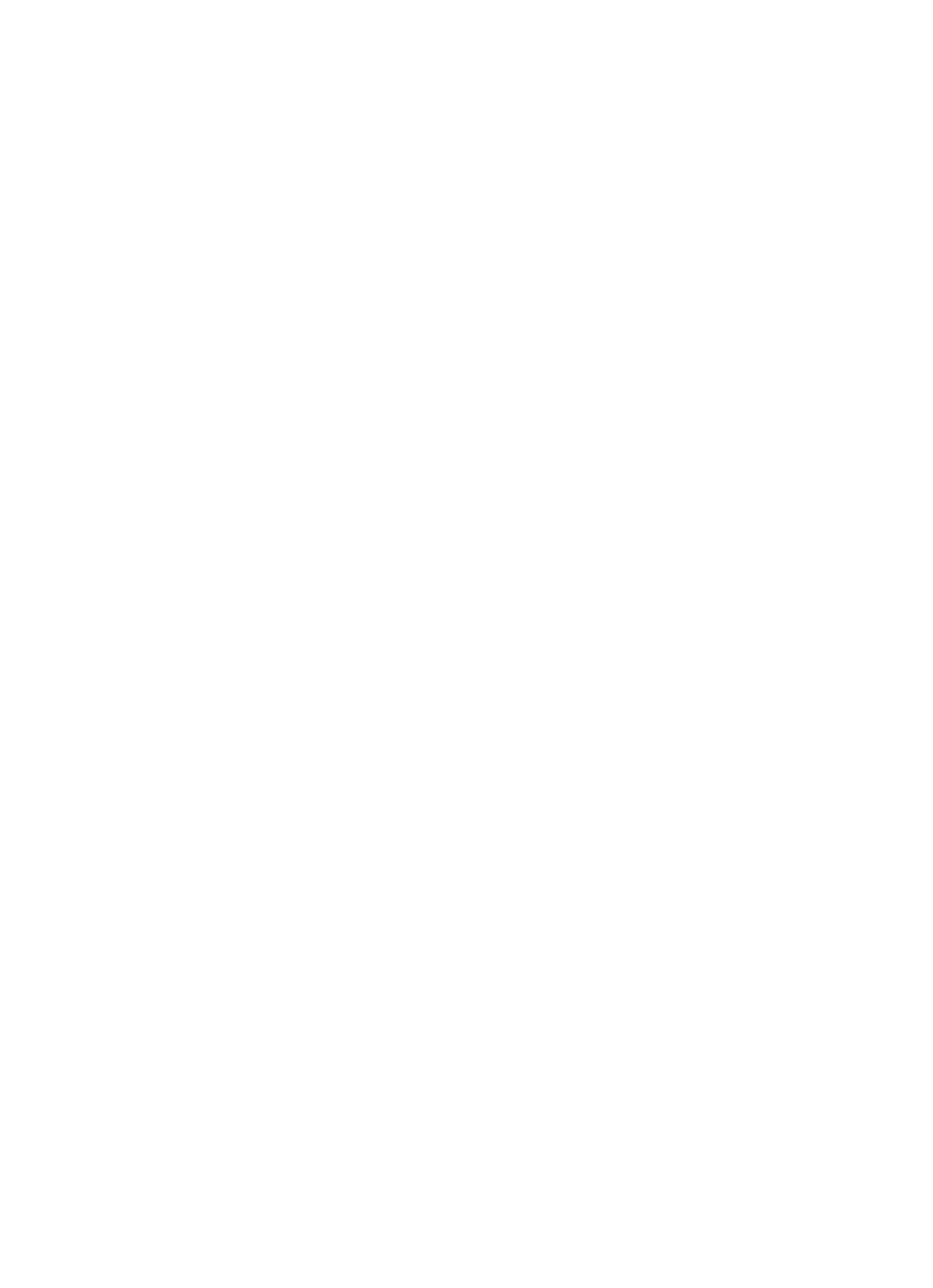


O2081000 ROANOKE RIVER NEAR SCOTLAND NECK, N.C.

LOCATION,--Lat $36^{\circ} 12 \cdot 33^{\prime \prime}$, long $77^{\circ} 13^{\circ} 02^{\prime \prime}$, Hallfax County, at bridge on U.S. Highway 258,3 miles downstream irom Bridgers Creek, 5.8 miles north of Scotland Neck, and at mile 102.5 .

DRAINAGE AREA. $--8,700 \mathrm{sq} \mathrm{ml}$. PERIOD OF RECORD.--Chemical analyses: October 1944 to September 1945 , October 1953 to September 1954 (da1ly),
October 1967 to September 1970 (partial record).

EXTREMES, -- Period of record:

Dissolved solids: Maxd mum, $173 \mathrm{mg} / 1 \mathrm{Apr} .1-10,1945$; minimum, $47 \mathrm{mg} / 1$ Oct. 1-10, 1944.

Hardness: Maximum, $57 \mathrm{mg} / 1 \mathrm{Apr}, 1-10,1945 ;$ minimun, $18 \mathrm{mg} / 1$ Oct $1-10,1944$.
Water temperatures: Maximum, $29.5^{\circ} \mathrm{C}$ July $3,4,6,7,8,1945 ;$ midimum, $0.5^{\circ} \mathrm{C}$ Dec. $31,1953$. REMARKS. - Miscellaneous samples of chemical data published for water years 1947, 1949, 1952, 1955-56, 1960-67. The CHEMICAL ANALYSES, WAIER YEAR OCTOBER 1969 TO SEPTEMBER 1970

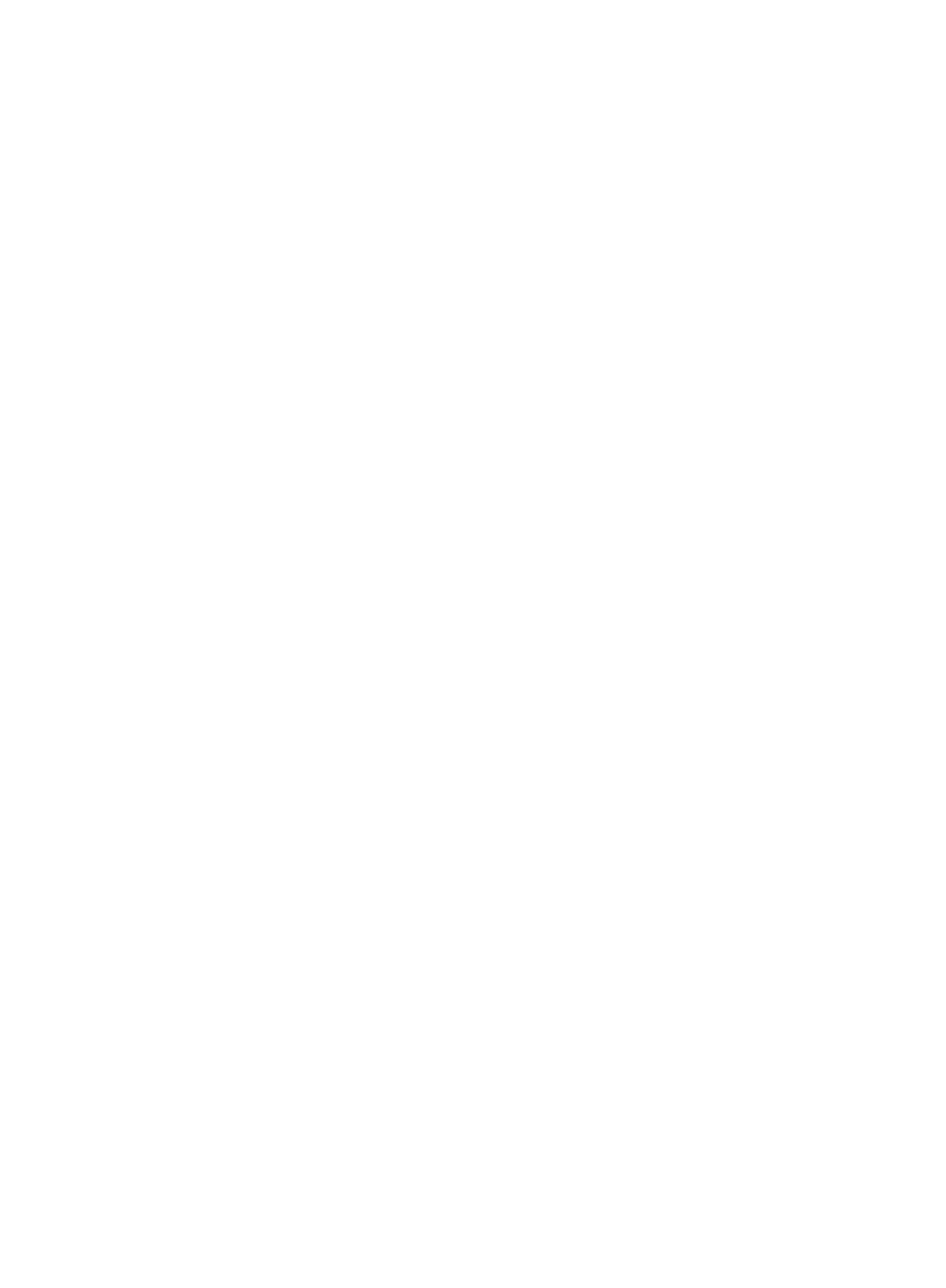


O2081022 ROANOKE RIVER NEAR OAK CITY, N.C.

LOCATION. - Lat $36^{\circ} 01^{\prime} 49^{\prime \prime}$, long $77^{\circ} 15^{\prime} 49^{\prime \prime}$, Nartin County, at bridge on state Highway $11,1.9$ miles downstream from Klans Gut and 5,2 miles northeast of Oak C1ty.

DRAINAGE AREA. $--8,830 \mathrm{sq} \mathrm{mi}$, approximately.

PERIOD OF RECORD.--Chemical analyses: October 1967 to September 1970 (part1al record).

REMARKS.--The second of two samples collected at the same time is a field determination. CHEMICAL ANALYSES, WATER YEAR OCTOBER 1969 TO SEPTEMBER 1970

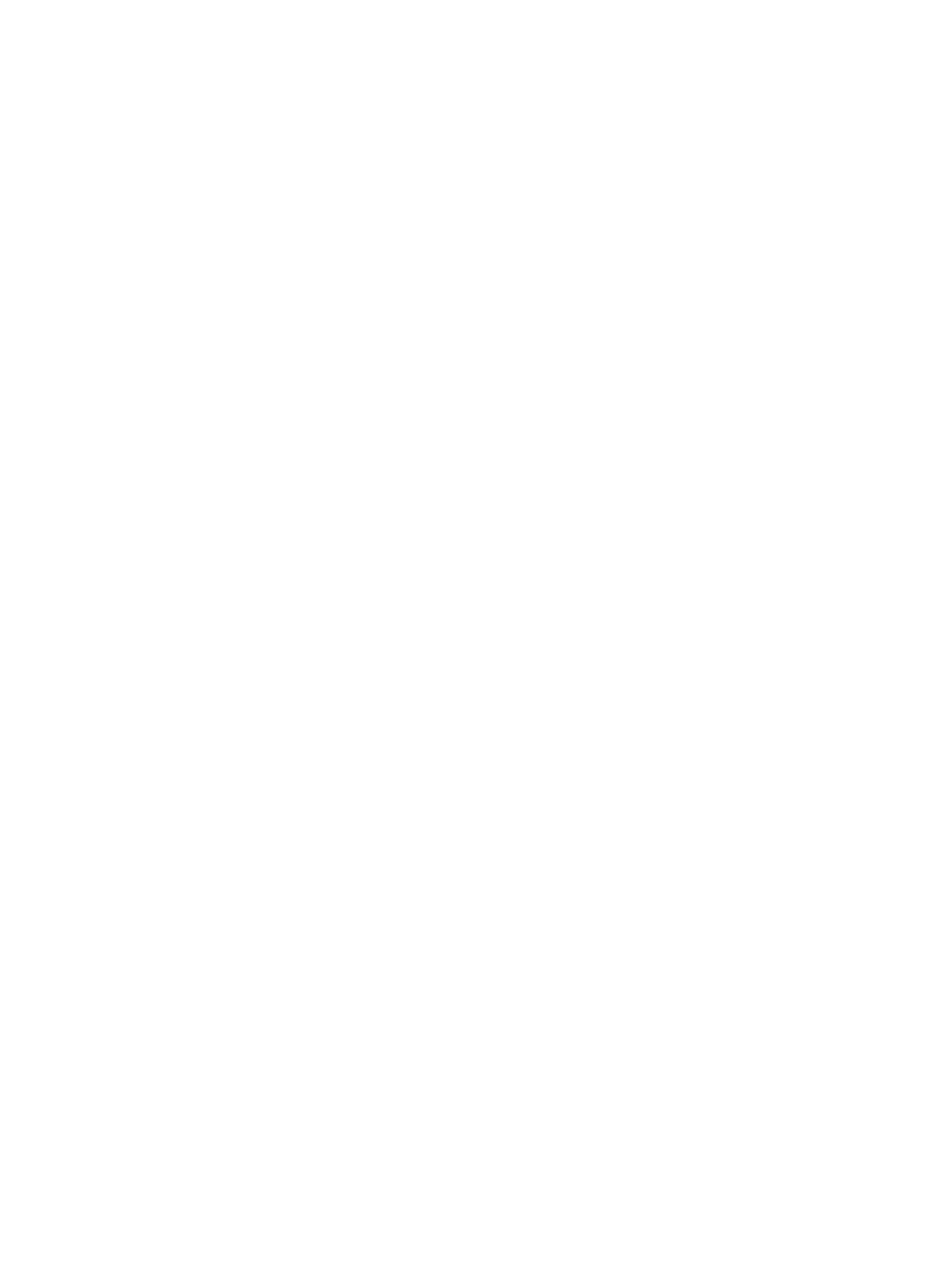


ALBEMARLE SOUND

02081155 ALBEMARLE SOUND NEAR EDENTON, N.C.

LOCATION, - Lat $35^{\circ} 59^{\prime} 13^{\prime \prime}$, long $76^{\circ} 30^{\prime} 14^{\prime \prime}$, Chowan County, at drawbridge on state Highway $32,5.1$ miles east of Norfolk Southern Raliroad and $7.8 \mathrm{miles}$ southeast of Edenton.

DRAINAGE AREA.-.14,800 sq $\mathrm{m} 1$, approximately.

PERIOD OF RECORD.--Chemical analyses: October 1957 to September 1967 (daily), October 1967 to September 1970

water temperatures: October 1957 to september 1967.

EXTREMES, ..- Period of record

Chloride: Maximum, $12,100 \mathrm{mg} / 1$ Nov. $3-6$ (B), 1958: minimum, $3.1 \mathrm{mg} / 1 \mathrm{Apr}, 11$ (T), 1966

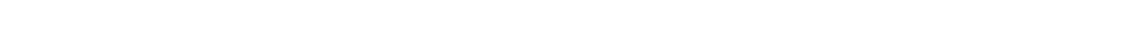
water temperatures: Maximum, $31.0^{\circ} \mathrm{C}$ July 14 (T), 1966; minimum, freezing point on several days in 1961 , 1966,
1967 ,

REMARKS.--Salinity station prior to October 1967; top (T) and bottom (B) samples were collected once daily. Miscel skinnersville. The second of two samples collected at the same time is a field determination.

CHEMICAL ANALYSES, hater YEAR OCTOBER 1969 TO SEPTEMBER 1970

\begin{tabular}{|c|c|c|c|c|c|c|c|c|c|c|c|}
\hline DATE & TIME & $\begin{array}{l}\text { SILICA } \\
\text { ISIOZI } \\
\text { IMGILI) }\end{array}$ & $\begin{array}{l}\text { DIS- } \\
\text { SOLVED } \\
\text { IRON } \\
\text { (FE) } \\
\text { (UGIL) }\end{array}$ & $\begin{array}{l}\text { CAL- } \\
\text { CIUM } \\
\text { (CA) } \\
\text { (MG/L) }\end{array}$ & $\begin{array}{c}\text { MAG- } \\
N E- \\
\text { SIUM } \\
\text { (MG) } \\
\text { (MG/L) }\end{array}$ & $\begin{array}{l}\text { SODIUM } \\
\text { (NA) } \\
\text { (MGIL) }\end{array}$ & $\begin{array}{l}\text { PO- } \\
\text { TAS- } \\
\text { SIUM } \\
\text { (K) } \\
\text { (MG LLI }\end{array}$ & $\begin{array}{l}\text { BICAR- } \\
\text { BONATE } \\
\text { (HCOB) } \\
\text { (MG/L) }\end{array}$ & $\begin{array}{l}\text { CAR - } \\
\text { BONATE } \\
\text { (CDY) } \\
\text { (AGNL }\end{array}$ & $\begin{array}{l}\text { SULFATE } \\
\text { (S04) } \\
\text { (NG/L) }\end{array}$ & $\begin{array}{l}\text { CHLO- } \\
\text { RIOE } \\
\text { (CL) } \\
\text { (MGIL) }\end{array}$ \\
\hline $\begin{array}{l}\text { OC, T. } \\
13 \ldots . .\end{array}$ & 1650 & 8.2 & 40 & 8.7 & 14 & 110 & 8.4 & 27 & 0 & 35 & 192 \\
\hline JAN. & & & & & & & & & & & \\
\hline${ }_{\text {JULY }}^{27 . . .}$ & 1510 & 8.1 & 63 & 11 & 27 & 112 & 8.7 & 37 & 0 & 39 & 224 \\
\hline $\begin{array}{l}\text { OI... } \\
\text { SEPT. }\end{array}$ & 1245 & 3.5 & 23 & 4.2 & 12 & 76 & 6.5 & 18 & 0 & 26 & 130 \\
\hline $23 \ldots$ & 1300 & 6.6 & 0 & 9.9 & 23 & 186 & 11 & 29 & 0 & 48 & 320 \\
\hline & & & & $\begin{array}{l}\text { OIS- } \\
\text { SOLVED }\end{array}$ & ot $5-$ & & NON- & SOD I UN & & $\begin{array}{l}\text { ME THY- } \\
\text { LENE }\end{array}$ & \\
\hline & $\begin{array}{l}\text { FLUO- } \\
\text { RIOE }\end{array}$ & NITRATE & $\begin{array}{l}\text { PHOS- } \\
\text { PHATE }\end{array}$ & $\begin{array}{l}\text { IRES I- } \\
\text { OUE AT }\end{array}$ & $\begin{array}{l}\text { SOIDS } \\
\text { ITONS }\end{array}$ & $\begin{array}{l}\text { HARO- } \\
\text { NESS }\end{array}$ & $\begin{array}{l}\text { BONATE } \\
\text { HARD- }\end{array}$ & SORP- & PERCENT & $\begin{array}{c}\text { ACIIVE } \\
\text { SUB- }\end{array}$ & $\begin{array}{l}\text { LINITY } \\
\text { AS }\end{array}$ \\
\hline DATE & $\begin{array}{l}\text { (F) } \\
\text { (NG/L) }\end{array}$ & $\begin{array}{l}\text { (NO3) } \\
\text { (MG/L) }\end{array}$ & $\begin{array}{l}(P 04) \\
\text { (MG/L) }\end{array}$ & $\begin{array}{l}280 \mathrm{Cl} \\
(\mathrm{MG} / \mathrm{L})\end{array}$ & $\begin{array}{c}\text { PER } \\
\text { AC } C-F()\end{array}$ & $\begin{array}{r}(C A, M G) \\
(M G / L)\end{array}$ & $\begin{array}{l}\text { NESS } \\
\text { IMG/LI }\end{array}$ & RATIO & SODIUM & $\begin{array}{l}\text { STANCE } \\
\text { (MG/L) }\end{array}$ & $\begin{array}{l}\text { CACOS } \\
\text { (MG/L) }\end{array}$ \\
\hline
\end{tabular}

OC

\begin{tabular}{|c|c|c|c|c|c|c|c|c|c|c|}
\hline $\begin{array}{l}\text { OCT. } \\
13 \ldots . . . \\
\text { JAR. }\end{array}$ & .1 & .5 & .00 & 421 & .57 & 80 & 57 & 5.4 & 73 & .22 \\
\hline $27 \ldots$ & .2 & .6 & .00 & 483 & .66 & 98 & 68 & 4.9 & 69 & .05 \\
\hline $\begin{array}{c}\text { JULY } \\
01 \ldots . . .\end{array}$ & .2 & 1.4 & .00 & 279 & .38 & 56 & 42 & 4.4 & 72 & .10 \\
\hline SEPT. & 1 & .2 & .00 & 641 & .87 & 120 & 96 & 7.4 & 75 & -- \\
\hline
\end{tabular}

\begin{tabular}{|c|c|c|c|c|c|c|}
\hline DATE & $\begin{array}{l}\text { DIS- } \\
\text { SOLVED } \\
\text { CXYGEN } \\
\text { IMG/LI }\end{array}$ & $\begin{array}{l}\text { SPECI- } \\
\text { FIC } \\
\text { CDND- } \\
\text { UCTANCE } \\
\text { (MICRD- } \\
\text { MHOS) }\end{array}$ & $\begin{array}{c}\text { PH } \\
\text { (UNITS) }\end{array}$ & $\begin{array}{l}\text { TEMP- } \\
\text { ERATURE } \\
\text { (OEG C) }\end{array}$ & $\begin{array}{l}\text { AIR } \\
\text { TEMP- } \\
\text { ERATURE } \\
\text { (DEG C) }\end{array}$ & $\begin{array}{l}\text { COLOR } \\
\text { IPLAT } \\
\text { INUM- } \\
\text { COBAL. } \\
\text { UNITS }\end{array}$ \\
\hline ocr. & & & & & & \\
\hline $13 \ldots$ & -- & $6: 7$ & 6.8 & $\cdots$ & $\cdots$ & $3 n$ \\
\hline JAN. & 7.8 & -- & -- & 23.5 & -- & - \\
\hline $27 \ldots$ & -- & 806 & 0.7 & 3.7 & -- & 50 \\
\hline $27 \ldots$ & 13.9 & -- & -- & 3.3 & -- & - \\
\hline ח & -- & 500 & 6.4 & 30.0 & $\cdots$ & $2^{n}$ \\
\hline $01 \ldots$ & 7.5 & -- & 7.5 & 30.7 & 27.0 & -- \\
\hline $\begin{aligned} \text { SEPT. } \\
23 . \ldots\end{aligned}$ & - & 1110 & 0.9 & -- & -- & 10 \\
\hline
\end{tabular}

PAMLICO RÍIER BASIN

02082526 TAR RI VER AT ROCKY MOUNT, N.C.

LOCATION.--Lat $35^{\circ} 57^{\prime} 08^{\prime \prime}$, long $77^{\circ} 49^{\prime} 08^{\prime \prime}$, Nash County, at bridge on U.S. Highway $64,0.8$ mile upstream from Stony Creek and $1.8 \mathrm{miles}$ west of hocky Mount.

DRAINAGE AREA.--800 sq $\mathrm{mi}$, approximately.

PERIOD OF RECORD.--Chemical analyses: October 1967 to September 1970 (partial record).

REMARKS. - The second of two samples collected at the same time is a field determination.

CHEMICAL ANALYSES, WATER YEAR OCTOBER 1969 TO SEPTEMBER 1970

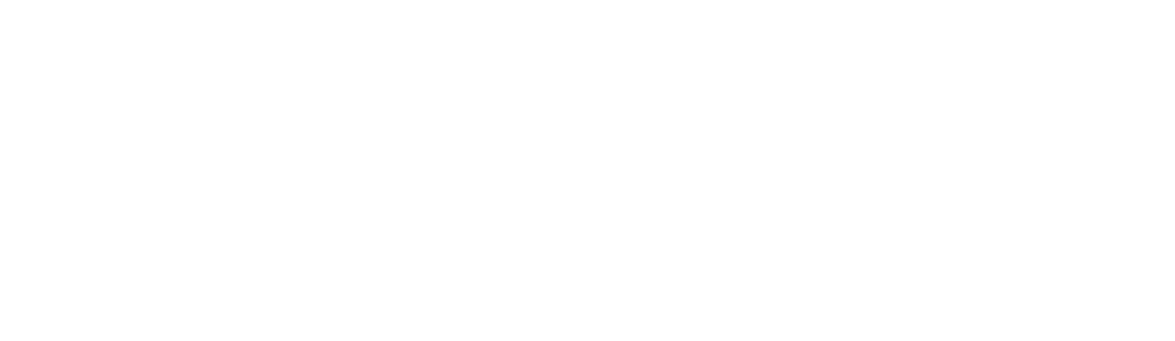


PAMLICO RIVER BASIN

02082526 TAR RIVER AT ROCKY MOUNT, N.C.--COntinued

C.HEMICAL ANALYSES, WATER YEAR OCTOBER 1969 TO SEPTEMBER 1970

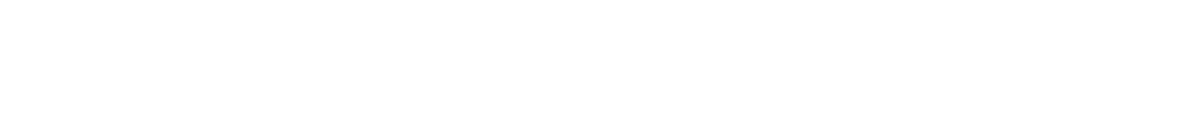

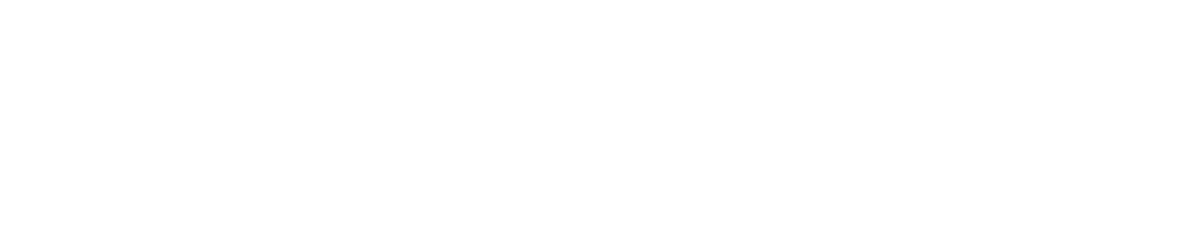

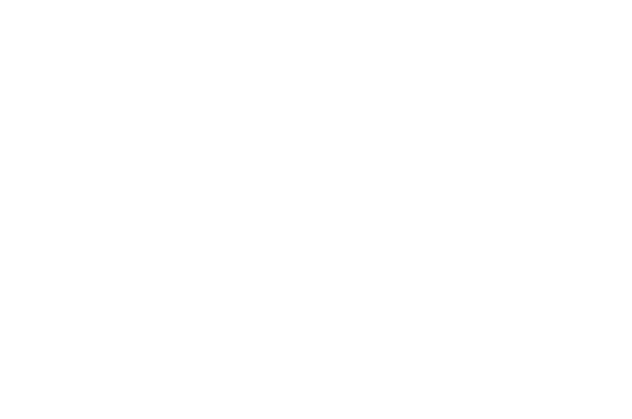

LOCATION.--Lat $35^{\circ} 53.38^{\prime \prime}$, long $77^{\circ} 32^{\prime} 00^{\prime \prime}$, Edgecombe County, at gaging station near right bank on downstream end of pier of bridge on U. S. Highway 64 in Tarboro, $6.5 \mathrm{miles}$ downstream from Fishing Creek and $49.2 \mathrm{miles}$ upstream
from Pamlico River at washington.

DRAINAGE AREA, $-2,140$ sq mi, approximately.

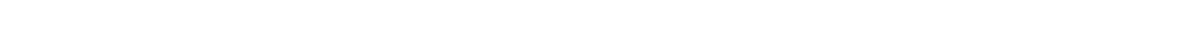

water temperatures: October 1944 to September 1945, October 1953 to September 1954, October 1961 to September 1967.

Sediment records: January 1958 to December 1967.

EXTREMES. - - Period of record

Dissolved solidis (1944-45, 1953-54, 1961-67): Maximum, $111 \mathrm{mg} / 1$ Oct 22-31, 1963; minimum, $40 \mathrm{mg} / 1$ (calculated)

Hardness (1944-45, 1953-54, 1961-67): Maximum, $33 \mathrm{mg} / 1$ Nov, 4, 1963 ; minimum, $9 \mathrm{mg} / 1 \mathrm{Jan}, 21-31,1954$.

Specific conductance (1961-67): Maximum daf1y, 270 micromhos Nov, 4, 1963; minimum daily, 34 micromhos

Aug. 22, 1967,
Water temperatures $(1944-45,1953-54,1961-67)$ : Maximum, $30.0^{\circ} \mathrm{C}$ Aug. 30,1966 ; minimum, freezing point on

several days in $1963,1966$.

Sediment concentrations (1958-67): Maximum daily, $465 \mathrm{mg} / 1$ June 22, 1967; minimum daily, $2 \mathrm{mg} / 1 \mathrm{Dec} .2,1965$,

Sept. 15-18, 1966, Dec. 4, 1967.

Sediment discharge (1958-67): Maximum daily, 6,130 tons May 12, 1958; minimum daily, 1 ton on several days in $1963,1966$.

REMARKS.--Miscellaneous samples of chemical data published for water years 1944, 1947, 1955-61. The second of two samples collected at the same time is a fleld determination.

CHEMICAL ANALYSES, WATER YEAR OCTOBER 1969 TO SEPIEMBER 1970

\begin{tabular}{|c|c|c|c|c|c|c|c|c|c|c|c|c|}
\hline DATE & TIME & $\begin{array}{l}\text { OIS- } \\
\text { CHARGE } \\
\text { (CFS) }\end{array}$ & $\begin{array}{l}\text { SILICA } \\
(S I O 2) \\
(M G L)\end{array}$ & $\begin{array}{l}\text { DIS- } \\
\text { SOAVED } \\
\text { IRON } \\
\text { (FE) } \\
\text { (UG/L) }\end{array}$ & $\begin{array}{l}\text { CAL- } \\
\text { CIUM } \\
(C A) \\
(M G / L)\end{array}$ & $\begin{array}{l}\text { MAG- } \\
\text { NE- } \\
\text { SIUM } \\
\text { (MG) } \\
(M G / 2)\end{array}$ & $\begin{array}{l}\text { SDDIUM } \\
\text { (NA) } \\
\text { (MG/L) }\end{array}$ & $\begin{array}{l}\text { PO- } \\
\text { TAS- } \\
\text { SIUM } \\
\text { (K) } \\
\text { ( } \mathrm{NGLL} \text { ) }\end{array}$ & $\begin{array}{l}\text { BICAR- } \\
\text { BONATE } \\
\text { (HCO3) } \\
\text { (MG/L) }\end{array}$ & $\begin{array}{l}\text { CAR- } \\
\text { BONATE } \\
\text { (CDZ) } \\
\text { (MG/L) }\end{array}$ & $\begin{array}{l}\text { SULFATE } \\
\text { (SO4) } \\
\text { (MG/L) }\end{array}$ & $\begin{array}{l}\text { CHLO- } \\
\text { RIDE } \\
\text { (CL) } \\
\text { (MG/L) }\end{array}$ \\
\hline $\begin{array}{c}\text { OCT. } \\
29 . \ldots \\
29 . \ldots\end{array}$ & $\begin{array}{l}1840 \\
1840\end{array}$ & $\begin{array}{l}434 \\
434\end{array}$ & 18 & 90 & 8.0 & 2.0 & 7.3 & 2.1 & $\begin{array}{l}34 \\
36\end{array}$ & - & 6.0 & 8.2 \\
\hline $\begin{array}{l}\text { JAN. } \\
27 \ldots \\
27 \ldots \\
\text { SEPT. }\end{array}$ & $\begin{array}{l}1014 \\
1014\end{array}$ & $\begin{array}{l}1230 \\
1230\end{array}$ & 13 & 73 & $\begin{array}{c}5.0 \\
-.\end{array}$ & 1.7 & 8.0 & 1.7 & 22 & -- & 6.4 & 9.2 \\
\hline $14 \ldots$ & $\begin{array}{l}1630 \\
1630\end{array}$ & $\begin{array}{l}106 \\
106\end{array}$ & 13 & - & 6.7 & 2.1 & 7.0 & 2.9 & 28 & -0 & 7.2 & ${ }^{10}$ \\
\hline DATE & $\begin{array}{l}\text { FLUD- } \\
\text { RIDE } \\
\text { (F) } \\
\text { (MG/L) }\end{array}$ & $\begin{array}{l}\text { NI IRA IE } \\
\text { (NO3) } \\
\text { (MG / L ) }\end{array}$ & $\begin{array}{l}\text { OR THO } \\
\text { PHOS- } \\
\text { PHATE } \\
\text { (PO4) } \\
\text { (NG/L) }\end{array}$ & $\begin{array}{l}\text { DIS- } \\
\text { SOL VEO } \\
\text { SOLIDS } \\
\text { IRESI- } \\
\text { DUE AT } \\
\text { IBO CI } \\
\text { IMG/L) }\end{array}$ & $\begin{array}{l}\text { OIS- } \\
\text { SOLVEO } \\
\text { SOLIDS } \\
\text { (TONS } \\
\text { PER } \\
\text { AC-FT) }\end{array}$ & $\begin{array}{l}\text { DIS- } \\
\text { SOLVED } \\
\text { SOLIDS } \\
\text { I TONS } \\
\text { PER } \\
\text { DAYI }\end{array}$ & $\begin{array}{l}\text { HARD- } \\
\text { NESS } \\
\text { (CA, MG) } \\
\text { (MG/L) }\end{array}$ & $\begin{array}{l}\text { NON- } \\
\text { CAR- } \\
\text { BONATE } \\
\text { HARD- } \\
\text { NESS } \\
\text { (MG/L) }\end{array}$ & $\begin{array}{l}\text { SODIUM } \\
\text { AD- } \\
\text { SORP- } \\
\text { TION } \\
\text { RATIO }\end{array}$ & $\begin{array}{l}\text { PERCENT } \\
\text { SOOIUM }\end{array}$ & $\begin{array}{l}\text { METHY- } \\
\text { LENE } \\
\text { SLUE } \\
\text { ACTIVE } \\
\text { SUB- } \\
\text { STANCE } \\
\text { IMG/L) }\end{array}$ & $\begin{array}{l}\text { ALKA- } \\
\text { LINITY } \\
\text { AS } \\
\text { CACO3 } \\
\text { (MG/L) }\end{array}$ \\
\hline $\begin{array}{r}\text { OCT. } \\
29 . . . \\
29 . \ldots \\
\text { JAN. }\end{array}$ & $\therefore$ & 2.2 & .19 & 16 & .10 & 89.1 & 28 & -1 & -6 & 34 & .02 & $\begin{array}{l}28 \\
30\end{array}$ \\
\hline $\begin{array}{r}\text { JAN. } \\
27 \ldots \\
27 \ldots\end{array}$ & $\because 1$ & 1.1 & 11 & 65 & .09 & $216 \ldots$ & 18 & -1 & $\div 8$ & 45 & .15 & 18 \\
\hline $\begin{array}{l}\text { SEPT. } \\
14 \ldots \ldots \\
14 \ldots . .\end{array}$ & $\because 2$ & 2.0 & .44 & 82 & 11 & 23.5 & 26 & -3 & .6 & 34 & .07 & $\begin{array}{l}23 \\
34\end{array}$ \\
\hline
\end{tabular}


PAMLICO RIVER BASIN

02083500 TAR RIVER AT TARBORO, N.C.--Cont1nued

CHEMICAL ANALYSES, WATER YEAR OCTOBER 1969 TO SEPTEMBER 1970

\begin{tabular}{|c|c|c|c|c|c|c|}
\hline & $\begin{array}{l}\text { DIS- } \\
\text { SOLVED } \\
\text { OXYGEN }\end{array}$ & $\begin{array}{l}\text { FECAL } \\
\text { COLI- } \\
\text { FDRM } \\
\text { ICOL. } \\
\text { PER }\end{array}$ & $\begin{array}{l}\text { SPECI- } \\
\text { FIC } \\
\text { COND- } \\
\text { UCTANCE } \\
\text { IMICRO- }\end{array}$ & $\mathrm{PH}$ & $\begin{array}{c}\text { TEMP- } \\
\text { ERATURE }\end{array}$ & $\begin{array}{l}\text { COLOR } \\
\text { IPLAT- } \\
\text { INUM- } \\
\text { COBALT }\end{array}$ \\
\hline ATE & $(M G / L)$ & $100 \mathrm{ML})$ & MHOS I & (UNITS) & $(D E G C)$ & UNITSI \\
\hline
\end{tabular}

\begin{tabular}{|c|c|c|c|c|c|c|}
\hline $29 \ldots$ & -- & $\cdots$ & 87 & 7.1 & 13.0 & 20 \\
\hline $\begin{array}{l}29 \ldots . . \\
\text { JAN. }\end{array}$ & 10.4 & -- & - & - & 13.0 & - \\
\hline $27 \ldots$ & - & - & 81 & 6.4 & 3.0 & 15 \\
\hline 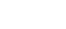 & 11.7 & $\cdots$ & -- & 7.9 & 3.0 & - \\
\hline$\underset{\text { SEP }}{27 . . .}$ & -- & 40 & -- & - & - & - \\
\hline $\begin{array}{l}14 \ldots \\
14 \ldots\end{array}$ & 8.2 & - & 106 & $\begin{array}{l}6.2 \\
6.4\end{array}$ & $\begin{array}{l}26.0 \\
26.0\end{array}$ & 15 \\
\hline
\end{tabular}

02084356 TRANTERS CREEK NEAR LATHAN, N.C.

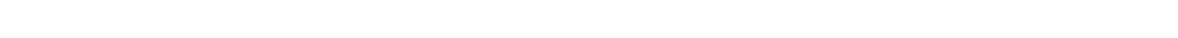

DRAINAGE AREA.--224 sq mi.

PERIOD OF RECORD.--Chemical analyses: October 1967 to September 1970 (partial record).

REMARKS. - The second of two samples collected at the same time is a field determination. CHEMICAL ANALYSES, WATER YEAR OCTBBER 1969 TO SEPTEMBER 1970

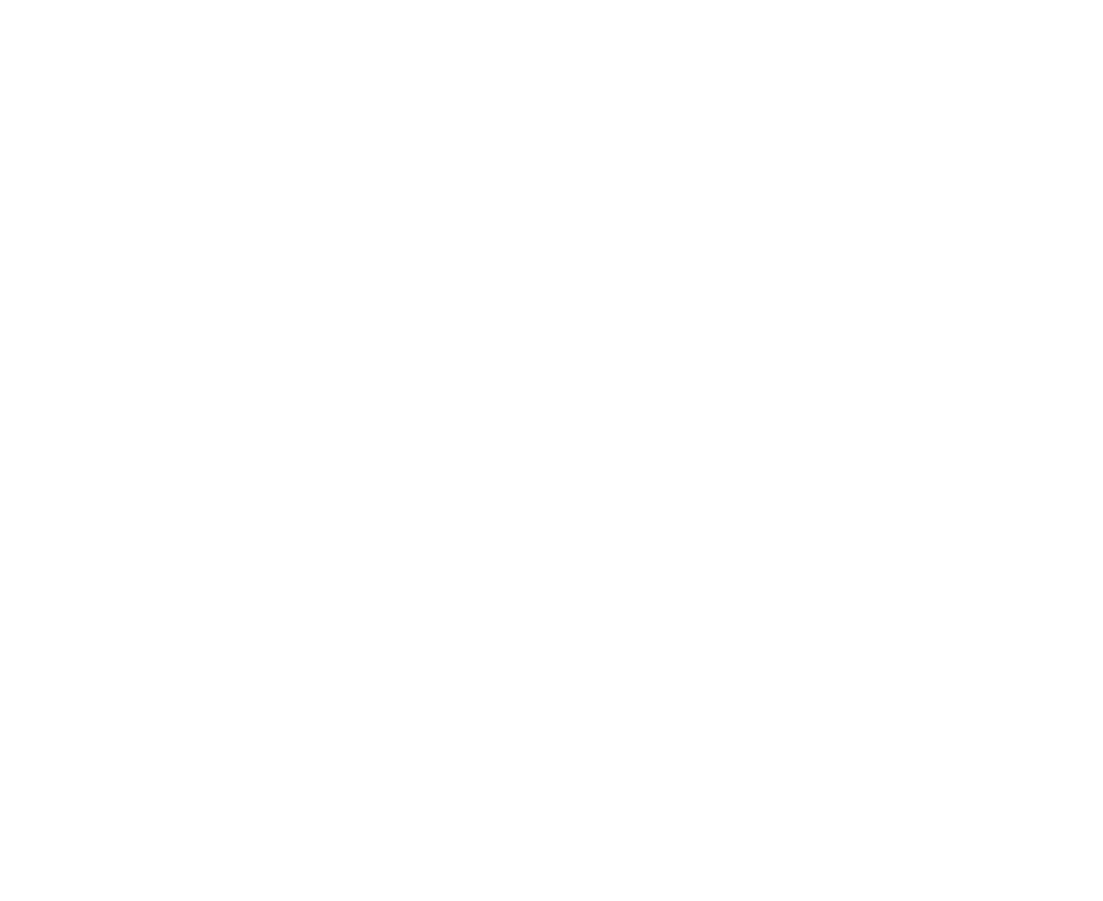


PAMLICO RI VER BASIN

02084578 PAMLICO RI VER NEAR GERHANTOWN, N.C.

LOCATION,.-Lat $35^{\circ} 20^{\prime} 28^{\prime \prime}$, long $76^{\circ} 28^{\prime} 39^{\prime \prime}$, Hyde County, at middle of river midway between willow and Pamlico points, about 2 miles upstream from mouth, and 6.3 miles south of Germantown.

DRAINAGE AREA.--4,220 sq mi, approximately.

PERIOD OF RECORD, --Chemical analyses: October 1969 to September 1970 (partial record).

REMARKS.-.Samples collected by boat. The second of two samples collected at the same time is a field determination. CHEMICAL ANALYSES, hater yeAR OCTOBER 1969 TO SEPTEHBER 1970

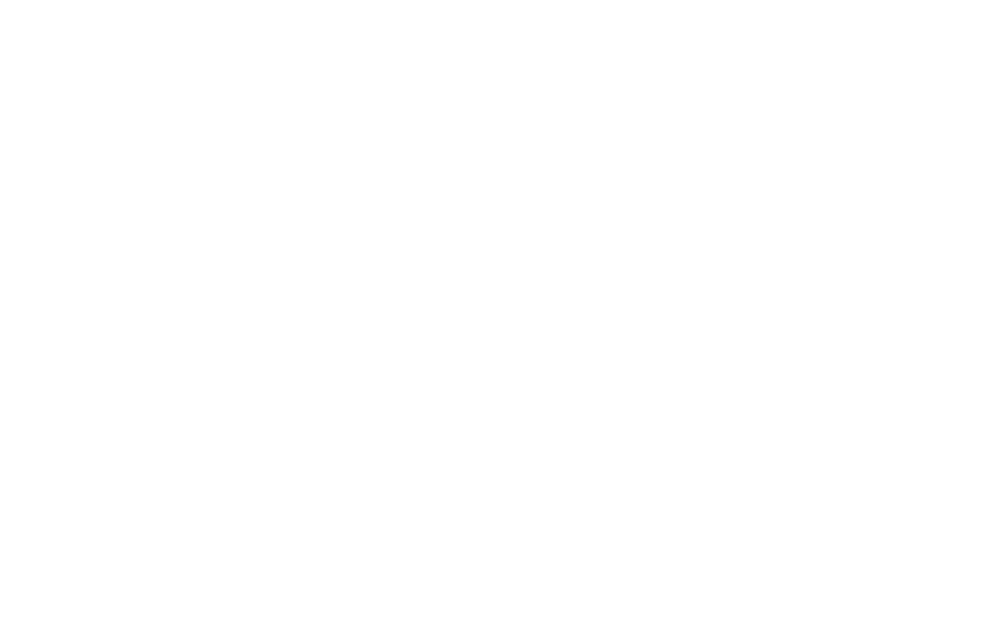

LOCATION.--Lat $35^{\circ} 56^{\prime} 27^{\prime \prime}$, long $78^{\circ} 34^{\prime} 57^{\prime \prime}$, wake County, at bridge on Secondary Road 2000 at Falls, 0.2 miles downstream from Honeycutt Creek and 0.3 mile upstream from gaging station.

DRAINAGE AREA, $\ldots 770 \mathrm{sq} \mathrm{mi}$.

PERIOD OF RECORD.--Chemical analyses: October 1953 to September 1954, November 1980 to September 1967 (da1ly), October 1967 to September 1970 (partial record).

Water temperatures: October 1953 to September 1954, November 1960 to september 1967.

EXTRENES. - - Period of record

Dissolved solids: Maximum, $140 \mathrm{mg} / 1$ Nov. $1-5,1963 ; \mathrm{minimum}, 38 \mathrm{mg} / 1 \mathrm{Jan} .15-17,1961$

Hardness: Maximum, $56 \mathrm{mg} / 1$ Sept. 22, 1966; minimum, $11 \mathrm{mg} / 1$ July $2,1963$.

Specific conductance (1960-67): Maximum daily, 355 micromhos Sept. 22, 1966; minimum da11y, 37 micromhos Aug. 4 , 1961.

water temperatures: Maximum, $27.0^{\circ} \mathrm{C}$ July 15, 1954, July 12, Aug. 23, 1966; minimum, freezing point on many days during 1960-62.

REMARKS.--The second of two samples collected at the same time is a field determination. CHEMICAL ANALYSES, WATER YEAR OCTOBER 1969 TO SEPTEMBER 1970

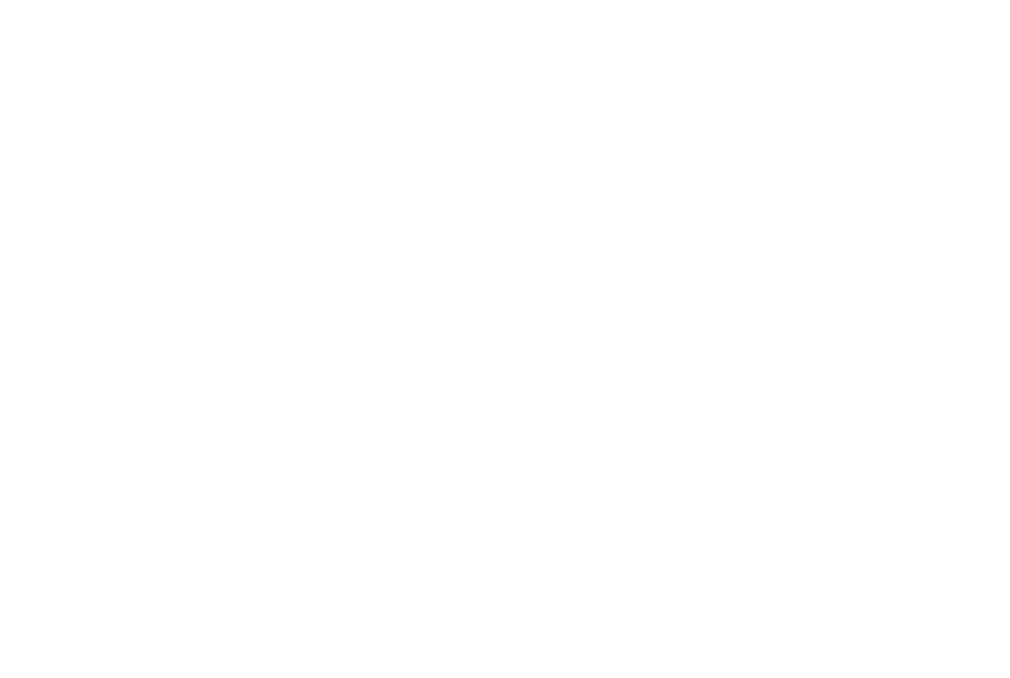




\section{NEUSE RIVER BASIN}

O2087182 NEUSE RIVER AT FALLS, N.C...COntinued

CHEMICAL ANALYSES, WATER YEAR OCTOBER 1969 TO SEPTEMBER 1970

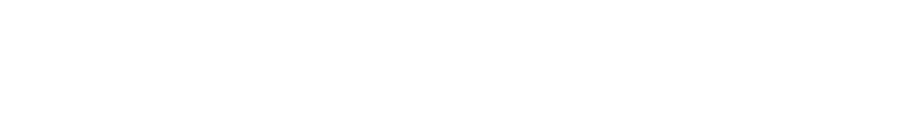

\begin{tabular}{|c|c|c|c|c|c|c|c|c|c|}
\hline NOV. & 1,5 & 53 & 20 & 43 & -- & 137 & 6.0 & 9.5 & 10 \\
\hline $18 \ldots$ & 10 & - & - & -- & 7.5 & - & 1.2 & 9.5 & - \\
\hline $\begin{array}{l}\text { MAR. } \\
12 \ldots\end{array}$ & .8 & 42 & .11 & 21 & -- & 101 & 6.6 & 11.0 & 25 \\
\hline $\begin{array}{l}\text { MAY } \\
14 \ldots\end{array}$ & .7 & 38 & .02 & 25 & - & 95 & 6.7 & 16.0 & 20 \\
\hline $14 \ldots$ & $\because$ & 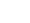 & - & $=$ & 11.4 & 120 & 7.1 & 16.0 & $\therefore$ \\
\hline SEP. & & & & & & & & & \\
\hline $24 \%$ & $\begin{array}{r}1.5 \\
-.5\end{array}$ & 48 & - & $\begin{array}{l}46 \\
-2\end{array}$ & 8.8 & 200 & 7.2 & 27.0 & 13 \\
\hline
\end{tabular}

02087500 NEUSE RIVER NEAR CLAYTON, N.C.

LOCATION, - Lat $35^{\circ} 38^{\prime} 50^{\prime \prime}$, long $78^{\circ} 24^{\prime} 21^{\prime \prime}$, Johnston County, at gaging station on left bank at bridge on State Highway $42,2.3$ miles upstream from Mill Creek and 3 miles east of Clayton.

DRAINAGE AREA.-1,140 sq m, approximately.

PERIOD OF RECORD.--Chemical analyses: October 1943 to September 1944, October 1955 to February 1956 (unpublished) (daily), October 1963 to September 1970 (partial record).

Water temperatures: October 1943 to September 1944 , October 1955 to February 1956 (unpublished).

EXTREKES.---period of record:

D1ssolved solids: Maximum, $103 \mathrm{mg} / 1$ Jan. 1-10, 21-31, 1956; minimum, $47 \mathrm{mg} / 1$ Feb, 11-2D, 1944.

Hardness: Maximum, $26 \mathrm{mg} / 1$ Oct 1-10, 1943; minimum, 14 mg/1 Feb. 11-20, Mar. 11-20, 21-31, Apr. $11-20,1944$. Water temperatures: Maximum, $29.5^{\circ} \mathrm{C}$ June 18 , July 25-28, 1944; minimum, freezing point Dec. 19 , 1943.

REMARKS.-Miscellaneous samples of chemical data published for water years 1947, 1949, 1955, 1958-63. The second of of two samples collected at the same time is a field determination. CHEMICAL ANALYSES, WATER YEAR OCTOBER 1969 TO SEPTEMBER 1970

\begin{tabular}{|c|c|c|c|c|c|c|c|c|c|c|}
\hline DATE & TIME & $\begin{array}{l}\text { DIS- } \\
\text { CHARGE } \\
\text { (CFS) }\end{array}$ & $\begin{array}{l}\text { SILICA } \\
\text { IS IO2) } \\
\text { (MG/L) }\end{array}$ & $\begin{array}{l}\text { DIS- } \\
\text { SOLVED } \\
\text { IRON } \\
\text { IFEI } \\
\text { IUG/L, }\end{array}$ & $\begin{array}{l}\text { OIS- } \\
\text { SOLVED } \\
\text { CAL- } \\
\text { OIUH } \\
\text { (CA) } \\
\text { (MG/L) }\end{array}$ & $\begin{array}{l}\text { DIS- } \\
\text { SOLVED } \\
\text { MAG- } \\
\text { NE- } \\
\text { SI UMA } \\
\text { (MG) } \\
(M G / L)\end{array}$ & $\begin{array}{l}\text { SOOIUM } \\
\text { (NA) } \\
\text { (MGIL) }\end{array}$ & $\begin{array}{l}\text { PO- } \\
\text { TAS- } \\
\text { SIUM } \\
(K) \\
(M G / L)\end{array}$ & $\begin{array}{l}\text { BICAR- } \\
\text { BDNATE } \\
\text { IHCOZ) } \\
\text { (MG/L) }\end{array}$ & $\begin{array}{l}\text { CAR- } \\
\text { BOVATE } \\
\text { (CO3) } \\
\text { (MG/L) }\end{array}$ \\
\hline $\begin{array}{l}27 . . . \\
27 .\end{array}$ & & & & & & & & & & \\
\hline $27 \ldots$ & 1300 & 188 & 17 & 20 & $8 \cdot 3$ & $2 \cdot 1$ & 27 & 5.3 & 36 & 0 \\
\hline $\begin{array}{l}27 \ldots \\
F E B\end{array}$ & 1300 & 188 & -- & -- & -- & - & -- & -- & - & - \\
\hline $02 \ldots$ & 1145 & 904 & 11 & 82 & 5.3 & 2.6 & 10 & 1.8 & 22 & 0 \\
\hline$\underset{\text { MAY }}{02 \cdots}$ & 1145 & 904 & -- & $=-$ & -- & $\cdots$ & - & -- & - & - \\
\hline $08 \ldots$ & 1200 & 852 & 14 & 110 & 6.3 & 2.0 & 10 & 2.4 & 22 & 0 \\
\hline $08 \ldots$ & 1200 & 852 & -- & -- & - & - & + & $\theta$ & $\sim$ & -- \\
\hline UATE & $\begin{array}{l}\text { SULFATE } \\
\text { (SO4) } \\
\text { (MGIL) }\end{array}$ & $\begin{array}{l}\text { CHLO- } \\
\text { RIDE } \\
\text { ICL) } \\
(M G / L)\end{array}$ & $\begin{array}{l}\text { DIS- } \\
\text { SOLVEO } \\
\text { FL UO- } \\
\text { RIDE } \\
\text { (F) } \\
\text { IMG/LI) }\end{array}$ & $\begin{array}{l}\text { NITRAIE } \\
\text { (NO3) } \\
\text { (MG/L) }\end{array}$ & $\begin{array}{l}\text { OIS- } \\
\text { SOLVED } \\
\text { ORTHO } \\
\text { PHOS- } \\
\text { PHATE } \\
\text { IPO4) } \\
\text { (MGIL) }\end{array}$ & $\begin{array}{l}\text { DIS- } \\
\text { SOL VEO } \\
\text { SOL IOS } \\
\text { (RESI- } \\
\text { DUE AT } \\
\text { IBO C) } \\
\text { (MG } / \text { L) }\end{array}$ & $\begin{array}{l}\text { OLS- } \\
\text { SOLVED } \\
\text { SOLIOS } \\
\text { (TONS } \\
\text { PER } \\
\text { AC-F TI }\end{array}$ & $\begin{array}{l}\text { DIS- } \\
\text { SOLVED } \\
\text { SOLIOS } \\
\text { ITONS } \\
\text { PER } \\
\text { DAYI }\end{array}$ & $\begin{array}{l}\text { HARO- } \\
\text { NESS } \\
\text { (CA, MG) } \\
\text { (MG/L) }\end{array}$ & $\begin{array}{l}\text { NON- } \\
\text { CAR- } \\
\text { BONATE } \\
\text { HARD- } \\
\text { NESS } \\
\text { (MG/L) }\end{array}$ \\
\hline OCT. & & & & & & & & & & \\
\hline $27 \ldots$ & 8.8 & 39 & $\cdot 2$ & 9.6 & 1.6 & 144 & .20 & 73.1 & 30 & 0 \\
\hline $\begin{array}{l}27 \ldots \\
F E B .\end{array}$ & - & -- & $\sim$ & $\cdots$ & -- & -+ & - & $=$ & - & - \\
\hline $\begin{array}{l}02 \ldots \\
02 \ldots \\
Y A Y\end{array}$ & 12 & 13 & $\div 2$ & 1.5 & $\cdot 82$ & 83 & .11 & $203 \ldots$ & 24 & - \\
\hline $\begin{array}{l}08 \ldots \\
08 \ldots\end{array}$ & $\begin{array}{l}7.6 \\
-.\end{array}$ & 12 & $\begin{array}{l} \pm 2 \\
\text { METHY }\end{array}$ & 4.3 & .87 & 82 & 11 & 189 & 24 & -6 \\
\hline VATE & $\begin{array}{l}\text { SOOIUM } \\
\text { AD- } \\
\text { SORP- } \\
\text { TION } \\
\text { RAIIO }\end{array}$ & $\begin{array}{l}\text { PERCENT } \\
\text { SOJIUM }\end{array}$ & $\begin{array}{l}\text { LENE } \\
\text { BLUE } \\
\text { ACTIVE } \\
\text { SUB- } \\
\text { SIANCE } \\
\text { IMGLLI }\end{array}$ & $\begin{array}{l}\text { ALKA- } \\
\text { LIVITY } \\
\text { AS } \\
\text { CACO3 } \\
\text { IMG/LI I }\end{array}$ & $\begin{array}{l}\text { DIS- } \\
\text { SOLVED } \\
\text { OXYGEN } \\
\text { (MG/L) }\end{array}$ & $\begin{array}{l}\text { SPEEI- } \\
\text { FIC } \\
\text { COND- } \\
\text { UCTAVCE } \\
\text { (MICRO- } \\
\text { MHOS) }\end{array}$ & $\begin{array}{c}\text { PH } \\
\text { CUNITSI }\end{array}$ & $\begin{array}{l}\text { TEMP- } \\
\text { ERATUR } \\
\text { IOEG C }\end{array}$ & $\begin{array}{l}\text { COLOR } \\
\text { I PLAT } \\
\text { INUM- } \\
\text { COBAL } \\
\text { UNITS }\end{array}$ & \\
\hline
\end{tabular}

\begin{tabular}{|c|c|c|c|c|c|c|c|c|c|}
\hline $27 \ldots$ & 2.2 & 62 & .11 & 30 & - & 185 & 6.5 & 20.0 & 20 \\
\hline $\begin{array}{c}27 \ldots \\
F E B .\end{array}$ & -- & - & - & -- & 6.1 & $\rightarrow$ & - & 20.0 & - \\
\hline $02 \ldots$ & .9 & 45 & .10 & 18 & -- & 116 & 0.2 & 4.0 & 50 \\
\hline${ }_{\text {MAY }}^{02} \ldots$ & -- & -- & - & $\because$ & 9.9 & $\rightarrow$ & 7.4 & 4.0 & -- \\
\hline$O B \ldots$ & .9 & 45 & .00 & 18 & - & 100 & 6.3 & $1 \mathrm{~B} .0$ & 25 \\
\hline & -- & -- & -- & -- & 7.8 & -- & 0.7 & 18.0 & \\
\hline
\end{tabular}


02089116 NEUSE RIVER NEAR WHITEHALL, N.C. LOCATION.--Lat $35^{\circ} 14^{\prime} 40^{\prime \prime}$, long $77^{\circ} 54^{\prime} 40^{\prime \prime}$, Wayne County, at bridge on State Highway $111,1.5$ miles downstream from
Sleepy Creek and 4.2 miles northwest of Whitehall,

DRAINAGE AREA,--2,460 sq $\mathrm{mi}$, approximately.

PERIOD OF RECORD,--Chemical analyses: October 1969 to September 1970 (partial record).

REMARKS.--The second of two samples collected at the same time is a field determination.

CHEMICAL ANALYSES, WATER YEAR OCTOBER 1969 TO SEPTEMBER 1970

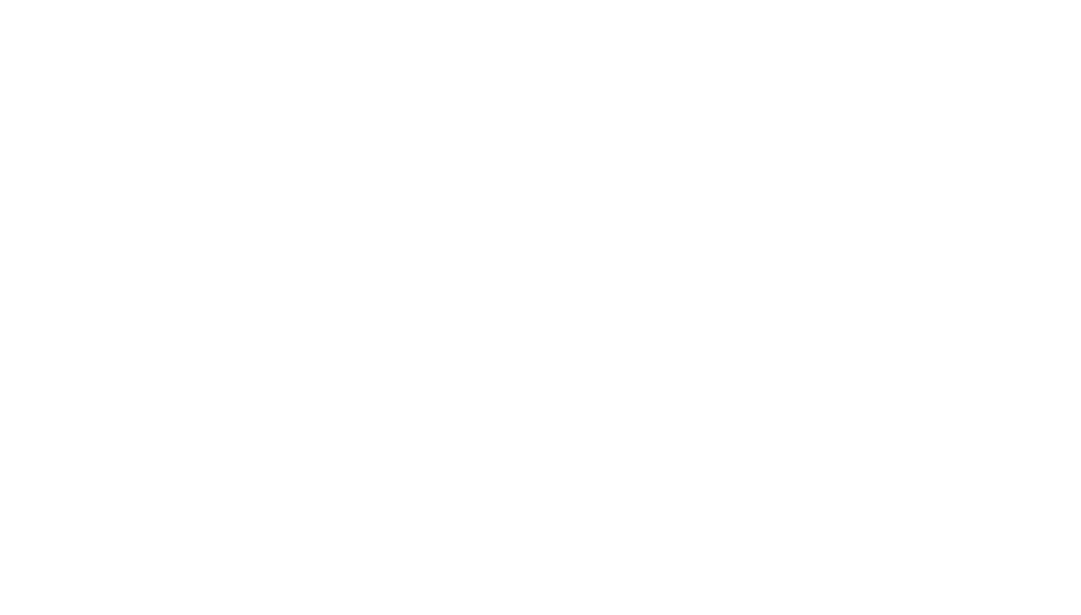

LOCATION (revised).--Lat $35^{\circ} 25^{\prime} 38^{\prime \prime}$, long $77^{\circ} 35^{\prime} 09^{\prime \prime}$, Greene County, at bridge on State Highway 123 at Hookerton, 0.3 mile downstream from gaging station and 2.2 miles upstream from theat Swamp Creek.

DRAINAGE AREA.-- 729 sq mi.

PERIOD OF RECORD.--Chemical analyses: October 1949 to September 1950 (dai1y), October 1968 to September 1970 (partial record).

vater temperatures: October 1949 to September 1950.

EXTREMES, - - Period of record:

Dissolved solids: Yaximum, $63 \mathrm{mg} / 1$ June $11-20,1950$; minimum, $45 \mathrm{mg} / 1$ Apr, 21-30, 1950

Dissolved solids: Kaximum, $63 \mathrm{mg} / 1 \mathrm{June} 11-20,1950 ;$ minimum, $45 \mathrm{mg} / 1 \mathrm{Apr}, 21-30,1950$.
Hardness: Maximum, $17 \mathrm{mg} / 1$ Nov. 1-10, 21-30, May $21-31,1950 ;$ minimum, $12 \mathrm{mg} / 1 \mathrm{Mar}$. 21-31, Aug. 21-31, Sept, 1-10, 1950; 17 mg/1 Nov. 1-10, 21-30, Hay 21-31, 1950; mintmum, $12 \mathrm{mg} / 1$ Mar. $21-31$

water temperatures: Maximum, $29.0^{\circ} \mathrm{C}$ June $27,28,1950$; minimum, $7.0^{\circ} \mathrm{C} \mathrm{Dec} .6-10,1950$.

REMARKS, - Miscellaneous samples of chemical data published for water years 1945, 1947.49, 1955.67. The second of two samples collected at the same time is a field determination.

CHEMICAL ANALYSES, WATER YEAR OCTOBER 1969 TO SEPTEMBER 1970

\begin{tabular}{|c|c|c|c|c|c|c|c|c|c|c|}
\hline DATE & TIME & $\begin{array}{l}\text { OIS- } \\
\text { CHARGE } \\
\text { ICFSI }\end{array}$ & $\begin{array}{l}S I L I C A \\
\text { ISIOZ) } \\
\text { (MG/L) }\end{array}$ & $\begin{array}{l}\text { DIS- } \\
\text { SOLVED } \\
\text { IRJN } \\
\text { IFEI } \\
\text { IUG/LI }\end{array}$ & $\begin{array}{l}\text { OIS- } \\
\text { SJLVED } \\
\text { CAL- } \\
\text { CIUM } \\
\text { (CA) } \\
\text { (MG/L) }\end{array}$ & $\begin{array}{l}\text { DIS- } \\
\text { SOL VED } \\
\text { MAG- } \\
\text { NE- } \\
\text { SIUM } \\
\text { (MG) } \\
\text { (MG/L) }\end{array}$ & $\begin{array}{l}\text { SODIUM } \\
\text { (NA) } \\
\text { (MG/L) }\end{array}$ & $\begin{array}{l}\text { PO- } \\
\text { TAS- } \\
\text { SIUM } \\
\text { IK } \\
\text { (MGLL) }\end{array}$ & $\begin{array}{l}\text { BICAR- } \\
\text { BONATE } \\
\text { (HCOB) } \\
\text { (MG/L) }\end{array}$ & $\begin{array}{l}\text { CAR- } \\
\text { BONATE } \\
\text { (CO3) } \\
\text { (MG/L) }\end{array}$ \\
\hline OCT. & 1800 & 198 & 11 & 90 & 4.5 & 1.4 & 8.0 & 2.0 & 12 & D \\
\hline JAN. & 1600 & 198 & - & -- & - & - & - & -- & -- & - \\
\hline $28 \ldots$ & $\begin{array}{l}1127 \\
1127\end{array}$ & $\begin{array}{l}543 \\
543\end{array}$ & 9.0 & 129 & 4.1 & 1.3 & 9.0 & 1.7 & -- & -- \\
\hline MAY & & & & & & & & & & \\
\hline $05 \ldots$ & $\begin{array}{l}1345 \\
1345\end{array}$ & $\begin{array}{l}426 \\
426\end{array}$ & $\begin{array}{r}6.7 \\
--\end{array}$ & $\begin{array}{r}609 \\
--2\end{array}$ & $\begin{array}{l}3.9 \\
--\end{array}$ & 1.3 & 6.2 & 1.9 & 12 & -- \\
\hline DATE & $\begin{array}{l}\text { SULFATE } \\
\text { (SD4) } \\
\text { (MGIL) }\end{array}$ & $\begin{array}{l}\text { CHL J- } \\
\text { RIDE } \\
(C L) \\
(M G / L)\end{array}$ & $\begin{array}{l}\text { DIS- } \\
\text { SOLVED } \\
\text { FLUD- } \\
\text { RIDE } \\
\text { (F) } \\
\text { (MG/L) }\end{array}$ & $\begin{array}{l}\text { NITRATE } \\
\text { (NJ3) } \\
\text { (MG/L) }\end{array}$ & $\begin{array}{l}\text { DIS- } \\
\text { SOLVED } \\
\text { ORTHO } \\
\text { PHOS- } \\
\text { PHATE } \\
\text { IPOAI } \\
\text { (MGIL) }\end{array}$ & $\begin{array}{l}\text { DIS- } \\
\text { SOLVED } \\
\text { SOL IDS } \\
\text { IRESI- } \\
\text { DUE AT } \\
180 \text { CI } \\
\text { IMG LLI }\end{array}$ & $\begin{array}{l}\text { OIS- } \\
\text { SOLVED } \\
\text { SDLIDS } \\
\text { IIONS } \\
\text { PER } \\
\text { AC-FTI }\end{array}$ & $\begin{array}{l}\text { DIS- } \\
\text { SOLVED } \\
\text { SOLLOS } \\
\text { (TONS } \\
\text { PER } \\
\text { DAYI }\end{array}$ & $\begin{array}{l}\text { HARD- } \\
\text { NE SS } \\
(C A, M G) \\
(M G / L)\end{array}$ & $\begin{array}{l}\text { NON- } \\
\text { CAR- } \\
\text { BDNATE } \\
\text { HARD- } \\
\text { NESS } \\
\text { IMG/L, }\end{array}$ \\
\hline DCr. & 9.2 & 12 & DD & 4.5 & .35 & 50 & .07 & 26.7 & $\begin{array}{l}17 \\
--\end{array}$ & -7 \\
\hline JAN. & & & & & $\cdot 32$ & & . D8 & 88.0 & 15 & 9 \\
\hline MAT & 5.8 & 8.2 & -2 & 2. 0 & .33 & 61 & .08 & 70.2 & 15 & -5 \\
\hline $05 . .$. & - & -- & - & -- & - & - & - & - & 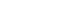 & \\
\hline
\end{tabular}




\section{NEUSE RIVER BASIN}

02091500 CONTENTNEA CREEK AT HOOKERTON, N.C.--COnt1nued

CHEMICAL ANALYSES, WATER YEAR DCTOBER 1969 TO SEPTEMBER 1970

\begin{tabular}{|c|c|c|c|c|c|c|c|c|c|}
\hline DAIE & $\begin{array}{l}\text { SODIUM } \\
\text { AD- } \\
\text { SORP- } \\
\text { TION } \\
\text { RATIO }\end{array}$ & $\begin{array}{l}\text { PERCENT } \\
\text { SODIUM }\end{array}$ & $\begin{array}{l}\text { METHY- } \\
\text { LENE } \\
\text { BLUE } \\
\text { ACTIVE } \\
\text { SUB- } \\
\text { STANCE } \\
\text { IMGLLI }\end{array}$ & $\begin{array}{c}\text { ALKA- } \\
\text { LINITY } \\
\text { AS } \\
\text { CACD } \\
\text { (MGILI) }\end{array}$ & $\begin{array}{l}\text { DIS- } \\
\text { SOLVED } \\
\text { OXYGEN } \\
\text { (MG/LI) }\end{array}$ & $\begin{array}{l}\text { SPECI- } \\
\text { FIC } \\
\text { CQND- } \\
\text { UCTANCE } \\
\text { IMLERO- } \\
\text { MHOSI }\end{array}$ & $\begin{array}{c}\text { PH } \\
\text { (UNIIS) }\end{array}$ & $\begin{array}{l}\text { TEMP- } \\
\text { ERATURE } \\
\text { SOEG CI }\end{array}$ & $\begin{array}{l}\text { COLOR } \\
\text { IPLAT- } \\
\text { INUM- } \\
\text { COBALT } \\
\text { UNITSI }\end{array}$ \\
\hline \multicolumn{10}{|l|}{ OCT. } \\
\hline $27 \ldots$ & .8 & 47 & .06 & 10 & - & 73 & 6.5 & 17.0 & 20 \\
\hline JAN. & -- & -- & -- & 13 & 7.6 & $\cdots$ & 7.3 & 17.0 & $\rightarrow$ \\
\hline $28 \ldots$ & 1.0 & 52 & .02 & 7 & - & 81 & 6.0 & 3.0 & 20 \\
\hline $28 \ldots$ & -- & -- & -- & 3 & 10.9 & - & -- & 3.0 & -- \\
\hline MAY & & & & & & & & & \\
\hline $05 \ldots$ & .7 & 44 & .09 & 10 & -- & 71 & 6.2 & 20.0 & 85 \\
\hline $05 \ldots$ & -- & - & -- & 13 & 10.8 & - & 6.6 & 20.0 & -- \\
\hline
\end{tabular}

LOCATION (revised).--Lat $35^{\circ} 32^{\prime} 08^{\prime \prime}$, long $77^{\circ} 30^{\circ} 41^{\prime \prime}$, P1tt County, at gaging station on downstream side of U.S. High-

way $264,1.5$ miles upstream from Middle Sqamp and 5.5 miles southeast of Farmville.

DRAINAGE AREA. $--93.3 \mathrm{sq}$ m1.

PERIOD OF RECORD.--Chemical analyses: October 1968 to September 1970 (partial record).

REMARKS.--Miscellaneous samples of chemical data published for water years 1956-67. The second of two samples collected at the same time is a field determination. CHEMICAL ANALYSES, WATER YEAR OCTORFR 1969 TO SEPTEMBER 1970

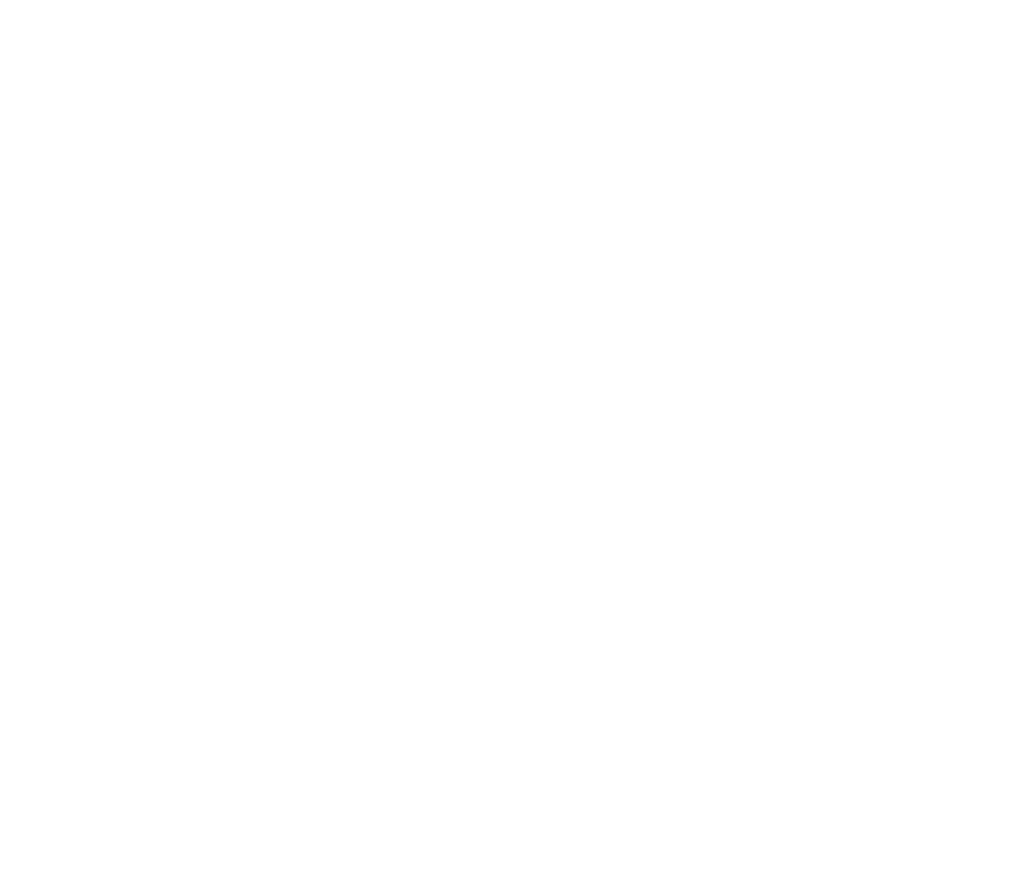

LOCATION.--Lat $35^{\circ} 22^{\prime} 00^{\prime \prime}$, long $77^{\circ} 26^{\prime} 30^{\prime \prime}$, Pitt County, at bridge on State Highway $11,0.5$ mile southwest of Grifton, 4.7 miles upstream from mouth.

DRAINAGE AREA.--980 sq mi, approximately.

PERIOD OF RECORD, .-Chemical analyses: October 1967 to September 1970 (partial record).

REMARKS,--Miscellaneous samples of chemical data published for water year 1949. The second of two samples collected at the same time is a field determination.

\begin{tabular}{|c|c|c|c|c|c|c|c|c|c|c|c|c|}
\hline OATF & TIME & $\begin{array}{l}\text { OIS- } \\
\text { CHARGE } \\
\text { (CFSI }\end{array}$ & $\begin{array}{l}\text { SILICA } \\
\text { ISIOZI } \\
\text { (HG/L) }\end{array}$ & $\begin{array}{l}\text { ANALYSF } \\
\text { DIS- } \\
\text { SOLVEO } \\
\text { IRDN } \\
\text { (FE) } \\
\text { (UG/L) }\end{array}$ & $\begin{array}{l}\text { WATER Y } \\
\text { CAL- } \\
\text { CIUM } \\
\text { (CA) } \\
\text { (MGILI }\end{array}$ & $\begin{array}{l}\text { AR OCTOB } \\
\text { MAG- } \\
\text { NE- } \\
\text { SIUM } \\
\text { (MG) } \\
\text { (MG/L) }\end{array}$ & $\begin{array}{l}\text { SODIUM } \\
\text { (NA) } \\
\text { (MG/L) }\end{array}$ & $\begin{array}{l}\text { SEPTENB } \\
\text { PO- } \\
\text { TAS- } \\
\text { SIUM } \\
\text { (K) } \\
\text { (MGLL) }\end{array}$ & $\begin{array}{l}\text { BICAR - } \\
\text { BONAYE } \\
\text { (HCD3) } \\
\text { (MG/L) }\end{array}$ & $\begin{array}{l}\text { CAR- } \\
\text { BONATE } \\
\text { (CO3) } \\
\text { (MG L ) }\end{array}$ & $\begin{array}{l}\text { SULFATE } \\
\text { (SO4) } \\
\text { (MG/L) }\end{array}$ & $\begin{array}{l}\text { CHLO- } \\
\text { RIDE } \\
\text { (CL) } \\
\text { (MG } / L)\end{array}$ \\
\hline $\begin{array}{l}\text { Nov. } \\
17 \ldots . . \\
17 \ldots\end{array}$ & $\begin{array}{l}1030 \\
1030\end{array}$ & $\begin{array}{l}509 \\
509\end{array}$ & 10 & 260 & 5.4 & 1.4 & 7.0 & 2.8 & 15 & -- & 9.6 & 11 \\
\hline MAR. & 1145 & - & 5.9 & 197 & 4.7 & 1.3 & 8.0 & 2.4 & 10 & 0 & 8.8 & 11 \\
\hline $\begin{array}{l}\text { JUNE } \\
12 \ldots . . \\
\text { SEPI. }\end{array}$ & 0925 & - & 2.4 & 225 & 7.9 & 1.8 & 12 & 2.8 & 30 & 0 & 8.8 & 16 \\
\hline $22 \ldots$ & $\begin{array}{l}1530 \\
1530\end{array}$ & $\begin{array}{l}75 \\
75\end{array}$ & 9.0 & 500 & 9.0 & 2.0 & 11 & 2.9 & 31 & -2 & 8.4 & 13 \\
\hline
\end{tabular}


NEUSE RIVER BASIN

02091764 CONTENTNEA CREEK AT GRI FTON, N,C. . COntinued

CHEMICAL ANALYSES, HATER YEAR OCTOBER 1969 TD SEPIEABER $197 \mathrm{C}$

\begin{tabular}{|c|c|c|c|c|c|c|c|c|c|c|c|c|}
\hline ITE & $\begin{array}{l}\text { FLUO- } \\
\text { RIOE } \\
\text { (F) } \\
\text { (MG/L) }\end{array}$ & $\begin{array}{l}\text { NITRATE } \\
\text { (NO3) } \\
\text { (MG/L) }\end{array}$ & $\begin{array}{l}\text { ORTHO } \\
\text { PHOS- } \\
\text { PHATE } \\
\text { (PO\&) } \\
\text { (HG/L) }\end{array}$ & $\begin{array}{l}\text { DIS- } \\
\text { SDLVED } \\
\text { SOLIOS } \\
\text { IRESI- } \\
\text { DUE AI } \\
\text { IBO C) } \\
\text { (MG/L) }\end{array}$ & $\begin{array}{l}\text { DIS- } \\
\text { SOLVED } \\
\text { SOLIDS } \\
\text { ITONS } \\
\text { PER } \\
\text { AC-FT) }\end{array}$ & $\begin{array}{l}\text { DIS- } \\
\text { SOLVED } \\
\text { SOLIDS } \\
\text { (TONS } \\
\text { PER } \\
\text { DAY) }\end{array}$ & $\begin{array}{l}\text { MARD- } \\
\text { NESS } \\
\text { (CA,MG) } \\
\text { (AG/L) }\end{array}$ & $\begin{array}{l}\text { NON- } \\
\text { CAR- } \\
\text { BONATE } \\
\text { HARD- } \\
\text { NESS } \\
\text { (MG/L) }\end{array}$ & $\begin{array}{l}\text { SODIUH } \\
\text { AD- } \\
\text { SDRP- } \\
\text { TION } \\
\text { RATIO }\end{array}$ & $\begin{array}{l}\text { PERCENT } \\
\text { SOO IUH }\end{array}$ & $\begin{array}{l}\text { METHY- } \\
\text { LENE } \\
\text { BLUE } \\
\text { ACTIVE } \\
\text { SUB- } \\
\text { STANCE } \\
\text { (MG/L) }\end{array}$ & $\begin{array}{l}\text { ALKA- } \\
\text { LINITY } \\
\text { AS } \\
\text { CACO3 } \\
\text { (AG/L) }\end{array}$ \\
\hline
\end{tabular}

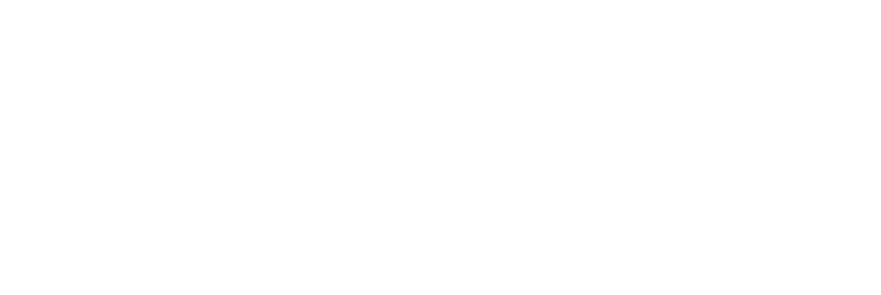

\begin{tabular}{|c|c|c|c|c|c|c|}
\hline $\begin{array}{l}\text { Nov. } \\
17 \ldots . .\end{array}$ & -- & 76 & 5.8 & 9.8 & $\cdots$ & 45 \\
\hline $17 \ldots$ & 6. 3 & - & 6.1 & 9.8 & -- & 45 \\
\hline $\begin{array}{l}\text { MAR. } \\
10 \ldots\end{array}$ & $\cdots$ & R9 & 6.1 & 10.3 & -- & 35 \\
\hline $\begin{array}{l}\text { JUNE } \\
12 \ldots . .\end{array}$ & -- & 120 & 6.6 & 25.7 & - & 25 \\
\hline SEPT. & 8.5 & $12 ?$ & 6.8 & 25.0 & $\cdots$ & + \\
\hline $22 \ldots$ & 9.5 & 115 & $\begin{array}{l}6.7 \\
7.4\end{array}$ & $\begin{array}{l}27.4 \\
27.4\end{array}$ & 30.1 & 25 \\
\hline
\end{tabular}

02091836 NEUSE RIVER AT STREETS FERRY NEAR VANCEBORO, N.C.

LOCATION.--Lat $35^{\circ} 12^{\prime} 20^{\prime \prime}$, long $77^{\circ} 07^{\prime} 40^{\prime \prime}$, Craven County, at bridge on Secondary Road 1400 at Streets Ferry, $1.4 \mathrm{miles}$ above the Gut and $7 \mathrm{miles}$ south of Vanceboro.

DRAIMAGE AREA.--4,040 $\mathrm{sq} \mathrm{mi}$.

PERIOD OF RECORD.--Chemical ana1yses: October 1954 to September 1966 (daily), October 1968 to September 1970

Water temperatures: October 1954 to september 1964.

EXTREYES, - Period of record:

Chloride: Haximum, 6,630 mg/l oct. 15, 1954; minimum, $3.0 \mathrm{mg} / 1$ June 22-30, 1961 ,

Specific conductance: Maximum daily, 17,800 micromhos Oct. 15, 1954; mintmum daily, 25 micromhos Yar. $11,1966$. water temperatures; -.Maximum, $33.5^{\circ} \mathrm{C}$ June 29,30 (T), 1959, July 7,22 (T), 1962; minimum, $0.5^{\circ} \mathrm{C}$ Feb. 19 (B), 1958 .

REKARKS.--Salinity station prior to october 1966; chemical analyses and temperature values were uetermined on integrated samples collected three times daily from September 1954 to September 1957, and top (T) and bot tom (B) years 1965.66 due to dally from October 1957 to September 1964. Extremes were not published during water ductance occurred in water year 1966. Daily records of specific conductance for water years 1954-64 available in files of district office in Raleigh, N.C. Records prior to water year 1958 published as Neuse River near Vanceboro. The second of two samples collected at the same time is a field determination.

CHEMICAL ANALYSES, WATER YEAR OCTOBER 1969 TO SEPTEMBER 1970

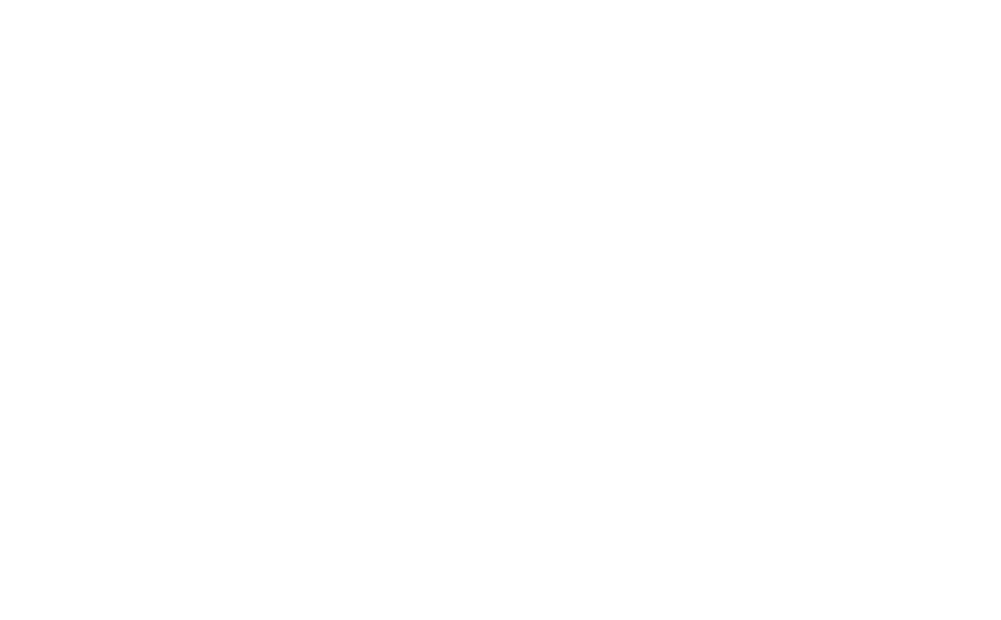


NEUSE RIVER BASIN

02091836 WEUSE RIVER AT STREETS FERRY NEAR VANCEBORO, N.C.--Continued

CHEMICAL ANALYSES, WATER YEAR OCTOBER 1969 TO SEPTEMBER 1970

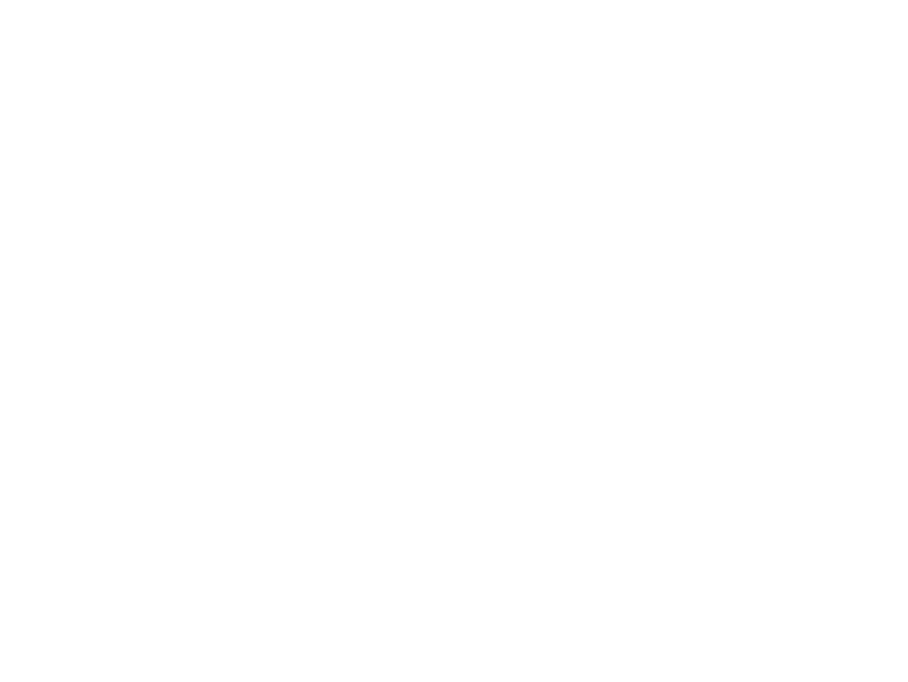

LOCATION.--Lat $35^{\circ} 00^{\prime} 35^{\prime \prime}$, long $77^{\circ} 13^{\prime} 10^{\prime \prime}$, Jones County, at bridge on U.S. Highway 17 , 0.2 mile northeast of Pollocksville and 0.4 mile upstream from $M 1 l 1$ Creek.

DRAINAGE AREA.--370 sq mi, approximately.

PERIOD OF RECORD, --Chemical analyses: January 1955 to November 1958, October 1961 to May 1967 (daily), October 1967 to september 1970 (partial record).

EXTREKES. -- Period of record:

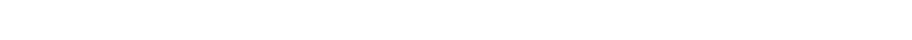

Specific conductance: Maximum daily, 9,230 micromhos Jan. 19, 1955; minimum daily, 36 micromhos Sept. 22, 23, 1955.

water temperatures: Maximum, $31.0^{\circ} \mathrm{C}$ June 7,1956 ; minimum, freezing point on many days in 1957 , $1958,1966$.

REMARKS.--Salinity station prior to October 1967; samples collected once daily. Unpublished records of specific conductance of daily samples January 1955 to September 1958 available in district of fice at Raleigh, N.C. Records of chemical analyses and daily specific conductance and water temperature collected at site $2.7 \mathrm{miles}$ downstream December 1958 to September 1959 were published as Trent River below Mill Creek near Pollocksville. collected at the same time is a field determination. CHEMICAL ANALYSES, WATER YEAR OCTOBER 1969 TO SEPTEMBER 1970

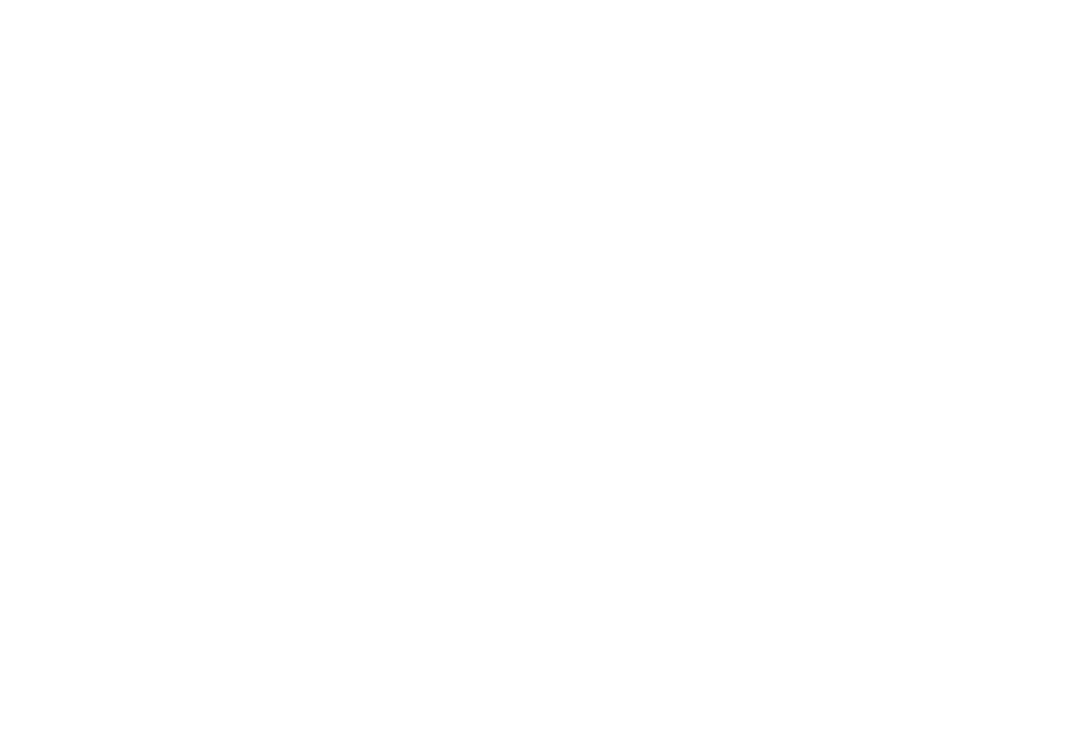


02092689 NEUSE RI VER AT MOUTH, NEAR MAW POINT, N.C.

LOCATION.--Lat $35^{\circ} 06^{\prime} 10^{\prime \prime}$, long $79^{\circ} 29^{\prime} 25^{\prime \prime}$, Pamlico County, at mouth on Carteret and Pamlico County 11 ne, 2.3 miles northwest of Point of Marsh in Carteret County and 3,1 miles southwest of Maw Point in Pamlico County.

DRAINAGE AREA.--5, $598 \mathrm{sq} \mathrm{mi}$.

PERIOD OF RECORD:--Chemical analyses: October 1968 to Saptember 1970 (partial record).

REMARKS.--The second of two samples collected at the same time is a field determination. CHEMICAL, ANALYSES, hATER YEAR OCTOBER 1969 TO SEPTEMBER 1970

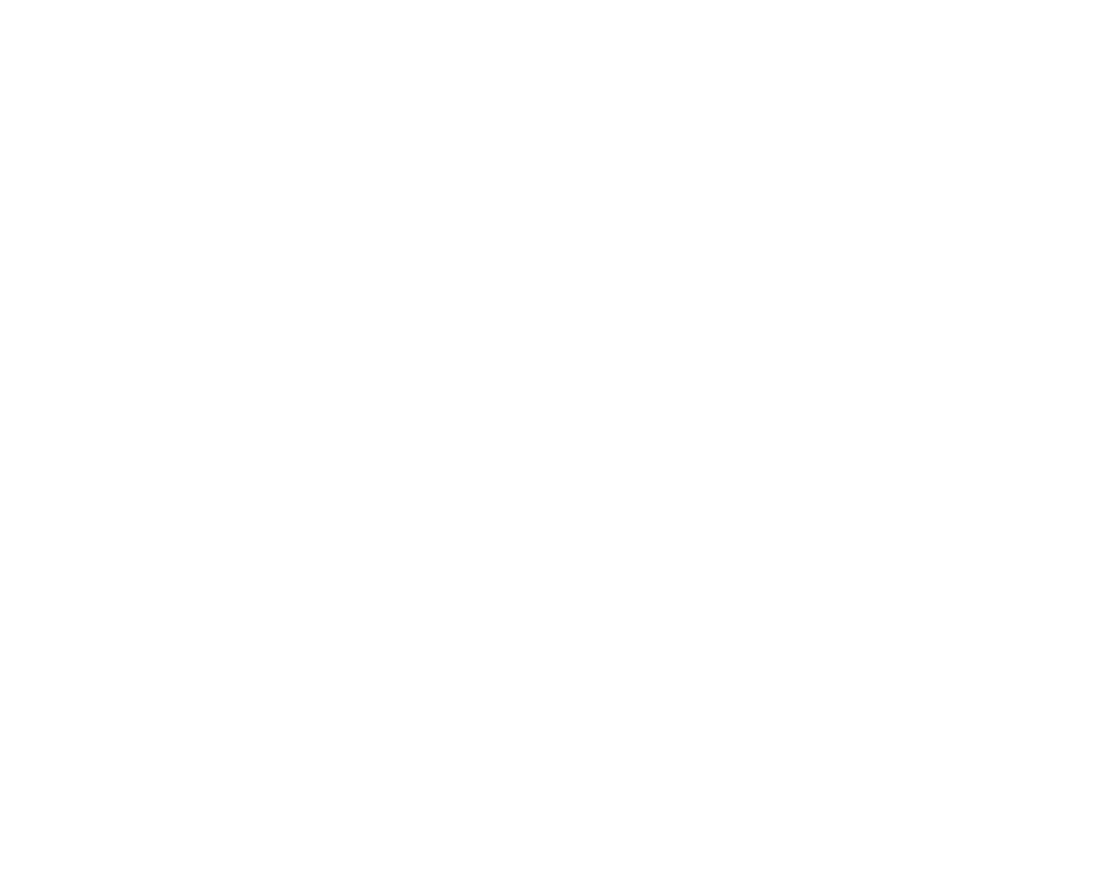

LOCATION.--Lat $34^{\circ} 46^{\prime} 28^{\prime \prime}$, long $77^{\circ} 09^{\prime} 14^{\prime \prime}$, Carteret County, at bridge 0.2 mile west of Stella, 1.0 mile upstream ff rom Webb creek.

DRAINAGE AREA, --216 sq mi.

PERIOD OF RECORD.--Chemical analyses: October 1967 to September 1970 (partial record).

REMARKS.--The second of two samples collected at the same time is a fleld determination. CHEMICAL ANALYSES, NATER YEAR OCTOBER 1969 TO SEPTEMBER 1970

\begin{tabular}{|c|c|c|c|c|c|c|c|c|c|c|c|}
\hline OATE & TIME & $\begin{array}{l}\text { SILICA } \\
\text { (SI OLZ) } \\
(\mathrm{MG} / \mathrm{L})\end{array}$ & $\begin{array}{l}\text { OIS- } \\
\text { SOLVED } \\
\text { IRON } \\
\text { (FE) } \\
\text { (UG/L) }\end{array}$ & $\begin{array}{l}\text { CAL- } \\
\text { CIUM } \\
(C A) \\
(M G / L)\end{array}$ & $\begin{array}{l}\text { MAG- } \\
\text { NE- } \\
\text { SIUM } \\
\text { (MG) } \\
(M G / L)\end{array}$ & $\begin{array}{l}\text { SODIUM } \\
\text { (NA) } \\
\text { (MG/L) }\end{array}$ & $\begin{array}{l}\text { PO- } \\
\text { TAS- } \\
\text { SIUM } \\
\text { (K) } \\
\text { (HG/L) }\end{array}$ & $\begin{array}{l}\text { BICAR- } \\
\text { BONATE } \\
\text { (HCO3) } \\
\text { (MG/L) }\end{array}$ & $\begin{array}{l}\text { CAR- } \\
\text { 6DNATE } \\
\text { (CO3) } \\
\text { (MG/L) }\end{array}$ & $\begin{array}{l}\text { SULFAIE } \\
\text { (S04) } \\
\text { (MG/L) }\end{array}$ & $\begin{array}{l}\text { CHLO- } \\
\text { RIDE } \\
\text { (CL) } \\
\text { (HG }\end{array}$ \\
\hline $\begin{array}{l}\text { DEC. } \\
\text { IB... } \\
\text { FEB. }\end{array}$ & 0815 & 6.9 & 211 & 50 & 91 & 820 & 55 & 49 & 0 & 224 & 1650 \\
\hline $\begin{array}{l}24 \ldots . . \\
\text { JUNE }\end{array}$ & 1415 & 5.7 & 165 & 15 & 2.7 & 20 & 1.0 & 33 & 0 & 12 & 96 \\
\hline $\begin{array}{l}16 \ldots . . \\
17 . .\end{array}$ & $\begin{array}{l}1545 \\
1950\end{array}$ & $\overline{-}$ & -- & $\begin{array}{l}225 \\
250\end{array}$ & $\begin{array}{l}310 \\
335\end{array}$ & - & -- & -- & -- & $\overline{-}$ & $\begin{array}{r}6500 \\
10000\end{array}$ \\
\hline $22 \ldots$ & 1145 & 4.8 & 250 & 120 & 292 & 2500 & - & 68 & 0 & 600 & 4480 \\
\hline DATE & $\begin{array}{l}\text { FLUO- } \\
\text { RIDE } \\
\text { (F) } \\
\text { (MG } / L)\end{array}$ & $\begin{array}{l}\text { NI TRATE } \\
\text { (NO3) } \\
\text { (MG/L) }\end{array}$ & $\begin{array}{l}\text { ORTHD } \\
\text { PHOS- } \\
\text { PHATE } \\
\text { (PO4) } \\
\text { (MG/L) }\end{array}$ & $\begin{array}{l}\text { DIS- } \\
\text { SOL VED } \\
\text { SOLIOS } \\
\text { (RESI- } \\
\text { DUE AT } \\
\text { IBO C) } \\
\text { (MGIL) }\end{array}$ & $\begin{array}{l}\text { DIS- } \\
\text { SOLVEO } \\
\text { SOLIDS } \\
\text { (TONS } \\
\text { PER } \\
\text { AC-FT) }\end{array}$ & $\begin{array}{l}\text { HARD- } \\
\text { NESS } \\
\text { (CA,MG) } \\
(M G / L)\end{array}$ & $\begin{array}{l}\text { NON- } \\
\text { CAR- } \\
\text { BONAIE } \\
\text { HARD- } \\
\text { NESS } \\
\text { (MG/L) }\end{array}$ & $\begin{array}{l}\text { SODIUM } \\
\text { AD- } \\
\text { SORP- } \\
\text { TION } \\
\text { RATIO }\end{array}$ & $\begin{array}{l}\text { PERCENT } \\
\text { SODIUM }\end{array}$ & $\begin{array}{l}\text { METHY- } \\
\text { LENE } \\
\text { BLUE } \\
\text { ACTIVE } \\
\text { SUB- } \\
\text { SI ANCE } \\
\text { (MG/L) }\end{array}$ & $\begin{array}{l}\text { ALKAA- } \\
\text { LINITY } \\
\text { AS } \\
\text { CACO3 } \\
\text { I MG /LI) }\end{array}$ \\
\hline $\begin{array}{l}\text { DEC. } \\
18 . . \\
\text { FEB. }\end{array}$ & .5 & + & .04 & 3045 & 4.14 & 499 & 459 & 16 & 76 & .27 & 40 \\
\hline JUNE & .2 & .6 & .07 & 149 & .20 & 48 & 22 & 1.2 & 47 & .04 & 27 \\
\hline $\begin{array}{l}16 \ldots \\
17 \ldots\end{array}$ & -+ & $=$ & $=-$ & $=$ & $\overline{-}$ & $\begin{array}{l}1830 \\
2000\end{array}$ & $\overline{-}$ & $\overline{-}$ & $=$ & $=$ & - \\
\hline $22 \ldots$ & .5 & - & $\rightarrow$ & $=-$ & - & -- & - & 28 & 78 & - & 56 \\
\hline
\end{tabular}


WHITE OAK RIVER BASIN

02092744 WHITE OAK RIVER AT STELLA, N.C._-_Cont1nued

CHEMICAL ANALYSES, WATER YEAR OCTOBER 1969 TO SEPTEMBER 1970

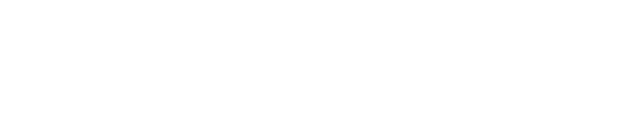

\begin{tabular}{|c|c|c|c|c|c|c|}
\hline $\begin{array}{l}\text { DEC. } \\
18 \ldots . . \\
18 \ldots\end{array}$ & 9.8 & $\begin{array}{r}4680 \\
--\end{array}$ & $\begin{array}{l}6.8 \\
7.6\end{array}$ & $\begin{array}{l}8.0 \\
8.0\end{array}$ & $=$ & $\begin{array}{r}40 \\
--\end{array}$ \\
\hline $\begin{array}{l}\text { FEB. } \\
24 \ldots . .\end{array}$ & -- & 224 & 6.8 & 10.0 & $\ldots$ & 160 \\
\hline $24 \ldots$ & 9.6 & - & 0.6 & 10.2 & $\sim$ & 100 \\
\hline JUNE & & & & & & \\
\hline $16 \ldots$ & - & 24000 & 6.6 & - & $\cdots$ & $\ldots$ \\
\hline $16 \ldots$ & 6.8 & 22000 & 7.7 & 28.0 & 28.4 & $=$ \\
\hline $17 \ldots$ & - & 27000 & 6.9 & + & -- & -- \\
\hline SEPT. & 7.0 & -- & 7.8 & 28.0 & -- & -- \\
\hline $\begin{array}{l}22 \ldots \\
22 \ldots\end{array}$ & $\overline{t .3}$ & 13000 & $\begin{array}{l}6.8 \\
6.8\end{array}$ & $\begin{array}{l}28.2 \\
28.2\end{array}$ & $=$ & 200 \\
\hline
\end{tabular}

NEW RIVER BASIN

02093197 NEW RIVER NEAR SNEEDS FERRY, N.C.

LOCATrON, - Lat $34^{\circ} 34^{\prime} 41^{\prime \prime}$, long $77^{\circ} 24^{\prime} 58^{\prime \prime}$, Onslow County, at drawbridge on State Highway $172,1.9 \mathrm{~m} 1$ les north of Sneeds Ferry and 5.1 miles upstream from mouth.

DRAINAGE AREA, - -430 sq mi, approximately.

PERIOD OF RECORD.--Chemical analyses: October 1967 to September 1970 (partial record).

REMARKS. - The second of two samples collected at the same time is a field determination.

CHEMICAL ANALYSES, WATER YEAR OCTOBER 1969 TO SEPTEMBER 1970

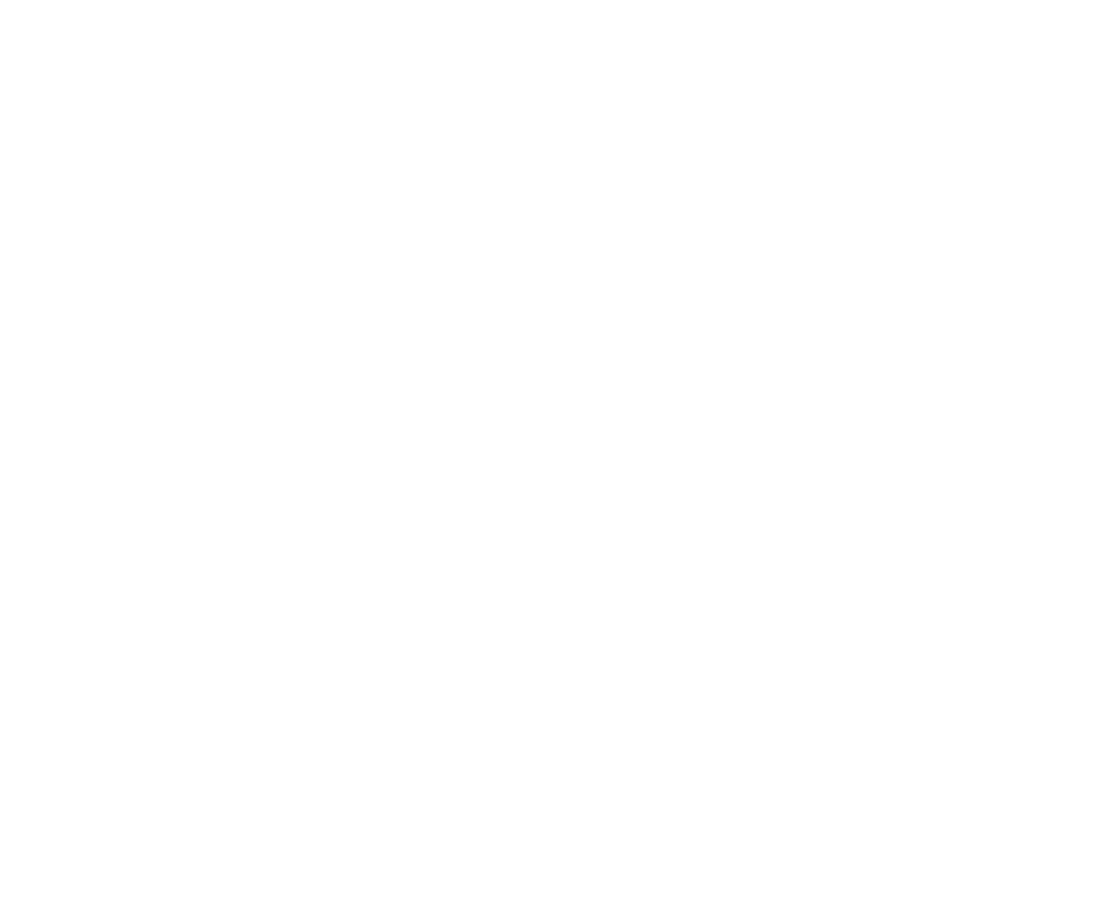


LOCATION.--Lat $35^{\circ} 42^{\prime} 97^{\prime \prime}$, long $79^{\circ} 05^{\prime} 12^{\prime \prime}$, Chatham County, at gaging station on left bank 100 ft upstream from Robeson Creek, $1,000^{\prime} \mathrm{ft}$ downstream from bridge on secondary Road 1943,2 miles downstream from bridge on R.S. Highway 64 , and 5 miles east of Pittsboro.

DRAI NAGE AREA.--1,310 sq mi, approximately.

PERI OD OF RECORD,--Chemical analyses: October 1967 to September 1970 (partial record).

REMARKS.--Miscellaneous samples of chemical data published for water years 1954-67, and miscellaneous samples of instantaneous sediment concentrations during rises published for water year 1970. Records of chemical analyses and daily water temperatures at station upstream, Haw River at Bynum, drainage area 1 , 280 sq mi, published for
October 1955 to September 1967. The second of two samples collected at the same time is a field determination. CHEMical analyses, water year dCtOBER 1969 to SEPTEMBER 1970

\begin{tabular}{|c|c|c|c|c|c|c|c|c|c|c|c|c|}
\hline DATE & TIME & $\begin{array}{l}\text { DIS- } \\
\text { CHARGE } \\
\text { (CFS) }\end{array}$ & $\begin{array}{l}\text { SILICA } \\
\text { (SIOL) } \\
\text { (MG/L) }\end{array}$ & $\begin{array}{l}\text { DIS- } \\
\text { SO VED } \\
\text { IRON } \\
\text { (FE) } \\
\text { (UG/L) }\end{array}$ & $\begin{array}{l}\text { CAL- } \\
\text { CIUM } \\
\text { ICA) } \\
\text { (MG/L) }\end{array}$ & $\begin{array}{c}\text { MAG- } \\
\text { NE- } \\
\text { SIUM } \\
\text { (MG) } \\
\text { (MG/L) }\end{array}$ & $\begin{array}{l}\text { SOD IUM } \\
\text { (NAA) } \\
\text { (MG/L) }\end{array}$ & $\begin{array}{l}\text { PO- } \\
\text { TAS- } \\
\text { SIUM } \\
\text { IK) } \\
\text { (MG/L) }\end{array}$ & $\begin{array}{l}\text { BICAR- } \\
\text { BDNATE } \\
\text { (HCO3) } \\
\text { IMGLL) }\end{array}$ & $\begin{array}{l}\text { CAR- } \\
\text { BONATE } \\
\text { (CO3) } \\
\text { (MG/L) }\end{array}$ & $\begin{array}{l}\text { SULFATE } \\
\text { (SO4) } \\
\text { (MG/L) }\end{array}$ & $\begin{array}{l}\text { CHLO- } \\
\text { RIDE } \\
\text { ICLI) } \\
\text { ( } \mathrm{HGAL})\end{array}$ \\
\hline $\begin{array}{l}\text { OCI. } \\
14 \ldots . \\
14 \ldots\end{array}$ & $\begin{array}{l}1130 \\
1130\end{array}$ & $1 \overline{129}$ & 16 & $\stackrel{0}{-}$ & 9.5 & 3.1 & ${ }^{44}$ & 6.0 & 64 & $\begin{array}{r}0 \\
-\end{array}$ & 22 & 41 \\
\hline $\begin{array}{l}\text { JAN. } \\
20 . . .\end{array}$ & 1345 & 562 & 14 & 120 & 8.3 & 3.8 & 24 & 2.2 & 44 & 0 & 16 & 20 \\
\hline $\begin{array}{c}\text { FEB. } \\
06 . . \\
\text { MAYY. }\end{array}$ & 1010 & 1420 & 14 & 73 & 7.0 & 2.6 & 12 & 2.8 & 28 & 0 & 14 & 14 \\
\hline $\begin{array}{l}06 \ldots \\
06 . . .\end{array}$ & $\begin{array}{l}1200 \\
1200\end{array}$ & $\begin{array}{l}2810 \\
2810\end{array}$ & 12 & $\begin{array}{r}237 \\
--\end{array}$ & 7.0 & 2.7 & 9.0 & 2.6 & 28 & - & 12 & 8.3 \\
\hline DATE & $\begin{array}{l}\text { FLUO- } \\
\text { RIOE } \\
\text { (F) } \\
\text { (MG/L) }\end{array}$ & $\begin{array}{c}\text { NI TRATE } \\
\text { (NO3) } \\
\text { (MG/L) }\end{array}$ & $\begin{array}{l}\text { ORTHO } \\
\text { PHOS- } \\
\text { PHATE } \\
\text { (PO4) } \\
\text { (MG/L) }\end{array}$ & $\begin{array}{l}\text { DIS- } \\
\text { SOLVED } \\
\text { SOLIOS } \\
\text { RRES I } \\
\text { DUE AT } \\
\text { I80 CI } \\
\text { IMG/LI }\end{array}$ & $\begin{array}{l}\text { DIS- } \\
\text { SOLVED } \\
\text { SOL IDS } \\
\text { ITONS } \\
\text { PER } \\
\text { AC-FT }\end{array}$ & $\begin{array}{l}\text { DIS- } \\
\text { SOLVED } \\
\text { SOLIDS } \\
\text { ITONS } \\
\text { PER } \\
\text { DAYI }\end{array}$ & $\begin{array}{l}\text { HARO- } \\
\text { NESS } \\
(C A, M G) \\
(M G / L)\end{array}$ & $\begin{array}{l}\text { NON- } \\
\text { CAR- } \\
\text { BONATE } \\
\text { HARD- } \\
\text { NESS } \\
\text { (MG/L) }\end{array}$ & $\begin{array}{l}\text { SODIUM } \\
\text { AD- } \\
\text { SORP- } \\
\text { IION } \\
\text { RATIO }\end{array}$ & $\begin{array}{l}\text { PERC ENT } \\
\text { SOD IUT }\end{array}$ & $\begin{array}{l}\text { MESHYY- } \\
\text { LENEE } \\
\text { BLUE } \\
\text { ACTIVE } \\
\text { SUE- } \\
\text { SIANCE } \\
\text { IMG/LI }\end{array}$ & $\begin{array}{l}\text { ALKA- } \\
\text { LINITY } \\
\text { AS } \\
\text { CACO3 } \\
\text { (MG /L) }\end{array}$ \\
\hline
\end{tabular}

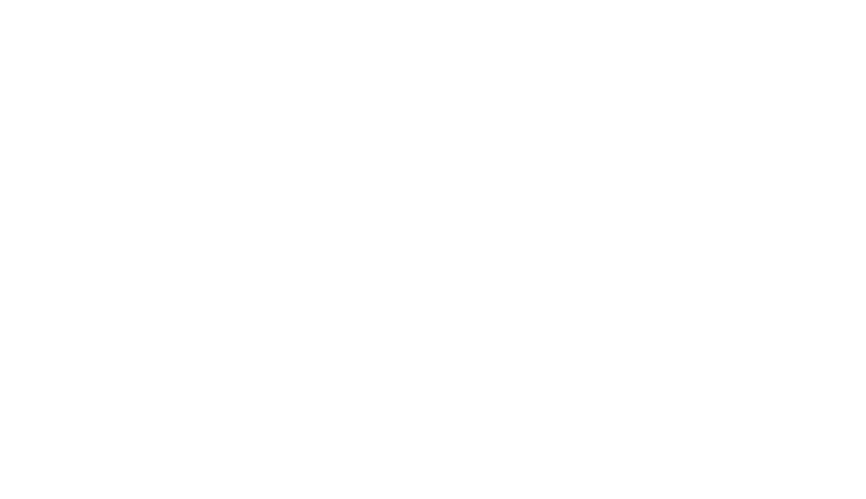

SUSPENDED-SEDIMENT DISCHARGE MEASUREMENTS, WATER YEAR OCTOBER 1969 TD SEPTEMBER 1970

\begin{tabular}{|c|c|c|c|c|c|c|c|c|c|c|}
\hline & OATE & TIME & $\begin{array}{l}\text { DISCHARGE } \\
\text { (CFS) }\end{array}$ & $\begin{array}{l}\text { CONCEN- } \\
\text { TRATION } \\
\text { (MG IL) }\end{array}$ & $\begin{array}{l}\text { SUSPENOED } \\
\text { SEDIMENT } \\
\text { DISCHARGE } \\
\text { (TONS/OAY) }\end{array}$ & DATE & TIME & $\begin{array}{l}\text { DISCHARGE } \\
\text { (CFS) }\end{array}$ & $\begin{array}{l}\text { CONCEN- } \\
\text { TRATION } \\
\text { IMGLL) }\end{array}$ & $\begin{array}{l}\text { SUSPENDED } \\
\text { SEDIMENT } \\
\text { DISCHARGE } \\
\text { (TONS/OAY) }\end{array}$ \\
\hline
\end{tabular}

SUSPENDED-SEDIMENT DISCHARgE MEASUREMENTS AND PARTICLE-SIZE DISTRIBUTION, WATER YEAR OCTOBER 1969 TO SEPIEMBER 1970 (METHODS OF ANALYSIS: B, BOTTOM WITHDRAWAL TUBE; C, CHEMICALLY DISPERSEDI N, IN NATIVE WATERI P, PIPETI S, SIEVE
V, VISUAL ACCUMULATION TUBE; W, IN DISTILLED WATER)

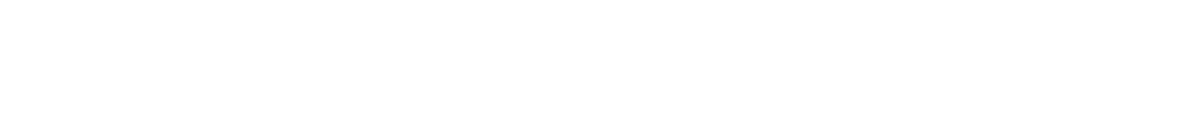




\section{CAPE FEAR RIVER BASIN}

02104000 CAPE FEAR RIVER AT FAYETTEVILLE, N.C.

LOCATION, --Lat $35^{\circ} 02^{\prime} 49^{\prime \prime}$, long $78^{\circ} 51^{\prime} 36^{\prime \prime}$, Cumberland County, at bridge on Person Street at Fayetteville, 0.3 mile downstream from cross creek and at mile 145 .

DRAI NAGE AREA. $--4,370 \mathrm{sq} \mathrm{mi}$.

PERIOD OF RECORD.--Chem1cal analyses: October 1948 to September 1949, October 1964 to September 1967 (da1ly), October 1967 to September 1970 (partial record).

EXTREMES, --Period of record:

Dissolved solids: Maximum, $63 \mathrm{mg} / 1 \mathrm{Mar} 15,1949 ; \mathrm{mln} 1 \mathrm{mum}, 39 \mathrm{mg} / 1 \mathrm{Jan}, 15,1949$.

REMARKS. - Miscellaneous samples of chemical data published for water years 1955, 1956, 1960-62. The second of two samples collected at the same time is a fleld determination. CHEMICAL ANALYSES, WATER YEAR OCTOBER 1969 TO SEPTEMBER 1970

\begin{tabular}{|c|c|c|c|c|c|c|c|c|c|c|c|}
\hline DATE & T I ME & $\begin{array}{l}\text { SILICA } \\
\text { (SIOZ) } \\
\text { (MG/L) }\end{array}$ & $\begin{array}{l}\text { OIS- } \\
\text { SOLVED } \\
\text { IRON } \\
\text { IFEI } \\
\text { IUG/LI }\end{array}$ & $\begin{array}{l}\text { CAL- } \\
\text { CIUA } \\
\text { (CA) } \\
(\mathrm{MG} / \mathrm{L})\end{array}$ & $\begin{array}{l}\text { MAG- } \\
\text { NE- } \\
\text { SIUM } \\
\text { (MG) } \\
\text { IMG/L) }\end{array}$ & $\begin{array}{l}\text { SODIUM } \\
\text { (NA) } \\
\text { ING/LI }\end{array}$ & $\begin{array}{l}\text { PO- } \\
\text { TAS- } \\
\text { SIUM } \\
\text { IKI } \\
\text { (MG/L) }\end{array}$ & $\begin{array}{l}\text { BICAR- } \\
\text { BONATE } \\
\text { (HCO3) } \\
\text { (HG/L) }\end{array}$ & $\begin{array}{l}\text { CAR- } \\
\text { BDNATE } \\
\text { (CO3) } \\
\text { (AG/L) }\end{array}$ & $\begin{array}{l}\text { SULFATE } \\
\text { (SO4) } \\
\text { (NG/L) }\end{array}$ & $\begin{array}{l}\text { CHLO- } \\
\text { RIDE } \\
\text { (CLI) } \\
\text { (MG/L) }\end{array}$ \\
\hline $\begin{array}{c}\text { BCT. } \\
23 . . \\
\text { JAN. }\end{array}$ & 1500 & 8.2 & 140 & 4.6 & 1.6 & 14 & 3.0 & 21 & 0 & 9.2 & 14 \\
\hline $\begin{array}{l}26 \ldots \\
26 \ldots\end{array}$ & $\begin{array}{l}1110 \\
1110\end{array}$ & 9.4 & 112 & 5.0 & 1.9 & 13 & 1.4 & $\begin{array}{l}23 \\
36\end{array}$ & 0 & 10 & 15 \\
\hline $29 \ldots$ & 1215 & 11 & 49 & 5.3 & 1.9 & $16^{-}$ & $2 . \overline{1}$ & 27 & 0 & $12^{--}$ & 25 \\
\hline MAY $29 .$. & 1215 & - & -- & - & - & - & - & 30 & - & - & - \\
\hline $\begin{array}{l}25 \ldots . . \\
\text { AUG. }\end{array}$ & 1430 & 9.0 & 68 & 6.0 & 2.6 & 18 & 1.8 & 29 & 0 & 16 & 14 \\
\hline $17 \ldots$ & 1600 & 10 & 107 & 5.5 & 2.3 & 7.4 & 2.9 & 17 & 0 & 10 & 7.8 \\
\hline DATE & $\begin{array}{l}\text { FLUO- } \\
\text { RIOE } \\
\text { (F) } \\
\text { (MG/L) }\end{array}$ & $\begin{array}{l}\text { NI TRATE } \\
\text { (NO3) } \\
\text { (MG / I ) }\end{array}$ & $\begin{array}{l}\text { ORTHO } \\
\text { PHOS- } \\
\text { PHATE } \\
\text { (PO4) } \\
\text { (MG/L) }\end{array}$ & $\begin{array}{l}\text { OIS- } \\
\text { SOL VED } \\
\text { SOLIDS } \\
\text { IRES I- } \\
\text { DUE AT } \\
180 \mathrm{Cl} \\
\text { ( } \mathrm{MG/L} \text { ) }\end{array}$ & $\begin{array}{l}\text { DIS- } \\
\text { SOLVED } \\
\text { SOLIOS } \\
\text { (TONS } \\
\text { PER } \\
\text { AC-FTI }\end{array}$ & $\begin{array}{l}\text { HARO- } \\
\text { NESS } \\
\text { (CA,MG) } \\
\text { (MG/L) }\end{array}$ & $\begin{array}{l}\text { NON- } \\
\text { CAR- } \\
\text { BONATE } \\
\text { HARD- } \\
\text { NESS } \\
\text { (MG/L, }\end{array}$ & $\begin{array}{l}\text { SODIUM } \\
\text { AO- } \\
\text { SORP- } \\
\text { TION } \\
\text { RATIO }\end{array}$ & $\begin{array}{l}\text { PERCENT } \\
\text { SDOIUM }\end{array}$ & $\begin{array}{l}\text { METHY- } \\
\text { LENE } \\
\text { BLUE } \\
\text { ACTIVE } \\
\text { SUB- } \\
\text { STANCE } \\
\text { IMG/L) }\end{array}$ & $\begin{array}{l}\text { ALKA- } \\
\text { LINITY } \\
\text { AS } \\
\text { CACO3 } \\
\text { (MG/L) }\end{array}$ \\
\hline
\end{tabular}

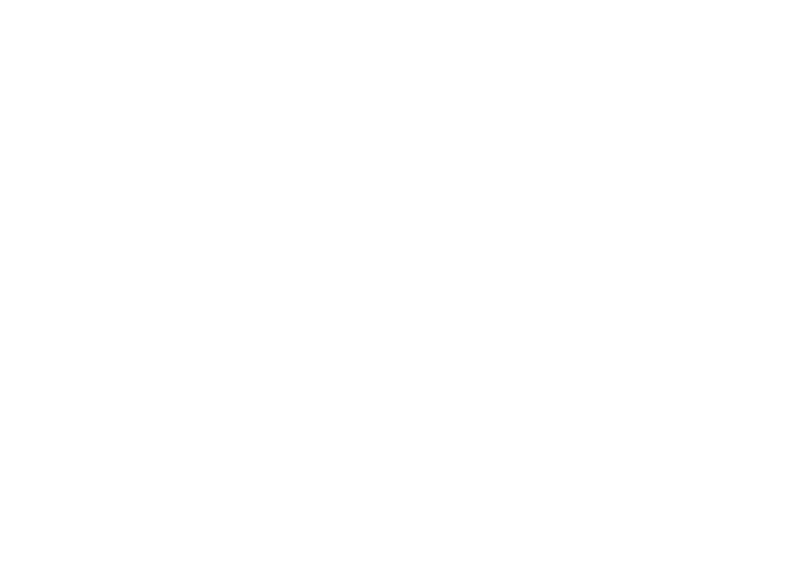

02105771 CAPE FEAR RIVER NEAR ACME, N.C.

LOCATION.--Lat $35^{\circ} 23^{\prime} 48^{\prime \prime}$, long $78^{\circ} 16^{\prime} 05^{\prime \prime}$, Bladen County, at bridge on State Highway $141,0.8 \mathrm{mile}$ downstream from Natmore Creek and $6, i$ miles nor thwest of Acme, Columbus County.
Nat

DRAINAGE AREA, $--5,230 \mathrm{sq} \mathrm{ml}$.

PERIOD OF RECORD..-Chemical analyses: October 1956 to September 1967 (da11y), October 1967 to September 1970 Water temperatures: October 1956 to September 1961.

EXTREMES. - - Perlod of record:

Dissolved solids: Maximum, $94 \mathrm{mg} / 1$ oct, 3-10, 1959; min1mum, $30 \mathrm{mg} / 1$ Sept. 15-18, 1958.

Hardness: Maximum, $27 \mathrm{mg} / 1$ oct. 3-10, 1959; minlmum, $11 \mathrm{mg} / 1 \mathrm{Mar} 1 \mathrm{1-10}, 1957, \mathrm{Apr} .11-20,1958$

Spec1f1c conductance: Maximum dally, 148 micromhos Oct, 6, 8, 1959; minimum da1ly, 40 micromhos Feb. $12,1960$. Water temperatures: Nax1mum, $30.0^{\circ} \mathrm{C}$ on several days during sumer periods; m1n1mum, 0.5 $5^{\circ} \mathrm{C}$ Jan. 12,1958

REMARKS.--The second of two samples collected at the same time is a field determination. CHEMICAL ANALYSES, WATER YEAR OCTOBER 1969 TO SEPTEMBER 1970

\begin{tabular}{|c|c|c|c|c|c|c|c|c|c|c|c|}
\hline DATE & TI ME & $\begin{array}{l}\text { SIL ICA } \\
\text { I } I \text { IOZ I } \\
\text { ( } \mathrm{MG} / \mathrm{L} \text { ) }\end{array}$ & $\begin{array}{l}\text { DIS- } \\
\text { SOLVED } \\
\text { IRON } \\
\text { IFE) } \\
\text { (UG/LI }\end{array}$ & $\begin{array}{l}\text { CAL- } \\
\text { CIUM } \\
\text { (CA) } \\
(M G / L)\end{array}$ & $\begin{array}{c}\text { MAG- } \\
\text { NE- } \\
\text { SIUM } \\
\text { (MG) } \\
\text { (MG/L) }\end{array}$ & $\begin{array}{l}\text { SOOI UM } \\
\text { (NA) } \\
\text { IMG/LI }\end{array}$ & $\begin{array}{l}\text { PO- } \\
\text { IAS- } \\
\text { SIUN } \\
\text { (K) } \\
\text { (MG/L) }\end{array}$ & $\begin{array}{l}\text { BI CAR- } \\
\text { BONATE } \\
\text { (HCO3) } \\
\text { (MG/L) }\end{array}$ & $\begin{array}{l}\text { CAR- } \\
\text { BONATE } \\
\text { ICOBI } \\
\text { (NG/LI }\end{array}$ & $\begin{array}{l}\text { SULFATE } \\
\text { (SOA) } \\
\text { (MG/L) }\end{array}$ & $\begin{array}{l}\text { CHLD- } \\
\text { RIDE } \\
(C L) \\
(A G / L)\end{array}$ \\
\hline $\begin{array}{l}\text { OCr. } \\
23 . . .\end{array}$ & 1100 & 9.1 & 180 & 4.0 & 1.1 & 7.7 & 2.2 & 15 & 0 & 6.4 & 8.2 \\
\hline JAA. $29 . .$. & 1235 & 10 & 63 & 4.3 & 1.6 & 13 & 1.6 & 19 & 0 & 8.6 & 14 \\
\hline $\begin{array}{l}\text { FEB. } \\
\begin{array}{r}23 \\
\text { MAY }\end{array}\end{array}$ & 1420 & 7.9 & 113 & 3.4 & 1.6 & 5.3 & 1.5 & 9 & D & 9.2 & 5.9 \\
\hline $26 \ldots$ & 1040 & 13 & 47 & 7.0 & 2.3 & 10 & 1.9 & 24 & 0 & 12 & 12 \\
\hline $\begin{array}{c}\text { AUGG. } \\
18 . . .\end{array}$ & 0930 & 9.2 & 161 & 4.8 & 1.9 & 7.5 & 3.0 & 15 & 0 & 10 & 7.6 \\
\hline
\end{tabular}


CAPE FEAR RIVER BASIN

02105771 CAPE FEAR RIVER NEAR ACME, N.C.--Continued

CHEMICAL ANAL YSES, WATER YEAR OCTOBER 1969 TO SEPTEMBER 1970

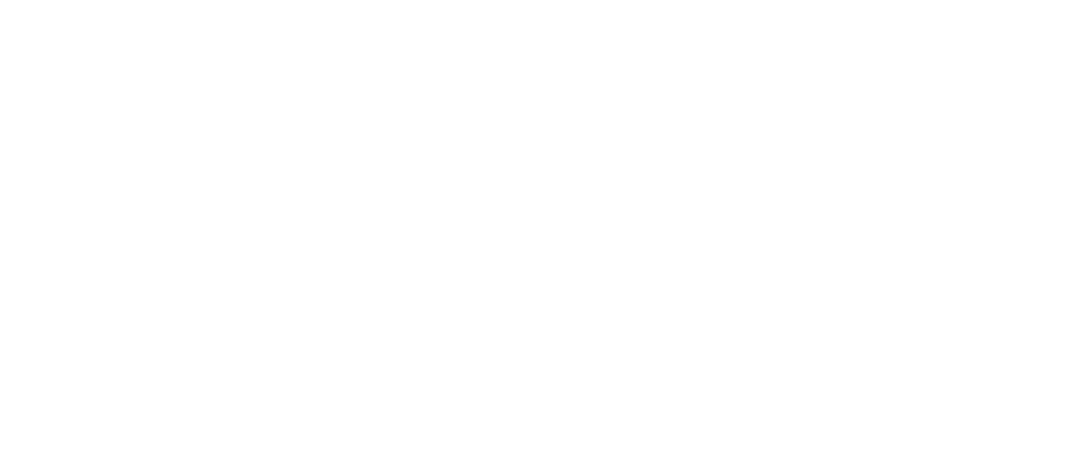

\begin{tabular}{|c|c|c|c|c|c|c|}
\hline $\begin{array}{l}0 C t . \\
23 . \ldots\end{array}$ & -- & 63 & 6.? & -- & - & \\
\hline $23 \ldots$ & 7.5 & - & 5.1 & 17.3 & -- & - \\
\hline JAN. & & & & & & \\
\hline $29 . \ldots$ & - & 97 & 6.9 & $3 . ?$ & -- & 55 \\
\hline $29 .$. & 12.2 & -- & 8.3 & $3 . ?$ & -- & -- \\
\hline FEA. & & & & & & \\
\hline $23 \ldots$ & 10.5 & 59 & 5.3 & 9.3 & -- & 75 \\
\hline $23 \ldots$ & 10.5 & -- & 6.3 & 9.0 & -- & -- \\
\hline MAY & & & & & & \\
\hline $26 \ldots$ & -- & 131 & 6.3 & 24.5 & - & 25 \\
\hline $\begin{array}{l}26 . . \\
\text { AUG.. }\end{array}$ & 9.4 & -- & 7.5 & 24.5 & -- & -- \\
\hline $18 \ldots$ & -- & gn & 6.1 & 25.9 & - & 170 \\
\hline $18 \ldots$ & 6.8 & -- & 5.4 & 25.8 & 28.0 & - \\
\hline
\end{tabular}

D2108637 NORTHEAST CAPE FEAR RIVER NEAR CASTLE HAYNE, N.C.

LOCATION.--Lat $34^{\circ} 20^{\prime} 20^{\prime \prime}$, long $77^{\circ} 59^{\prime} 40^{\prime \prime}$, Pender County, at end of Secondary hoad $1428,4.2 \mathrm{miles}$ downstream from Long Creek and 5.8 miles west of Castile Hayne.

DRAINAGE AREA. $--1,690 \mathrm{sq} \mathrm{mi}$, approximately.

PERIOD OF RECORD. -. Chemical analyses: October 1969 to September 1970 (partial record).

REMARKS. - The second of two samples collected at the same time is a field determination.

CHEMICAL ANALYSES, WATER yeAR OCTOBER 1969 TO SEPTEMBER 1970

\begin{tabular}{|c|c|c|c|c|c|c|c|c|c|c|c|}
\hline DATE & T I ME & $\begin{array}{l}\text { SILICA } \\
\text { (SIOL) } \\
\text { (MG/L) }\end{array}$ & $\begin{array}{l}\text { DIS- } \\
\text { SOLVED } \\
\text { IRON } \\
\text { (FE) } \\
\text { (UG/L) }\end{array}$ & $\begin{array}{l}\text { CAL- } \\
\text { CIUM } \\
\text { (CA) } \\
\text { IMG/L) }\end{array}$ & $\begin{array}{l}\text { MAG- } \\
\text { NE- } \\
\text { SIUM } \\
\text { IMG I } \\
\text { (MG/L) }\end{array}$ & $\begin{array}{l}\text { SODIUM } \\
\text { (NA) } \\
\text { IMG/L) }\end{array}$ & $\begin{array}{l}P O- \\
\text { IAS- } \\
\text { SIUM } \\
\text { (K) } \\
(M G / L)\end{array}$ & $\begin{array}{l}\text { BICAR- } \\
\text { BONATE } \\
\text { (HCDS) } \\
\text { (MG/L) }\end{array}$ & $\begin{array}{l}\text { CAR- } \\
\text { BONATE } \\
\text { (COB) } \\
(M G / L)\end{array}$ & $\begin{array}{l}\text { SULFATE } \\
\text { (SO4) } \\
\text { (MG/L) }\end{array}$ & $\begin{array}{l}\text { CHLD- } \\
\text { RIDE } \\
\text { (CL) } \\
\text { (MG/L) }\end{array}$ \\
\hline \multirow[t]{2}{*}{$\begin{array}{l}\text { JULY } \\
23 \ldots . .\end{array}$} & 1835 & 5.9 & 36 & 21 & 3.0 & 20 & 4.5 & 57 & 0 & 18 & 35 \\
\hline & $\begin{array}{l}\text { FLUO- } \\
\text { RIDE } \\
\text { (F) } \\
\text { (MG/L) }\end{array}$ & $\begin{array}{l}\text { NITRATE } \\
\text { (NOJ) } \\
\text { (MG/L) }\end{array}$ & $\begin{array}{l}\text { ORTHO } \\
\text { PHOS- } \\
\text { PHATE } \\
\text { (PO4) } \\
\text { (MG/L) }\end{array}$ & 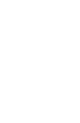 & $\begin{array}{l}\text { DIS- } \\
\text { SOLVED } \\
\text { SQLIDS } \\
\text { (TONS } \\
\text { PER } \\
\text { AC-FT) }\end{array}$ & $\begin{array}{l}\text { HARD- } \\
\text { NESS } \\
(C A, M G) \\
(M G / L)\end{array}$ & $\begin{array}{l}\text { NON- } \\
\text { CAR- } \\
\text { BONATE } \\
\text { HARD- } \\
\text { NESS } \\
\text { (MG/L) }\end{array}$ & $\begin{array}{l}\text { SODIUM } \\
\text { AD- } \\
\text { SORP- } \\
\text { TION } \\
\text { RATIO }\end{array}$ & $\begin{array}{l}\text { PERCENT } \\
\text { SODIUM }\end{array}$ & $\begin{array}{l}\text { MEIHY- } \\
\text { LENE } \\
\text { BLUE } \\
\text { ACTIVE } \\
\text { SUB- } \\
\text { STANCE } \\
\text { (MG LL) }\end{array}$ & $\begin{array}{l}\text { ALKA- } \\
\text { LINITY } \\
\text { AS } \\
\text { CACD3 } \\
\text { (MG/L) }\end{array}$ \\
\hline $\begin{array}{l}\text { JULY } \\
23 \ldots\end{array}$ & .3 & 1.8 & .00 & 135 & .18 & 65 & 18 & 1.1 & 38 & .00 & 47 \\
\hline & & & DATE & $\begin{array}{l}\text { DIS- } \\
\text { SOLVED } \\
\text { SXYGEN } \\
\text { (MG/LI }\end{array}$ & $\begin{array}{l}\text { SPECI- } \\
\text { FIC } \\
\text { COND- } \\
\text { UCTANCE } \\
\text { IMICRO- } \\
\text { MHOSI }\end{array}$ & $\begin{array}{c}\text { PH } \\
\text { (UNITS) }\end{array}$ & $\begin{array}{l}\text { TEMP- } \\
\text { ERATURE } \\
\text { (DEG CI }\end{array}$ & $\begin{array}{l}\text { COLDR } \\
\text { (PLAT- } \\
\text { INUM- } \\
\text { COBALT } \\
\text { UNITS I }\end{array}$ & & & - \\
\hline & & & $\begin{array}{l}\text { JULY } \\
23 \ldots \ldots \\
23 \ldots\end{array}$ & 4.5 & 232 & $\begin{array}{l}6.6 \\
6.2\end{array}$ & $\begin{array}{l}28.0 \\
28.0\end{array}$ & 60 & & & \\
\hline
\end{tabular}


CAPE FEAR RIVER BASIN

02108850 CAPE FEAR RIVER AT SUNNY POINT, N.C.

LOCATION.--Lat $33^{\circ} 59^{\prime} 00^{\prime \prime}$, long $77^{\circ} 56^{\prime} 40^{\prime \prime}$, Brunswick County, on right bank at Sunny Point Army Ocean Terminal loading dock at Sunn point and $2.0 \mathrm{miles}$ upstream from valden creek.

DRAINAGE AREA. $--9,070 \mathrm{sq} \mathrm{ml}$, approximately.

PERIOD OF RECORD.--Chemlcal analyses: October 1969 to september 1970 (partial record).

REUARKS. - The second of two samples collected at the same time is a field determination.

CHEMICAL ANALYSES, WATER YEAR OCTOBER 1969 TO SEPTEMBER 1970

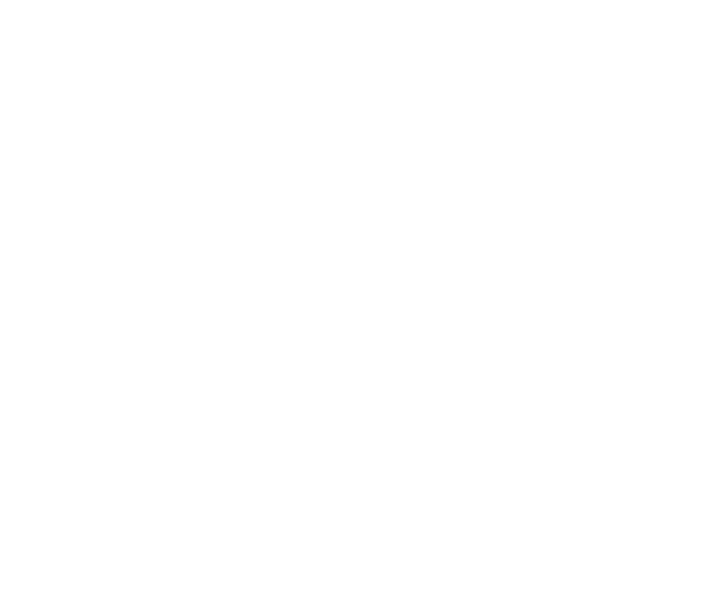

LOCATION,--Lat $34^{\circ} 05^{\prime} 43^{\prime \prime}$, long $78^{\circ} 32 \cdot 56^{\prime \prime}$, Brunswick County, at gaging station on left bank 150 ft downstream from New Britton bridge on State Highway i3o, 1 mile southwest of Freeland, 7 miles downstream from Juniper Creek, and 117 miles upstream from mouth in winyah Bay.

DRAINAGE AREA, .-706 sq $\mathrm{ml}$.

PERIOD OF RECORD. - Chemical analyses: October 1950 to September 1951, October 1956 to September 1962 (daily),

October $: 967$ to Sept ber 1970 (partial record).
water temperatures: October 1950 to September 1951 , June 1960 to Septomber 1961 , October 1962 to September 1967.

EXTREMES. - - Period of record:

Dissolved solids $(1950-51)$ : Maximum, $116 \mathrm{mg} / 1$ Sept, 1-10, 1951; mintmum, $56 \mathrm{mg} / 1$ Mar, $11-20,1951$.

Hardness $(1950-51)$ : Maximum, 27 mg/1 Sept. 1-10, 1951; minimum, 02 mg/1 Dec. 11-20, 21-31, i950, Jan. 1-10,

veter

Kaximum, $35.5^{\circ} \mathrm{C}$ June $18,19,1960$; minimum, freezing point Feb. 1, 1966.

REMARKS. --Yonthly samples collected october 1956 to September 1962 . Miscellaneous samples of chemical data pub.

lished for water years 1945, 1950, 1955-56, 1963-67. The second of two samples collocted at the same time is

CHEMiCAL ANALYSES, hater year october 1969 TO SEPTEMBER 1970

\begin{tabular}{|c|c|c|c|c|c|c|c|c|c|c|c|}
\hline OATE & I I ME & $\begin{array}{l}\text { SILICA } \\
\text { (SIO2) } \\
\text { (NG/L) }\end{array}$ & $\begin{array}{l}\text { DIS- } \\
\text { SOLVED } \\
\text { IRON } \\
\text { (FE) } \\
\text { (UG/L) }\end{array}$ & $\begin{array}{l}\text { CAL- } \\
\text { CIUM } \\
\text { (CA) } \\
\text { (MG/L) }\end{array}$ & $\begin{array}{l}\text { MAG- } \\
\text { NE- } \\
\text { SIUM } \\
\text { (MG) } \\
\text { (MG/L) }\end{array}$ & $\begin{array}{l}\text { SODIUM } \\
\text { (NA) } \\
\text { (MG/L) }\end{array}$ & $\begin{array}{l}\text { PO- } \\
\text { TAS- } \\
\text { SIUM } \\
\text { (K) } \\
\text { (MG/L) }\end{array}$ & $\begin{array}{l}\text { BICAR- } \\
\text { BONATE } \\
\text { (HCO3) } \\
\text { (MG/L) }\end{array}$ & $\begin{array}{l}\text { CAR- } \\
\text { BONATE } \\
\text { (CO3) } \\
\text { (AG/L) }\end{array}$ & $\begin{array}{c}\text { SULFATE } \\
\text { (SOH) } \\
\text { (NG/L) }\end{array}$ & $\begin{array}{l}\text { CHLO- } \\
\text { RIOE } \\
\text { (CL) } \\
\text { (AG/L) }\end{array}$ \\
\hline
\end{tabular}

$\begin{array}{clllllllllll}\text { JULY } & & & & & & & & & & & \\ 23 \ldots & 1605 & 4.7 & 239 & 6.3 & 1.0 & 7.9 & 1.1 & 12 & 0 & 8.2 & 10\end{array}$

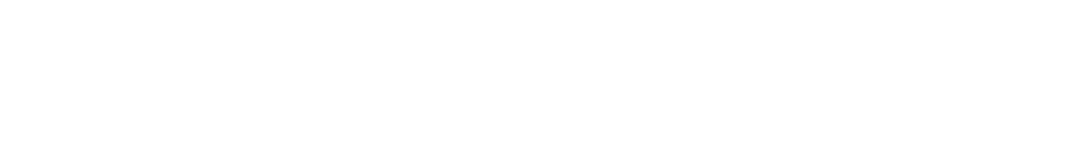

$\begin{array}{llll}\text { JulY } & & & \\ 23 . . . & .3 & 2.6 & .03\end{array}$

$95 \quad .13 \quad 20 \quad 10$

.05

10

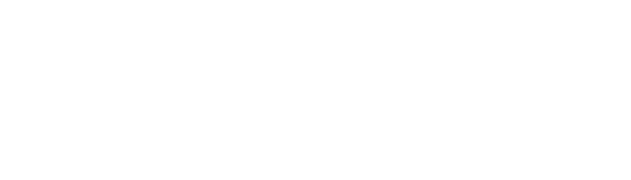


02115051 YADKIN RIVER AT DONNAHA, N.C.

LOCATION, .. Lat $36^{\circ} 12^{\prime} 52^{\prime \prime}$, 1ong $80^{\circ} 25^{\prime} 57^{\prime \prime}$, Forsyth County, at bridge on state Highway 67, $0.8 \mathrm{mile}$ south of Donnaha and 3.5 miles upstream from Fries Creek.

DRAINAGE AREA, --1,650 sq $\mathrm{m1}$, approximately.

PERIOD OF RECORD..-Chemical analyses: October 1967 to september 1970 (partial record).

REMARXs.-. The second of two samples collected at the same time is a field determination.

CHEMICAL ANALYSES, WATER YEAR OCTOBER 1969 TO SEPTEMBER 1970

\begin{tabular}{|c|c|c|c|c|c|c|c|c|c|c|c|c|}
\hline DATE & TIME & $\begin{array}{l}\text { DIS- } \\
\text { CHARGE } \\
\text { (CFS) }\end{array}$ & $\begin{array}{l}\text { SILICA } \\
\text { (SIO2) } \\
\text { (MG/L) }\end{array}$ & $\begin{array}{l}\text { DIS- } \\
\text { SOLVED } \\
\text { IRON } \\
\text { IFE I } \\
\text { (UG/L) }\end{array}$ & $\begin{array}{l}C \dot{C A}- \\
C I U M \\
(C A \mid \\
(M G / L)\end{array}$ & $\begin{array}{l}\text { MAG- } \\
\text { NE- } \\
\text { SIUM } \\
\text { (MG) } \\
\text { (MG/L) }\end{array}$ & $\begin{array}{l}\text { SDOIUM } \\
(N A) \\
(M G / L)\end{array}$ & $\begin{array}{l}\text { PO- } \\
\text { TAS- } \\
\text { SIUM } \\
\text { (K) } \\
\text { (MG/L) }\end{array}$ & $\begin{array}{l}\text { BICAR- } \\
\text { BONATE } \\
\text { (HCD3) } \\
\text { (NG/L) }\end{array}$ & $\begin{array}{l}\text { CAR- } \\
\text { BONATE } \\
\text { (CO3) } \\
\text { (MG/L) }\end{array}$ & $\begin{array}{l}\text { SULFATE } \\
\text { (SO4) } \\
\text { (MG/L) }\end{array}$ & $\begin{array}{l}\text { CHLO- } \\
\text { RIDE } \\
\text { (CL) } \\
\text { (MG/LI) }\end{array}$ \\
\hline $\begin{array}{l}\text { NOV. } \\
19 . . . \\
19 . . .\end{array}$ & $\begin{array}{l}0830 \\
0830\end{array}$ & $\begin{array}{l}1240 \\
1240\end{array}$ & 10 & -7 & 2.4 & $\therefore$ & 3.8 & 1.0 & 17 & -0 & 3.6 & 4.0 \\
\hline $\begin{array}{l}\text { JUNE } \\
10 \ldots . . \\
10 \ldots\end{array}$ & $\begin{array}{l}1900 \\
1900\end{array}$ & $\begin{array}{l}1400 \\
1400\end{array}$ & 12 & 17 & 4.4 & $\because 3$ & 3.9 & 2.4 & 18 & -0 & 2.8 & $\begin{array}{r}3.8 \\
--\end{array}$ \\
\hline $\begin{array}{l}\text { SEPT. } \\
15 . . \\
15 . .\end{array}$ & $\begin{array}{l}1100 \\
1100\end{array}$ & $\begin{array}{l}1320 \\
1320\end{array}$ & 11 & 20 & 2.9 & 1.2 & 3.4 & 1.5 & 20 & -0 & 2.4 & 2.8 \\
\hline DATE & $\begin{array}{l}\text { FLUO- } \\
\text { RIOE } \\
\text { IFI } \\
\text { (MG/L) }\end{array}$ & $\begin{array}{l}\text { NITRATE } \\
\text { (NO3) } \\
\text { (MG/L) }\end{array}$ & $\begin{array}{l}\text { ORTHD } \\
\text { PHDS- } \\
\text { PHATE } \\
\text { (PD4) } \\
\text { (MG/L) }\end{array}$ & $\begin{array}{l}\text { OIS- } \\
\text { SDLVED } \\
\text { SOLIDS } \\
\text { IRESI- } \\
\text { DUE AT } \\
\text { I8O C) } \\
\text { (MG L ) }\end{array}$ & $\begin{array}{l}\text { DIS- } \\
\text { SOLVED } \\
\text { SOLIOS } \\
\text { ITONS } \\
\text { PER } \\
\text { AC-FTI }\end{array}$ & $\begin{array}{l}\text { OIS- } \\
\text { SOLVEO } \\
\text { SOLIOS } \\
\text { ITONS } \\
\text { PER } \\
\text { OAYI }\end{array}$ & $\begin{array}{l}\text { HARO- } \\
\text { NESS } \\
(C A, M G) \\
(M G / L)\end{array}$ & $\begin{array}{l}\text { NON- } \\
\text { CAR- } \\
\text { BONATE } \\
\text { HARO- } \\
\text { NESS } \\
\text { (MG/L) }\end{array}$ & $\begin{array}{l}\text { SOOIUA } \\
\text { AO- } \\
\text { SORP- } \\
\text { TION } \\
\text { RATIO }\end{array}$ & $\begin{array}{l}\text { PERCENT } \\
\text { SODIUM }\end{array}$ & $\begin{array}{l}\text { METHY- } \\
\text { LENE } \\
\text { BLUE } \\
\text { ACTIVE } \\
\text { SUB- } \\
\text { ST ANCE } \\
\text { I MG/LI }\end{array}$ & $\begin{array}{l}\text { ALKA- } \\
\text { LINITY } \\
\text { AS } \\
\text { CACO3 } \\
\text { (MG /L) }\end{array}$ \\
\hline $\begin{array}{l}\text { NOV. } \\
19 . \ldots \\
19 . . . \\
\text { JUNE }\end{array}$ & $=1$ & .5 & .00 & 23 & .03 & 77.0 & 18 & - & .5 & 43 & .12 & 14 \\
\hline $\begin{array}{l}10 \ldots \\
10 . . . \\
\text { SEPT. }\end{array}$ & $=1$ & .5 & .20 & 41 & .06 & 155 & 12 & $\underline{0}$ & $\div$ & 36 & .05 & 15 \\
\hline $15 . \ldots$ & \pm 1 & -3 & .01 & 40 & .05 & $143 \ldots$ & 12 & - & $\because 4$ & 34 & .01 & 16 \\
\hline & & & DATE & $\begin{array}{l}\text { DIS- } \\
\text { SOLVED } \\
\text { DXYGEN } \\
\text { (NG/LI) }\end{array}$ & $\begin{array}{l}\text { SPECI- } \\
\text { FIC } \\
\text { COND- } \\
\text { UCTANCE } \\
\text { IMICRO- } \\
\text { MHOSI }\end{array}$ & $\begin{array}{c}\text { PH } \\
\text { (UNITS) }\end{array}$ & $\begin{array}{l}\text { TEMP- } \\
\text { ERATURE } \\
\text { (DEG C) }\end{array}$ & $\begin{array}{l}\text { AIR } \\
\text { TEMP- } \\
\text { ERATURE } \\
\text { (DEG C I }\end{array}$ & $\begin{array}{l}\text { COLOR } \\
\text { IPLAT- } \\
\text { INUM- } \\
\text { COBALT } \\
\text { UNITSI }\end{array}$ & & & \\
\hline & & & $\begin{array}{l}\text { NIV. } \\
19 . . . \\
19 . . \\
\text { JUNE. }\end{array}$ & $10 . \overline{0}$ & $\begin{array}{l}39 \\
42\end{array}$ & $\begin{array}{l}5.8 \\
7.9\end{array}$ & $\begin{array}{l}8.1 \\
8.1\end{array}$ & $=$ & 10 & & & \\
\hline & & & $\begin{array}{l}1 \cap \ldots \\
\text { SEPT. }\end{array}$ & $7 .-8$ & $\begin{array}{l}45 \\
38\end{array}$ & $\begin{array}{l}6.1 \\
7.3\end{array}$ & $\begin{array}{l}24.5 \\
24.5\end{array}$ & 26.0 & -- & & & \\
\hline & & & $\begin{array}{l}15 \ldots \\
15 . .\end{array}$ & 6.8 & $\begin{array}{l}42 \\
57\end{array}$ & $\begin{array}{l}6.8 \\
6.4\end{array}$ & $\begin{array}{l}23.5 \\
23.5\end{array}$ & 25.0 & 5 & & & \\
\hline
\end{tabular}
LOCATION.--Lat $35^{\circ} 46^{\prime} 49^{\prime \prime}$, long $80^{\circ} 30^{\prime} 24^{\prime \prime}$, Davie county, at bridge on U.S. Highway $601,1.5 \mathrm{~m} 1$ les downstream from

DRAINAGE AREA. -- 760 sq mi, approximately.

PERIOD OF RECORD.--Chemical analyses: October 1967 to September 1970 (partial record). REMARKS.--The second of two samples collected at the same time is a field determination. CHEMICAL ANALYSES, WATER YEAR OCTOBER 1969 TO SEPTEMBER 1970

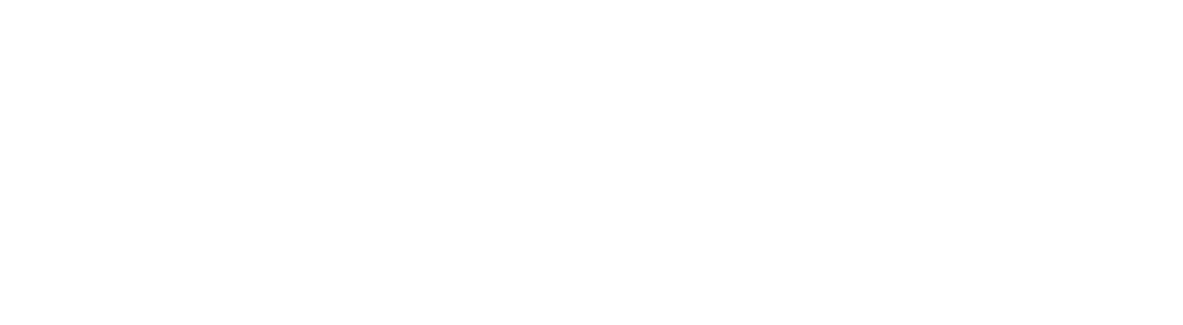


PEE DEE RIVER BASIN

02120668 SOUTH YADKIN RIVER NEAR FRANKLIN, N. C.--Cont1nued CHEMICAL ANALYSES, WATER YEAR OCTOBER 1969 TO SEPTEMBER 1970

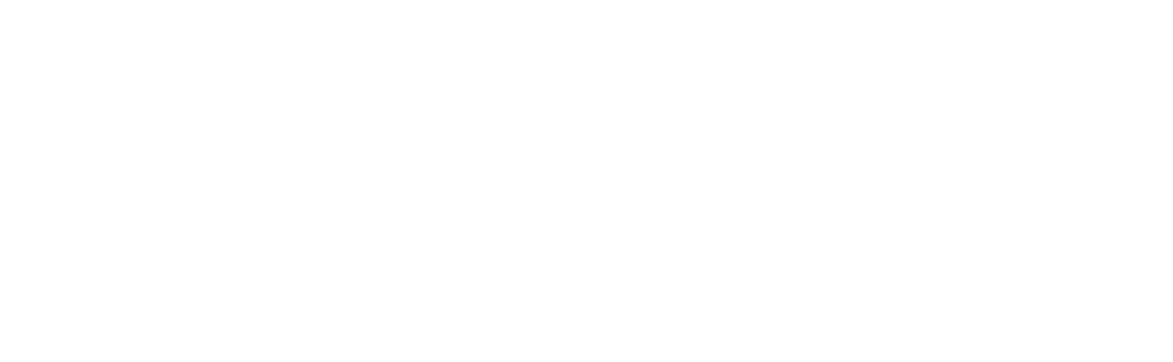

\begin{tabular}{|c|c|c|c|c|c|c|c|}
\hline & & $\begin{array}{l}\text { FECAL } \\
\text { COLI- }\end{array}$ & $\begin{array}{l}\text { SPECF - } \\
\text { FIC }\end{array}$ & & & & COLOR \\
\hline & D15- & & COND- & & & AIR & $\begin{array}{l}\text { IPLAT- } \\
\text { INUM- }\end{array}$ \\
\hline & $\begin{array}{l}\text { SOLVE? } \\
\text { OXYCEN }\end{array}$ & $\begin{array}{l}\text { ICOL. } \\
\text { PER }\end{array}$ & $\begin{array}{l}\text { UCTANCE } \\
\text { IMICRO- }\end{array}$ & PH & $\begin{array}{l}\text { TEMP- } \\
\text { ERATURE }\end{array}$ & $\begin{array}{l}\text { TEMP- } \\
\text { ERATURE }\end{array}$ & $\begin{array}{l}\text { INUM- } \\
\text { COBALT }\end{array}$ \\
\hline DATF & (NG/L) & $1 \cap 0 \mathrm{ML}]$ & MHOSI & (UNITS) & $(D=G(1)$ & (DEG C) & UNITSI \\
\hline
\end{tabular}

\begin{tabular}{|c|c|c|c|c|c|c|c|}
\hline $\begin{array}{l}\text { NoV. } \\
13 . . .\end{array}$ & - & - & 71 & & & & 5 \\
\hline $\begin{array}{l}13 \ldots \\
13 \ldots \\
\text { FER. }\end{array}$ & 9.6 & $=$ & 82 & 7.9 & 9.6 & - & $=$ \\
\hline $05 \ldots$ & -- & -- & 52 & 6.2 & 4.0 & -- & 25 \\
\hline n5... & 8.7 & -- & 64 & 7.2 & 4.0 & $\ldots$ & $\cdots$ \\
\hline JUNE & & & & & & & \\
\hline $1 \geqslant \ldots$ & -- & -- & 72 & 6.5 & 21.0 & -- & 5 \\
\hline $12 \ldots$ & 4.8 & $\sim$ & $4 ?$ & 7.2 & $21 . n$ & -- & -- \\
\hline JULY & & & & & & & \\
\hline $\begin{array}{l}14 \ldots . \\
\text { SEPT. }\end{array}$ & -- & $\mathrm{KBC}$ & -- & -- & $-\infty$ & -- & - \\
\hline $17 \ldots$ & -- & -- & 71 & 6.5 & 22.5 & -- & 5 \\
\hline $17 \ldots$ & 5.5 & -- & 78 & $\cdots$ & 22.5 & 25.5 & -- \\
\hline
\end{tabular}

02122500 YADKIN RIVER AT HIGH ROCK, N,C.

LOCATION, --Lat $35^{\circ} 35^{\prime} 46^{\prime \prime}$, long $80^{\circ} 13^{\prime} 59^{\prime \prime}$, Davidson County, 0.3 mile downstream from High Rock Dam, 0.6 mile west of High hock, 1.8 miles upstream from Lick Creek, and at mile 252 .

DRAINAGE AREA. $--4,000$ sq mi.

PERIOD OF RECORD.--Chemical analyses: October 1947 to September 1948 (daily), October 1967 to September 1970 (partial record).

Water temperatures: October 1947 to September 1948 ,

EXTREMES, - - Period of record:

Dissolved solids: Maximum, $53 \mathrm{mg} / 1$ Nov. 11-20, 1947; minimum, $36 \mathrm{mg} / 1$ Apr. 1-10, 1948

Hardness: Maximum, $21 \mathrm{mg} / 1$ July $1-10$, 1948 ; minimum, $13 \mathrm{mg} / \mathrm{l}$ Oct, $1-10,1947$, Aug, 11-20, 1948

Water temperatures: Maximum, $27.0^{\circ} \mathrm{C}$ July $20,22,23,24$, Aug. 2, 1948; minimum, 3.0 ${ }^{\circ} \mathrm{C}$ Jan. 25, Feb. 1-7. 10, $12,14,1948$.

REKARKS.--Miscellaneous samples of chemical data published for water years 1944, 1955-62. The second of two samples collected at the same time is a field determination. CHEMICAL ANALYSES, WATER YEAR OCTOBER 1969 TO SEPTEMBER 1970

\begin{tabular}{|c|c|c|c|c|c|c|c|c|c|c|}
\hline DATE & TIME & $\begin{array}{l}\text { UIS- } \\
\text { CHARGE } \\
\text { (CFS) }\end{array}$ & $\begin{array}{l}\text { SILICA } \\
\text { ISIOZI) } \\
\text { (MG/LI) }\end{array}$ & $\begin{array}{l}\text { DIS- } \\
\text { SOLVED } \\
\text { IRON } \\
\text { (FE) } \\
\text { (UG/L) }\end{array}$ & $\begin{array}{l}\text { UIS- } \\
\text { SOLVEO } \\
\text { CAL- } \\
\text { CIUM } \\
\text { (CA) } \\
\text { I MUILI }\end{array}$ & $\begin{array}{l}\text { OIS- } \\
\text { SOE VED } \\
\text { MAG- } \\
\text { NEE- } \\
\text { SIUM } \\
\text { (MG) } \\
\text { (MG/L) }\end{array}$ & $\begin{array}{l}\text { SODIUM } \\
\text { (NA) } \\
\text { (MU/L) }\end{array}$ & $\begin{array}{l}P O- \\
\text { TAS- } \\
S I U M \\
(K) \\
(Y G / L)\end{array}$ & $\begin{array}{l}\text { BICAR - } \\
\text { BONATE } \\
\text { (HCO3) } \\
(M G / L)\end{array}$ & $\begin{array}{l}\text { CAR- } \\
\text { BJVATE } \\
\text { (CD } 31 \\
\text { (MG/L) }\end{array}$ \\
\hline Nuv. & & & & & & & & & & \\
\hline $\begin{array}{l}17 \ldots \\
17 \ldots \\
F \in 8 .\end{array}$ & $\begin{array}{l}1000 \\
1000\end{array}$ & $\begin{array}{l}7970 \\
7970\end{array}$ & 14 & $\begin{array}{r}4 \\
--\end{array}$ & 4.4 & 1.4 & 8.4 & 3.0 & 29 & -1 \\
\hline $\begin{array}{l}05 \ldots \\
05 \ldots\end{array}$ & $\begin{array}{l}1530 \\
1530\end{array}$ & $\begin{array}{l}7935 \\
7935\end{array}$ & 13 & 11 & 4.2 & $\begin{array}{r}1.7 \\
-.-\end{array}$ & 6.2 & 1.7 & $\begin{array}{l}23 \\
--\end{array}$ & $\therefore$ \\
\hline $\begin{array}{l}14 \ldots \\
14 \ldots\end{array}$ & $\begin{array}{l}11110 \\
11110\end{array}$ & $\begin{array}{l}7800 \\
7800\end{array}$ & 12 & 20 & 5.1 & 1.5 & 5.9 & 2.0 & 27 & 0 \\
\hline JUNE & & & & & & & 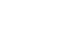 & & $\cdots$ & - \\
\hline $\begin{array}{c}12 \ldots \\
12 \ldots \\
\text { AUb. }\end{array}$ & $\begin{array}{l}0915 \\
0915\end{array}$ & 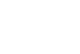 & $13 \ldots$ & 28 & $\begin{array}{r}5.3 \\
-2\end{array}$ & 2.6 & 5.3 & $\begin{array}{r}2.7 \\
--\end{array}$ & 30 & $\begin{array}{r}0 \\
--\end{array}$ \\
\hline $04 \ldots$ & 1530 & 7840 & 13 & 20 & 5.3 & 1.9 & 8.5 & 2.7 & 30 & 0 \\
\hline $\begin{array}{l}04 \ldots \\
\text { SEP. }\end{array}$ & 1530 & 7840 & -- & -- & - & -- & -- & -- & -- & $-\cdots$ \\
\hline $\begin{array}{l}17 \ldots \\
17 \ldots\end{array}$ & $\begin{array}{l}1415 \\
1415\end{array}$ & $\begin{array}{l}7585 \\
7585\end{array}$ & $12 \ldots$ & -2 & $\begin{array}{r}5.5 \\
--.\end{array}$ & 1.7 & 6.3 & $\begin{array}{r}2.5 \\
--\end{array}$ & 26 & 0 \\
\hline
\end{tabular}


PEE DEE RIVER BASIN

02122500 YADKIN RIVER AT HIGH ROCK, N.C.L-Continued

CHEMICAL ANALYSES, WATER YEAR OCTOBER 1969 TO SEPTEMBER 1970

\begin{tabular}{|c|c|c|c|c|c|c|c|c|c|}
\hline DATE & $\begin{array}{l}\text { SULFATE } \\
\text { (SO4) } \\
\text { (MG/L) }\end{array}$ & $\begin{array}{l}\text { CHLO- } \\
\text { RIOE } \\
(C L) \\
(M G / L)\end{array}$ & $\begin{array}{l}\text { DIS- } \\
\text { SOLVED } \\
\text { FLUD- } \\
\text { RIDE } \\
\text { (F) } \\
\text { (MG/L) }\end{array}$ & $\begin{array}{l}\text { N(TRATE } \\
\text { (NO3) } \\
\text { (MG/L) }\end{array}$ & $\begin{array}{l}\text { OIS- } \\
\text { SOLVEO } \\
\text { OR THO } \\
\text { PHOS- } \\
\text { PHATE } \\
\text { (P Q4) } \\
\text { (MG/L) }\end{array}$ & $\begin{array}{l}\text { OLS- } \\
\text { SOLVEO } \\
\text { SOLIDS } \\
\text { (RESI- } \\
\text { DUE AT } \\
\text { IBD C) } \\
\text { (MGIL) }\end{array}$ & $\begin{array}{l}\text { OLS- } \\
\text { SOLVED } \\
\text { SOLIOS } \\
\text { (TONS } \\
\text { PER } \\
\text { AC-FT) }\end{array}$ & $\begin{array}{l}\text { DLS- } \\
\text { SOLVED } \\
\text { SOLIDS } \\
\text { ITONS } \\
\text { PER } \\
\text { DAY) }\end{array}$ & $\begin{array}{c}\text { SODLUY } \\
\text { AD- } \\
\text { SORP- } \\
\text { TLON } \\
\text { RATIO }\end{array}$ \\
\hline $\begin{array}{l}\text { Nuv. } \\
17 . . .\end{array}$ & 5.6 & 6.6 & - & 2.4 & 10 & 51 & .08 & 1310 & .9 \\
\hline & -- & -- & - & - & -- & - & 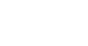 & 1300 & $\because$ \\
\hline $\begin{array}{l}05 \ldots \\
05 \ldots \\
\text { MAY }\end{array}$ & 5.6 & 5.2 & $\therefore 1$ & .7 & .01 & 55 & .07 & 1180 & $\div 6$ \\
\hline $\begin{array}{l}14 \ldots \\
\text { JUNE }\end{array}$ & $\begin{array}{c}5.6 \\
--.\end{array}$ & $\begin{array}{r}5.7 \\
---\end{array}$ & $\therefore$ & 1.7 & $\because 08$ & 46 & .06 & $969 \ldots$ & .6 \\
\hline $\begin{array}{l}12 \ldots \\
12 \ldots \\
\text { AUG. }\end{array}$ & 4.8 & $\begin{array}{r}5.6 \\
--0\end{array}$ & .2 & 1.2 & .00 & 62 & .08 & $=$ & $\because 5$ \\
\hline $\begin{array}{l}04 \ldots \\
04 \ldots \\
S E P\end{array}$ & 4.8 & 7.0 & -1 & 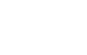 & .01 & 60 & .08 & 1270 & $\therefore 8$ \\
\hline $17 \ldots$ & 5.2 & 5.2 & .2 & 1.1 & .03 & 59 & .08 & 1210 & $\therefore 6$ \\
\hline $\begin{array}{l}\text { DATE } \\
\text { NOV. }\end{array}$ & $\begin{array}{l}\text { PERCENT } \\
\text { SOOLUM }\end{array}$ & $\begin{array}{l}8 \text { IO- } \\
\text { CHEM- } \\
\text { ICAL } \\
\text { OXYGEN } \\
\text { DEMAND } \\
\text { (MGIL) }\end{array}$ & $\begin{array}{l}\text { ME THY- } \\
\text { LENE } \\
\text { BLUE } \\
\text { ACTLVE } \\
\text { SUB- } \\
\text { STANCE } \\
\text { (MGLL) }\end{array}$ & $\begin{array}{l}\text { ALKA- } \\
\text { LLNITY } \\
\text { AS } \\
\text { CACOB } \\
\text { (MG/L) }\end{array}$ & $\begin{array}{l}\text { DLS- } \\
\text { SOLVED } \\
\text { OXYGEN } \\
\text { (MG/L) }\end{array}$ & $\begin{array}{l}\text { SPECI - } \\
\text { FIC } \\
\text { CONO- } \\
\text { UCIANCE } \\
\text { (MICRO- } \\
\text { MHOSI }\end{array}$ & $\begin{array}{c}\text { PH } \\
\text { (UNITS) }\end{array}$ & $\begin{array}{l}\text { TEMP- } \\
\text { ERATURE } \\
\text { IUEG C) }\end{array}$ & $\begin{array}{l}\text { COLOR } \\
\text { IPLAT- } \\
\text { I NUM- } \\
\text { COBAL } \\
\text { UNL TSI }\end{array}$ \\
\hline $\begin{array}{l}17 \ldots \\
\text { FEB. }\end{array}$ & $\begin{array}{l}47 \\
--\end{array}$ & $\overline{--}$ & .01 & 24 & 8.5 & $\begin{array}{l}89 \\
85\end{array}$ & $\begin{array}{l}6.0 \\
7.8\end{array}$ & $\begin{array}{l}11.1 \\
11.1\end{array}$ & 15 \\
\hline $\begin{array}{l}05 \ldots . . \\
\text { MAY }\end{array}$ & 41 & $=$ & .02 & 19 & $8 . \overline{5}$ & $\begin{array}{l}63 \\
70\end{array}$ & $\begin{array}{l}6.4 \\
7.1\end{array}$ & $\begin{array}{l}5.0 \\
5.0\end{array}$ & 15 \\
\hline $\begin{array}{l}14 \ldots . \\
\text { IUNE } \\
\text { JUNE }\end{array}$ & 37 & $=$ & .07 & $\begin{array}{l}22 \\
22\end{array}$ & 5.5 & 77 & $\begin{array}{l}6.3 \\
6.8\end{array}$ & $\begin{array}{l}22.0 \\
22.0\end{array}$ & -5 \\
\hline $\begin{array}{l}12 \ldots \\
12 \ldots \\
\text { AUG. }\end{array}$ & 30 & $\because$ & .02 & 25 & $\begin{array}{l}4.4 \\
4.4\end{array}$ & 80 & $\begin{array}{l}6.3 \\
6.9\end{array}$ & $\begin{array}{l}24.2 \\
24.2\end{array}$ & 10 \\
\hline $\begin{array}{l}04 \ldots . \\
04 \ldots \\
\text { SEP. }\end{array}$ & 43 & 4.9 & .07 & $\begin{array}{l}30 \\
30\end{array}$ & $\begin{array}{l}4.9 \\
4.9\end{array}$ & 90 & $\begin{array}{l}6.7 \\
6.7\end{array}$ & $\begin{array}{l}29.0 \\
29.0\end{array}$ & 10 \\
\hline $\begin{array}{l}17 \ldots \\
17 \ldots\end{array}$ & $\begin{array}{l}36 \\
--\end{array}$ & $=$ & .03 & 21 & 4.8 & $\begin{array}{l}51 \\
79\end{array}$ & $\begin{array}{l}6.4 \\
6.4\end{array}$ & $\begin{array}{l}26.5 \\
26.5\end{array}$ & 10 \\
\hline
\end{tabular}

02126000 ROCKY RIVER NEAR NORWOOD, N.C.

LOCATION.--Lat $35^{\circ} 08^{\prime} 50^{\prime \prime}$, long $80^{\circ} 10^{\prime} 26^{\prime \prime}$, Stanley County, at gaging station on left bank 1 , 000 ft downstream from Lanes Creek, 1.5 miles upstream from bridge on Secondary Road 1935, 6 miles southwest of Norwood, and 11.2 miles

DRAINAGE AREA.--1,370 sq ml, approximately.

PERIOD OF RECORD.--Chemical analyses: October 1967 to September 1970 (partial record).

REMARKS. - Miscellaneous samples of chemical data published for water years 1945, 1948, 1955-56, 1958, 1960, 1964, 1966. The second of two samples collected at the same time is a fleld determination.

CHEMICAL ANALYSES, WATER YEAR OCTOBER 1969 TO SEPTEMBER 1970

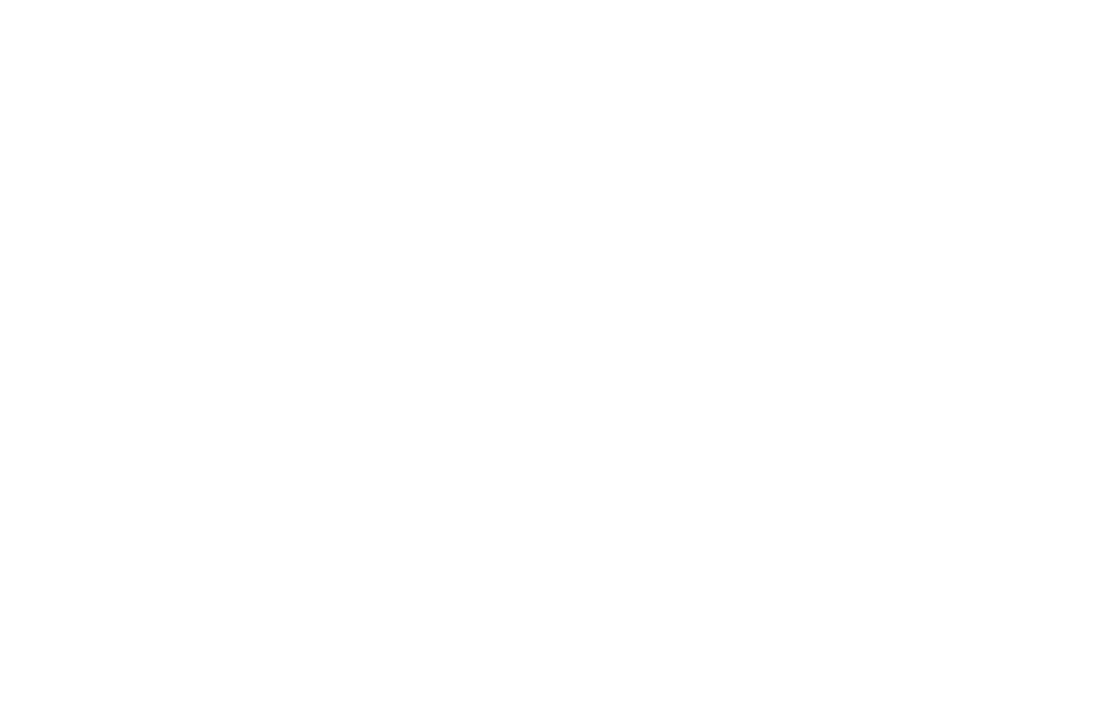


PEE DEE RIVER BASIN

02127500 PEE DEE RIVER NEAR ANSONVILLE, N,C.

LOCATION,--Lat $35^{\circ} 05^{\prime} 07^{\prime \prime}$, long $79^{\circ} 59^{\prime} 57^{\prime \prime}$, Anson County, at bridge on State Highway 109 , 1.0 mile downstream from Brown Creek, 6.0 miles east of Ansonville, and 212 miles upstream from mouth in winyah Bay.

DRAINAGE AREA.--6,330 sq mi, approximately.

PERIOD OF RECORD,--Chemical analyses: October 1969 to September 1970 (partial record).

REHARKS. - The second of two samples collected at the same time is a field determination. CHEMICAL ANALYSES, HATER YEAR OCTOBER 1969 TO SEPTEMBER 1970

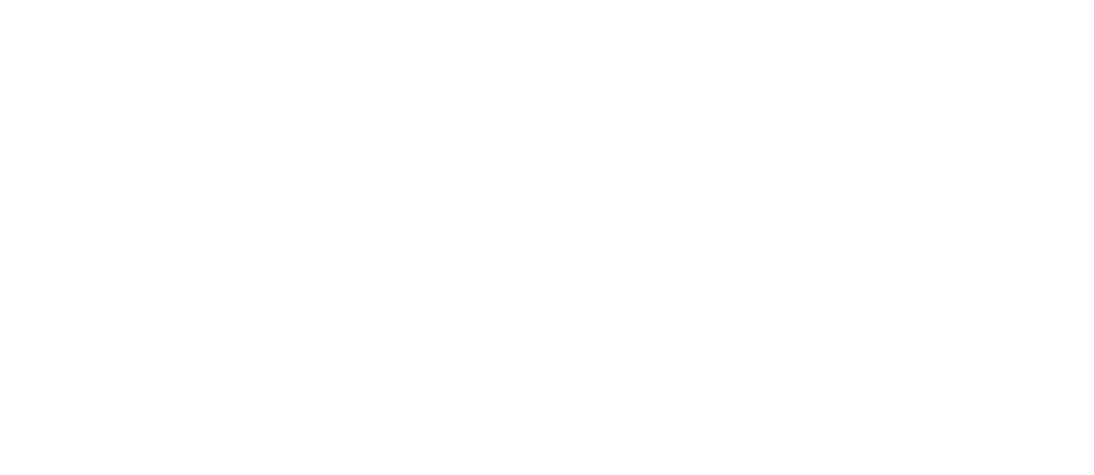

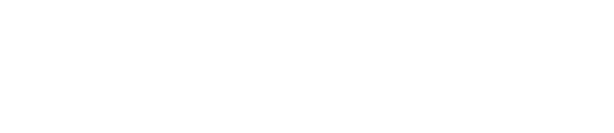

LOCATION.--Lat $34^{\circ} 37^{\prime} 58^{\prime \prime}$, long $79^{\circ} 01^{\prime} 40^{\prime \prime}$, Robeson County, 0.5 mlle downstream from Raft Swamp and 2 mlles northwest of Lumberton.

DRAINAGE AREA, $--674 \mathrm{sq} \mathrm{mi}$.

PERIOD OF RECORD.--Chemtcal analyses: October 1967 to September 1970 (partial record).

RELARKS.-- The second of two samples collected at the same, time is a fleld determination.

CHEMICAL ANALYSES, WATER YEAR OCTOBER 1969 TO SEPTEMBER 1970

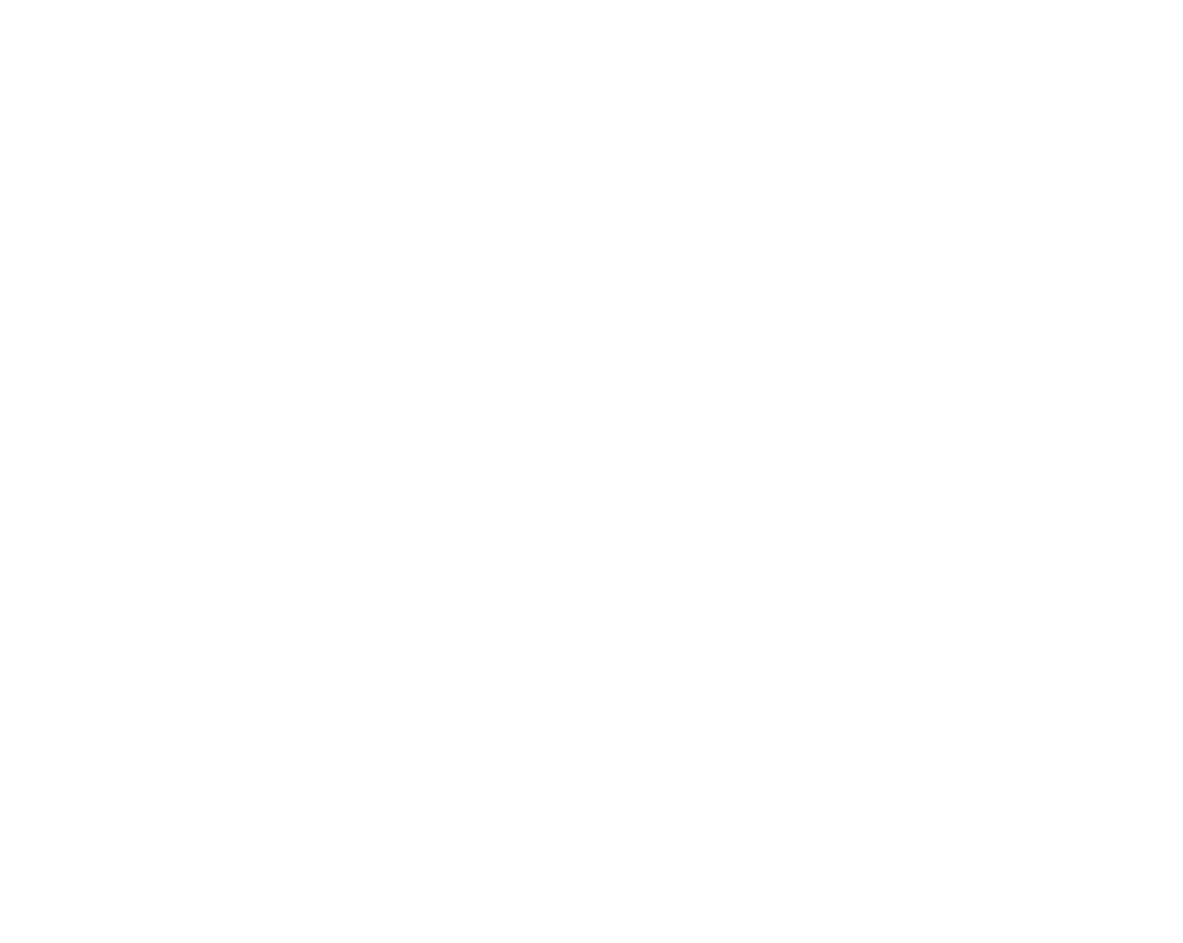


02138000 CATAWBA RI VER NEAR MARION, N.C.

LOCATION, --Lat $35^{\circ} 42^{\prime} 26^{\prime \prime}$, long $82^{\circ} 02^{\prime} 00^{\prime \prime}$, NcDowell County, at gaging station on right bank 15 ft downstream from bridge on U.S. Highray $221,0.2 \mathrm{mlle}$ downstream from Tom Creek, and $2.2 \mathrm{miles}$ northwest of Marion.

DRAINAGE AREA.--171 sq mi, Including area of small downstream tributary.

PERIOD OF RECORD.--Chemical analyses: October 1945 to September 1946 (da1ly), October 1967 to September 1970 (partial record).

EXTREMES, - Period of record.

Dissolved solids: Maximum, $36 \mathrm{mg} / 1$ Sept. $11-20,1946$; minlmum, $25 \mathrm{mg} / 1$ Jan, 1-10, 1946.

Hardness: Maximum, $12 \mathrm{mg} / 1$ Aug. $1-10,1946$; minimum, $8 \mathrm{mg} / 1$ Jan. $1-10$, Mar. 11-20, 21-31, May 11-20, 1946.

Water temperatures: Haximum, $26.0^{\circ} \mathrm{C}$ July $11,14,1946$; minimum, freezing point Dec. 18,1945 .

REMARKS. - Miscellaneous samples of chemical data published for water years 1945, 1948-49, 1955-57. The second of
two samples collected at the same time is a field determination.

CHEMICAL ANALYSES, WATER YEAR OCTOBER 1969 TO SEPTEMBER 1970

\begin{tabular}{|c|c|c|c|c|c|c|c|c|c|c|c|c|}
\hline DATE & TIME & $\begin{array}{l}\text { DIS- } \\
\text { CHARGE } \\
\text { (CFS) }\end{array}$ & $\begin{array}{l}\text { SILICA } \\
\text { ISIO2) } \\
\text { IMGIL) }\end{array}$ & $\begin{array}{l}\text { OIS- } \\
\text { SOLVED } \\
\text { IRON } \\
\text { (FE) } \\
\text { (UG/L) }\end{array}$ & $\begin{array}{l}\text { CAL- } \\
\text { CIUM } \\
(C A) \\
(M G / L)\end{array}$ & $\begin{array}{l}\text { MAG- } \\
\text { NE- } \\
\text { SIUM } \\
\text { (MG) } \\
(M G / L)\end{array}$ & $\begin{array}{l}\text { SOD I UM } \\
\text { (NA) } \\
(M G / L)\end{array}$ & $\begin{array}{l}\text { PO- } \\
\text { TAS- } \\
\text { SI UM } \\
\text { (K) } \\
\text { (MG/L) }\end{array}$ & $\begin{array}{l}\text { BICAR- } \\
\text { BONATE } \\
\text { (HCO3) } \\
\text { IMG/L) }\end{array}$ & $\begin{array}{l}\text { CAR- } \\
\text { BONATE } \\
\text { (COBI) } \\
\text { IMG/L I }\end{array}$ & $\begin{array}{l}\text { SULFATE } \\
\text { (SO4) } \\
\text { (MG/L) }\end{array}$ & $\begin{array}{l}\text { CHLO- } \\
\text { RIDE } \\
\text { (CL) } \\
\text { (MG/L) }\end{array}$ \\
\hline $\begin{array}{l}\text { DEC. } \\
16 . . .\end{array}$ & 0930 & 386 & 9.6 & 0 & 2.7 & .8 & 7.3 & .9 & 16 & 0 & 4.0 & 7.6 \\
\hline APR. & 0930 & 386 & $\rightarrow$ & - & - & - & - & - & $=$ & - & - & - \\
\hline $13 \ldots$ & 1020 & 350 & 11 & 28 & 2.3 & .7 & 6.9 & .9 & 20 & 0 & 2.4 & 4.6 \\
\hline$\underset{\text { JUNE }}{13 . . .}$ & 1020 & 350 & - & -- & - & - & -- & - & -- & - & -- & - \\
\hline $17 .$. & 1500 & 198 & 13 & 86 & 3.0 & 1.0 & 12 & 1.3 & 19 & 0 & 2.8 & 12 \\
\hline $17 .$. & 1500 & 198 & - & - & - & - & - & - & - & 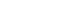 & - & - \\
\hline DATE & $\begin{array}{l}\text { FLUO- } \\
\text { RIOE } \\
\text { (F) } \\
\text { (MG/L) }\end{array}$ & $\begin{array}{l}\text { NI TRATE } \\
\text { (NO3) } \\
\text { (MG/L) }\end{array}$ & $\begin{array}{l}\text { OR THO } \\
\text { PHOS- } \\
\text { PHAIE } \\
\text { (PO4) } \\
\text { (MG/L) }\end{array}$ & $\begin{array}{l}\text { DIS- } \\
\text { SALVED } \\
\text { SOLIDS } \\
\text { IRESI- } \\
\text { DUE AT } \\
\text { IBO C) } \\
\text { (MG/L) }\end{array}$ & $\begin{array}{l}\text { DIS- } \\
\text { SOLVED } \\
\text { SOLIDS } \\
\text { ITONS } \\
\text { PER } \\
\text { AC-FTI }\end{array}$ & $\begin{array}{l}\text { DIS- } \\
\text { SOLVED } \\
\text { SOLIDS } \\
\text { ITONS } \\
\text { PER } \\
\text { DAY) }\end{array}$ & $\begin{array}{l}\text { HARO- } \\
\text { NESS } \\
\text { ICA,MG) } \\
\text { (MG/L) }\end{array}$ & $\begin{array}{l}\text { NON- } \\
\text { CAR- } \\
\text { BONATE } \\
\text { HARD- } \\
\text { NESS } \\
\text { (MG/L) }\end{array}$ & $\begin{array}{l}\text { SODIUIH } \\
\text { AO- } \\
\text { SORP- } \\
\text { TION } \\
\text { RATIO }\end{array}$ & $\begin{array}{l}\text { PERCENT } \\
\text { SODIUM }\end{array}$ & $\begin{array}{l}\text { ME IHY- } \\
\text { LENE } \\
\text { BLUE } \\
\text { ACTIVE } \\
\text { SUB- } \\
\text { ST ANCE } \\
\text { (MGIL) }\end{array}$ & $\begin{array}{l}\text { ALKA- } \\
\text { LINITY } \\
\text { AS } \\
\text { CACO3 } \\
\text { (MG/L) }\end{array}$ \\
\hline
\end{tabular}

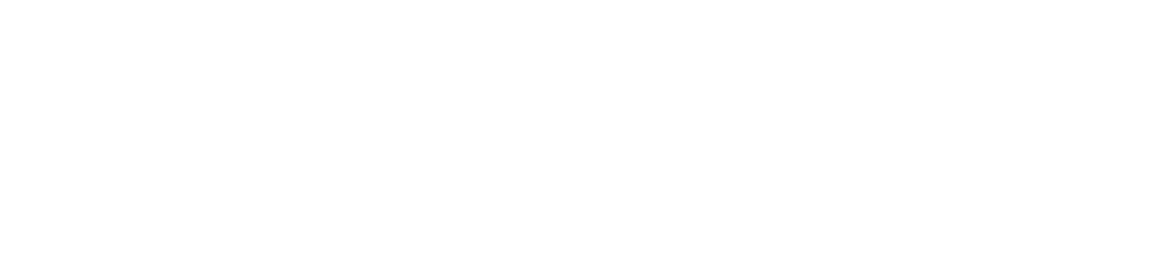

\begin{tabular}{|c|c|c|c|c|c|c|c|}
\hline $16 . \ldots$ & - & 5700 & 48 & 6.1 & 4.0 & - & 5 \\
\hline$\underset{A P R_{0}}{16 . . .}$ & 11.7 & $=$ & -- & 7.5 & 4.0 & -- & - \\
\hline $13 \ldots$ & - & $\cdots$ & 53 & 6.3 & 14.0 & -- & 5 \\
\hline $13 \ldots$ & 13.4 & -- & -- & 6.7 & 14.0 & 14.0 & - \\
\hline $\begin{array}{l}\text { JUNE } \\
17 \ldots\end{array}$ & & & & & & & \\
\hline $17 \ldots$ & 9.0 & $\cdots$ & $\approx$ & 6.8 & 25.0 & 32.0 & $\therefore$ \\
\hline
\end{tabular}

02139282 CATAWBA RIVER AT MORGANTON, N.C.

LOCATION.--Lat $35^{\circ} 44^{\prime} 58^{\prime \prime}$, long $81^{\circ} 42^{\prime} 20^{\prime \prime}$, Burke County, at bridge on State Highway 181 , 0.8 mile downstream from Silver Creek and 1 mile northwest of Morganton.

DRAINAGE AREA. --593 sq $m 1$.

PERIOD OF RECORD.--Chemical analyses: October 1967 to September 1970 (partial record).

REKARKS. - Mlscellaneous samples of chemical data published for 1963 water year. The second of two samples collected at the same time is a field determination.

CHEMICAL ANALYSES, WATER YEAR OCTOBER 1969 TO SEPIEMBER 1970

\begin{tabular}{|c|c|c|c|c|c|c|c|c|c|c|c|c|}
\hline DATE & TI I ME & $\begin{array}{l}\text { DIS- } \\
\text { CHARGE } \\
\text { (CFS) }\end{array}$ & $\begin{array}{l}\text { SILICA } \\
\text { (SIOZ) } \\
\text { (MG/L) }\end{array}$ & $\begin{array}{l}\text { OIS- } \\
\text { SOLVED } \\
\text { IRON } \\
\text { (FE) } \\
\text { (UG/L) }\end{array}$ & $\begin{array}{l}\text { CAL- } \\
\text { CIUM } \\
\text { (CA) } \\
\text { (MG/L) }\end{array}$ & $\begin{array}{l}\text { MAG- } \\
\text { NE- } \\
\text { SIUM } \\
\text { (NGG) } \\
\text { I MG LI I }\end{array}$ & $\begin{array}{l}\text { SODIUM } \\
\text { (NA) } \\
\text { IHG/L) }\end{array}$ & $\begin{array}{l}\text { PO- } \\
\text { TAS- } \\
\text { SIUM } \\
\text { (X) } \\
\text { (MG/L) }\end{array}$ & $\begin{array}{l}\text { BICAR- } \\
\text { BONATE } \\
\text { (HCO3) } \\
\text { IMG/L I }\end{array}$ & $\begin{array}{l}\text { CAR- } \\
\text { BONATE } \\
\text { ICO3) } \\
\text { (MG/LI }\end{array}$ & $\begin{array}{l}\text { SULFATE } \\
\text { (SO4) } \\
\text { (MG/L) }\end{array}$ & $\begin{array}{l}\text { CHLO- } \\
\text { RIDE } \\
\text { ICLI) } \\
\text { (MG/L) }\end{array}$ \\
\hline $\begin{array}{l}\text { DEC. } \\
30 \ldots \\
30 \ldots\end{array}$ & $\begin{array}{l}0930 \\
0930\end{array}$ & $\begin{array}{l}1940 \\
1940\end{array}$ & 7.4 & 0 & 3.0 & 1.1 & 6.3 & 1.6 & 18 & - & 4.4 & 6.0 \\
\hline $\begin{array}{c}\text { FEB. } \\
09 \ldots . . \\
09 \ldots\end{array}$ & $\begin{array}{l}1100 \\
1100\end{array}$ & $\begin{array}{l}440 \\
440\end{array}$ & 10 & $\begin{array}{r}0 \\
--\end{array}$ & 2.7 & 1.0 & 6.5 & 1.1 & 14 & -2 & 4.D & 6.9 \\
\hline $\begin{array}{l}\text { JUNE } \\
\text { OS... } \\
\text { O5... } \\
\text { SEPT. }\end{array}$ & $\begin{array}{l}1720 \\
1720\end{array}$ & $\begin{array}{l}2920 \\
2920\end{array}$ & 10 & 221 & 3.1 & 1.2 & 8.4 & 2.4 & 18 & -0 & 3.2 & 0.0 \\
\hline $\begin{array}{l}18 \ldots . . \\
18 . \ldots\end{array}$ & $\begin{array}{l}0930 \\
0930\end{array}$ & $\begin{array}{l}220 \\
220\end{array}$ & 9.6 & 17 & 2.9 & 1.1 & 6.6 & $\therefore$ & 20 & -0 & 2.8 & 6.4 \\
\hline
\end{tabular}


SANTEE RIVER BASIN

O2139282 CATAWBA RIVER AT MORGANTON, N.C. - Continued

CHEMICAL ANALYSES, WATER YEAR OCTOBER 1969 TO SEPTEMBER 1970

\begin{tabular}{|c|c|c|c|c|c|c|c|c|c|}
\hline TH & $\begin{array}{l}\text { DIS- } \\
\text { SOLVEO } \\
\text { SOLIOS }\end{array}$ & $\begin{array}{l}\text { OIS- } \\
\text { SOLVEO }\end{array}$ & $\begin{array}{l}\text { DIS- } \\
\text { SOLVED }\end{array}$ & & $\begin{array}{l}\text { NON- } \\
\text { CAR- }\end{array}$ & $\begin{array}{c}\text { SODIUM } \\
\text { AD- }\end{array}$ & & $\begin{array}{l}\text { ME THY- } \\
\text { LENE } \\
\text { BLUE }\end{array}$ & ALKA- \\
\hline tos- & IRES I- & SOLIDS & SOLIOS & HARD- & BONATE & SORP- & & ACTIVE & LINITY \\
\hline HATE & DUE AI & IIONS & ITONS & NESS & HARD- & IION & PERCENT & SUB- & AS \\
\hline $\begin{array}{l}(P O 4) \\
(M G / L)\end{array}$ & $\begin{array}{l}180 C) \\
(M G / L)\end{array}$ & $\begin{array}{c}\text { PER } \\
A C-F I I\end{array}$ & $\begin{array}{l}\text { PER } \\
\text { DAYI }\end{array}$ & $\begin{array}{r}(C A, M G) \\
(M G / L)\end{array}$ & $\begin{array}{l}\text { NESS } \\
\text { (MG LL) }\end{array}$ & RATIO & SODIUM & $\begin{array}{l}\text { ST ANCE } \\
\text { (MG/L) }\end{array}$ & $\begin{array}{l}\mathrm{CACO3} \\
(\mathrm{MG} / \mathrm{L})\end{array}$ \\
\hline
\end{tabular}

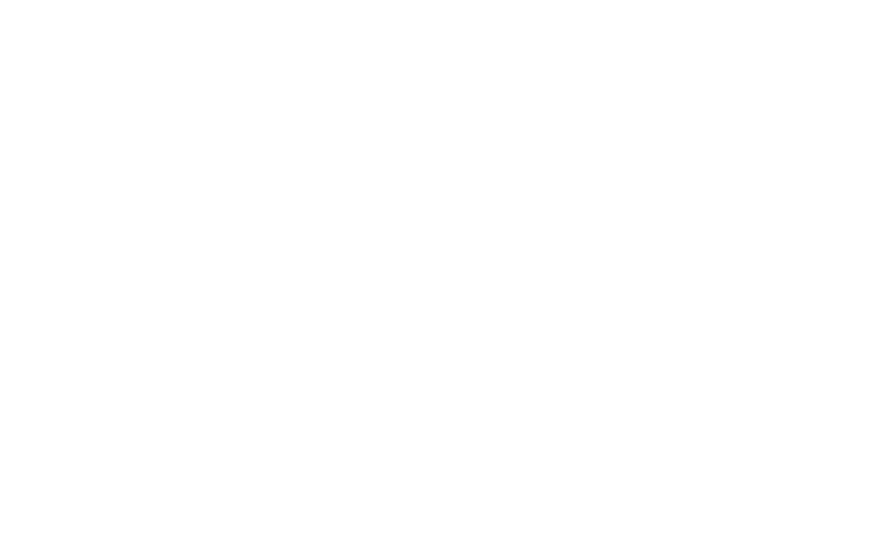

02141500 CATAMBA RIVER AT RHODHISS, N.C.

LOCATION.--Lat $35^{\circ} 46^{\prime} 22^{\prime \prime}$, long $81^{\circ} 26^{\prime} 14^{\prime \prime}$, Caldwell County, at bridge on Rhodh1ss Road at Rhodh1ss, 0.2 mile downstream from Rhodhiss Dam and 242 miles upstream from mouth of Wateree River.

DRAI NAGE AREA. - - 1, $090 \mathrm{sq} \mathrm{m} 1$, approximately.

PERIOD OF RECORD.-.Chemical analyses: October 1967 to September 1970 (partial record).

REMARKS, --The second of two samples collected at the same time is a field determination.

CHEMICAL ANALYSES, hater year octOBER 1969 TO SEPIEMBER 1970

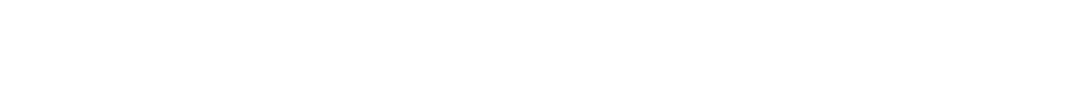

DEC.

\begin{tabular}{|c|c|c|c|c|c|c|c|c|c|c|c|}
\hline $\begin{array}{l}31 \ldots A \\
31 \ldots . . .8 \\
31 \ldots . \\
E B B .\end{array}$ & $\begin{array}{l}0915 \\
0935 \\
0955\end{array}$ & $\begin{array}{l}8.9 \\
9.3 \\
9.4\end{array}$ & $\begin{array}{l}0 \\
0 \\
0\end{array}$ & $\begin{array}{l}2.9 \\
3.0 \\
2.9\end{array}$ & $\begin{array}{l}1.0 \\
1.0 \\
1.0\end{array}$ & $\begin{array}{l}6.0 \\
6.4 \\
5.9\end{array}$ & $\begin{array}{c}1.6 \\
1.6\end{array}$ & $\begin{array}{l}17 \\
18 \\
18\end{array}$ & $\begin{array}{l}0 \\
0 \\
0\end{array}$ & $\begin{array}{l}4.0 \\
4.0 \\
4.8\end{array}$ & $\begin{array}{c}5.8 \\
15 \\
5.8\end{array}$ \\
\hline $\begin{array}{l}09 \ldots . . A \\
09 \ldots . \text { B } \\
09 \ldots . . C\end{array}$ & $\begin{array}{l}0845 \\
0910 \\
0930\end{array}$ & $\begin{array}{c}9.3 \\
13 \\
9.0\end{array}$ & $\overline{11}$ & $\begin{array}{l}2.6 \\
2.9 \\
2.5\end{array}$ & $\begin{array}{l}1.0 \\
1.3 \\
1.2\end{array}$ & $\begin{array}{l}6.4 \\
7.5 \\
6.5\end{array}$ & $\begin{array}{l}2.1 \\
1.2 \\
1.0\end{array}$ & $\begin{array}{l}15 \\
18 \\
15\end{array}$ & $\begin{array}{l}0 \\
0 \\
0\end{array}$ & $\begin{array}{l}4.0 \\
3.0 \\
4.4\end{array}$ & $\begin{array}{l}8.3 \\
8.1 \\
7.5\end{array}$ \\
\hline $\begin{array}{l}\text { JUNE } \\
05 \ldots . . . \\
05 . . . \text { B } \\
05 \ldots . .8 \\
\text { BEPI. }\end{array}$ & $\begin{array}{l}1300 \\
1310 \\
1315\end{array}$ & $\begin{array}{l}9.9 \\
9.9 \\
9.8\end{array}$ & $\begin{array}{l}51 \\
17 \\
14\end{array}$ & $\begin{array}{l}3.0 \\
3.0 \\
3.0\end{array}$ & $\begin{array}{l}1.1 \\
1.1 \\
1.1\end{array}$ & $\begin{array}{l}7.3 \\
6.6 \\
6.6\end{array}$ & $\begin{array}{l}4.8 \\
1.2 \\
1.2\end{array}$ & $\begin{array}{l}20 \\
18 \\
19\end{array}$ & $\begin{array}{l}0 \\
0 \\
0\end{array}$ & $\begin{array}{l}4.6 \\
4.8 \\
3.6\end{array}$ & $\begin{array}{r}10 \\
6.2 \\
7.8\end{array}$ \\
\hline $\begin{array}{l}18 \ldots A \\
18 \ldots . .8 \\
18 \ldots .\end{array}$ & $\begin{array}{l}1040 \\
1045 \\
1045\end{array}$ & $\begin{array}{l}10 \\
10 \\
10\end{array}$ & $\begin{array}{l}0 \\
0 \\
0\end{array}$ & $\begin{array}{l}2.7 \\
3.2 \\
3.0\end{array}$ & $\begin{array}{l}1.9 \\
1.1 \\
1.1\end{array}$ & $\begin{array}{l}6.7 \\
6.8 \\
6.8\end{array}$ & $\begin{array}{l}1.4 \\
1.6 \\
1.4\end{array}$ & $\begin{array}{l}19 \\
19 \\
19\end{array}$ & $\begin{array}{l}0 \\
0 \\
0\end{array}$ & $\begin{array}{l}3.2 \\
3.6 \\
2.6\end{array}$ & $\begin{array}{l}6.6 \\
6.8 \\
6.8\end{array}$ \\
\hline
\end{tabular}

ANALYSES DF ADDITIONAL SAMPLES

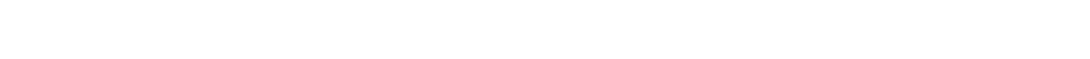

A SAMPLE COLLECTED AT QUARTER-POINT NEAREST LEFT BANK, LOOKING UPSIREAM.

B SAMPLE COLLECTED AT MIDPOINT OF STREAM. 
SANTEE RIVER BASIN

02141500 CATAWBA RIVER AT RHODHISS, N.C. - Continued

CHEMICAL ANALYSES, WATER YEAR OCTOBER 1969 TO SEPTEMBER 1970

\begin{tabular}{|c|c|c|c|c|c|c|c|c|c|c|c|}
\hline DATE & $\begin{array}{l}\text { FLUO- } \\
\text { RIDE } \\
\text { (F) } \\
\text { (MG/L) }\end{array}$ & $\begin{array}{l}\text { NI TRATE } \\
\text { (NO3) } \\
\text { (MG/L) }\end{array}$ & $\begin{array}{l}\text { OR THO } \\
\text { PHOS- } \\
\text { PHATE } \\
\text { (POL) } \\
\text { (MG/L) }\end{array}$ & $\begin{array}{l}\text { DIS- } \\
\text { SOLVED } \\
\text { SOLIDS } \\
\text { (RES I- } \\
\text { DUE AT } \\
\text { I BO C) } \\
\text { (MGIL) }\end{array}$ & $\begin{array}{l}\text { DIS- } \\
\text { SOLVED } \\
\text { SOLIDS } \\
\text { (TONS } \\
\text { PER } \\
\text { AC-FT) }\end{array}$ & $\begin{array}{l}\text { HARD- } \\
\text { NESS } \\
(C A, M G) \\
\text { (NG/L) }\end{array}$ & $\begin{array}{l}\text { NON- } \\
\text { CAR- } \\
\text { BONATE } \\
\text { HARD- } \\
\text { NESS } \\
\text { IMG /LI I }\end{array}$ & $\begin{array}{l}\text { SODIUM } \\
\text { AD- } \\
\text { SORP- } \\
\text { TION } \\
\text { RATIOO }\end{array}$ & $\begin{array}{l}\text { PERCENT } \\
\text { SODIUM }\end{array}$ & $\begin{array}{l}\text { METHY- } \\
\text { LENE } \\
\text { BLUE } \\
\text { ACTIVE } \\
\text { SUB- } \\
\text { STANCE } \\
\text { IMG/L) }\end{array}$ & $\begin{array}{l}\text { ALKA- } \\
\text { LINITY } \\
\text { AS } \\
\text { CACOB } \\
\text { INGIL) }\end{array}$ \\
\hline
\end{tabular}

\begin{tabular}{|c|c|c|c|c|c|c|c|c|c|c|c|}
\hline $\begin{array}{l}\text { DEC. } \\
31 \ldots A \\
31 \ldots B \\
31 \ldots C\end{array}$ & $\begin{array}{l}.1 \\
.0 \\
.0\end{array}$ & $\begin{array}{r}1.4 \\
.5 \\
.6\end{array}$ & $\begin{array}{l}.17 \\
.00 \\
.01\end{array}$ & $\begin{array}{l}34 \\
56 \\
35\end{array}$ & $\begin{array}{l}.05 \\
.08 \\
.05\end{array}$ & $\begin{array}{l}11 \\
12 \\
11\end{array}$ & $\begin{array}{l}0 \\
0 \\
0\end{array}$ & $\begin{array}{l}.8 \\
.8 \\
.8\end{array}$ & $\begin{array}{l}49 \\
34 \\
49\end{array}$ & $\begin{array}{l}.08 \\
.10 \\
.10\end{array}$ & $\begin{array}{l}14 \\
15 \\
15\end{array}$ \\
\hline $\begin{array}{l}\text { FEB. } \\
\text { O9... A } \\
09 \ldots \ldots B \\
09 \ldots \ldots C \\
\text { JUNE }\end{array}$ & $\begin{array}{l}.1 \\
.1 \\
.0\end{array}$ & $\begin{array}{r}.9 \\
2.2 \\
.6\end{array}$ & $\begin{array}{l}.30 \\
.18 \\
.10\end{array}$ & $\begin{array}{l}56 \\
48 \\
44\end{array}$ & $\begin{array}{l}.08 \\
.07 \\
.06\end{array}$ & $\begin{array}{l}10 \\
12 \\
11\end{array}$ & $\begin{array}{l}0 \\
0 \\
0\end{array}$ & $\begin{array}{l}.9 \\
.9\end{array}$ & $\begin{array}{l}51 \\
54 \\
53\end{array}$ & $\begin{array}{l}.01 \\
.00 \\
.03\end{array}$ & $\begin{array}{l}12 \\
15 \\
12\end{array}$ \\
\hline $\begin{array}{l}05 \ldots A \\
05 \ldots B \\
05 \ldots C \\
\text { SEPT. }\end{array}$ & $\begin{array}{l}.1 \\
.1 \\
.0\end{array}$ & $\begin{array}{l}.4 \\
.4 \\
.3\end{array}$ & $\begin{array}{l}.15 \\
.09 \\
.06\end{array}$ & $\begin{array}{l}51 \\
45 \\
46\end{array}$ & $\begin{array}{l}.07 \\
.08 \\
.06\end{array}$ & $\begin{array}{l}12 \\
12 \\
12\end{array}$ & $\begin{array}{l}0 \\
0 \\
0\end{array}$ & $\begin{array}{l}.9 \\
.8 \\
.8\end{array}$ & $\begin{array}{l}47 \\
51 \\
51\end{array}$ & $\begin{array}{l}.00 \\
.00 \\
.00\end{array}$ & $\begin{array}{l}16 \\
15 \\
16\end{array}$ \\
\hline $\begin{array}{l}18 \ldots . . A \\
18 \ldots \ldots B \\
18 \ldots \ldots C\end{array}$ & $\begin{array}{l}.1 \\
.1\end{array}$ & $\begin{array}{r}.9 \\
1.0 \\
.8\end{array}$ & $\begin{array}{l}.05 \\
.04 \\
.04\end{array}$ & $\begin{array}{l}49 \\
50 \\
51\end{array}$ & $\begin{array}{l}.07 \\
.07 \\
.07\end{array}$ & $\begin{array}{l}15 \\
13 \\
12\end{array}$ & $\begin{array}{l}0 \\
0 \\
0\end{array}$ & $\begin{array}{l}.8 \\
.8 \\
.9\end{array}$ & $\begin{array}{l}47 \\
50 \\
52\end{array}$ & $\begin{array}{l}.03 \\
.02 \\
.03\end{array}$ & $\begin{array}{l}16 \\
16 \\
16\end{array}$ \\
\hline
\end{tabular}

ANALYSES OF AOOITIONAL SAMPLES

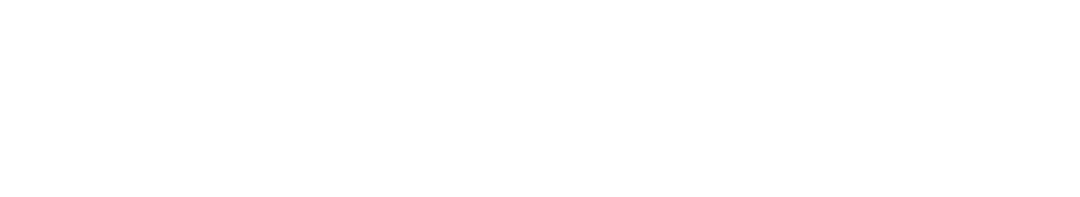

DEC.

\begin{tabular}{|c|c|c|c|c|c|c|}
\hline $31, \ldots A$ & - & 48 & 6.8 & 5.0 & - & 5 \\
\hline $31 \ldots$ & 9.2 & - & 6.7 & 5.0 & -- & -- \\
\hline $31, \ldots B$ & -- & 74 & 6.2 & 4.5 & -- & 5 \\
\hline $31 .$. & 9.3 & 77 & 6.7 & 4.5 & -- & - \\
\hline $31 \ldots c$ & - & 48 & 6.5 & 5.1 & -- & 5 \\
\hline $31 \ldots$ & 9.9 & -- & 6.7 & 5.0 & -- & -- \\
\hline $09 . .$. A & -- & 55 & 6.5 & 5.3 & -- & $3 n$ \\
\hline & 8.7 & 66 & 7.4 & 5.7 & -- & - \\
\hline $09 \ldots$ B & - & 63 & 6.8 & 5.0 & - & 7 \\
\hline $09 . .$. & 8. 0 & 63 & 7.5 & 5.7 & -. & - \\
\hline $39 \ldots . . c$ & - & 52 & 6.4 & 5.0 & -- & 15 \\
\hline $09 . .$. & B. 2 & 65 & 7.4 & 5.3 & -- & - \\
\hline JUNE & & & & & & \\
\hline ก5...A & -- & 73 & 6.6 & 1ค.0 & - & 3 \\
\hline $05 \ldots$ & B. 0 & 64 & 6.8 & 18.0 & -- & $=$ \\
\hline $05 \ldots B$ & - & 61 & 6.4 & 18.0 & -- & 3 \\
\hline & 7.8 & 65 & 6.7 & 18.0 & -- & -- \\
\hline $05 . . c$ & - & 61 & 6.5 & 18.2 & -- & 3 \\
\hline $05 \ldots$ & 7.8 & 64 & 6.9 & 19.0 & 26.0 & - \\
\hline SEPT. & & & & & & \\
\hline 1B...A & - & 61 & 6.3 & 23.5 & -- & 5 \\
\hline 18. & 5.7 & 65 & $\cdots$ & 23.5 & 27.5 & - \\
\hline 18. & - & 61 & 6.4 & 23.5 & - & 5 \\
\hline 18. & 5.6 & 62 & 6,7 & 23.5 & 27.5 & 5 \\
\hline
\end{tabular}

ANALYSES OF ADOITIONAL SAMPLES

$\begin{array}{ccccccc}\text { DEC. } & & & & & \\ 31 \ldots . & -. & 48 & 6.8 & 5.3 & - & 5 \\ 31 \ldots & - & 49 & 6.5 & 5.1 & -- & 5\end{array}$

A SAMPLE COLLECTED AT QUARTER-PחINT NEAREST LEFT BANK, LODKING UPSTREAM.

B SAMPLE COLLECTED AT MIDPOINT OF STREAM.

02143084 SOUTH FORK CATANBA RIVER NEAR LINCOLNTON, N.C.

LOCATION,--Lat $35^{\circ} 29^{\prime} 00^{\prime \prime}$, 10ng $81^{\circ} 16^{\prime} 50^{\prime \prime}$, Lincoln County, at bridge on Secondary Road $1008,0.2$ mile upstream from C1ark Creek and 1.5 miles northwest of Lincolnton.

DRAINAGE AREA,--260 sq mi, approximately.

PERIOD OF RECORD..--Chemical analyses: October 1969 to September 1970 (partial record).

REMARKS..-The second of two samples collected at the same time is a fleld determination.

CHEMICAL ANALYSES, WATER YEAR OCTOBER 1969 TO SEPTEMBER 1910

\begin{tabular}{|c|c|c|c|c|c|c|c|c|c|c|c|c|}
\hline DATE & TIME & $\begin{array}{l}\text { DIS- } \\
\text { CHARGE } \\
\text { (CFS) }\end{array}$ & $\begin{array}{l}\text { SILICA } \\
\text { ISIOLI } \\
\text { I MG/LI }\end{array}$ & $\begin{array}{l}\text { UIS- } \\
\text { SOLVED } \\
\text { IRON } \\
\text { (FE) } \\
\text { (UG/L) }\end{array}$ & $\begin{array}{l}\text { CAL- } \\
\text { CIUM } \\
(C A) \\
(M G / L)\end{array}$ & $\begin{array}{l}\text { MAG- } \\
\text { NE- } \\
\text { SIUA } \\
\text { (MG) } \\
\text { (MG/L) }\end{array}$ & $\begin{array}{l}\text { SODIUM } \\
\text { (NA) } \\
\text { (MG/L) }\end{array}$ & $\begin{array}{l}\text { PO- } \\
\text { TAS- } \\
\text { SIUM } \\
\text { IKI } \\
\text { ING/LI }\end{array}$ & $\begin{array}{l}\text { BICAR- } \\
\text { BONATE } \\
\text { (HCQ3) } \\
\text { (MG/L) }\end{array}$ & $\begin{array}{l}\text { CAR- } \\
\text { BONATE } \\
\text { (CO3) } \\
\text { (MG/L) }\end{array}$ & $\begin{array}{l}\text { SULFATE } \\
\text { (SO4) } \\
\text { (MG/L) }\end{array}$ & $\begin{array}{l}\text { CHLO- } \\
\text { RIDE } \\
\text { (CL) } \\
(M G / L)\end{array}$ \\
\hline $\begin{array}{l}\text { JUNE } \\
\text { O8.... } \\
\text { OB.... } \\
\text { SEPT. }\end{array}$ & $\begin{array}{l}1030 \\
1030\end{array}$ & $\begin{array}{l}221 \\
221\end{array}$ & 12 & 14 & 2.8 & 1.1 & 3.8 & 2.7 & 16 & -2 & 4.0 & 4.0 \\
\hline $18 \ldots$. & $\begin{array}{l}1345 \\
1345\end{array}$ & $\begin{array}{l}192 \\
192\end{array}$ & 12 & $\underline{0}$ & 2.9 & 1.6 & $\begin{array}{r}5.8 \\
--\end{array}$ & 1.8 & 18 & -0 & 3.2 & 6.0 \\
\hline
\end{tabular}


SANTEE RIVER.BASIN

02143084 SOUTH FORX CATANBA RIVER NEAR LINCOLNTON, N.C.--Cont1 nued CHEMICAL ANALYSES, WATER YEAR OCTOBER 1969 TO SEPTEMBER 1970

\begin{tabular}{|c|c|c|c|c|c|c|c|c|c|c|c|c|}
\hline DATE & $\begin{array}{l}\text { FLUO- } \\
\text { RIDE } \\
\text { (F) } \\
\text { (AG/L) }\end{array}$ & $\begin{array}{l}\text { NI TRATE } \\
\text { (NO3) } \\
\text { (MG/L) }\end{array}$ & $\begin{array}{l}\text { ORTHO } \\
\text { PHOS- } \\
\text { PHATE } \\
\text { (PO4) } \\
\text { (AG/L) }\end{array}$ & $\begin{array}{l}\text { DIS- } \\
\text { SOLVED } \\
\text { SOLIDS } \\
\text { IRESI- } \\
\text { OUE AT } \\
\text { IOO CS } \\
\text { ING/LI }\end{array}$ & $\begin{array}{l}\text { DIS- } \\
\text { SOLVED } \\
\text { SOLIOS } \\
\text { ITONS } \\
\text { PER } \\
\text { AC-FT I }\end{array}$ & $\begin{array}{l}\text { DIS- } \\
\text { SOLVED } \\
\text { SOLIDS } \\
\text { (TONS } \\
\text { PER } \\
\text { DAY) }\end{array}$ & $\begin{array}{l}\text { HARD- } \\
\text { NESS } \\
\text { (CA,MG) } \\
\text { (MG/L) }\end{array}$ & $\begin{array}{l}\text { NON- } \\
\text { CAR- } \\
\text { BONATE } \\
\text { HARD- } \\
\text { NESS } \\
\text { ING/LI }\end{array}$ & $\begin{array}{l}\text { SODIUN } \\
\text { AO- } \\
\text { SORP- } \\
\text { TION } \\
\text { RATIO }\end{array}$ & $\begin{array}{l}\text { PERCEIIT } \\
\text { SODIUM }\end{array}$ & $\begin{array}{l}\text { ME THY- } \\
\text { LENE } \\
\text { BLUE } \\
\text { ACTIVE } \\
\text { SUB- } \\
\text { STANCE } \\
\text { IMGSL, }\end{array}$ & $\begin{array}{l}\text { ALXAT } \\
\text { LINIT } \\
\text { AS } \\
\text { CACOS } \\
\text { INSS L }\end{array}$ \\
\hline $\begin{array}{l}\text { JUNE } \\
\text { O8... } \\
08 \ldots . . \\
\text { SEPT. }\end{array}$ & $\because 0$ & 1.2 & .27 & 42 & .06 & 25.1 & 10 & -0 & $\because 5$ & 36 & .00 & 13 \\
\hline
\end{tabular}

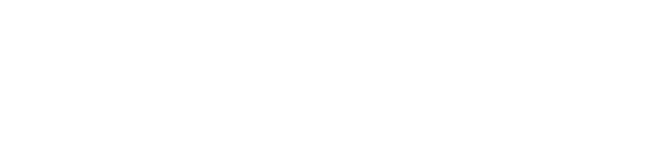

\begin{tabular}{|c|c|c|c|c|c|c|}
\hline $\begin{array}{l}\text { JUNE } \\
08 . . . \\
\text { OB... } \\
\text { SEPY. }\end{array}$ & 7.8 & $\begin{array}{l}47 \\
--\end{array}$ & $\begin{array}{l}6.2 \\
6.9\end{array}$ & $\begin{array}{l}19.0 \\
19.0\end{array}$ & $=$ & 5 \\
\hline $18 \ldots$ & 6.8 & $\begin{array}{l}61 \\
82\end{array}$ & 6.2 & $\begin{array}{l}22.5 \\
22.5\end{array}$ & $\overrightarrow{30.0}$ & 5 \\
\hline
\end{tabular}

02149377 BROAD RI VER NEAR RETHERFORDTON, N.C.

LOCATION, --Lat $35^{\circ} 17^{\prime} 28^{\prime \prime}$, long $8^{\circ} 59^{\prime} 36^{\prime \prime}$, Ruthertora County, at bridge on Secondary Road 1005 , 0.2 mile downstream from cleghorn Creek and 5.8 miles south of Rutherfordton.

DRAINAGE AREA.--270 sq mi, approximately.

PERIOD OF RECORD,--Chemical analyses: October 1967 to September 1970 (partial record).

REMARKS.-. The second of two samples collected at the same time is a Iifld determination.

Chemical anAlyses, water year OCtober 1969' to SEPTEMBER 1970

\begin{tabular}{|c|c|c|c|c|c|c|c|c|c|c|c|c|}
\hline DATE & TIME & $\begin{array}{l}\text { OIS- } \\
\text { CHARGE } \\
\text { ICFS: }\end{array}$ & $\begin{array}{l}\text { SILICA } \\
\text { ISIOLI) } \\
\text { (MG/LI) }\end{array}$ & $\begin{array}{l}\text { DIS- } \\
\text { SOLVEO } \\
\text { IRON } \\
\text { IFE) } \\
\text { (UG/L) }\end{array}$ & $\begin{array}{l}\text { CAL= } \\
C I U H \\
(C A) \\
(M G / L)\end{array}$ & $\begin{array}{c}\text { MAG- } \\
\text { NE- } \\
\text { SIUM } \\
\text { (MGG) } \\
\text { (MG/L) }\end{array}$ & $\begin{array}{l}\text { SOD IUH } \\
\text { (NA) } \\
\text { (NG/L) }\end{array}$ & $\begin{array}{l}\text { PO- } \\
\text { TAS- } \\
\text { SIUM } \\
(K) \\
(M G / L)\end{array}$ & $\begin{array}{l}\text { BICAR- } \\
\text { BONATE } \\
\text { (HCO3) } \\
\text { (MG/L) }\end{array}$ & $\begin{array}{l}\text { CAR- } \\
\text { BONATE } \\
\text { (CO3) } \\
\text { (AG/L) }\end{array}$ & $\begin{array}{l}\text { SULFATE } \\
\text { (SO4) } \\
\text { (MG/L) }\end{array}$ & $\begin{array}{l}\text { CHLO- } \\
\text { RIOE } \\
\text { ICL) } \\
\text { (AG/L) }\end{array}$ \\
\hline $\begin{array}{r}\text { OEC. } \\
30 . . . \\
30 . . \\
\text { FEB. }\end{array}$ & $\begin{array}{l}1150 \\
1150\end{array}$ & $\begin{array}{l}680 \\
680\end{array}$ & 12 & -0 & 2.7 & -9 & 2.8 & 1.3 & 15 & $\begin{array}{r}0 \\
--\end{array}$ & 2.8 & 1.4 \\
\hline $\begin{array}{l}11 \ldots \\
11 \ldots\end{array}$ & $\begin{array}{l}1230 \\
1230\end{array}$ & $\begin{array}{l}492 \\
492\end{array}$ & 12 & 78 & 2.1 & 1.2 & 2.8 & $\because 8$ & 15 & $\stackrel{0}{--}$ & 2.4 & 2.0 \\
\hline $\begin{array}{l}24 \ldots . . \\
24 \ldots \\
\text { SEPT. }\end{array}$ & $\begin{array}{l}1700 \\
1700\end{array}$ & $\begin{array}{l}420 \\
420\end{array}$ & 16 & 18 & 3.4 & 1.2 & 4.2 & 1.2 & 24 & - & 1.6 & $\underline{3.1}$ \\
\hline $\begin{array}{l}25 \ldots \\
25 \ldots\end{array}$ & $\begin{array}{l}1000 \\
1000\end{array}$ & $\begin{array}{l}142 \\
142\end{array}$ & 18 & 17 & 3.8 & 1.3 & 4.3 & 1.3 & 26 & - & 2.4 & 3.0 \\
\hline DATE & $\begin{array}{l}\text { FLUD- } \\
\text { RIOE } \\
\text { (FI } \\
\text { ( } M G / L \text { ) }\end{array}$ & $\begin{array}{l}\text { NITRATE } \\
\text { (NO3) } \\
\text { (MG/L) }\end{array}$ & $\begin{array}{l}\text { ORTHO } \\
\text { PHOS- } \\
\text { PHATE } \\
\text { (POS) } \\
\text { (MG/L) }\end{array}$ & $\begin{array}{l}\text { DIS- } \\
\text { SOLVED } \\
\text { SOLIOS } \\
\text { IRESI- } \\
\text { DUE AT } \\
\text { I80 C) } \\
\text { (MGIL) }\end{array}$ & $\begin{array}{l}\text { DIS- } \\
\text { SOLVED } \\
\text { SOL IDS } \\
\text { I TONS } \\
\text { PER } \\
\text { AC-FTI }\end{array}$ & $\begin{array}{l}\text { DIS- } \\
\text { SOLVED } \\
\text { SOLIOS } \\
\text { (TONS } \\
\text { PER } \\
\text { DAY) }\end{array}$ & $\begin{array}{l}\text { HARO- } \\
\text { NESS } \\
\text { (CA, MG) } \\
(\text { MG } / L)\end{array}$ & $\begin{array}{l}\text { NON- } \\
\text { CAR- } \\
\text { BONATE } \\
\text { HARD- } \\
\text { NESS } \\
\text { (MG/L) }\end{array}$ & $\begin{array}{l}\text { SODIUA } \\
\text { AD- } \\
\text { SORP- } \\
\text { TION } \\
\text { RATID }\end{array}$ & $\begin{array}{l}\text { PERCEAT } \\
\text { SODIUK }\end{array}$ & $\begin{array}{l}\text { METHY- } \\
\text { LENE } \\
\text { BLUE } \\
\text { ACTIVE } \\
\text { SUB- } \\
\text { STANCE } \\
\text { (MGIL) }\end{array}$ & $\begin{array}{l}\text { ALKA- } \\
\text { LIAITY } \\
\text { AS } \\
\text { CACOO } \\
\text { (HGG }\end{array}$ \\
\hline
\end{tabular}

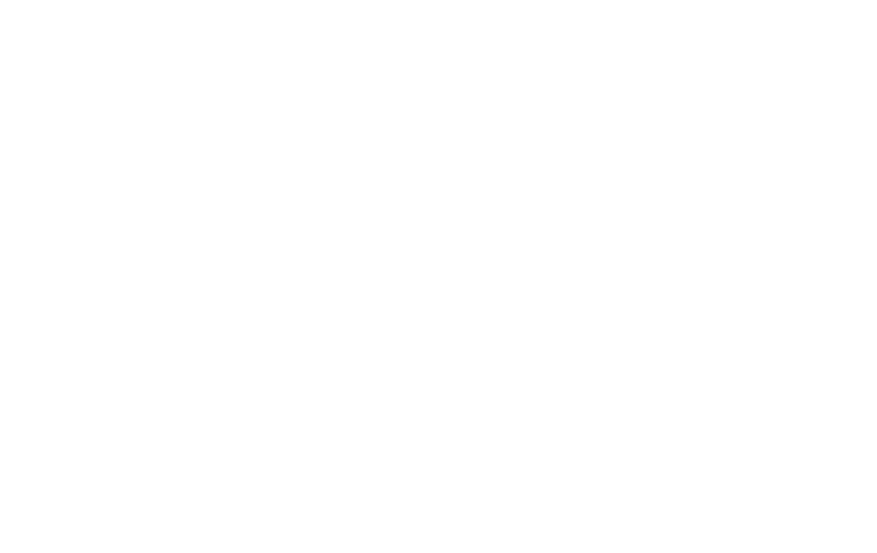


SANTEE RIVER BASIN

02150062 GREEN RIVER NEAR GREEN RIVER, N.C.

LOCATION,-Lat $35^{\circ} 15^{\prime} 36^{\prime \prime}$, long $81^{\circ} 59^{\prime} 02^{\prime \prime}$, Polk County, at bridge on Secondary Road 1302,1 mile upstream from mouth and 4 miles east of Green River.

DRAINAGE AREA, --240 sq $\mathrm{ml}$, approximately.

PERIOD OF RECORD,--Chemical analyses: October 1967 to September 1970 (partial record).

REMARKS. - The second of two samples collected at the same time is a fleld determination. CHEMICAL ANALYSES, HATER YEAR OCTOBER 1969 TO SEPTEMBER 1970

\begin{tabular}{|c|c|c|c|c|c|c|c|c|c|c|}
\hline$D A T E$ & TI ME & $\begin{array}{l}\text { UIS- } \\
\text { EHARGE } \\
\text { (CFS) }\end{array}$ & $\begin{array}{l}\text { SILICA } \\
\text { ISIOZ) } \\
\text { (MGIL) }\end{array}$ & $\begin{array}{l}\text { DIS- } \\
\text { SOLVED } \\
\text { IRON } \\
\text { (FE) } \\
\text { (UGIL) }\end{array}$ & $\begin{array}{l}\text { DIS- } \\
\text { SOLVED } \\
\text { CAL- } \\
\text { CIUM } \\
\text { (CA) } \\
\text { (MG/LI) }\end{array}$ & $\begin{array}{l}\text { DIS- } \\
\text { SOL VED } \\
\text { MAG- } \\
\text { NE- } \\
\text { SI UM } \\
\text { (MG) } \\
\text { (MGIL) }\end{array}$ & $\begin{array}{l}\text { SODI UM } \\
\text { (NA) } \\
\text { (MGIL) }\end{array}$ & $\begin{array}{l}\text { PO- } \\
\text { TAS- } \\
\text { SIUM } \\
\text { (K) } \\
\text { (MGIL) }\end{array}$ & $\begin{array}{l}\text { B [CAR- } \\
\text { BONATE } \\
\text { (HCD3) } \\
\text { (4G/L) }\end{array}$ & $\begin{array}{l}\text { CAR- } \\
\text { BONATE } \\
\text { (CO3) } \\
(M G / L)\end{array}$ \\
\hline $\begin{array}{l}\text { UEC. } \\
30 \ldots\end{array}$ & 1435 & 244 & 11 & 0 & 2.8 & 1.1 & 2.6 & 1.3 & 14 & 0 \\
\hline $\begin{array}{l}30 . . \\
\text { FEB. }\end{array}$ & 1435 & 244 & -- & -- & -- & - & $\cdots$ & -- & - & $-\infty$ \\
\hline $11 \ldots$ & 1330 & 200 & 11 & 41 & 2.2 & 1.1 & 2.5 & .7 & 15 & 0 \\
\hline JUNE & 1330 & 200 & -- & -- & -- & -- & -- & $\sim$ & -- & -- \\
\hline $\begin{array}{l}24 \ldots \\
24 \ldots\end{array}$ & $\begin{array}{l}1540 \\
1540\end{array}$ & $\begin{array}{l}240 \\
246\end{array}$ & 12 & -2 & 2.3 & $\therefore 9$ & 2.5 & 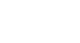 & 15 & -0 \\
\hline SEP. & & & & & & & & & & \\
\hline $\begin{array}{l}25 \ldots \\
25 \ldots\end{array}$ & $\begin{array}{l}0835 \\
0835\end{array}$ & $\begin{array}{l}247 \\
247\end{array}$ & $14 \ldots$ & $\begin{array}{r}0 \\
--\end{array}$ & 2.4 & $\begin{array}{l}-9 \\
--\end{array}$ & $\begin{array}{r}2.5 \\
--\end{array}$ & $\therefore 9$ & 17 & $\begin{array}{r}0 \\
-.\end{array}$ \\
\hline UATE & $\begin{array}{l}\text { SULFATE } \\
\text { (SO4) } \\
\text { (MG/L) }\end{array}$ & $\begin{array}{l}\text { CHLO- } \\
\text { RIUE } \\
(C L) \\
(M G / L)\end{array}$ & $\begin{array}{l}\text { DIS- } \\
\text { SOLVED } \\
\text { FLUD- } \\
\text { RIDE } \\
\text { IFI } \\
\text { IMG/LI }\end{array}$ & $\begin{array}{l}\text { NITRATE } \\
\text { (ND3) } \\
\text { (MG/L) }\end{array}$ & $\begin{array}{l}\text { DIS- } \\
\text { SDL VED } \\
\text { ORTHO } \\
\text { PHOS- } \\
\text { PHATE } \\
\text { (POA) } \\
\text { (MGLL) }\end{array}$ & $\begin{array}{l}\text { DIS- } \\
\text { SOL VED } \\
\text { SOL IUS } \\
\text { (RESI- } \\
\text { OUE AT } \\
\text { LBO C) } \\
\text { (MG LL) }\end{array}$ & $\begin{array}{l}\text { DIS- } \\
\text { SOLVED } \\
\text { SOLIDS } \\
\text { (TONS } \\
\text { PER } \\
\text { AC-FT) }\end{array}$ & $\begin{array}{l}\text { DIS- } \\
\text { SOLVED } \\
\text { SOL IUS } \\
\text { I TONS } \\
\text { PER } \\
\text { DAY) }\end{array}$ & $\begin{array}{l}\text { HARD- } \\
\text { NESS } \\
\text { (CA, MG) } \\
\text { (MG /L) }\end{array}$ & $\begin{array}{l}\text { NON- } \\
\text { CAR- } \\
\text { BONATE } \\
\text { HARD- } \\
\text { NESS } \\
\text { (MG/L) }\end{array}$ \\
\hline $\begin{array}{l}\text { OEC. } \\
30 \ldots . .\end{array}$ & & & & & & & & & & \\
\hline $\begin{array}{l}30 \ldots \\
30 \ldots\end{array}$ & 2.8 & 1.8 & .1 & 2.4 & .06 & 32 & .04 & 21.1 & 12 & 1 \\
\hline $\begin{array}{l}30 \ldots \\
+E B .\end{array}$ & -- & -- & -- & -- & - & -- & -- & -- & -- & -- \\
\hline $11 \ldots$ & 2.2 & 1.9 & .1 & .8 & .02 & 35 & .05 & 18.9 & 10 & 0 \\
\hline JUNE & -- & -- & -- & - & -- & - & -- & -- & - & -- \\
\hline $24 \ldots$ & 2.2 & 1.8 & .1 & .7 & .00 & 31 & .04 & 20.6 & 9 & 0 \\
\hline $\begin{array}{l}24 \ldots . \cdots \\
\text { SEP. }\end{array}$ & -- & -- & -- & -- & - & -- & -- & -- & - & -- \\
\hline $25 \ldots$ & .8 & 1.8 & .0 & .1 & .00 & 32 & .04 & 21.3 & 15 & 1 \\
\hline $23 \ldots$ & -- & -- & -- & -- & $\cdots$ & -- & -- & - & $=$ & $\cdots$ \\
\hline & $\begin{array}{l}\text { SODI UM } \\
\text { AD- } \\
\text { SORP- }\end{array}$ & & $\begin{array}{l}\text { METHY- } \\
\text { LENE } \\
\text { SLUE } \\
\text { ACTIVE }\end{array}$ & $\begin{array}{l}\text { ALKA- } \\
\text { LINITY }\end{array}$ & 015- & $\begin{array}{l}\text { SPECI- } \\
\text { FIC } \\
\text { COND- }\end{array}$ & & & AIR & $\begin{array}{l}\text { COLOR } \\
\text { IPLAT- }\end{array}$ \\
\hline UAFE & $\begin{array}{r}\text { TIUN } \\
\text { RATIO }\end{array}$ & $\begin{array}{l}\text { PERCENT } \\
\text { SODIUM }\end{array}$ & $\begin{array}{l}\text { SUB- } \\
\text { STANCE } \\
\text { (MG/L) }\end{array}$ & $\begin{array}{c}\text { AS } \\
\text { CACD } \\
\text { (MG/L) }\end{array}$ & $\begin{array}{l}\text { SOLVED } \\
\text { OXYGEN } \\
\text { (MG/L) }\end{array}$ & $\begin{array}{l}\text { UCTANCE } \\
\text { (MICRO- } \\
\text { MHOS) }\end{array}$ & $\begin{array}{c}\text { PH } \\
\text { (UNITS) }\end{array}$ & $\begin{array}{l}\text { TEMP- } \\
\text { ERATURE } \\
\text { (DEG C) }\end{array}$ & $\begin{array}{l}\text { TEMP- } \\
\text { ERATURE } \\
\text { I DEG CI }\end{array}$ & $\begin{array}{l}\text { INUY- } \\
\text { COBALT } \\
\text { UNITSI }\end{array}$ \\
\hline UEC. & & & & & & & & & & \\
\hline $30 \ldots$ & .3 & 30 & .02 & 11 & - & 36 & 6.3 & 3.5 & -- & 5 \\
\hline $\begin{array}{l}30 \ldots \\
\text { FEB. }\end{array}$ & -- & -- & -- & - & 11.3 & -- & 6.4 & 3.5 & -- & -- \\
\hline $11 \ldots$ & .3 & 33 & .00 & 12 & - & 34 & 6.4 & 6.5 & - & 7 \\
\hline DUNE & - & & & & 9.0 & 40 & 6.1 & 6.5 & -- & $\rightarrow$ \\
\hline $\begin{array}{l}24 \ldots \\
24 \ldots\end{array}$ & .4 & 34 & .02 & 12 & - & 31 & 6.1 & 26.0 & - & 0 \\
\hline $\begin{array}{l}24 \ldots \\
\text { SEP. }\end{array}$ & -- & -- & & & 8.5 & $\cdots$ & & 26.0 & 31.5 & - \\
\hline $23 \ldots$ & $\therefore 3$ & 33 & .00 & 14 & $7 . \overline{6}$ & $\begin{array}{l}35 \\
38\end{array}$ & $\begin{array}{l}6.4 \\
7.3\end{array}$ & $\begin{array}{l}25.0 \\
25.0\end{array}$ & $30 . \overline{0}$ & 5 \\
\hline
\end{tabular}

02151000 SECOND BROAD RIVER AT CLIFFSIDE, N,C.

LOCATION.--Lat $35^{\circ} 14^{\prime} 08^{\prime \prime}$, long $81^{\circ} 45^{\prime} 57^{\prime \prime}$, Rutherford County, at gaging station on left bank 0.2 mile downstream from dam at Cliffide Milis at Cliffide and 1.3 miles upstream from mouth.

DRAI NAGE AREA, --211 sq $\mathrm{m} 1$.

PERIOD OF RECORD.--Chemical analyses: October 1948 to September 1949, October 1956 to September 1960 (daily),

October 1967 to September 1970 (part1al record)
Water temperatures: October 1948 to September 1949 , october 1956 to september 1960.

EXTREMES, - - Period of record:

Dissolved solids: Max1mum, $77 \mathrm{mg} / 1$ Oct, $11-20,1956$; m1n1mum, $36 \mathrm{mg} / 1$ Nov, 21-30, 1948.

Dissolved solids: Maximum, $77 \mathrm{mg} / 1$ oct. 11-20, 1956; minimum, $36 \mathrm{mg} / 1$ Nov. 21-30, 1948.

Hardness: Maximum, $23 \mathrm{mg} / 1$ Oct. 21-31, 1957; minimum, $6 \mathrm{mg} / 1$ June 2, 1959 .

Specific conductance (1956-60): Maximum da1ly, 137 micromhos Oct. 5, 1956; minimum daily, 26 micromhos Feb. 6, 1960 .

Water temperatures: Maximum, $26,5^{\circ} \mathrm{C}$ June $26-29$, July 28, 1949; minimum, freezing point Feb. 17-19, 1958, Jan, 22, 196D.

REKARKS. -.Miscellaneous samples of chemical data published for water years 1945, 1955-56, 1961-67. The second of two samples collected at the same time is a fleld determination. CHEMICAL ANALYSES, WATER YEAR OCTDBER 1969 TD SEPTEMBER 1970

\begin{tabular}{|c|c|c|c|c|c|c|c|c|c|c|}
\hline DATE & TIME & $\begin{array}{l}\text { DIS- } \\
\text { CHARGE } \\
\text { (CFSI }\end{array}$ & $\begin{array}{l}\text { SILICA } \\
\text { (SIOL) } \\
\text { (MG/L) }\end{array}$ & $\begin{array}{l}\text { ULS- } \\
\text { SOLVED } \\
\text { IRON } \\
\text { (FE) } \\
\text { (UG/L) }\end{array}$ & $\begin{array}{l}\text { DIS- } \\
\text { SOLVED } \\
\text { CAL- } \\
\text { CLUM } \\
\text { (CA) } \\
\text { (MG/LI) }\end{array}$ & $\begin{array}{l}\text { DIS- } \\
\text { SOL VED } \\
\text { MAG- } \\
\text { NE- } \\
\text { SIUM } \\
\text { (MG) } \\
\text { (MG/L) }\end{array}$ & $\begin{array}{l}\text { SODIUM } \\
\text { INA) } \\
\text { (MG/L) }\end{array}$ & $\begin{array}{l}\text { PO- } \\
\text { TAS- } \\
\text { SIUM } \\
\text { (K) } \\
\text { (MG/L) }\end{array}$ & $\begin{array}{l}\text { B ICAR- } \\
\text { BONATE } \\
\text { (HCO3) } \\
\text { (MG/L) }\end{array}$ & $\begin{array}{l}\text { CAR- } \\
\text { BONATE } \\
\text { (COB) } \\
\text { (MGIL) }\end{array}$ \\
\hline $24 \ldots$ & 1330 & 271 & 13 & 50 & 3.3 & 1.5 & 9.6 & 1.6 & 23 & 0 \\
\hline JUNE & 1330 & 271 & -- & -- & + & - & - & - & - & -- \\
\hline $04 \ldots$ & 1340 & $=$ & $\overline{--}$ & $=$ & $=$ & $=$ & $=$ & 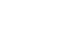 & - & $=$ \\
\hline $\begin{array}{l}04 \ldots \\
S E P .\end{array}$ & 1340 & 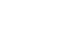 & - & 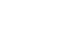 & 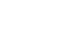 & $\cdots$ & 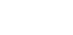 & $\cdots$ & -- & - \\
\hline $02 \ldots$ & 1240 & -- & -- & -- & -- & -- & -- & -- & - & -- \\
\hline
\end{tabular}


02151000 SECOND BROAD RIVER AT CLIFFSIDE, N.C.--Continued CHEMICAL ANALYSES, WATER YEAR OCTOBER 1969 TO SEPTEMBER 1970

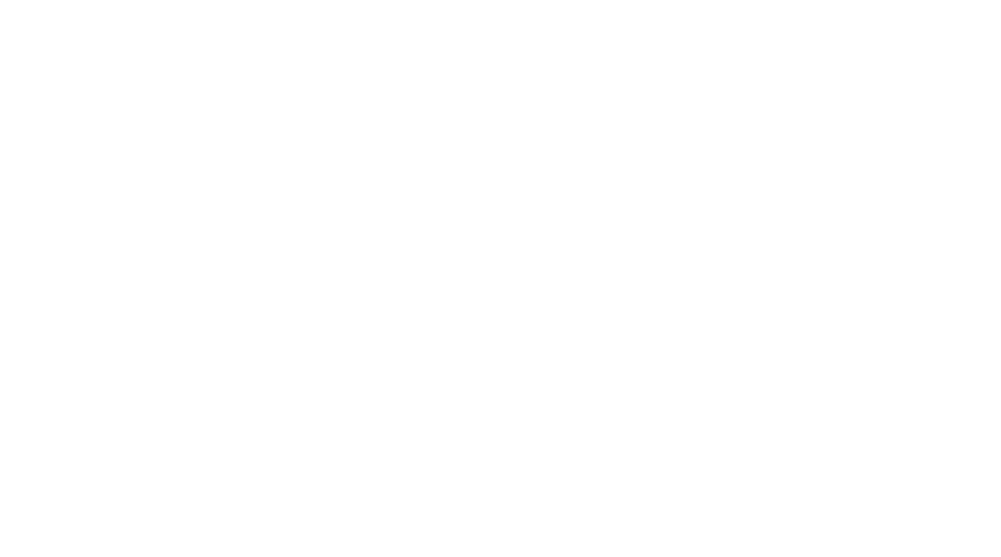
LOCATION,-Lat $35^{\circ} 13^{\prime} 03^{\prime \prime}$, long $81^{\circ} 37^{\prime} 37^{\prime \prime}$, Cleveland County, at bridge on Secondary Road $1140,3 \mathrm{miles}$ upstream from
mouth and 4.8 miles northwest of Eari.

DRAINAGE AREA.--292 sq mi.

PERIOD OF RECORD.--Chemical analyses: October 1967 to September 1970 (partial record). REMARKS.--The second of two samples collected at the same time is a field determination. CHEMICAL ANALYSES, hATER YEAR OCTOBER 1969 TO SEPTEMBER 1970

\begin{tabular}{|c|c|c|c|c|c|c|c|c|c|c|c|c|}
\hline DATE & TIME & $\begin{array}{l}\text { OIS- } \\
\text { CHARGE } \\
\text { (CFS I }\end{array}$ & $\begin{array}{l}\text { SILICA } \\
\text { ISIOLI) } \\
\text { (MGIL) }\end{array}$ & $\begin{array}{l}\text { DIS- } \\
\text { SOLVED } \\
\text { IRDN } \\
\text { (FE) } \\
\text { (UGIL) }\end{array}$ & $\begin{array}{c}\text { CAL- } \\
\text { CIUM } \\
\text { (CA) } \\
\text { ( } \mathrm{MG/L)}\end{array}$ & $\begin{array}{c}\text { MAG- } \\
\text { NE- } \\
\text { SIUM } \\
\text { (MG) } \\
\text { (MG/L) }\end{array}$ & $\begin{array}{c}\text { SDOIUM } \\
\text { (NA) } \\
\text { (MG/L) }\end{array}$ & $\begin{array}{l}\text { PO- } \\
\text { YAS- } \\
\text { SIUM } \\
\text { (K) } \\
(\mathrm{HG} / \mathrm{L})\end{array}$ & $\begin{array}{l}\text { BICAR- } \\
\text { BONATE } \\
\text { (HCO3) } \\
\text { (MG/L) }\end{array}$ & $\begin{array}{l}\text { CAR- } \\
\text { BONATE } \\
\text { (CO3) } \\
\text { (MG/L) }\end{array}$ & $\begin{array}{l}\text { SULFATE } \\
\text { (SO\&) } \\
\text { (MG/L) }\end{array}$ & $\begin{array}{l}\text { CHLO- } \\
\text { RIOE } \\
\text { (CL) } \\
\text { (HG/L) }\end{array}$ \\
\hline $\begin{array}{l}\mathrm{OCr} . \\
30 \ldots \ldots \\
30 \ldots . \\
\text { Nov. }\end{array}$ & $\begin{array}{l}1300 \\
1300\end{array}$ & $\begin{array}{l}215 \\
215\end{array}$ & 12 & $\begin{array}{r}0 \\
-\end{array}$ & 3.2 & 1.2 & 7.5 & 2.0 & 21 & -0 & 3.8 & 10 \\
\hline $24 \ldots \ldots$ & $\begin{array}{l}1100 \\
1100\end{array}$ & $\begin{array}{l}260 \\
260\end{array}$ & 12 & 22 & 2.9 & 1.1 & 3.8 & 1.8 & 16 & $\begin{array}{r}0 \\
--\end{array}$ & 3.4 & 4.0 \\
\hline $\begin{array}{l}\text { FEB. } \\
11 \ldots \\
11 \ldots \\
\text { MAY }\end{array}$ & $\begin{array}{l}1015 \\
1015\end{array}$ & $\begin{array}{l}360 \\
360\end{array}$ & 9.2 & 130 & 3.1 & 1.1 & $\begin{array}{l}5.0 \\
--\end{array}$ & 2.2 & 13 & -0 & $\begin{array}{l}3.6 \\
--\end{array}$ & 7.3 \\
\hline $21 \ldots$ & $\begin{array}{l}1445 \\
1445\end{array}$ & $\begin{array}{l}231 \\
231\end{array}$ & 12 & 17 & 3.3 & 1.0 & $\begin{array}{r}5.9 \\
--\end{array}$ & 1.9 & 17 & -0 & 2.4 & 8.1 \\
\hline $\begin{array}{c}\text { SEPY. } \\
24 \ldots . . \\
24 \ldots\end{array}$ & $\begin{array}{l}1525 \\
1525\end{array}$ & $\begin{array}{l}176 \\
176\end{array}$ & 12 & $\underline{0}$ & 3.3 & 1.2 & 5.9 & 2.0 & 20 & -- & $\begin{array}{r}3.6 \\
--\end{array}$ & 7.2 \\
\hline DATE & $\begin{array}{l}\text { FLUD- } \\
\text { RIDE } \\
\text { (F) } \\
\text { (MG/L) }\end{array}$ & $\begin{array}{c}\text { NITRATE } \\
\text { (NO3) } \\
\text { (MG IL) }\end{array}$ & $\begin{array}{l}\text { ORTHO } \\
\text { PHOS- } \\
\text { PHATE } \\
\text { (PO4) } \\
\text { (MG/L) }\end{array}$ & $\begin{array}{l}\text { OIS- } \\
\text { SOLVED } \\
\text { SOL IOS } \\
\text { IRESI- } \\
\text { DUE AY } \\
\text { IBO C) } \\
\text { (MG/L) }\end{array}$ & $\begin{array}{l}\text { OIS- } \\
\text { SDLVEO } \\
\text { SOLIDS } \\
\text { (TONS } \\
\text { PER } \\
\text { AC-FT) }\end{array}$ & $\begin{array}{l}\text { DIS- } \\
\text { SOLVEO } \\
\text { SDLIDS } \\
\text { I TONS } \\
\text { PER } \\
\text { DAYI }\end{array}$ & $\begin{array}{l}\text { HARD- } \\
\text { NESS } \\
\text { (CA, MG) } \\
(M G / L)\end{array}$ & $\begin{array}{l}\text { NON- } \\
\text { CAR- } \\
\text { BONATE } \\
\text { HARD- } \\
\text { NESS } \\
\text { (MG/L) }\end{array}$ & $\begin{array}{l}\text { SODIUM } \\
\text { AD- } \\
\text { SORP- } \\
\text { TION } \\
\text { RAYID }\end{array}$ & $\begin{array}{l}\text { PERCENT } \\
\text { SODIUM }\end{array}$ & $\begin{array}{l}\text { ME THY- } \\
\text { LENE } \\
\text { OLUE } \\
\text { ACTIVE } \\
\text { SUB- } \\
\text { STANCE } \\
\text { (MG/L) }\end{array}$ & $\begin{array}{l}\text { ALKA- } \\
\text { LINITY } \\
\text { AS } \\
\text { CACO3 } \\
\text { (MG/L) }\end{array}$ \\
\hline $\begin{array}{l}\text { OCt. } \\
30 . \ldots \\
30 \ldots \\
\text { Nov. }\end{array}$ & \pm 1 & -3 & .17 & 55 & .07 & 31.9 & 13 & $\underline{0}$ & .9 & 51 & $\overline{-}$ & 17 \\
\hline $\begin{array}{l}24 \ldots \\
24 \ldots \\
F E B .\end{array}$ & .2 & 2.9 & .37 & $\begin{array}{l}41 \\
--\end{array}$ & .06 & 28.8 & 12 & $\underline{0}$ & .5 & $\begin{array}{l}37 \\
--\end{array}$ & .11 & 13 \\
\hline $\begin{array}{l}11 \ldots . \\
11 \ldots \\
\text { MAY }\end{array}$ & 1 & 2.8 & .20 & 45 & .06 & 43.7 & 12 & -- & .6 & 42 & .00 & 11 \\
\hline $\begin{array}{r}21 \ldots . \\
21 \ldots . \\
\text { SEPY. }\end{array}$ & .0 & 3.0 & .28 & 60 & .08 & 37.4 & 12 & $\underline{0}$ & .7 & $\begin{array}{l}46 \\
--\end{array}$ & .03 & 14 \\
\hline $24 \ldots$ & $=1$ & 1.1 & .37 & $\begin{array}{l}52 \\
--\end{array}$ & .07 & 24.7 & $=$ & 13 & $\therefore$ & 45 & .02 & 16 \\
\hline & & & DATE & $\begin{array}{l}\text { DIS- } \\
\text { SOLYED } \\
\text { OXYGEN } \\
\text { (MG/L) }\end{array}$ & $\begin{array}{l}\text { SPECI- } \\
\text { FIC } \\
\text { CDND- } \\
\text { UCTANCE } \\
\text { (NICRO- } \\
\text { MHOS) }\end{array}$ & $\begin{array}{c}P H \\
\text { (UNITS) }\end{array}$ & $\begin{array}{l}\text { TEMP- } \\
\text { ERATURE } \\
\text { (DEG CI }\end{array}$ & $\begin{array}{c}\text { ATR } \\
\text { TEMP- } \\
\text { ERATURF } \\
\text { (DEG C) }\end{array}$ & $\begin{array}{l}\text { COLOR } \\
\text { IPLAT- } \\
\text { INUM- } \\
\text { CDEALT } \\
\text { UNITSI }\end{array}$ & & & \\
\hline & & & $\begin{array}{c}\text { ост. } \\
3 \cap \ldots . . \\
30 . .\end{array}$ & 9.3 & $\begin{array}{l}43 \\
77\end{array}$ & $\begin{array}{l}5.8 \\
6.7\end{array}$ & $\begin{array}{l}9.5 \\
8.5\end{array}$ & $\therefore$ & $2 n$ & & & \\
\hline & & & $\begin{array}{l}\text { NOV. } \\
24 \ldots \\
24 \ldots \\
\text { FEB... }\end{array}$ & 9.9 & $\begin{array}{l}47 \\
65\end{array}$ & $\begin{array}{l}5.9 \\
6.8\end{array}$ & $\begin{array}{l}6.5 \\
8.5\end{array}$ & $\overline{--}$ & $=$ & & & \\
\hline & & & $\begin{array}{l}11 \ldots \\
11 \ldots \\
\text { MAY }\end{array}$ & 8.5 & $\begin{array}{l}53 \\
67\end{array}$ & $\begin{array}{l}6.4 \\
6.5\end{array}$ & $\begin{array}{l}5.0 \\
5.3\end{array}$ & $=$ & 15 & & & \\
\hline & & & $\begin{array}{r}21 \ldots . . \\
\text { SEPT. }\end{array}$ & 7.3 & $\begin{array}{l}61 \\
82\end{array}$ & $\begin{array}{l}6 . ? \\
0.9\end{array}$ & $\begin{array}{l}21.5 \\
21.5\end{array}$ & $=$ & $\begin{array}{r}5 \\
--\end{array}$ & & & \\
\hline & & & $24 \ldots \ldots$ & 7.5 & $\begin{array}{l}71 \\
73\end{array}$ & $\begin{array}{l}6.1 \\
7.0\end{array}$ & $\begin{array}{l}26.7 \\
26.7\end{array}$ & 32.5 & -5 & & & \\
\hline
\end{tabular}


02176912 CHATOOGA RIVER NEAR HIGHLANDS, N.C.

LOCATION, - - Lat $35^{\circ} 00^{\prime} 57^{\prime \prime}$, long $83^{\circ} 07 \cdot 36^{\prime \prime}$, Macon County, at bridge on Secondary Road 1603, upstream from Ammons Branch and 4.7 miles southwest of Highlands.

DRAINAGE AREA. $-22.9 \mathrm{sq} \mathrm{ml}$.

PERIOD OF RECORD...-Chemical analyses: OCtober 1988 to September 1970 (part1al record).

Rmurxs.-.The second of two samples colleoted at the same time is a fleld determination. CHEMICAL ANALYSES, WATER YEAR OCTOBER 1969 TO SEPTEMBER 1970

\begin{tabular}{|c|c|c|c|c|c|c|c|c|c|}
\hline DATE & TIME & $\begin{array}{l}\text { DIS- } \\
\text { CHARGE } \\
\text { (CFS) }\end{array}$ & $\begin{array}{l}\text { SILICA } \\
\text { (SIDZ) } \\
\text { (MG/L) }\end{array}$ & $\begin{array}{l}\text { DIS- } \\
\text { SDLVED } \\
\text { IRON } \\
\text { IFEI } \\
\text { IUG/LI }\end{array}$ & $\begin{array}{l}\text { DIS- } \\
\text { SDLVED } \\
\text { CAL- } \\
\text { CIUM } \\
\text { ICA) } \\
\text { IMGIL) }\end{array}$ & $\begin{array}{l}\text { DIS- } \\
\text { SDLVED } \\
\text { MAG- } \\
\text { NE- } \\
\text { SIUM } \\
\text { IMGI } \\
\text { (MG/LI }\end{array}$ & $\begin{array}{l}\text { SODI UA } \\
\text { INAI } \\
\text { ING/LI }\end{array}$ & $\begin{array}{l}\text { PD- } \\
\text { TAS- } \\
\text { SIUM } \\
\text { IKI } \\
\text { I MG/LI }\end{array}$ & $\begin{array}{l}\text { BICAR- } \\
\text { BONATE } \\
\text { (HCO3) } \\
\text { (MG/L) }\end{array}$ \\
\hline 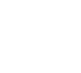 & $\begin{array}{l}1230 \\
1230\end{array}$ & $\begin{array}{l}100 \\
100\end{array}$ & 5.7 & - & .7 & $\because 2$ & 1.3 & -3 & -4 \\
\hline $\begin{array}{l}15 \ldots . . \\
\text { JUNE }\end{array}$ & $\begin{array}{l}1405 \\
1405\end{array}$ & $\begin{array}{l}55 \\
55\end{array}$ & $\begin{array}{r}6.7 \\
--\end{array}$ & $\begin{array}{r}7 \\
--\end{array}$ & $\div$ & $\div 2$ & 1.3 & -1 & -1 \\
\hline $\begin{array}{l}11 \ldots . . . \\
11 \ldots . .\end{array}$ & $\begin{array}{l}1425 \\
1425\end{array}$ & $\begin{array}{l}54 \\
54\end{array}$ & 6.6 & $\begin{array}{l}27 \\
--\end{array}$ & 1.0 & -5 & 1.3 & $\div$ & -- \\
\hline $23 \ldots$ & $\begin{array}{l}1145 \\
1145\end{array}$ & $=$ & 8.3 & 69 & 1.0 & $\because 2$ & $\stackrel{1.5}{-}$ & $\because 4$ & -1 \\
\hline DATE & $\begin{array}{l}\text { CAR- } \\
\text { BONATE } \\
\text { (CO3) } \\
\text { (MG/L) }\end{array}$ & $\begin{array}{l}\text { SULFATE } \\
\text { (SOA) } \\
\text { (MG/L) }\end{array}$ & $\begin{array}{l}\text { CHLD- } \\
\text { RIDE } \\
\text { ICLI } \\
\text { IMG/LI }\end{array}$ & $\begin{array}{l}\text { DIS- } \\
\text { SOLVED } \\
\text { FLUO- } \\
\text { RIDE } \\
\text { (F) } \\
\text { I HG/L) }\end{array}$ & $\begin{array}{l}\text { NI TRATE } \\
\text { (NO3) } \\
\text { (MG/L) }\end{array}$ & $\begin{array}{l}\text { OIS- } \\
\text { SOLVED } \\
\text { ORTHO } \\
\text { PHOS- } \\
\text { PHATE } \\
\text { (PO4) } \\
\text { (MG/L) }\end{array}$ & $\begin{array}{l}\text { DIS- } \\
\text { SDLVED } \\
\text { SOLIDS } \\
\text { IRESI- } \\
\text { DUE AT } \\
180 \text { CI } \\
\text { IMGILI }\end{array}$ & $\begin{array}{l}\text { DIS- } \\
\text { SOLVED } \\
\text { SOLIDS } \\
\text { I TONS } \\
\text { PER } \\
\text { AC-FTI }\end{array}$ & $\begin{array}{l}\text { DIS- } \\
\text { SOLVED } \\
\text { SOL IDS } \\
\text { ITONS } \\
\text { PER } \\
\text { DAYI }\end{array}$ \\
\hline $\begin{array}{l}\text { FEB. } \\
05 \ldots \\
05 \ldots \\
\text { OPR. }\end{array}$ & -0 & .6 & 2.5 & 1 & $\stackrel{.2}{--}$ & .00 & 15 & 02 & $\begin{array}{r}4.05 \\
--\end{array}$ \\
\hline $\begin{array}{l}15 \ldots \\
15 \ldots . \\
\text { JUNE }\end{array}$ & - & $\because 4$ & 2.2 & -1 & $\because 0$ & .00 & 13 & .02 & 1.93 \\
\hline $\begin{array}{l}11 \ldots . . \\
11 \ldots\end{array}$ & $\underline{0}$ & 1.0 & 2.0 & $\because 1$ & -4 & .00 & 18 & .02 & 2.62 \\
\hline $23 \ldots$ & 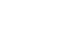 & $\because 8$ & .6 & .0 & $\stackrel{3}{-}$ & .00 & 19 & .03 & $=$ \\
\hline DATE & $\begin{array}{l}\text { SODIUM } \\
\text { AO- } \\
\text { SORP- } \\
\text { TION } \\
\text { RATIO }\end{array}$ & $\begin{array}{l}\text { PERCENT } \\
\text { SODIUM }\end{array}$ & $\begin{array}{l}\text { ME THY- } \\
\text { LENE } \\
\text { BLUE } \\
\text { ACTIVE } \\
\text { SUB- } \\
\text { SIANCE } \\
\text { IMG/L) }\end{array}$ & $\begin{array}{l}\text { ALKA- } \\
\text { LINITY } \\
\text { AS } \\
\text { CACOB } \\
\text { IAG/LI) }\end{array}$ & $\begin{array}{l}\text { DIS- } \\
\text { SOL VED } \\
\text { OXYGEN } \\
\text { (MGIL) }\end{array}$ & $\begin{array}{l}\text { SPECI- } \\
\text { FIC } \\
\text { COND- } \\
\text { UCTANCE } \\
\text { IMICRD- } \\
\text { MHOSI }\end{array}$ & $\begin{array}{c}\text { PH } \\
\text { CUNITSI }\end{array}$ & $\begin{array}{l}\text { TEMP- } \\
\text { ERATURE } \\
\text { (DEG C) }\end{array}$ & $\begin{array}{l}\text { COLOR } \\
\text { IPLAT- } \\
\text { INUM- } \\
\text { CDBALIT } \\
\text { UNITSI }\end{array}$ \\
\hline $\begin{array}{l}\text { FEB. } \\
\text { O5 ... } \\
05 \ldots \\
\text { APR. }\end{array}$ & -4 & 49 & .00 & 3 & 19.0 & 12 & $\begin{array}{l}6.2 \\
6.3\end{array}$ & $\begin{array}{l}1.0 \\
1.0\end{array}$ & 10 \\
\hline $\begin{array}{l}15 \ldots . . \\
\text { JUNE }\end{array}$ & $\therefore$ & 51 & .02 & $\begin{array}{l}3 \\
6\end{array}$ & $12 . \overline{3}$ & 13 & $\begin{array}{l}6.0 \\
6.9\end{array}$ & $\begin{array}{l}13.0 \\
13.0\end{array}$ & -4 \\
\hline $\begin{array}{l}11 \ldots . . \\
\text { SEP. }\end{array}$ & $\div$ & 36 & .01 & 5 & 11.0 & 14 & $\begin{array}{l}6.1 \\
7.0\end{array}$ & $\begin{array}{l}19.0 \\
19.0\end{array}$ & 10 \\
\hline $\begin{array}{l}23 \ldots \\
23 \ldots\end{array}$ & -4 & 46 & .00 & $\begin{array}{l}6 \\
8\end{array}$ & 7.9 & 16 & $\begin{array}{l}6.3 \\
6.5\end{array}$ & $\begin{array}{l}20.0 \\
20.0\end{array}$ & 10 \\
\hline
\end{tabular}

02189000 SAVANNAH RIVER NEAR CALHOUN FALLS, S.C.

LOCATION,--Lat $34^{\circ} 04^{\prime} 15^{\prime \prime}$, long $82^{\circ} 38^{\prime} 30^{\prime \prime}$, Abbeville County, on left bank 150 ft upstream from bridge on State Highway 72,1 mile downstream from Seaboard Coast Line Rail road bridge, 1.5 miles downstream from Rocky River,

3 miles southest of Calhoun Falls, and at mile 279.7 .

DRAINAGE AREA. $--2,876 \mathrm{sq} \mathrm{mi}$.

PERIOD OF RECORD,--Chemical analyses: November 1969 to September 1970 (part1al record).

REMARKS, - -laboratory chemical analyses by Georgia Water Quality Control Board. Field determination of discharge, water temperature, $\mathrm{PH}$, and dissolved oxygen by U.S. Geological Survev.

CHEMICAL ANALYSES, WATER YEAR OCTOBER 1969 TO SEPTEMBER 1970

\begin{tabular}{|c|c|c|c|c|c|}
\hline UATE & TIME & $\begin{array}{l}\text { OIS- } \\
\text { CHARGE } \\
\text { (CFS) }\end{array}$ & $\begin{array}{c}P H \\
\text { (UNITS) }\end{array}$ & $\begin{array}{l}\text { TEMH- } \\
\text { ERATURE } \\
\text { (DEG C) }\end{array}$ & $\begin{array}{l}\text { DIS- } \\
\text { SOLVFD } \\
\text { OXYGEN } \\
\text { (MG/L) }\end{array}$ \\
\hline $\begin{array}{l}\text { WOV. } \\
\text { MLE... }\end{array}$ & $113 n$ & 2400 & 7.1 & 15.0 & 8.9 \\
\hline $\begin{array}{l}02 \ldots \\
\text { IAAY }\end{array}$ & 1445 & $\operatorname{nan} 3$ & 7.4 & $\cdots$ & 8.4 \\
\hline 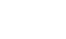 & 2010 & 641 & -- & $21 \cdot n$ & -- \\
\hline $01 \ldots$ & 1745 & 1120 & 7.4 & 22.0 & 7.5 \\
\hline
\end{tabular}


SAVANNAH RIVER BASIN

02189000 SAVANNAK RIVER NeAr CALHOUN FALLS, 8.C.--Continued

CHEMICAL ANALYSES, WATER YEAR OCTOBER 1969 TO SEPTEMBER 1970

\begin{tabular}{|c|c|c|c|c|c|c|c|c|c|c|}
\hline OATE & $\begin{array}{l}\text { SILICA } \\
\text { (SIOZ) } \\
(M G / L)\end{array}$ & $\begin{array}{l}\text { TOYAL } \\
\text { IRON } \\
\text { (FE) } \\
\text { (UG/L) }\end{array}$ & $\begin{array}{l}\text { TOTAL } \\
\text { MAN- } \\
\text { GANESE } \\
\text { (MN) } \\
\text { (UG/L) }\end{array}$ & $\begin{array}{l}\text { DIS- } \\
\text { SOLVED } \\
\text { CAL- } \\
\text { CIUM } \\
\text { (CA) } \\
\text { (MG/L) }\end{array}$ & $\begin{array}{l}\text { DIS- } \\
\text { SOLVEO } \\
\text { MAG- } \\
\text { NE- } \\
\text { SIUM } \\
\text { (MGG) } \\
(M G / L)\end{array}$ & $\begin{array}{l}\text { SODIUNA } \\
\text { (NA) } \\
\text { (MG/L) }\end{array}$ & $\begin{array}{l}\text { PO- } \\
\text { TAS- } \\
\text { SIUM } \\
\text { (KI) } \\
(M G / L)\end{array}$ & $\begin{array}{l}\text { ALKA- } \\
\text { LINIIY } \\
\text { AS } \\
\text { CACO3 } \\
\text { (MG/L) }\end{array}$ & $\begin{array}{l}\text { SULFATE } \\
(S O 4) \\
(M G / L)\end{array}$ & $\begin{array}{l}\text { CHLO- } \\
\text { RIOE } \\
\text { (CL) } \\
\text { (MG/L) }\end{array}$ \\
\hline $\begin{array}{l}\text { NOV. } \\
12 . . .\end{array}$ & 6.0 & 300 & $<50$ & 3.1 & 1.2 & 4.6 & 2.1 & 18 & 3.0 & 2.8 \\
\hline$\underset{M A Y}{\text { MaR.... }}$ & 11 & 300 & $<50$ & 3.2 & 1.2 & 4.2 & 1.7 & 17 & 4.0 & 3.0 \\
\hline $\begin{array}{l}\text { 2S... } \\
\text { SEPT. }\end{array}$ & 10 & 350 & $<50$ & 3.3 & 1.2 & 4.6 & 2.1 & 17 & 5.0 & 2.5 \\
\hline $01 \ldots$ & 9.0 & 250 & $<50$ & 2.4 & .9 & 4.1 & 1.6 & 13 & 2.0 & 2.4 \\
\hline DATE & $\begin{array}{l}\text { NITHATE } \\
\text { (N) } \\
\text { (MG/L) }\end{array}$ & $\begin{array}{l}\text { PHOS- } \\
\text { PHATE } \\
\text { (PO4) } \\
\text { (MG/L) }\end{array}$ & $\begin{array}{l}\text { TOTAL } \\
\text { FILT- } \\
\text { RABLE } \\
\text { RESIDUE }\end{array}$ & $\begin{array}{l}\text { TOIAL } \\
\text { NON- } \\
\text { FILT- } \\
\text { RABLE } \\
\text { RESIOUE } \\
(M G / L)\end{array}$ & $\begin{array}{l}\text { HARD- } \\
\text { NESS } \\
\text { (CA,MG) } \\
\text { (MG/L) }\end{array}$ & $\begin{array}{l}\text { SPECI - } \\
\text { FIC } \\
\text { COND- } \\
\text { UCTANCE } \\
\text { (MICRO- } \\
\text { MHOS) }\end{array}$ & $\begin{array}{l}\text { COLOR } \\
\text { (PLAT- } \\
\text { INUM- } \\
\text { COBALT } \\
\text { UNITS) }\end{array}$ & $\begin{array}{l}\text { TUR- } \\
\text { BIO- } \\
\text { ITY } \\
\text { (JTU) }\end{array}$ & $\begin{array}{l}\text { BIO- } \\
\text { CHEM- } \\
\text { ICAL } \\
\text { OXYGEN } \\
\text { DEMAND } \\
\text { (MG/L) }\end{array}$ & $\begin{array}{l}\text { FECAL } \\
\text { COLI- } \\
\text { FORM } \\
\text { (COL. } \\
\text { PER } \\
100 \mathrm{ML}) \\
\text { (MPN) }\end{array}$ \\
\hline
\end{tabular}

NOV.

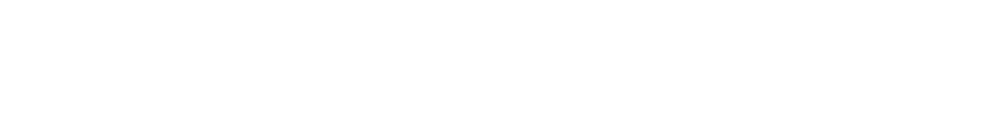

02191000 NORTH FORK BROAD RIVER NEAR CARNESVILLE, GA.

LOCATION.--Lat $34^{\circ} 19^{\prime} 25^{\prime \prime}$, long $83^{\circ} 11^{\prime} 10^{\prime \prime}$, Franklin County, at bridge on state Highway 51 , 1 mile downstream from Unawati Creek, 3 miles upstream from confluence wi th yidde Fork Broad River, and 4.5 miles southeast of Carnesville.

DRAINAGE AREA. - - 119 sq mi.

PERIOD OF RECORD.--Chemical Analyses: November 1969 to September 1970 (partial record).

REMARKS, - Laboratory chemical analyses by Georgia Water quality Control Board. Fleld determination of discharge, water temperature, $\mathrm{pH}$, and dissolved oxygen by U.S. Geological Survey.

CHEMICAL ANALYSES, WATER YEAK OCTOBER 1969 TO SEPTEMBER 1970

\begin{tabular}{|c|c|c|c|c|c|}
\hline DATE & TIME & $\begin{array}{l}\text { UIS- } \\
\text { CHAKGE } \\
\text { (CFS) }\end{array}$ & $\begin{array}{c}P H \\
\text { (UNITS) }\end{array}$ & $\begin{array}{l}\text { TEMP- } \\
\text { ERATURE } \\
\text { (DEG C) }\end{array}$ & $\begin{array}{l}\text { OIS- } \\
\text { SOLVED } \\
\text { OXYGEN } \\
\text { (MG/L) }\end{array}$ \\
\hline $\begin{array}{l}\text { NOV. } \\
11 . . . \\
\text { MAR. }\end{array}$ & 1200 & 99 & 6.4 & 10.0 & 9.8 \\
\hline MAY & 1000 & 115 & 6.4 & 10.0 & 8.9 \\
\hline $\begin{array}{l}25 \ldots . . \\
\text { SEPT. }\end{array}$ & 1730 & 95 & 6.2 & 21.0 & 7.9 \\
\hline $01 \ldots$ & 1430 & h> & 7.6 & 27.10 & 7.2 \\
\hline
\end{tabular}

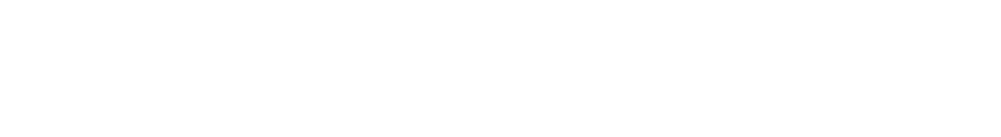

NOV.

\begin{tabular}{|c|c|c|c|c|c|c|c|c|c|c|}
\hline $\begin{array}{l}\text { NOV. } \\
11 . . .\end{array}$ & 8.0 & 1100 & $<50$ & 3.3 & 1.4 & 3.4 & 15 & 20 & 2.0 & 14 \\
\hline & 17 & 1200 & $<50$ & 3.2 & 1.2 & 2.8 & 1.1 & 18 & $<2.0$ & 2.0 \\
\hline & 16 & 1400 & 70 & 3.5 & 1.3 & 3.0 & 1.5 & 16 & $<2.0$ & 1.6 \\
\hline $01 \ldots$ & 18 & 890 & $<50$ & 3.2 & 1.3 & 3.8 & 1.8 & 19 & $<2.0$ & 1.8 \\
\hline DATE & $\begin{array}{l}\text { NITRATE } \\
\text { (N) } \\
\text { (MG/L) }\end{array}$ & $\begin{array}{l}\text { PHOS- } \\
\text { PHATE } \\
(\text { PO } 4) \\
(M G / L)\end{array}$ & $\begin{array}{l}\text { TOTAL } \\
\text { FILT- } \\
\text { KABLE } \\
\text { RESIDUE } \\
\text { (MG/L) }\end{array}$ & $\begin{array}{l}\text { TOIAL } \\
\text { NON- } \\
\text { FILT- } \\
\text { RABLE } \\
\text { RESIDUE } \\
\text { (MG/L) }\end{array}$ & $\begin{array}{l}\text { HARO- } \\
\text { NESS } \\
\text { (CA,MG) } \\
\text { (MG/L) }\end{array}$ & $\begin{array}{l}\text { SPECI- } \\
\text { FIC } \\
\text { COND- } \\
\text { UCTANCE } \\
\text { (MICRO- } \\
\text { MHOS) }\end{array}$ & $\begin{array}{l}\text { COLOR } \\
\text { (PLAT- } \\
\text { INUM- } \\
\text { COBALT } \\
\text { UNITS) }\end{array}$ & $\begin{array}{l}\text { TUR- } \\
\text { BID- } \\
\text { ITY } \\
\text { (JTU) }\end{array}$ & $\begin{array}{l}\text { BIO- } \\
\text { CHEM- } \\
\text { ICAL } \\
\text { OXYGEN } \\
\text { DEMAND } \\
\text { (MG/L) }\end{array}$ & $\begin{array}{c}\text { FECAL } \\
\text { COLI- } \\
\text { FORM } \\
\text { (COL. } \\
\text { PER } \\
100 \mathrm{ML}) \\
\text { (MPN) }\end{array}$ \\
\hline
\end{tabular}

NOV.

\begin{tabular}{|c|c|c|c|c|c|c|c|c|c|c|}
\hline MAR... & .2 & .25 & 55 & 5 & 12 & 101 & 35 & 20 & .6 & 930 \\
\hline$\underset{\text { MAY }}{03 \ldots}$ & .3 & .05 & 51 & 28 & 10 & 46 & 35 & 20 & .6 & 230 \\
\hline SEPT. & .5 & .09 & 34 & 30 & 15 & 45 & 35 & 26 & .8 & 2300 \\
\hline $01 \ldots$ & .4 & .21 & 76 & 22 & 14 & 52 & 20 & 19 & .6 & 7500 \\
\hline
\end{tabular}




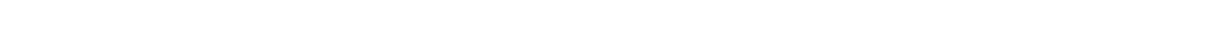
on State Highway 15 at Homer, $3.6 \mathrm{miles}$ upstream from webb Creek, and $10.8 \mathrm{miles}$ upstream from Grove Creek. DRAINAGE AREA. - -61.1 sq $\mathrm{mi}$.

PERIOD OF RECORD.--Chemical analyses: November 1969 to September 1970 (partial record).

REMARKS. - Laboratory chemical analyses by Georgia water Quality Control Board. Field determination of discharge, water temperature, $\mathrm{pH}$, and dissolved oxygen by U.S. Geological Survey. CHEMICAL AIVALYSES, WATEH YEAR OCTOBER 1969 TO SEPTEMBER 1970

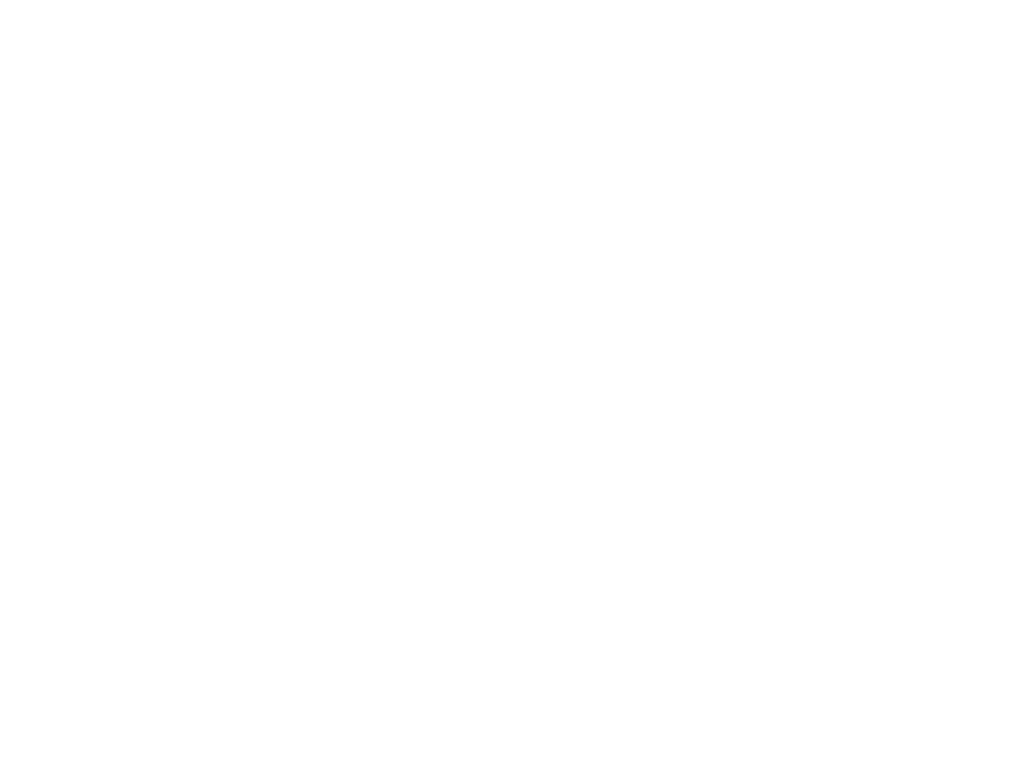

02192000 BROAD RIVER NEAR BELL, GA.

LOCATION,--Lat $33^{\circ} 58^{\circ} 27^{\prime \prime}$, long $82^{\circ} 46^{\prime} 12^{\prime \prime}$, Elbert County, at gaging station at downstream side of main channel pier CATION.--Lat $33^{\circ} 58^{\prime} 27^{\prime \prime}$, long $82^{\circ} 46^{\prime} 12^{\prime \prime}$, Elbert County, at gaging station at downstream side of main channel
of bridge on State Highway $17,0.5$ mile downstream from Long Creek, 1 mile south of Bell's Crossroads, and of bridge on State Highway 17 ,
12 miles southeast of Elberton.

DRA INAGE AREA. - -1,430 sq m1, approximately.

PERIOD OF RECORD.--Chemical analyses: November 1969 to September 1970 (partial record).

REMARKS.--Laboratory chemical analyses by Georgia Water Quality Control Board, Field determination discharge, water temperature, $\mathrm{pH}$, and dissolved oxygen by U.S. Geological Survey. CHEMICAL ANALYSES, WATER YEAR OCTOBER 1969 TO SEPTEMBER 1969

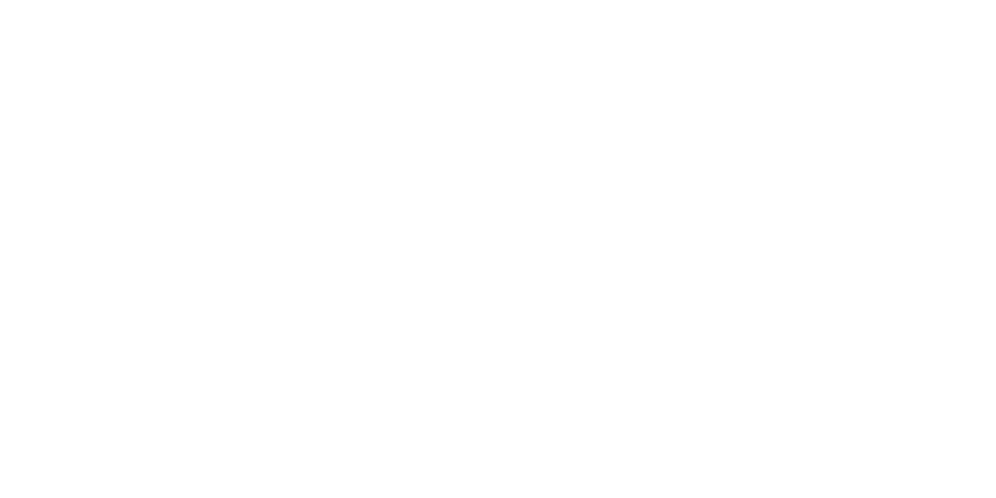


SAVANNAH RIVER BASIN

02192000 BROAD RIVER NEAR BELL, GA.--Continued

CHEMICAL ANALYSES, WATER YEAR OCTOBER 1969 TO SEPTEMBER 1970

\begin{tabular}{|c|c|c|c|c|c|c|c|c|c|c|}
\hline & & & $\begin{array}{l}\text { TUTAL } \\
\text { FILI- }\end{array}$ & $\begin{array}{l}\text { TOTAL } \\
\text { NON- } \\
\text { FILI- }\end{array}$ & & $\begin{array}{l}\text { SPECI- } \\
\text { FIC }\end{array}$ & COLOR & & $\begin{array}{l}\text { B10- } \\
\text { CHEM- }\end{array}$ & $\begin{array}{l}\text { FECAL } \\
\text { COLI- }\end{array}$ \\
\hline & NIIKAT & $\begin{array}{l}\text { PHOS- } \\
\text { PHATE }\end{array}$ & $\begin{array}{l}\text { KABLLE } \\
\text { RESIDUNt. }\end{array}$ & $\begin{array}{l}\text { RABLLE } \\
\text { RESIOUEE }\end{array}$ & $\begin{array}{l}\text { HARO- } \\
\text { NESS }\end{array}$ & $\begin{array}{l}\text { COND- } \\
\text { UCTANCEE }\end{array}$ & $\begin{array}{l}\text { IPLAT- } \\
\text { INUM- }\end{array}$ & $\begin{array}{l}\text { TUR- } \\
\text { BID- }\end{array}$ & $\begin{array}{l}\text { ICAL } \\
\text { OXYGEN }\end{array}$ & $\begin{array}{c}\text { FORM } \\
\text { ICOL. PER }\end{array}$ \\
\hline $\begin{array}{l}\text { DATE } \\
\text { NOV. }\end{array}$ & $\begin{array}{c}(\cdot) \\
(M i j L)\end{array}$ & $\begin{array}{l}\left(\mathrm{PO}_{4}\right) \\
(\mathrm{MG} / \mathrm{L})\end{array}$ & $(\mathrm{i}+\mathrm{G} / \mathrm{L})$ & $(M G / L)$ & $\begin{array}{r}(C A, M G) \\
(M G / L)\end{array}$ & $\begin{array}{l}\text { (MICRO- } \\
\text { MHOS) }\end{array}$ & $\begin{array}{l}\text { COBALT } \\
\text { UNITSS }\end{array}$ & $\begin{array}{l}\text { ITY } \\
\text { (JTU) }\end{array}$ & $\begin{array}{l}\text { DEMAND } \\
\text { (MG/L) }\end{array}$ & $\begin{array}{c}100 \mathrm{ML}) \\
(\mathrm{MPN})\end{array}$ \\
\hline MAK. & .1 & לג. & 60 & 9 & 13 & 47 & 35 & 18 & .6 & 230 \\
\hline WIAY & .1 & .20 & 68 & 18 & 16 & so & 20 & 19 & .4 & 140 \\
\hline SE... & .3 & .06 & 57 & 21 & 18 & 57 & 25 & 21 & 1.0 & 91 \\
\hline v2... & .3 & S.05 & 68 & 31 & 18 & 54 & 35 & 21 & .4 & 230 \\
\hline
\end{tabular}

02197000 SAVANNAH RIVER AT AUGUSTA, Ga.

LOCATION. - - Lat $33^{\circ} 22^{\prime} 25^{\prime \prime}$, long $81^{\circ} 56^{\prime} 35^{\prime \prime}$, Richmond County, at gaging station at New Savannah Bluff lock and dam, 0.2 mile upstream from Butler Creek, 12 miles downstream from Augusta, and at mile 203 .

DRAINAGE AREA.--7,508 sq mi, including that of Butler Creek.

PERIOD OF RECORD.--Chemical analyses: February 1968 to September 1970 (partial record).

REMARKS, - Laboratory chemical analyses by Georgia water quality Control Board. Field determination of discharge, water temperature, $\mathrm{pH}$, and dissolved oxygen by U.S. Geological Survey.

CHEMICAL AIJALYSES. WATEK YEAH OCIOHER IGGG TO SEPTEMHEP 1970

\begin{tabular}{|c|c|c|c|c|c|}
\hline DATE & TIMF & $\begin{array}{l}\text { DIS- } \\
\text { CHADGE } \\
\text { (CFS) }\end{array}$ & $\begin{array}{c}\text { PH } \\
\text { (UNITS) }\end{array}$ & $\begin{array}{l}\text { TEMP- } \\
\text { FRATUPE } \\
\text { TPEG CI }\end{array}$ & $\begin{array}{l}\text { DIS- } \\
\text { SOLVED } \\
\text { OXYGFN } \\
\text { (MG/L) }\end{array}$ \\
\hline uT. & $111 b$ & 5400 & 6.3 & 18.0 & 10.5 \\
\hline $10 \ldots$ & $n 930$ & KO80 & $6 . B$ & $11 . n$ & 11.2 \\
\hline $21 \ldots$ & $(x+30$ & 7000 & 6.5 & 6.0 & 13.0 \\
\hline $\begin{array}{l}\text { FEH. } \\
\text { C6.... } \\
\text { ANK. }\end{array}$ & 1) 445 & H53n & 6.4 & $R \cdot 0$ & 12.0 \\
\hline MAY... & 0715 & 7600 & -- & 14.0 & 10.0 \\
\hline $\operatorname{JUL}_{\text {JUL }} 1 \ldots$ & 11430 & 4.130 & 6.4 & 17.5 & $\mathrm{H} .5$ \\
\hline $\begin{array}{lll}01 & 1\end{array}$ & 1030 & 2430 & 7.2 & 19.0 & 7.6 \\
\hline $\begin{array}{c}12 \ldots . . \\
\text { SFNT. }\end{array}$ & 1100 & bhen & 0.5 & 18.0 & B. 0 \\
\hline $23 .$. & ט 07 & R.5611 & 0.9 & 21.0 & 7.8 \\
\hline
\end{tabular}

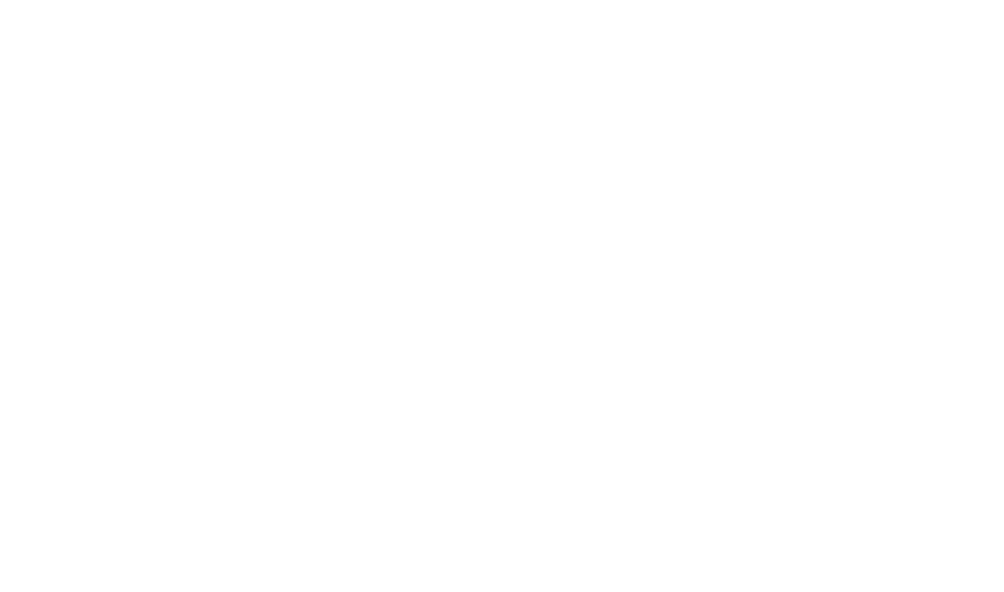

OCT

\begin{tabular}{|c|c|c|c|c|c|c|c|c|c|c|}
\hline $\begin{array}{r}061 . . . \\
24 . .\end{array}$ & .1 & .18 & 41 & 1 & 10 & 53 & 15 & 6.0 & .8 & 230000 \\
\hline $\begin{array}{l}\text { DEC. } \\
10 \ldots\end{array}$ & .1 & 1.0 & 49 & 3 & 12 & 55 & 20 & 10 & 1.6 & 93000 \\
\hline $\begin{array}{l}\text { JAN. } \\
21 \ldots . .\end{array}$ & .1 & .06 & 48 & 12 & 12 & 60 & 20 & 11 & 2.8 & 43000 \\
\hline FEB. & -- & .20 & 42 & 4 & 12 & 60 & 15 & 8.0 & 1.1 & 15000 \\
\hline MAY 07 & .1 & .33 & 61 & 14 & 12 & 51 & 40 & 13 & .9 & 4300 \\
\hline $21 \ldots$ & .2 & .14 & 56 & 19 & 14 & 61 & 30 & 9.0 & .8 & 43000 \\
\hline $\begin{array}{l}\text { JULY } \\
\text { OI.... } \\
\text { AUG. }\end{array}$ & .4 & $\langle 0\rangle$ & 42 & 10 & 14 & 53 & 20 & 14 & .7 & 75000 \\
\hline $12 \ldots$ & .3 & .08 & -- & 1 & 13 & 51 & 40 & 9.0 & 1.1 & 230000 \\
\hline $23 .$. & .2 & $<.05$ & 24 & 1 & 12 & 53 & 10 & 10 & 1.0 & 15000 \\
\hline
\end{tabular}


O2198000 BRIER CREEK AT MILLHAVEN, GA.

LOCATION.--Lat $32^{\circ} 56^{\prime} 00^{\prime \prime}$, long $81^{\circ} 39^{\prime} 05^{\prime \prime}$, Screven County, at gaging station near right bank on downstream side of pier of highway bridge at Millhaven, ' 8,5 miles upstream from Beaver Dam Creek.

DRAINAGE AREA. - - $848 \mathrm{sq} \mathrm{mi}$.

PERIOD OF RECORD.--Chemical Analyses: January to September 1970 (partial record).

REHARKS.--Laboratory chemical analyses by Georgia water Quality Control Board. Field determination of discharge, water temperature, $\mathrm{pH}$, and dissolved oxygen by U.S. Geological Survey. CHEMICAL ANALYSES, wATEK YEAR OCTOBER 1969 TO SFPTEMBER 1970

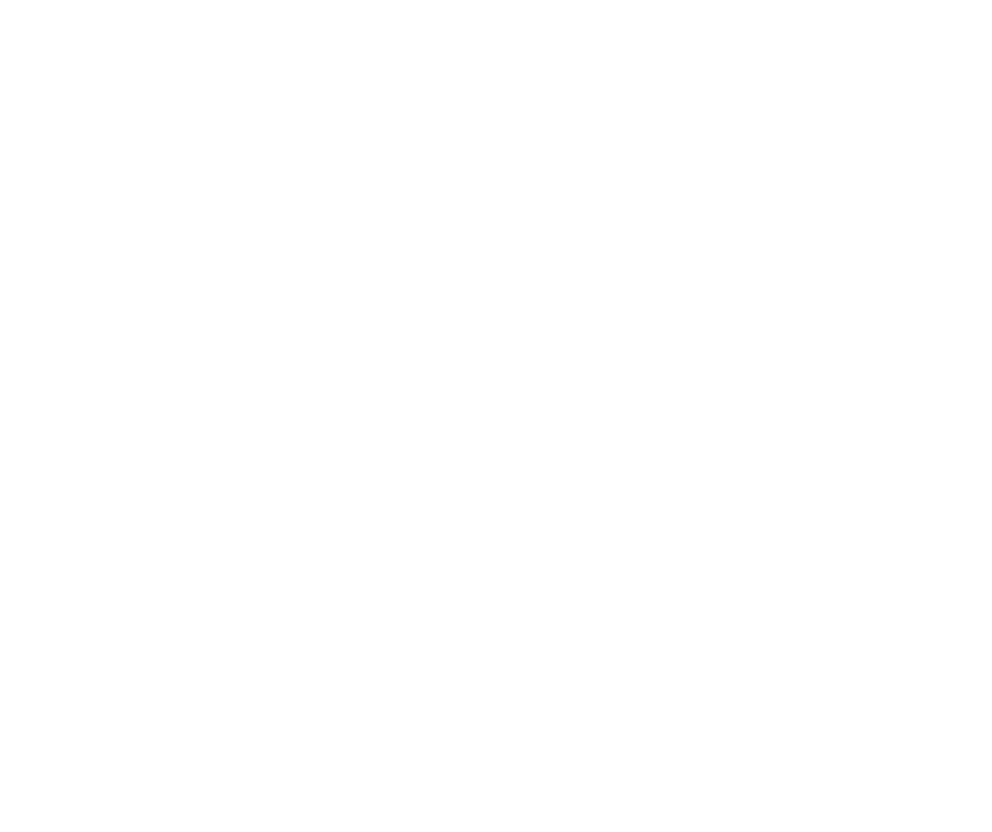

LOCATION, --Lat $32^{\circ} 31^{\prime} 30^{\prime \prime}$, long $81^{\circ} 15^{\prime} 45^{\prime \prime}$, Effingham County, at gaging station on downstream side of center pier of drawspan of bridge on Seaboard Coast Line Rajlroad, 3 miles north of Clyo and at mile 65 .

DRAINAGE AREA.--9,850 sq mi, approximately.

PERIOD OF RECORD. -. Chemfical analyses: May 1938 to April 1939, October 1964 to September 1970 (partial record). Water temperatures: May 1938 to April 1939.

REMARKS, .-Laboratory chem1cal analyses by Georgia Water Quality Control Board. Field determination of discharge, water temperature, $\mathrm{pH}$, and dissolved oxygen by U.S. Geological Survey. CHEMICAL ANALYSFS, WATER YEAR OCTOBER 1969 TO SEPTEMHER 1970

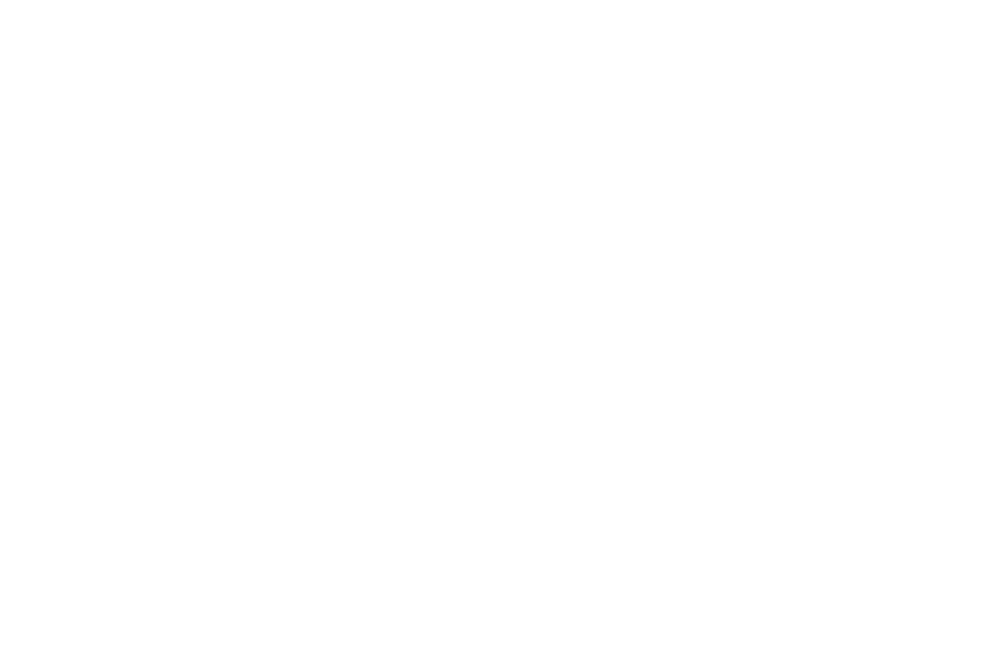


SAVANMAH RIVER BASIN

O2198500 SAVANNAH RIVER NEAR CLYO, GA.---Cont1nued

CHEMICAL ANALYSES, WATER YEAR OCTOBER 1969 TO SEPTEMBER 1970

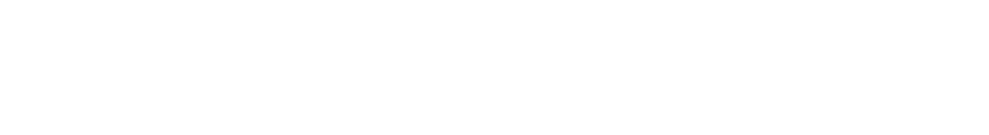

\begin{tabular}{|c|c|c|}
\hline $\begin{array}{l}\text { JAN. } \\
07 \ldots\end{array}$ & .2 & .28 \\
\hline $\begin{array}{l}\text { FEB. } \\
16 . .\end{array}$ & & \\
\hline MAR.". & .0 & .38 \\
\hline$\underset{\text { JUNE }}{25 \ldots}$ & .2 & .29 \\
\hline JULY & .4 & .18 \\
\hline $14 \ldots$ & .2 & .18 \\
\hline $16 \ldots$ & .4 & .15 \\
\hline
\end{tabular}

58
38
82
53
--
62

2
8
55
10
--
7

$\begin{array}{ll}17 & 67 \\ 14 & 48 \\ 16 & 59 \\ 18 & 44 \\ 16 & 70 \\ 16 & 70\end{array}$

$67 \quad 30$

$\begin{array}{rrr}15 & 1.3 & 930 \\ 20 & 1.6 & 230 \\ 49 & 1.8 & 4300 \\ 12 & 2.5 & <30 \\ 33 & 1.5 & -- \\ 7.0 & .6 & <30\end{array}$

OGEECHEE RIVER BASIN

O2202000 OGEECHEE RIVER AT SCARBORO, GA.

LOCATION,--Lat $32^{\circ} 42^{\prime} 38^{\prime \prime}$, long $81^{\circ} 52^{\prime} 46^{\prime \prime}$, Jenkins County, at gaging station on left bank 15 ft downstream from abandoned highway bridge' at Scarboro, 3.5 miles downstream from Sculls Creek, 6.5 miles upstream from Horse Creek, and 7.5 miles southeast of yillen.

DRAINAGE AREA.--1,940 sq ml, approximately.

PERIOD OF RECORD.--Chemical analyses: January to September 1970 (partial record).

REMARKS. --Laboratory chemical analyses by Georgta Water Quality Control Board. Field determination of discharge, water temperature, pH, and dissolved oxygen by U.S. Geologtcal Survey. CHEMICAL ANALYSES, WATER YEAR OCTOBER 1969 TO SEPTEMBER 1970

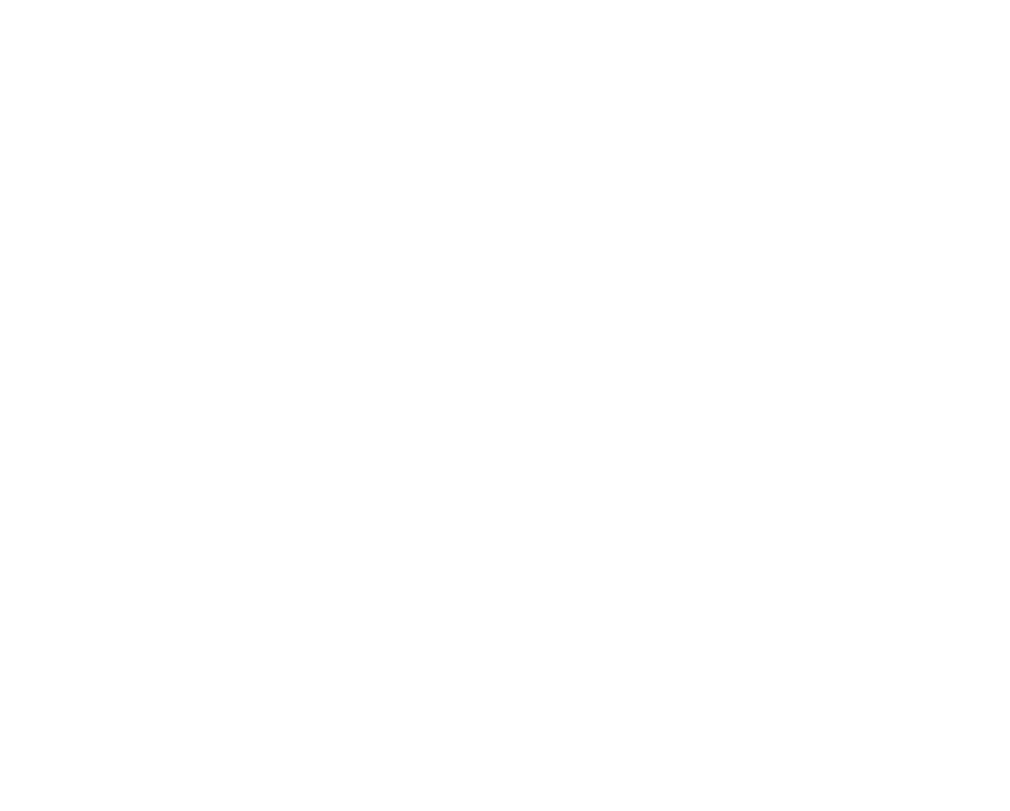


OGEECHEE RI VER BASIN

02202500 OGEECHEE RI VER NEAR EDEN, GA. bridge on U.S. Highways 25,80 and 280,2 miles west' of Eden, 2 miles upstream from Seaboard Coast Line Railroad bridge, and 3 miles upstream from Black Creek.

DRAINAGE AREA. $-2,650 \mathrm{sq} \mathrm{mi}$, approximately.

PERIOD OF RECORD.--Chemical analyses: February 1968 to September 1970 (partial record).

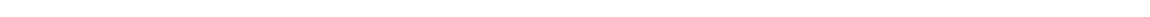
water temperature, $\mathrm{pH}$, and dissolved oxygen by U.S. Geological Survey.

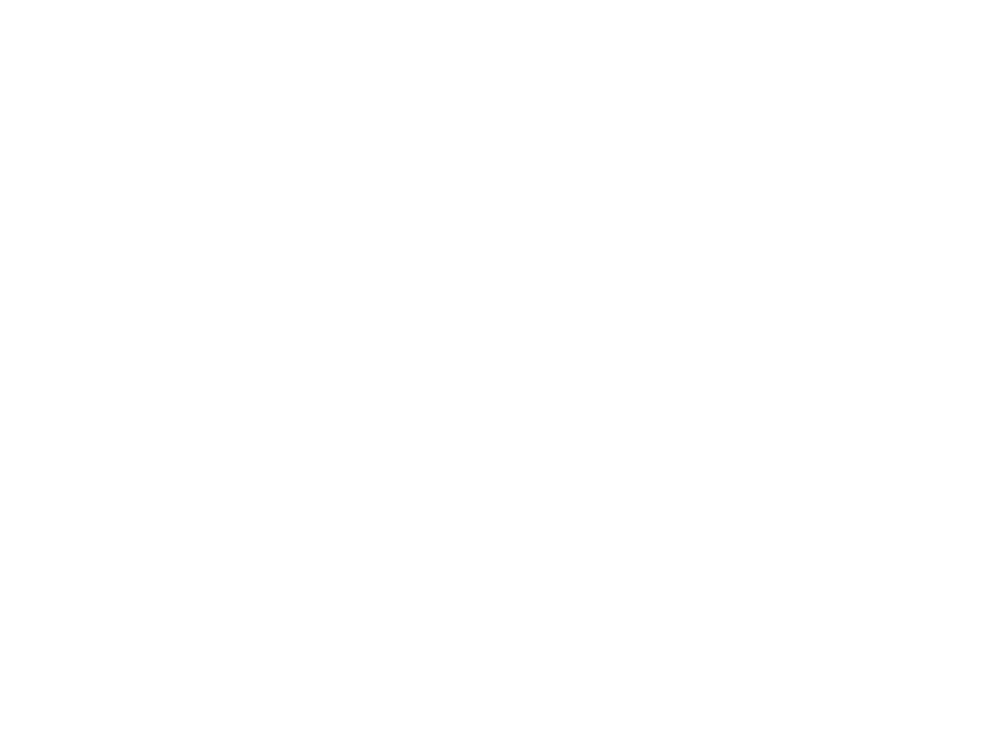
LOCATION.--Lat $32^{\circ} 11^{\prime} 05^{\prime \prime}$, long $81^{\circ} 53^{\circ} 20^{\prime \prime}$, Evans County, at gaging station on right bank 400 ft upstream from bridge
on State Highwa 73,2 miles northeast of Claxton, and 10 miles upstream from Lotts Creek.

DRAINAGE AREA.--555 sq mi, approximate1y.

PERIOD OF RECORD.--Chemical analyses: February 1968 to September 1970 (partial record).

REMARKS.-- Laboratory chemical analyses by Georgia Water Quality Control Board. Field determination of discharge, water temperature, $\mathrm{pH}$, and dissolved oxygen by U.S. Geological Survey.

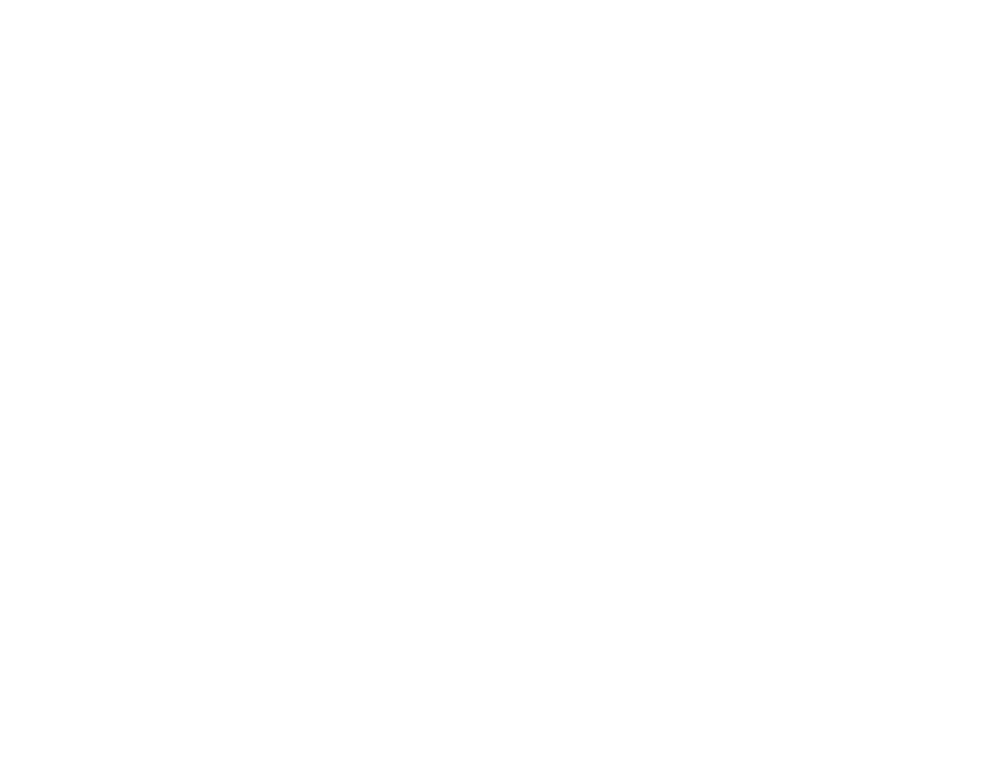


02203559 PEACOCK CREEK NEAR MCINTOSH, GA.

LOCATION.--Lat $31^{\circ} 48^{\prime} 49^{\prime \prime}$, long $81^{\circ} 31^{\prime} 13^{\prime \prime}$, Liberty County, at gaging station on upstream stde of bridge on dirt road, $0.4 \mathrm{mile}$ southwest of U.S. Highway 82 and 0.9 mile south of McIntosh.

DRAINAGE AREA. $-33.0 \mathrm{sq} \mathrm{m}$.

PERIOD OF RECORD,--Chemical analyses: September 1966 to September 1970 (partial record).

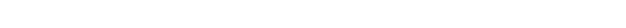

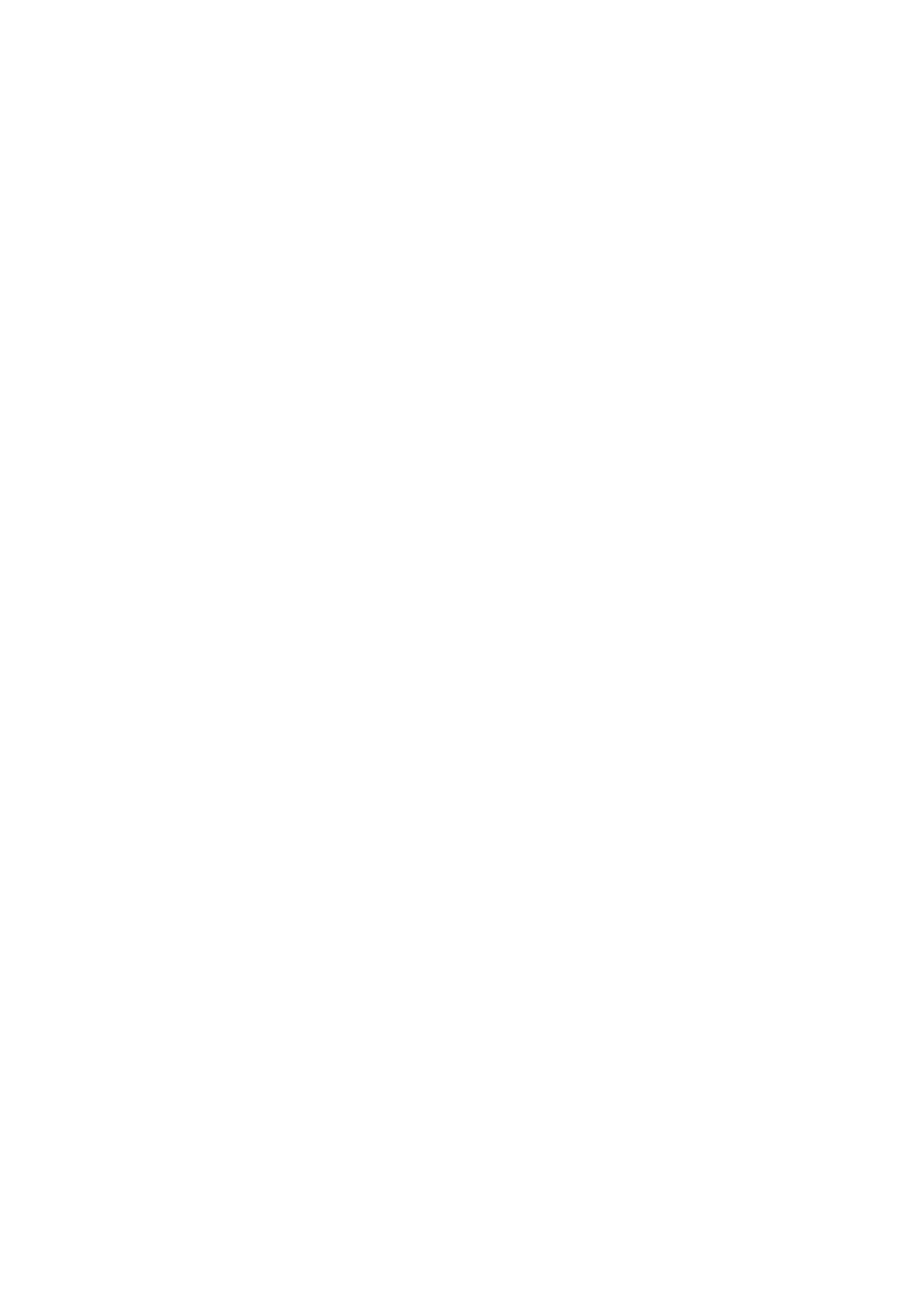


O2203566 RICEBORO CREEK NEAR RICEBORO, GA.

LOCATION,--Lat $31^{\circ} 45^{\prime} 16^{\prime \prime}$, long $81^{\circ} 27^{\prime} 38^{\prime \prime}$, Liberty County, at gaging station on north side of stream, 0.4 mile northwest of the Riceboro and Barrington Ferry Road and 2.4 miles northwest of Riceboro.

DRAINAGE AREA...29.2 sq $\mathrm{mi}$.

PERIOD OF RECORD.--Chemical analyses: September 1966 to September 1970 (partial record). CHHICAL AWALYSES. "AJER YFAK UCTOHE I HSO TO SEPTEMHED 1970

\begin{tabular}{|c|c|c|c|c|c|}
\hline vATE & F1Mr & 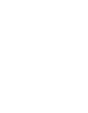 & $\begin{array}{c}\text { PH } \\
\text { (IJNITS) }\end{array}$ & $\begin{array}{l}\text { TH MP- } \\
\text { ENATURA } \\
\text { (1)EG C) }\end{array}$ & $\begin{array}{l}\text { PIS- } \\
\text { SOLVEI) } \\
\text { OXYGEN } \\
\text { (MG/L) }\end{array}$ \\
\hline $\begin{array}{l}\text { uct. } \\
\text { lat... } \\
\text { utive. }\end{array}$ & 1 كיל & hid & -- & 20.11 & 3.0 \\
\hline $\begin{array}{l}114 \ldots . \\
1,0 .\end{array}$ & $13 r_{i} r_{1}$ & $S_{H}$ & 7.5 & 15.7 & 4.5 \\
\hline$j_{0+1}^{11} \cdot .$. & $1413 \%$ & 74 & -- & 11.4 & H. I \\
\hline & $1341^{\prime}$ & an & 6.7 & 11.7 & 6.7 \\
\hline $\begin{array}{ll}111 . . \\
\text { ack. }\end{array}$ & 14311 & $4 \pi$ & 7.0 & 19.7 & 7.0 \\
\hline$\underset{\text { Jut }}{e l .}$ & Iniph & 74 & 6.2 & $23 . \pi$ & - \\
\hline H.M. & $1+15$ & 3111 & 7.2 & PH. 1 & 3.4 \\
\hline$=1 \ldots$ & $141, n$ & 1"b/1 & 7.3 & 24.11 & 5.8 \\
\hline
\end{tabular}

\begin{tabular}{|c|c|c|c|c|c|c|c|c|c|c|}
\hline UATE & 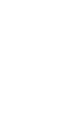 & 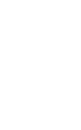 & $\begin{array}{l}\text { IJLS- } \\
\text { SILV= I I } \\
\text { LAL- } \\
\text { CIU. } \\
\text { (CA) } \\
\text { (IIGLL) }\end{array}$ & 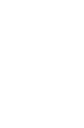 & 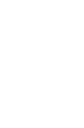 & $\begin{array}{l}P \cap- \\
T \Delta S- \\
=1,1= \\
(K) \\
(j / 1)\end{array}$ & $\begin{array}{l}\text { HICAK- } \\
\text { mINATE } \\
\text { (HCOB) } \\
\text { (MG/L) }\end{array}$ & $\begin{array}{l}A L K A- \\
\text { LINITY } \\
A S \\
C A C O 3 \\
(H G / L)\end{array}$ & $\begin{array}{l}\text { SULFATE } \\
\text { (SO4) } \\
\text { (MG/L) }\end{array}$ & $\begin{array}{l}\text { CHLO- } \\
\text { PIDE } \\
\text { (CL) } \\
(\mathrm{MG} / \mathrm{L})\end{array}$ \\
\hline $\begin{array}{l}\text { נCT. } \\
14 \ldots . . . \\
\text { YUV. }\end{array}$ & 40 & Anst & 1.1 & 4.5 & ל. & . 0 & 14 & 11 & .4 & 10 \\
\hline $\begin{array}{l}1) 4 \ldots \\
D \in C .\end{array}$ & 1.4 & 74.1 & 3.6 & 1.7 & 4.1 & 1.3 & 10 & H & .8 & $\mathrm{H.A}$ \\
\hline Ja', $31,$. & $\Rightarrow \cdot n$ & 106 & n. & 2.7 & .7 & .4 & M & 7 & .0 & 16 \\
\hline ¿7... & $n .7$ & $14 i j$ & 0.7 & יn & n. & .4 & 18 & 10 & .0 & 18 \\
\hline${ }_{n+16 . .}^{10 .}$ & 3.1 & 2111 & 1.4 & 7.1 & E.S & .9 & 12 & 10 &. $\mathrm{H}$ & 17 \\
\hline$\underset{J_{1} \ldots \Vdash}{<1} \ldots$ & 2.1 & - & b.e & 2.2 & 1.4 & 3.9 & $1^{4}$ & 15 & . 4 & 14 \\
\hline MULY & H. & -- & n. 7 & 2,1 & $\mathrm{~s}_{\mathrm{j}}$ & 3.4 & 35 & 30 & 19 & 76 \\
\hline $21 \ldots$ & H. Th & -- & $1+$ & 11 & $\ln n$ & $M 3$ & 54 & 44 & 100 & $25 ?$ \\
\hline WAIE & 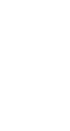 & $\begin{array}{l}+11-1 \mathrm{rt} \\
(11 \mathrm{~N}) \\
(1+, \mathrm{L})\end{array}$ & $\begin{array}{l}\text { NITRdt } \\
(103) \\
(1+1,1)\end{array}$ & 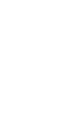 & 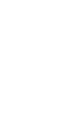 & 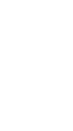 & $\begin{array}{l}\text { COLOH } \\
\text { (FLAT- } \\
\text { INUM- } \\
\text { COHALT } \\
\text { UNITS) }\end{array}$ & $\begin{array}{l}\text { PIO- } \\
\text { CHEM- } \\
\text { ICAL } \\
\text { OXYGSV } \\
\text { DEMAVD } \\
\text { (MG/L) }\end{array}$ & $\begin{array}{c}\text { COLI- } \\
\text { FORM } \\
\text { (CDL- } \\
\text { ONIES } \\
\text { PER } \\
100 \mathrm{ML}) \\
\text { (MPN) }\end{array}$ & $\begin{array}{c}\text { FECAL } \\
\text { COLI- } \\
\text { FORM } \\
\text { (COL. } \\
\text { PER } \\
100 \text { ML) } \\
\text { (MPN) }\end{array}$ \\
\hline $\begin{array}{c}U C T . \\
14 \ldots . . . \\
s(O V \\
114 \ldots\end{array}$ & .1 & -- & .11 & 44 & 36 & לי & $741)$ & $1 . ?$ & 930 & 930 \\
\hline $\begin{array}{c}114 \ldots \\
v f-C . \\
311 . .\end{array}$ & $\cdot c$ & -- & $\cdot 1$ & 3) & Cí & 12 & 210 & 1.7 & 1500 & 91 \\
\hline 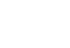 & $\begin{array}{l}\cdot c \\
. c\end{array}$ & - & .1 & 44 & $e^{4}$ & $>1$ & $\begin{array}{l}1011 \\
\ln n\end{array}$ & .4 & - & 30 \\
\hline Mar. &.-1 & . H & . & 47 & 27 & 17 & $1>0$ & 1.5 & $43 n$ & 36 \\
\hline $\begin{array}{l}\text { ANR. } \\
\text { Nint }\end{array}$ & $\cdot z$ & .14 & $\cdot "$ & 44 & 20 & 1] & lo? & 1.1 & $4.3 n$ & 30 \\
\hline 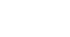 & .4 & .14 & 1.1 & $14 / 4$ & AH & 4 & 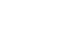 & 2.0 & -- & 1200 \\
\hline $21 \ldots$ & .3 & כ1יט. & $\therefore \cdot 1$ & $n>1$ & $11=$ & 71 & $14 n$ & $\therefore \rightarrow$ & - & 91 \\
\hline
\end{tabular}


02203570 RICEBORO CREEK AT RICEBORO, Ga.

LOCATION, --Lat $31^{\circ} 44^{\prime} 43^{\prime \prime}$, long $81^{\circ} 25^{\prime} 37^{\prime \prime}$, Liberty County, at gaging station 0.1 mile downstream from Seaboard Line Rallroad bridge and 0.5 mile northeast of Riceboro.

DRAINAGE AREA. - - 31.7 sq mi.

PERIOD OF RECORD.--Chemical analyses: September 1966 to septumber 1970 (partial record). CHE IICAL ANALYSES. NATER YEAR'OCTOMEN 1969 TO SEPTEMBER 1970

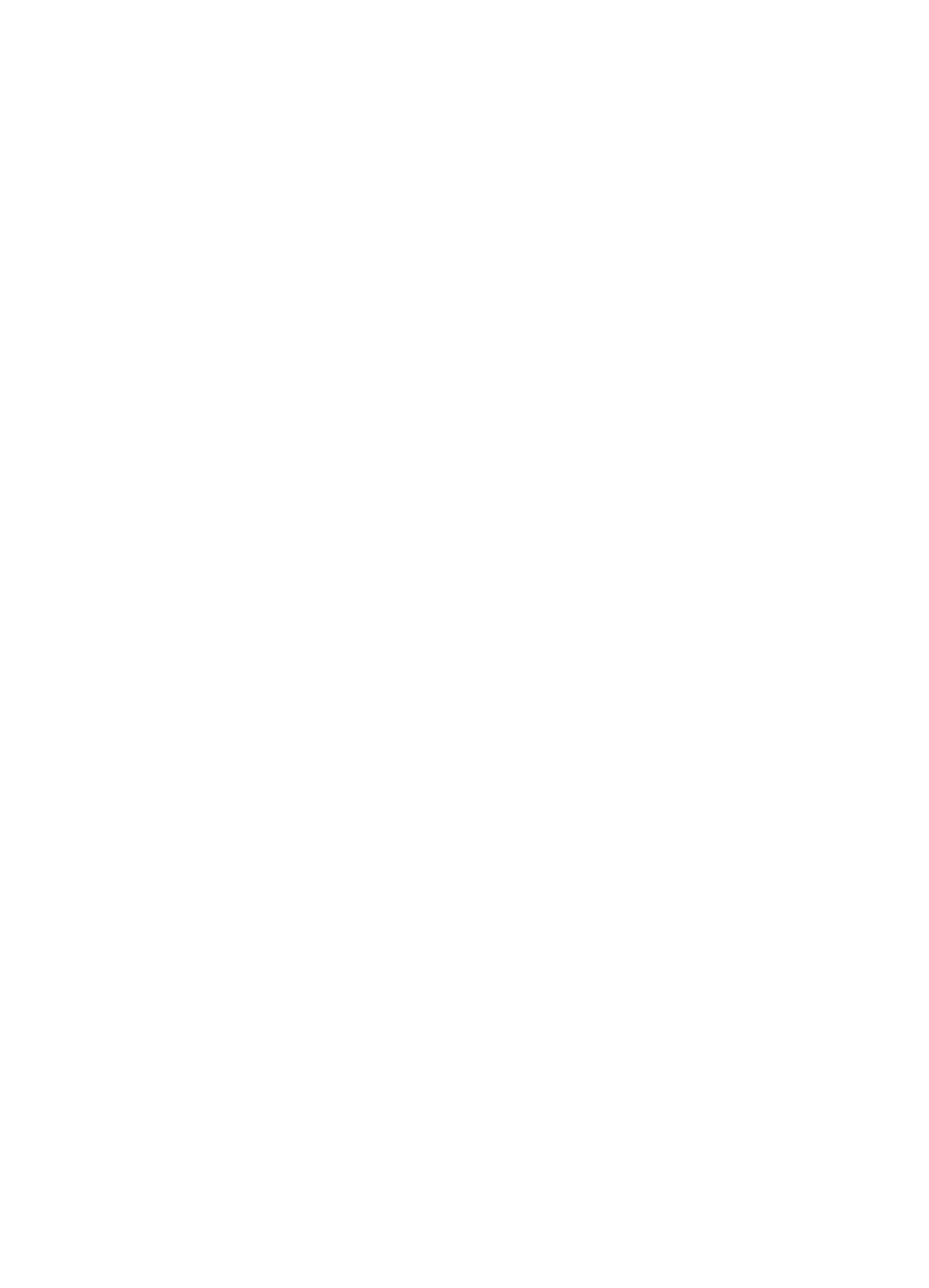


02203574 NORTH NEWPORT RIVER NEAR SEABROOK, GA.

LOCATION.--Lat $31^{\circ} 42^{\prime} 10^{\prime \prime}$, long $81^{\circ} 19^{\prime} 54^{\prime \prime}$, Liberty County, $2.5 \mathrm{mlles}$ south of Seabrook, $6.5 \mathrm{mlles}$ southeast of R1ceboro, and at mile 14,5 .

DRAINAGE AREA, _- 144 sq mi.

PERIOD OF RECORD,-.-Chemlcal analyses: September 1966 to September 1970 (partial record).

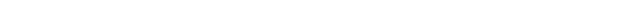

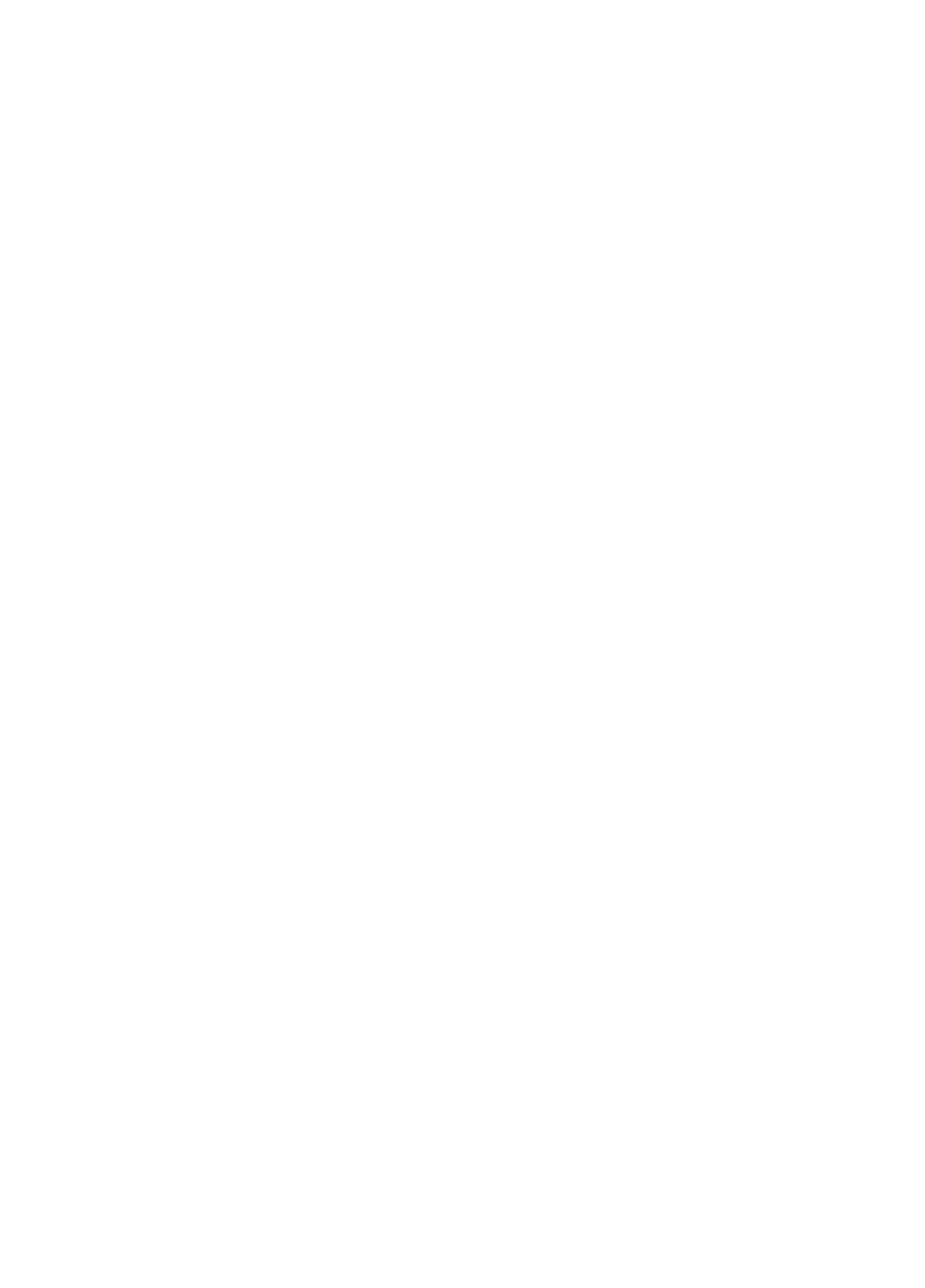


NORTH NEWPORT RIVER BASIN

02203576 CROSS TIDE CREEK NEAR HALFMOON LANDING, GA.

LOCATION,--Lat $31^{\circ} 41^{\prime} 34^{\prime \prime}$, long $81^{\circ} 16^{\prime} 23^{\prime \prime}$, Liberty County, at gaging station 2.2 miles southwest of Halfmoon Landing and 6 miles east of U.S. Highway 17 .

DRAINAGE AREA.--0.93 sq mi (only local drainage channels considered).

PERIOD OF RECORD,--Chemical analyses: September 1966 to september 1970 (partial record).

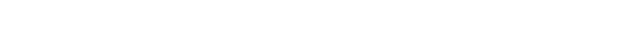

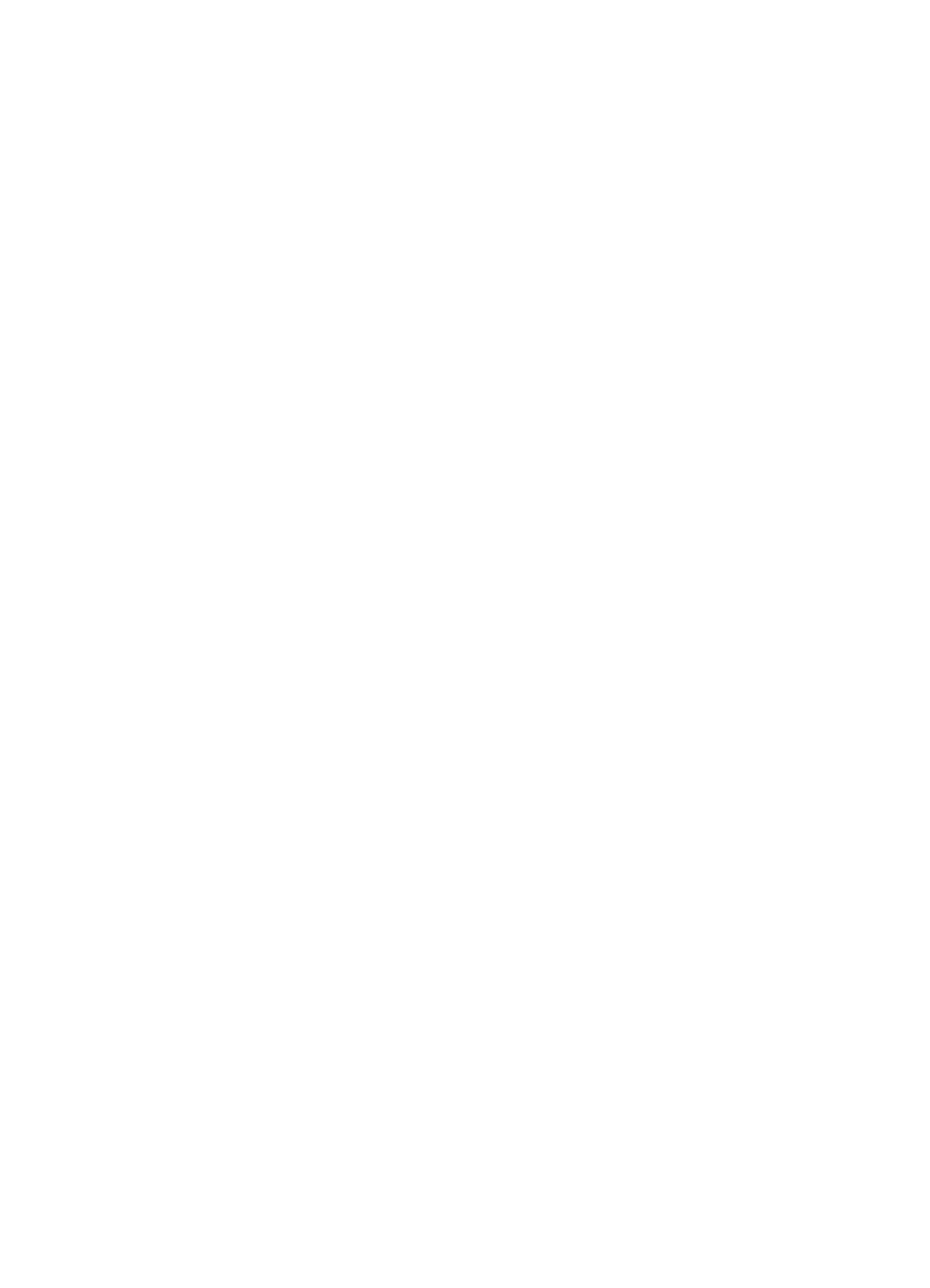


02203578 NORTH NEWPORT RIVER AT HALFHOON LANDING, GA. LOCATION.--Lat $31^{\circ} 40^{\prime} 39^{\prime \prime}$, long $81^{\circ} 18^{\circ} 05^{\prime \prime}$, Liberty County, at gaging station on dock of Halfmoon Landing and at
mile $9.9^{\circ}$

DRAINAGE AREA. - - $157 \mathrm{sq}$ mi.

PERIOD OF RECORD. -. Chemical analyses: September 1966 to September 1970 (partial record).

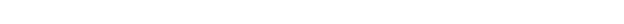

\begin{tabular}{|c|c|c|c|c|c|}
\hline UATE & $11 \mathrm{Mr}$ & $\begin{array}{l}\text { SPECI- } \\
\text { FIC } \\
\text { COND } \\
\text { UCTANCE } \\
\text { (MICRO- } \\
\text { MHOS) }\end{array}$ & (UIVITS) & $\begin{array}{l}\text { TEMP- } \\
\text { FHATUHE } \\
\text { UUEG CI }\end{array}$ & $\begin{array}{l}\text { DIS- } \\
\text { SOLVED } \\
\text { OXYGEN } \\
\text { (MG/L) }\end{array}$ \\
\hline $\begin{array}{l}\text { ICr. } \\
14 \ldots . . \\
\text { vove. }\end{array}$ & 1100 & Canonon & -- & $24 . H$ & 5.7 \\
\hline $\begin{array}{l}14 . \ldots \\
\text { urc. }\end{array}$ & 1115 & 170000 & 6.4 & 17.5 & 7.2 \\
\hline & ldou & 250001 & -- & 11.0 & 9.6 \\
\hline $\begin{array}{l}-7 . \ldots \\
A \Delta K_{0}\end{array}$ & $114 t$ & $240 n n$ & 7.5 & A. 4 & 8.6 \\
\hline 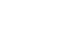 & $1<0 . \cdot$ & 33004 & 7.6 & 16.0 & 9.1 \\
\hline${ }_{\Delta \Delta Y}<1 \ldots$ & $113 n$ & $|x+1| 0 \mid$ & 7.? & $>7 . n$ & -- \\
\hline 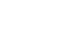 & 1305 & dminno & 7.5 & 25.5 & 0.5 \\
\hline $\sin _{\gamma}^{23} \cdots$ & $1 \leq 21$ & 2Nonot & 7.4 & 29.4 & 5.1 \\
\hline 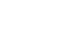 & 1220 & -- & $7 . h$ & 74.9 & 5.0 \\
\hline $31 \cdots$ & $1<0 " 1$ & 24000 & 7.0 & $26 . n$ & 3.8 \\
\hline
\end{tabular}

\begin{tabular}{|c|c|c|c|c|c|c|c|c|c|c|}
\hline DATt & $\begin{array}{l}\text { SILILA } \\
\text { ISIOL) } \\
\text { (MG/L) }\end{array}$ & $\begin{array}{l}\text { DIS- } \\
\text { buL Vto } \\
\text { IRON } \\
\text { (Fr) } \\
\left(1 \mathrm{Jr}_{3} / \mathrm{L}\right)\end{array}$ & $\begin{array}{l}\text { DIS- } \\
\text { SOL.VED } \\
\text { CAL- } \\
\text { CIUM } \\
\text { (CA) } \\
\text { (MG/L) }\end{array}$ & $\begin{array}{l}\text { DIS- } \\
\text { SOLVED } \\
\text { MAGNE- } \\
\text { SIUM } \\
\text { (MG) } \\
\text { (MG/L) }\end{array}$ & $\begin{array}{c}\text { SODIUM } \\
\text { (NA) } \\
(M G / L)\end{array}$ & $\begin{array}{l}\left.P_{0}\right) \\
T \Delta \varepsilon- \\
S 1 U_{11} \\
(K) \\
(1,1) / L)\end{array}$ & $\begin{array}{l}\text { PICAK- } \\
\text { HONATE } \\
\text { (HCOZ) } \\
\text { (MG/L) }\end{array}$ & $\begin{array}{l}\text { ALKA- } \\
\text { LINITY } \\
\text { AS } \\
\text { CACO } 3 \\
\text { (MCJ/L) }\end{array}$ & $\begin{array}{l}\text { SULFATE } \\
\text { (51)4) } \\
\text { (MG/L) }\end{array}$ & $\begin{array}{l}\text { CHLO- } \\
\text { HIDE } \\
\text { (CL) } \\
\text { (MG/L }\end{array}$ \\
\hline $\begin{array}{l}\text { OCT. } \\
14 \ldots . . . \\
\text { Nov. }\end{array}$ & 7.1 & so & 224 & 707 & $\sin \theta$ & 210 & $1 n_{4}$ & 85 & 1340 & 10600 \\
\hline 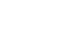 & 7.0 & Dי & $15 c$ & 455 & 39180 & $15 n$ & 84 & 69 & 920 & 6950 \\
\hline $\begin{array}{l}30 . . \\
\text { JAN. }\end{array}$ & 4.5 & $4 n$ & $24 B$ & 709 & क्रित0 & $26 \mathrm{H}$ & $11 ?$ & 92 & 1600 & 11500 \\
\hline MAF... & 3.7 & 411 & $\mathrm{CZs}$ & 720 & Уमसाl & 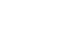 & $10 n$ & $\mathrm{H} 2$ & 1440 & 10400 \\
\hline${ }_{\text {ark. }}^{10}:$. & 3.7 & 70 & 243 & $16^{t}$ & 7050 & $>92$ & 105 & 86 & $166 n$ & 12000 \\
\hline$\underset{\text { MAY }}{21} \cdots$ & 5.5 & -- & 130 & 405 & 3420 & 135 & 64 & 52 & 850 & 6100 \\
\hline$\underset{\text { JUNE }}{26 . . .}$ & 5.2 & -- & $24 c$ & 747 & मलBu & $P>A$ & $9 ?$ & 75 & 1480 & 10600 \\
\hline JULY $23 .$. & h. h & -- & 2611 & 7yx & $035 \%$ & 220 & $9 H$ & 80 & 1470 & 10900 \\
\hline S1... & 7.8 & -- & 305 & libn & 7500 & 300 & 120 & YR & 1860 & 13800 \\
\hline $30 \ldots$ & $\cdots$ & -- & 240 & 850 & 1400 & 240 & -- & 10 & 1800 & 12500 \\
\hline DATE & $\begin{array}{l}\text { UIS- } \\
\text { SULVE" } \\
\text { FLUI)- } \\
\text { HIUE } \\
\text { (F) } \\
\text { (YG/L) }\end{array}$ & 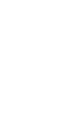 & $\begin{array}{l}\text { NITKATE } \\
\text { (INU3) } \\
\text { (MG/L) }\end{array}$ & $\begin{array}{l}\text { DIS- } \\
\text { SOLVED } \\
\text { SOLIUS } \\
\text { (SIM OF } \\
\text { CUNSTI- } \\
\text { rUt VIS) } \\
\text { ("'G/L) }\end{array}$ & $\begin{array}{l}\text { HARU- } \\
\text { (NE,SS } \\
\text { (CA.MIS) } \\
\text { (MG/L) }\end{array}$ & $\begin{array}{l}\text { NON- } \\
\text { CAHE- } \\
\text { HUNATE } \\
\text { RARD- } \\
\text { NFSS } \\
\text { (HASLL) }\end{array}$ & $\begin{array}{l}\text { CULOH } \\
\text { (HLAT- } \\
\text { lNUM- } \\
\text { COMALT } \\
\text { UNITS) }\end{array}$ & $\begin{array}{l}\text { HIO- } \\
\text { CHEM- } \\
\text { ICAL } \\
\text { OXYGEN } \\
\text { DEMAND } \\
\text { (MG/L) }\end{array}$ & $\begin{array}{c}\text { COLI- } \\
\text { FORM } \\
\text { (COL- } \\
\text { ONIES } \\
\text { PER } \\
\text { 100 ML) } \\
\text { (MPN) }\end{array}$ & $\begin{array}{c}\text { FECAL } \\
\text { COLI- } \\
\text { FORM } \\
\text { (COL. } \\
\text { PER } \\
100 \mathrm{ML} \\
\text { (MPN) }\end{array}$ \\
\hline $\begin{array}{l}\text { CT. } \\
14 \ldots . . \\
\text { nov. }\end{array}$ & .4 & -- & .11 & 14000 & $34 \times 5$ & $34 \pi 0$ & $5 n$ & 1.0 & 30 & 30 \\
\hline $\begin{array}{l}\text { OI } 4 \ldots . . \\
\text { CIEC. }\end{array}$ & .7 & -- & $\cdot 1$ & $126=10$ & $2 ?>0$ & $>100$ & 100 & 1.2 & 140 & 36 \\
\hline $\begin{array}{l}30 . . \\
\text { JAN. }\end{array}$ & $\mathrm{Cos}$ & $\cdots$ & $\cdot 0$ & 2041111 & 3758 & 3650 & $2 n$ & 1.0 & -- & 30 \\
\hline $\begin{array}{l}27 . . \\
\text { MAK. } \\
10 . .\end{array}$ & .9 & -- & .1 & |yith: & 354 & 34511 & $4 \pi$ & 1.5 & 36 & 30 \\
\hline $\begin{array}{c}10 \ldots . . \\
{ }_{4} P_{K} \\
21\end{array}$ & 1.0 & - nl & $\cdot 0$ & 22110 & $5 A 00$ & 3770 & 20 & 1.0 & 30 & 30 \\
\hline MAY $11 . \cdots$ & $\cdot 3$ & .02 & $\cdot \frac{1}{2}$ & 11100 & 1990 & 1940 & $\ln n$ & .9 & 36 & $3 n$ \\
\hline$\underset{\text { JiNkt. }}{26 . . .}$ & $\cdot \rightarrow$ & .192 & . & 19e00 & $36 \pi 0$ & 36011 & ח & 1.1 & -- & $3 n$ \\
\hline $\operatorname{JULY}_{\ln }^{23} \cdots$ & 1.1 & -12 & .9 & $\sin 100$ & $377^{\circ}$ & 3690 & $3 \ell_{1}$ & 1.1 & - & 30 \\
\hline Stri... & $1 \cdot 1$ & .01 & .11 & 249170 & $S \cap A \cap$ & 4440 & ח & 1.2 & - & 30 \\
\hline $30 \ldots$ & -- & $=$ & -- & - & 3950 & $\cdots$ & 50 & $1 . n$ & -- & $3 n$ \\
\hline
\end{tabular}


NORTH NETPORT RIVER BASIN

02203585 TIMONS RIVER NEAR YELLON BLUFF, GA.

LOCATION.--Lat $31^{\circ} 40^{\prime} 37^{\prime \prime}$, 10ng $81^{\circ} 13^{\circ} 09^{\prime \prime}$, Liberty County, 0.5 mile downstream from the division of North Newport and Timmons Rivers, 2.5 miles southwest of Yellow Bluff, and at mile 5.5 .

DRAI NAGE AREA. - -161 sq ml.

PERIOD OF RECORD.-.-Chemica1 analyses: September 1966 to September 1970 (partial record). CHEMICAL ANALYSES. WATER YEAR OCTOBER 1969 TO SEPTEMBER 1970

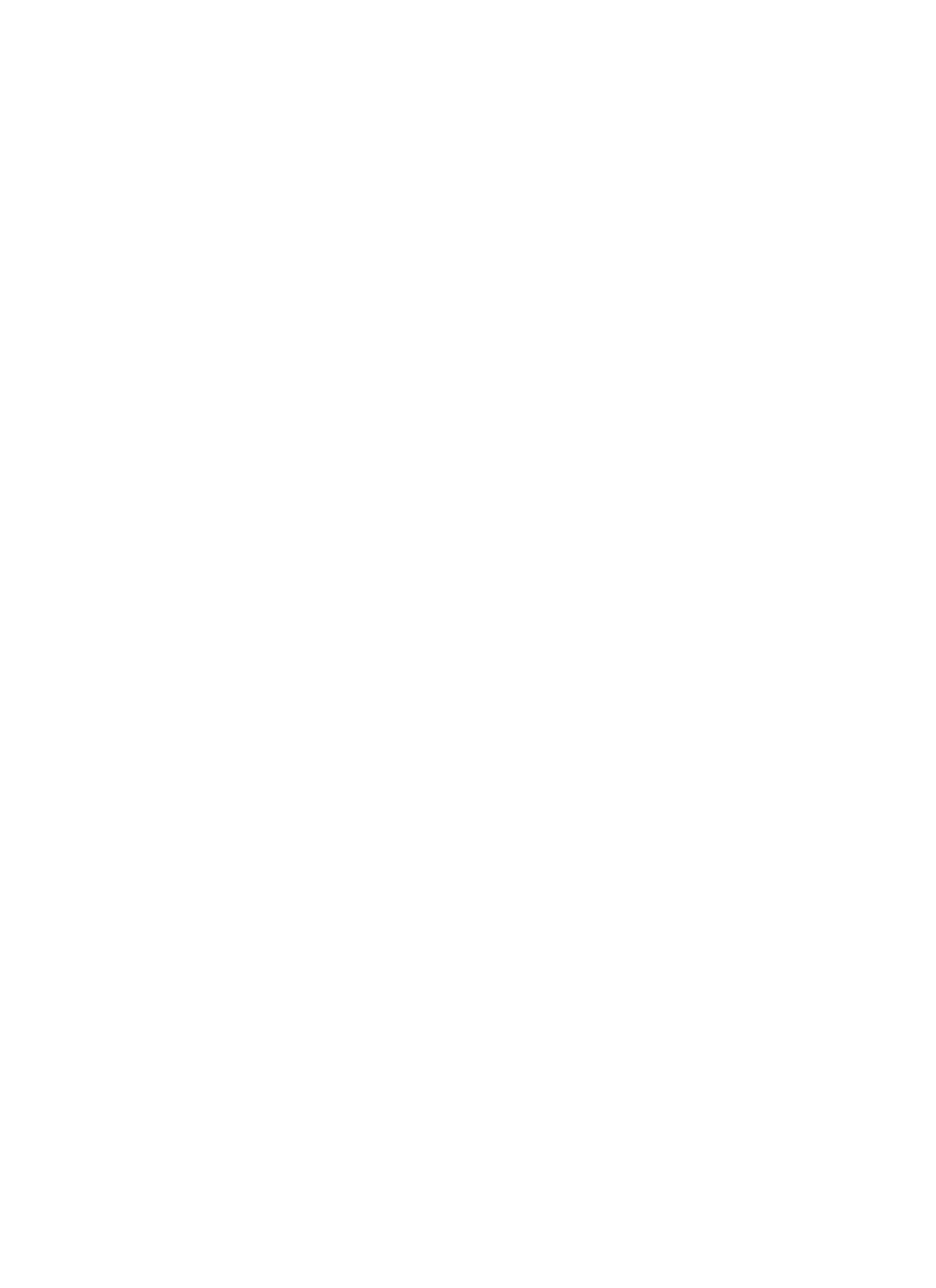


02203596 SOUTH NEWPORT RIVER NEAR HARRIS NECK, GA.

LOCATION.--Lat $31^{\circ} 39^{\prime} 05^{\prime \prime}$, long $81^{\circ} 17^{\prime} 21^{\prime \prime}$, Liberty County, 1 mile downstream from confluence of South Newport River, Hampton Creek, Cross' Tide Creek, and'South Newport Cut, and at Liberty-McIntosh County Eine,

DRAINAGE AREA.--126 sq mi.

PERIOD OF RECORD.--Chemical analyses: October 1966 to September 1970 (partial record).

CHE"ICAL AIHALYSES, IATER YEHM OCTOHEH $19 K 9$ TO SEPTFMBER 1970

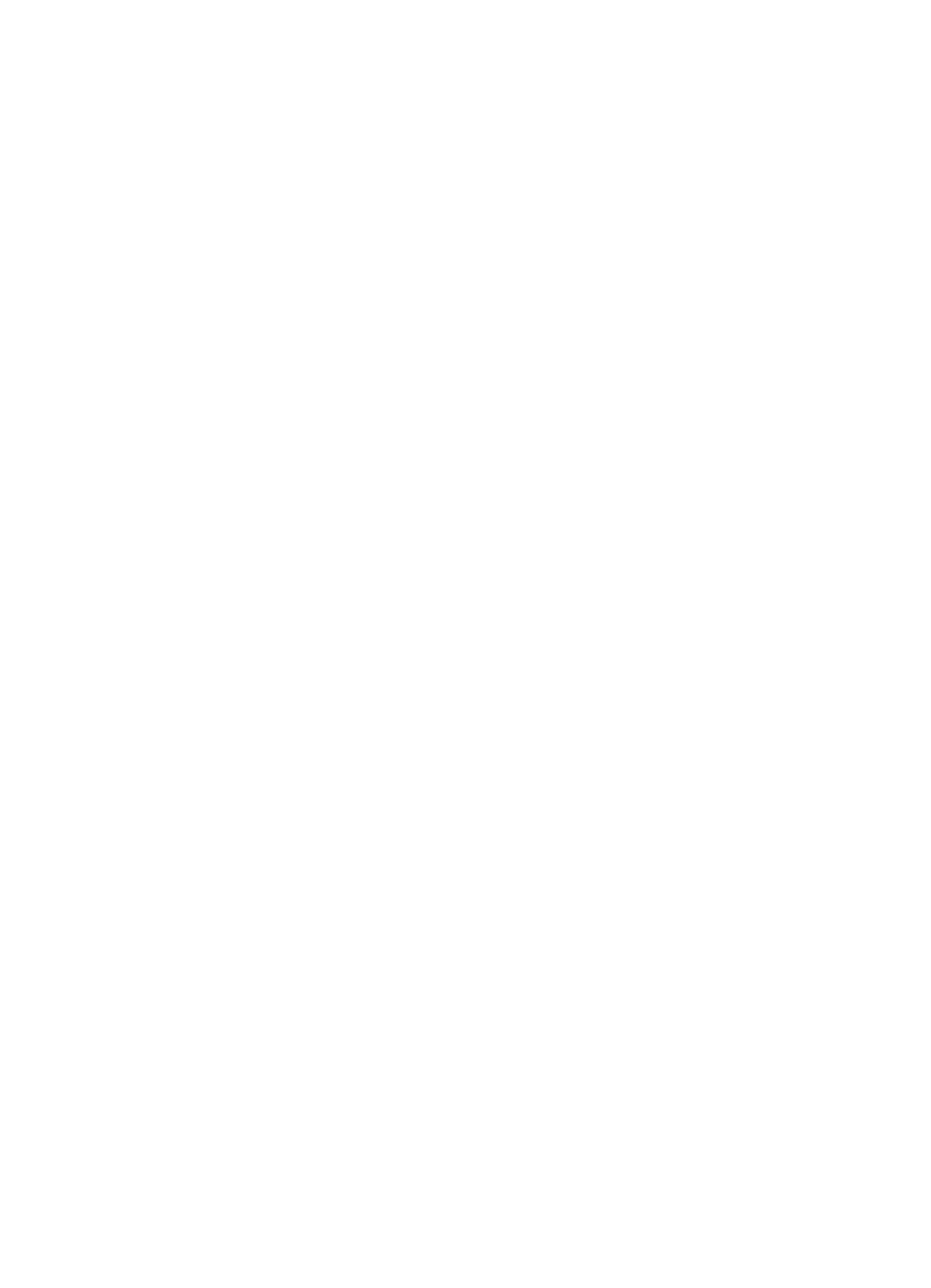


ALTAKAHA RIVER BASIN

02206500 YELLOW RIVER NEAR SNELLVILLE, GA.

LOCATION,--Lat $33^{\circ} 51^{\prime} 11^{\prime \prime}$, long $84^{\circ} 04^{\prime} 45^{\prime \prime}$, Gwinnett County, at gaging station on left bank at downstream side of county highway bridge, 3.2 miles west of Snellville, 4 miles downstream from Sweetwater Creek, 6.5 miles northeast of town of Stone Mountain, and 7.5 miles upstream from Stone Mountain Creek,

DRAINAGE AREA. - - $134 \mathrm{sq} \mathrm{m} 1$.

PERIOD OF RECORD.--Chemical analyses: November 1969 to September 1970 (partial record).

REMARKS, --Laboratory chemical analyses by Georgia Water Quality Control Board. Field determination of discharge, water temperature, $\mathrm{PH}$, and dissolved oxygen by U.S. Geological Survey.

CHEMICAL ANALYSES, NATER YEAR OCTOBER 1969 TO SEPTEMBER 1970

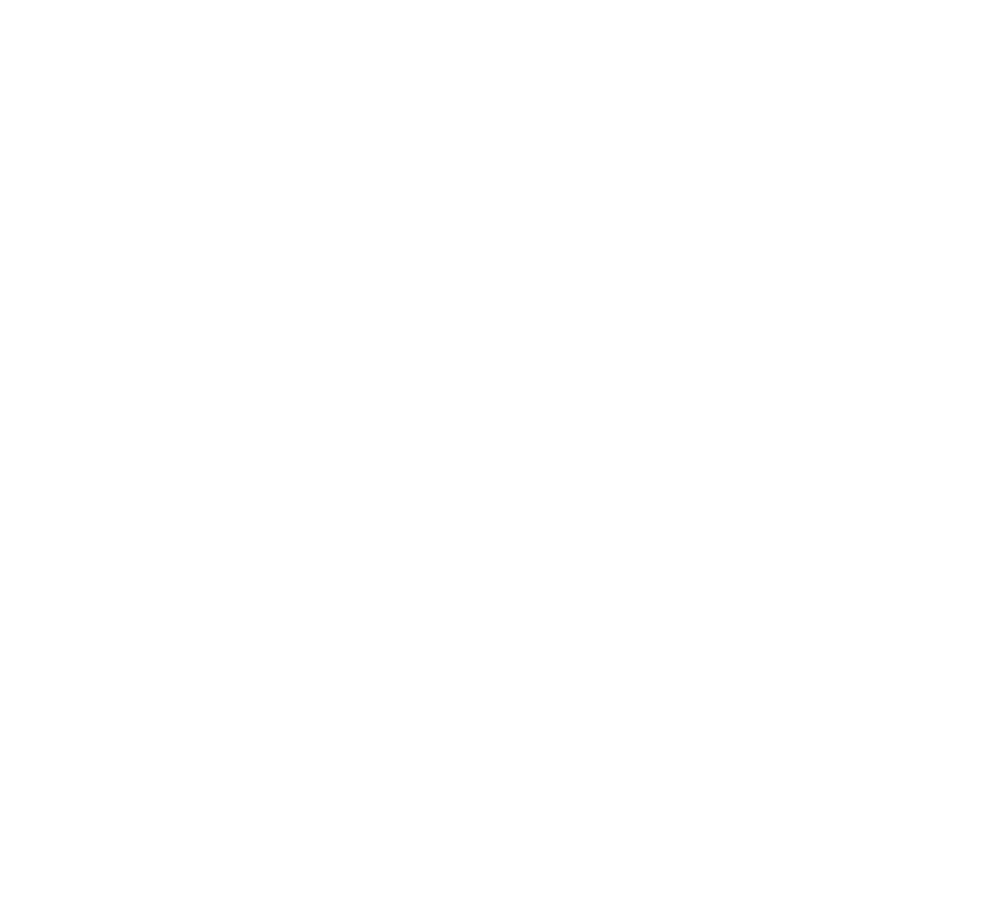

02213000 OCMULGEE RIVER AT MACON, GA.

LOCATION, - - Lat $32^{\circ} 50^{\prime} 19^{\prime \prime}$, long $83^{\circ} 37^{\prime} 14^{\prime \prime}$, Bibb County, at gaging station at downstream end of center p1er of Fifth Street Bridge in Hacón, 1.5 miles upstream from walnut Creek, and at mile 205.0.

DRAINAGE AREA. $--2,240 \mathrm{sq} m i$, approximately.

PERIOD OF RECORD..--Chemical analyses: March 1968 to September 1970 (partial record).

REMARKS, - -Laboratory chemical analyses by Georgia water Quality Control Board. Fleld determination of discharge, water temperature, $\mathrm{pH}$, and dissolved oxygen by U.S. Geological Survey.

CHEMICAL AIVALYSE, WATER YEAR OCTOBER 1969 TO SEPTEMBER 1970

\begin{tabular}{|c|c|c|c|c|c|}
\hline UATE & TIME & $\begin{array}{l}\text { DIS- } \\
\text { CHARGE } \\
\text { (CFS) }\end{array}$ & $\begin{array}{c}\text { PH } \\
\text { (UNITS) }\end{array}$ & $\begin{array}{l}\text { TEMP- } \\
\text { ERATURE } \\
\text { (DEG C) }\end{array}$ & $\begin{array}{l}\text { DIS- } \\
\text { SOLVED } \\
\text { OXYGFN } \\
\text { (MG/L) }\end{array}$ \\
\hline $\begin{array}{l}\text { INUV. } \\
18 . . . \\
\text { OEC. }\end{array}$ & 1530 & 645 & 7.3 & 15.0 & 9.8 \\
\hline $\begin{array}{l}29 . . . \\
\text { FEH. }\end{array}$ & 1100 & 1270 & 8.3 & 7.0 & -- \\
\hline $\begin{array}{l}12 \ldots \\
\text { MAR. }\end{array}$ & 1445 & 1670 & 6.2 & 9.7 & 10.0 \\
\hline$\underset{\text { MAY }}{25 \ldots}$ & 1315 & 6350 & 6.1 & 11.0 & 7.1 \\
\hline JUNE... & 11930 & 2320 & 6.2 & 19.0 & 8.9 \\
\hline${ }_{\text {JULY }}^{17 \%}$ & 0930 & 829 & 7.3 & 22.0 & 7.5 \\
\hline $\begin{array}{l}\text { ZE... } \\
\text { SEPT. }\end{array}$ & 1030 & 2280 & 7.5 & 28.0 & 6.6 \\
\hline $08 \ldots$ & 1600 & 670 & 7.2 & 30.5 & 6.? \\
\hline
\end{tabular}


02213000 OCYULGEE RIVER AT MACON, GA.--Continued

CHEMICAL ANALYSES, WATER YEAR OCTOBER 1969 TO SEPTEMBER 1970

\begin{tabular}{|c|c|c|c|c|c|c|c|c|c|c|}
\hline DATE & $\begin{array}{l}\text { SILICA } \\
\text { (SIOLI) } \\
\text { (MG/L) }\end{array}$ & $\begin{array}{l}\text { TOTAL } \\
\text { IRON } \\
\text { (FE) } \\
\text { (UG/L) }\end{array}$ & $\begin{array}{l}\text { TOTAL } \\
\text { MAN- } \\
\text { GANESE } \\
\text { (MN) } \\
\text { (UG/L) }\end{array}$ & $\begin{array}{l}\text { DIS- } \\
\text { SOLVED } \\
\text { CAL- } \\
\text { CIUM } \\
\text { (CA) } \\
(M G / L)\end{array}$ & $\begin{array}{l}\text { DIS- } \\
\text { SOLVED } \\
\text { MAG- } \\
\text { NE- } \\
\text { SIUM } \\
\text { (MG) } \\
\text { (MG/L) }\end{array}$ & $\begin{array}{l}\text { SODIUM } \\
\text { (NA) } \\
\text { (MG/L) }\end{array}$ & $\begin{array}{l}\text { PO- } \\
\text { TAS- } \\
\text { SIUM } \\
\text { (K) } \\
(M G / L)\end{array}$ & $\begin{array}{l}\text { ALKA- } \\
\text { LINITY } \\
\text { AS } \\
\text { CACO3 } \\
\text { (MG/L) }\end{array}$ & $\begin{array}{l}\text { SULFATE } \\
\text { (S04) } \\
(M G / L)\end{array}$ & $\begin{array}{l}\text { CHLO- } \\
\text { RIDE } \\
(\mathrm{CL}) \\
(M G / L)\end{array}$ \\
\hline $\begin{array}{l}\text { NOV. } \\
18 . . . \\
\text { DEC.. }\end{array}$ & 13 & 250 & $<50$ & 4.4 & 1.7 & 8.1 & 2.7 & 27 & 5.0 & 5.1 \\
\hline $\begin{array}{l}29 . . . \\
\text { FEB. }\end{array}$ & -- & 600 & $<50$ & 4.6 & 1.6 & 6.7 & 2.0 & 21 & 5.0 & 5.1 \\
\hline MAR.. & 13 & 1200 & $<50$ & 15 & 1.4 & 5.8 & 1.9 & 18 & 4.0 & 23 \\
\hline$\underset{\text { MAY }}{25 \ldots}$ & 10 & 5600 & 140 & 3.0 & 1.3 & 2.6 & 2.2 & 11 & $<2,0$ & 2.5 \\
\hline JUNE & 7.5 & 1000 & 80 & 3.9 & 1.5 & 5.8 & 1.9 & 21 & 6.0 & 3.8 \\
\hline $\operatorname{JUL}_{Y}^{17} \cdot$. & 11 & $<00$ & $<50$ & 3.8 & 1.6 & 6.8 & 2.3 & 23 & 5.0 & 4.5 \\
\hline $\begin{array}{l}28 . . . \\
\text { SEPT. }\end{array}$ & 12 & 2600 & 50 & 3.6 & 1.6 & 7.0 & $2 \cdot 8$ & 20 & 7.0 & 4.9 \\
\hline $08 \ldots$ & 7.0 & 200 & $<50$ & 3.3 & 1.8 & 7.9 & 2.8 & .25 & 6.0 & 5.8 \\
\hline DATE & $\begin{array}{c}\text { NI TRATE } \\
(N) \\
(M G / L)\end{array}$ & $\begin{array}{l}\text { PHOS- } \\
\text { PHATE } \\
\text { (PO4) } \\
\text { (MG/L) }\end{array}$ & $\begin{array}{l}\text { TOTAL } \\
\text { FILT- } \\
\text { RABLE } \\
\text { RESIDUE } \\
\text { (MG/L) }\end{array}$ & $\begin{array}{l}\text { TOTAL } \\
\text { NON- } \\
\text { FILT- } \\
\text { RABLE } \\
\text { RESIDUE } \\
\text { (MG/L) }\end{array}$ & $\begin{array}{l}\text { HARD- } \\
\text { NESS } \\
\text { (CA,MG) } \\
(M G / L)\end{array}$ & $\begin{array}{l}\text { SPECI- } \\
\text { FIC } \\
\text { COND- } \\
\text { UCTANCE } \\
\text { (MICRO- } \\
\text { MHOS) }\end{array}$ & $\begin{array}{l}\text { COLOR } \\
\text { (PLAT- } \\
\text { INUM- } \\
\text { COBALT } \\
\text { UNITS) }\end{array}$ & $\begin{array}{l}\text { TUR- } \\
\text { BIO- } \\
\text { ITY } \\
\text { (JTU) }\end{array}$ & $\begin{array}{l}\text { BIO- } \\
\text { CHEM- } \\
\text { ICAL } \\
\text { OXYGEN } \\
\text { DEMAND } \\
\text { (MG/L) }\end{array}$ & $\begin{array}{c}\text { FECAL } \\
\text { COLI- } \\
\text { FORM } \\
\text { (COL. } \\
\text { PER } \\
\text { 1OO ML) } \\
\text { (MPN) }\end{array}$ \\
\hline
\end{tabular}

NO

\begin{tabular}{|c|c|c|c|c|c|c|c|c|c|c|}
\hline DEC... & .3 & .18 & 60 & 4 & 17 & 81 & 10 & 3.0 & .4 & $<30$ \\
\hline $\begin{array}{r}29 . . . \\
\text { FË. }\end{array}$ & .3 & .40 & 68 & 12 & 17 & 78 & 30 & 12 & 2.1 & 750 \\
\hline $\begin{array}{l}12 \ldots . . \\
\text { MAR. }\end{array}$ & .4 & .55 & 122 & 20 & 40 & 150 & 45 & 20 & 1.9 & 9300 \\
\hline$\underset{\text { MAY }}{25} \cdots$ & .5 & .43 & 92 & 89 & 11 & 42 & 275 & 91 & 1.8 & 15000 \\
\hline JUNE & $\cdot 3$ & .18 & 43 & 26 & 16 & 77 & 20 & 15 & 1.4 & 930 \\
\hline $\operatorname{JULY}_{17}$ & . 1 & .12 & 69 & 16 & 18 & 71 & 25 & 8.0 & 2.0 & 150 \\
\hline $\begin{array}{l}28 . . \\
\text { SEPT. }\end{array}$ & .5 & .27 & 74 & 109 & 16 & 63 & 50 & 66 & 1.2 & 7500 \\
\hline $08 \ldots$ & .3 & .13 & 49 & 2 & 16 & 82 & 10 & 3.0 & 1.7 & 21000 \\
\hline
\end{tabular}

02213500 TOBESOFKEE CREEK NEAR MACON, GA.

LOCATION, .-Lat $32^{\circ} 48^{\prime} 32^{\prime \prime}$, long $83^{\circ} 45^{\prime} 30^{\prime \prime}$, Bibb County, at gaging station on right bank at downstream end of pier of bridge on U.S. Highwáy BO, $8 \mathrm{miles}$ west of Macon and $14 \mathrm{miles}$ upstream from mouth.

DRAINAGE AREA.--182 sq mi.

PERIOD OF RECORD..-Chemical analyses: October 1968 to September 1970 (partial record).

REMARKS. - Laboratory chemical analyses by Georgia Water quality Control Board, Field determination of discharge, water temperature, $\mathrm{pH}$, and dissolved oxygen by U.S. Geological Survey. CHEMICAL ANALYSES. WATER YL.AR OCTOBER 1969 TO SEPTEMBER 1970

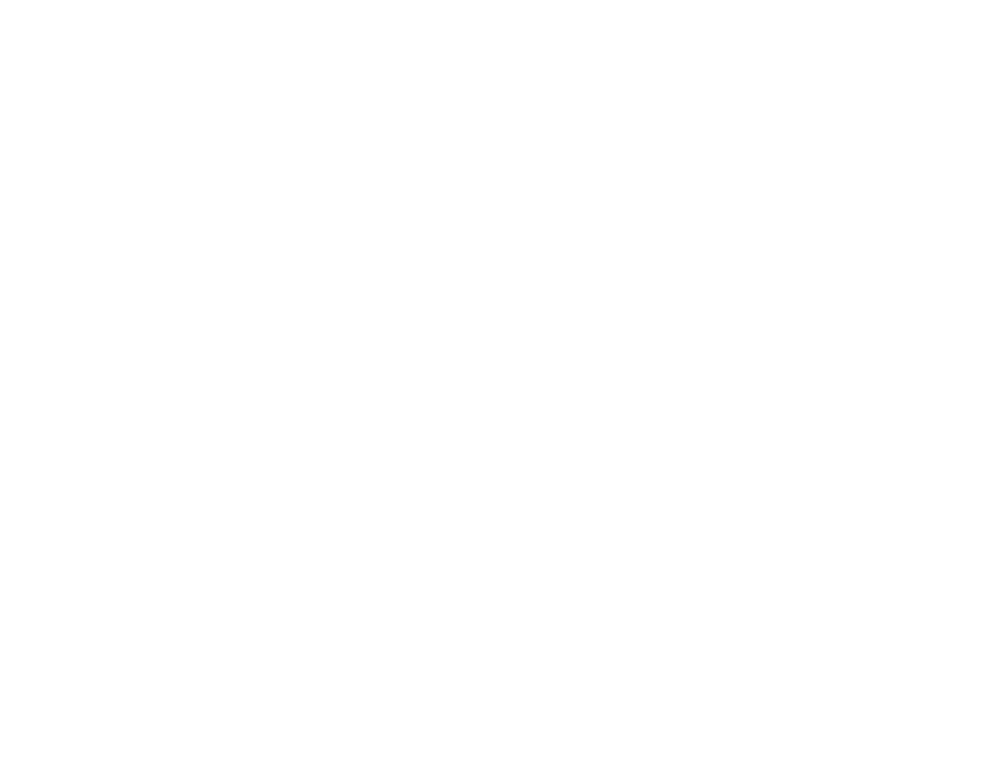


02214500 BIG INDIAN CREEK AT PERRY, GA.

LOCATIOK,--Lat $32^{\circ} 27^{\prime} 20^{\prime \prime}$, long $83^{\circ} 44^{\prime} 21^{\prime \prime}$, Bouston County, at gaging station at municipal waterworks at perry, on left bank $300 \mathrm{ft}$ downstream from bridge on U.S. Highway 41,1 mile downstream from Bay Creek, and $3.2 \mathrm{miles}$ up-
stream from Flat Creek.

DRAINAGE AREA.--108 sq mi.

PERIOD OF RECORD.--Chemical analyses: December 1969 to September 1970 (partial record).

REMARKS.--Laboratory chemical analyses by Georgth Water Quality Control Board. Field determination of discharge, water temperature, $\mathrm{PB}$, and dissolved oxygen by U.S. Geological Survey. CHEMICAL ANALYSES, WATER YEAR OCTOBER 1969 TO SEPTEMBER 1970

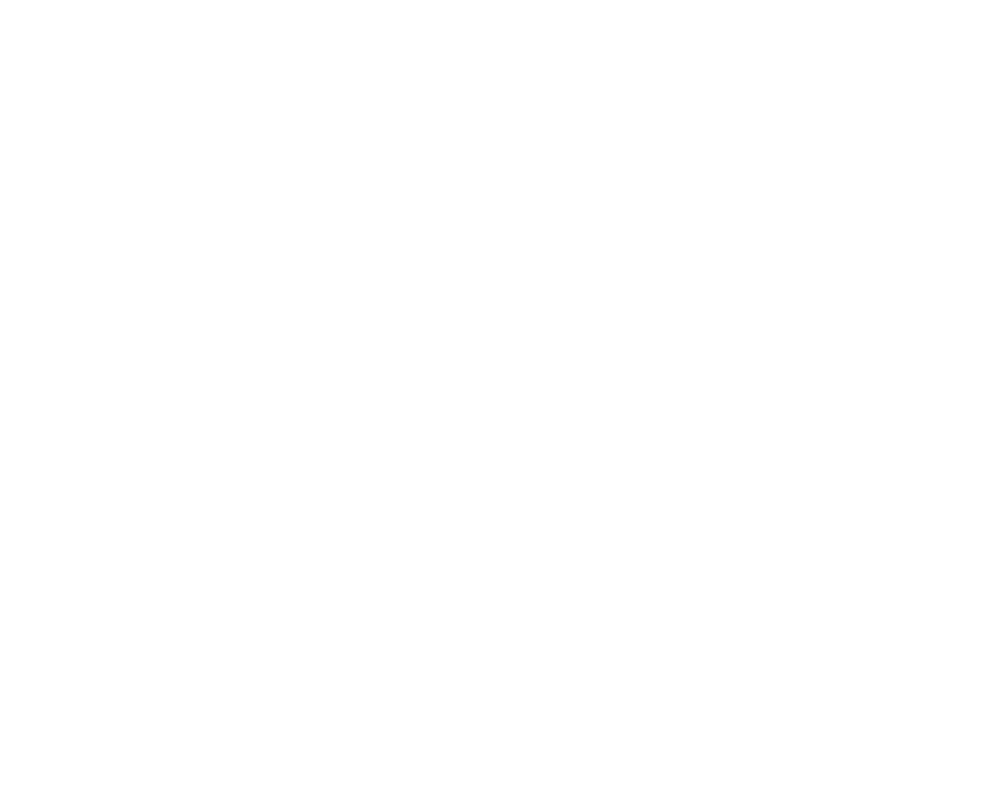

O2215500 OCIULGEE RIVER AT LUIBERTCITY, GA.

LOCATION.--Lat 31 $55^{\prime} 06^{\prime \prime}$, long $82^{\circ} 40^{\prime} 26^{\prime \prime}$, Telfatr County, at gaging station near left bank on downstream end of pler of bridge on U.S. Highway 341 at Lumber City, $500 \mathrm{ft}$ downstream fron Southern Railway bridge, 1 mile upstream of bridge on U.S. Highway 341 at Lumber City, 500 ft downstream fron Southern Railway

DRAIAAGE AREA. . 5,180 sq mi, approximately.

PERIOD OF RECORD.--Chemical analyses: February 1968 to September 1970 (partial record).

REMARKS. - Laboratory chemical analyses by Georgia water quality Control Board. Field determination of discharge, water temperature, $\mathrm{pB}$, and dissolved oxygen by U.S. Goological Survey. CHEMICAL ANALYSES, WATER YEAR OCTOBER 1969 TO SEPTEMBER 1970

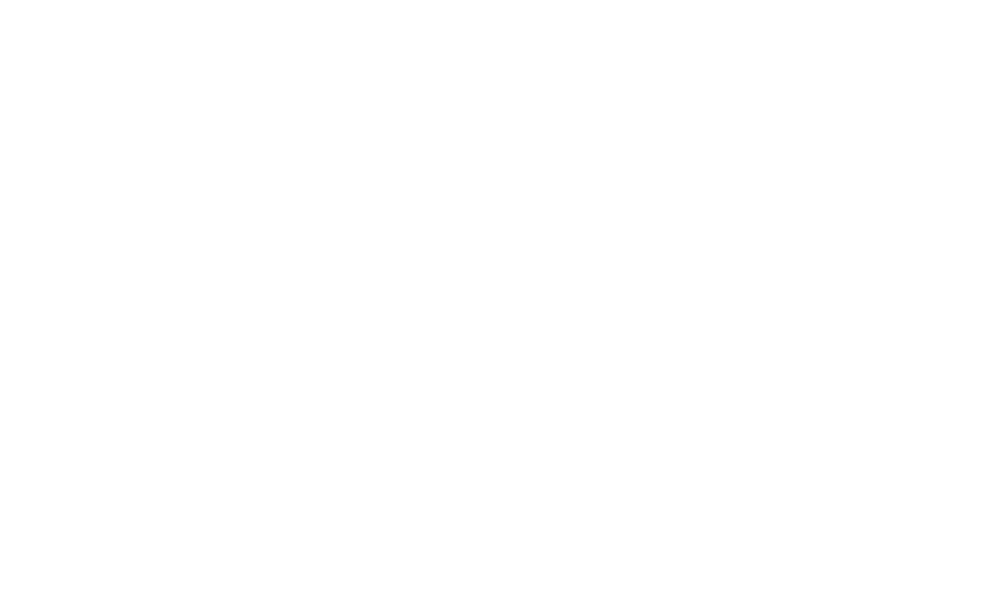


ALTAMAHA RIVER BASIN

02215500 OCMULGEE RIVER AT LUMBER CITY, GA.--Continued

CHEMICAL ANALYSES, WATER YEAR OCTOBER 1969 TO SEPTEMBER 1970

\begin{tabular}{|c|c|c|c|c|c|c|c|c|c|c|}
\hline DATE & $\begin{array}{c}\text { NI TRATE } \\
\text { (N) } \\
\text { (MG/L) }\end{array}$ & $\begin{array}{l}\text { PHOS- } \\
\text { PHATE } \\
\text { (PO4) } \\
\text { (MG/L) }\end{array}$ & $\begin{array}{l}\text { TOTAL } \\
\text { FILT- } \\
\text { RAULE } \\
\text { RESIDUE } \\
\text { (MG/L) }\end{array}$ & $\begin{array}{c}\text { TOTAL } \\
\text { NON- } \\
\text { FILT- } \\
\text { RABLE } \\
\text { RESIDUE. } \\
(M G / L)\end{array}$ & $\begin{array}{l}\text { HARU- } \\
\text { NESS } \\
\text { (CA,MG) } \\
(M G / L)\end{array}$ & $\begin{array}{l}\text { SPECI - } \\
\text { FIC } \\
\text { COND- } \\
\text { UCIANCE } \\
\text { (MICRO- } \\
\text { MHOS) }\end{array}$ & $\begin{array}{l}\text { COLOR } \\
\text { IPLAT- } \\
\text { INUM- } \\
\text { COBALT } \\
\text { UNITSI }\end{array}$ & $\begin{array}{l}\text { TUR- } \\
\text { BIO- } \\
\text { ITY } \\
\text { (JTU) }\end{array}$ & $\begin{array}{l}\text { BIO- } \\
\text { CHEM- } \\
\text { ICAL } \\
\text { OXYGEN } \\
\text { DEMAND } \\
\text { (MG/L) }\end{array}$ & $\begin{array}{c}\text { FECAL } \\
\text { COLI- } \\
\text { FORM } \\
\text { (COL. } \\
\text { PER } \\
100 \mathrm{ML}) \\
\text { (MPN) }\end{array}$ \\
\hline $\begin{array}{l}\text { oct. } \\
22 . . .\end{array}$ & .3 & .34 & 89 & 10 & 39 & 138 & 35 & 13 & 1.0 & I 50 \\
\hline $\begin{array}{l}\text { JAN. } \\
\text { O6.... }\end{array}$ & .1 & .38 & 77 & 24 & 25 & 84 & 40 & 20 & 1.5 & 230 \\
\hline $\begin{array}{l}\text { FEH. } \\
\text { O4.... }\end{array}$ & .1 & .28 & 68 & 19 & 19 & 70 & 60 & 20 & 2.5 & 150 \\
\hline $\begin{array}{l}\text { MAY } \\
06 . . .\end{array}$ & .3 & .19 & 69 & 21 & $2 \mathrm{~B}$ & 90 & 50 & 18 & .9 & $<30$ \\
\hline $\begin{array}{l}\text { AUG. } \\
05 . . .\end{array}$ & .3 & .25 & 94 & 72 & 29 & 101 & 45 & 38 & .7 & 2300 \\
\hline
\end{tabular}

LOCATION.-.Lat $33^{\circ} 56^{\prime} 48^{\prime \prime}$, long $83^{\circ} 25^{\prime} 22^{\prime \prime}$, Clarke County, at gaging station on left bank 0.5 mile upstrean from U.S. Highway 29,2 miles west of Athens, and 5 miles upstream from Barber Creek.

DRAINAGE AREA. $--398 \mathrm{sq} \mathrm{mi}$.

PERIOD OF RECORD.--Chemical analyses: February 1968 to September 1970 (partial record).

REMARKS. - Laboratory chemical analyses by Georgia Water Quality Control Board. Field determination of discharge, water temperature, $\mathrm{pH}$, and dissolved oxygen by U.S. Geological Survey. CHEMICAL ANALYSES, WATER YEAR OCTOBER 1969 TO SEPTEMBER 1970

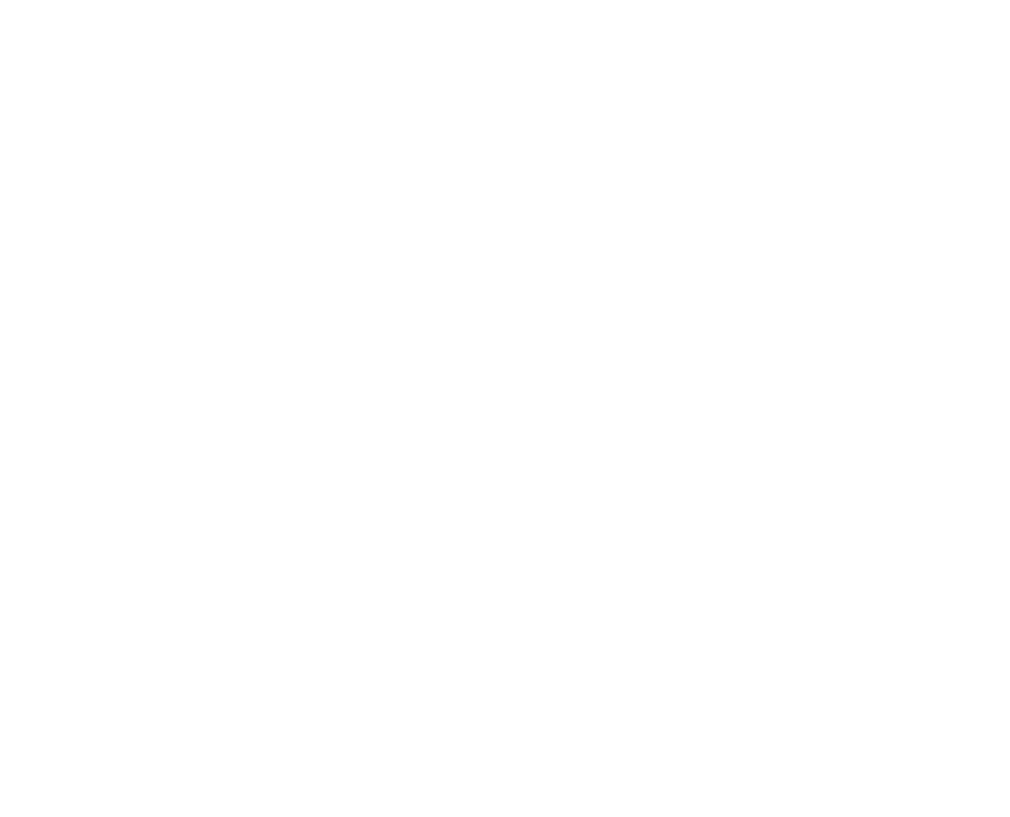

02218500 OCONEE RIVER NEAR GREENSBORO, GA.

LOCATION.--Lat $33^{\circ} 34^{\prime} 52^{\prime \prime}$, long $83^{\circ} 16^{\prime 22}$ ", Greene County, at gaging station on right bank 300 ft downstream from bridge on State Highway 12, 1 mile downstrean from Town Creek, 5 miles upstream from Apalachee River, 5 miles west of Greensboro, 12 miles downstream from Barnett Shoals Dam, and at mile 198.9.

DRAINAGE AREA, - -1,090 sq mi, approximately.

PERIOD OF RECORD.--Chemical analyses: November 1969 to September 1970 (partial record).

REMARKS.--Laboratory chemical analyses by Georgia Water Quality Control Board. Field determination of discharge, water temperature, $\mathrm{pH}$, and dissolved oxygen by U.S. Geological Survey.

CHEMICAL ANALYSES, WATER YEAP OCTOBER 1969 TO SEPTEMRER 1970

\begin{tabular}{|c|c|c|c|c|c|}
\hline DATE & TIME & $\begin{array}{l}\text { UIS- } \\
\text { CHAPGE } \\
\text { (CFS) }\end{array}$ & $\begin{array}{c}\text { PH } \\
\text { (UNITS) }\end{array}$ & $\begin{array}{l}\text { TEMP- } \\
\text { EPATURE } \\
\text { (DEG C) }\end{array}$ & $\begin{array}{l}\text { OIS- } \\
\text { SOLVED } \\
\text { OXYGEN } \\
\text { (MG/L) }\end{array}$ \\
\hline $\begin{array}{l}\text { Nov. } \\
24 \ldots . . \\
\text { FE. H. }\end{array}$ & 1030 & 744 & 6.6 & 8.0 & 10.4 \\
\hline${ }_{M A Y}^{24} \cdots$ & 1215 & 937 & 5.7 & 10.0 & 9.2 \\
\hline $\begin{array}{l}26 \ldots . . \\
\text { AUG. }\end{array}$ & 1545 & 690 & 6.2 & 23.0 & 8.3 \\
\hline $24 \ldots$ & 1630 & 438 & 7.2 & 27.0 & 6.2 \\
\hline
\end{tabular}


ALTAMAHA RIVER BASIN

02218500 OCONEE RIVER NEAR GREENSBORO, GA.--Cont InUed

CHEMICAL ANALYSES, WATER YEAR OCTOBER 1969 TO SEPTEMBER 1970

\begin{tabular}{|c|c|c|c|c|c|c|c|c|c|c|}
\hline UATE & $\begin{array}{l}\text { SILICA } \\
\text { ISIOL) } \\
\text { (MG/L) }\end{array}$ & $\begin{array}{l}\text { TOFAL } \\
\text { IRON } \\
\text { (FE) } \\
\text { (UG/L) }\end{array}$ & $\begin{array}{l}\text { TOTAL } \\
\text { MAN- } \\
\text { GANESE } \\
\text { (MN) } \\
\text { (UG/L) }\end{array}$ & $\begin{array}{l}\text { DIS- } \\
\text { SOLVED } \\
\text { CAL- } \\
\text { CIUM } \\
\text { (CA) } \\
\text { (MG/L) }\end{array}$ & $\begin{array}{l}\text { UIS- } \\
\text { SOLVEO } \\
\text { MAG- } \\
\text { NE- } \\
\text { SIUM } \\
\text { (MG) } \\
\text { (MG/L) }\end{array}$ & $\begin{array}{l}\text { SODIUM } \\
\text { (NA) } \\
\text { (MG/L) }\end{array}$ & $\begin{array}{l}\text { PO- } \\
\text { TAS- } \\
\text { SIUM } \\
\text { (K) } \\
\text { (MG/L) }\end{array}$ & $\begin{array}{l}\text { ALKA- } \\
\text { LINITY } \\
\text { AS } \\
\text { CACO3 } \\
\text { (MG/L) }\end{array}$ & $\begin{array}{l}\text { SULFATE } \\
(S O 4) \\
(M G / L)\end{array}$ & $\begin{array}{l}\text { CHLO- } \\
\text { RIDE } \\
(C L) \\
(M G / L)\end{array}$ \\
\hline $\begin{array}{l}\text { NOV. } \\
24 \ldots \\
\text { FEB. }\end{array}$ & 16 & 420 & $<50$ & 3.7 & 1.4 & 4.6 & 1.7 & 21 & 2.0 & 3.2 \\
\hline & -- & 750 & $<50$ & 3.8 & 1.4 & 3.6 & 1.2 & 19 & $<2,0$ & 2.8 \\
\hline $\begin{array}{l}26 . . \\
\text { AUG. }\end{array}$ & 18 & 2100 & 60 & 4.1 & 1.6 & 4.7 & 1.8 & 20 & 7.0 & 2.8 \\
\hline $24 \ldots$ & 14 & 1200 & $<50$ & 4.5 & 1.6 & 5.8 & 2.2 & 21 & 5.0 & 3.9 \\
\hline DATE & $\begin{array}{c}\text { NITRATL } \\
\text { (N) } \\
\text { (MG/L) }\end{array}$ & $\begin{array}{l}\text { PHOS- } \\
\text { PHATE } \\
\text { (PO4) } \\
\text { (MG/L) }\end{array}$ & $\begin{array}{l}\text { TOTAL } \\
\text { FILT- } \\
\text { RABLE } \\
\text { RESIUUE } \\
\text { (MG/L) }\end{array}$ & $\begin{array}{c}\text { TOTAL } \\
\text { NON- } \\
\text { FILT- } \\
\text { RABLE } \\
\text { RESIDUE } \\
\text { (MG/L) }\end{array}$ & $\begin{array}{l}\text { HARD- } \\
\text { NESS } \\
\text { (CA,MG) } \\
\text { (MG/L) }\end{array}$ & $\begin{array}{l}\text { SPECI- } \\
\text { FIC } \\
\text { COND- } \\
\text { UCTANCE } \\
\text { (MICRO- } \\
\text { MHOS) }\end{array}$ & $\begin{array}{l}\text { COLOR } \\
\text { (PLAT- } \\
\text { INUM- } \\
\text { COBALT } \\
\text { UNITS) }\end{array}$ & $\begin{array}{l}\text { TUR- } \\
\text { RIO- } \\
\text { ITY } \\
\text { (JTU) }\end{array}$ & $\begin{array}{l}\text { BIO- } \\
\text { CHEM- } \\
\text { ICAL } \\
\text { OXYGEN } \\
\text { DEMAND } \\
\text { (MG/L) }\end{array}$ & $\begin{array}{c}\text { FECAL } \\
\text { COLI- } \\
\text { FORM } \\
\text { (COL. } \\
\text { PER } \\
\text { 10O ML) } \\
\text { (MPN) }\end{array}$ \\
\hline
\end{tabular}

NO

\begin{tabular}{|c|c|c|c|c|c|c|c|c|c|c|}
\hline $24 \ldots$ & . 4 & .48 & by & 15 & 16 & 60 & 25 & 14 & 1.0 & 9300 \\
\hline $24 \ldots$ & . 4 & .43 & 52 & 16 & 14 & 45 & 20 & 15 & 2.2 & 2300 \\
\hline $\begin{array}{l}\text { MAY } \\
26 . . .\end{array}$ & . 5 & .26 & 59 & 35 & 18 & 61 & 35 & 30 & 1.1 & 2300 \\
\hline AUG. & & & & & & & & & & 750000 \\
\hline $24 \ldots$ & .9 & .40 & 42 & 36 & 17 & 72 & -- & 27 & .8 & 150000 \\
\hline
\end{tabular}

LOCATION,--Lat $33^{\circ} 36^{\prime} 31^{\prime \prime}$, long $83^{\circ} 20^{\prime} 58^{\prime \prime}$, Morgan County, at gaging station at downstream side of right bank pier of bridge on State Highway 12, 2 miles downstream from Hard Labor Creek, 3 miles northeast of Buckhead, and 9 miles upstream from mouth.

DRAINAGE AREA. $--436 \mathrm{sq} \mathrm{mi}$.

PERIOD OF RECORD..-Chemical analyses: November 1969 to September 1970 (partial record).

REMARKS. - Laboratory chemical analyses by Georgia Water Quality Control Board. Field determination of discharge, water temperature, $\mathrm{pH}$, and dissolved oxygen by U.S. Geological Survey.

CHEMICAL ANALYSES. WATER YEAR OCTOBER 1969 TO SEPTEMBER 1970

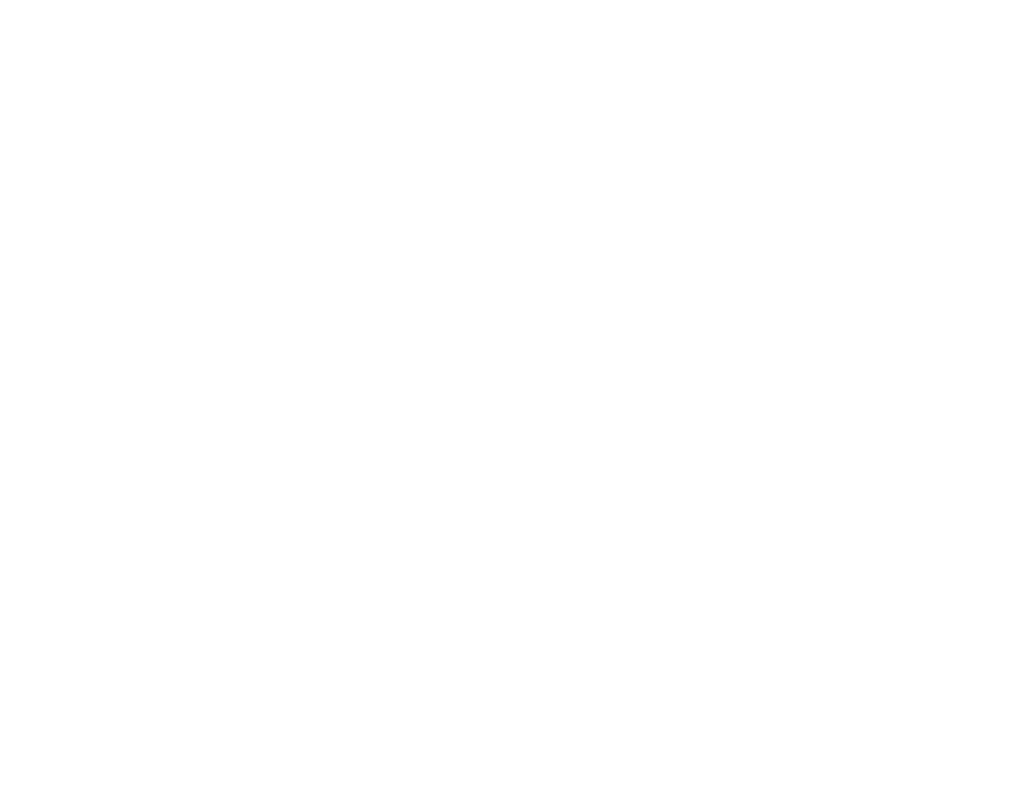


02223000 OCONEE RIVER AT MILLEDGEVILLE, GA.

LOCATION.--Lat $33^{\circ} 04^{\prime} 58^{\prime \prime}$, long $83^{\circ} 12^{\prime} 51^{\prime \prime}$, Baldwin County, at gaging station at right bank on City of Milledgeville

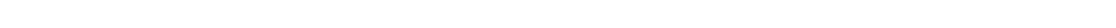
water works intake structure, at Milledgeville, 0.5 mile upstream from

DRAINAGE AREA. -.2,950 sq mi, approximately.

PERIOD OF RECORD.--Chemical analyses: March 1968 to September 1970 (parttal record).

REXARKS.-- Laboratory chemical analyses by Georgia water Quality Control Board. Field determination of discharge, water temperature, $\mathrm{pH}$, and dissolved oxygen by U.S. Geological Survey. CHEMICAL. ANALYSES, WATER YEAR OCTOBER 1969 TO SEPTEMBER 1970

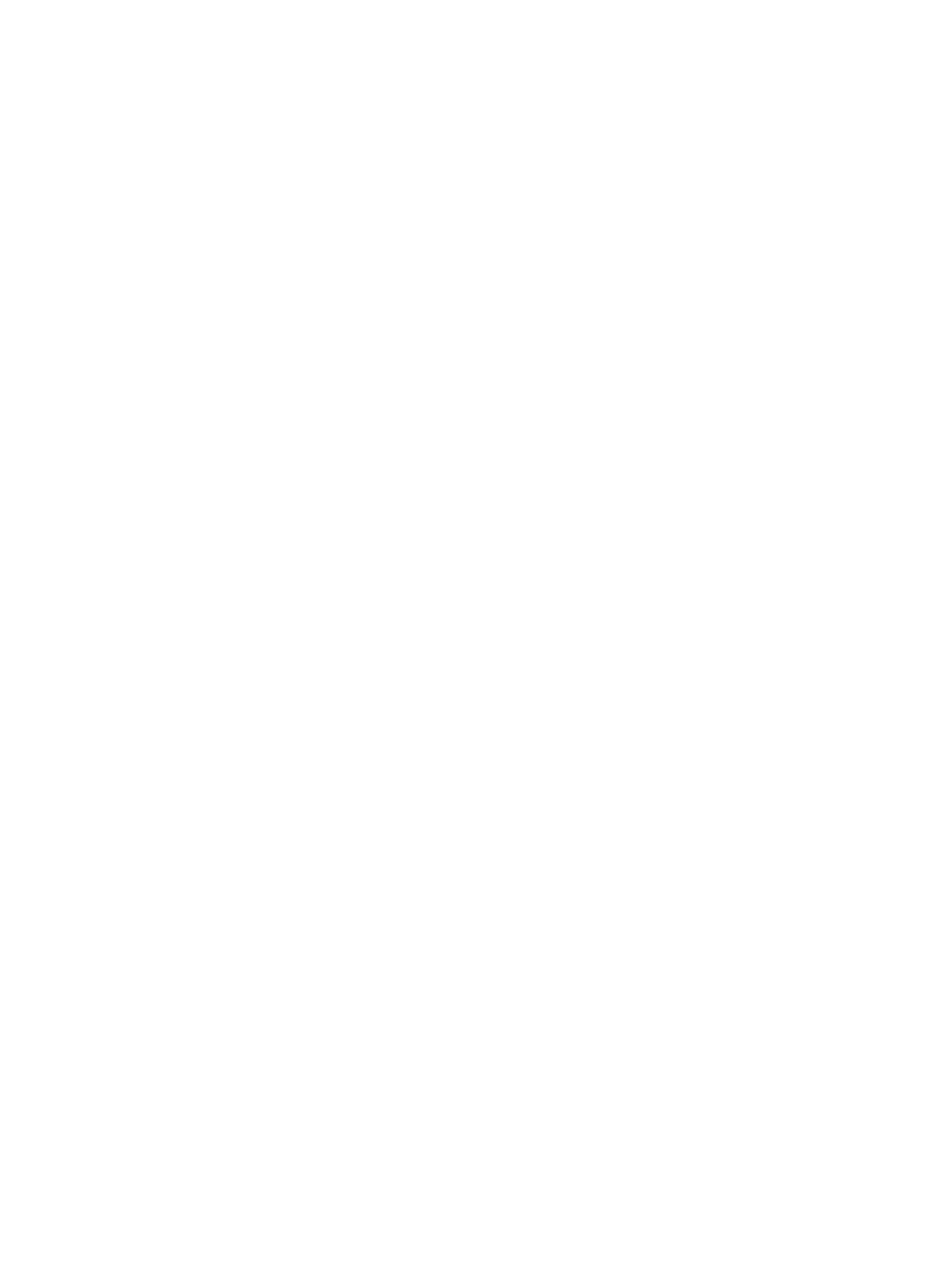


LOCATION,--Lat $32^{\circ} 32^{\prime} 40^{\prime \prime}$, long $82^{\circ} 53^{\prime} 41^{\prime \prime}$, Laurens County, at gaging station near left bank on downstream end of pier of bridge on U, S. Highway 80 at Dublin and at mile 77.9 .

DRAINAGE AREA, - -4,400 sq mi, approximately.

PERIOD OF RECORD.--Chemical analyses: February 1968 to September.1970 (partial record)

REMRKS. - Laboratory chemical analyses by Georgia mater Quality Control Board. Field determination of discharge, water temperature, pH, and dissolved oxygen by U.S. Geological survey.

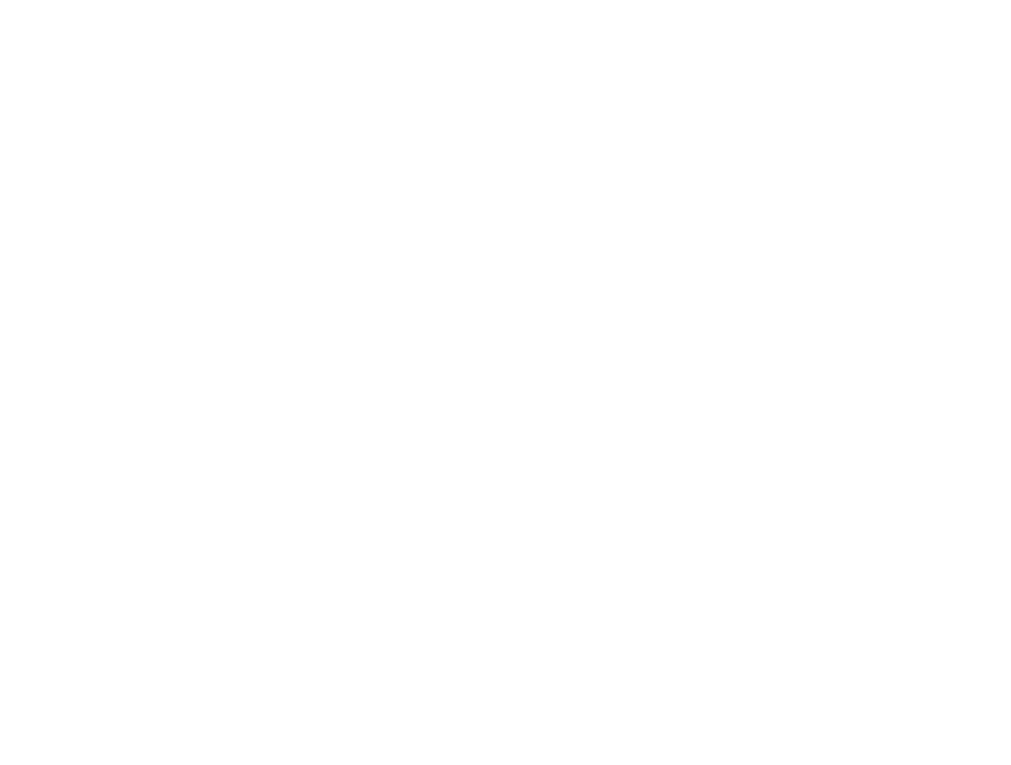

LOCATION.--Lat $32^{\circ} 04^{\prime} 42^{\prime \prime}$, Iong $82^{\circ} 10^{\prime} 39^{\prime \prime}$, Tatna1l County, at gaging station on downstream side of p1er near center of span of bridge on'state H1ghway $56,0.5$ mile downstream from Brazells Creek, 1.5 miles downstream from Rocky Creek, 3,5 miles west of Reidsvilie, 6 miles downstream from Pendleton Creek, and 14 miles upstream from mouth. DRAINAGE AREA. $-1,110 \mathrm{sq} \mathrm{mi}$, approximately .

PERIOD OF RECORD.--Chemical analyses: February 1968 to september 1970 (partial record). REMARKS. - -Laboratory chemical analyses by Georgia Water Quality Control Board. Field determination of discharge,
water temperature, pH, and dissolved oxygen by U.S. Geological Survey. CHEMICAL ANALYSES, NATER YEAR OCYOBER 1969 TO SEPTFMBER 1970

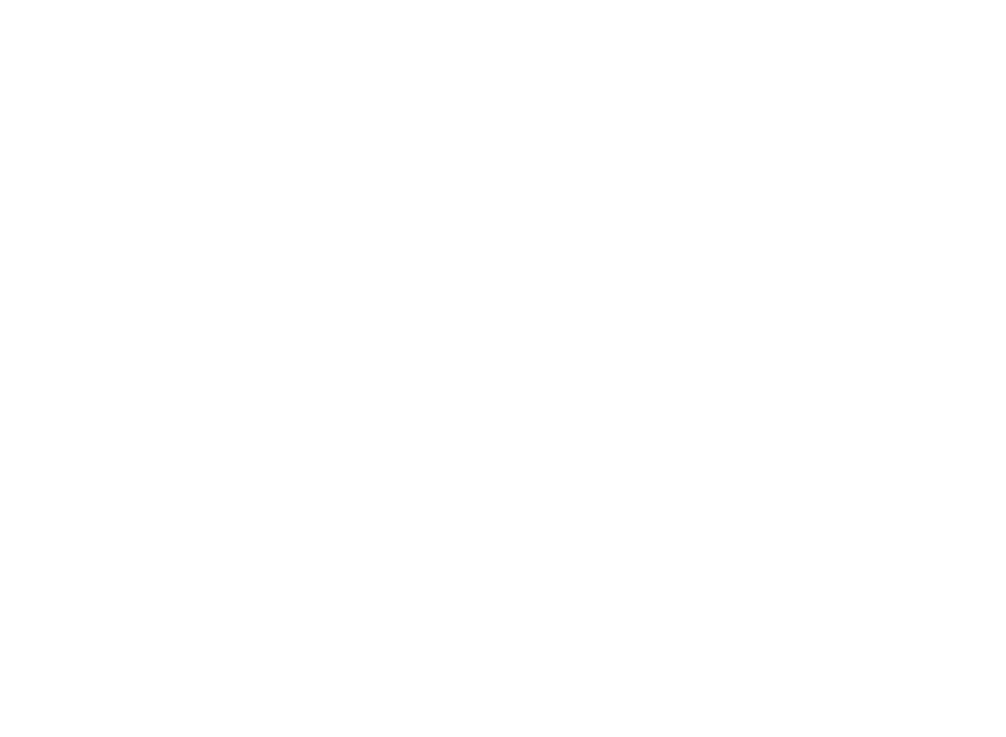


02226500 SATILLA RIVER NEAR WAYCROSS, GA.

LOCATION.--Lat $31^{\circ} 14^{\prime} 17^{\prime \prime}$, long $82^{\circ} 19^{\prime} 29^{\prime \prime}$, ware County, at gaging station on downstream side of pier near center of span of bridge on state Highway 38,3 miles northeast of Waycross and 16 miles upstream from Alabaha River.

DRAINAGE AREA, --1,200 sq mi, approximately.

PERIOD OF RECORD,--Chemical analyses: February 1968 to September 1970 (partial record).

REMARKS, - Laboratory chemical analyses by Georgia Water Quality Control Board. Field determination of discharge, water temperature, $\mathrm{pH}$, and dissolved oxygen by U.S. Geological Survey.

CHEMICAL ANALYSES, WATEK YEAR OCTOBER 1969 TO SEPTEMBER 1970

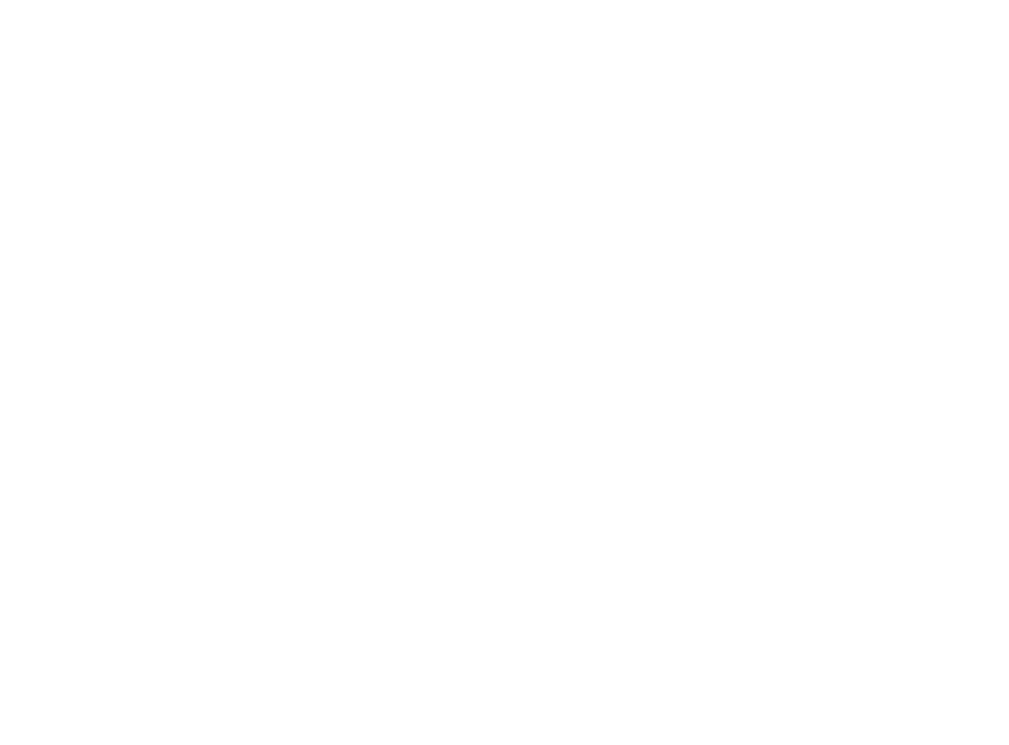

02227500 LITTLE SATILLA RIVER NEAR OFFERHAN, GA.

LOCATION.--Lat $31^{\circ} 27^{\prime} 04^{\prime \prime}$, long $82^{\circ} 03^{\prime} 17^{\prime \prime}$, Pierce County, at gaging station at right bank pier of steel truss span of Seaboard Coast Line Railroad bridge, 1,500 ft domstream from bridge on state Highway 38,4 miles northeast of of ferman, and 16 miles upstream from mouth.

DRAINAGE AREA.--646 sq $\mathrm{mi}$.

PERIOD OF RECORD.--Chemical analyses: October 1969 to September 1970 (partial record).

REMARKS. - - Laboratory chemical analyses by Georgia Water Quality Control Board. Field determination of diseharge, water temperature, $\mathrm{pH}$, and dissolved oxygen by U.S. Geological Survey.

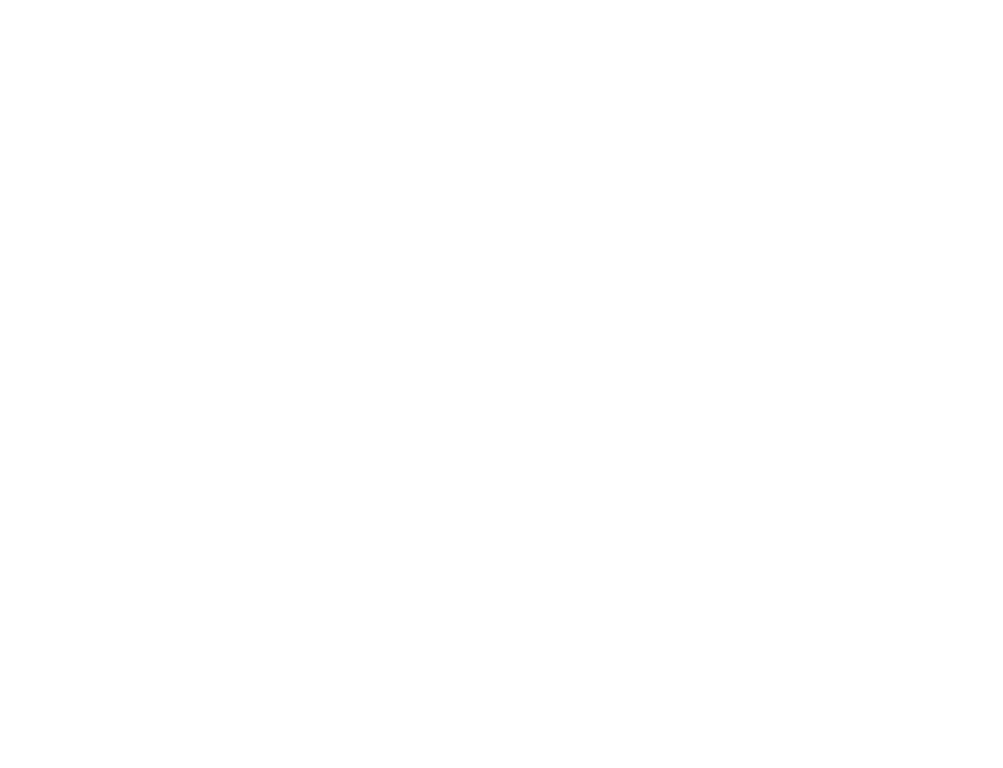


SATILLA RIVER BASIN

02228000 SATILLA RIVER AT ATKINSON, GA.

LOCATION,--Lat $31^{\circ} 13^{\prime} 16^{\prime \prime}$, Iong $81^{\circ} 52 \cdot 03^{\prime \prime}$, Brantley County, at gaging station on left-bank piling 25 ft upstream from bridge on U.S. Highway 84, 400 ft downstream from seaboard Coast Line Ratlroad bridge and 1 mile west of Atkinson.

DRAINAGE AREA.,-2,790 sq mi, approximately.

PERIOD OF RECORD.--Chemica1 analyses: February 1968 to September 1970 (partial record).

REMARKS, - Laboratory chemical analyses by Goorgia Water Quality Control Board. Field determination of discharge, water temperature, $\mathrm{pH}$, and dissolved oxygen by U.S. Geological Survey.

CHEMICAL AINALYSES, HATEF YEAK OCTOHEP 1969 TO SEPTEMRER 1970

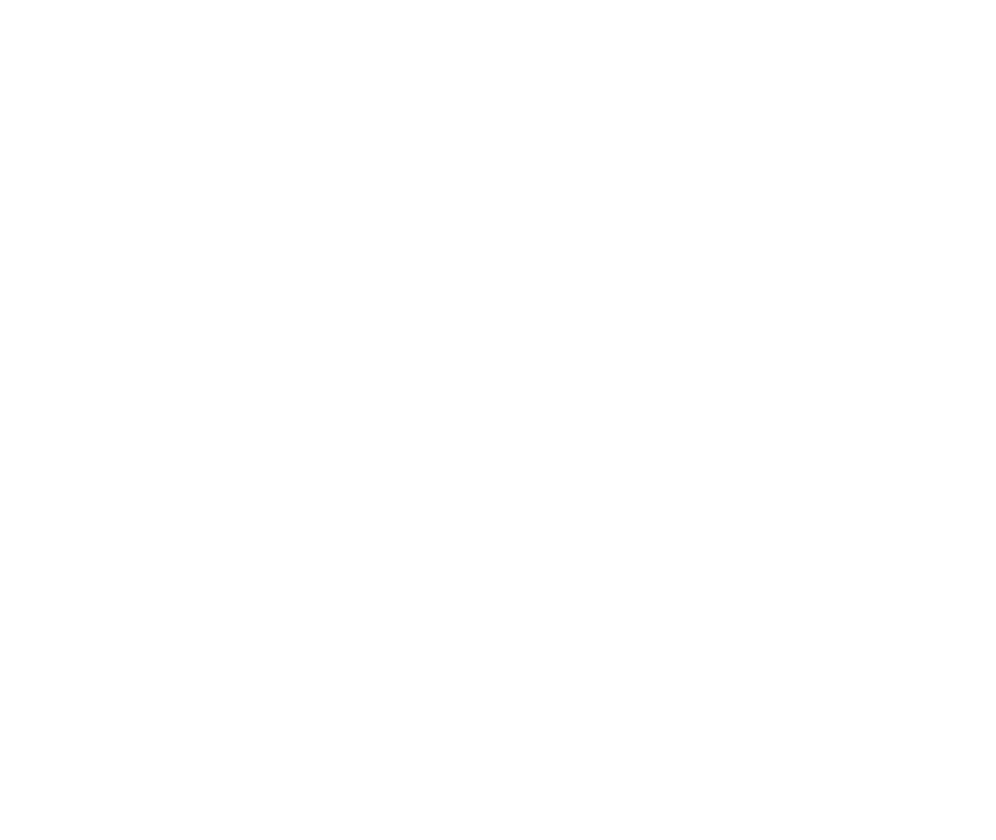

02314500 SUWANNEE RIVER AT FARGO, GA.

LOCATION. - Lat $30^{\circ} 40^{\circ} 50^{\prime \prime}$, long $82^{\circ} 33^{\prime} 38^{\prime \prime}$, Clinch County, at gaging station on downstream side of right bank pler of bridge on U.S. Highway 441 at Fargo, 4 miles upstream from Suwanoochee Creek and 12 miles downstream from Mixons

DRAINAGE AREA. - -About 1,260 sq $\mathrm{ml}$ (includes part of watershed in Okefenokee Swamp, which is indeterminate).

PERIOD OF RECORD.--Chemical analyses: February 1968 to September 1970 (partial record).

REMARKS. - Laboratory chemical analyses by Georgia water Quality Control Board. Field determination of discharge, water temperature, $\mathrm{pH}$, and dissolved oxygen by U.S. Geological Survey. CHEMICAL AMALYSES, WATER YLAR OCTORER 1969 TH SEHTFMEER 1970

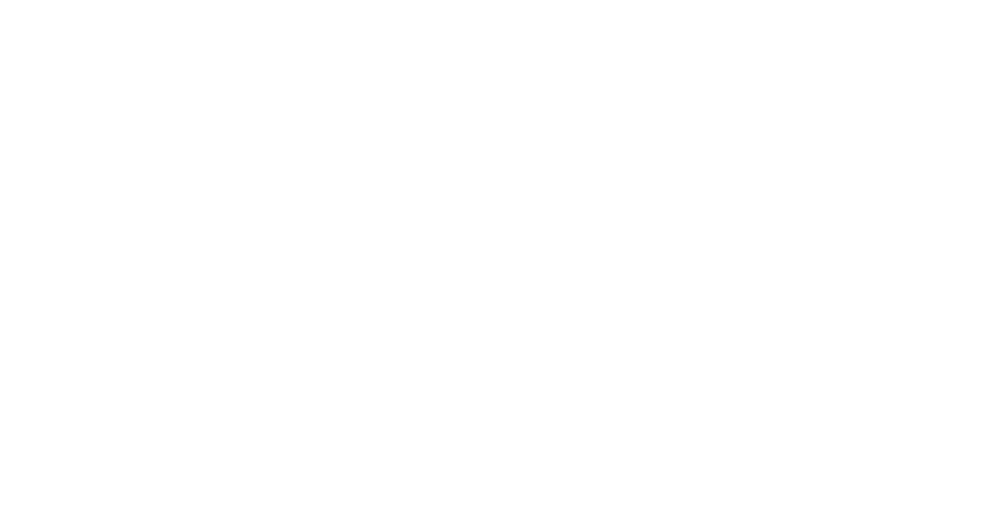




\section{SUWANNEE RIVER BASIN}

02314500 SUWANNEE RIVER AT FARGO, GA.--Continued CHEMICAL ANALYSES, WATER YEAR OCTOBER 1969 TO SEPTEMBER 1970

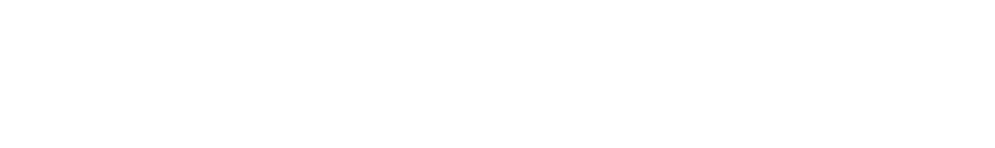

\begin{tabular}{|c|c|c|c|c|c|c|c|c|c|c|}
\hline $\begin{array}{l}\mathrm{OCT} . \\
\text { 2I.... } \\
\text { FEB. }\end{array}$ & .0 & .08 & 97 & 17 & 6 & 53 & 325 & 5.0 & 1.8 & $<30$ \\
\hline & .0 & .15 & 74 & 4 & 4 & 46 & 200 & 3.0 & 1.2 & 2300 \\
\hline OU.... & .0 & .05 & 93 & 2 & $B$ & 42 & 320 & 2.0 & 2.3 & $<30$ \\
\hline$n 4 \ldots$ & .0 & .05 & IUI & 22 & 4 & 49 & 250 & 2.0 & .8 & $<30$ \\
\hline
\end{tabular}

02316000 alapaHa RIVER NEAR alapaHa, Ga.

LOCATION. - Lat $31^{\circ} 23^{\prime} 03^{\prime \prime}$, long $83^{\circ} 11^{\prime} 33^{\prime \prime}$, Berrien County, at gaging station near rtght bank on downstream side of bridge on state Bighway 50,2 miles east of Alapaha and 6 miles upstream from 111 acoochee River.

DRAI NAGE AREA. $--663 \mathrm{sq} \mathrm{ml}$.

PERIOD OP RECORD.--Chemlcal analyses: October 1969 to September 1970 partial record).

REMARXS.--Laboratory chemical analyses by Georgla Water Quality Control Board. Field determination of discharge, water temperature, pH, and dissolved oxygen by U.S. Geological Survey.

CHEMICAL ANALYSES, WATEK YEAK OCTOHER 1969 TO SEFTEMBER I 970

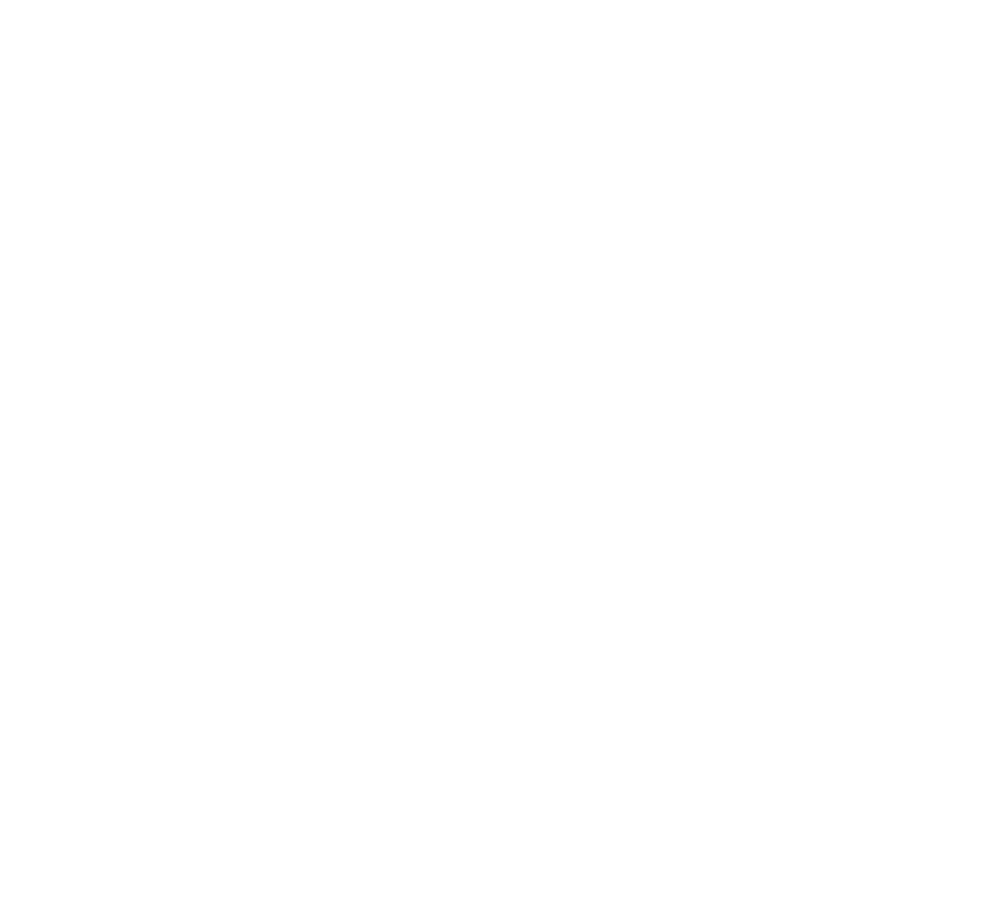


SUWANNEE RIVER BASIN

02317500 ALAPAHA RIVER AT STATENYILLE, GA.

LOCATION.--Lat $30^{\circ} 42^{\prime} 14^{\prime \prime}$, long $83^{\circ} 02^{\prime} 00^{\prime \prime}$, Echols County, at gaging station at downstream side of left bank pler of bridge on State Highway $94,0.2$ mile west of Statenvilie.

DRAINAGE AREA. - -1,400 sq m1, approximate1y.

PERIOD OF RECORD..-Chemical analyses: February 1968 to September 1970 (partial recora).

REMARKS. - Laboratory chemical analyses by Georgia Water qua1ity Control Board. Field determination of discharge, water temperature, pH, and dissolved oxygen by U.S. Geological Survey.

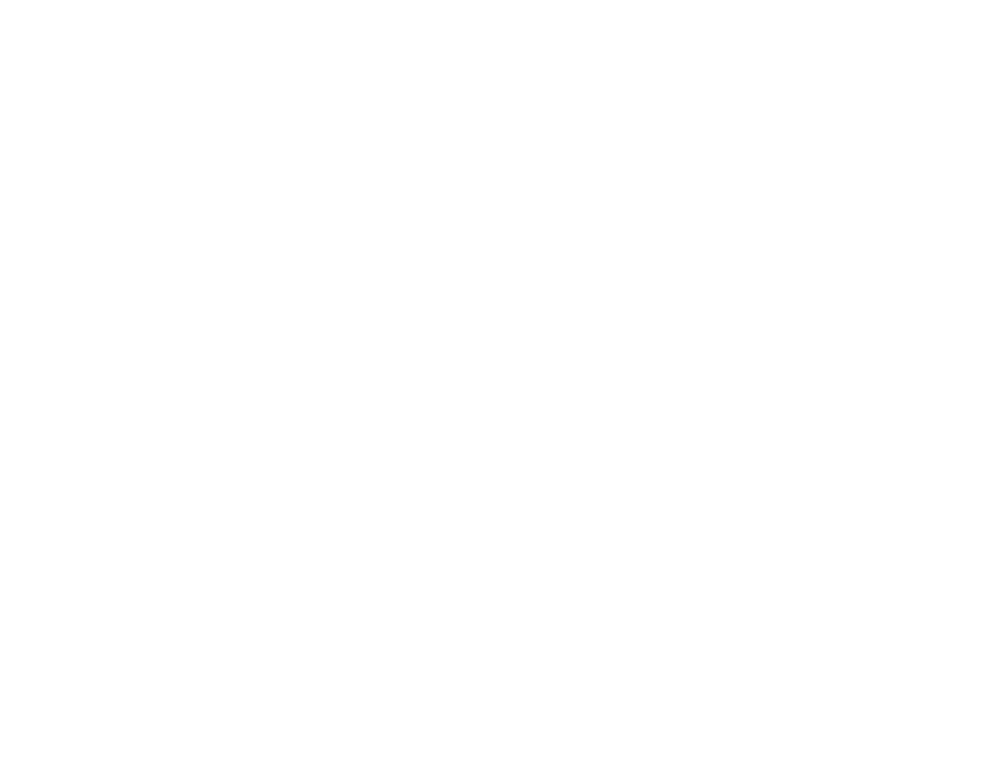

LOCATION.--Lat $31^{\circ} 09^{\prime} 18^{\prime \prime}$, long $83^{\circ} 32^{\prime} 38^{\prime \prime}$, Cook County, at'geging station on right benk 500 ft downstreem from bridge on State Highway $37,0.5$ mile downstream from Georgla and Fiorida Railroad bridge, 5.5 miles upstream from Bear creek, 6 miles dowastreem from Werrior Creek, and 7 miles west of Adel.

DRAI NAGE AREA, - $-577 \mathrm{sq}$ mi.

PERIOD OF RECORD.-.-Chemical anelyses: Januery to September 1970 (pertiel record).

REMARKS.--Leboretory chemicel enelyses by Georgie weter quelity Control Boerd, Field determinetion of discherge, water temperature, $\mathrm{pH}$, and dissolved oxygen by U.S. Geological Survey.

$$
\text { CHEMICAL ANALYSES, WATER YFAR OCIOBER } 1969 \text { TO SEPTEMBER } 1970
$$

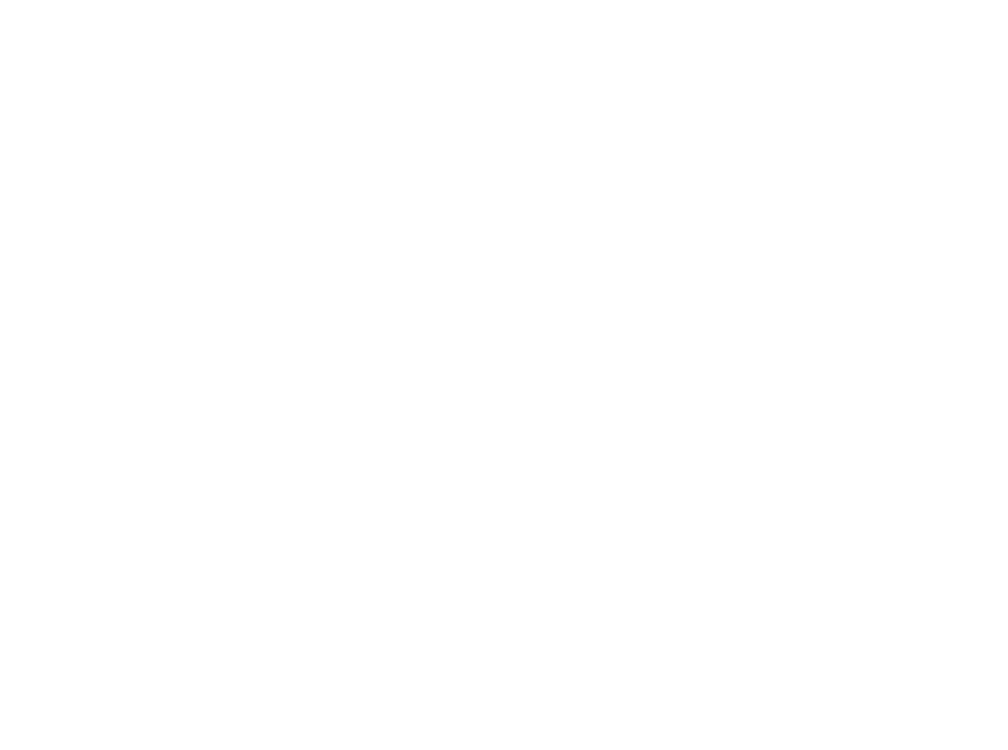


OCHLOCKONEE RIVER BASIN

02327500 OCHLOCKONEE RIVER NEAR THOMASVILLE, GA,

LOCATION.-- Lat $30^{\circ} 52 \cdot 32^{\prime \prime}$, long $84^{\circ} 02 \cdot 44^{\prime \prime}$, Thomas County, at gaging station on downstream side of left bank pier of bridge on U.S. Highway 84,2 miles upstream from Seaboard Coast Line Railroad bridge, 4 miles upstream from Barnetts Creek, 5 miles northwest of Thomasville, and 6 miles dowastream from Little ochlockonee River.

DRAINAGE AREA. - 550 sq mi, approximately.

PERIOD OF RECORD.--Chemical analyses: February 1968 to September 1970 (partial record).

REKARKS. - -Laboratory chemical analyses by Georgia water Quality Control Board. Field determination of discharge, water temperature, $\mathrm{pH}$, and dissolved oxygen by U.S. Geological Survey.

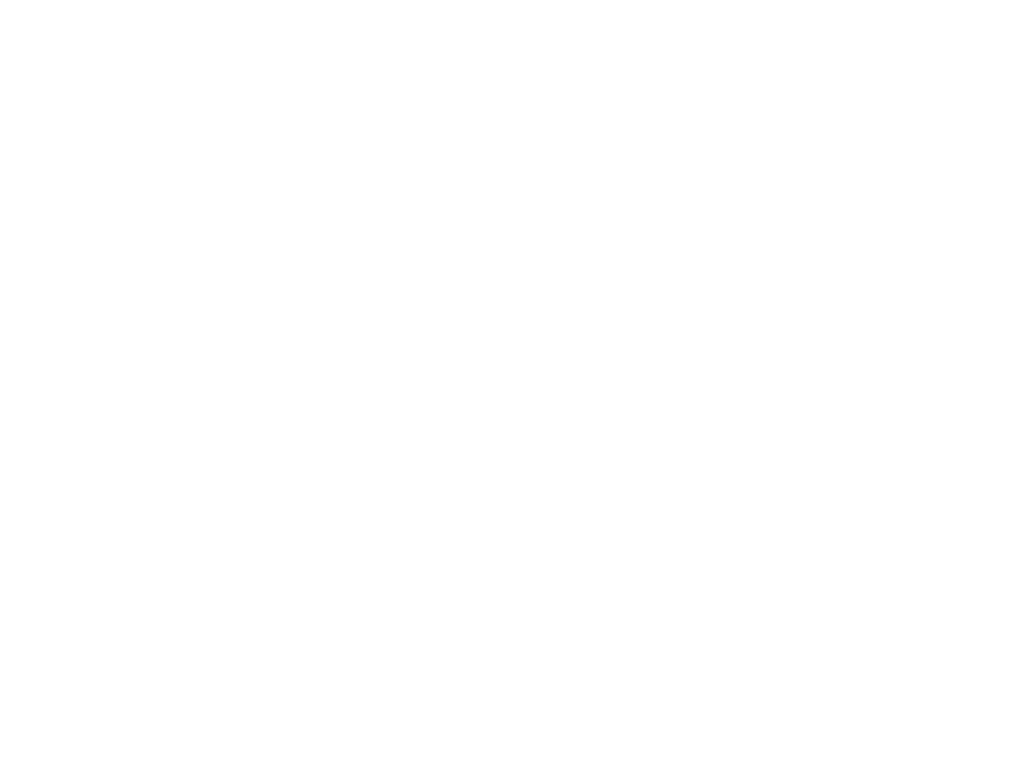

02331000 CHATTAHOOCHEE RIVER NEAR LEAF, GA.

LOCATION, - - Lat $34^{\circ} 34^{\prime} 37^{\prime \prime}$, long $83^{\circ} 38^{\circ} 09^{\prime \prime}$, Habersham County, at gaging station on left bank 700 ft upstream from bridge on State Highway $115,1.5$ miles east of Leaf, 2.5 mlles downstream from Blue Creek, 3 m1les upstream fromSoque River, 7.5 miles southeast of cleveland, and at mile 405.6 .

DRAINAGE AREA, - -150 sq mi.

PERIOD OF RECORD.--Chemical analyses: February 1968 to September 1970 (partial record).

REMARKS.--Laboratory chemical analyses by Georgia water Quality Control Board. Field determination of discharge, water temperature, $\mathrm{pH}$, and dissolved oxygen by U.S. Geological Survey.

$$
\text { CHEMICAL ANALYSES, WATER YEAR OCTOBER I969 TO SEPTEMBER } 1970
$$

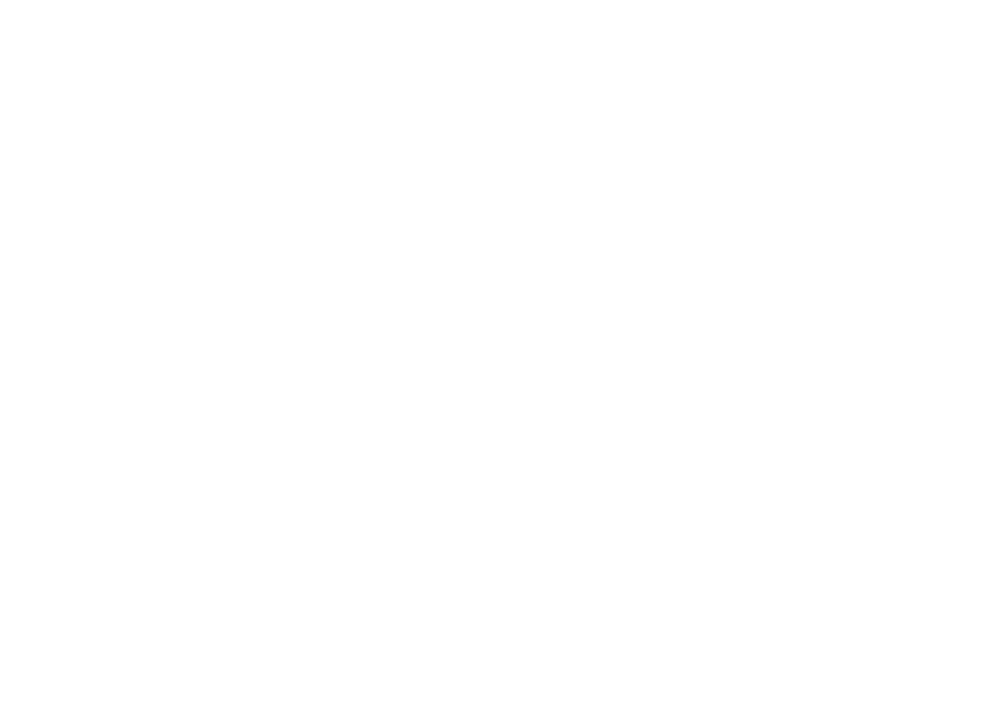


02331600 CHATTAHOOCHEE RIVER NEAR CORNELIA, GA.

LOCATION...-Lat $34^{\circ} 32^{\prime} 27^{\prime \prime}$, long $83^{\circ} 37^{\prime} 14^{\prime \prime}$, White County, at gaging station on downstream side of Duncan Bridge, 1 mile downstream from Soque River, 6 miles northwest of Corneila, and at mile 401.5 .

DRAI NAGE AREA. --315 sq mi.

PERIOD OF RECORD.--Chemical analyses: February 1968 to September 1970 (partial record).

REMARKS.--Laboratory chemical analyses by Georgia Water Quality Control Board, Field determination of discharge, water temperature, $\mathrm{pH}$, and dissolved oxygen by U.S. Geological Survey. CHEMICAL ANALYSES, WATER YEAH OCTOBER 1 YGG TO SEPTEMEER 1 \%70

\begin{tabular}{|c|c|c|c|c|c|c|c|c|c|c|}
\hline & \multicolumn{3}{|c|}{ IJATE } & $T I / A F$ & Si & $\begin{array}{l}\text { TEM } \\
\text { FRAT } \\
\text { (1)EG }\end{array}$ & $\begin{array}{l}\text { OI } \\
\text { SOL } \\
\text { OXY } \\
\text { IMG }\end{array}$ & & & \\
\hline & & $\begin{array}{l}\text { NODV } \\
\text { MI } \\
\text { MAR }\end{array}$ & & & 521 & . 6 & $2 \cdot n$ & . & & \\
\hline & & $\begin{array}{r}03 \\
\text { MAY }\end{array}$ & & & 557 & .4 & 0.0 & .9 & & \\
\hline & & $\begin{array}{r}25 \\
S \in P\end{array}$ & & & 655 & ל & 0.0 & .7 & & \\
\hline & & 01 & & & 396 & . 5 & $4 . n$ & 8 & & \\
\hline DATE & $\begin{array}{l}>1 L 1 C) \\
(>10 \Omega) \\
(M \cup / L)\end{array}$ & $\begin{array}{l}\text { TOTAL } \\
\text { 1HON } \\
\text { (FE) } \\
\text { (UG'L) }\end{array}$ & $\begin{array}{l}\text { TUTAL } \\
\text { MAN- } \\
\text { GANESE } \\
\text { (MN) } \\
\text { (IJG/L) }\end{array}$ & $\begin{array}{l}\text { OIS- } \\
\text { SOLVEO } \\
\text { CAL- } \\
\text { CIUM } \\
\text { (CA) } \\
\text { (MG/L) }\end{array}$ & $\begin{array}{l}\text { UIS- } \\
\text { SULVEO } \\
\text { MAG- } \\
\text { INE- } \\
\text { SIUM } \\
\text { (MG) } \\
\text { (MGIL) }\end{array}$ & $\begin{array}{l}\text { SOOIUM } \\
\text { (NA) } \\
\text { (MG/L) }\end{array}$ & $\begin{array}{l}\text { PO- } \\
\text { TAS- } \\
\text { SIUM } \\
\text { (K) } \\
(M G / L)\end{array}$ & $\begin{array}{l}\text { ALKA- } \\
\text { LINITY } \\
\text { AS } \\
\text { CACO3 } \\
\text { (MG L ) }\end{array}$ & $\begin{array}{l}\text { SULFATE } \\
\text { (SOL) } \\
(M G / L)\end{array}$ & $\begin{array}{l}\text { CHLO- } \\
\text { RIDE } \\
\text { (CL) } \\
(M G / L)\end{array}$ \\
\hline $\begin{array}{l}\text { Nov. } \\
11 . . .\end{array}$ & 2.1) & $3 \mathrm{st}$ & < 0 & 1.5 & .6 & 1.4 & .8 & 8 & $<2.0$ & 1.1 \\
\hline $\begin{array}{l}\text { Mat. } \\
03 . . .\end{array}$ & $f .4$ & 350 & $<50$ & 1.4 & .6 & 1,3 & 1.2 & & $<2.0$ & 1.8 \\
\hline MAY & & & & & & & & & & \\
\hline $\begin{array}{l}25 . . . \\
\text { StP. }\end{array}$ & Y. 11 & 300 & $<50$ & 1.6 & .6 & 1.5 & 1.0 & 8 & $<2,0$ & 1.0 \\
\hline $01 \ldots$ & 4.0 & 570 & $<s(j)$ & 1.5 & .7 & 1.8 & 1.1 & 9 & $<2.0$ & 1.3 \\
\hline vatt. & $\begin{array}{l}\text { MITHOTE } \\
(\text { (N) } \\
(m(s / L)\end{array}$ & $\begin{array}{l}\text { HOS- } \\
\text { WATE } \\
(\text { HOL) } \\
(M G / L)\end{array}$ & $\begin{array}{l}\text { TOTAL } \\
\text { F ILI- } \\
\text { RAHL } \\
\text { RESIUUE } \\
\text { (MG/L) }\end{array}$ & $\begin{array}{l}\text { TOTAL } \\
\text { WON- } \\
\text { FILT- } \\
\text { RABLE } \\
\text { RESIDUE. } \\
\text { (MG/L) }\end{array}$ & $\begin{array}{l}\text { HAPC)- } \\
\text { NESS } \\
(C A, M G) \\
(M G / L)\end{array}$ & $\begin{array}{l}\text { SPECI- } \\
\text { FIC } \\
\text { COND- } \\
\text { UCTANCE } \\
\text { (MICRO- } \\
\text { MHOSI }\end{array}$ & $\begin{array}{l}\text { COLOR } \\
\text { (PLAT- } \\
\text { INUM- } \\
\text { COEALT } \\
\text { UNITS) }\end{array}$ & $\begin{array}{l}\text { TUR- } \\
\text { BID- } \\
\text { ITY } \\
\text { (JTU) }\end{array}$ & $\begin{array}{l}\text { BIO- } \\
\text { CHEM- } \\
\text { ICAL } \\
\text { OXYGEN } \\
\text { DEMAND } \\
\text { (MG/L) }\end{array}$ & $\begin{array}{l}\text { FECAL } \\
\text { COLI- } \\
\text { FORM } \\
\text { (COL. } \\
\text { PER } \\
\text { 100 ML) } \\
\text { (MPN) }\end{array}$ \\
\hline ruve. & & & & & & & & & & \\
\hline $\begin{array}{l}11 . . . \\
M \Delta K .\end{array}$ & .0 & .22 & 23 & 1 & 5 & 21 & 10 & 7.0 & .6 & 430 \\
\hline UAY & .0 & .05 & ל3 & 10 & 4 & 25 & 20 & 9.0 & $\cdot 5$ & 2300 \\
\hline ste... & .? & .04 & is & 21 & 7 & 21 & 25 & 20 & 1.1 & 930 \\
\hline $01 \ldots$ & .2 & .08 & 38 & 19 & 7 & 26 & 25 & 11 & .5 & 7500 \\
\hline
\end{tabular}

LOCATION.--Lat $33^{\circ} 49^{\prime} 10^{\prime \prime}$, long $84^{\circ} 24^{\prime} 28^{\prime \prime}$, Fulton County, at gaging station on downstream side of bridge on Northside Drive at Atlanta, 0.4 mile downstream from Tanyard Branch and 4 miles upstream from mouth.

DRAINAGE AREA. $--86.8 \mathrm{sq} \mathrm{mi}$.

PERIOD OF RECORD..-Chemical analyses: November 1969 to September 1970 (partial record).

REMARKS,--Laboratory chemical analyses by Georgia Water Quality Control Board. Field determination of discharge, water temperature, $\mathrm{pH}$, and dissoloved oxygen by U.S. Geological Survey.

CHEMICAL AINALYSES. WATER YEAK UCTOBER 1969 TO SEPTEMBER 1970

\begin{tabular}{|c|c|c|c|c|c|}
\hline OATE & TINE & $\begin{array}{l}\text { OIS- } \\
\text { CHARGE } \\
\text { (CFS) }\end{array}$ & $\begin{array}{c}\text { PH } \\
\text { (UNITS) }\end{array}$ & $\begin{array}{l}\text { TEMP- } \\
\text { ENATURE } \\
\text { (DEG C) }\end{array}$ & $\begin{array}{l}\text { DIS- } \\
\text { SOLVED } \\
\text { OXYGFV } \\
\text { (MG/L) }\end{array}$ \\
\hline $\begin{array}{c}\text { Nov. } \\
12 . .\end{array}$ & $n y 0 n$ & 421 & 0.7 & 14.0 & 7.8 \\
\hline $22 \ldots$ & 1350 & Ge & 7.2 & 4.0 & 11.0 \\
\hline MAK... & 1600 & 178 & 6.6 & 5.0 & 11.1 \\
\hline $\begin{array}{c}16 \ldots . . \\
\triangle A P R .\end{array}$ & 1010 & 38 & 6.3 & 7.0 & 12.0 \\
\hline$\underset{\text { JUNE }}{29 . \ldots}$ & U & 74 & 6.3 & 20.13 & 4.2 \\
\hline 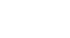 & 1130 & $5 b$ & 6.3 & 21.0 & 6.7 \\
\hline $\begin{array}{c}20 . . . \\
\text { AUG. }\end{array}$ & 1300 & 29 & 6.9 & 19.0 & 6.9 \\
\hline $31 \ldots$ & $143 n$ & 25 & 7.3 & 29.0 & 6.5 \\
\hline
\end{tabular}




\section{APALACHICOLA RIVER BASIN}

02336300 PEACHTREE CREEK AT ATLANTA, GA.---Continued

CHEMICAL ANALYSES, WATER YEAR OCTOBER 1969 TO SEPTEMBER 1970

\begin{tabular}{|c|c|c|c|c|c|c|c|c|c|c|}
\hline DATE & $\begin{array}{l}\text { SILICA } \\
\text { (SIOC) } \\
\text { (MU/L) }\end{array}$ & $\begin{array}{l}\text { TOTAL } \\
\text { IHON } \\
\text { (FE) } \\
\text { (JIJCL) }\end{array}$ & $\begin{array}{l}\text { TUTAL } \\
\text { MAN- } \\
\text { GANE } \triangle E E \\
\text { (MIN) } \\
(U G / L)\end{array}$ & $\begin{array}{c}\text { HIS- } \\
\text { SOLVEU } \\
\text { CAL- } \\
\text { C1UM } \\
\text { (CA) } \\
(M G / L)\end{array}$ & $\begin{array}{l}\text { WIS- } \\
\text { SOLVED } \\
\text { MAG- } \\
\text { NE- } \\
\text { SIUM } \\
\text { (MG) } \\
\text { (MGLL) }\end{array}$ & $\begin{array}{l}\text { SORJUM } \\
\text { (NA) } \\
\text { (WG/L) }\end{array}$ & $\begin{array}{l}\text { PO- } \\
\text { TAS- } \\
\text { SIUM } \\
\text { (K) } \\
\text { (MG/L) }\end{array}$ & $\begin{array}{l}\text { ALKA- } \\
\text { LINITY } \\
\text { AS } \\
\text { CACO3 } \\
\text { (MG } L \text { ) }\end{array}$ & $\begin{array}{l}\text { SULFATE } \\
\text { (SO4) } \\
\text { (MG/L) }\end{array}$ & $\begin{array}{l}\text { CHLO- } \\
\text { RIDE } \\
(\mathrm{CL}) \\
(M G / L)\end{array}$ \\
\hline wov. & $9 . \mathrm{M}$ & $\sin 0$ & 180 & in & $1 . H$ & 3.4 & 3.9 & 24 & R. 0 & 4.7 \\
\hline $\begin{array}{l}\text { DEC. } \\
\text { C2... } \\
\text { REb. }\end{array}$ & 10) & 42010 & so & 4.4 & 1.8 & 4.0 & 3.0 & 21 & $9 \cdot n$ & 5.0 \\
\hline & -- & 4501 & प:0 & 9.2 & 1.9 & 3.6 & 3.0 & 19 & 8.0 & $4 \cdot 2$ \\
\hline 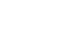 & 14 & 610 & $1<0$ & 13 & 2.8 & 7.9 & 2.1 & 43 & 8.0 & 7.0 \\
\hline$\underset{\text { JuNe }}{24 \ldots}$ & 17 & 1400 & 111 & 15 & 2.5 & 11 & 3.5 & 60 & 12 & 9.2 \\
\hline JuL & 15 & 1200 & 160 & is & 2.8 & 7.5 & 2.8 & 45 & 11 & 6.5 \\
\hline $\begin{array}{c}20 \ldots . \cdots \\
\text { AUG. }\end{array}$ & 13 & $1 M 50$ & חלב & 13 & 2.4 & 7.0 & 3.6 & 38 & 9.0 & 14 \\
\hline $31 \ldots$ & 10 & 670 & 120 & 15 & 2.8 & 10 & 3.9 & 57 & 12 & 8.7 \\
\hline DATE & $\begin{array}{c}\text { JIRATR } \\
(N) \\
\text { (MG/L) }\end{array}$ & $\begin{array}{l}\text { PHUS- } \\
\text { PHATE } \\
\text { (PO4) } \\
\text { (MUCL) }\end{array}$ & $\begin{array}{l}\text { POTAL } \\
\text { FILT- } \\
\text { RABLE } \\
\text { RESILUE } \\
\text { (MG L) }\end{array}$ & $\begin{array}{l}\text { TOTAL } \\
\text { NON- } \\
\text { FILT- } \\
\text { HAGLE } \\
\text { RFSIJUE } \\
\text { (MG/L) }\end{array}$ & $\begin{array}{l}\text { HARO- } \\
\text { NESS } \\
\text { (CA,MG) } \\
(M G / L)\end{array}$ & $\begin{array}{l}\text { SPECI- } \\
\text { FIC } \\
\text { COND- } \\
\text { UCTAHCE } \\
\text { (MICHO- } \\
\text { MHOS) }\end{array}$ & $\begin{array}{l}\text { COLOR } \\
\text { (PLAT- } \\
\text { INUM- } \\
\text { COBALT } \\
\text { UNITS) }\end{array}$ & $\begin{array}{l}\text { TUR- } \\
\text { BID- } \\
\text { ITY } \\
\text { (JTU) }\end{array}$ & $\begin{array}{l}\text { BIO- } \\
\text { CHEM- } \\
\text { 1CAL } \\
\text { OXYGEN } \\
\text { DEMAND } \\
\text { (MG/L) }\end{array}$ & $\begin{array}{c}\text { FECAL } \\
\text { COLI- } \\
\text { FORM } \\
\text { (COL. } \\
\text { PER } \\
100 \mathrm{ML}) \\
\text { (MPN) }\end{array}$ \\
\hline $\begin{array}{l}\text { Nov. } \\
\text { De... } \\
\text { DEC. }\end{array}$ & .3 & .05 & 82 & 274 & 31 & 91 & 70 & 100 & -- & 7500 \\
\hline $\begin{array}{l}2 c \ldots . . \\
+\in B .\end{array}$ & .2 & .35 & 102 & 90 & 24 & 96 & 90 & $10 n$ & 3.8 & 15000 \\
\hline $\begin{array}{l}\text { U3... } \\
\text { MAH. }\end{array}$ &.$<$ & כי. & 70 & 361 & 26 & 90 & 30 & 350 & 3.6 & 15000 \\
\hline ב... & $\cdot b$ & .52 & 81 & 1 & 39 & 143 & 10 & 9.1 & 4.5 & 43000 \\
\hline JUNiE & $\cdot c$ & 2.5 & 124 & 44 & 45 & 175 & 20 & 24 & $\cdots$ & 4600000 \\
\hline 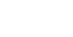 & .6 & .22 & 94 & 74 & 46 & 135 & 30 & $2 ?$ & 1.3 & 3900 \\
\hline $\begin{array}{l}20 . . . \\
\text { AUG. }\end{array}$ & $\cdot 3$ & .28 & $y y$ & 4 & 40 & 125 & 25 & 45 & 2.6 & 230000 \\
\hline $31 \ldots$ & - b & .60 & 110 & 20 & 51 & 150 & 20 & 9.0 & 1.6 & 4300 \\
\hline
\end{tabular}

02337000 SWEETWATER CREEK NEAR AUSTELL, GA.

LOCATION. --Lat $33^{\circ} 46^{\prime} 22^{\prime \prime}$, long $84^{\circ} 36^{\prime} 53^{\prime \prime}$, Douglas County, at gaging station on right bank 100 ft upstream from bridge on Interstate Highway 20 ( $400 \mathrm{ft}$ upstream from Blair Bridge), 3 miles southeast of Austell, and 5.5 miles upstream from mouth.

DRAINAGE AREA, - - $246 \mathrm{sq} \mathrm{mi}$.

PERIOD OF RECORD.--Chemical analyses: February 1968 to September 1970 (partial record).

REMARKS.--Laboratory chemical analyses by Georgia Water Quality Control Board. Field determination of discharge, water temperature, $\mathrm{pH}$, and dissolved oxygen by $\mathrm{O} . \mathrm{S}$. Geological Survey.

CHFMICAL AINALYSES, WATER YEAK OCTOBEH 1969 TO SEPTEMBEN 1970

\begin{tabular}{|c|c|c|c|c|c|}
\hline UATE & TIMF & $\begin{array}{l}\text { DIS- } \\
\text { CHAPGE } \\
\text { (CF S) }\end{array}$ & $\begin{array}{c}\text { PH } \\
\text { (UNITS) }\end{array}$ & $\begin{array}{l}\text { TEMF- } \\
\text { FHATURF } \\
\text { (DEG C) }\end{array}$ & $\begin{array}{l}\text { D1S- } \\
\text { SOL VE) } \\
\text { OXYGFN } \\
\text { (MGLL) }\end{array}$ \\
\hline $\begin{array}{l}\text { OCT. } \\
15 \ldots .\end{array}$ & 1030 & 56 & 0.7 & $16 . n$ & 7.1 \\
\hline $\begin{array}{l}\text { NITV. } \\
\text { Il... } \\
\text { DEC. }\end{array}$ & 1730 & $9 b$ & 6.6 & 11.0 & 8.7 \\
\hline $\begin{array}{l}\text { Pट... } \\
F \in M .\end{array}$ & 1145 & 305 & 6.4 & 4.0 & 12.0 \\
\hline $\begin{array}{l}\text { FEK. } \\
\text { Ma3... } \\
\text { MAK. }\end{array}$ & 1400 & 349 & 6.7 & 6.0 & 11.7 \\
\hline $16 \ldots$ & 1132 & 110 & 6.3 & 8. & 11.0 \\
\hline$\underset{\text { Jink }}{\text { ca.... }}$ & 1345 & 534 & 6.3 & $2 n .0$ & $8 . ?$ \\
\hline $\operatorname{JuL}_{Y} \cdots$ & -- & 210 & 5.8 & 21.0 & 5.1 \\
\hline $\begin{array}{c}20 \ldots . . \\
\text { Au }\end{array}$ & $142 \hbar$ & 34 & 7.? & $22 . n$ & 5.8 \\
\hline $31 \ldots$ & b15 & 49 & 7.1 & 25.0 & 4.8 \\
\hline
\end{tabular}


APALACEICOLA RIVER BASIN

02337000 SWEETWATER CREEK NEAR AUSTELL, GA.--Cont I nued

CHEMICAL ANALYSES, WATER YEAR DCTOBER 1969 TO SEPTEMBER 1970

\begin{tabular}{|c|c|c|c|c|c|c|c|c|c|c|}
\hline DATE & $\begin{array}{l}\text { SILICA } \\
\text { (SIOZ) } \\
(M G / L)\end{array}$ & $\begin{array}{l}\text { TOTAL } \\
\text { IRON } \\
\text { (FE) } \\
\text { (UG/L) }\end{array}$ & $\begin{array}{l}\text { TOTAL } \\
\text { MAN- } \\
\text { GANESE } \\
\text { (MN) } \\
\text { (UG/L) }\end{array}$ & $\begin{array}{l}\text { OIS- } \\
\text { SOLVED } \\
\text { CAL- } \\
\text { CIUM } \\
\text { (CA) } \\
\text { (MG/L) }\end{array}$ & $\begin{array}{l}\text { DIS- } \\
\text { SOLVED } \\
\text { MAG- } \\
\text { NE- } \\
\text { SIUM } \\
\text { (MG) } \\
\text { (MG/L) }\end{array}$ & $\begin{array}{l}\text { SODIUM } \\
\text { (NA) } \\
(M G / L)\end{array}$ & $\begin{array}{l}\text { PO- } \\
\text { TAS- } \\
\text { SIUM } \\
\text { (K) } \\
(M G / L)\end{array}$ & $\begin{array}{l}\text { ALKA- } \\
\text { LINITY } \\
\text { AS } \\
\text { CACO3 } \\
\text { (MG/L) }\end{array}$ & $\begin{array}{l}\text { SULFATE } \\
\text { (SO4) } \\
\text { (MG/L) }\end{array}$ & $\begin{array}{l}\text { CHLO- } \\
\text { RIOE } \\
\text { (CL) } \\
\text { (MG/L) }\end{array}$ \\
\hline $\begin{array}{l}\text { OCT. } \\
15 . . \\
\text { Nov. }\end{array}$ & 18 & 1200 & 80 & 6.2 & 2.2 & 7.4 & 1.9 & 30 & 5.0 & 6.2 \\
\hline IJEC. & 16 & 1000 & 50 & 5.4 & 2.0 & 6.4 & 1.7 & 25 & 6.0 & 5.5 \\
\hline $\begin{array}{c}22 . . . \\
F E \theta .\end{array}$ & 14 & $200 n$ & 50 & 5.3 & 1.8 & 5.0 & 1.6 & 21 & 6.0 & 5.0 \\
\hline $\begin{array}{l}03 . . . \\
\text { MAK. }\end{array}$ & 12 & 1600 & 100 & 4.7 & 1.8 & 4.8 & 1.2 & 19 & 9.0 & 4.4 \\
\hline $\begin{array}{l}16 . . \\
\triangle P R .\end{array}$ & 16 & 940 & 220 & 5.0 & 1.7 & 5.9 & .9 & 22 & 5.0 & 4.9 \\
\hline JIJNE & 14 & 2500 & $<50$ & 4.4 & 1.5 & 3.6 & 1.3 & 21 & 5.0 & 3.0 \\
\hline JuL ${ }^{09} .$. & 13 & 1100 & $<50$ & 5.4 & 1.7 & 5.0 & 1.4 & 20 & 7.0 & 3.7 \\
\hline $\begin{array}{l}20 . . . \\
\text { AUG. }\end{array}$ & 16 & 450 & 80 & 6.3 & 2.1 & 8.1 & 2.0 & 26 & 9.0 & 13 \\
\hline $31 \ldots$ & $\begin{array}{c}\text { NITRATH } \\
\text { (N) } \\
(M G / L)\end{array}$ & $\begin{array}{l}\text { PHOS- } \\
\text { PHATE } \\
\text { (PO) } 4) \\
\text { (MG/L) }\end{array}$ & $\begin{array}{c}120 \\
\text { TOTAL } \\
\text { FILT- } \\
\text { RABLE } \\
\text { RESIDUE } \\
\text { (MG } / L)\end{array}$ & $\begin{array}{c}6.6 \\
\text { TOTAL } \\
\text { NON- } \\
\text { FILT- } \\
\text { RABLE } \\
\text { RES1DUE } \\
\text { (MG } / \text { ) }\end{array}$ & $\begin{array}{l}\text { HARD- } \\
\text { NESS } \\
\text { (CA,MG) } \\
(M G / L)\end{array}$ & $\begin{array}{l}9.0 \\
\text { SPECI- } \\
\text { FIC } \\
\text { COND- } \\
\text { UCTANCE } \\
\text { (MICRO- } \\
\text { MHOS) }\end{array}$ & $\begin{array}{l}\text { COLOR } \\
\text { (PLAT- } \\
\text { INUM- } \\
\text { COBALT } \\
\text { UN1TS) }\end{array}$ & $\begin{array}{l}\text { IUR- } \\
\text { BID- } \\
\text { ITY } \\
\text { (JTU) }\end{array}$ & $\begin{array}{c}8.0 \\
\text { BIO- } \\
\text { CHEM- } \\
\text { ICAL } \\
\text { OXYGEN } \\
\text { DEMAND } \\
\text { (MG/L) }\end{array}$ & $\begin{array}{c}6,2 \\
\text { FECAL } \\
\text { COLI- } \\
\text { FORM } \\
\text { (COL. } \\
\text { PER } \\
100 \mathrm{ML} \text { ) } \\
\text { (MPN) }\end{array}$ \\
\hline $\begin{array}{l}\text { OCT. } \\
15 \ldots \\
\text { NOV. }\end{array}$ & .3 & .80 & 105 & 6 & 22 & 93 & 30 & 14 & 2.4 & 39000 \\
\hline DEC.”. & .3 & .68 & 78 & 4 & 21 & 90 & 45 & .11 & 2.4 & 4300 \\
\hline $\begin{array}{c}22 \ldots \\
\text { FEB. }\end{array}$ & $\cdot 2$ & .38 & 70 & 30 & 19 & 72 & 50 & 45 & 3.1 & 23000 \\
\hline MAR:. & .3 & .38 & 67 & 28 & 18 & 80 & 30 & 32 & 1.8 & 430 \\
\hline $\begin{array}{l}16 . . \\
A P R .\end{array}$ & -4 & $\cdot 32$ & 46 & 1 & 19 & 88 & 25 & 9.0 & 2.1 & 73 \\
\hline $\begin{array}{l}28 \ldots \\
\text { JUNE }\end{array}$ & $\cdot 1$ & $\cdot 30$ & 56 & 29 & 15 & 62 & 90 & 30 & $2 \cdot 4$ & 430 \\
\hline${ }_{\text {JuL }}^{09}$. & .4 & .22 & 79 & 22 & 21 & 68 & 40 & 20 & 1.8 & 1500 \\
\hline AUG... & $\cdot 3$ & .75 & 91 & 8 & 22 & 97 & 25 & 11 & 3.2 & 15000 \\
\hline $31 \ldots$ & .4 & .70 & 79 & 15 & 27 & 96 & 40 & 9.0 & 2.9 & 930 \\
\hline
\end{tabular}

02337170 CHATTAHOOCHEE RI VER NEAR FAIRBURN, GA.

LOCATION.--Lat $33^{\circ} 39^{\prime} 24^{\prime \prime}$, long $84^{\circ} 40^{\prime} 25^{\prime \prime}$, Fulton County, at gaging station at dowstream end of pier of bridge on State Highways 74 and $92,1.4$ miles downstream from Deep Creek, 8.5 miles northwest of Fairburn, and at mile 281,8 .

DRAINAGE AREA.--2,060 sq $\mathrm{mi}$.

PERIOD OF RECORD.--Chemical analyses: February 1968 to September 1970 (partial record).

REMARKS. - Laboratory chemical analyses by Georgia water quality Control Board. Field determination of discharge, water temperature, $\mathrm{pH}$, and dissolved oxygen by U.S. Geological Survey.

CHEMICAL ANALYSES, WATER YEAR OCTOBER 1969 TO SEPTEMBER 1970

\begin{tabular}{|c|c|c|c|c|c|}
\hline DATE & TIME & $\begin{array}{l}\text { DIS- } \\
\text { CHARGE } \\
\text { (CFS) }\end{array}$ & $\begin{array}{c}\text { PH } \\
\text { (UNITS) }\end{array}$ & $\begin{array}{l}\text { TEMP- } \\
\text { ERATURE } \\
\text { (DEG C) }\end{array}$ & $\begin{array}{l}\text { DIS- } \\
\text { SOLVED } \\
\text { OXYGEN } \\
\text { (MG/L) }\end{array}$ \\
\hline $\begin{array}{l}\text { OCT. } \\
\text { 15:.. } \\
\text { NOV. }\end{array}$ & 1145 & 1350 & 6.8 & 23.0 & 1.0 \\
\hline DEC... & 1700 & 5970 & 6.3 & 12.0 & 7.8 \\
\hline & 1015 & 2120 & 6.2 & 8.0 & 6.9 \\
\hline MAR.". & 1330 & 2530 & 6.3 & 9.0 & 7.6 \\
\hline $\begin{array}{l}16 \ldots . . \\
A H R .\end{array}$ & 1340 & 1240 & 6.2 & 12.0 & 4.6 \\
\hline$\underset{\text { JUNE }}{28 . .}$ & 1445 & 2180 & 6.0 & 22.0 & 2.4 \\
\hline JuLY.". & 1330 & 3160 & 5.9 & -- & 2.7 \\
\hline $\begin{array}{l}20 . . . \\
\text { Aug. }\end{array}$ & 2015 & 1100 & 6.5 & 23.0 & .7 \\
\hline $31 \ldots$ & 1630 & 1110 & 6.8 & 28.0 & .6 \\
\hline
\end{tabular}


APALACHICOLA RIVBR BASIN

02337170 CHATTAHOOCHEE RIVER NEAR FAIRBURN, GA.--Cont1 nued

CHEMICAL ANALYSES, WATER YEAR DCTOBER 1969 TO SEPTEMBER 1970

\begin{tabular}{|c|c|c|c|c|c|c|c|c|c|c|}
\hline UATE & $\begin{array}{l}\text { SILICA } \\
\text { (SIOC) } \\
\text { (MG/L) }\end{array}$ & $\begin{array}{l}\text { TOTAL } \\
\text { IKON } \\
\text { (FE) } \\
\text { (UG/L) }\end{array}$ & $\begin{array}{l}\text { TOTAL } \\
\text { MAN- } \\
\text { GANESE } \\
\text { (MN) } \\
\text { (UG/L) }\end{array}$ & $\begin{array}{l}\text { DIS- } \\
\text { SOLVEO } \\
\text { CAL- } \\
\text { CIUM } \\
\text { (CA) } \\
(M G / L)\end{array}$ & $\begin{array}{l}\text { OIS- } \\
\text { SOLVED } \\
\text { MAG- } \\
\text { NE- } \\
\text { SIUM } \\
\text { (MG) } \\
\text { (MG/L) }\end{array}$ & $\begin{array}{l}\text { SOOIUM } \\
\text { (NA) } \\
(M G / L)\end{array}$ & $\begin{array}{l}P O- \\
\text { TAS- } \\
\text { SIUM } \\
\text { (K) } \\
(M G / L)\end{array}$ & $\begin{array}{l}\text { ALKA= } \\
\text { LINITY } \\
\text { AS } \\
\text { CACO3 } \\
\text { (MG } M \text { L })\end{array}$ & $\begin{array}{l}\text { SULFATE } \\
(\mathrm{SO} 4) \\
(\mathrm{MG} / \mathrm{L})\end{array}$ & $\begin{array}{l}\text { CHLO- } \\
\text { RIDE } \\
(C L) \\
(M G / L)\end{array}$ \\
\hline $\begin{array}{l}\text { OCr. } \\
\text { IS... }\end{array}$ & 12 & 2000 & 350 & 5.8 & 1.3 & 10 & 2.6 & 28 & 9.0 & 8.8 \\
\hline $\begin{array}{l}\text { NOV. } \\
\text { I1... } \\
\text { UEC. }\end{array}$ & 7.5 & 1400 & 50 & 3.0 & 1.0 & 2.8 & 1.3 & 15 & 3.0 & 2.5 \\
\hline $\begin{array}{c}22 . . . \\
\text { FE } 8 .\end{array}$ & 8.2 & 1800 & $<50$ & 7.5 & 1.6 & 5.4 & 2.1 & 22 & 8.0 & 5.0 \\
\hline MA3... & 7.5 & 1000 & $<50$ & 5,3 & I. 5 & 7.2 & 2.2 & 24 & 11 & 5.0 \\
\hline $\begin{array}{l}16 \ldots . . . \\
\text { APR. }\end{array}$ & Y. 11 & 400 & $<50$ & 5.4 & 1.4 & 7.2 & 1.9 & 25 & 6.0 & 6.3 \\
\hline JUNE & 11 & 1400 & 50 & 5.2 & 1.4 & 6.4 & 2.1 & 32 & 8.0 & 6.0 \\
\hline$\underset{\text { juL }}{04 . .}$ & $\pi .0$ & 1200 & 50 & 5.2 & 1.3 & 8.0 & 2.3 & 24 & 8.0 & 5.4 \\
\hline AUG... & 8.1 & $4 n 0$ & 90 & 6.0 & 1.4 & 9.2 & 2.6 & 27 & 11 & 12 \\
\hline $31 \ldots$ & 7.5 & 470 & on & $4 \cdot 4$ & 1.3 & 8.7 & 2.5 & 25 & 9.0 & 5.9 \\
\hline DATE & $\begin{array}{l}\text { NITKATE } \\
\text { (IU) } \\
\text { (MULL) }\end{array}$ & $\begin{array}{l}\text { PHOS- } \\
\text { PHATE } \\
(\text { PU4) } \\
(H(3 / L)\end{array}$ & $\begin{array}{l}\text { TUTAL } \\
\text { FILT- } \\
\text { HABLE } \\
\text { RESIDUE } \\
\text { (MG/L) }\end{array}$ & $\begin{array}{l}\text { TOTAL } \\
\text { NON- } \\
\text { FILT- } \\
\text { RABLE } \\
\text { RESIDUE } \\
\text { (MG/L) }\end{array}$ & $\begin{array}{l}\text { HARD- } \\
\text { NESS } \\
(C A, M G) \\
(M G / L)\end{array}$ & $\begin{array}{l}\text { SPECI- } \\
\text { FIC } \\
\text { CONO- } \\
\text { UCIANCE } \\
\text { (MICRO- } \\
\text { MHOS) }\end{array}$ & $\begin{array}{l}\text { COLOR } \\
\text { (PLAT- } \\
\text { INUM- } \\
\text { COBALT } \\
\text { UNITS) }\end{array}$ & $\begin{array}{l}\text { TUR- } \\
\text { BID- } \\
\text { ITY } \\
\text { (JTU) }\end{array}$ & $\begin{array}{l}\text { BIO- } \\
\text { CHEM- } \\
\text { ICAL } \\
\text { OXYGEN } \\
\text { DEMAND } \\
\text { (MG/L) }\end{array}$ & $\begin{array}{c}\text { FECAL } \\
\text { COLI- } \\
\text { FORM } \\
\text { (COL. } \\
\text { PER } \\
\text { IOO ML) } \\
\text { (MPN) }\end{array}$ \\
\hline OCT. & .1 & 2.4 & 93 & 32 & 18 & 112 & 25 & 26 & 6.0 & 4600000 \\
\hline $\begin{array}{l}\text { NOV. } \\
11 . . . \\
\text { DEC. }\end{array}$ & .3 & .92 & 36 & 39 & 11 & 44 & 20 & 39 & 4.6 & 93000 \\
\hline $\begin{array}{l}22 . . \\
\text { FEB. }\end{array}$ & - $c$ & 1.4 & bs & 64 & 20 & 85 & 45 & 58 & $=$ & 290000 \\
\hline MAK... & .2 & .25 & 77 & 155 & 17 & 95 & 40 & 60 & -- & 150000 \\
\hline $\begin{array}{l}\text { If... } \\
\text { APR. }\end{array}$ & .2 & 1.4 & 55 & 11 & 18 & 100 & 20 & 15 & $\cdots$ & 43000 \\
\hline$\underset{\text { JUNE }}{28 . .}$ & $\cdot 2$ & 1.5 & 70 & 25 & 18 & 92 & 60 & 30 & 4.9 & 230000 \\
\hline 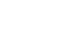 & .3 & 1.3 & 71 & 42 & 18 & B6 & 30 & 28 & 4.0 & 230000 \\
\hline 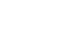 & .2 & 2.0 & 88 & 22 & 19 & 105 & 25 & 19 & 4.4 & 750000 \\
\hline $31 \ldots$ & .1 & .98 & 60 & 22 & 18 & 90 & 20 & 8.0 & 3.7 & 75000 \\
\hline
\end{tabular}

LOCATION.--Lat $33^{\circ} 28^{\prime} 37^{\prime \prime}$, long $84^{\circ} 54^{\prime} 04^{\prime \prime}$, Carroll County, at gaging station at downstream end of right bank pier of bridge on State Highway $16,0.5$ mile upstream from Central of Georgia Railroad bridge, 1.2 miles southeast of Whi tesburg, 1.5 miles downstream from Cedar Creek, 2.0 miles downstream from Snake Creek, and at mile 260 .

DRAI NAGE AREA. --2,430 sq mi, approximately.

PERIOD OF RECORD.--Chemical analyses: Pebruary 1968 to September 1970 (partial record).

REMARKS. - Laboratory chemical analyses by Georgia Fater Quality Control Board. Field determination of discharge, water temperature, $\mathrm{pH}$, and dissolved oxygen by U.S. Geological Survey. CMEMICAL ANALYSES, WATER YEAR OCTOBER 1969 TO SEPIEMBER 1970

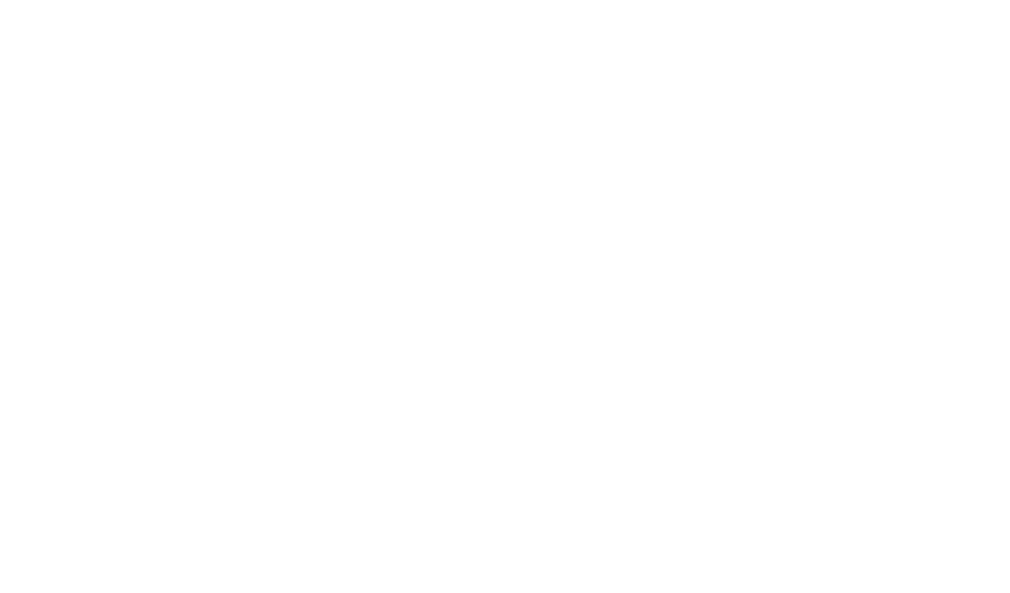


APALACHICOLA RIVER BASIN

02338000 CHATTAHOOCHEE RIVER NEAR WHITESBURG, GA.--Cont1 nued

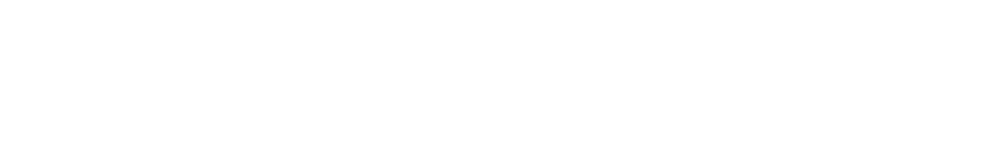

VCT.

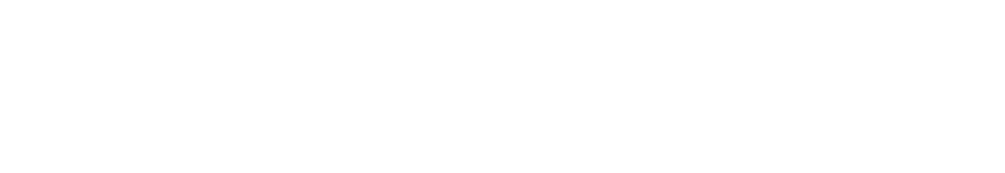

02339500 CHATTAHOOCHEE RIVER AT WEST POINT, GA.

LOCATION, - Lat $32^{\circ} 53^{\prime} 10^{\prime \prime}$, long $85^{\circ} 10^{\prime} 56^{\prime \prime}$, Troup County, at gaglng station on right bank just downstream from Osellgee Creek at West Point, 1 m1 le upstream from bridge on U.S. Highway 29, and at m1le 198.9 .

DRAINAGE AREA, $--3,550 \mathrm{sq} \mathrm{m} 1$, approximately.

PERIOD OF RECORD.--Chemical analyses: February 1968 to September 1970 (part1al record).

REXARKS. - - Laboratory chemical analyses by Georg1a Water Quality Control Board. F1eld determination of discharge, water temperature, $\mathrm{pH}$, and dissolved oxygen by $\mathrm{U}_{\mathbf{S}} \mathrm{S}$. Geological Survey.

CHEMICAL ANALYSES, WATER YEAR OCTOBER 1960 TO SEPTEMBER 1970

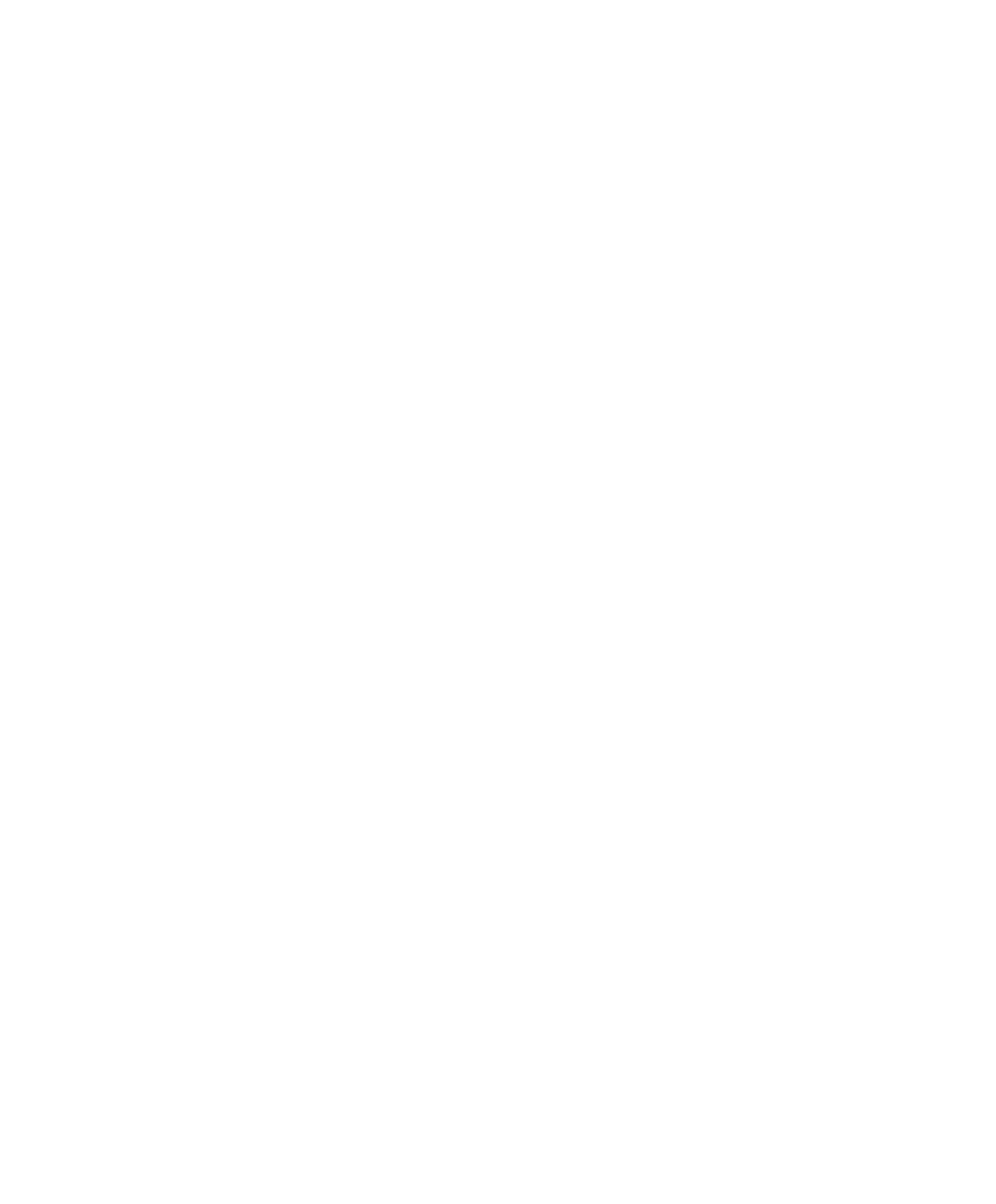




\section{APALACHICOLA RI VER BASIN}

02341500 CHATTAHOOCHEE RIVER AT COLULBUS, GA.

LOCATION, --Lat $32^{\circ} 27^{\circ} 45^{\prime \prime}$, long $84^{\circ} 59^{\circ} 52^{\prime \prime}$, Muscogee County, at gaging station on downstream side of center pier of Central of Georgia Rálway bridge at Columbus, 0.5 mile downstream from Eagle and Phenix Dam, $1.2 \mathrm{miles}$ down. stream from C1ty mills Dam, 2.6 miles downstream from North Highlands Dam, 3.3 miles downstream from oliver Dam,
17.5 miles downstream from Bartletts Ferry Dam, and at mile 159.9.

DRAI NAGE AREA. - - 4,670 sq mi, approximately.

PERIOD OF RECORD.--Chemical analyses: February 1968 to September 1970 (partial record).

REMARKS.--Laboratory chemical analyses by Georgia Water Quality Control Board. Field determination of discharge, water temperature, pH, and dissolved oxygen by U.S. Geological Survey.

CHEMICAL ANALYSES, WAFR YEAR OCTOBER 1969 TO SEPTEMBER 1970

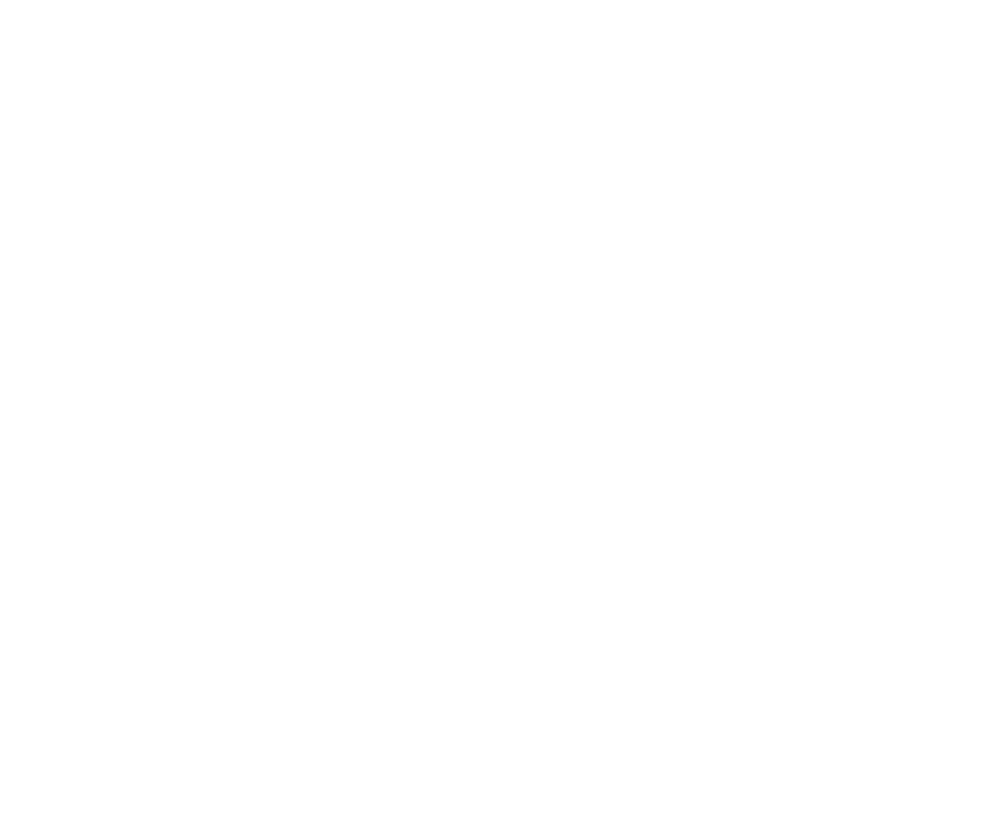

02344000 Chattahoochee RIVER AT ALAGa, ala.

LOCATION, --Lat $31^{\circ} 06^{\prime} 54^{\prime \prime}$, long $85^{\circ} 02^{\prime} 43^{\prime \prime}$, Ear1y County, Ga., at gaging station near right bank on downstream end of pier of bridge on U.S. Highway $84,0,5$ mile downstream from Seaboard Coast Line Railroad bridge, 0.5 mile south DRAI NAGE AREA. - - 8,340 sq mi, approximately.

PERIOD OF RECORD.--Chemical analyses: February 1968 to September 1970 (part1al record). REMARKS. -. Laboratory chemical analyses by Georgia Water Quality control Board. Field determination of discharge,
water temperature, $\mathrm{pH}$, and dissolved oxygen bv U.S. Geological Survey.

CHEMICAL ANALYSES, WATER YEAK OCTOBER 1959 TO SEPTEMBER 1970

\begin{tabular}{|c|c|c|c|c|c|}
\hline DATE & IIMF & $\begin{array}{l}\text { 'HS- } \\
\text { CHARGE } \\
\text { (CFS) }\end{array}$ & $\begin{array}{c}\text { PH } \\
\text { (UNITS) }\end{array}$ & $\begin{array}{l}\text { TEMP- } \\
\text { ERATURE } \\
\text { (DEG C) }\end{array}$ & $\begin{array}{l}\text { OIS- } \\
\text { SOLVEU } \\
\text { OXYGEN } \\
\text { (MG/L) }\end{array}$ \\
\hline $\begin{array}{l}\text { UCT. } \\
20 . .\end{array}$ & 1345 & 9530 & -- & 23.0 & - \\
\hline $\begin{array}{l}\text { FEH. } \\
\text { UC... } \\
\text { MAR. }\end{array}$ & 1345 & 11400 & 7.3 & 10.0 & 11.7 \\
\hline $16 \ldots$ & 1020 & 9900 & 7.2 & 13.0 & 11.0 \\
\hline $\mathrm{JULY}_{\mathrm{J}}^{04 \ldots}$ & 1415 & 7060 & 7.0 & 20.0 & 8.1 \\
\hline $\begin{array}{r}07 . . \\
\text { 4116. }\end{array}$ & OHOS & 5220 & 7.2 & 27.0 & 8.0 \\
\hline $03 \ldots$ & 1430 & 7490 & 7.6 & 30.0 & 7.2 \\
\hline
\end{tabular}


APALACHICOLA RIVER BASIN

02344000 CHATTAHOOCHEE RIVER AT ALAGA, ALA.-Continued

CHEMICAL ANALYSES, WATER YEAR OCTOBER 1969 TO SEPTEMBER 1970

\begin{tabular}{|c|c|c|c|c|c|c|c|c|c|c|}
\hline DATE & $\begin{array}{l}\text { SILICA } \\
\text { (S1OZ) } \\
\text { (MG/L) }\end{array}$ & $\begin{array}{l}\text { TOTAL } \\
\text { IRON } \\
\text { (FE) } \\
(U G / L)\end{array}$ & $\begin{array}{l}\text { TOTAL } \\
\text { MAN- } \\
\text { GANESE } \\
\text { (MN) } \\
\text { (UG L ) }\end{array}$ & $\begin{array}{l}\text { DIS- } \\
\text { SOLVEO } \\
\text { CAL- } \\
\text { CIUM } \\
\text { (CA) } \\
\text { (MG/L) }\end{array}$ & $\begin{array}{l}\text { OIS- } \\
\text { SOLVED } \\
\text { MAG- } \\
\text { NE- } \\
\text { SIUM } \\
\text { (MG) } \\
\text { (MG/L) }\end{array}$ & $\begin{array}{l}\text { SODIUM } \\
\text { (NA) } \\
(M G / L)\end{array}$ & $\begin{array}{l}\text { PO- } \\
\text { TAS- } \\
\text { SIUM } \\
\text { (K) } \\
\text { (MG/L) }\end{array}$ & $\begin{array}{l}\text { ALKA- } \\
\text { LINIT } \\
\text { AS } \\
\text { CACO3 } \\
\text { (MG } / L)\end{array}$ & $\begin{array}{l}\text { SULFATE } \\
\text { (SO4) } \\
\text { (MG/L) }\end{array}$ & $\begin{array}{l}\text { CHLO- } \\
\text { RIDE } \\
\text { (CLL) } \\
(M G / L)\end{array}$ \\
\hline $\begin{array}{l}\text { OCT. } \\
20 . . . \\
\text { FËH. }\end{array}$ & 6.3 & 200 & $<50$ & 5.4 & 1.1 & 8.9 & 1.9 & 25 & 8.0 & 4.2 \\
\hline $\begin{array}{l}02 . . \\
\text { MAR. }\end{array}$ & 2.0 & 350 & $<50$ & 5.5 & 1.2 & 5.8 & 1.6 & 21 & 6.0 & 3.2 \\
\hline $\operatorname{MAY} \cdots$ & 4.5 & 360 & $<50$ & 6.3 & 1.1 & 6.0 & 1.3 & 23 & 8.0 & 4.5 \\
\hline JULY & 6.5 & 2200 & 50 & 5.0 & 1.0 & 4.1 & 1.6 & 17 & 6.0 & 3.0 \\
\hline $\begin{array}{l}07 \ldots \\
\text { AUG. }\end{array}$ & 5.0 & 500 & 60 & 7.0 & 1.4 & 7.8 & 1.9 & 31 & 8.0 & 3.8 \\
\hline $03 \ldots$ & $\begin{array}{l}\text { NITRATE } \\
\text { (N) } \\
\text { (MG/L) }\end{array}$ & $\begin{array}{l}\text { PHOS- } \\
\text { PHATE } \\
\text { (PO4) } \\
\text { (MG/L) }\end{array}$ & $\begin{array}{c}50 \\
\text { TOTAL- } \\
\text { FILT- } \\
\text { RABLE } \\
\text { RESIDUE } \\
\text { (MG LL) }\end{array}$ & $\begin{array}{r}7.5 \\
\text { TOTAL } \\
\text { NON- } \\
\text { FILT- } \\
\text { RABLE } \\
\text { RES IDUE } \\
\text { (MG/L) }\end{array}$ & $\begin{array}{l}\text { HARD- } \\
\text { NESS } \\
\text { (CA,MG) } \\
(M G / L)\end{array}$ & $\begin{array}{l}\text { SPECI- } \\
\text { FIC } \\
\text { COND- } \\
\text { UCTANCE } \\
\text { (MICRO- } \\
\text { MHOS) }\end{array}$ & $\begin{array}{l}\text { COLOR } \\
\text { (PLAT- } \\
\text { INUM- } \\
\text { COBALT } \\
\text { UNITS) }\end{array}$ & $\begin{array}{l}\text { TUR- } \\
\text { BID- } \\
\text { ITY } \\
\text { (JTU) }\end{array}$ & $\begin{array}{c}9.0 \\
\text { BIU- } \\
\text { CHEM- } \\
\text { ICAL } \\
\text { OXYGEN } \\
\text { DEMAND } \\
\text { (MG/L) }\end{array}$ & $\begin{array}{c}4.99 \\
\text { FECAL } \\
\text { COLI- } \\
\text { FORM } \\
\text { (COL. } \\
\text { PER } \\
\text { IOO ML) } \\
\text { (MPN) }\end{array}$ \\
\hline $\begin{array}{l}\mathrm{OCT} . \\
20 \ldots \\
\text { FEH. }\end{array}$ & .4 & .12 & 62 & 5 & 16 & 86 & 20 & 9.0 & 2.0 & 930 \\
\hline MAR:. & $\cdot 1$ & .25 & 48 & 23 & 18 & 68 & 20 & 18 & 2.6 & 4300 \\
\hline $16 \ldots$ & .2 & .15 & 56 & 8 & 19 & 83 & 30 & 9.0 & 2.8 & 36 \\
\hline $\operatorname{JUL}_{\mathrm{J}} 04 \ldots$ & .4 & .14 & 55 & 12 & 16 & 63 & 120 & 41 & 1.3 & 230 \\
\hline $\begin{array}{c}07 . . \\
\text { AUG. }\end{array}$ & .1 & .06 & 64 & 20 & 23 & 88 & 25 & 10 & 1.4 & -- \\
\hline & .0 & .14 & 55 & 16 & 22 & 80 & 10 & 7.0 & 1.4 & 3900 \\
\hline
\end{tabular}

023465DO POTATO CREEK NEAR THOMASTON, GA.

LOCATION.--Lat $32^{\circ} 54^{\prime} 15^{\prime \prime}$, long $84^{\circ} 21^{\prime} 45^{\prime \prime}$, Upson County, at gaging station on right bank 300 ft downstream from State Highiay 74,600 $\mathrm{ft}$ downstream from Básin Creek, 1,000 it downstream from Central of Georgla Railway bridge,

Highway 74,600 ft downstream from Basin Creek, $1,000 \mathrm{ft}$ downstream from Ce

DRAINAGE AREA, - 188 sq mi.

PERIOD OF RECORD,--Chemical analyses: November 1969 to September 1970 (part1al record).

REMARKS, - Laboratory chemical analyses by Georgia Water Quality Control Board. F1eld determination of discharge, water temperature, $\mathrm{pH}$, and dissolved oxygen by U.S. Geological Survey. CHEMICAL ANALYSES. WATER YEAR OCTOBER 1969 TO SEPTEMBER 1970

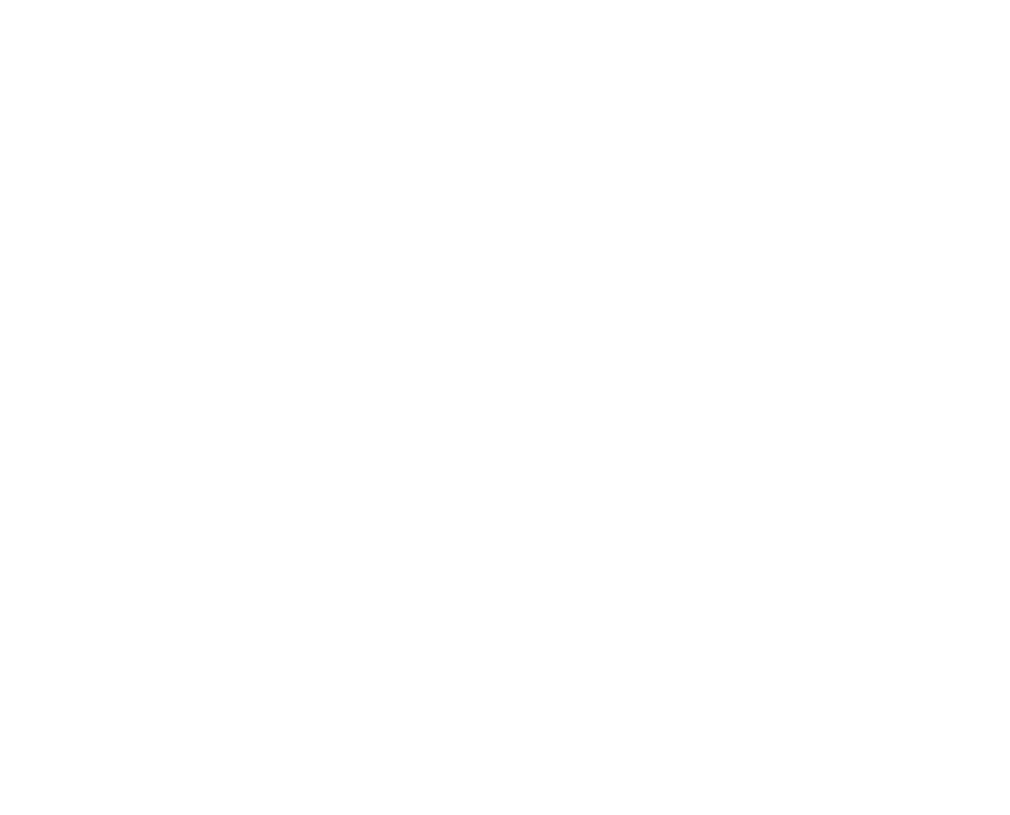


APALACHICOLA RIVER BASIN

02347500 FLINT RIVER NEAR CULLODEN, GA.

LOCATION.--Lat $32^{\circ} 43^{\prime} 17^{\prime \prime}$, long $84^{\circ} 13^{\prime} 57^{\prime \prime}$, Upson County, at gaging station on left bank underneath bridge on U.S. High way 19,4 miles upstream from Auchumpkee Creek, 5 miles downstream from Swift Creek, 13 miles southwest of Cul-

DRAINAGE AREA.--1,850 sq $\mathrm{ml}$, approximately.

PERIOD OF RECORD.--Chemical analyses: March 1968 to September 1970 (partial record).

REYARKS. --Laboratory chemical analyses by Georgia Water quality Control Board. Field determination of discharge, water temperature, $\mathrm{pH}$, and dissolved oxygen by U.S. Geological Survey.

CHEMICAL ANAL.YSES. WATEK YEAR OCTOHER 1969 TO SEPTEMBER 1970

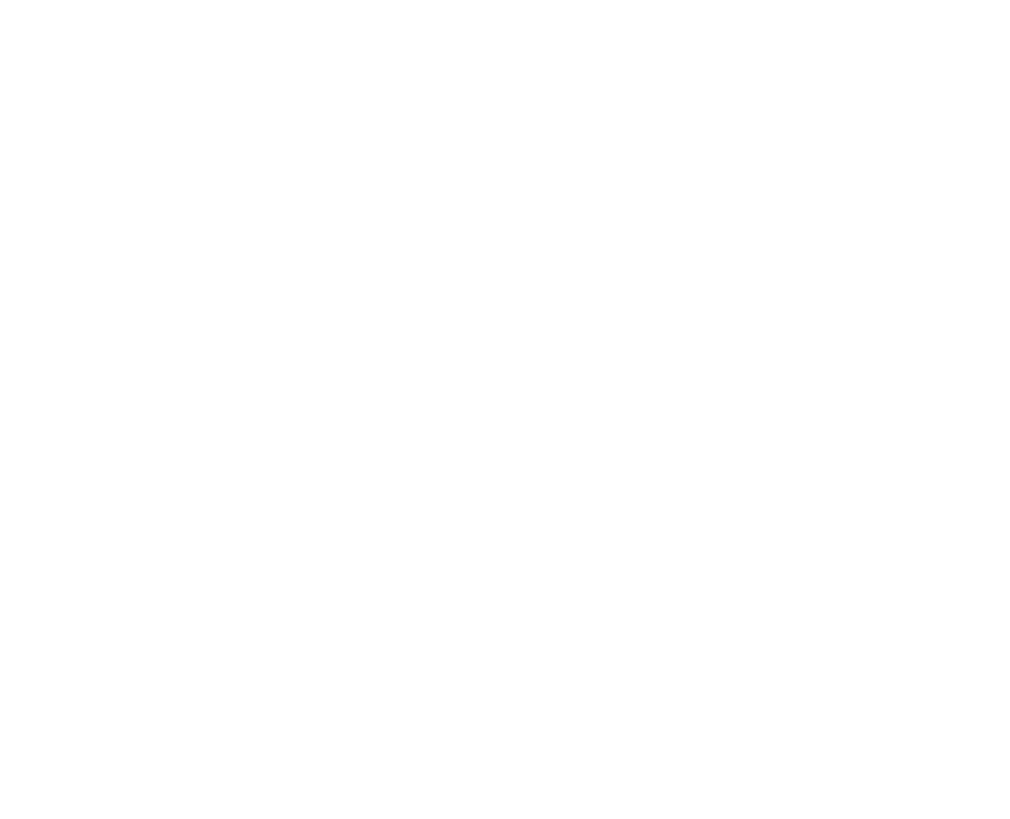

02349500 FLINT RIVER AT MONTEZUKA, GA.

LOCATION.--Lat $32^{\circ} 17^{\circ} 53^{\prime \prime}$, long $84^{\circ} 02^{\prime} 38^{\prime \prime}$, Macon County, at gaging station near left bank on downstream end of pier of bridge on state Righways 26 and $49,1,000 \mathrm{ft}$ upstream from Central of Georgla Rad lway bridge, $1,400 \mathrm{ft}$ up. stream from Seaboard Coast Line Rafl road (formerly Atlanta, B.
from Buck Creek, 1 mile west of Nontezuma, and at mile 180.8.

DRAINAGE AREA.--2,900 sq $\mathrm{mi}$, approximately; includes that of Buck Creek,

PERIOD OF RECORD,--Chemical analyses: February 1968 to September 1970 (partial record).

REMARKS, --Laboratory chemtcal analyses by Georgia Water quality Control Board. Field determination of discharge, water temperature, pH, and dissolved oxveen by U.S. Geological Survey.

CHEMICAL ANALYSES. WATEK YEAR UCTOHER 1969 TO SEPTEMBER 1970

\begin{tabular}{|c|c|c|c|c|c|}
\hline DATE & TIME & $\begin{array}{l}\text { UIS- } \\
\text { CHANP, } \\
\text { (CFS) }\end{array}$ & $\begin{array}{c}P H \\
\text { (UNITS) }\end{array}$ & $\begin{array}{l}\text { TEMP- } \\
\text { ERATURE } \\
\text { (OEG C) }\end{array}$ & $\begin{array}{l}\text { DIS- } \\
\text { SOLVEO } \\
\text { OXYGEN } \\
\text { (MG/L) }\end{array}$ \\
\hline $\begin{array}{l}\text { UEC. } \\
\text { 15:.. }\end{array}$ & 1000 & 2850 & 0.3 & 7.0 & 10.6 \\
\hline$\underset{\text { JUNE }}{23 \ldots}$ & $154 b$ & 24900 & 6.5 & 13.0 & 7.8 \\
\hline $\begin{array}{l}08 . . \\
\text { SEPT. }\end{array}$ & 1645 & 4430 & 7.6 & 22.0 & 7.0 \\
\hline $14 \ldots$ & 1145 & 1400 & 7.2 & $24 . n$ & 8.5 \\
\hline
\end{tabular}


APALACHICOLA RIVER BASIN

02349500 FLINT RIVER AT hONTEZUMA, GA.--Continued

CHEMICAL ANALYSES, WATER YEAR OCTOBER 1969 TO SEPTEMBER 1970

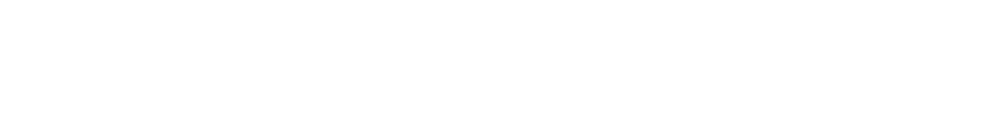

\begin{tabular}{|c|c|c|c|c|c|c|c|c|c|c|}
\hline $\begin{array}{l}\text { DEC. } \\
15 . . \\
\text { MAR. }\end{array}$ & 12 & 1500 & $<50$ & 2.4 & 1.1 & 6.8 & 1.8 & 16 & 4.0 & 4.7 \\
\hline $\begin{array}{l}23 . . \\
\text { JUNE }\end{array}$ & 8.5 & b & 80 & 1.7 & .9 & 1.9 & 2.2 & 8 & 2.0 & 2.3 \\
\hline $\begin{array}{c}08 \ldots . . \\
\text { StPT. }\end{array}$ & 10 & 3400 & 50 & 2.9 & I .0 & 4.0 & 1.7 & 13 & 4.0 & 3.2 \\
\hline $14 \ldots$ & 10 & 930 & $<50$ & 2.5 & 1.2 & 5.4 & 1.6 & 18 & 2.0 & 3.6 \\
\hline DATE & $\begin{array}{c}\text { NITRATt } \\
\text { (N) } \\
(M U / L)\end{array}$ & $\begin{array}{l}\text { PHOS- } \\
\text { PHATE } \\
\text { (POL) } \\
\text { (MG/L) }\end{array}$ & $\begin{array}{l}\text { TOTAL } \\
\text { FILT- } \\
\text { RAOLE } \\
\text { RESIDUE } \\
\text { (MG/L) }\end{array}$ & $\begin{array}{l}\text { TOTAL } \\
\text { NON- } \\
\text { FILT- } \\
\text { KAHLE } \\
\text { RESIDUE } \\
\text { (MGNL) }\end{array}$ & $\begin{array}{l}\text { HAPD- } \\
\text { NESS } \\
(C A, M G) \\
(M G / L)\end{array}$ & $\begin{array}{l}\text { SPECI- } \\
\text { FIC } \\
\text { COND- } \\
\text { UCTANCE } \\
\text { (MICRO- } \\
\text { MHOS) }\end{array}$ & $\begin{array}{l}\text { COLOR } \\
\text { (PLAT- } \\
\text { INUM- } \\
\text { CUBALT } \\
\text { UNITSI }\end{array}$ & $\begin{array}{l}\text { TUR- } \\
\text { BID- } \\
\text { ITY } \\
\text { (JTU) }\end{array}$ & $\begin{array}{l}\text { BIO- } \\
\text { CHEM- } \\
\text { ICAL } \\
\text { OXYGEN } \\
\text { DEMAND } \\
\text { (MG/L) }\end{array}$ & $\begin{array}{c}\text { FECAL } \\
\text { COLI- } \\
\text { FORM } \\
\text { (COL. } \\
\text { PER } \\
\text { 1OOML) } \\
\text { (MPN) }\end{array}$ \\
\hline
\end{tabular}

\begin{tabular}{|c|c|c|c|c|c|c|c|c|c|c|}
\hline $15 \ldots$ & .1 & .30 & 75 & 24 & 10 & 56 & 55 & 22 & 1.1 & 36 \\
\hline JUNE & . 3 & .28 & 89 & 60 & 7 & 31 & 300 & 100 & 2.1 & 2300 \\
\hline SERT.. & .2 & .23 & 28 & 52 & 12 & 42 & 90 & 49 & 1.2 & 930 \\
\hline $14 \ldots$ & .2 & .08 & 44 & 45 & 11 & 60 & 25 & 12 & .6 & 930 \\
\hline
\end{tabular}

02350600 KI NCHAFOONEE CREEK AT PRESTON, GA.

LOCATION.--Lat $32^{\circ} 03^{\prime} 13^{\prime \prime}$, long $84^{\circ} 322^{\prime} 53^{\prime \prime}$, webster County, at gaging station near right bank at downstream side of

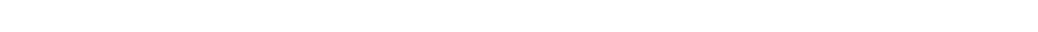

DRAINAGE AREA. - -197 sq $\mathrm{ml}$.

PERIOD OF RECORD,--Chemical analyses: December 1969 to September 1970 (partial record).

REMARKs. --Laboratory chemical analyses by Georgia Mater Quality Control Board. Field determination of dtscharge, water temperature, $\mathrm{PH}$, and dissolved oxyen by U.S. Geological Survey.

CHEMICAL ANALYSES, WATER YEAR OCTOBER 1969 TO SEPTEMBER 1970

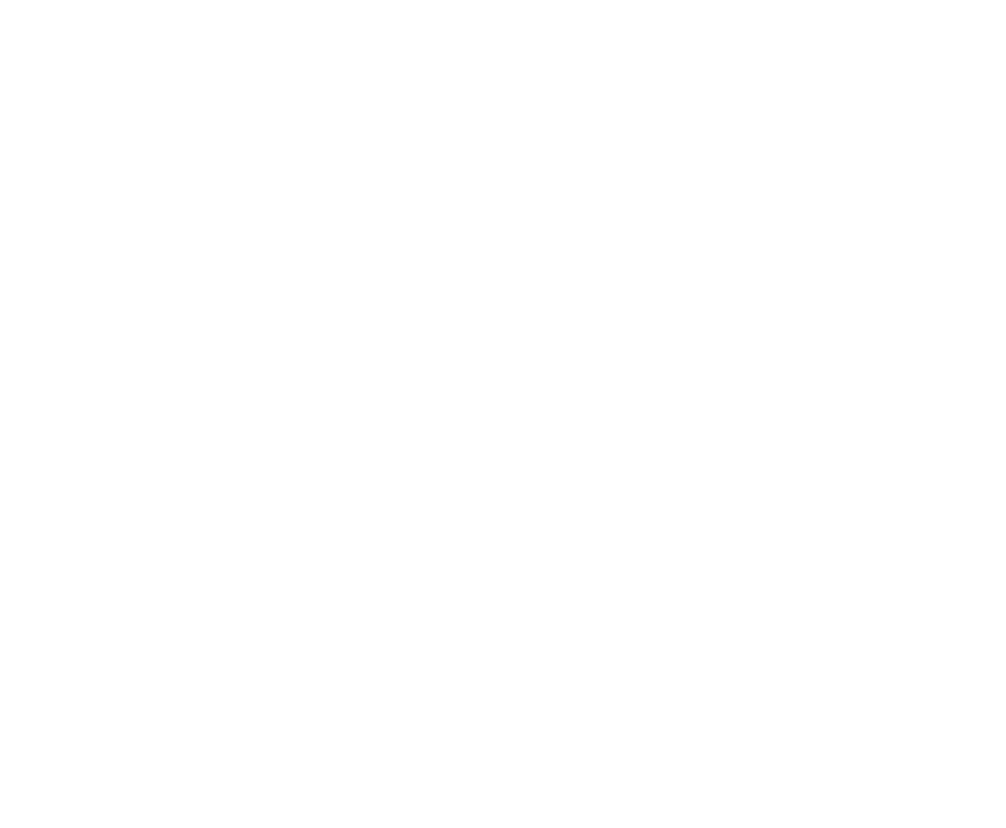


02352500 FLINT RIVER AT ALBANY, GA.

LOCATION.--Lat $31^{\circ} 35^{\prime} 39^{\prime \prime}$, long $84^{\circ} 08^{\prime} 39^{\prime \prime}$, Dougherty County, at gaging station on right bank at downstream side of Georgia Northern Radiway bridge in aibany and at mile io3.4.

DRAINAGE AREA.--5,310 sq mi, approximately.

PERIOD OF RECORD.--Chemical analyses: February 1968 to September 1970 (partial record).

REMARKS. --Laboratory chemical analyses by Georgia Water quality Control Board. Fiela determination of discharge, water temperature, $\mathrm{pH}$, and dissolved oxygen by U.S. Geological Survey.

$$
\begin{aligned}
& \text { CHEMICAL ANALYSES. WATER YEAR OCTOHER } 1969 \text { TO SEPTEMBER } 1970
\end{aligned}
$$

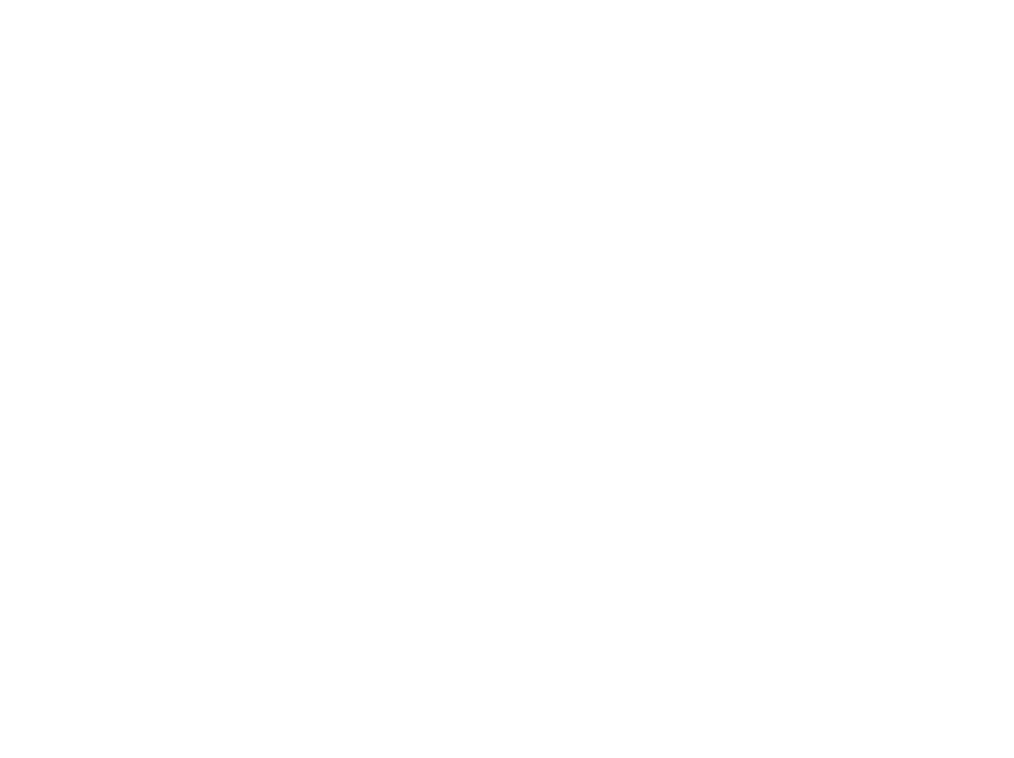

LOCATION.--Lat $31^{\circ} 18^{\prime} 34^{\prime \prime}$, long $84^{\circ} 20^{\circ} 06^{\prime \prime}$, Baker County, at gaging gtation on downstream side of pier of bridge on State Highwy 37 at Newton, 1 mile downstream from Cooleewahee Creek and at mile 72,4

DRAINAGE AREA, $\ldots 5,740 \mathrm{sq} m 1$, approximate $1 \mathrm{y}$

PERIOD OF RECORD.--Chemical analyses: February 1968 to September 1970 (partial record).

RELARKS.--Laboratory chemical analyses by Georgia Water quality Control Board. Field determination of discharge, water temperature, $\mathrm{pH}$, and dissolved oxygen by U, S, Geological survey.

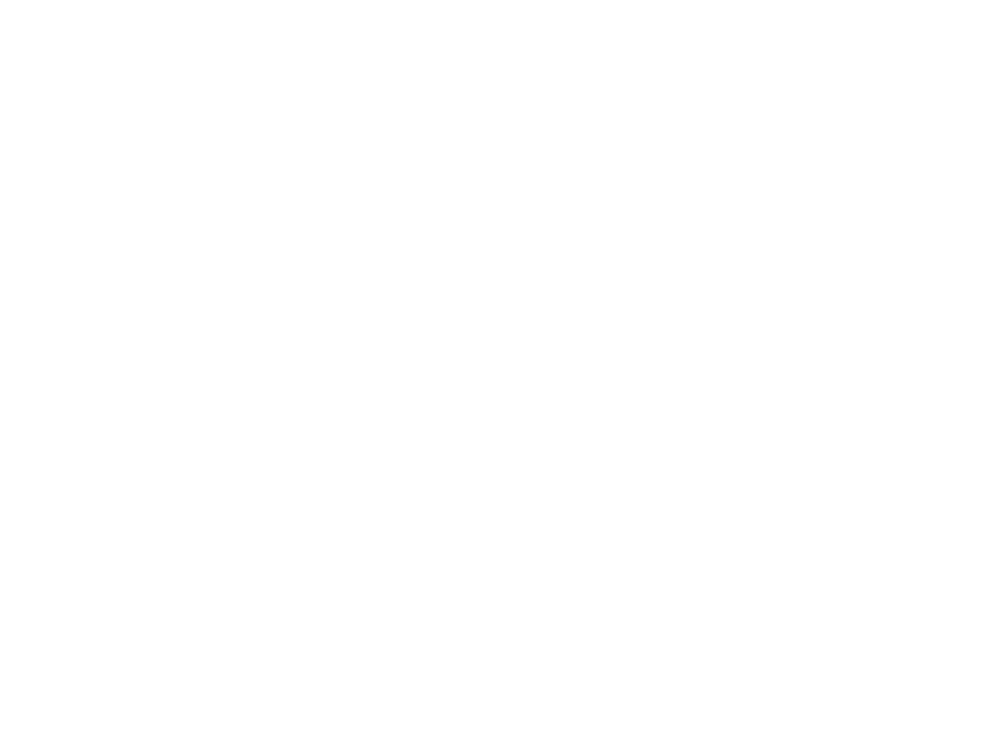


02356000 FLINT RIVER AT BAINBRIDGE, GA.

LOCATION. --Lat $30^{\circ} 54^{\prime} 41^{\prime \prime}$, long $84^{\circ} 34^{\prime} 48^{\prime \prime}$, Decatur County, at gagimg atation on downstream aide of right major pier of Decatur County Nemorial Bridge on'U.S. Highway 84 at Bainbridge, 0.2 mile downstream from Seaboard Coast Line Rallread bridge, at m1le 29.0 , and 29.2 miles upstream from Jim Woodruff Dam.

DRAINAGE AREA, - 7,570 sq mi, approximately.

PERIOD OF RECORD.,--Chemical analyses: February 1968 to september 1970 (partial record).

REMARKS,.-D1scherge records furnished by Corps of Engineers. Laboratory chemlcal analyses by Georgia water Quality Control Board, Field determination of water temperature, pH, and dissolved oxsgen by U.S. Geolasteal Survey. CHEMICAL ANALYSES, WATER YEAR OCTOBER 1969 TU SEPTEMBER 1970

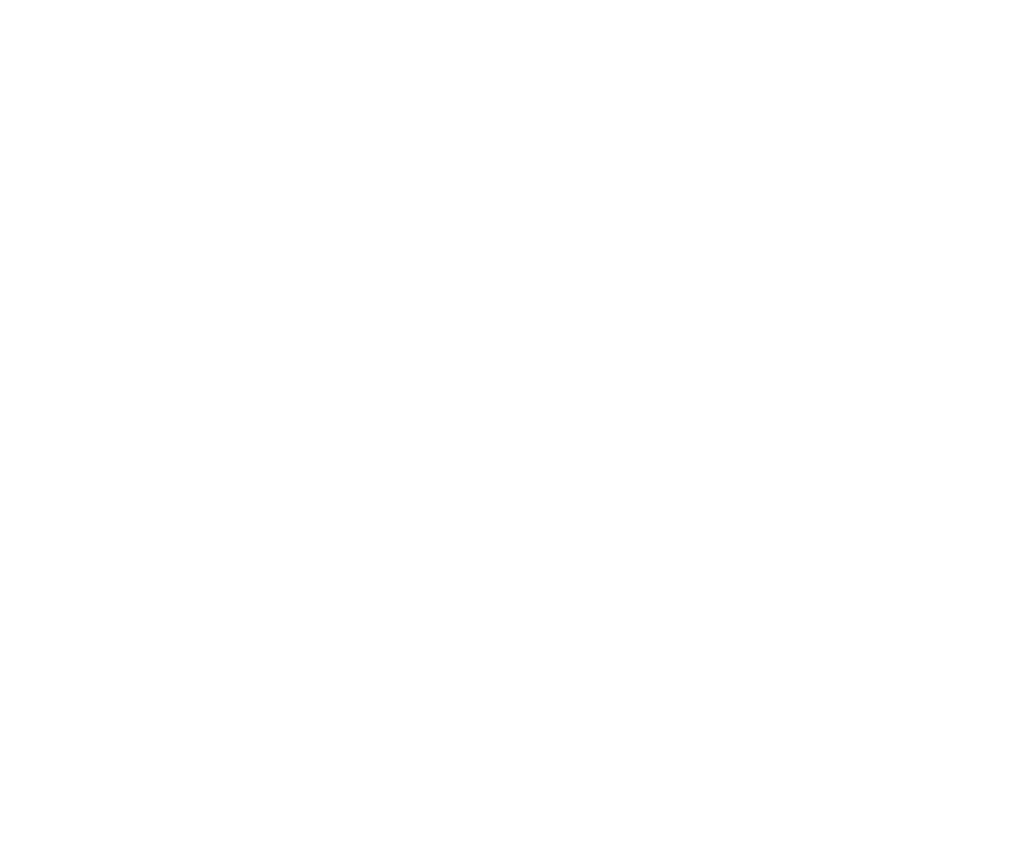

LOCATION, - - Lat $34^{\circ} 41^{\prime} 06^{\prime \prime}$, Long $84^{\circ} 28^{\prime} 40^{\prime \prime}$, Gilmer County, at gaging station on left bank at dowstream side of bridge

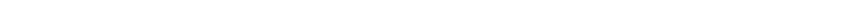

DRAINAGE AREA. - -90 sq mi, approximately.

PERIOD OF RECORD.--Chem1cal analyses: November 1969 to September 1970 (partial record).

REMARKS, --Laboratory chemical analyses by Georgia water quality Control Bord. Field determimation of discharge, water temperature, $\mathrm{pH}$, and dissolved oxygen by $U, S$, Geological Survey. CHEMICAL ANALYSES, WATER YEAR OCTOBER 1969 TO SEPTEMBER 1970

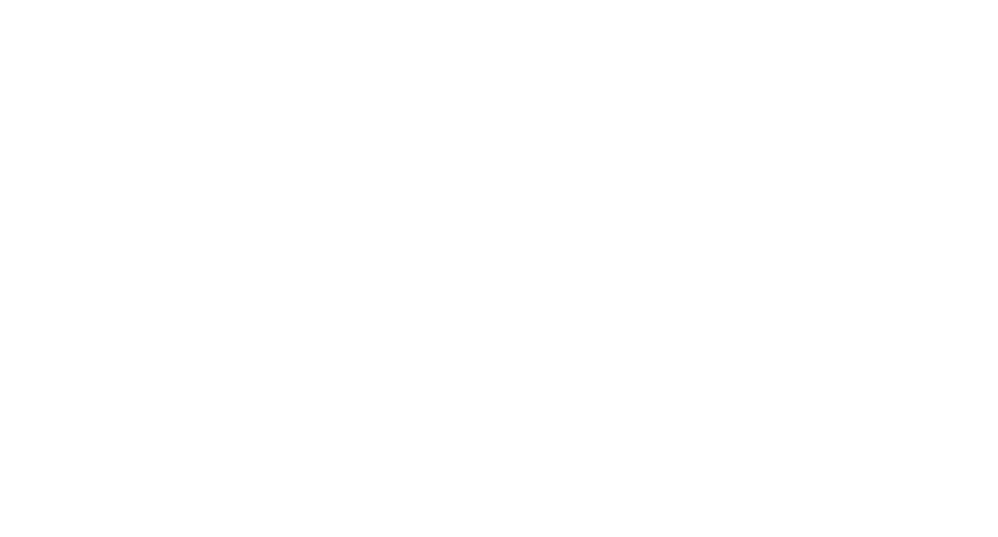


NOBILE RIVER BASIN

02380000 ELLIJAY RIVER AT ELLIJAY, GA.--Cont 1 nued

CHEMICAL ANALYSES, WATER YEAR OCTOBER 1969 TO SEPTEMBER 1970

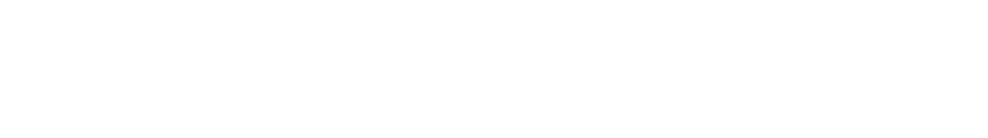

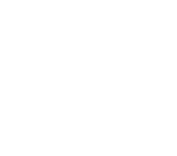

$\begin{array}{rr}.23 & 30 \\ .10 & 30 \\ .10 & 12 \\ .05 & 35\end{array}$

$\begin{array}{rrr}1 & 8 & 31 \\ 4 & 7 & 25 \\ 6 & 8 & 22 \\ 18 & 10 & 28\end{array}$

$\begin{array}{rrrr}20 & 4.0 & .5 & 2300 \\ 10 & 3.0 & .6 & 150 \\ 20 & 9.0 & .6 & 2300 \\ 20 & 14 & 7.0 & 75000\end{array}$

O2380500 COOSAWATTEE RIVER NEAR ELLIJAY. GA.

LOCATION. --Lat $34^{\circ} 40^{\prime} 18^{\prime \prime}$, long $84^{\circ} 30^{\prime} 31^{\prime \prime}$, G11mer County, at gaging station on right bank 0.5 mile downstream erom State Highway 5,2 miles southwest of Eli1jay and 2,2 miles downtream from confluence of Cartecay and Elifjay Rivers.

DRAINAGE AREA. $--238 \mathrm{sq} m 1$.

PERIOD OF RECORD.--Chemical analyses: March 1968 to September 1970 (partial record),

REMARKS.--Laboratory chemical ana1yses by Georgia Water Quality Control Board. Field deternination of discharge, water temperature, $\mathrm{pH}$, and dissolved oxygen by U.S. Geological Survey. CHEMICAL ANALYSES, WATER YEAR OCTOBER 1969 TO SEPTEMBER 1970 CHEMICAL ANALYSES, WATEK YEAR OCTOBER 1969 TO SEPTEMBER 1970

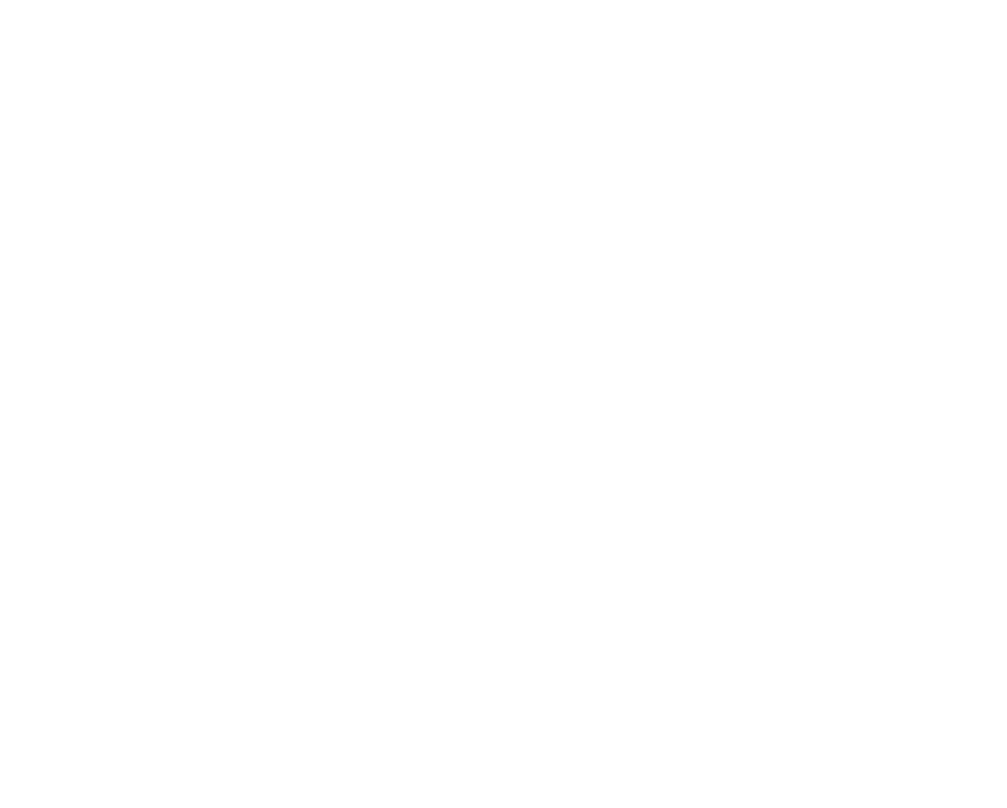




\section{MOBILE RIVER BASIN}

02382500 COOSANATTEE RIVER AT CARTERS, GA.

LOCATION.--Lat $34^{\circ} 36^{\prime} 15^{\prime \prime}$, long $84^{\circ} 41^{\prime} 29^{\prime \prime}$, Murray County, at gaging station on downstream side of left bank pler of bridge on U,S. Highway 411 at Carters, $200 \mathrm{ft}$ upstream from Louisville and Nashville Railroad bridge, and 0.6 mile downstrean from Talking Rock Creek.

DRAINAGE AREA.--531 sq $\mathrm{mi}$.

PERIOD OF RECORD,.-Chemical analyses: March 1968 to September 1970 (partial record).

REMARKS.--Laboratory chemical analyses by Georgia nater Quality Control Board. Field determination of discharge, water temperature, $\mathrm{pH}$, and dissolved oxygen by U.S. Geological Survey.

$$
\text { CHEMICAL aivalyses, watth yEAK OCTUHER } 1969 \text { TO SEPTEMBER } 1970
$$

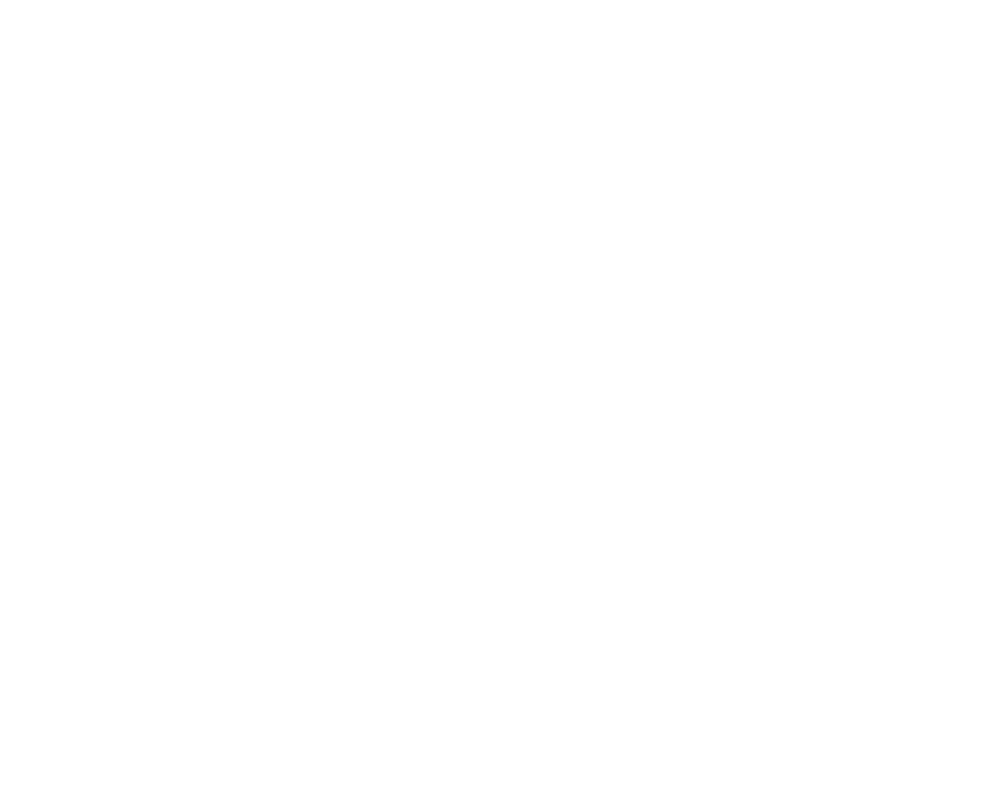

02385800 HOLLY CREEK NEAR CHATSWORTH, GA.

LOCATION, .- Lat $34^{\circ} 43^{\prime} 00^{\prime \prime}$, long $84^{\circ} 46^{\prime} 12^{\prime \prime}$, Jurray County, at gaging station on right bank 100 ft upstream from bridge on county road, 3 miles upstream from Rock Creek, and 3.3 miles south of Chatsworth.

DRAINAGE AREA. - -64.B sq mi.

RECORDS AVAILABLE.--Chemical analyses: March 1968 to September 1970 (part1al record).

REMARKS. - Laboratory chemical analyses by Georgia Fater quality Control Board. Field determination of discharge, water temperature, $\mathrm{pH}$, and dissolved oxygen by U.S. Geological Survey.

CHEMICAL ANAL YSES, WAFER YEAR OCTOHER 1969 TO SEPTEMBER 1970

\begin{tabular}{|c|c|c|c|c|c|}
\hline DATE & I IME & $\begin{array}{l}\text { 1)IS- } \\
\text { CHARGE } \\
\text { (CFS) }\end{array}$ & $\begin{array}{c}\text { PH } \\
\text { (UNIYS) }\end{array}$ & $\begin{array}{l}\text { TEMP- } \\
\text { FRATURE. } \\
\text { (DEG C) }\end{array}$ & $\begin{array}{l}\text { ULS- } \\
\text { SOLVED } \\
\text { OXYGEN } \\
\text { (MG/L) }\end{array}$ \\
\hline $\begin{array}{l}\text { NuV. } \\
04 \ldots . .\end{array}$ & 1000 & 16 & 6.5 & 10.0 & 4.4 \\
\hline $\begin{array}{l}\text { DEC. } \\
15 . . . \\
J_{\Delta \Delta^{N}}\end{array}$ & 1400 & 27 & 6.7 & $6 . n$ & 11.0 \\
\hline 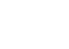 & 1430 & 134 & 7.8 & 5.0 & 12.0 \\
\hline $\begin{array}{l}10 \ldots \\
\triangle D Q . .\end{array}$ & 1400 & 45 & 6.4 & 11.0 & 11.0 \\
\hline$\underset{J I J N E}{21} \ldots$ & 1315 & 72 & 7.5 & 17.0 & 7.9 \\
\hline vil. & 1300 & 19 & 7.1 & 20.5 & 6.8 \\
\hline $\begin{array}{l}14 \ldots . \\
\text { AUG. }\end{array}$ & $123 n$ & 8.2 & 7.0 & $24 . n$ & 5.9 \\
\hline $25 \ldots$ & 1245 & 1? & 7.2 & 22.0 & 6.0 \\
\hline
\end{tabular}


MOBILE RIVER BASIN

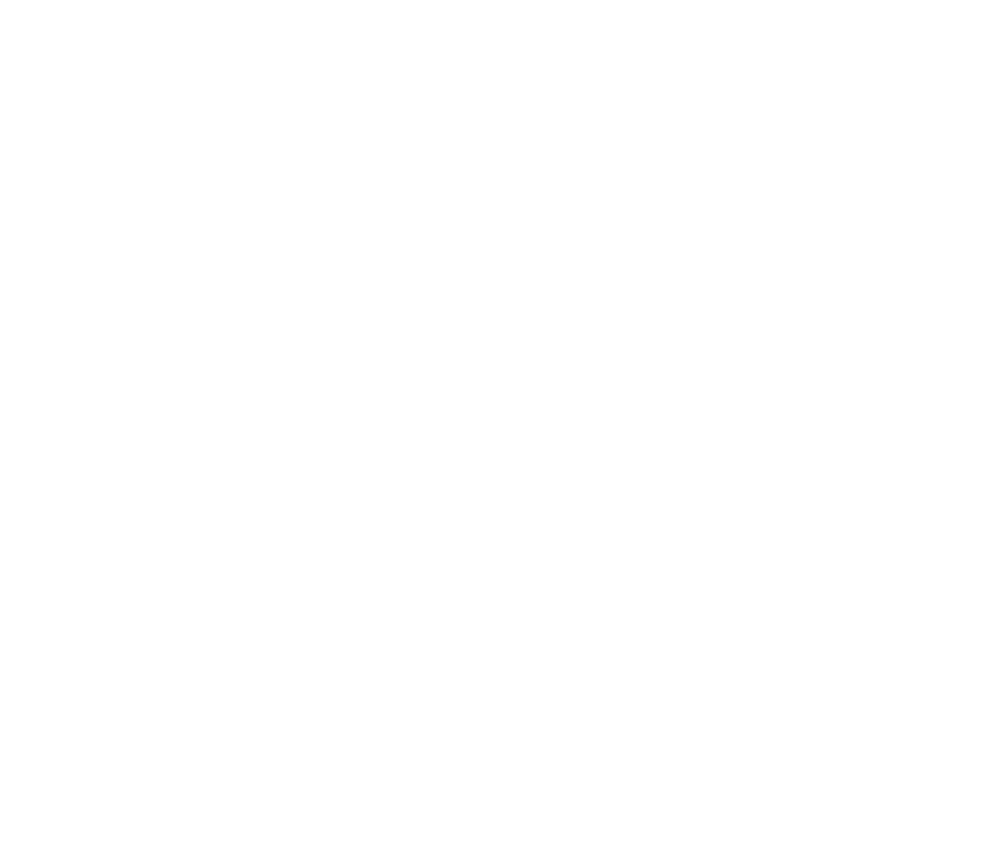

02387000 CONASAUGA RIVER AT TILTON, GA.

LOCATION,--Lat $34^{\circ} 40^{\circ} 00^{\prime \prime}$, long $84^{\circ} 55^{\prime} 42^{\prime \prime}$, Murray County, at gaging station on left bank 250 ft downstream from high-

way bridge, $0,2 \mathrm{mile}$ downstream from Swamp Creek, 0.5 mile northeast of Tilton, and 12 miles upstream from confluence with Coosawattee River.

DRAINAGE AREA. --682 sq mi,

PERIOD OF RECORD.--Chemical analyses: March 1968 to September 1970 (partial record).

REILARKS.--Laboratory chemical analyses by Georgia water quality Control Board. Field determination of discharge, water temperature, pH, and dissolved oxygen by U.S. Geological Survey.

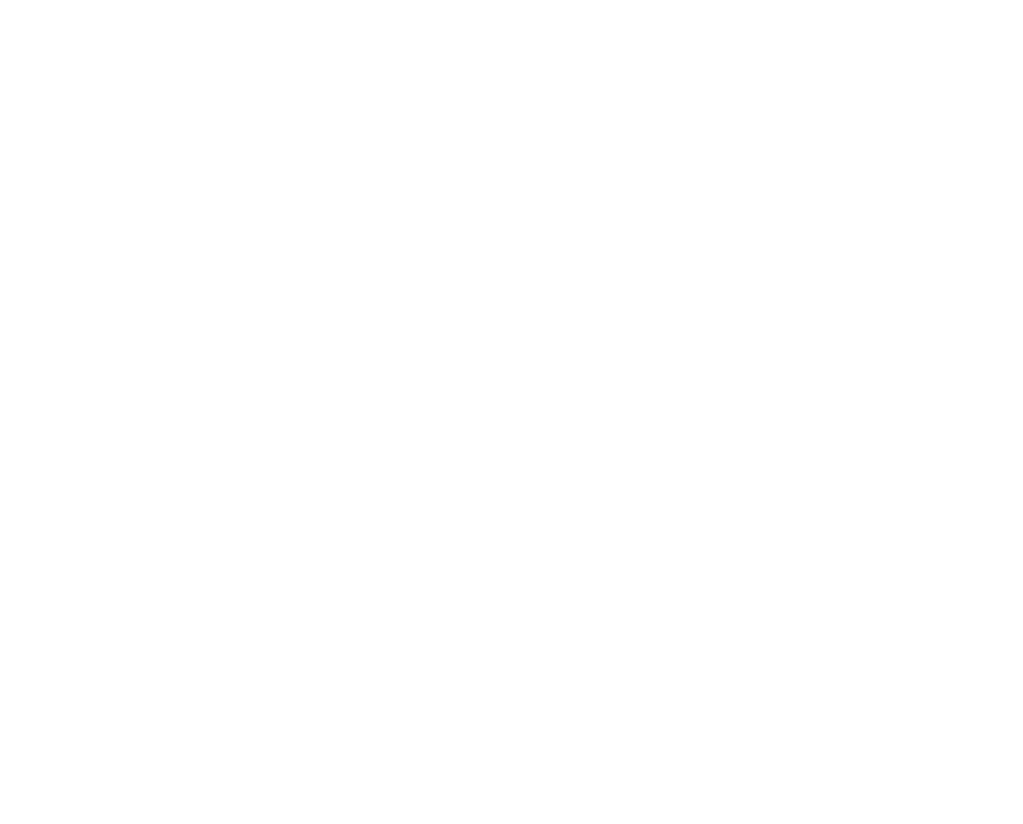


MOBILE RIVER BASIN

02387000 CONASAUGA RIVER AT TILTON, GA.--Cont1nued CHEMICAL ANALYSES, WATER YEAR OCTOBER 1969 TO SEPTEMBER 1970

\begin{tabular}{|c|c|c|c|c|c|c|c|c|c|c|}
\hline DATE & $\begin{array}{c}\text { NITHATE } \\
\text { (N) } \\
\text { (MG/L) }\end{array}$ & $\begin{array}{l}\text { PHOS= } \\
\text { PHATE } \\
\text { (PO4) } \\
\text { (MG/L) }\end{array}$ & $\begin{array}{l}\text { TOTAL } \\
\text { FILI- } \\
\text { RABLE } \\
\text { RESIDUE } \\
(M G / L)\end{array}$ & $\begin{array}{c}\text { TOTAL } \\
\text { NON- } \\
\text { FILT- } \\
\text { RABLE } \\
\text { RES IDUE } \\
\text { (MG/L) }\end{array}$ & $\begin{array}{l}\text { HARD- } \\
\text { NESS } \\
\text { (CA,MG) } \\
\text { (MG/L) }\end{array}$ & $\begin{array}{l}\text { SPECI- } \\
\text { FIC } \\
\text { COND- } \\
\text { UCIANCE } \\
\text { (MICRO- } \\
\text { MHOS) }\end{array}$ & $\begin{array}{l}\text { COLOR } \\
\text { (PLAT- } \\
\text { INUM- } \\
\text { COBALT } \\
\text { UNITS) }\end{array}$ & $\begin{array}{l}\text { TUR- } \\
\text { BID- } \\
\text { ITY } \\
\text { (JTU) }\end{array}$ & $\begin{array}{l}\text { BIO- } \\
\text { CHEM- } \\
\text { ICAL } \\
\text { OXYGEN } \\
\text { DEMAND } \\
\text { (MG/L) }\end{array}$ & $\begin{array}{c}\text { FECAL } \\
\text { COLI- } \\
\text { FORM } \\
\text { (COL. } \\
\text { PER } \\
\text { 10O ML) } \\
\text { (MPN) }\end{array}$ \\
\hline $\begin{array}{l}\text { NOV. } \\
03 . . . \\
\text { DEC. }\end{array}$ & .0 & .78 & 148 & 17 & 73 & 224 & 35 & 15 & 2.2 & 21000 \\
\hline $\begin{array}{l}15 . . \\
\text { JAN. }\end{array}$ & .0 & .88 & 139 & 10 & so & 150 & 30 & 10 & 2.2 & 93000 \\
\hline $\begin{array}{l}27 . . . \\
\text { MAR. }\end{array}$ & .2 & 1.4 & 98 & 114 & 58 & 170 & 55 & 135 & 3.4 & 21000 \\
\hline $\begin{array}{l}10 \ldots \\
\triangle P R\end{array}$ & .1 & 1.8 & 107 & 18 & 58 & 185 & 30 & 12 & 2.2 & 43000 \\
\hline JUNE & $\cdot 2$ & 2.6 & 114 & 116 & 62 & 163 & 40 & 66 & 2.8 & 390000 \\
\hline 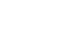 & $\cdot 3$ & 1.2 & 87 & 2 & 74 & 175 & 20 & 11 & 1.4 & 2300 \\
\hline $\begin{array}{l}14 . . \\
\text { AUG. }\end{array}$ & .2 & 2.0 & $\cdots$ & -- & 82 & 185 & -- & 4.0 & 2.2 & 9300 \\
\hline $25 .$. & .1 & 2.4 & 152 & 10 & 82 & 251 & -- & 10 & 1.8 & 4300 \\
\hline
\end{tabular}

02394000 ETOWAH RIVER AT ALLATOONA DAK, ABOVE CARTERSVILLE, GA.

LOCATION, --Lat $34^{\circ} 09^{\prime} 47^{\prime \prime}$, long $84^{\circ} 44^{\prime} 28^{\prime \prime}$, Bartow County, at gaging station on right bank 0.8 m1le dowstream from Allatoona Dai, 2 miles upstream from Nashville, Chattanooga and $8 t$. Louis Railway bridge, and 3 miles east of Cartersilile.

DRAI NAGE AREA.--1,110 sq mi, approximately.

PERIOD OF RECORD.--Chemical analyses: March 1968 to September 1970 (part1al record).

REMARKS.--Laboratory chemical analybes by Georgla water quality Control Board. Field determination of discharge, water temperature, $\mathrm{pH}$, and dissolved oxygen by U.S. Geological Survey. CHEMICAL ANALYSES, WATER YEAR OCTOBER 1969 TO SEPIEMBER 1970

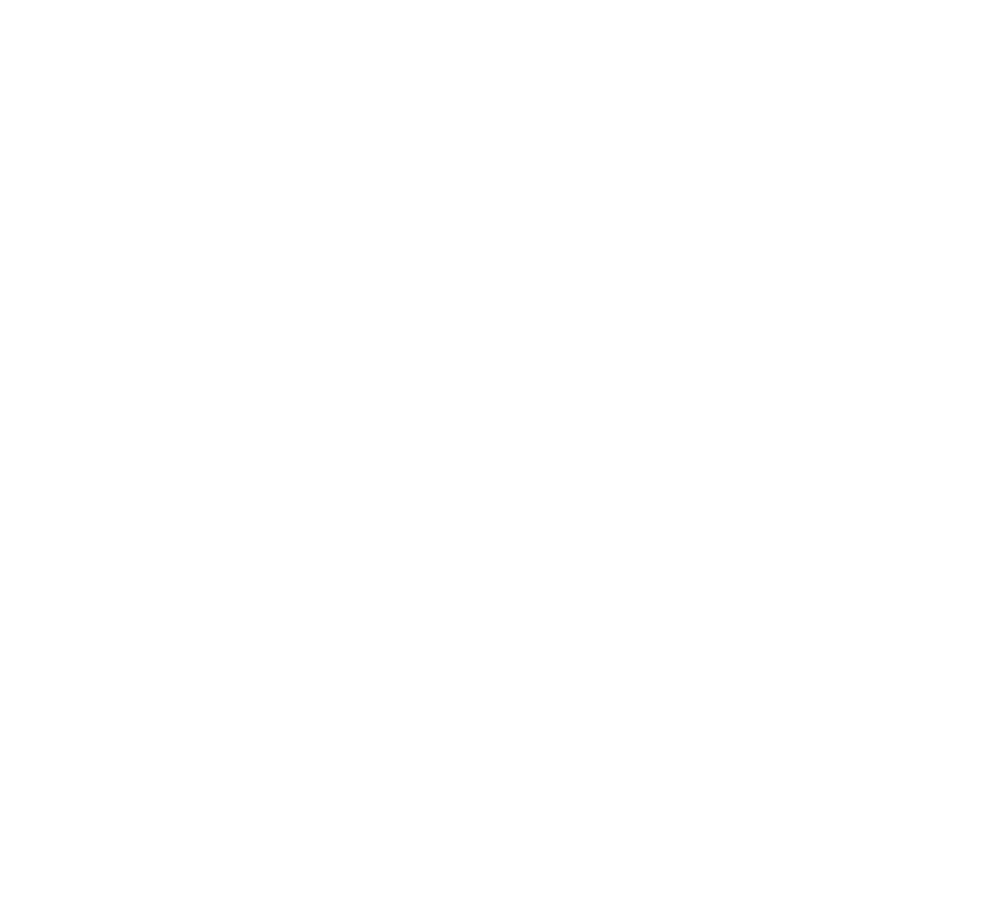


02395000 ETOWAH RIVER NEAR KINGSTON, GA.

LOCATION.--Lat $34^{\circ} 12^{\prime} 24^{\prime \prime}$, long $84^{\circ} 58^{\prime} 44^{\prime \prime}$, Bartow County, at gaging station on downstream side of center pier of bridge on U.S. Highway 411, 1 mile upstream from Two Run Creek, 1.5 miles upstrean from Connesena Creek, and 2.5 miles southwest of Kingston.

DRAINAGE AREA. - -1,630 sq m1, approx1mately.

PERIOD OF RECORD.--Chemical analyses: October 1969 to September 1970 (partial record).

REMARKS, --Laboratory chemical analyses by Georgia water Quality Control Board. Field determination of discharge, water temperature, $\mathrm{pH}$, and dissolved oxygen by $\mathrm{W} S$, Geological Survey.

CHEMICAL ANALYSES, WATER YEAR OCTOBER 1969 TO SEPTEMBER 1970

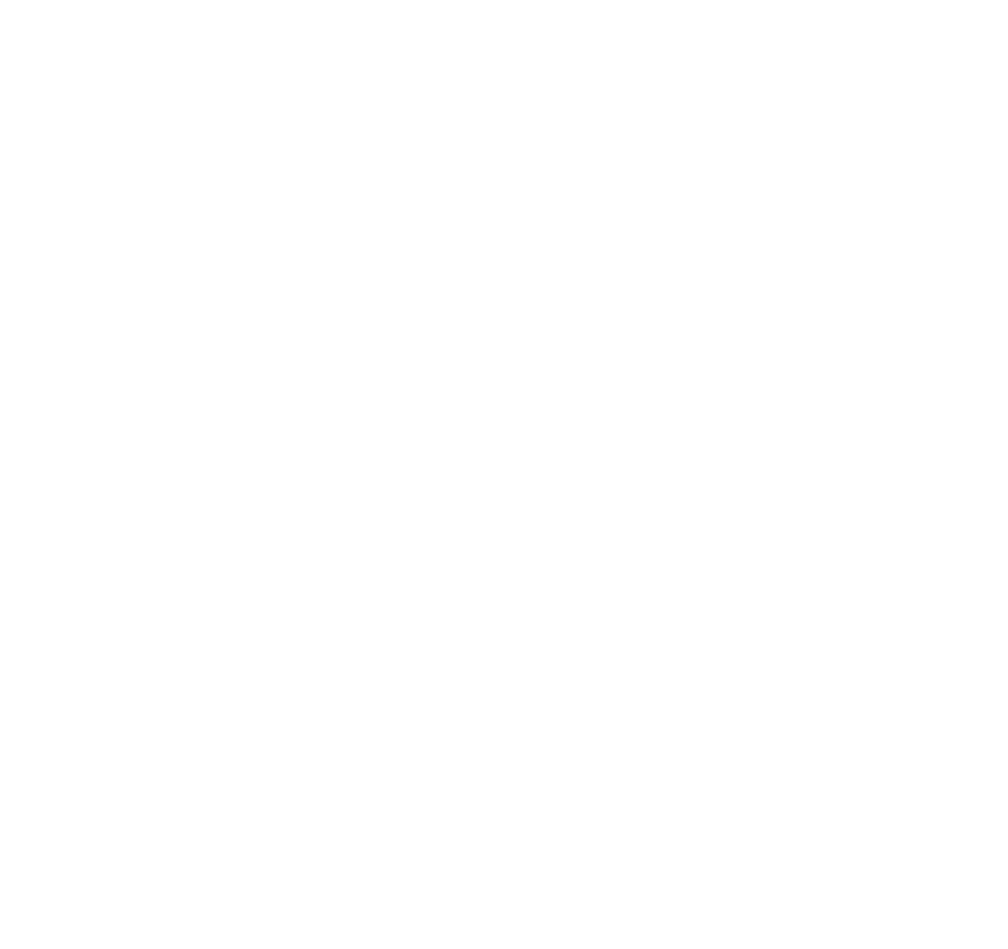

02397000 COOSA RIVER NRAR BOAT, GA.

LOCATION.--Lat $34^{\circ} 12^{\prime} 01^{\prime \prime}$, long $85^{\circ} 15^{\prime} 24^{\prime \prime}$, Hloyd County, at gaging station on left bank attached to shoreward side of lock wall of Yayo Bar lock near upstream end, 1.5 miles upgtream from Webb Creek, 6 m1les gouthwest of Rome, 7.5 miles downstream from confluence of Dostanaula and Etowah Rivers, and at mile 279.

DRAINAGE AREA. --4,040 sq ml, approximately.

PERIOD OF RECORD. --Chemlcal analyses: Uarch 1968 to September 1970 (partlal record).

REMARKs. --Laboratory chemlcal analyses by Georgla Water quality Control Board. Fleld determinatlon of discharge, watex temperature, $\mathrm{pH}$, and dissolved oxygen by U.S. Goolog lcal Survey.

CHEMLCAL ANALYSES. WATER YEAR OCTOBER 1969 TO SEPTEMBER 1970

\begin{tabular}{|c|c|c|c|c|c|}
\hline OATE & TIME & $\begin{array}{l}\text { DIS- } \\
\text { CHARGE } \\
\text { (CFS) }\end{array}$ & $\begin{array}{c}\mathrm{PH} \\
\text { (UNITS) }\end{array}$ & $\begin{array}{l}\text { TEMP- } \\
\text { ERATURE } \\
\text { (DEG C) }\end{array}$ & $\begin{array}{l}\text { DIS- } \\
\text { SOLVED } \\
\text { OXYGEN } \\
\text { (MG/L) }\end{array}$ \\
\hline $\begin{array}{l}\text { OCT. } \\
14 \ldots . . \\
\text { DEC. }\end{array}$ & 0825 & 5180 & 7.5 & 21.0 & 7.8 \\
\hline FEB... & 1745 & 1510 & 6.5 & 9.0 & 9.8 \\
\hline MAY & 1550 & 2740 & 7.5 & 8.0 & 9.5 \\
\hline AUG:. & -- & 4920 & 6.8 & 20.0 & 6.8 \\
\hline $03 . \ldots$ & 2015 & 1040 & 7.5 & 26.0 & 30.2 \\
\hline
\end{tabular}


MOBILE RIVER BASIN

02397000 COOSA RIVER NEAR ROME, GA,--Cont Inued

CHEMICAL ANALYSES, WATER YEAR OCTOBER 1969 TO SEPTEMBER 1970

\begin{tabular}{|c|c|c|c|c|c|c|c|c|c|c|}
\hline UATE & $\begin{array}{l}\text { SILICA } \\
\text { (SIOZ) } \\
\text { (MG/L) }\end{array}$ & $\begin{array}{l}\text { TOTAL } \\
\text { IRON } \\
\text { (FE) } \\
\text { (UG/L) }\end{array}$ & $\begin{array}{l}\text { TUTAL } \\
\text { MAN- } \\
\text { GANESE } \\
\text { (MNN) } \\
\text { (UG/L) }\end{array}$ & $\begin{array}{l}\text { DIS- } \\
\text { SOLVEO } \\
\text { CAL- } \\
\text { CIUM } \\
\text { (CA) } \\
\text { (MG/L) }\end{array}$ & $\begin{array}{l}\text { OIS- } \\
\text { SOLVED } \\
\text { MAG- } \\
\text { NE- } \\
\text { SIUM } \\
\text { (MG) } \\
\text { (MG/L) }\end{array}$ & $\begin{array}{l}\text { SODIUM } \\
\text { (NA) } \\
(M G / L)\end{array}$ & $\begin{array}{l}\text { PO- } \\
\text { TAS- } \\
\text { SIUM } \\
(K) \\
(M G / L)\end{array}$ & $\begin{array}{l}\text { ALKA- } \\
\text { LINITY } \\
\text { AS } \\
\text { CACO3 } \\
\text { (MG/L) }\end{array}$ & $\begin{array}{l}\text { SULFATE } \\
\text { (SO4) } \\
\text { (MG/L) }\end{array}$ & $\begin{array}{l}\text { CHLO- } \\
\text { R IOE } \\
(\mathrm{CL}) \\
(\mathrm{MG} / \mathrm{L})\end{array}$ \\
\hline $\begin{array}{l}\text { OCT. } \\
14 \ldots . . \\
\text { OEC. }\end{array}$ & 8.5 & 450 & $<50$ & 16 & 5.6 & 2.4 & 1.4 & 57 & 4.0 & 2.7 \\
\hline & 8.8 & 250 & $<50$ & 13 & 3.2 & 7.8 & 1.3 & 48 & 6.0 & 9.1 \\
\hline $\operatorname{MAY} \ldots$ & 3.2 & 400 & $<50$ & 14 & 3.4 & 4.3 & 1.0 & 47 & 5.0 & 5.3 \\
\hline $\begin{array}{c}12 \ldots . . \\
A \cup G .\end{array}$ & 11 & 250 & $<50$ & 16 & 5.6 & 3.1 & 1.3 & 65 & 6.0 & 9.4 \\
\hline $03 \ldots$ & 9.1 & 450 & & $\begin{array}{c}14 \\
\text { TOTAL }\end{array}$ & 3.6 & 6.0 & 1.0 & 43 & 7.0 & FECAL \\
\hline DATE & $\begin{array}{l}\text { NITHATE } \\
(N) \\
(M(j / L)\end{array}$ & $\begin{array}{l}\text { PHOS- } \\
\text { PHATE } \\
\text { (PO4) } \\
\text { (MG/L) }\end{array}$ & $\begin{array}{l}\text { TOTAL } \\
\text { FILT- } \\
\text { RABLE } \\
\text { RESIDUE } \\
\text { (MG/L) }\end{array}$ & $\begin{array}{l}\text { NON- } \\
\text { FILT- } \\
\text { RAELE. } \\
\text { RESIOUE } \\
(M G / L)\end{array}$ & $\begin{array}{l}\text { HARO- } \\
\text { NESS } \\
\text { (CA.MG) } \\
\text { (MG/L) }\end{array}$ & $\begin{array}{l}\text { SPECI- } \\
\text { FIC } \\
\text { CONO- } \\
\text { UCTANCE } \\
\text { (MICRO- } \\
\text { MHOS) }\end{array}$ & $\begin{array}{l}\text { COLOR } \\
\text { (PLAT- } \\
\text { INUM- } \\
\text { COBALT } \\
\text { UNITS }\end{array}$ & $\begin{array}{l}\text { TUR- } \\
\text { BID- } \\
\text { ITY } \\
\text { (JTU) }\end{array}$ & $\begin{array}{l}\text { BIO- } \\
\text { CHEM- } \\
\text { ICAL } \\
\text { OXYGEN } \\
\text { DEMAND } \\
\text { (MG/L) }\end{array}$ & $\begin{array}{c}\text { COLI- } \\
\text { FORM } \\
\text { (COL. } \\
\text { PER } \\
\text { IOO ML) } \\
(\text { MPN) }\end{array}$ \\
\hline $\begin{array}{l}\text { OCT. } \\
14 \ldots \\
\text { UEC... }\end{array}$ & .1 & .35 & 92 & 34 & 58 & 137 & 10 & 20 & . 8 & 93000 \\
\hline FE⿰.... & .1 & .97 & 72 & 2 & 44 & 131 & 20 & 8.0 & 1.6 & 93000 \\
\hline MAY $15 .$. & $\cdot 1$ & .70 & 64 & 1 & 44 & 128 & 15 & 9.5 & .9 & 230000 \\
\hline Aug... & .4 & .34 & 79 & 20 & 61 & 136 & 25 & 18 & .6 & 21000 \\
\hline $03 \ldots$ & .2 & .99 & 73 & 20 & 46 & 130 & 10 & 15 & .9 & 230000 \\
\hline
\end{tabular}

02397500 CEDAR CREEK NEAR CEDAKTOMN, GA.

LOCATION...Lat $34^{\circ} 03^{\prime} 38^{\prime \prime}$, long $85^{\circ} 18^{\prime} 41^{\prime \prime}$, Polk County, at gaging station on left bank 700 ft downstream from bridge on State Highway 161; 4.5 miles upstream from Lake Creek, and $4.5 \mathrm{miles}$ northwest of Cedartown.

DRAITAGE AREA.--109 sq mt.

PERIOD OF RECORD, --Chemical analyses: March 1968 to September 1970 (partial record).

REMARKS. - Laboratory chemical analyses by Georgia Water quality Control Board. Field determination of discharge, water temperature, pH, and dissolved oxygen by U.S. Geological Survey.

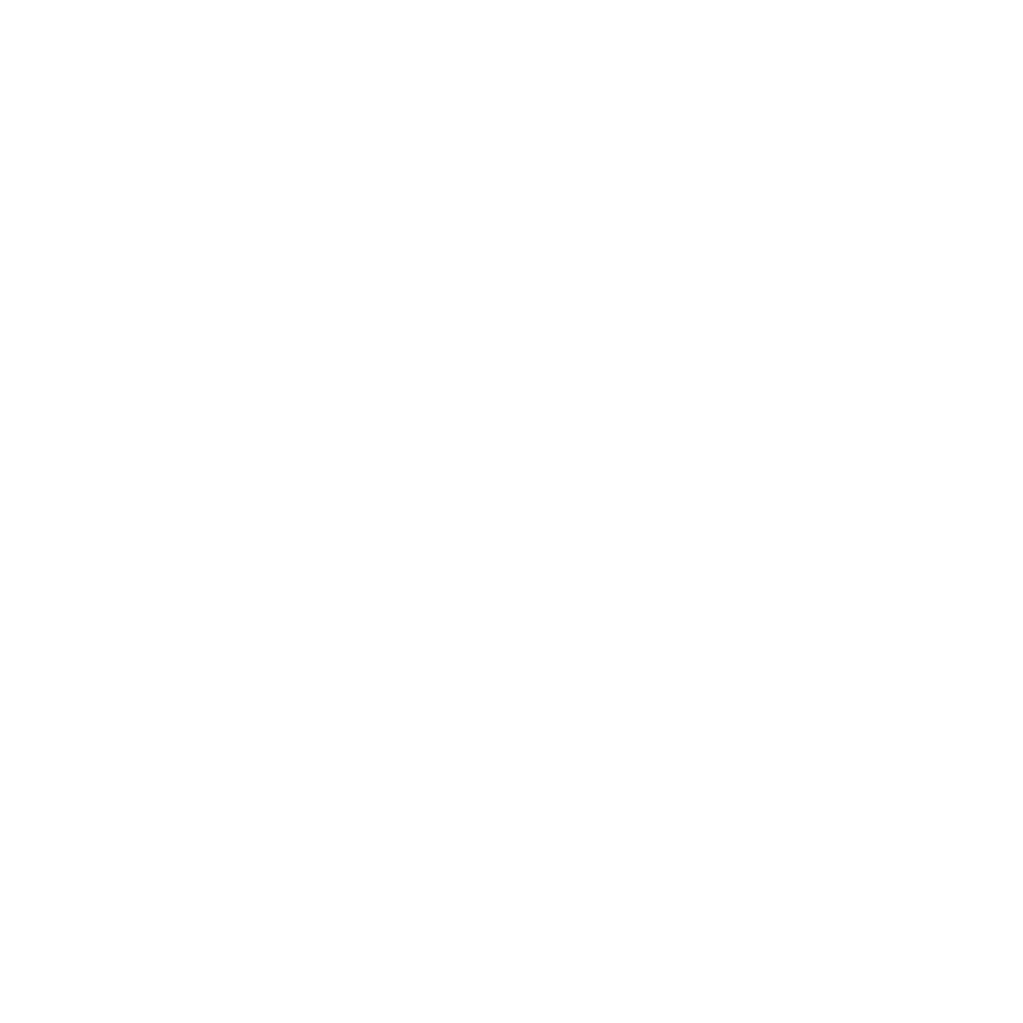


02398000 CHATTOOGA RIVER AT SUMGERILLE, GA.

LOCATION..-Lat $34^{\circ} 28^{\prime} 03^{\prime \prime}$, Iong $85^{\circ} 20^{\prime} 19^{\prime \prime}$, Chattooga County, at gaging station on left bank 600 ft downstream from bridge on $\mathrm{U} . \mathrm{S}$. Highway 27,1 mile southeast of Summerville, and 4 miles upstream from Raccoon Creek.

DRAINAGE AREA, --193 sq

PERIOD OF RECORD.--Chemical analyses: March 1968 to September 1970 (partial record).

pruarks.--Laboratory chemical analyses by Georgia water Quality Control Board. Field determination of discharge, - ter temperature, $\mathrm{pH}$, and dissolved oxygen by U.S. Geological Survey.

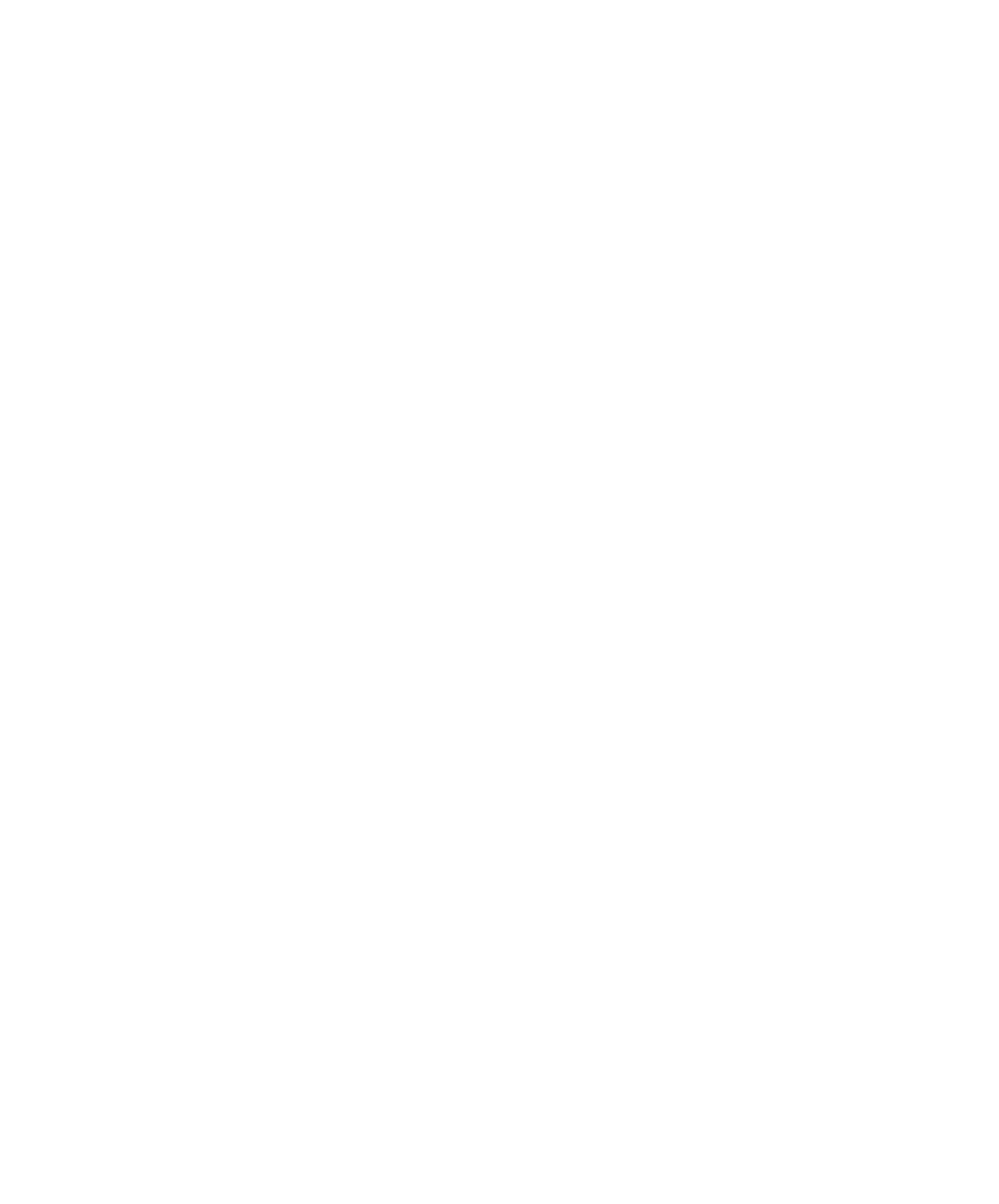




\section{MOBILE RIVER BASIN}

02433500 TOMBIGBEE RIVER AT BIGBEE, MISS.

LOCATION, - -Lat $34^{\circ} 00^{\prime} 40^{\prime \prime}$, Iong $88^{\circ} 30^{\prime} 50^{\prime \prime}$, 1n SW 1 NE 1 sec.25, T.12 s., R. 7 E., Chickasaw meridian, Monroe County, at

gaging station at bridge on State Highway $6,0.2$ mile upstream from St. Louls-San Francisco Rallway bridge,
0.5 mile southeast of Bigbee, 2 miles northwest of fmory, and 3.7 miles upstream from West Fork Tombigbee River. DRAINAGE AREA.--1,194 sq mi.

PERIOD OF RECORD.--Chemical analyses: Novemher 1969 to September 1970 (partial record).

CHEMICAL ANALYSES, WATER YEAR NOVEMBER 1969 TO SEPTEMBER 1970

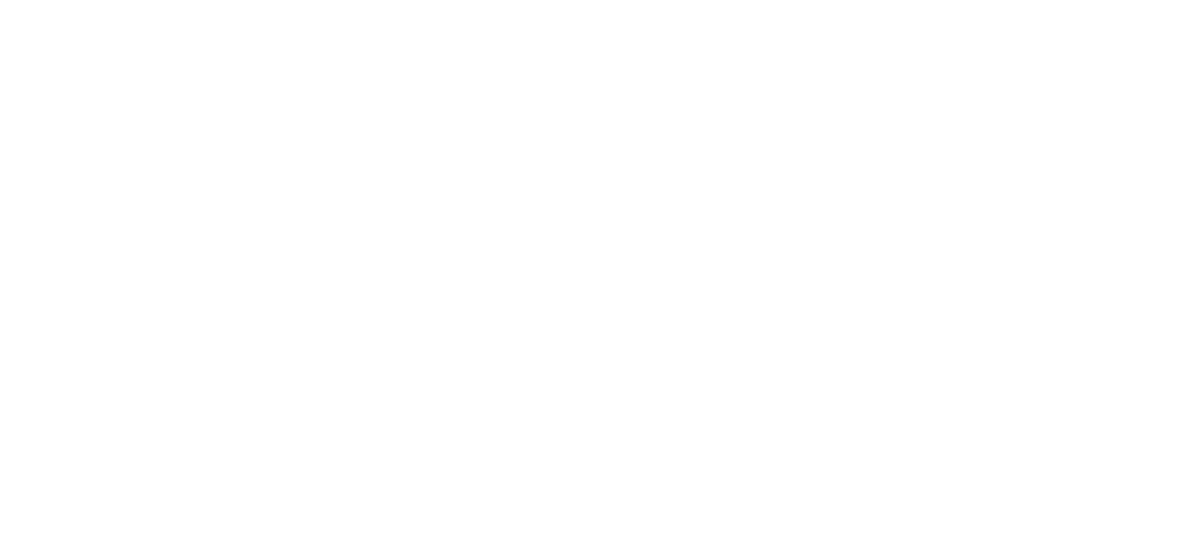

\begin{tabular}{|c|c|c|c|c|c|c|c|c|c|c|c|}
\hline $\begin{array}{l}\text { Nov. } \\
17 . \ldots \\
17 . .\end{array}$ & 0.00 & 0.11 & 16 & 13 & 3.0 & 3.5 & 0.2 & 14 & 1.6 & $11 \ldots$ & $\begin{array}{r}300 \\
--\end{array}$ \\
\hline OEC. & -- & - & -- & -- & -- & -- & -- & -- & -- & - & -- \\
\hline OPR... & -- & - & -- & $\rightarrow$ & -- & -- & -- & -- & -- & - & -- \\
\hline $29 .$. & 0.00 & 0.20 & 23 & 18 & $\cdots$ & - & - & -- & -- & 5.8 & 400 \\
\hline JUNE & - & $-\infty$ & -- & -- & -- & - & -- & -- & - & $\cdots$ & -- \\
\hline SEPT. & 0.00 & 0.04 & 21 & 14 & 7.0 & 5.0 & 0.3 & 15 & -- & 3.3 & 3800 \\
\hline $09 . .$. & 0.10 & 0.04 & 20 & 15 & 5.0 & 4.8 & 0.3 & 15 & 0.9 & 2.8 & 660 \\
\hline & DATE & $\begin{array}{l}\text { DIS- } \\
\text { SOL VED } \\
\text { SOL. IDS } \\
\text { (TONS } \\
\text { PER } \\
\text { DAY) }\end{array}$ & $\begin{array}{l}\text { DIS- } \\
\text { SOLVEO } \\
\text { SJLIOS } \\
\text { ITONS } \\
\text { PER } \\
\text { AC-FT) }\end{array}$ & $\begin{array}{l}\text { NITRATE } \\
\text { (NOZ) } \\
\text { (MG/L) }\end{array}$ & $\begin{array}{l}\text { ALKA- } \\
\text { LINITY } \\
\text { AS } \\
\text { CACO3 } \\
\text { (MG/L) }\end{array}$ & $\begin{array}{l}\text { TOTAL } \\
\text { RESI- } \\
\text { DUE } \\
\text { (MG/L) }\end{array}$ & $\begin{array}{l}\text { LOSS } \\
\text { ON } \\
\text { IGNI- } \\
\text { TION } \\
\text { (MG LI) }\end{array}$ & $\begin{array}{l}\text { OIS- } \\
\text { SOLVED } \\
\text { SOLIOS } \\
\text { (AG/L) }\end{array}$ & $\begin{array}{l}\text { SUS- } \\
\text { PENOED } \\
\text { SOLIOS } \\
\text { (MGIL) }\end{array}$ & $\begin{array}{l}\text { NITR I IE } \\
\text { (VD2) } \\
\text { (MG/L) }\end{array}$ & $\begin{array}{l}\text { BIO- } \\
\text { CHEM- } \\
\text { ICAL } \\
\text { OXYGEN } \\
\text { OEMAND } \\
\text { (MG/LI }\end{array}$ \\
\hline & Nov. & 171 & 0.11 & 0.0 & -- & - & - & -- & -- & $\ldots$ & -- \\
\hline & OEC... & - & - & - & -- & - & -- & -- & -- & - & -- \\
\hline & $\begin{array}{l}17 \ldots \\
\text { FE } 8 .\end{array}$ & - & - & - & - & - & - & -- & -- & $-\cdots$ & -- \\
\hline & $\begin{array}{l}05 . . \\
\text { APR. }\end{array}$ & -- & -- & -- & -- & - & - & -- & -- & - & - \\
\hline & $29 \ldots$ & -- & $\rightarrow$ & -- & 27 & 197 & 77 & 129 & 68 & 0.00 & -- \\
\hline & JUNE & -- & - & - & -- & -- & - & -- & -- & -- & -- \\
\hline & $\begin{array}{l}10 . . . \\
\text { SEPT. }\end{array}$ & - & -- & -- & -- & 120 & 50 & 67 & 53 & 0.00 & 2.0 \\
\hline & $09 .$. & -- & -- & -- & 16 & 87 & 37 & 63 & 24 & 0.00 & 0.8 \\
\hline
\end{tabular}




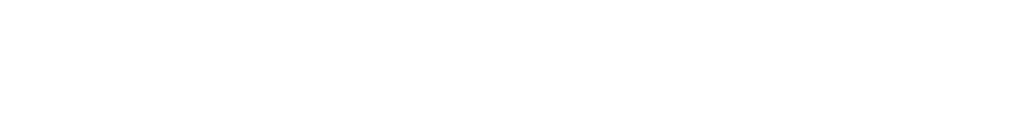

\section{APALACHI COLA RIVER BASIN}

02342500 UCHEE CREEK NEAR FORT MITCHELL (LAT 321900 LONG 0850054 )

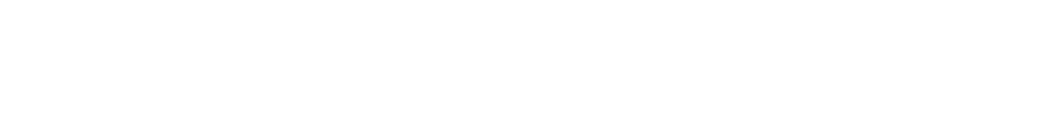

A DAILY MEAN DISCHARGE.

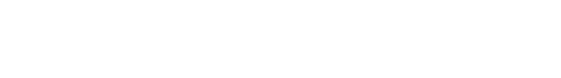

02344000 CHATTAHOOCHEE RIVER AT ALAGA (LAT 310654 LONG 850243 )

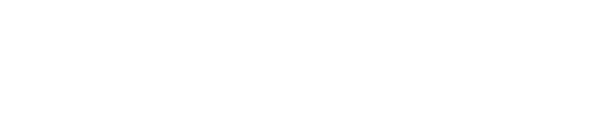

DAT

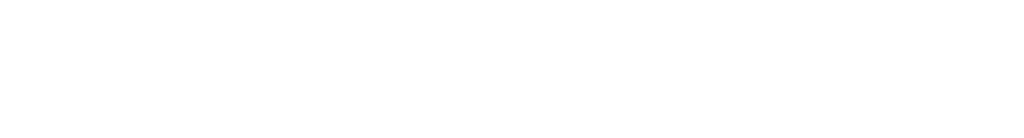

\begin{tabular}{|c|c|c|c|c|c|c|c|c|c|c|c|}
\hline $\begin{array}{l}\text { OCT } \\
\text { FEB } \\
\text { MAR } \\
\text { MAY } \\
\text { JUL } \\
\text { AUG }\end{array}$ & 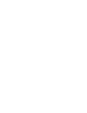 & $\begin{array}{l}6.3 \\
2.0 \\
4.5 \\
6.5 \\
6.0 \\
7.0\end{array}$ & $\begin{array}{r}200 \\
350 \\
360 \\
2200 \\
600 \\
250\end{array}$ & $\begin{array}{r}<50 \\
<50 \\
<50 \\
50 \\
60 \\
50\end{array}$ & $\begin{array}{l}5.4 \\
5.5 \\
6.3 \\
5.0 \\
7.0 \\
7.5\end{array}$ & $\begin{array}{l}1.1 \\
1.2 \\
1.1 \\
1.0 \\
1.4 \\
1.2\end{array}$ & $\begin{array}{l}8.9 \\
5.8 \\
6.0 \\
4.1 \\
7.8 \\
6.0\end{array}$ & $\begin{array}{l}1.9 \\
1.6 \\
1.3 \\
1.6 \\
1.9 \\
1.8\end{array}$ & $\begin{array}{l}25 \\
21 \\
23 \\
17 \\
31 \\
25\end{array}$ & $\begin{array}{l}8.0 \\
6.0 \\
8.0 \\
6.0 \\
8.0 \\
9.0\end{array}$ & $\begin{array}{l}4.2 \\
3.2 \\
4.5 \\
3.0 \\
3.8 \\
4.9\end{array}$ \\
\hline & DATE & $\begin{array}{c}\text { NI TRATE } \\
\text { (N) } \\
\text { (MG/L) }\end{array}$ & $\begin{array}{l}\text { PHOS- } \\
\text { PHATE } \\
\text { (PO4) } \\
\text { (MG/L) }\end{array}$ & $\begin{array}{l}\text { TOTAL } \\
\text { FILT- } \\
\text { RABLE } \\
\text { RESIDUE } \\
\text { (MG/L) }\end{array}$ & $\begin{array}{c}\text { TOTAL } \\
\text { NON- } \\
\text { FILT- } \\
\text { RABLE } \\
\text { RESIDUE } \\
\text { (MG/L) }\end{array}$ & $\begin{array}{l}\text { HARD- } \\
\text { NESS } \\
\text { (CA,MG) } \\
\text { (MG/L) }\end{array}$ & $\begin{array}{l}\text { SPE- } \\
\text { CIFIC } \\
\text { CON- } \\
\text { DUCT- } \\
\text { ANCE } \\
\text { (MICRO- } \\
\text { MHOS) }\end{array}$ & $\begin{array}{l}\text { COLOR } \\
\text { IPLAT- } \\
\text { INUM- } \\
\text { COBAL } \\
\text { UNITS }\end{array}$ & $\begin{array}{l}\text { TUR- } \\
\text { BID- } \\
\text { ITY } \\
\text { (JTU) }\end{array}$ & $\begin{array}{l}\text { BIO- } \\
\text { CHEM- } \\
\text { ICAL } \\
\text { OXYGEN } \\
\text { DEMAND } \\
\text { (MG/L) }\end{array}$ & $\begin{array}{l}\text { FECAL } \\
\text { COLI- } \\
\text { FORM } \\
\text { (MPN) }\end{array}$ \\
\hline $\begin{array}{l}\text { OCT } \\
\text { FEB } \\
\text { MAR } \\
\text { MAY } \\
\text { JUL } \\
\text { AUG }\end{array}$ & 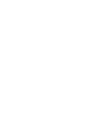 & $\begin{array}{l}.4 \\
.1 \\
.2 \\
.4 \\
.1 \\
.0\end{array}$ & $\begin{array}{l}.12 \\
.25 \\
.15 \\
.14 \\
.06 \\
.14\end{array}$ & $\begin{array}{l}62 \\
48 \\
56 \\
55 \\
64 \\
55\end{array}$ & $\begin{array}{r}5 \\
23 \\
8 \\
12 \\
20 \\
16\end{array}$ & $\begin{array}{l}16 \\
18 \\
19 \\
16 \\
23 \\
22\end{array}$ & $\begin{array}{l}86 \\
68 \\
83 \\
63 \\
88 \\
80\end{array}$ & $\begin{array}{r}20 \\
20 \\
30 \\
120 \\
25 \\
10\end{array}$ & $\begin{array}{l}9.0 \\
18 \\
9.0 \\
41 \\
10 \\
7.0\end{array}$ & $\begin{array}{l}2.8 \\
2.6 \\
2.8 \\
1.3 \\
1.4 \\
1.4\end{array}$ & $\begin{array}{r}930 \\
4300 \\
36 \\
230 \\
- \\
3900\end{array}$ \\
\hline & & TIME & $\begin{array}{l}\text { OIS- } \\
\text { CHARGE } \\
\text { (CFS) }\end{array}$ & $\begin{array}{l}\text { BICAR- } \\
\text { BONATE } \\
\text { (HCO3) } \\
\text { (MG/L) }\end{array}$ & $\begin{array}{l}\text { CAR- } \\
\text { BONATE } \\
\text { (CO3) } \\
\text { (MG/L) }\end{array}$ & $\begin{array}{l}\text { CHLO- } \\
\text { RIDE } \\
\text { (CL) } \\
\text { (MG/L) }\end{array}$ & $\begin{array}{l}\text { HARD- } \\
\text { NESS } \\
(C A, M G) \\
(M G / L)\end{array}$ & $\begin{array}{l}\text { NUN- } \\
\text { CAR- } \\
\text { BDNATE } \\
\text { HARD- } \\
\text { NESS } \\
\text { ( MG/L) }\end{array}$ & $\begin{array}{l}\text { SPECI - } \\
\text { FIC } \\
\text { COND- } \\
\text { UCTANCE } \\
\text { (MICRO- } \\
\text { MHOS) }\end{array}$ & $\begin{array}{c}P H \\
\text { (UNITS) }\end{array}$ & $\begin{array}{l}\text { TEMP- } \\
\text { ERATURE } \\
\text { (DEG C) }\end{array}$ \\
\hline
\end{tabular}

MOBILE RIVER BASIN

02415000 HILLABEe CREeK NEAR hACKNEYVILLE (LAT 330400 LONG 0855300 )

\begin{tabular}{|c|c|c|c|c|c|c|c|c|c|c|}
\hline $\begin{array}{l}\text { OCT., } 1969 \\
15 \ldots . .\end{array}$ & 1300 & 70 & 17 & 0 & 1.6 & 12 & 0 & 36 & 7.6 & 17.0 \\
\hline NOV. & 1415 & 67 & 15 & 0 & 2.0 & 8 & 0 & 45 & 7.2 & 10.0 \\
\hline $\begin{array}{l}\text { JAN.. } 1970 \\
\text { O6... } \\
\text { FEB. }\end{array}$ & 0910 & 246 & 14 & 0 & 1.8 & 11 & 0 & 32 & 7.6 & 4.0 \\
\hline APR... & 1100 & 324 & 12 & 0 & 2.0 & 8 & 0 & 32 & 6.9 & 10.0 \\
\hline $\begin{array}{l}\text { O3... } \\
\text { JUNE }\end{array}$ & 1220 & 528 & 11 & 0 & 2.0 & 6 & 0 & 35 & 6.7 & 14.5 \\
\hline SEP. & 0900 & 126 & 16 & 0 & 2.0 & 10 & 0 & 38 & 6.8 & 23.0 \\
\hline $17 \ldots$ & $\begin{array}{l}1000 \\
1200\end{array}$ & $\begin{array}{l}48 \\
48\end{array}$ & $\begin{array}{l}14 \\
14\end{array}$ & $\begin{array}{l}0 \\
0\end{array}$ & $\begin{array}{l}6.0 \\
6.0\end{array}$ & $\begin{array}{l}8 \\
8\end{array}$ & $\begin{array}{l}0 \\
0\end{array}$ & $\begin{array}{l}33 \\
33\end{array}$ & $\begin{array}{l}6.6 \\
6.6\end{array}$ & $\begin{array}{l}25.0 \\
25.0\end{array}$ \\
\hline
\end{tabular}




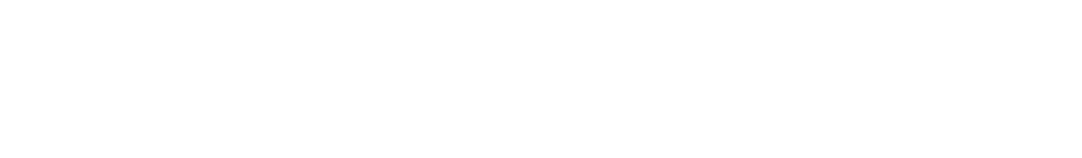

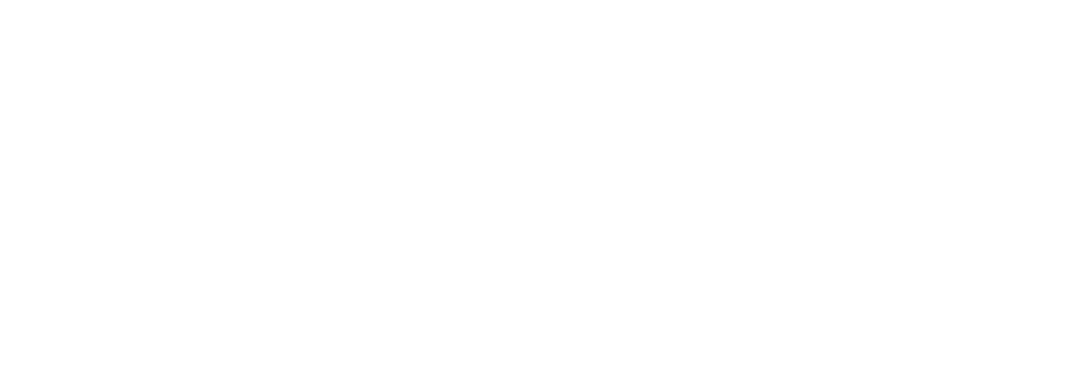

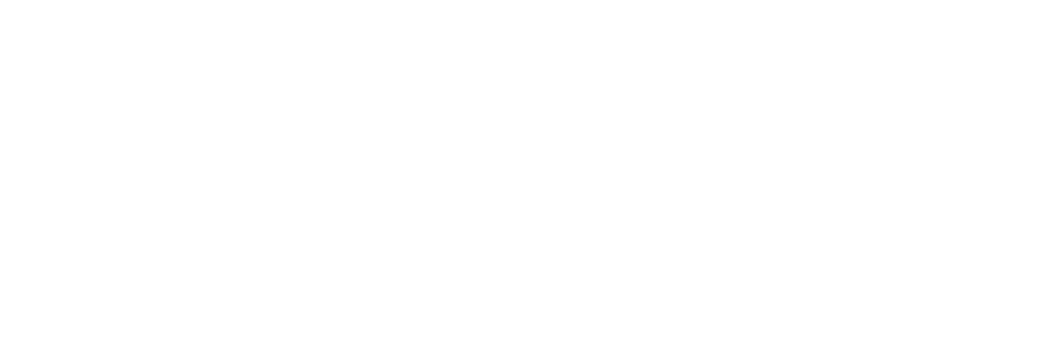

02422500 MULBERRY CREEK AT JONES ILAT $32 \quad 3458$ LONG OB6 54 13)

\begin{tabular}{|c|c|c|c|c|c|c|c|c|c|c|c|}
\hline $\begin{array}{l}\text { NOV. } 1969 \\
18 \ldots .1 \\
\text { JAN. } 1970\end{array}$ & 1440 & 80 & -- & -- & - & $\cdots$ & -- & 13 & 0 & -- & 2.4 \\
\hline $\begin{array}{l}\text { O8... } \\
\text { FEB. }\end{array}$ & 1335 & 307 & - & - & 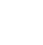 & - & $\cdots$ & 10 & 0 & - & 2.6 \\
\hline MAR. & 1030 & 198 & - & -- & - & -- & -- & 10 & 0 & - & 3.0 \\
\hline$\underset{\text { MAY }}{27} \cdots$ & 1440 & 443 & -- & -- & - & - & -- & 8 & 0 & -- & 2.4 \\
\hline $\begin{array}{l}\text { OB.... } \\
\text { JUNE }\end{array}$ & 1250 & 193 & 10 & 2.5 & 1.1 & 1.5 & .8 & 8 & 0 & 4.0 & 2.2 \\
\hline $\begin{array}{l}19 . . . \\
\text { SEP. }\end{array}$ & 1045 & 90 & 13 & 2.6 & 1.2 & 1.6 & 1.1 & 13 & 0 & 2.0 & 2.8 \\
\hline $08 \ldots$ & 1030 & 134 & -- & - & - & - & -- & 17 & 0 & $\cdots$ & 3.2 \\
\hline
\end{tabular}

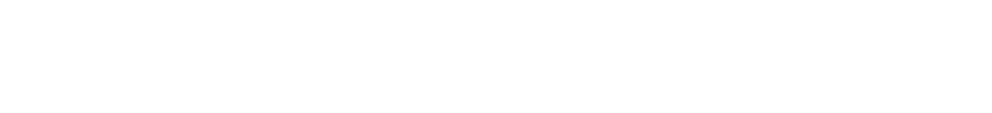

\begin{tabular}{|c|c|c|c|c|c|c|c|c|c|c|}
\hline $\begin{array}{l}\text { NOV.., }: 969 \\
18 . . . \\
\text { JAN., } 1970\end{array}$ & -- & -- & -- & -- & -- & 10 & 0 & 43 & 6.8 & 15.0 \\
\hline FEB... & -- & -- & -- & - & - & 10 & 2 & 37 & 7.2 & 7.0 \\
\hline MAR:. & -- & -- & -- & $=$ & -- & 10 & 2 & 38 & 6.8 & 6.0 \\
\hline $\operatorname{MAY}^{27} \cdots$ & -- & -- & -- & -- & - & 8 & 1 & 30 & 6.7 & 15.0 \\
\hline $\begin{array}{l}\text { OR.... } \\
\text { JUNE }\end{array}$ & .1 & .2 & 22 & 26 & .03 & 11 & 1 & 37 & 6.3 & 20.0 \\
\hline SEP. & $\cdot 1$ & $\cdot 1$ & 18 & 30 & .02 & 8 & 0 & 38 & 6.8 & 22.0 \\
\hline 08... & -- & -- & - & -- & -- & 14 & 0 & 44 & 6.9 & 24.0 \\
\hline
\end{tabular}




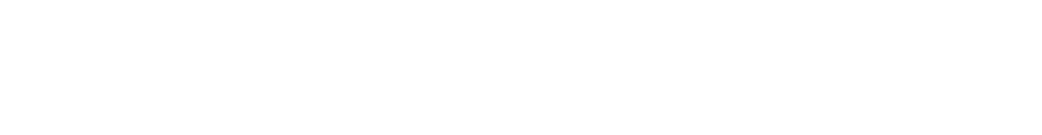

MOBILE RIVER BASIN--CONTINUED

02422780 ALABAMA RIVER AT U.S. HIGHWAY 8O CROSSING, NEAR SELMA (LAT 322310 LONG O86 59 45) JUN

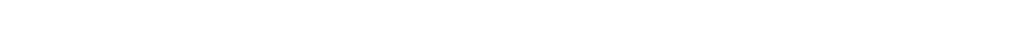

\begin{tabular}{|c|c|c|c|c|c|c|c|c|c|c|}
\hline ATE & TIME & $\begin{array}{l}\text { DIS- } \\
\text { CHARGE } \\
\text { (CFS) }\end{array}$ & $\begin{array}{l}\text { BICAR- } \\
\text { BONATE } \\
\text { (HCO3) } \\
\text { (MG/L) }\end{array}$ & $\begin{array}{l}\text { CAR- } \\
\text { BONATE } \\
\text { (CO3) } \\
\text { (MG/L) }\end{array}$ & $\begin{array}{l}\text { CHLO- } \\
\text { RIDE } \\
\text { (CL) } \\
(M G / L)\end{array}$ & $\begin{array}{l}\text { HARD- } \\
\text { NESS } \\
(C A, M G) \\
(M G / L)\end{array}$ & $\begin{array}{c}\text { NON- } \\
\text { CAR- } \\
\text { BONATE } \\
\text { HARD- } \\
\text { NESS } \\
\text { (MG/L) }\end{array}$ & $\begin{array}{l}\text { SPE- } \\
\text { CIFIC } \\
\text { CON- } \\
\text { DUCT- } \\
\text { ANCE } \\
\text { (MICRO- } \\
\text { MHOS) }\end{array}$ & $\begin{array}{l}\text { PH } \\
\text { (UNI TS) }\end{array}$ & $\begin{array}{l}\text { TEMPER- } \\
\text { ATURE } \\
\text { (DEG C) }\end{array}$ \\
\hline & 02429615 & & & & & & $\begin{array}{lll}31 & 14 & 04\end{array}$ & LONG 087 & 0551 & \\
\hline
\end{tabular}

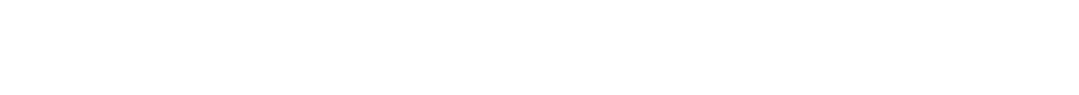

\begin{tabular}{|c|c|c|c|c|c|c|c|c|c|c|}
\hline $\begin{array}{l}\text { MAY } 291970 \\
\text { JUL } 09 . \ldots .\end{array}$ & $\begin{array}{l}1045 \\
141 E\end{array}$ & - & $\begin{array}{l}46 \\
50\end{array}$ & $\begin{array}{l}0 \\
0\end{array}$ & $\begin{array}{l}6.4 \\
6.0\end{array}$ & $\begin{array}{l}41 \\
42\end{array}$ & $\begin{array}{l}3 \\
1\end{array}$ & $\begin{array}{l}119 \\
118\end{array}$ & $\begin{array}{l}7.4 \\
7.0\end{array}$ & 28.0 \\
\hline OATE & $\begin{array}{l}\text { DIS- } \\
\text { CHARGE } \\
\text { (CFS) }\end{array}$ & $\begin{array}{l}\text { SILICA } \\
\text { (SIDL) } \\
\text { (MG IL) }\end{array}$ & $\begin{array}{l}\text { JOT AL } \\
\text { IRON } \\
\text { (FE) } \\
\text { (UG/L) }\end{array}$ & $\begin{array}{l}\text { CAL- } \\
\text { CIUM } \\
\text { (CA) } \\
\text { (MGIL) }\end{array}$ & $\begin{array}{c}\text { MAG- } \\
\text { NE- } \\
\text { SIUM } \\
\text { (MG) } \\
\text { (MGIL) }\end{array}$ & $\begin{array}{c}\text { SODIUM } \\
\text { (NA) } \\
\text { (MG/L) }\end{array}$ & $\begin{array}{l}\text { PO- } \\
\text { TAS- } \\
\text { SIUM } \\
\text { (K) } \\
\text { (MG/L) }\end{array}$ & $\begin{array}{l}\text { BICAR- } \\
\text { BONATE } \\
\text { (HCO3) } \\
\text { (MGIL) }\end{array}$ & $\begin{array}{l}\text { CAR- } \\
\text { BONATE } \\
\text { (CO3) } \\
\text { (MG/L) }\end{array}$ & $\begin{array}{l}\text { SULFAYE } \\
\text { (SO4) } \\
\text { (MGAL) }\end{array}$ \\
\hline
\end{tabular}

02455000 LOCUST FORK NEAR CLEVELAND (LAT $34 \quad 02 \quad 00$ LONG $086 \quad 34001$

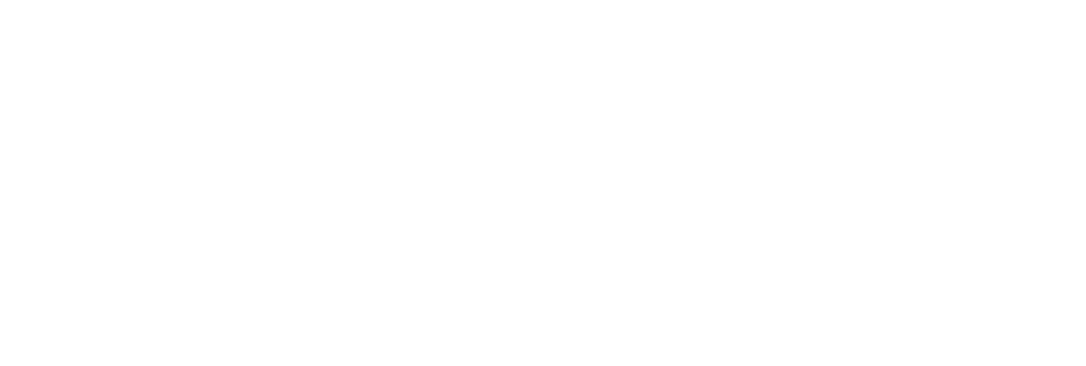

OCT. 1969

\begin{tabular}{|c|c|c|c|c|c|c|c|c|c|c|c|}
\hline $\begin{array}{l}07 . . . \\
\text { Nov. }\end{array}$ & 6.2 & .1 & 1.1 & -- & 114 & .16 & 87 & 34 & 220 & 7.0 & 19.7 \\
\hline $\begin{array}{l}\text { 17.... } \\
\text { JAN., } 1970\end{array}$ & 5.4 & -- & -- & -- & -- & $\sim$ & 92 & 31 & 215 & 6.9 & 3.0 \\
\hline FEB... & 5.0 & .1 & 4.9 & -- & 48 & .07 & $2 B$ & 16 & 85 & 6.4 & 7.0 \\
\hline$\underset{\text { MAY }}{24 \ldots}$ & 4.2 & .1 & 3.2 & -- & 47 & .06 & 31 & 11 & 85 & 5.6 & - \\
\hline AUG... & 4.0 & .1 & 2.4 & 70 & 77 & .10 & 59 & 20 & 141 & 6.6 & -- \\
\hline $04 \ldots$ & 5.6 & -1 & 5.0 & 113 & 110 & .15 & 84 & 22 & 190 & 6.9 & 29.0 \\
\hline
\end{tabular}




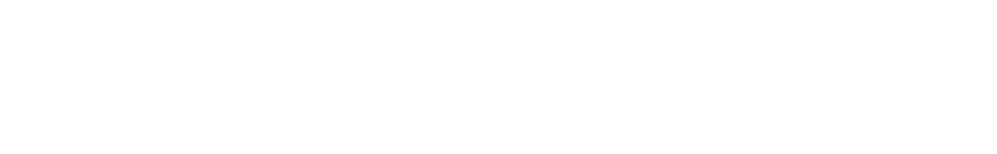

02456000 TURKEY CREEK AT MORRIS (LAT 334425 LONG D86 4845 )

\begin{tabular}{|c|c|c|c|c|c|c|c|c|c|c|}
\hline OCT., 1969 & 1015 & 17 & 152 & 0 & 2.6 & 134 & 9 & 272 & 7.5 & 19.0 \\
\hline NOV. & 1205 & 32 & 79 & 0 & 3.0 & 172 & 107 & 391 & 7.3 & 8.5 \\
\hline $27 . .$. & 1120 & 110 & 50 & 0 & 3.4 & 92 & 51 & 186 & 7.5 & 7.0 \\
\hline AUG... & 1215 & 33 & 134 & - & 2.4 & 116 & 6 & 236 & 7.3 & - \\
\hline $27 \ldots$ & 1745 & 17 & 104 & 0 & 3.6 & 136 & 51 & 311 & 7.0 & 24.0 \\
\hline
\end{tabular}

02456500 LOCUST FORK AT SAYRE (LAT 334235 LONG $0 B 65900$ I

$\begin{array}{lrr}\text { OCI... } 1969 & & \\ \text { O6... } & 1205 & 115 \\ \text { NDV. } & & \\ 14 \ldots . .1 & 1530 & 88 \\ \text { JAN..1 } 1970 & & \\ 26 . . . & 1345 & 730 \\ \text { JUNE } & & \\ 10 \ldots . . & 1100 & 454 \\ \text { JULY } & & \\ \text { 31... } & 1600 & 99 \\ \text { AUG. } & & \\ \text { 27... } & 1130 & 110\end{array}$

DATE

84
96
42
52

$\begin{array}{rr}0 & 4 . \\ 0 & 4.0 \\ 0 & 3.4 \\ - & 2 . \\ 0 & 3 . \\ 0 & 3.2\end{array}$

$\begin{array}{lr}4.1 & 103 \\ 4.0 & 124 \\ 3.4 & 62 \\ 2.8 & 61 \\ 3.2 & 108 \\ 3.2 & 96 \\ \text { HAG- } & \end{array}$

$\begin{array}{rr}103 & 34 \\ 124 & 4 \\ 62 & 33 \\ 61 & 27 \\ 108 & 6 \\ 96 & 45\end{array}$

$\begin{array}{ll}34 & 236 \\ 45 & 276 \\ 33 & 127 \\ 27 & 152 \\ 61 & 256 \\ 45 & 228\end{array}$

7.3 21.0

$1.4 \quad 10.0$

1.26 .5

6.921 .5

$6.7 \quad--$

6.923 .0

\section{$\begin{array}{lll}\text { TOTAL } & \text { CAL- } & \text { NAG- } \\ \text { IRON } & \text { CIUM } & \text { SIUM } \\ \text { IFEI } & \text { ICAI } & \text { IMGI }\end{array}$}

NE- PO-

TAS- BICAR-

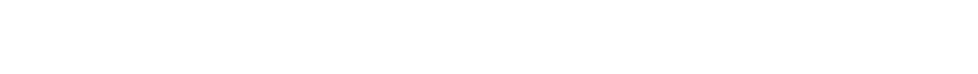
02457700 FIVE MILE CREEK AT LINN CROSSING (LAT 334020 LONG 0865752 )

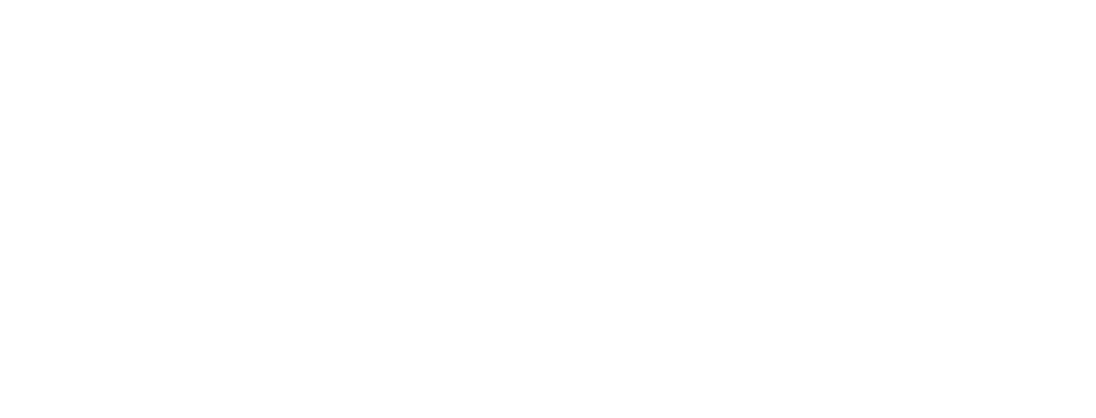

\begin{tabular}{|c|c|c|c|c|c|c|c|c|c|c|c|}
\hline No6... & 19 & 1.2 & 31 & 626 & 576 & .85 & 220 & 81 & 999 & 7.1 & 21.1 \\
\hline JAN... 1970 & $0^{20}$ & 1.0 & 31 & 584 & 537 & .79 & 228 & 123 & 930 & 6.6 & 9.0 \\
\hline FEB... & 14 & .6 & 19 & -- & 478 & .65 & 193 & 109 & 694 & 6.8 & 6.0 \\
\hline $\begin{array}{l}25 \ldots . . \\
\text { APR. }\end{array}$ & 11 & .8 & 27 & $=-$ & 512 & .70 & 216 & 142 & 762 & 6.7 & - \\
\hline$\underset{\text { JUNE }}{10 . .}$ & 10 & .6 & 4.1 & $=$ & 424 & .58 & 194 & 107 & 645 & 6.9 & 17.0 \\
\hline JULY & 13 & .6 & 5.7 & $-\infty$ & - & -- & 183 & 10 & 859 & 6.8 & 23.0 \\
\hline $\begin{array}{l}\text { 31.... } \\
\text { AUG. }\end{array}$ & 15 & 1.0 & 2.8 & 550 & 555 & .75 & 199 & 116 & 960 & 6.9 & - \\
\hline & 8.4 & .3 & .7 & 321 & 284 & .44 & 133 & 55 & 483 & 6.7 & 24.0 \\
\hline
\end{tabular}

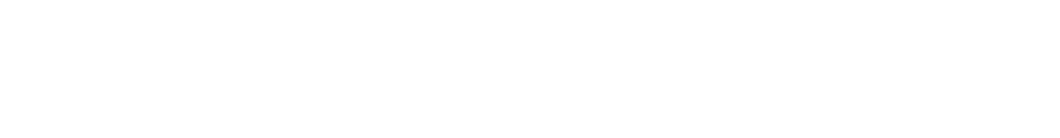

\begin{tabular}{|c|c|c|c|c|c|c|c|c|c|c|c|c|c|c|c|c|c|}
\hline \multirow{2}{*}{\multicolumn{3}{|c|}{ JUL 181970}} & -- & -- & & 5.0 & 0 & 1. & .0 & 2.0 & & 6 & & 16 & & 6.1 & - \\
\hline & & & 02469 & 692 & JAMES & CREEK & NEAR & PARAGDN & ILAT & 315223 & 3 LONG & ; 088 & 24 & 361 & & & \\
\hline \multirow[t]{2}{*}{ DEC } & 03 & 1969 & 0815 & -- & 30 & 06 & 0 & 59 & & 245 & & 0 & & 674 & & 7.9 & 1.0 \\
\hline & & & 02469722 & SUR & IEYORS & CREEK & NEAR & WOMACK & HILL 1 & ILAT 31 & 3240 & LONG & 088 & 13 & 301 & & \\
\hline EEB & 05 & 1970 & 0940 & -- & & 14 & 0 & 13 & & 25 & & 14 & & 96 & & 6.9 & 4.0 \\
\hline
\end{tabular}

02464380 BINNION CREEK NEAR SAMANTHA (LAT 332433 LONG OB,7 3648 ) 
CHEMICAL ANALYSES, WATER YEAR OCTOBER 1969 TO SEPTEMBER 1970

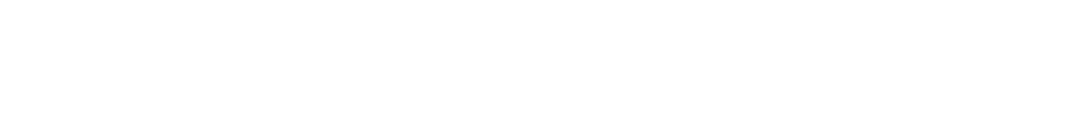

02470035 JACKSON CREEK NEAR SALITPA (AT STATE HIGHWAY 69 CROSSING) (LAT 313530 LONG 087 5825 )

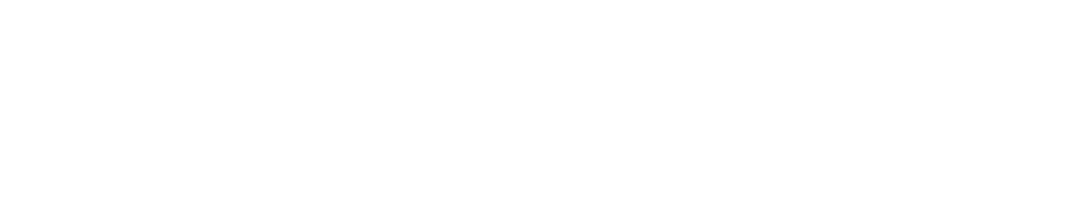

\begin{tabular}{|c|c|c|c|c|c|c|c|c|c|c|}
\hline & .1 & .4 & $=-$ & 76 & .10 & 56 & 5 & 123 & 7.3 & $-\infty$ \\
\hline $23 \ldots$ & .1 & -2 & 77 & 62 & .10 & 48 & 1 & 110 & 7.0 & 25.0 \\
\hline DATE & TIME & $\begin{array}{l}\text { DIS- } \\
\text { CHARGE } \\
\text { (CFS) }\end{array}$ & $\begin{array}{l}\text { BICAR- } \\
\text { BONATE } \\
\text { (HCO3) } \\
\text { (MG/L) }\end{array}$ & $\begin{array}{l}\text { CAR- } \\
\text { BDNATE } \\
\text { (CO3) } \\
\text { (MG/L) }\end{array}$ & $\begin{array}{l}\text { CHLD- } \\
\text { RIDE } \\
\text { (CL) } \\
\text { (MG/L) }\end{array}$ & $\begin{array}{l}\text { HARD- } \\
\text { NESS } \\
\text { (CA,MG) } \\
\text { (MG/L) }\end{array}$ & $\begin{array}{l}\text { NON- } \\
\text { CAR- } \\
\text { BONATE } \\
\text { HARD- } \\
\text { NESS } \\
\text { (MG/L) }\end{array}$ & $\begin{array}{l}\text { SPECI- } \\
\text { FIC } \\
\text { COND- } \\
\text { UCTANCE } \\
\text { IMICRD- } \\
\text { MHOSI }\end{array}$ & $\begin{array}{c}\text { PH } \\
\text { (UNITS) }\end{array}$ & $\begin{array}{l}\text { TEMP- } \\
\text { ERATURE } \\
\text { (DEG C) }\end{array}$ \\
\hline
\end{tabular}

72470607 BULL BRANCH CREEK NEAR CITRONELLE (LAT 310238 LONG O8B O6 00)

\begin{tabular}{|c|c|c|c|c|c|c|c|c|c|c|}
\hline $06 \ldots$ & 1030 & -- & 6 & 0 & 3.6 & 6 & 1 & 24 & 6.3 & 13.0 \\
\hline OEC. & 0815 & 5.0 & 2 & 0 & 2.9 & 4 & 2 & 22 & 5.9 & 8.0 \\
\hline $29 \ldots$ & 1530 & 2.0 & 4 & 0 & 2.8 & 4 & 1 & 23 & 5.6 & 23.0 \\
\hline 02 & 0800 & 1.5 & 2 & 0 & 3.4 & 2 & 1 & 14 & 5.5 & 22.0 \\
\hline
\end{tabular}

02470610 CEDAR CREEK AT CEDAR CREEK FALLS (LAT 310323 LONG DB8 O4 23)

Nov., 1969

\begin{tabular}{|c|c|c|c|c|c|c|c|c|c|c|}
\hline $\begin{array}{l}\text { NOV..'1969 } \\
\text { O6... } \\
\text { APR..1970 }\end{array}$ & 0950 & -- & 2 & 0 & 17 & 11 & 9 & 70 & 6.0 & 13.0 \\
\hline $29 \ldots$ & 1400 & 20 & 2 & 0 & 14 & 9 & 7 & 74 & 6.0 & 23.0 \\
\hline & 1640 & 6.0 & 4 & 0 & 28 & 15 & 12 & 99 & 6.6 & 23.0 \\
\hline SEP. & 1100 & 8.0 & 4 & 0 & 24 & 16 & 13 & 110 & 5.8 & 19.0 \\
\hline & TIME & $\begin{array}{l}\text { DIS- } \\
\text { CHARGE }\end{array}$ & $\begin{array}{l}\text { BICAR- } \\
\text { BONATE } \\
\text { I HCO } 3 \text { I }\end{array}$ & $\begin{array}{l}\text { CAR- } \\
\text { BONATE } \\
\text { (CO3) }\end{array}$ & $\begin{array}{l}\text { CHLO- } \\
\text { RIOE } \\
\text { ICLI) }\end{array}$ & $\begin{array}{l}\text { HARD- } \\
\text { NESS } \\
\text { (CA, MG) }\end{array}$ & $\begin{array}{l}\text { NON- } \\
\text { CAR- } \\
\text { BONATE } \\
\text { HARD- } \\
\text { NESS } \\
\text { HGGS }\end{array}$ & $\begin{array}{l}\text { SPECI- } \\
\text { FIC } \\
\text { COND- } \\
\text { UCTANCE } \\
\text { (MICRD- }\end{array}$ & $\begin{array}{c}\mathrm{PH} \\
\text { (UNITS) }\end{array}$ & $\begin{array}{l}\text { TEMPER- } \\
\text { ATURE } \\
\text { (DEG C) }\end{array}$ \\
\hline
\end{tabular}

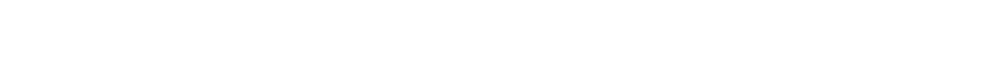

PASCAGOULA RIVER BASIN

02479465 PUPPY CREEK AT CITRONELLE (LAT 310424 LONG 0881450 )

\begin{tabular}{|c|c|c|c|c|c|c|c|c|c|c|}
\hline $\begin{array}{l}\text { O6... } \\
\text { DEC. }\end{array}$ & 1015 & -- & 0 & 0 & 470 & 225 & 225 & 1680 & 4.1 & 13.0 \\
\hline $\begin{array}{l}02 \ldots . .1970 \\
\text { FE8.. } 1970\end{array}$ & 1045 & -- & 2 & 0 & 476 & 245 & 244 & 1530 & 4.8 & 10.0 \\
\hline $\begin{array}{l}\text { D4... } \\
\text { MAR. }\end{array}$ & 1120 & -- & 6 & 0 & 523 & 288 & 283 & 1730 & 5.6 & 5.0 \\
\hline $\begin{array}{l}03 . . . \\
\text { APR. }\end{array}$ & 0800 & 2.0 & 9 & 0 & 248 & 138 & 131 & 841 & 5.8 & 14.0 \\
\hline JUNE & 0800 & 1.5 & 20 & D & 254 & 141 & 125 & 855 & 6.4 & 22.0 \\
\hline${ }_{\text {JUL }}^{03} \cdots$ & 1100 & 4.0 & 8 & 0 & 83 & 48 & 41 & 313 & 5.9 & 20.0 \\
\hline $\begin{array}{l}\text { O3... } \\
\text { 30... } \\
\text { SEP. }\end{array}$ & $\begin{array}{l}1515 \\
0820\end{array}$ & $\begin{array}{l}1.0 \\
3.0\end{array}$ & $\begin{array}{r}20 \\
0\end{array}$ & $\begin{array}{l}0 \\
0\end{array}$ & $\begin{array}{r}202 \\
3400\end{array}$ & $\begin{array}{r}108 \\
1800\end{array}$ & $\begin{array}{r}92 \\
1800\end{array}$ & $\begin{array}{r}682 \\
9590\end{array}$ & $\begin{array}{l}6.1 \\
3.5\end{array}$ & $\begin{array}{l}24.0 \\
23.0\end{array}$ \\
\hline $\begin{array}{l}01 \ldots \\
30 . \ldots\end{array}$ & $\begin{array}{l}1530 \\
0940\end{array}$ & $\begin{array}{l}1.5 \\
1.2\end{array}$ & $\begin{array}{l}0 \\
7\end{array}$ & $\begin{array}{l}0 \\
0\end{array}$ & $\begin{array}{r}1480 \\
17\end{array}$ & $\begin{array}{r}738 \\
16\end{array}$ & $\begin{array}{r}738 \\
10\end{array}$ & $\begin{array}{r}4790 \\
79\end{array}$ & $\begin{array}{l}3.6 \\
6.1\end{array}$ & $\begin{array}{l}26.0 \\
18.5\end{array}$ \\
\hline
\end{tabular}




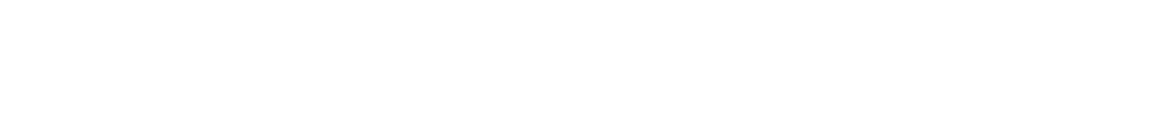

ST. MAPYS RIVER BASIN

02228500 - NORTH PRONG ST. MARYS RIVER AT MONIAC, GA. (LAT 303103 LONG 08? 13 50)

$\operatorname{MAY}_{06 . .} 197048$

MaY, 1970

20.0

02230500 - SO PRONG ST MARYS R NR GLEN ST MARY FL (LAT $3016 \quad 40$ LONG OB2 OB 40)

20.

PIGEON CREEK AT BOULOUGNE FLA (LAT 304539 LONG 081 5 A 04 )

MAY, 1970

02231250 - LITTLE ST MARYS $K$ NR HILLIARD FLA ILAT 304355 LONG ORI 5335 ,

\section{MAY 1970 \\ $13 . .$.}

25.5

02231253 - ST MARYS R NR GROSS FLA (LAT 3 N 4429 LONG $08141 \quad 17$ )

MAY, 1970

25.0

110

3.4

COASTAL BASINS BETHEEN ST. MARYS RIVER, AND ST, JUHNS RIVER

0223128 - THOMAS CREEK NR CRAWFOKD FLA (LAT $30>739$ LONG 08149571

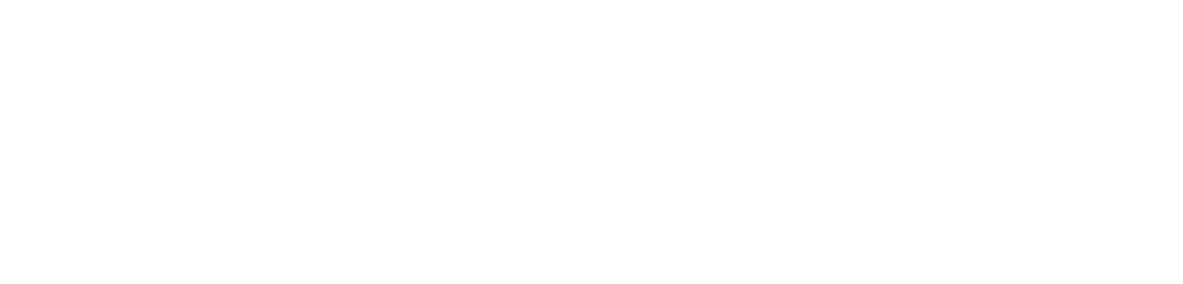

ST. JOHNS RIVER BASIN

02231342 - FT DRUM CREEK AT SS MKWY NR FI DKUM FL (LAT 273406 LONG 0804747 I

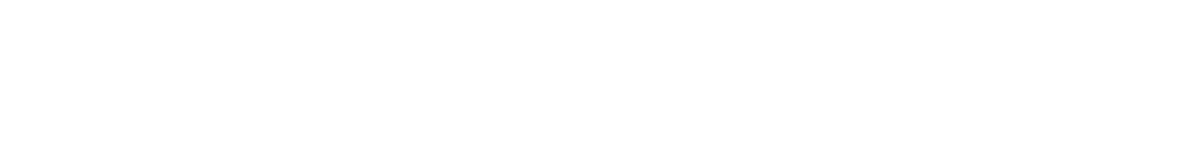

02231350 - ST JOHNS HOWATERS NR VERO BCH FLA (LAT 274132 LONG OBN 2500 )

\begin{tabular}{|c|c|c|c|c|c|c|c|c|c|c|c|c|}
\hline $\begin{array}{l}\text { OCT.. } 1969 \\
21 \ldots \ldots 1970 \\
\text { JAN.. } 1970\end{array}$ & - & 28.5 & 408 & 70 & 46 & 5.6 & 440 & 25 & 2.5 & 138 & 0 & I 38 \\
\hline MAY $27 \ldots$ & - & 15.5 & 540 & 10 & 64 & 8.3 & 600 & 35 & 2.5 & 166 & $n$ & 7.7 \\
\hline JULi: & -- & 28.0 & 505 & 50 & 54 & 6.8 & 590 & 38 & .7 & 158 & - & 7.9 \\
\hline $22 \ldots$ & -- & 28.5 & 550 & 50 & 56 & 8.8 & $71 n$ & 44 & 1.3 & 150 & 0 & 7.3 \\
\hline
\end{tabular}

02231372 - PLUE CYPRESS C TP NU 2 NK LONOSEE FLA (LAT 274641 LDNG 0805528 )

JULY, 1970

02231375 - BLUE CYPRESS C TR NO 3 AT LOKOSEE FLA (LAT 274531 LONG 08 N 54 28)

MAY, 1970

02231396 - BLUE CYPRFSS CREEK NEAR FELLSMERE FLA LLAT 274340 LONG 080 48191

\begin{tabular}{|c|c|c|c|c|c|c|c|c|c|c|c|c|}
\hline JAN." 1970 & - & 25.0 & 69 & 580 & 7.4 & 1.4 & 60 & 4.7 & .3 & 15 & 0 & 6.5 \\
\hline $\operatorname{JUL}_{\mathrm{Ju}}^{30} \ldots$ & 1.2 & 24.0 & 162 & 320 & 20 & 2.2 & 110 & 10 & .3 & 58 & - & 7.4 \\
\hline $21 \ldots$ & 12 & 26.0 & 168 & 560 & 20 & 2.8 & 100 & 10 & .8 & 48 & 0 & 7.0 \\
\hline
\end{tabular}


CHEMICAL ANALYSES, WATER YEAR OCTOBER 1969 TO SEPTEMBER 1970 (MAJOR CONSTITUENTS)

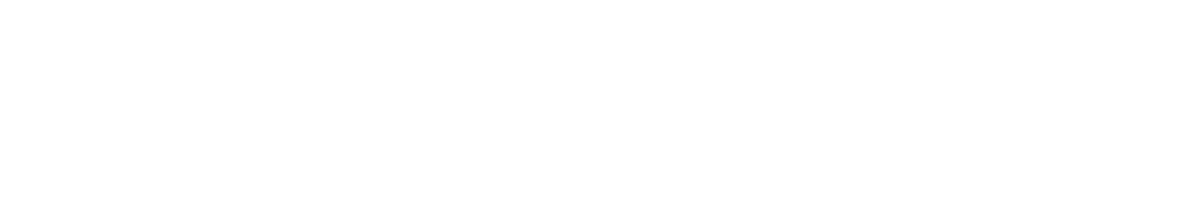

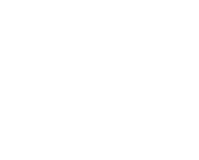

02230500 - SO PRONG ST MARYS R NR GLEN ST MARY FL ILAT 301640 LONG 0820840 ,

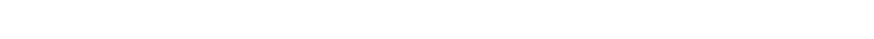

02231230 - PIGEON CREEK AT BOULOUGNE FLA (LAT 304539 LONG 0815904 )

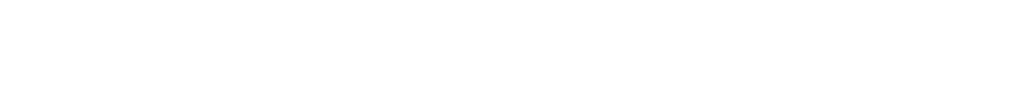

MAY 1970 1.I 11

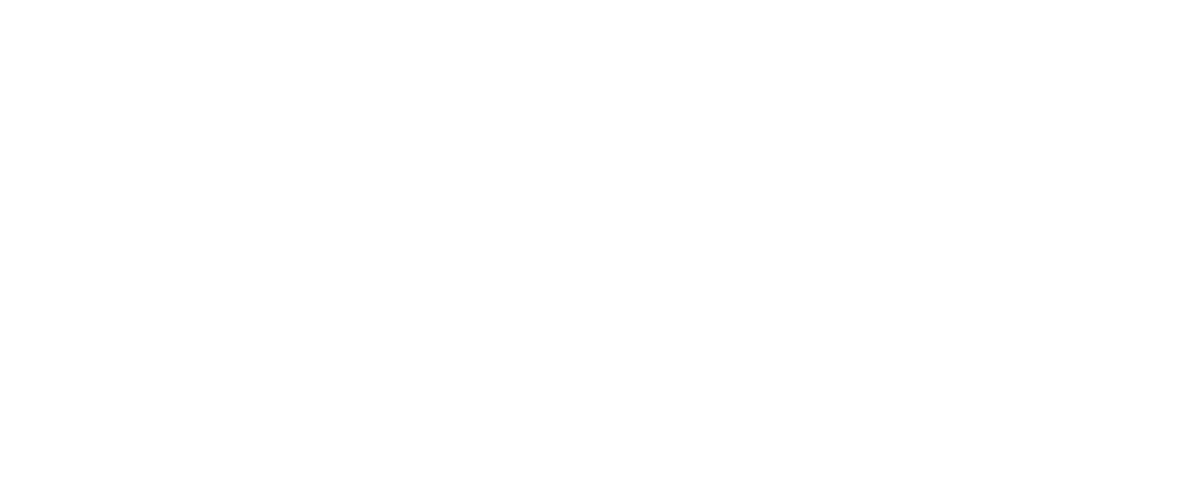

ST. JDHNS RIVER BASIN--CONTINUED

02231342 - FT DRUM CREEK AT SS PKWY NR FT DRUM FL (LAT 2734 O6 LONG 0804747 )

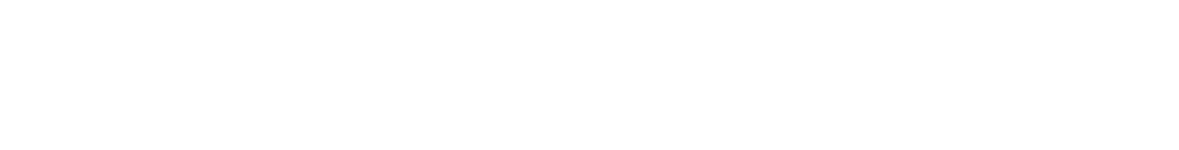

02231350 - ST JOHNS HDWATERS NR VERO BCH FLA ILAT 274132 LONG 08025001

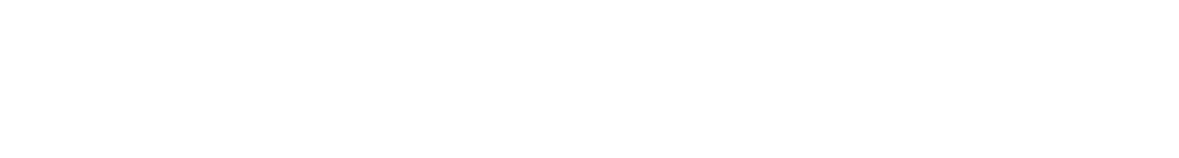

02231372 - BLUE CYPRESS C TR NO 2 NP LOKOSEE FLA (LAT 274641 LONG 11805528 )

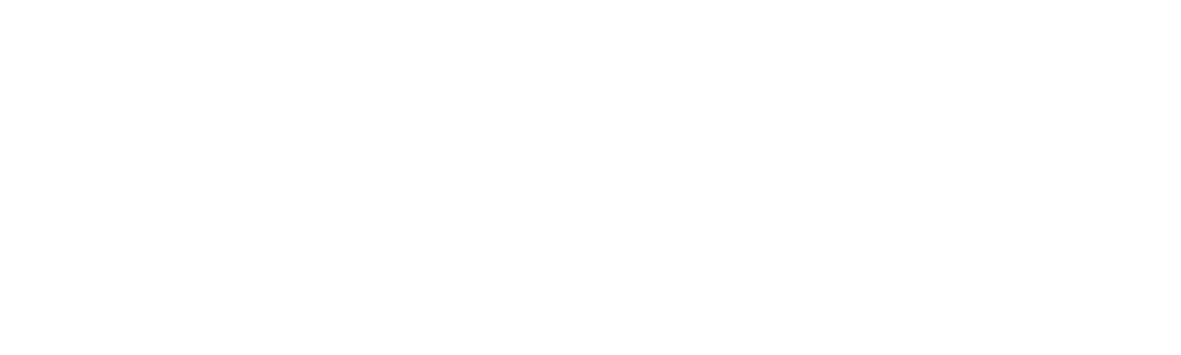




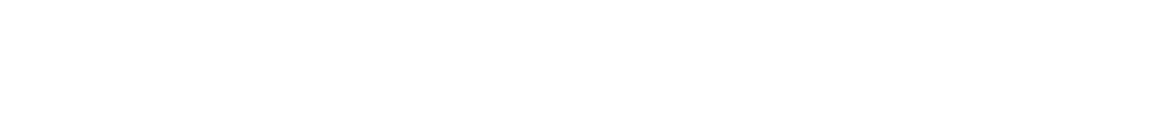

ST. JUHNS RIVER BASIN--CONTINUED

02231400 - BLUE CYPRESS LAKE NRIFELLSMERE FLA (LAT 274334 LONG 0804632 )

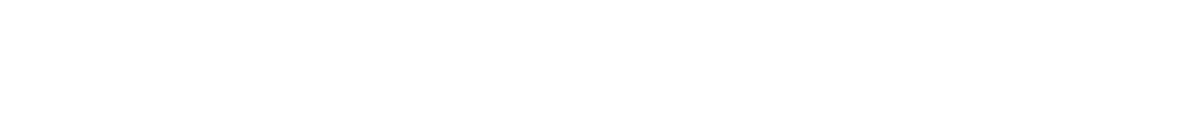

02231450 - ST JOHNS HOWATERS NR KENANSVILLE FLA ILAT 274917 LONG 08048431

$\begin{array}{cccccccccccc}\text { MAY } & 1970 \\ 01 . .0 & - & 27.5 & 710 & - & 56 & 16 & - & 59 & 1.6 & 116 & 0\end{array}$

02231467 - ST JOHNS R AB LK HELEN BLAZES NR MELBO (LAT 275943 LONG 0804730 )

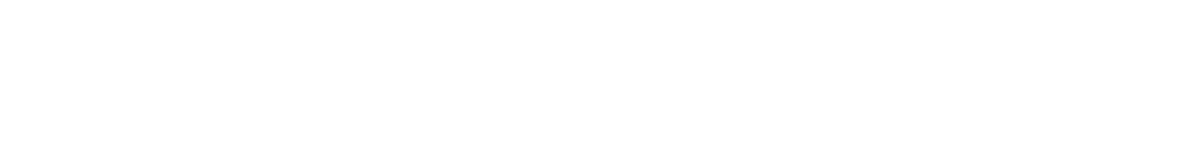

02231471 - LAKE HELEN BLAZES NEAR DEER PARK, FLA. (LAT 280130 LONG 0804756 )

\begin{tabular}{|c|c|c|c|c|c|c|c|c|c|c|c|c|}
\hline $\begin{array}{l}\text { OCT.. } 1969 \\
28 . . . \\
\text { FE8.. } 1970\end{array}$ & $=$ & 25.0 & 132 & 320 & 13 & 2.2 & 190 & 9.8 & 1.0 & 36 & 0 & 6.9 \\
\hline $\begin{array}{l}05 \ldots \\
\text { MAY }\end{array}$ & $-\infty$ & 11.0 & 191 & 170 & 17 & 3.0 & 240 & 17 & 2.1 & 44 & 0 & 7.2 \\
\hline JuLY... & - & 26.0 & 242 & 150 & 20 & 3.6 & 450 & 22 & .2 & 51 & -- & 7.4 \\
\hline & -- & 30.0 & 361 & 240 & 34 & 5.8 & 640 & 28 & .9 & 84 & $n$ & 7.3 \\
\hline
\end{tabular}

02231600 - JANE GREEN CREEK NR DEER PARK FLA (LAT 28 0427 LONG 0805318 )

Ocr., 1969

01... 899

21... 225

NOV... 987

JAN.: 1970

$\begin{array}{ll}07 \ldots . .2 & 497 \\ 27 . . . & 280\end{array}$

APR.

28...

JULY

21... 6.2

27.0
25.0

19.0

$\begin{array}{lll}13.0 & 108 & \\ 14.5 & 105 & 200\end{array}$

400
200
230

11.7

$1.4 \quad 7$

$8.0 \quad 1.3 \quad-$

7.0
5.6

$\begin{array}{rrrr}.8 & 30 & -. & 6.7 \\ .6 & 21 & 0 & 6.5\end{array}$

$23 \ldots 64$

$28.0 \quad 136$

9.4

$1.6 \quad 20$

7.9

.616

9.4

$\begin{array}{ll}.6 & 24 \\ .5 & 22\end{array}$

.530

$1.7 \quad 70 \quad 11$

$-\quad=420$

14
26

$3.3 \quad 80 \quad 17$

.832

SAMGRASS LAKE NEAR MELBOURNE FLA (LAT 280435 LONG 0804626 )

\begin{tabular}{|c|c|c|c|c|c|c|c|c|c|c|c|c|}
\hline $230 . .1909$ & -- & 26.5 & 113 & 390 & 12 & 1.9 & 190 & 8.0 & 1.0 & 32 & 0 & 6.9 \\
\hline MAY $03 . .$. & - & 16.0 & 160 & 140 & 14 & 2.4 & 160 & 15 & 1.4 & 34 & 0 & 7.0 \\
\hline JuLY... & -- & 26.0 & 223 & 120 & 18 & 3.2 & 370 & 21 & .2 & 46 & - & 7.4 \\
\hline $\begin{array}{l}23 \ldots \\
28 \ldots\end{array}$ & $=$ & $31 . \overline{0}$ & 330 & $\begin{array}{r}60 \\
180\end{array}$ & $30^{--}$ & $5 . \overline{2}$ & $\mathbf{5 3 0}$ & $26^{--}$ & 1.4 & 73 & $-\overline{0}$ & $\overline{8.1}$ \\
\hline
\end{tabular}

02232100 - LK WASHINGTON NR EAU GALLIE FLA ILAT 280850 LONG 08044101

\begin{tabular}{|c|c|c|c|c|c|c|c|c|c|c|c|c|}
\hline 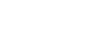 & -- & 26.5 & 135 & 300 & 13 & 2.2 & 230 & 11 & .8 & 32 & 0 & 7.3 \\
\hline$\underset{\text { MAY }}{03 . . .}$ & - & 17.0 & 180 & 140 & 15 & 2.6 & 240 & 16 & 1.7 & 34 & 0 & 7.2 \\
\hline JuLY... & $=$ & 27.0 & 250 & 140 & 21 & 3.3 & 390 & 22 & .5 & 50 & - & 7.7 \\
\hline & - & - & - & 90 & - & $\cdots$ & 570 & 33 & .9 & $=$ & $=$ & $=$ \\
\hline
\end{tabular}

02232162 - EST JOHNS TRIB CA NR OEER PARK (LAT 281253 LONG 08051 13)

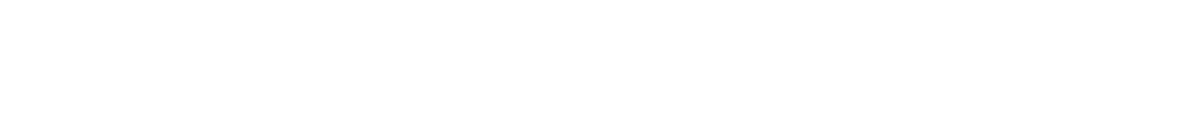


CHEMICAL ANALYSES, WATER YEAR OCTOBER 1969 TO SEPTEMBER 1970 WATER YEAR OCTOBER 1968
(MAJOR CONSTITUENTS)

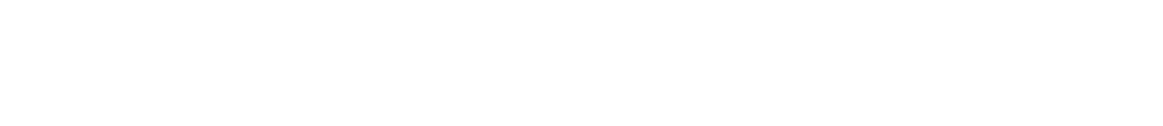
ST. JDHNS RIVER BASIN--CONTINUED

02231400 - BLUE CYPRESS LAKE NR FELLSMERE FLA ILAT 274334 LONG 08046321

\begin{tabular}{|c|c|c|c|c|c|c|c|c|c|c|c|c|}
\hline $\begin{array}{l}\text { OCT., } 1969 \\
22 . .1 \\
\text { JAN.: } 1970\end{array}$ & .8 & 23 & .2 & 34 & 14 & 21 & 105 & 67 & - & .14 & 3.5 & 1.0 \\
\hline $\begin{array}{l}28 \ldots \\
\text { APR. }\end{array}$ & $\cdot 8$ & 32 & .2 & 42 & 19 & 23 & 131 & 81 & -- & .18 & 3.4 & \\
\hline
\end{tabular}

02231450 - ST JOHNS hOWATERS NR KENANSVILLE FLA ILAT $2749 \quad 17$ LONG 0804843 )

MAY. 1970
$01 . .$.

02231471 - LAKE HELEN BLAZES NEAR DEER PARK, FLA. (LAT 280130 LONG 0804756 )

\begin{tabular}{|c|c|c|c|c|c|c|c|c|c|c|c|c|}
\hline $\begin{array}{ll}\text { OCT., } 1969 \\
28 . . .1\end{array}$ & .8 & 19 & .2 & 42 & 12 & 30 & 114 & 70 & $\cdots$ & .16 & 3.9 & 1.0 \\
\hline MAY 05 & 4.4 & 34 & .3 & 56 & 20 & 36 & 144 & 102 & - & .20 & 3.3 & - \\
\hline JULY... & 6.4 & 42 & ?? & 66 & 24 & 42 & 178 & 126 & - & .24 & 2.0 & 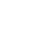 \\
\hline & 12 & 60 & .3 & 110 & 41 & 69 & 283 & 191 & $\ldots$ & . 38 & 2.9 & 1.0 \\
\hline
\end{tabular}

02231600 - JANE GREEN CREEK NR DEER PARK FLA ILAT 280427 LONG 080 53181

\begin{tabular}{|c|c|c|c|c|c|c|c|c|c|c|c|c|}
\hline OCT., 1969 & & & & & & & & & & & & \\
\hline $\begin{array}{l}01 \ldots . \\
21 \ldots\end{array}$ & .2 & $\begin{array}{l}13 \\
13\end{array}$ & .3 & $\begin{array}{l}34 \\
27\end{array}$ & 10 & $\begin{array}{l}25 \\
17\end{array}$ & $\begin{array}{l}96 \\
62\end{array}$ & $\begin{array}{l}54 \\
45\end{array}$ & $\begin{array}{l}233 \\
37.7\end{array}$ & $\begin{array}{l}.13 \\
.08\end{array}$ & 5.1 & $\begin{array}{l}1.0 \\
1.0\end{array}$ \\
\hline $\begin{array}{l}\text { NOV. } \\
\text { JAN... } 1970\end{array}$ & 1.0 & 16 & .2 & 26 & 13 & 13 & 87 & 48 & 232 & .12 & - & - \\
\hline $\begin{array}{l}07 \ldots \\
27 \ldots \\
A P R .\end{array}$ & $\begin{array}{r}1.2 \\
.4\end{array}$ & $\begin{array}{l}19 \\
21\end{array}$ & $\begin{array}{l}.2 \\
.2\end{array}$ & $\begin{array}{l}32 \\
30\end{array}$ & $\begin{array}{l}12 \\
12\end{array}$ & $\begin{array}{l}20 \\
18\end{array}$ & $\begin{array}{l}93 \\
99\end{array}$ & $\begin{array}{l}59 \\
57\end{array}$ & $\begin{array}{l}125 \\
73.5\end{array}$ & $\begin{array}{r}.13 \\
.13\end{array}$ & 3.8 & $=$ \\
\hline JULY... & -- & 22 & .2 & 42 & 18 & 25 & - & -- & - & - & - & -- \\
\hline$\underset{\text { SEP. }}{21}$ & 36 & 33 & $\cdot 2$ & 79 & 53 & 26 & 221 & 137 & 3.70 & .30 & 3.4 & 1.0 \\
\hline $23 \ldots$ & 1.6 & 18 & .4 & 40 & 17 & 23 & 138 & 66 & 23.9 & .19 & -- & - \\
\hline
\end{tabular}

02231980 - SAwgrass lake nEAR MELBourne fla (LAT 280435 LONG 080 4626 )

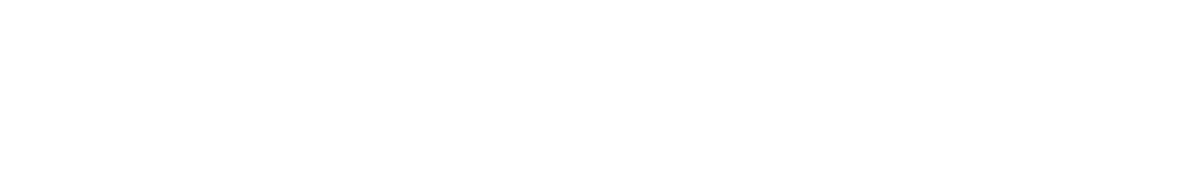

02232100 - LK WASHINGTON NR EAU GALLIE FLA (LAT 280850 LDNG 0804410 )

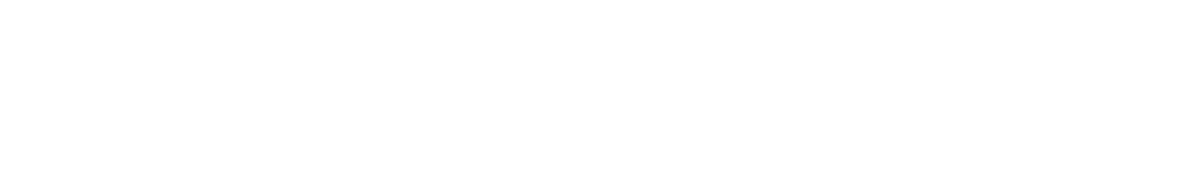

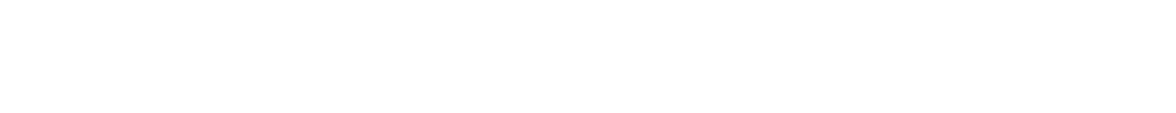




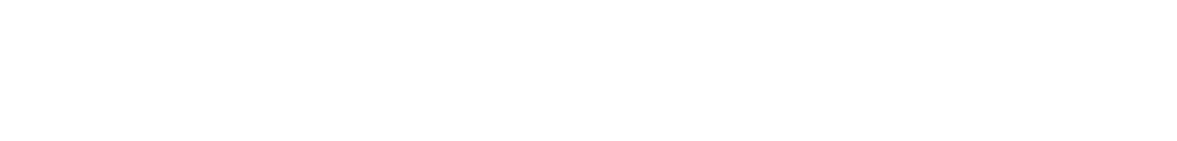

\section{ST. JOHNS RIVER BASIN--CONTINUED}

02232200 - WOLF CR NR DEER PARK FLA (LAT 281255 LONG 08054 n31

\begin{tabular}{|c|c|c|c|c|c|c|c|c|c|c|c|c|}
\hline $\begin{array}{r}\text { OCT.. } \\
21 . . . \\
\text { JAN.." }\end{array}$ & 69 & 24.0 & 107 & 410 & 11 & 1.9 & 70 & 7.6 & 1.2 & 30 & 0 & 7.0 \\
\hline $\begin{array}{r}26 . . . \\
A P R .\end{array}$ & 15 & 15.5 & 142 & 260 & 16 & 2.0 & $5 n$ & 11 & .8 & $4 B$ & 0 & 7.2 \\
\hline $\operatorname{JUL}_{\mathrm{JU}}^{28}$ & 1.2 & 24.0 & 168 & 320 & 20 & 1.9 & 100 & 11 & .8 & 62 & -- & 7.6 \\
\hline $21 \ldots$ & 4.4 & 25.5 & 196 & 380 & 24 & 2.1 & $\ln n$ & 12 & 1.4 & 74 & 0 & 7.1 \\
\hline
\end{tabular}

02232254 - LAKE INDEK NEAR BONAVENTURE, FLA. (LAT 281512 LONG 080 50 55)

\begin{tabular}{|c|c|c|c|c|c|c|c|c|c|c|c|c|}
\hline $\begin{array}{l}\text { NOV... } 1969 \\
\text { O5... } \\
\text { FEH... } 1970\end{array}$ & $=$ & 20.0 & 185 & 200 & 15 & 2.7 & 330 & 16 & 1.3 & 38 & 0 & 7.4 \\
\hline $\begin{array}{l}04 \ldots \\
\text { MAY }\end{array}$ & $=$ & 12.5 & 218 & 130 & 17 & 3.2 & 290 & 20 & 1.8 & 38 & 0 & 7.2 \\
\hline $29 . \ldots$ & $=$ & 34.0 & 723 & 220 & 48 & 12 & 1900 & 73 & 4.2 & 78 & 0 & 7.5 \\
\hline
\end{tabular}

02232285 - ROCKIEOGE CREEK NEAR ROCKLEDGE FLA (LAT 281843 LONG 0804734 )

\begin{tabular}{|c|c|c|c|c|c|c|c|c|c|c|c|c|}
\hline 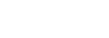 & $\cdots$ & 22.0 & 1130 & 180 & 48 & 16 & 2100 & 142 & 1.8 & 66 & - & 7.6 \\
\hline
\end{tabular}

02232300 - LK POINSETT NR COCOA FLA (LAT 282101 LONG OBO 48 56)

\begin{tabular}{|c|c|c|c|c|c|c|c|c|c|c|c|c|}
\hline FEB... 1970 & - & 20.0 & 173 & 250 & 14 & 2.6 & 300 & 15 & 1.1 & 36 & 0 & 7.3 \\
\hline MAY $04 .$. & - & 11.5 & 241 & 130 & 18 & 3.6 & 350 & 24 & $? .2$ & 38 & 0 & 7.0 \\
\hline JULY... & - & 24.5 & 360 & 160 & 25 & 4.8 & 620 & 36 & .7 & 48 & - & 7.7 \\
\hline $29 . \ldots$ & - & 32.0 & 838 & 200 & 50 & 14 & 2300 & 88 & 4.8 & 78 & 0 & 7.4 \\
\hline
\end{tabular}

- 02232413 - TAYLOR CREEK AT S 164 NEAR COCOA FLA (LAT 282023 LONG 080 56 06)

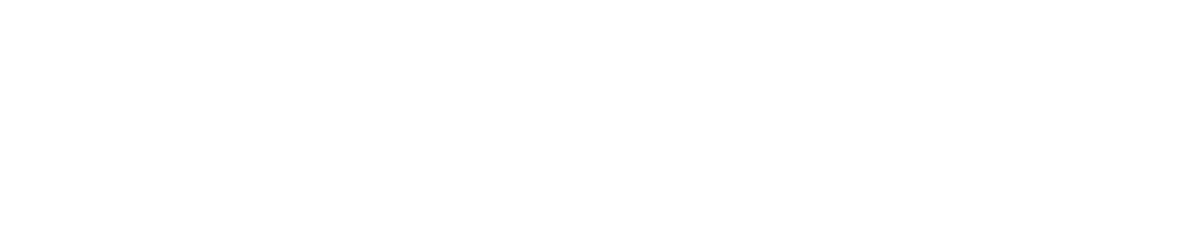

02232430 - 5 T JOHNS RIVER AT CSG NO.7 NEAR COCOA (LAT 282921 LONG 0805255 )

$\begin{array}{lllllllllllll}\text { MAY, } 1970 & - & 24.5 & 588 & - & 29 & 9.2 & 0 & 71 & 1.1 & 76 & --\end{array}$

02232450 - JIM CREEK NR CHRISTMAS FLA (LAT 2826 O7 LONG 0805758 )

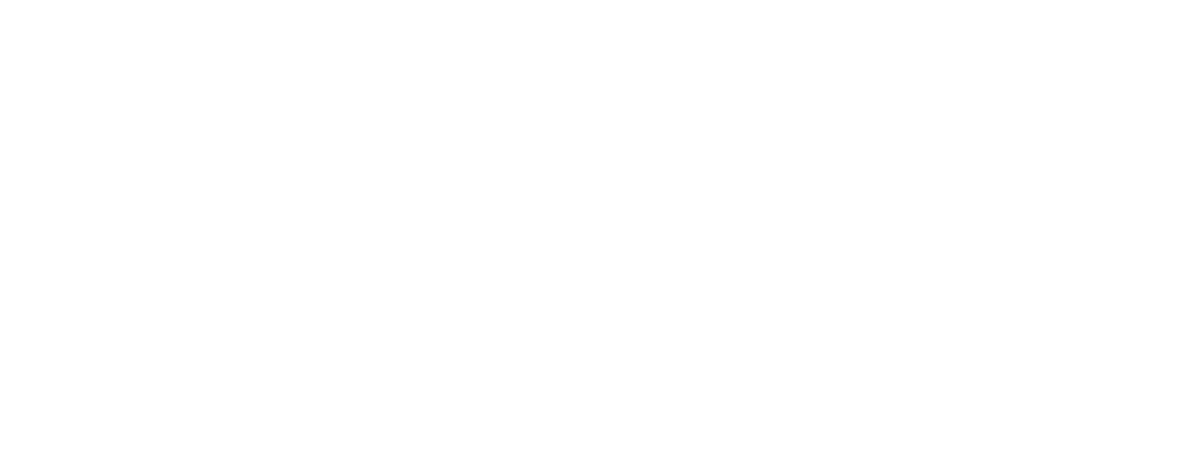


CHEMICAL ANALYSES, HATER YEAR OCTOBER 1969 TO SEPTEMBER 1970 (MAJOR CONSTITUENTS)

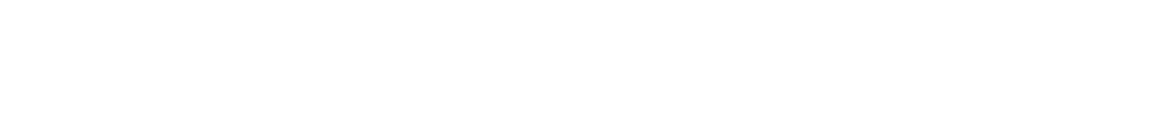
ST. JOHNS RIVER BASIN--CONTINUED

02232200 - WOLF CR NR DEER PARK FLA ILAT 281255 LONG 080 b4 031

\begin{tabular}{|c|c|c|c|c|c|c|c|c|c|c|c|c|}
\hline $\begin{array}{l}\text { OCT.\#1969 } \\
21 \ldots \ldots 1970 \\
\text { JAN." } 1970\end{array}$ & .4 & - 16 & .2 & 36 & 11 & 25 & $: 04$ & 60 & 11.9 & .14 & 3.4 & 1.0 \\
\hline APR... & .4 & 21 & .2 & 48 & 10 & 39 & 107 & 80 & 4.48 & .15 & 2.5 & - \\
\hline JULY & $\cdot 8$ & 18 & .1 & 58 & 7 & 51 & 123 & 89 & .40 & .17 & 1.8 & -- \\
\hline $21 \ldots$ & .0 & 21 & .2 & 69 & 8 & 61 & 152 & 104 & 1.81 & .21 & 1.9 & 1.0 \\
\hline
\end{tabular}

02232254 - LAKE WINDER NEAR BONAVENTURE, FLA. (LAT 281512 LONG 08050 55)

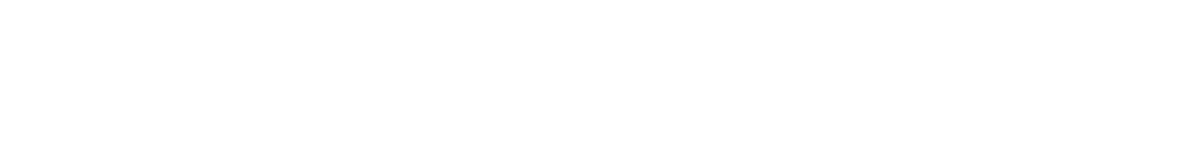

02232285 - RDCKLEDGE CREEK NEAR ROCKLEDGE FLA (LAT 281843 LONG 0804734 )

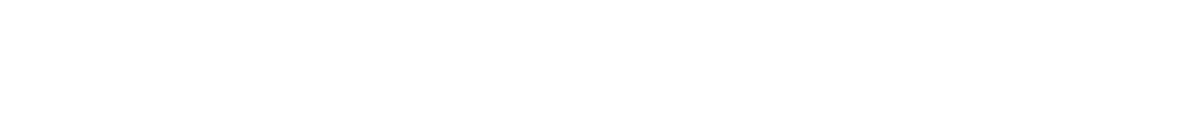

02232300 - LK POINSETT NR COCOA FLA ILAT 282101 LONG 08048 56)

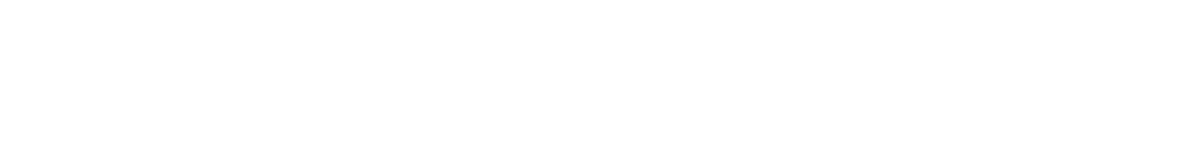

02232413 - TAYLOR CREEK AT S 164 NEAR COCOA FLA (LAT 282023 LONG 080 56 06)

\begin{tabular}{|c|c|c|c|c|c|c|c|c|c|c|c|c|}
\hline 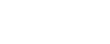 & .0 & 11 & .2 & 28 & 8 & 20 & 88 & 46 & 166 & .12 & 4.8 & 1.0 \\
\hline $\begin{array}{l}26 \ldots \\
\text { APR.. }\end{array}$ & .8 & 13 & .1 & 23 & 8 & 15 & 81 & 43 & 92.9 & .11 & 4.6 & -- \\
\hline $27 \ldots$ & .0 & 17 & .2 & 32 & 10 & 22 & 96 & 54 & 76.5 & .13 & 2.9 & -- \\
\hline $27 \ldots$ & -- & - & $\cdots$ & -- & -- & - & - & -- & - & - & -- & .9 \\
\hline $27 \ldots$ & -- & - & -- & - & - & - & -- & -- & - & - & -- & 6.0 \\
\hline $27 \ldots$ & - & -- & -- & - & $=-$ & - & - & -- & -- & -- & -- & A. 0 \\
\hline $20 \ldots$ & -- & $=$ & -- & - & -- & - & - & - & -- & -- & -- & 4.0 \\
\hline $20 \ldots$ & 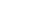 & $=-$ & -- & - & -- & - & - & $\cdots$ & -- & - & -- & 6.0 \\
\hline $20 \ldots$ & $=$ & - & -- & - & - & $=$ & -- & -- & - & $=$ & - & 8.0 \\
\hline $20 \ldots$ & .8 & 19 & . 1 & 34 & 8 & 26 & 102 & 64 & .00 & .14 & 2.5 & 1.0 \\
\hline
\end{tabular}

02232430 - ST JOHNS RIVER AT CSG NO.? NEAR COCOA (LAT 2829 21 LONG N8N 52 55)

MAY, $197055 \quad 133$

0223245 - JIM CREEK NR CHRISTMAS FLA (LAT 282607 LONG 08057 58)

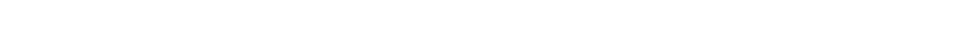

02233102 - ECONLOCKHATCHEE R TRIA NR BITHLO FLA (LAT 283355 LONG 081 09 19)
\end{abstract}

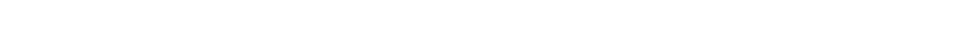

02233200 - LIITLE ECONLOCKHATCHEE R NR UNION PK F (LAT 283129 LONG ORI 14 39)
\end{abstract}

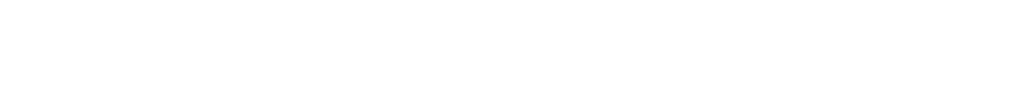

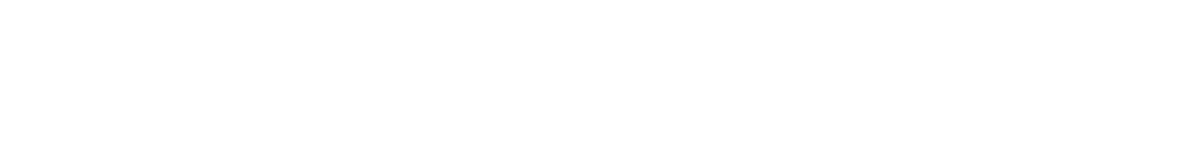




\begin{tabular}{|c|c|c|c|c|c|c|c|c|c|c|c|c|}
\hline ATE & $\begin{array}{l}\text { OIS- } \\
\text { CHARGE } \\
\text { (CFS) }\end{array}$ & $\begin{array}{l}\text { TEMPER- } \\
\text { ATURE } \\
\text { (DEG C) }\end{array}$ & $\begin{array}{l}\text { SPE- } \\
\text { CIFIC } \\
\text { CON- } \\
\text { DUCT- } \\
\text { ANCE } \\
\text { (MICRO- } \\
\text { MHOS) }\end{array}$ & $\begin{array}{l}\text { OIS- } \\
\text { SOLVEO } \\
\text { IRON } \\
\text { (FE) } \\
\text { (UG/L) }\end{array}$ & $\begin{array}{l}\text { DIS- } \\
\text { SOLVED } \\
\text { CAL- } \\
\text { CIUM } \\
\text { (CA) } \\
\text { (MG/L) }\end{array}$ & $\begin{array}{l}\text { DIS- } \\
\text { SOLVED } \\
\text { MAG- } \\
\text { NE- } \\
\text { SIUMA } \\
\text { (MG) } \\
\text { (MG/L) }\end{array}$ & $\begin{array}{l}\text { OIS- } \\
\text { SOLVED } \\
\text { STRON- } \\
\text { TIUM } \\
\text { (SR) } \\
\text { (UG/L) }\end{array}$ & $\begin{array}{l}\text { DIS- } \\
\text { SOL VED } \\
\text { SODIUM } \\
\text { (NA) } \\
\text { (MGYL) }\end{array}$ & $\begin{array}{l}\text { OIS- } \\
\text { SOLVED } \\
\text { PO- } \\
\text { TAS- } \\
\text { SIUM } \\
\text { (K) } \\
\text { (MG/L) }\end{array}$ & $\begin{array}{l}\text { BICAR- } \\
\text { BONATE } \\
\text { (HCO3) } \\
\text { (MG/L) }\end{array}$ & $\begin{array}{l}\text { CAR- } \\
\text { BONATE } \\
\text { (CO3) } \\
\text { (MG/L) }\end{array}$ & $\begin{array}{c}P H \\
\text { (UNITS) }\end{array}$ \\
\hline
\end{tabular}

$$
\text { ST. JOHNS RIVER BASIN--CONTINUED }
$$

02234000 - ST JOHNS R AB L HARNEY NR GENEVA FLA (LAT 284250 LONG 08102 06)

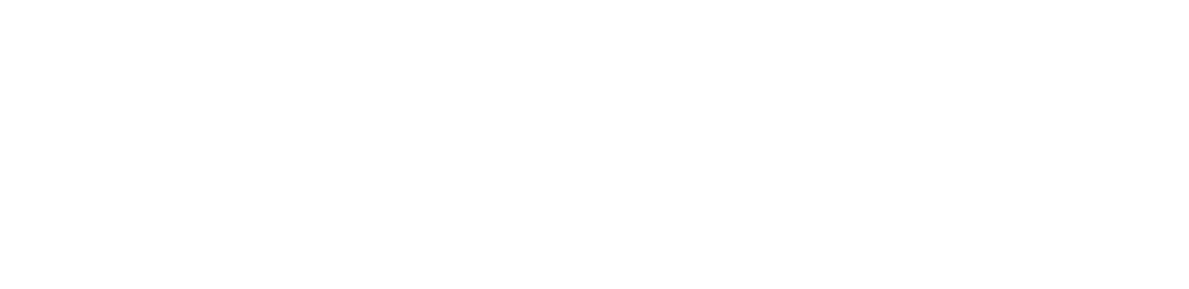

02234160 - L WINNEMISSET NR DELAND FLA (LAT 290110 LONG 08115 06)

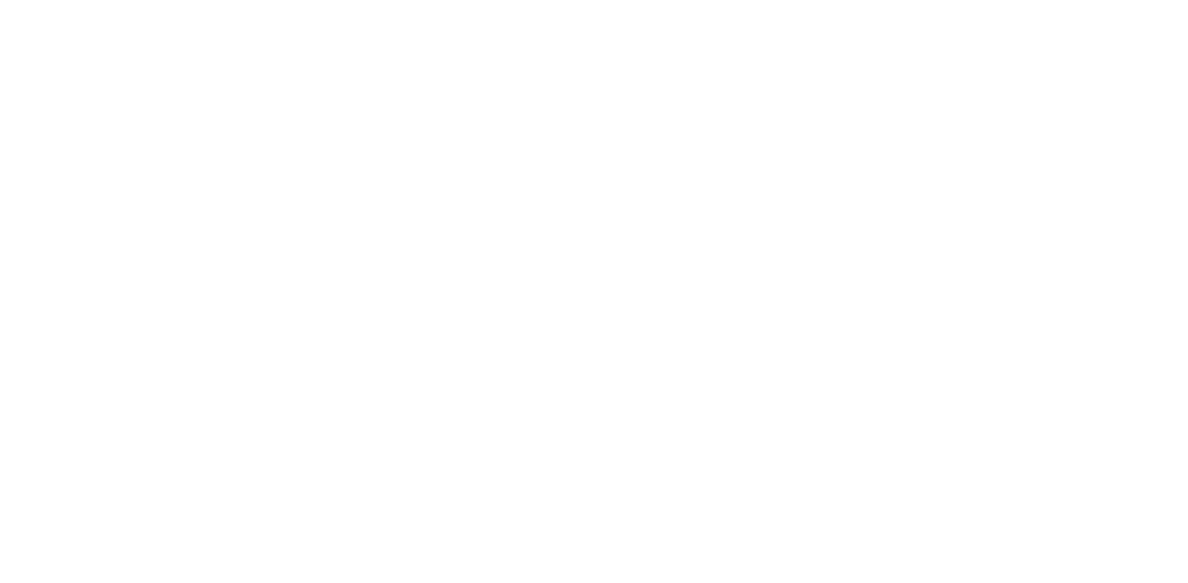

02234815 - LAKE WEKIVA OUTLET NEAR MAITLAND FLA LLAT 283610 LONG 0812538 )

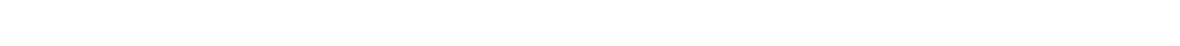

02235000 - WEKIVA RIVER NR SANFORD FLA (LAT 284854 LONG D81 25101

MAY, 1970

26.0

$8.5 \quad 0 \quad 8.9 \quad 0 \quad 110$

7.1

02235150 - LAKE DORR NR ALTOONA FLA ILAT 290010 LONG 08138 05)

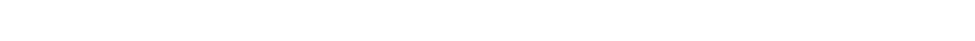

02235200 - BLACKWATER CR NR CASSIA FLA (LAT 285240 LONG 0812920 )

OCT., 1969

MAY 1970
16.2

$\begin{array}{rrrr}-- & 88 & 380 & 11 \\ 24.0 & 180 & -- & 24\end{array}$

2.6

$3.9 \quad 2.5 \quad 18$

18

6.6

02235500 - BLUE SPRINGS NR ORANGE CITY FLA (LAT 285638 LONG O81 20 24)

NOV., 1969

$25 . .167$

JAN." 1970

MAR:

03... 185

$23 . .$.

JULY... 184

SEP... 185

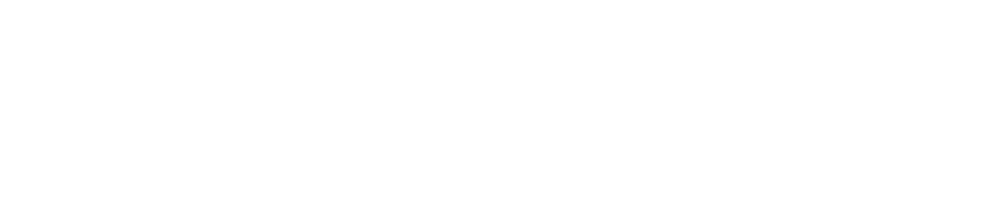


CHEMICAL ANALYSES, WATER YEAR OCTOBER 1969 TO SEPTEMBER 1970

(MAJOR CONSTITUENTS)

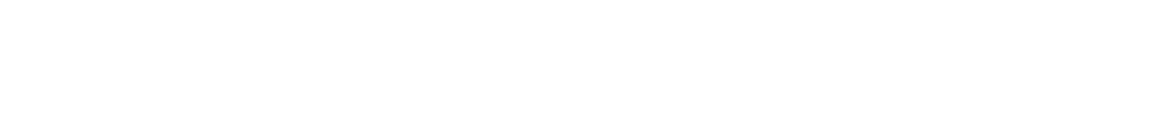

ST. JOHNS RIVER BASIN--CONTINUED

02234000 - ST JOHNS R AB L HARNEY NR GENEVA FLA (LAT 284250 LONG 08102 06)

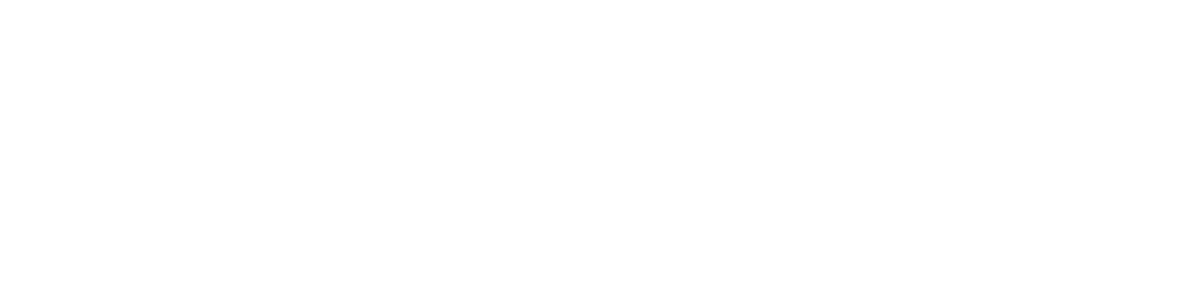

02234160 - L WINNEMISSET NR OELAND FLA LLAT 290110 LONG 08115061

MAY 1970

$\begin{array}{lllllllll}18 & .3 & 58 & 50 & \text { R } & 139 & 115 & -\end{array}$

02234435 - LAKE JesSUP OUTLET NR SANFORO , FLA. (LAT 284709 LONG 081 10 50)

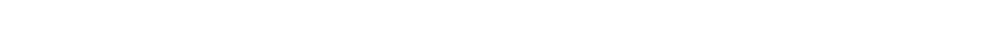

02234500 - ST JOHNS R NR SANFORD FLA (LAT $2850 \quad 13$ LONG O8\$ 1928 I

$\begin{array}{ccccccccccc}\text { MaY } .1970 & 197 & 240 & 8 & 159 & 116 & 43 & 550 & 509 & \ldots & .75\end{array}$

02234600 - WEKIVA SPRINGS NR APOPKA FLA (LAT 284243 LONG 081 2736 )

NOV., 1969

MAY 1797011

MAY 157013

21... 14

$\begin{array}{cccccccccccc}9.0 & .2 & 113 & 20 & 94 & 145 & 137 & 32.1 & .20 & \ldots & \ldots \\ 10 & .3 & 118 & 26 & 92 & 145 & 143 & - & .20 & \ldots & \ldots \\ 9.0 & .3 & 109 & 10 & 98 & 170 & 137 & 36.5 & .23 & \ldots & \ldots\end{array}$

02234610 - ROCK SPRINGS NEAR APOPKA FLA (LAT 284570 LONG 0812958 )

Nov., 1969

NOV.. 1969

MAY 1970

SEP. 17

$\begin{array}{llll}7.0 & .3 & 102 & 20 \\ 7.0 & .3 & 100 & 34 \\ 7.5 & .3 & 100 & 15\end{array}$

$82 \quad 132 \quad 128 \quad 26.7 \quad 0$

02234815 - LAKE WEKIVA OUTLET NEAR MAITLAND FLA (LAT 2836 10 LONG 08\$ 2538 )

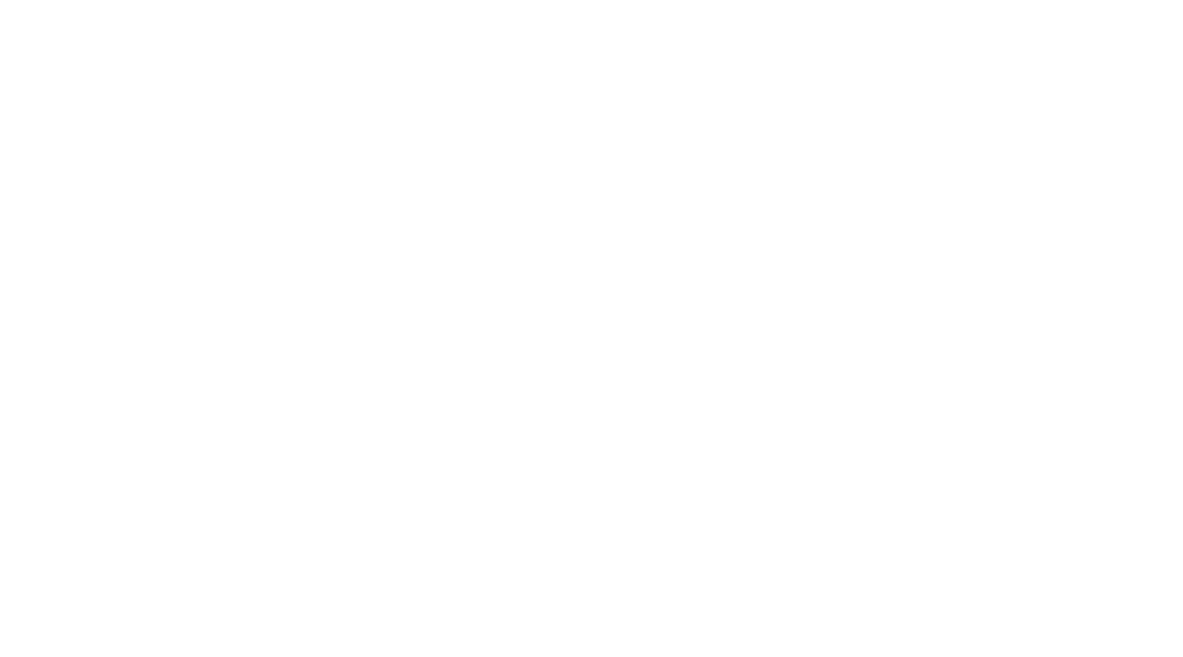


ANALYSES OF SAMPLES COLLECTED AT MISCELLANEOUS SITES IN FLORIDA CHEMICAL ANALYSES, WATER YEAR OCTOBER 1969 TO SEPTEMBER 1970 (MAJOR CONSTITUENTS)

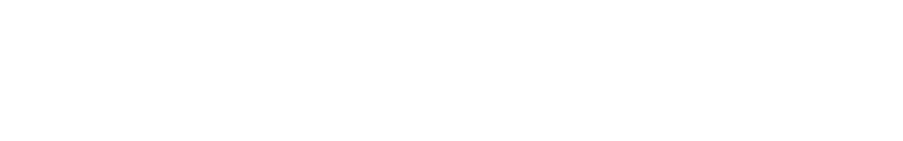

ST, JOHHS RIVER BASIN--CONTINUED

02236000 - ST JOHNS R NR OELAND FLA ILAT 290039 LONG 0812321 )

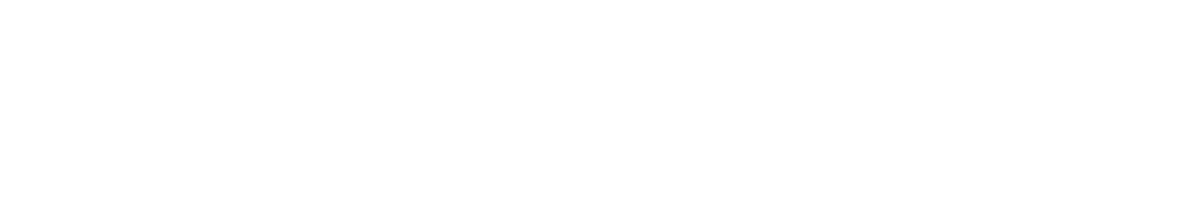

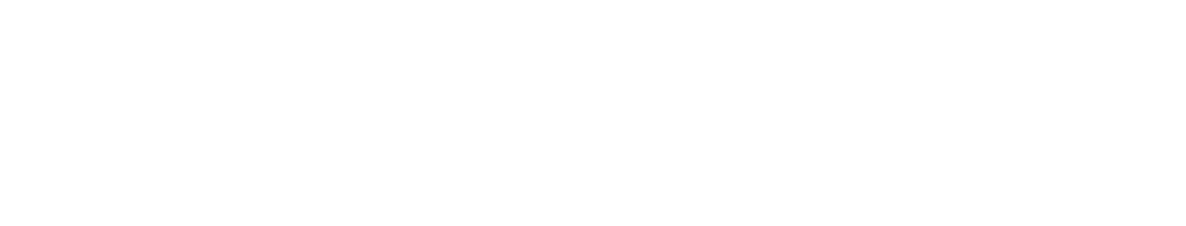

02236120 - DEEP CR NR BARBERVILLE FLA (LAT 290747 LONG 9812327 )

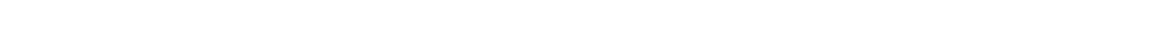

02236200 - LAKE KERR NR EUREKA FLA (LAT 292010 LONG 08146001

\begin{tabular}{|c|c|c|c|c|c|c|c|c|c|c|c|c|}
\hline $\begin{array}{l}\text { APR... } 1970 \\
29 . . . \\
\text { SEP. }\end{array}$ & - & 29.5 & 159 & 30 & & & & & & 4 & 0 & 6.4 \\
\hline $28 \ldots$ & -- & 30.5 & 105 & 40 & 6.2 & 2.1 & 120 & 11 & .7 & 13 & 0 & 6.4 \\
\hline
\end{tabular}

02236250 - LAKE LOWERY NR HAINES CITY FLA ILAT 280651 LONG 08140171

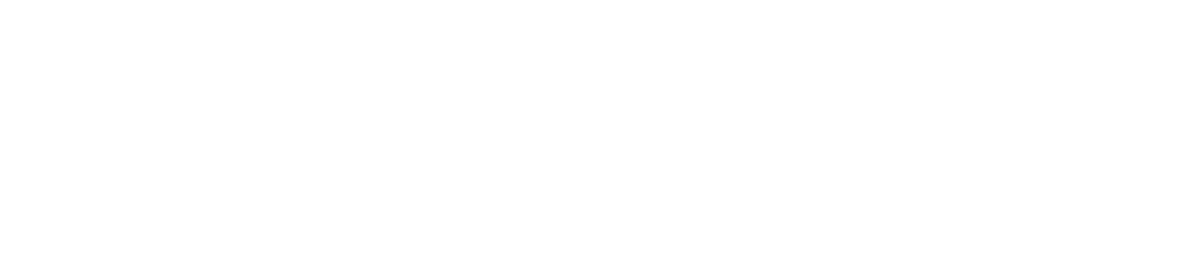

02236500 - BIG CREEK NR CLERMONT FLA (LAT 282651 LONG 0814425 ,

NOV.. 1969

JAN.: 1970104

JAN... 1970

MAR.

MAY 06.92

15.

JULY

$06 \ldots$

AUG.

$\begin{array}{lll}16.5 & 62 & - \\ 12.5 & 54 \\ 19.0 & 56 & 75 \\ 26.5 & 75 & - \\ 25.0 & 68\end{array}$

02236820 - LAKF LOUISA NR CLEHMOMT FLA (LAT 282953 LONG 08144 14)

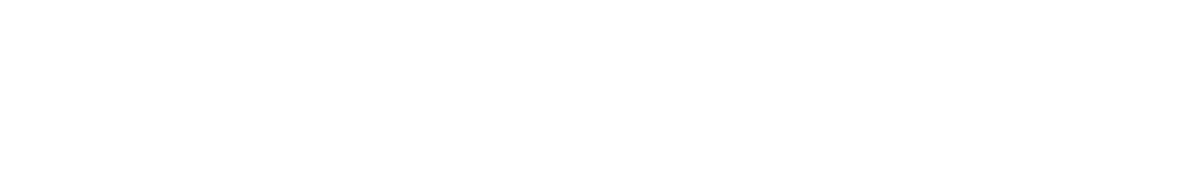


ANALYSES OF SAMPLES COLLECTED AT MISCELLANEOUS SITES IN FLORIDA

CHEMICAL ANALYSES, WATER YEAR OCTOBER 1969 TO SEPTEMBER 19TO

$$
\text { (MAJOR CONSTITUENTS) }
$$

\begin{tabular}{|c|c|c|c|c|c|c|c|c|c|c|c|c|}
\hline & $\begin{array}{l}\text { DIS- } \\
\text { SOLVEO } \\
\text { SULFATE } \\
\text { (S04) }\end{array}$ & $\begin{array}{l}\text { DIS- } \\
\text { SDLVEO } \\
\text { CHLO- } \\
\text { RIDE } \\
\text { (CL) }\end{array}$ & $\begin{array}{l}\text { DIS- } \\
\text { SOLVED } \\
\text { FLUO- } \\
\text { RIDE } \\
\text { (F) }\end{array}$ & $\begin{array}{l}\text { HARD- } \\
\text { NESS } \\
\text { (CA, MG) }\end{array}$ & $\begin{array}{l}\text { NON- } \\
\text { CAR- } \\
\text { BONATE } \\
\text { HARD- } \\
\text { NESS }\end{array}$ & $\begin{array}{l}\text { ALKA- } \\
\text { LINITY } \\
\text { AS } \\
\text { CACO3 }\end{array}$ & $\begin{array}{l}\text { DIS- } \\
\text { SOLVEn } \\
\text { SOLIDS } \\
\text { (RESI- } \\
\text { DUE AT } \\
180 \mathrm{C} \text { ) }\end{array}$ & $\begin{array}{l}\text { DIS- } \\
\text { SOLVEO } \\
\text { SOLIDS } \\
\text { (SUM OF } \\
\text { CONSTI- } \\
\text { TUENTS) }\end{array}$ & $\begin{array}{l}\text { DIS- } \\
\text { SOLVED } \\
\text { SOLIDS } \\
\text { (TONS } \\
\text { PER }\end{array}$ & $\begin{array}{l}\text { DIS- } \\
\text { SDLVED } \\
\text { SOLIDS } \\
\text { ITONS } \\
\text { PER } \\
\text { PC-FI) }\end{array}$ & $\begin{array}{l}\text { TANNIN } \\
\text { AND } \\
\text { LIGNIN } \\
\text { (MGIL) }\end{array}$ & $\begin{array}{l}\text { DEPTH } \\
\text { (FT) }\end{array}$ \\
\hline
\end{tabular}

ST. JOHNS RIVER BASIN--CONTINUED

02236000 - ST JOHNS $R$ NR DELAND FLA (LAT 290039 LONG 0812321 )

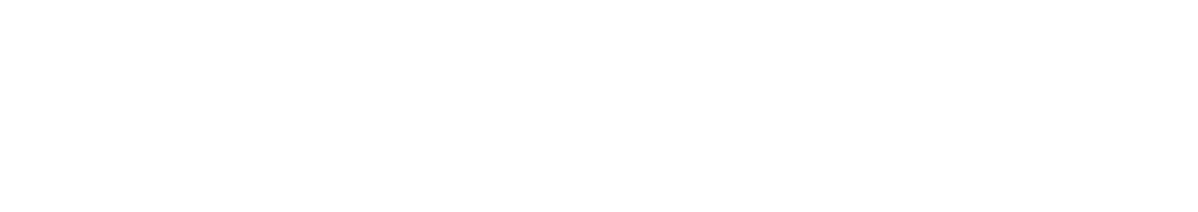

02236110 - PONCE DE LEON SPRINGS NR DELAND FLA (LAT 290802 LONG 0812147 )

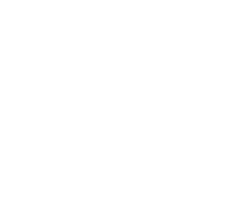

02236120 - DEEP CR NR BARGERVILLE TLA (LAT 290747 LONG 0812327 )

MAY, 1970

MAY $1970 \quad 1.0 \quad 105$

.311

6942

353

220

02236200 - LAKE KERR NR EUREKA FLA (LAT 292010 LONG 0814600$)$

$\begin{array}{lll}\text { APR., } 1970 & 12 \quad 17 \\ 29 . . . & 12 \quad 17\end{array}$

SEP. $\quad 17 \quad 17$

O236200 - LAKE KERR NR EUREKA FLA ILAT 292010 LONG 08146001

OCI... 1969
O8...

02236500 - 816 CHEEK NR CLERMONT FLA (LAT 282651 LONG 08144251

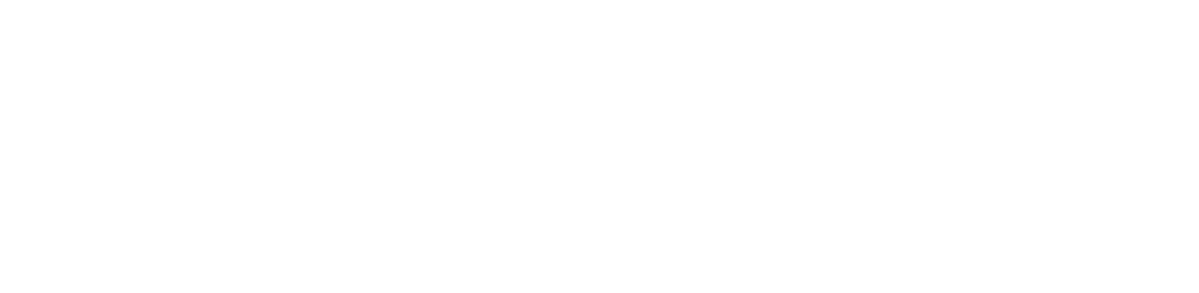

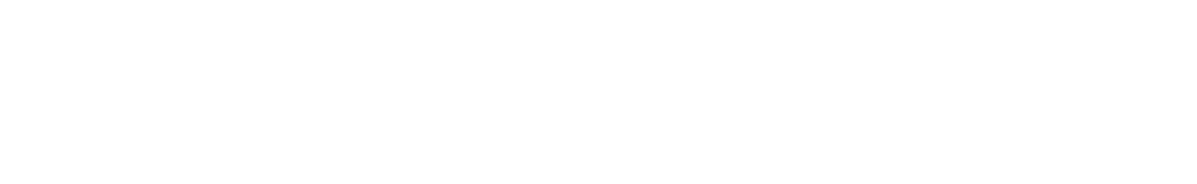




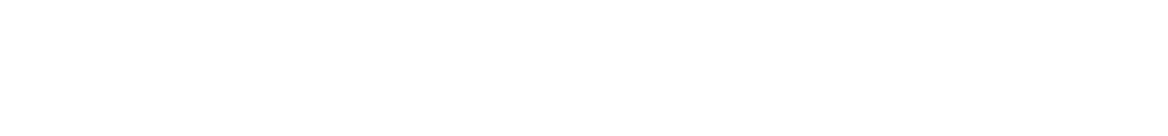

$$
\text { ST. JOHNS RIVER BASIN--CONTINUED }
$$

02236840 - LAKE MINNEHAHA AT CLERMONT FLA (LAT 283240 LONG 08145 18)

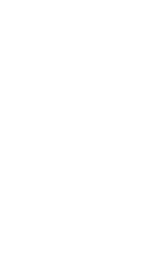

$\begin{array}{rrr}24.0 & 58 \\ 12.0 & 179 & \\ 24.0 & 58 & \\ 18.0 & 68 & - \\ 30.0 & 60 & \ldots \\ 28.0 & 58 & \\ 29.0 & 59 & \ldots \\ 28.5 & 58 & \ldots\end{array}$

02236860 - LAKE APSHAWA NR MINNEOLA FLA (LAT 283618 LONG 0814635

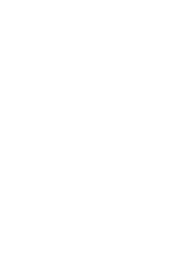

NoV., 1969 18... 1969204 JAN." 1970 MAR.

O3.... 322

JUNE

$30 \ldots 30$

AUG.... 1

$18 . . . \quad \mathrm{B} .5$

Nov., 1969

15... 204

JAN... 1970

MAR.

$03 . . .322$

$30 . . .30$

AUG.

$13 . . . \quad 11$

OCT.. 1969

$02 . . .168$

NoV.

JAN... $1970^{242}$

JAN.: 1970

MAR.

03... 374

MAY

$14 . .$.

JUNE

AUG

14 ... 45

18... 35

OCT., 1969

02... 168

NOV.

$17 . . .242$

JAN.: 1970

MAR.

03... 374

JUNE

UNE... 51

AUG.

14... 45
$21.0 \quad 230$

$14.0 \quad 220$

19.5

28.0

27.5

32.0

31.0

02236900

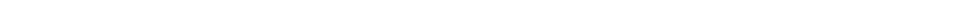

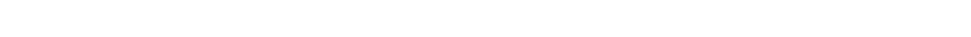

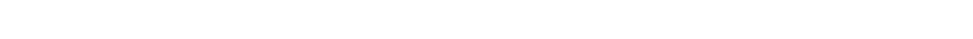

$$
\begin{aligned}
& \begin{array}{llllllllllll}
28.5 & 65 & - & - & - & - & - & - & - & - & - & -
\end{array} \\
& \begin{array}{lllllllllll}
27.5 & 60 & - & - & - & - & - & - & - & - &
\end{array}
\end{aligned}
$$

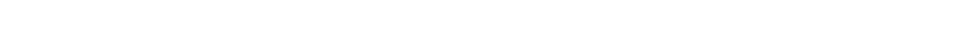

02236901 - PALATLAKAHA R BL CH LK OLT NR GROVELAN (LAT 283532 LONG 08149 21)

\begin{tabular}{|c|c|c|c|c|c|c|c|c|c|c|}
\hline 20.0 & 211 & - & -- & -- & -- & -- & - & -- & - & - \\
\hline 18.5 & 65 & -- & -- & - & $-\infty$ & - & - & - & -- & - \\
\hline 12.0 & 62 & -- & -- & - & - & - & $\cdots$ & - & $\cdots$ & + \\
\hline 20.5 & 63 & - & $\cdots$ & - & $\cdots$ & - & - & -- & - & 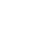 \\
\hline 28.0 & 65 & -- & 3.3 & 1.5 & - & 6.1 & .8 & 4 & 0 & 6.0 \\
\hline 29.0 & 65 & 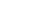 & - & - & 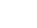 & $-\infty$ & 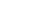 & - & - & - \\
\hline 29.0 & 64 & - & -- & - & $m$ & -- & -- & -- & 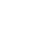 & $\cdots$ \\
\hline 30.0 & 62 & - & - & - & $=$ & - & $\cdots$ & - & - & \\
\hline
\end{tabular}

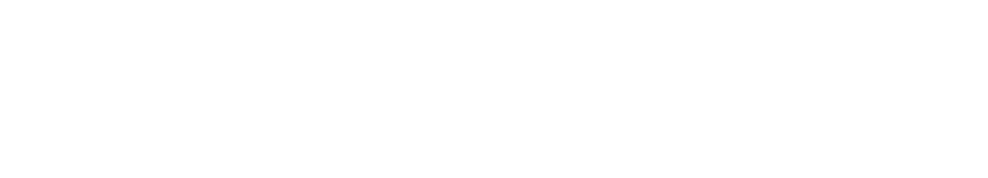

02237000 - PALATLAKAHA R NR MASCOTte FLA ILAT 203656 LONG OBI 51 53)

02237001 - PALATLAKAHA R BL SPWY NR MASCOTTEE FLA ILAT 283657 LONG 601 51 58)

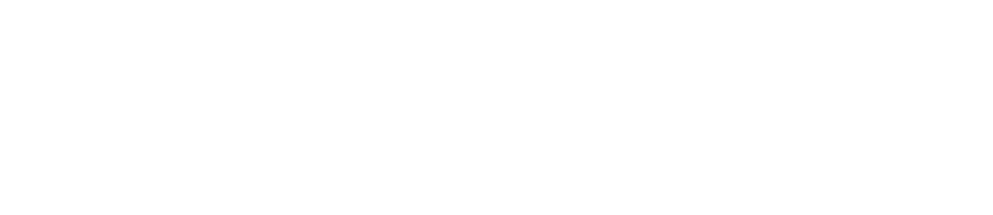


ANALYSES OF SAMPLES COLLECTED AT MISCELLANEOUS SITES IN FLORIDA

CHEMICAL ANALYSES, WATER YEAR OCTOBER 1969 TO SEPTEMBER 1970 (MAJOR CONSTITUENTS)

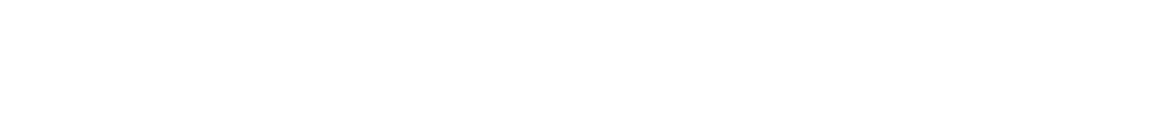

ST. JOHNS RIVER BASIN--CONTINUED

02236840 - LAKE MINNEHAHA AT CLERMONT FLA (LAT 283240 LONG 0814518 )

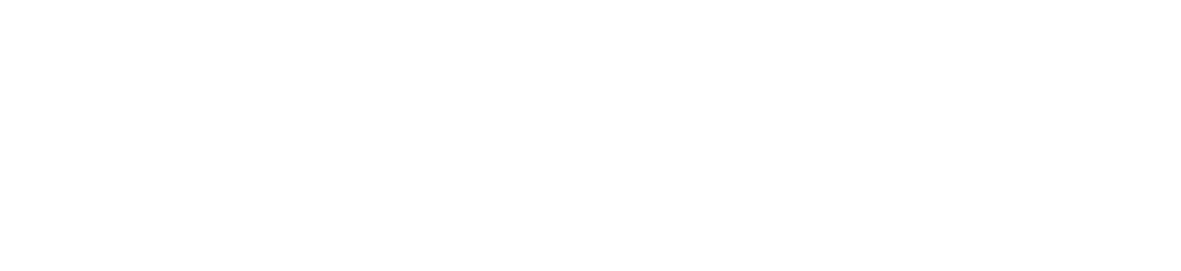

02236860 - LAKE APSHAWA NR MINNEOLA FLA (LAT 283618 LONG 0814635 )

NOV., 1969

$18 . \cdots 1070$

JAN.1 1970

TAR:

O6...

MAY ... 65

JULY

06.0.

$14 . .$.

SEP...

$$
65
$$

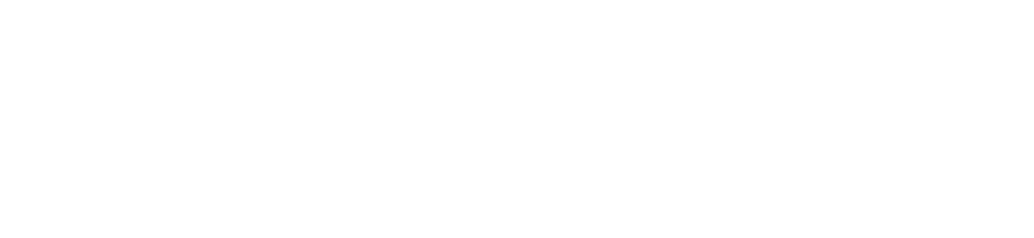

NOV.. 1969

18...

JAN." 1970

MAR.

03.

JUNE

AUG.

SEP.

02236900

PALATLAKAHA R AT CH LK DLT NR GRDVELD (LAT 283533 LONG 0814921 )

NOV., 1909

$15 . . .197$

JAN.. 1970

MAR...

JUNE

AUG.

$13 . .$.

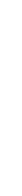

OCT., 1969

$02 . .$.

NOV.

JAN... 1970

JAN.. 1970

03...

MAY

JUNE

AUG.:

AUG.

SEP.

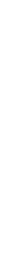

02237000

- $\quad-\infty$

02236901 - PALATLAKAHA R BL CH LK OLT NR GROVELAN (LAT 283532 LONG 0814921 )

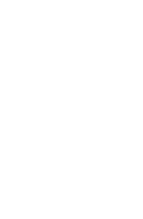

02237001 - PALATLAKAHA R BL SPWY NR MASCOTTEE FLA LLAT 203657 LONG 0815158 ) 


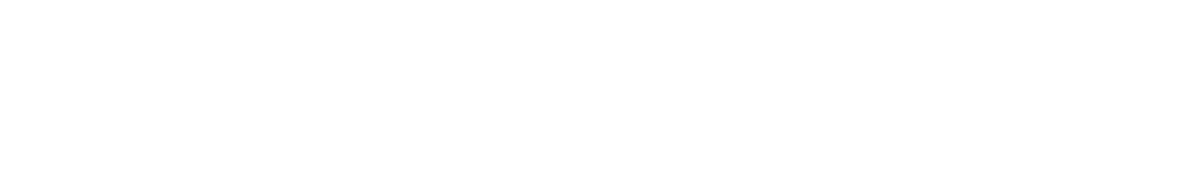

ST. JOHNS RIVER BASIN--CONTINUED

02237293 - PALATLAKAHA R AT STR M-1 NR OKAHUMPKA (LAT 284429 LONG 08152 22)

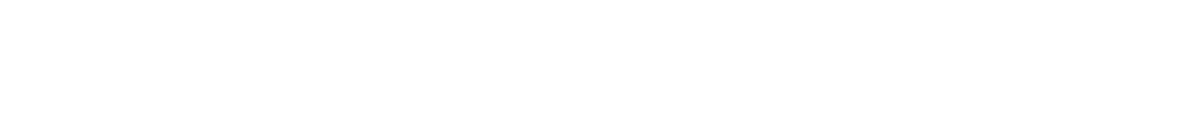

02237370 - CHURCH LAKE NR GROVELAND FLA (LAT 283840 LONG 0815047 )

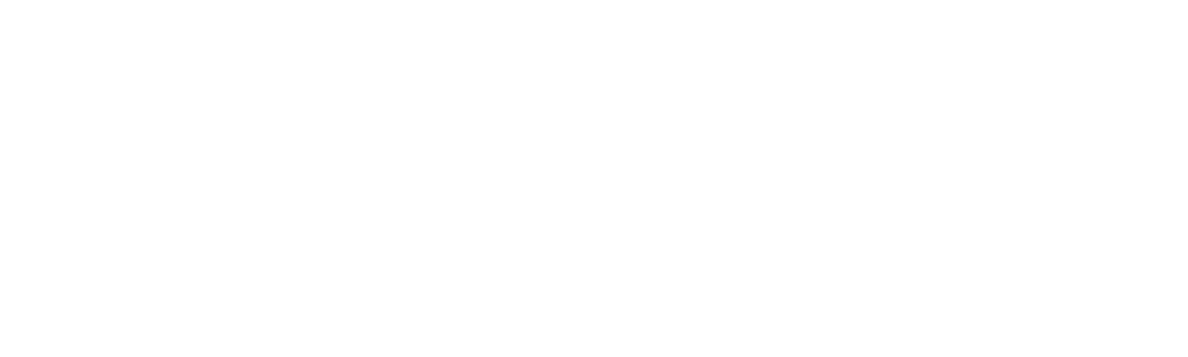

02237540 - JOHNS LAKE AT OAKLAND FLA ILAT 283246 LONG 0813744 )

\begin{tabular}{|c|c|c|c|c|c|c|c|c|c|c|c|c|}
\hline NOV., 1969 & -- & 18.0 & 160 & - & -- & -- & -- & -- & -- & -- & - & - \\
\hline O6.... & -- & 15.0 & 155 & -- & - & -- & -- & 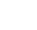 & -- & -- & - & - \\
\hline $\begin{array}{l}\text { MAR. } \\
\text { O3.... } \\
\text { JUNE }\end{array}$ & - & 18.5 & 162 & -- & -- & - & - & -- & -- & - & -- & - \\
\hline $30 \ldots$ & $-\infty$ & 26.5 & 170 & -- & -- & -- & -- & -- & - & - & $\cdots$ & - \\
\hline $17 \ldots$ & -- & 29.0 & 150 & -- & -- & -- & -- & - & -- & $=$ & - & - \\
\hline
\end{tabular}

02237560 - LAKE fRANCIS NEAR PLYMOUTH, FLA (LAT 284220 LONG 0813223 )

JUNE, 1970

29...

28.0

02237600 - LAKE APOPKA AT WINTER GAROEN FLA (LAT 283436 LONG 08135 13)

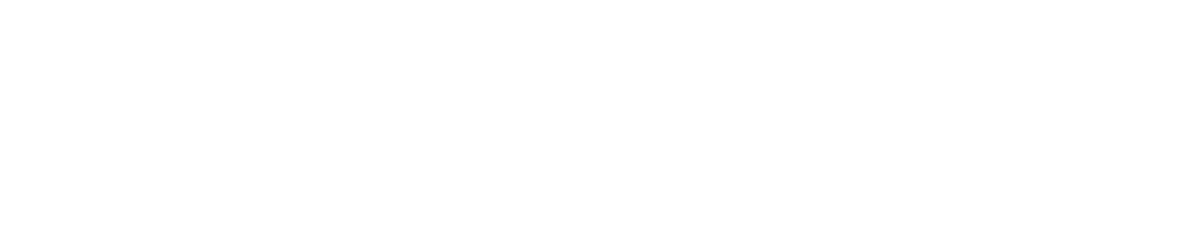

02237660 - LAKE FRANCIS NR PLYMOUTH FLA (LAT 284206 LONG 0813226 )

\begin{tabular}{|c|c|c|c|c|c|c|}
\hline${ }_{08, \ldots 1} 1969$ & $=$ & $28 . n$ & 59 & - & - & -- \\
\hline NOV. & & & & & & \\
\hline JAN... 1970 & -- & 16.0 & 59 & -- & -- & -- \\
\hline MAR... & -- & 12.0 & 58 & -- & -- & -- \\
\hline MAY & $\cdots$ & 18.0 & 61 & -- & - & - \\
\hline JUNE & - & 28.0 & 65 & -- & 3.0 & 1.6 \\
\hline $\begin{array}{l}29 . . . \\
\text { AUG. }\end{array}$ & -- & 28.0 & 62 & $m$ & -- & -- \\
\hline $17 .$. & $-\infty$ & 29.5 & 58 & $m$ & $\cdots$ & -- \\
\hline 17. & - & 28.0 & 55 & $\cdots$ & -- & - \\
\hline
\end{tabular}


CHEMICAL ANALYSES, HATER YEAR OCTOBER 1969 TO SEPTEMBER 1970 (MAJOR CONSTITUENTS)

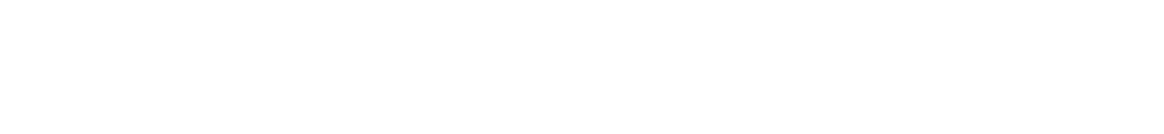

ST. JUHNS RIVER BASIN--CONTINUED

02237293 - PALATLAKAHA R AT STR M-1 NR OKAHUMPKA (LAT 284429 LONG 08152 22)

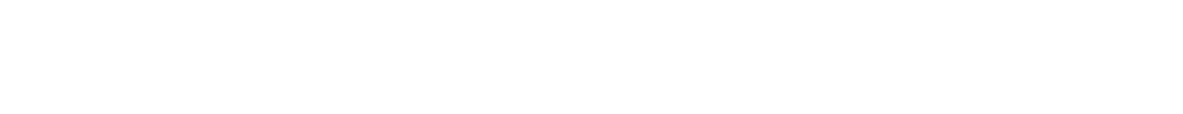

02237370 - CHURCh LAKE NR gROVELAND FLA (LAT 283840 LONG OB1 5047 )

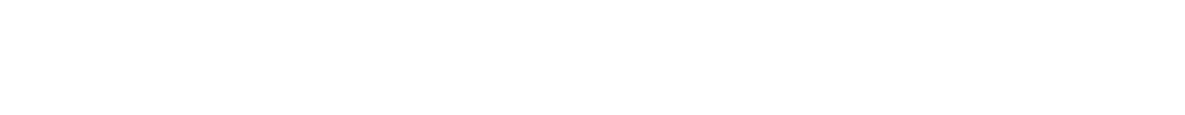

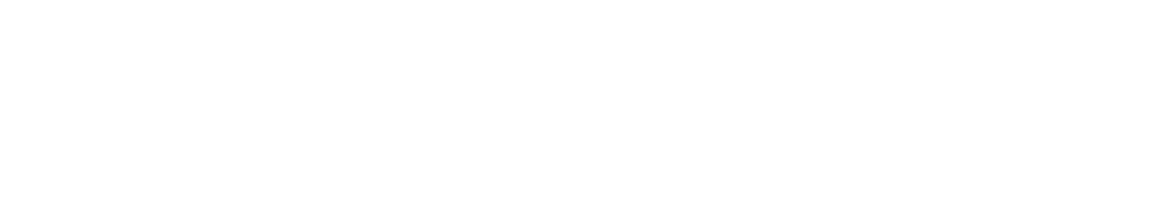
02237540 - JOHNS LAKE AT OAKLAND FLA (LAT 283246 LONG 0813744 )

NOV.. 1969
$20 \ldots . .1197$
JAN.. 1970
O6...
MAR.
O3...
JUNE
30...
SEP.
$17 \ldots$

02237560 - LAKE FRANCIS NEAR PLyMOUTH, FLA (LAT 284220 LONG 08132 23)

JUNE, 1970

$29 . .0$

02237600 - LAKE APOPKA AT WINTER GARDEN FLA (LAT 283436 LONG 0813513 )

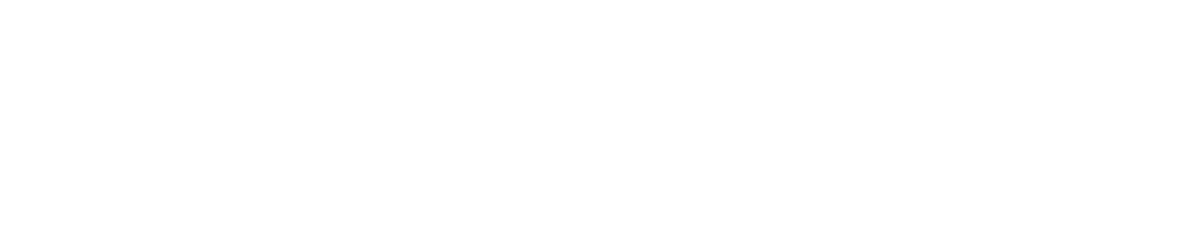

02237660 - LAKE FRANCIS NR PLYMOUTH FLA (LAT 284206 LONG 081 32 26)

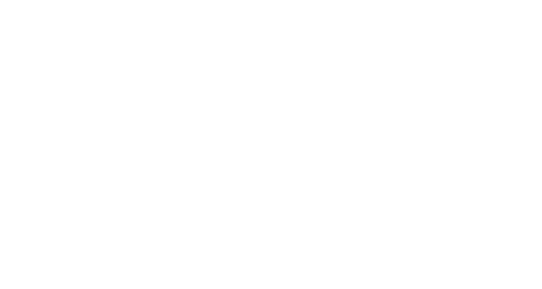



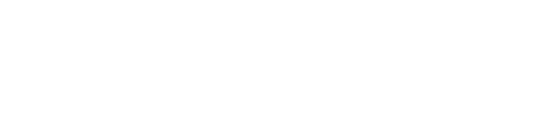

DOLVED

ST. JDHNS RIVER BASIN-- CONTINUED

02237700 - APOPKA-BEAUCLAIR CANAL NR ASTATULA FLA (LAT 284320 LONG 08141 06)

\begin{tabular}{|c|c|c|c|}
\hline JAN... & & $\cdots$ & -- \\
\hline${ }_{\text {MAY }}^{06 . . .}$ & 277 & $-\infty$ & - \\
\hline JULY... & & 42 & 15 \\
\hline $06 \ldots$ & 382 & $=$ & $\bar{z}$ \\
\hline
\end{tabular}

02237701 - APOPKA-BEAUCLAIR CA BL DAM NR ASTATULA (LAT 284320 LONG 08141061

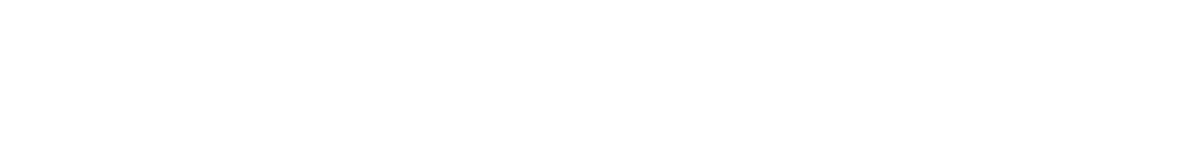

02237753 - WEST CROOKED LAKE NR EUSTIS FLA (LAT 284949 LONG 08140201

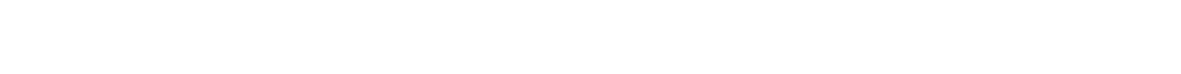

02237800 - LAKE DORA AT MT DORA FLA (LAT 284746 LONG 0813839 )

OCT... 1969
$03 . .$.

02237802 - OORA CANAL AT TAVARES FLA ILAT 284830 LONG 08144301

OCT., 1969

$03 . . .348$

NOV.

$19 . .1342$

N..1970

MAR.

DG... 420

MAY

$18 . . . \quad-$

JULY... 220

SEP.... 147

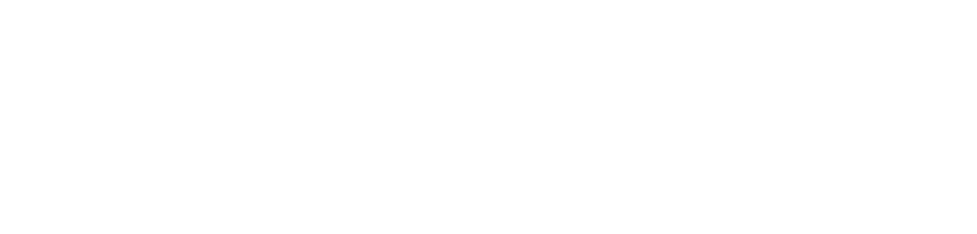

02237865 - Lake uMatilla at umatilla, fla. ILAT 285509 LONG 08139571

$\operatorname{MAY} .1970$
$14 . .$.


ANALYSES OF SAMPLES COLLECTED AT MYSCELLANEOUS SITES IN FLORIDA

CHEMICCAL ANALYSES, WATER YEAR OCTOBER 1969 TO SEPTEMBER 1970

(MAJOR CONSTITUENTS)

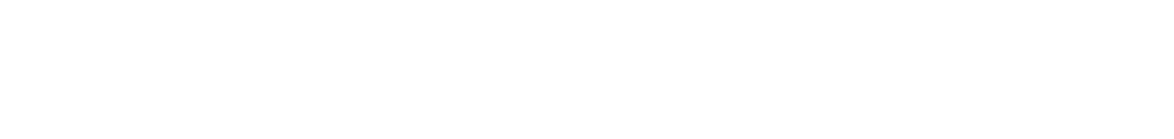

ST. JOHNS RIVER BASIN--CONTINUED

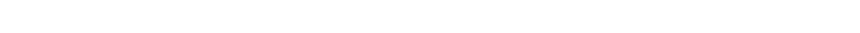

NOV.. 1969
$19 . . .1$

02237701 - APOPKA-BEAUCLAIR CA BL DAM NR ASTATULA (LAT 284320 LONG 081 41 06)

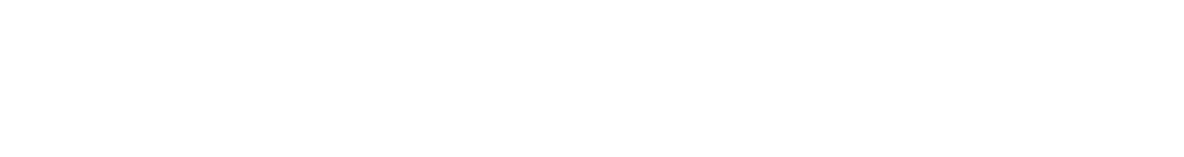

02237753 - WEST CPDOKED LAKE NR EUSTIS FLA ILAT 2月 4949 LONG $0 B 140201$

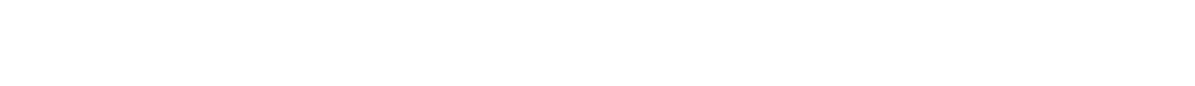

02237800 - LAKE DORA AT MT DORA FLA (LAT 284746 LONG OBI 3B 39)

OCT.. 1969
$03 . .0$
NOV.

02237802 - DORA CANAL AT TAVARES FLA (LAT 284830 LONG 0814430 )

OCI., 1969
$03 . \ldots$

02237865 - LAKE UMATILLA AT UMATILLA, FLA. ILAT 295509 LONG 0813957

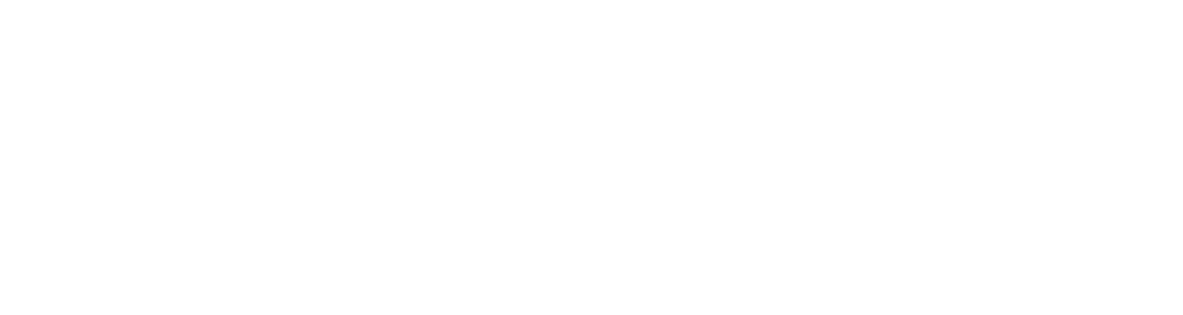



(MAJOR CONSTITUENTS)

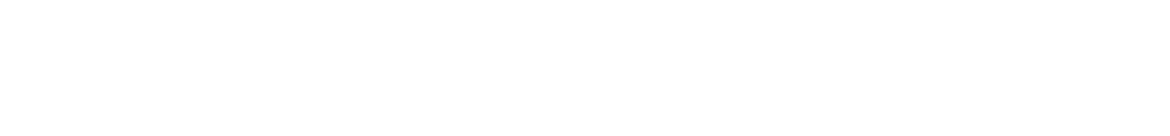
ST. JOHNS RIVER BASIN--CONTINUED

02238000 - HAINES CR AT LISBON FLA ILAT 285220 LONG O8I 4650 )

\begin{tabular}{|c|c|c|c|c|c|c|c|c|c|c|c|c|}
\hline $\begin{array}{l}\text { DEC., } \\
01 . . . \\
\text { JAN., }\end{array}$ & $\begin{array}{c}969 \\
663 \\
970\end{array}$ & 17.0 & 240 & - & - & -- & $\cdots$ & -- & $\cdots$ & $=$ & - & -- \\
\hline $\begin{array}{l}09 . . \\
\text { MAR." }\end{array}$ & 1070 & 13.0 & 240 & - & -- & -- & - & - & - & 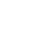 & -- & -- \\
\hline MAY & 1040 & 17.5 & 220 & - & -- & -- & - & - & 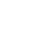 & - & - & - \\
\hline${ }_{J U L Y} 11 \ldots$ & 696 & - & 240 & 20 & 27 & 6.3 & 0 & 11 & 3.2 & 94 & - & 7.6 \\
\hline $10 .$. & 357 & 30.0 & 255 & - & - & -- & -- & -- & $m$ & -- & - & - \\
\hline $17 \ldots$ & 97 & 25.0 & 246 & -- & -- & $=$ & $=$ & -- & -. & -. & $=-$ & -- \\
\hline
\end{tabular}

02238001 - HAINES CR BL BURRELL UAM AT LISBON FLA (LAT 2852 ?0 LONG 0814650 )

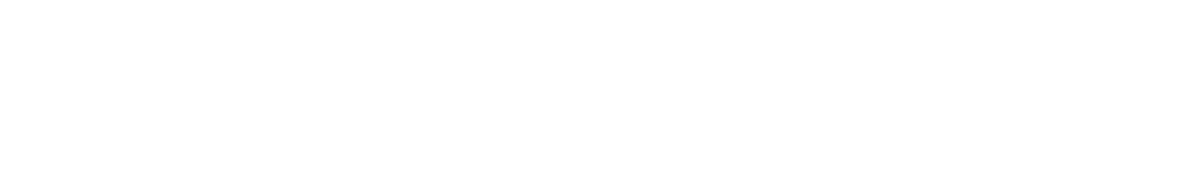

02238200 - LAKE YALE AT GRANO ISLAND FLA (LAT 285252 LONG 0814221 )

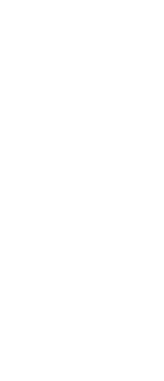

$30 . .$.

$\operatorname{maY}_{16 . . .}{ }^{1970} 44$

$\begin{array}{ll}23.0 & 120 \\ 16.0 & 122 \\ 15.5 & 140 \\ 14.0 & 135 \\ 14.5 & 138 \\ 20.5 & 950 \\ 24.5 & 230 \\ 27.0 & 235 \\ 27.0 & 240 \\ 30.5 & 260 \\ 30.5 & 160 \\ 25.0 & 168\end{array}$

02238204 -

$$
\begin{array}{llll}
-- & - & -- & - \\
-- & -- & -- & - \\
- & - & - & - \\
- & - & - & - \\
-- & -- & - & \\
870 & 20 & 6.9 & 10 \\
-- & -- & -- & - \\
-- & -- & -- & - \\
-- & -- & -- & - \\
-- & -- & -- & - \\
660 & 15 & 4.7 & 100
\end{array}
$$

YALE-GRIFFIN CANAL NR LISBON, FLA. (LAT 285517 LONG 0814626 )
$26.0 \quad 235$

02238300

NOV.. 1969
$19 . .$.
JAN..1970
MG...
MAR...
MAY..
MAY...
JULY
O9...

- LAKE gRIFFIN at LeEsBuRg fLA (LAT $2850 \quad 29$ LONG 08152 12)

$$
\begin{aligned}
& \begin{array}{lllllllllll}
17.0 & 270 & - & - & - & - & - & - & - & - & -
\end{array} \\
& \begin{array}{lllllllllll}
12.5 & 269 & - & - & - & - & - & - & - & - & -
\end{array} \\
& 18.0245 \\
& 25.0 \quad 178 \quad 40
\end{aligned}
$$

\begin{tabular}{|c|c|c|c|c|c|c|c|c|c|c|c|c|}
\hline $\begin{array}{r}F E 8 \ldots \\
20 \ldots\end{array}$ & $\begin{array}{l}70 \\
1210\end{array}$ & 16.5 & 239 & -- & $=$ & -- & -- & -- & -- & $=-$ & - & - \\
\hline $\begin{array}{l}\text { APR. } \\
\text { OG... }\end{array}$ & 1490 & 22.0 & 220 & -- & - & - & -- & $\cdots$ & $=$ & - & - & $\cdots$ \\
\hline $\begin{array}{c}\text { JUNE } \\
29 \ldots . .\end{array}$ & & 29.0 & 250 & -- & $\cdots$ & - & $=-$ & - & -- & $\cdots$ & - & \\
\hline $\begin{array}{l}\text { JULY } \\
27 \ldots\end{array}$ & 31 & 28.5 & 265 & $\cdots$ & - & - & - & 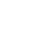 & $\cdots$ & - & -- & \\
\hline $\begin{array}{r}\text { SEP. } \\
25 . . .\end{array}$ & & 28.0 & 231 & -- & - & -- & -- & - & -- & - & -- & \\
\hline
\end{tabular}

02238499 - OKLAWAHA R AA MOSS BLUFF DAM AT MOSS B ILAT 290452 LONG 0815251 ) 
CHEMICAL ANALYSES, WATER YEAR OCTOBER 1969 TO SEPTEMBER 1970

\begin{tabular}{|c|c|c|c|c|c|c|c|c|c|c|c|c|}
\hline$a 7$ & $\begin{array}{l}\text { DIS- } \\
\text { SOLVED } \\
\text { SULFATE } \\
\text { (SO4) } \\
\text { (MG/L) }\end{array}$ & $\begin{array}{l}\text { DIS- } \\
\text { SOLVED } \\
\text { CHLO- } \\
\text { RIDE } \\
\text { (CL) } \\
\text { (MG/L) }\end{array}$ & $\begin{array}{l}\text { DIS- } \\
\text { SDLVEO } \\
\text { FLUO- } \\
\text { RIDE } \\
\text { (F) } \\
\text { (MG/L) }\end{array}$ & $\begin{array}{l}\text { HARO- } \\
\text { NESS } \\
\text { (CA,MG) } \\
\text { (MG/L) }\end{array}$ & $\begin{array}{l}\text { NON- } \\
\text { CAR- } \\
\text { BONATE } \\
\text { HAPD- } \\
\text { NESS } \\
\text { (MG/L) }\end{array}$ & $\begin{array}{l}\text { ALKA- } \\
\text { LINITY } \\
\text { AS } \\
\text { CACO3 } \\
\text { (MG/L) }\end{array}$ & $\begin{array}{l}\text { OIS- } \\
\text { SOLVED } \\
\text { SOLIDS } \\
\text { (RESI- } \\
\text { DUE AT } \\
\text { IBO C) } \\
\text { (MG/L) }\end{array}$ & $\begin{array}{l}\text { DIS- } \\
\text { SOLVEO } \\
\text { SOLIOS } \\
\text { ISUM OF } \\
\text { CONSTI- } \\
\text { TUENTSI } \\
\text { (MGIL) }\end{array}$ & $\begin{array}{l}\text { OIS- } \\
\text { SOLVEO } \\
\text { SOLIDS } \\
\text { (TONS } \\
\text { PER } \\
\text { DAY) }\end{array}$ & $\begin{array}{l}\text { DIS- } \\
\text { SOLVED } \\
\text { SOLIDS } \\
\text { (TONS } \\
\text { PER } \\
\text { AC-FT) }\end{array}$ & $\begin{array}{l}\text { TANN IN } \\
\text { AND } \\
\text { LIGNIN } \\
\text { (MG/L) }\end{array}$ & $\begin{array}{r}\text { REP TH } \\
(F T)\end{array}$ \\
\hline
\end{tabular}

ST. JDHNS RIVER BASIN--CONTINUED

02238000 - HAINES CR AT LISBON FLA (LAT 285220 LONG 0814650$)$

DEC.. 1969
OI...
JAN..1970

02238001 - HAINES CR BL BURRELL DAM AT LISBON FLA (LAT 285220 LONG 0814650 )

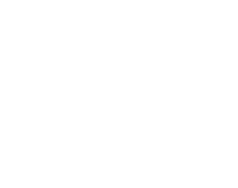

02238200 - LAKE YALE AT GRAND ISLAND FLA (LAT 285252 LONG 08142211

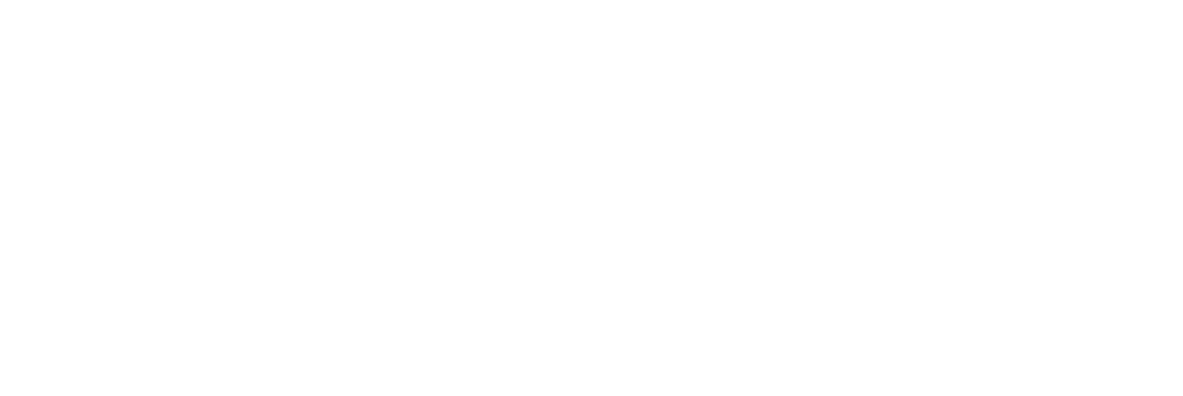

02238204 - YALE-GRIFFIN CANAL NR LISBON. FLA. (LAT 285517 LONG 0814626$)$

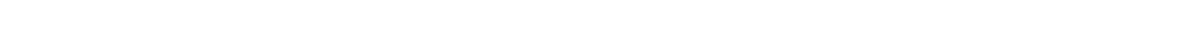
02238300 - LAKE GRIFFIN AT LEESAURG FLA (LAT 285029 LONG 08152 12)

\begin{tabular}{|c|c|c|c|c|c|c|c|c|c|c|c|}
\hline $\begin{array}{l}\text { NOV.: } 1969 \\
19 . . .\end{array}$ & $=-$ & -- & -- & -- & - & $\cdots$ & - & - & -- & -- & $=$ \\
\hline $\begin{array}{l}\text { JAN., } 1970 \\
\text { O6... } \\
\text { MAR. }\end{array}$ & -- & -- & -- & - & $\cdots$ & - & $=$ & -- & -- & $\cdots$ & -- \\
\hline MAY & - & $\cdots$ & - & -- & -- & - & - & - & -- & -- & $\cdots$ \\
\hline JULY... & 5.9 & 16 & .2 & 70 & 19 & 51 & 115 & 94 & $\Rightarrow$ & .16 & -- \\
\hline $09 . .$. & - & -- & -- & -- & $\cdots$ & $-\infty$ & - & $=$ & -- & 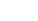 & -- \\
\hline
\end{tabular}

02238499 - DKLAWAHA R AB mOSS BLUFF DAM AT MOS5 B ILAT 290452 LONG 0815251 )

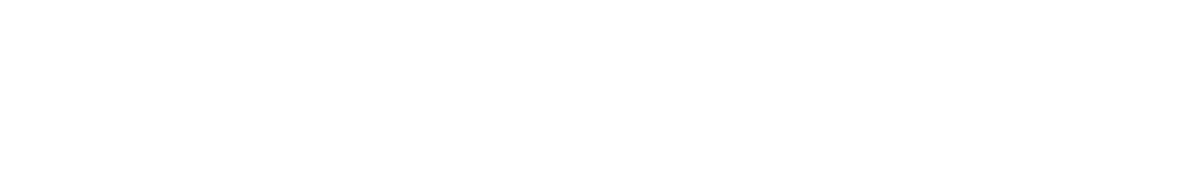


CHEMICAL ANALYSES, WATER YEAR OCTOBER 1969 TO SEPTEMBER 1970 (MAJOR CONSTITUENTS)
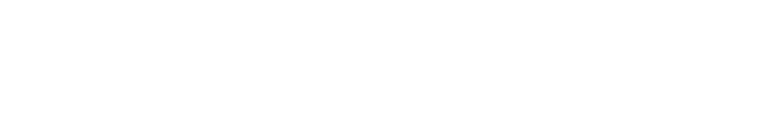

DIS-

(FE) (CA) (MG) (SR) (NA) SIUM

(K) (HCO3) BONATE

ST. JOHNS RIVER BASIN--CONTINUED

02238800 - LAKE wEIR AT OKLAWAHA FLA (LAT 290230 LONG 08155401

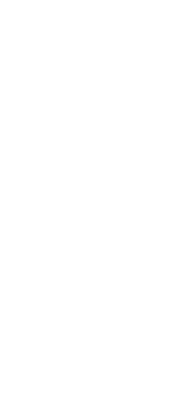

$\begin{array}{ll}24.0 & 137 \\ 16.0 & 139 \\ 15.5 & 135 \\ 14.0 & 143 \\ 13.0 & 147 \\ 22.5 & 140 \\ 24.5 & 138 \\ 26.0 & 140 \\ 27.5 & 138 \\ 30.5 & 160 \\ 31.5 & 160 \\ 27.5 & 138\end{array}$

$\begin{array}{cccc}-- & - & - & - \\ -- & - & - & - \\ - & - & - & - \\ -- & - & - & - \\ -- & -- & - & 10 \\ 30 & 3.1 & 3.5 & - \\ -- & -- & - & - \\ -- & -- & -- & - \\ -- & -- & - & 40 \\ 40 & 4.1 & 2.9 & 40\end{array}$

$\begin{array}{cccc}-- & -- & - & - \\ -- & - & - & - \\ -- & - & - & - \\ -- & - & - & - \\ -- & -- & -- & - \\ 100 & 16 & 2.1 & 1 \\ -- & -- & -- & - \\ -- & -- & -- & - \\ - & -- & -- & - \\ - & -- & - & - \\ 40 & 16 & 2.1 & 14\end{array}$

02239497 - SILVER SPRINGS AT SILVER SPRINGS FLA ILAT 291252 LONG OB2 03151

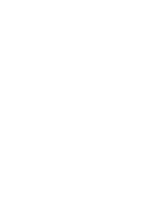

$\begin{array}{rrrrrr}23.0 & 400 & -- & - & - & \\ 23.0 & 425 & -- & -- & - & - \\ 24.5 & 469 & -- & 73 & 10 \\ 23.0 & 409 & -- & -- & - & \\ 23.0 & 415 & 20 & 65 & 8.3 & 5 \\ 24.5 & 400 & 20 & 67 & 8.6 & 500\end{array}$

$\begin{array}{ccc}-- & -- & - \\ -- & -- & - \\ -- & 6.7 & . \\ -- & -- & - \\ 510 & 6.0 & . \\ 500 & 6.3 & .\end{array}$

$\begin{array}{rrrr}-- & -- & -- & 7.5 \\ -- & -- & -- & -- \\ .6 & 214 & 0 & 7.6 \\ -- & -- & -- & -- \\ .5 & 196 & 0 & 7.7 \\ .6 & 203 & 0 & 7.8\end{array}$

02239500 - SILVER SPRINGS NR OCALA FLA ILAT 291252 LONG 0820315

JULY, 1970

23...

23.0

02240000 - OKLAWAHA R NR CONNER FLA LLAT 291250 LONG 08159103

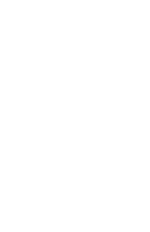

$\begin{array}{ll}17.5 & 330 \\ 15.0 & 320 \\ 17.5 & 330 \\ 19.5 & 290 \\ 23.0 & 387 \\ 24.0 & 350 \\ 25.5 & 380\end{array}$

$$
\begin{aligned}
& \begin{array}{llll}
-- & - & -
\end{array} \\
& \begin{array}{rrrrrr}
- & - & - & - & - & -- \\
- & -- & -- & -- & -- & -- \\
- & -- & -- & -- & -- & -- \\
- & -- & -- & -- & -- & 7.7 \\
- & -- & -- & -- & -- & 7.5 \\
- & -- & -- & -- & -- & 7.9
\end{array}
\end{aligned}
$$

02240500 - OKLAMAHA RIVER AT EUREKA FLA (LAT 292200 LONG 0815400 )

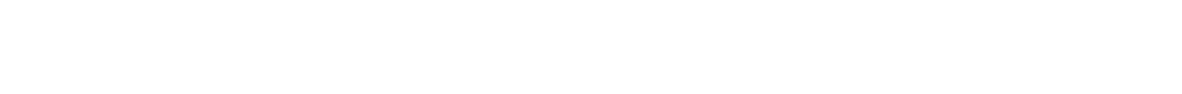

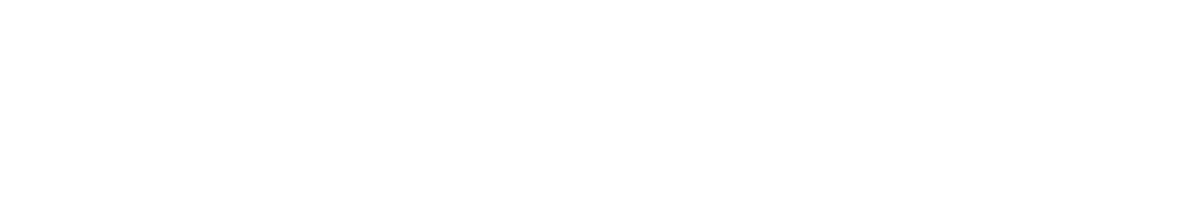

02240950 - HOGTOWN CR NR GAINESVILLE (LAT 293901 LONG 0822232 )

APR., 1970

$23.0-190$

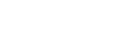

02241800 - LOCHLDOSA CREEK NEAR MELROSE FLA (LAT 294207 LONG 08208 02)

MAY
19.1970 320 -- 56 
ANALYSES OF SAMPLES COLLECTED AT MISCELLANEOUS SITES IN FLORIDA

CHEMICAL ANALYSES, WATER YEAR OCTOBER 1969 TO SEPTEMBER 1970

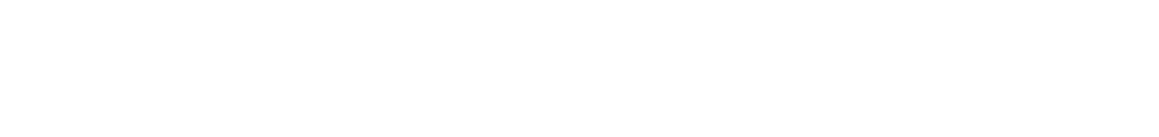

\section{ST. JOHNS RIVER BASIN--CONTINUED}

02238800 - LAKE HEIR AT OKLAWAHA FLA (LAT 290230 LONG 0815540 )

OCT., 1969
$30 . .0$

02239497 - SILVER SPRINGS AT SILVER SPRINGS FLA (LAT 291252 LONG 0 R2 03 15)

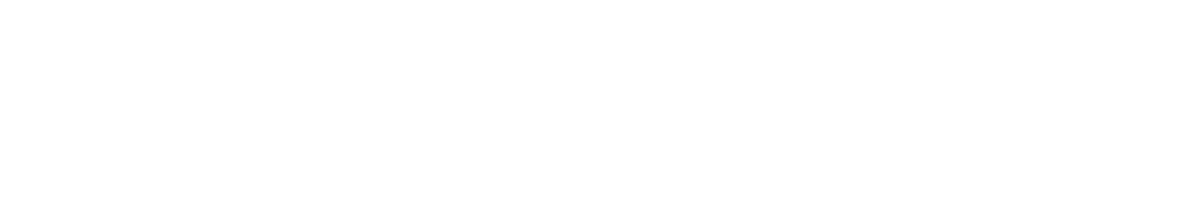

02239500 - SILVER SPRINGS NR OCALA FLA (LAT 29 IL \L LONG OR2 03 15)

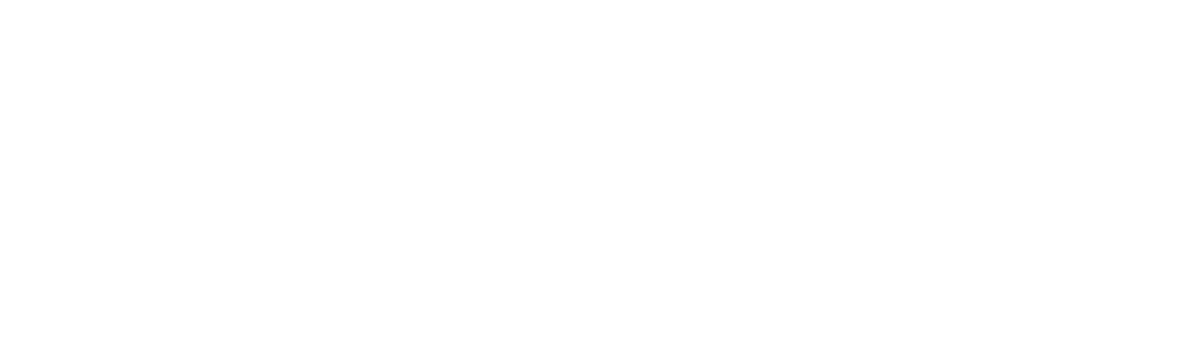

02240500 - OKLAWAHA RIVER AT EUREKA FLA (LAT 2922 00 LONG 0815400 )

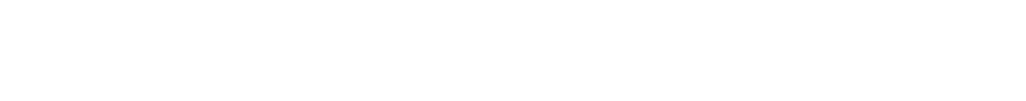

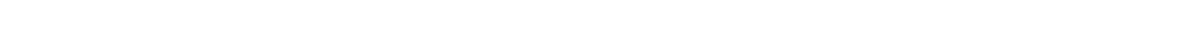
02240920 - FAIRFIELD SINK URAIN AT FAIRFIELD FLA (LAT 292158 LONG 082 I5 17)

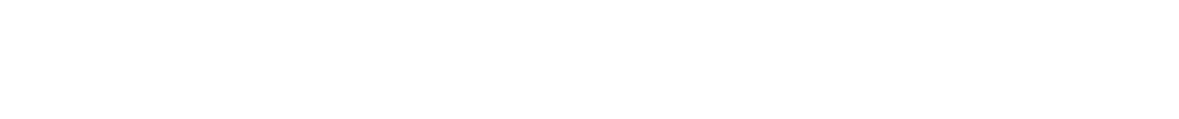
02240950 - HOGTOWN CR NR GAINESVILLE (LAT 293901 LONG 0822232 )

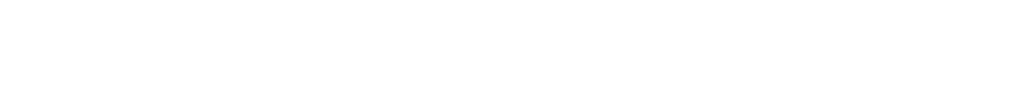

$\begin{array}{llllllllll}\text { MAY. } 1970 & & & & & & & & & \end{array}$ 

(MAJOR CONSTITUENTS)

\begin{tabular}{|c|c|c|c|c|c|c|c|c|c|c|c|c|}
\hline DATE & $\begin{array}{l}\text { DIS- } \\
\text { CHARGE } \\
\text { (CFS) }\end{array}$ & $\begin{array}{l}\text { TEMPER- } \\
\text { ATURE } \\
\text { (DEG C) }\end{array}$ & $\begin{array}{l}\text { SPE- } \\
\text { CIFIC } \\
\text { CON- } \\
\text { DUCT- } \\
\text { ANCE } \\
\text { (MICRO- } \\
\text { MIOS) }\end{array}$ & $\begin{array}{l}\text { DIS- } \\
\text { SOLVED } \\
\text { IRON } \\
\text { (FE) } \\
\text { (UG/L) }\end{array}$ & $\begin{array}{l}\text { OIS- } \\
\text { SOLVED } \\
\text { CAL- } \\
\text { CIUM } \\
\text { (CA) } \\
\text { (MG } / L)\end{array}$ & $\begin{array}{l}\text { DIS- } \\
\text { SOLVEO } \\
\text { MAG- } \\
\text { NE- } \\
\text { SIUM } \\
\text { (MG) } \\
\text { (MG/L) }\end{array}$ & $\begin{array}{l}\text { OIS- } \\
\text { SOLVEO } \\
\text { SIRON- } \\
\text { TIUM } \\
\text { (SR) } \\
\text { (UG/L) }\end{array}$ & $\begin{array}{l}\text { OIS- } \\
\text { SOLVED } \\
\text { SODIUM } \\
\text { (NA) } \\
\text { (MG/L) }\end{array}$ & $\begin{array}{l}\text { DIS- } \\
\text { SOLVEO } \\
\text { PO- } \\
\text { TAS- } \\
\text { SIUM } \\
\text { (K) } \\
\text { (MG/L) }\end{array}$ & $\begin{array}{l}\text { BICAR- } \\
\text { BONATE } \\
\text { (HCO3) } \\
\text { (MG/L) }\end{array}$ & $\begin{array}{l}\text { CAR- } \\
\text { BONATE } \\
\text { (CO3) } \\
\text { (MG }\end{array}$ & $\begin{array}{c}\text { PH } \\
\text { (UNITS) }\end{array}$ \\
\hline
\end{tabular}

ST. JOHNS RIVER BASIN--CONTINUED

02242400 - LOCHLOOSA LAKE AT LOCHLOOSA FLA (LAT 2930 19 LONG 082 06 08)

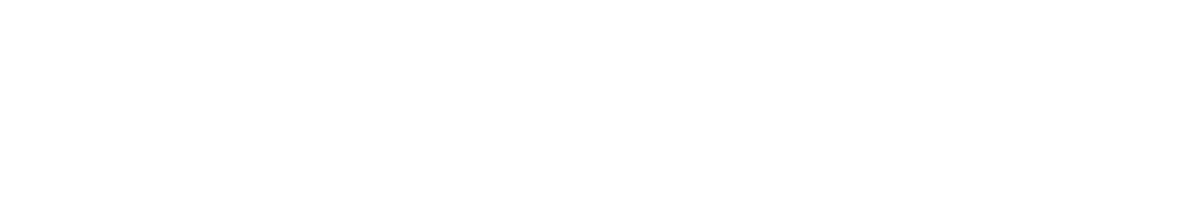

02243000 - ORANGE CR AT ORANGE SPRINGS FLA ILAT 293034 LONG 08156471

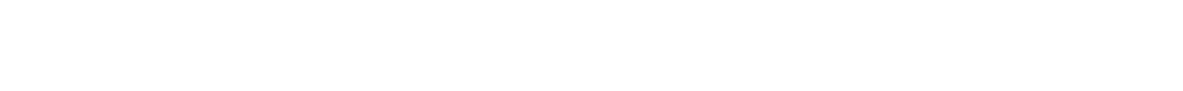

02243800 - DEEP CR NR RODMAN FLA (LAT 293228 LONG 0815012 )

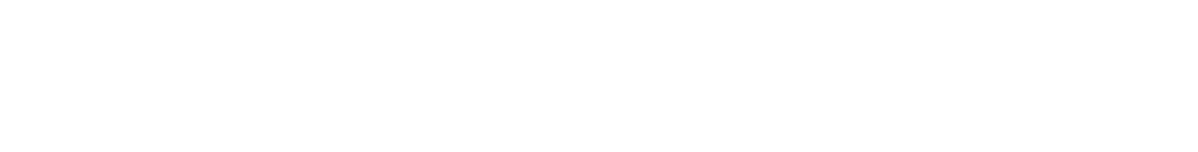

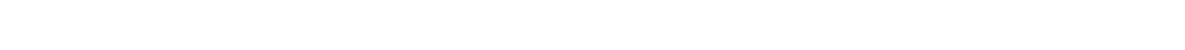

02243959 - OKLAWAHA R AG RODMAN DAM NR ORANGE SPG (LAT 293030 LONG 08148 15)

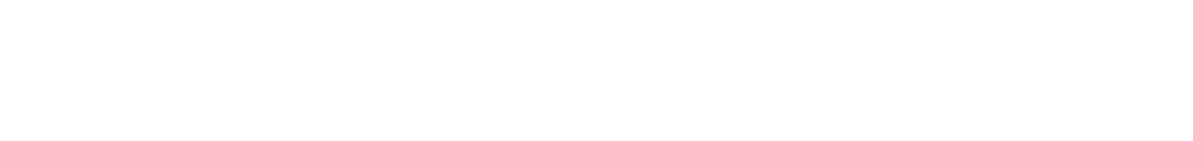

n2243960 - OKLAWAHA R AT RODMAN UAM NR ORANGE SPR (LAT 293030 LONG 08148 15)

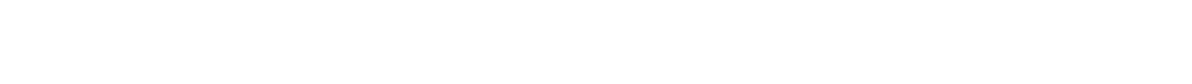

02244000 - OKLAWAHA R AT RSIUE LDG NR ORANGE SPGS (LAT 293000 LONG 08148 00)

OCT. 1969

$07 \ldots 3610$

DEC.

O1... 24

JUNE, 1970

02... 2340

$02 \ldots 1660$

\begin{tabular}{|c|c|c|c|c|c|c|c|c|c|}
\hline 26.0 & 275 & $=-$ & - & -- & -- & -- & -- & -- & - \\
\hline 17.0 & 350 & - & - & + & -- & -- & - & - & - \\
\hline 26.5 & 410 & -- & - & -- & -- & -- & -- & - & -- \\
\hline 32.0 & 410 & -- & - & -- & -- & -- & -- & -- & - \\
\hline
\end{tabular}

02244030 - CFBC ABOVE ST JOHNS LOCK NEAR PALATKA (LAT 293240 LONG O8! 43501

\begin{tabular}{|c|c|c|c|c|c|c|c|c|c|c|c|c|}
\hline $\begin{array}{l}\text { NOV... } 1969 \\
19 . . .\end{array}$ & -- & 18.0 & $20 n$ & -- & - & - & - & -- & - & - & $\cdots$ & 7.0 \\
\hline $\begin{array}{l}\text { JAN.., } 1970 \\
19 . . .\end{array}$ & -- & 16.0 & 160 & -- & -- & -- & $=$ & -- & -- & - & $=$ & 7.0 \\
\hline MAR. & - & 20.5 & 155 & -- & -- & $-\infty$ & -- & -- & $\cdots$ & - & - & -- \\
\hline $\begin{array}{l}\text { MAY } \\
18 \ldots . .\end{array}$ & - & 26.5 & 287 & - & - & - & $\cdots$ & - & - & - & $\cdots$ & 7.5 \\
\hline $\begin{array}{l}\text { JULY } \\
24 \ldots . .\end{array}$ & -- & 29.0 & 340 & -- & - & - & -- & $m$ & -- & -- & - & 7.4 \\
\hline $\begin{array}{l}\text { SEP. } \\
24 \ldots .\end{array}$ & -- & 29.0 & 318 & -- & -- & - & -- & $=-$ & -- & - & -- & 7.8 \\
\hline
\end{tabular}

02244032 - CFBC BELOW ST JOHNS LOCK NR PALATKA FL ILAT 293245 LONG 08143351

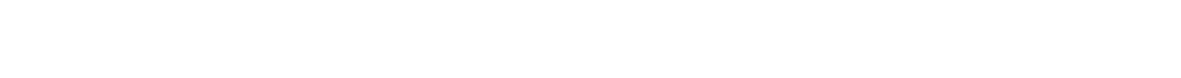

02244350 - LAKE WINONA NR DELAND FLA (LAT 291050 LONA OB1 2006 )

MAY 1970

105

$-\quad 3.6 \quad 3.9$

$6.6 \quad 2.9 \quad 8$

6.0 

CHEMICAL ANALYSES, HATER YEAR OCTOBER 1969 TO SEPTEMBER 1970 (MAJOR CONSTITUENTS)

\begin{tabular}{|c|c|c|c|c|c|c|c|c|c|c|c|c|}
\hline & $\begin{array}{l}\text { DIS- } \\
\text { SOLVED } \\
\text { SULFATE } \\
\text { (SO4) }\end{array}$ & $\begin{array}{l}\text { OIS- } \\
\text { SOLVED } \\
\text { CHLO- } \\
\text { RIOE } \\
\text { (CL) }\end{array}$ & $\begin{array}{l}\text { OIS- } \\
\text { SOLVEO } \\
\text { FLUO- } \\
\text { RIDE } \\
\text { (F) }\end{array}$ & $\begin{array}{l}\text { HARD- } \\
\text { NESS } \\
\text { (CA,MG) }\end{array}$ & $\begin{array}{l}\text { NON- } \\
\text { CAR- } \\
\text { BONATE } \\
\text { HARD- } \\
\text { NESS }\end{array}$ & $\begin{array}{l}\text { ALKA- } \\
\text { LINITY } \\
\text { AS } \\
\text { CACO3 }\end{array}$ & $\begin{array}{l}\text { DIS- } \\
\text { SOLVEO } \\
\text { SOLIOS } \\
\text { (RESI- } \\
\text { DUE AT } \\
180 \mathrm{CI}\end{array}$ & $\begin{array}{l}\text { DIS- } \\
\text { SOLVED } \\
\text { SOLIDS } \\
\text { (SUM OF } \\
\text { CONSTI- } \\
\text { TUENTS) }\end{array}$ & $\begin{array}{l}\text { DIS- } \\
\text { SOLVED } \\
\text { SOLIOS } \\
\text { ITONG } \\
\text { PER }\end{array}$ & $\begin{array}{l}\text { DIS- } \\
\text { SOLVED } \\
\text { SOLIDS } \\
\text { CTONS } \\
\text { PER }\end{array}$ & $\begin{array}{l}\text { TANNIN } \\
\text { AND } \\
\text { LIGNIN }\end{array}$ & DEPT \\
\hline
\end{tabular}

ST. JOHNS RIVER BASIN--CONTINUED

02242400 - LOCHLOOSA LAKE AT LOCHLOOSA FLA (LAT 293019 LONG 082 06 08)

\begin{tabular}{|c|c|c|c|c|c|c|c|c|c|c|c|c|c|c|c|c|}
\hline $\begin{array}{l}\text { APR... } 1970 \\
28 . . .\end{array}$ & .8 & 8.0 & .2 & 25 & & 10 & & 15 & 73 & & 36 & 6 & - & & .10 & -- \\
\hline & & 02242450 & - & ORANGE & LAKE & AT & ORANGE & E LAKE & FLA & ILAT & 292 & 2550 & LONG & 082 & 12101 & \\
\hline $30 \ldots$ & .8 & 8.5 & .3 & 21 & & 4 & & 17 & 42 & & 35 & 35 & -- & & .06 & - \\
\hline
\end{tabular}

02243000 - ORANGE CR AT ORANGE SPRINGS FLA (LAT 293034 LONG 0815647 ,

\begin{tabular}{|c|c|c|c|c|c|c|c|c|c|c|c|}
\hline $\begin{array}{l}\text { MAY . } 1970 \\
\text { O1... } \\
\text { SEP.: } \\
22 . . .\end{array}$ & $\begin{array}{l}.8 \\
--\end{array}$ & 7.2 & .2 & 19 & - & 15 & 49 & 30 & - &.$n 7$ & - \\
\hline
\end{tabular}

02243800 - DEEP CR NR ROOMAN FLA (LAT 293228 LONG 0815012 )

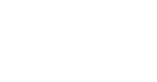

SEP.

02243958 - LAKE OCKLAWAHA NEAR ORANGE SPRINGS FLA (LAT 293030 LONG 08148 15)

SEP., 1970 30 .3

135

43

$92 \quad 236$

189

02243959 - OKLAWAHA R AB RDDMAN DAM NR ORANGE SPG (LAT 293030 LONG 08148 15)

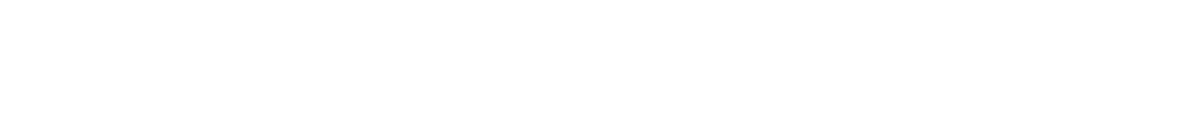
02243960 - OKLAWAHA R AT RODMAN DAM NR ORANGE SPR (LAT 293030 LONG 08148 15)

\begin{tabular}{|c|c|c|c|c|c|c|c|c|c|c|c|}
\hline $\begin{array}{l}\text { MAY, } 1970 \\
\text { O7... } \\
\text { SEP. }\end{array}$ & 26 & 29 & .3 & 116 & 33 & 84 & 215 & 171 & & .29 & - \\
\hline $23 .$. & 32 & 31 & .3 & 138 & 37 & 102 & 249 & 201 & 1350 & .34 & - \\
\hline
\end{tabular}

02244000 - OKLAWAHA R AT RSIDE LOG NR ORANGE SPGS (LAT 293000 LONG 0814800 )

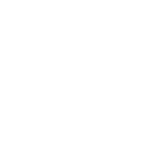

0

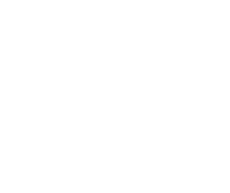

02244030 - CFBC ABOVE ST JOHNS LOCK NEAR PALATKA (LAT 293240 LONG 0814350 )

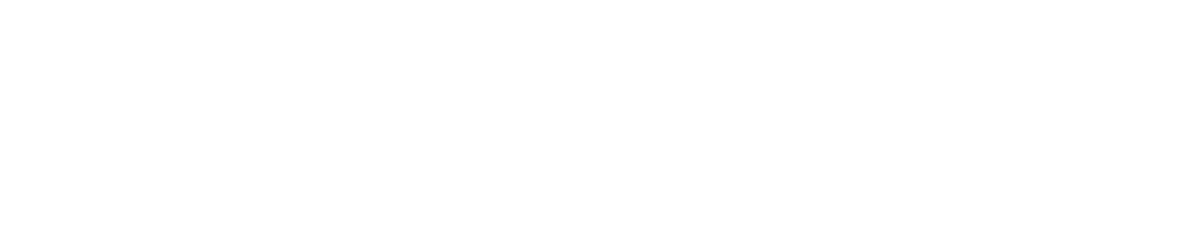
02244032 - CFBC BELOW ST JOHNS LOCK NR PALATKA FL (LAT 293245 LONG 0814335 )

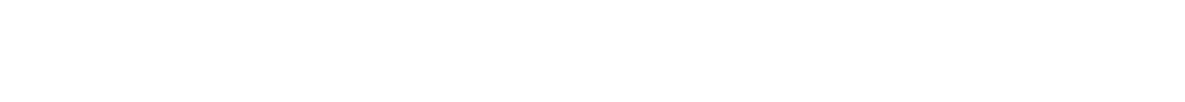

02244350 - LAKE WINONA NR OELANO FLA (LAT 291050 LONG 08120 06)

MAY 1970

11

$.2 \quad 25 \quad 19$ 


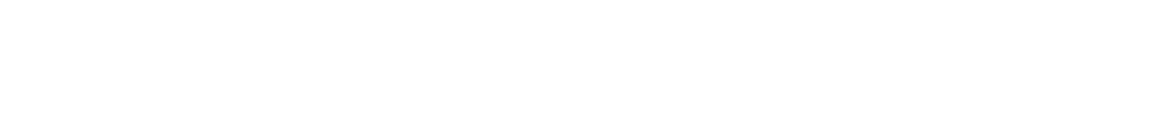
ST. JDHNS RIVER BASIN--CONTINUED

02244420 - LITTLE HAW CR NR SEVILLE FLA (LAT 291920 LONG 0812310 )

$\begin{array}{llllllllllllll}\text { MAY } & 1970 . . . & 6.9 & 22.0 & 75 & -- & 3.8 & 1.1 & -0 & 6.2 & .7 & 2 & --\end{array}$

02244450 - ST JOHNS R AT PALATKA FLA ILAT 293837 LONG 0813736 ,

\begin{tabular}{|c|c|c|c|c|c|c|c|c|c|c|c|c|}
\hline $\begin{array}{l}\text { MAY } 1970 \\
18 . . .+\end{array}$ & $\cdots$ & 27.0 & 738 & 70 & 37 & 17 & 640 & 99 & 3.9 & Bo & 0 & 7.5 \\
\hline $21 \ldots$ & -- & 30.0 & 671 & 130 & 43 & 13 & 510 & 71 & 3.0 & 104 & 0 & B.0 \\
\hline
\end{tabular}

02244600 - SAND HILL L NR KEYSTONE HEIGHTS FLA (LAT 295101 LONG 0820110 )

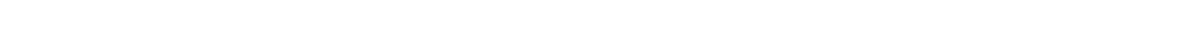

02244750 - 9ROOKLYN L NR KEYSTONE MEIGHTS FLA (LAT 294746 LONG 0820121 )

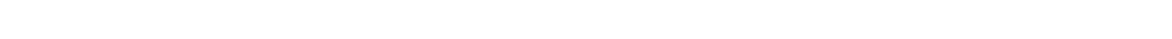

02244800 - L GENEVA AT KEYSTONE HEIGHTS FLA (LAT 294626 LONG 0820159 \}

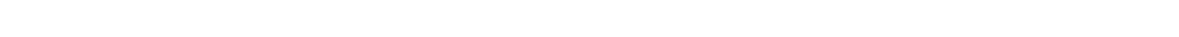

02244850 - PEBELE L NR KEYSTONE HGTS FLA (LAT 294931 LONG OBI 5710$\}$

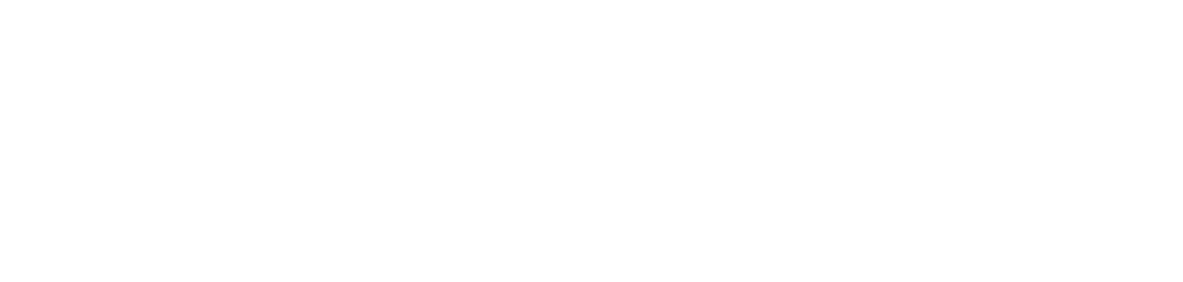

02245300 - CLARKS CREEK NR GREEN COVE SPGS FLA (LAT 295240 LONG 0813952 )

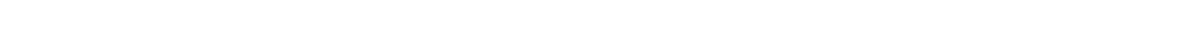

02245400 - SO FORK BLACK CR NR CAMP BLANOING FLA ILAT 295633 LONG 0815352 )

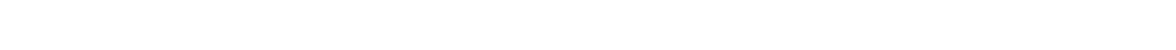

02245470 - GREENS CR NR PENNEY FARMS FLA ILAT 295438 LONG OBI 4740 )

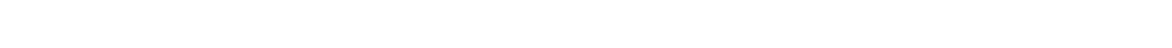

02245500 - SO FORK BLACK CR NR PENNEY FARMS FLA (LAT 295845 LONG 08151 OB)

MAY 1970

$22.0 \quad 32$

02245700 - KINGSLEY L AT CAMP BLANDING FLA (LAT 295828 LONG 0815922 )

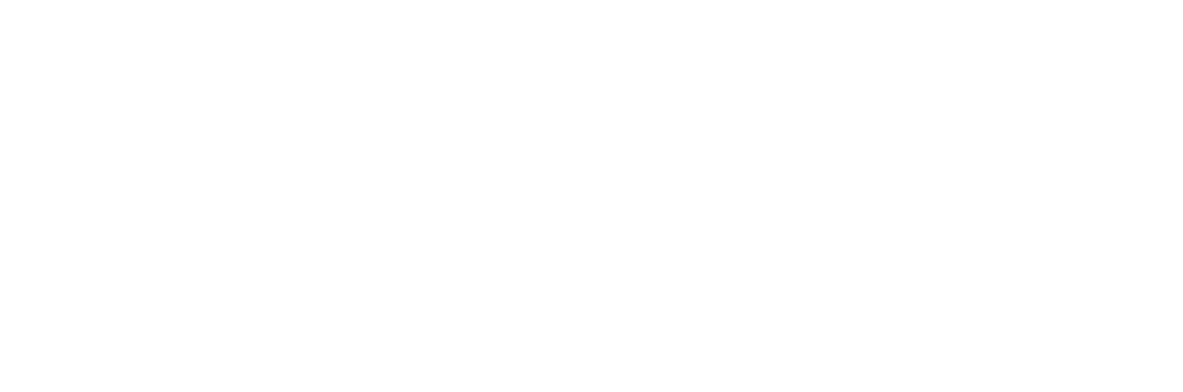


CHEMICAL ANALYSES, WATER YEAR DCTOBER 1969 TO SEPTEMBER 1970 (MAJOR CONSTITUENTS)

\begin{tabular}{|c|c|c|c|c|c|c|c|c|c|c|c|c|}
\hline TE & $\begin{array}{l}\text { DIS- } \\
\text { SOLVED } \\
\text { SULFATE } \\
\text { (SO4) } \\
\text { (MG/L) }\end{array}$ & $\begin{array}{l}\text { DIS- } \\
\text { SOLVED } \\
\text { CHLO- } \\
\text { RIDE } \\
\text { (CL) } \\
\text { (MG/L) }\end{array}$ & $\begin{array}{l}\text { DIS- } \\
\text { SDLVED } \\
\text { FLUD- } \\
\text { RIDE } \\
\text { (F) } \\
\text { (MG/L) }\end{array}$ & $\begin{array}{l}\text { HARD- } \\
\text { NESS } \\
\text { (CA,MG) } \\
\text { (MG/L) }\end{array}$ & $\begin{array}{l}\text { NDN- } \\
\text { CAR- } \\
\text { BONATE } \\
\text { HARD- } \\
\text { NESS } \\
\text { (MG/L) }\end{array}$ & $\begin{array}{l}\text { ALKA- } \\
\text { LINITY } \\
\text { AS } \\
\text { CACO3 } \\
\text { (MG/L) }\end{array}$ & $\begin{array}{l}\text { DIS- } \\
\text { SOLVEO } \\
\text { SOLIDS } \\
\text { (RESI- } \\
\text { DUE AT } \\
180 \mathrm{C} \text { ) } \\
(\mathrm{MG} / \mathrm{L} \text { ) }\end{array}$ & $\begin{array}{l}\text { DIS- } \\
\text { SDLVED } \\
\text { SDLIDS } \\
\text { (SUM OF } \\
\text { CONSTI- } \\
\text { TUENTS) } \\
\text { (MG L.) }\end{array}$ & $\begin{array}{l}\text { DIS- } \\
\text { SOLVED } \\
\text { SOLIDS } \\
\text { (TONS } \\
\text { PER } \\
\text { DAY) }\end{array}$ & $\begin{array}{l}\text { DIS- } \\
\text { SOLVED } \\
\text { SOLIDS } \\
\text { TOONS } \\
\text { PER } \\
\text { AC-FT) }\end{array}$ & $\begin{array}{l}\text { TANNIN } \\
\text { AND } \\
\text { LIGNIN } \\
\text { (MG/L) }\end{array}$ & $\begin{array}{l}\text { DEPTH } \\
\text { (F T) }\end{array}$ \\
\hline
\end{tabular}

ST. JQHNS RIVER BASIN--CONTINUED

02244420 - LITJLE HAW CR NR SEVILLE FLA (LAT 291920 LONG O8I 23 10)

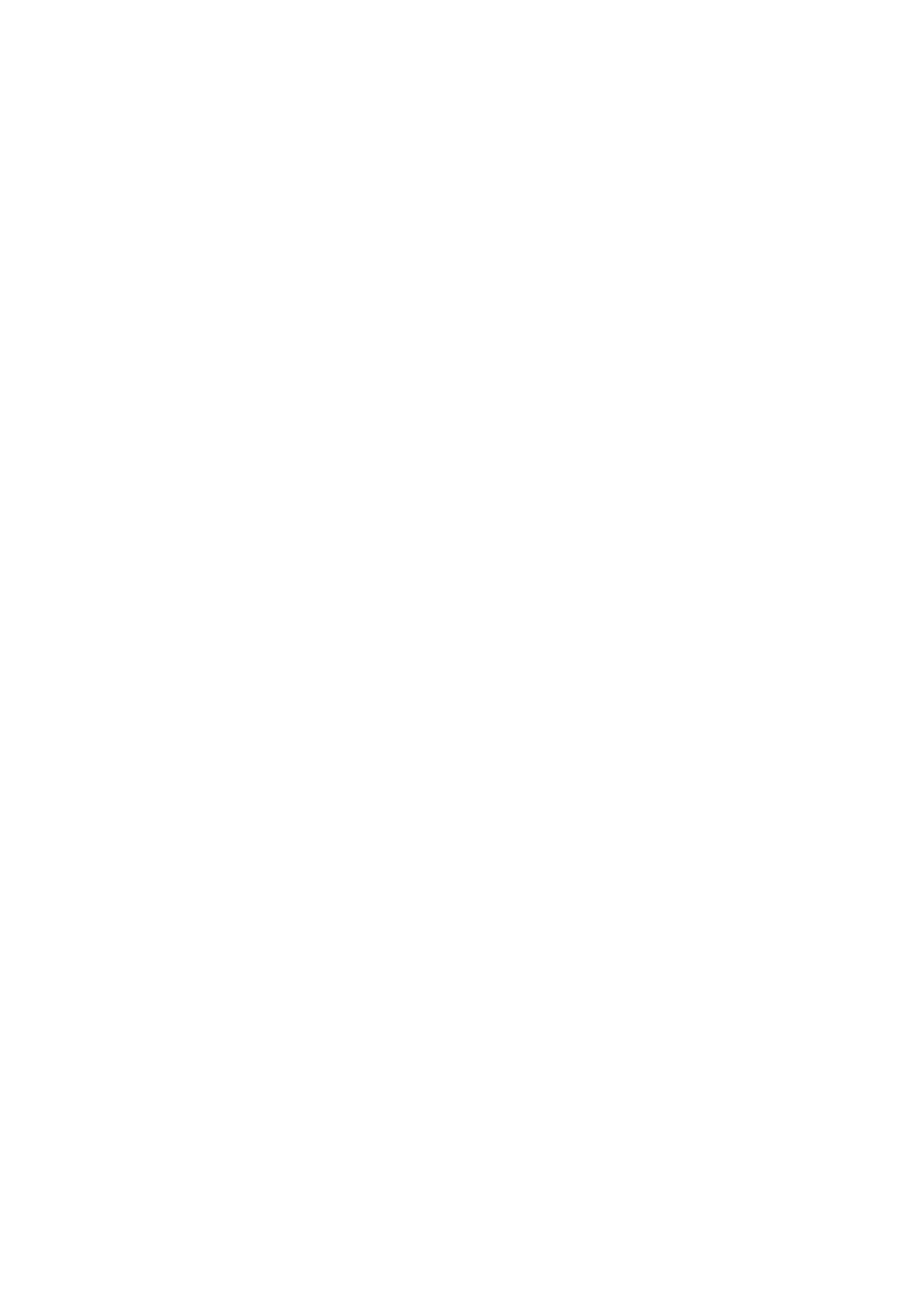


CHEMICAL ANALYSES, WATER YEAR OCTOBER 1969 TO SEPTEMBER 1970 (MAJOR CONSTITUENTS)

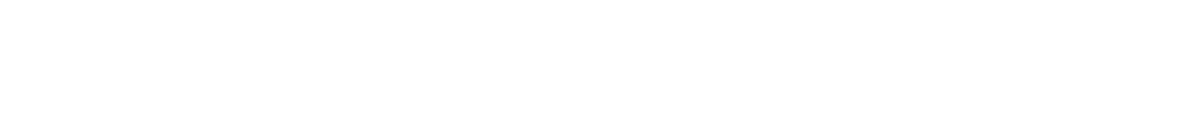

\section{ST. JOHNS RIVER BASIN--CONTINUED}

02246150 - BIG DAVIS CR AT BAYARO FLA (LAT 300905 LONG 0813134 )

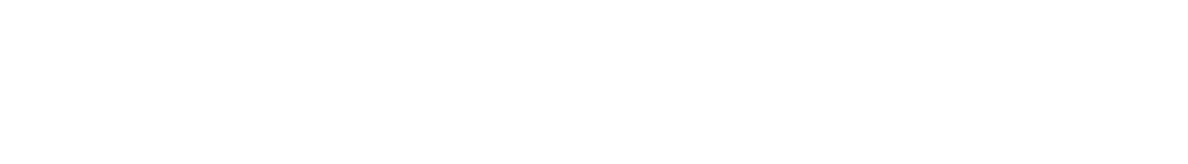

02246200 - DURBIN CR NR DURBIN FLA (LAT 300557 LONG 08131 34)

$\begin{array}{llllllllllll}\operatorname{mar}, 1970 & 190 & 19.0 & 200 & -0 & 25 & 2.8 & - & 10 & 1.1 & 81 & 0\end{array}$

02246250 - ST JOHNS RIVER AT NAVAL AIR STA FLA (LAT 301339 LONG A80 3958 )

\begin{tabular}{|c|c|c|c|c|c|c|c|c|c|c|c|c|}
\hline $\begin{array}{l}\text { OCT... } 1969 \\
08 \ldots . .\end{array}$ & $\cdots$ & 26.0 & 600 & - & - & -- & - & -- & -- & -- & - & $\cdots$ \\
\hline $\begin{array}{l}\text { JAN., } 1970 \\
\text { O6... } \\
\text { MAR. }\end{array}$ & - & 12.0 & 440 & - & -- & - & - & -- & - & -- & - & $=$ \\
\hline MAY & -- & 16.0 & 395 & - & - & - & - & -- & -- & -- & $\cdots$ & $=$ \\
\hline JUNE & -- & 28.5 & 480 & - & 24 & 9.0 & - & 52 & 2.7 & 56 & -- & 6.6 \\
\hline $24 \ldots$ & -- & 30.5 & $423 n$ & - & -- & 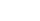 & - & -- & -- & -- & - & - \\
\hline
\end{tabular}

G2246300 - ORTEGA RIVER NR JACKSONVILLE FLA (LAT 301450 LONG 0814749 )

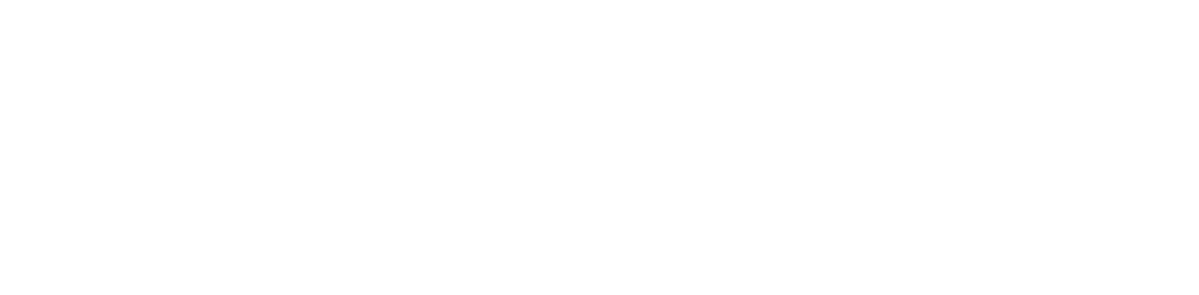

02246500 - ST JOHNS R AT JACKSONVILLE FLA (LAT 3n 1926 LONG 0813912 )

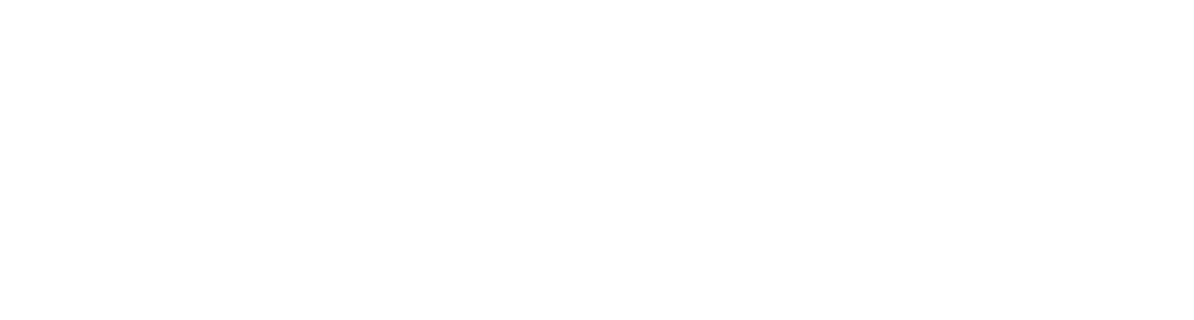
02246530 - ST JOHNS R AT DHEDGE LEPOT NR JAXVL FL (LAT 302125 LONG 08137 18)

OCT..1969
OB...
JAN..1970
O6...

02246600 - TROUT R AT DINSMORE FLA (LAT 30 2551 LONG 0814607 )

MAY 1970 
CHEMICAL ANALYSES, WATER YEAR DCTOBER 1969 TO SEPTEMBER 1970 (MAJOR CONSTITUENTS)

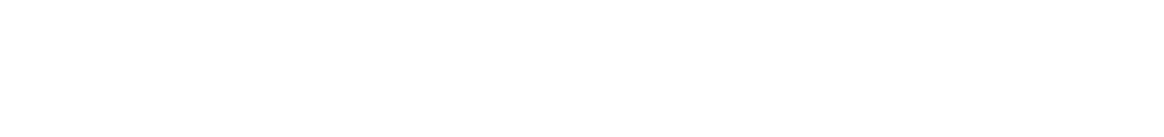

ST. JDHNS RIVER BASIN--CONTINUED

02246150 - 8IG DAVIS CR AT EAYARO FLA ILAT 3009 OS LONG 0813134 )

\begin{tabular}{|c|c|c|c|c|c|c|c|c|c|c|c|c|}
\hline $09 \ldots$. & - & 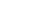 & -- & - & - & -. & - & - & - & - & -- & - \\
\hline JAN... 1970 & - & -- & -- & - & -- & -- & $-\infty$ & - & -- & -- & -- & -- \\
\hline MAY & -- & $-\infty$ & $=-$ & -- & -- & -- & - & - & -- & - & $-\infty$ & -- \\
\hline $\operatorname{JULY}_{\text {JU }}^{20}$ & .8 & 9.5 & .1 & 48 & 30 & 45 & 81 & 69 & .24 & .11 & $m$ & -- \\
\hline $15 \ldots$ & - & - & -- & - & $\cdots$ & -- & - & -- & 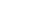 & -- & $-\infty$ & - \\
\hline
\end{tabular}

02246200 - DURBIN CR NR DURBIN FLA (LAT 300557 LONG 0813134 )

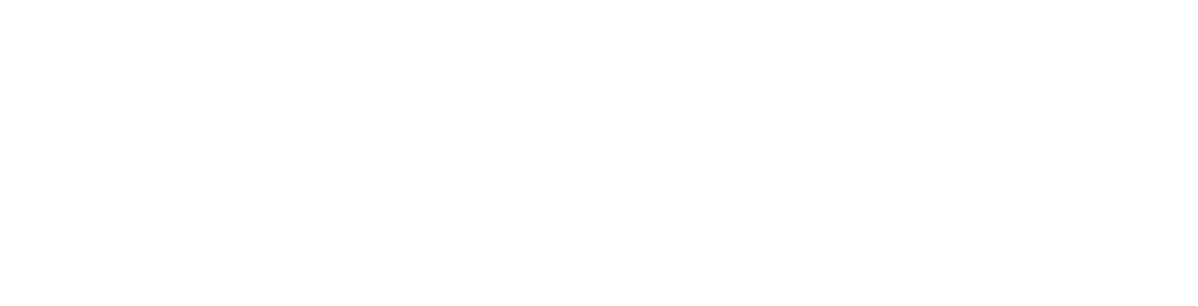

02246300 - ORTEGA RIVER NR JACKSONVILLE FLA ILAT 301450 LONG 0814749 )

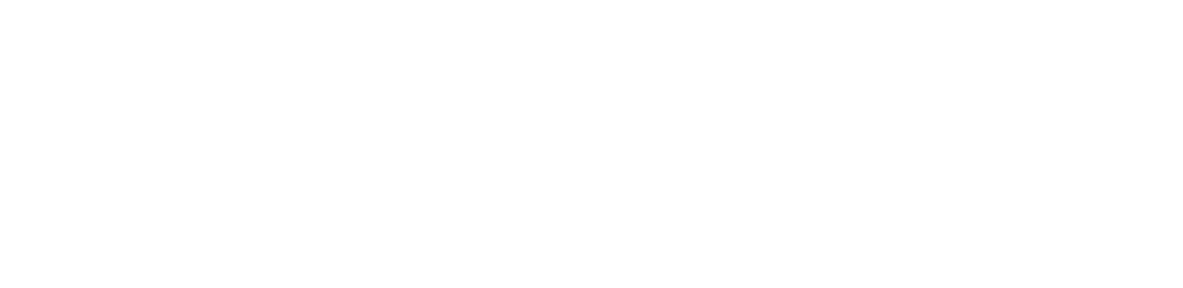

02246500 - ST JOHNS R AT JACKSONVILLE FLA (LAT 301926 LONG 08139 12)

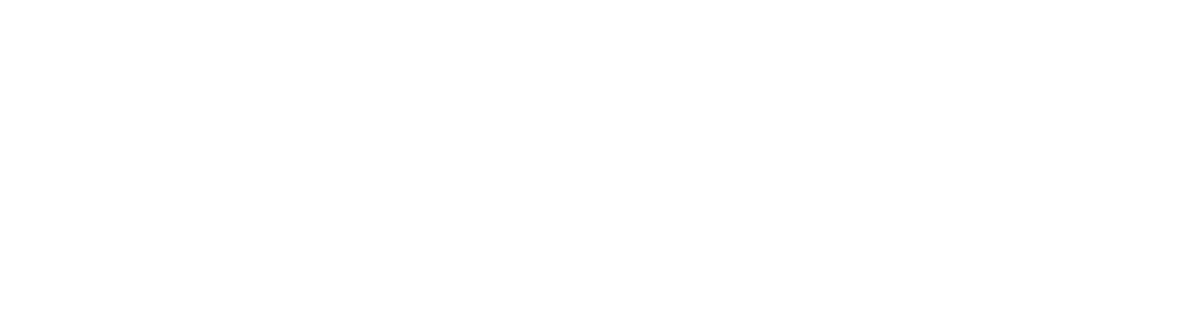

02246530 - ST JOHNS R AT OREDGE DEPOT NR JAXVL FL ILAT 302125 LONG 08137 18)

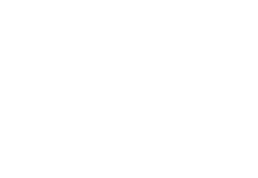

02246600 - TROUT R AT DINSMORE FLA (LAT 302551 LONG $08146 \quad 07$ )

MAY 1970

$13 . . .16$

$.3 \quad 68$

62

149

105 


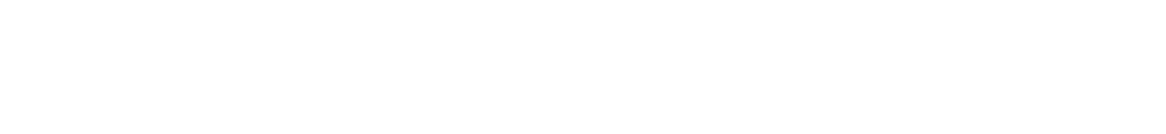
COASTAL BASIN BETHEEN ST. JOHNS RIVER AND TURKEY CREEK

02246900 - MOULTRIE CR AT SH 207 NR ST AUGUSTINE (LAT 295050 LONG 081 21 39)

\begin{tabular}{|c|c|c|c|c|c|c|c|c|c|c|c|}
\hline $\begin{array}{l}\text { APR... } 1970 \\
29 \ldots . . \\
\text { SEP. }\end{array}$ & - & 23.0 & 418 & 400 & 21 & 9.4 & 350 & 48 & 3.4 & 12 & 0 \\
\hline $28 \ldots$ & 1.6 & 23.5 & 175 & 560 & 14 & 3.2 & 160 & 18 & 1.6 & 36 & 0 \\
\hline
\end{tabular}

02247510 - TOMOKA R NR HOLLY HILL FLA (LAT 291302 LONG 0810632 )

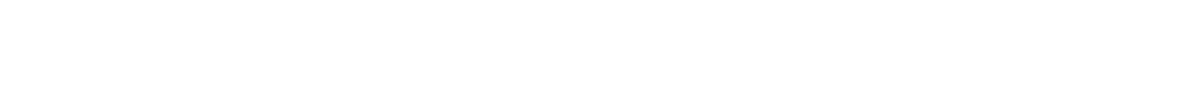

02252500 - NORTH CANAL NR VERO BEACH FLA (LAT 274132 LONG 08025001

Nov., 1969

03... 65

JAN." 1970

07... 72

O2... 11

MAY

JUNE

$29 . . .13$

AUG... 8.4

$$
24 .
$$$$
710
$$$$
17.0
$$$$
25.0
$$$$
27.0
$$$$
26.0
$$

30.0

710
510
600
1360
1000
750

$\begin{array}{lccc}-- & -- & - & - \\ -- & -- & - & - \\ -- & - & -- & - \\ - & 92 & 34 & - \\ - & -- & - & -\end{array}$ $\begin{array}{rrrrr}- & - & - & -- \\ -- & -- & -- & - \\ -- & -- & -- & -- \\ - & 140 & 6.8 & 200 \\ - & -- & -- & -- \\ - & a & 3.0 & 186\end{array}$

TURKEY CREEK AND COASTAL BASINS SOUTH TO ST. LUCIE RIVER

02253000 - MAIN CANAL AT VERO BEACH FLA (LAT 273854 LONG $08024 \quad 10$ )

Nov., 1969

O4... 132

JAN... 1970

MAR.

MAY 11

O2... 380

JUNE

29... 102

SEP.

$\begin{array}{rr}24.0 & 725 \\ 16.5 & 480 \\ 21.5 & 950 \\ 28.0 & 1780 \\ 29.5 & 1250 \\ 29.0 & 870\end{array}$

$$
\begin{array}{rrrrrrrrr}
-- & -- & -- & -- & - & -- & - & - & - \\
-- & -- & - & -- & -- & -- & -- & -- & - \\
-- & -- & - & -- & -- & - & -- & -- & - \\
-- & 96 & 44 & -- & 192 & 9.6 & 200 & 8 & 8.5 \\
-- & -- & -- & -- & -- & - & -- & -- & -- \\
-- & 76 & 18 & -- & 74 & 44 & 188 & 8 & 8.5
\end{array}
$$

02253500 - SOUTH CANAL NR VERO BEACH FLA (LAT 273611 LONG 08023 24)

NOV.. 1969

O4... 1969

JAN., 1970

07... 748

MAR... 9.6

MAY

$04 \ldots 27$

JUNE 27

$29 . . . \quad 8.4$

O1... 4.9

$\begin{array}{rrrrrr}24.5 & 720 & -- & - & - & - \\ 17.0 & 425 & -- & -- & - & - \\ 21.0 & 495 & - & - & - & - \\ 29.0 & 1550 & - & 92 & 38 & - \\ 30.0 & 800 & -- & - & - & - \\ 28.0 & 755 & - & 72 & 8.6 & -\end{array}$

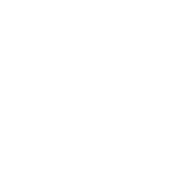

02253600 - MOORE CR AT FT PIERCE FLA (LAT 272658 LONG 0801937$)$

MAY 1970

28.0

485

65 

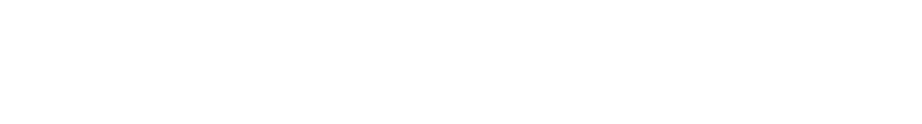

SOLIDS TANNIN

TONS AND

PER LIGNIN DEPTH

COASTAL BASIN BETWEEN ST. JDHNS RIVER AND TURKEY CREEK--CDNTINIIFD

02246900 - MOULTRIE CR AT SH 207 NR ST AUGUSTINE ILAT 295050 LONG 08121391

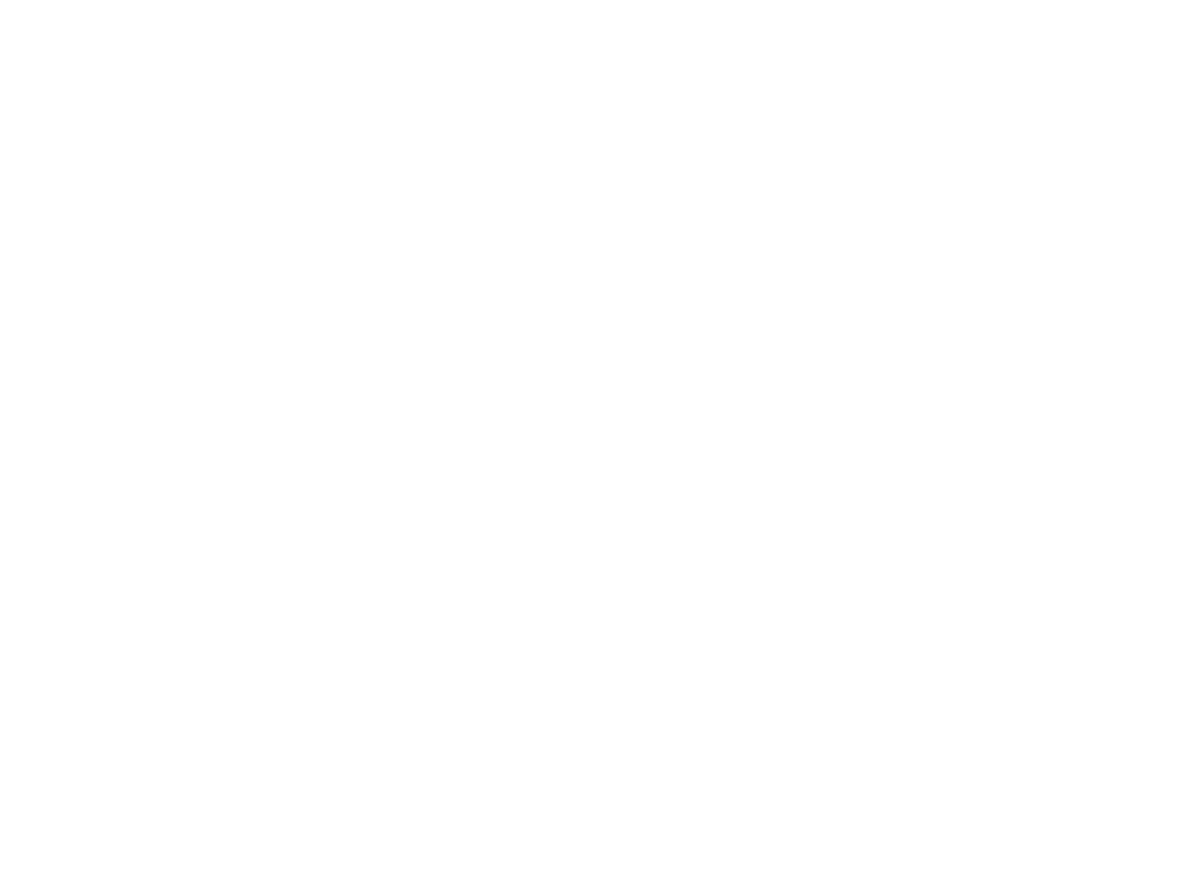

TURKEY CREEK AND COASTAL BASINS SOUTH TO $5 T$. LUCIE RIVER--CONTINUED

02253000 - MAIN CANAL at VERO BEACM FLA (LAT 273854 LDNG 08024 10)

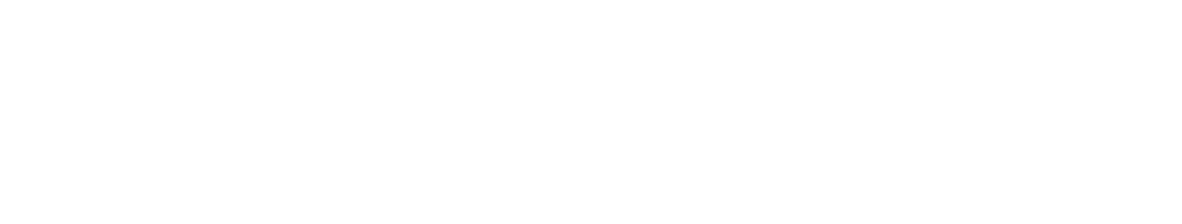

n2253500 - SOUTH CANAL NR VERO BEACH FLA (LAT 273611 LDNG OBO 23241

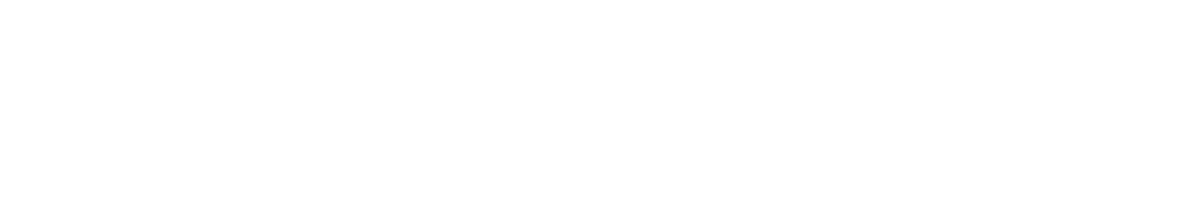

02253600 - MOORE CR AT FT PIERCE FLA ILAT 272658 LONG 08019371

MAY, 1970

42

$\begin{array}{lll}28 & 161 & 334\end{array}$

280

$.99 \quad .45$ 


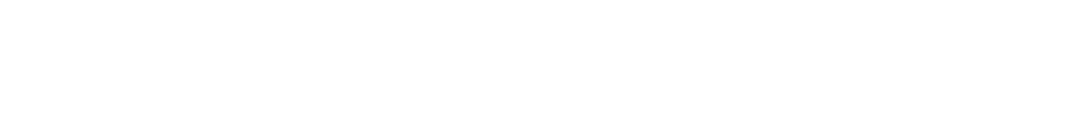

LAKE DKEECHOBEE AND THE EVERGLADES BASINS

02257000 - FISHEATING CP AT LAKEPORT FLA (LAT 265750 LONG OBI $0710 \%$

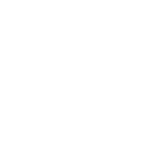

OCT., 1969

01... 800

$\begin{array}{ll}01 \ldots . . & 860 \\ 31 \ldots . & 280\end{array}$

DEC.

O1... $1970 \quad .00$

JAN., $1970 \quad .00$

FEF. $02 . . \quad .00$

$\begin{array}{ll}\text { MAR... } & .00 \\ 02 . . . & .00\end{array}$

O2... $\quad .00$

OPR... 3990

$01 \ldots .00$

$14 \ldots . .00$

AUG... .00

$02 . . . \quad .00$

$\begin{array}{ll}25.0 & 100 \\ 15.0 & 119 \\ 19.0 & 135 \\ 12.0 & 110\end{array}$

02257800

$\begin{array}{llll}28.0 & 158 & - & - \\ 28.0 & 155 & - & - \\ 24.0 & 130 & -- & - \\ 22.0 & 310 & -- & - \\ 18.5 & 185 & -- & -- \\ 19.0 & 250 & -- & -- \\ 19.5 & 300 & -- & - \\ 27.0 & 150 & -- & - \\ 27.0 & 190 & -- & -- \\ 27.0 & 180 & -- & 17 \\ 31.0 & 200 & -- & - \\ 30.0 & 135 & -- & 11\end{array}$

$$
\begin{array}{llll}
7.3 & 2.3 & -- & 9.7 \\
6.4 & 2.4 & -- & 12 \\
7.7 & 2.7 & -- & 14 \\
4.8 & 2.2 & -- & 13
\end{array}
$$

$\begin{array}{lll}9.7 & 1.0 & 17\end{array}$

.514

1.118

1.310

6.3

6.6

6.5

6.3

02257801 - HARNEY PONO CANAL BELOW S-71 NR LAKEPO (LAT 2702 DO LONG 0810415 )

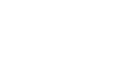

DEC

01.00

JAN., $1970 \quad .00$

P...

P2... .00

MAR.

$02 . . . \quad .00$

$\begin{array}{ll}\text { MAY } & \\ 01 . . . & .00\end{array}$

$14 \ldots . .0 \quad 00$

UUG.

$02 \ldots .00$

$\begin{array}{rrrr}28.0 & 155 & -- & -- \\ 24.0 & 134 & -- & - \\ 21.0 & 315 & -- & -- \\ 18.5 & 590 & -- & -- \\ 19.0 & 255 & -- & -- \\ 19.5 & 290 & -- & -- \\ 27.0 & 210 & -- & -- \\ 28.0 & 280 & -- & 27 \\ 31.5 & 19 & -- & -- \\ 30.0 & 150 & -- & 14\end{array}$

02258000

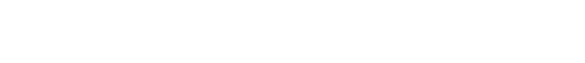

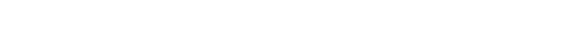

$$
\begin{aligned}
& \begin{array}{lllllll}
-- & - & - & - & - & - & - \\
- & - & - & - & -
\end{array} \\
& \begin{array}{ccccccc}
-- & -- & -- & -- & -- & -- & -- \\
-- & - & -- & -- & -- & -- & 7 .-4
\end{array} \\
& \text {-. }
\end{aligned}
$$

JAN.., 1970

1600.

.00

242

HARVEY POND CA NR LAKEPORT FLA (LAT $2700 \quad 00$ LONG ORI 0405 )

02259200 - INOIAN PRAIKIE CANAL AT S-72 NR OKFECH (LAT 270535 LONG NBI ON 25)

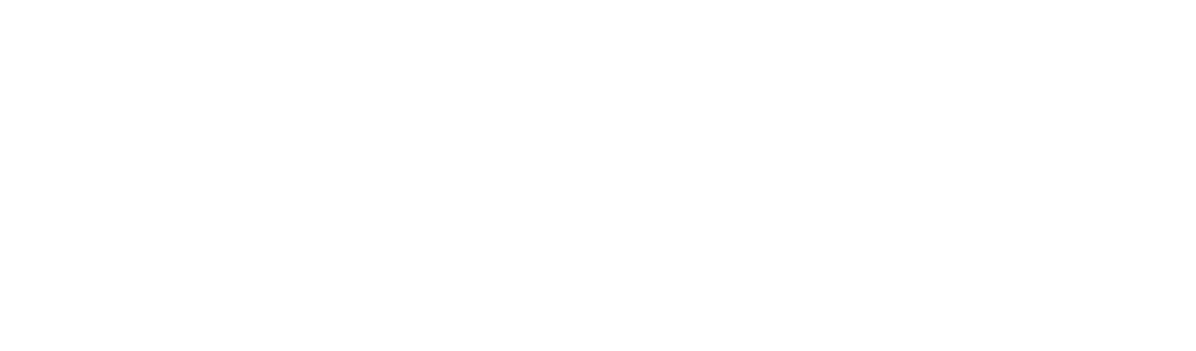


CHEMICAL ANALYSES, WATER YEAR OCTOBER 1969 TO SEPTEMBER 1970 (MAJOR CONSTITUENTS)
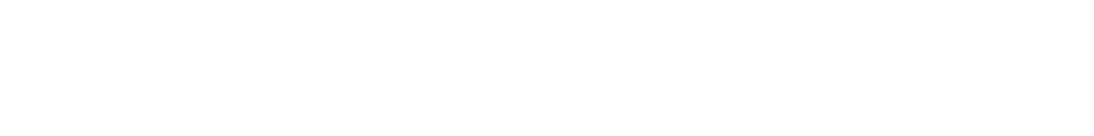

LAKE OKEECHOBEE AND THE EVERGLADES BASINS--CONTINUED

02257000 - FISHEATING CR AT LAKEPORT FLA ILAT 265750 LONG 08107101

\begin{tabular}{|c|c|c|c|c|c|c|c|c|c|c|c|c|}
\hline${ }_{27 \ldots}^{\text {OCT. } 1969}$ & .0 & 17 & .2 & 28 & 14 & 14 & 102 & 53 & -- & .14 & -- & - \\
\hline $\begin{array}{l}\text { NOV. } \\
21 \ldots . . \\
\text { OEC. }\end{array}$ & .0 & 26 & .2 & 26 & 15 & 11 & 108 & 60 & -- & .15 & - & - \\
\hline $\begin{array}{l}09 . . .1970 \\
\text { JAN.. } 1970\end{array}$ & .8 & 30 & .3 & 30 & 15 & 15 & 117 & 70 & - & .16 & - & - \\
\hline $14 \ldots$ & .0 & 24 & .6 & 21 & 13 & 8 & 103 & 54 & -- & .14 & -- & .0 \\
\hline
\end{tabular}

02257800 - HARNEY POND CANAL AT S-71 NR LAKEPORT (LAT 270200 LONG 08104 15)

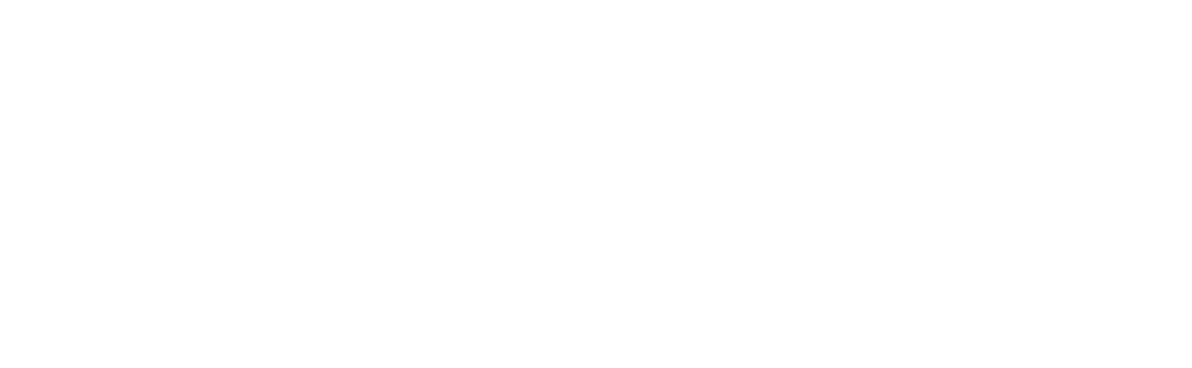

02257801 - HARNEY PONO CANAL BELOW S-71 NR LAKEPO (LAT 270200 LONG 0810415 )

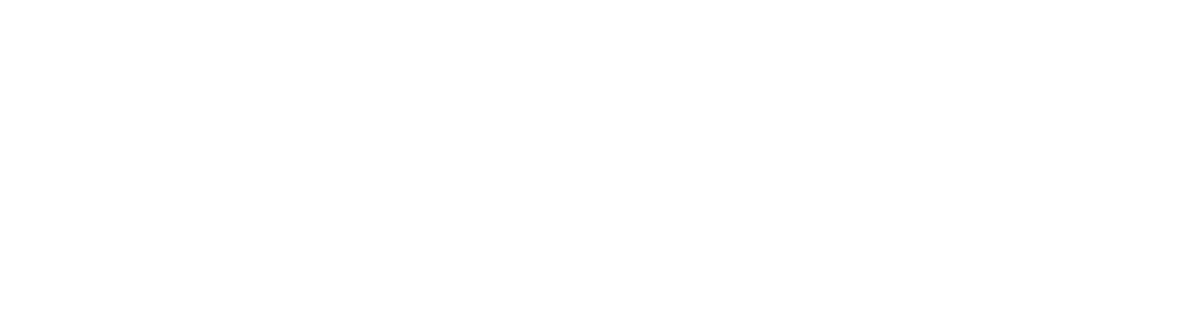

02258000 - HARVEY POND CA NR LAKEPORT FLA ILAT 270000 LONG 08104051

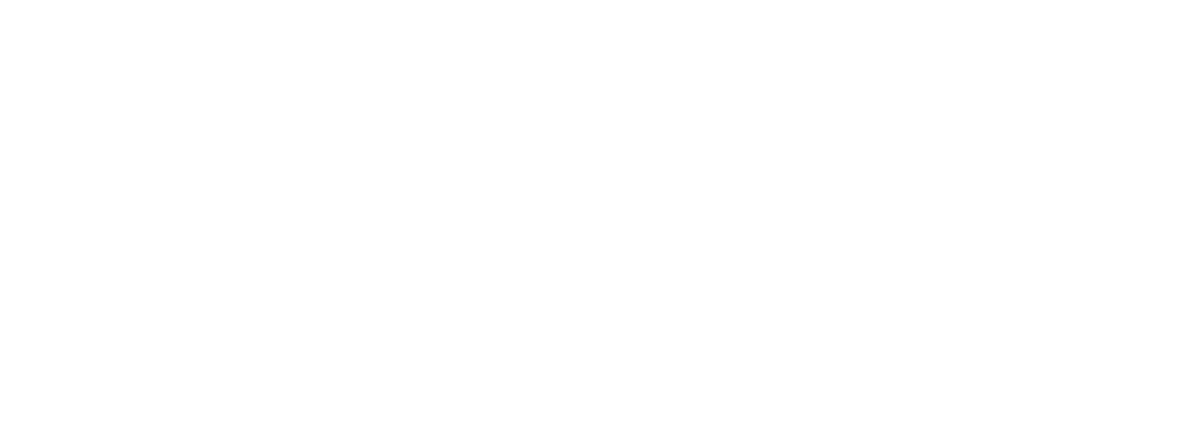




\begin{tabular}{|c|c|c|c|c|c|c|c|c|c|c|c|c|}
\hline ATE & $\begin{array}{l}\text { DIS- } \\
\text { CHARGE } \\
\text { (CFS) }\end{array}$ & $\begin{array}{l}\text { TEMPER- } \\
\text { ATURE } \\
\text { (DEG C) }\end{array}$ & $\begin{array}{l}\text { SPE- } \\
\text { CIFIC } \\
\text { CON- } \\
\text { DUCT- } \\
\text { ANCE } \\
\text { (MICRO- } \\
\text { MHOS) }\end{array}$ & $\begin{array}{l}\text { DIS- } \\
\text { SOLVED } \\
\text { IRON } \\
\text { (FE) } \\
\text { (UG/L) }\end{array}$ & $\begin{array}{l}\text { DIS- } \\
\text { SOLVED } \\
\text { CAL- } \\
\text { CIUM } \\
\text { (CA) } \\
\text { (MG/L) }\end{array}$ & $\begin{array}{l}\text { OIS- } \\
\text { SOLVED } \\
\text { MAG- } \\
\text { NE- } \\
\text { SIUM } \\
\text { (MG) } \\
\text { (MG/L) }\end{array}$ & $\begin{array}{l}\text { DIS- } \\
\text { SOLVED } \\
\text { STRON- } \\
\text { TIUM } \\
\text { (SR) } \\
\text { (UGR) }\end{array}$ & $\begin{array}{l}\text { DIS- } \\
\text { SOLVED } \\
\text { SODIUM } \\
\text { (NA) } \\
\text { (MG/L) }\end{array}$ & $\begin{array}{l}\text { DIS- } \\
\text { SOLVED } \\
\text { PO- } \\
\text { TAS- } \\
\text { SIUM } \\
\text { (K) } \\
\text { (MG/L) }\end{array}$ & $\begin{array}{l}\text { BICAR- } \\
\text { BONATE } \\
\text { (HCO3) } \\
\text { (MG/L) }\end{array}$ & $\begin{array}{l}\text { CAR- } \\
\text { BONATE } \\
(\mathrm{COB}) \\
(M G / L)\end{array}$ & $\begin{array}{c}\text { PH } \\
\text { CUNITS }\end{array}$ \\
\hline
\end{tabular}

LAKE OKEECHOBEE AND THE EVERGLADES BASINS--CONTINUED

02259201 - INDIAN PRAIRIE CA BL S-72 NR OKEECHOBE (LAT 270535 LONG 0810025 )

\begin{tabular}{|c|c|c|c|c|c|c|c|c|c|c|c|c|}
\hline OCT... 1969 & .00 & 23.5 & 175 & - & -- & - & - & - & - & - & - & - \\
\hline $\begin{array}{l}\text { DEC. } \\
\text { OA... } \\
\text { JAN.. } 1970\end{array}$ & .00 & 19.5 & 335 & - & -- & - & - & -- & - & - & - & - \\
\hline FER... & .00 & 18.5 & 315 & - & -- & -- & - & -- & - & -- & -- & $\cdots$ \\
\hline $\begin{array}{l}02 . . . \\
\text { MAR. }\end{array}$ & .00 & 19.0 & 275 & - & $-\infty$ & - & - & $=$ & - & - & - & - \\
\hline $\begin{array}{l}02 \ldots . . . \\
\text { APR. }\end{array}$ & .00 & 20.5 & 430 & - & $\cdots$ & 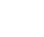 & - & - & - & - & - & - \\
\hline$\underset{\text { MAY }}{01} \cdots$ & .00 & 28.0 & 170 & - & - & $\cdots$ & - & $\cdots$ & - & $\cdots$ & -- & - \\
\hline $\begin{array}{l}01 \ldots . . \\
05 . . \\
\text { AUG. }\end{array}$ & .00 & $\begin{array}{l}27.5 \\
28.0\end{array}$ & $\begin{array}{l}290 \\
241\end{array}$ & 850 & $28^{-\infty}$ & 6.0 & 700 & $16^{--}$ & $1 . \overline{5}$ & 45 & $\overline{0}$ & 7.5 \\
\hline $03 \ldots$ & .00 & 32.5 & 315 & - & - & - & $m$ & 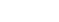 & - & -- & - & \\
\hline
\end{tabular}

02259500 - INDIAN PRAIRIE CA NR OKEECHOBEE FLA ULAT 270357 LONG 08059 121

$\begin{array}{llllllllllllll}\text { JAN., } 1970 & - & 15.5 & 222 & 280 & 21 & 4.2 & \ldots & 15 & 2.9 & 29 & 0 & 6.8\end{array}$

02260800 - ALLIGATOR LAKE NR ASHTON FLA (LAT 281355 LONG OB1 1117

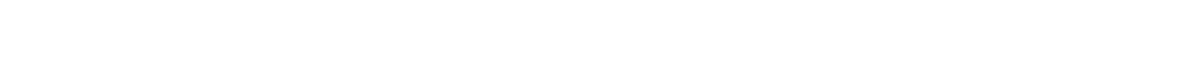

02261900 - LAKE MARY JANE NR NARCOOSSEE FLA ILAT 282246 LONG OB1 11 15!

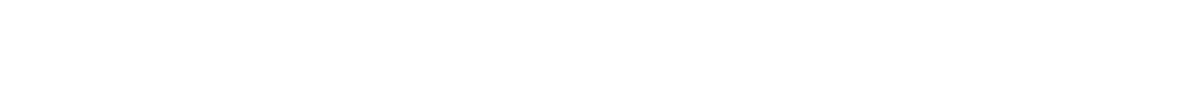

02262800 - LAKE CONHAY AT PINE CASTLE FLA ILAT 282755 LONG 08121231

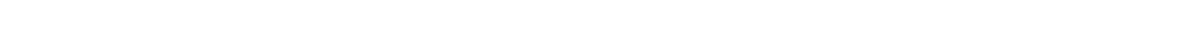
02262900 - BOGGY CR NR TAFT FLA CLAT 282216 LONG 08118391

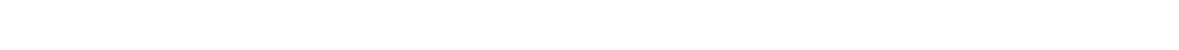
02263800 - SHINGLE CR AT AIRPORT NR KISSIMMEE FLA (LAT 281814 LONG O81 2704 )

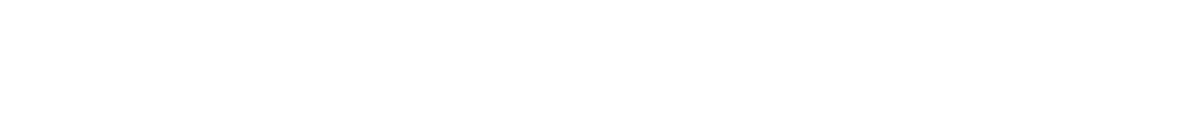

02263852 - BAY LK OLT BL S-105A NR VINELAND FLA ILAT 282448 LONG 0813327 )

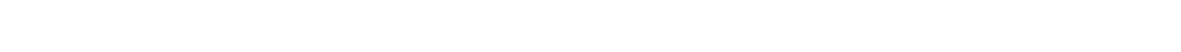

02263869 - SOUTH LK OUTLET AB S-15 NR VINELAND FL (LAT 282445 LONG 081 32 17)

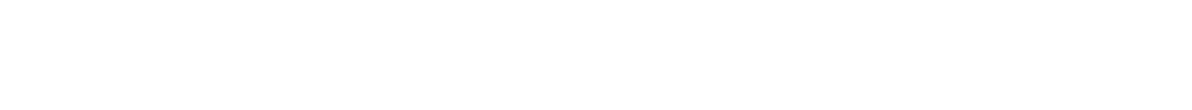

02263870 - SOUTH LK OLT BL S-15 NR VINELAND FLA ILAT 282445 LONG OBI 32 17)

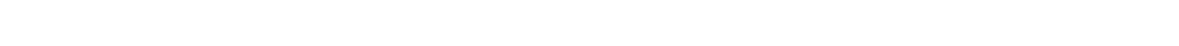

02263900 - LAKE BUTLER AT WINOERMERE FLA ILAT 282926 LONG 081 32 n4I

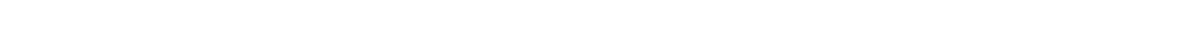

02264000 - CYPRESS CR AT VINELAND FLA ILAT 282325 LONG O8I 31111

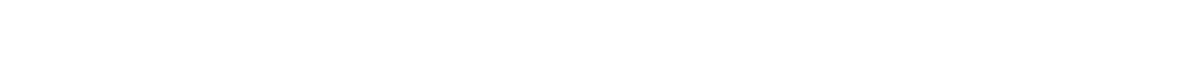


CHEMICAL ANALYSES, WATER YEAR OCTOBER 1969 TO SEPTEMBER 1970 (MAJOR CONSTITUENTS)

\begin{tabular}{|c|c|c|c|c|c|c|c|c|c|c|c|c|}
\hline ATE & $\begin{array}{l}\text { DIS- } \\
\text { SOLVEO } \\
\text { SULFATE } \\
\text { (SO4) } \\
\text { (MG/L) }\end{array}$ & $\begin{array}{l}\text { OIS- } \\
\text { SOLVED } \\
\text { CHLO- } \\
\text { RIDE } \\
\text { (CL) } \\
\text { (MG/L) }\end{array}$ & $\begin{array}{l}\text { DIS- } \\
\text { SOLVED } \\
\text { FLUO- } \\
\text { RIDE } \\
\text { (F) } \\
\text { (MG/L) }\end{array}$ & $\begin{array}{l}\text { HARD- } \\
\text { NESS } \\
\text { (CA,MG) } \\
(M G / L)\end{array}$ & $\begin{array}{l}\text { NON- } \\
\text { CAR- } \\
\text { BONATE } \\
\text { HARO- } \\
\text { NESS } \\
\text { (MG/L) }\end{array}$ & $\begin{array}{l}\text { ALKA- } \\
\text { LINITY } \\
\text { AS } \\
\text { CACO3 } \\
\text { (MG/L) }\end{array}$ & $\begin{array}{l}\text { OIS- } \\
\text { SOLVEO } \\
\text { SOL IDS } \\
\text { (RESI- } \\
\text { DUE AT } \\
\text { I80 C) } \\
\text { (MG } / \text { ) }\end{array}$ & $\begin{array}{l}\text { OIS- } \\
\text { SOLVED } \\
\text { SOLIDS } \\
\text { (SUM OF } \\
\text { CONSTI - } \\
\text { TUENTS) } \\
\text { (MG/L) }\end{array}$ & $\begin{array}{l}\text { DIS- } \\
\text { SOLVEO } \\
\text { SOLIOS } \\
\text { (TONS } \\
\text { PER } \\
\text { DAY) }\end{array}$ & $\begin{array}{l}\text { DIS- } \\
\text { SOLVED } \\
\text { SOLIDS } \\
\text { (TONS } \\
\text { PER } \\
\text { AC-FT) }\end{array}$ & $\begin{array}{l}\text { TANNIN } \\
\text { AND } \\
\text { LIGNIN } \\
\text { (MG/L) }\end{array}$ & $\begin{array}{l}\text { DEPTH } \\
\text { (FT) }\end{array}$ \\
\hline
\end{tabular}

LAKE OKEECHOBEE AND THE EVERGLADES BASINS--CONTINUED

02259201 - INDIAN PRAIRIE CA BL $\$+72$ NR OKEECHOBE (LAT 27 O5 35 LONG 081 OO 25)

OCT.. 1969
31...
DEC...

02259500 - INOIAN PRAIRIE CA NR OKEECHOBEE FLA (LAT 270357 LONG 080 59 12)

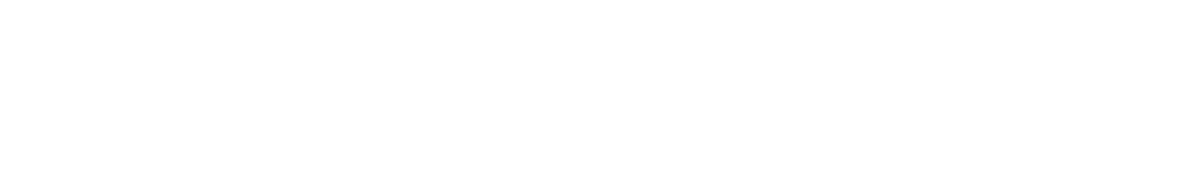

02261900 - LAKE MARY JANE NR NARCOOSSEE FLA (LAT 282246 LONG 081 11 15)

$\begin{array}{llllllllllll}\begin{array}{l}\text { MAY }, 1970 \\ 16 . . .\end{array} & 3.2 & 12 & .2 & 15 & 10 & 6 & 86 & 41 & \ldots & .12 & \ldots \\ \begin{array}{c}\text { AUG. } \\ \text { 21... }\end{array} & 6.0 & 15 & .1 & 16 & 12 & 3 & 87 & 38 & \ldots & .12 & -.\end{array}$

02262800 - LAKE CONMAY AT PINE CASTLE FLA (LAT 282755 LONG 0812123 )

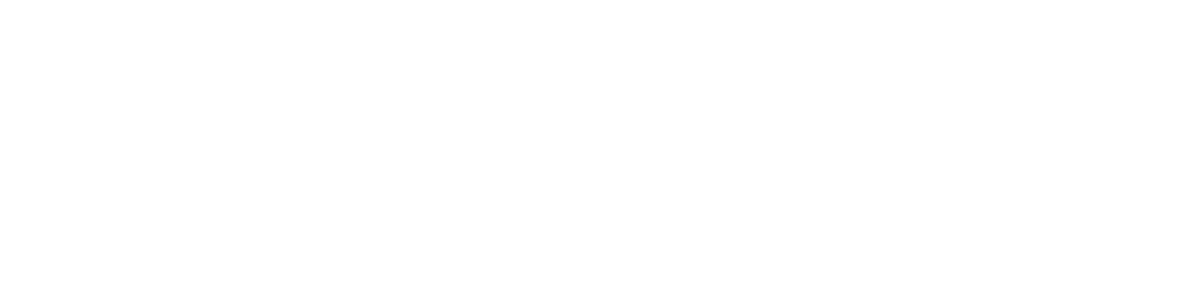
02263852 - BAY LK OLT BL S-105A NR VINELAND FLA (LAT $2824 \quad 48$ LONG 0813327 )

$\operatorname{MAY}_{21} 1970$ 14

02263869 - SOUTH LK OUTLET AB S-15 NR VINELAND FL (LAT $2824 \quad 45$ LONG 08132 17)

MAY, 1970

19...

AUG.

14

$\begin{array}{lll}.2 & 21 & 19\end{array}$

$\begin{array}{lll}19 & 2 & 8 \\ 54 & 0 & 8\end{array}$

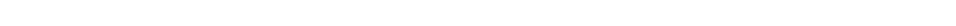

02263870 - SOUTH LK OLT 8L S-I5 NR VINELAND FLA (LAT $2824 \quad 45$ LONG OAL 32 17)

MAY 1970 13

02263900 - LAKE BUTLER AT WINDERMERE FLA (LAT 282926 LONG 0813204 )

MAY, 1970

21

02264000 - CYPRESS CR AT VINELAND FLA (LAT 282325 LONG DB1 31 11)

MAY, 1970 . 22

$\begin{array}{ccc}\text { AUG. } & \bullet & 22 \\ 27 . . . & .8 & 15\end{array}$

$\begin{array}{lll}-2 & 16 & 16 \\ -- & 12 & 12\end{array}$

$\begin{array}{llll}139 & 50 \quad .05 & .19\end{array}$ 


\begin{tabular}{|c|c|c|c|c|c|c|c|c|c|c|c|c|}
\hline & $\begin{array}{l}\text { DIS- } \\
\text { CHARGE } \\
\text { (CFS) }\end{array}$ & $\begin{array}{l}\text { TEMPER- } \\
\text { ATURE } \\
\text { (DEG C) }\end{array}$ & $\begin{array}{l}\text { SPE- } \\
\text { CIFIC } \\
\text { CON- } \\
\text { OUCT- } \\
\text { ANCE } \\
\text { (MICRO- } \\
\text { MHOS) }\end{array}$ & $\begin{array}{l}\text { DIS- } \\
\text { SOLVED } \\
\text { IRON } \\
\text { (FE) } \\
\text { (UG/L) }\end{array}$ & $\begin{array}{l}\text { OIS- } \\
\text { SOLVED } \\
\text { CAL- } \\
\text { CIUM } \\
\text { (CA) } \\
\text { (MG LL) }\end{array}$ & $\begin{array}{l}\text { DIS- } \\
\text { SOLVED } \\
\text { MAG- } \\
\text { NE- } \\
\text { SIUM } \\
\text { (MG) } \\
\text { (MG/L) }\end{array}$ & $\begin{array}{l}\text { OIS- } \\
\text { SOLVED } \\
\text { STRON- } \\
\text { TIUM } \\
\text { (SR) } \\
\text { (UG/L) }\end{array}$ & $\begin{array}{l}\text { DIS- } \\
\text { SOLVED } \\
\text { SODIUM } \\
\text { (NA) } \\
\text { (MG/L) }\end{array}$ & $\begin{array}{l}\text { DIS- } \\
\text { SOLVEI } \\
\text { PO- } \\
\text { TAS- } \\
\text { SIUM } \\
\text { (K) } \\
\text { (MG/L) }\end{array}$ & $\begin{array}{l}\text { BICAR- } \\
\text { BONATE } \\
\text { (HCO3) } \\
\text { (MG/L) }\end{array}$ & $\begin{array}{l}\text { CAR- } \\
\text { BONATF } \\
\text { (CO3) } \\
\text { (MG/L) }\end{array}$ & $\begin{array}{c}\mathrm{PH} \\
\text { (UNITS) }\end{array}$ \\
\hline
\end{tabular}

LAKE OKEECHOBEE AND THE EVERGLADES BASINS--CONTINUED

02264100 - BONNET CR NR VINELAND FLA (LAT 281958 LONG 0813120 )

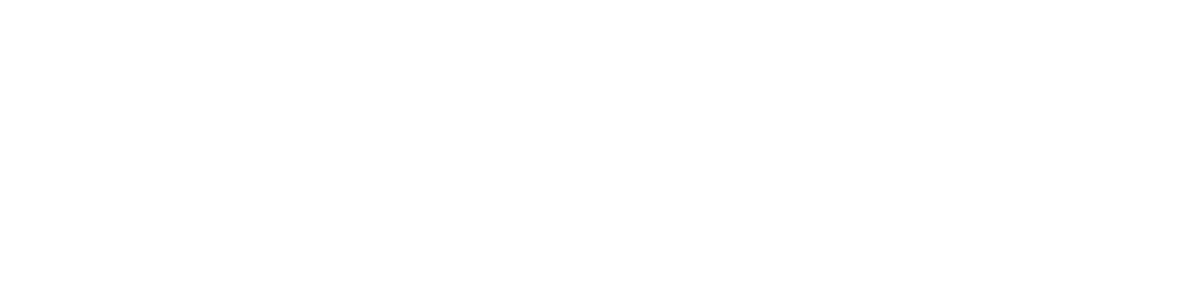

02266025 - REEOY CR CANAL AT S-46 NR VINELANO FLA (LAT $2824 \quad 14$ LONG 0813642 )

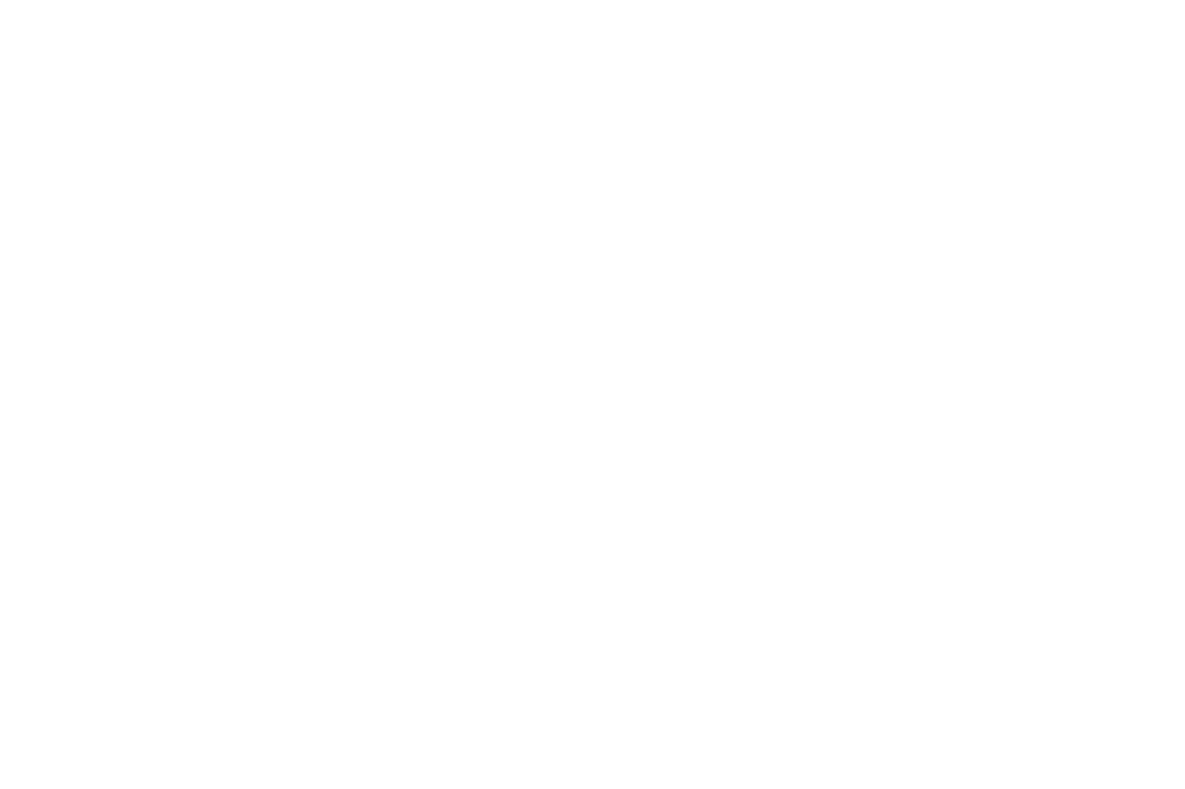

02266480 - DAVENPORT CREEK NEAR LOUGHMAN FLA (LAT 281615 LONG 08135 28)

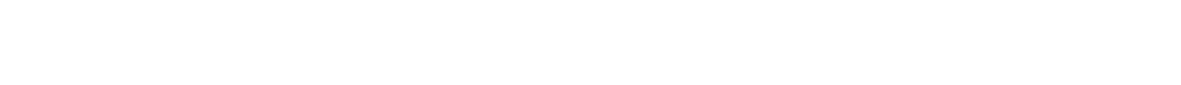

02266500 - REEDY CREEK NEAR LOUGHMAN FLA (LAT $28 \quad 154$ ) LONG 08132 12)

MAY 1970

23

94

02266500 - CYPRESS LAKE NR ST CLOUO FLA (LAT 28 O3 40 LONG 0811958 )

\begin{tabular}{|c|c|c|c|c|c|c|c|c|c|c|c|}
\hline $\begin{array}{l}\text { MAY , } 1970 \\
\text { OB.... } \\
\text { SFP. }\end{array}$ & -- & 25.0 & 110 & -- & 6.6 & 2.6 & -- & 9.7 & 1.8 & 18 & 0 \\
\hline
\end{tabular}

02266650 - LAKE MARION NR HAINES CITY FLA (LAT 2A 0556 LONG 0813151 )

\begin{tabular}{|c|c|c|c|c|c|c|c|c|c|c|c|}
\hline $\begin{array}{l}\text { MAY. } 1970 \\
11 . . . \\
\text { SEP. }\end{array}$ & - & 26.0 & 120 & - & 11 & 3.4 & $\sim$ & 5.0 & 1.2 & 36 & 0 \\
\hline $21 \ldots$ & $\cdots$ & 29.0 & 120 & - & 11 & 3.6 & $=$ & 5.3 & 1.2 & 36 & $n$ \\
\hline
\end{tabular}


ANALYSES OF SAMPLES COLLECTED AT MISCELLANEOUS SITES IN FLORIDA

CHEMICAL ANALYSES, WATER YEAR OCTOBER 1969 TO SEPTEMBER 1970 (MAJOR CONSTITUENTS)

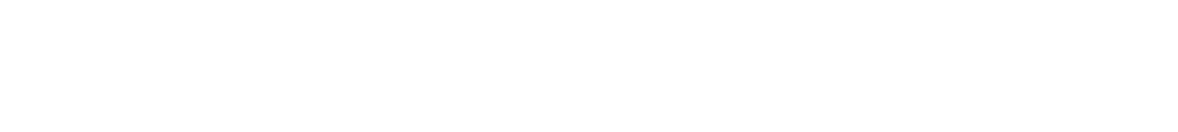

LAKE OKEECHOBEE AND THE EVERGLADES BASINS--CDNTINUED

02264100 - BONNET CR NR VINELAND FLA (LAT $28 \quad 1958$ LONG 0813120 )

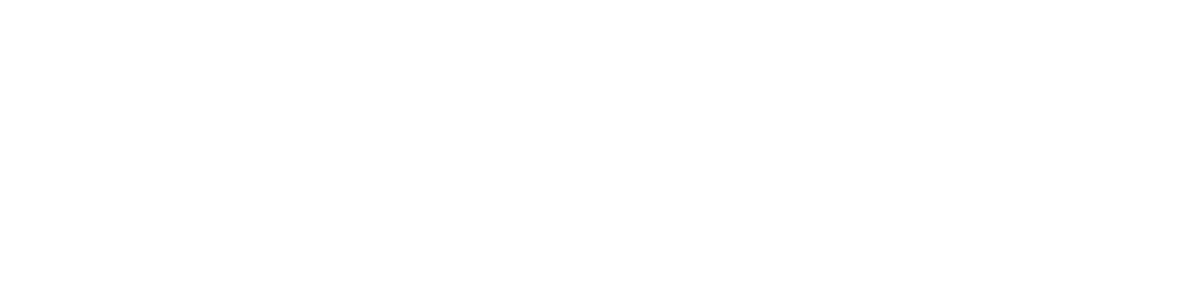

02266025 - REEDY CR CANAL AT S-46 NR VINELAND FLA (LAT 282414 LONG 02136 42)

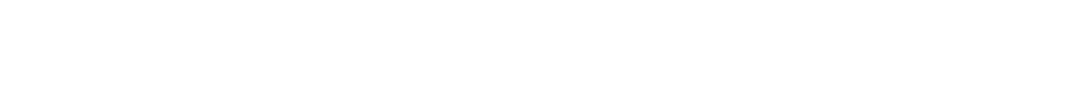

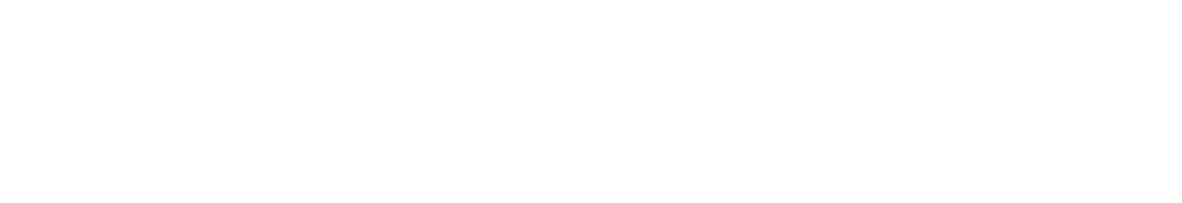

02266239 - TROUT LAKE NR CLERMONT FLA (LAT 282704 LONG 08143001

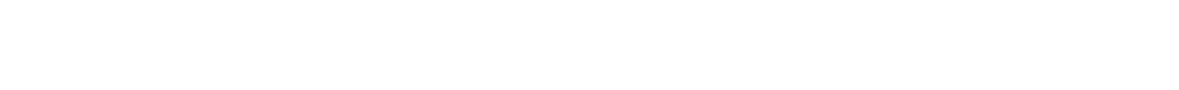

02266291 - LATERAL 405 AT S-405A NR DR PHILLIPS F (LAT 282534 LONG 08136 23)

MAY 1970

02266292 - LATERAL 405 AL S405A NR DR PHILLIPS FL (LAT 282534 LONG 08136 32)

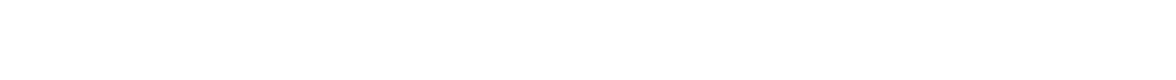

02266300 - REEDY CR NR VINELAND FLA (LAT 281957 LONG 0813448 )

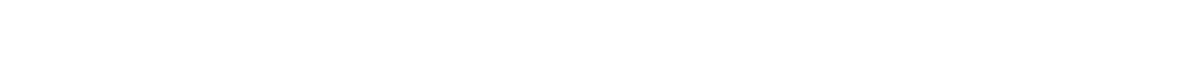

02266480 - DAVENPORT CREEK NEAR LOUGMMAN FLA (LAT 2A 1615 LONG 081 35 28)

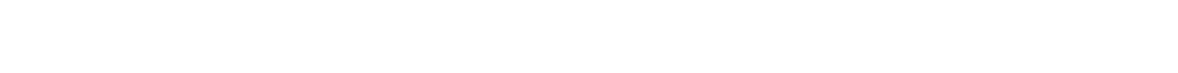

02266500 - REEDY CREEK NEAR LOUGHMAN FLA LLAT $28 \quad 1541$ LONG 08132 12)

MAY 1970

7.9

02266600 - CYPRESS LAKE NR ST CLOUD FLA (LAT 280340 LONG 0811958 )

$\begin{array}{ccc}\text { MAY } & 1970 \\ \text { O8. } & 13 & 16 \\ 04 . . & 11 & 16\end{array}$

$\begin{array}{lllllllllll}16 & .2 & 27 & 12 & 15 & 92 & 62 & -- & .13 & -. & \ldots \\ 16 & .2 & 24 & 14 & 10 & 90 & 57 & -- & .12 & \ldots & -\end{array}$

02266650 - LAKE MARION NR HAINES CITY FLA ILAT 280556 LONG 08131511

$\begin{array}{llllllllllll}\text { MAY . } 1970 \\ \text { I1... } & 9.6 & 8.5 & .2 & 42 & 12 & 30 & 85 & 59 & \ldots & .12 & -- \\ \text { SEP. } & 10 & 10 & .3 & 43 & 13 & 3 n & 83 & 64 & -. & .11 & -\end{array}$


CHEMICAL ANALYSES, WATER YEAR OCTOBER 1969 TO SEPTEMBER 1970 CHEMICAL ANALYSES, WATER YEAR OCTOBER 1965

\begin{tabular}{|c|c|c|c|c|c|c|c|c|c|c|c|c|}
\hline DATE & $\begin{array}{l}\text { DIS- } \\
\text { CHARGE } \\
\text { ICFSI }\end{array}$ & $\begin{array}{l}\text { TEMPER- } \\
\text { ATURE } \\
\text { (DEG C) }\end{array}$ & $\begin{array}{l}\text { SPE- } \\
\text { CIF IC } \\
\text { CON- } \\
\text { DUCT- } \\
\text { ANCE } \\
\text { (MICRO- } \\
\text { MHOS) }\end{array}$ & $\begin{array}{l}\text { DIS- } \\
\text { SOLVED } \\
\text { IRON } \\
\text { (FE) } \\
\text { (UG/L) }\end{array}$ & $\begin{array}{l}\text { DIS- } \\
\text { SOLVED } \\
\text { CAL- } \\
\text { CIUA } \\
\text { (CA) } \\
\text { (MG/L) }\end{array}$ & $\begin{array}{l}\text { DIS- } \\
\text { SOLVED. } \\
\text { MAG- } \\
\text { NE- } \\
\text { SIUM } \\
\text { (MG) } \\
\text { (MG L) }\end{array}$ & $\begin{array}{l}\text { DIS- } \\
\text { SOLVED } \\
\text { STRON- } \\
\text { TIUM } \\
\text { (SR) } \\
\text { (UG/L) }\end{array}$ & $\begin{array}{l}\text { DIS- } \\
\text { SOLVED } \\
\text { SDDIUM } \\
\text { (NA) } \\
\text { (MG/L) }\end{array}$ & $\begin{array}{l}\text { OIS- } \\
\text { SOL YEO } \\
\text { PO- } \\
\text { TAS- } \\
\text { SIUM } \\
\text { (K) } \\
\text { (MG/L) }\end{array}$ & $\begin{array}{l}\text { BICAR- } \\
\text { BONATE } \\
\text { (HCO3) } \\
\text { (MG/L) }\end{array}$ & $\begin{array}{l}\text { CAR- } \\
\text { BONATE } \\
\text { (CO3) } \\
\text { (MG/L) }\end{array}$ & $\begin{array}{c}\text { PH } \\
\text { (UNITS) }\end{array}$ \\
\hline & & & & & & & & & & & & \\
\hline
\end{tabular}

02267000 - CATFISH CR NR LAKE WALES FLA (LAT 275740 LONG 08129 48)

\begin{tabular}{|c|c|c|c|c|c|c|c|c|c|c|c|}
\hline $\begin{array}{l}\text { MAY . } 1970 \\
\text { O9... }\end{array}$ & - & 24.0 & 113 & $=$ & 11 & 3.4 & $-\infty$ & 5.0 & 1.7 & 34 & 0 \\
\hline
\end{tabular}

02268200 - LAKE WALES AT L WALES FLA ILAT 275413 LONG 08134 44)

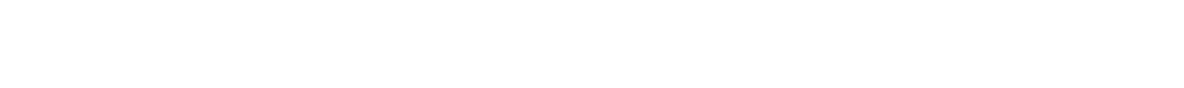

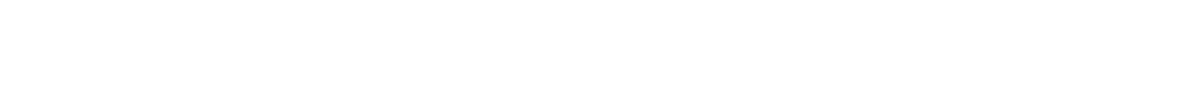

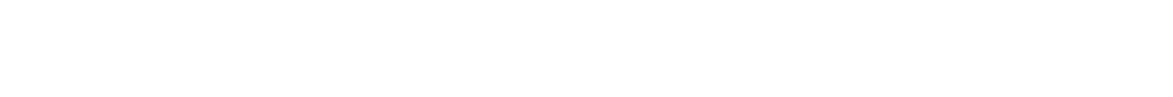

02268800 - LAKE MARION NR KENANSVILLE FLA ILAT 275209 LONG 081002 36)

\begin{tabular}{|c|c|c|c|c|c|c|c|c|c|c|c|}
\hline $\begin{array}{l}\text { APR.. } 1970 \\
\text { O2... } \\
\text { AUG. } \\
\text { 31... }\end{array}$ & $\cdots$ & $\begin{array}{l}28.0 \\
30.0\end{array}$ & $\begin{array}{l}105 \\
100\end{array}$ & -- & $\begin{array}{l}6.4 \\
6.5\end{array}$ & $\begin{array}{l}21 \\
2.1\end{array}$ & - & $\begin{array}{l}8.5 \\
8.5\end{array}$ & $\begin{array}{l}1.4 \\
1.4\end{array}$ & $\begin{array}{l}18 \\
21\end{array}$ & 0 \\
\hline
\end{tabular}

02268903 - KISSIMMEE RIVER AT S-65 NR LAKE WALES (LAT 274814 LONG OBI 11 53)

MAY 1970

SEP... $\quad .00$

$$
24
$$

$24.0 \quad 102$

$31.0 \quad 88$

340

7.3

2.3

180

$\begin{array}{lll}6.2 & 2.1 & 30\end{array}$

$9.5 \quad 1.3 \quad 16$

16

0

7.4

SEP.. 1970

.00

31.0

n2269200 - CROOKED LAKE NR BABSON PARK FLA (LAT 274938 LONG 0813326 )

MAY 1970

28.0

4 - KISSIMMEE RIVER BL S-65 NR LAKE WALES (LAT 274814 LONG 0811153 )

47

02269500 - REEDY CR NR FROSTPROOF FLA (LAT 274313 LONG 0812840 )

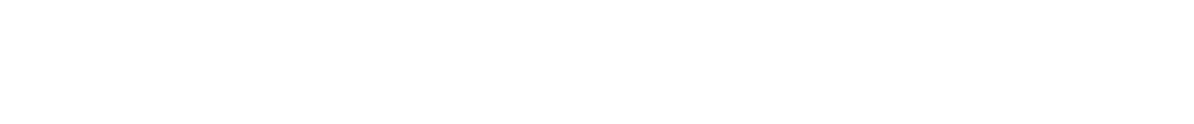

\begin{tabular}{|c|c|c|c|c|c|c|c|c|c|c|c|c|}
\hline MaY , 1970 & - & 25.0 & 115 & - & 8.5 & 3.4 & -- & 7.5 & 1.7 & 23 & 0 & 6.9 \\
\hline $\begin{array}{l}\text { SEP. } \\
24 \ldots .\end{array}$ & $=$ & 27.0 & 114 & -- & 7.8 & 3.6 & - & 7.5 & 1.6 & 20 & 0 & 6.7 \\
\hline
\end{tabular}

02269790 - LAKE LOTELA NR AVON PK FLA ILAT 273505 LDNG 08128551

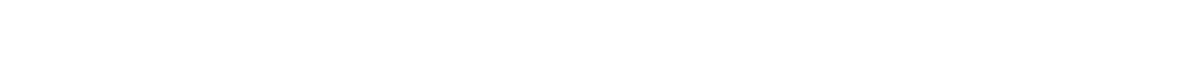

02270500 - ARBUCKLE CR NR DE SOTO CITY FLA (LAT 272632 LONG 0811751 )

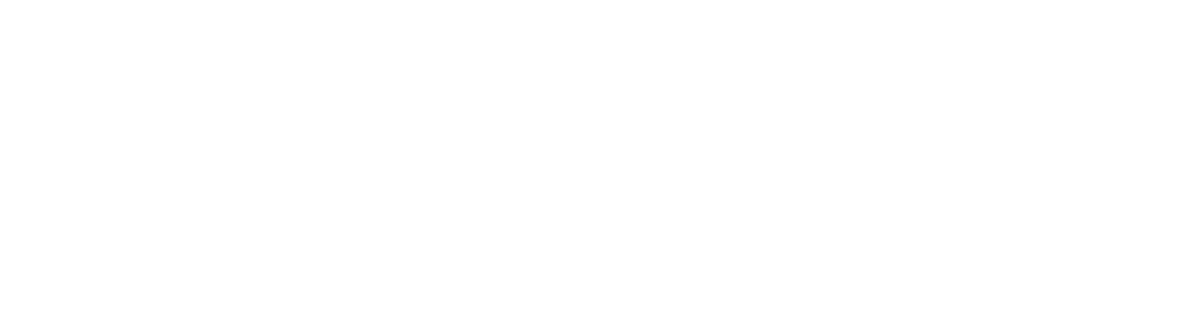


CHEMICAL ANALYSES, WATER YEAR OCTOBER 1969 TO SEPTEMBER 1970 (MAJOR CONSTITUENTS)

\begin{tabular}{|c|c|c|c|c|c|c|c|c|c|c|c|c|}
\hline$A T E$ & $\begin{array}{l}\text { DIS- } \\
\text { SOLVED } \\
\text { SULFATE } \\
\text { (SO4) } \\
\text { (MG/L) }\end{array}$ & $\begin{array}{l}\text { DIS- } \\
\text { SOLVED } \\
\text { CHLO- } \\
\text { RIDE } \\
(C L) \\
\text { (MG/L) }\end{array}$ & $\begin{array}{l}\text { DIS- } \\
\text { SOLVED } \\
\text { FLUD- } \\
\text { RIDE } \\
\text { (F) } \\
(M G / L)\end{array}$ & $\begin{array}{l}\text { HARD- } \\
\text { NESS } \\
(C A, M G) \\
(M G / L)\end{array}$ & $\begin{array}{l}\text { NON- } \\
\text { CAR- } \\
\text { BONATE } \\
\text { HARD- } \\
\text { NESS } \\
\text { (MG/L) }\end{array}$ & $\begin{array}{l}\text { ALKA- } \\
\text { LINITY } \\
\text { AS } \\
\text { CACO3 } \\
\text { (MG } / L)\end{array}$ & $\begin{array}{l}\text { DIS- } \\
\text { SOL VED } \\
\text { SOLIDS } \\
\text { (RESI- } \\
\text { DUE AT } \\
\text { I80 C) } \\
\text { (MG/L) }\end{array}$ & $\begin{array}{l}\text { DIS- } \\
\text { SOLVFI } \\
\text { SOLIDS } \\
\text { (SUM OF } \\
\text { CONSTI- } \\
\text { TUENTS) } \\
\text { (MG LI) }\end{array}$ & $\begin{array}{l}\text { DIS- } \\
\text { SOLVED } \\
\text { SOLIDS } \\
\text { (TONS } \\
\text { PER } \\
\text { DAY) }\end{array}$ & $\begin{array}{l}\text { ORS- } \\
\text { SOLVED } \\
\text { SOLINS } \\
\text { (TONS } \\
\text { PER } \\
\text { AC-FT) }\end{array}$ & $\begin{array}{l}\text { TANNIN } \\
\text { AND } \\
\text { LIGN IN } \\
\text { (MG/L) }\end{array}$ & $\begin{array}{l}\text { DEPTH } \\
\text { (FT) }\end{array}$ \\
\hline
\end{tabular}

LAKE OKEECHOBEE AND THE EVERGLADES BASINS--CDNTINUED

02267000 - CATFISH CR NR LAKE WALES FLA (LAT 275740 LONG O81 2948 )

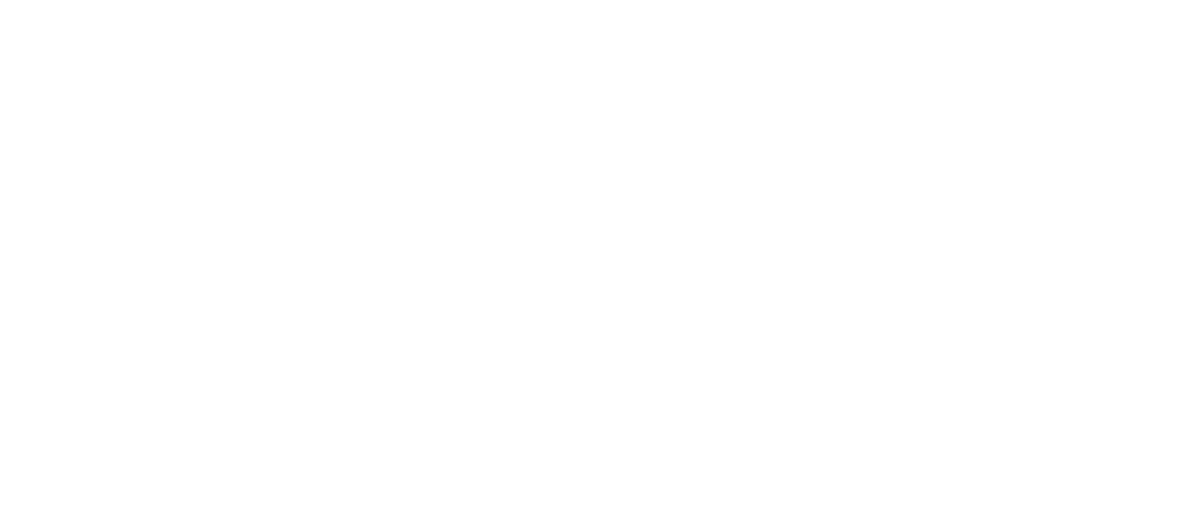

02268903 - KISSIMMEE RIVER AT S-65 NR LAKE WALES (LAT 274814 LONG 0811153 )

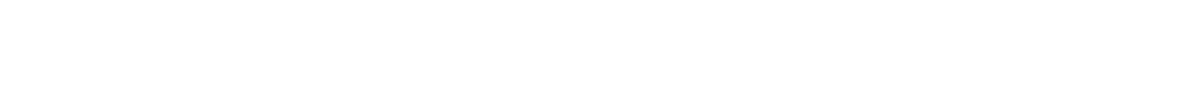

02268904 - KISSIMMEE RIVER BL S-65 NR LAKE WALES (LAT 274814 LONG OBI 1153 )

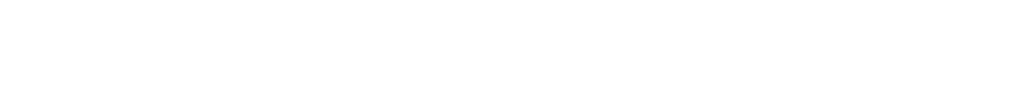

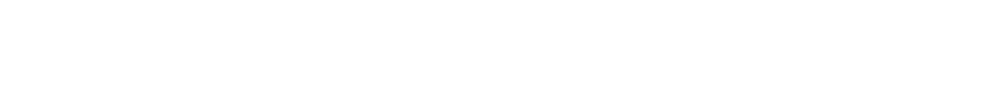

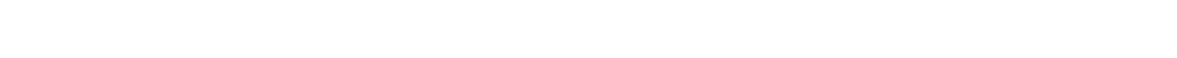
02269600 - LAKE ARBUCKLE NEAR AVON PARK FLA (LAT 273950 LONG 0812241 )

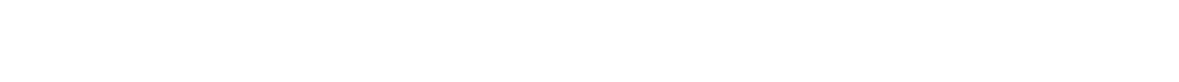

,02269790 - LAKE LOTELA NR AVON PK FLA ILAT 273505 LONG 0812855 ,

$\operatorname{MAY}_{12 . . .} 197020$

02270500 - ARBUCKLE CR NR DE SOTO CITY FLA (LAT 272632 LONG 0811751 )

OCT., 1969
I5...
NOV.. 


\begin{tabular}{|c|c|c|c|c|c|c|c|c|c|c|c|c|}
\hline ATE & $\begin{array}{l}\text { DIS- } \\
\text { CHARGE } \\
\text { (CFS) }\end{array}$ & $\begin{array}{l}\text { TEMPER- } \\
\text { ATURE } \\
\text { (DEG C) }\end{array}$ & $\begin{array}{l}\text { SPE- } \\
\text { CIFIC } \\
\text { CON- } \\
\text { OUCT- } \\
\text { ANCE } \\
\text { (MICRO- } \\
\text { MHOS) }\end{array}$ & $\begin{array}{l}\text { DIS- } \\
\text { SOL } \checkmark E D \\
\text { IRON } \\
\text { (FE) } \\
\text { (UG/L) }\end{array}$ & $\begin{array}{l}\text { DIS- } \\
\text { SOLVED } \\
\text { CAL- } \\
\text { CIUM } \\
\text { (CA) } \\
\text { (MG/L) }\end{array}$ & $\begin{array}{l}\text { DIS- } \\
\text { SOLVED } \\
\text { MAG- } \\
\text { NE- } \\
\text { SIUM } \\
\text { (MG) } \\
(M G / L)\end{array}$ & $\begin{array}{l}\text { DIS- } \\
\text { SOLVED } \\
\text { STRON- } \\
\text { TIUM } \\
\text { (SR) } \\
\text { (UG/L) }\end{array}$ & $\begin{array}{l}\text { DIS- } \\
\text { SOLVED } \\
\text { SODIUM } \\
\text { (NA) } \\
\text { (MG/L) }\end{array}$ & $\begin{array}{l}\text { DIS- } \\
\text { SOLVED } \\
\text { PO- } \\
\text { TAS- } \\
\text { SIUM } \\
\text { (K) } \\
\text { (MG/L) }\end{array}$ & $\begin{array}{l}\text { BICAR- } \\
\text { BONATE } \\
\text { (HCO3) } \\
\text { (MG/L) }\end{array}$ & $\begin{array}{l}\text { CAR- } \\
\text { HONATE } \\
\text { (CO3) } \\
\text { (MG/L) }\end{array}$ & $\begin{array}{c}\mathrm{PH} \\
\text { (UNITS) }\end{array}$ \\
\hline
\end{tabular}

LAKE OKEECHOTEE ANT THE EVERGLADES DASINS--CTNTINUED

02270550 - LAKE JACKSON AT SEBRING FLA (LAT 272805 LONG 0812730 )

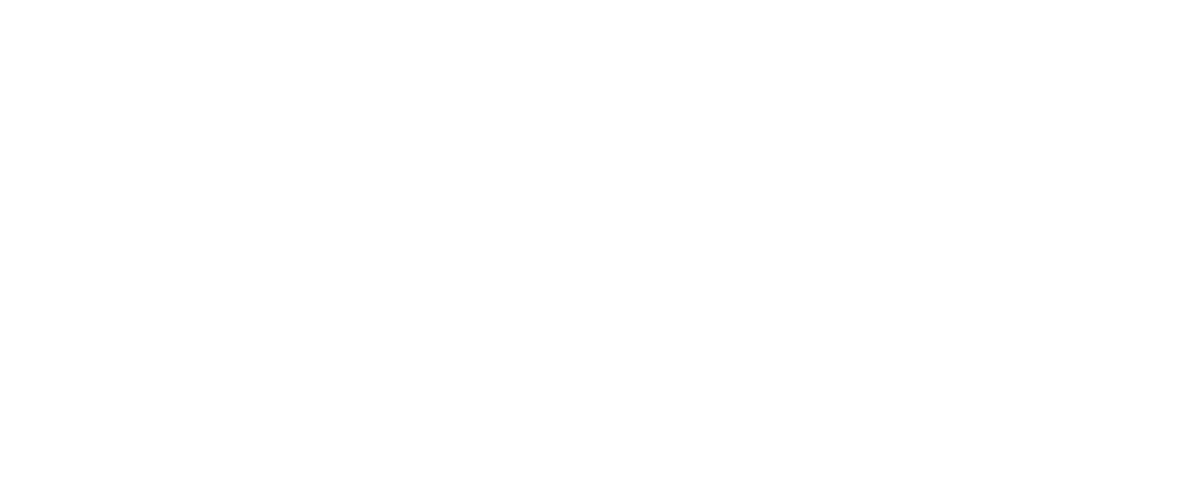

02271500 - JOSEPHINE CR NP DE SOTO CITP FLA ILAT 272226 LONG 0812337 I

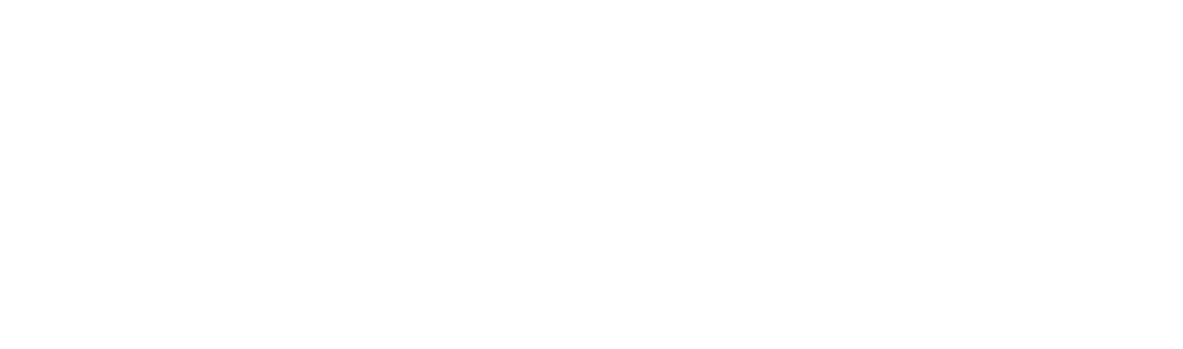

02273300 - CANAL 41 A AT 5-84 NEAR OKEECHOBEE. FLA (LAT 271255 LONG 0805855 )

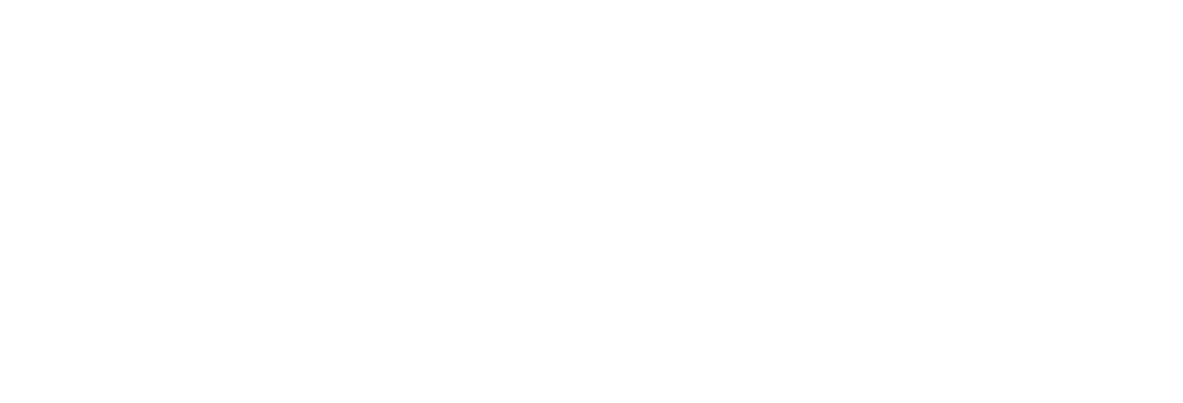

02274000 - TAYLOR CREEX NR BASINGFR, FLA. (LAT 272339 LONG OBO 5344 )

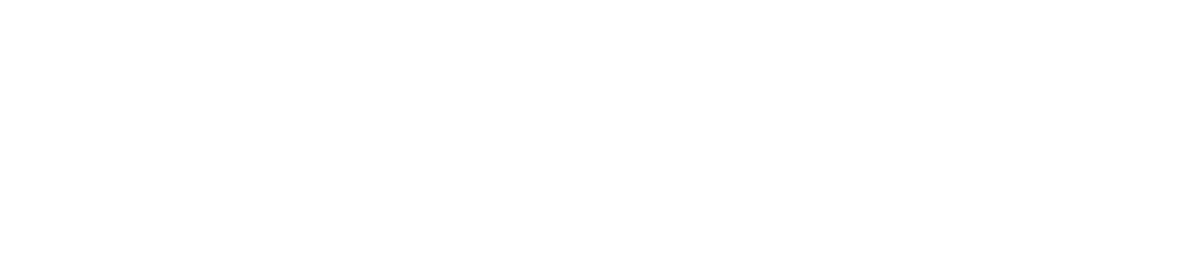




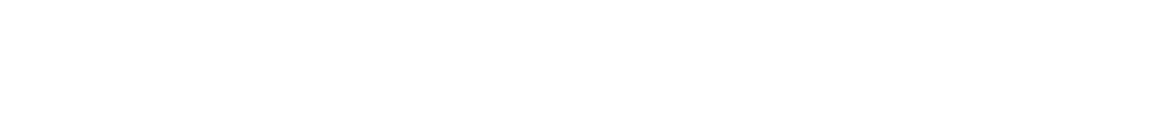

LAKE OKEECHOBEE AND THE EVERGLADES BASINS--CONTINUED

02270550 - LAKE JACKSON AT SEaHING FLA ILAT 2728 05 LONG 0812730 ?

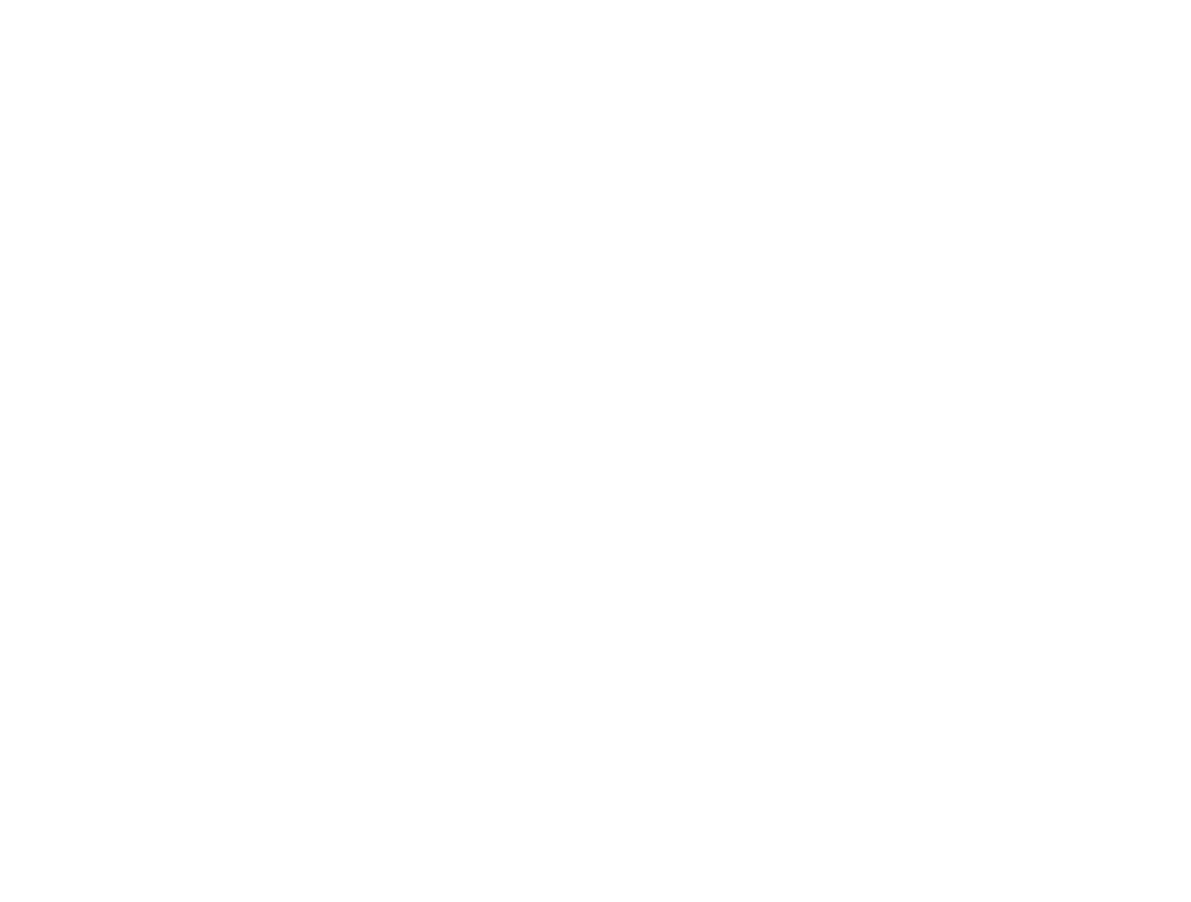

02273300 - CANAL 41A AT S-84 NEAR OKEECHOBEE, FLA (LAT 271255 LONG 0805855 )

$$
\text { MAY. } 197020
$$$$
\text { MAY } 1970
$$

02273301 - CANAL $42 A$ BL S-84 NR OKEECHOBEE, FLA, (LAT 271255 LONG 0805854 )

$.2 \quad 30 \quad 22$

$8 \quad 88$

$58 \quad .00$

.12

$-$

02273436 - KISSIMMEE RIVER AT LAKE OKEECHOBEE FLA ILAT 270853 LONG 08052211

\begin{tabular}{|c|c|c|c|c|c|c|c|c|c|c|c|}
\hline$\underset{27 \ldots . .1969}{\text { OCT., } 1969}$ & 5.2 & 14 & .2 & 56 & 18 & 38 & 115 & 77 & -- & .16 & -- \\
\hline $\begin{array}{l}\text { NDV. } \\
21 . . . \\
\text { DEC. }\end{array}$ & 11 & 14 & .3 & 48 & 14 & 34 & 107 & 76 & -- & .15 & $\omega$ \\
\hline JAN... 1970 & 14 & 16 & .3 & 55 & 18 & 38 & 113 & 86 & -- & .15 & -- \\
\hline APR. & 8.0 & 13 & .6 & 44 & 14 & 30 & 105 & 68 & -- & .14 & -- \\
\hline $21 \ldots$ & 11 & 13 & .2 & 41 & 15 & 26 & 100 & 65 & -- & .14 & - \\
\hline
\end{tabular}

02274000 - TAYLOR CREEK NR BASINGER, FLA. ILAT 272339 LONG 08053441

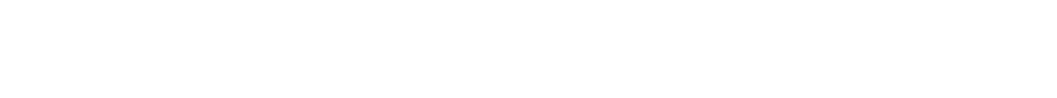

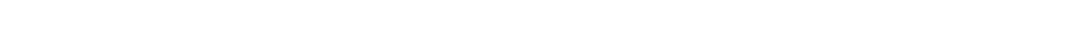

02274495 - WILLIAMSON DITCH AT S-7 NR OKEECHOBEE ILAT 271745 LONG 08049051

$\begin{array}{ccccccccccc}\text { MAY. } & 1970 \\ 05 . . & 216 & 640 & .5 & 539 & 386 & 153 & \ldots & 1480 & 16.0 & 2.01\end{array}$ 
ANALYSES OF SAMPLES COLLBCTBD AT MISCELLANEOUS SITES IN FLORIDA CHEMTCAL ANALYSES, WATER YEAR OCTOBER 1969 TO SEPTEMBER 1970 (MAJOR CQNSTITUENTS)

\begin{tabular}{|c|c|c|c|c|c|c|c|c|c|c|c|c|}
\hline & $\begin{array}{l}\text { OIS- } \\
\text { CHARGE } \\
\text { (CFS) }\end{array}$ & $\begin{array}{l}\text { TEMPER- } \\
\text { ATURE } \\
\text { (DEG C) }\end{array}$ & $\begin{array}{l}\text { SPE- } \\
\text { CIFIC } \\
\text { CON- } \\
\text { DUCT- } \\
\text { ANCE } \\
\text { (MICRO- } \\
\text { MHOS) }\end{array}$ & $\begin{array}{l}\text { DIS- } \\
\text { SOLVEO } \\
\text { IRON } \\
\text { (FE) } \\
\text { (UG/L) }\end{array}$ & $\begin{array}{l}\text { OIS- } \\
\text { SOLVEO } \\
\text { CAL- } \\
\text { CIUM } \\
\text { (CA) } \\
\text { (MG/L) }\end{array}$ & $\begin{array}{l}\text { DIS- } \\
\text { SOLVED } \\
\text { MAG- } \\
\text { NE- } \\
\text { SIUM } \\
\text { (MG) } \\
\text { (MG/L) }\end{array}$ & $\begin{array}{l}\text { DIS- } \\
\text { SOLVED } \\
\text { STRON- } \\
\text { TIUM } \\
\text { (SR) } \\
\text { (UG/L) }\end{array}$ & $\begin{array}{l}\text { DIS- } \\
\text { SOLVED } \\
\text { SODIUM } \\
\text { (NA) } \\
\text { (MG/L) }\end{array}$ & $\begin{array}{l}\text { DIS- } \\
\text { SOLVEO } \\
\text { PO- } \\
\text { TAS- } \\
\text { SIUM } \\
\text { (K) } \\
\text { (MG/L) }\end{array}$ & $\begin{array}{l}\text { BICAR- } \\
\text { BONATE } \\
\text { (HCO3) } \\
\text { (MG/L) }\end{array}$ & $\begin{array}{l}\text { CAR- } \\
\text { BONATE } \\
\text { (CO3) } \\
\text { (MG/L) }\end{array}$ & $\mathrm{PH}$ \\
\hline
\end{tabular}

LAKE OKEECHOBEE AND THE EVERGL.ADES BASINS--CONTINUED

02275500 - TAYLOR CREEK NEAR OKEECHOBEE FLA (LAT 271235 LONG O80 47 56)

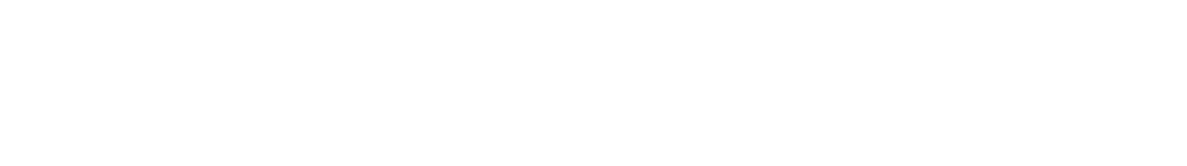

02275606 - NUBBIN SLOUGH NR SHERMAN FLA (LAT 271136 LONG 0804545 )

\begin{tabular}{|c|c|c|c|c|c|c|c|c|c|c|c|c|}
\hline $\begin{array}{l}\text { OCT.". } 1969 \\
28 . . . \\
\text { NOV. }\end{array}$ & - & 25.0 & 195 & 400 & 14 & 4.2 & - & 17 & 3.4 & 37 & 0 & 6.6 \\
\hline $20 \ldots$ & -- & 19.0 & 178 & 300 & 13 & 3.5 & 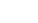 & 14 & 2.8 & 35 & 0 & 6.8 \\
\hline
\end{tabular}

02276401 - LAKE OKEECHOBEE AT POINT I FLA (LAT 262745 LONG 08051101

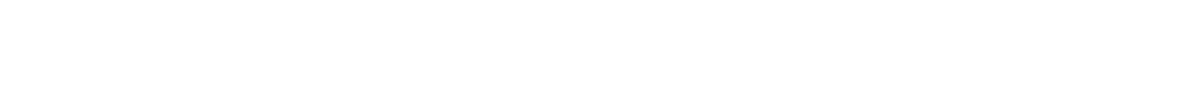

02276402 - LAKE OKEECHOBEE AT POINT 2 FLA (LAT 264930 LONG 08047 OSI

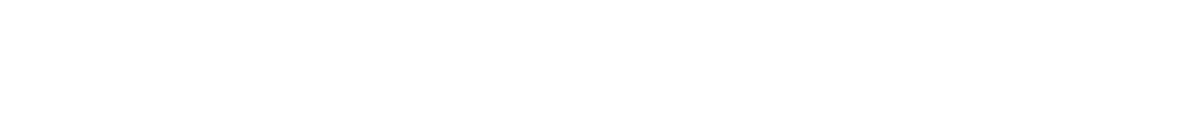

02276403 - LAKE OKEECHOBEE AT POINT 3 FLA (LAT 265205 LONG 0805105 )

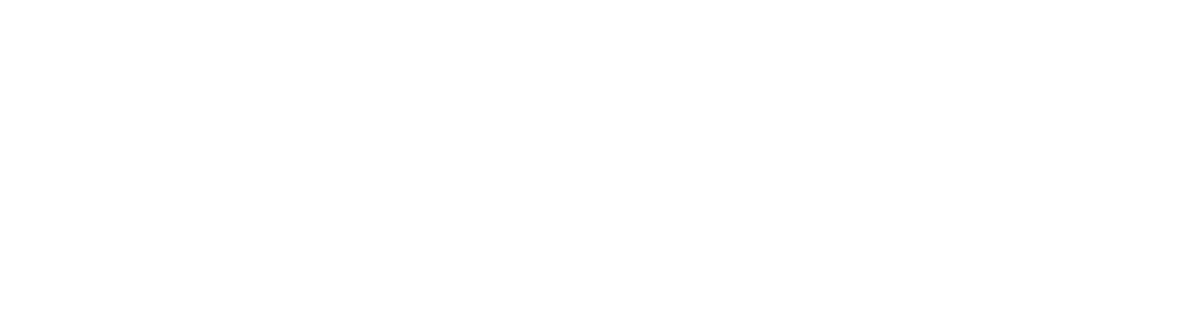

02276406 - LAKE OKEECHOBEE AT POINT 6 FLA (LAT 265945 LONG 08055 00)

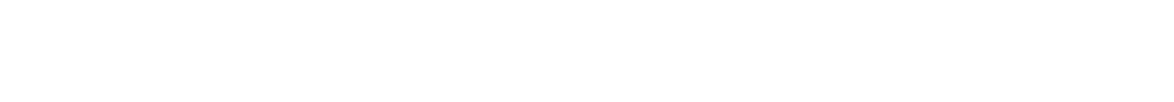

02276407 - LAKE OKEECHOBEe AT POINT 7 FLA ILAT 270230 LONG OBO 51 05I

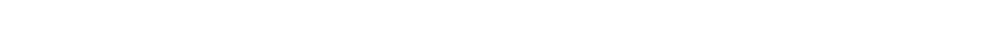

02276408 - LAKE OKEECHOBEE AT POINT 8 FLA ILAT 270505 LONG 08047101

\begin{tabular}{|c|c|c|c|c|c|c|c|c|c|c|c|}
\hline \multirow{3}{*}{$\begin{array}{l}\text { JAN..1 } 1970 \\
12 \ldots \\
\text { APR... } \\
21 . . . \\
\text { JULY } \\
16 . . .\end{array}$} & - & 14.0 & 199 & 160 & 29 & 3.3 & - & 11 & 1.6 & 65 & 0 \\
\hline & - & 25.5 & 388 & - & 37 & 9.4 & $\cdots$ & 27 & 2.2 & 114 & 0 \\
\hline & - & 29.0 & 420 & -- & 41 & 10 & - & 29 & 2.4 & 136 & 0 \\
\hline
\end{tabular}

02276409 - LAKE OKEECHOBEE AT POINT 9 FLA (LAT 270930 LONG 08047101

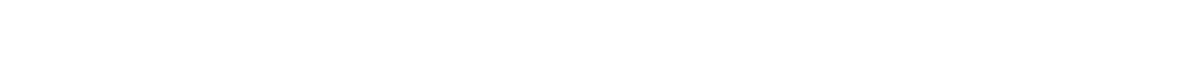

02276410 - LAKE OKEECHOBEE AT POINT 10 FLA (LAT 270305 LONG OBO 43551

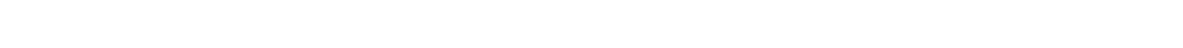


CHEMICAL ANALYSES, WATER YEAR OCTOBER 1969 TO SEPTEMBER 1970

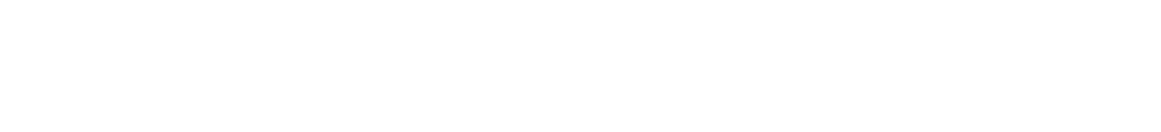

LAKE OKEECHOBEE AND THE EVERGLADES BASINS--CONTINUED

02275500 - TAYLOR CREEK NEAR OKEECHOBEE FLA (LAT 271235 LONG O80 47 56)

\begin{tabular}{|c|c|c|c|c|c|c|c|c|c|c|c|}
\hline $\begin{array}{l}\text { OCT.. } 1969 \\
\text { 27... } \\
\text { NOV. }\end{array}$ & 7.0 & 32 & .3 & 55 & 25 & 30 & 155 & 108 & -- & .21 & $\Rightarrow$ \\
\hline JAN.: 1970 & 28 & 79 & .4 & 126 & 51 & 75 & 293 & 245 & -- & .40 & - \\
\hline $14 \ldots$ & 20 & 46 & .2 & 82 & 35 & 48 & 208 & 162 & -- & .28 & - \\
\hline
\end{tabular}

02275606 - NUBBIN SLOUGH NR SHERMAN FLA (LAT 271136 LONG 08045451

$\begin{array}{rrr}\text { OCT., } 1969 & & \\ 28 . . . & 10 & 33 \\ \text { NOV. } & & \\ 20 . . . & 8.0 & 28\end{array}$

02276401 - LAKE OKEECHOBEE AT POINT I FLA (LAT 262745 LONG 08051 10)

$\begin{array}{ccc}\text { JAN... } 1970 \\ 15 \ldots . . & 34 & 53 \\ 15 \ldots & 34 & 53 \\ 15 \ldots . . & 34 & 5 \\ 15 \ldots & 40 & 53\end{array}$

02276402 - LAKE OKEECHOBEE AT POINT 2 FLA (LAT 264930 LONG 0804705 )

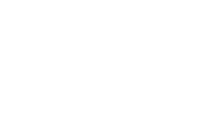

$\begin{array}{lllllllllll}55 & -- & -- & -. & -- & 313 & -- & .43 & -- & - \\ 45 & .4 & 160 & 47 & 113 & 305 & 274 & -- & .41 & -. & .0 \\ 45 & .3 & 141 & 41 & 100 & 266 & 226 & -- & .36 & -- & .0 \\ 45 & .4 & 144 & 36 & 108 & 265 & 230 & -- & .36 & -. & --\end{array}$

JAN.: 1970

02276403 - LAKE OKEECHOBEE AT POINT 3 FLA ILAT 265205 LONG 08051 05)

02276404 - LAKE OKEECHOBEE AT POINT 4 FLA ILAT 265500 LONG OBO 55001

$\begin{array}{lll}\text { JAN. } 1970 & \\ 15 . . & 39\end{array}$

02276405 - LAKE OKEECHOBEE AT POINT 5 FLA ILAT 265547 LONG 080 58401 JAN.P 1970 42 57 $\begin{array}{lll}\text { JULY } & \\ 16 \ldots & 45 & 55\end{array}$ 21 ... $56 \quad 60$

57
65

$\begin{array}{lll}.3 & 162 \\ .5 & 206\end{array}$

$$
46
$$

116

322

278

$-.44$

$-.51$

$121 \quad 333 \quad 270$

02276406 - LAKE OKEECHOBEE AT POINT 6 FLA ILAT 265945 LONG 08055001

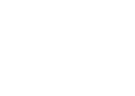

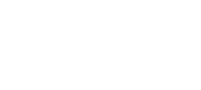

44
42
46
43

107
107
107
110 $\begin{array}{ll}282 & 258 \\ 282 & 258 \\ 287 & 258 \\ 292 & 262\end{array}$

$\begin{array}{ll}=- & .38 \\ =- & .39 \\ = & .39 \\ = & .40\end{array}$

$\begin{array}{ll}= & .0 \\ = & 6.0 \\ = & 13\end{array}$

02276407 - LAKE OKEECHOBEE AT POINT 7 FLA (LAT 27 O2 30 LONG 08051 05)

JAN.. 1970

32

$\begin{array}{llllll}.3 & 108 & 30 & 18 & 202 & 171\end{array}$

02276408 - LAKE OKEECHOBEE AT POINT B FLA ILAT 2705 05 LONG 08047108

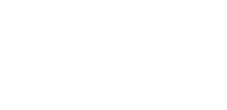

$$
\begin{aligned}
& 19 \\
& 41 \\
& 46
\end{aligned}
$$

$\begin{array}{rrr}.3 & 76 & 23 \\ .3 & 131 & 38 \\ .4 & 144 & 32\end{array}$

$\begin{array}{rrr}53 & 152 & 110 \\ 94 & 251 & 212 \\ 112 & 265 & 232\end{array}$

$\begin{array}{ll}-. & .21 \\ - & .34 \\ - & .36\end{array}$

02276409 - LAKE OKEECHOBEE AT POINT 9 FLA ILAT 270930 LONG 08047101

$\begin{array}{ll}\text { JAN.. } 1970 \\ 12 \ldots . . & 18 \\ \text { APR. } & \\ 21 \ldots . . & 18\end{array}$

$$
\begin{aligned}
& 28 \\
& 38
\end{aligned}
$$$$
.2 \quad 91 \quad 26
$$$$
65 \quad 179 \quad 140
$$$$
-.24
$$

02276410 - LAKE OKEECHOBEE AT POINT 10 FLA LLAT 270305 LONG 0804355

JAN.: 197032

41

.3

$13 \quad 38$

92

241

212

.33 


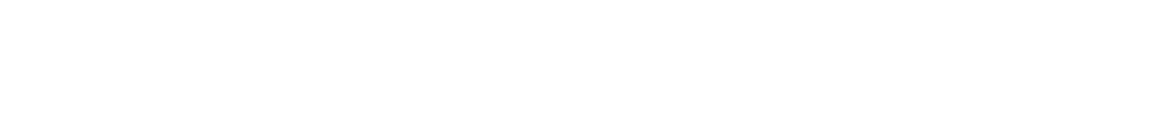

LAKE OKEECHOBEe AND THE EVERGLADES basins--CONTINUED

02276411 - LAKE OKEECHOBEE AT POINT 11 FLA (LAT 270100 LONG 08040 15)

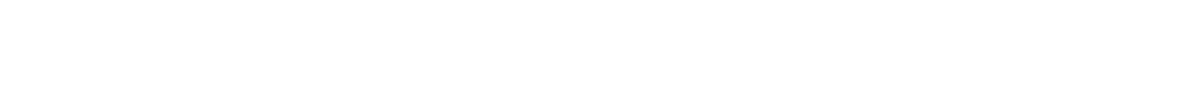

02276412 - LAKE OKEECHOBEE AT POINT 12 FLA (LAT 2659 O5 LONG 08037101

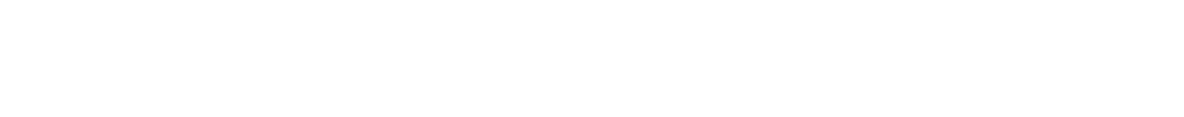

02276413 - LAKE OKEECHOBEE AT POINT 13 FLA (LAT 265555 LONG 0304055 )

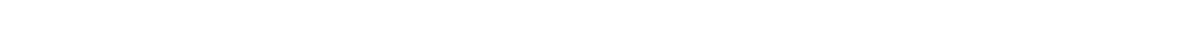

02276414 - LAKE OKEECHOBEE AT POINT I4 FLA (LAT 265245 LONG 0804405 )

$\begin{array}{llllllllllllll}\text { JAN.. } 1970 & - & 12.0 & 444 & 50 & 42 & 11 & - & 33 & 2.5 & 136 & 0\end{array}$

02276415 - LAKE OKEECHOBEE AT POINT 15 FLA LLAT 265530 LONG 08047551

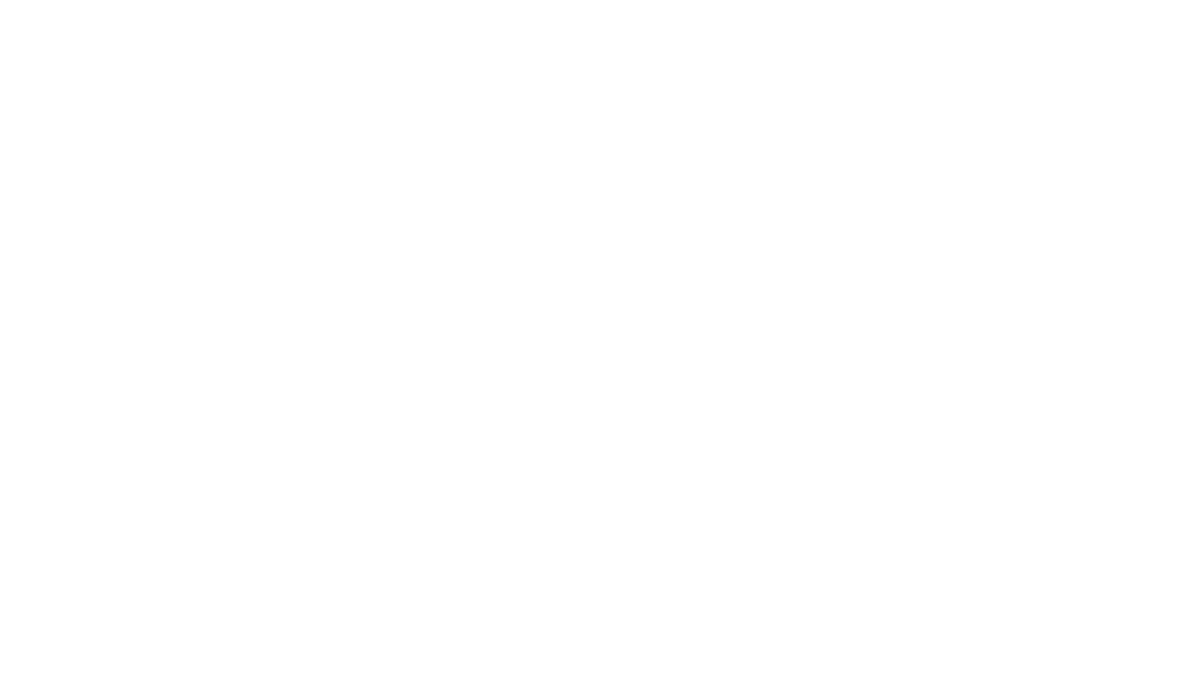

02277700 - SWF LOXAHATCHEE R AT S 46 NR JUPITER F (LAT 265602 LONG OBO OB 31 )

\begin{tabular}{|c|c|c|c|c|c|c|c|c|c|c|c|}
\hline $18 \ldots$ & -- & 21.0 & 250 & 120 & 33 & 2.4 & 200 & 14 & 1.0 & 96 & 0 \\
\hline
\end{tabular}

02277900 - CANAL M NEAR MANGONIA PARK FLA (LAT 264500 LONG 080 06 33)

\begin{tabular}{|c|c|c|c|c|c|c|c|c|c|c|c|c|}
\hline $01 \ldots$ & 51 & & 27.0 & $17 n$ & -- & 17 & 2.2 & $15 n$ & 12 & 1.4 & 56 & 0 \\
\hline
\end{tabular}

02277950 - CANAL 17 ABOVE S-44 NEAR LAKE PARK FLA (LAT 264901 LONG 08004 55) 
CHEMICAL ANALYSES, WATER YEAR OCTOBER 1969 TO SEPTEMBER 1970

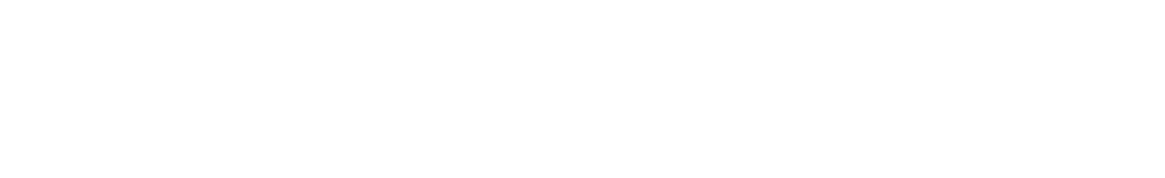

LAKE DKEECHDBEE AND THE EVERGLADES BASINS--CONTINUED

02276411 - LAKE OKEECHOBEE AT POINT 11 FLA (LAT 270100 LONG 08040151

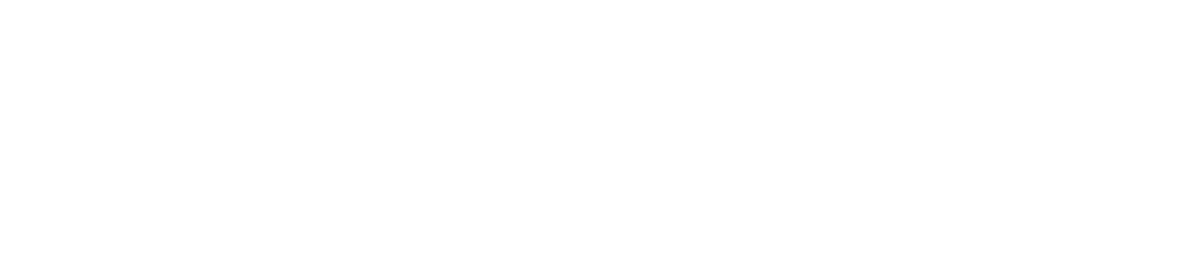

02276413 - LAKE OKEECHOBEE AT POINT 13 FLA ILAT 265555 LONG 08040551

JAN. 1970

JAN.: 1970

$\begin{array}{lll}\text { JAN., } 1970 & & \\ 13 . . . & 33 & 48 \\ \text { APR. } & & 45 \\ \text { 21... } & 33 & 45 \\ \text { JULY } & & 46 \\ \text { 16... } & 36 & \end{array}$

JAN., 1970

OCT... 1969

MAY, 197025

$15 . . .^{1969} 30$

OCT., 1969

$\begin{array}{rr}28 . . . & 31 \\ \text { NOV... } & 30\end{array}$

JAN.: 197030

JAN... 1970

OCT.. 1969

$15 \ldots . .0408 \quad 49$

I8... $197010 \quad 24$

02277900 - CANAL M NEAR MANGONIA PARK FLA (LAT 264500 LONG 08006331

MAR., 1970

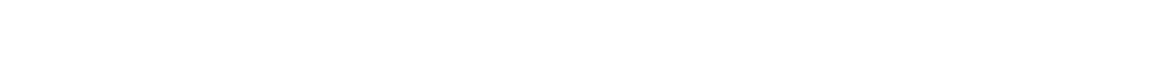

02277950 - CANAL 17 ABOVE S-44 NEAR LAKE PARK FLA (LAT 264901 LONG 080 04 55)

02276414 - LAKE OKEECHOBEE AT POINT 14 FLA ILAT 265245 LONG 0804405 I

02276415 - LAKE OKEECHOBEe AT POINT 15 FLA (LAT 265530 LONG 0804755 )

$\begin{array}{rllllllllll}48 & .3 & 146 & 41 & 105 & 262 & 237 & -- & .36 & -- & .0 \\ 45 & .3 & 141 & 38 & 103 & 270 & 234 & -- & .37 & -. & .- \\ 46 & .4 & 144 & 32 & 112 & 267 & 233 & -- & .36 & -. & .0\end{array}$

32276418 - LAKE OKEECHOBEE AT POINT 18 FLA (LAT 264852 LONG 0805650 )

02276708 - RIM DITCH AT S49 NR WHITE CITY FLA ILAT 272016 LONG 0803049 )

56

02276800 - MONREVE RANCH DRAINAGE CA NR STUART (LAT 270340 LONG 0801911 )

02276802 - CANAL 23 AT 5448 NEAR PALM CITY FLA (LAT 271205 LONG 08017511

02276870 - ST LUCIE CANAL AT LAKE OKEECHOBEE FLA (LAT 265900 LONG 08037 00)

$\begin{array}{llllllllllll}53 & .3 & 148 & 36 & 112 & 280 & 249 & 4610 & .38 & \ldots & -- \\ 46 & .4 & 140 & 39 & 102 & 256 & 226 & 4640 & .35 & -- & -- \\ 58 & .3 & 168 & 41 & 128 & 323 & 271 & -. & .44 & -- & .0\end{array}$

2277700 - SWF LOXAHATCHEE R AT S 46 NR JUPITER F (LAT 2656 n2 LONG 08008 31)

MAR., 1970

37

$.2 \quad 17$

$153 \quad 274 \quad 243$ 


\begin{tabular}{|c|c|c|c|c|c|c|c|c|c|c|c|c|}
\hline & $\begin{array}{l}\text { DIS- } \\
\text { CMARGE } \\
\text { (CFS) }\end{array}$ & $\begin{array}{l}\text { TEMPER- } \\
\text { ATURE } \\
\text { (DEG C) }\end{array}$ & $\begin{array}{l}\text { SPE- } \\
\text { CIFIC } \\
\text { CON- } \\
\text { DUCT- } \\
\text { ANCE } \\
\text { (MICRO- } \\
\text { MHOSI }\end{array}$ & $\begin{array}{l}\text { DIS- } \\
\text { SOLVED } \\
\text { IRON } \\
\text { (FE) } \\
\text { (UG/L) }\end{array}$ & $\begin{array}{l}\text { DIS- } \\
\text { SOLVED } \\
\text { CAL- } \\
\text { CIUM } \\
\text { (CA) } \\
\text { (MG/L) }\end{array}$ & $\begin{array}{l}\text { DIS- } \\
\text { SOLVED } \\
\text { MAG- } \\
\text { NE- } \\
\text { SIUM } \\
\text { (MG) } \\
\text { (MG/L) }\end{array}$ & $\begin{array}{l}\text { DIS- } \\
\text { SOLVED } \\
\text { STRON- } \\
\text { TIUM } \\
\text { (SR) } \\
\text { (UG/L) }\end{array}$ & $\begin{array}{l}\text { DIS= } \\
\text { SOLVED } \\
\text { SODIUM } \\
\text { (NA) } \\
\text { (MG/L) }\end{array}$ & $\begin{array}{l}\text { DIS- } \\
\text { SOLVED } \\
\text { PO- } \\
\text { TAS- } \\
\text { SIUM, } \\
\text { (K) } \\
\text { (MG/L) }\end{array}$ & $\begin{array}{l}\text { BICAR- } \\
\text { BONATE } \\
\text { (HCO3) } \\
\text { (MG/L) }\end{array}$ & $\begin{array}{l}\text { CAR- } \\
\text { BONATE } \\
\text { (CO3) } \\
\text { (MG/L) }\end{array}$ & $\begin{array}{c}\text { RH } \\
\text { (UNITS) }\end{array}$ \\
\hline
\end{tabular}

LAKE OKEeCHDBEe AND tHE EVIRGLADES Basins--CDNTINUED

02278450 - WEST PALM BCH CA AB S-5A NR LOXAHATCHE (LAT 264105 LONG 08022 15)

\begin{tabular}{|c|c|c|c|c|c|c|c|c|c|c|c|}
\hline $\begin{array}{l}\text { JAN.. } 1970 \\
21 . \cdots \\
\text { MAR. }\end{array}$ & -- & 18.0 & 1800 & $=$ & - & $=$ & -- & - & -- & -- & - \\
\hline MAY $20 .$. & - & 22.0 & 1800 & -- & 104 & 41 & - & 220 & 8.0 & 446 & $\cdots$ \\
\hline
\end{tabular}

02278500 - DIV TO CDN AI AT S-5A AND S-5AS NR LOX (LAT 264100 LONG 08022 10)

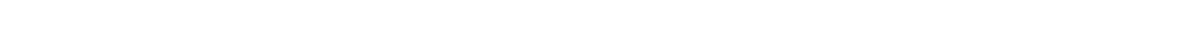

02278501 - CON AREA NO 1 BL S-5 COMP NR LOX (LAT 264100 LONG 0802210 )

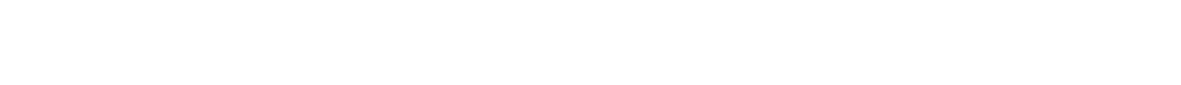

02278550 - LEVEE 8 CA AT PALM BCH CA NR LOXA. F ILAT 264105 LONG 08021 35)

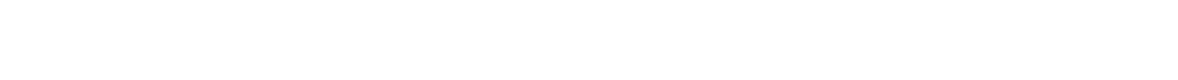

02278600 - PALM BCH CA BL S5AE NR LOXAHATCHEE F (LAT 264105 LDNG 0802150 )

$\begin{array}{rrrrrrrrrrrr}\text { MAY. } 1970 \\ 01 . . . & 259 & 26.5 & 400 & -- & 39 & 7.9 & -- & 32 & .2 .2 & 132 & 0\end{array}$

02279000 - WEST PALM BCH CA AT WEST PALM BCH, FLA (LAT 263840 LONG 0800332 )

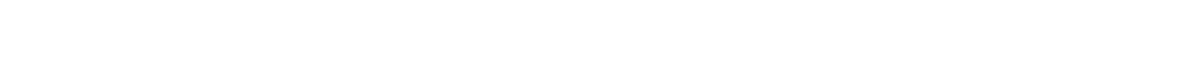

02279500 - BOYNTON CANAL AT BOYNTON BEACH FLA (LAT 263220 LONG 0800310 )

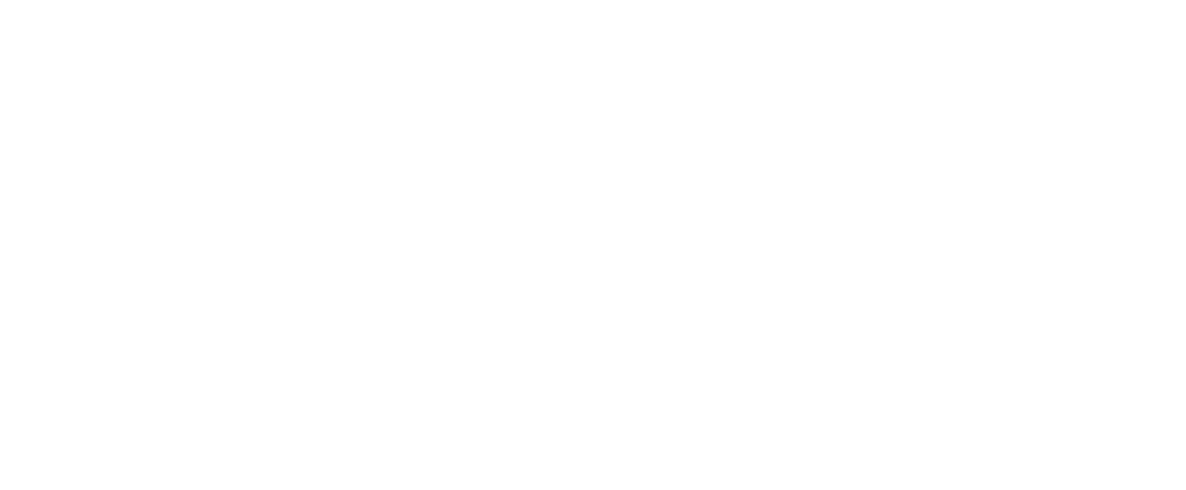

02281301 - HILLSBORO CANAL BL S39 NR DEERFLD BCH (LAT 262120 LONG 0801750 )

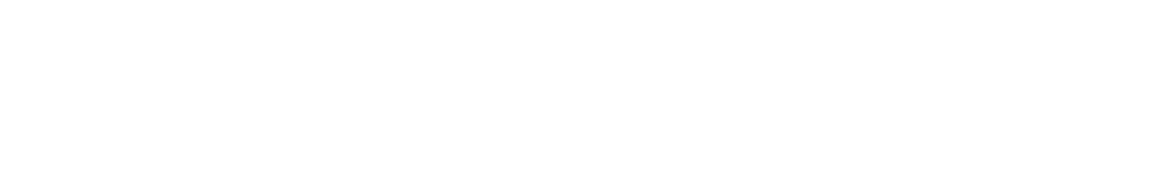

02281425 - EQUALIZING CA I NR DELRAY BCH FLA (LAT 262712 LONG 0801215 )

\begin{tabular}{|c|c|c|c|c|c|c|c|c|c|c|c|c|}
\hline $\begin{array}{l}\text { MAR... } 1970 \\
16 \ldots . . . \\
\text { MAY } \\
01 . . .\end{array}$ & .0 & $\begin{array}{l}20.0 \\
27.0\end{array}$ & $\begin{array}{l}502 \\
720\end{array}$ & $\begin{array}{r}110 \\
\ldots\end{array}$ & 67 & 6.3 & -- & 28 & $\begin{array}{l}11 \\
3.7\end{array}$ & $\begin{array}{l}189 \\
207\end{array}$ & $\begin{array}{r}0 \\
--\end{array}$ & 7.0 \\
\hline
\end{tabular}




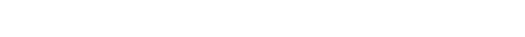

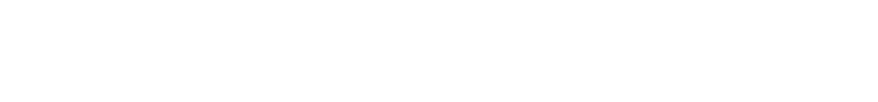

LAKE OKEECHOBEE AND THE EVERGLADES BASINS--CONTINUED

02278450 - WEST PALM BCH CA AB S-5A NR LOXAHATCHE (LAT 2641 n5 LONG 08022 15)

JAN.. 1970
$21 \ldots$

02278500 - DIV to CON AL AT 5-5A AND 5-5AS 'NR LOX (LAT 264100 LONG 08022 10) AUG.. $1970 \quad 2.8$
D6...

02278501 - CON AREA NO, 1 BL S-5 COMP NR LOX (LAT 264100 LONG 0802210 )

\begin{tabular}{|c|c|c|c|c|c|c|c|c|c|c|c|}
\hline $\begin{array}{l}\text { NOV... } 1969 \\
21 . . .1970 \\
\text { APR..'1 } 1970\end{array}$ & 28 & 126 & .4 & 144 & 34 & 110 & 444 & 376 & -- & .60 & 2.1 \\
\hline
\end{tabular}

02278550 - LEVEE \& CA AT W PALM BCH CA NR LOXA. F (LAT 264105 LONG ABO 2135 )

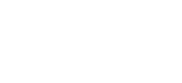

49

$3 \quad 142$

$24 \quad 118$

276

$239 \quad 193$

02278600 - W PALM BCH CA BL S5AE NR LOXAHAIEMEE F (LAT 264105 LONG 0802150 )

MAY 197029

38

$\begin{array}{llll}.3 & 130 & 22 & 108\end{array}$

$261 \quad 221 \quad 183$

02279000 - WEST PALM BCH CA AT WEST PALM BCH. FLA (LAT 263840 LONG $080 \quad 0332$ )

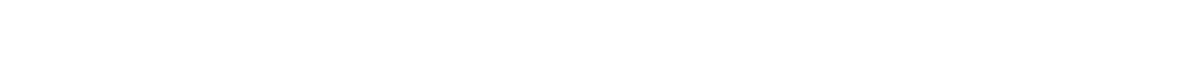

02279500 - BOYNTON CANAL AT BOYNTON BEACH FLA (LAT 263220 LONG 0800310$)$

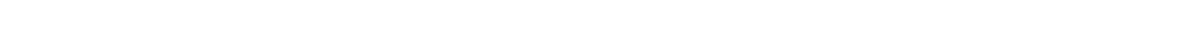

02281295 - EVERGLADES STA 1-15 NR DELPAY GEACH FL (LAT 262345 LDNG 0801740 )

APR.: 1970

$28 \ldots$

$06 . . .250$

(1)

$\begin{array}{rrrr}.3 & 18 & 6 & 11 \\ .0 & 14 & 4 & 10 \\ .2 & 24 & 7 & 17\end{array}$

$70 \quad 36$

14

.2

02281300 - HILLS8ORO CANAL AT S-39 NR DEERF IELD \& (LAT 262120 LONG 08017 58)

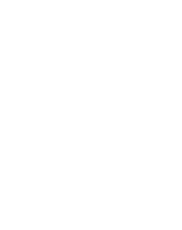

$\begin{array}{rrr}198 & .9 & 3 ? 9 \\ -- & -- & -- \\ 168 & .9 & 285 \\ -- & -- & -- \\ 32 & .3 & 92 \\ 54 & .3 & 190 \\ 222 & 1.0 & 352\end{array}$

$\begin{array}{rrr}46 & 284 & 813 \\ -- & -- & -- \\ 32 & 253 & 675 \\ - & -- & -- \\ 3 & 89 & 196 \\ 17 & 174 & 325 \\ 83 & 269 & 896\end{array}$

$\begin{array}{cc}727 & - \\ - & - \\ 607 & - \\ -- & - \\ 153 & -0 \\ 296 & -00 \\ 802 & .00\end{array}$

02281301 - HILLSBORO CANAL BL S39 NP DEERFLD BCH (LAT 262120 LONG 0B0 17 59)

SEP., 197098

192

$1.0 \quad 34$

77

$271 \quad 848$

02281419 - EqualizING CANAL 1 NEAR GRACRES CITY (LAT 263701 LONG 08012 16)

$\begin{array}{ll}\text { MAR.. } & 1970 \\ 18 . . . & 13 \\ \text { MAY } & \\ 01 \ldots . . & 34\end{array}$

66

$.4 \quad 173$

$24 \quad 148 \quad 256$

221

02281425

$\begin{array}{lll}.3 & 188\end{array}$

$153 \quad 325$

314

.00

MAR... 197026

MAY 1926

49

.6
.7

193

38

155

341

293

11

$.7 \quad 188$

$17 n$

475

395 

(MAJOR CONSTITUENTS

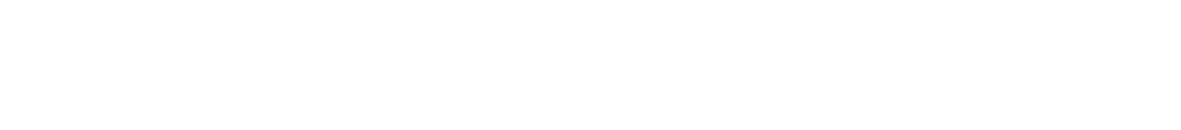

LAKE OKEECHOBEE AND THE EVERGLADES BASINS--CDNTINUED

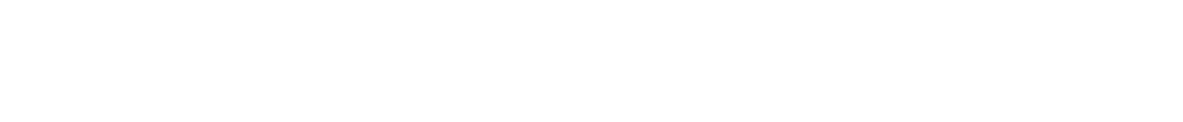

02281513 - EQUALIZING CANAL 3 NR GREENACRES CITY (LAT 263707 LONG 08007 49)

\begin{tabular}{|c|c|c|c|c|c|c|c|c|c|c|c|}
\hline $\begin{array}{l}\text { MAR.. } 1970 \\
\text { MAY... } \\
\text { MAY }\end{array}$ & -- & -- & 425 & 140 & 68 & 3.8 & -- & 15 & 3.1 & 187 & 0 \\
\hline $01 \ldots$ & .00 & 27.0 & 480 & $-\infty$ & 70 & 4.9 & -- & 27 & 3.3 & 200 & $\cdots$ \\
\hline
\end{tabular}

02291532 - EQUALIZING CANAL 3 NEAR DELRAY HEACH F (LAT 262727 LONG 08007 52)

$\begin{array}{cccccccccccccc}\text { MAY. } 1970 & 190 & 26.0 & 395 & -- & 55 & 3.5 & 740 & 19 & 2.8 & 170 & 0 & 8.1\end{array}$

02281544 - EQUALIZING CANAL 3 NEAR BOCA RATON FLA (LAT 262204 LONG 0800746 )

$\begin{array}{lllllllllllllll}\text { MAY }, 1970 & 00 & 25.0 & 285 & -- & 31 & 2.6 & 250 & 19 & 2.9 & 82 & 0\end{array}$

02281569 - LAKE CLARK NR LAKE WORTH FLA (LAT 263755 LONG 0800432 )

\begin{tabular}{|c|c|c|c|c|c|c|c|c|c|c|c|}
\hline $\begin{array}{l}\text { MAR } \ldots 1970 \\
17 \ldots \ldots \\
\text { MAY }\end{array}$ & -- & 19.0 & 540 & 130 & 61 & 7.3 & 760 & 37 & 5.7 & 171 & 0 \\
\hline
\end{tabular}

022815 HZ - LAKE OSBORNe neak laNtana fLA (LAT 263514 LONG 0800442 )

\begin{tabular}{|c|c|c|c|c|c|c|c|c|c|c|c|}
\hline $\begin{array}{l}\text { MAR., } 1970 \\
\text { MAY }\end{array}$ & -- & 21.0 & & 60 & 57 & 4.8 & 570 & 18 & 7.5 & 143 & 0 \\
\hline
\end{tabular}

02281600 - LAKE IDA NEAR DELRAY BEACH FLA (LAT 262832 LONG 08005111

\begin{tabular}{|c|c|c|c|c|c|c|c|c|c|c|c|}
\hline $16 \cdots$ & -- & 20.0 & $45 n$ & 70 & 51 & 6.7 & 530 & 26 & 11 & 121 & 0 \\
\hline
\end{tabular}

02281625 - EL RIO CA AT BOCA RATON FLA (LAT $26 \quad 2200$ LONG 0BO 05 44)

\begin{tabular}{|c|c|c|c|c|c|c|c|c|c|c|c|}
\hline $\begin{array}{l}\text { MAR., } 1970 \\
16 \ldots \\
\text { MAY }\end{array}$ & -- & 18.0 & $34 n$ & 260 & 54 & 2.8 & 380 & 14 & 1.1 & $14 \mathrm{a}$ & 0 \\
\hline
\end{tabular}

02281700 - CYPRESS CREEK CA AT S-38 NQ POMP BCH F (LAT 261345 LONG 08017 50)

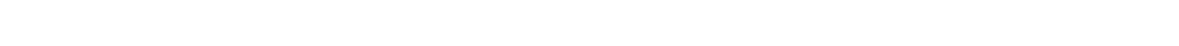

02281701 - PQMPANO CA BL 539 NR POMPANO BEACH FLA ILAT 261345 LONG 0 HO 1750 )

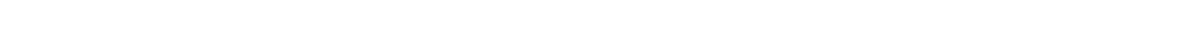

O2282000 - POMPANO CANAL AT POMPANO RCH FLA (LAT $26 \quad 1351$ LONG 08007 28)

$\begin{array}{llllllllllllll}\text { FEP., } 1970 & - & - & 485 & 70 & 86 & 2.1 & 570 & 15 & 1.2 & 248 & 0 & 7.6\end{array}$

022R2100 - CYPRESS CR CA AT S-37A NR POMPANO BEACH F ILAT 26 12 20 LONG, 080 07 571

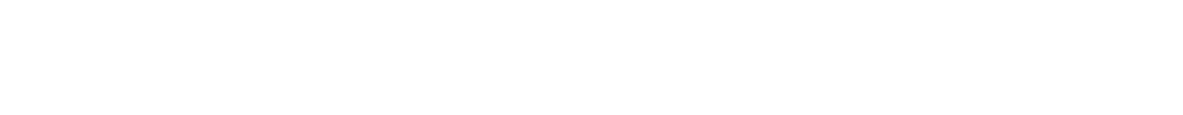

02282700 - MIOOLE K CA AT S-36 NR FT LAUDERDALE F (LAT 261022 LONG 080 1047 )

\begin{tabular}{|c|c|c|c|c|c|c|c|c|c|c|c|c|}
\hline $\begin{array}{l}\text { FEB.. } 1970 \\
13 \ldots \\
\text { MAY }\end{array}$ & -- & 18.0 & 640 & 70 & 100 & 2.6 & 960 & 16 & 1.3 & $2 \mathrm{H}_{2}$ & 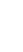 & 7.4 \\
\hline $11 \ldots$ & .00 & 25.5 & 648 & - & 108 & 3.2 & -- & 28 & .4 & 287 & 4 & 8.3 \\
\hline
\end{tabular}


CHEMICAL ANALYSES, WATER YEAR OCTOBER 1969 TO SEPTEMBER 1970

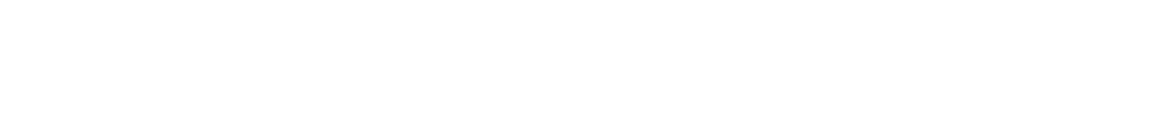

LAKE OKEECHOBEE AND THE EVERGLADES BASINS--CONTINUED

02291500 - HILLSBORO CANAL NEAR DEERF IELD BEACH F ILAT 26 I9 39 LONG 08007 52)

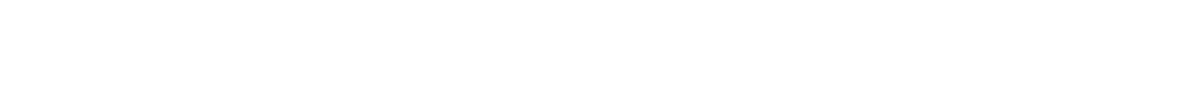

02281513 - EQUALIZING CANAL 3 NR GREENACRES CITY ILAT 263707 LONG 0800749 I

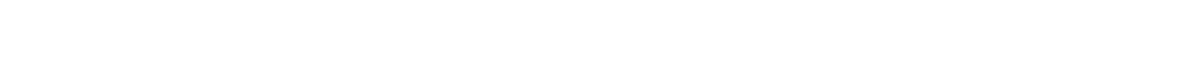

02281532 - EQUALIZING CANAL 3 NEAR DELRAY BEACH F (LAT 262727 LONG 0800752$)$

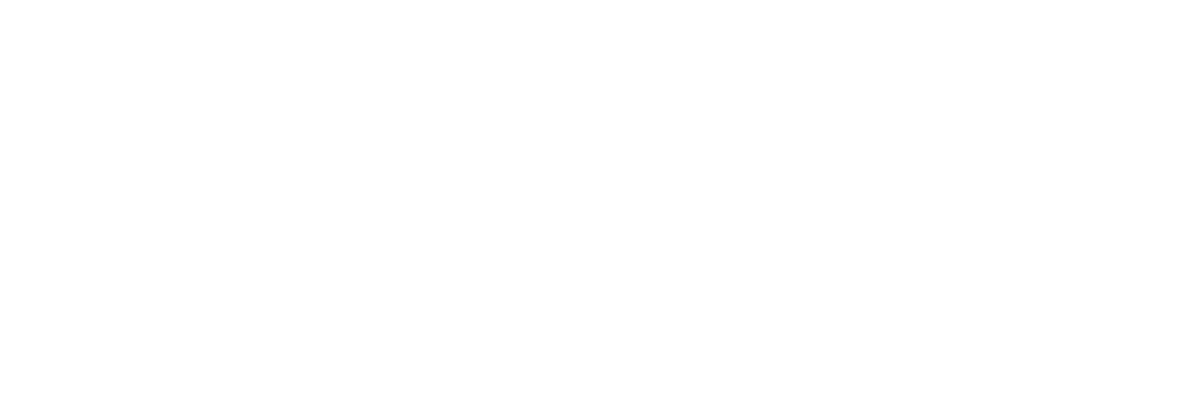

02281600 - LAKE IDA NEAR DELRAY BEACH FLA ILAT 262832 LONG 0BO 05111

$\begin{array}{lll}\text { MAR., } & 1970 & \\ 16 . . . & 37 & 42 \\ \text { MAY } & 21 & 28\end{array}$

$$
42
$$

$.4 \quad 155 \quad 56$

$.2 \quad 163 \quad 32$
$99 \quad 295 \quad 260$

$131 \quad 256 \quad 215$

02281625 - EL RIO CA AT BOCA RATON FLA ILAT 262200 LONG 08005 44)

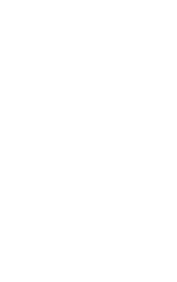

$16 \ldots 34$

24

28

$\begin{array}{llllll}.3 & 147 & 26 & 121 & 223 & 195 \\ .2 & 186 & 15 & 171 & 274 & 233\end{array}$

$\begin{array}{llllll}.3 & 147 & 26 & 121 & 223 & 195 \\ .2 & 186 & 15 & 171 & 274 & 233\end{array}$

CYPRESS CREEK CA AT S-38 NR POMP BCH F ILAT 261345 LONG ORO 1750 I

99

217

02281701 - POMPANO CA BL S38 NR POMPANO BEACH FLA ILAT 241345 LONG 08017501 140

$\begin{array}{lllll}270 & 27 & 243 & 618 & 523\end{array}$

02282000 - POMPANO CANAL AT POMPANO BCH FLA (LAT 261351 LONG O80 0728 )

FEB., 1970

24

.3224

21

203

302

02282100 - CYPRESS CR CA AT S-37A NR POMPANO BEACH F ILAT 261220 LONG OBO 07571

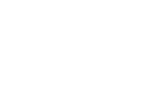

67

104

$\begin{array}{lll}.4 & 277 & 30 \\ .4 & 209 & 22 \\ .5 & 231 & 29\end{array}$

$\begin{array}{ll}247 & 470 \\ 187 & 467 \\ 202 & 406\end{array}$

404

36.3

02282700 - MIDDLE R CA AT S-36 NP FT LAUDERDALE F (LAT 261022 LONG OBO 1047 )

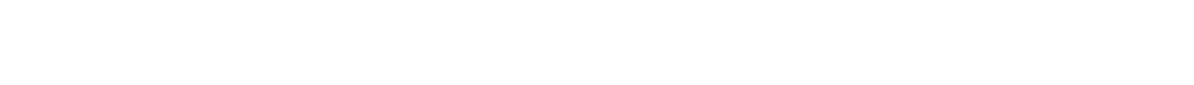




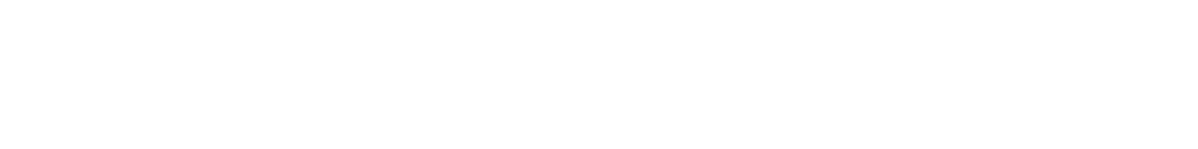

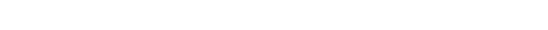

$02282800-$ MIDDLE R CA AT US HWY'I NR FT LAUD FLA (LAT 26 O9 26 LONG 08007 03)

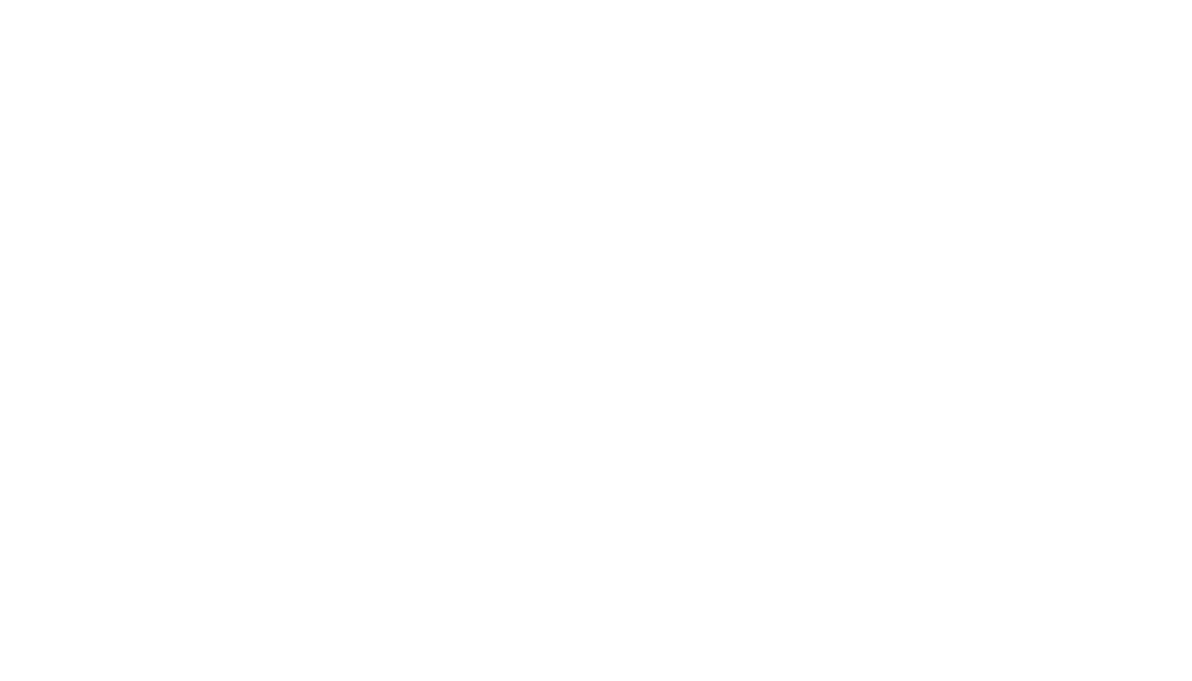

02284642 - EVERGLADES STA 2-17 NR ANDYTONN FLA (LAT 261650 LONG 0802510 )

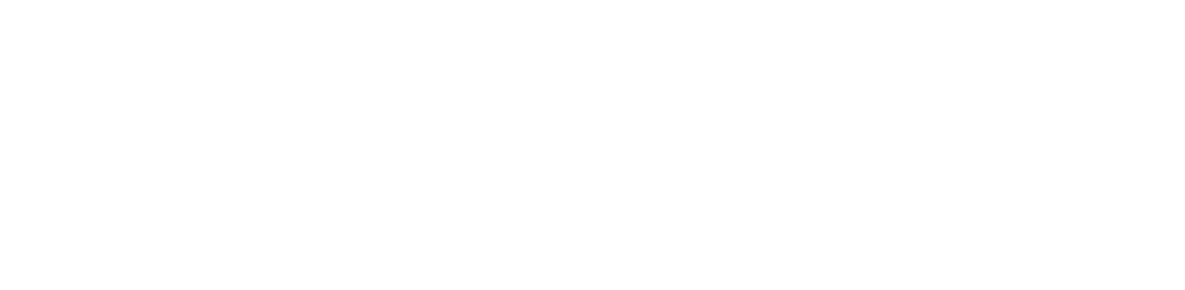

02284700 - N NEW R CA AT S34 NR FT LAUDERDALE FLA (LAT 260843 LONG 0802625 )

\begin{tabular}{|c|c|c|c|c|c|c|c|c|c|c|c|}
\hline $\begin{array}{l}\text { FEB.. } 1970 \\
16 . . . \\
\text { SEP. } \\
29 .\end{array}$ & -- & 24.0 & $\begin{array}{l}785 \\
894\end{array}$ & $\begin{array}{l}260 \\
250\end{array}$ & 75 & $\begin{array}{l}19 \\
22\end{array}$ & 1300 & $\begin{array}{l}61 \\
79\end{array}$ & $\begin{array}{l}2.7 \\
2.6\end{array}$ & $\begin{array}{l}332 \\
360\end{array}$ & $\begin{array}{r}0 \\
-\end{array}$ \\
\hline
\end{tabular}

02284800 - N NEW R CA AB hOL LAT NR FT LAUD FLA (LAT 260640 LONG 0801750 )

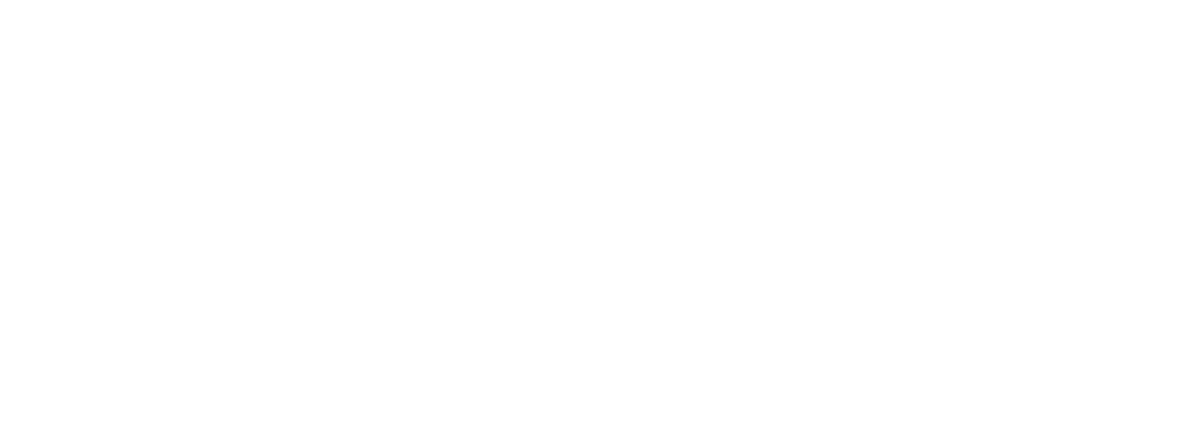


CHEMICAL ANALYSES, WATER YEAR OCTOBER 1969 TO SEPTEMBER 1970 (MAJOR CONSTITUENTS)

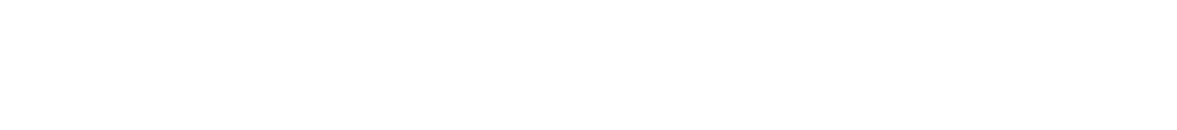

LAKE OKEECHOBEE AND THE EVERGLADES BASINS--CONTINUED

02282800 - MIDDLE R CA AT US HWY I NR FT LAUD FLA ILAT 260926 LONG 08007031

FEB., 1970

02282990 - FLORIDA TURNPIKE CA AT FT LAUDEROALE F (LAT $26 \quad 0603$ LONG 08013031

FEB., 1970

21

02283200 - PLANTATION RD CA AT S-33 NR FT LAUD FL (LAT 260805 LONG 080 I1 42 )

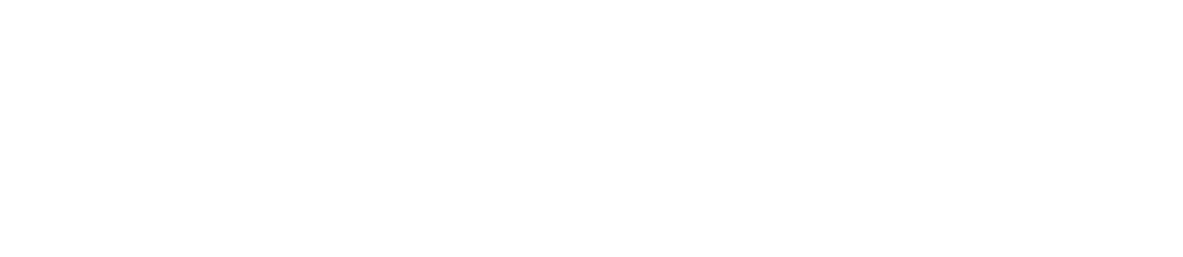

02284520 - DIVERSION CANAL AT S143 NP ANOYTOWN FL (LAT 260900 LONG 0802630 )

\begin{tabular}{|c|c|c|c|c|c|c|c|c|c|c|c|}
\hline $\begin{array}{l}\text { OCT.. } 1969 \\
22 . . . \\
\text { DEC. }\end{array}$ & 75 & 128 & $\cdot 8$ & 385 & 88 & 297 & 708 & 629 & - & .96 & 1.6 \\
\hline MAY & 30 & 130 & .8 & 221 & 23 & 198 & 535 & 473 & .00 & .73 & $=$ \\
\hline $06 \ldots$ & 47 & 160 & .9 & 297 & 31 & 266 & 734 & 610 & .00 & 1.00 & -- \\
\hline
\end{tabular}

02284642 - EVERGLADES STA 2-17 NR ANDYTOWN FLA ILAT 261650 LONG 08025101

\begin{abstract}
AUG., 1970
$06 . . . \quad 55$

152

0.29

29533

02284690 - EVERGLADES STATION 2-21 NEAR ANDYTOWN (LAT 28 OB 05 LONG 080 22 05)
\end{abstract}

JULY, 1970

60

116

02284699 - N NEW R CA AB S34 NR FT LAUDERDALE FLA (LAT $26 \quad 0859$ LONG 0802633 )

MAY 1970
$05 \ldots .$.
SFP..
22...

160

103

$.9 \quad 321 \quad 50 \quad 271$

701

622
436

02284700 - N NEW R CA AT 534 NR FT LAUDEROALE FLA (LAT 260843 LONG 0802625 )

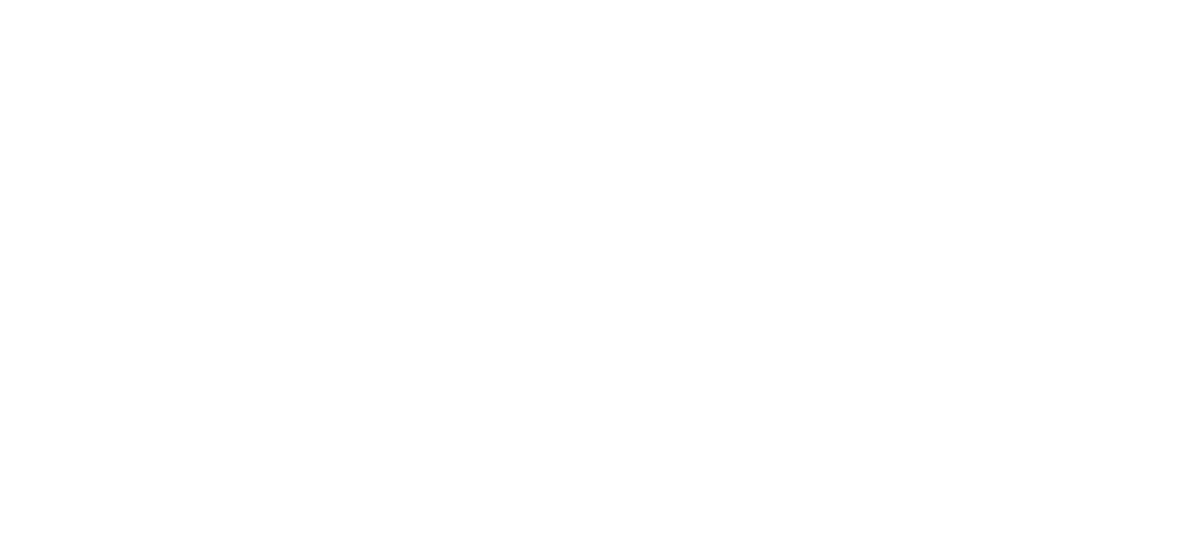



WATER YEAR OCTOBER 1969
(MAJOR CONSTITUENTS)

\begin{tabular}{|c|c|c|c|c|c|c|c|c|c|c|c|c|}
\hline ATE & $\begin{array}{l}\text { OIS- } \\
\text { CHARGE } \\
\text { (CFS) }\end{array}$ & $\begin{array}{l}\text { TEMPER- } \\
\text { ATURE } \\
\text { (DEG C) }\end{array}$ & $\begin{array}{l}\text { SPE- } \\
\text { CIFIC } \\
\text { CON- } \\
\text { DUCT- } \\
\text { ANCE } \\
\text { (MICRO- } \\
\text { MHOS) }\end{array}$ & $\begin{array}{l}\text { DIS- } \\
\text { SOLVED } \\
\text { IRON } \\
\text { (FE) } \\
\text { (UG/L) }\end{array}$ & $\begin{array}{l}\text { DIS- } \\
\text { SOLVED } \\
\text { CAL- } \\
\text { CIUM } \\
\text { (CA) } \\
\text { MG }(L)\end{array}$ & $\begin{array}{l}\text { DIS- } \\
\text { SOLVED } \\
\text { MAG- } \\
\text { NE- } \\
\text { SIUM } \\
\text { (MG) } \\
\text { (MG/L) }\end{array}$ & $\begin{array}{l}\text { DIS- } \\
\text { SOLVED } \\
\text { STRON- } \\
\text { TIUM } \\
\text { (SR) } \\
\text { (UGIL) }\end{array}$ & $\begin{array}{l}\text { DIS- } \\
\text { SOLVED } \\
\text { SODIUIM } \\
\text { (NA) } \\
\text { (MG/L) }\end{array}$ & $\begin{array}{l}\text { DIS- } \\
\text { SOLVED } \\
\text { PO- } \\
\text { TAS- } \\
\text { SIUM } \\
\text { (K) } \\
\text { (MG/L) }\end{array}$ & $\begin{array}{l}\text { BICAR- } \\
\text { BONATE } \\
\text { (HCO3) } \\
\text { (MG } / L)\end{array}$ & $\begin{array}{l}\text { CAR- } \\
\text { RONATE } \\
\text { (CO3) } \\
\text { (MG L I }\end{array}$ & $\begin{array}{c}P H \\
\text { (UNITS) }\end{array}$ \\
\hline
\end{tabular}

LAKE OKEECHOBEE AND THE EVERGLADES BASINS--CDNTINUED

02286050 - SOUTH NR CA AT S-13A NR DAVIE ILAT 260350 LONG 080 17201

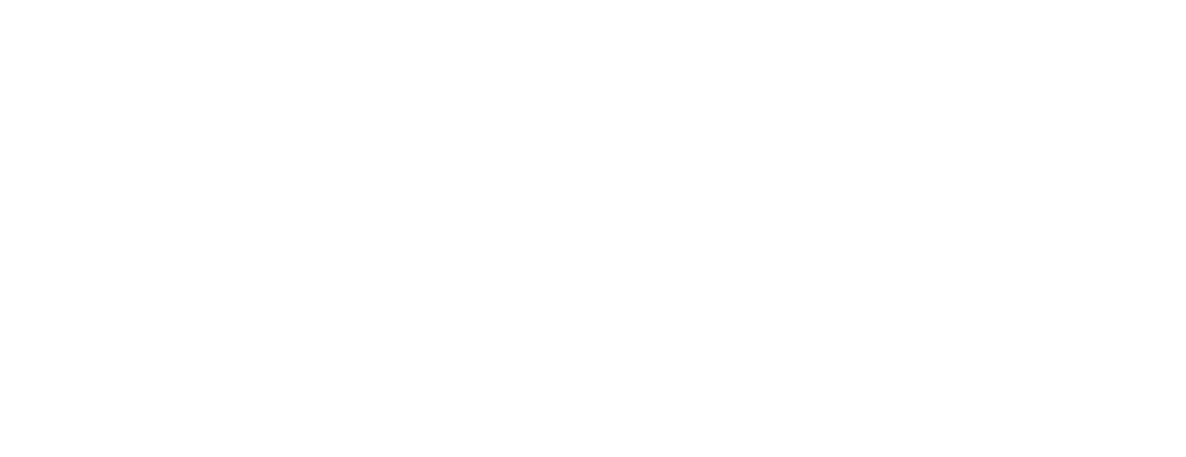

022863 nO - SNAKE CREEK CANAL AT S-29 AT N MIAMI B (LAT 255541 LONG ORO 09 22)

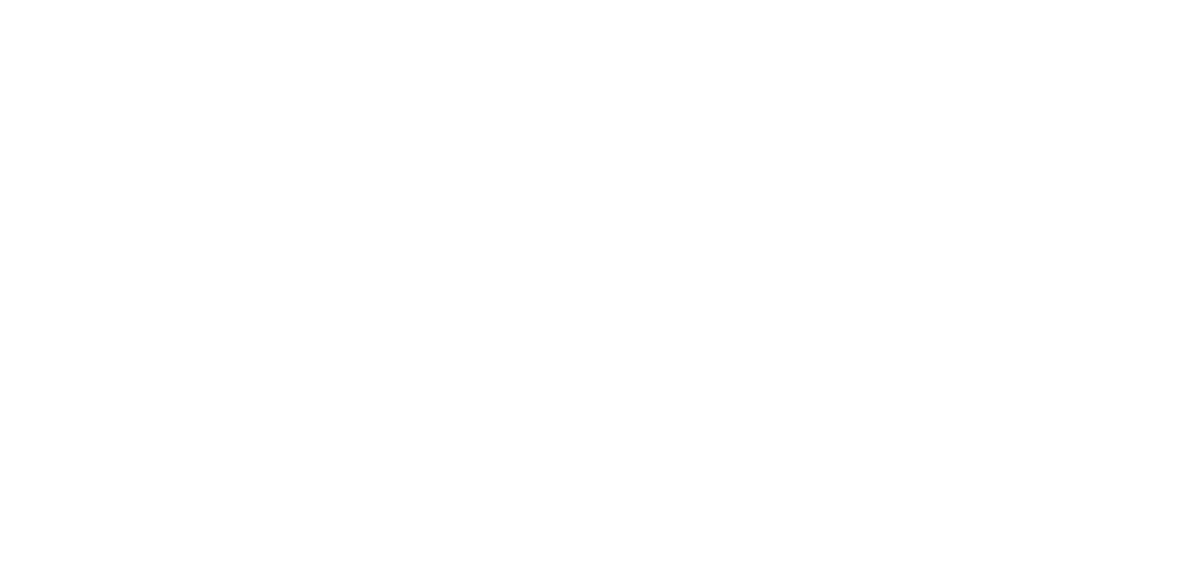

02287500 - MIAMI CA AT PENNSUCO NR MIAMI FLA (LAT 255340 LONG 0802245$)$

MAY, 1970

02288200 - MIAMI CANAL at PALMETTO BYPASS NR HIAL (LAT 255111 LONG nRO 19 2?)

MAY. 1970

$\begin{array}{lllllllll}25.0 & 750 & -- & 64 & 17 & 1100 & 65 & 2.2 & 268\end{array}$

02288600 - MIAMI CANAL AT NW 36TH ST MIAMI, FLA. (LAT 254829 LONG 0801544 )

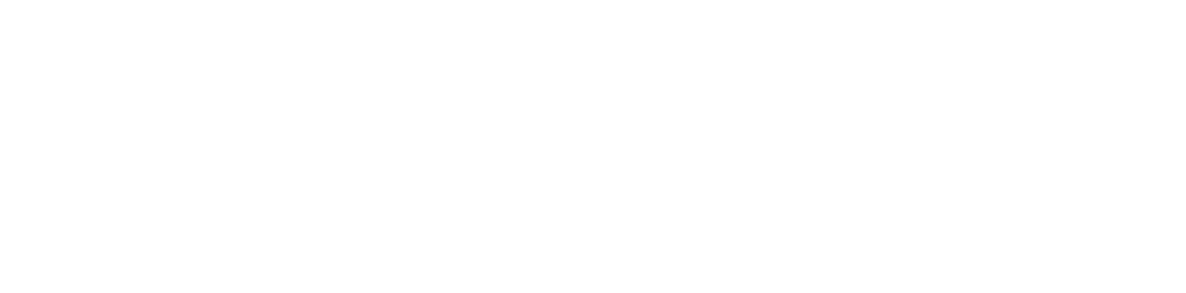


CHEMICAL ANALYSES, WATER YEAR OCTOBER 1969 TO SEPTEMBER 1970 (MAJOR CONSTITUENTS)

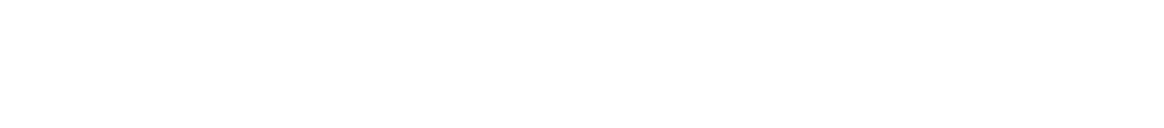

LAKE OKEECHOBEE AND THE EVERGLADES BASINS--CONTINUED

02286050 - SOUTH N R CA AT S-13A NR DAVIE (LAT 260350 LONG 0801720 )

SEP., 1970
$29 . .$.

02286150 - HOLLYWOOD CANAL AT DANIA FLA ILAT $2603 \quad 13$ LONG 0900919 )

$\begin{array}{ccccccccc}\text { SEP.. } 1970 & & & & & & & & \end{array}$

02286200 - SNAKE CR CA AT NW 67 AVE NR HIALEAH FL (LAT 255750 LONG 08018 40)

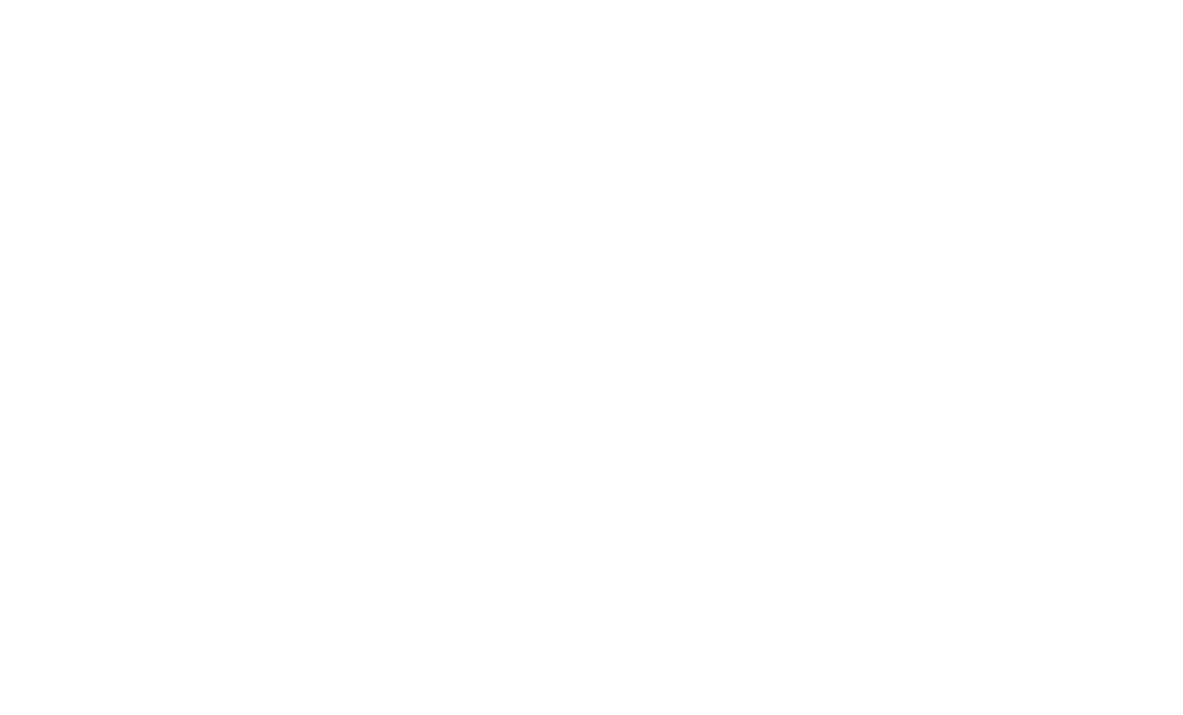

02287500 - MIAMI CA AT PENNSUCD NR MIAMI FLA (LAT 255340 LONG 0802245$)$

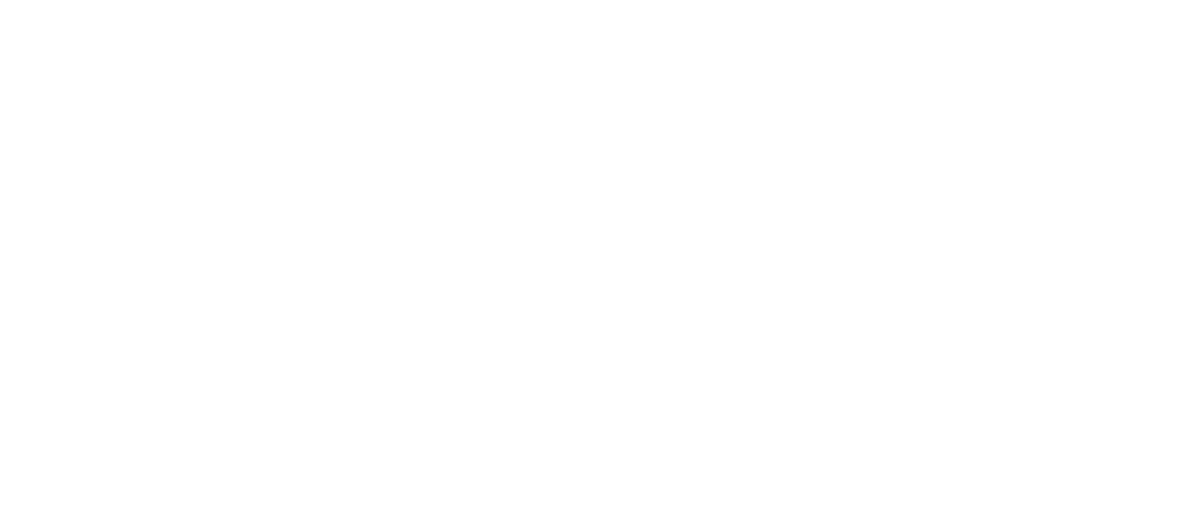



WATER YEAR OCTOBER 196
(MAJOR CONSTITUENTS)

\begin{tabular}{|c|c|c|c|c|c|c|c|c|c|c|c|c|}
\hline & $\begin{array}{l}\text { DIS- } \\
\text { CHARGE } \\
\text { (CFS) }\end{array}$ & $\begin{array}{l}\text { TEMPER- } \\
\text { ATURE } \\
\text { (DEG C) }\end{array}$ & $\begin{array}{l}\text { SPE- } \\
\text { CIFIC } \\
\text { CON- } \\
\text { OUCT- } \\
\text { ANCE } \\
\text { (MICRO- } \\
\text { MHOS) }\end{array}$ & $\begin{array}{l}\text { DIS- } \\
\text { SOLVEO } \\
\text { IRON } \\
\text { (FE) } \\
\text { (UG/L) }\end{array}$ & $\begin{array}{l}\text { DIS- } \\
\text { SOLVED } \\
\text { CAL- } \\
\text { CIUM } \\
\text { (CA) } \\
\text { (MG/L) }\end{array}$ & $\begin{array}{l}\text { DIS- } \\
\text { SOLVED } \\
\text { MAG- } \\
\text { NE- } \\
\text { SIUM } \\
\text { (MG) } \\
\text { (MG/L) }\end{array}$ & $\begin{array}{l}\text { OIS- } \\
\text { SOLVED } \\
\text { STRON- } \\
\text { TIUM } \\
\text { (SR) } \\
\text { (UG/L) }\end{array}$ & $\begin{array}{l}\text { DIS- } \\
\text { SOLVED } \\
\text { SODIUM } \\
\text { (NA) } \\
\text { (MG/L) }\end{array}$ & $\begin{array}{l}\text { DIS- } \\
\text { SOLVED } \\
\text { PO- } \\
\text { TAS- } \\
\text { SIUM } \\
\text { (K) } \\
\text { (MG/L) }\end{array}$ & $\begin{array}{l}\text { BICAR- } \\
\text { BONATE } \\
\text { (HCO3) } \\
\text { (MG/L) }\end{array}$ & $\begin{array}{l}\text { CAR- } \\
\text { BONATE } \\
\text { (CO3) } \\
\text { (MG/L) }\end{array}$ & PH \\
\hline
\end{tabular}

LAKE OKEECHOBEE AND THE EVERGLADES BASINS--CONTINUED

02288780 - TAMIAMI CA AT BR 77 NR CARNESTOWN FLA (LAT 2554 O0 LONG 08121 00)

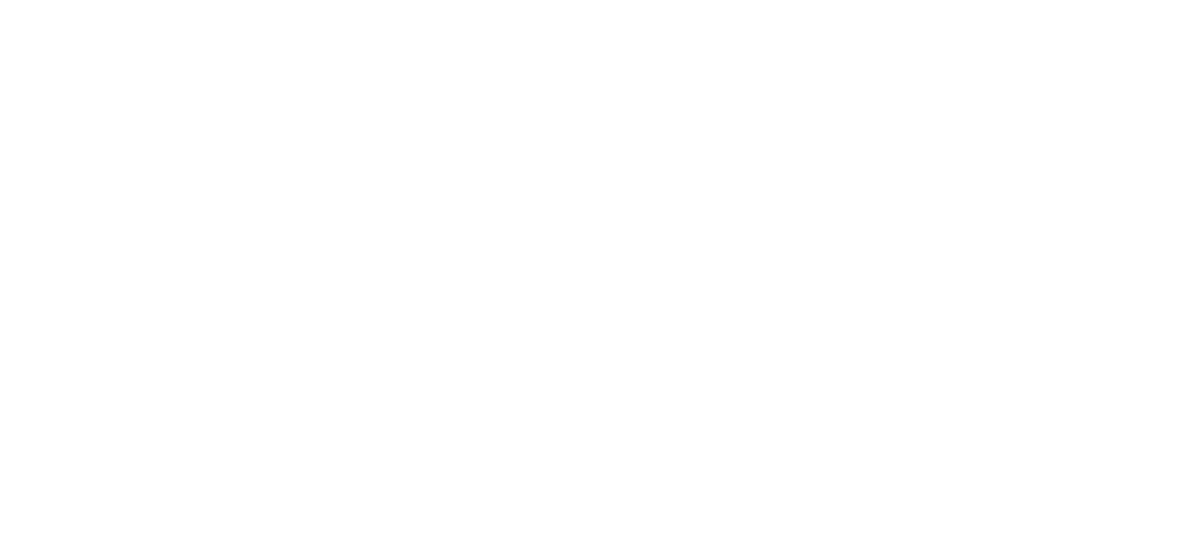

$022 B 8906$ - TAMIAMI CANAL AT 40 MI BEND NR MIAMI F ILAT 254550 LONG 0804950 ,

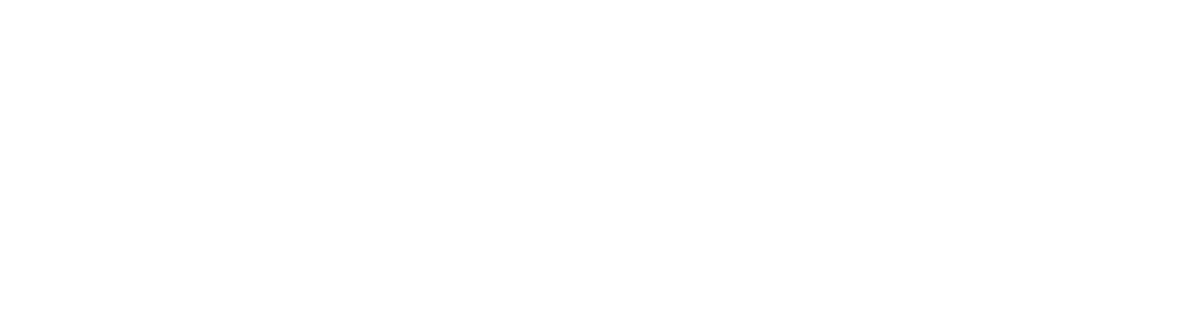

12289019 - TAMIAMI CA BL S-12B NR MIAMI FLA (LAT 284540 LONG $08046 \quad 05$ I

\begin{tabular}{|c|c|c|c|c|c|c|c|c|c|c|c|c|c|c|c|c|}
\hline $\begin{array}{l}\text { MAY } 1970 \\
13 . . .\end{array}$ & - & - & 365 & & 180 & 51 & 4.3 & 29 & & 18 & & .6 & 178 & & 0 & 7.9 \\
\hline & & 022 & 9030 & - & LEVEE & 3 CA NR & CLEWISTON & FLA & (LAT & 262550 & LONC & $G 080$ & 56501 & & & \\
\hline $\begin{array}{l}\text { MAY. } 1970 \\
19 . . .\end{array}$ & .00 & 25.0 & 380 & & $\rightarrow$ & 52 & 5.2 & & $=$ & 22 & & .4 & 168 & & 8 & 8.4 \\
\hline & & 02289033 & - & BIG & CYP SWP & AT EVER & PKY NR BIG & CYP & IND & ILAT 261 & 1008 & 18 LONG & 308105 & 151 & & \\
\hline
\end{tabular}

02289040 - TAMIAMI CA O L67A TO 40 MI BEND NR MIA (LAT 254542 LONG 0804334 )

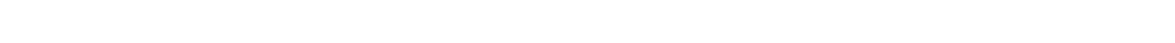

02289041 - TAMIAMI CA BELOW SIZC NR MIAMI FLA (LAT 254540 LONG 0804334 )

JULY, 1970

17... 453

02289043 - EVERGLADES STATION 3-28 NEAR PENNSUCO (LAT 254855 LONG 08043151

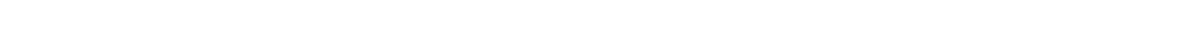

02289060 - TAMIAMI CA O AT BRIUGE 45 NR MIAMI FLA (LAT 254540 LONG 0803740 )

MAY 1970
$13 . .$.

$27.0 \quad 590$

$590 \quad--\quad 90$

$4.5 \quad 490 \quad 29$

$.4 \quad 294$ 
CHEMICAL ANALYSES, WATER YEAR OCTOBER 1969 TO SEPTEMBER 1970 (MAJOR CONSTITUENTS)

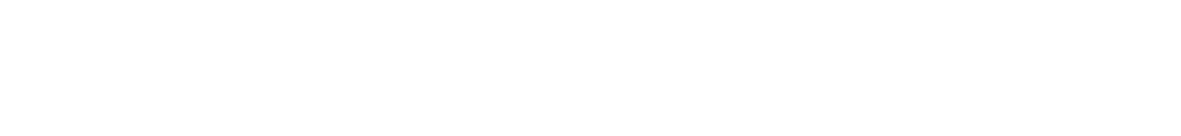

LAKE DKEECHOBEE AND THE EVERGLADES BASINS--CONTINUED

02288780 - TAMIAMI CA AT GR 77 NR CARNESTOWN FLA (LAT 255400 LONG 0812100 )

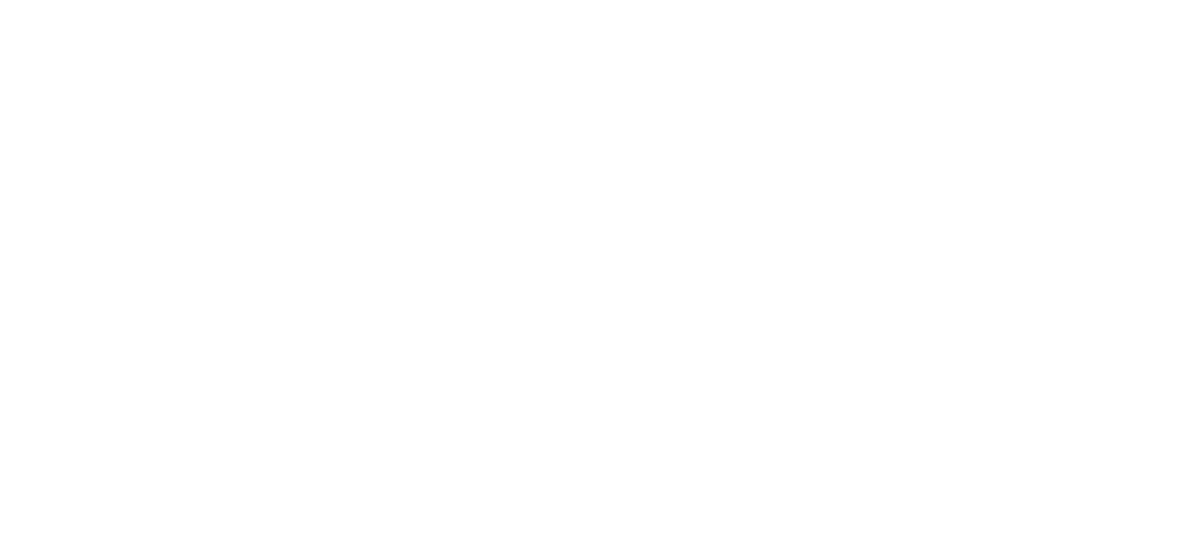

0ZzBA906 - TAMIAMI CANAL AT 40 MI REND NR MIAMI F (LAT 254550 LONG ORO 4950 )

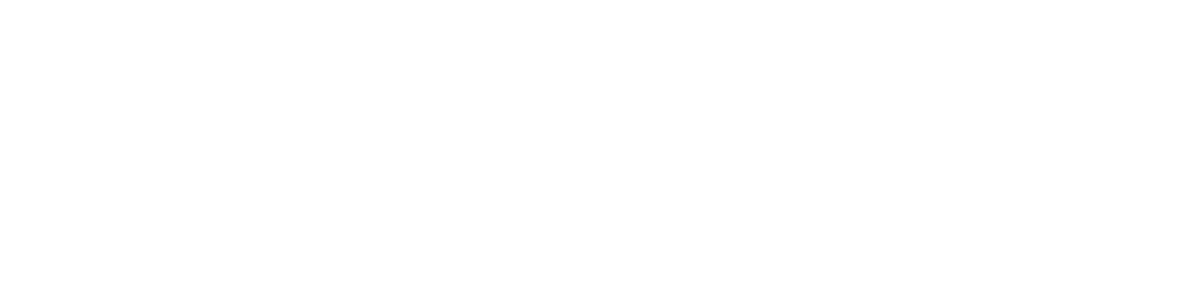

n2289019 - TAMIAMI CA BL 5-126 NR MIAMI FLA (LAT 284540 LONG O8O 46 05)

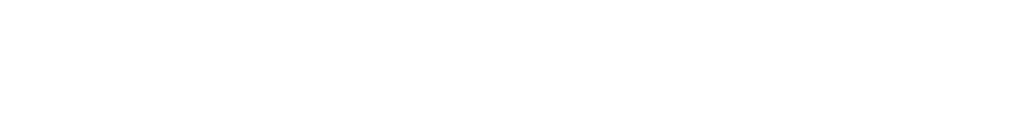

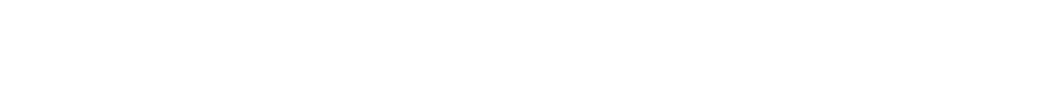

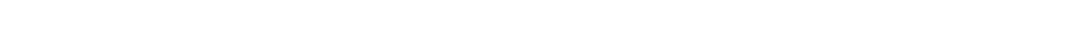

02289040 - TAMIAMI CA O L67A TO 40 MI BENO NR MIA (LAT 254542 LONG 08 4334 )

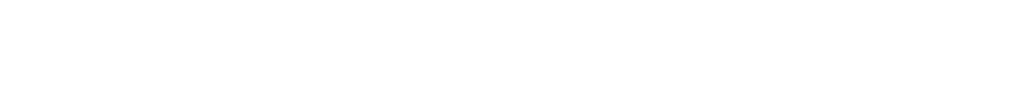

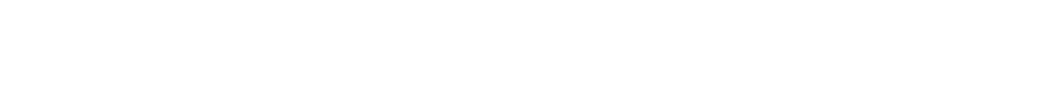

$\begin{array}{lllllllll}\text { AUG.. } 1970 & .8 & 18 & .2 & 94 & 9 & 85 & 143 & 123\end{array}$

02289060 - TAMIAMI CA O AT BRIUGE 45 NR MIAMI FLA LLAT 254540 LONG 0803740 )

MAY, 197

02 


\begin{tabular}{|c|c|c|c|c|c|c|c|c|c|c|c|c|}
\hline & & & CHEMICAL & ANALYSE & $\begin{array}{l}\text { WATER } \\
\text { SMAJOF }\end{array}$ & $\begin{array}{l}\text { YEAR DCTO } \\
\text { CONSTITU }\end{array}$ & $\begin{array}{l}\text { R } 1964 \\
\text { (TS) }\end{array}$ & SEPT & ER 1970 & & & \\
\hline TE & $\begin{array}{l}\text { DIS- } \\
\text { CHAKGE } \\
\text { (CFS) }\end{array}$ & $\begin{array}{l}\text { TEMPER- } \\
\text { ATURE } \\
\text { (DEG C) }\end{array}$ & $\begin{array}{l}\text { SPE- } \\
\text { CIFIC } \\
\text { CON- } \\
\text { DUCT- } \\
\text { ANCE } \\
\text { (MICRO- } \\
\text { MHOS) }\end{array}$ & $\begin{array}{l}\text { OIS- } \\
\text { SOLVED } \\
\text { IRON } \\
\text { (FE) } \\
\text { (UG/L) }\end{array}$ & $\begin{array}{l}\text { DIS- } \\
\text { SOLVED } \\
\text { CAL- } \\
\text { ClUM } \\
\text { (CA) } \\
\text { (MG/L) }\end{array}$ & $\begin{array}{l}\text { OIS- } \\
\text { SOLVEO } \\
\text { MAG- } \\
\text { NE- } \\
\text { SIUM } \\
\text { (MG) } \\
\text { (MG/L) }\end{array}$ & $\begin{array}{l}\text { DIS- } \\
\text { SOLVED } \\
\text { STRON- } \\
\text { TIUM } \\
\text { (SR) } \\
\text { (UG/L) }\end{array}$ & $\begin{array}{l}\text { OIS- } \\
\text { SOLVEO } \\
\text { SOOIUM } \\
\text { (NA) } \\
\text { (MG/L) }\end{array}$ & $\begin{array}{l}\text { DIS- } \\
\text { SOLVEO } \\
\text { PO- } \\
\text { TAS- } \\
\text { SIUM } \\
\text { (K) } \\
\text { (MG/L) }\end{array}$ & $\begin{array}{l}\text { BICAR- } \\
\text { BONATE } \\
\text { (HCO3) } \\
\text { (MG/L) }\end{array}$ & $\begin{array}{l}\text { CAR- } \\
\text { BONATF } \\
\text { (CO3) } \\
\text { (MG/L) }\end{array}$ & $\begin{array}{c}P H \\
\text { (UNITS) }\end{array}$ \\
\hline
\end{tabular}

LAKE DKEECHOBEE AND THE EVERGLADES BASINS--CONTINUED

02289075 - TAMIAMI CNL AT L-29-1 NP COOPERTOWN FLA (LAT 254539 LONG 080 3338 )

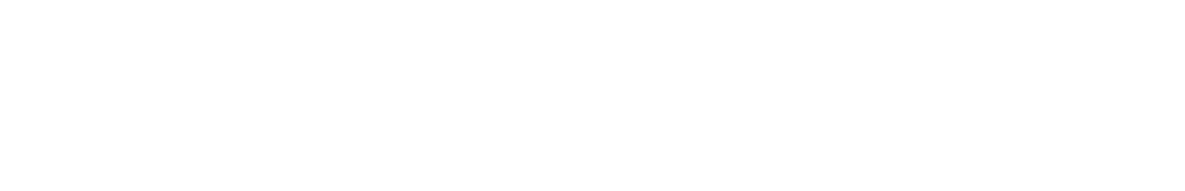

02290500 - TAMIAMI CANAL AT REO RO MIAMI FLA (LAT 254649 LONG 0801720 )

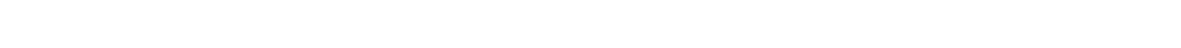

02290600 - SNAPPER CR CA NR CORAL GABLES. FLA. (LAT $25454 n$ LONG 08073 05)

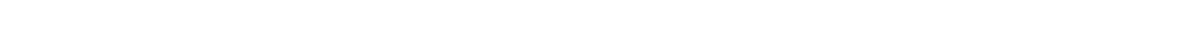

02290620 - SNAPPER CR CA AT MILLER DR NR S MIAMI (LAT 254256 LONG 0802259 )

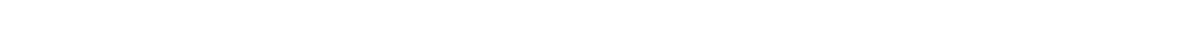

02290700 - SNAPPER CR CA AT S-22 NR SOUTH MIAMI F ILAT 254011 LONG O8N 17 03)

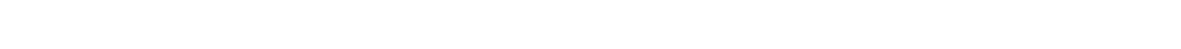

02290704 - CUTLER DRAIN CA AT S-123 NR PERRINE FL (LAT 253633 LONG OEO 18 32)

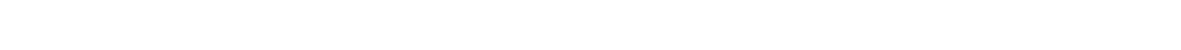

02290707 - BLACK CPEEK CA NEAR RICHMDND HEIGHTS F (LAT 253939 LONG O80 28 46)

\begin{tabular}{|c|c|c|c|c|c|c|c|c|c|c|c|c|}
\hline $\begin{array}{l}\text { JAN., } 1970 \\
12 \ldots . .\end{array}$ & - & 21.0 & 465 & -- & 77 & 4.6 & $\cdots$ & 16 & .5 & 220 & 6 & 7.8 \\
\hline $15 \ldots$ & -- & 24.0 & 530 & - & 88 & 5.2 & - & 22 & .4 & 274 & 6 & 8.3 \\
\hline
\end{tabular}

02290710 - BLACK CREEK CA AT S-21 NEAR GOULOS FLA (LAT 253243 LONG 080 1955 )

\begin{tabular}{|c|c|c|c|c|c|c|c|c|c|c|c|c|}
\hline MAY, & & & & & & & & & & & & \\
\hline $04 \ldots$ & .00 & 27.0 & 500 & -- & 85 & 3.1 & -- & 20 & 2.3 & 236 & n & 7.4 \\
\hline SEP. & & & 515 & 40 & 83 & 3.4 & 780 & 24 & 2.4 & 229 & 4 & 8.3 \\
\hline $28 \ldots$ & .00 & 28.0 & 477 & 40 & 80 & 6.0 & 820 & 16 & $? .2$ & 249 & $\theta$ & 7.7 \\
\hline
\end{tabular}

02290711 - BLACK CREEE CA BL S-21 NR GOULDS FLA (LAT 253243 LONG ORO 19 55)

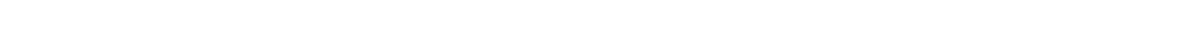
02290714 - CANAL 102 NR GOULNS FLA (LAT 2531 OB LONG 0802047 )

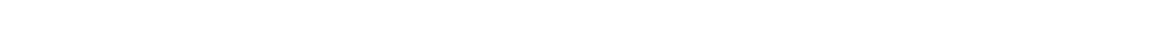
02290720 - MILITARY CA NR HOMESTFAD, FLA. (LAT 252920 LONG 0802055$)$

\begin{tabular}{|c|c|c|c|c|c|c|c|c|c|c|c|}
\hline $\begin{array}{l}13 . . . \\
\text { SEP. }\end{array}$ & - & - & 9800 & 50 & 146 & 240 & 2200 & 1610 & 64 & 149 & 34 \\
\hline
\end{tabular}

02290721 - MILITARY CA BL CT NR HOMESTEAD FLA (LAT 252920 LONG 0802055 )

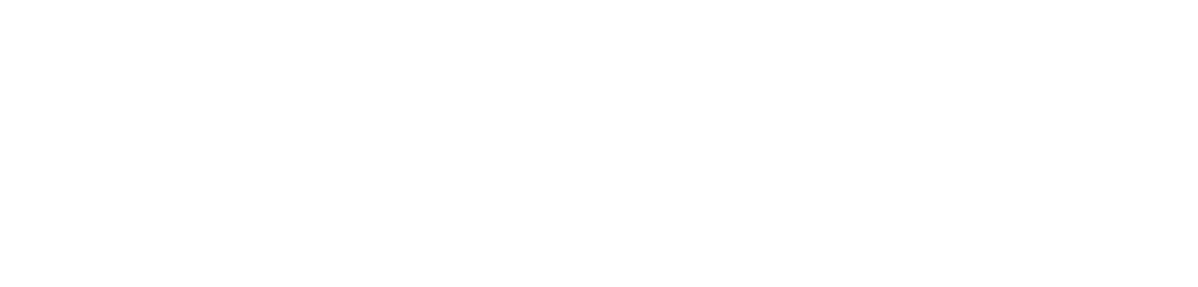




\begin{tabular}{|c|c|c|c|c|c|c|c|c|c|c|c|c|}
\hline ATE & $\begin{array}{l}\text { DIS- } \\
\text { SOLVED } \\
\text { SULFATE } \\
\text { (SO4) } \\
\text { (MG/L) }\end{array}$ & $\begin{array}{l}\text { DIS- } \\
\text { SOLVED } \\
\text { CHLO- } \\
\text { RIOE } \\
\text { (CL) } \\
\text { (MG/L) }\end{array}$ & $\begin{array}{l}\text { DIS- } \\
\text { SOL VED } \\
\text { FLUO- } \\
\text { RIDE } \\
\text { (F) } \\
\text { (MG/L) }\end{array}$ & $\begin{array}{l}\text { HARD- } \\
\text { NESS } \\
\text { (CA,MG) } \\
\text { (MG/L) }\end{array}$ & $\begin{array}{l}\text { NON- } \\
\text { CAR- } \\
\text { BONATE } \\
\text { HARO- } \\
\text { NESS } \\
\text { (MG/L) }\end{array}$ & $\begin{array}{l}\text { ALKA- } \\
\text { LINITY } \\
\text { AS } \\
\text { CACO3 } \\
\text { (MG/L) }\end{array}$ & $\begin{array}{l}\text { DIS- } \\
\text { SOLVED } \\
\text { SOLIDS } \\
\text { (RESI- } \\
\text { OUE AT } \\
190 \text { C) } \\
(M G / L)\end{array}$ & $\begin{array}{l}\text { OIS- } \\
\text { SOLVEO } \\
\text { SOL IDS } \\
\text { ISUM OF } \\
\text { CONSTI- } \\
\text { TUENTS) } \\
\text { (MG/L) }\end{array}$ & $\begin{array}{l}\text { DIS- } \\
\text { SOLVEN } \\
\text { SOL IDS } \\
\text { (TONS } \\
\text { PER } \\
\text { DAY) }\end{array}$ & $\begin{array}{l}\text { OIS- } \\
\text { SOLVEN } \\
\text { SOLINS } \\
\text { (TONS } \\
\text { PER } \\
\text { AC-FT) }\end{array}$ & $\begin{array}{l}\text { TANN IM } \\
\text { AND } \\
\text { LIGNIN } \\
\text { (MG/L) }\end{array}$ & $\begin{array}{l}\text { DEPTH } \\
\text { (FT) }\end{array}$ \\
\hline
\end{tabular}

LAKE OKEECHOBEE AND THE EVERGLADES BASINS-CONTINUED

02289075 - TAMIAMI CNL AT L-29-1 NR COOPERTOWN FLA (LAT 254539 LONG 08033 38)

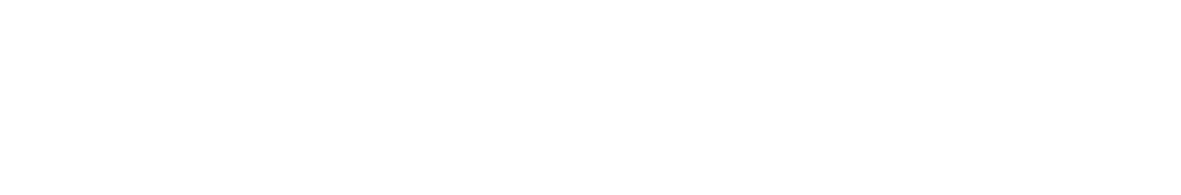

02290500 - TAMIAMI CANAL AT RED RD MIAMI FLA ILAT 254649 LONG 0801720 )

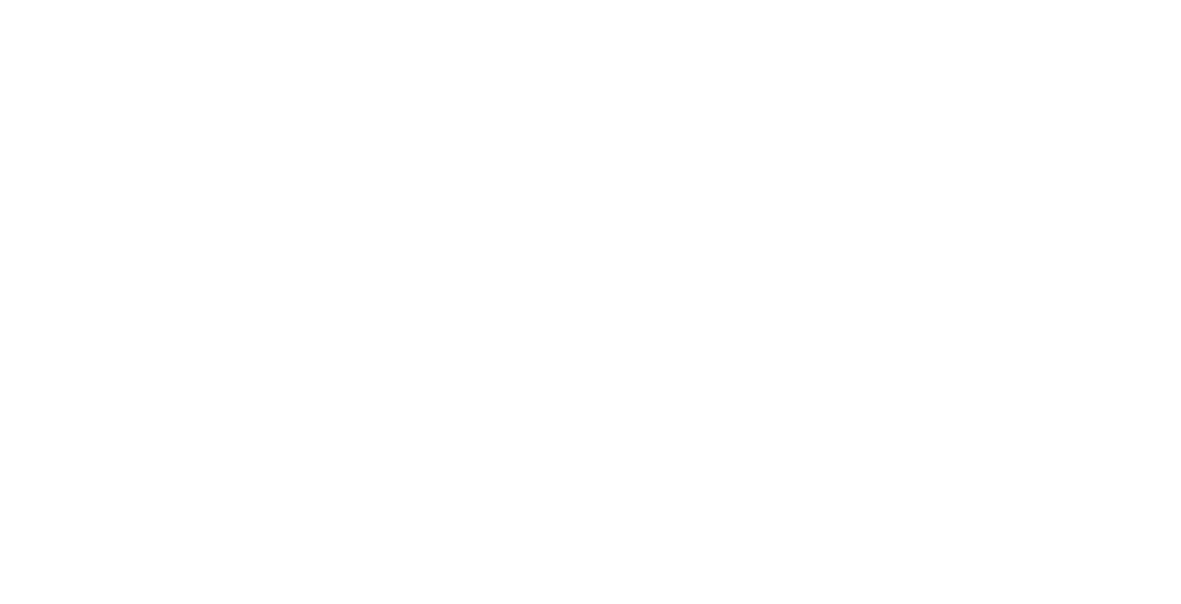

02290710 - BLACK CREEK CA AT S-21 NEAR GOULDS FLA (LAT 253243 LONG 080 19 55)

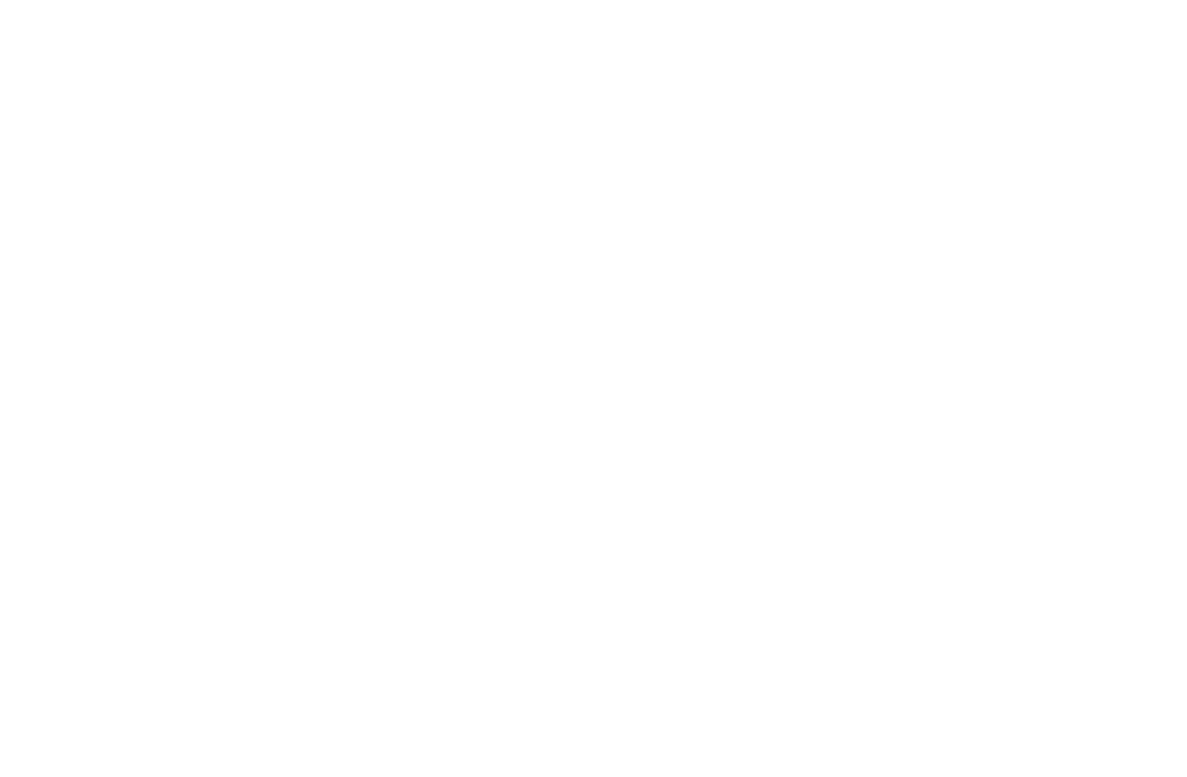


02290769 - CA 111 AT 5-18C NR FLOR1DA C1TY FLA ILAT 251949 LONG 0813131 )

\begin{tabular}{|c|c|c|c|c|c|c|c|c|c|c|c|c|}
\hline \multirow{2}{*}{$\begin{array}{l}\text { MAY. } 1970 \\
18 . . .\end{array}$} & $\begin{array}{ll} & \\
& .00\end{array}$ & 26.5 & 305 & $=$ & 37 & 2.3 & 550 & 18 & 1.3 & 116 & \multirow[t]{2}{*}{0} & \multirow{2}{*}{8.2} \\
\hline & & 02290770 & - & CA 111 & $B L S-18 C \quad N R$ & FLORIDA CIT & TY FLA & ILAT 25 I9 & 949 LONG & $G 080 \quad 31311$ & & \\
\hline \multirow[t]{2}{*}{$\begin{array}{l}\text { MAY . } 1970 \\
18 . . .\end{array}$} & 10 & 26.5 & $45 n$ & $\cdots$ & 54 & 4.7 & 610 & 26 & 1.8 & 176 & 0 & 8.2 \\
\hline & & 02290800 & - & TAYLOR & SLOUGH NEAR & HOMESTEAO, & FLA, & (LAT $25 \quad 24$ & 05 LONG & $080 \quad 36 \quad 251$ & & \\
\hline $\begin{array}{l}\text { OCT.. } 196 \\
\text { O3.... } \\
\text { DEC. }\end{array}$ & 59 & 27.5 & 191 & - & 34 & 1.5 & -- & 4.5 & .3 & 106 & - & 7.9 \\
\hline $\begin{array}{l}05 . . .197 \\
\text { MAR.. } 197\end{array}$ & - & 18.5 & 346 & -- & 61 & 2.8 & -- & B.3 & .2 & 198 & - & 7.9 \\
\hline $\operatorname{MAY}_{\operatorname{MAY}}$ & .00 & 24.0 & 360 & -- & 65 & 3.1 & - & 7.9 & .4 & 212 & 0 & 8.2 \\
\hline $\operatorname{JuLY}_{\text {JuL }}^{18 . .}$ & .00 & 25.0 & 660 & - & 110 & 5.2 & -- & 19 & 15 & 288 & 12 & 8.5 \\
\hline $\begin{array}{l}n 2 \ldots \\
30 \ldots \\
\text { SEP.. }\end{array}$ & $\begin{array}{r}140 \\
.00\end{array}$ & $\begin{array}{l}29.5 \\
27.5\end{array}$ & $\begin{array}{l}329 \\
296\end{array}$ & 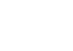 & $\begin{array}{l}56 \\
45\end{array}$ & $\begin{array}{l}2.7 \\
3.0\end{array}$ & $=$ & $13^{9.7}$ & .4 & $\begin{array}{l}182 \\
148\end{array}$ & $\begin{array}{l}0 \\
n\end{array}$ & $\begin{array}{l}8.1 \\
8.1\end{array}$ \\
\hline $30 \ldots$ & 30 & 25.0 & 346 & - & 60 & 2.8 & $-\infty$ & 9.0 & .4 & 198 & $\cdots$ & 8.2 \\
\hline
\end{tabular}

02290803 - IAYLOR SLU AT ROYAL PALM NR HOMESTEAD (LAT 252407 LONG 08040 15)

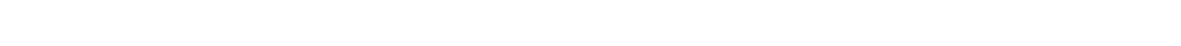

02290810 - EVERGLADES P-37 NR HOMESTEAD, FLA. (LAT 251730 LONG 0804030 )

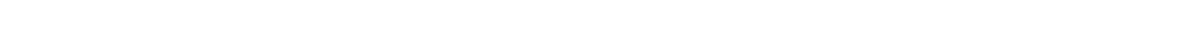

02290812 - ALLIGATOR HO AT CTNMOUTH CP NR HOMESTE (LAT 253810 LONG O80 4420 )

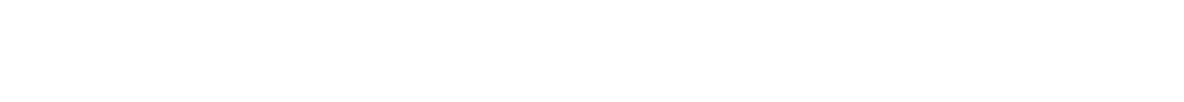

02290813 - OPEN GLADES NR CTNMOUTH CP NR HOMESTEA LLAT 2538 O0 LONG 0804400 )

NOV., 1909

$18 . .$.

0

02290815 - EVERGLADES P-33 NEAR HOMESTEAD FLA (LAT 253630 LONG ORO 4130 )

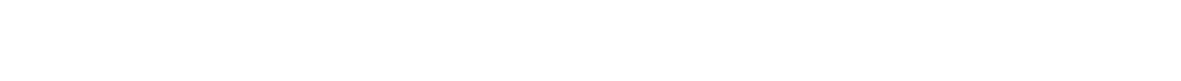

02290820 - EVERGLADES P-3B NEAR HOMESTEAD FLA (LAT 252230 LONG 0804900 )

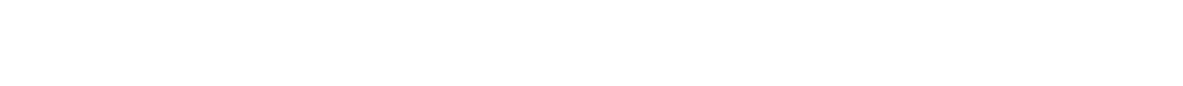

02290828 - EVEHGLADES P-36 NEAR HOMESTEAD, FLA. (LAT 253230 LONG 08047 00)

$A P R+1970$

$06 . .$. 10.6

02290830 - EVERGLAOES P-35 NEAR HOMESTEAD, FLA. ILAT 252720 LONG 08052301

\begin{tabular}{|c|c|c|c|c|c|c|c|c|c|c|c|}
\hline $\begin{array}{l}\text { O9... } \\
\text { APR., } 1970 \\
\text { O9... }\end{array}$ & $=$ & 23.3 & 430 & - & 48 & 8.8 & - & 28 & . 8 & 186 & - \\
\hline
\end{tabular}

02290841 - ROOKERY GRANCH NR HOMESTEAD FLA (LAT 252648 LONG OBO 5330 )

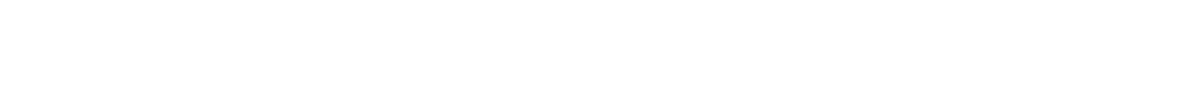

02290870 - EVERGLADES P-34 NEAR HOMESTEAD FLA (LAT 253630 LONG 0805530 )

\begin{tabular}{|c|c|c|c|c|c|c|c|c|c|c|c|}
\hline \multirow{2}{*}{ 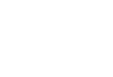 } & $\cdots$ & 21.0 & 285 & $=$ & 48 & 2.5 & - & 8.0 & $\cdot 3$ & 154 & $=$ \\
\hline & -- & 26.0 & $38 n$ & 100 & 65 & 3.7 & 400 & 14 & .5 & 212 & n \\
\hline
\end{tabular}


CHEMICAL ANALYSES, WATER YEAR OCTOBER 1969 TO SEPTEMBER 1970 (MAJOR CONSTITUENTS)

\begin{tabular}{|c|c|c|c|c|c|c|c|c|c|c|}
\hline $\begin{array}{l}\text { DIS- } \\
\text { SOLVED } \\
\text { SULFATE } \\
\text { (SO4) } \\
\text { (MG/L) }\end{array}$ & $\begin{array}{l}\text { NIS- } \\
\text { SOLVED } \\
\text { CHLO- } \\
\text { RIDE } \\
\text { (CL) } \\
\text { (MG/L) }\end{array}$ & $\begin{array}{l}\text { DIS- } \\
\text { SOLVED } \\
\text { FLUO- } \\
\text { RIDE } \\
\text { (F) } \\
\text { (MG/L) }\end{array}$ & $\begin{array}{l}\text { HARD- } \\
\text { NESS } \\
\text { (CA,MG) } \\
\text { (MG/L) }\end{array}$ & $\begin{array}{l}\text { NON- } \\
\text { CAR- } \\
\text { BONATE } \\
\text { HARD- } \\
\text { NESS } \\
\text { (MG/L) }\end{array}$ & $\begin{array}{l}\text { ALKA- } \\
\text { LINITY } \\
\text { AS } \\
\text { CACO3 } \\
\text { (MG/L) }\end{array}$ & $\begin{array}{l}\text { DIS- } \\
\text { SOL VED } \\
\text { SOLIDS } \\
\text { (RESI - } \\
\text { DUE AT } \\
180 \mathrm{C} \text { ) } \\
\text { (MG/L) }\end{array}$ & $\begin{array}{l}\text { DIS- } \\
\text { SOLVED } \\
\text { SOLIDS } \\
\text { ISUM OF } \\
\text { CONSTI- } \\
\text { TUENTS) } \\
\text { (MG LL) }\end{array}$ & $\begin{array}{l}\text { DIS- } \\
\text { SOLVEO } \\
\text { SOLIDS } \\
\text { (TONS } \\
\text { PER } \\
\text { DAY) }\end{array}$ & $\begin{array}{l}\text { OIS- } \\
\text { SOLVED } \\
\text { SOL IDS } \\
\text { (TONS } \\
\text { PER } \\
\text { AC-FT) }\end{array}$ & $\begin{array}{l}\text { TANNIN } \\
\text { AND } \\
\text { LIGNIN } \\
\text { \{MG/L) }\end{array}$ \\
\hline
\end{tabular}

LAKE OKEECHOBEE AND THE EVERGLADES BASINS--CONTINUED

02290769 - CA 111 AT 5-18C NF FLORIOA CITY FLA ILAT 251949 LONG 08131311

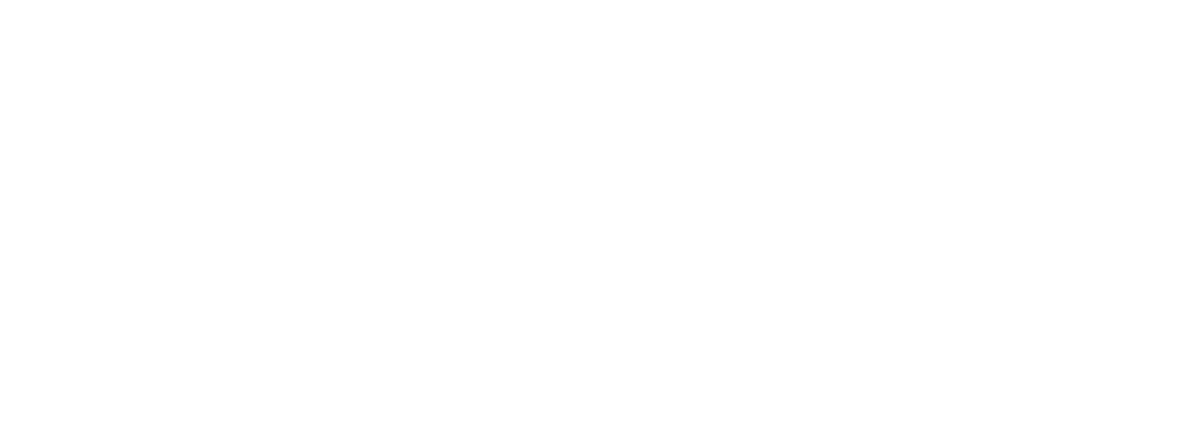

02290803 - TAYLOR SLU AT ROYAL PALM NR HOMESTEAD ILAT 252407 LONG 08040 15)

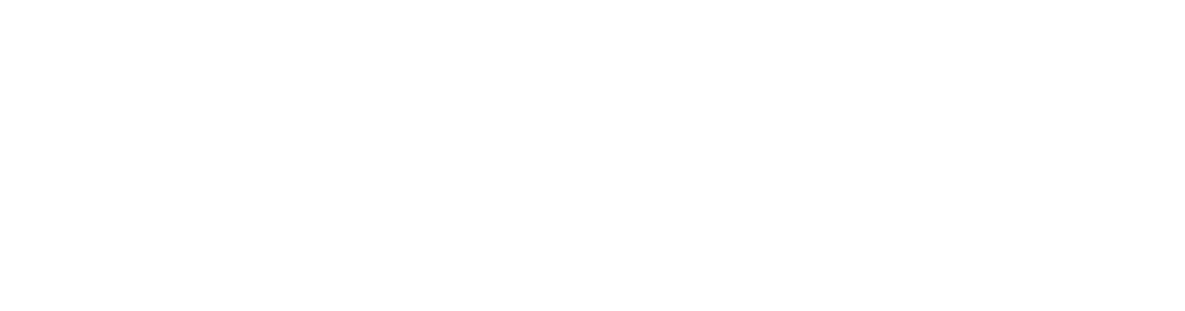
02290813 - OPEN GLADES NR CTNMOUTH CP NR HOMESTEA (LAT 2538 nO LONG 08044 00)

\begin{tabular}{|c|c|c|c|c|c|c|c|c|c|c|c|c|c|c|c|c|}
\hline $\begin{array}{l}\text { Nov., } 1969 \\
18 . . .\end{array}$ & 7.2 & 44 & .2 & 152 & 11 & & 141 & 255 & & 227 & & $-\infty$ & & .35 & & .9 \\
\hline & & 02290815 & - & EVERGLADES & $P=33$ & NEAR & HOMESTEAD & $F L A$ & ILAT & 2536 & 30 & LONG & 080 & 41 & 30) & \\
\hline $06 \ldots$ & 6.8 & 66 & $\cdot 3$ & 188 & 4 & & 184 & 360 & & 307 & & $-\infty$ & & .49 & & - \\
\hline
\end{tabular}
02290820 - EVERGLADES P-38 NEAR hOMESTEAD FLA ILAT 252230 LONG 08049001

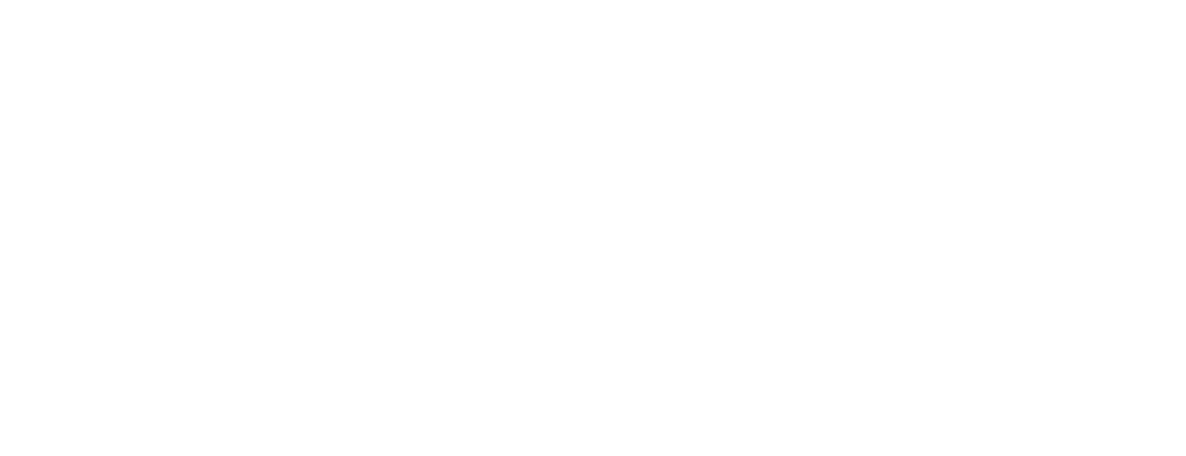
02290870 - EVERGLADFS P-34 NEAR HDMESTEAD FLA ILAT 253630 LONG 08055301

\begin{tabular}{|c|c|c|c|c|c|c|c|c|c|c|c|}
\hline APR... 1970 & .4 & 12 & +1 & 131 & 5 & 126 & 168 & $14 B$ & -- & .23 & - \\
\hline
\end{tabular}




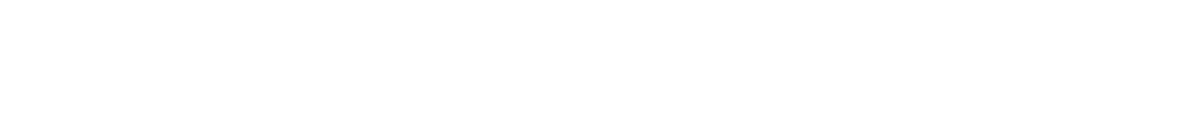

LAKE OKEECHOBEE AND THE EVERGLADES BASINS--CONTINUED

02291000 - GARRON RIVER CANAL NR EVERGLAOES FLA (LAT 255300 LONG 0.1 21 00)

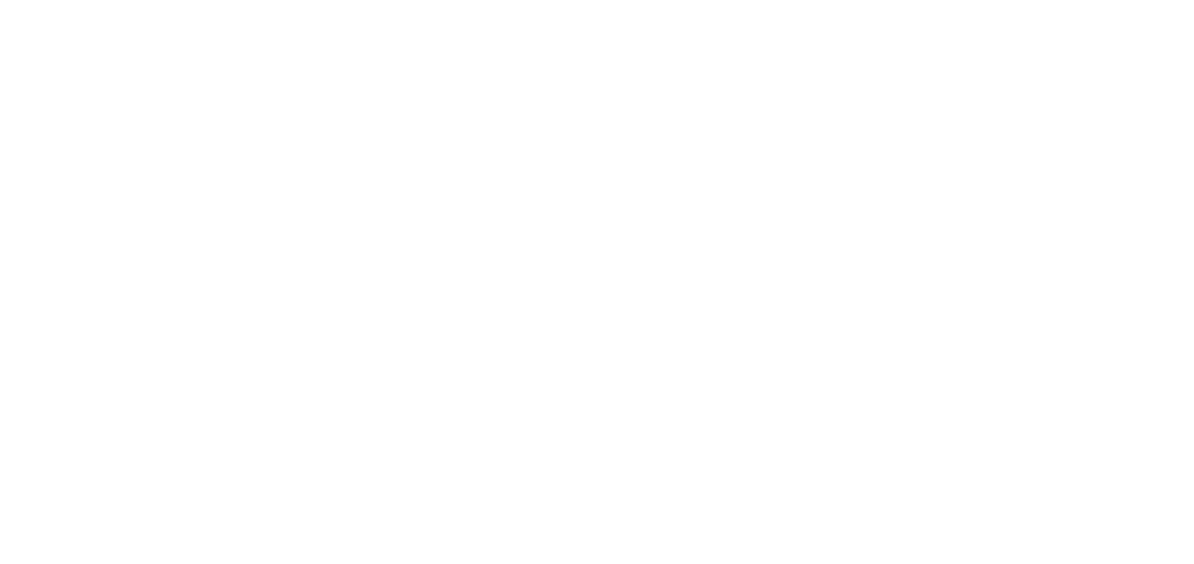

02291393 - COCOHATCHEE R CA NR NAPLES PARK FLA (LAT 261621 LONG 081 45 53)

$\begin{array}{llllllllllllllll}\text { MAY } & 1970 \\ 19 . . . & .94 & 22.5 & 500 & -- & 98 & 2.6 & -0 & 12 & .8 & 258 & 0\end{array}$

02291400 - COCOHATCHEE R CA NR NAPLES FLA ILAT 261620 LONG 08147001

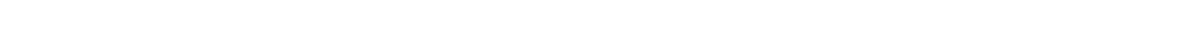

02291600 - ESTERO R NR ESTERO FLA (LAT 2626 O4 LONG OB1 48 18)

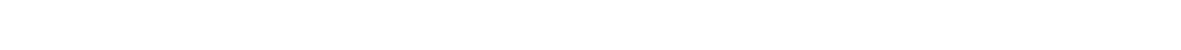

02292900 - CALOOSAHATCHEE RIVER AT S-79 NR OLGA, (LAT 264325 LONG 081 4155 )

\begin{tabular}{|c|c|c|c|c|c|c|c|c|c|c|c|c|}
\hline 06.... 1969 & - & 27.0 & -- & 190 & 47 & 6.9 & -- & 22 & 2.6 & -- & -- & -- \\
\hline $\begin{array}{l}\text { Nov. } \\
05 . . .\end{array}$ & - & $=$ & $=$ & 150 & 40 & 7.5 & -- & 24 & $? .6$ & $=$ & $n$ & $=-$ \\
\hline DEC. & & & & & & & & & & & & \\
\hline JAN... 1970 & - & 19.5 & - & 60 & 39 & 8.8 & -- & 27 & 2.1 & -- & 0 & - \\
\hline $09 \ldots$ & + & $\cdots$ & -- & 30 & 39 & 7.4 & 500 & .23 & 2.0 & -- & $n$ & - \\
\hline MAR... & - & 17.0 & 367 & 2 & 40 & 8.5 & -- & 26 & 2.1 & - & -- & -- \\
\hline $\begin{array}{l}05 . . \cdot \\
\text { APR. }\end{array}$ & - & 20.0 & 440 & 20 & 47 & 9.9 & -- & $3 n$ & 2.0 & -- & -- & -- \\
\hline MAY $\cdots$ & - & 27.0 & -- & 40 & 34 & 4.8 & -- & 13 & 1.9 & -- & - & - \\
\hline JUW... 3280 & & 27.0 & -- & 40 & 49 & 12 & 660 & 34 & 2.4 & -- & - & - \\
\hline $03 \ldots$ & -- & 26.0 & - & 120 & 53 & 9.7 & $=-$ & ?9 & 2.7 & -- & $\infty$ & \\
\hline
\end{tabular}

02293050 - ORANGE R AT BUCKINGHAM NR FT MYERS FLA (LAT 264012 LONG 0814356 )

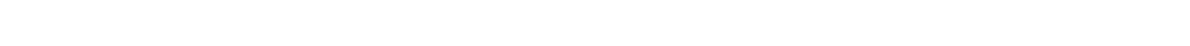

CIASTAL. BASINS BETWEEN LAKE TKEECHOBEE AND THE EVERTLADES ANT DEACE PIVER

02293400 - ALLIGATOR CK NR PUNTA GORDA FLA ILAT 265308 LONG 0820022 )

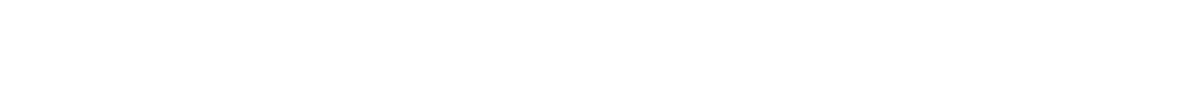

02293461 - LAKE ALFREJ AT LAKE ALFWE.", FLA. (LAT 280548 LONG $081440 \%$

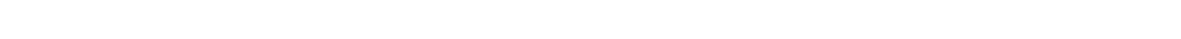


CHEMICAL ANALYSES, WATER YEAR OCTOBER 1969 TO SEPTEMBER 1970 (MAJOR CONSTITUENTS)

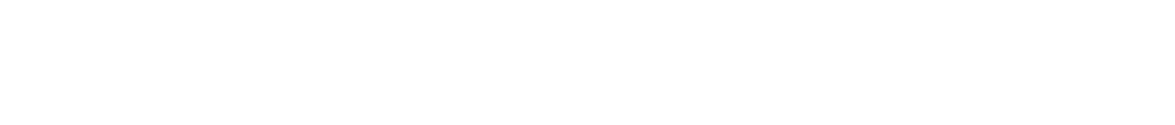

LAKE OKEECHOBEE AND THE EVERGLADES BASINS--CONTINUED

02291000 - BARRON RIVER CANAL NR EVERGLADES FLA ILAT 2558 O0 LONG 0R1 21001

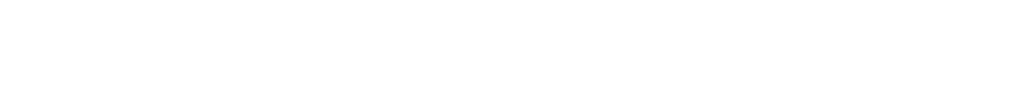

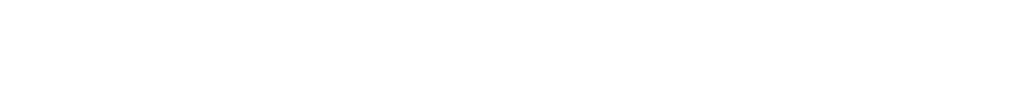

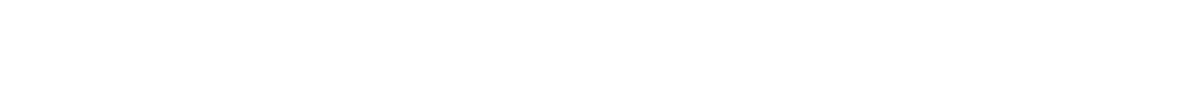

02291270 - HENDERSON CREEK CA NR NAPLES FLA (LAT 26 O5 59 LONG D81 4114 )

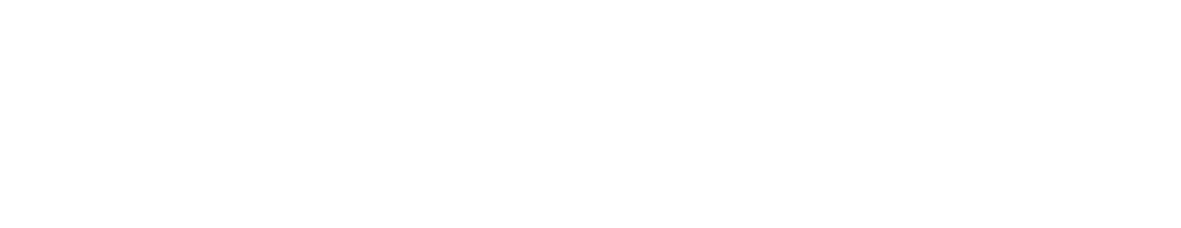

02291393 - COCOHATCHEE R CA NR NAPLES PARK FLA ILAT 261621 LONG 08145 S3)

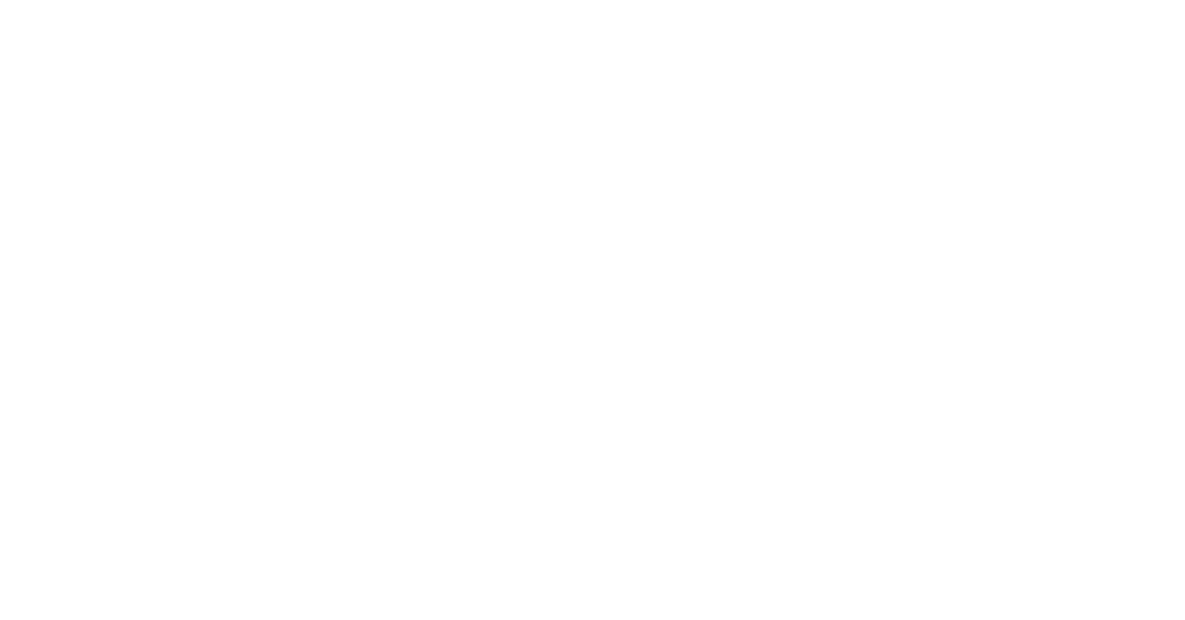

02293050 - ORANGE R AT BUCKINGHAM NP FT MYERS FLA (LAT 2640 12 LONG 08143561

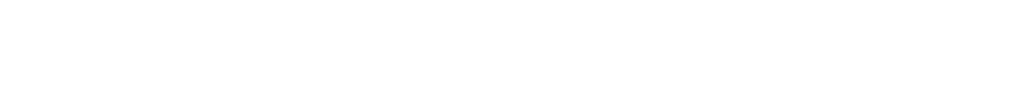

02293400 - ALLIGATOR CR NR PUNTA GORDA FLA (LAT 2653 OM LONG OBP 00 22)

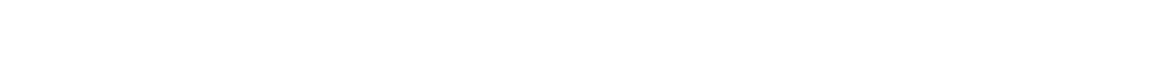

PEACE RIVER BASIN--CTNTIHIJED

02293461 - LaKe alfreu at lake alfFev, FLA. (LAT $2 A 0548$ LONG 0814400 )

MAY 1970

$\begin{array}{llllll}33 & .3 & 44 & 17 & 27 & 137\end{array}$ 


\begin{tabular}{|c|c|c|c|c|c|c|c|c|c|c|c|c|}
\hline DATE & $\begin{array}{l}\text { DIS- } \\
\text { CHARGE } \\
\text { (CFS) }\end{array}$ & $\begin{array}{l}\text { TEMPER- } \\
\text { ATURE } \\
\text { (DEG C) }\end{array}$ & $\begin{array}{l}\text { SPE- } \\
\text { CIFIC } \\
\text { CON- } \\
\text { DUCT- } \\
\text { ANCE } \\
\text { (MICRO- } \\
\text { MHOS) }\end{array}$ & $\begin{array}{l}\text { DIS- } \\
\text { SOLVED } \\
\text { IRON } \\
\text { (FE) } \\
\text { (UG/L) }\end{array}$ & $\begin{array}{l}\text { DIS- } \\
\text { SOLVED } \\
\text { CAL- } \\
\text { CIUM } \\
\text { (CA) } \\
\text { (MG/L) }\end{array}$ & $\begin{array}{l}\text { DIS- } \\
\text { SDLVED } \\
\text { MAG- } \\
\text { NE- } \\
\text { SIUM } \\
\text { (MG) } \\
\text { (MG/L) }\end{array}$ & $\begin{array}{l}\text { DIS- } \\
\text { SOLVEO } \\
\text { STRON- } \\
\text { TIUM } \\
\text { (SR) } \\
\text { (UG/L) }\end{array}$ & $\begin{array}{l}\text { DIS- } \\
\text { SOLVED } \\
\text { SODIUM } \\
\text { (NA) } \\
\text { (MG/L) }\end{array}$ & $\begin{array}{l}\text { OIS- } \\
\text { SOLVED } \\
\text { PO- } \\
\text { TAS- } \\
\text { SIUM } \\
\text { (K) } \\
\text { (MG/L) }\end{array}$ & $\begin{array}{l}\text { BICAR- } \\
\text { BONATE } \\
\text { (HCO3) } \\
\text { (MG/L) }\end{array}$ & $\begin{array}{l}\text { CAR- } \\
\text { BONATE } \\
\text { (CO3) } \\
\text { (MG/L) }\end{array}$ & $\begin{array}{c}\mathrm{PH} \\
\text { (UNITS) }\end{array}$ \\
\hline & & & & & CE RIV & BASIN- & NT INUE & & & & & \\
\hline
\end{tabular}

02293518 - L FANNIE NR FLORENCE VILLA FLA (LAT 280250 LONG 0814115 )

$\begin{array}{lllllllllll}\text { MAY. } 1970 & & & & & & & & & & \end{array}$

02293545 - L OTIS AT WINTER HAVEN FLA (LAT 280110 LONG 0814235 )

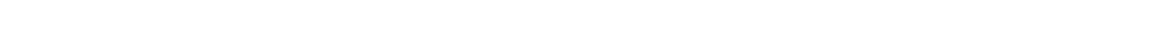

02293664 - L HAMILTON OLT AT S P8 NR L MAMLTN FLA (LAT 280154 LONG 0813842 )

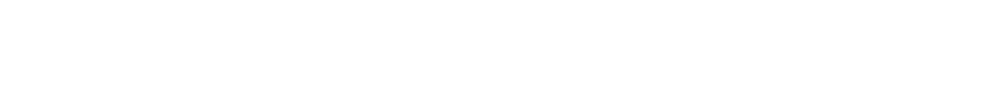

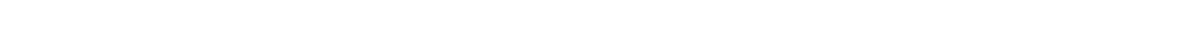

02293785 - LAKE EFFIE AT L WALES FLA (LAT 275431 LONG 0813011 )

$\begin{array}{llllllllllll}\text { MAY, } 1970 & - & 27.0 & 460 & - & 46 & 10 & 36 & 11 & 249 & 0\end{array}$

02293823 - LAKE MYKLE NR LAKE WALES FLA (LAT 2757 O8 LONG O8I 3858 )

MAY. 1970
$12 . .$.

02293986 - PEACE CR DRAINAGE CA NR ALTURAS FLA (LAT 275523 LONG OBI 42 28)

$\operatorname{MAY}_{13 . .1970}{ }^{10}$

$\begin{array}{llllllllllll}-- & 289 & - & 25 & 6.6 & - & 24 & 5.6 & 138 & - & 7.0\end{array}$

02294036 - LAKE HOWARD AT WINTER HAVEN FLA (LAT 280120 LONG 0814416$)$

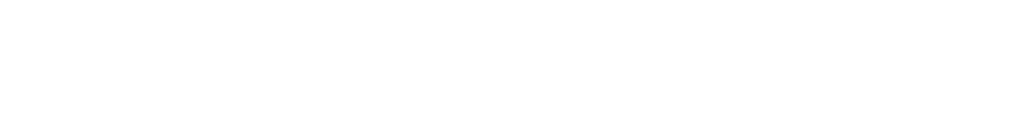

$\begin{array}{lllllllllllll}\text { MAY } & 1970 \\ 11 . . . & 2.7 & 30.0 & 329 & -- & 28 & 7.4 & -- & 30 & 4.6 & 159 & -- & 7.6\end{array}$

02294071 - LAKE MCLEOD AT EAGLE LAKE FLA (LAT 275825 LONG 08145001

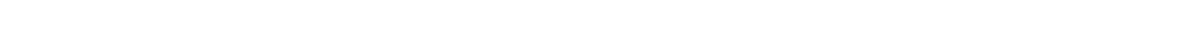

02294112 - LAKE GARF IELD NR ALTURAS FLA ILAT 275348 LONG O81 4328 )

$\begin{array}{lllllllllll}\text { MAY. } 1970 & & & & & & & & & & \\ 12 . . . & -- & 27.0 & 90 & - & 3.6 & 2.0 & -- & 10 & 2.3 & 5\end{array}$

02294214 - SADDLE CREEK NR LAKELAND FLA ILAT 280252 LONG 08152351

$\begin{array}{llllllllllll}\text { JUNE, } 1970 & - & 26.0 & 405 & - & 44 & 15 & -- & 16 & .6 & 91 & 4\end{array}$

02294224 - LAKE GIBSON NR LAKELAND FLA (LAT 280640 LONG 08157 18)

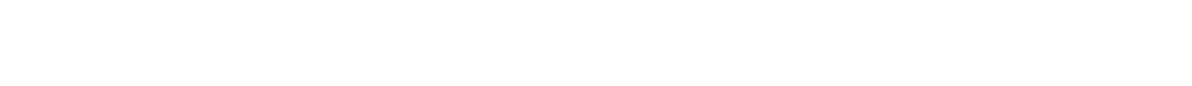

02294259 - LAKE PARKER AT LAKELAND FLA (LAT 280259 LONG 0815522 )

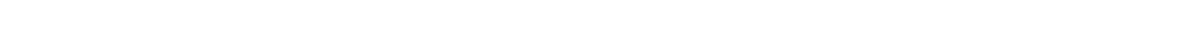

02294260 - LAKE PARKER OLT NR LAKELAND FLA ILAT 280334 LONG 08154523

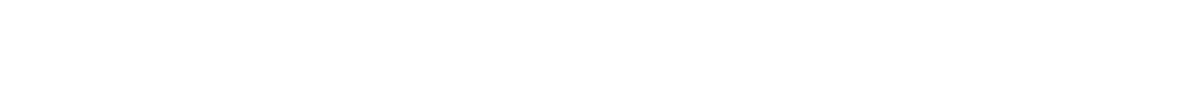

$\begin{array}{lllllllllll}\text { MAY. } 1970 & - & 24.0 & 208 & - & 13 & 6.5 & -- & 17 & 3.9 & 4 n\end{array}$ 


\begin{tabular}{|c|c|c|c|c|c|c|c|c|c|c|c|c|}
\hline ATE & $\begin{array}{l}\text { DIS- } \\
\text { SOLVED } \\
\text { SULFATE } \\
\text { (SD } 4) \\
\text { (MG/L) }\end{array}$ & $\begin{array}{l}\text { D1S- } \\
\text { SOLVED } \\
\text { CHLO- } \\
\text { QIDE } \\
\text { (CL) } \\
\text { (MG/L) }\end{array}$ & $\begin{array}{l}\text { DIS- } \\
\text { SOLVED } \\
\text { FLUO- } \\
\text { RIDE } \\
\text { (F) } \\
\text { (MG/L) }\end{array}$ & $\begin{array}{l}\text { HARD- } \\
\text { NESS } \\
\text { (CA,MG) } \\
\text { (MG/L) }\end{array}$ & $\begin{array}{l}\text { NON- } \\
\text { CAR- } \\
\text { BONATE } \\
\text { HARD- } \\
\text { NESS } \\
\text { (MG/L) }\end{array}$ & $\begin{array}{l}\text { ALKA- } \\
\text { LINITY } \\
\text { AS } \\
\text { CACO3 } \\
\text { (MG/L) }\end{array}$ & $\begin{array}{l}\text { DIS- } \\
\text { SOLVED } \\
\text { SOLIDS } \\
\text { (RESI- } \\
\text { DUE AT } \\
1 \text { SO C) } \\
\text { (MG } / \text { ) }\end{array}$ & $\begin{array}{l}\text { DIS- } \\
\text { SOLVED } \\
\text { SOLIDS } \\
\text { (SUM OF } \\
\text { CONSTI- } \\
\text { TUENTS) } \\
\text { (MG/L) }\end{array}$ & $\begin{array}{l}\text { DIS- } \\
\text { SOLVED } \\
\text { SOLIDS } \\
\text { (TONS } \\
\text { PER } \\
\text { OAY) }\end{array}$ & $\begin{array}{l}\text { DIS- } \\
\text { SOLVEO } \\
\text { SOLIDS } \\
\text { (TONS } \\
\text { PER } \\
\text { AC-FT) }\end{array}$ & $\begin{array}{l}\text { TANN IN } \\
\text { AND } \\
\text { LIGNIN } \\
\text { (MG/L) }\end{array}$ & $\begin{array}{c}\text { DEPTH } \\
\text { (FT) }\end{array}$ \\
\hline
\end{tabular}

PEACE RIVER BASIN--CONTINUED

02293518 - L FANNIE NR FLORENCE VILLA FLA (LAT 280250 LONG OA1 41 15)

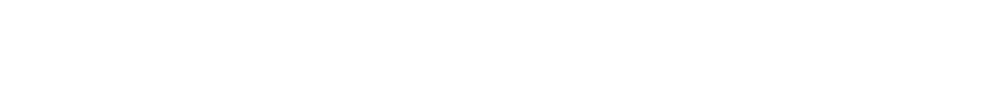

02294259 - LAKE PARKER AT LAKELAND FLA (LAT $28 \quad 0259$ LONG 08155 ?2)

1

$\begin{array}{llllllll}.5 & 32 & 17 & 15 & 85 & 75 & - & .12\end{array}$
02294260 - LAKE PARKER OLT NR LAKELANO FLA (LAT 290334 LONG 0815452 )

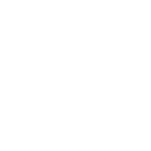




\begin{tabular}{|c|c|c|c|c|c|c|c|c|c|c|c|c|}
\hline OATE & $\begin{array}{l}\text { DIS- } \\
\text { CHARGE } \\
\text { (CFS) }\end{array}$ & $\begin{array}{l}\text { TEMPER- } \\
\text { ATURE } \\
\text { (DEG C) }\end{array}$ & $\begin{array}{l}\text { SPE- } \\
\text { CIF IC } \\
\text { CON- } \\
\text { DUCT- } \\
\text { ANCE } \\
\text { (MICRD- } \\
\text { MHOS) }\end{array}$ & $\begin{array}{l}\text { DIS- } \\
\text { SOLVED } \\
\text { IRON } \\
\text { (FE) } \\
\text { (UG/L) }\end{array}$ & $\begin{array}{l}\text { DIS- } \\
\text { SOLVED } \\
\text { CAL- } \\
\text { CIUM } \\
\text { (CA) } \\
(M G / L)\end{array}$ & $\begin{array}{l}\text { DIS- } \\
\text { SOLVED } \\
\text { MAG- } \\
\text { NE- } \\
\text { SIUM } \\
\text { (MG) } \\
\text { (MG LI) }\end{array}$ & $\begin{array}{l}\text { DIS- } \\
\text { SOLVED } \\
\text { STRON- } \\
\text { TIUM } \\
\text { (SR) } \\
\text { (UG/L) }\end{array}$ & $\begin{array}{l}\text { DIS- } \\
\text { SDLVED } \\
\text { SODIUM } \\
\text { (NA) } \\
\text { (MG/L) }\end{array}$ & $\begin{array}{l}\text { DIS- } \\
\text { SOLVEO } \\
\text { PO- } \\
\text { TAS- } \\
\text { SIUM } \\
\text { (K) } \\
\text { (MGLL) }\end{array}$ & $\begin{array}{l}\text { BICAR- } \\
\text { BONATE } \\
\text { (HCOT) } \\
\text { (MG/L) }\end{array}$ & $\begin{array}{l}\text { CAR- } \\
\text { BONATF } \\
\text { (CO3) } \\
\text { (MG/L) }\end{array}$ & $\begin{array}{c}\mathrm{PH} \\
\text { (UNITS) }\end{array}$ \\
\hline AIE & & & & & & & & & & & & \\
\hline
\end{tabular}

02294342 - LK HDLLINGSWORTH AT LAKELAND FLA ILAT 230105 LONG 081 56501

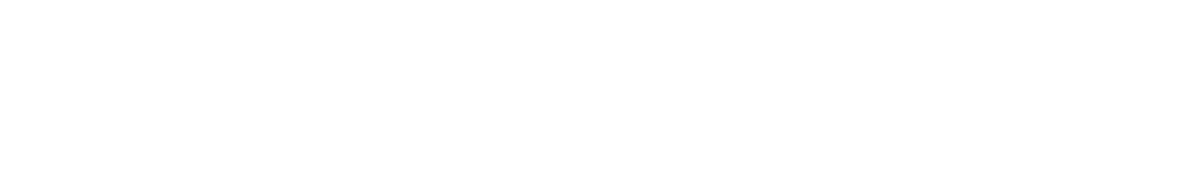

02294442 - EAGLE LAKE AT EATLE LAKE FLA ILAT 275835 LOMA 08146321

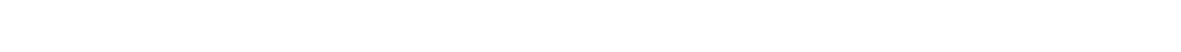

02294462 - LAKE HANCOCK NR HIGHLAND CITY FLA (LAT 275748 LONG 08151291

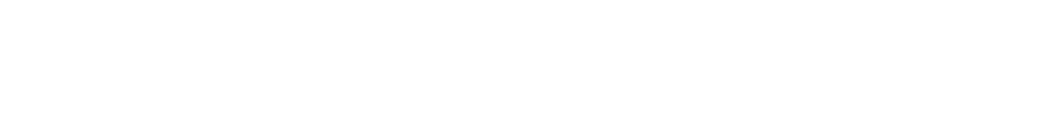

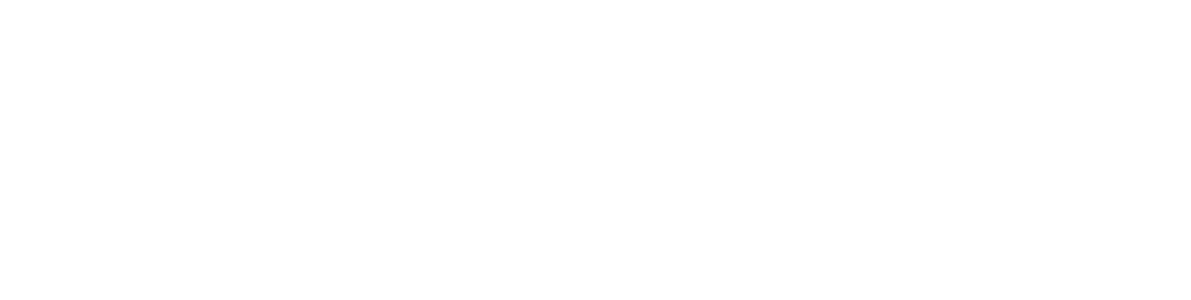

02295420 - PAYNE CR NR BOWLING GREEN FLA (LAT 273713 LONG 0814933 )

\begin{tabular}{|c|c|c|c|c|c|c|c|c|c|c|c|}
\hline $\begin{array}{l}\text { APR.. } 1970 \\
28 \ldots . . \\
\text { JUNE }\end{array}$ & -- & 21.5 & 286 & -- & 27 & 9.9 & - & 14 & .6 & 48 & - \\
\hline $11 \ldots$ & -- & 27.0 & 260 & -- & 24 & 8.6 & -- & 13 & .7 & 28 & - \\
\hline
\end{tabular}

02295435 - HOG BRANCH NR WAUCHULA FLA Llat 273532 LONG 08149291

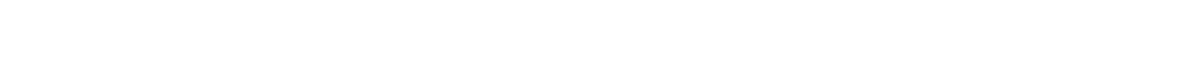

02295607 - PEACE R AT WACHULA FLA LLAT 273301 LONG OR1 4738 1

$\begin{array}{llllllllllll}\text { MAY } & 1970 \\ 14 \ldots & -2 & 24.5 & 500 & -- & 57 & 18 & -- & 21 & 1.0 & 76 & 0\end{array}$

02295977 - PEACE RIVER NEAR BROWNVILLE FLA ILAT 2718 OR LONG O81 50471

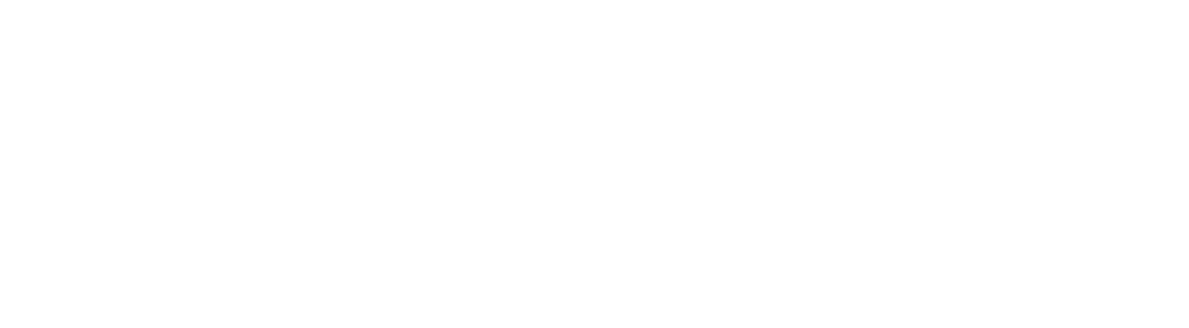


CHEMICAL ANALYSES, WATER YEAR OCTOBER 1969 TO SEPTEMBER 1970

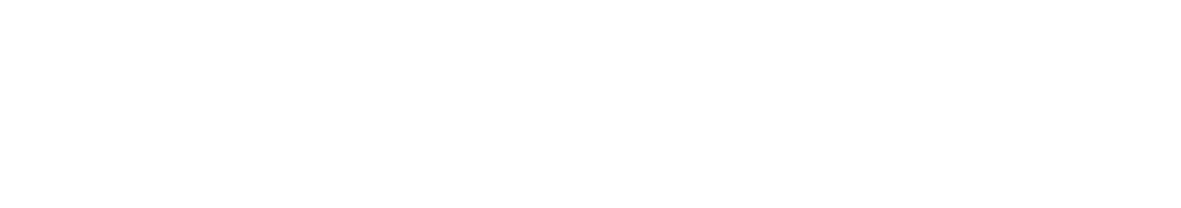

02294342 - LK HOLLINGSWORTH AT LAKELAND FLA (LAT 29 0105 LONG 0815650 )

JUNE, 1970
$09 . .$.

02294402 - BANANA LAKE NQ HIGHLAND CITY FLA ILAT 275852 LONG 08153501

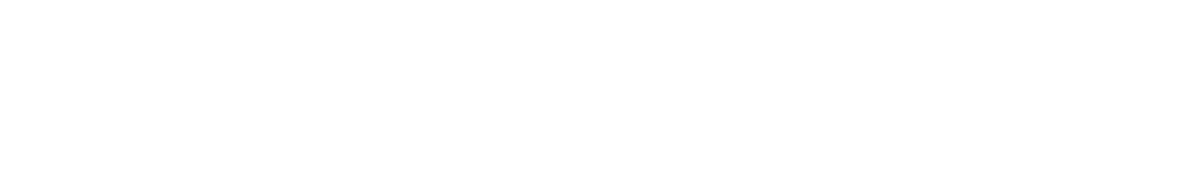

02294462 - LAKE HANCOCK NR HIGHLAND CITY FLA ILAT 275748 LONG $[1815129$ )

MAY, 1970
$09 . .$.

$\begin{array}{llllllllllllll}\operatorname{MAY}, 1970 & 12 . . & 23 & 24 & 1.1 & 100 & 19 & 81 & 206 & 168 & .00 & .28 & -.\end{array}$

02294553 - SADDLE CF NR BARTOW FLA ILAT 275511 LONG 08149271

JUNE, 1970
$10 . .$.

02294650 - PEACE RIVER AY BARTOW FLA ILAT 2754 O7 LONG 081 $4903 \%$

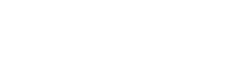

$\begin{array}{llllllll}2.5 & 176 & 121 & 55 & 313 & 277 & \ldots & .43\end{array}$

$10 \ldots 31 \quad 31$

02295420 - PAYINE CR NR BONLING GREEN FLA ILAT 273713 LONG 08149331

\begin{tabular}{|c|c|c|c|c|c|c|c|c|c|c|c|}
\hline $11 \ldots$ & $7_{0}$ & 13 & 1.4 & 96 & 73 & 23 & 209 & 156 & -- & $.2 B$ & - \\
\hline
\end{tabular}

02295435 - HOG HRANCH NR MAUCHULA FLA ILAT 273532 LONG 081 49201

$\operatorname{Mar}, 1970 \quad 3.5 \quad 1$

02295607 - PEACE R AT WACHULA FLA ILAT 273301 LONG ABI 4738 )

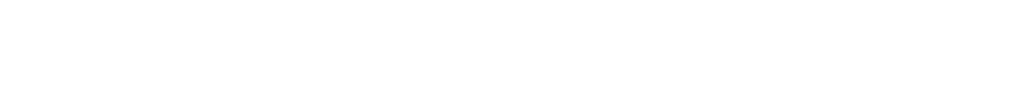

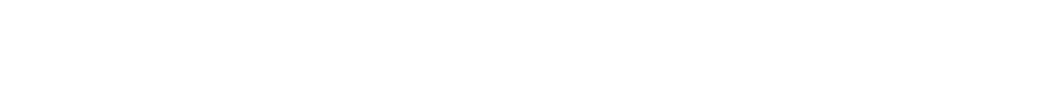

MAY $1970 \quad 0 \quad 12$

$12 \quad+15 \quad 15$

02296500 - CHARLIE CR NR GARDNER FLA (LAT 272229 LONF 0814749 )

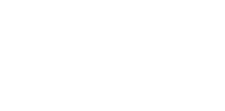

$\begin{array}{rrrrrrrrrr}.6 & 68 & 19 & 48 & 129 & 100 & -. & .19 & \ldots & -. \\ .6 & 77 & 14 & 61 & 133 & 113 & 1.87 & .18 & -. & \ldots \\ .3 & 38 & 23 & 16 & 121 & 73 & -. & .16 & -. & \ldots\end{array}$




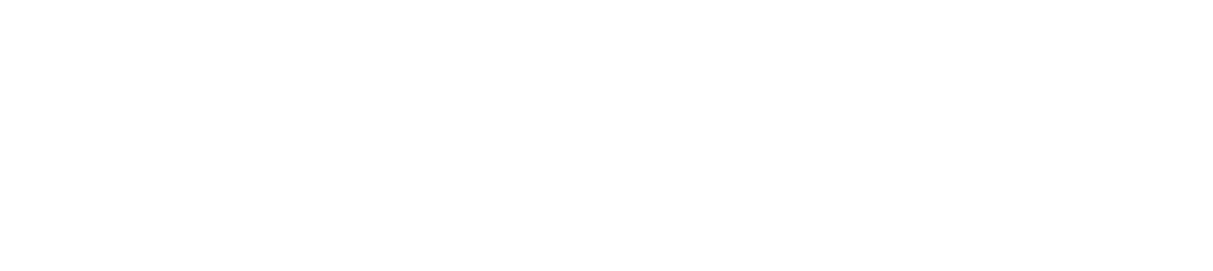

02297090 - HAWTHORNE CR NR NOCATEE FLA ILAT 270927 LONG 081 S1 431

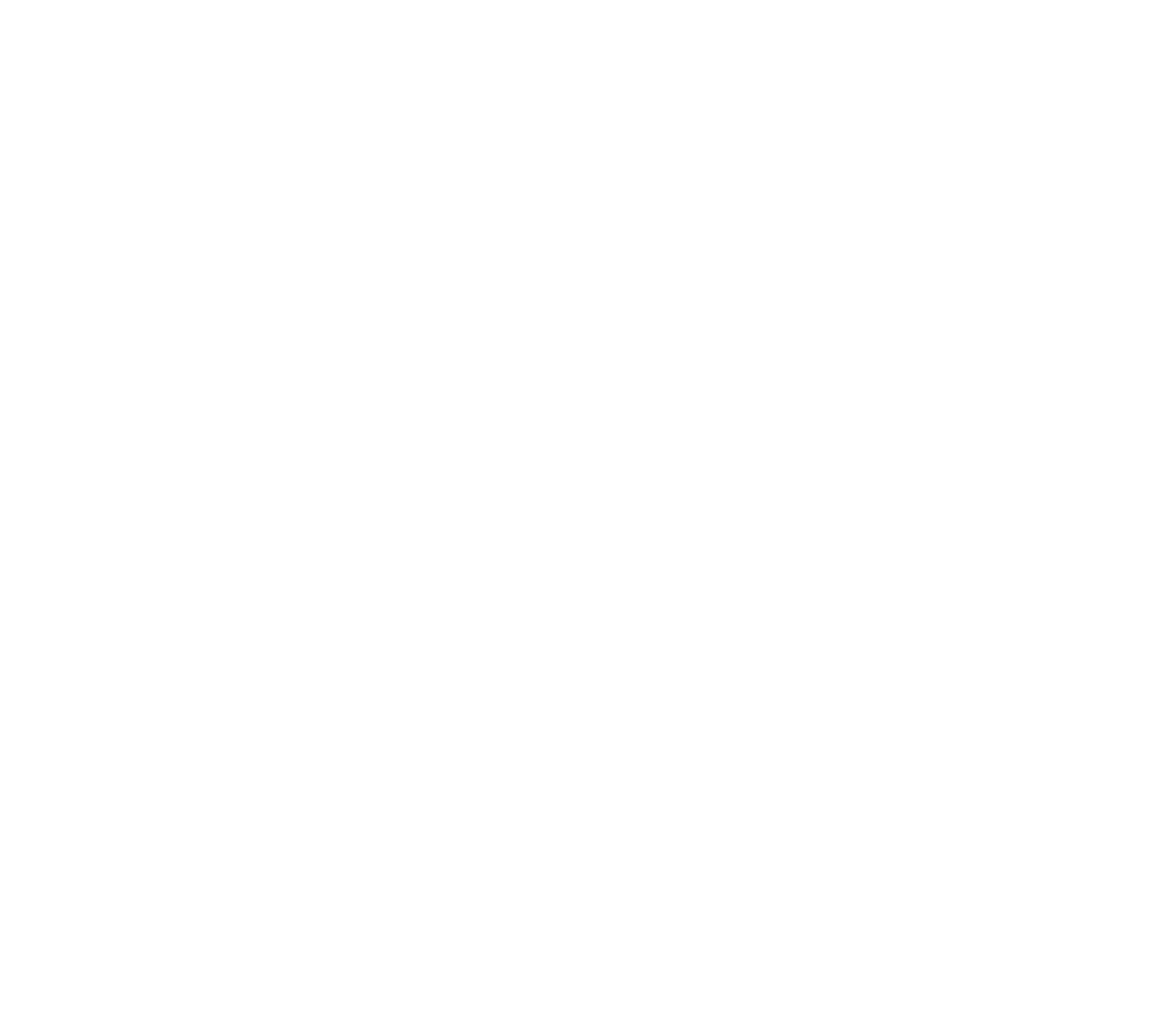

02299410 - BIG SLOUGH CA NR MYAKKA CITY FLA ILAT 271135 LONG 0820840 )

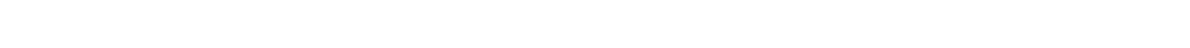

02299470 - BIG SLOUGH NR MURDOCK FLA (LAT 270415 LONG 0821305 )

OCT., 1969

N1... 105

NOV... 99

DEC. 76

IUNE: $1970^{76}$

JUNE, 1970

$\begin{array}{rrrrrrrrr}26.5 & 170 & -- & 17 & 4.4 & -. & 10 & .3 & 40 \\ 18.0 & 211 & -- & 19 & 5.5 & -. & 14 & .7 & 46 \\ 15.0 & 231 & - & 21 & 5.5 & \ldots & 16 & 1.1 & 44 \\ 28.0 & 140 & -- & 13 & 4.0 & -. & 7.4 & .9 & 37\end{array}$

COASTAL. RASINS BETWEEN MYAKKA RIVER AND HILLSAOROUSH RIVER--CONTINUED

02299800 - PHILLJPPI CR AT SARASOTA FLA (LAT 271920 LONG 0823020 )

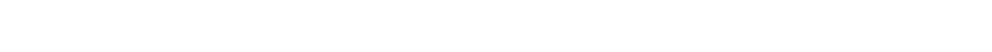

02299950 - MANATEE R NR MYAKKA HEAD FLA (LAT 272824 LONG 0821241 )

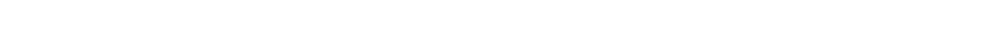


CHEMICAL ANALYSES, WATER YEAR OCTDBER 1969 TO SEPTEMBER 1970 WATER YEAR OCTDBER 1968
(MAJOR CONSTITUENTS)

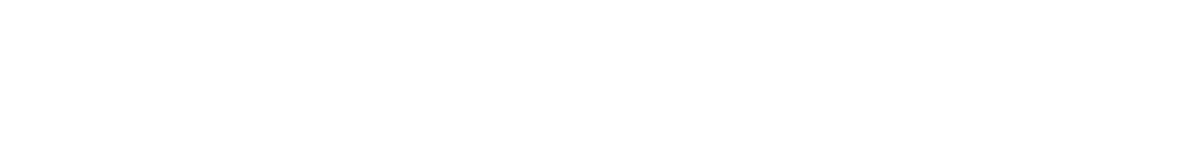

PEACE RIVER DASIN--CONTINUED

02297090 - HAWTHONNE CH NR NOCATEE FLA (LAT 270927 LONG 08151431 APR., $1970{ }_{138} 94$

$\begin{array}{lll}\text { JUNE } & \\ 10 \ldots & 74 & 53\end{array}$

JUNE, 1970 $10 \ldots . . \quad 34$

UNE, 1970

10... 64

JUNE, 1970 2.0

JUNE, 1970

$10 \ldots 5$ 5.5
6.8

$$
\begin{aligned}
& 8.0 \\
& 8.5
\end{aligned}
$$

02297310

. 268

154

117

485

429

02297100 - JOSHUA CR AT NOCATEE FLA ILAT 270959 LONG 08152473

$\begin{array}{lllllllllll}22 & .4 & 87 & 43 & 44 & 190 & 137 & 29.2 & .26 & -. & = \\ 24 & .4 & 94 & 48 & 46 & 168 & 150 & -- & .23 & -. & -\end{array}$

0229710S - PEACE FIVER AT NOCATEE FLA (LAT 270943 LONG 08154 06)

$\begin{array}{lllllllll}4 & 1.0 & 100 & 58 & 43 & 168 & 162 & -. & .23\end{array}$

02297251 - HORSE CREEK NEAR LIMESTONE FLA (LAT 27 21 58 LONG 08158 2S) 7. 0

JUNE, 1970

29... $197017 \quad 34$

$\begin{array}{lll}\text { JUNE } & & \\ 09 \ldots & 29 & 31 \\ 10 . . . & 19 & 37\end{array}$

JUNE, 1970

IO... 27

31

1

02298123 - PRAIRIE CR NR FT OGDEN FLA ILAT $2703 \quad 06$ LONG 08147051

$\begin{array}{rrrrrrrrrr}.3 & 114 & 22 & 95 & 228 & 178 & -- & .31 & -- & -- \\ .3 & 75 & 53 & 22 & 15 n & 118 & -- & .20 & -- & - \\ .4 & 79 & 30 & 48 & 198 & 137 & 84.5 & .27 & -- & -\end{array}$

02298202 - 5 SHELL CR NF PUNTA GORDA FLA ILAT 265904 LONG 0B1 56091

02298830 - MYAKKA RIVER NR SARASOTA FLA (LAT 271425 LONG OR2 18501

NOV.. 1969

\begin{tabular}{|c|c|}
\hline DEC.. & 6.0 \\
\hline JUNE, 1970 & 9.6 \\
\hline
\end{tabular}

11... 8.6 B.?

02299410 - BIG SLOUGH CA NR MYAKKA CITY FLA (LAT 271135 LONG 08208401

JUNE, 1970

UCT., 1969

$01 \ldots 20$

NOV... $21 \quad 26$

$16 \ldots 26 \quad 31$

JUNE, $197014 \quad 13$

JUNE, 1970

I1...

02299950 - MANATEE R NR MYAKKA HEAD FLA (LAT 272824 LONG 0821241 )

$\begin{array}{lll}.4 & 26 & 13 \\ .5 & 33 & 18 \\ .3 & 31 & 12\end{array}$

$\begin{array}{lllll}12 & 77 & 45 & 58.6 & .10\end{array}$

$15 \quad 96 \quad 60 \quad 72.3$

19

$93 \quad 51 \quad 399$

.13

02299470 - BIG SLOUGH NR MURDOCK FLA (LAT $2704 \quad 15$ LONG 0821305 )

$\begin{array}{rrrrrrrrrr}.3 & 61 & 28 & 33 & 130 & 95 & 36.9 & .18 & \ldots & \ldots \\ .4 & 70 & 33 & 38 & 159 & 115 & 42.6 & .22 & -. & \ldots \\ .4 & 75 & 39 & 36 & 179 & 127 & 36.7 & .24 & \ldots & \ldots \\ .3 & 49 & 19 & 30 & 90 & 75 & 12.4 & .12 & \ldots & \ldots\end{array}$

CDASTAL BASINS AETWEEN MYAKKA RIVER AND HILLSBOROUGH RTVFR

02299800 - PHILLIPPI CN AT SARASOTA FLA (LAT 271920 LONG 0823020$)$

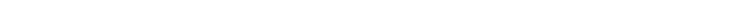

JUNE, 1970

88

$3.1 \quad 100$

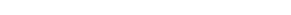




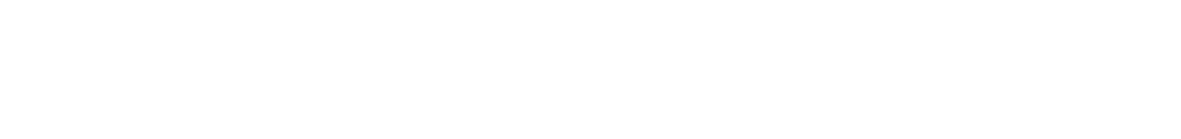

CDASTAL BASINS BETWEEN MYAKKA RIVER AND HILLSBOROUGH RIVER--CONTINUED

02300040 - BRADEN R NP BRADENTON FLA (LAT 29 PG 01 LONF O82 2913 )

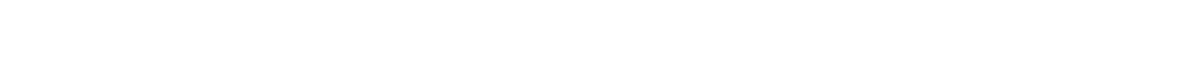

02300100 - L MANATEE R NR FT LONFSOME FLA (LAT 274216 LONG 0821153 )

JUNE, 1970

15... 1970 4.6

02300200 - SO FORK L MANATEE R NR DUETTE FLA ILAT 273525 LONG 0821057 ,

JUNE,
$15.0^{1970} 33$

02300700 - HULLFROG CR NR WIMAUMA FLA (LAT 274730 LONG 08? 21 n9)

MAY, 1970

31

02300852 - N PRONG ALAFIA R AT MULRFRRY FLA (LAT $2753 \geq 1$ LONG OAZ 58 P5)

JUNE, 197 औ

$09 . .$.

25.

680

02300882 - NORTH PRONG ALAFIA R NR NICHOLS, FLA. ILAT $2753>4$ LONG 8820043

JUNE. 1970

$09 . .$. 25.5

02300900 - SCOTt LAKE NR LAKELAND FLA (LAT 2757 EN LONG 08156 nO)

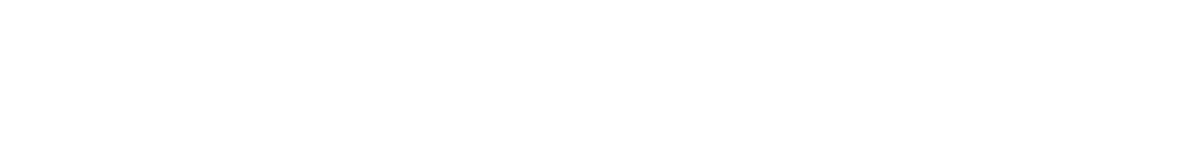

22.5

02300978 - ENGI ISH CR NR MULBERRY FLA (LAT 275536 LONG D8? 0356 )

$\begin{array}{llllllllllllll}\text { JUNE, } 1970 & - & 24.5 & 560 & - & 28 & 9.9 & -- & 72 & 1 \mathrm{~h} & 41 & 0\end{array}$

02301314 - MIZELLE CREEK NEAP KEYSUILLE FLA ULAT 275014 LDNG $08 ? 0517$ I

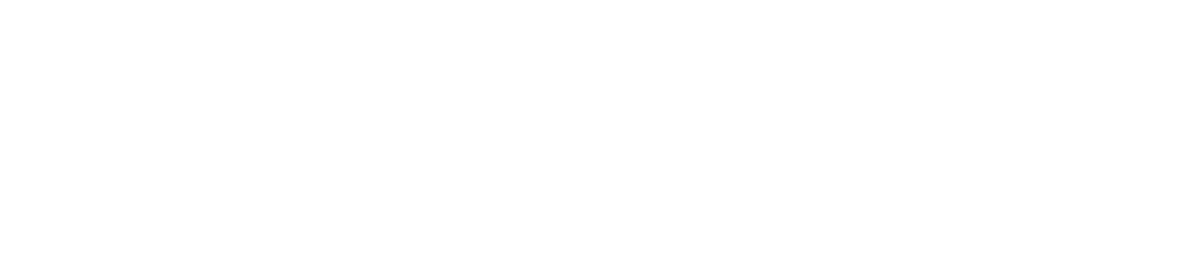

02301370 - L ALAFIA R AT T CR RO AT PLEASANT GRON (LAT 275434 LONG OB2 10 15)

MAY 1970

02301602 - LITHIA SPGS (MINOK) NR LITHIA FLA (LAT 275154 LONG OR2 13 bI)

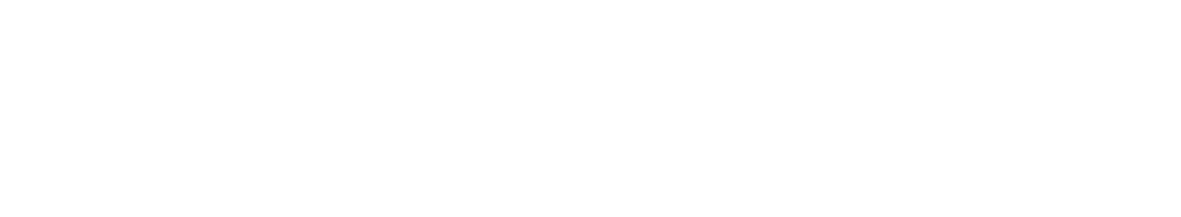




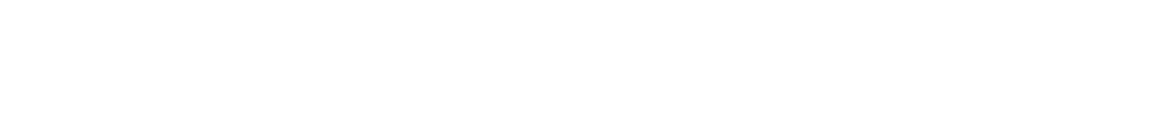

COASTAL BASINS BETWEEN MYAKKA RIVER AND HILLSBJROUGH RIVER--CONTINUED

02300040 - BRADEN R NR BRADENTON FLA (LAT 29 PG 01 LONG OT2 29 13)

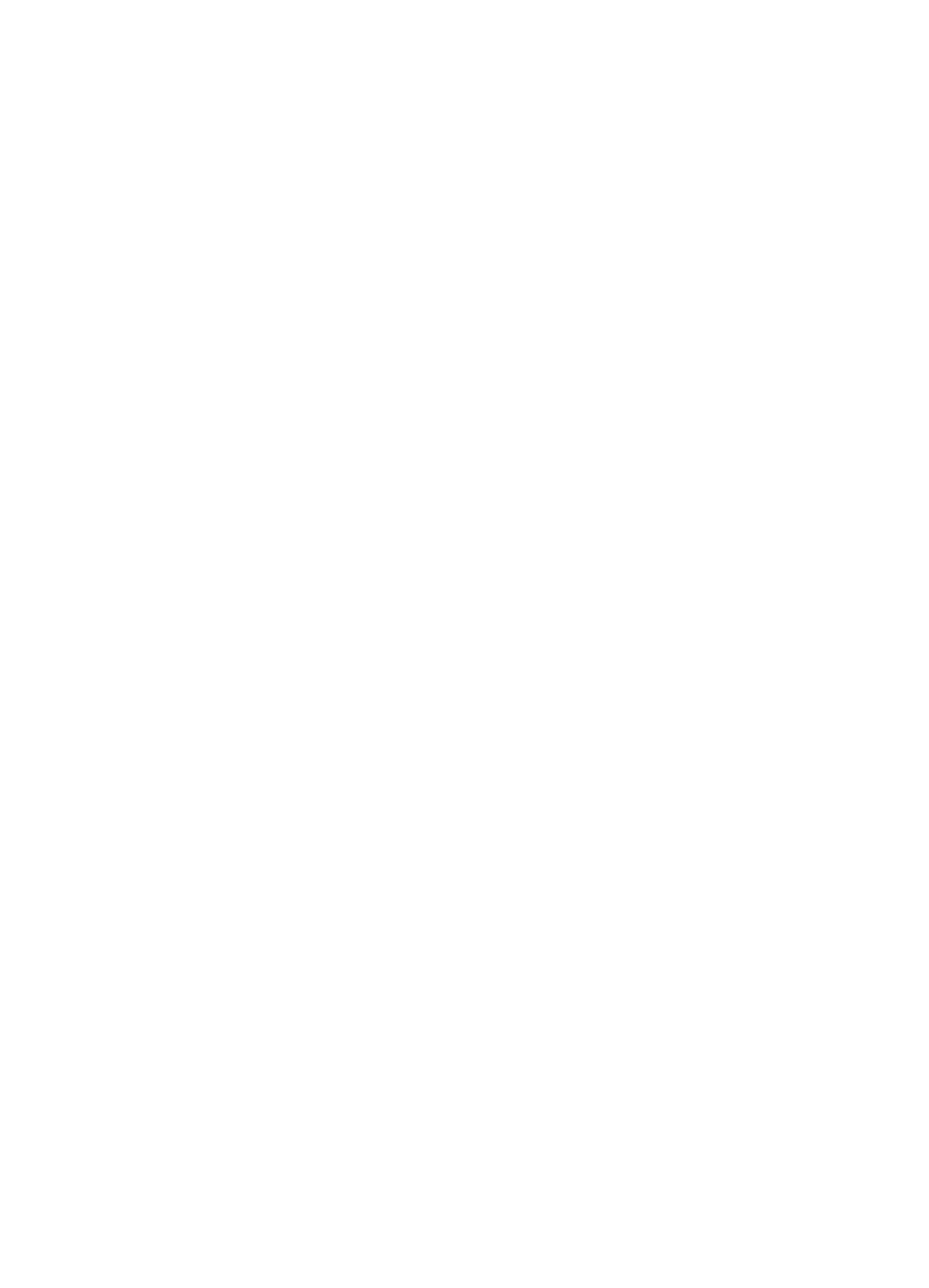




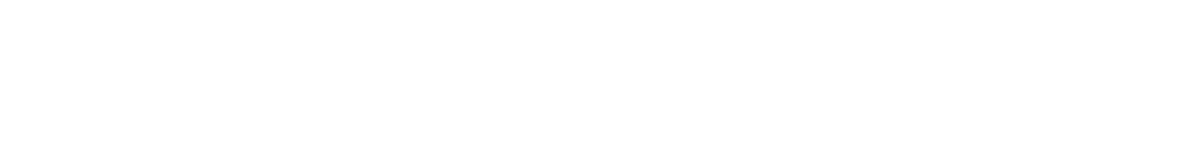

COASTAL BASINS BETWEEN MYAKKA RIVER AND HILLSBOROUGH RIVER--CONTINUED

02301718 - ALAFIA RIVER AT RIVERVIEW FLA (LAT 275206 LONG 0921936 )

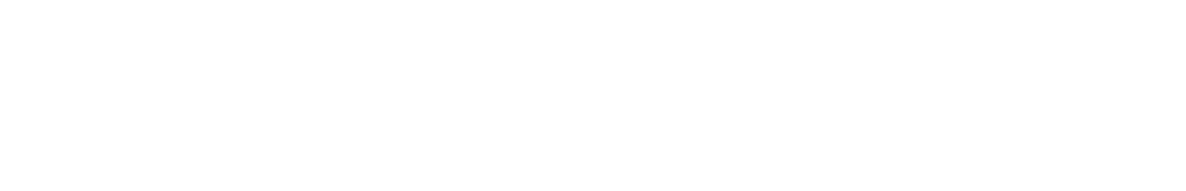

02301870 - HILLSGOROUGH R NR RICHLANO FLA (LAT 281532 LONG 0820620 )

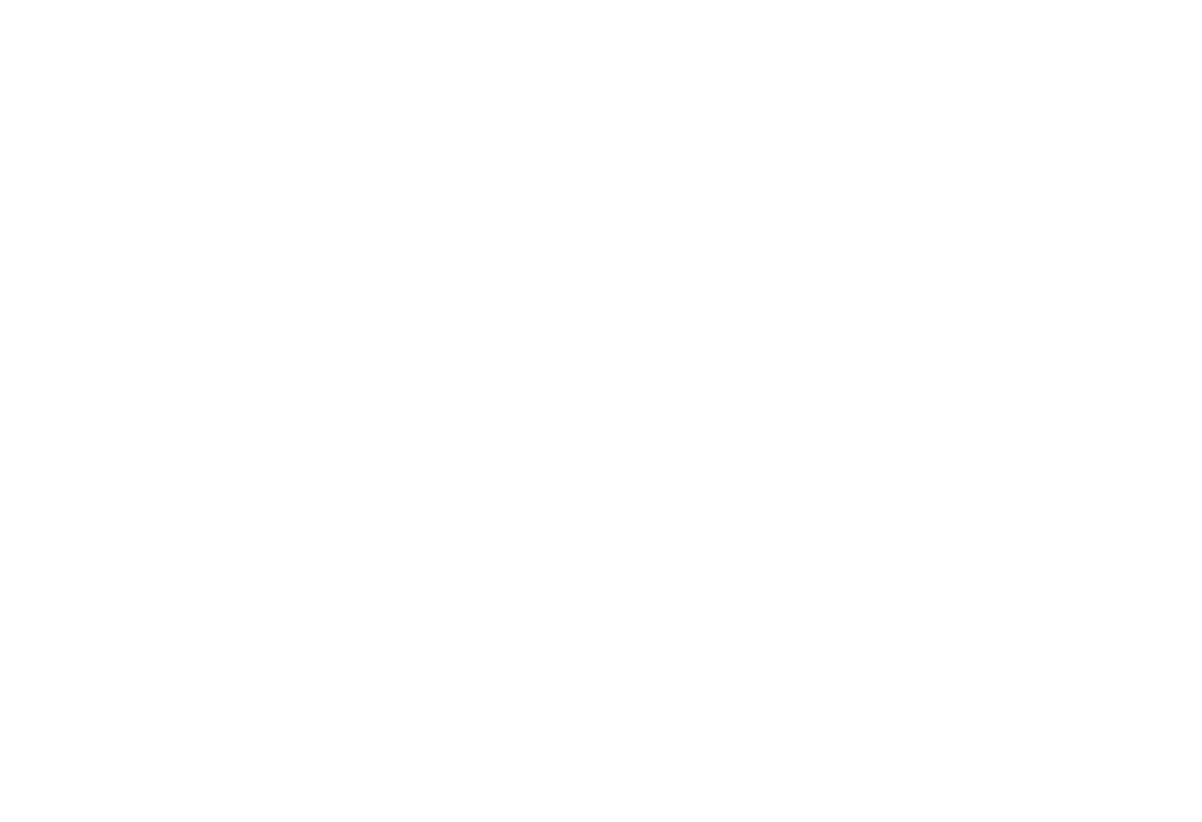

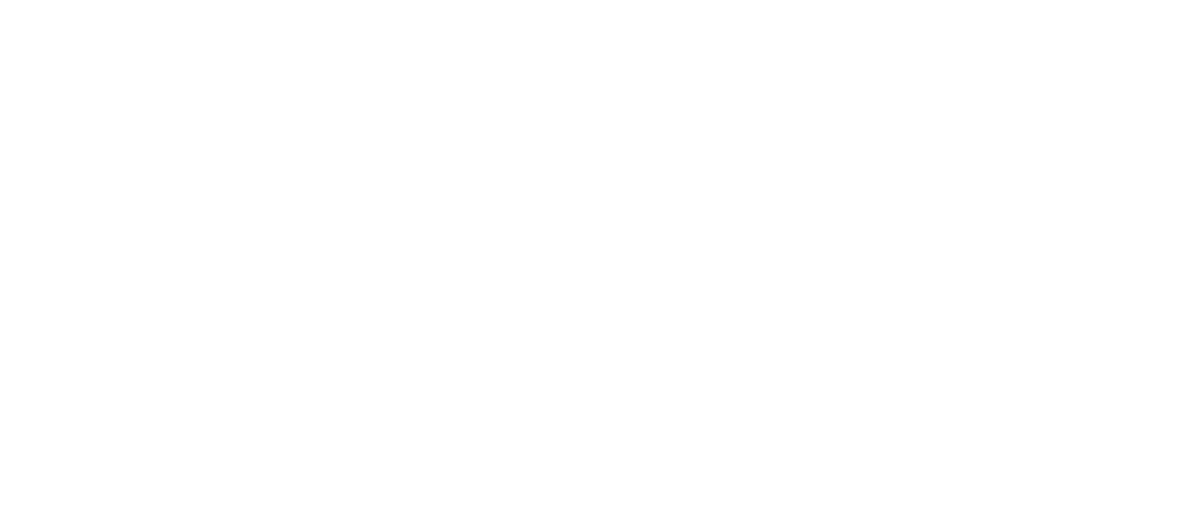


CHEMICAL ANALYSES, WATER YEAR DCTOBER 1969 TO SEPTEMBER 1970

$$
\text { (MAJOR CONSTITUENTS) }
$$

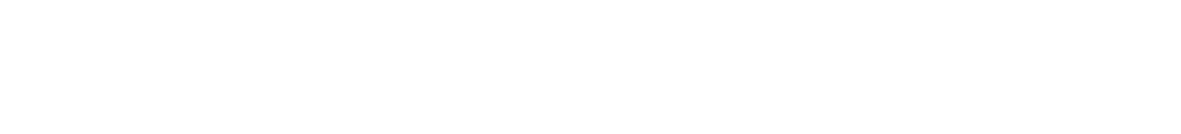

COASTAL BASINS BETWEEN MYAKKA RIVER AND HILLSBOROUGH RIVER--CONTINUED

02301718 - ALAFIA RIVER AT RIVFUVIEW FLA ILAT 275206 LONG 0821936 )

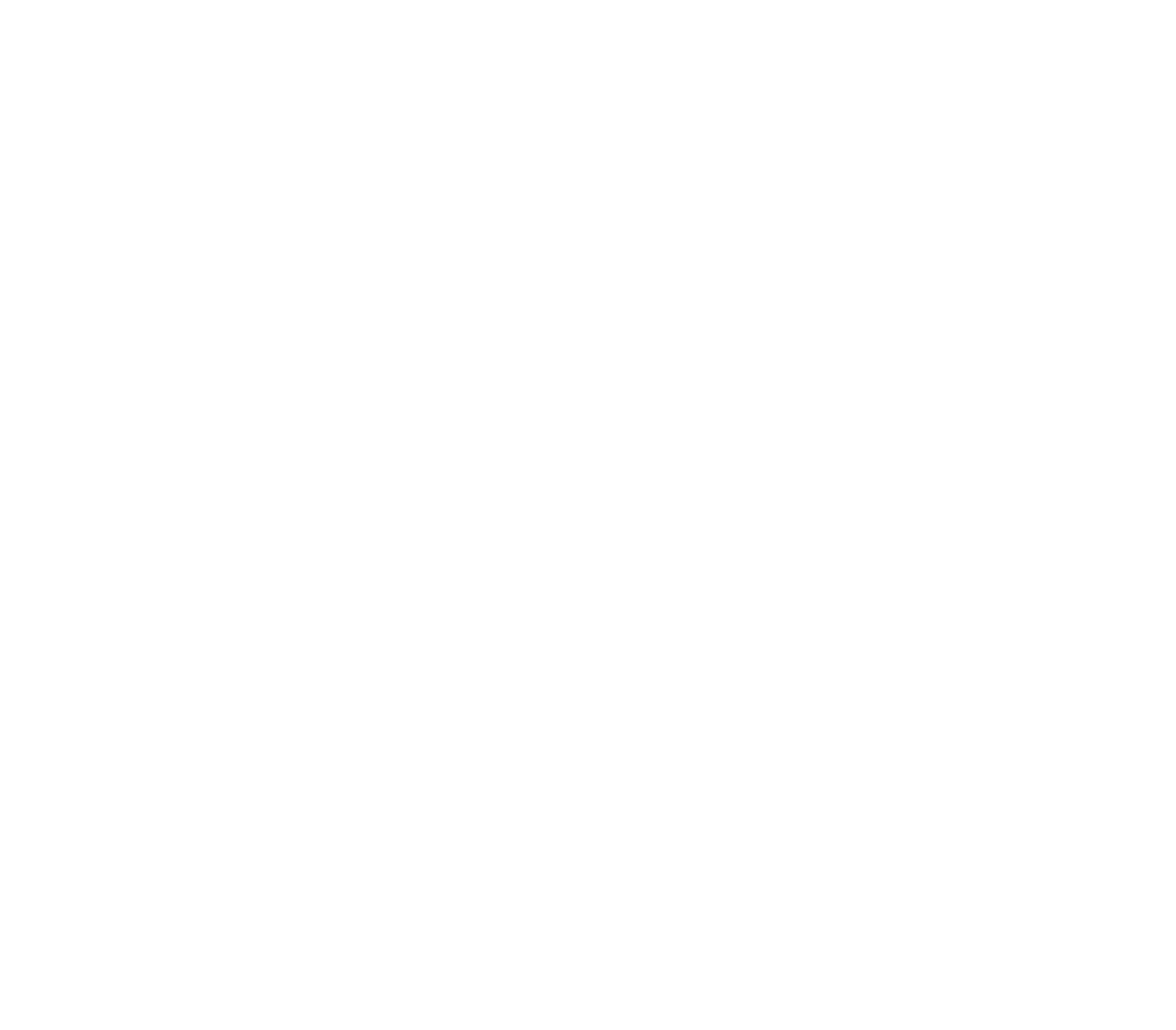

02303000 - HILLSBOROUGH RIVER NR ZEPHYRHILLS FLA (LAT 280859 LONG 08213 57)

\begin{tabular}{|c|c|c|c|c|c|c|c|c|c|c|c|c|}
\hline $\begin{array}{l}\text { OCT. } 1969 \\
\text { 30... } \\
\text { JAN.॰ } 1970\end{array}$ & 13 & 13 & .4 & 119 & 20 & 98 & 185 & 156 & 109 & .25 & $=-$ & -- \\
\hline MAR.. & 10 & 13 & .3 & 100 & 11 & 89 & 157 & 134 & 1.13 & .21 & -- & - \\
\hline APR... & $8 . ?$ & 12 & . 6 & 77 & 14 & 63 & 129 & 108 & 221 & .18 & -- & -- \\
\hline JUNE & 9.7 & 10 & .2 & 135 & 20 & 128 & 166 & 158 & 64.1 & .23 & -- & -- \\
\hline JUL.... & 21 & 14 & .4 & 135 & 28 & 107 & 209 & 181 & -- & .28 & $=-$ & -- \\
\hline SEP... & 16 & 12 & .5 & 117 & 18 & 98 & 170 & 154 & 69.8 & .23 & - & -- \\
\hline $23 .$. & 15 & 11 & .2 & 149 & 24 & 125 & 183 & 190 & 50.4 & .25 & - & \\
\hline
\end{tabular}

02303100 - NEW RIVER NR ZEPHYRHILLS FLA (LAT 280955 LONG 08215 S5)

JUNE, 1970

$08 . .1970 \quad 9.6$

$\begin{array}{lllllllll}.8 & .4 & 18 & 13 & 5 & 72 & 35 & .86 & .10\end{array}$

02303271 - BAKER CREEK NEAR THONOTOSASSA FLA ILAT 29 O2 52 LONG O82 16041

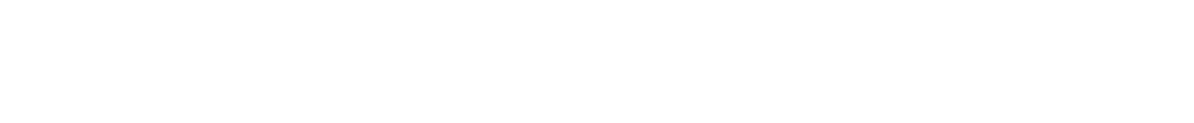


CHEMICAL ANALYSES, WATER YEAR OCTOBER 1969 TO SEPTEMBER 1970 (MAJOR CONSTITUENTS)

\begin{tabular}{|c|c|c|c|c|c|c|c|c|c|c|c|c|}
\hline DATE & $\begin{array}{l}\text { DIS- } \\
\text { CHAKGE } \\
\text { (CFS) }\end{array}$ & $\begin{array}{l}\text { TEMPER- } \\
\text { ATURE } \\
\text { (DEG C) }\end{array}$ & $\begin{array}{l}\text { SPE- } \\
\text { CIFIC } \\
\text { CON- } \\
\text { DUCT- } \\
\text { ANCE } \\
\text { (MICRO- } \\
\text { MHOS) }\end{array}$ & $\begin{array}{l}\text { DIS- } \\
\text { SOLVED } \\
\text { IRON } \\
\text { (FE) } \\
\text { (UG/L) }\end{array}$ & $\begin{array}{l}\text { DIS- } \\
\text { SOLVED } \\
\text { CAL- } \\
\text { CIUM } \\
\text { (CA) } \\
\text { (MG/L) }\end{array}$ & $\begin{array}{l}\text { DIS- } \\
\text { SOL VEO } \\
\text { MAG- } \\
\text { NE- } \\
\text { SIUM } \\
\text { (MG) } \\
\text { (MG/L) }\end{array}$ & $\begin{array}{l}\text { DIS- } \\
\text { SOLVED } \\
\text { STRON- } \\
\text { TIUM } \\
\text { (SR) } \\
\text { (UG/L) }\end{array}$ & $\begin{array}{l}\text { DIS- } \\
\text { SOLVED } \\
\text { SODIUM } \\
\text { (NA) } \\
\text { (MG/L) }\end{array}$ & $\begin{array}{l}\text { DIS- } \\
\text { SOLVED } \\
\text { PO- } \\
\text { TAG- } \\
\text { SIUM } \\
\text { (K) } \\
\text { (MG/L) }\end{array}$ & $\begin{array}{l}\text { BICAR- } \\
\text { BONATF } \\
\text { (HCOZ) } \\
\text { (MG/L) }\end{array}$ & $\begin{array}{l}\text { CAR- } \\
\text { RONATE } \\
\text { (CO3) } \\
\text { (NG/L) }\end{array}$ & $\begin{array}{c}P H \\
\text { (UNITS) }\end{array}$ \\
\hline
\end{tabular}

HILLSBOROUGH RIVER BASIN--CONTINUED

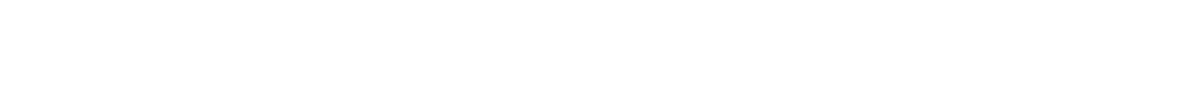

02303320 - FLINT CREEK AT SH-5H2 NEAR THONOTOSASS (LAT 280430 LONG 0B? 15 5n)

\begin{tabular}{|c|c|c|c|c|c|c|c|c|c|c|c|c|}
\hline $\begin{array}{l}\text { MAY } \\
20 . . . \\
\text { JUNE }\end{array}$ & & - & 26.0 & 198 & $R_{0}$ & 20 & 4.5 & 100 & 12 & 3.5 & 68 & $n$ \\
\hline $\begin{array}{l}01 \ldots \\
11 \ldots\end{array}$ & 191 & -- & $\begin{array}{l}26.0 \\
30.0\end{array}$ & $\begin{array}{l}190 \\
170\end{array}$ & 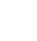 & $\begin{array}{l}15 \\
18\end{array}$ & $\begin{array}{l}3.7 \\
4.0\end{array}$ & $=$ & $\begin{array}{c}12 \\
9.7\end{array}$ & $\begin{array}{l}3.1 \\
3.6\end{array}$ & $\begin{array}{l}54 \\
56\end{array}$ & $\overline{0}$ \\
\hline
\end{tabular}

02303330 - HILLS R AT MORRIS BR NR THONOTOSASSA F ILAT 2F 0550 LONG MRP 1945 )

$\operatorname{MAY} \cdot 1970$

02303358 - CYPRESS CH NH DARHY FLA ILAT 282232 LONG 0821947

$05.0^{0.0}$

25.0

$\begin{array}{llllllll}78 & - & 6.2 & 2.0 & - & 5.4 & 5.4 & 2.4\end{array}$

02303440 - L PAOGETT NR LUTZ FLA ILAT ZR 1212 LONG O82 27431

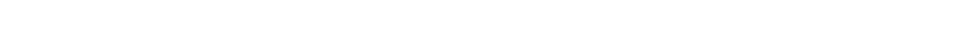

02303700 - LAKE STEMPER NK LUTZ FLA ILAT 28 08 99 LONG 08227221
\end{abstract}

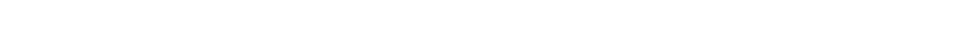

02303800 - CYPRESS CR NR SULPHUR SPRINGS FLA ILAT P8 05 20 LONG AR2 24331
\end{abstract}

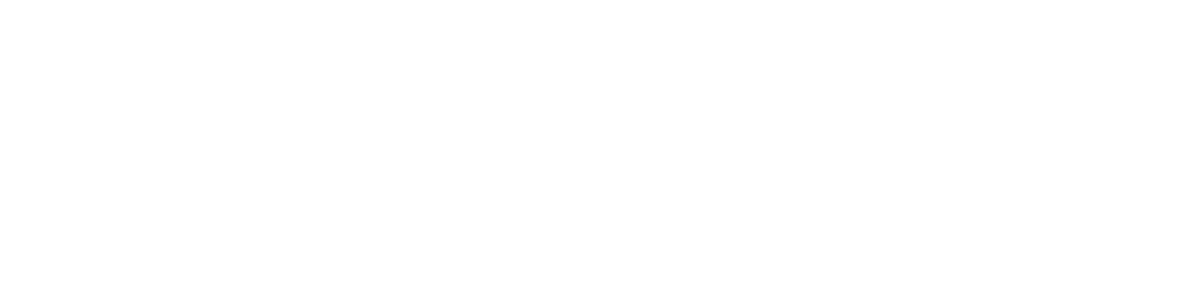

02304700 - LAKE HOSBS NR LUTZ FLA ILAT 28 O9 30 LONG 0R2 28 NO)

$\begin{array}{llllllllllll}\operatorname{MAY}, 1970 & - & 28.0 & 180 & -- & 11 & 5.0 & -- & 10 & 4.4 & 10 & 0\end{array}$

02305175 - CRENGHAW LAKE NEAR LUTZ FLA (LAT 290732 LONG 0822946.01

APR., 1970

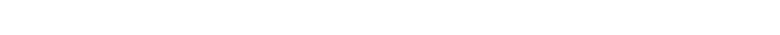

02305178 - SADDLEHACK LAKF NEAR LUTZ FLA ILAT 280706 LONG 08229 45)

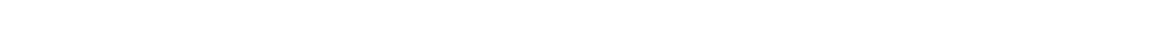

02305200 - ROUNO LAKE NR LUTZ FLA (LAT 2807 15 LONG 9823004$)$

$A D R ., 1970 \quad .00$
$07 .$.

25.

$28 \mathrm{~A}$

-- 50

$\begin{array}{lllll}1.8 & - & 5.2 & .6 & 160\end{array}$ 
CHEMICAL ANALYSES, WATER YEAR DCTOBER 1969 TO SEPTEMBER 1970 (MAJOR CONSTITUENTS)

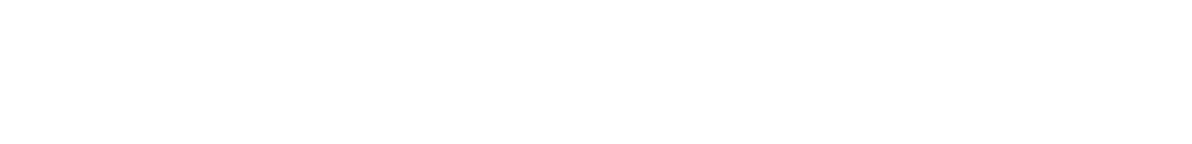

HILLSBOROUGH RIVEP BASIN--CINTINUED

02303290 - L THONOTOSASSA AT THONDTOSASSA FLA (LAT $2803 \quad 33$ LONG OBZ 1709 I

JUNE, 1970
O1...

14

02303300 - FLINT CR NR FHONOTOSASSA FLA (LAT 280404 LONG 08216 04)

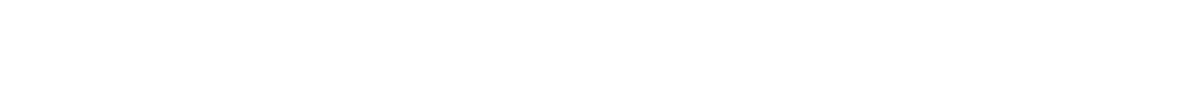

02303320 - FLINT CREEK AT SH-582 NEAR THONOTOSASS (LAT 280430 LONG 08215501

\begin{tabular}{|c|c|c|c|c|c|c|c|c|c|c|c|}
\hline JUNE & 18 & 16 & .5 & 69 & 13 & 56 & 122 & 111 & 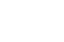 & .17 & -- \\
\hline
\end{tabular}

02303330 - HILLS Q AT MORPIS 8R NR THONOTOSASSA F (LAT 280550 LONG 08? 18 45)

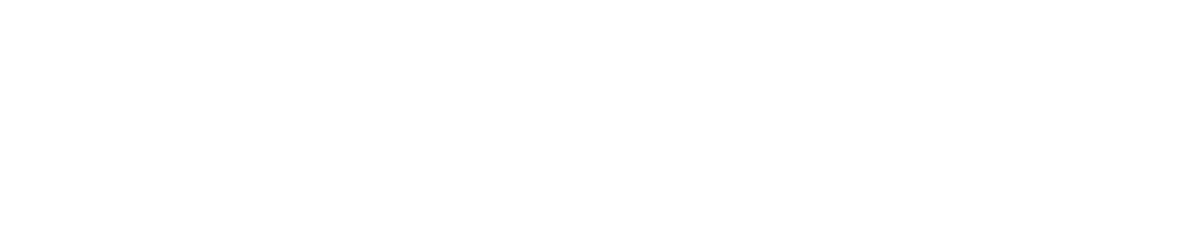

02303700 - LAKE STEMPER NR LUTZ FLA ILAT 28 09 09 LONG 08227221

MAY $27970 \quad 17$

02303800 - CYPRESS CR NR SULPHUR SPRINGS FLA ILAT 29 0520 LONG 0R2 2433 )

$\begin{array}{ll}\text { MAY }, 1970 & \\ 22.0 & 2.0\end{array}$

02303990 - COWHOUSE CR NR TE PLE TERRACE FLA ILAT ?R 0330 LONG 022 21 10)

$\begin{array}{ll}\text { MAY } & 1970 \\ 22 . . & 71\end{array}$

7.0

$188 \quad 83$

105

273

02304000 - HILLSBORO R AT FOWLER AVE MR TAMPA FLA (LAT 280315 LONG 09221 SO)

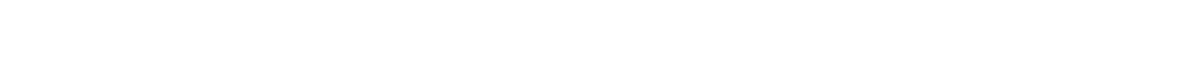

02304700 - LAKE HOGBS NR LUTZ FLA (LAT 280930 LONG 08228001

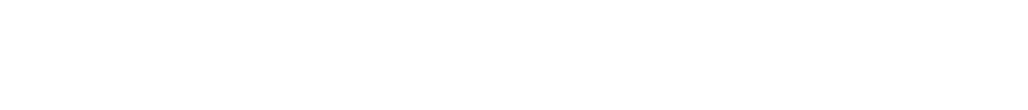

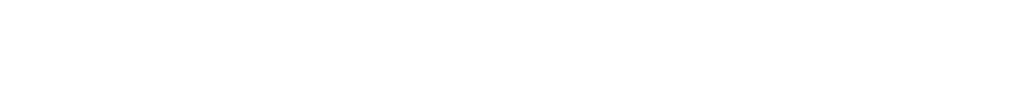

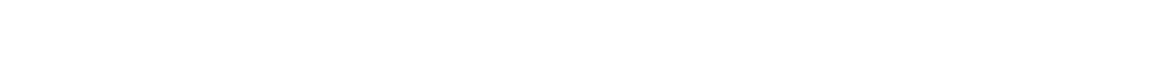
02305200 - ROUNO LAKE NR LUTZ FLA (LAT 28 O7 16 LONG NB2 $30 \quad 04$ )

APR., $1970 \quad 2.0 \quad 10$

C33 


\begin{tabular}{|c|c|c|c|c|c|c|c|c|c|c|c|c|}
\hline & $\begin{array}{c}\text { DIS- } \\
\text { CHARGE }\end{array}$ & $\begin{array}{l}\text { TEMPER- } \\
\text { ATURE }\end{array}$ & $\begin{array}{l}\text { SPE- } \\
\text { CIFIC } \\
\text { CON- } \\
\text { OUCT- } \\
\text { ANCE } \\
\text { (MICRO- }\end{array}$ & $\begin{array}{l}\text { DIS- } \\
\text { SOLVED } \\
\text { IRON } \\
\text { (FE) }\end{array}$ & $\begin{array}{l}\text { DIS- } \\
\text { SOLVED } \\
\text { CAL- } \\
\text { CIUM } \\
\text { (CA) }\end{array}$ & $\begin{array}{l}\text { DIS- } \\
\text { SOLVED } \\
\text { MAG- } \\
\text { NE- } \\
\text { SIUM } \\
\text { (MG) }\end{array}$ & $\begin{array}{l}\text { OIS- } \\
\text { SOLVED } \\
\text { STRON- } \\
\text { TIUM } \\
\text { ISRI }\end{array}$ & $\begin{array}{l}\text { DIS- } \\
\text { SOLVED } \\
\text { SODIUM } \\
\text { (NA) }\end{array}$ & $\begin{array}{l}\text { DIS- } \\
\text { SOLVED } \\
\text { PO- } \\
\text { TAS- } \\
\text { SIUM } \\
\text { (K) }\end{array}$ & $\begin{array}{l}\text { BICAR- } \\
\text { BONATE } \\
\text { (HCO3) }\end{array}$ & $\begin{array}{l}\text { CAR- } \\
\text { BONATE } \\
\text { (CO3) }\end{array}$ & PH \\
\hline$A T E$ & (CFS) & $(D E G \quad C)$ & MHOS) & (UG/L) & $(M G / L)$ & $(M G / L)$ & (UG/L) & $(M G / L)$ & $(M G / L)$ & $(M G / L)$ & $(M G / L)$ & (UNITS) \\
\hline
\end{tabular}

YILLSBOROUGH RIVER BASIN--CONTINUED

02305288 - LAKE CHARLES NEAR LUT7, FLA, (LAT 280656 LDNG 08228521

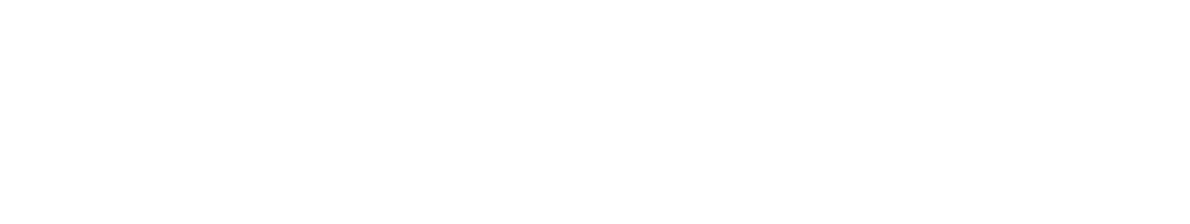

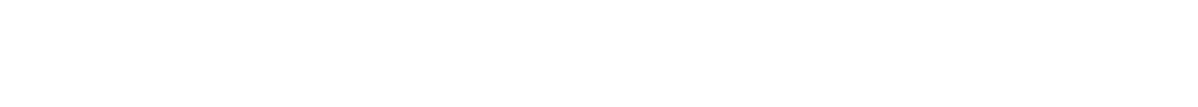


CHEMICAL ANALYSES, WATER YEAR OCTOBER 1969 TO SEPTEMBER 1970 (MAJOR CONSTITUENTS)

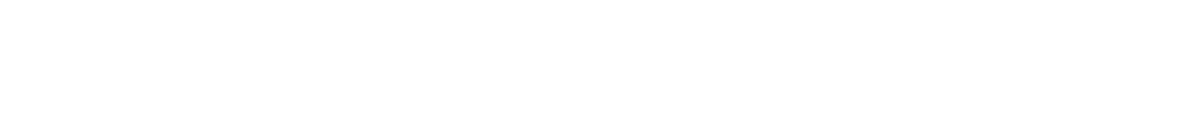

HILLSBOROUGH RIVER RASIN--CINTINUED

02305288 - LAKE CHAKLES NEAR LUT. FLA. (LAT 28 O6 56 LONG 0822852$)$

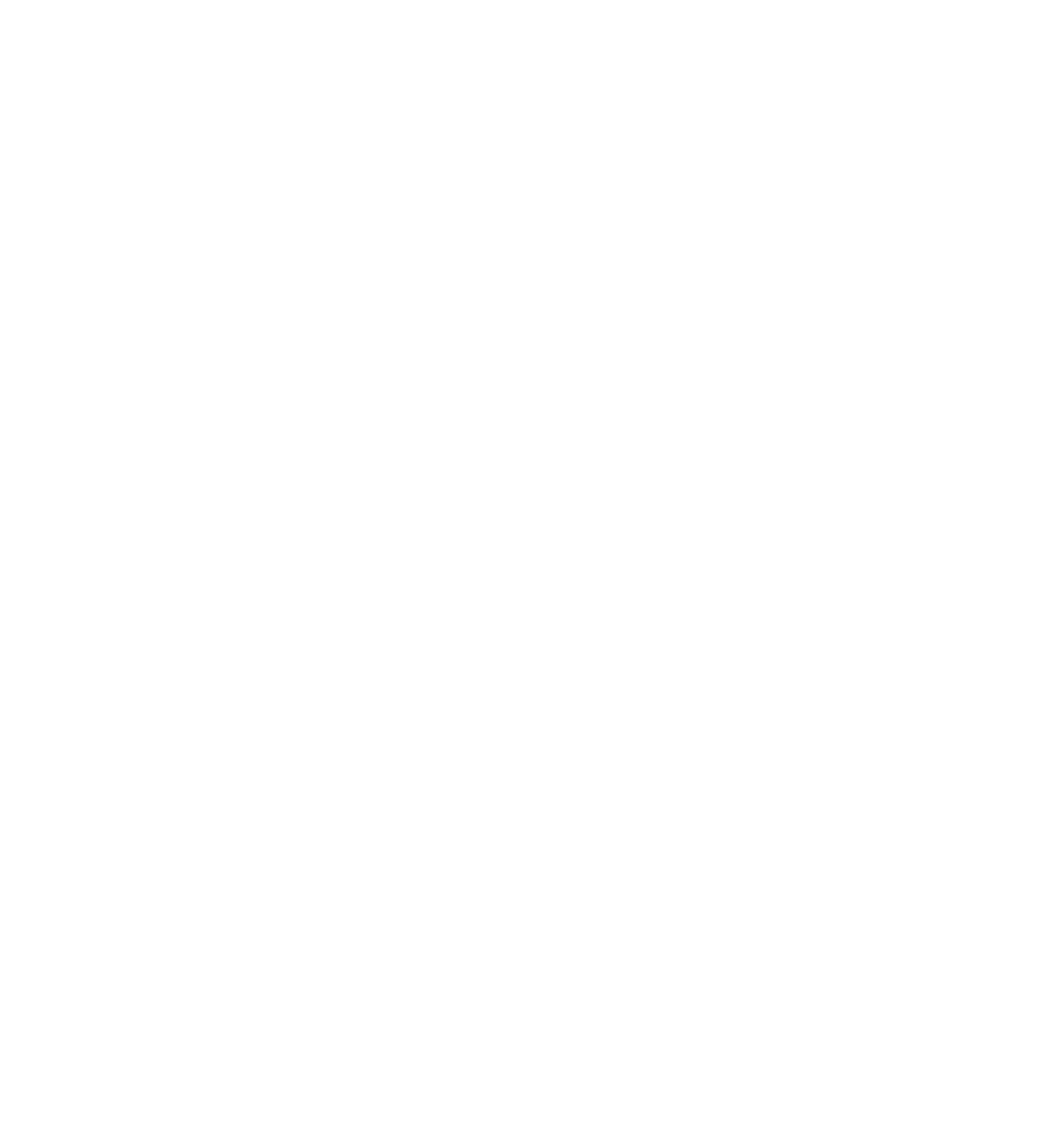

02307206 - BROOKER CREEK NR CITRUS PARK FLA (LAT 28 OT 24 LONG OB2 3430 )

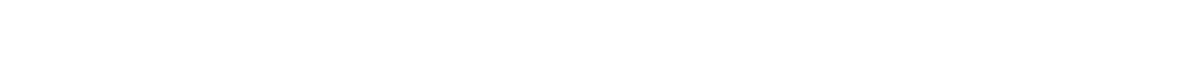

02307227 - CALM LAKE NR ODESSA FLA ILAT 280825 LONG 08235051

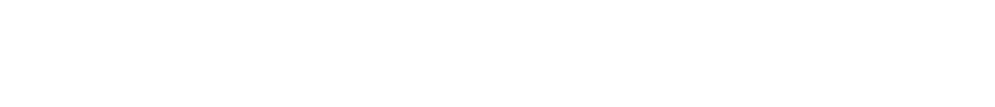

MAY 1970 II 12 (1) 


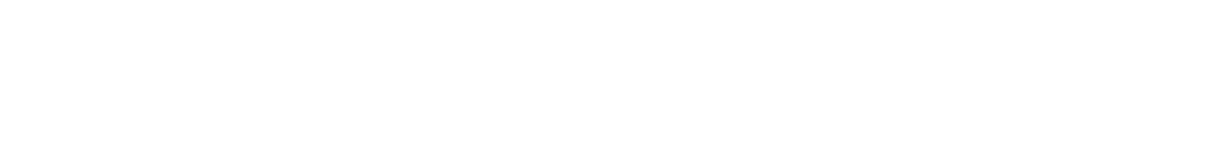

COASTAL BASINS BETWEEN HILLSBRROUSH RIVER AND WITHLACONCHEE RIVER--CONTINUES

02307359 - BROOKER CR NR TARPON SPRGS FLA (LAT 280545 LONG OE? 41 15)

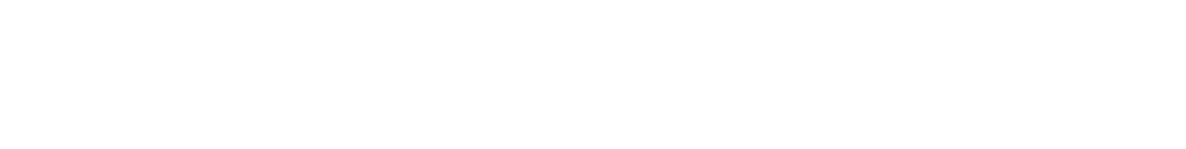

02307462 - LAKE TARPDN SINK NEAR TARPON SPRINGS F (LAT 280734 LONG $08244 \quad 13$ )

\begin{tabular}{|c|c|c|c|c|c|c|c|c|c|c|c|c|}
\hline $\begin{array}{l}\text { MAY } 1970 \\
\text { O7.... } \\
\text { JUNE. }\end{array}$ & $\cdots$ & 27.5 & 4820 & - & 77 & 100 & $\cdots$ & 760 & 27 & 76 & - & 7.1 \\
\hline $22 \ldots$ & -- & 31.0 & $520 n$ & - & 70 & 106 & - & 900 & 34 & 28 & -- & 7.0 \\
\hline
\end{tabular}

02307542 - NORTH FORK BISHOP CK NR OLOSMAR, FLA. ILAT 290111 LONG 0824121 )

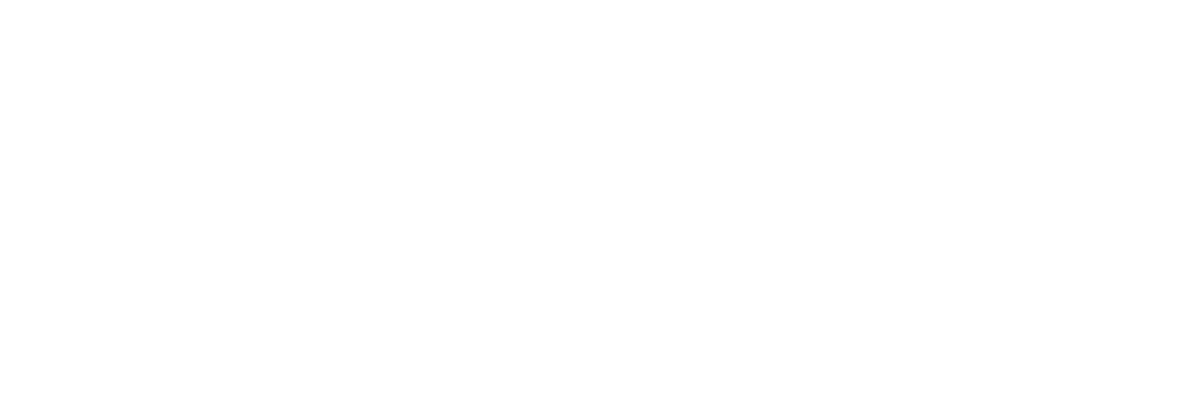

02308889 - SEMINOLE L OUTLET NR LARGO FLA (LAT 275020 LONG OR2 465 )

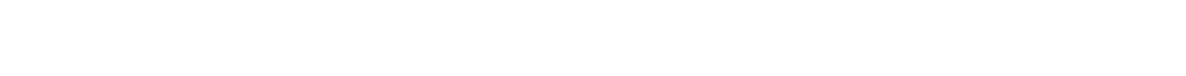

02309044 - MCKAY CR AT WALSINGHAM RV NR INOIAN RK ILAT 275245 LONG DE? 48 35)

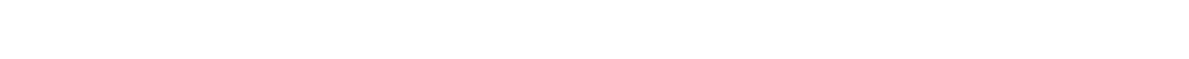

02309258 - STEVENSON CPEEK AT CLEAPMATEK, FLA. ILAT 275819 LONG 08245541

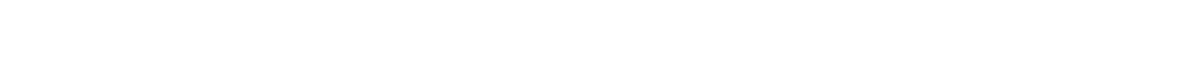

02309421 - CURLEW CR NR OZONA FLA (LAT PB 0224 LONG 0824451 )

$\begin{array}{ccccccccccc}\text { MAY. } 1970 & - & 22.0 & 250 & -- & 31 & 5.1 & - & 14 & 1.4 & 99\end{array}$

02309584 - LAKE THOMAS AT DREXEL FLA (LAT 281414 LONG 0822809 )

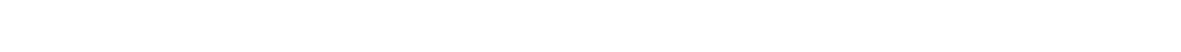

02309814 - CAMP LAKE NEAR DENHAM, FLA. (LAT 281103 LONG 082 29 26)

$\begin{array}{lllllllllll}\text { MaY. } 1970 & -- & 29.0 & 68 & -- & 2.6 & 1.7 & -- & 5.4 & 1.8 & 1\end{array}$

02309872 - PARKER LAKE NR ODESSA FLA (LAT $28 \quad 1033$ LONG 0823438 )

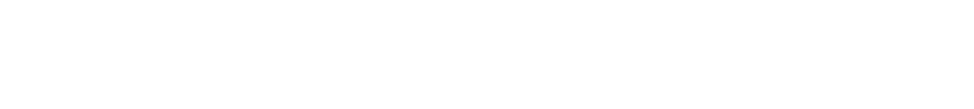

$\begin{array}{cccccccccccccc}\text { MAY. } 1970 & - & 25.9 & 68 & \ldots & 1.6 & 1.0 & \ldots & 4.0 & .5 & 0\end{array}$

n2310150 - HOLLIN CREEK TRIB NR TARPON SPRINGS FL ILAT 280948 LONG 0824246 )

MAY 1970

$21.9 \quad 991 \quad--$ 
CHEMICAL ANALYSES, WATER YEAR OCTOBER 1969 TO SEPTEMBER 1970

$$
\text { (MAJOR CONSTITUENTS) }
$$

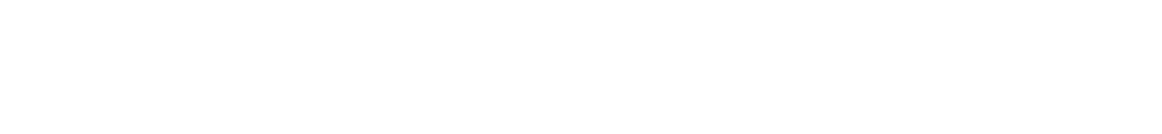

COASTAL BASINS BETWEEN HILLSBOROUGH RIVER AND WITHLACODCHEE RIVER--CONTINUED

02307359 - BROOKER CR NR TARPON SPRGS FLA ILAT 280545 LONG ORZ 41151

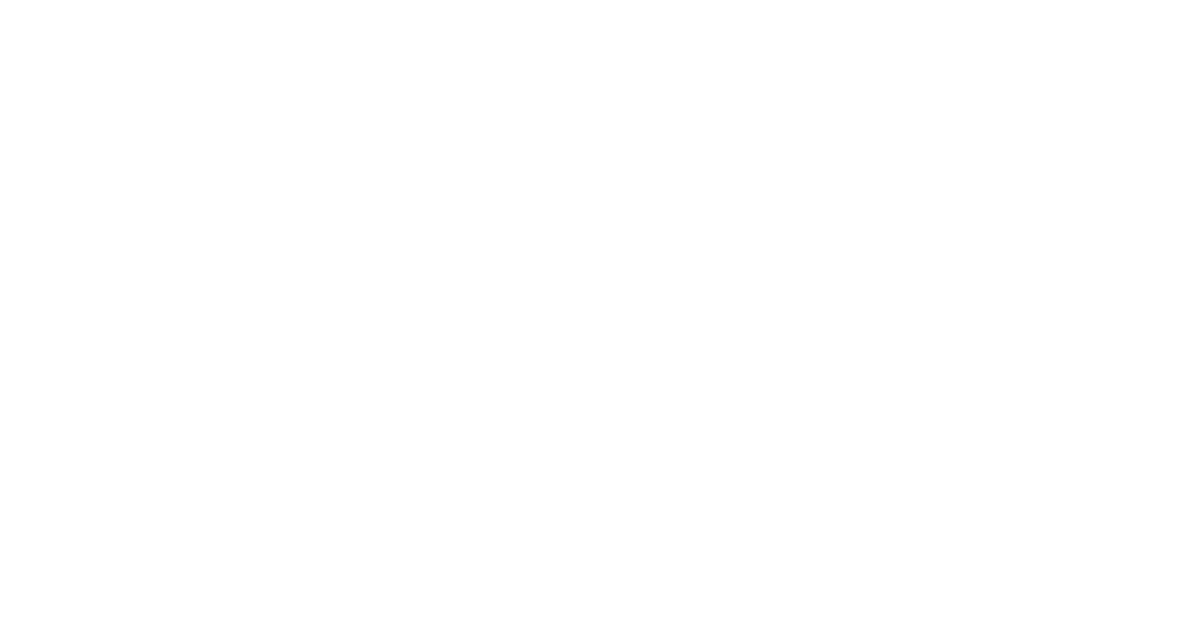

02308888 - SEMINOLE LK NR LARGO FLA (LAT 275020 LONG $082465 n$ )

MAY 1970

$08 . .1970$

$08 . . . \quad 42$

56

.5

$\begin{array}{llll}172 & 52 & 120 & 347 \\ 203 & 54 & 149 & 4\end{array}$

$\begin{array}{llll}47 & 29 n & -- & .47 \\ 2 n & 371 & -- & .57\end{array}$

$\begin{array}{lll}47 & -- & --\end{array}$

02308889 - SEMINOLE L OUTLET NR LARGO FLA ILAT 275020 LONG 08246501

MAY 1970

52

$.5 \quad 163 \quad 56$

$107 \quad 314$

2 he

02309044 - MCKAY CR AT WALSINGHAM RV NR INDIAN RK ILAT 27 S? 45 LONG ORE 4835 )

MAY 197018

02309258 - STEVENSON CREEK AT CLEARWATER, FLA. (LAT 275819 LONG O82 46 54)

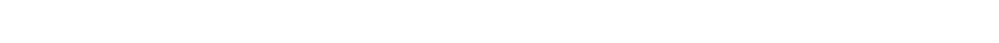

02309421 - CURLEW CR NR OZONA FLA ILAT 280224 LONG 08244511

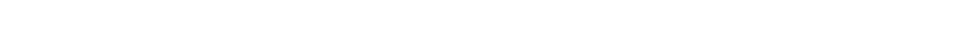

02309584 - LAKE thOMAS AT DREXEL FLA (LAT 281414 LONG 0822808 )

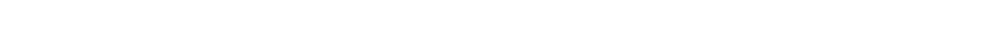

$0 ? 309814$ - CAMP LAKE NEAR DENHAM, FLA. (LAT 281103 LONG 08? 79 >6)

$\begin{array}{ccccccccccc}\text { MAY } & 1970 \\ 27 . . . & 7.2 & 12 & .2 & 14 & 13 & 1 & 57 & 32 & \ldots\end{array}$

02309872 - PARKER LAKE NR ODESSA FLA (LAT 28 in 33 LONF 0823438 )

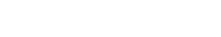

02310100 - LAKE DAN NR ODESSA FLA ILAT 2810 90 LONG 082 38551

MAY, $1970 \quad 2.8$

02310150 - HOLLIN CREEK TRIH NR TARPON SPRINGS FL ILAT 280948 LONG 0824246 )

MAY. 1970 


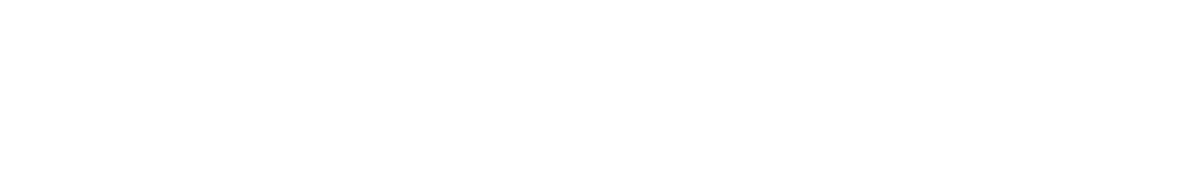
02310166 - ANCLOTE RIVER N̦EAR TARPON SPRINGS FLA (LAT 280924 LONG 0824449 )

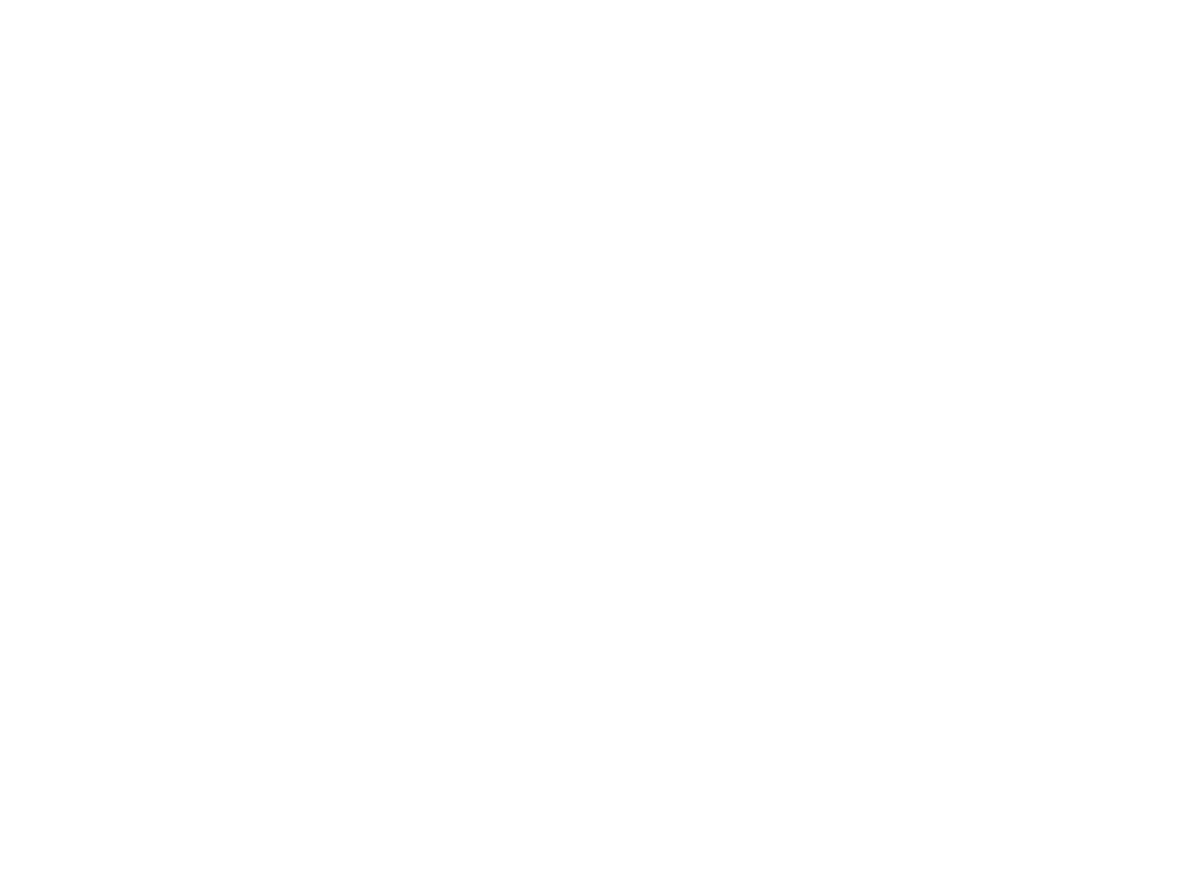

02310307 - PITHLACHASCOTEE RIVER AT NEWPORT RICHE (LAT 281424 LONG 08243 12)

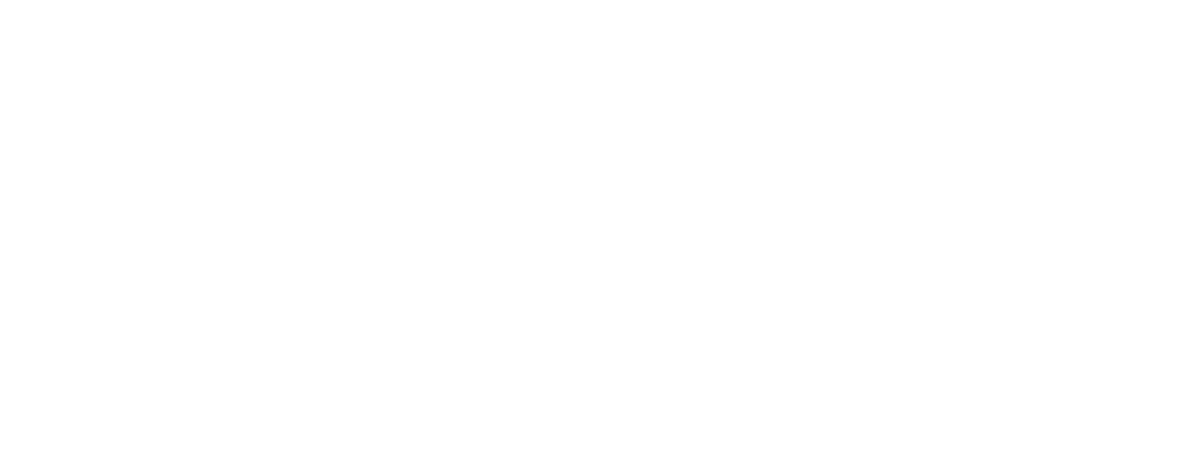

02310500 - WEEKIWACHEE SPRINGS NF BROOKSVILLF FLA (LAT 2831 ON LONG 08234251

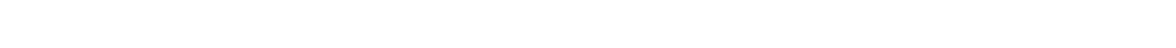
02310600 - GULF OF MEXICO NR BAYPORT FLA ILAT 283200 LONG 08239 nII

JUNE, 1970

$-148 \quad 324$

$-2760 \quad 110$
0

158 
CHEMICAL ANALYSES, WATER YEAR OCTOBER 1969 TO SEPTEMBER 1970

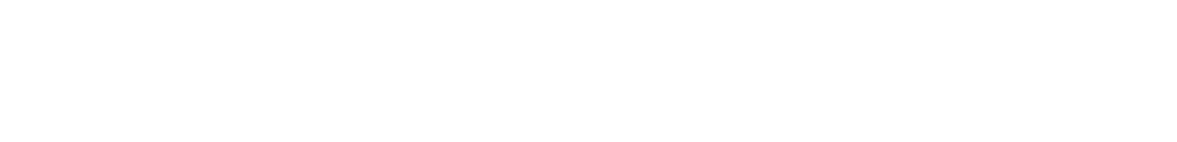

COASTAL BASINS BETWEEN HILLSBOROUGH RIVER AND WITHLACOOCHEE RIVER--CONTINUED

02310166 - ANCLOTE RIVER NEAR TARPON SPRINGS FLA ILAT 2B 09 24 LCNG DB2 44 49)

\begin{abstract}
MAY 1970
5700

$\begin{array}{lllll}1.0 & 4820 \quad 4710 \quad 113 & 28300\end{array}$

02310200 - SPRING AAYOU NR TARPON SPRINGS FLA LLAT 280845 LONG OB2 45301
\end{abstract}

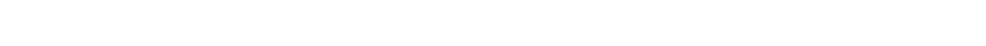

02310220 - NEFF LAKE NR BROOKSVILLE FLA ILAT 2B 2844 LONG 082 I9 14 )

$\begin{array}{ccccccccccc}\text { JUNE. } 1970 & .8 & 10 & .2 & 17 & 9 & 7 & 59 & 29 & -. & .08 \\ 05 . . . & .8 & 10 & .0 & \end{array}$

02310230 - LAKE IOLA NR SAN ANTONIO FLA (LAT $28 \quad 2328$ LONG 0821754 )

$\begin{array}{ccccccccccc}\text { JUNE, } & 1970 \\ 05 . . . & 23 & 13 & .1 & 37 & 21 & 16 & 7 n & 70 & \ldots\end{array}$

02310240 - JUMPING GULLY NR LOYCE FLA ILAT 2B 2305 LONG 0922922 )

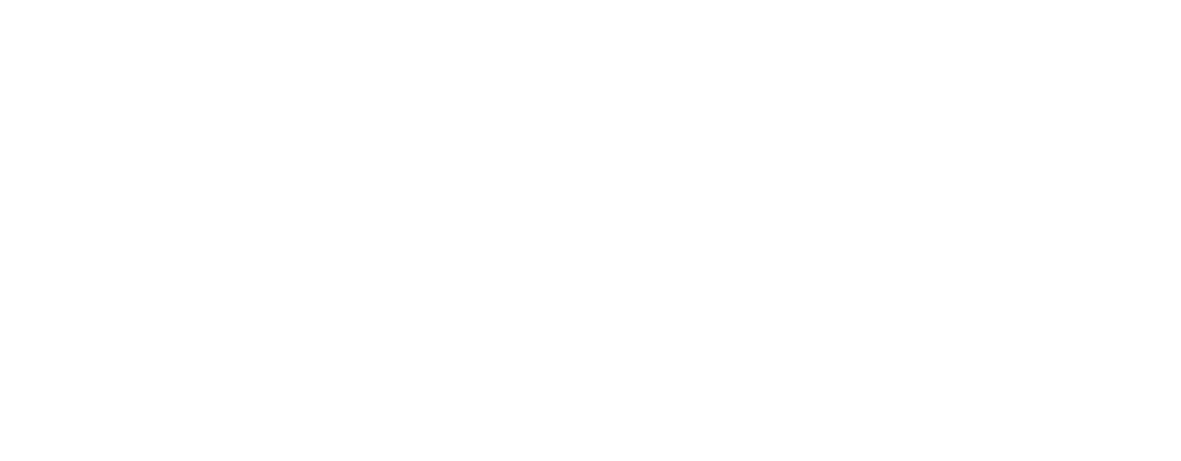

02310307 - PITHLACHASCOTEE RIVER AT NEWPORT RICHE (LAT 281424 LONG 08? 43 12)

JUNE, $1970105 \quad$ BS

02310310 - PITHLACHASCUTEE RIVER AT PORT RICHEY F (LAT 281210 LDNG 0824336 )

JUNE, 1970

9430

02310350 - BEAR CREEK NR HUDSON FLA ILAT 29 I9 10 LONG 082 3906)

MAY, 1970
$05 . .$.

02310373 - UNNAMEO SPRINGS NEAR ARIPEKA FLA ILAT 2R 2352 LONG OB2 4027

OCT. 1969

27.1969 61

MAR.. 197061

$02 \ldots . .62 \quad 434$

13... $49 \quad 370$

JUNE $\quad 29 \quad 340$

$\begin{array}{rrr}.2 & 308 & 148 \\ .1 & 305 & 147 \\ .2 & 271 & 130 \\ .1 & 260 & 98\end{array}$

$\begin{array}{lr}161 & 1020 \\ 158 & 1030 \\ 154 & 925 \\ 162 & 853\end{array}$

$946 \quad .00 \quad 1.39$

951

825

760

n2310500 - WEEKIWACHEE SPRINGS NR BROOKSVILLE FLA (LAT 2831 OO LONG OBZ 34 25)

JUNE, 1970

$02 . P^{1970} 4.8$

6.0

140

133

163

155

02310600 - GULF DF MEXICO NR RAYPORT FLA ILAT 283200 LONG 08239011

JUNE, 1970 

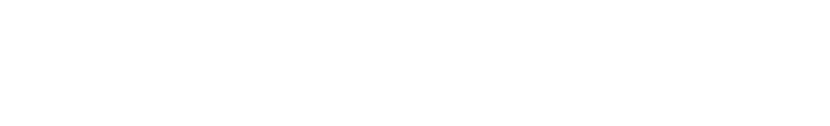

$\begin{array}{lll}\text { BICAR- } & \text { CAR- } & \\ \text { BONATE } & \text { BONATE } & \text { PH } \\ \text { (HCO3) } & \text { (CO3) } & \\ \text { (MG/L) } & \text { (MG/L) } & \text { (UNITS) }\end{array}$

CDASTAL BASINS BETWEEN HILLSBOROUGH RIVER AND HITHLACDOCHEE RIVER--CONTINUED

02310678 - HOMOSASSA SPPGS AT HOMOSASSA SPRGS FLA RAT 284758 LONG O82 35201

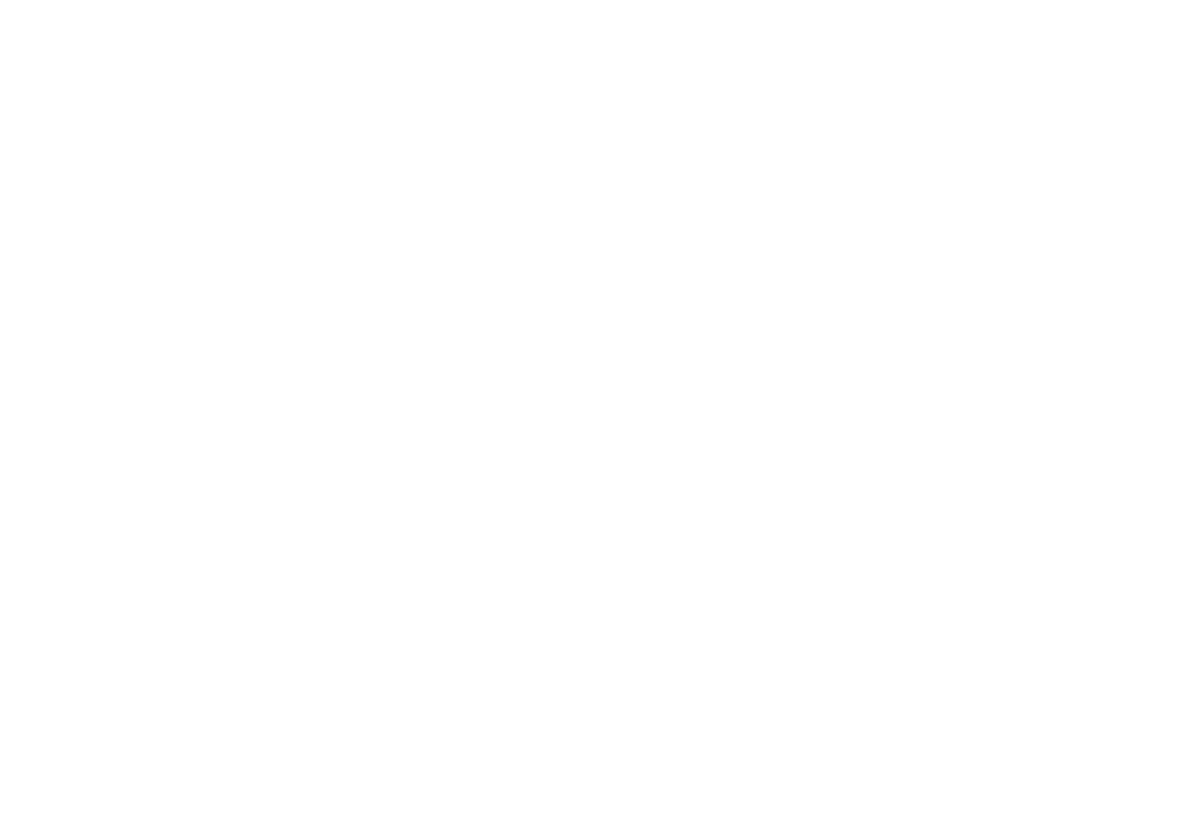

02310850 - L HELENE NR POLK CITY FLA ILAT 281025 LONG 081 49211

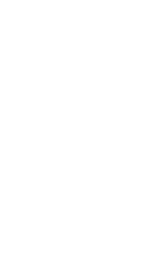

OCT 1969

OI... 1969

NOV. 287

JAN.: 1970

05 ... 549

25... 333

$\begin{array}{lll}M A Y & \\ 07 . . . & --\end{array}$

22... 18

UUG.

$12 \ldots 30$

SEP.

23... 85

\begin{tabular}{|c|c|c|c|c|}
\hline 28.0 & 121 & -- & $=$ & - \\
\hline 18.5 & 120 & -- & $\cdots$ & - \\
\hline 16.0 & 122 & -- & -- & -- \\
\hline 18.0 & 120 & -- & $\cdots$ & - \\
\hline 27.0 & 125 & -- & 4.3 & 4.2 \\
\hline 31.0 & 130 & -- & -- & - \\
\hline 29.0 & 135 & - & -- & - \\
\hline 29.5 & 132 & $\sim$ & -- & -- \\
\hline
\end{tabular}

02310947 - WITHLACOOCMEE R NR CUMPRESSCO FLA ILAT 281842 LONG 08203 22) 
CHEMICAL ANALYSES, WATER YEAR OCTOBER 1969 TO SEPTEMBER 1970 (MAJOR CONSTITUENTS)

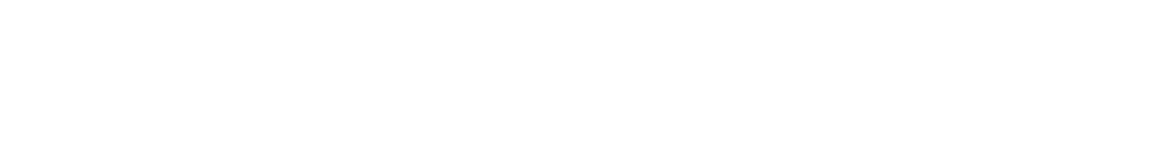

COASTAL BASINS BETWEEN HILLSBOROUGH RIVER AND WITHLACOOCHEE RIVER--CDNTINUED

02310678 - HOMOSASSA SPRGS AT HOMOSASSA SPRGS FLA (LAT 284758 LONG 08235 20)

$\begin{array}{rrrrrrrrrrrrr}\text { JUNE, } & 1970 \\ 01 . . . & 105 & 750 & 43 & 382 & 277 & 105 & 1610 & 1470 & 513 & 2.19 & \ldots\end{array}$

02310680 - MORRISON POND AT LECANTO FLA (LAT 285126 LONG 08229 04)

JUNE. 1970 11

4.5

02310688 - SE FORK HOMOSASSA SPGS AT HOMOSAS SPGS (LAT 284751 LONG 08235 23)

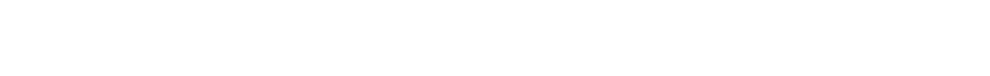

JUNE, 197080

02310700 - HOMOSASSA R AT HOMOSASSA FLA (LAT 284706 LONG 08237 05)

02310750 - CHYSTAL RIVER NR CHYSTAL Q FLA (LAT 293417 LONG 0823813 )

JUNE, 1970

$08 . .197083 \quad 600$

600

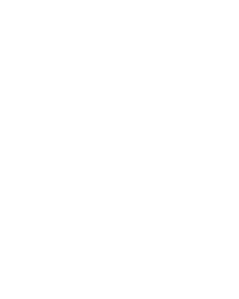

02310760 - L JULIANA NR PULM CITY FLA ILAT 280751 LONG OBI 47453

OCT.P 1969

(0.....

NOV.

$20 . .$.

JAN.: 1970

FEB.

MAY

$07 \ldots 22 \quad 17$

$\begin{array}{llllll}\text { JUNE } & & & & & \\ 22, . . & -- & -- & -- & -- & - \\ \text { AUG. } & & & & & \end{array}$

$\begin{array}{llllll}05 . . . & -- & - & - & - & -\end{array}$

23... --

02310947 - WITHLACOOCHEE R NR CUMPRESSCO FLA ULAT 281842 LONG 08? 03 2?)

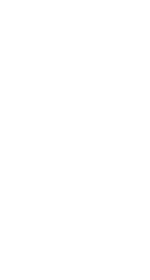


CHEMICAL ANALYSES, WATER YEAR OCTOBER 1969 TO SEPTEMBER 1970 (MAJOR CONSTITUENTS)

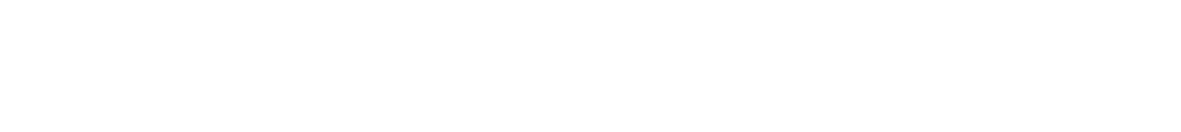
WITHLACOOCHEE RIVER BASIN--CONTINUED

02310950 - LAKE DEESON NR LAKELANO FLA (LAT 280637 LONG 0815551 )

\begin{tabular}{|c|c|c|c|c|c|c|c|c|c|c|c|c|}
\hline $\begin{array}{l}\text { OCT.. } 1969 \\
\text { O8.... } \\
\text { NOV. }\end{array}$ & - & 29.0 & 65 & -- & - & $\cdots$ & -- & - & $=-$ & -- & - & - \\
\hline $20 \ldots$ & -- & 18.0 & 64 & -- & 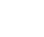 & - & $\cdots$ & $\cdots$ & - & - & - & -- \\
\hline $\begin{array}{l}\text { O6... } \\
\text { FER. }\end{array}$ & - & 16.0 & 62 & -- & -- & - & $\cdots$ & - & 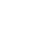 & $-\infty$ & - & - \\
\hline MAY $25 . \cdots$ & -- & 18.0 & 64 & $-=$ & - & $=$ & - & - & $-\infty$ & - & - & -. \\
\hline $\begin{array}{l}\text { O7.... } \\
\text { JUNE }\end{array}$ & -- & 27.0 & 68 & $\cdots$ & 2.7 & 1.7 & -- & 5.8 & .4 & 2 & 0 & 6.0 \\
\hline AUG... & $=-$ & 32.0 & 65 & -- & $\cdots$ & $\cdots$ & - & $-\infty$ & - & -- & $\infty$ & - \\
\hline SEP... & -- & 30.5 & 68 & - & $\cdots$ & -- & - & - & - & $-\infty$ & 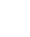 & - \\
\hline $\begin{array}{l}23 \ldots \\
23 \ldots\end{array}$ & $=$ & $\begin{array}{l}29.5 \\
30.0\end{array}$ & $\begin{array}{r}132 \\
72\end{array}$ & $\ddot{--}$ & $m$ & $=$ & $=$ & $=$ & 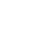 & $=$ & 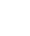 & $=$ \\
\hline
\end{tabular}

02311600 - CLEAR LAKE AT SAN ANTONIO FLA (LAT 2A 2020 LONG 0821602 )

\begin{tabular}{|c|c|c|c|c|c|c|c|c|c|c|c|c|}
\hline $\begin{array}{l}\text { NOV.. } 1969 \\
18 . \cdots 1 \\
\text { FEB.: } 1970\end{array}$ & -- & 20.5 & 205 & - & -- & -- & $=-$ & - & - & $=-$ & $-\infty$ & -- \\
\hline MAY $26 .$. & -- & 14.0 & 177 & -- & $=-$ & -- & $-\infty$ & -- & -- & $m$ & -- & - \\
\hline JUNE & -- & 25.5 & 180 & -- & 14 & 4.6 & -- & 13 & 3.4 & 48 & 0 & 7.4 \\
\hline $\begin{array}{l}24 \ldots . . \\
\text { AUG. }\end{array}$ & $-\infty$ & 30.0 & 180 & $\cdots$ & $-\infty$ & $-\infty$ & - & $=-$ & $\rightarrow$ & -- & $=$ & -- \\
\hline $\begin{array}{l}13 . . . \\
\text { SEP. }\end{array}$ & -- & 28.0 & 175 & $=-$ & $\cdots$ & - & $=$ & - & - & - & $=$ & $\cdots$ \\
\hline $25 \ldots$ & $=$ & 27.5 & 178 & -- & -- & - & -- & - & -- & $\rightarrow$ & - & \\
\hline
\end{tabular}

02311700 - DADE CITY CA NR DADE CITY FLA LLAT 282252 LONG 0821112$\}$

DEC., 1969

\begin{tabular}{|c|c|c|c|c|c|c|c|c|c|c|c|}
\hline JAN... 1970 & 2.0 & 22.0 & 320 & - & -- & -- & -- & - & -- & - & -- \\
\hline $\begin{array}{l}26 . . . \\
\text { JUNE }\end{array}$ & 72 & 27.0 & 340 & -- & -- & -- & - & -- & - & - & $\because$ \\
\hline AUG... & 65 & 30.0 & 305 & -- & $\cdots$ & -- & - & $\cdots$ & $\cdots$ & - & - \\
\hline SEP... & 12 & 28.0 & 240 & - & - & $-\infty$ & $m$ & $-\infty$ & -- & - & $=-$ \\
\hline $25 \ldots$ & 21 & 25.0 & 302 & -- & - & -- & $\cdots$ & - & - & $=$ & - \\
\hline
\end{tabular}

02312000 - NITHLACOOCHEE R AT TRILBY FLA ILAT 282847 LONG 08210401

OCT.. 1969

01... 662

NOV... 527

JAN." 1970

06... 1000

FER... 940

MAY... -

JUNE $\quad 88$

AUG. $1 . .1$ B2

SEP.

82

\begin{tabular}{|c|c|c|c|c|c|c|c|c|c|}
\hline 24.5 & 76 & $m$ & - & -- & $=$ & $=$ & $m$ & $=$ & - \\
\hline 16.5 & 104 & -- & - & - & - & - & $=$ & - & -- \\
\hline 11.5 & 87 & -- & -- & -- & $\cdots$ & - & $=$ & $=$ & - \\
\hline 15.5 & 101 & -- & $=-$ & -- & -- & - & - & -- & - \\
\hline 25.0 & 290 & - & 47 & 4.2 & $=$ & 8.2 & .3 & 156 & 0 \\
\hline 30.0 & 320 & - & - & - & $-\infty$ & $\cdots$ & -- & -- & - \\
\hline 29.0 & $22 n$ & -- & $\cdots$ & -- & -- & -- & - & - & - \\
\hline 25.5 & 221 & - & - & $=$ & $\cdots$ & $-\infty$ & 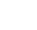 & 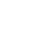 & - \\
\hline
\end{tabular}

02312100 - SPRING LAKE NR BROOKSVILLE FLA (LAT 282935 LONG 082 I7 52)

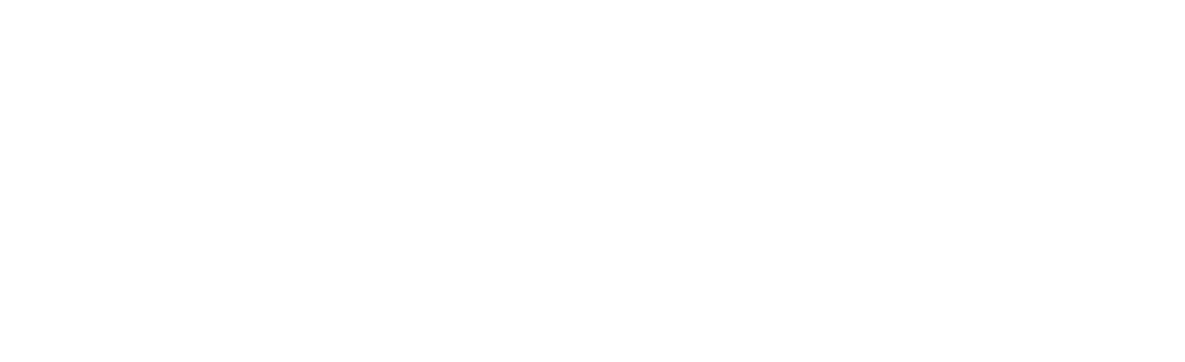


CHEMICAL ANALYSES, WATER YEAR OCTOBER 1969 TO SEPTEMBER 1970 (MAJOR CONSTITUENTS)

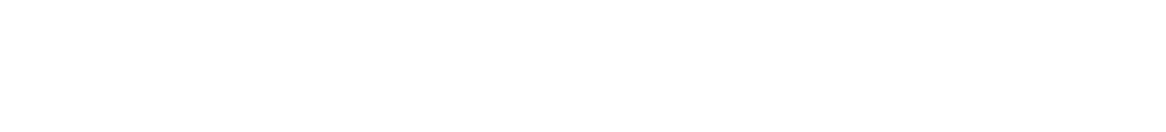

WITHLACDOCHEE RIVER, BASIN--CONTINUED

02310950 - LAKE DEESON NR LAKELAND FLA (LAT 280637 LONG O81 5551 )

0 OCT.. 1969
$08 . .$.

02311600 - CLEAR LAKE AT SAN ANTONIO FLA (LAT 282020 LONG 08216 02)

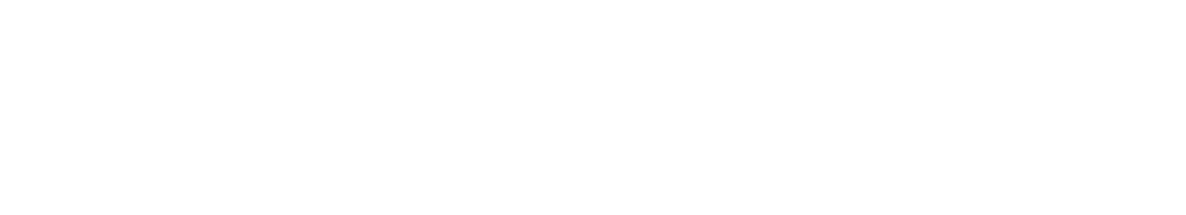

02311700 - DADE CITY CA NR DADE CITY FLA (LAT 2A 2252 LONG 0821112 )

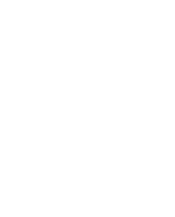

$\begin{array}{lll}-- & -- & - \\ -- & -- & - \\ -- & -- & - \\ -- & -- & - \\ -- & -- & -\end{array}$

02312000 - WITHLACOOCHEE R AT TRILEY FLA (LAT 282847 LONG OB2 1040 )

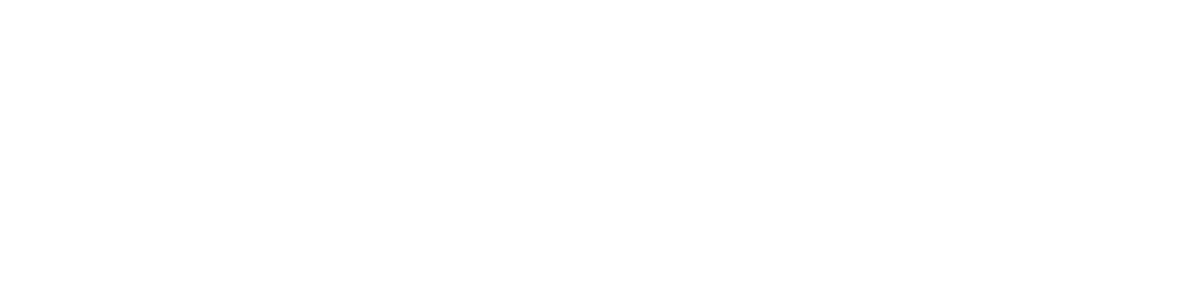

02312100 - SPRING LAKE NR 8ROOKSVILLE FLA (LAT 282935 LONG nB2 1752 )

\begin{tabular}{|c|c|c|c|c|c|c|c|c|c|c|c|c|c|}
\hline $\begin{array}{l}\text { MAY }, 1970 \\
07 . . .\end{array}$ & 3.0 & 13 & .3 & 133 & 0 & 135 & 169 & 168 & -- & .23 & & -- & -- \\
\hline & & 02312140 & - & BAYROOT SLOUGH & HDWTRS & NR BAY & LAKE FLA & ILAT $28 \quad 27$ & 23 LONG & 08155 & 14) & & \\
\hline NOV.., 1969 & & & & & & & & & & & & & \\
\hline $02 \ldots$ & $\cdots$ & -- & -- & -- & - & $=-$ & -- & -- & -- & -- & & -- & 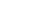 \\
\hline 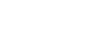 & $-\infty$ & $\cdots$ & -- & - & -- & -- & -- & -- & $-\infty$ & -- & & -- & $\cdots$ \\
\hline $08 \ldots$ & -- & -- & $\cdots$ & $-\infty$ & - & - & - & -- & -- & - & & -- & - \\
\hline FEB. & - & -- & -- & -- & -- & 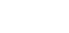 & - & -- & - & - & & $=-$ & - \\
\hline MAY $24 \ldots$ & - & - & -- & -- & -- & - & - & - & $\cdots$ & -- & & -- & $\cdots$ \\
\hline AU... & 1.6 & 12 & .2 & 13 & 12 & 2 & 86 & 27 & -- & .12 & & -- & - \\
\hline $\begin{array}{l}\text { O5... } \\
\text { SEP. }\end{array}$ & 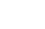 & -- & -- & - & - & - & - & $\cdots$ & $\cdots$ & -- & & $-\infty$ & - \\
\hline $23 \ldots$ & -- & -- & -- & -- & - & $\cdots$ & -- & -- & -- & -- & & -- & - \\
\hline
\end{tabular}




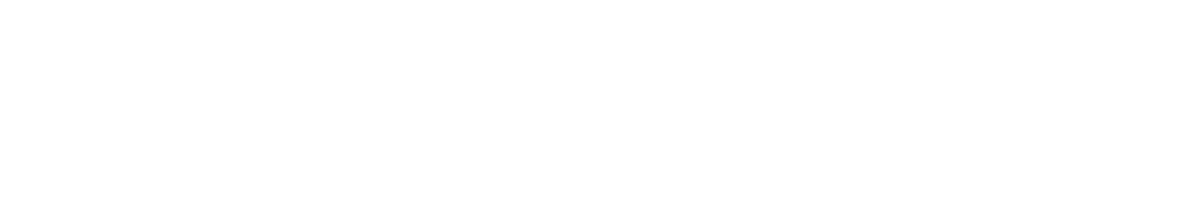
WITHLACDNCHEE RIVER BASIN--CONTINUED

02312150 - L CATHERINE AT GROVELANO FLA ILAT 283427 LONG 08151371

\begin{tabular}{|c|c|c|c|c|c|c|c|c|c|c|c|c|}
\hline $\begin{array}{l}\text { NOV., } 1969 \\
18 \ldots . .1970 \\
\text { JAN., } 1990\end{array}$ & - & 17.5 & $25 n$ & -- & - & -- & -- & $\cdots$ & -- & - & 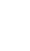 & -- \\
\hline $\begin{array}{l}07 . \ldots \\
\text { FEB. }\end{array}$ & -- & 14.0 & 271 & -- & -- & -- & -- & -- & -- & -- & - & -- \\
\hline MAY $24 \ldots$ & -- & 16.5 & 301 & -- & - & - & -- & -- & -- & - & -- & -- \\
\hline JUNE & -- & 24.5 & $3 n 6$ & -- & 46 & 4.4 & -- & 12 & 4.3 & 164 & $n$ & 7.4 \\
\hline $\begin{array}{l}22 . . . \\
\text { AUG. }\end{array}$ & -- & 30.0 & 310 & -- & $\cdots$ & - & -- & -- & -- & -- & - & $\cdots$ \\
\hline SEP... & $\cdots$ & 31.0 & 250 & - & - & -- & -- & - & -- & -- & - & $=$ \\
\hline $23 \ldots$ & -- & - & $25 ?$ & -- & -- & -- & - & -- & -- & -- & -- & - \\
\hline
\end{tabular}

02312190 - LITTLE WITHLACOOCHEE RIVEF NR TARRYTOW (LAT 283117 LONG nA2 03 1H)

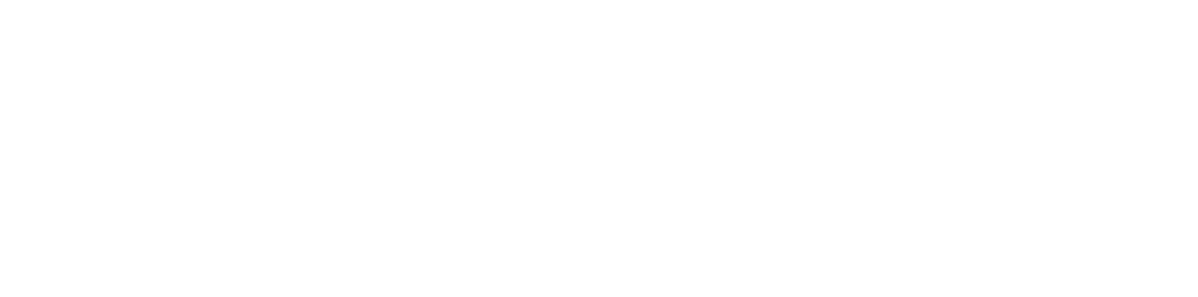

02312194 - BIG GANT CA AT STR S-1I NR WEBSTER, FL ILAT 283447 LONG OB? 05 451

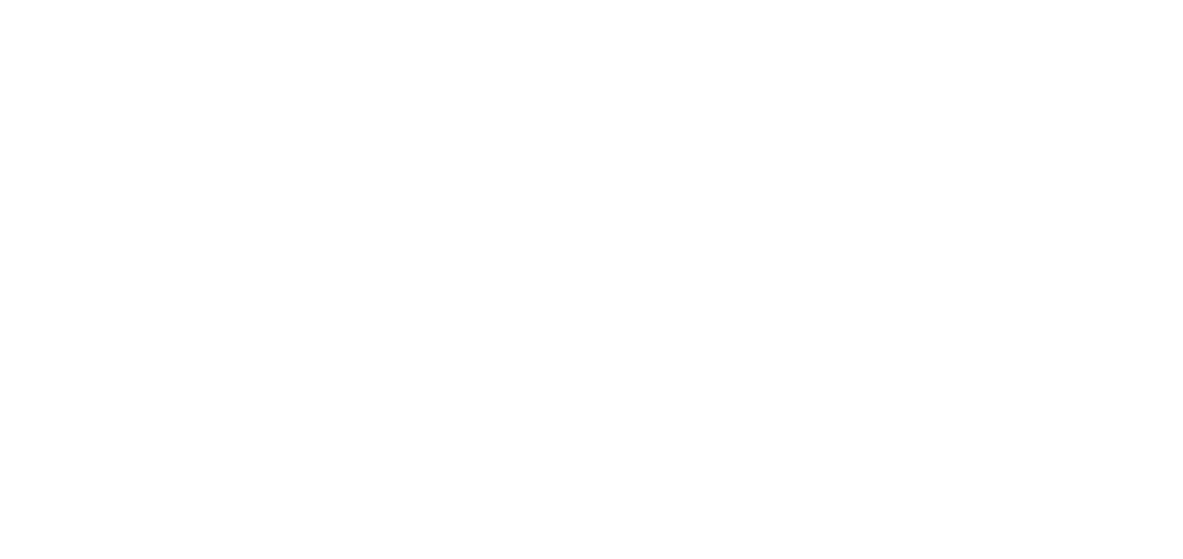

02312500 - WITHLACUOCHEE R AT CROOM FLA (LAT 283533 LONG O82 13 ?n)

\begin{tabular}{|c|c|c|c|c|c|c|c|c|c|c|c|c|c|}
\hline nov... & 1010 & & 24.0 & 84 & - & $=-$ & -- & -- & -- & -- & -- & -- & -- \\
\hline $\begin{array}{l}\text { 19..." } \\
\text { JAN., }\end{array}$ & $1970^{911}$ & & 17.0 & 124 & $m$ & - & -- & -- & -- & -- & -- & - & -- \\
\hline MAR.. & 1540 & & 12.5 & 105 & - & -- & -- & -- & - & -- & - & -- & - \\
\hline $\begin{array}{l}03 . . . \\
\text { MAY }\end{array}$ & 1070 & & 19.5 & 125 & -- & -- & - & $=$ & $\cdots$ & - & -- & -- & -- \\
\hline $\begin{array}{l}13 \ldots . . \\
\text { JUNE. }\end{array}$ & & -- & 25.5 & 290 & -- & 51 & 3.5 & $\cdots$ & $6 . n$ & .3 & 166 & -- & 7.8 \\
\hline $\begin{array}{l}24 \ldots . \\
\text { AUG. }\end{array}$ & 176 & & 29.0 & 305 & -- & $=-$ & -- & -- & -- & -- & -- & -- & -- \\
\hline O6... & 151 & & 29.5 & $24 n$ & - & - & - & -- & - & -- & -- & -- & -- \\
\hline $28 \ldots$ & 240 & & 27.0 & 242 & - & - & $=$ & $\infty$ & -- & -- & -- & -. & - \\
\hline
\end{tabular}


CHEMICAL ANALYSES, WATER YEAR OCTOBER 1969 TO SEPTEMBER 1970 (MAJOR CONSTITUENTS)

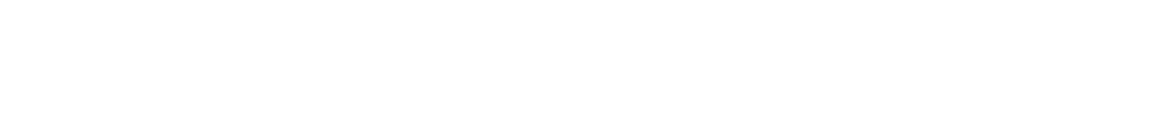

WITHLACONCHEE RIVER BASIN--CDNTINUED

02312150 - L CATHERINE AT GROVELAND FLA (LAT 283427 LONG 08151 37)

NOV., 1969
$18 . . .1970$ 02312180 - LITTLE WITHLACOOCHEL RIVLR NR TARRYTOW \&LAT 283117 LONG 08> 03 18)

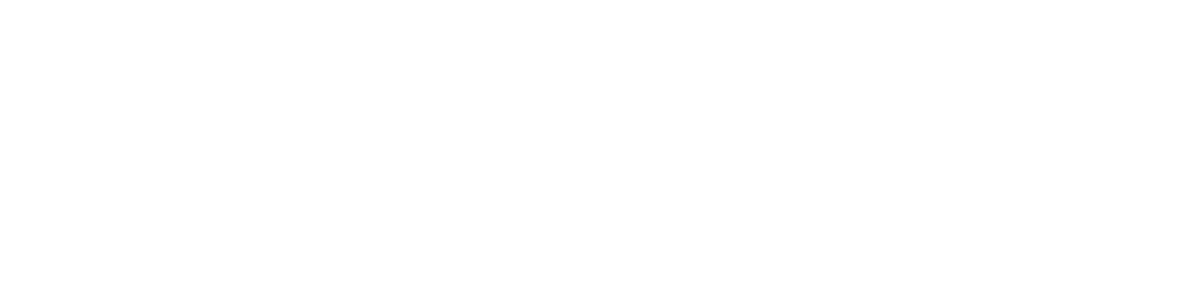

02312194 - BIG GANT CA AT STR S-11 NR WEBSTER, FL ILAT 283447 LONG BBP 0545 ।

SEP.. 1970

02312197 - BIG GANT CA AT STR WC-2 AT RERDELL FLA (LAT 283416 LONG 9BZ 08 521

SEP., 1970

02312198 - BIG GANT CA BL STR AC-2 AT RERDELL FLA (LAT 28 $34 \quad 16$ LONG 08208 b4)

SEP.. 1410

02312200 - LITTLE WITHLACOOCHEE R AT QERDELL FLA (LAT 283421 LONG 0RZ 0920 )

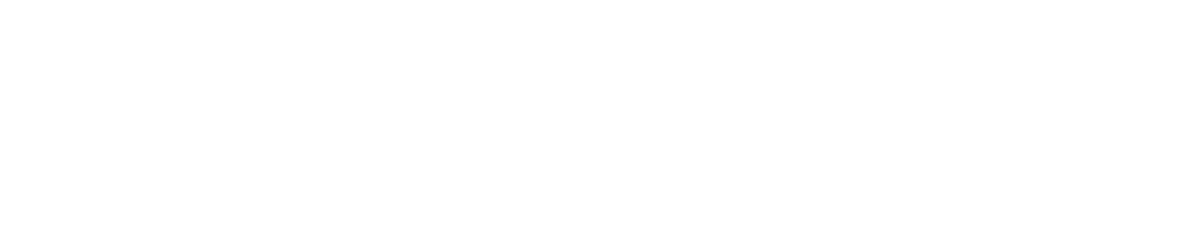

02312500 - WITHLACOOCHEE R AT CPOOM FLA (LAT 2A 3533 LONG OR2 13 20)

\begin{tabular}{|c|c|c|c|c|c|c|c|c|c|c|c|}
\hline $\begin{array}{l}\text { ост... } 1969 \\
\text { 01... }\end{array}$ & -- & -- & -- & -- & -- & -- & -- & -- & -- & - & - \\
\hline $\begin{array}{l}\text { NDV. } \\
19 \ldots . .1970 \\
\text { JAN.. } 1970\end{array}$ & $-\infty$ & - & $\infty$ & -- & -- & -- & -- & $\cdots$ & -- & $-\infty$ & -- \\
\hline $07 \ldots$ & -- & - & -- & -- & $\cdots$ & -- & -- & - & -- & -- & -- \\
\hline $03 . .$. & -- & - & -- & $\cdots$ & -- & - & -- & -- & -- & -- & -- \\
\hline $\begin{array}{l}\text { MAY } \\
13 . . .\end{array}$ & 6.6 & 9.0 & .2 & 142 & 6 & 136 & 175 & 166 & -- & .24 & -- \\
\hline $\begin{array}{l}24 \ldots . . \\
A \cup G .\end{array}$ & $-\infty$ & -- & -- & - & - & -- & - & -- & - & -- & -- \\
\hline SEP... & -- & -- & -- & -- & -- & - & -- & - & - & -- & $\cdots$ \\
\hline & - & -- & $\cdots$ & -- & $\cdots$ & -- & $=$ & - & $\cdots$ & - & -- \\
\hline
\end{tabular}




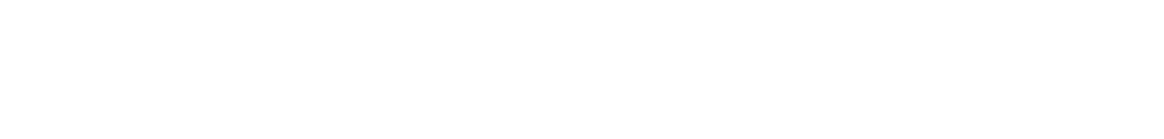

WI THLACONCHEE RIVER BASIN--CNNTINUED

02312530 - BLUE SINK DRAIN NR GR0OKSVILLE FLA (LAT 283630 LONG OB2 2021 )

\begin{tabular}{|c|c|c|c|c|c|c|c|c|c|c|c|c|}
\hline $\begin{array}{l}\text { JAN.". } \\
\text { O6... } \\
\text { FER." }\end{array}$ & 13 & 13.5 & 88 & - & - & - & $=$ & - & - & - & - & - \\
\hline $\begin{array}{l}04 \ldots \\
\text { MAR... }\end{array}$ & 90 & 11.0 & 75 & - & - & - & -- & -- & - & - & - & - \\
\hline $24 \ldots$ & .54 & 21.5 & 99 & -- & - & - & -- & - & - & $=$ & - & - \\
\hline $\begin{array}{l}\text { MAY } \\
\text { O1... } \\
\text { SEP. }\end{array}$ & .00 & 26.5 & 135 & - & 19 & 2.9 & - & 4.3 & 2.9 & 64 & 0 & 7.0 \\
\hline $15 \ldots$ & -- & 28.0 & 111 & - & - & - & -- & - & -- & -- & - & \\
\hline
\end{tabular}

02312600 - WITHLACOOCHEE R NR FLORAL CITY FLA (LAT 284436 LONG 0821313 )

NOV., 1969

$21 \cdots 822$

JAN., 1970

$02 \ldots 13$

MAY

$12 \ldots$

26... 280

26...

14 ... 268

$29 . . .198$

OCT., 1969

Nov...

$19 \ldots . .{ }^{43}$

JAN., 197065

(2)

26... 92

MAY

OUNE...

24... 19

SEP... 26

25... 29

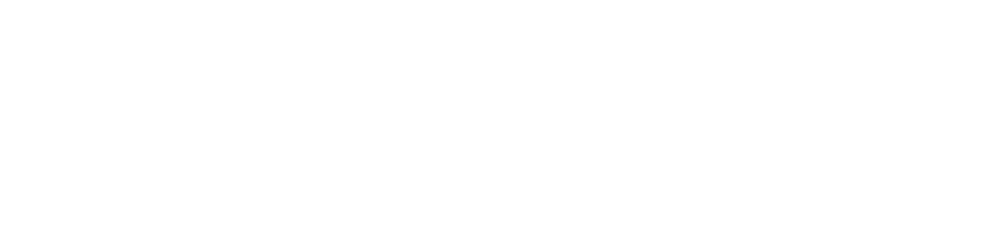

02312640 - JUMPER CR CA NR BUSHNELL FLA (LAT 284145 ( ONG 08206 34)

\begin{tabular}{|c|c|c|c|c|c|c|c|c|c|}
\hline 25.0 & 480 & -- & -- & $-\infty$ & - & -- & -- & -- & - \\
\hline 19.0 & 405 & - & - & $-=$ & - & $\rightarrow$ & -- & -- & - \\
\hline 11.0 & 320 & - & - & - & -- & -- & - & $=$ & - \\
\hline 19.0 & 325 & -- & - & - & -- & -- & 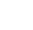 & -- & $=$ \\
\hline 27.5 & 420 & -- & 80 & 1.9 & $=$ & 8.1 & .2 & 248 & 0 \\
\hline 30.0 & 415 & -- & $=$ & -- & - & -- & - & $\infty$ & - \\
\hline 26.0 & 430 & -- & -- & - & $=$ & -- & - & - & - \\
\hline 24.0 & 373 & -- & $\cdots$ & -- & -- & - & -- & - & $\cdots$ \\
\hline
\end{tabular}

02312685 - WALLED SINK DRAIN NR COLEMAN, FLA. (LAT 29 4505 LONG 08202 05)

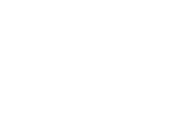

18.0
19.5
26.5
27.0

02312694

LADY LAKE NR LADY LAKE, FLA. ILAT 2855 OO LONG OAI 5350 )

MAY, 1970

15...

$30.0 \quad 100$

$\begin{array}{lllll}30 & 3.1 & 2.6 & 0 & 11\end{array}$

$2.0 \quad 3$

6.2

02312698 - L PANASOFFKEE NR L PANASOFFKEE FLA ILAT 284830 LONG 0820810 )

\begin{tabular}{|c|c|c|}
\hline $\begin{array}{l}\text { OCT., } 1969 \\
\text { O2... } \\
\text { Nov. }\end{array}$ & -- & 25.0 \\
\hline JAN... 1970 & -- & 15.5 \\
\hline $\begin{array}{l}07 \ldots \\
\text { FEB. }\end{array}$ & -- & 12.5 \\
\hline $27 \ldots$ & -- & 15.0 \\
\hline JUNE & -- & 27.0 \\
\hline AUG.." & $\cdots$ & 30.0 \\
\hline $\begin{array}{l}\text { O6... } \\
\text { SEP.... }\end{array}$ & - & 32.5 \\
\hline
\end{tabular}




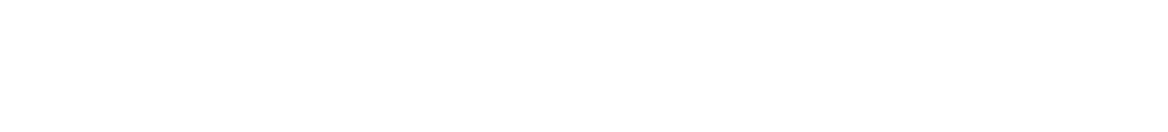

HITHLACATCHEE RIVER BASIN--CONTINUED

02312530 - BLUE SINK DRAIN NR BROOKSVILLE FLA (LAT 293630 LONG 08220211

\begin{tabular}{|c|c|c|c|c|c|c|c|c|c|c|c|c|}
\hline $\begin{array}{l}\text { JAN., } 1970 \\
\text { O6.... } \\
\text { FEB. }\end{array}$ & - & - & -- & -- & -- & $=$ & - & $=$ & -- & -- & - & -- \\
\hline MAR... & - & - & - & -- & -- & -- & -- & -- & -- & $m$ & 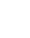 & - \\
\hline MAY $24 \cdots$ & $\cdots$ & - & - & -- & - & - & -- & -- & -- & -- & - & -- \\
\hline $\begin{array}{l}01 \ldots \\
\text { SEP. }\end{array}$ & 1.0 & 7.5 & .2 & 60 & 7 & 52 & 86 & 72 & .00 & .12 & -- & -- \\
\hline $15 \ldots$ & -- & -- & -- & -- & - & -- & - & -- & -- & - & $\cdots$ & - \\
\hline
\end{tabular}

02312600 - WITHLACOOCHEE R NR FLORAL CITY FLA (LAT 284436 LDNG 0821313 )

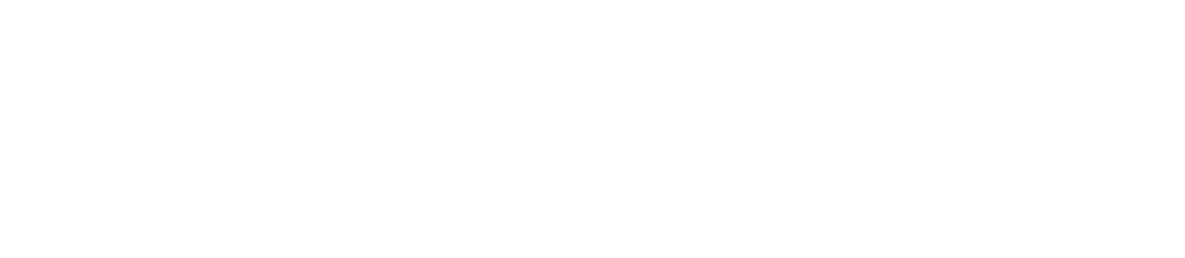
02312640 - JUMPER CR CA NR BUSHNFLL FLA (LAT 284145 LONG OBP NG 34)

OCT. 1969

$01 .$.

NOV.

$19 . . .1970$

JAN... 1970
J6...

ER.

26...

MAY

OB...

$24 .$.
AUG.

AUG.

SEP.

25 ..

$\begin{array}{llll}- & - & - & - \\ -- & - & - & - \\ -- & -- & - & - \\ -- & -- & - & - \\ -- & -2 & 208 & - \\ - & -- & - & -\end{array}$

02312585 - WALLED SINK ORAIN NR COLEMAN, FLA. (LAT 29 4505 LONG 08? 0205 )

FEB.. 1970
$03 . .$.

02312694 - LADY LAKE NR LADY LAKE, FLA. (LAT 285500 LONG 081 5350 )

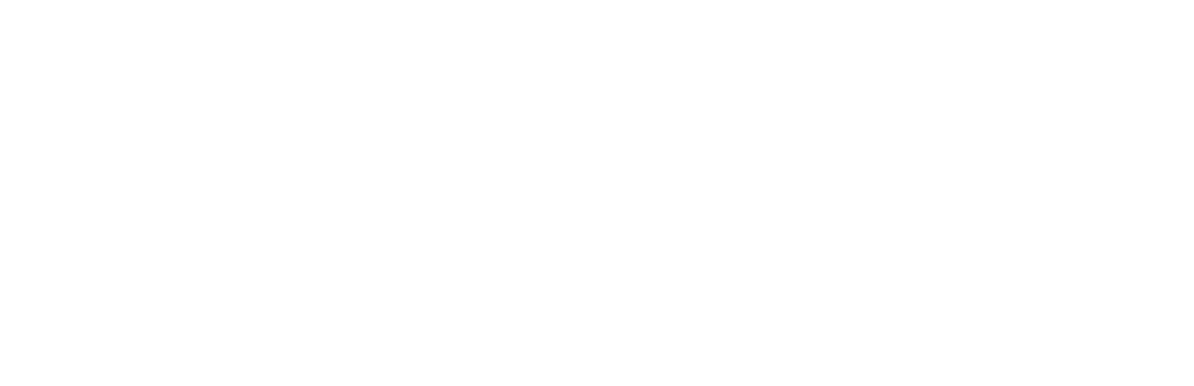




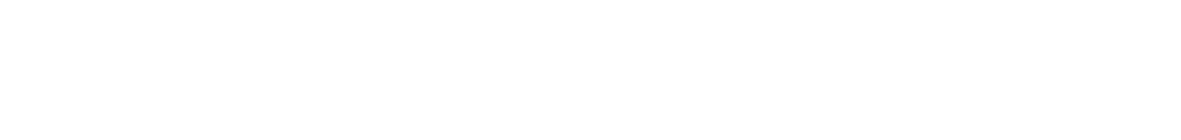

WITHLACOOCHEE RIVER BASIN--CONTINUET

02312700 - OUTLET RIVER AT PANACOOCHEE RETREATS, (LAT 2848 30 LONG OBP 08101

ОСТ., 1969

O2... 258

20... 256

JAN.: 1970

$07 \ldots 337$

FER.

$27 \ldots . .498$

MAY

JUNE

$21 \ldots 186$

AUG. 244

SEP. 29

300

UTLET RIVER AT PANACOOCHE

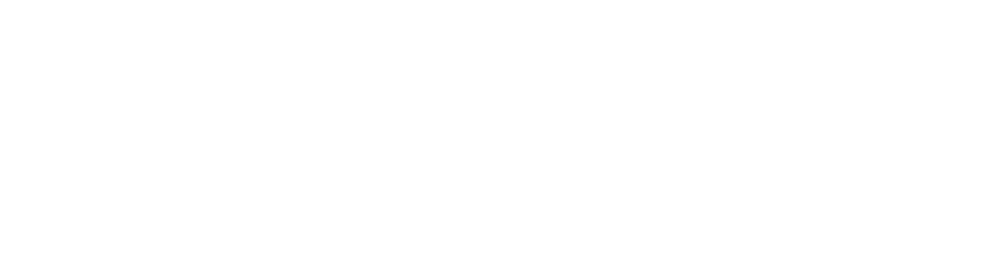

02312719 - WITHLACOOCHEE R AB WYSONG RAM AT CARLS (LAT 284924 LONG 08210 59)

FEB., 1970
27... 2310
SEP.

$28 . .522$

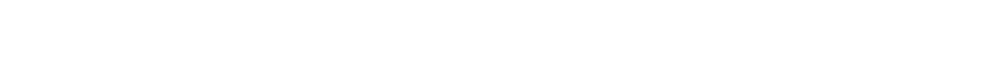

02312720 - WIHLACOOCHEE R AT WYSONG OAM AT CARLS ILAT 284924 LONG OR? 10 59)

OCT. 1969

NOS. 1320

$20 \ldots 1390$

JAN., 1970

07... 2260

FEB.
$27 . . .2310$

14... 500

O6... 518

$28 . . .522$

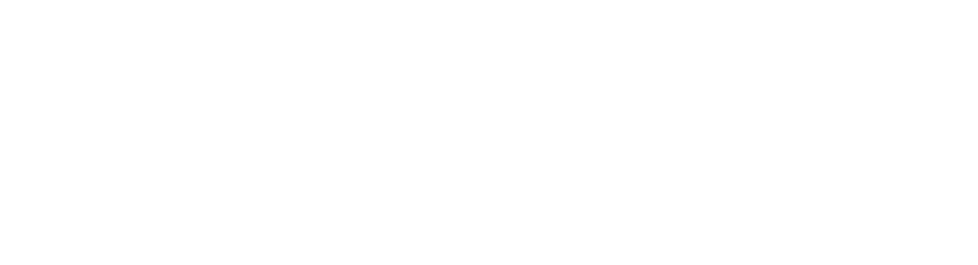

02312772 - LESLIE-HE IFNER CANAL NR FLORAL CITY FL (LAT 284520 LONG 08213501

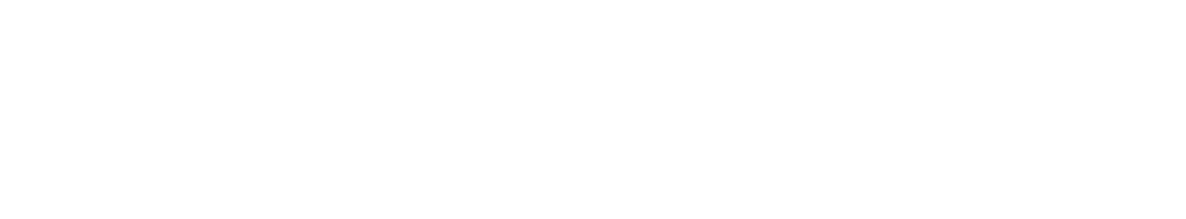

02312786 - THE ORANGE STATE CA NR FLORAL CITY FLA (LAT $2844 \quad 48$ LONG 0821549 )

\begin{tabular}{|c|c|c|c|c|c|c|c|c|c|c|c|c|}
\hline $\begin{array}{r}\text { NOV.: } \\
21 . . . \\
\text { JAN.. }\end{array}$ & $1790^{47}$ & 12.5 & 126 & -- & -- & - & - & - & $\cdots$ & -- & - & - \\
\hline MAR... & 172 & 9.0 & 112 & $m$ & -- & -- & -- & -- & - & $=$ & - & $\cdots$ \\
\hline${ }_{\text {MAY }}^{02 \ldots}$ & 139 & 15.5 & 122 & 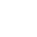 & -- & $=$ & - & - & - & -- & - & - \\
\hline JUNE & - & 25.0 & 135 & -- & 24 & 1.5 & $m$ & 5.2 & .1 & 65 & $n$ & 7.1 \\
\hline $\begin{array}{l}26 . . \\
\text { AUG. }\end{array}$ & .00 & 28.0 & 165 & - & $\cdots$ & -- & $\Rightarrow$ & - & $\cdots$ & - & - & - \\
\hline $\begin{array}{l}14 \ldots \\
\text { SEP.: }\end{array}$ & .00 & 25.5 & 215 & -- & -- & -- & - & $\cdots$ & - & - & - & $=$ \\
\hline $29 \ldots$ & 13 & 25.0 & 251 & - & -- & -- & -- & - & $\cdots$ & $\infty$ & $-\infty$ & \\
\hline
\end{tabular}

02312800 - TSALA APOPKA LK AT FLORAL CITY FLA (LAT $2 B 4503$ LONG OB2 1649 )

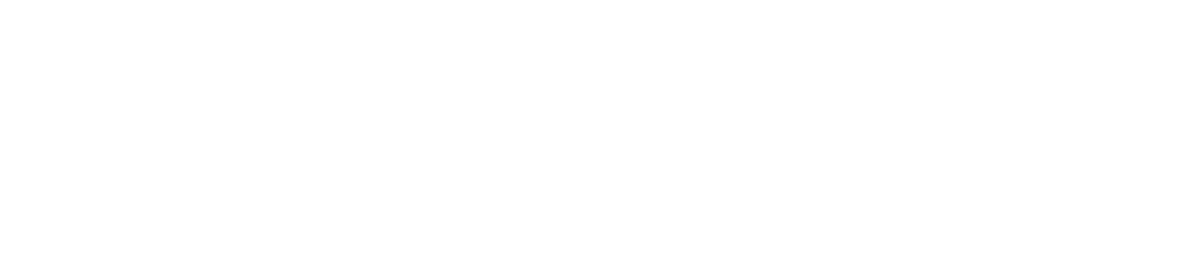


CHEMICAL ANALYSES, WATER YEAR OCTOBER 1969 TO SEPTEMBER 1970

CHEMICAL ANALYSES, WATER YEAR OCTOBER
(MAJOR CONSTITUENTS)

\begin{tabular}{|c|c|c|c|c|c|c|c|c|c|c|}
\hline $\begin{array}{l}\text { DIS- } \\
\text { SOLVED } \\
\text { SULFATE } \\
\text { (SO4) } \\
\text { (MG/L) }\end{array}$ & $\begin{array}{l}\text { OIS- } \\
\text { SOLVED } \\
\text { CHLO- } \\
\text { RIDE } \\
\text { (CL) } \\
\text { (MG/L) }\end{array}$ & $\begin{array}{l}\text { DIS- } \\
\text { SOLVED } \\
\text { FLUO- } \\
\text { RIDE } \\
\text { (F) } \\
\text { (MG/L) }\end{array}$ & $\begin{array}{l}\text { HARD- } \\
\text { NESS } \\
\text { (CA,MG) } \\
\text { (MG/L) }\end{array}$ & $\begin{array}{l}\text { NON- } \\
\text { CAR- } \\
\text { BONATE } \\
\text { HARD- } \\
\text { NESS } \\
\text { (MG L }\end{array}$ & $\begin{array}{l}\text { ALKA- } \\
\text { LINITY } \\
\text { AS } \\
\text { CACO3 } \\
\text { (MG/L) }\end{array}$ & $\begin{array}{l}\text { DIS- } \\
\text { SOLVED } \\
\text { SOLIDS } \\
\text { (RESI - } \\
\text { DUE AT } \\
180 \text { C) } \\
\text { (MG L) }\end{array}$ & $\begin{array}{l}\text { DIS- } \\
\text { SOLVED } \\
\text { SOLIDS } \\
\text { (GUM OF } \\
\text { CONSTI- } \\
\text { TUENTS) } \\
\text { (MG/L) }\end{array}$ & $\begin{array}{l}\text { DIS- } \\
\text { SOLVED } \\
\text { SOLINS } \\
\text { (TONS } \\
\text { PER } \\
\text { DAY) }\end{array}$ & $\begin{array}{l}\text { DIS- } \\
\text { SOLVED } \\
\text { SOLIDS } \\
\text { ITONS } \\
\text { PER } \\
\text { AC-FTI }\end{array}$ & $\begin{array}{l}\text { TANN IN } \\
\text { ANN } \\
\text { LIGNIN } \\
\text { (MG/L) }\end{array}$ \\
\hline
\end{tabular}

WI THLACOOCHEE RIVER BASIN--CONTINUED

- 02312700 - outlet river at panacoochee retreats, (llat 284830 long 08208 in)

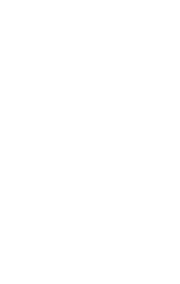

02312719 - WITHLACOOCHEE R AB WYSONG DAM AT CARLS ILAT 244924 LONG OBZ 10591

FEB., 1970

27 ...

SEP.

OCT., 1969

$0, \ldots .0$

NOV....
JAN.: 1970

JAN... 1970

FEB.

$27 . .$.

$\begin{array}{ll}14 \ldots . . & 9.1 \\ 26 . . . & -1\end{array}$

AUG.

SE....

28 ...

NOV.. 1969

21 ...

JAN.: 1970

$08 .$. .

MAR.

02 ..

JUNE

AUG.

SEP.

$29 .$.

NOV., 1969

21... 1969

JAN.. 1970

$08 \ldots$

O2..

MAY

12 JUNE.

$26 .$.

SEP.

29...

NOV., 1969

JAN... 1970

$08 . .$.

MAR.

MAY

MAY $12 .$.

JUNE

AUG.

AUG.

SEP.

$24 .$.

02312720 - WITHLACOOCHEE R AT WYSONG DAM AT CAPLS \&LAT 294924 LONG 0821059 ।

\begin{tabular}{|c|c|c|c|c|c|c|c|c|c|}
\hline-- & -- & -- & -- & $m$ & 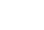 & 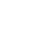 & $=$ & - & $=$ \\
\hline-- & $=$ & -- & -- & -- & - & -- & -- & -- & - \\
\hline-- & - & -- & -- & - & - & $=$ & - & - & - \\
\hline-- & -- & - & -- & -- & -- & - & $=$ & -- & -- \\
\hline $\begin{array}{r}8.6 \\
--\end{array}$ & -3 & $1 \geq 8$ & 14 & 115 & 172 & $\begin{array}{r}148 \\
-D\end{array}$ & $\ddot{z}$ & .23 & $=$ \\
\hline- & -- & - & -- & -- & -- & $=-$ & -- & -- & -- \\
\hline-- & + & -- & -- & -- & - & -- & -- & - & -- \\
\hline
\end{tabular}

02312772 - LESLIE-HEIFNER CANAL NR FLORAL CITY FL ILAT 284520 LONG 08213501

\begin{tabular}{|c|c|c|c|c|c|c|c|c|c|c|}
\hline- & -- & -- & -- & - & -- & - & - & -- & - & $m$ \\
\hline- & - & -- & - & -- & -- & -- & -- & - & - & - \\
\hline- & -- & -- & $=$ & - & - & -- & -- & -- & -- & $=$ \\
\hline-- & $=$ & $=-$ & - & - & $=$ & - & $\cdots$ & -- & - & -- \\
\hline -- & -- & -- & $=$ & -- & - & -- & -- & - & $=$ & - \\
\hline -- & - & -- & - & -- & -- & -- & -- & - & -- & \\
\hline
\end{tabular}

02312785 - THE ORANGE STATE CA NR FLORAL CITY FLA (LAT 284448 LONG 092 I5 49)

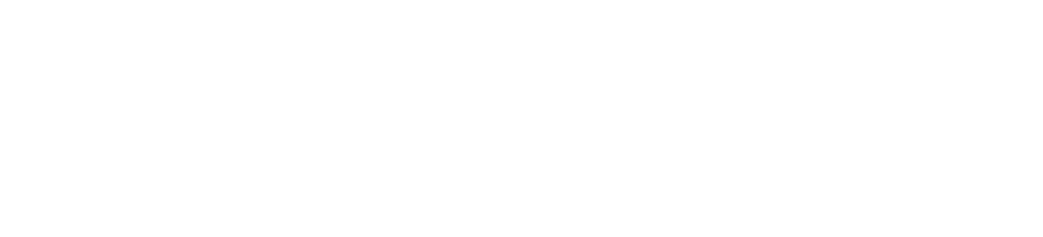

02312800 - TSALA APOPKA LK AT FLORAL CITY FLA ILAT $>84503$ LONG 08216491 


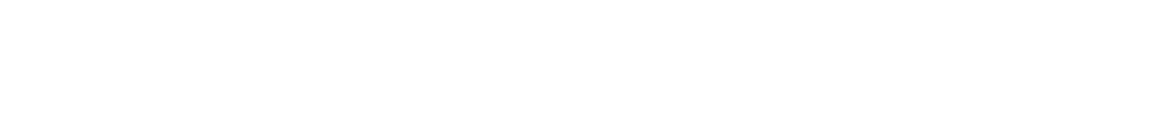

WITHLACODCHEE RIVER BASIN--CONTINUED

02312900 TSALA APOPKA L AT INVERNESS FLA (LAT 285039 LONG 08219211

\begin{tabular}{|c|c|c|c|c|c|c|c|c|c|c|c|c|}
\hline vov... 1969 & -- & 17.0 & 118 & - & $-\infty$ & -- & - & - & - & $\cdots$ & - & 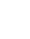 \\
\hline $07 . .$. & - & 13.5 & 114 & - & -- & -- & - & - & - & - & - & $\infty$ \\
\hline & - & 20.0 & 108 & - & - & $\cdots$ & - & - & -- & $\cdots$ & - & - \\
\hline $\begin{array}{l}26 . . . \\
\text { AUG. }\end{array}$ & - & 30.0 & 420 & -- & - & - & - & - & - & -- & - & - \\
\hline SEP... & - & 34.0 & 130 & - & -- & - & - & - & - & -- & - & \\
\hline $24 \ldots$ & $m$ & 28.5 & 132 & - & -- & $\cdots$ & $m$ & - & - & $m$ & $=$ & \\
\hline
\end{tabular}

02312950 - TSALA APOPKA LK AT HERNANDO FLA ILAT 285409 LONG 0822231 )

\begin{tabular}{|c|c|c|c|c|c|c|c|c|c|c|c|c|}
\hline $\begin{array}{l}\text { NOV... }{ }^{1969} \\
21 . \ldots{ }^{2} \\
\text { JAN... } 1970\end{array}$ & $=$ & 17.0 & 119 & $-\infty$ & - & $=$ & - & -- & - & - & - & - \\
\hline $\begin{array}{l}07 . . . \\
\text { MAR. }\end{array}$ & $m$ & 13.0 & 117 & -- & -- & -- & -- & $\cdots$ & - & -- & - & $\cdots$ \\
\hline MAY & $\cdots$ & 20.0 & 121 & - & - & -- & - & -- & - & -- & - & $\cdots$ \\
\hline JUNE & $-\infty$ & 31.0 & 115 & - & 18 & 1.5 & 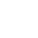 & 5.0 & .1 & 53 & 0 & 7.3 \\
\hline $\begin{array}{l}26 \ldots . . \\
\text { AUG. }\end{array}$ & - & 30.0 & 120 & - & -- & -- & - & - & - & - & $\cdots$ & $\cdots$ \\
\hline SEP.. & - & 28.0 & 110 & - & -- & - & - & $\cdots$ & $\cdots$ & $\cdots$ & $\cdots$ & $\cdots$ \\
\hline $29 .$. & - & 27.5 & 116 & - & - & -- & -- & - & - & - & - & - \\
\hline
\end{tabular}

02312975 - ISALA APOPKA OUTFALL CA AT S353 NR HER (LAT 285719 LONG 0822013 )

OCT., 1969

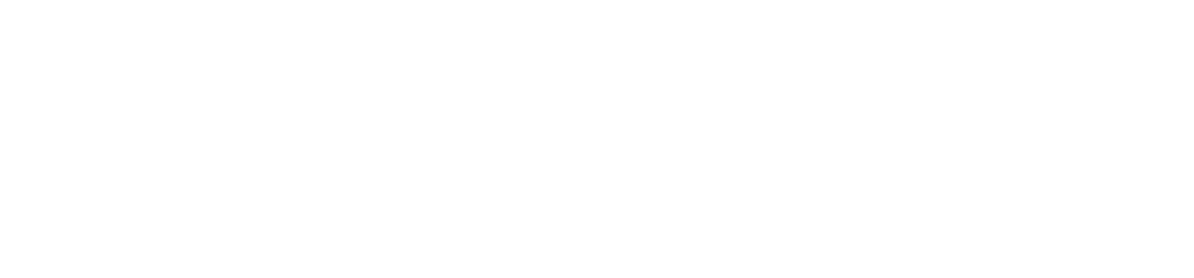

02312976 - TSALA AFUPKA OUTFALL CA SL S353 NR HER (LAT 28 5T 19 LONG 08220 13)

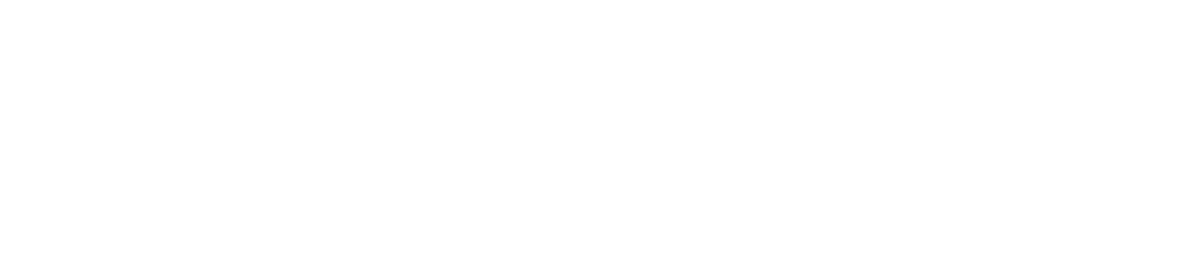

02313180 - BLUE RUN AT DUNNELLDN, FLA. ILMT 290257 LONG 0822653 )

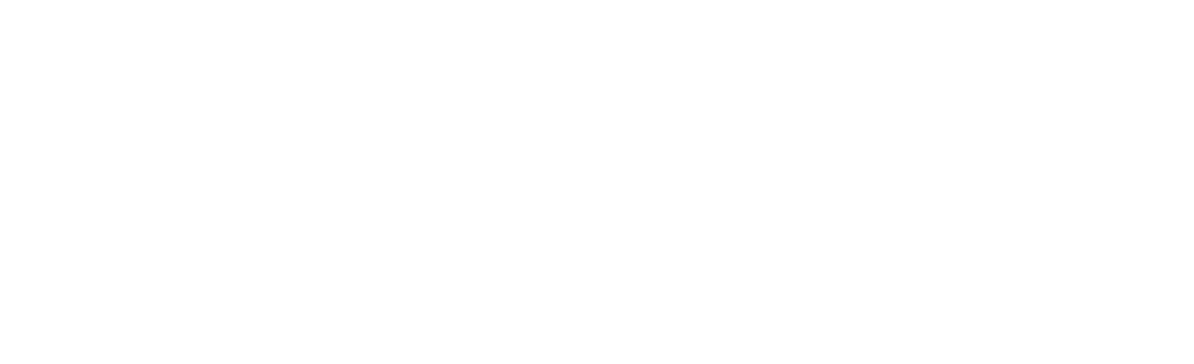


CHEMICAL ANALYSES, WATER YEAR OCTOBER 1969 TO SEPTEMBER 1970
(MAJOR CONSTITUENTS)

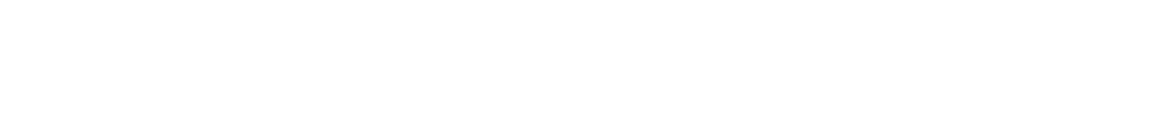

WITHLACODCHEE RIVER BASIN--CONTINUED

02312900 - TSALA APOPKA L AT INVERNESS FLA ILAT 29 SO 39 LONG $0 B 21921$

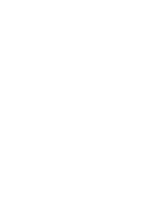

NOV.. 1969

JAN., 1970

$07 . .$.

MAR.

MAY ...

JUNE...

26...

SEP...

$29 .$.

02312950 - TSALA APOPKA LK AT HERNANDO FLA ILAT 285409 LONG 08222311

OCT., 1969

nOV...

JAN...

OA... 1970

AR.

OI...

MAY

$13 . .$.

JUNE

AUG.. - -

19... -- -

SEP.

$$
+-
$$

(

$\begin{array}{ll}- & - \\ -- & - \\ -- & - \\ -- & - \\ -- & -\end{array}$

$\begin{array}{lll}- & - & - \\ - & - & - \\ -- & -- & - \\ -- & -- & - \\ -- & -- & --\end{array}$

$\begin{array}{llll}- & -- & -- & - \\ - & - & - & - \\ -- & -- & - & - \\ - & -- & -- & - \\ - & - & -- & - \\ - & -- & -- & -\end{array}$

02312976 - TSALA APOPKA OUTFALL LA BL S353 NR HER (LAT 2857 19 LONG 08220 13)

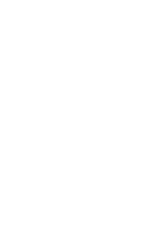

02312975 - TSALA APOPKA OUTFALL CA AT S353 NR HER ILAT 285719 LONG 0B2 20 13)

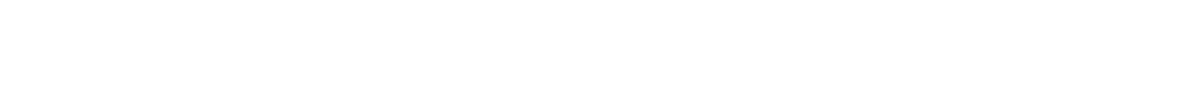

02313200 - WITHLACOOCHEE AT OUNNELLON FLA ILAT 290245 LONG DB2 2753 )

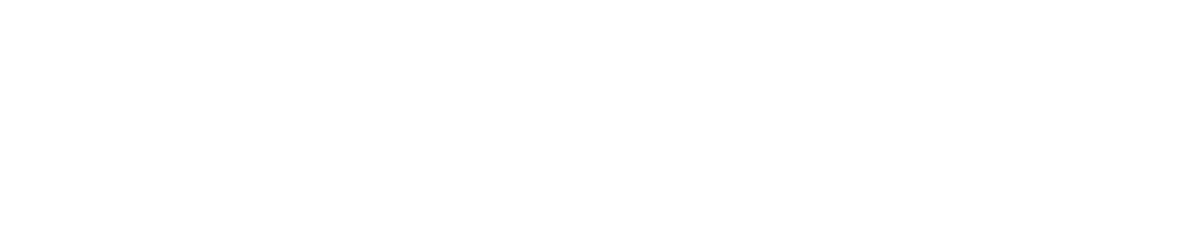




\begin{tabular}{|c|c|}
\hline $\begin{array}{l}\text { DIS- } \\
\text { CHARGE } \\
\text { (CFS) }\end{array}$ & $\begin{array}{l}\text { TEMPEP- } \\
\text { ATURE } \\
\text { (DEG C) }\end{array}$ \\
\hline
\end{tabular}
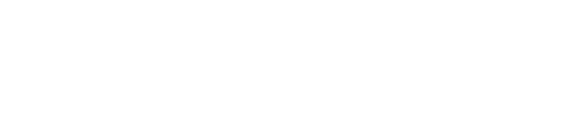

DIS-
SOLVEC
PO-
TAS-

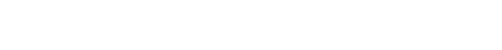

WITHLACMOCHEE RIVER BASIN--CONTINUED

n2313230 - WITHLACOOCHEE R AT INGLIS DAM NR DUNNE ILAT 29 OO 36 LONG ก82 37 00)

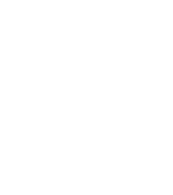

$$
\begin{aligned}
& 25.5 \quad 210 \\
& 16.5 \text { 22ก } \\
& 10.5 \quad 210 \\
& \begin{array}{lll}
- & -- \\
-2 & --
\end{array} \\
& \begin{array}{lcc}
-- & -- & -- \\
-- & -- & -- \\
-- & -- & -- \\
-- & -- & -- \\
.4 & 190 & 4.2 \\
-- & -- & --
\end{array} \\
& \begin{array}{rrrr}
-- & -- & -- & -- \\
-- & -- & -- & -- \\
-- & -- & -- & -- \\
-1 & 130 & 0 & 7.6 \\
-- & -- & -- & 7.9
\end{array}
\end{aligned}
$$

02313231 - WITHLACOOCHEE R BL INGLIS DAM NR DUNNE (LAT 2Y ON 36 LONG 08237 00)

OCT.. 1969

NOV.

25.5

17... 3000

JAN., 1970

$13 . . .1730$

MAY

SEP... -

\begin{tabular}{|c|c|c|c|c|c|c|c|c|c|c|}
\hline 21.5 & 224 & -- & $\cdots$ & -- & - & -- & - & -- & - & 7.2 \\
\hline 20.5 & 212 & -- & -- & -- & -- & -- & -- & -- & - & - \\
\hline 26.0 & 3400 & - & - & $=$ & -- & -- & -- & -- & -- & 7.5 \\
\hline-- & 225 & $-\infty$ & -- & -- & $=$ & $=$ & -- & - & - & 7.5 \\
\hline 28.0 & $24 R$ & -- & -- & - & - & - & $=-$ & -- & -- & 8.0 \\
\hline
\end{tabular}

$16.5 \quad 221$

$10.5 \quad 21 \mathrm{f}$

\begin{tabular}{|c|c|c|c|c|c|c|c|c|c|c|c|}
\hline \multirow{2}{*}{$\begin{array}{l}\text { MAY . } 1970 \\
20 \ldots \\
\text { SEP.. } \\
18 \ldots .\end{array}$} & - & 26.0 & 330 & -- & 42 & 5.9 & 190 & 15 & .5 & 130 & 0 \\
\hline & -- & 27.0 & 250 & -- & -- & -- & -- & - & 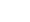 & $=-$ & $=$ \\
\hline
\end{tabular}

$27.0 \quad 255$

$28.5 \quad 239$

$\begin{array}{lllll}-- & -- & -- & -- & -- \\ - & -- & -- & -- & -- \\ - & - & -- & -- & --\end{array}$

$\begin{array}{cccc}-- & - & - & -- \\ -- & -- & -- & -- \\ -- & -- & -- & -- \\ -- & - & -- & 7.9 \\ -- & -- & -- & 8.1\end{array}$

02313236 - CFBC AB INGLIS LOCK NEAR INGL IS FLA (LAT 290131 LONG 08236 42)

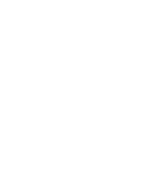

02313251 - WITHLACOOCHEE R BL BYPASS CHL STR NR I (LAT 290115 LONG 0823820 )

02313263 - CFBC AT INGLIS LOCK NEAR INGL IS FLA (LAT 29 0130 LONG 08237 00)

\begin{tabular}{|c|c|c|c|c|c|c|c|c|c|c|c|c|}
\hline $\begin{array}{l}07 \ldots \\
\text { FEB.. }\end{array}$ & $70^{2.9}$ & 12.0 & 84 & -- & - & 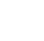 & - & $\cdots$ & - & $=$ & - & -- \\
\hline $04 \ldots$ & 148 & 10.5 & 38 & $\cdots$ & $\rightarrow$ & $=$ & $\cdots$ & $\cdots$ & $\cdots$ & $=-$ & -- & $\cdots$ \\
\hline $\begin{array}{l}\text { APR. } \\
27 . . \\
\text { JUNE }\end{array}$ & - & 23.0 & 57 & - & 8.1 & 1.4 & - & 2.2 & .1 & 20 & 0 & 6.6 \\
\hline $\begin{array}{l}24 \\
\text { JULY }\end{array}$ & 14 & 25.0 & 70 & -- & -- & -- & -- & -- & - & - & $-\infty$ & - \\
\hline $\begin{array}{l}29 . . \\
\text { SEP. }\end{array}$ & 8.4 & 25.0 & 85 & -- & -- & -- & - & -- & -- & - & $\cdots$ & \\
\hline $22 \ldots$ & 10 & 25.0 & 57 & - & -- & $-\infty$ & -- & - & -- & -- & -- & \\
\hline
\end{tabular}

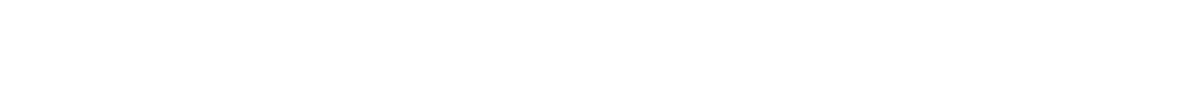
02313265 - WITHLACOOCHEE R AT CRACKERTONN FLA (LAT 290149 LONG 0824041 )

$\begin{array}{llllllllllll}\operatorname{MAY}, 1970 & - & 26.0 & 330 & - & 43 & 5.7 & - & 16 & .6 & 132 & -\end{array}$

COASTAL RASTMG TFTIEEN HITHLACTICHEE RIVER AND SUHANNEE RIVER

02313400 - NACCASASSA R NK BRONSON FLA ILAT 292932 IONG O82 4? 59)

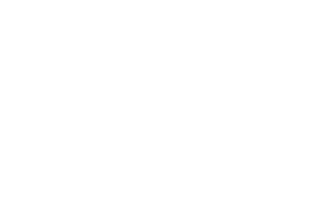

02313448 - L WACCASASSA R NR BRONSON FLA ILAT 292834 LONG OB2 41 13)

Nov., 1969 
CHEMICAL ANALYSES, HATER YEAR OCTOBER 1969 TO SEPTEMBER 1970 (MAJOR CONSTITUENTS)

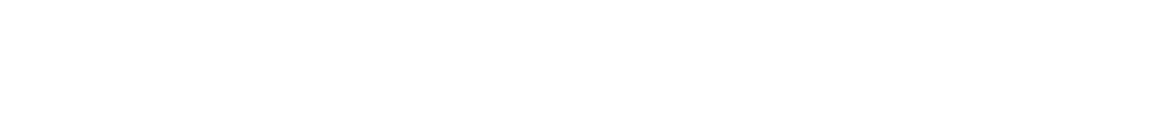

WITHLACDOCHEE RIVER BASIN---CONTINUED

02313230 - WITHLACOOCHEE R AT INGLIS DAM NR DUNNE ILAT 29 ON 36 LONG 0823700 )

OCT... 1969
$06 . .$.
NOV.

02313231 - WITHLACOOCHEE R BL INGL IS DAM NR DUNNE (LAT 290036 LONG 08237 00)

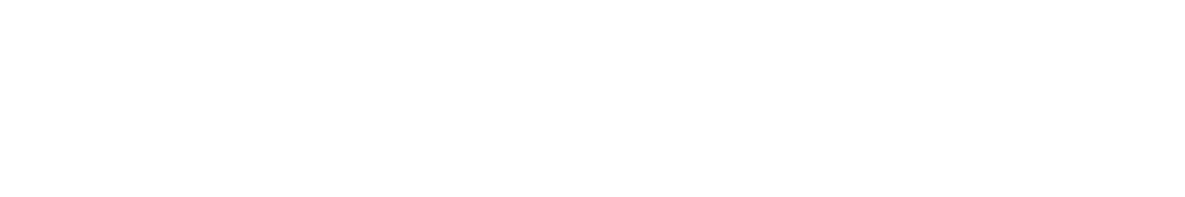

02313236 - CFBC AB INGLIS LOCK NEAR INGLIS FLA (LAT 79 OI 31 LONG 0823642 )

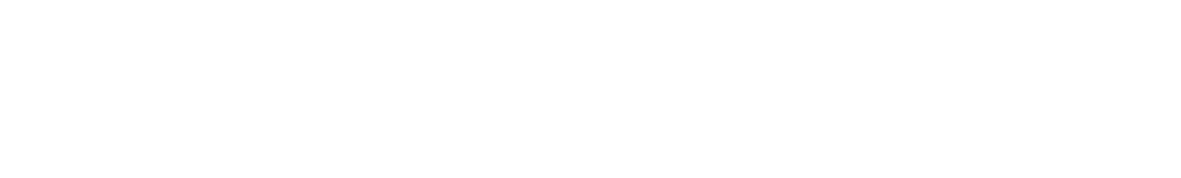

02313251 - WITHLACOOCHEE R BL BYPASS CHL STR NR I (LAT 290115 LONG 0823820 )

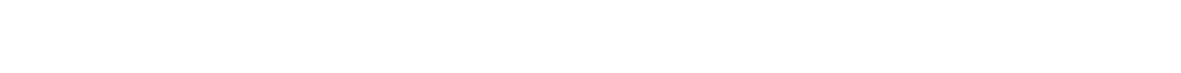

02313263 - CFBC AT INGLIS LOCK NEAR INGLIS FLA (LAT 290130 LONG 08237 00)

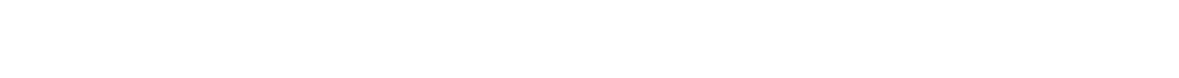

02313265 - WITHLACOOCHEE R AT CRACKERTOWN FLA (LAT 290149 LONG ORZ 4041 )

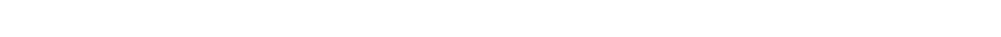

CDASTAL BASINS BETWEEN WITHLACOMCHEE RIVER AND SUHANNEE RIVER--CONTINUED

02313400 - MACCASASSA R NR BRONSON FLA (LAT 292432 LONG OR2 42 ל8)

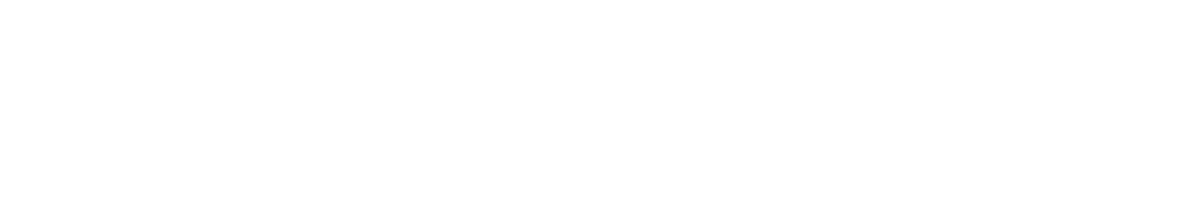

02313448 - L WACCASASSA R NR BRONSON FLA (LAT 292934 LONG 0824113 )

NoY., 1969

$07 \ldots$

FEB., 1970

APR.

27 .

JUNE

24

JULY.

SEP. 


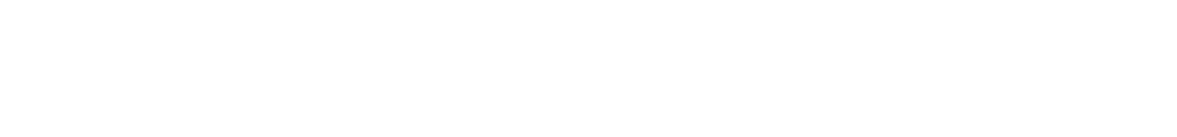

COASTAL BASINS BETWEEN WITHLACOOCHEE RIVER AND SUWANNEE RIVER--CONTINUFD

02313450 - BLUE SPRING NR BRONSON FLA ILAT 292702 LONG 0824157 )

\begin{tabular}{|c|c|c|c|c|c|c|c|c|c|c|c|}
\hline $\begin{array}{l}\text { NOV.: } 1969 \\
07 . . . \\
\text { FEB.:" } 1970\end{array}$ & 8.1 & 23.0 & 180 & - & - & $\cdots$ & -- & -- & - & - & -- \\
\hline JUNE & - & 23.0 & 180 & $m$ & 28 & 4.1 & $\cdots$ & 2.1 & .2 & 106 & 0 \\
\hline $\operatorname{JULY}^{24}$ & 11 & 23.5 & 170 & -- & - & $\cdots$ & $\cdots$ & - & 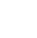 & -- & - \\
\hline SEP... & 11 & 23.5 & 180 & - & - & $=$ & $\cdots$ & - & $\cdots$ & -- & $\cdots$ \\
\hline
\end{tabular}

02313510 - CHUNKY POND NR BRONSON FLA ILAT 292336 LONG 08237191

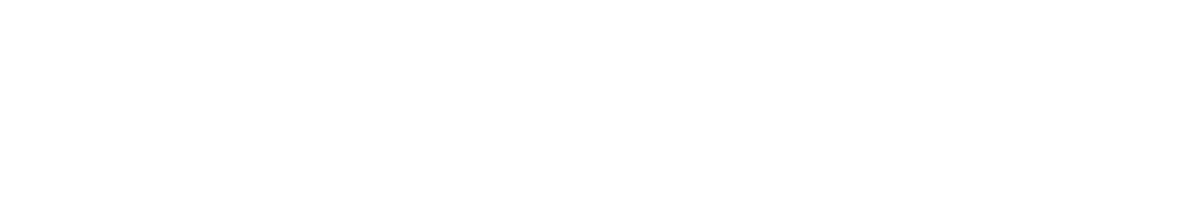

02313600 - WEKIVA SPGS NR GULF HAMMOCK FLA (LAT 291649 LONG OB2 3923 )

NOV.: 1969
OPR:. 1970

APR.,

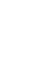

$23.0 \quad 170$

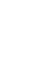

\section{$02313700-$}

WACCASASSA R NR GULF HAMMOCK FLA ILAT 29121 . LONG 0824609 )

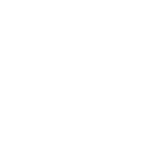

$$
\begin{array}{ll}
16.0 & 210 \\
23.5 & 213 \\
27.0 & 225 \\
26.5 & 360
\end{array}
$$$$
410
$$

29...

02314200

TENMILE CR AT LEBANON STATION FLA ILAT 290939 LONG 08238211

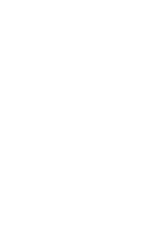

$\begin{array}{rrr}24.0 & 109 \\ 15.0 & 150 \\ 9.0 & 90 & - \\ 19.0 & 80 & - \\ 22.5 & 54 & - \\ 26.0 & 205 & - \\ 26.5 & 410\end{array}$

02314205

HORSE HOLE CR NR LEBANON STATION FLA (LAT 29 OB 01 LONG 08238 ;4)

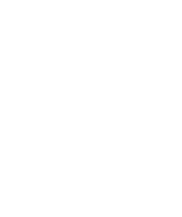

$\begin{array}{rrr}24.0 & 155 \\ 15.0 & 160 & - \\ 8.5 & 129 & - \\ 18.0 & 125 & - \\ 25.0 & 127 & \ldots \\ 26.5 & 230 & -\end{array}$

02315000 - SUWANNEE R NR BENTON FLA ILAT 303030 LONG DB2 41501

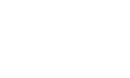

$$
\begin{aligned}
& 15.9 \\
& 21.0
\end{aligned}
$$

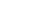

$\begin{array}{llll}-- & - & - & - \\ -- & - & - & - \\ - & -- & - & - \\ - & - & - & - \\ - & - & - & - \\ - & -- & -- & -\end{array}$

$\begin{array}{lllll}- & - & - & - & - \\ -- & -- & - & - & - \\ - & -- & -- & - & - \\ - & -- & - & - & -- \\ -- & -- & -- & -- & - \\ - & -- & -- & -- & -\end{array}$

02315005 - HUNTER CREEK NEAR BELMONT FLA (LAT 302920 LONG DB2 41 40)

NOV., 1969

05....

MAY 1970 $\begin{array}{ll}\cdots & 12.0\end{array}$ 
ANALYSES OF SAMPLES COLLECTED AT MISCELLANEOUS SITES IN FLORIDA

CHEMICAL ANALYSES, HATER YEAR OCTDBER 1969 TO SEPTEMBER 1970 (MAJOR CONSTITUENTS)

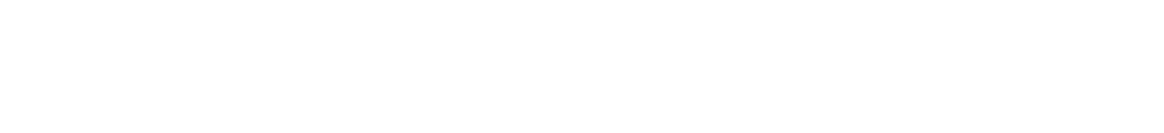

COASTAL BASINS BETWEEN WITHLACNICHEE RIVER AND SUWANNEE RIVER--CONTINUED

02313450 - BLUE SPRING NR BRONSON FLA (LAT 292702 LONG 0824157 )

NOV.. 1969
$07 \ldots . .$.

02313510 - CHUNKY POND NR RRONSON FLA ILAT 292336 LONG 08237191

NOV., 1969

FER:1 1970

$04 \ldots$

PRR.

$27 \ldots .8$

$24 .$.

JUL

SEP.

$22 .$.

NOV., 1969

NOV.: 1969
O7...
APR.. 1970

APR.:

4.4

3.0

83

280

93

95

02313700 - WACCASASSA R NR GULF HAMMOCK FLA (LAT 291214 LONG 08246091

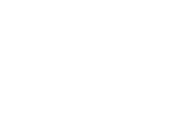

$\begin{array}{cc}-- & \\ 9.0 & - \\ -- & -\end{array}$

02314200 - TENMILE CR AT LEBANON STATION FLA ILAT 290939 LONG 082 3821

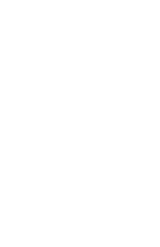

$$
\begin{array}{lll}
-- & - & - \\
-- & - & - \\
-- & - & - \\
-- & -- & -2 \\
7.9 & .2 & - \\
-- & -- & - \\
-- & - & -
\end{array}
$$

02314205 - HORSE HOLE CR NR LEBANON STATION FLA (LAT 290801 LONG 082 3R 14)

$$
\begin{array}{llllll}
-- & -- & -- & -- & -- & - \\
-- & -- & -- & -- & -- & - \\
-- & -- & -- & -- & - & - \\
-- & -- & -- & -- & -- & - \\
-- & -- & -- & -- & - & - \\
-- & -- & -- & -- & -- & --
\end{array}
$$

02315000 - SUWANNEE R NR BENTON FLA ILAT 303030 LONG 082 $4150 \mathrm{I}$

NOV., 1969

$05 . . .079$

MAY 1970

8

9.8
5.5

02315005 - HUNTER CREEK NEAR BELMONT FLA ILAT 302920 LONG 0824140

NOV., 1969

MAY 1970

9.

$5.0 \quad 1.2$

22

8
34

189

143 
CHEMICAL ANALYSES, WATER YEAR OCTOBER 1969 TO SEPTEMBER 1970 (MAJOR CONSTITUENTS)

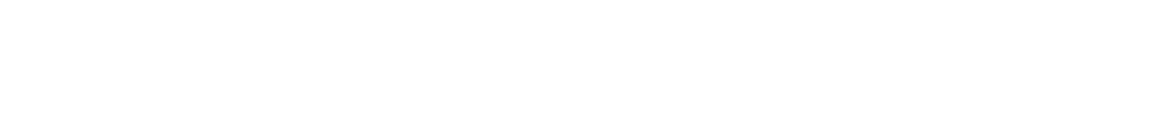
SIIWANNEE RIVER BASIN

02315090 - ROARING CRELK NEAR BELMONT FLA (LAT 302550 LONG 08240 OO)

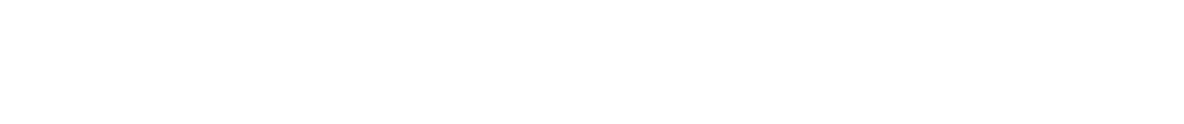

02315500 - SUWANNEE R AT WHITE SPRINGS FLA ILAT 301932 LONG OR2 4418 I

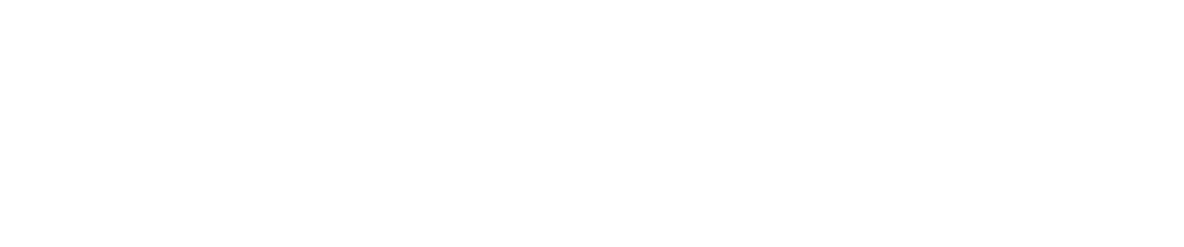

02315518 - OCCIDENTAL MINE DR D AT ST 137 NR GENOA FLA (LAT 302505 LONG O82 4725 )

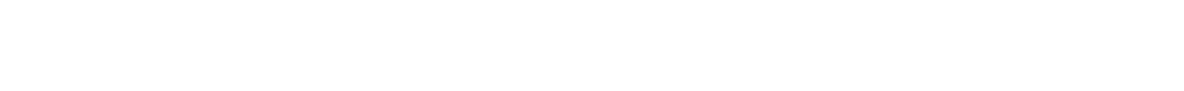

02315520 - SWIFT CR AT FACIL FLA ILAT 302214 LONG 08? 48001

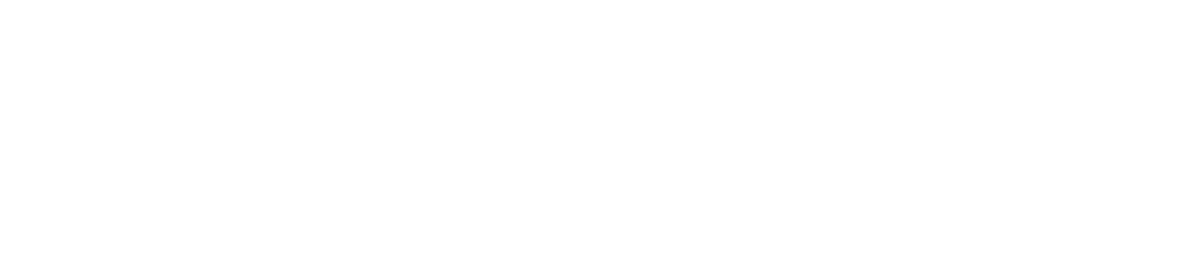

02315534 - ROCKY CREEK TRIBUTARY NR WELLUORN FLA ILAT 301851 LONG 08249501

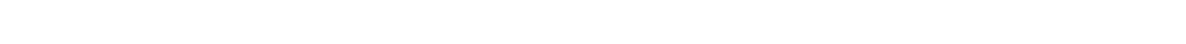
02315550 - SUWANNEE R AT SUWANNEE SPRINGS FLA ILAT 30 2334 LONG 08256001

\begin{tabular}{|c|c|c|c|c|c|c|c|c|c|c|c|c|}
\hline $\begin{array}{c}\text { OCT... } 1969 \\
15 \ldots . \\
150\end{array}$ & & 22.5 & 46 & -- & - & -- & -- & -- & -- & -- & -- & 4.9 \\
\hline NOV. & - & 17.5 & 60 & + & 5.1 & 1.7 & -- & 3.7 & .4 & 6 & 0 & 5.6 \\
\hline DEC. & -- & - & - & -- & 5.3 & 1.6 & -- & 3.4 & .3 & -- & - & -- \\
\hline $\begin{array}{l}\text { FER.. } 1970 \\
10 \ldots . \\
\text { APR. }\end{array}$ & -- & 11.0 & 55 & - & -- & -- & -- & -- & -- & -- & -- & - \\
\hline MAY 0810200 & & 19.0 & 45 & - & - & - & - & -- & - & -- & - & - \\
\hline $\begin{array}{l}26 \ldots \\
\text { AUG... }\end{array}$ & - & 24.5 & 115 & - & 16 & 2.8 & 40 & 4.0 & .3 & 41 & 0 & 5.9 \\
\hline $12 \ldots 3700$ & & 24.0 & -- & -- & -- & -- & $=$ & -- & -- & -- & - & - \\
\hline
\end{tabular}

02315600 - SUWANMFF SPRINTS NK LIVF OAK FLA (LAT 3 N 2339 LONG 0325604 )

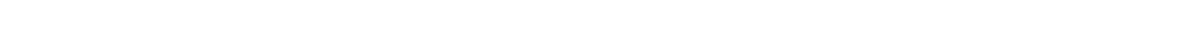
02317630 - ALAPAHA R NR JASPER FLA (LAT 303142 LONG $08302 \quad 17 \%$

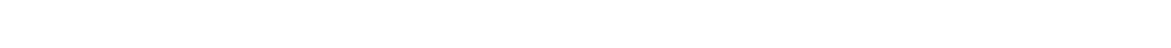

02319500 - SUWANNEE R AT ELLAVILLE FLA ILAT 302304 LONG 082 in 191

MAY, 1970 
CHEMICAL ANALYSES, WATER YEAR OCTOBER 1969 TO SEPTEMBER 1970 (MAJDR CONSTITUENTS)

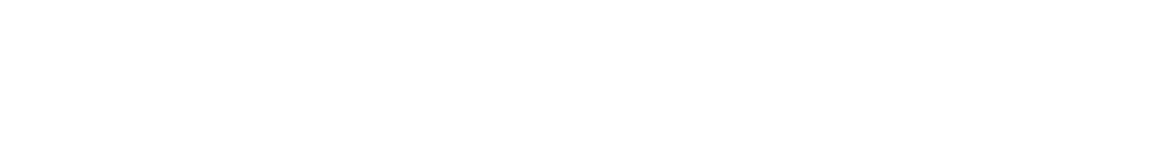

SUWANNEE RIVEP BASIN--CONTINUED

02315090 - ROARING CPEEK NEAR BELMONT FLA (LAT 302550 LONG OA2 40 00)

\begin{tabular}{|c|c|c|c|c|c|c|c|c|c|c|c|c|}
\hline $\begin{array}{l}\text { NOV., } 1969 \\
\text { O5.... } \\
\text { MAY, } 1970\end{array}$ & 1.2 & 9.5 & .5 & 21 & 21 & 0 & 158 & 29 & -- & .21 & -- & - \\
\hline & 4.0 & 6.5 & .4 & 18 & 18 & 0 & 147 & 29 & 1.03 & .20 & -- & -- \\
\hline $12 \ldots$ & - & -- & .3 & -- & -- & -- & -- & -- & -- & -- & -- & -- \\
\hline
\end{tabular}

02315500 - SUWANNEE R AT WHITE SPRINGS FLA LLAT 30 I9 32 LONG OAZ 4416.

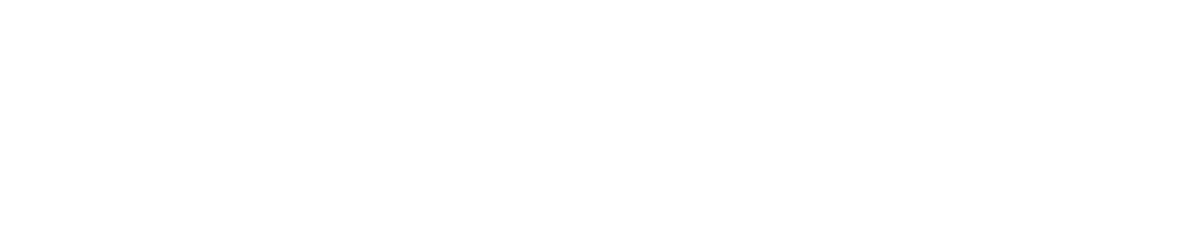

02315518 - OCCIDENTAL MINE DR D AT SH 137 NR GENOA FLA (LAT 3025 O5 LONG 08247 25)

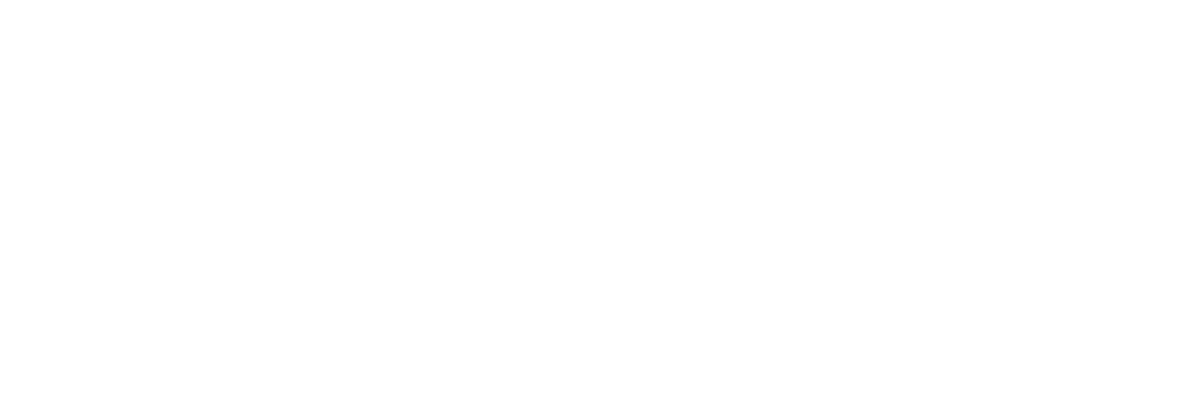

02315534 - ROCKY CREEK TRIBUTARY NR WELLBORN FLA (LAT 301 19 51 LONG ORZ 49 50)

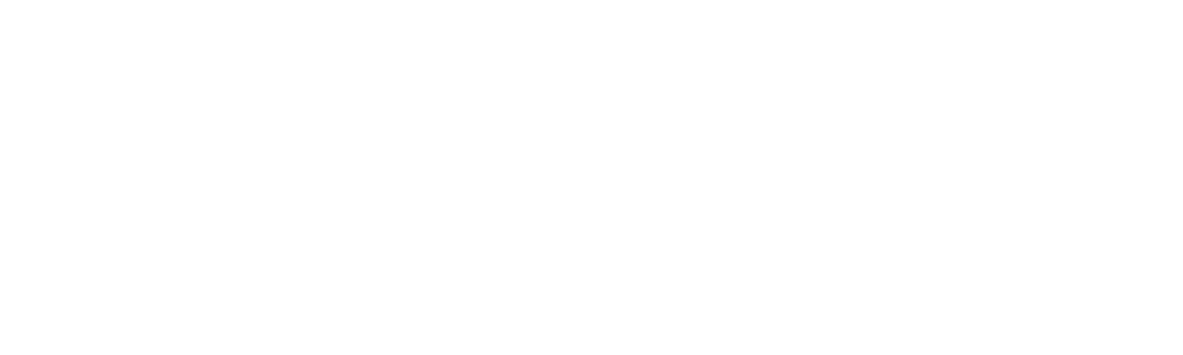

02315600 - SUWANNEE SPRINGS NR LIVE OAK FLA (LAT 302339 LONG 0H2 56 04)

$\begin{array}{cccccccccccccc}\operatorname{MAY}, 1970 & 9.0 & 4.0 & .3 & 143 & 15 & 128 & 164 & 157 & -. & .22 & -\end{array}$ 02317630 - ALAPAHA R NR JASPER FLA (LAT 303142 LONG 08302171

\footnotetext{
MAY $19 . . .+10$

.316

02319500 - SUWANNEE R AT ELLAVILLE FLA (LAT 302304 LONG 0R2 IO 191
}

MAY, 197016 


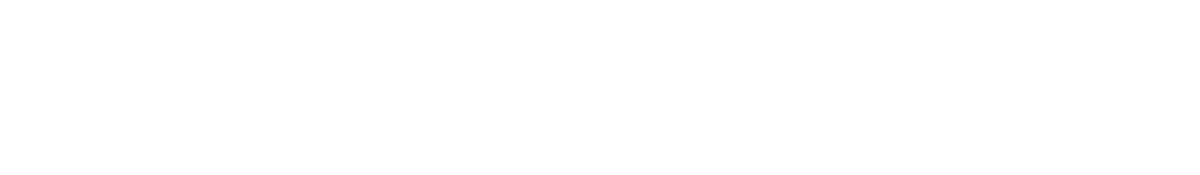

02320000 - SUWANNEe R AT LURAVILLE FLA (LAT 300559 LONG 08310 18)

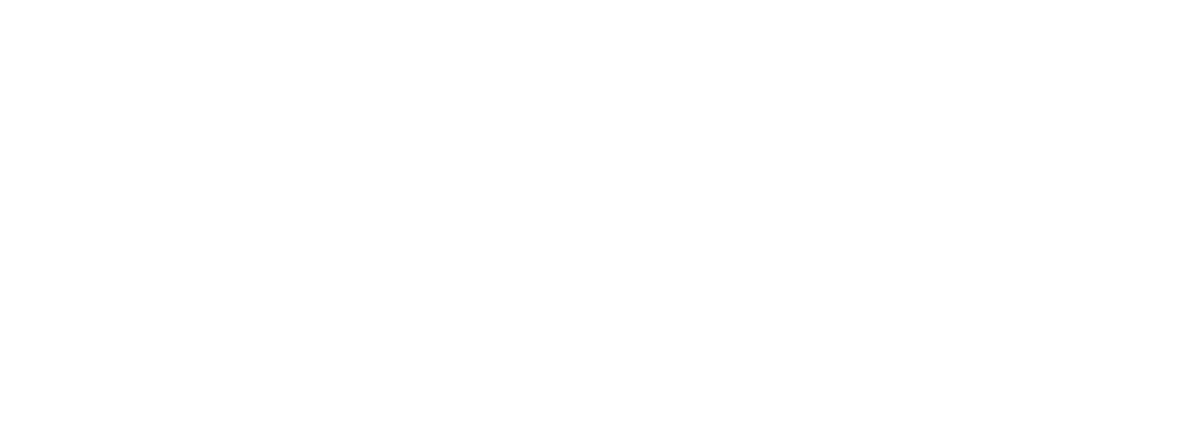

02321000 - NEW R NR L BUTLER FLA (LAT 295953 LONG 0821627 )

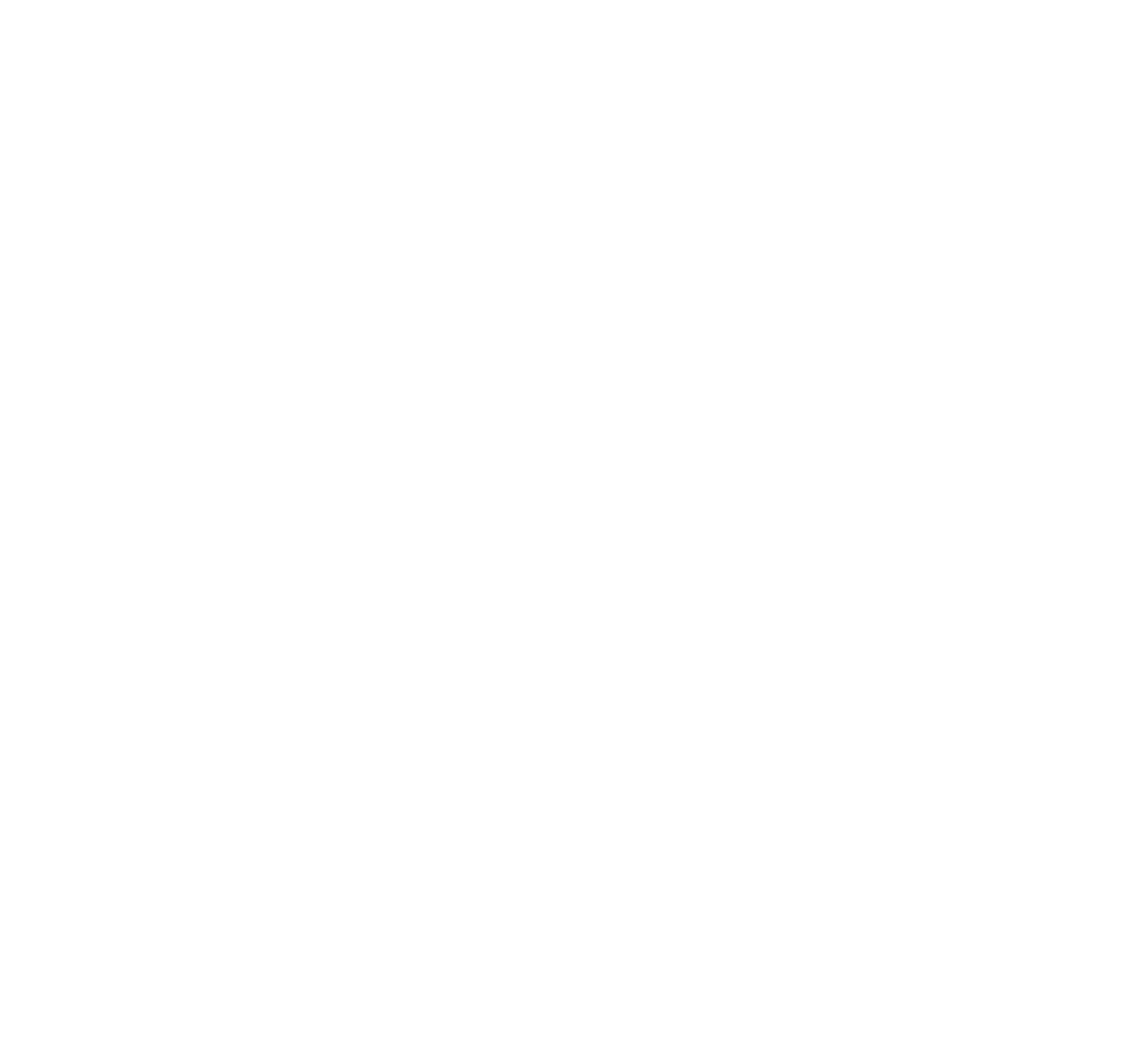


CHEMICAL ANALYSES, WATER YEAR OCTOBER 1969 TO SEPTEMBER 1970 (MAJOR CONSTITUENTS)

\begin{tabular}{|c|c|c|c|c|c|c|c|c|c|c|c|c|}
\hline ATE & $\begin{array}{l}\text { DIS- } \\
\text { SOLVED } \\
\text { SULFATE } \\
\text { (SO4) } \\
\text { (MG L) }\end{array}$ & $\begin{array}{l}\text { DIS- } \\
\text { SOLVED } \\
\text { CHLO- } \\
\text { RIDE } \\
\text { (CLL) } \\
\text { (MG/L) }\end{array}$ & $\begin{array}{l}\text { DIS- } \\
\text { SOLVED } \\
\text { FLUO- } \\
\text { RIDE } \\
\text { (F) } \\
\text { (MG/L) }\end{array}$ & $\begin{array}{l}\text { HARO- } \\
\text { NESS } \\
\text { (CA,MG) } \\
(M G / L)\end{array}$ & $\begin{array}{l}\text { NON- } \\
\text { CAR- } \\
\text { BONATE } \\
\text { HARD- } \\
\text { NESS } \\
\text { (MG/L) }\end{array}$ & $\begin{array}{l}\text { ALKA- } \\
\text { LINITY } \\
\text { AS } \\
\text { CACO3 } \\
\text { (MG/L) }\end{array}$ & $\begin{array}{l}\text { OIS- } \\
\text { SOLVED } \\
\text { SOLIDS } \\
\text { (RESI- } \\
\text { OUE AT } \\
\text { 180 C) } \\
\text { (MG/L) }\end{array}$ & $\begin{array}{l}\text { DIS- } \\
\text { SOLVEO } \\
\text { SOLIDS } \\
\text { (SUM OF } \\
\text { CONSTI- } \\
\text { TUENTS) } \\
\text { (MG LL) }\end{array}$ & $\begin{array}{l}\text { OIS- } \\
\text { SOLVEO } \\
\text { SOLIDS } \\
\text { (TONS } \\
\text { PER } \\
\text { DAY) }\end{array}$ & $\begin{array}{l}\text { OIS- } \\
\text { SOLVED } \\
\text { SOLIOS } \\
\text { (TONS } \\
\text { PER } \\
\text { AC-FT) }\end{array}$ & $\begin{array}{l}\text { TANNIN } \\
\text { AND } \\
\text { LGNIN } \\
\text { (MG/L) }\end{array}$ & $\begin{array}{l}\text { DEPTH } \\
\text { (FT) }\end{array}$ \\
\hline A. & & & & & & & & & & & & \\
\hline
\end{tabular}

02320000 - SUWANNEE * AT LUPAVILLE FLA (LAT 300559 LONG 0831018 )

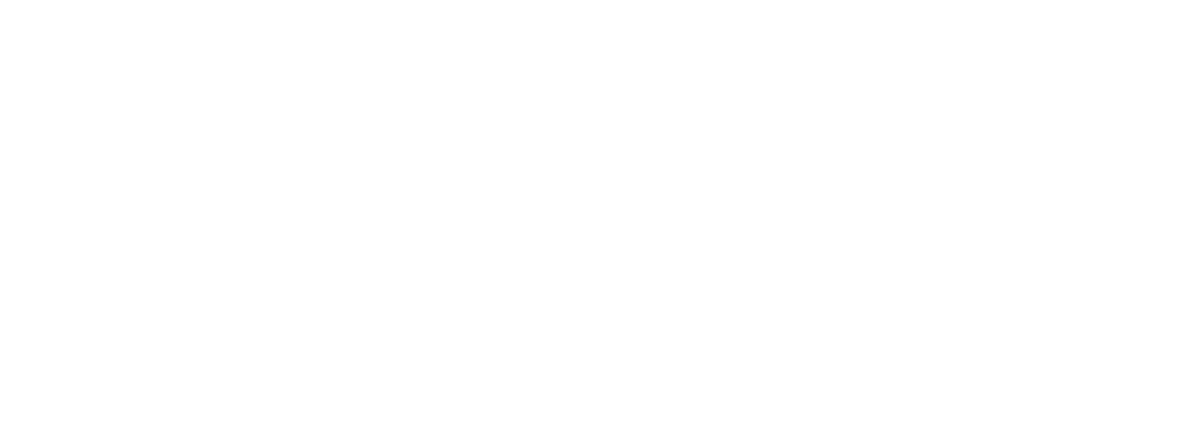

02321000 - NEW R NR L BUTLER FLA (LAT 295953 LONG 9821627 )

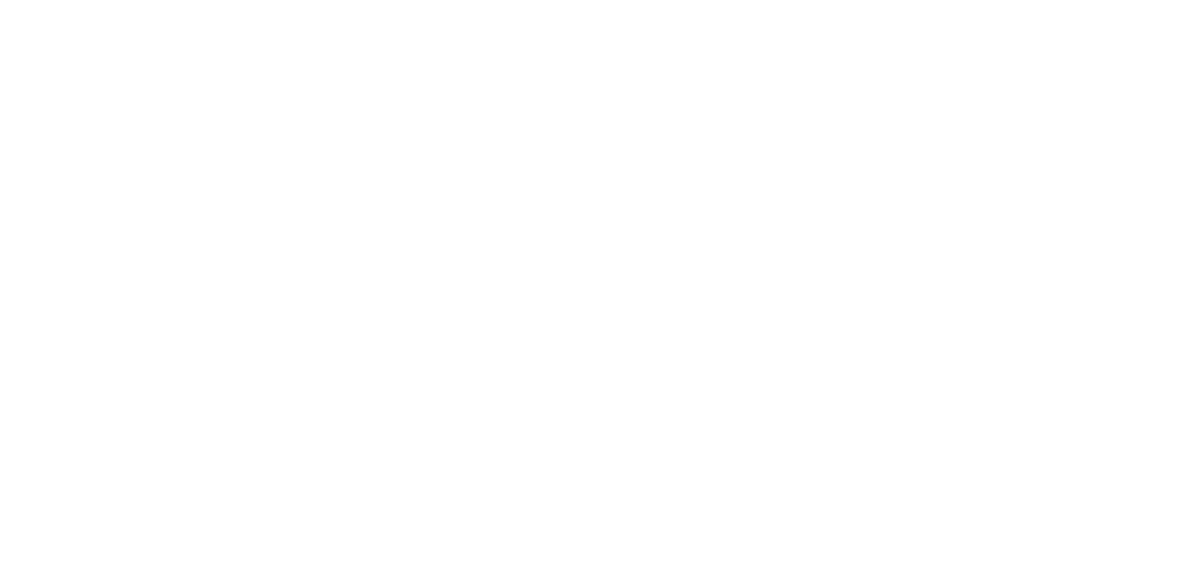

02322600 - ALLIGATOR L AT LAKE CITY FLA (LAT 301031 LONG 0823755 )

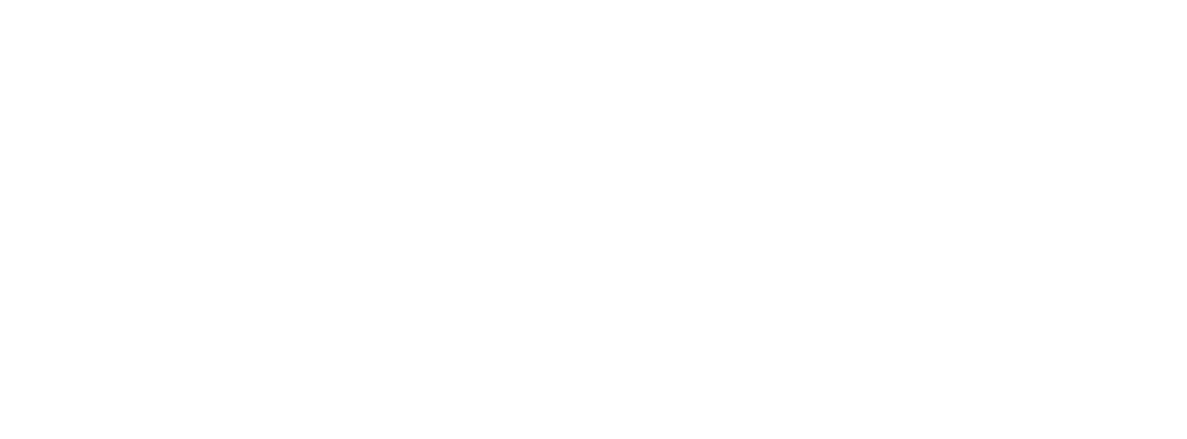



CHEMICAL ANALYSES, WATER YEAR OCTOBER 1969 TO SEPTEMBER 1970 (MAJOR CONSTITUENTS)

\begin{tabular}{|c|c|c|c|c|c|c|c|c|c|c|c|c|}
\hline & $\begin{array}{l}\text { DIS- } \\
\text { CHARGE }\end{array}$ & TEMPER- & $\begin{array}{l}\text { SPE- } \\
\text { CIFIC } \\
\text { CON- } \\
\text { DUCT- } \\
\text { ANCE } \\
\text { IMICRO- }\end{array}$ & $\begin{array}{l}\text { DIS- } \\
\text { SOLVED } \\
\text { IRON } \\
\text { (FE) }\end{array}$ & $\begin{array}{l}\text { DIS- } \\
\text { SOLVED } \\
\text { CAL- } \\
\text { CIUM } \\
\text { (CA) }\end{array}$ & $\begin{array}{l}\text { DIS- } \\
\text { SOLVED } \\
\text { MAG- } \\
\text { NE- } \\
\text { SIUM } \\
\text { (MG) }\end{array}$ & $\begin{array}{l}\text { DIS- } \\
\text { SOLVED, } \\
\text { STRON- } \\
\text { TIUM } \\
\text { (SR) }\end{array}$ & $\begin{array}{l}\text { DIS- } \\
\text { SOLVED } \\
\text { SODIUM } \\
\text { (NA) } \\
\text { (MG/) }\end{array}$ & $\begin{array}{l}\text { DIS- } \\
\text { SOLVED } \\
\text { PO- } \\
\text { TAS- } \\
\text { SIUM } \\
\text { (K) } \\
\text { (MG/L) }\end{array}$ & $\begin{array}{l}\text { BICAR- } \\
\text { BONATE } \\
\text { (HCO3) } \\
\text { (MG/L) }\end{array}$ & $\begin{array}{l}\text { CAR- } \\
\text { BNNATE } \\
\text { (CO3) } \\
\text { (MG/L) }\end{array}$ & $\begin{array}{c}\mathrm{PH} \\
\text { (UNITS) }\end{array}$ \\
\hline DATE & (nes) & (DEG C) & MHOS) & $(U G / L)$ & $(M G / L)$ & $(M G / L)$ & & & & & & (UNITS) \\
\hline
\end{tabular}

COASTAL BASINS BETWEEN SIHAMNAFF PIVEP NHIT AIIT TILA DTYFP

02324000 - STEJNHATCHFE R NR CROSS CITY FLA (LAT $29471110 N 6$ CQ3 19 18)

APR.. 1970
$30 . . \quad 288$

$29 . . .1970$

APR., 1970

$\begin{array}{rr}30 \ldots . . & 124 \\ \text { AUG.... } & 1060\end{array}$

$\underset{06 . . . \quad 207}{\operatorname{Mar}}$

APR.. ${ }^{1970} 178$

MAY 1970

APR . 1970

28... 398

$25 \ldots 96$

MAY, 1970

MAY, 1970

MAY, 1970
$07 . . .6$

MAY 1970

MAY, 1970

$\begin{array}{ll}\text { SEP. } & \\ 02 . . & 800\end{array}$

APR.. 1970

APR... 19

$23.0 \quad 135$

02324400 - FENHOLLOWAY P NR FOLEY FLA ILAT 300553 LONG 08328 19)

$24.0 \quad 52$

02324500 - FENHOLLOWAY R AT FOLEY FLA (LAT 300353 LONG 08332011

$32.5 \quad 138$

$27.0 \quad 390$

$350 \quad 27$

$460 \quad 7.9$

8.0 $50 \quad 257$

$2.3 \quad: 98$

$2.3 \quad \ln \quad 73$

02325000 - FENHOLLONAY R NR PERRY FLA ILAT 300416 LONG OH3 39 4b)

23.5930

02326000 - ECONFINA F NR PERRY FLA ILAT 301014 LONG NR3 49 26)

$\begin{array}{lllllllll}22.5 & 138 & - & 22 & 5.1 & - & 3.1 & -2 & 73\end{array}$

\section{AIMCILLA RIVER RASIN}

02326250 - AUCILLA F INR AUCILLA FLA (LAT 30 2931 LONG 08343531

$21.5 \quad 45$

02326261 - LITTLE AUCILLA RIVER NEAR CHERRY LAKE (LAT 303736 LONG 09329 44)

02326500

1.7

\section{.}

AUC

$\begin{array}{llllllllll}23 . & 55 & 1300 & 5.4 & 1.6 & 0 & 3.9 & .7 & 8\end{array}$

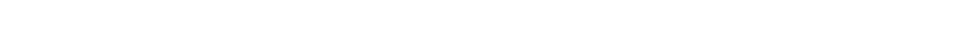

COASTAL BASINS BETHEEN AUCILLA PIVER ANT RCHLACYMNFF PTVFP

0232659 - CANEY CREEK NE AN MONTICELLO FLA (LAT 3030 SC LONG O83 5624 )

$19.0 \quad 27$

02326600 - LAKE MICCOSUKEE NA MICCOSUKEE FLA (LAT 303614 LONG 08400 15)

02326700 - LLOYD CR AT LLOYO FLA ILAT 302841 LONG 0840031 )

18.0

02326900 - ST MARKS R NR NEWPORT FLA ILAT 301600 LONG 08409003

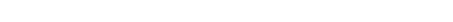

02327000 - WAKULLA SPG NR CRAWFORDVILLE FLA ILAT 3n 1405 LONG O84 18 05)

$\begin{array}{rrrrrrrrrrr}20.0 & 260 & 20 & 37 & 9.1 & 0 & 4.5 & .6 & 148 & -. & 7.9 \\ 21.5 & 245 & 30 & 35 & 7.9 & 70 & 4.5 & .5 & 136 & 0 & 7.9\end{array}$

02327010 - LK gRadforo NR TALLAHASSEe fLA ILAT 302410 LONG 0842005 )

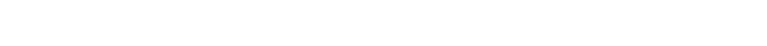

02327020 - MCBRIDE SLOUGM NR CRAMFOROVILLE FLA (LAT 3012 In LONG 0841535 )

MAY 1970

$19.0 \quad 299 \quad-\quad 53$

$5.4 \quad 3.0 \quad 0 \quad 5 \quad 177$ 
ANALYSES OF SAMPLES COLLECTED AT MISCELLANEOUS SITES IN FLORIDA

CHEMICAL ANALYSES, WATER YEAR OCTOBER 1969 TO SEPTEMBER 1970 (MAJOR CONSTITUENTS)

\begin{tabular}{|c|c|c|c|c|c|c|c|c|c|c|c|c|}
\hline ATE & $\begin{array}{l}\text { DIS- } \\
\text { SOLVED } \\
\text { SULFATE } \\
\text { (SO4) } \\
\text { (MG/L) }\end{array}$ & $\begin{array}{l}\text { DIS- } \\
\text { SOLVED } \\
\text { CHLO- } \\
\text { RIDE } \\
\text { (CL) } \\
\text { (MG/L) }\end{array}$ & $\begin{array}{l}\text { DIS- } \\
\text { SOLVED } \\
\text { FLUO- } \\
\text { RIDE } \\
\text { (F) } \\
\text { (MG/L) }\end{array}$ & $\begin{array}{l}\text { HARD- } \\
\text { NESS } \\
(C A, M G) \\
(M G / L)\end{array}$ & $\begin{array}{l}\text { NON- } \\
\text { CAR- } \\
\text { BONATE } \\
\text { HARD- } \\
\text { NESS } \\
\text { (MG/L) }\end{array}$ & $\begin{array}{l}\text { ALKA- } \\
\text { LINITY } \\
\text { AS } \\
\text { CACO3 } \\
\text { (MG/L) }\end{array}$ & $\begin{array}{l}\text { DIS- } \\
\text { SOLVEO } \\
\text { SOLIDS } \\
\text { (RESIE } \\
\text { DUE AT } \\
\text { I } 80 \text { C) } \\
\text { (MG L ) }\end{array}$ & $\begin{array}{l}\text { OIS- } \\
\text { SOLVEN } \\
\text { SOLIDS } \\
\text { (SUM OF } \\
\text { CONSTI - } \\
\text { TUENTS) } \\
\text { (MG/L) }\end{array}$ & $\begin{array}{l}\text { OIS- } \\
\text { SOLVEO } \\
\text { SOLIOS } \\
\text { (TONS } \\
\text { PER } \\
\text { DAY) }\end{array}$ & $\begin{array}{l}\text { OIS- } \\
\text { SOLVED } \\
\text { SOLINS } \\
\text { (TONS } \\
\text { PER } \\
\text { AC-FT) }\end{array}$ & $\begin{array}{l}\text { TANNIN } \\
\text { ANI } \\
\text { LIGNIN } \\
\text { (NG/L) }\end{array}$ & $\begin{array}{c}\text { DEPTH } \\
\text { (FT) }\end{array}$ \\
\hline
\end{tabular}

COASTAL BASINS 3ETHEEN SUIAMNEE DIVEP. ANT AIJILLA RIVER--CONTINUFD

02324000 - STEINHATCHEE K NR CROSS CITY FLA (LAT 294711 LONG D83 19 IP)

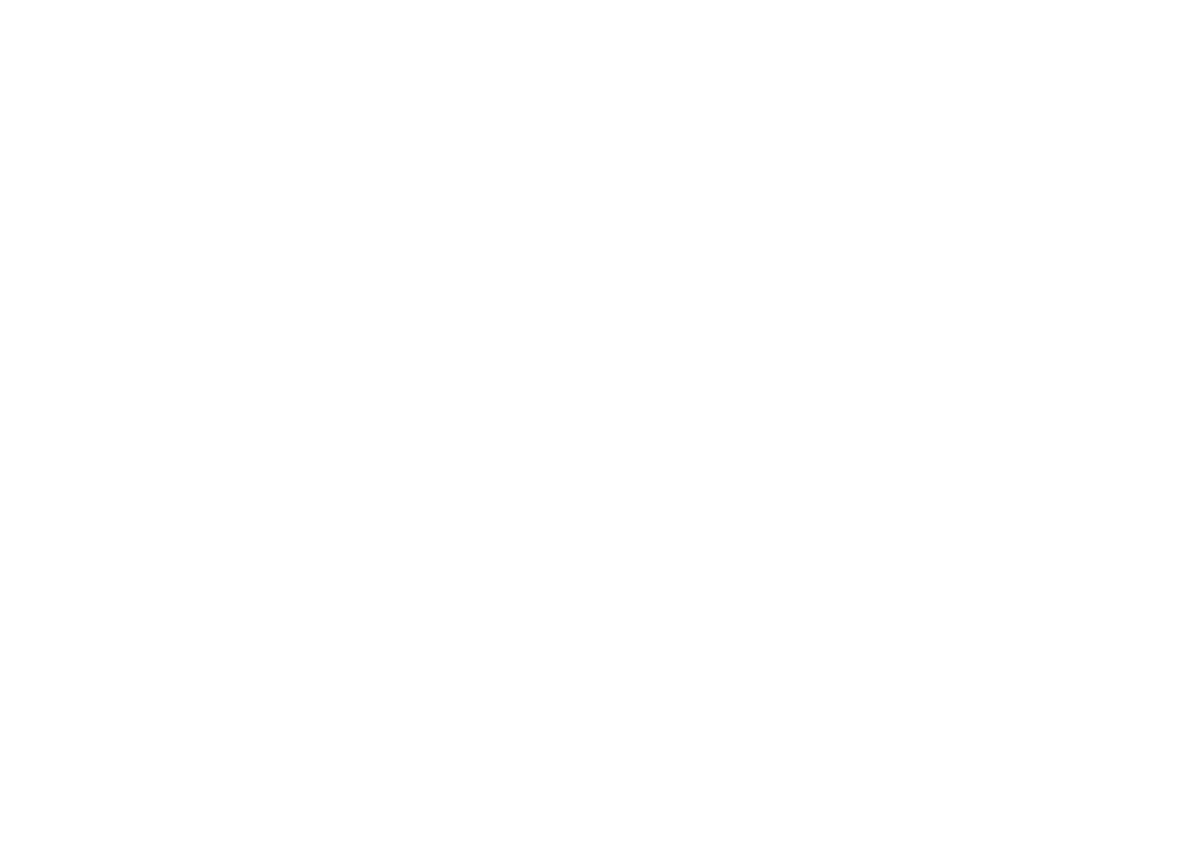

COASTAL BASINS BETWEEN AUCILLA RIVED AND OC,ULOCYONEE RIVER-OCONTINIJET

02326598 - CANEY CKEFK NEAK MONTICELLO FLA ILAT 303052 LOHG nB3 bK 24 )

$\begin{array}{llllllllllll}\text { MAY } 1970 & 0 & 5.0 & .2 & 6 & 2 & 4 & 34 & 20 & .14 & .05 \\ 07 . . . & 02326600 & - & \text { LAKE MICCOSUKEE NR MICCOSUKEE FLA ILAT } 30 & 36 & 14 & \text { LONG OS4 } & 00 & 15\end{array}$

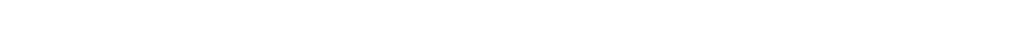

02326700 - LLOYO CR AT LLOYD FLA ILAT 302841 LONG 0940031 )

\begin{tabular}{|c|c|c|c|c|c|c|c|c|c|c|c|c|c|}
\hline $\begin{array}{l}\text { MAY , } 1970 \\
07 \ldots . .\end{array}$ & .8 & 4.8 & $\cdot 1$ & 15 & & 4 & 11 & 46 & 31 & .83 & .06 & - & $\sim$ \\
\hline & & $0232 t$ & 900 & ST $\mathrm{N}$ & MARKS & R NR & NEWPORT FLA & ILAT 30 & 1500 & LONG 08.09 & oni & & \\
\hline \multirow[t]{2}{*}{$\begin{array}{l}\text { MAY. } 1970 \\
08 . . .\end{array}$} & .2 & 5.0 & .3 & 136 & & 11 & 125 & 160 & 147 & 193 & .22 & - & $=$ \\
\hline & & 02327000 & - & WAKULLA & A SPG & NR CR & RAWFORDVILLE & FLA ILAT & 3014 & 05 IONG 084 & 18051 & & \\
\hline $\begin{array}{l}\text { MAY, } 1970 \\
\text { O4... } \\
\text { SEP. }\end{array}$ & 9.6 & 5.0 & .3 & 130 & & 9 & 121 & 163 & 151 & 162 & .22 & -- & $=$ \\
\hline $02 \ldots$ & 9.6 & 7.5 & .3 & 120 & & 9 & 112 & 152 & 143 & 328 & .21 & -- & -- \\
\hline
\end{tabular}

02327010 - LK BRADFORD NR TALLAHASSEE FLA (LAT 302410 LONG OR4 20 05)

$A P R . .1970$

$27 \ldots$

$3.2 \quad+1 \quad 3$

02327020 - MCBRIDE SLOUGH NR CRAWFORDVILLE FLA (LAT 301210 LONG OQ4 1535 ) 


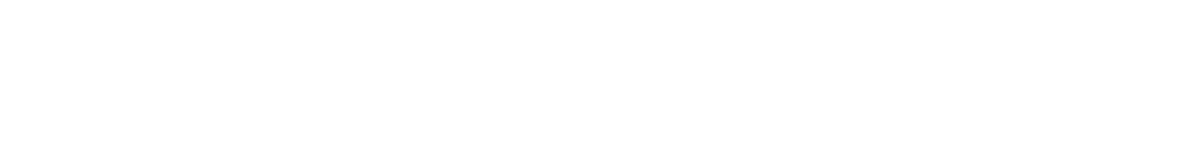

COASTAL BASINS BETHEEN AUCILLA RIVER AND OCHLDCKONEE RIVER--CONTINUED

02327050 - SOPCHOPPY R NR ARRAN FLA (LAT 301350 LONG 08432201

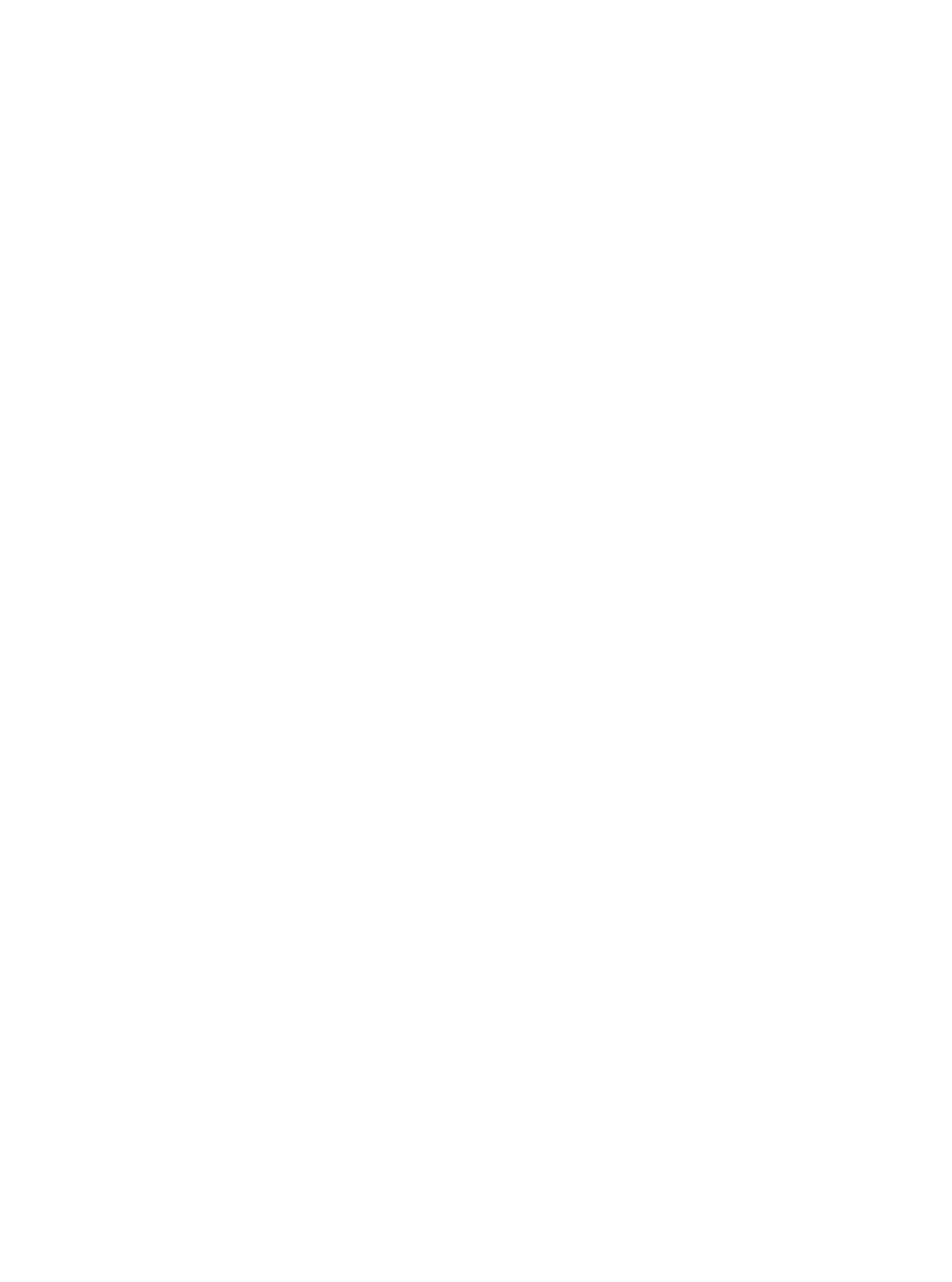


ANALYSES OF SAMPLES COLLECTED AT MISCELLANEOUS SITES IN FLORIDA

CHEMICAL ANALYSES, WATER YEAR OCTOBER 1969 TO SEPTEMBER 1976 (MAJDR CONSTITUENTS)

\begin{tabular}{|c|c|c|c|c|c|c|c|c|c|c|c|}
\hline DATE & $\begin{array}{l}\text { OIS- } \\
\text { SOLVED } \\
\text { SULFAIE } \\
\text { (SOA) } \\
\text { (MG/L) }\end{array}$ & $\begin{array}{l}\text { DIS- } \\
\text { SOLVED } \\
\text { CHLO- } \\
\text { RIDE } \\
\text { (CL) } \\
\text { (MG/L) }\end{array}$ & $\begin{array}{l}\text { DIS- } \\
\text { SOLVEO } \\
\text { FLUO- } \\
\text { RIDE } \\
\text { (F) } \\
\text { (MG/L) }\end{array}$ & $\begin{array}{l}\text { HARO- } \\
\text { NESS } \\
\text { (CA,MG) } \\
\text { (MG/L) }\end{array}$ & $\begin{array}{l}\text { NON- } \\
\text { CAR- } \\
\text { BONATE } \\
\text { HAKD- } \\
\text { NESS } \\
\text { (MG/L) }\end{array}$ & $\begin{array}{l}\text { ALKA- } \\
\text { LINITY } \\
\text { AS } \\
\text { CACO3 } \\
\text { (MG/L) }\end{array}$ & $\begin{array}{l}\text { DIS- } \\
\text { SOLVED } \\
\text { SOLIDS } \\
\text { (RESI- } \\
\text { DUE AT } \\
180 \quad \text { C) } \\
\text { (MG } / \text { ) }\end{array}$ & $\begin{array}{l}\text { DIS- } \\
\text { SOLVED } \\
\text { SOLIDS } \\
\text { (SUM OF } \\
\text { CONST I- } \\
\text { TUENTS) } \\
\text { (MG /L) }\end{array}$ & $\begin{array}{l}\text { DIS- } \\
\text { SOLVED } \\
\text { SOLIDS } \\
\text { (TONS } \\
\text { PER } \\
\text { DAY) }\end{array}$ & $\begin{array}{l}\text { OIS- } \\
\text { SOLVED } \\
\text { SOLIDS } \\
\text { ITONS } \\
\text { PER } \\
\text { AC-FT) }\end{array}$ & $\begin{array}{l}\text { TANN IN } \\
\text { AND } \\
\text { L GNIN } \\
\text { (MG/L) }\end{array}$ \\
\hline
\end{tabular}

CDASTAL BASINS BETWEEN AUCILLA RIVER AND DCHLOCKONEE RIVER--CDNTINUED

02327050 - SOPCHOPPY R NR ARRAN FLA (LAT 301350 LONG 0843220 )

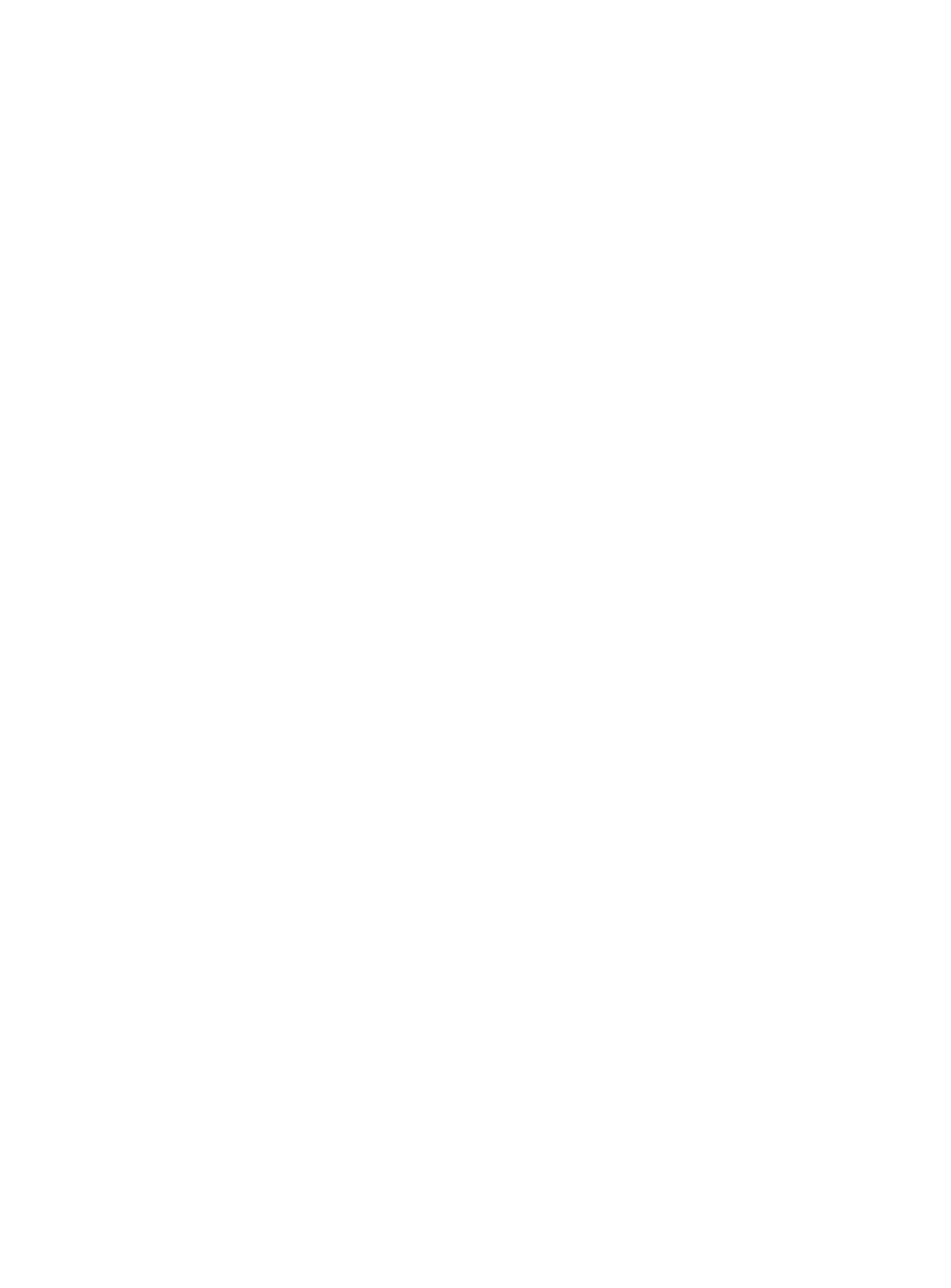




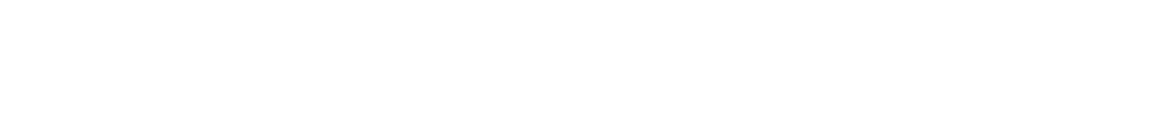

COASTAL BASINS BETWEEN APALACHICOLA RIVER AND CHOCTANHATCHEE RIVER--CONTINUED

02359550 - BEAR CREEK NR YOUNGSTOWN, FLA. (LAT 301910 LONG OB5 2720 )

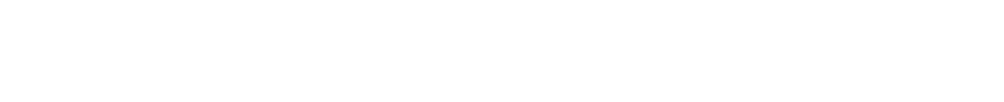




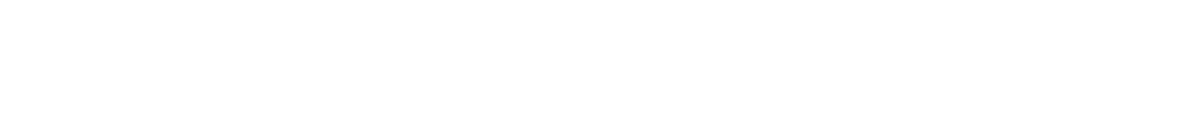

COASTAL BASINS BETWEEN APALACHICOLA RIVER AND CHOCTAMHATCHEE RIVER--CONTINUED

02359550 - BEAR CREEK NR YOUNGSTOWN, FLA. (LAT 301910 LONG 0852720 )

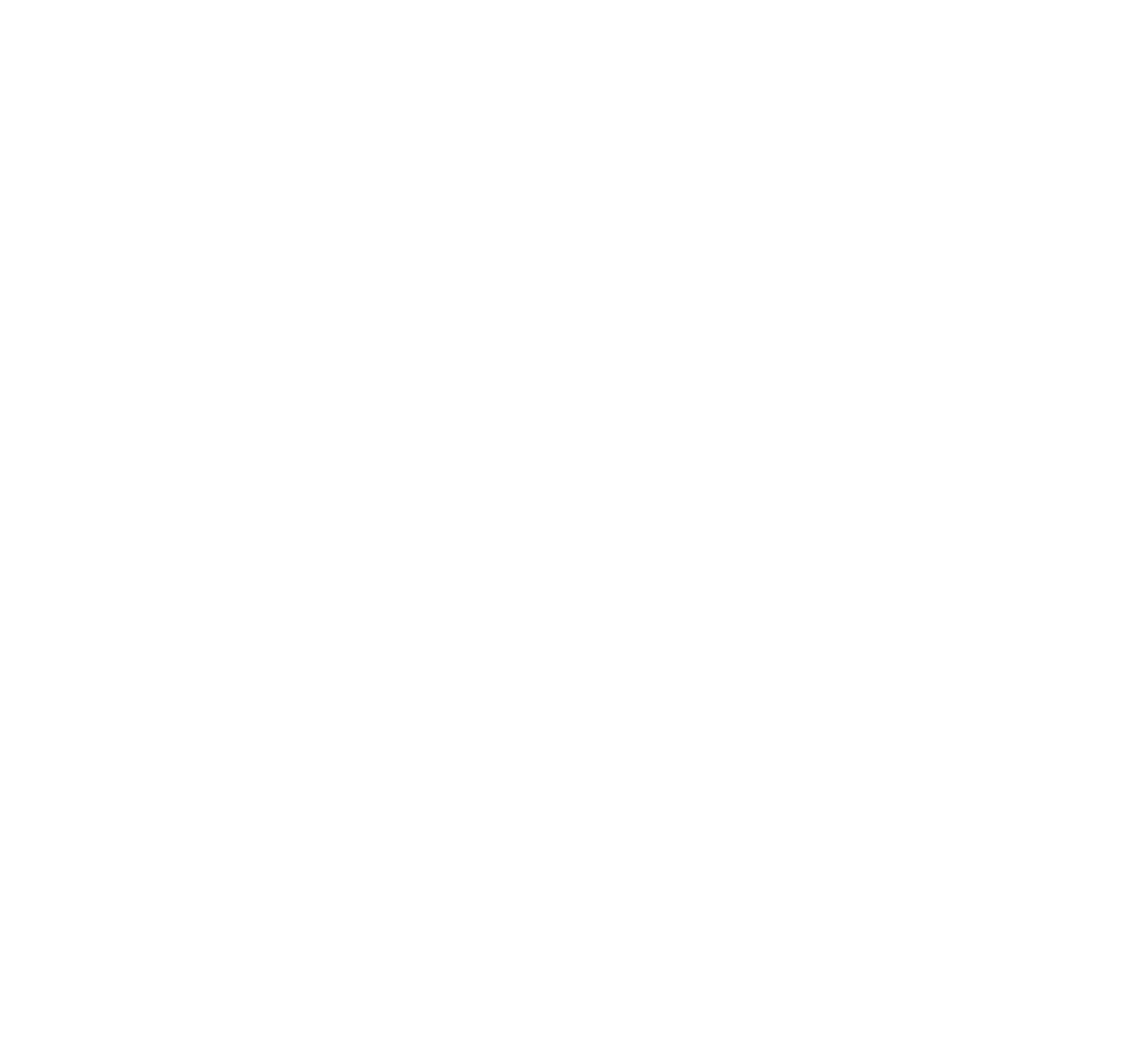

02365658 - SANDY CREEK NEAR ARGYLE, FLA. (LAT 304549 LONG 0860122 )

MAY 1970
I4...
SEP....

3.0

02365700 - SANDY CR AT FONCE DE LEON FLA (LAT 304328 LONG OH5 56 12)

$\begin{array}{ll}\text { MAY } & 1970 \\ 27 . . . & .8\end{array}$

02365726 - BRUCE CREEK NR DEFUNIAK SPRINGS, FLA. ILAT 304153 LONG $086045 \mathrm{n}$ I

MAY, 1970

$20 . .$.

$5.7 \quad 1 \quad 10$

02365728 - DEFUNIAK LAKE AT DEFUNIAK SPRINGS, FLA (LAT 304309 LONG 085 O6 42 )

MAY 1970

$2.8 \quad .0 \quad 7$

02365758 - BRUCE CREEK NEAR RED BAY, FLA. (LAT 303651 LONG O86 00 5n)

MAY, 1970

SEP.

.63 .4

4

$23 . .$.

$3.0 \quad .1 \quad 4$ 

(MAJOR CONSTITUENTS)

\begin{tabular}{|c|c|c|c|c|c|c|c|c|c|c|c|c|}
\hline ATE & $\begin{array}{l}\text { DIS- } \\
\text { CHARGE } \\
\text { (CFS) }\end{array}$ & $\begin{array}{l}\text { TEMPER- } \\
\text { ATURE } \\
\text { (DEG C) }\end{array}$ & $\begin{array}{l}\text { SPE- } \\
\text { CIFIC } \\
\text { CON- } \\
\text { DUCT- } \\
\text { ANCE } \\
\text { (MICRO- } \\
\text { MHOS) }\end{array}$ & $\begin{array}{l}\text { DIS- } \\
\text { SOLVED } \\
\text { IRON } \\
\text { (FE) } \\
\text { (UG/L) }\end{array}$ & $\begin{array}{l}\text { OIS- } \\
\text { SOLVEO } \\
\text { CAL- } \\
\text { CIUM } \\
\text { (CA) } \\
\text { (MG/L) }\end{array}$ & $\begin{array}{l}\text { OIS- } \\
\text { SOLVED } \\
\text { MAG- } \\
\text { NE- } \\
\text { SIUM } \\
\text { (MG) } \\
\text { (MG/L) }\end{array}$ & $\begin{array}{l}\text { DIS- } \\
\text { SOLVED } \\
\text { STRON- } \\
\text { TIUM } \\
\text { (SR) } \\
\text { (UG/L) }\end{array}$ & $\begin{array}{l}\text { DIS- } \\
\text { SOLVED } \\
\text { SODIUM } \\
\text { (NA) } \\
\text { (MG/L) }\end{array}$ & $\begin{array}{l}\text { OIS- } \\
\text { SOLVED } \\
\text { PO- } \\
\text { TAS- } \\
\text { SIUM } \\
\text { (K) } \\
\text { (MG/L) }\end{array}$ & $\begin{array}{l}\text { BICAR= } \\
\text { BONATE } \\
\text { (HCO3) } \\
\text { (MG/L) }\end{array}$ & $\begin{array}{l}\text { CAR- } \\
\text { BONATE } \\
\text { (CO3) } \\
\text { (MG/L) }\end{array}$ & $\begin{array}{c}\mathrm{PH} \\
\text { (UNITS) }\end{array}$ \\
\hline
\end{tabular}

02365800 - SEVEN RUNS CREEK NEAR RED BAY, FLA. (LAT 303218 LONG 08555 14)

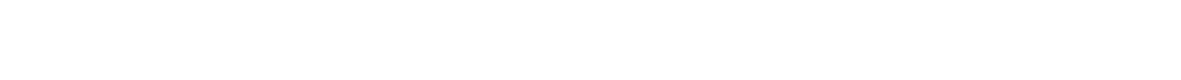

02366000 - HOLMES CR AT VERNON FLA (LAT 303735 LONG 0854245 )

MAY, 1970

$\begin{array}{lllllllll}23.5 & 220 & - & 37 & 4.5 & -5 & 4.4 & .5 & 127\end{array}$

7.9

02366164 - REEOY BRANCH AT NEW HOPE FLA (LAT 303508 LONG 08548 05)

MAY 1970

$\begin{array}{lllllllll}23.0 & 22 & \ldots & 1.2 & .3 & \ldots & 1.7 & .4 & 2\end{array}$

02366500 - CHOCTAWHATCHEE R NR BRUCE FLA (LAT 302703 LONG 0855354 )

MAY, 1970

$\begin{array}{llllllll}26.0 & 143 & - & 21 & 2.8 & -7 & 4.9 & .7\end{array}$

02366836 - BLACK CREEK NEAR BRUCE, FLA, (LAT 302826 LONG 0855920 )

MAY, 197011

20

$\begin{array}{llllllllllll}\text { MAY }, 1970 & 196 & 26.0 & 42 & \ldots & 2.5 & 1.2 & \ldots & 2.1 & 1.5 & 3 & -.\end{array}$

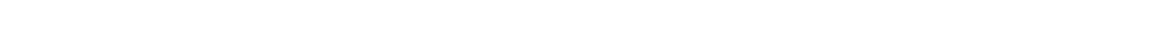

02366859 - PATE BRANCH NR FREEPORT FLA (LAT 302844 LONG 086 04 25)

COASTAL BASINS BETWEEN CHOCTAWHATCHEE RIVER AND YELLDW RIVER

02366900 - MAGNOLIA CREEK NEAR FREEPORT FLA (LAT 303148 LONG 08605 15)

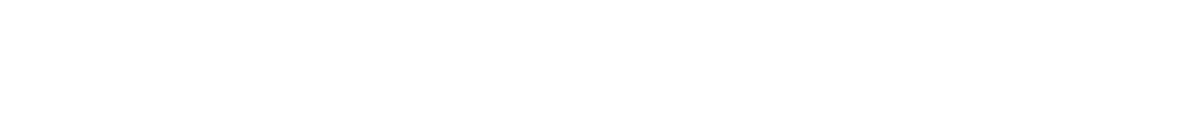

02366911 - LAFAYETTE CREEK AT FREEPORT, FLA. (LAT 302935 LONG 0860733 )

MAY 1970

26.

02367000 - ALAQUA CR NR DE FUNIAK SPGS FLA ILAT 303700 LONG 08609501

MAY 1970 21.5

02367165 - BASIN CREEK NEAR PORTLAND, FLA, (LAT 303102 LONG 0861409$)$

MAY 20.197021

$\begin{array}{lllllllllll}21.0 & 19 & \ldots & .6 & .4 & -0 & 1.4 & .3 & 1 & 0 & 5.6\end{array}$

02367242 - LITTLE ROCKY CREEK NR NICEVILLE FLA ILAT 303634 LONG 08625 31)

MAY $25 .{ }^{1970} 13$

23.5

02367250 - ROCKY CR NR NICEVILLE FLA (LAT 3032 O7 LONG 0862255 )

MAY, 1970
$14 . .$.

21.0

13

02367310 - JUNIPER CR AT SH 85 NR NICEVILLE FLA (LAT 303326 LONG 0 OB6 31 10)

MAY 1970

22.0

YELLOW RIVER BASIN

02368300 - BAGGETT CR NR MILLIGAN FLA ILAT 304340 LONG 0863935 )

$29:{ }^{A P R} 1970$

22.5

17

$\begin{array}{llllll}- & .6 & .4 & \ldots & 1.6 & .2\end{array}$

06.1

02368337 - CANEY CREEK NH GORDON FLA ILAT 305246 LONG 0801311 , 
CHEMICAL ANALYSES, WATER YEAR OCTOBER 1969 TO SEPTEMBER 1970 (MAJOR CONSTITUENTS)

\begin{tabular}{|c|c|c|c|c|c|c|c|c|c|c|c|c|}
\hline ATE & $\begin{array}{l}\text { DIS- } \\
\text { SOLVED } \\
\text { SULFATE } \\
\text { (SO4) } \\
\text { (MG/L) }\end{array}$ & $\begin{array}{l}\text { OIS- } \\
\text { SOLVEO } \\
\text { CHLO- } \\
\text { RIDE } \\
\text { (CL) } \\
\text { (MG/L) }\end{array}$ & $\begin{array}{l}\text { DIS- } \\
\text { SOLVEO } \\
\text { FLUO- } \\
\text { RIDE } \\
\text { (F) } \\
\text { (MG/L) }\end{array}$ & $\begin{array}{l}\text { HARD- } \\
\text { NESS } \\
\text { (CA,MG) } \\
\text { (MG/L) }\end{array}$ & $\begin{array}{l}\text { NON- } \\
\text { CAR- } \\
\text { BONATE } \\
\text { HARD- } \\
\text { NESS } \\
\text { (MG/L) }\end{array}$ & $\begin{array}{l}\text { ALKA- } \\
\text { LINITY } \\
\text { AS } \\
\text { CACO3 } \\
\text { (MG/L) }\end{array}$ & $\begin{array}{l}\text { DIS- } \\
\text { SOLVED } \\
\text { SOLIDS } \\
\text { (RESI- } \\
\text { DUE AT } \\
\text { IAO C) } \\
\text { (MG/L) }\end{array}$ & $\begin{array}{l}\text { DIS- } \\
\text { SOLVED } \\
\text { SOLIDS } \\
\text { (SUM OF } \\
\text { CONSTI- } \\
\text { TUENTS) } \\
\text { (MG/L) }\end{array}$ & $\begin{array}{l}\text { OIS- } \\
\text { SOLVED } \\
\text { SOLIDS } \\
\text { (TONS } \\
\text { PER } \\
\text { DAY) }\end{array}$ & $\begin{array}{l}\text { DIS- } \\
\text { SOLVED } \\
\text { SOLINS } \\
\text { (TONS } \\
\text { PER } \\
\text { AC-FT) }\end{array}$ & $\begin{array}{l}\text { TANNIN } \\
\text { AND } \\
\text { LGNIN } \\
\text { (MG/L) }\end{array}$ & $\begin{array}{c}\text { QEPTH } \\
\text { (FT) }\end{array}$ \\
\hline
\end{tabular}

CHOCTAWHATCHEE RIVER BASIN--CONTINUED

02365800 - SEVEN RUNS CREEK NEAR RED BAY, FLA. ILAT 303218 LONG 0855514 )

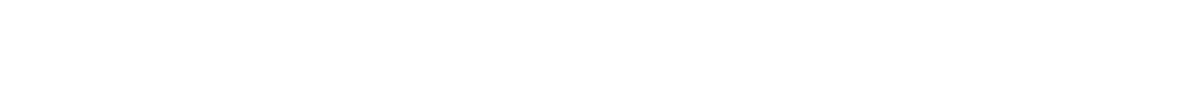

02366000 - HOLMES CR AT VERNON FLA ILAT 303735 LONG 0854245 )

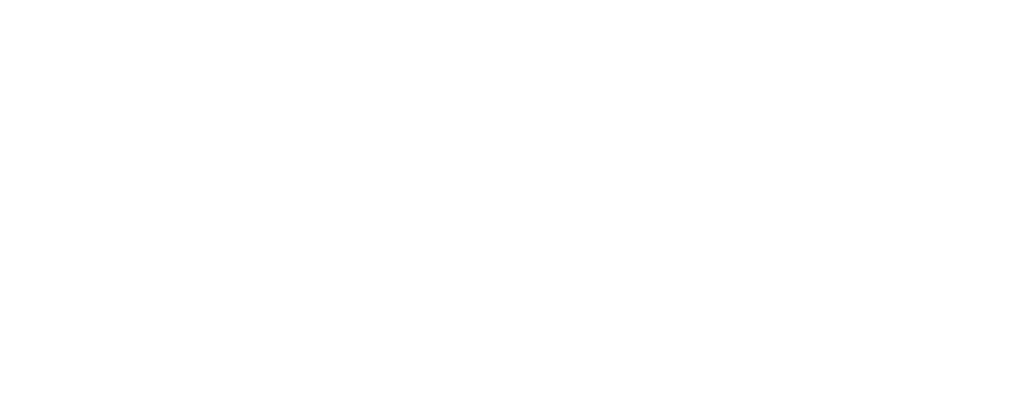

MaY, 1970

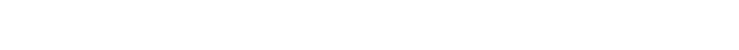
02366900 - MAGNOLIA CREEK NEAR FREEPORT FLA (LAT 303148 LONG 08605 15)

\begin{tabular}{|c|c|c|c|c|c|c|c|c|c|c|c|c|}
\hline $\begin{array}{l}\text { MAR., } 1970 \\
12 \ldots . . . \\
\text { MAY }\end{array}$ & 1.0 & 8.4 & .0 & 14 & 14 & 0 & 55 & 35 & 7.42 & .07 & $=$ & $=$ \\
\hline SEP... & .2 & 10 & .1 & 19 & 19 & $n$ & 58 & 45 & -- & .08 & $=$ & - \\
\hline $23 .$. & .8 & 9.8 & .1 & 20 & 20 & 0 & 60 & 48 & -- & .08 & - & -- \\
\hline
\end{tabular}

02366911 - LAFAYETTE CREEK AT FREEPORT. FLA. ILAT 3n 2935 LONG 08607331

MAY, 1970

$8.1 \quad 0 \quad 14$

02367000 - ALAQUA CR NR DE FUNIAK SPGS FLA ILAT 303700 LONG 08609501

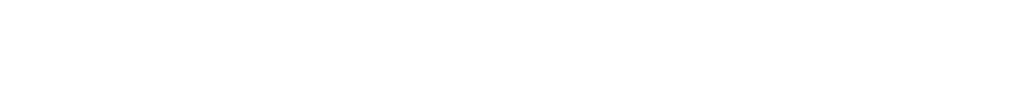

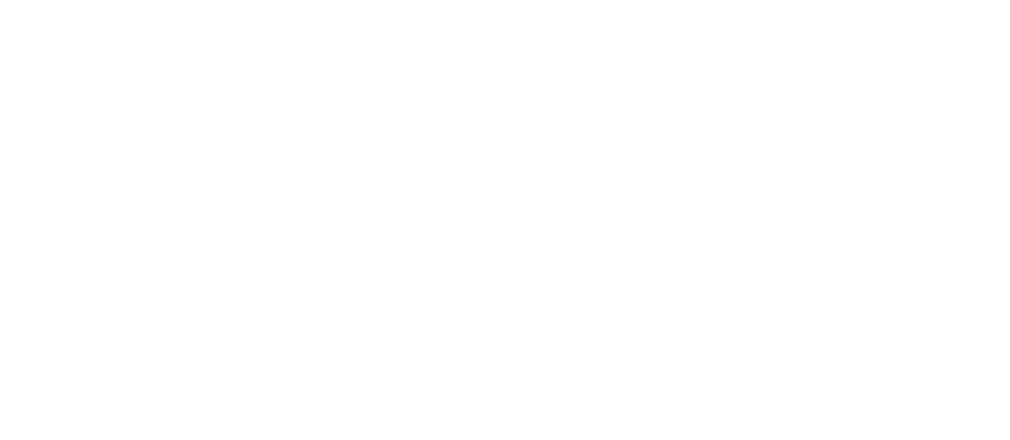

APR., 1970

$29 . .$.

02368337 - CANEY CREEK NR GOROON FLA ILAT $3052 \quad 46$ LONG 08013111

MAY 1970 


\begin{tabular}{|c|c|c|c|c|c|c|c|c|c|c|c|c|}
\hline & & & CHEMICAL & ANALYSES, & $\begin{array}{l}\text { WATER Y } \\
\text { (MAJOR }\end{array}$ & $\begin{array}{l}\text { AR OCTOI } \\
\text { ONSTITUE }\end{array}$ & $\begin{array}{l}R 1969 \\
T S)^{2}\end{array}$ & SEPTE & R 1970 & & & \\
\hline DATE & $\begin{array}{l}\text { DIS- } \\
\text { CHARGE } \\
\text { (CFS) }\end{array}$ & $\begin{array}{l}\text { TEMPER- } \\
\text { ATURE } \\
\text { (DEG C) }\end{array}$ & $\begin{array}{l}\text { SPE- } \\
\text { CIF IC } \\
\text { CON- } \\
\text { DUCT- } \\
\text { ANCE } \\
\text { (MICRO- } \\
\text { MHOS) }\end{array}$ & $\begin{array}{l}\text { DIS- } \\
\text { SOLVED } \\
\text { IRON } \\
\text { (FE) } \\
(U G / L)\end{array}$ & $\begin{array}{l}\text { OIS- } \\
\text { SOLVED } \\
\text { CAL- } \\
\text { CIUM } \\
\text { (CA) } \\
\text { (MG/L) }\end{array}$ & $\begin{array}{l}\text { DIS- } \\
\text { SOL VED } \\
\text { MAG- } \\
\text { NE- } \\
\text { SIUM } \\
\text { (MG) } \\
(M G / L)\end{array}$ & $\begin{array}{l}\text { DIS- } \\
\text { SOLVED } \\
\text { STRON- } \\
\text { TIUM } \\
\text { (SR) } \\
(U G / L)\end{array}$ & $\begin{array}{l}\text { DIS- } \\
\text { SOL VED } \\
\text { SODIUM } \\
\text { (NA) } \\
\text { (MG/L) }\end{array}$ & $\begin{array}{l}\text { DIS- } \\
\text { SOLVEO } \\
\text { PO- } \\
\text { TAS- } \\
\text { SIUM } \\
\text { (K) } \\
\text { (MG/L) }\end{array}$ & $\begin{array}{l}\text { AICAR- } \\
\text { BONATE } \\
\text { (HCO }) \\
\text { (MG/L) }\end{array}$ & $\begin{array}{l}\text { CAR- } \\
\text { BONATF } \\
\text { (CO3) } \\
\text { (MG/L) }\end{array}$ & $\begin{array}{c}\text { PH } \\
\text { IUNITSI }\end{array}$ \\
\hline
\end{tabular}

02368450 - GUM CREEK NR DE FUNIAK SPRINGS FLA (LAT 3048 06 LONG 08611421

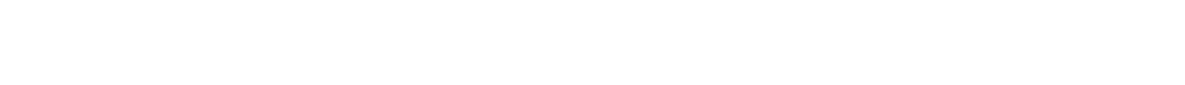

n2368500 - SHOAL R NR MOSSY HEAD FLA ILAT 304745 LONG O86 1925 )

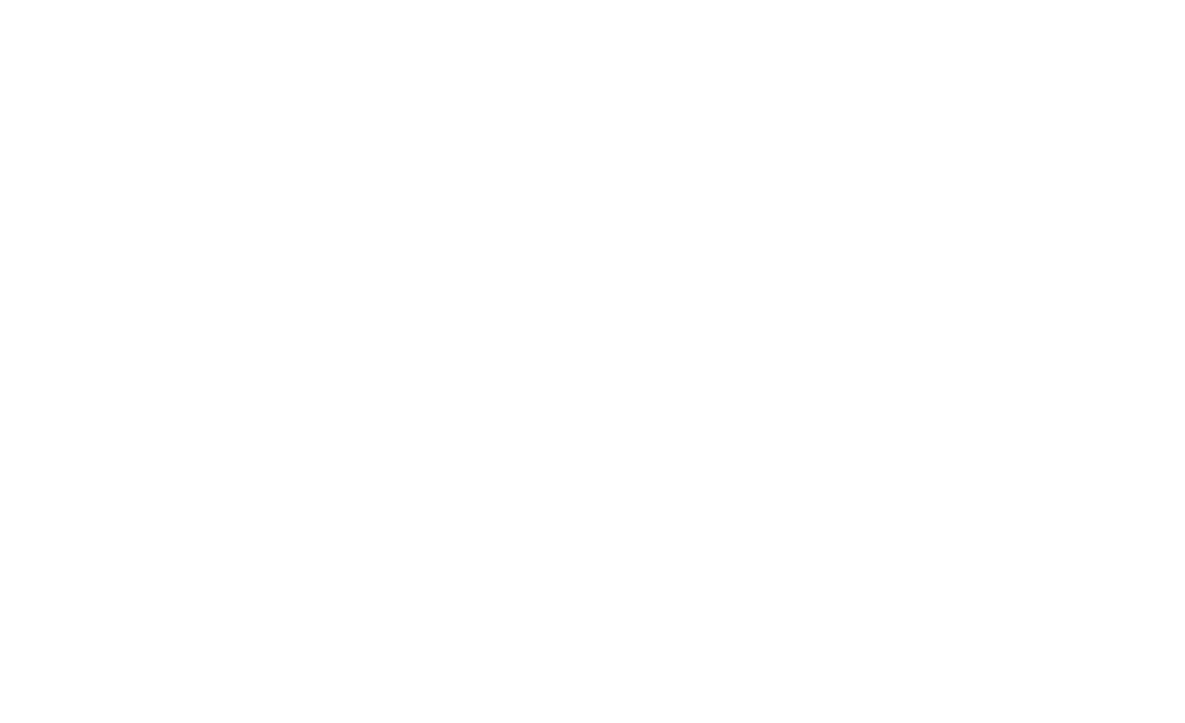

02370015 - MUDOY BRANCH NEAR GEAVER CREEK FLA (LAT 305101 LONG 0864654 )

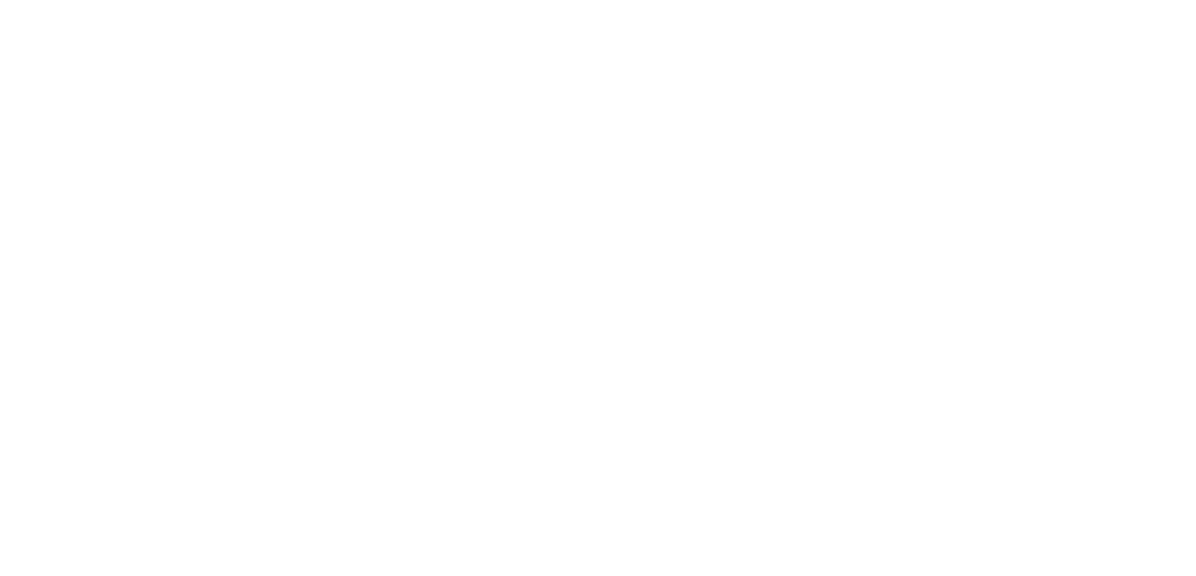

02376000 - PINE BARREN CR NR BARTH FLA ILAT 304755 LONG 08722051 
CHEMICAL ANALYSES, WATER YEAR OCTOBER 1969 TO SEPTEMBER 1970

(MAJOR CONSTITUENTS)

\begin{tabular}{|c|c|c|c|c|c|c|c|c|c|c|c|c|}
\hline DATE & $\begin{array}{l}\text { DIS- } \\
\text { SOLVED } \\
\text { SULFATE } \\
\text { (SO4) } \\
\text { (MG/L) }\end{array}$ & $\begin{array}{l}\text { CIS- } \\
\text { SOLVED } \\
\text { CHLO- } \\
\text { RIDE } \\
\text { (CL) } \\
\text { (MG/L) }\end{array}$ & $\begin{array}{l}\text { DIS- } \\
\text { SOLVED } \\
\text { FLUO- } \\
\text { RIDE } \\
\text { (F) } \\
\text { (MG/L) }\end{array}$ & $\begin{array}{l}\text { HARD- } \\
\text { NESS } \\
\text { (CA,MG) } \\
(M G / L)\end{array}$ & $\begin{array}{l}\text { NON- } \\
\text { CAR- } \\
\text { GONATE } \\
\text { HARD- } \\
\text { NESS } \\
\text { (MG/L) }\end{array}$ & $\begin{array}{l}\text { ALKA- } \\
\text { LINIIY } \\
\text { AS } \\
\text { CACO3 } \\
\text { (MG L }\end{array}$ & $\begin{array}{l}\text { OIS- } \\
\text { SOLVED } \\
\text { SOLIDS } \\
\text { (RESI- } \\
\text { UUE AT } \\
\text { IBO C) } \\
\text { (MGAL) }\end{array}$ & $\begin{array}{l}\text { DIS- } \\
\text { SOLVEI) } \\
\text { SOLIIIS } \\
\text { ISUM OF } \\
\text { CONSTI- } \\
\text { TUENTS) } \\
\text { (MG IL) }\end{array}$ & $\begin{array}{l}\text { DIS- } \\
\text { SOLVEU } \\
\text { SOLIISS } \\
\text { ITONS } \\
\text { PER } \\
\text { OAYI }\end{array}$ & $\begin{array}{l}\text { DIS- } \\
\text { SOLVEN } \\
\text { SOLIISS } \\
\text { ITONS } \\
\text { PER } \\
\text { AC-FTI }\end{array}$ & $\begin{array}{l}\text { TANNIN } \\
\text { ANO } \\
\text { LIGNIN } \\
\text { (MG IL) }\end{array}$ & $\begin{array}{l}\text { OEPTH } \\
\text { (FI) }\end{array}$ \\
\hline
\end{tabular}

02368450 - GUM CREEK NR DE FUNIAK SPRINGS FLA (LAT 3048 O6 LONG 0861142 )

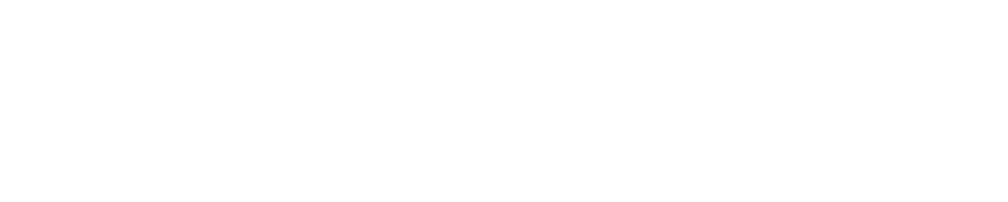

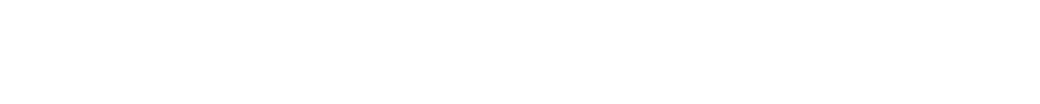

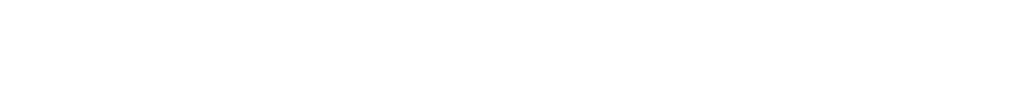

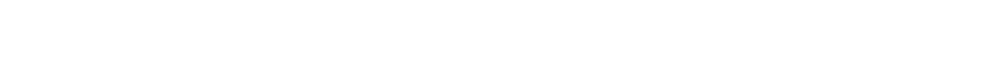

02368944 - TIII CREEK NR MOSSY HEAD FLA (LAT $3042 \quad 07$ LONG 05523 16)

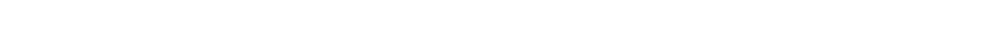

02369000 - SHOAL R NR CRESTVIEN FLA (LAT 304148 LONG 08634 17)

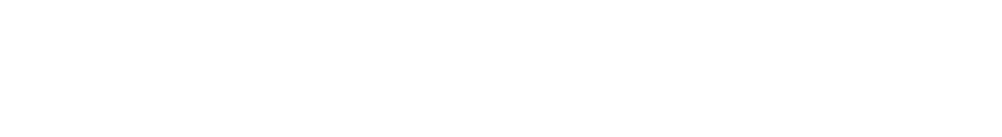

\begin{tabular}{|c|c|c|c|c|c|c|c|c|c|c|c|}
\hline $\begin{array}{l}\text { MAY } 1970 \\
19 . . . \\
\text { 5EP. }\end{array}$ & .8 & 2.0 & .0 & 6 & 2 & 3 & 22 & 15 & 42.6 &.$\cap 3$ & - \\
\hline $22 \ldots$ & .4 & 3.0 & .1 & 4 & 1 & 2 & 19 & 16 & 7.03 & .03 & - \\
\hline
\end{tabular}

02370015 - MUDDY RRANCH NEAR BEAVER CREEK FLA (LAT 305101 LONG OR6 4654 )

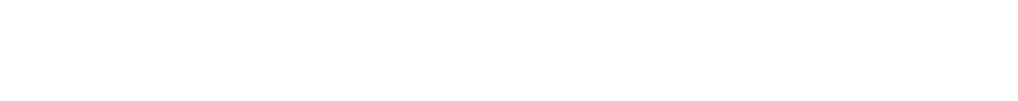

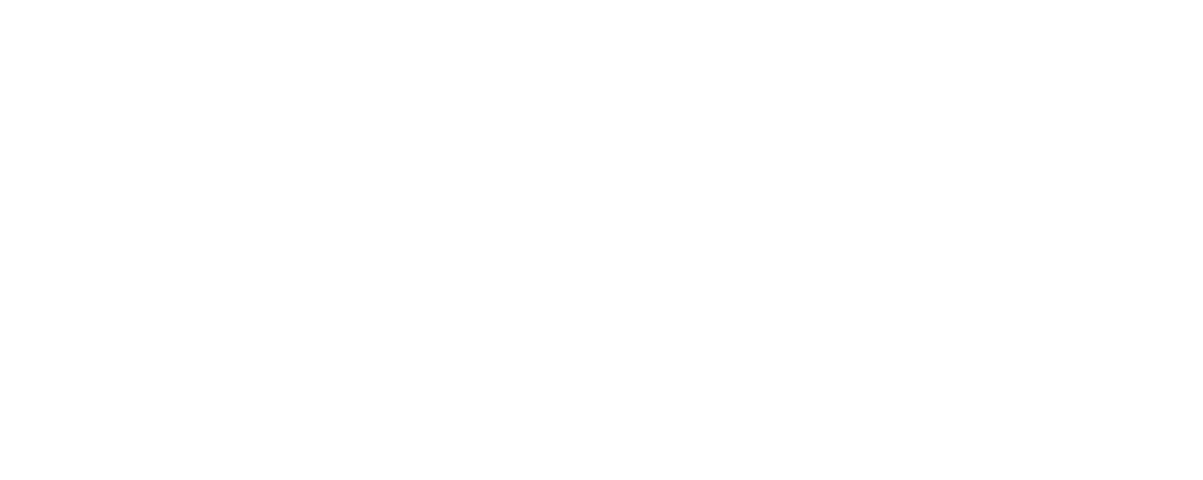

02376000 - PINE BARREN CR NR BARTH FLA (LAT 304755 LONG OR7 22 n5)

APR., 1970

27... 


\begin{tabular}{|c|c|c|c|c|c|c|c|c|c|c|c|c|}
\hline & $\begin{array}{l}\text { DIS- } \\
\text { CHARGE } \\
\text { (CFS) }\end{array}$ & $\begin{array}{l}\text { TEMPER- } \\
\text { ATURE } \\
\text { (DEG C) }\end{array}$ & $\begin{array}{l}\text { SPE- } \\
\text { CIFIC } \\
\text { CON- } \\
\text { DUCT- } \\
\text { ANCE } \\
\text { (MICRO- } \\
\text { MHOS) }\end{array}$ & $\begin{array}{l}\text { DIS- } \\
\text { SOLVED } \\
\text { IRON } \\
\text { (FE) } \\
\text { (UG/L) }\end{array}$ & $\begin{array}{l}\text { DIS- } \\
\text { SOLVED } \\
\text { CAL- } \\
\text { CIUM } \\
\text { (CA) } \\
\text { (MG/L) }\end{array}$ & $\begin{array}{l}\text { DIS- } \\
\text { SOLVED } \\
\text { MAG- } \\
\text { NE- } \\
\text { SIUM } \\
\text { (MG) } \\
(M G / L)\end{array}$ & $\begin{array}{l}\text { DIS- } \\
\text { SOLVED } \\
\text { STRON- } \\
\text { TIUM } \\
\text { (SRI } \\
\text { (UG/L) }\end{array}$ & $\begin{array}{l}\text { OIS- } \\
\text { SOLVED } \\
\text { SODIUM } \\
\text { (NA) } \\
\text { (NG/L) }\end{array}$ & $\begin{array}{l}\text { DISL } \\
\text { SOLVED } \\
\text { PO- } \\
\text { TAS- } \\
\text { SIUM } \\
\text { (K) } \\
\text { (MG/L) }\end{array}$ & $\begin{array}{l}\text { BICAR- } \\
\text { BONATE } \\
\text { (HCO3) } \\
\text { (MG/1) }\end{array}$ & $\begin{array}{l}\text { CAR- } \\
\text { BONATE } \\
\text { (CO3) } \\
\text { (MG/L) }\end{array}$ & $\begin{array}{c}\text { PH } \\
\text { (UNITS) }\end{array}$ \\
\hline
\end{tabular}

COASTAL BASINS BETWEEN ESCAMBIA RIVER AND MOBILE RIVER

02376108 - ELEVENMILE CREEK NR ENSLEY FLA (LAT 303252 LONG 0871949 )

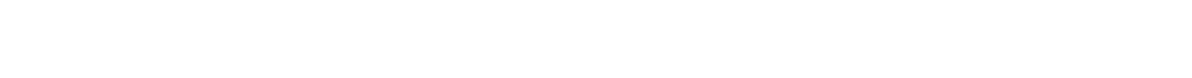

02376300 - BRUSHY CR NR WALNUT HILL FLA (LAT 305321 LONG OBT 32 24)

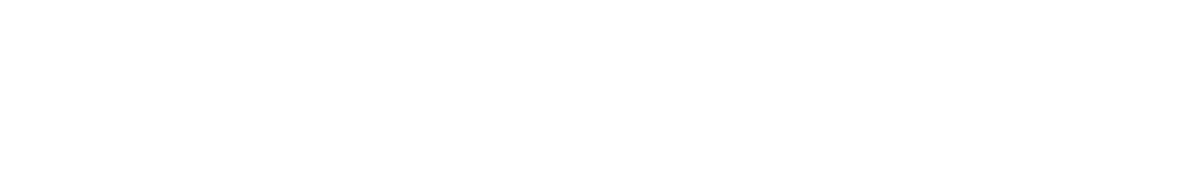

02376551 - CHURCH HOUSE BRANCH NEAR BARRINEAU PARK, FLA ILAT 304027 LONG 08723431

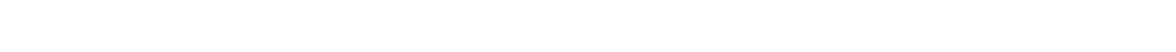


ANALYSES OF SAMPLES COLLECTED AT MISCELLANEOUS SITES IN FLORIDA

CHEMICAL ANALYSES, WATER YEAR OCTOBER 1969 TO SEPTEMBER 1970 (MAJOR CONSTI TUENTS)

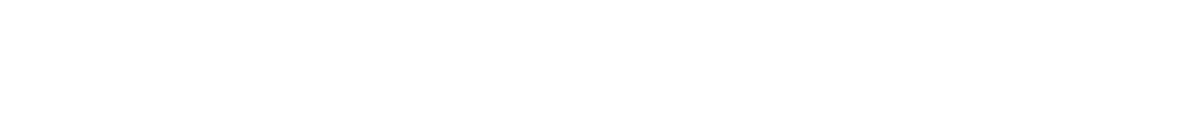

COASTAL BASINS BETWEEN ESCAMBIA RIVER AND MOBILE RIVER--CONTINUED

02376108 - ELEVENMILE CREEK NR ENSLEY FLA (LAT 303252 LONG 0871949 )

\begin{tabular}{|c|c|c|c|c|c|c|c|c|c|c|c|}
\hline $23 .$. & 75 & 118 & .4 & 119 & 0 & 225 & 640 & 558 & 112 & .87 & - \\
\hline
\end{tabular}

02376300 - BRUSHY CR NR WALNUT HILL FLA (LAT 305321 LONG 08732 24)

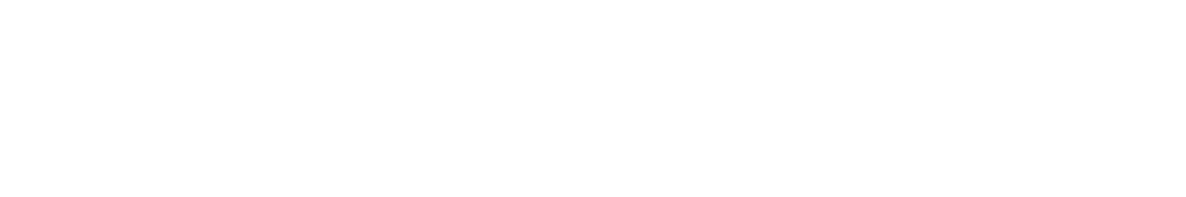

02376551 - CHURCH HOUSE BRANCH NEAR BARPINEAU PARK, FLA (LAT 304027 LONG 0872343 )

APR., 1970

28....

3.4



(MAJOR CONSTITUENTS)

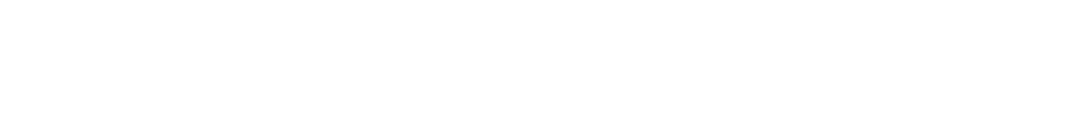

LAKE UKEECHOBEE AND THE EVERGLADES BASINS

252353080342200 -

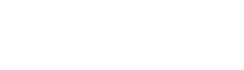

$253400080570000-$ \$UG... $197030.0 \quad 280$

254021081051500 SEP., 1970

$23 . . .29 .0 \quad 309$

$\angle 54450080563000$ MAR., 1970

MAR.P $1970 \quad--\quad 398$

254500080580000 Nov., 1969

19... 26.0270

254715081055000 MAR., 1970

25... -- 357

II.. -- 330

254812080182000

Nov.. $196923.0 \quad 293$

254819080160100 Nov., 1969

255040080555000 NOV., 1969

$18 . .1969=27$

255120080523000 NOV.. 1969 -

JUNE. 1970 32.0

JULY $32.0 \quad 32.0$

AUG. $14, \quad$-- 244

$13 \ldots 234.0 \quad 213$

$16 \ldots 230.0 \quad 219$

255120080540000 JUNE, 1970

JUNE. 197029.0

JULY $14 \ldots . .290$

AUG..

$13 . . .219$

15... $29.0 \quad 260$

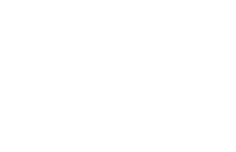

255231080522000 -

$17 . .029 .0 \quad 572$

LEVEE 31 W CA AT HWY 27 NR HONESTEAD F (LAT 24 2353 LONG 0 BO 34 22)

$\begin{array}{rrrrrrrrr}-- & 69 & 3.0 & -- & 16 & .4 & 160 & -- & 7.7 \\ -- & 71 & 3.0 & -- & 13 & .6 & 210 & 4 & 8.4\end{array}$

ROGERS RIV HEADWATEHS NK PINECHEST FLA ILAT 253400 LONG 080 57001

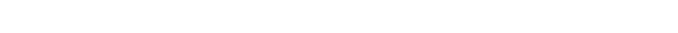

POND IN WESTERN PAKT GUM SLQUGH NR MON (LAT 254021 LONG 082 a 25 15!

$\begin{array}{lllllll}70 & 49 & 2.8 & 100 & 17 & .5 & 160\end{array}$

UNIVER OF MIAMI POND AT SR 94 NR MIAMI (LAT 254450 LONG OBN 5630 )

$\begin{array}{lllllllllll}- & 70 & 3.1 & 450 & 15 & .6 & 20\end{array}$

CILVERT 24 ON LO ROAD NR PINECREST F ILST 2545 OO LONG OHN 58001

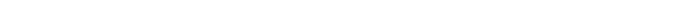

CYPRESS STRAND OFF ST RT 94 MR PINECRE (LAT 7547 I5 LONA 081 05 50)

\begin{tabular}{|c|c|c|c|c|c|c|c|}
\hline $3 n$ & 63 & $2 \cdot 1$ & 160 & 12 & .4 & 194 & - \\
\hline 110 & of & 2.0 & 100 & 8.7 & .4 & 190 & 0 \\
\hline
\end{tabular}

HORROW PIT CA AT LUDLUM RO MIAMI FLA (LAT 25 4H 12 LONG ORH 18 20)

$\begin{array}{lllllll}-- & 45 & 2.0 & 0 & 17 & 1.7 & 142\end{array}$

DPAIN UITCH NE COR MIAMI INT AIRPORT M ILAT PS 48 18 LONG 03016 011

-

TAMIAMI CA AT JETPOQT ENTRANCE NR MIAM (LAT 25 SO 40 LONG OSO 5550 )

$\begin{array}{lllllll}20 & 37 & 1.9 & 0 & 6.6 & .6 & 114\end{array}$

$\begin{array}{rrrrrrrrr}- & 44 & 2.1 & 0 & 0.2 & .6 & 128 & 0 & 7.5 \\ 40 & 40 & 3.0 & 32 n & 11 & .5 & 180 & 0 & 4.2 \\ 30 & 44 & 1.8 & 120 & 6.2 & .6 & 127 & 0 & 7.6 \\ 40 & 36 & 1.7 & 160 & 5.4 & .4 & 99 & -. & 7.7 \\ 50 & 34 & 2.15 & 200 & 6.3 & .5 & 116 & 0 & 8.1\end{array}$

CYPRESS SWP NQ JETPOKT BORROW PIT 3 HNR (LAA 25 S1 20 LONG 0805400 )

$\begin{array}{rrrrrrrrr}120 & 72 & 3.9 & 320 & 17 & .9 & 192 & 0 & 7.9 \\ 80 & 53 & 2.6 & 180 & 7.5 & .9 & 156 & 0 & 7.6 \\ 90 & 37 & 1.8 & 160 & 5.9 & .5 & 113 & \ldots & 7.7 \\ 90 & 47 & 2.8 & 200 & 11 & 1.2 & 134 & 0 & 9.0\end{array}$

JETPORT HOHROW PIT S NR MIAMI FLA ILAT 255230 LONG OKO 55 NO)

$\begin{array}{rrrrrrrrr}2 n & 50 & 3.8 & 280 & 18 & .4 & 144 & 0 & 4.1 \\ 20 & 50 & 3.8 & 220 & 18 & .6 & 140 & 0 & 7.9 \\ 0 & 47 & 3.9 & 293 & 18 & .6 & 134 & 3 & 8.5 \\ -8 & 48 & 2.4 & 360 & 15 & 1.5 & 169 & -5 & 7.0 \\ 60 & 53 & 4.1 & 300 & 17 & .7 & 164 & 0 & 9.2\end{array}$

CYPRESS 5 WP NR JP PIT \#4 NFAP PINECRES (LAT 255231 LONG nEO 52 20) 
CHEMICAL ANALYSES, WATER YEAR OCTOBER 1969 TO SEPTEMBER 1970 (MAJOR CONSTITUENTS)

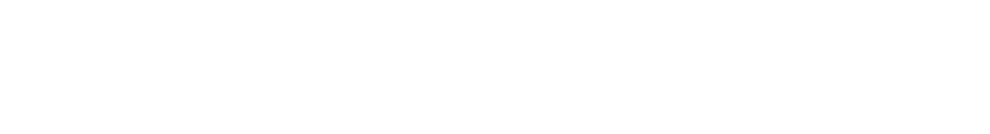

LAKE OKEECHOBEE AND THE EVERGLADES BASINS--CONTINUED

252353090342200 - LEVEE 31 W CA AT HWY 27 NP HOMESTFAD F (LAT 252353 LONG 090 34 2?)

$\begin{array}{llllllllll}\begin{array}{l}\text { JAN., 1970 } \\ 12 . . .\end{array} & 7.2 & 24 & .2 & 185 & 54 & 131 & 251 & 202 & .34 \\ \begin{array}{l}\text { MAY } \\ 15 \ldots\end{array} & 9.6 & 21 & .2 & 190 & 11 & 179 & 234 & 230 & .32\end{array}$

253400080570000 - ROGERS RIV HEADWATERS NR PINFCREST FLA (LAT 2534 0O LONG 0805700$)$

254021081051500 - PONN IN WESTERN PART GUM SLOIJGH NR MON ILAT 254021 LONG 08105 (S)

SEP., 1970

254450080563000 - UNIVER OF MIAMI POND AT SR 94 NR MIAMI ULAT 254450 LONG 0ON 5630

$\begin{array}{lllllllllll}26 \ldots . . & 1.2 & 23 & .2 & 190 & 18 & 171 & 244 & 220 & .34\end{array}$

254500080580000 - CULVERT 24 ON LUOP ROAD NR PINECREST F (LAT 2545 OO LONG OBO 5 O OU)

19...

254715081055000 - CYPRESS STRAND OFF ST RT 94 NR PINECRF (LAT $2547 \quad 15$ LONG 0810550 )

\begin{tabular}{|c|c|c|c|c|c|c|c|c|c|c|}
\hline $25 \ldots$ & .0 & 19 & -1 & 166 & 7 & 159 & 215 & 197 & .29 & $1 . n$ \\
\hline $11 . .$. & .8 & 14 & .2 & 163 & 7 & 156 & 201 & 184 &.$\geqslant 7$ & 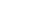 \\
\hline
\end{tabular}

254812080182000 - BORROW PIT CA AT LUOLUM RO MIAMI FLA (LAT 254912 LONG O8O 1820 )

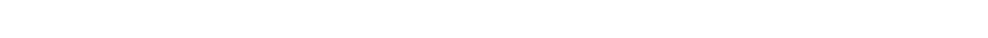

254818080160100 - DRAIN DITCH NE COR MIAMI INT AIRPORT M (LAT 2548 IR LONG 08O IS OI)

Nov., 1969

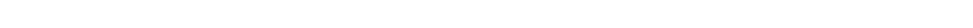

255040080555000 - TAMIAMI CA AT JETPORT ENTPANCE NR MIAM (LAT 255040 LONG O80 55 50) NOV., 1969

$\begin{array}{llllllllll}\text { NOV.. } & 1969 \\ 18 . . . & .0 & 12 & .0 & 101 & 7 & 94 & 129 & 115 & .19\end{array}$

255120080523000 - JETPORT BORROW PIF \#4 NR MIAMI FLA (LAT 255120 LONG ORO 5230 )

\begin{tabular}{|c|c|c|c|c|c|c|c|c|c|c|}
\hline JUNE: 1970 & 12 & 11 & .1 & 119 & 14 & 105 & 157 & 140 & .21 & .7 \\
\hline $\begin{array}{l}17 . \ldots \\
\text { JULY }\end{array}$ & 8.8 & 17 & -1 & 163 & 15 & 148 & 218 & 191 & . $3 n$ & $\infty$ \\
\hline $\begin{array}{l}14 \ldots . . \\
\text { AUG. }\end{array}$ & 6.4 & 10 & .0 & 118 & 14 & 104 & 192 & 134 & .26 & - \\
\hline $\begin{array}{l}13 \ldots \\
\text { SEP. }\end{array}$ & 11 & 8.7 & .5 & 97 & 16 & B1 & $1>5$ & 114 & .17 & -- \\
\hline $16 \ldots$ & 5.6 & 14 & .3 & 103 & 8 & 95 & 141 & $1 ? 6$ & .19 & \\
\hline
\end{tabular}

255120080540000 - CYPKESS SWP NR JETPONT BORROW RIT 3 NR (LAT 255120 LONG DRN 5400 )

\begin{tabular}{|c|c|c|c|c|c|c|c|c|c|c|}
\hline $17 \ldots$ & 32 & 28 & .2 & 196 & 39 & 157 & 262 & 251 & .36 & - \\
\hline $\begin{array}{l}14 \ldots \\
146 .\end{array}$ & 5.6 & 16 & .0 & 143 & 15 & 128 & 211 & 164 & .29 & -- \\
\hline $13 \ldots$ & .8 & 8.7 & .2 & 100 & 8 & 93 & 178 & 112 & .17 & 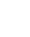 \\
\hline 15. & .0 & 18 & .4 & 117 & 7 & $11 n$ & $17 \mathrm{~A}$ & 144 & .24 & - \\
\hline
\end{tabular}

255230090550000 - JETPDRT HORROW PIT 5 NR MIAMI FLA (LAT 255230 LONG 09055 ONO)

\begin{tabular}{|c|c|c|c|c|c|c|c|c|c|}
\hline $\begin{array}{l}\text { JUNE, } 1970 \\
17 \ldots . . \\
\text { JULY }\end{array}$ & 15 & 26 & $\cdot 1$ & 141 & 20 & 121 & 213 & 194 & .29 \\
\hline AUG... & 14 & 29 & .0 & 141 & 27 & 115 & 256 & 191 & .35 \\
\hline $13 \ldots$ & $\begin{array}{l}16 \\
6.4\end{array}$ & $\begin{array}{l}25 \\
16\end{array}$ & .2 & $\begin{array}{l}134 \\
131\end{array}$ & $\begin{array}{r}16 \\
0\end{array}$ & $\begin{array}{l}118 \\
139\end{array}$ & $\begin{array}{l}198 \\
189\end{array}$ & $\begin{array}{l}198 \\
181\end{array}$ & $\begin{array}{l}.26 \\
.25\end{array}$ \\
\hline SEP. & 15 & 26 & .3 & 150 & 15 & 135 & 214 & 205 & .30 \\
\hline
\end{tabular}

255231080522000 - CYPRESS S*P NR JP PIT $\$ 4$ NEAR PINECRES (LAT 255231 LOMG 08052 20)

JUNE, 1970

$17 \ldots$ 66

$24 \quad .2 \quad 266$

$72 \quad 194$

$\begin{array}{lll}373 & 327 \quad .51\end{array}$ 


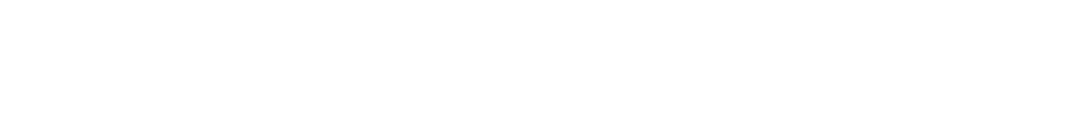

\section{LAKE OKEECHOBEE AND tHE EVERGLADES BASINS--CONTINUED}

$255307081281900 \quad-$ MAR.: $1970 \quad--\quad 8900$ SEP. $28.0 \quad 9300$

$255329081302400-$ MAR., $1970 \quad-\quad 2450$ SEP.. $\quad-\quad 2450$ 21... $28.0 \quad 4000$

255520080562200 MAR.. 1970
$30 . .$.

JUNE

16... $28.0 \quad 281$

JULY 30.0

$14 \ldots$

$13.02 \quad 28.0$

SEP.

$15 . . .26 .0$

$255741080154500 \quad-$

JaN., $197020.5 \quad 620$

$\begin{array}{lll}\text { MAY } & 20.5 & 620 \\ 15 \ldots . . & 25.0 & 750\end{array}$

255830080041000 -

AUG., $1970 \quad 31.0$

255840081232100

$J$ NoV. 1969

18... $196922.0 \quad 315$

260031080145300

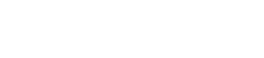

260114081242300 -

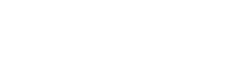

260114081245000 SEP.. 1970

S1... $27.0 \quad 385$

260258081412000 FEB., 1970

$09 .$. .

260333080084300 -

$\begin{array}{lll}\text { FEB.. } 1970 & \\ 13 \ldots . . & 20.0 \quad 11000\end{array}$

260514080110800 -

FE8.. $197021.0 \quad 610$

$\begin{array}{lll}\text { SEP. } & \\ 29 . . . & 33.0 & 645\end{array}$

260018080121700 -

FEB., 1970

16... $197023.0 \quad 230$

260702080085800

FEB., 1970

$17 . . . .^{1970} 22.0$
$177 \quad 120 \quad 1500$

$\begin{array}{lllllllll}100 & 110 & 194 & 1300 & 1650 & 65 & 202 & 0 & 8.0\end{array}$

65

176

$\begin{array}{lllllllll}100 & 110 & 194 & 1300 & 1650 & 65 & 202 & 0 & 8.0\end{array}$

7.8

$\begin{array}{rrrrrrrrr}370 & 90 & 42 & 110 & 338 & 14 & 240 & 0 & 7.5 \\ 120 & 130 & 77 & 600 & 610 & 24 & 308 & 0 & 8.1\end{array}$

CYPRESS POND NW OF JETPORT NR MIAMI FL ILAT 255520 LONG 08056221

$\begin{array}{rrrrrrrrr}40 & 38 & 1.4 & 120 & 5.0 & .3 & 116 & 0 & 7.1 \\ 100 & 43 & 1.5 & 170 & 15 & .2 & 128 & 0 & 7.6 \\ 30 & 32 & 1.1 & 50 & 4.4 & .3 & 92 & 0 & 7.1 \\ 30 & 29 & 1.1 & 70 & 3.5 & .2 & 94 & -- & 8.2 \\ 80 & 32 & 1.2 & 100 & 3.2 & .3 & 96 & 0 & 8.0\end{array}$

SNAKE CREEK AT NW 37 AVE NEAR CAROL CI (LAT 255741 LONG OBO 15 45)

$\begin{array}{rrrrrrrrr}-- & 78 & 9.4 & -- & 40 & .9 & 252 & 12 & 9.0 \\ -- & 73 & 11 & 860 & 66 & 1.6 & 280 & 4 & 8.3\end{array}$

CORPS OF ENGP GAGE 3-4 NR ANOYTOWN FLA (LAT 2558 3n LONG O80 04 10)

$\begin{array}{llllllll}170 & 28 & 2.3 & 230 & 9.3 & .5 & 96 & 0\end{array}$

8.2

ANES SCENIC DRIVE CANAL NEAR COPELAND FL (LAT 255840 LONG 0812321 )

$\begin{array}{llllllll}30 & 50 & 2.8 & - & 11 & .7 & 160 & 0\end{array}$

7.4

DAVIE RD CNL PEMBROKE PINES AT HOL BL, ILAT 26 00 31 LONG 08014531

$\begin{array}{lllllll}130 & 102 & 7.4 & 830 & 15 & 1.2 & 306\end{array}$

8.2

LK IN FAKHAT STND OFF JANES SC DR NR C (LAT $26 \quad 01 \quad 14$ LONG 0812423$)$

$\begin{array}{rrrrrrrrr}3.0 & 100 & 5.3 & 210 & 25 & 1.6 & 308 & 0 & 7.8 \\ 330 & 69 & 3.7 & 160 & 19 & .7 & 210 & 0 & 7.5 \\ 540 & 67 & 3.8 & 200 & 16 & .8 & 206 & 0 & 8.0\end{array}$

CANAL OFF JANES SCENIC DR NR COPELAND (LAT 26 OI 14 LONG 0812450 )

$\begin{array}{llllllll}80 & 61 & 3.4 & 100 & 15 & 1.0 & 194 & 0\end{array}$

N SPG HENOERSON CR FINGER CA NR NAPLES (LAT 26 02 58 LONG 0814120 )

DANIA CUTOFF CA W OF FECRR BR AT DANIA (LAT $2603 \quad 33$ LONG 080 OA 43)

$\begin{array}{llllllll}120 & 156 & 236 & 2000 & 1840 & 75 & 272 & 0\end{array}$

NORTH NEW RIV CA AT SW 31 AVE AT FT LA (LAT $2605 \quad 14$ LONG 08011 08)

$\begin{array}{rrrrrrrrr}260 & 75 & 8.2 & 810 & 39 & 1.4 & 260 & 0 & 7.7 \\ 160 & 73 & 9.2 & 83 & 51 & 1.7 & -- & -- & 8.0\end{array}$

BOR PIT NR DIXIE WELL FLD AT LAUDERDAL (LAT $2606 \quad 18$ LONG 0801217 )

NEW RIVER AT SW 4TH 6 TTH AVE FT LAUDE (LAT 260702 LONG 080 08 58) 
LAKE OKEECHOBEE AND THE EVERGLADES BASINS--CONTINUED

255307081281900 - FERGUSON R AT MOUTH NR EVERGLADES CITY (LAT 255307 LONG n81 28 19)

MAR .. 1970

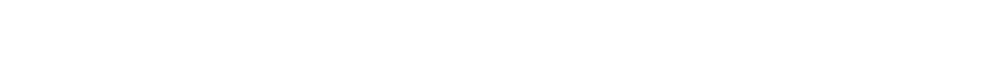

255329081302400 - FAKA UNION CANAL AT MOUTH NR EVERGLADE (LAT 255329 LONG 081 30 24)

MAR., 1970

$\begin{array}{llllllllll}21 \ldots & 160 & 1100 & .3 & 642 & 389 & 253 & \ldots & 2760 & 3.07\end{array}$

255520080562200 - CYPRESS PONN NW OF JETPORT NR MIAMI FL (LAT 2555 2N LONG OBO 56 22)

\begin{tabular}{|c|c|c|c|c|c|c|c|c|c|c|}
\hline $\begin{array}{l}30 . . . \\
\text { JUNE }\end{array}$ & . 8 & 10 & .3 & 101 & 6 & 95 & 132 & -- & .18 & 1.0 \\
\hline JULY & .0 & 22 & .1 & 114 & 9 & 105 & $J A 6$ & 150 & .25 & -- \\
\hline $\begin{array}{l}14 \ldots . . \\
\text { AUG. }\end{array}$ & .0 & 7.0 & .0 & 85 & 9 & 75 & 134 & 93 & .18 & - \\
\hline SEP." & .4 & 6.4 & .2 & 77 & 0 & 77 & 96 & 89 & .13 & -- \\
\hline $15 \ldots$ & .4 & 10 & .2 & 85 & 7 & 79 & 1114 & 96 & .16 & $=$ \\
\hline
\end{tabular}

255741080154500 - SNAKE CREEK AT NW 37 AVE NFAR CAPOL Cl (LAT 2557 41 LONG 080 I5 45)

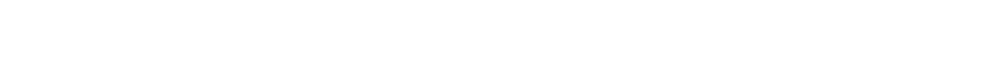

255830080041000 - COKPS OF ENGP GAGE 3-4 NP ANDYTOIN FLA (LAT 255930 LONG OZO O4 10 ) AUG.. 1970

(1)

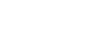

$79 \quad 10 \quad 106 \quad .15$

255840081232100 - JANES SCENIC DPIVE CANAL NEAR COPELAND FL ILAT 25 SR 40 LONG 09323211

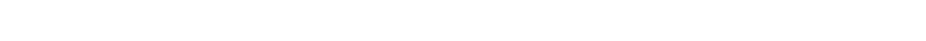

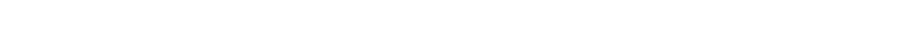

$30 . .1970$

260114081242300 - LK IN FAKHAT STIND OFF JANES SC DR NR C ILAT 26 0114 LONG O81 2423 )

\begin{tabular}{|c|c|c|c|c|c|c|c|c|c|c|}
\hline $01 . .$. & 4.3 & 50 & .3 & 270 & 19 & 253 & 378 & 346 & .51 & $\cdots$ \\
\hline $\begin{array}{l}30 . . \\
\text { SEP. }\end{array}$ & .8 & 34 & .2 & 187 & 15 & 172 & 26] & 234 & .35 & 1.7 \\
\hline $15 \ldots$ & . 8 & 29 & .3 & 183 & 140 & 169 & 255 & 224 & .35 & -- \\
\hline
\end{tabular}

260114081245000 - CANAL OFF JANES SCENIC DR NR COPELAND (LAT 26 O1 14 LONG OH1 24 5n!

SEP.. 1970

\section{CANAL OFF JANES SCENIC DR NR COPELAND}

260258081412000 - N SPG HENDERSON CR FINGER CA NR NAPLES ILAT 26 O2 58 LONG 08$\} 41201$

FEB., 1970

260333080084300 - DANIA CUTOFF CA W OF FECRR BR AT DANIA (LAT 26 O3 33 LONG 080 OR 43)

FEB., 1970

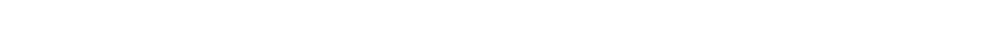

260514080110800 - NORTH NEW RIV CA AT SW 31 AVE AT FT LA (LAT 260514 LONG 08011 08)

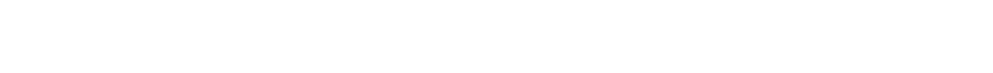

260618080121700 - BOR PIT NR DIXIE WELL FLD AT LAUDEROAL (LAT $2 A$ O6 18 LONG O8N 12 17)

FEB., 1970

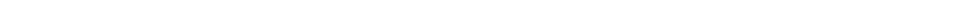

260702080085800 - NFW KIVER AT SW 4TH \& 7TH AVF FT LAUDE (LAT 26 O7 O2 LONG OBO OB 58)

FE8.. 1970

17... 1970

450

$.4 \quad 359 \quad 149$

21 


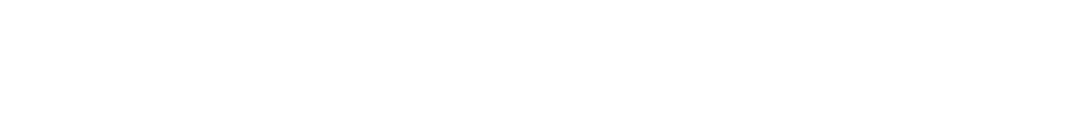

LAKE OKEECHOBEE AND THE EVERGLADES BASINS--CONTINUED

260729080074400

NFW RIVER AT SE 15TH AVE AT FT LAUDERN (LAT 26 97 29 LONG 08007 44)

FER.. $197022.5 \quad 6600$

$\begin{array}{llllllll}100 & 114 & 124 & 1400 & 900 & 37 & 251 & 0\end{array}$

260743080103100

NORTH FK NEW RIV AT NW 6TH ST FT LAUDE (LAT $26 \quad 0743$ LONG 0801031 )

FEE.. $197021.5 \quad 550$

SEP. $32.0 \quad 32 . n \quad 449$

$200 \quad 7$

$3.6 \quad 01 \% \quad 27$

3.3219

ก 7.1

$260807080140200-$

PLANTATION RO CA AT INW 65 AVE IN PLANT ILAT 26 OR 07 LONH OHO 14 OZ)

FEB.. $197022.0 \quad 693$

SEP... $30.0 \quad 6 n 3$

$200919080172300 \quad-$ SEP.. $197030.0 \quad 30.028$

261000080553000 MAR., $1970 \quad$.. 242 $\begin{array}{rrr}\text { 3n... } & -. & 242 \\ \text { SEP... } & 25.0 & 263 \\ 11 \ldots & \end{array}$

$261030080131400=$ SEP.. $197031.0 \quad 639$

261057090442000 AUG... 197029.0

261131090105800 $\begin{array}{lll}\text { FE } 8 \ldots 1970 & \\ 16 \ldots & 21.0 & 400\end{array}$

261148080114900 -

FEt.. 1970
$16 . .$.

$\begin{array}{lllllllll}100 & \text { k2 } & 3.5 & 680 & 43 & 6.6 & 247 & 0 & 7.3 \\ 70 & 64 & 4.4 & 640 & 44 & 6.4 & 120 & -- & 7.2\end{array}$

MIDULE RIVER CANAL NR LAUDHWHILL FLA ILAT $24: 9$ I9 LOMIG 08O 17 23)

$\begin{array}{lllllllll}420 & 103 & 3.9 & \text { InON } & \text { 2h } & 1.1 & 31 & 0.1\end{array}$

CYPRESS POND OFF EVERGLADES PKWY NR FT (LAT $26 \quad 1000$ LONG 0805530 )

$\begin{array}{llllllllll}- & 41 & 2.1 & 9 & 90 & 6.5 & .4 & 128 & 0 & 7.2\end{array}$

MIDULE K CA (C-13) AT LAUDEFHILL rLA LAT 261030 LONG ORO 13 14)

$\begin{array}{lllllllll}370 & 106 & 3.7 & 1200 & 25 & 8.1 & 310 & 6.2\end{array}$

CORPS OF ENGINEERS GAGF 3-2 NR ANBYTON ILAT 26 10 57 (ONG 0804436 )

$\begin{array}{llllllll}540 & 28 & 2.5 & 180 & 0.9 & .4 & 94 & 0\end{array}$

GORRON PIT ON PKOSPECT KOAD NI FT LAUN (LAT 251131 LONG ORO IO SR)

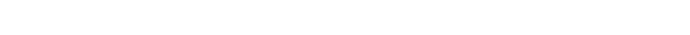

7.5

FT LAUDFKHaLE PROSPECT LK NF FT LAUDE (LAT 261148 LONG 0801148 )

261240080494000 AUG., 1970

AUG., 1970 11.0

261306080543000 -

AUG., $1970 \quad 31.0 \quad 438$

261317080061300

FEt... $1970 \quad 21.0 \quad 10800$

261324080211800 - $1-35$ BORPOA CAIUAL IN CA 24 NR ANUYTOW (LAT 261324 LOHG UHO 21 1A)

AUG... 197029.0

261345090274501

AUG., 197

$06 \ldots 29.0 \quad 62$

261349080121700

$\begin{array}{lll}\text { FER.. } 1970 & \\ 18 . . . & 745\end{array}$

261351080102100

FEB., $1970 \quad$-.

$\begin{array}{lll}18 . . & \cdots & 725 \\ \text { SEP. } & & \end{array}$

(O)

$29.0 \quad 634$

AB

$6.4 \quad 1300 \quad 42$

$1200 \quad 38$

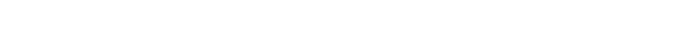

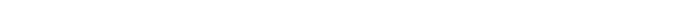

5-11 C AT L 38E NK ANUYTOMN FLA (LAT 261345 LONG ORN 2745 )

$\begin{array}{ccccccc}100 & 50 & 16 & 1300 & 56 & 2.9 & 30 A \\ \text { POMPANO CA AT SR } 7 \text { AT MARGATE FLA ILAT } 26 & 13 & 49 & \text { LONG OHO } & 12 & 17\end{array}$

$\begin{array}{llllll}50 & 101 & 6.6 & 1400 & 43 & 2.4\end{array}$ 
CHEMICAL ANALYSES, WATER YEAR OCTOBER 1969 TO SEPTEMBER 1970 (MAJOR CONSTITUENTS)

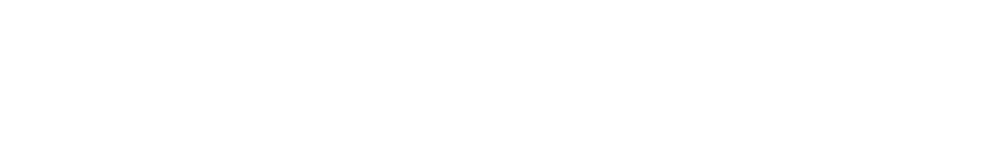

LAKE OKEECHOBEe AND THE EVERGLADES BASINS--CONTINUED

260720080074400 - NEW RIVER AT SE 15 TH AVE AT FT LAUUERN (LAT 26 O7 29 LONG 08007 44) FE8., 1970

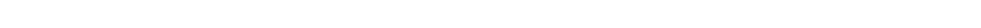

260743080103100 - NORTH FK NEW RIV AT NW OTH ST FT LAUDF ILAT ZA OT 43 LOHG 03010311

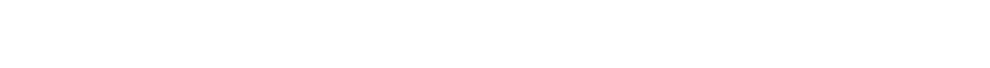

260807080140200 - PLANTATION RO CA AT NW b5 AVE IN PLANT (LAT 26 08 07 LONG 03O 14 02) FER., 1970

$\begin{array}{rrrrrrrrrrr}17 \ldots . . & 34 & 54 & 1.3 & 220 & 18 & 203 & 430 & 344 & .40 & 1.7 \\ \text { SEP. } & 38 & 61 & 1.1 & 178 & 73 & 10 & 404 & 319 & .55 & \ldots\end{array}$

260919080172300 - MIDOLE RIVER CANAL NR LAUDEHHILL FLA (LAT 26 I9 19 LONG 08017 23) SEP.. 1970

$\begin{array}{llllllllll}30 . . & 14 & 44 & .5 & 274 & 20 & 254 & 397 & 355 & .54\end{array}$ 261000080553000 - CYPRESS POND OFF EVEKGLADES PKWY NR FT ILAT 2610 DO LONG 08055301

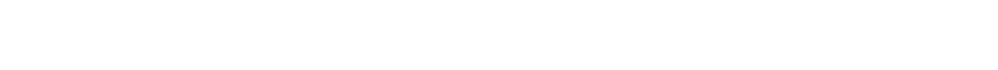

261030080131400 - MIODLE He CA (C-13) AT LAUDEDHILL FLA ILAT 26 in 30 LONG 08B 13 14)

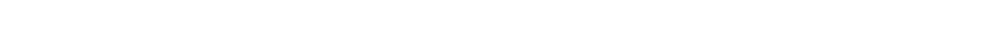
261057080442600 - CORPS OF ENGINEERS GAGE 3-2 NP ANNYTON (LAT 26 IO $5 T$ LONIG D8N 44 26) AUG.. 1970

$\begin{array}{lllllllllll}07 . . . & 2.0 & 12 & .3 & \forall 1 & 0 & 80 & 127 & 106 & .17\end{array}$

261131080105800 - AORROW PIT ON PROSPECT ROAO NR FT LAUN ILAT ZK II 31 ON!G DSO 10581

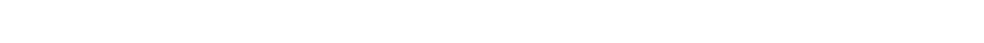
261148080114800 - FT LAUDERDALE PROSPECT LK NP FT LAUDE (LAT $2 A 114 \mathrm{H}$ LONG OHA) 11 48) FEP.. 1970 $\begin{array}{lllllllllllll}16 \ldots & 15 & 22 & .2 & 158 & 21 & 138 & 779 & 201 & .31 & .5\end{array}$ 261240080494000 - L-28 BORROW CA AB S-140 NR ANTYTON FL (LAT 2O 1240 LOMAB O30 4940 ) AUG., 1970 261300080543000 - LEVEE 28 INTERCEPTOR NK ANDYTOKN FLA (LAT 261300 LONG ORD 5430$)$ AUG.. 1970

$\begin{array}{llllllllllll}07 \ldots . .0 & 8.0 & 32 & .4 & 190 & 9 & 180 & 271 & 249 & .37 & \ldots\end{array}$ 261317080061300 - POMPANO CA AT US HWy 1 AT POMPANO BEAT ILAT $2 A 1317$ LONI OHO OK 13) $\begin{array}{llllllllll}F E B .1 & 1970 \\ 18 . .{ }_{486} & 3350 & .5 & 1400 & 1180 & 219 & \ldots & 6280 & 9.54 & 1.1\end{array}$ 261324080211800 - L-35B BORROW CANAL IN CA 2A NR ANOYTOW ILAT 261324 LONF ndO 21181

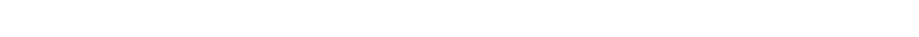
261345080274500 - S-11 C AT L 38E NR ANDYTOMN FLA ILAT 261345 LONG OSO 77 45) $\begin{array}{cccccccccc}\text { AUG., } & 1970 \\ 06 . . . & 20 & 80 & .6 & 193 & 9 & 184 & 38 R & 347 & .53\end{array}$ 261349080121700 - POMPANO CA AT SR 7 AT MARGATE FLA ILAT 261749 LONG O8N 1217 17,

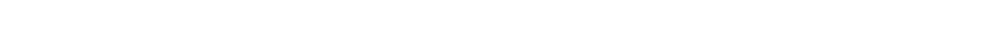
261351080102100 - POMPANO CAE OF FLA TURNPIKE NR POMDAN ILAT $2 A 13$ bl LONG OYN In 211 FEB.. 1970

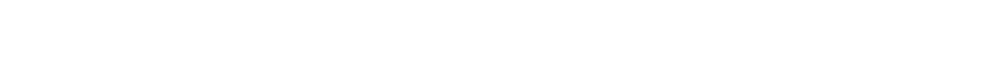



CHEMICAL ANALYSES, WATER YEAR OCTOBER 1969 TO SEPTEMBER 1970
(MAJOR CONSTITUENTS)

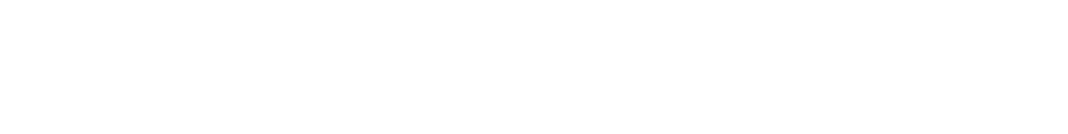

LAKE OKEECHOBEe AND THE EVERGLADES BaSINS--CONTINUED

261630080435800

C-123 AT OLD MIAMI CANAL NR ANDYTOWN F ILAT $26 \quad 1630$ LONG OHO 4358 )

AUG.. $1970 \quad 31.0 \quad 497$

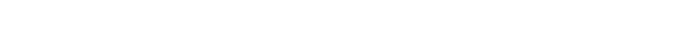

261737081270500 - CANAL ON OILFIELO ROAD NEAR IMMOKALEE (LAT 261737 LONG OKL 27 05)

NOV.. $196921.0 \quad 495$

$261918080055200-$ FEP., 1970

$13 \ldots 197021.0 \quad 21400$

261938080124900

$\begin{array}{lll}\text { SEP. } 1970 & \\ 30 \ldots & 27.0 & \end{array}$

262134080480300 -

$\begin{array}{lll}\text { AUG... } & 1970 & \\ 07 \ldots . & & \end{array}$

262517080242000 AUG.. 1970

$06 \ldots 197030.0$

$262518080042500 \quad-$

$\begin{array}{lll}\text { MAR.. } 1970 & \\ 16 . . . & & \end{array}$

$262625081162000 \quad-$ NOV., 196

18... 196928.3

CANAL AT JNCT S-840 AND S-84K NR IMMOK ILAT $2626 \quad 25$ LONG $081 \quad 1020$ )

263219080072300 - HOYNTON CA AT SH 809 NR BOYNTON BCH FL (LAT 263219 LONG $080 \quad 0723$ ) AUG., 1970

$12 \ldots .07970 \quad 30.0 \quad 440$

263221080052800 AUG., 1970

$\begin{array}{lll}12 \ldots & 29.0 \\ 12 \ldots & 29.0 & 391\end{array}$

264042080092800 -

AUG., $1970 \quad 28.0 \quad 516$

264043080102800 AUG., 1970

$11 . .197029 .0$

264047080120800 - WEST PALM BCH CA AT SH 80 NP IEST PALM (LAT 264047 LONG 0801208 ) MAR., 1970

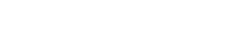

264255080035000 $200 \quad 68 \quad 9.1 \quad 520$

CLEAR LAKE AT WEST PALM GEACH FLA ILAT $26 \quad 42 \quad 55$ LONG 08003501 MAR.. 1970

17... 197019.0

$60 \quad 22$

$3.5 \quad 300 \quad 17$

$1.6 \quad 68$

7.0

264531080051800 - CANAL 17 AT SH 702 NEAR MANGONIA PARK (LAT 264531 LONG 080 05 (B) AUG., 1970

$11 . .2028 .0 \quad 388$

$220 \quad 60$

$3.1 \quad 500 \quad 19$

1.6

166

8.0 
CHEMICAL ANALYSES, WATER YEAR OCTOBER 1969 TO SEPTEMBER 1970 (MAJOR CONSTITUENTS)

DATE

DIS-
SOLVED
SULFATE
(SOL)
(MGAL)
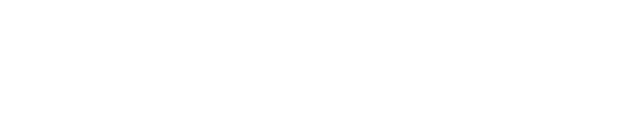

SOLVEO SOLIIIS TANNIN (TONS ANT LIGNIN

LAKE OKEECHOBEE AND THE EVERGLADES BASINS--CONTINUED

261630080435800 - C-123 AT OLD MIAMI CANAL NR ANUYTOWN F (LAT 261630 LOAG 0804358 )

$07 \ldots 1970$

261737081270500 - CANAL ON OILFIELD POAD NEAR IMMOKALEE ILAT $26 \quad 1737$ LONG ORI $2705 \%$

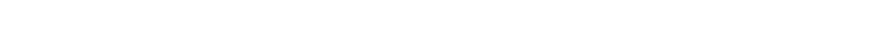
261918080055200 - HILLSHORO CA E OF UIXIE HWY AT DEERFIE ILAT 261918 LING 08N 05521 FER., 1970

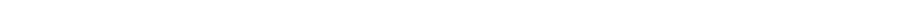

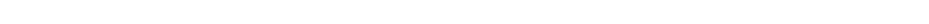

$\begin{array}{lllllllll}\text { SEP., } 1970 & & & & & & & & \end{array}$

262134 AR0480300 - MIAMI CANAL N OF 5-28 NH ANUYTONN FLA (LAT 26 2I 34 LONG 080 4R 03) AUG., 1970

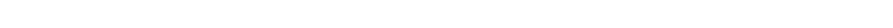

2625170802420 A0 - HILLSBORO CANAL I MILE WLST OF S-10 NR ILAT 267517 LONG OBO 24201 AUG., 1970

$\begin{array}{lllllllll}06 . . & 40 & 102 & .6 & 103 & 35 & 128 & 437 & 37 ?\end{array}$

262S18080042500 - CANAL 15 ABONE S-40 NEAK JFLLAY BEACH ILAT 257519 LONG OSO O4 25)

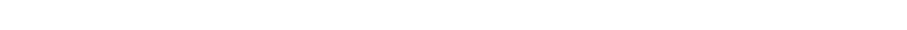

262625081162000 - CANAL. AT JNCT S-H40 AND S-B4A NR IMMOK ULAT 262625 LONG OH1 16 20) NOV.. 1969

263219080072300 - HOYNTON CA AT SH 809 NK BOYNTON FCH FL ILAT 263219 LONG 0800723

$\begin{array}{llllllllll}12 . . & 26 & 35 & 3 & 108 & 26 & 142 & 275 & 247 & .37\end{array}$

2632210800528R0 - BOYNTON CA AT CONGRESS AVE NH ROYNTON (LAT 263221 LONG OH3 05 28)

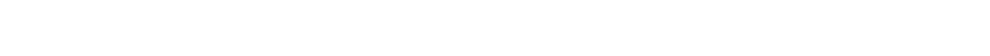

264042080092800 - WEST PALM ACH CH AT CLEAKY RD NR N.EST (LAT 764042 LONG OBO 0928 )

264043080102800 - WFST PALM HCH CA AT HENOIST FARMS ROAD ILAT 264043 IONG 080 In 28 $\triangle U G ., 1970$

$\begin{array}{lllllllllllll}11 \ldots & 32 & 50 & .3 & 196 & 36 & 159 & 373 & 298 & .44 & -.\end{array}$

264047080120806 - WEST PALM BCH CA AT SH 80 NR WEST PALM (LAT TA 4047 LOMIG NBO 17 08)

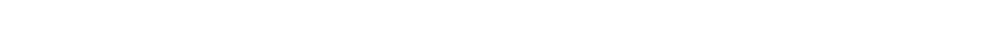

26425つ0RA035000 - CLFAK LAKE AT WEST PALM BEACH FLA (LAT 76 4? 55 LONG 080 03 5n) $M A R_{0}, 1970$

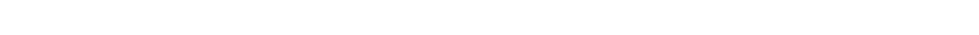

264531080051800 - CANAL 17 AT SH 702 NEAR MANGONIA PARK (LAT 264531 LONG 080 05 18) AUG., 1970

$11 \ldots \quad 1$

31

163 


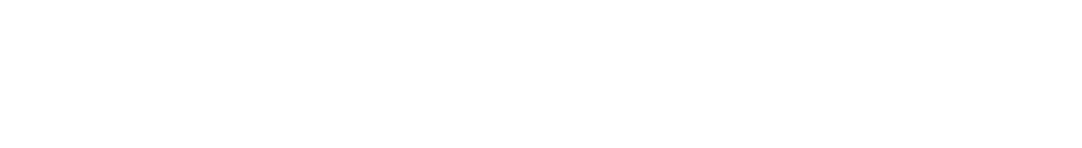

\section{MYAKKA RIVER BASIN}

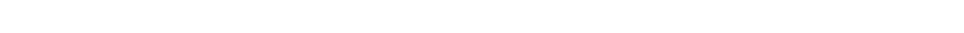

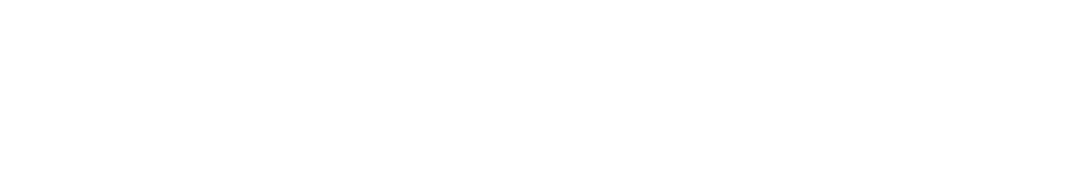

270332001451400 - MYYTLt. CKEEK HK FT UGOEN FLA (LAT 2703 3? LONG TRI 4 E 14)

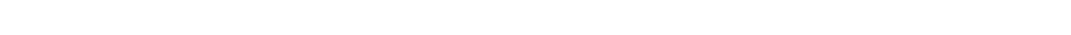

270351051573100 - THORNTON HRANCH AT US 1 / NR FT OGNEN F (LAT 270351 LONG OBI 5731 ) JIINE, 1970 . 2500

2705170813 3700 - PEACE RIV AT HT 761 NP NOCATFE FLA (LAT 27 O5 17 . LONG 091 29 19)

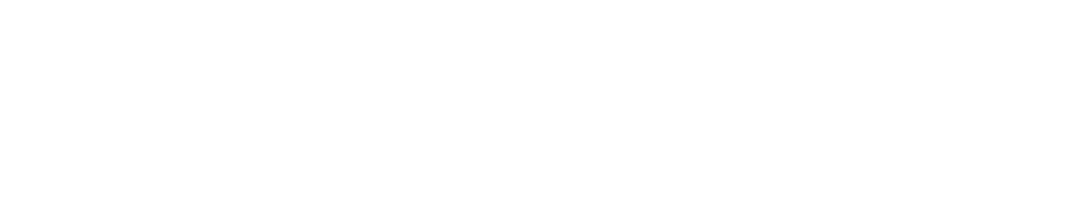

$2709300 M 1574200$ - HORSE CHEEK AT RT 7HI NH NOCATFE FLA ILAT 27 19930 LONG ORI 57581 APR.P. $197024.0 \quad 210$

271231081404200 - PRAILIE C TRIH NO 2 NH AKCAMIA FLA ILAT 271231 LDNG ORI 40 421

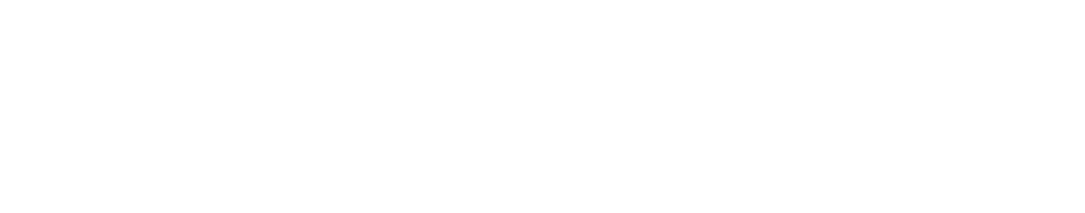

271257081404100 - IPHIGATION II AT TROP R GROVE UH AHCAOI ILAT 271257 LONI, OBI 4 H 411

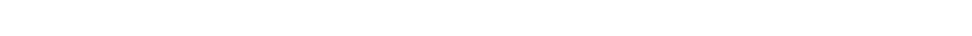

2713UGOBISZzQRO - PEACE RIVER TRIH AT APCADIA fLA (LAT 2713 n6 LONI OHI 52 28)

$\begin{array}{llllllllllll}\text { APR.. } 1970 \\ 29 . . . & 23.0 & 475 & - & 48 & 20 & -- & 17 & 2.5 & 96 & -. & 9.7\end{array}$

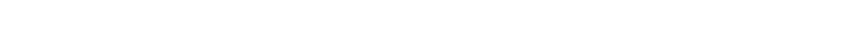
JUNE. 1970

$11 . . .23 .0 \quad 23 n$

273515081461600 - L CHARLIE CR AT RT 664A NR NAUCHULA FL ILAT 273515 IONG 0\$1 46 16)

\begin{tabular}{|c|c|c|c|c|c|c|c|c|c|c|}
\hline JUAE... & 21.5 & 385 & -- & 31 & 18 & -- & 17 & 3.3 & 95 & -- \\
\hline $11 \ldots$ & 26.5 & 130 & -- & in & 5.4 & - & 8.0 & 1.7 & 24 & -- \\
\hline
\end{tabular}

COASTAL BASINS BETWEEN MYAKKA RIVER AND ALAFIA RIVER--CONTINUED

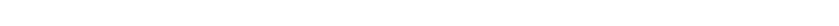

JUNE, 1970

-- $9 ? \quad 36$

$--\quad 121$

15

PEACE RIVER BASIN--CONTINUED

$273444 \pi 914 R 0500$ - PEACE RIVER NR BOWLING GREEN FLA ULAT 273444 LONG $0814 \%$ 05

\begin{tabular}{|c|c|c|c|c|c|c|c|c|c|c|}
\hline $\begin{array}{l}28 \ldots \\
\text { JUNE }\end{array}$ & 23.5 & 395 & -- & 42 & 13 & - & 18 & 1.5 & 91 & - \\
\hline $11 \ldots$ & 28.0 & 355 & -- & 38 & 12 & $=$ & 14 & 1.2 & 80 & 0 \\
\hline
\end{tabular}


CHEMICAL ANALYSES, WATER YEAR OCTOBER 1969 TO SEPTEMBER 1970 (MAJOR CONSTITUENTS)
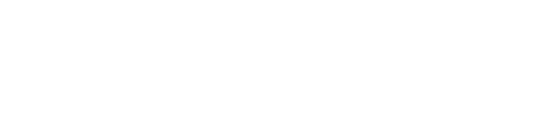

DIS-

SOLVEN TANIN

TALNIN

(MG/L) (MG/L) (MG/L) (MG/L)

PFO LIGNTN

MYAKKA RTVER BASIN--CONTINUED

270241082142701 - COCOA PLUM WATERWAY NR PUNTA RUHTA FLA (LAT 270241 LONG OH2 14 27.01)

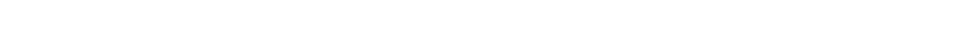

270242032142300 - EIG SLOUGH AT WATER PLANT NH MURUOCK F ILAT 270242 LONG 08214231 NOV., 1969

$18 \ldots \quad 18$

$\begin{array}{llll}.3 & 53 & 27 & 25\end{array}$

PEACE RIVER BASIN--CONTINUED

270332061461400 - MYRTLE CHEEK NH FT OGDEN FLA ILAT 270332 LONG OA1 46 141

$\begin{array}{ccccccccccc}\text { JUNE, } 1970 \\ 09 . . .^{19} & 6.8 & 27 & \text { ? } & 88 & 7 & \text { SI } & 17 n & 140 & .23 & -.\end{array}$

270351081573100 - THOKNTON BRANCH AT US 17 IJR FT OGOEN F (LAT 270351 LONG 08 L 5731 )

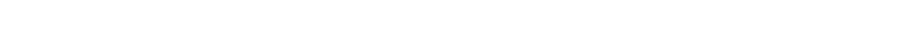

270517081593800 - PEACE RIV AT KT 761 NH MOCATEE FLA ILAT 27 II5 17 LONG 081 S9 3A)

270930081575400 - HOHSE CREEK AT ET 761 NH NOCATEE FLA ILAT 27 J9 30 LONG 18157581 $\begin{array}{llllllllll}A R R . .1970 & 17 & 15 & .5 & 40 & 25 & 65 & 147 & 119 & .20\end{array}$

271231081404200 - PRATRIF C TRIB NO 2 NK ARCADIA FLA (LAT 27 12 31 LONG 0814042$)$

\begin{tabular}{|c|c|c|c|c|c|c|c|c|c|}
\hline $29 .$. & $22 B$ & 35 & 1.0 & 334 & 245 & 94 & $5 A 6$ & 474 & . 30 \\
\hline $10 \ldots$ & 130 & $5 \mathrm{~J}$ & .6 & 134 & 78 & 57 & 358 & 336 & .49 \\
\hline
\end{tabular}

271232081343300 - PRAIHIE CPEEK TRIB NR AHCADIA FLA (LAT 271232 LONA O81 34 33)

\begin{tabular}{|c|c|c|c|c|c|c|c|c|c|c|}
\hline $29 \ldots$ & .9 & 22 & .1 & 15 & 11 & 3 & 76 & 45 & .10 & -- \\
\hline & 5.4 & 45 & .3 & 24 & 14 & 10 & 134 & 94 & .19 & \\
\hline
\end{tabular}

271257081404100 - IRFIGATION U AT TROP R GROVE NR ARCADI (LAT 271257 LONG 08140 41)

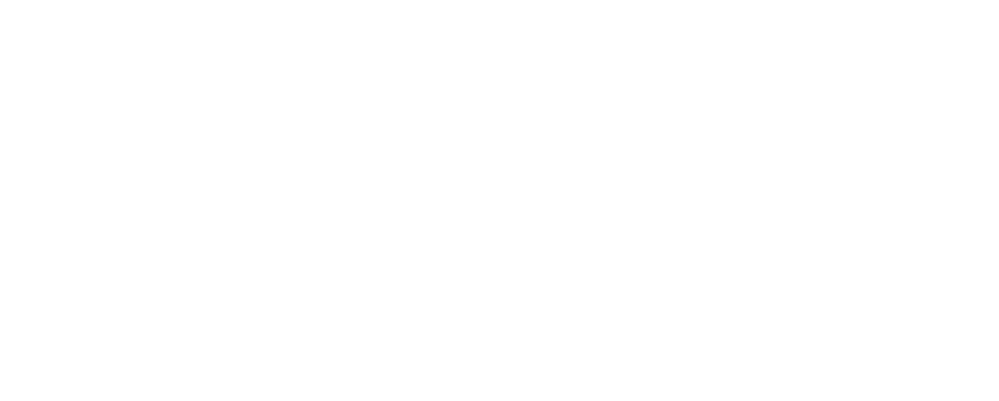

COASTAL BASINS BETWEEN MYAKKA RIVER AND ALAFIA RIVER--CONTINUED

273724082322300 - TAMPA GAY THIS NR PALMETTO FLA (LAT 273774 LONG OA2 32 23) JUNE. 1970
0806

\section{$7.8 \quad 378 \quad 374$}

PEACE RIVER BASIN--CONTINUED

273844081480500 - PEACE RIVER NR HOWLIVG GREEN FLA ILAT 27 39 44 LONG+ 081 49 05) 
CHEMICAL ANALYSES, WATER YEAR OCTOBER 1969 TO SEPTEMBER 1970 (MAJOR CONSTI TUENTS)

\begin{tabular}{|c|c|c|c|c|c|c|c|c|c|c|c|}
\hline & $\begin{array}{l}\text { TEMPER- } \\
\text { ATURE } \\
\text { (DEG C) }\end{array}$ & $\begin{array}{l}\text { SPE- } \\
\text { CIFIC } \\
\text { CON- } \\
\text { DUCT- } \\
\text { ANCE } \\
\text { (MICRO- } \\
\text { MHOS) }\end{array}$ & $\begin{array}{l}\text { DIS- } \\
\text { SOLVED } \\
\text { IRON } \\
\text { IFE) }\end{array}$ & $\begin{array}{l}\text { DIS- } \\
\text { SOLVED } \\
\text { CAL- } \\
\text { CIUM } \\
\text { (CA) } \\
\text { (MG }\end{array}$ & $\begin{array}{l}\text { OIS- } \\
\text { SOLVED } \\
\text { MAG- } \\
\text { NE- } \\
\text { SIUM } \\
\text { (MG) }\end{array}$ & $\begin{array}{l}\text { OIS- } \\
\text { SOLVED } \\
\text { STRON- } \\
\text { TIUM } \\
\text { (SR) } \\
\text { (UG/L) }\end{array}$ & $\begin{array}{l}\text { DIS- } \\
\text { SOLVED } \\
\text { SODIUM } \\
\text { (NA) } \\
\text { (MG/L) }\end{array}$ & $\begin{array}{l}\text { DIS- } \\
\text { SOLVED } \\
\text { PO- } \\
\text { TAS - } \\
\text { SIUM } \\
\text { (K) } \\
\text { (MG/L) }\end{array}$ & $\begin{array}{l}\text { BICAR- } \\
\text { BONATE } \\
\text { (HCO3) } \\
\text { (MG L) }\end{array}$ & $\begin{array}{l}\text { CAR- } \\
\text { BONATE } \\
\text { (CO3) } \\
\text { (MG/L) }\end{array}$ & $\begin{array}{c}P H \\
\text { (UNITS) }\end{array}$ \\
\hline & & & & & & & & & & & \\
\hline
\end{tabular}

\section{ALAFIA RIVER BASIN}

275301082055900 - N PRONG ALAFIA R AT SR 676 NR KFYSVILL (LAT 275301 LONG 08205 59)

$\begin{array}{cccccccccc}\text { JUNE. } 1970 & & & & & & & & & \\ 09 . .0^{26.0} & 850 & - & 92 & 12 & -- & 70 & 4.0 & 16 & 0\end{array}$

275709091580600 - MINE PINU AT CHKISTINA PARK FLA (LAT 275709 LONG 081 58 06) JUNE, 1970

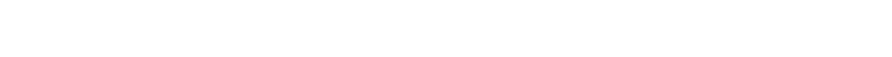

HILLSBOROUGH RIVER BASIN AND COASTAL BASIN NORTH OF ALAFIA RIVER

280033082080700 - DRAINAGE IITCM AT SAL RF AT PLANT CITY (LAT 28 OD 33 LONG B82 09 07 )

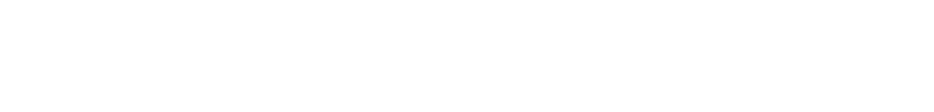

\section{$\begin{array}{lll}\text { JUNE, } 1970 & 1902 \\ 08 . . . & 26.0 & 102\end{array}$}

$280053082081300-$ JUNE, 1970

O... $28.0 \quad 335$

280058082202200 -

JUNE, $197035.5 \quad 1300$

280102082202200 JUNE. $197032.0 \quad 560$

280103082201400 JUNE, $197035.5 \quad 550$

280104082200300 JUNE, 1970 11...

280104082203700 JUNE, 1970 $\begin{array}{ll}\text { JUNE, } 1970 & \\ 11 . . & 28.0\end{array}$ 250132082111300 $\begin{array}{ll}\text { JUNE, } 1970 & \\ 08 . . .^{26.0} & 88\end{array}$

280150082111400 JUNE, 1970 OB... $30.0 \quad 335$

$280208082095100-$ JUNE, 1970 OB... $28.0 \quad 350$ 280227082341700 FEE.. $197012.0 \quad 43$

$280228092342200-$ $\begin{array}{ll}\text { FFB., } 1970 \\ \text { OS... } \\ \text { JUNE } 12.0 \\ 16 \ldots . . . & 29.0\end{array}$

\section{COASTAL ALSIN BETWEEN HILLSBOROUGH RIVER AND WITHLACOOCHEE RIVER}

280228082343000 - ROCKY CHEEK OL MUMP NF TAMPA FLA (LAT 28 O? 28 LDNG O8? 34 30)

DRAINAGE IJITCH AT REYNDLDS ROAO AT PLA (LAT 280053 LONG OBZ OH 13)

SOUTH PERIMETER DITCH AT CL EUREKA SPR (LAT 280058 LONG OBZ 20 22) EUREKA SP SANT LNDFL OXIDATION PD NR T LLAT 280102 LONG 08220 22) SANIT LNDFL SUMP NR EUREKA SPRINGS FLA (LAT 280103 LONG 082 2n 19) $-092 \quad 13$

EUREKA SPKINGS CA NR THONOTOSASSA FLA ILAT $2801 \quad 04$ LONG 08220031

CANAL N END EUREKA SPR LNDFL E NR EURE (LAT 28 01 04 LONG OR2 2037 ) $-67$

SPARTMAN GKANCH NR PLANT CITY FLA (LAT 280132 LONG 08211 13) $\begin{array}{lllllll}-- & 8.5 & 2.2 & -- & 6.0 & 1.0 & 17\end{array}$ MILL CREEK AT FORBES PD NK PLANT CITY ILAT 28 OI 50 LONG 08211141 $\begin{array}{llllllll}-- & 43 & 8.4 & - & 16 & 5.7 & 152\end{array}$ MILL CKEEK AT THONOTOSASSA RD NR PLANT (LAT 290208 LONG 08? 09 51)

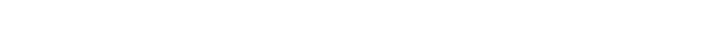
SE PERIMETER OTCH NR LINCOLN AVE TAMPA (LAT $2802 \quad 27$ LONG $08234 \quad 17$ ) $\begin{array}{llllllll}- & 1.9 & 1.0 & 10 & 4.0 & .4 & 4 & 0\end{array}$ SE PERM UTCH ROCKY CR LNDFL NR TAMPA (LAT 290228 LONG 0823422 )

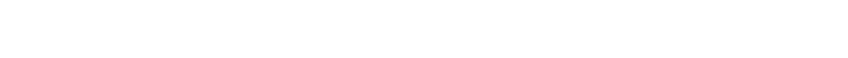

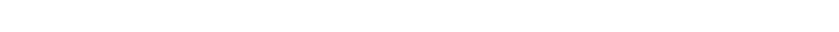
8.0 6.5 JUNE, 1970

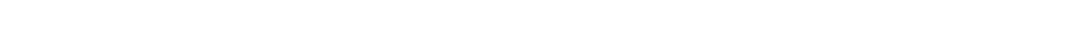




\begin{tabular}{|c|c|c|c|c|c|c|c|c|c|c|}
\hline & DIS- & $\begin{array}{l}\text { DIS- } \\
\text { SOLVEn }\end{array}$ & $\begin{array}{l}\text { UIS- } \\
\text { SOL VEI) }\end{array}$ & & $\begin{array}{l}\text { NON= } \\
\text { CAP- }\end{array}$ & ALKAD- & $\begin{array}{l}\text { DIS- } \\
\text { SOLVFD } \\
\text { SOL IDS }\end{array}$ & $\begin{array}{l}\text { DIS- } \\
\text { SOLVEN } \\
\text { SOLIOS }\end{array}$ & $\begin{array}{l}\text { DIS- } \\
\text { SOL.VER }\end{array}$ & \\
\hline & SOLVEO & CHLO- & FLUO- & HaF'n- & HONATE & L.INITY & (RESI- & (SUM of & SOLI IS & TANININ \\
\hline E & $\begin{array}{l}\text { SULFATE } \\
(\angle 04) \\
(M G / L)\end{array}$ & $\begin{array}{l}\text { PIUE } \\
\text { (CL) } \\
\text { (MG/L) }\end{array}$ & $\begin{array}{l}R I D E \\
(F) \\
(M G / L)\end{array}$ & $\begin{array}{l}\text { NESS } \\
(C A, M G) \\
(M G / L)\end{array}$ & $\begin{array}{l}\text { HAKD- } \\
\text { NESS } \\
\text { MGGS }\end{array}$ & $\begin{array}{c}\text { AS } \\
\text { CACO3 }\end{array}$ & $\begin{array}{l}\text { DUE AT } \\
\text { IBO C) }\end{array}$ & $\begin{array}{l}\text { CONSTI - } \\
\text { TUENTSI }\end{array}$ & $\begin{array}{l}\text { ITONS } \\
\text { PER }\end{array}$ & $\begin{array}{l}\text { ANO } \\
\text { LIGNIV }\end{array}$ \\
\hline
\end{tabular}

ALAFIA RIVER BASIN--CONTINUED

275301082055900 - N PRONG ALAFIA A SR 670 NK REYSVILL (LAT 2753 0I LONG 083 05 59) JUNE. 1970

275709081540600 - MINE PINI) AT CHFISTINA PARK FLA (LAT 27 ST n9 LONG n8I 58 n6)

JUNE, 1970
$09 . .$.

HILLSBOROUGH RIVER BASIN AND COASTAL. BASIN NORTH OF ALAFIA RIVER--CONTINUED

280033082080700 - BPAINAGE UITCH AT SAL RK AT PLANT CITY (LAT 28 O0 33 LONG 082 0S 07)

$\begin{array}{ccccccccccc}\text { JUNE, } 1970 & 19 & 19 & .7 & 120 & 63 & 57 & 220 & 195 & .30 & \ldots\end{array}$

280047082152500 - EAKER CKEEK NEAK SEFFNER FLA (LAT 280047 LONG OR2 1525 )

$\begin{array}{ccccccccc}\text { JUNE, } 1970 \\ 08 . . . & 10 & 12 & 32 & 14 & 13 & 91 & 55 & .12\end{array}$

280053082081300 - DRAINAGE DITCH AT REYNOLDS ROAD AT PLA (LAT 29 OO 53 LONG OHZ OR 13)

JUNE, 1970

$9.7 \quad 11$

280058082202200 - SOUTH PERIMETER OITCH AT CL. FUREKA SPR (LAT 2R 00 58 LONG $88 ?$ 20 22)

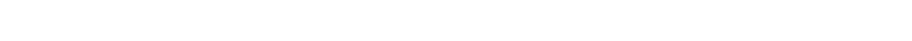

$280102082202 Z 00$ - EUREKA SP SANT LNOFL OXIOATION PD NR T (LAT 2R OI O2 LONG 0B2 20 22)

JUNE, 1970

$11 \ldots$ 91

14

$1.2-260$

28010308220I900 - SANIT LNOFL SUMP NH EUREKA SPRINGS FLA (LAT PR 0103 LONG 082 20 19)

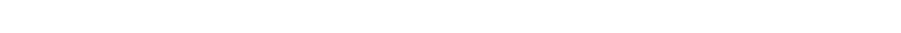

280104082200300 - EIPEKA SPRINGS CA NH THONOTOSASSA FLA (LAT 28 01 04 LONG 0322003 )

JUNE, 1970

$11 \ldots$

280104082203700 - CANAL N ENU EUTREKA SPR LNOFL E NR EURE (LAT 29 OI 04 LONG 08220 37) JUNE, 1970

11.001970

2801320 B2111300 - SPARTMAN BRANCH NR PLANT CITY FLA (LAT 28 OI 32 LONG 082 11 13)

JUNE, 1970

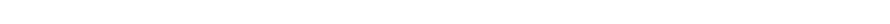

280150082111400 - MILL CREEK AT FORBES RD NG PLANT CITY (LAT 2R O1 50 LONG 082 11 14)

$\begin{array}{llllllll}\text { JUNE, } 1970 & 17 & 23 & .5 & 142 & 18 & 125 & 233\end{array}$

28020\&082095100 - MILL CREEK AT THONOTOSASSA RD NR PLANT (LAT 2R OZ OA LONG G82 09 51)

JUNE, 1970

$\begin{array}{lllllllllllll}08 \ldots & 16 & 21 & .5 & 154 & 20 & 134 & 244 & 214 & .33\end{array}$ 280227002341700 - SE PERIMFTER DTCH NR LINCOLN AVE TAMPA LLAT 28 O2 27 LONG 0823417

FEt.. 1910

$05 . . .1910 \quad 2.0$

28022804234220n - SE PEHM OTCH ROCKY CP LNDFL NR TAMPA (LAT 28 N2 28 LONG OB2 34 22)

FEG. 1970

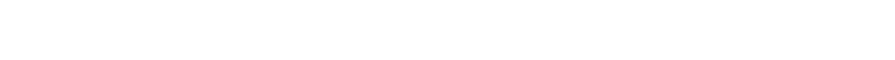

COASTAL BASIN BETWEEN HILLSBOROUGH RIVER AND WITHLACOOCHEE RIVER--CONTINUED

280220082343000 - ROCKY CREEK BL. PUMP NH TAMPA FLA (LAT 24 O2 28 LONG 0823430 )

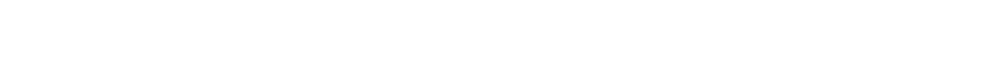


CHEMICAL ANALYSES, WATER YEAR OCTOBER 1969 TO SEPTEMBER 1970 (MAJOR CONSTITUENTS)

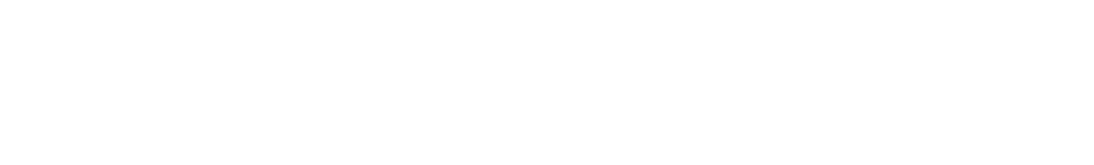

COASTAL BASIN BETWEEN HILLSBOROUGH RIVER AND WITHLACOOCHEE RIVER--CONTINUED

280228002343230 - SH PEHIM DITH AT ROCKY CF LMOFL NA TAM (LAT 29 N2 28 LONG OAZ 3432 )

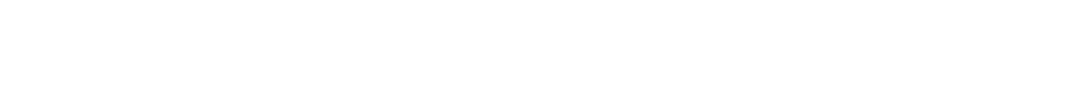

280235082342500 - NA SAMT LNDFL OXID PD NK SULPHUR SPG F ILAT 24 O2 35 LONG 0 K2 34 25I

\begin{tabular}{|c|c|c|c|c|c|c|c|c|c|c|}
\hline 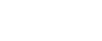 & 10.0 & 46 & 40 & 2.4 & .7 & 2 & 3.5 & .6 & 5 & 0 \\
\hline $16 \ldots$ & 30.0 & 124 & -- & 6.0 & 1.5 & $\cdots$ & 11 & 8.2 & $2 ?$ & 0 \\
\hline
\end{tabular}

280243082342200 - NF PERIM UITH AT ROCKY CR LNUFL NH TAM ILAT ZM O? 43 LONG 11 HZ 34221

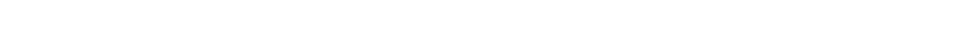
HILLSBOROUGH RIVER BASIN AND COASTAL BASIN NORTH OF ALAFIA RIVER--CONTINUED

280448082042300 - ITCHEFACKFSASSA CH NH LAKELLANO FLA (LAT 28 O4 48 LONG 0 R2 04231

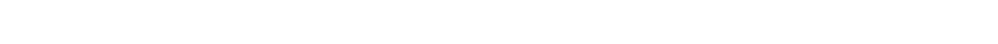
COASTAL BASIN BETWEEN HILLSBOROUGH RIVER AND WITHLACOOCHEE RIVER--CONTINUED

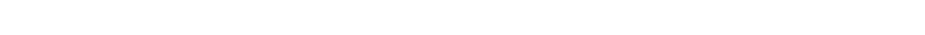

$\begin{array}{llllllllll}\text { JUNE, } 1970 \\ 11 . . & 31.0 & 40700 & - & 325 & 950 & -- & 8200 & 315 & 136\end{array}$

290449042442500 - ANCLUTE HIVER AT US HWY 19 WFAR TARPON ILAT PR D9 49 LONG OA? 44251

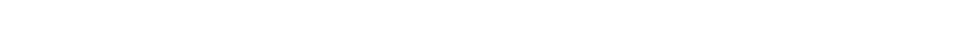

281333082373300 - ANCLOTE RIVER AT POWEH LINF INP ONESSA ILAT P8 1333 LONG 08237331 JUNE, 1970

$10 \ldots \quad 23.0 \quad 132$

281424082310100 - PITHLACHASCOTEE R AT ALT 19 AT NEW PORT R ILAT 281424 LONF OB? 31 0II JUNE, 1970

$10 . .28 .0 \quad 6400$

COASTAL BASIN BETWEEN ST, JOHNS RIVER AND TURKEY CREEK

302200081242500 - HOKROW OIT LAKF SE AT JACKSONVILLE HEA ILAT 3022 ON LONG OAI 24 26) JUNE, 1970 $\begin{array}{llllllll}-- & 116 & 60 & - & & & & \end{array}$

302700081243000 JINE, 1970 -. 3110 $17 \ldots 302201081242400 \quad 3110$ JUNE, 1970

JUNE,
17.

302204081242400 JUNE, 1970

17 ...

302210081243000 -

JUNE, 1970

73

$302211041242200 \quad-$ JUNE, 1970

$17 . .$.

302700086751600 MAY , 1970

30... $24.0 \quad 216000$

$\begin{array}{lll}\text { SEP. } & & \\ 23 . . & 30.0 & 27800\end{array}$
HORROW PIT LAKF SW AT JACKSONVILLE REA ILAT $3 \cap 2200$ LONG NHI 2430 )

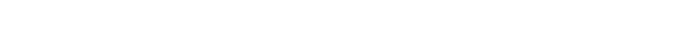
HORROW PIT LAKE NE DIKED AREA JAX BEAC (LAT 3N 2201 LONS 0812424 )

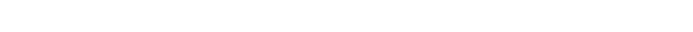

7.8

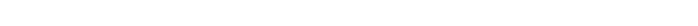

$\begin{array}{llllllll}- & 118 & 14 & - & - & - & & \end{array}$

BORROW PIT 4 AT JACKSONVILLE BEACH FLA ILAT 30 22 10 LONG O8I 2430

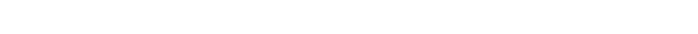
ST. JOHNS RIVER BASIN

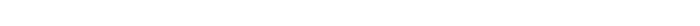

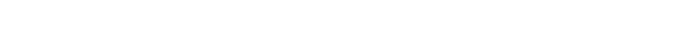

CHOCTANHATCHEE RIVER BASIN

CHOCTAWHATCHEE GAY NH VILLA TASSO FLA (LAT 302700 LONG 0862516 )

$\begin{array}{lllllllll}90 & 102 & 450 & 3500 & 4000 & 146 & 72 & 0 & 7.5 \\ 60 & 215 & 645 & 3400 & 5180 & 210 & 88 & 0 & 7.7\end{array}$




\begin{tabular}{|c|c|c|c|c|c|c|c|c|c|}
\hline ris- & $\begin{array}{l}\text { UIS- } \\
\text { SOLVEO }\end{array}$ & $\begin{array}{l}\text { BIS- } \\
\text { SOLVEU }\end{array}$ & & $\begin{array}{l}\text { NON- } \\
\text { CAR- }\end{array}$ & ALKA- & $\begin{array}{l}\text { DIS- } \\
\text { SOLVED } \\
\text { SOLIOS }\end{array}$ & $\begin{array}{l}\text { NIS- } \\
\text { SOLVEO } \\
\text { SOLIOS }\end{array}$ & $\begin{array}{l}\text { I'IS- } \\
\text { SOLYFn }\end{array}$ & \\
\hline SOLVEO & CHLO- & FLUO- & HAKD - & GONATF & LINITY & (RESI- & $15 U M$ of & SOLInS & TANNIV \\
\hline SULFATE & RIDE & FIDE & NESS & HAYO- & AS & RUE $A T$ & CONSTI- & ITONE & ANII \\
\hline $\begin{array}{l}1504) \\
(M G / 4)\end{array}$ & $(C L)$ & (F) & $(C A, M G)$ & NESS & $\mathrm{CACO} 3$ & $180 \mathrm{Cl}$ & TUENTSI & DER & LIGNIN \\
\hline
\end{tabular}

COASTAL BASIN BETWEEN HILLSBOROUGH RIVER AND WITHLACOOCHEE RIVER--CONTINUED

280228082343200 - SW PERIM DIFH AT ROCKY CR LNOFL NR TAM ILAT 2802 2H LONG O32 3432 )

FEB., 1970

$\begin{array}{ccccccccccc}\text { FEB... } \\ \begin{array}{c}\text { JUNE } \\ \text { I5... }\end{array} & 4.4 & 6.8 & .1 & 12 & 7 & 5 & 46 & 29 & .06 & .5 \\ & 4.9 & 8.8 & .0 & 11 & 6 & 5 & 36 & 36 & .05 & \ldots\end{array}$

¿80235082342500 - NW SANT LNUFL OXID PD NK SULPHUR SPG F ILAT 2\% 02 35 LONG ONZ $34>5$ )

FEB., 1970

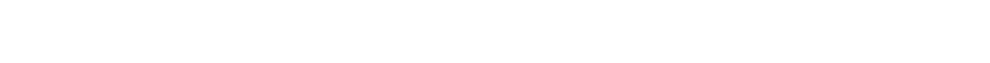

280243092342200 - NE PERIM DITH AT ROCKY CP LNDFL NR TAM ILAT 20 O2 43 LONG, 0 A2 34 27)

JUNE, 1970

HILLSBOROUGH RIVER BASIN AND COASTAL BASIN NORTH OF ALAFIA RIVER--CONTINUED

280448082047300 - 1TCHEPACKESASSA CH NH LAKELANR FLA ILAT 2R T4 4R LONG 0R2 04 23)

$\begin{array}{llllllllll}09 . \ldots & 19 & 16 & .6 & 92 & 20 & 77 & 172 & 145 & .23\end{array}$

COASTAL BASIN BETWEEN HILLSBOROUGH RIVER AND WIGHLACOOCHEE RIVER--CONTINUED

280926082452500 - ANCLOTE RIVER AT ALT IS AT FAPPON SPFG (LAT $2 H$ H9 26 LONG (1A3 45 25)

$\begin{array}{ccccccccc}\text { JUNE. } 1970 \\ 11 . .0^{1170} \quad 15100 & 1.3 & 4720 & 4610 & 112 & \ldots & 26100 & 35.5\end{array}$

280949082442500 - ANCLOTE RIVER AT US HWY 19 NEAH TAKPON ILAT $2 \$ 11949$ LONG 1924425 ) JUNE, 1970

$10 \ldots 1020 \quad 13000 \quad 1.0 \quad 4250 \quad 4140 \quad 112 \quad 0.622500 \quad 30.4$

281333082373300 - ANCLOTE RIVER AT PUWER LINE NR ODESSA (LAT 281333 LONG 082 3: 33) JUNE, 1970

$10 \ldots 15$

If

111

$28142408<310100$ - PITHLACHASCOTEE R AT ALT 19 AT NEW PORT R ILAT 2R 1424 LONG 092 31 01

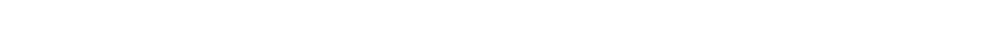
COASTAL BASIN BETWEEN ST. JOHNS RIVER AND TURKEY CREEK--CONTINUED

302200081242000 - HORROW PIT LAKE SE AT JACKSONVILLE GEA (LAT 30 2200 LOHG ORI 24 PG) JUNE, 1970

$17.0 \quad 113 \quad 820$

302200081243000

- hokrow pit lake Sw at jacksonville gea ILat 3122 on long o81 2430

JUNE, 1970

302201081242400

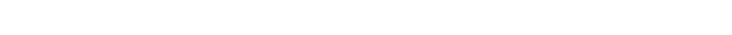

JUNE, 1970

$17 \ldots 26$

60 $\quad 127$

302204081242400

- BORROW PIT 2 AT JACKSONVILLE heACH FLA (LAT 3n 22 U4 LONG 104I 24 24)

JUNE, 1970

$\begin{array}{lllllll}17.0 & 3.5 & 140 & - & 352 & 50 & 302\end{array}$

302210081243000 - MORROW PIT 4 AT JACKSONVILLE REACH FLA (LAT 30 22 10 LONG 0BI 24 30)

JUNE, 1970

55

ST. JOHNS RIVER BASIN--CONTINUED

302211081242200 - BORROW PIT 3 AT JACKSONVILLE HEACH FLA ILAT 30 2211 LONG 0HI 24221

JUNE, 1970 21

95

CHOCTAHHATCHEE RIVER BASIN--CONTINUED

302700086251600

- choctawhatchee hay inR villa tasso fla Ilat 3027 on long o86 25161

MAY, 1970

30... 940

6780

9500

.52200

2200

59

$-12500$

17.

23... 124n

$.7 \quad 3200$

3120

72

-- 17000

23.1 

CHEMICAL ANALYSES, WATER YEAR OCTOBER 1969 TO SEPTEMBER 1970
(MAJOR CONSTITUENTSI

\begin{tabular}{|c|c|c|c|c|c|c|c|c|c|c|c|}
\hline DATE & $\begin{array}{l}\text { TEMPER- } \\
\text { ATURE. } \\
\text { (DEG C) }\end{array}$ & $\begin{array}{l}\text { SPE- } \\
\text { CIFIC } \\
\text { CON- } \\
\text { DUCT- } \\
\text { ANCE } \\
\text { (MICRO- } \\
\text { MHOS) }\end{array}$ & $\begin{array}{l}\text { OIS- } \\
\text { SOLVEU } \\
\text { IRON } \\
(F E) \\
(U G / L)\end{array}$ & $\begin{array}{l}\text { DIS- } \\
\text { SOLVED } \\
\text { CAL- } \\
\text { CIUM } \\
\text { (CA) } \\
\text { (MG/L) }\end{array}$ & $\begin{array}{l}\text { DIS- } \\
\text { SOLVED } \\
\text { MAG- } \\
\text { NE- } \\
\text { SIUM } \\
\text { (MG) } \\
\text { (MG/L) }\end{array}$ & $\begin{array}{l}\text { DIS- } \\
\text { SOLVED } \\
\text { STRON- } \\
\text { TIUM } \\
\text { (SR) } \\
\text { (UG/L) }\end{array}$ & $\begin{array}{l}\text { DIS- } \\
\text { SOLVED } \\
\text { SODIUM } \\
\text { (NA) } \\
\text { (MG/L) }\end{array}$ & $\begin{array}{l}\text { OIS- } \\
\text { SOLVED } \\
\text { PO- } \\
\text { TAS- } \\
\text { SIUM } \\
\text { (K) } \\
\text { (MG/L) }\end{array}$ & $\begin{array}{l}\text { BICAR- } \\
\text { BONATE } \\
\text { (HCO3) } \\
\text { (MG/L) }\end{array}$ & $\begin{array}{l}\text { CAR- } \\
\text { BONATE } \\
\text { (CO3) } \\
\text { (MG/L) }\end{array}$ & $\begin{array}{c}\text { PH } \\
\text { (UNITS) }\end{array}$ \\
\hline & & & & & & & & & & & \\
\hline
\end{tabular}

302722084232500 - UNNAMED) LAKE NEAK TALLAMASSEE FLA (LAT 302722 LONG 0842325 )

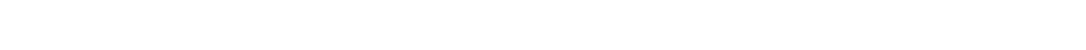
ESCAMBIA RIVER BASIN AND COASTAL BASIN

303110087085800 - ESCAMBIA BAY AT IIO NR PENSACOLA FLA (LAT 3031 10 LONG 08708 58) MAY, 1970 $19 \ldots 25.5 \quad 16800$

SEP. $\quad 30.0 \quad 19800$

$40 \quad 135 \quad 369$

$2800 \quad 3200$

119

64

$\begin{array}{lll}70 & 141 & 392\end{array}$

$2300 \quad 3570$

136

68

, 
ANALYSES OF SAYPLES COLLECTED AT MISCELLANEOUS SITES IN FLORIDA

CHEMICAL ANALYSES, WATER YEAR OCTOBER 1969 TO SEPTEMBER 1970

(MAJDR CONSTITUENTS)

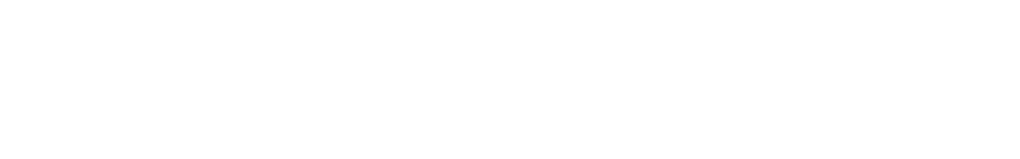

OCHLOCKONEE RIVER BASIN AND COASTAL BASIN--CONTINUED

302722094232500 - UNNAMEU LAKE. NEAM TALLAMASSEE FLA ILAT 302722 LONG 08423 ?5)

$\begin{array}{lllllllll}\text { DEC.. } 1969 & & & & & & & & \\ 16 . . . & 2.0 & 9.0 & 40 & 0 & 108 & 126 & 106 & .17\end{array}$

ESCAMBIA RIVER BASIN AND COASTAL BASIN--CONTINUED

303110087085800 - ESCAMBIA BAY AT III) NH PENSACOLA FLA (LAT 3N 31 10 LONG 08708 58)

MAY 1970

$19 . . .780 \quad 5520$

SEP.

6300

$\begin{array}{ll}.4 & 1860 \\ .6 & 197\end{array}$

1810

52

$-\quad 10200$

13.9

1910

56 -- 11500

15.6 -. 


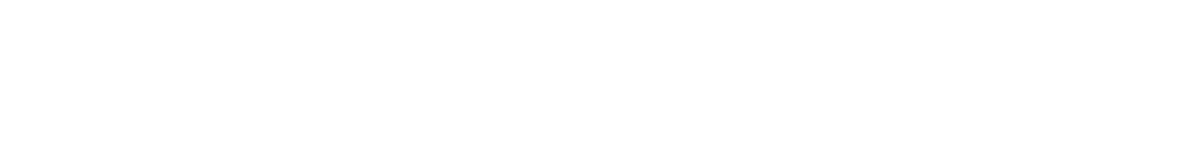

\section{ST. MARYS RIVER BASIN}

02228500 - NORTH PRONG ST. MARYS RIVER AT MONIAC, GA. $11.4 T 303103$ LONG OR? 13501

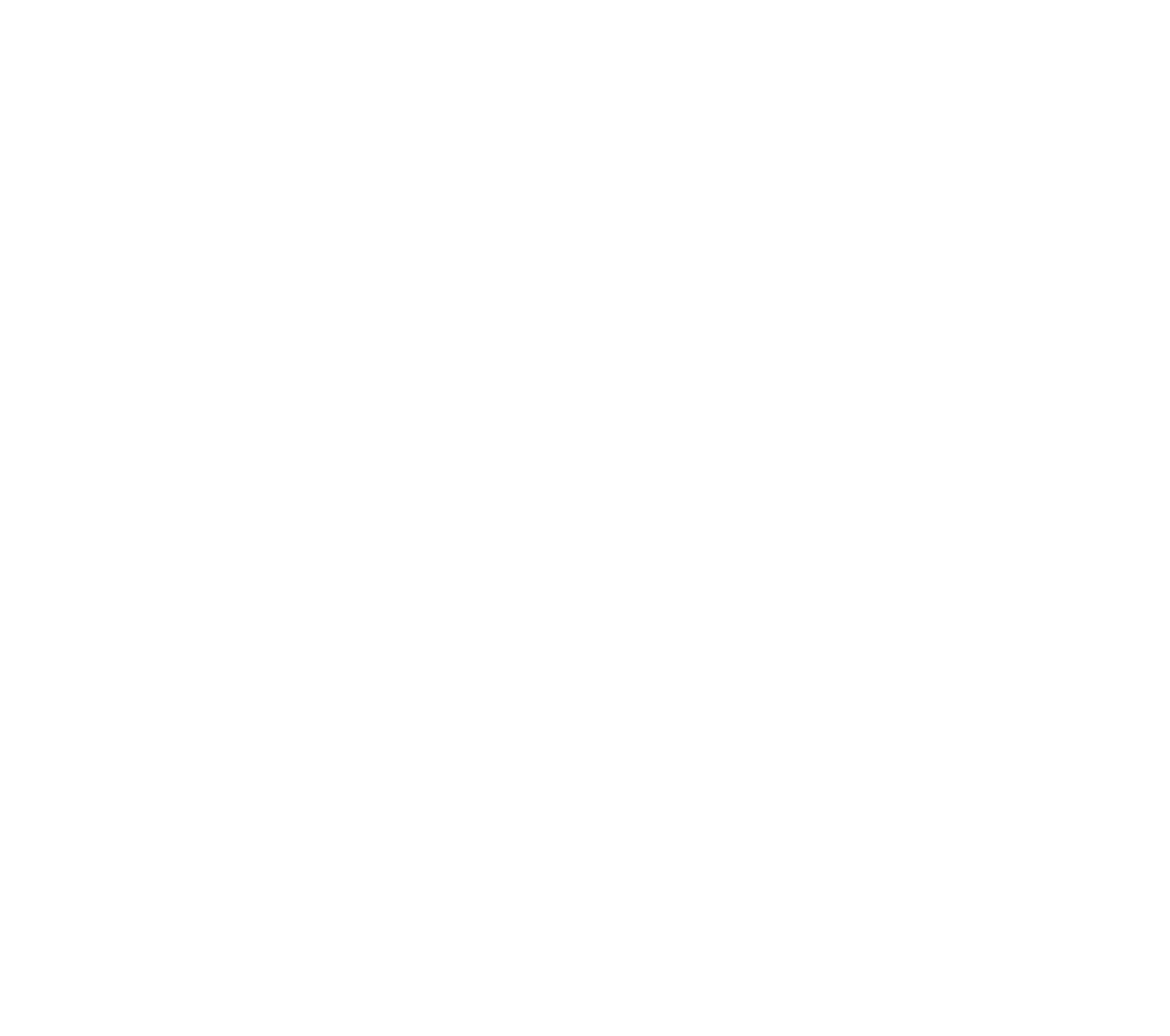

02231372 - HLUE CYPRESS C TR NO 2 NR LOKOSEE FLA (LAT 274641 LONG OBN 55 28)

JULY. 1970

21...

02231375 - FLUE CYPHESS C TK NO 3 AT LOKOSEE FLA (LAT 274531 LONG OAN b4 2H)

MAY, 1970

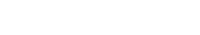

02231396 - HLUE CYPRESS CREEK NEAR FELLSMERE FLA (LAT 274340 LONG n81 48 19)

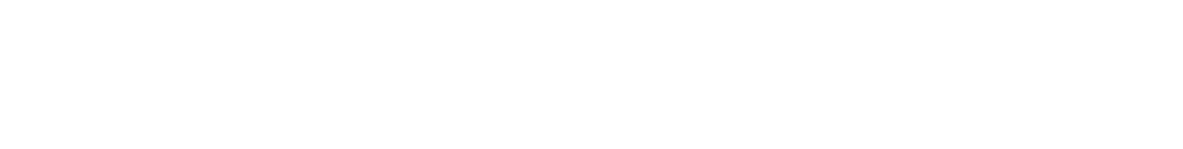


CHEMICAL ANALYSES, WATER YEAR OCTOBER 1969 TO SEPTEMBER 1970 (MACRONUTRIENTS AND OTHER RELATED CONSTITUENTS)

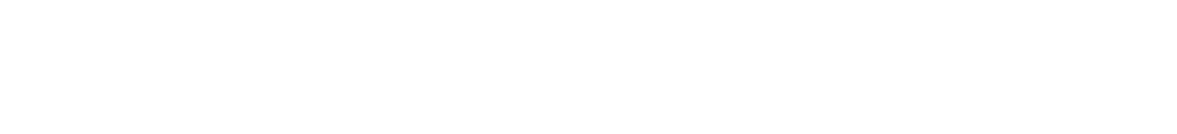

ST. JOHNS RIVER BASIN--CONTINUED

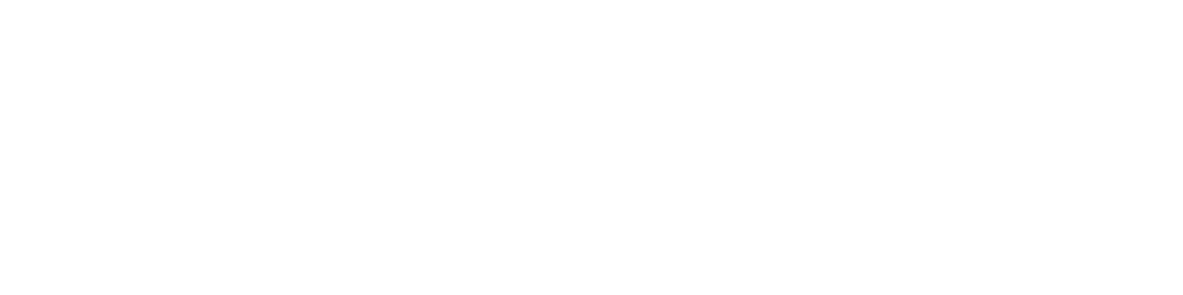

$\begin{array}{ll}\text { MAY } & 1970 \\ 01 . . . & .09\end{array}$

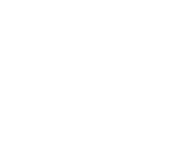

02231450 - ST JOHNS HOWATERS NR KENANSVILLE FLA (LAT 274917 LONG ORO 4843 )

02231467 - ST JOHNS R AB LK HELEN BLA7ES NR MFLBO (LAT 775943 LONG 0804730 )

\begin{tabular}{|c|c|c|c|c|c|c|c|c|c|c|}
\hline .02 & -1 & 1.3 & .13 & .20 & 5.5 & $?$ & 150 & 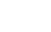 & 1.0 & 1.0 \\
\hline .02 & .2 & 1.7 & .05 & .19 & 1.5 & 1 & 100 & -- & .8 & -- \\
\hline .03 & .0 & 99. & .07 & .09 & 5.3 & -- & 100 & 19 & .0 & - \\
\hline $\begin{array}{r}.04 \\
-2\end{array}$ & $\ddot{1}$ & 1.0 & .12 & .22 & $\begin{array}{r}9.2 \\
--\end{array}$ & $\begin{array}{r}4 \\
--\end{array}$ & $\begin{array}{r}160 \\
--\end{array}$ & $\begin{array}{l}33 \\
29\end{array}$ & -2 & 1.0 \\
\hline
\end{tabular}

02231471 - LAKE HELEN bLAZES NEAR DEER PARK. FLA. (LAT 280130 LONG 0804756 )

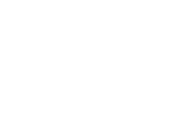

$\begin{array}{rrrrrrrrrrr}.01 & .0 & 1.3 & .07 & .17 & 5.3 & 3 & 200 & 21 & 1.0 & 1.0 \\ .02 & .3 & .89 & .06 & .13 & 1.5 & 1 & 120 & \ldots & .4 & - \\ .02 & .0 & 1.4 & .05 & .15 & 5.7 & -- & 120 & 19 & 2.0 & -- \\ .03 & .0 & 1.3 & .04 & .17 & 8.3 & 3 & 120 & 29 & .7 & 1.0\end{array}$

02231600 - JANE GREEN CREEK NK DEER PARK FLA (LAT 780427 LONG 08O 53 18)

$\begin{array}{ll}.03 & \\ .02 & \\ .02 & . \\ .01 & \\ .01 & \\ -- & - \\ - & - \\ .04 & - \\ .04 & . \\ .05 & .\end{array}$

02231980

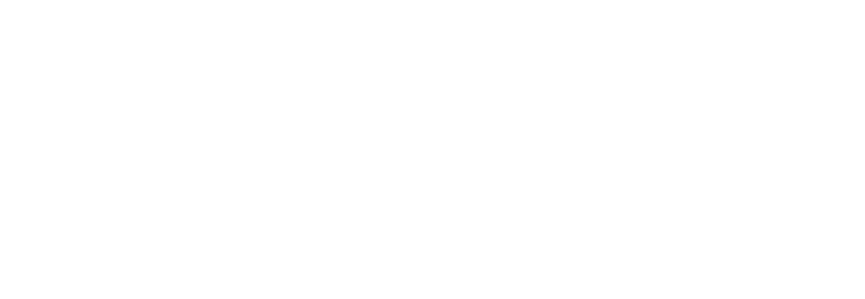

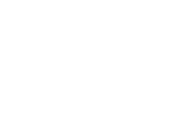

.02
.02
.03
.03

$\begin{array}{ll}.0 & 1.6 \\ .2 & 1.4 \\ .0 & 1.0 \\ .0 & 1.2\end{array}$

.20
.04
.04
.03

.12
.11
.11
.15

5.1
1.2
4.9
8.6

3

$\begin{array}{ll}8 & 190 \\ 3 & 120 \\ -- & 110 \\ 4 & 120\end{array}$

20

$\begin{array}{rr}.8 & 1.0 \\ .7 & -- \\ .5 & -- \\ 1.7 & 1.0\end{array}$

02232100 - LK WASHINGTON NR EAU GALLIE FLA (LAT 28 g8 50 LONG 0AO 4410 )

\begin{tabular}{|c|c|c|c|c|c|c|c|c|c|c|c|c|}
\hline $\begin{array}{l}\text { OCT., } 1969 \\
22 \ldots . \\
23 . .\end{array}$ & 16 & 01 & $\because 0$ & 1.2 & .12 & .12 & 4.9 & $\begin{array}{r}2 \\
--\end{array}$ & $\begin{array}{r}180 \\
--\end{array}$ & 9.0 & $\because 5$ & 1.0 \\
\hline $\begin{array}{l}\text { FE8 . } 1970 \\
03 \ldots 1 \\
\text { MAY }\end{array}$ & .14 & .03 & .2 & $2 . n$ & .04 & .21 & 1.6 & 23 & 100 & -- & .7 & - \\
\hline $\begin{array}{l}\text { MAY } \\
04 \ldots . . \\
04 \ldots\end{array}$ & .06 & .03 & $\because 2$ & 1.81 & .07 & $\begin{array}{l}.11 \\
.07\end{array}$ & 4.0 & $\because$ & 120 & ${ }^{12}$ & $\therefore$ & $\because$ \\
\hline $\begin{array}{l}J U L Y \\
28 \ldots . . .\end{array}$ & .06 & .03 & .2 & -- & -- & -- & 1.1 & -- & - & 21 & -- & -- \\
\hline
\end{tabular}


CHEMICAL ANALYSES, HATER YEAR OCTOBER 1969 TO SEPTEMBER 1970 (MACRONUTR IENTS AND OTHER RELATED CONSTITUENTS)

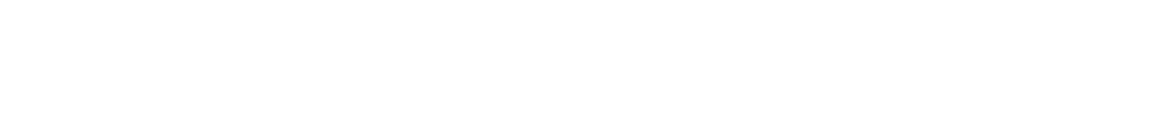

ST. JDHNS RIVER BASIN--CONTINUED

02232155 - PENNEYWASH CREEK NR OEER PARK FLA (LAT $2 B 1054$ LONG 0805344 )

MaY...

FE8.. 1970 .03

MAY

OG..

29.0 .00

(1)

02232162

JOHNS TRIB CA NR DEER PARK (LAT $28 \quad 1253$ LONG OBO 51 13)

OCT. 1969

OCT.. 1

21...

JAN., 1970

$26 . \cdots$

28...

JULY

2I...

$\begin{array}{ll}.02 & .1 \\ .02 & .0\end{array}$

$\begin{array}{lll}.57 & .26 & .37 \\ .55 & .04 & .09 \\ .04 & .22 & .30\end{array}$

8.

- $50 \quad 12$

02232200 - WOLF CR NR DEER PARK FLA ILAT 281255 LONG 0805403 )

NOV., 1969

No... 1969 .05

FEB. $1970 \quad .08$

MAY

$06 \ldots . . .05$

JULY

$\begin{array}{ll}.12 & . \\ .01 & . \\ .03 & . \\ .02 & .\end{array}$

$\begin{array}{cccc}.0 & 1.1 & .26 & .44 \\ -. & .- & .- & . . \\ .0 & .45 & .09 & .15 \\ .4 & .61 & .18 & .32 \\ .1 & .61 & .01 & .11\end{array}$

$\begin{array}{rr}6.7 & 21 \\ -. & -2 \\ 4.5 & 2 \\ 4.6 & -- \\ 7.3 & 9\end{array}$

$\begin{array}{rr}21 & 160 \\ -- & 10 \\ - & 80 \\ 9 & 100\end{array}$

160
100
80
100

$10^{--}$

$1.0 \quad 1.0$

02232254 - LAKE WINDER NEAR BONAVENTUPE, FLA. ILAT 29 1512 LONG 08050551

NOV.: $1969 \quad .05$

$\begin{array}{rcccccccccc}.01 & .0 & 1.1 & .07 & .10 & 6.2 & 4 & 200 & -- & .5 & 1.0 \\ .02 & .1 & .82 & .04 & .08 & 1.5 & 1 & 100 & -- & .4 & -- \\ .03 & .1 & .93 & .06 & .12 & 3.4 & -- & 200 & 12 & -- & -- \\ .03 & .0 & 1.0 & .14 & .29 & 9.8 & 4 & 120 & 21 & 1.4 & 1.0\end{array}$

02232285 - ROCKLEDGE CREEK NEAR ROCKLEDGE FLA (LAT 291843 LONG 0804734 )

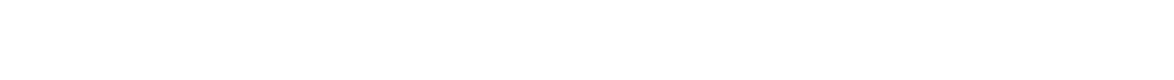

$29 . . \quad .05$

.02

02232300 - LK POINSETT NR COCOA FLA ILAT 2A 21 OI LONG O8N 4856 )

NOV.. 1969

NOS... 1969.06

FEB.11970 04.16

MAY

$06 \ldots . .06$

$29 . \ldots \quad .02$

\begin{tabular}{|c|c|c|c|c|c|c|c|c|c|c|}
\hline .02 & .0 & 1.2 & .05 & .11 & 6.3 & 5 & 180 & $=$ & .7 & 1.0 \\
\hline .02 & .1 & .93 & .04 & .12 & 1.7 & 2 & 100 & $=-$ & .2 & - \\
\hline $\begin{array}{l}.03 \\
.02\end{array}$ & .1 & $\begin{array}{l}1.1 \\
1.2\end{array}$ & .06 & .12 & $\begin{array}{r}3.2 \\
--\end{array}$ & $\ddot{--}$ & 100 & $\because 0$ & 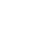 & $=$ \\
\hline .02 & -0 & $1 . \overline{5}^{-\infty}$ & .13 &.$\overline{27}$ & $8 . \overline{5}$ & -- & $1 \overline{20}$ & $\begin{array}{l}18 \\
21\end{array}$ & 1.2 & \\
\hline
\end{tabular}

02232413 - TAYLOR CREEK AT S 164 NEAR COCOA FLA (LAT 282023 LONG 08056 06)

OCT., 1969

$20 . . .1969$

JAN.. $1970 \bullet 14$

26... .07

APR. $27 . .$.

$27 \ldots . .0 \quad=$

$27 . .$.

30.00

$20 \ldots .00$

$20 \ldots . . \quad \quad .00$

$20 \ldots . . \quad .00$

.03
.02
.05
.03
.04
.02
.02
.03
.02
.03

$\begin{array}{ll}.0 & 1.0 \\ .1 & \\ -0 & \\ .2 & \\ .0 & \\ .0 & \\ .0 & \\ .0 & \\ .0 & \end{array}$

$\begin{array}{cc}1.0 & .13 \\ .97 & .16 \\ .89 & .08 \\ -.- & .09 \\ -. & .14 \\ .91 & .16 \\ .87 & .05 \\ .92 & .05 \\ .98 & .19 \\ .86 & .04 \\ & .05\end{array}$

.13
.16
.08
.09
.14
.16
.05
.05
.19
.04
.05

$\begin{array}{ll}.26 & 6.3 \\ .30 & 3 \\ .16 & 1 \\ .11 & \\ .16 & \\ .19 & \\ .20 & \\ .34 & \\ .23 & 2 \\ .17 & \end{array}$

$\begin{array}{ll}6.3 \\ 3.4 \\ 1.2 \\ = \\ = \\ = \\ = \\ = & = \\ - & =\end{array}$

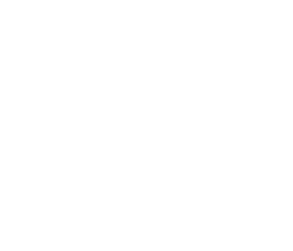

1.0

02232430 - ST JOHNS RIVER AT CSG NO.7 NEAR COCOA (LAT 282921 LONG OAN 52 55)

MAY. $1970 \quad 12$

02232450 - JIM CREEK NR CHRISTMAS FLA (LAT 282607 LONG 08057 58)

MAY 1970

$02 . .1$

.27

.05

.2

.74

.09

.11 
CHEMICAL ANALYSES, WATER YEAR OCTOBER 1969 TO SEPTEMBER 1970 (MACRONUTR IENTS AND OTHER RELATED CONSTITUENTS)

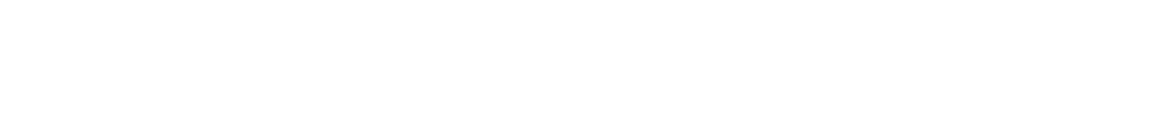

ST. JOHNS RIVER BASIN--CONTINUED

02233102 - ECONLOCKHATCHEE R TRIB NR BITHLO FLA (LAT 283355 LONG DE1 D9 19)

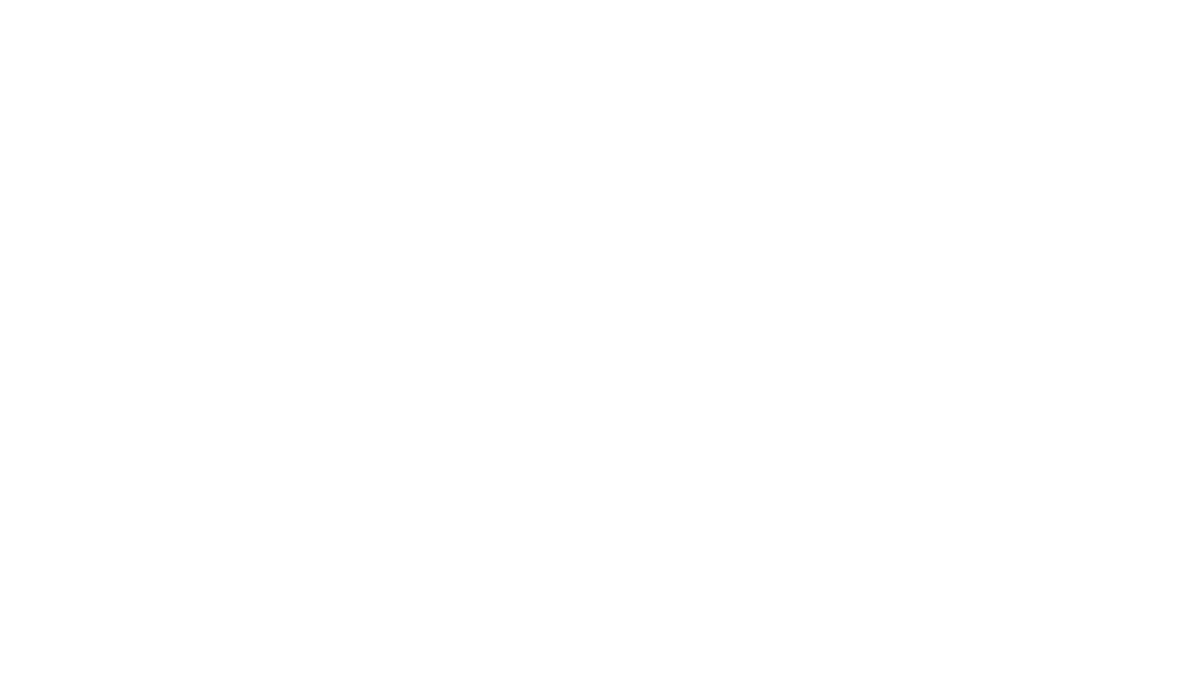

02234160 - L WINNEMISSFT NK DELAND FLA (LAT 290110 LONG 081 15 D6)

MAY, 1970

$15 . .0 \quad 02$

02234435 - LAKE JESSUP OUTLET NR SANFORN, FLA. ILAT 284709 LONG 0811050 I

MAY 1970

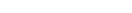

. $n$

02234500 - ST JOHNS R NR SANFDRD FLA (LAT 285013 LONG 0811928 )

MAY, 1970

02234600 - WEKIVA SPRINGS NR APOPKA FLA (LAT 284243 LONG O8I 27 36)

Nov., 1969

$17 . . .1969$

MAY 1970

15 ...

$\begin{array}{rrrrrrr}.01 & 4.4 & -. & -- & -- & 10 & \ldots \\ .05 & 6.0 & .03 & .34 & .34 & 9.1 & 0 \\ .01 & .9 & -. & .- & -. & 9.0 & -\end{array}$

02234610 - ROCK SPRINGS NEAR APOPKA FLA (LAT 2845 70 LONG ORI 29 58)

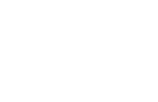

.015

.02

$-$

.01

02234815 - LAKE WEKIVA OUTLET NEAR MAITLAND FLA (LAT 2836 In LONG ORI 2538 )

\footnotetext{
MAY, $1970 \quad .07$

02235000 - WEKIVA RIVER NR SANFOPD FLA (LAT 28 4A 54 LONG 0812510 )
}

MAY, 1970

16... 1970 .01

.0

02235150 - LAKE DORR NR ALTOONA FLA (LAT 290010 LONG 08138 05)

MAY, 1970

.01

.05

$.40 \quad .11$

.13

3.1 
CHEMICAL ANALYSES, WATER YEAR OCTOBER 1969 TO SEPTEMBER 1970 (MACRONUTR IENTS AND OTHER RELATED CONSTITUENTS)

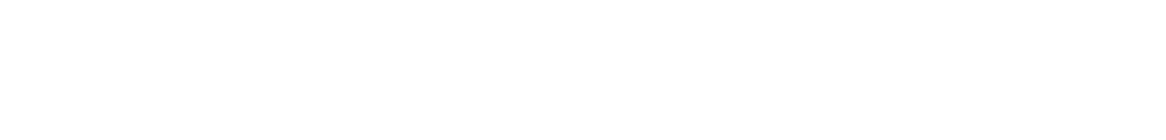
ST. JOHNS RIVER BASIN--CONTINUED

02235200 - RLACKWATER CR NR CASSIA FLA CLAT 285240 LONG 08129201

\begin{tabular}{|c|c|c|c|c|c|c|c|c|c|c|c|}
\hline $\begin{array}{l}\text { OCT., } 1909 \\
\text { O3... } \\
\text { MAY } 1970\end{array}$ & -- & -- & .1 & -- & .06 & .06 & 6.3 & - & $28 n$ & -- & -- \\
\hline $16 \ldots$ & .06 & .06 & $1 . n$ & . א? & .18 & .24 & 6.5 & 9 & 160 & - & - \\
\hline
\end{tabular}

02235500 -

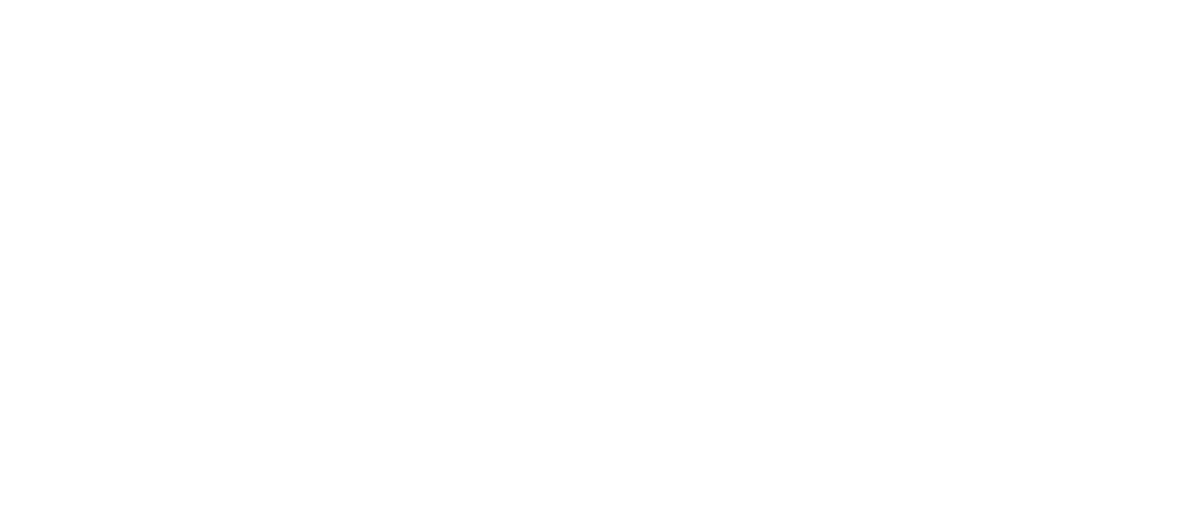

02236110 - PONCE DE LEON SPRINGS NR DELANO FLA (LAT 290802 L.ONG OB1 2147 )

\begin{tabular}{|c|c|c|c|c|c|c|c|c|c|c|c|c|}
\hline $\begin{array}{l}\text { MAY } 1970 \\
14 \ldots .\end{array}$ & -- & -- & -- & .10 & .16 & .19 & 6.4 & ? & 5 & -- & -- & -- \\
\hline $\begin{array}{l}\text { JULY } \\
06 \ldots . . .\end{array}$ & .04 & .05 & 1.3 & .10 & .16 & .19 & 6.4 & 2 & 5 & 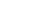 & $=$ & - \\
\hline
\end{tabular}

02236120 - DEFP CR NK GARBERVILLE FLA (LAT 290747 LONG 0812327 )

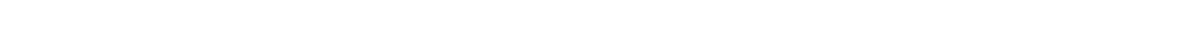

02236200 - LAKE KERR NK EUREKA FLA ILAT 292010 LONG OAL 46001

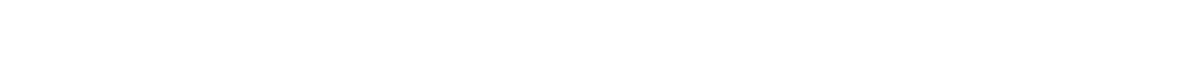

02236250 - LAKE LOWERY NR HAINES CITY FLA ILAT 280651 LONG OB1 40 17)

\begin{tabular}{|c|c|c|c|c|c|c|c|c|c|c|c|}
\hline $02 \ldots$ & .11 & .02 & .0 & 1.3 & .07 & .10 & . $B$ & -- & $5 \pi$ & - & 6.9 \\
\hline
\end{tabular}

02236500 - aIG CREEK NR CLERMONT FLA (LAT 382651 LONG OR1 44 25)

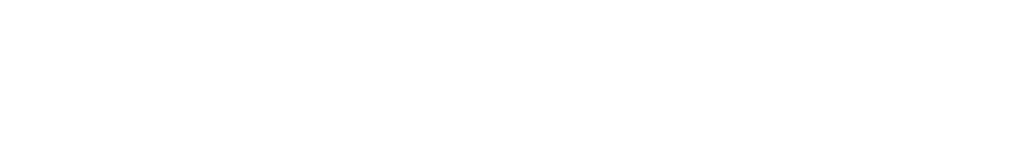

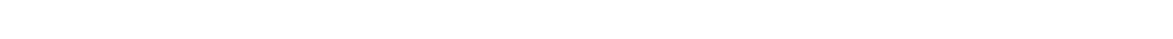
02236840 - LAKE MINNEHAHA AT CLERMONT FLA (LAT 283240 LONG 08145 18)

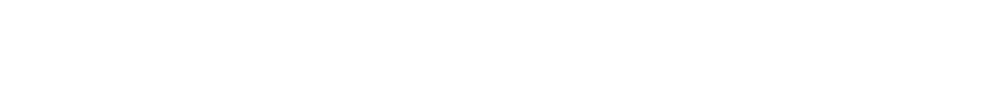

MAY 1970

MAY... 1970

.03

.01

1.5

$.71 \quad .00$

.07

.3

12 
CHEMICAL ANALYSES, HATER YEAR DCTOBER 1969 TO SEPTEMBER 1970 (MACRONUTRIENTS AND OTHER RELATED CONSTITUENTS)

\begin{tabular}{|c|c|c|c|c|c|c|c|c|c|c|c|c|}
\hline DATE & $\begin{array}{l}\text { TOTAL } \\
\text { AMMONIA } \\
\text { (NH4) } \\
\text { (MG/L) }\end{array}$ & $\begin{array}{l}\text { TOTAL } \\
\text { NITRITE } \\
\text { (NOZ) } \\
\text { (MG/L) }\end{array}$ & $\begin{array}{l}\text { TOTAL } \\
\text { NITRATF } \\
\text { (NO3) } \\
\text { (MG/L) }\end{array}$ & $\begin{array}{l}\text { ORGANIC } \\
\text { NITRO- } \\
\text { GEN } \\
\text { (N) } \\
\text { (MG/L) }\end{array}$ & $\begin{array}{l}\text { NIS- } \\
\text { SOLVEU } \\
\text { ORTHN } \\
\text { PHOS- } \\
\text { PHATE } \\
\text { (PO4) } \\
\text { (MG/L) }\end{array}$ & $\begin{array}{l}\text { PHOS- } \\
\text { PHATE } \\
\text { (PO4) } \\
\text { (MG/L) }\end{array}$ & $\begin{array}{l}\text { OIS- } \\
\text { SOL VED } \\
\text { SILICA } \\
\text { (SIOZ) } \\
\text { (MGIL) }\end{array}$ & $\begin{array}{l}\text { TUR- } \\
\text { BID- } \\
\text { ITY } \\
\text { (JTU) }\end{array}$ & $\begin{array}{l}\text { COLOP } \\
\text { (PLAT - } \\
\text { INUM- } \\
\text { COBAL T } \\
\text { UNITS) }\end{array}$ & $\begin{array}{l}\text { TOTAL } \\
\text { ORGANIC } \\
\text { CARBON } \\
\text { (C) } \\
\text { (MG/L) }\end{array}$ & $\begin{array}{l}\text { HIN- } \\
\text { CHEM- } \\
\text { ICAL } \\
\text { OXYGEN } \\
\text { DEMAND } \\
\text { (MGAL) }\end{array}$ & $\begin{array}{l}\text { DEP TH } \\
\text { (FT) }\end{array}$ \\
\hline
\end{tabular}

ST. JOHNS RIVER BASIN--CONTINUED

02236900 - PALATLAKAHA R AT CH LK OLT NR GROVELO (LAT 283533 LONG OB1 49 21)

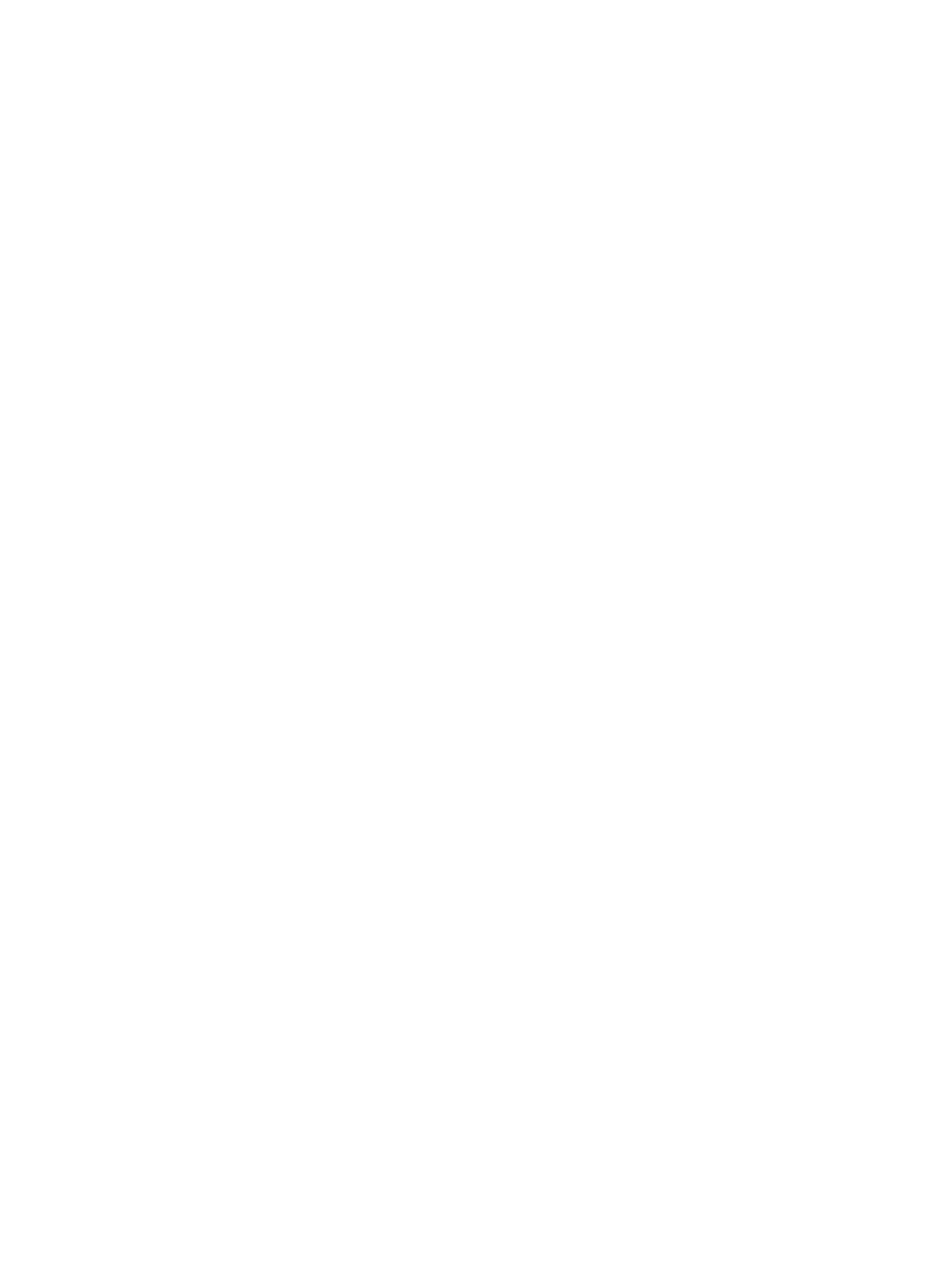




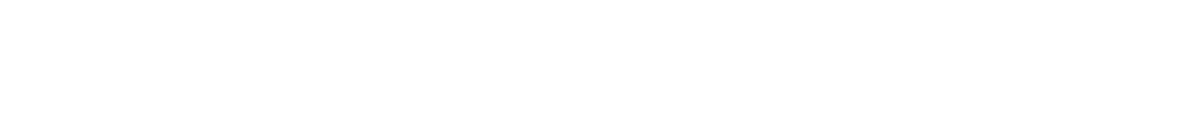

\section{ST. JOHNS RIVER BASIN--CONTINUED}

02238204 - YALE-GRIFFIN CANAL NR LISBON, FLA. (LAT 285517 LONG OBI 46 26)

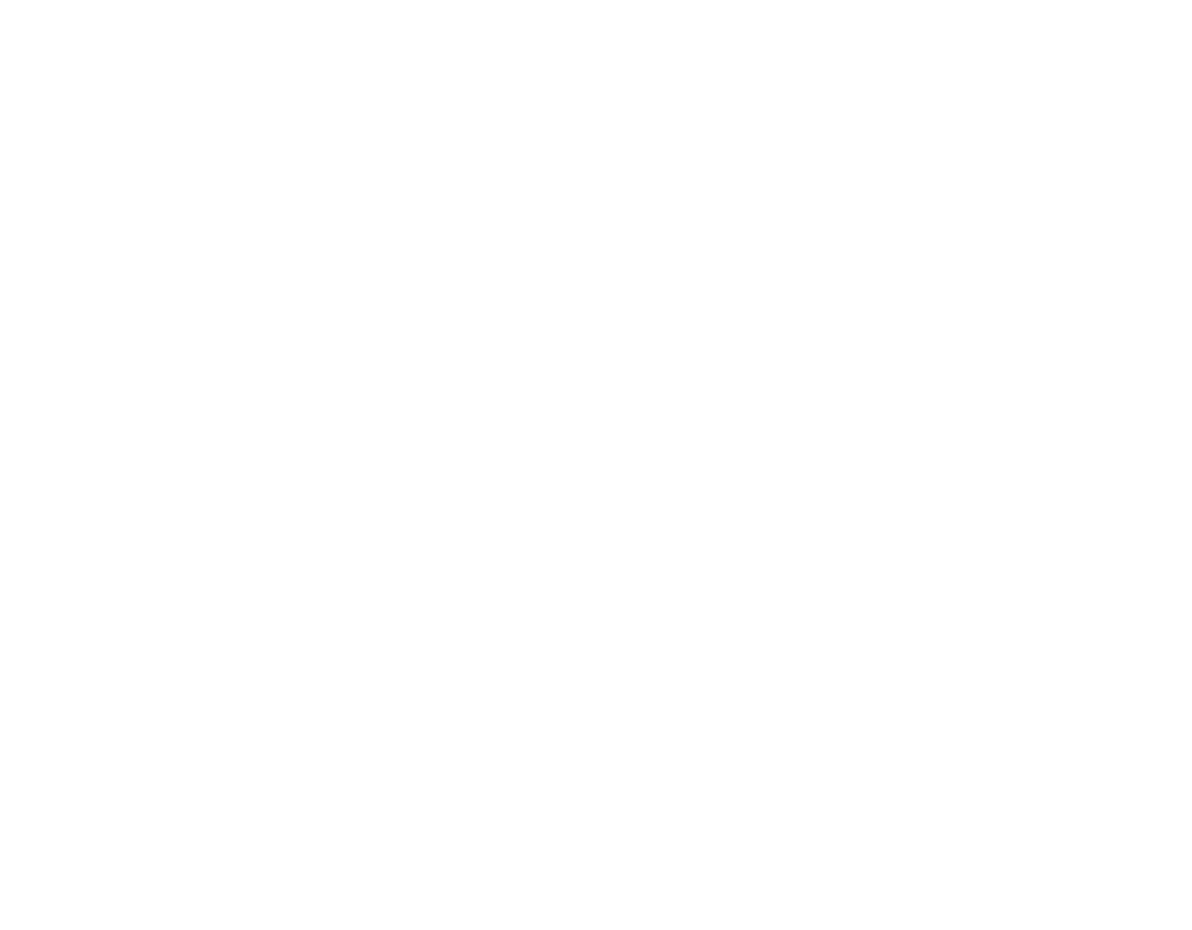

02240500 - OKLAWAHA RIVER AT EUREKA FLA ILAT 292200 LONG OBI 54 00)

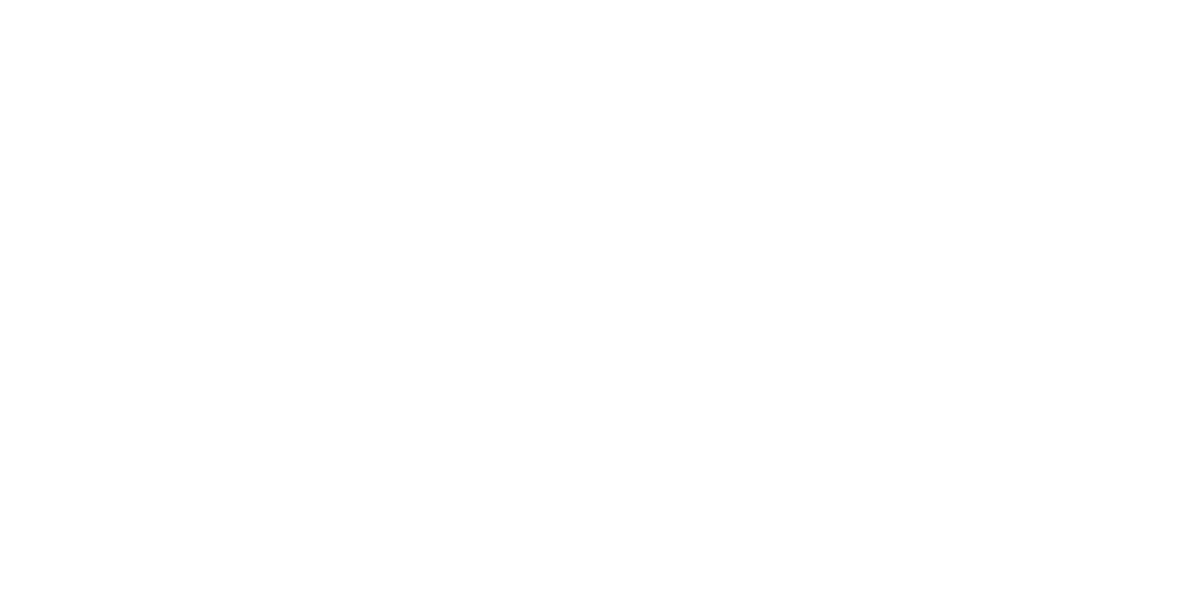


CHEMICAL ANALYSES, WATER YEAR OCTOBER 1969 TO SEPTEMBER 1970

(MACRONUTR IENTS AND OTHER RELATED CONSTITUENTS)

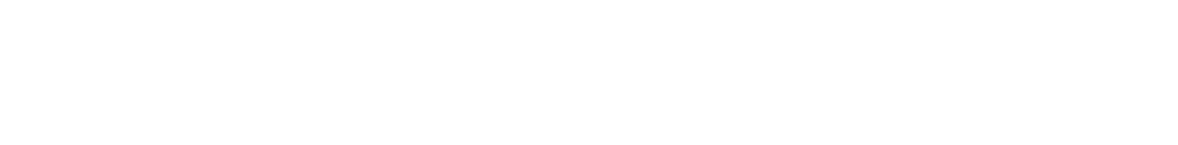

ST. JOHNS RIVER BASIN--CONTINUED

02243000 - ORANGE CR AT ORANGE SPRINGS FLA (LAT 293034 LONG 081 56 47)

\begin{tabular}{|c|c|c|c|c|c|c|c|c|c|c|c|}
\hline $\begin{array}{l}\text { O1.... } \\
\text { SEP. }\end{array}$ & .07 & .04 & .1 & 1.5 & .14 & 19 & & 7 & & -- & .9 \\
\hline
\end{tabular}

02243800 - DEEP CR NR ROOMAN FLA ILAT 293228 LONG 081 50121

\begin{tabular}{|c|c|c|c|c|c|c|c|c|c|c|c|}
\hline $\begin{array}{l}19 . . . \\
\text { SEP. }\end{array}$ & .03 & .05 & .0 & .89 & .32 & .42 & - & 5 & 220 & $\because$ & 1.6 \\
\hline
\end{tabular}

02243958 - LAKE OCKLAWAHA NEAR ORANGE SPRINGS FLA (LAT 293030 LONG 08148 15)

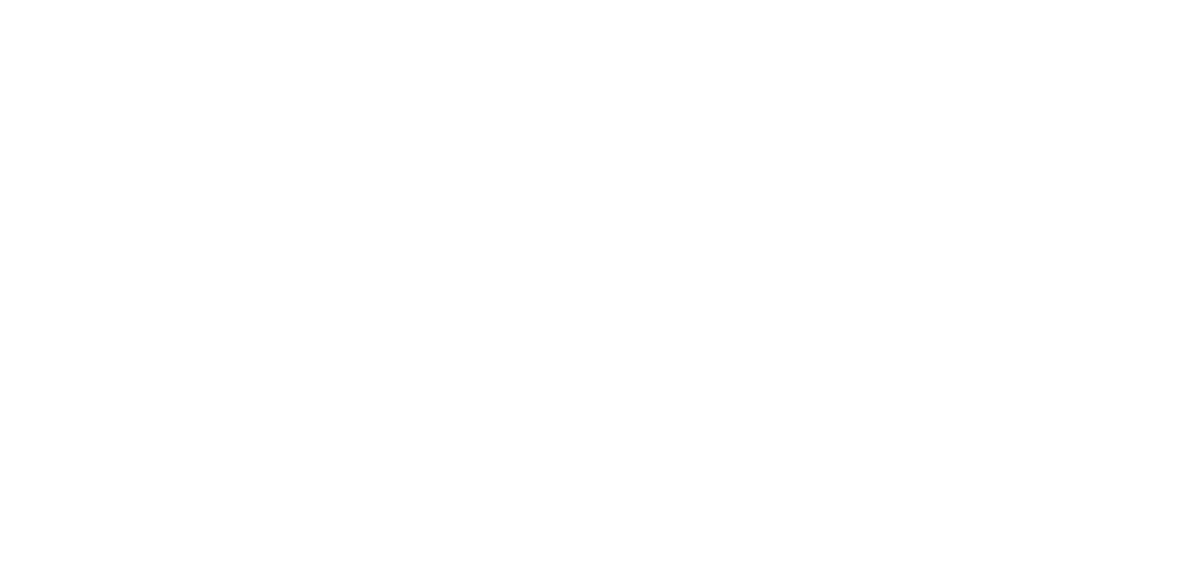

0224403? - CFBC BFLOW ST JOHNS LOCK NR PALATKA FL (LAT 293245 LONG 08143351

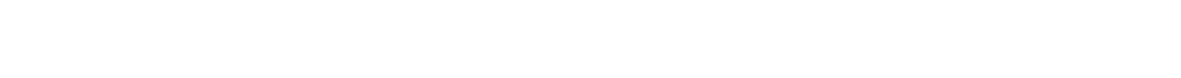

02244350 - LAKE WINONA NN OFLAND FLA (LAT 291050 LONG 081 2006 )

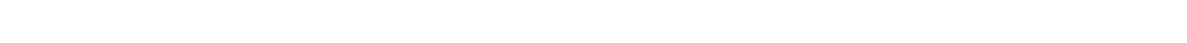

0?244420 - LITTLE HAW CR NR SEVILLE FLA (LAT 291920 LONG 081 23 10)

$\begin{array}{cllllllllll}\operatorname{MaY} .1970 & .17 & .04 & .1 & .58 & .11 & .14 & 3.9 & 1 & 240\end{array}$

02244450 - ST JOHNS R AT PALATKA FLA (LAT 293837 LONG 0813736 )

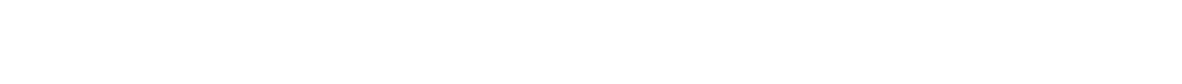

02244600 - SANC HILL L NF KEYSTONE HEIGHTS FLA (LAT 295101 LONG OR2 01 10)

MAY, 1970

02244750 - BROOKLYN L NR KEYSTONE HEIGHTS FLA (LAT 294746 LONG 082 0121 )

MAY 1970

$\begin{array}{llllll}.01 & .0 & .06 & .02 & .04 & 3.1\end{array}$

MAY 1970

02244800 - L GENEVA AT KEYSTONE HEIGHTS FLA LLAT 294626 LONG 08201591

$16 . .^{1970}$

.01 


\begin{tabular}{|c|c|c|c|c|c|c|c|c|c|c|c|c|}
\hline DATE & $\begin{array}{l}\text { TOTAL } \\
\text { AMMONIA } \\
\text { (NH4) } \\
\text { (MG/L) }\end{array}$ & $\begin{array}{l}\text { TOTAL } \\
\text { NITRITE } \\
\text { (NOL) } \\
\text { (MG/L) }\end{array}$ & $\begin{array}{l}\text { TOTAL } \\
\text { NITRATE } \\
\text { (NO3) } \\
\text { (MG/L) }\end{array}$ & $\begin{array}{c}\text { ORGAIHIC } \\
\text { NITRO- } \\
\text { GEN } \\
\text { (N) } \\
(M G / L)\end{array}$ & $\begin{array}{l}\text { OIS- } \\
\text { SOLVE, } \\
\text { OFTHO } \\
\text { PHOS- } \\
\text { PHATE } \\
\text { (HOL) } \\
\text { (MG/L) }\end{array}$ & $\begin{array}{l}\text { PMOS- } \\
\text { PHATE } \\
(P O 4) \\
(M G / L)\end{array}$ & $\begin{array}{l}\text { DIS- } \\
\text { SOLVEU } \\
\text { SILICA } \\
\text { (SIOZ) } \\
\text { (MG/L) }\end{array}$ & $\begin{array}{l}\text { TUR- } \\
\text { RID- } \\
\text { ITY } \\
\text { (JTU) }\end{array}$ & $\begin{array}{l}\text { COLOR } \\
\text { (PLAT- } \\
\text { INUM- } \\
\text { COBALT } \\
\text { UNITS' }\end{array}$ & $\begin{array}{c}\text { TOTAL } \\
\text { ORGANIC } \\
\text { CARBDN } \\
\text { (C) } \\
\text { (MG/L) }\end{array}$ & $\begin{array}{l}\text { MIO- } \\
\text { CHEM- } \\
\text { ICAL } \\
\text { OXYGEM } \\
\text { DEMAND } \\
\text { (MG/L) }\end{array}$ & $\begin{array}{c}\text { DEPTH } \\
\text { (FT) }\end{array}$ \\
\hline
\end{tabular}

\title{
ST. JOHNS RIVER BASIN--CONTINUED
}

02244850 - PE,BRLE L NR KFYSTONE HGTS FLA (LAT 294931 LONG 0815710 )

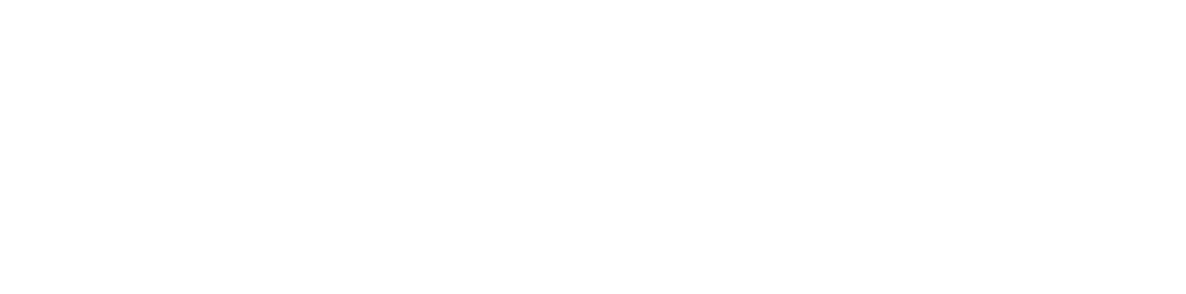

02245300 - ClaRKS CREEK NR GREEN COVE SPGS FLA (LAT 295240 LONG TAI 3952 )

\begin{abstract}
$\operatorname{maY} 1970$
$.02 \quad .0 \quad .19 \quad .13 \quad .14 \quad 7.5$

02245400 - SO FORK BLACK CR NR CAMP BLANOING FLA (LAT $2956 \quad 33$ LONG 08153 b2)

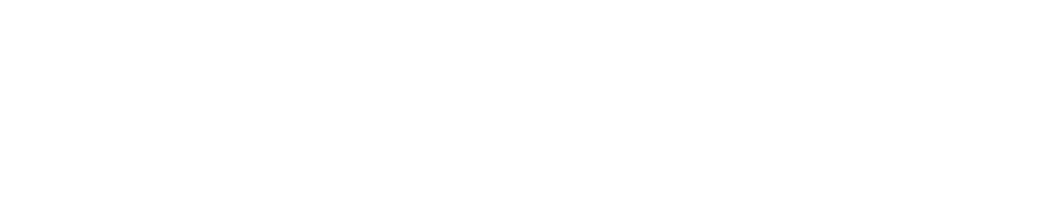

MAY, 1970

.0

02245700 - KINUSLEY L AT CAMP RLANDING FLA LLAT 29 LQ 29 LONG ONI 59221

MAY 1970

$16 . .1970 \quad .00$

.02

02245900 - YELLOW WATER CREEK NR MAXVILLE FLA (LAT 301344 LONG NAI 5517 )

MAY, 1970

.0

02246000 - NO FORK BLACK CR NK MIDDLERURG FLA (LAT 300647 LONG 0815424 )

MAY 1970

NO FORK

02246150 - BIG DAVIS CR AT BAYARD FLA (LAT 300905 LONG 08131341

MAY 1970

02246200 - DURBIN CR NR DURGIN FLA (LAT 700557 LONG 0813134 )

25.1970 $.10 \quad-8$

02246250 - ST JOHNS RIVER AT NAVAL AIR STA FLA (LAT 301339 LONG OHO 39 59)

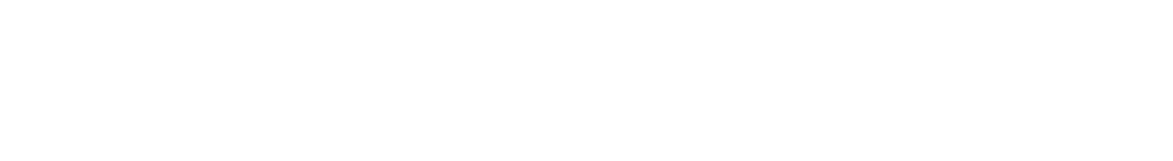

02246300 - OKTEGA RIVER NK JACKSONVILLE FLA (LAT 301450 LONG 0814749 )

$\begin{array}{llllllll}\operatorname{MAY}, 1970 & .12 & .06 & 3.0 & .43 & 1.1 & 1.2 & 8.4\end{array}$ 
CHEMICAL ANALYSES, WATER YEAR OCTOBER 1969 TO SEPTEMBER 1970 (MACRONUTR IENTS AND OTHER RELATED CONSTITUENTS)

\begin{tabular}{|c|c|c|c|c|c|c|c|c|c|c|c|c|}
\hline A TE & $\begin{array}{l}\text { TOTAL } \\
\text { AMMONIA } \\
\text { (NHA) } \\
\text { (MG/L) }\end{array}$ & $\begin{array}{l}\text { TOTAL } \\
\text { NITPITE } \\
\text { (NOC) } \\
\text { (MG/L) }\end{array}$ & $\begin{array}{l}\text { TOTAL } \\
\text { NITRATE } \\
\text { (NO3) } \\
\text { (MG/L) }\end{array}$ & $\begin{array}{l}\text { URGANIC } \\
\text { NITRO- } \\
\text { GEN } \\
\text { (N) } \\
\text { (MG/L) }\end{array}$ & $\begin{array}{l}\text { DIS- } \\
\text { SOLVED } \\
\text { OPTHO } \\
\text { PHOS- } \\
\text { PHATE } \\
\text { (PO4) } \\
\text { (MG/L) }\end{array}$ & $\begin{array}{l}\text { PHOS- } \\
\text { PHATE } \\
\text { (P04) } \\
\text { (MG/L) }\end{array}$ & $\begin{array}{l}\text { DIS- } \\
\text { SOLVFO } \\
\text { SILICA } \\
\text { (SIOZ) } \\
\text { (MG/L) }\end{array}$ & $\begin{array}{l}\text { TUR- } \\
\text { BID- } \\
\text { ITY } \\
\text { (JTUI }\end{array}$ & $\begin{array}{l}\text { COLOR } \\
\text { (PLAT- } \\
\text { INUM- } \\
\text { COBALT } \\
\text { UNITS) }\end{array}$ & $\begin{array}{l}\text { TOTAL } \\
\text { ORGANIC } \\
\text { CARBON } \\
\text { (C) } \\
\text { (MG/L) }\end{array}$ & $\begin{array}{l}\text { BIO- } \\
\text { CHEM- } \\
\text { ICAL } \\
\text { OXYGEN } \\
\text { OEMAND } \\
\text { (MG/L) }\end{array}$ & $\begin{array}{c}\text { DEPTH } \\
\text { (FT) }\end{array}$ \\
\hline
\end{tabular}

ST. JOHNS RIVER BASIN--CONTINUED

02246500 - ST JOHNS R AT JACKSONVILLE FLA (LAT 301926 LONG ORI 39 12)

\begin{tabular}{|c|c|c|c|c|c|c|c|c|c|c|c|c|}
\hline${ }_{22 . \ldots 1}^{\text {ocr.. } 1969}$ & - & .02 & 2.? & -- & .44 & .47 & 4.6 & $m$ & $14 n$ & $-\infty$ & -- & -- \\
\hline DEC. & -- & .02 & 2.2 & -- & .30 & .30 & 6.2 & -- & -- & -- & - & - \\
\hline 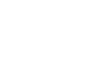 & $=$ & .02 & $\begin{array}{l}.1 \\
.0\end{array}$ & $=$ & .17 & .19 & $\begin{array}{l}6.4 \\
5.0\end{array}$ & $\overline{-}$ & $\overline{12 n}$ & $=$ & $=$ & $=-$ \\
\hline $\begin{array}{l}03 \ldots \\
30 \ldots\end{array}$ & $=$ & $\begin{array}{l}.02 \\
.02\end{array}$ & $\begin{array}{l}1.6 \\
1.3\end{array}$ & $=$ & .37 & .38 & $\begin{array}{l}3.0 \\
1.3\end{array}$ & $\overline{--}$ & 100 & $\because$ & $=$ & $=$ \\
\hline $\begin{array}{l}\text { MAY } \\
\text { I5.... }\end{array}$ & .18 & .04 & 1.1 & .79 & .41 & .46 & 3.0 & 1 & 12 & 18 & 3.9 & -- \\
\hline $24 \ldots$ & -- & .00 & 1.3 & - & .36 & .43 & 2.3 & -- & -- & - & -- & - \\
\hline $25 \ldots$ & -- & .01 & 1.4 & - & -- & -- & 2.0 & - & 40 & -- & -- & -- \\
\hline
\end{tabular}

02246530 - ST JDHNS R AT DREDGE DEPOT NR JAXVL FL (LAT 302125 LONG 08137 18)

\begin{tabular}{|c|c|c|c|c|c|c|c|c|c|c|c|}
\hline MAR... & - & .02 & .0 & - & .10 & .12 & $5 . ?$ & -- & - & -- & - \\
\hline JUNE & .10 & .03 & .2 & .60 & .46 & .63 & 2.0 & 12 & 100 & -- & $\cdots$ \\
\hline $24 \ldots$ & $=$ & .02 & .6 & $=-$ & .34 & .41 & 2.3 & $\rightarrow$ & - & $=$ & - \\
\hline
\end{tabular}

02246600 - TROUT R AT DINSMOQF FLA (LAT 302551 LONG 0BI 46 07)

MAY 1970

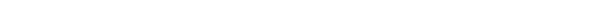

COASTAL BASINS BETWEEN ST. JOHN'S RIVER AND TURKEY CREEK

02246900 - MOULTRIE CR AT SH 207 NR ST AUGUSTINE (LAT 295050 LONG 0812139 )

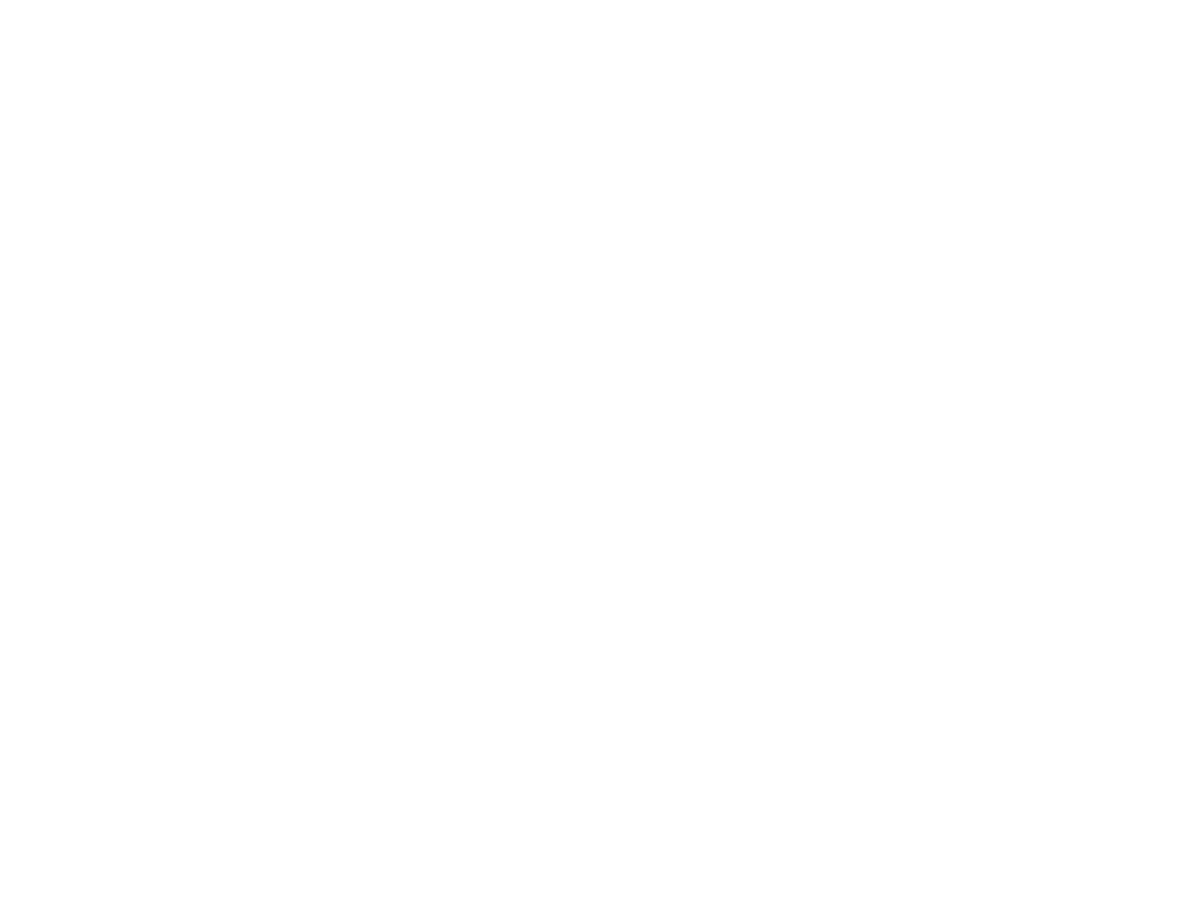




\begin{tabular}{|c|c|c|c|c|c|c|c|c|c|c|c|c|}
\hline ATE & $\begin{array}{l}\text { TOTAL } \\
\text { AMMONI } \\
\text { (NH4) } \\
(M G / L)\end{array}$ & $\begin{array}{l}\text { TOTAL } \\
\text { NITRITE } \\
\text { (NOZ) } \\
\text { (MG/L) }\end{array}$ & $\begin{array}{l}\text { TOTAL } \\
\text { NITRATE } \\
\text { (NO3) } \\
\text { (MG/L) }\end{array}$ & $\begin{array}{l}\text { ORGANIC } \\
\text { NITRO- } \\
\text { GEN } \\
\text { (N) } \\
\text { (MG/L) }\end{array}$ & $\begin{array}{l}\text { DIS- } \\
\text { SOL VED } \\
\text { ORTHO } \\
\text { PHOS- } \\
\text { PHATE } \\
\text { (P04) } \\
\text { (MG/L) }\end{array}$ & $\begin{array}{l}\text { PHOS- } \\
\text { PHATE } \\
\text { (PO4) } \\
\text { (MG/L) }\end{array}$ & $\begin{array}{l}\text { DIS- } \\
\text { SOLVEO } \\
\text { SILICA } \\
\text { (SIOZ) } \\
\text { (MG/L) }\end{array}$ & $\begin{array}{l}\text { TUR- } \\
\text { BID- } \\
\text { ITY } \\
\text { (JTU) }\end{array}$ & $\begin{array}{l}\text { COLOR } \\
\text { (PLAT- } \\
\text { INUM- } \\
\text { COBALT } \\
\text { UNITS) }\end{array}$ & $\begin{array}{l}\text { TOTAL } \\
\text { ORGANIC } \\
\text { CARBON } \\
\text { (C) } \\
\text { (MG/L) }\end{array}$ & $\begin{array}{l}\text { OIO- } \\
\text { CHEM- } \\
\text { ICAL } \\
\text { OXYGEN } \\
\text { DEMAND } \\
\text { (MG/L) }\end{array}$ & $\begin{array}{c}\text { DEPTH } \\
\text { (FT) }\end{array}$ \\
\hline
\end{tabular}

TURKEY CREEK AND COASTAL BASINS SOUTH TO ST, LUCIE RIVER--CONTINUED

02253500 - SOUTH CANAL NR VERO BEACH FLA IIAT 273611 LONG 0802324 )

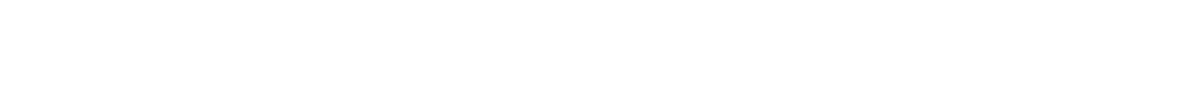

02253600 - MOORE CR AT FT PIERCE FLA LLAT 272658 LONG 08N 1937

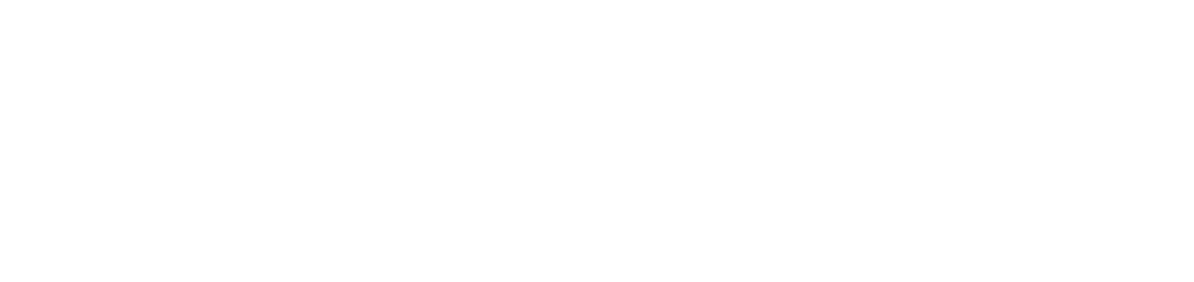

02257800 - HARNEY POND CANAL AT S-71 NR LAKEPORT (LAT 270200 LONG 08104 15)

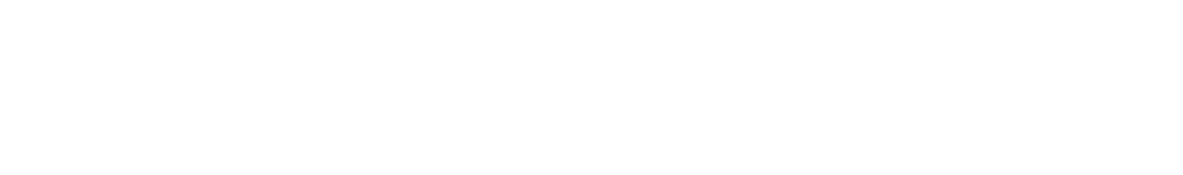

02257801 - HARNEY POND CANAL BELOW S-71 NR LAKEPO (LAT 270200 LONG 08104 15)

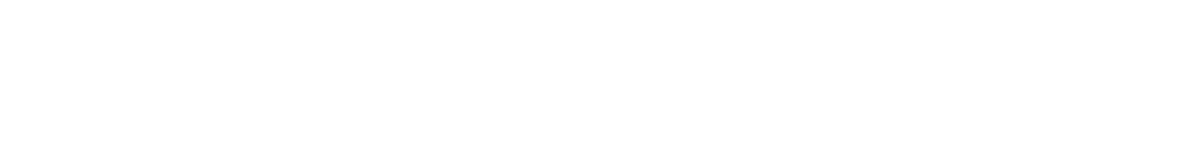

02258000 - HARVEY POND CA NR LAKEPORT FLA ILAT 270000 LONG 08104051

JAN.. 1970
$16 \ldots$

$\begin{array}{llllll}.03 & .6 & 1.1 & .31 & .34 & 6.3\end{array}$

02259200 - INDIAN PRAIRIE CANAL AT S 72 NR OKEECH (LAT 270535 LONG 081 00 25)

\begin{tabular}{|c|c|c|c|c|c|c|c|c|c|c|c|}
\hline MAR...'1970 & - & .02 & 2.6 & - & .26 & .16 & $\Rightarrow$ & 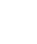 & -- & - & $\cdots$ \\
\hline $\begin{array}{l}\text { D2... } \\
\text { APR. }\end{array}$ & -- & .02 & 4.2 & -- & .15 & .19 & 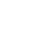 & 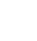 & $=$ & $-\infty$ & $\cdots$ \\
\hline $\operatorname{mar}$ & $=$ & .02 & 2.2 & $=-$ & .41 & .45 & $m$ & - & -- & $=$ & $\cdots$ \\
\hline JUNE & .14 & .03 & .3 & 1.2 & .20 & .28 & 4.6 & -- & 100 & 20 & 3.9 \\
\hline $01 \ldots$ & -- & .01 & .7 & $\cdots$ & - & $\rightarrow$ & 2.9 & -- & 100 & - & -- \\
\hline
\end{tabular}

02259201 - INDIAN PRAIRIE CA BL S-72 NR OKEECHOBE (LAT 270535 LONG D81 00 25)

\begin{tabular}{|c|c|c|c|c|c|c|c|c|c|c|c|c|}
\hline $\begin{array}{l}\text { OEC.:. } 1969 \\
01 . . .1 \\
\text { MAR... } 1970\end{array}$ & -- & .01 & .0 & -- & .02 & .02 & - & - & - & - & $=$ & -- \\
\hline MAY $01 .$. & -- & .02 & 2.0 & -- & .50 & .52 & $=$ & -- & -- & - & - & \\
\hline $05 \ldots$ & .21 & .04 & .6 & .99 & .31 & .49 & 7.2 & 13 & 120 & 20 & $1 . n$ & \\
\hline
\end{tabular}

02259500 - INDIAN PRAIRIE CA NR OKEECHOBEE FLA (LAT 270357 LONG 08059 12)

JAN., 1970

$16 \ldots$

1.80

02260800 - ALLIGATOR LAKF NR ASHTON FLA ILAT 281355 LONG 081 11 17)

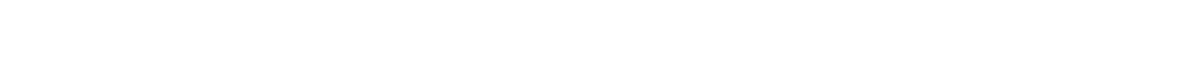


CHEMICAL ANALYSES, WATER YEAR OCTOBER 1969 TO SEPTEMBER 1970 (MACRONUTRIENTS AND DTHER RELATED CONSTITUENTSI

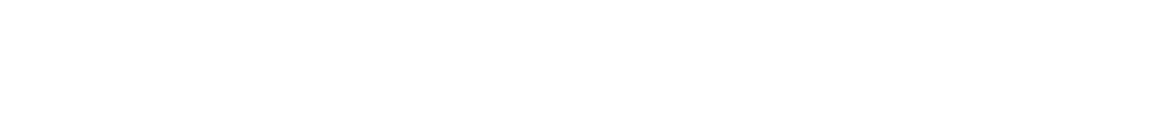

LAKE OKEECHDBEE AND THE EVERGLADES BASINS--CONTINUED 02261900 - LaKe MARY Jane NR NARCOOSSEe FLA (LAT 282246 LONG (81 1115 )

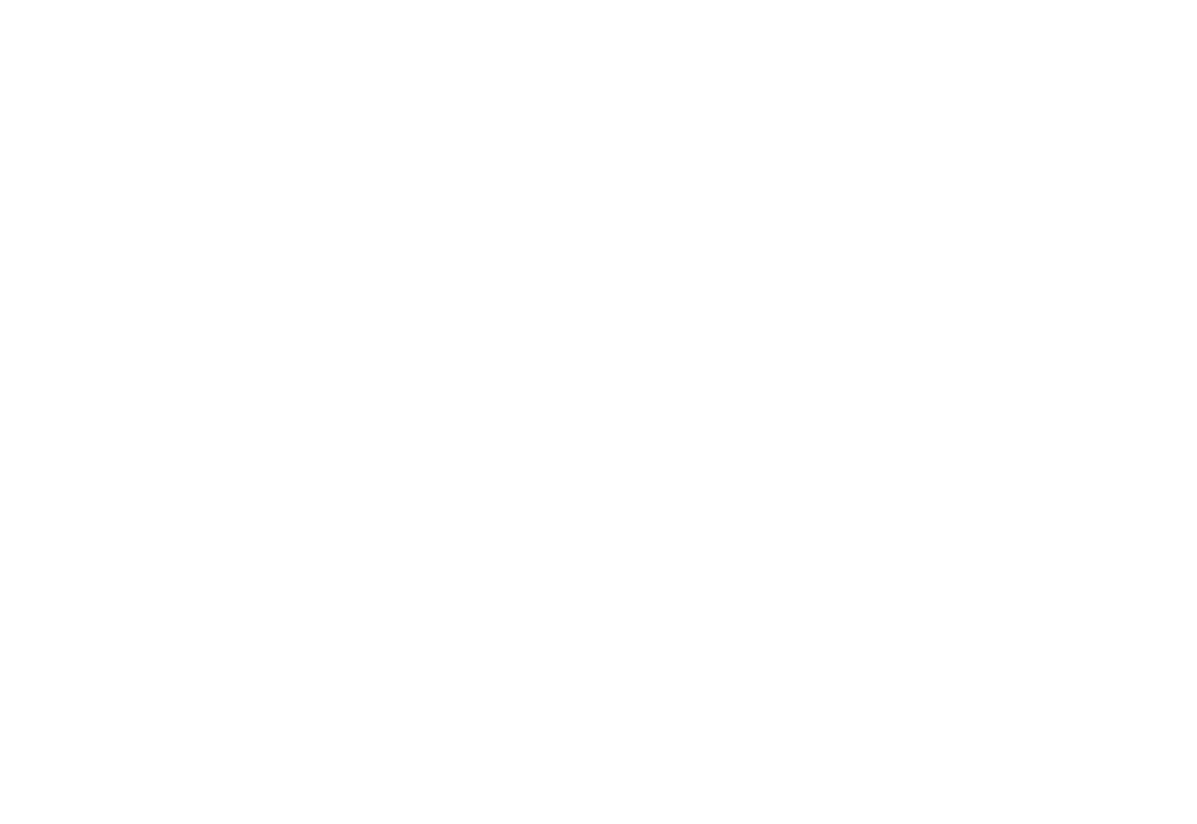

02263870 - SOUTH LK OLT 8L S-I5 NR VINELANO FLA (LAT $2824 \quad 45$ LONG $08132 \quad 17$ )

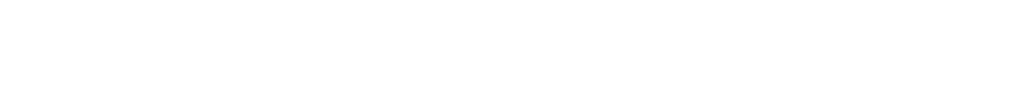

MAY, 1970

$18 . .1970 \quad 08$ .01

02264000 - CYPRESS CR AT VINELANO FLA (LAT 282325 LONG 0813111 )

$24 \ldots 1969$

MAY 1970

$18 \ldots .09$

$27 \cdots \quad \quad 10$

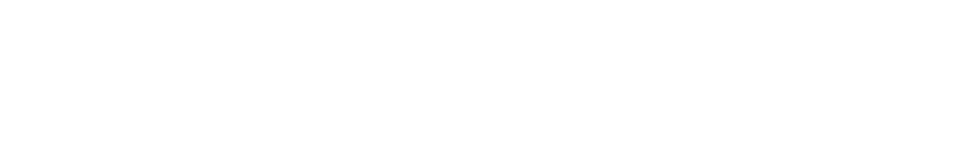

02264100 - BONNET CH NR VINELANO FLA (LAT 2819 S8 LONG 0813120 )

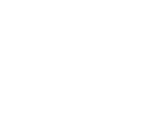

$\begin{array}{ccccccccc}-- & - & -- & -- & -- & 120 & -- & - \\ -- & -- & -- & -- & -- & -- & - & -- & - \\ -02 & -7 & -\overline{51} & .07 & -- & -- & -- & -- & 34\end{array}$

02264495 - SHINGLE CREEK AT CAMPBELL FLA (LAT 281601 LONG 08126 53)

MAY, 1970

02264900 - L TOHOPEKALIGA AT KISSIMMEE FLA (LAT 281720 LONG 0812420 )

$\begin{array}{ll}\operatorname{MAY} .1970 & \\ 04 \ldots & .20 \\ \text { SEP. } & \\ 10 \ldots . . & .08\end{array}$

1.1

1.11.

$5.83 ?$

.04

$.0 \quad .68$

$1.4 \quad 1.7$ 
CHEMICAL ANALYSES, WATER YEAR OCTOBER 1969 TO SEPTEMBER 1970 (MACRONUTR IENTS AND OTHER RELATED CONSTITUENTS)

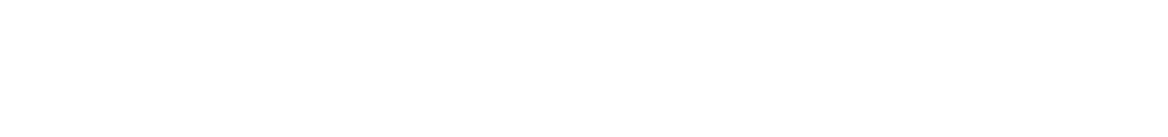

LAKE OKEECHOBEE AND THE EVERGLADES BASINS--CONTINUED

02266025 - REEOY CR CANAL AT S-46 NR VINELAND FLA (LAT 282414 LONG 0813642 )

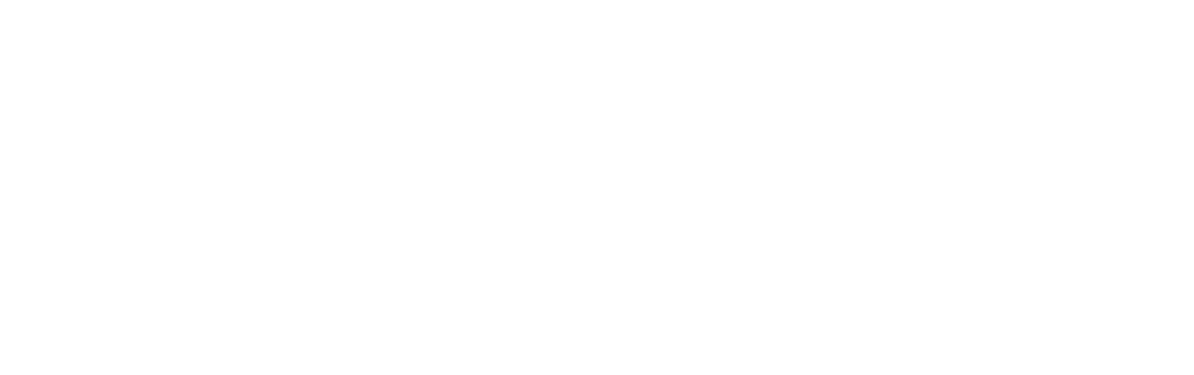

02266239 - TROUT LAKE NR CLERMONT FLA (LAT 282704 LONG 08143 On)

MAY 1970

NOV.. 1969

MAY 241970

$\begin{array}{lll}20.1 . & 0\end{array}$

2266291 - LATERAL 405 AT S-405A NR DR PHILLIPS F (LAT 282534 LONG 0813623 )

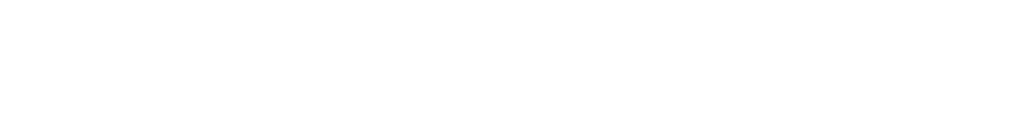

02266292 - LATERAL 405 BL S40SA NR OR PHILLIPS FL ILAT 282534 LONG 0813632 )

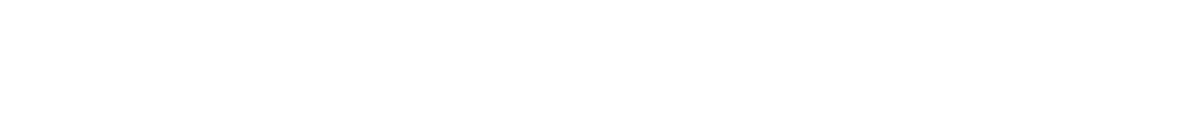

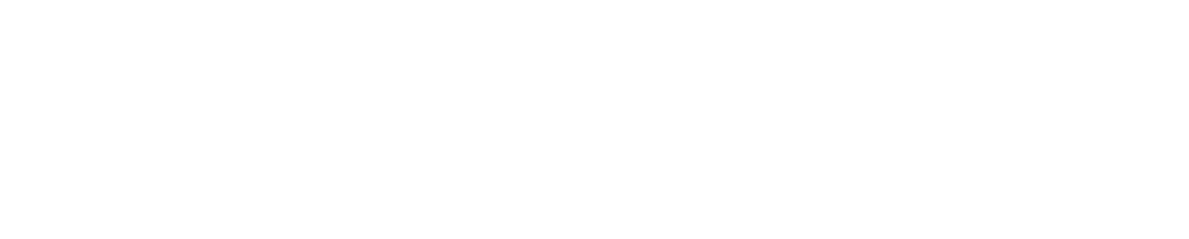

02266480 - UAVENPORT CREEK NEAR LOUGHMAN FLA (LAT 2H 1615 LONG 0813528 )

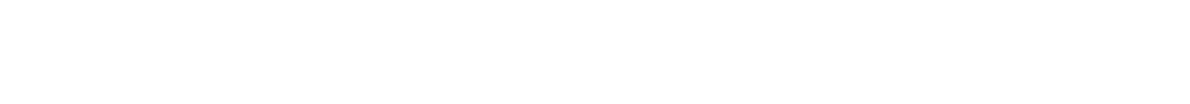

02266500 - REEDY CREEK NEAR LOUGHMAN FLA (LAT 281541 LONG O81 32 12)

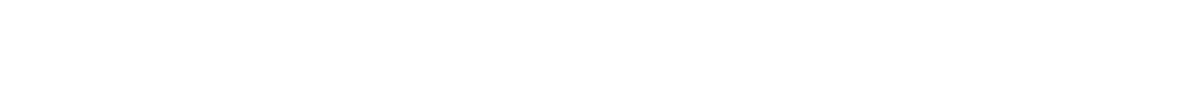

02266600 - CYPRESS LAKE NR ST CLOUD FLA (LAT 280340 LONG 081 I9 58)

$\begin{array}{cccccccccccc}\operatorname{MAY} .1970 & .05 & .02 & .0 & 1.1 & .14 & .24 & 2.9 & 14 & 70 & - & -- \\ \text { SE... } & .05 & .18 & .03 & .0 & .33 & .10 & .17 & 4.6 & 7 & 80 & --\end{array}$

02266650 - LAKE MAPION NR HAINES CITY FLA (LAT 280556 LONG 0813151 )

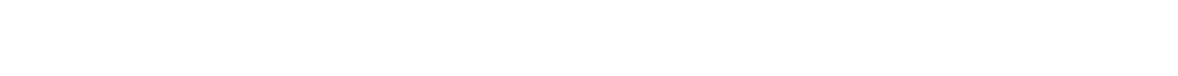


CHEMICAL ANALYSES, WATER YEAR OCTOBER 1969 TO SEPTEMBER 1970 (MACRONUTRIENTS AND OTHER RELATED CONSTITUENTS)

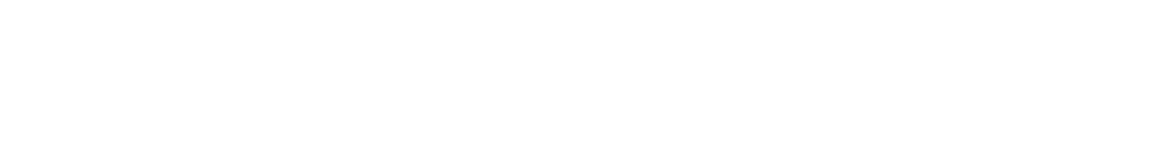

LAKE OKEECHOBEE AND THE EVERGLADES BASINS--CONTINUED

\begin{abstract}
MAY , 1970267000 - CATFISH CR NR LAKE WALES FLA (LAT 275740 LONG 0812948$)$
\end{abstract}
02268290 - LAKE WALES AT L WALES FLA (LAT $2754 \quad 13$ LONG 0813444 )

\begin{abstract}
MAY 1970
$\begin{array}{lllllll}.02 & .0 & .43 & .02 & .07 & .3\end{array}$

02268400 - L WEOHYAKAPKa AT INDIAN L ESTATES FLA (LAT $2748 \quad 50$ LONG 0BI 23 16)
\end{abstract}

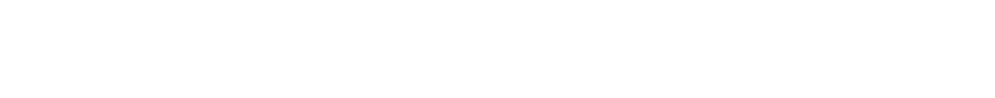

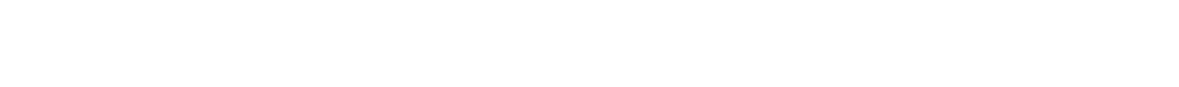

02268800 - LAKE MARION NR KENANSVILLE FLA (LAT 275209 LONG 081 02 36)

$\begin{array}{llllll}A P R ., 1970 & 12 & .02 & .1 & 1.1\end{array}$

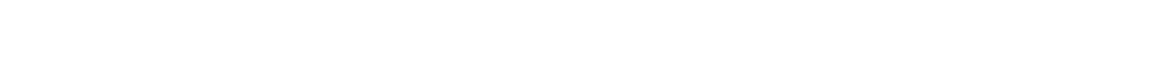

02268903 - KISSIMMEE RIVER AT S-65 NR LAKE WALES (LAT 274814 LONG 0811153 )

\begin{tabular}{|c|c|c|c|c|c|c|c|c|c|c|c|}
\hline $\begin{array}{l}\text { MAY ...1 } 1970 \\
05 . . \\
\text { SEP... } \\
10 . . .\end{array}$ & .47 & .05 & .9 & 1.2 & .19 & $.3 n$ & 3.4 & 14 & 100 & - & 2.1 \\
\hline
\end{tabular}

02768904 - KISSIMMEE RIVER BL S-65 NR LAKE WALES (LAT $2748 \quad 14$ LONG 11811153 )

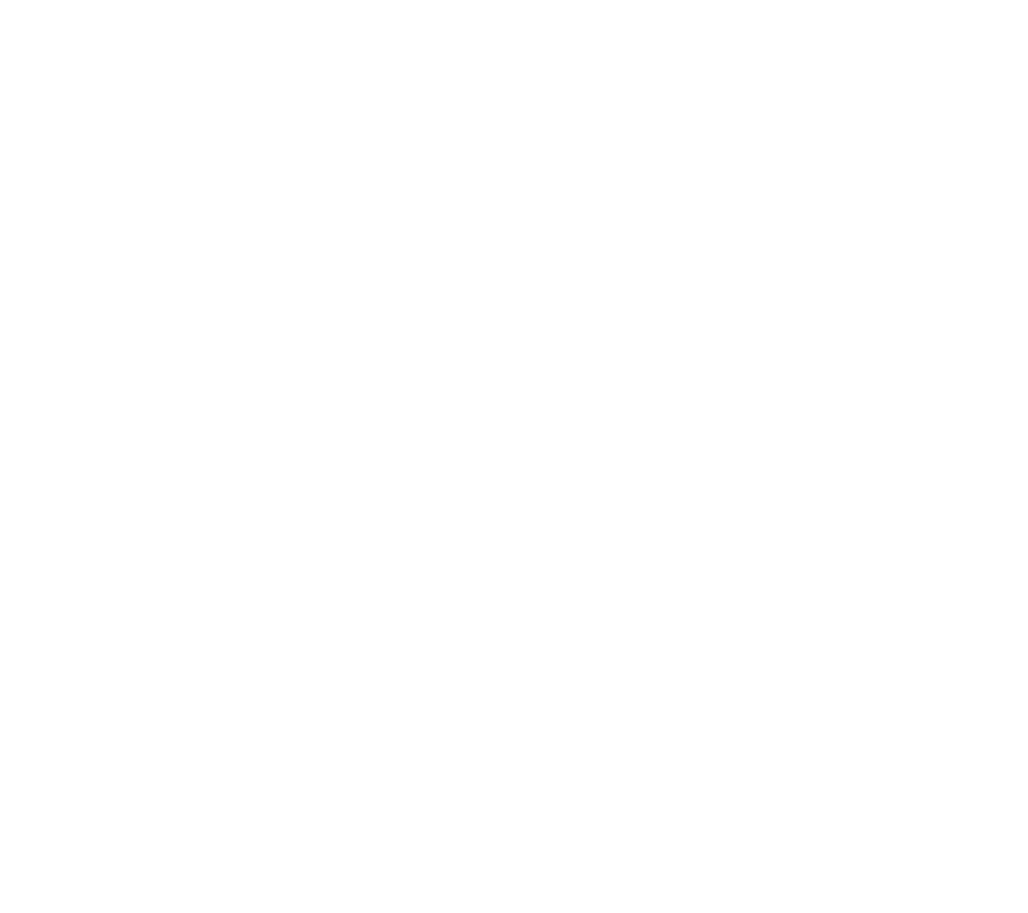

MAY 1970

.02

$.25 \quad .01$ 


\begin{tabular}{|c|c|c|c|c|c|c|c|c|c|c|c|c|}
\hline ATE & $\begin{array}{l}\text { TOTAL } \\
\text { AMMONIA } \\
\text { (NH4) } \\
\text { (MG/L) }\end{array}$ & $\begin{array}{l}\text { TOTAL } \\
\text { NITRITE } \\
\text { (NO?) } \\
\text { (MG/L) }\end{array}$ & $\begin{array}{l}\text { TOTAL } \\
\text { NITRATE } \\
\text { (NO3) } \\
\text { (MG/L) }\end{array}$ & $\begin{array}{c}\text { ORGANIC } \\
\text { NITRO- } \\
\text { GEN } \\
\text { (N) } \\
(M G / L)\end{array}$ & $\begin{array}{l}\text { DIS- } \\
\text { SOLVED } \\
\text { ORTHO } \\
\text { PHOS- } \\
\text { PHATE } \\
\text { (PO4) } \\
\text { (MG/L) }\end{array}$ & $\begin{array}{l}\text { PHOS- } \\
\text { PHATE } \\
\text { (PO } 4 \text { ) } \\
\text { (MG/L) }\end{array}$ & $\begin{array}{l}\text { OIS- } \\
\text { SOLVEO } \\
\text { SILICA } \\
\text { (SIOZ) } \\
\text { (MG/L) }\end{array}$ & $\begin{array}{l}\text { TUR- } \\
\text { B ID- } \\
\text { ITY } \\
\text { (JTU) }\end{array}$ & $\begin{array}{l}\text { COLOOR } \\
\text { (PLAT- } \\
\text { INUM- } \\
\text { COBALT } \\
\text { UNITS') }\end{array}$ & $\begin{array}{l}\text { TOTAL } \\
\text { ORGANIC } \\
\text { CARBON } \\
\text { (C) } \\
\text { (MG/L) }\end{array}$ & $\begin{array}{l}\text { BIO- } \\
\text { CHEM- } \\
\text { ICAL } \\
\text { OXYGEN } \\
\text { OEMANO } \\
\text { (MG/L) }\end{array}$ & $\begin{array}{l}\text { OEPTH } \\
\text { (FT) }\end{array}$ \\
\hline
\end{tabular}

LAKE OKEECHOBEE AǸD THE EVERGLADES BASINS--CONTINUED

02270900 - LAKE SIRENA AT L PLACID FLA ILAT 271710 LONG 08122.001

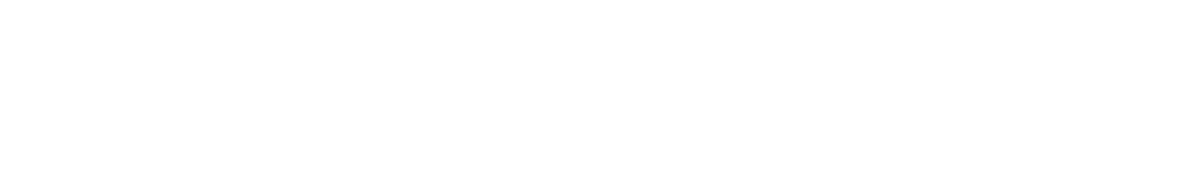

02271500 - JOSFPHINE CR NP DE SOTO CITY FLA (LAT 272226 LONG (181 2337 )

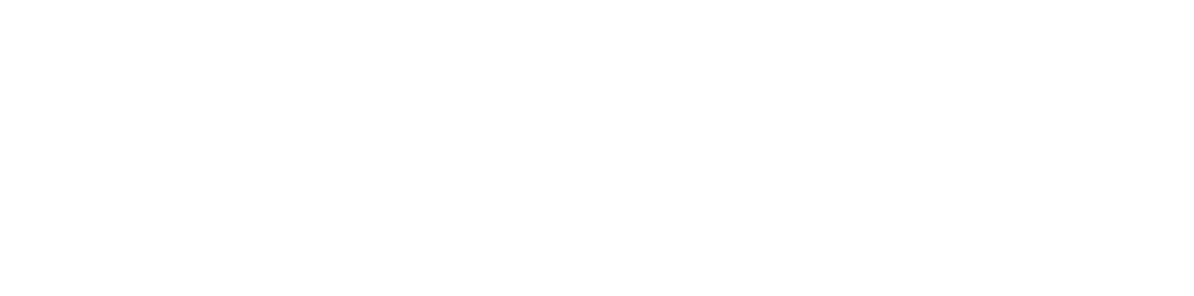

02273300 - CANAL 41 A AT S-84 NEAR OKEECHOBEE, FLA (LAT 271255 LONG OBO 5855 )

$\operatorname{MAY}_{14 \ldots} 1970$

02273301 - CANAL 41 A BL S-84 NR OKEECHOBEE, FLA. (LAT 271255 LONG 0805854 )

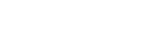

02273436 - KISSIMMEE RIVER AT LAKE OKEECHOBEE FLA (LAT 270853 LONG 08052 21)

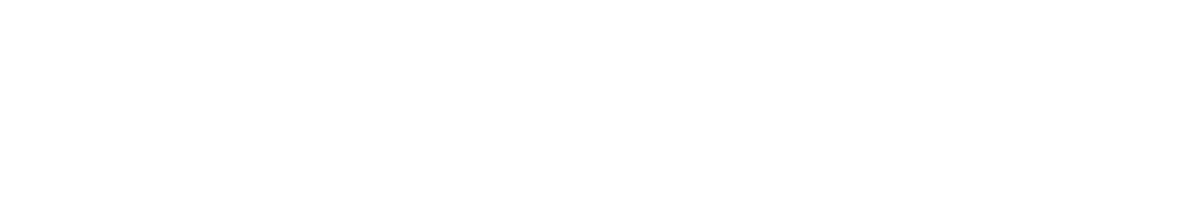

02274000 - TAYLOR CREEK NR BASINGER, FLA. (LAT 272339 LONG 0805344 )

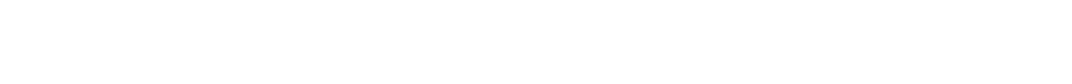

MAY $1970 \quad .09$

02274495 - WILLIAMSON DITCH AT S-7 NR OKEECHOBEE (LAT 271745 LONG 0804905 )

MAY * 1970

05.1970 .26

$\begin{array}{llllllll}.05 & .4 & .58 & 1.1 & 1.2 & 5.0 & 58 & 40\end{array}$

02275500 - TAYLOR CREEK NEAR OKEECHOREE FLA (LAT 271235 LONG 0804756 )

OCT... 1969

NOV. $20 . . \quad-11$

DEC... 20.11

OAN...

14... $1970 \quad .34$

$$
\begin{aligned}
& .05 \\
& .05 \\
& .10 \\
& .05
\end{aligned}
$$

.05
.05
.10
.05

$\begin{array}{ccc}.6 & 1.0 & 2.8 \\ .3 & .72 & 1.7 \\ 1.2 & 1.1 & 1.9 \\ .6 & .83 & 1.8\end{array}$

$2.8 \quad 8.6$

1.7

4.8

2.1

$1.3 \quad \ldots \quad 130$

02275606 - NUBBIN SLOUGH NR SHERMAN FLA (LAT 271136 LONG 0804545 )

OCT., 1969

58... 81

.06

.06

$.0 \quad 1.4 \quad 2.0$

2.0

$9.9 \quad-2 \quad 200$

$\begin{array}{lllll}1.3 & 1.4 & 5.6 & \ldots & 160\end{array}$ 
CHEMICAL ANALYSES, WATER YEAR OCTOBER 1969 TO SEPTEMBER 1970 (MACRONUTRIENTS AND OTHER RELATED CONSTITUENTS)

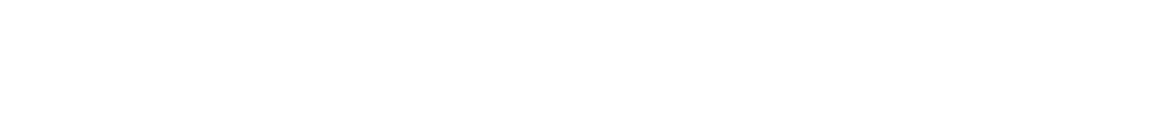

Lake okeEchobee and the everglades basins--CONtinued

02276401 - LAKE OKEECHOBEE AT POINT I FLA (LAT 262745 LONG OBO 51101

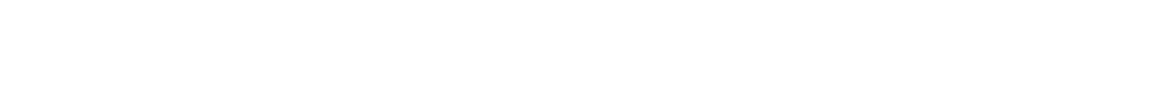

02276402 - LAKE OKEECHOBEE AT POINT 2 FLA ILAT 264930 LONG 08047051

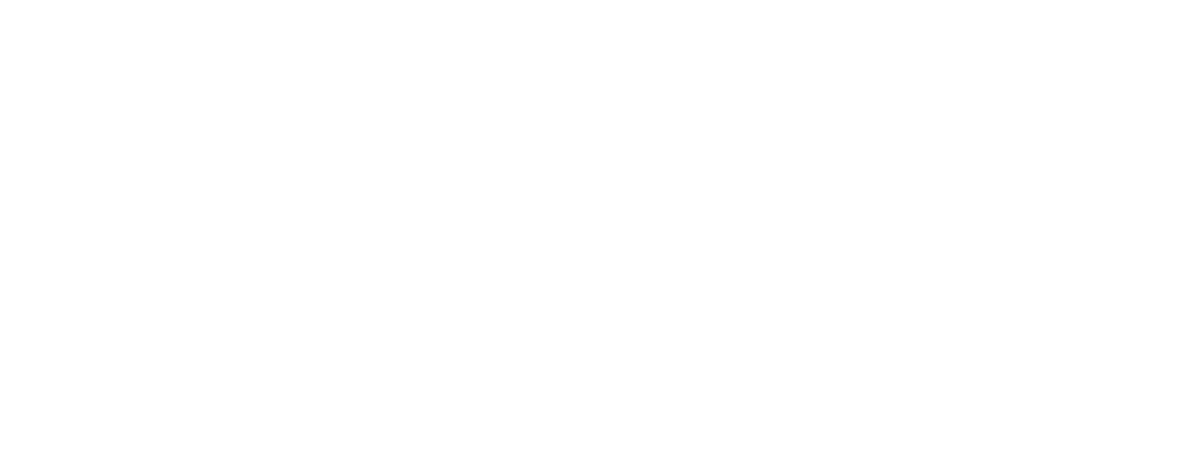

02276400 - LAKE OKEECHOBEE AT POINT 6 FLA ILAT 265945 LONG 08055001

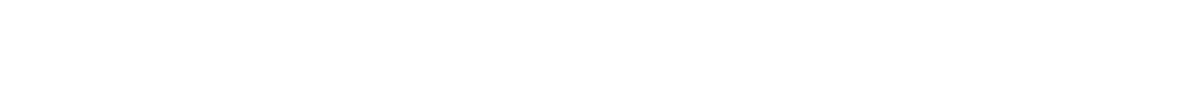

02276407 - LAKE OKEECHOREE AT POINT 7 FLA ILAT 270230 LONG 08051 OSI

JAN., 1970

02276408 - LAKE OKEECHOBEE AT POINT A FLA ILAT 270505 LONG OBO 4710 )

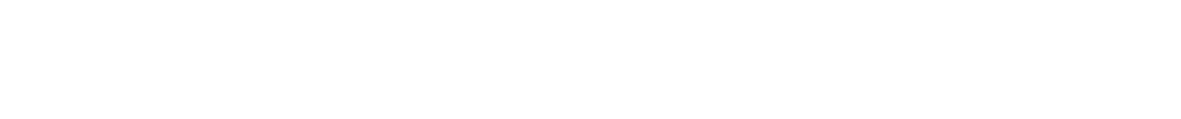

02276409 - LAKE OKEECHOBEE AT POINT 9 FLA LLAT 27 O9 30 LONG O8N 47101

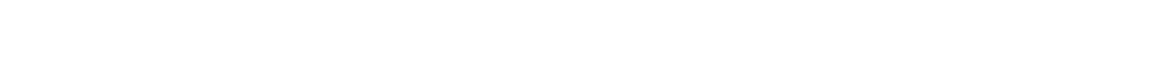

02276410 - LAKE OKEECHOBEE AT POINT IO FLA ILAT 2703 OS LONG OBO 43551

JAN.. 1970

$13 \ldots . . .00$

03

02276411 - LAKE OKEECHOBEE AT POINT 11 FLA ILAT 270100 LONG 08040151

JAN., 1970
$13 \ldots$
$13 \ldots .$.
$13 \ldots$
$13 \ldots$

$\begin{array}{lllllllllll}.00 & .7 & .59 & .06 & .09 & 9.4 & - & 40 & -. & -- & .0 \\ .00 & .7 & .59 & .06 & .09 & 9.4 & 34 & 40 & -- & -- & 7.0 \\ .03 & .99 & 1.9 & .24 & .29 & 9.9 & 35 & 60 & -. & -- & 15\end{array}$

02270412 - LAKE OKEECHOBEE AT POINT 12 FLA ILAT 265905 LONG 08037 IOI

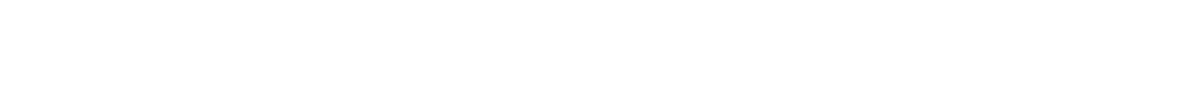




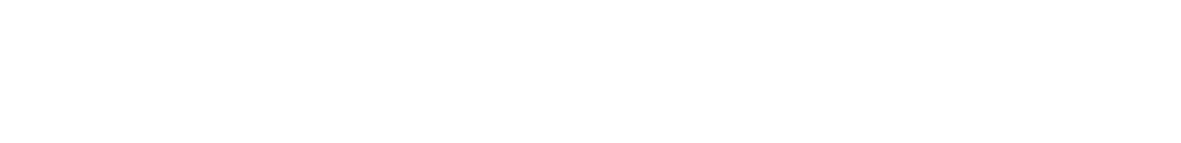

LAKE OKEECHOBEE AND THE EVERGLADES BASINS--CONTINUED

02276413 - LAKE OKEECHOBEE AT POINT 13 FLA ILAT 265555 LONG 0304055 I

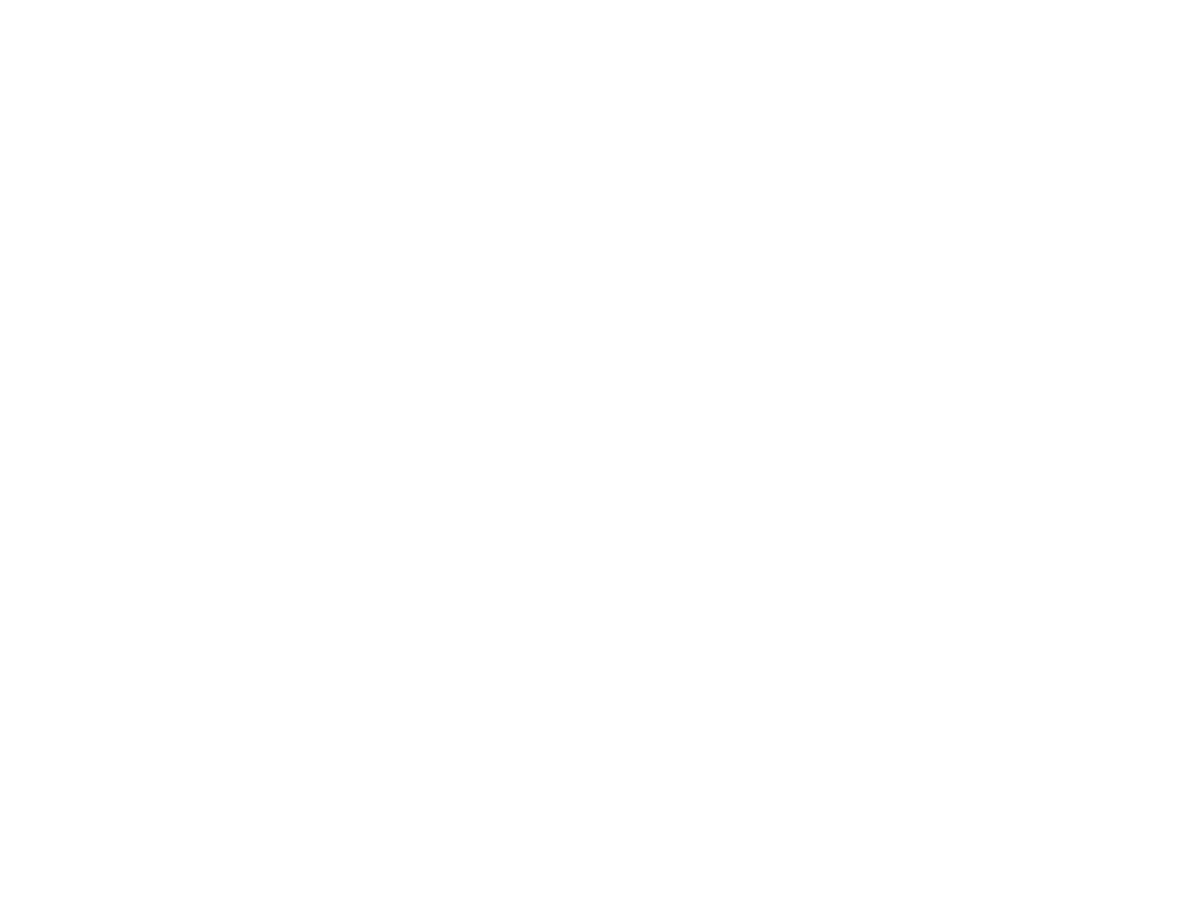

02277700 - SWF LOXAHATCHFE H AT $S 46$ NR JUPITER F (LAT 265602 LNAI, DEO OB 31)

OCT., 1969

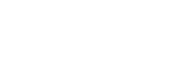

02277900 - CANAL M NEAH MANGONIA PARK FLA (LAT 264500 LONG D890 06 33)

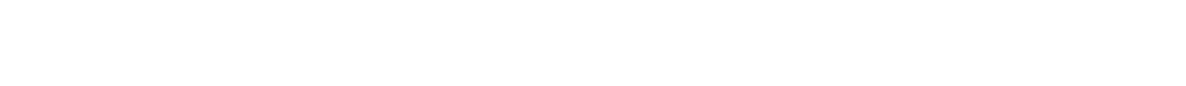

02277950 - CANAL 17 AROVE 5-44 NEAF LAKE PARK FLA ILAT 2649 O1 LONG C80 04 55)

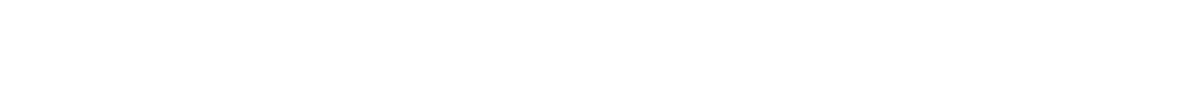

02278450 - WEST PALM BCH CA AR 5-5A NR LOXAHATCHE (LAF 2641 ก5 LONG OAII 22 15)

\begin{tabular}{|c|c|c|c|c|c|c|c|c|c|c|c|}
\hline $\begin{array}{l}\text { MAY } \\
\text { MAY.. }\end{array}$ & -- & .04 & 15 & -- & -- & $-\sim$ & 34 & $\cdots$ & 100 & $=-$ & -- \\
\hline $18 \ldots$ & 1.5 & .31 & 1.7 & 2.0 & .45 & .46 & 40 & 17 & -- & $=-$ & - \\
\hline
\end{tabular}

02278500 - DIV TO CON AI AT S-SA AND S-5AS NR LOX ILAT 264100 LONG OSO Z2 1 In? 
CHEMICAL ANALYSES, WATER YEAR OCTOBER 1969 TO SEPTEMBER 1970 (MACRONUTRIENTS AND OTHER RELATED CONSTITUENTS)

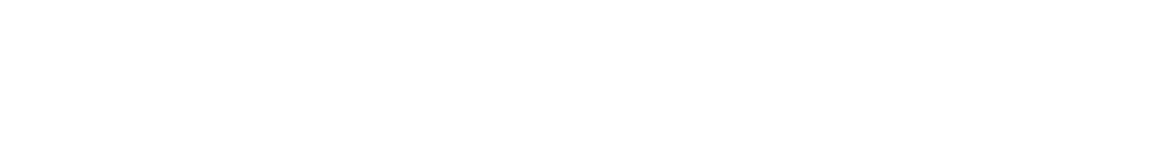

LAKE OKEECHOBEE AND THE EVERGLADES BASINS--CONTINUED

0227850 I - CON AREA NO 1 BL S-5 COMP NR LOX (LAT 2641 ON LONG 0802210 )

\begin{tabular}{|c|c|c|c|c|c|c|c|c|c|c|c|c|}
\hline APR., 1970 & -- & -- & - & 1.4 & .02 & .03 & 17 & -- & 110 & - & -- & -- \\
\hline $\begin{array}{l}28 \ldots \\
\text { AUG. }\end{array}$ & - & .34 & 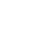 & .82 & .16 & $.2 n$ & 13 & 3 & 140 & 45 & - & -- \\
\hline $06 \ldots$ & -- & - & - & -- & -- & - & -- & -- & $\rightarrow$ & 39 & - & - \\
\hline
\end{tabular}

02278550 - LEVEE \& CA AT WALM BCH CA NR LOXA, F (LAT 264105 LONG 0802135 )

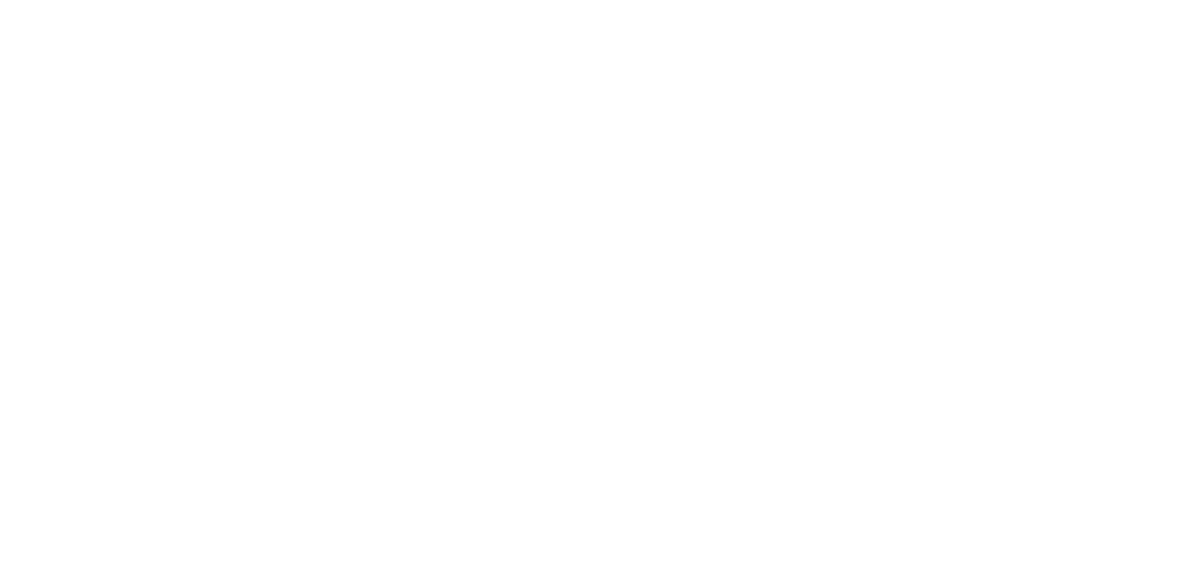

02281300 - HILLSEOHD CANAL AT S-39 NP DEERFIELO B (LAT 262120 LONG 0RO 17 59)

\begin{tabular}{|c|c|c|c|c|c|c|c|c|c|c|c|c|}
\hline $\begin{array}{l}17 \ldots \\
\text { OEC. }\end{array}$ & .33 & .02 & .0 & 1.0 & .21 & .22 & 23 & -- & $? 00$ & $=$ & -- & -- \\
\hline JAN...' 1470 & .26 & .02 & .1 & 1.2 & .04 & .07 & $=$ & 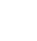 & -- & -- & -- & - \\
\hline MAR... & $\cdots$ & .07 & 1.1 & 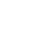 & .02 & .04 & 14 & -- & $10 n$ & 26 & -- & -- \\
\hline$\underset{\text { MAY }}{20} \cdot \cdots$ & .08 & .20 & 1.5 & 1.5 & .05 & - 08 & -- & -- & -- & -- & $\cdots$ & -- \\
\hline $\begin{array}{l}07 \ldots \\
11 \ldots\end{array}$ & $\begin{array}{l}.09 \\
.10\end{array}$ & $\begin{array}{l}.02 \\
.02\end{array}$ & .0 & $\begin{array}{l}1.3 \\
1.1\end{array}$ & $\begin{array}{l}.05 \\
.06\end{array}$ & .09 & $\begin{array}{l}9.1 \\
7.9\end{array}$ & $\begin{array}{l}\text { ln } \\
\text { ?? }\end{array}$ & $\begin{array}{l}70 \\
50\end{array}$ & ${ }^{3 n}-$ & 2.8 & $=$ \\
\hline $\begin{array}{l}\text { JULY } \\
06 \ldots \\
30 \ldots .\end{array}$ & $\begin{array}{l}.38 \\
.10\end{array}$ & $\begin{array}{r}.03 \\
.10\end{array}$ & .09 & $\begin{array}{l}.95 \\
.85\end{array}$ & $\begin{array}{l}.08 \\
.20\end{array}$ & .15 & $\begin{array}{l}12 \\
12\end{array}$ & $\begin{array}{r}16 \\
5\end{array}$ & $=-$ & $=$ & $=$ & $=$ \\
\hline $\begin{array}{l}\text { SEP. } \\
29 . .\end{array}$ & .11 & .05 & .1 & 1.1 & .04 & $.1 n$ & 26 & 11 & $>00$ & - & -- & \\
\hline
\end{tabular}

02281301 - HILLSHORO CANAL BL S39 NR DEERFLD BCH (LAT 262120 LONG O8D 1750$)$

$\operatorname{SEP}_{29.1970}{ }^{19}$

.50

$\cdot$

$\begin{array}{llll}1.8 & .05 \quad 07 \quad 25\end{array}$

02281419 - LUALIZING CANAL I NEAR GPNACRES CIIY (LAT 263701 LONG OBO 12 1G)

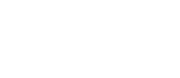

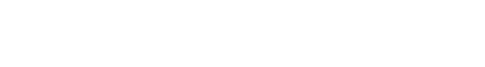

02281425 - EQUALIZING CA 1 NH DFLPAY BCH FLA (LAT 242712 LOHG ORO 12151

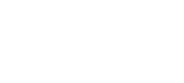

$\begin{array}{ccccccccccccc}.61 & 2.8 & -- & 3.6 & 3.7 & 5.7 & -- & 100 & -- & .9 & \ldots \\ .11 & .0 & 1.6 & .35 & .41 & 14 & i 7 & 120 & -- & \ldots & \ldots\end{array}$

n228150n - HILLSBORO CANAL NEAR DEERFIELO BEACH F (LAT 261939 LONG 0RO OT h21

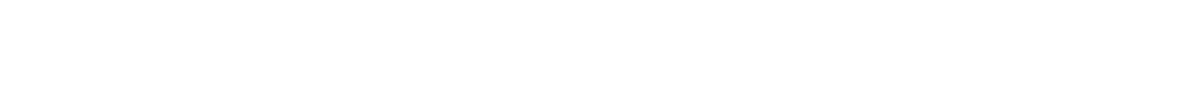




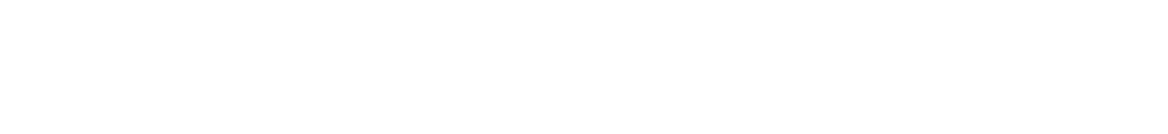

LAKE DKEeCHOBEe AND THE EVERGLAdES BASINS--CONTINUED

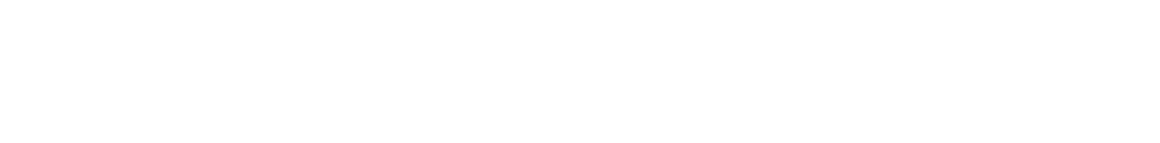

\begin{tabular}{|c|c|c|c|c|c|c|c|c|c|c|c|}
\hline $\begin{array}{l}\text { MAR... } 1970 \\
18 \ldots . .\end{array}$ & - & .19 & 2.2 & $-\infty$ & .32 & .89 & 5.9 & - & 60 & - & 1.9 \\
\hline $\begin{array}{l}\text { MAY } \\
01 . . .\end{array}$ & .07 & .02 & .2 & .69 & .50 & .54 & 3.9 & 20 & 60 & 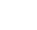 & - \\
\hline
\end{tabular}

02281532 - EQUALIZING CANAL 3 NEAR DELRAY BEACH F (LAT 262727 LONG OBO O7 52)

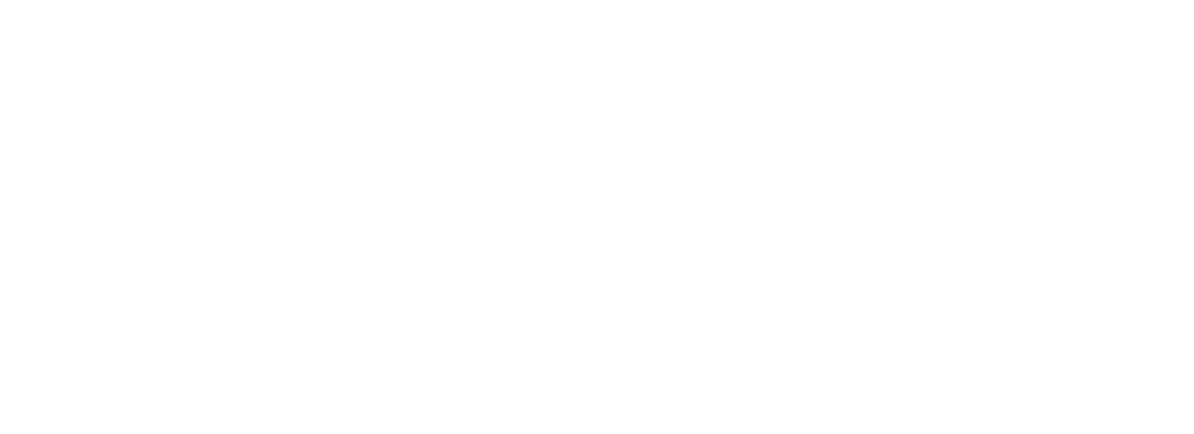

02281600 - LAKE IDA NEAR DELRAY BEACH FLA (LAT 262832 LONG 08005111

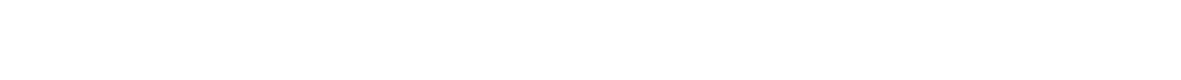

02281625 - EL RIO CA AT BOCA RATON FLA (LAT 262200 LONG 08005 44)

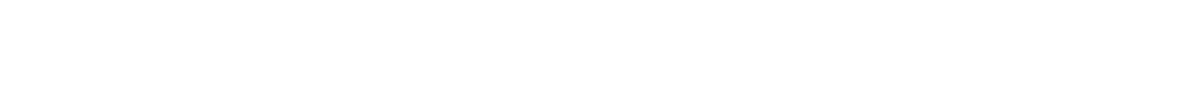
02281700 - CYPRESS CREEK CA AT S-38 NR POMP BCH F (LAT 261345 LONG 0801750 )

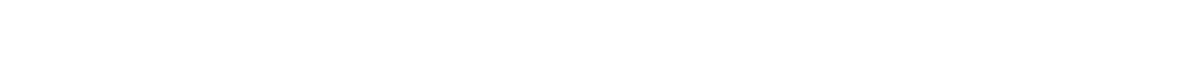

02281701 - POMPANO CA BL S38 NR POMPANO BEACH FLA (LAT 261345 LONG OBO 1750 )

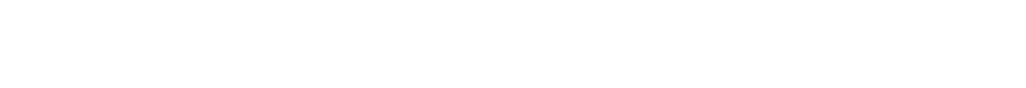

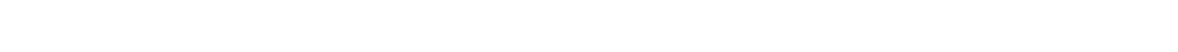
02282100 - CYPRESS CR CA AT S-37A NR POMPANO BEACH F (LAT 261220 LONG OBO O7 57)

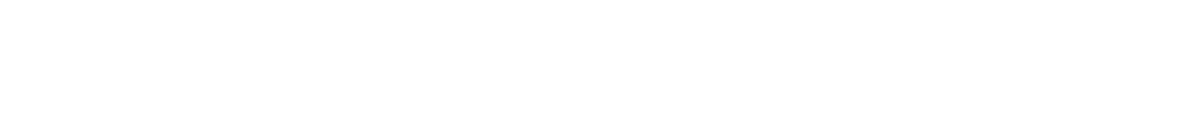


CHEMICAL ANALYSES, WATER YEAR OCTOBER 1969 TO SEPTEMBER 1970 (MACRONUTR IENTS AND OTHER RELATED CONSTITUENTS)

\begin{tabular}{|c|c|c|c|c|c|c|c|c|c|c|c|}
\hline DATE & $\begin{array}{l}\text { TOTAL } \\
\text { AMMONIA } \\
\text { (NH4) } \\
\text { (MG/L) }\end{array}$ & $\begin{array}{l}\text { TOTAL } \\
\text { NITRITE } \\
\text { (NOZ) } \\
\text { (MG/L) }\end{array}$ & $\begin{array}{l}\text { TOTAL } \\
\text { NITRATE } \\
\text { (NO3) } \\
\text { (MG/L) }\end{array}$ & $\begin{array}{c}\text { ORGANIC } \\
\text { NITRO- } \\
\text { GEN } \\
\text { (N) } \\
\text { (MG/L) }\end{array}$ & $\begin{array}{l}\text { DIS- } \\
\text { SOLVED } \\
\text { ORTHO } \\
\text { PHOS- } \\
\text { PHATE } \\
\text { (PO4) } \\
\text { (MG/L) }\end{array}$ & $\begin{array}{l}\text { PHOS- } \\
\text { PHATE } \\
\text { (PO4) } \\
\text { (MG/L) }\end{array}$ & $\begin{array}{l}\text { UIS- } \\
\text { SOLVED } \\
\text { SILICA } \\
\text { (SIO2) } \\
\text { (MG/L) }\end{array}$ & $\begin{array}{l}\text { TUR- } \\
\text { BID- } \\
\text { ITY } \\
\text { (JTU) }\end{array}$ & $\begin{array}{l}\text { COLOR } \\
\text { (PLAT- } \\
\text { INUM- } \\
\text { COBALT } \\
\text { UNITS) }\end{array}$ & $\begin{array}{c}\text { TOTAL } \\
\text { ORGANIC } \\
\text { CARRON } \\
\text { (C) } \\
\text { (MG/L) }\end{array}$ & $\begin{array}{l}\text { BIO- } \\
\text { CHEM- } \\
\text { ICAL } \\
\text { OXYGEN } \\
\text { DEMAND } \\
\text { (MG/L) }\end{array}$ \\
\hline
\end{tabular}

\section{LAKE OKEECHOBEE AND THE EVERGLADES BASINS--CONTINUED}

02292700 - MIDDLE R CA AT S-36 NR FT LAUDERDALE F (LAT 26 in 22 LONG 0801047 )

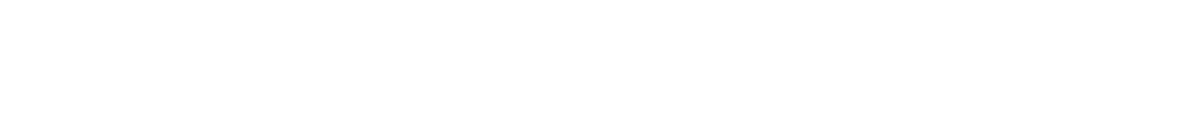

02282800 - MIUULE R CA AT US HWY I NR FT LAUO FLA (LAT 26 09 26 LONG 0800703 )

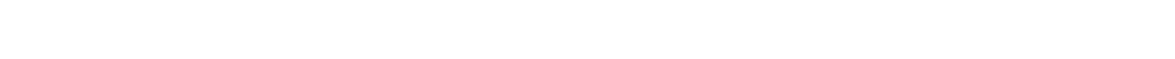

02282990 - FLORIUA TURNPIKE CA AT FT LAUDERUALE F (LAT 26 O6 03 LONG 08013 03)

FEP., 1970

$16 . . .08$

02243200 - PLANTATION RU CA AT S-33 NR FT LAUD FL (LAT 26 O8 05 LONG 0RN 1142 )

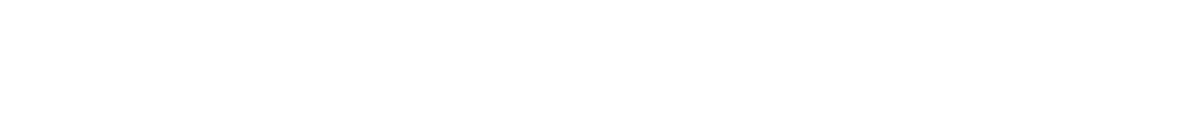

02283498 - N NEW R CA AT S-2 ANU HGS-4 NR S BAY, (LAT 264200 LONG ORO 42 55)

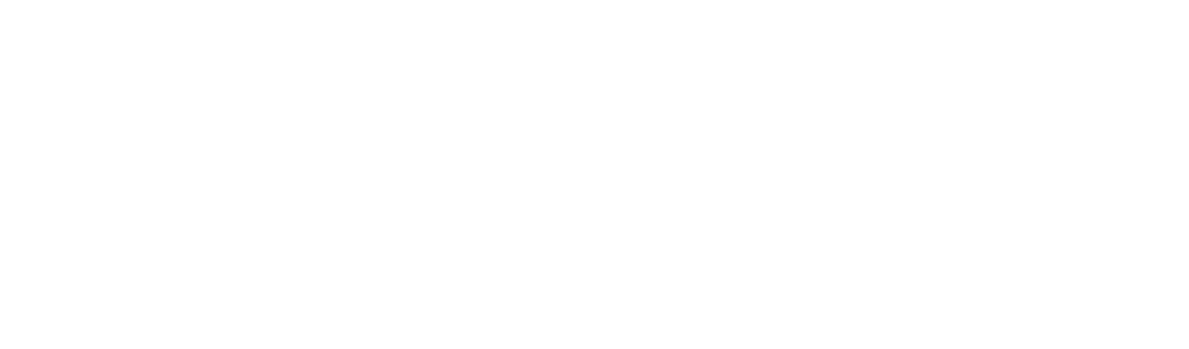

02284642 - EVERGLADES STA 2-17 NR ANOYTOWN FLA (LAT 261650 LONG OHO 25 10)

AUG:, 1970

$06 . .1970 \quad .08$

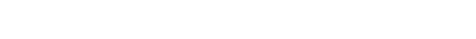

$21 \quad 60 \quad 26$

02784690 - EVERGLADES STATION 2-21 NEAR ANOYTOWN RLAT 2808 05 LONG OAO 22 05)

JULY, 1970

02284699 - N NEW R CA AB 534 NR FT LAUDEROALE FLA ILAT 26 O8 59 LONG 080 26 33)

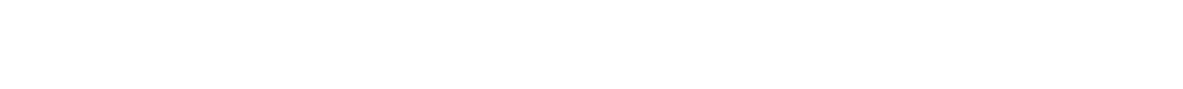

02284700 - N NEN Q CA AT 534 NR FT LAUDEROALE FLA (LAT 260843 LONG OBO 26 25)

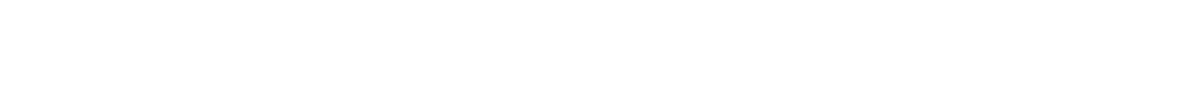

02284800 - N NEW H CA AB HOL LAT NR FT LAUD FLA (LAT 260640 LONG MRO 1750 )

SEP.. 1970
$30 .$.

02284810 - HOLLAWAY LATERAL NR FT LAUNEROALE, FLA. (LAT 260340 LONG OBO 17 55)

MAY, 1970

11... 1970 
CHEMICAL ANALYSES, WATER YEAR OCTOBER 1969 TO SEPTEMBER 1970 (MACRONUTRIENTS AND OTHER RELATED CONSTITUENTS)

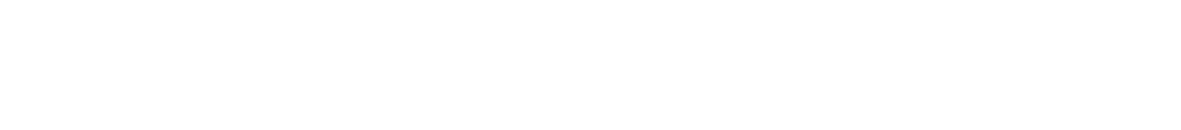

LAKE OKEECHOBEE AND THE EVERGLADES BASINS--CONTINUED

02285399 - SN P CA,CON AREA 3 AT S-9 NH "IAVIE FL ILAT 260340 LONG 0903630 )

\begin{tabular}{|c|c|c|c|c|c|c|c|c|c|c|c|c|c|c|}
\hline $\begin{array}{l}\text { MAY, } 1970 \\
\text { 06... }\end{array}$ & .03 & .02 & - n & .25 & .05 & - 188 & 12 & $1 ?$ & & 70 & -- & & -- & - \\
\hline & & 02285400 & - & SOUTH NEW & RIVEN CANAL & AT $5-9$ & NRR DAVIE & ILAT $2 \mathrm{~K}$ & 03 & 40 LONG & $080 \quad 26$ & 301 & & \\
\hline MAY, 1470 & & & & & & & & & & & & & & \\
\hline $06 \ldots$ & .23 & .03 & .0 & .25 & .08 & .08 & 13 & 4 & & 60 & - & & -- & -- \\
\hline $07 \ldots$ & $=$ & .01 &.$n$ & -- & .03 & .04 & 14 & 15 & & 40 & -- & & -- & -- \\
\hline $11 \ldots$ & .17 & - $\cap B$ & .4 & .00 & .08 & .11 & 10 & 31 & & 60 & -- & & $\cdots$ & -- \\
\hline $\begin{array}{l}\text { AUG. } \\
04 \ldots . .\end{array}$ & .40 & .03 & .0 & .71 & .07 & $.1 n$ & 12 & 24 & & -- & -- & & -- & $=$ \\
\hline SEP. & & & & & & & & & & & & & & \\
\hline $29 \ldots$ & -- & .03 & .0 & $-\infty$ & .02 & .03 & 14 & 17 & & $5 n$ & -- & & - & - \\
\hline
\end{tabular}

02286050 - SOUTH N H CA AT S-13A NR DAVIE ILAT 260350 LONG $080172 n$ I

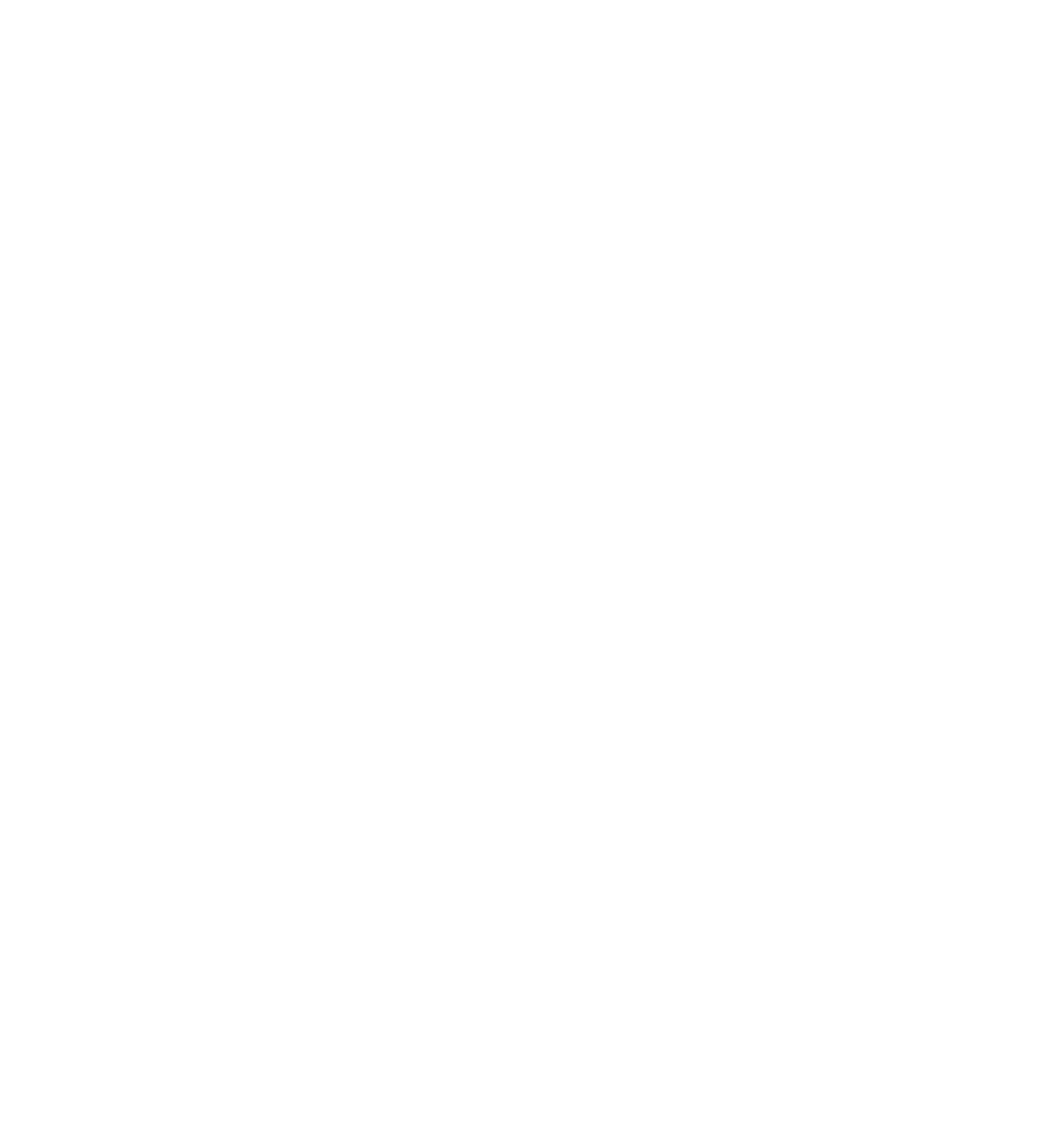


CHEMICAL ANALYSES, WATER YEAR OCTOBER 1969 TO SEPTEMBER 1970 (MACRONUTRIENTS AND OTHER RELATED CONSTITUENTS)

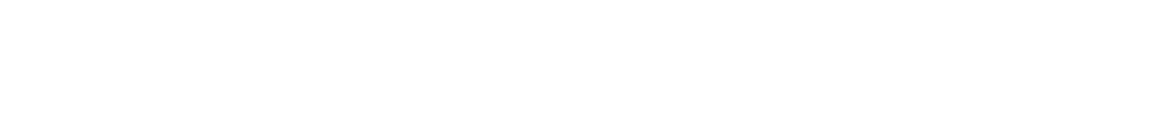

LAKE OKEECHOBEE AND THE EVERGLADES BASINS--CONTINUED

02287500 - MIAMI CA AT PENNSUCO NR MIAMI FLA (LAT 255340 LONG 080 ?2 45)

\begin{tabular}{|c|c|c|c|c|c|c|c|c|c|c|c|c|c|}
\hline \multirow[t]{2}{*}{$\begin{array}{l}\text { MAY } 1970 \\
06 \ldots . .\end{array}$} & \multirow[t]{2}{*}{.12} & .02 & .0 & \multicolumn{2}{|c|}{1.0} & .01 & .104 & 3.4 & In & 60 & - & -- & \multirow[t]{2}{*}{-} \\
\hline & & 02288200 & - & MI AMI & CANAL & AT PALMETTO & BYPASS & NR HIAL & (LAT 2551 & 11 LONG & $0801^{\mathrm{c}}$ & 22) & \\
\hline \multirow[t]{2}{*}{$\begin{array}{l}\text { MAY } 1970 \\
06 . . .\end{array}$} & .10 & .07 & .1 & & .78 & .03 & .05 & 9.4 & 12 & 50 & - & $m$ & - \\
\hline & & 02288600 & - & MIAMI & II CANAL & $\angle$ AT NW 36TH & ST MIAN & MI. FLA. & (LAT $254 \mathrm{H}$ & 29 LONG & \multicolumn{2}{|c|}{08015441} & \\
\hline $\begin{array}{l}\text { OCT . } 1969 \\
\text { OT... } \\
\text { DEC. }\end{array}$ & -- & -- & 4.6 & & -- & -- & -- & 9.5 & $\cdots$ & 45 & -- & .9 & -- \\
\hline $\begin{array}{l}03 . . . \\
\triangle P R . .1970\end{array}$ & -- & -- & 2.5 & & -- & -- & -- & 0.2 & -- & 45 & -- & 1.7 & - \\
\hline $01 \ldots$ & $=$ & .01 & 99 & & -- & -- & -- & 7.2 & $-\infty$ & $7 n$ & -- & 1.3 & -- \\
\hline $\begin{array}{l}02 \ldots \\
\text { MAY }\end{array}$ & $=-$ & .01 & 2.1 & & - & - & - & 6.1 & - & 45 & - & .4 & - \\
\hline $\begin{array}{l}05 \ldots \\
07 \ldots\end{array}$ & $\begin{array}{l}.16 \\
.08\end{array}$ & $\begin{array}{l}.03 \\
.02\end{array}$ & $\begin{array}{l}.2 \\
.2\end{array}$ & & .10 & $\begin{array}{l}.07 \\
.02\end{array}$ & $\begin{array}{l}.10 \\
.05\end{array}$ & $\begin{array}{l}10 \\
9.4\end{array}$ & $\begin{array}{l}13 \\
21\end{array}$ & $\begin{array}{l}40 \\
50\end{array}$ & 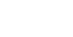 & $\overline{1.1}$ & $=$ \\
\hline JUNE & & & & & & & & & & & & & \\
\hline $\begin{array}{l}03 \ldots \\
\text { AUG. }\end{array}$ & - & .01 & 2.8 & & -- & -- & -- & 6.3 & -- & 50 & -- & 1.4 & - \\
\hline $\begin{array}{l}05 \ldots \\
\text { SEP. }\end{array}$ & .49 & .04 & .1 & & .63 & .05 & .11 & 7.0 & 21 & 30 & 16 & 1.2 & - \\
\hline $28 \ldots$ & .95 & .04 & .0 & & .04 & .09 & .14 & 7.2 & 28 & 35 & -- & 1.0 & -- \\
\hline
\end{tabular}

02288780 - TAMIAMI CA AT BR 77 NR CARNESTOWN FLA (LAT 2554 OO LONG 081 ?1 00)

MAY , 1470

$13 \ldots 0^{1970} .08$

02ZR8800 - TAMIAMI CA OTLS MONFOĔ TO CARNESTOWN F (LAT $2553 \quad 10$ LONG $081 \quad 1530$ )

\begin{tabular}{|c|c|c|c|c|c|c|c|c|c|c|c|}
\hline SEP... & .10 & .02 & .1 & .18 & .03 & .07 & 3.4 & 7 & 30 & 10 & 1.0 \\
\hline
\end{tabular}

02288804 - TAMIAMI CANAL AT GPIOGE 86 NR OCHOPPE. FLA. ULAT 2552 3n LONG 091 13301

AUG. 1970

$14 \ldots$

02288830 - BIG SWP AT EVERGLADES PKY NR SUNNILANO (LAT 2610 09 LONG 081 05 15)

Nov., 1969

$18 . .$.

.

02288900 - TAM CA DLS 40 MI BEND TO MONROE NR MIA ILAT 2551 nS LONG 0805850 )

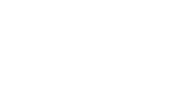

$\begin{array}{rrrrrrrrrrrrr}.01 & .1 & .53 & .00 & .03 & 2.2 & 1 & 20 & \ldots & \ldots & \ldots \\ .01 & .0 & 1.1 & .29 & .37 & 2.0 & 19 & 15 & 12 & 7.5 & \ldots \\ .02 & .1 & .30 & .02 & .07 & 1.0 & 5 & 15 & -- & 1.8 & \ldots\end{array}$

02288906 - TAMIAMI CANAL AT 40 MI BEND NP MIAMI F (LAT 254550 LONG 0804950 )

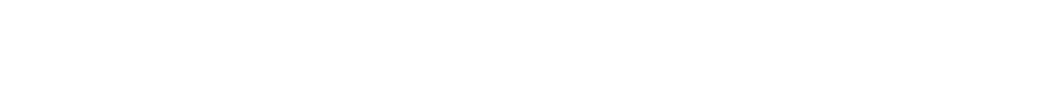

MAY, 1970

.01

02289018 - TAMIAMI CA AB $\triangle-128$ NR MIAMI FLA ILAT 254542 LONG 080 46 05)

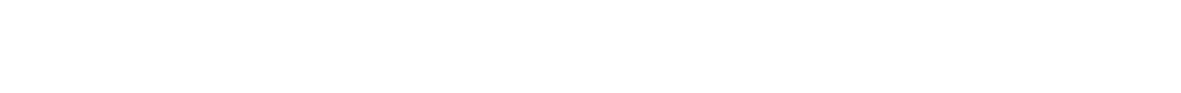

n2289019 - TAMIAMI CA BL S-12B NR MIAMI FLA ILAT 28 4540 LONG 080 46051

MAY 1970

.19

.01

.2

1.1

.02

.03

3.6 


\begin{tabular}{|c|c|c|c|c|c|c|c|c|c|c|c|c|}
\hline DATE & $\begin{array}{l}\text { TOTAL } \\
\text { AMMONIA } \\
\text { (NH4) } \\
\text { (MG/L) }\end{array}$ & $\begin{array}{l}\text { TOTAL } \\
\text { NITRITE } \\
\text { (NO2) } \\
\text { (MG/L) }\end{array}$ & $\begin{array}{l}\text { TOTAL } \\
\text { NITRATE } \\
\text { (NO3) } \\
\text { (MG/L) }\end{array}$ & $\begin{array}{l}\text { ORGANIC } \\
\text { NITRO- } \\
\text { GEN } \\
\text { (N) } \\
\text { (MG/L) }\end{array}$ & $\begin{array}{l}\text { OIS- } \\
\text { SOLVED } \\
\text { ORTHO } \\
\text { PHOS- } \\
\text { PHATE } \\
\text { (PO4) } \\
\text { (MG/L) }\end{array}$ & $\begin{array}{l}\text { PHOS- } \\
\text { PHATE } \\
\text { (PO4) } \\
\text { (MG } / \text { ) }\end{array}$ & $\begin{array}{l}\text { OIS- } \\
\text { SOLVEO } \\
\text { SILICA } \\
\text { (SIOZ) } \\
\text { (MG/L) }\end{array}$ & $\begin{array}{l}\text { TUR- } \\
\text { BID- } \\
\text { ITr } \\
\text { (JTU) }\end{array}$ & $\begin{array}{l}\text { COLOR } \\
\text { (PLAT- } \\
\text { INUM- } \\
\text { COBALT } \\
\text { UNITSI) }\end{array}$ & $\begin{array}{c}\text { TOTAL } \\
\text { ORGANIC } \\
\text { CARBON } \\
\text { (C) } \\
\text { (MG/L) }\end{array}$ & $\begin{array}{l}\text { BIO- } \\
\text { CHEM- } \\
\text { ICAL } \\
\text { OXYGEN } \\
\text { DEMAND } \\
\text { (MG/L) }\end{array}$ & $\begin{array}{c}\text { DEPTH } \\
\text { (FT) }\end{array}$ \\
\hline
\end{tabular}

LaKe okeechobee and the eVerglades basins--CONTINUEd

02289030 - LEVEE 3 CA NR CLENISTON FLA (LAT 262550 LONG 080 56.501

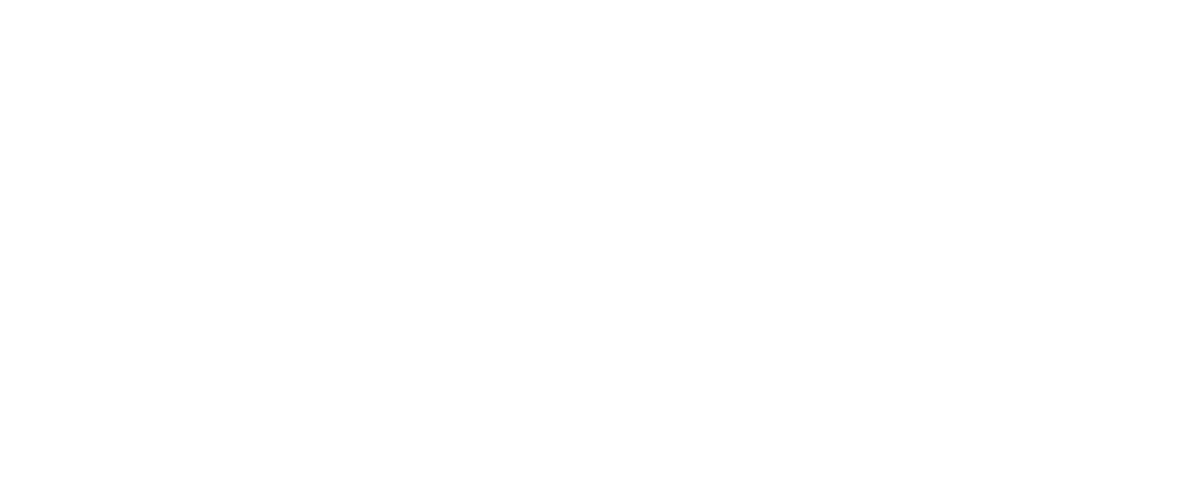

02289060 - TAMIAMI CA O AT BRIDGE 45 NR MIAMI FLA ILAT 254540 LONG 0803740 )

\begin{abstract}
MAY 1970
$\begin{array}{lllllll}.04 & .0 & .51 & .01 & .03 & 5.3 & 34\end{array}$

02289075 - TAMIAMI CNL AT L-29-1 NR COOPERTOWN FLA (LAT 254539 LONG 0803338 )
\end{abstract}

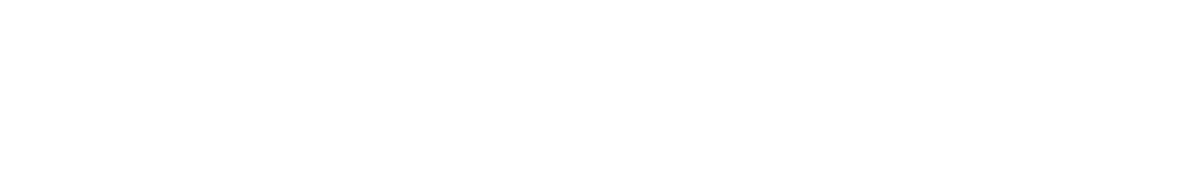
02290500 - TAMIAMI CANAL AT RED RD MIAMI FLA (LAT 254649 LONG 0801720 )

Nov., 1969

$17 . .0$ .53

MaY 1970

MAY... 19701.8

MAY -1970

$04 . . . \quad .62$

$\begin{array}{ll}\text { JULY } \\ 28 . . . & .58\end{array}$

MAY, 1970

$04 \ldots . .07$
.02

02290600 - SNAPPER CR CA NR CORAL GABLES, FLA. (LAT 254540 LONG 080 23 05)

02290620 - SNAPPER CR CA AT MILLER DR NR S MIAMI (LAT 254256 LONG 0802259 )

$\begin{array}{lllllll}.08 & .2 & .98 & 1.6 & 1.9 & 5.4 & 29\end{array}$

02290700 - SNAPPER CR CA AT S-22 NR SOUTH MIAMI F (LAT 254011 LONG 08017 03)

$\begin{array}{cccccccccccc}.16 & .6 & 1.0 & 2.1 & 2.3 & 5.0 & 10 & 30 & \ldots & \ldots & \ldots \\ .07 & .2 & .74 & .68 & .87 & 4.5 & 15 & -\infty & \ldots & \ldots & \ldots\end{array}$

02290704 - CUTLER DRAIN CA AT 5-123 NR PERRINE FL (LAT 253633 LONO 080 18 32)

2290707 - BLACK CREEK CA NEAR RICHMOND HETGHTS F (LAT 253939 LONG 08028 46)

\begin{tabular}{|c|c|c|c|c|c|c|c|c|c|c|c|}
\hline $\begin{array}{l}\text { JAN.: } 1970 \\
\text { MAY... }\end{array}$ & 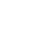 & .01 & 1.9 & - & - & 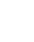 & 5.7 & -- & 40 & $=$ & $=$ \\
\hline $15 \ldots$ & - & .00 & 3.6 & - & .02 & -- & 5.6 & $=-$ & 30 & - & -- \\
\hline
\end{tabular}




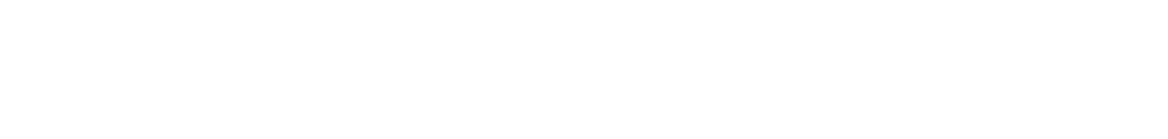

LAKE OKEECHOBEE AND THE EVERGLADES BASINS--CONTINUED

n2290710 - BLACK CREEK CA AT 5-21 NEAR GOULDS FLA (LAT 253243 LONG 0801955 )

\begin{tabular}{|c|c|c|c|c|c|c|c|c|c|c|c|}
\hline \multirow{3}{*}{$\begin{array}{l}\text { MAY , } 1970 \\
04 \ldots . . \\
13 \ldots \\
\text { SEP... } \\
28 . . .\end{array}$} & & & & & 3.7 & & & 12 & 10 & -- & \\
\hline & $: 11$ & $\begin{array}{l}.12 \\
.12\end{array}$ & $\begin{array}{r}3.1 \\
2.7\end{array}$ & $\begin{array}{l}.85 \\
.64\end{array}$ & $\begin{array}{l}3.1 \\
3.7\end{array}$ & 3.9 & $\begin{array}{l}4.4 \\
3.0\end{array}$ & $\begin{array}{r}12 \\
4\end{array}$ & 10 & $10^{\circ-}$ & 4.1 \\
\hline & .43 & .14 & 1.3 & .08 & 1.2 & 1.2 & 4.7 & 12 & 5 & $m$ & 1.4 \\
\hline
\end{tabular}

02290711 - BLACK CREEK CA BL S-21 NR GOULOS FLA (LAT 253243 LONG ORO 19 55)

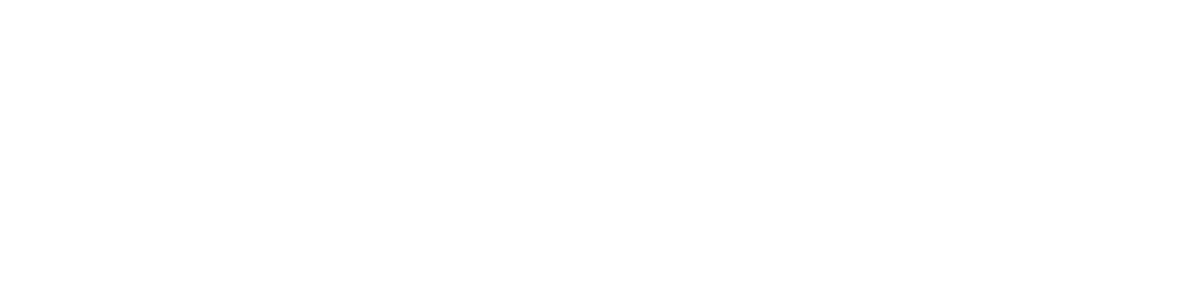

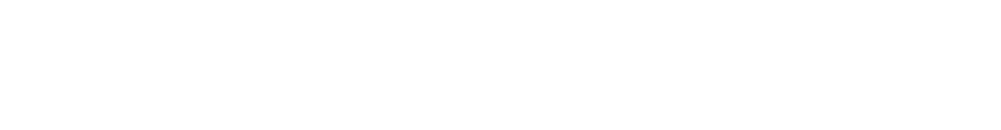

MAY 1970

02290725 - MOWFY CA NR HOMESTEAD FLA (LAT 25 29 13 LONG O80 $205 \mathrm{I}$ )

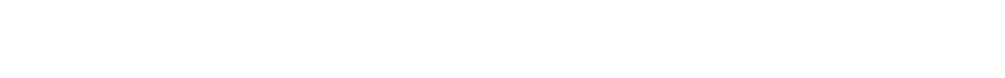

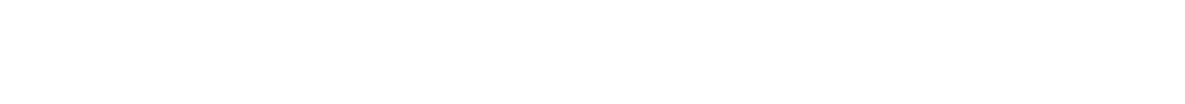

02290769 - CA 111 AT S-18C NR FLORIDA CITY FLA ILAT 251949 LONG NB1 31311

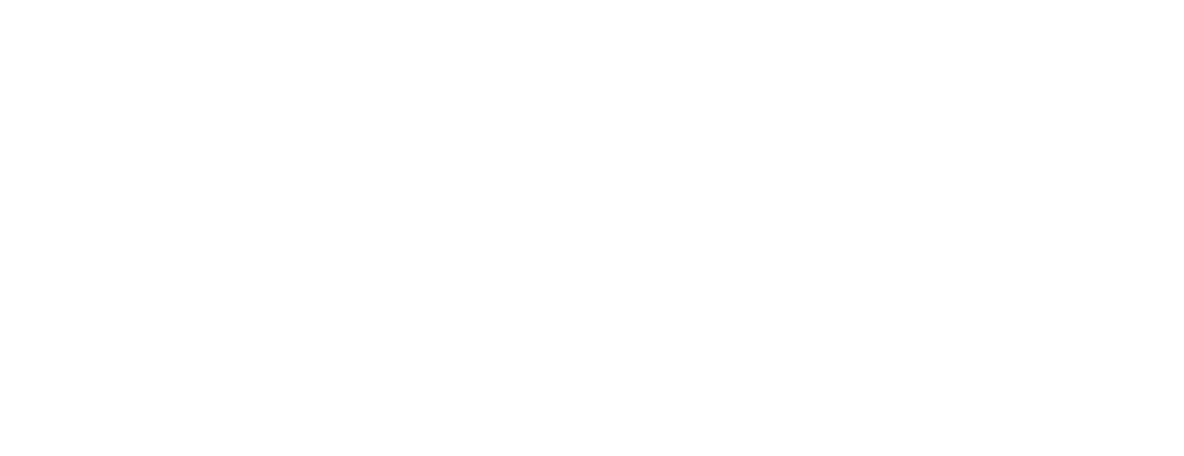

02290803 - TAYLOR SLU AT ROYAL PALM NR HOMESTEAD (LAT 2524 OT LONG 08040 15)

MAY 1970

$.05 \quad .0 \quad 1.0$

.12

3.n

$21 \quad 10$

02290810 - EVERgLADES P-37 NR HOMESTEAD, FLA. (LAT 251730 LONG 08040301

DEC., 1969

D9... 
CHEMICAL ANALYSES, WATER YEAR OCTOBER 1969 TO SEPTEMBER 1970

(MACRONUTRIENTS AND OTHER RELATED CONSTITUENTS)

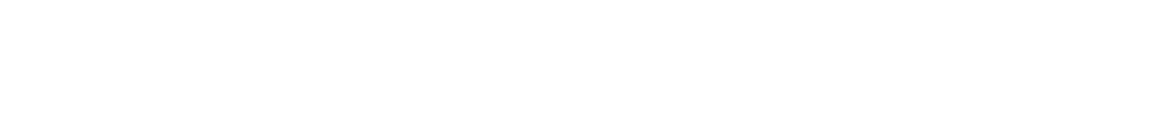

LAKE OKEECHOBEE AND THE EVERGLADES BASINS--CONTINUED

02290812 - ALLIGATOR HO AT CTNMOUTH CP NR HOMESTE (LAT 253810 LONG O80 4420 )

\begin{tabular}{|c|c|c|c|c|c|c|c|c|c|c|c|c|}
\hline $\begin{array}{l}\text { NOV.., } 1969 \\
18 . . .1 \\
\text { AUG., } 1970\end{array}$ & . $2 \mathrm{I}$ &.$n 0$ & .0 & 1.7 & .02 & .03 & 4.7 & $\cdots$ & 25 & - & - & $=$ \\
\hline $13 \ldots$ & .38 & .00 & $\because 0$ & .22 & .03 & .04 & $\begin{array}{l}12 \\
1.1\end{array}$ & 10 & $\begin{array}{l}60 \\
10\end{array}$ & $21^{--}$ & -- & $=$ \\
\hline
\end{tabular}

02290813 - OPEN GLADES NR CTNMOUTH CP NR HOMESTEA (LAT 253800 LONG 08044 00)

Nov.. 1969

$\begin{array}{lllllllll}.00 & 0 & 1.2 & .02 & .03 & 4.6 & . & 0 & \end{array}$

02290815 - EVERGLADFS P-33 NEAR HOMFSTEAD FLA (LAT 253630 LONG O80 4I 30)

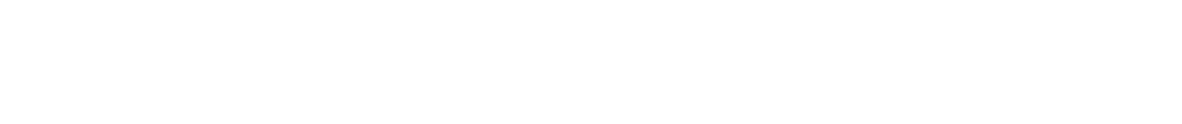

02290820 - EVERgL ADES P-3H NEAR HOMESTEAD FLA ILAT PS 2230 LONG O80 49001

OPR:. 1970

$09 \ldots . .35$

$16 \ldots$-..

.01

.01

.n2

$\begin{array}{lll}-0 & -\infty & -1\end{array}$

1.5

02290828 - EVERGLADES P-36 NEAR hOMESTEAD, fLA. (LAT 253230 LONG 0804700 )

$A P R, 1970$

$06 . . . \quad .14$

02

02290830 - EVERGLADES P-35 NEAR hOMESTEAD, FLA. (LAT 252720 LDNG O80 5230 )

\begin{tabular}{|c|c|c|c|c|c|c|c|c|c|c|c|c|}
\hline OEC., 1969 & -- & .01 & .0 & -. & -- & -- & 1.6 & -- & 30 & -- & - & -- \\
\hline $\begin{array}{l}\text { APR., } 1970 \\
09 . . .\end{array}$ & .24 & .02 & .8 & 1.7 & .01 & .05 & 7.1 & -- & 50 & -- & -- & - \\
\hline SEP. & -- & 00 & I & -- & 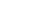 & 04 & -. & 7 & $=$ & -- & -- & -- \\
\hline
\end{tabular}

02290841 - ROOKERY BRANCH NR HOMESTEAD FLA ILAT 25 2h 48 LONG 0BO 53301

$\begin{array}{ll}\text { APR.. } \\ \text { MAY } \\ 14 . \ldots & -\end{array}$

.01

02290870 - EVERGLADES P-34 NEAR hOMESTEAD FLA (LAT 253630 LONG 090 5530 )

DEC., 1969

$09 . .$.

APR., 1970

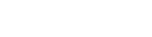

$16 . .$.

.01

$.0 \quad .46 \quad .03$

.02

02291000 - BARRON RIVÉR CANAL NR EVEPGLADES FLA (LAT 2558 nO LONG 08121 00)

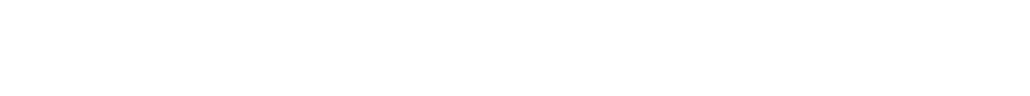

02291000 -

FEE.. 1970

02291200 - LAKE TRAFFORO NR IMMOKALEE, FLA. (LAT 2F 2508 LONG 081 29 25)

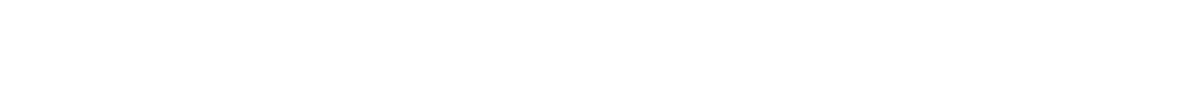

02291270 - HENDERSON CREEK CA NR NAPLES FI A (LAT 26 O5 59 LONG 0914114 )

MAY, 1970

19.:. 1970

.07

$.07 \quad .0$

.24

$.03 \quad .05 \quad 13$

13 
CHEMICAL ANALYSES, WATER YEAR OCTOBER 1969 TO SEPTEMBER 1970 (MACRONUTRIENTS AND OTHER RELATED CONSTITUENTS)

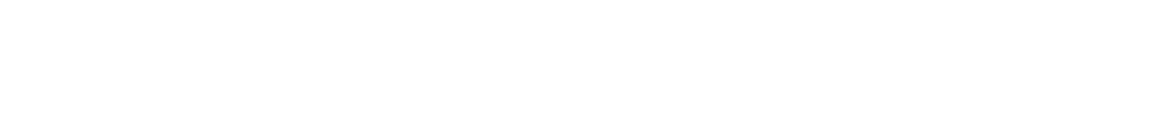

LAKE OKEECHOBEE AND THE EYERGLADES BASINS- CONTINUED

02291300 - GOLDEN GATE CA AT NAPLES FLA (LAT 261001 LONG OBI 46 02)

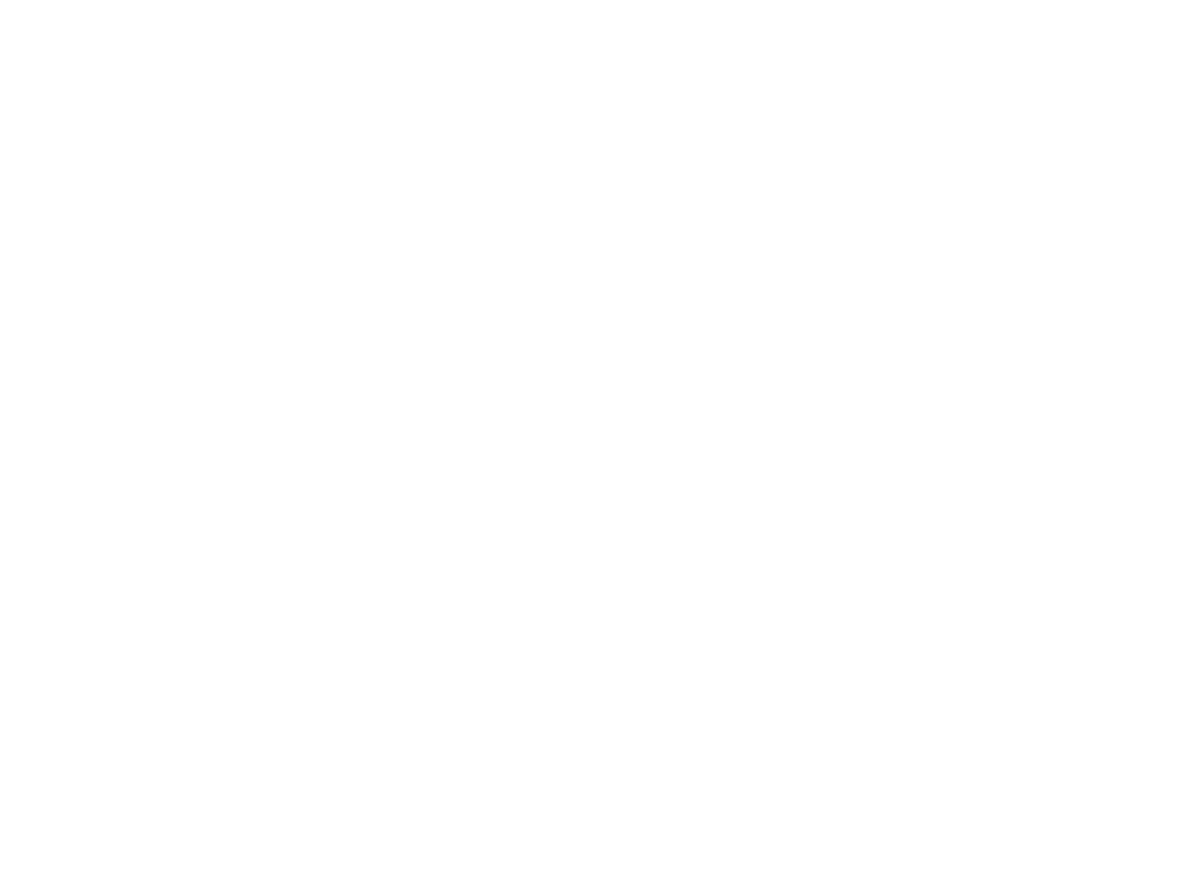

02293050 - ORANGE R AT BUCKINGHAM NR FT MYERS FLA ILAT $26 \quad 4012$ LONG 0814356 )

MAY, 1970

$18 . .1970$.

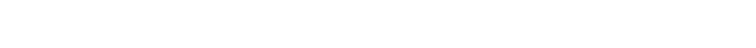

02293400 - ALLIGATOR CR NR PUNTA GORDA FLA ILAT 265308 LONG OB2 ON 22)

JUNE, 1970

09...

$.02 \quad-.0 \quad-62$

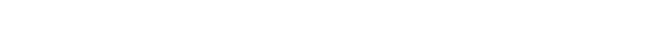

PEACE RIVER BASIN

02293461 - LAKE ALFRED AT LAKE ALFRED, FLA. (LAT 280548 LONG $292 \div 00$ )

MAY , 1970

$11 . . . \quad 04$

.0

02293518 - L FANNIE NR FLORENCE VILLA FLA ILAT 280250 LONG 081 41 15)

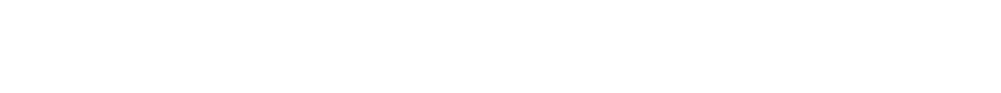

MAY 1970

02293664 - L HAMILTON OLT AT S PB NR L HAMLTN FLA (LAT 28 01 54 LONG 0813842 )

MAY, 1970

MAY 1970 .17 
CHEMICAL ANALYSES, WATER YEAR OCTOBER 1969 TO SEPTEMBER 1970 (MACRONUTRIENTS AND OTHER RELATED CONSTITUENTS)

\begin{tabular}{|c|c|c|c|c|c|c|c|c|c|c|c|c|}
\hline DATE & $\begin{array}{l}\text { TOTAL } \\
\text { AMMONIA } \\
\text { (NHA) } \\
\text { (MG/L) }\end{array}$ & $\begin{array}{l}\text { TOTAL } \\
\text { NITRITE } \\
\text { (NOL) } \\
\text { (MGLL) }\end{array}$ & $\begin{array}{l}\text { TOTAL } \\
\text { NITRATE } \\
\text { (NO3) } \\
\text { (MG/L) }\end{array}$ & $\begin{array}{l}\text { ORGANIC } \\
\text { NITRO- } \\
\text { GEN } \\
\text { (N) } \\
\text { (MG/L) }\end{array}$ & $\begin{array}{l}\text { DIS- } \\
\text { SOLVEO } \\
\text { ORTHO } \\
\text { PHOS- } \\
\text { PHATE } \\
\text { (PO4) } \\
\text { (MG/L) }\end{array}$ & $\begin{array}{l}\text { PHOS- } \\
\text { PHAYE } \\
\text { (PO4) } \\
\text { (MG/L) }\end{array}$ & $\begin{array}{l}\text { DIS- } \\
\text { SOLVED } \\
\text { SILICA } \\
\text { (SIO2) } \\
\text { (MG/L) }\end{array}$ & $\begin{array}{l}\text { TUR- } \\
\text { BID- } \\
\text { ITY } \\
\text { (JTU) }\end{array}$ & $\begin{array}{l}\text { COLOR } \\
\text { (PLAT- } \\
\text { INUM- } \\
\text { COBALI } \\
\text { UNITS) }\end{array}$ & $\begin{array}{l}\text { TOTAL } \\
\text { ORGANIC } \\
\text { CARBON } \\
\text { (C) } \\
\text { (MG/L) }\end{array}$ & $\begin{array}{l}\text { BIO- } \\
\text { CHEM- } \\
\text { ICAL } \\
\text { OXYGEN } \\
\text { DEMANO } \\
\text { (MG/L) }\end{array}$ & $\begin{array}{c}\text { DEPTH } \\
\text { (FT) }\end{array}$ \\
\hline
\end{tabular}

PEACE R\&VER BASIN--CONTINUED

02293774 - MOUNTAIN LAKE NR L WALES FLA (LAT 275601 LONG 0813459 )

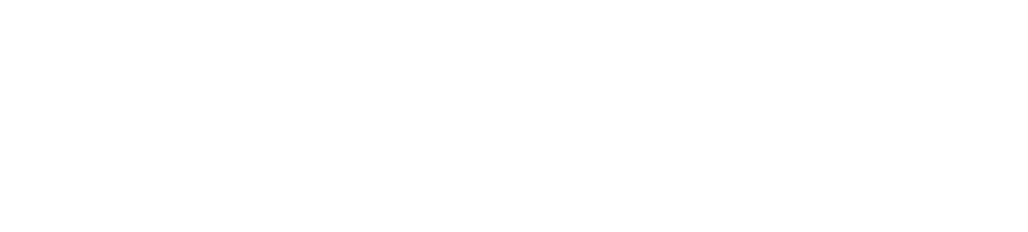

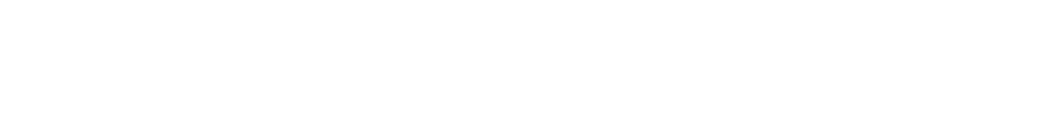

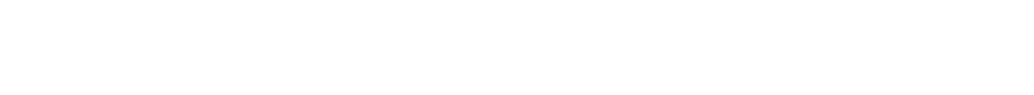

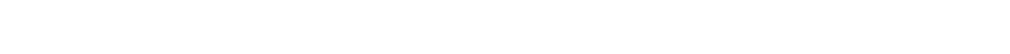

02294068 - LAKE LULU OUTLET AT ELOISE FLA (LAT 275903 LONG 0814347 )

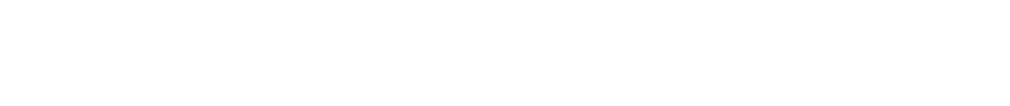

$\begin{array}{llllllllll}\text { MAY } & 1970 \\ 12 . . & .08 & .03 & 2.3 & .55 & .01 & .09 & .7 & 16 & 10\end{array}$

02294112 - LAKE GARFIELD NR ALTURAS FLA (LAT 275348 LONG 0814328 )

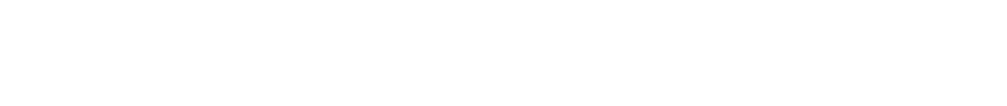

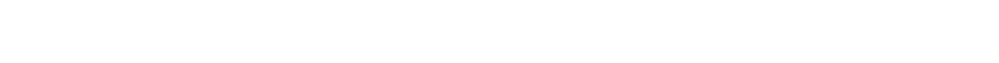

02294224 - LAKE GIBSON NR LAKELAND FLA (LAT 280640 LONG 08157 18)

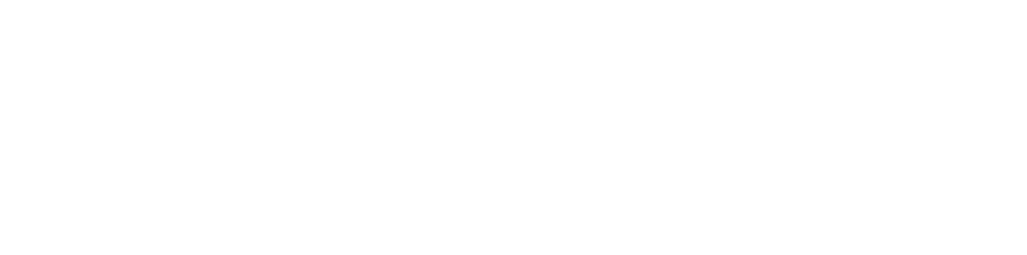

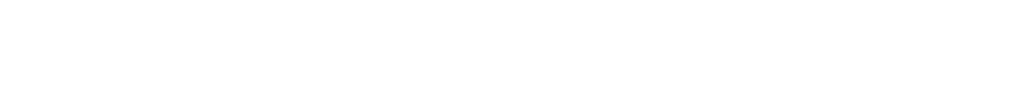

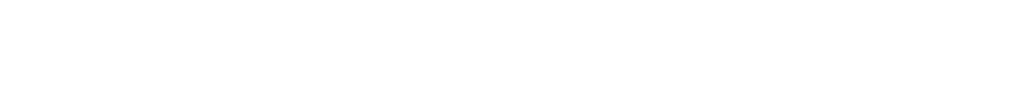

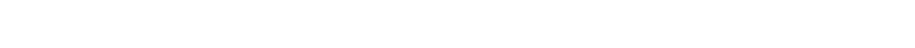

02294402 - BANANA LAKE NR HIGHLAND CITY FLA (LAT 275852 LONG 08I 5350 )

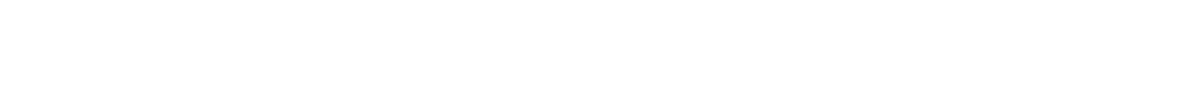


CHEMICAL ANALYSES, HATER YEAR OCTOBER 1969 TO SEPTEMBER 1970 (MACRONUTR IENTS AND OTHER RELATED CONSTITUENTS)

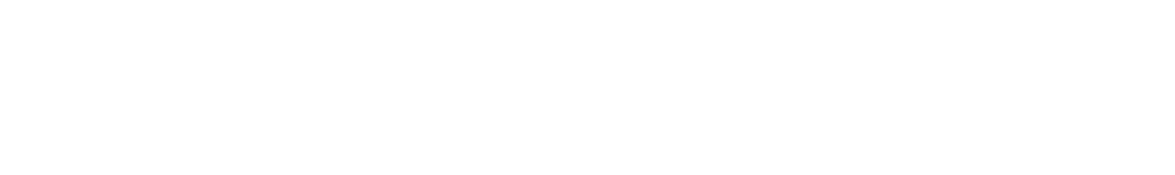

02294442 - EAGLE LAKE AT EAGLE LAKE FLA (LAT 275835 LONG 08146321

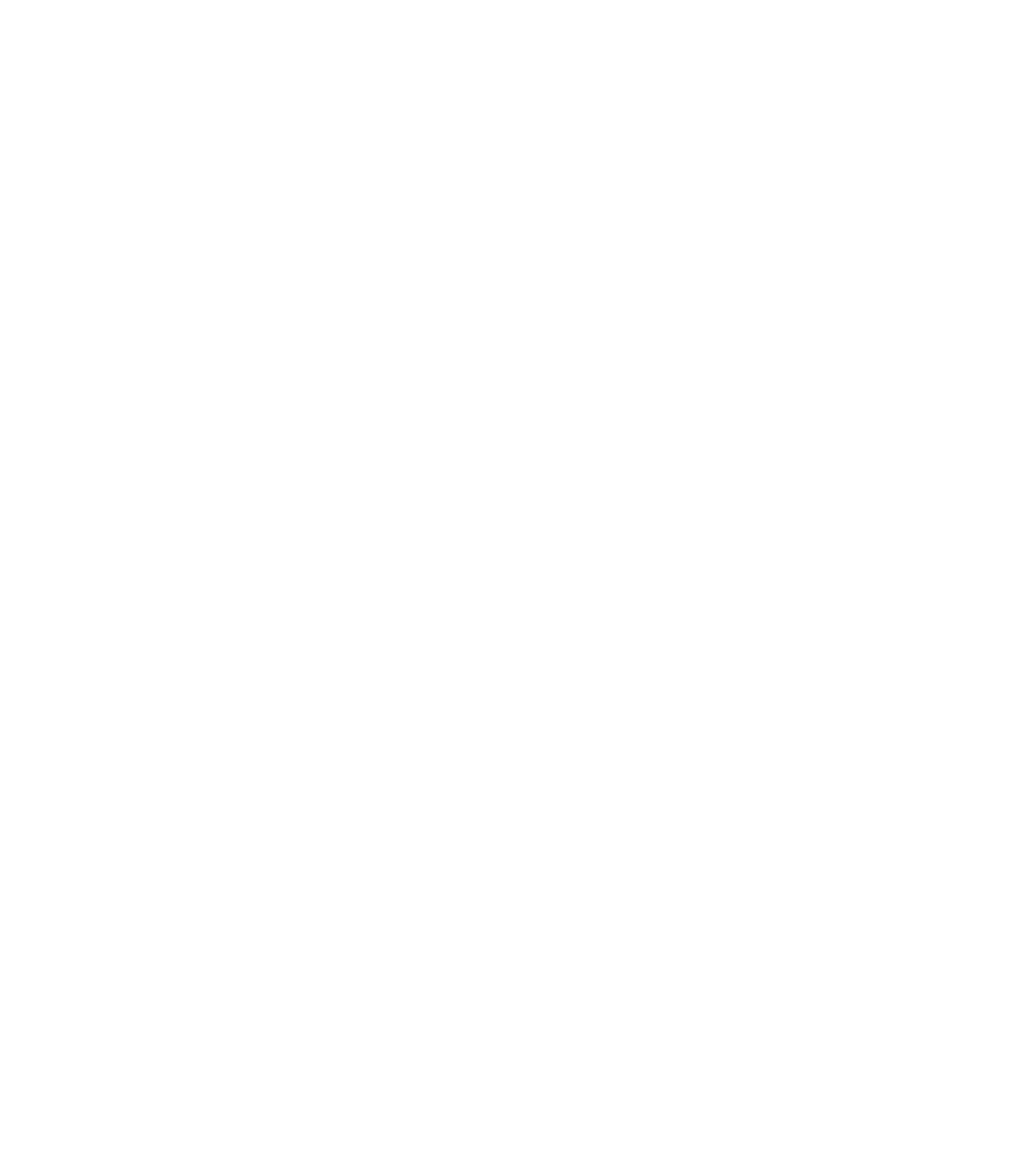

02295977 - PEACE RIVER NEAR BROWNVILLE FLA (LAT 271808 LONG 0815047 )

JUNE, 1970 --
$11 .$.

02296222 - L CHARLEY BOWLEGS CR AB CONT NR SEBRIN ILAT 272840 LONG 0813325 ,

MAY 1970

.08 
CHEMICAL ANALYSES, WATER YEAR OCTOBER 1969 TO SEPTEMBER 1970 (MACRONUTRIENTS AND OTHER RELATED CONSTITUENTS)

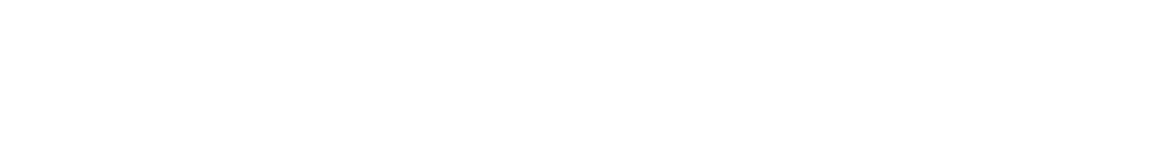

PEACE RIVER BASIN--CONTINUED

D2296500 - CHARLIE CR NR GARDNER FLA (LAT 272229 LONG 8814748 )

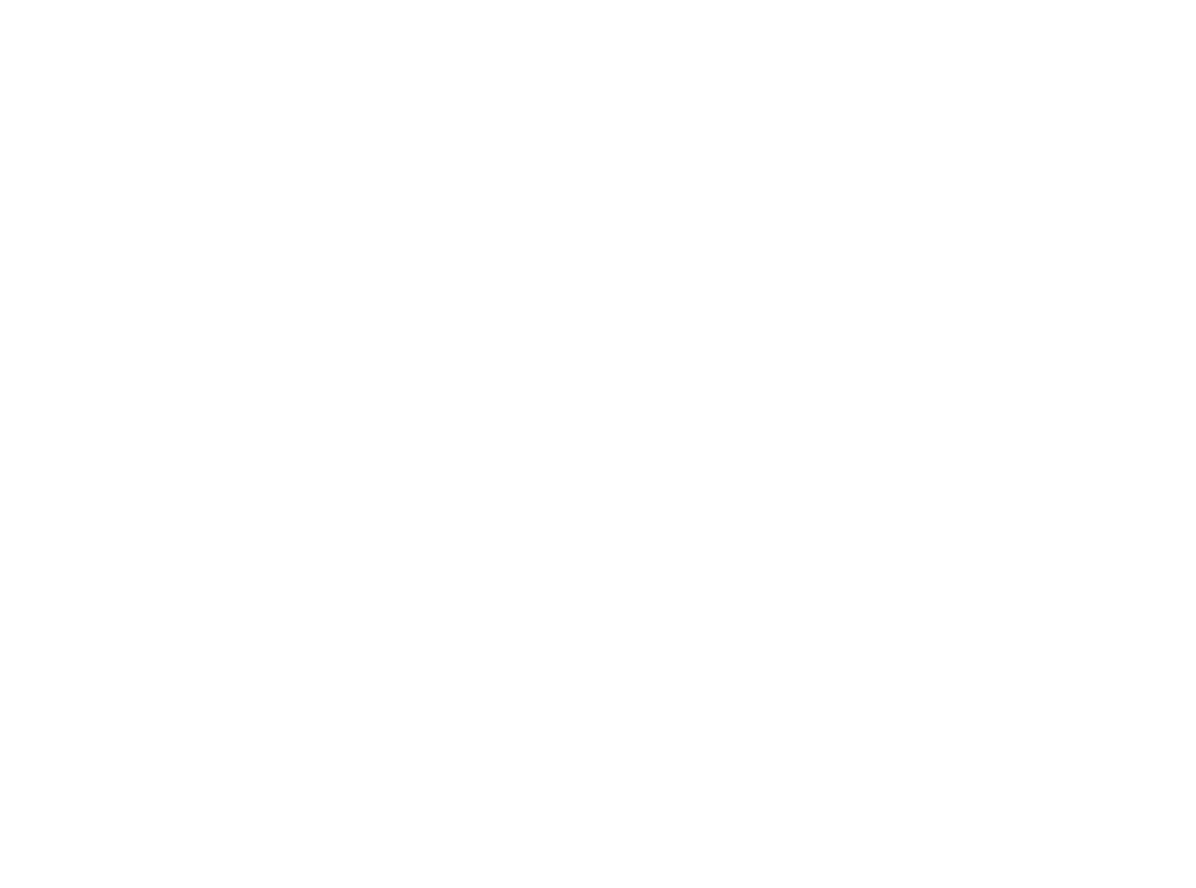

02297090 - 4AWTHDRNE CR NR NOCATEE FLA (LAT 270927 LONG 0815143 )

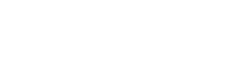

$$
.00
$$$$
\begin{array}{rrrrrrr}
3.8 & -- & -- & -- & 11 & - & 30 \\
2.5 & -- & -- & -- & 6.0 & -- & 30
\end{array}
$$

02297100 - JOSHUA CR AT NOCATEE FLA (LAT 270959 LONG 0815247 )

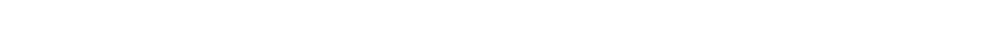

$$
\begin{aligned}
& 02297105 \text { - DEACE RIVER AT NOCATEE FLA (LAT } 270943 \text { LONG } 08154 \text { OS) } \\
& \text { SUNE, } 1970 \\
& 0
\end{aligned}
$$$$
10 \ldots .
$$

02297251

HORSE CREEK NEAR LIMESTONE FLA (LAT $27 \quad 2158$ LONG N81 58 251

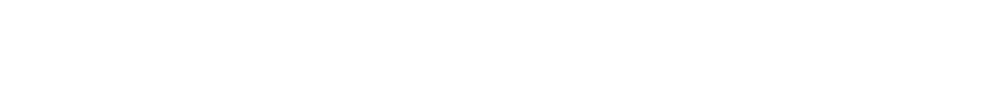

JAN. 1970
$27 \ldots .$. 
CHEMICAL ANALYSES, WATER YEAR OCTOBER 1969 TO SEPTEMBER 1970 (MACRONUTRIENTS AND OTHER RELATED CONSTITUENTS)

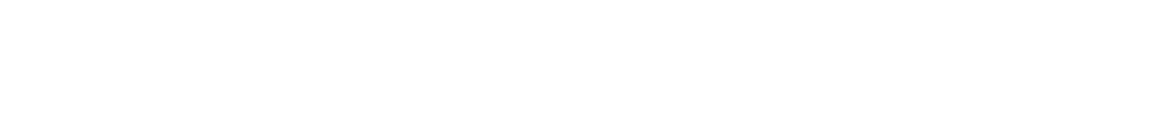

PEACE RIVER BASIN--CONTINUED

02297340 - PEACE RIVER NR FT OGDEN FLA (LAT 270517 LONG ORI 59 38)

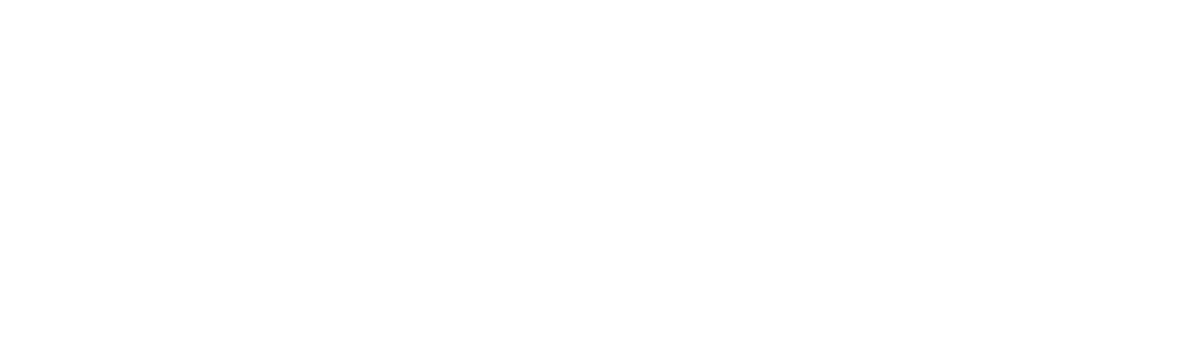

02298202 - SHELL CR NR PUNTA GORDA FLA LLAT 265904 LONG 08156 09)

JUNE, $1970 \quad .05 \quad .03$

02298830 - MYAKKA RIVER NR SARASOTA FLA (LAT 271425 LONG OB2 I8 50)

\begin{tabular}{|c|c|c|c|c|c|c|c|c|c|c|c|}
\hline $\begin{array}{l}04 \ldots . . \\
\text { OEC. }\end{array}$ & -- & .02 & .6 & $\cdots$ & -- & -- & 5.7 & -- & 100 & $-\infty$ & $\cdots$ \\
\hline MAR.. & -- & $=$ & -- & $=$ & -- & - & $\cdots$ & 12 & -- & - & - \\
\hline $18 \ldots$ & - & -- & $=-$ & - & $=-$ & - & -- & 70 & -- & - & 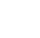 \\
\hline JUNE & - & -- & -- & - & -- & -- & -- & 46 & -- & - & -- \\
\hline
\end{tabular}

JUNE, 1970

02299410 - BIG SLOUGH CA NR MYAKKA CITY FLA (LAT 27 1135 LONG 08? 09 40)

2299470 - BIG SLOUGH NR MUROOCK FLA (LAT 270415 LONG 08? 13 05)

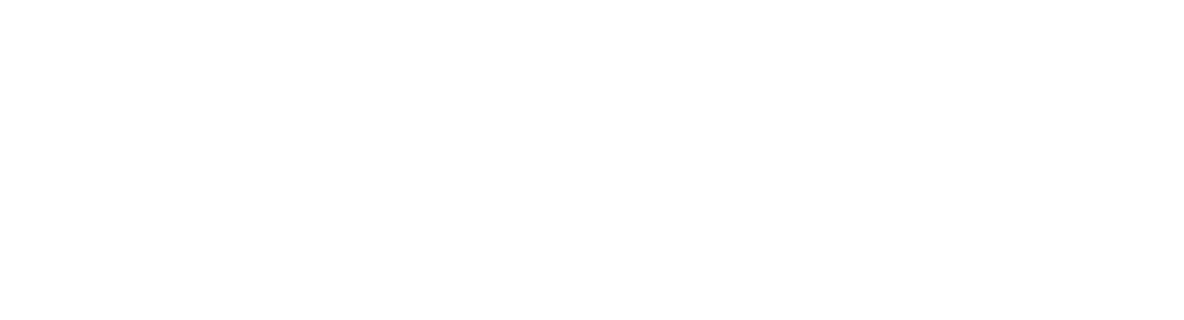

COASTAL BASINS BETWEEN MYAKKA RIVER AND HILLSBOROUGH RIVER

02299800 - PHILLIPPI CR AT SARASOTA FLA (LAT 271920 LONG $0823020 \%$

JUNE, 1970

II...

17

$1.1 \quad 1.0 \quad 3.1 \quad 3.1$

6.3

23

02299950 - MANATEE $R$ NR MYAKKA HEAO FLA (LAT 272924 LONG 0821241 )

12...

02300040 - GRAOEN R NR BRADENTON FLA (LAT 292601 LDNG 08229 13)

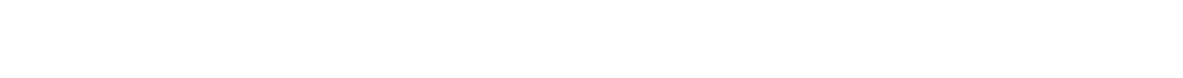




\begin{tabular}{|c|c|c|c|c|c|c|c|c|c|c|c|c|}
\hline TE & $\begin{array}{l}\text { TOTAL } \\
\text { AMMONIA } \\
\text { (NH4) } \\
\text { (MG/L) }\end{array}$ & $\begin{array}{l}\text { TOTAL } \\
\text { NITRITE } \\
\text { (NO2) } \\
\text { (MG/L) }\end{array}$ & $\begin{array}{l}\text { TOTAL } \\
\text { NITRATE } \\
\text { (NO3) } \\
\text { (MG/L) }\end{array}$ & $\begin{array}{l}\text { ORGANIC } \\
\text { NITRO- } \\
\text { GEN } \\
\text { (N) } \\
\text { (MG/L) }\end{array}$ & $\begin{array}{l}\text { DIS- } \\
\text { SOLVED } \\
\text { ORTHO } \\
\text { PHOS- } \\
\text { PHATE } \\
\text { (PDA) } \\
\text { (MG/L) }\end{array}$ & $\begin{array}{l}\text { PHOS- } \\
\text { PHATE } \\
\text { (PO4) } \\
\text { (MG/L) }\end{array}$ & $\begin{array}{l}\text { DIS- } \\
\text { SOLVED } \\
\text { SILICA } \\
\text { (SIOZ) } \\
\text { (MG/L) }\end{array}$ & $\begin{array}{l}\text { TUR- } \\
\text { BID- } \\
\text { ITY } \\
\text { (JTU) }\end{array}$ & $\begin{array}{l}\text { COLOR } \\
\text { (PLAT- } \\
\text { INUM- } \\
\text { COBALT } \\
\text { UNITS) }\end{array}$ & $\begin{array}{l}\text { TOTAL } \\
\text { ORGANIC } \\
\text { CARBON } \\
\text { (C) } \\
\text { (MG/L) }\end{array}$ & $\begin{array}{l}\text { BIO- } \\
\text { CHEM- } \\
\text { ICAL } \\
\text { OXYGEN } \\
\text { DEMAND } \\
\text { (MG/L) }\end{array}$ & $\begin{array}{c}\text { DEPTH } \\
\text { (FT) }\end{array}$ \\
\hline
\end{tabular}

COASTAL BASINS BETWEEN MYAKKA RIVER AND HILLSBOROUGH RIVER-CONTINUED 02300100 - L MANATEE R NR FT LONESOME FLA (LAT 274216 LONG 0821153 !

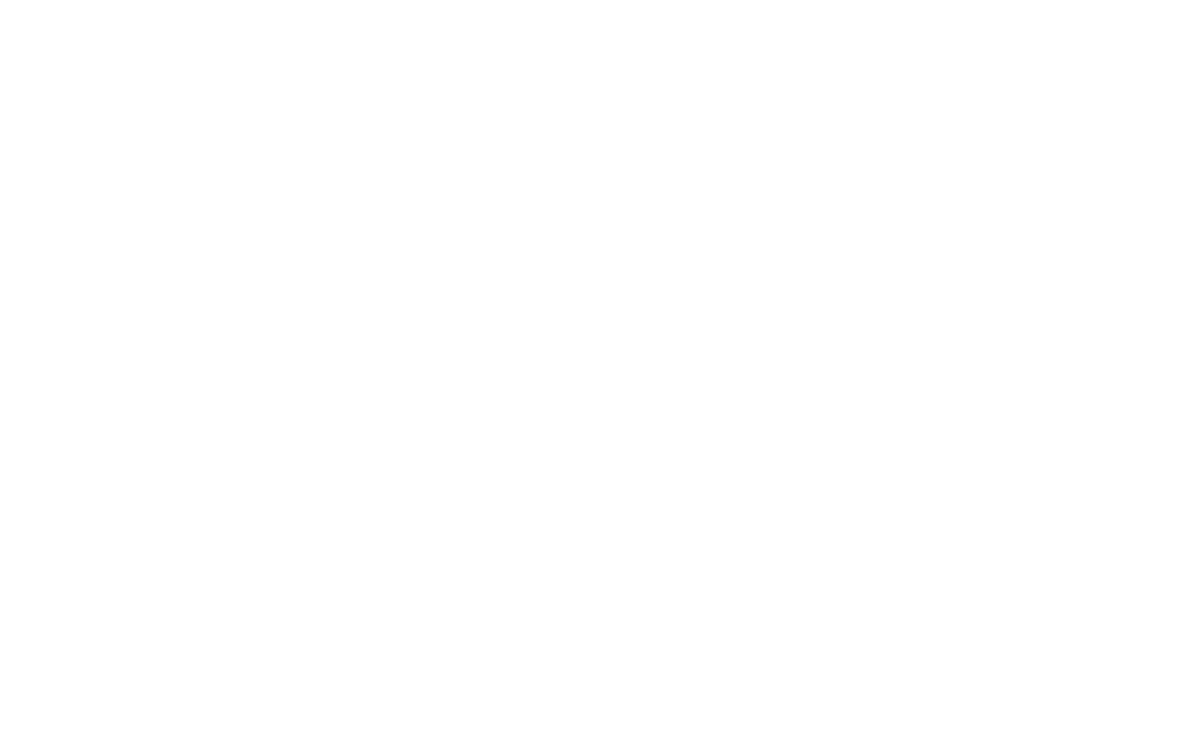

02300700 - BULLFROG CR NR WIMAUMA FLA (LAT 274730 LONG 0822109 )

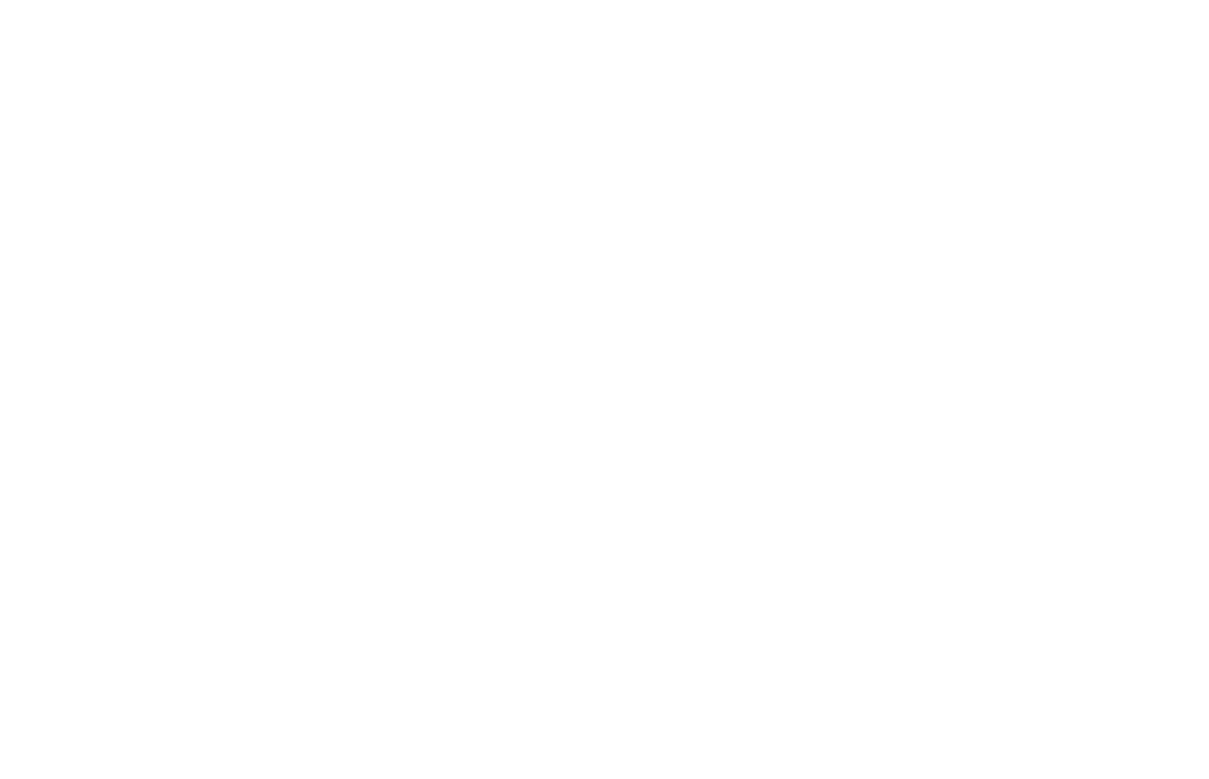


CHEMICAL ANALYSES, WATER YEAR OCTOBEK 1969 TO SEPTEMBER 1970 (MACRDNUTRIENTS AND OTHER RELATED CONSTITUENTS)

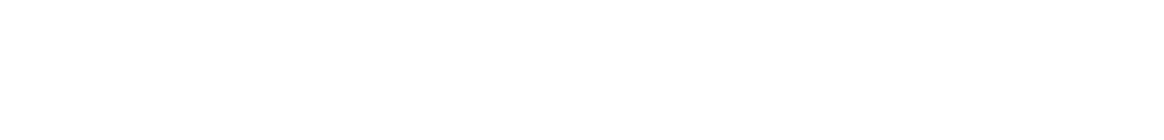

COASTAL BASINS BETWEEN MYAKKA RIVER AND HILLSBOROUGH RIVER--CONTINUED

02301350 - LITTLE ALAFIA R NR HOPEWELL FLA (LAT 275615 LONG O82 09 23)

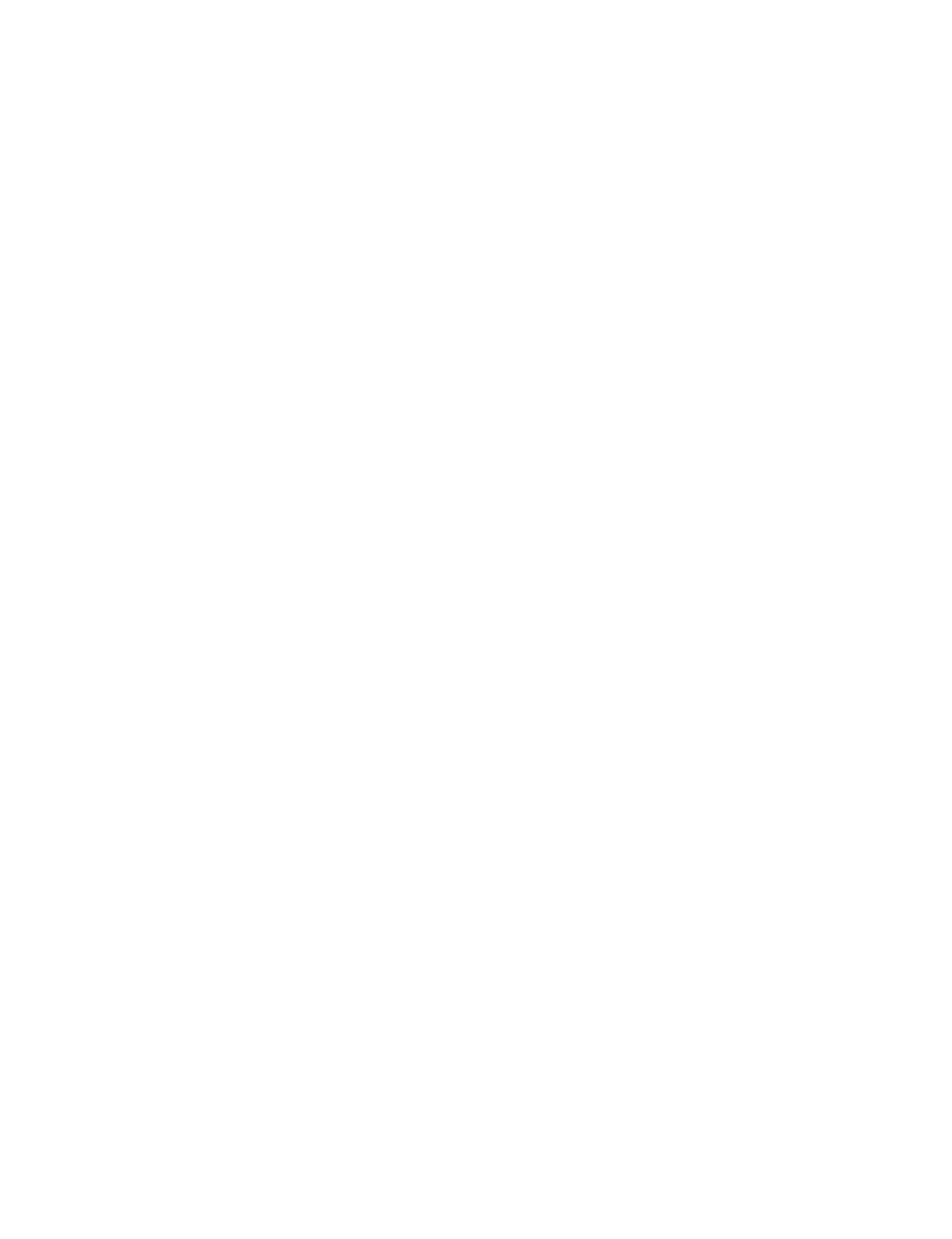


CHEMICAL ANALYSES, WATER YEAR OCTOBER 1969 TO SEPTEMBER 1970 (MACRONUTRIENTS AND OTHER RELATED CONSTITUENTS)

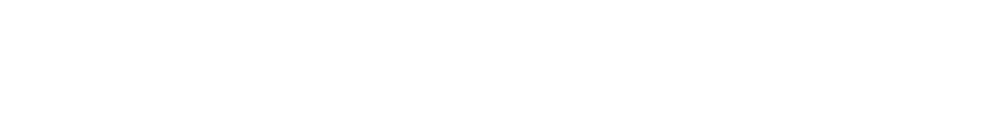

HILLSBOROUGH RIVER BASIN--CONTINUED

02303000 - HILLSPOROUGH PIVER NR ZEPHYRHILLS FLA (LAT $28 \quad 0859$ LONG 0821357 )

\begin{tabular}{|c|c|c|c|c|c|c|c|c|c|c|c|}
\hline $\begin{array}{r}\text { OCT.” } 1969 \\
\text { 30.... } \\
\text { JAN.. } 1970\end{array}$ & -- & .01 & $3 . ?$ & - & $m$ & -- & 10 & - & 100 & $\rightarrow$ & - \\
\hline OPR... & - & .02 & 5.1 & -- & -- & -- & 3.6 & $\Rightarrow$ & 70 & -- & -- \\
\hline JUNE & - & .00 & .8 & 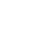 & -- & - & .6 & -- & 40 & -- & - \\
\hline JULY... & .10 & .17 & 5.7 & 1.1 & 3.5 & 3.6 & 10 & 17 & 40 & -- & .9 \\
\hline SEP. & - & $\cdot n 2$ & 5.5 & - & 1.6 & 1.6 & $\cdots$ & 1 & -- & 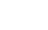 & - \\
\hline $23 .$. & .10 & .01 & 4.1 & 1.2 & 1.5 & 1.5 & 9.1 & 3 & 5 & 5.0 & -- \\
\hline
\end{tabular}

02303100 - NEW RIVER NR ZEPHYRHILLS FLA (LAT 28 O9 55 LONG O82 15 55)

JUNE, 1970

$08 . . . \quad 07$

n

26...

02303200 - PEMBERTON CKEEK NR DOVER FLA (LAT $2 R$ AL 34 LONG 0821412 )

MAR., 1970

$\begin{array}{llll}18,0 & -- & -- & --\end{array}$

$02303271-$

$1 . \overline{3}$

$4 . \overline{5}$

$\because \quad--\quad+-$

BAKEK CKEEK NEAR THONOTOSASSA FLA (LAT 280252 LONG 0821604 )

MAR., 1970

$18 . . .1970 \quad-$

$\begin{array}{ll}18 \ldots . & -- \\ \text { MAY } & \\ 20 & .09\end{array}$

JUNE $20 \cdots$

OR... 11

$12 \ldots$

$24 \ldots . .18$

$=$

.281.

.05

.08

.89

$\begin{array}{cc}1.9 & -- \\ 2.9 & 19 \\ -. & 7.0 \\ 3.8 & -- \\ 2.4 & 14\end{array}$

$\begin{array}{rrrrr}-- & -- & 180 & -- & - \\ 11 & 50 & -- & 2.5 & - \\ 22 & 120 & -- & -- & - \\ 33 & -- & -- & -- & - \\ 76 & 5 n & 48 & -- & -\end{array}$

02303290 - L THONOTOSASSA AT THONOTOSASSA FLA (LAT $2803 \quad 33$ LONG $082 \quad 1709$ )

\begin{tabular}{|c|c|c|c|c|c|c|c|c|c|c|c|}
\hline $\begin{array}{l}01 \ldots \\
\text { AUG.. }\end{array}$ & .06 & .02 & $\cdot n$ & 1.1 & 2.2 & 2.3 & $2 \cdot 0$ & 2 & 50 & -- & - \\
\hline $24 \ldots$ & -- & .09 & .4 & -- & 1.6 & 1.7 & -- & 14 & -- & - & -. \\
\hline
\end{tabular}

02303300 - FLINT CR NR THONOTOSASSA FLA (LAT 280404 LONG 08216 N4)

MAR., 1970

$19 \ldots$

JuLY

$20 .$.

SFP.

$24 . .$.

$$
\begin{aligned}
& -- \\
& -- \\
& .20
\end{aligned}
$$

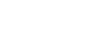

$$
\begin{array}{ll}
.01 & 14 \\
.01 & 3 .
\end{array}
$$

.02
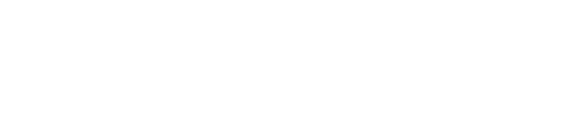

$\begin{array}{cccc}- & 250 & = & = \\ - & 250 & -- & = \\ 35 & -- & -- & = \\ 25 & -- & -- & = \\ 20 & 105 & -- & --\end{array}$

02303320 - FLINT CREEK AT SH-582 NEAR THONOTOSA5S (LAT 280430 LONG 0821550$)$

\begin{tabular}{|c|c|c|c|c|c|c|c|c|c|}
\hline .01 & .0 & 1.3 & 2.6 & 2.6 & .7 & 14 & 50 & -- & 3.2 \\
\hline $\begin{array}{l}.02 \\
.02\end{array}$ & .00 & $\begin{array}{l}1.1 \\
1.4\end{array}$ & 2.3 & 2.4 & $\begin{array}{l}2.1 \\
3.4\end{array}$ & 17 & $\begin{array}{l}80 \\
60\end{array}$ & $=$ & $=$ \\
\hline .02 & .0 & -- & 1.5 & 1.6 & -- & 19 & -- & -- & -- \\
\hline -- & -. & -- & & -- & -- & -- & -. & & -- \\
\hline
\end{tabular}

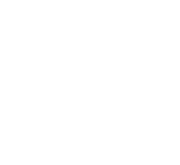

02303330 - HILLS R AT MORRIS GR NR THONOTOSASSA F ILAT 2A 05 50 LONG O82 1845 )

MAY 1970
$22 . .$.

$$
.02
$$

U2303350 - TROUT CR NR SULPHUR SPRINGS FLA ILAT 28 08 20 LONG OR2 21501 
CHEMICAL ANALYSES, WATER YEAR OCTOBER 1969 TO SEPTEMBER 1970 (MACRONUTR IENTS AND OTHER RELATED CONSTITUENTS)

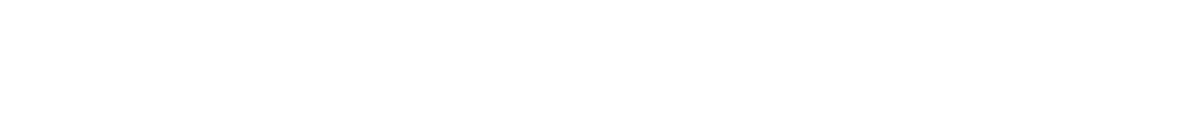

HILLSBOROUGH RIVER BASIN--CONTINUED

02303358 - CYPRESS CR NR DARBY FLA ILAT $2 A \quad 2232$ LONG 08219471

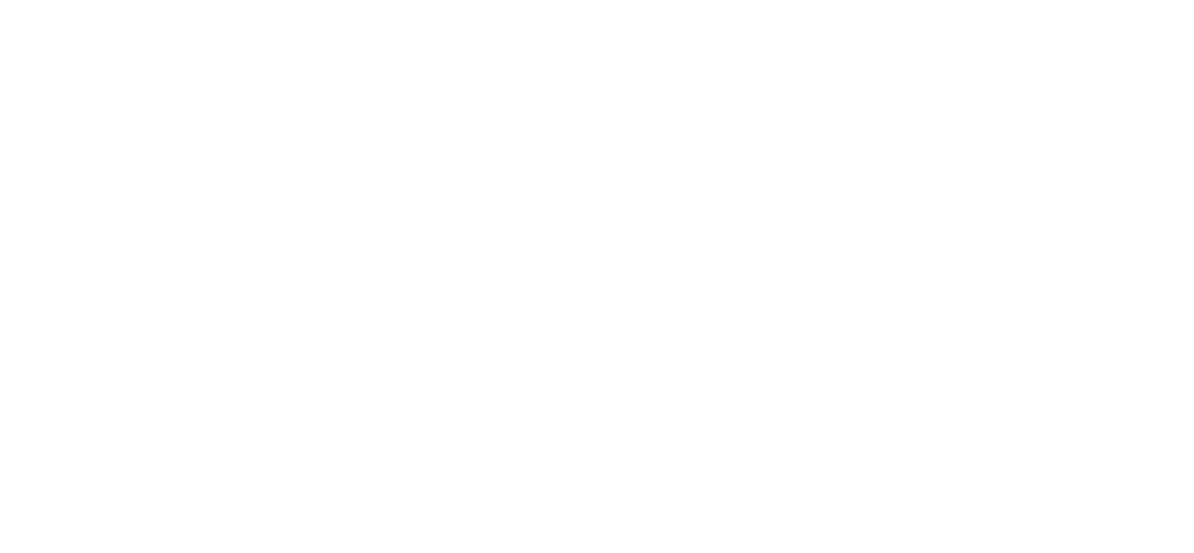

02303420 - CYPRESS CR AT WORTHINGTON GARDENS FLA (LAT 28 II 06 LONG 08224 13)

SEP. 1970

02303440 - L PADGETT NR LUTZ FLA (LAT 281212 LONG $082 \quad 2743$ )

\begin{tabular}{|c|c|c|c|c|c|c|c|c|c|c|c|}
\hline $\begin{array}{l}\text { MAY, } 1970 \\
27 \ldots \\
\text { SEP. }\end{array}$ & .00 & .01 & 0 & .41 & .03 & .07 & .5 & 1 & 0 & - & - \\
\hline $25 \ldots$ & $-\infty$ & -- & - & -- & -- & -- & $=-$ & -- & -- & 31 & $=$ \\
\hline
\end{tabular}

02303700 - LAKE STEMPER NR LUTZ FLA ILAT 28 OS 09 LONG $082 \quad 27221$

$\begin{array}{ccccccccc}\operatorname{MAY}, 1970 & 09 & .02 & .0 & .72 & .11 & .15 & .2 & 1\end{array}$

02303800 - CYPRESS CR NR SULPHUR SPRINGS FLA (LAT 280520 LONG 0822433 )

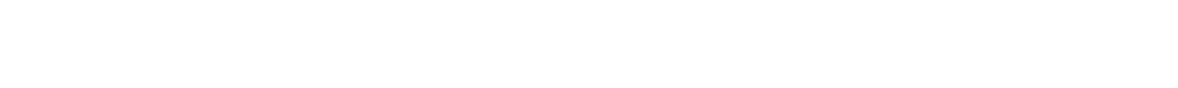

02303990 - COWHOUSE CR NR TEMPLE TERRACE FLA (LAT 380330 LONG 08? 21 10)

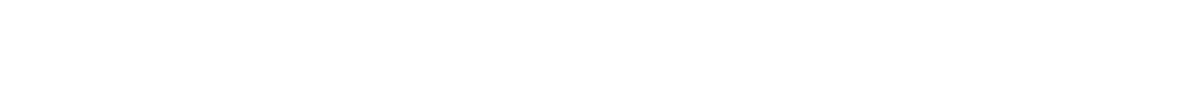

02304000 - HILLSBORO R AT FOWLER AVE NR TAMPA FLA (LAT 280315 LONG OR2 21 SO)

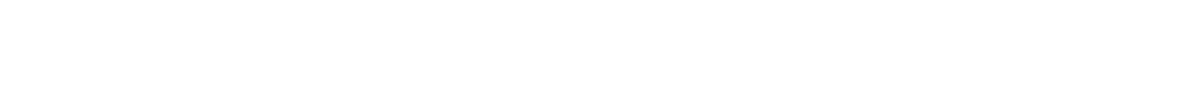

02304700 - LAKE HOBBS NR LUTZ FLA ILAT 240930 LONG CB2 28001

MAY, 1970

$27 \ldots . .01970$

.0

02305175 - CRENSHAW LAKE NEAR LUTZ FLA (LAT 2A 0732 LONG OA2 2946.01

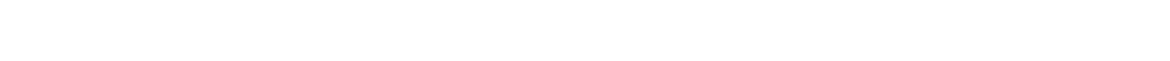




\begin{tabular}{|c|c|c|c|c|c|c|c|c|c|c|c|c|}
\hline & $\begin{array}{l}\text { TOTAL } \\
\text { AMMONIA } \\
\text { (NH4) } \\
\text { (MG/L) }\end{array}$ & $\begin{array}{l}\text { TOTAL } \\
\text { NITRI TE } \\
\text { (NOZ) } \\
\text { (MG/L) }\end{array}$ & $\begin{array}{l}\text { TOTAL } \\
\text { NI TRATE } \\
\text { (NO3) } \\
\text { (MG/L) }\end{array}$ & $\begin{array}{l}\text { ORGANIC } \\
\text { NITRO- } \\
\text { GEN } \\
\text { (N) } \\
\text { (MG/L) }\end{array}$ & $\begin{array}{l}\text { DIS- } \\
\text { SOLVED } \\
\text { ORTHO } \\
\text { PHOS- } \\
\text { PHATE } \\
\text { (P04) } \\
\text { (MG/L) }\end{array}$ & $\begin{array}{l}\text { PHOS- } \\
\text { PHATE } \\
\text { (PO4) } \\
\text { (MG/L) }\end{array}$ & $\begin{array}{l}\text { OIS- } \\
\text { SOLVEO } \\
\text { SILICA } \\
\text { (SIOZ) } \\
\text { (MG/L) }\end{array}$ & $\begin{array}{l}\text { TUR- } \\
\text { BID- } \\
\text { I TY } \\
\text { (JTUI }\end{array}$ & $\begin{array}{l}\text { COLOR } \\
\text { (PLAT- } \\
\text { INUM- } \\
\text { COBALT } \\
\text { UNITS) }\end{array}$ & $\begin{array}{c}\text { TOTAL } \\
\text { ORGANIC } \\
\text { CARBON } \\
\text { (C) } \\
\text { (MG/L) }\end{array}$ & $\begin{array}{l}\text { BIO- } \\
\text { CHEM- } \\
\text { ICAL } \\
\text { OXYGEN } \\
\text { OEMAND } \\
\text { (MG/L) }\end{array}$ & $\begin{array}{c}\text { DEPTH } \\
\text { (FT) }\end{array}$ \\
\hline
\end{tabular}

HILLSBOROUGH RIVER BASIN--CONTINUED

02305178 - SADDLEBACK LAKE NEAR LUTZ FLA (LAT 2807 O6 LONG 08229 45)

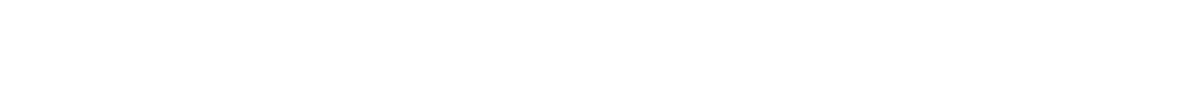

02305200 - ROUNO LAKE NR LUTZ FLA (LAT 280716 LONG 0823004 )

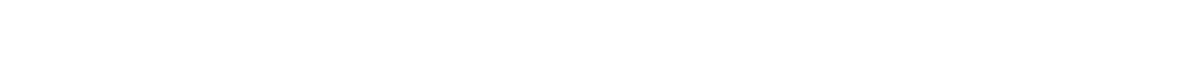
02305288 - LAKE CHARLES NEAR LUTZ, FLA. (LAT 280656 LONG 0822852 )

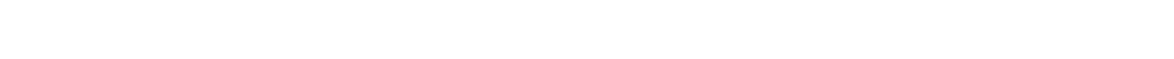
02306000 - SULPHUR SPRINGS AT SULPHUR SPRINGS, FL (LAT $2801 \quad 15$ LONG 0822707 )

MAY... $1970 \quad .05$ .01

COASTAL BASINS BETHEEN HILLSBOROUGH RIVER AND WITHLACOOCHEE RIVER 02306100 - OLD TAMPA BAY AT ROCKY POINT AT TAMPA (LAT 275759 LONG 0823357 )

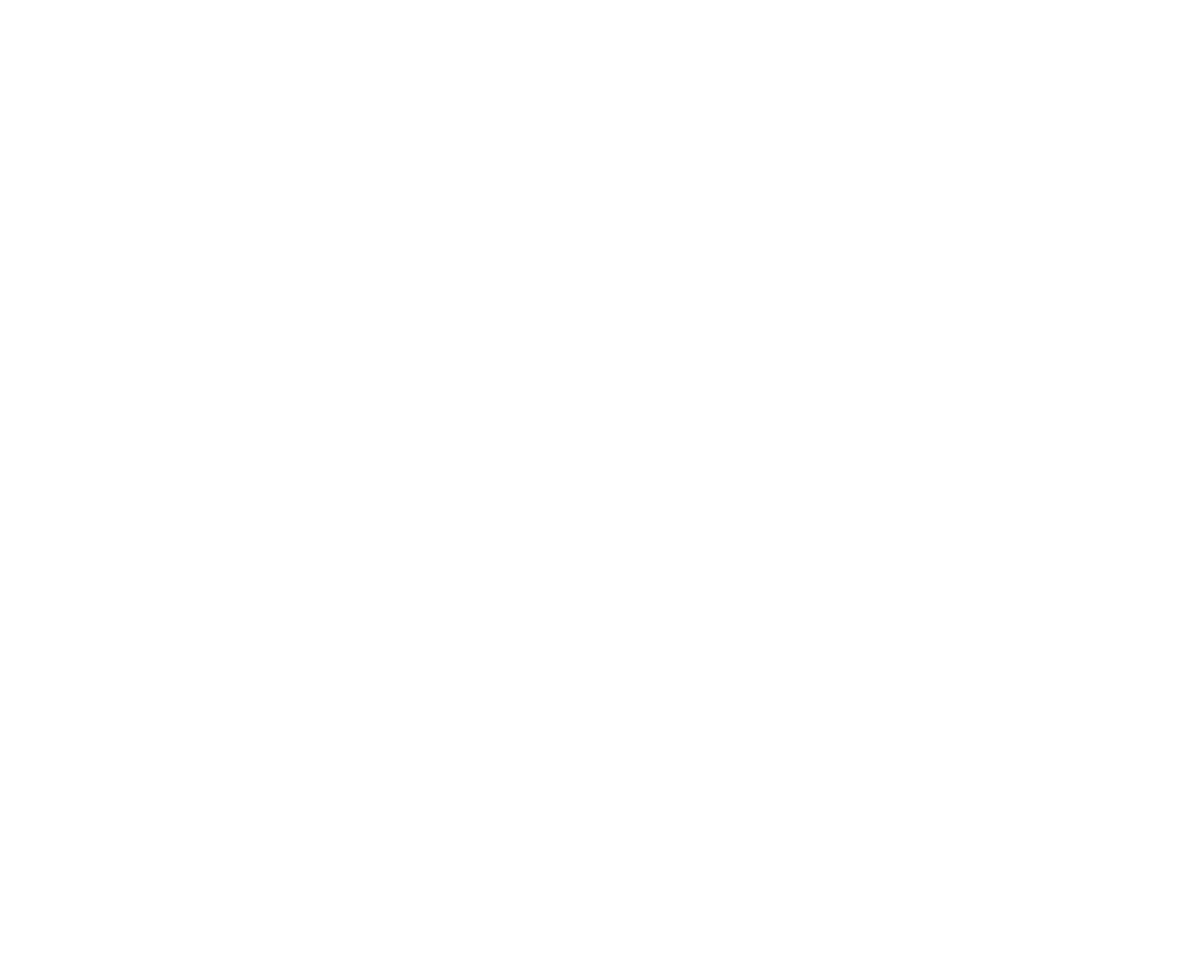




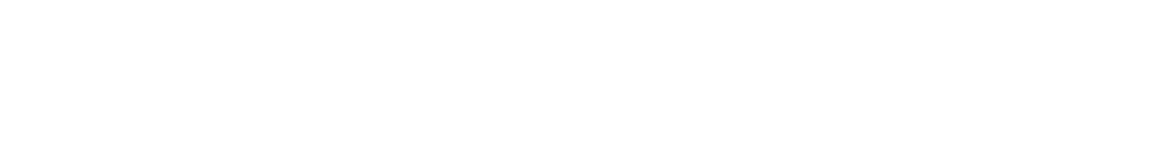

COASTAL BASINS BETWEEN HILLSBDROUGH RIVER AND HITHLACOOCHEE RIVER--CONTINUED

02307000 - ROCKY CR NR SULPHUR SPRGS FLA (LAT 2B O2 23 LONG 0823431 )

\begin{tabular}{|c|c|c|c|c|c|c|c|c|c|c|c|c|}
\hline $13 \ldots$. & -- & .01 & .0 & -- & $=$ & - & .1 & $=$ & 100 & - & $=-$ & $=$ \\
\hline Nov. & - & .03 &.$S$ & - & .50 & .65 & - & - & -- & -- & $\cdots$ & -- \\
\hline $20 \ldots$ & - & .01 & 2.2 & - & $\cdots$ & - & 3.6 & -- & 100 & 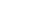 & -- & $=$ \\
\hline DEC... & - & .01 & 2.5 & -- & .39 & .44 & - & -- & -- & -- & -- & -- \\
\hline JAN... 1970 & -- & .03 & 2.2 & - & .32 & .38 & $\cdots$ & -- & -- & $\cdots$ & - & $\cdots$ \\
\hline $07 \ldots$ & - & .02 & 1.8 & $\overline{-}$ & $\bar{z}$ & $\ddot{36}$ & 2.1 & $=$ & 80 & - & $=$ & - \\
\hline FER. & - & .03 & 1.8 & - & .32 & .36 & - & -- & -- & -- & -- & - \\
\hline $09 \ldots$ & $=-$ & .03 & 1.3 & -- & - & -- & 1.4 & -- & 120 & -- & -- & - \\
\hline $\begin{array}{l}28 \ldots . . \\
\text { MAR. }\end{array}$ & $\cdots$ & .06 & .8 & $\cdots$ & .27 & .31 & - & -- & $=-$ & -- & - & -- \\
\hline $23 .$. & - & .02 & .0 & -- & -- & -- & .7 & -- & 80 & - & -- & -- \\
\hline $30 \ldots$ & - & .08 & .6 & -- & .59 & .69 & -- & -- & -- & - & - & -- \\
\hline $\begin{array}{l}\text { APR } \\
30 \ldots\end{array}$ & -- & & ? & - & 30 & & - & $\pi$ & ( & 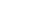 & & \\
\hline MAY & & cos & .0 & & .50 & $\cdot 4 x$ & & 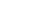 & 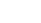 & 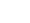 & 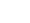 & . \\
\hline $02 \ldots$ & .03 & .04 & .1 & .81 & .25 & .31 & 4.5 & 5 & 50 & $\cdots$ & $\cdots$ & - \\
\hline JUNE & 2 & .02 & $\cdot 9$ & 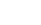 & .50 & .52 & - & $\cdots$ & -- & - & $\cdots$ & - \\
\hline $18 \ldots$ & $=-$ & .02 & 1.6 & -- & - & -- & 3.3 & -- & 30 & -- & - & -- \\
\hline $28, \ldots$ & .10 & .02 & .0 & .20 & .09 & .17 & 4.7 & 72 & -- & - & $=$ & - \\
\hline AUG. & -- & 00 & 0 & - & 84 & 98 & -7 & & & & & \\
\hline & 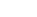 & 00 & $\bullet 0$ & 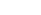 & 104 & .98 & 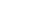 & 3 & - & - & $\cdots$ & \\
\hline
\end{tabular}

02307001 - ROCKY CREEK BL CONT NR SULPHUR SPRINGS ILAT 280223 LONG 0823431 )

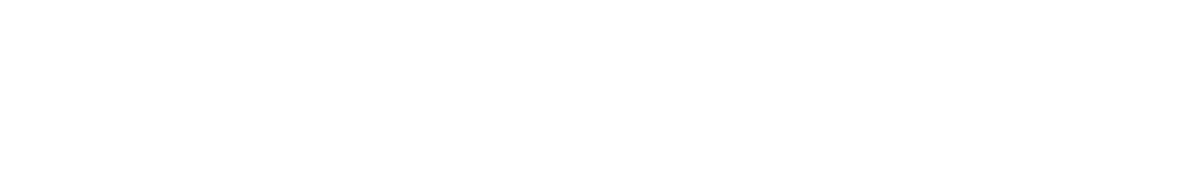

02307227 - CALM LAKE NR ODESSA FLA (LAT 280825 LONG 0823505 )

MAY 1970

02307243 - BROOKER CR NR ODESSA FLA (LAT 28 OR 50 LONG 08235401

MAY - 1970

$11 . . .1970 \quad .00$

02307359 - BROOKER CR NR TARPON SPRGS FLA (LAT 280545 LONG OR2 41 15)

MAY, 1970

.07

02307378 - CHURCH LK NR CITRUS PARK FLA IL.AT 28 n6 15 LONG 08236001

MAY 1970

$.02 \quad .0 \quad-34$

02307462 - LAKE TARPON SINK NFAR TARPON SPRINGS F (LAT 280734 LONG $\cap 8244 \quad 13$ )

MAY, 1970
$07 . .$.
JUNE
$22 . .$.

$\begin{array}{llll}.06 & 1.0 \quad 0.73 \quad 04 \quad .09\end{array}$

$.02 \quad .0$

02307542 - NORTH FORK BISHOP CR NR OLOSMAR. FLA. (LAT 280111 LONG 0824121 )

MAY $1970 \quad .11$

02307578 - OLD TAMPA BAY AT SAFETY HARBOR FLA (LAT 275917 LONG 0824107 )

MAY, 1970

$06 . . .02$

.0

02307697 - ALLIGATOR CR AT SAFETY HARROR FLA (LAT 275845 LONG OR2 41 45)

MAY, 1970

.0

3

1.1

.70

.89

3.5

13

50 

(MACRONUTRIENTS AND OTHER RELATED CONSTITUENTS)

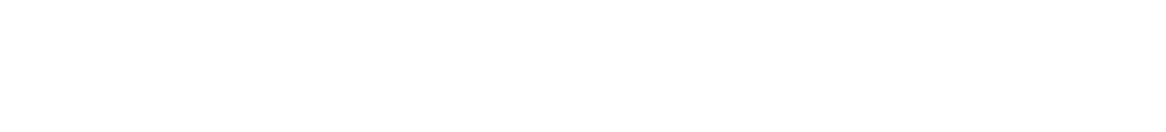

COASTAL BASINS BETWEEN HILLSBOROUGH RIVER AND WITHLACOOCHEE RIVER--CONTINUED

02308888 - SEMINOLE LK NM LARGO FLA ILAT 275020 LONG MR? 4650

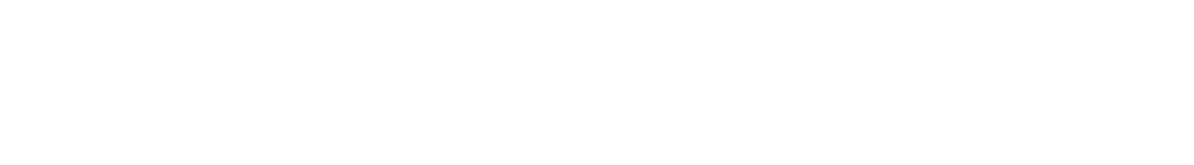

02309044 - MCKAY CH AT WALSINGHAM RV MR INDIAN RK (LAT 275245 LONIT OB? 48 35)

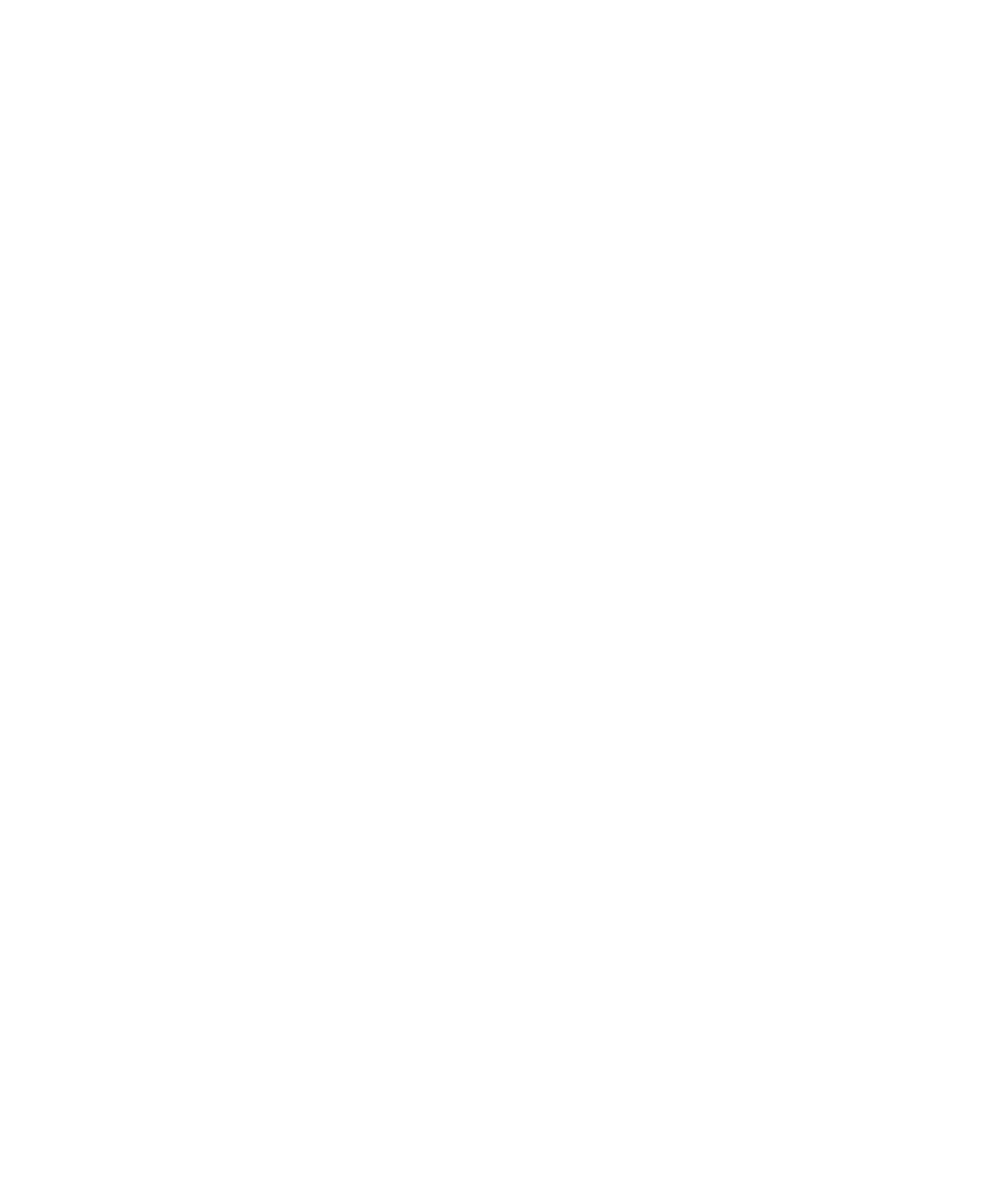


CHEMICAL ANALYSES, WATER YEAR OCTOBER 1969 TO SEPTEMBER 1970 MACRONUTRIENTS AND OTHER RELATED CONSTITUENTS

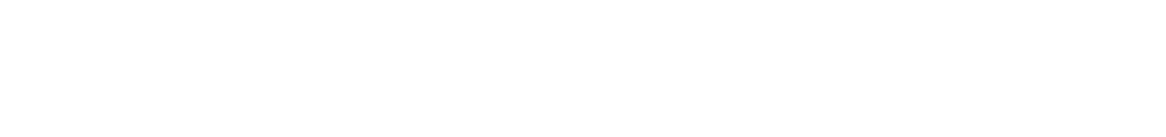

COASTAL BASINS BETWEEN HILLSBOROUGH RIVER AND WITHLACOOCHEE RIVER--CONTINUED

02310280 - PITHLACHASCATEE P NR FIVAY JCT FLA (LAT 2H 1944 LING 0833213 )

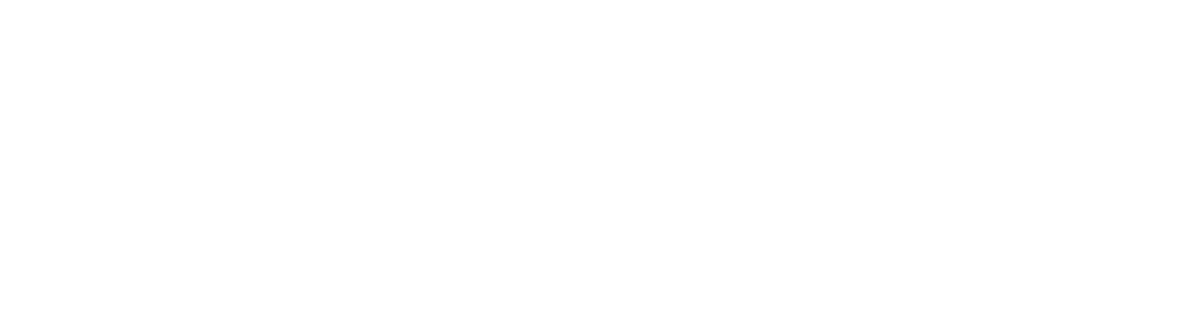

02310307 - PITHLACHASCOTEE RIVER AT NEWPORT RICHE (LAT 281424 LONG MBP 43 12)

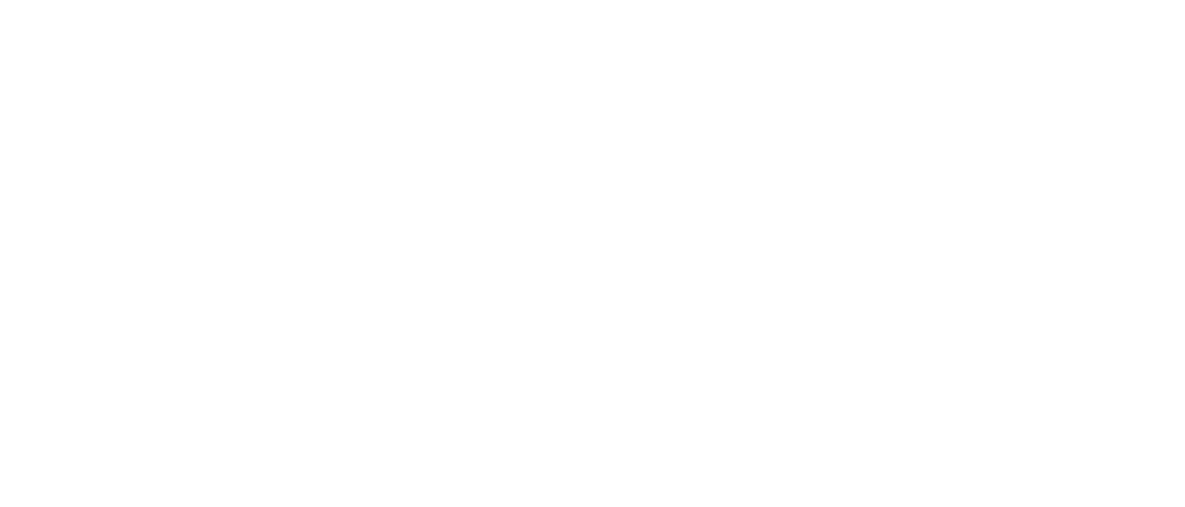

02310500 - WEEKIWACHEE SPRINGS NR BROOKSVILLE FLA ILAT 283100 LONG 08234251

\begin{tabular}{|c|c|c|c|c|c|c|c|c|c|c|c|c|}
\hline $\begin{array}{l}\text { FEB.. } 1970 \\
\text { JUNE }\end{array}$ & -- & .01 & .5 & -- & .03 & .06 & - & $n$ & -- & -- & - & 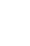 \\
\hline $02 \ldots$ & .05 & .01 & .1 & .12 & .03 & .03 & 4.3 & $n$ & 5 & 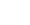 & -- & -- \\
\hline $\begin{array}{l}A U G . \\
17 \ldots\end{array}$ & - & .01 & .3 & -- & .03 & .05 & - & 0 & -- & - & $=$ & - \\
\hline
\end{tabular}

02310600 - GULF OF MEXICO NR BAYPORT FLA ILAT PR 3200 LING RPZ 3901 )

JUNE, 1970

$03 . . . \quad \quad .00$

02310678 - HOMOSASSA SPRGS AT HOMOSASSA SPRGS FLA (LAT 284758 LONG OBP 35 20)

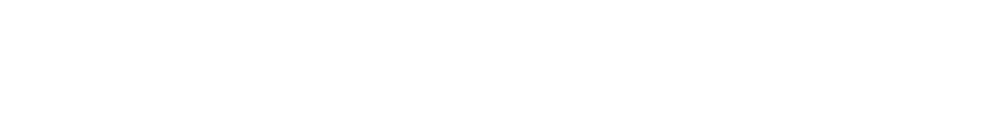

JUNE, 1970

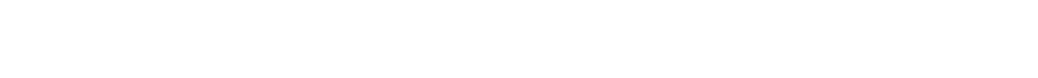

02310680 - MORRISON POND AT LECANTO FLA ILAT 285126 LONG 08229941

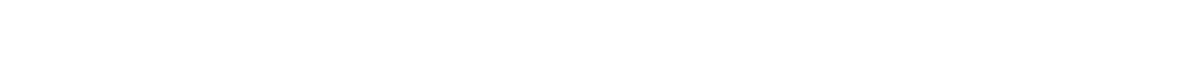

02310700 - HOMOSASSA R AT hOMOSASSA FLA ILAT 2R 47 OG LONG TR? 37 05) 
CHEMICAL ANALYSES, WATER YEAR OCTOBER 1969 TO SEPTEMBER 1970 (MACRONUTRIENTS AND OTHER"RELATED CONSTITUENTS);

\begin{tabular}{|c|c|c|c|c|c|c|c|c|c|c|c|c|}
\hline & $\begin{array}{l}\text { TOTAL } \\
\text { AMMONI A } \\
\text { (NHA) }\end{array}$ & $\begin{array}{l}\text { TOTAL } \\
\text { NITRITE } \\
\text { (NO2) } \\
\text { (MGI) }\end{array}$ & $\begin{array}{l}\text { TOTAL } \\
\text { NITRATE } \\
\text { (NO3) } \\
\text { (MGAL) }\end{array}$ & $\begin{array}{l}\text { ORGANIC } \\
\text { NITRO- } \\
\text { GEN } \\
\text { (N) } \\
\text { (MG/L) }\end{array}$ & $\begin{array}{l}\text { OIS- } \\
\text { SOLVEO } \\
\text { ORTHO } \\
\text { PHOS- } \\
\text { PHATE } \\
\text { (P04I } \\
\text { (MG/L) }\end{array}$ & $\begin{array}{l}\text { PHOS- } \\
\text { PHATE } \\
\text { (PO4) } \\
\text { (MG/L) }\end{array}$ & $\begin{array}{l}\text { DIS- } \\
\text { SOLVED } \\
\text { SILICA } \\
\text { (SIOZ) } \\
\text { (MG/L) }\end{array}$ & $\begin{array}{l}\text { TUR- } \\
\text { BID- } \\
\text { IYY } \\
\text { (JTU) }\end{array}$ & $\begin{array}{l}\text { COLOR } \\
\text { (PLAT- } \\
\text { INUM- } \\
\text { COBALT } \\
\text { UNITS) }\end{array}$ & $\begin{array}{c}\text { TOTAL } \\
\text { ORGANIC } \\
\text { CARBON } \\
\text { (C) } \\
\text { (MG/L) }\end{array}$ & $\begin{array}{l}\text { BIO- } \\
\text { CHEM- } \\
\text { ICAL } \\
\text { OXYGEN } \\
\text { OEMAND } \\
\text { (MGAL) }\end{array}$ & $\begin{array}{l}\text { DEPTH } \\
\text { (FT) }\end{array}$ \\
\hline
\end{tabular}

COASTAL BASINS BETWEEN HILLSBOROUGH RIVER AND WITHLACHDOCHEE RIVER-CONTINUED 02310750 - CRYSTAL RIVER NR CRYSTAL R FLA (LAT 285417 LONG 08238 13)

$\begin{array}{cccccccccccc}\text { JUNE, } 1970 & .02 & .01 & .0 & .17 & .07 & .11 & 7.3 & 0 & 5 & \ldots \\ \text { O8... } & .02 & .02 & .1 & -. & .08 & .10 & \ldots & 1 & \ldots & 206 & \ldots\end{array}$

\section{WITHLACOOCHEE RIVER BASIN}

02310760 - L JULIANA NR POLK CITY FLA (LAT 280751 LONG 08147 45)

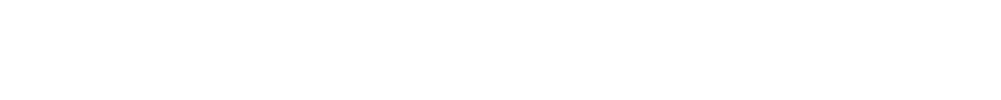

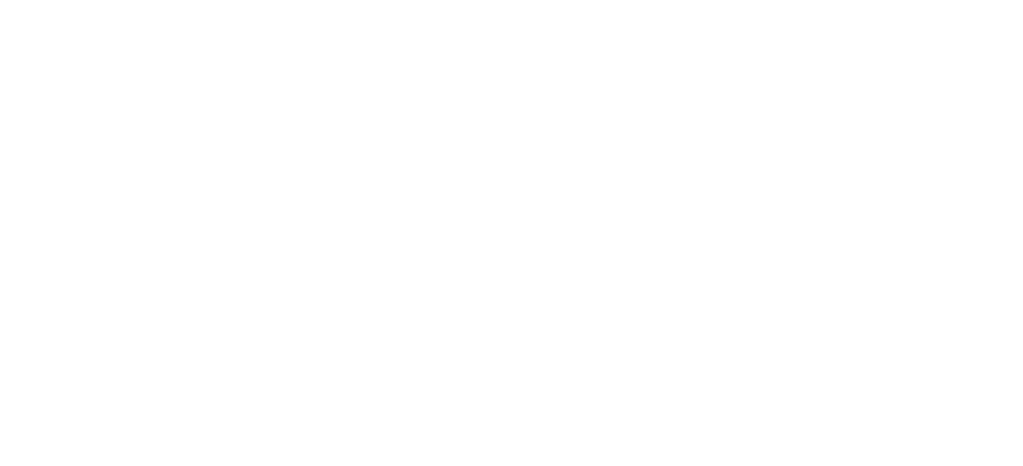

$\begin{array}{cccccccccc}\operatorname{MAY}, 1970 & 11 & .01 & .1 & .73 & .13 & .17 & 7.5 & \ldots & 50\end{array}$

02312100 - SPRING LAKF NR BROOKSVILLE FLA (LAT 282935 LONG 0821752 )

$\begin{array}{cccccccccccc}\text { MAY } & 1970 \\ 07 . . . & .07 & .01 & .0 & .95 & .02 & .25 & 2.8 & 20 & 20 & -\end{array}$

02312140 - BRYROOT SLOUGH HOWTRS NR BAY LAKE FLA (LAT 282723 LONG 08155 14)

\begin{tabular}{|c|c|c|c|c|c|c|c|c|c|c|c|}
\hline \multirow[t]{2}{*}{$\begin{array}{l}\text { MAY, } 1970 \\
07 \ldots \\
\text { SEP.. } \\
23 \ldots .\end{array}$} & .06 & .05 & -0 & .90 & .11 & .19 & .8 & I & 240 & - & -- \\
\hline & $=$ & $=$ & -- & $=-$ & $=$ & - & - & $=-$ & -- & 29 & -- \\
\hline
\end{tabular}

02312150 - L CATHERINE AT GROVELAND FLA (LAT 283427 LONG 0815137 )

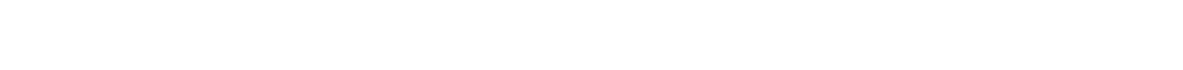

02312180 - LITTLE WITHLACOOCHEE RIVER NR TARRYTOW ILAT $2831 \quad 17$ LONG 08203 18)

$\begin{array}{ccccccccccc}\text { MAY, } 1970 & .05 & .05 & .0 & 1.2 & .07 & .13 & .4 & 0 & 200 & \ldots\end{array}$ 02312200 - LITTLE WITHLACO0CHEE R AT RERDELL FLA (LAT 283421 LONG 0820920 )

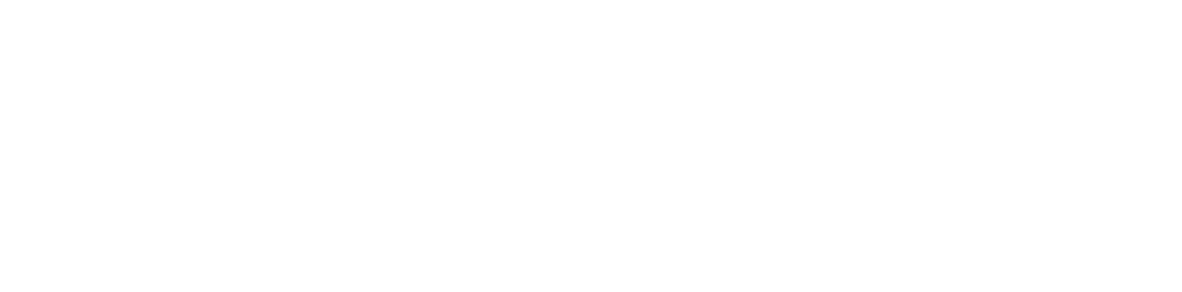


CHEMICAL ANALYSES, WATER YEAR OCTOBER 1969 TO SEPTEMBER 1970

(MACRONUTRIENTS AND OTHER RELATED CONSTITUENTS)

\begin{tabular}{|c|c|c|c|c|c|c|c|c|c|c|c|c|}
\hline ATE & $\begin{array}{l}\text { TOTAL } \\
\text { AMMONIA } \\
\text { (NHA) } \\
\text { (MG/L) }\end{array}$ & $\begin{array}{l}\text { TOTAL } \\
\text { NITR1TE } \\
\text { (NO2) } \\
\text { (MG/L) }\end{array}$ & $\begin{array}{c}\text { TOTAL } \\
\text { NITRATE } \\
\text { (NO3) } \\
\text { (MGL) }\end{array}$ & $\begin{array}{c}\text { ORGANIC } \\
\text { NITRO- } \\
\text { GEN } \\
\text { (N) } \\
(N G / L)\end{array}$ & $\begin{array}{l}\text { DIS- } \\
\text { SOLVED } \\
\text { ORTHO } \\
\text { PHOS- } \\
\text { PHATE } \\
\text { (PO4) } \\
\text { (MG/L) }\end{array}$ & $\begin{array}{l}\text { PHOS- } \\
\text { PHATE } \\
\text { (PO4) } \\
\text { (MG/L) }\end{array}$ & $\begin{array}{l}\text { DIS- } \\
\text { SOLVED } \\
\text { SILICA } \\
\text { (SIOZ) } \\
\text { (MG/L) }\end{array}$ & $\begin{array}{l}\text { TUR- } \\
\text { BID- } \\
\text { ITY } \\
\text { (JTU) }\end{array}$ & $\begin{array}{l}\text { COLOR } \\
\text { (PLAT- } \\
\text { INUM- } \\
\text { COBALT } \\
\text { UNITS) }\end{array}$ & $\begin{array}{c}\text { TOTAL } \\
\text { ORGANIC } \\
\text { CARBON } \\
\text { (C) } \\
\text { (MG/L) }\end{array}$ & $\begin{array}{l}\text { BIO- } \\
\text { CHEM- } \\
\text { ICAL } \\
\text { OXYGEN } \\
\text { DEMAND } \\
\text { (MG /L) }\end{array}$ & $\begin{array}{l}\text { DEPTH } \\
\text { (FT) }\end{array}$ \\
\hline
\end{tabular}

WITHLACHOOCHEE RIVER BASIN--CONTINUED

02312600 - WITHLACOOCHEE R NR FLORAL CITY FLA (LAT 284436 LONG 08213 13)

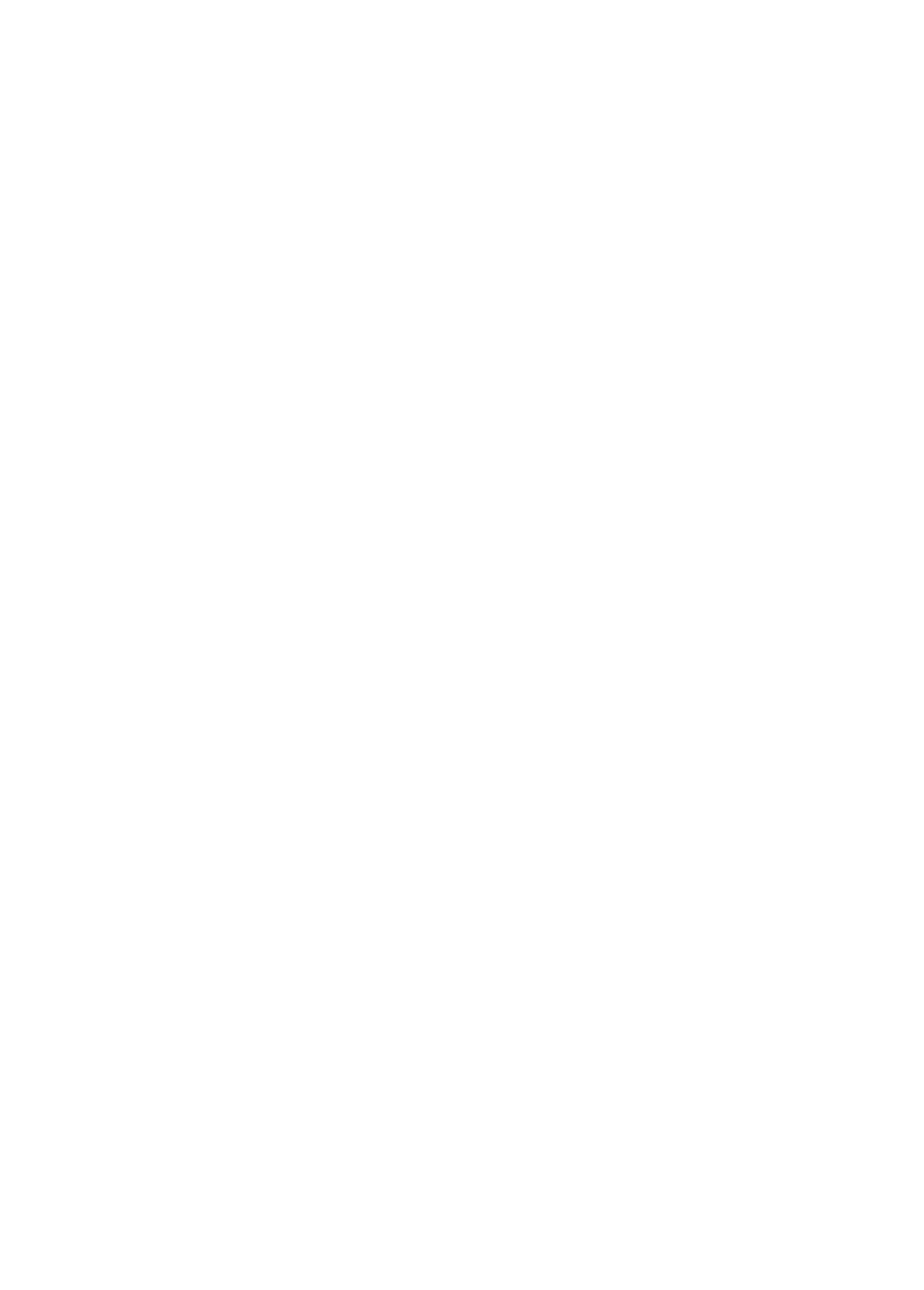




$\begin{array}{lll}\text { TOTAL } & \text { TOTAL } & \text { TOYAL } \\ \text { AMMONIA } & \text { NITRITE } & \text { NITRATE } \\ \text { (NH4) } & \text { (NO2) } & \text { (NO3) } \\ \text { (MG/L) } & \text { (MG/L) } & \text { (MG/L) }\end{array}$

ORGANIC
NITRO-
GEN
(N)
(MG/L)
UIS-
SOLVED
ORTHO THO

WITHLACHOOCHEE RIVER BASIN--CONTINUED

02313180 - ALUE RUN AT DUNNELLON. FLA. ILAT 290257 LONG 08226531

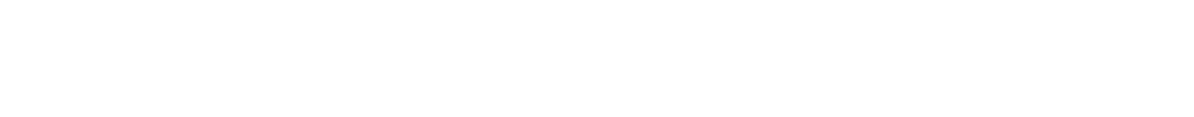

02313200 - WITHLACOOCHEE R AT DUNNELLON FLA (LAT 29 O2 45 LONG 08? 27531

APR., 1970

01

02313230 - WITHLACOOCHEE R AT INGLIS DAM NR DUNNE ILAT 29 ON 36 LONG n8Z 3700 )

\begin{tabular}{|c|c|c|c|c|c|c|c|c|c|c|c|c|}
\hline $\begin{array}{l}\text { JAN..1 } 1970 \\
21 . . .\end{array}$ & .08 & .01 & .1 & $\cdot 93$ & .09 & .11 & - & $1 ?$ & 80 & - & .7 & 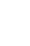 \\
\hline$\underset{\text { SEP. }}{20 . .}$ & .02 & .01 & .0 & .41 & .04 & .09 & 5.1 & 5 & 30 & -- & $\cdot \theta$ & - \\
\hline $18 \ldots$ & .06 & .01 & .1 & .31 & .06 & .10 & $5 . n$ & 14 & -- & - & 3.1 & $=-$ \\
\hline
\end{tabular}

02313231 - WITHLACOOCHEE R BL INGLIS DAM NR OUNNE ILAT 29 ON 36 LONG OB2 37 001

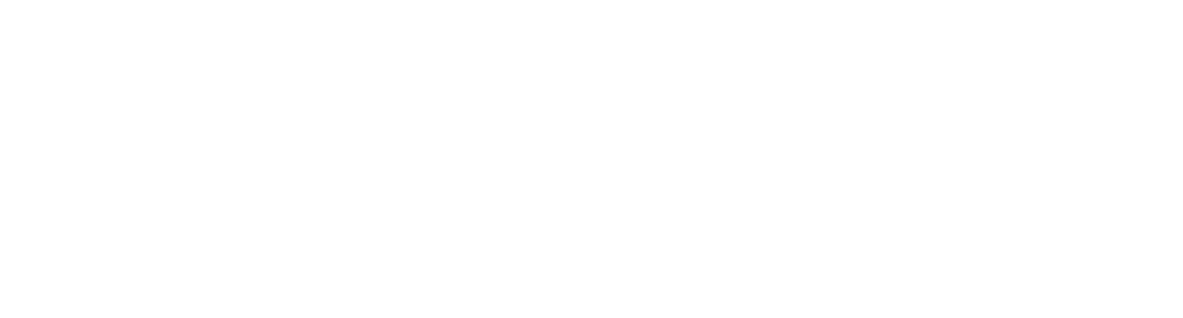

0231325] - WITHLACOOCHEE R BL BYPASS CHL STR NR I ILAT 290115 LONG OR2 3R 201

MAY, 1970

\begin{tabular}{|c|c|c|c|c|c|c|c|c|c|c|c|}
\hline $\begin{array}{l}20 . . . \\
\text { SEP. }\end{array}$ & .01 & .01 & $\cdot n$ & .21 & .08 & .13 & 5.3 & 3 & 25 & -- & .3 \\
\hline
\end{tabular}

02313263 - CFBC AT INGLIS LOCK NEAR INGLIS FLA (LAT 29 0130 LONG 08237001

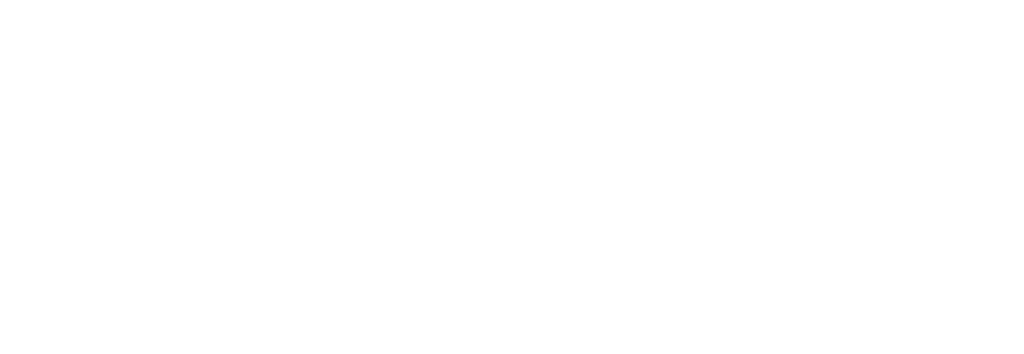
APR.. 1970
$27 . .$.
SEP...

$22 .$.

02313450 - BLUE SPRING NR GRONSON FLA ILAT 292702 LONE 0824157 )

MAY, 1970

MEP.
S2...

$\begin{array}{llllll}.00 & .6 & .30 & .13 & .15 & 6.4\end{array}$

02313510 - CHUNKY PONU NR BRONSON FLA ILAT P9 2336 LONG 0B2 37191

APR.. 1970

010 


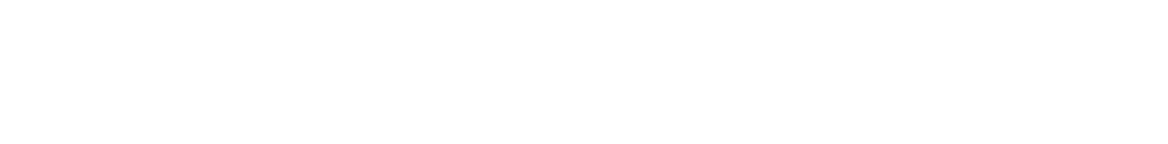

COASTAL BASINS BETWEEN WITHLACOOCHEE RIVER AND SUWANNEE RIVER--CONTINUED

02313600 - WEKIVA SPGS NR GULF HAMMOCK FLA LAT 29 I6 49 LONG OB2 3923 )

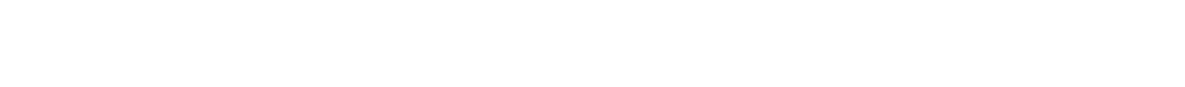

02313700 - WACCASASSA R NR GULF HAMMOCK FLA (LAT 291214 LONG 08246093

$\begin{array}{cccccccccccccc}A P R . .1970 & .09 & .03 & .2 & .50 & .16 & .21 & 5.2 & \ldots & 100 & \ldots & .9\end{array}$

02314200 - TENMILE CR AT LEBANON STATION FLA ILAT 290939 LONG OR2 38211

\begin{tabular}{|c|c|c|c|c|c|c|c|c|c|c|c|}
\hline $\begin{array}{l}\text { APR..' } 1970 \\
29 . . . \\
\text { SEP. }\end{array}$ & .15 & .04 & .2 & .81 & .10 & .15 & 1.4 & -- & 280 & + & $\cdots$ \\
\hline
\end{tabular}

02314205 - HORSE HOLE CR NR LEBANON STATION FLA (LAT 290801 LONG 08238 14)

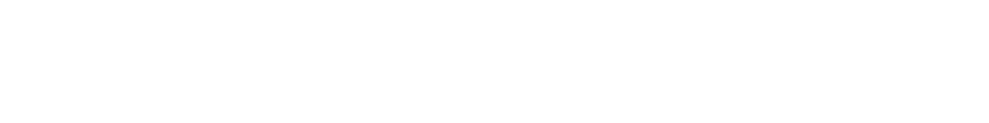

NOV.. 1969
$05 . .0$

02315005 - HUNTER CREEK NEAR BELMONT FLA ILAT 3029 20 LONG 08241401

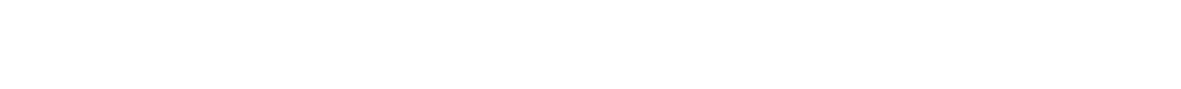

02315090 - ROARING CREEK NEAR BELMONT FLA (LAT 302550 LONG 08240001

\begin{tabular}{|c|c|c|c|c|c|c|c|c|c|c|c|c|}
\hline $\begin{array}{l}\text { NOV... } 1969 \\
05 \ldots . .\end{array}$ & $\cdots$ & .07 & .0 & -- & .78 & - & 7.1 & - & 400 & -- & -- & $=$ \\
\hline O4.... & .03 & .15 & . 0 & .88 & 1.0 & 1.7 & 7.1 & 5 & 560 & 71 & .5 & -- \\
\hline $12 \ldots$ & - & $=$ & -- &.$>8$ & .48 & .48 & 5.2 & 4 & -- & - & 1.6 & \\
\hline
\end{tabular}

02315500 - SUWANNEE R AT WHITE SPRINGS FLA (LAT 301932 LONG OR2 4418 )

\begin{tabular}{|c|c|c|c|c|c|c|c|c|c|c|c|}
\hline $\begin{array}{l}\text { OCT.. } 1969 \\
14 \ldots . . \\
\text { NOV. }\end{array}$ & - & .04 & .0 & -- & .32 & .33 & - & $I^{f}$ & - & - & .3 \\
\hline FER..."1970 & - & .06 & .0 & - & .50 & .54 & 5.4 & 55 & 200 & $=$ & .7 \\
\hline $\begin{array}{l}10 \ldots \\
\text { APR. }\end{array}$ & -- & .05 & .0 & - & .40 & .40 & - & 72 & - & - & .7 \\
\hline MAY $08 . \cdots$ & - & .06 & .0 & - & .20 & .18 & -- & 35 & $\cdots$ & -- & .9 \\
\hline
\end{tabular}

02315518 - OCCIDENTAL MINE DR D AT S HWY 137 (LAT 302505 LONG 0824725 )

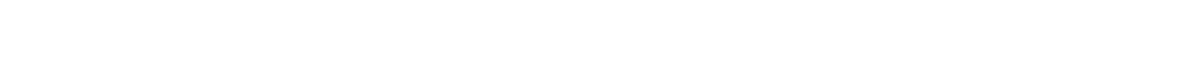

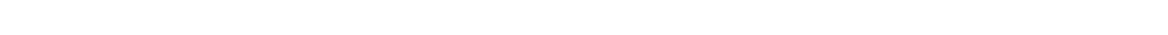

OCT., 1969
$14 \ldots$



CMACRONUTRIENTS AND OTHER RELATED CONSTITUENTSI

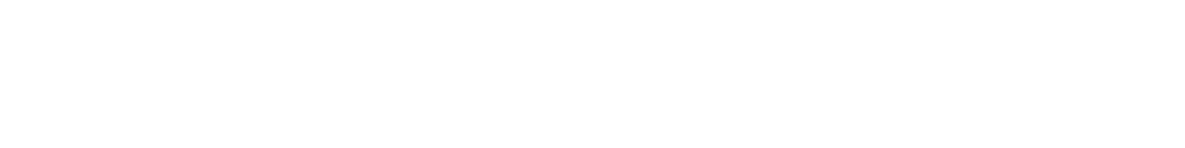

SUHANNEE RIVER BASIN--CONTINUED

02315534 - ROCKY CREEK TRIBUTARY NR WELLBORN FLA (LAT 301851 LONG OB2 49501

\begin{tabular}{|c|c|c|c|c|c|c|c|c|c|c|c|c|c|c|c|}
\hline $\begin{array}{l}\text { MAY, } 1970 \\
19 . . .\end{array}$ & - Il & .04 & 1.3 & .81 & .58 & & . 58 & 7.5 & & 3 & 120 & & -- & - & - \\
\hline & & 02315550 & - & SUWANNEE & $R$ AT $S$ & SUWANNEE & E SPRINGS & $S F L A$ & (LAT & $\begin{array}{ll}30 & 23\end{array}$ & 34 LONG & 082 & $\begin{array}{lll}56 & 001\end{array}$ & & \\
\hline $\begin{array}{l}0 \mathrm{OT} \ldots 1969 \\
15 . . . \\
\text { NOV. }\end{array}$ & $\cdots$ & .04 & .2 & - & .52 & & .53 & $-\infty$ & & 95 & -- & & - & .9 & - \\
\hline DEC... & -- & .06 & .0 & $\sim$ & - & & - & 5.2 & & - & 320 & & $\cdots$ & - & - \\
\hline FEB.\#1970 & $-\infty$ & .07 & .0 & -- & 1.1 & 1. & .1 & -- & & 69 & 200 & & - & 1.1 & $-\infty$ \\
\hline APR.” & $\rightarrow$ & .04 & .0 & - & .43 & & .50 & -- & & 33 & - & & $\infty$ & .8 & - \\
\hline MAY $08 . \cdots$ & -- & .06 & .0 & - & 2.8 & 2. & . 8 & -- & & 30 & - & & $\cdots$ & .9 & $\sim$ \\
\hline $\begin{array}{l}26 . . . \\
\text { AUG. }\end{array}$ & .04 & .08 & .6 & .50 & 1.4 & 1. & .6 & 6.1 & & 6 & 200 & & - & 2.0 & -. \\
\hline $\begin{array}{l}12 \ldots \\
12 \ldots\end{array}$ & $=$ & $=$ & $=$ & .24 & 1.7 & & 9 & 5.0 & & -5 & $=$ & $\begin{array}{l}38 \\
38\end{array}$ & & $: 3$ & $=$ \\
\hline
\end{tabular}

02315600 - SUWAINEE SPRINGS NR LIVE OAK FLA (LAT 302339 LONG 08256041

MAY 1970

$19 . .$.

02317630 - ALPAHA R NR JASPER FLA (LAT 303142 LONG 0830217 )

\begin{abstract}
$19 . . .01070$
.04

02319500 - SUWANNEE R AT ELLAVILLE FLA ILAT 302304 LONG 08210191
\end{abstract}

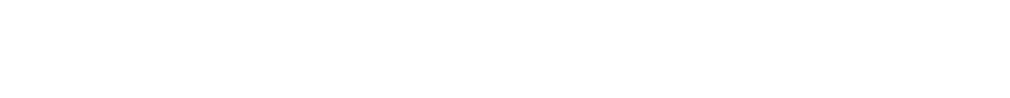

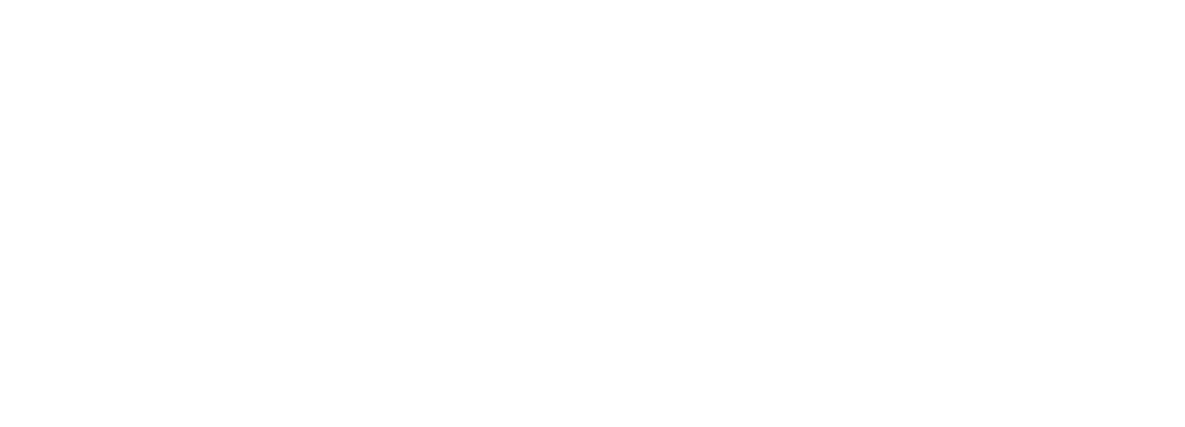

02321000 - NEW R NR L BUTLER FLA LLAT 295953 LONG 0821627

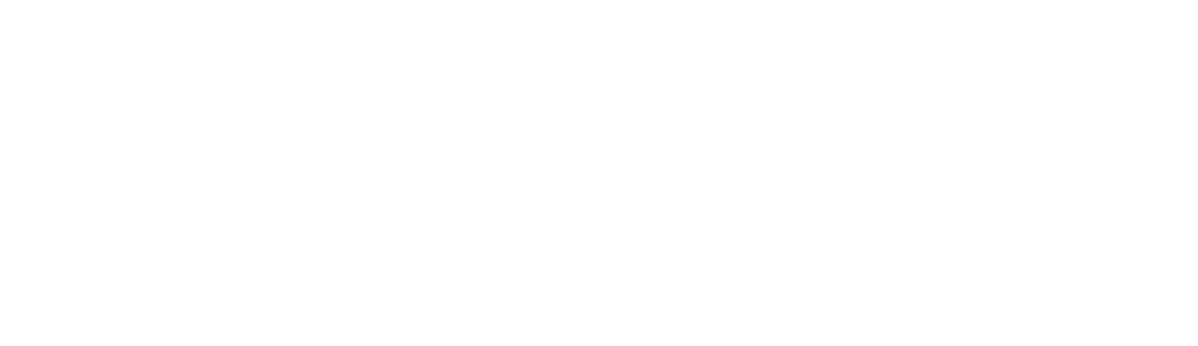


CHEMICAL ANALYSES, WATER YEAR OCTOBER 1969 TO SEPTEMBER 1970 IMACRONUTRIENTS AND OTHER RELATED CONSTITUENTSI

\begin{tabular}{|c|c|c|c|c|c|c|c|c|c|c|c|c|}
\hline & $\begin{array}{l}\text { TOTAL } \\
\text { AMMONIA } \\
\text { (NH4) }\end{array}$ & $\begin{array}{l}\text { TOTAL } \\
\text { NITRITE } \\
\text { (NO2) }\end{array}$ & $\begin{array}{l}\text { TOTAL } \\
\text { NITRATE } \\
\text { (NO3) }\end{array}$ & $\begin{array}{l}\text { ORGANIC } \\
\text { NITRO- } \\
\text { GEN } \\
\text { (N) }\end{array}$ & $\begin{array}{l}\text { DIS- } \\
\text { SOLVED } \\
\text { ORTHO } \\
\text { PHOS- } \\
\text { PHATE } \\
\text { (P04) }\end{array}$ & $\begin{array}{l}\text { PHOS- } \\
\text { PHATE } \\
\text { (P04) }\end{array}$ & $\begin{array}{l}\text { DIS- } \\
\text { SOL VED } \\
\text { SILICA } \\
\text { (SIOZ) }\end{array}$ & $\begin{array}{l}\text { TUR- } \\
\text { BID- } \\
\text { ITY }\end{array}$ & $\begin{array}{l}\text { COLOR } \\
\text { (PLAT- } \\
\text { INUM- } \\
\text { COBALT }\end{array}$ & $\begin{array}{l}\text { TOTAL } \\
\text { ORGANIC } \\
\text { CARBON } \\
\text { (C) }\end{array}$ & $\begin{array}{l}\text { RIO- } \\
\text { CHEM- } \\
\text { ICAL } \\
\text { OXYGEN } \\
\text { DEMAND }\end{array}$ & EPTH \\
\hline
\end{tabular}

SUWANNEE RIVER BASIN--CONTINUED

02322500 - SAVTA FE R NR FT WHITE FLA (LAT 295100 LONG 0824250 )

\begin{tabular}{|c|c|c|c|c|c|c|c|c|c|c|c|c|}
\hline $\begin{array}{l}13 \ldots \\
\text { DEC... }\end{array}$ & -- & .02 & .6 & -- & .39 & .40 & $=$ & 98 & -- & $=-$ & 1.0 & - \\
\hline $\begin{array}{l}10 \ldots \ldots 1970 \\
\text { FEB... } 1970\end{array}$ & -- & .06 & .7 & - & .27 & .29 & - & 14 & 160 & -- & .5 & -+ \\
\hline $\begin{array}{l}09 . . \\
\triangle P R\end{array}$ & - & .04 & .0 & -- & .25 & .32 & -- & 22 & $=$ & - & 1.2 & -- \\
\hline & $\cdots$ & .04 & .2 & - & .34 & .34 & $\rightarrow$ & 22 & -- & - & 1.1 & - \\
\hline $\begin{array}{l}22 . . . \\
\text { AUG. }\end{array}$ & .00 & .02 & 2.1 & .04 & .25 & .26 & 7.8 & 3 & 10 & 8.0 & 1.0 & \\
\hline $11 \ldots$ & $=$ & -- & $\omega$ & -- & - & - & -- & -- & $=-$ & 4.0 & - & \\
\hline
\end{tabular}

02322600 - ALLIGATOR L AT LAKE CITY FLA (LAT 301031 LONG 0823755 )

MAY, 1970

19.070

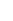

02322700 - ICHATUCKNEE SPGS NR HILDRETH FLA (LAT 295710 LONG $08247 \quad 10)$

MAY, 1970

22... $18 \quad .02$

\begin{tabular}{|c|c|c|c|c|c|c|c|c|c|c|c|c|}
\hline $\begin{array}{l}17 \ldots \\
\text { DEC. }\end{array}$ & - & .02 & .7 & $-\infty$ & .35 & .35 & $=$ & 20 & - & -- & 1.5 & -- \\
\hline $\begin{array}{l}12 \ldots \\
F E B, 11970\end{array}$ & -- & .00 & .9 & $-\infty$ & .28 & .31 & -- & 7 & 100 & $-\infty$ & .4 & $-\infty$ \\
\hline APR. & -- & .04 & - 1 & + & .29 & .28 & - & 22 & -- & -- & 1.3 & + \\
\hline$\underset{M A Y}{09 . . .}$ & - & .05 & .0 & - & .55 & .56 & - & 29 & 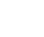 & - & 1.1 & - \\
\hline $\begin{array}{l}27 . \ldots \\
\text { AUG. }\end{array}$ & .02 & .04 & 2.2 & .18 & .38 & .38 & 7.2 & 7 & 30 & 9.0 & .4 & $\cdots$ \\
\hline $13 \ldots$ & .12 & .02 & 1.2 & .21 & .35 & .39 & 6.6 & 5 & -- & - & 1.1 & \\
\hline
\end{tabular}

COASTAL BASINS BETWEEN SUWANNEE RIVER AND AUCILLA RIVER

02324000 - STEINHATCMEF R NR CHOSS CITY FLA (LAT 294711 LONG 0831918 )

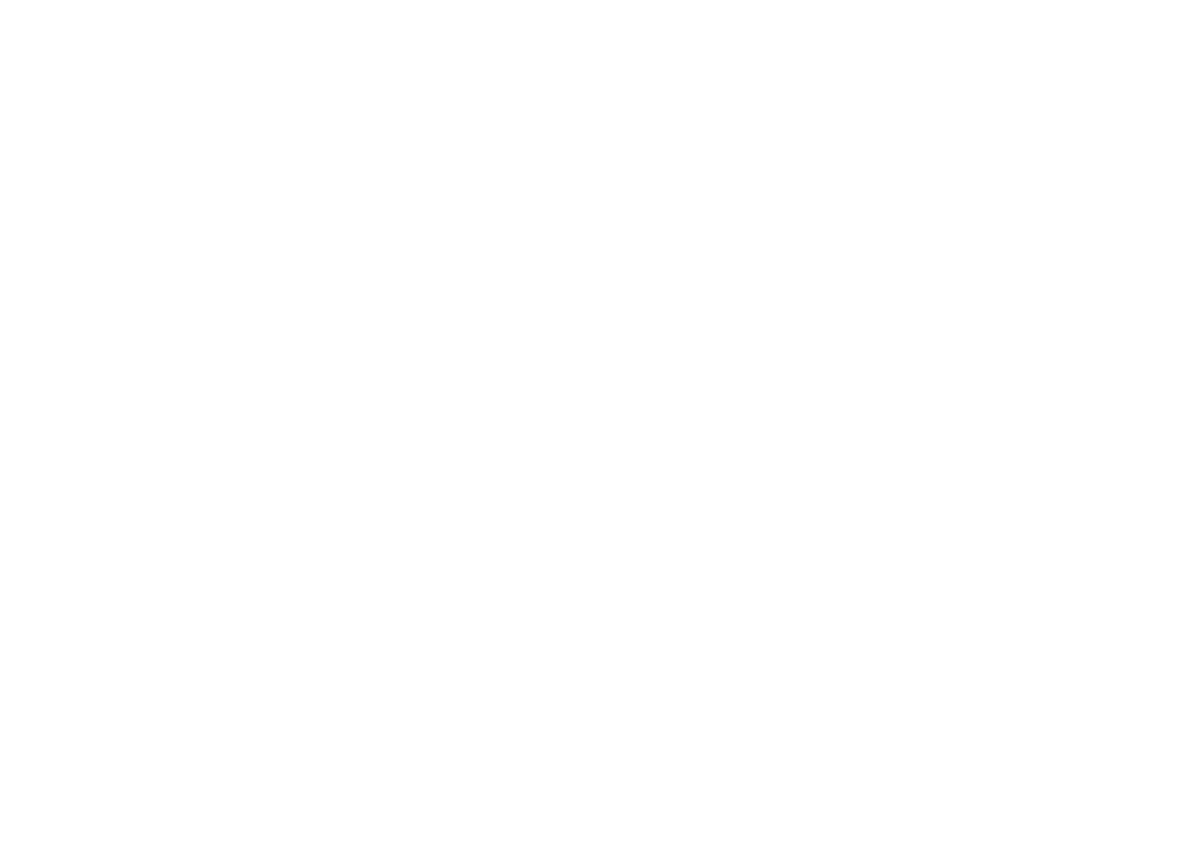



(MACRONUTRIENTS AND OTHER RELATED CONSTITUENTS)

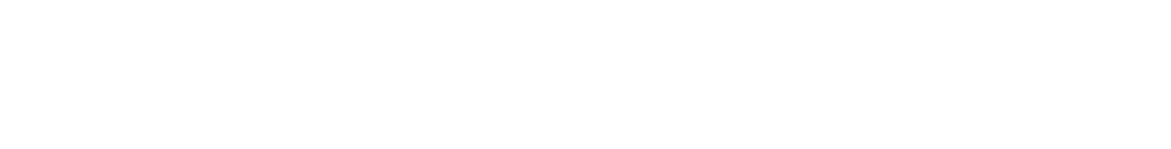

CDASTAL BASINS BETWEEN AUCILLA RIVER AND OCHLOCKDNEE RIVER 02320540 - CAMEY CFEEK NEAR MONTICELLO FLA (LAT 303052 LONG 88356 74)

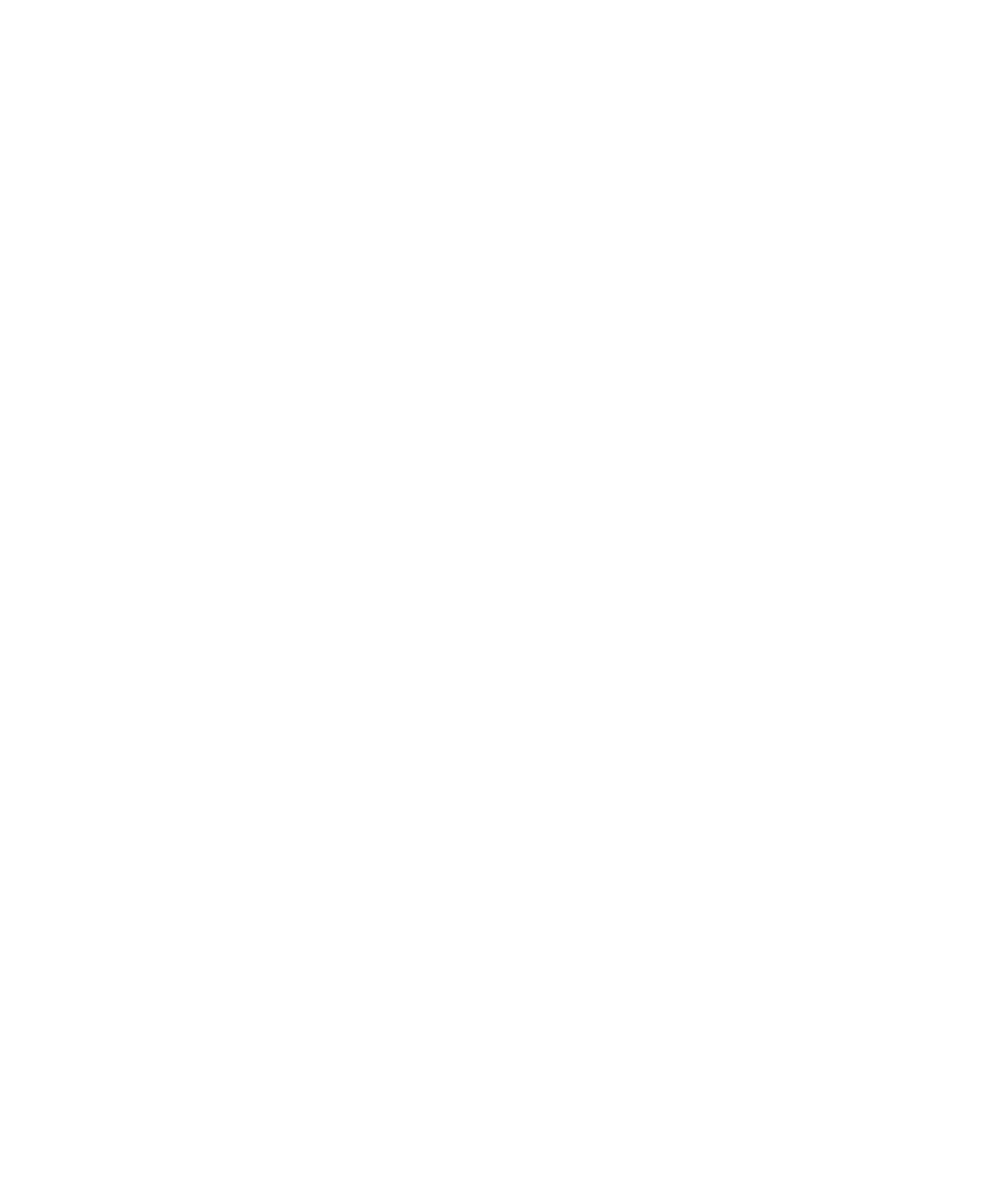


CHEMICAL ANALYSES, NATER YEAR OCTOBER 1969 TO SEPTEMBER 1970 (MACRONUTRIENTS AND OTHER RELATED CONSTITUENTS)

\begin{tabular}{|c|c|c|c|c|c|c|c|c|c|c|c|c|}
\hline DATE & $\begin{array}{c}\text { TOTAL } \\
\text { AMMONIA } \\
\text { (NH4) } \\
\text { (MG/L) }\end{array}$ & $\begin{array}{l}\text { TOTAL } \\
\text { NITRITE } \\
\text { (NO2) } \\
\text { (MG/L) }\end{array}$ & $\begin{array}{l}\text { TOTAL } \\
\text { NITRATE } \\
\text { (NO3) } \\
\text { (MG/L) }\end{array}$ & $\begin{array}{c}\text { ORGANIC } \\
\text { NITRO- } \\
\text { GEN } \\
\text { (N) } \\
\text { (MG/L) }\end{array}$ & $\begin{array}{l}\text { DIS- } \\
\text { SOL VED } \\
\text { ORTHO } \\
\text { PHOS- } \\
\text { PHATE } \\
\text { (PO4) } \\
\text { (MG/L) }\end{array}$ & $\begin{array}{l}\text { PHOS- } \\
\text { PHATE } \\
\text { (PO4) } \\
\text { (MG/L) }\end{array}$ & $\begin{array}{l}\text { OIS- } \\
\text { SOLVED } \\
\text { SILICA } \\
\text { (SIOZ) } \\
\text { (MG/L) }\end{array}$ & $\begin{array}{l}\text { TUR- } \\
\text { BIO- } \\
\text { ITY } \\
\text { (JTU) }\end{array}$ & $\begin{array}{l}\text { COLOR } \\
\text { (PLAT- } \\
\text { INUM- } \\
\text { CORALT } \\
\text { UNITS) }\end{array}$ & $\begin{array}{l}\text { TOTAL } \\
\text { ORGANIC } \\
\text { CAREON } \\
\text { (C) } \\
\text { (MG/L) }\end{array}$ & $\begin{array}{l}\text { HIO- } \\
\text { CHEM- } \\
\text { ICAL } \\
\text { OXYGEN } \\
\text { OEMANO } \\
\text { (MG/L) }\end{array}$ & $\begin{array}{c}\text { OEPTH } \\
(F T)\end{array}$ \\
\hline
\end{tabular}

APALACHICOLA RIVER BASIN

02358998 - HOLLIMAN BRANCH NP ALTHA FLA (LAT 303243 LONG 025 09 33)

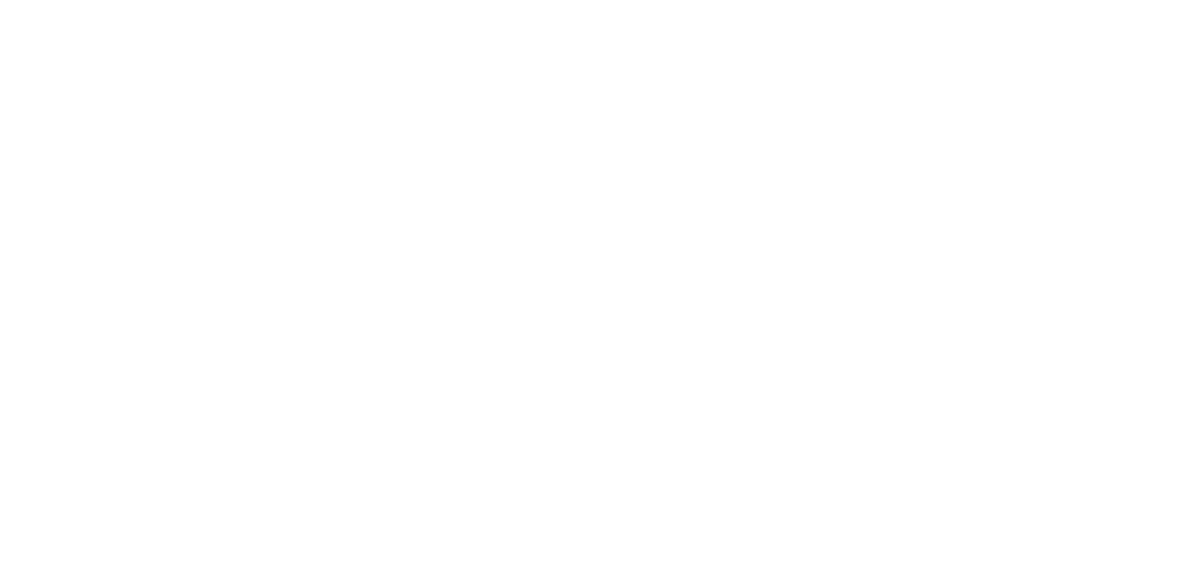

02359550 - BEAR CREEK NR YOUNGSTOWN. FLA. (LAT 301910 LONG 0852720 )

$$
\begin{aligned}
& \text { JUNE, } 1970 \\
& \text { OL... } \\
& .02
\end{aligned}
$$

\begin{tabular}{|c|c|c|c|c|c|c|c|c|c|c|c|}
\hline $\begin{array}{l}\text { JUNE, } 1970 \\
\text { O3... }\end{array}$ & .01 & .01 & .0 & .17 & .04 & .07 & 2.7 & 2 & 20 & 69 & . $^{2}$ \\
\hline
\end{tabular}

$$
\begin{aligned}
& \text { MAY }, 1970 \\
& 28.1
\end{aligned}
$$

02359660 - DEER POINT LAKE NEAR PANAMA CITY, FLA. (LAT 301745 LONG 0853455 ) CHOCTAHHATCHEE RIVER BASIN

02364620 - EIGHTMILE CREEK NEAK GASKIN, FLA. (LAT 305850 LONG 08610 4S)

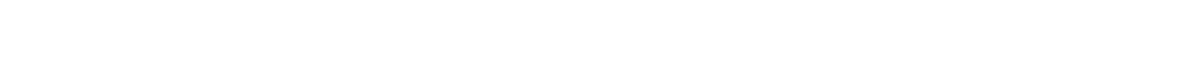

02364769 - SPRING BRANCH NEAR GASKIN. FLA. (LAT 3N 5818 LONG 086 05 53)

MAY, 1970

19...

.01

02364781 - LIMESTONE CREEK NEAR GASKIN. FLA. (LAT 3 N 5910 LONG 0860241 )

MAY 1970

.01

02365237 - FOWLER BRANCH NF LEONIA FLA (LAT 305517 LONG 0855601 )

$\begin{array}{ccccccc}\operatorname{MAY}, 1970 & .01 & .29 & 1.1 & .37 & .00 & .07\end{array}$ 


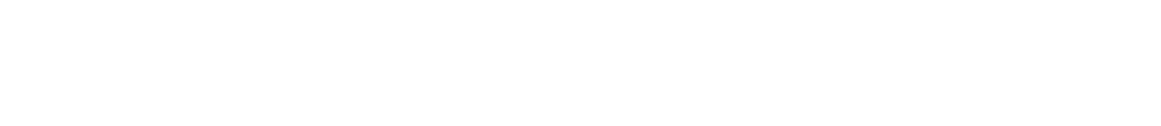

CHOCTAMHATCHEE RIVER BASIN--CONTINUED

\begin{tabular}{|c|c|c|c|c|c|c|c|c|c|c|c|c|}
\hline $01 \ldots . .1909$ & -- & - & .7 & -- & -- & - & 9.3 & - & 30 & -- & .7 & \\
\hline $\begin{array}{l}13 \ldots . . \\
31 \ldots:\end{array}$ & $=$ & $\begin{array}{l}.01 \\
.01\end{array}$ & :99 & $=$ &.$\overline{07}$ & .09 & $\begin{array}{l}8.6 \\
--\end{array}$ & $=$ & -- & $=$ & $=$ & $=$ \\
\hline Novi:... & -- & .03 & .8 & -- & -- & .07 & -- & -- & -- & -- & -. & - \\
\hline $\begin{array}{l}\text { OEC. } \\
\text { OE... }\end{array}$ & .- & -- & .3 & -- & -- & -- & 8.1 & .. & 10 & -- & .4 & \\
\hline $\begin{array}{l}100: \\
{ }_{31}^{1} \ldots:\end{array}$ & $\because$ & $\begin{array}{l}.01 \\
.04\end{array}$ & $: 00$ & $=$ &.$\pi$ &.$\overline{13}$ & 5.7 & $\because$ & 5 & $\because=$ & $\because$ & $\ddot{z}$ \\
\hline JAN.: 1970 & -- & .03 & 1.2 & -- & .04 & .06 & -- & -- & -- & -- & -- & $=$ \\
\hline FEB: & .- & .. & .5 & .. & -. & .. & 5.5 & -- & 90 & $\ldots$ & 2 & 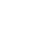 \\
\hline $\begin{array}{l}04 \ldots: \\
04 \ldots: \\
288 .\end{array}$ & $\because$ & .02 & .8 & $\because$ & - & $-\overline{06}$ & 5.8 & $\because$ & 40 & $\because$ & $\because$ & $=$ \\
\hline MAR:" & & & & & & & & & & & & \\
\hline $\begin{array}{l}30 \ldots: \\
31 \ldots:\end{array}$ & -- & $\begin{array}{l}.00 \\
.06\end{array}$ & 9 & - & .08 & .70 & 3.0 & $=$ & $=0$ & $\because$ & - & $\because$ \\
\hline 102...: & $=$ & .02 & $1: 2$ & $=$ &.$\overline{07}$ & .70 & 3.8 & $=$ & 35 & $\because$ & 1.5 & $\because$ \\
\hline $\begin{array}{l}\operatorname{mar} \\
27 . . .\end{array}$ & .14 & .04 & .7 & .29 & .11 & .15 & 6.2 & 28 & 0 & 6.0 & - & -- \\
\hline JUNE & - & - & 1.3 & - & .02 & .07 & -- & -- & -- & -- & - & - \\
\hline${ }_{30}^{03}: .:$ & $\because$ & $\begin{array}{l}: 02 \\
.03\end{array}$ & $1: 3^{\circ}$ & $=$ &.$\overline{06}$ &.$\overline{10}$ & 5.8 & $\because$ & 3E & $\because$ & $\stackrel{1.5}{-5}$ & $=$ \\
\hline $28 . \cdots$ & .26 & .01 & $0^{3}$ & .13 & .08 & .14 & 7.4 & - & -- & -- & -- & $=$ \\
\hline SEP.: & & .01 & 1.0 & & .04 & .08 & & - & -- & - & & \\
\hline $23 \ldots$ & .05 & .03 & .9 & .12 & .23 & .23 & 7.6 & 21 & 20 & -- & 1.0 & $\ldots$ \\
\hline
\end{tabular}

02365658 SANOY CREEK NEAR ARGYLE, FLA. ILAT 304549 LONG 08601221

\begin{tabular}{|c|c|c|c|c|c|c|c|c|c|c|c|}
\hline $\begin{array}{l}\operatorname{MAY}, 1970 \\
14 \ldots . . \\
\text { SEP. }\end{array}$ & .08 & .01 & .6 & .50 & .37 & .51 & 3.3 & 7 & 40 & $=$ & $=$ \\
\hline
\end{tabular}

02365700 - SANOY CR AT PONCE DE LEON FLA (LAT 304328 LONG 08556 12)

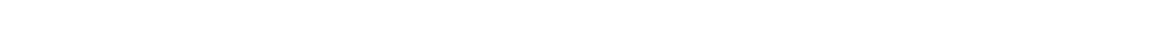

02365726 - BRUCE CREEK NR DEFUNIAK SPRINGS, FLA. (LAT 304153 LONG 0860450 )

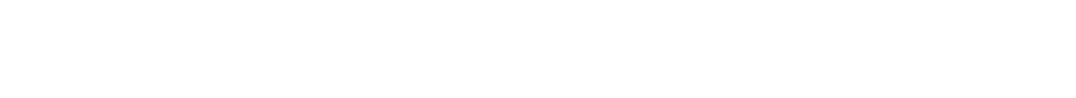

$\begin{array}{ccccccccccc}\text { MAY } & 1970 \\ 20 . . . & .07 & .00 & .0 & .52 & .01 & .08 & .5 & 3 & 5 & \ldots\end{array}$

02365758 - BRUCE CREEK NEAR RED BAY, FLA. ILAT 303651 LONG 0860050 )

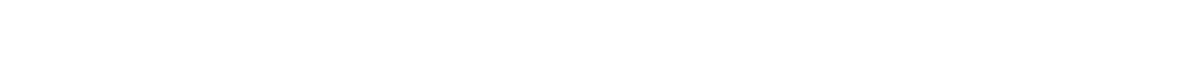

02365800 - SEVEN RUNS CREEK NEAR RED BAY, FLA. (LAT 303218 LONG B85 55 (4)

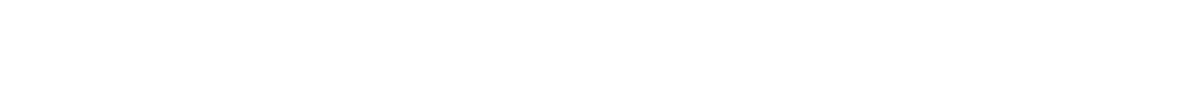

02366000 - HOLMES CR AT VERNON FLA (LAT 303735 LONG 0854245 )

MAY, 1970

26...

02366164 - REEDY BRANCH AT NEW HOPE FLA (LAT 3035 OB LONG 08548 05)

MAY, 1970

$26 .: .34$

.04

02366500 - CHOCTAWHATCHEE R NR BRUCE FLA (LAT 302703 LONG 08553 54)

MAY 1970

.11

.02

$1 \cdot 2$

.16

.03

$.09 \quad 7.6$ 
CHEMICAL ANALYSES, HATER YEAR OCTOBER 1969 TO SEPTEMBER 1970 (MACRONUTRIENTS AND OTHER RELATED CONSTITUENTS)

\begin{tabular}{|c|c|c|c|c|c|c|c|c|c|c|c|c|}
\hline DATE & $\begin{array}{l}\text { TOTAL } \\
\text { AMMONIA } \\
\text { (NH4) } \\
\text { (MG/L) }\end{array}$ & $\begin{array}{l}\text { TOTAL } \\
\text { NITRITE } \\
\text { (NO2) } \\
\text { (MG/L) }\end{array}$ & $\begin{array}{l}\text { TOTAL } \\
\text { NITRATE } \\
\text { (NO3) } \\
\text { (MG } / \text { L) }\end{array}$ & $\begin{array}{l}\text { ORGANIC } \\
\text { NITRO- } \\
\text { GEN } \\
\text { (N) } \\
\text { (MG/L) }\end{array}$ & $\begin{array}{l}\text { OIS- } \\
\text { SOLVED } \\
\text { ORTHO } \\
\text { PHOS- } \\
\text { PHATE } \\
\text { (PO4) } \\
\text { (MG L ) }\end{array}$ & $\begin{array}{l}\text { PHOS- } \\
\text { PHATE } \\
\text { (PO4) } \\
\text { (MG/L) }\end{array}$ & $\begin{array}{l}\text { DIS- } \\
\text { SOLVEO } \\
\text { SILICA } \\
\text { (SIOZ) } \\
\text { (MGIL) }\end{array}$ & $\begin{array}{l}\text { TUR- } \\
\text { BID- } \\
\text { ITY } \\
\text { (JTU) }\end{array}$ & $\begin{array}{l}\text { COLOR } \\
\text { (PLAT- } \\
\text { INUM- } \\
\text { COBALT } \\
\text { UNITS) }\end{array}$ & $\begin{array}{c}\text { TOTAL } \\
\text { ORGANIC } \\
\text { CARBON } \\
\text { (C) } \\
\text { (MG/L) }\end{array}$ & $\begin{array}{l}\text { BIO- } \\
\text { CHEM- } \\
\text { ICAL } \\
\text { OXYGEN } \\
\text { DEMAND } \\
\text { (MG/L) }\end{array}$ & $\begin{array}{l}\text { DEPTH } \\
\text { (FT) }\end{array}$ \\
\hline
\end{tabular}

CHOCTAWHATCHEE RIVER BASIN--CONTINUED

02366836 - BLACK CREEK NEAR BRUCE, FLA. (LAT $30>826$ LONG 0855920 )

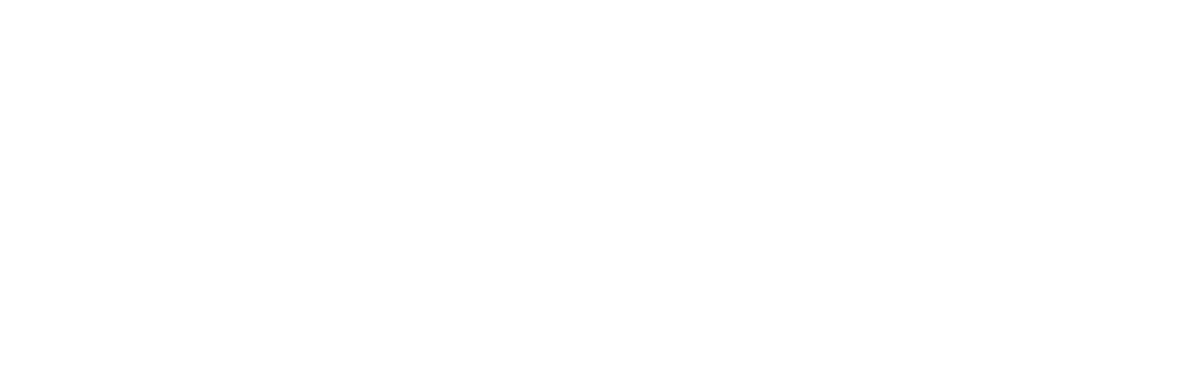

n2366911 - LAFAYFTTE CREEK AT FREEPORT, FLA. (LAT 3n 2935 LONG $086 \quad 0733$ I

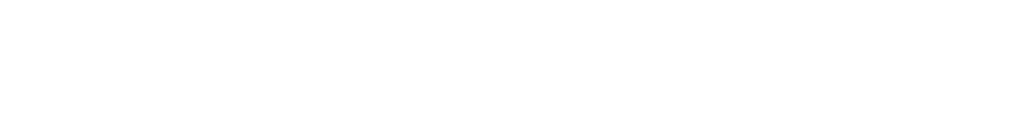

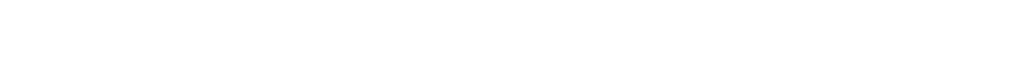
02367165 - BASIN CREEK NEAR PORTLAND, FLA. ULAT 3N 3102 LONG 08614091

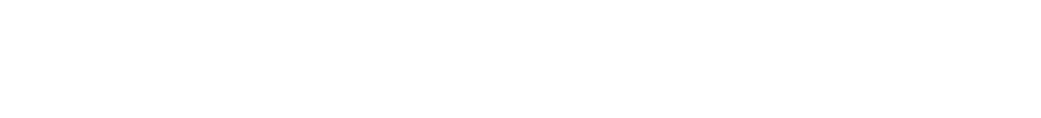

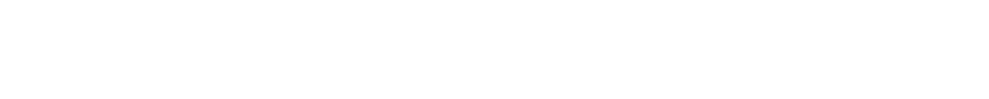

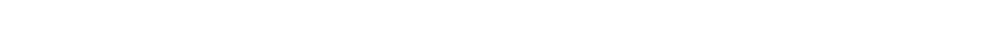
02367310 - JUNIPER CR AT SH 85 ND NICEVILLE FLA (LAT 3ก 3326 LONG OA6 31 10)

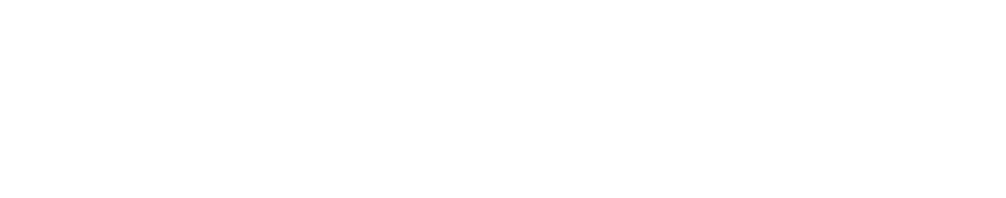
MAY 1970

02368500 - SHOAL R NR MOSSY HEAO FLA ILAT 304745 LONG 08618251

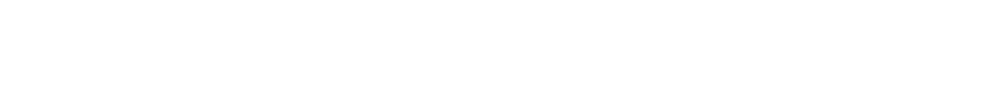
MAY 1970

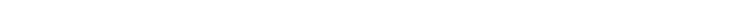

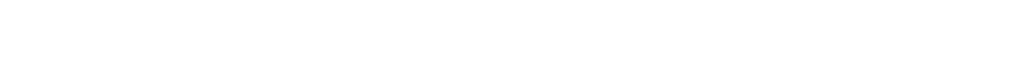
MAY, 1970 $\begin{array}{llllllll}.01 & .2 & .24 & .03 & .08 & 6.2 & 6 & 20\end{array}$ 
CHEMICAL ANALYSES, WATER YEAR OCTOBER 1969 TO SEPTEMBER 1970 (MACRONUTRIENTS AND OTHER RELATED CONSTITUENTS)

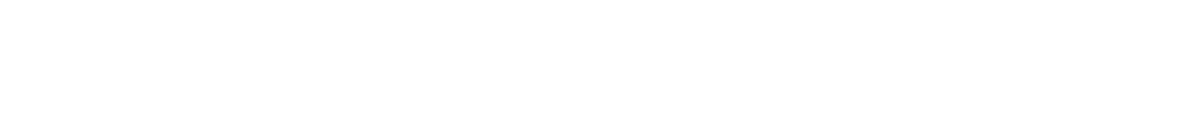

COASTAL BASINS BETWEEN CHOCTAWHATCHEE RIVER AND YELLOW RIVER--CONTINUED 02368836 - LONG CREEK NEAR MOSSY HEAD, FLA. (LAT 3N 4942 LONG 08620 26)

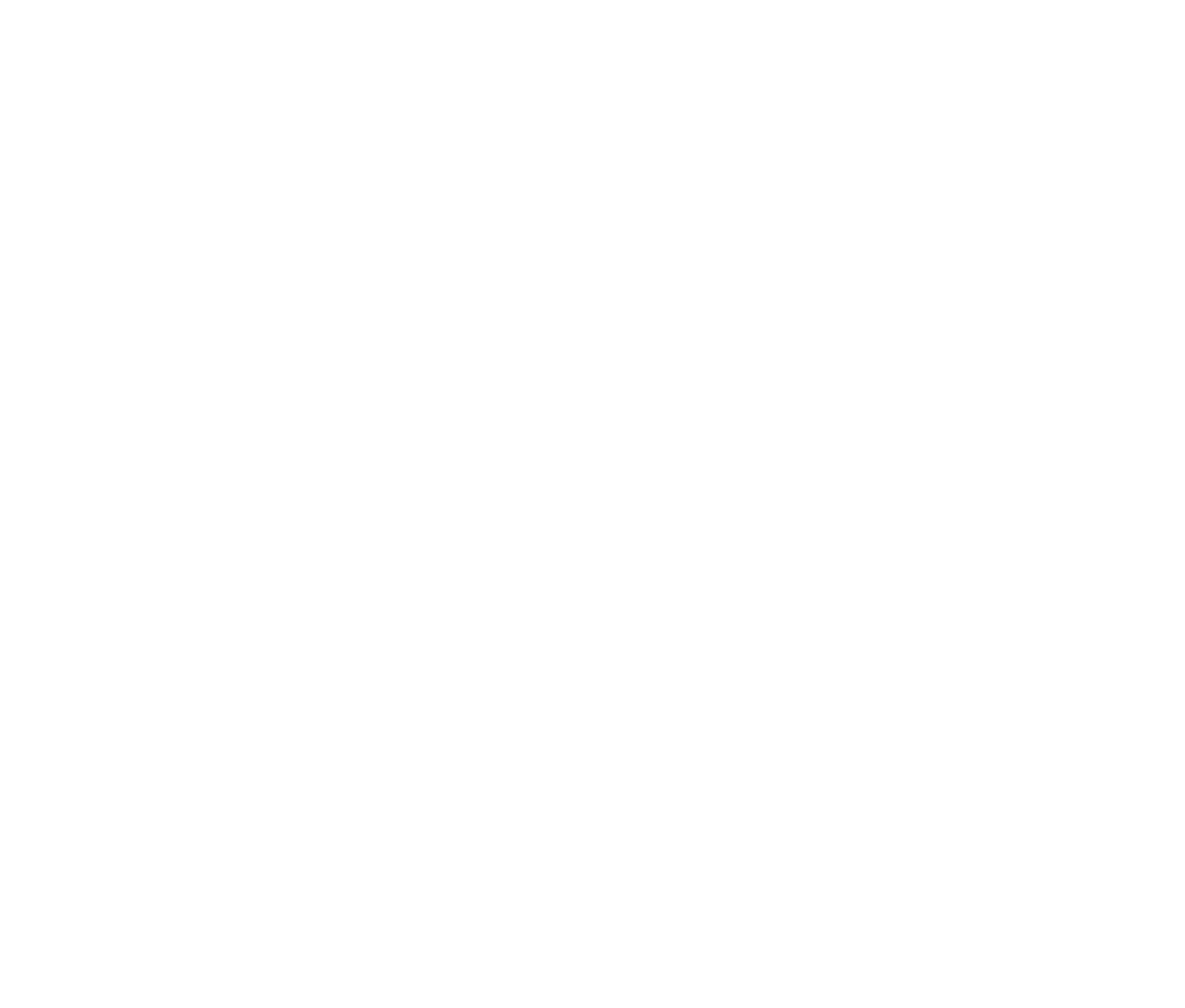

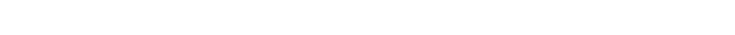

$A P R ., 1970$

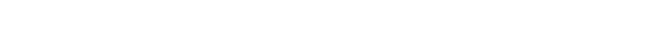

CDASTAL BASINS BETWEEN ESCAMBIA RIVER AND MOBILE RIVER

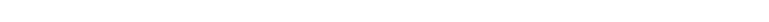

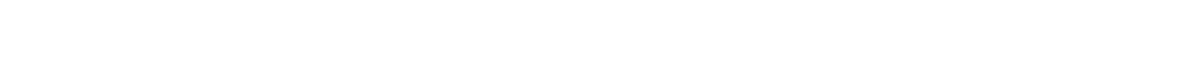

n2376300 - BRUSHY CR NR WALNUT HILL FLA (LAT 305321 LONG OA7 32 24)

AFR., 1970

$.01 \quad 1$.

02376500 - PEROIDO RIVER AT RARRINEAU PARK FLA (LAT 3n 41 25 LONG 0R7 36 25)

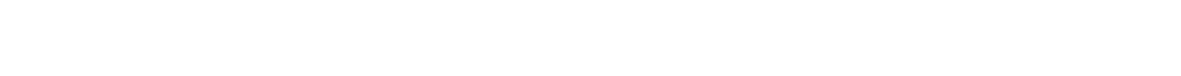

02376551 - CHUKCH HOISE RRANCH NEAR BARRIMFAU PARK. FLA (LAT 304027 LONG ORT 2343 )

$\begin{array}{llllllll}\text { APR., } 1970 & & & & & & & \\ 28 . . . & .05 & .01 & .0 & .19 & .03 & .06 & 5.3\end{array}$ 
CHEMICAL ANALYSES, WATER YEAR OCTOBER 1969 TO SEPTEMBER 1970

(MACRONUTRIENTS AND OTHER RELATED CONSTITUENTS)

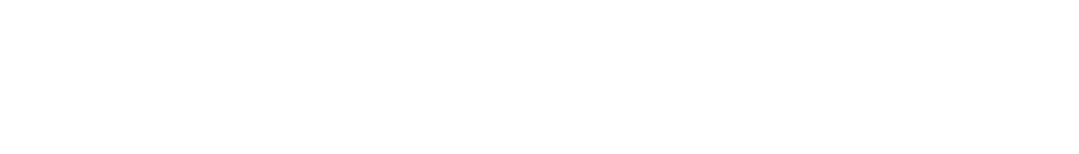

LAKE OKEECHOBEE AND THE EVERGLADES BASINS

252353080342200 - LEVEE 31 w CA AT HWY 27 IN MOMESTEAD F (LLT 252353 LOTVG O20 3422 )

\begin{tabular}{|c|c|c|c|c|c|c|c|c|c|c|}
\hline $\begin{array}{l}\text { JAN., } 1970 \\
\text { I2... }\end{array}$ & $\cdots$ & .01 & -0 & $\cdots$ & $\cdots$ & -- & 3.1 & -- & 10 & -- \\
\hline $15 \ldots$ & - & -- & - & -- & .00 & -- & 3.4 & - & 5 & -- \\
\hline
\end{tabular}

253251081124500 - GUL OF MEX AT LOS RIV RAN STA NR EVEPG (LAT 253251 LONG 0811245$)$ MAY . 1970

$19 . . . \quad .10 \quad .01$

253400080570000 AUG., 1970

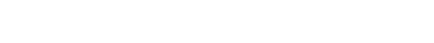

ROGERS RIV HEADWATEKS NR PINECREST FLA ILAT 753400 LONG 0 HO 5700 ?

.. $21 \quad .1$

254021081051500 SEP. 1970

$23 . .$.

254450080563000

UNIVER OF MIAMI PONO AT SR 94 NR MIAMI ILAT 254450 LONG 0305030 MAR, 1970

MAR...

.0001970

$254500080580000-$ NOV., 1969

$19 . .$.

$.12 \quad .00$

CULVERT 24 ON LOOP ROAD NR PINECREST F ULAT 254500 LONG 0805900 )

$2547150 R 1055000-$

$\begin{array}{lll}\text { MAF., 1970 } & & \\ 25 . . . & .00 & .01 \\ \text { MAY } & & \\ 12 . . . & .20 & .02 \\ \text { SEP... } & .13 & .01 \\ 11 . . . & .13\end{array}$

$11 \ldots . .013$

254719080181300 . NOV.. 1969

$\begin{array}{lll}17 \ldots . . & .16 & .51 \\ 18 \ldots & .13 & .01\end{array}$

254735080155200 NOV.. 1969

$17 . . .^{1969} .37 \quad .08$

254612080182000 -

BORRON PIT CA AT LULLUM RO MIAMI FLA LLAT $2548 \quad 12$ LONG OAO 18301

Nov.. 1969 $.26 \quad .05$

CYPRESS STRAINO OFF ST RT 94 NR PINECRF ILAT $2547 \quad 15$ LONG N8I 05501

254818080160100 - DRAIN OITCH NE COR MIAMI INT ALRPORT M LLAT 2549 IB IONG OHO IS OI) NOV.. 1969

$17 \ldots$

255040080555000 NOV., 1967

$18 . . . \quad .10 \quad .01$

$255120080523000-$

NOV.. 1969

\begin{tabular}{|c|c|}
\hline $\begin{array}{l}18 . . . \\
\text { JUNE, } 1970\end{array}$ & .30 \\
\hline JuL $17 . \cdots$ & .02 \\
\hline $14 \ldots$ & .03 \\
\hline $\begin{array}{l}\text { AUG. } \\
13 \ldots . \\
13 \ldots\end{array}$ & .16 \\
\hline SEP. & .07 \\
\hline
\end{tabular}

TAMIAMI CA AT JETHORT ENTRANCE NR MIAM (LAT 255040 LONG OUO 5550 )

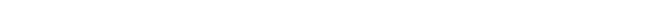

$\begin{array}{ccccccccc}.0 & 1.4 & .03 & .03 & .5 & -. & 10 & 11 & \ldots \\ .0 & .68 & .02 & .07 & 1.5 & 1 & 20 & -- & - \\ .0 & -. & .01 & .04 & 1.4 & 5 & 0 & \ldots & - \\ --0 & .-11 & .02 & .05 & 1.4 & -. & -- & 7.0 & - \\ .2 & .65 & .02 & .05 & 2.2 & 4 & 20 & \ldots & -\end{array}$




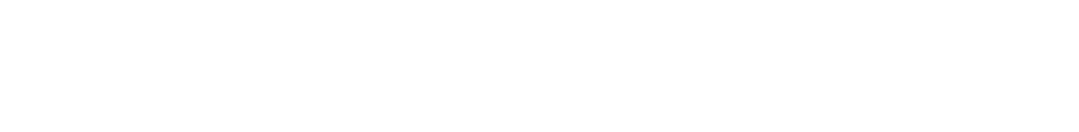

\section{LAKE OKEECHOBEE AND THE EVERGLADES BASINS--CDNTINUED}

255120080540000 - CYPRESS SWP NR JETPORT GORROW PIT 3 NR (LAT 255120 LONG 0805400$)$

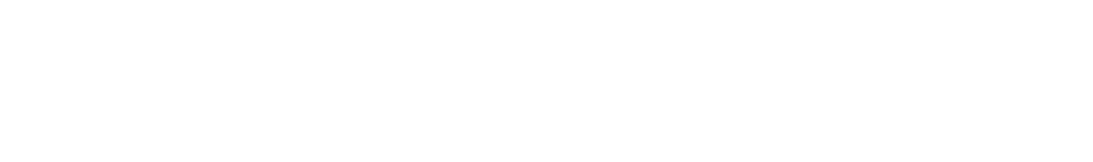

255230080522200 - JETPORT RORROW PIT NO 1 NEAR PINECREST (LAT 255230 LONG 08052 22) NOV., 1969

255230080550000 - JETPORT BORROW PIT 5 NR MIAMI FLA ILAT 255230 LONG 0805500 )

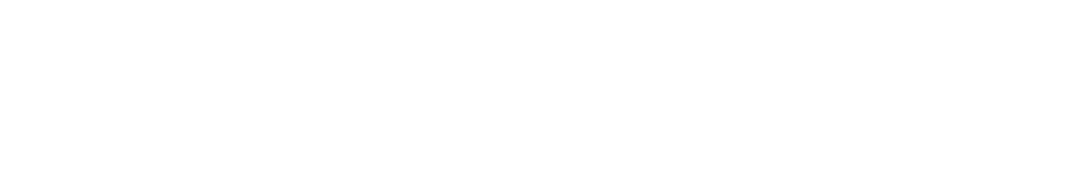

255231080520000 - ROGERS RIVER HEADWATERS NR EVERGLADES \&LAT 255231 LONG 08052008 AUG., 1970 $14 \ldots$

255231080522000 JUNE. 1970 $17 .$.

255307081281900

$\begin{array}{lll}\text { MAR., } 1970 & \\ 30 \ldots . . & .00 & .0 \\ \text { MAY } & & \\ 19 . . . & .10 & .0 \\ \text { SEP. } & & \\ 21 \ldots . . & .16 & .0 \\ 21 \ldots & . & \end{array}$

255329081302400 MAR.P 1970

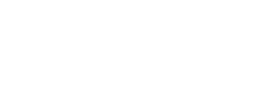

$\begin{array}{ccc}21 . . . & .09 & .01 \\ 21 . . . & -. & -.\end{array}$

255520080562200 CYPRESS SWP NR JP PIT \#4 NEAR PINECRES ILAT 255231 LONG O8O 52201 1970

\begin{tabular}{|c|c|}
\hline JUNE & .00 \\
\hline $16 \ldots$ & .28 \\
\hline JULY & \\
\hline $14 \ldots$ & .04 \\
\hline SEP. & .18 \\
\hline $15 .$. & .04 \\
\hline
\end{tabular}

255741080154500 FERGUSON R AT MOUTH NR EVERGLADES CITY ILAT 255307 LONG 08128 19)

$$
\begin{array}{cccc}
2.8 & 1.2 & .06 & .09 \\
.0 & .32 & .07 & .10 \\
.0 & .61 & .05 & .09 \\
.- & .- & .0 & 0
\end{array}
$$
FAKA UNION CANAL aT MOUTH NR EVERGLADE ILAT 255329 LONG 08130241

$\begin{array}{ccccccccc}1.6 & .43 & .04 & .06 & 3.9 & 1 & 50 & \ldots & \ldots \\ .0 & .34 & .03 & .07 & 6.5 & 6 & -- & \ldots & \ldots \\ .0 & .34 & .30 & .10 & 5.2 & 6 & 30 & \ldots & \ldots \\ -. & -. & -. & -. & -. & -- & -- & 14 & \ldots\end{array}$

CYPRESS PONO NW OF JETPORT NR MIAMI FL ILAT 255520 LONG DBO 56 22)

$\begin{array}{ccccccccc}- & .00 & .01 & .04 & .5 & 2 & 25 & \ldots & \ldots \\ .0 & 1.2 & .15 & .26 & 5.4 & 1 & 30 & \ldots & \ldots \\ .0 & .54 & .02 & .06 & 2.8 & 1 & 20 & \ldots & \ldots \\ .0 & .05 & .02 & .04 & 2.0 & 2 & 20 & \ldots & \ldots \\ .0 & .04 & .02 & .03 & 2.0 & 2 & 20 & \ldots & \ldots\end{array}$

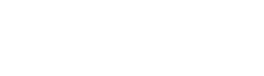

255830080041000 SNAKE CREEK AT NW 37 AVE NEAR CAROL CI ILAT 255741 LONG 0801545 I UG.. $1970 \quad .12 \quad .05$

255840081232100 - JANES SCENIC DRIVE CANAL NEAR COPELAND FL (LAT 255840 LONG 08123211 NOV., 1969 $18 . .1969$ .00 
CHEMICAL ANALYSES, WATER YEAR OCTOBER 1969 TO SEPTEMBER 1970

(MACRONUTRIENTS AND OTHER RELATED CONSTITUENTS)

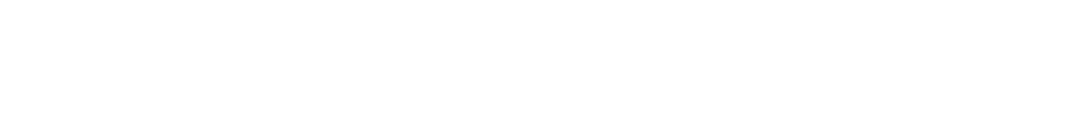

LAKE OKEECHOBEE AND THE EVERGLADES BASINS--CONTINUED

tho031080145300 - JAVIE RO CNL PEMBROKE PINES AT HOL BL ILAT 26 DO 31 LONG D80 14531

SEP.. 1970

200114081242300

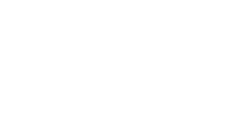

.03

IN FAKHAT STNO OFF JANES SC DR NR C ILAT $26 \quad 01214$ LONIG 0 OBI $24 \quad 23$ )

240114081245000

CANAL OFF JANES SCENIC UR NR COPELAND (LAT 26 OI 14 LONG 0812450 )

$\begin{array}{ccc}\text { MAY. } 1970 & & \\ 12 \ldots . .0 & .10 & .01 \\ 12 \ldots & .10 & .01\end{array}$

$\begin{array}{lll}12 . . . & .10 & .01 \\ 210 . & .10 \quad .01\end{array}$

260333080024300

DANIA CUTOFF CA W OF FECRR HR AT DANIA ILAT $26 \quad 03 \quad 33$ LONG OBO DR 431 FEN., 1970

$\begin{array}{llllllllll}13 . . . & .25 & 1.1 & .1 & .86 & .17 & .17 & 6.2 & 12 & 45\end{array}$

260514080110800 - WORTH NEN RIV CA AT SW JI AVE AT FT LA ILAT 2B OS 14 LOHG 09011081

FEH.: 1970

$\begin{array}{ccc}17 \cdots & .57 & .10 \\ 17 \cdots & -0 & -0\end{array}$

$29 . . . \quad .53 \quad .09$

260618080121700

$-$ FEF., 1970

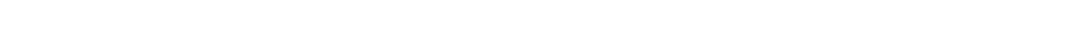

260702000085800 - NEW RIVER AT SW 4TH \& 7 TH AVE FT LAUDE ILAT ZG 0702 LONG 080 0R S8I

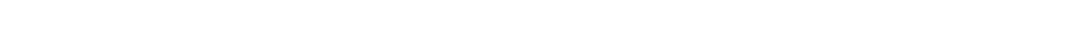

ZMOT29080074400 - NEW KIVER AT SE 15TH AVE AT FT LAUDERD ILAT 260729 LONG 08007441

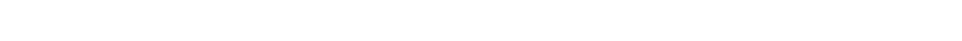

260743080103100 - NORTH FK NEW LIV AT NW 6TH ST FT LAUDE ILAT 2A OT 43 LONG OBO In 311

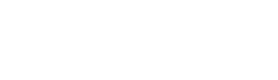

$\begin{array}{ccccccccc}.3 & .92 & 7.7 & 7.8 & 8.2 & 61 & 45 & -- & \ldots \\ 0.1 & .00 & 9.4 & 0.4 & 7.4 & 14 & 40 & \ldots & \ldots\end{array}$

260807080140200 - PLANTATION RO CA AT NW 65 AVE IN PLANT (LAT 26 OB OT LONG 080 14 02)

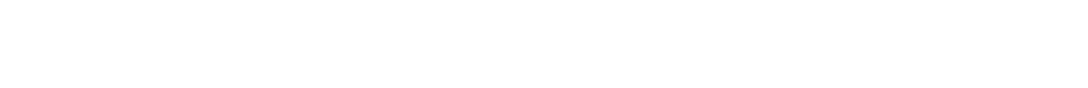

260919080172300 - MIDOLE RIVEF CANAL NR LAUDERHILL FLA (LAT 26 O9 19 LONG DAO 1723 )

SEP.: $1970 \quad 1.3$

261000080553000

CYPRESS POND OFF EVERGLADES PKWY NR FT (LAT 261000 LONG 0805530 )

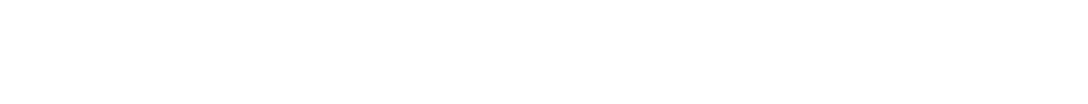




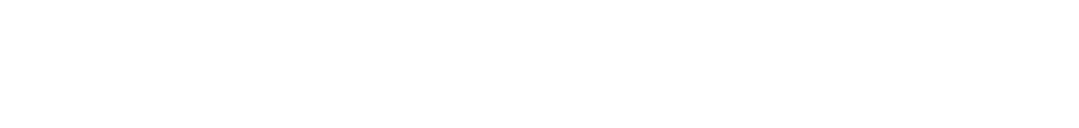

LAKE OKEECHOBEE AND THE EVERGLADES BASINS--CONTINUED

201000080703000 - CYPRFSS PONO OFF EVERGLQDES PAKKWAY NR FT L ILAT 2- 10 ON LONG 0807030$)$ WAY, 1970

$18 . .0$

MIODLE Q CA (C-13) AT LAUNERMILL FLA (LAT 26 IO 30 LONF ORO 13 14) SEP.. 1970

$311 .$.

2610340800935nO - CA-13 FEERER CA AT IOTH AVE FT LAUDERO (LAT 2H IN 34 IONG ORO OY 35) FER... 1970

261057080442600

AUG.. $1970 \quad .05$

261131040105000 -

RCRPOW PIT ON PROSPECF HOAI MP FT LAUT IIT 251131 LONG 08010 59) FEH., 1970

261148080114800

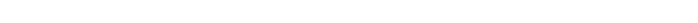
FEF., 1970

$\begin{array}{lll}\text { FEF., } 1970 & .17 \\ 16 \ldots & -. .0\end{array}$

261240080494000 L-2B HORRON CA AH S-140 NK ANFOYTOWN FL ILAT 2 K 12 4n LONG nan 4940 ) AUG., 1970

$261300080543000-$ LEVEF ZH INTE.RCFPTOR NH ANUYTOWN FLA (LAT 2 A 1300 LONG 0 RO 54 30) AUG., 1970

261317080061300

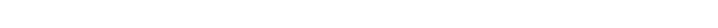
$\begin{array}{lll}\text { FER.. } 1970 \\ 18 . . . & .21 & 1.0 \\ 18 . . & -\end{array}$

$261324040211 \times 00$

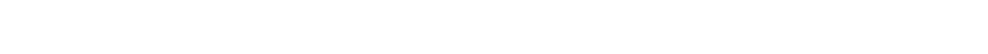
261345080274500 - S-II CATL $18 B$ NR ANOYTOUN FLA ILAT 261345 LONO OBO 27 45) AUG., 1970 $06 \ldots .07 \quad .11$

261349080121700 FE. 1970 $\begin{array}{lll}18 \ldots & .33 & -36\end{array}$

261351080102100 FEt., 1970

$\begin{array}{ccc}\text { FEE.. } 1970 & & \\ 18 . . . & .55 & .09 \\ \text { I8... } & -- & - \\ \text { SEP. } & & \\ 30 . . . & -. & .-\end{array}$

261630080435800 AUG., 1970

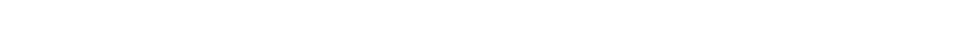

261737081270500 CANAL ON OILFIELD ROAD NEAR IMMOKALEE ILAT $26 \quad 1737$ LONG 0812705 NOV.P 1969

$18 . .$. .13 POMPANO CA AT SH 7 AT MARGATE FLA (LAT 26 1349 LONG NBO 12 17)

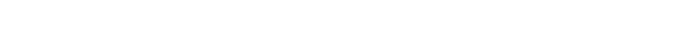
PIMPANO CA OF FLA TIIRNPIKE NP HOMPAN (LAT 261351 LONG DAO 1021 ) $\begin{array}{lllllllll}1.1 & .96 & 1.1 & 1.1 & 5.4 & 390 & 45 & 18\end{array}$ $\begin{array}{llllllll}- & .44 & .56 & .58 & 7.7 & 8 & 50\end{array}$ C-123 AT OLD MIAMI C.ANAL INR AMIDYTOWN F (LAT PA IA 30 LOHG 080 43 58) $\begin{array}{lll}1.0 & . \overline{0} & . \overline{1}\end{array}$ 
CHEMICAL ANALYSES, WATER YEAR OCTOBER 1969 TO SEPTEMBER 1970

(MACRONUTRIENTS AND OTHER RELATED CONSTITUENTS)

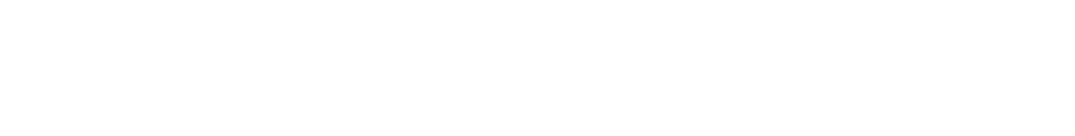

LAKE OKEECHOBEE AND THE EVERGLADES BASINS--CONTINUED

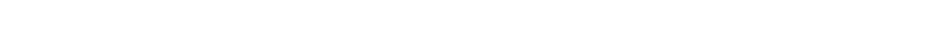

$\begin{array}{lll}\text { FE8.. } 1970 & & \\ 13 \ldots & -- & -- \\ 13 \ldots & .14 & 1.1\end{array}$

261938080124900 SEP.. 1970

$30 .$.

262134080480300 AUG., 1970

$0 ? . .$.

262517080242000 AUG., 1970

$06 \ldots$

262518080042500 MAR., 1970

$$
-
$$

HILLSHORO CANAL AT US 441 AT DEEOFIELD ILAT 26193 H LUHG 0801249 )

MIAMI CANAL N OF S-28 NH AMIYYOWN FLA (LAT $26 \quad 2134$ LONG D8O 48 O3) $2.6 \quad 1.4$

HILLSHORO CANAL 1 MILE WEST OF S-10 NR (LAT 262517 LONG nEO 24 20\% $+7$

CANAL IS ABOVE S-40 NEAR OELRAY REACH ILAT 26 P5 19 LONG 08004 ग4)

262625081162000 Nov., 1969

$18 \ldots$

263219080072300

AUG.. $1970 \quad .64 \quad .05$

263221080052800 - BOYNTON CA AT CONGRESS AVE NR GOYNTON LLAT 263221 LONG ORO 05 28?

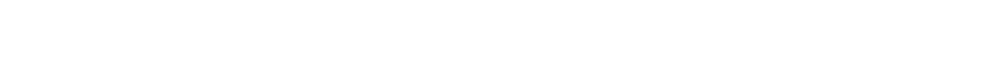

263227080122000 - C-16 AT EJUALIZING CA INR BOYNTON BCH F ILAT 2 G 3227 LONG 08012201 AUG., 1970 $12 \ldots$

264037080064500 - WEST PALM BEACH AT P B FLA (LAT 264037 LONG OBO O6 45) AUG. 1970

$11 \ldots$

264042080092800 - WEST PALM BCH CA AT CLEARY RD NR WEST (LAT 264042 LONIS $080 \quad 0928$ ) AUG.. 1970

$11 \ldots$

264043080102800

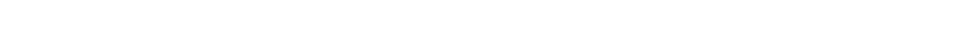

264047080120800 - WEST PALM 8CM CA AT SH BO NR WTST PALM (LAT 264047 LONG 03012 OR)

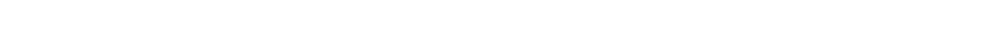

264755080035000 - CLEAR LAKE AT WEST PALM BEACH FLA (LAT 764255 LONG n80 03 50)

$\begin{array}{lll}M A R & 1470 \\ 17 \ldots & 12\end{array}$

264531080051800

AUG., $1970 \quad \ldots \quad .00$
$11 \ldots .$.

264829080050900 AUG., 1970

$11 \ldots$ 


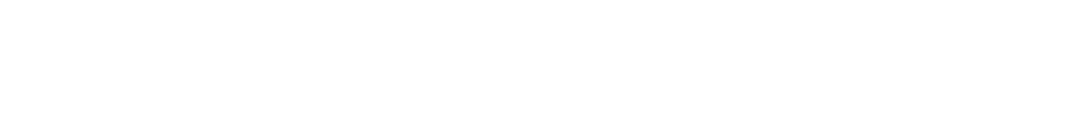

MYAKKA RIVER BASIN

270241082142701 - COCOA PLUM WATERWAY NR PUNTA GORDA FLA ILAT 270241 LONG 0821427.011 JUNE, $1970 \quad \ldots \quad .02$

PEACE RIVER BASIN

$2702420 \$ 2142300$ - BIG SLOUGH AT WATEK PLANT NR MURDOCK F ILAT 270242 LONG 08214231 NOV.. 1969

$2703320 \$ 1461400$ - MYRTLE CREEK NR FT OGDEN FLA (LAT 270332 LONG 08146141 JUNE, 1970

ONE. 1970 -

270351081573100 - THORNTON BRANCH AT US 17 NR FT OGDEN F (LAT 270351 LONG 0815731 ) JUNE. 1970

$10 . .$.

270517081593800

PEACE RIV AT RT 761 NR NOCATEE FLA ILAT 270517 LONG 08159381 APR., $1970 \quad-. \quad .00$

MYAKKA RIVER BASIN--CONTINUED

270908082253200 - COW PEN SLUUGH AT OAM NEAP VENICE FLA ILAT 27 09 08 LONG 08225321 JUNE, $1970 \quad--\quad .01$
$08 .$.

\section{PEACE RIVER BASIN--CONTINUED}

270930081575800 - MORSE CRFEK AT RT 761 NH NOCATEE FLA (LAT 2709 30 LONG 081 57581 APR., 1970

271231081404200 PRAIRIE C. TKIB NO 2 NR ARCADIA FLA ILAT 2712 31 LONG 08140421 29... - - .00 IONE

271232081343300 $\triangle P R ., 1970$
$29, \ldots$
JUNE
$10 .$.

$271257081404100-$ IRRIGATION D AT TROP R GROVE NR ARCADI (LAT $27 \quad 1257$ LONG 0814041 APR. 1970 29...

271306081522800 - PEACF RIVER TRIB AT AHCAOIA FLA (LAT 2713 T6 LONG 0RI 52 28) APR., 1970
$29 .$.

272854081514300 - TROUBLESOME CF NK ZOLFO SPGS FLA ILAT 272854 LONG OBI 51431 JUNE, 1970 $11 . .$.

273515081461600

L CHARLIE CR AT RT 664E NR WAUCHULA FL ILAT 273515 LONG $08146 \quad 161$

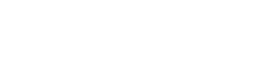

$$
\begin{array}{cccccc}
13 & -- & -- & -- & 17 & - \\
2.9 & -- & -- & -- & 4.2 & -
\end{array}
$$

COASTAL BASINS BETHEEN MYAKKA RIVER AND ALAFIA RIVER

273724082322300 - TAMPA BAY TRIB NR PALMETTO FLA ILAT 273724 LONG 08? 32 ?3) JUNE, 1970 $08 .$.

PEACE RIVER BASIN--CONTINUED

273444081480500 - PEACE KIVER NR BOWLING GREFN FLA ILAT 273844 LONG 08148051

\begin{tabular}{|c|c|c|c|c|c|c|c|c|c|c|c|}
\hline $\begin{array}{l}\text { APR... } 1970 \\
28 \ldots . .\end{array}$ & 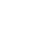 & .00 & 4.2 & - & - & -- & 8.9 & $\cdots$ & 40 & $\cdots$ & -- \\
\hline $\begin{array}{l}\text { JUNE } \\
11 \ldots .\end{array}$ & -- & - & - & $\cdots$ & -- & $\cdots$ & 6.3 & - & 20 & -- & $-\infty$ \\
\hline
\end{tabular}


CHEMICAL ANALYSES, WATER YEAR OCTOBER 1969 TO SEPTEMBER 1970 (MACRONUTRIENTS AND OTHER RELATED CONSTITUENTS)

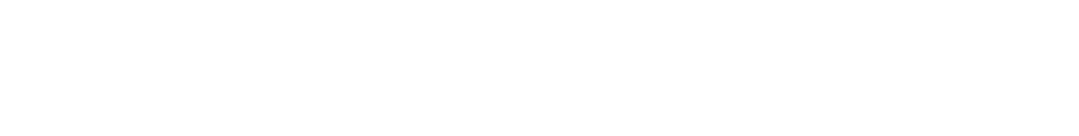

ALAFIA RIVER BASIN

275301082055900 - N PRONG ALAFIA A AT SK O76 NG KEYSVILL (LAT 2753 nI LONG 082 0S 59) JUNE, 1970

275709 NPISBOGHO - MINE PINU AT CHRISTINA PARK FLA (LAT 275709 LONG 08158 061 JUNE, 1970
$09 .$. HILLSBOROUGH RIVER BASIN AND COASTAL BASIN NORTH OF ALAFIA RIVER

280033082080700 - DRAINAGE DITCH AT SAL RR AT PLANT CITY (LAT 28 0I 33 LONG 08? 08 07)

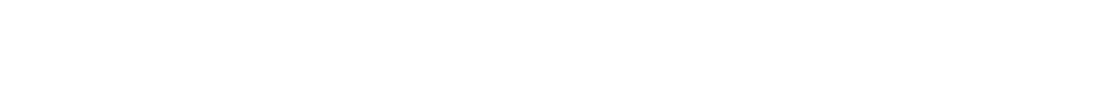
280047082157500 - BAKEQ CKFEK NEAH SEFFNEF FLA (LAT 28 00 47 LONG 0821525 I

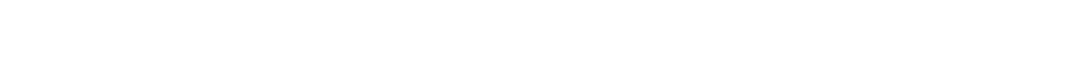

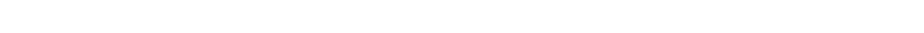

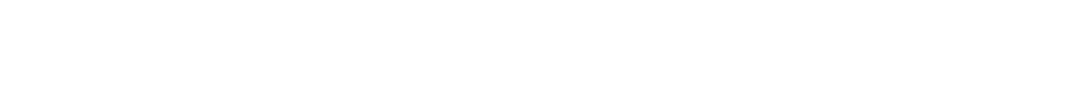

CH00580H2Z0Z200 - SOUTH PERIMETER UITCH AT CL EUREKA SPQ (LAT 28 OO 58 LONG OH? 20 22) Jup.r, 1970

$11 \ldots$

240102083202300

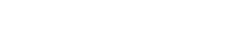

280103082201900 JUNE, 197 11 ...

280104082203700 JUNE, 1970 $11 \ldots$

240132042111300

EUREKA SP SANT LNOFL OXIDOTION PO NR T ILAT 240102 LONG OBZ 20221

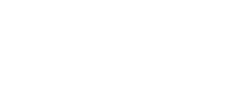

$280150082111400-$

MAR., 1970
$18 . .$.
$18 .$.

$00 .$.

CDO208042095100 A..., 1970 $18 .$. JUNE

2000227082341700. Ftr., 1970

$28022 \times 042342200$ FER.. 1970

O5... 1970 .06 JUNE

$.06 \quad .01$

SANIT LNOFL SIMP NR EUREKA SPRINGS FLA (LAT $29 \quad 0103$ LONG $082 \quad 20 \quad 19$ )

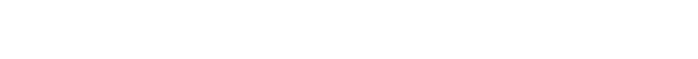

$$
\begin{array}{llll}
0 & 0 & - & .10
\end{array}
$$

SPARTMAN GRANCH NR PLANT CITY FLA ILAT 280132 LONE OBZ 11131

$$
\begin{array}{rrrrrrrrr}
-- & -- & -- & -- & -- & - & - & 220 & - \\
-- & .52 & 1.7 & 1.8 & -- & -- & -- & -- & - \\
.4 & .76 & -- & -- & 7.2 & 150 & 200 & -- & -
\end{array}
$$

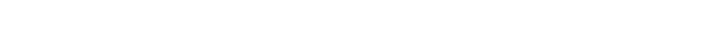

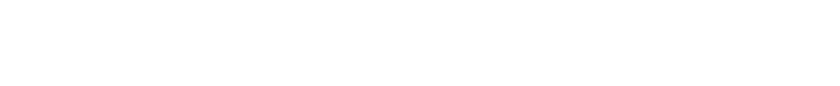

MILL CREEK at THONOTUSASSA RO NR PLANT (LAT 2802 O8 LONG OB2 0951 ) 


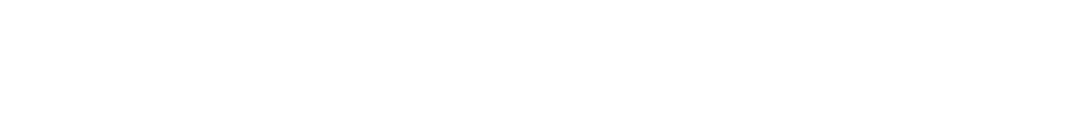

ROASTAL BASINS BETWEEN HILLSBOROUGH RIVER AND WITHLACDOCHEE RIVER

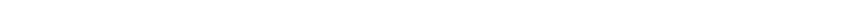

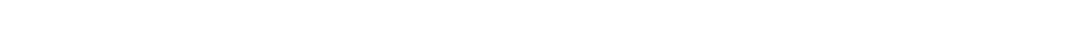

200228002343200 - S. PERIM DITH AT ROCKY CK LNOFL NR TAM ILAT $2 F$ OZ ZA LONG OHZ 34321

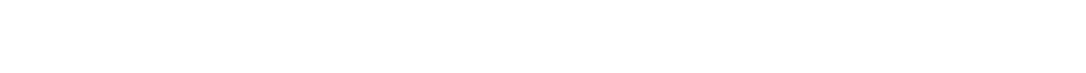

PA0235082342500 - NW SANT LNUFL OX10 PD NK SULPHUR SPG F ILNT 240235 LONG 08234251

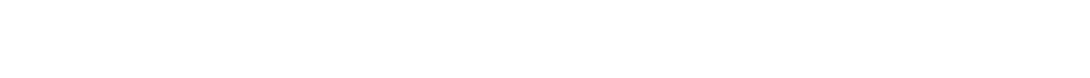

2M02430ה2342200 - NE PERIM DITH AT ROCKY CR LNDL NR TAM ILAT PA O? 43 LONG MB? 34 22I JUNE, 1970

HILLSBOROUGH RIVER BASIN AND COASTAL BASIN NORTH OF ALAFIA RIVER--CONTINUED

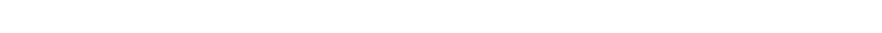
JUNF, 1970

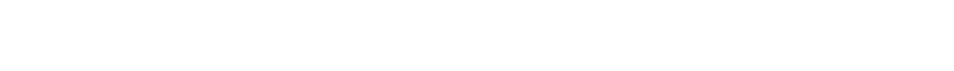

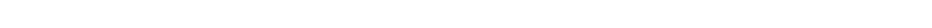
JUNE. 1970

$11 \ldots$

280949082442500

$\begin{array}{ll}1.9 \quad-. & .30\end{array}$

$.32 \quad 2.1$

ARICLOTE RIVER AT US HWY I9 NEAR TARPON ILAT 2 H 0949 LONG OB? 44 25) JUNE, 1970

$10 . . . \quad-01$

281333082373300 - ANCLUTE RIVER AT POWER LINE NR ODESSA ILAT 281333 LONG O82 37331 JUNE, 1970

ZO1424082310100 - PITHLACHASCOTEE R AT ALT 19 AT NEW POPT R LLAT 2P 1424 LONG $082310 I 1$ $\begin{array}{ll}\text { JUNE. } 1970 \quad-0 \quad .01 & 3.0\end{array}$

CHOCTAWHATCHEE RIVER BASIN

302700086251600 - CHOCTAWHATCHEE RAY NE VILLA TASSO FLA (LAT 307700 LONG 08625161

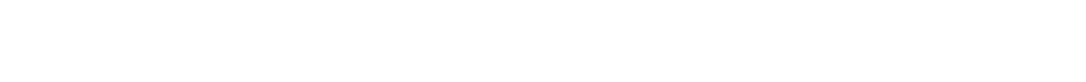
DCHLOCKONEE BASIN AND COASTAL AREA

302722084232500 - UNMAMED LAKE NEAH TALLAHASSEE FLA ILAT 302722 LONG 08423751 OEC.. 1959

ESCAMBIA RIVER BASIN AND BASIN AREA

303110087085800 - FSCAMBIA yAY AT 110 NR PENSACOLA FLA (LAT 303110 LONG O87 0858 )

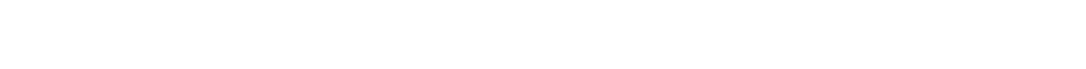


ST. MARYS RIVER BASIN

02228500 - N PRONG ST MAKYS RIVER AT MONIAC GA (LAT 303103 LONG 0821350 )

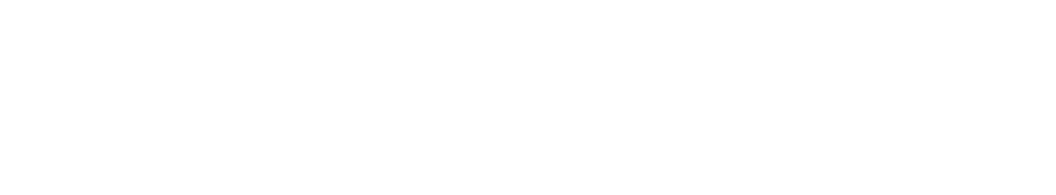

02231250 - LITTLE ST MARYS R NR HILLIARD FLA (LAT 304355 LONG 0815335 )

MAY 1970

MAY 1970

MAY 1970

15.01

02231280 - THOMAS CREEK NR CRAWFORD FLA (LAT 302739 LONG 0814957 )

22... 1630

$29 . . . \quad 0820$

MAY ... 1015

JULY 1015

OCT. 1969

OCT.. 1969 21745

JAN.: 1970 1640

O1... 1500

JULY $22 . .11630$

7.40

CDASTAL BASINS BETWEEN ST, MARY'S RIVER AND ST, JOHN'S RIVER

02231342 - FT DRUM CREEK AT SS PKWY NR FT ORUM FL (LAT 273406 LONG 0804 ? 47 )

$\begin{array}{rrrrrrrrrrr}-- & 180 & 26.0 & 2.9 & 35 & 94 & 6.4 & 23 & 0 & \ldots & \ldots \\ -- & 50 & 17.0 & 6.7 & 69 & 110 & 6.7 & 26 & \ldots & \ldots & -. \\ -- & .24 & 24.0 & 8.5 & 100 & 125 & 7.2 & 42 & -. & -\ldots & \ldots \\ -- & 41 & 26.0 & 4.9 & 60 & 136 & 6.9 & 36 & \ldots & \ldots & \ldots\end{array}$

02231350 - ST JOHNS HDWATERS NR VERO BCH FLA (LAT 274132 LONG 08025001

MAY. 1970 \$700

$\begin{array}{rrrrrrrrrrr}8.13 & -- & 28.5 & - & - & 408 & 7.3 & 133 & 0 & \ldots & \ldots \\ 7.44 & -- & 15.5 & 8.0 & 79 & 545 & 7.5 & 170 & \ldots & \ldots & \ldots \\ 5.91 & -- & 28.0 & 5.5 & 70 & 510 & 7.5 & 156 & \ldots & \ldots & \ldots \\ 4.80 & -- & 28.5 & 6.5 & 82 & 540 & 7.6 & 151 & \ldots & \ldots & \ldots\end{array}$

02231375 - BLUE CYPRESS C TR NO 3 AT LOKOSEE FLA (LAT 274531 LONG 0805428 )

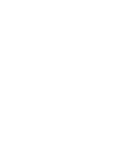

02231396 - 8LUE CYPRESS CREEK NEAR FELLSMERE FLA (LAT 274340 LONG 08048191

ОСт., 1969

22... 0845

JAN.. 1970

$28 \ldots .1245$

APR.

30... $\quad 0900$

JULY

$22 \ldots .1150$

$22 \ldots . . \quad 1225$

MAY, 19701800

$\begin{array}{rrrrrrrrr}- & -- & 25.0 & 5.4 & 64 & 70 & 6.4 & 18 \\ -- & -- & 14.6 & 8.5 & 82 & 110 & 6.8 & 23 \\ - & 1.2 & 24.0 & 5.3 & 62 & 165 & 7.2 & 60 & - \\ - & 12 & 26.0 & 6.3 & 77 & 161 & 7.2 & 48\end{array}$

02231400 - BLUE CYPRESS LAKE NR FELLSMERE FLA ILAT 274334 LONG 0804632 )

\begin{tabular}{|c|c|c|c|c|c|c|c|c|c|c|}
\hline 26.36 & -- & 26.0 & 4.9 & 20 & 125 & 6.7 & 28 & 0 & -- & + \\
\hline $\begin{array}{l}26.42 \\
26.42\end{array}$ & $=$ & $\begin{array}{l}19.5 \\
15.0\end{array}$ & $\begin{array}{l}8.9 \\
6.6\end{array}$ & $\begin{array}{l}96 \\
65\end{array}$ & 169 & 7.4 & 31 & $=$ & $\begin{array}{l}47 \\
--\end{array}$ & $\because$ \\
\hline 23.38 & -- & 28.5 & 7.5 & 97 & 190 & 7.6 & 34 & - & -- & - \\
\hline $\begin{array}{r}22.00 \\
= \\
0\end{array}$ & $\begin{array}{l}=- \\
=-\end{array}$ & $\begin{array}{l}29.0 \\
28.5 \\
28.0\end{array}$ & $\begin{array}{r}7.9 \\
7.7 \\
-.\end{array}$ & $\begin{array}{r}101 \\
97 \\
--\end{array}$ & $\begin{array}{r}199 \\
201\end{array}$ & $\begin{array}{l}9.1 \\
9.0 \\
8.8\end{array}$ & $\begin{array}{l}28 \\
29 \\
30\end{array}$ & $\begin{array}{r}-5 \\
2 n\end{array}$ & $=$ & $\begin{array}{l}-.0 \\
8.0\end{array}$ \\
\hline
\end{tabular}

02231450 - ST JOHNS HDWATERS NR KENANSVILLE FLA ILAT 274917 LONG 0804843 )

$\begin{array}{lllllll}5.35 & -- & 27.5 & 5.4 & 68 & - & -\end{array}$ 


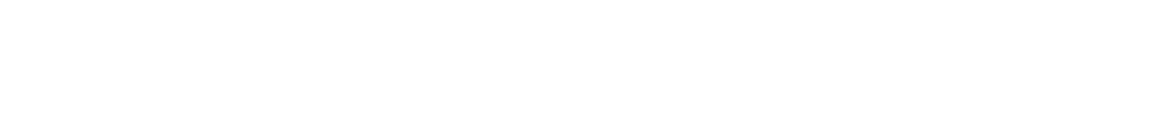
ST. JOHNS RIVER BASIN--CONTINUED

02231467 - ST JOHNS P AB LK HELEN BLAZES NR MELBO (LAT 275943 LONG 0804730 )

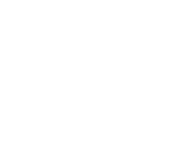

$$
\begin{array}{rrrrrrrrrrr}
-- & -- & 24.0 & 2.0 & 24 & 125 & 6.3 & 35 & 0 & -. & -- \\
-- & -- & 11.0 & 7.5 & 74 & 200 & -7.1 & 44 & -- & 46 & -- \\
-- & 71 & 25.5 & 4.5 & 54 & 210 & 6.6 & 46 & -- & -- & -- \\
- & 96 & 30.0 & 3.2 & 42 & 365 & 6.9 & 89 & 0 & -. & \ldots
\end{array}
$$

02231471 - LAKE HELEN BLAZES NEAR DEER PARK, FLA. (LAT 280130 LONG 08047 56)

$\begin{array}{rrrrrrrrrrr}-- & -- & 25.0 & 2.5 & 30 & 129 & 6.4 & 46 & 0 & -- & -. \\ -- & -- & 11.0 & 9.5 & 86 & 198 & 7.3 & 44 & -- & 47 & - \\ -- & -- & 26.0 & 8.2 & 100 & 245 & 7.5 & 54 & -- & -- & -. \\ -- & -- & 30.0 & 5.6 & 74 & 375 & 7.6 & 84 & 0 & -- & --\end{array}$

02231600 - JANE GREEN CREEK NR DEER PARK FLA (LAT 280427 LONG 0805318 I

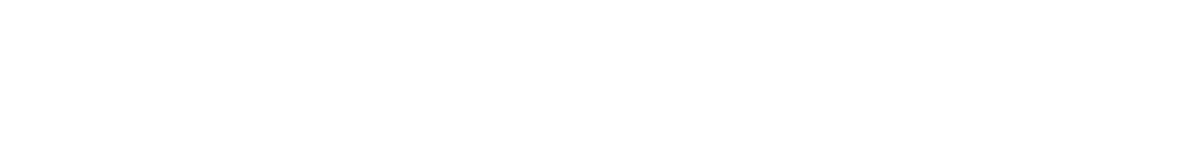

02231980 - SAWGRASS LAKE NEAR MELBOURNE FLA (LAT 280435 LONG 0804626 )

OCT., 1969

OB... 19701315

$05 \ldots 1615$

28... 1410

OCF., 1969

23... 1500

FEB.. 1970 1400

MAY
$04 \ldots . .11715$

${ }_{06.1{ }^{M}, 1315}$

O6... 1315

29... 1225

OCT. 1969

$21 . .20830$

26... 197015

28... $\$ 900$

21... 0915

NOV.. 1969

FEB.. 1970

O4... 1500

06... 1500

JULY $29 . .1320$

NOV.. 19691530

MAY 19701025

JULY...

29... 1500

$\begin{array}{rrrrrrrrrrr}- & - & 26.5 & 1.0 & 12 & 110 & 6.3 & 38 & 0 & -. & 1.0 \\ - & -- & 16.0 & -- & - & 162 & 7.2 & 33 & -. & -- & \ldots \\ - & - & 26.0 & -- & -- & 220 & 7.5 & 47 & \ldots & \ldots & --\end{array}$

02232100 - LK WASHINGTON NR EAU GALLIE FLA (LAT 280850 LONG 0804410 )

$\begin{array}{rrrrrrrrrrr}6.97 & - & 26.3 & 4.9 & 60 & 135 & 6.7 & 35 & 0 & \ldots & \ldots \\ 5.01 & -- & 17.0 & 7.3 & 75 & 180 & 7.4 & 36 & \ldots & 12 & \ldots \\ 3.48 & -- & 27.0 & 7.8 & 96 & 250 & 7.7 & 50 & \ldots & \ldots & \ldots\end{array}$

02232162 - ST JOHNS TRIB CA NR DEER PARK FLA (LAT 281253 LONG O7O 51 13)

$\begin{array}{rrrrrrrrrrr}3.48 & 24 & -- & -- & - & 250 & \ldots 7 & \ldots & \ldots & \ldots & \ldots \\ 3.48 & 60 & 31.0 & 7.8 & 96 & 851 & 7.1 & 114 & 0 & \ldots & \ldots\end{array}$

02232200 - WOLF CR NR DEER PARK FLA (LAT 281255 LONG 0805403 )

$\begin{array}{lllllllllll}4.54 & 42 & 24.0 & 5.7 & 67 & 100 & 6.7 & 36 & 0 & \ldots & \ldots \\ 4.01 & 15 & 15.5 & 7.0 & 69 & 138 & 7.1 & 48 & \ldots & \ldots & \ldots \\ 3.26 & 1.2 & 24.0 & 4.7 & 55 & 169 & 7.1 & 62 & \ldots & \ldots & \ldots \\ 3.54 & 4.4 & 25.5 & 5.4 & 65 & 195 & 7.2 & 75 & 0 & \ldots & \ldots\end{array}$

02232254 - LAKE MINDER NEAR GONAVENTURE, FLA. (LAT 281512 LONG 0805055 )

$\begin{array}{rrrrrrrrrrr}-- & - & 20.0 & 6.7 & 73 & 170 & 6.9 & 39 & 0 & -- & - \\ -- & -- & 12.5 & 10.6 & 99 & 220 & 7.6 & 39 & -- & 42 & -- \\ - & -- & 24.5 & 8.0 & 95 & 280 & 7.7 & 52 & -. & -. & - \\ -- & -- & 32.0 & 7.0 & 94 & 740 & 8.0 & 78 & 0 & \ldots & \ldots\end{array}$

02232285 - ROCKLEDGE CREEK NEAR ROCKLEDGE FLA (LAT 281843 LONG 0804734 )

$\begin{array}{rrrrrrrrrrrr}-- & -- & 20.0 & 4.0 & 43 & 612 & 6.7 & 59 & 0 & -. & - \\ -- & -- & 21.0 & 7.0 & 78 & 1180 & 7.3 & 60 & -. & \ldots & \ldots \\ -- & -- & 32.5 & 8.7 & 118 & 2500 & 8.4 & 77 & 0 & - & \ldots\end{array}$


CHEMICAL ANALYSES, WATER YEAR OCTOBER 1969 TO SEPTEMBER 1970

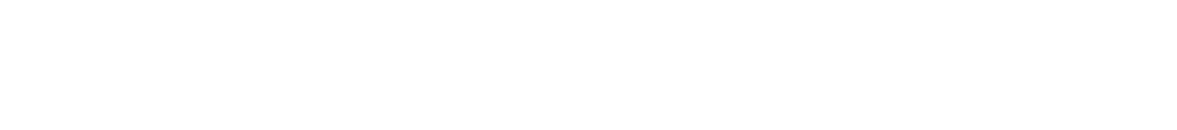

$$
\text { ST. JOHNS RIVER BASIN--CONTINUED }
$$

02232300 - LK POINSETT NR COCNA FLA RLAT 282101 LONG 0804856 )

NOV., 1969

$05 . .11350$

FEQ.: 1970

MAY

06... 1650

JULY.. $\quad 1430$

OCT.. 1969

JAN." 19701300

26... 1200

$27 \ldots 1300$

$27 \ldots . .1632$

$27 \ldots \quad 1635$

JULY

20... 1213

$20 \ldots . .1215$

$20 \ldots \ldots 1217$

$20 \ldots . \quad 1220$

MAY 1970

MAY ${ }_{16 .}{ }^{1970} 1720$

MAY.: $1_{0270}$

OCT.. 19691500

29... 1970 1330

MAY

02... 1030

$\begin{array}{ll}\text { JULY } & 1030 \\ 24 \ldots & 1130\end{array}$

OCT.., 1969

$\begin{array}{ll}01 \ldots . . . & 1100 \\ 27 \ldots . . & 1030\end{array}$

DEC.

O2.... 1100

30... 1040

MAR.

31... $\quad 1100$

MAY $08 . . . \quad 1215$

JUNE

03... 1145

JULY 0920

$\begin{array}{ll}24 \ldots . . & 0920 \\ 30 . . . & 1130\end{array}$

MAY, 1970

MAY. 1970,1730

MAY 1970

$\begin{array}{rrrrrrrrrrr}-- & -- & 20.0 & 6.8 & 74 & 165 & 6.9 & 37 & 0 & -. & \ldots \\ -- & -- & 11.5 & 10.4 & 95 & 241 & 7.5 & 38 & -- & 24 & \ldots \\ -- & -- & 24.5 & 8.3 & 98 & 365 & 7.8 & 52 & -- & -- & -- \\ -- & -- & 32.0 & 6.8 & 92 & 845 & 7.7 & 76 & 0 & -- & -.\end{array}$

02232413 - TAYLOR CREEK AT S 164 NEAR COCOA FLA (LAT 282023 LONG OBO 56 06)

\begin{tabular}{|c|c|c|c|c|c|c|c|c|c|c|}
\hline 39.08 & 700 & 26.0 & .3 & 4 & 80 & 6.0 & 26 & 0 & $=$ & - \\
\hline 38.90 & 425 & 14.5 & 8.5 & 82 & 77 & 6.6 & 20 & -- & 27 & - \\
\hline $\begin{array}{r}33.28 \\
=- \\
=-\end{array}$ & $295=$ & $\begin{array}{l}27.0 \\
28.0 \\
26.0 \\
24.0\end{array}$ & $\begin{array}{r}4.0 \\
3.5 \\
.4 \\
.0\end{array}$ & $\begin{array}{r}49 \\
44 \\
5 \\
0\end{array}$ & $\begin{array}{r}114 \\
=- \\
=-\end{array}$ & $\begin{array}{r}6.7 \\
=- \\
=-\end{array}$ & $\begin{array}{l}28 \\
=- \\
=-\end{array}$ & $\begin{array}{l}-- \\
=- \\
=-\end{array}$ & $\begin{array}{l}40 \\
=- \\
=-\end{array}$ & $\begin{array}{l}.9 \\
4.0 \\
6.0 \\
8.0\end{array}$ \\
\hline $\begin{array}{r}33.30 \\
.33 \\
33.30 \\
33.30 \\
33.30\end{array}$ & $\begin{array}{l}= \\
=- \\
=0\end{array}$ & $\begin{array}{l}30.5 \\
29.0 \\
29.0 \\
27.5 \\
31.0\end{array}$ & $\begin{array}{r}5.9 \\
1.3 \\
.4 \\
.1 \\
6.0\end{array}$ & $\begin{array}{r}77 \\
17 \\
5 \\
0 \\
80\end{array}$ & $\begin{array}{r}122 \\
0 \\
135 \\
14 \\
122\end{array}$ & $\begin{array}{l}7.0 \\
6.7 \\
6.5 \\
6.3 \\
7.0\end{array}$ & $=$ & $=$ & $=$ & $\begin{array}{l}1.0 \\
4.0 \\
6.0 \\
8.0 \\
1.0\end{array}$ \\
\hline
\end{tabular}

02232450 - JIM CREEK NR CHRISTMAS FLA ILAT 282607 LONG 0805758 \%

$\begin{array}{llll}1.50 & 00 \quad 22.5 & 3.0 & 35\end{array}$

02233102 - ECONLOCKHATCHEE R TRIB NR BITHLO FLA (LAT 283355 LONG 08109 19)

2.17

02233200 - LITTLE ECONLOCKHATCHEE R NR UNION PK F (LAT 283129 LONG 0811439 )

5.39

02233500 - ECONLOCKHATCHEE R NR CHULUOTA FLA (LAT 284040 LONG 081 06 51 )

$\begin{array}{rrrrrrrrrrr}9.08 & 1280 & 22.5 & 5.8 & 67 & 92 & 6.2 & 14 & 0 & \ldots & 1.0 \\ 4.14 & 248 & 17.5 & 7.1 & 74 & 240 & 6.7 & 30 & -- & \ldots & \ldots \\ 1.08 & 48 & 24.5 & 4.8 & 57 & 522 & 7.1 & 69 & -- & \ldots & \ldots \\ 1.65 & 78 & 26.5 & 2.8 & 34 & 389 & 7.3 & 79 & -- & \ldots & \ldots\end{array}$

02234000 - ST JOHNS R AB L HARNEY NR GENEVA FLA (LAT 284250 LONG 0810206 )

\begin{tabular}{|c|c|c|c|c|c|c|c|c|c|c|}
\hline $\begin{array}{l}5.96 \\
7.25\end{array}$ & 6900 & -- & $\begin{array}{l}26.5 \\
22.5\end{array}$ & $\begin{array}{l}5.0 \\
7.1\end{array}$ & $\begin{array}{l}61 \\
82\end{array}$ & $\begin{array}{l}625 \\
540\end{array}$ & $\begin{array}{l}6.9 \\
7.1\end{array}$ & $\begin{array}{l}38 \\
42\end{array}$ & $\begin{array}{l}0 \\
0\end{array}$ & $=$ \\
\hline 5.88 & & $-=$ & 14.5 & 8.2 & 80 & 485 & 7.1 & 42 & 0 & $\cdots$ \\
\hline 4.95 & 3350 & & 19.0 & 7.9 & 84 & 748 & 7.3 & 42 & $=$ & $\cdots$ \\
\hline 3.15 & & - & 25.5 & 6.5 & 78 & 842 & 7.2 & 44 & -- & 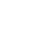 \\
\hline 1.37 & 1210 & & 25.5 & 8.0 & 96 & 950 & 7.7 & 58 & $=$ & - \\
\hline .74 & & -- & 28.0 & 10.0 & 127 & 1180 & 7.6 & 62 & $=$ & -- \\
\hline $\begin{array}{l}1.15 \\
1.22\end{array}$ & 1000 & -- & $\begin{array}{l}27.5 \\
31.5\end{array}$ & $\begin{array}{l}5.4 \\
5.4\end{array}$ & $\begin{array}{l}68 \\
72\end{array}$ & $\begin{array}{l}2040 \\
1850\end{array}$ & $\begin{array}{l}7.2 \\
6.8\end{array}$ & $\begin{array}{l}33 \\
--\end{array}$ & $\therefore$ & $=$ \\
\hline
\end{tabular}

02234160 - L WINNEMISSET NEAR DE LAND FLA (LAT 290110 LONG OB1 1506 )

\section{$59.91 \quad-2 \quad 27.0 \quad 8.0 \quad 99 \quad 210$}

02234435 - LAKE JESSUP OUTLET NR SANFORD , FLA. (LAT 284709 LONG 0811050 ) 


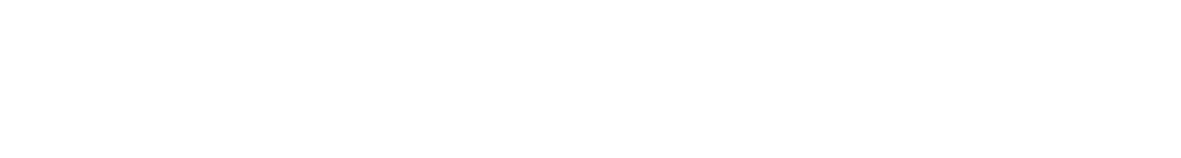

02234610 - ROCK SPRINGS NEAR APOPKA FLA (LAT 284570 LONG 0812958 )

$\begin{array}{ll}\text { MAY } & 1970 \\ \text { 15... } & 1200 \\ \text { SEP. } & \end{array}$

02234815 - LAKE WEKIVA OUTLET NEAR MAITLAND FLA (LAT 283610 LONG 08125 38)

MAY, 19700835

MAY 1970

MAY 19701300

MAY, 19701010

MAY, 19700930

$\begin{array}{ll}23 . . . & 0930 \\ \text { SEP... } & 1115\end{array}$

OCT.. 1969

01... 1500

31... 1045

$31 \ldots 1230$

JAN., 1970

29... 1030

26... 1000

MAR. 1500

$31 \ldots 1500$

APR.

$\begin{array}{ll}30 \ldots . . & 0935 \\ 30 . . . & 1230\end{array}$

JUNE

$30 . . .0$

JULY

30... 1400

SEP... 1330

MAY 19701350

MAY , 1970

APR., 1970

29... 1430

28... 1400

SEP.. 1970

MAY $1970 \quad 0930$

$1.38 \quad .00 \quad 26.0 \quad 1.6$

02235000 - WEKIVA RIVER NK SANFORO FLA (LAT 284854 LONG OBI 2510 )

$2.65 \quad--\quad 26.0 \quad 7.6 \quad 93$

02235150 - LAKE DORR NR ALTOONA FLA ILAT 290010 LONG 08138051

$\begin{array}{lllll}59.96 \quad-- & 27.0 & 8.6 & 106\end{array}$

02235200 - $\quad$ 8LACKWATER CR NR CASSIA FLA (LAT 285240 LONG 0812920 )

$\begin{array}{llll}5.34 & 29 & 24.0 & 6.2\end{array}$

02235500 - BLUE SPRINGS NR ORANGE CITY FLA ILAT 285638 LONG 08120241

$\begin{array}{rrrrrrrrrrr}1.18 & -- & 22.0 & 1.4 & 160 & - & 7.6 & -- & -. & -. & \ldots \\ 2.06 & 185 & 10.0 & 1.2 & 13 & -- & 7.7 & - & -. & \ldots & -.\end{array}$

02236000 - ST JOHNS R NR DELAND FLA (LAT 290039 LONG 0812321 )

\begin{tabular}{|c|c|c|c|c|c|c|c|c|c|c|}
\hline $\begin{array}{l}4.44 \\
4.85\end{array}$ & & $=$ & $\begin{array}{l}27.0 \\
22.5\end{array}$ & $\begin{array}{l}3.1 \\
4.2\end{array}$ & $\begin{array}{l}38 \\
48\end{array}$ & 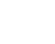 & $=$ & $=$ & $=$ & $=$ \\
\hline 3.40 & & -- & 16.5 & 0.2 & 62 & 490 & 6.9 & -- & -- & $=-$ \\
\hline 3.35 & & -- & 15.5 & 6.8 & 67 & 523 & 6.9 & - & $=$ & -- \\
\hline 3.22 & & 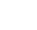 & 15.5 & 7.6 & 75 & 545 & 6.9 & -- & - & - \\
\hline 2.60 & & -- & 24.5 & 5.7 & 67 & 688 & 7.2 & -- & - & -- \\
\hline $\begin{array}{l}1.68 \\
1.68\end{array}$ & $\begin{array}{l}2550 \\
2560\end{array}$ & & $27 . \overline{5}$ & $\begin{array}{l}7.5 \\
7.5\end{array}$ & $\overline{85}$ & 844 & $7 . \overline{4}$ & $=$ & 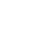 & 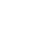 \\
\hline $\begin{array}{l}1.75 \\
1.76\end{array}$ & & $=$ & $\begin{array}{l}28.5 \\
27.5\end{array}$ & $\begin{array}{l}9.2 \\
6.7\end{array}$ & $\begin{array}{r}116 \\
84\end{array}$ & $\begin{array}{l}888 \\
930\end{array}$ & $\begin{array}{l}8.6 \\
7.7\end{array}$ & $=$ & $=$ & $=$ \\
\hline .52 & & -- & 33.5 & 7.8 & -- & 1048 & 8.2 & -- & - & -- \\
\hline 1.27 & & $=$ & 27.5 & 5.8 & 72 & -- & 8.0 & - & $=$ & $-\infty$ \\
\hline
\end{tabular}

02236110 - PONCE OE LEON SPRINGS NR OELAND FLA (LAT 290802 LONG 08121471

$\begin{array}{llll}4.46 & 39 & 23.0 & 3.5\end{array}$

02236120 - DEEP CR NR BARGERVILLE FLA (LAT 290747 LONG 0812327 )

$-12 \quad 21.0 \quad 2.8 \quad 31$

02236200 - LAKE KERR NR EUREKA FLA (LAT 292010 LONG 0814600 )

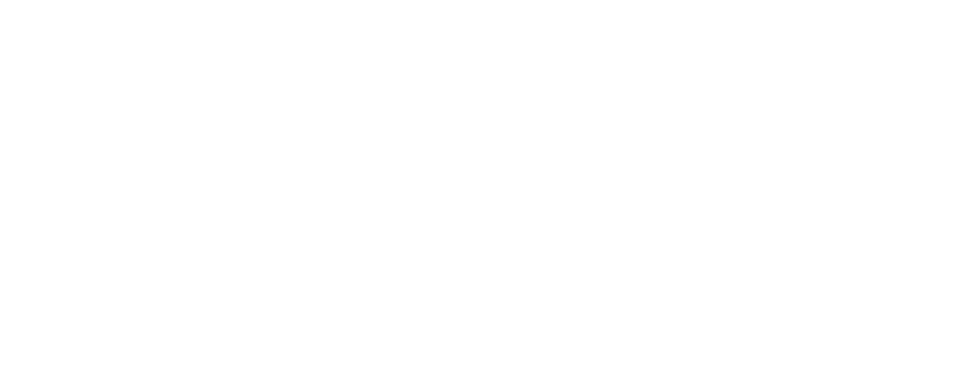

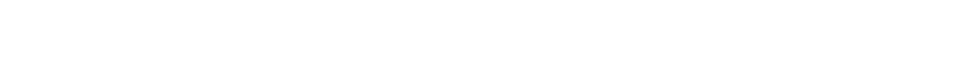

02236250 - LAKE LOWERY NR HAINES CITY FLA (LAT 280651 LONG 0814017 )

02237293 - PALATLAKAHA R AT STR M-1 NR OKAHUMPKA (LAT 284429 LONG 0815222 )

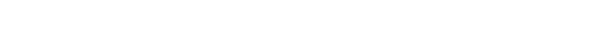


CHEMICAL ANALYSES, WATER YEAR OCTOBER 1969 TO SEPTEMBER 1970

WATER YEAR OCTOBER 1969
(FIELD MEASUREMENTS)

MATE
DAIME

02237700 - APOPKA-BEAUCLAIR CANAL NR ASTATULA FLA (LAT 284320 LONG 0814106 )

MAY 1970

${ }_{14 . . .}^{\text {MAY }} 1970$

MAY , 1970 1340

MAY 1970

$\begin{array}{rr}11 . . . & 1315 \\ \text { SEP... } & 1335\end{array}$

SEP.. 1970

$30 \ldots .0930$

SEP.. 1970

SEP., 1970

23... 0930

JAN., 1970

$19 \ldots .1115$

MAR. $19 . . \quad 1040$

$18 \ldots .1130$

MAY, 1970

$18 . . . \quad 1200$

MAR., 1970

30.1130

MAY , 1970

$04 \ldots .1445$

${ }_{\text {OC7. } 1969} 162$

$\begin{array}{llllll}66.79 & - & 26.0 & 7.2 & 88 & 340\end{array}$

02237753 - WEST CROOKEO LAKE NR EUSTIS FLA ILAT 284949 LONG 081 40201 70.9

02237865 - LAKE UMATILLA AT UMATILLA, FLA. (LAT 285509 LONG 08139 \$7) 67.98

02238000 - HAINES CR AT LISBON FLA ILAT 285220 LONG 08146501

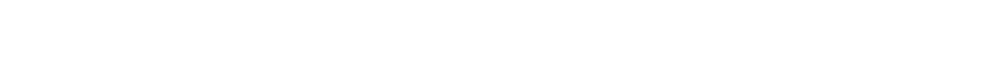

02238200 - LAKE YALE AT GRANo ISLAND FLA ILAT 295252 LONG 08142211

$59.21 \quad--\quad 25.0 \quad 2.9 \quad 35$

02238800 - LAKE WEIR AT OKLAWAHA FLA ILAT 290230 LONG O8I 55401

58.04

27.5

02243958 - LAKE ockLaWaHa neAR ORANGe SPRINGS FLA (LAT 293030 LONG 08148 15)

NEAR ORANGE SPRINGS FLA (LAT 29 30 30 LONG OBI 4 B 15)

02244030 - CFBC ABOVE ST JOHNS LOCK NEAR PALATKA (LAT 293240 LONG 0814350 )

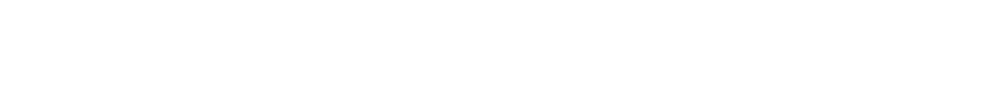

02244032 - CFBC BELOW ST JOHNS LOCK NP PALATKA FL ILAT 293245 LONG 08143351

$16.00 \quad--\quad 26.5 \quad 5.5 \quad 66$

02246500 - ST JDHNS R AT JACKSONVILLE FLA (LAT 301926 LONG 08139 12)

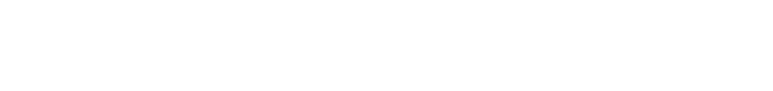

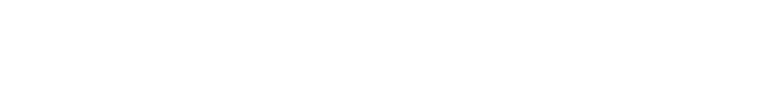




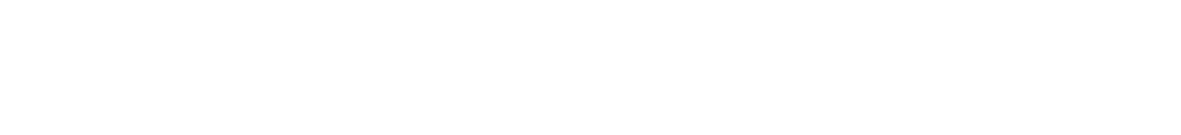

LAKE OKEECHOBEE AND THE EVERGLADES BASINS-CONT JNUED

02258000 - HARNEY POND CA NR LAKEPORT FLA (LAT $2700 \quad 00$ LONG 0810405 )

JAN.: 1970

02259500 - INDIAN PRAJRJE CA NR OKEECHOBEE FLA (LAT 270357 LONG 08059 12)

JAN., 19701000

MAY 1970

SEP., 1970

MAY 1970

MAY 1970

MAY. 1970 1055

SEP., $_{21 . . .}{ }_{1455}$

${ }_{21 \ldots . .}{ }^{\text {SEP. }} 1340$

MAY . $1970_{0825}$

$\operatorname{MAY}_{140.1970}$

MAY 1970

OCT., 1969

27... 1400

NOV. 1400

$\begin{array}{ll}\text { OEC. } & 1500\end{array}$

${ }_{28 \ldots}^{\text {OCF... }} 1969$

JAN... 1970

$\begin{array}{ll}15 \ldots . . & 1430 \\ 15 . . . & 1432\end{array}$

JAN.. 19701600

$$
\text { - }
$$

02260800 - ALLIGATOR LAKE NR ASHTON FLA (LAT 281355 LONG 081 il 17 )

02263800 - SHINGLE CR AT AIRPORT NR KISSIMMEE FLA (LAT 281814 LONG 0812704 )

$4.45 \quad 3$

02263870 - SOUTH LK OLT BL S-15 NR VINELAND FLA (LAT 282445 LONG 08132 17)

87.2

02263900 - LAKE BUTLER AT WINDERMERE FLA (LAT 282926 LONG 081 32 04) 3.0

02267000 - CATFISH CR NR LAKE WALES FLA (LAT 275740 LONG 0812948 )

$3.82 \quad--\quad 24.0 \quad 6.2 \quad 73$

02268400 - L WEOHYAKAPKA AT INDIAN L ESTATES FLA (LAT 274850 LONG 08123 16)

$\begin{array}{llllll}61.02 & - & 30.0 & 8.1 & 107 & 86\end{array}$

02268600 - LAKE ROSALIE NR L WALES FLA ILAT 275720 LONG 0812440 )

$2.18 \quad--\quad 30.0 \quad 7.8 \quad 103 \quad 90$

02270550 - LAKE JACKSON AT SEBRING FLA (LAT 272805 LONG 0812730 )

5.35

02273300 - CANAL 4IA AT S-84 NEAR OKEECHOBEE, FLA (LAT 271255 LONG 08058 55)

$13.55 \quad .00 \quad 26.0 \quad 6.3 \quad 77$

02273301 - CANAL 41 A BL S-84 NR OKEECHOBEE, FLA. (LAT 271255 LONG 0805854 )

$14.20 \quad .00 \quad 28.0 \quad 7.5 \quad 95$

02275500 - TAYLOR CREEK NEAR OKEECHOBEE FLA (LAT 2 I 1235 LONG 0804756 )

$-136$

$-.00$

$25.0 \quad 4.0$

$-.00$

18.0

8.0

48

204

6.

.03

$18.0 \quad 7.4 \quad 78$

490

02275606 - NUBEIN SLOUGH NR SHERMAN FLA (LAT $27 \quad 1136$ LONG 0804545 )

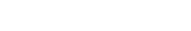

02276401 - LAKE OKEECHOBEE AT POINT 1 FLA (LAT 262745 LONG 08051 10)

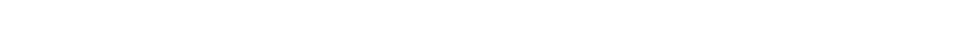
02276402 - LAKE OKEECHOBEE AT POINT 2 FLA (LAT 264930 LONG 0804705 ) 
LAKE OKEECHOBEe AND THE EVERGLADES BASINS--CONTINUED

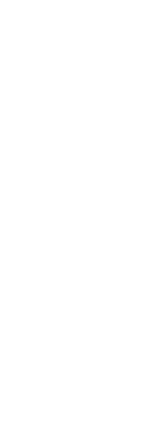
02276403 - LAKE OKEECHOBEe AT POINT 3 FLA ILAT 265205 LONG 0805105 )

02276404 - LAKE OKEECHOBEE AT POINT 4 FLA (LAT 265500 LONG 0805500 ) 02276405 - LAKE OKEECHOBEE AT POINT 5 FLA ILAT 265547 LONG 0805840 )

$\begin{array}{rrrrrrrrrrr}-- & -- & 11.0 & 9.5 & 85 & 491 & 8.1 & 164 & 0 & -. & .0 \\ -- & -- & 30.0 & -- & -- & 580 & 8.9 & -- & -- & -. & -.\end{array}$
02276406 - LAKE OKEECHOBEE AT POINT 6 FLA (LAT 265945 LONG 08055 00) $\begin{array}{rrrrrrrrrrr}-- & -- & 10.5 & 11.2 & 100 & 455 & 8.4 & 146 & 8 & 6 & -- \\ -- & -- & 11.0 & 11.1 & 100 & 400 & 8.4 & 142 & 6 & -- & 13\end{array}$ 02276407 - LAKE OKEECHOBEE AT POINT 7 FLA (LAT 270230 LONG 0805105 ) 02276408 - LAKE OKEECHOBEE AT POINT 8 FLA (LAT 270505 LONG 08047 10) $\begin{array}{rrrrrrrrrrr}-- & -- & 14.0 & 9.8 & 94 & 210 & 8.2 & 76 & 0 & -. & .0 \\ -- & -- & 25.0 & -- & -- & 385 & 9.3 & -- & -. & -. & .0\end{array}$ 02276409 - LAKE OKEECHOBEE AT POINT 9 FLA (LAT 270930 LONG 08047 10)

\begin{tabular}{|c|c|c|c|c|c|c|c|c|}
\hline-- & 14.0 & 10.5 & 101 & 238 & $8 . ?$ & 74 & 0 & - \\
\hline- & 32.0 & -- & - & 370 & 8.9 & -- & $=$ & - \\
\hline
\end{tabular}
02276410 - LAKE OKEECHOBEe AT POINT 10 FLA (LAT 270305 LONG 0804355 ) $\begin{array}{lllllllllllllllll}- & - & - & 11.5 & - & - & & - & 380 & 8.4 & 124 & 0 & - & .0\end{array}$ 02276411 - LAKE OKEECHOBEE AT POINT 11 FLA (LAT 270100 LONG 08040 15)

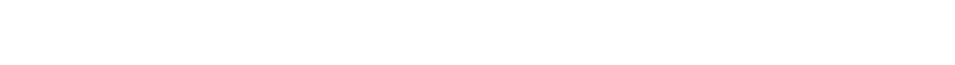
02276412 - LAKE OKEECHOBEE AT POINT 12 FLA (LAT 265905 LONG 0803710 )

\begin{tabular}{|c|c|c|c|c|c|c|c|c|}
\hline-- & 12.0 & 8.8 & 81 & 370 & 8.2 & 132 & 0 & -- \\
\hline -- & 27.5 & -- & -- & 310 & 8.4 & - & -- & -- \\
\hline
\end{tabular}
02276413 - LAKE OKEECHOBEE AT POINT 13 FLA (LAT 265555 LONG 0804055 ) 02276414 - LAKE OKEECHOBEE AT POINT 14 FLA ILAT 265245 LONG 08044 05) $\begin{array}{lccccccc}-- & 12.0 & 10.0 & 93 & 400 & 8.2 & 144 & 0 \\ 02276415- & - \text { LAKE OKEECHOBEE AT POINT } 15 \text { FLA ILAT } 2655 \text { 30 LONG } 0804755 \text {, }\end{array}$

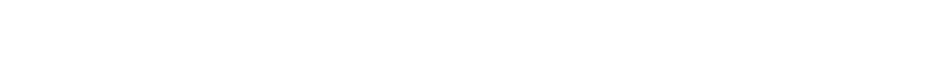
02276416 - LAKE OKEECHOBEE AT PAHOKEE FLA (LAT 264930 LONG $08040 \quad 05$ ) 


$$
\begin{aligned}
& \text { (F PELD MEASUREMENTS) }
\end{aligned}
$$

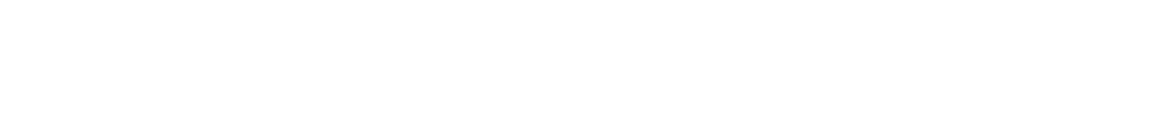

LAKE OKEECHOBEE AND THE EVERGLADES BASINS--CONTINUED 02276418 - LAKE OKEECHOBEE AT POINT I8 FLA (LAT 264852 LONG 08 O 5650 )

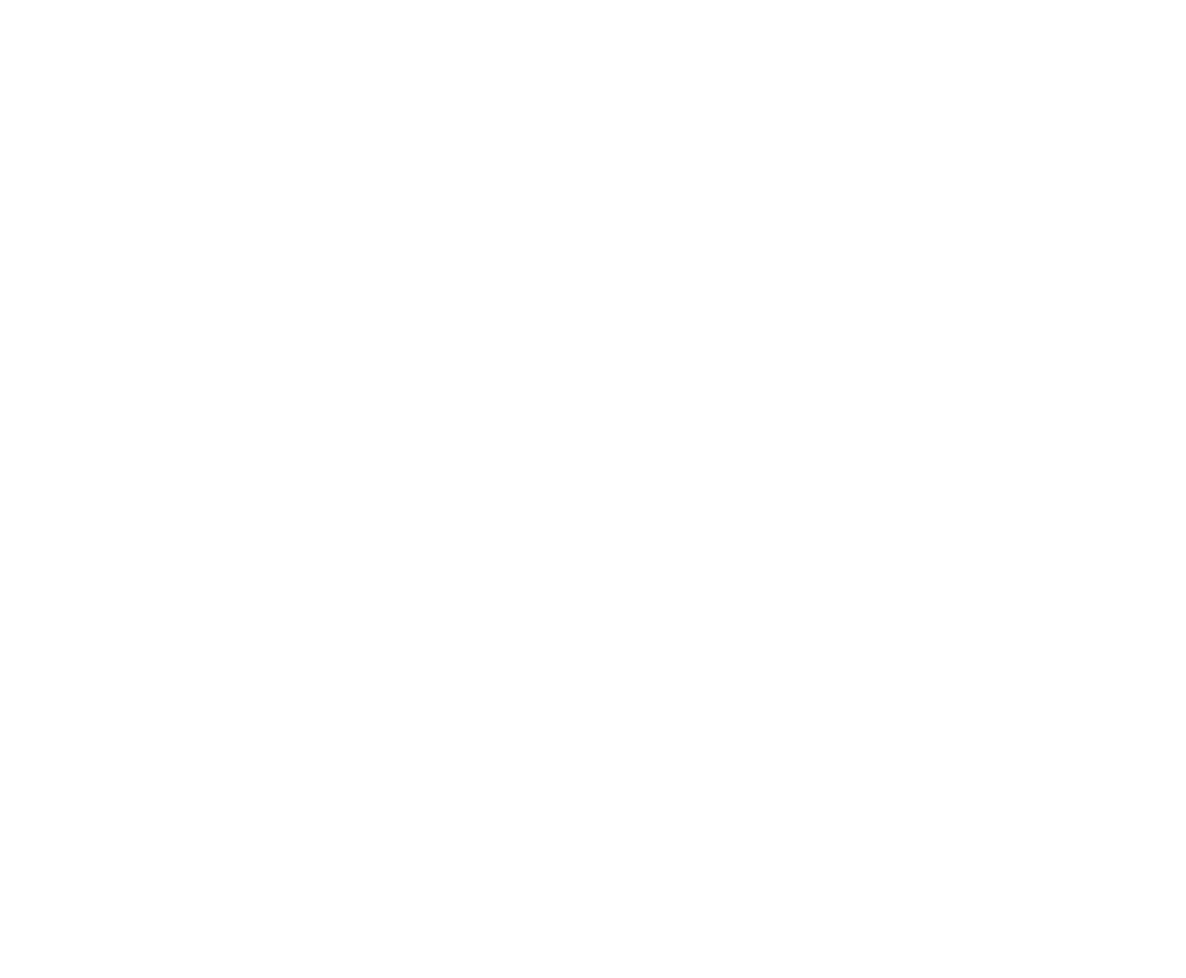

02284810 - hOLLAWAY LATERAL NR FT LAUDERDALE, FLA. (LAT 260340 LONG 0801755 )

MAY 1970
$12 . .$.

$8.86 \quad 5.0 \quad 25.0 \quad 1.1 \quad 13$

02285399 - SN R CA.CON AREA 3 AT S-9 NR DAVIE FL (LAT 260340 LONG 0802630 )

MAY. 19700945

$\begin{array}{llll}10.18 & .00 & 24.5 & 3.4\end{array}$

02385400 - 5OUTH NEW RIVER CANAL AT S-9 NR DAVIE ILAT $2603 \quad 40$ LONG 0802630 I

MAY 1970
O6... 0930
SEP.

22.0

-. $\quad-\quad 32.0 \quad 1.5$

02286100 - SOUTH NEW RIVER CANAL AT S-13 NEAR DAV (LAT 260357 LONG 0801232 )

MAY, 1970

$1.79 \quad 77$

$24.0 \quad 2.3$

02286200 - SNAKE CR CA AT NW 67 AVE NR HIALEAH FL (LAT 255750 LONG 08018401

MAY 19700740

2.51344

$24.5 \quad 7.2 \quad 85$

02286300 - SNAKE CREEK CANAL. AT S-29 AT N MIAMI B ILAT 255541 LONG O80 0922

MAY. 19700930

2.18296

$25.0 \quad 8.4 \quad 100$ 


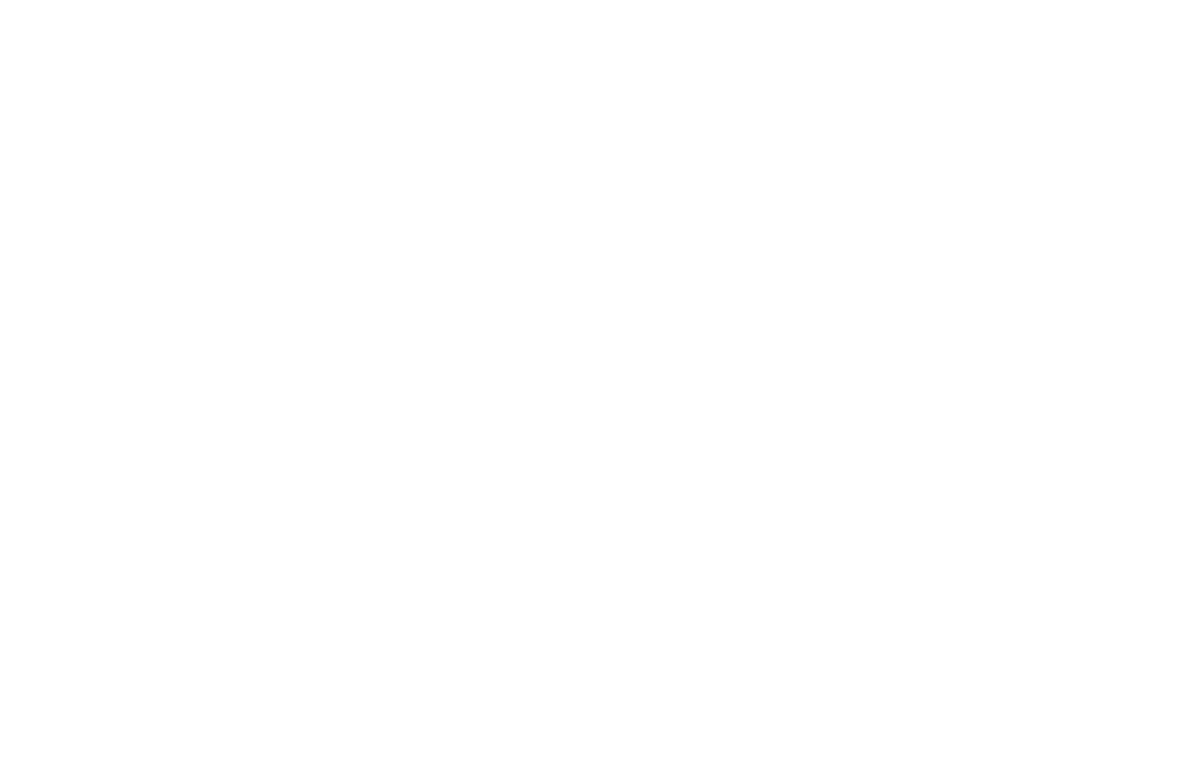

02288900 - TAM CA OLS 40 MI BEND TO MONROE NR MIA (LAT 255105 LONG 08058501

SEP., 1970

02290710 - BLACK CREEK CA AT S-21 NEAR GOULOS FLA (LAT 253243 LONG 0801955 )

SEP., 1970

$\begin{array}{llll}-- & 00 \quad 28.0 \quad 3.3 & 40\end{array}$

02290720 - MILITARY CA NR HOMESTEAD, FLA. (LAT 252920 LONG OBO 20 55)

SEP.. 1970

$-.00 \quad 26.0$

02290732 - BISCAYNE BAY NR HOMESTEAD FLA (LAT 252745 LONG 08020161

SEP. 1970

$-$

02290830 - EVERGLADES P-35 NR HOMESTEAD (LAT 252720 LONG 0805230 )

SEP.. 1970

02291200 - LAKE TRAFFORD NR IMMOKALEE, FLA. (LAT 262608 LONG 08129251

MAY 1970

3.67

02291270 - HENDERSON CREEK CA NR NAPLES FLA (LAT 260559 LONG 0814114 )

MaY 1970

5.253 .1

$29.0 \quad 12.4 \quad 159$

02291600 - ESTERO R NR ESTERO FLA ILAT $26 \quad 2604$ LONG $08148 \quad 181$

MAY, 19701520

1.01

$28.0 \quad 6.0 \quad 76 \quad 17000$

02292000 - CAloosahatchee CANAL AT mOORE haVEN FL (LAT 265000 LONG 08105001

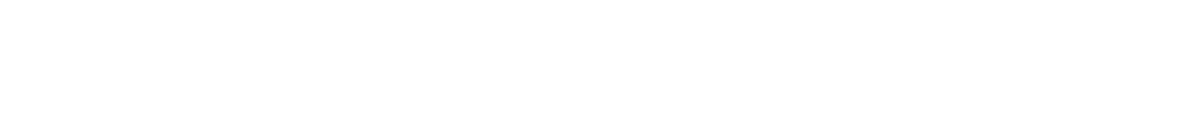




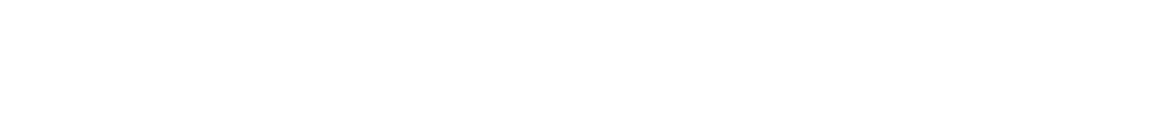

LAKE OKEECHOBEe AND THE EVERGLADES BASINS-CONTINUED

02292900 - CALOOSAHATCHEE RIVER AT S-79 NR OLGA, ILAT 264325 LONG 081 4155 I

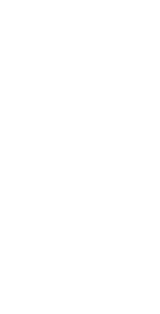

MAY . 1970

MAY $1970 \$ 140$

MAY 1970

MAY $12 . .{ }^{1970} 1520$

MAY $1970 \quad 1705$

MAY 1970 OB45

MAY 1970

MAY. 19701800

MAY 1970

JUNE, 1970
$08 . .$.

MAY, 19701145

O9... 1145

$09 . . . \quad 1030$

MAY.: 19701245

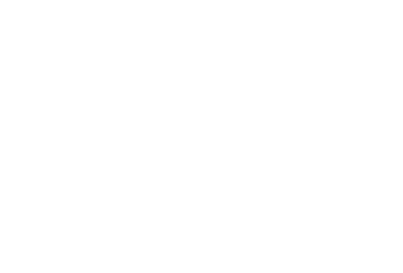

CO $26.0 \quad 6.0$ 02293545 - L OTIS AT WINTER HAVEN FLA ILAT 2801 IO LONG 08142 35)

02293664 - L HAMILTON OLT AT S PB NR L HAMLTN FLA ILAT 280154 LONG 0813842 )

02293774 - MOUNTAIN LAKE NR L WALES FLA (LAT 275601 LONG 08134591

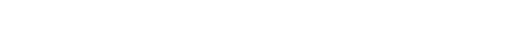

02293785 - LAKE EFFIE AT L WALES FLA ILAT 275431 LONG 08136111

$\begin{array}{llllll}7.45 \quad-\quad & 27.0 & 8.4 & 104 & 680\end{array}$

02293823 - LAKE MYRTLE NR LAKE WALES FLA (LAT 2757 O8 LONG 08138581

$\begin{array}{lllll}39.19 \quad 2- & 26.0 & 8.0 & 98 & 155\end{array}$

02293986 - PEACE CR DRAINAGE CA NR ALTURAS FLA ILAT 275523 LONG 081 4228 I

\section{$3.48 \quad 10$}

02294036 - LAKE HOWARO AT WINTER HAVEN FLA (LAT 280120 LONG 08144 16)

$11.40 \quad-2 \quad 25.0 \quad 7.5 \quad 89 \quad 280$

02294068 - LAKE LULU OUTLET AT ELOISE FLA ILAT 275903 LONG 0814347 )

$\begin{array}{llllll}5.50 & 2.7 & 30.0 & 15.1 & 199 & 485\end{array}$

02294071 - LAKE MCLEOD AT EAGLE LAKE FLA (LAT 275825 LONG 0814500 )

$\begin{array}{llllll}6.15 & -- & 25.5 & 4.5 & 54 & 340\end{array}$

02294214 - SADDLE CREEK NR LAKELANO FLA ILAT 280252 LONG 0815235

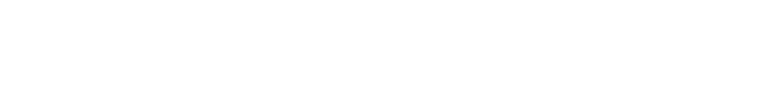

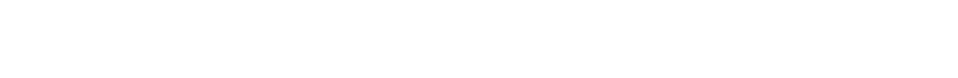

02294259 - LAKE PARKER AT LAKELAND FLA ILAT 280259 LONG 08155221 


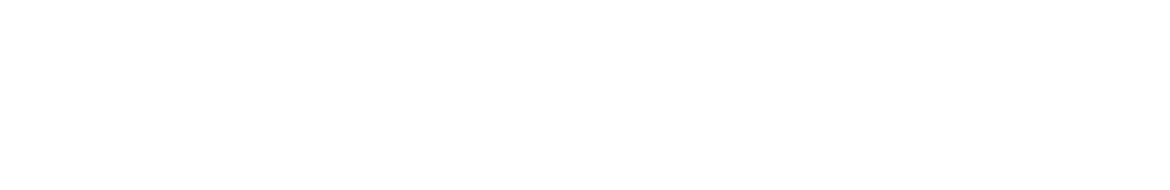

02294462 - LAKE HANCOCK NR HIGHLAND CITY FLA (LAT 275748 LONG 0815129 ) $\begin{array}{lllll}5.06 \quad-2 & 26.0 & 4.3 & 52 & 350\end{array}$

02294490 - SADOLE CR AT ST PII NR BARTOW FLA ILAT 275617 LONG 081 51 05) $\begin{array}{llllll}13.63 & .00 & 24.0 & .3 & 4 & 310\end{array}$

02294553 - SADDLE CR NR BARTOW FLA (LAT 275511 LONG 0814927 )

$\begin{array}{llllll}-- & - & 29.0 & 12.2 & 156 & 275\end{array}$

02294650 - PEACE RIVER AT BARTOW FLA (LAT 275407 LONG 08149 03)

02295435 - HOG BRANCH NP WAUCHULA FLA (LAT 273532 LONG 0814920 )

$\begin{array}{llllll}1.14 & .04 & 25.0 & 3.5 & 42 & 165\end{array}$

02295607 - PEACE R AT WACHULA FLA (LAT 273301 LONG 08147 38)

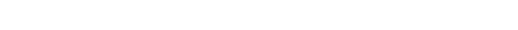

02295977 - PEACE RIVER NEAP, BROWNVILLE FLA (LAT 271808 LDNG 0815047 )

02296222 - L CHARLEY ROWLEGS CR AB CONT NR SEBRIN (LAT 272840 LONG 0813325 )

$\begin{array}{llllll}13.60 & .06 & 22.0 & 2.8 & 32 & 80\end{array}$

02296500 - CHARLIE CR NR GARONER FLA (LAT 272229 LONG 0814748 )

\begin{tabular}{|c|c|c|c|c|c|c|c|c|c|}
\hline 2.63 & 5.2 & 29.0 & 9.0 & 115 & 300 & - & -- & - & - \\
\hline 4.04 & 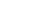 & 27.0 & 5.4 & 67 & - & -- & - & - & $\Rightarrow$ \\
\hline
\end{tabular}

02297100 - JOSHUA CR AT NOCATEE FLA (LAT 270959 LONG 0815247 )

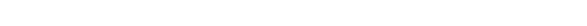

02297251 - HORSE CREEK NEAR LIMESTONE FLA (LAT 272158 LONG 0815825 ) 


\begin{tabular}{|c|c|c|c|c|c|c|c|c|c|c|c|c|}
\hline ATE & TIME & $\begin{array}{l}\text { STAGE } \\
\text { (FT } \\
\text { ABOVE } \\
\text { DATUM) }\end{array}$ & $\begin{array}{l}\text { OIS- } \\
\text { CHARGE } \\
\text { (CFS) }\end{array}$ & $\begin{array}{l}\text { TEMPER- } \\
\text { ATURE } \\
\text { (OEG C) }\end{array}$ & $\begin{array}{l}\text { OIS- } \\
\text { SOLVEO } \\
\text { OXYGEN } \\
\text { (MG/L) }\end{array}$ & $\begin{array}{l}\text { PER- } \\
\text { CENT } \\
\text { SATUR- } \\
\text { ATION }\end{array}$ & $\begin{array}{l}\text { SPE- } \\
\text { CIF IC } \\
\text { CON- } \\
\text { OUCT- } \\
\text { ANCE } \\
\text { (MICRO- } \\
\text { MHOS) }\end{array}$ & (UNITS) & $\begin{array}{l}\text { BICAR- } \\
\text { BONATE } \\
\text { (HCO3) } \\
\text { (MG/L) }\end{array}$ & $\begin{array}{l}\text { CAR= } \\
\text { BONATE } \\
\text { (CO3) } \\
\text { (MG/L) }\end{array}$ & $\begin{array}{l}\text { IRANS- } \\
\text { PAR- } \\
\text { ENCY } \\
\text { SFCCHI } \\
\text { DISK } \\
\text { IINI }\end{array}$ & $\begin{array}{l}\text { DEPTH } \\
\text { (FT) }\end{array}$ \\
\hline
\end{tabular}

COASTAL BASINS BETWEEN LAKE OKEECHOBEE AND THE EVERGLADES AND PEACE RIVER--CONTINUED 02297310 - HOPSE CPEEK NR ARCADIA FLA (LAT 271157 LONG 08159 19)

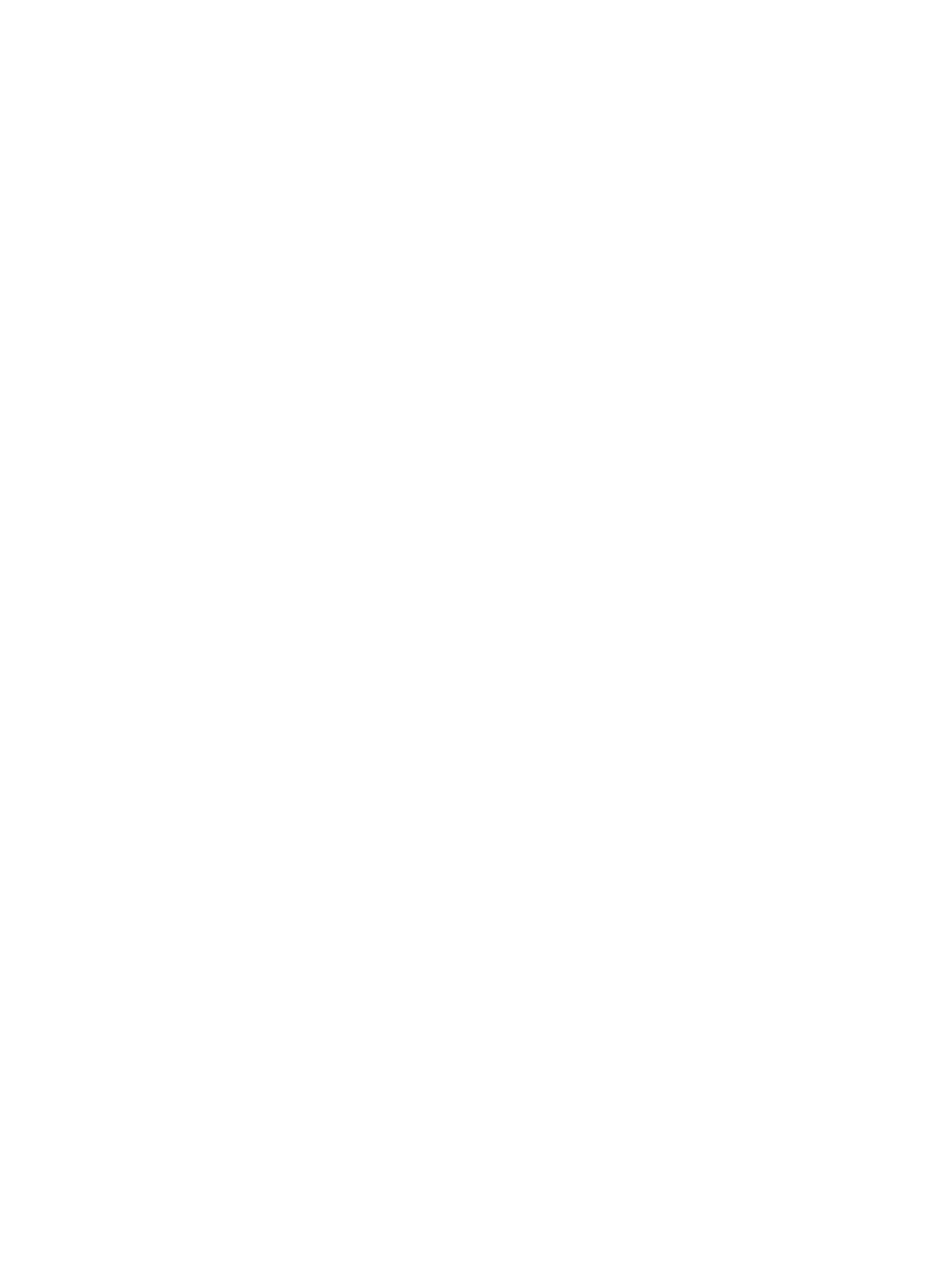




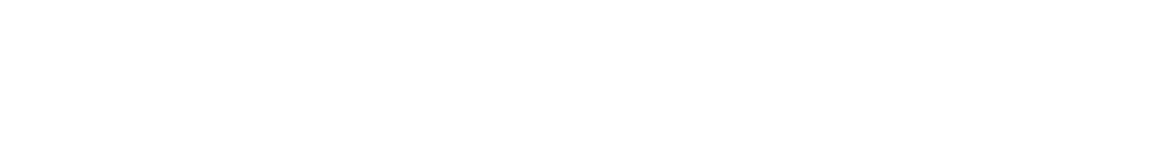

HILLSBOROUGH RIVER BASIN--CONTINUED

02303100 - NEW RIVER NR ZEPHYRHILLS FLA ILAT 28 n9 55 LONG 08215 55)

JUNE, 1970 08 . 0900 JUNE, 1970

JUNE, 1970

SEP.. 1970

25... ${ }^{1970} 1315$

JUNE, $1970{ }_{1410}$

JUNE, 1970

02 ... 1515

JUNE, 1970

08... 1250

$28 . . . \quad 1740$

JAN., 1970

$20 \ldots 1500$

SEP.. 1970
$24 \ldots .$.

mar. 19700810

SEP.. 1970

AUG. 1970

DEC., 1969

$10 \ldots 1415$

FEB.. 19700830

$08 . . .0845$

MAY

25... 1130

$11 \ldots . .1530$

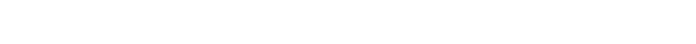

02310220 - NEFF LAKE NR BROOKSVILLE FLA ILAT 2A 2944 LONG DR2 19 14)

02310230 - LAKE 1OLA NR SAN ANTONIO FLA ILAT 282328 LONG 0821754

$\begin{array}{llllll}-- & - & 26.0 & 8.1 & 99 & 123\end{array}$

02310373 - UNNAMED SPRINGS NEAR ARIPEKA FLA ILAT 282352 LONG 0824027 $2.22 \quad .00 \quad 24.0 \quad 2.2 \quad 26$

02310600 - GULF OF MEXICO NR BAYPORT FLA ILAT 283200 LONG 08239011

$\begin{array}{llllll}11.10 & 143 & 24.0 & 6.6 & 78 & 1320\end{array}$

02310680 - MORRISON POND AT LECANTO FLA ILAT 285126 LONG 08229 04)

$\begin{array}{llllll}1.62 & - & 28.0 & 8.2 & 104 & 128\end{array}$

02310700 - hOMOSASSA R AT hOMOSASSA FLA ILAT 2847 06 LONG 0823705 )

02310750 - CRYSTAL RIVER NR CFYSTAL R FLA ILAT 285417 LONG 08238 131

$\begin{array}{ccccccccccc}-- & -- & 26.0 & 8.0 & 98 & 2390 & -- & -- & -- & -- & - \\ -- & -- & 29.0 & 7.1 & -- & 6300 & -- & -- & - & -- & - \\ & & & \text { WITHLACOOCHEE RIVER BASIN } & & & & & \end{array}$

02311000 - WITHLACOOCHEE-HILLSHORO OFL NR RICHLAN ILAT 281616 LONG 08205531

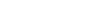

8. 0

02311500 - WITHLACOOCHEE R NR DADE CITY FLA (LAT 2A 21 0R LONG 0820734 )

$\begin{array}{lllll}70.96 & 85 & 26.0 & 3.0 & 37\end{array}$

02312150 - L CATHERINE AT GROVELAND FLA ILAT 283427 LONG 08151371

$11.23 \quad--\quad 24.5 \quad 8.7$

02313180 - BLUE RUN AT DUNNELLON, FLA. (LAT 290257 LONG 092 26 53)

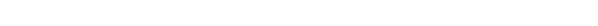

SUWANNEE RIVER BASIN

02315090 - ROARING CREEK NEAR BELMONT FLA ILAT 302550 LONG 08240 00)

$8,08 \quad 181$

02315500

10.162500

$14.98 \quad 4300$

$29.78 \quad 11500$

$4.08 \quad 511$

$9.94 \quad 2450$
23.5

SUWANNEE R AT WHITE SPRINGS FLA (LAT $30 \quad 1932$ LONG $08244 \quad 18$ )

$\begin{array}{rrrrrrrrr}13.5 & 8.5 & 81 & 36 & 4.7 & -- & -- & -- & - \\ 9.5 & 10.2 & 113 & 30 & 4.2 & -- & -- & -- & - \\ 18.5 & 4.9 & 52 & 32 & 4.4 & -- & -- & -- & - \\ 25.0 & 7.3 & 87 & 40 & 5.5 & -- & -- & -- & - \\ 24.0 & 6.4 & 75 & 40 & 4.8 & -- & -- & -- & --\end{array}$




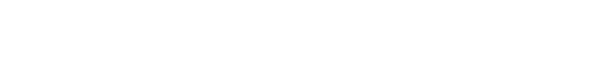

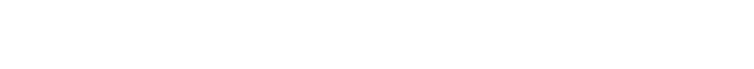

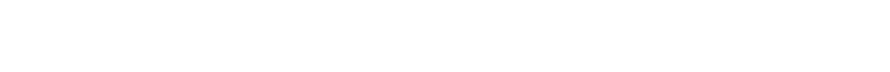

\section{SUWANNEE RIVER BASIN--CONTINUED}

02315520 - SWIFT CR AT FACIL FLA ILAT 302214 LONG 08248001

OEC., 1969

11... 19691645

FEB.. 1970

APR.

APR... 1020

MAY..

25... 1430

$12 . . . \quad 1030$

DEC., 1969

10... 1530

$10 \ldots 1515$

APR.

08... 1540

26... 0830

AUG. $12 . . . \quad 1530$

OEC.) 1969

OEC.: 19691400

FEB.. 19701000

11... 1000

09... 1110

MAY $26 . . . \quad 1045$

AUG. $13 . . .103$

OEC., 19691100

O9... 19700950

APR.

$07 . \ldots \quad 0940$

MAY $\cdots$

AUG... 0930

11...

DEC., 1969

08... 1415

FEE. 1970

APR.

APR. 1115

MAY $23 . . \quad 1130$

$\begin{array}{rr}10.58 & 139 \\ 11.83 & 88 \\ 9.99 & 251 \\ 12.88 & 31 \\ 10.76 & 168\end{array}$

02315550

$\begin{array}{rrrr}14.5 & 7.1 & 69 & 267 \\ 9.0 & 9.2 & 100 & 210 \\ 16.0 & 6.9 & 71 & 456 \\ 24.5 & 5.4 & 64 & 462 \\ 25.0 & 5.3 & 63 & 398\end{array}$

$\begin{array}{rrrr}13.0 & 8.3 & 78 & 45 \\ 11.0 & 7.9 & 71 & 33 \\ 19.0 & 4.4 & 47 & 42 \\ 24.5 & 6.6 & 78 & 112 \\ 24.0 & 6.4 & 75 & 55\end{array}$

WITHLACOOCHEE R NR PINETTA FLA CLAT 303543 LONG $083 \quad 15351$

$\begin{array}{rr}7.82 & 620 \\ 12.66 & 3750 \\ 20.96 & 9150 \\ 7.00 & 274 \\ 11.67 & 3100\end{array}$

$8.59 .2 \quad 78$

$17.5 \quad 5.3 \quad 55$

$24.5 \quad 4.5 \quad 54$

$25.0 \quad 5.6 \quad 67$

02320700

- SANTA FE R NR GRAHAM FLA ILA

$\begin{array}{rr}5.98 & 60 \\ 11.30 & 420 \\ 11.44 & 450 \\ 4.80 & 22 \\ 5.35 & 42\end{array}$

$\begin{array}{llll}12.5 & 7.8 & 72 & 55 \\ 10.5 & 8.4 & 75 & 31 \\ 17.5 & 6.6 & 69 & 29 \\ 22.5 & 6.4 & 74 & 50 \\ 24.0 & 6.4 & 75 & 47\end{array}$

5.0
4.6
5.0
5.1
6.0

02321500

$\begin{array}{rrrrrr}12.93 & 510 & 13.5 & 7.3 & 70 & 66 \\ 19.16 & 3800 & 11.5 & 7.8 & 70 & 28 \\ 18.10 & 2900 & 17.5 & 5.6 & 58 & 35 \\ 8.80 & 64 & 25.0 & 6.3 & 75 & 80\end{array}$

6.3
5.6
5.9
6.9

02322500 - SANTA FE K NR FT WHITE FLA (LAT 295100 LONG 0824250 )

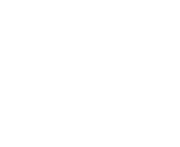

$$
\begin{array}{rrr}
1.67 & 1710 \\
7.55 & 6750 \\
-5 & \\
1.87 & 1930 \\
& \multicolumn{2}{r}{\text { COAS }} \\
& 02323500 \\
3.89 & 7300 \\
7.74 & 15000 \\
11.87 & 25700 \\
3.35 & 10000 \\
0.05 & 11400
\end{array}
$$

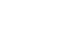

$\begin{array}{rrr}5.9 & 62 & 265 \\ 6.5 & 60 & 40 \\ 5.3 & 56 & 65 \\ 6.7 & 79 & 353\end{array}$

$\begin{array}{ll}7.3 & -- \\ 6.8 & - \\ 6.6 & - \\ 7.7 & -\end{array}$

COASTAL BASINS BETHEEN SUWANNEE RIVER AND AUCILLA RIVER 02323500 - SUWANNEE R NR WILCOX FLA (LAT 293520 LONG $08256 \quad 101$

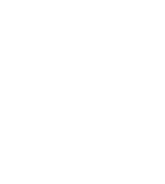

$\begin{array}{rrrr}17.0 & 6.9 & 71 & 237 \\ 11.5 & 7.6 & 68 & 53 \\ 19.5 & 3.9 & 42 & 50 \\ 24.5 & 6.6 & 79 & 298 \\ 24.5 & 6.3 & 75 & 242\end{array}$

$\begin{array}{ll}7.6 & -- \\ 6.7 & - \\ 6.5 & - \\ 7.7 & - \\ 7.8 & -\end{array}$

02324400 - FENHOLLOWAY R NR FOLEY FLA (LAT 300553 LONG 08328 19) 


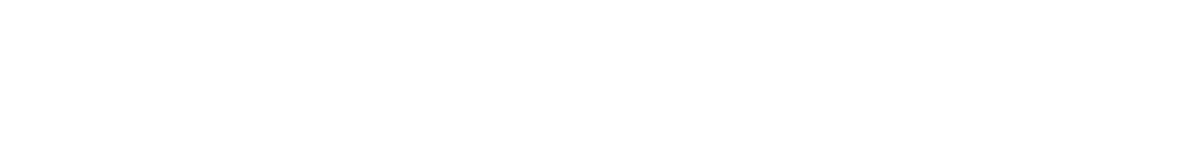

COASTAL BASINS BETWEEN SUWANNEE RIVER AND AUCILLA RIVER--CONTINUED

02324500 - FENHOLLOWAY R AT FOLEY FLA ILAT 300353 LONG $0833 ? 011$

APR.. 1970

$30 \ldots 19701650$

$11.80 \quad 124$
$32.5 \quad 3.9 \quad 53 \quad 135$

OCHLOCKONEE RIVER BASIN

02329000 - OCHLOCKONEE RIVER NR HAVANA FLA (LAT 303314 LONG 0842303 )

JUNE, 1970

$30 . .0940$

$13.62 \quad 335$

$25.0 \quad 6.5 \quad 77 \quad 185$

COASTAL BASINS BETWEEN APALACHICOLA RIVER AND CHOCTAWATCHEE RIVER

02359500 - ECONFINA CREEK NEAL BENNETT FLA (LAT 302304 LONG 08532 (

OCT.. 19691220

01... 1220

DEC.: 1230

FEE. 19701330

$04 \ldots 1330$

APR. 1400

JUNE $13 . .1100$

JULY $28 . . .1255$

$\begin{array}{ll}\text { SEP. } & \\ 23 . \ldots & 1435\end{array}$

\begin{tabular}{|c|c|c|c|c|c|}
\hline 6.42 & & $=$ & 22.0 & 6.8 & 77 \\
\hline 5.90 & 395 & & 17.0 & 7.9 & - \\
\hline 6.74 & & -- & 13.5 & 9.7 & 92 \\
\hline 6.63 & & -- & 20.5 & 6.0 & 66 \\
\hline 6.22 & 460 & & 22.0 & 6.3 & 72 \\
\hline 6.11 & 445 & & 23.5 & 5.8 & 67 \\
\hline -- & & $=$ & 23.0 & 5.9 & 68 \\
\hline
\end{tabular}

02365500 - CHOCTAWHATCHEE R AT CARYVILLE FLA ILAT 304632 LONG $0854940^{\circ}$

OCT., 19690840

$01 \ldots 0840$

DEC.

$03 . . .10930$

$04 \ldots 1100$

$02 \ldots 1130$

UNE

$03 . . . \quad 0845$

$28 \ldots \quad 1045$$$
0.52
$$

$\begin{array}{lllll}6.22 & - & 20.5 & 7.2 & 78\end{array}$

$\begin{array}{lllll}2.65 & 1840 & 10.0 & 8.8 & 78\end{array}$

$9.41 \quad--\quad 8.0 \quad 9.7 \quad 82$

$11.99 \quad--\quad 17.5 \quad 5.0 \quad 5$

$7.30 \quad 5000$

23.5

$6.5 \quad 76$

4.963000

28.0

$6.7 \quad 85$

$\begin{array}{lll}91 & 7.8 & 47 \\ 82 & 7.7 & 92 \\ 54 & 7.3 & 42 \\ 70 & 6.8 & 38 \\ 75 & 7.6 & 39 \\ 93 & 8.0 & -- \\ 110 & 6.9 & --\end{array}$

COASTAL BASINS BETWEEN CHOCTAWHATCHEE RIVER AND YELLOW RIVER

02368000 - YELLOW R AT MILLIGAN FLA (LAT 304510 LONG 0863745 )

AUG.. 1970

4.25945

28.0

$6.7 \quad 85$

BLACKWATER RIVER BASIN

02375500 - ESCAMBIA R NR CENTURY FLA (LAT 305725 LONG 0871400 ?

MAY 1970

AUG. $18 . . . \quad 1000$

$3.64 \quad 1540$

$21.2 \quad 6.8$

$76 \quad 113$

6.9

5.522760

$27.0 \quad 7.4$

91

105

02376108 - ELEVENMILE CREEK NR ENSLEY FLA (LAT 303252 LONG 0871949 )

SEP. 1970

$-65$

1.7

$22 \quad 860$

7.5

COASTAL BASINS BETWEEN ESCAMBIA RIVER AND MOBILE RIVER

02376551 - CHURCHHOUSE BRANCH NK BARRINEAU PK FLA (LAT 304027 LONG 0872353 ) 


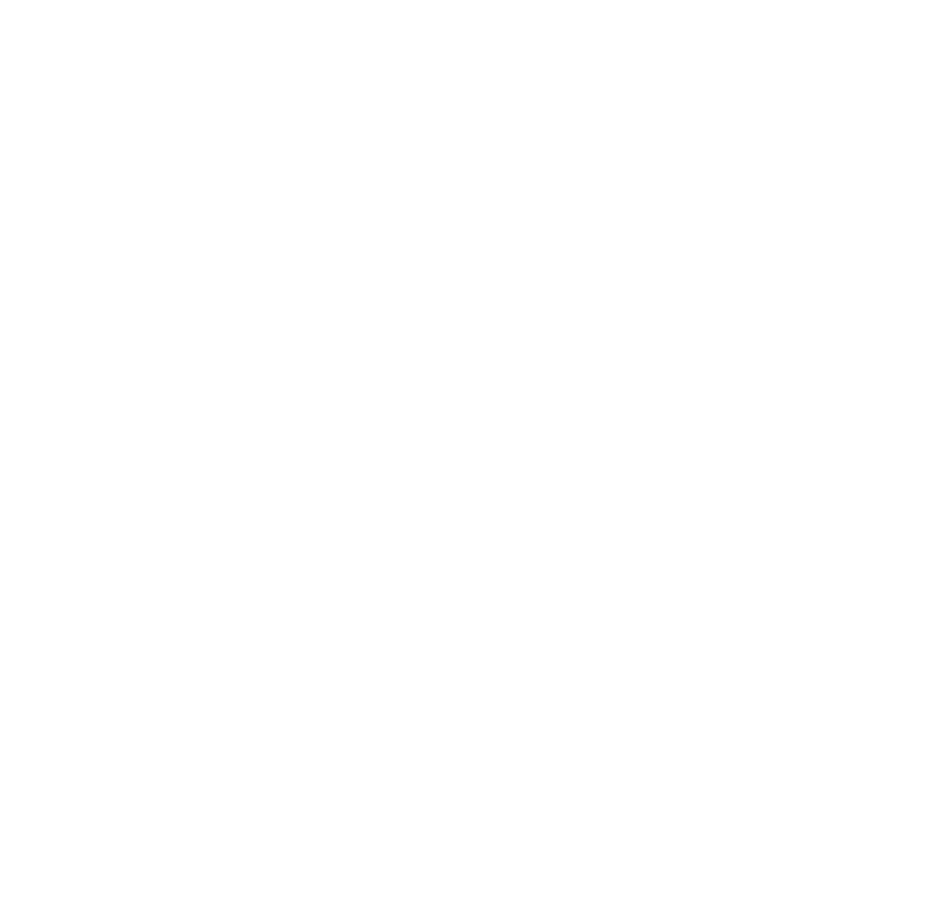


CHEMICAL ANALYSES, WATER YEAR DCTOBER 1969 TO SEPTEMBER 1970 (ORGANOCHLDRIDE COMPOUNDS IN SEDIMENTS)

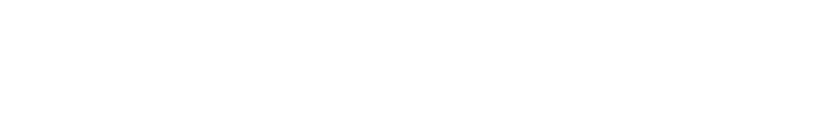

ST. JOHNS RIVER BASIN

02231350 - ST JOHNS HDWATERS NR VERO BCH FLA (LAT 274132 LONG 0802500 )

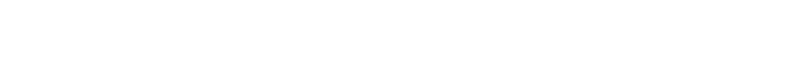

02231396 - $\quad$ BLUE CYPRESS CREEK NEAR FELLSMERE FLA (LAT $2743 \quad 40$ LONG OBO 4813

OCT., 1969

APR: 221970

$30 \ldots . .07$

$\begin{array}{lllllll}.0 & .0 & - & .0 & .0 & .0 & .0\end{array}$

02831400 - BLUE CYPRESS LAKE NR FELLSMEPE FLA (LAT 274334 LONG O80 4532 )

\begin{tabular}{|c|c|c|c|c|c|c|c|c|}
\hline JULY & .0 & 2.7 & .0 & .0 & . n & .0 & .0 & .0 \\
\hline $22 \ldots$ & .0 & 2.1 & 1.4 & .0 & .0 & .0 & .0 & .0 \\
\hline
\end{tabular}

02231467 - ST JOHNS R AB LK HELEN BLAZES NR MELBO (LAT 275943 LONG 0804730 ) MAY 1970

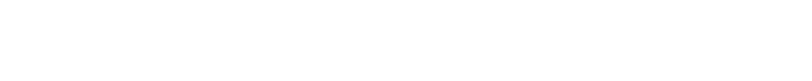

02231471 - LAKE hELEN BLAZES NEAR DEER PARK, FLA. (LAT 280130 LONG 08047 S6) OCT., 1969

28...

02231600 - JANE GREEN CREEK NR DEER PARK FLA (LAT 29 0427 LONG O80 5318 ?

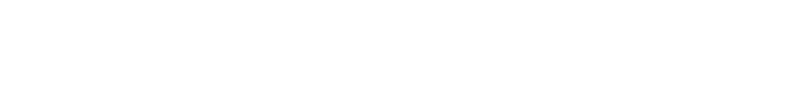

02232100 - LK WASHINGTON NR EAU GALLIE FLA (LAT 280850 LONG OAO $44 \quad 10$ )

\begin{tabular}{|c|c|c|c|c|c|c|c|c|}
\hline MAY 1970 & .0 & .0 & .0 & 2.3 & .0 & $\cdot n$ & - $n$ & . 0 \\
\hline JULY... & .0 & 22 & 8.4 & -0 & .0 & - & .0 & .0 \\
\hline $\begin{array}{l}28 \ldots \\
28 \ldots\end{array}$ & $\begin{array}{l}.0 \\
.0\end{array}$ & $\begin{array}{l}6.6 \\
6.6\end{array}$ & 1.7 & .00 & .0 & .0 & .00 & .00 \\
\hline
\end{tabular}

02232200 - WOLF CR NR DEER PARK FLA ILAT 28 1255 LONG 0RO 54033

\begin{tabular}{|c|c|c|c|c|c|c|c|c|}
\hline 21... & .0 & .0 & $\cdot 0$ & .3 & .0 & .0 & .0 & .0 \\
\hline $\operatorname{JULY}_{28}$ & $\cdot 0$ & .0 & .0 & . n & $\bullet 0$ & . & .0 & .0 \\
\hline $21 \ldots$ & .0 & .0 & .0 & . & .0 &.$n$ & .0 & .0 \\
\hline
\end{tabular}

02232300 - LK POINSETT NR COCOA FLA (LAT 29 ?I 11 LONG OBO 4 B 56)

\begin{tabular}{|c|c|c|c|c|c|c|c|c|}
\hline MAY 1970 & .0 & 2.0 & .0 & .0 &.$n$ & . n & .0 & 1.0 \\
\hline JULYY & . & .0 & .0 & - & .0 & .7 & .0 & .0 \\
\hline $\begin{array}{l}29 \ldots \\
29 . .\end{array}$ & 0 & $\begin{array}{l}1.0 \\
1.0\end{array}$ & $\begin{array}{l}: 0 \\
.0\end{array}$ & $\begin{array}{r}0 \\
.0\end{array}$ & .0 & $\begin{array}{l}0 \\
0\end{array}$ & 0 & $: 0$ \\
\hline
\end{tabular}

02232413 - TAYLOR CREEK AT S 164 NEAR COCOA FLA ULAT 28 2023 LONG 0BO 56 061

OCT. 1969

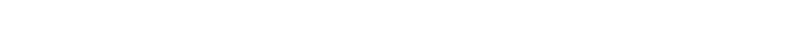

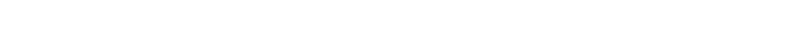

$\begin{array}{llllllllll}20 . . . & 0 & 0 & 0 & .0 & .0 & .0 & .0 & .0 & .0\end{array}$

02334000 - ST JOHNS R AB L HAKNEY NK GENEVA FLA (LAT 2842 SO LONG 081 O2 06)

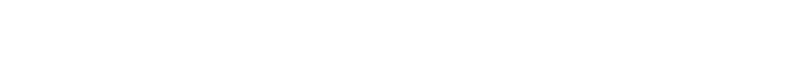


CHEMICAL ANALYSES, WATER YEAR OCTOBER 1969 TO SEPTEMBER 1970 (ORGANOCHLORIDE COMPOUNDS IN SEDIMENTS)

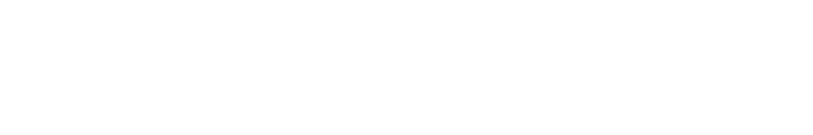

$$
\text { ST. JOHNS RIVER BASIN--CONTINUED }
$$

02240500 - OKLAWAHA RIVER AT EUREKA FLA (LAT 292200 LONG 0815400 ) SEP. 1970

02243960 - OKLAWAHA R AT ROOMAN DAM NR ORANGE SPR (LAT 293030 LONG 08148 15) SEP.. 1970

LAKE OKEECHOBEE AND THE EVERGLADES BASINS

02263869 - SOUTH LK OUTLET AU S-15 NR VINELAND FL (LAT 282445 LONG 0813217 ) SEP.. 1970

$01 \ldots$...

02264000 - CYPRESS CR AT VINELAND FLA (LAT 282325 LONG 0813111 ) AUG., 1970

02266200 - WHITTENHORSE CR NR VINELAND FLA (LAT 2B 23 OS LONG OBI 37 00) AUG., 1970

$\begin{array}{llllllll}\text { AUG... } 1970 & .0 & 3.4 & 5.4 & .0 & 1.1 & .0 & .0\end{array}$

02266292 - LATERAL 405 BL \$405A NR OR PHILLIPS FL (LAT 282534 LONG 0813632 ) AUG.. 1970

02266300 - REEOY CR NR VINELAND FLA (LAT 281957 LONG 081 34 48) AUG.. 1970
$27 . .$. $\begin{array}{lllllllll}\text { AUG.. } 1970 & & & & & & & & \\ 31 . .0 & 0 & 7.1 & 9.6 & 0.5 & .8 & .0 & .0 & .0\end{array}$ 02278500 - DIV TO CON AI AT S-5A AND S-5AS NR LOX (LAT 264100 LONG OBO 2210 ) $\begin{array}{llllllll}\text { AUG.. } 1970 & 0 & 270 & B 5 & 22 & .0 & .0 & .0\end{array}$ 02278501 - CON AREA NO 1 BL S-5 COMP NR LOX (LAT 2641 0O LONG OBO 2210 ) $\begin{array}{cccccccc}A P R .01 & 1970 & & & & & & \\ 28 . . . & .0 & 2300 & 770 & 860 & 20 & .0 & .0\end{array}$ 02279000 - WEST PALM BCH CA AT WEST PALM BCH, FLA ILAT 263840 LONG 0800332 )

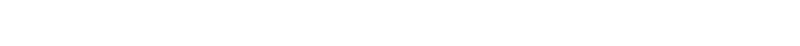
02281295 - EVERGLADES STA 1-15 NR DELRAY HEACH FL ILAT 262345 LONG 08017403 NoV.. 1969

\begin{tabular}{|c|c|c|c|c|c|c|c|c|}
\hline $\begin{array}{l}20 \ldots \\
20 \ldots\end{array}$ & $\because 0$ & 17 & 4.7 & 9.0 & .0 & .0 & .0 & .0 \\
\hline${ }_{A P R .: "}^{20 . .} 1970$ & $\cdot 0$ & & 4.7 & 9.0 & .0 & .0 & .0 & .0 \\
\hline $\begin{array}{l}28 . . . \\
\text { AUG. }\end{array}$ & .0 & 63 & 40 & .0 & .0 & .0 & .0 & .0 \\
\hline $06 \ldots$ & .0 & .1 & .6 & 2.2 & .0 & .0 & .0 & .0 \\
\hline
\end{tabular}

02284642 - EVERGLADES STA 2-17 NR ANDYTOWN FLA (LAT 261650 LCNG ORO 2510 ) AUG., 1970

n6...

.016

$17 \cdot 0$

02290720 - MILITARY CA NR HOMESTEAD, FLA. (LAT 252920 LONG 0802055 ) MAR.. 1970

$\begin{array}{llllllll}11 . . . & .0 & 8.0 & 3.1 & .0 & 4.4 & .0 & .0\end{array}$

02290721 - MILITARY CANAL BL CONT NR HOMESTEAD FL (LAT 252920 LONG 08020 55.01) MAR., 1970 TO 
CHEMICAL ANALYSES, WATER YEAR OCTOBER 1969 TO SEPTEMBER 1070 (ORGANOCHLORIDE COMPOUNDS IN SEDIMENTS)

\begin{tabular}{|c|c|c|c|c|c|c|c|c|}
\hline & ALORIN & DOD & DOE & ODT & $\begin{array}{l}\text { UI- } \\
\text { ELOHIN }\end{array}$ & ENDEIN & $\begin{array}{l}\text { HEPTA- } \\
\text { CHLOP }\end{array}$ & LINDAME \\
\hline & IN & IN & IN & IN & IN & IN & IN & IN \\
\hline & HOTTON: & ВOTTOM & ВОTTOM & ВOTTOM & ROITOM & BotTon & АОТТОМ & POTTOM \\
\hline & $\begin{array}{l}\text { DE- } \\
\text { POSITS }\end{array}$ & $\begin{array}{l}\text { DE- } \\
\text { POSITS }\end{array}$ & $\begin{array}{l}\text { UE- } \\
\text { POSITS }\end{array}$ & $\begin{array}{l}\text { DE- } \\
\text { POSITS }\end{array}$ & $\begin{array}{l}\text { UE- } \\
\text { POSITS }\end{array}$ & $\begin{array}{l}\text { DE- } \\
\text { POSITS }\end{array}$ & $\begin{array}{c}\text { DE- } \\
\text { POSITS }\end{array}$ & $\begin{array}{l}\text { DE- } \\
\text { PDSITS }\end{array}$ \\
\hline ATE & $(U G / K G)$ & $(U G / K G)$ & $(U G / K G)$ & (UG/KG) & (UG/KG) & (UOG/KG) & $(U G / K G)$ & (UG/KT) \\
\hline
\end{tabular}

\section{SUWANNEE RIVER BASIN}

02315500 - SUWANNEE R AT WHITE SPEINGS FLA ILAT 3N 1932 LONG OB2 4418 I

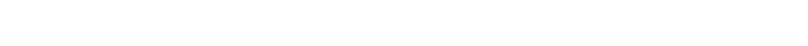

COASTAL BASINS BETWEEN CHOCTAWHATCHEE RIVER AND YELLOW RIVER

02366900 - MAGNOLIA CREEK NEAK FREEPOKT FLA ILAT 3031 4\% LONG 08605151 JUNE, 1970

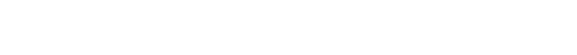

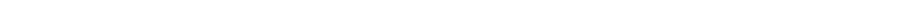
QuG.. 1970

255120080523000 - JETPURT GORPO PIT \#4 NL MIAMI FLA (LAT 255120 LONG OMO 52301 NOV.. 1964 $18 . . .19$

255230000550009 JF.TPORT BURROIV PIT 5 NH MIAMI FLA ILAT 255730 LONG OAN 55 OOI $\Delta 46 . .1970$ I3...

$255830080041000 \quad-$

CORPS OF FINGF GAGE 3-4 PHK ANIDYTDNN FLA ILAT 2558 3n LONG 08004101

A. $11 \%, 1970$

261057190442600

CORPS OF ENGINEERS GAGE 3-2 NR ANDYTOQ (LAT 24 IO 47 LONG DSO 44261 AUG.. 1470

$261324080211800-$

L-3SH RORROW CANAL IN CA 24 NR ANUYTOH ILAT 251324 L ONF MEO 21181 Ál'i.: 1470

261345080274500 Alis., 197 त

263219080072300 AUG., 1970 1201970

263221080052800 ROYNTON CA AT CONGKESG AVF NA BOYNTON (LAT 2532 21 LON, 0EO 05 29) ALIG.. 1970 $12 \ldots$

$263227080122000-$ C-IO AT EINUALIZING CA NHE BOYNTIIN BCH F (LAT 2N 3227 LONG 0 ORO 12 PO) AUG., 1970 AUG... 129

264042080092800 Auta. 1970 11...

264043080102800 4UG.. I 970 $11 . . .19$

264047080120400 4UG.. 1970

264531080051800 -

AUG... 197ก

264829000050900 AUT. . 1970

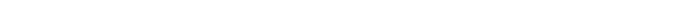
$\begin{array}{lllllll}0 & .0 & .0 & .0 & .0 & .0 & .0\end{array}$ $\cdot 0$ $\begin{array}{llllllll}.0 & 100 & \text { is } & 5.3 & 7.1 & .0 & .0\end{array}$ R'FST PALM HCH CA AT CLEARY HO NR WEST ILAT 264042 LONG nEO 09 PBI $\begin{array}{llllllllll}.0 & 11 & 6.4 & 4.1 & .6 & .0 & .0 & .0\end{array}$ WEST PALM BCH CA AT GFNOIST FARMG ROAD (T.AT ZA $40 \quad 43$ LONG OAO IN 2.8 ) $\begin{array}{lllllll}. n & 170 & 74 & 16 & 4.7 & . n & .0\end{array}$ WFST PALM OCH CA AT SH OO NR WEST PALM ILAT 264047 LONG OBN 12 OB) $\begin{array}{lllllll}.1 & 1.5 & .0 & .0 & .0 & .0 & .0\end{array}$ CANAL 17 AT FH 7 Z NEAK MANGOMIA PARK (LAT 264531 LONG ORO O5 1R) $\begin{array}{llllllllll}0 & 0 & 0 & 0 & 0 & 0 & 0 & 0 & 0 & .0\end{array}$ CANAL 17 AT SH-8חY NO LAKE PARK FLA ILAT 264829 LONG ORO 05 n9) $11 . .$. 


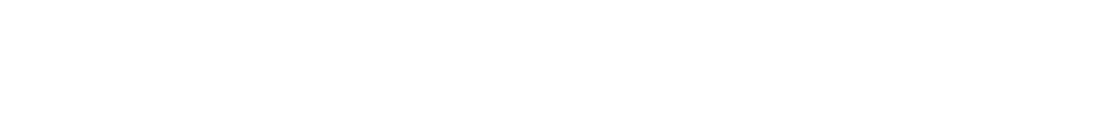
ST. JOHNS RIVER BASIN

02231350 - ST JOHNS HDWATERS NK VERO BCH FLA (LAT 7741 aZ LOMG 0802500 )

\begin{tabular}{|c|c|c|c|c|c|c|c|c|c|c|}
\hline $\begin{array}{l}\text { OCT." } 1969 \\
21 . \cdots 1 \\
\text { MAY } 1970\end{array}$ & .00 & - & .00 & .01 & .00 & . on & . 0 n & .00 & -- & .00 \\
\hline $01 \ldots$ & .00 & - & .00 & .00 & .00 & .00 & $.0 n$ & .00 & - & .00 \\
\hline
\end{tabular}

02231396 - BLUE CYPRFSS CREEK NEAR FFLLSMEPE FLA \{LAT 274340 LONG ORO 4819$\}$ $\underset{22.1969}{0.1}$

02231400 - RLUE CYPRESS LAKE NR FELLSMEPE FLA (LAT 774334 LONG 080 4532 )

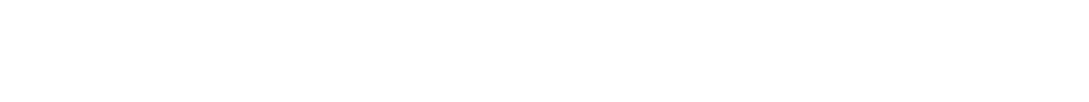

02231467 - ST JOHNS R AB LK HELEN BLMZES NP MELHO (LAT 275943 LONG 0804730 )

\begin{tabular}{|c|c|c|c|c|c|c|c|c|c|c|}
\hline JULY & .00 & $\cdots$ & .00 & & & & & .00 & - & .00 \\
\hline $28 . \ldots$ & .00 & $\cdots$ &. no & .00 & .00 & .00 & $.0 n$ & .00 & -- & .00 \\
\hline
\end{tabular}

02231471 - LAKE HELEN BLATES NEAR UEER PARK, FLA. (LAT 28 01 30 LONG 090 4756 )

0CT. 1969.00

02231600 - JANE GREEN CREEK NR DEFR PARK FLA (LAT 280427 LONG OBO 53 18)

OCT.. 1969

IPR: $1970 \quad 00$

$28 \ldots . .070$

$28 \ldots .00$

$21 . . . \quad .00$

$\begin{array}{lll}- & .00 & .00 \\ = & .00 & .00 \\ - & .00 & .00 \\ - & .00 & .00\end{array}$

$.01 \quad .00$

.00

$--$

$.00 \quad .00$

02232100 - LK NASHINGTON NR EAU GALLIE FLA (LAT 290850 LONG 08 R 44 1n)

กCT., 1969

23...

MAY, 1970 .00

n4...

$28 \ldots . . .00$

$\begin{array}{ccc}-- & .00 & .00 \\ -- & - & .00 \\ -- & -- & .00 \\ - & -- & 1.7\end{array}$

$\begin{array}{lll}.00 & .00 & .00 \\ .00 & .00 & .00 \\ .01 & .00 & .00\end{array}$

.00

.00

0.00

$28 \ldots$

02232200

MOLF CR NR DEER PAKK FLA (LAT 29 1255 LONG 080 54 03)

OCT., 1969

$58 . .$.

APR., $1970 \quad 00$

$28 . . . \quad 00$

JULY $21 . . . \quad .00$

$\begin{array}{ccccccccc}-- & .00 & .00 & .02 & .00 & .00 & .00 & \ldots & .00 \\ -- & .00 & .00 & .00 & .00 & .00 & .00 & \ldots & .00 \\ - & .00 & .00 & .00 & .00 & .00 & .00 & \ldots & .00\end{array}$

02232300 - LK POINSETT NR COCOA FLA (LAT 282101 LONG 08048 56)

NOV., 1969

$05 \ldots . .00$

MAY... 1970

JULY $29 . . . \quad .00$

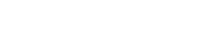

$--$

02232423 - TAYLOP CHEEK AT S 164 NEAR COCOA FLA (LAT $2 R 2023$ LONG OBO 56 06)

OCT., 1969

$50 . . .0 .1970$

APR.. $1970 \quad 00$

$27 \ldots$

JU...

TAYLOP CHEEK

.

$.00 \quad .00$

$.00-00$

$.00 \quad .00$

$00 \quad .00$

$.00 \quad .00$

$\begin{array}{lllll}.00 & .00 & .00 & \ldots & .00\end{array}$

$00 \quad .00 \quad .00$

$20 \ldots .00$

02234000 - ST JOHNS D AB L. HAPNEY NR GENEVA FLA (LAT $>94250$ LONG 08202 06)

OCT., 1969

MAY 1970.00

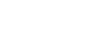

$08 . . . \quad 00$

02238500

SEP ., 1968

$18 \ldots$

.00

$.00 \quad .0$

.00 .01

$.01 \quad .00 \quad .00$

$.00 \quad .00$ 
CHEMICAL ANALYSES, WATER YEAR OCTOBER 1969 TO SEPTEMBER 1970

(ORGANOCHLORIDE COMPOUNDS IN WATER)

\begin{tabular}{|c|c|c|c|c|c|c|c|c|c|c|c|}
\hline DATE & $\begin{array}{l}\text { ALDRIN } \\
\text { (UG/L) }\end{array}$ & $\begin{array}{l}\text { CHLOR- } \\
\text { OANE } \\
\text { (UG/L) }\end{array}$ & 000 & $\begin{array}{l}\text { DOE } \\
\text { (UG/L) }\end{array}$ & $\begin{array}{c}\text { DDT } \\
\text { (UG/L) }\end{array}$ & $\begin{array}{c}\text { DI- } \\
\text { ELORIN } \\
\text { (UG/L) }\end{array}$ & $\begin{array}{l}\text { ENDPIN } \\
\text { (UG/L) }\end{array}$ & $\begin{array}{l}\text { HEPT A- } \\
\text { CHLOR } \\
\text { (H) }\end{array}$ & $\begin{array}{l}\text { HEPTA- } \\
\text { CHLOR } \\
\text { EPOXIDE } \\
\text { (1JG/L) }\end{array}$ & $\begin{array}{l}\text { I INDANE } \\
\text { (UG/L) }\end{array}$ & $\begin{array}{l}\text { TOX- } \\
\text { APHENE } \\
\text { (UG/L) }\end{array}$ \\
\hline
\end{tabular}

ST. JOHNS RIVER BASIN--CONTINUED

02238500 - OKLAWAHA R AT MOSS BLUFF FLA (LAT 290455 LONG 08153 05)

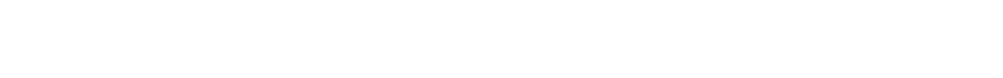

02239497 - SILVER SPRINGS AT SILVFR GPRINGS FLA (LAT 391252 LONG 08203 15)

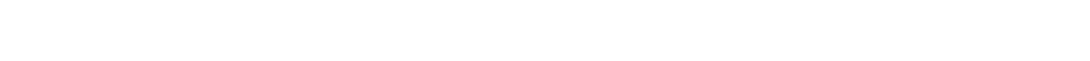

02240000 - OKLAWAHA R NR CONNER FLA (LAT 291250 LONG 0 HI 5910 )

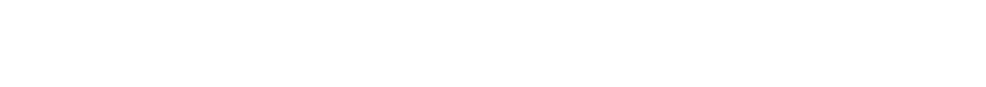

02243000 - ORANGE CR AT ORANGE SPPINGS FLA (LAT 293034 (ONG 0B) 5647 )

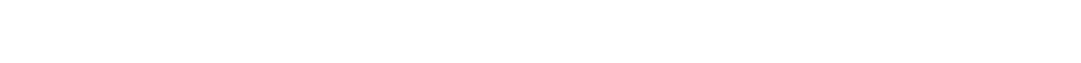
02243800 - DEEP CR NR RODMAN FLA ILAT 2932 2P LONG OR1 50121

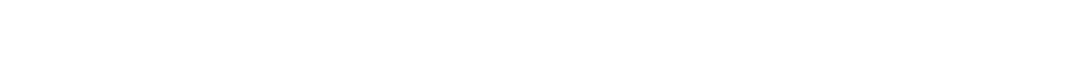
02244450 - ST JOHNS R AT PALATKA FLA (LAT 293837 LONG 0813736 )

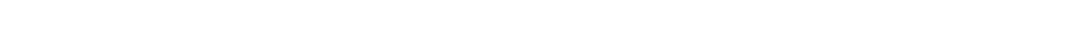
02263869 - SOUTH LK OUTLET AB S-15 NR VINELANI FL (LAT $2924 \quad 45$ LONG D81 32 17) SEF., 1970 $\begin{array}{lllllllllll}01 . . & .00 & -. & .00 & .00 & .01 & .00 & .00 & .00 & 0 & .0\end{array}$ LAKE OKEECHOBEE AND THE EVERGLADES BASINS

02264000 - CYPRESS CH AT VINELAND FLA (LAT 282325 LONG O81 31111

$\begin{array}{cccccccccccc}\text { AUG., } 1970 \\ 27 . . . & .00 & -- & .00 & .00 & .00 & .00 & .00 & .00 & \ldots & .00 & \ldots\end{array}$

02266200 - WHITTEVHORSE CP NR VINFLAND FLA (LAT 282305 LOHG 0813700 )

$\begin{array}{llllllllllllll}\text { AUG.. } 1970 & .00 & - & .00 & .00 & .01 & .00 & .00 & .00 & \ldots & .00\end{array}$

02266292 - LATERAL 405 8L S405A NR DR PHILLIPG FL (LAT 282534 LONG 0813632 )

$\begin{array}{ccccccccccc}\text { AUG. I I } 270 \\ 27 . \ldots & .00 & -- & .00 & .00 & .00 & .00 & .00 & .00 & -. & .00\end{array}$ 02266300 - REEDY CR NR VINELAMID FLA (LAT 29 1957 LONG 0813448 )

$\begin{array}{lllllllllll}\text { AUG.. } 1970 & .00 & \ldots & .00 & .00 & .00 & .00 & .00 & .00 & \ldots & .00\end{array}$

02266480 - DAVENPORT CREEK NEAP LOUGHMAN FLA (LAT 291615 LONG 0H1 3528 )

AUG., 1970

$31 \ldots .00$

02276437 - HEADER CA AT ORANGE AVE NR FT PIERCE, (LAT 272650 LONG 0802451 )

$\operatorname{OCT}_{07 \ldots 1908}$

02276651 - C-?2 AT STATE ROAU 70 NEAR FT PIERCE F (LAT 2722 O3 LONG OBO 32 48)

OCT.. 1968

02277110 - ST LUCIE ESTUARY AT AIA AR NR STUART (LAT $2711 \quad 5 \%$ LONG $08012 \quad 26$ )

SEP., 1969

\begin{tabular}{|c|c|c|c|c|c|c|c|c|c|c|c|}
\hline $11: \ldots 1969$ & $<.00$ & $<.0$ & $<.01$ & $<.01$ & $<.02$ & $<. n 1$ & $<.02$ & $<.00$ & $<.01$ & .00 & $<. ?$ \\
\hline${ }_{\text {MAY }}^{21} \cdots$ & $<.00$ & $<.0$ & $<.01$ & $<.01$ & $<.02$ & .01 & $<.02$ & $<.00$ & $<.01$ & .00 & $<.2$ \\
\hline JUNE & $<.00$ & $<.0$ & $<.01$ & $<.01$ & $<.02$ & $<.01$ & $<.02$ & $<.00$ & $<.0 \mathrm{I}$ & .00 & $<.2$ \\
\hline AUG... & $<.00$ & $<.0$ & $<.01$ & $<.01$ & $<.09$ & .06 & $<.0 ?$ & $<.00$ & $<.01$ & .00 & $<.2$ \\
\hline $07 . .$. & $<.00$ & $<.0$ & $<, 01$ & $<.01$ & $<.02$ & $<.01$ & $<.02$ & $<.00$ & $<.01$ & .00 & $<.2$ \\
\hline
\end{tabular}


CHEMICAL ANALYSES, MATER YEAR OCTOBER 1969 TO SEPTEMBER 1970 (ORGANOCHLORIDE COMPOUNDS IN WATER)

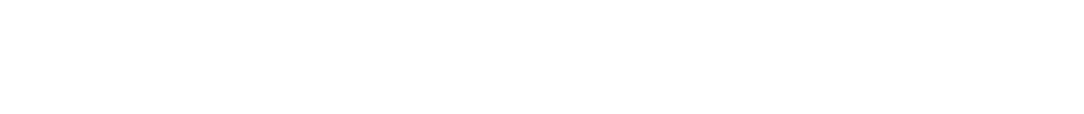

LAKE OKEECHOBEe AND THE GVERGLADES BASINS--CONTINUED

02278501 - CON AREA NQ 1 BL S-5 COMP NR LOX ILAT 2641 OO LONG 0BO 22 10)

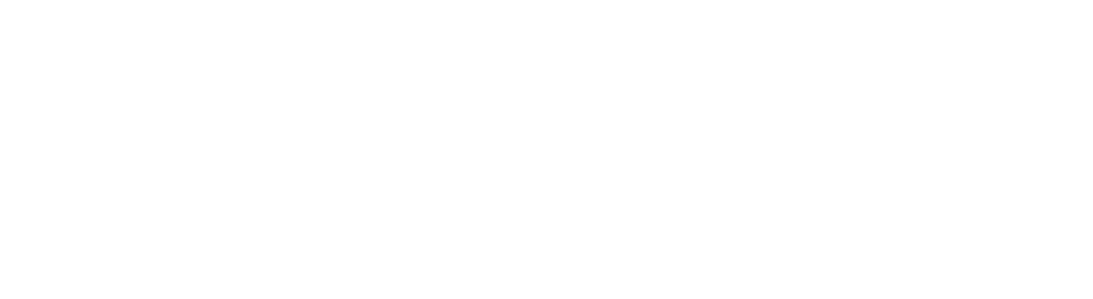

02281300 - HILLSBOHO CANAL AT S-39 NF DEERFIELD B (LAT 262120 LONG 0BO 17 58)

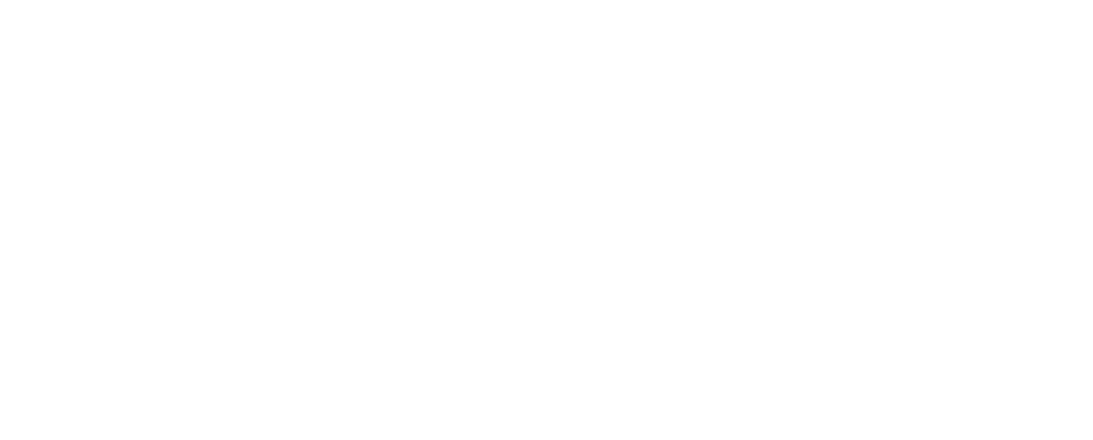

02282100 - CYPRESS CR CA AT S-37A NR POMPANO BEACH F LLAT $26 \quad 1220$ LONG 0800757 )

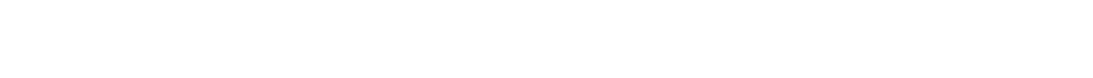

02282700 - MIOOLE R CA AT S-3K NR FT LAUDERDALE F (LAT 261022 LONG OBO 1047 )

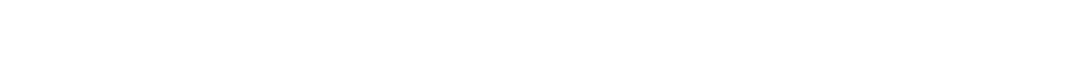

0228?740 - NF MID FIV CANAL EXT AT FT LAUDEPDALE (LAT 261117 LONG 0 OBO 1114 14)

$\begin{array}{cccccccccccccccc}\text { OEC.. } & 1968 \\ 05 . . . & .00 & -- & .00 & .00 & .01 & .00 & .00 & .00 & \ldots & .00 & \ldots\end{array}$

02282743 - NF MID R CA EXT IPROSPECT RD) AT FT LAUD ILAT 261120 LONG ORO 1032

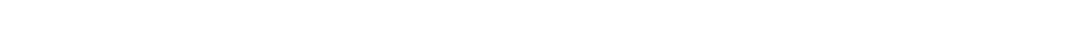

02282800 - MIDOLE R CA AT US HWY 1 NR FT LAUD FLA (LAT 260926 LONG 0800703 )

FE. 1970

02282990 - FLORIDA TURNPIKE CA AT FT LAUDEROALE F (LAT $26 \quad 0603$ LONG $08013 \quad 03$ )

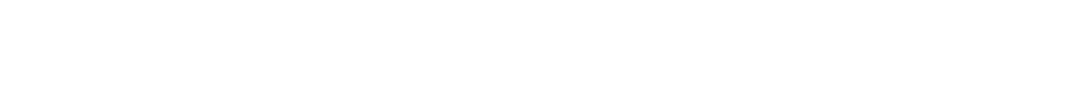

02283200 - PLANTATION RD CA AT S-33 NR FT LAUD FL (LAT 260805 LONG 0801142 )

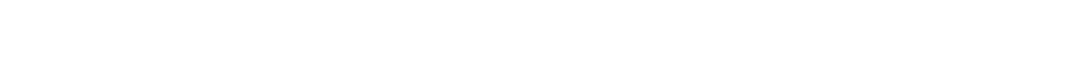




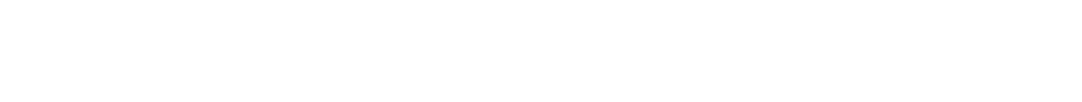

LAKE OKEECHOBEE AND THE EVERGLADES BASINS--CONTINUED

02284642 - EVERGLAOES STA 2-13 NR ANDYTOWN FLA ILAT 261650 LONG DAO 2510 )

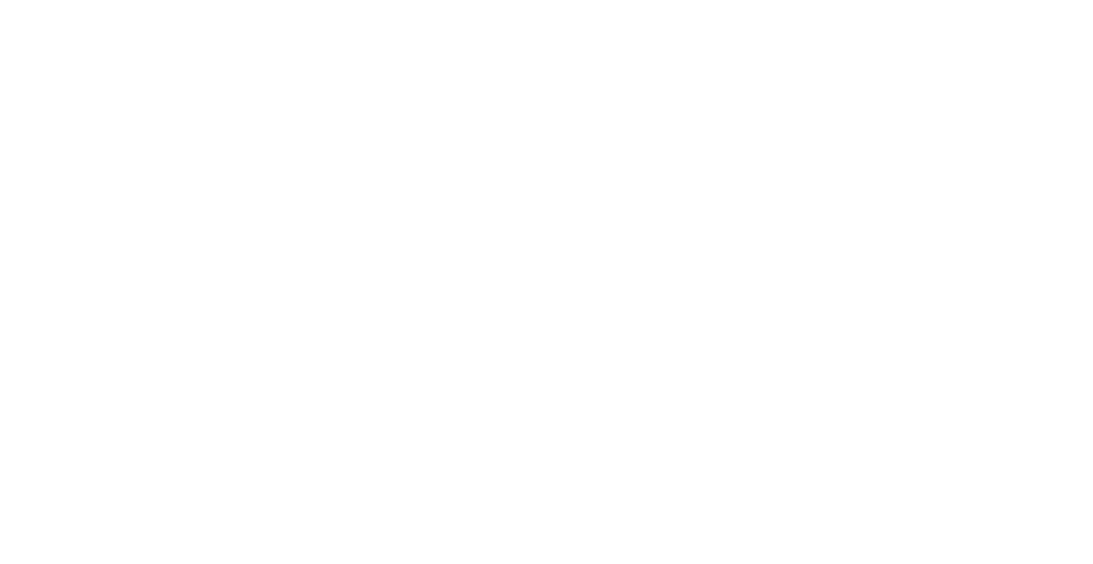

02289500 - TAMIAMI CA NR COKAL GABLES FLA (LAT 254543 LONG OBO 1942 )

\begin{tabular}{|c|c|c|c|c|c|c|c|c|c|c|}
\hline $\begin{array}{l}\text { JAN., } 1970 \\
\text { MAY }\end{array}$ & .00 & $\cdots$ & .00 & .00 & $\cdots$ & .00 & .00 & .00 & $\sim$ & .00 \\
\hline $15 \ldots$ & .00 & -- & .00 & .00 & .00 & .00 & .00 & .00 & -- & .00 \\
\hline
\end{tabular}

02290710 - DLACK CREEK CA AT S-21 NEAR GOULOS FLA (LAT 253243 LONG nAO 19 55)

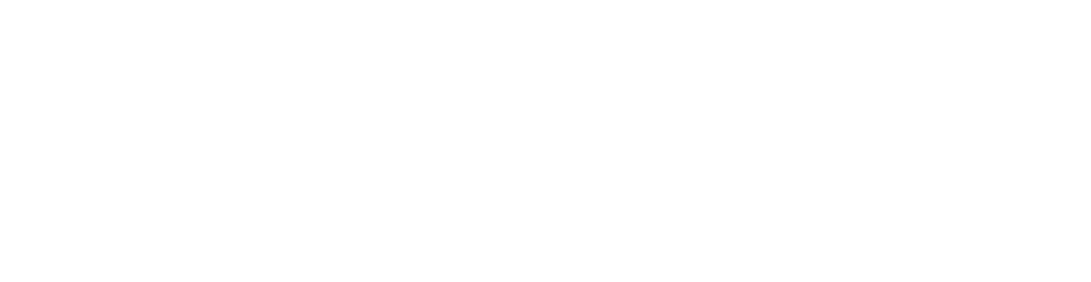

02290812 - ALLigator hO AT CTNMOUTH CP NR HOMESTE (LAT 253810 LONG 0804420 )

AUG., 1970

02290815 - EVERGLaOeS P-33 NEAR hOMESTEAD FLA (LAT 253630 LONG 08041301

FEF.. 1968

OC....

OCT... $\quad .00$

FE甘., 1968

FE甘... $1968 \quad .00$

$03 . . . \quad .00$

02290830 - FVERGLADES P-35 NEAH HOMESTEAD. FLA. ILAT 252720 LONG OBO 5230

MAR., 1968

MAR.. $1968 \quad .00$

$04 \ldots$

$01 . . . \quad .00$

MAR., 1968

$04 \ldots . .0660$

$01 . .0$

03...:

02290858 - SHARK R AT MK O8 NR HOMESTEAD FLA ILAT 252007 LONG 08106 44)

$+$

$\begin{array}{lll}.00 & .00 & .0 \\ .00 & .00 & .01 \\ .00 & .00 & .01\end{array}$

$.01 \quad .00$

$.00 \quad .00$

$.00 \quad 00$

$.00 \quad 000$

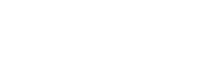




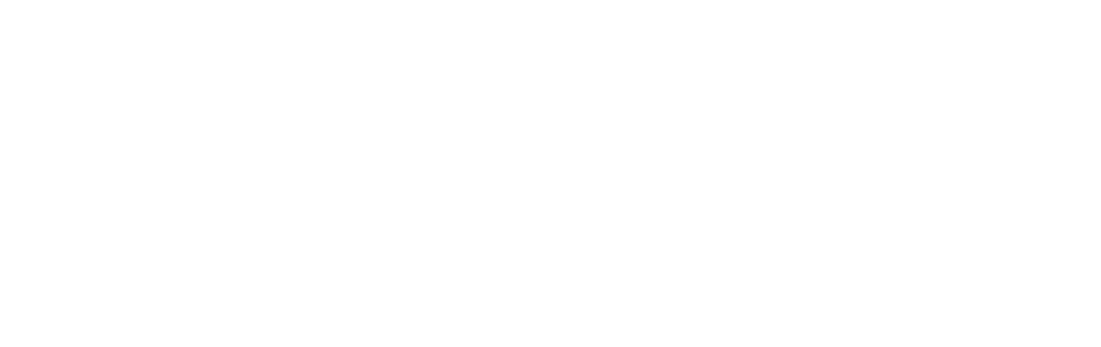

02303300 - FLINT CK NF THUNOTOSASSA FLA (LAT 28 OL OA LONG OBZ 16 n4)

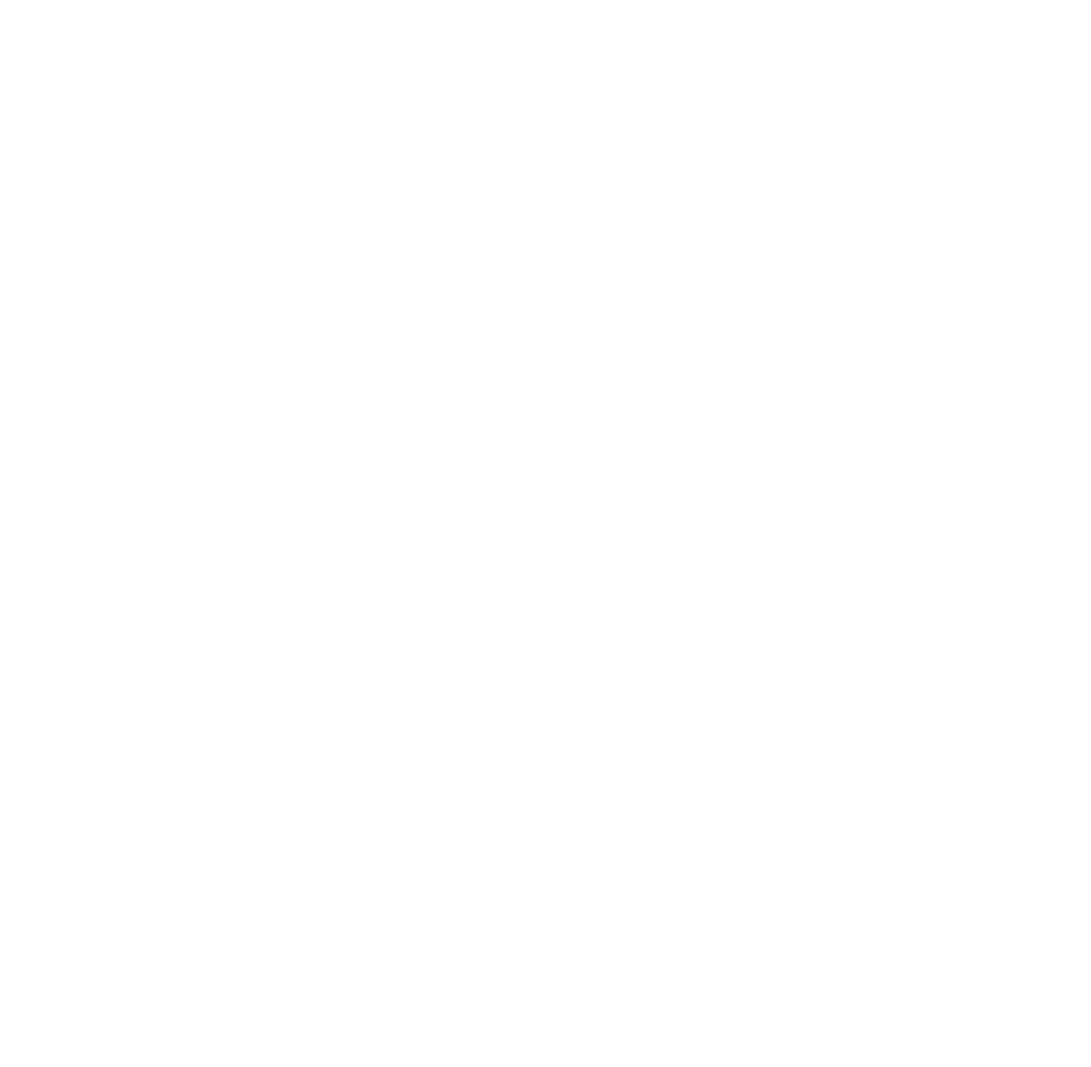

COASTAL BASINS BETWEEN CHOCTAWHATCHEE RIVER AND YELLON RIVER

02366900 - MAGNOL IA CREEK NEAR FREEPORT FLA (LAT 37 3146 LONG 1860515 ) 
ANALYSES OF SAMPLES COLLECTED AT MISCELLANEOUS SITES IN FLORIDA

613 CHEMICAL ANALYSES, HATER YEAR OCTOBER 1969 TO SEPTEMBER 1970 (ORGANOCHLOR IDE COMPOUNDS IN HATER

ALDFIN DDO DDE DOT ELORIN ENDRIN CHLOR I INDANE

DATF (UG/L) (UG/L) (UG/L) (UG/L) (UG/L) (US.LL) (UG/L) (UG/L)

LAKE OKEECHOBEE AND THE EVERGLADES BASINS

252353080342200 - LEVEE 31 W CA AT HWY 27 NH HOMESTEAR F (LAT 252353 LONS $0 \mathrm{mO} 34221$

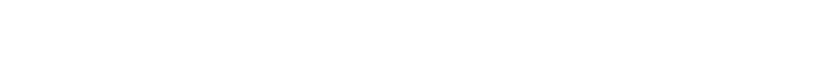

253400080570000 - ROGERS RIV HEADWATERS NK PINECHEST FLA ILAT 2534 OO LONT 080 57001

$$
\begin{array}{cccccccc}
\text { AUG.. } 1970 & .00 & .00 & .00 & .00 & .00 & .00 & .00
\end{array}
$$

253938080285300 - OLACK CREEK NR PICHMOND HEIGHTS FLA (LAT 253939 LONG OBR 29 L3)

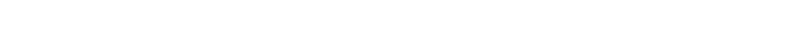

255120080523000 - JETPORT HORRO PIF \#4 NR MIAMI FLA ILAT 2551 2ח LONG gAO 5? 30)

$$
\text { NoV.. } 1969
$$

255120080540000 - CYPRESS SWP NR JFTPOHT HORRUW PIT 3 NP LLAT PE 512010 OMG ORN 54 On)

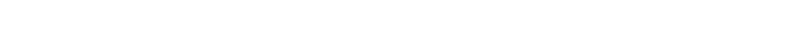

255741080154500 - SNAKE CHEEK AT INW 37 AVE NEAR CAROL CI ILAT 255741 LONG 090 15 45)

$$
\begin{aligned}
& \text { JAN., } 1970
\end{aligned}
$$

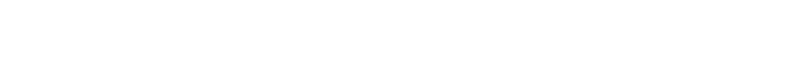

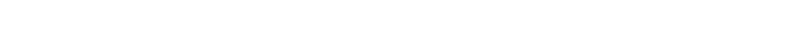

260333080084300 - DANIA CUTOFF CA W OF FECFR BR AT DANIA (LAT 2A 0333 LONG 080 OA 43)

$$
\text { FEA.. } 1970
$$

260514080110800- NORTH NEW RIV CA AT IW 31 AVE AT FT LA (LAT 26 05 14 LONIG 0801108$\}$

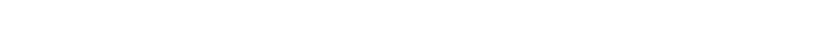

260619080121700 - EOR PIT NR UIX1E WELL FLD AT LAUDEROAL (LAT 2A DG 18 LONA UAO IP 17\}

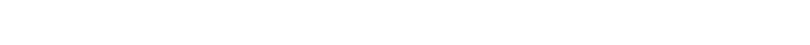

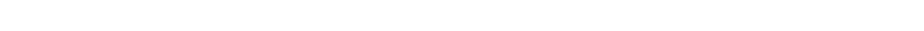

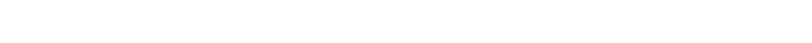

260729080074400 - NEW KIVER AT SE 15TH AVE AT FT LAUNERO (LAT 26 O7 24 10 ONG 0800744$)$

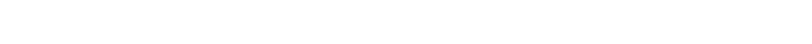

260743080103100 - WORTH FK NEW RIV AT NW GTH ST FT LAUNE (LAT 26 O7 43 LONG OKA In 31 )

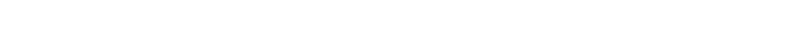

260807080140200 - PLANTATIUN LO CA AT NW 65 AVF IN PLANT ILAT ZS 08 O7 LONG 0HO 14 02)

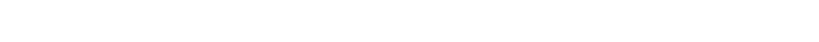

261034080093500 - CA-13 HEEIJER (A AT 1UTH AVE FT LAUDEFD (LAT On In 34 I 0M1, 040 09 35)

$$
\text { FER.. } 1970
$$

261057090442600 - CORF5 OF FIJIINEERS GAGE 3-2 NH ANUYTOA (LAT OK 1057 LONT OBO 44 26)

$$
\text { AUG.. } 1970
$$

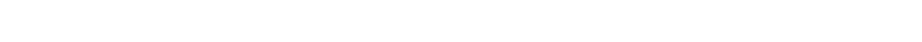

$$
\text { FEG., } 1970
$$


CHEMICAL ANALYSES, NATER YEAR OCTOBER 1969 TO SEPTEMBER 1970 IORGANOCHLORIDE COMPOUNDS IN WATER,

$\begin{array}{ccccccccc}\text { ALDRIN } & \text { DDD } & \text { NDE } & \text { DOT } & \text { ELDRIN } & \text { ENDRIN } & \begin{array}{l}\text { HEPTA- } \\ \text { CHLOR }\end{array} & \text { LINDANE } \\ \text { DATE } & (U G / L) & \text { (UG/L) } & (U G / L) & \text { (UG/L) } & \text { (UG/L) } & \text { (UG/L) } & \text { (UG/L) } & \text { (UG/L) }\end{array}$

LAKE OKEECHOBEE AND THE EVERGLADES BASINS--CONTINUED

26I148080114800 = FT LAUDERDALE PROSPECT'LK NR FT LAUNE (LAT 261148 LONG 0801148 )

$$
\text { FEF, } 1470
$$

$\begin{array}{llllllll}10.0 & .00 & .00 & .00 & .00 & .00 & .00 & .00\end{array}$

201317080061300 - POMPaNO CA AT US HWY 1 AT POMPANO BEAC (LAT $26 \quad 1317$ LDNG OBO OS 13)

$\begin{array}{llllllll}\text { FER.. } 1970 & & & & & & & \\ 18 . . .0 & .00 & .00 & \ldots & .00 & .00 & .00 & .00\end{array}$

261324080211800 - L-35B JORROW CANAL IN CA 2A NR ANOYTOW (LAT 201324 LONG 080 21 18)

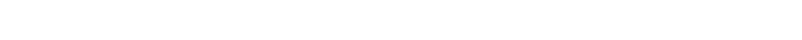

261349n8ח12170n - POMPANO CA AT SH 7 AT MARGATE FLA ILAT 261349 LONG nBN 12171 FFA.. 1970

$\begin{array}{llllllll}14 . .0 & .00 & .00 & .00 & .00 & .00 & .00 & .00\end{array}$

261351080102100 - POMPANO CA E. OF FLA TURNPIKE NR POMPAN ILAT 261351 LONG 080 10211

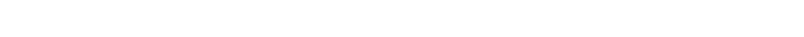

261630080435800 - C-123 AT OLU M1AMI CANAL NR ANUYTOWN F ILAT 261630 LONG 0804358 )

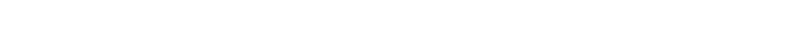

261918080055200 - HILLSEOHO CA E OF OIX1E HWY $\triangle T$ DEERFIE (LAT 2619 18 LONG n80 05 52) FEB., 1970

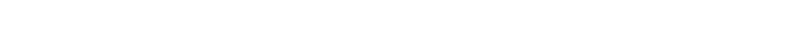

263219080072300 - GOYNTON CA AT SH 809 NR GOYNTON BCH FL ILAT 263219 LONG 08007231 $\begin{array}{cccccccc}\text { Aug... } 1970 & .00 & . & .00 & .00 & .00 & .00 & .00\end{array}$ 263221080052808 - BOYNTON CA AT CONGRESS AVE NR BOYNTON (LAT 2632 L LONG O80 05 28 I AUG. 1970

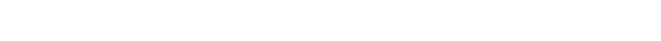

26322708012200 - C-16 AT EQUALIZING CA NK HOYNTON BCHF ILAT 263227 LONG O80 12 201 AUG., 1970
$12 . .0$ 204037080064500 - WEST PALM BEACH AT I P H FLA (LAT $2640 \quad 37$ LONG 0800645 ) $\begin{array}{llllllll}\text { AUG.. } 1970 & & .00 & .00 & .00 & .00 & .00 & .00\end{array}$ 264042090092900 - WEST PALM HCH CA AT CLEARY RO NR WEST (LAT 264042 LONG 080 09 28)

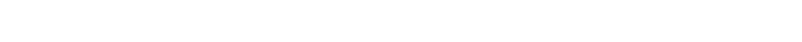
264043080102000 - WFST PALM BCH CA AT BENOIST FAFMS ROAD (LAT 2A 4043 LONG 000 10 28) AUG., 1970

264S310RO051800 - CANAL 17 AT SH 702 NEAR MANGONIA PARK (LAT 264531 LONG 080 05 18) AUG. 1970 $\begin{array}{lllllllllllllll}11 \ldots & .00 & .00 & .00 & .00 & .00 & .00 & .00 & .00\end{array}$

264829090050900 - CANAL 17 AT SH-8OY NR LAKE PARK FLA (LAT 2648 ?9 LONG 0PO 05 09) AUS., 1970

AUก... 19

$.00 \quad .00 \quad .00 \quad .00 \quad .00 \quad .00$ 
CHEMICAL ANALYSES, HATER YEAR OCTOBER 1969 TO SEPTEMBER 1970

$$
\text { (TRACE METALS) }
$$

\begin{tabular}{|c|c|c|c|c|c|c|c|c|c|c|c|c|}
\hline DATE & $\begin{array}{l}\text { DIS- } \\
\text { SOLVED } \\
\text { ALUM- } \\
\text { INUM } \\
\text { (AL) } \\
\text { (UG/L) }\end{array}$ & $\begin{array}{c}\text { OIS- } \\
\text { SOLVEO } \\
\text { ARSENIC } \\
\text { (AS) } \\
\text { (UG/L) }\end{array}$ & $\begin{array}{c}\text { OIS- } \\
\text { SOLVED } \\
\text { BORON } \\
\text { (B) } \\
\text { (UG/L) }\end{array}$ & $\begin{array}{l}\text { OIS- } \\
\text { SOLVED } \\
\text { CAD- } \\
\text { MIUM } \\
\text { (CD) } \\
\text { (UG/L) }\end{array}$ & $\begin{array}{l}\text { HEXA- } \\
\text { VALENT } \\
\text { CHRO- } \\
\text { MIUM } \\
\text { (CRG) } \\
\text { (UG/L) }\end{array}$ & $\begin{array}{l}\text { DIS- } \\
\text { SOLVED } \\
\text { CHRO- } \\
\text { MIUM } \\
\text { ICR) } \\
\text { (UGAL) }\end{array}$ & $\begin{array}{l}\text { DIS- } \\
\text { SOL VED } \\
\text { COPPER } \\
\text { (CU) } \\
\text { (UG/L) }\end{array}$ & $\begin{array}{l}\text { DIS- } \\
\text { SOLVED } \\
\text { IRON } \\
\text { (FE) } \\
\text { (UG/L) }\end{array}$ & $\begin{array}{l}\text { OIS- } \\
\text { SOLVED } \\
\text { LEAD } \\
\text { (PA) } \\
\text { (UGA) }\end{array}$ & $\begin{array}{l}\text { DIS- } \\
\text { SOLVED } \\
\text { MAN- } \\
\text { GANESE } \\
\text { (MN) } \\
\text { (UG/L) }\end{array}$ & $\begin{array}{c}\text { TOTAL } \\
\text { MERCURY } \\
\text { (HG) } \\
\text { (UG/L) }\end{array}$ & $\begin{array}{l}\text { DIS- } \\
\text { SOLVED } \\
\text { ZINC } \\
\text { (ZN) } \\
\text { (UG/L) }\end{array}$ \\
\hline
\end{tabular}

\section{ST. JOHNS RIVER BASIN}

02231342 - FT DRUM CREEK AT SS PKWY NR FT DRUM FL ILAT 273406 LONG 0804747 I

\begin{tabular}{|c|c|c|c|c|c|c|c|c|c|c|c|c|}
\hline 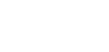 & -- & 0 & $n$ & 0 & -- & 0 & 10 & 47 & $n$ & 0 & - & I0 \\
\hline $29 \ldots$ & -- & -- & - & -- & - & $\rightarrow$ & $n$ & 230 & -- & 0 & -- & 10 \\
\hline JiJl... & $\rightarrow$ & -- & - & -- & - & 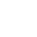 & 0 & $17 n$ & -- & 0 & -- & 20 \\
\hline $23 \ldots$ & -- & -- & -- & 0 & -- & -- & 0 & $35 n$ & -- & 0 & -- & 20 \\
\hline
\end{tabular}

02231350 - ST JOHNS HDWATERS NK VFKO BCH FLA (LAT 774132 LONG 08025 OO)

\begin{tabular}{|c|c|c|c|c|c|c|c|c|c|c|c|c|}
\hline $\begin{array}{l}\text { OCT.. } 1969 \\
\text { 21... } \\
\text { JAN.. } 1970\end{array}$ & -- & 0 & 0 & 0 & -- & -- & 0 & 70 & 0 & 10 & 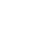 & 10 \\
\hline MAY 27 & $\rightarrow$ & - & - & - & $\cdots$ & 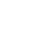 & 0 & 10 & -- & 10 & - & 10 \\
\hline JULY & -- & 10 & 80 & 0 & -- & - & 0 & 50 & 0 & 10 & - & 20 \\
\hline $22 \ldots$ & - & - & - & 0 & - & -- & 0 & So & -- & 0 & - & 30 \\
\hline
\end{tabular}

02231396 - BLUE CYPRESS CREEK NEAR FELLSMERE FLA (LAT 274340 LONG 08048 19)

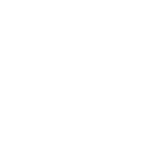

$$
\begin{array}{rrrrrrrrrrr}
10 & 0 & 0 & -- & - & 0 & 520 & 30 & 20 & \ldots & 20 \\
-- & - & -- & - & -- & 0 & 290 & -- & 10 & - & 0 \\
-- & -- & -- & -- & - & 0 & 320 & -- & 20 & - & 40 \\
- & -- & 0 & -- & - & 0 & 560 & -- & 10 & \ldots & 30
\end{array}
$$

02231400 - BLUE CYPRESS LAKE NR FELLSMERE FLA (LAT 274334 LONG 090 4632 )

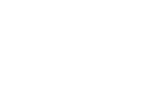

$$
\begin{array}{rrrrrrrrrrr}
0 & 0 & 0 & -- & -- & 10 & 350 & 0 & 10 & -. & 20 \\
-- & -- & -- & - & - & 3 & 190 & \ldots & 0 & -- & 10 \\
20 & 5 n & 10 & -- & -- & 0 & 200 & 0 & 0 & \ldots & 20
\end{array}
$$

\begin{tabular}{|c|c|c|c|c|c|c|c|c|c|}
\hline$-\infty$ & -- & $\cdots$ & -- & -- & - & $35 n$ & -- & 0 & -- \\
\hline-- & -- & -- & - & $\rightarrow$ & $n$ & 190 & -- & 0 & - \\
\hline 10 & 50 & 0 & -- & -- & 0 & 170 & 10 & 10 & -- \\
\hline 20 & $4 n$ & 0 & -- & - & 0 & 340 & 10 & 10 & - \\
\hline
\end{tabular}

02231467 - ST JOHNS R AB LK HELEN BLAZES NH MELAO (LAT 275943 LON, 0804730 )

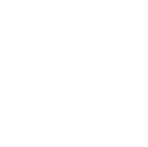

02231471 - LAKE HELEN BLAZLS NEAR DEER PARK, FLA. (LAT 280130 LONG 0804756 )

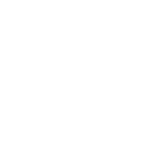

$$
\begin{array}{ccccccc}
0 & 0 & 0 & - & - & 0 \\
- & -- & -- & - & -- & 0 \\
-- & -- & - & - & - & 0 \\
- & - & - & - & - & 0
\end{array}
$$

\begin{tabular}{|c|c|c|c|c|c|c|c|c|c|c|c|c|}
\hline 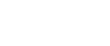 & -- & 20 & $n$ & 0 & -- & $\rightarrow$ & 0 & $45 n$ & 20 & 20 & -- & 20 \\
\hline $\begin{array}{l}27 \ldots \\
\triangle P R\end{array}$ & -- & $\cdots$ & -- & - & 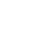 & -- & 0 & 200 & - & 0 & 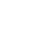 & 10 \\
\hline JULY & - & 10 & $1 n$ & 0 & - & -- & 0 & $23 n$ & 0 & $>0$ & - & 10 \\
\hline $21 \ldots$ & - & 10 & 80 & 0 & -- & - & 0 & 420 & 10 & 30 & - & 30 \\
\hline
\end{tabular}

\begin{tabular}{|c|c|c|c|c|c|c|c|c|c|c|c|c|}
\hline $\begin{array}{l}\text { OCT.1 } 1969 \\
23 \ldots . .19 \\
\text { FEB., } 1970\end{array}$ & -- & -- & - & -- & $=$ & 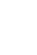 & $m$ & 390 & - & 20 & - & $=$ \\
\hline MAY & -- & -- & - & -- & - & -- & 0 & 140 & -- & 0 & $-\infty$ & 20 \\
\hline JULY... & - & - & - & $m$ & -- & -- & $n$ & $12 n$ & -- & 10 & -- & 30 \\
\hline $23 \ldots$ & 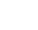 & $\overline{-}$ & - & $-\overline{0}$ & $=$ & - & $-\overline{0}$ & 60 & -- & 10 & - & 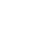 \\
\hline
\end{tabular}

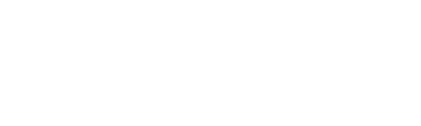

02231600 - JANE GREEN CHEEK NK DEER PAPK FLA (LAT 28 O4 27 LONG 0805318 )

02231980 - SAHGrass lake near mflgourne fla (LAT 280435 LONG 0804626 ) 

(TRACE METALS)

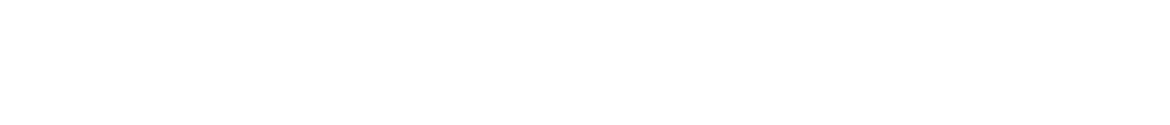

\section{ST. JOHNS RIVER BASIN--CONTINUED}

02232100 - WASHINGTON NK EAU FALLIE FLA ILAT 2R OB 50 LONS OHO 44 10)

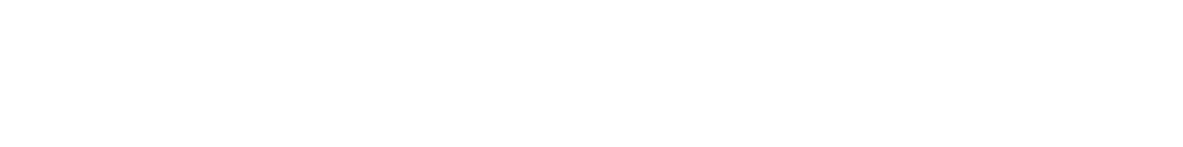

02232162 - JIHNS TRIS CA NR OFER PARK (LAT 28 1? 53 LING 0RO 51 13)

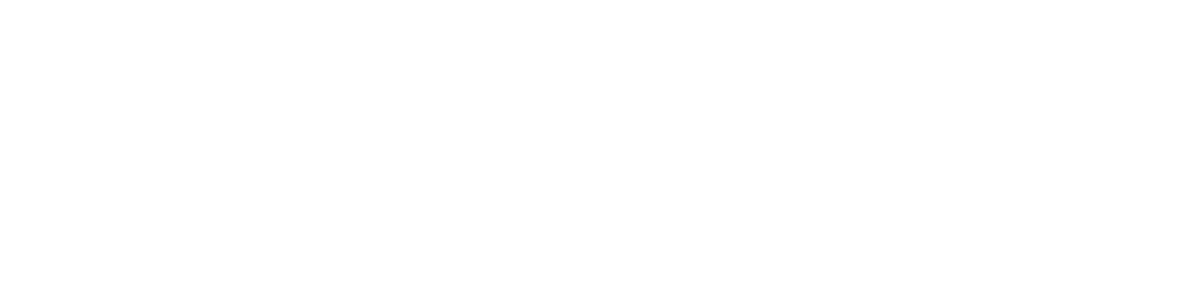

02232254 - LAKE WINOEK NEAR BONAVENTURE, FLA. (LAT 231512 LONG D80 5055 )

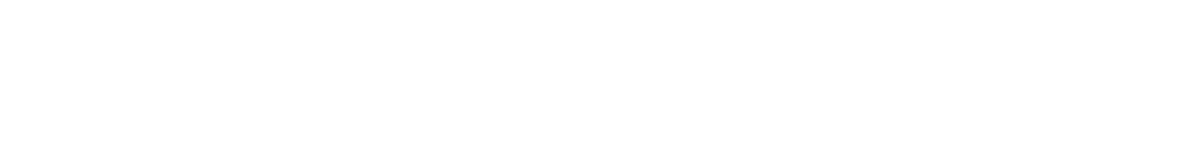

02232785 - ROCKLEDGE CHEEK NEAR ROCKLENGE FLA (LAT P8 1843 LONG DRO 4734 )

$05 . . .2$

MAY $06 . . .1970$

JULY

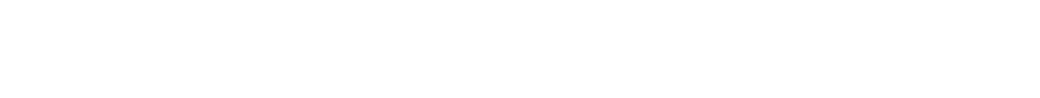

02732300 - POINSETT NR COCDA FLA ILAT 28 PI OI LONG 08048561

NOV., 1969

NOV., 1969

FER.: 1970

$04 \ldots$

MAY

JULYY..

$29 . .$.

--
--
--

10
20
10

0
--
70
60

$\begin{array}{lll}0 & - & - \\ - & - \\ 0 & -- \\ 0 & -- & -\end{array}$

$\begin{array}{ll}- & 0 \\ - & 0 \\ - & 0 \\ - & 0\end{array}$

$25 n$

$\begin{array}{rrrr}0 & 10 & \cdots & 10 \\ - & 0 & - & 10 \\ 0 & 0 & \cdots & 20 \\ 10 & 10 & \cdots & 30\end{array}$

02232413 - TAYLO CPEEK AT 5164 NEAF COCOA FLA (LAT 282023 LONG OAO 56 D6)

\begin{tabular}{|c|c|c|c|c|c|c|c|c|c|c|c|}
\hline $\begin{array}{l}20 \ldots . .1909 \\
\text { JAN., } 1970\end{array}$ & -- & 0 & 0 & 0 & - & - & B & 250 & 0 & 40 & - \\
\hline${ }_{J U L}^{27}{ }_{Y} \cdot$. & -- & $n$ & 70 & 0 & -- & 0 & 10 & IPO & 10 & 10 & -- \\
\hline $20 \ldots$ & -- & 10 & $4 n$ & 10 & -- & -- & $n$ & $17 n$ & 10 & 10 & -- \\
\hline
\end{tabular}

n2233500 - ECONLOCKHATCHEE R NR CHULUOTA FLA ILAT 284040 LONG OB1 0651 )

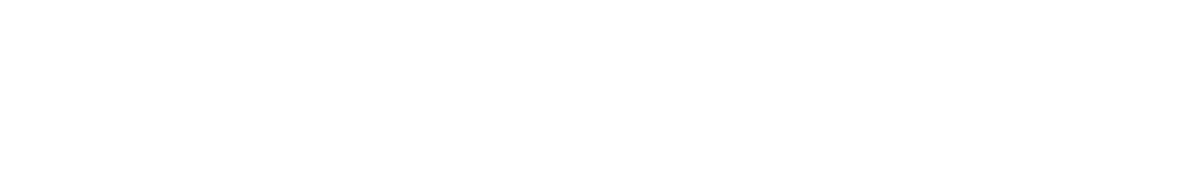


CHEMICAL ANALYSES, NATER YEAR OCTOBER 1969 TO SEPTEMBER 1970

$$
\text { (TRACE METALS) }
$$

\begin{tabular}{|c|c|c|c|c|c|c|c|c|c|c|c|}
\hline $\begin{array}{l}\text { DIS- } \\
\text { SOLVED } \\
\text { ALUM- } \\
\text { INUM } \\
\text { (AL) } \\
\text { (UG/L) }\end{array}$ & $\begin{array}{l}\text { OIS- } \\
\text { SOLVED } \\
\text { ARSENIC } \\
\text { (AS) } \\
\text { (UG/L) }\end{array}$ & $\begin{array}{c}\text { OIS- } \\
\text { SOLVEO } \\
\text { BORON } \\
\text { (B) } \\
\text { (UG/L) }\end{array}$ & $\begin{array}{l}\text { DIS- } \\
\text { SOLVED } \\
\text { CAD- } \\
\text { MIUM } \\
\text { (CD) } \\
\text { (UG/L) }\end{array}$ & $\begin{array}{l}\text { HEXA- } \\
\text { VALENT } \\
\text { CHRO- } \\
\text { MIUM } \\
\text { (CRG) } \\
\text { (UGLL) }\end{array}$ & $\begin{array}{l}\text { OIS- } \\
\text { SOLVED } \\
\text { CHRO- } \\
\text { MIUM } \\
\text { (CR) } \\
\text { (UG/L) }\end{array}$ & $\begin{array}{l}\text { DIS- } \\
\text { SOLVED } \\
\text { COPPER } \\
\text { (CU) } \\
\text { (UG/L) }\end{array}$ & $\begin{array}{l}\text { OIS- } \\
\text { SOLVFO } \\
\text { IRON } \\
\text { (FE) } \\
\text { (UG/L) }\end{array}$ & $\begin{array}{l}\text { DIS- } \\
\text { SOLVEO } \\
\text { LEAD } \\
\text { (PR) } \\
\text { (UG/L) }\end{array}$ & $\begin{array}{l}\text { DIS- } \\
\text { SOLVED } \\
\text { MAN- } \\
\text { GANESE } \\
\text { (MN) } \\
(U G / L)\end{array}$ & $\begin{array}{c}\text { TOTAL } \\
\text { MERCURY } \\
\text { (HG) } \\
\text { (UG/L) }\end{array}$ & $\begin{array}{l}\text { DIS- } \\
\text { SOLVED } \\
\text { ZINC } \\
\text { (ZN) } \\
\text { (UG/L) }\end{array}$ \\
\hline
\end{tabular}

ST. JOHNS RIVER BASIN--CONTINUED

02234000 - ST JOHNS R AB L HARNEY NR GENEVA FLA (LAT 28 +2 50 LONG $0810 ?$ 06)

\begin{tabular}{|c|c|c|c|c|c|c|c|c|c|c|c|c|}
\hline $\begin{array}{l}\text { ocr... } 1969 \\
01 \ldots . .\end{array}$ & -- & - & -- & -- & -- & -- & -- & $35 n$ & - & $\cdots$ & -- & - \\
\hline $27 \ldots$ & -- & 20 & 0 & 0 & -- & 0 & 0 & 270 & 0 & 10 & -- & 20 \\
\hline $\begin{array}{l}\text { DEC. } \\
\text { O2... } \\
\text { JAN. } 1970\end{array}$ & -- & -- & -- & -- & - & -- & - & 260 & -- & -- & - & -- \\
\hline $03 . .$. & -- & $=$ & -- & - & -- & -- & $\cdots$ & - & -- & in & - & - \\
\hline $\begin{array}{l}30 . . . \\
\text { MAR. }\end{array}$ & -- & $\cdots$ & -- & -- & -- & -- & 0 & 90 & - & - & - & 20 \\
\hline MAY & $=$ & -- & - & - & -- & -- & -- & 170 & - & -- & -- & -- \\
\hline JUNE & - & 30 & 80 & 0 & -- & 0 & 0 & 150 & 0 & 10 & -- & 20 \\
\hline JULL & $\cdots$ & -- & -- & $\cdots$ & - & -- & $\cdots$ & 50 & -- & $\cdots$ & -- & -- \\
\hline $24 \ldots$ & -- & 10 & 100 & 0 & - & 0 & 20 & $2+0$ & 10 & 30 & - & 40 \\
\hline
\end{tabular}

02235200 - RLACKWATER CR NR CASSIA FLA (LAT 28 5? 40 LONG nRI 29 ?n)

OCr., 1969

$03 . .$.

02235500 - 8LUE SPRINGS NR ORANGE CITY FLA (LAT 29 5638 LONG OHI 2024 )

MAY 1970

29...

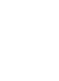

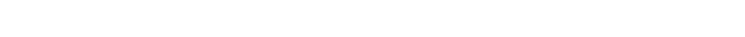$$
02336000 \text { - }
$$

OCT.. 1969

$31 \cdots 1070$

$30 \div 1970$

$--$

02236000

02236200 - LAKE KERR NR EUREKA FLA ILAT 292010 LONG OBI 46001

APR.. 1970
$29 . .$.
SEP.:.

MAY 1970

$02 . . .2$

SE... 130

MAY $1970 \quad 15$

MAY, 1970

$12 . .$.

40

02236250 - LAKE LOWERY NR HAINES CITY FLA (LAT 2A 0651 LONG 0814017 )

$\begin{array}{rrrrrrrrrrr}10 & -- & -- & -- & -- & 10 & 190 & 0 & 50 & -- & 70 \\ 0 & -- & -- & -- & -- & 20 & 160 & 19 & 20 & - & 90\end{array}$

02237293 - PALATLAKAHA A AT STR M-1 NR OKAHUMPKA (LAT 284429 LONG 08152 22)

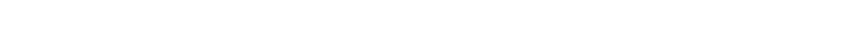

490

02237370 - CHURCH LAKE NR GKOVELAND FLA (LAT 283840 LONG OBI 50 47 )

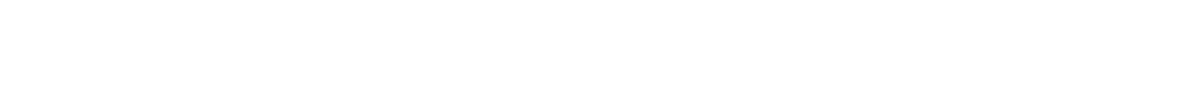

02237700 - APOPKA-REAUCLAIR CANAL NR ASTATULA FLA ILAT 284320 LONG OR1 4106 )

\begin{abstract}
02237753 - WEST CROOKEO LAKE NR FUSTIS FLA IIAT 224949 LONG O81 4020 ,
\end{abstract}
Mar, 1970 10

02237800 - LAKF DORA AT MT DORA FLA (LAT 284746 LONG 08138 39)

MAY, 1970

30

$--$ 


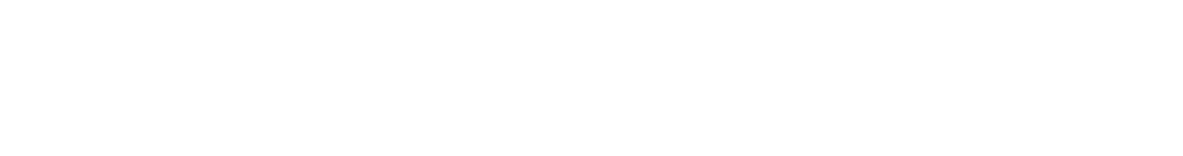
'223786S - LAKE UMATILLA AT UMATILLA, FLA. ILAT 2R 5509 LONG 0813957

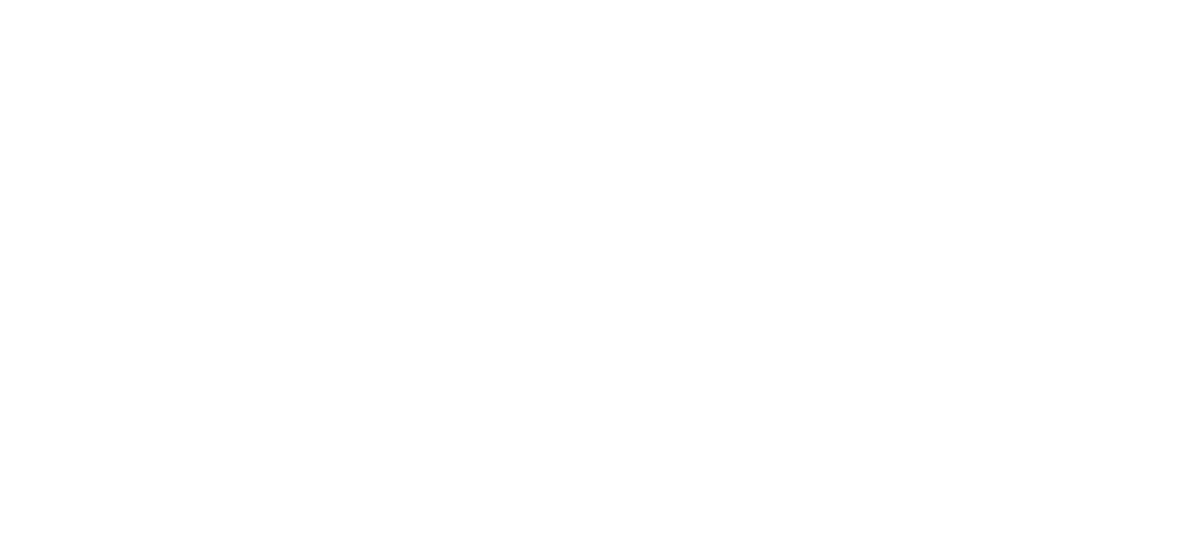

02239497 - SILVER SPRINGS AT SILVER SPRINGS FLA ILAT 29 I2 52 LONG $08203 \quad 151$

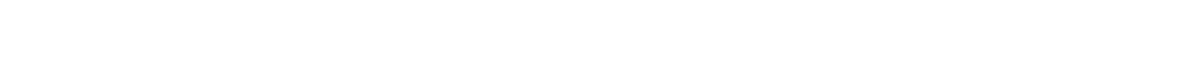

02242450 - ORANGE LAKE AT UKANGE LAKE FLA (LAT 292550 LONG $08212 \mathrm{in)}$

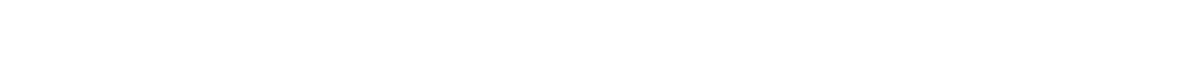

02243960 - OKLAWAHA R AT RODMAN DAM NR DRANGE SPR ILAT 293030 LONG 08148 15)

MAY, 1970

MAY
$01 . . .1970$

80

$-\dot{0}$

$-$

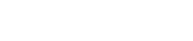

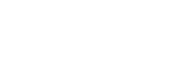

$1 \overline{110}$

$\overline{10} \quad-\frac{1}{0}$

$=\overline{10}$

10

02244450 - ST JOHNS R AT PALATKA FLA ILAT 293837 LONG 0813736 )

$\begin{array}{lrrrrrrrrrrrr}\text { MAY }, 1970 & -- & 0 & - & -- & - & -- & 0 & 70 & 20 & 0 & -- & 20 \\ 18 . . . & - & 20 & -- & -- & - & -- & 30 & 130 & 0 & 10 & -- & 110\end{array}$

02245200 - RICE CR NR PALATKA FLA (LAT 294157 LONG O81 3948 )

\begin{tabular}{|c|c|c|c|c|c|c|c|c|c|c|c|c|}
\hline $\begin{array}{l}\text { APR., } 1970 \\
29 . . .\end{array}$ & -- & 10 & -- & - & -- & $=-$ & 0 & 400 & 20 & 90 & -- & 400 \\
\hline
\end{tabular}

02246500 - ST JDHNS R AT JACKSONVILLE FLA ILAT 301926 LONG 08139121

MAY, 1970

MAY....

$-\infty$

10250

10

COASTAL BASINS BETWEEN ST. JOHNS RIVER AND TURKEY CREEK

02246900 - MOULTRIE CR AT SH 207 NR ST AUGUSTINE (LAT 295050 LONG 0812139 )

\begin{tabular}{|c|c|c|c|c|c|c|c|c|c|c|c|c|}
\hline $\begin{array}{l}\text { APR." } 1970 \\
29 . . .\end{array}$ & $\cdots$ & 0 & - & - & - & -- & 0 & 400 & 10 & 20 & $\cdots$ & 600 \\
\hline $\begin{array}{l}\text { SEP. } \\
28 \ldots\end{array}$ & - & 30 & -. & - & - & $\rightarrow$ & 0 & 560 & 0 & 10 & -- & 890 \\
\hline
\end{tabular}


CHEMICAL ANALYSES, WATER YEAR OCTOBER 1969 TO SEPTEMBER 1970

(TRACE METALS)

02257000 - FISHEATING CR AT LAKEPOPT FLA ILAT 265750 LONG 081 OT 101

\begin{tabular}{|c|c|c|c|c|c|c|c|c|c|c|c|}
\hline $\begin{array}{l}\text { UCT. } 1969 \\
27 \ldots . . \\
\text { NOV. }\end{array}$ & - & - & - & - & - & -- & -- & 510 & -- & -- & - \\
\hline DEC... & -- & -- & -- & -- & -- & -- & -- & 270 & -- & -- & -- \\
\hline JAN... 1970 & -- & - & - & - & - & -- & - & 130 & -- & -- & -- \\
\hline $14 \ldots$ & - & $\cdots$ & -- & -- & -- & -- & $\cdots$ & 120 & $-=$ & $=-$ & -- \\
\hline
\end{tabular}

02258000 - HAKVEY PÓND CA NF LAKEPORT FLA ILAT 27 ON 00 LONG 08104051

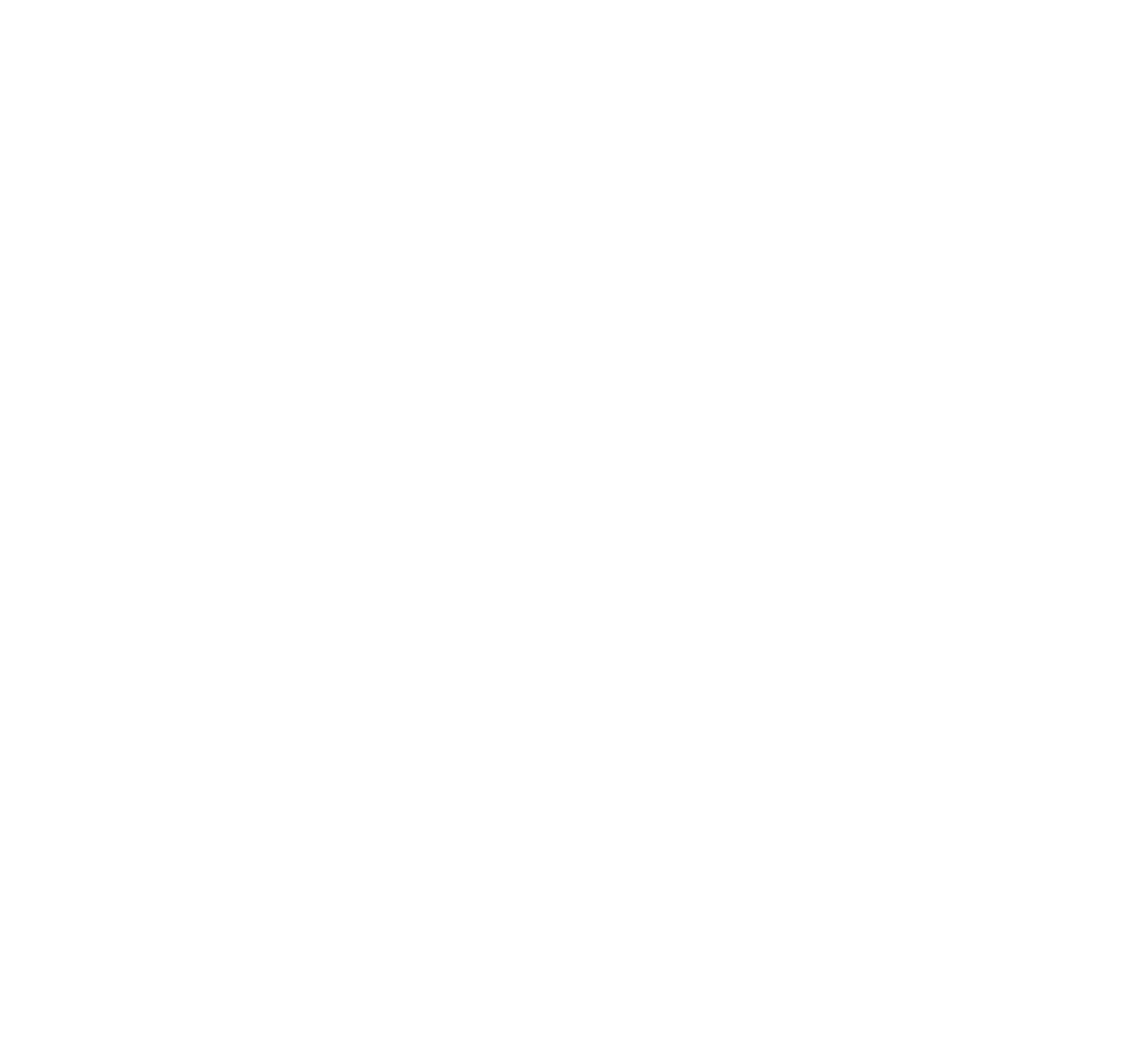

02266026 - REEOY CREFK BELOW S-46 NR VINELAND FLA (LAT 282414 LONG 09136 42)

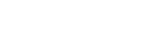

02266200 - WHITTENHORSE CR NR VINELAND FLA (LAT $22 \quad 2305$ LONG 08137 00)

AUG., 1970

MAY 1970

02266239 - TROUT LAKE NR CLERMONT FLA (LAT $2827 \quad 04$ LONG 08143001 
CHEMICAL ANALYSES, WATER YEAR OCTOBER 1969 TO SEPTEMBER 1970 (TRACE METALS)

\begin{tabular}{|c|c|c|c|c|c|c|c|c|c|c|c|c|}
\hline DATE & $\begin{array}{l}\text { DIS- } \\
\text { SDLVED } \\
\text { ALUM- } \\
\text { INUM } \\
\text { (AL) } \\
\text { (UG/L) }\end{array}$ & $\begin{array}{l}\text { DIS- } \\
\text { SOLVED } \\
\text { ARSENIC } \\
\text { (AS) } \\
\text { (UG/L) }\end{array}$ & $\begin{array}{c}\text { OIS- } \\
\text { SOLVED } \\
\text { BORON } \\
\text { (B) } \\
\text { (UG/L) }\end{array}$ & $\begin{array}{l}\text { OIS- } \\
\text { SOLVFD } \\
\text { CAD- } \\
\text { MIIJM } \\
\text { (CD) } \\
\text { (UG/L) }\end{array}$ & $\begin{array}{l}\text { HEXA- } \\
\text { VALENT } \\
\text { CHRO- } \\
\text { MIUM } \\
\text { (CRG) } \\
\text { (UG/L) }\end{array}$ & $\begin{array}{l}\text { DIS- } \\
\text { SOLVED } \\
\text { CHHO- } \\
\text { MIUM } \\
\text { (CR) } \\
\text { (UG/L) }\end{array}$ & $\begin{array}{l}\text { DIS- } \\
\text { SOLVED } \\
\text { COPPER } \\
\text { (CU) } \\
\text { (UG/L) }\end{array}$ & $\begin{array}{l}\text { DIS- } \\
\text { SOL VED } \\
\text { IRON } \\
\text { (FE) } \\
\text { (UG/L) }\end{array}$ & $\begin{array}{l}\text { DIS- } \\
\text { SOL VEO } \\
\text { LEAO } \\
\text { (PB) } \\
\text { (UG/L) }\end{array}$ & $\begin{array}{l}\text { DIS- } \\
\text { SOLVED } \\
\text { MAN- } \\
\text { GANFSE } \\
\text { (MN) } \\
\text { (UG/L) }\end{array}$ & $\begin{array}{c}\text { TOTAL } \\
\text { MERCURY } \\
\text { (HG) } \\
\text { (UG/L) }\end{array}$ & $\begin{array}{l}\text { DIS- } \\
\text { SOLVED } \\
\text { ZINC } \\
\text { (ZN) } \\
(U G / L)\end{array}$ \\
\hline
\end{tabular}

02266291 - LATERAL 405 AT S-40SA NR DR PHILLIPS F (LAT 2 A 2534 LONG ORI 36 23)

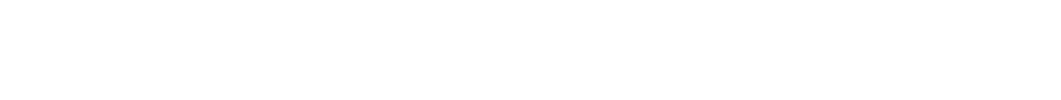


CHEMICAL ANALYSES, WATER YEAR DCTOBER 1969 TO SEPTEMBER 1970

(TRACE METALS)

02276405 - LAKE OKEECHOBEE AT'POINT 5 FLA ILAT 265547 LONG 0805840

JAN., 1970
$13 . .$.

02276407 - LAKE OKEECHOBEE AT POINT 7 FLA (LAT 270230 LONG 0805105 )

JAN.. 2970

$13 . .$.

02276408 - LAKE OKEECHOBEE AT POINT 8 FLA (LAT 270505 LNMG 08047 10)

JAN., 2970

$12 \ldots$

02276409 - LAKE OKEECHOHEE AT POINT 9 FLA (LAT 270930 LONG 08047 10)

JAN., 1970

12 ....

02276410 - LAKE OKEECHOBEE AT POINT 10 FLA (LAT 270305 LONG 080 43 55)

JAN., 1970

JAN.. 1970

$13 . .$.

$13 \ldots$

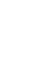

02276411 - LAKE OKEECHOBEE AT POINT II FLA (LAT 270100 LONG 08040 15)

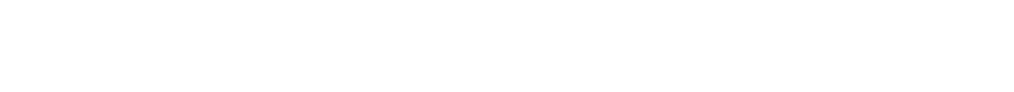

JAN., 1970

$13 . .$.

02276412 - LAKE OKEECHOBEe at POINT 12 FLA (LAT 265905 LONG 03037 20)

02276413 - LAKE OKEECHOBEE AT POINT 13 FLA (LAT 265555 LONG 030 4 月 55 )

JAN. 1970

$14 . .$.

02276414 - LAKE OKEECHOBEE AT POINT 14 FLA (LAT 265245 LONG 0804405 )

JAN., 1970

02276415 - LAKE OKEECHOBEE AT POINT 15 FLA (LAT 2655 31) LONG OHO 4755 )

JAN.. 1970
$13 . .$.
APR.
$21 . .$.

$\begin{array}{ll}-+ & -\end{array}$

02276418 - LAKE OKEECHOBEE AT POINT 18 FLA (LAT 264 A 52 LONG DBO 5650 )

JAN., 1970

$15 . .$.

02276708 - RIM DITCH AT S49 NR WHITE CITY FLA (LAT 2720 16 LONG 080 30 44)

OCT. 1969

$15 . .$.

02276802 - CANAL 23 AT S-48 NEAR PALM CITY FLA ILAT 271205 LONG 08017511

$\underset{15 . .1969}{0.1969}$

02276870 - ST LUCIE CANAL AT LAKE OKEECHOBEE FLA (LAT 265900 LONG 08037001

\begin{tabular}{|c|c|c|c|c|c|c|c|c|c|c|c|}
\hline $\begin{array}{l}\text { OCT. . } 1969 \\
28 . . .\end{array}$ & $=$ & -+ & -- & -- & -- & - & - & 67 & $\because$ & - & -- \\
\hline $\begin{array}{l}\text { NOV. } \\
20 . . .\end{array}$ & - & -- & -- & -- & $\cdots$ & -- & - & 100 & $\cdots$ & -- & - \\
\hline JAN., 1970 & & & & & & & & 70 & & 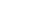 & - \\
\hline
\end{tabular}


CHEMICAL ANALYSES, WATER YEAR OCTOBER 1969 TO SEPTEMBER 1970

\begin{tabular}{|c|c|c|c|c|c|c|c|c|c|c|c|}
\hline $\begin{array}{l}\text { DIS- } \\
\text { SOLVED } \\
\text { ALUM- } \\
\text { INUM } \\
\text { (AL) } \\
\text { (UG/L) }\end{array}$ & $\begin{array}{l}\text { DIS- } \\
\text { SOLVED } \\
\text { ARSENIC } \\
\text { (AS) } \\
\text { (UG/L) }\end{array}$ & $\begin{array}{c}\text { DIS- } \\
\text { SOLVED } \\
\text { BORON } \\
\text { (B) } \\
\text { (UG/L) }\end{array}$ & $\begin{array}{l}\text { DIS- } \\
\text { SOLVEO } \\
\text { CAD- } \\
\text { MIUM } \\
\text { (CD) } \\
\text { (UGAL) }\end{array}$ & $\begin{array}{l}\text { HEXA- } \\
\text { VALENT } \\
\text { CHRO- } \\
\text { MIUM } \\
\text { (CRG) } \\
\text { (UG/L) }\end{array}$ & $\begin{array}{l}\text { OIS- } \\
\text { SOLVED } \\
\text { CHRO- } \\
\text { MIUM } \\
\text { (CR) } \\
\text { (UG/L) }\end{array}$ & $\begin{array}{l}\text { UIS- } \\
\text { SOLVED } \\
\text { COPPER } \\
\text { (CU) } \\
\text { (UG/L) }\end{array}$ & $\begin{array}{l}\text { DIS- } \\
\text { SOLVED } \\
\text { IRON } \\
\text { (FE) } \\
\text { (UG/L) }\end{array}$ & $\begin{array}{l}\text { OIS- } \\
\text { SOLVED } \\
\text { LEAD } \\
\text { (PB) } \\
\text { (UG/L) }\end{array}$ & $\begin{array}{l}\text { DIS- } \\
\text { SOL VEO } \\
\text { MAN- } \\
\text { GANESE } \\
\text { (MN) } \\
\text { (UG/L) }\end{array}$ & $\begin{array}{l}\text { TOTAL } \\
\text { MERCURY } \\
\text { (HG) } \\
\text { (UG/L) }\end{array}$ & $\begin{array}{l}\text { DIS- } \\
\text { SOLVED } \\
\text { ZINC } \\
\text { (ZN) } \\
\text { (UG/L) }\end{array}$ \\
\hline
\end{tabular}

LAKE OKEECHOBEE AND THE EVERGLADES BASINS--CONTINUED

02277700 - SWF LOXAHATCHEE R AT S.46 NR JUPITER F ILAT 265602 LONG 080 OB 31)

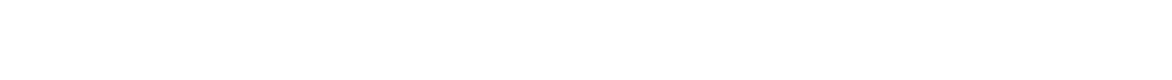

02277900 - CANAL M NEAR MANGONIA PARK FLA (LAT 264500 LONG 080 06 33)

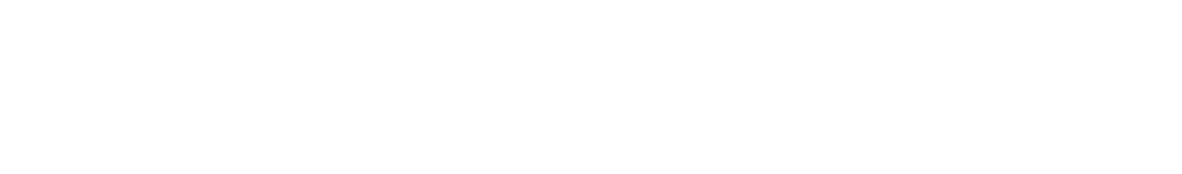

02278500 - DIV TO CON AL AT S-5A AND S-SAS NR LOX (LAT 264100 LONG OBO 22 10)

AUG., 1970
OG....

20 -

02278501 - CON AREA NO 1 BL S-5 COMP NR LOX (LAT 264100 LONG 08O 2210 )

\begin{tabular}{|c|c|c|c|c|c|c|c|c|c|c|c|}
\hline $21 \ldots{ }_{1970}$ & $=$ & & & -- & -- & 10 & & & 10 & 0 & - \\
\hline $28 \ldots$ & $=$ & 10 & - & -- & -- & 0 & 10 & 110 & 0 & 0 & -- \\
\hline
\end{tabular}

02279000 - WEST PALM 8CH CA AT WEST PALM BCH. FLA (LAT 263840 LONG ORO O3 32)

MAR., 1970

$\begin{array}{llllllllll}0 & 90 & - & - & - & - & 10 & 190 & 0 & 10\end{array}$

02279500 - BOYNTON CANAL AT BOYNTON BEACH FLA ILAT 263220 LONG 08003 IOI

MAR., 1970

0

$022 B 1295$ - EVERGLADES STA 1-15 NR DELRAY BEACH FL ILAT 262345 LONG 0801740 )

NOV., 1969
$20, \ldots 1970$
APR., 1970
$28 . .$.
AUG:
O6...

02281300 - HILLSBOHO CANAL AT S-39 NR DEERFIELD A ILAT 2621 PO LONG O80 17581

\begin{tabular}{|c|c|c|c|c|c|c|c|c|c|c|c|c|}
\hline$\underset{17 . . .1}{0 c 7 ., 1969}$ & -- & 20 & 0 & -- & -- & -- & 20 & 120 & 10 & 70 & $\cdots$ & 30 \\
\hline $\begin{array}{l}\text { JAN." } 1970 \\
22 \ldots \ldots \\
\text { MAY }\end{array}$ & $\cdots$ & 20 & 0 & $=$ & - & -- & 40 & 30 & 20 & 0 & - & 30 \\
\hline $\begin{array}{l}\text { D7... } \\
\text { SEP. }\end{array}$ & - & 30 & $\rightarrow$ & - & - & $\cdots$ & 30 & 30 & 10 & 10 & $=$ & 50 \\
\hline $29 .$. & 20 & 10 & - & - & - & -- & 10 & - & 10 & 0 & -- & 130 \\
\hline
\end{tabular}

02281301 - HILLSAORO CANAL BL 539 NR DEERFLD BCH ILAT 262120 LONG 0801750 '

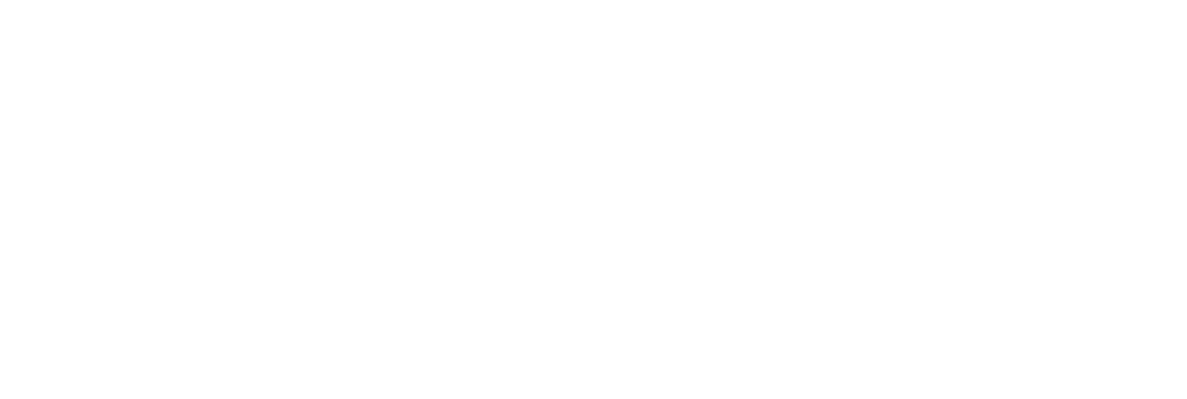


CHEMICAL ANALYSES, WATER YEAR OCTOBER 1969 TD SEPTEMBER 1970

$$
\begin{aligned}
& \text { TER YEAR OCTOBER } \\
& \text { (TRACE METALS) }
\end{aligned}
$$

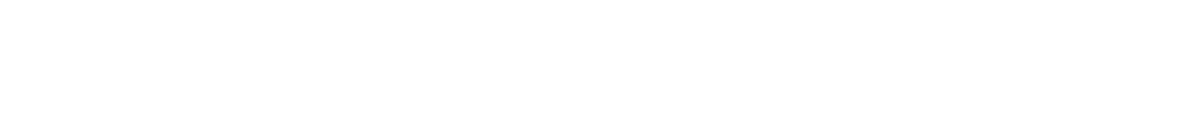

LAKE DKEECHOBEE AND THE EVERGLADES BASINS--CONTINUED

02281513 - EOUALIZING CANAL 3 NR'GREENACRES CITY (LAT 263707 LONG 08007 49)

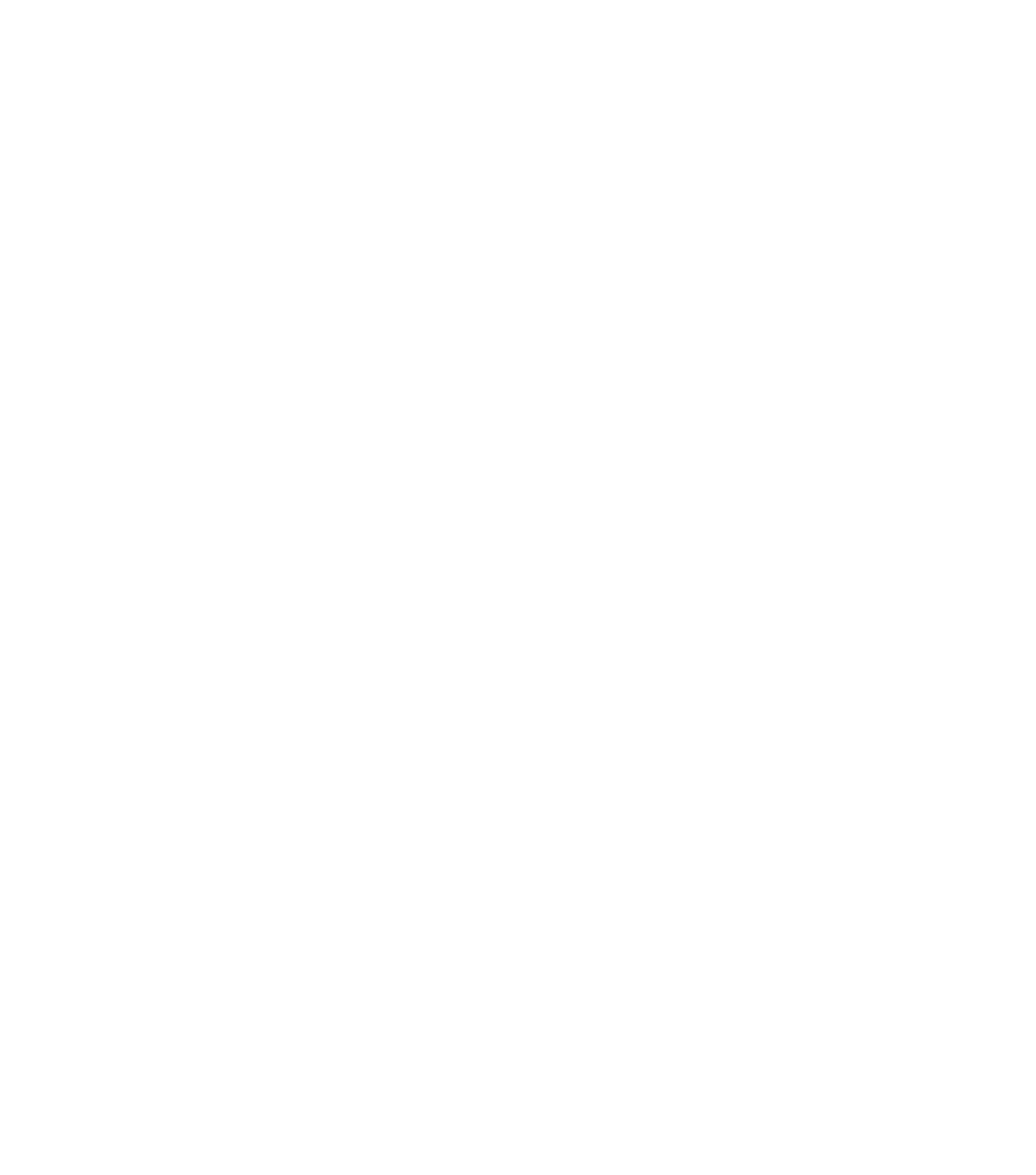

02283498 - N NEW R CA AT S-2 AND HGS-4 NR S BAY, (LAT 264200 LONG 08042 55)

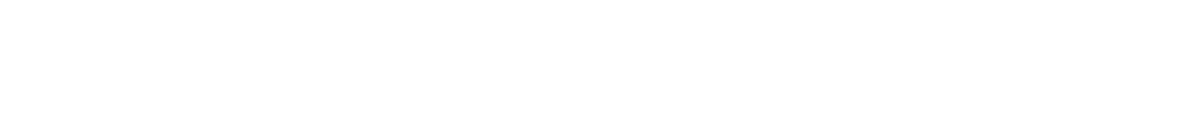


$022 R 4520$ - DIVERSION CANAL AT S143.NR ANDYTOWN FL (LAT $2 H$ O9 OO LONG OBO 26301

\begin{tabular}{|c|c|c|c|c|c|c|c|c|c|c|c|c|}
\hline $\begin{array}{l}\text { Oct.:1 } 1969 \\
22 . . .11970 \\
\text { FE8., } 1970\end{array}$ & -- & 10 & n & - & -- & -- & 20 & 40 & 50 & 0 & - & 40 \\
\hline MAY & -- & - & - & - & -- & - & 0 & 50 & 90 & 0 & - & 30 \\
\hline $06 . .$. & $=$ & 30 & - & $-\infty$ & -- & - & 10 & 0 & 10 & 0 & -- & 30 \\
\hline
\end{tabular}

02284642 - EVERGLAUES STA 2-17 NR ANUYTUWN FLA ILAT 26 I6 50 LONG OBO 2510 )

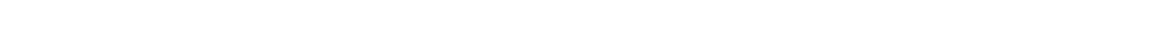

02284690 - EVERGLADES STATION 2-21 NEAP ANDYTOWN (LAT 28 08 05 LONG 090 22 05)

JULY. 1970

02284699 - N NEW 4 CA AH S34 NR FT LAUOERDALE FLA (LAT 260859 (ONG 080 26 33)

\begin{tabular}{|c|c|c|c|c|c|c|c|c|c|c|c|}
\hline $22 . \ldots$ & 80 & 10 & - & -- & - & 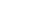 & 10 & -- & 20 & in & - \\
\hline
\end{tabular}

02284700 - N NEW R CA AT $\$ 34$ NR FT LAUDEPUALE FLA (LAT 260943 LONG OBO 26 25)

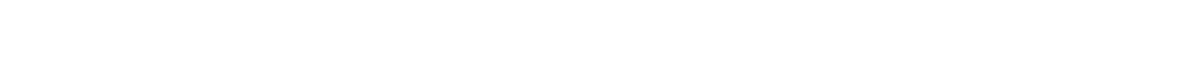

02284900 - N NEW R CA AB HOL LAT NR FT LAUD FLA (LAT 26 OG 40 L.ONG OBO 1750 )

SEP.. 1970

60

02385400 - SOUTH NEW RIVEK CANAL AT S-9 NR DAVIE ILAT PG 034 L LONG OBO 2630 )

\begin{tabular}{|c|c|c|c|c|c|c|c|c|c|c|c|}
\hline $\begin{array}{l}\text { MAY , } 1970 \\
07 . . . \\
\text { SEP. }\end{array}$ & 80 & 20 & -- & - & -- & - & 10 & - & in & 20 & -- \\
\hline
\end{tabular}

02286050 - SOUTH NR CA AT S-13A NR DAVIF ILAT P6 O3 50 LONG ORO $17>01$

SEP.. 1970

$29 .$.

30

\begin{abstract}
NOUTH N R CA AT
\end{abstract}
02280100 - SOUTH NEW RIVER CANAL AT S-13 NEAF DAV (LAT PG 0357 LONG nBO 1232 )

\begin{tabular}{|c|c|c|c|c|c|c|c|c|c|c|c|c|}
\hline $\begin{array}{l}\text { FEH.. } 1970 \\
12 \ldots \\
\text { SEP. }\end{array}$ & - & 10 & $4 \pi$ & $\cdots$ & -- & $=$ & 0 & 130 & 0 & 0 & - & \\
\hline & $\cdots$ & 0 & 30 & -- & -- & - & $n$ & 270 & 2 & 20 & $\cdots$ & 40 \\
\hline
\end{tabular}

02286150 - HOLLYwOOO CANAL AT DANIA FLA (LAT 26 n3 13 LONG OBO O9 I9)

SEP. $1970 \quad-$.

n22H6200 - SNAKE CL CA AT NW G7 AVE NP HIALEAH FL (LAT 255750 LONG DBO 18 40)

\begin{tabular}{|c|c|c|c|c|c|c|c|c|c|c|c|c|c|c|c|c|}
\hline $\begin{array}{l}\text { SEP.. } 1970 \\
30 \ldots\end{array}$ & 60 & 20 & $37 n$ & & 0 & -- & 0 & & 10 & & 290 & & 10 & 20 & -- & 30 \\
\hline & & 02287105 & - & MIAMI & CANAL & AT $5-31$ & NE AR & MIAMII & FLA & ILAT & 2556 & 00 & LONG OAO & 27301 & & \\
\hline $\begin{array}{l}\text { OCT.. } 1969 \\
\text { Of... }\end{array}$ & -- & 0 & 100 & & - & $m$ & -- & & $n$ & & -- & & 60 & -- & - & 10 \\
\hline $\begin{array}{l}\text { JAN.. } 1970 \\
26 . . . \\
\text { MAY }\end{array}$ & -- & - & - & & - & -- & -- & & $\ln$ & & 80 & & 100 & 10 & $\cdots$ & 40 \\
\hline JULY & -- & $2 n$ & -- & & - & - & - & & 10 & & $4 n$ & & 10 & 10 & -- & 30 \\
\hline $08 . .$. & 50 & 10 & -- & & - & - & -- & & 10 & & -- & & 10 & 10 & -- & 60 \\
\hline
\end{tabular}


CHEMICAL ANALYSES, WATER YEAR OCTOBER 1969 TO SEPTEMBER 1970

(TRACE METALS)

DATE

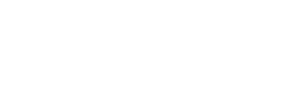

MEXA- DIS-
VALENT SOLVEO

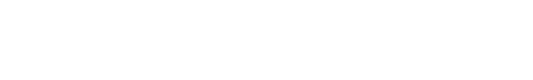

MIUM MIUM MIUM

$\begin{array}{lll}(C D) & (C R G) & (C R) \\ (U G / L) & (U G / L) & (U G / L)\end{array}$

(CU)

(UGA) (FE)

(FE) (PR)

TUTAL
UGAL) (MNA) MERCUR

(MN) (HG) TINC (UGA) (UG/L) (UG/L)

LAKE DKEECHOBEE AND THE EVERGLADES BASINS--CONTINUED

02288600 - MIAMI CANAL AT NW 36TH ST MIAMI, FLA. ILAT 254829 LONG 080 1544 )

\begin{tabular}{|c|c|c|c|c|c|c|c|c|c|c|c|c|}
\hline $\begin{array}{l}\text { OCT... } 1969 \\
07 \ldots . . \\
\text { OEC. }\end{array}$ & -- & 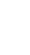 & - & -- & -- & - & -- & sin & - & -- & -- & - \\
\hline APR.:1970 & -- & -- & -- & -- & -- & -- & -- & $15 n$ & -- & - & - & -- \\
\hline $\begin{array}{l}01 \ldots \ldots \\
02 \ldots \ldots \\
\text { MAY }\end{array}$ & 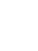 & 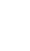 & 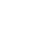 & $\overline{--}$ & $=$ & $\overline{--}$ & $=$ & $\begin{array}{l}50 \\
50\end{array}$ & $\overline{-}$ & $\overline{--}$ & $=$ & $=$ \\
\hline JUNE & -- & 40 & -- & -- & -- & 20 & 0 & 100 & 10 & $n$ & -- & 40 \\
\hline $\begin{array}{l}03 . . . \\
\text { SEP. }\end{array}$ & -- & -- & -- & -- & -- & -- & -- & $19 n$ & - & - & $\cdots$ & - \\
\hline $28 \ldots$ & $=$ & 0 & -- & - & -- & 10 & in & 250 & 6 & in & -- & 40 \\
\hline
\end{tabular}

02288800 - TAMIAMI CA OTLS MONRUE TO CAHNESTOWN F (LAT 255310 LON', OBS 15 30)

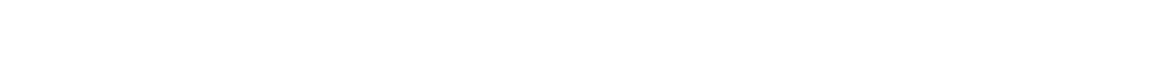

02288830 - BIG SWP AT EVERGLADES PKY NR SUNNILAND ILAT 2610 OB LONG OQRI 05 151

Nov., 1969

$18 . .$.

02288900 - TAM CA OLS $4 U$ MI BENU TO MONROE NR MIA ILAT 2551 O5 LONG ORO 58501

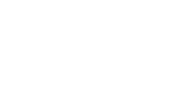

$\begin{array}{rrrrrrrrrrr}10 & 0 & -- & - & - & 0 & 4 n & 10 & 0 & -- & 30 \\ 20 & - & - & -- & -- & n & 110 & 10 & 50 & -- & 40 \\ 10 & -- & - & - & -- & 10 & 4 n & 7 & n & -- & 40\end{array}$

02288960 - TAMIAMI CA AT BR 96 AT MONROE FLA ILAT PS SZ OO LONG OBI O6 OOI

MAY 1970

02289018 - TAMIAMI CA AG S-12G NR MIAMI FLA ILAT $25454210 N G$ OHO 46 n5)

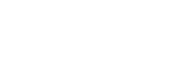

$$
\begin{array}{rrrrrrrrrrr}
40 & -- & -- & -- & -- & 0 & 12 n & 10 & 10 & \ldots & 50 \\
10 & -- & -- & -- & -- & 0 & -- & 40 & 20 & \ldots & 4 n
\end{array}
$$

n2289019 - TAMIAMI CA BL S-12B NR MIAMI FLA (LAT 294540 LONG 0804605 )

$$
\text { MAY } 1970
$$

02289033 - B1G CYP SWP AT EVER PKY NR BIG CYP IND ILAT 2610 AR LONG 081 05 15)

NOV.. 1969
$18 .$.

02299040 - TAMIAMI CAO L67A TO 40 MI BENO NR MIA (LAT 254542 LONG 08043 34)

JAN.P $1970 \quad-$.
$26 . .$.

02289041 - TAMIAMI CA BELOW S12C NF MIAMI FLA ILAT 254540 LONG ORO 43 34)

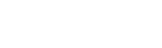

02289043 - EVERGLADES STATION 3-28 NEAR PENNSUCO ILAT 254955 LONG $108043 \quad 15$ )

AUG., $1970 \quad 10$

02290500 - TAMIAMI CANAL AT RED RD MIAMI FLA (LAT 394649 LONG 0801720 )

Nov., 1969

$17 . .$.

$0 \quad 7$

02290710 - BLACK CREEK CA AT S-21 NEAR GOULOS FLA ILAT 253243 LONG 080 19 55)

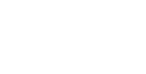




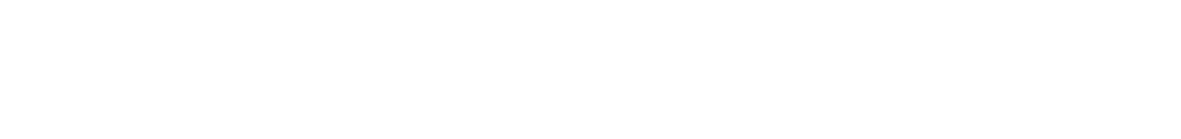
LAKE OKEECHOBEE AND THE EVERGLADES BASINS--CONTINUED

02290720 - MILITARY CA NR HOMESTEAD, FLA. ILAT 252920 LONG 08020 55)

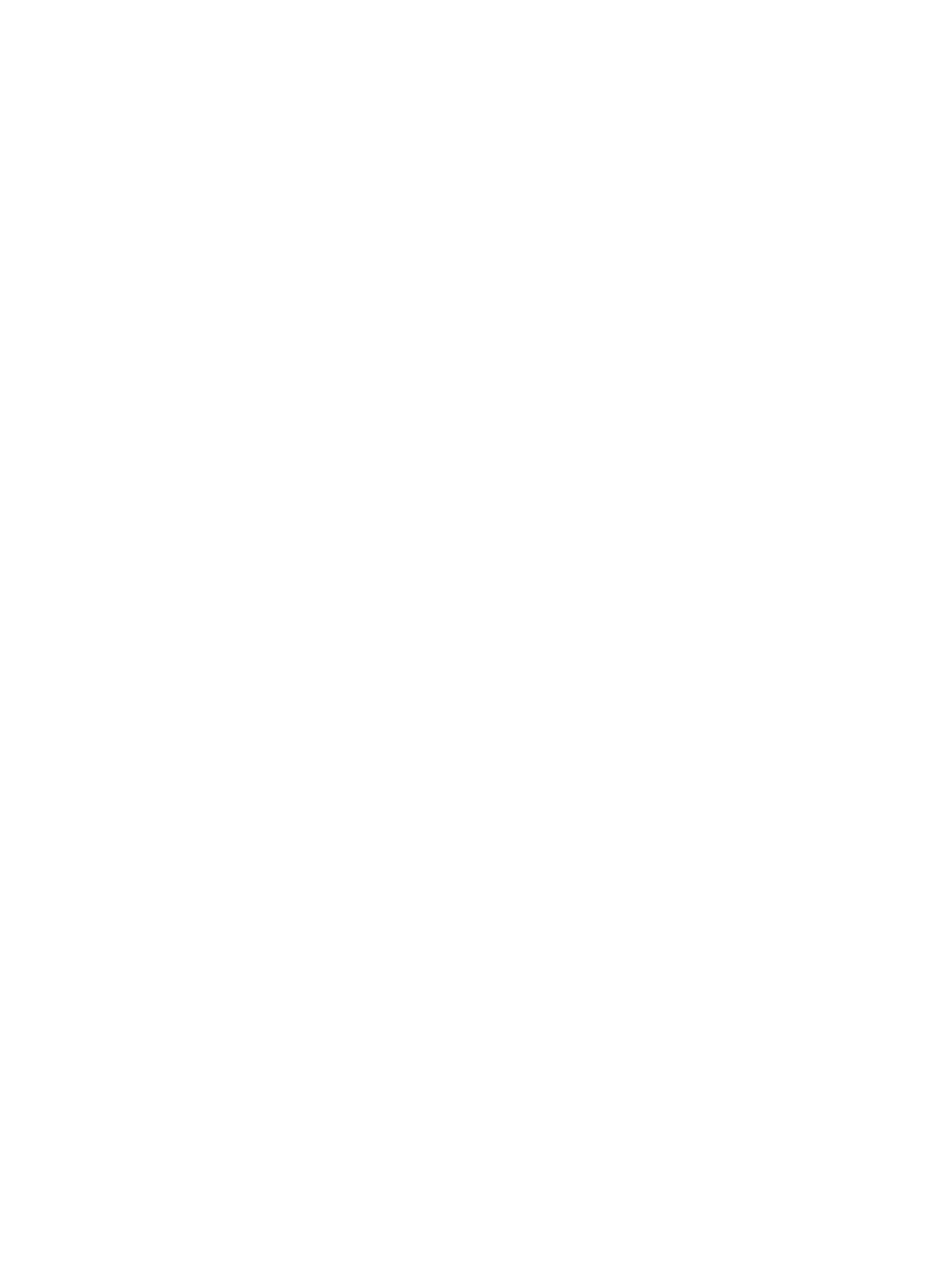


CHEMICAL ANALYSES, WATER YEAR OCTOBER 1969 TO SEPTEMBER 1970

(TRACE METALS)

DATE

OIS-
SOLVEO DIS-
ALUM-
INUM
SOLVEO
(AL) ARSENIC
(UGNL) (ASI)
(UGIL)

\begin{tabular}{|c|c|c|c|c|}
\hline $\begin{array}{l}\text { DIS- } \\
\text { SOLVED } \\
\text { BORON }\end{array}$ & $\begin{array}{l}\text { DIS- } \\
\text { SOLVEU } \\
\text { CAD- } \\
\text { MIUM }\end{array}$ & $\begin{array}{l}\text { HEXA- } \\
\text { VALENT } \\
\text { CHRO- } \\
\text { MIUM }\end{array}$ & $\begin{array}{l}\text { DIS- } \\
\text { SOLVED } \\
\text { CHRO- } \\
\text { MIUM }\end{array}$ & $\begin{array}{l}\text { DIS- } \\
\text { SOLVED } \\
\text { COPPER }\end{array}$ \\
\hline (B) & (CD) & (CRG) & (CR) & (CU) \\
\hline
\end{tabular}

PEACE RIVER BASIN

02294650 - PEACE RIVER AT BARTOW FLA ILAT $2754 \quad 07$ LONG 081490.31

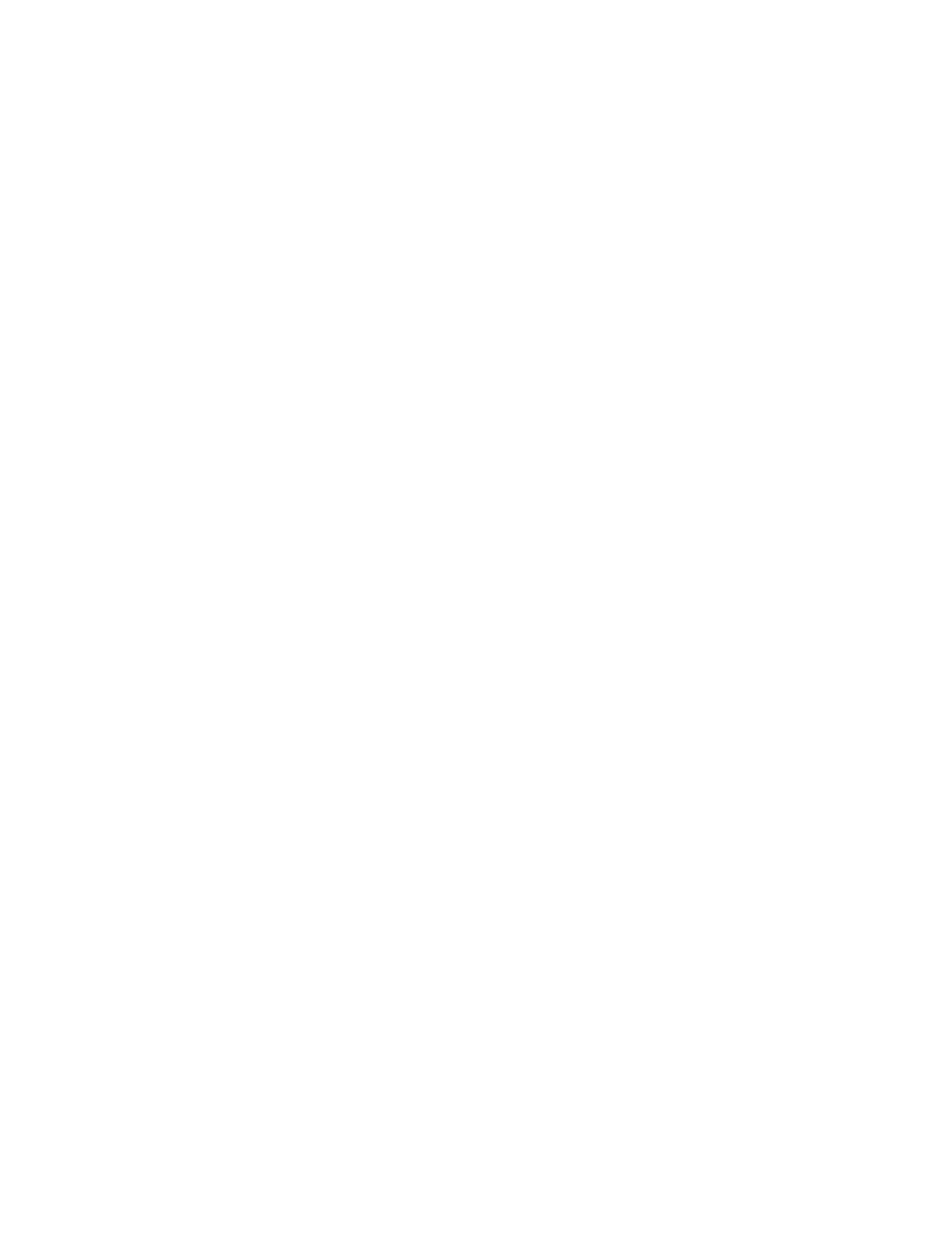




\begin{tabular}{|c|c|c|c|c|c|c|c|c|c|c|c|c|}
\hline & $\begin{array}{l}\text { DIS- } \\
\text { SOLVEN } \\
\text { ALUM- } \\
\text { INUM } \\
\text { (AL) }\end{array}$ & $\begin{array}{l}\text { DIS- } \\
\text { SOLVEU } \\
\text { ARSENIC } \\
\text { (AS) }\end{array}$ & $\begin{array}{l}\text { DIS- } \\
\text { SOLVED } \\
\text { BORON } \\
\text { (B) }\end{array}$ & $\begin{array}{l}\text { DIS- } \\
\text { SOLVEO } \\
\text { CAD- } \\
\text { MIUM } \\
\text { (CD) }\end{array}$ & $\begin{array}{l}\text { HEXA- } \\
\text { VALFNT } \\
\text { CHRO- } \\
\text { MIUM } \\
\text { (CRG) }\end{array}$ & $\begin{array}{l}\text { DIS- } \\
\text { SOLVED } \\
\text { CHRO- } \\
\text { MIUM } \\
\text { (CP) }\end{array}$ & $\begin{array}{l}\text { DIS- } \\
\text { SOLVED } \\
\text { COPPER } \\
\text { (CU) }\end{array}$ & $\begin{array}{l}\text { OIS- } \\
\text { SOLVED } \\
\text { IRON } \\
\text { (FE) }\end{array}$ & $\begin{array}{l}\text { OIS- } \\
\text { SOLVEO } \\
\text { LEAD } \\
(P A)\end{array}$ & $\begin{array}{l}\text { OIS- } \\
\text { SOLVED } \\
\text { MAN- } \\
\text { GANESE } \\
\text { (MN) }\end{array}$ & $\begin{array}{l}\text { TOTAL } \\
\text { MERCURY } \\
\text { (HG) }\end{array}$ & $\begin{array}{l}\text { DIS- } \\
\text { SOLVED } \\
\text { ZINC } \\
\text { (ZN) }\end{array}$ \\
\hline TE & (UG/L) & $(U G / L)$ & $(U G / L)$ & (UG/L) & (UG/L) & (UG/L) & $(U G / L)$ & $(1) G / L)$ & $(U G / L)$ & $(U G / L)$ & (UG/L) & (UG/L) \\
\hline
\end{tabular}

COASTAL BASINS BETWEEN MYAKKA RIVER AND HILLSBDROUGH RIVER--CONTINUED

02300978 - IOG ENGLISH CR NR MULBERRY FLA (LAT 275536 LDNG 0820356 )

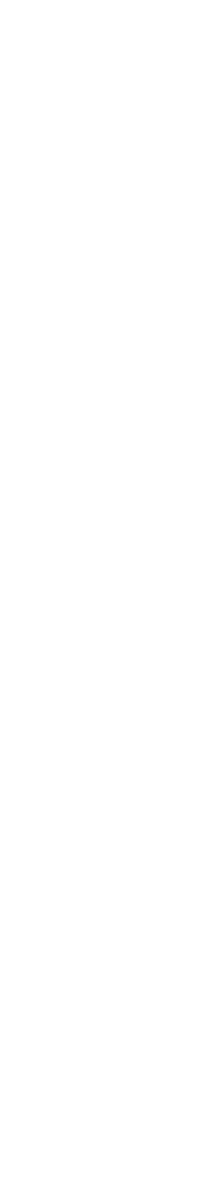

02301000 - N PRONG aLAfIA R AT KFYSVILLF FLA (LAT 275301 LONG OB? 06 011

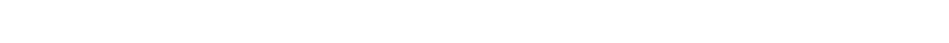

02301328 - ALAFIA R NR KEYSVILLE FLA (LAT 275158 LONG 0820839 )

02301500 - ALAFIA RIVER AT LITHIA FLA UAT 27 5? 19 LONG n82 12411

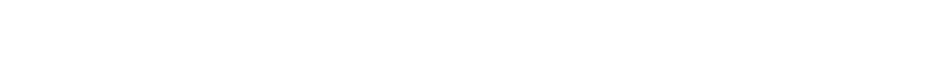

02301718 - ALAFIA HIVER AT RIVERVIEW FLA (LAT 2752 O6 LONG 082 1936 )

HILLSBOROUGH RIVER BASIN

02303000 - HILLSHOKOUGH RIVER INK ZEPHYEHILLS FLA (LAT 28 O8 59 LONG 082 1357 )

\begin{tabular}{|c|c|c|c|c|c|c|c|c|}
\hline 30 & -- & -- & -- & - & 10 & 170 & 0 & $?$ \\
\hline 0 & - & 0 & 0 & $-\infty$ & $n$ & $3 n$ & 1 & \\
\hline
\end{tabular}

n2303271 - BAKER CREEK NEAR THONOTOSASSA FLA (LAT 28 n2 SE LONG n82 16 041

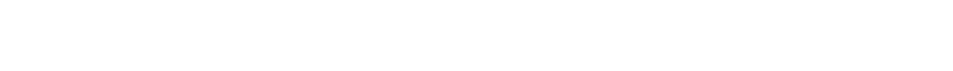

02303300 - FLINT CR NR THONOTOSASSA FLA (LAT 2804 n4 LONG DRP 16 04)

02303320 - FLINT CREEK AT SH-5H2 NEAR THONOTOSASS (LAT 28 04 30 LUNG n8? 15 50)

$\begin{array}{lllllllllll}10 & -- & - & - & - & 10 & 90 & 0 & 10 & -- & 20 \\ 10 & -- & - & -- & -- & -- & -- & -- & -- & -- & -\end{array}$

02304000 - HILLSBORD R AT FOWLER AVE NR TAMPA FLA (LAT 280315 LONG TEZ ZI 50)

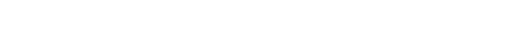

COASTAL BASINS BETWEEN HILLSBOROUGH RIVER AND WITHLACOOCHEE RIVER

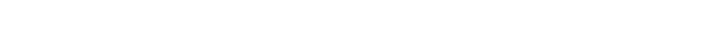

MAY...

02307578 - OLD TAMPA BAY AT SAFETY HARBOH FLA (LAT 275917 LONG N82 41 ก7)

MAY 1970 -.

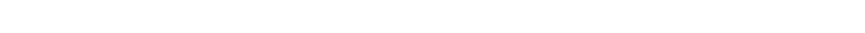

02310300 - PITHLACHASCOTEE R NR NEWPOPT PICHEY FL (LAT 281519 LONG 0823937 )

MAY, 1970

DG....

D2310500 - WEEKIWACHEE SPRINGS NR BROOKSVILLE FLA (LAT 2831 nO LOMG OA? 34 25) 
ANALYSES OF SAMPLES COLLECTED AT MISCELLANEOUS SITES IN FLORIDA

CHEMICAL ANALYSES, WATER YEAR OCTOBER 1969 TO SEPTEMBER 1970

(TRACE METALS)

\begin{tabular}{|c|c|c|c|c|c|c|c|c|c|c|c|c|}
\hline ATE & $\begin{array}{l}\text { OIS- } \\
\text { SOLVED } \\
\text { ALUM- } \\
\text { INUM } \\
\text { (AL) } \\
\text { (UG/L) }\end{array}$ & $\begin{array}{l}\text { DIS- } \\
\text { SOLVED } \\
\text { ARSENIC } \\
\text { (AS) } \\
\text { (UG/L) }\end{array}$ & $\begin{array}{c}\text { D1S- } \\
\text { SOLVED } \\
\text { BORON } \\
\text { (B) } \\
\text { (UG/L) }\end{array}$ & $\begin{array}{l}\text { DIS- } \\
\text { SOLVEO } \\
\text { CAD- } \\
\text { MIUM } \\
\text { (CD) } \\
\text { (UG/L) }\end{array}$ & $\begin{array}{l}\text { HEXA- } \\
\text { YALENT } \\
\text { CHRO- } \\
\text { MIUM } \\
\text { (CRO) } \\
\text { (UG/L) }\end{array}$ & $\begin{array}{l}\text { UIS- } \\
\text { SUL VED } \\
\text { CHRO- } \\
\text { MIUM } \\
\text { (CR) } \\
\text { (UG/L) }\end{array}$ & $\begin{array}{l}\text { DIS- } \\
\text { SOL VED } \\
\text { COPPER } \\
\text { (CU) } \\
\text { (UG/L) }\end{array}$ & $\begin{array}{l}\text { DIS- } \\
\text { SOLVED } \\
\text { IRON } \\
\text { (FF) } \\
\text { (UG/L) }\end{array}$ & $\begin{array}{l}\text { DIS- } \\
\text { SOLVED } \\
\text { LEAD } \\
\text { (PA) } \\
\text { (UG/L) }\end{array}$ & $\begin{array}{l}\text { DIS- } \\
\text { SOLVED } \\
\text { MAN- } \\
\text { GANESE } \\
\text { (MN) } \\
\text { (UG/L) }\end{array}$ & $\begin{array}{c}\text { TOTAL } \\
\text { MERCURY } \\
\text { (HG) } \\
\text { (UG/L) }\end{array}$ & $\begin{array}{l}\text { DIS- } \\
\text { SOLYVED } \\
\text { ZINC } \\
\text { (ZN) } \\
\text { (UG/L) }\end{array}$ \\
\hline
\end{tabular}

02352694 - LAUY LAKE NP LAUY LAKE, FLA. (LAT 245500 LUNG g8I 5350$)$

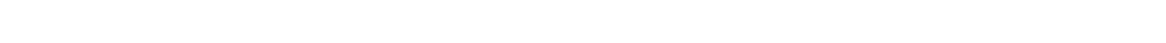

COASTAL BASINS BETWEEN WITHLACOOCHEE RIVER AND SUWANNEE RIVER

02313700 - MACCASASSA R NR GULF HAMMOCK FLA (LAT 291214 LONG 00246091

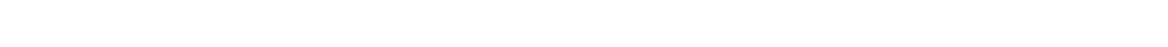

SUWANNEE RIVER BAS.

02335005 - HUNTER CREEK NEAK BELMONT FLA ILAT 3O 20 ?O LONG 0 R2 41408

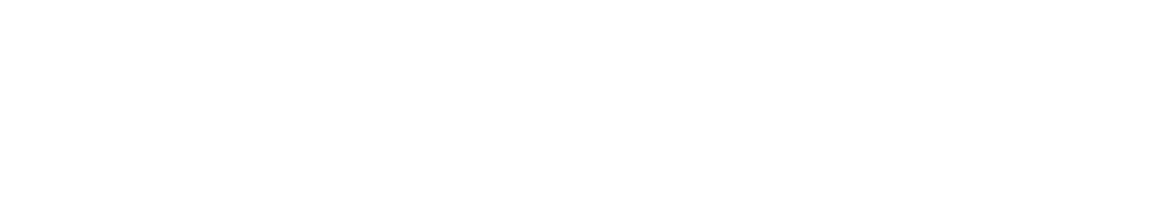

02315500 - SUWANNEE R AT WHITE SPRINGS FLA (LAT 3N 1932 LONG 0824418 )

MAY
$25 . .1970$

02315518 - ICCIDENTAL MINE DR D AT S HWY 137, FLA (LAT 301856 LONG O82 5042 )

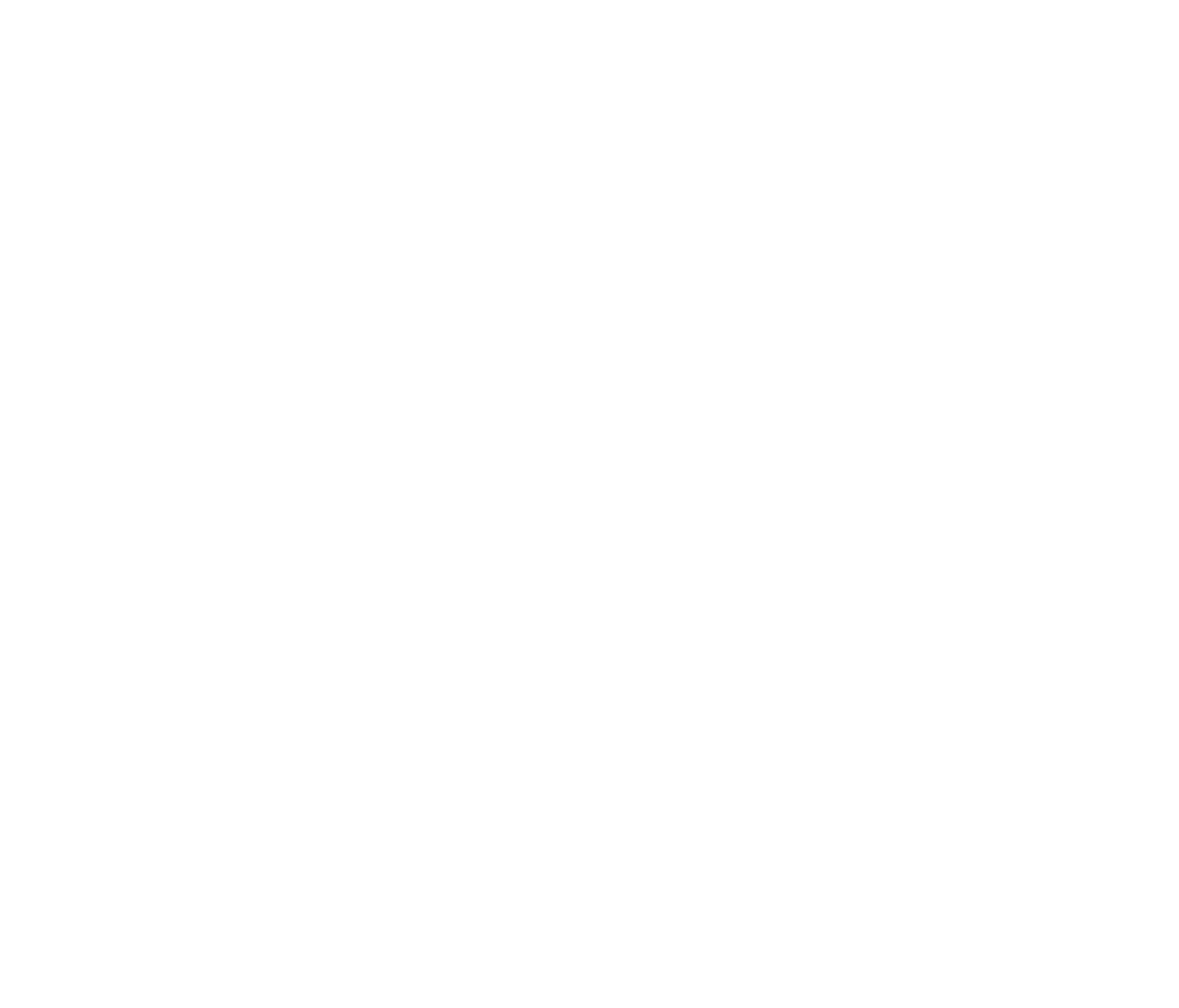




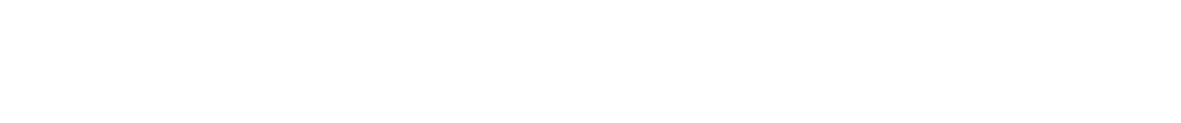

COASTAL BASINS BETWEEN AUCILLA RIVER AND OCHLOCKONEE RIVER

02327000 - WAKILLA SPG NR CRAWFOROVILLE FLA (LAT 301405 LONG 08418051

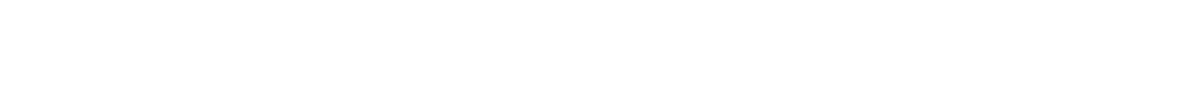

02329200 - LK JACKSON NR TALLAHASSEE FLA ILAT 303143 LONG 08421301

MAY - 1970

22...

$03 .$.
OCT., 1969

DEC...

DEC.

FEB. 197

O4...

APR.

JUNE

JULY...

JULY $28 .$.

$23 . .$.

JUNE, 1970

SEP.

23...

ОСТ ., 1969

OCT...
O1...

DEC...

O3...

EB., 1970

OPR..

02 .

MAY

$27 \ldots$

JUNE

Sहि...

23...

02359660 - DEER POINT LAKE NEAK PANAMA CITY. FLA. (LAT 301745 LONG 0853455 )

COASTAL BASINS BETWEEN APALACHICOLA RIVER AND CHOCTAWHATCHEE RIVER

02359500 - ECONFINA CREEK NEAK BFNNETT FLA ILAT 302304 LONG 08533241

\begin{tabular}{|c|c|c|c|c|c|c|c|c|c|}
\hline$=-$ & -- & $=$ & $=$ & -- & -- & 20 & -- & -- & - \\
\hline-- & -- & -- & -- & + & $\cdots$ & 10 & - & - & $\cdots$ \\
\hline -- & -- & $\cdots$ & -- & -- & $\cdots$ & 50 & -- & 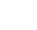 & -- \\
\hline$=$ & $=$ & -- & - & -- & -- & 0 & $=$ & -- & -- \\
\hline -- & $=$ & -- & -- & - & - & $3 n$ & $=$ & $=$ & -- \\
\hline-- & -- & -- & - & -- & -- & 0 & - & - & -- \\
\hline-- & - & -- & - & $=$ & $\Rightarrow$ & 0 & -- & - & -- \\
\hline
\end{tabular}

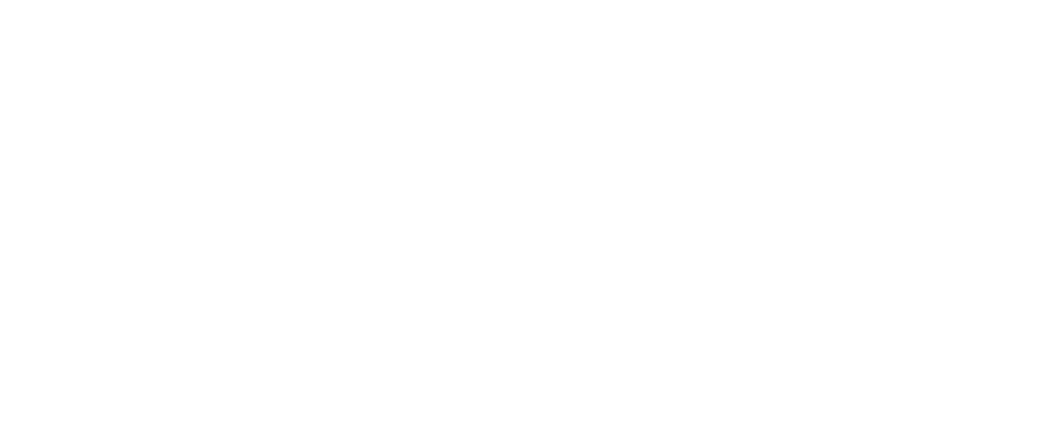

\section{BLACKWATER RIVER BASIN}

02370000 - BLACKWATER R NR BAKER FLA (LAT $3050 \quad 00$ LONG 0864405 )

MAY 1970

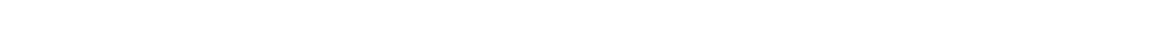

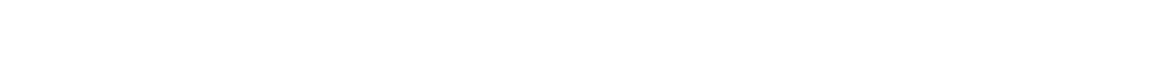

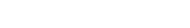

02375500 - ESCAMHIA K NH CENTURY FLA ILAT 305725 LONG 08714001

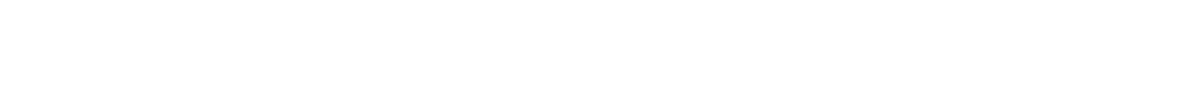

COASTAL BASINS BETWEEN ESCAMBIA RIVER AND MOBILE RIVER

02376108 - ELEVENMILE CREEK NR ENSLEY FLA (LAT 303252 LONG 0871949 )

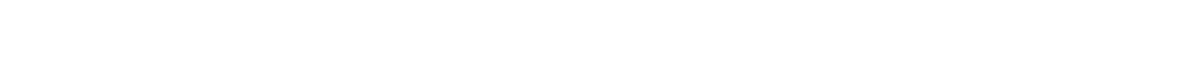


CHEMICAL ANALYSES, WATER YEAR OCTOBER 1969 TO SEPTEMBER 1970

$$
\text { (TRACE METALS) }
$$

\begin{tabular}{|c|c|c|c|c|c|c|c|c|c|c|c|c|}
\hline ATE & $\begin{array}{l}\text { DIS- } \\
\text { SOLVED } \\
\text { ALUM- } \\
\text { INUM } \\
\text { (AL) } \\
\text { (UG I) }\end{array}$ & $\begin{array}{l}\text { OIS- } \\
\text { SOLVED } \\
\text { ARSENIC } \\
\text { (AS) } \\
\text { (UG ) }\end{array}$ & $\begin{array}{l}\text { DIS- } \\
\text { SOLVED } \\
\text { BORON } \\
\text { (B) } \\
\text { (UG/L) }\end{array}$ & $\begin{array}{l}\text { DIS- } \\
\text { SOLVED } \\
\text { CAD- } \\
\text { MIUM } \\
\text { (CD) } \\
\text { (UG/L) }\end{array}$ & $\begin{array}{l}\text { HEXA- } \\
\text { VALENT } \\
\text { CHRO- } \\
\text { MIUM } \\
\text { (CR6) } \\
\text { (UG/L) }\end{array}$ & $\begin{array}{l}\text { OIS- } \\
\text { SOLVED } \\
\text { CHRO- } \\
\text { MIUM } \\
\text { (CR) } \\
\text { (UG/L) }\end{array}$ & $\begin{array}{l}\text { DIS- } \\
\text { SOLVED } \\
\text { COPPER } \\
\text { (CU) } \\
\text { (UG/L) }\end{array}$ & $\begin{array}{l}\text { DIS- } \\
\text { SOLVEO } \\
\text { IRON } \\
\text { (FE) } \\
\text { (UG/L) }\end{array}$ & $\begin{array}{l}\text { DIS- } \\
\text { SOLVED } \\
\text { LEAD } \\
\text { (PR) } \\
\text { (UG/L) }\end{array}$ & $\begin{array}{l}\text { DIS- } \\
\text { SOLVED } \\
\text { MAN- } \\
\text { GANESE } \\
\text { (MN) } \\
\text { (UG/L) }\end{array}$ & $\begin{array}{c}\text { TOTAL } \\
\text { MERCURY } \\
\text { (HG) } \\
\text { (UGA) }\end{array}$ & $\begin{array}{l}\text { DIS- } \\
\text { SOLVED } \\
\text { ZINC } \\
\text { (ZN) } \\
\text { (UG L ) }\end{array}$ \\
\hline
\end{tabular}
COASTAL BASINS BETWEEN ESCAMBIA RIVER AND MOBILE RIVER--CONTINUED

02376500 - PERDIUO RIVER AT BARRINEAU PARK FLA (LAT 304125 LONG 0872625 )

\begin{tabular}{|c|c|c|c|c|c|c|c|c|c|c|c|c|}
\hline $\begin{array}{l}\text { MAY } 1970 \\
19 . . .\end{array}$ & -- & 0 & - & -- & -- & -- & 0 & 250 & 20 & 10 & - & 220 \\
\hline SE.... & -- & 10 & -- & -- & -- & $m$ & 0 & 170 & 10 & 20 & - & 20 \\
\hline
\end{tabular}

LAKE DKEECHOBEE AND THE EVERGLADES BASINS

2534U00\$OS7000N - ROGERS RIV HEADWATH.FS NR PINLCKEST FI.A (LAT 2534 ON LONG OBO 57 0OS

$14 \ldots 1970$

254021081051500 - PONO IN WFSTERN PART GUM SLOUGH NP MON ILAT 2540 P1 LONG 081 0S 151 SEP. 1970

254500080590000 - CULVENT 24 ON LUOP ROAD NK PINECREST F (LAT 2545 ON LOMG IIAO 59 ON $110 \mathrm{~N}, 1960$

2547I5081055000 - CYPRESS STKAND OFF ST RT 94 NR PINECRF ILAT 254715 LONF OHI OS 501

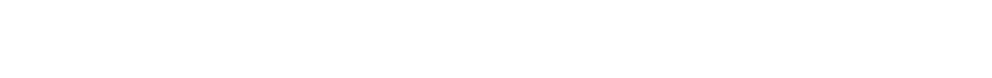

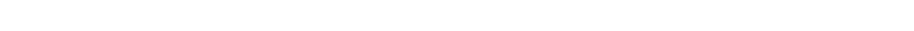
NOV., 1969

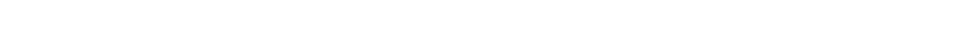

25481800160100 - DRAIN UITCH NF COL MIAMJ INT AIRPORT M (IAT 25 4O 19 IONG OHO 16 01) Nov., 1969

$17 \ldots$

255040uHO555000 - TAMIAMI CA AT JH.TPURT EIVTRANCE NR MIAM (LAT 25 SO 4O LONG URO 5550 ) NOV., 1949

2551200RU523000 - JETPORT HOR2OI PIT \#4 NK MIAMI FLA ILAT 255120 LONG OHO 52 30)

NOV... 1969
$18 . \ldots$

255120080540000 - CYPRESS SWH NRR JFTHOKT MORPOW PIT 3 NE ILAT 255120 LOWG OHO 54 ONS

\begin{tabular}{|c|c|c|c|c|c|c|c|c|c|c|}
\hline JUL ${ }^{\prime} \cdots$ & $=$ & in & $\cdots$ & -- & $n$ & 0 & $1 \geqslant 0$ & $3 n$ & $n$ & 500 \\
\hline $\begin{array}{l}14 \ldots \\
\text { our... }\end{array}$ & -- & 20 & -- & - & $n$ & 0 & on & 10 & 10 & 30 \\
\hline $13 \ldots$ & 30 & 0 & -- & -- & $1 n$ & 0 & an & 7 & 10 & 60 \\
\hline $15 \ldots$ & -- & $n$ & -- & -- & $1 n$ & 10 & on & 50 & in & 31) \\
\hline
\end{tabular}

2552300\%0JF0000 - JETPORT BOKPOW PIT 5 NR MIAMI FLA (LAT 2552 30 LONA OHO 55 00)

\begin{tabular}{|c|c|c|c|c|c|c|c|c|c|c|}
\hline JULY & - & 10 & - & - & $n$ & $n$ & 20 & 10 & 40 & bno \\
\hline $\begin{array}{ll}14 \ldots \\
\Delta U \sigma_{i}\end{array}$ & -- & 0 & - & -- & 0 & 0 & ? & 10 & 0 & $4 \pi$ \\
\hline SEP... & 50 & 10 & -- & -- & 0 & 0 & $n$ & 5 & I0 & 40 \\
\hline $16 \ldots$ & -- & 0 & -- & -- & 10 & 10 & hi) & 0 & 10 & $5 n$ \\
\hline
\end{tabular}

2552310005?2000 - CYPHESS SWF NF JP F1T \#4 NEAR PINFCRES LLAT 255231 LONG OY90 52 20) JUNE. 1970

1700

1)
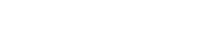


\begin{tabular}{|c|c|c|c|c|c|c|c|c|c|c|c|c|}
\hline DATE & $\begin{array}{l}\text { DIS- } \\
\text { SOLVED } \\
\text { ALUM- } \\
\text { INUM } \\
\text { (AL) } \\
\text { (UG/L) }\end{array}$ & $\begin{array}{c}\text { DIS- } \\
\text { SOLVED } \\
\text { ARSENIC } \\
\text { (AS) } \\
\text { (UG/L) }\end{array}$ & $\begin{array}{l}\text { DIS- } \\
\text { SOLVFO } \\
\text { EORON } \\
\text { (B) } \\
\text { (UG/L) }\end{array}$ & $\begin{array}{l}\text { DIS- } \\
\text { SOLVED } \\
\text { CAD- } \\
\text { MIUM } \\
\text { (CO) } \\
\text { (UG/L) }\end{array}$ & $\begin{array}{l}\text { MEXA- } \\
\text { VALENT } \\
\text { CHRO- } \\
\text { MIUM } \\
\text { (CRG) } \\
\text { (UG/L) }\end{array}$ & $\begin{array}{l}\text { DIS- } \\
\text { SOLVED } \\
\text { CHAO- } \\
\text { MIUM } \\
\text { (CR) } \\
\text { (UG/L) }\end{array}$ & $\begin{array}{l}\text { DIS- } \\
\text { SOLVED } \\
\text { COPPER } \\
\text { (CU) } \\
\text { (UGL) }\end{array}$ & $\begin{array}{l}\text { OI S- } \\
\text { COLVEN } \\
\text { IRON } \\
\text { (FE) } \\
\text { (UG/L) }\end{array}$ & $\begin{array}{l}\text { DIS- } \\
\text { SOEVEO } \\
\text { LEAD } \\
(P R) \\
(U G / L)\end{array}$ & $\begin{array}{l}\text { DIS- } \\
\text { SOLVED } \\
\text { MAN- } \\
\text { GANESE } \\
\text { (MN) } \\
\text { (UG/L) }\end{array}$ & $\begin{array}{c}\text { TOT AL } \\
\text { MERCURY } \\
\text { (HG) } \\
\text { (UG/L) }\end{array}$ & $\begin{array}{l}\text { DIS- } \\
\text { SOLVFD } \\
\text { ZINC } \\
\text { (ZN) } \\
\text { (UG/L) }\end{array}$ \\
\hline
\end{tabular}
LAKE OKEECHOBEE AND THE EVERGLADES BASINS--CONTINUED

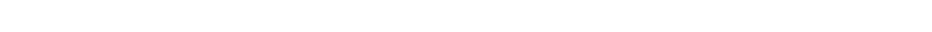

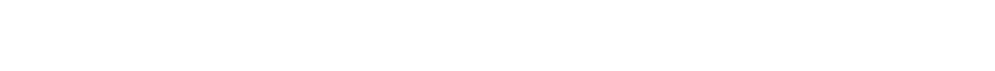

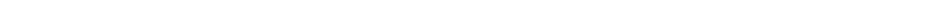
$11 \Delta 2 .+1970$

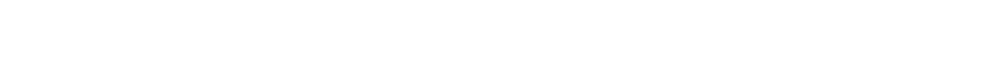

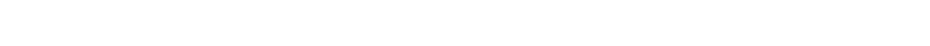
NAK.. $1 \rightarrow 70$

\begin{tabular}{|c|c|c|c|c|c|c|c|c|c|c|}
\hline JUHE... & -- & 3 & 40 & -- & 1) & n & $4 \pi$ & 10 & 10 & $3 n$ \\
\hline 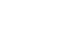 & -- & 10 & $\cdots$ & -- & $1^{n}$ & n & $10 n$ & 1" & -- & $4 \pi n$ \\
\hline $\begin{array}{l}14 \ldots . \\
\text { Aur,... }\end{array}$ & -- & $1 n$ & -- & -- & $n$ & n & 30 & 0 & in & $4 n$ \\
\hline${ }_{\text {SFP. }}^{13}$ & 50 & 0 & 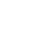 & $=$ & $n$ & $n$ & $3 n$ & 3 & $n$ & Rn \\
\hline $15 \ldots$ & -- & "1 & - & - & 10 & IC & 4.t & 13 & 20 & 60 \\
\hline
\end{tabular}

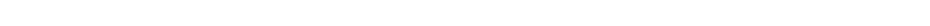
AUG., 1970

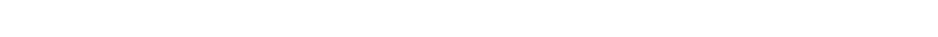
rov. 146,9

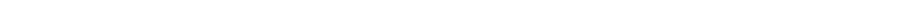
CFP.. 1970

1014 3

$11 n$

12

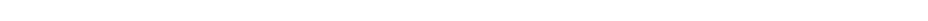

MAK... 19711

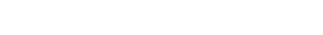

CFi...

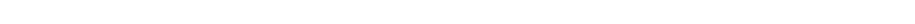

SEP. 1470

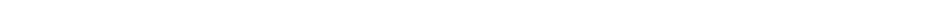

FEP. 1970

$09 . .$.

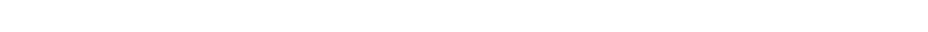

FEA.. 14/1

$13 \ldots$...

$i^{i j}$

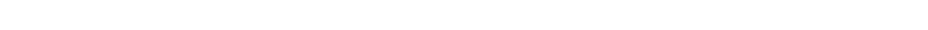

$17 \ldots . .0$

¿9...

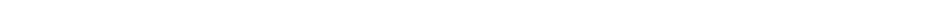

FEx. 1970

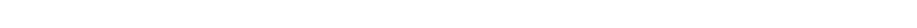

FEH., 1470

(1) 200

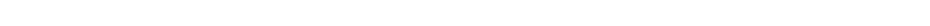

FEH., 1977

10

1nn 
CHEMICAL ANALYSES, HATER YEAR OCTOBER 1969 TO SEPTEMBER 1970 (TRACE METALS)

\begin{tabular}{|c|c|c|c|c|c|c|c|c|c|c|}
\hline & OIS- & & & UIS- & OIS- & & & & IS- & \\
\hline & SOLVEO & DIs- & DIS- & SOLVEH & SULVE? & OIs- & DIS- & UIC- & SOLVE, & $1119-$ \\
\hline & $A L U M_{-}$ & SOLVED & SOLVEU & CAD - & $C H L O=$ & solven & SOLVF.U & SOLVE! & $\mathrm{NAN}_{-}$ & SOLVER \\
\hline & INUM & ARSENIC & BORON & MIUM & MIUM & COPHER & IPOM & LE $\triangle D$ & GANFGF & $Z \mathrm{I} \cong \mathrm{C}$ \\
\hline & $(\Delta L)$ & $(\Delta S)$ & $(x)$ & $(\mathrm{CO})$ & (CR) & (cli1) & (FF) & $(P+i)$ & (MN) & (ZN1) \\
\hline DATE & $(U G / L)$ & $(\cup G / L)$ & $(U G / L)$ & $(11 G / L)$ & (UG/L) & $(U G / L)$ & $\left(1 G_{G / 1}\right)$ & $(U(, / L)$ & $\left(U_{1} / L\right)$ & $(11,0 / L)$ \\
\hline
\end{tabular}

LAKE OKEECHOBEE AND THE EVERGLADES BASINS--CONTINUED

260743080103100 - NORTH FK NEN HIV AT NW OTH ST FT LAUEF (LAT 2R O7 43 (n.: O8R 10 31)

FEE.. 1970
$17 . .$.

200807080140200 - PLANTATION RO CA AT NW 65 AVE IN JLANT (LAT PA OR O7 IOAT OEM 14021

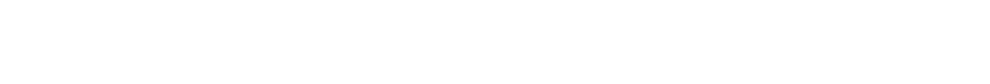

260919080172300 - MIODLE RIVER CANAL NQ LAUDEPHILL FLA ILAT 24 19 19 LONG, OMO $17>31$

$30 \ldots$

261000080553000 - CYPRESS PONO OFF EVERGLAUES PKWY NR FT LLAT 2610 ON LONG OKO G', 301

\begin{tabular}{|c|c|c|c|c|c|c|c|c|c|}
\hline $\begin{array}{l}\text { MAR., } \\
30 \ldots 70\end{array}$ & -- & -- & 30) & -- & -- & $\cdots$ & - & - & - \\
\hline StP. & -. & 10 & -- & -- & ln & 0 & 110 & 0 & $\therefore$ \\
\hline
\end{tabular}

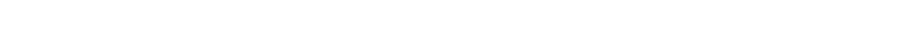

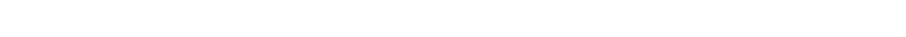
AUG.. 1970

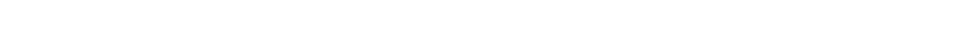

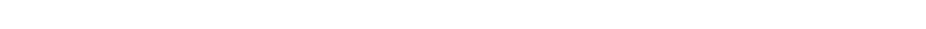
0 so $\quad$ s.

$26114 \pi 000114400$ - FT LAUNERDALE PHOSPECT LK NHFT LAUOH ILAT 761144 LONG, fHMO $114 \mu$ ) FËP. . 1970

$16 . .$.

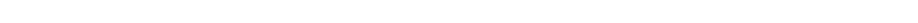
AUT.. $197 \%$

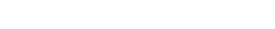

30

$47 n$

in $3 n$

120

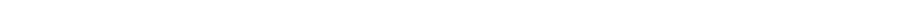
AUto. 1970

$07 . .$.

261317080061300 - POMPANO CA AT US HWY 1 AT POMPANO BEAC (1.AT PA 13 l $l$ LOMG OAO OK 13)

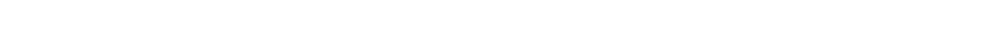

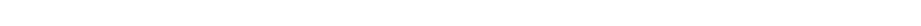
AUG., 1970

$00 . .$.

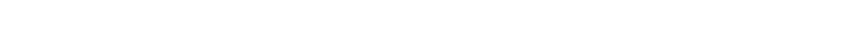

$A L 15, ., 1970$
$06 . .$.

2613490 R0121700 - POMPANU CA AT SR 7 AT MAFGATE FLA (LAT PG 13 49 LONR, ORO 1217 FEH., 1970

$18 . .$.

20 - $\quad$ in $\quad$ hn $\quad$ in $\quad$ in

?n

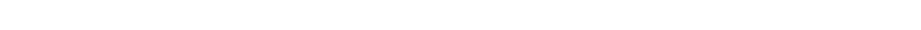

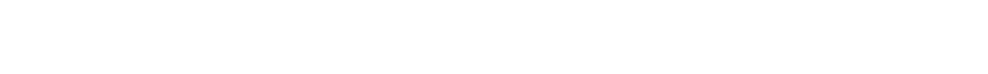


262517080242000 - HILLSBORO CANAL 1 MILE WEST OF 5-10 NR (LAT 262517 LONG 0802420 )

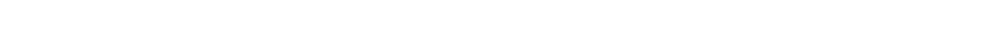
262518080042500 - CANAL 15 ABOVE S-40 NEAK DELRAY BEACh (LAT 2625 B LONG 0800425$)$ $\begin{array}{ccccccccc}\text { MAR., } 1970 & & & & & & & & \\ 16 . . . & 0 & 50 & 0 & 10 & 10 & 130 & 0\end{array}$ 262625081162000 - CANAL AT JNCT S-840 ANU S-846 NR 1MMOK ILAT 262625 LONG 081 1620 ) NeV.. 1969

263219080072300 - FOYNTON CA AT SH 809 NR BOYNTON BCH FL (LAT 263219 LONG 08007 23) 12...

263221080052800 - BOYNTON CA AT CONGRESS AVE NR BOYNTON (LAT 263221 LONG 080 05 28) AUG.. 1970

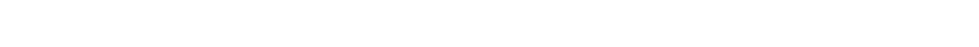
264042080092800 - WFST PALM BCH CA AT CLEARY RO NR NEST ILAT 264042 LONG 080 09 28 ? Al1.., 1970

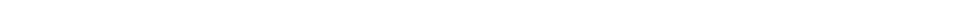
264043080102800 - WEST PALM BCH CA AT GENOIST FARMS ROAD (LAT 2K 4043 LONG OAO 10 28) AUG., 1970

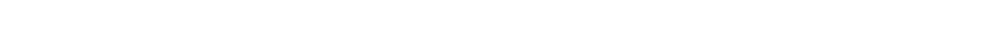
264047080120800 - WEST PALM GCH CA AT SH 80 NR WEST PALM (LAT 264047 LONG 08012083 MAR.. 1970

264255080035000 - CLEAR LAKE AT WEST PALM BEACH FLA LLAT 264255 LONG 08003501 MAR., 1970

$17 \ldots$

204531080051800 - CANAL 17 AT SH 702 NEAP MANGONIA PARK (LAT 264531 LONG 08005 18) AUG., 1970

11...

CANAL 17 AT SH 702 NEAP MANGONIA PARK LAT 264531 LONG 0800519

270241082142701 - COCOA HLUM WATERWAY NR PUNTA GORIJA FLA ILAT 27 O2 41 LONG O82 14 27.01\% JUNE, 1970 08 ... 


$$
\text { (TRACE METALS) }
$$

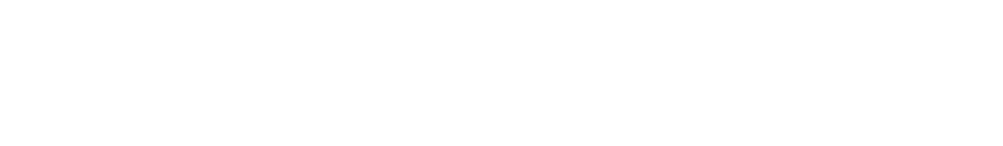

28005308CUO1300 - OPAINAGE DITCH AT REYNOLUS ROAON AT PLA (LAT 29 nO 53 LONE 082 na 13)

JUNE, 1970

OS...

28013200?111300 - SPARTMAN AHANCH NR PLANT CITY FLA (LAT 230132 LONG OAP 11 13)

JUNE, 397 ก

$08 . .$.

280150082111400 - MILL CREFK AT FORBES RD NR PLANT CITY (LAT ZR II SO LONG OR2 11 14)

JUNE, $197 n$

08...

280208082095100 - MILL CHEEK AT THONOTOSASSA RII NL PLANT (LAT $2 F$ OZ OH LONG ON2 OY 51)

JUNE, 1970

$08 . .$.

280220082343260 - SW PERIM NITH IT RUCKY CP LNDFL NH TAM (LAT 29 OZ 29 LONG MAP 34 32)

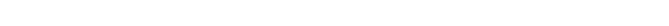

140

280235082342500 - N* SANT LNDFL DX1O PU NR SULPHUP SPG F (LAT 29 B2 35 LONG nB2 34 25) FEH.. 1970

2H0243082342200 - NF PFRIA DITH AT ROCKY LK LNIIFL NR TAM ILAT 3H 1243 LONG 7023425$)$

JUNE, 1970

JUNE, 397

$3077000862516 \%$ - CHOCTAWHATCMEE GAY NK VILLA FASSO FLA (LAT 3027 00 LONG AAS 25 (6)

MAY 1970

$30 . . .2140$

S3... -.

n $\quad--\quad$ in $\quad$ in

41) $0-10$

$30272703423250 \pi$ - UNNAMEO LAME NEAM TALLAHASSEE FLA IIAT 307722 LONG n84 23253

NEC.. 1969

$10 . .$.

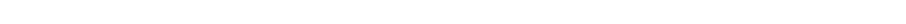

HAY , 1970

$\begin{array}{lllllllllll}19 . . . & 120 & 0 & -- & -- & 10 & 10 & 4 n & 10 & 0 & 400\end{array}$

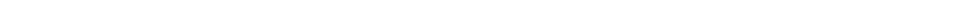

270341081573100 - THORNTON HHANCH AT US 17 NK FT OGUEN F ILAT 270351 LONG ORI 5731 )

JUME, 1970

10...

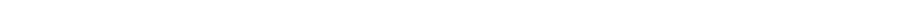

JUINE, 1970

ox...

273724032372300 - TAMPA HAY TRIB NH PALMFTTO FLA ILAT 773724 LONG OHZ 32 231 JUNE, 1970

0 है...

$2736440814 \times n 51) 0$ - PEACE RIVED NR H)WLING GREEIN FLA (LAT 273944 LONG 08148 05) Ji) Nit, 1970

11 ...

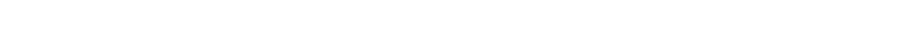
JUNE, 1970

07...

275709002243700 - MCKAY RAY THIO NH TAMPA FLA ILAT 2757 09 LONG OR2 2437 !

MAY 1970 -- IN

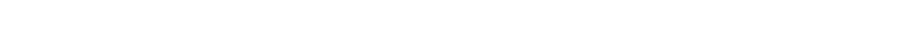

JUKE. 1970

$08 .$. . 
ANALYSES OF SAMPLES COLLECTED AT MISCELLANEOUS SITES IN FLORIDA

CHEMICAL ANALYSES, WATER YEAR OCTOBER 1969 TO SEPTEMBER 1970 (HERBICIDES AND ORGANOPHOSPHORUS INSECTICIDES IN WATER AND SEDIMENT)

\begin{tabular}{|c|c|c|c|c|c|c|c|}
\hline DATE & $\begin{array}{l}2,4=0 \\
(U G / L)\end{array}$ & $\begin{array}{c}2,4,5-1 \\
\text { (UG/L) }\end{array}$ & $\begin{array}{l}\text { SILVEX } \\
\text { (UG/L) }\end{array}$ & $\begin{array}{l}\text { DI- } \\
\text { AZINON } \\
\text { (UG/LI }\end{array}$ & $\begin{array}{l}\text { MALA- } \\
\text { THION } \\
\text { (1)G/L) }\end{array}$ & $\begin{array}{l}\text { METHYL } \\
\text { PARA- } \\
\text { THION } \\
\text { (UGAL) }\end{array}$ & $\begin{array}{l}\text { PARA- } \\
\text { THION } \\
\text { (UGML) }\end{array}$ \\
\hline
\end{tabular}

ST. JOHNS RIVER BASIN

02231350 - OGE ST JOHNS MRWATERS NR VERO BCH FLA (LAT 274132 LONG 080 ?5 00)

MAY 1970

MaY.:.

$.00 \quad .00$

02231400 - O9E BLUE CYPRESS LAKE NH FELLSMERE FLA (LAT 274334 LONG 0804632 ) APR., 1970

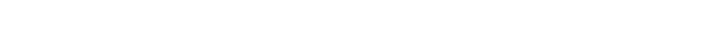

02231467 - O9E ST JOHNS $W$ AB LK HELEN BLAZKS NR MELRO ILAT 275943 LONG 08047301

MAY 1970

02231600 - 09E JANE GFEEN CREEK NR DEER PARK FLA (LAT 290427 LONG 0802318 )

$\triangle P P_{1}, 1970$

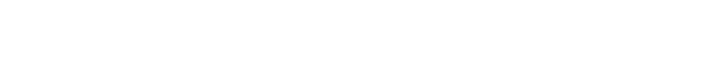

02232100 - 09E LK WASHINGTON NK EAU GALLIE FLA ILAT 22 T9 50 LONG 0BO 44101

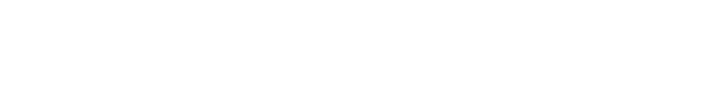

02232200 - O9E WOLF CR NR DEEK PARK FLA ULAT 2H 1255 LONG ORO 54 03)

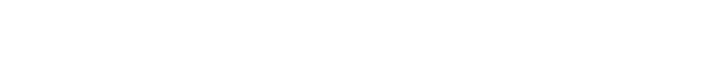

02232413 - 09E TAYLOR CKEEK AT 5164 NEAR COCOA FLA (LAT 2 H 2023 LONG ORO 56 06) APR., 1970

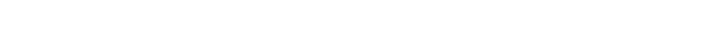

02234000 - O9E ST JOHNS $R$ AB L HARNEY NP GENEVA FLA (LAT $2 \sim 42$ IN LONG 0RI O? 06) MAY 1970

02240500 - O9E OKLAWAHA RIVER AT FURFKA FLA (LAT 29 ?P OD LONG 0915400 ) SEP. 1970

23...

02243960 - O9E OKLAWAHA R AT RODMAN GAM NR ORANGE SPR (LAT 293030 LONG n81 48 15)

SE.P. 1970

LAKE OKEECHOBEE aND THE EVERgLades BASINS

02277110 - ST LUCIE FSTUAKY AT ALA BP NP STUART (LAT 271154 LONG ORO 12 26)

\begin{tabular}{|c|c|c|c|c|c|c|c|}
\hline $\begin{array}{l}\text { SE.P. } 1969 \\
11 \ldots \ldots 1970 \\
\text { AFR.. } 1970\end{array}$ & -- & -- & $=-$ & $<.20$ & $<.20$ & $<.02$ & $<.04$ \\
\hline $\operatorname{MAY}_{\operatorname{Ma}} 11 \cdots$ & -- & -- & - & $<.20$ & $<.20$ & $<.02$ & $<.04$ \\
\hline JUNE & -- & -- & -- & $<.20$ & $<.20$ & $<.02$ & $<.04$ \\
\hline $\begin{array}{l}18 . . . \\
\text { AUG. }\end{array}$ & -- & - & -- & $<.20$ & $<.20$ & $<.02$ & $<.04$ \\
\hline $07 \ldots$ & - & $\cdots$ & -- & $<.20$ & $<.20$ & $<.0$ ? & $<.04$ \\
\hline
\end{tabular}

02278501 - CON ADEA NO 1 BL S-5 COMP NR LOX ILAT 264100 LONG ORO 22 InI

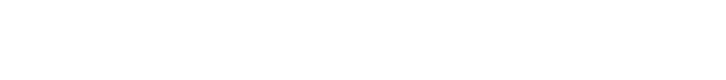

02279090 - WEST PALM BCH CA AT WEST PALM ACH. FLA LLAT 26 39 40 LONG 080 03 32) AUG. 1970

Il... 1970 
CHEMICAL ANALYSES, HATER YEAR OCTOBER 1969 TO SEPTEMBER 1970 IHERBICIDES AND ORGANOPHOSPHORUS INSECTICIDES IN WATER AND SEDIMENT)

\begin{tabular}{|c|c|c|c|c|c|c|c|}
\hline & $2,4=0$ & $2,4,5-T$ & & $\begin{array}{c}\text { DI- } \\
\text { AZINON }\end{array}$ & $\begin{array}{l}\text { MALA- } \\
\text { THION }\end{array}$ & $\begin{array}{l}\text { METHYL } \\
\text { PARA- } \\
\text { THION }\end{array}$ & $\begin{array}{l}\text { PARA- } \\
\text { THION }\end{array}$ \\
\hline$T$ & $(U G / L)$ & $(U G / L)$ & $(U G / L)$ & $(U G / L)$ & $(U G / L)$ & $(1 J G / L)$ & (UG/L) \\
\hline
\end{tabular}

LAKE OKEECHOBEe AND THE EVERgLADES BASINS--CONTINUED

022R12\%3 - EVERGLADES STA 1-15 NR DELRAY BEACH FL (LAT 262345 LONG 0801740$)$

\begin{tabular}{|c|c|c|c|c|c|c|}
\hline OCT. 1968 & .00 & .00 & .00 & $\cdots$ & -- & -- \\
\hline $20 . . .1969$ & .00 & .00 & .00 & - & -- & - \\
\hline $\begin{array}{l}20 \ldots \ldots \\
\end{array}$ & .00 & .00 & .00 & -- & - & -- \\
\hline $28 \ldots$ & .00 & .06 & .00 & -- & - & - \\
\hline $\begin{array}{l}\text { AUG. } \\
06 . . .\end{array}$ & .00 & .00 & .00 & - & - & -- \\
\hline
\end{tabular}

02281300 - HILLSBORO CANAL AT S-39 NR DEERFIELO \& (LAT 2621 20 LONG OBO 1758 )

JAN. , 1970

J2...

02291500 - HILLSBORO CANAL NEAR OEERFIELD BEACH F (LAT 261939 LONG 0800752 )

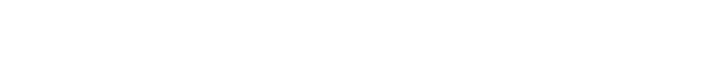

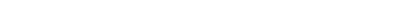

02281700 - CYPRESS CREEK CA AT S-38 NR POMP BCH F (LAT 261345 LONG 0801750 ) FEB., 1970

I6....

02282000 - pompano canal at pompano ach FLA LLAT 261351 LONG 090 07 28 )

OCT., 1968

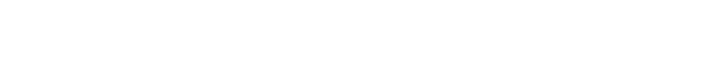

02242100 - CYPRESS CR CA AT S-37A NR POMPANO BEACH F (LAT 2A 1220 LONG 08007571

ОСТ.. 1968

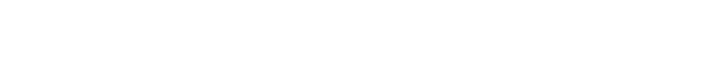

02282700 - MIODLE R CA AT S-36 NK FT LAUDERDALE F (LAT 261022 LONG 0801047 )

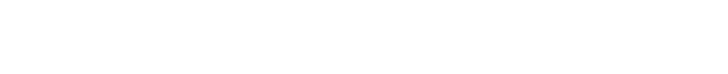

02282740 - NF MIU FIV CANAL EXT AT FT LAUDERDALE (LAT 261117 LONG 0801114 )

OEC., 1968

$\begin{array}{llll}0 . . . & .00 & .00 & .00\end{array}$

02282743 - NF MID R CA EXT (PROSPECT RO) AT FT LAUD (LAT 2611 P0 LONG OBO 10 32)

NEC.. 1968

$05 . .$.

02282800 - MIDOLE R CA AT US HWY I NR FT LAUD FLA (LAT 260926 LONG 0800703 )

FEB., 1970

130.

$.00 \quad .00 \quad .00$

022R2990 - FLORIDA TURNPIKE CA AT FT LAUDERDALE F (LAT 26 06 03 LONG D80 13 03)

DEC., 1968

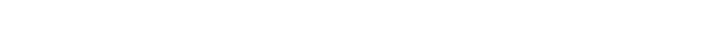

02283200 - PLANTATION RD CA AT S-33 NR FT LAUE FL (LAT 2608 O5 LONG 08011421

ОСТ.. 1968

$\begin{array}{rllllll}04 \ldots 190 & .00 & .00 & 1.0 & -- & - & -\end{array}$

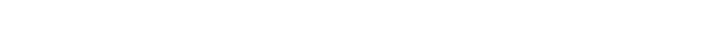

02284642 - EVERGLADES STA 2-17 NR ANDYTOWN FLA (LAT 2616 50 LONG 08025101

AUG., 1970

$06 . .0$

.00

$.00 \quad .00$ 
CHEMICAL ANALYSES, HATER YEAR OCTOBER 1969 TO SEPTEMBER 1970 (HERBICIDES AND ORGANOPHOSPHORUS INSECTICIDES IN HATER AND SEDIMENT)

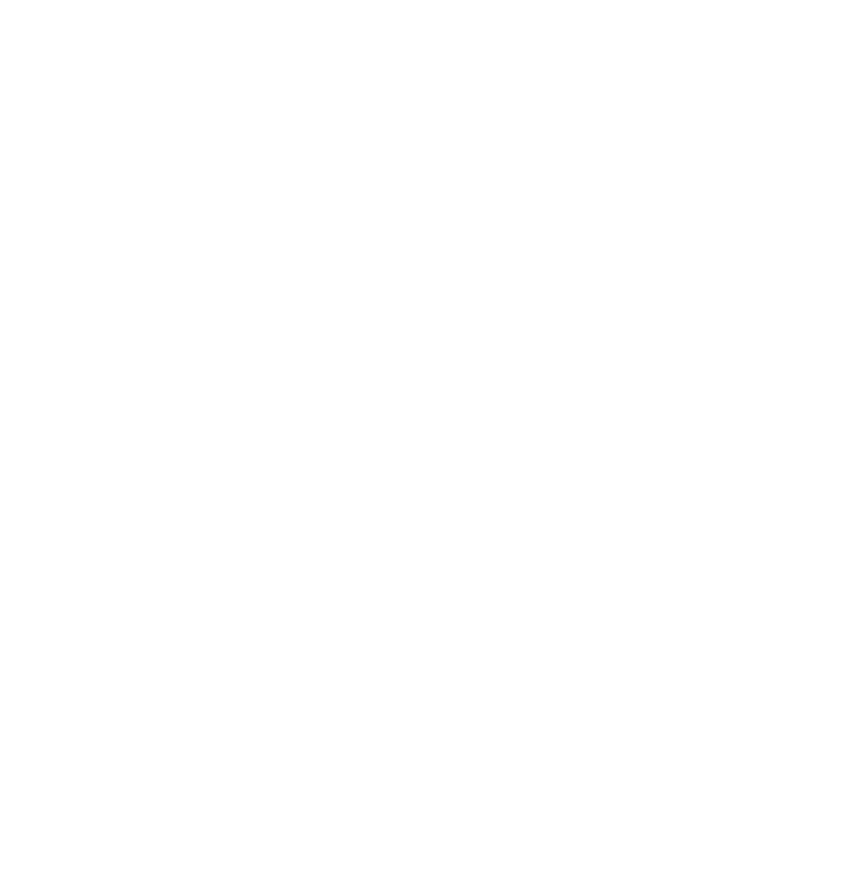

02290710 - BLACK CREEK CA AT S-21 NEAR GOULOS FLA (LAT 253243 LONG 080 19 55) JAN., 1970

02290796 - LITTLE MADEIRA BAY NR KEY LARG0, FLA. (LAT 251030 LONG 0803800 ) ост., 1968

02290800 - TAYLOR SLOUGH NEAR HOMESTEAD, FLA. ILAT 252405 LONG 08036251

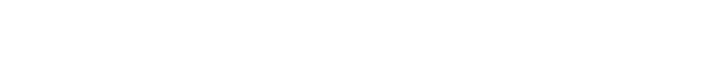

$\begin{array}{lllllll}07 . . & .00 & .00 & .00 & -- & - & -\end{array}$

02290812 - ALLIGATOR HO AT CTNMOUTH CP NR HOMESTE (LAT 253810 LONG 0804420 ) AUG., 1970

$14 \ldots .$.

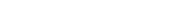

02290815 - EVERGLADES P-33 NEAR hOMESTEAD FLA (LAT 253630 LONG 0804130 ) FEB.. 1968

02290828 - EVERGLADES P-36 NEAR HOMESTEAU, FLA. ILAT 253230 LONG 0804700 ) FEB.. 1968

28 ... 00

02290930 - EVERGLADES P-35 NEAR HOMESTEAD, FLA. ILAT 252720 LONG 0805230 ) MAR., 1968

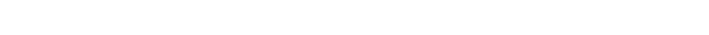
02290858 - SHARK P AT MK 68 NR HOMESTEAD FLA (LAT 252007 LONG 08106 44) MAR., 1968

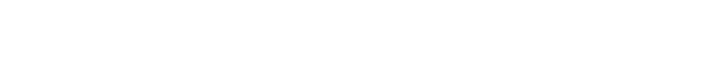


CHEMICAL ANALYSES, HATER YEAR OCTOBER 1969 TO SEPTEMBER 1970 (HERBICIDES AND ORGANOPHOSPHORUS INSECTICIDES IN WATER AND SEDIMENT)

\begin{tabular}{|c|c|c|c|c|c|c|c|}
\hline DATE & $2,4-0$ & $2,4,5-T$ & SILVEX & $\begin{array}{l}\text { OI- } \\
\text { AZINON }\end{array}$ & MALA- & $\begin{array}{l}\text { METHYL } \\
\text { PARA- } \\
\text { THION }\end{array}$ & $\begin{array}{l}\text { PARA- } \\
\text { THION }\end{array}$ \\
\hline & (UG/L) & $(\mathrm{UG} / \mathrm{L})$ & (UG/L) & (UG/L) & & & \\
\hline
\end{tabular}

02292900 - CALOOSAHATCHEE KIVER AT 5-79 NR OLGA, (LAT 264325 LONG 081 41 55)

\begin{tabular}{|c|c|c|c|c|c|c|c|}
\hline $\begin{array}{l}\text { OCT... } 1969 \\
\text { NG... } \\
\text { JUNE, I } 970\end{array}$ & -- & $\cdots$ & -- & $<.20$ & $<.20$ & $<.02$ & $<.04$ \\
\hline $03 \ldots$ & $=$ & - & -- & $<.20$ & $<.20$ & $<.02$ & $<.04$ \\
\hline $\begin{array}{l}\text { AUG. } \\
05 . . .\end{array}$ & - & -- & $=-$ & $<.20$ & $<.20$ & $<.02$ & $<.04$ \\
\hline
\end{tabular}

HILLSBOROUGH RIVER BASIN

02303300 - FLINT CR MK THONOTOSASSA FLA (LAT 280404 LONG 0821604 )

JUNE, 1970

$10 . .$.

$.00 \quad .00$

\section{SUWANNEE RIVER BASIN}

02315500 - SUWANNEE R AT WHITE. SPRINGS FLA (LAT 3N 1932 LONG 08244 18)

SEP., 1970

$16 . .$.

. no $\quad .00 \quad .00$

02323500 - SUWANNEE R NR WILCOX FLA (LAT 293520 LONG 0825610 )

AUG., 1969

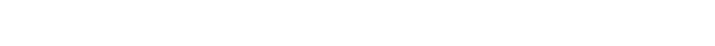

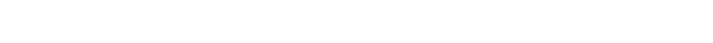

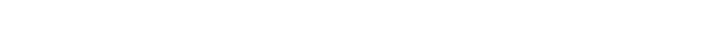

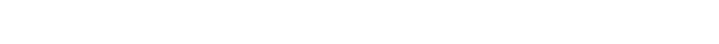

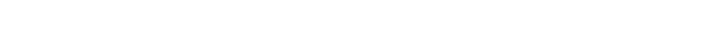

COASTAL BASINS BETWEEN AUCILLA RIVER AND DCHLOCKONEE RIVER

02327100 - SOPCHOPPY HIVEK IN SOPCHOPPY FLA (LAT 300745 LONG Od4 2940 ) JUNE, 1968

21...

COASTAL BASINS BETWEEN CHOCTAWHATCHEE RIVER AND YELLOW RIVER

02366900 - MAGNOL LA CREEK NEAK FREEPOKT FLA (LAT 3 N 3148 LONIJ OUS OS 15) JUNE, 1970

$18 . .$.

$.00 \quad .00 \quad .00$ 
CHEMICAL ANALYSES, WATER YEAR OCTOBER 1969 TO SEPTEMBER 1970 (HERBICIDES AND ORGANOPHOSPHORUS INSECTICIDES IN WATER AND SEDIMENT)

$$
\begin{array}{rrr}
2,4-D & 2,4,5-T & \text { SILVEX } \\
\text { DATE (UG/L) } & \text { (UG/L) } & \text { (UG/L) }
\end{array}
$$

LAKE OKEECHOBEE AND THE EVERGLADES BASINS

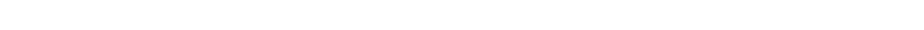

$\begin{array}{llll}\text { JAN... } 1970 & & & \\ 12 \ldots . .00 & .00 & .00 & .00 \\ \text { MAY } & & \\ 15 \ldots . . . & .00 & .00 & .00\end{array}$

253400080570000 - JOH NOGENS RIV HEADWATKR'S NP PTNFCAEST FIA ILAT 253400 IONÖ OMO 57001

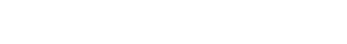

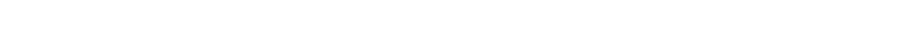

$$
\begin{array}{lll}
\text { MAYY. } 1970 \quad .00 \quad .00 \quad \text {.nO } \\
15 . . .
\end{array}
$$

255120080523000 - 10 HETPUPT GOKROM PIT \#4 INK MIAMI FLA ILAT 2551 20 LONG 0AO 3230

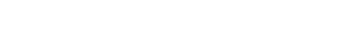

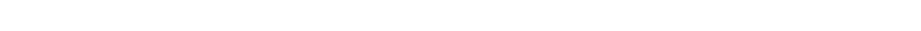

$$
\Delta 1,5,1471,
$$

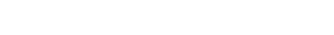

255741030154500 - 106 SNAKE CLFEK AT $N$ S7 AVE NEAQ CAROL CI ILAT 255741 LOHG 080 15451

$$
\begin{aligned}
& \text { JaN.. } 1970 \text {.0 .0 .0 } \\
& \begin{array}{ccc}
\text { MAY } & .00 & .00
\end{array}
\end{aligned}
$$

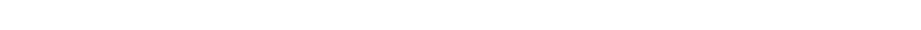

$$
\text { FE., } 1970 \text {.00 . . . .0 }
$$

260S14UMO110800 - 10S NONTH NEW KIV CA AT SW 31 AVE AT FT LA (LAT OH O5 14 LONG OPO 11 OB)

$$
\text { FEH... } 1970 \text {.no .no .on }
$$

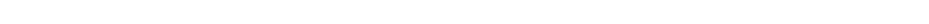

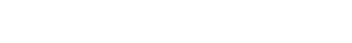

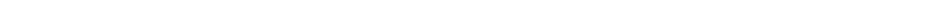

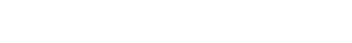

200729080074400 - 10N NFW RIVER AT SE 15TH AVE AT FT LAUOEHO (LAT 2N O7 29 LOMG 0800744 )

$$
\text { FtH...1910 .00 .00 }
$$

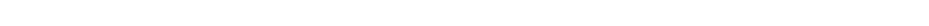

$\begin{array}{lll}\text { HE... } 1970 \text {.00 .00 } & .00\end{array}$

200807080140200 - JOE PLANTATION RO CA AT NW AS AVF IN PLAMT LLAT 26 OB 07 LONG OOO 14 OĈ) FEF... 1970 .00 .00

261034080093300 - CA-13 FEEDËH CA AT 1OTH AVE FT LAVOERD (LAT 261034 LONG O80 0935 )

$$
\text { FFH... } 1970 \text {.0 } 130 \text {.00 .00 }
$$

261037080442600 - COHPS OF FNGINEERS GAGE 3-2 NR ANOYTOW ILAT 361057 LONG 0804426 )

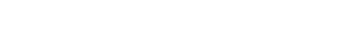

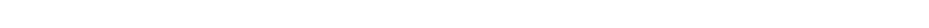
fH... 1470 .00 .0 
CHEMICAL ANALYSES, WATER YEAR OCTOBER 1969 TO SEPTEMBER 1970 (HERBICIDES AND ORGANOPHDSPHORUS INSECTICIDES IN WATER AND SEDIMENT)

UATE (UG/L) (UT,L) $\quad \begin{array}{lll}2.4-0 & 2.4 .5-T & \text { SILVEX } \\ \text { UUG }\end{array}$

LAKE OKEECHOBEE AND THE EVERGLADES BASINS--CONTINUED

261148080114800 - FT LAUIENIIALE PKOSPECT LK NR FT LAUDF (LAT 261149 LONG OAO 11 4R) FER., 1970
$16 . .$.

P61317UR0061300 - POMPANO CA AT US HWY 1 AT POMPANO GEAC (LAT OG 13 IT LONG DBO OA 13)

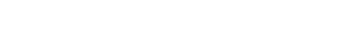

26132408U211800 - L-35B BORROW CANIAL IN CA 2A NR ANDYTON (LAT OS 1324 LONG OBO 2118 : AUG.. $1970 \quad .00 \quad .00 \quad .00$
$0 . .$.

261349480121700 - POMPANO CA AT SR 7 AT MARGATE FLA (LAT 261349 LONG OAN 12 17)

FER.. 1970

$10 . .0 \quad .00 \quad .00 \quad .00$

2616300010435800 - C-123 AT OLIS MIAMI CANAL NE ANUTTOWN F (LAT 261630 LONG 0RO 43 5R) Q.J6., 1970

$05 . . .00 .000$

26191A08U055200 - HILLSAORO CAE UF OLXIF HAY OT DEEHFIF II 4 T 26 I9 IK LONG ORO OS 521

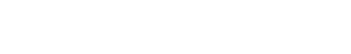

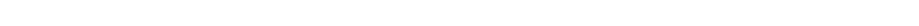

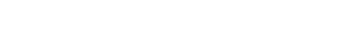

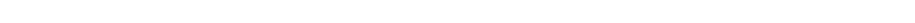

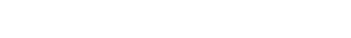

2K3227080122000 - C-16 AT EJUALIZING CA NR BOMMTON HCH F (LAT 263227 LOMG, OSO 1> 201

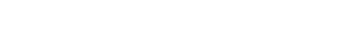

264037080064500 - WEST PALM HEACH AI W P F FLA (LAT 264 Tी 37 LONG O80 06 45)

$$
\begin{array}{llll}
\Delta 4 G \ldots 70 & 00 & .00 & .00
\end{array}
$$

264042080092000 - WEST PALM GCH CA AT CLEAKY RO INP WEST (LAT 264042 LONG DRO 09 28)

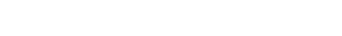

264043080102800 - INE WEST PALM HCH CA AT RENOIST FARMS ROAN (LAT 264043 LOAG 080 IN 28

$\begin{array}{lll}\text { AHG.. } 1970 & .00 \quad .00 \quad .00\end{array}$

264531060051800 - 10B CANAL 17 AI SH 702 NEAR MANGONIA PAKK (LAT 264531 LONF OBO 05 18) AUG.. 1470 .DO .nO

264829080050900 - 10 B CANAL 17 AT SH-ROY NP LAKE PAKK FLA (LAT 26 49 29 LONG 0HO 05 O91

$$
\text { AUG., } 1970 \quad-. .00 \quad .00
$$




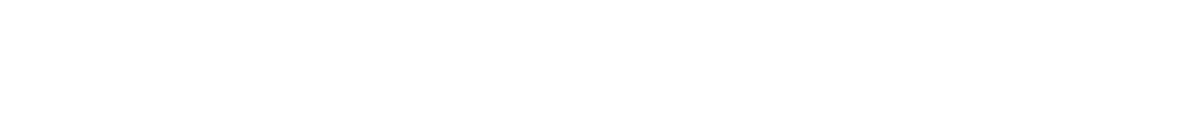

ST. JOHNS RIVER BASIN

0223134, - FT (URUMA CKEEK AT SS PKWY NR FT URUM FL ILAT 2734 MA LONG 0804747 )

OCT., $19+9$

22...

MAY... 1300

JULY

>3...

OCT., 190

21... 1969 3200

MAY. 1970 7h

JULY

5?...

OCT.. 1969

22... प⿺辶

HILY
21...

$O C T+1969$
$22 \ldots 190$
$30 \ldots 1970$

${ }_{\text {OCT... } 1969}$

MAY 197

$05 \ldots$

JILY

OCT., 1949

MAY : 1470

Jut $Y$.

$>4$...

DCT. 1469

21... 1969

$\triangle P R \ldots 1970$ 1450

28...

21...

FER., 1970

JuLY
गु...

29... -

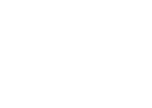

JULY, 1970

$29 . .$.

OCT.. IYHA

$21 . . .197$

28... 1970

JIILY

21 ...

O2P31350 - ST JOHNS HDWATERS MHR VERO BCH FLA ILAT 274132 LONG D8O 25 DO)

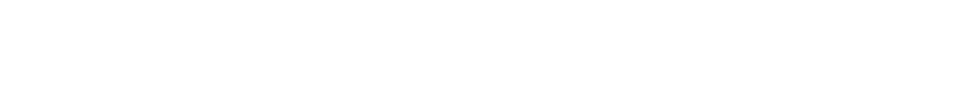

n22331396 - HLUE CYPNESS CKEEK INEAP FELLSMEKE FLA (LAT $2743 \quad 40$ LONG 08048 19)

\begin{tabular}{|c|c|c|c|c|c|c|c|c|c|c|c|}
\hline- & -- & $\cdot \cap 18$ & - & n & -- & $n$ & -- & , & - & - & - \\
\hline-- & -- & - & 1.1 & -- & $=$ & -- & -- & 、 & - & 0 & \\
\hline
\end{tabular}

n2231400 - ALUE CYPLFSS LAKF NR FFLLLMFLE FLA (LAT 274334 LONG MRO 46 3?)

\begin{tabular}{|c|c|c|c|c|c|c|c|c|c|c|}
\hline-- & - & $\cdot n$ & $\sim$ & 0 & - & 0 & -- & -- & - & - \\
\hline$\Rightarrow$ & -- & .112 & -- & 0 & -- & 200 & -- & - & - & $\cdots$ \\
\hline
\end{tabular}

R2231467 - ST JOHNS R AB LK HFLEN BLATFS NW MFLHO (LAT 775943 LUNG 0804730 )

$$
\begin{array}{ccccccccccc}
-- & -- & -- & -- & -- & -- & -- & -- & -1 & - \\
-- & -- & .31 & .43 & n & -- & 100 & -- & -- & -- & -- \\
-- & -- & -- & 1 . & -- & -- & 1 & -- & -- & 0 & --
\end{array}
$$

n2231471 - LUKE MELEN BLAZES NHAK DFFR PAYK, FLA. (LAT 28 OI 30 LONG n80 47 S6)

nP231E00 - JANE T,FEEN CMEEK NK OEEP PARK FLA (LAT $2 R 1.427$ LONG OQN 53 I8)

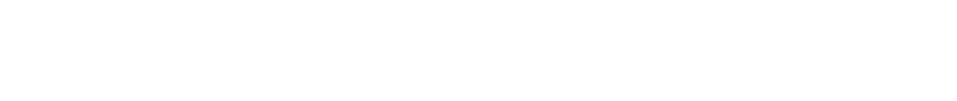

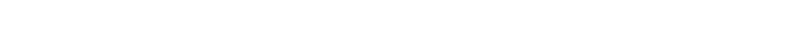

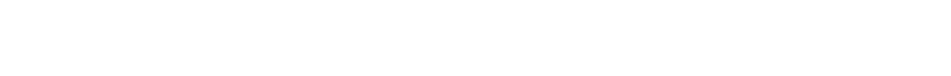

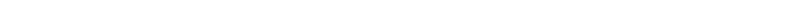

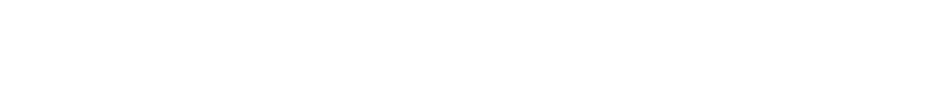

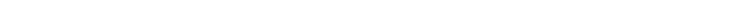

1233?200 - MOLF CR NH DEFH PAEK FLA (LAT PU 1255 LONG nR0 5403 )

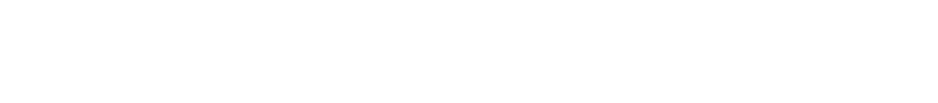


CHEMICAL ANALYSES, WATER YEAR OCTOBER 1969 TO SEPTEMBER 1970

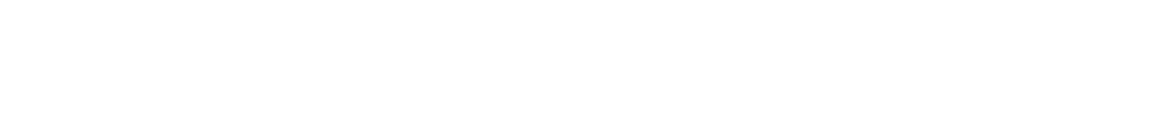

\section{ST. JOHNS RIVER BASIN--CONTINUED}

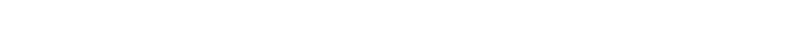

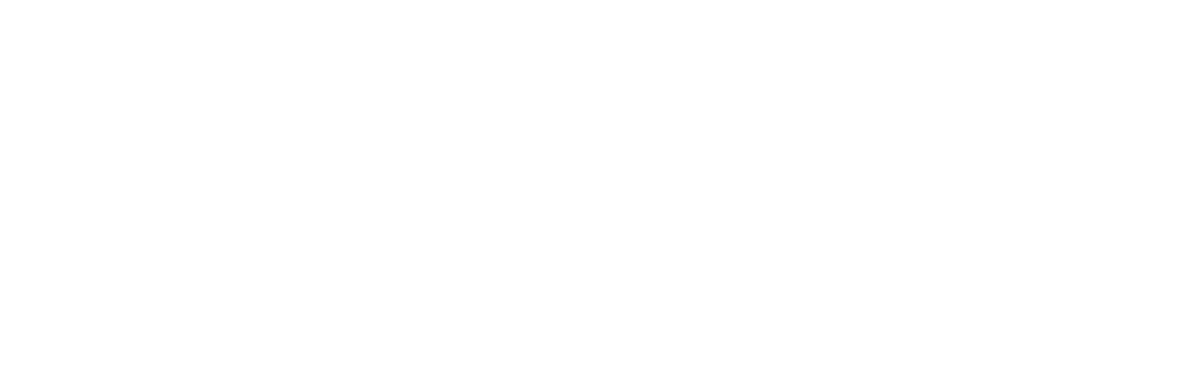

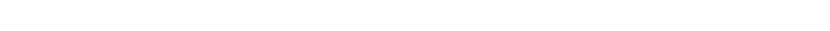

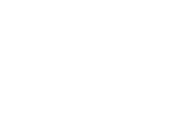

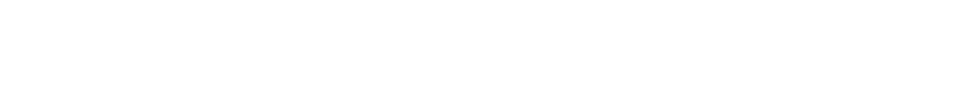

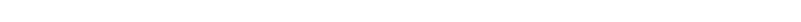

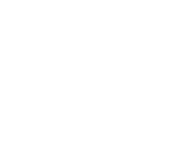

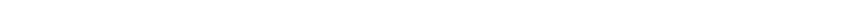

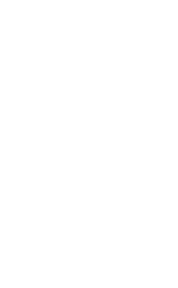

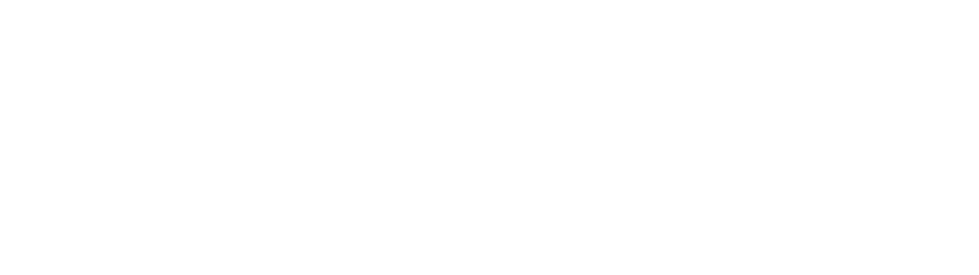

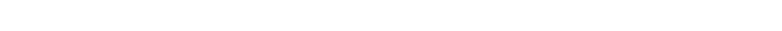

MAY, $1 y 71$
$\because 3 . .$.

DEC.. $19+9$

JAN. 1470 19R0

FE'

$>6 . . . \quad 271,1$

MAL. $110 \mathrm{BHB}$

$\triangle P R$.

$30 . .2 \quad 3+12 n$

$30 . \cdots \quad 5+101$

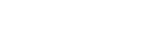

HILY

3 ... 350

$29 . . . \quad 115011$

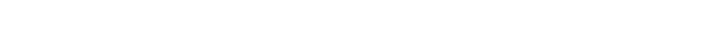

$\operatorname{mar}_{12 . . .} 1970$

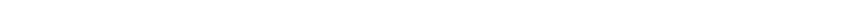




\begin{tabular}{|c|c|c|c|c|c|c|c|c|c|c|c|}
\hline $\begin{array}{l}\text { I MME - } \\
\text { DIATE }\end{array}$ & $\begin{array}{c}\text { DFLAYEII } \\
\text { COLI- }\end{array}$ & & $\begin{array}{c}\text { ME THY - } \\
\text { Lridr }\end{array}$ & $\begin{array}{c}\text { UIS- } \\
\text { SULVELI }\end{array}$ & & & & & & & \\
\hline COLI- & FUFM & & BLUF & Oruanil & & & TOT AL & "15- & & UIS- & $1) I c_{-}$ \\
\hline FULM & $1 \mathrm{COL}-$ & OIL & $\Delta C T I V E$ & NITH?- & & & ALUM_- & SOL VE: & $T \cap T \Delta L$ & SOLVFI? & SOLVEO \\
\hline 1CUL. & $a^{n} 1 \mathrm{t}^{\mathrm{c}}$ & $A+U$ & S1te- & I,EV & PHE WOLS & IUDIDE & I sus & COtALLT & Iuny & LITHIUM & MERCURY \\
\hline
\end{tabular}

\section{ST. JOHNS RIVER BASIN--CONTINUED}

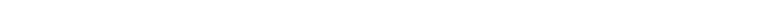

MAY P 197n

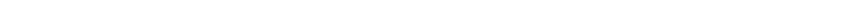

$M \Delta Y, 1+71$,

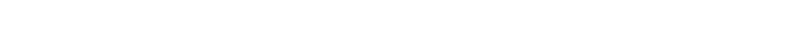

MAY $14 \ldots 70$

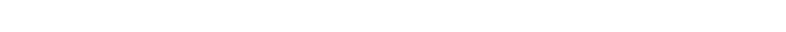

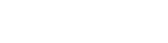

MAY $11+1$ 2U1111]

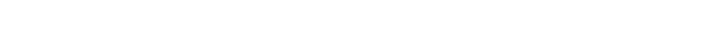

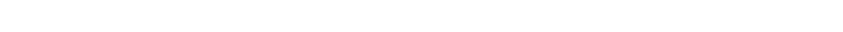

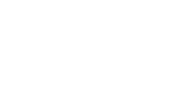

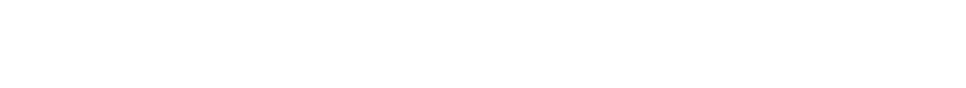

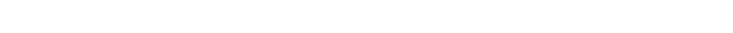

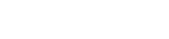

MAR.

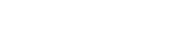

$\operatorname{MaY}$
19

$74 \ldots$

$\begin{array}{llll}-- & -- & -- & -- \\ -- & -- & -- & -- \\ -- & -- & -- & -- \\ -- & -- & -- & --\end{array}$

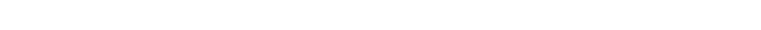

SF... 1971 10101

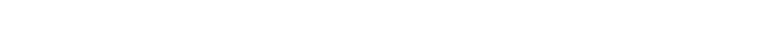

$A F R \cdot 1 \% 11$

วr...

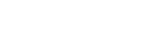

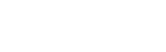

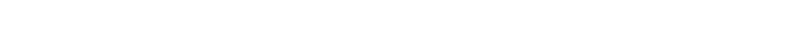

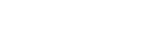

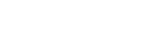

$\begin{array}{llll}-- & -- & -- & -- \\ -- & -- & -- & --\end{array}$

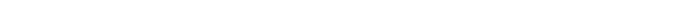

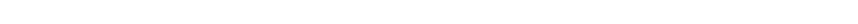

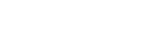

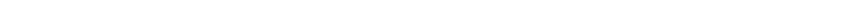

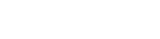

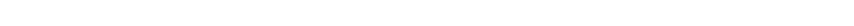

Mar
rit... $1+71$
sip.
$>3 . .$. 


\section{T. JOHNS RIVER BASIN--CONTINUED}

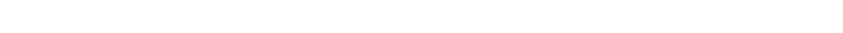

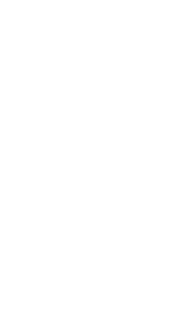

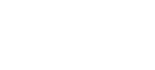

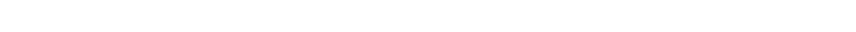

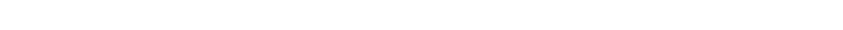

MAY , 1970

ShP.

21...

APK. I I 7 7I

$30, \ldots$

$3 x^{\circ}$

ADP. . 1970

$39 . .$.

A115... 1474

mov... Jun

$24 . .1$ का:1

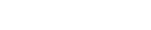

vov.. 14t

$24 \ldots$ a no

NOV.. lanc

$74 \ldots$ 75

(1) $31 . .197^{\circ}$

MAY D. 1978

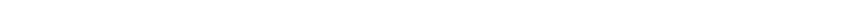

\section{LAKE OKEECHOBEe AND THE EVERGLADES BASINS}

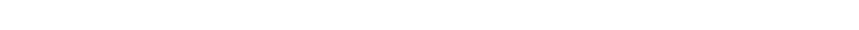

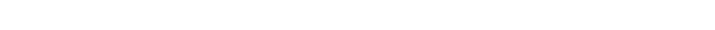

$$
\begin{array}{lllllllllll}
- & -- & - & -- & -- & -- & -- & -- & - & - \\
-- & -- & -- & -- & -- & -- & -- & -- & -- & -- & -2
\end{array}
$$

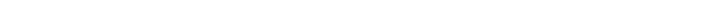

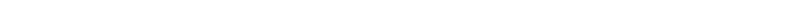

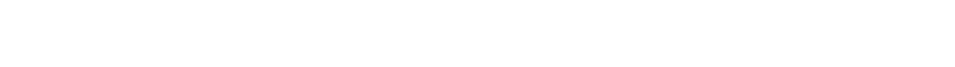

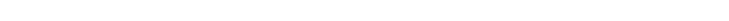

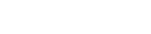

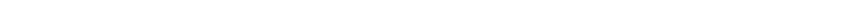




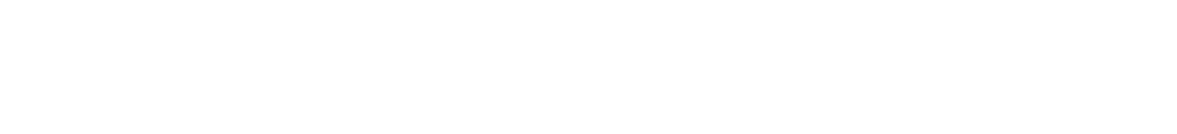

LAKE OKEECHOBEE AND THE EVERGLADES BASINS--CONTINUED

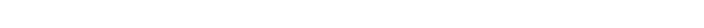

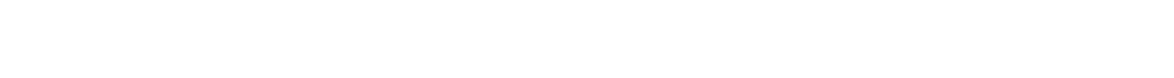

DZZhO4MG - DAVENPOHT CREEK NEAL LOUGHMAN FLA (LAT PA 1615 LONG. O91 35 28)

Aur., $197 \pi$
$31 \ldots$

n2260500 - HFtuY CHEK NFAF LOUGHMAN FLA LLAT 29 1541 LONG AM1 32121

NOV. $14+9$
$24 . .1$

02276415 - LANE OKEECHOBEE AT POINT IS FLA ILAT 26553 IONG OCO 4755 I

ANR... 1970

$21 \ldots$

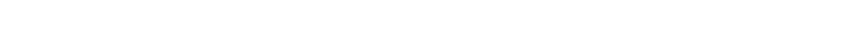

$M \triangle R . . P Y$
$18 .$.

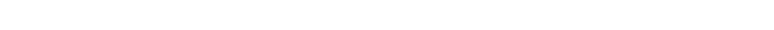

MAR., 1970

$17 . .$.

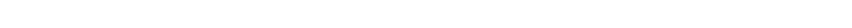

MAR.. 197

$17 .$.

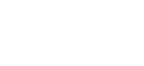

П22785A1 - CON AYHA NO 1 HL S-5 COMP NO LOX ULAT 2641 OOR LONG OMO $? 2$ 1O

$29 . .$.

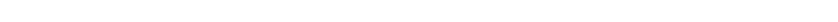

MAR.. 1970

$17 \ldots$

MAR.. 1970

$16 \ldots$

nezRlzth - EVERGHAUES STA L-1S NK DELLAY REACH FL LLOT 262345 LONG DEU 1740 I

NOV.. 19H4

$50 \ldots$

APR.: 1970

122785011

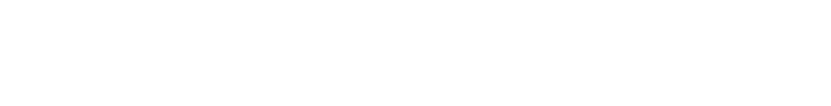

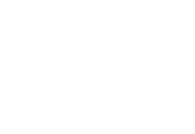

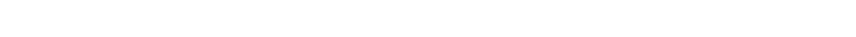

$S F P 1970$
20.1

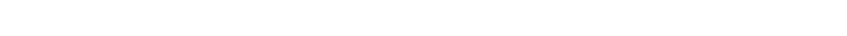

OCPM1419 - TWUALILINI, LANAL I NFAR GRINACPES CITY ILAT IA 37 II LONG O8B 12 16)

MAR., 1970

$19 . .$.

OPPUIAZS - EWUALIZ1NG CM 1 INR DFLAAY HCH FLA (LAT DS 2712 LONG OBO 1215 )

MAR. 197 R

$16 . .$. 


\begin{tabular}{|c|c|c|c|c|c|c|c|c|c|c|c|c|}
\hline & $\begin{array}{l}\text { IMAAL- } \\
\text { DIATE }\end{array}$ & $\begin{array}{c}\text { JFI I } F=0 \\
\text { COLL }=\end{array}$ & & $\begin{array}{l}\text { nec TraY- } \\
\text { LFISFF }\end{array}$ & $\begin{array}{c}\text { UIS- } \\
\text { SULVEU }\end{array}$ & & & & & & & \\
\hline & Cill I- & FUn:1 & & FLIJS & OW ANIC & & & TOT AI & nIs- & & $015-$ & JIS- \\
\hline & Fontol & $(c) L-$ & OIL & acTIVr & . & & & $A L(J) M=$ & $5 X V F_{2}$ & TOTAL & SOLVEN & SOL VEO \\
\hline & $\underset{\mathrm{PF}^{\mathrm{ICOL}}}{\mathrm{ICO}}$ & $0+11 c^{-6}$ & Givil & Sur- & $(x) 1$ & NHENDLS & $10010 \mathrm{OE}$ & INUM & CUAALT & IFti & LITHIUMA & $\begin{array}{c}\text { MERCURY } \\
\text { (HG) }\end{array}$ \\
\hline
\end{tabular}

\section{LAKE OKEECHOBEe AND THE EVERGLADES BASIN--CONTINUED}

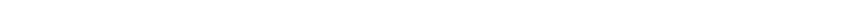

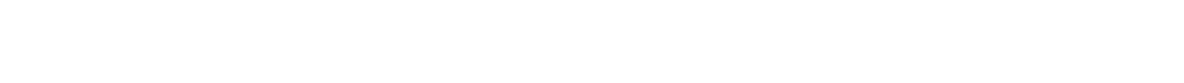

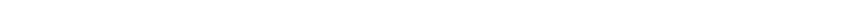

MAK.. 1471

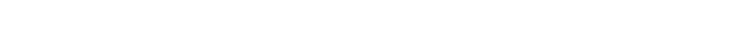

MAR.. 1970

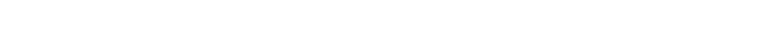

MAP.. ILI

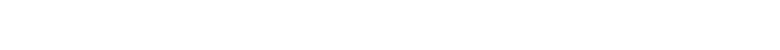

$\operatorname{MAP}: 147$

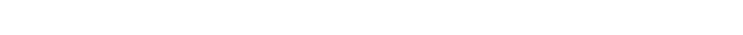

Mar.. 147 (16...

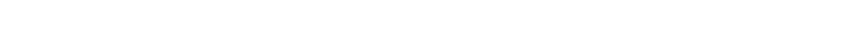

$S E P$ SOP $1+11$

$29 .$.

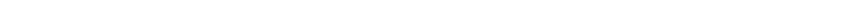

FFH... $1+7$

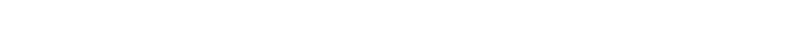

FFH.. 177 ,

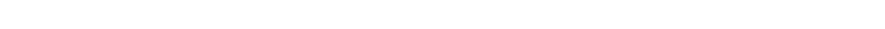

FEn. 1470

$10 . .$.
SFP.
3n....

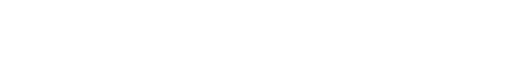

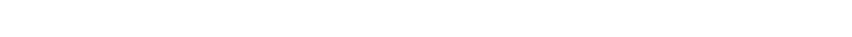

$F+\ldots 1=7$

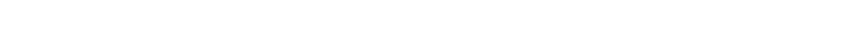

FrR.. 147

$13 .$.

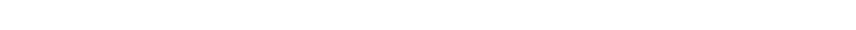

FEH... $14 \overline{\mathrm{T}}$

$16 \ldots$

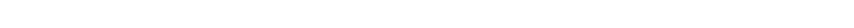

FFix.. $147 \%$

$17 \ldots$

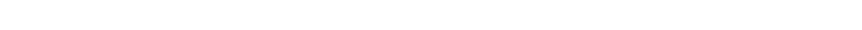

Gor., $19-4$

FFin, 14,1

$14 \ldots$.

$--$

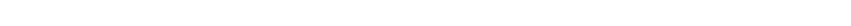




\begin{tabular}{|c|c|c|c|c|c|c|c|c|c|c|c|c|}
\hline & $\begin{array}{l}\text { IMME- } \\
\text { DI } \triangle \mathrm{TE}\end{array}$ & $\begin{array}{l}\text { UELAYFU } \\
\text { COLI- }\end{array}$ & & $\begin{array}{l}\text { NETHY- } \\
\text { LEISE }\end{array}$ & $\begin{array}{c}\text { LIS- } \\
\text { SOLVEO }\end{array}$ & & & & & & & \\
\hline & COL $1-$ & $\begin{array}{l}\text { FORM } \\
\text { (COL- }\end{array}$ & & HLUE & DREGANIC & & & TOTAL & DIS- & & DIS- & $\begin{array}{l}\text { OIS- } \\
\text { SOLVED }\end{array}$ \\
\hline & $\begin{array}{l}\text { FOKA } \\
\text { icul. }\end{array}$ & $\begin{array}{l}\text { CCOL- } \\
\text { ONILS }\end{array}$ & OIL & ACT IVE & $\begin{array}{l}\text { NI TRU- } \\
\text { GEN }\end{array}$ & & & ALUM- & SOLVED & TOTAL & SOLVED & $\begin{array}{l}\text { SOLVED } \\
\text { MERCURY }\end{array}$ \\
\hline & PER & PEQ & GREASE & STANCE & (N) & PHENOL S & (I) & (AL) & (CO) & (FE) & (LI) & $\begin{array}{c}\text { (HG) } \\
(U G / L)\end{array}$ \\
\hline & $100 \mathrm{MLI}$ & $100 \mathrm{ML})$ & $(M G / L)$ & $(M G / L)$ & $(M G / L)$ & $(U G / L)$ & $(M G / L)$ & $\left(U f_{2} / L\right)$ & $(1) G / L)$ & $(1 J G / L)$ & (UG/L) & (UG/L) \\
\hline
\end{tabular}

\section{LAKE OKEECHOBEE AND THE EVERGLADES BASINS-CONTINUED}

02284700 - N FH. D CA AT 534 NH FT LAUDEFUALF FLA (LAT 260843 LONG 08026 25)

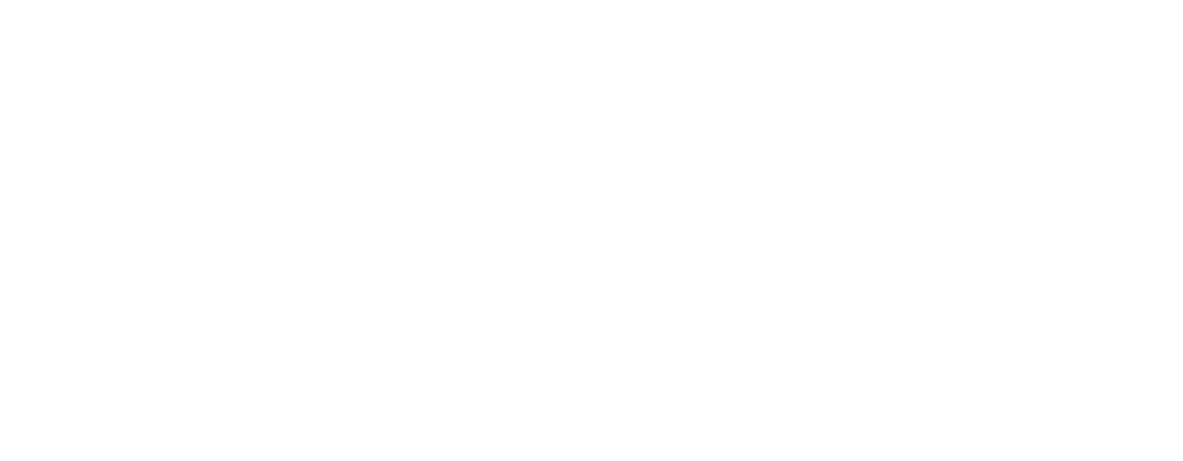

DZZMAOFO - SUITH N K CA AT S-13A NK DAVIE ILAT $2 A$ O3 50 LONG OBO 17 Z0I

SEP., 197 H

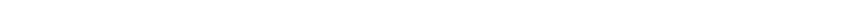

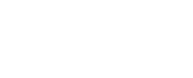

$\begin{array}{rrrrrr}- & \ldots & . n \pi & \ldots & - & .000 \\ - & \ldots & \ldots & \ldots & - & \ldots\end{array}$

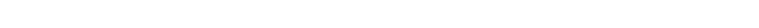

SEP.. 1970

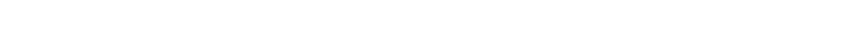

SFD. 1970

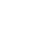

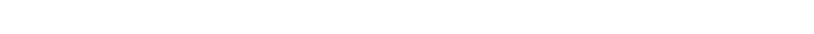

OCT.. 1969

JAN...

JR....

JILYY

$-$

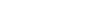

-

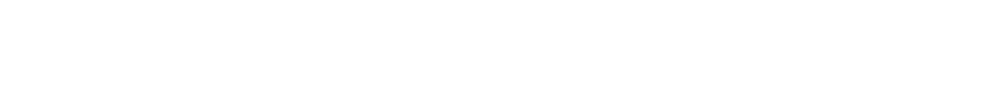

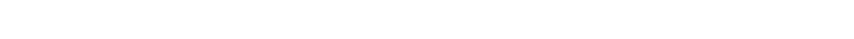

\footnotetext{
OCT. 19K9

$\begin{array}{ll}07 . . . & 19000 \\ \text { UEC. } & \end{array}$

03... 5500

APR.. 1976 10000

$02 \ldots$ > 30000

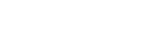

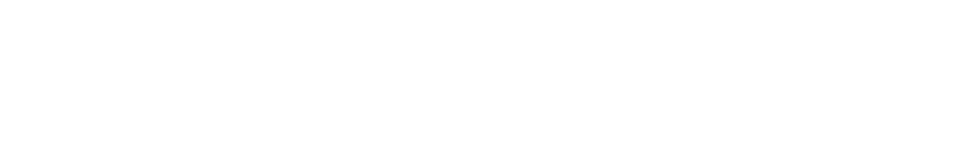

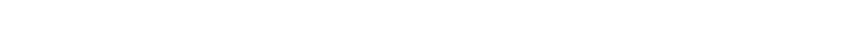

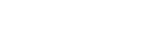

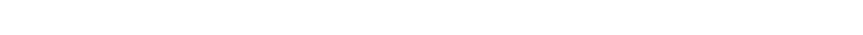

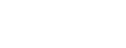

OZZ̈9018 - TAMIAMI CA AM S-12N R MIAMI FLA (LAT 254542 LO:4G OAR 4605 ) 


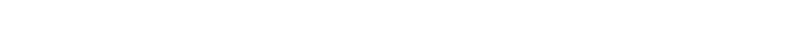

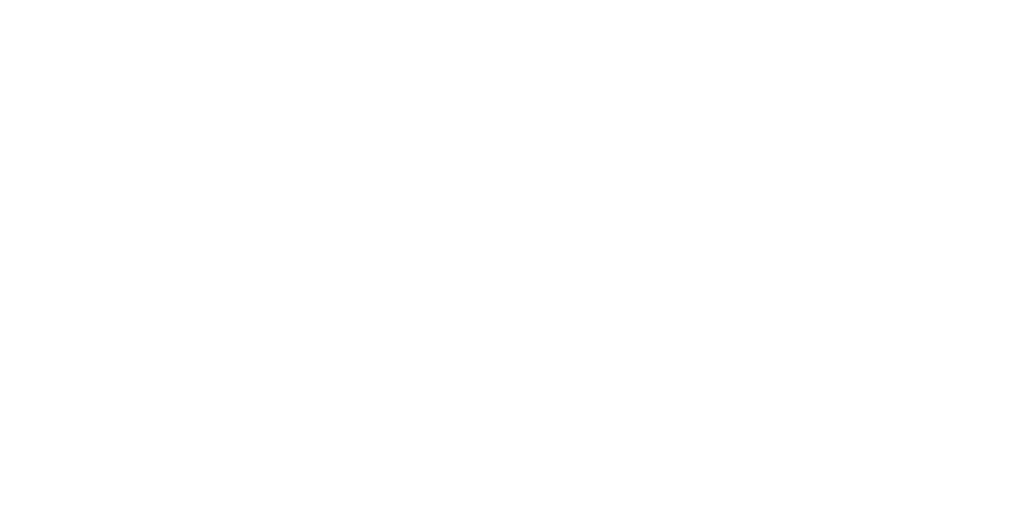




\begin{tabular}{|c|c|c|c|c|c|c|c|c|c|c|c|c|}
\hline & $\begin{array}{l}\text { IMMF - } \\
\text { DIATE }\end{array}$ & $\begin{array}{c}\text { CUE I AYFO } \\
\text { COLL- }\end{array}$ & & $\begin{array}{l}\text { NETHY } \\
\text { LF_NT }\end{array}$ & $\begin{array}{l}\text { UIS- } \\
\text { SULVeO }\end{array}$ & & & & & & & \\
\hline & COL $]-$ & triten & & RLUE & OBGANIC & & & TOTAL & nIs- & & DIS- & \\
\hline & Forna & $1 \mathrm{COL}-$ & UIL & active & NITH()- & & & $\triangle L U M-$ & SOLYEIS & TOTAL & SOLVEN & $\begin{array}{l}\text { SOLVED } \\
\text { MERCURY }\end{array}$ \\
\hline & $\begin{array}{l}\text { ICUL- } \\
\text { PFD }\end{array}$ & De $10=$ & GNES & $\begin{array}{l}\text { SIMT- } \\
\text { STANCE }\end{array}$ & $\begin{array}{l}\text { GEIN } \\
\text { (N) }\end{array}$ & PHEMULS & $\begin{array}{l}\text { TODIDF } \\
\text { (1) }\end{array}$ & INUM & $\begin{array}{c}C O H A L T \\
\text { (CII) }\end{array}$ & $\begin{array}{l}\text { IRPD. } \\
\text { (FE) }\end{array}$ & $\begin{array}{l}\text { CITHIUM } \\
\text { (LI) }\end{array}$ & $\begin{array}{l}\text { MERCURY } \\
\text { (HG) }\end{array}$ \\
\hline
\end{tabular}

\section{MYAKKA RIVER BASIN}

ILC279410 - OIF SLGHGH CA NL MYAKKA CITY FLA ILAT 27 II 34 LONG NAZ OA 40 I

$$
\begin{aligned}
& \text { JUNE, IYTo } \\
& \text { IN... }
\end{aligned}
$$

HILLSBOROUGH RIVER BASIN

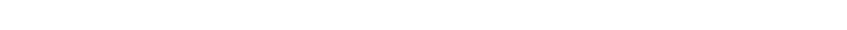

$550.147 i$

\section{WI THLACOOCHEE RIVER BASIN}

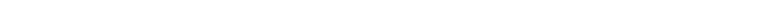

MAY 1976120

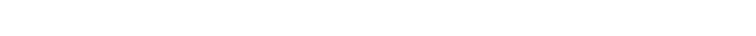

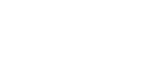

$\begin{array}{ll}-- & - \\ -- & -\end{array}$

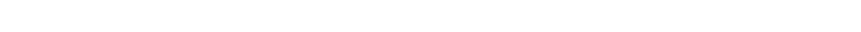

\begin{tabular}{|c|c|}
\hline $\begin{array}{l}\text { JAN. } \\
21 \ldots . \\
\operatorname{MAY}\end{array}$ & की \\
\hline & $100(10$ \\
\hline 1 1... & $10 n$ \\
\hline
\end{tabular}

$\begin{array}{llll}-- & - & -- & - \\ - & -- & -- & - \\ -- & -- & -- & --\end{array}$

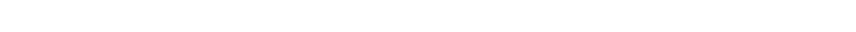

MAY 1977

SO... hron

SEP.

1....

$+-$

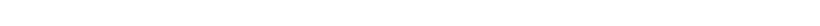

Nov.. 1964

$18 . . .640$

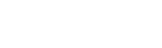

20... 330

18.0

$$
\begin{array}{ll}
-- & - \\
-- & - \\
-- & -
\end{array}
$$

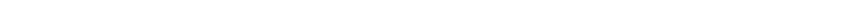

$\operatorname{MAY} .1970$
$21 . .$.
SEP... 36r
$19 . .$.

MAY. 1470
$20 . .$.
SEP.
1 1...

COASTAL BASINS BETWEEN WITHLACOOCHEE RIVER AND SUWANNEE RIVER

APR., 1971

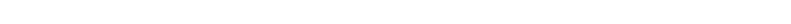

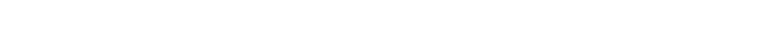

MAY 1970

R23150YO - HMARING CREEK NETH HELMONT FLA ILAT 3N 2550 LONG O82 40 OOI 


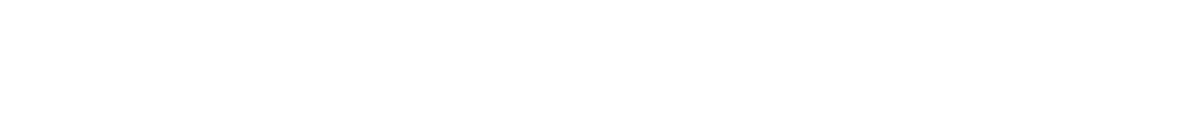

COASTAL BASINS BETHEEN WITHLACOOCHEE RIVER AND SUWANNEE RIVER--CONTINUED

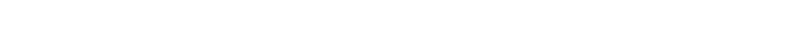

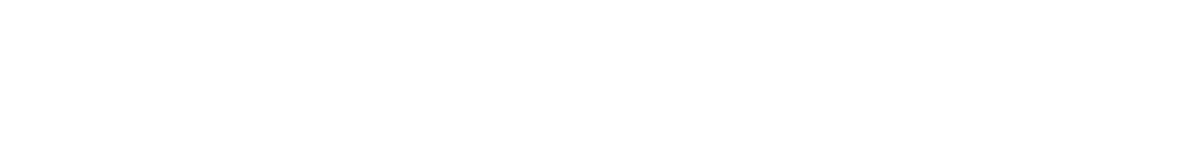

02315518 - OCCIDENTAL MINE DR D AT S HSY 137 (LAT 301856 LONG 0825042 )

MAY 14713 $04 \ldots$

SUHANNEE RIVER BASIN

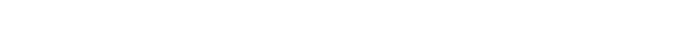

IICT, 1 , 1Yt.

$14 \ldots$

UF 11 ... $1+$ a

HAY $\because\left\{T_{11}\right.$

a1 $14 . \cdots$

$17 .$.

OrT., 192

1 .....

afr.

$10 .$.
DOR

तम... Juा

atiling

$12 .$.

UCT 146

$15 . .$.

DE. $11 . .$. x+

FFH... 147 nat

$A+B$.

กQ...

MAY 1+Ut

urr.. 1450

$13 . .$.

UEC.

Fin... ${ }_{14711} \ln ^{n}$

Ft $19.014711>71.1$

n?..

$\mathrm{MAY}$
$>\mathrm{P} . .$.

$11 .$.

may 1 147
$\geqslant 7 . . .9^{-}$

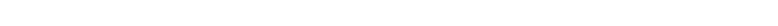

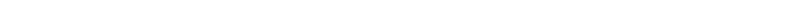

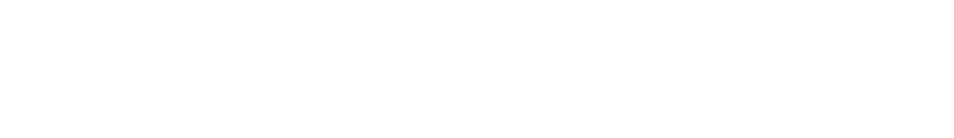

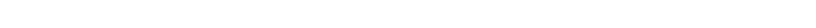

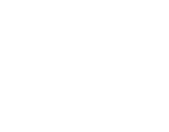

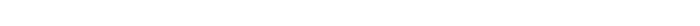

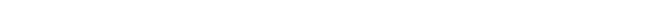

NaY. 147.

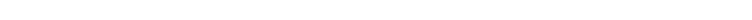



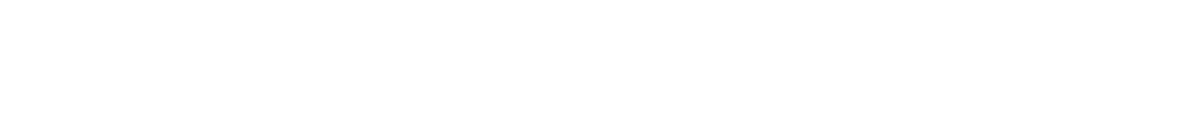

\section{SUWANNEE RIVER BASIN--CONTINUED}

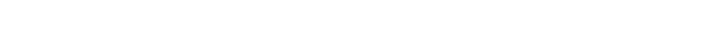

\begin{tabular}{|c|c|c|c|c|c|c|c|c|c|c|c|}
\hline $\begin{array}{l}10 \ldots \\
A P R . .1970\end{array}$ & 1400 & -- & -- & -- & -- & -- & $-\infty$ & -- & -- & -- & -- \\
\hline $\begin{array}{l}n 7 \ldots \\
\text { MAY }\end{array}$ & anti & -- & - & $\cdots$ & -- & -- & - & $\rightarrow$ & -- & -- & -- \\
\hline$p>\ldots$ & $34: 1$ & -- & -- & -- & $-\infty$ & -- & -- & -- & - & -- & - \\
\hline
\end{tabular}

MAY,$~$
$22 \times 7 \%$

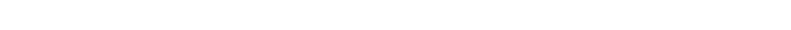

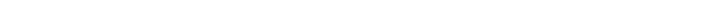

\begin{tabular}{|c|c|c|c|c|c|c|c|c|c|c|c|c|}
\hline $\begin{array}{l}17 \ldots \\
\text { DEC. }\end{array}$ & -- & $(1-\mathrm{mi}$ & -- & $\cdots$ & - & - & - & $\cdots$ & -- & -- & - & -- \\
\hline$F=2 \ldots 1971$ & donfi & -- & -- & -- & -- & $\cdots$ & + & - & -- & -- & -- & -- \\
\hline${ }_{A D N}^{11 . . .}$ & $34 i$ & - & -- & -- & -- & -- & $\cdots$ & -- & -- & -- & -- & -- \\
\hline$\underset{n}{n 9 . . .}$ & $4 m a n$ & -- & - & -- & -- & - & -- & $\cdots$ & -- & -- & -- & -- \\
\hline aur... & $34 n$ & -- & $=-$ & - & $\cdots$ & -- & -- & 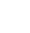 & -- & -- & -- & $\cdots$ \\
\hline $17 \ldots$ & $114 \pi$ & -- & $\cdots$ & $\cdots$ & - & -- & -- & -- & - & -- & -- & \\
\hline
\end{tabular}

\section{COASTAL BASINS BETWEEN SUWANNEE RIVER AND AUCILLA RIVER}

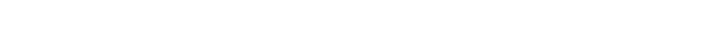

$A C R . .1970$
$30 . .$.

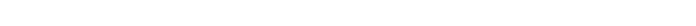

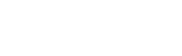

COASTAL BASINS BETWEEN AUCILLA RIVER AND OCHLOCKONEE RIVER

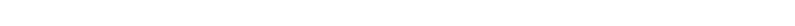

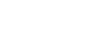

\section{OCKLOCKONEE RIVER BASIN}

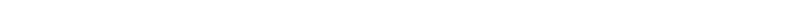

$\sim A Y, 147 r$

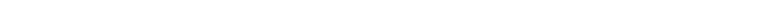

$\begin{array}{ll}M \Delta y & 1+70 \\ 2 ?+\cdots & \end{array}$

COASTAL BASINS BETWEEN APALACHICOLA RIVER AND CHOCTAWHATCHEE RIVER

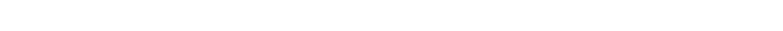

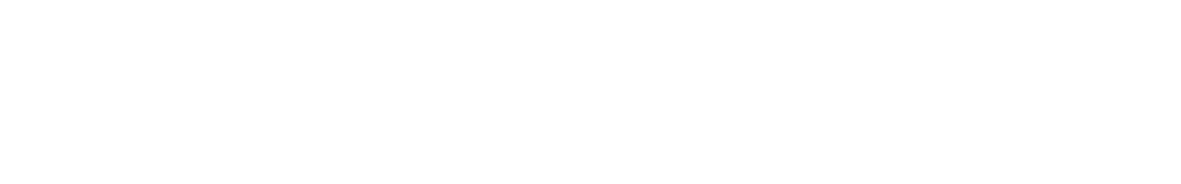


CHEMICAL ANALYSES, WATER YEAR OCTOBER 1969 TO SEPTEMBER 1970

\begin{tabular}{|c|c|c|c|c|c|c|c|c|c|c|c|c|}
\hline & $\begin{array}{l}\text { IMME- } \\
\text { UIATE }\end{array}$ & $\begin{array}{c}\text { It L LYYEC } \\
\text { CoLI- }\end{array}$ & & $\begin{array}{l}\text { At TAY - } \\
\text { LEt at }\end{array}$ & $\begin{array}{c}\text { U⿺辶- } \\
\text { SI,LVEU }\end{array}$ & & & & & & & \\
\hline & COL 1- & Fun. & & HLUR & URTA $\backslash I C$ & & & TOTAL_ & He- & & DIS- & D15- \\
\hline & FONM & $100 \mathrm{~L}-$ & OIL & ACTIVr. & atran- & & & $\Delta L U M-$ & SULVF. & TOTAL & SOLVEO & SOL VEO \\
\hline & ICOL. & OMIES & 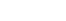 & sols- & SEN & PrEENOL & I Jut tort & I vilu & Cur $\Delta L T$ & [won & LITHIUM & MERCURY \\
\hline & PEK & PEK & GREASF & ST $\triangle N C E$ & (w) & & (I) & $(A t)$ & $(C))$ & (FE) & (LT) & $\left(H_{U}\right)$ \\
\hline
\end{tabular}
CHOCTANHATCHEE RIVER BASIN

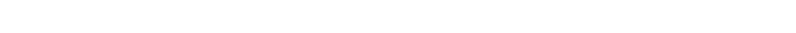

\begin{tabular}{|c|c|c|c|c|c|c|c|c|c|c|c|}
\hline FEH... & $170 \mathrm{M}$ & - & 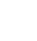 & -- & $=$ & -- & -- & -- & - & $\cdots$ & - \\
\hline$\underset{M \Delta Y}{0 Z \ldots}$ & shon & -- & -- & -- & -- & -- & -- & -- & - & - & - \\
\hline$\underset{\text { JINEE }}{27 . \cdots}$ & -- & -- & - & -- & -- & -- & - & $1 \ldots \ldots$ & -- & $-\infty$ & - \\
\hline
\end{tabular}

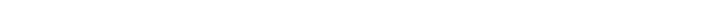

MAY, $141^{\text {th }}$

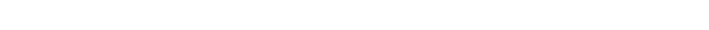

MAR., 1970

$04 . . .00310$

MAY 20.1020100

$--$

$--$

$-$

COASTAL BASINS BETWEEN ESCAMBIA RIVER AND MOBILE RIVER

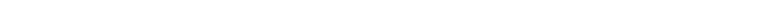

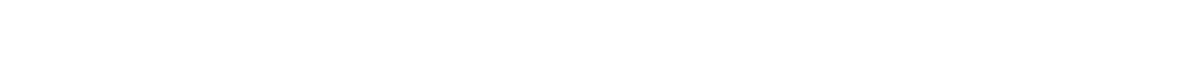

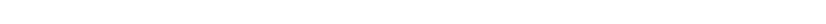

MAY, 1977

$19 . .$. 


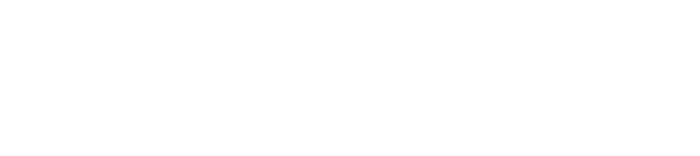

\section{LAKE OKEECHOBEE AND THE EVERGLADES BASINS}

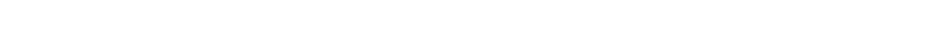

$114 . \ldots 1970$

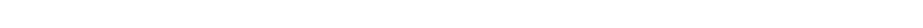

st... 1970

z3...

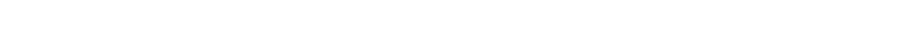

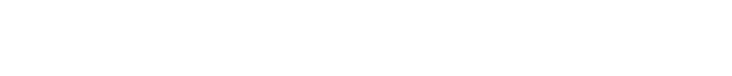

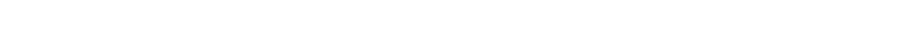
, 00.1909

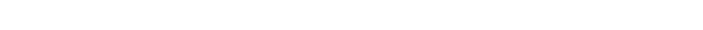

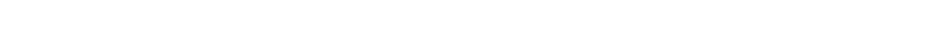

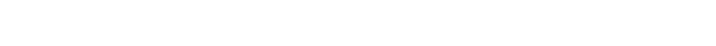

2551140080555000 - TAMIAMI CA AT JETPORT ENTPANCF NH MIAM (LAT 25 hO 40 LONG OOO 55501

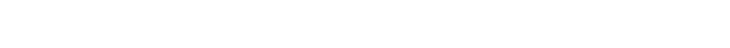

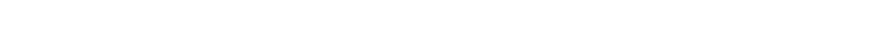

\begin{tabular}{|c|c|c|c|c|c|c|c|}
\hline $\begin{array}{ll}10 v \ldots 1964 \\
19 . \ldots 1\end{array}$ & $\cdots$ & -- & - & -- & 0 & $3 n$ & 0 \\
\hline $17 \ldots$ & -- & -- & $\cdots$ & - & 50 & -- & - \\
\hline $\begin{array}{l}466 . . \\
13 . .\end{array}$ & ." & - & -- & -- & MI & - & $m$ \\
\hline $1 \cap \ldots$ & - & -- & $\cdots$ & -- & lan & -- & -- \\
\hline
\end{tabular}

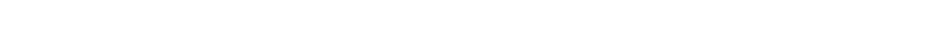

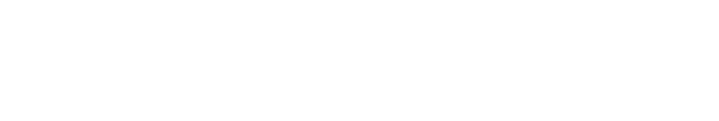

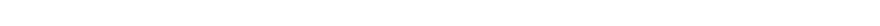

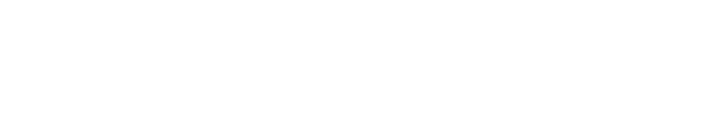

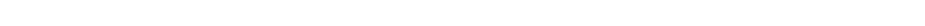

MINE, IY70

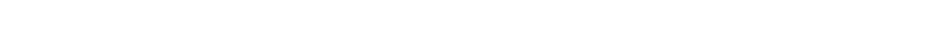

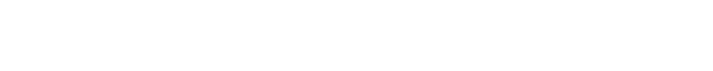

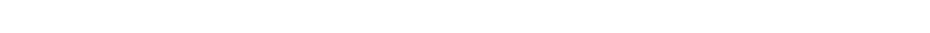

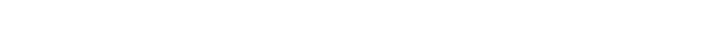

$$
\begin{aligned}
& \begin{array}{cccccccc}
30 \ldots . . . & -- & -- & - & -- & 30 n & - & 0 \\
21 . \ldots & -- & -- & -- & -- & 3 n & -- & -
\end{array}
\end{aligned}
$$


CHEMICAL ANALYSES, WATER YEAR OCTOBER 1969 TO SEPTEMBER 1970

\begin{tabular}{|c|c|c|c|c|c|c|}
\hline & $\begin{array}{l}\text { ETrY } \\
\text { LH, } \\
\text { H I U }\end{array}$ & $\begin{array}{l}\text { DIL- } \\
\text { SOLVEU }\end{array}$ & & T T A & & הותו \\
\hline IIL & MCIIVE & AI TRr- & & ALUIN- & TITTAL & siturit \\
\hline and & $3 \operatorname{lis}$ & GEN & $I(m I n)+$ & $I^{N(I M M}$ & Iron & LITHIUN \\
\hline $\begin{array}{l}\text { of }+\Delta S_{0} \\
\left(A_{6} / 1\right)\end{array}$ & $\begin{array}{l}4 T A^{*} C t \\
(A(2,1))\end{array}$ & $\begin{array}{l}\text { (P.) } \\
(M, / L)\end{array}$ & $\begin{array}{l}(I) \\
([+\sqrt{3}) /())\end{array}$ & $\begin{array}{l}(A L) \\
(1+1,11)\end{array}$ & $\begin{array}{c}\text { (FE) } \\
(I G M)\end{array}$ & (LT) \\
\hline
\end{tabular}

\section{LAKE OKEECHOBEE AND THE EVERGLADES BASIN--CONTINUED}

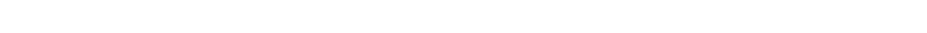

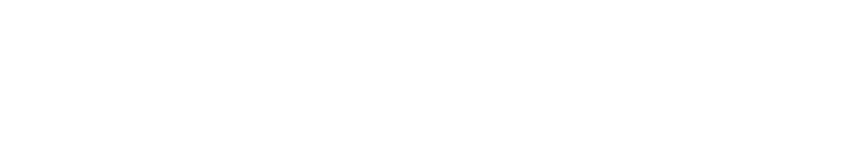

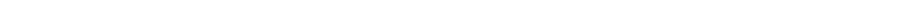

$4+0.1+7)$

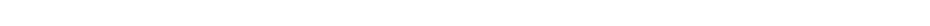

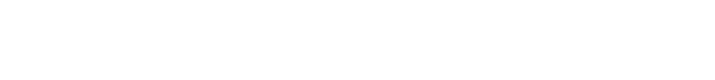

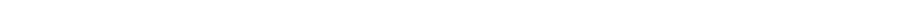

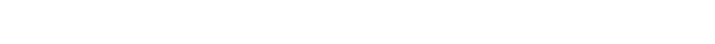

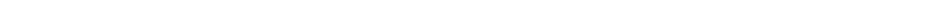

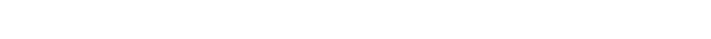

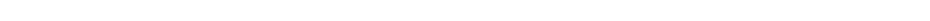

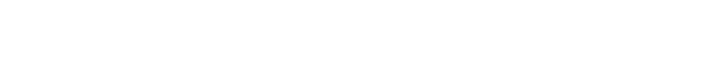

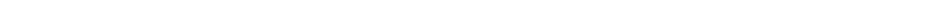

$$
16+\ldots 147011
$$

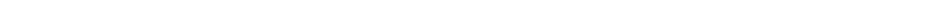
$17 \ldots 1970$

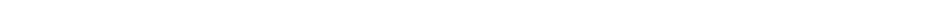

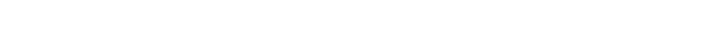

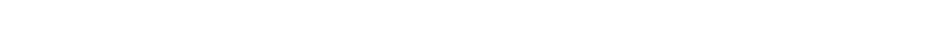

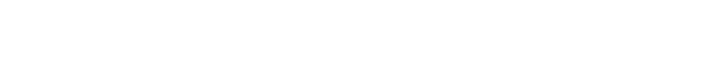

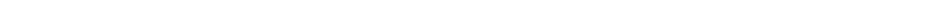

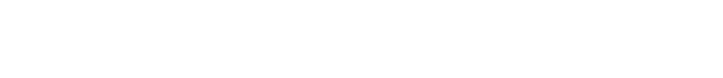

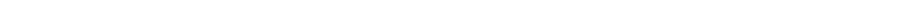

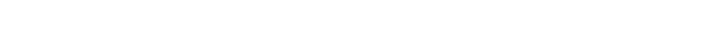

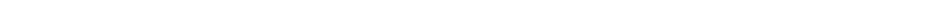

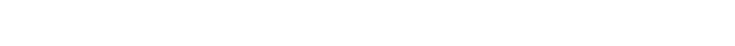

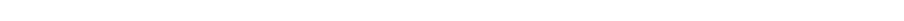

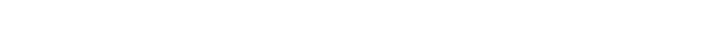




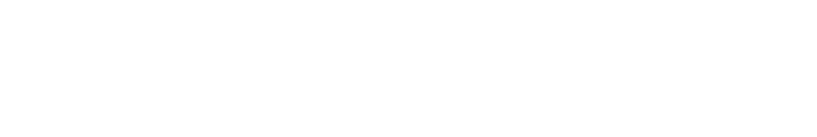

LAKE OKEECHOBEE AND THE EVERGLADES BASINS--CONTINUED

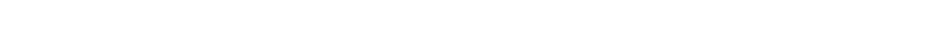

$$
\operatorname{Fr}+\ldots 1+\ldots+n
$$

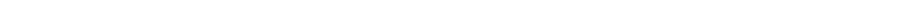
$\operatorname{lr}_{1 \rightarrow . . .} 1+70$

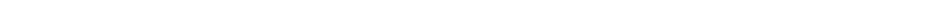

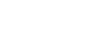

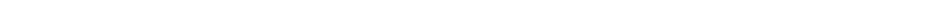

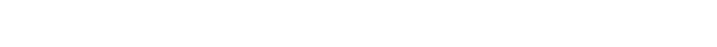

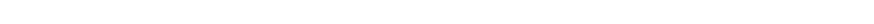

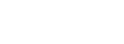

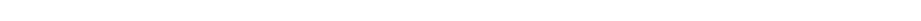

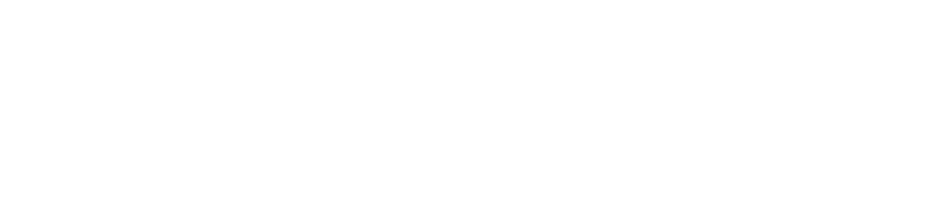

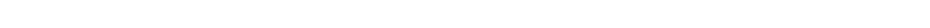

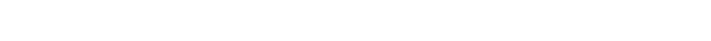

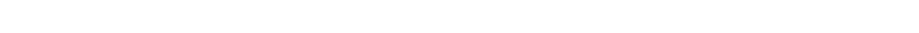

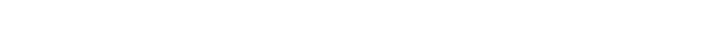

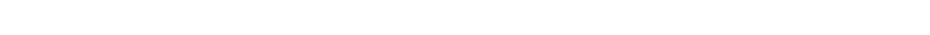

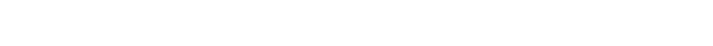

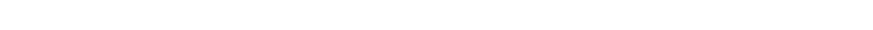
A $17 \ldots 1 \rightarrow 7 \|$

\section{MYAKKA RIVER BASIN}

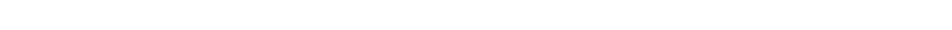

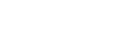

PEACE RIVER BASIN

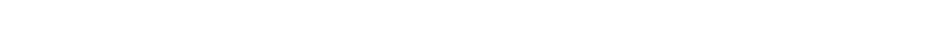

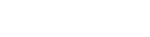

COASTAL BASIN BETWEEN MYAKKA RIVER AND ALAFIA RIVER

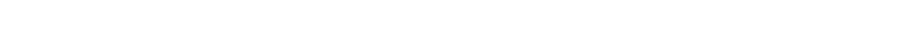

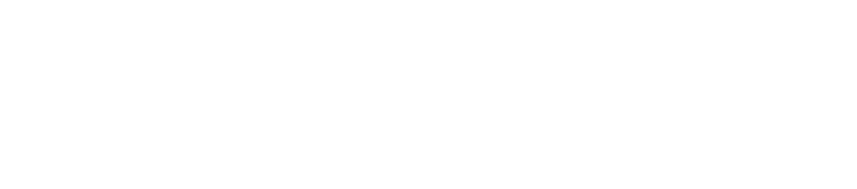

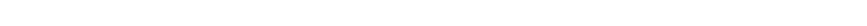
$31+1 ., 1+10$
$11 . .$. 
CHEMICAL ANALYSES, WATER YEAR OCTOBER 1969 TO SEPTEMBER 1970

\begin{tabular}{|c|c|c|c|c|c|c|c|c|c|c|c|}
\hline DATE & $\begin{array}{l}\text { DIS- } \\
\text { CHARGE } \\
\text { (CFS) }\end{array}$ & $\begin{array}{l}\text { SILICA } \\
\text { (SIOZ) } \\
\text { (MG/L) }\end{array}$ & $\begin{array}{l}\text { DIS- } \\
\text { SOLVED } \\
\text { IRON } \\
\text { (FE) } \\
\text { (UG/L) }\end{array}$ & $\begin{array}{l}\text { CAL- } \\
\text { CIUM } \\
\text { (CA) } \\
\text { (MG/L) }\end{array}$ & $\begin{array}{c}\text { MAG- } \\
\text { NE- } \\
\text { SIUM } \\
\text { (MG) } \\
\text { (MG/L) }\end{array}$ & $\begin{array}{l}\text { SODIUM } \\
\text { (NA) } \\
\text { (MG/L) }\end{array}$ & $\begin{array}{l}\text { PO- } \\
\text { TAS- } \\
\text { SIUM } \\
\text { (K) } \\
\text { (MG/L) }\end{array}$ & $\begin{array}{l}\text { BICAR- } \\
\text { BONATE } \\
\text { (HCO3) } \\
\text { (MG/L) }\end{array}$ & $\begin{array}{l}\text { SULFATE } \\
\text { (SO4) } \\
\text { (MG/L) }\end{array}$ & $\begin{array}{l}\text { CHLO- } \\
\text { RIDE } \\
\text { (CL) } \\
\text { (MG/L) }\end{array}$ & $\begin{array}{l}\text { FLUO- } \\
\text { RIDE } \\
\text { (F) } \\
\text { (MG/L) }\end{array}$ \\
\hline \multicolumn{12}{|c|}{ MOBILE RIVER BASIN } \\
\hline & & & NOXUBEE & IVE & BROOKS & ILLE ILAT & $\begin{array}{lll}33 & 13 & 30\end{array}$ & LONG 088 & 42101 & & \\
\hline
\end{tabular}

\begin{tabular}{|c|c|c|c|c|c|c|c|c|c|c|c|}
\hline \multirow[t]{2}{*}{$\begin{array}{ll}\text { DEC } & 05 \\
\text { MAY } & 06\end{array}$} & $\begin{array}{r}17 \\
3230\end{array}$ & $\begin{array}{l}8.5 \\
7.3\end{array}$ & -- & $\begin{array}{l}7.7 \\
4.4\end{array}$ & $\begin{array}{l}1.6 \\
1.2\end{array}$ & $\begin{array}{l}8.6 \\
3.5\end{array}$ & $\begin{array}{l}2.6 \\
1.6\end{array}$ & $\begin{array}{l}39 \\
14\end{array}$ & $\begin{array}{l}5.8 \\
8.6\end{array}$ & $\begin{array}{l}6.0 \\
2.2\end{array}$ & $\begin{array}{l}.2 \\
.1\end{array}$ \\
\hline & \multicolumn{2}{|c|}{02467200} & SUCARNOOCHEE & $=$ RIVER N & NEAR POT & ERVILLE ILA & AT $32 \quad 420$ & 00 LONG 08 & 829001 & & \\
\hline \multirow[t]{2}{*}{ MAY 05} & 80 & 12 & -- & 2.2 & 1.3 & 2.9 & 1.1 & 8 & 6.8 & 3.5 & .1 \\
\hline & $\begin{array}{l}\text { NITRATE } \\
\text { (NO3) } \\
\text { (MG/L) }\end{array}$ & $\begin{array}{l}\text { DIS- } \\
\text { SOLVED } \\
\text { SOLIDS } \\
\text { (RESI- } \\
\text { DUE AT } \\
\left.180^{\circ} \mathrm{C}\right) \\
\text { (MG/L) }\end{array}$ & $\begin{array}{l}\text { DIS- } \\
\text { SOLVED } \\
\text { SOLIDS } \\
\text { (SUM OF } \\
\text { CONSTI- } \\
\text { TUENTS) } \\
\text { (MGIL) }\end{array}$ & $\begin{array}{l}\text { DIS- } \\
\text { SOLVED } \\
\text { SOLIDS } \\
\text { (TONS } \\
\text { PER } \\
\text { AC-FT) }\end{array}$ & $\begin{array}{l}\text { DIS- } \\
\text { SOLVED } \\
\text { SOLIDS } \\
\text { (TONS } \\
\text { PER } \\
\text { DAY) }\end{array}$ & $\begin{array}{l}\text { HARD- } \\
\text { NESS } \\
\text { (CA,MG) } \\
\text { (MG } / L)\end{array}$ & $\begin{array}{c}\text { NON- } \\
\text { CAR- } \\
\text { BONATE } \\
\text { HARD- } \\
\text { NESS } \\
\text { (MG/L) }\end{array}$ & $\begin{array}{l}\text { SPE- } \\
\text { CIFIC } \\
\text { CON- } \\
\text { DUCT- } \\
\text { ANCE } \\
\text { (MICRO- } \\
\text { MHOS) }\end{array}$ & $\begin{array}{l}\text { PH } \\
\text { (UNITS) }\end{array}$ & $\begin{array}{l}\text { TEMPER- } \\
\text { ATURE } \\
\text { (DEG C) }\end{array}$ & $\begin{array}{l}\text { CQLOR } \\
\text { (PLAT- } \\
\text { INUM } \\
\text { COBALT } \\
\text { UNITS) }\end{array}$ \\
\hline DATE & & 2447500 & NOXUBEE RIV & IVER NEAR & AR BROOKS & VILLE ILAT & $\begin{array}{lll}33 & 13 & 30\end{array}$ & LONG $08 B$ & 42101 & & \\
\hline
\end{tabular}

\begin{tabular}{|c|c|c|c|c|c|c|c|c|c|c|c|}
\hline $\begin{array}{ll}\text { DEC } & 05 \\
\text { MAY } & 06\end{array}$ & $\begin{array}{l}.3 \\
.5\end{array}$ & $\begin{array}{l}71 \\
52\end{array}$ & $\begin{array}{l}60 \\
36\end{array}$ & $\begin{array}{l}.10 \\
.07\end{array}$ & $453^{3.26}$ & $\begin{array}{l}26 \\
16\end{array}$ & $\begin{array}{l}0 \\
5\end{array}$ & $\begin{array}{l}97 \\
54\end{array}$ & $\begin{array}{l}7.1 \\
6.3\end{array}$ & $19 . \overline{0}$ & $\begin{array}{l}15 \\
80\end{array}$ \\
\hline
\end{tabular}

MAY 05

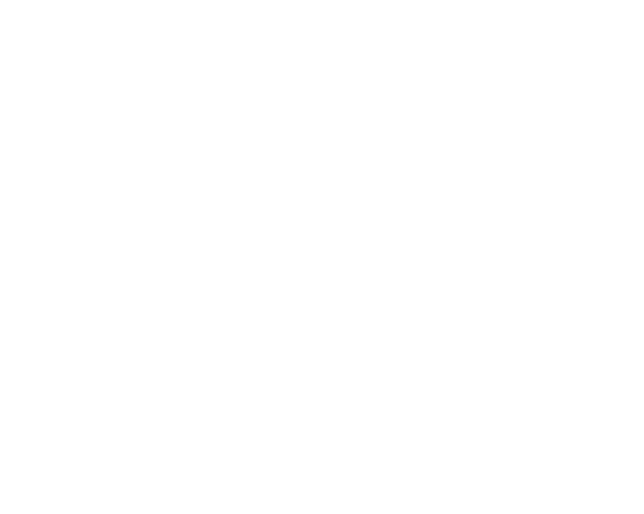

02472500 BOWIE CREEK NEAR HATTIESBURG \{LAT 312532 LONG 0892453 \}

\begin{tabular}{|c|c|c|c|c|c|c|}
\hline OCT & 28 & 137 & 18.0 & 25 & - & -- \\
\hline NOV & 20 & 205 & 11.0 & 32 & 8,4 & 7.3 \\
\hline $\mathrm{DEC}$ & 08 & 549 & 9.0 & 34 & - & - \\
\hline JAN & 08 & 490 & 4.0 & 30 & 12.5 & 6.0 \\
\hline & 26 & 196 & 13.0 & 33 & & \\
\hline FEB & 19 & 338 & 13.0 & 35 & 10.0 & 5.4 \\
\hline MAR & 10 & 323 & 12.0 & 55 & - & - \\
\hline & 31 & 326 & 17.0 & 36 & 9.1 & 6.0 \\
\hline$A P R$ & 24 & 182 & 22.0 & 45 & -1 & - \\
\hline MAY & 11 & 170 & 22.0 & 90 & 8.0 & 5.5 \\
\hline JUN & 04 & 306 & 22.0 & 50 & 7.8 & 6.9 \\
\hline AUG & 12 & 133 & 27.0 & 30 & 7.7 & 6.2 \\
\hline SEP & 23 & 112 & 26.0 & - & 7.6 & - \\
\hline
\end{tabular}

02472850 OKATOMA CREEK AT SANFORD (LAT $32 \quad 2920$ LONG 0892600 )

$\begin{array}{llrrrr}\text { NOV 20 } & -- & 10.0 & 38 & 8.9 & 7.2 \\ \text { JAN O8 } & -- & 4.0 & 44 & 12.7 & 5.8 \\ \text { FEB } 17 & -- & 10.2 & 50 & 10.0 & 5.3 \\ \text { MAR 31 } & -- & 17.0 & 50 & 9.5 & 6.4 \\ \text { MAY 11 } & -- & 24.0 & 115 & 7.5 & 6.5 \\ \text { JUN 22 } & -- & 29.0 & 60 & 6.4 & 6.4 \\ \text { AUG 12 } & -- & 26.0 & 40 & 6.0 & 5.7 \\ \text { SEP 23 } & -- & 26.0 & 45 & 6.8 & 6.3\end{array}$

02473000 LEAF RIVER AT HATTIESBURG (LAT 312033 LONG 0891646 )

$\begin{array}{lrrrrr}\text { OCT 28 } & \text { A496 } & 20.0 & 70 & -- & -- \\ \text { DEC OB } & \text { A2660 } & 9.0 & 39 & -- & =- \\ \text { JAN 26 } & \text { A1070 } & 12.0 & 155 & -- & - \\ \text { MAR 10 } & \text { A2440 } & 12.0 & 70 & -- & - \\ \text { APR 23 } & \text { A1790 } & 21.0 & 1050 & -- & - \\ \text { JUN 02 } & \text { A1200 } & 24.0 & 600 & -- & -\end{array}$

A DAILY MEAN DISCHARGE. 


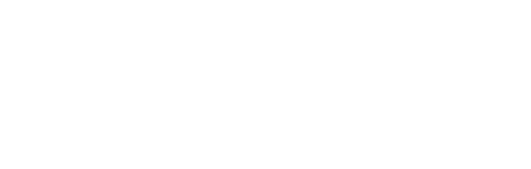

02473480 TALLAHATTA CREEK NEAR WALDRUP (LAT 315140 LONG 0890510 )

\begin{tabular}{|c|c|c|c|c|c|c|}
\hline OCT & 15 & .27 & 16.0 & 3000 & - & -- \\
\hline NOV & 12 & .45 & - & 3000 & -- & -- \\
\hline DEC & 04 & .36 & 11.0 & 2800 & -- & - \\
\hline & 04 & 36 & 7.0 & 3000 & 10.4 & 7.1 \\
\hline JAN & 06 & 40 & 4.0 & 420 & 11.3 & 7.0 \\
\hline & 29 & 12 & 11.0 & 1100 & -- & -- \\
\hline FEB & 17 & 57 & 10.0 & 520 & - & - \\
\hline & $1 \mathrm{~B}$ & 57 & 10.2 & 520 & 10.6 & 6.5 \\
\hline MAR & 09 & 30 & 13.0 & 620 & - & - \\
\hline & 31 & 21 & $1 \mathrm{~B} .0$ & 900 & -- & -- \\
\hline & 31 & 21 & 18.0 & 875 & 9.1 & 6.7 \\
\hline$A P R$ & 20 & 94 & 19.0 & 450 & -- & -- \\
\hline MAY & 11 & 4.2 & 23.0 & 1350 & -- & - \\
\hline & 21 & 4.2 & 23.0 & 2350 & 7.7 & 6.4 \\
\hline JUN & 01 & 8.6 & 22.0 & 1800 & - & - \\
\hline & 04 & 4.0 & 26.0 & 2200 & 8.2 & 6.2 \\
\hline & 22 & .13 & 31.0 & 3500 & -- & -- \\
\hline $\begin{array}{l}\text { AUG } \\
\text { SEP }\end{array}$ & $\begin{array}{l}10 \\
22\end{array}$ & $\begin{array}{l}4.0 \\
.60\end{array}$ & $\begin{array}{r}26.0 \\
-.\end{array}$ & $\begin{array}{r}875 \\
3400\end{array}$ & $\begin{array}{l}6.5 \\
6.7\end{array}$ & $\begin{array}{l}6.0 \\
6.9\end{array}$ \\
\hline
\end{tabular}

02473500 TALLAHALA CREEK AT LAUREL (LAT 314050 LONG 0890952 )

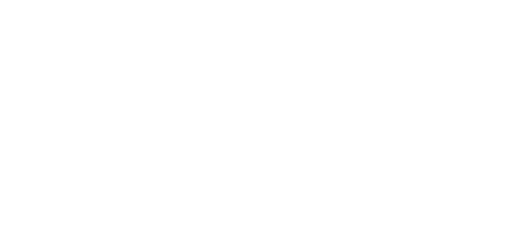

02474100 TALLAHOMA CREek NeAR LAUREL ILAT 314245 LONG 08909521

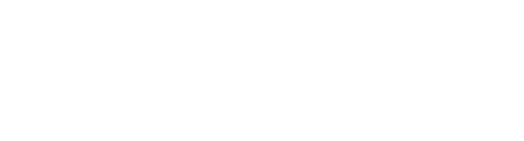

02474300 TALLAHALA CREEK NEAR ELLISVILLE (LAT 313530 LONG B9 1000 )

$\begin{array}{llrrrr}\text { DEC O4 } & -- & 8.0 & 360 & .6 & 7.2 \\ \text { JAN O6 } & -- & 4.0 & 170 & 7.0 & 7.1 \\ \text { FEB } 17 & -- & 11.0 & 150 & 5.0 & 5.2 \\ \text { MAR 31 } & -- & 18.0 & 150 & 2.0 & 5.9 \\ \text { MAY 11 } & -- & 25.0 & 180 & .0 & 5.6 \\ \text { JUN O4 } & -- & 25.0 & 170 & 1.5 & 6.1 \\ \text { AUG 10 } & -- & 28.0 & 190 & .0 & 6.1 \\ \text { SEP 22 } & -- & 28.0 & 360 & -- & -\end{array}$

02474670 BOGUE HOMO NEAR NEW AUGUSTA (LAT $31 \quad 1542$ LONG OB9 0010 )

$\begin{array}{llrrrr}\text { NOV 21 } & -- & 9.0 & 145 & 9.1 & 6.5 \\ \text { JAN 06 } & -- & 9.0 & 145 & 9.1 & 6.5 \\ \text { FEB 17 } & -- & 13.0 & 175 & 10.5 & 5.3 \\ \text { MAR 30 } & -- & 15.0 & 165 & 9.1 & 5.8 \\ \text { MAY 11 } & -- & 25.0 & 240 & 8.1 & 6.4 \\ \text { JUN 04 } & -- & 26.0 & 160 & 8.8 & 6.5 \\ \text { AUG 10 } & -- & 29.0 & 180 & 8.4 & 5.9 \\ \text { SEP 21 } & -- & 28.0 & 200 & 9.0 & 6.4\end{array}$

02474820 THOMPSON CREEK NEAR HINTONVILLE (LAT 311540 LONG OB8 54 OB)

$\begin{array}{llrrrr}\text { NOV } 21 & -- & 10.0 & 46 & 8.8 & 5.6 \\ \text { JAN } 06 & -- & 6.0 & 50 & 11.3 & 5.6 \\ \text { FEB } 17 & -- & 9.0 & 58 & 10.0 & 5.1 \\ \text { MAR } 30 & -- & 14.0 & 44 & 8.1 & 5.6 \\ \text { MAY 11 } & -- & 23.0 & 83 & 7.9 & 5.0 \\ \text { JUN 04 } & -- & 26.0 & 80 & 7.6 & 6.7 \\ \text { AUG 10 } & -- & 28.0 & 44 & 7.9 & 5.7 \\ \text { SEP 21 } & -- & 27.0 & 95 & 9.8 & 5.2\end{array}$

02475000 LEAF RIVER AT MCLAIN I. AT 31 O6 10 LONG 0BB 48301

\begin{tabular}{|c|c|c|c|c|c|c|}
\hline OCT & 01 & 808 & 21.0 & 450 & -- & -- \\
\hline NOV & $\begin{array}{l}20 \\
29\end{array}$ & $\begin{array}{l}978 \\
947\end{array}$ & 13.0 & $\begin{array}{r}73 \\
75\end{array}$ & $\begin{array}{l}8.0 \\
---\end{array}$ & 6.9 \\
\hline DEC & 10 & 4040 & B.O & 78 & -- & -- \\
\hline JAN & $\begin{array}{l}06 \\
28\end{array}$ & $\begin{array}{l}2820 \\
1810\end{array}$ & $\begin{array}{r}\text { B. } \\
11.0\end{array}$ & $\begin{array}{l}125 \\
125\end{array}$ & 8.9 & 5.5 \\
\hline FEB & 17 & 4710 & 12.0 & 130 & 7.4 & 6.2 \\
\hline MAR & 11 & 5950 & 12.0 & 105 & - & -- \\
\hline & 31 & 5480 & 25.0 & 80 & 6.4 & 5.7 \\
\hline APR & 21 & 5080 & 20.0 & 250 & - & \\
\hline MAY & 11 & 2210 & 25.0 & 550 & 3.8 & 5.7 \\
\hline JUN & 02 & 1530 & 24.0 & 500 & - & - \\
\hline & 04 & 1990 & 26.0 & 560 & 8.0 & 6.7 \\
\hline & $\angle 2$ & -- & 32.0 & 850 & 9.5 & 6.2 \\
\hline AUG & 10 & 2150 & 29.0 & 220 & B. 5 & 7.1 \\
\hline SEP & 22 & 840 & 30.0 & 300 & 10.2 & 7.9 \\
\hline
\end{tabular}


CHEMICAL ANALYSES, WATER YEAR OCTOBER 1968 TO SEPTEMBER 1970

\begin{tabular}{|c|c|c|c|c|c|c|c|c|c|c|c|}
\hline TE & $\begin{array}{l}\text { DIS- } \\
\text { CHARGE } \\
\text { (CFS) }\end{array}$ & $\begin{array}{l}\text { SILICA } \\
\text { (SIOZ) } \\
(M G / L)\end{array}$ & $\begin{array}{l}\text { DIS- } \\
\text { SOLVED } \\
\text { IRDN } \\
\text { (FE) } \\
\text { (UG/L) }\end{array}$ & $\begin{array}{l}\text { CAL- } \\
\text { CIUM } \\
(C A) \\
(M G / L)\end{array}$ & $\begin{array}{l}\text { MAG- } \\
\text { NE- } \\
\text { SIUM } \\
\text { (MG) } \\
\text { (MG/L) }\end{array}$ & $\begin{array}{l}\text { SODI UM } \\
\text { (NA) } \\
(M G / L)\end{array}$ & $\begin{array}{l}\text { PO- } \\
\text { TAS- } \\
\text { SIUM } \\
\text { (K) } \\
\text { (MG/L) }\end{array}$ & $\begin{array}{l}\text { BICAR- } \\
\text { BDNATE } \\
\text { (HCO3) } \\
\text { (MG/L) }\end{array}$ & $\begin{array}{l}\text { SUCFATE } \\
(S O 4) \\
(M G / L)\end{array}$ & $\begin{array}{l}\text { CHLO- } \\
\text { RIDE } \\
(\mathrm{CL}) \\
(\mathrm{MG} / \mathrm{L})\end{array}$ & $\begin{array}{l}\text { FLUD- } \\
\text { RIDE } \\
\text { (F) } \\
\text { (MG/L) }\end{array}$ \\
\hline
\end{tabular}

PASCAGOULA RIVER BASIN--CONTINUED

02475082 LEAF RIVER AT MERRILL (LAT 3059 O0 LONG 0884400 )

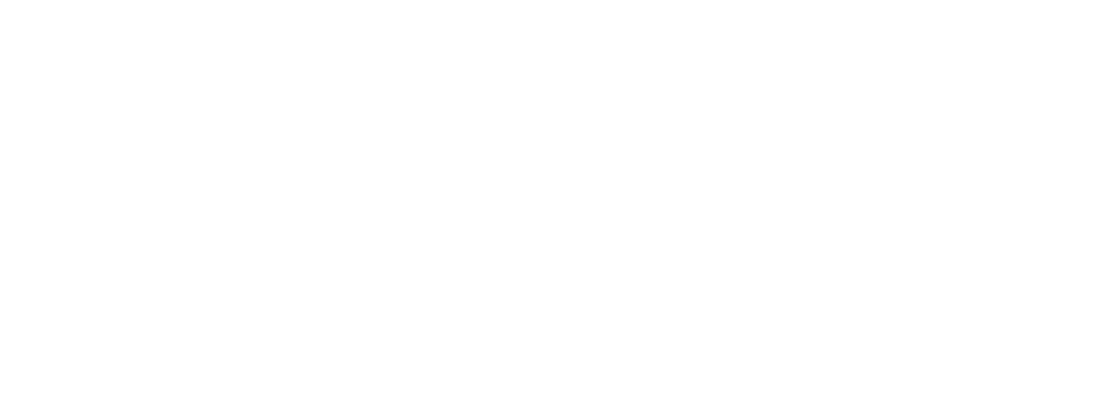

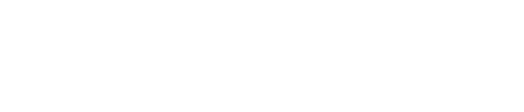

A DAILY MEAN DISCHARGE.

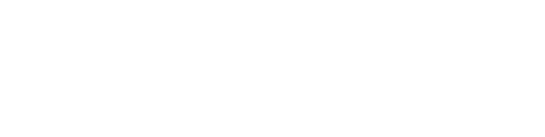

02475700 CHUNKY RIVER NEAR ENTERPRISE (LAT 321149 LONG 0884900 )

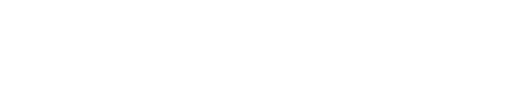

02476000 OKATIBBEE CREEK NEAR MERIDIAN (LAT $32 \quad 2115$ LONG 0884525 )

\begin{tabular}{|c|c|c|c|c|c|c|}
\hline DEC & & 66 & 9.0 & 82 & 11.2 & 7.6 \\
\hline JA & & 137 & 4.0 & $\overline{-}$ & -- & - \\
\hline & $\begin{array}{l}21 \\
04\end{array}$ & $\begin{array}{l}137 \\
806\end{array}$ & $\begin{array}{r}2.0 \\
13.5\end{array}$ & $\begin{array}{l}70 \\
48\end{array}$ & $\begin{array}{r}12.0 \\
8.6\end{array}$ & $\begin{array}{l}6.3 \\
6.7\end{array}$ \\
\hline$A P R$ & $\begin{array}{l}44 \\
17\end{array}$ & 95 & 17.0 & 60 & 8.1 & 6.2 \\
\hline MAY & 26 & 19 & -4.0 & 65 & 6.0 & 6.7 \\
\hline UG & 05 & 69 & 30,0 & 95 & 5.5 & 9.9 \\
\hline
\end{tabular}

02476500 SOWASHEE CREEK AT MERIDIAN (LAT $32 \quad 2210$ LONG 0884040 )

\begin{tabular}{|c|c|c|c|c|c|c|}
\hline NOV & 13 & 3.0 & 13.0 & 110 & -- & -- \\
\hline $\mathrm{DEC}$ & 02 & 1.7 & 9.0 & 95 & 10.4 & 7.1 \\
\hline JAN & 07 & 83 & 3.0 & - & - & -- \\
\hline & 21 & 13 & 2.2 & 90 & 12.5 & 6.4 \\
\hline FEB & 10 & 22 & 10.0 & 75 & -- & \\
\hline MAR & 04 & 597 & 13.4 & 50 & 8.2 & 6.4 \\
\hline & 24 & 94 & 13.0 & 55 & -- & \\
\hline APR & 14 & 54 & 18.0 & 75 & 9.2 & 6.1 \\
\hline MAY & 05 & 59 & 14.0 & 60 & -- & -- \\
\hline & 26 & $4 \cdot 3$ & 22.0 & 95 & 5.7 & 6.8 \\
\hline JUN & 03 & 12 & 24.0 & 105 & 7.5 & 6.7 \\
\hline AUG & 20 & 6.3 & 28.0 & 90 & 6.6 & $6 . T$ \\
\hline
\end{tabular}

02476600 OKATIBBEE CREEK AT ARUNDEL (LAT $32 \quad 1755$ LONG 08845 15)

$\begin{array}{lrrrrrr}\text { OCT } & 16 & 29 & 19.0 & 260 & -- & -- \\ \text { NOV } & 12 & 55 & 17.0 & 195 & -- & -- \\ \text { DEC } & 02 & 75 & 10.0 & 150 & 8.1 & 7.3 \\ \text { JAN } & 06 & 1080 & 2.0 & -- & -- & -- \\ & 21 & 202 & 4.0 & 105 & 11.3 & 0.2 \\ \text { FEB } & 10 & 140 & 11.0 & 105 & -- & -- \\ \text { MAR } & 04 & 1380 & 14.0 & 65 & 7.7 & 5.2 \\ & 12 & 300 & 12.0 & -- & -- & - \\ & 24 & 1110 & 13.0 & 55 & -- & - \\ \text { APR } & 14 & 244 & 18.0 & 100 & 7.0 & 6.1 \\ \text { MAY } & 05 & 1030 & 14.0 & 54 & -- & -- \\ & 26 & 47 & 25.0 & 165 & 1.9 & 0.4 \\ \text { AUG } & 25 & 500 & 27.0 & 95 & 5.2 & 6.2\end{array}$




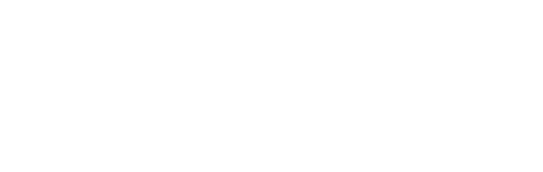

02477350 CHICKASAWHAY RIVER AT SHUBUTA ILAT 315100 LONG 0884200 I

\begin{tabular}{|c|c|c|c|c|c|}
\hline DEC 03 & 214 & 8.0 & 100 & 10.5 & 7.3 \\
\hline JAN 21 & 640 & 5.2 & 95 & 11.6 & 5.3 \\
\hline MAR 04 & 3030 & 14.0 & 82 & 8.8 & 6.9 \\
\hline APR 14 & 2200 & 17.0 & 70 & 8.0 & 6.3 \\
\hline MAY 26 & 135 & 29.0 & 150 & 7.9 & 7.2 \\
\hline AUG 25 & 1350 & 26.0 & 80 & 5.4 & \\
\hline
\end{tabular}

02477500 CHICKASAWHAY RIVER NEAR WAYNESBORO ILAT 314100 LONG 0884100 I

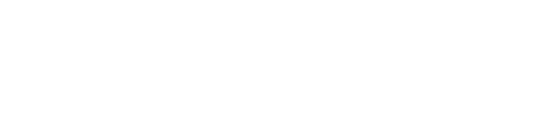

02477940 BUCKATUNNA CREEK NEAR MATHERVILLE (LAT 314752 LONG 0882915 )

\begin{tabular}{|c|c|c|c|c|c|}
\hline DEC 0 & -- & 8.0 & 145 & 11.5 & 7.3 \\
\hline JAN 2 & -- & 5.0 & 180 & 12.1 & 6.5 \\
\hline MAR 0 & -- & 14.0 & 140 & 8.6 & 6.3 \\
\hline APR 1 & -- & 17.0 & 70 & 8.3 & 6.0 \\
\hline MAY 2 & -- & 26.0 & 250 & 7.4 & 0.6 \\
\hline AUG 2 & & 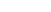 & & & \\
\hline
\end{tabular}

02478030 BUCKATUNNA CREEK NEAR BUCKATUNNA (LAT $3131 \quad 15$ LONG 0883045 )

\begin{tabular}{|c|c|c|c|c|c|}
\hline DEC & 85 & 11.0 & 100 & 11.0 & 7.2 \\
\hline JAN & 400 & 5.2 & 150 & 11.9 & 6.5 \\
\hline MAR 0 & -- & 14.0 & 80 & 8.6 & 6.4 \\
\hline APR I & 1350 & 17.0 & 120 & 9.0 & 6.3 \\
\hline MAY & 56 & 24.0 & 140 & 7.8 & 6.6 \\
\hline AUG & 240 & 25.0 & 140 & 6.5 & 6.4 \\
\hline
\end{tabular}

02478500 CHICKASAWHAY RIVER AT LEAKESVILLE ILAT 310800 LONG 0883300 I

$\begin{array}{rrrrrrr}\text { OCT } & 02 & 479 & 24.0 & 250 & -- & -- \\ \text { NOV } & 20 & 444 & 13.0 & 300 & -- & -- \\ \text { DEC } & 03 & 480 & 11.0 & 320 & 11.0 & 7.4 \\ & 29 & 2800 & 10.0 & -- & -- \\ \text { JAN } 22 & 1940 & 5.5 & 190 & 11.8 & 6.6 \\ \text { FEB } 09 & 2310 & 12.0 & 140 & -- & -- \\ \text { MAR } 05 & 11800 & 14.0 & 50 & 8.7 & 6.5 \\ & 25 & 12300 & 13.0 & 80 & -- & -- \\ \text { APR } & 15 & 5400 & 18.0 & 130 & 8.0 & 6.8 \\ \text { MAY } & 06 & 5800 & 15.0 & 110 & -- & -\overline{-} \\ & 27 & 800 & 28.0 & 215 & 8.4 & 6.7 \\ \text { JUN } & 04 & 990 & 25.0 & 215 & 8.4 & 6.5 \\ & 17 & 501 & 33.0 & 270 & -- & --\end{array}$

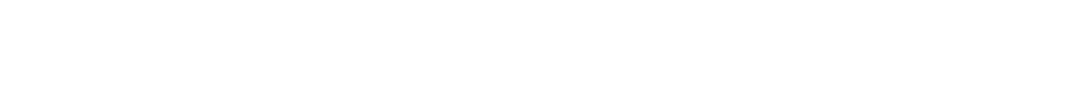

02478999 CHICKASAWHAY RIVER AT MERRILL (LAT 305900 LONG 0884350 )

\begin{tabular}{|c|c|c|c|c|c|c|c|c|c|c|c|}
\hline MAY 28 & $\rightarrow-$ & 13 & -- & 12 & 1.9 & 25 & 1.6 & 30 & 7.2 & 41 & .2 \\
\hline DATE & $\begin{array}{l}\text { NI TRATE } \\
\text { (NO3) } \\
\text { (MG/L) }\end{array}$ & $\begin{array}{l}\text { DIS- } \\
\text { SOLVED } \\
\text { SOLIDS } \\
\text { (RESI- } \\
\text { DUE AT } \\
\left.180^{\circ} \mathrm{C}\right) \\
(M G / L)\end{array}$ & $\begin{array}{l}\text { DIS- } \\
\text { SOLVED } \\
\text { SOLIDS } \\
\text { (SUM DF } \\
\text { CONSII- } \\
\text { TUENTS) } \\
\text { (MG/L) }\end{array}$ & $\begin{array}{l}\text { DIS- } \\
\text { SOLVED } \\
\text { SOLIDS } \\
\text { (TONS } \\
\text { PER } \\
\text { AC-FT) }\end{array}$ & $\begin{array}{l}\text { DIS- } \\
\text { SOLVED } \\
\text { SOLIDS } \\
\text { (TONS } \\
\text { PER } \\
\text { DAY) }\end{array}$ & $\begin{array}{l}\text { HARD- } \\
\text { NESS } \\
\text { (CA,MG) } \\
\text { (MG/L) }\end{array}$ & $\begin{array}{l}\text { NON- } \\
\text { CAR- } \\
\text { BONATE } \\
\text { HARD- } \\
\text { NESS } \\
(M G / L)\end{array}$ & $\begin{array}{l}\text { SPE- } \\
\text { CIFIC } \\
\text { CON- } \\
\text { DUCT- } \\
\text { ANCE } \\
\text { (MICRO- } \\
\text { MHOS) }\end{array}$ & $\begin{array}{c}\text { PH } \\
\text { (UNITS) }\end{array}$ & $\begin{array}{l}\text { TEMPER } \\
\text { ATURE } \\
\text { (DEG C) }\end{array}$ & $\begin{array}{l}\text { CDLOR } \\
\text { (PLATI- } \\
\text { NUM } \\
\text { COBALY } \\
\text { UNITS) }\end{array}$ \\
\hline MAY 28 & .2 & 141 & 117 & $\begin{array}{l}\text { DIS- } \\
\text { CHARGE } \\
\text { (CFS) }\end{array}$ & $\begin{array}{l}\text { TEMPER- } \\
\text { ATURE } \\
\text { (DEG C) }\end{array}$ & $\begin{array}{l}38 \\
\text { SPE- } \\
\text { CIFIC } \\
\text { CON- } \\
\text { DUCT- } \\
\text { ANCE } \\
\text { (MICRO- } \\
\text { MHOS) }\end{array}$ & $\begin{array}{l}\text { DIS- } \\
\text { SOLVED } \\
\text { OXYGEN } \\
(M G / L)\end{array}$ & $\begin{array}{c}\text { PH } \\
\text { (UNITS) }\end{array}$ & 7.0 & 28.0 & 15 \\
\hline
\end{tabular}

02479100 BLACK CREEK NEAR PURVIS (LAT 311100 LONG 0892300 )

\begin{tabular}{|c|c|c|c|c|c|c|}
\hline NOV & 20 & -- & 10.0 & 80 & 8.7 & 6.7 \\
\hline JAN & 07 & 360 & 1.0 & 90 & 10.9 & 5.3 \\
\hline FEB & 18 & 1720 & 10.2 & 50 & 9.3 & 5.0 \\
\hline APR & 01 & - & 17.0 & 40 & 7.6 & 5.8 \\
\hline MAY & 17 & $5 T$ & 22.0 & 95 & $T .2$ & 5.5 \\
\hline JUN & 04 & 80 & 21.0 & 50 & 6.5 & 7.1 \\
\hline & 23 & - & 26.0 & 120 & 6.4 & 6.3 \\
\hline AUG & 11 & 150 & 25.0 & 95 & 6.1 & 5.6 \\
\hline SEP & 22 & 50 & 26.0 & 130 & 6.2 & \\
\hline
\end{tabular}

02479130 BLACK CREEK AT BROOKLYN ILAT 3103 O6 LONG 08912151

$\begin{array}{llrrrr}\text { NOV 21 } & -- & 11.0 & 50 & 9.4 & 6.8 \\ \text { JAN O7 } & -- & 4.0 & 65 & 11.6 & 5.7 \\ \text { FEB 18 } & -- & 12.0 & 40 & 10.4 & 5.3 \\ \text { APR O1 } & -- & 18.0 & 40 & 8.5 & 6.2 \\ \text { AUG I1 } & -- & 27.0 & 40 & 7.0 & 6.0 \\ \text { SEP 22 } & -- & 27.0 & 80 & 7.4 & 5.9\end{array}$


CHEMICAL ANALYSES, WATER YEAR OCTOBER 1969 TO SEPTEMBER 1970

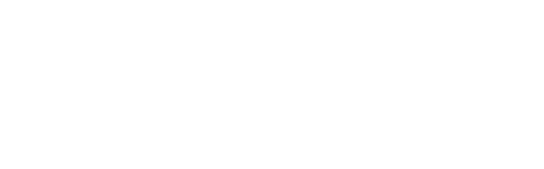

02479191 RED CREEK AT PERKINSTON (LAT 304702 LONG 0890810 )

$\begin{array}{lrrrrr}\text { NOV } 21 & -- & 11.0 & 110 & 9.6 & 6.7 \\ \text { JAN } 07 & 250 & 5.0 & 90 & 11.5 & 5.6 \\ \text { FEB } 18 & 330 & 14.0 & 128 & 10.4 & 5.2 \\ \text { APR } 01 & 250 & 19.0 & 80 & 8.4 & 5.4 \\ \text { MAY } 12 & -- & 24.0 & 70 & 8.0 & 5.6 \\ \text { JUN } 03 & -- & 29.0 & 100 & 7.8 & 6.4 \\ \text { AUG } 23 & -- & 29.0 & 70 & 8.6 & 6.6 \\ \text { SEP 22 } & -- & 28.0 & 95 & 7.4 & 5.7 \\ \text { SEP } & -- & 28.0 & 110 & -- & 6.0\end{array}$

02479300 RED CREEK AT VESTRY (LAT $3044 \quad 10$ LONG 0884650 )

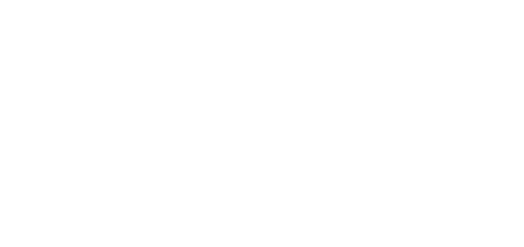

02479330 PASCAGOULA RIVER AT CUMBEST BLUFF (LAT 303502 LONG 0883415 )

$\begin{array}{llrrrr}\text { JAN } 06 & -- & 8.0 & 100 & 10.2 & 5.6 \\ \text { FEB } 19 & -- & 12.0 & 100 & 8.5 & 5.8 \\ \text { APR } 01 & -- & 19.0 & 93 & 5.5 & 5.8 \\ \text { MAY 12 } & -- & 24.0 & 170 & 5.5 & 5.9 \\ \text { AUG 11 } & -- & 29.0 & 140 & 6.3 & 6.1 \\ \text { SEP 22 } & -- & 31.0 & 115 & 5.5 & 6.4\end{array}$

02479580 ESCATAWPA RIVER NEAR HARLESTON (LAT 304340 LONG 0882720 )

DATE

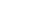

$\begin{array}{llrrrr}\text { NOV 20 } & -- & 12.0 & 150 & 9.0 & 5.9 \\ \text { JAN } 07 & -- & 12.0 & 48 & 12.5 & 6.2 \\ \text { FEB } 18 & -- & 12.0 & 90 & 10.4 & 4.3 \\ \text { MAR } 07 & -- & 15.0 & 80 & 8.8 & 4.2 \\ \text { MAY 12 } & -- & 25.0 & 52 & 7.9 & 5.9 \\ \text { JUN 22 } & -- & 29.0 & 40 & 7.1 & 5.5 \\ \text { AUG 11 } & -- & 26.0 & 46 & 7.8 & 4.4 \\ \text { SEP 22 } & -- & 27.0 & 85 & 7.0 & 4.2\end{array}$

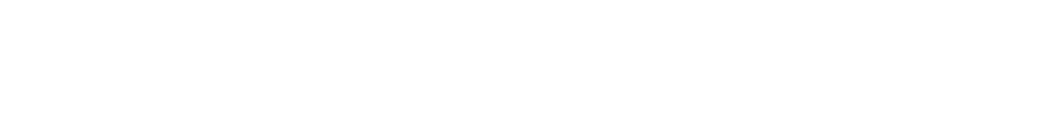

O2481950 KENTAWKA CREEK NEAR PHILADELPHIA (LAT 3246 00 LONG 089 OB 00)

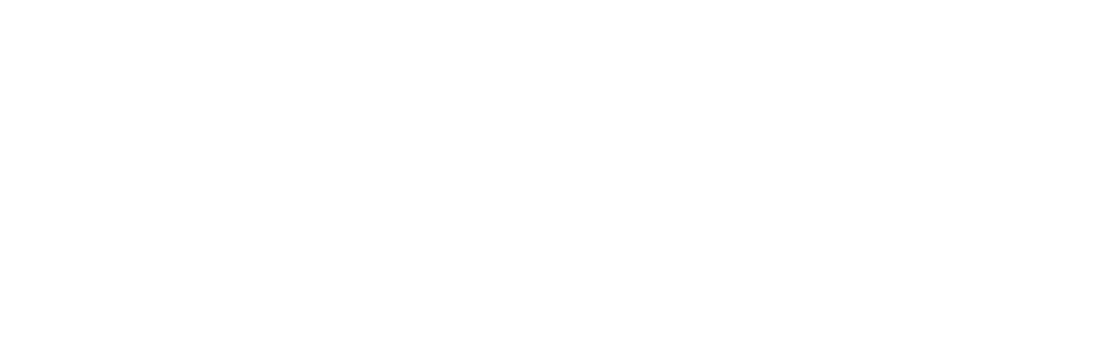

02481950 KENTAHKA CREEK NEAR PHILADELPHIA (LAT 324600 LONG 0890800 )

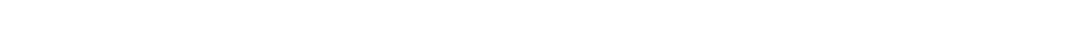

02482290 STANDING PINE CREEK NEAR FREENY (LAT 324200 LONG 0892700 )

$\begin{array}{llllllllllll}\text { MAY } 06 & .4 & 78 & 68 & .11 & 9.48 & 44 & 0 & 111 & 6.8 & 18.0 & 40\end{array}$

02482500 LOBUTCHA CREEK NEAR CARTHAGE (LAT 324600 LONG 0892800 )

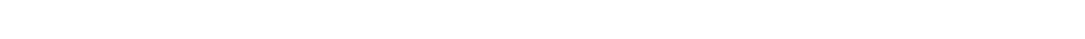




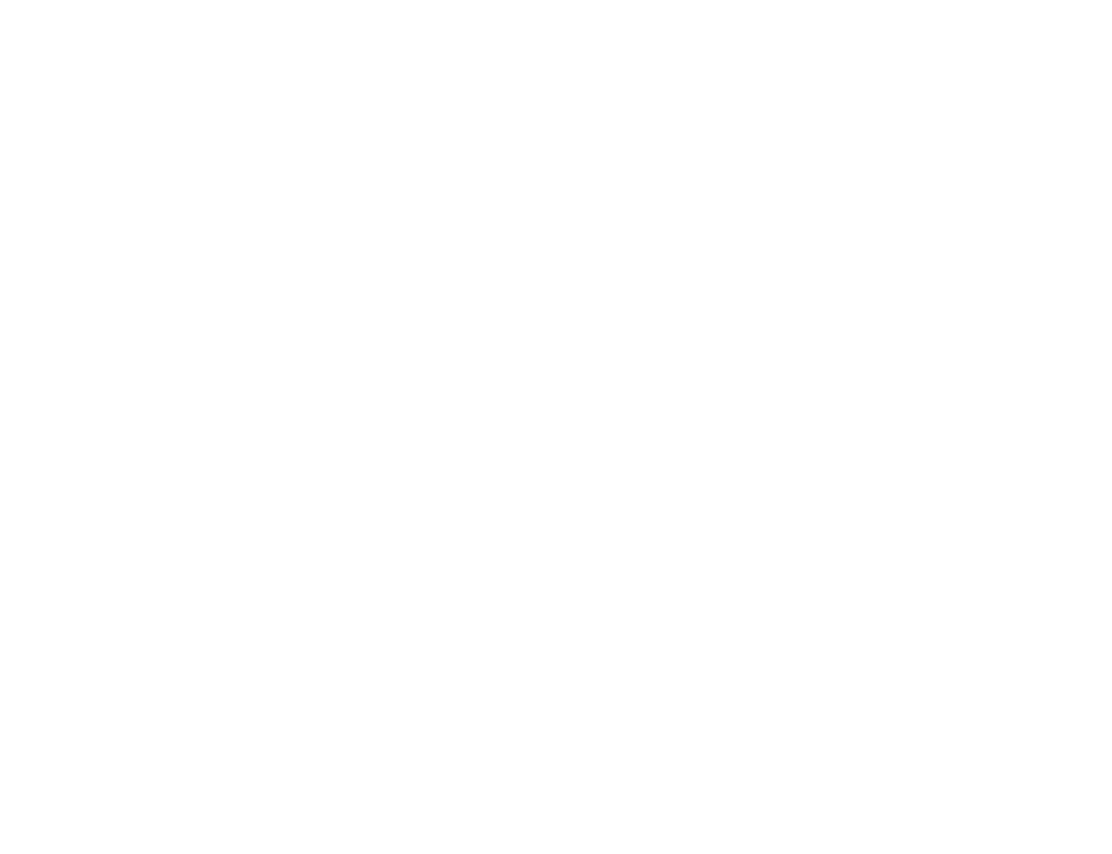



SUSPENDED-SEDIMENT DISCHARGE MEASUREMENTS, WATER YEAR OCTOBER 1969 TO SEPTEMBER 1970

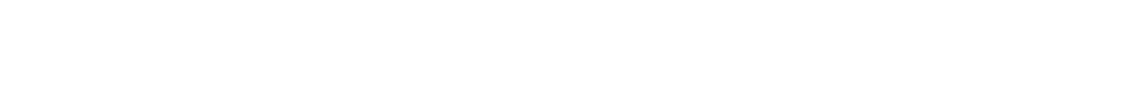

PAMLICO RIVER BASIN

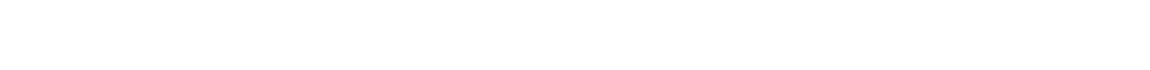

02081800 CEDAR CREEK NEAR LOUISBURG (LAT $36 \quad 03 \quad 14$ LONG $078 \quad 2024$ )

\begin{tabular}{|c|c|c|c|c|c|c|c|c|c|c|}
\hline \multirow[t]{2}{*}{$\begin{array}{l}F E B \\
F E B\end{array}$} & $\begin{array}{l}171970 \\
17 \ldots \ldots\end{array}$ & $\begin{array}{l}1400 \\
1645\end{array}$ & $\begin{array}{l}482 \\
554\end{array}$ & $\begin{array}{l}123 \\
169\end{array}$ & $\begin{array}{l}160 \\
253\end{array}$ & $\begin{array}{llll}\text { FEB } & 18 & 1970 \\
\text { FEB } & 19 & \ldots\end{array}$ & $\begin{array}{l}1400 \\
1315\end{array}$ & $\begin{array}{l}498 \\
170\end{array}$ & $\begin{array}{l}89 \\
34\end{array}$ & $\begin{array}{r}120 \\
16\end{array}$ \\
\hline & & & 02082000 & TAR RIVER & NEAR NASHVILLE ～ & (LAT $35 \quad 50 \quad 57$ L & LONG 07755 & 5511 & & \\
\hline \multirow[t]{2}{*}{$\begin{array}{l}A P R \\
A P R \\
\text { APR }\end{array}$} & $\begin{array}{l}02 \quad 1970 \\
02 \ldots \ldots \\
02 \ldots \ldots\end{array}$ & $\begin{array}{l}1100 \\
1440 \\
1800\end{array}$ & $\begin{array}{l}3300 \\
3460 \\
3630\end{array}$ & $\begin{array}{l}163 \\
136 \\
126\end{array}$ & $\begin{array}{l}1450 \\
1270 \\
1230\end{array}$ & $\begin{array}{lll}\text { APR } & 03 & 1970 \\
\text { APR } & 03 & \ldots \ldots \\
\text { APR } & 03 & \ldots\end{array}$ & $\begin{array}{l}0830 \\
1220 \\
1400\end{array}$ & $\begin{array}{l}3750 \\
3650 \\
3600\end{array}$ & $\begin{array}{l}93 \\
76 \\
79\end{array}$ & $\begin{array}{l}942 \\
749 \\
768\end{array}$ \\
\hline & & & 02082500 & SAPONY CREE & EK NEAR NASHVILLE & E ILAT 35530 & 7 LONG 077 & 54421 & & \\
\hline \multirow[t]{2}{*}{$\begin{array}{l}A P R \\
A P R\end{array}$} & $\begin{array}{l}021970 \\
02 \ldots \ldots\end{array}$ & $\begin{array}{l}1230 \\
1510\end{array}$ & -- & $\begin{array}{l}30 \\
22\end{array}$ & $=-$ & $\begin{array}{lll}\text { APR } & 03 & 1970 \\
\text { APR } & 03 & \ldots \ldots\end{array}$ & $\begin{array}{l}0845 \\
1210\end{array}$ & $=$ & $\begin{array}{l}19 \\
16\end{array}$ & -- \\
\hline & & & 02082770 & SWIFT CREEK & K AT HILLIARDSTON & N ILAT $3606 \quad 42$ & 2 LONG 077 & 55161 & & \\
\hline \multirow[t]{2}{*}{$\begin{array}{l}A P R \\
A P R\end{array}$} & $\begin{array}{l}021970 \\
02 . \ldots \ldots\end{array}$ & $\begin{array}{l}1255 \\
1550\end{array}$ & $\begin{array}{l}689 \\
791\end{array}$ & $\begin{array}{r}73 \\
114\end{array}$ & $\begin{array}{l}136 \\
243\end{array}$ & $\begin{array}{lll}A P R & 03 & 1970 \\
A P R & 03 & \ldots \ldots\end{array}$ & $\begin{array}{l}0935 \\
1300\end{array}$ & $\begin{array}{l}773 \\
742\end{array}$ & $\begin{array}{l}73 \\
63\end{array}$ & $\begin{array}{l}152 \\
126\end{array}$ \\
\hline & & & 02082950 & TLE FISHING & CREEK NEAR WHITE & E OAK (LAT 36 & 1108 LONG & 07752 & 34) & \\
\hline \multirow[t]{3}{*}{$\begin{array}{l}\triangle P P R \\
A P R\end{array}$} & $\begin{array}{l}021970 \\
02 \ldots \ldots\end{array}$ & $\begin{array}{l}1345 \\
1650\end{array}$ & $\begin{array}{l}794 \\
830\end{array}$ & $\begin{array}{l}117 \\
117\end{array}$ & $\begin{array}{l}251 \\
262\end{array}$ & $\begin{array}{lll}A P R & 03 & 1970 \\
A P R & 03 & \ldots\end{array}$ & $\begin{array}{l}0945 \\
1315\end{array}$ & $\begin{array}{l}762 \\
758\end{array}$ & $\begin{array}{l}56 \\
77\end{array}$ & $\begin{array}{l}115 \\
158\end{array}$ \\
\hline & & & & & NEUSE RIVER & BASIN & & & & \\
\hline & & & 02085000 & ENO RIVER & AT HILLSBOROUGH & (LAT $36 \quad 04 \quad 18$ & LONG 0790 & 06141 & & \\
\hline $\begin{array}{l}\text { FEB } \\
\text { FEB } \\
F E B \\
\text { FEB } \\
\text { AUG }\end{array}$ & $\begin{array}{l}17 \quad 1970 \\
17 \ldots \ldots \\
18 \ldots \ldots \\
18 \ldots \ldots \\
10 \ldots \ldots\end{array}$ & $\begin{array}{l}1350 \\
1730 \\
0835 \\
1125 \\
1505\end{array}$ & $\begin{array}{r}1050 \\
701 \\
284 \\
251 \\
104\end{array}$ & $\begin{array}{r}250 \\
185 \\
70 \\
63 \\
127\end{array}$ & $\begin{array}{r}709 \\
350 \\
54 \\
43 \\
36\end{array}$ & $\begin{array}{l}\text { AUG } 101970 \\
\text { AUG } 11 \ldots \ldots \\
\text { AUG } 11 \ldots \ldots \\
\text { AUG } 11 \ldots \ldots \\
\text { AUG } 12 \ldots \ldots\end{array}$ & $\begin{array}{l}1845 \\
0725 \\
1015 \\
1350 \\
0745\end{array}$ & $\begin{array}{r}151 \\
157 \\
132 \\
113 \\
47\end{array}$ & $\begin{array}{r}157 \\
109 \\
108 \\
95 \\
61\end{array}$ & $\begin{array}{l}64 \\
46 \\
38 \\
29 \\
7.7\end{array}$ \\
\hline
\end{tabular}

02085070 ENO RIVER NEAR DURHAM (LAT $36 \quad 04 \quad 18$ LONG 07854331

OCT $021969 \quad 1320$ $\begin{array}{lll}\text { OCT } & 02 \ldots \cdots & 1630 \\ \text { OCT } & 02 \ldots \cdots & 1850\end{array}$ $\begin{array}{llll}\text { OCT } & 02 & 1969 & 1350 \\ \text { OCT } & 02 & \cdots \cdots & 1700\end{array}$ OCT $03 . . . .1345$

OCT $021969 \quad 1420$ $\begin{array}{lll}\text { OCT } & 02 \ldots \ldots . & 1540 \\ \text { OCT } & 02 \ldots \ldots & 1740\end{array}$

FEB $17 \quad 1970 \quad 1230$ FEB $17 \ldots \ldots$... 1500 FEB $18, \ldots . \quad 1230$

OCT $291969 \quad 1200$ NOV $26 \ldots \ldots, \quad 1000$ DEC $29, \ldots$ i. $\quad 1100$

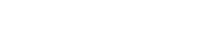

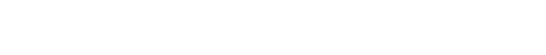

$34^{--}$

93
62

O2085220 LITTLE RIVER NEAR ORANGE FACTORY (LAT $36 \quad 0820 \quad$ LONG 0785424 )

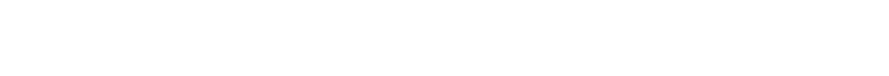

02086000 DIAL CREEK NEAR BAHAMA (LAT $36 \quad 0136$ LONG 0785124 )

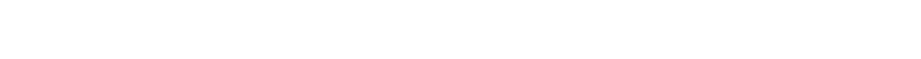

02087000 NEUSE RIVER NEAR NORTHSIDE (LAT 360254 LONG 0784450 )

\begin{tabular}{|c|c|c|c|c|c|c|c|c|}
\hline $\begin{array}{l}3140 \\
3370\end{array}$ & $\begin{array}{l}595 \\
520\end{array}$ & $\begin{array}{l}504 \\
912\end{array}$ & $\begin{array}{l}\text { FEB } \\
F E B\end{array}$ & $\begin{array}{ll}18 & 1970 \\
19 & \ldots \ldots\end{array}$ & $\begin{array}{l}1630 \\
1130\end{array}$ & $\begin{array}{l}5360 \\
4340\end{array}$ & $\begin{array}{r}105 \\
65\end{array}$ & $\begin{array}{r}1520 \\
763\end{array}$ \\
\hline 5230 & 132 & 1860 & FEB & $19 \ldots \ldots$ & 1430 & 4220 & 62 & 706 \\
\hline 5200 & 114 & 1600 & & & & & & \\
\hline
\end{tabular}

02089000 NEUSE RIVER NEAR GOLDSBORO (LAT $35 \quad 2014$ LONG 0775951 )

\begin{tabular}{|c|c|c|c|c|c|c|c|}
\hline $\begin{array}{l}536 \\
784\end{array}$ & $\begin{array}{r}16 \\
112\end{array}$ & $\begin{array}{r}23 \\
237\end{array}$ & $\begin{array}{lll}\text { MAR } & 30 & 1970 \\
\text { APR } & 29 & \ldots \ldots\end{array}$ & $\begin{array}{l}1030 \\
1030\end{array}$ & $\begin{array}{l}4330 \\
2680\end{array}$ & $\begin{array}{l}19 \\
54\end{array}$ & $\begin{array}{l}222 \\
391\end{array}$ \\
\hline 3770 & 101 & 1030 & MAY $21 \ldots$. & 0930 & 672 & 33 & 60 \\
\hline 1280 & 16 & 55 & JUN $10, \ldots$. & 1130 & 324 & 27 & 24 \\
\hline
\end{tabular}

CAPE FEAR RIVER BASIN

02096500.1 HAW RIVER AT HAW RIVER (LAT $36 \quad 0513$ LONG 0792202 )

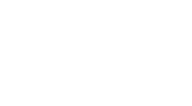

4550
4360

$\begin{array}{ll}755 & 9280 \\ 613 & 7220 \\ 377 & 3410 \\ 326 & 2760 \\ 294 & 2440 \\ 261 & 2030\end{array}$

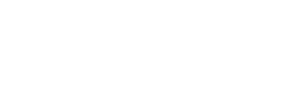

$\begin{array}{ll}926 & 3850 \\ 657 & 3210 \\ 680 & 4020 \\ 578 & 3560 \\ 553 & 3340 \\ 258 & 1370\end{array}$

02096850 CANE CREEK NEAR TEER (LAT $3556 \quad 34$ LONG 0791446 )

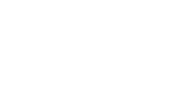

$\begin{array}{rr}648 & 300 \\ 325 & 169 \\ 109 & 49 \\ 95 & 54 \\ 12 & 63\end{array}$

$\begin{array}{rr}300 & 525 \\ 169 & 148 \\ 49 & 14 \\ 54 & 14 \\ 63 & 2.0\end{array}$

\begin{tabular}{|c|c|c|}
\hline $\begin{array}{l}\text { AUG } 101970 \\
\text { AUG } 11 \ldots \ldots \\
\text { AUG } 11 \ldots \ldots \\
\text { AUG } 12 \ldots \ldots\end{array}$ & $\begin{array}{l}1805 \\
0915 \\
1255 \\
0955\end{array}$ & \\
\hline ILAT 354400 & LONG & 79 \\
\hline $\begin{array}{l}\text { APR } 041970 \\
\text { AUG } 11 \ldots \ldots \\
\text { AUG } 11 \ldots \ldots \\
\text { AUG } 11 \ldots \ldots \\
\text { AUG } 12 \ldots \ldots \\
\text { AUG } 12 \ldots \ldots\end{array}$ & $\begin{array}{l}0900 \\
0800 \\
1015 \\
1300 \\
0830 \\
1030\end{array}$ & $\begin{array}{r}1990 \\
171 \\
171 \\
171 \\
260 \\
265\end{array}$ \\
\hline
\end{tabular}

74
145
118
57 3.8
$10^{5.7}$
.95

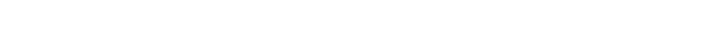

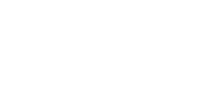

$\begin{array}{lll}1160 & 63 & 197 \\ 1260 & 66 & 225 \\ 1330 & 64 & 230 \\ 1750 & 83 & 392 \\ 1790 & 56 & 271 \\ 1860 & 46 & 231\end{array}$

1030

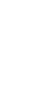




\begin{tabular}{|c|c|c|c|c|c|c|c|c|c|}
\hline DATE & TIME & $\begin{array}{c}\text { DISCHARGE } \\
\text { (CFS) }\end{array}$ & $\begin{array}{l}\text { CONCEN- } \\
\text { TRATION } \\
\text { (MG/L) }\end{array}$ & $\begin{array}{l}\text { SUSPENDED } \\
\text { SEDIMENT } \\
\text { DISCHARGE } \\
\text { (TONS/DAY) }\end{array}$ & DATE & TIME & $\begin{array}{l}\text { DISCHARGE } \\
\text { (CFS) }\end{array}$ & $\begin{array}{l}\text { CONCEN- } \\
\text { TRATION } \\
\text { (MG/L) }\end{array}$ & $\begin{array}{l}\text { SUSPENDED } \\
\text { SEDIMENT } \\
\text { DISCHARGE } \\
\text { (TONS/DAY) }\end{array}$ \\
\hline
\end{tabular}

$$
\text { CAPE FEAR RIVER BASIN--CONTINUED }
$$

O2098200 HAW RIVER NEAR HAYWOOD (LAT 353850 LONG 07903 54)

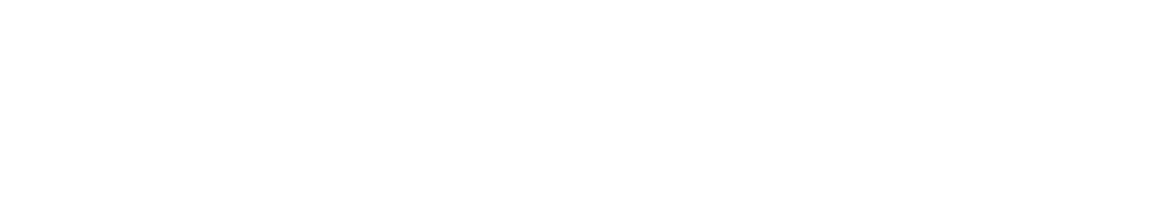

SUSPENDED-SEDIMENT DISCHARGE MEASUREMENTS AND PARTICLE-SIZE DISTRIBUTION, WATER YEAR OCTOBER 1969 TO SEPTEMBER 1970 SUSPENDED-SEDIMENT DISCHARGE MEASUREMENTS AND PARTICLE-SIZE DISTRIBUTION, WATER YEAR OCTOBER 1969 TO SEPTEMBER 1970
(METHODS OF ANALYSIS: B, BOTTOM WITHDRAWAL TUBE; C, CHEMICALLY DISPERSED; N, IN NATIVE WATER; P, PIPET; S, SIEVE;

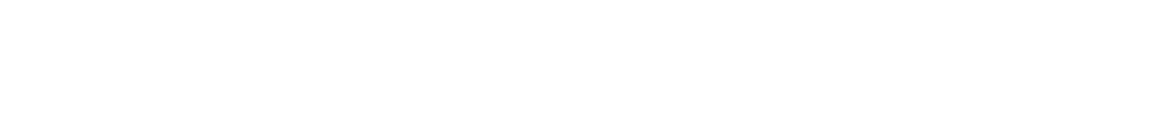

$$
\begin{aligned}
& \text { O2082000 TAR RIVER NEAR NASHVILLE (LAT } 355057 \text { LONG } 07755 \text { 51) }
\end{aligned}
$$

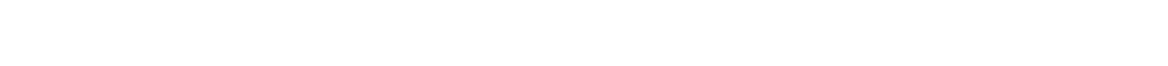

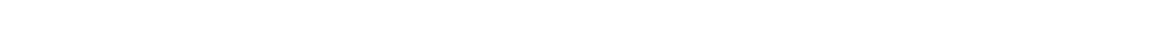

$$
\begin{aligned}
& 02082950 \text { LITTLE FISHING CREEK NEAR WHITE OAK (LAT } 361108 \text { LONG } 0775234 \text { ) }
\end{aligned}
$$

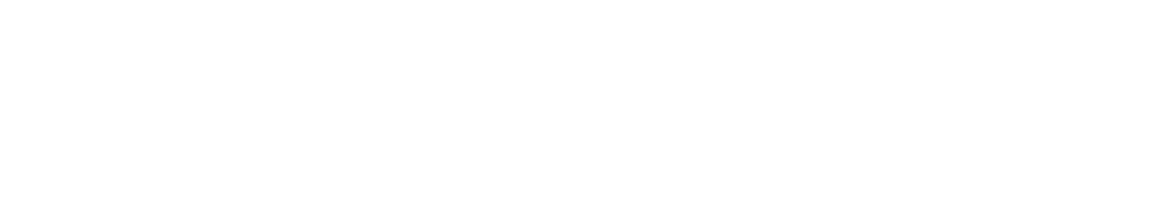




\section{INDEX}

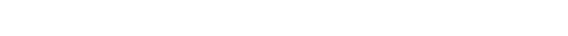

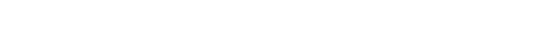

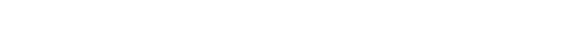
Alafia River, at Lithia, Fia................... 216-218 South Prong, near tithia, Fla, .......... 214,587

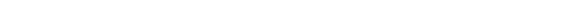
Alapaha River at Statenvilie, Ga............. 381 near Alapaha, Ga......................... 380 Albemarle Sound near Edenton, N.C.......... 331 Al tamaha R1ver at Doctortown, Ga.............. 160-162 Al tavista, Ya, Roanoke (Staunton) River at,.... $42-43$ Al tha, Fla., Chi pola River near.............. 258.260 Aluminum................................ Anclote River near Elfers, Fla..............227-228 Andersonville, Va. , Hollday Creek near............ Apalachee River near Buckhead, Ga...

34
375
258 Apalachicola River at Chat tahoochee, Fia....... 256 258 Apa lach1cola River basin $255-260,382-393,403,506-507,577$ Arcadia, Fla, , peace River at................207-211

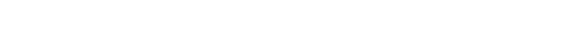
Aucilla River basin................... $504-505,575,629$

Bariumn

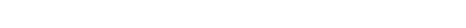

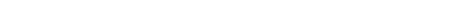

Beaufort River at Beaufort, S..$\ldots \ldots \ldots \ldots \ldots$
Beaver pond Branch at mouth, near citronel ie

Beaver pond Branch at mouth, near citronel le,

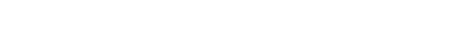
Benndale, Miss., Black Creek near

pascagoula River near.

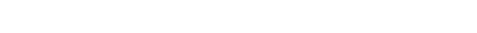

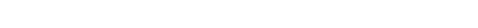

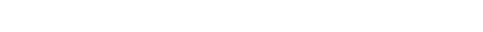

Biochemical oxygen demand.

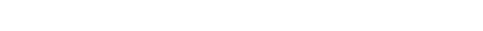

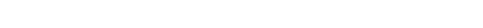

Black Creek near Benndal e, Miss......................

Black warrior River at Tuscaloosa, Ala....... 290.293

Blackwater River basin. ........ 512-513,580,603,630,653

Boardman, N.C. , Lumber River at............ 108-109

Bogalusa, La., pearl River near............. 319.322

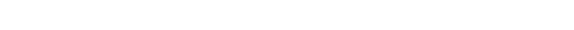

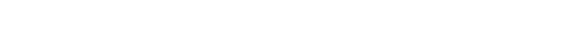

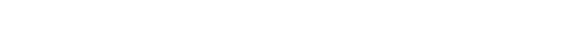

Brantley, Ala, Conecuh River at.............

Broad River, near Bell, Ga..................... 358.359

near Carlisle, s.C....................... 127

near Earl,

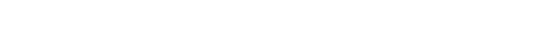

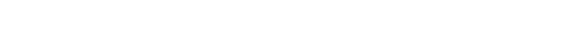

Buchanan, Va, James River at.................... ${ }^{28-30}$

Buram, Miss, pearl River above.................... 121-122

Cadmiun

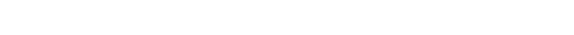
Caloosahatchee River at $\mathrm{S}-79$, near ólga,

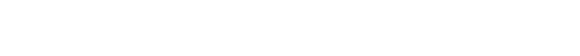

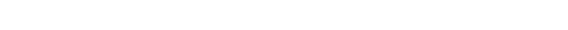
Canal point, Fla , ér claxton, Ga can $190-191$ Canton ${ }^{2}$. Cape Fear River, at Fayetteviile, $\mathrm{N} . \mathrm{C} \ldots \ldots \ldots$

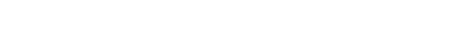

at Lock 2 nea

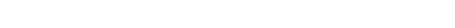
at sunny point, N. C..................... 345

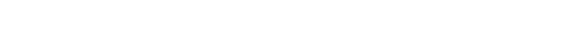
Cape Fear River basin.............74-87,342-345,663-664

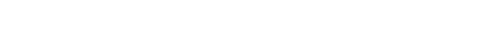

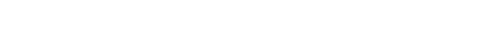

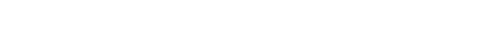

Catama River, at Mormanton, N.C.

350-351

at State Highway 49 near Pineviiie $\ldots \ldots \ldots \ldots .351-352$

near warion, N.C.......................................

South Fork, near Elmores crossroads, $\mathrm{k}, \mathrm{c} . \ldots \ldots$ Cayce, s.c., Congaree River near...................
Cedar Creek near Cedartown, Ga...............

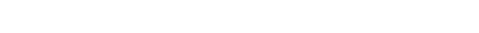
Chassahowitzka River near Homosassa, Fla........ 232-234 Chassahowitzka springs near homosassa, Fla..... 231-232 Chattahoochee, Fla., Apalachicola River at ..... 256.258 Chat tahoochee River, at Alaga, Ala ........... 388-389

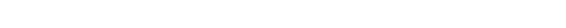
at Hest Point, Ga ........................ 387 near Cornelia, Ga ................... $\begin{array}{r}383 \\ 385-386\end{array}$

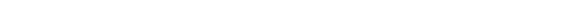

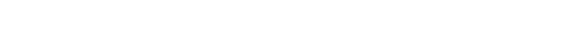
near whitesburg, Ga................... 386-387 Chattooga River at Summervilie, Ga........... $\quad 400$

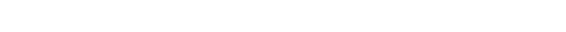
Chavers Creek, Ala,, Liti Escambia creek

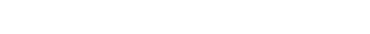

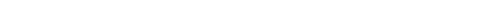
Chemical quality.

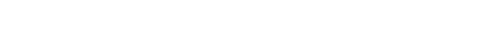
Cheraw, s.C., pee Dee River at..................... Chickahominy River near Providence Forge, Va.... kasaw Creek at county bridge, near

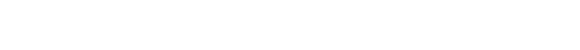
Childersburg, Ala, Coosa River at............ 274-275

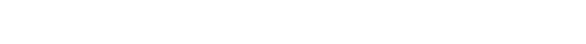

Choctawhatchee River, at $\ldots \ldots \ldots \ldots \ldots \ldots \ldots \ldots \ldots$
Caryville, Fla.......... $262,508-509,578,603,630$ near Newton, Ála.

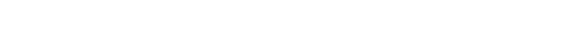
basin. 261-262, 508-511,528-529,577-579,588,630,653 Chowan River, at winton, N.C............. $\begin{array}{r}326 \\ 36-38\end{array}$

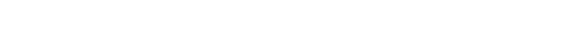
Chowan River basin........ River near............ 170-172

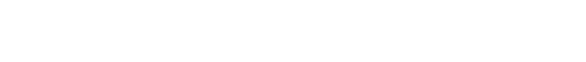

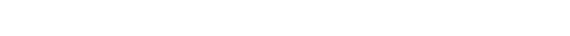

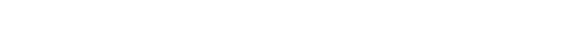
Clayton, Ga., Chattooga River near............. 148 Coastal basins between, Apa 3 chicoia River and $\ldots$ 149-150 Choctawhatchee River..... 506-509,577,603,630,652 Auci11a River and Ochlockonee
River.........249-252,504-507, 576,630,639,652 Choctawhatche River and Yellow River.......... 510-511,
Escambia River and Mobile $514-515,580,603,630,632,653$

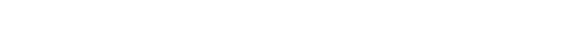
Hillsborough River and Wi thlacoochee River... $223-234$, Lake Okeechobee and the Everglades, and Peace River.............4 464-465, 557,598-600 Myakka River and Alafia River.... 524-525,586,604,656

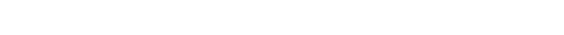
Ochlockonee River and Apalachicola River.. 506-507,576

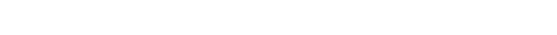
St. Marys River and St, Johns River...... 408.409,533 Suwannee River and Aucilla River......... $57304-505$, Withlacoochee River and Suwannee River..... $496-499$ Coatopa, Ala., Tombigbee River near.......... 294 Cobalt ..................... Cocoa, fia., st. Johns River near............. 167-170 Coffeyville; Ala., Tombigbee River near.......... 297-298 Collection and examination of data........... 4 .5

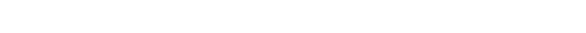
Columbia, S.C., Saluda River near................... Combahee River near Greenpond, $s . C_{\ldots \ldots \ldots \ldots \ldots} \quad 146$ Composition of surface waters............ 8 8.20 Conecuh River at Brantley, Ala.................. 265

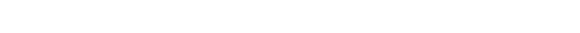
near Ft. Wotte, S.C........................ 138 Contentnea Creek, at Grifton, N.C.......... 337-338 Conway, N.C., Waccamaw River at............... 88 Conway, s.c., pee Dee River near............... ${ }_{110}$

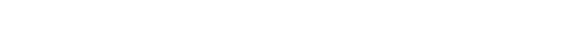
Coosa River, at Childersburg, Aia............. 272-273 at Gadsden, Ala $\ldots \ldots \ldots \ldots \ldots \ldots \ldots \ldots \ldots \ldots \ldots .272-273$

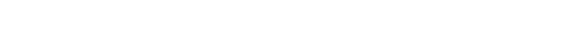
near Ellijay, Ga...................... 394

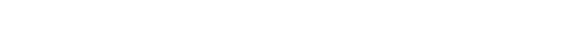


Crystal Springs, Fla, B1g ditch near........ near San Anton10, Fla..................22i.222,665

Dade C1ty, Fla., Withlacoochee River near...... 237-238 Dan R1ver, at Eden, N.C................ 53.55

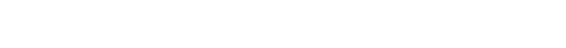
Deep River at U,S, Highway $i$, at Moncure, N,...

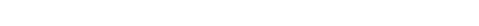
Dissolved solids. ......................12-13,15

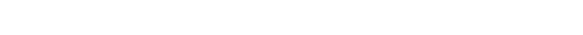
Double Creek near Roseville, N.C.............. 6

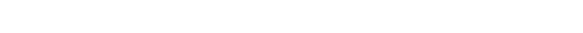

Ear1, N.C., Broad River near.

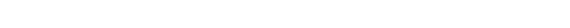

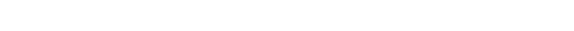

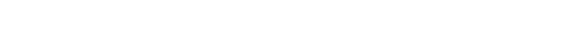

Edward, N.C., Durham Creek at................ 143-145

Effingham, s, c., Lynches River at........... 106-107 Elizabethtown, N.C., Cape Fear River at Lock 2 .

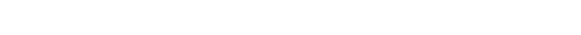

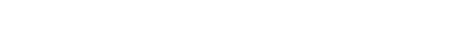

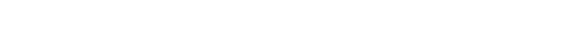
130-131 Enterpr1se, H1ss., Ch1ckasa whay River at........... 304-305 Escambia River basin................ $265-266,512-513$

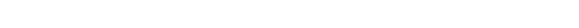
Etowah River, at Allatoona Dam, above

Cartersvil le, Ga.................... 397

at Canton, Ga $\ldots \ldots \ldots \ldots \ldots \ldots \ldots \ldots \ldots \ldots \ldots \ldots \ldots \ldots \ldots, \quad 270$

at Rome, Ga........................... $\quad 271$

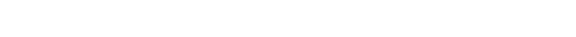

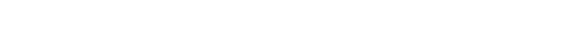

Expression of resul ts.....................

Falrmont, S.C., North Tyger River near........ 128 Falling Creek near Jullette, Ga.............. 158-159 Falling Spring, Va., Jackson River at......... 25-27

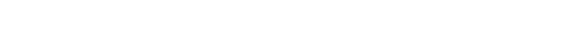

Flint River, at Albany, Ga.................. 392

at Balnbridge, Ga... G................... 393

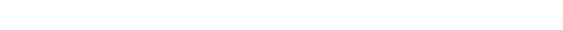

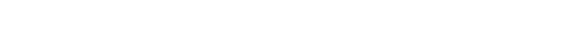

Fl uoride.

Fort Lauderdale, Fia., North New River Canai

near.......................... 195-197

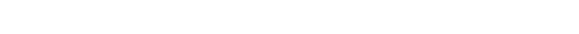

Gadsden, Ala., Coosa River at

$272-273$

Gaffney, S.C.', Broad River near................. 272-273

Ga1 nesvil le, Ala., Tombigbee River at...........

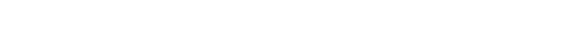

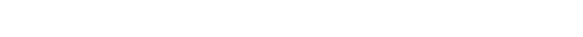

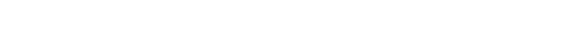

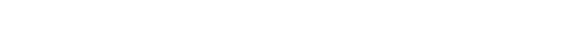

Givhans, S.C., Edisto River near..............

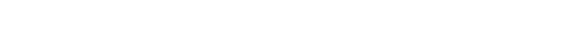

Greenpond, s.c., Combahee River near..........

Greenwood, Ala.; Shades Creek near........... 262-283

Gulferest, Aia., Chickasa near............. 121-122

H

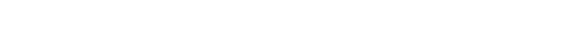
below S-71 near Lakeport, Fla............. 436-437 Havana, Fla., Ochlockonee River near............ 253.255 Haw River, néar Moncure, N, c............... 74-75 near Pittsboro, N.C..................... 342 H11 soboro Canal below HGS-4, near South Bay, Fla.............................. 192.193

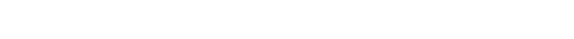
Hoboloch1 t to Creek near P1cayune, Hiss. $612,628,639,65$ Holder, Fla., withlacoochee River near............239-240 Holiday Creek near Andersonville, va........... 39 Holly Creek near Chatsworth, Ga ............. 395-396 Homosassa, Fla., Chassahow 1 tzka River near....... 232-234 Chassahowi tzka Springs near ................... 231-232 of Alafia River................526.529,587-588

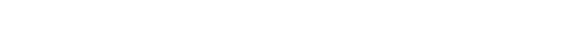

Hyco River at HcGehees Hill, N.C........... 62-64

Ind1an Creek near Laboratory, N.C........... 111-113 Indian prairte Canal at $\$-72$, near Okeechobee, $436-437$

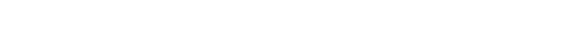

Iodide $\ldots \ldots \ldots \ldots \ldots \ldots \ldots \ldots \ldots \ldots \ldots \ldots \ldots \ldots \ldots, r_{8}^{11}$

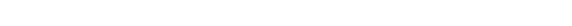

J-

Jackson, Ala., Tombigbee River near.......... 298.299

Jackson, Ala., Tombigbee River near.......... 298.299

Jackson River at Falling Spring, va.......... $\begin{array}{r}25-27 \\ \text { Jackoro, S.C., Edisto River at........... }\end{array}$

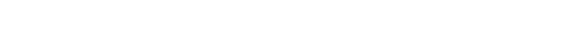

James River, at Buchanan, va................ 28 -30

at Cartersville, va.........................

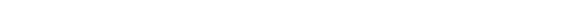

Janice, wiss., Cypress Creek near...............

Keysville, Fla., North Prong Alafia River at.... 214 K1nchafoonee Creek at Preston, Ga............ $\begin{array}{r}391 \\ \text { Kis }\end{array}$

\section{L}

Laboratory, N.C., Indian Creek near........... 111-113 Lake Harbor, Fla, , H1am1 canal at............. 197-199 Lake Okeechobee and the Everglades basins... 178-203,436465,618-523, $32,643-557,581-58,593-598,604-606$,

$649,654.656$

Lake Okeechobee, at Pahokee, Fla............ 186-187

Lake Plac1d, Fla, , Canal 41A near........... 182-184

Lake Teir at Oklawaha, Fla.......

Lake Yale at Grand Isiand, Fia................ 424-425

Laurel, Miss., Bogue Homo near................ 304

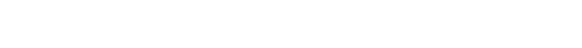

Leasburg, N.C., Hyco Creek near............ $\begin{array}{r}59 \\ \text { B. }\end{array}$

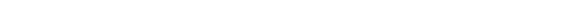

Limestone Creek near Monroeville, Ala........... 284

Li tera ture c1 ted....................... $23-24$

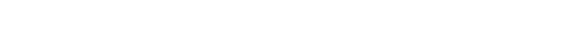

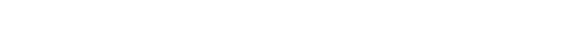

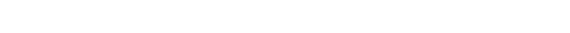

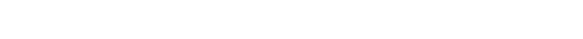

Little Escambia Creek, below Chavers Creek,

Ala.................................. 266

below poilard oil Field, Aia.................. 266

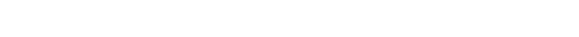

Little H111 Creek, at Gilbertown, Ala.......... 295

at mouth, near Gilbertown, Ala............. 296

Little R1ver near Ade1, Ga ................. $\quad 381$

Little Satilla River near offerman, Ga......... 378

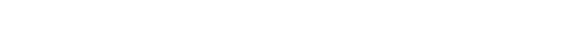

at water intake, at Lumberton, N.C.......... $\begin{array}{r}349 \\ \text { Lynches R1ver, at Effingham, S.C.............. 106-107 }\end{array}$

Lynches River, at Effingham, S.C............ 106-107

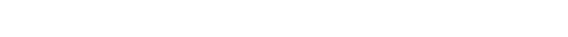

Macclenny, Fla, St. Marys River near......... 163-164

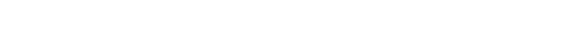

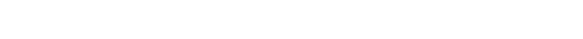

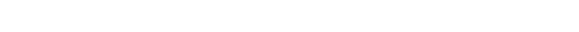

Mayo River near Price, N.C................ 49.50

McGehees Mil1, $N_{.}$. Hyco River at.......... 62 .64

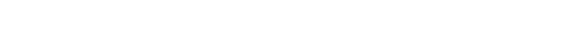

Mercury...................................... 164-167

Merrili, Miss ., Pascagoula River at........... 305-306

Miami, Fla,, Miami Canal near..... Zä........... 199-201 Fla................................... 197-199

east of levee 30 , near Mtami, Fla........... 199-201
Hiddle Oconee River near Athens, Ga...........

Middle Oconee River near Athens, Ga......... 156.157

Millhaven, Ga., Savannah River near.......... 156-157

Hineral constituents in solution...... $\ldots \ldots \ldots \ldots$

sites in, Alabama $\ldots \ldots \ldots \ldots \ldots \ldots \ldots \ldots \ldots, 403-407$

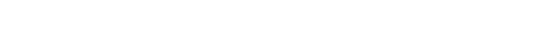

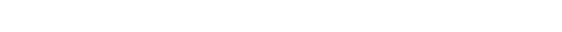

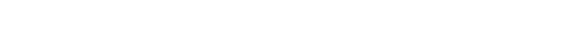

Mobile River basin... $267-300,338-339,393-401,403-407,657$

Mocksvilie, N.C., South Yadkin River.near...... $96-97$

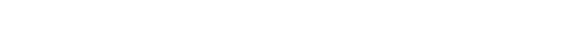

Honroeville, Ala., Limestone creek neä............

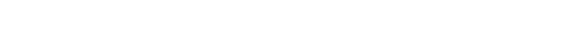

Monticello, Miss, , Pearl River near............. Moore Haven, Fla, , Caloosaha tchee Canal at...... 201-203 Moss Point, Hiss., Esca tawpa R1ver at $, \ldots \ldots \ldots, \ldots, 311-312$ 
Navassa, N.C., Cape Fear Rtver near......... $\mathbf{8 1 - 8 4}$ Neuse River, at Falls, N.C............... 334-335

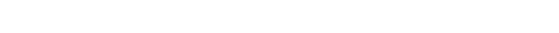
at $\mathrm{s}$ treets Ferry, near vanceboro, $\mathrm{N} . \mathrm{c} . \ldots \ldots \ldots . \ldots 38.339$

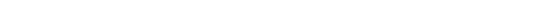

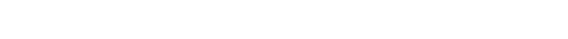

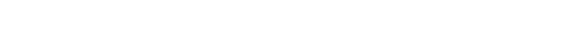
New Bern, N.C., Neuse River at.............. $\begin{array}{r}70-71 \\ \text { New Ellenton, S.c., Upper Three Runs near...... 153-155 }\end{array}$ New River, at Jacksonville, N.C.............. $72-73$ near Sneeds Ferry, N.C...................... 34 New River basin...............................
Newton, Ala, , Choctawhatchee

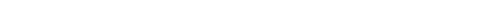
Nitrate.

Nitrogen...........

Nitrogen, ammonia.

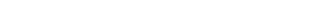

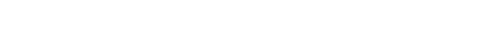
New River Canal, below HGS-4, near South

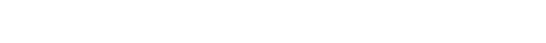
$\begin{array}{cr}\text { near Fort } & 368 \\ \text { North Newport River, at Halfmoon Landing, }\end{array}$ near Seabrook, Ga $\ldots \ldots \ldots \ldots \ldots \ldots \ldots \ldots \ldots \ldots \ldots$
North Newport River basin, North Pacolet River near Sandy piains, $\mathrm{N} . \mathrm{C}_{\ldots} \ldots \ldots$ 124-125 $\begin{array}{rr}\text { North Pacolet River near San Klafia River at Keysille, Fla...... } & 214 \\ \text { North } & \text { Prong }\end{array}$ $\begin{array}{lr}\text { North Tyger River near Fairmont, s.C........... } & 128 \\ \text { Northeast Cape Fear River, at Wilmington, } \mathrm{N} . \mathrm{C} . . & \mathbf{8 6 - 8 7}\end{array}$ near Castle Hayne, N.C..................

Ochlockonee River, near Havana, Fla.......... 253-255

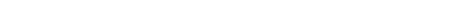

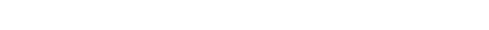
basin.......253-255,382,506-507,576,603,630,652 ocmulgee River, at Lumber City, Ga,........... $373-374$

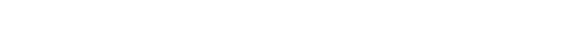

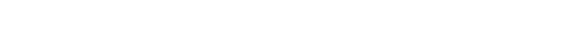
at Nilledgeville, Ga.................... 376 near Greensboro, Ga ........................ 374-375 Ofahoma, Hiss., Yockanookany Hiver near........ 313-314

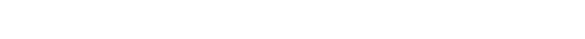

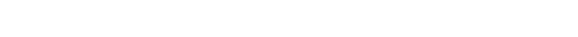
Ohoopee River near Reldsville, Ga........... $\quad \begin{aligned} & 377 \\ & 297\end{aligned}$

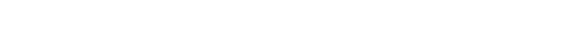
Taylor Creek above.... $\ldots \ldots \ldots \ldots \ldots \ldots \ldots \ldots \ldots \ldots$
oklawaha River, at at State Highway 19, near Salt Springs, Fia... 175-177 Oostanaula River, at Resaca, Ga............. 267-268 organtcs,

Paces, Va., Dan River at.

Pacolet Mills, s.C., Pacoiet River at................

pacolet River at Pacolet Mills, S.C.

Pageland, S.C., Lynches River near.

pahokee, Fla., Lake Okeechobee at............ 186-187

pamlico hiver, at Washington, N.C............ 67-68

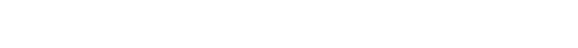
Pascagoula River, at Nerril1, Miss..................305.306

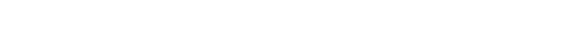
Pasquotank River at Elizabeth City, N.C........207-2i1, 324 Peace River, at Arcadia, Fla............. 207-211,560 at Zolfo Springs, Fla.............

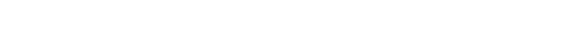

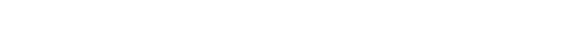
pearl River, above Byram, Miss....................315-316 at Georgetown, Miss...............................

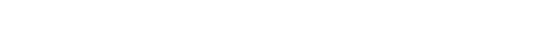
near Carthage, (1ss..................... 312-313

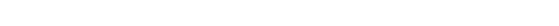

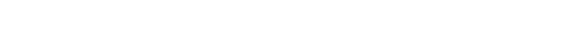

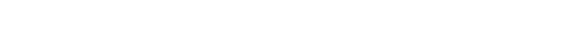

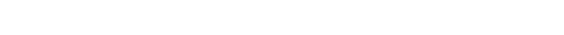

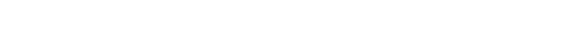
near Conway, s.c. $\ldots \ldots \ldots \ldots \ldots \ldots \ldots \ldots \ldots \ldots \ldots, \quad \begin{array}{r}110 \\ \text { near }\end{array}$

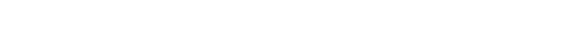

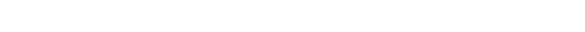
peedee, S.C., pee Dee River at $\ldots \ldots \ldots \ldots \ldots$

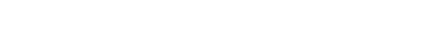

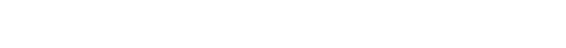

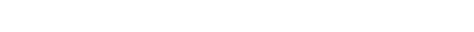
Pinetta, Fla., Withlacoochee River near.

Pineville, N.C., Catawba River near.

River near

pithlachascotee River near Richey Lakes, Fia..... 229-230

pollard, Ala., Little Escambla Creek near....... 266

pollard oil Field, Ala., Little Escambia Creek

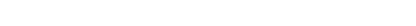

potato Creek near Thomaston, Ga.................

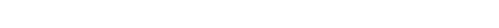

Properties and characteristics of water..........

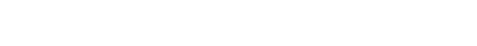
Puppy Creek, at County Bridge, near citroneile,

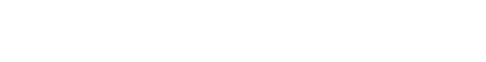

Rainbow Springs near Dunnellon, Fla....

$241-242,571$ Randolph, $\mathrm{Va}$, , Roanoke (Staunton) River

Reedy Rt ver, near Greenviji $\ldots \ldots \ldots \ldots \ldots \ldots \ldots$, $\ldots \ldots \ldots \ldots$

near Ware Shoals, s.c.

Resaca, Ga., Oostanaula Hiver at............... 267-268

Riceboro Creek, at Riceboro, Ga............ 365

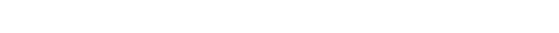

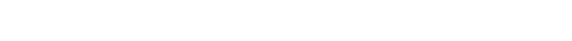

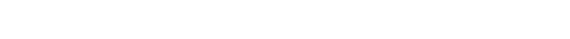

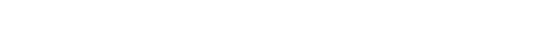

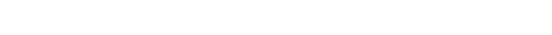
near Sans Souci, N.C................. 65-66

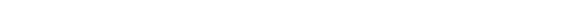
Roakingham, $N$.C., pee Dee River near.......... 98.99 Rockingham, N.C., Pee Dee River near........

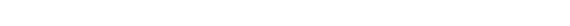

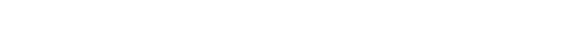
Oostanaula River near $\ldots \ldots \ldots \ldots \ldots \ldots \ldots \ldots \ldots$
Roseville, $N$. C. , Double Creek near. South Hyco Creek near................... Roswell, Ga., Chat tahoochee River near......... 255-25 Royster, $N . C .$, Cape Fear River at.............
Runnelstown,

St. Johns River, at Jacksonville, F1a..... 432-433,542 near Christmas, Fla................... 170-172

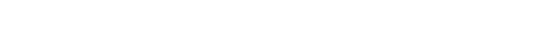

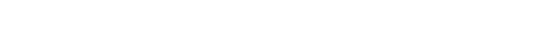
St. Johns River basin , 164-177, 408-433,528-529, 533-542 St. Lucie Canal at lock, near Stuart, Fla...... 188-189 St. Marys River near Jacclenny, Fla......... 163.164 St. Marys River basin........... 163-164,408-409,533,590 Stit Springs, Fia,., Oklawaha River, near.......... 175-177 Saluda Hiver, near' Oklawaha River, near......... 175-17 near silverstreet, S.C...................... 135

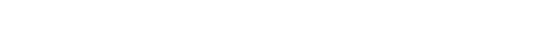
San Antonio, Fla., Cypress Creek near.......... 221-222 Sandy plains, N.C. , North Pacolet River -near.... $124-12$ Santa Fe River at Worthington Springs,

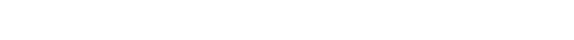

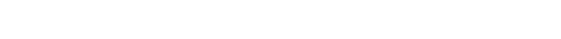

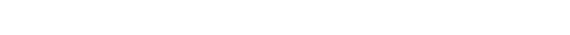
Sat11la River, at Atkinson, Ga............. $\quad 379$

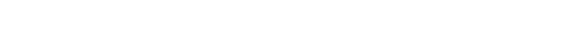
Savannah River, at Augusta, Ga,............. at Burtons Ferry bridge, near Mi ihaven, Ga.... 156-157

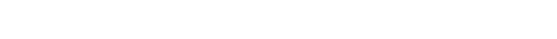

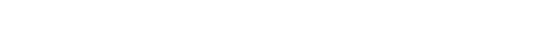
near Iva, s. c............................ Second Broad River at cilifide, N.c...........354-355

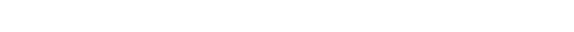
Selma, Ala., Ai abama kiver at $\ldots \ldots \ldots \ldots \ldots \ldots \ldots \ldots$ 280-281

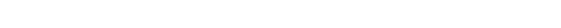

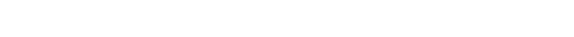

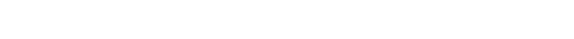

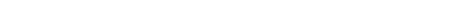
sodium and potassium.

Sopchoppy River near Sopchoppy, Fia............. 249-252 South Atlantic slope and eastern Guif of Mexico

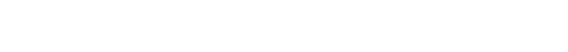

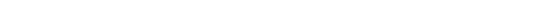
South Fork Catawba River, near Elmores

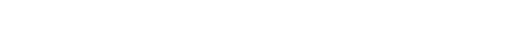

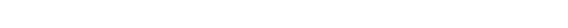
South Hyco Creek near Roseville, N.C...........
South Newport RIver near Harris Neck, Ga....... South Newport River near Harris South Yadkin River, near Franklin, N.C..........346-347

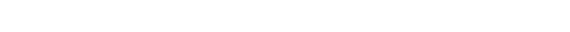

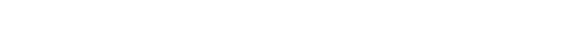

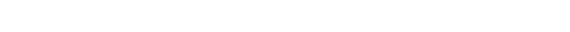
Stuart, fia., st. Lucie canai near................ 188-189 Stuart, Fla., St. Lucle Canal near............ 188-18 Sulfate.

Sulphur sprints, $r i a_{,}$, Rocky $\ddot{c} r e{ }_{k}$

Surveyors Creek near Barrytown ${ }^{\text {near }} \ldots \ldots \ldots \ldots \ldots \ldots$ 223-224 Surveyors Creek near Barry town,
Suwannee River, at Branford, Fia................... at Fargo, Ga $\ldots \ldots \ldots \ldots$
Suwannee Suwannee River basin.... 242-249,379-381, 500-503,573-575 Sweetwater Creek near Austel1, Ga............ 384-385 
Tallahala Creek near Runnelstown, wiss..........

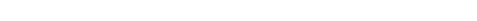
nelow Tallassee,

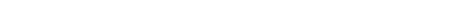

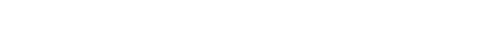

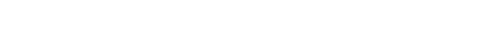

immons River near Yellow Bluff, Ga.

Tobesofkee Creek near Macon, Ga,

372

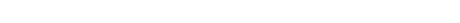

at Demopolis lock and dam, near Coatopa, Ala.

t Gainesville, Ala.

feyville lock and dam, near coffeyvilie

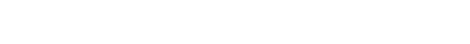

near Jackson, Ala $\ldots \ldots \ldots \ldots \ldots \ldots \ldots \ldots \ldots \ldots$

Tranters Creek near Latham, . . . . . . . . . . . .

locksville, $\mathrm{N}$,

Turbidity.

creek and coastai basins south

to St. Lucie River............ 434-435,532-542

Tyscaloosa, Ala., Black , s. C. ...........290-293

$$
\text { U }
$$

Unnamed tributary to Beaver Pond Branch at

Upper Three Runs near New Eilenton, s............ $\begin{array}{r}310 \\ \text { U. }\end{array}$

$$
\text { \% }
$$

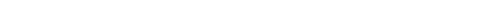

$\begin{array}{ll}\text { Page } & \text { Pan }\end{array}$

Waccamaw River, at Freeland, N.C........... $\quad \mathbf{3 4 5}$

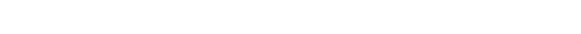
Tare Shoals, s.c., Reedy River near..............

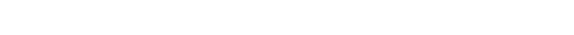

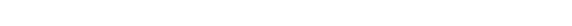
Fater-quality stations, in downstream order, for which records are published.

mest palm Beach Canal at HGS-5, at Canai point; 190-191

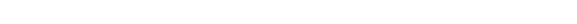
Tilkesboro, N.C. Yadkin River at ............89-92 Tilmington, $N$, Northeast Cape Fear River at 86.87 Himauma, Fla, Little Hanatee River near . . ... 212-213 Nithlacoochee River, near Dade City, Fla ...... 237-238

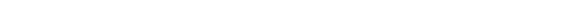

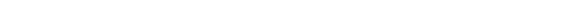
near P1netta, Fla....... Titr-lacoochee River basin . . $57007032,601,612,629,650$ Worthington Springs, F1a., Santa Fe River at.... 247-249 $\mathbf{Y}$

Yadkin College, N.C., Yadkin River at......... 93-95 Yadkin River, at Donnaha, N.C................ 346 at High Rock, N.C..................... 347-348 at 1 ijkesboro, N.C. $\ldots \ldots \ldots \ldots \ldots \ldots \ldots \ldots \ldots \ldots, \quad 89.92$ at Yadkin College, $N . C \ldots \ldots \ldots \ldots \ldots \ldots \ldots \ldots$ 263-264 Yellow River, at Willigan, Fla............. 263-264 yellow River basin.......................

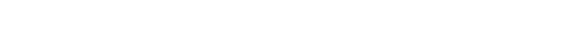

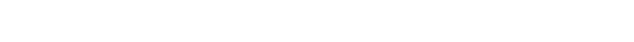

